\title{
Financial Statistics of Major U.S. Investor-Owned Electric Utilities 1992
}

December 1993
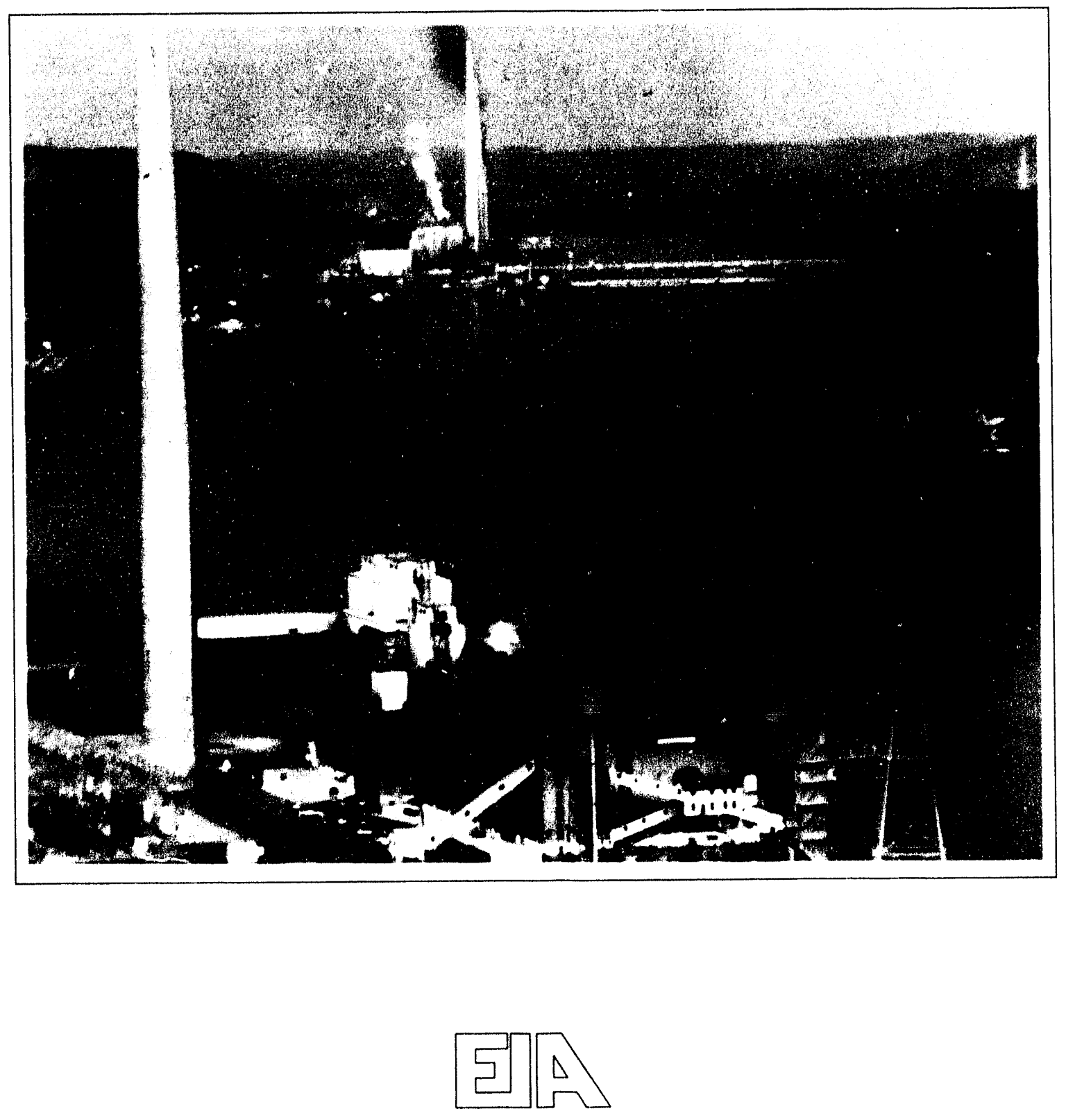

Energy Information Administration 
This publication and other Energy Information Administration (EIA) publications may be purchased from the Superintendent of Documents, U.S. Government Printing Office.

\title{
All telephone orders should be directed to:
}

\author{
U.S. Government Printing Office \\ McPherson Square Bookstore \\ 1510 H Streel, N.W. \\ Washington, DC 20005 \\ (202)653-2050
}

FAX (202)376-5055

9 a.m. to 5 p.m., eastern time, M-F
Superintendent of Documents

U.S. Government Printing Office

Washington, DC 20402

(202)783-3238

FAX (202)512-2233

8 a.m. to 5 p.m., eastern time, M-F

\section{All mail orders should be directed to:}

\author{
U.S. Government Printing Office \\ c/o Mellon Bank \\ P.O. Box 371954 \\ Pittsburgh, PA 15250-7954
}

Complimentary subscriptions and single issues are available to certain groups of subscribers, such as public and academic libraries, Federal, State, local and foreign governments, EIA survey respondents, and the media. For further information and for answers to questions on energy statistics, please contact EIA's National Energy Information Center. Address, telephone numbers, and hours are as follows:

National Energy Information Center, EI-231

Energy Information Administration

Forrestal Building, Room 1F-048

Washington, DC 20585

(202)586-8800

Telecommunications Device for the Hearing

Impaired Only: (202)586-1181

9 a.m. to 5 p.m., eastern time, M-F

\section{Cover photo:}

The Toronto Plant (foreground) and the W.H. Sammis Plant are coal-fired plants that are located near Toronto, Ohio, and are operated by the Ohio Edison Company. 


\section{Financial Statistics of Major U.S. Investor-Owned Electric Utilities 1992}

\section{December 1993}

Enorgy Information Administration

Office of Coal, Nuclear, Electric and Alternate Fuels

U.S. Department of Energy

Washington, DC 20585 


\section{Contacts}

The Financial Statistics of Major U.S. Investor-Owned Electric Utilities is prepared annually by the Survey Management Division: Office of Coal, Nuclear, Electric and Alternate Fuels (CNEAF); Energy Information Administration (EIA); U.S. Department of Energy (DOE).

General information regarding the contents of this publication may be obtained from the National Energy Information Center (202/586-8800). General information about the data appearing in this publication may be obtained from Howard L. Walton
(202/254-5500), Director of the Survey Management Division, or Fred Mayes (202/254-5300), Chief of the Renewable and Financial Data Systems and Outreach Branch.

Questions and comments may be referred to Roger $\mathrm{L}$. Sacquety (202/254-5440), Financial Systems Team Leader. Specific information about data contained in the FERC Form 1 may be obtained from Jerome A. Sancierson $(202 / 254-5463)$ or Thomas S. Williams (202/254-5436). 


\section{Contents}

Page

Contacts

Introduction

Summary Statistics of the Major U.S. Investor-Owned Electric Utilities Financial Performance ............................

Detailed Statistics of the Major Investor-Owned Electric Utilities Selected Financial Indicators

Appendices
A. Classifications of Major U.S. Investor-Owned Electric Utilities
B. Bond Ratings for Major U.S. Investor-Owned Electric Utilities
C. Other U.S. Entities Jurisdictional to the FERC
D. Technical Notes
E. Glossary 


\section{Tables}

1. Selected Electric Utility Data by Ownership, 1992

2. Selected Data for Major U.S. Investor-Owned Electric Utilities in This Report Compared With All U.S. Investor-Owned Electric Utilities, 1992

3. Electric Operating Revenue and Net Electric Operating Income for Major U.S. Investor-Owned Electric Utilities, 1988-1992

4. Original Plant Cost for Plants that Began Commercial Operation by Major U.S. Investor-Owned Electric Utilities During 1992

5. Investments in Environmental Protection and Construction Work in Progress for Major U.S.

Investor-Owned Electric Utilities on December 31, 1988-1992

..........................

6. Composite Statement of Income and Retained Earnings for Major U.S. Investor-Owned Electric Utilities, $1988-1992 \quad \ldots \ldots \ldots \ldots \ldots \ldots \ldots \ldots \ldots \ldots \ldots \ldots \ldots \ldots \ldots \ldots \ldots \ldots \ldots \ldots \ldots 16$

7. Ratios Based on the Composite Statement of Income and Retained Earnings for Major U.S. Investor-Owned Electric Utilities, $1988-1992 \quad \quad \ldots \ldots \ldots \ldots \ldots \ldots \ldots \ldots \ldots \ldots \ldots \ldots \ldots \ldots$

8. Composite Balance Sheet for Major U.S. Investor-Owned Electric Utilities on December 31, 1988-1992 20

9. Composite Financial Indicators for Major U.S. Investor-Owned Electric Utilities, 1988-1992 $\ldots$. . . . 22

10. Composite Statement of Cash Flows for Major U.S. Investor-Owned Electric Utilities, 1988-1992 23

11. Electric Operation and Maintenance Expenses for Major U.S. Investor-Owned Electric Utilities, 1988-1992 24

12. Ratios Based on Electric Operation and Maintenance Expenses for Major U.S. Investor-Owned Electric Utilities, 1988-1992

13. Percent of Total Electric Operation and Maintenance Expenses for Major U.S. Investor-Owned Electric

14. Average Power Production Expenses for Plants Owned by Major U.S. Investor-OWned Electric Ütilities, 1988-1992

15. Number of Consumers, Sales, and Operating Revenue for Major U.S. Investor-Owned Electric Utilities, 1988-1992

16. Ratios Based on Number of Consumers, Sales, and Operating Revenue for Major U.S. Investor-Owned

17. Comparison of Selected Statement of Income and Financial Data for Major U.S. Investor-Owned Electric Utilities, 1988-1992

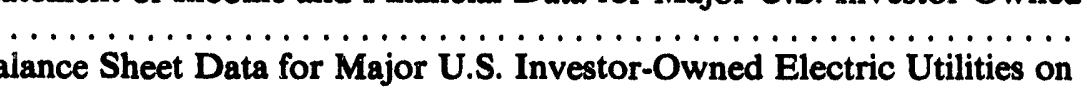

18. Comparison of Selected Balance Sheet Data for Major U.S. Investor-Owned Electric Utilities on December 31, 1988-1992 30

Net Income and Allowance for Funds Used During Construction for Major U.S. Investor-Owned Electric Utilities, 1988-1992

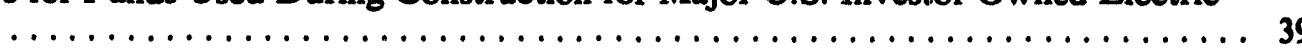

20. Total Debt for Major U.S. Investor-Owned Electric Utilities on December 31, 1988-1992 _.....

21. Disposition of Net Income for Major U.S. Investor-Owned Electric Utilities, 1988-1992 $\quad \ldots \ldots \ldots .40$

22. Net Income per Share of Common Stock for Major U.S. Investor-Owned Electric Utilities, 1988-1992 40

23. Source and Disposition of Revenue for Major U.S. Investor-Owned Electric Utilities, 1988-1992 $\quad \ldots 41$

24. Electric Construction Work in Progress for Major U.S. Investor-Owned Electric Utilities on December 31, 1988-1992

25. Outstanding Electric Construction Work in Progress as a Share of Total or Net Electric Utility Plant for Major U.S. Investor-Owned Electric Utilities on December 31, 1988-1992 $\ldots \ldots \ldots \ldots \ldots \ldots \ldots 4$

26. Changes in Electric Utility Plant for Major U.S. Investor-Owned Electric Utilities, $1988-1992 \ldots \ldots \ldots \ldots 4$

27. Electric Utility Plant in Service for Major U.S. Investor-Owned Electric Utilities on December 31, 1988-1992

28. Electric Utility Plant for Major U.S. Investor-Owned Electric Utilities on December 31, 1988-1992

29. Capital Accounts for Major U.S. Investor-Owned Electric Utilities on December 31, 1988-1992 $\ldots 48$

30. Eiectric Energy Account for Major U.S. Investor-Owned Electric Utilities, 1988-1992 _...... 49

31. Ten Largest U.S. Investor-Owned Electric Utilities Ranked by Revenue from Sales to Ultimate Consumers, 1992

32. Ten Largest U.S. Investor-Owned Electric Utilities Ranked by Revenue from Sales for Resale, 1992

33. Ten Largest U.S. Investor-Owned Electric Utilities Ranked by Electric Operating Revenue, 1992

34. Ten Largest U.S. Investor-Owned Electric Utilities Ranked by Net Electric Operating Income, 1992

35. Ten Largest U.S. Investor-Owned Electric Utilities Ranked by Gross Electric Utility Plant on December 31, 1992 
36. Ten Largest. U.S. Investor-Owned Electric Utilities Ranked by Net Electric Utility Plants on December 31,1992

37. Statement of Income and Retained Earnings by Major Investor-Owned Electric Utility Within State, 199254

38. Balance Sheet by Major Investor-Owned Electric Utility Within State on December 31, $1992 \quad \ldots 144$

39. Statement of Cash Flows by Major Investor-Owned Electric Utility Within State, $1992 \quad \ldots 204$

40. Number of Consumers, Sales, and Operating Revenue by Major Investor-Owned Electric Utility Within

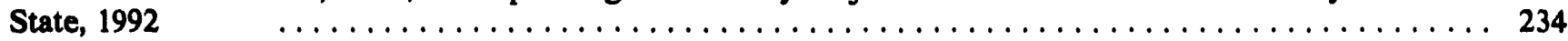

41. Electric Operation and Maintenance Expenses by Major Investor-Owned Electric Utility Within State,

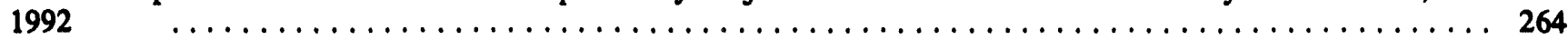

42. Utility Plant by Major Investor-Owned Electric Utility Within State on December 31, $1992 \quad \ldots 28$

43. Electric Energy Account by Major Investor-Owned Electric Utility Within State, $1992 \quad \ldots \ldots .474$

44. Selected Financial Indicators by Major Investor-Owned Electric Utility Within State, $1992 \quad \ldots 2$

45. Investments in Environmental Protection by Major Investor-Owned Electric Utility Within State on December 31, $1992 \quad \ldots \ldots \ldots \ldots \ldots \ldots \ldots \ldots \ldots \ldots \ldots \ldots \ldots \ldots \ldots \ldots \ldots . \ldots \ldots$

46. Expenditures for Environmental Protection by Major Investor-Owned Electric Utility Within State, 1992529

A1. Major U.S. Investor-Owned Electric Utilities Added and Deleted, 1988-1992 _.......... 541

A2. Major and Nonmajor Classifications of U.S. Electric Utilities by the FERC, 1988-1992 _..... 543

A3. Major U.S. Investor-Owned Electric Utilities with Holding Company Status Under the Public Utility Holding Company Act of 1935

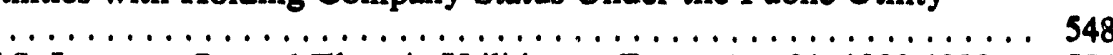

B1. Summary of Bond Ratings for Major U.S. Investor-Owned Electric Utilities on December 31, 1988-1992 554

B2. Bond Ratings by Major U.S. Investor-Owned Electric Utility on December 31, 1988-1992 _.... 555

C1. Statement of Income and Retained Earnings by Other U.S. Entity Within State, $1992 \quad \ldots \ldots \ldots \ldots .562$

C2. Balance Sheet by Other U.S. Entity Within State on December 31, $1992 \quad \ldots \ldots \ldots \ldots \ldots \ldots \ldots .568$

C3. Statement of Cash Flows by Other U.S. Entity Within State, $1992 \quad \ldots \ldots \ldots \ldots \ldots \ldots \ldots \ldots \ldots .572$

C4. Number of Consumers, Sales, and Operating Revenue by Other U.S. Entity Within State, $1992 \quad \ldots 2574$

C5. Electric Operation and Maintenance Expenses by Other U.S. Entity Within State, $1992 \ldots \ldots \ldots$

C6. Utility Plant by Other U.S. Entity Within State on December 31, $1992 \quad \ldots \ldots \ldots \ldots \ldots \ldots \ldots \ldots .584$

C7. Electric Energy Account by Other U.S. Entity Within State, $1992 \quad \ldots \ldots \ldots \ldots \ldots \ldots \ldots \ldots \ldots \ldots$

D1. Sources of Data Used in Formulas and Calculations $\quad \ldots \ldots \ldots \ldots \ldots \ldots \ldots \ldots \ldots \ldots \ldots \ldots$ 


\section{Illustrations}

Page

1. Average Revenue per Kilowatthour for Major U.S. Investor-Owned Electric Utilities, 1988-1992

2. Sales of Electricity for Major U.S. Investor-Owned Electric Utilities, 1988-1992 _ . . . . . . . . . 35

3. Total Proprietary Capital of Major U.S. Investor-Owned Electric Utilities, 1988-1992 A . . . . . . 38

4. Total Long-term Debt of Major U.S. Investor-Owned Electric Utilities, 1988-1992 _ . . . . . . . . . 38

5. Outstanding Electric Construction Work in Progress for Major U.S Investor-Owned Electric Utilities on

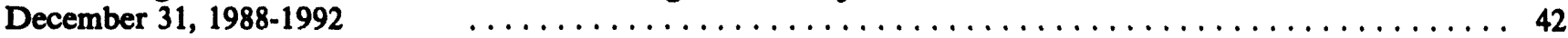

6. Investments in Air Pollution Control for Major U.S. Investor-Owned Electric Utilities, 1988-1992

7. Investments in Water Pollution Control for Major U.S. Investor-Owned Electric Utilities, 1988-1992 528

A1. Number of States Served by the Major U.S. Investor-Owned Electric Utilities, $1992 \quad \ldots \quad \ldots$. . . . . . 542

A2. Corporate Headquarters of Major U.S. Investor-Owned Electric Utilities, 1992 


\section{Introduction}

The Financial Statistics of Major U.S. Investor-Owned Electric Utilities publication presents summary and detailed financial accounting data on the investorowned electric utilities. The objective of the publication is to provide Federal and State governments, induscry, and the general public with current and historical data that can be used for policymaking and decisionmaking purposes related to investor-owned electric utility issues.

\section{Background}

The Financial Statistics of Major U.S. Investor-Owned Electric Utilities publication is prepared by the Renewable and Financial Data Systems and Outreach Branch; Survey Management Division; Office of Coal, Nuclear, Electric and Alternate Fuels; Energy Information Administration (EIA); U.S. Department of Energy. Financial statistics for major investor-owned electric utilities have been compiled and published annually since 1938 to satisfy the requirements for accurate, readily available data regarding the electric power industry. The format was designed to be used by a variety of private, electric power industry, and government users. The publication contents and format have evolved over the years to better serve the needs and requirements of the targeted audience.

As the result of the Federal Power Act of 1935, the Federal Power Commission (FPC), which was the predecessor to the Federal Energy Regulatory Commission (FERC), began collecting financial statistics for investor-owned electric utilities in 1938. The EIA upon its establishment in October 1977 took over the responsibilty of gathering and publishing the financial statistics on behalf of the FERC. In 1982, the EIA combined the contents of two publications containing financial statistics of investor-owned (private) and publicly owned electric utilities into a single volume, the Financial Statistics of Selected Electric Utilities. The 1989 edition reverted to the two separate publications, the Financial Statistics of Selected Investor-Owned Electric Utilities and the Financial Statistics of Selected Publicly Owned Electric Utilities . In 1991, the publication titles were changed to the Financial Statistics of Major Investor-Owned Electric Utilities and the Financial Sta- tistics of Major Publicly Owned Electric Utilities . In 1992, the publications titles were further changed to the Financial Statistics of Major U.S. Investor-Owned Electric Utilities and the Financial Statistics of Major U.S. Publicly Owned Electric Utilities .

The U.S. electric power industry is a combination of electric utilities (investor-owned, publicly owned, Federal, and cooperatives) and nonutility power producers. Investor-owned electric utilities account for over three-fourths of the sales and revenue in the industry. Historically, the investor-owned electric utilities serve the large consolidated markets. There is substantial diversity among the investor-owned electric utilities in terms of services, size, fuel usage, and prices charged. Most investor-owned electric utilities generate, transmit, and distribute electric power. Investor-owned electric utilities operate in all States except Nebraska; Hawaii is the only State in which all electricity is supplied by investor-owned electric utilities.

\section{Data Users}

The Financial Statistics of Major U.S. Investor-Owned Electric Utilities publication provides information about the financial results of operations of investorowned electric utilities for use by government, industry, electric utilities, financial organizations and educational institutions in energy planning. In the private sector, the readers of this publication are researchers and analysts associated with the financial markets, the policymaking and decisionmaking members of electric utility companies, and economic development organizations. Other organizations that may be interested in the data presented in this publication include manufacturers of electric power equipment and marketing organizations. In the public sector, the readers of this publication include analysts, researchers, statisticians, and other professionals engaged in regulatory, policy, and program areas. These individuals are generally associated with the Congress, other legislative bodies, State public utility commissions, universities, and national strategic planning organizations. 


\section{Coverage of Sources}

The source of financial information for the major investor-owned electric utilities is the Federal Energy Regulatory Commission (FERC) Form 1, "Annual Report of Major Electric Utilities, Licensees and Others," for calendar year 1992 and prior years. This survey is processed and published by EIA for the FERC. Major investor-owned electric utilities are defined as those investor-owned electric utilities that have had, in the past three consecutive calendar years, sales or transmission services that exceeded one or more of the following:

- 1 million megawatthours of total annual sales

- 100 megawatthours of annual sales for resale

- 500 megawatthours of annual power exchanges delivered

- 500 megawatthours of annual wheeling for others (deliveries plus losses).

The 1992 summary data are based on reports from 180 major investor-owned electric utilities. The FFRC has also required six independent power producers (Catalyst Old River Hydroelectric Limited Partnership; Entergy Power, Incorporated; Nevada Sun-Peak Limited Partnership; Ocean State Power; Ocean State Power II; and Terra Comfort Corporation) to be under FERC jurisdiction and must submit the FERC Form 1 for 1992. The FERC has also determined that Golden Spread Electric Cooperative and Old Dominion Electric Cooperative should file a FERC Form 1 under Section 201 of the Federal Power Act. Detail statistics for these six independent power producers and two cooperatives are reported separately in Appendix C. The 1991 summary data in this publication excludes the five independent power producers (Catalyst Old River Hydroelectric Limited Partnership, Entergy Power Incorporated, Nevada Sun-Peak Limited Partnership, Ocean State Power, and Terra Comfort Corporation) that were included in last year's publication.

In 1991, Public Service Company of New Hampshire emerged from bankruptcy after an approved merger with Northeast Utilities. Due to fresh-start accounting, only data from May 16 through December 31 are included in the 1991 summary statistics. Pursuant to the reorganization plan resulting from the bankruptcy, the interest in the Seabrook plant was acquired on June 5, 1992, by North Atlantic Energy Corporation, also a subsidiary of Northeast Utilities. Both Public Service Company of New Hampshire and North Atlantic Energy Corporation submitted a separate FERC Form 1 for 1992 and are thus included in both the summary and detail statistics.

Centel Corporation was acquired by UtiliCorp United, Incorporated, effective September 30, 1991, and therefore, will not appear in this publication. In 1992, FaleSafe, Incorporated, and Warm Springs Power Enterprises were declared exempt by the FERC and thus did not file a FERC Form 1. UGI Corporation, which changed its name to UGI Utilities, Incorporated, on April 10, 1992, became a nonrzajor electric utility. In addition to North Atlantic Energy Corporation mentioned in the prior paragraph, Great Bay Power Corporation, Kanawha Valley Power Company, and Pioneer Power and Light Company also became jurisdictional to the Federal Energy Regulatory Commission.

Iowa Power, Incorporated, and Iowa Public Service Company merged into Midwest Power Systems, Incorporated. Kansas Power and Light Company was acquired by Western Resources, Incorporated. Michigan Power Company merged with Indiana Michigan Power Company. As a result of these mergers, data are reported only for Midwest Power Systems, Incorporated; Indiana Michigan Power Company; and Western Resources, Incorporated.

\section{Industry Proflle}

In 1992, there were 3,232 investor-owned, publicly owned, Federal, and cooperative electric utilities. Table 1 reports 1992 selected electric utility data for the total universe of electric utilities. The data are compiled from the Form EIA 861, "Annual Electric Utility Report." The 262 investor-owned electric utilities represent only 8.1 percent of the total number of electric utilities, but provide the majority of sales to ultimate consumers and sales for resale. 


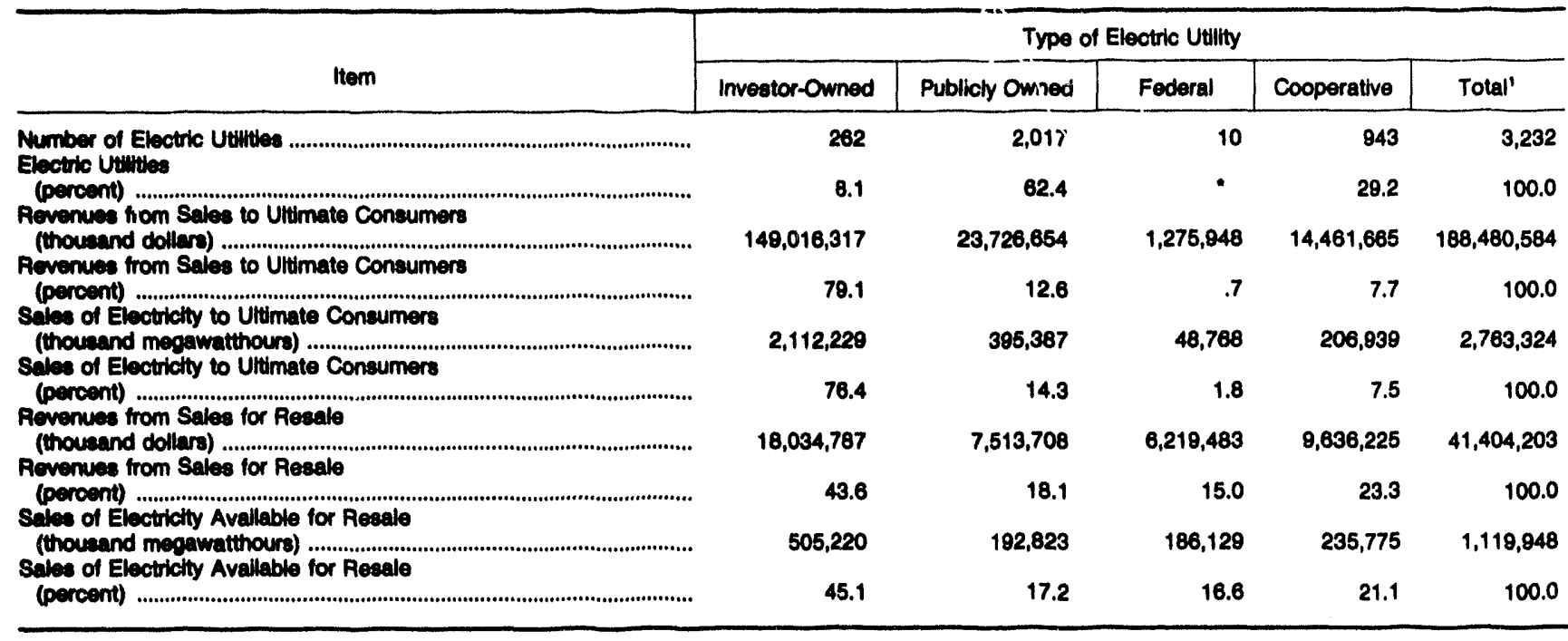

'Includes only thoee electric utilties in the United States and the District of Columbla. Excluded are the six independent power producers jurisdictional to the Federal Energy Regulatory Commiasion in 1992.

Value lese than 0.5 percent.

Note: Data are preliminary. Total may not equal sum of components because of independent rounding.

Source: Energy Information Administration, Form EIA-861, "Annual Electric Utility Report."

Key facts concerning sales and revenues in 1992 (Table 1) are as follows:

- The 262 investor-owned electric utilities (8.1 percent of all electric utilities) accounted for 79.1 percent of all revenues from sales of electricity to ultimate consumers and 43.6 percent of all revenues from sales for resale.

- The 2,017 publicly owned electric utilities $(62.4$ percent of all electric utilities) accounted for $\mathbf{1 2 . 6}$ percent of all revenues from sales to ultimate consumers and 18.1 percent of all revenues from sales for resale.

- The 10 Federal electric utilities accounted for 0.7 percent of all revenues from sales to ultimate consumers and 15.0 percent of all revenues from sales for resale.

- The 943 cooperative borrowers (29.2 percent of all electric utilities) accounted for 7.7 percent of all revenues from sales to ultimate consumers and 23.3 percent of all revenues from sales for resale.

Selected operational data for the 180 major investorowned are compared to all 262 investor-owned electric utilities in the United States that submit the Form EIA-861 (Table 2). In 1992, the 180 investor-owned electric utilities included in this publication (68.7 percent of all the investor-owned electric utilities) accounted for 99.6 percent of the revenues from sales to ultimate consumers and 96.8 percent of the revenues from sales for resale of all investor-owned electric utilities.
All of the remaining tables use the data reported on the FERC Form 1. Summary tables that contain historical data for 1988 through 1992 display aggregate financial statistics for investor-owned electric utilities classified as major for each year (Tables 3 and 5 through 30). Six tables contain ranking data on investor-owned electric utilities (Tables 31 through 36). Detailed data in State by electric utility sequence are also provided (Tables 37 through 46). For consistency, each investor-owned electric utility has been listed in the State where the corporate headquarters are located, rather than in the State where the majority of its sales occured. Note that Holyoke Power and Electric Company is now shown in Massachusetts versus Connecticutt in the prior publications.

Effective with this publication, data covering new plants that began commercial operation during the year are included (Table 4). Also, average power production expenses for plants owned by major investorowned electric utilities for the last five years are shown (Table 14). These data were previously reported in Electric Plant Cost and Power Production Expenses (DOE/EIA-0455).

Deleted from the 1992 publication are data covering transmission and distribution systems and expenditures for research, development, and demonstration. The transmission and distribution data will appear biennially in .Electric Trade in the United States (DOE/EIA-0531) beginning with the 1992 publication. 
Appendix A presents three tables containing the classification of investor-owned electric utilities. Table A1 lists the electric utilities added to and deleted from this publication for 1988 through 1992. Table A2 provides the "major" and "nonmajor" investor-owned electric utilities from 1988 through 1992. Table A3 indicates the holding company status under the Public Utility Holding Company Act of 1935.

Appendix B contains the bond ratings for major investor-owned electric utilities provided by Standard and Poor's. Table B1 is a summary of ratings for the years 1988 through 1992 and Table B2 lists the individual rating by major investor-owned electric utilities.

Appendix C contains 1992 detailed statistics covering the six independent power producers and the two cooperatives jurisdictional to the Federal Regulatory Commission.

Appendix D contains the Technical Notes.

Table 2. Selected Data for Major U.S. Investor-Owned Electric Utilitles In This Report Compared With All U.S. Investor-Owned Electric Utillties, 1992

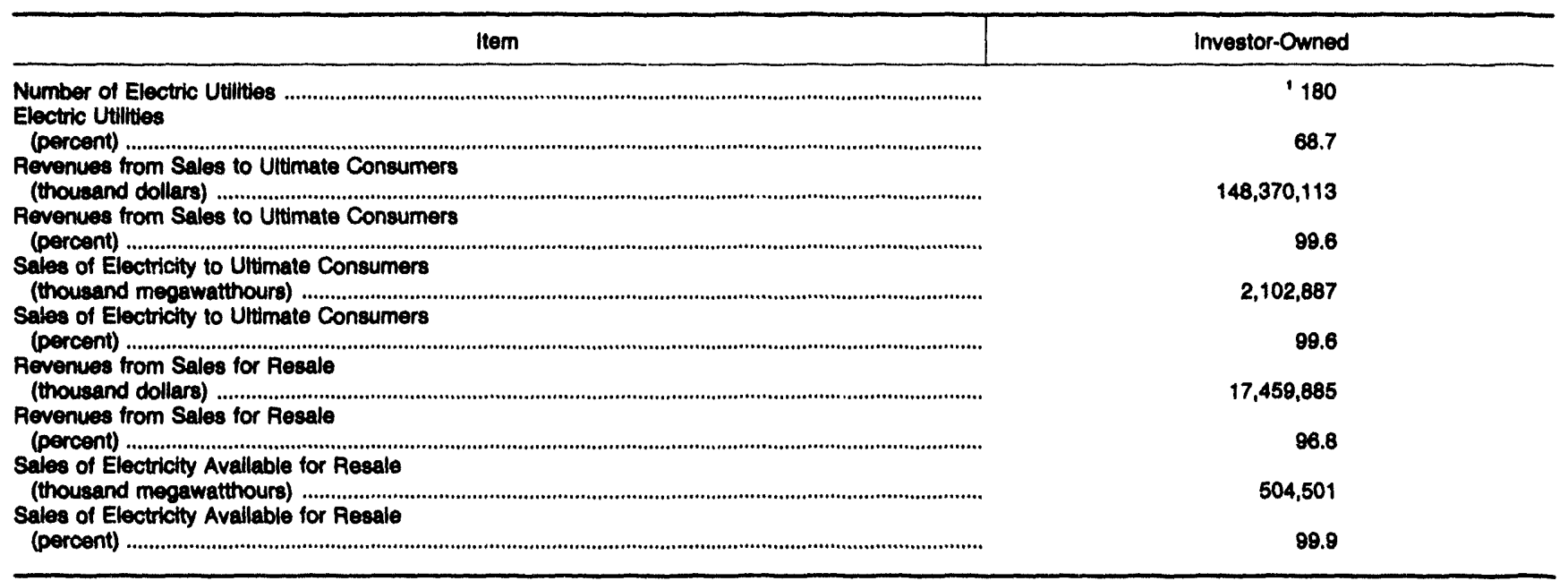

' Excluded are the six independent power producers and two cooperatives jurisdictional to the Federal Energy Regulatory Commission in 1992. Note: Data are preliminary.

Source: Energy Information Administration, Form EIA-861, "Annual Electric Utility Report." 


\section{Summary Statistics of the Major U.S. Investor-Owned Electric Utilities 1992}

The Beaver Valley Nuclear Plant (foreground) and the Bruce Mansfield Plant, a coel-fired plant is located near Shippingport,

Pennsylvania, and operated by Duquesne Light Company.

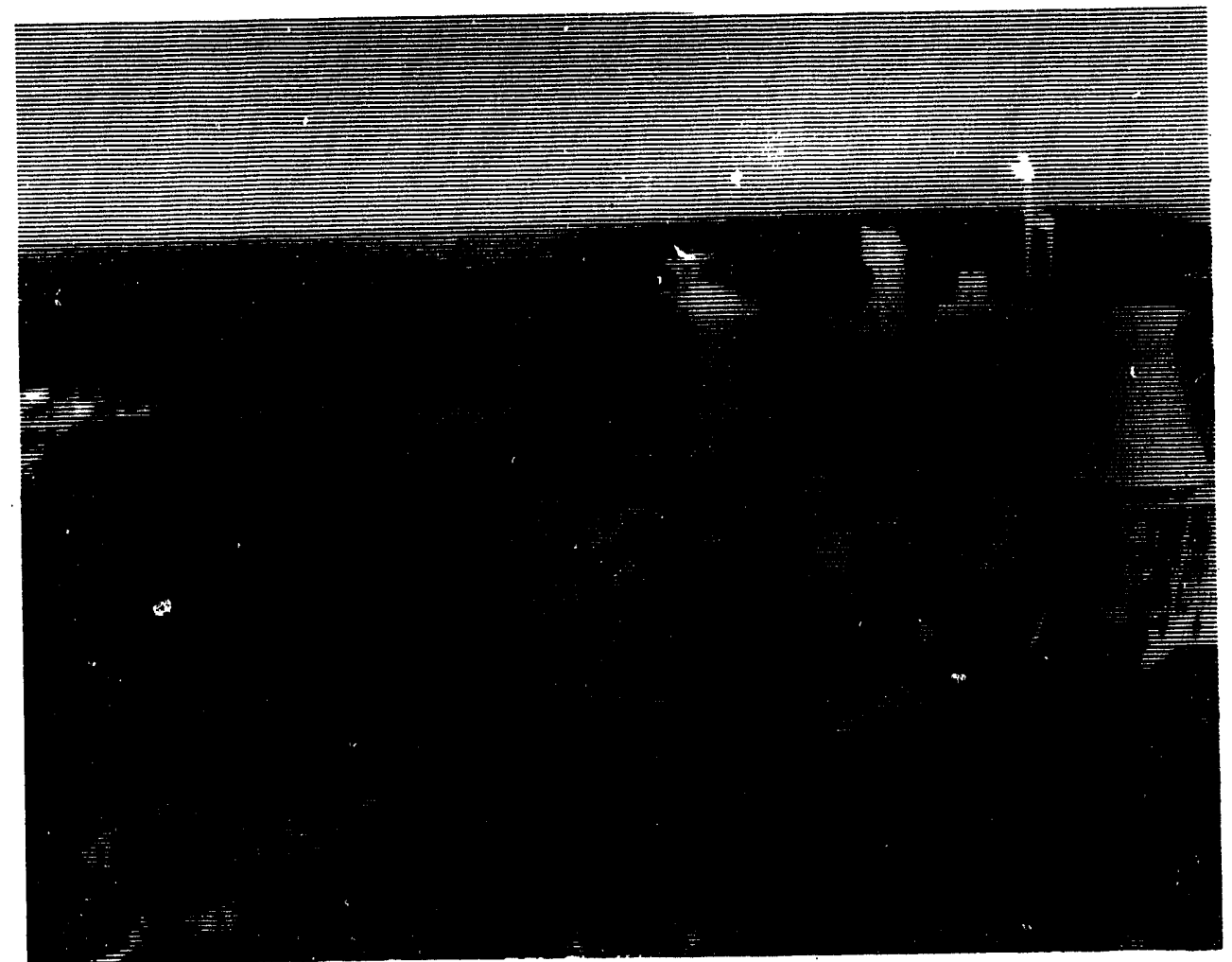




\section{Financial Performance}

\section{Overview}

Highlights. The major investor-owned electric utilities improved their financial performance in 1992 despite a slowly improving economy and milder than normal weather conditions.

- Net income was up significantly in 1992, increasing 8.5 percent to $\$ 18.4$ billion. However, the gain was due largly to a net increase of $\$ 1.6$ billion unrelated to utility operations. Earnings quality also continued to improve, with allowance for funds used during construction (AFUDC) as a percent of net income declining to 6.4 percent from 7.9 percent in 1991.

- Electric utility operating revenues were up a modest 1.6 percent, increasing $\$ 2.7$ billion to $\$ 169.5$ billion. However, electric operating expenses rose $\$ 3.1$ billion, more than offetting the increase in operating revenues. Revenues from sales for resale continued to grow faster than sales to ultimate consumers, increasing 2.9 percent versus 1.0 percent. Sales for resale represented over $\mathbf{1 0 . 5}$ percent of the revenues from the sale of electricity despite being sold at an average of less than half (in terms of mills per kilowatthour) of the average revenue collected from sales to ultimate consumers.

- The reduction in miscellaneous nonoperating income deductions represented a critical element in the improvement of the electric utilities reported earnings. Miscellaneous nonoperating income deductions declined to $\$ 1.5$ billion in 1992 from over $\$ 4.1$ billion in 1991. Nuclear plant writeoffs plagued the 1991 figure.

- Improved earnings supported the increased payout of common and preferred stock dividends, up 3.3 and 4.8 percent, respectively, over the prior year's values. The payout ratio improved to 91.1 percent versus 96.2 percent in 1991.

- Net cash from operating activities declined marginally by $\$ 0.2$ billion to $\$ 39.7$ billion. As noted above, net income improved significantly over the prior year. However, the largest change in contribution to cash operating activities came from the "other" category. This figure went from contributing $\$ 3.6$ billion in 1991 to requiring a cash outflow of $\$ 1.5$ billion in $19 \$ 2$. Over the last year, cash flows from operating activities have shown the impact of companies beginning to apply SFAS No. 109 (Accounting for Income Taxes).

- The year 1992 was a banner year for debt refinancing and other financial restructuring on the part of the electric utilities. Cash inflows from financing activities in 1992 were $\$ 53.9$ billion, up $\$ 29.2$ billion over 1991. Debt refinancings dominated the cash flows from financing. New issues of debt were $\$ 39.8$ billion, while debt retirements were $\$ 38.2$ billion. While still quite modest in dollar terms, the electric utilities returned to issuing preferred stock in 1992, posting a modest $\$ 0.2$ billion excess in new issues over retirements.

- Investments in associated companies and subsidiaries required $\$ 0.7$ billion more cash, ending with an outflow of $\$ 1.7$ billion. The major change in this category was due to a $\$ 1.2$ billion cash outflow by Western Resources, Incorporated, the holding company containing Kansas Gas and Electric Company and the newly acquired Kansas Power and Light Company.

- Iowa Power, Incorporated, and Iowa Public Service Company merged into Midwest Power Systems, Incorporated. Kansas Power and Light Company was acquired by Western Resources, Incorporated. Michigan Power Company merged with Indiana Michigan Power Company.

- No new nuclear units were introduced into service during 1992 for the second consecutive year. The only remaining investor-owned nuclear unit under construction (reported in electric construction work in progress) was Comanche Peak Unit 2 owned by the Texas Utilities Electric Company, which was subsequently placed in commercial service during April 1993.

- While nuclear plant investments and operating expenses continue to have major influences on the electric utility industry, the risk has now shifted to the economic operation of these units versus the capital cost containment of prior years. A clear example of this was the decision by Portland General Electric Company to shut down the Trojan nuclear plant. In the coming years, similar decisions regarding the risk/return of continued operation of these nuclear facilities will be facing many other owners of nuclear plants. The passage of the Energy Policy Act of 1992 with its increased emphasis on competition in this industry will only serve to increase the pressure on these companies to contain the costs of operating these facilities or watch their cost competitiveness deteriorate. 
Economic Context. The year 1992 can be characterized as one of very slow recovery from the recession of 1990-91. While the recession was relatively short and shallow compared to previous post-war recessions, nonfarm payroll employment remained stagnant for over a year following the trough, and the unemployment rate peaked more than a year after the decline in real gross domestic product (GDP) had ended. Real GDP grew at only 2.1 percent for the year, but the economy did pick up during the second half of 1992, with real GDP growing 3.2 percent and unemployment falling. The upward trend, although slow, tended to boost electricity sales in 1992.

Weather. Countering the economy's positive influence on electric utility sales, weather worked against the industry in 1992. The year began with heating degree days being lower than normal and lower than first quarter 1991. The summer cooling season, as measured by annual cooling degree days, was 25.8 percent lower in 1992 than in 1991; however, during the fourth quarter, the weather turned around for the industry. By year's end, heating degree days were up slightly over the prior year (3.7 percent) due to a colder fourth quarter than occurred in 1991. In spite of the very mild summer, electric utility sales to ultimate consumers overall were up slightly at 0.1 percent over last year's sales. Industrial sales grew at 2.5 percent over 1991 in response to the economic recovery, while residential sales declined 2.4 percent in response to the mild weather. Thus, the economic recovery's boost to industrial sales more than compen- sated for the weather, keeping the electric utility industry in a growth mode.

Both the weather and the economic impacts on electric utilities were uneven regionally. Weather by its nature does not impact electric utilities uniformly. State unemployment rates indicated that the 1990-91 recession and slow recovery affected States differently. Illinois and Michigan experienced high unemployment due to restructuring in the automobile industry. California and the New England States were hurt due to defense industry cutbacks. California, the Northeast, and Florida also experienced problems due to overbuilding in commercial real estate and restructuring of the finance and insurance industries. As a result, individual electric utility and regional electric utility sales results varied considerably from the electric industry aggregate.

Debt Refinancing. Interest rates declined even further in 1992 from the low rates experienced in 1991, and investor-owned electric utilities continued to refinance large quantities of long-term debt at the lower interest rates. Corporate Aaa (Moody's) bonds at 8.14 percent were at their lowest levels since 1977, and short-term interest rates for 3- and 6-month treasury bonds dropped to their lowest levels in nearly 30 years $(3.45$ percent for 3-month and 3.57 percent for 6-month treasury bonds). In response to these low rates, over $\$ 12.1$ billion in electric utility long-term debt was refinanced in 1992, compared with $\$ 4.0$ billion in 1991, according to Ebasco Services. Incorporated. 


\section{Income Statement}

The Composite Statement of Income and Retained Earnings for major investor-owned electric utilities for the years 1988 through 1992 is presented in this publication (Table 6). Selected details for the gas and other utility operations of these companies are also included.

The Bottom Line. Unusually mild weather did not hold back electric utility earnings in 1992, which rose 8.3 percent before extraordinary items. Similarly, net income increased 8.5 percent to $\$ 18.4$ billion in 1992 . Earnings quality continued to improve with allowance for funds used during construction (AFUDC) declining to 6.4 percent of 1992 net income (versus 7.9 percent in 1991). Dividends declared continued to increase, rising 3.3 percent to $\$ 14.9$ billion in 1992 . Preferred dividends reversed a downward trend and increased 4.8 percent to $\$ 2.0$ billion over the prior year. While the deferring impact of phase-in plants declined, total miscellaneous nonoperating income increased a significant 14.0 percent, virtually wiping out the 14.4-percent decline that occurred between 1990 and 1991.

Revenues. Total electric operating revenues increased a modest 1.6 percent, an increase of $\$ 2.7$ billion, to $\$ 169.5$ billion. Revenues $\mathrm{t}$, m sales to ultimate consumers increased even less, 1.0 percent, while revenues from sales for resale increased 2.9 percent. Wholesale customer revenues of $\$ 17.5$ billion provided 10.5 percent of total electric revenues, virtually identical to 1991. Other operating revenues and provisions for rate refunds both increased significantly, but remained a relatively small portion of total operating revenues, 2.4 percent and 0.2 percent, respectively.

Average revenues from sales to ultimate consumers increased to 70.6 mills per kilowatthour, a mere 0.9-percent higher than the previous years value of 69.9 mills per kilowatthour. Total sales to ultimate consumers increased a minimal 0.1 percent. This figure masked the decline in residential sales of 2.4 percent and the increase in industrial sales of 2.5 percent. The small increase in overall sales contributed only 13.9 percent of the $\$ 1.5$ billion increase in revenues from sales to ultimate consumers. (The increase in average revenues contributed the largest share of the increase, i.e., $\$ 1.3$ billion, or 86.1 percent.)

Average revenues from wholesale sales declined to 34.6 mills per kilowatthour, down from 35.0 mills per kilowatthour in 1991. This decline was more than offset by the 2.5-percent increase in sales volume mentioned above. Wholesale kilowatthour volume increased from 18.8 percent of total sales in 1991 to 19.3 percent in 1992. As such, wholesale sales continued to increase in importance in the overall revenue mix of the electric power industry.

Operating Expenses. Total electric operating expenses increased 2.3 percent to $\$ 139.0$ billion in 1992 . These expenses represented 82.0 percent of electric utility operating revenue, up from 81.5 percent in 1991. The most significant increases in electric utility operating expenses were in the following categories:

- Operating expenses: up 1.6 percent, an increase of $\$ 1.3$ billion.

- Net effect of deferred taxes: up \$0.7 billion over the prior year's values (provision for deferred income taxes less credit for deferred income taxes). The impact of this increase in net deferred taxes was offset by the decline in current income taxes of $\$ 0.4$ billion.

- Depreciation expense: up 3.2 percent, an increase of \$0.5 billion.

Electric Operation and Maintenance Expenses. These expenses increased $\$ 1.5$ billion, from $\$ 98.0$ billion in 1991 to $\$ 99.5$ billion in 1992 . However, with total sales increasing 0.9 percent, the cost per kilowatthour sold increased to 38.1 mills per kilowatth our in 1992. In 1991, the corresponding figure was 9 mills per kilowatthour. Operation expenses had the greatest increase from 33.2 to 33.5 mills per kilowatthour. Maintenance remained unchanged at 4.7 mills per kilowatthour in 1992.

Operating Expenses. Total electric operation expenses rose 1.6 percent to $\$ 87.3$ billion in 1992 . Fossil-fueled steam-electric nonfuel operation expenses increased 3.8 percent, while nuclear nonfuel operation expenses increased 0.4 percent. Fuel expenses on a mills per kilowatthour generated basis were down 2.3 percent and 8.8 percent, respectively, for fossil-fueled steamelectric and nuclear steam-electric generation. Conventional hydroelectric generation, which was 2.9 percent of total generation, experienced a 6.6-percent increase in operation expenses and an 11.6-percent increase in terms of mills per kilowatthour generated.

Maintenance Expenses. In 1992, nuclear and hydroelectric maintenance expenses increased 9.1 and 9.0 percent, respectively. In contrast, fossil-fueled steamelectric maintenance expenses decreased 1.1 percent. On a mills per kilowatthour generated basis, maintenance expenses increased 7.8 and 14.2 percent for nuclear and hydroelectric, respectively, and decreased 1.0 percent for fossil-fueled steam-electric.

Electric Operating Income. The $\$ 2.7$ billion increase in electric utility operating revenue was more than offset by a $\$ 3.1$ billion increase in electric utility operating expenses. The result was a $\$ 0.4$ billion decline in net electric operating income to $\$ 30.5$ billion (1.2 percent).

Interest Expenses Inter $/$ st expenses associated with long-term det, (including amortization of debt discount, losse: $i$ on reacquired debt, and related expenses) derreased from $\$ 15.1$ billion in 1991 to $\$ 14.7$ billion in 1992 . The average embedded interest rate declined from 8.9 percent in 1991 to 8.5 percent in 1992. These estimates are based on the average of the current and prior years' ending balances of longterm debt. Average outstanding long-term debt increased from $\$ 169.9$ billion in 1991 to $\$ 173.0$ billion in 1992, an increase of 1.8 percent. Average total debt 
(including notes payable) increased from $\$ 177.3$ billion to $\$ 180.9$ billion or $\$ 3.6$ billion. The average embedded interest rate based on average outstanding total debt declined from 8.9 percent to 8.6 percent. The lower interest rates contributed to a $\$ 0.6$ billion reduction in interest expense which was only partially offset by the $\$ 0.3$ billion increase in interest expense due to the higher levels of outstanding debt.

Other Income and Deductions. Miscellaneous nonoperating income of $\$ 1.2$ billion was overshadowed by $\$ 1.5$ billion in miscellaneous nonoperating deductions. The difference of $\$ 0.2$ billion is significantly lower than the 1991 corresponding figure of $\$ 3.0$ billion. This reduction of $\$ 2.8$ billion in net deductions was the largest contributor to the increase in total electric utility earnings in 1992.

The electric u'ilities with the largest nonoperating deductions in 1991 were Texas Utilities Electric Company with a $\$ 1.4$ billion charge due to writeoffs surrounding its investments in the Comanche Peak Unit 2 nuclear power station. Commonwealth Edison Company, Arizona Public Service Company, and Consumers Power Company each had significant nuclear plant writeoffs in 1991 as well.
Earnings. Net income was up significantly in 1992, amounting to $\$ 18.4$ billion. Net income increased 8.5 percent over the prior year's value. Interest coverage ratios (before tax) showed a significant improvement rising to 2.70 times with allowance for funds used during construction and 2.62 times excluding allowance for funds used during construction. The return on average common stock equity increased to 12.0 percent from 11.3 percent in 1991. The profit margin (net income as a percent of operating revenues) improved to 9.9 percent versus 9.3 percent in 1991 .

Dividends. Earnings available for common stock (after the payout to preierred and preference dividends), amounted to $\$ 16.5$ billion in 1992 . Preferred stock dividends declared increased 4.8 percent over the prior year while common stock dividends declared increased 3.3 percent. The average dividend rate on common stock and preferred stock were 9.7 percent and 8.1 percent, respectively.

The payout ratio based on declared common stock dividends was an improved 91.1 percent in 1992 versus 96.2 percent in 1991 .

Table 3. Electric Operating Revenue and Net Electric Operating Income for Major U.S. Investor-Owned Electric Utilitles, 1988-1992

\begin{tabular}{|c|c|c|c|c|}
\hline Year & $\begin{array}{l}\text { Electric Operating } \\
\text { Revenues } \\
\text { (thousend dollars) }\end{array}$ & Percent Change & $\begin{array}{c}\text { Net Electric } \\
\text { Operating Income } \\
\text { (thousand dollars) }\end{array}$ & Percent Change \\
\hline 1988 & $143,930,420$ & ' 3.8 & $28,582,794$ & 25.8 \\
\hline 1989 & $150,803,317$ & 4.8 & $29,351,25 / 3$ & 2.7 \\
\hline 1990 & $157,278,537$ & 4.2 & $29,377,903$ & .1 \\
\hline $1991^{2}$ & $166,803,843$ & 6.1 & $30,855,852$ & 5.0 \\
\hline 1992 & $169,488,035$ & 1.6 & $30,478,942$ & -1.2 \\
\hline
\end{tabular}

1 Electric Operating Revenues were 138,548,938 thousand dollars in 1987.

- Net Electric Operating Iricome was 26,991,564 thousand dollars in 1987.

- Excluded are five independent power producers jurtedictional to the Federal Energy Regulatory Commission which were included in the prior year's publication.

Note: Due to its emergence from bankruptcy, the 1991 financial statements for the Public Service Company of New Hampshire are from May 16 through December 31. Excluded are the independent power producers and cooperatives juriedictional to the Federal Energy Regulatory Commission. Summary data are provided in Table 6.

Source: Federal Energy Regulatory Commiseion, FERC Form 1, "Annual Peport of Major Electric Utilities, Licensees and Others." 


\section{Balance Sheet}

The Composite Balance Sheet for investor-owned electric utilities continued to reflect the slowing of investment in new production plant due to slow demand growth, reliance on nonutility generation, and demand-side management (Table 8).

Assets and Other Debits. Assets and other debits totaled \$506.4 billion in 1992, which was 3.9-percent higher than in 1991. This increase was considerably higher than the 2.0-percent increase experienced between 1990 and 1991. Almost half of the $\$ 18.8$ billion increase came from net electric utility plant, while deferred debits contributed $\$ 8.0$ billion of the gain. Investments in other property increased $\$ 0.7$ billion over 1991, which was a turnaround from the S0.3 billion reduction experienced from 1990 to 1991. Total current and accrued assets changed very little, increasing 0.2 percent or $\$ 0.1$ billion.

Gross electric utility plant assets increased, growing 3.8 percent or $\$ 18.3$ billion over 1991 . The increase in production plant was 1.8 percent, in transmission plant assets 4.1 percent, in distribution plant assets 6.0 percent, and in other general plant assets 13.9 percent. The production plant increase from 1991 to 1992 was due mainly to additions of $\$ 3.5$ billion in steam production plant and \$2.2 billion in nuclear plant. All steam plants added were gas-fueled. The most striking feature of the plant additions was that additions to production plant were less than distribution plant in 1992. While production plant accounted for 33.7 percent of total electric plant additions, transmission and distribution comprised 55.1 percent of the additions.

Construction work in progress (CWIP) experienced an increase of $\$ 2.6$ billion in 1992 due to an increase in construction expenditures. This reversed the downward trend that resulted from a number of remaining nuclear plants being completed and, therefore, reclassified from CWIP into plant in service. The second unit at Comanche Peak was still reflected in CWIP in 1992. The CWIP as a percent of net electric utility plant excluding CWIP climbed slightly from 5.3 percent in 1991 to 6.0 percent in 1992 . This was still significantly below 13.2 percent in 1988, which reflected a number of large units still under construction that were subsequently reclassified into plant in service.

Other property and investments increased \$0.7 billion to end the year at $\$ 18.0$ billion. The increase was due mainly to an additional $\$ 1.1$ billion in special funds, which was countered by decreases in the two categories, investments in subsidiary companies and other investments.

Current and accrued assets changed very little from the 1991 ending balance, although individual items within the category changed. The largest dollar increase was from miscellaneous current and accrued assets, which rose \$0.9 billion. The largest decline was in receivables from associated companies, which decreased $\$ 0.7$ billion. The ratio of current assets to current liabilities dropped slightly from 1.00 in 1991 to 0.95 in 1992. This continued a do'wnward trend that began in 1985 when the ratio was 1.23. An increase from 0.94 in 1990 to 1.00 in 1991 w'as the only interruption of this decline.

Deferred debits showed a 15.9-percent increase over 1991 , ending the year at $\$ 58.0$ billion. Most of the $\$ 8.0$ billion increase was due to a $\$ 5.4$ billion increase in the other-deferred-debits category. No single electric utility dominated the other deferred debit increase, and the reasons for the increase were varied. The two electric utilities contributing the largest increase were Consumers Power Company and Virginia Electric and Power Company, both of which increased \$0.7 billion over 1991. Consumers Power Company's otherdeferred-debit increase was mainly due to two events: application of SFAS 106 (Other Postretirement Employment Benefits) and a FERC settlement of a liquid natural gas (LNG) rate dispute. The SFAS 106 application resulted in Consumers Power Company adding a $\$ 0.4$ billion regulatory asset to the balance sheet along with a compensating liability. In the LNG rate dispute, Consumers Power Company will pay over time an additional \$0.1 billion to the LNG supplier, which was recorded as a liability and a corresponding regulatory asset under miscellaneous debits. Virginia Electric and Power Company's increase in other deferred debits was mainly due to implementation of SFAS 109 (Accounting for Income Taxes) whereby $\$ 0.4$ billion was established as a net regulatory asset with a corresponding increase in deferred income tax liability. Also contributing to the increase was a $\$ 0.1$ billion increase in deferred fuel capacity costs and a \$0.1 billion increase for Virginia Electric and Power Company's share of future fuel enrichment cleanup costs, mandated under the 1992 Energy Policy Act.

Several other classifications under deferred debits were also interesting. The record level of refinancings caused the unamortized loss on reacquired debt to grow $\$ 1.0$ billion from 1991 to 1992 . The increase in unrecovered plant and regulatory study costs was dominated by Portland General Electric Company's abandonment of the Trojan nuclear plant. Portland General Electric Company's unrecovered plant costs increased by $\$ 0.7$ billion over 1991.

Liabilities and Other Credits. In 1992, investor-owned electric utilities maintained their overall 1991 leverage. Long-term debt declined slightly to 48.9 percent of capitalization in 1992 from 49.3 percent in 1991. Preferred stock held constant at 7.2 percent, and the remaining proprietary capital increased slightly to 43.9 percent.

As interest tates reached their lowest levels in decades, investor-owned electric utilities found it attractive to issue common and preferred stocks, which were selling at good prices and relatively low yields (dividend to price ratios). In spite of the low yields, investors had few good options and found electric utilities to be attractive. As a result, common stock issued increased $\mathbf{\$ 2 . 2}$ billion or 3.7 percent over 
1991. This was significantly higher than than the 1.4-percent increase in 1991 over 1990. Preferred stock issued increased 1.1 percent, reversing a long downward trend. Short-term debt or notes payable also increased both in magnitude and in share of total debt (long-term plus short-term), increasing to 4.8 percent from 3.9 percent in 1991. Short-term debt ended the year 25.8-percent higher than year-end 1991.

Total noncurrent liabilities increased 24.5 percent to end the year at $\$ 8.6$ billion, primarily due to an increase in obligations under capital leases of $\$ 1.2$ billion. The two electric utilities most responsible for this increase were Public Service Company of New Hampshire and Tucson Electric Power Company, showing $\$ 0.8$ billion and $\$ 0.7$ billion increases, respectively.

Public Service Company of New Hampshire filed for reorganization under Chapter 11 of the Bankruptcy Code in 1988. As part of the final reorganization plan accepted by the Bankruptcy Court, it was acquired by Northeast Utilities and established as a new Northeast Utilities subsidiary. Upon completion of the acquisition in June 1992, Public Service Company of New Hampshire's 35.6-percent share of Seabrook 1 and other related assets were transferred to another Northeast Utilities subsidiary, North Atlantic Energy Corporation. Public Service Company of New Hampshire entered into a power contract to buy power from the North Altantic Energy Corporation. Public Service Company of New Hampshire classified this trans- action by keeping the plant (with a new contractestablished value) on the asset side of the balance sheet, by showing the contract obligation to purchase as a capital lease.

Tucson Electric Power Company, facing severe financial problems, was allowed to follow a restructuring plan to avoid bankruptcy that included reclassifying the company's leases on Springerville Unit 1 and common facilities and on Irvington Unit 4 as capital leases. This resulted in an increase in plant of $\$ 0.7$ billion and a corresponding increase in capital lease obligations of $\$ 0.7$ billion.

Deferred credits showed a strong 8.7-percent increase of $\$ 7.7$ billion to end the year at $\$ 96.1$ billion. The largest part was due to the increase in accumulated deferred income taxes of $\$ 5.8$ billion. Deferred income taxes increase when accelerated depreciation being used for tax purposes is greater than book depreciation (which is calculated on a straight-line basis). This is the case early in the life of a plant. Later in a plant's life, the situation reverses and deferred income taxes decline. The increases in accumulated deferred income tax on the electric utility balance sheet were mainly due to the large new plants that have come on-line over the past several years, hence their large positive differences between accelerated and book depreciation. In addition, deferred income taxes increased as companies began adopting SFAS 109. Virginia Electric and Power Company showed the largest increase (\$0.6 billion) in deferred debits of the investor-owned electric utilities. 


\section{Cash Flow}

The major cash requirements for the investor-owned ele tric utilities as presented on the Composite Statement of Cash Flows were for plant additions. However, cash was also needed for increases in working capital and returns to shareholders (dividends). The cash was provided internally from operations or externally from increases to debt or equity. As electric industry capital expenditure programs for new generating capacity declined, cash from operations was able to cover most of the cash needs for electric utilities.

Cash and cash equivalents for the investor-owned electric utilities were at $\$ 3.0$ billion at the end of 1992, compared with $\$ 3.9$ billion at the end of 1991. Net cash outflows from investing were $\$ 30.0$ billion, which was $\$ 5.2$ billion higher than cash outflows for investing in 1991. However, net cash from operating activities stayed almost the same level as last year, declining slightly ( $\$ 0.2$ billion) to end the year at $\$ 39.7$ billion. This resulted in the need for more external financing than in 1991. Net cash from financing prior to dividend outflows was \$6.4 billion versus $\$ 1.8$ billion in 1991. After dividends, net cash flows outflow from financing was $\$ 10.5$ billion versus an outflow of $\$ 14.0$ billion in 1991 .

Cash Flows from Operating Activities. While net cash from operating activities did not change appreciably from last year, net income increased by 8.5 percent from 1991 to add \$1.4 billion more to cash from operations than in 1991. Net income, depreciation and amortization contributed $\$ 38.8$ billion to the $\$ 39.7$ billion net cash from operating activities. The largest change from 1991 in contributions to operating cash flow, however, was due to a decline in the "other" category from a positive contribution of $\$ 3.6$ billion in 1991 to a cash outflow in 1992 of $\$ 1.5$ billion. This resulted in a decline of $\$ 5.1$ billion to net cash from operating activities from its 1991 contribution. A major reason for the high 1991 value was due to a one-time charge of $\$ 1.4$ billion by Texas Utilities Company due to disallowances associated with the Comanche Peak Unit 1 nuclear plant. The $\$ 1.4$ billion cash-flow adjustment to net income was put in the "other" category. The second-largest change in the operating cash flows from 1991 was a cash inflow increase in deferred taxes of $\$ 1.6$ billion in 1991. Deferred taxes contributed a total of $\$ 3.2$ billion to net cash from operations, which amounted to 8.0 percent of the net cash from operating activities in 1992, versus 4.0 percent in 1991. Some of this increase was due to electric utilities beginning to apply SFAS 109 (Accounting for Income Taxes).

Cash Flows From Investing. Cash flows from investing showed the major cash outflows for plant investments and cash changes due to working capital needs. Cash outflows for plant in 1992 increased $\$ 1.3$ billion or 5.1 percent over 1991, reaching $\$ 27.3$ billion. Cash outflows for plant in 1991 grew 4.6 percent over 1990. Cash outflows from plant investments also took a larger percentage of operating cash this year than last year (68.7 percent versus 65.1 percent). While cash outflows for plant increased $\$ 1.3$ billion, net cash outflows from investments increased $\$ 5.2$ billion. This additional increase of $\$ 3.9$ billion for nonplant cash needs was due mainly to changes in contributions from the "other" category and from increased outflows in the investments in and advances to associated companies and subsidiaries. The "other" category went from providing a cash inflow of $\$ 1.5$ billion in 1991 to requiring a cash outflow of $\$ 1.4$ billion in 1992. This was due mainly to one-time cash increases experienced by several electric utilities in 1991. For example, Consumers Power Company showed a cash increase of $\$ 1.0$ billion in 1991 due to a return of proceeds from a sale/leaseback arrangement on the Midland plant made by the MCV Partnership. (The MCV Partne ship was formed by subsidiaries of Consumers Power Company and Dow Chemical Company to convert the Midland nuclear plant to a gas-fueled combined cycle facility.) Additionally, several other electric utilities had large disallowances (Arizona Public Service Company took \$0.6 billion on the Palo Verde nuclear plant, and Commonwealth Edison Company took \$0.6 billion on the Byron and Braidwood nuclear plants) that required positive cash adjustments to the net income. These one-time positive adjustments were in the "other" category, resulting in a significant decline from 1991 to 1992. Investments in associated companies and subsidiaries required \$0.7 billion more cash in 1992 than in 1991, ending the year with a cash outflow of $\$ 1.7$ billion. The acquisition of Kansas Gas and Electric Company by Western Resources, Incorporated, in March 1992 resulted in a $\$ 1.1$ billion cash outflow of the the $\$ 1.2$ billion the company claimed under investments in associated companies and subsidiaries, causing the 1992 value to decline substantially from 1991.

Cash Flows From Financing. This portion of the cash flow statement highlights the banner year for debt refinancing due to the low interest rates. Cash inflow from outside sources (external financing) in 1992 was $\$ 53.8$ billion, a substantial $\$ 29.2$ billion increase over 1991. This was due mainly to a $\$ 22.4$ billion increase in issuance of long-term debt. However, retirements of long-term debt also showed a record increase of \$22.0 billion. Most of the long-term debt issues were for refinancing, as issues of long-term debt exceeded retirements by only $\$ 1.6$ billion, $\$ 0.3$ billion more than issues exceeded retirements in 1991. Issues of common stock, however, exceeded retirements by $\$ 4.2$ billion. In 1991, issues of common stock exceeded retirements by only $\$ 1.8$ billion. As described in the balance sheet section, the healthy stock market of electric utilities in 1992 encouraged new issues. Issues of preferred stock exceeded retirements slightly at $\$ 0.2$ billion. The lowyield market (low dividend to price ratio) of 1992 encouraged electric utilities to buy back preferred stock and reissue new preferred stock at the lower yields. Short-term debt grew this year with increases exceeding declines by $\$ 1.1$ billion. In 1991, short-term debt shrank, with increases falling short of declines by $\$ 2.0$ billion. Consistent with a net increase in common stock, the cash needed for dividends on common stock increased by $\$ 1.0$ billion or 7.6 percent over cash required in 1991. 


\section{Electric Utility Consumers and Sales}

Sales to ultimate consumers for the investor-owned electric utilities stayed almost flat, increasing only 0.1 percent in 1992 over 1991. This was a considerable decline from the 1.8-percent growth experienced between 1990 and 1991 and the 2.0-percent growth experienced from 1989 to 1990 . The slowing in 1992 was due to the unusually mild weather, which resulted in residential sales declining 2.4 percent from 1991 to 1992 . The decline in residential sales was countered by the growth in the industrial sector as the economy began its slow recovery. Industrial sales grew 2.5 percent from 1991 to 1992 following the 0.2-percent decline experienced from 1990 to 1991 . Commercial sales stayed relatively unchanged, growing only 0.3 percent between 1991 and 1992.

The mix of sales to ultimate consumers changed slightly, consistent with growth patterns. Residential sales lost share, moving from 32.8 percent of ultimate consumers sales in 1991 to 32.0 percent in 1992 . Industrial sales increased from a 34.8-percent share of sales in 1991 to 35.6 percent in 1992. Commercial sales share of ultimate consumer sales remained unchanged at 29.6 percent.

Average revenues (mills per kilowatthour) from ultimate consumers increased 0.6 mills from 69.9 mills in 1991 to 70.6 mills in 1992 . This was much smaller than the 2.2-mill increase experienced from 1990 to 1991. Residentiai consumers saw a 1.8-mill increase, bringing residential average revenue to 86.4 mills in 1992. Commercial consumers averaged 78.4 mills, which was a 1.0-mill increase over their 1991 average revenues, and industrial consumers saw no increase. The industrial consumers continued to average 49.7 mills in 1992. All other ultimate consumers averaged 72.1 mills in 1992, which was 1.1 mills higher than the 1991 average revenue.

From 1991 to 1992, total revenues from ultimate consumers increased only 1.0 percent, compared with the 5.2-percent increase experienced between 1990 and 1991. While total ultimate consumer revenues increased $\$ 1.5$ billion, revenue contribution in 1992 from residential consumers declined by $\$ 0.2$ billion ( -0.4 percent) from 1991 . Industrial revenues increased by $\$ 0.9$ billion ( 2.5 percent) over 1991 and commercial revenues increased $\$ 0.8$ billion ( 1.7 percent) over 1991.
The decline in residential revenues was due solely to the residential sales decline, since average revenues (mills per kilowatthour) increased. The increase in industrial revenues was due to the sales increase, since the average industrial mills per kilowatthour stayed at the same level. The commercial sector's revenue increase, however, benefitted from both the sales increase and the average revenue increase. In the commercial sector, average mills per kilowatthour accounted for over 80 percent of the revenue increase, while sales growth caused the remaining increase in revenue.

On the average, residential consumers of investorowned electric utilities paid $\$ 772$ during 1992. This was $\$ 10$ less than in 1991 due to the mild weather. Industrial consumers on an average paid $\$ 93,215$, which was only 0.2 percent higher than in 1991. Commercial consumers also paid more annually, increasing from $\$ 5,111$ in 1991 to $\$ 5,169$ in 1992.

\section{Emerging Factors}

A number of factors have emerged during the 1990's in the business environment of the electric utility industry. Perhaps the most widely discussed was the passage of the Clean Air Act Amendments (CAAA) in 1990. While not having an immediate impact on the financial operations of the electric utilities, the passage of this act will result in the potential for significant incremental investments in pollution control equipment (e.g., SOx scrubbers), the potential shifting from high sulfur coal to lower sulfur coal where feasible to achieve the emissions standards, the potential shift to a greater utilization of natural gas as a generating fuel and the emergence of a market for the trading of emission allowances. Implementation is to be done in two phases. Phase $I$ is directed at certain large electric utility units (greater than 100 megawatts) in order to reduce their sulphur dioxide emissions below $2.5 \mathrm{lbs}$ per million Btu during the years 1995 to 2000. Phase II, which begins January 1, 2000, expands the program to include most electric utility units that emit sulphur dioxide. Phase II sulphur dioxide emission limits vary depending on different characteristics of the units, but most limitations are established around a goal of being at or below $1.2 \mathrm{lbs}$ per million Btu. As the industry attempts to respond to the provisions of the CAAA, the impact on the financial performance and relative competitiveness of electric power will become more evident. 
The Federal Energy Regulatory Commission (FERC) has begun a number of initiatives that could eventually result in a more competitive electric power industry, as demonstrated by its adoption of rates on some power sales that were arrived at through competitive bidding versus the traditional cost-of-service approach. Many States have also adopted competitive procurement as a mechanism to encourage alternative power sources rather than continue with cost-ofservice regulation. Some States are going even further and requiring demand-side management (DSM) and conservation measures to be included along with the alternative power supply options being considered by electric utilities. Congress passed the Public Utility Regulatory Policies Act of 1978 that would require States to consider least-cost planning to promote DSM and energy conservation strategies. As this trend towards more innovative supply/demand planning and pricing of electric power unfolds, it could have a significant impact on the financial operations of electric utilities, particularly those with relatively high cost per kilowatt of installed capacity.

The most significant legislation passed in 1992 that will have an immediate impact on the electric power industry was the Energy Policy Act of 1992. This act contains many provisions that significantly will impact this industry and eventually will be reflected in the financial data included in this publication. Among the many issues addressed are the following:

- Transmission access/regional transmission groups

- Global warming (greenhouse gases)

- Foreign utility ownership

- Enrichment facility cleanup/utility assessments

- Nuclear energy initiatives

- Public Utility Holding Company Act reform/Exempt Wholesale Generator investments (filing requirements)

\section{New Plants}

For 1992, only hydroelectric and gas turbine electric plants were placed in commercial service (Table 4).

Table 4. Original Plant Cost for Plants that Began Commerclal Operation During 1992, by Major U.S. Investor-Owned Electric Utilities

\begin{tabular}{|c|c|c|c|c|c|}
\hline $\begin{array}{l}\text { Plant Type } \\
\text { Plant Name }\end{array}$ & State & Eloctric Utulty Company & $\begin{array}{l}\text { Original Plant Coat } \\
\text { (thousand dollars) }\end{array}$ & $\begin{array}{l}\text { Conerator Nameplate } \\
\text { (megawatts) }\end{array}$ & $\begin{array}{l}\text { Cost per Kllowett } \\
\text { (dollare) }\end{array}$ \\
\hline \multicolumn{6}{|l|}{$\begin{array}{l}\text { Fosell-Fueled Stean-Electric } \\
\text { None }\end{array}$} \\
\hline $\begin{array}{l}\text { Nuclear Steam-Electric } \\
\text { None }\end{array}$ & & & & & \\
\hline 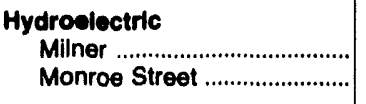 & $\begin{array}{l}\text { ID } \\
\text { WA }\end{array}$ & $\begin{array}{l}\text { Idaho Power Co } \\
\text { Washington Water Power Co }\end{array}$ & $\begin{array}{l}49,065 \\
17,326\end{array}$ & $\begin{array}{l}59.5 \\
14.8\end{array}$ & $\begin{array}{r}825 \\
1,171\end{array}$ \\
\hline 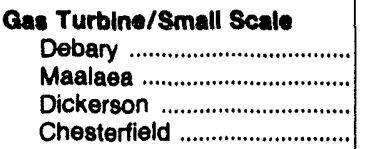 & $\begin{array}{l}F L \\
H I \\
M D \\
V A\end{array}$ & $\begin{array}{l}\text { Florida Power Corp } \\
\text { Maul Electric Co Ltd } \\
\text { Potomac Electric Power Co } \\
\text { Virginia Electric \& Power Co }\end{array}$ & $\begin{array}{r}94,270 \\
31,233 \\
139,587 \\
81,205\end{array}$ & $\begin{array}{r}460.0 \\
20.0 \\
163.0 \\
219.0\end{array}$ & $\begin{array}{r}205 \\
1,562 \\
856 \\
371\end{array}$ \\
\hline
\end{tabular}

Source: Federal Energy Regulatory Commission, FERC Form 1, "Annual Report of Major Electric Utillties, Licensees and Others." 


\section{Environmental Protection}

On December 2, 1975, the FERC issued Order No. 542 which established the reporting of capital costs and annual expenses for operating environmental protection facilities and activities.

Investments in environmental protection facilities applicable to electric utility plant increased by $\$ 0.1$ billion to $\$ 58.1$ billion in 1992. By the end of 1992 , this represented 11.2 percent of the investment in electric utility plant. In addition, $\$ 3.5$ billion of environ- mental protection facilities construction work in progress was included in electric utility plant and represented 16.9 percent of the electric utility plant construction work in progress (Table 5). Detailed information on environmental protection facilities indicates that air pollution control investments accounted for \$24.1 billion of the \$58.1 billion invested in environmental protection (Table 45).

In 1992, the major investor-owned electric utilities recorded operating expenses of $\$ 3.0$ billion related to environmental protection facilities. This represented 2.1 percent of totul electric operating expenses (Table 46).

Table 5. Investments in Environmental Protection and Conatruction Work in Progress for Major U.S. Investor-Owned Electric Utilities on December 31, 1988-1992

\begin{tabular}{|c|c|c|c|c|c|c|}
\hline Year & $\begin{array}{l}\text { Environmental } \\
\text { Investments } \\
\text { (thousand dollars) }\end{array}$ & $\begin{array}{c}\text { Electric } \\
\text { Utillty Plant' } \\
\text { (thousand dollars) }\end{array}$ & $\begin{array}{c}\text { Percent of } \\
\text { =lectric Utility Plant }\end{array}$ & $\begin{array}{l}\text { Environmental CWIP } \\
\text { (thousand dollare) }\end{array}$ & $\begin{array}{l}\text { Electric Utillty } \\
\text { CWIP' } \\
\text { (thousand dollars) }\end{array}$ & $\begin{array}{l}\text { Percent of } \\
\text { Electric Utility CWIP }\end{array}$ \\
\hline $1988 \ldots \ldots . . . . . . . .$. & $47,005,176$ & $409,092,233$ & 11.6 & $4,548,741$ & $40,298,296$ & 11.3 \\
\hline 1889 & $49,370,594$ & $428,700,561$ & 11.5 & $4,454,276$ & $33,714,655$ & 13.2 \\
\hline $1980 \ldots$ & $55,644,943$ & $458,081,342$ & 12.1 & $3,086,321$ & $22,658,728$ & 13.7 \\
\hline $1991^{\circ} \ldots \ldots . . . .$. & $58,016,486$ & $479,822,229$ & 12.1 & $2,502,552$ & $18,077,211$ & 13.8 \\
\hline $1992 \ldots . . . . . . . . .$. & $58,102,361$ & $498,118,599$ & 11.7 & $3,480,260$ & $20,648,234$ & 16.8 \\
\hline
\end{tabular}

- Excludes cost of nuclear fuel.

- Excludes other utillty plant CWIP.

- Excluded are flve independent power producers jurisdictional to the Federal Energy Rejulatory Commiacion which were included in the prior year's publication.

Note: Due to the emergence from bankruptcy, the 1991 financlal statements for the Public Service Company of New Hampahire are from May 16 through December 31. Excluded are the independent power producers and cooperattves jurisdictional to the Federal Energy Fegulatory Commisesion. Summary data are provided in Table 8 and detall data in Table 45. Source: Federal Energy Regulatory Commiseion, FERC Form 1, "Annual Report of Mafor Electric Utiltiee, Lucensees and Others." 
Table 6. Composite Statement of Income and Retained Earnings for Major U.S. Investor-Owned Electric Utilities, 1988-1992 (Thousand Dollars)

\begin{tabular}{|c|c|c|c|c|c|}
\hline Item & 1992 & $1891^{\prime}$ & 1990 & 1989 & 1988 \\
\hline 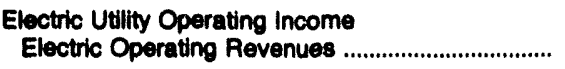 & $169,488,035$ & $166,803,843$ & $157,278,537$ & $150,903,317$ & $143,830,420$ \\
\hline 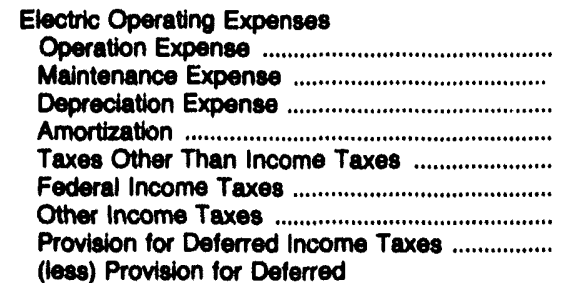 & $\begin{array}{r}87,272,134 \\
12,194,805 \\
15,984,394 \\
1,107,359 \\
12,760,152 \\
6,135,824 \\
1,061,858 \\
9,912,989\end{array}$ & $\begin{array}{r}85,933,743 \\
12,024,427 \\
15,494,155 \\
633,021 \\
12,270,379 \\
6,570,371 \\
1,120,150 \\
9,821,725\end{array}$ & $\begin{array}{r}81,086,488 \\
11,779,489 \\
14,536,599 \\
351,985 \\
11,433,264 \\
6,155,755 \\
991,104 \\
7,813,656\end{array}$ & $\begin{array}{r}76,451,124 \\
11,271,632 \\
14,059,747 \\
973,214 \\
10,796,423 \\
5,954,609 \\
893,760 \\
8,386,173\end{array}$ & $\begin{array}{r}72,742,004 \\
10,913,539 \\
13,208,874 \\
260,481 \\
10,319,912 \\
5,197,301 \\
882,903 \\
7,781,173\end{array}$ \\
\hline $\begin{array}{l}\text { Income Taxes (credit) .................................. } \\
\text { Investment Tax Credit Adjustments (net) .......... } \\
\text { (less) Gains from Disposition of Utility Plant .... } \\
\text { Losses from Disposition of Utility Plant ............. }\end{array}$ & $\begin{array}{r}6,895,654 \\
-510,586 \\
15,621 \\
1,449\end{array}$ & $\begin{array}{r}7,527,049 \\
-381,016 \\
12,727 \\
812\end{array}$ & $\begin{array}{r}5,958,279 \\
-253,564 \\
36,630 \\
766\end{array}$ & $\begin{array}{r}6,906,547 \\
-312,894 \\
22,059 \\
6,878\end{array}$ & $\begin{array}{r}5,703,013 \\
-246,462 \\
10,358 \\
1,272\end{array}$ \\
\hline Total Electric Operating Expenses ................. & $139,009,008$ & $135,947,901$ & $127,900,634$ & $121,552,060$ & $116,347,628$ \\
\hline Not Electric Operating Income .......................... & $30,470,842$ & $30,855,852$ & $29,377,003$ & $29,351,256$ & $28,682,794$ \\
\hline $\begin{array}{l}\text { Gas Utility Operating Income } \\
\text { Gas Operating Revenues }\end{array}$ & $14,937,370$ & $14,560,221$ & $14,611,056$ & $15,118,408$ & $14,580,945$ \\
\hline 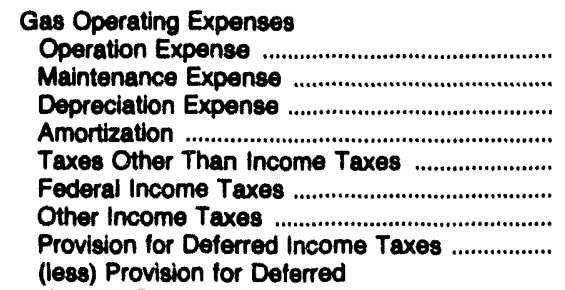 & $\begin{array}{r}10,968,502 \\
476,785 \\
829,654 \\
58,545 \\
949,625 \\
234,188 \\
45,430 \\
569,585\end{array}$ & $\begin{array}{r}10,832,265 \\
516,414 \\
781,273 \\
35,696 \\
896,006 \\
240,252 \\
68,404 \\
467,495\end{array}$ & $\begin{array}{r}11,118,073 \\
437,222 \\
725,880 \\
36,713 \\
857,830 \\
354,173 \\
73,934 \\
323,575\end{array}$ & $\begin{array}{r}11,552,345 \\
419,280 \\
692,597 \\
35,115 \\
880,534 \\
283,589 \\
53,071 \\
380,930\end{array}$ & $\begin{array}{r}11,144,445 \\
411,858 \\
652,679 \\
25,785 \\
835,601 \\
286,225 \\
44,766 \\
388,979\end{array}$ \\
\hline $\begin{array}{l}\text { Income Taxes (credit) ............................... } \\
\text { Investment Tax Credit Adjustments (net) ......... } \\
\text { (less) Gains from Disposition of Utility Plant .... } \\
\text { Losses from Disposition of Utility Plant ............. }\end{array}$ & $\begin{array}{r}427,470 \\
-14,051 \\
539 \\
0\end{array}$ & $\begin{array}{r}427,139 \\
-3,662 \\
507 \\
-129\end{array}$ & $\begin{array}{r}410,347 \\
7,007 \\
905 \\
1\end{array}$ & $\begin{array}{r}317,164 \\
-7,645 \\
447 \\
2\end{array}$ & $\begin{array}{r}311,194 \\
-5,854 \\
219 \\
0\end{array}$ \\
\hline Total Cas Operating Expensese .......................... & $13,691,253$ & $13,406,370$ & $13,523,155$ & $13,972,207$ & $13,473,072$ \\
\hline Net Ces Utllity Operating Income .................. & $1,246,117$ & $1,163,852$ & $1,087,901$ & $1,147,200$ & $1,107,873$ \\
\hline 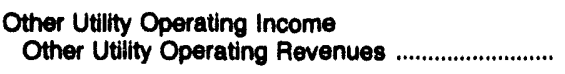 & $1,068,053$ & $1,086,663$ & $1,110,362$ & $1,044,871$ & 976,899 \\
\hline 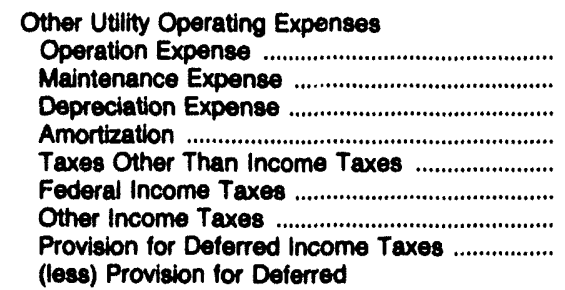 & $\begin{array}{r}781,002 \\
55,812 \\
54,053 \\
891 \\
77,446 \\
25,428 \\
1,528 \\
3,494\end{array}$ & $\begin{array}{r}803,727 \\
64,301 \\
50,897 \\
839 \\
78,121 \\
2,708 \\
822 \\
37,634\end{array}$ & $\begin{array}{r}838,535 \\
71,747 \\
51,051 \\
3,749 \\
79,332 \\
7,834 \\
-29 \\
29,018\end{array}$ & $\begin{array}{r}773,309 \\
63,082 \\
51,119 \\
1,776 \\
74,244 \\
14,356 \\
2,124 \\
53,508\end{array}$ & $\begin{array}{r}729,283 \\
61,693 \\
47,060 \\
-2,661 \\
67,269 \\
13,808 \\
2,113 \\
58,038\end{array}$ \\
\hline 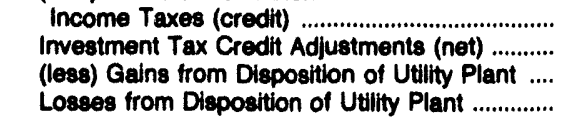 & $\begin{array}{r}15,730 \\
-1,695 \\
145 \\
0\end{array}$ & $\begin{array}{r}30,078 \\
-1,425 \\
37 \\
0\end{array}$ & $\begin{array}{r}32,886 \\
-771 \\
1 \\
0\end{array}$ & $\begin{array}{r}56,001 \\
-1,558 \\
0 \\
0\end{array}$ & $\begin{array}{r}65,647 \\
-1,286 \\
0 \\
0\end{array}$ \\
\hline Total Other Utilly Operating Expenses ...... & 892,083 & $1,007,600$ & $1,047,580$ & 975,058 & $\cos , 650$ \\
\hline Not Other villty Oporating Incoms .............. & $\mathbf{8 5 , 9 7 0}$ & 79,055 & 62,782 & 68,913 & 67,240 \\
\hline
\end{tabular}

See endnotes at end of this table. 
Table 6. Composite Statement of Income and Retained Earnings for Major U.S. Investor-Owned Electric Utilities, 1988-1992 (Continued) (Thousand Dollars)

\begin{tabular}{|c|c|c|c|c|c|}
\hline Item & 1992 & $1991^{\prime}$ & 1990 & 1989 & 1988 \\
\hline $\begin{array}{l}\text { Total Utilly Operating Income } \\
\text { Total Utility Operating Revenues ........................... }\end{array}$ & $185,493,458$ & $182,450,728$ & $172,999,954$ & $167,067,596$ & $159,488,265$ \\
\hline 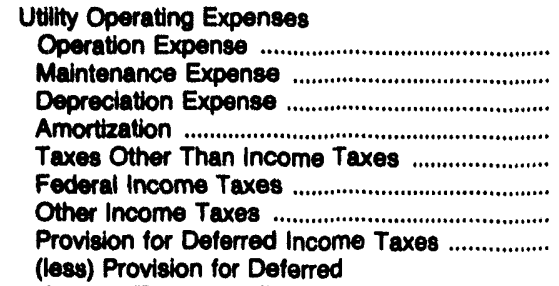 & $\begin{array}{r}99,022,638 \\
12,727,401 \\
16,868,101 \\
1,166,794 \\
13,787,223 \\
6,395,440 \\
1,108,816 \\
10,486,068\end{array}$ & $\begin{array}{r}97,569,736 \\
12,605,143 \\
16,326,426 \\
669,556 \\
13,244,505 \\
6,813,331 \\
1,189,375 \\
10,326,854\end{array}$ & $\begin{array}{r}93,043,096 \\
12,288,458 \\
15,313,530 \\
392,447 \\
12,370,426 \\
6,517,762 \\
1,065,010 \\
8,166,249\end{array}$ & $\begin{array}{r}88,776,778 \\
11,753,994 \\
14,803,462 \\
1,010,105 \\
11,751,202 \\
6,252,554 \\
948,955 \\
8,820,611\end{array}$ & $\begin{array}{r}84,615,732 \\
11,387,090 \\
13,908,613 \\
283,605 \\
11,222,772 \\
5,497,334 \\
929,782 \\
8,228,190\end{array}$ \\
\hline $\begin{array}{l}\text { Income Taxes (credit) .............................. } \\
\text { Investment Tax Credit Adjustments (net) ........ } \\
\text { (lese) Gains from Disposition of Utillty Plant .... } \\
\text { Losses from Disposition of Utility Plant ............ }\end{array}$ & $\begin{array}{r}7,338,854 \\
-526,342 \\
16,304 \\
1,449\end{array}$ & $\begin{array}{r}7,984,266 \\
-386,102 \\
13,271 \\
683\end{array}$ & $\begin{array}{r}6,401,511 \\
-247,328 \\
37,536 \\
766\end{array}$ & $\begin{array}{r}7,279,712 \\
-322,097 \\
22,505 \\
6,880\end{array}$ & $\begin{array}{r}6,079,854 \\
-253,602 \\
10,577 \\
1,272\end{array}$ \\
\hline Total Utillty Operating Expensese ..................... & $163,602,429$ & $150,361,969$ & $142,471,369$ & $136,500,226$ & $129,730,357$ \\
\hline Not Uttlity Operating Incoms ............................ & $31,811,029$ & $32,088,758$ & $30,528,685$ & $30,567,370$ & $29,757,908$ \\
\hline $\begin{array}{l}\text { Other income and Deductions } \\
\text { Other Income }\end{array}$ & & & & & \\
\hline 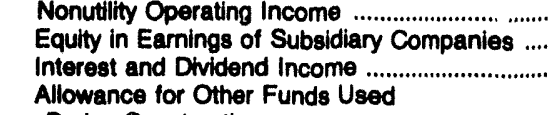 & $\begin{array}{r}14,431 \\
-19,161 \\
883,419\end{array}$ & $\begin{array}{r}2,955 \\
813,875 \\
1,058,368\end{array}$ & $\begin{array}{r}-10,348 \\
360,611 \\
1,116,789\end{array}$ & $\begin{array}{r}3,987 \\
939,353 \\
1,074,676\end{array}$ & $\begin{array}{r}-2,975 \\
431,359 \\
1,082,220\end{array}$ \\
\hline 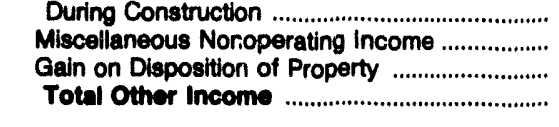 & $\begin{array}{r}611,514 \\
1,248,421 \\
120,752 \\
2,850,377\end{array}$ & $\begin{array}{r}706,102 \\
1,094,726 \\
239,936 \\
3,915,963\end{array}$ & $\begin{array}{r}1,080,217 \\
1,278,994 \\
258,374 \\
4,084,637\end{array}$ & $\begin{array}{r}1,202,004 \\
1,826,605 \\
168,829 \\
5,215,554\end{array}$ & $\begin{array}{r}1,615,721 \\
1,819,591 \\
84,194 \\
5,030,110\end{array}$ \\
\hline 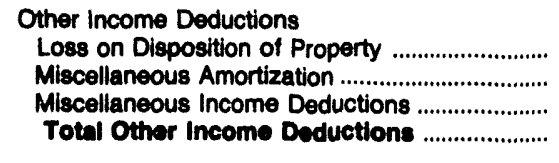 & $\begin{array}{r}27,819 \\
33,672 \\
1,488,302 \\
1,549,793\end{array}$ & $\begin{array}{r}63,137 \\
67,526 \\
4,114,554 \\
4,245,217\end{array}$ & $\begin{array}{r}59,848 \\
26,362 \\
2,557,378 \\
2,643,589\end{array}$ & $\begin{array}{r}922,356 \\
35,642 \\
2,640,070 \\
3,598,088\end{array}$ & $\begin{array}{r}5,048 \\
32,027 \\
4,024,046 \\
4,061,121\end{array}$ \\
\hline 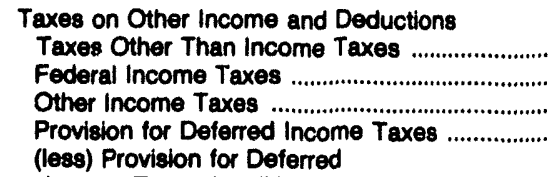 & $\begin{array}{r}30,501 \\
-239,227 \\
-39,345 \\
458,156\end{array}$ & $\begin{array}{r}8,358 \\
-31,841 \\
3,615 \\
491,421\end{array}$ & $\begin{array}{r}36,797 \\
-310,347 \\
-38,471 \\
833,319\end{array}$ & $\begin{array}{r}25,640 \\
-604,294 \\
-87,638 \\
1,065,950\end{array}$ & $\begin{array}{r}24,563 \\
-436,002 \\
-81,874 \\
809,832\end{array}$ \\
\hline 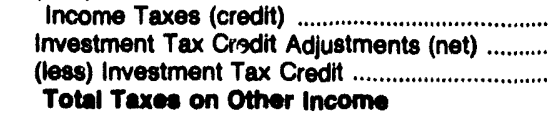 & $\begin{array}{r}485,782 \\
-38,985 \\
64,779\end{array}$ & $\begin{array}{r}1,211,410 \\
960 \\
114,684\end{array}$ & $\begin{array}{r}732,446 \\
-90,884 \\
87,417\end{array}$ & $\begin{array}{r}1,137,542 \\
-75,422 \\
129,869\end{array}$ & $\begin{array}{r}1,248,717 \\
-22,857 \\
115,626\end{array}$ \\
\hline 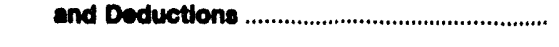 & $-379,461$ & $-862,579$ & $-389,448$ & $-943,175$ & $-1,070,684$ \\
\hline Not Other Income and Deductions ................. & $1,689,045$ & 523,325 & $1,830,496$ & $2,560,660$ & $2,039,670$ \\
\hline $\begin{array}{l}\text { Interest Charges } \\
\text { Interest on Long-term Debt ......................... } \\
\text { Amortization of Debt Discount and Expenses .. } \\
\text { Amortization of Loss on Reaquired Debt ......... } \\
\text { (less) Amortization of Premium } \\
\text { on Debt (credit) }\end{array}$ & $\begin{array}{r}14,203,575 \\
200,441 \\
293,376\end{array}$ & $\begin{array}{r}14,725,810 \\
165,026 \\
218,870\end{array}$ & $\begin{array}{r}14,815,559 \\
166,843 \\
222,364\end{array}$ & $\begin{array}{r}14,472,102 \\
157,771 \\
214,194\end{array}$ & $\begin{array}{r}14,360,633 \\
160,933 \\
198,194\end{array}$ \\
\hline 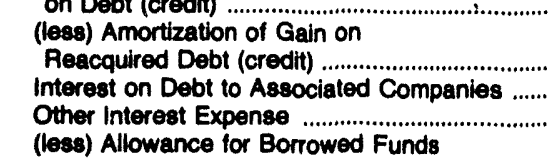 & $\begin{array}{r}4,716 \\
15,021 \\
65,837 \\
1,038,029\end{array}$ & $\begin{array}{r}16,620 \\
68,166 \\
1,216,372\end{array}$ & $\begin{array}{r}6,386 \\
19,388 \\
102,369 \\
1,268,498\end{array}$ & $\begin{array}{r}20,211 \\
106,024 \\
1,069,885\end{array}$ & $\begin{array}{r}37,629 \\
45,419 \\
927,071\end{array}$ \\
\hline 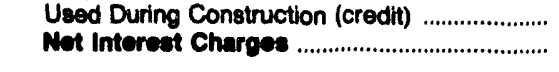 & $\begin{array}{r}558,348 \\
15,223,174\end{array}$ & $\begin{array}{r}635,525 \\
15,736,246\end{array}$ & $\begin{array}{r}814,229 \\
15,735,630\end{array}$ & $\begin{array}{r}1,142,007 \\
14,852,295\end{array}$ & $\begin{array}{r}1,261,283 \\
14,386,924\end{array}$ \\
\hline Income Before Extraordinary Items ............... & $18,276,900$ & $16,875,836$ & $16,623,461$ & $18,276,735$ & $17,410,653$ \\
\hline
\end{tabular}

See endnotes at end of this table. 
Table 6. Compoalte Statement of Income and Rotalned Earnings for Major U.S. Investor-Owned Electric Utilities, 1988-1902 (Continued) (Thousand Dollars)

\begin{tabular}{|c|c|c|c|c|c|}
\hline Item & 1902 & $1891^{\prime}$ & 1890 & 1989 & 1888 \\
\hline 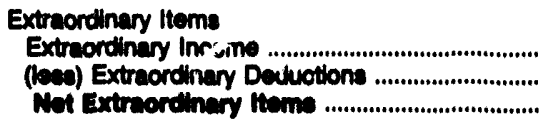 & $\begin{array}{r}189,668 \\
38,031 \\
160,028\end{array}$ & $\begin{array}{r}164,901 \\
10,986 \\
188,016\end{array}$ & $\begin{array}{l}654,477 \\
285,619 \\
394,860\end{array}$ & $\begin{array}{r}89,107 \\
1,061,378 \\
-972,271\end{array}$ & $\begin{array}{r}619,408 \\
2,368,496 \\
-1,749,007\end{array}$ \\
\hline $\begin{array}{l}\text { (leas) Federal and Other Income Taxes ........... } \\
\text { Extreordinary hemo After Taxes ................... }\end{array}$ & $\begin{array}{r}43,081 \\
107,844\end{array}$ & $\begin{array}{l}80,088 \\
72,096\end{array}$ & $\begin{array}{r}96,143 \\
273,716\end{array}$ & $\begin{array}{r}-9,297 \\
-02,074\end{array}$ & $\begin{array}{r}-380,141 \\
-1,340,840\end{array}$ \\
\hline 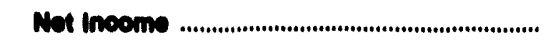 & $18,2 x 4,444$ & $16,040,644$ & $16,607,186$ & $17,312,701$ & $16,041,707$ \\
\hline \multicolumn{6}{|l|}{ Unepproportated Rotalned Eaminge } \\
\hline Roteined Earninge - Becinning of Year ............. & $47,089,070$ & $4,721,070$ & $47,946,276$ & $47,090,097$ & $47,001,240$ \\
\hline 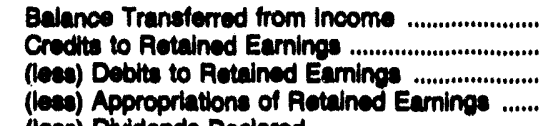 & $\begin{array}{r}18,408,040 \\
467,468 \\
301,008 \\
46,705\end{array}$ & $\begin{array}{r}16,175,083 \\
140,300 \\
322,284 \\
8,030\end{array}$ & $\begin{array}{r}16,562,936 \\
28,747 \\
290,615 \\
22,002\end{array}$ & $\begin{array}{r}16,373,989 \\
57,168 \\
43,706 \\
14,838\end{array}$ & $\begin{array}{r}15,685,831 \\
32,304 \\
380,814 \\
31,033\end{array}$ \\
\hline Proferred Stock & $2,030,440$ & $1,046,213$ & $2,025,167$ & $2,417,200$ & $2,204,464$ \\
\hline 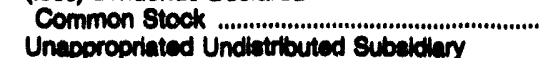 & $14,897,608$ & $14,427,670$ & $14,189,677$ & $14,030,562$ & $13,617,081$ \\
\hline 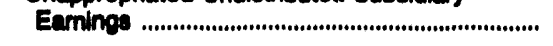 & 334,864 & 634,086 & 271,608 & 681,138 & 370,300 \\
\hline Rotanned Eaminge - End of Year ........................... & $40,692,707$ & 44,07e,392 & $47,001,404$ & $47,846,448$ & $40,008,702$ \\
\hline $\begin{array}{l}\text { Appropriated Rotained Earninge ............................ } \\
\text { Approprlated Rotained Earninge . }\end{array}$ & 66,036 & 33,824 & 61,274 & 47,839 & 37,843 \\
\hline Amorttzation, Reserve, Federal ............................ & 116,601 & 85,022 & 57,641 & 51,697 & 64,230 \\
\hline 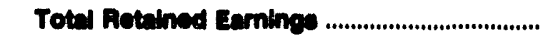 & $40,712,342$ & $40,078,296$ & $40,070,210$ & $47,746,164$ & $47,077,085$ \\
\hline
\end{tabular}

1 Excluded are the independent power producere Jurtedictional to the Federal Energy Regulatory Commiasion which were included in the prior yeares publication.

Pecificorp took a 3587.9 million lose in this sccount.

Note: Totals may not equal wim of components because of independent rounding. Detall data are provided in Table 37 . Due to its emergence trom bankruptoy, the 1991 financial statements for the Pubile Service Company of New Hampechire are from May 16 through December 31 . Excluded are the Independent power producers and cooperattves furisdlotiond to the Federal Eneroy Reoulatory Commlanion.

Source: Federal Energy Regulationy Commiselon, FERC Form 1, "Annual Report of Malor Electric Utilties, Liceneses and Othere." 
Table 7. Rattos Baced on the Composite Statement of Income and Rotained Earnings for Major U.S. Inveator-Owned Electric Utilities, 1988-1892

\begin{tabular}{|c|c|c|c|c|c|}
\hline Ratio & 1802 & $1001^{2}$ & 1890 & 1989 & 1988 \\
\hline \multicolumn{6}{|l|}{ Enetuls Operations } \\
\hline 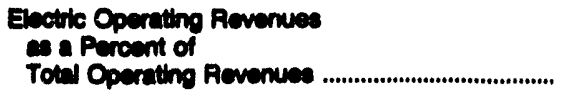 & 01.4 & 91.4 & $\boldsymbol{\infty 0 . 8}$ & $\infty 0.3$ & 80.2 \\
\hline 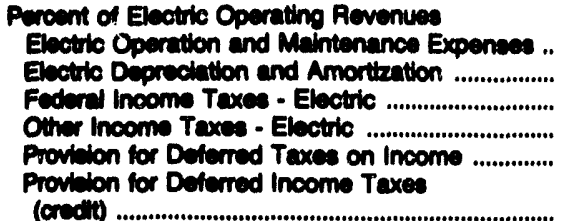 & $\begin{array}{r}68.7 \\
10.1 \\
3.6 \\
8.2 \\
5.8 \\
4\end{array}$ & $\begin{array}{r}58.7 \\
8.7 \\
3.0 \\
8.0 \\
5.0\end{array}$ & $\begin{array}{r}59.0 \\
9.5 \\
3.9 \\
7.8 \\
5.0 \\
3.9\end{array}$ & $\begin{array}{r}68.1 \\
10.0 \\
3.9 \\
7.7 \\
5.6\end{array}$ & $\begin{array}{r}58.1 \\
9.4 \\
3.6 \\
7.8 \\
5.4\end{array}$ \\
\hline 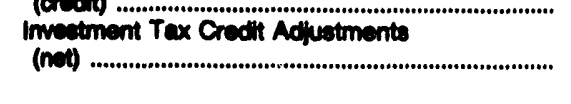 & -.3 & -.2 & $\begin{array}{l}3.8 \\
-.2\end{array}$ & $\begin{array}{r}4.6 \\
-.2\end{array}$ & $\begin{array}{l}4.0 \\
-.2\end{array}$ \\
\hline Total Electric Operating Expenses .......................... & 82.0 & 81.6 & 81.3 & 80.5 & 80.1 \\
\hline 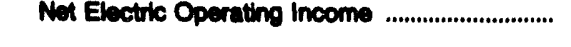 & 18.0 & 18.5 & 18.7 & 18.5 & 18.9 \\
\hline \multicolumn{6}{|l|}{ Al Utulty Oparations } \\
\hline 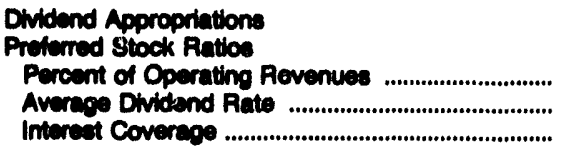 & $\begin{array}{l}1.1 \\
8.1 \\
9.0\end{array}$ & $\begin{array}{l}1.1 \\
7.6 \\
8.7\end{array}$ & $\begin{array}{l}1.2 \\
7.8 \\
8.3\end{array}$ & $\begin{array}{l}1.4 \\
9.2 \\
7.2\end{array}$ & $\begin{array}{l}1.4 \\
8.5 \\
7.1\end{array}$ \\
\hline 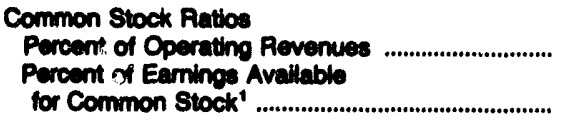 & $\begin{array}{r}8.0 \\
81.1\end{array}$ & $\begin{array}{r}7.9 \\
86.2\end{array}$ & $\begin{array}{r}8.2 \\
85.4\end{array}$ & $\begin{array}{r}8.4 \\
94.2\end{array}$ & $\begin{array}{r}8.5 \\
98.1\end{array}$ \\
\hline $\begin{array}{l}\text { Percant of Average Common Equity } \\
\text { Dividend Appropriation - Common Stock .............. }\end{array}$ & 9.7 & 8.6 & 8.7 & 8.7 & 8.5 \\
\hline 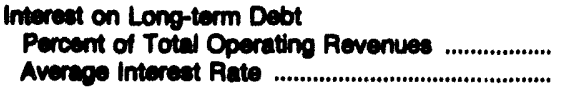 & $\begin{array}{l}7.7 \\
8.2\end{array}$ & $\begin{array}{l}8.1 \\
8.7\end{array}$ & $\begin{array}{l}8.6 \\
9.0\end{array}$ & $\begin{array}{l}8.7 \\
8.8\end{array}$ & $\begin{array}{l}9.0 \\
8.0\end{array}$ \\
\hline 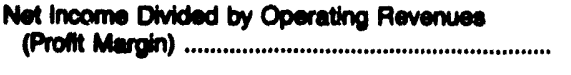 & 8.8 & 8.3 & 8.8 & 10.4 & 10.1 \\
\hline
\end{tabular}

\footnotetext{
includes carnings on equity investments in subeidiary companies.

- Exctuded are five independent power producere juriadictional to the Federal Energy Regulatory Commiedion which were included in the prior yeare publication.

Note: Totals may not equal sum of components because of independent rounding. Dus to the emergence from bankruptcy, the 1981 financial statememts for the Public Service Company of New Hampehire are from May 16 through December 31. Excluded are the independent power producers and cooperatives furiedictional to the Federal Energy Reoulatory Commieak: $n$.

Source: Federal Eneroy Regulatory Commiecion, FERC Form 1, "Annual Report of Major Electric Utillites, Licensees and Others."
} 
Table 8. Composite Balance Sheet for Major U.S. Investor-Owned Electric Utilities on December 31, 1988-1992

(Thousand Dollars)

\begin{tabular}{|c|c|c|c|c|c|}
\hline Item & 1992 & $1891^{\prime}$ & 1980 & 1989 & 1988 \\
\hline 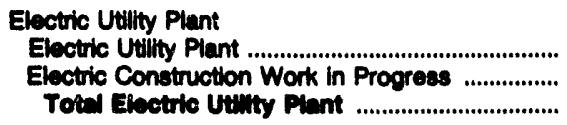 & $\begin{array}{r}488,118,699 \\
20,648,234 \\
518,768,033\end{array}$ & $\begin{array}{r}479,822,229 \\
18,077,211 \\
407,090,490\end{array}$ & $\begin{array}{r}468,081,342 \\
22,558,726 \\
460,040,060\end{array}$ & $\begin{array}{r}428,700,561 \\
33,714,555 \\
402,416,116\end{array}$ & $\begin{array}{r}409,092,233 \\
40,298,296 \\
440,300,620\end{array}$ \\
\hline 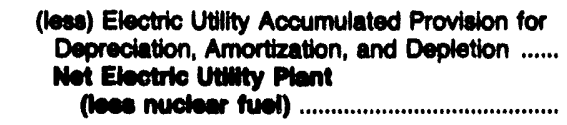 & $\begin{array}{l}160,466,573 \\
360,300,250\end{array}$ & $\begin{array}{l}148,288,414 \\
340,611,025\end{array}$ & $\begin{array}{l}135,727,298 \\
344,912,770\end{array}$ & $\begin{array}{l}124,954,834 \\
337,400,182\end{array}$ & $\begin{array}{l}113,523,644 \\
335,860,284\end{array}$ \\
\hline 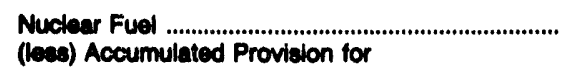 & $19,795,168$ & $19,481,857$ & $19,525,373$ & $19,159,604$ & $18,937,767$ \\
\hline $\begin{array}{l}\text { Amortization of Nuclear Fuel Assemblles } \\
\text { Not Nucter.......... }\end{array}$ & $\begin{array}{r}12,958,447 \\
6,836,710\end{array}$ & $\begin{array}{r}12,570,312 \\
6,011,648\end{array}$ & $\begin{array}{r}11,713,335 \\
7,812,030\end{array}$ & $\begin{array}{r}10,458,860 \\
8,700,944\end{array}$ & $\begin{array}{l}9,295,068 \\
9,042,090\end{array}$ \\
\hline 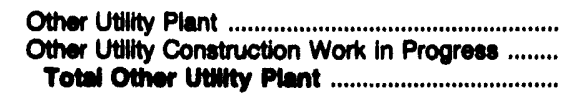 & $\begin{array}{r}31,623,922 \\
1,764,010 \\
33,307,033\end{array}$ & $\begin{array}{r}29,881,239 \\
1,166,878 \\
31,046,110\end{array}$ & $\begin{array}{r}27,634,678 \\
800,965 \\
28,636,692\end{array}$ & $\begin{array}{r}25,472,399 \\
813,465 \\
26,205,863\end{array}$ & $\begin{array}{r}23,057,220 \\
675,704 \\
24,632,022\end{array}$ \\
\hline 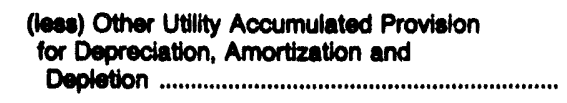 & $11,680,173$ & $10,799,084$ & $9,850,377$ & $9,223,285$ & $8,503,331$ \\
\hline Net Other Utilty Plant ................................................ & $21,727,780$ & $20,240,039$ & $18,605,255$ & $17,002,608$ & $18,128,601$ \\
\hline 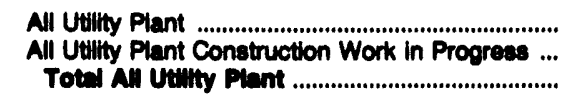 & $\begin{array}{r}549,537,687 \\
22,412,245 \\
571,949,032\end{array}$ & $\begin{array}{r}529,185,424 \\
19,244,089 \\
540,429,613\end{array}$ & $\begin{array}{r}505,241,391 \\
23,459,682 \\
529,701,074\end{array}$ & $\begin{array}{r}473,332,564 \\
34,528,009 \\
807,000,573\end{array}$ & $\begin{array}{r}451,987,220 \\
40,973,008 \\
402,600,318\end{array}$ \\
\hline 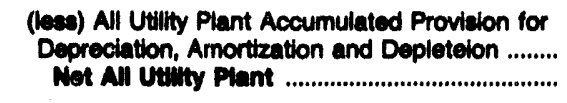 & $\begin{array}{l}185,085,193 \\
306,064,730\end{array}$ & $\begin{array}{l}171,657,810 \\
378,771,703\end{array}$ & $\begin{array}{l}157,391,010 \\
371,310,063\end{array}$ & $\begin{array}{l}144,637,178 \\
303,223,396\end{array}$ & $\begin{array}{l}131,322,062 \\
301,630,268\end{array}$ \\
\hline 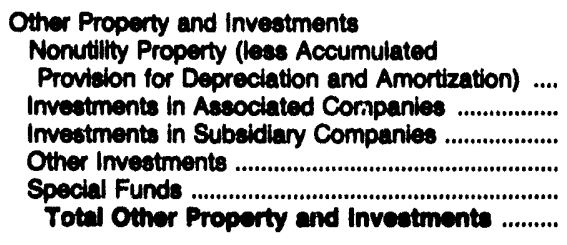 & $\begin{array}{r}848,973 \\
371,319 \\
10,237,686 \\
1,171,397 \\
5,416,600 \\
10,045,077\end{array}$ & $\begin{array}{r}838,351 \\
364,032 \\
10,485,648 \\
1,384,478 \\
4,312,805 \\
17,345,416\end{array}$ & $\begin{array}{r}895,511 \\
258,278 \\
10,083,115 \\
2,219,681 \\
3,349,345 \\
17,703,020\end{array}$ & $\begin{array}{r}708,977 \\
216,759 \\
11,290,976 \\
1,342,530 \\
2,579,516 \\
16,189,767\end{array}$ & $\begin{array}{r}676,442 \\
192,624 \\
11,098,177 \\
1,386,502 \\
1,846,037 \\
16,200,003\end{array}$ \\
\hline 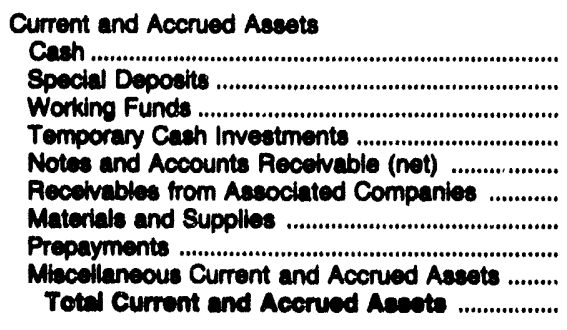 & $\begin{array}{r}142,095 \\
1,181,027 \\
150,496 \\
2,768,246 \\
13,246,568 \\
2,697,124 \\
12,772,374 \\
1,882,827 \\
8,608,226 \\
\mathbf{4 3 , 4 4 7 , 0 7 1}\end{array}$ & $\begin{array}{r}300,414 \\
681,730 \\
151,209 \\
3,285,856 \\
13,684,473 \\
3,364,053 \\
12,591,442 \\
1,795,368 \\
7,673,239 \\
49,367,706\end{array}$ & $\begin{array}{r}389,681 \\
479,786 \\
128,179 \\
2,785,227 \\
12,820,406 \\
2,760,603 \\
12,729,310 \\
1,838,697 \\
7,614,782 \\
41,634,692\end{array}$ & $\begin{array}{r}286,224 \\
875,967 \\
128,347 \\
3,687,090 \\
14,067,358 \\
2,684,812 \\
10,712,687 \\
1,822,486 \\
7,480,394 \\
41,816,168\end{array}$ & $\begin{array}{r}193,604 \\
1,305,123 \\
99,029 \\
4,213,715 \\
13,070,039 \\
1,720,485 \\
10,185,087 \\
1,718,692 \\
6,614,832 \\
30,122,200\end{array}$ \\
\hline 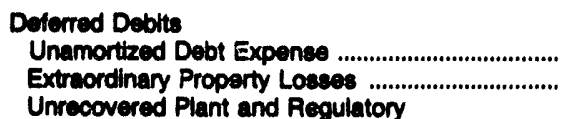 & $\begin{array}{r}1,520,830 \\
540,243\end{array}$ & $\begin{array}{r}1,240,157 \\
619,681\end{array}$ & $\begin{array}{r}1,078,859 \\
528,373\end{array}$ & $\begin{array}{r}1,074,403 \\
483,859\end{array}$ & $\begin{array}{r}1,016,195 \\
520,073\end{array}$ \\
\hline 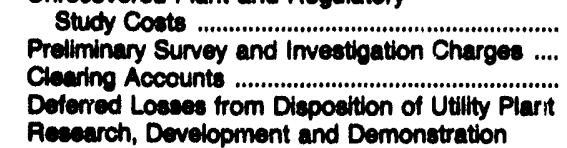 & $\begin{array}{r}6,025,486 \\
526,689 \\
64,017 \\
104\end{array}$ & $\begin{array}{r}5,595,665 \\
346,025 \\
65,107 \\
51\end{array}$ & $\begin{array}{r}6,755,844 \\
330,731 \\
59,028 \\
68\end{array}$ & $\begin{array}{r}7,341,130 \\
305,174 \\
60,574 \\
162\end{array}$ & $\begin{array}{r}3,608,138 \\
270,243 \\
66,820 \\
515\end{array}$ \\
\hline 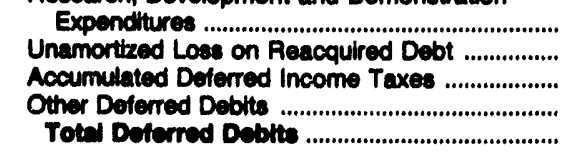 & $\begin{array}{r}33,215 \\
3,680,516 \\
12,580,405 \\
33,022,261 \\
57,903,875\end{array}$ & $\begin{array}{r}29,093 \\
2,730,346 \\
11,808,867 \\
27,689,027 \\
60,024,020\end{array}$ & $\begin{array}{r}100,007 \\
2,549,286 \\
11,095,917 \\
24,029,271 \\
47,322,374\end{array}$ & $\begin{array}{r}88,613 \\
2,554,856 \\
10,163,730 \\
22,774,121 \\
44,046,422\end{array}$ & $\begin{array}{r}31,617 \\
2,387,254 \\
8,158,073 \\
22,223,038 \\
\mathbf{3 3 , 3 9 8 , 6 9 4}\end{array}$ \\
\hline Total Acestes and Other Deblte. & $806,362,461$ & $407,600,023$ & $477,071,020$ & $406,722,037$ & $464,256,490$ \\
\hline
\end{tabular}

See endnotes at end of this table. 
Table 8. Compoalte Balance Sheet for Major U.S. Investor-Owned Electrlc Utilities on December 31, 1988-1892 (Continued)

(Thousand Dollars)

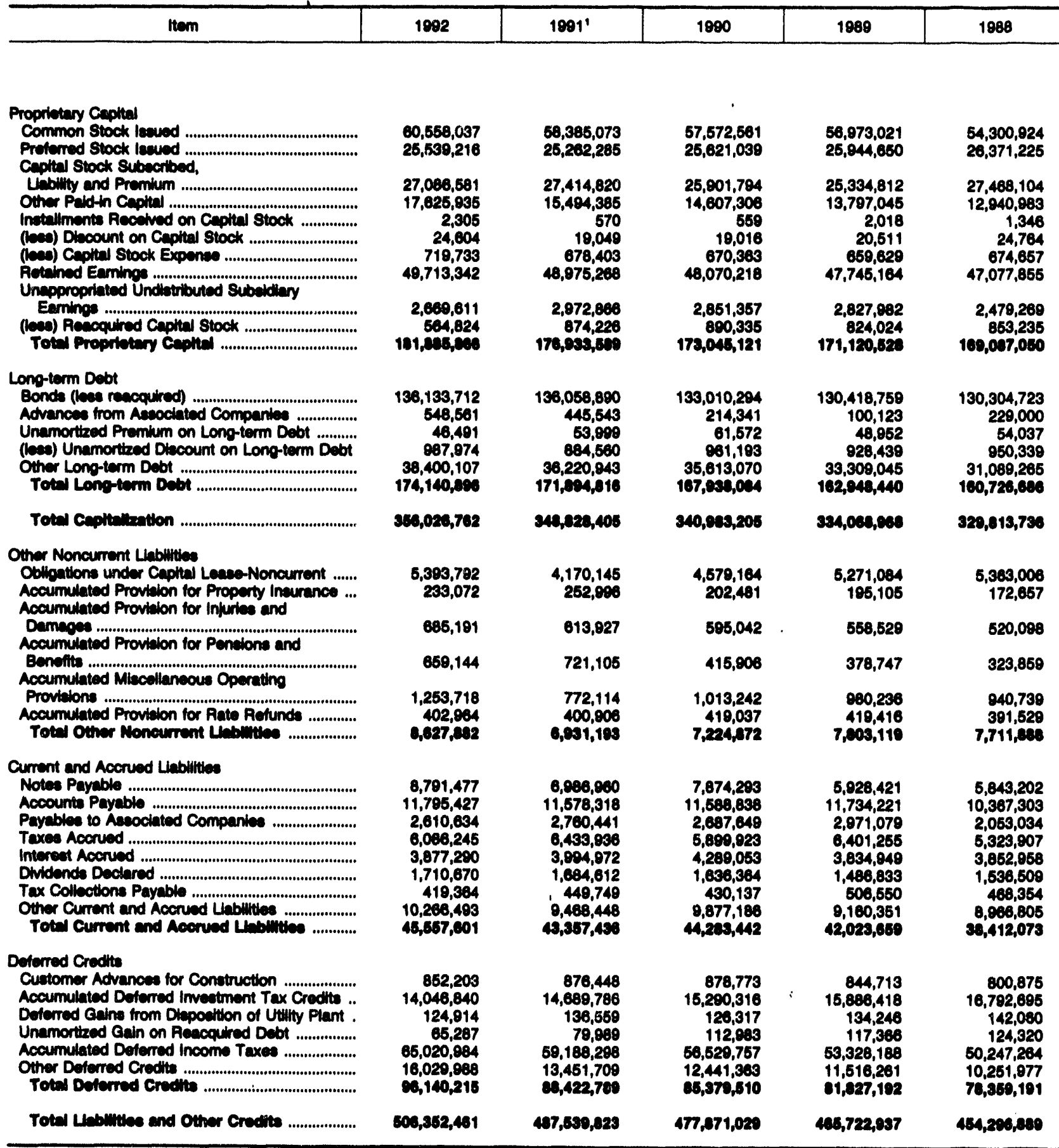

' Excluded are five Independent power producers furbelictional to the Federal Energy Regulatory Commiacion which were included in the prior year's publication.

Note: Totals may not equal eum of components because of independent rounding. Detall data are provided in Table 38 . Due to its omergence from bankruptoy, the 1901 tinancial statements for the Publlc Service Company of Now Hampehire are from May 16 through December 31 . Excluded are the independent power producere and cooperatives furladictional to the Federal Eneroy Reoulatory Commiacion.

Source: Federal Eneroy Regulatory Commbalon FERC Form 1, "Annual Report of Major Electric Utillities, Liconsees and Othere." 
Table 9. Composite Financial Indlcators for Major U.S. Investor-Owned Electric Utilitios, 1988-1992

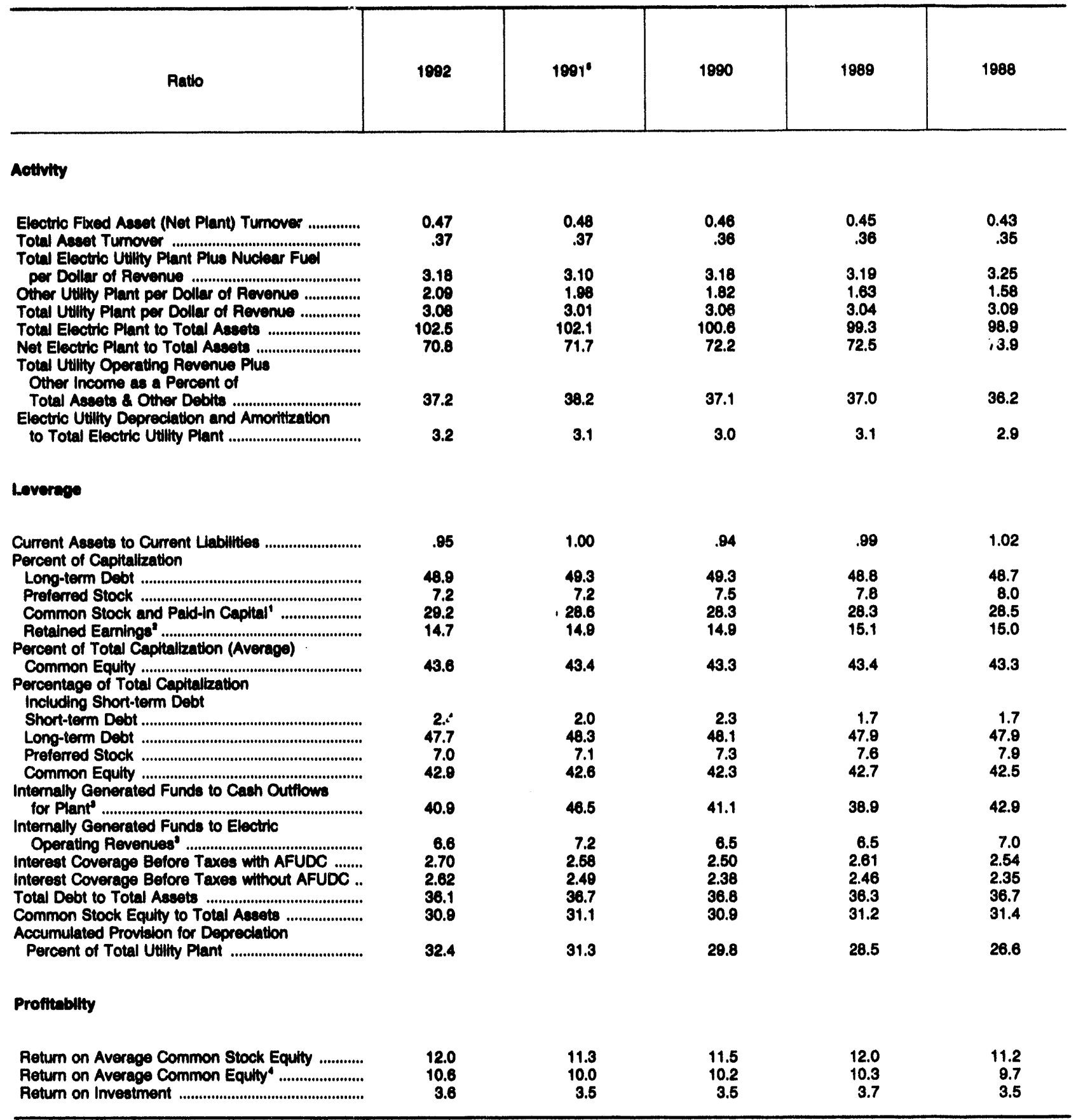

Includes reacquired cepital stock.

Includes Unappropriated Undistributed Subsidiary Earninge.

- Calculation revised in 1902.

- Includes Equily in Earnings of Subsidlary Companies.

- Excluded are five independent power producers juriedictional to the Federal Eneroy Regulatory Commission which were included in the prior year's publication.

Note: Totals may not equal sum of components because of independent rounding. Due to its emergence from bankruptcy, the 1991 financial statements for the Publlc Service Company of New Hampahire are from May 16 through December 31. Excluded are the independent power producers and cooperatives jurledictional to the Federal Energy Regulatory Commiasion.

Source: Federal Energy Regulatory Comiseion, FERC Form 1, "Annual Report of Major Electric Utilities, Licensees and Others." 
Table 10. Composite Statement of Cash Flows for Major U.S. Investor-Owned Electrlc Utillities, 1988-1992

(Thousand Dollars)

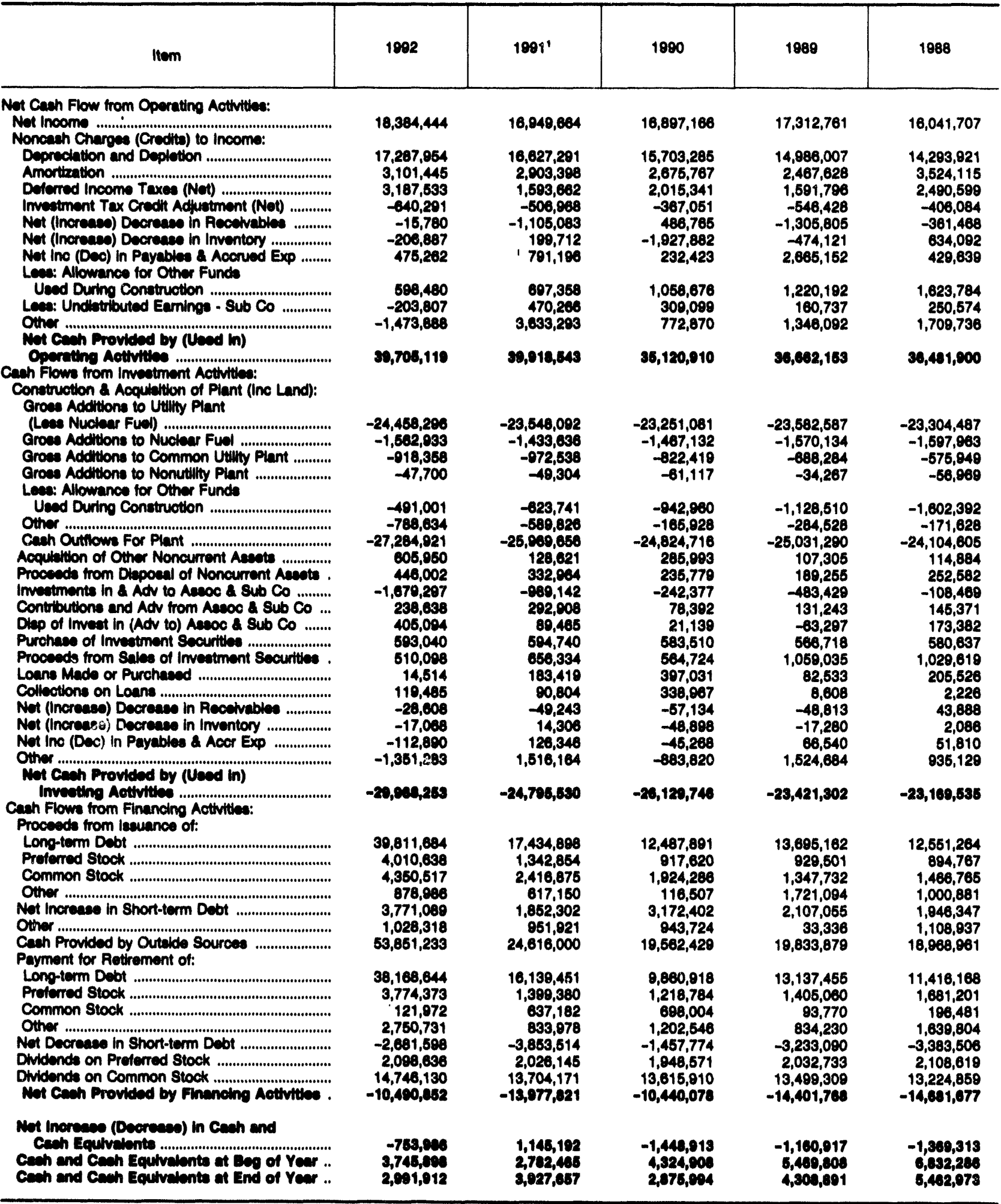

' Excluded are five independent power producere Juriadiotional to the Federal Energy Regulatory Commiasion which were included in the prior year's publication. In addition, four values were modffied dus to incorrect plant claselfications. See Technical Notes.

Note: Totala may not equal aum of components because of independent rounding. Detall data are provided in Table 39. Due to its emergence from bankruptey, the 1991 financial statemente for the Public Service Company of New Hampahire are from May 16 through December 31. Exciuded we the independent power producers and cooperatives juriedictional to the Federal Energy Regulatory Commission. Source: Federal Energy Regulatory Commlealon, FERC Form 1, "Annual Report of Major Electric Utilities, Licensees and Others." 
Table 11. Electrlc Operation and Malntenance Expeneses for Major U.S. Investor-Owned Electric Utilities, 1988-1992 (Thousand Dollars)

\begin{tabular}{|c|c|c|c|c|c|}
\hline Item & 1992 & $1891^{\prime}$ & 1090 & 1989 & 1988 \\
\hline 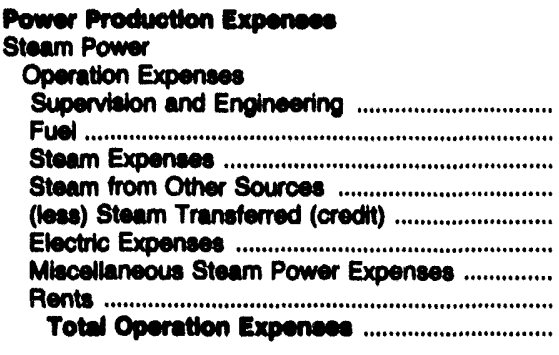 & $\begin{array}{r}591,095 \\
26,680,582 \\
930,021 \\
110,609 \\
33,463 \\
529,392 \\
1,051,946 \\
457,350 \\
30,317,631\end{array}$ & $\begin{array}{r}560,726 \\
27,424,151 \\
922,032 \\
125,271 \\
32,550 \\
445,382 \\
1,029,731 \\
464,073 \\
30,028,016\end{array}$ & $\begin{array}{r}534,654 \\
28,632,812 \\
882,744 \\
129,7988 \\
33,186 \\
432,608 \\
984,483 \\
472,880 \\
32,038,002\end{array}$ & $\begin{array}{r}513,673 \\
28,925,897 \\
868,462 \\
135,699 \\
34,626 \\
424,813 \\
902,272 \\
342,451 \\
32,076,041\end{array}$ & $\begin{array}{r}490,216 \\
27,829,886 \\
840,768 \\
140,021 \\
34,336 \\
428,919 \\
867,637 \\
327,171 \\
30,080,280\end{array}$ \\
\hline 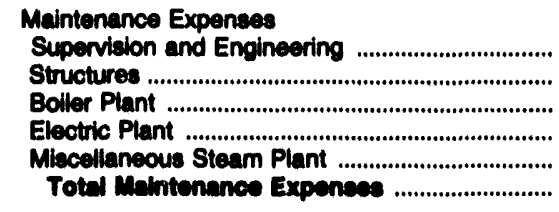 & $\begin{array}{r}488,505 \\
347,944 \\
2,457,681 \\
825,801 \\
287,489 \\
4,507,420\end{array}$ & $\begin{array}{r}500,081 \\
344,456 \\
2,480,515 \\
925,231 \\
307,417 \\
4,857,700\end{array}$ & $\begin{array}{r}491,463 \\
337,417 \\
2,491,829 \\
865,990 \\
293,397 \\
4,890,005\end{array}$ & $\begin{array}{r}476,798 \\
314,782 \\
2,411,316 \\
922,184 \\
275,188 \\
4,400,248\end{array}$ & $\begin{array}{r}451,834 \\
325,141 \\
2,421,938 \\
968,387 \\
280,000 \\
4,445,300\end{array}$ \\
\hline $\begin{array}{l}\text { Total steam Power Production } \\
\text { Expeneed }\end{array}$ & $34,824,051$ & $35,486,516$ & $39,616,037$ & $36,476,000$ & $35,335,579$ \\
\hline 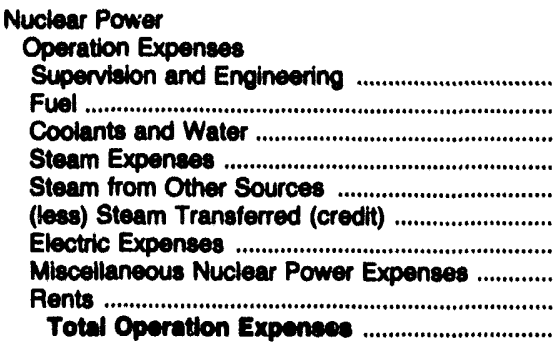 & $\begin{array}{r}1,656,843 \\
3,160,030 \\
140,437 \\
865,569 \\
69 \\
-1 \\
133,741 \\
2,075,250 \\
512,657 \\
8,544,590\end{array}$ & $\begin{array}{r}1,647,843 \\
3,430,697 \\
139,616 \\
802,299 \\
62 \\
-1 \\
116,857 \\
2,127,297 \\
529,295 \\
8,703,606\end{array}$ & $\begin{array}{r}1,480,778 \\
3,495,777 \\
131,570 \\
768,971 \\
245 \\
-1 \\
120,817 \\
1,892,230 \\
492,818 \\
8,303,200\end{array}$ & $\begin{array}{r}1,339,139 \\
3,274,944 \\
116,875 \\
740,819 \\
226 \\
-7 \\
105,613 \\
1,782,110 \\
436,503 \\
7,706,236\end{array}$ & $\begin{array}{r}1,118,589 \\
3,548,836 \\
118,120 \\
682,835 \\
105 \\
-38 \\
104,585 \\
1,880,774 \\
383,643 \\
7,828,694\end{array}$ \\
\hline 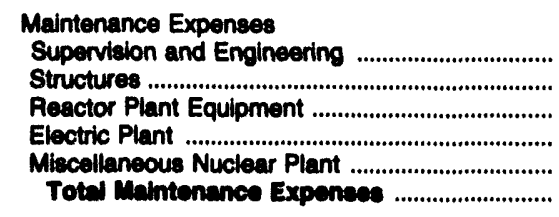 & $\begin{array}{r}716,714 \\
282,763 \\
1,018,768 \\
485,288 \\
550,871 \\
3,004,603\end{array}$ & $\begin{array}{r}670,910 \\
222,349 \\
919,134 \\
431,668 \\
665,795 \\
2,800,065\end{array}$ & $\begin{array}{r}876,427 \\
210,023 \\
942,502 \\
401,072 \\
538,976 \\
2,703,090\end{array}$ & $\begin{array}{r}641,004 \\
187,063 \\
897,632 \\
382,344 \\
489,542 \\
2,578,494\end{array}$ & $\begin{array}{r}529,388 \\
187,485 \\
809,834 \\
332,240 \\
468,095 \\
2,327,040\end{array}$ \\
\hline 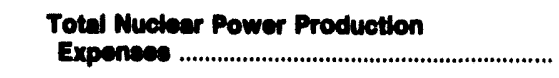 & $11,600,101$ & $11,003,021$ & $11,147,205$ & $10,374,720$ & $10,185,074$ \\
\hline 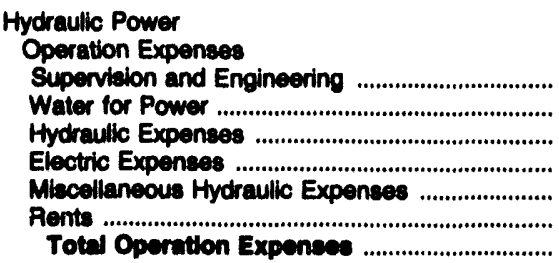 & $\begin{array}{r}31,934 \\
26,167 \\
35,128 \\
57,678 \\
52,151 \\
43,963 \\
247,020\end{array}$ & $\begin{array}{r}31,538 \\
26,405 \\
33,145 \\
54,709 \\
46,840 \\
39,081 \\
231,717\end{array}$ & $\begin{array}{r}30,685 \\
23,679 \\
28,658 \\
52,043 \\
43,043 \\
39,642 \\
21,643 \\
210,300\end{array}$ & $\begin{array}{r}27,849 \\
21,576 \\
31,444 \\
51,254 \\
42,083 \\
39,287 \\
213,403\end{array}$ & $\begin{array}{r}29,889 \\
26,192 \\
26,506 \\
51,504 \\
39,231 \\
38,218 \\
211,040\end{array}$ \\
\hline
\end{tabular}

See endnotes at end of this table. 
Table 11. Electric Operation and Maintenance Expenses for Major U.S. Investor-Owned Electric Utilities, 1988-1992 (Continued) (Thousand Dollars)

\begin{tabular}{|c|c|c|c|c|c|}
\hline Item & 1992 & $1991^{1}$ & 1990 & 1989 & 1888 \\
\hline 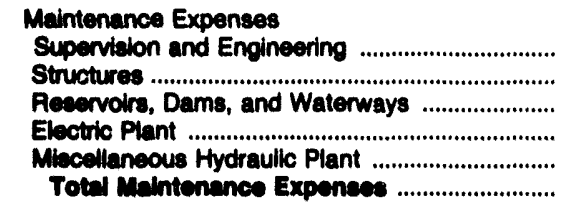 & $\begin{array}{r}26,829 \\
19,133 \\
44,775 \\
73,800 \\
23,443 \\
187,980\end{array}$ & $\begin{array}{r}25,657 \\
18,405 \\
42,140 \\
64,319 \\
21,987 \\
172,608\end{array}$ & $\begin{array}{r}23,276 \\
15,664 \\
46,338 \\
61,045 \\
21,914 \\
168,237\end{array}$ & $\begin{array}{r}21,682 \\
14,669 \\
42,508 \\
60,737 \\
16,734 \\
166,331\end{array}$ & $\begin{array}{r}20,113 \\
15,201 \\
34,271 \\
61,399 \\
13,830 \\
144,815\end{array}$ \\
\hline 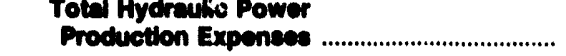 & 434,990 & 404,225 & 389,536 & 390,824 & 364,465 \\
\hline 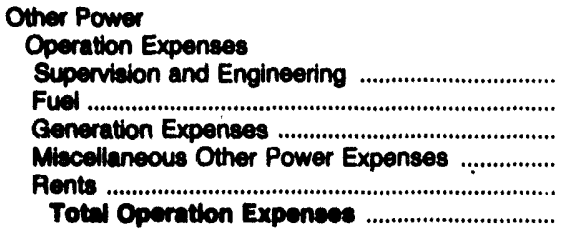 & $\begin{array}{r}16,454 \\
413,786 \\
33,312 \\
29,310 \\
68,207 \\
561,089\end{array}$ & $\begin{array}{r}17,140 \\
457,372 \\
31,523 \\
26,966 \\
66,353 \\
590,365\end{array}$ & $\begin{array}{r}15,989 \\
506,257 \\
30,953 \\
22,406 \\
66,844 \\
\mathbf{6 4 2 , 4 4 0}\end{array}$ & $\begin{array}{r}14,938 \\
736,675 \\
29,283 \\
20,868 \\
54,782 \\
\mathbf{9 5 6 , 6 4 6}\end{array}$ & $\begin{array}{r}12,951 \\
524,708 \\
24,788 \\
19,857 \\
50,583 \\
\mathbf{8 3 2 , 8 4 9}\end{array}$ \\
\hline 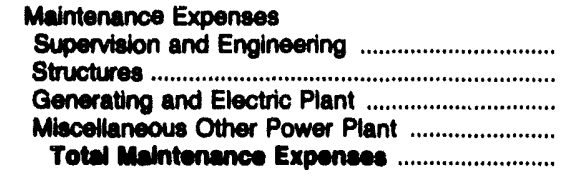 & $\begin{array}{r}17,268 \\
13,398 \\
134,004 \\
11,196 \\
175,864\end{array}$ & $\begin{array}{r}18,831 \\
14,001 \\
145,026 \\
13,209 \\
191,087\end{array}$ & $\begin{array}{r}17,898 \\
11,123 \\
149,160 \\
11,949 \\
180,131\end{array}$ & $\begin{array}{r}16,205 \\
11,111 \\
146,689 \\
8,266 \\
182,251\end{array}$ & $\begin{array}{r}15,547 \\
8,560 \\
131,145 \\
10,288 \\
165,686\end{array}$ \\
\hline $\begin{array}{l}\text { Total Other Power Production } \\
\text { Expenses }\end{array}$ & 736,983 & 790,422 & 832,580 & $1,038,797$ & 709,392 \\
\hline 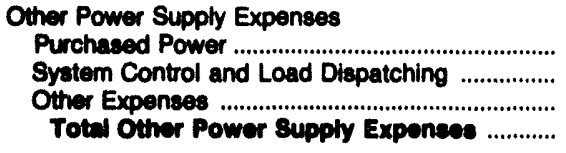 & $\begin{array}{r}26,212,238 \\
249,527 \\
847,822 \\
27,300,687\end{array}$ & $\begin{array}{r}24,169,252 \\
228,623 \\
1,149,801 \\
25,547,676\end{array}$ & $\begin{array}{r}20,340,504 \\
220,010 \\
659,689 \\
21,220,202\end{array}$ & $\begin{array}{r}17,959,051 \\
213,058 \\
120,868 \\
18,292,977\end{array}$ & $\begin{array}{r}16,061,339 \\
211,762 \\
349,831 \\
16,622,932\end{array}$ \\
\hline Totel Power Production Expenses ................. & $74,915,572$ & $73,832,858$ & $70,203,510$ & $68,553,227$ & $63,269,022$ \\
\hline 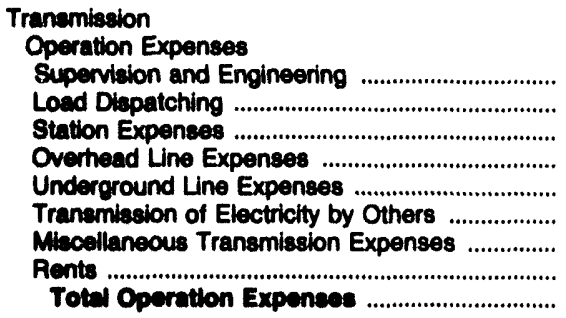 & $\begin{array}{r}151,808 \\
125,917 \\
166,684 \\
45,960 \\
34,108 \\
463,126 \\
126,328 \\
193,970 \\
1,308,101\end{array}$ & $\begin{array}{r}141,495 \\
125,892 \\
169,186 \\
47,293 \\
4,825 \\
461,310 \\
130,575 \\
166,609 \\
1,247,286\end{array}$ & $\begin{array}{r}139,787 \\
120,783 \\
164,349 \\
41,018 \\
4,583 \\
408,801 \\
116,164 \\
134,786 \\
1,130,272\end{array}$ & $\begin{array}{r}139,249 \\
116,339 \\
154,267 \\
40,011 \\
4,444 \\
417,629 \\
108,505 \\
133,104 \\
1,113,647\end{array}$ & $\begin{array}{r}138,005 \\
110,681 \\
151,278 \\
41,113 \\
5,324 \\
348,596 \\
105,254 \\
128,615 \\
1,028,891\end{array}$ \\
\hline
\end{tabular}

Sen endnotes at end of this table. 
Table 11. Electric Opreration and Malntenance Expenses for

Major U.S. Investor-Owned Electric Utilities, 1988-1992 (Continued)

(Thousand Dollars)

\begin{tabular}{l|c|c|c|c|c|}
\hline Itom & 1982 & $1991^{\prime}$ & 1990 & 1989 & 1988 \\
\hline
\end{tabular}

Maintenance Expenses

Superviaion and Enginearing

Structures.

Station Equioment

Overhead Lines

Underoround Lines

miseion Plant

Total Tranamleslon Expenses

Dietribution

Operation Expenses

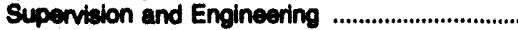

Loed Dispatching

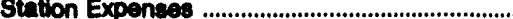

Overhead Line Expenses

Underground Line Expenses ...................................

Street Lighting and Signal System Expenses ....

Meter Expenses

Customer Installations Expenses ............................

Miscellaneous Distribution Expenses

Pents

Totel Operation Expenses.

\section{6,591}

18,046

305,490

278,708

23,672

26,038

718,439

$2,028,538$

$$
\begin{array}{r}
64,771 \\
18,579 \\
316,329 \\
289,333 \\
19,823 \\
17,754
\end{array}
$$

728,589

$1,973,875$

$1,820,684$
59,498

16,10

288,158

271,371

20,311

16,397

671,838

$1,785,385$

$1,667,810$

Maintenance Expenses

Supervision and Engineoring

Structures

Station Equipment

Overheed Lines

Underground Lir

Line Transformers

Street Lighting and Signal Systems

Moters

Miscellaneous Distribution Plant ...........................

Totw Maimtenence Expenses

Total Distribution Expensee

..................................

Customer Accounts Expenses

Superviaion

Meter Reading Expenses

Customer Records and Collection Expenses ....

Uncollectible Accounts ...........................................

Mbcellaneous Customer Accounts Expenses ...

Total Customer Accounts Expenses

Customer Senvice and Informational Expenses

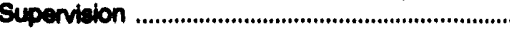

Customer Aseistance Expenses .............................

Informational and Instructional Expenses ............

Miscellaneous Customer Service

and Intormational Expenses

Totw Cutomer Eervice and

Informationd Expenses ..

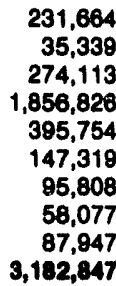

$5,691,381$

163,820

588,822

$1,851,268$

665,207

88,012

$3,347,124$

$1,124,816$

117,072

153,779

$1,531,389$

$$
\begin{array}{r}
421,963 \\
69,636 \\
214,828 \\
336,189 \\
170,901 \\
57,446 \\
376,255 \\
203,087 \\
578,366 \\
101,821 \\
2,530,490
\end{array}
$$

398,378
68,095
214,805
321,395
171,209
55,898
370,780
196,112
550,194
86,893
$2,443,850$

390,959

65,091

211,722

311,274

169,330

56,191

362,081

187,468

536,518

93,328

$2,393,944$

218,724

30,052

265,733

$1,804,712$

377,753

145,972

93,477

60,276

59,549

$\mathbf{3}, 056,247$

$3,220,512$

$5,751,002$

$5,500,108$

211,788

30,811

258,081

$1,763,250$

359,758

154,537

87,876

59,427

47,340

$2,972,868$

382,312

62,076

213,889

302,390

157,785

53,263

351,808

188,085

520,135

89,207

$2,331,160$

204,050

29,175

257,631

$1,679,381$

356,511

157,057

80,550

57,617

59,307

$2,001,270$

$6,222,430$

151,999
543,662
$1,859,297$
555,328
92,926
$3,903,212$

148,354

527,928

$1,797,786$

689,683

83,493

$3,247,245$

138,812

510,602

$1,737,881$

528,543

76,990

$2,002,820$

132,403

499,603

$1,637,602$

544,148

80,424

$2,004,170$

See endinotes at end of this table.

125,049
$1,088,346$
145,592

101,928

867,586

132,293

92,519

78,828

$1,180,638$
97,306

686,843

114,442

94,813

621,056

113,041

60,883

59,053

950,473
897,093 
Table 11. Electric Operation and Maintenance Expenses for Major U.S. Investor-Owned Electric Utilities, 1988-1992 (Continued) (Thousand Dollars)

\begin{tabular}{|c|c|c|c|c|c|}
\hline Item & 1992 & $1991^{1}$ & 1990 & 1989 & 1888 \\
\hline 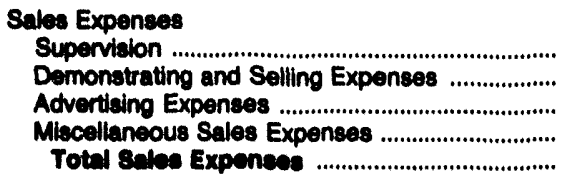 & $\begin{array}{r}23,620 \\
120,627 \\
19,614 \\
34,786 \\
196,647\end{array}$ & $\begin{array}{r}24,239 \\
113,456 \\
20,483 \\
45,053 \\
203,230\end{array}$ & $\begin{array}{r}23,213 \\
123,168 \\
28,369 \\
37,484 \\
212,233\end{array}$ & $\begin{array}{r}24,062 \\
118,986 \\
31,401 \\
34,195 \\
200,066\end{array}$ & $\begin{array}{r}19,932 \\
102,128 \\
29,049 \\
25,808 \\
177,000\end{array}$ \\
\hline 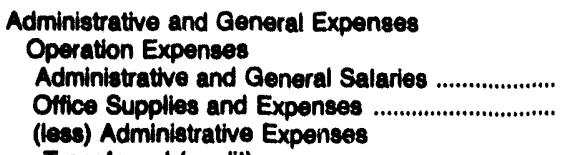 & $\begin{array}{l}2,899,916 \\
1,362,608\end{array}$ & $\begin{array}{l}2,767,379 \\
1,365,296\end{array}$ & $\begin{array}{l}2,723,577 \\
1,293,454\end{array}$ & $\begin{array}{l}2,511,485 \\
1,168,659\end{array}$ & $\begin{array}{l}2,388,678 \\
1,0^{-}, 9,120\end{array}$ \\
\hline 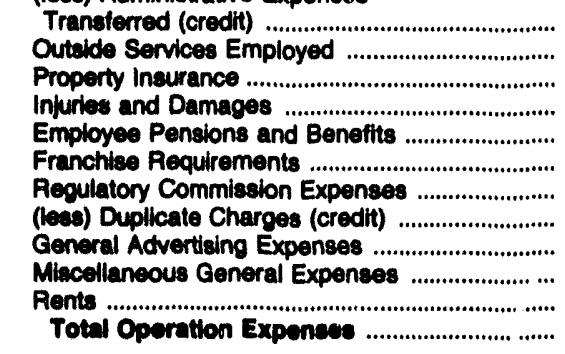 & $\begin{array}{r}368,353 \\
979,922 \\
470,929 \\
820,673 \\
3,492,234 \\
279,022 \\
327,141 \\
232,344 \\
47,079 \\
961,507 \\
368,243 \\
11,400,575\end{array}$ & $\begin{array}{r}357,776 \\
985,932 \\
479,444 \\
768,207 \\
3,344,941 \\
265,953 \\
322,476 \\
192,527 \\
51,408 \\
1,059,616 \\
338,140 \\
11,169,480\end{array}$ & $\begin{array}{r}348,980 \\
890,416 \\
503,111 \\
787,732 \\
2,924,205 \\
251,935 \\
315,916 \\
197,050 \\
55,921 \\
633,717 \\
337,220 \\
10,371,198\end{array}$ & $\begin{array}{r}312,018 \\
756,540 \\
528,754 \\
721,772 \\
2,548,579 \\
227,431 \\
260,654 \\
183,466 \\
53,953 \\
897,799 \\
371,641 \\
9,546,703\end{array}$ & $\begin{array}{r}307,1565 \\
767,177 \\
588,020 \\
788,4,36 \\
2,424,239 \\
211,000 \\
2 /, 7,199 \\
179,107 \\
56,008 \\
863,730 \\
305,672 \\
8,294,602\end{array}$ \\
\hline 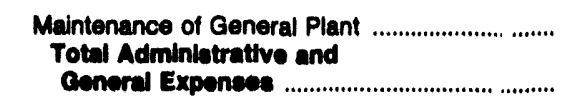 & $\begin{array}{r}357,752 \\
11,768,327\end{array}$ & $\begin{array}{r}346,197 \\
11,642,687\end{array}$ & $\begin{array}{r}330,388 \\
10,701,683\end{array}$ & $\begin{array}{r}309,582 \\
9,058,375\end{array}$ & $\begin{array}{r}288,622 \\
0,587,126\end{array}$ \\
\hline 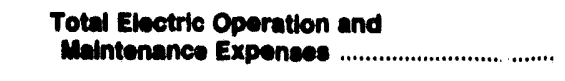 & $99,466,938$ & $97,058,171$ & $92,895,977$ & $87,722,760$ & $\mathbf{8 3 , 6 5 6 , 6 4 9}$ \\
\hline 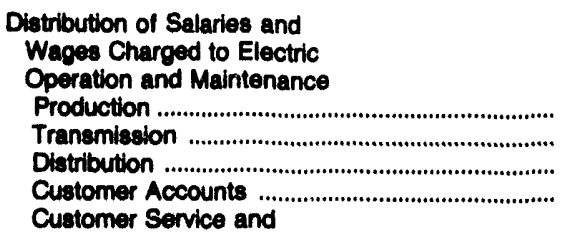 & $\begin{array}{r}6,070,543 \\
544,844 \\
2,712,704 \\
1,606,282\end{array}$ & $\begin{array}{r}6,210,064 \\
581,234 \\
2,765,725 \\
1,588,841\end{array}$ & $\begin{array}{r}5,980,703 \\
570,024 \\
2,681,582 \\
1,642,789\end{array}$ & $\begin{array}{r}5,754,165 \\
565,592 \\
2,634,407 \\
1,505,837\end{array}$ & $\begin{array}{r}5,428,706 \\
587,588 \\
2,558,238 \\
1,463,769\end{array}$ \\
\hline 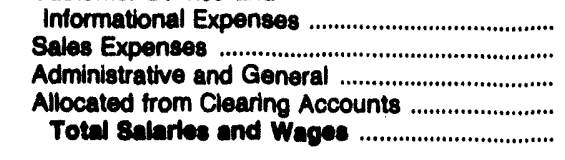 & $\begin{array}{r}414,655 \\
98,071 \\
2,7-1,709 \\
1,075,861 \\
16,000,250\end{array}$ & $\begin{array}{r}413,890 \\
94,619 \\
2,713,028 \\
1,559,857 \\
15,027,268\end{array}$ & $\begin{array}{r}385,871 \\
82,801 \\
2,658,147 \\
1,447,489 \\
15,349,506\end{array}$ & $\begin{array}{r}361,424 \\
96,397 \\
2,530,457 \\
1,422,958 \\
14,061,236\end{array}$ & $\begin{array}{r}352,369 \\
75,542 \\
2,413,811 \\
1,429,187 \\
14,267,210\end{array}$ \\
\hline 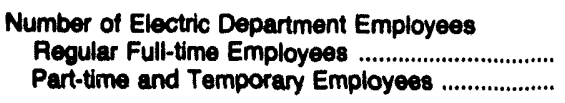 & $\begin{array}{r}466,253 \\
14,752\end{array}$ & $\begin{array}{r}482,127 \\
15,003\end{array}$ & $\begin{array}{r}484,651 \\
16,758\end{array}$ & $\begin{array}{r}475,068 \\
18,837\end{array}$ & $\begin{array}{r}474,054 \\
32,722\end{array}$ \\
\hline Total Enctric Departmont Employees .......... & 481,005 & 497,130 & 501,400 & 494,003 & 606,776 \\
\hline
\end{tabular}

- Excluded are five independent power producers jurisdictional to the Federal Energy Regulatory Commiseion which were included in the prior year's publication.

Note: Operating expenses include fuel expenditures. Totals may not equal sum of components because of independent rounding. Detall data are provided in Table 41. Due to Its emergence from bankruptcy, the 1991 financial statements for the Publlc Service Company of New Hampahire financial statements for 1981 are from May 16 through December 31. Excluded are the independent power producers and cooperatives juriadictional to the Federal Energy Regulatory Commission.

Source: Federal Energy Regulatory Commission, FERC Form 1, "Annual Report of Major Electric Utillities, Licensees and Others." 
Table 12. Ratios Based on Electric Operation and Maintenance Expences for Major U.S. Investor-Owned Electric Utilities, 1888-1982

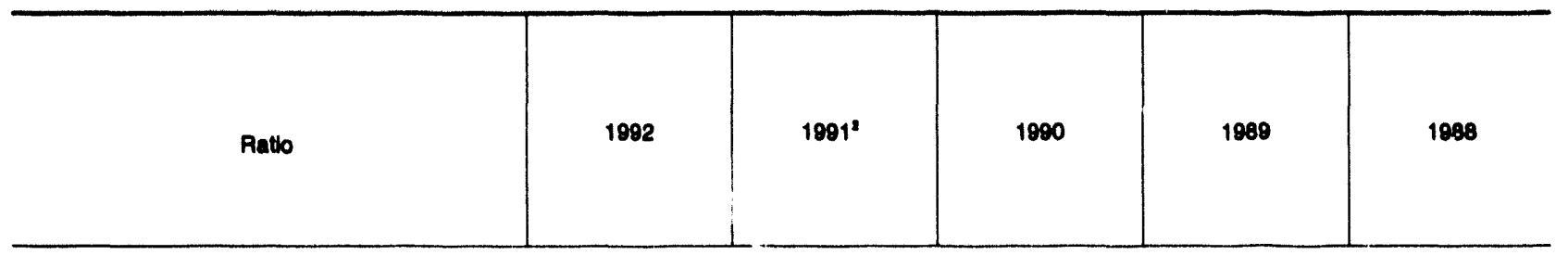

Operation and Maintenance Expenses

es Percent of

Electric Operating Aevenues

68.7

53.7

59.0

58.1

68.1

2ules Expense

Percent of Total Electric

Operation and Maintenance Expenses ................

Percent of Electric Operating Revenues

per Klowntthour Sold (mills)

per Customer (dollara)

Customer Senvice and Informational Expenses

Percent of Total Electrio

Operation and Manintenance Expenses.

Percent of Electric Operating Revenues ..............

per Kilowatthour Sold (mills)

per Customer (dollart)

Customer Accounts Expenses

Percent of Total Electric

Operation and Malntenance Expenses

Percent of Electric Operating Revenues .............. per Kllowatthour Sold (mills)

per Customer (dollars)

Maintenance Charges

Percent of Total Electric

Operation and Maintenance Expenses

Percent of Electric Operating Revenues ...............

Percent of Gross Electric Plant

Procuction Expenses

Percent of Total Electric

Operation and Maintenance Expenses

Percent of Electric Operating Revenues

44.2

per Klowntthour Sold (mille)

Tranemisaion Expenses

Percent of Total Electric

Operation and Meintenance Expenses

Percent of Electric Operating Revenues

per Kllowatthour Sold (milli)

Distribution Expenses

Percent of Total Electric

Operation and Maintenance Expenses ................

Percent of Electric Operating Revenues ..............

per Kllowatthour Sold (mills)

per Customer (dollars)

$\begin{array}{rr}5.7 & 5.9 \\ 3.4 & 3.4 \\ 2.2 & 2.2 \\ 66.56 & 67.98\end{array}$

5.9
3.5
2.2
65.95

Fund Cost'

Percent of Total Electric

Operation and Maintenance Expenses

Percent of Electric Operating Revenues 
Table 12. Ratlos Based on Electric Oporation and Malntenance Expenses for Major U.8. Investor-Owned Electric Utilitios, 1988-1992 (Continued)

\begin{tabular}{l|c|c|c|c|c}
\hline Ratio & 1992 & $1901^{2}$ & 1090 & 1989 & 1068 \\
\hline
\end{tabular}

Nucher Fuel Costs

Percent of Total Electric

Operation and Maintenance Expenees .................

Percent of Electio Operating Aevenum

per Kllowntthour Sold (millo)

3.5

2.1

1.3

28.4
16.5

10.1

24.7
14.5

14.5
0.4

21.9
12.9

12.9
8.3

20.5

11.8

7.5

19.2

11.2

6.8

Adminiatrative and General Expenses

Percent of Total Eloctric Electric Operation

and Maintenance Expenses

Percent of Electirc Operrating Pevenum

per Klowatthour sold (millb)

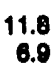

6.9

4.5

11.8
6.0
4.6

11.6
6.8
4.4

11.2
6.8
4.1

11.4

6.6

Solerive and Weres

Percent of Total Electrio

Operntion and Mintenance Expenses .................

Pereent of Electric Operating Revenues

per Klowatthour Sold (millo)

$\begin{array}{rr}15.9 & 16.3 \\ 9.3 & 9.5 \\ 6.1 & 6.2\end{array}$

16.6
9.8
6.3

16.9
9.8

17.0

Penaions and Benefits

Percent of Total Electric

Operation and Maintenance Expenses .................

Percent of Electric Operating Revenues

3.5

2.1

3.4

2.0

3.1

1.8
1.2

2.9

1.7

2.9

1.3

1.3

2.8

2.8

3.0

2.0

2.6

as a percent of Adminietrative and

Ceneral Expenses ....................................................

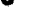

I Excludes cost of muclear tuel.

- Excluded are five independent power producers furbdictional to the Federal Energy Regulatory Commiacion which were included in the prior year's publication.

Note: Totals may not equal sum of components because of independent rounding. Due to its emergence from bankruptoy, the 1891 financid statemente for the Public service Company of New Hampehine are from May 18 through December 31 . Excluded are the independent power pro. ducere and cooperative Jurisdictional to the Federal Energy Regulatory Commiadion.

Source: Federal Enengy Regulatory Commiasion, FERC Form 1. "Annual Report of Major Electric Uthltiee, Licensees and Othere." 
Table 13. Pereont of Total Electric Operation and Maintenance Expenees for Major U.8. Inveator-Owned Electrlc Utilltios, 1988-1092

\begin{tabular}{|c|c|c|c|c|c|}
\hline Item & 1902 & $1901^{\prime}$ & 1980 & 1889 & 1988 \\
\hline \multicolumn{6}{|l|}{$\begin{array}{l}\text { Steam Power } \\
\text { Operation Expenees }\end{array}$} \\
\hline Other Operation Expenees & $\begin{array}{r}26.8 \\
3.7 \\
30.6\end{array}$ & $\begin{array}{r}28.0 \\
3.6 \\
31.6\end{array}$ & $\begin{array}{r}30.8 \\
3.7 \\
34.5\end{array}$ & $\begin{array}{r}33.0 \\
3.6 \\
36.6\end{array}$ & $\begin{array}{r}33.3 \\
3.7 \\
38.8\end{array}$ \\
\hline 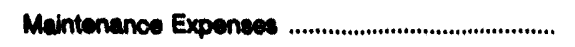 & 4.5 & 4.7 & 4.9 & 6.0 & 5.3 \\
\hline Total Evean Power Proctuotion & 38.0 & 30.2 & 39.4 & 41.8 & 42.2 \\
\hline \multicolumn{6}{|l|}{$\begin{array}{l}\text { Nuclear Power } \\
\text { Operation Expenses }\end{array}$} \\
\hline Futher Operation Expencee & $\begin{array}{l}3.2 \\
6.4 \\
8.8\end{array}$ & $\begin{array}{l}3.5 \\
5.5 \\
9.0\end{array}$ & $\begin{array}{l}3.8 \\
5.3 \\
9.0\end{array}$ & $\begin{array}{l}3.7 \\
6.2 \\
8.9\end{array}$ & $\begin{array}{l}4.2 \\
5.1 \\
9.4\end{array}$ \\
\hline 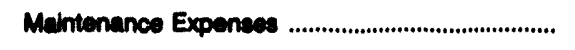 & 3.1 & 2.8 & 3.0 & 2.8 & 2.8 \\
\hline Totw Muclear Power Produotion & 11.7 & 11.8 & 12.0 & 11.8 & 12.1 \\
\hline 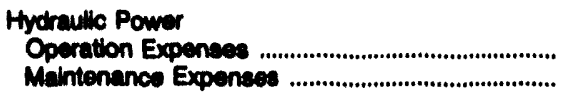 & .2 & .2 & .2 & $\begin{array}{l}.2 \\
.2\end{array}$ & .3 \\
\hline Total Hydraule Power & .4 & 4 & 4 & .4 & .4 \\
\hline \multicolumn{6}{|l|}{$\begin{array}{l}\text { Other Power } \\
\text { Operation Expenses }\end{array}$} \\
\hline $\begin{array}{l}\text { Fuel } \\
\text { Other } \\
\text { Total Operation Expensed }\end{array}$ & $\begin{array}{l}.4 \\
.1 \\
.6\end{array}$ & $\begin{array}{l}.5 \\
.1 \\
.6\end{array}$ & $\begin{array}{l}.5 \\
.1 \\
.7\end{array}$ & $\begin{array}{r}.8 \\
.1 \\
1.0\end{array}$ & $\begin{array}{l}.6 \\
.1 \\
.8\end{array}$ \\
\hline 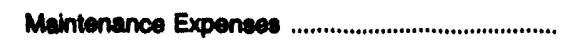 & .2 & .2 & .2 & .2 & .2 \\
\hline Totwl Other Powner Production & .7 & .8 &.$\bullet$ & 1.2 & 1.0 \\
\hline 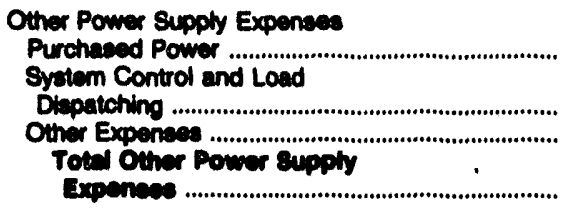 & $\begin{array}{r}26.4 \\
.3 \\
.9 \\
27.5\end{array}$ & $\begin{array}{r}24.7 \\
.2 \\
1.2 \\
29.1\end{array}$ & $\begin{array}{r}21.9 \\
.2 \\
.7 \\
22.9\end{array}$ & $\begin{array}{r}20.5 \\
.2 \\
.1 \\
20.9\end{array}$ & $\begin{array}{r}19.2 \\
.3 \\
.4 \\
10.9\end{array}$ \\
\hline $\begin{array}{l}\text { Total Power Production } \\
\text { Expenice ................................................... }\end{array}$ & 76.3 & 75.4 & 76.6 & 75.9 & 75.6 \\
\hline Operation Expenses & $\begin{array}{r}1.3 \\
.7\end{array}$ & $\begin{array}{r}1.3 \\
.7\end{array}$ & $\begin{array}{r}1.2 \\
.7\end{array}$ & $\begin{array}{r}1.3 \\
.8\end{array}$ & $\begin{array}{r}1.2 \\
.8\end{array}$ \\
\hline
\end{tabular}

See endriotes at end of this table. 
Table 13. Porcent of Total Electric Operation and Malntenance Expenses for Major U.S. Investor-Owned Electric Utilities, 1988-1992 (Continued)

\begin{tabular}{|c|c|c|c|c|c|}
\hline Item & 1092 & $1991^{\prime}$ & 1990 & 1889 & 1988 \\
\hline Toted Tranemienion Expences ............................ & 2.0 & 2.0 & 2.0 & 2.0 & 2.0 \\
\hline 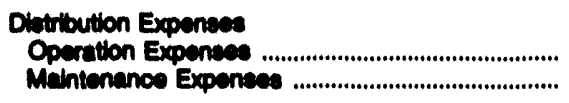 & $\begin{array}{l}2.6 \\
3.2\end{array}$ & $\begin{array}{l}2.6 \\
3.3\end{array}$ & $\begin{array}{l}2.6 \\
3.3\end{array}$ & $\begin{array}{l}2.7 \\
3.4\end{array}$ & $\begin{array}{l}2.8 \\
3.5\end{array}$ \\
\hline 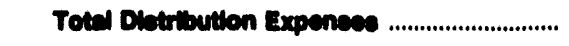 & 6.7 & 5.0 & 6.9 & 6.1 & 6.2 \\
\hline 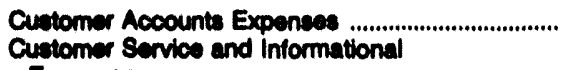 & 3.4 & 3.3 & 3.6 & 3.4 & 3.5 \\
\hline Expenece & $\begin{array}{r}1.5 \\
.2\end{array}$ & $\begin{array}{r}1.5 \\
.2\end{array}$ & $\begin{array}{r}1.3 \\
.2\end{array}$ & $\begin{array}{r}1.1 \\
.2\end{array}$ & $\begin{aligned} 1.1 & -1 \\
.2 & -1\end{aligned}$ \\
\hline Total Cubtomer Expentese ...................................... & 6.1 & $\mathbf{5 . 0}$ & 5.0 & 4.7 & 4.8 \\
\hline 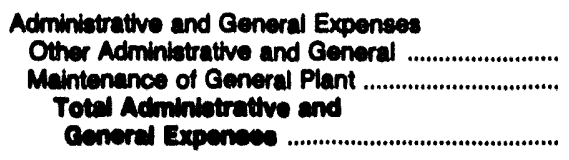 & $\begin{array}{r}11.5 \\
.4 \\
11.8\end{array}$ & $\begin{array}{r}11.4 \\
.4 \\
11.8\end{array}$ & $\begin{array}{r}11.2 \\
.4 \\
11.6\end{array}$ & $\begin{array}{r}10.9 \\
.4 \\
11.2\end{array}$ & $\begin{array}{r}11.0 \\
.4 \\
11.4\end{array}$ \\
\hline 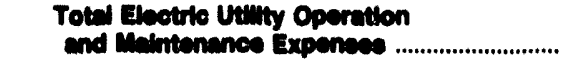 & 100.0 & 100.0 & 100.0 & 100.0 & 100.0 \\
\hline
\end{tabular}

1 Excluded are five independent power producers Juriadictional to the Federal Energy Regulatory Commiseion which were included in the prior year's publication.

Note: Totale may not equal sum of components because of independent rounding. Due to its emergence from bankruptcy, the 1991 financial statements for the Public Service Company of New Hampehire are from May 16 through December 31. Excluded are the Independent power producere and cooperatives jurlidictional to the Federal Energy Regulatory Commiseion.

Source: Federal Energy Regulatory Commiselion, FERC Form 1, "Annual Report of Major Electric Utilities, Licensees and Others." 
Table 14. Average Power Production Expenses for Plants Owned by Major U.S. Investor-Owned Electric Utilitles, 1988-1992

(Mills per Kilowatthour)

\begin{tabular}{|c|c|c|c|c|}
\hline Year & Operation' & Malntenance & Fual & Total \\
\hline 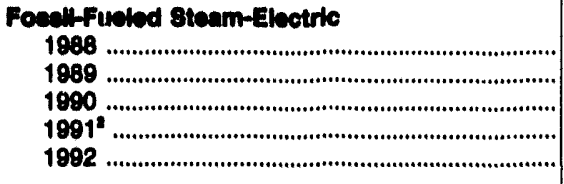 & $\begin{array}{l}1.86 \\
1.89 \\
2.21 \\
2.29 \\
2.38\end{array}$ & $\begin{array}{l}2.86 \\
2.78 \\
2.97 \\
2.98 \\
2.95\end{array}$ & $\begin{array}{l}17.98 \\
18.28 \\
18.56 \\
17.91 \\
17.49\end{array}$ & $\begin{array}{l}22.70 \\
23.05 \\
23.72 \\
23.17 \\
22.83\end{array}$ \\
\hline 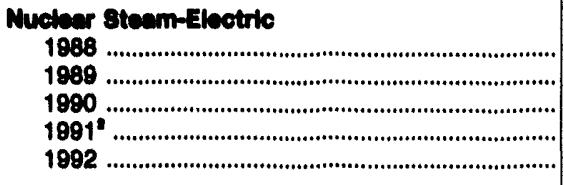 & $\begin{array}{r}9.50 \\
10.29 \\
10.04 \\
10.49 \\
10.43\end{array}$ & $\begin{array}{l}5.17 \\
5.87 \\
5.68 \\
5.50 \\
5.93\end{array}$ & $\begin{array}{l}7.88 \\
7.46 \\
7.18 \\
6.71 \\
6.12\end{array}$ & $\begin{array}{l}22.65 \\
23.61 \\
22.81 \\
22.70 \\
22.48\end{array}$ \\
\hline 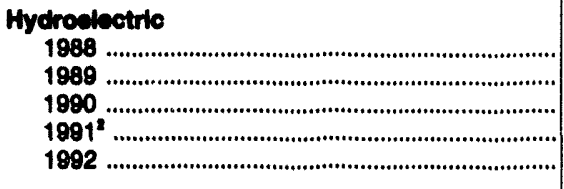 & $\begin{array}{l}4.45 \\
3.27 \\
3.35 \\
3.88 \\
4.33\end{array}$ & $\begin{array}{l}3.05 \\
2.39 \\
2.58 \\
2.89 \\
3.30\end{array}$ & $\begin{array}{l}\text { - } \\
\cdots \\
\cdots \\
\cdots\end{array}$ & $\begin{array}{l}7.60 \\
5.68 \\
5.93 \\
6.76 \\
7.63\end{array}$ \\
\hline 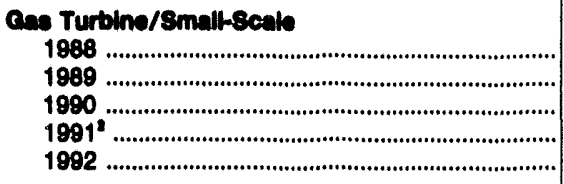 & $\begin{array}{r}6.61 \\
5.66 \\
8.76 \\
9.61 \\
10.18\end{array}$ & $\begin{array}{r}10.11 \\
8.60 \\
12.23 \\
12.93 \\
12.15\end{array}$ & $\begin{array}{l}32.08 \\
34.77 \\
32.57 \\
30.96 \\
28.59\end{array}$ & $\begin{array}{l}48.78 \\
49.03 \\
53.58 \\
53.51 \\
50.92\end{array}$ \\
\hline
\end{tabular}

'Operation expenses include rent.

Excluded are five independent power producers jurisdictional to the Federal Energy Regulatory Commission which were included in the prior year's publication.

Note: Totals may not equal sum of components because of independent rounding. Hydroelectric data include pumped storage.

Small-scale electric plants include internal combustion, wind, and solar. Due to its emergence from bankruptcy, the 1891 financtal statements for the Public Service Company of New Hampshire are from May 16 through December 31. Excluded are the independent power producers and cooperathes jurisdictional to the Federal Energy Regulatory Commission.

Source: Federal Energy Regulatory Commission, FERC Form 1, "Annual Report of Major Electric Utilities, Licensees and Others." 
Table 15. Number of Consumers, Sales, and Operating Revenue for Major U.S. Investor-Owned Electric Utilities, 1988-1992

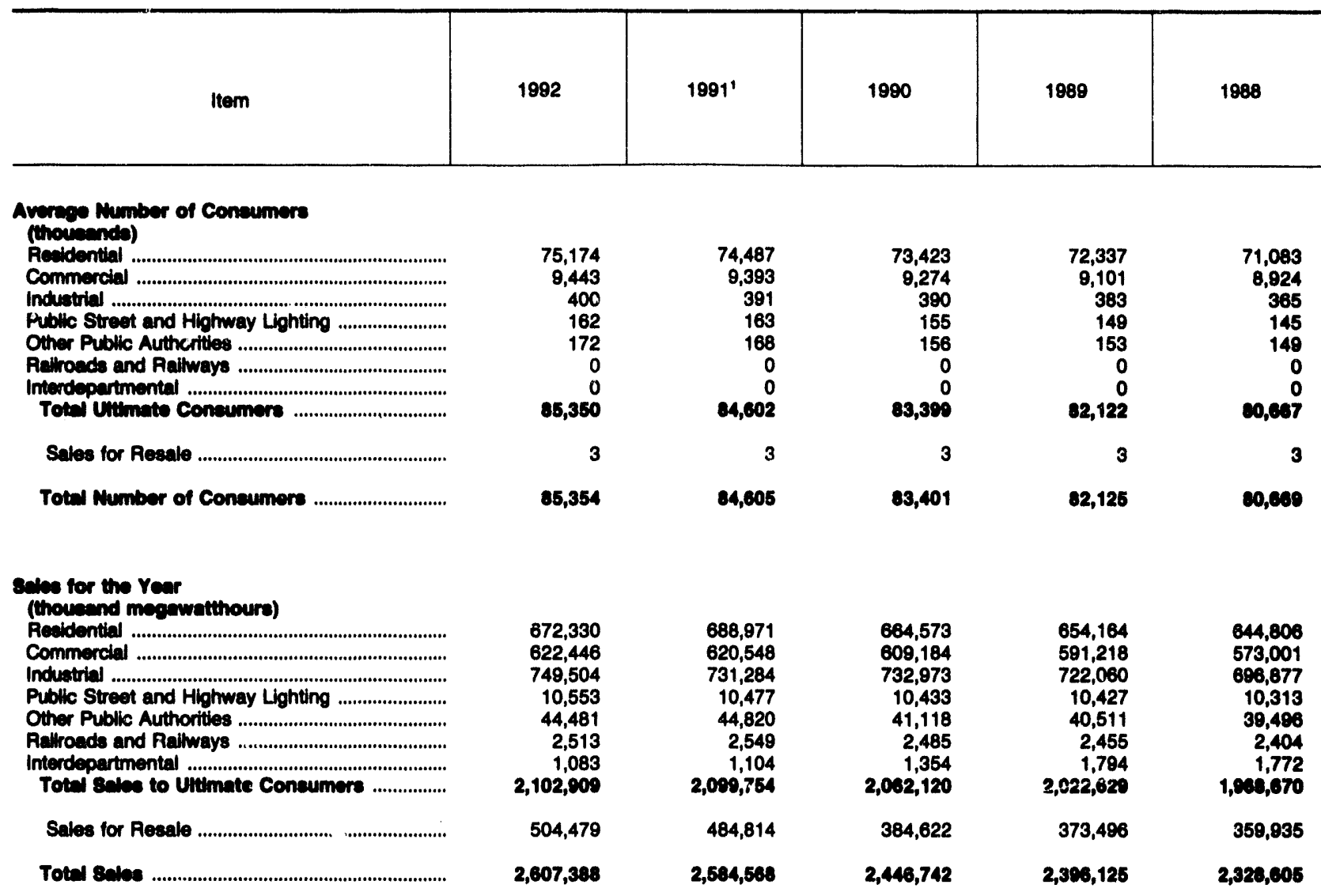

\section{Operating Rovenuse for the Year \\ (thousend dollers) \\ Rosidential \\ Industrial. \\ Public Street and Highway Lighting \\ Other to Public Authorities \\ Rallroads and Raikways \\ Interdepartmental \\ Toted Revenues from seles to \\ Uitimate Consumere \\ Sales for Resale \\ Total Rovenues from seles of Eloctively}

(leas) Provision for Rate Refunds

Net Revenuse from sabe of Electrictly

Other Operating Revenues

Totel Elective Uanty

Operating Revenues

\section{$58,064,724$ \\ $48,809,327$ \\ $37,268,708$ \\ $1,308,057$ \\ $2,671,873$ \\ 178,349 \\ 69,805}

$148,370,842$

$17,459,169$

$165,830,011$

348,036

$185,481,976$

$4,006,060$

$169,498,035$

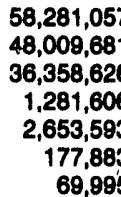

$54,505,586$

$45,641,027$

$35,557,713$

$1,237,564$

$2,395,695$

166,013

$\mathbf{9 6 , 8 0 4}$

$146,832,442$

$16,975,779$

$163,008,221$

168,309

$183,639,912$

$3,163,931$

$168,803,843$

$130,600,402$

$14,936,606$

:."

$154,637,00$

480,251

$154,059,757$

$3,221,779$

$157,278,537$
$52,144,247$

$43,368,826$

$34,335,497$

$1,202,698$

2,326,252

157,708

101,653

$50,202,932$

$41,098,216$

$32,865,918$

$1,176,527$

2,237,873

149,870

110,092

$133,634,080$

$127,041,62$

$14,349,788$

$13,741,443$

$147,094,04$

$141,602,971$

179,937

182,075

$147,004,731$

141,390,009

$3,088,586$

$2,538,524$

$150, \bullet 03,317$

$148,980,480$

- Excluded are ifve independent power producers jurisdictional to the Federal Energy Regulatory Commission which were included in the prior year's publication.

Note: Totals may not equal sum of components because of independent rounding. Detall data are provided in Table 40 . Dus to its emergence from bankruptcy, the 1891 financial statements for the Public Service Company of New Hampshire are from May 16 through December 31 ; the January 1 through May 15, 1991, data values are 2,374 thousands megawatthours $(199,489$ thousand dollars) for 8 ales to ultimate consumers and 1,765 thousand megawatthours (47,893 thousand dollars) for sales for resale. Excluded are the independent power producers and cooperatives jurisdictional to the Federal Energy Regulatory Commission.

Source: Federal Energy Regulatory Commission, FERC Form 1, "Annual Report of Major Electric Utilities, Licensees and Others." 
Table 16. Ratios Based on Number of Consumers, Sales, and Operating Revenue for Major U.S. Investor-Owned Electric Utilities, 1988-1992

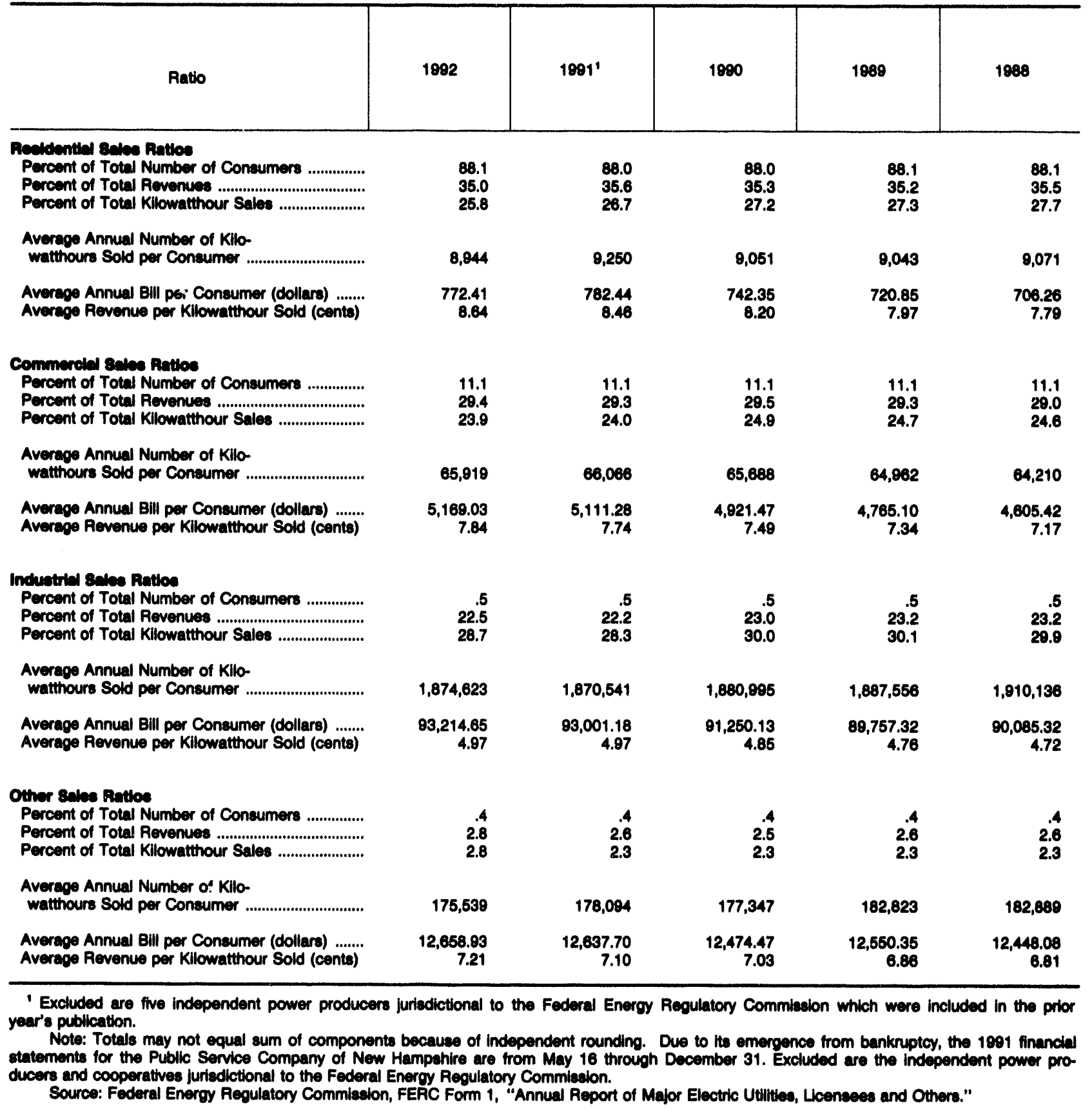


Figure 1. Average Revenue per Kllowatthour for Major U.S. Investor-Owned Electric Utilities, 1988-1982

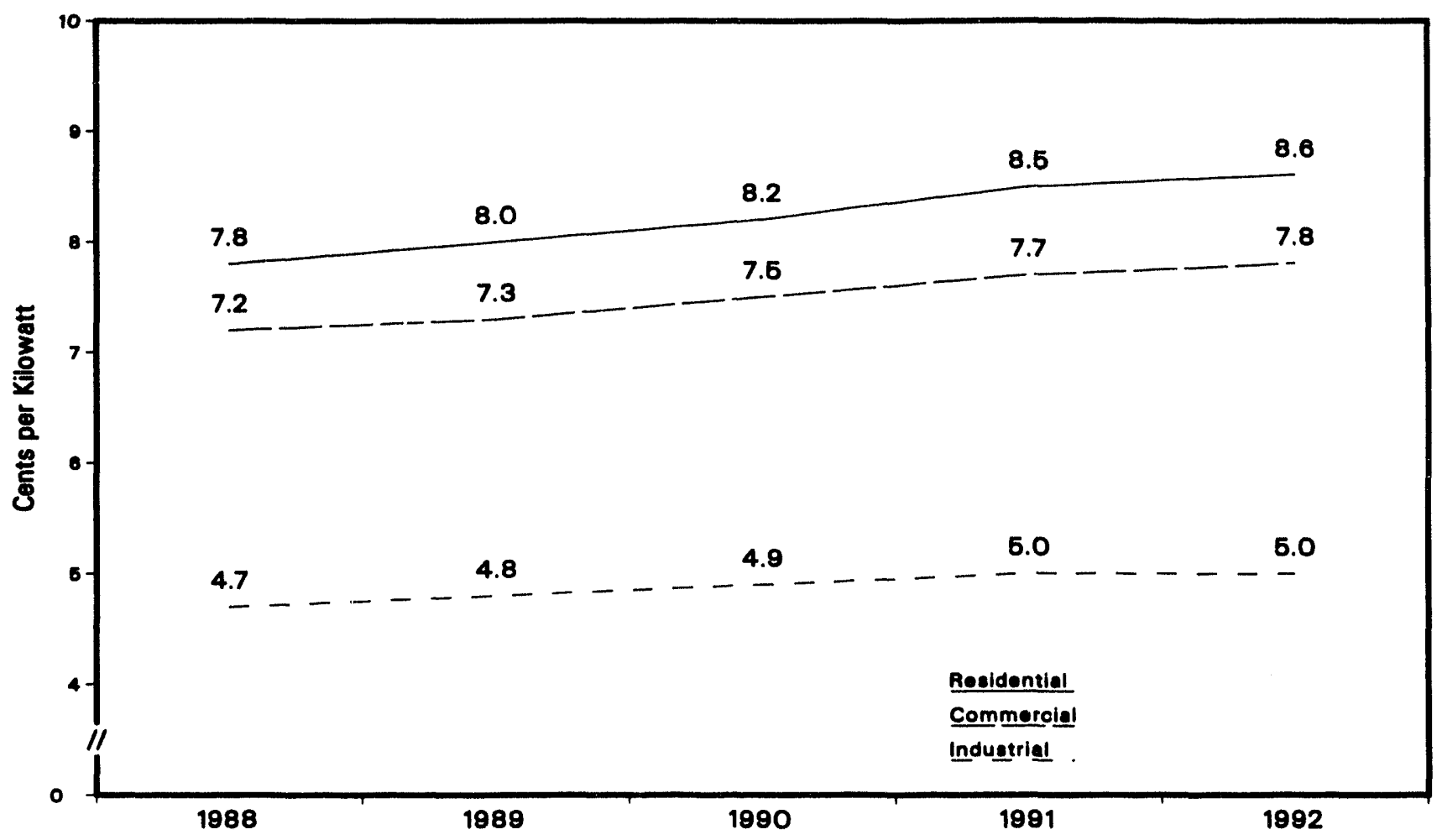

Note: Summary Date ere provided in Table 10

Souroe: Federal Energy Reguletory Commiesion, FERC Form 1. 'Annual Report of Mejor Electric Utilities, Liceneses, and Othere.'

Figure 2. Sales of Electricity for Major U.S. Investor-Owned Electric Utilitles, 1988-1992

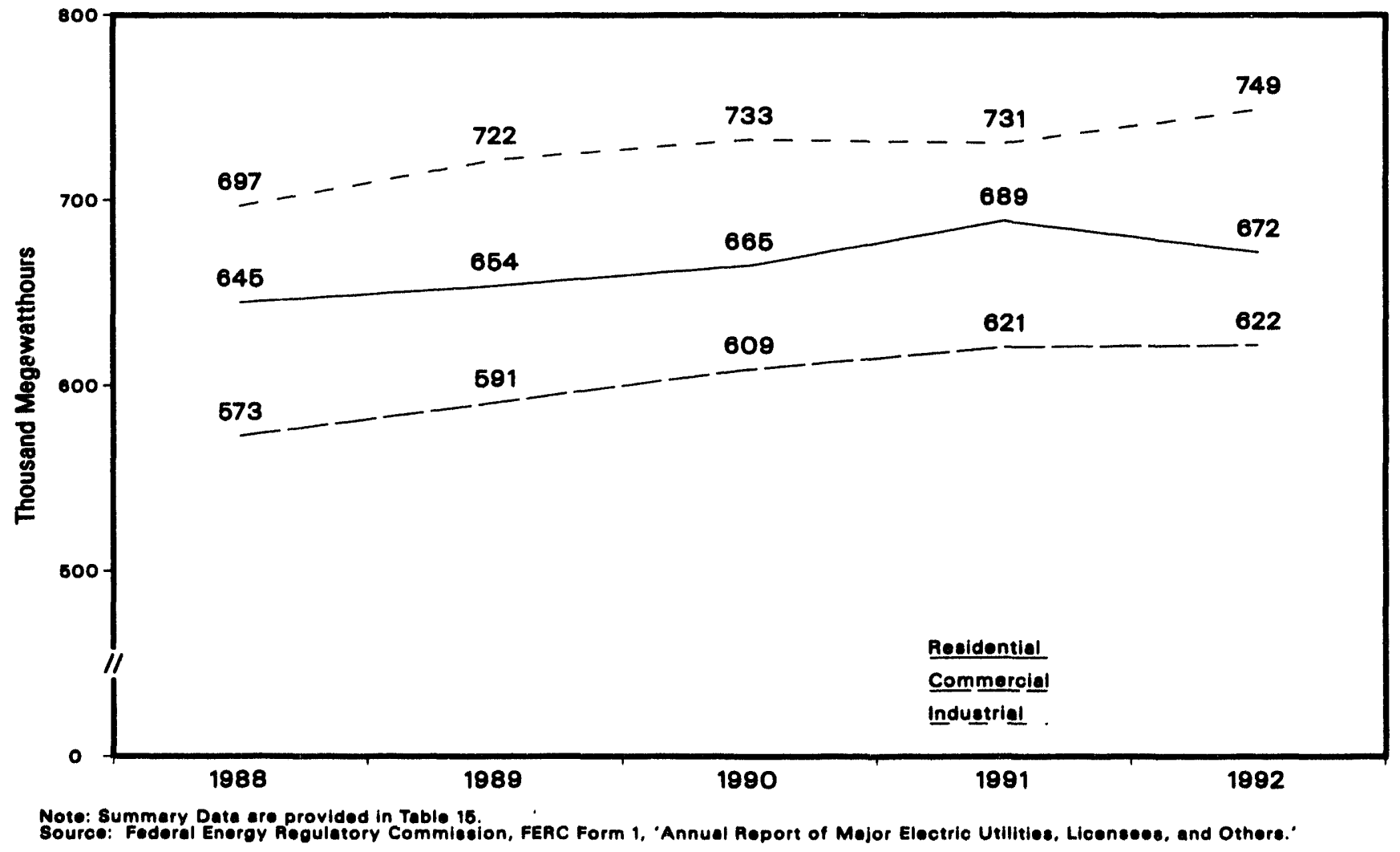


Table 17. Comparison of Selected Statement of Income and Financlal Data for Major U.S. Inveator-Owned Electric Utilities, 1988-1992

\begin{tabular}{|c|c|c|c|c|c|}
\hline ltem & $\begin{array}{l}1892 \\
\text { (bllion } \\
\text { dolliara) }\end{array}$ & $\begin{array}{l}1991^{\prime} \\
\text { (billion } \\
\text { dollare) }\end{array}$ & $\begin{array}{l}1980 \\
\text { (billion } \\
\text { dollars) }\end{array}$ & $\begin{array}{l}1989 \\
\text { (billion } \\
\text { dollare) }\end{array}$ & $\begin{array}{l}1888 \\
\text { (billion } \\
\text { dollare) }\end{array}$ \\
\hline 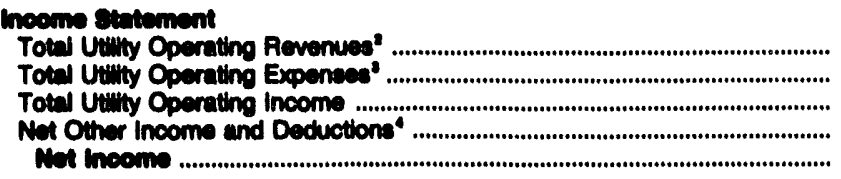 & $\begin{array}{r}185.5 \\
153.7 \\
31.8 \\
-13.4 \\
18.4\end{array}$ & $\begin{array}{r}182.6 \\
150.4 \\
32.1 \\
-15.1 \\
18.0\end{array}$ & $\begin{array}{r}173.0 \\
142.5 \\
30.5 \\
-13.6 \\
18.9\end{array}$ & $\begin{array}{r}167.1 \\
136.5 \\
30.6 \\
-13.3 \\
17.3\end{array}$ & $\begin{array}{r}159.5 \\
129.7 \\
29.8 \\
-13.7 \\
18.0\end{array}$ \\
\hline Operating Acthrition & $\begin{array}{l}18.4 \\
21.3 \\
30.7\end{array}$ & $\begin{array}{l}16.9 \\
23.0 \\
30.0\end{array}$ & $\begin{array}{l}16.9 \\
18.2 \\
35.1\end{array}$ & $\begin{array}{l}17.3 \\
19.3 \\
39.7\end{array}$ & $\begin{array}{l}16.0 \\
20.4 \\
39.5\end{array}$ \\
\hline 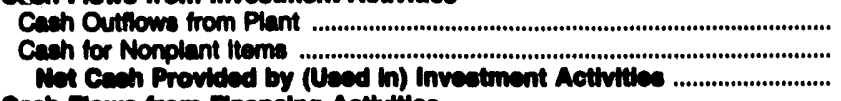 & $\begin{array}{r}-27.3 \\
-2.8 \\
-20.0\end{array}$ & $\begin{array}{r}-28.0 \\
1.0 \\
-24.0\end{array}$ & $\begin{array}{r}-24.8 \\
-1.3 \\
-28.1\end{array}$ & $\begin{array}{r}-25.0 \\
1.5 \\
-23.4\end{array}$ & $\begin{array}{r}-24.1 \\
.9 \\
-23.2\end{array}$ \\
\hline 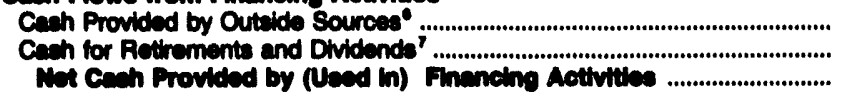 & $\begin{array}{r}68.9 \\
-64.3 \\
-10.8\end{array}$ & $\begin{array}{r}24.6 \\
-38.6 \\
-14.0\end{array}$ & $\begin{array}{r}18.8 \\
-30.0 \\
-10.4\end{array}$ & $\begin{array}{r}19.8 \\
-34.2 \\
-14.4\end{array}$ & $\begin{array}{r}18.0 \\
-33.7 \\
-14.7\end{array}$ \\
\hline 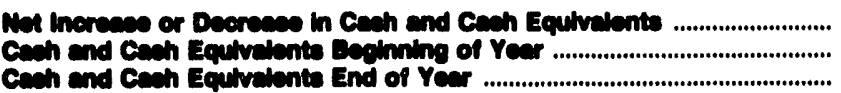 & $\begin{array}{l}-0 \\
3.7 \\
3.0\end{array}$ & $\begin{array}{l}1.1 \\
2.8 \\
3.0\end{array}$ & $\begin{array}{r}-1.4 \\
4.3 \\
2.0\end{array}$ & $\begin{array}{r}-1.2 \\
6.5 \\
4.8\end{array}$ & $\begin{array}{r}-1.4 \\
6.8 \\
6.5\end{array}$ \\
\hline
\end{tabular}

See tootnotes at end of table.

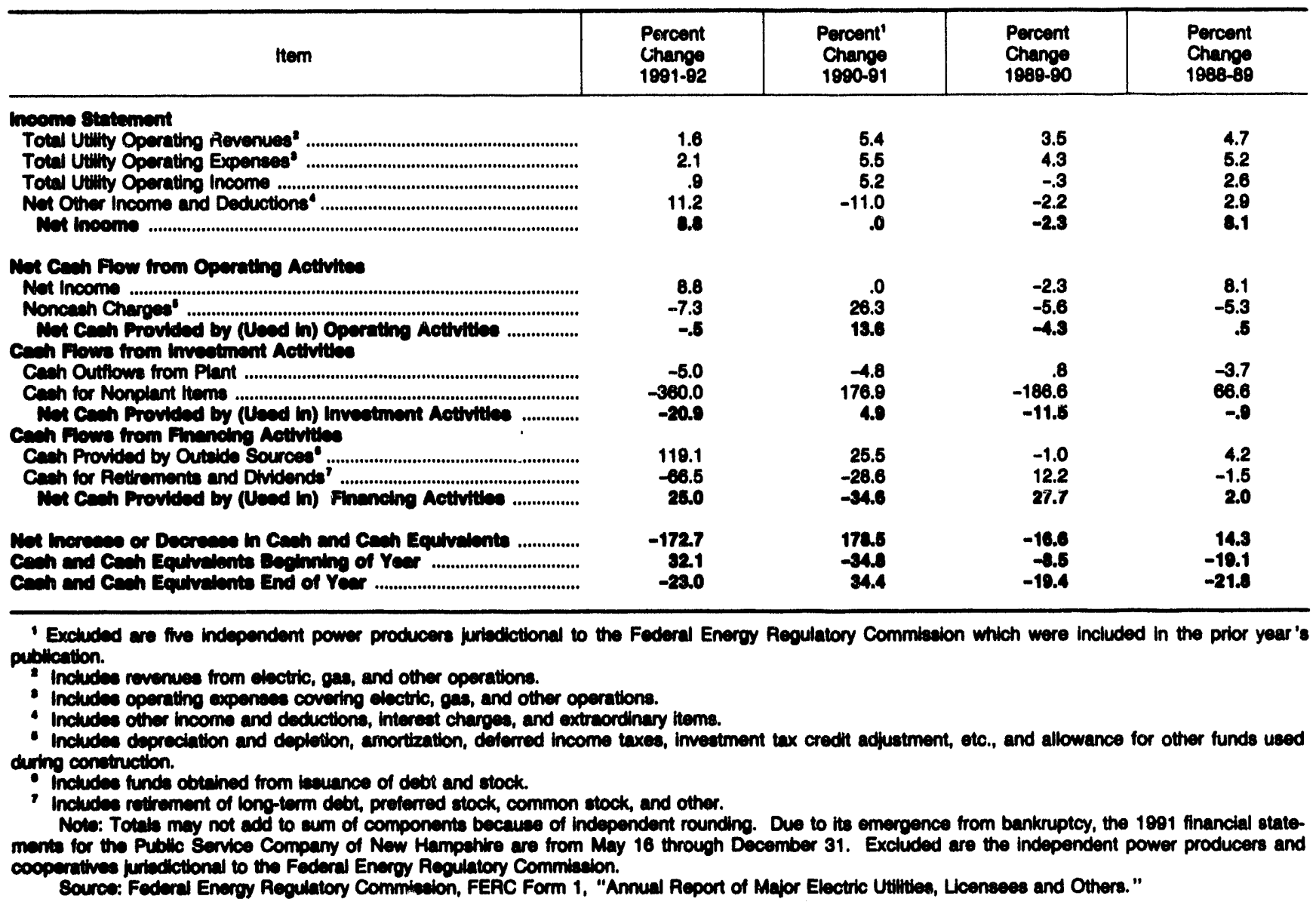


Table 18. Comparieon of Selected Balance Sheet Data for Major

U.S. Investor-Owned Electrlc Utillties on December 31, 1988-1992

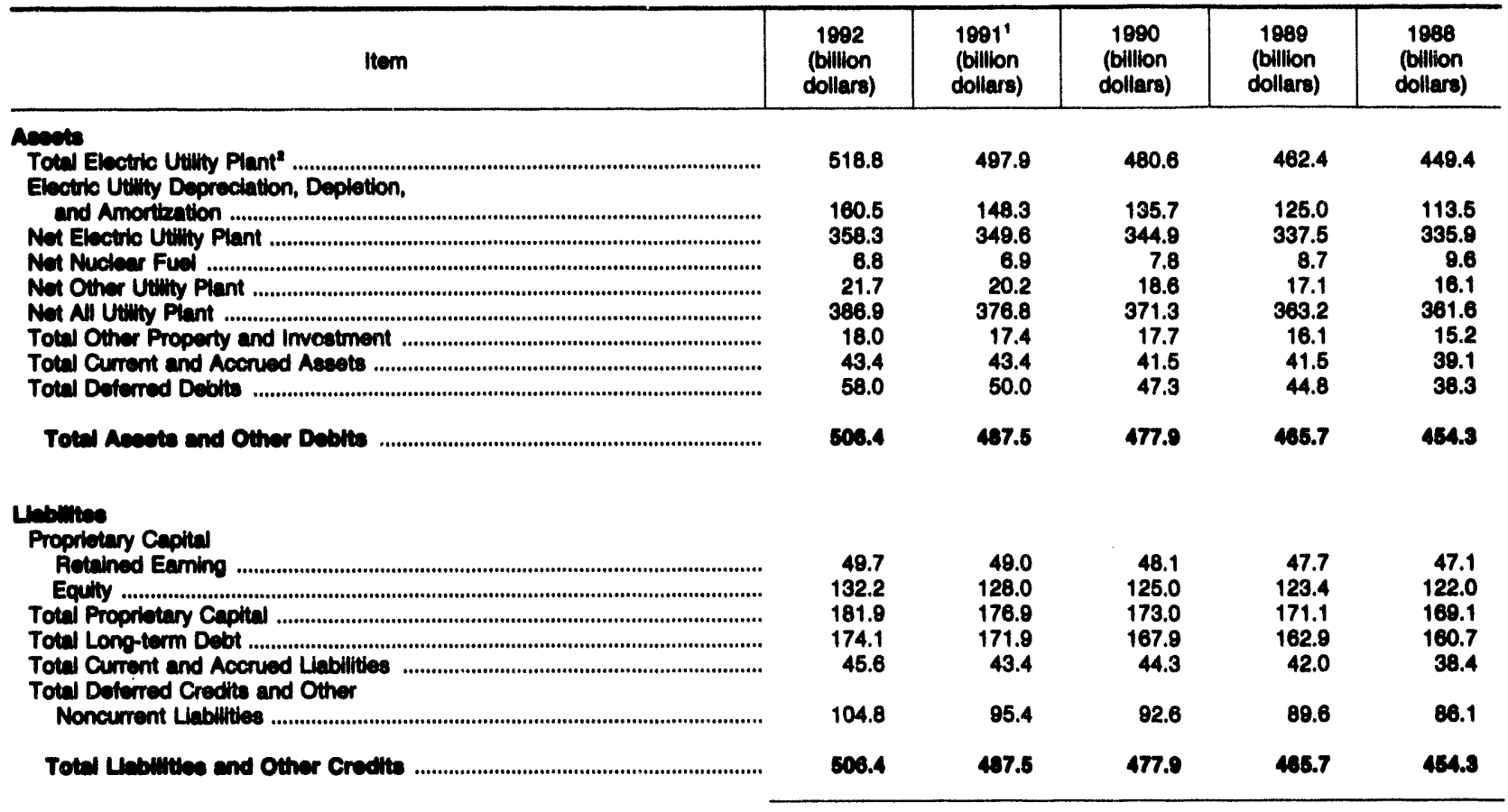

See tootnotes at end of table.

\begin{tabular}{|c|c|c|c|c|}
\hline Item & $\begin{array}{l}\text { Percent } \\
\text { Change } \\
1991-92 \\
\end{array}$ & $\begin{array}{c}\text { Percent' } \\
\text { Change } \\
1990-91 \\
\end{array}$ & $\begin{array}{l}\text { Percent } \\
\text { Change } \\
1889-80 \\
\end{array}$ & $\begin{array}{l}\text { Percent } \\
\text { Change日 } \\
1988-89 \\
\end{array}$ \\
\hline Acetse & 4.2 & 3.6 & 3.8 & 2.8 \\
\hline Electric Utility Depreciation, Depletion, & 8.2 & 9.3 & 8.6 & 10.1 \\
\hline 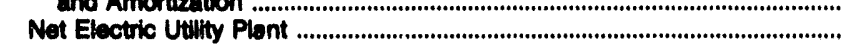 & 2.5 & 1.4 & 2.0 & $\begin{array}{r}10.1 \\
.6\end{array}$ \\
\hline 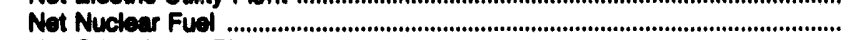 & -1.3 & -11.4 & -10.2 & -9.3 \\
\hline 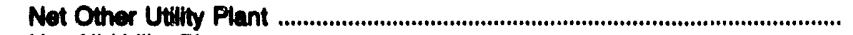 & 7.4 & 8.6 & 8.8 & 6.2 \\
\hline 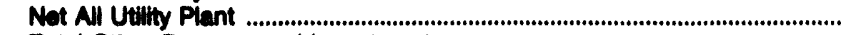 & 2.7 & 1.5 & 2.2 & .4 \\
\hline 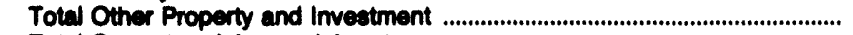 & 3.4 & -1.6 & 9.8 & 5.8 \\
\hline 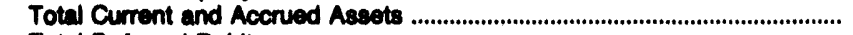 & .2 & 4.6 & .0 & 6.1 \\
\hline 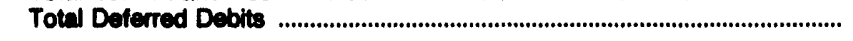 & 16.0 & 5.7 & 5.6 & 17.0 \\
\hline Total Aceets and Other Dablts ... & 3.8 & 2.0 & 2.6 & 2.6 \\
\hline \multicolumn{5}{|l|}{ Labuitice } \\
\hline $\begin{array}{l}\text { Proprlatary Capital } \\
\text { Reteined Earning }\end{array}$ & 1.4 & 1.9 & .8 & 1.3 \\
\hline Equity & 3.3 & 2.4 & 1.3 & 1.1 \\
\hline 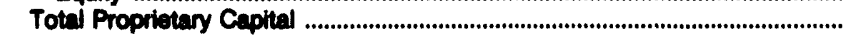 & 2.8 & 2.3 & 1.1 & 1.2 \\
\hline 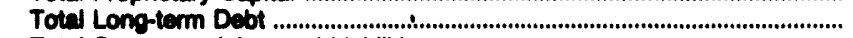 & 1.3 & 2.4 & 3.1 & 1.4 \\
\hline 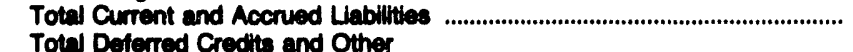 & 5.1 & -1.8 & 5.5 & 8.4 \\
\hline 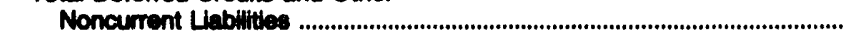 & 9.8 & 3.0 & 3.3 & 4.1 \\
\hline Totel Lubinities and Other Credts. & 3.0 & 2.0 & 2.6 & 2.6 \\
\hline
\end{tabular}

'Excluded are five independent power producers furiedictional to the Federal Energy Regulatory Commission which were included in the prior year's pubilication.

Inctudes construction work in progreas, but excludes nuclear fuel.

Note: Totals may not add to sum of components because of independent rounding. Due to its emergence from bankruptcy, the $1981 \mathrm{fi}$ nancial statements for the Public Service Company of New Hampehire are from May 16 through December 31. Excluded are the independent power producers and cooperatives jurisdictional to the Federal Energy Regulatory Commiseton.

Source: Federal Energy Regulatory Commisalon, FERC Form 1. "Annual Report of Major Electric Utilities, Licensees and Others." 
Figure 3. Total Propriotary Capital of Major U.S. Investor-Owned Electric Utillitles, 1988-1992

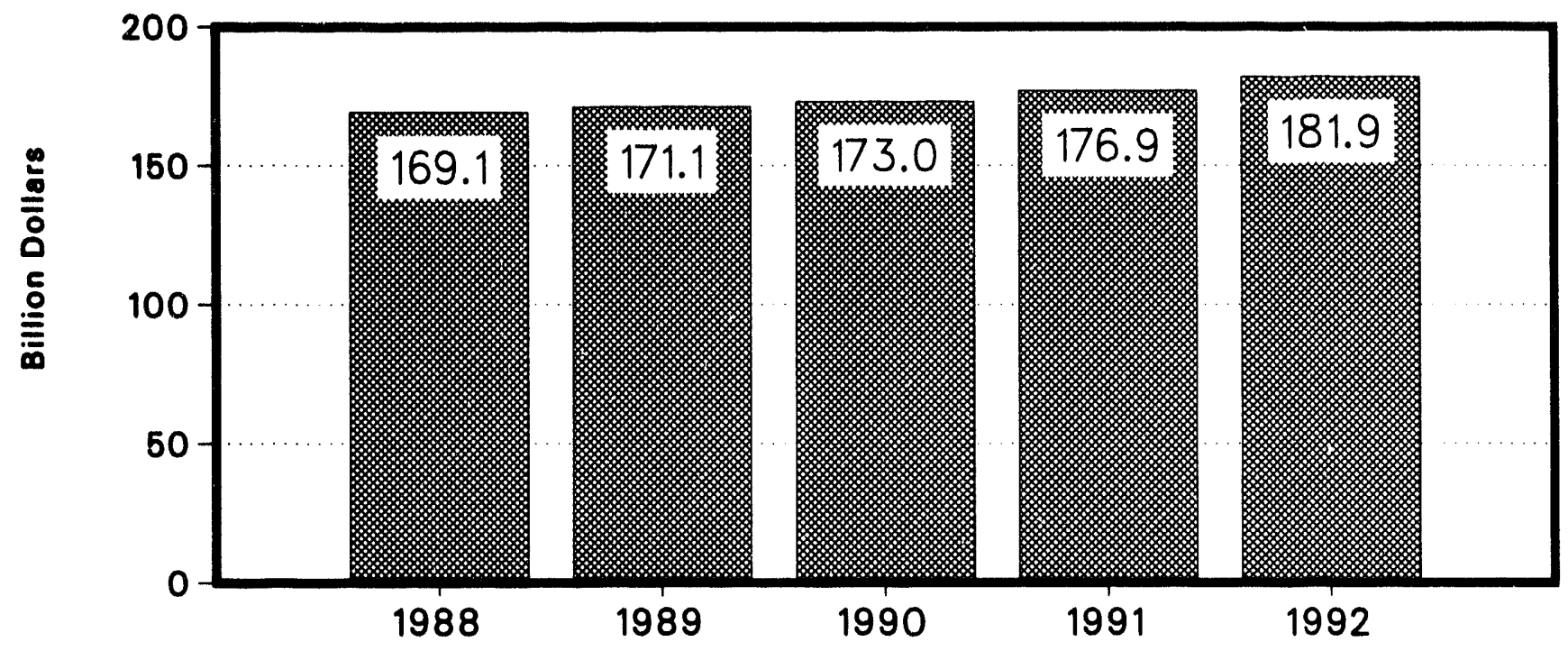

Note: Summary data are provided in Table 8.

Source: Federal Energy Regulatory Commission, FERC Form 1. Annual Report of Major Electric Utilities, Licensees and Others"

Figure 4. Total Long-term Debt of Major U.S. Investor-Owned Electric Utilities, 1988-1992

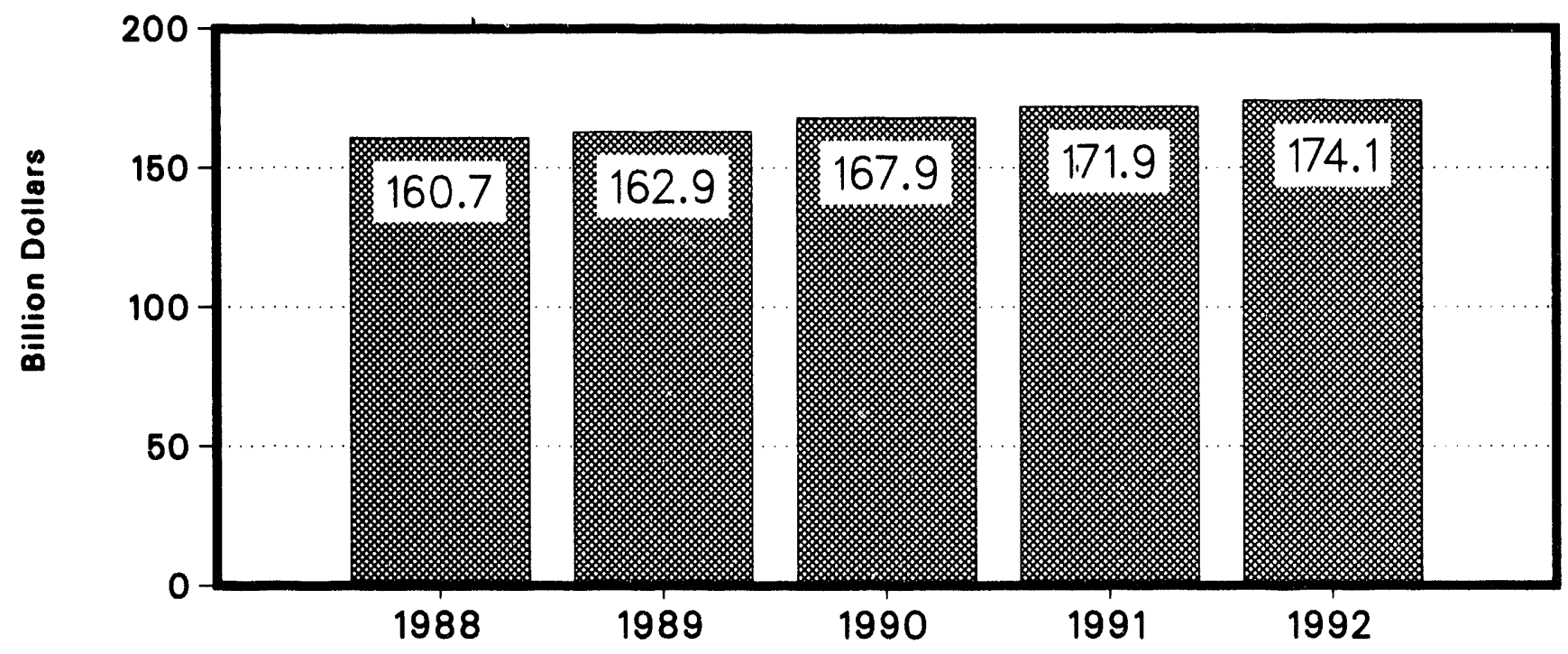

Note: Summary date are provided in Table 8

Source: Federal Energy Regulatory Commission, FERC Form 1. 'Annual Report of Major Electric Utilities, Licensees and Others' 
Table 19. Not Income and Allowance for Funds Used During Construction for Major U.S. Investor-Owned Electric Utilities, 1988-1992

\begin{tabular}{|c|c|c|c|c|}
\hline Year & $\begin{array}{c}\text { Net } \\
\text { Income } \\
\text { Reported } \\
\text { (thousand dollars) }\end{array}$ & $\begin{array}{l}\text { Allowance } \\
\text { for Funds } \\
\text { Used During } \\
\text { Construction } \\
\text { (thousand dollars)' }\end{array}$ & $\begin{array}{c}\text { Percent } \\
\text { of } \\
\text { Net } \\
\text { income }\end{array}$ & $\begin{array}{l}\text { Dollar } \\
\text { Per Share of } \\
\text { Common } \\
\text { Stock }\end{array}$ \\
\hline 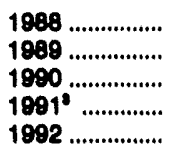 & $\begin{array}{l}16,041,707 \\
17,312,761 \\
16,897,168 \\
16,949,684 \\
18,384,444\end{array}$ & $\begin{array}{l}2,877,004 \\
2,344,011 \\
1,894,446 \\
1,341,627 \\
1,169,862\end{array}$ & $\begin{array}{r}17.9 \\
13.5 \\
11.2 \\
7.9 \\
6.3\end{array}$ & $\begin{array}{r}0.53 \\
.40 \\
.34 \\
.23 \\
.19\end{array}$ \\
\hline
\end{tabular}

- Includes Allowances for Borrowed Funds Used During Construction (AFUDC). Data taken from Table 6.

- AFUDC divided by Number of Shares of Common Stock Outstanding, Tabla 21.

- Excluded are five independent power producers jurisdictional to the Federal Energy Regulatory Commission which were included in the prior year's publication.

Note: Due to its emergence from bankruptcy, the 1991 financial statements for the Public Service Company of New Hampshire are from May 16 through December 31. Excluded are the independent power producers and cooperatives juriedictional to the Federal Energy Regulatory Commiseion.

Source: Federal Energy Regulatory Commission, FERC Form 1, "Annual Report of Major Electric Utilities, Licensees and Others."

Table 20. Total Debt for Major U.S. Investor-Owned Electric Utilitles on December 31, 1988-1992

\begin{tabular}{|c|c|c|c|c|c|}
\hline Year & $\begin{array}{c}\text { Long-term } \\
\text { Debt } \\
\text { (thousand dollars)' }\end{array}$ & $\begin{array}{c}\text { Short-term } \\
\text { Debt } \\
\text { (thousand dollars)' }\end{array}$ & $\begin{array}{c}\text { Total Debt } \\
\text { Inc Short-term } \\
\text { (thousand dollars) }\end{array}$ & $\begin{array}{c}\text { Total Interest } \\
\text { Charges } \\
\text { (thousand dollars) }\end{array}$ & $\begin{array}{l}\text { Average } \\
\text { Debt Cost } \\
\text { (percent) }\end{array}$ \\
\hline 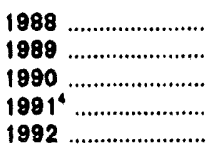 & $\begin{array}{l}160,726,686 \\
162,948,440 \\
167,938,084 \\
171,894,816 \\
348,281,792\end{array}$ & $\begin{array}{l}5,843,202 \\
5,928,421 \\
7,874,293 \\
6,986,960 \\
8,791,477\end{array}$ & $\begin{array}{l}166,569,888 \\
168,876,861 \\
175,812,377 \\
178,881,776 \\
182,932,373\end{array}$ & $\begin{array}{l}15,648,207 \\
15,994,303 \\
16,549,859 \\
16,371,773 \\
15,781,522\end{array}$ & $\begin{array}{l}9.39 \\
9.47 \\
9.41 \\
9.15 \\
8.62\end{array}$ \\
\hline
\end{tabular}

Data taken from Table $\dot{8}$.

- Data taken from Table 6. Data exclude Allowance for Borrowed Funds Used During Construction (credit) which is capitalized interest during construction.

Average Debt Cost equals Total Interest Charges divided by Total Debt.

- Excluded are five independent power producers jurisdictional to the Federal Energy Regulatory Commission which were included in the prior year's publication.

- Data not available.

Note: Due to its emergence from bankruptcy, the 1991 financial statements for the Public Service Company of New Hampshire are from May 16 through December 31. Excluded are the independent power producers and cooperatives jurisdictional to the Federal Energy Regulatory Commiseion.

Source: Federal Energy Regulatory Commission, FERC Form 1, "Annual Report of Major Electric Utilities, Licensees and Others." 
Table 21. Dlaposition of Net Income for Major U.S. Investor-Owned Electric Utilitios, 1988-1992 (Thousand Dollars)

\begin{tabular}{|c|c|c|c|c|c|}
\hline Item' & 1992 & $1891^{2}$ & 1990 & 1989 & 1888 \\
\hline 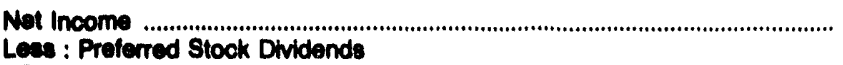 & $18,384,444$ & $16,849,664$ & $16,897,166$ & $17,312,761$ & $16,041,707$ \\
\hline 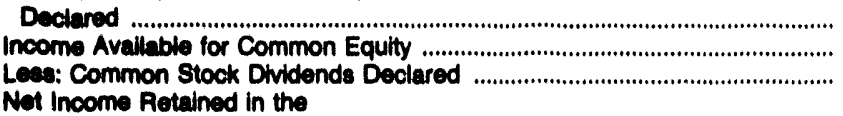 & $\begin{array}{r}2,039,449 \\
16,344,995 \\
14,897,608\end{array}$ & $\begin{array}{r}1,845,213 \\
15,004,451 \\
14,427,570\end{array}$ & $\begin{array}{r}2,025,167 \\
14,872,009 \\
14,189,677\end{array}$ & $\begin{array}{r}2,417,239 \\
14,895,522 \\
14,030,582\end{array}$ & $\begin{array}{r}2,284,454 \\
13,777,253 \\
13,517,681\end{array}$ \\
\hline Buainese & $1,447,387$ & 576,881 & 682,332 & 864,960 & 259,572 \\
\hline \multicolumn{6}{|l|}{ Number of Shares of Common Stock } \\
\hline Outatanding (thousands) & $6,261,284$ & $5,932,492$ & $5,950,833$ & $5,824,221$ & $5,400,881$ \\
\hline
\end{tabular}

- Data, except Number of Shares of Common Stock Outstanding, taken from Table 6.

Excluded are five independent power producers jurlsdictional to the Federal Energy Regulatory Commission which were included in the prior yoar's publication.

Note: Due to its emergence from bankruptcy, the 1901 financial statements for the Public Service Company of New Hampshire are from May 16 through December 31. Excluded are the independent power producers and cooperatives jurisdictional to the Federal Energy Regulatory Commise aion.

Source: Federal Energy Regulatory Commission, FERC Form 1, "Annual Report of Major Electric Utilities, Licensees and Others."

Table 22. Not Income per Share of Common Stock for Major U.S. Investor-Owned Electric Utilitles, 1988-1992

\begin{tabular}{|c|c|c|c|c|c|}
\hline Year & $\begin{array}{c}\text { Net Income } \\
\text { Reported } \\
\text { (thousand dollars) } \\
\text { (1) }\end{array}$ & $\begin{array}{c}\text { Preterred } \\
\text { Stock } \\
\text { Dividends } \\
\text { (thousand dollars) } \\
\text { (2) }\end{array}$ & $\begin{array}{l}\text { Net Income } \\
\text { after } \\
\text { Preferred Stock } \\
\text { Dividends } \\
\text { (thousand dollars) } \\
\text { (3) }\end{array}$ & $\begin{array}{l}\text { Number of } \\
\text { Shares of } \\
\text { Common } \\
\text { Stock } \\
\text { (thousands) } \\
\text { (4) }\end{array}$ & $\begin{array}{l}\text { Net Income } \\
\text { per Share } \\
\text { of Common } \\
\text { Stock } \\
\text { (5) }\end{array}$ \\
\hline 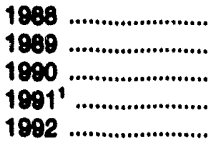 & $\begin{array}{l}16,041,707 \\
17,312,761 \\
16,897,168 \\
16,949,684 \\
18,384,444\end{array}$ & $\begin{array}{l}2,264,454 \\
2,417,239 \\
2,025,157 \\
1,945,213 \\
2,039,449\end{array}$ & $\begin{array}{l}13,777,253 \\
14,895,522 \\
14,872,009 \\
15,004,451 \\
16,344,995\end{array}$ & $\begin{array}{l}5,400,881 \\
5,824,221 \\
5,950,933 \\
5,932,492 \\
6,261,284\end{array}$ & $\begin{array}{l}2.55 \\
2.56 \\
2.50 \\
2.53 \\
2.61\end{array}$ \\
\hline
\end{tabular}

1 Excluded are five independent power producers jurisdictional to the Federal Energy Regulatory Commission which were included in the prior year's publication.

Note: Column (1) minus Column (2) equals Column (3). Column (3) divided by Column (4) equals Column (5). Due to its emergence from benkruptcy. the 1991 financial statements for the Public Service Company of New Hampshire are from May 16 through December 31 . Excluded are the independent power producers and cooperatives jurisdictional to the Federal Energy Regulatory Commission.

Source: Federal Energy Regulatory Commission, FERC Form 1, "Annual Report of Major Electric Utilties, Licensees and Others." 
Table 23. Source and Disposition of Revenue for Major U.S. Investor-Owned Eloctric Utilitios, 1988-1982

(Percent)

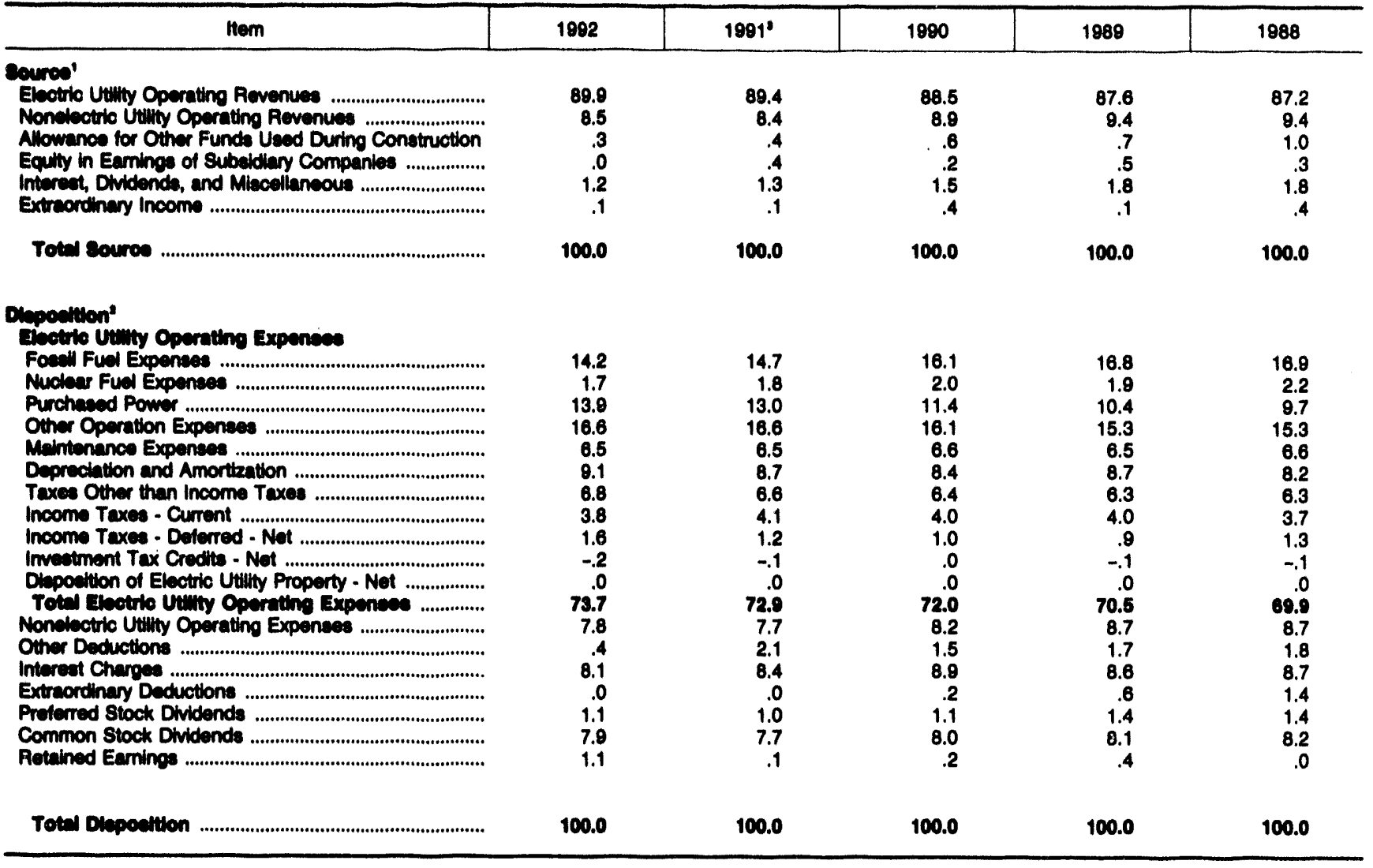

- Data based on information computed from Table 6.

- Datra based on information computed from Tables 6 and 13.

- Excluded are five independent power producers jurisdictional to the Federal Energy Regulatory Commission which were included in the prior year's pubilication.

Note: Totals may not equal sum of components because of independent rounding. Due to its emergence from bankruptcy, the 1991 financial statements for the Public Service Company of New Hampahire are from May 16 through December 31 . Excluded are the independent power producers and cooperatives juriedictional to the Federal Energy Regulatory Commiseion.

Source: Federal Energy Regulatory Commiseion, FERC Form 1, "Annual Report of Major Eloctric Utilities, Licensees and Others."

Table 24. Electric Construction Work in Progress for Major U.S. Investor-Owned Electric Utilities on December 31, 1988-1992

\begin{tabular}{|c|c|c|c|}
\hline Year & $\begin{array}{c}\text { Amount } \\
\text { (thousand dollars) }\end{array}$ & Change & Percent Change \\
\hline $\begin{array}{l}1888 \\
1889 \\
1890 \\
1891 \\
1892\end{array}$ & $\begin{array}{l}40,298,298 \\
33,714,565 \\
22,558,726 \\
18,077,211 \\
20,648,234\end{array}$ & $\begin{array}{r}-10,730,821 \\
-6,583,741 \\
-11,155,829 \\
-4,481,515 \\
2,571,023\end{array}$ & $\begin{array}{r}-21.0 \\
-16.3 \\
-33.1 \\
-19.9 \\
14.2\end{array}$ \\
\hline
\end{tabular}

- Excluded are five independent power producers juriedictional to the Federal Energy Regulatory Commission which were included in the prior year's publication.

Note: Quanttative change and percent change are calculated before rounding. Due to its emergence from bankruptcy, the 1991 financial statements for the Public Service Company of New Hampshire are from May 16 through December 31 . Excluded are the independent power producers and cooperatives jurledictional to the Federal Energy Regulatory Commission.

Source: Federal Energy Regulatory Commiselon, FERC Form 1, "Annual Peport of Major Electric Utilities, Licensees and Others." 
Table 25. Outstanding Electric Construction Work In Progreas as a share of Total or Not Eloctric Utility Plant for Major Investor-Owned Electrle Utilities on Decomber 31, 1988 - 1992

\begin{tabular}{|c|c|c|c|c|c|}
\hline Year & $\begin{array}{c}\text { CWIP } \\
\text { (thousend dollare) }\end{array}$ & $\begin{array}{c}\text { Total Electrio } \\
\text { Utility Plant } \\
\text { (thousanci dollars)' }\end{array}$ & $\begin{array}{c}\text { CWIP/Total } \\
\text { Electric Utility } \\
\text { Plant } \\
\text { (percent) }\end{array}$ & $\begin{array}{c}\text { Not Electric } \\
\text { Utility Plant } \\
\text { (thousand dollare)' }\end{array}$ & $\begin{array}{c}\text { CWIP/(Net } \\
\text { Electric Utility } \\
\text { Plant - CWIP) } \\
\text { (percent) }\end{array}$ \\
\hline $\begin{array}{l}1988 \\
1080 \\
1900 \\
1901^{2}\end{array}$ & $\begin{array}{l}40,298,296 \\
30,714,566 \\
22,568,726 \\
18,077,211 \\
20,648,234\end{array}$ & $\begin{array}{l}488,328,296 \\
481,574,720 \\
500,165,441 \\
517,381,396 \\
538,561,999\end{array}$ & $\begin{array}{l}8.6 \\
7.0 \\
4.5 \\
3.5 \\
3.8\end{array}$ & $\begin{array}{l}346,509,665 \\
346,180,828 \\
352,724,808 \\
358,622,670 \\
365,136,979\end{array}$ & $\begin{array}{r}13.2 \\
10.8 \\
6.8 \\
5.3 \\
6.0\end{array}$ \\
\hline
\end{tabular}

- Includee nuclear tuel.

- Excluded are five independent power producers jurledictional to the Federal Energy Regulatory Commisaion which were included in the prior year's publication.

Note: Computed by uaing data from Table 7 to eliminate the impact of independent rounding. Due to its emergence from bankruptcy, the 1991 financial statements for the Public Service Company of New Hempshire are from May 16 through December 31 . Excluded are the independent power producers and cocperattves jurisdictional to the Federal Energy Regulatory Commisaion.

Source: Federal Energy Regulatory Commission, FERC Form 1, "Annual Report of Major Electric Utilities, Licensees and Others."

Figure 5. Outetanding Electric Construction Work In Progress for Major U.S Investor - Owned Electric Uillities on December 31, 1988 - 1992

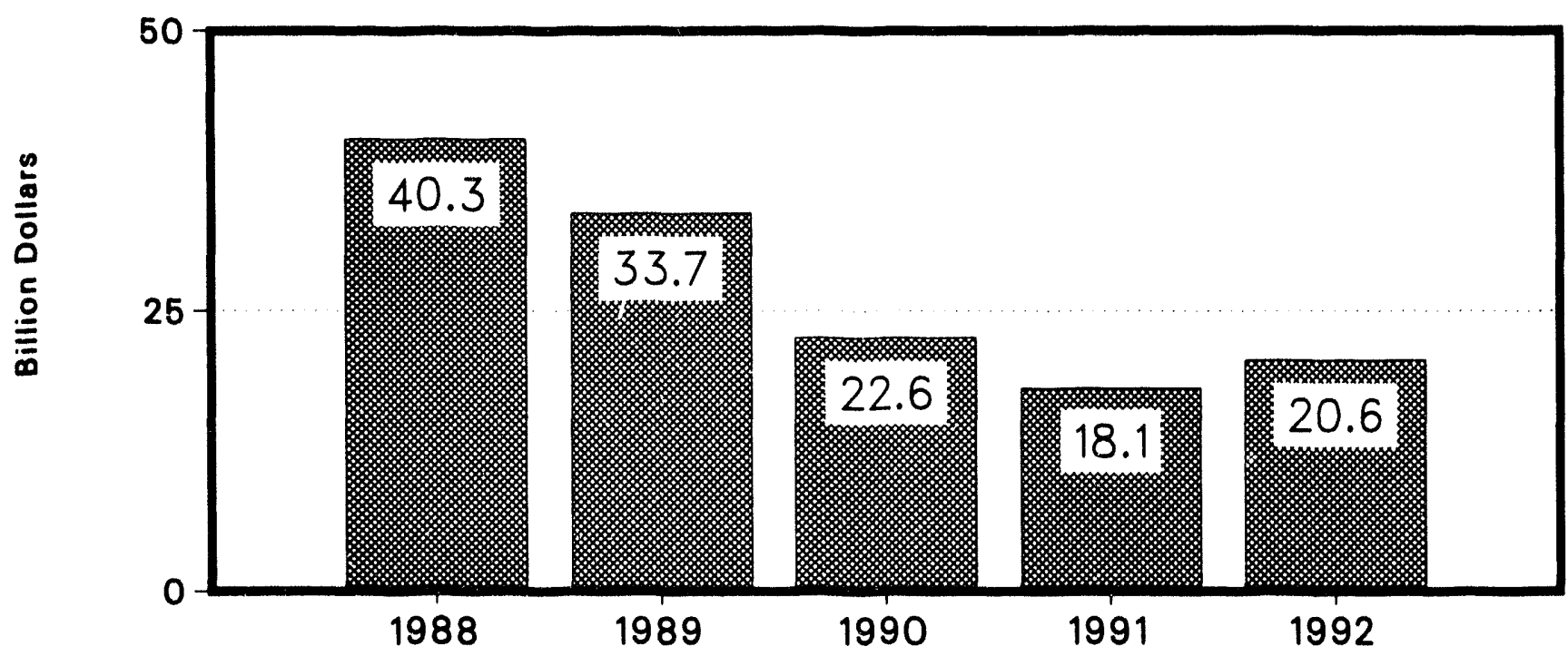

Note: Summary date are provided in Table 25.

Source: Federal Energy Regulatory Commission. FERC Form 1, Annual Report of Major Elestric Utilities, Licensegs and Others. 
Tablo 26. Changes in Eleotric Utility Plant for Major U.8. Investor-Owned Eloctric Utilities, 1988-1992

\begin{tabular}{|c|c|c|c|c|}
\hline Item & $\begin{array}{l}\text { Amount } \\
\text { (thousand } \\
\text { dollars) } \\
1891-1992\end{array}$ & $\begin{array}{l}\text { Amount } \\
\text { (thousand } \\
\text { dollars) } \\
1090-1991^{\prime}\end{array}$ & $\begin{array}{l}\text { Amount } \\
\text { (thousand } \\
\text { dollars) } \\
1989 \times 1890\end{array}$ & $\begin{array}{l}\text { Amount } \\
\text { (thousand } \\
\text { dollars) } \\
1988-1989\end{array}$ \\
\hline 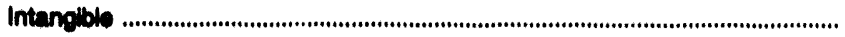 & $-123,015$ & 237,988 & 495,916 & 89,618 \\
\hline 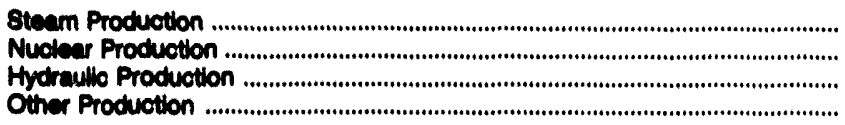 & $\begin{array}{r}2,608,103 \\
1,232,604 \\
316,413 \\
725,704\end{array}$ & $\begin{array}{r}6,273,326 \\
950,185 \\
1,222,014 \\
624,819\end{array}$ & $\begin{array}{r}3,491,204 \\
13,974,188 \\
246,422 \\
269,711\end{array}$ & $\begin{array}{r}3,386,828 \\
4,832,652 \\
216,842 \\
333,868\end{array}$ \\
\hline Total Produdton & $4,042,028$ & $8,970,344$ & $17,081,828$ & $9,769,188$ \\
\hline 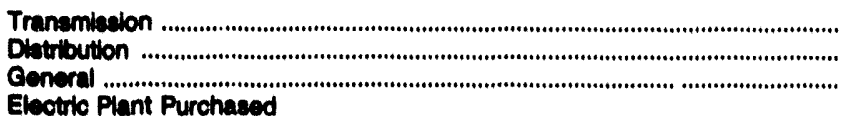 & $\begin{array}{l}2,230,328 \\
7,458,870 \\
2,500,868\end{array}$ & $\begin{array}{l}2,069,072 \\
7,316,150 \\
1,402,709\end{array}$ & $\begin{array}{r}2,665,402 \\
7,691,934 \\
998,305\end{array}$ & $\begin{array}{r}2,160,179 \\
7,527,440 \\
947,120\end{array}$ \\
\hline 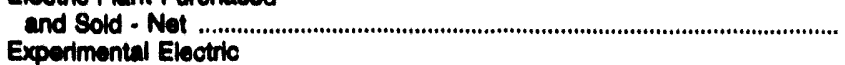 & 490,345 & 413,279 & 69,049 & $-27,020$ \\
\hline Plant Unolasalifed & 5,672 & 72,614 & $-5,837$ & 19,324 \\
\hline 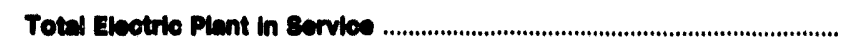 & $17,443,998$ & $20,492,156$ & $29,7 \bullet 0,2 \bullet$ & $10,495,051$ \\
\hline $\begin{array}{l}\text { Nuclear Full . } \\
\text { Construction Work in Progrese } \\
\text { Other }\end{array}$ & $\begin{array}{r}313,209 \\
2,571,024 \\
852,377\end{array}$ & $\begin{array}{r}-43,416 \\
-4,481,516 \\
1,258,732\end{array}$ & $\begin{array}{r}365,769 \\
-11,155,829 \\
-415,514\end{array}$ & $\begin{array}{r}221,837 \\
-6,583,740 \\
112,477\end{array}$ \\
\hline 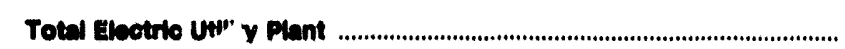 & $21,100,603$ & $17,215,085$ & $18,890,721$ & $13,246,424$ \\
\hline
\end{tabular}

See footnotes at en: "table.

\begin{tabular}{|c|c|c|c|c|}
\hline Item & $\begin{array}{l}\text { Percent of } \\
\text { Change in } \\
\text { Total Plant } \\
1091-82\end{array}$ & $\begin{array}{l}\text { Percent of } \\
\text { Change in } \\
\text { Total Plant } \\
1800-81\end{array}$ & $\begin{array}{l}\text { Percent of } \\
\text { Change in } \\
\text { Total Plant } \\
1889-80\end{array}$ & $\begin{array}{l}\text { Percent of } \\
\text { Change in } \\
\text { Total Plant } \\
1988-88\end{array}$ \\
\hline Intangble & 0.5 & 1.4 & 2.7 & 0.8 \\
\hline $\begin{array}{l}\text { Steam Production } \\
\text { Nuclear Production } \\
\text { Hydraulic Production } \\
\text { Other Production }\end{array}$ & $\begin{array}{r}12.3 \\
5.8 \\
1.5 \\
3.4\end{array}$ & $\begin{array}{r}36.4 \\
5.5 \\
7.1 \\
3.0\end{array}$ & $\begin{array}{r}18.8 \\
75.2 \\
1.3 \\
1.5\end{array}$ & $\begin{array}{r}25.6 \\
36.5 \\
1.6 \\
2.5\end{array}$ \\
\hline Toted Produetion & 23.1 & 52.1 & $\boldsymbol{9 9 . 7}$ & 89.2 \\
\hline 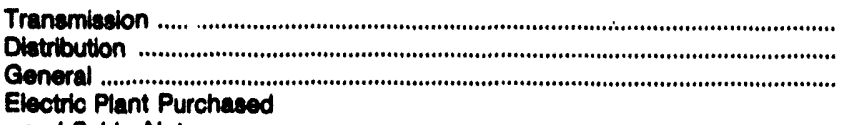 & $\begin{array}{l}10.6 \\
35.2 \\
11.8\end{array}$ & $\begin{array}{r}12.0 \\
42.5 \\
8.1\end{array}$ & $\begin{array}{r}14.3 \\
40.8 \\
5.4\end{array}$ & $\begin{array}{r}16.3 \\
58.8 \\
7.2\end{array}$ \\
\hline 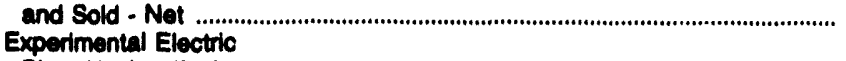 & 2.3 & 2.4 & .4 & .1 \\
\hline 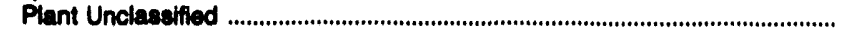 & .0 & .4 & .0 & .1 \\
\hline 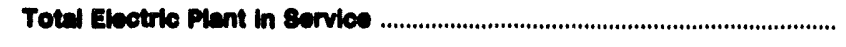 & 82.4 & 119.0 & 180.3 & 147.2 \\
\hline $\begin{array}{l}\text { Nuclear Fuel } \\
\text { Contruction Work in Progress } \\
\text { Other }\end{array}$ & $\begin{array}{r}1.5 \\
12.1 \\
4.0\end{array}$ & $\begin{array}{r}.2 \\
25.9 \\
7.3\end{array}$ & $\begin{array}{r}2.0 \\
59.9 \\
2.1\end{array}$ & $\begin{array}{r}1.7 \\
49.6 \\
.8\end{array}$ \\
\hline 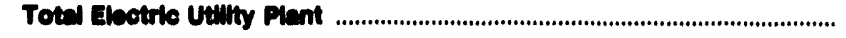 & 100.0 & 100.0 & 100.0 & 100.0 \\
\hline
\end{tabular}

1 Excluded are five independent power producers jurisdlctional to the Federal Energy Regulatory Commisaion which were included in the prior year's publication.

Note: Totals may not equal sum of components because of independent rounding. Due to its emergence from bankruptcy, the 1991 tinancial statements for the Publle Service Company of New Hampshire are from May 16 through December 31 . Excluded are the independent power producers and cooperatives Juriedictional to the Federal Energy Regulatory Commission.

Source: Federal Energy Regulatory Commission. FERC Form 1, "Annual Report of Major Electric Utilities, Licensees and Others." 
Table 27. Electrle Utility Plant In Sorvice for Major U.8. Inveotor-Owned Electric Utilitios on Docember 31, 1989-1992

\begin{tabular}{|c|c|c|c|c|c|c|}
\hline \multirow[b]{2}{*}{ Item } & \multicolumn{2}{|c|}{1992} & \multicolumn{2}{|c|}{$1001^{\prime}$} & \multicolumn{2}{|c|}{1090} \\
\hline & $\begin{array}{l}\text { Percent } \\
\text { of } \\
\text { Eloctrio } \\
\text { Plant } \\
\text { in Servios }\end{array}$ & $\begin{array}{c}\text { Percent } \\
\text { of } \\
\text { Total Electrlo } \\
\text { Utilly Plant }\end{array}$ & $\begin{array}{l}\text { Percent } \\
\text { of } \\
\text { Elecotric } \\
\text { Pian: } \\
\text { in Service }\end{array}$ & $\begin{array}{l}\text { Percent } \\
\text { of } \\
\text { Total Electric } \\
\text { Utility Plant }\end{array}$ & $\begin{array}{l}\text { Percent } \\
\text { of } \\
\text { Eleotrio } \\
\text { Plant } \\
\text { in Service }\end{array}$ & $\begin{array}{l}\text { Percent } \\
\text { of } \\
\text { Total Eleotrito } \\
\text { Uellty Plant }\end{array}$ \\
\hline 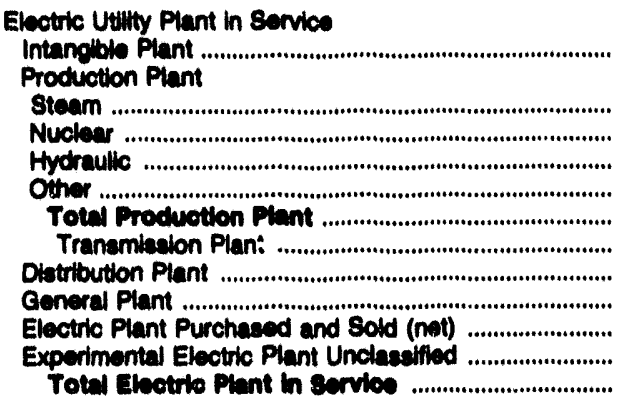 & $\begin{array}{r}0.2 \\
26.6 \\
27.8 \\
2.4 \\
1.3 \\
87.0 \\
11.6 \\
28.8 \\
4.2 \\
\\
100.0\end{array}$ & 01.5 & $\begin{array}{r}0.3 \\
26.9 \\
28.6 \\
2.4 \\
1.2 \\
82.1 \\
11.5 \\
26.2 \\
3.8 \\
\\
100.0\end{array}$ & 01.0 & $\begin{array}{r}0.2 \\
26.7 \\
29.7 \\
2.2 \\
1.1 \\
02.7 \\
11.6 \\
26.8 \\
3.7 \\
: \\
100.0\end{array}$ & 91.0 \\
\hline 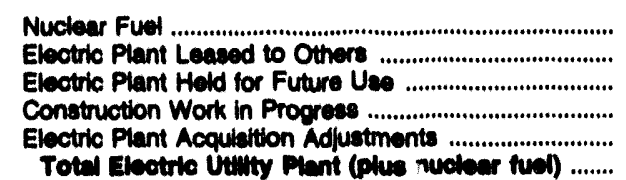 & & $\begin{array}{r}3.7 \\
.0 \\
.7 \\
3.8 \\
8.0\end{array}$ & & $\begin{array}{r}3.8 \\
.0 \\
.7 \\
3.5 \\
3.0\end{array}$ & & $\begin{array}{r}3.9 \\
.0 \\
.0 \\
.0 \\
\mathbf{2 . 0}\end{array}$ \\
\hline
\end{tabular}

See footnotes at end of table.

\begin{tabular}{|c|c|c|c|c|}
\hline \multirow[b]{2}{*}{ Item } & \multicolumn{2}{|c|}{1889} & \multicolumn{2}{|c|}{1888} \\
\hline & $\begin{array}{c}\text { Percent } \\
\text { of } \\
\text { Electric } \\
\text { Plant } \\
\text { in Service }\end{array}$ & $\begin{array}{c}\text { Percent } \\
\text { of } \\
\text { Total Electric } \\
\text { Utillyy Plant }\end{array}$ & $\begin{array}{c}\text { Percent } \\
\text { of } \\
\text { Electric } \\
\text { Plant } \\
\text { in Service }\end{array}$ & $\begin{array}{c}\text { Percent } \\
\text { of } \\
\text { Total Electric } \\
\text { Uttlity Plant }\end{array}$ \\
\hline
\end{tabular}

Electric Utilly Plant in Service
Intanolble Plant
Production Plant
Steam

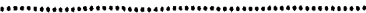
Nuclear

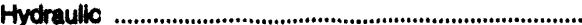
Other ...
Totel Production Pient
Tranemisaion Plant
Dlatribution Piant
Genoral Plant
Electric Plant Purchased and Sold (net)
Experimental Electric Plant Unclaseified
Total Electric Plant in Eervies ..................................
Nuclear Fuel
Electric Plant Leased to Others
Electric Plant Held for Future Use
Construction Work in Progress ..........
Toth Plant Acquition Adustments ........................

Total Electric Utinty Pient (plus nuclear fuel) .......

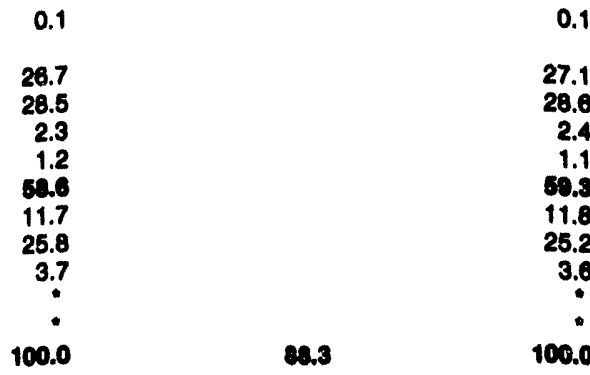

\begin{tabular}{rr}
0.1 & \\
27.1 & \\
28.6 & \\
2.4 & \\
1.1 & \\
50.3 & \\
11.8 & \\
25.2 & \\
3.6 & \\
\hline & \\
100.0 & \\
& \\
& \\
& 4.0 \\
& .0 \\
& .0 \\
& .0
\end{tabular}

- Excluded are five independent power producers jurbdictional to the Federal Energy Regulatory Commiacion which were included in the prior years publication.

Value less than 0.05 percent.

Note: Totals may not equal sum of components because of independent rounding. Due to its emergence from bankruptcy, the 1891 financial statements for the Publlc Service Company of New Hampahire are from May 16 through December 31. Excluded are the independent power producers and cooperatives Jurbdictional to the Federal Energy Regulationy Commiacion.

Source: Federal Energy Regulatory Commiseion, FERC Form 1, "Annual Report of Major Electric Utillties, Licensees and Others." 
Tablo 28. Electric Utility Plant for Major U.8. Investor-Owned Electric Utilities on Docombor 31, 1988-1992

(Thousand Dollars)

\begin{tabular}{|c|c|c|c|c|c|}
\hline Hem & 1092 & $1091^{\prime}$ & 1890 & 1889 & 1988 \\
\hline 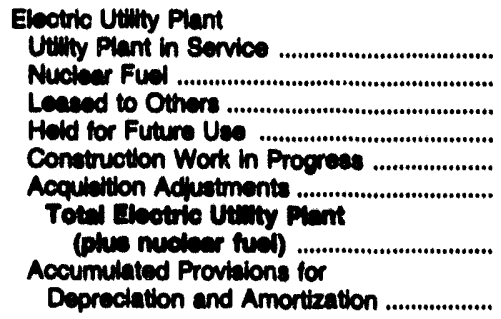 & $\begin{array}{r}492,987,625 \\
19,795,166 \\
81,081 \\
3,802,139 \\
20,648,234 \\
1,246,059 \\
804961,009 \\
173,425,020\end{array}$ & $\begin{array}{r}475,643,632 \\
19,481,967 \\
81,210 \\
3,895,622 \\
18,077,211 \\
361,865 \\
617,391,306 \\
160,868,726\end{array}$ & $\begin{array}{r}455,061,377 \\
19,625,373 \\
80,673 \\
2,620,521 \\
22,558,726 \\
318,872 \\
400,040,090 \\
135,727,298\end{array}$ & $\begin{array}{r}425,265,082 \\
19,169,604 \\
80,689 \\
3,047,145 \\
33,714,655 \\
307,745 \\
402,415,116 \\
124,954,034\end{array}$ & $\begin{array}{r}405,769,231 \\
18,937,767 \\
86,205 \\
2,967,446 \\
40,298,296 \\
289,350 \\
499,390,528 \\
113,523,644\end{array}$ \\
\hline 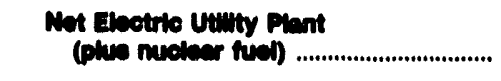 & $346,183,070$ & $363,622,670$ & $344,012,770$ & $337,400,162$ & $396,696, e 94$ \\
\hline 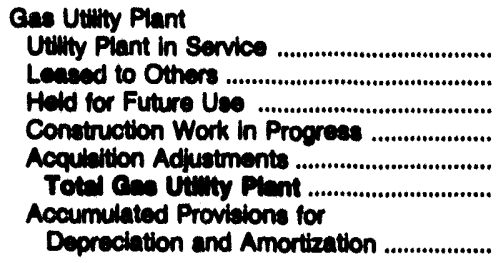 & $\begin{array}{r}22,217,284 \\
12,287 \\
146,474 \\
1,029,231 \\
63,088 \\
28,462,246 \\
8,655,022\end{array}$ & $\begin{array}{r}21,189,620 \\
12,182 \\
144,210 \\
678,567 \\
-23,834 \\
21,600,648 \\
8,081,639\end{array}$ & $\begin{array}{r}19,710,442 \\
12,058 \\
144,894 \\
487,631 \\
-81,172 \\
20,273,763 \\
7,473,112\end{array}$ & $\begin{array}{r}18,244,262 \\
12,129 \\
145,289 \\
423,682 \\
-88,363 \\
18,737,009 \\
6,888,839\end{array}$ & $\begin{array}{r}17,468,690 \\
12,047 \\
146,576 \\
384,656 \\
-84,073 \\
17,018,034 \\
6,497,843\end{array}$ \\
\hline 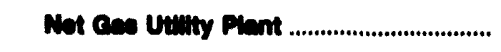 & $14,607,322$ & $13,009,000$ & $12,000,041$ & $11,240,160$ & $11,417,000$ \\
\hline 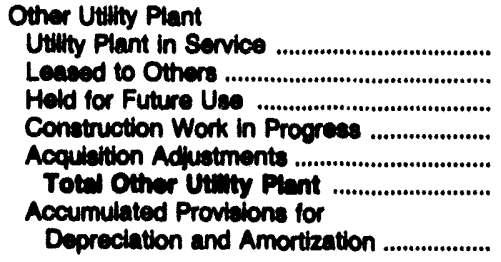 & $\begin{array}{r}8,086,566 \\
? \\
7,325 \\
740,779 \\
80,920 \\
9,026,698 \\
3,005,151\end{array}$ & $\begin{array}{r}8,478,470 \\
0 \\
14,588 \\
588,311 \\
68,103 \\
0,147,473 \\
2,737,446\end{array}$ & $\begin{array}{r}7,771,897 \\
67 \\
11,118 \\
413,424 \\
65,282 \\
8,201,879 \\
2,477,265\end{array}$ & $\begin{array}{r}7,085,824 \\
149 \\
7,583 \\
389,763 \\
65,525 \\
7,640,045 \\
2,334,446\end{array}$ & $\begin{array}{r}6,392,928 \\
0 \\
12,682 \\
281,049 \\
30,436 \\
6,718,190 \\
2,005,488\end{array}$ \\
\hline Net Other Uitity Plant ................................... & $6,020,497$ & $6,410,027$ & $6,794,614$ & $8,214,390$ & $4,710,703$ \\
\hline 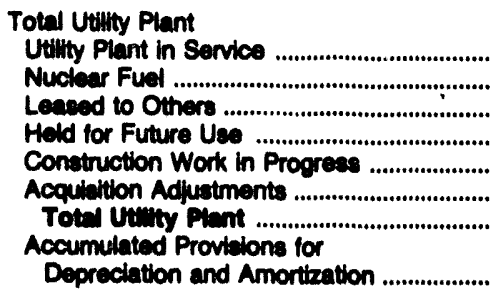 & $\begin{array}{r}624,291,375 \\
19,795,166 \\
94,248 \\
3,955,931 \\
22,412,245 \\
1,400,967 \\
671,940,092 \\
185,085,193\end{array}$ & 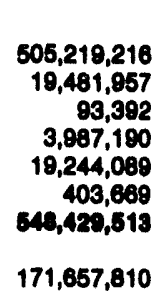 & $\begin{array}{r}482,543,815 \\
19,525,373 \\
92,688 \\
2,776,533 \\
23,469,682 \\
302,982 \\
628,701,074 \\
167,391,010\end{array}$ & $\begin{array}{r}450,595,168 \\
19,159,604 \\
92,867 \\
3,200,018 \\
34,528,008 \\
284,907 \\
507,060,673 \\
144,687,178\end{array}$ & $\begin{array}{r}429,618,784 \\
18,937,767 \\
98,252 \\
3,126,704 \\
40,973,098 \\
205,713 \\
492,060,310 \\
131,322,062\end{array}$ \\
\hline 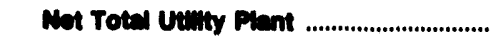 & $300,044,730$ & $376,771,703$ & $371,310,003$ & $363,223,396$ & $301,689,260$ \\
\hline 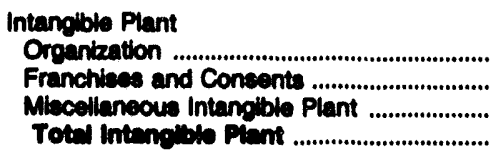 & $\begin{array}{r}34,893 \\
77,186 \\
1,073,337 \\
1,105,626\end{array}$ & $\begin{array}{r}34,131 \\
74,944 \\
1,189,465 \\
1,309,840\end{array}$ & $\begin{array}{r}33,707 \\
63,419 \\
973,428 \\
1,070,652\end{array}$ & $\begin{array}{r}33,700 \\
53,688 \\
467,238 \\
574,698\end{array}$ & $\begin{array}{r}7,677 \\
46,394 \\
420,945 \\
476,017\end{array}$ \\
\hline 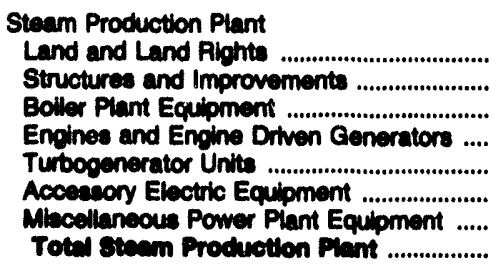 & $\begin{array}{r}814,986 \\
20,457,450 \\
69,288,486 \\
17,018 \\
23,462,722 \\
9,471,252 \\
2,291,908 \\
126,003,032\end{array}$ & $\begin{array}{r}798,218 \\
20,165,624 \\
67,830,163 \\
19,307 \\
22,846,167 \\
9,340,289 \\
2,196,969 \\
123,196,730\end{array}$ & $\begin{array}{r}736,640 \\
19,158,082 \\
64,524,610 \\
19,293 \\
21,761,290 \\
8,706,894 \\
2,015,694 \\
116,022,404\end{array}$ & $\begin{array}{r}722,617 \\
18,677,691 \\
62,469,802 \\
21,374 \\
21,084,456 \\
8,461,646 \\
1,983,613 \\
113,431,200\end{array}$ & $\begin{array}{r}697,515 \\
18,209,852 \\
60,661,585 \\
19,525 \\
20,465,009 \\
8,174,264 \\
1,827,624 \\
110,045,374\end{array}$ \\
\hline
\end{tabular}

See endnotes at end of this table. 
Table 28. Electric Utllity Plant for Major U.8. Inveator-Owned Electric Utilitios on December 31, 1988-1982 (Continued) (Thousand Dollars)

\begin{tabular}{|c|c|c|c|c|c|}
\hline Item & 1892 & $1991^{\prime}$ & 1990 & 1889 & 1888 \\
\hline 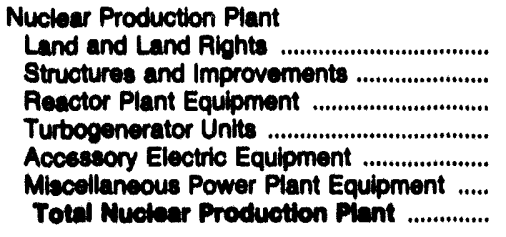 & $\begin{array}{r}324,542 \\
38,282,431 \\
61,575,572 \\
15,651,954 \\
17,255,788 \\
6,122,810 \\
137,213,106\end{array}$ & $\begin{array}{r}325,346 \\
35,889,956 \\
61,225,875 \\
16,856,241 \\
17,029,945 \\
5,653,137 \\
136,000,801\end{array}$ & $\begin{array}{r}324,490 \\
35,424,318 \\
61,388,357 \\
16,887,422 \\
17,026,757 \\
4,969,972 \\
135,030,316\end{array}$ & $\begin{array}{r}292,306 \\
32,010,582 \\
54,345,225 \\
14,793,208 \\
14,797,677 \\
4,817,130 \\
121,088,128\end{array}$ & $\begin{array}{r}260,042 \\
30,838,951 \\
52,018,655 \\
14,518,953 \\
13,951,339 \\
4,685,635 \\
118,228,475\end{array}$ \\
\hline 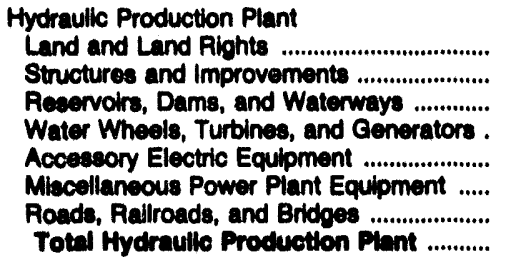 & $\begin{array}{r}530,012 \\
1,581,323 \\
6,070,233 \\
2,331,222 \\
723,842 \\
215,021 \\
150,337 \\
11,001,901\end{array}$ & $\begin{array}{r}528,261 \\
1,661,603 \\
5,809,636 \\
2,243,686 \\
697,005 \\
198,146 \\
149,041 \\
11,296,678\end{array}$ & $\begin{array}{r}526,169 \\
1,403,221 \\
5,229,121 \\
2,059,212 \\
552,149 \\
167,811 \\
125,881 \\
10,038,684\end{array}$ & $\begin{array}{r}522,183 \\
1,351,482 \\
5,112,677 \\
2,034,530 \\
616,170 \\
155,681 \\
124,229 \\
9,817,142\end{array}$ & $\begin{array}{r}509,375 \\
1,330,164 \\
5,003,848 \\
2,001,402 \\
480,479 \\
161,306 \\
128,728 \\
9,600,300\end{array}$ \\
\hline 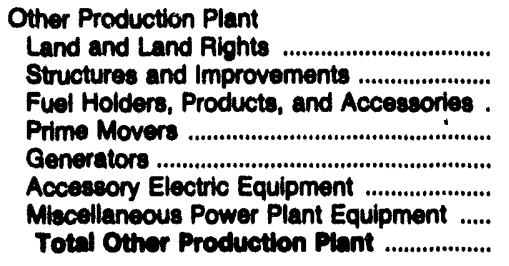 & $\begin{array}{r}47,324 \\
457,822 \\
476,681 \\
1,811,219 \\
3,104,130 \\
455,893 \\
72,851 \\
6,428,019\end{array}$ & $\begin{array}{r}34,720 \\
422,118 \\
408,987 \\
1,570,983 \\
2,782,768 \\
407,521 \\
65,239 \\
6,700,314\end{array}$ & $\begin{array}{r}34,098 \\
404,377 \\
371,006 \\
1,491,434 \\
2,424,953 \\
388,737 \\
60,891 \\
\mathbf{5 , 1 7 5 , 4 9 6}\end{array}$ & $\begin{array}{r}29,800 \\
360,150 \\
401,689 \\
1,333,151 \\
2,354,952 \\
368,270 \\
57,722 \\
4,908,705\end{array}$ & $\begin{array}{r}27,501 \\
308,652 \\
342,095 \\
1,229,697 \\
2,255,421 \\
355,450 \\
55,101 \\
4,671,016\end{array}$ \\
\hline Totel Production Plant ................................ & $281,044,040$ & $276,102,128$ & $287,101,700$ & $249,210,284$ & $240,441,008$ \\
\hline 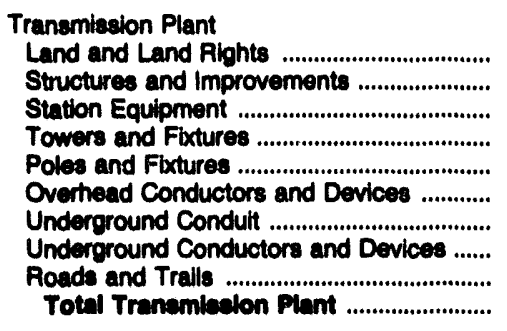 & $\begin{array}{r}3,712,222 \\
1,391,570 \\
23,494,634 \\
7,513,027 \\
7,293,482 \\
10,917,425 \\
1,050,763 \\
1,395,615 \\
161,617 \\
\mathbf{8 , 0 3 0 , 3 5 5}\end{array}$ & $\begin{array}{r}3,612,188 \\
1,326,886 \\
22,357,769 \\
7,359,417 \\
6,932,210 \\
10,577,689 \\
1,013,213 \\
1,354,926 \\
165,680 \\
84,700,027\end{array}$ & $\begin{array}{r}3,543,543 \\
1,262,615 \\
21,365,485 \\
7,261,573 \\
6,682,215 \\
10,228,812 \\
860,239 \\
1,292,971 \\
163,402 \\
52,830,065\end{array}$ & $\begin{array}{r}3,443,207 \\
1,154,487 \\
20,115,558 \\
7,068,848 \\
6,074,526 \\
9,804,571 \\
933,124 \\
1,234,744 \\
138,490 \\
49,965,653\end{array}$ & $\begin{array}{r}3,376,577 \\
1,104,910 \\
18,958,175 \\
6,971,379 \\
5,721,210 \\
9,490,493 \\
904,104 \\
1,148,380 \\
130,146 \\
47,805,374\end{array}$ \\
\hline 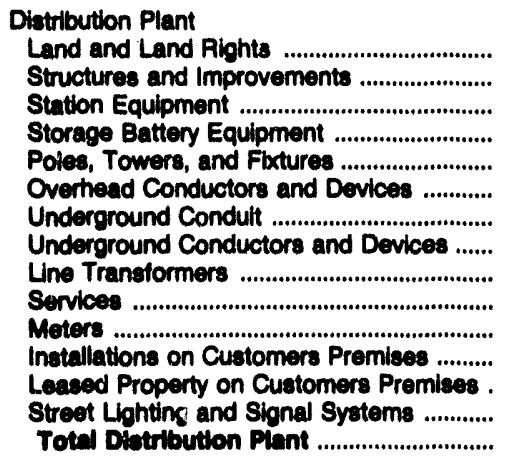 & $\begin{array}{r}1,316,144 \\
1,586,938 \\
16,565,505 \\
2,443 \\
18,780,091 \\
19,594,546 \\
7,937,134 \\
18,499,910 \\
23,919,109 \\
11,756,658 \\
7,479,800 \\
808,236 \\
54,833 \\
3,875,969 \\
132,246,417\end{array}$ & $\begin{array}{r}1,233,876 \\
1,453,631 \\
15,488,545 \\
21 \\
17,746,512 \\
18,521,500 \\
7,426,317 \\
17,174,813 \\
22,914,511 \\
11,051,465 \\
7,195,614 \\
831,857 \\
56,594 \\
3,694,293 \\
124,789,547\end{array}$ & $\begin{array}{r}1,177,811 \\
1,419,802 \\
14,561,108 \\
-54 \\
16,777,796 \\
17,397,856 \\
6,890,804 \\
15,755,021 \\
21,811,369 \\
10,374,988 \\
6,876,164 \\
746,870 \\
52,859 \\
3,483,677 \\
117,473,397\end{array}$ & $\begin{array}{r}1,122,459 \\
1,341,505 \\
13,640,916 \\
19 \\
15,793,916 \\
16,327,582 \\
6,350,092 \\
14,361,974 \\
20,765,689 \\
9,661,625 \\
6,525,146 \\
655,434 \\
54,807 \\
3,280,289 \\
109,881,403\end{array}$ & $\begin{array}{r}1,062,926 \\
1,277,850 \\
12,826,622 \\
17 \\
14,868,152 \\
15,208,200 \\
5,830,681 \\
12,880,284 \\
19,480,653 \\
8,952,489 \\
6,163,894 \\
568,951 \\
54,836 \\
3,083,460 \\
102,354,028\end{array}$ \\
\hline
\end{tabular}

See endriotes at end of this table. 
Table 28. Electric Utility Plant for Major U.S. Investor-Owned Electric Utilities on Decomber 31, 1988-1992 (Continued) (Thousand Dollars)

\begin{tabular}{|c|c|c|c|c|c|}
\hline Item & 1992 & $1981^{\prime}$ & 1990 & 1989 & 1988 \\
\hline 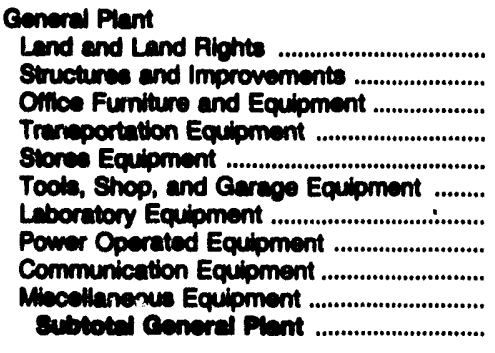 & $\begin{array}{r}454,391 \\
6,067,036 \\
3,012,243 \\
2,341,562 \\
168,364 \\
795,677 \\
625,531 \\
482,761 \\
3,412,237 \\
345,770 \\
17,704,671\end{array}$ & $\begin{array}{r}437,604 \\
5,693,642 \\
2,762,535 \\
2,229,015 \\
159,139 \\
745,440 \\
574,766 \\
483,109 \\
3,069,166 \\
352,078 \\
16,500,708\end{array}$ & $\begin{array}{r}421,668 \\
5,270,856 \\
2,493,425 \\
2,149,447 \\
152,150 \\
702,424 \\
522,901 \\
480,964 \\
2,781,340 \\
268,729 \\
15,243,605\end{array}$ & $\begin{array}{r}399,490 \\
4,865,287 \\
2,188,548 \\
2,072,545 \\
143,503 \\
681,469 \\
473,658 \\
436,723 \\
2,418,691 \\
217,094 \\
13,977,205\end{array}$ & $\begin{array}{r}355,669 \\
4,538,863 \\
1,929,097 \\
1,868,898 \\
134,647 \\
609,555 \\
443,760 \\
416,827 \\
2,132,352 \\
208,092 \\
12,723,760\end{array}$ \\
\hline 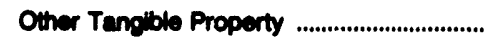 & $2,818,725$ & $1,521,635$ & $1,375,814$ & $1,644,208$ & $1,850,534$ \\
\hline Total Conered Plant ........................................ & $20,528,306$ & $18,022,428$ & $16,610,710$ & $15,621,414$ & $14,074,294$ \\
\hline $\begin{array}{l}\text { Electric Plant Purchaeed and Sold (net) ....... } \\
\text { Experimental Electric Plant Unclaselfied ... }\end{array}$ & $\begin{array}{l}941,808 \\
115,076\end{array}$ & $\begin{array}{l}451,463 \\
109,404\end{array}$ & $\begin{array}{r}38,184 \\
36,780\end{array}$ & $\begin{array}{r}-30,865 \\
42,627\end{array}$ & $\begin{array}{l}-3,845 \\
23,303\end{array}$ \\
\hline Toted Eloctric Uimty Plant in service... & $402,097,625$ & $476,649,632$ & $465,031,377$ & $426,266,042$ & $405,760,231$ \\
\hline Additions & 251,082 & 178,301 & 152,853 & 146,824 & 91,228 \\
\hline 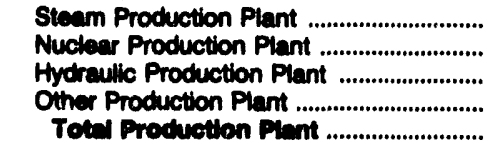 & $\begin{array}{r}3,536,259 \\
2,241,408 \\
352,084 \\
784,937 \\
6,914,606\end{array}$ & $\begin{array}{r}7,975,136 \\
2,535,119 \\
1,236,327 \\
501,171 \\
12,247,753\end{array}$ & $\begin{array}{r}4,412,349 \\
15,346,013 \\
282,107 \\
301,829 \\
20,342,297\end{array}$ & $\begin{array}{r}3,803,485 \\
4,912,866 \\
2229,434 \\
338,059 \\
0,283,044\end{array}$ & $\begin{array}{r}2,408,787 \\
16,541,288 \\
288,523 \\
149,628 \\
10,302,228\end{array}$ \\
\hline 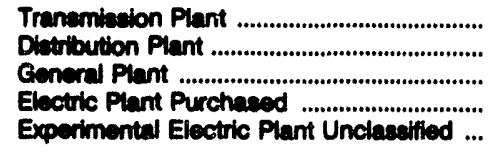 & $\begin{array}{r}2,453,444 \\
8,869,623 \\
1,762,390 \\
307,102 \\
42,004\end{array}$ & $\begin{array}{r}2,201,223 \\
8,619,150 \\
2,118,818 \\
427,315 \\
72,929\end{array}$ & $\begin{array}{r}2,763,819 \\
8,820,069 \\
1,841,380 \\
213,010 \\
4,018\end{array}$ & $\begin{array}{r}2,178,279 \\
8,578,251 \\
1,448,583 \\
2,439 \\
19,376\end{array}$ & $\begin{array}{r}1,809,237 \\
7,835,873 \\
1,951,475 \\
35,600 \\
19,253\end{array}$ \\
\hline Total Evectist Plant Addulions .................. & $20,600,100$ & $25,063,400$ & $34,137,446$ & $21,655,606$ & $31,224,970$ \\
\hline $\begin{array}{l}\text { Retirements } \\
\text { Intangible Plant ............................................... } \\
\text { Production Plant }\end{array}$ & 35,480 & 17,406 & 18,090 & 19,501 & 8,060 \\
\hline 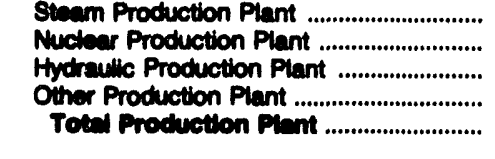 & $\begin{array}{r}848,704 \\
1,680,186 \\
17,289 \\
62,095 \\
2,618,276\end{array}$ & $\begin{array}{r}1,020,357 \\
329,046 \\
14,605 \\
37,583 \\
1,401,501\end{array}$ & $\begin{array}{r}556,069 \\
331,870 \\
17,472 \\
33,186 \\
930,597\end{array}$ & $\begin{array}{r}642,013 \\
494,009 \\
8,059 \\
23,168 \\
1,163,160\end{array}$ & $\begin{array}{r}614,242 \\
907,936 \\
16,872 \\
64,020 \\
1,603,071\end{array}$ \\
\hline 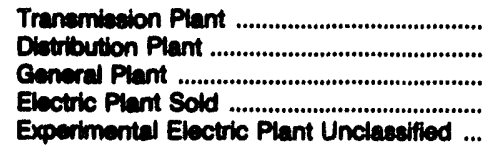 & $\begin{array}{r}247,608 \\
1,303,732 \\
511,187 \\
-56,112 \\
7,772\end{array}$ & $\begin{array}{r}208,925 \\
1,263,067 \\
464,112 \\
1,464 \\
0\end{array}$ & $\begin{array}{r}206,315 \\
1,181,075 \\
345,091 \\
1,806 \\
220\end{array}$ & $\begin{array}{r}155,711 \\
1,128,732 \\
367,161 \\
17,049 \\
0\end{array}$ & $\begin{array}{r}194,868 \\
1,085,628 \\
295,387 \\
88 \\
17,345\end{array}$ \\
\hline 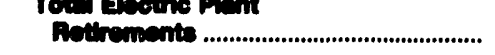 & $4,740,166$ & 3,356,656 & 2,602,202 & $2,056,304$ & $3,204,540$ \\
\hline
\end{tabular}

'Excluded are five independent power producers Jurisdictional to the Federal Energy Regulatory Commisalon which were included in the prior yarte publication.

Note: Totals may not equal sum of components because of independent rounding. Detail data are provided in Table 42 . Due to its emergence from banknuplcy, the 1891 financial statements for the Public Service Company of New Hampahire are from May 16 through December 31. Exchuded are the independent power producers and cooperatives furisdictional to the Federal Eneroy Regulatory Commiseion.

Source: Federal Energy Regulatory Commiseion, FERC Form 1, "Annual Report of Major Electric Utilties, Licensees and Others." 
Table 29. Capital Accounts for Major U.S. Investor-Owned Electric Utillities on December 31, 1988-1992

\begin{tabular}{|c|c|c|c|c|c|}
\hline Item & 1982 & $1991^{*}$ & 1990 & 1989 & 1988 \\
\hline \multicolumn{6}{|l|}{ Amount (blllon dollere) } \\
\hline 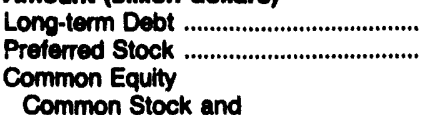 & $\begin{array}{r}174.1 \\
25.5\end{array}$ & $\begin{array}{r}171.9 \\
25.3\end{array}$ & $\begin{array}{r}167.9 \\
25.6\end{array}$ & $\begin{array}{r}162.9 \\
25.9\end{array}$ & $\begin{array}{r}160.7 \\
26.4\end{array}$ \\
\hline $\begin{array}{l}\text { Other Paid-in Capital' ..................... } \\
\text { Unappropriated Undistributed }\end{array}$ & 104.0 & 89.7 & 96.5 & 94.6 & 93.2 \\
\hline 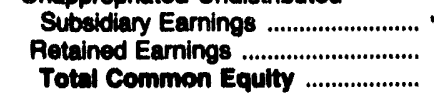 & $\begin{array}{r}2.7 \\
49.7 \\
168.3\end{array}$ & $\begin{array}{r}3.0 \\
49.0 \\
161.7\end{array}$ & $\begin{array}{r}2.8 \\
46.1 \\
147.4\end{array}$ & $\begin{array}{r}2.8 \\
47.8 \\
145.2\end{array}$ & $\begin{array}{r}2.5 \\
47.1 \\
142.7\end{array}$ \\
\hline Total Capital Structure ................... & 366.0 & 348.8 & 341.0 & 334.1 & 320.8 \\
\hline \multicolumn{6}{|l|}{ Percent of Total Capltalization } \\
\hline 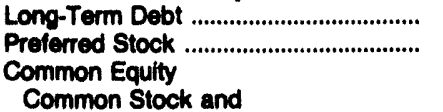 & $\begin{array}{r}48.9 \\
7.2\end{array}$ & $\begin{array}{r}49.3 \\
7.2\end{array}$ & $\begin{array}{r}49.3 \\
7.5\end{array}$ & $\begin{array}{r}48.8 \\
7.8\end{array}$ & $\begin{array}{r}48.7 \\
8.0\end{array}$ \\
\hline $\begin{array}{l}\text { Other Paid-in Capital' ....................... } \\
\text { Unappropriated Undistributed }\end{array}$ & 29.2 & 28.6 & 28.3 & 28.3 & 28.2 \\
\hline 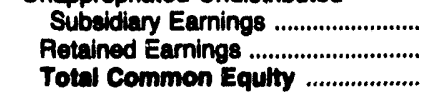 & $\begin{array}{r}.7 \\
14.0 \\
48.0\end{array}$ & $\begin{array}{r}.9 \\
14.0 \\
43.6\end{array}$ & $\begin{array}{r}.8 \\
14.1 \\
43.2\end{array}$ & $\begin{array}{r}.8 \\
14.3 \\
43.5\end{array}$ & $\begin{array}{r}.8 \\
14.3 \\
43.3\end{array}$ \\
\hline Total Capltal Structure .................... & 100.0 & 100.0 & 100.0 & 100.0 & 100.0 \\
\hline
\end{tabular}

' Includes common stock issued, capltal stock subscribed, other paid-in capital, instaliments received on capital stock, discount on cepital stock, capital stock expense, and reacquired capital stock.

Excluded are five independent power producers jurisdictional to the Federal Energy Regulatory Commisesion which were included in the prior year's publication.

Note: Totals may not equal sum of components because of independent rounding. Due to its emergence from bankruptcy, the 1891 financial statements for the Public Service Company of New Hampahire are from May 16 through December 31 . Excluded are the independent power producers and cooperatives juriedictional to the Federal Energy Regulatory Commission.

Source: Federal Energy Ragulatory Commission, FERC Form 1, "Annual Report of Major Electric Utilties, Licensees and Others." 
Table 30. Electric Energy Account for Major U.S. Investor-Owned

Electric Utilitios, 1988-1992

(Thousand Megawatthours)

\begin{tabular}{|c|c|c|c|c|c|}
\hline Item & 1992 & $1981^{*}$ & 1980 & 1989 & 1988 \\
\hline \multicolumn{6}{|l|}{ Generation (excluding station use) } \\
\hline 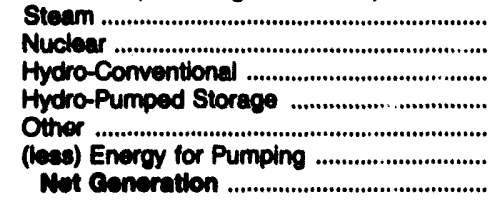 & $\begin{array}{r}1,525,417 \\
516,465 \\
61,253 \\
12,630 \\
14,471 \\
16,865 \\
2,113,370\end{array}$ & $\begin{array}{r}1,531,494 \\
511,255 \\
64,205 \\
12,990 \\
14,772 \\
17,422 \\
2,117,295\end{array}$ & $\begin{array}{r}1,543,763 \\
486,580 \\
68,780 \\
11,629 \\
15,546 \\
15,220 \\
2,111,087\end{array}$ & $\begin{array}{r}1,582,702 \\
439,356 \\
70,177 \\
12,247 \\
21,185 \\
17,086 \\
2,109,581\end{array}$ & $\begin{array}{r}1,547,617 \\
450,354 \\
52,709 \\
13,536 \\
16,366 \\
18,701 \\
2,081,882\end{array}$ \\
\hline \multicolumn{6}{|l|}{ Purchases } \\
\hline 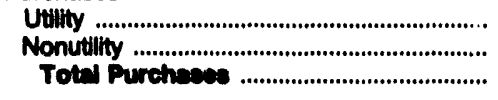 & $\begin{array}{l}483,481 \\
164,190 \\
647,671\end{array}$ & $\begin{array}{l}479,020 \\
136,278 \\
616,298\end{array}$ & $\begin{array}{l}370,983 \\
112,301 \\
483,285\end{array}$ & $\begin{array}{r}354,898 \\
86,750 \\
441,740\end{array}$ & $\begin{array}{r}341,319 \\
65,370 \\
403,699\end{array}$ \\
\hline \multicolumn{6}{|l|}{ Exchanges } \\
\hline 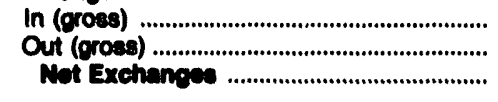 & $\begin{array}{r}123,218 \\
116,259 \\
6,900\end{array}$ & $\begin{array}{r}154,108 \\
145,147 \\
8,059\end{array}$ & $\begin{array}{r}330,553 \\
325,987 \\
4,598\end{array}$ & $\begin{array}{r}339,458 \\
329,522 \\
9,937\end{array}$ & $\begin{array}{r}311,401 \\
290,788 \\
20,812\end{array}$ \\
\hline \multicolumn{6}{|l|}{ Tranemiseion for Others (wheeling) } \\
\hline 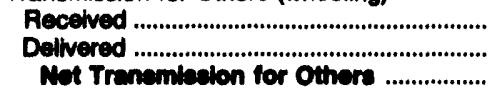 & $\begin{array}{r}240,507 \\
237,559 \\
2,047\end{array}$ & $\begin{array}{r}231,443 \\
228,024 \\
3,419\end{array}$ & $\begin{array}{r}230,730 \\
226,180 \\
4,550\end{array}$ & $\begin{array}{r}210,918 \\
208,452 \\
2,466\end{array}$ & $\begin{array}{r}175,635 \\
174,498 \\
1,197\end{array}$ \\
\hline Trenemiadon by Othere Loesee' ................ & $-\infty$ & -721 & -980 & NA & $\mathbf{N A}$ \\
\hline \multicolumn{2}{|l|}{ Totel Net Energy } & $2,744,250$ & $2,802,570$ & $2,502,732$ & $2,400,320$ \\
\hline Sales to Ultimate Consumers ............................. & $2,102,909$ & $2,099,754$ & $2,062,120$ & $2,022,629$ & $1,968,670$ \\
\hline Requirements Sales for Resale ${ }^{2} \ldots \ldots \ldots \ldots \ldots \ldots . . . . . . . .$. & 164,067 & 176,418 & 184,301 & 373,496 & 359,835 \\
\hline Non-requirements Sales for Resale ${ }^{2}$............ & 340,412 & 308,396 & 200,321 & NA & NA \\
\hline Energy Fumished Without Charge .................. & 1,598 & 1,424 & 1,904 & 1,262 & 1,815 \\
\hline \multicolumn{6}{|l|}{ Energy Used by Company (exc station } \\
\hline (480) & 5,726 & 5,638 & 5,384 & 5,570 & 5,586 \\
\hline 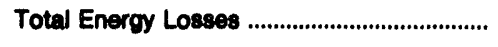 & 155,251 & 152,621 & 148,540 & 159,774 & 154,313 \\
\hline Toted sales and Diepoestion .................... & $2,789,964$ & $2,744,260$ & $2,602,67$ & $2,682,732$ & $2,490,320$ \\
\hline
\end{tabular}

1 Data reporting initiated in 1990.

Data prior to 1890 were reported as Sales for Resale (one entry) which is shown as Requirements for Resale for the years $1888-1989$.

- Excluded are five independent power producers jurisdictional to the Federal Energy Regulatory Commission which were included in the prior year's publication.

NA $=$ Not avallable.

Note: Totals may not equal sum of components because of independent rounding. Double counting occurs in components of both sources and disposition of energy and thus neither provides a true total. Purchases from utilities, net interchanges, and net wheeling (except for imports) are included in net generation. Sales for resale is included in sales to ultimate consumers. Detail data are provided in Table 43 . Due to its emergence from banknuptcy, the 1891 financial statements for the Pubilc Service Company of New Hampshire are from May 16 through December 31 ; the January 1 through May 15, 1991 dara values are 2,374 thousand megawatthours for sales to ultimate consumers and 1,765 thousand megawatthours (234 for requirements and 1,531 for non-requirements) for sales for resale with 4,420 thousand megatthours for total sales and disposition. Excluded are the independent power producers and cooperatives jurisdictional to the Federal Energy Regulatory Commission.

Source: Federal Energy Regulatory Commission, FERC Form 1, "Annual Report of Major Electric Utilities, Licensees and Others." 
Table 31. Ten Largest U.S. Investor-Owned Electric Utilitles Ranked by Revenue from Sales to Uitimate Consumers, 1992

\begin{tabular}{|c|c|c|}
\hline Electric Utilty Name & Thousand Dollars & Percentage \\
\hline 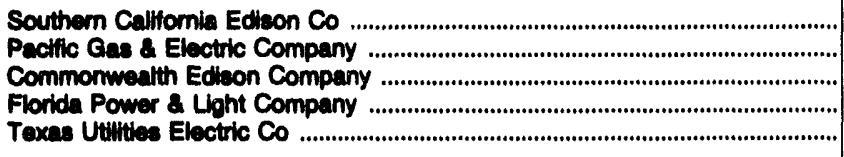 & $\begin{array}{l}7,461,648 \\
7,413,401 \\
5,874,986 \\
4,808,289 \\
4,554,964\end{array}$ & $\begin{array}{l}5.03 \\
5.00 \\
3.96 \\
3.24 \\
3.07\end{array}$ \\
\hline $\begin{array}{l}\text { Consolldated Edison Co-NY, Inc } \\
\text { Houston Lighting \& Power Co } \\
\text { Vrginia Eloctric \& Power Co } \\
\text { Georgla Power Company } \\
\text { Ouke Power Co }\end{array}$ & $\begin{array}{l}\mathbf{4 , 4 8 8 , 9 7 5} \\
\mathbf{3 , 6 7 6 , 5 7 5} \\
\mathbf{3 , 6 0 4 , 7 3 1} \\
\mathbf{3 , 5 3 7 , 4 3 7} \\
\mathbf{3 , 4 7 5 , 4 8 3}\end{array}$ & $\begin{array}{l}3.03 \\
2.48 \\
2.43 \\
2.38 \\
2.34\end{array}$ \\
\hline Subtotal & $49,090,470$ & 32.89 \\
\hline
\end{tabular}

Note: Data taken from Tabie 40.

Source: Federal Energy Regulatory Commiseion, FERC Form 1, "Annual Report of Major Electric Utilties, Licensees and Others."

Table 32. Ten Largeat U.S. Investor-Owned Electric Utilitles Ranked by Revenue from Sales for Reaale, 1992

\begin{tabular}{|c|c|c|}
\hline Electric Utility Name & Thousand Dollars & Percentage \\
\hline 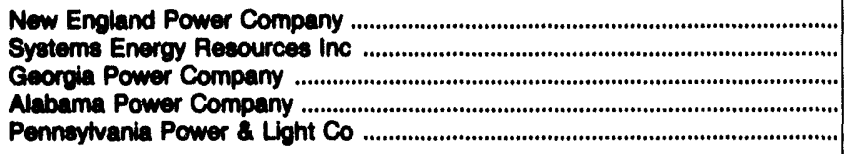 & $\begin{array}{r}1,501,982 \\
723,410 \\
708,447 \\
565,878 \\
509,974\end{array}$ & $\begin{array}{l}8.60 \\
4.14 \\
4.06 \\
3.24 \\
2.82\end{array}$ \\
\hline $\begin{array}{l}\text { Carolina Power \& Light Company } \\
\text { Ohio Power Co } \\
\text { Duke Power Company } \\
\text { Pacticorp } \\
\text { Arkansas Power \& Light Company }\end{array}$ & $\begin{array}{l}497,950 \\
464,351 \\
443,012 \\
430,053 \\
384,170\end{array}$ & $\begin{array}{l}2.86 \\
2.66 \\
2.54 \\
2.46 \\
2.20\end{array}$ \\
\hline Subtotw & $6,229,237$ & 35.86 \\
\hline
\end{tabular}

Note: Data taken from Table 40.

Source: Federal Energy Regulatory Commission, FERC Form 1, "Annual Report of Major Electric Utilities, Licensees and Others."

Table 33. Ten Largest U.S. Investor-Owned Electric Utilities Ranked by Electric Operating Revenue, 1992

\begin{tabular}{|c|c|c|}
\hline Electric Utility Name & Thousand Dollars & Percentage \\
\hline 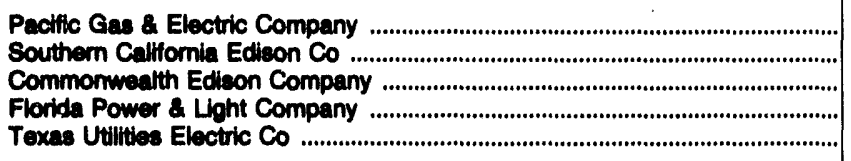 & $\begin{array}{l}7,755,780 \\
7,713,133 \\
\mathbf{6 , 0 2 6 , 3 2 0} \\
\mathbf{5 , 1 0 0 , 4 6 3} \\
\mathbf{5 , 0 2 9 , 2 8 1}\end{array}$ & $\begin{array}{l}4.58 \\
4.55 \\
3.66 \\
3.01 \\
2.97\end{array}$ \\
\hline 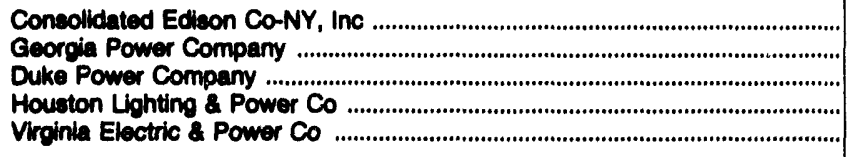 & $\begin{array}{l}4,805,524 \\
4,297,438 \\
3,961,484 \\
3,826,841 \\
3,679,621\end{array}$ & $\begin{array}{l}2.89 \\
2.54 \\
2.34 \\
2.28 \\
2.17\end{array}$ \\
\hline Sebtoted & $52,205,802$ & 80.88 \\
\hline
\end{tabular}

Note: Data taken from Table 37.

Source: Federal Energy Regulationy Commission, FERC Form 1, "Annual Report of Major Electric Utilities, Licensees and Others." 
Table 34. Ten Largest U.S. Investor-Owned Electric Utilitles Ranked by Net Electric Operating Income, 1992

\begin{tabular}{|c|c|c|}
\hline Electric Utility Name & Thousand Dollars & Percentage \\
\hline 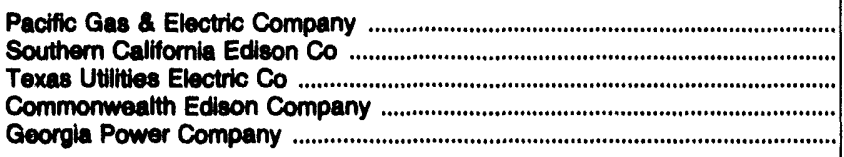 & $\begin{array}{r}1,560,233 \\
1,230,432 \\
1,200,338 \\
1,190,433 \\
982,160\end{array}$ & $\begin{array}{l}5.12 \\
4.04 \\
3.94 \\
3.91 \\
3.22\end{array}$ \\
\hline 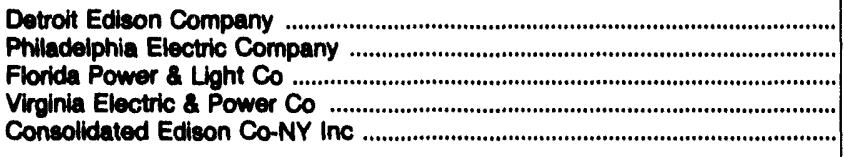 & $\begin{array}{l}956,642 \\
956,132 \\
764,391 \\
761,568 \\
755,421\end{array}$ & $\begin{array}{l}3.14 \\
3.14 \\
2.51 \\
2.50 \\
2.48\end{array}$ \\
\hline Serbtoted & $10,357,748$ & 33.98 \\
\hline
\end{tabular}

Note: Data taken from Table 37.

Source: Federal Energy Regulatory Commission, FEAC Form 1, "Annual Report of Major Electric Utilities, Licensees and Others."

Table 35. Ten Largest U.S. Investor-Owned Electric Utilitles Ranked by Gross Electric Utility Plant on December 31, 1992

\begin{tabular}{|c|c|c|}
\hline Electric Utility Name & Thousand Dollars & Percentage \\
\hline $\begin{array}{l}\text { Commomwealth Edison Company } \\
\text { Texas Utilities Electric Co } \\
\text { Pacific Gas \& Electric Company } \\
\text { Southern California Edison Co } \\
\text { Florida Power \& Light Company }\end{array}$ & $\begin{array}{l}25,214,650 \\
21,549,988 \\
20,828,822 \\
18,519,313 \\
14,415,676\end{array}$ & $\begin{array}{l}4.86 \\
4.15 \\
4.15 \\
3.57 \\
2.78\end{array}$ \\
\hline $\begin{array}{l}\text { Georgia Power Company } \\
\text { Virginia Electric \& Power Co } \\
\text { Philadelphia Electric Company } \\
\text { Detroit Edison Company } \\
\text { Duke Power Company }\end{array}$ & $\begin{array}{l}13,986,320 \\
12,977,136 \\
12,867,009 \\
12,538,970 \\
12,535,351\end{array}$ & $\begin{array}{l}2.70 \\
2.50 \\
2.48 \\
2.42 \\
2.42\end{array}$ \\
\hline Subtotal & $185,433,395$ & 31.89 \\
\hline
\end{tabular}

Note: Data taken from Table 38.

Source: Federal Energy Regulatory Commission, FERC Form 1, "Annual Report of Major Electric Utilities, Licensees and Others."

Table 36. Ten Largest U.S. Investor-Owned Electric Utilities Ranked by Net Electric Utility Plant on December 31, 1992

\begin{tabular}{|c|c|c|}
\hline Electric Utility Name & Thousand Dollars & Percentage \\
\hline $\begin{array}{l}\text { Texas Utilities Electric Co } \\
\text { Commonwealth Edison Company } \\
\text { Pactific Gas \& Electric Company } \\
\text { Southern Calfornia Edison Co } \\
\text { Georgia Power Company }\end{array}$ & $\begin{array}{l}17,808,868 \\
17,188,671 \\
13,524,186 \\
11,807,806 \\
10,422,138\end{array}$ & $\begin{array}{l}4.97 \\
4.80 \\
3.77 \\
3.30 \\
2.91\end{array}$ \\
\hline $\begin{array}{l}\text { Philadelphia Electric Company } \\
\text { Florida Power \& Light Company } \\
\text { Virginia Electric \& Power Co } \\
\text { Detroit Edison Company } \\
\text { Houston Lighting \& Power Co }\end{array}$ & $\begin{array}{l}\mathbf{9 , 6 0 1 , 9 5 8} \\
\mathbf{9 , 3 5 7 , 4 3 5} \\
\mathbf{9 , 1 2 4 , 6 2 8} \\
\mathbf{8 , 8 0 2 , 6 0 8} \\
\mathbf{8 , 5 3 2 , 1 4 8}\end{array}$ & $\begin{array}{l}2.68 \\
2.61 \\
2.55 \\
2.46 \\
2.38\end{array}$ \\
\hline Bubtotel & $116,170,548$ & 32.42 \\
\hline
\end{tabular}

Note: Data taken from Table 38.

Source: Federal Energy Regulatory Commission, FERC Form 1, "Annual Report of Major Electric. Utillties, Licensees and Others." 


\section{Detailed Statistics of the Major U.S. Investor-Owned Electric Utilities 1992}

The Cayuga Plant, a coalfired plant, is located near Cayuga, Indiana and is owned by PSi Energy incorporated.

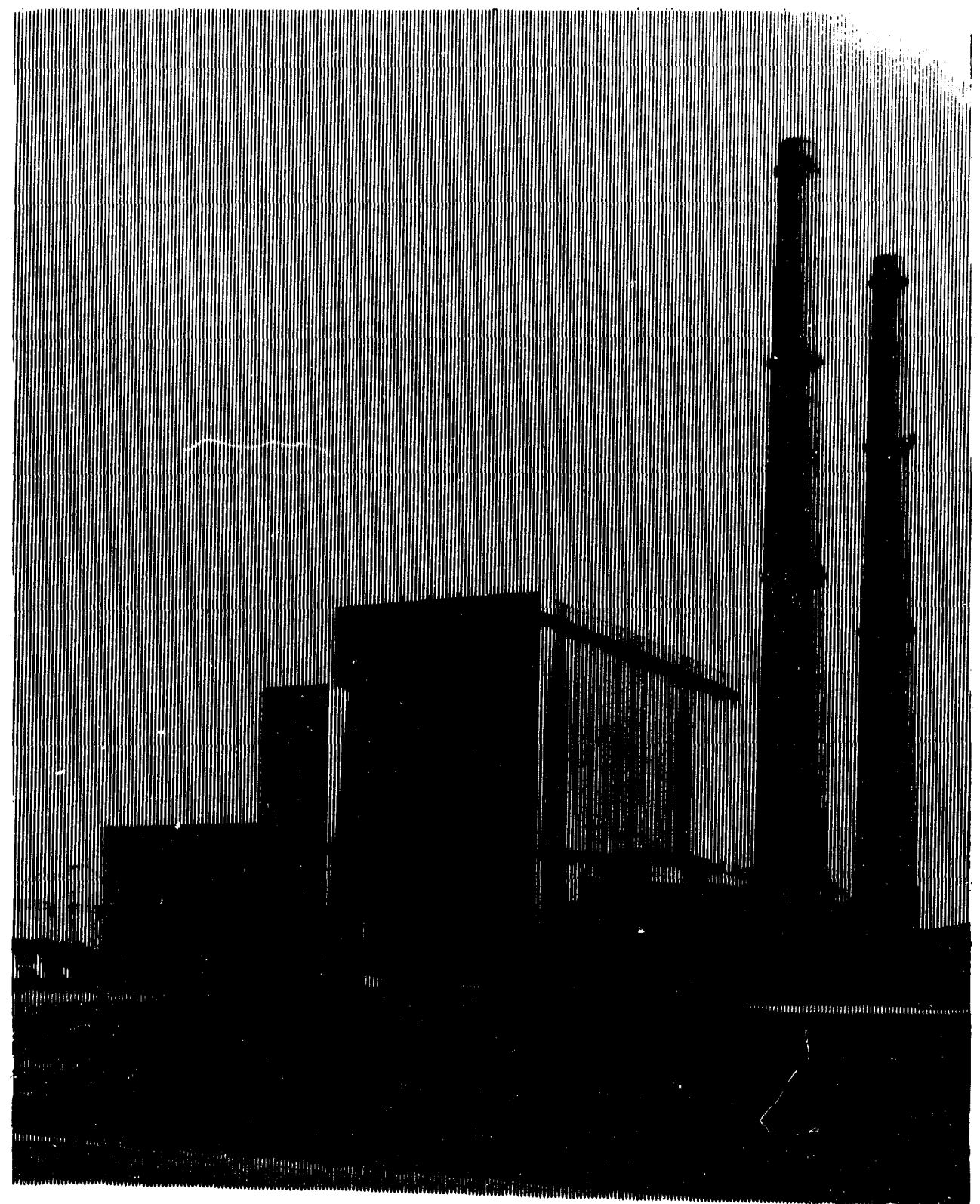


Table 37. Statement of Income and Rotalned Earnings

by Major U.S. Investor-Owned Electric

Utility Within State, 1982

(Thousand Dollars)

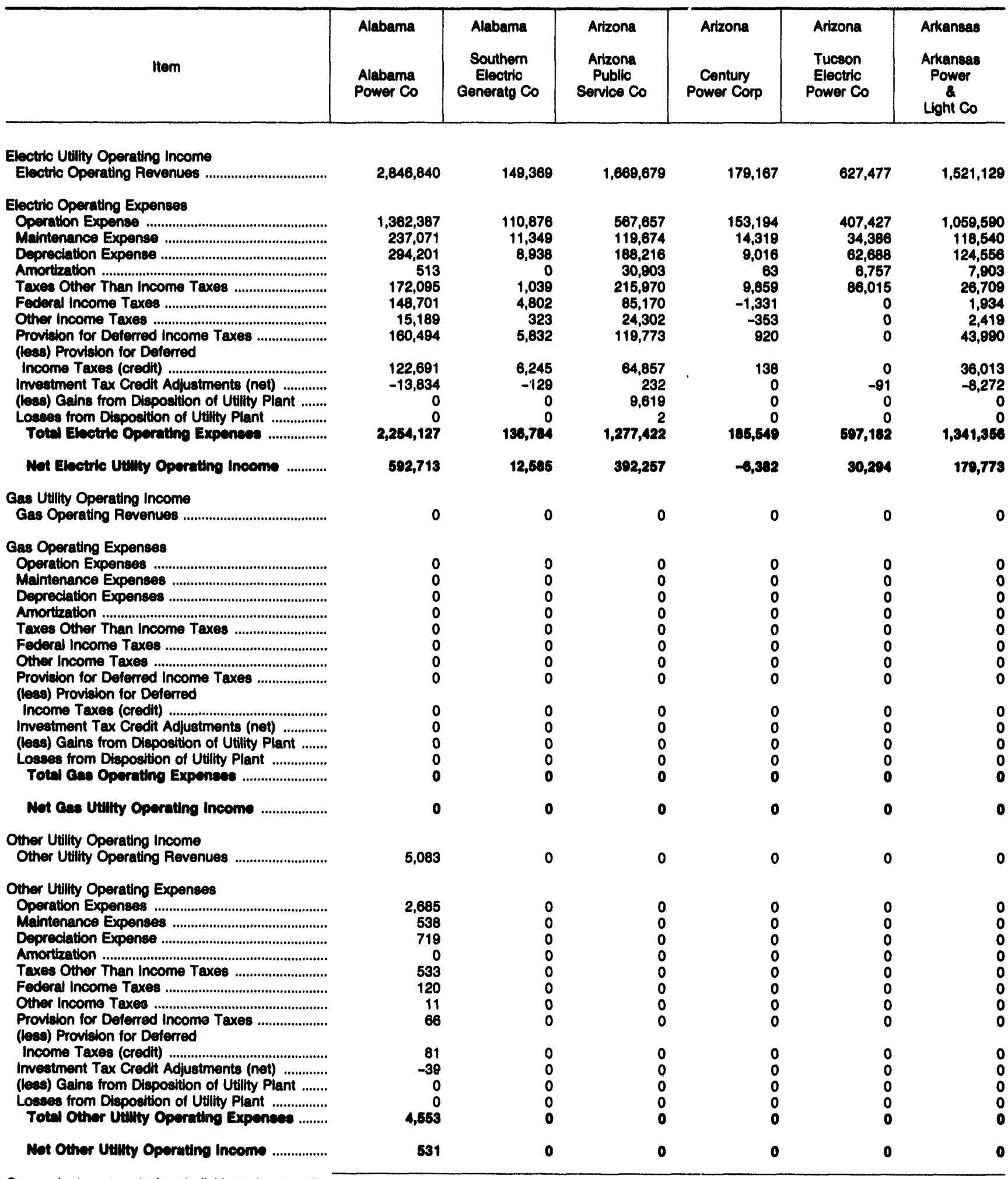

See endnotes at end of an individual electric utility. 
Table 37. Statement of Income and Retalned Earnings

by Major U.S. Investor-Owned Eloctric

Utility Within state, 1992 (Continued)

(Thousand Dollars)

\begin{tabular}{|c|c|c|c|c|c|c|}
\hline Item & $\begin{array}{l}\text { Alabama } \\
\text { Alabama } \\
\text { Power Co }\end{array}$ & $\begin{array}{l}\text { Alabama } \\
\text { Southern } \\
\text { Electric } \\
\text { Generatg Co }\end{array}$ & $\begin{array}{l}\text { Arizona } \\
\text { Arizona } \\
\text { Public } \\
\text { Service Co }\end{array}$ & $\begin{array}{l}\text { Arizona } \\
\text { Century } \\
\text { Power Corp }\end{array}$ & $\begin{array}{l}\text { Arizona } \\
\text { Tucson } \\
\text { Electric } \\
\text { Power Co }\end{array}$ & $\begin{array}{l}\text { Arkansas } \\
\text { Arkansas } \\
\text { Power } \\
8 \\
\text { Light Co }\end{array}$ \\
\hline $\begin{array}{l}\text { Total Utility Operating Income } \\
\text { Total Utility Operating Revenues .............................. }\end{array}$ & $2,851,923$ & 149,369 & $1,669,679$ & 179,167 & 627,477 & $1,521,129$ \\
\hline 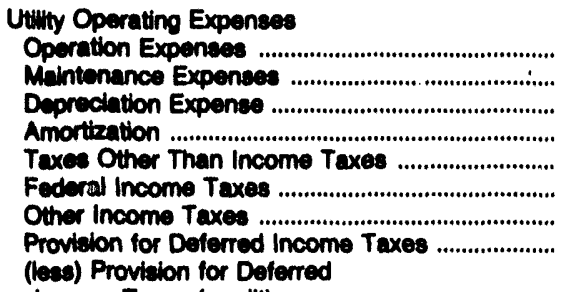 & $\begin{array}{r}1,365,072 \\
237,609 \\
294,020 \\
513 \\
172,628 \\
148,821 \\
15,200 \\
160,560\end{array}$ & $\begin{array}{r}110,876 \\
11,349 \\
8,938 \\
0 \\
1,039 \\
4,802 \\
323 \\
5,832\end{array}$ & $\begin{array}{r}567,657 \\
119,674 \\
188,216 \\
30,903 \\
215,970 \\
85,170 \\
24,302 \\
119,773\end{array}$ & $\begin{array}{r}153,194 \\
14,319 \\
9,016 \\
63 \\
9,859 \\
-1,331 \\
-353 \\
920\end{array}$ & $\begin{array}{r}407,427 \\
34,386 \\
62,688 \\
6,757 \\
86,015 \\
0 \\
0 \\
0\end{array}$ & $\begin{array}{r}1,059,580 \\
118,540 \\
124,556 \\
7,803 \\
26,709 \\
1,834 \\
2,419 \\
43,980\end{array}$ \\
\hline 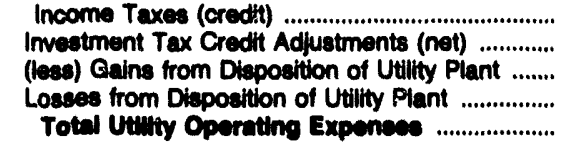 & $\begin{array}{r}122,772 \\
-13,872 \\
0 \\
0 \\
2,258,679\end{array}$ & $\begin{array}{r}6,245 \\
-129 \\
0 \\
0 \\
138,784\end{array}$ & $\begin{array}{r}64,857 \\
232 \\
9,619 \\
2 \\
1,277,422\end{array}$ & $\begin{array}{r}138 \\
0 \\
0 \\
0 \\
185,540\end{array}$ & $\begin{array}{r}0 \\
-91 \\
0 \\
0 \\
597,182\end{array}$ & $\begin{array}{r}36,013 \\
-8,272 \\
0 \\
0 \\
1,341,388\end{array}$ \\
\hline 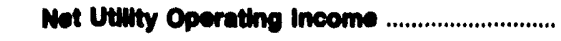 & 693,244 & 12,505 & 392,257 & $-6,382$ & 30,204 & 179,773 \\
\hline $\begin{array}{l}\text { Other Income and Deductions } \\
\text { Other Income }\end{array}$ & & & & & & \\
\hline 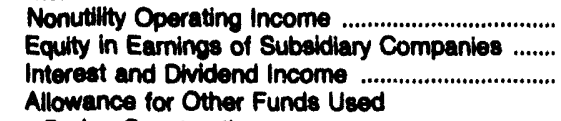 & $\begin{array}{r}-93 \\
12,463 \\
14,804\end{array}$ & $\begin{array}{l}0 \\
0 \\
0\end{array}$ & $\begin{array}{r}19 \\
-1,879 \\
3,723\end{array}$ & $\begin{array}{r}0 \\
2 \\
1,065\end{array}$ & $\begin{array}{r}108 \\
-42,806 \\
17,169\end{array}$ & $\begin{array}{r}1,123 \\
2 \\
13,849\end{array}$ \\
\hline 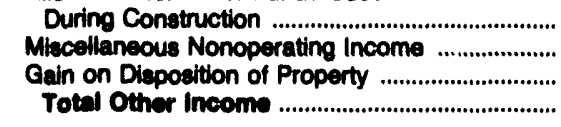 & $\begin{array}{r}2,071 \\
11,361 \\
66 \\
40,673\end{array}$ & $\begin{array}{r}617 \\
13 \\
0 \\
631\end{array}$ & $\begin{array}{r}3,103 \\
70,222 \\
132 \\
75,320\end{array}$ & $\begin{array}{r}6 \\
1,501 \\
0 \\
2,573\end{array}$ & $\begin{array}{r}19 \\
27,577 \\
37 \\
2,103\end{array}$ & $\begin{array}{r}4,173 \\
67,307 \\
33,823 \\
120,278\end{array}$ \\
\hline 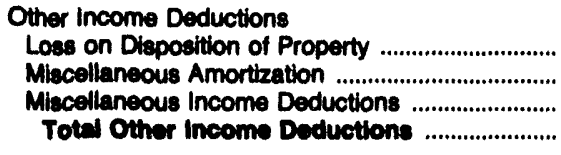 & $\begin{array}{r}356 \\
0 \\
39,932 \\
40,286\end{array}$ & $\begin{array}{l}0 \\
0 \\
1 \\
1\end{array}$ & $\begin{array}{r}2 \\
0 \\
9,608 \\
9,610\end{array}$ & $\begin{array}{r}0 \\
12,732 \\
2,387 \\
15,110\end{array}$ & $\begin{array}{r}0 \\
0 \\
30,803 \\
30,803\end{array}$ & $\begin{array}{r}1 \\
42 \\
2,206 \\
2,240\end{array}$ \\
\hline 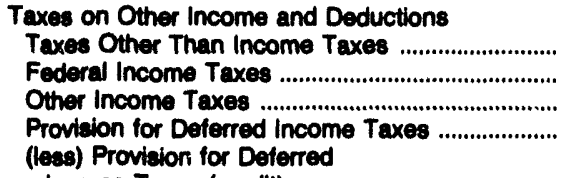 & $\begin{array}{r}879 \\
-6,143 \\
781 \\
2,797\end{array}$ & $\begin{array}{r}0 \\
-58 \\
11 \\
0\end{array}$ & $\begin{array}{r}174 \\
-4,249 \\
-1,161 \\
29,583\end{array}$ & $\begin{array}{r}0 \\
-945 \\
-270 \\
1,605\end{array}$ & $\begin{array}{l}0 \\
0 \\
0 \\
0\end{array}$ & $\begin{array}{r}11 \\
43,898 \\
8,738 \\
0\end{array}$ \\
\hline 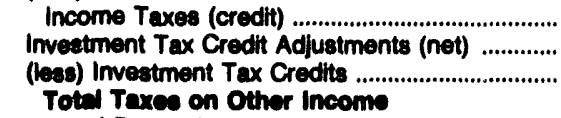 & $\begin{array}{r}6,267 \\
-4,092 \\
0\end{array}$ & $\begin{array}{r}0 \\
-54 \\
0\end{array}$ & $\begin{array}{r}402 \\
0 \\
7,036\end{array}$ & $\begin{array}{r}0 \\
0 \\
877\end{array}$ & $\begin{array}{r}0 \\
0 \\
5,854\end{array}$ & $\begin{array}{r}4,487 \\
-1,717 \\
0\end{array}$ \\
\hline 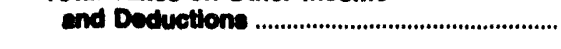 & $-12,045$ & -101 & 16,900 & -488 & $-5,654$ & 46,643 \\
\hline Net Other Income and Deductions .................. & 12,420 & 731 & 48,802 & $-12,058$ & $-23,046$ & 71,494 \\
\hline
\end{tabular}

See endnotes at end of an individual electric utility. 
Table 37. Statement of Income and Rotained Earnings

by Major U.S. Inveator-Owned Electrlc

Utility Within State, 1992 (Continued)

(Thousand Dollars)

\begin{tabular}{|c|c|c|c|c|c|c|}
\hline ltem & $\begin{array}{l}\text { Alabama } \\
\text { Alabama } \\
\text { Power Co }\end{array}$ & $\begin{array}{l}\text { Alabama } \\
\text { Southern } \\
\text { Electrio } \\
\text { Generato Co }\end{array}$ & $\begin{array}{l}\text { Artzona } \\
\text { Artzona } \\
\text { Publlo } \\
\text { Service Co }\end{array}$ & $\begin{array}{l}\text { Arizon } \\
\text { Century } \\
\text { Power Corp }\end{array}$ & $\begin{array}{l}\text { Artzona } \\
\text { Tucson } \\
\text { Electrilo } \\
\text { Power Co }\end{array}$ & $\begin{array}{c}\text { Arkansas } \\
\text { Arkanase } \\
\text { Power } \\
\text { \& } \\
\text { Light Co }\end{array}$ \\
\hline
\end{tabular}

Interast Charges

Interest on Lona-term Debt

Amortization of Dobt Diecount and Expense

Amortization of Loss on Reacquired Debt ...........

(lese) Amortization of Premium on Debt (credit)

(less) Amortization of Gain on

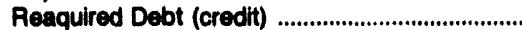

Interest on Debt to Associated Companies ........

Other Interest Expense ...........................................

(less) Allowance for Borrowed Funds

Used During Construction (credit)

Net Interest Charees .............................................

Income Eotore Extreordinary ttems

Extraordinary ltems

Extraordinary Income

(less) Extraordinary Deductions

Nos Extraordinary liems

(less) Federal and Other Income Taxes

Extraordinary ltems After Taxes

Not Income
4,626

23
103

1,641

3,179

22

407

23,086

2,416

281,099

$\mathbf{3 7 3 , 7 4 0}$

0
0
0

0

373,740

9,270

219,00

$-08,170$

$-347,312$

39,181

Balance Transferred from Income

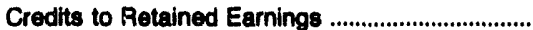

(less) Debits to Retained Earnings

(ess) Appropriations of Retained Earnings

(less) Dividends Declared - Preferred Stock .......

(less) Dividends Declared - Common Stock ........

Unappropriated Undistributed Subsidiary

Earnings

Rotalned Eamings - End of Yoar

r..........

Appropriated Retained Earnings

Appropriated Retained Earnings -

Amortization Reserve, Federal

Totel Rotained Earnings
31,330

835,751

$$
9,270
$$

361,277

4,154

35,295

273,300

11,001

995,281

\section{0}

0

805,281

28,605

0

20,00

$\begin{array}{rr}8,270 & 248,683 \\ 0 & 0 \\ 0 & 428 \\ 0 & 0 \\ 0 & 32,452 \\ 12,002 & 170,000\end{array}$

27,928

$-82,724$

0

0

0
0

42,847

$-397,100$

420,470

234,000

$-87,24$

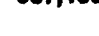

2

0

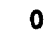

0

6

0

0

0

244,017

$-67,24$

$-397,100$

480,470

Note: Totals may not equal sur. If components because of independent rounding. Summary data are provided in Table 6.

Source: Federal Energy Regulatury Commission, FERC Form 1, "Annual Report of Major Electric Utilities, Licensees and Others." 
Table 37. Statoment of Inoome and Rotalned Eaminges

by Major U.8. Inveotor-Owned Eleotrito

Utilly Whin state, 1902 (Continued)

(Thousand Dollars)

\begin{tabular}{|c|c|c|c|c|c|c|}
\hline $\mathrm{Hem}$ & $\begin{array}{l}\text { Cellitomin } \\
\text { Pacillo } \\
\text { Case } \\
\text { Electio Co }\end{array}$ & $\begin{array}{c}\text { Cellomin } \\
\text { Een Dieco } \\
\text { Cas } \\
\text { Enctio Co }\end{array}$ & $\begin{array}{l}\text { Callomia } \\
\text { Southem } \\
\text { Callomia } \\
\text { Edvon Co }\end{array}$ & $\begin{array}{l}\text { Colorado } \\
\text { Publlo } \\
\text { Serviou } \\
\text { Co } \\
\text { of Colorado }\end{array}$ & $\begin{array}{l}\text { Connectiout } \\
\text { Citizens } \\
\text { Utilties Co }\end{array}$ & $\begin{array}{l}\text { Connecticut } \\
\text { Conneotiout } \\
\text { Lught } \\
\text { Power Co }\end{array}$ \\
\hline 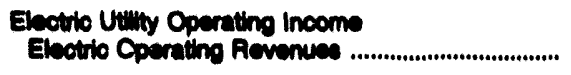 & $7,766,700$ & $1,443,600$ & $7,713,133$ & $1,228,700$ & 139,436 & $2,316,451$ \\
\hline 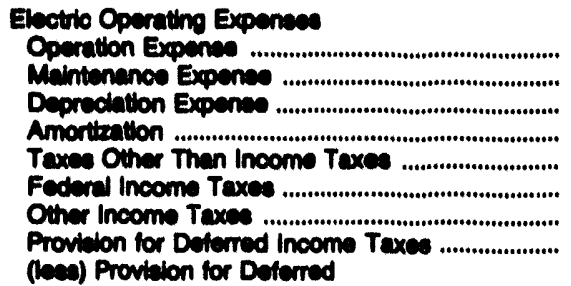 & $\begin{array}{r}3,028,007 \\
411,000 \\
868,007 \\
11,104 \\
208,450 \\
418,700 \\
162,097 \\
240,040\end{array}$ & $\begin{array}{r}782,046 \\
63,627 \\
163,244 \\
11,006 \\
39,790 \\
119,004 \\
24,000 \\
65,076\end{array}$ & $\begin{array}{r}4,628,942 \\
303,792 \\
757,316 \\
16,187 \\
202,101 \\
403,368 \\
132,251 \\
997,780\end{array}$ & $\begin{array}{r}748,660 \\
60,146 \\
89,611 \\
6,446 \\
60,126 \\
46.793 \\
4,777 \\
37,263\end{array}$ & $\begin{array}{r}88,378 \\
5,200 \\
11,032 \\
6 \\
6 \\
13,243 \\
3,534 \\
813 \\
1,417\end{array}$ & $\begin{array}{r}1,203,801 \\
197,461 \\
209,461 \\
73,879 \\
171,642 \\
74,126 \\
32,117 \\
151,342\end{array}$ \\
\hline 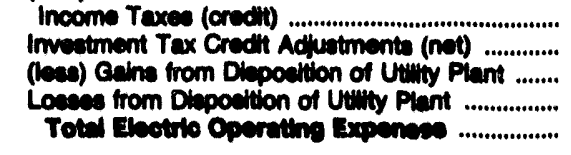 & $\begin{array}{r}62,686 \\
-8,184 \\
4 \\
0 \\
0,184,158\end{array}$ & $\begin{array}{r}54,613 \\
-4,802 \\
1,676 \\
0 \\
1,172,09\end{array}$ & $\begin{array}{r}284,469 \\
-18,569 \\
0 \\
13 \\
0,422,700\end{array}$ & $\begin{array}{r}10,686 \\
-3,690 \\
0 \\
0 \\
1,034,374\end{array}$ & $\begin{array}{r}651 \\
-456 \\
0 \\
0 \\
122,616\end{array}$ & $\begin{array}{r}79,120 \\
-6,230 \\
0 \\
0 \\
2,028,940\end{array}$ \\
\hline 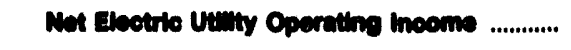 & $1,000,203$ & 200,700 & $1,200,492$ & 184,396 & 18,810 & 207,011 \\
\hline $\begin{array}{l}\text { Gas Ut Uty Operating Income } \\
\text { Gas Operating Revenues }\end{array}$ & $2,578,620$ & 461,840 & 773 & 521,372 & 176,639 & \\
\hline 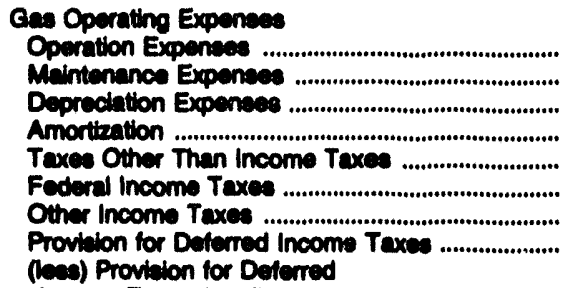 & $\begin{array}{r}1,826,080 \\
67,308 \\
221,720 \\
0 \\
51,749 \\
94,608 \\
34,880 \\
31,815\end{array}$ & $\begin{array}{r}868,703 \\
6,314 \\
28,062 \\
715 \\
5,031 \\
12,438 \\
4,101 \\
13,653\end{array}$ & $\begin{array}{r}589 \\
40 \\
35 \\
0 \\
12 \\
39 \\
13 \\
3\end{array}$ & $\begin{array}{r}456,335 \\
8,069 \\
13,346 \\
238 \\
14,297 \\
630 \\
-576 \\
3,675\end{array}$ & $\begin{array}{r}135,612 \\
4,875 \\
8,433 \\
0 \\
7,297 \\
3,083 \\
-440 \\
1,044\end{array}$ & $\begin{array}{l}0 \\
0 \\
0 \\
0 \\
0 \\
0 \\
0 \\
0\end{array}$ \\
\hline 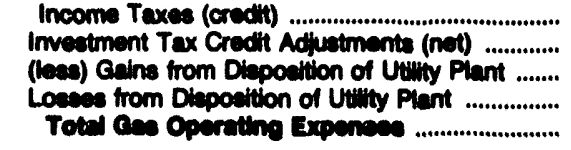 & $\begin{array}{r}17,251 \\
0 \\
2 \\
0 \\
2,910,607\end{array}$ & $\begin{array}{r}11,751 \\
-343 \\
0 \\
0 \\
424,012\end{array}$ & $\begin{array}{r}35 \\
0 \\
0 \\
0 \\
0\end{array}$ & $\begin{array}{r}3,224 \\
-702 \\
0 \\
0 \\
402,070\end{array}$ & $\begin{array}{r}13 \\
-328 \\
0 \\
0 \\
169,693\end{array}$ & $\begin{array}{l}0 \\
0 \\
0 \\
0 \\
0\end{array}$ \\
\hline Net cas Utity Operating inooms ..................... & 203,028 & 97,224 & 77 & 20,203 & 17,076 & ( \\
\hline $\begin{array}{l}\text { Other Utilly Opernting Income } \\
\text { Other Utility Operating Revenues .............................. }\end{array}$ & 6,853 & 1,875 & 980 & 6,111 & 18,694 & 0 \\
\hline 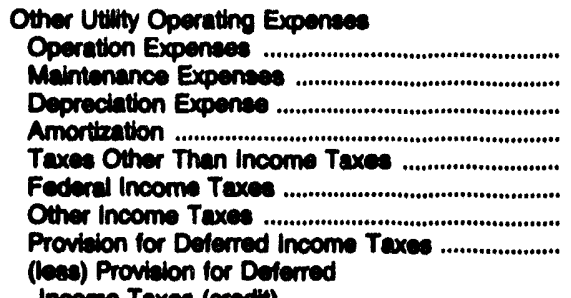 & $\begin{array}{r}6,623 \\
414 \\
642 \\
0 \\
207 \\
-773 \\
-176 \\
101\end{array}$ & $\begin{array}{r}962 \\
200 \\
273 \\
0 \\
48 \\
0 \\
0 \\
0\end{array}$ & $\begin{array}{r}467 \\
328 \\
187 \\
0 \\
65 \\
-76 \\
-19 \\
0\end{array}$ & $\begin{array}{r}4,757 \\
694 \\
531 \\
34 \\
278 \\
-278 \\
-62 \\
205\end{array}$ & $\begin{array}{r}16,118 \\
1,120 \\
2,277 \\
0 \\
2,103 \\
1,269 \\
412 \\
1,243\end{array}$ & $\begin{array}{l}0 \\
0 \\
0 \\
0 \\
0 \\
0 \\
0 \\
0\end{array}$ \\
\hline 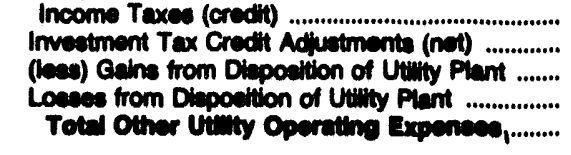 & $\begin{array}{r}65 \\
0 \\
0 \\
0 \\
7,200\end{array}$ & $\begin{array}{r}0 \\
0 \\
0 \\
0 \\
1,494\end{array}$ & $\begin{array}{r}0 \\
0 \\
0 \\
0 \\
240\end{array}$ & $\begin{array}{r}2 \\
-9 \\
0 \\
0 \\
0,144\end{array}$ & $\begin{array}{r}301 \\
-83 \\
0 \\
0 \\
24,150\end{array}$ & $\begin{array}{l}0 \\
0 \\
0 \\
0 \\
0\end{array}$ \\
\hline Net Other Utinty Opereting lnoems .................. & -800 & 201 & 67 & -33 & $-4,403$ & $\mathbf{0}$ \\
\hline
\end{tabular}

See endinotes at end of an individual electric utility. 
Table 37. Statement of Income and Rotained Earnings by Major U.8. Investor-Owned Electrie Utility Whin 8tate, 1902 (Continued) (Thousand Dollars)

\begin{tabular}{|c|c|c|c|c|c|c|}
\hline $\mathrm{item}$ & 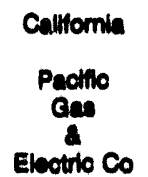 & $\begin{array}{l}\text { Calliomia } \\
\text { san Dieso } \\
\text { Cese } \\
\text { Electrio Co }\end{array}$ & $\begin{array}{l}\text { Calliomia } \\
\text { Southern } \\
\text { Calliomia } \\
\text { Edion Co }\end{array}$ & $\begin{array}{l}\text { Colorado } \\
\text { Publlo } \\
\text { Eervice } \\
\text { Co } \\
\text { of Colorado }\end{array}$ & $\begin{array}{l}\text { Connectiout } \\
\text { Citteons } \\
\text { Utiltiee Co }\end{array}$ & $\begin{array}{l}\text { Connectlout } \\
\text { Connectiout } \\
\text { Light } \\
\text { Power Co }\end{array}$ \\
\hline
\end{tabular}

Total Ui"ity Operating Inoome

Total Utity Opernting Revenues

$10,841,272$

$1,007,380$

$7,714,002$

$1,768,101$

335,708

$2,316,461$

Uethy Operating Exponaes

Opertion Exomente.

Mintinence Expente.

Depredition Expence

Amortiation

Federel Inoom Taxes

Otrer Incoms Texee

(ina) Provition for Doferred

Incoms Taxes (oredit)

Imvectoment Tax Crecti Adjuetmonts (not) .............

(kav) Cing from Dispostion of Utility Piant........

Loeses from Depowtion of Utilly Piant

Totel Utisty Operating Expensese

.........................

Nes Vumby Operating Inoems
$1,110,710$

73,040

193,409

12,711

46,709

131,682

28,110

0.028

69,234

$-8,146$

1,67

$1,800,69$

0,818,ses

$1,927,978$

807,408
$4,624,088$

304,188

767,687

16,187

202,178

408,319

132,240

$0.07,708$

004,404

$-18,680$

$-18,650$

0,44,2es

$1,280,894$
240,108
11,108
21,741
6
22,044
7,887
784
3,704
806
-808
0
0
80,297

20,491
$1,208,801$

107,461

200,461

73,870

171,042

74,120

32,117

181,342

70,120

$-0,260$

$2,024,40$

207,011

$$
\begin{array}{r}
1,204,681 \\
68,898 \\
108,488 \\
8,718 \\
74,008 \\
47,144 \\
4,130 \\
41,148 \\
13,892 \\
-4,401
\end{array}
$$

202,808

-80
-11.070

6,110

7,850

1,727

138,139

830

$-78,024$

2,787

oin on Diapotion of Propety

Toul Ouner income

20,388

0,800
100,093

877
18,240

670
87,340
3,048

334

8,014

2,612

3,088

1,718

65,902

157

110,214

a,ros

Other Income Deductions

Lose on Diaposition of Property

Miscellaneous Amortzation ............

4,068

168

0
0
5,19

688
0

60,111

4,463
4,262

5,160
8,160

16
0
4,812

4,812
4,99

0
10
1,829

1,820

0
1,280
4,019

4,019
8,200

Texes on Other Income and Deductione

Federal Income Taxe

Other Income Texee ................................................

Proviaion for Deferred Income Taxes

(kev) Provicion for Deferred

Income Texes (oredti)

Imuetiment Tox Credt Adhutmente (net)

(ke) invetment Tax Credth

Tould Tares en Other inoem

and bechotion

276
14,330
4,021
672
$-3,088$
$-16,682$
0

318

0,378

385

$-14,340$

$-13,319$

$-6,190$

$-46,268$

3,244

$-300$

0

27
-988
-103

0
$-1,424$

$-483$

234

$-12,362$

$-4,0.4$

8,803

2,068

0

7,498

8,405

$-75,038$

$-1,120$

$-1,007$

$-10,090$

124,

4,037

$-87,040$

$-94$

110,892

74,4s

seo endnotes at end of an individual electric vality. 
Table 37. statoment of Inoome and Rotained Eaminge

by Malor U.8. Investor-Owned Eleotrio

utility Whinin 8tate, 1902 (Continued)

(Thousand Dollars)

\begin{tabular}{|c|c|c|c|c|c|c|}
\hline Mem & $\begin{array}{c}\text { Callomia } \\
\text { Pecillo } \\
\text { Cas } \\
\text { encotio Co }\end{array}$ & $\begin{array}{l}\text { Calliomia } \\
\operatorname{san} \text { Diepo } \\
\text { Gias } \\
\text { Evectic Co }\end{array}$ & $\begin{array}{l}\text { Callomia } \\
\text { southem } \\
\text { Callomia } \\
\text { Edison Co }\end{array}$ & $\begin{array}{l}\text { Colorido } \\
\text { Publio } \\
\text { serviou } \\
\text { Co } \\
\text { of Coloredo }\end{array}$ & 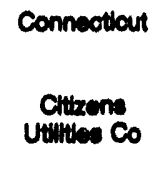 & $\begin{array}{l}\text { Connectiout } \\
\text { Connectiout } \\
\text { Light } \\
\text { Power Co }\end{array}$ \\
\hline
\end{tabular}

Interext Cheres

Inveret on Long-term Dabt .......................................

Amortiention of Debt Discount end Expenes ......

Amortiration of Low on Resogited Dort ............

(bas) Amortintion of Premilum on Dest (credil).

(ine) Amortivition of Cein on

Rengy'sed Dobt (crecil) ............................................... Imorest on Debt to Aseociated Comperies ........

Othrer Intereet Expense

(bes) Alownice for Borrownd Funde

Uand Duing Conethution (cred

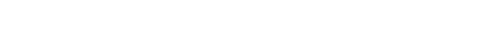

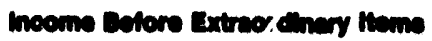

n.....................

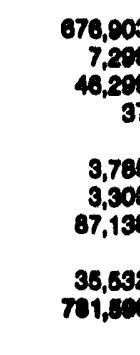

1,170,.91

Extreortiney them

Extroordiney Inoome

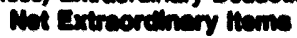

(ken) Federd and Other Income Taxee

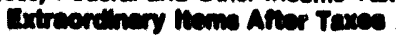

net boens

$1,170,091$

210.093

o7s.90.

388,877

17,692

81

0

18,324
80,076

16,631

$\mathbf{0 0 , 0 1 2}$

ereses

210.063

$\mathbf{0}$
$\mathbf{0}$
$\mathbf{0}$

0
0
0

$?$

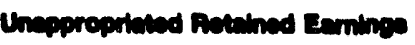

Rotulned enmince - Becinming of Yere

$2,294,16$

628,69

$2,414,293$

100,902

$-\infty, 160$

710,037

Balance Traneterred from Income

$\begin{array}{rr}1,141,094 & 224,17 \\ 0 & \\ 17,001 & 040 \\ 0 & \\ 81,394 & 9,583 \\ 744,277 & 164,04 \\ -242 & \end{array}$

673,104

4,842
849

848

620,858

(ke) Dividend Dectered - Pretemed Stock

(aes) Dividends Deciered - Common 8tock ......

Uneppropilated Unciotributed Subuideny

Eaminos.

Retined Eeminge - End of Yeer

$2.492,247$

678,249

$2,410,338$

149,079

88,722
2,003

2,003
123

0
0

118,301

115,640

20,816

201,822

$-126,975$

724,692

Appropitated Retaind Eernings

Appropilated Rotained Eaninos

Amortivation Recerve, Federe

0

642

$2,692,100$
12,528

673,240

$2,490 \mathrm{men}$

231,802

198,699

1,725

0
31,977

164,278

7,020

Totw Retulind Eeninge

Nowe: Totels may not cauel eum of components beceuse of independent rounding. Summany data are provided in Table 6.

Source: Federd Energy Regulationy Comminelon, FEAC Form 1, "Annul Peport of Major Electric Ututhies, Licensees and Others." 
Table 37. Statement of Income and Rotained Earninge

by Major U.8. Investor-Owned Electric

Utilty Within 8tate, 1902 (Continued)

(Thousand Dollars)

\begin{tabular}{|c|c|c|c|c|c|c|}
\hline $\mathrm{Item}$ & $\begin{array}{l}\text { Connectiout } \\
\text { Conneotiout } \\
\text { Yankes } \\
\text { Atom } \\
\text { Pw Co }\end{array}$ & $\begin{array}{l}\text { Conneotiout } \\
\text { United } \\
\text { Illuminating } \\
\text { Co }\end{array}$ & $\begin{array}{l}\text { Delaware } \\
\text { Delmarva } \\
\text { Power } \\
\text { Lught Co }\end{array}$ & $\begin{array}{l}\text { District of } \\
\text { Columbia } \\
\text { Potomieo } \\
\text { Electric } \\
\text { Pown Co }\end{array}$ & $\begin{array}{c}\text { Florida } \\
\text { Florida } \\
\text { Power } \\
\mathbf{a} \\
\text { Light co }\end{array}$ & $\begin{array}{l}\text { Floride } \\
\text { Florida } \\
\text { Power Corp }\end{array}$ \\
\hline 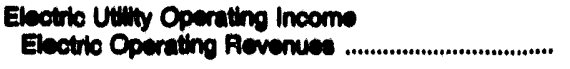 & 200,831 & 667,326 & 780,176 & $1,001,658$ & $5,100,468$ & $1,774,128$ \\
\hline 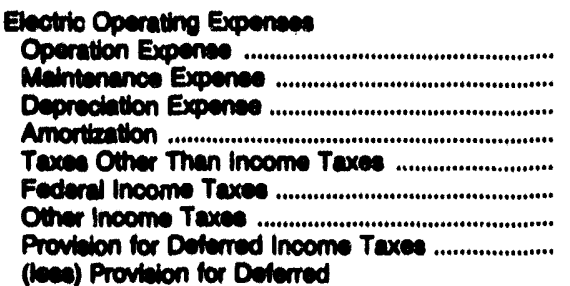 & $\begin{array}{r}99,014 \\
28,271 \\
19,016 \\
0 \\
10,402 \\
12,778 \\
6,072 \\
2,401\end{array}$ & $\begin{array}{r}362,005 \\
38,304 \\
49,876 \\
17,246 \\
59,231 \\
28,400 \\
8,377 \\
36,039\end{array}$ & $\begin{array}{r}408,406 \\
71,211 \\
88,136 \\
2,011 \\
38,380 \\
28,209 \\
5,809 \\
56,760\end{array}$ & $\begin{array}{r}816,118 \\
90,760 \\
138,688 \\
7,212 \\
184,180 \\
41,920 \\
6,338 \\
79,380\end{array}$ & $\begin{array}{r}2,675,084 \\
388,376 \\
478,043 \\
84,086 \\
485,587 \\
171,571 \\
29,224 \\
190,068\end{array}$ & $\begin{array}{r}919,441 \\
139,734 \\
207,736 \\
1,792 \\
138,290 \\
75,691 \\
13,625 \\
68,960\end{array}$ \\
\hline 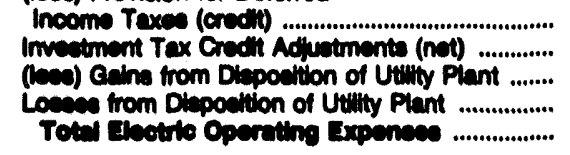 & $\begin{array}{r}2,447 \\
-612 \\
0 \\
0 \\
174,064\end{array}$ & $\begin{array}{r}18,352 \\
-762 \\
181 \\
0 \\
600,803\end{array}$ & $\begin{array}{r}43,871 \\
-933 \\
0 \\
0 \\
040,217\end{array}$ & $\begin{array}{r}49,046 \\
-3,316 \\
0 \\
0 \\
1,322,104\end{array}$ & $\begin{array}{r}111,985 \\
-22,899 \\
96 \\
10 \\
4,393,072\end{array}$ & $\begin{array}{r}47,479 \\
-7,009 \\
0 \\
0 \\
1,004,608\end{array}$ \\
\hline Met Electric Uniny Operatting Ineoms ............. & 31,970 & 105,022 & 131,050 & 270,469 & 704,201 & 200,440 \\
\hline 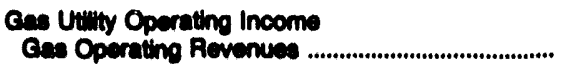 & 0 & 0 & 89,869 & $\mathbf{0}$ & 0 & $\mathbf{0}$ \\
\hline 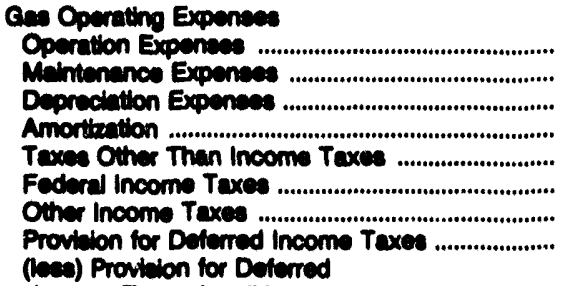 & $\begin{array}{l}0 \\
0 \\
0 \\
0 \\
0 \\
0 \\
0 \\
0\end{array}$ & $\begin{array}{l}0 \\
0 \\
0 \\
0 \\
0 \\
0 \\
0 \\
0\end{array}$ & $\begin{array}{r}66,481 \\
4,003 \\
6,612 \\
210 \\
3,684 \\
2,686 \\
780 \\
7,034\end{array}$ & $\begin{array}{l}0 \\
0 \\
0 \\
0 \\
0 \\
0 \\
0 \\
0\end{array}$ & $\begin{array}{l}0 \\
0 \\
0 \\
0 \\
0 \\
0 \\
0 \\
0\end{array}$ & $\begin{array}{l}0 \\
0 \\
0 \\
0 \\
0 \\
0 \\
0 \\
0\end{array}$ \\
\hline 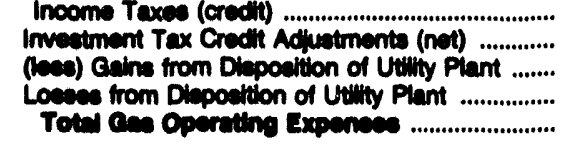 & $\begin{array}{l}0 \\
0 \\
0 \\
0 \\
0\end{array}$ & $\begin{array}{l}0 \\
0 \\
0 \\
0 \\
0\end{array}$ & $\begin{array}{r}5,883 \\
-6 \\
0 \\
0 \\
74,680\end{array}$ & $\begin{array}{l}0 \\
0 \\
0 \\
0 \\
0\end{array}$ & $\begin{array}{l}0 \\
0 \\
0 \\
0 \\
0\end{array}$ & $\begin{array}{l}0 \\
0 \\
0 \\
0 \\
0\end{array}$ \\
\hline 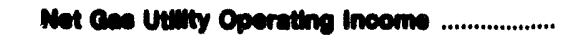 & $\mathbf{0}$ & 0 & 9,311 & - & 0 & $\mathbf{0}$ \\
\hline $\begin{array}{l}\text { Other Utity Operating Income } \\
\text { Other Utitity Operating Rovenues ........................... }\end{array}$ & 0 & 0 & 0 & 0 & 0 & 0 \\
\hline 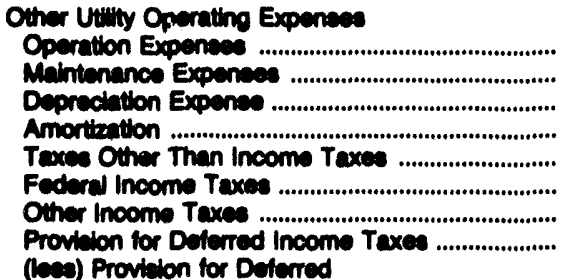 & $\begin{array}{l}0 \\
0 \\
0 \\
0 \\
0 \\
0 \\
0 \\
0\end{array}$ & $\begin{array}{l}0 \\
0 \\
0 \\
0 \\
0 \\
0 \\
0 \\
0\end{array}$ & $\begin{array}{l}0 \\
0 \\
0 \\
0 \\
0 \\
0 \\
0 \\
0\end{array}$ & $\begin{array}{l}0 \\
0 \\
0 \\
0 \\
0 \\
0 \\
0 \\
0\end{array}$ & $\begin{array}{l}0 \\
0 \\
0 \\
0 \\
0 \\
0 \\
0 \\
0\end{array}$ & $\begin{array}{l}0 \\
0 \\
0 \\
0 \\
0 \\
0 \\
0 \\
0\end{array}$ \\
\hline 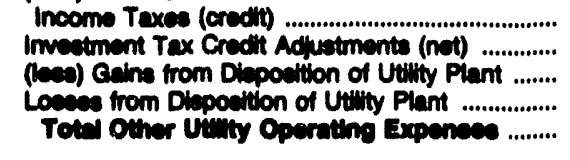 & $\begin{array}{l}0 \\
0 \\
0 \\
0 \\
0\end{array}$ & $\begin{array}{l}0 \\
0 \\
0 \\
0 \\
0\end{array}$ & $\begin{array}{l}0 \\
0 \\
0 \\
0 \\
0\end{array}$ & $\begin{array}{l}0 \\
0 \\
0 \\
0 \\
0\end{array}$ & $\begin{array}{l}0 \\
0 \\
0 \\
0 \\
0\end{array}$ & $\begin{array}{l}0 \\
0 \\
0 \\
0 \\
0\end{array}$ \\
\hline Net Other viulty Oparating Imome ................. & $\mathbf{0}$ & 0 & 0 & 0 & 0 & 0 \\
\hline
\end{tabular}

see endnotes at end of an Individual aic tric uttilty. 
Table 37. Statement of Income and Rotained Earnings

by Major U.S. Investor-Owned Eleotric

Utility Whith state, 1992 (Continued)

(Thousand Dollars)

\begin{tabular}{|c|c|c|c|c|c|c|}
\hline Hem & $\begin{array}{l}\text { Connectiout } \\
\text { Connectiout } \\
\text { Yankeo } \\
\text { Atom } \\
P w C_{0}\end{array}$ & $\begin{array}{l}\text { Connectiout } \\
\text { United } \\
\text { Illuminating } \\
\text { Co }_{0}\end{array}$ & $\begin{array}{l}\text { Delawere } \\
\text { Delmarva } \\
\text { Power } \\
\text { Loht Co }\end{array}$ & $\begin{array}{l}\text { Dietrict of } \\
\text { Columbia } \\
\text { Potomac } \\
\text { Electrlo } \\
\text { Power Co }\end{array}$ & $\begin{array}{l}\text { Florida } \\
\text { Florida } \\
\text { Power } \\
\text { Loht Co }\end{array}$ & $\begin{array}{l}\text { Florida } \\
\text { Florida } \\
\text { Power Corp }\end{array}$ \\
\hline
\end{tabular}

Total Utity Operating Income

Total Uitity Operating Rovenues.

697,325

804,044

$1,601,658$

$5,100,460$

$1,774,126$

Utitity Operating Expencece.

Operation Expenteces ...

Mintenance Expenes.

Depreciation Expentes

Amortbation

Taxes Other Than income Taxes

Fedierd Incoms Texes

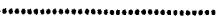

Provilion for Deferred incoms Taxea ........................

(ises) Proviaion for Deterred

Incoms Taxes (credit)

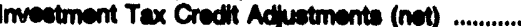

(loas) Geline from Dlepoeltion of Utitity Plant .......

Losece from Dlepoetition of Utivty Plant

Tot-1 Unity Opersting Expermen

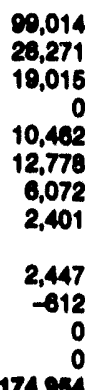

174,98

31,070

352,005
38,304
43,076
17,246
69,231
23,400
8,377
36,030
18,362
-762
161
0
860,203

494,887

75,214

91,747

3,128

37,014

30,005

6,778

69,704

49,765

$-839$

0

722,778

Not Unimy Operniting inoome

Other Income and Daductione

Other Income

Nonutilty Operating Income

intereat and Dividend Income

Allownes for Other Funds Used

During Construction

Mbcellaneous Nonoperating Income

Gain on Dlapoction of Property

Totel Other income

$\begin{array}{rr}0 & -1,722 \\ 0 & 1,340 \\ 3,557 & 6,681 \\ -7 & 1,003 \\ 0 & 18,846 \\ 101 & 7,104 \\ 3,651 & 38,261\end{array}$

1,612
614
2,154
5,631
18,710
20
20,741

28,151

895

816,118

90,768

138,608

7,212

104,180

41,820

6,338

79,380

49,046

$-3,316$

$1,322,104$

105,022

141,200

270,463

$2,675,004$

368,378

478,045

84,088

405,587

171,571

29,224

199,068

111,985

$-22,809$

80

$4,393,072$

704,901

910,441

139,734

207,730

1,792

138,296

76,691

13,625

68,050

47,479

$-7,909$

0

$1,604,600$

200,440

16,089

4,735

80,218

-3
0
9,606

-45
-82

769

30,667

177

2,270

10,431

239

621
11,2020

Other Income Deductions

Loes on Dlapoetition of Property

Miscellaneous Amortization.

Mrecellaneous income Deductions

Toty other Incem Dedvetion

$\begin{array}{rr}0 & 0 \\ 0 & 1,183 \\ 33 & -3,458\end{array}$

$-2,276$

0
0
1,469
1,400

0
0
2,718

2,718

$\begin{array}{rr}4 & 0 \\ 0 & 37 \\ 3,763 & 2,404 \\ 3,767 & 2,441\end{array}$

Taxes on Other Income and Deductions

Texes Other Than Incoms Taxes

Federal income Taxes

Other income Taxes

Taxes

Pres) Providion for Deferred

Income Taxes (credit)

criment Tax Credit Adjuatments (net)

Toci) Invertment Tax Credtis

Totw Taxes on Otrer inoome

and Deduotions.

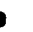

-............

Net Other Income and Decuctione

Mes Ounar Incorno and Daductions
610

6,608

1,341

7,412

7,741

0
1,478

0,762

$-12,650$

3,428

4,006

20,850
241
1,389

832

4,608

7,195

0

$-146$

so,eces
141
-217
-19
122
30
0
0
-10

See endinoles at end of an inclividual electric utility. 
Table 37. Statement of income and Rotalned Eaminge

by Major U.S. Investor-Owned Electric

Utility Whthin State, 1902 (Continued)

(Thousand Dollars)

\begin{tabular}{|c|c|c|c|c|c|c|}
\hline Hem & $\begin{array}{l}\text { Connectiout } \\
\text { Connectiout } \\
\text { Yankee } \\
\text { Atom } \\
\text { Pw Co }\end{array}$ & $\begin{array}{l}\text { Connectiout } \\
\text { Unitiod } \\
\text { Imuminating } \\
\text { Co }\end{array}$ & $\begin{array}{l}\text { Dolawere } \\
\text { Doimarva } \\
\text { Power } \\
\text { Lotit Co }\end{array}$ & $\begin{array}{l}\text { Dictuict of } \\
\text { Columbla } \\
\text { Potominec } \\
\text { Eloctrio } \\
\text { Powner Co }\end{array}$ & $\begin{array}{c}\text { Fiorida } \\
\text { Fiorida } \\
\text { Power } \\
\text { L Lint Co }\end{array}$ & $\begin{array}{l}\text { Florida } \\
\text { Florida } \\
\text { Power Corp }\end{array}$ \\
\hline
\end{tabular}

Intereat Charges

Intereet on Lono-term Dabt

(n)

Amortention of Debt Discount and Expenes .....

Amortbation of Loes on Reacepired Dabt ............

(tace) Amortication of Premium on Debt (credtit).

(aes) Amortbation of Cain on

Resquired Debt (credit) .............................................

Intereat on Dobt to Asecciated Companies...........

Other Interest Expenses

(bes) Allowance for Borrowed Funds

Ueed During Construction (creatt)

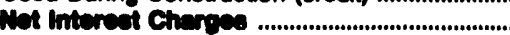

Incoms Before Extreordinary theme

Extreordinary ltems

Extreordinary income.

(less) Extreordinary Deductions

Net Extreorelinary ftems

(leee) Federal and Other Income Taxea

Extreore"inary Heme After Taxes

Net lneome

$\begin{array}{rr}16,589 & 88,685 \\ 324 & 790 \\ 108 & 8,100 \\ 0 & 0 \\ 305 & 0 \\ 0 & 0 \\ 1,895 & 3,894 \\ 213 & 2,289 \\ 17,298 & 90,318\end{array}$

18,018

89,703

18,018

8,700
129,780
1,782

1,782
1,107

55

0
0
5,479

13,849

124,49

$200,7.0$

0.9.57

46,715

16,175

20.040

13,618

10,020

02.697

216,72

514,000

10.977

Unepropitated Rotemed Eemine:

Retalind Eeminge - Becinning of Yeer

Balance Tranolerred from Income

Credits to Retained Earninos ...

(low) Deblts to Retained Eamings ........................

(tess) Appropriations of Retained Earnings ..........

(leas) Dividends Declared - Preferred Stock .......

(lees) Dividends Declared - Common Stock ........

Uneppropriated Undistributed Subeidlary

Eaminge

Roteined Eeminges - End of Year

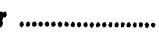

Appropriated Retained Eeminos

Approprlated Retained Eaminos

Amortzation Reserve, Federal

Totel Roteined Eeminges
116,197

274,122

aneas

000,514

077,29

18,016

56,428

97,913

188,69

0
0
0

14,380

179,820

614,800

1,858

282

46,819

461,816

12,000

capose

017.045

002,150

0

o

0

0

0

0

201,127

690.490

017,9.4

02,168

Note: Totals may not equal sum of componemts because of independent rounding. Summan dath are provided in Teble 6 .

Source: Federal Energy Regulatory Commiselon, FERC Form 1, "Amnual Report of Major Electrlc Ut"uties, Loensees and Othere." 
Table 37. Statement of Income and Rotalned Earninge

by Major U.S. Inveator-Owned Electrlc

Utility Within State, 1992 (Continued)

(Thousand Dollars)

\begin{tabular}{|c|c|c|c|c|c|c|}
\hline Itom & $\begin{array}{l}\text { Florida } \\
\text { Gutf } \\
\text { Power co }\end{array}$ & $\begin{array}{l}\text { Florida } \\
\text { Tampa } \\
\text { Eleotric Co }\end{array}$ & $\begin{array}{l}\text { Georgin } \\
\text { Georgia } \\
\text { Power Co }\end{array}$ & $\begin{array}{l}\text { Georgin } \\
\text { Savannah } \\
\text { Electik } \\
\text { \& Powrer } \\
\text { Co }\end{array}$ & $\begin{array}{l}\text { Hawall } \\
\text { Hawalian } \\
\text { Electric } \\
\text { Co Inc }\end{array}$ & $\begin{array}{l}\text { Hawell } \\
\text { Maul } \\
\text { Electric } \\
\text { Co } \\
\text { Litd }\end{array}$ \\
\hline $\begin{array}{l}\text { Electric Utilty Operating Income } \\
\text { Electric Operating Revenues .................................... }\end{array}$ & 670,002 & $1,005,782$ & $4,297,436$ & 102,284 & 686,682 & 105,343 \\
\hline 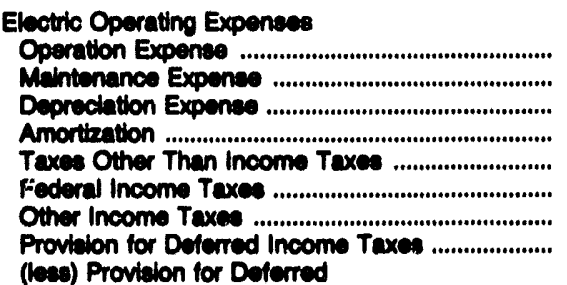 & $\begin{array}{r}309,168 \\
41,847 \\
50,346 \\
5,268 \\
37,808 \\
24,258 \\
4,162 \\
20,765\end{array}$ & $\begin{array}{r}841,681 \\
68,601 \\
100,007 \\
1,173 \\
78,626 \\
60,026 \\
8,025 \\
26,004\end{array}$ & $\begin{array}{r}2,160,741 \\
234,710 \\
372,086 \\
18,760 \\
179,460 \\
174,467 \\
31,241 \\
300,760\end{array}$ & $\begin{array}{r}102,634 \\
14,232 \\
17,260 \\
238 \\
10,231 \\
7,117 \\
1,200 \\
0,070\end{array}$ & $\begin{array}{r}376,733 \\
29,651 \\
39,132 \\
2,813 \\
52,037 \\
24,461 \\
2,680 \\
-14,750\end{array}$ & $\begin{array}{r}68,742 \\
6,700 \\
6,050 \\
0 \\
0,788 \\
4,084 \\
-443 \\
-672\end{array}$ \\
\hline 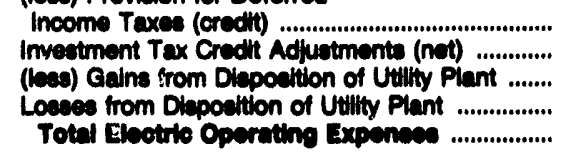 & $\begin{array}{r}17,462 \\
-2,241 \\
0 \\
0 \\
474,600\end{array}$ & $\begin{array}{r}18,607 \\
-4,138 \\
32 \\
0 \\
0.2,640\end{array}$ & $\begin{array}{r}128,313 \\
-21,581 \\
0 \\
0 \\
3,918,276\end{array}$ & $\begin{array}{r}3,487 \\
-684 \\
0 \\
0 \\
160,002\end{array}$ & $\begin{array}{r}201 \\
580 \\
0 \\
0 \\
512,072\end{array}$ & $\begin{array}{r}-125 \\
025 \\
0 \\
0 \\
02,044\end{array}$ \\
\hline Net Eloctrio Utility Operating Ineoms ............. & 90,401 & 163,290 & 202,160 & 38,671 & 68,710 & 12,070 \\
\hline $\begin{array}{l}\text { Gas Utillty Operating Income } \\
\text { Gas Operating Revenues }\end{array}$ & 0 & 0 & 0 & 0 & 0 & 0 \\
\hline 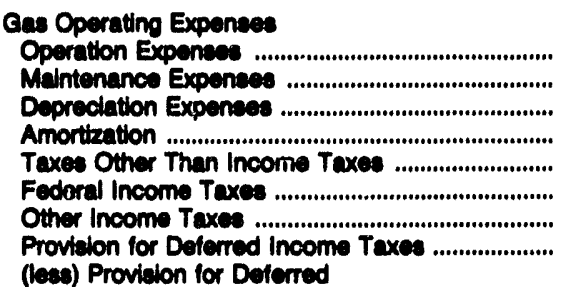 & $\begin{array}{l}0 \\
0 \\
0 \\
0 \\
0 \\
0 \\
0 \\
0\end{array}$ & $\begin{array}{l}0 \\
0 \\
0 \\
0 \\
0 \\
0 \\
0 \\
0\end{array}$ & $\begin{array}{l}0 \\
0 \\
0 \\
0 \\
0 \\
0 \\
0 \\
0\end{array}$ & $\begin{array}{l}0 \\
0 \\
0 \\
0 \\
0 \\
0 \\
0 \\
0\end{array}$ & $\begin{array}{l}0 \\
0 \\
0 \\
0 \\
0 \\
0 \\
0 \\
0\end{array}$ & $\begin{array}{l}0 \\
0 \\
0 \\
0 \\
0 \\
0 \\
0 \\
0\end{array}$ \\
\hline 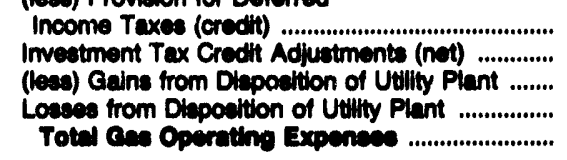 & $\begin{array}{l}0 \\
0 \\
0 \\
0 \\
0\end{array}$ & $\begin{array}{l}0 \\
0 \\
0 \\
0 \\
0\end{array}$ & $\begin{array}{l}0 \\
0 \\
0 \\
0 \\
0\end{array}$ & $\begin{array}{l}0 \\
0 \\
0 \\
0 \\
0\end{array}$ & $\begin{array}{l}0 \\
0 \\
0 \\
0 \\
0\end{array}$ & $\begin{array}{l}0 \\
0 \\
0 \\
0 \\
0\end{array}$ \\
\hline Not cas Uutity Opernting Incoms ...................... & 0 & 0 & 0 & 0 & 0 & $\mathbf{0}$ \\
\hline $\begin{array}{l}\text { Other Utillty Operating Incoms } \\
\text { Other Utility Operating Rovenues ............................ }\end{array}$ & 0 & 0 & 0 & 0 & 0 & o \\
\hline 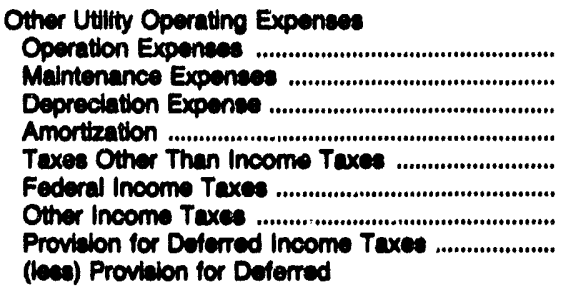 & $\begin{array}{l}0 \\
0 \\
0 \\
0 \\
0 \\
0 \\
0 \\
0\end{array}$ & $\begin{array}{l}0 \\
0 \\
0 \\
0 \\
0 \\
0 \\
0 \\
0\end{array}$ & $\begin{array}{l}0 \\
0 \\
0 \\
0 \\
0 \\
0 \\
0 \\
0\end{array}$ & $\begin{array}{l}0 \\
0 \\
0 \\
0 \\
0 \\
0 \\
0 \\
0\end{array}$ & $\begin{array}{l}0 \\
0 \\
0 \\
0 \\
0 \\
0 \\
0 \\
0\end{array}$ & $\begin{array}{l}0 \\
0 \\
0 \\
0 \\
0 \\
0 \\
0 \\
0\end{array}$ \\
\hline 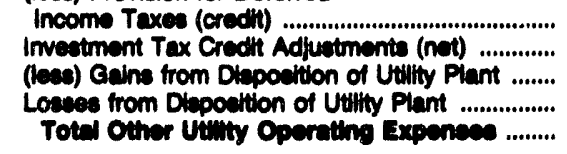 & $\begin{array}{l}0 \\
0 \\
0 \\
0 \\
0\end{array}$ & $\begin{array}{l}0 \\
0 \\
0 \\
0 \\
0\end{array}$ & $\begin{array}{l}0 \\
0 \\
0 \\
0 \\
0\end{array}$ & $\begin{array}{l}0 \\
0 \\
0 \\
0 \\
0\end{array}$ & $\begin{array}{l}0 \\
0 \\
0 \\
0 \\
0\end{array}$ & $\begin{array}{l}0 \\
0 \\
0 \\
0 \\
0\end{array}$ \\
\hline Net Other Utitty Operating Inooms .................. & $\mathbf{0}$ & 0 & 0 & 0 & $\mathbf{0}$ & 0 \\
\hline
\end{tabular}

See endnotes at and of an indwidual electric utilty. 
Table 37. Statement of Income and Rotained Earnings

by Major U.S. Investor-Owned Electric

Utility Within State, 1902 (Continued)

(Thousand Dollars)

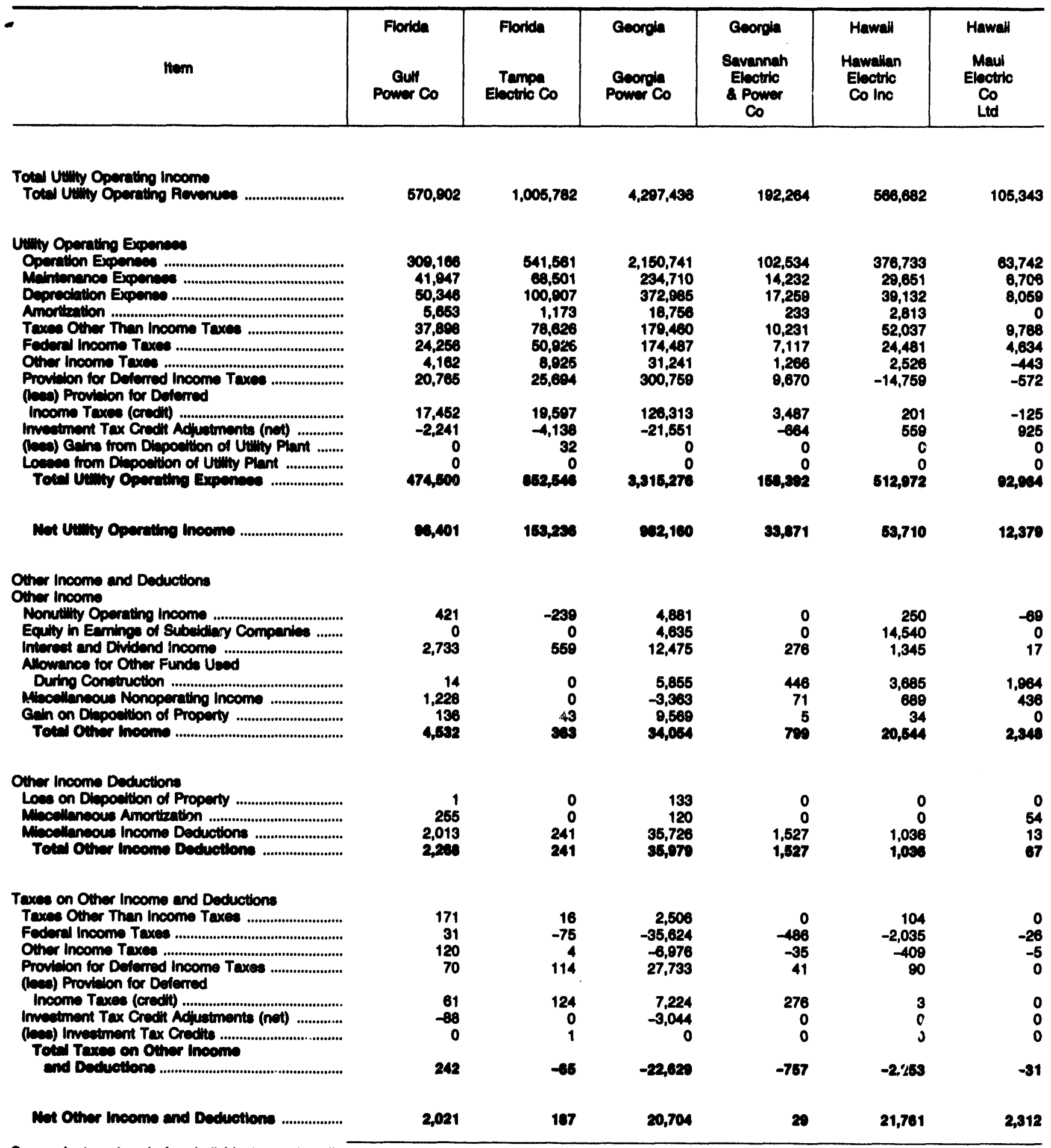

See endinotes at end of an individual electric utilty. 
Table 37. Statement of Income and Rotained Earnings

by Major U.S. Investor-Owned Electric

Utility Within State, 1902 (Continued)

(Thousand Dollars)

\begin{tabular}{|c|c|c|c|c|c|c|}
\hline Item & $\begin{array}{l}\text { Florida } \\
\text { Gulf } \\
\text { Power co }\end{array}$ & $\begin{array}{l}\text { Florida } \\
\text { Tampa } \\
\text { Electric Co }\end{array}$ & $\begin{array}{l}\text { Georgia } \\
\text { Georgia } \\
\text { Power Co }\end{array}$ & $\begin{array}{l}\text { Georgia } \\
\text { Savannah } \\
\text { Electric } \\
\text { \& Power } \\
\text { Co }\end{array}$ & $\begin{array}{l}\text { Hawail } \\
\text { Hawalian } \\
\text { Electric } \\
\text { Co inc }\end{array}$ & $\begin{array}{l}\text { Hawall } \\
\text { Maui } \\
\text { Electric } \\
\text { Co } \\
\text { Ltd }\end{array}$ \\
\hline
\end{tabular}

\section{Intereat Charges}

Interest on Long-term Debt

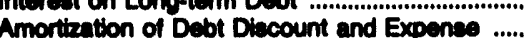

Amortention of Loes on Rescquired Debt ...........

(leas) Amortization of Premium on Debt (credit)

(bes) Amortization of Guin on

Reaquired Debt (credit)

Interest on Debt to Asecciated Compenia...........

Other Intereet Expenes

(kes) Alowence for Borrowed Funds

Used During Constnuction (credit)

Wen interent chernes.

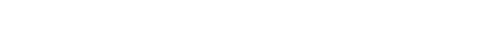

Income Eetere Extucorinery Heme

.....................

Extraordinary hems

Extreordinary Income

(lese) Extreordinary Daductions

net Extreordinory thems

(lees) Federal and Other Income Taxes

Extreortinary lteme Aftior Taxee.

Net lnoems

Uneppropriated Retined Eeminges

Rotained Eeminge - Becinming of Year

Balance Tranaferred from Income

Credits to Retained Eaminge

(bas) Debits to Retained Earninges ........................

(bes) Appropriations of Retained Eamings .........

(leas) Dividends Dectared - Preterred Stock .......

(leas) Dividends Declared - Common Stock ......

Unappropriated Undistributed Subeidiany

Earnings.

Reteined Eemings - End of Year

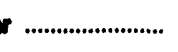

Approprlated Retained Eaminos

Appropriated Retained Earnings

Amortization Reserve, Federal

Totel Rotinged Eeminge
35,78

35,792
340

701

38,319

620

402,542

2,763

5,382

0

2,451

46

(1)

50,109

110,705
670,400

0

22,119

8,310

424,89
10,870

49
370

1

0

481

289

11,400

22,412

89,670

17,647

484

0

0

4,575

1,128

21,702

0,023

0
0
0

$$
\begin{aligned}
& 0 \\
& 0 \\
& 0
\end{aligned}
$$

0

0
0
0

0
0
0

0

0

0
0

0,19

110,705

670,410

22,412

$\mathbf{8 3 , 6 7 0}$

0,093

\begin{tabular}{|c|c|c|c|c|c|}
\hline 194,373 & 101,496 & $1,021,496$ & 00,028 & 181,094 & 84,131 \\
\hline $\begin{array}{r}59,183 \\
311 \\
593 \\
0 \\
5,104 \\
39,800\end{array}$ & $\begin{array}{r}110,785 \\
0 \\
0 \\
0 \\
3,588 \\
108,379\end{array}$ & $\begin{array}{r}573,845 \\
0 \\
15,170 \\
0 \\
57,842 \\
384,000\end{array}$ & $\begin{array}{r}22,412 \\
0 \\
0 \\
0 \\
1,800 \\
22,000\end{array}$ & $\begin{array}{r}39,139 \\
0 \\
0 \\
0 \\
4,525 \\
16,121\end{array}$ & $\begin{array}{r}9,823 \\
0 \\
0 \\
0 \\
1,053 \\
4,421\end{array}$ \\
\hline 0 & 0 & 6,001 & 0 & 0 & 0 \\
\hline
\end{tabular}

149,200

112,273

$1,144,100$

eq4as

$1 C 0,159$

20,4

0

0

878

0

0

0

0

0

0

$1,146,077$

ex,4ss

100,163

2,40

Note: Totals may not equal aum of comoonents because of independent rounding. Summany data are provided in Table 6.

Source: Federal Energy Regulatory Commisuion, FERC Form 1, "Amul Report of Major Electric Utimites, Licensees and Others." 
Table 37. Statoment of Income and Rotained Earnings

by Major U.S. Inveotor-Owned Electric

Utility Within State, 1902 (Continued)

(Thousand Dollars)

\begin{tabular}{|c|c|c|c|c|c|c|}
\hline Itam & $\begin{array}{l}\text { Idano } \\
\text { Idano } \\
\text { Power Co }\end{array}$ & $\begin{array}{l}\text { Illinols } \\
\text { Contral } \\
\text { Illinole } \\
\text { Loht Co }\end{array}$ & $\begin{array}{l}\text { Illinols } \\
\text { Central } \\
\text { Illinols } \\
\text { Pub } \\
\text { Serv Co }\end{array}$ & $\begin{array}{c}\text { Illinols } \\
\text { Commonwealth } \\
\text { Edieon Co }\end{array}$ & $\begin{array}{l}\text { Illinois } \\
\text { Electric } \\
\text { Energy Inc }\end{array}$ & $\begin{array}{l}\text { Illinols } \\
\text { IIIinois } \\
\text { Power Co }\end{array}$ \\
\hline $\begin{array}{l}\text { Electric Uituty Operating Inoome } \\
\text { Electric Operating Revenued ...................................... }\end{array}$ & 498,092 & 288,800 & 596,642 & $6,026,320$ & 274,504 & $1,180,832$ \\
\hline 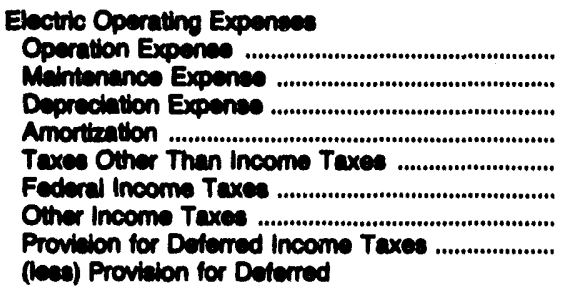 & $\begin{array}{r}268,865 \\
35,888 \\
50,681 \\
307 \\
20,646 \\
14,886 \\
229 \\
18,887\end{array}$ & $\begin{array}{r}146,504 \\
24,323 \\
37,332 \\
139 \\
19,832 \\
19,606 \\
13,001 \\
3,091 \\
10,115\end{array}$ & $\begin{array}{r}301,337 \\
60,219 \\
66,345 \\
2,567 \\
41,974 \\
6,801 \\
-862 \\
69,265\end{array}$ & $\begin{array}{r}2,421,376 \\
575,501 \\
827,893 \\
4,108 \\
738,152 \\
138,023 \\
20,976 \\
436,300\end{array}$ & $\begin{array}{r}223,846 \\
15,891 \\
5,823 \\
0 \\
1,838 \\
8,220 \\
779 \\
0\end{array}$ & $\begin{array}{r}498,760 \\
92,785 \\
138,786 \\
8,060 \\
103,681 \\
20,834 \\
0 \\
132,357\end{array}$ \\
\hline 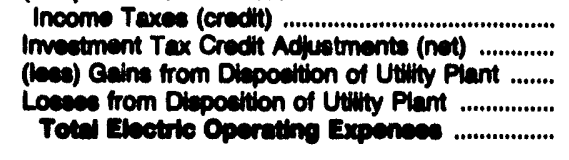 & $\begin{array}{r}10,326 \\
-1,416 \\
42 \\
-29 \\
205,202\end{array}$ & $\begin{array}{r}9,683 \\
-1,402 \\
0 \\
0 \\
249,021\end{array}$ & $\begin{array}{r}27,544 \\
-3,125 \\
0 \\
0 \\
006,706\end{array}$ & $\begin{array}{r}294,168 \\
-32,286 \\
497 \\
536 \\
4,035,600\end{array}$ & $\begin{array}{r}1,101 \\
0 \\
0 \\
0 \\
255,266\end{array}$ & $\begin{array}{r}74,095 \\
178 \\
0 \\
0 \\
921,328\end{array}$ \\
\hline Met Enetule Univity Operating incems ............ & 102,730 & 46,070 & 8,874 & $1,190,433$ & 10,200 & 269,608 \\
\hline $\begin{array}{l}\text { Geas Utithy Operating Income } \\
\text { Gas Operating Revenuce ........................................ }\end{array}$ & 0 & 144,867 & 139,760 & 0 & 0 & 288,617 \\
\hline 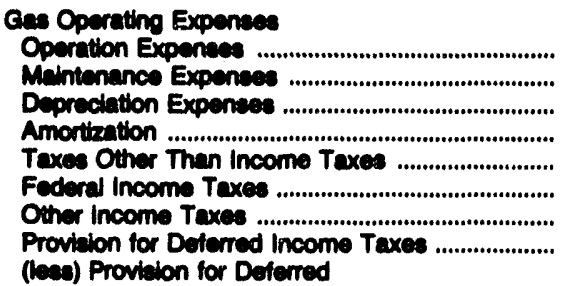 & $\begin{array}{l}0 \\
0 \\
0 \\
0 \\
0 \\
0 \\
0 \\
0\end{array}$ & $\begin{array}{r}100,967 \\
4,237 \\
13,912 \\
18 \\
9,229 \\
5,122 \\
1,152 \\
3,776\end{array}$ & $\begin{array}{r}104,669 \\
3,873 \\
4,791 \\
461 \\
9,132 \\
258 \\
102 \\
6,462\end{array}$ & $\begin{array}{l}0 \\
0 \\
0 \\
0 \\
0 \\
0 \\
0 \\
0\end{array}$ & $\begin{array}{l}0 \\
0 \\
0 \\
0 \\
0 \\
0 \\
0 \\
0\end{array}$ & $\begin{array}{r}216,563 \\
9,373 \\
18,342 \\
707 \\
18,555 \\
2,096 \\
0 \\
27,362\end{array}$ \\
\hline 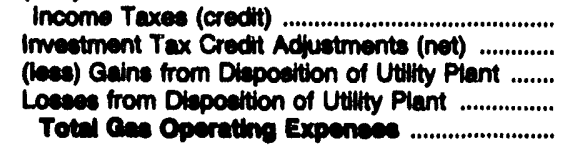 & $\begin{array}{l}0 \\
0 \\
0 \\
0 \\
0\end{array}$ & $\begin{array}{r}5,675 \\
-292 \\
0 \\
0 \\
132,446\end{array}$ & $\begin{array}{r}4,165 \\
-211 \\
0 \\
0 \\
126,201\end{array}$ & $\begin{array}{l}0 \\
0 \\
0 \\
0 \\
0\end{array}$ & $\begin{array}{l}0 \\
0 \\
0 \\
0 \\
0\end{array}$ & $\begin{array}{r}21,875 \\
-697 \\
0 \\
0 \\
271,416\end{array}$ \\
\hline Net Cas Uunty Operating Incoms ..................... & $\mathbf{0}$ & 12,522 & 0,400 & $\mathbf{0}$ & $\mathbf{0}$ & 17,202 \\
\hline $\begin{array}{l}\text { Other Utilty Operating Income } \\
\text { Other Utillty Operating Revenues .......................... }\end{array}$ & 0 & 0 & 0 & 0 & 0 & 0 \\
\hline 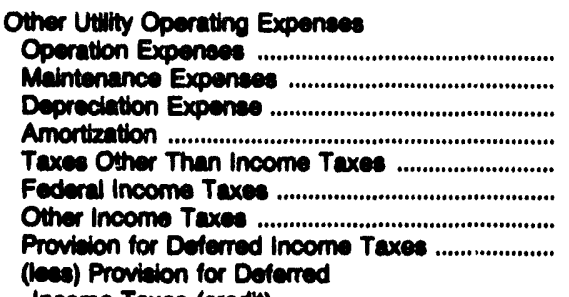 & $\begin{array}{l}0 \\
0 \\
0 \\
0 \\
0 \\
0 \\
0 \\
0\end{array}$ & $\begin{array}{l}0 \\
0 \\
0 \\
0 \\
0 \\
0 \\
0 \\
0\end{array}$ & $\begin{array}{l}0 \\
0 \\
0 \\
0 \\
0 \\
0 \\
0 \\
0\end{array}$ & $\begin{array}{l}0 \\
0 \\
0 \\
0 \\
0 \\
0 \\
0 \\
0\end{array}$ & $\begin{array}{l}0 \\
0 \\
0 \\
0 \\
0 \\
0 \\
0 \\
0\end{array}$ & $\begin{array}{l}0 \\
0 \\
0 \\
0 \\
0 \\
0 \\
0 \\
0\end{array}$ \\
\hline 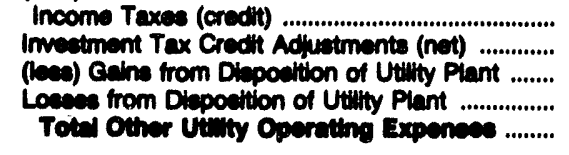 & $\begin{array}{l}0 \\
0 \\
0 \\
0 \\
0\end{array}$ & $\begin{array}{l}0 \\
0 \\
0 \\
0 \\
0\end{array}$ & $\begin{array}{l}0 \\
0 \\
0 \\
0 \\
0\end{array}$ & $\begin{array}{l}0 \\
0 \\
0 \\
0 \\
0\end{array}$ & $\begin{array}{l}0 \\
0 \\
0 \\
0 \\
0\end{array}$ & $\begin{array}{l}0 \\
0 \\
0 \\
0 \\
0\end{array}$ \\
\hline Met Other Uituity Operating Ineoms .................. & 0 & 0 & 0 & $\mathbf{0}$ & $\mathbf{0}$ & $\mathbf{0}$ \\
\hline
\end{tabular}

See endinotes at end of an individual electric utillity. 
Table 37. Statement of Income and Rotained Earninge

by Major U.S. Inveotor-Owned Electric

Utility Whthin State, 1992 (Continued)

(Thousand Dollars)

\begin{tabular}{|c|c|c|c|c|c|c|}
\hline them & $\begin{array}{l}\text { Idaho } \\
\text { Idaho } \\
\text { Powner Co }\end{array}$ & $\begin{array}{l}\text { Ilinots } \\
\text { Central } \\
\text { Ilinois } \\
\text { Loht Co }\end{array}$ & $\begin{array}{l}\text { Illinols } \\
\text { Central } \\
\text { IIIinots } \\
\text { Pub } \\
\text { Serv Co }\end{array}$ & $\begin{array}{c}\text { Illinois } \\
\text { Commommealth } \\
\text { Edieon Co }\end{array}$ & $\begin{array}{c}\text { Illinols } \\
\text { Electuic } \\
\text { Energy Inc }\end{array}$ & $\begin{array}{l}\text { Illinols } \\
\text { Illinols } \\
\text { Power Co }\end{array}$ \\
\hline
\end{tabular}

Totel Uitily Operating Income

Totel Utimy Operating Revenuse

U:min Operating Expentas

Deprectation Expones

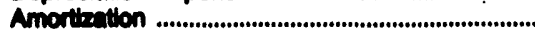

Texes Other Than Incoms Taxe

Foderel Incom Texes

Other Incoms Texes

Provilion for Deferred Income Taxes .....................

(kes) Provition for Dotierred

Incoms Texes (credil)

Imvertment Tax Credit Ad,ustments (not) .............

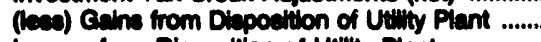

Loseces from Diaposition of Uitity Plant

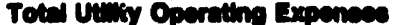

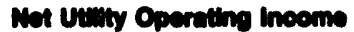

483,887

729,402

$6,028,320$

274,504

$1,479,449$

35,898

60,681

807

20,546

14,898

18,867

10,328

$-1,416$

42

$-28$

10278

247,472

28,681

51,244

151

29,110

18,728

4,243

13,890

16,388

$-1,684$

0
0

sroses

07,600

405,806
64,092

71,138

3,018

61,108

6,859

$-760$

65,707

31,700

$-3,388$

0

692,09:

07,372

2,421,376

575,501

827,893

4,108

738,152

138,028

20,870

438,300

294,180

29,280

497

638

4.e96,ese

$1,190,439$

223,84
15,89

15,891
5,828

6,823

1,838

8,220

778

1,101

0

0

$265,2 \times 9$

10,200

Other Incoms and Deductions

Other Income

Nomintity Operating Income

Equity in Exminges of Subaidiary Companiea ......

intereet and Dividend Incoms ...

Alomence for Other Funde Ueed

During Construction

Mincellancous Nonoperating income

Gain on Dimpocition of Property

Tetel Otree lnoeme

2,400

$-285$

$-14$

13,478

894

2,639

1,056

4,145

18,268

19,880

2,162

2,324

20,289

281

13,492

63,809

143
0
3,670

0
713
1,018

1,732

0
0
318
318

13
0
9,007

0,020

15

62

-770
-168

$-1,453$

$-282$

5

1,922

1,823

$-2,613$

$-3,335$

581
0
0

Income Texes (credit)

(Con) Imvertment Tex Cred"t

Toul Toxes on Othes income

and Dechetions ......................................................

$-1,362$

$-2,001$

11,015
768

1,305

371
0

505

17
0

2,90

1,005

10,160

80,649
$-3,680$

2,646

307

1,633

180
180

1,206

See endnotes at end of an individual electric vitity. 
Table 37. Statement of Income and Rotained Eamings

by Major U.8. Invector-Owned Eloctric

Utility Whthin State, 1902 (Continued)

(Thousand Dollars)

\begin{tabular}{|c|c|c|c|c|c|c|}
\hline Item & $\begin{array}{l}\text { Idaho } \\
\text { Iodaho } \\
\text { Power co }\end{array}$ & $\begin{array}{l}\text { Illinole } \\
\text { Central } \\
\text { Iilinole } \\
\text { Liont Co }\end{array}$ & $\begin{array}{l}\text { Illinot } \\
\text { Central } \\
\text { Illinois } \\
\text { Pub } \\
\text { Sen Co }\end{array}$ & $\begin{array}{c}\text { Illinote } \\
\text { Commommalth } \\
\text { Edicon Co }\end{array}$ & $\begin{array}{l}\text { Illinols } \\
\text { Electric } \\
\text { Energy Inc }\end{array}$ & $\begin{array}{c}\text { Illinols } \\
\text { Illinols } \\
\text { Power Co }\end{array}$ \\
\hline
\end{tabular}

Inverext Cherew

Inverest on Lono-term Debt

Amortintion of Dobt Discount and Expenas .......

Amortertion of Loes on Recoquired Debt ...........

(bea) Amortiention of Premium on Debt (credit)

(has) Amorteation of Cain on

Resquired Dobt (credit)

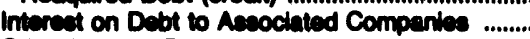

Ower Intereat Expenes

(lees) Alowence for Borrowed Fund:

Uead During Conotruction (credili)

Net Inereet Charciose

Inocme Botere Extuceremery ltems

Extreordinary ltems

Extreondinery Income

(bee) Extreordinary Deductions

Net Extracerdining ltems

(bee) Federal and Other Income Taxes

Extreontinasy thems After Taxes

net ineome

Unippropriated Rotemed Eeminges

Rotined Eemines - Becinming of Year

Balance Traneferred from income

Crectis to Rotained Eemin

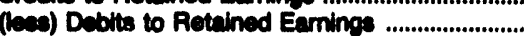

(leas) Appropitations of Retained Earnings .........

(teno) Dividends Dectared - Preferred Stock ........

(bea) Dividends Declared - Common Stock .......

Unappropriated Undietributed Subeldiary

Eamina

Returned Eumines - End of Year

....

Appropitated Rotained Eaminge

Appropriated Rotained Eaminges -

Amortation Reserve, Federal

Toted Retelned Eamines

\begin{tabular}{|c|}
\hline $\begin{array}{r}52,021 \\
468 \\
582 \\
71\end{array}$ \\
\hline $\begin{array}{r}10 \\
847 \\
1,109\end{array}$ \\
\hline $\begin{array}{r}2,086 \\
03,758\end{array}$ \\
\hline
\end{tabular}

20,747

179

264

0
0

2,628

215

28,670

s.ses

35,534

403

678,302
6,378

8,376
13,817

303
22

37

0

$-412$

0
0

54,686

17,129

1,084

9,021

726 ,ess

72,001

618,091

5,147

147
28
0
0

160,705

1,486

2,884
3

5
0

7,834

3,682

0
$6,0.56$

189,307

13,396

122,09

\section{0
0}

0
0
0

0
0
0

0
0
0

0
0
0

$$
\begin{aligned}
& 0 \\
& 0
\end{aligned}
$$

s.69

72.601

513,01

19,295

122,09

21.01

02,074

gapes

976,400

2,09

78,511

52,378

35,618
0
0
0
4,441

72,548

609,838

13,335

121,869

640

305
0

4,650

5,518
85,043

31,787

5,000

0

0
628
24

70,102

489,768

1,100

13,335

51,592

105,802

0

o2,a4

897,360

20,

2,894

39,495

207,890

o

1,544

0

0

200,374

92,94

87,950

287,003

2,094

89,405

Note: Totats may not equal eum of components because of independent rounding. Summany data are provided in Table 6. Source: Federal Eneroy Regulatory Commisaion, FERC Form 1, "Annual Report of Major Electric Utiltiea, Lloensees and Others." 
Table 37. Statement of Income and Rotained Earnings

by Major U.8. Investor-Owned Electric

Utility Within State, 1992 (Continued)

(Thousand Dollars)

\begin{tabular}{|c|c|c|c|c|c|c|}
\hline item & $\begin{array}{l}\text { Illinols } \\
\text { Mit } \\
\text { Carmel } \\
\text { Public } \\
\text { Utilly Co }\end{array}$ & $\begin{array}{l}\text { Indiana } \\
\text { Aloos } \\
\text { Cenerating } \\
\text { Corp }\end{array}$ & $\begin{array}{l}\text { Indiana } \\
\text { AEP } \\
\text { Generating } \\
\text { Co }\end{array}$ & $\begin{array}{c}\text { Indlana } \\
\text { Commonwealth } \\
\text { Edieon } \\
\text { Co } \\
\text { IN Inc } \\
\end{array}$ & $\begin{array}{l}\text { Indiana } \\
\text { Indiana } \\
\text { Michioan } \\
\text { Power Co }\end{array}$ & $\begin{array}{l}\text { Indiana } \\
\text { Indianapolis } \\
\text { Power } \\
\text { Light Co } \\
\end{array}$ \\
\hline $\begin{array}{l}\text { Electric Utitity Operating Income } \\
\text { Electric Operaling Revenues ...................................... }\end{array}$ & 9,086 & 103,620 & 238,232 & 69,852 & $1,196,755$ & 599,204 \\
\hline 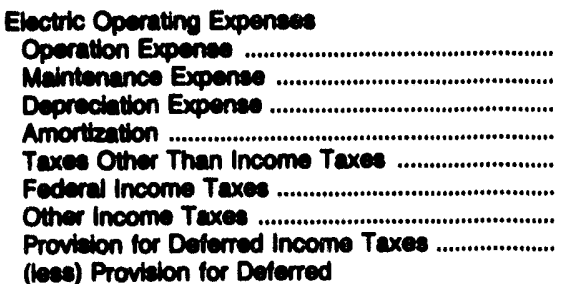 & $\begin{array}{r}7,114 \\
317 \\
489 \\
0 \\
620 \\
173 \\
27 \\
-35\end{array}$ & $\begin{array}{r}83,278 \\
11,686 \\
4,239 \\
0 \\
1,377 \\
-522 \\
0 \\
1,078\end{array}$ & $\begin{array}{r}178,488 \\
10,268 \\
21,443 \\
4 \\
3,988 \\
577 \\
150 \\
10,734\end{array}$ & $\begin{array}{r}34,931 \\
12,277 \\
7,457 \\
0 \\
5,757 \\
1,834 \\
554 \\
906\end{array}$ & $\begin{array}{r}638,932 \\
172,147 \\
133,080 \\
-32,692 \\
59,907 \\
9,122 \\
2,281 \\
111,080\end{array}$ & $\begin{array}{r}246,754 \\
57,192 \\
71,457 \\
4,737 \\
29,865 \\
48,124 \\
7,422 \\
27,033\end{array}$ \\
\hline 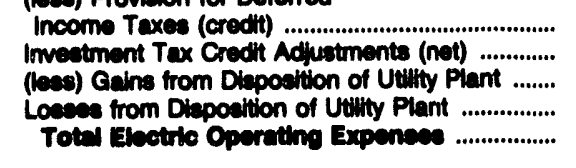 & $\begin{array}{r}0 \\
-18 \\
0 \\
0 \\
0,08\end{array}$ & $\begin{array}{r}0 \\
-241 \\
0 \\
0 \\
100,708\end{array}$ & $\begin{array}{r}3,828 \\
-3 \\
0 \\
0 \\
221,000\end{array}$ & $\begin{array}{r}205 \\
-220 \\
0 \\
0 \\
03,3202\end{array}$ & $\begin{array}{r}85,218 \\
-9,028 \\
0 \\
0 \\
90,021\end{array}$ & $\begin{array}{r}23,355 \\
-3,382 \\
0 \\
2 \\
406,845\end{array}$ \\
\hline Not Enetrite Utiuty Operating Income ............ & 370 & 2,020 & 17,432 & 6,470 & 107,134 & 133,368 \\
\hline 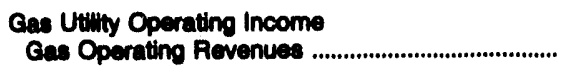 & 1,737 & 0 & 0 & 0 & 0 & 0 \\
\hline 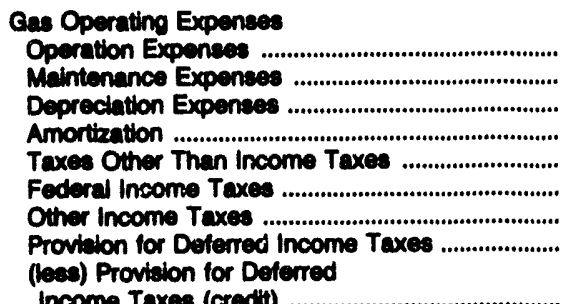 & $\begin{array}{r}1,400 \\
91 \\
86 \\
0 \\
02 \\
02 \\
0 \\
0 \\
0 \\
0\end{array}$ & $\begin{array}{l}0 \\
0 \\
0 \\
0 \\
0 \\
0 \\
0 \\
0\end{array}$ & $\begin{array}{l}0 \\
0 \\
0 \\
0 \\
0 \\
0 \\
0 \\
0\end{array}$ & $\begin{array}{l}0 \\
0 \\
0 \\
0 \\
0 \\
0 \\
0 \\
0\end{array}$ & $\begin{array}{l}0 \\
0 \\
0 \\
0 \\
0 \\
0 \\
0 \\
0\end{array}$ & $\begin{array}{l}0 \\
0 \\
0 \\
0 \\
0 \\
0 \\
0 \\
0\end{array}$ \\
\hline 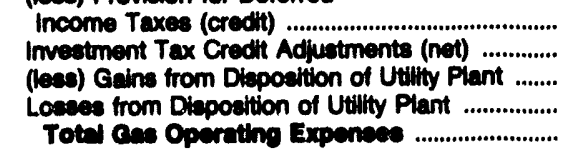 & $\begin{array}{r}0 \\
-2 \\
0 \\
0 \\
1,677\end{array}$ & $\begin{array}{l}0 \\
0 \\
0 \\
0 \\
0\end{array}$ & $\begin{array}{l}0 \\
0 \\
0 \\
0 \\
0\end{array}$ & $\begin{array}{l}0 \\
0 \\
0 \\
0 \\
0\end{array}$ & $\begin{array}{l}0 \\
0 \\
0 \\
0 \\
0\end{array}$ & $\begin{array}{l}0 \\
0 \\
0 \\
0 \\
0\end{array}$ \\
\hline Not cas Utinty Operating Incoms .................... & 60 & 0 & $\mathbf{0}$ & $\mathbf{0}$ & $\mathbf{0}$ & $\mathbf{0}$ \\
\hline $\begin{array}{l}\text { Other Utility Operating Income } \\
\text { Other Utifly Operating Revenues ............................. }\end{array}$ & 0 & 0 & 0 & 0 & 0 & 34,000 \\
\hline 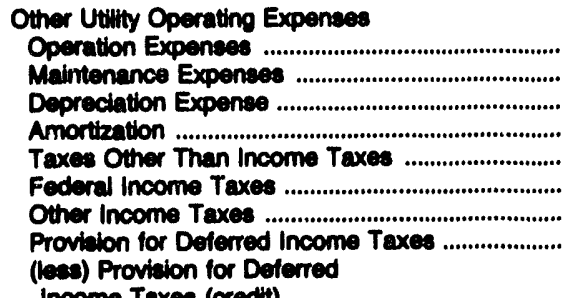 & $\begin{array}{l}0 \\
0 \\
0 \\
0 \\
0 \\
0 \\
0 \\
0\end{array}$ & $\begin{array}{l}0 \\
0 \\
0 \\
0 \\
0 \\
0 \\
0 \\
0\end{array}$ & $\begin{array}{l}0 \\
0 \\
0 \\
0 \\
0 \\
0 \\
0 \\
0\end{array}$ & $\begin{array}{l}0 \\
0 \\
0 \\
0 \\
0 \\
0 \\
0 \\
0\end{array}$ & $\begin{array}{l}0 \\
0 \\
0 \\
0 \\
0 \\
0 \\
0 \\
0 \\
0\end{array}$ & $\begin{array}{r}24,182 \\
5,264 \\
2,418 \\
0 \\
1,493 \\
375 \\
78 \\
784 \\
\\
1,398\end{array}$ \\
\hline 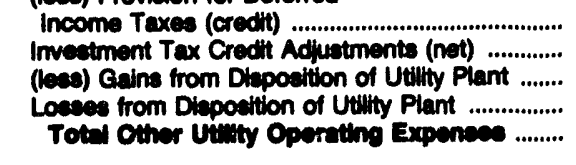 & $\begin{array}{l}0 \\
0 \\
0 \\
0 \\
0\end{array}$ & $\begin{array}{l}0 \\
0 \\
0 \\
0 \\
0\end{array}$ & $\begin{array}{l}0 \\
0 \\
0 \\
0 \\
0\end{array}$ & $\begin{array}{l}0 \\
0 \\
0 \\
0 \\
0\end{array}$ & $\begin{array}{l}0 \\
0 \\
0 \\
0 \\
0\end{array}$ & $\begin{array}{r}1,388 \\
-78 \\
0 \\
0 \\
38,110\end{array}$ \\
\hline Net Other Uunty Operating Incoms ................. & $\mathbf{0}$ & 0 & $\mathbf{0}$ & 0 & $\mathbf{0}$ & 62 \\
\hline
\end{tabular}

see endnotes at end of an individual electric utility. 
Table 37. Statement of Income and Rotained Earnings

by Major U.8. Investor-Owned Electric

Utility Whthin 8tate, 1902 (Continued)

(Thousand Dollars)

\begin{tabular}{|c|c|c|c|c|c|c|}
\hline ltem & $\begin{array}{l}\text { Ilimois } \\
\text { Mit } \\
\text { Cemmel } \\
\text { Public } \\
\text { utinty Co }\end{array}$ & $\begin{array}{l}\text { Indiana } \\
\text { Alood } \\
\text { Cenerating } \\
\text { Corp }\end{array}$ & $\begin{array}{l}\text { Inciana } \\
\text { AEP } \\
\text { Cenerating } \\
\text { Co }\end{array}$ & $\begin{array}{c}\text { Indiane } \\
\text { Commonmeatth } \\
\text { Edteon } \\
\text { Co } \\
\text { IN ine }\end{array}$ & $\begin{array}{l}\text { Indiana } \\
\text { Indiene } \\
\text { Mohiogn } \\
\text { Power Co }\end{array}$ & $\begin{array}{l}\text { Indiana } \\
\text { Indianapoll: } \\
\text { Power } \\
\text { Lont Co }\end{array}$ \\
\hline
\end{tabular}

Total Utity Operating income

Total Utity Operating Revenues

Uithy Operating Expenees

Operation Expenies ......

Melntenence Expeneses.

Depredation Expense

Amortiantion

Texes Other Than Income Taxes

Federal income Texes

Other Income Taxes

Proviaion for Deterred income Taxes .....................

(ieve) Provieion for Doferred

Income Texes (credt)

Imvertment Tax Crecit Ackuetments (net) ............

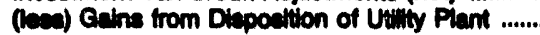

Loeses from Dieposition of Uitity Piant

Totel Utimy Opereting Expenses

Het Uimity Opernting Incems
108,620

289,232

60,852

$1,189,756$

683,208
0

241
0

$100, \pi)$

10.92

49

2425
178,488

10,288

21,449

3,069

877

160

10,734

3,898

$-3$
34,031
12,277
7,467
0
5,757
1,834
564
098
206
-220
0
0

enen

8,470
688,082

172,147

133,080

$-32,602$

69,007

0,122

2,281

111,000

85,218

$-9,028$

2019

17,49

0

00,921

107,184

270,086

62,448

$\mathbf{7 3 , 8 7 5}$

4,797

31,348

48,604

7,600

27,017

24,743

$-0.469$

2

4ecess

194,240

Other income and Deduction

Other Income

Nonutility Operating Income ................................... Equity in Eamings of Subaldary Companies ....... Intereet and Dividend Income

Allowance for Other Funds Used

During Conetruction

Mhcellaneous Nonoperating Income .....................

Gein on Diepodtion of Property

Totel Outer Ineome............

$\begin{array}{rr}0 & 29 \\ 0 & 0 \\ 12 & 0 \\ 249 & 0 \\ 0 & 16\end{array}$

$\begin{array}{rr}1,136 & 13 \\ 147 & 1 \\ 14,130 & 672 \\ 1,015 & 1,896 \\ 186 & 24 \\ 0 & 128 \\ 17,629 & 2,710\end{array}$

Other Income Deductions

Loes on Diapoedtion of Property

Miecellaneous Amortization ....

Miscellaneous Income Deductions

Tot'l Other Inocme Deduction

Taxes on Other Income and Dectuction

Texes Other Than Income Taxes

Federal Income Taxed ....................................................

Other Income Texes

Proutuion for Defered Income Taxes

(lees) Provition for Deterred

Income Taxes (credit) ...........................................

Imvestment Tax Credt Actustuments (net)

(leas) Imvestment Tax Cred"ts

Totil Toxes on Other incoms

and Decuctions .....................................................

Met Otrer inoome and Dockotions

..................

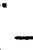

See endnotes at end of an individual electric utility.

$\begin{array}{rrrr}0 & 0 & 2,873 & 19 \\ 747 & 210 & -3,160 & -1,114 \\ 0 & 3 & 0 & -20 \\ 901 & 0 & 10,849 & 0\end{array}$

0
$-3,341$

4,077

$-646$

0
0
0

$-1,099$

5,960

$-1,124$

277

0,706

17,273

285 
Table 37. Statoment of Income and Rotalned Earnings

by Major U.8. Investor-Owned Electric

Utility Within stato, 1902 (Continued)

(Thousand Dollars)

\begin{tabular}{|c|c|c|c|c|c|c|}
\hline ltem & $\begin{array}{l}\text { Illinole } \\
\text { Mit } \\
\text { Carmel } \\
\text { Publio } \\
\text { Uutlty Co }\end{array}$ & $\begin{array}{l}\text { Inditana } \\
\text { Aloos } \\
\text { Generating } \\
\text { Corp }\end{array}$ & $\begin{array}{c}\text { Indiana } \\
\text { AEP } \\
\text { Gonerating } \\
\text { Co }\end{array}$ & $\begin{array}{c}\text { Indiana } \\
\text { Commonwealth } \\
\text { Edison } \\
\text { Co } \\
\text { IN ino }\end{array}$ & $\begin{array}{l}\text { Indiana } \\
\text { Indlana } \\
\text { Milohloan } \\
\text { Power Co }\end{array}$ & $\begin{array}{l}\text { Indlana } \\
\text { Indianapolla } \\
\text { Power } \\
\text { Light Co }\end{array}$ \\
\hline
\end{tabular}

interest Charges

Interest on Lono-tem Debt

Amortation of Dabt Diecount and Expenes ......

Amortarition of Lose on Acacquired Debt ...........

(kes) Amortination of Premium on Debt (credit).

(bev) Amortization of Gain on

Resquired Debt (credtit) ..........................................

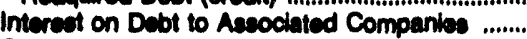

Other Intereet Expense ...............................................

(bea) Allowance for Borrowed Funds

Ued During Construction (credil)

Inooms Eotore Extracrilinery tems

Extraordinary liems

Extreordinary Income

(teas) Extreordinary Deductions

Niel Extracordinary Items

(leas) Federal and Other Income Taxes

Extracendinery ltems After Taxes

Net Income

\begin{abstract}
Aotalned Eeminge
\end{abstract}
Unepproperlated Rotalned Eaminge

Roteined Eeminge - Eeginning of Year

Balance Tranofered from income

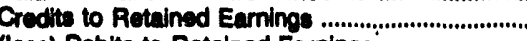

(leev) Debitu to Retained Eaminga

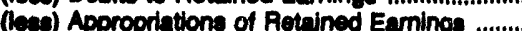

(kes) Dividends Declared - Preferred Stook ........

(leen) Dividende Declared - Common Stock ....... Insppropriated Undistributed Subaidiary

Earninges

Roteined Eeminge - End of Year

...................

Aproprlated Rotained Earnings

Appropilated Retained Earnings .

Approprlated Retained Earnings -

Amortization Reserve, Federal

Totul Retalned Eeminge

149
10
12
12

10,817

356
0

0
0
0

1,825

22
0

0

0

280

84

2,028

4,040

12,001
83,295

714

320
10

0

3,220

1,855

06,09

120,722
42,689

208

24

0
0

1,251

3,098

41,49

067

$$
\begin{aligned}
& 0 \\
& 0 \\
& 0 \\
& 0 \\
& 0
\end{aligned}
$$

\begin{tabular}{|c|c|c|c|c|c|}
\hline 4,697 & 3,004 & 32,080 & 16,028 & 149,032 & 340,117 \\
\hline $\begin{array}{r}698 \\
0 \\
0 \\
0 \\
0 \\
400\end{array}$ & $\begin{array}{r}2,800 \\
0 \\
0 \\
0 \\
0 \\
0\end{array}$ & $\begin{array}{r}12,801 \\
0 \\
0 \\
0 \\
0 \\
21,784\end{array}$ & $\begin{array}{r}4,949 \\
0 \\
0 \\
0 \\
1,100 \\
0\end{array}$ & $\begin{array}{r}128,675 \\
147 \\
0 \\
75 \\
15,417 \\
106,484\end{array}$ & $\begin{array}{r}93,058 \\
0 \\
0 \\
0 \\
3,182 \\
73,687\end{array}$ \\
\hline 0 & 0 & 0 & 0 & -147 & 0 \\
\hline $4,7 e 0$ & 0,803 & 23,173 & 20,777 & 184,680 & 893,805 \\
\hline$n$ & 0 & 0 & 0 & 0 & 200 \\
\hline 0 & 0 & 0 & 0 & $18 \%$ & 0 \\
\hline $4,7 \oplus 0$ & 0,008 & 28,173 & 20,777 & 184,816 & 389,605 \\
\hline
\end{tabular}

98,057

Note: Totals may not equal eum of components because of independent rounding. Summary data are provided in Table 6. Sourca: Federal Energy Regulatory Commiecion, FERC Form 1, "Annual Report of Mafor Electrio Utillties, Llcensees and Others." 
- Table 37. Statoment of Income and Rotained Earnings by Major U.8. Invector-Owned Electrito Utility Within State, 1992 (Continued) (Thousand Dollars)

\begin{tabular}{|c|c|c|c|c|c|c|}
\hline $1 \mathrm{tem}$ & $\begin{array}{l}\text { Indiana } \\
\text { Northom } \\
\text { Indiana } \\
\text { Pub Sen } \\
\text { Co }\end{array}$ & $\begin{array}{l}\text { Indian } \\
\text { Pes } \\
\text { Energy ino }\end{array}$ & $\begin{array}{l}\text { Indiana } \\
\text { Southem } \\
\text { indiana Cass } \\
\text { S Elso Co }\end{array}$ & $\begin{array}{l}\text { lown } \\
\text { Imternetate } \\
\text { Power Co }\end{array}$ & $\begin{array}{c}\text { lowe } \\
\text { lown } \\
\text { Electric } \\
\text { Light \& Power } \\
\text { Co }\end{array}$ & $\begin{array}{l}\text { lown } \\
\text { lown } \\
\text { Southern } \\
\text { Utilltes } \\
\text { Co }\end{array}$ \\
\hline $\begin{array}{l}\text { Electuic Utillty Operating Income } \\
\text { Electric Operating Revenues }\end{array}$ & 916,135 & $1,072,183$ & 243,077 & 209,193 & 345,291 & 117,708 \\
\hline 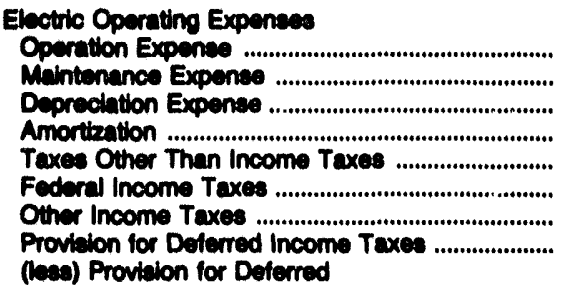 & $\begin{array}{r}411,006 \\
70,296 \\
128,618 \\
4,290 \\
47,084 \\
62,373 \\
9,761 \\
16,601\end{array}$ & $\begin{array}{r}601,076 \\
86,046 \\
113,873 \\
3,218 \\
42,334 \\
48,266 \\
7,403 \\
38,021\end{array}$ & $\begin{array}{r}112,007 \\
20,001 \\
32,572 \\
214 \\
11,427 \\
16,358 \\
2,403 \\
3,002\end{array}$ & $\begin{array}{r}137,790 \\
16,311 \\
23,203 \\
640 \\
16,395 \\
6,951 \\
2,164 \\
6,492\end{array}$ & $\begin{array}{r}181,711 \\
29,273 \\
44,768 \\
2,108 \\
23,680 \\
11,943 \\
3,789 \\
14,760\end{array}$ & $\begin{array}{r}69,868 \\
8,143 \\
12,813 \\
18 \\
9,849 \\
4,876 \\
285 \\
3,680\end{array}$ \\
\hline 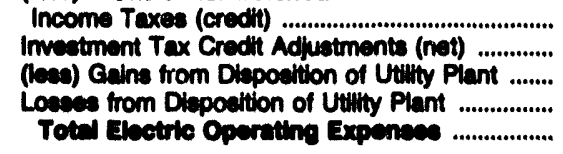 & $\begin{array}{r}18,097 \\
-6,111 \\
0 \\
0 \\
726,424\end{array}$ & $\begin{array}{r}23,763 \\
-4,436 \\
0 \\
0 \\
\cos , 79\end{array}$ & $\begin{array}{r}3,176 \\
-1,761 \\
0 \\
0 \\
198,371\end{array}$ & $\begin{array}{r}3,503 \\
-977 \\
0 \\
0 \\
202,497\end{array}$ & $\begin{array}{r}16,253 \\
-1,813 \\
0 \\
0 \\
202,746\end{array}$ & $\begin{array}{r}1,282 \\
-724 \\
0 \\
0 \\
07,404\end{array}$ \\
\hline Not Eketric Uuily Operating Income ............. & 100,711 & 108,446 & 40,70 & $\mathbf{3 4 , 7 2 0}$ & 81,540 & 20,304 \\
\hline 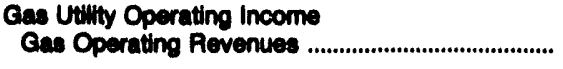 & 688,160 & 0 & 62,870 & 46,105 & 110,050 & 30,359 \\
\hline 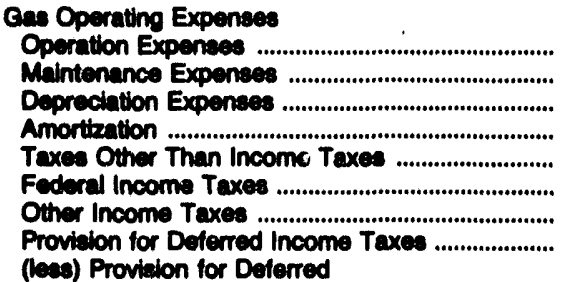 & $\begin{array}{r}482,613 \\
14,347 \\
49,894 \\
820 \\
20,700 \\
-1,890 \\
1,778 \\
31,894\end{array}$ & $\begin{array}{l}0 \\
0 \\
0 \\
0 \\
0 \\
0 \\
0 \\
0\end{array}$ & $\begin{array}{r}64,384 \\
1,675 \\
3,427 \\
0 \\
2,783 \\
-185 \\
52 \\
497\end{array}$ & $\begin{array}{r}43,600 \\
1,656 \\
2,026 \\
17 \\
1,139 \\
-777 \\
-242 \\
928\end{array}$ & $\begin{array}{r}90,046 \\
1,082 \\
2,849 \\
97 \\
2,078 \\
2,403 \\
763 \\
2,272\end{array}$ & $\begin{array}{r}27,137 \\
597 \\
1,070 \\
6 \\
1,080 \\
-119 \\
-68 \\
416\end{array}$ \\
\hline 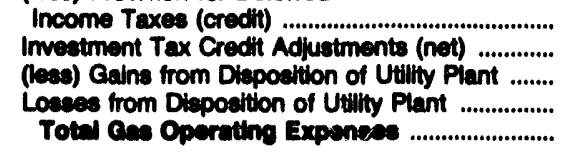 & $\begin{array}{r}16,146 \\
-1,305 \\
0 \\
0 \\
02,776\end{array}$ & $\begin{array}{l}0 \\
0 \\
0 \\
0 \\
0\end{array}$ & $\begin{array}{r}740 \\
-112 \\
0 \\
0 \\
01,029\end{array}$ & $\begin{array}{r}647 \\
-62 \\
0 \\
0 \\
47,947\end{array}$ & $\begin{array}{r}3,044 \\
-120 \\
0 \\
0 \\
104,416\end{array}$ & $\begin{array}{r}338 \\
-21 \\
0 \\
0 \\
20,770\end{array}$ \\
\hline Net Cas Utilty Operating Income ....................... & 53,376 & $\mathbf{0}$ & 1,249 & $-1,842$ & 5,634 & $\mathbf{5 e 0}$ \\
\hline $\begin{array}{l}\text { Other Utillty Operating Income } \\
\text { Other Utithy Operating Revenues ............................. }\end{array}$ & 0 & 0 & 0 & 0 & 6,854 & 0 \\
\hline 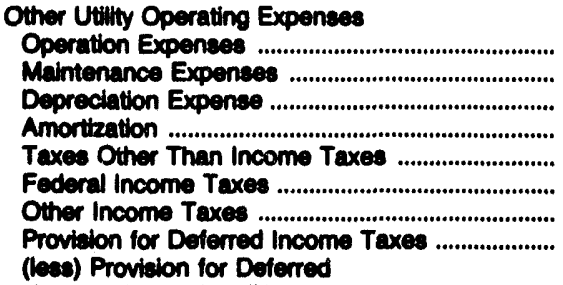 & $\begin{array}{l}0 \\
0 \\
0 \\
0 \\
0 \\
0 \\
0 \\
0\end{array}$ & $\begin{array}{l}0 \\
0 \\
0 \\
0 \\
0 \\
0 \\
0 \\
0\end{array}$ & $\begin{array}{l}0 \\
0 \\
0 \\
0 \\
0 \\
0 \\
0 \\
0\end{array}$ & $\begin{array}{l}0 \\
0 \\
0 \\
0 \\
0 \\
0 \\
0 \\
0\end{array}$ & $\begin{array}{r}4,614 \\
478 \\
389 \\
10 \\
279 \\
110 \\
35 \\
120\end{array}$ & $\begin{array}{l}0 \\
0 \\
0 \\
0 \\
0 \\
0 \\
0 \\
0\end{array}$ \\
\hline 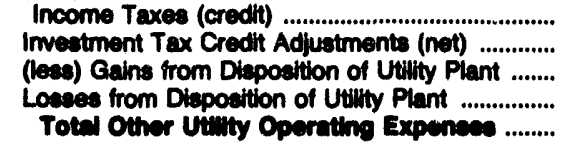 & $\begin{array}{l}0 \\
0 \\
0 \\
0 \\
0\end{array}$ & $\begin{array}{l}0 \\
0 \\
0 \\
0 \\
0\end{array}$ & $\begin{array}{l}0 \\
0 \\
0 \\
0 \\
0\end{array}$ & $\begin{array}{l}0 \\
0 \\
0 \\
0 \\
0\end{array}$ & $\begin{array}{r}23 \\
-4 \\
0 \\
0 \\
5,020\end{array}$ & $\begin{array}{l}0 \\
0 \\
0 \\
0 \\
0\end{array}$ \\
\hline Net Other Utwity Operating Incoms ................. & $\mathbf{0}$ & $\mathbf{0}$ & 0 & $\mathbf{0}$ & $\omega 8$ & $\mathbf{0}$ \\
\hline
\end{tabular}

See endinotes at end of an individual electric utility. 
Table 37. Statement of Income and Rotalned Earninge

by Major U.8. Inveator-Owned Electric

Utility Within state, 1902 (Continued)

(Thousand Dollars)

\begin{tabular}{|c|c|c|c|c|c|c|}
\hline Item & $\begin{array}{l}\text { Indiana } \\
\text { Northom } \\
\text { Indtunn } \\
\text { Pub Een } \\
\text { Co }\end{array}$ & $\begin{array}{l}\text { Indina } \\
\text { PeI } \\
\text { Enerey ino }\end{array}$ & $\begin{array}{l}\text { Indien } \\
\text { Southem } \\
\text { Indinn Ges } \\
\text { A Eleo Co }\end{array}$ & $\begin{array}{l}\text { lowa } \\
\text { Interetate } \\
\text { Power Co }\end{array}$ & $\begin{array}{c}\text { lowa } \\
\text { lowa } \\
\text { Electrle } \\
\text { Light a Power } \\
\text { Co }\end{array}$ & $\begin{array}{l}\text { lown } \\
\text { lowa } \\
\text { southem } \\
\text { Utilties } \\
\text { Co }\end{array}$ \\
\hline $\begin{array}{l}\text { Total Uitity Operating Income } \\
\text { Total Utilly Operating Revenues ............................ }\end{array}$ & $1,852,286$ & $1,072,183$ & 305,947 & 285,298 & 462,105 & 148,087 \\
\hline 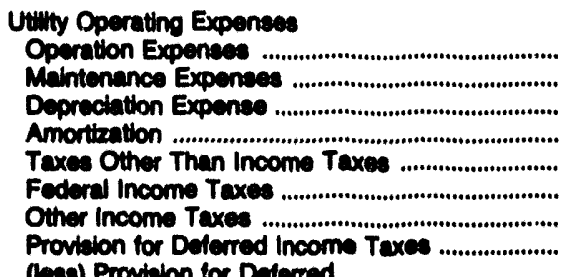 & $\begin{array}{r}894,300 \\
84,649 \\
170,382 \\
5,113 \\
68,683 \\
60,474 \\
11,629 \\
48,686\end{array}$ & $\begin{array}{r}591,876 \\
89,046 \\
113,873 \\
3,218 \\
42,384 \\
48,265 \\
7,400 \\
39,021\end{array}$ & $\begin{array}{r}169,431 \\
21,690 \\
35,909 \\
214 \\
14,210 \\
16,188 \\
2,646 \\
3,689\end{array}$ & $\begin{array}{r}181,391 \\
16,868 \\
25,280 \\
657 \\
16,683 \\
6,174 \\
1,928 \\
6,418\end{array}$ & $\begin{array}{r}282,370 \\
30,838 \\
47,888 \\
2,214 \\
25,918 \\
14,466 \\
4,678 \\
17,162\end{array}$ & $\begin{array}{r}87,003 \\
8,738 \\
13,880 \\
24 \\
10,929 \\
4,768 \\
200 \\
3,905\end{array}$ \\
\hline 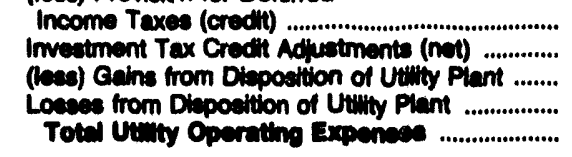 & $\begin{array}{r}34,183 \\
-7,416 \\
0 \\
0 \\
1,342,200\end{array}$ & $\begin{array}{r}23,758 \\
-4,495 \\
0 \\
0 \\
0.790\end{array}$ & $\begin{array}{r}3,922 \\
-1,873 \\
0 \\
0 \\
244,007\end{array}$ & $\begin{array}{r}4,160 \\
-1,028 \\
0 \\
0 \\
280,114\end{array}$ & $\begin{array}{r}19,320 \\
-2,087 \\
0 \\
0 \\
104,140\end{array}$ & $\begin{array}{r}1,620 \\
-745 \\
0 \\
0 \\
127,174\end{array}$ \\
\hline Net Utimly Operating incoms .............................. & 244,05 & 192,448 & so,eso & 36,194 & 80,049 & 20,003 \\
\hline $\begin{array}{l}\text { Other Income and Deductions } \\
\text { Other Income }\end{array}$ & & & & & & \\
\hline $\begin{array}{l}\text { Nomutily Operating Income ................................... } \\
\text { Equity in Eaminge of Subeidiary Companied ........ } \\
\text { Intereet and Dividend Income .................................. } \\
\text { Allowance for Other Funde Ueed }\end{array}$ & $\begin{array}{r}-690 \\
-401 \\
308\end{array}$ & $\begin{array}{r}-187 \\
0 \\
1,228\end{array}$ & $\begin{array}{r}-2 \\
2,321 \\
724\end{array}$ & $\begin{array}{r}159 \\
9 \\
600\end{array}$ & $\begin{array}{r}-17 \\
0 \\
1,198\end{array}$ & $\begin{array}{r}957 \\
0 \\
530\end{array}$ \\
\hline 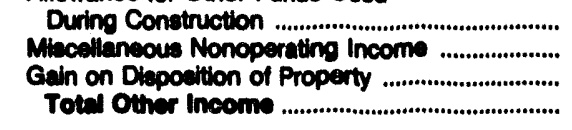 & $\begin{array}{r}31 \\
232 \\
0 \\
-480\end{array}$ & $\begin{array}{r}4,853 \\
520 \\
85 \\
6,474\end{array}$ & $\begin{array}{r}988 \\
888 \\
0 \\
4,916\end{array}$ & $\begin{array}{r}184 \\
482 \\
12 \\
1,349\end{array}$ & $\begin{array}{r}1,034 \\
531 \\
0 \\
2,746\end{array}$ & $\begin{array}{r}797 \\
42 \\
0 \\
2,327\end{array}$ \\
\hline 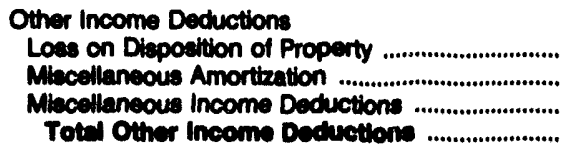 & $\begin{array}{r}3 \\
0 \\
330 \\
393\end{array}$ & $\begin{array}{r}0 \\
0 \\
4,278 \\
4,270\end{array}$ & $\begin{array}{r}0 \\
342 \\
649 \\
992\end{array}$ & $\begin{array}{r}69 \\
0 \\
180 \\
260\end{array}$ & $\begin{array}{r}-1 \\
92 \\
789 \\
670\end{array}$ & $\begin{array}{r}0 \\
0 \\
248 \\
240\end{array}$ \\
\hline 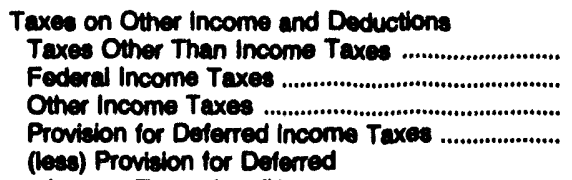 & $\begin{array}{r}0 \\
-1,128 \\
-158 \\
0\end{array}$ & $\begin{array}{r}118 \\
-1,166 \\
-104 \\
0\end{array}$ & $\begin{array}{r}15 \\
180 \\
52 \\
0\end{array}$ & $\begin{array}{r}8 \\
271 \\
84 \\
0\end{array}$ & $\begin{array}{r}10 \\
-607 \\
-232 \\
857\end{array}$ & $\begin{array}{r}0 \\
20 \\
-14 \\
-35\end{array}$ \\
\hline 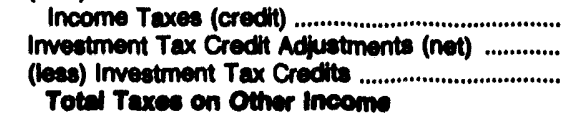 & $\begin{array}{r}-830 \\
0 \\
0\end{array}$ & $\begin{array}{r}1,528 \\
0 \\
0\end{array}$ & $\begin{array}{l}0 \\
0 \\
0\end{array}$ & $\begin{array}{l}0 \\
0 \\
0\end{array}$ & $\begin{array}{r}688 \\
0 \\
0\end{array}$ & $\begin{array}{l}0 \\
0 \\
0\end{array}$ \\
\hline 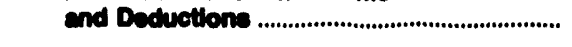 & -462 & $-2,090$ & 247 & 393 & -600 & -20 \\
\hline Net Other Incoms end Dectuotions ................... & -201 & 4,048 & 8,677 & 724 & 2,628 & 2,108 \\
\hline
\end{tabular}


Table 37. 8tatement of Income and Rotalned Eamings

by Major U.8. Inveator-Owned Eleotrie

Utility Whinin state, 1992 (Continued)

(Thousend Dollars)

\begin{tabular}{|c|c|c|c|c|c|c|}
\hline Hem & $\begin{array}{l}\text { Indiane } \\
\text { Northem } \\
\text { Indiana } \\
\text { Pub } 8 \text { en } \\
\text { co }\end{array}$ & $\begin{array}{c}\text { Indian } \\
\text { PeI } \\
\text { Enerey ino }\end{array}$ & $\begin{array}{l}\text { Inciana } \\
\text { southam } \\
\text { Indianm Gas } \\
\text { a Elec Co }\end{array}$ & $\begin{array}{c}\text { lowe } \\
\text { Imteretate } \\
\text { Power Co }\end{array}$ & $\begin{array}{c}\text { lown } \\
\text { lown } \\
\text { Electric } \\
\text { Loint \& Power } \\
\text { Co }\end{array}$ & $\begin{array}{l}\text { lowa } \\
\text { lown } \\
\text { Southem } \\
\text { Utillites } \\
\text { Co }\end{array}$ \\
\hline
\end{tabular}

Interest Charges

interest on Lonotem Dabt ..............unu...

Amorthrtion of Debt Decount and Expenes .......

Amortiation of Loes on Rescopired Debt ............

(kes) Amortiention of Premium on Dabt (oredili).

(kw) Amortiation of Cans on

Renquined Debt (arectil) .............................................

Interext on Debt to Aasociated Companies .........

(eve) Alowence for Bomound Fund

Ueed Duin Construction (credil) .........................

Net mineret Grarem ...............................................

Incems Eefore Extrecrentery Mem

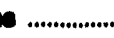

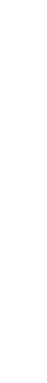

$\begin{array}{rrr}89,700 & 80,078 & 17,7 \\ 683 & 497 & \\ 2,082 & 2,048 \\ 77 & 24 & \\ 0 & 0 \\ 0 & 89 \\ 7,068 & 9,408 \\ 843 & \mathbf{6 , 0 7 2} & \end{array}$

17,768
347
130
30
0
0
80
404
17,800

10,017

276

anses

cring

14,414

102970

$\boldsymbol{2 n , 7 e 7}$

Extraordinary them

Extreordinary Incoms.

(ive) Extreordinery Deduction:

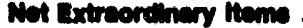

(keo) Federal and Other incoms Taxe

Entwertinary thems Afrer Taxee

Net Inoems

10.970

83,707

14,937

Uneppropitatid Retelned Eemince

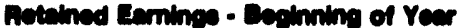

Belance Transterred from incoms

(lece) Appropitations of Retained Eeninings .........

(kev) Dividende Dectared - Preferred 8tock .......

(2aes) Dividends Declered - Common Stock .......

Uneppropitated Undiotributed Subuldiary

Eaminge ........................................................................

Retelned Eeminge - End of Year

\begin{tabular}{|c|c|c|c|c|c|}
\hline 140,10 & 2es,ess & $172, \mathrm{cst}$ & cerses & 02,049 & 05,000 \\
\hline $\begin{array}{r}149,868 \\
41 \\
246 \\
0 \\
10,688 \\
134,016\end{array}$ & $\begin{array}{r}108,070 \\
641 \\
681 \\
-12 \\
7,808 \\
68,680\end{array}$ & $\begin{array}{r}34,446 \\
0 \\
525 \\
0 \\
1,285 \\
24,602\end{array}$ & $\begin{array}{r}19,208 \\
0 \\
0 \\
0 \\
2,975 \\
18,380\end{array}$ & $\begin{array}{r}30,424 \\
0 \\
0 \\
0 \\
978 \\
7,989\end{array}$ & $\begin{array}{r}14,867 \\
0 \\
587 \\
0 \\
761 \\
16,782\end{array}$ \\
\hline 0 & 0 & 0 & 0 & 0 & 0 \\
\hline 149me & 492.39 & 181,148 & 00,400 & 00,010 & 82,057 \\
\hline 0 & 0 & 0 & 0 & 0 & 0 \\
\hline 0 & 408 & 0 & 0 & 0 & 0 \\
\hline 142pe & $4 \times 2,74$ & 101,145 & 0,400 & $0,4 \times 0$ & 82,967 \\
\hline
\end{tabular}

Appropriated Retained Earninos

Appropiated Rotained Eamings

Amorthation Reaerve, Federal

Tot Rotinged Eaming

2,097

Nots: Total my not cqual eum of components because of independent rounding. Summery dath are provided in Table 8.

Source: Federal Eneroy Reculatory Commiscion, FEAC Form 1, "Annual Report of Major Eleotric Utitties, Licenaeces and Othere." 
Table 37. Statement of Income and Rotalned Earnings by Major U.S. Investor-Owned Electric Utility Within State, 1992 (Continued) (Thousand Dollars)

\begin{tabular}{|c|c|c|c|c|c|c|}
\hline Item & $\begin{array}{c}\text { lowa } \\
\text { lowa. } \\
\text { Ilinole } \\
\text { Gasdelectric } \\
\text { Co }\end{array}$ & $\begin{array}{l}\text { lowa } \\
\text { Mindweat } \\
\text { Power } \\
\text { Syatems } \\
\text { Inc } \\
\end{array}$ & $\begin{array}{c}\text { Kaneas } \\
\text { Kaneas } \\
\text { Cass } \\
2 \\
\text { Electric Co }\end{array}$ & $\begin{array}{l}\text { Kaneas } \\
\text { Westem } \\
\text { Resourcee } \\
\text { Inc }\end{array}$ & $\begin{array}{l}\text { Kentucky } \\
\text { Kentucky } \\
\text { Power Co }\end{array}$ & $\begin{array}{l}\text { Kentucky } \\
\text { Kentucky } \\
\text { Utilltes Co }\end{array}$ \\
\hline $\begin{array}{l}\text { Electric Utilly Operating Income } \\
\text { Electric Operating Revenues }\end{array}$ & 312,667 & 623,360 & 662,246 & 468,682 & 313,216 & 575,821 \\
\hline 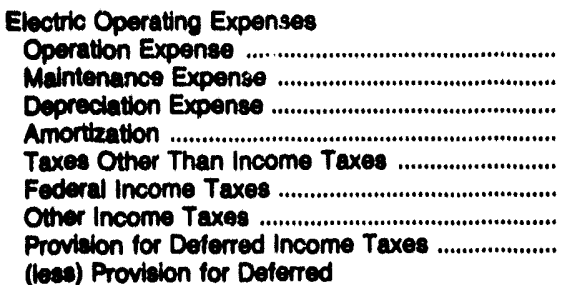 & $\begin{array}{r}134,001 \\
34,656 \\
46,055 \\
4,695 \\
28,345 \\
8,298 \\
2,270 \\
13,362\end{array}$ & $\begin{array}{r}331,047 \\
46,000 \\
70,608 \\
3,608 \\
51,320 \\
14,208 \\
4,388 \\
12,889\end{array}$ & $\begin{array}{r}224,172 \\
46,702 \\
71,200 \\
20,857 \\
40,400 \\
13,137 \\
2,792 \\
34,140\end{array}$ & $\begin{array}{r}217,093 \\
37,021 \\
49,893 \\
408 \\
33,817 \\
12,976 \\
587 \\
16,507\end{array}$ & $\begin{array}{r}211,270 \\
22,231 \\
21,541 \\
39 \\
6,380 \\
5,970 \\
1,900 \\
12,184\end{array}$ & $\begin{array}{r}295,138 \\
61,118 \\
58,618 \\
34 \\
13,359 \\
30,838 \\
7,961 \\
14,247\end{array}$ \\
\hline 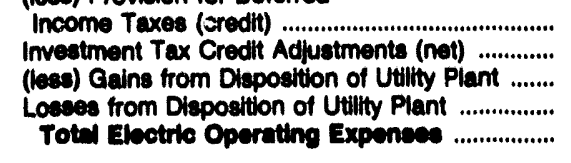 & $\begin{array}{r}8,884 \\
-2,108 \\
0 \\
0 \\
280,712\end{array}$ & $\begin{array}{r}6,811 \\
-3,384 \\
0 \\
0 \\
620,070\end{array}$ & $\begin{array}{r}27,643 \\
-1,967 \\
0 \\
0 \\
0 \\
122,014\end{array}$ & $\begin{array}{r}8,624 \\
-2,610 \\
0 \\
0 \\
367,164\end{array}$ & $\begin{array}{r}15,421 \\
-1,148 \\
0 \\
0 \\
204,093\end{array}$ & $\begin{array}{r}11,418 \\
-130 \\
0 \\
0 \\
409,963\end{array}$ \\
\hline Net Ebetric Uthity Operating Income ............. & 89,966 & $n 7,200$ & 128,391 & 101,818 & 40,262 & 105,090 \\
\hline 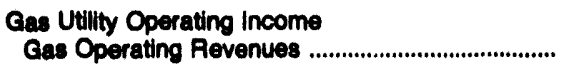 & 186,009 & 299,820 & $\mathbf{0}$ & 673,363 & 0 & 0 \\
\hline 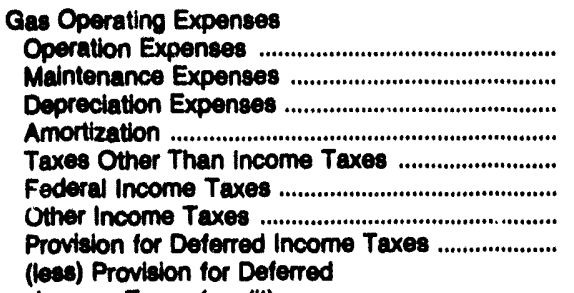 & $\begin{array}{r}153,035 \\
4,880 \\
7,367 \\
337 \\
7,482 \\
4,309 \\
1,193 \\
2,452\end{array}$ & $\begin{array}{r}250,991 \\
6,134 \\
11,205 \\
1,029 \\
12,320 \\
998 \\
303 \\
2,380\end{array}$ & $\begin{array}{l}0 \\
0 \\
0 \\
0 \\
0 \\
0 \\
0 \\
0\end{array}$ & $\begin{array}{r}589,638 \\
28,607 \\
31,669 \\
6,602 \\
36,697 \\
-9,354 \\
-1,260 \\
17,417\end{array}$ & $\begin{array}{l}0 \\
0 \\
0 \\
0 \\
0 \\
0 \\
0 \\
0\end{array}$ & $\begin{array}{l}0 \\
0 \\
0 \\
0 \\
0 \\
0 \\
0 \\
0\end{array}$ \\
\hline 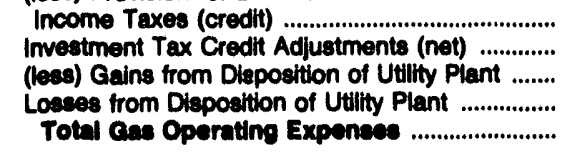 & $\begin{array}{r}4,375 \\
-218 \\
0 \\
0 \\
176,463\end{array}$ & $\begin{array}{r}787 \\
-434 \\
0 \\
0 \\
204,140\end{array}$ & $\begin{array}{l}0 \\
0 \\
0 \\
0 \\
0\end{array}$ & $\begin{array}{r}5,133 \\
-854 \\
0 \\
0 \\
843,727\end{array}$ & $\begin{array}{l}0 \\
0 \\
0 \\
0 \\
0\end{array}$ & $\begin{array}{l}0 \\
0 \\
0 \\
0 \\
0\end{array}$ \\
\hline Not ans Utillty Operating Income ..................... & 0,540 & 18,691 & $\mathbf{0}$ & 20,637 & $\mathbf{0}$ & $\mathbf{0}$ \\
\hline $\begin{array}{l}\text { Other Utillty Operating Income } \\
\text { Other Utility Operating Revenues }\end{array}$ & $-1,142$ & 0 & 2,005 & 688 & 0 & 0 \\
\hline 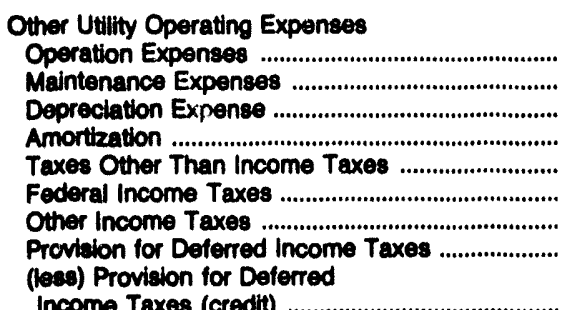 & $\begin{array}{r}-1,142 \\
0 \\
0 \\
0 \\
0 \\
0 \\
0 \\
0\end{array}$ & $\begin{array}{l}0 \\
0 \\
0 \\
0 \\
0 \\
0 \\
0 \\
0\end{array}$ & $\begin{array}{r}0 \\
0 \\
174 \\
0 \\
0 \\
0 \\
0 \\
0\end{array}$ & $\begin{array}{r}467 \\
126 \\
0 \\
0 \\
63 \\
3 \\
1 \\
0\end{array}$ & $\begin{array}{l}0 \\
0 \\
0 \\
0 \\
0 \\
0 \\
0 \\
0\end{array}$ & $\begin{array}{l}0 \\
0 \\
0 \\
0 \\
0 \\
0 \\
0 \\
0\end{array}$ \\
\hline 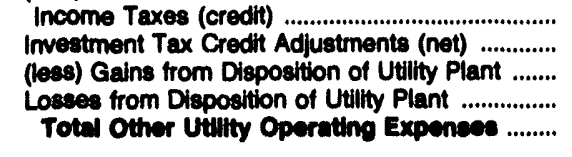 & $\begin{array}{r}0 \\
0 \\
0 \\
0 \\
-1,142\end{array}$ & $\begin{array}{l}0 \\
0 \\
0 \\
0 \\
0\end{array}$ & $\begin{array}{r}0 \\
0 \\
0 \\
0 \\
174\end{array}$ & $\begin{array}{r}12 \\
0 \\
0 \\
0 \\
040\end{array}$ & $\begin{array}{l}0 \\
0 \\
0 \\
0 \\
0\end{array}$ & $\begin{array}{l}0 \\
0 \\
0 \\
0 \\
0\end{array}$ \\
\hline Net Other Utilly Operating Income ................. & $\mathbf{0}$ & 0 & 1,091 & 17 & 0 & o \\
\hline
\end{tabular}

See endnotes at end of an individual electric utility. 
Table 37. Statement of Income and Rotained Earninge

by Major U.S. Investor-Owned Electric

Utility Within State, 1992 (Continued)

(Thousand Dollars)

\begin{tabular}{|c|c|c|c|c|c|c|}
\hline Nem & $\begin{array}{c}\text { lowa } \\
\text { lowa- } \\
\text { llinois } \\
\text { GasdElectric } \\
\text { Co }\end{array}$ & $\begin{array}{l}\text { Lowa } \\
\text { Midwest } \\
\text { Power } \\
\text { Systems } \\
\text { Inc }\end{array}$ & $\begin{array}{c}\text { Kanses } \\
\text { Kansas } \\
\text { Gas } \\
8 \\
\text { Electric Co }\end{array}$ & $\begin{array}{l}\text { Kanass } \\
\text { Weetern } \\
\text { Resources } \\
\text { Inc }\end{array}$ & $\begin{array}{l}\text { Kentuchy } \\
\text { Kentucky } \\
\text { Power Co }\end{array}$ & $\begin{array}{l}\text { Kentuchy } \\
\text { Kentuchy } \\
\text { Utilities Co }\end{array}$ \\
\hline
\end{tabular}

Total Utilty Operating Income

Total Utilty Operating Revenues

497,534

928,180

554,251

$1,132.7$

Utilty Operating Expenses

Operation Expenses

Melntenance Expentes

Depreciation Expenses

Amoriter

Taxes Other Then Income Taxes

Federal income Taxes

Other Income Taxes

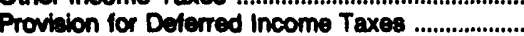

(leas) Proviaion for Deferred

Income Taxes (credit)

Imvestunent Tax Credit Adjustments (net) ............

(lea) Gains from Disposition of Utility Plant .......

Loseses from Disposition of Utility Plant

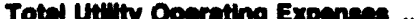

Not Ututy Oporating Income

$7 b$.

65,

27,543

$-1,957$

42409

810,210

112,971

180,189

81,5 .

6,00

70,577

3,625

$-672$

38,823

13,688

$-3,480$

131,172

40,262

$0 .$.
.041
399
6,
$5,0,0$
1,800
12,184
15,421
$-1,148$
0
0
29,99

295,138

61,118

58,816

34

13,358

30,838

7,851

14,247

11,418

$-130$

0

490,058

105,093

Other Income and Deductions

Other Income

Nonutithy Operating Income

Interest and Dividend Income

Allowance for Other Funds Used

During Congtruction

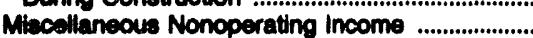

Gain on Disposition of Property

Totel Other Ineom

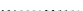

Other Income Deductions

Loss on Disposition of Property

Miscellaneous Amortization

Miscellaneous income Deductions

Totel Other Income Deducthons

$-98$

9,476

227

0

9

634
0
807
1,213
2,429
0
5,003

1,382

93
0
4,572
4,685

127

824

303

312

1,574

(less) Provision for Delerred

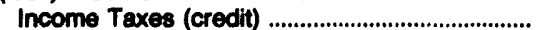

Investment Tax Credit Adjustments (net)

(less) Invertment Tax Credits ...

Totil Toxes on Other Income

and Deduction:

\section{.}

Net Other Incoms end Deductions

8,928
$-1,058$
0
1,428

1,428

0
10,819

12

11,213

157
18
$-7,672$
$-7,807$

$-7,807$

3
$-1,505$

$-1,505$
-520

2,110

-481
73,818
4,284

62
0
498
130
45
0
723

3
2,639
6,611

6,611

119

218
70

0,631

02,49

$-\hat{-E}$
1,295
085

$\begin{array}{rr}0 & 14 \\ 0 & 0 \\ 591 & 1,297 \\ 501 & 1,311\end{array}$

0
-275

$-19$

1e.7es

2,002

0
1,707
323
2,643

48

$-83$

-8
168

104

$-216$

2,081

$1,871 \quad 78$

79
-183
0

837

4,020

$-2,95$

393

18,708

78,00

221

11,94

See endnotes at end of an individual electric utillity. 
Table 37. Statement of Income and Rotained Earnings by Major U.S. Investor-Owned Electrlc Utility Whin State, 1902 (Continued) (Thousand Dollars)

\begin{tabular}{c|c|c|c|c|c|c}
\hline & lowa & lowa & Kansas & Kansas & Kentucky \\
Item & $\begin{array}{c}\text { lowa- } \\
\text { Illinols } \\
\text { GasaElectric } \\
\text { Co }\end{array}$ & $\begin{array}{c}\text { Midwest } \\
\text { Power } \\
\text { Systems } \\
\text { Inc }\end{array}$ & $\begin{array}{c}\text { Kansas } \\
\text { Gas } \\
8 \\
\text { Electric Co }\end{array}$ & $\begin{array}{c}\text { Western } \\
\text { Resources } \\
\text { inc }\end{array}$ & $\begin{array}{c}\text { Kentucky } \\
\text { Power Co }\end{array}$ & $\begin{array}{c}\text { Kentucky } \\
\text { Utilities Co }\end{array}$ \\
\hline
\end{tabular}

Interest Charges

Interest on Lono-term Debt

Amortzation of Debt Discount and Expense ......

Amortzation of Lose on Reacquired Debt ............

(ke⿰)) Amortization of Premium on Debt (credit)

(bes) Amortzation of Gain on

Resquired Dabt (credit)

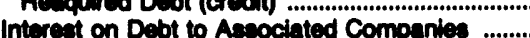

Other Intereat Expense ..............................

(lese) Allowance for Borrowed Fund

Ueed During Conatruction (credit)

Net Intereet Chargen

Inoome Defore Extracerdinery ltemis

.............................

(n...

Extraordinary ltems

Extreordinary Income

(lese) Extracordinary Deductions

Net Extraordinary ltems

(leas) Federal and Other Income Taxes

Extracreninan liems After Taxes

$\begin{array}{rr}25,783 & 59,465 \\ 228 & 657 \\ 414 & 1,382 \\ 1 & 7 \\ 205 & 58 \\ 0 & -51 \\ 1,872 & 2,281 \\ 1,104 & 1,024 \\ 28,004 & 2,24\end{array}$

80,600

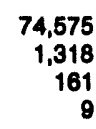

0
0

6,761

821

81,095

127,984

77,eer
39,217

162

247

56

0
0
1,394

50

40,015

76,293

Net Ineoms

50,660

77,992

127,894

26,537

76,290

Uneppropolated Roteined Eeminges

Rotelnod Eeminas - Decinming of Yeer

211,890

170,69

392,970

$\mathbf{4 , 7 7 1}$

200,490

Balance Transterred from Income

Credits to Retained Eaminge ................................

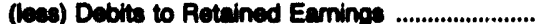

(leas) Appropriations of Retained Earninge .........

(less) Dividende Declared - Preferred Stock .......

(bees) Dividends Declered - Common Stock .......

Unappropitated Undistributed Subeidiary

Earninges

35,857
78
5,02
48,592

50,650
85
859
0
3,708
73,844

77,882
0
163,103
0
205
13,380

54,086

26,537

73,658

14
0

12,751

99,134

0
0
0

21,350

108,898

o

0

0

0

2,586

119,42

123,695

71,91

826,045

09,057

225,225

Appropriated Retained Eaminges

Appropriated Retained Eamings -

Amortization Reserve, Federal

$\mathbf{0}$

0

0

0

$\mathbf{0}$

0

0

0

0

0

115

Tot Retinged Eeminge

193,4e2

$19 \mathrm{sen}$

71,91

325,045

09,057

226,340

Note: Totale may not cqual eum of components because of independent rounding. Summary data are provided in Table 6,

Source: Federd Energy Requlatory Commisalon, FEAC Form 1. "Anmual Report of Major Electric Utulties, Lcencees and Others." 
Table 37. Statement of Income and Rotained Earninge

by Major U.S. Inveetor-Owned Electric

Utility Within State, 1902 (Continued)

(Thousand Dollars)

\begin{tabular}{|c|c|c|c|c|c|c|}
\hline Item & $\begin{array}{l}\text { Kentucky } \\
\text { Louiovilis } \\
\text { Case } \\
\text { Electiric Co }\end{array}$ & $\begin{array}{l}\text { Kentuchy } \\
\text { Union Light } \\
\text { Heat \& Power } \\
\text { Co }\end{array}$ & $\begin{array}{l}\text { Louldana } \\
\text { Central } \\
\text { Louidiana } \\
\text { Elec } \\
\text { Co Inc }\end{array}$ & $\begin{array}{l}\text { Loublana } \\
\text { Loulaiana } \\
\text { Power } \\
\text { Light Co }\end{array}$ & $\begin{array}{l}\text { Louidiana } \\
\text { Now Orloane } \\
\text { Public } \\
\text { Service inc }\end{array}$ & $\begin{array}{l}\text { Loulaiana } \\
\text { Souttwwestern } \\
\text { Electric } \\
\text { Power Co }\end{array}$ \\
\hline $\begin{array}{l}\text { Electric Utilty Operating Income } \\
\text { Electric Operating Revenued }\end{array}$ & 521,670 & 160,600 & 351,613 & $1,568,745$ & 382,221 & 778,438 \\
\hline 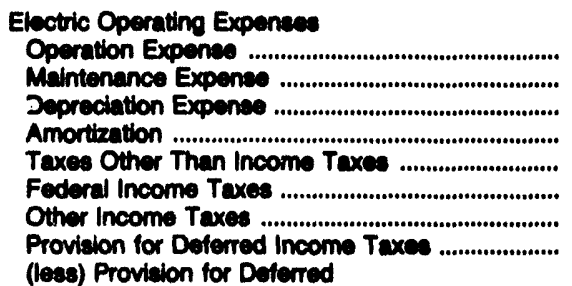 & $\begin{array}{r}246,319 \\
40,869 \\
64,625 \\
3,344 \\
12,074 \\
10,007 \\
5,890 \\
26,604\end{array}$ & $\begin{array}{r}144,602 \\
4,207 \\
5,000 \\
0 \\
2,025 \\
-607 \\
-174 \\
713\end{array}$ & $\begin{array}{r}176,117 \\
28,207 \\
34,468 \\
355 \\
25,466 \\
8,008 \\
1,290 \\
15,231\end{array}$ & $\begin{array}{r}842,899 \\
92,383 \\
132,288 \\
34,425 \\
49,607 \\
38,128 \\
6,794 \\
188,128\end{array}$ & $\begin{array}{r}275,738 \\
13,013 \\
13,776 \\
3,952 \\
22,511 \\
17,343 \\
-149 \\
18,287\end{array}$ & $\begin{array}{r}439,781 \\
42,191 \\
73,537 \\
-1,297 \\
40,710 \\
30,372 \\
1,897 \\
17,667\end{array}$ \\
\hline 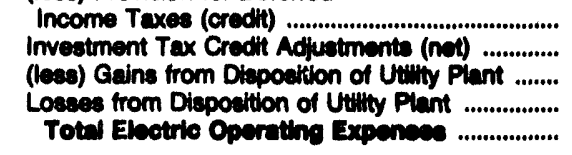 & $\begin{array}{r}6,807 \\
-4,447 \\
0 \\
0 \\
407,220\end{array}$ & $\begin{array}{r}201 \\
-213 \\
0 \\
0 \\
168,603\end{array}$ & $\begin{array}{r}4,344 \\
-1,830 \\
0 \\
0 \\
291,011\end{array}$ & $\begin{array}{r}141,213 \\
-851 \\
0 \\
0 \\
1,296,486\end{array}$ & $\begin{array}{r}19,449 \\
-60 \\
-65 \\
0 \\
346,027\end{array}$ & $\begin{array}{r}7,409 \\
-6,864 \\
0 \\
0 \\
630,645\end{array}$ \\
\hline Not Electric Utility Opernting Incoms ............ & 114,972 & 4,167 & 70,602 & 910,240 & 47,184 & 147,793 \\
\hline $\begin{array}{l}\text { Gas Utility Operating Income } \\
\text { Gas Operating Revenues }\end{array}$ & 178,528 & 62,604 & 0 & 0 & 73,062 & 0 \\
\hline 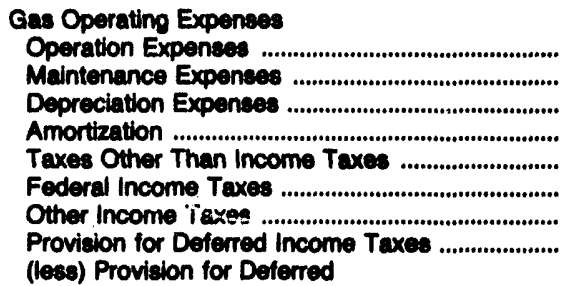 & $\begin{array}{r}144,680 \\
6,072 \\
7,800 \\
1,130 \\
3,760 \\
1,600 \\
515 \\
3,120\end{array}$ & $\begin{array}{r}49,610 \\
2,281 \\
3,159 \\
158 \\
1,601 \\
-387 \\
-\infty 0 \\
-141\end{array}$ & $\begin{array}{l}0 \\
0 \\
0 \\
0 \\
0 \\
0 \\
0 \\
0\end{array}$ & $\begin{array}{l}0 \\
0 \\
0 \\
0 \\
0 \\
0 \\
0 \\
0\end{array}$ & $\begin{array}{r}61,242 \\
4,026 \\
2,843 \\
-1,300 \\
4,977 \\
-2,276 \\
-26 \\
11,102\end{array}$ & $\begin{array}{l}0 \\
0 \\
0 \\
0 \\
0 \\
0 \\
0 \\
0\end{array}$ \\
\hline 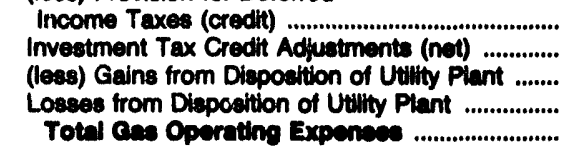 & $\begin{array}{r}1,274 \\
-309 \\
0 \\
0 \\
107,000\end{array}$ & $\begin{array}{r}-1,441 \\
-77 \\
0 \\
0 \\
57,484\end{array}$ & $\begin{array}{l}0 \\
0 \\
0 \\
0 \\
0\end{array}$ & $\begin{array}{l}0 \\
0 \\
0 \\
0 \\
0\end{array}$ & $\begin{array}{r}10,281 \\
-111 \\
0 \\
0 \\
70,197\end{array}$ & $\begin{array}{l}0 \\
0 \\
0 \\
0 \\
0\end{array}$ \\
\hline Not Ces Utilty Operating Income ..................... & 11,467 & 8,160 & $\mathbf{0}$ & 0 & 2,065 & 0 \\
\hline $\begin{array}{l}\text { Other Utility Operating Income } \\
\text { Other Utility Operating Revenues ............................ }\end{array}$ & 0 & 0 & 0 & 0 & 0 & 0 \\
\hline 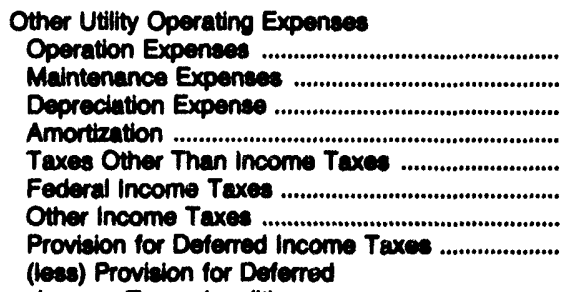 & $\begin{array}{l}0 \\
0 \\
0 \\
0 \\
0 \\
0 \\
0 \\
0\end{array}$ & $\begin{array}{l}0 \\
0 \\
0 \\
0 \\
0 \\
0 \\
0 \\
0\end{array}$ & $\begin{array}{l}0 \\
0 \\
0 \\
0 \\
0 \\
0 \\
0 \\
0\end{array}$ & $\begin{array}{l}0 \\
0 \\
0 \\
0 \\
0 \\
0 \\
0 \\
0\end{array}$ & $\begin{array}{l}0 \\
0 \\
0 \\
0 \\
0 \\
0 \\
0 \\
0\end{array}$ & $\begin{array}{r}0 \\
0 \\
135 \\
0 \\
0 \\
0 \\
0 \\
0\end{array}$ \\
\hline 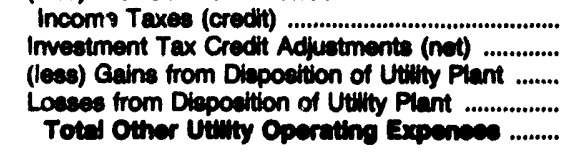 & $\begin{array}{l}0 \\
0 \\
0 \\
0 \\
0\end{array}$ & $\begin{array}{l}0 \\
0 \\
0 \\
0 \\
0\end{array}$ & $\begin{array}{l}0 \\
0 \\
0 \\
0 \\
0\end{array}$ & $\begin{array}{l}0 \\
0 \\
0 \\
0 \\
0\end{array}$ & $\begin{array}{l}0 \\
0 \\
0 \\
0 \\
0\end{array}$ & $\begin{array}{r}0 \\
0 \\
0 \\
0 \\
135\end{array}$ \\
\hline Net Other Utilty Operating Inoems ................. & 0 & 0 & 0 & 0 & 0 & -185 \\
\hline
\end{tabular}

See endnotes at end of an individual electric cutiumy. 
Table 37. Statement of Income and Rotained Earninge by Major U.8. Inveotor-Owned Electric

Utility Within State, 1902 (Continued)

(Thousand Dollars)

\begin{tabular}{|c|c|c|c|c|c|c|}
\hline them & $\begin{array}{l}\text { Kentucky } \\
\text { Loulovilis } \\
\text { Case } \\
\text { Encotite Co }\end{array}$ & $\begin{array}{l}\text { Kentucky } \\
\text { Union Light } \\
\text { Heat \& Power } \\
\text { Co }\end{array}$ & 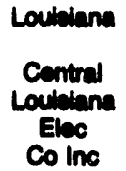 & $\begin{array}{l}\text { Loulwiana } \\
\text { Loulatian } \\
\text { Power } \\
\text { Lont Co }\end{array}$ & $\begin{array}{l}\text { Louleiana } \\
\text { Now Orleans } \\
\text { Publlc } \\
\text { Servios Inc }\end{array}$ & $\begin{array}{l}\text { Louldiana } \\
\text { Southweatern } \\
\text { Electrle } \\
\text { Power Co }\end{array}$ \\
\hline
\end{tabular}

Total Utilly Operating Income

Total Utilty Operating Rovenuse

Utility Operating Expenses

Operntion Expensen

Meintenence Expentece

Depreciation Expence

Amortintion

Federd Income Texes

Other Income Texes

(eas) Provision for Doterred

Income Taxes (credit)

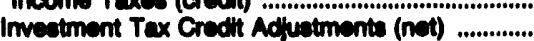

(leas) Calns from Dispoetiton of Utillty Plant ......

Loeses from Diepostion of Uthlty Plant

Totel Uimly Operating Expences

Net Uinty Operating Inoome

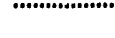

Other Income and Deductions

Other income

Nonutllty Operating Income .....................................

Equity in Earninges of Subuidiary Companies ......

Intereat and Dividend Income

Allowance for Other Funds Used

During Conetruction

Miacellaneous Nonoperating Income

Gain on Diapoation of Property ...

Total Other income

Other Income Deductions

Loes on Diepo 'tion of Property

Miecellaneous Amortzation.

Miscellansous Income Deductions

Totel Other Incems Deduotions

Taxes on Other Income and Deductions

Taxes Other Than Income Taxes

Federel income Texes

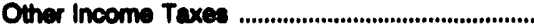

Provition for Deterred income Taxes

(lese) Provition for Doferred

Income Texes (credii) .

Imvertment Tax Credit Adtuetmen

(loas) Imvestment Tax Cred"ts .....

Total Taxes on Other income

and Doduotions

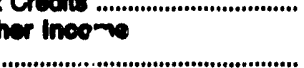

Net Other Ineoms and Dedustions
222,29

851,013

$1,668,746$

465,273

778,438
170,117

104,106

8,647

8,168

168

3,020

$-954$

$-204$

672

$-1,240$

$-200$

8,081

$-4,818$

74,

212,

124,90

0,007

2.,207

34,409

365

25,468

8,089

1,200

16,251

4,344

$-1,850$

(

a1,011

70,ere

842,000

02,388

132,288

34,426

49,807

33,128

0,794

$188,1 \%$

141,213

$-851$

$1,205,4$

s14as

388,880

17,039

18,619

2,062

27,487

15,087

$-175$

29,300

29,730

$-170$

$-65$

416,224

00,049

439,781

42,191

73,673

$-1,287$

40,710

30,372

1,697

17,667

7,400

$-6,884$

0
0

980,700

147,060

$-3,476$

1,080

-82
0

0
182

-18
0

1,097

182
0

6,820

-7
0

4,037

1,714

691

374

611

$-48$

in

60

2.20

77
0,702

118
0
-27

4,122

0
0
078

073

0
0
946
040

3,037

0

8,092

4,498
4,499

10

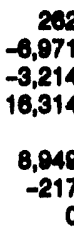

0
-607

-71
2

0
$-2,803$

$-655$

6,977

0
-488
0

3,063

0
1,608
175
0

0
-717

$-74$

82

$-720$

$-2,776$

17

$-2,000$

$-27$

$\mathbf{8 , 4 9 6}$

6,997

1,408

$-1,292$

Ses endnotes at end of an individual electric utimy. 
Table 37. Statement of Income and Rotalned Earnings by Major U.S. Investor-Owned Electric Utility Within State, 1992 (Continued) (Thousand Dollars)

\begin{tabular}{|c|c|c|c|c|c|c|}
\hline $1 \mathrm{tem}$ & $\begin{array}{c}\text { Kentucky } \\
\text { Loubeville } \\
\text { Gass } \\
8 \\
\text { Electric Co }\end{array}$ & $\begin{array}{l}\text { Kentucky } \\
\text { Union Light } \\
\text { Heat \& Power } \\
\text { Co }\end{array}$ & $\begin{array}{l}\text { Louldiana } \\
\text { Central } \\
\text { Loulaiana } \\
\text { Elec } \\
\text { Co Inc }\end{array}$ & $\begin{array}{c}\text { Louisiana } \\
\text { Louisiana } \\
\text { Power } \\
\text { Light Co }\end{array}$ & $\begin{array}{l}\text { Lovisiana } \\
\text { Now Orleans } \\
\text { Public } \\
\text { Service Inc }\end{array}$ & $\begin{array}{l}\text { Loulitana } \\
\text { Southwestern } \\
\text { Electric } \\
\text { Power Co }\end{array}$ \\
\hline
\end{tabular}

Intereat Changes

Intereat on Lono-term Debt

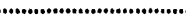

Amortization of Debt Discount and Expenses.....

Amortination of Loss on Peacquired Debt ..........

(beas) Amortization of Premium on Debt (credit)

(bas) Amortizhtion of Gein on

Resquired Debt (credit)

Interest on Debt to Aesociated Companies ........

Other Interest Expense

(leas) Allowance for Borromed Fund

Used During Conatruction (credt)

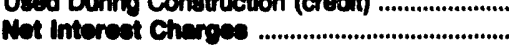

Incoms Bators Extracordinery item

Extreordinary liteme

Extreordinary income

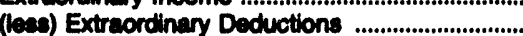

Not Extreordinary them

(leas) Federal and Other Income Taxes

Exturecrlinery thems Atter Toxes

Net insemo

\section{Unepproprtated Retained Eeminges}

Rotined Eeminge - Beginning of Year

61,818

134,201

117,220

106,341

204,220

Balance Tranoferred from Income

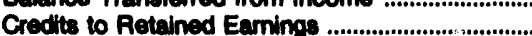

(leep) Deblts to Retained Eaming:

(leas) Appropriations of Rotnined Eamings ..........

(less) Dividendis Declared - Preferred Stock ...

(leas) Dividends Declared - Common Stock .......

Unappropriated Undistributed Subeldiary

Eamings

Roteined Eaminge - End of Year

........................

Appropriated Retained Earnings

Appropriated Retained Earnings -

Amortzation Reserve, Federal

Totel Rotined Eeminges

.......................................
181,694

48,748

432

30

8
0

0

40,099

79,708

73,793

2,147

0
7,173

67,500

0

174,687

0

0

170,697

\section{1,102}

0
0
0
0
0

46,16

3,148

30,526

0

62,915

148,775

0

46,019

92,918

192,704

182,889

3,28

0
28,416

174,600

26,424

$\mathbf{9 4 , 8 8 1}$

0
1
0

3,445

80,000

1,989

80,000
0

Source: Federal Energy Regulatory Commiacion, FERC Form 1, "Annual Report of Malor Electric Utilities, Licensees and Others." 
Table 37. Statement of Income and Rotained Earninge

by Major U.S. Inveotor-Owned Electrle

Utility Within State, 1992 (Continuod)

(Thousand Dollars)

\begin{tabular}{|c|c|c|c|c|c|c|}
\hline Item & $\begin{array}{l}\text { Maine } \\
\text { Bangor } \\
\text { Hydro- } \\
\text { Electric } \\
\text { Co }\end{array}$ & $\begin{array}{l}\text { Maine } \\
\text { Central } \\
\text { Maine } \\
\text { Power } \\
\text { Co }\end{array}$ & $\begin{array}{l}\text { Maine } \\
\text { Maine } \\
\text { Electric } \\
\text { Power } \\
\text { Co Inc }\end{array}$ & $\begin{array}{l}\text { Maine } \\
\text { Maine } \\
\text { Publlc } \\
\text { Service } \\
\text { Co }\end{array}$ & $\begin{array}{l}\text { Maine } \\
\text { Maine } \\
\text { Yankee } \\
\text { Atomic } \\
\text { Power Co }\end{array}$ & $\begin{array}{l}\text { Maryland } \\
\text { Baltimore } \\
\text { Gas } \\
\text { Electric Co }\end{array}$ \\
\hline $\begin{array}{l}\text { Electric Utillty Operating Income } \\
\text { Electric Operating Revenues ..................................... }\end{array}$ & 177,313 & 872,403 & 11,608 & 56,455 & 187,259 & $1,967,923$ \\
\hline 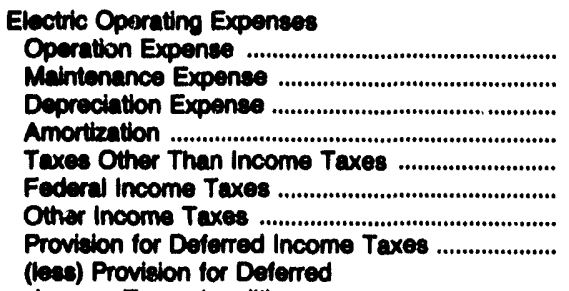 & $\begin{array}{r}136,928 \\
5,664 \\
4,112 \\
2,676 \\
3,897 \\
1,842 \\
1,417 \\
7,910\end{array}$ & $\begin{array}{r}633,178 \\
40,067 \\
38,249 \\
10,932 \\
24,487 \\
13,281 \\
3,887 \\
31,229\end{array}$ & $\begin{array}{r}9,167 \\
682 \\
1,143 \\
107 \\
220 \\
287 \\
82 \\
21\end{array}$ & $\begin{array}{r}38,118 \\
1,545 \\
1,843 \\
1,802 \\
1,420 \\
1,641 \\
502 \\
7,407\end{array}$ & $\begin{array}{r}102,606 \\
31,209 \\
23,993 \\
469 \\
11,289 \\
4,777 \\
1,571 \\
3,549\end{array}$ & $\begin{array}{r}1,018,272 \\
160,375 \\
184,090 \\
7,880 \\
155,522 \\
93,405 \\
285 \\
174,560\end{array}$ \\
\hline 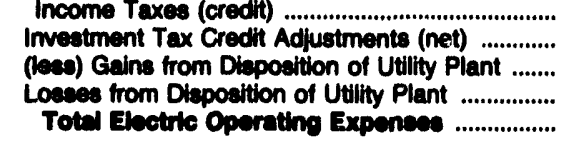 & $\begin{array}{r}6,240 \\
673 \\
0 \\
0 \\
158,670\end{array}$ & $\begin{array}{r}28,498 \\
-1,650 \\
-1 \\
0 \\
705,146\end{array}$ & $\begin{array}{r}304 \\
-40 \\
0 \\
0 \\
11,343\end{array}$ & $\begin{array}{r}6,167 \\
-77 \\
0 \\
0 \\
4,136\end{array}$ & $\begin{array}{r}8,483 \\
-538 \\
0 \\
0 \\
170,443\end{array}$ & $\begin{array}{r}169,109 \\
-7,699 \\
582 \\
0 \\
1,616,990\end{array}$ \\
\hline Net Electrle Utility Operating Income ............. & 18,434 & 107,265 & 205 & 8,310 & 16,016 & 360,923 \\
\hline 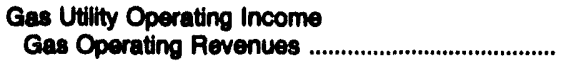 & 0 & 0 & 0 & 0 & 0 & 402,837 \\
\hline 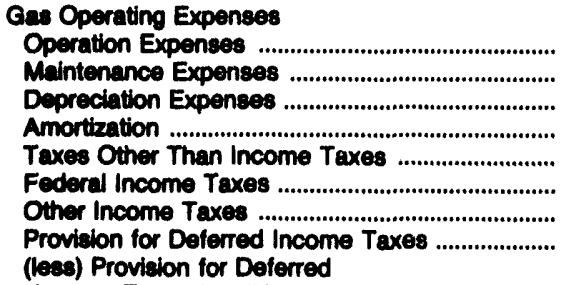 & $\begin{array}{l}0 \\
0 \\
0 \\
0 \\
0 \\
0 \\
0 \\
0\end{array}$ & $\begin{array}{l}0 \\
0 \\
0 \\
0 \\
0 \\
0 \\
0 \\
0\end{array}$ & $\begin{array}{l}0 \\
0 \\
0 \\
0 \\
0 \\
0 \\
0 \\
0\end{array}$ & $\begin{array}{l}0 \\
0 \\
0 \\
0 \\
0 \\
0 \\
0 \\
0\end{array}$ & $\begin{array}{l}0 \\
0 \\
0 \\
0 \\
0 \\
0 \\
0 \\
0\end{array}$ & $\begin{array}{r}297,873 \\
11,298 \\
20,320 \\
1,044 \\
26,848 \\
6,456 \\
6 \\
61,488\end{array}$ \\
\hline 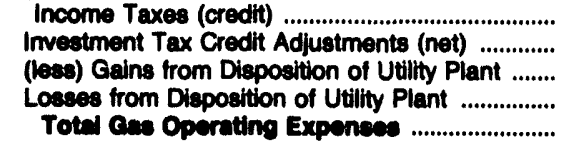 & $\begin{array}{l}0 \\
0 \\
0 \\
0 \\
0\end{array}$ & $\begin{array}{l}0 \\
0 \\
0 \\
0 \\
0\end{array}$ & $\begin{array}{l}0 \\
0 \\
0 \\
0 \\
0\end{array}$ & $\begin{array}{l}0 \\
0 \\
0 \\
0 \\
0\end{array}$ & $\begin{array}{l}0 \\
0 \\
0 \\
0 \\
0\end{array}$ & $\begin{array}{r}48,868 \\
-1,045 \\
0 \\
0 \\
365,424\end{array}$ \\
\hline Net Cas Utulty Operating Income ..................... & o & $\mathbf{0}$ & $\mathbf{0}$ & $\mathbf{0}$ & $\mathbf{0}$ & 37,513 \\
\hline $\begin{array}{l}\text { Other Utilty Operating Income } \\
\text { Other Utility Operating Revenues ........................... }\end{array}$ & 0 & 0 & 0 & 0 & 0 & 0 \\
\hline 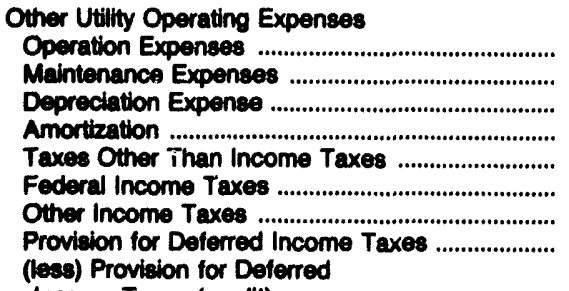 & $\begin{array}{l}0 \\
0 \\
0 \\
0 \\
0 \\
0 \\
0 \\
0\end{array}$ & $\begin{array}{l}0 \\
0 \\
0 \\
0 \\
0 \\
0 \\
0 \\
0\end{array}$ & $\begin{array}{l}0 \\
0 \\
0 \\
0 \\
0 \\
0 \\
0 \\
0\end{array}$ & $\begin{array}{l}0 \\
0 \\
0 \\
0 \\
0 \\
0 \\
0 \\
0\end{array}$ & $\begin{array}{l}0 \\
0 \\
0 \\
0 \\
0 \\
0 \\
0 \\
0\end{array}$ & $\begin{array}{l}0 \\
0 \\
0 \\
0 \\
0 \\
0 \\
0 \\
0\end{array}$ \\
\hline 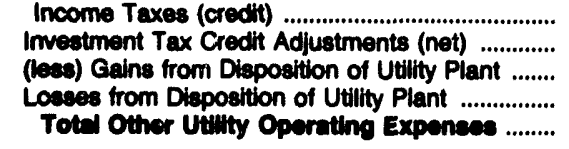 & $\begin{array}{l}0 \\
0 \\
0 \\
0 \\
0\end{array}$ & $\begin{array}{l}0 \\
0 \\
0 \\
0 \\
0\end{array}$ & $\begin{array}{l}0 \\
0 \\
0 \\
0 \\
0\end{array}$ & $\begin{array}{l}0 \\
0 \\
0 \\
0 \\
0\end{array}$ & $\begin{array}{l}0 \\
0 \\
0 \\
0 \\
0\end{array}$ & $\begin{array}{l}0 \\
0 \\
0 \\
0 \\
0\end{array}$ \\
\hline Net Other Ututhy Oporating Ineoms ................. & 0 & 0 & 0 & 0 & 0 & $\mathbf{0}$ \\
\hline
\end{tabular}

See endinotes at end of an irdividual electric utility. 
Table 37. Statement of Income and Rotained Earninge

by Major U.8. Inveotor-Owned Electric

Utility Within State, 1902 (Continued)

(Thousand Dollars)

\begin{tabular}{|c|c|c|c|c|c|c|}
\hline Item & $\begin{array}{c}\text { Mano } \\
\text { Bancor } \\
\text { Hydro- } \\
\text { Electilo } \\
\text { Co }\end{array}$ & $\begin{array}{l}\text { Mans } \\
\text { Central } \\
\text { Main } \\
\text { Pown } \\
\text { Co }\end{array}$ & $\begin{array}{l}\text { Maine } \\
\text { Maino } \\
\text { Eleotrio } \\
\text { Powrer } \\
\text { Co Ino }\end{array}$ & $\begin{array}{l}\text { Maino } \\
\text { Maine } \\
\text { Public } \\
\text { Service } \\
\text { Co }\end{array}$ & $\begin{array}{l}\text { Maine } \\
\text { Maine } \\
\text { Yankee } \\
\text { Atomic } \\
\text { Power Co }\end{array}$ & $\begin{array}{c}\text { Maryland } \\
\text { Baltimore } \\
\text { Gas } \\
\text { Electric Co }\end{array}$ \\
\hline
\end{tabular}

Total Utilly Operating Incoms

Total Utity Operating Rovenuse

Uitity Operating Expenses

Operation Expenses .

Depredith

Amortiention

men Income Toxes

Federal Income Texes

Other Incoms Texes ....................................................

Provialon for Deterred Incoms Taxes ......................

(ivo) Provition for Deterred

incoms Texes (credit)

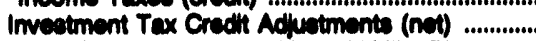

(tea) Calne from Dispoction of Utilty Plant ........

Losese from Diepoetion of Utility Plant

Totel vitily Operting Expences

177,313

872,405

11,609

$\mathbf{8 0 , 4 6 5}$

187,269

$2,370,880$

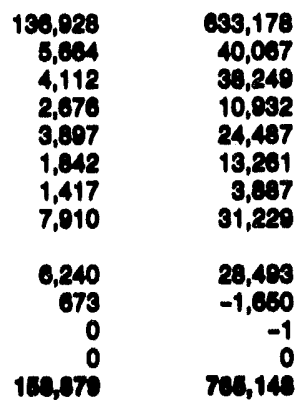

0,187

892

1,149

107

220

207

82
21

204

$-10$

704,14

1044

$107,2 x$

Ast Uunty Operating Insems

$$
\begin{array}{r}
38,118 \\
1,645 \\
1,043 \\
1,802 \\
1,420 \\
1,041 \\
602 \\
7,407 \\
6,187 \\
-77 \\
0 \\
0 \\
4,185
\end{array}
$$

11,249

$$
\begin{array}{r}
102,608 \\
31,200 \\
-1,803 \\
409 \\
11,289 \\
4,777 \\
1,571 \\
3,649 \\
8,483 \\
-638
\end{array}
$$

$1,318,146$

171,674

204,410

8,924

182,370

00,831

291

228,048

217,975

$-8,744$

882
0

770.49

$1,002,494$

0,310

10,010

99,49

29

Other Income and Deduction

Other Inoome

Nonutilty Operating Incoms ......................................

Equity in Eamings of Subalditary Companies .......

Interest and Dividend Income

Alowance for Other Funds Ueed

During Construction ...................................................

Mtecellinnous Nonoperating Incoms

Cuin on Disposition of Property

Totel Other Ineome

$\begin{array}{rr}0 & 8 \\ 1,344 & 6,770 \\ 697 & 727 \\ 1,205 & 1,080 \\ -494 & 1,600 \\ 0 & 70 \\ 2,49 & 10,700\end{array}$

Other Income Deductions

Lose on Dispostion of Property

Miscollaneous Amortzation .........

Miscellaneous Incoms Deductions

Tetel Ocher Inesme Deductions.

Taxes on Othe Income and Deduction:

Taxes Other Than incoms Texes

Foderal Incoms Taxes

Proviton for Det.................................................

(iov) Provition for Doferred

Incoms Taxes (ored'it).

Invertment Tox Creclt Adluntmente (net)

(bee) Imvetmont Tax Credits

Totid Taxes on Other ineome

and Deduotion

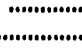

Net Other Inooms and Deduotions

0
1
250

28
8
310

281

29

1,005

$-7,288$

$\begin{array}{rr}0 & 19,862 \\ 5,880 & 13,712\end{array}$

65
-4
0

10,028

3,505

388

1,49

40,202

8,089

0
11
151
102

0
0
516

0
0
3,012

8,012

see endinotes at end of an Individual eleotrib vatility.

121

$-411$

$-132$

$-224$

0

29

2,20
0
-188
-60
0

348

308

128

131

52

75

0

321

$-240$

ตง

8,070

35,404 
Table 37. Statement of Income and Rotained Earninge

by Major U.S. Investor-Owned Electric

Utility Within State, 1992 (Continued)

(Thousand Dollars)

\begin{tabular}{|c|c|c|c|c|c|c|}
\hline Item & $\begin{array}{l}\text { Malno } \\
\text { Bangor } \\
\text { Hydro. } \\
\text { Electric } \\
\text { Co }\end{array}$ & $\begin{array}{l}\text { Maine } \\
\text { Centrel } \\
\text { Maine } \\
\text { Power } \\
\text { Co }\end{array}$ & $\begin{array}{l}\text { Maine } \\
\text { Maine } \\
\text { Eleotrle } \\
\text { Power } \\
\text { Co inc }\end{array}$ & $\begin{array}{l}\text { Mains } \\
\text { Malno } \\
\text { Publlic } \\
\text { Senvico } \\
\text { Co }\end{array}$ & $\begin{array}{l}\text { Maine } \\
\text { Maine } \\
\text { Yankee } \\
\text { Atomic } \\
\text { Power Co }\end{array}$ & $\begin{array}{c}\text { Maryland } \\
\text { Baltimore } \\
\text { Gas } \\
\& \\
\text { Electric Co }\end{array}$ \\
\hline
\end{tabular}

Intereat Charges

Intereat on Lona-term Debt

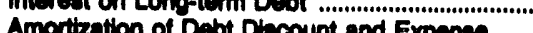

Amortization of Loss on Reacquired Debt ............

(lese) Amortzation of Premium on Debt (credili)

(lens) Amortization of Gain on

P.enquired Debt (credit)

Other Interest to Associated Companies ........

Other Intereet Expense

(lees) Allowance for Borrowed Funds

Ueed During Conatruction (credit)

Net Intereet Charges

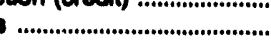

Incoms Eofore Extreordinary ltems

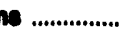

Extraordinary ltems

Extracotinary Income.

(lese) Extracordinary Deductions

Net Extreordinary litems.

$\begin{array}{rr}9,018 & 43,000 \\ 182 & 611 \\ 0 & 1,580 \\ 0 & 0 \\ 0 & 0 \\ 0 & 44 \\ 1,781 & 8,840 \\ 1,084 & 1,131 \\ 10,475 & 08921\end{array}$

288
11
1
0

4,025

458
0

13,852

134

158,017

611

0

0

1,121

, 37

69

4

1,131

$10,2.5$

cens

0

0
88

131

572

169

7,309

10

33

281

13,313

8,612

150,553

4,eas

9,173

294,347

(leas) Federal and Other Income Taxes

Extrasordinery liems After Taxes

Not Incoms

10,258

9.,855

284,347

Unepproprlated Rotalnod Eeminoe

Rotelned Eeminge - Beginning of Year

18,120

0,780

0

20,005

145

$1,045,848$

Balence Transferred from Income

Credits to Retained Earnings

$\begin{array}{rr}8,911 & 58,816 \\ 0 & 0\end{array}$

0
617

$1,20 i$

6,808

(lese) Appropriations of Retained Earnings

(leses) Dividends Declared - Preferred Stock ....

(lese) Dividends Declared - Common Stock ........

Uneppropriated Undiatributed Subeidtary

Eamings

7,122

47,89 ?

1,051

$\mathbf{6 , 6 8 7}$

5,103

0
0
0
0
2,922

9,173

244,484

105
0

0

105

0

$\begin{array}{rr}0 & 60 \\ 0 & 1,868\end{array}$

779

8,425

42,246

196,601

4,340

Roteined Emminos - End of Year

10,285

es,4as

31,170

114

$1,054,116$

Appropriated Rotained Earnings

Appropriated Retained Earnings -

Amortzation Reserve, Federel

$\begin{array}{rr}0 & 0 \\ 585 & 4,894\end{array}$

0

0

0
0

0

0

o

Totwl Retelned Eemines

19,910

101,950

0

81,170

114

$1,054,116$

Note: Totals may not equal sum of components because of independent rounding. Summary data ere provided in Table 6.

Source: Federal Energy Regulatory Commission, FERC Form 1, "Annual Report of Major Electric Uthlibes, Lloensees and Others." 
Table 37. Statement of Income and Retalned Earnings by Major U.S. Investor-Owned Electric Utility Within State, 1992 (Continued) (Thousand Dollars)

\begin{tabular}{|c|c|c|c|c|c|c|}
\hline Item & $\begin{array}{l}\text { Maryland } \\
\text { Potomac } \\
\text { Edison Co }\end{array}$ & $\begin{array}{l}\text { Maseachusetts } \\
\text { Boston } \\
\text { Edison Co }\end{array}$ & $\begin{array}{l}\text { Maseachusetts } \\
\text { Cambridge } \\
\text { Electric } \\
\text { Light Co }\end{array}$ & $\begin{array}{l}\text { Maseachusetts } \\
\text { Canal } \\
\text { Electic Co }\end{array}$ & $\begin{array}{l}\text { Maseachusetts } \\
\text { Commonwealth } \\
\text { Electric Co }\end{array}$ & $\begin{array}{l}\text { Massachusetts } \\
\text { Eastern } \\
\text { Edison Co }\end{array}$ \\
\hline $\begin{array}{l}\text { Electric Utility Operating Income } \\
\text { Electric Operating Revenues }\end{array}$ & 687,886 & $1,406,560$ & 112,948 & 221,685 & 409,483 & 263,014 \\
\hline 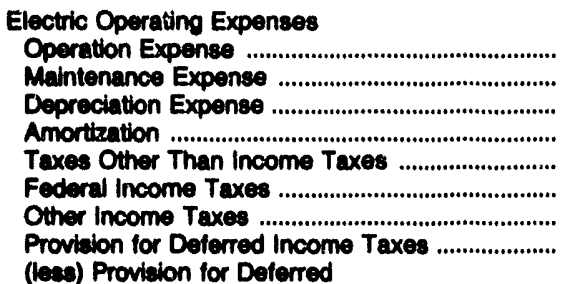 & $\begin{array}{r}414,939 \\
53,141 \\
53,446 \\
1 \\
45,791 \\
24,857 \\
-2,803 \\
31,089\end{array}$ & $\begin{array}{r}859,119 \\
86,007 \\
121,897 \\
30,589 \\
79,715 \\
-1,786 \\
618 \\
15,745\end{array}$ & $\begin{array}{r}89,838 \\
2,910 \\
3,601 \\
47 \\
3,081 \\
-1,676 \\
-137 \\
2,436\end{array}$ & $\begin{array}{r}161,815 \\
12,797 \\
15,019 \\
3,423 \\
4,078 \\
7,692 \\
1,138 \\
10,807\end{array}$ & $\begin{array}{r}347,031 \\
12,143 \\
15,012 \\
423 \\
7,740 \\
-65 \\
-45 \\
10,214\end{array}$ & $\begin{array}{r}219,871 \\
4,459 \\
8,275 \\
1 \\
3,272 \\
472 \\
817 \\
4,365\end{array}$ \\
\hline 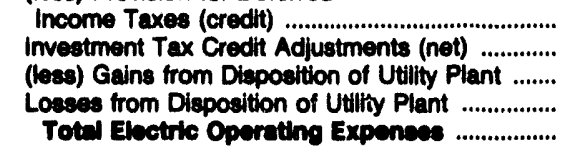 & $\begin{array}{r}22,278 \\
-2,442 \\
0 \\
0 \\
595,798\end{array}$ & $\begin{array}{r}-693 \\
-4,273 \\
0 \\
0 \\
1,192,324\end{array}$ & $\begin{array}{r}1,275 \\
-86 \\
0 \\
0 \\
109,700\end{array}$ & $\begin{array}{r}7,391 \\
-744 \\
0 \\
0 \\
199,684\end{array}$ & $\begin{array}{r}6,126 \\
-452 \\
0 \\
0 \\
398,876\end{array}$ & $\begin{array}{r}621 \\
-1,008 \\
0 \\
0 \\
289,602\end{array}$ \\
\hline Not Electric Utilly Operating Incoms ............ & 92,140 & 218,283 & 4,280 & 23,132 & 23,616 & 13,112 \\
\hline $\begin{array}{l}\text { Gas Utlity Operating Income } \\
\text { Gas Operating Revenues }\end{array}$ & 0 & 0 & 0 & 0 & 0 & $\mathbf{0}$ \\
\hline 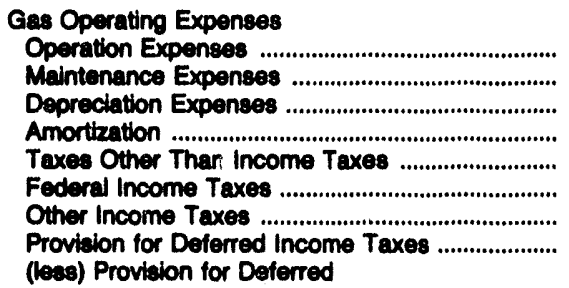 & $\begin{array}{l}0 \\
0 \\
0 \\
0 \\
0 \\
0 \\
0 \\
0\end{array}$ & $\begin{array}{l}0 \\
0 \\
0 \\
0 \\
0 \\
0 \\
0 \\
0\end{array}$ & $\begin{array}{l}0 \\
0 \\
0 \\
0 \\
0 \\
0 \\
0 \\
0\end{array}$ & $\begin{array}{l}0 \\
0 \\
0 \\
0 \\
0 \\
0 \\
0 \\
0\end{array}$ & $\begin{array}{l}0 \\
0 \\
0 \\
0 \\
0 \\
0 \\
0 \\
0\end{array}$ & $\begin{array}{l}0 \\
0 \\
0 \\
0 \\
0 \\
0 \\
0 \\
0\end{array}$ \\
\hline $\begin{array}{l}\text { Income Taxes (credit) ....................................... } \\
\text { Imvestment Tax Credit Adjustments (net) ........... } \\
\text { (leas) Gains from Disposition of Utility Plant ........ } \\
\text { Losees from Disposition of Utility Plant ............... } \\
\text { Total Cas Operating Expenses ....................... }\end{array}$ & $\begin{array}{l}0 \\
0 \\
0 \\
0 \\
0\end{array}$ & $\begin{array}{l}0 \\
0 \\
0 \\
0 \\
0\end{array}$ & $\begin{array}{l}0 \\
0 \\
0 \\
0 \\
0\end{array}$ & $\begin{array}{l}0 \\
0 \\
0 \\
0 \\
0\end{array}$ & $\begin{array}{l}0 \\
0 \\
0 \\
0 \\
0\end{array}$ & $\begin{array}{l}\mathbf{0} \\
\mathbf{0} \\
\mathbf{0} \\
\mathbf{0} \\
\mathbf{0}\end{array}$ \\
\hline Not Cas Utilty Operating Incoms .................... & $\mathbf{0}$ & $\mathbf{0}$ & 0 & $\mathbf{0}$ & $\mathbf{0}$ & $\mathbf{0}$ \\
\hline $\begin{array}{l}\text { Other Utility Operating Income } \\
\text { Other Utility Operating Revenues ............................ }\end{array}$ & 0 & 0 & 0 & 0 & 0 & $\mathbf{0}$ \\
\hline 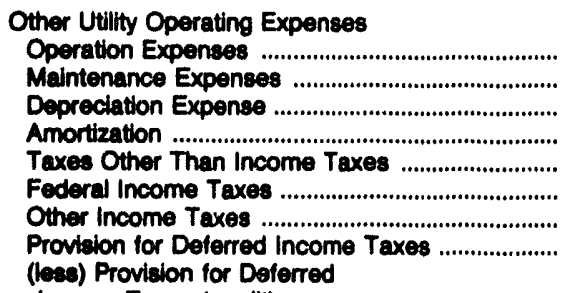 & $\begin{array}{l}0 \\
0 \\
0 \\
0 \\
0 \\
0 \\
0 \\
0\end{array}$ & $\begin{array}{l}0 \\
0 \\
0 \\
0 \\
0 \\
0 \\
0 \\
0\end{array}$ & $\begin{array}{l}0 \\
0 \\
0 \\
0 \\
0 \\
0 \\
0 \\
0\end{array}$ & $\begin{array}{l}0 \\
0 \\
0 \\
0 \\
0 \\
0 \\
0 \\
0\end{array}$ & $\begin{array}{l}0 \\
0 \\
0 \\
0 \\
0 \\
0 \\
0 \\
0\end{array}$ & $\begin{array}{l}0 \\
0 \\
0 \\
0 \\
0 \\
0 \\
0 \\
0\end{array}$ \\
\hline $\begin{array}{l}\text { Income Taxes (credit) .................................... } \\
\text { Imvestment Tax Credit Adjustments (net) ........... } \\
\text { (lese) Gains from Dieposition of Utillty Plant ....... } \\
\text { Loseses from Disposition of Utility Plant ............... } \\
\text { Totw Other Utilty Operating Expenses ........ }\end{array}$ & $\begin{array}{l}0 \\
0 \\
0 \\
0 \\
0\end{array}$ & $\begin{array}{l}0 \\
0 \\
0 \\
0 \\
0\end{array}$ & $\begin{array}{l}0 \\
0 \\
0 \\
0 \\
0\end{array}$ & $\begin{array}{l}0 \\
0 \\
0 \\
0 \\
0\end{array}$ & $\begin{array}{l}0 \\
0 \\
0 \\
0 \\
0\end{array}$ & $\begin{array}{l}0 \\
0 \\
0 \\
0 \\
0\end{array}$ \\
\hline Net Other Utity Operating Income ................ & $\mathbf{0}$ & $\mathbf{0}$ & $\mathbf{0}$ & $\mathbf{0}$ & $\mathbf{0}$ & $\mathbf{0}$ \\
\hline
\end{tabular}

See endnotes at end of an indlvidual electric utility. 
Table 37. Statement of Income and Rotained Earnings

by Major U.S. Investor-Owned Electric

Utility Within State, 1982 (Continuad)

(Thousand Dollars)

\begin{tabular}{|c|c|c|c|c|c|c|}
\hline Item & $\begin{array}{l}\text { Manyiand } \\
\text { Potomac } \\
\text { Edison Co }\end{array}$ & $\begin{array}{c}\text { Massachusetts } \\
\text { Boston } \\
\text { Edison Co }\end{array}$ & $\begin{array}{c}\text { Massachusetts } \\
\text { Cambridge } \\
\text { Electric } \\
\text { Ught Co }\end{array}$ & $\begin{array}{c}\text { Massachusetls } \\
\text { Canal } \\
\text { Electric Co }\end{array}$ & $\begin{array}{l}\text { Massachusetts } \\
\text { Commonwealth } \\
\text { Electric Co }\end{array}$ & $\begin{array}{c}\text { Massachusetts } \\
\text { Eastern } \\
\text { Edison Co }\end{array}$ \\
\hline
\end{tabular}

Total Utilty Operating Income

Total Utility Operating Revenues

$\begin{array}{rr}687,886 & 1,406,560 \\ & \\ 414,939 & 859,119 \\ 53,141 & 86,007 \\ 53,446 & 121,897 \\ 1 & 30,589 \\ 45,791 & 79,715 \\ 24,857 & -1,786 \\ -2,803 & 618 \\ 31,089 & 15,745 \\ 22,278 & \\ -2,442 & -693 \\ 0 & -4,273 \\ 0 & 0 \\ 505,730 & 0 \\ & 1,189,394\end{array}$

221,685

409,493

253,014

Utuity Operating Expences

Operation Expenees

Mulntenance Expenses

Derociation Expenes

Amortization

Taxes Other Than Incorne Taxe:

Federal income Taxes

Other Income Texee

Providion tor Deterred Income Taxe .....................

(Beas) Proviaion for Deferred

Income Texes (credit)

Invedtrnent Tax Credit Ad'uatments (net) .............

(bea) Gaine from Diapoeltion of Utilly Plant ........

Locees from Dieposition of Utility Plant

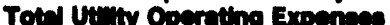

$1,183,324$

92,140

$$
\begin{array}{r}
2,910 \\
3,601 \\
47 \\
3,061 \\
-1,676 \\
-137 \\
2,436 \\
\\
1,275 \\
-96 \\
0 \\
0 \\
108
\end{array}
$$

99,838

Net Utiny Operating Income

$$
\begin{array}{r}
151,815 \\
12,797 \\
15,019 \\
3,423 \\
4,078 \\
7,592 \\
1,138 \\
10,807 \\
7,391 \\
-744 \\
0 \\
0 \\
190,534
\end{array}
$$

347,031

12,143

15,012

423

7,740

$-65$

$-45$

10,214

6,125

$-452$

219,871

4,459

1

3,272

472

817
4,365

621

$-1,008$

0
0

385,076

239,002

Other Income and Deductions

Other Income

Nonutitity Operating Income

Equity in Earninge of Subeldiary Companies ........

Intereed and Dividend Income

Allowance for Other Funds Used

During Construction

Mibcellaneous Nonoperating Income ......................

Gain on Dispoaltion of Property

Totel Other Income

$$
\begin{array}{r}
32 \\
-2,642 \\
11,970 \\
3,204 \\
707 \\
128
\end{array}
$$

13,400

Other Income Deductions

Loses on Dieposition of Property

Miacellaneous Amortzation

Miscellaneous income Deductions

Totel Other Income Deductions

reses on Other Income and Deductions

Texes Other Than Income Texes

Federal Income Tex

Other Income Taxes

Proviton for Deferred

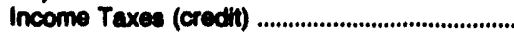

Investment Tax Credit Adjustments (net)

(leas) Imestment Tex Credits

Totw Taxes on Other Income

and Deductione.

Met Other Income and Deductione
218,236

4,230

17
4,722

4,722
559

474

1,322

$-1,287$

0
2
0

531

23,132

23,616

13,112

620
1,803

27,249

21,839

1,827

562
0

4,812

73
9

49,171

$\begin{array}{rr}0 & 0 \\ 0 & 0 \\ 301 & 9,540\end{array}$

0
0
284

0
0
$-1,208$

0
0
9,756

543

853

1,498

50

1,509

168

568

1742

0
0

861

$-105$

0
44
9

613

$-410$

-84
0

79

0

687

5,433

225

40,172

See endinoles at end of an individual electric utility. 
Table 37. Statoment of Income and Rotalned Earninge

by Major U.8. Inveotor-Owned Eloctric

Utility Within 8tate, 1092 (Continued)

(Thousand Dollars)

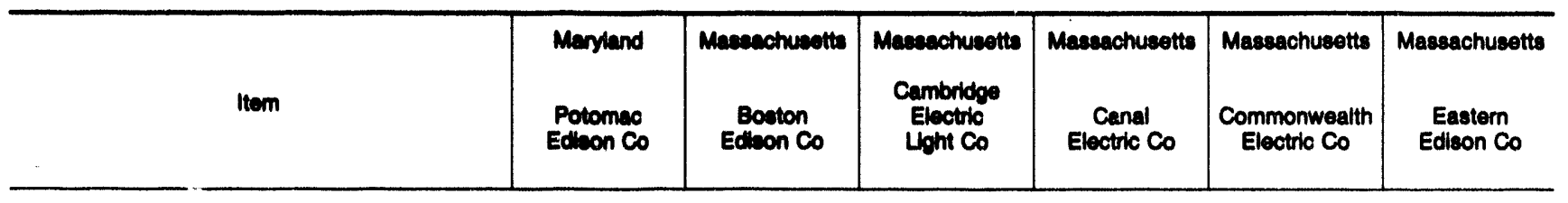

Interest Charges

Interest on Lono-term Debt ................................... Amortzation of Debt Dlecount and Expenas ......

Amortzation of Loses on Reacquired Debt ............

(leas) Amortization of Premium on Debt (credit).

(lese) Amortization of Gain on

Reaquired Debt (credit) ...............................

Interest on Debt to Acsociated Companies ........

Other Interest Expense .................................................

(leas) Allowance for Borrowed Funds

Used During Construction (credit)

Net Interest Cherres ..............................................

Inoome Betore Extreerdinary Hems

-...............

Extraordinary Items

Extraordinary Income

(tess) Extraordinary Deductions

Net Extracodinery lismo

(bese) Federal and Other Income Taxes

Extracrdinery liems After Texes

Not Income

Unepropilated Rotelned Eaminge

Rotained Eeminge - Bepinring of Year

189.9

88,081

518

0

37

0

13
816

2,165

37,20

$07,4 \%$

102,244

838

970

60

0
0

12,525

6,621

100,04

107,207

3,49

37
21
2

0
70

472

21

4,000

4

9,263
142
0
1
0
310
1,482
1,977
9,218

10,807

88
0

0

659

3,689

302

14,037

19,347

9,004

0
0

07,470

107,297

181,020

2,401

61,370

14,000

2,686

Balance Transferred from Income

70,118

102,575

0
789
0

0
0
0

16,875

71,951

6,059
53,732

5,381

78
0
0
0
0
485
0

18,826
0
0
0
17,517
0
0

8,829

25,211

0

613
0

3,676

(less) Dividends Declared - Preterred Stock .......

Unappropriated Undlatributed Subaidiary

Earnings .

0

181,000

2,004

63,08s

14,685

4,071

0

o

o

0

0

39

0

0

2,004

63,089

14,685

4,071

Totel Rotalned Eemines

19892

181,080

Note: Totals may not equal sum of components because of independent rounding. Summary data are provided in Table 6.
Source: Federal Energy Regulatory Commiacion, FERC Form 1, "Annual Report of Malor Electric Utillties, Licensees and Others." 
Table 37. 8tatoment of Income and Rotalned Eamings

by Major U.8. Inveotor-Owned Electrio

Utility Within 8tate, 1092 (Continued)

(Thousand Dollars)

\begin{tabular}{|c|c|c|c|c|c|c|}
\hline itom & $\begin{array}{l}\text { Maseachuectis } \\
\text { Fitohburs } \\
\text { Ges a } \\
\text { Elec Lloht Co }\end{array}$ & 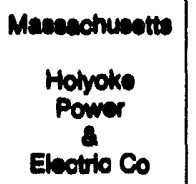 & $\begin{array}{l}\text { Masesechuestis } \\
\text { Hohyoke } \\
\text { Water } \\
\text { Power } \\
\text { Co }\end{array}$ & $\begin{array}{l}\text { Maseschuseotto } \\
\text { Mascacohusetts } \\
\text { Electrio Co }\end{array}$ & $\begin{array}{l}\text { Maseachusetts } \\
\text { Montaup } \\
\text { Electrlo Co }\end{array}$ & $\begin{array}{l}\text { Meseachueotts } \\
\text { New England } \\
\text { Hydro- } \\
\text { Tran } \\
\text { Eleo Co }\end{array}$ \\
\hline 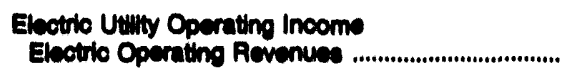 & 39,493 & 27,028 & 54,420 & $1,412,848$ & 356,080 & 44,670 \\
\hline 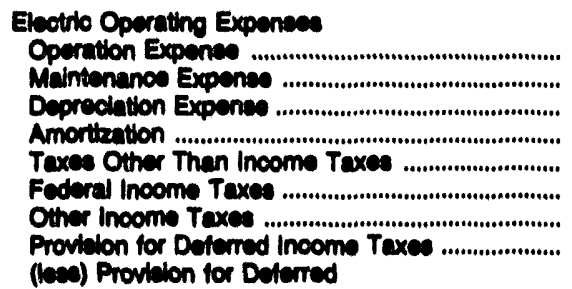 & $\begin{array}{r}26,860 \\
1,362 \\
1,734 \\
1,048 \\
1,184 \\
1,318 \\
287 \\
484\end{array}$ & $\begin{array}{r}27,280 \\
12 \\
46 \\
0 \\
30 \\
84 \\
17 \\
26\end{array}$ & $\begin{array}{r}44,798 \\
4,200 \\
1,763 \\
0 \\
1,681 \\
310 \\
-002 \\
1,275\end{array}$ & $\begin{array}{r}1,286,816 \\
34,160 \\
30,200 \\
0 \\
23,086 \\
4,301 \\
0 \\
26,388\end{array}$ & $\begin{array}{r}271,230 \\
8,005 \\
16,764 \\
1,002 \\
6,120 \\
7,704 \\
1,226 \\
6,706\end{array}$ & $\begin{array}{r}3,826 \\
722 \\
8,424 \\
32 \\
2,377 \\
1,820 \\
0 \\
4,804\end{array}$ \\
\hline 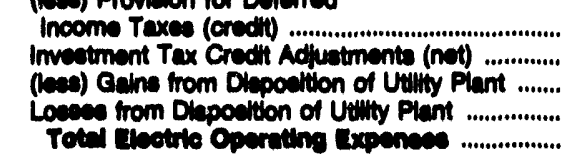 & $\begin{array}{r}98 \\
-72 \\
0 \\
0 \\
29,021\end{array}$ & $\begin{array}{r}240 \\
0 \\
0 \\
0 \\
27,295\end{array}$ & $\begin{array}{r}474 \\
-316 \\
0 \\
0 \\
82,161\end{array}$ & $\begin{array}{r}0,620 \\
-1,228 \\
0 \\
0 \\
1,242,297\end{array}$ & $\begin{array}{r}3,608 \\
-60 \\
0 \\
0 \\
216,097\end{array}$ & $\begin{array}{r}284 \\
689 \\
0 \\
0 \\
22,202\end{array}$ \\
\hline 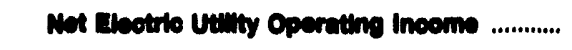 & 6,472 & -207 & 2,270 & 60,111 & 40,021 & $\mathbf{2 2 , 2 0 7}$ \\
\hline $\begin{array}{l}\text { Cas Utilty Operating Inooms } \\
\text { Gas Operating Revenues ...................................... }\end{array}$ & 10,281 & 0 & 0 & 0 & 0 & 0 \\
\hline 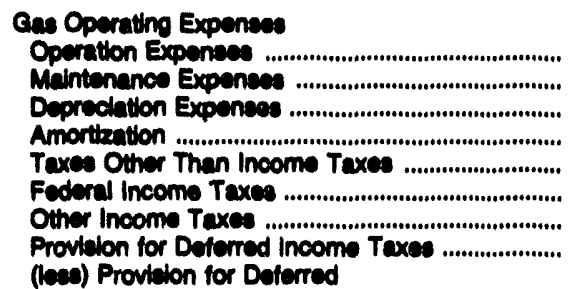 & $\begin{array}{r}14,818 \\
720 \\
640 \\
20 \\
380 \\
188 \\
102 \\
205\end{array}$ & $\begin{array}{l}0 \\
0 \\
0 \\
0 \\
0 \\
0 \\
0 \\
0\end{array}$ & $\begin{array}{l}0 \\
0 \\
0 \\
0 \\
0 \\
0 \\
0 \\
0\end{array}$ & $\begin{array}{l}0 \\
0 \\
0 \\
0 \\
0 \\
0 \\
0 \\
0\end{array}$ & $\begin{array}{l}0 \\
0 \\
0 \\
0 \\
0 \\
0 \\
0 \\
0\end{array}$ & $\begin{array}{l}0 \\
0 \\
0 \\
0 \\
0 \\
0 \\
0 \\
0\end{array}$ \\
\hline 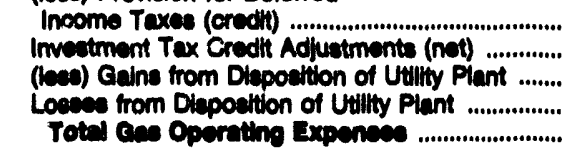 & $\begin{array}{r}20 \\
-35 \\
0 \\
0 \\
17,200\end{array}$ & $\begin{array}{l}0 \\
0 \\
0 \\
0 \\
0\end{array}$ & $\begin{array}{l}0 \\
0 \\
0 \\
0 \\
0\end{array}$ & $\begin{array}{l}0 \\
0 \\
0 \\
0 \\
0\end{array}$ & $\begin{array}{l}0 \\
0 \\
0 \\
0 \\
0\end{array}$ & $\begin{array}{l}0 \\
0 \\
0 \\
0 \\
0\end{array}$ \\
\hline Net ass Vitity Operating incoms .................... & 2,068 & 0 & 0 & $\mathbf{0}$ & 0 & 0 \\
\hline $\begin{array}{l}\text { Other Utitty Operating Income } \\
\text { Other Utifty Operatting Rovenues ........................... }\end{array}$ & 0 & $\mathbf{0}$ & 0 & 0 & 0 & \\
\hline 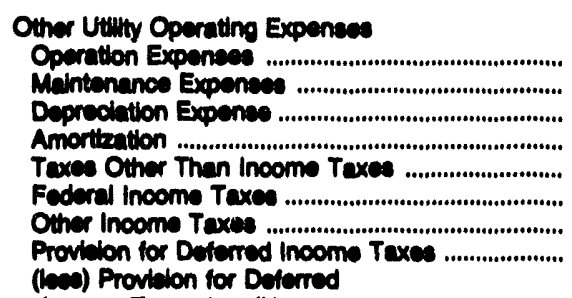 & $\begin{array}{l}0 \\
0 \\
0 \\
0 \\
0 \\
0 \\
0 \\
0\end{array}$ & $\begin{array}{l}0 \\
0 \\
0 \\
0 \\
0 \\
0 \\
0 \\
0\end{array}$ & $\begin{array}{l}0 \\
0 \\
0 \\
0 \\
0 \\
0 \\
0 \\
0\end{array}$ & $\begin{array}{l}0 \\
0 \\
0 \\
0 \\
0 \\
0 \\
0 \\
0\end{array}$ & $\begin{array}{l}0 \\
0 \\
0 \\
0 \\
0 \\
0 \\
0 \\
0\end{array}$ & $\begin{array}{l}0 \\
0 \\
0 \\
0 \\
0 \\
0 \\
0 \\
0\end{array}$ \\
\hline 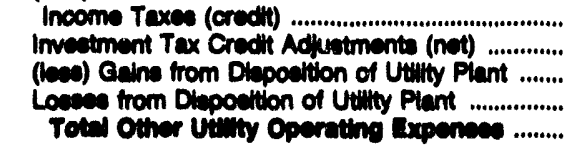 & $\begin{array}{l}0 \\
0 \\
0 \\
0 \\
0\end{array}$ & $\begin{array}{l}0 \\
0 \\
0 \\
0 \\
0\end{array}$ & $\begin{array}{l}0 \\
0 \\
0 \\
0 \\
0\end{array}$ & $\begin{array}{l}0 \\
0 \\
0 \\
0 \\
0\end{array}$ & $\begin{array}{l}0 \\
0 \\
0 \\
0 \\
0\end{array}$ & $\begin{array}{l}0 \\
0 \\
0 \\
0 \\
0\end{array}$ \\
\hline Net Other Usuty Opereting Ineoms ................ & $\mathbf{0}$ & $\mathbf{0}$ & $\mathbf{0}$ & $\mathbf{0}$ & $\mathbf{0}$ & 0 \\
\hline
\end{tabular}

8es endnotes at and of an individual electrio uthlly. 
Table 37. Statement of Income and Rotalned Earninga

by Major U.8. Inveator-Owned Eleotric

Utility Within 8tate, 1992 (Continued)

(Thousand Dollars)

\begin{tabular}{|c|c|c|c|c|c|c|}
\hline Hem & $\begin{array}{c}\text { Maraschusets } \\
\text { Fitohburg } \\
\text { Cas } \\
\text { Eno Wont Co }\end{array}$ & $\begin{array}{l}\text { Maseachusetts } \\
\text { Hohyoke } \\
\text { Power } \\
\text { Eleotric Co }\end{array}$ & $\begin{array}{l}\text { Masesechusetts } \\
\text { Hohyolke } \\
\text { Whiter } \\
\text { Power } \\
\text { Co }\end{array}$ & 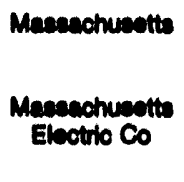 & $\begin{array}{l}\text { Mresenchuatts } \\
\text { Montaup } \\
\text { Eloctrio Co }\end{array}$ & $\begin{array}{l}\text { Maseanchusetts } \\
\text { Now England } \\
\text { Hydro- } \\
\text { Trun } \\
\text { Elec Co }\end{array}$ \\
\hline
\end{tabular}

Total Uitily Operating Income

Total Utily Operating Revenuses

68,784

27,020

54,420

$1,412,948$

358,059

44,679

Utithy Operating Expenses.

Operation Expentes....

Derreathtion Expe

40,675

2,081

2,380

Amortbation

Texes Other Than Income Taxes

Federal Income Taxea

Other Income Texes ......................................................

Provilon for Deferred Income Taxes .....................

(ves) Provision for Doferred

Incoms Texes (credit)

Imvestment Tax Credit Ad'ustments (nvt) .............

(leas) Geins from Diaposition of Utility Plant ........

Loseses from Dlaposition of Uitity Plant

Tot utinty Operating Expennes .....................

4,798

4,200

1,763

1,630

1,504

449

750

1,681

310

$-298$

1,276

118

$-108$

474

$-316$

62,181

$1,280,616$

34,163

30,200

271,230

8,905
16,754

15,764
1,062

20,95:

4,391

25,068

6,129

7,784

1,228
6,798

0,520

$-1,228$

3,699

$-69$

0

1,962,997

318,097

00,111

40,021

3,825

722

8,424
32

2,377

1,629

0
8.84

-.

s

0

Net Vinty Operating Incoms

0,528

$-207$

2,27

Other Income and Deductions

Other Income

Nonutility Operating Income ....................................

Equity in Earnings of Subsidiary Companies .......

Intereat and Dividerd Income...

Allowance for Othur Funds Used

During Conetruction

Miscellaneous Nonoperating Income

Gain on Disposition of Property

Totel Other inoom

Other income Deductions

Lose on Disposition of Property

Miscellaneous Amortization.

Mbcellaneous Income Deductions

Totel Other Income Deductions

$\begin{array}{rr}2 & 0 \\ 0 & 0 \\ 89 & 24 \\ 0 & 0 \\ 2 & 468 \\ 0 & 0 \\ 102 & 497\end{array}$

64
174
277
282
0
0
777

-913
0
2,820

0
1,953
010

-42
0

344

7,874

165

11,145

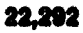

Texes on Other Income and Deductions

Taxes Other Than Income Taxes

Federal Income Taxes

Other Income Taxes

(lese) Provision for Deferred

Income Taxes (credit) .

Imvestment Tax Credt Adiustments (net)

(lese) Investment Tax Credits

Totel Taxee on Other Incoms

and Deductions

Net Other income and Deduetion

0
0
82
12

0
0
48

0
0
1,361

0
0
24
24

1,841

504

1,007

0
$n$
0
402

See endnotes at end of an individual electric utility.

12

0
-42
-9
0

171
-414
0

0
483

181
1,658

155

180
-75
0

1

702

$\begin{array}{rr}60 & 0 \\ 0 & 0 \\ 0 & 0\end{array}$

2,322

185

$-61$

103

80

8,790

27 
Table 37. Statemont of Income and Rotained Earnings

by Major U.S. Inveotor-Owned Electric

Utility Within 8tate, 1992 (Continued)

(Thousand Dollars)

\begin{tabular}{|c|c|c|c|c|c|c|}
\hline litem & $\begin{array}{l}\text { Maseachusetts } \\
\text { Fitchbure } \\
\text { Gas a } \\
\text { Elec Light Co }\end{array}$ & $\begin{array}{l}\text { Maseachuastis } \\
\text { Holyoke } \\
\text { Powror } \\
\text { Electric Co }\end{array}$ & $\begin{array}{l}\text { Mascasohusetts } \\
\text { Hohyoke } \\
\text { Water } \\
\text { Power } \\
\text { Co }\end{array}$ & $\begin{array}{l}\text { Maseachinsetts } \\
\text { Masasechureetts } \\
\text { Electric Co }\end{array}$ & $\begin{array}{l}\text { Maseachusetts } \\
\text { Montaup } \\
\text { Electrio Co }\end{array}$ & $\begin{array}{l}\text { Meseachusetts } \\
\text { Now England } \\
\text { Hydro } \\
\text { Tran } \\
\text { Elec Co }\end{array}$ \\
\hline
\end{tabular}

Interect Cherges

Interest on Lono-tem Debt

Der Dhoount and Expense......

of Lose on Reacequired Debt

(kev) Amortzation of Premium on Dabt (credit) .

(kev) Amortation of Gain on

Resquired Dobt (credit)

Intercet on Doby to Aseociated Companise

(feev) Allownce for Borrowed Fund

Uned During Conetruction (cred"i)

Net internet cherene

Ineoms Eofore Extreordinary tioms

(.....................

Extraordinery ltoms

Extreordinary Income

(kes) Extracordinary Deductions

Net Extreordinary titeme

(leas) Federal and Other Income Taxes

Extrcoritengy tiems After Taxes

Net inoome

Uneppropertated Rotained Eemines

Rotinined Ecminoe - Becinning of Yaar

Baiance Transierred from Income

Credth to Retained Eamings

(aes) Dobit to Petnined E

(leas) Appropriations of Retained Earnings ..........

(bee) Dividends Declared - Preferred Stock

(lese) Dividends Declared - Common Stock ........

Unepproprlated Undistributed Subeidiary

Eamings .

Rotuined Eeminge - End of Yoar

Approprlated Retained Earnings

Approprlated Retained Eamings

Amortization Reserve, Federa

Totel Roteloned Eeminges
3,389

60

0

0

44

808

0

4,311

4,220

0
0
0
0

1,284

32

0

0

21

138

167

174

1,622

21,588
140
228
24

0

2,740

214

26,963

34905

0
0
0

$\mathbf{0}$
$\mathbf{0}$
$\mathbf{0}$

0
0
0

$\begin{array}{ll}0 & 0 \\ 0 & 0\end{array}$

4,226

174

1,622

34,005

27,240

11,812

0,421

$-410$

10,402

121,893

9.029

23,004

$\begin{array}{rr}4,228 & 174 \\ 0 & 0 \\ 2 & 0 \\ 0 & 0 \\ 234 & 0 \\ 3,759 & 0 \\ 0 & 0\end{array}$

1,348
0
0
0
0
380
0

34,805
0
0
0
3,428
22,782
0

25,296

11,312

0

0

16,000

19,171

2,124

130,039

92,607

19,118

0.062

$-288$

11.40

4,637

0

0

11,400

194,670

92,097

19,110

Note: Totals may not equal sum of components because of independent rounding. Summary data are provided in Table 6.

Source: Federal Energy Regulatory Commiasion, FERC Form 1, "Annul Report of Major Electric Utilties, Liceneees and Oiriers." 


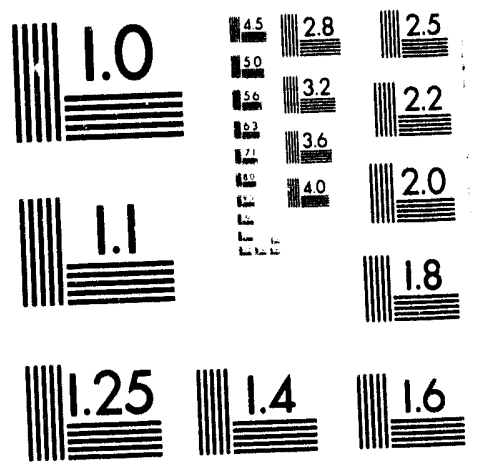



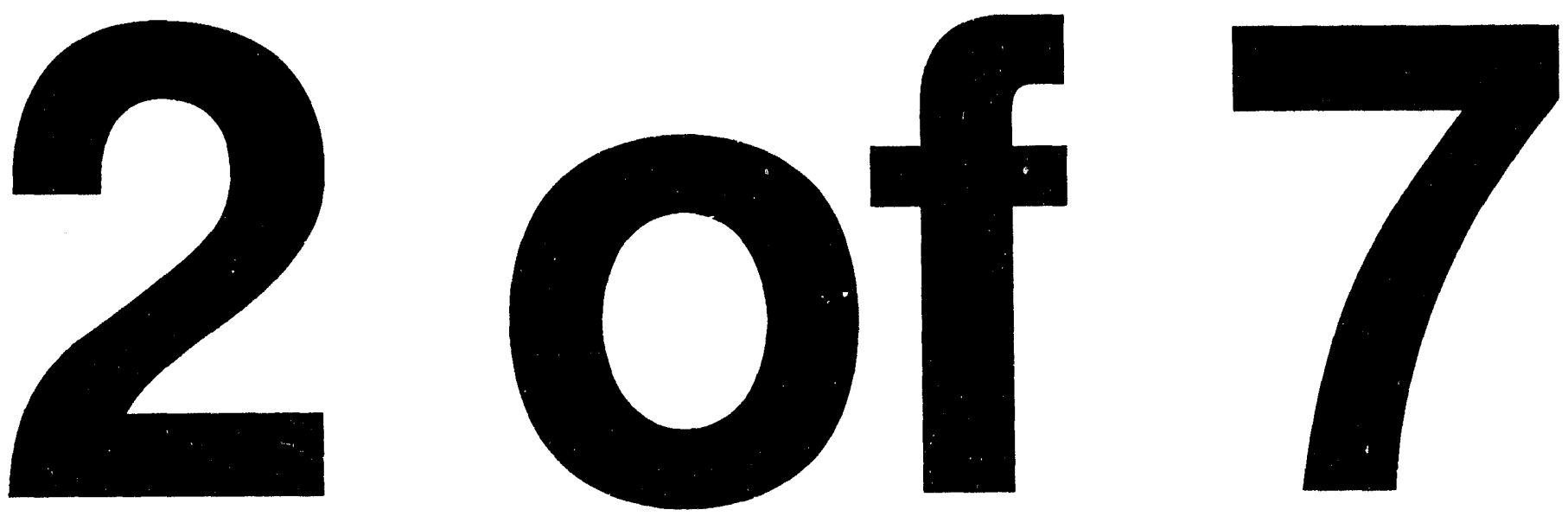
Table 37. Statement of Income and Retained Earnings

by Major U.S. Investor-Owned Electric

Utility Whthin State, 1992 (Continued)

(Thousand Dollars)

\begin{tabular}{|c|c|c|c|c|c|c|}
\hline Item & $\begin{array}{l}\text { Maseachusetts } \\
\text { New England } \\
\text { Power Co }\end{array}$ & $\begin{array}{l}\text { Maseachusetts } \\
\text { Weotem } \\
\text { Masaschusetts } \\
\text { Elec Co }\end{array}$ & $\begin{array}{l}\text { Michigan } \\
\text { Consumers } \\
\text { Power Co }\end{array}$ & $\begin{array}{l}\text { Michigan } \\
\text { Dotrot } \\
\text { Edison Co }\end{array}$ & $\begin{array}{l}\text { Mlohigan } \\
\text { Edison } \\
\text { Sault } \\
\text { Electric } \\
\text { Co }\end{array}$ & $\begin{array}{l}\text { Michigan } \\
\text { Upper } \\
\text { Peninsula } \\
\text { Power Co }\end{array}$ \\
\hline
\end{tabular}

Total Uinity Operating Income

Total Utithy Operating Revenuea

$1,530,875$

410,720

$2,884,121$

$3,553,632$

30,219

61,698

Uinity Operating Expenses
Operation Expenses .....

enance Expenses.

Depreciation Expenses

Amortbation

Taxes Other Than Income Taxes ............................

Federal Income Taxes

Other Income Taxes

Providon for Deferred Income Taxes ....................

(leses) Providion for Deferred

Income Taxes (credi)

Imveetment Tax Credth Adtuetmente (not)

(lese) Gains from Disposition of Utilty Plant .......

Losese from Dieposition of Utility Plant

Totel Utity Operation. Expences

Net Vunty Operating Inooms

Other Income and Deductions

Other Income

Nonutilly Operating Income ....................................

Equity in Eamings of Subaidiany Companies ......

Interest and Dividend Income

Allowance for Other Funds Used

During Construction

Miscellaneous Nonoperating Income ....................

Gain on Dieposition of Property

Totel Other Inoeme

Other Income Deductione

Loss on Dlapostion of Property

Miscellaneous Amortization

Miscellaneous Income Deductions

Totw Other Incem Deductione

958,356

114,210

57,646

86,867

61,889

63,080

52,250

45,284

$-1,328$

0
0

$1,347,700$

183,180

212,416

39,302

34,022

26,556

16,884

17,854

4,304

32,996

32,977

$-1,251$

0
0

350,207

$2,049,027$

197,345

281,482

34,251

177,450

55,862

$-465$

371,070

$\mathbf{3 8 8 , 9 8 0}$

$-6,787$

101

$2,772,277$

$1,370,491$

262,803

414717

$-7,628$

250,564

204,042

$228,72 \theta$

113,086

$-16,768$

0

$2,603,100$

00,619

211,244

850,632

20,217

2,082

2,043

1,646

738

598

487

$-72$

0

26,765

3,464

$-1,339$

6,252

6,092

35

2,170
462

553

$-5,287$
54,425

573

890

3,436

1,363

60,103

462

$\mathbf{6 0 , 8 2 7}$

0
15,853

504
5,774

0,046

4,688

61,676

$-29$

295

726

923
0
523,817

524,841

72
0
28,049
28,121

$\begin{array}{rr}2,388 & -554 \\ 791 & -25,667\end{array}$

42,603

35,421

218,263

1.677

?

7,623

$-172,481$

31,183

31

See endnotes at end of an inclividual electric utility. 
Table 37. Statement of income and Rotalned Earnings

by Major U.S. Investor-Owned Electric

Utility Within Stato, 1992 (Continued)

(Thousand Dollars)

\begin{tabular}{|c|c|c|c|c|c|c|}
\hline Mam & $\begin{array}{l}\text { Maseachusetto } \\
\text { Now Envland } \\
\text { Power Co }\end{array}$ & $\begin{array}{l}\text { Maserachusetts } \\
\text { Weatem } \\
\text { Maasachusetts } \\
\text { Elec Co }\end{array}$ & $\begin{array}{l}\text { Michigan } \\
\text { Conoumere } \\
\text { Power Co }\end{array}$ & $\begin{array}{l}\text { Michioan } \\
\text { Datrolt } \\
\text { Edibon Co }\end{array}$ & $\begin{array}{c}\text { Michioan } \\
\text { Edison } \\
\text { Sinut } \\
\text { Electric } \\
\text { Co }\end{array}$ & $\begin{array}{l}\text { Mictioan } \\
\text { Upper } \\
\text { Penineula } \\
\text { Power Co }\end{array}$ \\
\hline
\end{tabular}

Interest Chereses

Interest on Lono-tem Debt

Amortanton of Debt Dlact .......................................

Amortistion of Loes on Reacquired Debt ............

(kes) Amortation of Premium on Debt (oredit) (ina) Amortiontion of Cin on

Resquired Debt (credit) .........................................

Interect on Debt to Associated Companies .........

Other Intereat Expenas

(kes) Allowence for Borrowed Funds

Uend Duing Conaturution (credit)

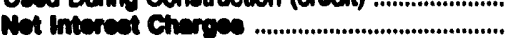

Incoms Eotor Extracerdinen theme

................

$\begin{array}{rr}57,343 & 30,855 \\ 685 & 240 \\ 1,423 & 623 \\ 40 & 22 \\ 0 & 3 \\ 1 & 535 \\ 2,089 & 958 \\ 1,689 & 1,023 \\ 80,013 & 32,163\end{array}$

\section{9,624}

1,365

$22 \quad 0$

3,411

0
630

530

12

0
0

5,165

618

184,028

1,386

398,93

37,022

$-249,700$

29,047

1,412

45
0
0

3,431

28

0

0

0
80

7

134,162

Extracondinary ltems

Extreordinary income.

(teas) Extraordinery Deductions

Not Extrecrinery thems

(bee) Federal and Other Income Taxes

Extreordinery theme After Toxes

Net income

37,022

89,047

3,450

Unepropotated Roteined Eemingo

Rotelned Eeminge - Decining of Year

274,724

4,821

$-117,328$

971,717

8,207

12,897

Balance Traneferred from income

Credits to Rotained Eeminos ....................................

(lece) Debits to Rotuined Earnings .........................

(lese) Appropriations of Rotained Eaminos .........

(kese) Dividiends Declared - Preterred Stock ......

(lese) Dividends Declared - Common Stock ......

Uneppropriated Undiatributed Subeidiary

Eaninge .......................................................................

Rotelned Eeminges - End of Yeer

127,899

34,85

$-238,479$

381,324

22,025

587,157

846

0
7,485

29,538

89,873

2,148

30,403

291,087

$\mathbf{5 , 9 3 2}$

asen

681

70

1,788

3,459

$-2$

0

38
554

3.654

802,001

es,ese

$-16,824$

$1,139,820$

6,07

12.29

Appropitated Retained Earinge

Appropitated Retuined Eamings -

Amortzation Reserve, Federal

0

0

11,011

880

4,813

0

0

1,840

0

$1,198,099$

Note: Totals my not equel sum of components because of independent rounding. Summary data are provided in Table 6.

Source: Federll Energy Reculatory Commiscion, FERC Form 1, "Annul Report of Major Electric Utilites, Licensees and Others." 
Table 37. Statement of Income and Rotalned Earninge by Major U.S. Inveotor-Owned Electrle Utility Whthin State, 1992 (Continued) (Thousand Dollars)

\begin{tabular}{|c|c|c|c|c|c|c|}
\hline Item & $\begin{array}{l}\text { Minnesota } \\
\text { Minneseta } \\
\text { Power } \\
\text { Ligit Co }\end{array}$ & $\begin{array}{l}\text { Minnecota } \\
\text { Northern } \\
\text { States } \\
\text { Power Co }\end{array}$ & $\begin{array}{c}\text { Minnsesota } \\
\text { Onter } \\
\text { Tall } \\
\text { Power } \\
\text { Co }\end{array}$ & $\begin{array}{l}\text { Macalacippl } \\
\text { Masaiasippl } \\
\text { Power } \\
\text { Loht Co }\end{array}$ & 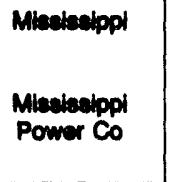 & $\begin{array}{l}\text { Miselacippl } \\
\text { Syatem } \\
\text { Eneroy } \\
\text { Resources } \\
\text { Inc }\end{array}$ \\
\hline $\begin{array}{l}\text { Electric Utilty Operating Income } \\
\text { Electric Operating Revenues .................................... }\end{array}$ & 398,391 & $1,716,245$ & 177,241 & 817,660 & $\mathbf{4 3 4 , 4 4 7}$ & 723,410 \\
\hline 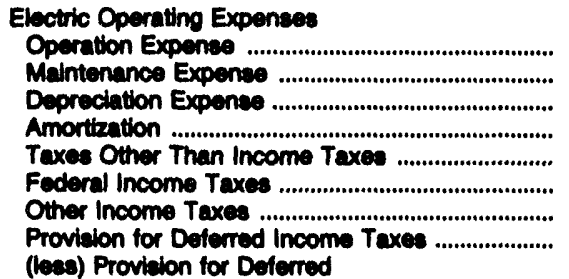 & $\begin{array}{r}231,312 \\
19,781 \\
29,810 \\
166 \\
33,740 \\
14,168 \\
3,806 \\
14,772\end{array}$ & $\begin{array}{r}946,380 \\
160,168 \\
102,024 \\
2,617 \\
173,187 \\
61,083 \\
14,087 \\
49,978\end{array}$ & $\begin{array}{r}80,092 \\
10,927 \\
18,961 \\
573 \\
10,034 \\
8,123 \\
1,936 \\
8,510\end{array}$ & $\begin{array}{r}568,811 \\
42,150 \\
31,133 \\
360 \\
40,738 \\
3,016 \\
-69 \\
78,576\end{array}$ & $\begin{array}{r}248,161 \\
43,165 \\
34,643 \\
-568 \\
34,684 \\
19,461 \\
2,781 \\
-1,828\end{array}$ & $\begin{array}{r}158,081 \\
29,370 \\
80,623 \\
5 \\
28,718 \\
60,268 \\
7,781 \\
48,317\end{array}$ \\
\hline 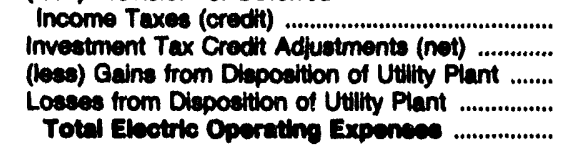 & $\begin{array}{r}12,388 \\
-1,560 \\
0 \\
0 \\
393,416\end{array}$ & $\begin{array}{r}44,722 \\
-7,996 \\
0 \\
0 \\
1,627,686\end{array}$ & $\begin{array}{r}4,630 \\
-1,152 \\
0 \\
0 \\
141,376\end{array}$ & $\begin{array}{r}59,097 \\
-1,746 \\
0 \\
0 \\
602,076\end{array}$ & $\begin{array}{r}4,037 \\
-1,186 \\
0 \\
0 \\
378,167\end{array}$ & $\begin{array}{r}10,063 \\
-3,865 \\
0 \\
0 \\
400,234\end{array}$ \\
\hline Not Eleotric Utilty Operating Incoms ............ & 82,978 & 100,710 & 98,697 & 124,774 & 58,280 & 323,178 \\
\hline 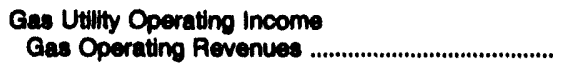 & 0 & 275,404 & 0 & 0 & 0 & 0 \\
\hline 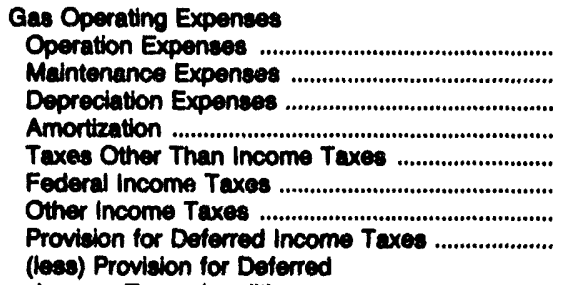 & $\begin{array}{l}0 \\
0 \\
0 \\
0 \\
0 \\
0 \\
0 \\
0\end{array}$ & $\begin{array}{r}215,192 \\
6,586 \\
13,781 \\
161 \\
18,327 \\
3,136 \\
860 \\
3,833\end{array}$ & $\begin{array}{l}0 \\
0 \\
0 \\
0 \\
0 \\
0 \\
0 \\
0\end{array}$ & $\begin{array}{l}0 \\
0 \\
0 \\
0 \\
0 \\
0 \\
0 \\
0\end{array}$ & $\begin{array}{l}0 \\
0 \\
0 \\
0 \\
0 \\
0 \\
0 \\
0\end{array}$ & $\begin{array}{l}0 \\
0 \\
0 \\
0 \\
0 \\
0 \\
0 \\
0\end{array}$ \\
\hline 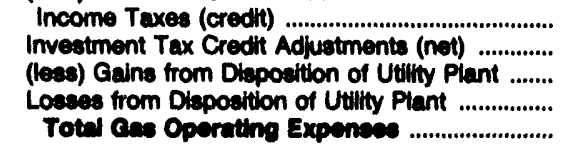 & $\begin{array}{l}0 \\
0 \\
0 \\
0 \\
0\end{array}$ & $\begin{array}{r}2,239 \\
-425 \\
0 \\
0 \\
201,102\end{array}$ & $\begin{array}{l}0 \\
0 \\
0 \\
0 \\
0\end{array}$ & $\begin{array}{l}0 \\
0 \\
0 \\
0 \\
0\end{array}$ & $\begin{array}{l}0 \\
0 \\
0 \\
0 \\
0\end{array}$ & $\begin{array}{l}0 \\
0 \\
0 \\
0 \\
0\end{array}$ \\
\hline Net Cas Utulty Operating Income .................... & o & 14,222 & $\mathbf{0}$ & 0 & 0 & $\mathbf{0}$ \\
\hline $\begin{array}{l}\text { Other Utllty Operating Income } \\
\text { Other Utillity Operating Revenues ........................... }\end{array}$ & 0 & 651 & 0 & 0 & 11,657 & 0 \\
\hline 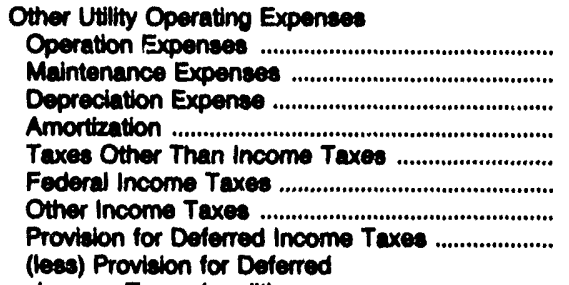 & $\begin{array}{l}0 \\
0 \\
0 \\
0 \\
0 \\
0 \\
0 \\
0\end{array}$ & $\begin{array}{l}0 \\
0 \\
0 \\
0 \\
0 \\
0 \\
0 \\
0\end{array}$ & $\begin{array}{l}0 \\
0 \\
0 \\
0 \\
0 \\
0 \\
0 \\
0\end{array}$ & $\begin{array}{l}0 \\
0 \\
0 \\
0 \\
0 \\
0 \\
0 \\
0\end{array}$ & $\begin{array}{r}1,293 \\
874 \\
1,463 \\
24 \\
1,424 \\
1,601 \\
247 \\
466\end{array}$ & $\begin{array}{l}0 \\
0 \\
0 \\
0 \\
0 \\
0 \\
0 \\
0\end{array}$ \\
\hline 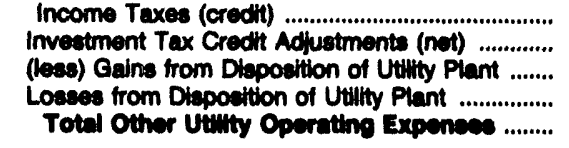 & $\begin{array}{l}0 \\
0 \\
0 \\
0 \\
0\end{array}$ & $\begin{array}{l}0 \\
0 \\
0 \\
0 \\
0\end{array}$ & $\begin{array}{l}0 \\
0 \\
0 \\
0 \\
0\end{array}$ & $\begin{array}{l}0 \\
0 \\
0 \\
0 \\
0\end{array}$ & $\begin{array}{r}75 \\
-95 \\
0 \\
0 \\
7,221\end{array}$ & $\begin{array}{l}0 \\
0 \\
0 \\
0 \\
0\end{array}$ \\
\hline Not Other Utilty Operating Incoms .................. & 0 & 061 & 0 & 0 & 4,436 & $\mathbf{0}$ \\
\hline
\end{tabular}

See ondnotes at end of an individual electric utility. 
Table 37. Statement of Income and Retained Earnings by Major U.S. Investor-Ovoned Electric Utility Within State, 1992 (Continued) (Thousand Dollars)

\begin{tabular}{|c|c|c|c|c|c|c|}
\hline Item & $\begin{array}{l}\text { Minnesota } \\
\text { Minnesota } \\
\text { Power } \\
\& \\
\text { Light Co }\end{array}$ & $\begin{array}{l}\text { Minnesota } \\
\text { Northern } \\
\text { States } \\
\text { Power Co }\end{array}$ & $\begin{array}{l}\text { Minnesota } \\
\text { Otter } \\
\text { Tall } \\
\text { Power } \\
\text { Co }\end{array}$ & $\begin{array}{l}\text { Miselasippi } \\
\text { Missiseippi } \\
\text { Power } \\
\& \\
\text { Uight Co }\end{array}$ & $\begin{array}{l}\text { Misalssippl } \\
\text { Mississippl } \\
\text { Power Co }\end{array}$ & $\begin{array}{l}\text { Mississippl } \\
\text { System } \\
\text { Energy } \\
\text { Resources } \\
\text { Inc }\end{array}$ \\
\hline 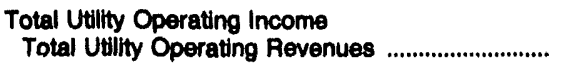 & 386,391 & $1,992,301$ & 177,241 & 817,850 & 446,103 & 723,410 \\
\hline 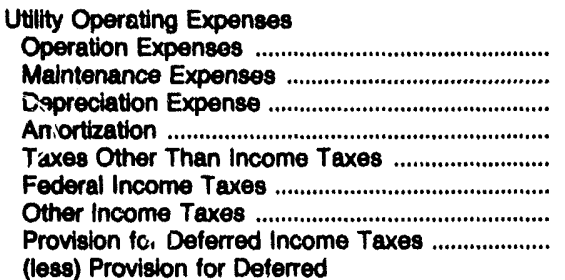 & $\begin{array}{r}231,312 \\
19,781 \\
29,610 \\
165 \\
33,740 \\
14,166 \\
3,806 \\
14,772\end{array}$ & $\begin{array}{r}1,160,572 \\
158,764 \\
206,705 \\
2,678 \\
191,514 \\
55,119 \\
14,937 \\
53,811\end{array}$ & $\begin{array}{r}80,092 \\
10,827 \\
16,881 \\
573 \\
10,034 \\
8,123 \\
1,936 \\
8,510\end{array}$ & $\begin{array}{r}556,811 \\
42,153 \\
31,133 \\
360 \\
40,738 \\
3,016 \\
-69 \\
79,576\end{array}$ & $\begin{array}{r}250,454 \\
44,038 \\
36,007 \\
-544 \\
36,088 \\
21,062 \\
3,027 \\
-1,360\end{array}$ & $\begin{array}{r}158,081 \\
29,370 \\
90,623 \\
5 \\
28,718 \\
50,268 \\
7,781 \\
49,317\end{array}$ \\
\hline 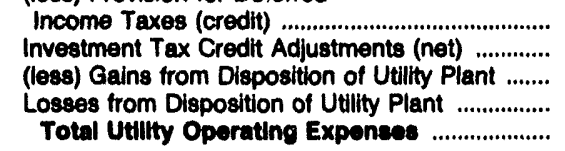 & $\begin{array}{r}12,388 \\
-1,550 \\
0 \\
0 \\
333,416\end{array}$ & $\begin{array}{r}46,861 \\
-8,421 \\
0 \\
0 \\
1,789,718\end{array}$ & $\begin{array}{r}4,630 \\
-1,152 \\
0 \\
0 \\
141,375\end{array}$ & $\begin{array}{r}59,087 \\
-1,746 \\
0 \\
0 \\
892,876\end{array}$ & $\begin{array}{r}4,112 \\
-1,282 \\
0 \\
0 \\
383,378\end{array}$ & $\begin{array}{r}10,063 \\
-3,865 \\
0 \\
0 \\
400,234\end{array}$ \\
\hline 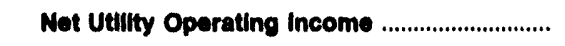 & 62,976 & 208,583 & 35,867 & 124,774 & 62,725 & 323,176 \\
\hline $\begin{array}{l}\text { Other income and Derluctions } \\
\text { Other Income }\end{array}$ & & & & & & \\
\hline 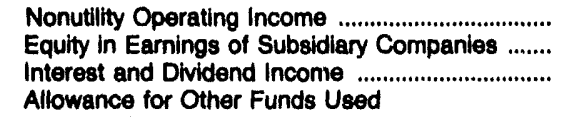 & $\begin{array}{r}-3,573 \\
14,178 \\
31,965\end{array}$ & $\begin{array}{r}8,557 \\
33,364 \\
3,120\end{array}$ & $\begin{array}{r}36 \\
1,562 \\
1,364\end{array}$ & $\begin{array}{r}1,231 \\
0 \\
4,523\end{array}$ & $\begin{array}{r}107 \\
0 \\
1,003\end{array}$ & $\begin{array}{r}0 \\
0 \\
4,908\end{array}$ \\
\hline 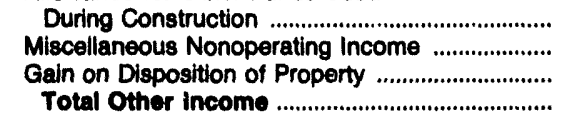 & $\begin{array}{r}374 \\
7,838 \\
52 \\
60,834\end{array}$ & $\begin{array}{r}8,086 \\
-301 \\
1,185 \\
54,022\end{array}$ & $\begin{array}{r}116 \\
259 \\
40 \\
3,377\end{array}$ & $\begin{array}{r}668 \\
8 \\
42 \\
6,471\end{array}$ & $\begin{array}{r}642 \\
-543 \\
1,380 \\
2,689\end{array}$ & $\begin{array}{r}681 \\
0 \\
111 \\
5,701\end{array}$ \\
\hline 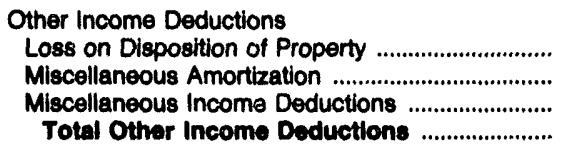 & $\begin{array}{r}0 \\
22 \\
479 \\
501\end{array}$ & $\begin{array}{r}0 \\
0 \\
10,079 \\
10,079\end{array}$ & $\begin{array}{r}12 \\
0 \\
596 \\
608\end{array}$ & $\begin{array}{r}23 \\
0 \\
1,190 \\
1,213\end{array}$ & $\begin{array}{r}812 \\
0 \\
1,655 \\
2,467\end{array}$ & $\begin{array}{r}-187 \\
0 \\
-608 \\
-787\end{array}$ \\
\hline 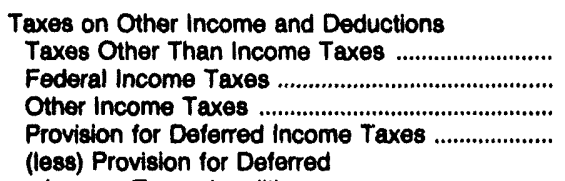 & $\begin{array}{r}825 \\
7,997 \\
2,139 \\
3,406\end{array}$ & $\begin{array}{r}1,206 \\
3,922 \\
691 \\
-4,551\end{array}$ & $\begin{array}{r}13 \\
-639 \\
-121 \\
689\end{array}$ & $\begin{array}{r}28 \\
1,516 \\
0 \\
0\end{array}$ & $\begin{array}{r}20 \\
-776 \\
-36 \\
0\end{array}$ & $\begin{array}{r}0 \\
-21,971 \\
-996 \\
9,308\end{array}$ \\
\hline 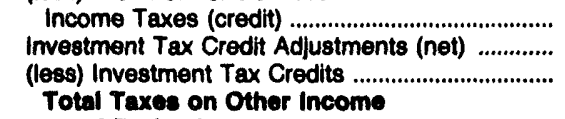 & $\begin{array}{r}6,847 \\
0 \\
0\end{array}$ & $\begin{array}{r}850 \\
-192 \\
0\end{array}$ & $\begin{array}{r}93 \\
-1 \\
0\end{array}$ & $\begin{array}{r}49 \\
0 \\
0\end{array}$ & $\begin{array}{r}0 \\
-134 \\
0\end{array}$ & $\begin{array}{r}24,913 \\
33,988 \\
0\end{array}$ \\
\hline 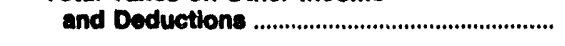 & 7,520 & 225 & -141 & 1,486 & -925 & $-4,584$ \\
\hline Net Other Income and Deductions .................. & 42,813 & 48,717 & 2,910 & 3,763 & 1,047 & 11,081 \\
\hline
\end{tabular}


Table 37. Statement of Income and Rotalned Earnings

by Major U.S. Investor-Owned Electric

Utility Within State, 1992 (Continued)

(Thousand Dollars)

\begin{tabular}{|c|c|c|c|c|c|c|}
\hline Item & $\begin{array}{l}\text { Minnesota } \\
\text { Minnesote } \\
\text { Power } \\
\& \\
\text { Light Co }\end{array}$ & $\begin{array}{l}\text { Minnesote } \\
\text { Northern } \\
\text { States } \\
\text { Power Co }\end{array}$ & $\begin{array}{c}\text { Minnesola } \\
\text { Otter } \\
\text { Tall } \\
\text { Power } \\
\text { Co }\end{array}$ & $\begin{array}{l}\text { Misalesippi } \\
\text { Milualseippi } \\
\text { Power } \\
\text { Light Co }\end{array}$ & $\begin{array}{l}\text { Mlodesippl } \\
\text { Miselesippl } \\
\text { Power Co }\end{array}$ & $\begin{array}{l}\text { Misolesippl } \\
\text { System } \\
\text { Energy } \\
\text { Resources } \\
\text { inc }\end{array}$ \\
\hline
\end{tabular}

Interest Charges

Interest on Long-term Debt ..................................

Amortization of Debt Discount and Expense ......

Amortization of Loss on Reacquired Debt ...........

(less) Amortzation of Premium on Debt (credit) .

(less) Amortization of Gain on

Reaquired Debt (credit)

Interest on Dabt to Associated Companles

Other Interest Expense

(less) Allowance for Borrowed Funds

Used During Construction (credit)

Not intereat Charge

Income Bofore Extreordinary Iteme

Extraordinary ltems

Extraordinary Income

(less) Extraordinary Deduc

Not Extreordinany iteme

(less) Federal and Other Income Taxes

Extreordinary lteme After Taxee

Net Inoome

$\begin{array}{rr}30,384 & 85,695 \\ 492 & 867 \\ 508 & 1,309 \\ 0 & 101 \\ & \\ 0 & 0 \\ 0 & 11 \\ 4,600 & 4,221 \\ 197 & 5,630 \\ 36,687 & 86,372\end{array}$

70,122

160,928

3,166

3,168

0

3,100

45,812

73,298

200,490

28,538

11,624
185

249

1,028

707

0

36

1,636

585

63,601

65,08

24,582

76,119

76,119

30,608

894,039

73,02

111,670

375,907

Balance Transferred from Income

Credits to Retained Earnings .....................................

(lese) Debits to Retained Earnings .........................

(less) Appropriations of Retained Earnings ..........

(leses) Dividends Declared - Preferred Stock .......

(less) Dividends Declared - Common Stock .......

Unappropriated Undistributed Subsidiary

Earnings

Rotained Earnings - End of Your

59,110

3,206

2,847

3,807

57,118

173,075

822

0
16,172

156,109

24,976

516

2,242

18,344

170

4,200

24,895

65,036

742

8,513

88,400

40,847
0
0
0
3,858

28,000

0

77,070

290,201

120,400

897,747

Appropriated Retained Earnings

Approprlated Retained Earnings

Amortzation Reservo, Foderal

188,899

919,500

0

67

0

0

168,890

919,697

77,970

280,201

120,884

397,747

Note: Totals may not equal sum of components because of independent rounding. Summary data are provided in Table 6.

Source: Federal Energy Regulatory Commiseion, FERC Form 1, "Annual Report of Major Electric Utillties, Licensees and Othere." 
Table 37. Statement of Ircome and Rotalned Earnings

by Major U.S. Investor-Owned Electrlc

Utility Within State, 1892 (Continued)

(Thousand Dollars)

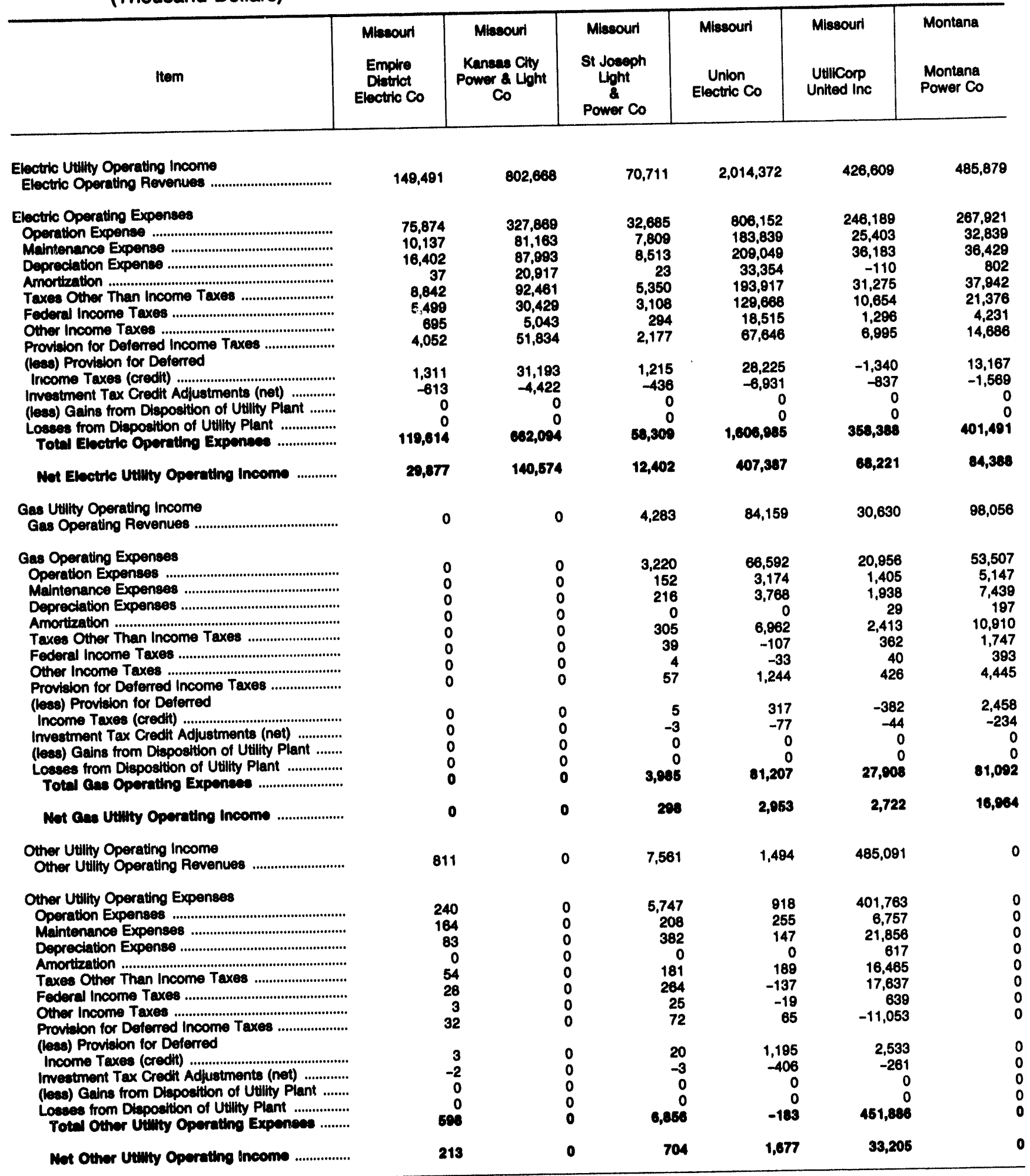

See endnotes at end of an indtvidual electric utility. 
Table 37. Statement of Income and Retained Earninge by Major U.S. Investor-Owned Eloctric Utility Within State, 1992 (Continued) (Thousand Dollars)

\begin{tabular}{|c|c|c|c|c|c|c|}
\hline Item & $\begin{array}{l}\text { Miseourt } \\
\text { Empire } \\
\text { District } \\
\text { Electric Co }\end{array}$ & $\begin{array}{l}\text { Miseour } \\
\text { Kansas City } \\
\text { Power \& Light } \\
\text { Co }\end{array}$ & $\begin{array}{l}\text { Missourt } \\
\text { St Joseph } \\
\text { Light } \\
\text { \&ower Co }\end{array}$ & $\begin{array}{l}\text { Misesouri } \\
\text { Union } \\
\text { Electric Co }\end{array}$ & $\begin{array}{l}\text { Misscurt } \\
\text { Utilicorp } \\
\text { United Inc }\end{array}$ & $\begin{array}{l}\text { Montana } \\
\text { Montana } \\
\text { Power Co }\end{array}$ \\
\hline $\begin{array}{l}\text { Total Utility Operating Income } \\
\text { Total Utility Operating Revenues }\end{array}$ & 150,302 & 802,668 & 82,555 & $2,100,026$ & 842,330 & 583,935 \\
\hline 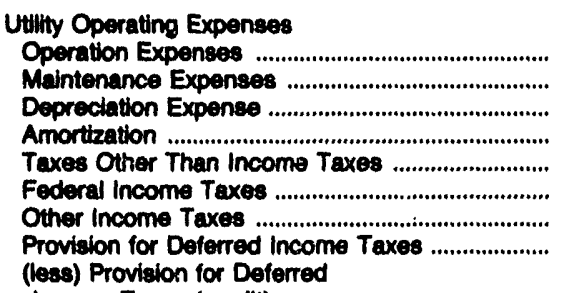 & $\begin{array}{r}76,114 \\
10,301 \\
16,485 \\
37 \\
8,886 \\
5,527 \\
688 \\
4,084\end{array}$ & $\begin{array}{r}327,869 \\
81,163 \\
87,893 \\
20,817 \\
92,461 \\
30,429 \\
5,043 \\
51,834\end{array}$ & $\begin{array}{r}41,652 \\
8,170 \\
9,111 \\
23 \\
5,838 \\
3,411 \\
323 \\
2,306\end{array}$ & $\begin{array}{r}873,682 \\
187,267 \\
212,885 \\
33,354 \\
201,089 \\
129,424 \\
18,463 \\
68,955\end{array}$ & $\begin{array}{r}668,907 \\
33,564 \\
59,976 \\
536 \\
50,154 \\
28,654 \\
1,975 \\
-3,632\end{array}$ & $\begin{array}{r}321,429 \\
37,885 \\
43,868 \\
1,000 \\
48,851 \\
23,123 \\
4,624 \\
19,131\end{array}$ \\
\hline 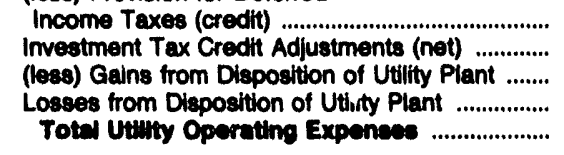 & $\begin{array}{r}1,314 \\
-615 \\
0 \\
0 \\
120,212\end{array}$ & $\begin{array}{r}31,193 \\
-4,422 \\
0 \\
0 \\
0.2,004\end{array}$ & $\begin{array}{r}1,240 \\
-441 \\
0 \\
0 \\
62,150\end{array}$ & $\begin{array}{r}29,737 \\
-7,414 \\
0 \\
0 \\
1,098,000\end{array}$ & $\begin{array}{r}810 \\
-1,142 \\
0 \\
0 \\
838,182\end{array}$ & $\begin{array}{r}15,625 \\
-1,803 \\
0 \\
0 \\
482,613\end{array}$ \\
\hline Net Vetity Operating income ................................ & 30,000 & 140,674 & 13,406 & 412,017 & 104,148 & 101,352 \\
\hline \multicolumn{7}{|l|}{$\begin{array}{l}\text { Other Income and Deductions } \\
\text { Other Income }\end{array}$} \\
\hline 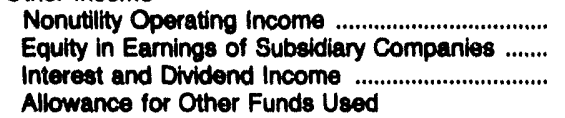 & $\begin{array}{r}0 \\
0 \\
115\end{array}$ & $\begin{array}{r}-5 \\
4 \\
812\end{array}$ & $\begin{array}{r}0 \\
0 \\
158\end{array}$ & $\begin{array}{r}118 \\
5,059 \\
2,580\end{array}$ & $\begin{array}{l}5,507 \\
3,134 \\
2,551\end{array}$ & $\begin{array}{r}33 \\
50,476 \\
2,116\end{array}$ \\
\hline 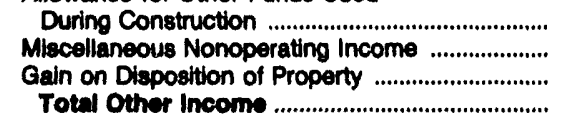 & $\begin{array}{r}0 \\
0 \\
13 \\
120\end{array}$ & $\begin{array}{r}1,073 \\
885 \\
3,105 \\
5,974\end{array}$ & $\begin{array}{r}183 \\
101 \\
0 \\
443\end{array}$ & $\begin{array}{r}3,115 \\
99 \\
34,987 \\
46,940\end{array}$ & $\begin{array}{r}897 \\
997 \\
46 \\
13,131\end{array}$ & $\begin{array}{r}1,178 \\
745 \\
7 \\
54,565\end{array}$ \\
\hline 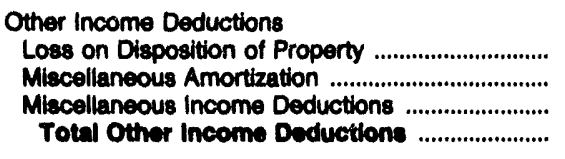 & $\begin{array}{r}0 \\
3 \\
379 \\
392\end{array}$ & $\begin{array}{r}22 \\
52 \\
2,208 \\
2,200\end{array}$ & $\begin{array}{r}0 \\
0 \\
95 \\
95\end{array}$ & $\begin{array}{r}835 \\
1,276 \\
5,165 \\
7,276\end{array}$ & $\begin{array}{r}54 \\
3,437 \\
5,493 \\
8,984\end{array}$ & $\begin{array}{r}114 \\
622 \\
796 \\
1,632\end{array}$ \\
\hline 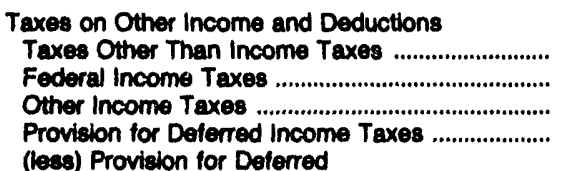 & $\begin{array}{r}0 \\
-27 \\
-3 \\
0\end{array}$ & $\begin{array}{r}26 \\
-2,348 \\
-387 \\
3,510\end{array}$ & $\begin{array}{r}0 \\
84 \\
9 \\
33\end{array}$ & $\begin{array}{r}35 \\
10,281 \\
1,472 \\
7,233\end{array}$ & $\begin{array}{r}540 \\
179 \\
555 \\
23\end{array}$ & $\begin{array}{r}28 \\
1,412 \\
203 \\
375\end{array}$ \\
\hline $\begin{array}{l}\text { Income Taxes (credit) .................................... } \\
\text { Imvestment Tax Credit Adjustments (net) ........... } \\
\text { (less) Imvestment Tax Credits ................................. } \\
\text { Total Texes on Other income }\end{array}$ & $\begin{array}{l}0 \\
0 \\
0\end{array}$ & $\begin{array}{r}171 \\
0 \\
99\end{array}$ & $\begin{array}{r}12 \\
0 \\
0\end{array}$ & $\begin{array}{r}1,501 \\
0 \\
0\end{array}$ & $\begin{array}{r}17 \\
0 \\
0\end{array}$ & $\begin{array}{r}2,445 \\
0 \\
0\end{array}$ \\
\hline 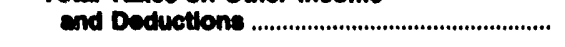 & -30 & 631 & 113 & 17,520 & 1,280 & -486 \\
\hline Net Other Income and Deductions ................. & -224 & 3,184 & 234 & 21,144 & 2,867 & 53,440 \\
\hline
\end{tabular}


Table 37. Statement of Income and Rotained Earninge

by Major U.S. Investor-Owned Electric

Utility Within 8tate, 1992 (Continued)

(Thousand Dollars)

\begin{tabular}{|c|c|c|c|c|c|c|}
\hline Hem & $\begin{array}{l}\text { Miscourl } \\
\text { Emplre } \\
\text { Dietriot } \\
\text { Electrio Co }\end{array}$ & $\begin{array}{c}\text { Mlesourt } \\
\text { Kansas City } \\
\text { Power \& Light } \\
\text { Co }\end{array}$ & $\begin{array}{l}\text { Misesouri } \\
\text { St Joseph } \\
\text { Lught } \\
\& \\
\text { Power Co }\end{array}$ & $\begin{array}{l}\text { Miseourt } \\
\text { Union } \\
\text { Electric Co }\end{array}$ & $\begin{array}{l}\text { Miseourt } \\
\text { UtillCorp } \\
\text { United Inc }\end{array}$ & $\begin{array}{l}\text { Montana } \\
\text { Montana } \\
\text { Power Co }\end{array}$ \\
\hline
\end{tabular}

Interest Charees

Intered on Lono-term Debt ...................................

Amortzation of Debt Discount and Expense ......

Amortzation of Loss on Reacquired Debt ...........

(lewe) Amortization of Premium on Dabt (oredit).

(lese) Amortization of Cain on

Reaquired Debt (credt)

Interest on Debt to Assoclated Companies ...........

Other Interest Expense ...............................................

(leas) Allowence for Borrowed Funds

Used During Construction (credt)

Net Intered Charees .............................................

Inoems Dofore Extreordinery ltem

Extreordinary thems

Extreordinary income

(bee) Extraordinary Deductions

Net Extrescrinary thems

(lese) Federal and Other Income Taxes

Extreordinary ltoms After Taxes

net Inooms

$\begin{array}{rr}12,335 & 54,268 \\ 285 & 423 \\ 0 & 1,282 \\ 0 & 10 \\ 0 & 3 \\ 0 & 0 \\ 460 & 3,230 \\ 119 & 1,785 \\ 12,091 & 67,409 \\ 18,905 & \\ & 86,994\end{array}$

4,670

4,670
24
23

771

3,651

148

0
0

13,892

4,807

130,413

88
4,091

8,088

302,748

62,010

46,414

247
0
0

45,682

1,858

129
5

103

0
0
8,982

1,547

84,106

1.718

1,542

47,795

107,005$$
\begin{aligned}
& 0 \\
& 0 \\
& 0
\end{aligned}
$$

0
0
0

0
0
0

0

16,908

86,334

8,068

302,748

52,010

107,096

Uneppropituted Rotalned Eeminos

Rotinged Eemings - Becinning of Year

$\begin{array}{rr}84,600 & 428,340 \\ 16,805 & 86,330 \\ 0 & 0 \\ 0 & 233 \\ 3 & 0 \\ 384 & 2,747 \\ 16,492 & 88,520 \\ 0 & \end{array}$

$6,8,83$

878,050

83,600

$-4,884$

Balance Translerred from Income

Credito to Retained Eaming

(leas) Debits to Retained Earninos

(keav) Dividends Declared - Common Stock .......

Uneppropitated Undistributed Subeldiary

Earnings .

84,023

421,160

58,877

$\mathbf{e s , 0 s}$

297,689

49,776

56,589

$-2,325$

3,789

79,420

14,058

230,800

6,883

56,700

33,339

Roteined Eominge - End of Year

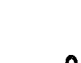

Appropilated Retained Earnings

Appropriated Retained Eaminge -

Amorthation Rearve Federal

0

57

0

0

0

0

421,160

65,877

4., 192

989,063

18,870

4,380

0

6,238

Note: Totals may not equal sum of components because of independent rounding. Summary data are provided in Table 6.

source: Federal Energy Requlatory Commisilon, FERC Form 1. "Annual Report of Major Electric Utilties, Licensees and Others." 
Table 37. Statement of Income and Retained Earnings

by Major U.S. Investor-Owned Electric

Utility Within State, 1992 (Continued)

(Thousand Dollars)

\begin{tabular}{|c|c|c|c|c|c|c|}
\hline Item & $\begin{array}{l}\text { Nevada } \\
\text { Nevada } \\
\text { Power Co }\end{array}$ & $\begin{array}{l}\text { Nevada } \\
\text { Sierra } \\
\text { Pacific } \\
\text { Power Co }\end{array}$ & \begin{tabular}{|c|} 
New Hampshire \\
Great \\
Bay \\
Power \\
Corp
\end{tabular} & $\begin{array}{c}\text { Now Hampshire } \\
\text { Now England } \\
\text { Eloc } \\
\text { Transmn } \\
\text { Corp }\end{array}$ & \begin{tabular}{|c|} 
New Hampshire \\
New England \\
Hydro- \\
Trans \\
Corp
\end{tabular} & $\begin{array}{l}\text { Now Hampshire } \\
\text { North } \\
\text { Atlantic } \\
\text { Energy Corp }\end{array}$ \\
\hline $\begin{array}{l}\text { Electric Utility Operating Income } \\
\text { Electric Operating Revenues }\end{array}$ & 600,923 & 401,851 & 23,027 & 12,708 & 35,558 & 78,444 \\
\hline 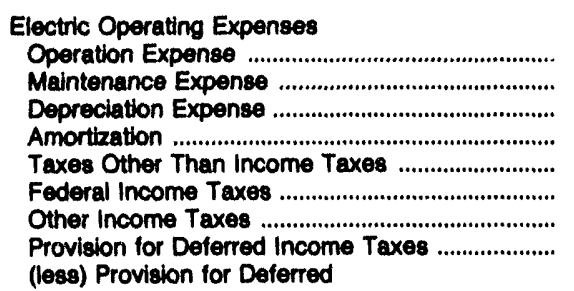 & $\begin{array}{r}377,179 \\
37,811 \\
39,433 \\
18 \\
16,121 \\
18,213 \\
165 \\
30,686\end{array}$ & $\begin{array}{r}239,264 \\
14,891 \\
37,411 \\
1,610 \\
12,012 \\
11,487 \\
390 \\
11,737\end{array}$ & $\begin{array}{r}23,845 \\
4,677 \\
8,793 \\
23 \\
6,077 \\
-22,453 \\
0 \\
04,841\end{array}$ & $\begin{array}{r}1,034 \\
407 \\
4,686 \\
4 \\
1,180 \\
284 \\
0 \\
0 \\
373\end{array}$ & $\begin{array}{r}9,710 \\
72 \\
5,538 \\
0 \\
0 \\
1,776 \\
921 \\
0 \\
0 \\
2,834\end{array}$ & $\begin{array}{r}27,500 \\
9,413 \\
12,837 \\
-439 \\
10,428 \\
-6,334 \\
0 \\
16,558\end{array}$ \\
\hline 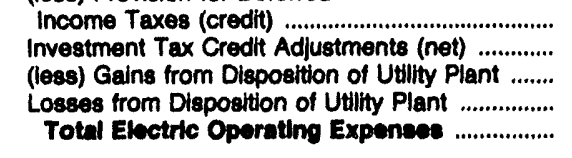 & $\begin{array}{r}17,306 \\
-1,618 \\
\ddots \\
0 \\
500,801\end{array}$ & $\begin{array}{r}0 \\
-1,536 \\
0 \\
0 \\
327,285\end{array}$ & $\begin{array}{r}2,595 \\
4,955 \\
0 \\
0 \\
68,163\end{array}$ & $\begin{array}{r}149 \\
-406 \\
0 \\
0 \\
7,414\end{array}$ & $\begin{array}{r}29 \\
364 \\
0 \\
0 \\
21,186\end{array}$ & $\begin{array}{r}7,641 \\
0 \\
0 \\
0 \\
62,322\end{array}$ \\
\hline Not Electric Utllity Operating Income ............. & 100,122 & 74,586 & $-45,136$ & 5,294 & 14,372 & 16,122 \\
\hline 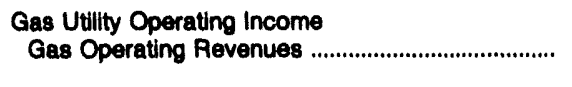 & 0 & 44,817 & 0 & 0 & 0 & 0 \\
\hline 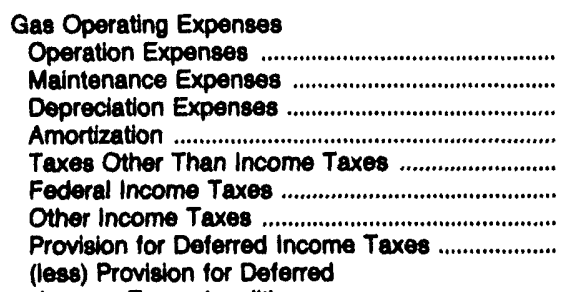 & $\begin{array}{l}0 \\
0 \\
0 \\
0 \\
0 \\
0 \\
0 \\
0\end{array}$ & $\begin{array}{r}35,452 \\
572 \\
3,054 \\
134 \\
1,005 \\
-406 \\
0 \\
1,731\end{array}$ & $\begin{array}{l}0 \\
0 \\
0 \\
0 \\
0 \\
0 \\
0 \\
0\end{array}$ & $\begin{array}{l}0 \\
0 \\
0 \\
0 \\
0 \\
0 \\
0 \\
0\end{array}$ & $\begin{array}{l}0 \\
0 \\
0 \\
0 \\
0 \\
0 \\
0 \\
0\end{array}$ & $\begin{array}{l}0 \\
0 \\
0 \\
0 \\
0 \\
0 \\
0 \\
0 \\
0\end{array}$ \\
\hline 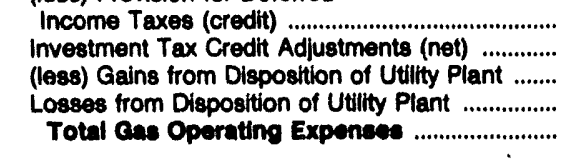 & $\begin{array}{l}0 \\
0 \\
0 \\
0 \\
0\end{array}$ & $\begin{array}{r}0 \\
-82 \\
0 \\
0 \\
41,460\end{array}$ & $\begin{array}{l}0 \\
0 \\
0 \\
0 \\
0\end{array}$ & $\begin{array}{l}0 \\
0 \\
0 \\
0 \\
0\end{array}$ & $\begin{array}{l}0 \\
0 \\
0 \\
0 \\
0\end{array}$ & $\begin{array}{l}0 \\
0 \\
0 \\
0 \\
0\end{array}$ \\
\hline Not aas Utilty Operating Income ................... & 0 & 3,468 & $\mathbf{0}$ & 0 & 0 & 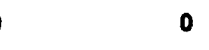 \\
\hline $\begin{array}{l}\text { Other Utilly Operating Income } \\
\text { Other Utility Operating Revenues }\end{array}$ & 0 & 31,461 & 0 & 0 & 0 & 0 \\
\hline 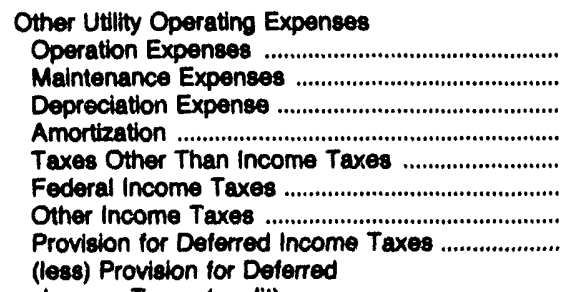 & $\begin{array}{l}0 \\
0 \\
0 \\
0 \\
0 \\
0 \\
0 \\
0\end{array}$ & $\begin{array}{r}14,382 \\
1,689 \\
4,186 \\
152 \\
1,556 \\
2,869 \\
0 \\
-133\end{array}$ & $\begin{array}{l}0 \\
0 \\
0 \\
0 \\
0 \\
0 \\
0 \\
0\end{array}$ & $\begin{array}{l}0 \\
0 \\
0 \\
0 \\
0 \\
0 \\
0 \\
0\end{array}$ & $\begin{array}{l}0 \\
0 \\
0 \\
0 \\
0 \\
0 \\
0 \\
0\end{array}$ & $\begin{array}{l}0 \\
0 \\
0 \\
0 \\
0 \\
0 \\
0 \\
0\end{array}$ \\
\hline 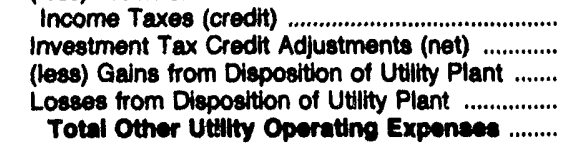 & $\begin{array}{l}0 \\
0 \\
0 \\
0 \\
0\end{array}$ & $\begin{array}{r}0 \\
-127 \\
0 \\
0 \\
24,682\end{array}$ & $\begin{array}{l}0 \\
0 \\
0 \\
0 \\
0\end{array}$ & $\begin{array}{l}0 \\
0 \\
0 \\
0 \\
0\end{array}$ & $\begin{array}{l}0 \\
0 \\
0 \\
0 \\
0\end{array}$ & $\begin{array}{l}0 \\
0 \\
0 \\
0 \\
0\end{array}$ \\
\hline Net Other Utilty Operating Income ................ & 0 & 6,779 & $\mathbf{0}$ & $\mathbf{0}$ & $\mathbf{0}$ & 0 \\
\hline
\end{tabular}

See endnotes at end of an individual electric utility. 
Table 37. Statement of income and Rotalned Eamings

by Major U.S. Investor-Owned Electric

Utility Whthin State, 1902 (Continued)

(Thousand Dollars)

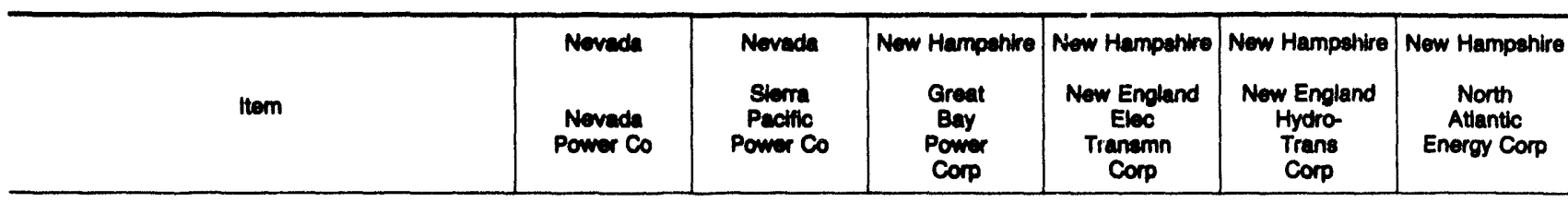

Total Uinity Operating Income

Total Uitily Operating Rovenues

Uti"ity Operating Expenses

Operation 5 pronees

Meintenance Expenses

Depreciation Expenses

Amortibation

Texes Other Than Incoms

Federel income Taxes

Other Income Texes

for Deferred Incoms Taxes

(beas) Proviaion for Deferred

income Texes (credit)

Imeatment Tax Credt Ad"ustments (not)

(leas) Geins from Diepoation of Utithy Plart ......

Loeses from Diepostion of Utility Plant

Total Utily Operating Expensese

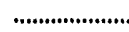

Net Uimb Oporating income

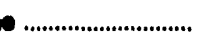

Other Income and Dedurtions

Other Income

Nonutitty Operating Incoms .....................................

Equity in Eaminos of Subeidlary Companies .......

Intereat and Dividend Income

Allowance for Other Funds Used

During Construction

Mursolianeous Nonoperating Income

Gain on Diapoation of Property ................................

Totel Other Incems

Other Income Deductions

Lows on Disposition of Property ..............................

(n) Amortization

Miccellaneau Incoms Dectuctions

Totit Otrer incems Deductions

600,923

478,229

23,027

12,708

35,558

78,444

377,179

37,911

39,433

16,121

18,213

165

30,608

17,308

$-1,618$

0

289,098

17,162

4,651

1,898

14,672

14,049

380

13,334

0
$-1,745$

0

303,407

100,122

04,92

23,845

4,677

0,793

207

6,077
$-22,453$

0
44,841

4,841

2,595

4,955

0
0
0,189

$-46,18$

407
4,686

4

1,180

284
0

373

148

$-408$

0
0

7,411

6,294

$$
\begin{array}{r}
9,710 \\
72 \\
5,538 \\
0
\end{array}
$$

9,710
72
5,538
0

1,776

821
0

2,834

29
364
0
0

21,105

14,372

0
$-2,388$

1,970

0

4,513

8,251

71

7,003

298
-48
0

4,704

14
0
10,478

0
0
1,310

1,310
1,810

10,409

1
$-4,041$
0

6
$-1,412$
0

624

Provition for Deferred Income Taxes

(lese) Provbion for Deferted

Income Texes (credti)

imvertment Tex Credt Adhutments (net)

(bee) imveatment Tax Credth

Totil Taxes on Otrer inoom.

and Deduction:

Net Other income and Deduction. .................

(n..............

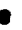

on Other Income and Daductions

4,225

$-2$

0
0
133
0
22
99
284

-1
0
1
0
0
0
-1

$\begin{array}{rr}-13 & 0 \\ 0 & 0 \\ 98 & 208 \\ & \\ 0 & 44 \\ 0 & 22,809 \\ 0 & 0 \\ 05 & 28,080\end{array}$

28,000

See endnotes at end of an individual electric utility. 
Table 37. Statement of Income and Rotained Earnings

by Major U.S. Inveator-Owned Electric

Utility Within State, 1992 (Continued)

(Thousand Dollars)

\begin{tabular}{|c|c|c|c|c|c|c|}
\hline Item & $\begin{array}{l}\text { Nevada } \\
\text { Nevada } \\
\text { Power Co }\end{array}$ & $\begin{array}{l}\text { Novada } \\
\text { Slerra } \\
\text { Pacific } \\
\text { Power Co }\end{array}$ & \begin{tabular}{|c|} 
Now Hainpahiro \\
Great \\
Bay \\
Power \\
Corp
\end{tabular} & $\begin{array}{c}\text { Now Hampahire } \\
\text { New England } \\
\text { Eleo } \\
\text { Tranemn } \\
\text { Corp }\end{array}$ & $\begin{array}{l}\text { Now Hampehire } \\
\text { Now England } \\
\text { Hydro- } \\
\text { Trans } \\
\text { Corp }\end{array}$ & $\begin{array}{c}\text { Now Hampahire } \\
\text { North } \\
\text { Attantc } \\
\text { Energy Corp }\end{array}$ \\
\hline
\end{tabular}

intereat Charges

Interest on Lono-term Dabt

Amorthation of Debt Dincount and Expenee

Amortization of Loses on Reacoulred Debt ...........

(kea) Amortzation of Premium on Debt (credit) .

(bav) Amortization of can on

Reaquired Debt (credtit) .............................................

Intereet on Debt to Aseociated Companies ........

Other Intereet Expense ...............................................

(lees) Allowance for Borrowed Funds

Used During Construction (credit)

Net interent chrorios

Incems Bofere Extrecrinary theme

Extreordinary liems

Extreordinary income.

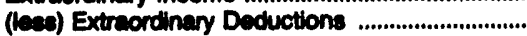

Not Extracrineny tiems.

(leas) Federal and Other Income Taxes

Extruentiniey fieme After Toxes.

Net income

Unepproprtatiod Rotelned Eerninge

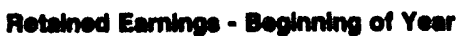

Balance Tranaferred from income ..........................

Credits to Retained Eamings.

(leas) Deblts to Retained Eamings ........................

(leas) Appropriations of Retained Earnings .........

(keos) Dividends Declared - Preferred Stock .......

(lees) Dividends Declared - Common Stock .......

Unappropriated Undistributed Subaldiary

Eerninge

Retained Eeminge - End of Year

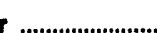

Appropriated Retined Eaminges

Appropriated Retained Earnings

Amortization Reserva, Federal

Totel Rotined Enmines

$\begin{array}{rr}45,013 & 37,183 \\ 646 & 333 \\ 238 & 389 \\ 2 & 21 \\ 3 & 0 \\ 0 & 0 \\ 2,853 & 2,528 \\ 4,219 & 1,178 \\ 44,527 & 30,214 \\ & \\ 63,700 & 49,843\end{array}$

0
0
0
0
0
0
1,386
0
1,386
$-47,488$

3,996

40

0

0

12
8

0
4,089

1,234

7,379

12,703

Note: Totals may not equal sum of components because of independent rounding. Summary data are provided in Table 6.

Source: Federal Eneroy Regulatory Commialion, FERC Form 1. "Annual Report of Major Electric Utilities, Licensees and Others." 
Table 37. Statement of Inc ome and Rotained Earnings

by Major U.S. Inveator-Owned Electric

Utility Within State, 1902 (Continued)

(Thousand Dollars)

\begin{tabular}{|c|c|c|c|c|c|c|}
\hline item & $\begin{array}{l}\text { Now Hampehire } \\
\text { Public } \\
\text { Service } \\
\text { Co } \\
\text { of NH }\end{array}$ & $\begin{array}{c}\text { New Jersey } \\
\text { Atlantic } \\
\text { City } \\
\text { Electric } \\
\text { Co }\end{array}$ & $\begin{array}{l}\text { New Jeney } \\
\text { Jereey } \\
\text { Central } \\
\text { Poweralight } \\
\text { Co }\end{array}$ & $\begin{array}{l}\text { Now Jersey } \\
\text { Public } \\
\text { Service } \\
\text { Electricalasas } \\
\text { Co }\end{array}$ & $\begin{array}{l}\text { New Jereey } \\
\text { Rockland } \\
\text { Electric Co }\end{array}$ & $\begin{array}{l}\text { Now Moxico } \\
\text { Public } \\
\text { Service } \\
\text { Co } \\
\text { of NM }\end{array}$ \\
\hline $\begin{array}{l}\text { Electric Utilty Operating Income } \\
\text { Electric Operating Pevenwes .................................... }\end{array}$ & 874,329 & 816,932 & $1,774,071$ & $3,407,819$ & 126,757 & 586,323 \\
\hline 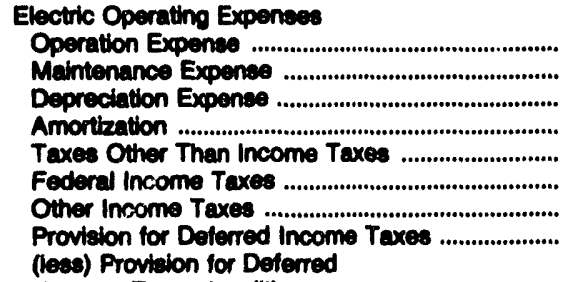 & $\begin{array}{r}509,061 \\
43,065 \\
46,586 \\
87,792 \\
36,732 \\
37,468 \\
79 \\
18,780\end{array}$ & $\begin{array}{r}413,811 \\
49,928 \\
67,280 \\
2,081 \\
110,083 \\
28,736 \\
0 \\
35,860\end{array}$ & $\begin{array}{r}1,029,331 \\
124,736 \\
144,535 \\
22,487 \\
215,807 \\
36,891 \\
47 \\
95,876\end{array}$ & $\begin{array}{r}1,382,147 \\
289,600 \\
378,051 \\
39,038 \\
466,967 \\
162,503 \\
1,971 \\
128,345\end{array}$ & $\begin{array}{r}90,760 \\
5,386 \\
3,605 \\
854 \\
17,075 \\
2,299 \\
0 \\
1,762 \\
\end{array}$ & $\begin{array}{r}375,868 \\
43,808 \\
59,061 \\
2,771 \\
32,324 \\
1,929 \\
2,923 \\
10,147\end{array}$ \\
\hline 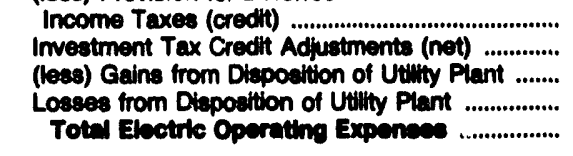 & $\begin{array}{r}41 \\
-649 \\
0 \\
0 \\
m 8,073\end{array}$ & $\begin{array}{r}20,028 \\
-2,534 \\
0 \\
0 \\
000,438\end{array}$ & $\begin{array}{r}82,249 \\
-6,944 \\
0 \\
0 \\
1,800,217\end{array}$ & $\begin{array}{r}108,602 \\
-17,604 \\
0 \\
0 \\
2,712,617\end{array}$ & $\begin{array}{r}2,287 \\
-137 \\
0 \\
0 \\
110,340\end{array}$ & $\begin{array}{r}2,097 \\
-5,903 \\
0 \\
0 \\
820,032\end{array}$ \\
\hline Not Electric Uuilty Opereting Ineome ............ & 95,460 & 130,490 & 103,054 & 686,302 & 7,400 & 76,491 \\
\hline 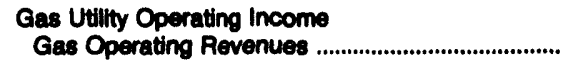 & 0 & 0 & 0 & $1,586,181$ & 0 & 230,606 \\
\hline 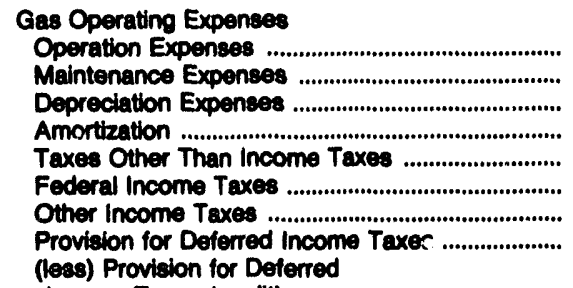 & $\begin{array}{l}0 \\
0 \\
0 \\
0 \\
0 \\
0 \\
0 \\
0\end{array}$ & $\begin{array}{l}0 \\
0 \\
0 \\
0 \\
0 \\
0 \\
0 \\
0\end{array}$ & $\begin{array}{l}0 \\
0 \\
0 \\
0 \\
0 \\
0 \\
0 \\
0\end{array}$ & $\begin{array}{r}1,115,441 \\
38,140 \\
80,882 \\
36,025 \\
182,800 \\
52,706 \\
0 \\
-4,687\end{array}$ & $\begin{array}{l}0 \\
0 \\
0 \\
0 \\
0 \\
0 \\
0 \\
0\end{array}$ & $\begin{array}{r}168,600 \\
7,381 \\
9,764 \\
3,860 \\
6,839 \\
-12,438 \\
-2,865 \\
21,682\end{array}$ \\
\hline 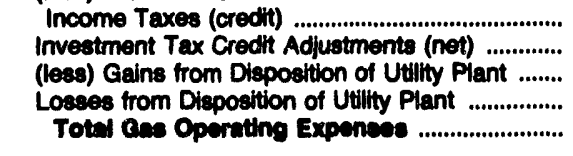 & $\begin{array}{l}0 \\
0 \\
0 \\
0 \\
0\end{array}$ & $\begin{array}{l}0 \\
0 \\
0 \\
0 \\
0\end{array}$ & $\begin{array}{l}0 \\
0 \\
0 \\
0 \\
0\end{array}$ & $\begin{array}{r}15,380 \\
-1,584 \\
0 \\
0 \\
1,402,332\end{array}$ & $\begin{array}{l}0 \\
0 \\
0 \\
0 \\
0\end{array}$ & $\begin{array}{r}1,079 \\
-102 \\
0 \\
0 \\
201,612\end{array}$ \\
\hline Not cas Utilty Operating Incoms ..................... & 0 & $\mathbf{0}$ & 0 & 93,040 & $\mathbf{0}$ & 20,005 \\
\hline $\begin{array}{l}\text { Other Utillty Operating Incorne } \\
\text { Other Utillty Operating Revenues ............................ }\end{array}$ & 0 & 0 & 0 & 0 & 0 & 13,672 \\
\hline 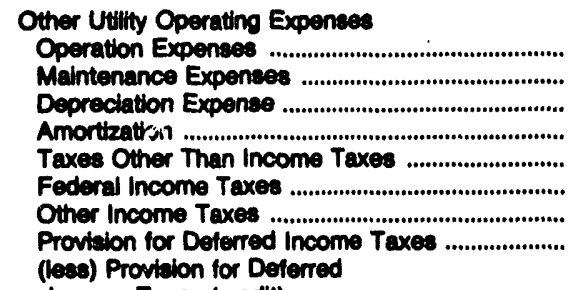 & $\begin{array}{l}0 \\
0 \\
0 \\
0 \\
0 \\
0 \\
0 \\
0\end{array}$ & $\begin{array}{l}0 \\
0 \\
0 \\
0 \\
0 \\
0 \\
u \\
0\end{array}$ & $\begin{array}{l}0 \\
0 \\
0 \\
0 \\
0 \\
0 \\
0 \\
0\end{array}$ & $\begin{array}{l}0 \\
0 \\
0 \\
0 \\
0 \\
0 \\
0 \\
0\end{array}$ & $\begin{array}{l}0 \\
0 \\
0 \\
0 \\
0 \\
0 \\
0 \\
0\end{array}$ & $\begin{array}{r}3,709 \\
753 \\
1,362 \\
28 \\
532 \\
2,013 \\
450 \\
-208\end{array}$ \\
\hline 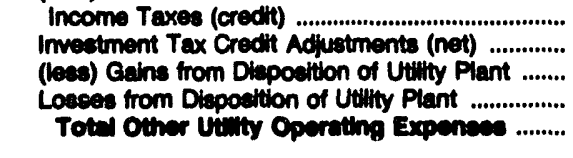 & $\begin{array}{l}0 \\
0 \\
0 \\
0 \\
0\end{array}$ & $\begin{array}{l}0 \\
0 \\
0 \\
0 \\
0\end{array}$ & $\begin{array}{l}0 \\
0 \\
0 \\
0 \\
0\end{array}$ & $\begin{array}{l}0 \\
0 \\
0 \\
0 \\
0\end{array}$ & $\begin{array}{l}0 \\
0 \\
0 \\
0 \\
0\end{array}$ & $\begin{array}{r}0 \\
-34 \\
0 \\
0 \\
8,605\end{array}$ \\
\hline Net Other Uunty Operating Incems ................. & $\mathbf{0}$ & $\mathbf{0}$ & $\mathbf{0}$ & 0 & 0 & 5,067 \\
\hline
\end{tabular}

See endnotes at end of an Individual slectric utility. 
Table 37. Statement of Income and Rotalned Earninge

by Major U.S. Inveotor-Owned Electrle

Utility Within State, 1902 (Continued)

(Thousand Dollers)

\begin{tabular}{|c|c|c|c|c|c|c|}
\hline $1 \mathrm{tem}$ & \begin{tabular}{|} 
New Hampehiro \\
Publlo \\
servioe \\
Co \\
of NH
\end{tabular} & $\begin{array}{l}\text { Now Jereoy } \\
\text { Attantio } \\
\text { City } \\
\text { Eleotilc } \\
\text { Co }\end{array}$ & $\begin{array}{l}\text { Now Jereey } \\
\text { Jareey } \\
\text { Central } \\
\text { Powerduliont } \\
\text { Co }\end{array}$ & $\begin{array}{l}\text { Now Jeney } \\
\text { Public } \\
\text { Service } \\
\text { Eleotriceias } \\
\text { Co }\end{array}$ & $\begin{array}{l}\text { Now Jerney } \\
\text { Rockland } \\
\text { Electric Co }\end{array}$ & $\begin{array}{l}\text { New Moxico } \\
\text { Publlo } \\
\text { Service } \\
\text { Co } \\
\text { of NM }\end{array}$ \\
\hline $\begin{array}{l}\text { Total Ually Operating Income } \\
\text { Total Utilty Operating Revenue ............................. }\end{array}$ & 874,329 & 816,032 & $1,774,071$ & $4,994,000$ & 126,767 & 840,601 \\
\hline 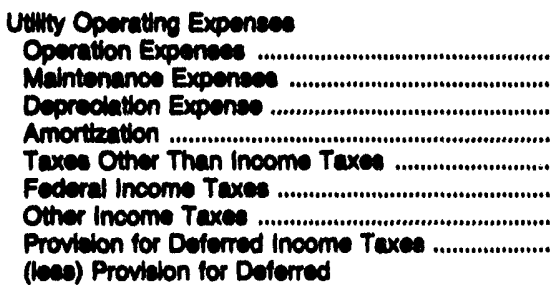 & $\begin{array}{r}509,081 \\
43,063 \\
46,580 \\
87,702 \\
36,732 \\
37,400 \\
70 \\
18,700\end{array}$ & $\begin{array}{r}113,011 \\
49,020 \\
67,200 \\
2,081 \\
110,083 \\
28,738 \\
0 \\
36,009\end{array}$ & $\begin{array}{r}1,020,391 \\
124,736 \\
144,636 \\
22,487 \\
216,607 \\
38,801 \\
47 \\
96,876\end{array}$ & $\begin{array}{r}2,497,687 \\
325,741 \\
468,033 \\
75,063 \\
649,787 \\
215,209 \\
1,971 \\
123,658\end{array}$ & $\begin{array}{r}90,760 \\
5,386 \\
3,606 \\
864 \\
17,075 \\
2,289 \\
0 \\
1,762\end{array}$ & $\begin{array}{r}546,175 \\
52,032 \\
70,187 \\
6,649 \\
39,606 \\
-8,603 \\
389 \\
31,621\end{array}$ \\
\hline 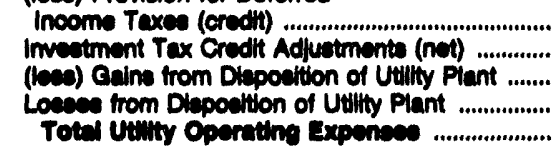 & $\begin{array}{r}41 \\
-649 \\
0 \\
0 \\
776,673\end{array}$ & $\begin{array}{r}20,028 \\
-2,634 \\
0 \\
0 \\
600,493\end{array}$ & $\begin{array}{r}82,249 \\
-6,944 \\
0 \\
0 \\
1,500,217\end{array}$ & $\begin{array}{r}123,991 \\
-19,089 \\
0 \\
0 \\
4,204,840\end{array}$ & $\begin{array}{r}2,267 \\
-137 \\
0 \\
0 \\
119,340\end{array}$ & $\begin{array}{r}3,177 \\
-6,118 \\
0 \\
0 \\
730,010\end{array}$ \\
\hline 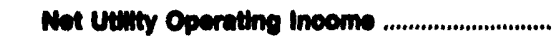 & 98,469 & 130,400 & 108,884 & 700,161 & 7,400 & 100,052 \\
\hline 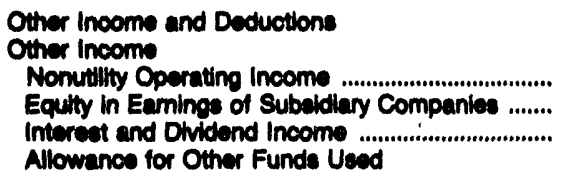 & $\begin{array}{r}0 \\
1,000 \\
2,044\end{array}$ & $\begin{array}{r}-512 \\
0 \\
3,685\end{array}$ & $\begin{array}{r}4 \\
0 \\
1,700\end{array}$ & $\begin{array}{r}-67 \\
-626 \\
39,360\end{array}$ & $\begin{array}{r}-9 \\
484 \\
167\end{array}$ & $\begin{array}{r}317 \\
803 \\
3,002\end{array}$ \\
\hline 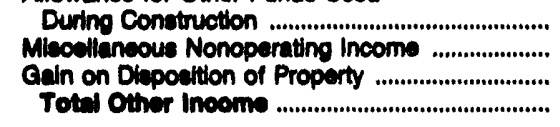 & $\begin{array}{r}-6 \\
353 \\
42 \\
4,392\end{array}$ & $\begin{array}{r}2,212 \\
30,865 \\
90 \\
30,361\end{array}$ & $\begin{array}{r}4,016 \\
21,470 \\
58 \\
27,247\end{array}$ & $\begin{array}{r}12,828 \\
61,248 \\
109 \\
112,062\end{array}$ & $\begin{array}{r}90 \\
427 \\
0 \\
1,160\end{array}$ & $\begin{array}{r}68 \\
25,981 \\
32 \\
30,183\end{array}$ \\
\hline 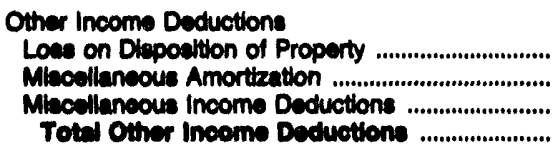 & $\begin{array}{r}-12,681 \\
171 \\
-737 \\
-12,186\end{array}$ & $\begin{array}{r}61 \\
0 \\
623 \\
684\end{array}$ & $\begin{array}{r}1 \\
0 \\
1,684 \\
1,686\end{array}$ & $\begin{array}{r}0 \\
0 \\
10,630 \\
10,630\end{array}$ & $\begin{array}{r}2 \\
0 \\
408 \\
411\end{array}$ & $\begin{array}{r}61 \\
165 \\
275,005 \\
276,221\end{array}$ \\
\hline 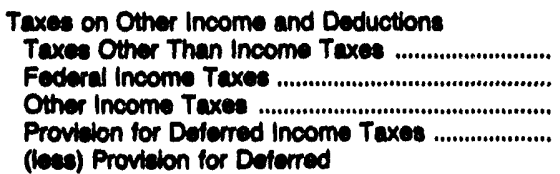 & $\begin{array}{r}27 \\
-34,487 \\
0 \\
7,438\end{array}$ & $\begin{array}{r}122 \\
9,925 \\
0 \\
304\end{array}$ & $\begin{array}{r}27 \\
318 \\
3 \\
8,417\end{array}$ & $\begin{array}{r}465 \\
16,854 \\
0 \\
8,815\end{array}$ & $\begin{array}{r}34 \\
-131 \\
0 \\
168\end{array}$ & $\begin{array}{r}48 \\
28,040 \\
2,614 \\
-118,278\end{array}$ \\
\hline 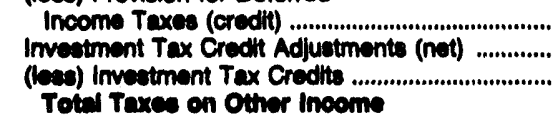 & $\begin{array}{r}0 \\
-19 \\
0\end{array}$ & $\begin{array}{r}180 \\
0 \\
0\end{array}$ & $\begin{array}{r}468 \\
0 \\
0\end{array}$ & $\begin{array}{l}0 \\
0 \\
0\end{array}$ & $\begin{array}{l}0 \\
0 \\
0\end{array}$ & $\begin{array}{r}0 \\
-16,271 \\
0\end{array}$ \\
\hline 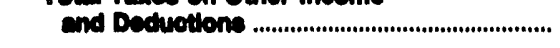 & $-27,041$ & 10,171 & 8,206 & 27,124 & 70 & $-108,069$ \\
\hline Net Other Inoome and Deductions .................. & 44,572 & 28,400 & 17,260 & 75,008 & 678 & $-130,004$ \\
\hline
\end{tabular}


Table 37. Statement of Income and Rotained Earnings

by Major U.S. Inveator-Owned Eloctric

Utility Within State, 1902 (Continued)

(Thousand Dollars)

\begin{tabular}{|c|c|c|c|c|c|c|}
\hline Ittem & $\begin{array}{c}\text { New Hampehire } \\
\text { Public } \\
\text { Service } \\
\text { Co } \\
\text { of NH }\end{array}$ & $\begin{array}{l}\text { Now Jersey } \\
\text { Attantic } \\
\text { Clyy } \\
\text { Electric } \\
\text { Co }\end{array}$ & $\begin{array}{l}\text { Now Jereoy } \\
\text { Jerney } \\
\text { Contral } \\
\text { Poweraliogt } \\
\text { Co }\end{array}$ & $\begin{array}{l}\text { Now Jersey } \\
\text { Publle } \\
\text { Service } \\
\text { Eloctricklase } \\
\text { Co }\end{array}$ & $\begin{array}{l}\text { New Jersey } \\
\text { Rockland } \\
\text { Electric Co }\end{array}$ & $\begin{array}{c}\text { Now Mexico } \\
\text { Publlic } \\
\text { Service } \\
\text { Co } \\
\text { of NM }\end{array}$ \\
\hline
\end{tabular}

Intereet Charges

Intereet on Lono-term Debt

Amortenthon of Dabt Dhecount

Amortration of Loes on Reacquired

(leas) Amortzation of Premium on Debl (crediti)

(bea) Amortzation of Gain on

Revoinged Dabt (credit)

Intereet on Dabt to Aneociated

Other Intereet Expense ..............................................

(bea) Allowance for Borrowed Funds

Ueed During Conatruction (credit)

Net interna

The

Incoms Before Extreordinery ftems

(.....................

Extraordinary Items

Extraordinary Income

Net Extreortinary ttema

(leas) Federal and Other income Taxes

Extraordinary ltems After Taxes

Net Income

$\begin{array}{rr}98,604 & 50,710 \\ 3,146 & 62 \\ 0 & 1,892 \\ 0 & 50 \\ 0 & \\ 0 & 0 \\ 6,657 & 2,678 \\ 10,558 & 1,414 \\ 97,051 & 84,549 \\ & \end{array}$

42,177

107,44

552

034

55

359,158

2,781

6,717

654

0
4,006

0

33,406

13,589

4,056

98,760

390,313

117,891

475,098

3,448

63,826

1,229

88

228

1,050

8,017

1,151

74,28

104,256<smiles>[3H]</smiles>

0

0
0
0

0

0

0

0

0
0
0

0

$\mathbf{0}$

0

42,177

107,449

117,391

475,098

4,442

$-104,255$

\section{Uneppropertated Retelned Eeminoe}

Retained Eeminge - Beginning of Year

\begin{abstract}
Blance Traneferred from Income
Credt's to Retair

(leas) Debits to Retained Eaminges .......................... (leas) Appropriations of Retained Eamings ......... (kes) Dividends Declared - Preferred Stock ...... (lese) Dividends Dectared - Common Stock ....... Unappropriated Undiatributed Subaidiary
\end{abstract}

Earning: .

Retalned Eaminge - End of Year

Appropriated Retained Earninos

Appropriated Retained Earnings -

Amortzation Reserve, Federal

Toted Rotained Eeminges

\begin{tabular}{|c|c|c|c|c|c|}
\hline 0 & 285,501 & 600,522 & $1,140,282$ & 70,741 & 52,372 \\
\hline $\begin{array}{r}40,277 \\
11,187 \\
0 \\
0 \\
13,251 \\
18,418\end{array}$ & $\begin{array}{r}107,446 \\
0 \\
5 \\
0 \\
17,812 \\
78,338\end{array}$ & $\begin{array}{r}117,361 \\
0 \\
2,380 \\
0 \\
20,604 \\
30,000\end{array}$ & $\begin{array}{r}476,562 \\
0 \\
412 \\
-25 \\
31,907 \\
486,000\end{array}$ & $\begin{array}{r}3,858 \\
0 \\
0 \\
0 \\
0 \\
0\end{array}$ & $\begin{array}{r}-101,498 \\
3,560 \\
1,362 \\
0 \\
7,105 \\
3,560\end{array}$ \\
\hline 1,080 & 0 & 0 & -343 & 0 & 0 \\
\hline 20,076 & 248,093 & e44,0es & $1,009,187$ & 74,698 & $-67,603$ \\
\hline 0 & 0 & 0 & 0 & 0 & 0 \\
\hline 0 & 0 & 0 & 173 & 0 & 0 \\
\hline 20,075 & 249,19 & e44,0es & $1,000,340$ & 74,609 & $-67,803$ \\
\hline
\end{tabular}

Note: Totals may not equal sum of components because of independent rounding. Summary data are provided in Table 6. Source: Federal Energy Regulatory Commiacion, FERC Form 1. "Annual Report of Major Electric Utilties, Llcensees and Others." 
Table 37. Statement of Income and Rotained Earnings by Major U.S. Investor-Owned Electric Utility Within State, 1982 (Continued) (Thousand Dollars)

\begin{tabular}{|c|c|c|c|c|c|c|}
\hline Item & $\begin{array}{l}\text { New York } \\
\text { Contral } \\
\text { Hudeon Gas } \\
\text { a Elec Corp }\end{array}$ & $\begin{array}{l}\text { Now York } \\
\text { Consolidated } \\
\text { Edison } \\
\text { Co. } \\
\text { NY inc }\end{array}$ & $\begin{array}{c}\text { New York } \\
\text { Long } \\
\text { loland } \\
\text { Lighting } \\
\text { Co }\end{array}$ & $\begin{array}{l}\text { Now York } \\
\text { Long } \\
\text { Seult Inc }\end{array}$ & $\begin{array}{l}\text { New York } \\
\text { Now York } \\
\text { State Elec } \\
\text { \& Gas Corp }\end{array}$ & $\begin{array}{l}\text { New York } \\
\text { Nlagara } \\
\text { Mohawk } \\
\text { Power Corp }\end{array}$ \\
\hline 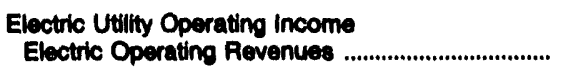 & 427,437 & $4,805,624$ & $2,176,577$ & 1,808 & $1,451,525$ & $3,123,284$ \\
\hline 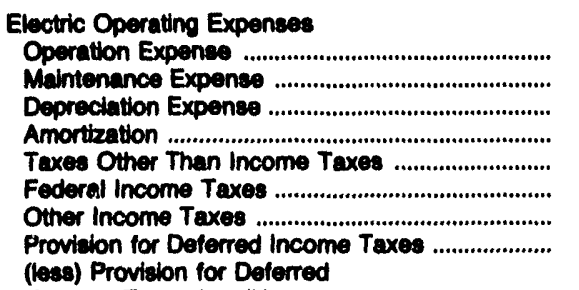 & $\begin{array}{r}216,446 \\
31,573 \\
35,952 \\
122 \\
57,088 \\
3,461 \\
0 \\
19,584\end{array}$ & $\begin{array}{r}2,078,079 \\
421,112 \\
330,174 \\
1,436 \\
1,037,461 \\
224,439 \\
0 \\
315,555\end{array}$ & $\begin{array}{r}854,682 \\
105,341 \\
104,034 \\
-58,286 \\
331,122 \\
530 \\
0 \\
345,847\end{array}$ & $\begin{array}{r}347 \\
783 \\
192 \\
0 \\
191 \\
66 \\
0 \\
34\end{array}$ & $\begin{array}{r}626,676 \\
88,329 \\
137,218 \\
13,331 \\
174,240 \\
38,740 \\
0 \\
75,350\end{array}$ & $\begin{array}{r}1,610,869 \\
200,079 \\
252,851 \\
1,005 \\
420,644 \\
114,958 \\
0 \\
103,815\end{array}$ \\
\hline 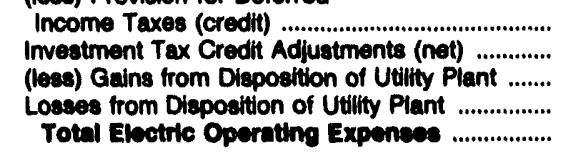 & $\begin{array}{r}1,673 \\
-4 \\
0 \\
0 \\
302,540\end{array}$ & $\begin{array}{r}245,734 \\
-12,300 \\
120 \\
0 \\
4,150,102\end{array}$ & $\begin{array}{r}187,040 \\
0 \\
0 \\
0 \\
1,469,341\end{array}$ & $\begin{array}{r}0 \\
0 \\
0 \\
0 \\
1,613\end{array}$ & $\begin{array}{r}25,465 \\
12,000 \\
42 \\
0 \\
1,146,576\end{array}$ & $\begin{array}{r}54,925 \\
-44 \\
0 \\
0 \\
2,649,247\end{array}$ \\
\hline Net Electrlc Utillty Operating Income ............ & 64,800 & 765,421 & 800,235 & 196 & 304,240 & 474,037 \\
\hline 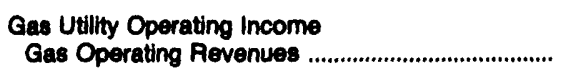 & 96,120 & 730,131 & 457,587 & 0 & 240,164 & 553,030 \\
\hline 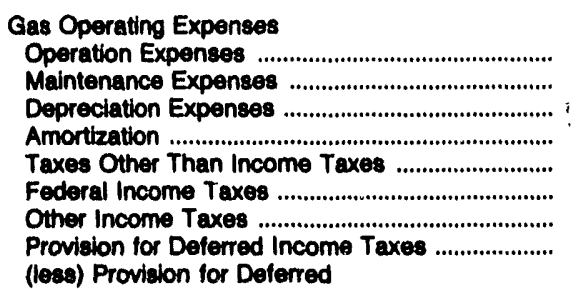 & $\begin{array}{r}67,342 \\
2,652 \\
3,517 \\
5 \\
9,252 \\
2,006 \\
0 \\
4,316\end{array}$ & $\begin{array}{r}379,753 \\
70,108 \\
39,916 \\
75 \\
115,372 \\
19,469 \\
0 \\
47,553\end{array}$ & $\begin{array}{r}289,891 \\
20,395 \\
15,108 \\
-86 \\
57,866 \\
-1,547 \\
0 \\
49,831\end{array}$ & $\begin{array}{l}0 \\
0 \\
0 \\
0 \\
0 \\
0 \\
0 \\
0\end{array}$ & $\begin{array}{r}176,175 \\
6,172 \\
8,454 \\
-27 \\
26,700 \\
-102 \\
0 \\
4,417\end{array}$ & $\begin{array}{r}386,800 \\
23,385 \\
18,709 \\
0 \\
61,040 \\
1,102 \\
0 \\
11,293\end{array}$ \\
\hline 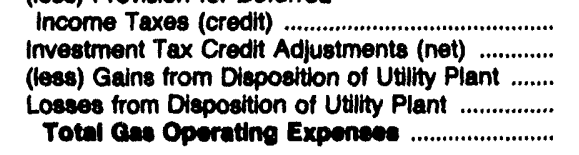 & $\begin{array}{r}2,579 \\
0 \\
0 \\
0 \\
86,511\end{array}$ & $\begin{array}{r}35,531 \\
-1,200 \\
425 \\
0 \\
835,001\end{array}$ & $\begin{array}{r}34,723 \\
0 \\
0 \\
0 \\
396,727\end{array}$ & $\begin{array}{l}0 \\
0 \\
0 \\
0 \\
0\end{array}$ & $\begin{array}{r}379 \\
-104 \\
0 \\
0 \\
221,307\end{array}$ & $\begin{array}{r}5,281 \\
0 \\
0 \\
0 \\
497,048\end{array}$ \\
\hline Not cas Utifty Operating Income .................... & 0,600 & 95,041 & 60,870 & $\mathbf{0}$ & 18,057 & 55,082 \\
\hline $\begin{array}{l}\text { Other Utilly Operating Income } \\
\text { Other Utility Operating Revenues ........................... }\end{array}$ & 0 & 314,075 & 0 & 52 & 0 & 226 \\
\hline 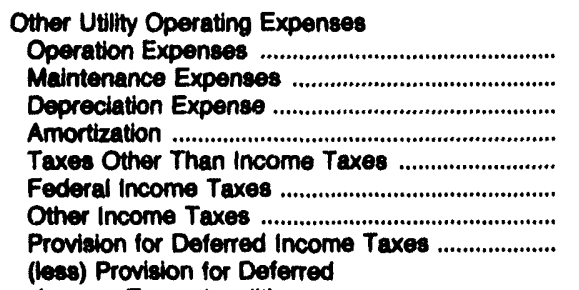 & $\begin{array}{l}0 \\
0 \\
0 \\
0 \\
0 \\
0 \\
0 \\
0\end{array}$ & $\begin{array}{r}202,883 \\
19,372 \\
9,259 \\
0 \\
46,741 \\
6,252 \\
0 \\
8,273\end{array}$ & $\begin{array}{l}0 \\
0 \\
0 \\
0 \\
0 \\
0 \\
0 \\
0\end{array}$ & $\begin{array}{r}0 \\
0 \\
31 \\
0 \\
20 \\
0 \\
0 \\
0\end{array}$ & $\begin{array}{r}0 \\
0 \\
0 \\
0 \\
0 \\
0 \\
0 \\
-288\end{array}$ & $\begin{array}{r}0 \\
0 \\
28 \\
1 \\
0 \\
0 \\
0 \\
0\end{array}$ \\
\hline 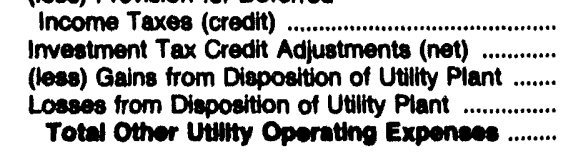 & $\begin{array}{l}0 \\
0 \\
0 \\
0 \\
0\end{array}$ & $\begin{array}{r}8,156 \\
-300 \\
145 \\
0 \\
284,170\end{array}$ & $\begin{array}{l}0 \\
0 \\
0 \\
0 \\
0\end{array}$ & $\begin{array}{r}0 \\
0 \\
0 \\
0 \\
52\end{array}$ & $\begin{array}{r}0 \\
0 \\
0 \\
0 \\
-200\end{array}$ & $\begin{array}{r}0 \\
0 \\
0 \\
0 \\
28\end{array}$ \\
\hline Net Other Utilty Operating Income ................. & 0 & 29,895 & 0 & 0 & 208 & 198 \\
\hline
\end{tabular}

See endnotes at end of an individual electric utility. 
Table 37. Statement of Income and Rotalned Earninge

by Major U.S. Inveotor-Owned Electric

Utility Within 8tato, 1992 (Continued)

(Thousand Dollars)

\begin{tabular}{|c|c|c|c|c|c|c|}
\hline litom & $\begin{array}{l}\text { Now York } \\
\text { Contral } \\
\text { Hudeon Cas } \\
\text { \& Eleo Corp }\end{array}$ & $\begin{array}{l}\text { New York } \\
\text { Coneolldated } \\
\text { Edison } \\
\text { Co- } \\
\text { NY Inc }\end{array}$ & $\begin{array}{c}\text { Now York } \\
\text { Long } \\
\text { laland } \\
\text { Lighting } \\
\text { Co }\end{array}$ & $\begin{array}{l}\text { Now York } \\
\text { Long } \\
\text { Sault inc }\end{array}$ & $\begin{array}{l}\text { New York } \\
\text { New York } \\
\text { State Eloo } \\
\text { Cas Corp }\end{array}$ & $\begin{array}{c}\text { Now York } \\
\text { Niagara } \\
\text { Mohawk } \\
\text { Power Corp }\end{array}$ \\
\hline
\end{tabular}

Total Utilly Operating Income

Total Utility Operating Rovenues

\begin{tabular}{|c|c|c|c|c|c|}
\hline 523,557 & $5,849,720$ & $2,634,174$ & 1,860 & $1,691,689$ & $3,676,640$ \\
\hline $\begin{array}{r}289,787 \\
34,228 \\
39,499 \\
127 \\
68,330 \\
5,467 \\
0 \\
23,000\end{array}$ & $\begin{array}{r}2,680,716 \\
510,593 \\
379,350 \\
1,512 \\
1,199,573 \\
250,160 \\
0 \\
371,381\end{array}$ & $\begin{array}{r}1,144,583 \\
126,737 \\
119,137 \\
-58,374 \\
388,988 \\
-1,017 \\
0 \\
395,778\end{array}$ & $\begin{array}{r}347 \\
783 \\
223 \\
0 \\
211 \\
68 \\
0 \\
34\end{array}$ & $\begin{array}{r}803,051 \\
102,601 \\
145,072 \\
13,305 \\
200,841 \\
36,638 \\
0 \\
79,469\end{array}$ & $\begin{array}{r}1,907,689 \\
228,484 \\
271,688 \\
1,008 \\
481,684 \\
116,060 \\
0 \\
115,108\end{array}$ \\
\hline $\begin{array}{r}4,252 \\
-4 \\
0 \\
0 \\
40,080\end{array}$ & $\begin{array}{r}289,421 \\
-13,800 \\
689 \\
0 \\
6,090,373\end{array}$ & $\begin{array}{r}221,768 \\
0 \\
0 \\
0 \\
1,008,099\end{array}$ & $\begin{array}{r}0 \\
0 \\
0 \\
0 \\
1,084\end{array}$ & $\begin{array}{r}25,846 \\
11,896 \\
42 \\
0 \\
1,397,606\end{array}$ & 60, \\
\hline
\end{tabular}

Utility Operating Expenses

Operation Expenses ....

Maintentance Expenses

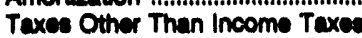

Federal Inoome Taxes

Providion

(leas) Provilion for Doterred

Income Texes (credti)

imventment Tex Credth Adtuatmente (not)

(kas) Galns from Dispoeition of Utllty Plant .......

Loseses from Dlepostiton of Utility Plent

Total Utility Operating Expenses

......................

Not Utilly Operating income

74,400

0,057

741,10

324,103

690,217

Other Income and Deductions

Other Income

Nonutillty Operating Income ......................................

Equity in Earnings of Subsidiary Companies ........

Interest and Dividend Income

Allowance for Other Funds Used

During Construction

Mlecellaneous Nonoperating Incoms .....................

Galn on Dispoaltion of Property .

Tothl Other Income

$\begin{array}{rrr}-1 & 550 & -31 \\ 634 & 1,658 & -467 \\ 485 & 17,651 & 12,627 \\ 586 & 9,313 & 4,726 \\ 4,694 & 645 & 63,46 \\ 0 & 0 & 454 \\ 0,409 & 29,817 & 80,47\end{array}$

$\begin{array}{rr}-1,200 & 654 \\ 0 & 16,352 \\ 1,518 & 1,908 \\ & \\ 2,566 & 9,648 \\ 2,633 & 16,877 \\ 80 & 108 \\ 5,607 & 48,890\end{array}$

Other Income Deductions

Lose on Dieposition of Property

Miscellaneous Amortization

Miscellaneous Income Deduotions

Total Other Inoome Deduetion.

Taxes on Other Income and Deductions

Taxes Other Than Income Taxes

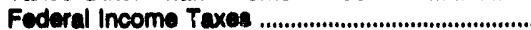

Other Income Taxes ..................................................

Prowilion for Deferred income Taxes

(lees) Provilion for Doterred

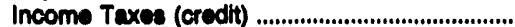

Investment Tax Credt Adfuctments (net) ...............

(lese) Invedtment Tax Credts .....

Totil Taxes on Other Inoome

and Deduotione

$\begin{array}{rr}90 & 1,309 \\ 7,789 & 1,790 \\ 0 & 0 \\ 4,851 & 1,730 \\ 11,992 & 790 \\ 0 & 0 \\ 1,398 & 0\end{array}$

1,468
0
0

31,178

0,091

60,742

Net Other Income and Deductions

$-868$

4,090

42,788

0
423

259

1,427

2,053

812

0

$\begin{array}{rr}-563 & 19,706 \\ 0 & 0\end{array}$

16,927

8,023

6,771

18,328

See endnotes at end of an indluldual eleotric utility.

68,880

10,141

21,004 
Table 37. Statement of Income and Retained Earnings

by Major U.S. Inveator-Owned Eloctric

Utility Within State, 1992 (Continued)

(Thousand Dollars)

\begin{tabular}{|c|c|c|c|c|c|c|}
\hline Itom & $\begin{array}{l}\text { Now York } \\
\text { Contral } \\
\text { Hudeon Gas } \\
\text { \&. Elec Corp }\end{array}$ & $\begin{array}{l}\text { Now York } \\
\text { Consolldated } \\
\text { Edleon } \\
\text { Co- } \\
\text { NY Ino }\end{array}$ & $\begin{array}{c}\text { Now York } \\
\text { Long } \\
\text { laland } \\
\text { Lohting } \\
\text { Co }\end{array}$ & $\begin{array}{l}\text { New York } \\
\text { Long } \\
\text { Sault inc }\end{array}$ & $\begin{array}{l}\text { New York } \\
\text { New York } \\
\text { State Elec } \\
\text { \& Gas Corp }\end{array}$ & $\begin{array}{c}\text { Now York } \\
\text { Niagara } \\
\text { Mohawk } \\
\text { Power Corp }\end{array}$ \\
\hline
\end{tabular}

Intereat Charges

Interest on Lono-term Debt

Amortzation of Loss on Reacquired Debt ............

(less) Amortization of Premium on Debt (credit)

(lese) Amortzation of Gain on

Reaquired Debt (credit) ......................................

Interest on Debt to Associated Companies .........

Other Interest Expense .

(less) Allowance for Borrowed Funds

Used During Construction (credit)

Net interest Charges.

Incems Before Extreordinary tiems

e....................

Extraordinary ltems

Extraordinary income

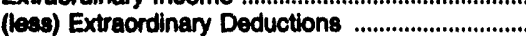

Not Extruordinary Itoms

(less) Federal and Other Income Taxes

Extreordinary Items After Taxes

Not Income

\section{d Rotained Earninge}

Unapproprlated Rotained Eamings
Rotalned Eeminos - Baginning of Year

Balance Transferred from Income ........................

Credts to Retained Earnings ...

(lees) Dabits to Retained Earninge

(less) Appropriations of Retained Earnings .........

(less) Dividends Declared - Preferred Stock .......

(tees) Dividends Declared - Common Stock .......

Unappropriated Undistributed Subsidiary

Earnings

Rotalned Eaminge - End of Year

Approprlated Retained Earnings

Appropriated Retained Earnings -

Amortization Reserve, Federal

Totel Rotained Eeminges

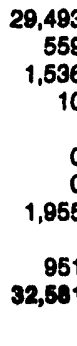

47.898

$$
\begin{array}{r}
450,621 \\
19,623 \\
22,418 \\
83
\end{array}
$$

9
0

19,836

7,386

605,020

301,974

0
0
0
0

$0 \quad 144,411$

$0 \quad 1,521$

$\begin{array}{rr}0 & 4,446 \\ 0 & 34\end{array}$

$0 \quad 145$

$\begin{array}{lr}0 & 0 \\ 0 & 3,634\end{array}$

3,557

180,270

183,098
278,221

12,905

278

121
0

16,641

11,783

205,580

258,432

$$
\begin{aligned}
& 0 \\
& 0 \\
& 0
\end{aligned}
$$

\begin{tabular}{|c|c|c|c|c|c|}
\hline 46,126 & $3,392,390$ & 820,232 & 432 & 308,323 & 161,213 \\
\hline $\begin{array}{r}47,054 \\
0 \\
0 \\
0 \\
5,544 \\
31,545\end{array}$ & $\begin{array}{r}602,430 \\
30,392 \\
20 \\
0 \\
36,343 \\
439,150\end{array}$ & $\begin{array}{r}302,529 \\
0 \\
278 \\
0 \\
62,386 \\
101,683\end{array}$ & $\begin{array}{r}214 \\
0 \\
0 \\
0 \\
0 \\
160\end{array}$ & $\begin{array}{r}183,968 \\
0 \\
0 \\
-48 \\
20,985 \\
144,621\end{array}$ & $\begin{array}{r}240,080 \\
0 \\
0 \\
20,000 \\
36,512 \\
103,784\end{array}$ \\
\hline 0 & 0 & 0 & 0 & 0 & 0 \\
\hline $58,0: 0$ & $3,469,608$ & 608,404 & 498 & 328,724 & 240,997 \\
\hline 0 & 0 & 0 & 0 & 0 & 68,000 \\
\hline 0 & 0 & 0 & 0 & 316 & 930 \\
\hline 56,090 & $3,499,090$ & 968,404 & 400 & 327,040 & 300,028 \\
\hline
\end{tabular}

$\mathbf{0}$
$\mathbf{0}$

$47,688 \quad 604,088 \quad 301,974$

$214 \quad 183,988$

258,492

Note: Totals may not equal sum of components because of independent rounding. Summary data are provided in Table 6.

Source: Federal Energy Regulatory Commission, FEAC Form 1, "Annual Report of Major Electric Utilties, Licensees and Others." 
Table 37. Statement of Income and Rotained Earnings

by Major U.S. Inveotor-Owned Elactrle

Utility Within State, 1902 (Continued)

(Thousand Dollars)

\begin{tabular}{|c|c|c|c|c|c|c|}
\hline Item & $\begin{array}{l}\text { New York } \\
\text { Orange } \\
\text { Rockland } \\
\text { Utils } \\
\text { Inc }\end{array}$ & $\begin{array}{l}\text { Now York } \\
\text { Roohoeter } \\
\text { Ges } \\
\text { Electric Corp }\end{array}$ & $\begin{array}{c}\text { North Carolina } \\
\text { Carolina } \\
\text { Power } \\
\mathbf{a} \\
\text { Light Co }\end{array}$ & $\begin{array}{l}\text { North Carolina } \\
\text { Duke } \\
\text { Power Co }\end{array}$ & $\begin{array}{c}\text { North Carolina } \\
\text { Nantahala } \\
\text { Power } \\
\text { Light Co }\end{array}$ & $\begin{array}{l}\text { North Carolina } \\
\text { Yadkin } \\
\text { Inc }\end{array}$ \\
\hline $\begin{array}{l}\text { Electric Utility Operating Income } \\
\text { Electric Operatting Reverues .................................... }\end{array}$ & 403,125 & 636,352 & $2,768,821$ & $3,961,484$ & 60,183 & 25,448 \\
\hline 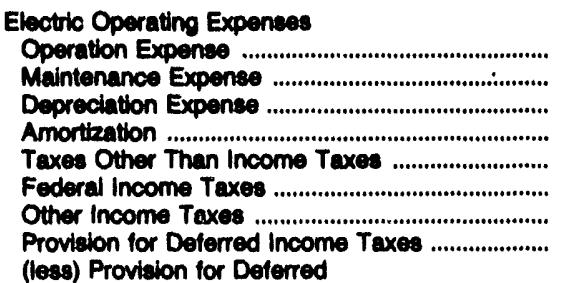 & $\begin{array}{r}211,058 \\
32,286 \\
22,793 \\
4,459 \\
57,082 \\
12,263 \\
0 \\
9,492\end{array}$ & $\begin{array}{r}259,743 \\
53,714 \\
72,459 \\
754 \\
94,841 \\
32,733 \\
0 \\
0,187\end{array}$ & $\begin{array}{r}1,236,713 \\
247,868 \\
305,887 \\
92,083 \\
131,897 \\
80,085 \\
36,875 \\
285,688\end{array}$ & $\begin{array}{r}1,868,012 \\
403,162 \\
408,110 \\
64,379 \\
215,493 \\
216,650 \\
47,116 \\
187,680\end{array}$ & $\begin{array}{r}40,384 \\
4,866 \\
4,683 \\
-46 \\
3,389 \\
1,248 \\
316 \\
727\end{array}$ & $\begin{array}{r}18,586 \\
3,431 \\
1,406 \\
0 \\
815 \\
366 \\
119 \\
36\end{array}$ \\
\hline 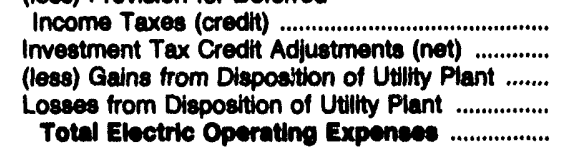 & $\begin{array}{r}4,689 \\
-126 \\
0 \\
0 \\
346,536\end{array}$ & $\begin{array}{r}3,072 \\
-602 \\
0 \\
0 \\
519,567\end{array}$ & $\begin{array}{r}173,013 \\
-11,265 \\
0 \\
0 \\
2,222,925\end{array}$ & $\begin{array}{r}149,643 \\
-11,262 \\
1 \\
0 \\
3,236,712\end{array}$ & $\begin{array}{r}53 \\
-130 \\
0 \\
0 \\
55,354\end{array}$ & $\begin{array}{r}0 \\
-64 \\
0 \\
0 \\
24,704\end{array}$ \\
\hline Not Eloctric Utilty Operating Inoome ............. & 67,587 & 116,704 & 643,080 & 724,772 & 4,020 & 744 \\
\hline 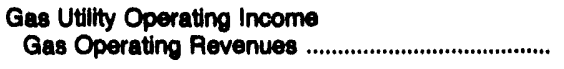 & 140,465 & 286,619 & 0 & 0 & 0 & 0 \\
\hline 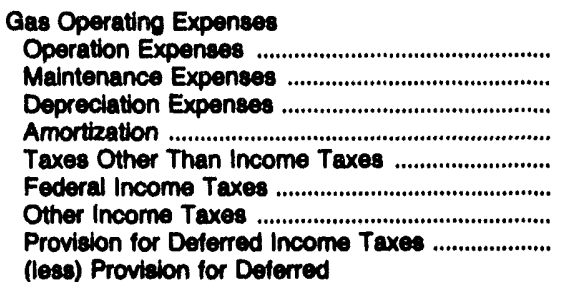 & $\begin{array}{r}97,945 \\
4,537 \\
5,813 \\
575 \\
15,101 \\
1,378 \\
0 \\
0 \\
3,067\end{array}$ & $\begin{array}{r}189,684 \\
9,006 \\
11,815 \\
0 \\
29,412 \\
3,368 \\
0 \\
132\end{array}$ & $\begin{array}{l}0 \\
0 \\
0 \\
0 \\
0 \\
0 \\
0 \\
0\end{array}$ & $\begin{array}{l}0 \\
0 \\
0 \\
0 \\
0 \\
0 \\
0 \\
0\end{array}$ & $\begin{array}{l}0 \\
0 \\
0 \\
0 \\
0 \\
0 \\
0 \\
0\end{array}$ & $\begin{array}{l}0 \\
0 \\
0 \\
0 \\
0 \\
0 \\
0 \\
0\end{array}$ \\
\hline 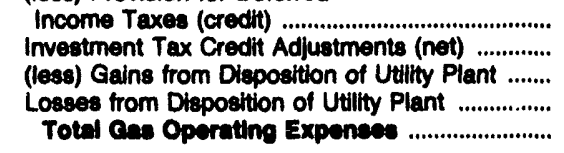 & $\begin{array}{r}1,049 \\
0 \\
0 \\
0 \\
127,387\end{array}$ & $\begin{array}{r}-2,044 \\
0 \\
0 \\
0 \\
245,471\end{array}$ & $\begin{array}{l}0 \\
0 \\
0 \\
0 \\
0\end{array}$ & $\begin{array}{l}0 \\
0 \\
0 \\
0 \\
0\end{array}$ & $\begin{array}{l}0 \\
0 \\
0 \\
0 \\
0\end{array}$ & $\begin{array}{l}0 \\
0 \\
0 \\
0 \\
0\end{array}$ \\
\hline Not Cas Utulty Operating Income ..................... & 13,008 & 21,140 & $\mathbf{0}$ & $\mathbf{0}$ & 0 & $\mathbf{0}$ \\
\hline $\begin{array}{l}\text { Other Utilly Operating Income } \\
\text { Other Utilly Operating Revenues ............................. }\end{array}$ & 0 & 0 & 0 & 8,187 & 0 & 0 \\
\hline 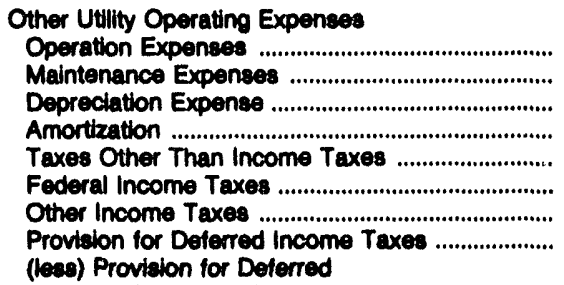 & $\begin{array}{l}0 \\
0 \\
0 \\
0 \\
0 \\
0 \\
0 \\
0\end{array}$ & $\begin{array}{l}0 \\
0 \\
0 \\
0 \\
0 \\
0 \\
0 \\
0\end{array}$ & $\begin{array}{l}0 \\
0 \\
0 \\
0 \\
0 \\
0 \\
0 \\
0\end{array}$ & $\begin{array}{r}3,016 \\
591 \\
693 \\
0 \\
689 \\
806 \\
212 \\
0\end{array}$ & $\begin{array}{l}0 \\
0 \\
0 \\
0 \\
0 \\
0 \\
0 \\
0\end{array}$ & $\begin{array}{l}0 \\
0 \\
0 \\
0 \\
0 \\
0 \\
0 \\
0\end{array}$ \\
\hline 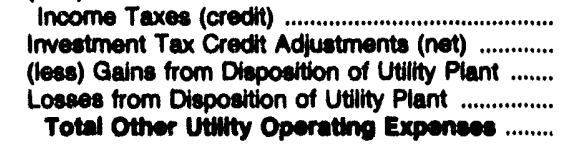 & $\begin{array}{l}0 \\
0 \\
0 \\
0 \\
0\end{array}$ & $\begin{array}{l}0 \\
0 \\
0 \\
0 \\
0\end{array}$ & $\begin{array}{l}0 \\
0 \\
0 \\
0 \\
0\end{array}$ & $\begin{array}{r}0 \\
-29 \\
0 \\
0 \\
6,050\end{array}$ & $\begin{array}{l}0 \\
0 \\
0 \\
0 \\
0\end{array}$ & $\begin{array}{l}0 \\
0 \\
0 \\
0 \\
0\end{array}$ \\
\hline Net Other Utility Operating Income ................ & 0 & 0 & $\mathbf{0}$ & 2,100 & 0 & $\mathbf{0}$ \\
\hline
\end{tabular}

See endnotes at end of an individual electric utility. 
Table 37. Statement of Income and Rotained Earnings by Major U.S. Investor-Owned Electric Utility Within State, 1992 (Continued) (Thousand Dollars)

\begin{tabular}{|c|c|c|c|c|c|c|}
\hline Hem & $\begin{array}{l}\text { Now York } \\
\text { Orange a } \\
\text { Rockland } \\
\text { Utils } \\
\text { ine }\end{array}$ & $\begin{array}{l}\text { Now York } \\
\text { Rocheater } \\
\text { Gas } \\
\text { Electric Corp }\end{array}$ & $\begin{array}{l}\text { North Carolina } \\
\text { Carollina } \\
\text { Power } \\
\text { Loht Co }\end{array}$ & $\begin{array}{l}\text { North Caroline } \\
\text { Duke } \\
\text { Power Co }\end{array}$ & $\begin{array}{l}\text { North Carolina } \\
\text { Nantahala } \\
\text { Power } \\
\mathbf{8} \\
\text { Light Co }\end{array}$ & $\begin{array}{l}\text { North Carolina } \\
\text { Yadkin } \\
\text { Inc }\end{array}$ \\
\hline $\begin{array}{l}\text { Total Utilly Operating Income } \\
\text { Total Utility Operating Revenues ............................. }\end{array}$ & 543,580 & 902,971 & $2,766,821$ & $3,869,651$ & 60,183 & 25,448 \\
\hline 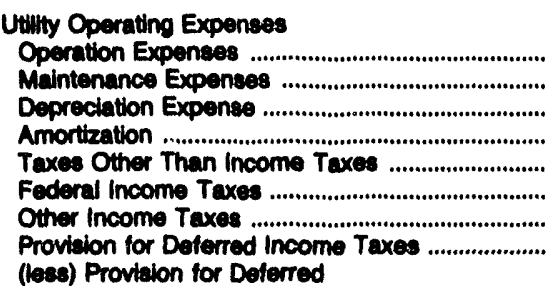 & $\begin{array}{r}309,803 \\
36,822 \\
28,600 \\
5,034 \\
72,182 \\
13,641 \\
0 \\
12,559\end{array}$ & $\begin{array}{r}449,437 \\
62,720 \\
84,274 \\
754 \\
124,252 \\
36,101 \\
0 \\
9,319\end{array}$ & $\begin{array}{r}1,236,713 \\
247,866 \\
305,987 \\
92,033 \\
131,897 \\
80,065 \\
36,875 \\
285,688\end{array}$ & $\begin{array}{r}1,859,028 \\
408,763 \\
408,803 \\
64,379 \\
216,162 \\
216,566 \\
47,328 \\
187,686\end{array}$ & $\begin{array}{r}40,364 \\
4,866 \\
4,663 \\
-46 \\
3,399 \\
1,248 \\
316 \\
727\end{array}$ & $\begin{array}{r}18,586 \\
3,431 \\
1,405 \\
0 \\
815 \\
366 \\
119 \\
36\end{array}$ \\
\hline 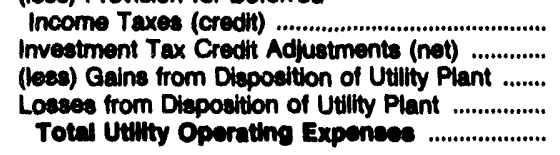 & $\begin{array}{r}5,718 \\
-126 \\
0 \\
0 \\
472,005\end{array}$ & $\begin{array}{r}1,028 \\
-802 \\
0 \\
0 \\
706,026\end{array}$ & $\begin{array}{r}173,013 \\
-11,265 \\
0 \\
0 \\
2,222,925\end{array}$ & $\begin{array}{r}148,643 \\
-11,291 \\
1 \\
0 \\
3,242,771\end{array}$ & $\begin{array}{r}53 \\
-130 \\
0 \\
0 \\
65,354\end{array}$ & $\begin{array}{r}0 \\
-64 \\
0 \\
0 \\
24,704\end{array}$ \\
\hline Not Uttity Operating Income ................................ & 70,675 & 137,043 & 543,090 & 728,800 & 4,820 & 744 \\
\hline $\begin{array}{l}\text { Other Income and Deductions } \\
\text { Other Income } \\
\text { Nonutilly Operating Income .............................. } \\
\text { Equily in Earnings of Subsidiary Companies ....... } \\
\text { Interest and Dhvidend Income .............................. } \\
\text { Allowance for Other Funds Used }\end{array}$ & $\begin{array}{r}-15 \\
4,384 \\
1,897\end{array}$ & $\begin{array}{r}0 \\
-731 \\
2,049\end{array}$ & $\begin{array}{r}631 \\
0 \\
24,755\end{array}$ & $\begin{array}{r}-901 \\
23,270 \\
19,841\end{array}$ & $\begin{array}{r}35 \\
0 \\
1\end{array}$ & $\begin{array}{l}0 \\
0 \\
0\end{array}$ \\
\hline 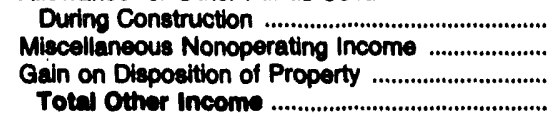 & $\begin{array}{r}259 \\
-178 \\
514 \\
8,841\end{array}$ & $\begin{array}{r}164 \\
6,232 \\
-13 \\
7,702\end{array}$ & $\begin{array}{r}7,832 \\
42,120 \\
264 \\
75,702\end{array}$ & $\begin{array}{r}15,476 \\
48,968 \\
279 \\
106,933\end{array}$ & $\begin{array}{r}0 \\
1 \\
0 \\
38\end{array}$ & $\begin{array}{l}0 \\
1 \\
0 \\
1\end{array}$ \\
\hline 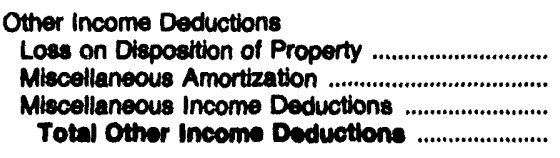 & $\begin{array}{r}6 \\
0 \\
1,546 \\
1,558\end{array}$ & $\begin{array}{r}4 \\
0 \\
1,278 \\
1,281\end{array}$ & $\begin{array}{r}5 \\
12 \\
-3,606 \\
-3,600\end{array}$ & $\begin{array}{r}543 \\
356 \\
20,860 \\
21,758\end{array}$ & $\begin{array}{r}0 \\
0 \\
81 \\
81\end{array}$ & $\begin{array}{l}0 \\
0 \\
0 \\
0\end{array}$ \\
\hline 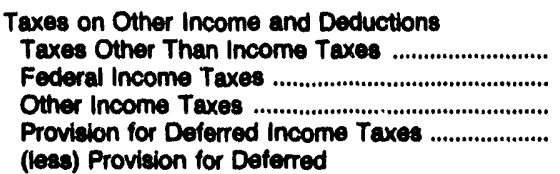 & $\begin{array}{r}61 \\
-110 \\
0 \\
21\end{array}$ & $\begin{array}{r}101 \\
-7,171 \\
0 \\
6,185\end{array}$ & $\begin{array}{r}112 \\
-2,603 \\
-527 \\
15,018\end{array}$ & $\begin{array}{r}705 \\
-13,138 \\
-3,178 \\
32,096\end{array}$ & $\begin{array}{r}27 \\
-22 \\
-6 \\
0\end{array}$ & $\begin{array}{l}0 \\
0 \\
0 \\
0\end{array}$ \\
\hline 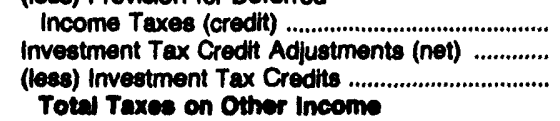 & $\begin{array}{r}-20 \\
0 \\
860\end{array}$ & $\begin{array}{r}783 \\
0 \\
2,426\end{array}$ & $\begin{array}{r}2,000 \\
0 \\
0\end{array}$ & $\begin{array}{r}14,369 \\
0 \\
0\end{array}$ & $\begin{array}{l}0 \\
0 \\
0\end{array}$ & \\
\hline and Deductions ................................................ & -800 & $-4,0024$ & 9,803 & 2,115 & $\mathbf{0}$ & 0 \\
\hline Not Other Income and Deductions ................. & 6,157 & 10,514 & 60,200 & 23,080 & -43 & 1 \\
\hline
\end{tabular}

See endnotes at end of an individual electric utility. 
Table 37. Statement of Income and Rotained Earnings by Major U.S. Investor-Owned Eloctrlc Utility Within state, 1992 (Continued) (Thousand Dollars)

\begin{tabular}{|c|c|c|c|c|c|c|}
\hline Item & $\begin{array}{l}\text { Now York } \\
\text { Orange a } \\
\text { Pockiand } \\
\text { Utlis } \\
\text { Inc }\end{array}$ & $\begin{array}{l}\text { New York } \\
\text { Rochester } \\
\text { Gas } \\
\text { Electric Corp }\end{array}$ & $\begin{array}{c}\text { North Carollina } \\
\text { Carolina } \\
\text { Power } \\
\& \\
\text { Light Co }\end{array}$ & $\begin{array}{c}\text { North Carolina } \\
\text { Duke } \\
\text { Power Co }\end{array}$ & $\begin{array}{c}\text { North Carolina } \\
\text { Nantahala } \\
\text { Power } \\
\text { Light Co }\end{array}$ & $\begin{array}{c}\text { North Carolina } \\
\begin{array}{c}\text { Yadkin } \\
\text { Inc }\end{array}\end{array}$ \\
\hline
\end{tabular}

Intereat Chargas

Interest on Long-term Debt

Amortization of Debt Discount

Amortization of Loss on Reacquired Debt ............

(less) Amorttzation of Premium on Debt (credit).

(less) Amortization of Gain on

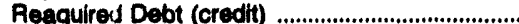

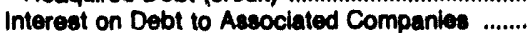

Other Interest Expense

(lese) Allowance for Borrowed Fund

Useed During Construction (credit)

Net Intereet Charges ..........................................

Incoms Betore Extreordinary Home

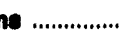

Extraordinary Items

Extraordinary Income

(less) Extraordinary Deductions

Net Extraordinary ltoms

(less) Federal and Other Income Taxes

Extreordinary Items After Taxee

Net income

Unappropriated Retalned Eaminge

Rotained Eamings - Beginning of Year

Balance Tranaferred from Income

Credits to Retained Earninge

(less) Deblts to Retained Earnings .........................

(less) Appropriations of Retained Earnings ..........

(less) Dividends Declared - Preferred Stock .......

(less) Dividends Declared - Common Stock ........

Unappropriated Undistributed Subaidlary

Earnings

Rotainad Eamings - End of Yoar

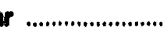

Approprlated Rotained Earnings

Approprlated Retained Earnings

Amortzation Reserve, Federal

Total Rotained Eaminge

\begin{tabular}{|c|c|}
\hline $\begin{array}{r}28,531 \\
389 \\
0 \\
35\end{array}$ & $\begin{array}{r}60,810 \\
2,010 \\
0 \\
28\end{array}$ \\
\hline $\begin{array}{r}0 \\
189 \\
1,882\end{array}$ & $\begin{array}{r}0 \\
0 \\
9,194\end{array}$ \\
\hline $\begin{array}{r}6 \\
31,020\end{array}$ & $\begin{array}{r}2,184 \\
80,803\end{array}$ \\
\hline 45,612 & 76,065 \\
\hline
\end{tabular}

223,168

4,322

223
32

257,149

2,674

5,837

114

0

369
41,814

6.763

301,086

cos,003

1,273

7

0

0
0

0
246

268

1,260

3,626

744

0
8,216

$-0,210$

0
-.218

70,439

370,835

1,650

97,860

62,807

$1,034,152$

1,925, 132

38,765

3,790

$\begin{array}{rr}41,448 & 71,1 \\ 0 & \\ 0 & \\ 0 & \\ 3,481 & \\ 32,587 & 8,2 \\ & 56,6 \\ 0 & \end{array}$

379,638

14,208

3,176

14,786

258,375

484,812

0

4,887
39

56,407

380,478

0

3,526

1,660

0

0

0

0

103,239

00,090

$1,163,647$

$1,989,134$

40,201

5,440

0

0

0

0

0

0

0

54

39

$1,163,647$

$1,000,172$

40,291

5,448

Note: Totals may not equal sum of components because of independent rounding. Summary data are provided in Table 6.

Source: Federal Energy Regulatory Commiseion, FERC Form 1, "Annual Report of Major Electric Utilities, Licensees and Others." 
Table 37. Statement of Income and Rotalned Earnings

by Major U.S. Investor-Owned Electrle

Utility Within State, 1922 (Continued)

(Thousand Dollars)

\begin{tabular}{|c|c|c|c|c|c|c|}
\hline Item & $\begin{array}{c}\text { North Dakota } \\
\text { MDU } \\
\text { Pesources } \\
\text { Group } \\
\text { Ino }\end{array}$ & $\begin{array}{c}\text { Ohio } \\
\text { Cincinnat } \\
\text { Gas } \\
\text { Electric Co }\end{array}$ & $\begin{array}{l}\text { Ohio } \\
\text { Cloveland } \\
\text { Eleotrio } \\
\text { Illum Co }\end{array}$ & $\begin{array}{l}\text { Ohlo } \\
\text { Columbus } \\
\text { Southern } \\
\text { Power Co }\end{array}$ & $\begin{array}{l}\text { Ohio } \\
\text { Dayton } \\
\text { Power } \\
\text { Lught Co } \\
\end{array}$ & $\begin{array}{l}\text { Onlo } \\
\text { Indlana- } \\
\text { Kentucky } \\
\text { Eleotrio } \\
\text { Corp }\end{array}$ \\
\hline $\begin{array}{l}\text { Electrio Utilty Operating Inoome } \\
\text { Electric Operating Pevenues .................................... }\end{array}$ & 128,808 & $1,128,116$ & $1,743,168$ & 843,808 & 813,112 & 140,710 \\
\hline 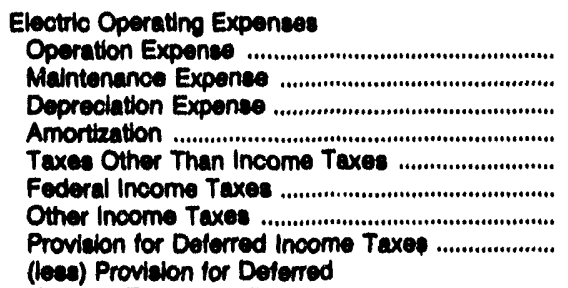 & $\begin{array}{r}63,970 \\
8,160 \\
14,695 \\
437 \\
6,467 \\
3,203 \\
690 \\
12,610\end{array}$ & $\begin{array}{r}405,810 \\
68,036 \\
110,619 \\
-36,653 \\
134,670 \\
56,747 \\
436 \\
68,027\end{array}$ & $\begin{array}{r}776,381 \\
122,769 \\
187,004 \\
-36,215 \\
226,394 \\
46,388 \\
0 \\
173,839\end{array}$ & $\begin{array}{r}487,347 \\
54,289 \\
84,335 \\
-20,690 \\
97,314 \\
-483 \\
0 \\
79,512\end{array}$ & $\begin{array}{r}330,785 \\
68,825 \\
97,490 \\
2,167 \\
80,497 \\
38,269 \\
175 \\
38,987\end{array}$ & $\begin{array}{r}115,629 \\
17,804 \\
3,841 \\
0 \\
3,252 \\
0 \\
98 \\
0\end{array}$ \\
\hline 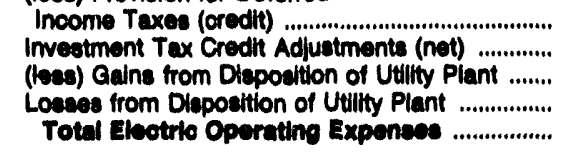 & $\begin{array}{r}8,802 \\
? \\
j \\
0 \\
101,321\end{array}$ & $\begin{array}{r}27,628 \\
5,262 \\
0 \\
0 \\
0 \\
096,116\end{array}$ & $\begin{array}{r}130,466 \\
-8,369 \\
0 \\
0 \\
1,360,624\end{array}$ & $\begin{array}{r}65,390 \\
-4,494 \\
0 \\
0 \\
721,091\end{array}$ & $\begin{array}{r}19,603 \\
-3,374 \\
0 \\
0 \\
643,210\end{array}$ & $\begin{array}{r}0 \\
0 \\
0 \\
0 \\
140,726\end{array}$ \\
\hline Net Electrite Utility Oparating Inoome ............ & 22,607 & 232,000 & 303,634 & 122,106 & 160,093 & $\rightarrow$ \\
\hline 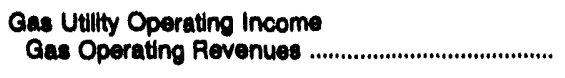 & 128,194 & 327,093 & 0 & 0 & 204,254 & 0 \\
\hline 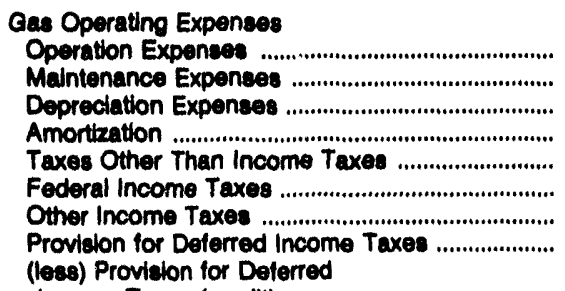 & $\begin{array}{r}112,791 \\
2,678 \\
4,782 \\
27 \\
3,406 \\
-919 \\
-153 \\
16,626\end{array}$ & $\begin{array}{r}260,321 \\
10,057 \\
11,885 \\
205 \\
35,610 \\
-2,262 \\
0 \\
4,810\end{array}$ & $\begin{array}{l}0 \\
0 \\
0 \\
0 \\
0 \\
0 \\
0 \\
0\end{array}$ & $\begin{array}{l}0 \\
0 \\
0 \\
0 \\
0 \\
0 \\
0 \\
0\end{array}$ & $\begin{array}{r}152,869 \\
6,067 \\
5,654 \\
0 \\
17,781 \\
-3,222 \\
0 \\
14,645\end{array}$ & $\begin{array}{l}0 \\
0 \\
0 \\
0 \\
0 \\
0 \\
0 \\
0\end{array}$ \\
\hline 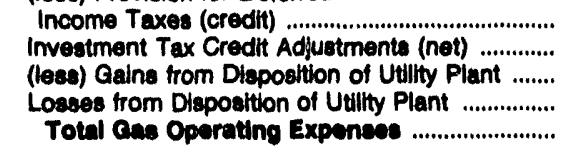 & $\begin{array}{r}14,607 \\
0 \\
0 \\
0 \\
124,732\end{array}$ & $\begin{array}{r}1,031 \\
284 \\
0 \\
0 \\
300,078\end{array}$ & $\begin{array}{l}0 \\
0 \\
0 \\
0 \\
0\end{array}$ & $\begin{array}{l}0 \\
0 \\
0 \\
0 \\
0\end{array}$ & $\begin{array}{r}5,386 \\
-81 \\
0 \\
0 \\
108,147\end{array}$ & $\begin{array}{l}0 \\
0 \\
0 \\
0 \\
0\end{array}$ \\
\hline Not Cas Utility Oporating Inoome .................... & 3,462 & 18,016 & 0 & 0 & 16,107 & o \\
\hline 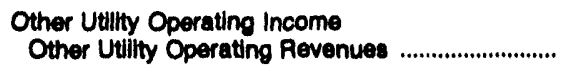 & 0 & 0 & 0 & 0 & 6,703 & 0 \\
\hline 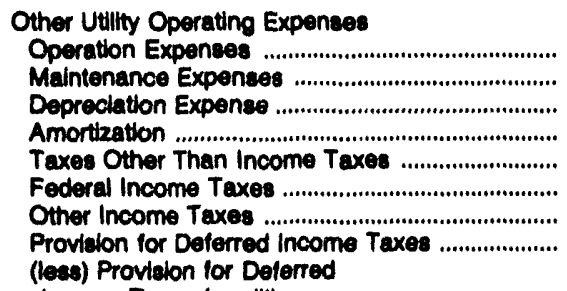 & $\begin{array}{l}0 \\
0 \\
0 \\
0 \\
0 \\
0 \\
0 \\
0\end{array}$ & $\begin{array}{l}0 \\
0 \\
0 \\
0 \\
0 \\
0 \\
0 \\
0\end{array}$ & $\begin{array}{l}0 \\
0 \\
0 \\
0 \\
0 \\
0 \\
0 \\
0\end{array}$ & $\begin{array}{l}0 \\
0 \\
0 \\
0 \\
0 \\
0 \\
0 \\
0\end{array}$ & $\begin{array}{r}4,001 \\
1,078 \\
300 \\
0 \\
897 \\
135 \\
0 \\
153\end{array}$ & $\begin{array}{l}0 \\
0 \\
0 \\
0 \\
0 \\
0 \\
0 \\
0\end{array}$ \\
\hline 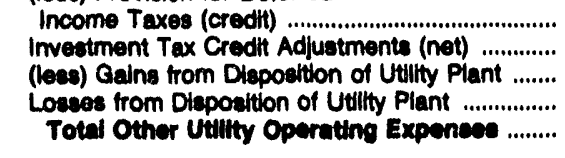 & $\begin{array}{l}0 \\
0 \\
0 \\
0 \\
0\end{array}$ & $\begin{array}{l}0 \\
0 \\
0 \\
0 \\
0\end{array}$ & $\begin{array}{l}0 \\
0 \\
0 \\
0 \\
0\end{array}$ & $\begin{array}{l}0 \\
0 \\
0 \\
0 \\
0\end{array}$ & $\begin{array}{r}297 \\
-6 \\
0 \\
0 \\
6,341\end{array}$ & $\begin{array}{l}0 \\
0 \\
0 \\
0 \\
0\end{array}$ \\
\hline Not Other Utilty Operating Inoome ................. & 0 & 0 & 0 & 0 & 382 & $\mathbf{0}$ \\
\hline
\end{tabular}

See endnotes at end of an individual electric utility. 
Table 37. Statement of Income and Retained Earnings

by Major U.S. Inveator-Owned Electric

Utility Within State, 1992 (Continued)

(Thousand Dollars)

\begin{tabular}{|c|c|c|c|c|c|c|}
\hline Item & $\begin{array}{l}\text { North Dakota } \\
\text { MDU } \\
\text { Resources } \\
\text { Group } \\
\text { Inc }\end{array}$ & $\begin{array}{c}\text { Ohio } \\
\text { Cincinnat } \\
\text { Gas } \\
2 \\
\text { Electric Co }\end{array}$ & $\begin{array}{l}\text { Ohlo } \\
\text { Cleveland } \\
\text { Electric } \\
\text { Illum Co }\end{array}$ & $\begin{array}{l}\text { Onio } \\
\text { Columbus } \\
\text { Southem } \\
\text { Power Co }\end{array}$ & $\begin{array}{l}\text { Ohio } \\
\text { Dayton } \\
\text { Power } \\
\& \\
\text { Lught Co }\end{array}$ & $\begin{array}{l}\text { Ohio } \\
\text { Indlana- } \\
\text { Kentucky } \\
\text { Electric } \\
\text { Corp }\end{array}$ \\
\hline
\end{tabular}

Total Utilty Operating Income

Utitity Operating Expenses

\section{Operation Expenses ...}

Maintenance Expenses

Deprecintion Expense

Amortization

Taxes Other Than Income Taxes

Federal Income Taxes

Other Income Taxes

Provilion for Deferred Income Taxes .....................

(leses) Provision for Deferred

Income Taxes (credt)

Investment Tax Credt Adjustments (net) .............

(less) Gains from Disposition of Utility Plant .......

Losses from Disposition of Utility Plant .

Totel Uuty Opernting Expenses

Net Utilty Operating Income

$\begin{array}{rr}176,761 & 746,132 \\ 10,828 & 98,092 \\ 19,477 & 131,50 \\ 464 & -35,448 \\ 9,874 & 170,180 \\ 2,284 & 54,48 \\ 5336 & 436 \\ 29,238 & 63,837 \\ 23,409 & 28,659 \\ 0 & 5,530 \\ 0 & \\ 0 & \\ 228,053 & 1,200,00\end{array}$

946,132

131,504

$-35,448$

70,180
54,484

435

63,837

$$
122,789
$$

776,361
122,789

$-35,215$

226,394

46,388

173,839

\section{4,289}

487,347
54,289

$\mathbf{8 4 , 3 3 5}$

$-20,590$

97,314

$-483$

79,512

130,456

$-8,369$

5,536

55,339

$-4,484$

$1,200,004$

$1,359,634$

721,091

487,655
75,870

103,353

2,167

108,175

35,182

175

53,784

25,195

$-3,461$

$-3,461$
0

937,708

17,804

3,841

0
3,252

0
98

8
0

$28,049 \quad 250,015$

383,634

122,105

186,362

Other Income and Deductions

Other income

Nonutility Operating Income

Equity in Eamings of Subaldiary Companieg

Interest and Dividend Income

$-231$

18,893

9,393

During Construction

0
1
0

28,022

Miscellaneous Nonoperating Income .....................

Gain on Disposition of Property

Total Other Income

Other Income Deductions

Loss on Disposition of Property

Miscollaneous Amortization .

Miscellaneous Income Deductions

Total Other Income Deduction:

$\begin{array}{rr}1 & 82 \\ 0 & 0 \\ 919 & 3,008 \\ 920 & 3,008\end{array}$

$$
\begin{array}{r}
0 \\
0 \\
-190 \\
-190
\end{array}
$$

12
0
945

$$
\begin{array}{r}
0 \\
216 \\
633
\end{array}
$$

Taxes on Other income and Deductions

Taxes Other Than Income Taxes

Other income Taxes

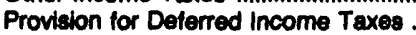

(less) Provision for Deterred

Income Taxes (credit)

Imvestment Tax Credit Adjustments (net) ..............

(less) Investment Tax Credits

Total Taxes on Other income

and Deduotione

no

Net Other Income and Deductions

$\begin{array}{rr}0 & 181 \\ -42 & -31,226 \\ -31 & 0 \\ 169 & 3,939 \\ 163 & 115 \\ 0 & 0 \\ 1,184 & 0 \\ -1,250 & -27,290\end{array}$

0
$-20,342$
0

28,720

286
$-4,185$
0

12,550

27
$-2,948$
0

8,053

4,369
0
0

28
-287

1,189

-29
0

3,914

0

20,397

57,857

84,554

47,390

57,490

827

See endnotes at end of an individual electric utility. 
Table 37. Statement of Income and Rotalned Earnings

by Major U.S. Investor-Owned Electric

Utility Within State, 1992 (Continued)

(Thousand Dollars)

\begin{tabular}{c|c|c|c|c|c|c|c}
\hline & $\begin{array}{c}\text { North Dakota } \\
\text { Item }\end{array}$ & $\begin{array}{c}\text { Ohio } \\
\text { MDU } \\
\text { Resources } \\
\text { Group } \\
\text { Inc }\end{array}$ & $\begin{array}{c}\text { Cincinnati } \\
\text { Gas } \\
\text { Electric co }\end{array}$ & $\begin{array}{c}\text { Ohio } \\
\text { Cleveland } \\
\text { Electric } \\
\text { Illum Co }\end{array}$ & $\begin{array}{c}\text { Columbus } \\
\text { Southern } \\
\text { Power Co }\end{array}$ & $\begin{array}{c}\text { Ohio } \\
\text { Dayton } \\
\text { Power } \\
\text { \& } \\
\text { Light Co }\end{array}$ & $\begin{array}{c}\text { Indiana- } \\
\text { Kentucky } \\
\text { Electric } \\
\text { Corp }\end{array}$ \\
\hline
\end{tabular}

Interest Charges

Interest on Long-term Dobt ...................................

Amortization of Debt Discount and Expense ......

Amortization of Loss on Reacquired Debt ............

(lese) Amortzation of Premium on Debt (credit) .

(leas) Amortization of Gain on

Reaquired Debt (credit)

Intereat on Deht to Asecociated Compa

Other Interest Expense

(lese) Allowance for Borrowed Funds

Used During Construction (credit)

Net interent Charees

Income Before Extraordinary item

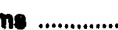

Incoms Botor Extrwordinary itomg

Extraordinary ltems

Extreordinary Income

Deduction

Not Extreordinary litoms

(less) Federal and Other Income Taxes

Extracondinary liems Aftor Taxea..

Net Income

Uneppropitated Rotalned Eaminge

Rotalnod Earninge - Beginning of Year

Balance Transferred from Income .........................

Credits to Retained Earnings ...................................

(less) Debits to Retained Earnings ........................

(less) Appropriations of Retained Earnings

(less) Dividends Declared - Preferred Stock .......

(lese) Dividends Declared - Common Stock .......

Unappropriated Undistributed Subsidiary

Eamings .................................................................

Rotalned Earninge - End of Year

Appropriated Retained Earnings

Appropriated Retained Earnings -

Amortization Reserve, Federal .

Total Retalned Eamings

$\begin{array}{rr}17,643 & 151,670 \\ 268 & 950 \\ 1,209 & 2,887 \\ 0 & 8 \\ 121 & \\ 0 & 11 \\ 1,105 & 1,904 \\ 37 & 51,934 \\ 20,004 & 105,60\end{array}$

35,371

202,208

204,035

233,608

1,867

3,855

32

320

516

3,939

379

249,152

$$
\begin{array}{r}
87,296 \\
956 \\
1,949 \\
13 \\
186 \\
0 \\
3,734 \\
495 \\
98,241
\end{array}
$$

76,244

141,013

87,380

9,966

882

0

136

3,930

186

101,930

0

0

0

0

35,371

202,283

204,985

76,244

141,013

0

541,097

572,440

128,608

320,760

0

15,479
0

201,019

202,695
0
2,576
0
40,746
194,697

75,801

139

10,548

68,760

201

0
187

0
9,359

103,618

27,718

27,610
141,132

12,528

3

0

23,944

599,717

837,526

125,342

360,532

0

$0 \quad 0$

0

0

0

23,844

590,717

637,526

0
69
0
0
0
0
9
0
0
142,947

0

Note: Totals may not equal sum of components because of independent rounding. Summary data are provided in Table 6 .

Source: Federal Energy Regulatory Commiseion, FERC Form 1, "Annual Report of Major Electric Utilities, Licensees and Others." 
Table 37. Statement of Income and Rotained Earninge

by Major U.S. Inveator-Owned Electric

Utility Within 8tate, 1902 (Continued)

(Thousand Dollars)

\begin{tabular}{|c|c|c|c|c|c|c|}
\hline Item & $\begin{array}{l}\text { Onio } \\
\text { Onio } \\
\text { Edison Co }\end{array}$ & $\begin{array}{l}\text { Onlo } \\
\text { Onlo } \\
\text { Power co }\end{array}$ & $\begin{array}{l}\text { Ohlo } \\
\text { Onlo } \\
\text { Valley } \\
\text { Electric } \\
\text { Corp }\end{array}$ & $\begin{array}{l}\text { Orio } \\
\text { Toledo } \\
\text { Edleon co }\end{array}$ & $\begin{array}{c}\text { Oklahoma } \\
\text { Oklahoma } \\
\text { Gas } \\
\& \\
\text { Electric Co }\end{array}$ & $\begin{array}{c}\text { Oklahoma } \\
\text { Public } \\
\text { Service } \\
\text { Co } \\
\text { of Oklahoma }\end{array}$ \\
\hline 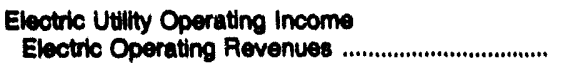 & $2,058,503$ & $1,702,430$ & 284,005 & 844,655 & $1,193,993$ & 622,082 \\
\hline 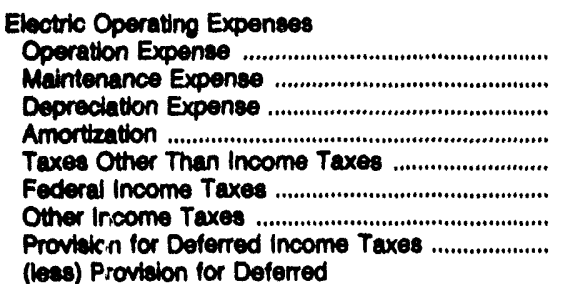 & $\begin{array}{r}807,568 \\
165,631 \\
188,309 \\
22,849 \\
203,480 \\
118,683 \\
4,961 \\
88,807\end{array}$ & $\begin{array}{r}973,083 \\
165,140 \\
123,763 \\
698 \\
159,213 \\
51,682 \\
1,082 \\
72,793\end{array}$ & $\begin{array}{r}256,734 \\
16,588 \\
108 \\
0 \\
5,207 \\
-199 \\
1 \\
5,971\end{array}$ & $\begin{array}{r}449,461 \\
61,394 \\
82,220 \\
-16,820 \\
91,384 \\
25,428 \\
0 \\
122,167\end{array}$ & $\begin{array}{r}775,823 \\
71,082 \\
99,194 \\
1,337 \\
40,206 \\
43,928 \\
7,535 \\
9,657\end{array}$ & $\begin{array}{r}389,474 \\
49,027 \\
59,012 \\
-2,009 \\
25,283 \\
1,225 \\
509 \\
37,131\end{array}$ \\
\hline 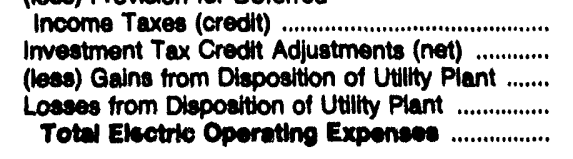 & $\begin{array}{r}93,787 \\
4,434 \\
0 \\
0 \\
1,619,928\end{array}$ & $\begin{array}{r}6 !, 311 \\
-1,732 \\
0 \\
0 \\
1,474,311\end{array}$ & $\begin{array}{r}431 \\
-1,449 \\
0 \\
0 \\
201,511\end{array}$ & $\begin{array}{r}114,883 \\
-5,303 \\
0 \\
0 \\
685,017\end{array}$ & $\begin{array}{r}6,873 \\
-5,465 \\
0 \\
0 \\
1,036,424\end{array}$ & $\begin{array}{r}15,804 \\
-2,710 \\
0 \\
-13 \\
540,224\end{array}$ \\
\hline Net Eloctric Utilty Operating Income ............ & 436,575 & 228,110 & 2,404 & 148,638 & 167,500 & 81,868 \\
\hline 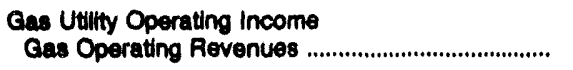 & 0 & 0 & 0 & 0 & 0 & 0 \\
\hline 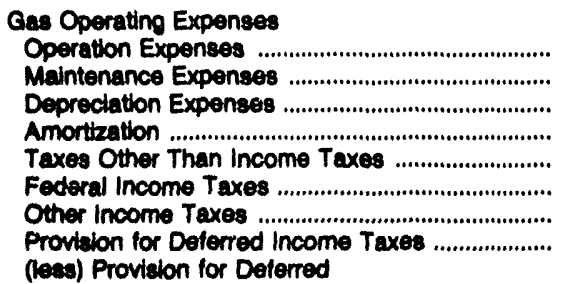 & $\begin{array}{l}0 \\
0 \\
0 \\
0 \\
0 \\
0 \\
0 \\
0\end{array}$ & $\begin{array}{l}0 \\
0 \\
0 \\
0 \\
0 \\
0 \\
0 \\
0\end{array}$ & $\begin{array}{l}0 \\
0 \\
0 \\
0 \\
0 \\
0 \\
0 \\
0\end{array}$ & $\begin{array}{l}0 \\
0 \\
0 \\
0 \\
0 \\
0 \\
0 \\
0\end{array}$ & $\begin{array}{l}0 \\
0 \\
0 \\
0 \\
0 \\
0 \\
0 \\
0\end{array}$ & $\begin{array}{l}0 \\
0 \\
0 \\
0 \\
0 \\
0 \\
0 \\
0\end{array}$ \\
\hline 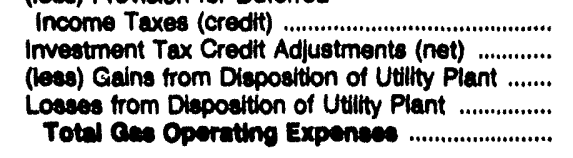 & $\begin{array}{l}0 \\
0 \\
0 \\
0 \\
0\end{array}$ & $\begin{array}{l}0 \\
0 \\
0 \\
0 \\
0\end{array}$ & $\begin{array}{l}0 \\
0 \\
0 \\
0 \\
0\end{array}$ & $\begin{array}{l}0 \\
0 \\
0 \\
0 \\
0\end{array}$ & $\begin{array}{l}0 \\
0 \\
0 \\
0 \\
0\end{array}$ & $\begin{array}{l}0 \\
0 \\
0 \\
0 \\
0\end{array}$ \\
\hline Not Ces Utulty Oparating Income ..................... & $\mathbf{0}$ & 0 & 0 & 0 & $\mathbf{0}$ & 0 \\
\hline $\begin{array}{l}\text { Other Utility Operating Income } \\
\text { Other Utilly Operating Revenues .............................. }\end{array}$ & 0 & 0 & 0 & 0 & 0 & 0 \\
\hline 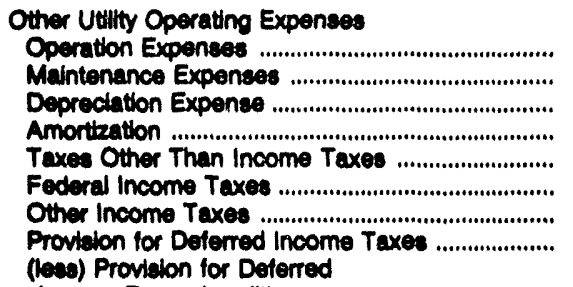 & $\begin{array}{l}0 \\
0 \\
0 \\
0 \\
0 \\
0 \\
0 \\
0\end{array}$ & $\begin{array}{l}0 \\
0 \\
0 \\
0 \\
0 \\
0 \\
0 \\
0\end{array}$ & $\begin{array}{l}0 \\
0 \\
0 \\
0 \\
0 \\
0 \\
0 \\
0\end{array}$ & $\begin{array}{l}0 \\
0 \\
0 \\
0 \\
0 \\
0 \\
0 \\
0\end{array}$ & $\begin{array}{l}0 \\
0 \\
0 \\
0 \\
0 \\
0 \\
0 \\
0\end{array}$ & $\begin{array}{l}0 \\
0 \\
0 \\
0 \\
0 \\
0 \\
0 \\
0\end{array}$ \\
\hline 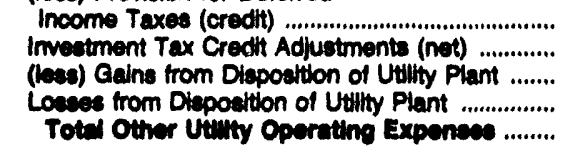 & $\begin{array}{l}0 \\
0 \\
0 \\
0 \\
0\end{array}$ & $\begin{array}{l}0 \\
0 \\
0 \\
0 \\
0\end{array}$ & $\begin{array}{l}0 \\
0 \\
0 \\
0 \\
0\end{array}$ & $\begin{array}{l}0 \\
0 \\
0 \\
0 \\
0\end{array}$ & $\begin{array}{l}0 \\
0 \\
0 \\
0 \\
0\end{array}$ & $\begin{array}{l}0 \\
0 \\
0 \\
0 \\
0\end{array}$ \\
\hline Not Other Utilty Operating Inoome ................. & $\mathbf{0}$ & 0 & 0 & $\mathbf{0}$ & $\mathbf{0}$ & $\mathbf{0}$ \\
\hline
\end{tabular}

See endnotes at end of an Individual electric utility. 
Table 37. Statement of Income and Rotained Earnings

by Major U.S. Investor-Owned Electric

Utility Within State, 1992 (Continued)

(Thousand Dollars)

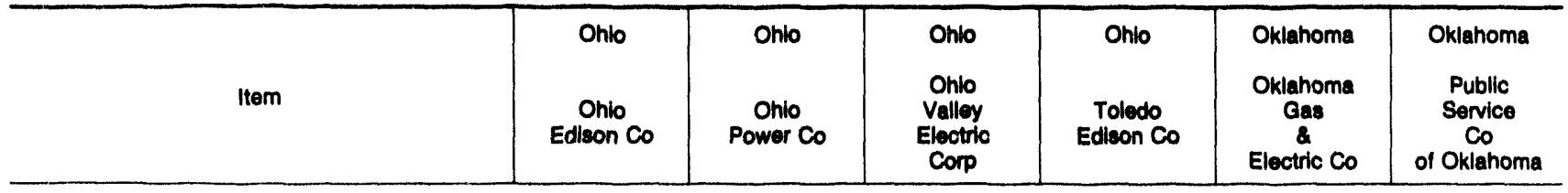

Total Utility Operating Income

Total Utility Operating Revenues

Utilty Operating Expenses

Operation Expenses

Maintenance Expenses.

Depreciation Expense

Amortization

Taxes Other Than Income Texes

Federal income Taxes

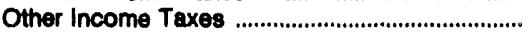

Provision for Deferred Income Taxes

(less) Provision for Deferred

Income Taxes (credit)

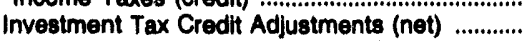

(less) Gains from Disposition of Utility Plant .......

Losses from Disposition of Utillty Plant

Total Utilty Operating Expenes

844,655

$1,193,893$

622,092

$\begin{array}{rr}907,558 & 973,083 \\ 165,631 & 155,140 \\ 188,309 & 123,763 \\ 22,849 & 689 \\ 203,490 & 159,213 \\ 119,683 & 51,58 \\ 4,951 & 1,082 \\ 96,807 & 72,793 \\ 93,787 & 61,31 \\ 4,434 & -1,732 \\ 0 & \\ 0 & \\ 1,819,928 & 1,474,311\end{array}$

$1,474,311$

Net Utility Operating Income

228,110

$$
\begin{array}{r}
258,734 \\
15,568 \\
108 \\
0 \\
5,207 \\
-199 \\
1 \\
5,871 \\
431 \\
-1,449 \\
0 \\
0 \\
281,511
\end{array}
$$

2,494

449,451
61,394
82,220
$-16,820$
91,364
25,428
0
122,167

114,883

$-5,303$

0

606,017

149,630

775,823

71,082

99,194

1,337

40,206

43,928

7,535

9,657

6,873

$-5,465$

0

$1,038,424$

157,689
Other Income and Deductions

Other Income

Nonutility Operating Income

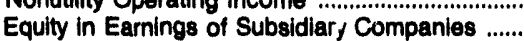

Interest and DWidend Income ...

Allowance for Other Funds Used

During Construction

Miscellaneous Nonoperating income

Gain on Disposition of Property

Tothl Other Income

$\begin{array}{rr}258 & -261 \\ 32,387 & 16,063 \\ 22,089 & 18,252 \\ 2,811 & \\ 107 & 1,480 \\ 6 & 1,401 \\ 57,738 & 934 \\ & 37,889\end{array}$

$$
\begin{array}{r}
0 \\
0 \\
786
\end{array}
$$

244

2,213

0
11,421
793

218

-200
440

1,048

41,114

0

44,619

0
0
0

12,213

348

31

862

Other Income Deductions

Loss on Disposition of Property

Miscellaneous Amortization .

Miscellaneous Income Deductions

Total Other Income Deductions

7,855

Taxes on Other Income and Deductions

Taxes Other Than Income Taxes

1,076

$-12,541$

$-21$

114

313

Other Income Taxes

29,068

$$
5,219
$$

11,954

$-21,332$

3,200

$-2,405$

Income Taxes (credit) ...........................

(less) Investment Tax Credits

Total Taxes on Other Income

and Deductions

(n)

$-15,705$

40

71,543

37,303
0
$-2,228$
-241

-241
0

170

0

$-2,638$

$-4,368$

See endnotes at end of an individual electric utility. 
Table 37. Statement of Income and Rotained Eaminge by Major U.S. Investor-Owned Electric Utility Whinin State, 1992 (Continued) (Thousand Dollars)

\begin{tabular}{|c|c|c|c|c|c|c|}
\hline them & $\begin{array}{l}\text { Orio } \\
\text { Orio } \\
\text { Edison co }\end{array}$ & $\begin{array}{l}\text { Onio } \\
\text { Onio } \\
\text { Power co }\end{array}$ & $\begin{array}{l}\text { Ohio } \\
\text { Ohio } \\
\text { Valley } \\
\text { Electic } \\
\text { Corp }\end{array}$ & $\begin{array}{l}\text { Onlo } \\
\text { Toledo } \\
\text { Edieon Co }\end{array}$ & $\begin{array}{c}\text { Oklahoma } \\
\text { Oklahoma } \\
\text { Gas } \\
\& \\
\text { Electric co }\end{array}$ & $\begin{array}{c}\text { Oklahoma } \\
\text { Public } \\
\text { Service } \\
\text { Co } \\
\text { of Oklahoma }\end{array}$ \\
\hline
\end{tabular}

Interest Charges

Intereat on Lonotiorm Debt ..

Amoringtion of Dabt Diccount and Expense......

Amortbetion of Loes on Reacoquired Debt ............

(ka) Amortzation of Premium on Dobt (credii)

(Nev) Amortiention of Gein on

Renquired Dobt (credit)

interest on Dabt to Aeacciated Companio.............

Other Interest Expense

(bee) Allowance for Borrowed Funds

Uesd During Construction (credit)

ine interent Chereses

Inoome Eefore Extreardinary fiems

Extreordinay tame

Extruordinary income

(Beas) Extreordinary Deduction

Net Extreordintery ltem

(leas) Federal and Other income Taxes

Extrecrelinery fteme Apter Toxes

Not incoine

Uneproported Roteined Eemises

Retuined Eomines - Decinning of Year

Balance Transterred from Income

Credits to Rotined Eaminos

(10en) Dobits to Retained Ear

(lees) Appropriations of Retained Eamings .........

(leav) Dividends Declared - Preferred Stock ....

(bees) Dividends Declared - Common Stock .......

Unappropriated Undistributed Subeldiary

Eamings .......................................................................

Roteined Eaminge - End of Year

(1)

Appropriated Retained Earningo

Appropriated Retained Eamings -

Amortization Reserve, Federal .

Totil Rotimned Enmines

$\begin{array}{rr}231,612 & 101,545 \\ 2,587 & 498 \\ 4,579 & 1,302 \\ 63 & 128 \\ 18 & 0 \\ 3,586 & 0 \\ -3,341 & 3,734 \\ 5,810 & 2,086 \\ 203,192 & 104,85\end{array}$

651
52
0

302

120

278,903

160,589
60,029

1,046

1,246
224
62

0

8,29

809

67,020

0,712

70,en

$$
\begin{aligned}
& 0 \\
& 0 \\
& 0
\end{aligned}
$$

$$
0
$$

270,096

100,689

1,650

70,690

9,712

46, 691

370,63

401,401

32
1,550
0
0
0
0
1,526

0,02

388,064

09,219

244,599

8,201

1,372

141
22,788

228,855

144,480
0
0
0
17,115
134,172

70,680

88,291

1,688

$\begin{array}{rr}0 & 1,588 \\ 0 & 0 \\ 24,018 & 2,317\end{array}$

107,237

17,107

0

11,882

396,093

0,289

401,760

411,002

87

124,698

0

0

189,69

39., 93

0,293

Note: Totals may not equal sum of components because of independent rounding. Summary data are provided in Table 6.

Source: Federal Energy Reoulatory Commiasion, FERC Form 1, "Annual Report of Mclor Electric Utilities, Licensees and Others." 
Table 37. Statement of Income and Rotained Eaminge by Major U.S. Investor-Owned Electric Utilly Within State, 1992 (Continued) (Thousand Dollars)

\begin{tabular}{|c|c|c|c|c|c|c|}
\hline litem & $\begin{array}{l}\text { Oreaon } \\
\text { Pecincorp }\end{array}$ & $\begin{array}{l}\text { Oregon } \\
\text { Portiand } \\
\text { General } \\
\text { Electric Co }\end{array}$ & $\begin{array}{l}\text { Pennoytvania } \\
\text { Duqueane } \\
\text { Loht Co }\end{array}$ & $\begin{array}{l}\text { Pennoytvania } \\
\text { Motropoltian } \\
\text { Edicon Co }\end{array}$ & $\begin{array}{l}\text { Pennoytvania } \\
\text { Pennoytvania } \\
\text { Electric Co }\end{array}$ & $\begin{array}{c}\text { Pennoytvania } \\
\text { Pennoytvania } \\
\text { Power } \\
2 \\
\text { Light Co }\end{array}$ \\
\hline $\begin{array}{l}\text { Eloctuic Utility Operating Income } \\
\text { Electic Operating Reveruee ..................................... }\end{array}$ & $2,301,498$ & 881,072 & $1,187,380$ & 821,734 & 896,337 & $2,741,616$ \\
\hline 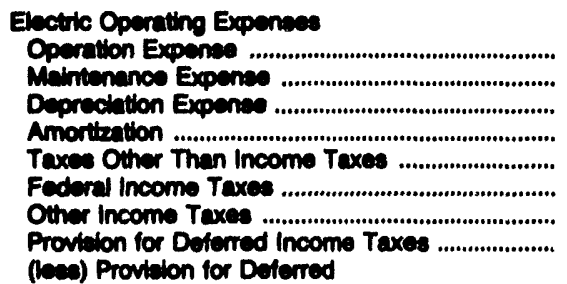 & $\begin{array}{r}1,145,281 \\
167,682 \\
246,725 \\
16,658 \\
108,628 \\
108,446 \\
13,048 \\
95,273\end{array}$ & $\begin{array}{r}423,461 \\
70,476 \\
112,279 \\
-12,712 \\
54,945 \\
50,736 \\
8,620 \\
39,451\end{array}$ & $\begin{array}{r}544,380 \\
79,146 \\
108,168 \\
19,768 \\
86,368 \\
64,188 \\
23,997 \\
79,575\end{array}$ & $\begin{array}{r}467,921 \\
54,979 \\
62,104 \\
25,917 \\
51,321 \\
46,505 \\
18,022 \\
116,380\end{array}$ & $\begin{array}{r}482,429 \\
70,645 \\
71,488 \\
12,717 \\
61,173 \\
43,428 \\
17,102 \\
140,682\end{array}$ & $\begin{array}{r}1,271,847 \\
200,780 \\
260,707 \\
791 \\
205,186 \\
139,032 \\
61,748 \\
115,002\end{array}$ \\
\hline 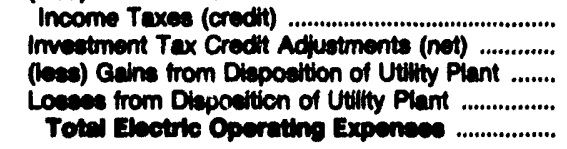 & $\begin{array}{r}37,885 \\
-6,431 \\
52 \\
682 \\
1,064,873\end{array}$ & $\begin{array}{r}24,956 \\
-712 \\
1,528 \\
0 \\
720,000\end{array}$ & $\begin{array}{r}64,048 \\
-5,438 \\
0 \\
0 \\
036,002\end{array}$ & $\begin{array}{r}130,807 \\
-2,775 \\
378 \\
0 \\
700,200\end{array}$ & $\begin{array}{r}127,244 \\
-3,308 \\
0 \\
0 \\
740,022\end{array}$ & $\begin{array}{r}76,404 \\
-13,803 \\
9 \\
44 \\
2,164,032\end{array}$ \\
\hline Net Electric Uuthy Operathng Inoome ............. & $\mathbf{5 0 6 , 0 2 5}$ & 161,012 & 262,307 & 112,634 & 147,316 & 576,695 \\
\hline 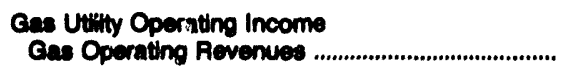 & 0 & 0 & 0 & 0 & 0 & 0 \\
\hline 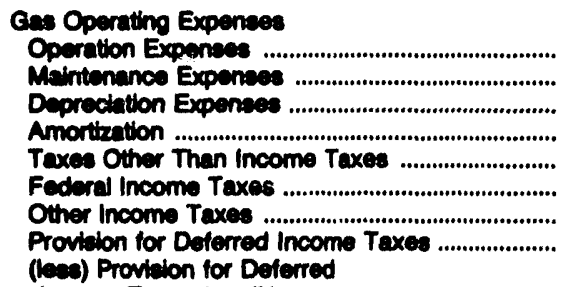 & $\begin{array}{l}0 \\
0 \\
0 \\
0 \\
0 \\
0 \\
0 \\
0\end{array}$ & $\begin{array}{l}0 \\
0 \\
0 \\
0 \\
0 \\
0 \\
0 \\
0\end{array}$ & $\begin{array}{l}0 \\
0 \\
0 \\
0 \\
0 \\
0 \\
0 \\
0\end{array}$ & $\begin{array}{l}0 \\
0 \\
0 \\
0 \\
0 \\
0 \\
0 \\
0\end{array}$ & $\begin{array}{l}0 \\
0 \\
0 \\
0 \\
0 \\
0 \\
0 \\
0\end{array}$ & $\begin{array}{l}0 \\
0 \\
0 \\
0 \\
0 \\
0 \\
0 \\
0\end{array}$ \\
\hline 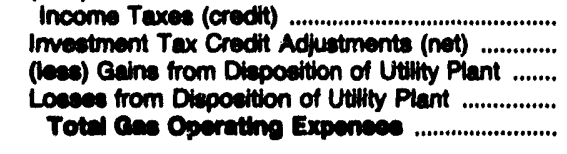 & $\begin{array}{l}0 \\
0 \\
0 \\
0 \\
0\end{array}$ & $\begin{array}{l}0 \\
0 \\
0 \\
0 \\
0\end{array}$ & $\begin{array}{l}0 \\
0 \\
0 \\
0 \\
0\end{array}$ & $\begin{array}{l}0 \\
0 \\
0 \\
0 \\
0\end{array}$ & $\begin{array}{l}0 \\
0 \\
0 \\
0 \\
0\end{array}$ & $\begin{array}{l}0 \\
0 \\
0 \\
0 \\
0\end{array}$ \\
\hline Met ace vituty Operating Incoms .................... & 0 & 0 & o & 0 & $\mathbf{0}$ & 0 \\
\hline $\begin{array}{l}\text { Other Utitity Operating Income } \\
\text { Other Utility Operating Revenues .............................. }\end{array}$ & 872 & 0 & 0 & 0 & 0 & 0 \\
\hline 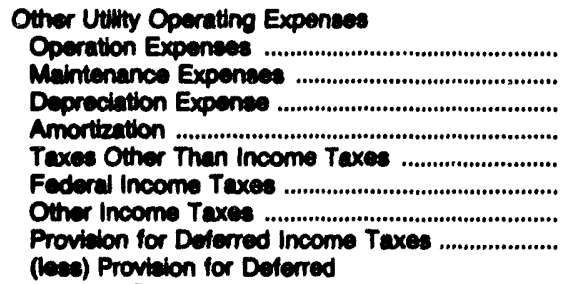 & $\begin{array}{r}719 \\
98 \\
34 \\
0 \\
28 \\
-3 \\
0 \\
0\end{array}$ & $\begin{array}{l}0 \\
0 \\
0 \\
0 \\
0 \\
0 \\
0 \\
0\end{array}$ & $\begin{array}{l}0 \\
0 \\
0 \\
0 \\
0 \\
0 \\
0 \\
0\end{array}$ & $\begin{array}{l}0 \\
0 \\
0 \\
0 \\
0 \\
0 \\
0 \\
0\end{array}$ & $\begin{array}{l}0 \\
0 \\
0 \\
0 \\
0 \\
0 \\
0 \\
0\end{array}$ & $\begin{array}{l}0 \\
0 \\
0 \\
0 \\
0 \\
0 \\
0 \\
0\end{array}$ \\
\hline 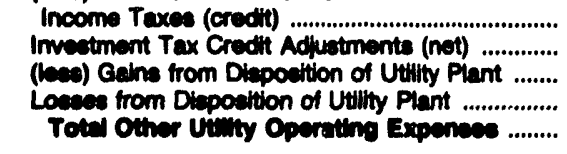 & $\begin{array}{r}0 \\
0 \\
0 \\
0 \\
076\end{array}$ & $\begin{array}{l}0 \\
0 \\
0 \\
0 \\
0\end{array}$ & $\begin{array}{l}0 \\
0 \\
0 \\
0 \\
0\end{array}$ & $\begin{array}{l}0 \\
0 \\
0 \\
0 \\
0\end{array}$ & $\begin{array}{l}0 \\
0 \\
0 \\
0 \\
0\end{array}$ & $\begin{array}{l}0 \\
0 \\
0 \\
0 \\
0\end{array}$ \\
\hline Net Other Ututty Operating Incems ................ & -4 & 0 & $\mathbf{0}$ & 0 & $\mathbf{0}$ & 0 \\
\hline
\end{tabular}


Table 37. Statement of Income and Rotained Earnings by Major U.S. Inveator-Owned Electric Utilty Within State, 1992 (Continued) (Thousand Dollars)

\begin{tabular}{|c|c|c|c|c|c|c|}
\hline Item & $\begin{array}{l}\text { Oregon } \\
\text { Pacificorp }\end{array}$ & $\begin{array}{l}\text { Oregon } \\
\text { Portiand } \\
\text { Coneral } \\
\text { Electric Co }\end{array}$ & $\begin{array}{l}\text { Penneytvania } \\
\text { Duquesne } \\
\text { Light Co }\end{array}$ & $\begin{array}{l}\text { Pennoytvania } \\
\text { Metropolitan } \\
\text { Edison Co }\end{array}$ & $\begin{array}{l}\text { Penneytvania } \\
\text { Penneytvania } \\
\text { Electric Co }\end{array}$ & $\begin{array}{l}\text { Penneytvania } \\
\text { Penneytvania } \\
\text { Power } \\
\& \\
\text { Lught Co }\end{array}$ \\
\hline $\begin{array}{l}\text { Total Utilly Operating Income } \\
\text { Total Utilty Operating Revenues }\end{array}$ & $2,362,370$ & 881,072 & $1,187,389$ & 821,734 & 898,337 & $2,741,616$ \\
\hline 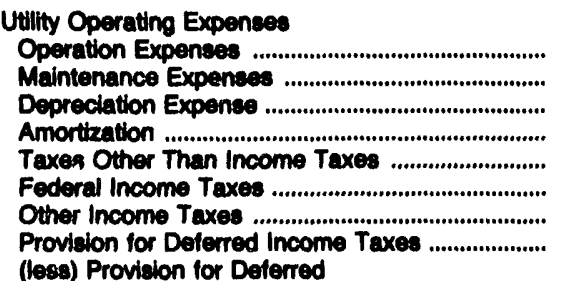 & $\begin{array}{r}1,146,000 \\
167,760 \\
245,758 \\
16,658 \\
108,556 \\
108,443 \\
13,048 \\
95,273\end{array}$ & $\begin{array}{r}423,461 \\
70,476 \\
112,279 \\
-12,712 \\
54,845 \\
50,736 \\
8,620 \\
38,451\end{array}$ & $\begin{array}{r}544,360 \\
79,146 \\
108,156 \\
19,768 \\
85,368 \\
64,198 \\
23,997 \\
79,575\end{array}$ & $\begin{array}{r}467,921 \\
54,979 \\
62,104 \\
25,917 \\
61,321 \\
46,505 \\
18,022 \\
116,390\end{array}$ & $\begin{array}{r}462,428 \\
70,645 \\
71,498 \\
12,717 \\
61,173 \\
43,428 \\
17,102 \\
140,582\end{array}$ & $\begin{array}{r}1,271,847 \\
200,780 \\
260,707 \\
791 \\
205,186 \\
139,082 \\
61,748 \\
115,002\end{array}$ \\
\hline $\begin{array}{l}\text { Income Texes (credit) ......................................... } \\
\text { Investment Tax Credit Adjustments (net) ............ } \\
\text { (less) Gains from Disposition of Utilty Plant ....... } \\
\text { Losees from Diaposition of Utilty Plant ............... } \\
\text { Total Uatily Operating Expences ................... }\end{array}$ & $\begin{array}{r}37,895 \\
-6,431 \\
52 \\
632 \\
1,865,740\end{array}$ & $\begin{array}{r}24,955 \\
-712 \\
1,528 \\
0 \\
720,000\end{array}$ & $\begin{array}{r}64,049 \\
-5,436 \\
0 \\
0 \\
985,092\end{array}$ & $\begin{array}{r}130,807 \\
-2,775 \\
378 \\
0 \\
700,200\end{array}$ & $\begin{array}{r}127,244 \\
-3,308 \\
0 \\
0 \\
749,022\end{array}$ & $\begin{array}{r}76,404 \\
-13,803 \\
9 \\
44 \\
2,184,932\end{array}$ \\
\hline Net Utilty Operating Inoom ............................... & 800,821 & 161,012 & 262,307 & 112,684 & 147,316 & $\mathbf{5 7 8 , 6 9 5}$ \\
\hline $\begin{array}{l}\text { Other Income and Deductions } \\
\text { Other Income } \\
\text { Nonutlity Operating Income .................................. } \\
\text { Equity in Earnings of Subsidiary Companies ....... } \\
\text { Interest and Dividend Income .................................. } \\
\text { Allowance for Other Funds Used }\end{array}$ & $\begin{array}{r}2,314 \\
-587,851 \\
637\end{array}$ & $\begin{array}{r}991 \\
-338 \\
2,758\end{array}$ & $\begin{array}{r}-176 \\
6,585\end{array}$ & $\begin{array}{r}2 \\
835 \\
633\end{array}$ & $\begin{array}{r}-7 \\
9 \\
453\end{array}$ & $\begin{array}{r}-14 \\
4,045 \\
4,639\end{array}$ \\
\hline 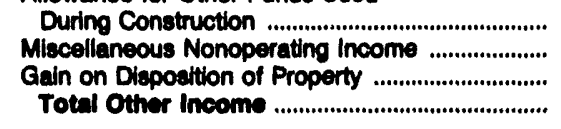 & $\begin{array}{r}7,328 \\
440 \\
-1,586 \\
-578,717\end{array}$ & $\begin{array}{r}311 \\
11,721 \\
52 \\
16,484\end{array}$ & $\begin{array}{r}2,588 \\
29,301 \\
82 \\
39,380\end{array}$ & $\begin{array}{r}1,557 \\
3,699 \\
15 \\
6,642\end{array}$ & $\begin{array}{r}0 \\
1,929 \\
66 \\
2,460\end{array}$ & $\begin{array}{r}6,771 \\
201 \\
370 \\
18,012\end{array}$ \\
\hline 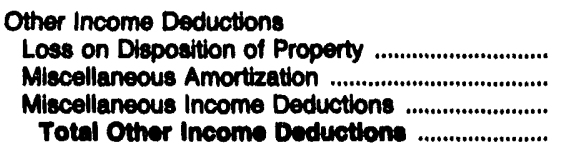 & $\begin{array}{r}2,730 \\
180 \\
22,765 \\
26,674\end{array}$ & $\begin{array}{r}0 \\
379 \\
6,742 \\
7,121\end{array}$ & $\begin{array}{l}2,164 \\
3,119 \\
2,358 \\
7,641\end{array}$ & $\begin{array}{r}0 \\
0 \\
1,020 \\
1,021\end{array}$ & $\begin{array}{r}0 \\
0 \\
2,633 \\
2,633\end{array}$ & $\begin{array}{r}4 \\
0 \\
6,782 \\
6,785\end{array}$ \\
\hline 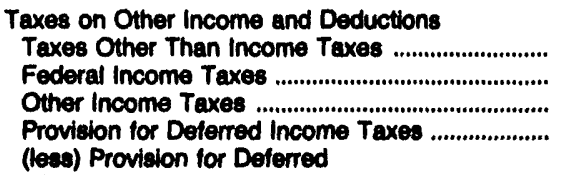 & $\begin{array}{r}178 \\
-5,264 \\
-678 \\
1,589\end{array}$ & $\begin{array}{r}1,232 \\
424 \\
123 \\
4,631\end{array}$ & $\begin{array}{r}0 \\
7,285 \\
2,983 \\
0\end{array}$ & $\begin{array}{r}3 \\
-52 \\
-22 \\
1,966\end{array}$ & $\begin{array}{r}13 \\
-242 \\
-103 \\
881\end{array}$ & $\begin{array}{r}80 \\
-249 \\
-108 \\
794\end{array}$ \\
\hline 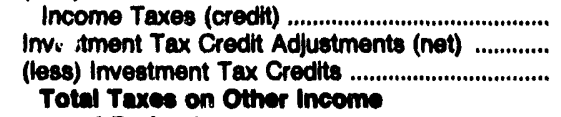 & $\begin{array}{r}5,364 \\
0 \\
3,039\end{array}$ & $\begin{array}{r}1,554 \\
0 \\
6,047\end{array}$ & $\begin{array}{r}0 \\
0 \\
533\end{array}$ & $\begin{array}{r}471 \\
0 \\
0\end{array}$ & $\begin{array}{r}540 \\
0 \\
0\end{array}$ & $\begin{array}{r}2,300 \\
0 \\
0\end{array}$ \\
\hline 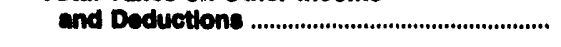 & $-12,676$ & $-1,101$ & 9,715 & 1,425 & 9 & $-1,781$ \\
\hline Net Other income and Deduetions .................. & $-601,814$ & 9,684 & 21,031 & 4,197 & -102 & 11,008 \\
\hline
\end{tabular}

Soe endnotes at end of an individual electric utility. 
Table 37. Statement of Income and Rotalned Earnings

by Major U.S. Investor-Owned Eloctric

Utility Within State, 1992 (Continued)

(Thousand Dollars)

\begin{tabular}{|c|c|c|c|c|c|c|}
\hline $1 \mathrm{tem}$ & $\begin{array}{l}\text { Oregon } \\
\text { Pacificorp }\end{array}$ & $\begin{array}{l}\text { Oregon } \\
\text { Portiand } \\
\text { General } \\
\text { Electrio Co }\end{array}$ & $\begin{array}{l}\text { Pennoytvania } \\
\text { Duqueane } \\
\text { Light Co }\end{array}$ & $\begin{array}{l}\text { Pennoytvania } \\
\text { Metropolitan } \\
\text { Edicon Co }\end{array}$ & $\begin{array}{l}\text { Penneytuanla } \\
\text { Pennoyivania } \\
\text { Electric Co }\end{array}$ & $\begin{array}{c}\text { Pennoytvania } \\
\text { Ponnaytvania } \\
\text { Power } \\
\text { Loht co }\end{array}$ \\
\hline
\end{tabular}

Interest Charges

Interest on Long-term Debt ....................................

Amortzation of Debt Discount and Expense .....

Amortination of Loss on Reacouired Debt .......

(kee) Amortation of Premium on Debt (oredit) .

(ke0) Amortization of Guin on

Reaquired Debt (credit) ............................................

Interest on Debt to Associated Companies ........

Other Intereet Expenes

(lees) Allowance for Borrowed Funds

Ueed During Conatruction (credit)

Net Interent chere.

(1)

Income Boton Extreordinary ltems

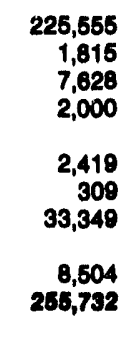

$-340,025$

105,692

61,008
668
1,738

1,736

13

0

4,155

2,459

85,014
Extreordinary ltems

Extraordinary Income

Deduction

Not Extracondinery ltems

(leap) Federal and Other Income Taxes

Extracrilinery items After Taxes

Net inoem

Unappropilated Rotalned Eaminge

Rotelned Eemines - Eexinning of Year

Balance Transferred from income ...........................

Credits to Rotained Earnings ....u.

(leas) Debits to Rotained Earnings .............

(bes) Appropriations of Retained Earnings .........

(leas) Dividends Declared - Preferred Stock .......

(lees) Dividends Dectared - Common Stock .......

Unappropriated Undiatrlbuted Subaldiary

Earnings.

Retelned Eeminges - End of Year

Appropriated Rotained Eamings

Aporoprated Rotained Eamings .

Amortzation Reaerve, Federal

Total Rotulnod Enminas

$\begin{array}{rr}00,162 & 114,302 \\ 246,925 & 105,801 \\ 1,274 & 7,483 \\ 542 & 3,496 \\ 0 & 0 \\ 39,045 & 12,688 \\ 410,724 & 70,670 \\ -473 & 0\end{array}$

$-142,42$

140,198
0

3,188

0

841

$-180,240$

141,724

301,900

169,270

209,998

940,184

149,945

0
0
0
10,405

141,000

0

300,890

72,241
0
0
0
10,289
45,000

09,736

342,880

11

932

40,495

242,865

2,160

$1,000,024$

300,580

170,422

278,410

$1,008,0097$

Note: Totale may not equal sum of components because of independent rounding. Summary dath are provided in Table 8 .

Source: Federal Eneroy Regulatory Commiealon, FERC Form 1, "Annual Report of Major Electric Utiltiee, Lloencees and Othere." 
Table 37. Statement of Income and Rotalned Earnings

by Major U.S. Investor-Owned Eloctric

Utility Within State, 1902 (Continued)

(Thousand Dollars)

\begin{tabular}{|c|c|c|c|c|c|c|}
\hline Item & $\begin{array}{l}\text { Pennoylvania } \\
\text { Pennoytvania } \\
\text { Power Co }\end{array}$ & $\begin{array}{l}\text { Pennoytvania } \\
\text { Phlladelphia } \\
\text { Electric Co }\end{array}$ & $\begin{array}{c}\text { Pennoytvania } \\
\text { Sate } \\
\text { Harbor } \\
\text { Water } \\
\text { Power Corp }\end{array}$ & $\begin{array}{l}\text { Pennoyivania } \\
\text { Suequehanna } \\
\text { Electrio Co }\end{array}$ & $\begin{array}{l}\text { Penneytvania } \\
\text { Wost } \\
\text { Penn } \\
\text { Power } \\
\text { Co }\end{array}$ & $\begin{array}{c}\text { Pennsylvania } \\
\text { York } \\
\text { Haven } \\
\text { Power } \\
\text { Co }\end{array}$ \\
\hline $\begin{array}{l}\text { Electric Utillty Operating Income } \\
\text { Electric Operating Revenues .................................... }\end{array}$ & 315,458 & $3,588,083$ & 28,367 & 27,440 & $1,076,841$ & 4,425 \\
\hline 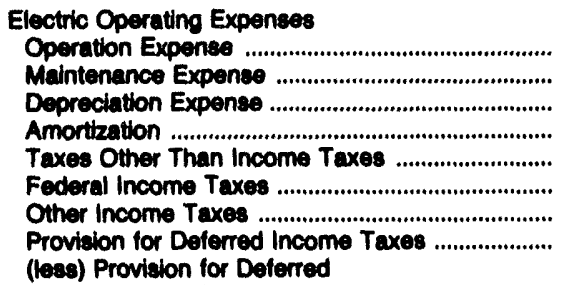 & $\begin{array}{r}150,091 \\
22,378 \\
30,550 \\
2,684 \\
22,162 \\
15,215 \\
7,686 \\
16,605\end{array}$ & $\begin{array}{r}1,402,732 \\
327,087 \\
362,571 \\
24,574 \\
254,423 \\
125,913 \\
74,949 \\
175,513\end{array}$ & $\begin{array}{r}6,667 \\
2,423 \\
3,343 \\
0 \\
1,444 \\
1,805 \\
773 \\
1,706\end{array}$ & $\begin{array}{r}18,785 \\
7,634 \\
0 \\
0 \\
814 \\
-56 \\
184 \\
48\end{array}$ & $\begin{array}{r}647,888 \\
03,087 \\
72,865 \\
504 \\
87,300 \\
37,524 \\
5,745 \\
38,812\end{array}$ & $\begin{array}{r}1,418 \\
798 \\
460 \\
0 \\
302 \\
404 \\
163 \\
94\end{array}$ \\
\hline 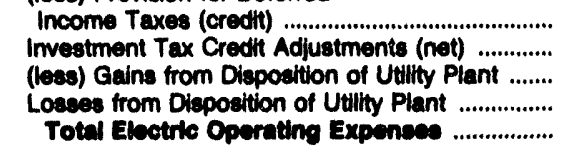 & $\begin{array}{r}17,479 \\
-959 \\
0 \\
0 \\
248,033\end{array}$ & $\begin{array}{r}132,837 \\
-2,972 \\
2 \\
0 \\
2,011,051\end{array}$ & $\begin{array}{r}184 \\
-245 \\
0 \\
0 \\
17,834\end{array}$ & $\begin{array}{r}-30 \\
0 \\
0 \\
0 \\
27,440\end{array}$ & $\begin{array}{r}35,407 \\
-2,594 \\
0 \\
0 \\
945,003\end{array}$ & $\begin{array}{r}1 \\
-2 \\
0 \\
0 \\
3,627\end{array}$ \\
\hline Not Eloctric Utilly Operating Income ............ & 86,628 & 956,132 & 10,532 & 0 & 130,938 & 708 \\
\hline $\begin{array}{l}\text { Gas Utillty Operating Income } \\
\text { Gas Operating Revenues }\end{array}$ & 0 & 365,328 & 0 & 0 & 0 & 0 \\
\hline 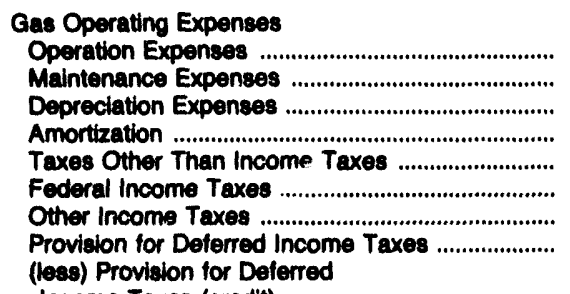 & $\begin{array}{l}0 \\
0 \\
0 \\
0 \\
0 \\
0 \\
0 \\
0\end{array}$ & $\begin{array}{r}223,346 \\
15,859 \\
22,834 \\
0 \\
21,425 \\
4,828 \\
2,493 \\
6,985\end{array}$ & $\begin{array}{l}0 \\
0 \\
0 \\
0 \\
0 \\
0 \\
0 \\
0\end{array}$ & $\begin{array}{l}0 \\
0 \\
0 \\
0 \\
0 \\
0 \\
0 \\
0\end{array}$ & $\begin{array}{l}0 \\
0 \\
0 \\
0 \\
0 \\
0 \\
0 \\
0\end{array}$ & $\begin{array}{l}0 \\
0 \\
0 \\
0 \\
0 \\
0 \\
0 \\
0\end{array}$ \\
\hline 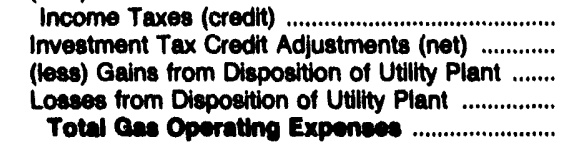 & $\begin{array}{l}0 \\
0 \\
0 \\
0 \\
0\end{array}$ & $\begin{array}{r}-3,868 \\
-398 \\
0 \\
0 \\
301,340\end{array}$ & $\begin{array}{l}0 \\
0 \\
0 \\
0 \\
0\end{array}$ & $\begin{array}{l}0 \\
0 \\
0 \\
0 \\
0\end{array}$ & $\begin{array}{l}0 \\
0 \\
0 \\
0 \\
0\end{array}$ & $\begin{array}{l}0 \\
0 \\
0 \\
0 \\
0\end{array}$ \\
\hline Net cas Utulty Oparating Income .................... & o & 63,000 & $\mathbf{0}$ & $\mathbf{0}$ & 0 & $\mathbf{0}$ \\
\hline $\begin{array}{l}\text { Other Utillty Operating Income } \\
\text { Other Utility Operating Revenues }\end{array}$ & 0 & 0 & 0 & 0 & 0 & 0 \\
\hline 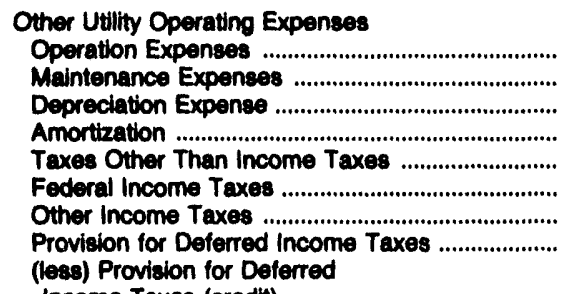 & $\begin{array}{l}0 \\
0 \\
0 \\
0 \\
0 \\
0 \\
0 \\
0\end{array}$ & $\begin{array}{l}0 \\
0 \\
0 \\
0 \\
0 \\
0 \\
0 \\
0\end{array}$ & $\begin{array}{l}0 \\
0 \\
0 \\
0 \\
0 \\
0 \\
0 \\
0\end{array}$ & $\begin{array}{l}0 \\
0 \\
0 \\
0 \\
0 \\
0 \\
0 \\
0\end{array}$ & $\begin{array}{l}0 \\
0 \\
0 \\
0 \\
0 \\
0 \\
0 \\
0\end{array}$ & $\begin{array}{l}0 \\
0 \\
0 \\
0 \\
0 \\
0 \\
0 \\
0\end{array}$ \\
\hline 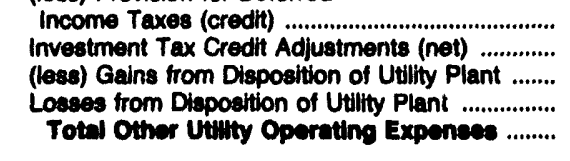 & $\begin{array}{l}0 \\
0 \\
0 \\
0 \\
0\end{array}$ & $\begin{array}{l}0 \\
0 \\
0 \\
0 \\
0\end{array}$ & $\begin{array}{l}0 \\
0 \\
0 \\
0 \\
0\end{array}$ & $\begin{array}{l}0 \\
0 \\
0 \\
0 \\
0\end{array}$ & $\begin{array}{l}0 \\
0 \\
0 \\
0 \\
0\end{array}$ & $\begin{array}{l}0 \\
0 \\
0 \\
0 \\
0\end{array}$ \\
\hline Net Other Utilly Operating Income .................. & $\mathbf{0}$ & 0 & 0 & o & 0 & $\mathbf{0}$ \\
\hline
\end{tabular}


Table 37. Statement of Income and Rotained Earnings

by Major U.S. Investor-Owned Electric

Utility Within State, 1902 (Continued)

(Thousand Dollars)

\begin{tabular}{|c|c|c|c|c|c|c|}
\hline litem & $\begin{array}{l}\text { Pennoytvania } \\
\text { Pennoytvania } \\
\text { Power Co }\end{array}$ & $\begin{array}{l}\text { Pennoytvania } \\
\text { Philadelphia } \\
\text { Electric Co }\end{array}$ & $\begin{array}{c}\text { Pennaytvania } \\
\text { Sate } \\
\text { Harbor } \\
\text { Water } \\
\text { Power Corp }\end{array}$ & $\begin{array}{l}\text { Pennoytvania } \\
\text { Susquehanna } \\
\text { Electric Co }\end{array}$ & $\begin{array}{c}\text { Pennoytvania } \\
\text { West } \\
\text { Penn } \\
\text { Power } \\
\text { Co }\end{array}$ & $\begin{array}{c}\text { Pennoytvania } \\
\text { York } \\
\text { Haven } \\
\text { Power } \\
\text { Co }\end{array}$ \\
\hline
\end{tabular}

Total Utilty Operating Income

Total Utity Operating Aevenues

Utilty Operating Expenses

Operation Expenses .

Mintenance Expenses.

Depreciation Expense

Taxes Other Than Income Taxe:

Federal income Texes

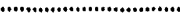

Provision for Deferred income Taxes

(leas) Provision for Deferred

Income Texes (credit)

Imveetment Tax Crodth Adtugtmento (not)

(less) Gains from Dispoestion of Utility Plant .......

Losses from Disposition of Utilly Plant

Totel Unity Operating Exponere

Not Uuthy Operating Incoms

\begin{tabular}{|c|c|}
\hline 315,468 & $3,833,412$ \\
\hline $\begin{array}{r}150,091 \\
22,378 \\
30,650 \\
2,684 \\
22,162 \\
16,215 \\
7,686 \\
16,605\end{array}$ & $\begin{array}{r}1,626,078 \\
342,946 \\
385,505 \\
24,574 \\
275,849 \\
130,741 \\
77,441 \\
182,498\end{array}$ \\
\hline $\begin{array}{r}17,478 \\
-859 \\
0 \\
0 \\
248,983\end{array}$ & $\begin{array}{r}128,869 \\
-3,369 \\
2 \\
0 \\
2,013,201\end{array}$ \\
\hline 68,626 & $1,020,120$ \\
\hline $\begin{array}{r}-28 \\
0 \\
889\end{array}$ & $\begin{array}{r}2,862 \\
8,545 \\
16,712\end{array}$ \\
\hline $\begin{array}{r}114 \\
1 \\
0 \\
1,077\end{array}$ & $\begin{array}{r}9,872 \\
-16,391 \\
59 \\
22,750\end{array}$ \\
\hline
\end{tabular}

28,367

6,687

2,428

3,343

1,444

1,806

773

1,708

184

$-245$

0

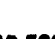

$1,076,841$

4,425

18,785
7,634
0
0
814
-56
184
48

-30
0
0
0
27,440

647,888

93,037

72,865

504

87,300

$\mathbf{3 7 , 5 2 4}$

5,745

38,812

35,407

$-2,594$

0

9.8.0

130,98

1,418

788

450

302

404

168

1

$-2$

-2
0
0

3,027

Other income and Deductions

Other Income

Nonutility Operating Income

Fquity in Earnings of Subeidiany

Interest and Dividend Income

Allowance for Other Funds Used

During Construction

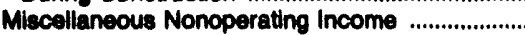

Gain on Dieposition of Property

Total Other Income

Other Income Deductions

Loss on Disposition of Property

Miscellaneous Amortization

Miscellaneous Income Deductions

Total Other Income Deduction:

$\begin{array}{rr}47 & 740 \\ 0 & 0 \\ 239 & 108,447 \\ 225 & 100,187\end{array}$

6
0
259
1
0
0
29

50

$-4,088$
19,823

5,010

269

14
21,098

100,187

$\begin{array}{rr}0 & 313 \\ -283 & -45,574 \\ -135 & -18,498 \\ 591 & 12,957 \\ 162 & 423 \\ 0 & 0 \\ 0 & 0\end{array}$

313

$-18,498$

12,857

423
0
0

$-51,228$

781

$-35,201$

Taxes on Other Income and Deductions

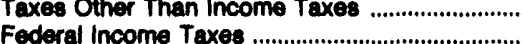

Other Income Taxes .............................................

(lese) Provision for Deferred

Income Taxes (Credit) .........................................

(less) Investment Tax Credits

Total Texes on Other Incoms

10

Net Other Income and Deductions

$\begin{array}{rr}123 & 0 \\ 370 & 0 \\ 124 & 0 \\ 0 & 0 \\ 0 & \\ 0 & 1 \\ 0 & 0 \\ 17 & 0\end{array}$

$617-1$

See endnotes at end of an individual electric utility. 
Table 37. Statoment of Inoome and Rotalned Earnings

by Major U.8. Investor-Owned Elootric

Utility Within 8tate, 1902 (Continued)

(Thousand Dollars)

\begin{tabular}{|c|c|c|c|c|c|c|}
\hline Item & $\begin{array}{l}\text { Pennoytvanla } \\
\text { Pennoytuanla } \\
\text { Power Co }\end{array}$ & $\begin{array}{l}\text { Ponnoytivanla } \\
\text { Philadolphla } \\
\text { Eleotric Co }\end{array}$ & $\begin{array}{c}\text { Ponnoytvania } \\
\text { 8ate } \\
\text { Hartoor } \\
\text { Water } \\
\text { Power Corp }\end{array}$ & $\begin{array}{l}\text { Pennoytuania } \\
\text { Suequehanna } \\
\text { Electrio Co }\end{array}$ & $\begin{array}{c}\text { Ponneytvania } \\
\text { Weot } \\
\text { Ponn } \\
\text { Power } \\
\text { Co }\end{array}$ & $\begin{array}{l}\text { Penneylvania } \\
\text { York } \\
\text { Haven } \\
\text { Power } \\
\text { Co }\end{array}$ \\
\hline
\end{tabular}

Intereet Charges

Intereet on Lona-term Debt ....................................

Amortention of Debt Disoount and Expense.....

Amortization of Loes on Reacquired Debt .............

(iea) Amortization of Premlum on Debt (oredit).

(ba) Amortintion of Gain on

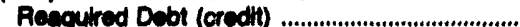

Interest on Debt to Associated Compunies ........

Other Intereet Expense

(bea) Allowance for Borrowed Funds

Ueed During Construction (credit)

Net Intereat Charges .............................................

Incoms Eofore Extreordinary Items

Extracordinary ltems

Extreordinary income

(leas) Extraordinary Deductions

Net Extreordinary Itoms

(leae) Federal and Other Income Taxes

Extreordinary lteme After Taxee

Not inoom

Uneppropilated Rotalned Eaminge

Rotalmed Eaminge - Beginning of Year

Balance Transferred from income

Credthe to Rotained Eemings

(leas) Debits to Retained Earnings

(leas) Approprtations of Retained Earnings ..........

(leve) Dividends Declared - Preferred Stock ......

(kea) Dividende Declared - Common Stock .......

Unappropriated Undiatributed Subsidlary

Earninges .

Roteined Eeminge - End of Yeer

...........................

Approprlated Retained Earninge

Approprlated Rotained Earnings

Amortization Reserve, Federal

Totel Rotained Eeminges

$\begin{array}{rr}35,707 & 484,146 \\ 302 & 4,627 \\ 381 & 18,490 \\ 16 & 46 \\ 0 & 1,171 \\ 478 & 0 \\ 87 & 31,656 \\ 678 & 9,625 \\ 88,880 & 805,970 \\ & \\ 30,083 & 470,941\end{array}$

24

0

0

0

0
4,897

6,400

0,189

53,768

382
47

0

282

829

3,286

82,380

838

0
0

0
0

0

0
0

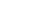

0

0

0

80,085

470,041

0,400

$-37$

09,163

98

$\begin{array}{rr}77,317 & 398,061 \\ 30,956 & 469,398 \\ 0 & 0 \\ 1,372 & 11,660 \\ 0 & 0 \\ 6,448 & 58,021 \\ 27,676 & 291,835 \\ 0 & 8,167\end{array}$

24,34

$-4$

382,032

6,312

6,400
0
0
0
0
6,480
0

$-37$

102,244

7,3

7,331

82,641

24,205

$-40$

394,200

6,147

$0 \quad 0$

0

0

0

0

0

0

0

415

191

72,777

512,008

24,208

$-40$

324,713

6,398

Note: Totals may not equal eum of components because of independent rounding. Summary data are provided in Table 6 .

Source: Federal Energy Regulatory Commiselon, FERC Form 1, "Annual Report of Major Electric Utilitiea, Llcensees and Others." 
Table 37. Statement of Income and Rotalned Earninge

by Major U.8. Inveator-Owned Electric

Utility Within state, 1902 (Continued)

(Thousand Dollars)

\begin{tabular}{|c|c|c|c|c|c|c|}
\hline Item & $\begin{array}{l}\text { Rhode leland } \\
\text { Blackutone } \\
\text { Valloy } \\
\text { Electric Co }\end{array}$ & $\begin{array}{l}\text { Ahode Ieland } \\
\text { Narraganeott } \\
\text { Eleotro Co }\end{array}$ & $\begin{array}{l}\text { Phode leland } \\
\text { Nemport } \\
\text { Electrlo } \\
\text { Corp }\end{array}$ & $\begin{array}{l}\text { South Carolina } \\
\text { Lookhart } \\
\text { Power Co }\end{array}$ & $\begin{array}{l}\text { South Carolina } \\
\text { South } \\
\text { Carollina } \\
\text { Eleotricsase } \\
\text { Co }\end{array}$ & $\begin{array}{c}\text { South Carolina } \\
\text { South } \\
\text { Carolina } \\
\text { Cenertg } \\
\text { Co Ine } \\
\end{array}$ \\
\hline 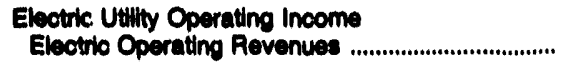 & 138,604 & 468,262 & 59,543 & 18,810 & 829,938 & 73,108 \\
\hline 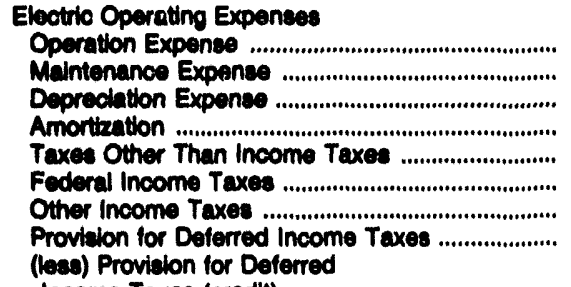 & $\begin{array}{r}112,885 \\
2,831 \\
4,774 \\
73 \\
9,116 \\
1,073 \\
8 \\
1,233\end{array}$ & $\begin{array}{r}356,085 \\
12,287 \\
19,826 \\
0 \\
35,172 \\
4,895 \\
0 \\
8,588\end{array}$ & $\begin{array}{r}60,326 \\
1,637 \\
2,131 \\
34 \\
3,124 \\
-1,984 \\
3 \\
2,040\end{array}$ & $\begin{array}{r}12,620 \\
635 \\
654 \\
0 \\
503 \\
562 \\
88 \\
-91\end{array}$ & $\begin{array}{r}409,639 \\
54,399 \\
82,182 \\
5,184 \\
69,207 \\
62,831 \\
8,055 \\
26,886\end{array}$ & $\begin{array}{r}48,214 \\
3,431 \\
6,611 \\
0 \\
0,136 \\
4,1,182 \\
-189 \\
3,371\end{array}$ \\
\hline 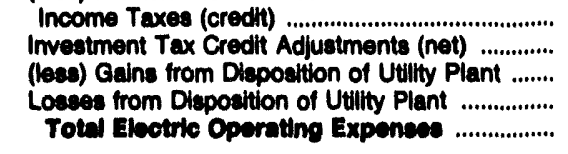 & $\begin{array}{r}9 \\
-289 \\
0 \\
0 \\
131,798\end{array}$ & $\begin{array}{r}4,076 \\
-608 \\
-11 \\
0 \\
432,360\end{array}$ & $\begin{array}{r}277 \\
-4 \\
290 \\
0 \\
68,741\end{array}$ & $\begin{array}{r}0 \\
-17 \\
0 \\
0 \\
14,863\end{array}$ & $\begin{array}{r}46,645 \\
-3,037 \\
0 \\
0 \\
659,802\end{array}$ & $\begin{array}{r}1,699 \\
-305 \\
0 \\
0 \\
62,380\end{array}$ \\
\hline Not Elcotric Utility Operating Incoms ............ & 8,800 & 35,892 & 2,802 & 967 & 170,336 & 10,718 \\
\hline $\begin{array}{l}\text { Gas Utllty Operating Income } \\
\text { Gas Operating Revenues ......................................... }\end{array}$ & 0 & 0 & 0 & 0 & 160,819 & 0 \\
\hline 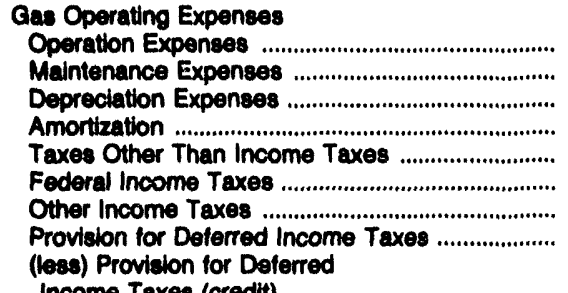 & $\begin{array}{l}0 \\
0 \\
0 \\
0 \\
0 \\
0 \\
0 \\
0\end{array}$ & $\begin{array}{l}0 \\
0 \\
0 \\
0 \\
0 \\
0 \\
0 \\
0\end{array}$ & $\begin{array}{l}0 \\
0 \\
0 \\
0 \\
0 \\
0 \\
0 \\
0\end{array}$ & $\begin{array}{l}0 \\
0 \\
0 \\
0 \\
0 \\
0 \\
0 \\
0\end{array}$ & $\begin{array}{r}118,928 \\
3,082 \\
9,464 \\
70 \\
5,752 \\
3,437 \\
418 \\
6,251\end{array}$ & $\begin{array}{l}0 \\
0 \\
0 \\
0 \\
0 \\
0 \\
0 \\
0\end{array}$ \\
\hline 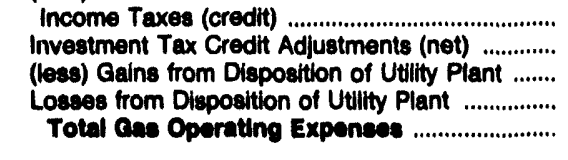 & $\begin{array}{l}0 \\
0 \\
0 \\
0 \\
0\end{array}$ & $\begin{array}{l}0 \\
0 \\
0 \\
0 \\
0\end{array}$ & $\begin{array}{l}0 \\
0 \\
0 \\
0 \\
0\end{array}$ & $\begin{array}{l}0 \\
0 \\
0 \\
0 \\
0\end{array}$ & $\begin{array}{r}4,065 \\
-193 \\
0 \\
0 \\
143,144\end{array}$ & $\begin{array}{l}0 \\
0 \\
0 \\
0 \\
0\end{array}$ \\
\hline Net Cas Uthilty Operating Income ..................... & 0 & 0 & o & 0 & 17,676 & 0 \\
\hline $\begin{array}{l}\text { Other UUlity Operating Income } \\
\text { Other Utillty Operating Revenues ............................ }\end{array}$ & 0 & 0 & 0 & 140 & 3,623 & 0 \\
\hline 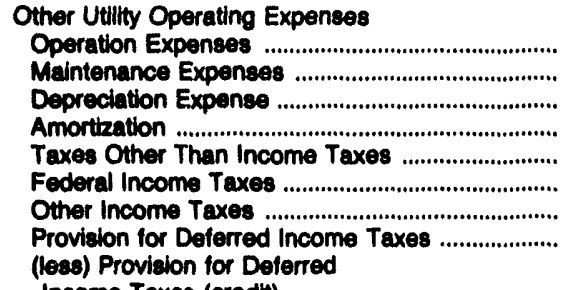 & $\begin{array}{l}0 \\
0 \\
0 \\
0 \\
0 \\
0 \\
0 \\
0\end{array}$ & $\begin{array}{l}0 \\
0 \\
0 \\
0 \\
0 \\
0 \\
0 \\
0\end{array}$ & $\begin{array}{l}0 \\
0 \\
0 \\
0 \\
0 \\
0 \\
0 \\
0\end{array}$ & $\begin{array}{r}98 \\
46 \\
6 \\
0 \\
5 \\
-6 \\
-1 \\
1\end{array}$ & $\begin{array}{r}9,328 \\
2,798 \\
158 \\
5 \\
636 \\
-2,985 \\
-463 \\
50\end{array}$ & $\begin{array}{l}0 \\
0 \\
0 \\
0 \\
0 \\
0 \\
0 \\
0\end{array}$ \\
\hline 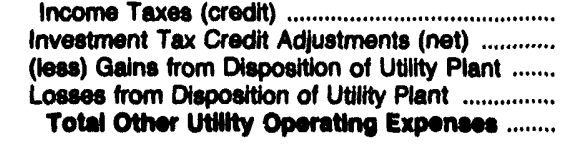 & $\begin{array}{l}0 \\
0 \\
0 \\
0 \\
0\end{array}$ & $\begin{array}{l}0 \\
0 \\
0 \\
0 \\
0\end{array}$ & $\begin{array}{l}0 \\
0 \\
0 \\
0 \\
0\end{array}$ & $\begin{array}{r}0 \\
0 \\
0 \\
0 \\
150\end{array}$ & $\begin{array}{r}145 \\
-14 \\
0 \\
0 \\
9,368\end{array}$ & $\begin{array}{l}0 \\
0 \\
0 \\
0 \\
0\end{array}$ \\
\hline Not Other Utilly Operating Incoms .................. & $\mathbf{0}$ & $\mathbf{0}$ & 0 & -9 & $-5,744$ & $\mathbf{0}$ \\
\hline
\end{tabular}


Table 37. Statement of Income and Rotained Earningo by Major U.S. Inveotor-Owned Electric Utility Within state, 1992 (Continued) (Thousand Dollars)

\begin{tabular}{|c|c|c|c|c|c|c|}
\hline them & $\begin{array}{l}\text { Phode laland } \\
\text { Blecketone } \\
\text { Vulley } \\
\text { Electrio Co }\end{array}$ & $\begin{array}{l}\text { Rhode Ialand } \\
\text { Narraganeott } \\
\text { Electric Co }\end{array}$ & $\begin{array}{l}\text { Rhode laland } \\
\text { Newport } \\
\text { Electrio } \\
\text { Corp }\end{array}$ & $\begin{array}{l}\text { South Curolin } \\
\text { Lookhert } \\
\text { Power Co }\end{array}$ & $\begin{array}{c}\text { South Carolina } \\
\text { South } \\
\text { Carollina } \\
\text { Electricaces } \\
\text { Co }\end{array}$ & $\begin{array}{l}\text { South Carolina } \\
\text { South } \\
\text { Carolina } \\
\text { Generto } \\
\text { Co Ine }\end{array}$ \\
\hline
\end{tabular}

Total Uilly Operating Incoms

Total Uitity Operating Revenues

138,604

468,252

69,645

16,960

094,381

73,108

Utilyy Operating Expenses

Operntion Expensea

Deprecintion Expen

Amortzation .................................................................

Texes Other Then Income Taxes

Federel income Taxes

Other Income Toxe:

Provision for Doterred income Taxee .....................

(teas) Provition for Doferred

Incoms Texes (credit)

Imvestment Tax Credit Adjustments (net) .............

(kes) Caline from Diapoeltion of Utllty Plant ......

Loases from Dieposition of Utilty Plant

Totel Uuitsy Operating Expenses.

Not Utilty Operating Inoome

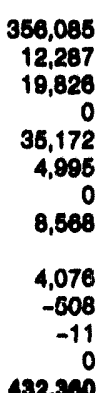

432,800

s6,002

6,600
12,718

$$
\begin{aligned}
& 680 \\
& 680
\end{aligned}
$$

600

508

566

87
-80

$$
0
$$$$
\begin{array}{r}
0 \\
-18
\end{array}
$$

0
18,002

9
637,795

60,279

01,805

6,259

65,695

68,283

8,011

33,187

49,855

$-3,245$

$-3,245$
0

812,114

182,297
48,214

3,431

4,136

$-1,182$

1,699
50,328

1,637

2,131

34
3,124

$-1,884$

$2,040^{3}$

277

$-4$

280
0

0.741

2,002
6,611

-189
-182

3,371

$-3,5$

0
0

92,300

10,710

Other Income and Deductiona

Other income

Nonutlity Operatiny income

Equity in Earnings of Subaldiary Companies ........

Interest and Dividend Income...

Allowance for Other Funds Used

During Construction

Miecellaneous Nonoperating Income

Gain on Dlaposition of Property

Totel Other Ineome.

Other Income Deductione

Loes on Disposition of Property

Miscellaneous Amortzation .

Miscellaneous income Deductions

Totel Other Incoms Deductions

Taxes on Other Income and Deductions

Texes Other Than Income Tuxes

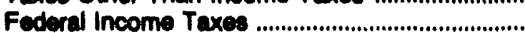

Other Income Taxes ....................................................

Provision for Deferred Income Taxes .....................

(leas) Provilion for Deferred

Income Taxes (credit)

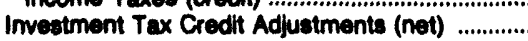

(lese) Investment Tax Credits

Tothl Taxes on Other Incoms

and Deduction

\section{mo}

Net Other Incoms and Deductions

$8 e e$ endnotes at end of an individual electric utility.

$\begin{array}{rr}-426 & 0 \\ 0 & 0 \\ 436 & 15 \\ & \\ 10 & 41 \\ 0 & 0 \\ -18 & 0 \\ 2 & 68\end{array}$

-545
0
847
4,577
1,987
74
7,088

0
0
61
93
0
0
184

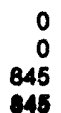

0
0
49
49

0
53
4,077

4,977
5,020

0
0
38
38

$\begin{array}{rr}0 & 97 \\ -13 & -386 \\ 0 & 0 \\ 0 & 69 \\ 0 & 2 \\ 0 & 0 \\ 0 & 0\end{array}$

0
-281
0
0
0
0
82

227

$-1,138$

$-158$

$-111$

$-181$

0
0

$-\infty 97$

380

3,000

107 
Table 37. Statement of Income and Rotained Earnings by Major U.8. Inveator-Owned Electrle Utility Within 8tate, 1902 (Continued) (Thousand Dollars)

\begin{tabular}{|c|c|c|c|c|c|c|}
\hline them & $\begin{array}{l}\text { Phode Ialand } \\
\text { Bleckotone } \\
\text { Valley } \\
\text { Electrio co }\end{array}$ & $\begin{array}{l}\text { Rhodo liland } \\
\text { Narraganeoit } \\
\text { Electrio Co }\end{array}$ & $\begin{array}{l}\text { Phode leland } \\
\text { Newport } \\
\text { Electrlo } \\
\text { Corp }\end{array}$ & $\begin{array}{l}\text { South Carolina } \\
\text { Lockhart } \\
\text { Power Co }\end{array}$ & $\begin{array}{c}\text { South Carollna } \\
\text { south } \\
\text { Carollina } \\
\text { Electricscas } \\
\text { Co }\end{array}$ & $\begin{array}{c}\text { South Carolina } \\
\text { South } \\
\text { Carolina } \\
\text { Genertg } \\
\text { Co Ino }\end{array}$ \\
\hline
\end{tabular}

Interest Charges

intereat on Lono-term Dabt

Amortination of Debt Discount and Expense .......

Amortantion of Lose on Reacquired Debt ............

(leas) Amortiention of Premlum on Debt (credii).

(lea) Amortization of Gain on

Pesquired Debt (credit) ...........................................

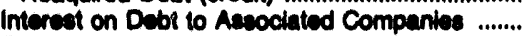

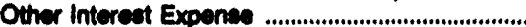

(bea) Allowence for Borrowed Funde

Used During Conotruction (credit)

Incoms Eoton Extreordinary Items

Extracolinary ltems

Extreordinary Income ..............................................

(leat) Extreordinary Deduotions

Net Extreordinary ltems

(lese) Federal and Other Income Taxes

Extracrinary tieme After Taxes

Net Inoome

$\begin{array}{rr}3,497 & 12,473 \\ 97 & 108 \\ 0 & 620 \\ 0 & 4 \\ 0 & 0 \\ 0 & 308 \\ 319 & 974 \\ 41 & 349 \\ 3,072 & 14,218\end{array}$

2,071

21,052

2,724

73

105
820

28

0

308

349

210

79,463

688

147

6,137

30

0

0
545

20
16

6,781

3,884

0,110

187

8,69

102,109

4,297

0

0

$$
\begin{aligned}
& 0 \\
& 0 \\
& 0
\end{aligned}
$$

0
0

0
0

0
0

0

0

2,871

21,062
0

co,cou

981

9,850

257,027

2,972

Rotalned Eaminge - Beginning of Year

Balance Tranaferred from income

Credits to Retained Earnings ...

(leep) Debits to Retained Earnings

(leas) Didende Declared - Preferred Stoc

(less) Divideinds Declared - Common Stock .......

Unappropriated Undistributed Subaldiary

Earnings .

Rotained Eaminge - End of Year

21,052

2,87

0
0
0

289

2,787

0
0
0
1,563

5,098

0

7,440

74,207

219
0
4
0
74
0
0

955

102,163

0
0
1,379

1,379
8,473

89,291

0

0

10,605

262,040

4,400

Appropriated Retained Earnings

Appropriated Retained Eamings -

Amortization Recerve, Federal

Total Rotalned Eaminges

0

0

0

o

0

0

0

0

0

10,216

0

Note: Totals may not equal sum of components because of independent rounding. Summary data are provided in Table 6.

Source: Federal Energy Regulatory Commisalon, FEAC Form 1, "Annual Report of Major Electrlc Utilites, Licensees and Others." 
Table 37. Statement of Income and Rotalned Earnings

by Major U.S. Inveotor-Owned Elootrle

Utility Within state, 1992 (Continued)

(Thousand Dollars)

\begin{tabular}{|c|c|c|c|c|c|c|}
\hline Hem & $\begin{array}{l}\text { South Dakota } \\
\text { Black } \\
\text { Hille Corp }\end{array}$ & $\begin{array}{l}\text { South Dakota } \\
\text { Northmeatem } \\
\text { Publlo } \\
\text { Sorvice Co }\end{array}$ & $\begin{array}{l}\text { Tenneseses } \\
\text { Kingeport } \\
\text { Power Co }\end{array}$ & $\begin{array}{l}\text { Tennecesee } \\
\text { Tapoco } \\
\text { Inc }\end{array}$ & $\begin{array}{c}\text { Toxas } \\
\text { Contral } \\
\text { Power } \\
2 \\
\text { Lught Co }\end{array}$ & $\begin{array}{c}\text { Texas } \\
\text { EI } \\
\text { Paso } \\
\text { Electric } \\
\text { Co } \\
\end{array}$ \\
\hline 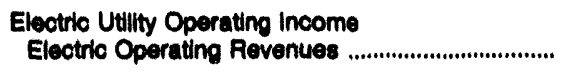 & 97,448 & 65,628 & 77,182 & 12,161 & $1,113,423$ & 639,106 \\
\hline 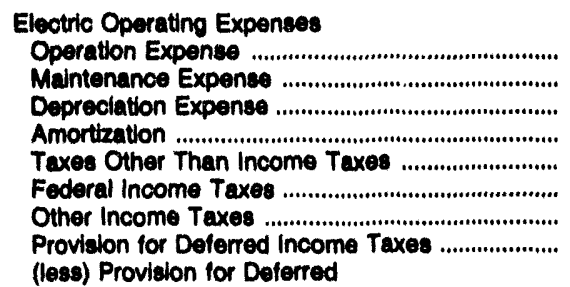 & $\begin{array}{r}54,613 \\
5,809 \\
9,462 \\
151 \\
3,931 \\
3,977 \\
29 \\
1,106\end{array}$ & $\begin{array}{r}26,246 \\
4,096 \\
8,434 \\
70 \\
3,973 \\
4,678 \\
42 \\
642\end{array}$ & $\begin{array}{r}64,980 \\
2,649 \\
1,029 \\
0 \\
0,316 \\
1,010 \\
0 \\
888\end{array}$ & $\begin{array}{r}4,662 \\
4,167 \\
1,689 \\
0 \\
962 \\
314 \\
-2 \\
-89\end{array}$ & $\begin{array}{r}497,291 \\
61,399 \\
126,165 \\
7,118 \\
70,343 \\
36,837 \\
0 \\
39,059\end{array}$ & $\begin{array}{r}314,732 \\
38,351 \\
33,370 \\
10,867 \\
50,241 \\
2,786 \\
-2,318 \\
37,131\end{array}$ \\
\hline 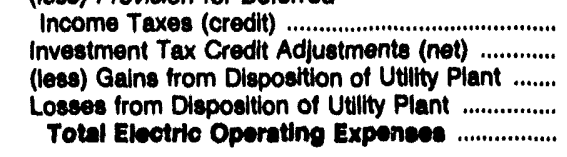 & $\begin{array}{r}0 \\
-512 \\
0 \\
0 \\
78,027\end{array}$ & $\begin{array}{r}646 \\
-618 \\
0 \\
0 \\
47,916\end{array}$ & $\begin{array}{r}823 \\
58 \\
0 \\
0 \\
73,008\end{array}$ & $\begin{array}{r}0 \\
-46 \\
0 \\
0 \\
11,517\end{array}$ & $\begin{array}{r}-9,714 \\
-5,837 \\
0 \\
0 \\
042,000\end{array}$ & $\begin{array}{r}40,296 \\
-2,349 \\
0 \\
0 \\
443,603\end{array}$ \\
\hline Net Electrle Utility Operating Income ............. & 18,021 & 17,712 & 3,194 & 698 & 271,334 & 98,603 \\
\hline $\begin{array}{l}\text { Gas Utllity Operating Income } \\
\text { Gas Operating Revenues }\end{array}$ & 0 & 52,216 & 0 & 0 & 0 & 0 \\
\hline 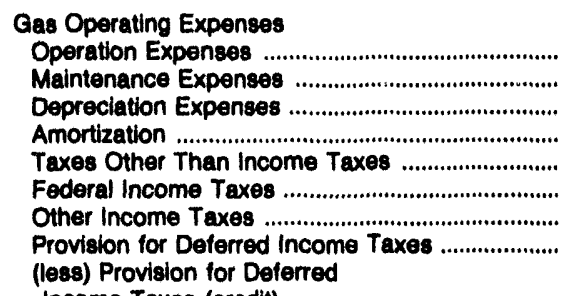 & $\begin{array}{l}0 \\
0 \\
0 \\
0 \\
0 \\
0 \\
0 \\
0\end{array}$ & $\begin{array}{r}45,727 \\
893 \\
1,537 \\
21 \\
1,146 \\
237 \\
245 \\
703\end{array}$ & $\begin{array}{l}0 \\
0 \\
0 \\
0 \\
0 \\
0 \\
0 \\
0\end{array}$ & $\begin{array}{l}0 \\
0 \\
0 \\
0 \\
0 \\
0 \\
0 \\
0\end{array}$ & $\begin{array}{l}0 \\
0 \\
0 \\
0 \\
0 \\
0 \\
0 \\
0\end{array}$ & $\begin{array}{l}0 \\
0 \\
0 \\
0 \\
0 \\
0 \\
0 \\
0\end{array}$ \\
\hline 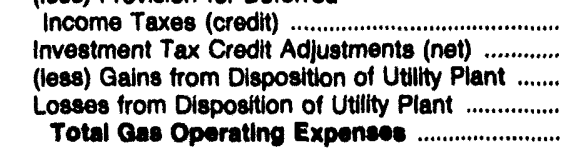 & $\begin{array}{l}0 \\
0 \\
0 \\
0 \\
0\end{array}$ & $\begin{array}{r}97 \\
-60 \\
0 \\
0 \\
50,360\end{array}$ & $\begin{array}{l}0 \\
0 \\
0 \\
0 \\
0\end{array}$ & $\begin{array}{l}0 \\
0 \\
0 \\
0 \\
0\end{array}$ & $\begin{array}{l}0 \\
0 \\
0 \\
0 \\
0\end{array}$ & $\begin{array}{l}0 \\
0 \\
0 \\
0 . \\
0\end{array}$ \\
\hline Net Cas Utilty Operating Income ....................... & $\mathbf{0}$ & 1,858 & 0 & 0 & 0 & 0 \\
\hline $\begin{array}{l}\text { Other Utility Operating Income } \\
\text { Other Utility Operating Revenues ............................. }\end{array}$ & 0 & 0 & 0 & 0 & 0 & 0 \\
\hline 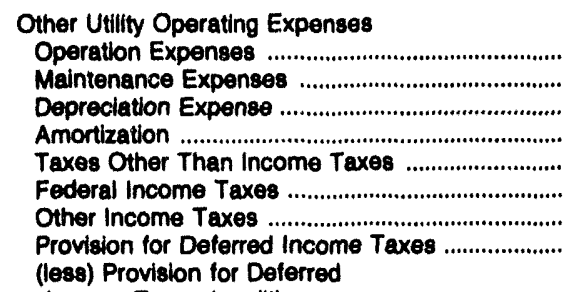 & $\begin{array}{l}0 \\
0 \\
0 \\
0 \\
0 \\
0 \\
0 \\
0\end{array}$ & $\begin{array}{l}0 \\
0 \\
0 \\
0 \\
0 \\
0 \\
0 \\
0\end{array}$ & $\begin{array}{l}0 \\
0 \\
0 \\
0 \\
0 \\
0 \\
0 \\
0\end{array}$ & $\begin{array}{l}0 \\
0 \\
0 \\
0 \\
0 \\
0 \\
0 \\
0\end{array}$ & $\begin{array}{l}0 \\
0 \\
0 \\
0 \\
0 \\
0 \\
0 \\
0\end{array}$ & $\begin{array}{l}0 \\
0 \\
0 \\
0 \\
0 \\
0 \\
0 \\
0\end{array}$ \\
\hline 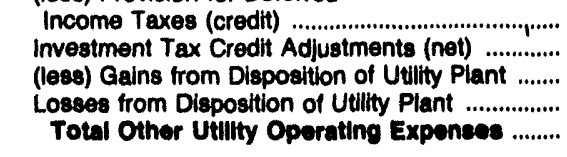 & $\begin{array}{l}0 \\
0 \\
0 \\
0 \\
0\end{array}$ & $\begin{array}{l}0 \\
0 \\
0 \\
0 \\
0\end{array}$ & $\begin{array}{l}0 \\
0 \\
0 \\
0 \\
0\end{array}$ & $\begin{array}{l}0 \\
0 \\
0 \\
0 \\
0\end{array}$ & $\begin{array}{l}0 \\
0 \\
0 \\
0 \\
0\end{array}$ & $\begin{array}{l}0 \\
0 \\
0 \\
0 \\
0\end{array}$ \\
\hline Net Other Utillty Operating Income ................. & $\mathbf{0}$ & 0 & $\mathbf{0}$ & 0 & $\mathbf{0}$ & 0 \\
\hline
\end{tabular}

See endnotes at end of an indlvidual electric utility. 
Table 37. Statement of Income and Rotalned Earnings

by Major U.8. Investor-Ownod Eleotric

Utility Within stato, 1092 (Continued)

(Thousand Dollars)

\begin{tabular}{|c|c|c|c|c|c|c|}
\hline Itom & $\begin{array}{l}\text { South Dakota } \\
\text { Blagk } \\
\text { Hills Corp }\end{array}$ & $\begin{array}{l}\text { South Dakota } \\
\text { Northweatern } \\
\text { Publle } \\
\text { Sorvios co }\end{array}$ & $\begin{array}{l}\text { Tonnosecee } \\
\text { Kingeport } \\
\text { Power Co }\end{array}$ & $\begin{array}{l}\text { Tonnoseces } \\
\text { Tapoco } \\
\text { Ine }\end{array}$ & $\begin{array}{l}\text { Toxas } \\
\text { Contral } \\
\text { Power } \\
\text { Luht co }\end{array}$ & $\begin{array}{l}\text { Toxas } \\
\text { EI } \\
\text { Paso } \\
\text { Eleotric } \\
\text { Co }\end{array}$ \\
\hline $\begin{array}{l}\text { Total Utilly Operating Income } \\
\text { Total Utilty Operating Revenues .............................. }\end{array}$ & 97,448 & 117,844 & 77,182 & 12,161 & $1,113,423$ & 839,106 \\
\hline 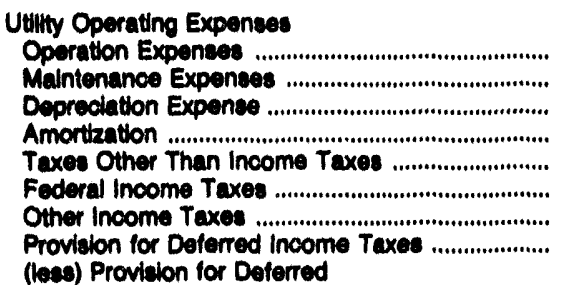 & $\begin{array}{r}54,613 \\
5,869 \\
0,402 \\
161 \\
3,831 \\
3,877 \\
29 \\
1,106\end{array}$ & $\begin{array}{r}70,872 \\
6,889 \\
10,071 \\
81 \\
8,118 \\
4,914 \\
280 \\
1,346\end{array}$ & $\begin{array}{r}64,060 \\
2,049 \\
1,029 \\
0 \\
3,316 \\
1,010 \\
0 \\
888\end{array}$ & $\begin{array}{r}4,862 \\
4,167 \\
1,658 \\
0 \\
952 \\
314 \\
-2 \\
-80\end{array}$ & $\begin{array}{r}497,291 \\
81,309 \\
126,186 \\
7,118 \\
70,343 \\
38,837 \\
0 \\
39,059\end{array}$ & $\begin{array}{r}314,7322 \\
30,351 \\
33,370 \\
10,357 \\
50,241 \\
2,785 \\
-2,319 \\
37,131\end{array}$ \\
\hline 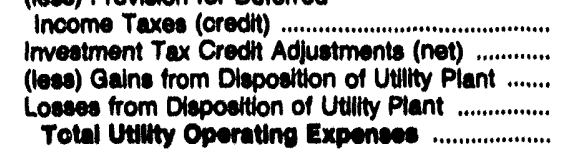 & $\begin{array}{r}0 \\
-612 \\
0 \\
0 \\
78,027\end{array}$ & $\begin{array}{r}743 \\
-689 \\
0 \\
0 \\
08,276\end{array}$ & $\begin{array}{r}823 \\
58 \\
0 \\
0 \\
73,000\end{array}$ & $\begin{array}{r}0 \\
-46 \\
0 \\
0 \\
11,817\end{array}$ & $\begin{array}{r}-0,714 \\
-6,837 \\
0 \\
0 \\
042,000\end{array}$ & $\begin{array}{r}40,296 \\
-2,349 \\
0 \\
0 \\
443,608\end{array}$ \\
\hline 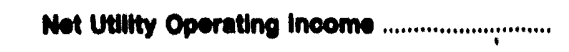 & 18,821 & 10,660 & 3,184 & 696 & 271,394 & 98,003 \\
\hline $\begin{array}{l}\text { Other Income and Deductions } \\
\text { Other Income } \\
\text { Nonutilly Operating Income .............................. } \\
\text { Equilty in Earnings of Subeldiary Companies ....... } \\
\text { Intereat and Dhidend Income .............................. } \\
\text { Allowance for Other Funde Used }\end{array}$ & $\begin{array}{r}0 \\
12,597 \\
579\end{array}$ & $\begin{array}{r}174 \\
473 \\
1,868\end{array}$ & $\begin{array}{r}6 \\
0 \\
168\end{array}$ & $\begin{array}{r}-82 \\
0 \\
0\end{array}$ & $\begin{array}{r}-54 \\
0 \\
3,312\end{array}$ & $\begin{array}{r}22 \\
0 \\
4,688\end{array}$ \\
\hline 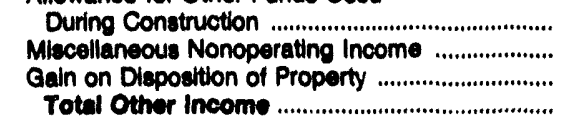 & $\begin{array}{r}94 \\
11 \\
0 \\
13,281\end{array}$ & $\begin{array}{r}106 \\
541 \\
0 \\
3,292\end{array}$ & $\begin{array}{r}0 \\
-1 \\
0 \\
173\end{array}$ & $\begin{array}{r}0 \\
-87 \\
0 \\
-170\end{array}$ & $\begin{array}{r}408 \\
82,521 \\
0 \\
86,107\end{array}$ & $\begin{array}{r}-5 \\
17,089 \\
0 \\
21,704\end{array}$ \\
\hline 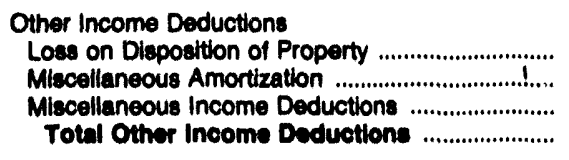 & $\begin{array}{r}0 \\
0 \\
239 \\
230\end{array}$ & $\begin{array}{r}0 \\
0 \\
571 \\
871\end{array}$ & $\begin{array}{r}0 \\
0 \\
65 \\
86\end{array}$ & $\begin{array}{l}0 \\
0 \\
0 \\
0\end{array}$ & $\begin{array}{r}7,357 \\
0 \\
2,001 \\
8,388\end{array}$ & $\begin{array}{r}0 \\
0 \\
3,180 \\
3,180\end{array}$ \\
\hline 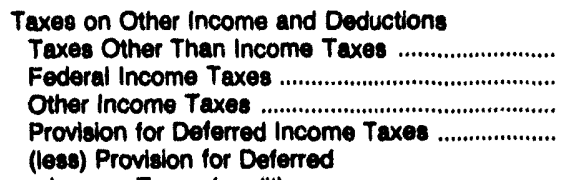 & $\begin{array}{l}0 \\
0 \\
0 \\
0\end{array}$ & $\begin{array}{r}0 \\
1,087 \\
0 \\
-649\end{array}$ & $\begin{array}{r}4 \\
32 \\
0 \\
27\end{array}$ & $\begin{array}{r}21 \\
0 \\
0 \\
0\end{array}$ & $\begin{array}{r}134 \\
-2,112 \\
0 \\
0\end{array}$ & $\begin{array}{r}8 \\
31 \\
0 \\
9,780\end{array}$ \\
\hline 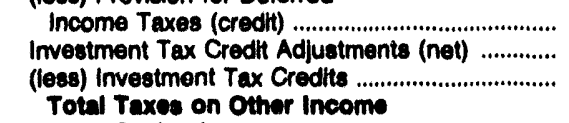 & $\begin{array}{l}0 \\
0 \\
0\end{array}$ & $\begin{array}{l}0 \\
0 \\
0\end{array}$ & $\begin{array}{r}0 \\
-79 \\
0\end{array}$ & $\begin{array}{l}0 \\
0 \\
0\end{array}$ & $\begin{array}{r}163 \\
0 \\
0\end{array}$ & $\begin{array}{r}3,782 \\
0 \\
570\end{array}$ \\
\hline and Deductions & $\mathbf{0}$ & 438 & -18 & 21 & $-2,140$ & 8,400 \\
\hline Not Other Income and Deductions ................. & 13,042 & 2,283 & 123 & -200 & 78,960 & 13,050 \\
\hline
\end{tabular}

See endnotes at end of an indivldual electric utility. 
Table 37. Statement of Income and Rotained Earninge

by Major U.S. Investor-Owned Electrlc

Utility Within State, 1992 (Continued)

(Thousand Dollars)

\begin{tabular}{|c|c|c|c|c|c|c|}
\hline item & $\begin{array}{c}\text { South Dakota } \\
\text { Black } \\
\text { Hills Corp }\end{array}$ & $\begin{array}{l}\text { South Dakota } \\
\text { Northweatern } \\
\text { Publlo } \\
\text { Service Co }\end{array}$ & $\begin{array}{l}\text { Tennesesee } \\
\text { Kingeport } \\
\text { Power Co }\end{array}$ & $\begin{array}{l}\text { Tenneseses } \\
\text { Tapoco } \\
\text { ino }\end{array}$ & $\begin{array}{c}\text { Toxas } \\
\text { Contral } \\
\text { Power } \\
\& \\
\text { Luht Co }\end{array}$ & $\begin{array}{c}\text { Texas } \\
\text { EI } \\
\text { Paso } \\
\text { Electric } \\
\text { Co }\end{array}$ \\
\hline
\end{tabular}

Intereat Charges

Intereat on Lono-term Debt

Amortention of Dobt Discount and Ex

Amortzation of Losa on Reacquired Debt ............

(bea) Amortization of Premium on Debt (credit). (kae) Amortization of Gain on

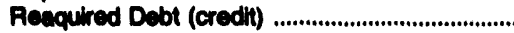

Interest on Debt to Aseoclated Companies .........

Other Intereat Expense

(bea) Allowance for Borrowed Funds

Used During Construction (credit)

Net intereot Cherees

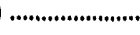

Inoome Eofore Extreordinary tiems

(...............

8,188
59
45
0
0
0
218
284
0,225

7,813

$\begin{array}{rr}7,813 \\ 5 & 129 \\ 0 & 0 \\ & 0\end{array}$

1,799

0

Extreondinary lloms

Extracordinary income

(lese) Extreordinary Deductions

Net Extreordinary ltoms

28,089

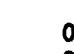

0

317

158

8,101

13,721

0

25,476

1,559
3,773

15

1,183

1,183
24
0

43

2,076

0

0
0
87

0
38,674

763

8
1,879

2,584

763
131,792

112,200

(lese) Federal and Other Income Taxes

Extreordinary ltems After Taxee

Net Inoome

13,721

1,439

3,474

$-3,548$

Unepropitated Rotelned Eaminge

Rotulned Eaminge - Beginning of Year

38,82

49,047

4.618

$-8,381$

854,650

$-14,926$

Balance Transterred from Income

Credth to Retained Eamings ...

$\begin{array}{rr}11,041 & 13,248 \\ 0 & 0 \\ 0 & 40 \\ 0 & 0 \\ 0 & 143\end{array}$

1,439

3,474

218,511

$-3,548$

(leas) Debits to Retained Earnings ........................

(leae) Appropriations of Retained Earnings .........

(loss) Dividends Declered - Preferred Stock ...

(1eas) Dividends Declared - Common Stock ......

Unappropriated Undlatributed Subsidiary

16,978

12,207

12,000

o

42,857

80,003

$-4,807$

$-25,080$

Appropriated Retained Earnings

0

0

0

112

16,070

193,000

0
0
0
6,613

6,613

o

Appropriated Retained Earnings -

Amortzation Reserve, Federal

Totel Rotinined Eaminges

42,097

60,003

4,467

$-4,007$

863,098

$-28,011$

Note: Totals may not equal sum of components because of independent rounding. Summary data are provided in Table 6 .

Source: Federal Energy Regulatory Commiseion, FERC Form 1, "Annual Report of Major Electric Utilties, Licensees and Others." 
Table 37. Statement of Income and Rotalned Earnings

by Major U.S. Investor-Owned Electric

Utility Within State, 1992 (Continued)

(Thousand Dollars)

\begin{tabular}{|c|c|c|c|c|c|c|}
\hline Item & $\begin{array}{c}\text { Texas } \\
\text { Gulf } \\
\text { States } \\
\text { Utillies } \\
\text { Co }\end{array}$ & $\begin{array}{c}\text { Toxas } \\
\text { Houston } \\
\text { Lighting } \\
\text { Power Co }\end{array}$ & $\begin{array}{l}\text { Texas } \\
\text { Southwestern } \\
\text { Electric } \\
\text { Serv Co }\end{array}$ & $\begin{array}{l}\text { Texas } \\
\text { Southwestem } \\
\text { Publlc } \\
\text { Service Co }\end{array}$ & $\begin{array}{c}\text { Texas } \\
\text { Texas } \\
\text { Utilities } \\
\text { Electric Co }\end{array}$ & $\begin{array}{l}\text { Texas } \\
\text { Texas- } \\
\text { Now Mexico } \\
\text { Power Co }\end{array}$ \\
\hline 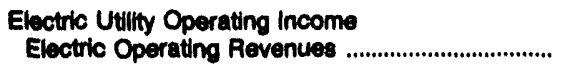 & $1,720,430$ & $3,828,841$ & 68,436 & 757,233 & $5,028,281$ & 443,827 \\
\hline 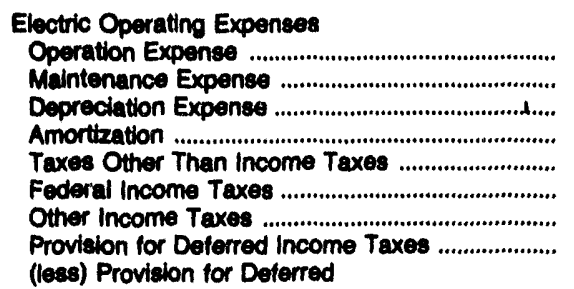 & $\begin{array}{r}871,963 \\
155,575 \\
177,403 \\
59,487 \\
88,573 \\
2,355 \\
0 \\
108,283\end{array}$ & $\begin{array}{r}2,108,425 \\
256,532 \\
320,224 \\
43,068 \\
228,238 \\
114,075 \\
0 \\
102,753\end{array}$ & $\begin{array}{r}53,644 \\
1,871 \\
3,054 \\
0 \\
3,155 \\
1,615 \\
0 \\
380\end{array}$ & $\begin{array}{r}442,222 \\
26,554 \\
58,986 \\
646 \\
36,528 \\
36,817 \\
1,740 \\
32,428\end{array}$ & $\begin{array}{r}2,459,880 \\
297,079 \\
404,886 \\
4,020 \\
423,505 \\
50,616 \\
0 \\
677,883\end{array}$ & $\begin{array}{r}287,818 \\
11,342 \\
35,098 \\
170 \\
29,260 \\
1,080 \\
339 \\
60,011\end{array}$ \\
\hline 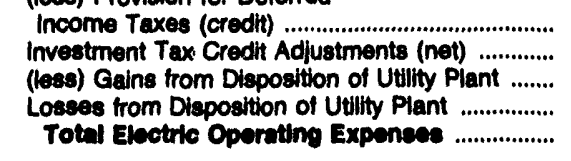 & $\begin{array}{r}66,106 \\
-2,055 \\
0 \\
0 \\
1,396,490\end{array}$ & $\begin{array}{r}36,856 \\
-18,818 \\
0 \\
0 \\
3,115,639\end{array}$ & $\begin{array}{r}0 \\
-97 \\
0 \\
0 \\
63,622\end{array}$ & $\begin{array}{r}18,143 \\
-250 \\
0 \\
0 \\
617,720\end{array}$ & $\begin{array}{r}468,903 \\
-20,323 \\
0 \\
0 \\
3,028,943\end{array}$ & $\begin{array}{r}58,664 \\
-444 \\
0 \\
0 \\
308,600\end{array}$ \\
\hline Net Ebctile Utilty Operating Income ............. & 324,051 & 711,202 & 4,814 & 130,504 & $1,200,330$ & 77,827 \\
\hline $\begin{array}{l}\text { Gas Utility Operating Income } \\
\text { Gas Operating Revenues .......................................... }\end{array}$ & 28,527 & 0 & 0 & 0 & 0 & 0 \\
\hline 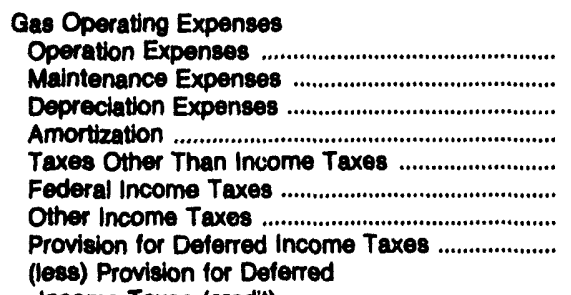 & $\begin{array}{r}22,832 \\
1,800 \\
1,424 \\
0 \\
2,391 \\
-125 \\
0 \\
188\end{array}$ & $\begin{array}{l}0 \\
0 \\
0 \\
0 \\
0 \\
0 \\
0 \\
0\end{array}$ & $\begin{array}{l}0 \\
0 \\
0 \\
0 \\
0 \\
0 \\
0 \\
0\end{array}$ & $\begin{array}{l}0 \\
0 \\
0 \\
0 \\
0 \\
0 \\
0 \\
0\end{array}$ & $\begin{array}{l}0 \\
0 \\
0 \\
0 \\
0 \\
0 \\
0 \\
0\end{array}$ & $\begin{array}{l}0 \\
0 \\
0 \\
0 \\
0 \\
0 \\
0 \\
0\end{array}$ \\
\hline 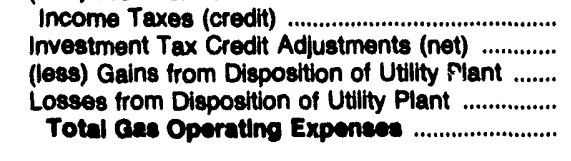 & $\begin{array}{r}178 \\
-32 \\
0 \\
0 \\
28,310\end{array}$ & $\begin{array}{l}0 \\
0 \\
0 \\
0 \\
0\end{array}$ & $\begin{array}{l}0 \\
0 \\
0 \\
0 \\
0\end{array}$ & $\begin{array}{l}0 \\
0 \\
0 \\
0 \\
0\end{array}$ & $\begin{array}{l}0 \\
0 \\
0 \\
0 \\
0\end{array}$ & $\begin{array}{l}0 \\
0 \\
0 \\
0 \\
0\end{array}$ \\
\hline Not cas Utulty Operating Income ................... & 217 & $\mathbf{0}$ & o & 0 & $\mathbf{0}$ & o \\
\hline $\begin{array}{l}\text { Other Utility Operating Income } \\
\text { Other Utility Operating Revenues }\end{array}$ & 50,315 & 0 & 0 & 0 & 0 & 0 \\
\hline 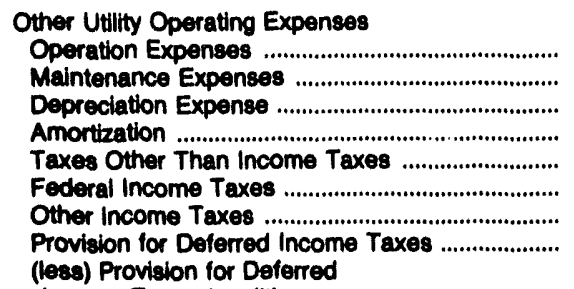 & $\begin{array}{r}34,035 \\
3,705 \\
3,025 \\
0 \\
776 \\
-780 \\
0 \\
2,295\end{array}$ & $\begin{array}{l}0 \\
0 \\
0 \\
0 \\
0 \\
0 \\
0 \\
0\end{array}$ & $\begin{array}{l}0 \\
0 \\
0 \\
0 \\
0 \\
0 \\
0 \\
0\end{array}$ & $\begin{array}{l}0 \\
0 \\
0 \\
0 \\
0 \\
0 \\
0 \\
0\end{array}$ & $\begin{array}{l}0 \\
0 \\
0 \\
0 \\
0 \\
0 \\
0 \\
0\end{array}$ & $\begin{array}{l}0 \\
0 \\
0 \\
0 \\
0 \\
0 \\
0 \\
0\end{array}$ \\
\hline 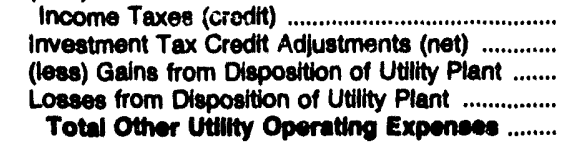 & $\begin{array}{r}1,167 \\
-113 \\
0 \\
0 \\
\$ 1,776\end{array}$ & $\begin{array}{l}0 \\
0 \\
0 \\
0 \\
0\end{array}$ & $\begin{array}{l}0 \\
0 \\
0 \\
0 \\
0\end{array}$ & $\begin{array}{l}0 \\
0 \\
0 \\
0 \\
0\end{array}$ & $\begin{array}{l}0 \\
0 \\
0 \\
0 \\
0\end{array}$ & $\begin{array}{l}0 \\
0 \\
0 \\
0 \\
0\end{array}$ \\
\hline Net Other Uttlity Operatting Income ................. & 8,630 & 0 & $\mathbf{0}$ & $\mathbf{0}$ & 0 & $\mathbf{0}$ \\
\hline
\end{tabular}

See endnotes at end of an individual electric utility. 
Table 37. Statemont of Income and Rotalned Earninge

by Major U.8. Inveotor-Owned Electric

Utility Within Stato, 1902 (Continued)

(Thousand Dollars)

\begin{tabular}{|c|c|c|c|c|c|c|}
\hline Item & $\begin{array}{c}\text { Teuns } \\
\text { Cull } \\
\text { States } \\
\text { Utillios } \\
\text { Co }\end{array}$ & $\begin{array}{l}\text { Toxas } \\
\text { Hounton } \\
\text { Lighting } \\
\text { Power Co }\end{array}$ & $\begin{array}{l}\text { Texas } \\
\text { Souttmuestem } \\
\text { Electric } \\
\text { Serv Co }\end{array}$ & $\begin{array}{c}\text { Texas } \\
\text { Southweotern } \\
\text { Publle } \\
\text { Senvice Co }\end{array}$ & $\begin{array}{c}\text { Texas } \\
\text { Texas } \\
\text { Utilites } \\
\text { Electric Co }\end{array}$ & $\begin{array}{c}\text { Texas } \\
\text { Texas- } \\
\text { New Mexico } \\
\text { Power Co }\end{array}$ \\
\hline
\end{tabular}

Total Utilly Operating Income

Total Uithy Operating $A$

$1,799,272$

Vitity Operating Expenses

Operation Exper

Meintenance Expenses

Deprechition Expense

Amoritation

Federal Income Texes

Other Income Taxes

Providion for Daferred Income Taxes

(leas) Provition for Deferred

Income Taxes (credil)

Imvestment Tax Cred"t Adlustments (net)

(leas) Cains from Diepostion of Utillty Plant .....

Loseses from Disposition of Utilty Plant

Totel Uututy Operating Expensese

Net Utilty Operating incoms

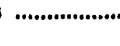

161,080

181,852

59,487

91,740

1,460

110,777

$3,820,841$

68,438

757,233

$5,029,281$

443,827

67,451

$-2,200$

2,108,425

258,532

228,238

114,075

102,763

38,856

$-18,818$

0
0

$3,115,680$

53,644
1,871
3,054
0
3,155
1,615
0
380

442,222

26,554

58,868

846

36,529

36,817

1,740

32,426

297,078

404,986

4,020

423,505

50,816

677,983

18,143

468,903

$-20,323$

0
-87
0
0

$-260$

89,022

617,72

$3,828,043$

287,818

11,342

35,098

170

29,260

1,080
339

60,011

58,664

$-444$

0

4,814

130,604

$1,200,338$

77,827

Other Income and Deductions

Other income

Nonutlity Operating Income ....................................

Equity in Earnings of Subaidlary Companies .......

Intereat and Dividend Income

Allowance for Other Funds Used

During Construction

Miecellaneous Nonoperating Income

Cain on Disposition of Property

Totil Other Incems

$-450$

$-76$

19,713

1,226

12,647

2,905

35,905

Other Income Deductions

Loses on Disposition of Property

Milecellanecus Amortization ...

Miscellaneous Income Deductions

Totel Other Incomo Deductions

Taxes on Other Income and Deductions

Taxes Other Than Income Taxes

Federal income Taxes

Provision for Doferre

(leas) Provision for Deferred

Income Texes (credit)

Imvertment Tax Cred't Adurtments (net)

(leas) Imvestment Tax Credits

Totid Taxes on Other income

and Daduction

Ket Other Inoome and Deductions - n-1.......

.......

See endnotes at end of an individual electric utility.

$-89,601$

175
0,114

0,114
0

21,040

61,618
-230
1,750
2,018
2,196
89
9
5,832

0

6,057

194,462

3,623

158,698

312
204,465

1,811

300

2,111

1,248
0

152

15,263
15,209

620
620

0
0
-2

$-2,284$
1,499

$\begin{array}{rr}6,802 & -50,858 \\ 0 & 0 \\ 0 & 0\end{array}$

80,078

0.,891

21

5,033

189,865 
Table 37. Statoment of Income and Rotalned Eaminge

by Major U.S. Inveator-Owned Electric

Utility Within state, 1902 (Continued)

(Thousand Dollars)

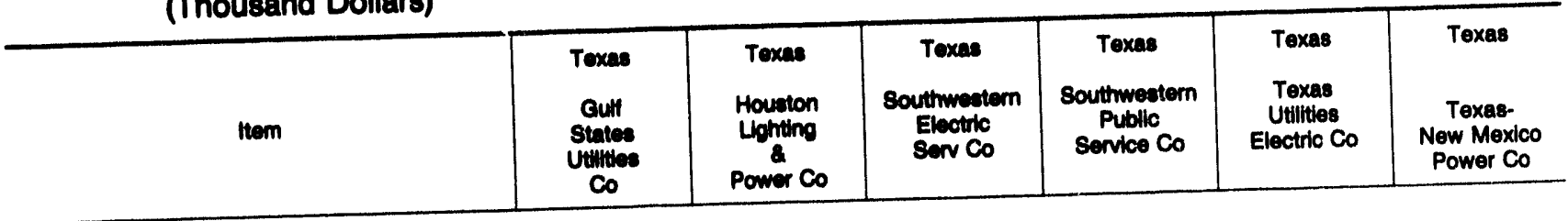

Intereat Charges

Interent on Lono-term Debt .....................................

Amortization of Debt Diecount and Expense .......

Amortization of Lose on Reacquired Debt ...........

(laes) Amortbration of Premium on Debt (credil) .

(lese) Amortization of Gain on

Reaquired Debt (credil) .........................................

Interest on Debt to Associated Companies ........

Other Interest Expense ............................................

(lese) Allowance for Borrowed Funds

Used During Construction (credit)

Not Interest Cherese .................................

Inooms Before Extracrdinery tiems

Extraordinary ltems

Extraordinary Income

(leas) Extreordinary Deductions

Not Extrecordinary Items

14,540

$-14,640$

(less) Federal and Other Income Taxes

$-4,944$

$-0,697$

120,167

491,203

310,286

2,848

2,808
107

1,831
1,688

40$$
107
$$

0
0
9,075

0
0
0

0,919

947
247,460

6,190
31090

18,300

41,203

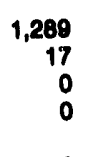

40,821
389

644

13

0
0

1,049

1,059

41,024

102,012

3,400

0
0
0

0
0
0

652,614
4,843

4,843

95
65

0
4310

4,310
17,813

109,736

579,080

821,123

Net Incom

\section{Unappropotated Rotained Eamine:}

Rotalnod Euminge - Beglinoing of Year

Balance Traneterred from Income

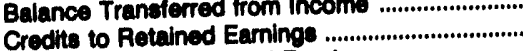

(less) Deblts to Retained Earnings ........................

(lese) Appropriations of Retained Earninge .........

(less) Dividends Declared - Preterred Stock ......

(lese) Dividends Declared - Common Stock ......

Unapproprtated Undiatributed Subeldlary

Eaming:

Rotained Earninge - End of Year

(.......................

Appropriated Retained Eamings

Aporopiated Retained Eaminge -

Amortzation Reserve, Federal

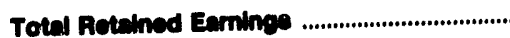

014,10

$1,769,779$

24,245

319,69

$1,424,974$

821,123

100,862

1,685

7,181

80,019

1,837

118,417

645,260

$$
\begin{array}{r}
39,327 \\
317,849
\end{array}
$$

1,681

0

0

o

$771,010 \quad 1,072,008$

28,010

321,674

$1,480,683$

$0 \quad 0$

0

$771,810 \quad 1,872,006$

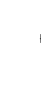

0

20,010
10,845

48,683

63,894

2,628

224
4

0

1,792

149

68,288

0
0
0

0

0,845

49,648

10,846

0

3,840

0

0

0

Note: Totals may not equal sum of components because of independent rounding. Summary data are provided in Table 6.

Commision, FERC Form 1, "Annual Report of Maior Electric Utillies, Licensees and Others." 
Table 37. Statement of Income and Rotained Earninge

by Major U.S. Investor-Owned Electrle

Utility Within State, 1992 (Continued)

(Thousand Dollars)

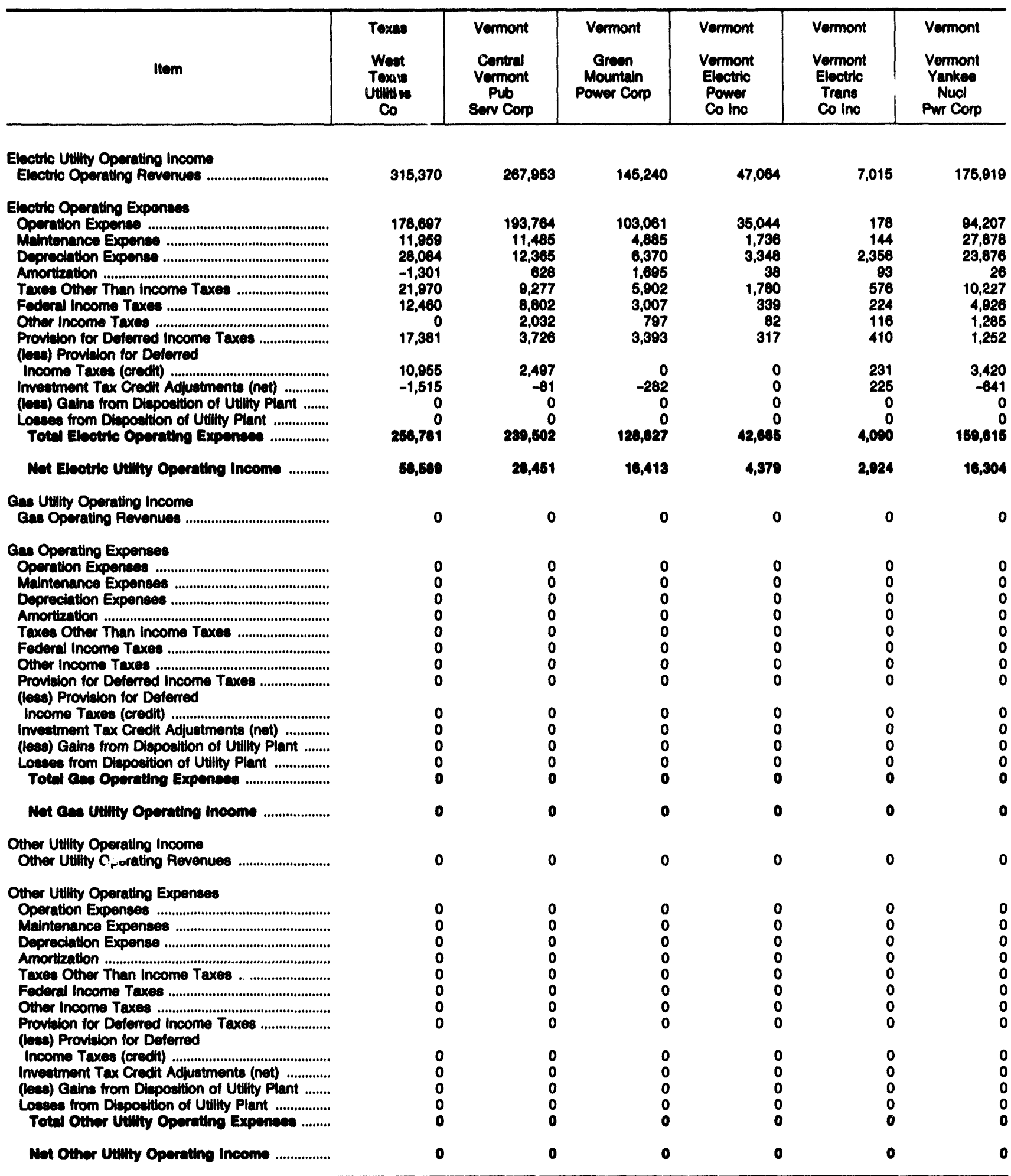

See endnotes at end of an individual electric utility. 
Table 37. Statement of Income and Rotained Earnings

by Major U.8. Investor-Owned Eloctric

Utility Within State, 1992 (Continued)

(Thousand Dollars)

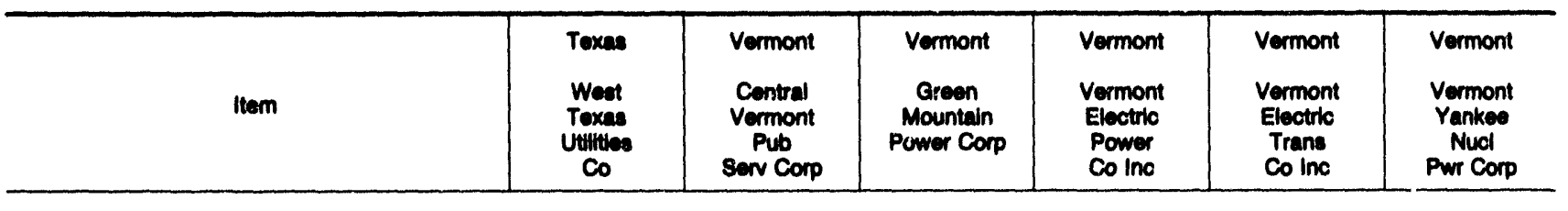

Total Utility Operating Income

Total Utilty Operating Revenues

Utiliy Operating Expenses

Operntion Expenses

Maintenance Expenses

Depreclation Expense

Texes Other Then Income Taxes

Federd Income Taxes

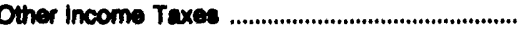

Provision for Deferred Income Taxes ....................

(leas) Provbion for Doterred

Income Texes (credti)

Imveotment Tax Credit Adjustments (not) ............

(leas) Geline from Dlapodtion of Utllity Plant ......

Loseses from Dispostion of Utility Plant

Totel Ut"ty Operating Expenese

Net Vuinty Operating Ineoms

315,370

287,853

145,240

47,084

7,015

$\begin{array}{rr}178,697 & 198,764 \\ 11,850 & 11,485 \\ 28,084 & 12,365 \\ -1,301 & 628 \\ 21,970 & 9,277 \\ 12,460 & 8,602 \\ 0 & 2,032 \\ 17,381 & 3,726 \\ & \\ 10,955 & 2,497 \\ -1,515 & -81 \\ 0 & 0 \\ 0 & 0 \\ 288,701 & 280,802\end{array}$

103,081

4,885

6,370

1,695

6,002

3,007

797

3,393

0

$-282$

0

128,027

18,413

20,451

co,ege

$\begin{array}{rr}466 & 684 \\ 0 & 5,130 \\ 1,413 & 1,186 \\ 51 & 267 \\ 460 & 732 \\ 11 & 24 \\ 2,401 & 8,023\end{array}$

1,850

32

495
2,477

1
6
2,505
2,512

120

Taxes on Other Income and Deduction

Taxes Other Than Income Taxes

Federal income Taxes

Other Income Taxes

Provition for Deferred Income Taxes.

(leas) Provicion for Doferred

Income Texes (credit)

Inventment Tax Credit Adiuetmente (net)

(leas) Imveotment Tax Credite

Toted Taxes on Other Inceme

and Deductions

Net Otwer Income and Deductions
390

1,791
305

188

38
0

2,711
4,926

1,285

1,262

3,420

$-641$

0

180,916

4,370

10,304

2,024

0

858
131

0

2,046

89

80

2,220

1,090

$$
\begin{array}{r}
0 \\
0 \\
398 \\
308
\end{array}
$$

0
0
285
208

See endnotes at end of an individual electric utility.

7
352
87
-348
62
0
288
-100

5,701
56
-2
0
0
0
0
0
54

2,260 
Table 37. Statement of Income and Retalned Earnings

by Major U.S. Investor-Owned Electric

Utility Within State, 1992 (Continued)

(Thousand Dollars)

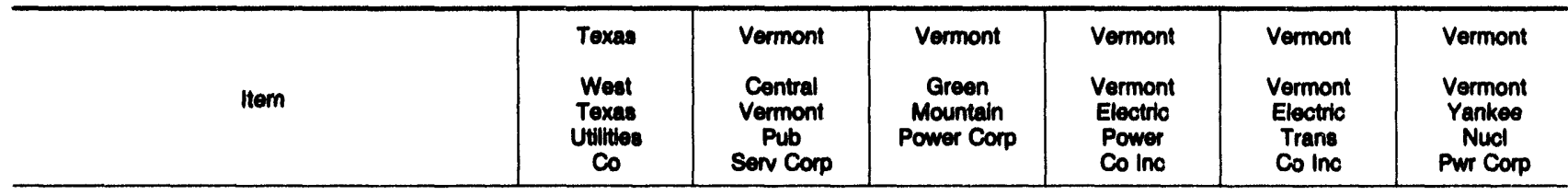

Intereat Charges

Interest on Long-term Debt

Amortization of Loss on Reacquired Debt ...........

(less) Amortzation of Premium on Debt (credit)

(lese) Amortzation of Gain on

Reaquired Debt (credit)

Interest on Debt to Associated Companies

Other Interest Expense .........

(less) Allowance for Borrowed Funds

Used During Construction (credit)

Net intereat Charge

Income Bofore Extraordinary lteme

.........................

Extraordinary ltems

Extraordinary Income

(less) Extraordinary Deductions

Not Extreordinary liems

(less) Federal and Other Income Taxes

Extraordinary items After Taxes

Net Income

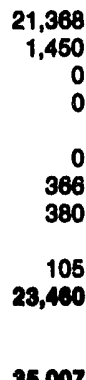

35,007

,

21,422

1,587

86

85

0

22

883

153

12,730

11,862

6,543

87
14
0

15

15
0
394

202

8,810

0
0

0

0
0

21,422

52,360

22,004

35,007

55

0
1,451

28,000

0

127,424

0

Appropriated Retained Earnings

Appropriated Retained Eamings

Amortization Reserve, Federal

Total Rotalned Eaminge
................................
16,292

60,228

16,292
0
0
0
2,658

10,081

19,162

4,007

25,058

0

259

715

26,312

61,642
0

127,424

3,782
36
0
0
0
0
295
83
4,030

1,916

51
0

0

0
0

77

0

058

1,494

9,836

204

97

571

244

339
$\square$
833

7,021

0

o

0
0
0

0

0

7,021

อร8

124

1,163

130

858

7,921

536

0
0

0
875

540

0

0

0
975

0

107

1,178

107

1,178

Note: Totals may not equal sum of components because of independent rounding. Summary data are provided in Table 6 .

Source: Federal Energy Regulatory Commiseion, FERC Form 1, "Annual Report of Major Electric Utilities, Liceneees and Others." 
Table 37. Statement of Income and Rotalned Earninge

by Major U.8. Investor-Owned Eloctrle

Utility Within state, 1902 (Continued)

(Thousand Dollars)

\begin{tabular}{|c|c|c|c|c|c|c|}
\hline Item & $\begin{array}{l}\text { Virginia } \\
\text { Appalachian } \\
\text { Power Co }\end{array}$ & $\begin{array}{l}\text { Virginia } \\
\text { Virginia } \\
\text { Eleotrio } \\
\text { a Power } \\
\text { Co }\end{array}$ & $\begin{array}{l}\text { Wauhington } \\
\text { Pugot sound } \\
\text { Power \& Lloht } \\
\text { Co }\end{array}$ & $\begin{array}{l}\text { Washington } \\
\text { Washington } \\
\text { Water } \\
\text { Power Co }\end{array}$ & $\begin{array}{l}\text { Weat Virginia } \\
\text { Kanawha } \\
\text { Valloy } \\
\text { Power Co }\end{array}$ & $\begin{array}{l}\text { Weat Virginia } \\
\text { Monongathala } \\
\text { Power Co }\end{array}$ \\
\hline $\begin{array}{l}\text { Electric Utifity Oparating Income } \\
\text { Electric Operating Revenues }\end{array}$ & $1,410,813$ & $3,679,621$ & $1,024,970$ & 424,413 & 4,273 & 631,064 \\
\hline 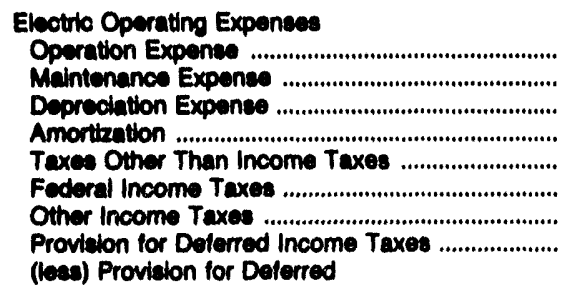 & $\begin{array}{r}805,306 \\
104,249 \\
116,733 \\
645 \\
101,818 \\
21,664 \\
2,564 \\
63,780\end{array}$ & $\begin{array}{r}1,744,470 \\
280,573 \\
398,380 \\
39,230 \\
233,211 \\
142,878 \\
2,094 \\
263,037\end{array}$ & $\begin{array}{r}\mathbf{4 8 5 , 0 9 3} \\
55,705 \\
92,850 \\
30,081 \\
84,466 \\
67,762 \\
0 \\
55,464\end{array}$ & $\begin{array}{r}193,967 \\
20,751 \\
32,465 \\
9,013 \\
34,434 \\
23,986 \\
1,524 \\
8,462\end{array}$ & $\begin{array}{r}1,225 \\
332 \\
236 \\
0 \\
809 \\
327 \\
86 \\
201\end{array}$ & $\begin{array}{r}372,003 \\
62,009 \\
53,761 \\
114 \\
33,207 \\
20,198 \\
787 \\
15,829\end{array}$ \\
\hline 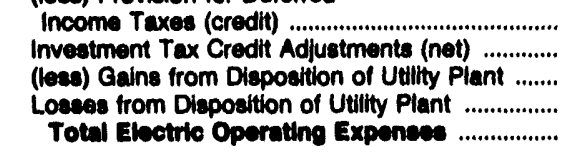 & $\begin{array}{r}36,130 \\
-2,530 \\
116 \\
0 \\
1,177,924\end{array}$ & $\begin{array}{r}157,270 \\
-18,395 \\
54 \\
0 \\
2,010,065\end{array}$ & $\begin{array}{r}46,748 \\
-4,018 \\
346 \\
0 \\
010,290\end{array}$ & $\begin{array}{r}1,383 \\
-652 \\
0 \\
0 \\
322,546\end{array}$ & $\begin{array}{r}43 \\
0 \\
0 \\
0 \\
3,171\end{array}$ & $\begin{array}{r}6,516 \\
-2,382 \\
0 \\
0 \\
548,202\end{array}$ \\
\hline Not Elcotric Utilty Operating Income ............ & 232,020 & 781,860 & 214,070 & 101,867 & 1,102 & 82,002 \\
\hline 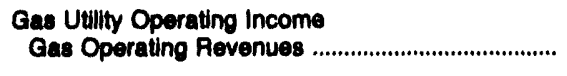 & 0 & 0 & 0 & 100,570 & 0 & 0 \\
\hline 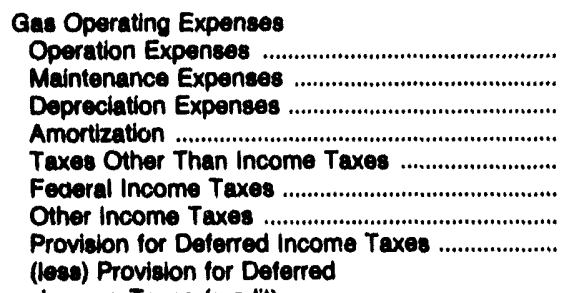 & $\begin{array}{l}0 \\
0 \\
0 \\
0 \\
0 \\
0 \\
0 \\
0\end{array}$ & $\begin{array}{l}0 \\
0 \\
0 \\
0 \\
0 \\
0 \\
0 \\
0\end{array}$ & $\begin{array}{l}0 \\
0 \\
0 \\
0 \\
0 \\
0 \\
0 \\
0\end{array}$ & $\begin{array}{r}71,162 \\
3,308 \\
7,849 \\
602 \\
5,823 \\
-1,014 \\
630 \\
3,442\end{array}$ & $\begin{array}{l}0 \\
0 \\
0 \\
0 \\
0 \\
0 \\
0 \\
0\end{array}$ & $\begin{array}{l}0 \\
0 \\
0 \\
0 \\
0 \\
0 \\
0 \\
0\end{array}$ \\
\hline 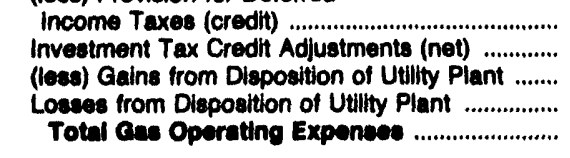 & $\begin{array}{l}0 \\
0 \\
0 \\
0 \\
0\end{array}$ & $\begin{array}{l}0 \\
0 \\
0 \\
0 \\
0\end{array}$ & $\begin{array}{l}0 \\
0 \\
0 \\
0 \\
0\end{array}$ & $\begin{array}{r}250 \\
-49 \\
0 \\
0 \\
91,502\end{array}$ & $\begin{array}{l}0 \\
0 \\
0 \\
0 \\
0\end{array}$ & $\begin{array}{l}0 \\
0 \\
0 \\
0 \\
0\end{array}$ \\
\hline Net Ces Utilty Operating Income ....................... & $\mathbf{0}$ & $\mathbf{0}$ & 0 & 0,068 & $\mathbf{0}$ & 0 \\
\hline $\begin{array}{l}\text { Other Utilly Operating Income } \\
\text { Other Utility Operating Revenues }\end{array}$ & 0 & 0 & 0 & 0 & 0 & 0 \\
\hline 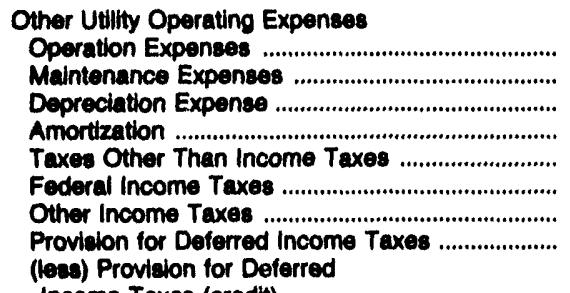 & $\begin{array}{l}0 \\
0 \\
0 \\
0 \\
0 \\
0 \\
0 \\
0\end{array}$ & $\begin{array}{l}0 \\
0 \\
0 \\
0 \\
0 \\
0 \\
0 \\
0\end{array}$ & $\begin{array}{l}0 \\
0 \\
0 \\
0 \\
0 \\
0 \\
0 \\
0\end{array}$ & $\begin{array}{l}0 \\
0 \\
0 \\
0 \\
0 \\
0 \\
0 \\
0\end{array}$ & $\begin{array}{l}0 \\
0 \\
0 \\
0 \\
0 \\
0 \\
0 \\
0\end{array}$ & $\begin{array}{l}0 \\
0 \\
0 \\
0 \\
0 \\
0 \\
0 \\
0\end{array}$ \\
\hline 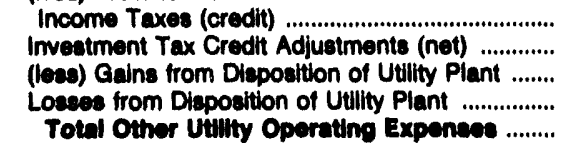 & $\begin{array}{l}0 \\
0 \\
0 \\
0 \\
0\end{array}$ & $\begin{array}{l}0 \\
0 \\
0 \\
0 \\
0\end{array}$ & $\begin{array}{l}0 \\
0 \\
0 \\
0 \\
0\end{array}$ & $\begin{array}{l}0 \\
0 \\
0 \\
0 \\
0\end{array}$ & $\begin{array}{l}0 \\
0 \\
0 \\
0 \\
0\end{array}$ & $\begin{array}{l}0 \\
0 \\
0 \\
0 \\
0\end{array}$ \\
\hline Net Other Utulty Operating Income .................. & 0 & 0 & 0 & 0 & $\mathbf{0}$ & $\mathbf{0}$ \\
\hline
\end{tabular}

See endnotes at end of an individual electric utility. 
Table 37. statement of Income and Rotained Earninge

by Major U.S. Investor-Owned Eloctrlc

Utility Within Stato, 1992 (Continued)

(Thousand Dollars)

\begin{tabular}{|c|c|c|c|c|c|c|}
\hline Item & $\begin{array}{l}\text { Virginia } \\
\text { Appalachian } \\
\text { Power Co }\end{array}$ & $\begin{array}{c}\text { Virginia } \\
\text { Virginia } \\
\text { Electric } \\
\text { a Power } \\
\text { Co }\end{array}$ & $\begin{array}{c}\text { Washington } \\
\text { Puget Sound } \\
\text { Power \& Light } \\
\text { Co }\end{array}$ & $\begin{array}{l}\text { Washington } \\
\text { Waghington } \\
\text { Water } \\
\text { Power Co }\end{array}$ & $\begin{array}{l}\text { West Virginia } \\
\text { Kanawha } \\
\text { Valley } \\
\text { Power Co }\end{array}$ & $\begin{array}{l}\text { Weat Virginie } \\
\text { Monongahele } \\
\text { Power Co }\end{array}$ \\
\hline
\end{tabular}

Tolal Utilly Operating income

Total Utility Operating Revenues

624,982

4,273

631,984

Uiiity Operating Expenses

Operation Expenses

Mintenance Expenses

Deprechtion Expense

Amortization

Taxes Other Than Income Taxes

Federal income Taxes

Other Income Taxes

Proviaton tor Deterred Income Tax

(leas) Provision for Deferred

income Taxes (credit)

Imvertment Tax Credit Adjustmente (net)

(leas) Gains from Disposition of Utillty Plant ......

Loseses from Disposition of Utility Plant

Total Uitity Operating Expenses

....................

Net Uatily Operating Income

$1,744,470$

280,573

398,380

39,230

233,211

142,878

2,894

253,037

68,780

36,130

$-2,530$

157,270

$-19,395$

0

$1,177,004$

$2,910,055$

$$
\begin{array}{r}
55,705 \\
92,850 \\
30,081 \\
84,466 \\
67,762 \\
0 \\
55,464 \\
46,749 \\
-4,018 \\
346 \\
0 \\
810,290
\end{array}
$$

465,093
55,705

214,070

285,129

24,058

40,304

8,615

40,257

22,972

2,153

11,804

1,643

$-702$

414,04

110,936

1,225

332
235

0
609

609
327

86

201

43

0
0
0

3,171

1,102

Other Income and Deductions

Other income

Nonutilly Operating Income ..................................

Equity in Earnings of Subsidiary Companies ......

Interest and Dividend income

Allowance for Other Funds Used

During Construction

Gain on Disposition of Property

Totes Other Income

Other Income Deductions

Loss on Disposition of Property

Miscellaneous Amortization

Miscellaneous Income Deductions

Totil Other Ineome Deductions

............................

....

Taxes on Other Income and Deductions

Taxes Other Than income Taxes

Other Income Texes

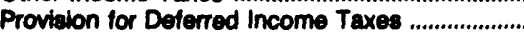

(less) Provision for Delerred

Income Taxes (credit)

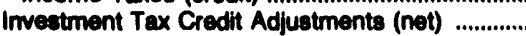

(leas) imvestment Tax Credits

Totil Taxes on Other Income

end Deduction.

Net Other Income and Deductions

See endnotes at end of an inchidual electric utility.

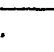

$-120$

621

3,894

0
501

501
57

5,055

$-2$

365

3,251

3,614

224

0
11,269

4,786

18,912

740
35,932

-974
-980

980
2,539

$-224$

10,695
3,139

443

14,477

3
17,499

1,392

2,586

17,569

$\begin{array}{rr}-27 & 227 \\ 0 & 1,377 \\ 2,750 & -212\end{array}$

2,723

-212
1,303

13,041
13,089

$$
\begin{array}{r}
7 \\
-88
\end{array}
$$

$-980$

0
1,009

0
$-2,565$

24

$-10,704$

3,005
186
$-6,080$
57

33,373

38,299

0
0

33,640
153
$-5,207$

$-5,207$

3,360

763

0
0

$-2,467$

17,204
36
$-2,778$

0
3,280

$-1,330$

1,330
0
0

1,877

14,320

10,305

167

50

0

0

283

94
$-2,551$
11,422
2,007
7
0
10,97

0
0
320
320 
Table 37. Statement of Income and Rotalned Earnings

by Major U.8. Investor-Owned Electric

Utilly Within State, 1992 (Continued)

(Thousand Dollars)

\begin{tabular}{|c|c|c|c|c|c|c|}
\hline Itom & $\begin{array}{l}\text { Virginia } \\
\text { Appalachian } \\
\text { Power Co }\end{array}$ & $\begin{array}{c}\text { Virginia } \\
\text { Virginia } \\
\text { Electric } \\
\text { a Power } \\
\text { Co }\end{array}$ & $\begin{array}{l}\text { Waahington } \\
\text { Puget Sound } \\
\text { Power \& Light } \\
\text { Co }\end{array}$ & $\begin{array}{l}\text { Washington } \\
\text { Washington } \\
\text { Water } \\
\text { Power Co }\end{array}$ & $\begin{array}{l}\text { Weat Virginia } \\
\text { Kanawha } \\
\text { Valley } \\
\text { Power co }\end{array}$ & $\begin{array}{l}\text { Weat Virginia } \\
\text { Monongahela } \\
\text { Power Co }\end{array}$ \\
\hline
\end{tabular}

Interest Charges

Interest on Long-term Debt

............................

Amortization of Loss on Rescquired Debt ...........

(lese) Amortization of Premium on Debt (credit).

(1ess) Amortization of Gain on

Aeaquired Debt (credit)

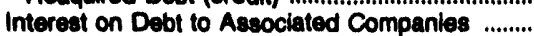

Other Interest Expense ............................................

(less) Allowance for Borrowed Funds

Used During Construction (credit)

Net interest Charees

Income Eofore Extreordinary Iteme

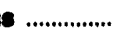

$\begin{array}{rr}102,163 & 300,858 \\ 658 & -1,160 \\ 722 & 4,439 \\ 65 & -1,778 \\ 1 & \\ 79 & \\ 2,816 & 24,44 \\ 1,058 & 4,705 \\ 105,318 & 325,607 \\ 131,419 & 480,580\end{array}$

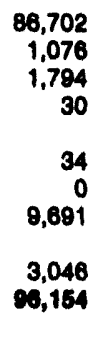

60,063

614

1,216

$-1,180$
4,438

$-1,778$

30

16

0
0

1,068

2,359

2,359
50,694

135,720

74,670

34,24

219

404

11

0

1,157

1,801

34,112

Extraordinary liems

Extraordinary income

(less) Extraordinary Deductions ..............................

Not Extraordinary lteme.

(less) Federal and Other income Taxes

Extraordinary Veme After Taxes

Not Income

912

$\mathbf{6 0 , 3 4 4}$

Unapproprlated Rotained Earninge

Rotained Eamings - Beginning of Yoar

$1,142,494$

192,441

48,990

1,292

164,089

Balance Transferred from Income

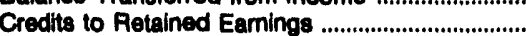

(less) Debits to Retained Earnings .........................

(less) Appropriations of Retained Earnings .........

(less) Dividends Declared - Preferred Stock .......

(lese) Dividends Declared - Common Stock .......

Unappropriated Undistributed Subsidiary

Earnings

130,797

516

469,520

134,740

$\begin{array}{rr}0 & 0 \\ 66 & 1,085 \\ 0 & 0 \\ 46,281 & 12,256\end{array}$

16,130

105,836

100,692

63,975

420

369,803

$-5,315$

6,868

61,525

3,600

207,033

43,500

174,168

Rotained Eaminge - End of Year

222,580

$1,195,884$

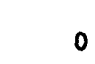

0

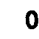

0

Appropriated Retained Earnings

Amortization Reserve, Federal

2,545

1,058

1,548

21

0

Total Rotwined Eaminge

225,074

$1,195,913$

208,091

46,048

2,225

174,169

Note: Totals may not equal sum of components because of independent rounding. Summary data are provided in Table 6.

Source: Federal Energy Regulatory Commlssion, FERC Form 1, "Annual Report of Major Electric Utilities, Licensees and Others." 
Table 37. Statoment of Ineome and Rotained Earninge

by Major U.8. Inveotor-Owned Eloctrio

Uillity Within 8tato, 1902 (Continuod)

(Thousand Dollars)

\begin{tabular}{|c|c|c|c|c|c|c|}
\hline Itom & $\begin{array}{l}\text { Weat Virginla } \\
\text { Wheolling } \\
\text { Power Co }\end{array}$ & $\begin{array}{l}\text { Wieconain } \\
\text { Coneolldated } \\
\text { Water } \\
\text { Power Co }\end{array}$ & $\begin{array}{l}\text { Wheoonein } \\
\text { Madison } \\
\text { Gase } \\
\text { Electric Co }\end{array}$ & $\begin{array}{l}\text { Wleconain } \\
\text { Northern } \\
\text { Statee } \\
\text { Power Co }\end{array}$ & $\begin{array}{l}\text { Wisconain } \\
\text { Northweatern } \\
\text { Wisconain } \\
\text { Elec Co }\end{array}$ & $\begin{array}{c}\text { Wheconen } \\
\text { Ploneer } \\
\text { Power } \\
\text { Light Co }\end{array}$ \\
\hline $\begin{array}{l}\text { Electric Utilly Operating Income } \\
\text { Electric Operating Revenues }\end{array}$ & 82,706 & 34,727 & 142,890 & 346,289 & 8,078 & 1,206 \\
\hline 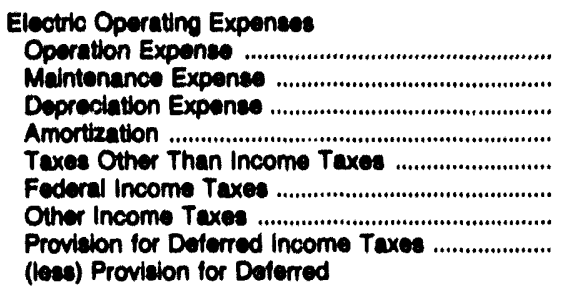 & $\begin{array}{r}85,224 \\
3,236 \\
2,344 \\
0 \\
4,680 \\
1,605 \\
256 \\
4,376\end{array}$ & $\begin{array}{r}30,393 \\
1,393 \\
843 \\
16 \\
329 \\
320 \\
86 \\
288\end{array}$ & $\begin{array}{r}71,600 \\
11,292 \\
18,813 \\
-240 \\
6,614 \\
6,668 \\
1,708 \\
3,731\end{array}$ & $\begin{array}{r}218,896 \\
20,473 \\
23,848 \\
22 \\
11,849 \\
14,420 \\
3,357 \\
10,711\end{array}$ & $\begin{array}{r}5,163 \\
350 \\
730 \\
0 \\
282 \\
257 \\
71 \\
0\end{array}$ & $\begin{array}{r}891 \\
112 \\
80 \\
0 \\
28 \\
18 \\
8 \\
0\end{array}$ \\
\hline 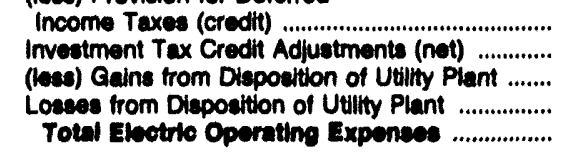 & $\begin{array}{r}4,647 \\
26 \\
0 \\
0 \\
77,210\end{array}$ & $\begin{array}{r}0 \\
0 \\
0 \\
0 \\
39,696\end{array}$ & $\begin{array}{r}1,523 \\
-603 \\
0 \\
0 \\
116,201\end{array}$ & $\begin{array}{r}6,899 \\
-895 \\
0 \\
0 \\
208,780\end{array}$ & $\begin{array}{r}23 \\
0 \\
0 \\
0 \\
6,830\end{array}$ & $\begin{array}{r}6 \\
-3 \\
0 \\
0 \\
1,100\end{array}$ \\
\hline Net Electric Utilty Operating Inooms ............ & 5,469 & 1,002 & 27,138 & 40,600 & 1,240 & 108 \\
\hline $\begin{array}{l}\text { Gas Utilly Operating Income } \\
\text { Gas Operating Revenues }\end{array}$ & 0 & 0 & 86,216 & 61,071 & 0 & \\
\hline 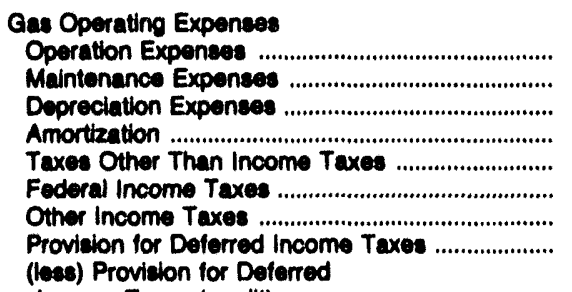 & $\begin{array}{l}0 \\
0 \\
0 \\
0 \\
0 \\
0 \\
0 \\
0\end{array}$ & $\begin{array}{l}0 \\
0 \\
0 \\
0 \\
0 \\
0 \\
0 \\
0\end{array}$ & $\begin{array}{r}67,791 \\
1,252 \\
4,854 \\
0 \\
1,493 \\
2,014 \\
555 \\
1,085\end{array}$ & $\begin{array}{r}50,229 \\
1,333 \\
2,856 \\
7 \\
1,076 \\
860 \\
224 \\
469\end{array}$ & $\begin{array}{l}0 \\
0 \\
0 \\
0 \\
0 \\
0 \\
0 \\
0\end{array}$ & 0 \\
\hline 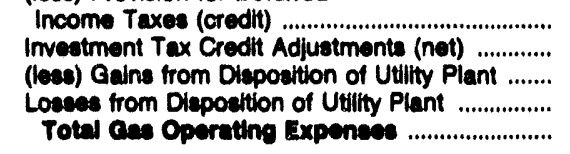 & $\begin{array}{l}0 \\
0 \\
0 \\
0 \\
0\end{array}$ & $\begin{array}{l}0 \\
0 \\
0 \\
0 \\
0\end{array}$ & $\begin{array}{r}702 \\
-156 \\
0 \\
0 \\
78,188\end{array}$ & $\begin{array}{r}107 \\
-61 \\
0 \\
0 \\
56,080\end{array}$ & $\begin{array}{l}0 \\
0 \\
0 \\
0 \\
0\end{array}$ & 0 \\
\hline Not Cas Utitity Operating Incoms ....................... & 0 & 0 & 8,031 & 4,085 & 0 & \\
\hline 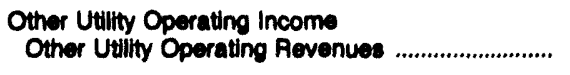 & 0 & 0 & 0 & 389 & 0 & \\
\hline 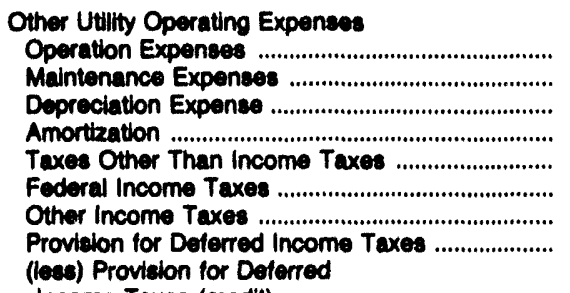 & $\begin{array}{l}0 \\
0 \\
0 \\
0 \\
0 \\
0 \\
0 \\
0\end{array}$ & $\begin{array}{l}0 \\
0 \\
0 \\
0 \\
0 \\
0 \\
0 \\
0\end{array}$ & $\begin{array}{l}0 \\
0 \\
0 \\
0 \\
0 \\
0 \\
0 \\
0\end{array}$ & $\begin{array}{r}0 \\
0 \\
38 \\
0 \\
0 \\
61 \\
17 \\
28\end{array}$ & $\begin{array}{l}0 \\
0 \\
0 \\
0 \\
0 \\
0 \\
0 \\
0\end{array}$ & \\
\hline 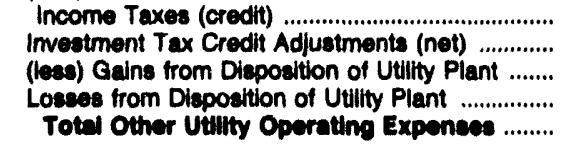 & $\begin{array}{l}0 \\
0 \\
0 \\
0 \\
0\end{array}$ & $\begin{array}{l}0 \\
0 \\
0 \\
0 \\
0\end{array}$ & $\begin{array}{l}0 \\
0 \\
0 \\
0 \\
0\end{array}$ & $\begin{array}{r}0 \\
0 \\
0 \\
0 \\
144\end{array}$ & $\begin{array}{l}0 \\
0 \\
0 \\
0 \\
0\end{array}$ & \\
\hline Net Other Utilly Operating Income ................. & 0 & $\mathbf{0}$ & 0 & 246 & 0 & \\
\hline
\end{tabular}

See endnotes at end of an individual electric utillty. 
Table 37. Statement of Income and Rotained Earnings

by Major U.8. Investor-Owned Electrio

Utility Within state, 1992 (Continued)

(Thousand Dollars)

\begin{tabular}{|c|c|c|c|c|c|c|}
\hline ltem & $\begin{array}{l}\text { Went Virginia } \\
\text { Wheeling } \\
\text { Power Co }\end{array}$ & $\begin{array}{l}\text { Wisconein } \\
\text { Consolldated } \\
\text { Water } \\
\text { Power Co }\end{array}$ & $\begin{array}{l}\text { Wieconain } \\
\text { Madison } \\
\text { Gess } \\
\text { Electrio Co }\end{array}$ & $\begin{array}{l}\text { Wleconsin } \\
\text { Northern } \\
\text { 8tates } \\
\text { Power Co }\end{array}$ & $\begin{array}{l}\text { Wisconsin } \\
\text { Northwesturn } \\
\text { Wisconsin } \\
\text { Elec Co }\end{array}$ & $\begin{array}{c}\text { Wisconein } \\
\text { Ploneer } \\
\text { Power } \\
\text { Light Co }\end{array}$ \\
\hline
\end{tabular}

Total Utilly Operating income

Total Utilty Operating Revenues

82,706

34,727

229,215

408,750

8,078

1,205

Utilly Operating Expenses

Operation Expenses

Depreointion Expense

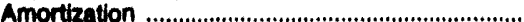

Taxes Other Than Income Taxes

Federal income Taxes

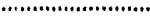

Provialon tor Deterred Income Taxes

(lese) Provision for Deferred

income Taxes (credit)

Investment Tex Credt Adjustments (net)

(less) Gains from Disposition of Utility Plant ......

Losees from Dispostion of Utility Plant ..............

Total Uatity Operating Expenese

65,224

3,236

2,344

4,690

1,605

256

4,376

4,547

26

0

77,210

Net Vutity Operating Income

8,490

139,291

12,544

21,687

$-240$

8,107

8,582

2,263

4,816

2,226

$-769$

0
0
184,048

33,098

269,124

21,806

26,842

29
12,926

15,341

3,698

11,208

7,007

$-958$

0
352,910

36,160

03,020

5,163

350
730

0

282

257
71

0

23

0

0

6,830

$1,0.92$

1,249

105

891

112

0

29

10
8
0

6

$-3$

1,100

Other Income and Deductions

Other Income

Nonutllity Operating Income ..................................

Equity in Earnings of Subsidiary Companies .......

Interest and Dividend Income

Allowance for Other Funds Used

During Construction ...

Mlacellaneous Nonoperating Income.....

Gain on Disposition of Property .

Total Other Incoms

$\begin{array}{rr}42 & 0 \\ 0 & 397 \\ 264 & 19 \\ & \\ 0 & 0 \\ 0 & 0 \\ 0 & 1 \\ 306 & 416\end{array}$

94
-86
2,920

1,020

12

4
0

42

42
17
18

3,000

907
34
30
2,000

Other Income Deductions

Lose on Disposition of Property ............................

Miscellaneous Amortization ........

Miecellaneous Income Deductions

Total Other Income Deductlone

0
0
206

53
0
289

332

Taxes on Other Income and Deductions

Taxes Other Than Income Taxes.

Federal Income Taxes.

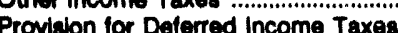

(leses) Proviaion for Deferred

Income Taxes (credit) ............................................

Investment Tax Credit Adjuatments (net)

(leae) Investment Tax Credts

Total Texes on Other Income

and Deductions

ne

$\begin{array}{rr}0 & 0 \\ 54 & 0\end{array}$

$0 \quad 34$

8

$-36$

44

2,148

$80 e$ endnotes at end of an individual electric utility. 
Table 37. 8tatement of Inoome and Rotalned Earninge

by Major U.8. Inveotor-Owned Electrle

Utility Within state, 1902 (Continued)

(Thousand Doliars)

\begin{tabular}{|c|c|c|c|c|c|c|}
\hline Item & $\begin{array}{l}\text { Weat Virginia } \\
\text { Wheeling } \\
\text { Power Co }\end{array}$ & $\begin{array}{l}\text { Whoconein } \\
\text { Coneolldated } \\
\text { Water } \\
\text { Power co }\end{array}$ & $\begin{array}{c}\text { Wheconain } \\
\text { Madison } \\
\text { Gas } \\
\text { A } \\
\text { Electrio Co }\end{array}$ & $\begin{array}{l}\text { Wheconain } \\
\text { Northern } \\
\text { Statee } \\
\text { Power Co }\end{array}$ & $\begin{array}{l}\text { Wheconain } \\
\text { Northweatern } \\
\text { Wleconsin } \\
\text { Elec Co }\end{array}$ & $\begin{array}{c}\text { Wheconain } \\
\text { Ploneer } \\
\text { Power } \\
\text { Light Co }\end{array}$ \\
\hline
\end{tabular}

Interest Charges

Interest on Long-term Debt

Amortzation of Dobt Diecount and Expenes

Amortization of Loes on Rencouired Debt .......

(lees) Amortantion of Premium on Debt (credit).

(bes) Amortization of Gain on

Reaquired Debt (credit) Interest on Debt to Associnted Companies ........

Other int

(lese) Allowance for Borrowed Funds

Uead During Conetruction (aredti) .

Not Intered Charee .............................................

Inooms Extere Extraordinary tiems

(3)...................

Extraordinary lteme

Extreordinary Income

(lese) Extraordinary Deductic

Not Extraordinary ltoms...

(less) Federal and Other Income $T$

Extraordinary ltems After Taxe

.......................

Net Inoom

Unapproprlated Rotalned Eamings

Rotained Eamings - Beginning of Yoar

Balance Transerred from income

Credts to Retained Earnings

(leas) Deblts to Retained Earnings .......................

(less) Appropriations of Retained Earnings .........

(lese) Dividends Declared - Preterred Stock .......

(less) Dividends Declared - Common Stock ......

Unappropriated Undistributed Subsidiary

Earnings .....................................................................

Rotained Eaminge - End of Year

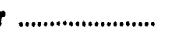

Appropriated Retained Earnings

Appropriated Rotained Earnings -

Amortization Reserve, Federal

Total Rotalned Eamings
2,677

0

0

0

0
371

10

3,085

2,095

1,507

28,207

13,249

73

0

0

0
216

29

13,000

17,269

133

311

0

329

688

17,967

30,200

90

0

0

0
0

80

2,096

1,807

23,007

30,200

698

6,49

11,928

65,492

178,970

515

1,164

$\begin{array}{rr}2,886 & 1,110 \\ 0 & 0 \\ 0 & 0 \\ 0 & 0 \\ 0 & 0 \\ 2,250 & 0 \\ 0 & 442\end{array}$

23,893

0
0
0
508

37,116

$\begin{array}{rr}683 \\ 0 & 0\end{array}$

0
0

19,148

24,895

688

13,478

60,731

191,780

1,258

0

0

0

0

0

0

587

0

6,002

13,470

69,731

192,376

๑21

1,263

Note: Totals may not equal sum of componenta because of independent rounding. Summary data are provided in Table 6.

Source: Federal Energy Regulatory Commiseion, FERC Form 1, "Annual Report of Major Electric Utilities, Licensees and Others." 
Table 37. Statement of Income and Rotained Earnings

by Major U.8. Investor-Owned Electric

Utility Within state, 1902 (Continued)

(Thousand Dollars)

\begin{tabular}{|c|c|c|c|c|c|c|}
\hline Item & $\begin{array}{l}\text { Wisconein } \\
\text { South } \\
\text { Bololt } \\
\text { Water } \\
\text { GasdElec co }\end{array}$ & $\begin{array}{l}\text { Wheconsin } \\
\text { superior } \\
\text { Wator } \\
\text { Lightserower } \\
\text { Co }\end{array}$ & $\begin{array}{l}\text { Wieconaln } \\
\text { Wieconein } \\
\text { Eleotrio } \\
\text { Power Co }\end{array}$ & $\begin{array}{l}\text { Wieconaln } \\
\text { Wieconein } \\
\text { Power } \\
\text { Light Co }\end{array}$ & $\begin{array}{l}\text { Wisconsin } \\
\text { Wisconsin } \\
\text { Public } \\
\text { Sorvice Corp }\end{array}$ & $\begin{array}{l}\text { Wieconein } \\
\text { Wisconsin } \\
\text { Alver } \\
\text { Power Co }\end{array}$ \\
\hline $\begin{array}{l}\text { Electrlo Utility Operating Income } \\
\text { Electric Operating Revenues }\end{array}$ & 8,486 & 24,814 & $1,298,723$ & 473,744 & 477,626 & 5,684 \\
\hline 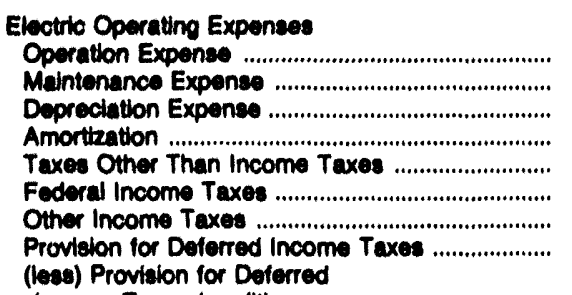 & $\begin{array}{r}5,030 \\
219 \\
219 \\
0 \\
52 \\
659 \\
-6 \\
44\end{array}$ & $\begin{array}{r}20,810 \\
269 \\
622 \\
0 \\
658 \\
421 \\
133 \\
211\end{array}$ & $\begin{array}{r}641,265 \\
142,111 \\
147,859 \\
0 \\
67,750 \\
60,910 \\
14,705 \\
29,821\end{array}$ & $\begin{array}{r}248,495 \\
41,037 \\
47,719 \\
1,616 \\
23,309 \\
21,163 \\
5,158 \\
7,204\end{array}$ & $\begin{array}{r}259,000 \\
43,634 \\
62,819 \\
1,713 \\
21,830 \\
16,161 \\
4,270 \\
18,487\end{array}$ & $\begin{array}{r}1,708 \\
388 \\
375 \\
4 \\
991 \\
711 \\
179 \\
28\end{array}$ \\
\hline 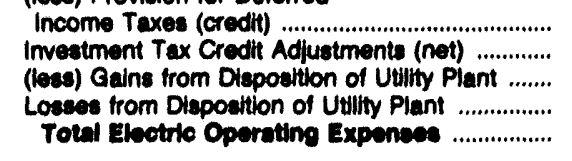 & $\begin{array}{r}25 \\
-9 \\
0 \\
0 \\
7,003\end{array}$ & $\begin{array}{r}0 \\
-18 \\
0 \\
0 \\
23,206\end{array}$ & $\begin{array}{r}19,846 \\
-3,938 \\
164 \\
0 \\
1,080,472\end{array}$ & $\begin{array}{r}2,530 \\
-1,894 \\
0 \\
0 \\
301,270\end{array}$ & $\begin{array}{r}12,308 \\
-1,864 \\
0 \\
0 \\
404,042\end{array}$ & $\begin{array}{r}48 \\
1 \\
0 \\
0 \\
4,391\end{array}$ \\
\hline Nef Electrito Utulty Operating Income ............. & 1,412 & 1,617 & 218,251 & 82,460 & 72,783 & 1,352 \\
\hline $\begin{array}{l}\text { Gas Utility Operating Income } \\
\text { Gas Operating Pevenues }\end{array}$ & 4,222 & 10,400 & 0 & 117,312 & 157,177 & 0 \\
\hline 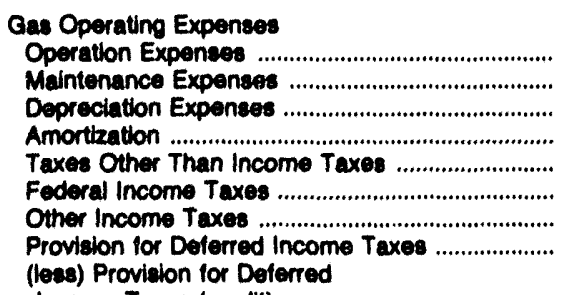 & $\begin{array}{r}3,525 \\
105 \\
208 \\
0 \\
37 \\
83 \\
58 \\
27\end{array}$ & $\begin{array}{r}9,452 \\
243 \\
282 \\
0 \\
211 \\
1 \\
1 \\
-52\end{array}$ & $\begin{array}{l}0 \\
0 \\
0 \\
0 \\
0 \\
0 \\
0 \\
0\end{array}$ & $\begin{array}{r}86,961 \\
3,066 \\
6,172 \\
198 \\
2,507 \\
-417 \\
4 \\
1,373\end{array}$ & $\begin{array}{r}138,212 \\
2,802 \\
5,773 \\
39 \\
2,529 \\
386 \\
90 \\
3,333\end{array}$ & $\begin{array}{l}0 \\
0 \\
0 \\
0 \\
0 \\
0 \\
0 \\
0\end{array}$ \\
\hline 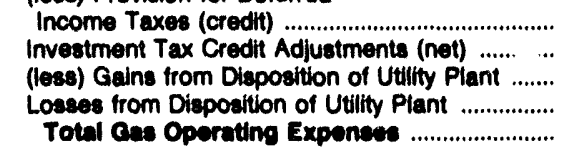 & $\begin{array}{r}0 \\
-8 \\
0 \\
0 \\
4,035\end{array}$ & $\begin{array}{r}0 \\
-5 \\
0 \\
0 \\
10,134\end{array}$ & $\begin{array}{l}0 \\
0 \\
0 \\
0 \\
0\end{array}$ & $\begin{array}{r}191 \\
-197 \\
0 \\
0 \\
100,476\end{array}$ & $\begin{array}{r}2,181 \\
-168 \\
0 \\
0 \\
160,814\end{array}$ & $\begin{array}{l}0 \\
0 \\
0 \\
0 \\
0\end{array}$ \\
\hline Net cas Utlltiy Operating Income ...................... & 187 & 206 & 0 & 7,836 & 6,363 & 0 \\
\hline 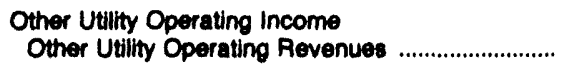 & 378 & 4,131 & 13,093 & 3,385 & 0 & 0 \\
\hline 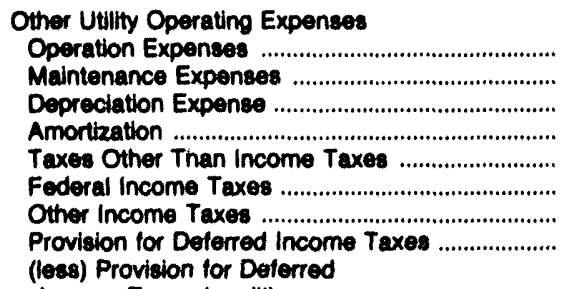 & $\begin{array}{r}102 \\
17 \\
39 \\
0 \\
15 \\
67 \\
-4 \\
5\end{array}$ & $\begin{array}{r}1,336 \\
361 \\
282 \\
0 \\
241 \\
420 \\
116 \\
69\end{array}$ & $\begin{array}{r}7,613 \\
1,507 \\
1,107 \\
0 \\
630 \\
325 \\
78 \\
121\end{array}$ & $\begin{array}{r}1,423 \\
638 \\
224 \\
20 \\
237 \\
-160 \\
-51 \\
380\end{array}$ & $\begin{array}{l}0 \\
0 \\
0 \\
0 \\
0 \\
0 \\
0 \\
0\end{array}$ & $\begin{array}{l}0 \\
0 \\
0 \\
0 \\
0 \\
0 \\
0 \\
0\end{array}$ \\
\hline 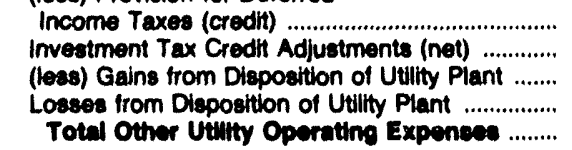 & $\begin{array}{r}5 \\
-1 \\
0 \\
0 \\
234\end{array}$ & $\begin{array}{r}0 \\
5 \\
0 \\
0 \\
2,820\end{array}$ & $\begin{array}{r}13 \\
-21 \\
0 \\
0 \\
11,346\end{array}$ & $\begin{array}{r}17 \\
-17 \\
0 \\
0 \\
2,678\end{array}$ & $\begin{array}{l}0 \\
0 \\
0 \\
0 \\
0\end{array}$ & $\begin{array}{l}0 \\
0 \\
0 \\
0 \\
0\end{array}$ \\
\hline Net Other Utilty Operatung Income ................. & 142 & 1,302 & 1,745 & 707 & 0 & 0 \\
\hline
\end{tabular}

See endnotes at end of an individual electric utility. 
Table 37. Statement of Income and Rotained Earninge

by Major U.S. Invector-Owned Eleotric

Utility Within stato, 1992 (Continued)

(Thousand Dollars)

\begin{tabular}{|c|c|c|c|c|c|c|}
\hline Item & $\begin{array}{l}\text { Wheonuln } \\
\text { South } \\
\text { Bololt } \\
\text { Water } \\
\text { Gasdelec Co }\end{array}$ & $\begin{array}{l}\text { Whoconain } \\
\text { Superior } \\
\text { Water } \\
\text { LightaPower } \\
\text { Co }\end{array}$ & $\begin{array}{l}\text { Wheconsin } \\
\text { Weconein } \\
\text { Electric } \\
\text { Power Co }\end{array}$ & $\begin{array}{l}\text { Wisconsin } \\
\text { Wheconsin } \\
\text { Power } \\
\& \\
\text { Light Co }\end{array}$ & $\begin{array}{l}\text { Wisconsin } \\
\text { Wisconsin } \\
\text { Public } \\
\text { Service Corp }\end{array}$ & $\begin{array}{l}\text { Wisconsin } \\
\text { Wisconsin } \\
\text { Plver } \\
\text { Power Co }\end{array}$ \\
\hline
\end{tabular}

Total Utilly Operating Income

Total Utility Operating Revenues

13,093

39,444

$1,311,816$

694,440

634,802

5,684

Utility Operating Expenses

Operation Expenees

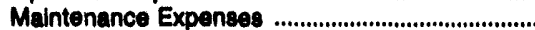

Depreciation Expense

Amortization

Taxes Other Than Income Taxes

Federal Income Taxes

Other Income Taxes

Prese) Provialon for Deferred

Income Taxes (credit)

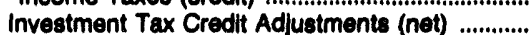

(less) Gains trom Disposition of Utility Plant .......

Losses from Disposition of Utility Plant ...............

Total Utilty Operating Expenses .

9,557
340
467
0
104
809
49
76

31
-18
0
0
11,352

$\mathbf{3 1 , 5 8 8}$

24,260

1,741

Not Utility Oporating Income

Other Income and Deductions

Other Income

Nonutillty Operating income

Equity in Earnings of Subsidiary Companies

Interest and Dividend Income

Allowance for Other Funds Used

During Construction ....

Miscelianeous Nonoperating Income

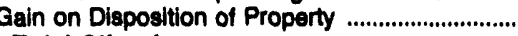

Total Other Incomo

Other Income Deductions

Loss on Disposition of Property

Miscellaneous Amortization ..........

Miscelleneous Income Deductions

Total Other Income Deductions

Taxes on Other income and Deductions

Taxes Other Than Income Taxes.

Federal Income Taxes

Provision for Deterroc

(less) Provision for Deterred

Income Taxes (credit)

Investment Tax Credit Adluatmente (not)

(less) Investment Tax Credits

Total Taxes on Other Income

and Deductions

Net Other Income and Deductione

See endnotes at end of an individual electric utllity.
883
1,386

1,386

1,110

842

261

228

0

$-18$

0

\section{8,878}

149,618

148,807

61,236

61,235
14,783

29,842

19,859

$-3,860$

164

$1,001,820$

3,106

219,000

478
0
13,623
6,936
7,456
63
28,658

-421
2,624

2,887

2,350

0
-249
0

$-210$

397,211

46,436

58,592

1,753

24,459

16,637

4,360

22,819

14,489

$-2,022$

0
655,656

91,000

79,146

1,708

386

375

99

711

179

28

49

1,352

7
2
7,449

$$
\begin{array}{r}
103 \\
1,292 \\
4,206 \\
494 \\
1,045 \\
5 \\
7,145
\end{array}
$$

-42
0

0

$-67$

32
-22

$\begin{array}{rr}0 & \\ 0 & \\ 41 & 1,1 \\ 41 & 1,124\end{array}$

$\begin{array}{rr}2 & 1 \\ 0 & 0 \\ 1,122 & 7,224 \\ 1,124 & 7,224\end{array}$

$\begin{array}{rr}91 & 5 \\ 0 & 6 \\ 364 & 18 \\ 455 & 29\end{array}$

1
-66
0

326

297

480

4,167

3,204

0
0

2,002

$-68$

$-105$

25,850

5,454

$-147$
346,879
44,741
54,116
1,833
26,053
20,687
5,111
8,956
2,738
$-2,107$
0
0
503,432 
Table 37. 8tatement of Ineome and Rotalned Earninge

by Major U.8. Inveator-Owned Elootrle

Utility Within 8tate, 1902 (Continuod)

(Thousand Dollars)

\begin{tabular}{|c|c|c|c|c|c|c|}
\hline Item & $\begin{array}{l}\text { Whooneln } \\
\text { South } \\
\text { Beloh } \\
\text { Water } \\
\text { GasaEleo Co }\end{array}$ & $\begin{array}{l}\text { Wheoonaln } \\
\text { superlor } \\
\text { Whter } \\
\text { Lightapower } \\
\text { Co }\end{array}$ & $\begin{array}{l}\text { Wieconain } \\
\text { Wieconain } \\
\text { Eleotrle } \\
\text { Power Co }\end{array}$ & $\begin{array}{l}\text { Wheoonaln } \\
\text { Whooonain } \\
\text { Power } \\
\text { Lignt Co }\end{array}$ & $\begin{array}{l}\text { Wiscondin } \\
\text { Wiecondin } \\
\text { Publlo } \\
\text { Sorvice Corp }\end{array}$ & $\begin{array}{l}\text { Wheconain } \\
\text { Wieconein } \\
\text { Fiver } \\
\text { Power Co }\end{array}$ \\
\hline
\end{tabular}

Intereat Charges

Intereet on Lono-term Debt .....................................

Amortzation of Debt Discount and Expense ....

Amortzation of Loses on Reacquired Debt ...........

(lees) Amortization of Premium on Debt (credit)

(16es) Amortization of Gain on

Reaquired Debt (credth) ..........................................

Intereat on Debt to Aasociated Companies ........

Other Interest Expense

(leas) Allowance for Borrowed Funds

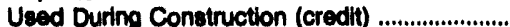

Net Interest Charees ............................................

Income Betors Extraordinary ltems

s...............

Extraordinary ltems

Extraordinary Income.

(lees) Extraordinary Deductions

Net Extraordinary ltems

(1083) Federal and Other Income Taxes ..............

Extraordinary ltems After Taxes.

Nat incom

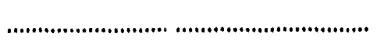

Unapproprlated Rotained Eaminge

Rotalned Eaminge - Beginning of Year

Balance Transferred from income

Credits to Rotained Earnings

(lese) Debits to Retained Earnings .........................

(less) Appropriations of Retained Earnings .........

(lese) Dividends Declared - Preferred Stock .......

(less) Dividends Declared - Common Stock .......

Uirappropriated Undistributed Subsidiany

Eamings

Retalned Eamings - End of Year

...............

Appropriated Retained Earnings

Appropriated Retained Earnings -

Amortzation Reserve, Federal

Total Rotained Earninge

0

1,741

710
18
0
0
0
182
122
0
1,031

$$
\begin{array}{r}
80,252 \\
647 \\
3,976 \\
32 \\
0 \\
0 \\
2,416 \\
3,653 \\
09,604
\end{array}
$$

161,742

60,210

29,264

1,460

0

0
0

2,686

1,329

32,071

1,050

$\begin{array}{rl}24,194 & 0 \\ 1,468 & 0 \\ 0 & 0 \\ 0 & 0 \\ 0 & 0 \\ 0 & 0 \\ 1,477 & 0 \\ 542 & 0 \\ 28,807 & 0\end{array}$

89,002

1,205

0
0
0

0
0
0

0
0
0

0
0
0

\begin{tabular}{|c|c|c|c|c|c|}
\hline 3,700 & 0,001 & 728,037 & 250,280 & 250,746 & 6,461 \\
\hline $\begin{array}{r}1,741 \\
0 \\
0 \\
0 \\
0 \\
4,000\end{array}$ & $\begin{array}{r}1,858 \\
292 \\
0 \\
0 \\
0 \\
2,200\end{array}$ & $\begin{array}{r}181,742 \\
0 \\
0 \\
-271 \\
5,028 \\
65,000\end{array}$ & $\begin{array}{r}56,594 \\
0 \\
36 \\
0 \\
3,811 \\
51,185\end{array}$ & $\begin{array}{r}57,445 \\
0 \\
0 \\
-17 \\
3,237 \\
40,150\end{array}$ & $\begin{array}{r}1,205 \\
0 \\
0 \\
0 \\
0 \\
0 \\
1,310\end{array}$ \\
\hline 0 & 0 & 0 & 4,000 & 455 & 0 \\
\hline 1,441 & 10,043 & 817,022 & 291,000 & 274,276 & 0,946 \\
\hline 0 & 0 & 0 & 0 & $-28,498$ & 0 \\
\hline 0 & 0 & 757 & 0 & 750 & 0 \\
\hline 1,441 & 10,043 & 818,670 & 281,000 & 246,528 & 6,349 \\
\hline
\end{tabular}

$\mathbf{0}$
$\mathbf{0}$

1,741

1,950

161,742

60,210

69,002

1,206

1,441

10,043

818,670

241,000

249,628

3,340

Note: Totale may not equal sum of components because of independent rounding. Summary data are provlded in Table 6.

Source: Federal Energy Requlatory Commission, FEAC Form 1, "Annual Peport of Major Electric Utilities, Licensees and Others." 
Table 38. Balance Sheet by Major U.S. Investor-Owned Electric Utility Within State on December 31, 1992

(Thousand Dollars)

\begin{tabular}{|c|c|c|c|c|c|c|}
\hline Item & $\begin{array}{l}\text { Alebama } \\
\text { Alabama } \\
\text { Power Co }\end{array}$ & $\begin{array}{l}\text { Alabama } \\
\text { Southern } \\
\text { Electric } \\
\text { Generatg Co }\end{array}$ & $\begin{array}{l}\text { Arizona } \\
\text { Arizona } \\
\text { Public } \\
\text { Service Co }\end{array}$ & $\begin{array}{l}\text { Arizona } \\
\text { Contury } \\
\text { Power Corp }\end{array}$ & $\begin{array}{l}\text { Arizona } \\
\text { Tucson } \\
\text { Electric } \\
\text { Power Co }\end{array}$ & $\begin{array}{c}\text { Arkansas } \\
\text { Arkansas } \\
\text { Power } \\
\text { \& } \\
\text { Light Co }\end{array}$ \\
\hline 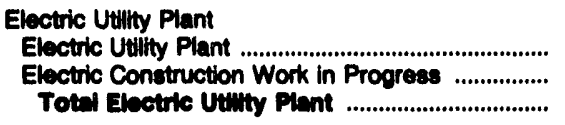 & $\begin{array}{r}9,470,158 \\
164,555 \\
9,034,714\end{array}$ & $\begin{array}{r}298,625 \\
4,443 \\
303,006\end{array}$ & $\begin{array}{r}6,197,459 \\
134,585 \\
6,332,044\end{array}$ & $\begin{array}{r}432,179 \\
97 \\
432,276\end{array}$ & $\begin{array}{r}2,670,486 \\
23,167 \\
2,098,653\end{array}$ & $\begin{array}{r}4,070,190 \\
174,909 \\
4,246,000\end{array}$ \\
\hline 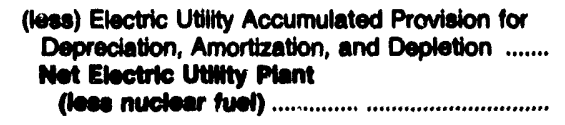 & $\begin{array}{l}3,122,332 \\
6,612,301\end{array}$ & $\begin{array}{l}163,404 \\
130,804\end{array}$ & $\begin{array}{l}1,897,433 \\
4,434,611\end{array}$ & $\begin{array}{l}217,409 \\
214,087\end{array}$ & $\begin{array}{r}660,871 \\
2,032,702\end{array}$ & $\begin{array}{l}1,421,844 \\
2,023,256\end{array}$ \\
\hline $\begin{array}{l}\text { Nuctoar Fuol } \\
\text { (less) Accumulated Provision for }\end{array}$ & 926,429 & 0 & 165,452 & 0 & 0 & 102,435 \\
\hline 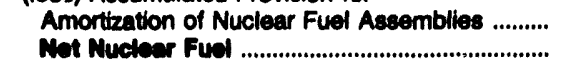 & $\begin{array}{l}825,301 \\
101,128\end{array}$ & $\begin{array}{l}0 \\
0\end{array}$ & $\begin{array}{l}76,266 \\
80,186\end{array}$ & $\begin{array}{l}0 \\
0\end{array}$ & $\begin{array}{l}0 \\
0\end{array}$ & $\begin{array}{r}0 \\
102,435\end{array}$ \\
\hline 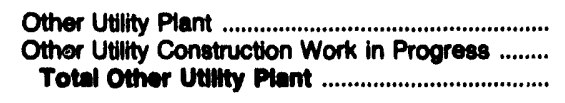 & $\begin{array}{r}20,925 \\
32 \\
20,957\end{array}$ & $\begin{array}{l}0 \\
0 \\
0\end{array}$ & $\begin{array}{l}0 \\
0 \\
0\end{array}$ & $\begin{array}{l}0 \\
1 \\
0\end{array}$ & $\begin{array}{l}0 \\
0 \\
0\end{array}$ & 0 \\
\hline 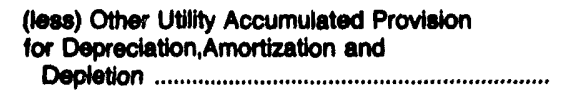 & 8,211 & 0 & 0 & 0 & 0 & 0 \\
\hline 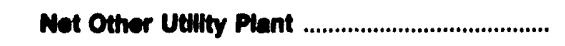 & 11,746 & $\mathbf{0}$ & $\mathbf{0}$ & $\mathbf{0}$ & 0 & $\mathbf{0}$ \\
\hline 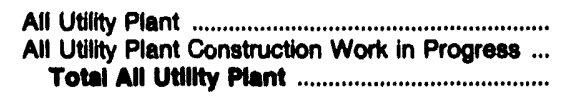 & $\begin{array}{r}10,417,512 \\
164,588 \\
10,582,10 r\end{array}$ & $\begin{array}{r}298,625 \\
4,443 \\
303,000\end{array}$ & $\begin{array}{r}6,362,910 \\
134,585 \\
6,497,495\end{array}$ & $\begin{array}{r}432,179 \\
97 \\
432,276\end{array}$ & $\begin{array}{r}2,670,486 \\
23,167 \\
2,693,653\end{array}$ & $\begin{array}{r}4,172,626 \\
174,909 \\
4,347,534\end{array}$ \\
\hline $\begin{array}{l}\text { (less) All Utillty Accumulated Provision for } \\
\text { Depreciation, Amortiz?tion and Depletion ........... } \\
\text { Not All Utilty Plant ........................................... }\end{array}$ & $\begin{array}{l}3,956,844 \\
6,825,256\end{array}$ & $\begin{array}{l}169,404 \\
139,684\end{array}$ & $\begin{array}{l}1,973,699 \\
4,523,797\end{array}$ & $\begin{array}{l}217,409 \\
214,667\end{array}$ & $\begin{array}{r}660,871 \\
2,032,782\end{array}$ & $\begin{array}{l}1,421,844 \\
2,025,000\end{array}$ \\
\hline 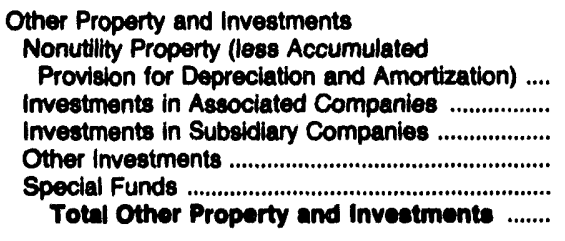 & $\begin{array}{r}6,335 \\
0 \\
42,386 \\
7,195 \\
32,789 \\
86,705\end{array}$ & $\begin{array}{r}3 \\
45 \\
0 \\
0 \\
4 \\
51\end{array}$ & $\begin{array}{r}12,600 \\
0 \\
1,563 \\
11,069 \\
33,469 \\
58,702\end{array}$ & $\begin{array}{r}0 \\
0 \\
211 \\
0 \\
413 \\
624\end{array}$ & $\begin{array}{r}1,209 \\
0 \\
57,432 \\
-171,852 \\
0 \\
-113,210\end{array}$ & $\begin{array}{r}1,493 \\
0 \\
11,232 \\
179 \\
14,564 \\
27,460\end{array}$ \\
\hline 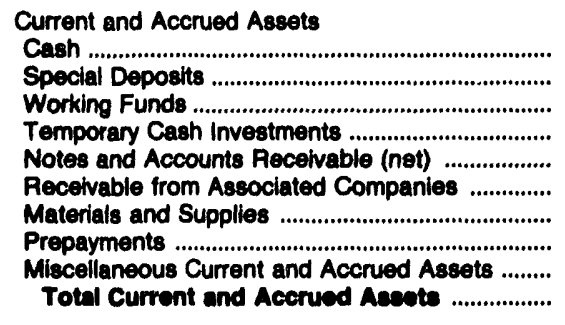 & $\begin{array}{r}13,152 \\
5,186 \\
478 \\
0 \\
286,937 \\
37,128 \\
316,839 \\
60,625 \\
93,747 \\
814,101\end{array}$ & $\begin{array}{r}112 \\
870 \\
0 \\
0 \\
3,308 \\
43,690 \\
0 \\
157 \\
0 \\
46,137\end{array}$ & $\begin{array}{r}1,152 \\
0 \\
239 \\
0 \\
151,735 \\
147 \\
132,646 \\
5,410 \\
52,179 \\
343,506\end{array}$ & $\begin{array}{r}-831 \\
0 \\
1 \\
17,729 \\
4,602 \\
0 \\
5,320 \\
502 \\
330 \\
27,552\end{array}$ & $\begin{array}{r}1,455 \\
462 \\
429 \\
153,275 \\
38,814 \\
122,905 \\
32,227 \\
6,907 \\
20,238 \\
376,711\end{array}$ & $\begin{array}{r}-6,041 \\
7,517 \\
342 \\
0 \\
73,684 \\
32,238 \\
143,098 \\
14,800 \\
3,157 \\
288,796\end{array}$ \\
\hline 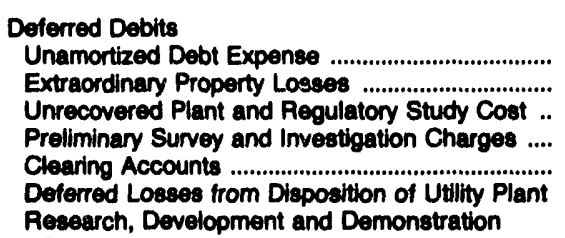 & $\begin{array}{r}6,118 \\
0 \\
0 \\
15,825 \\
1,848 \\
0\end{array}$ & $\begin{array}{r}172 \\
0 \\
0 \\
669 \\
0 \\
0\end{array}$ & $\begin{array}{r}17,107 \\
0 \\
42,241 \\
0 \\
-1,012 \\
0\end{array}$ & $\begin{array}{l}0 \\
0 \\
0 \\
0 \\
0 \\
0\end{array}$ & $\begin{array}{r}12,489 \\
0 \\
0 \\
192 \\
15 \\
0\end{array}$ & $\begin{array}{r}3,301 \\
0 \\
0 \\
19,979 \\
-3,778 \\
0\end{array}$ \\
\hline 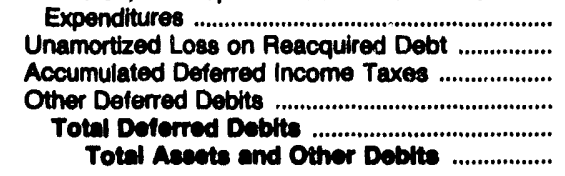 & $\begin{array}{r}3,216 \\
74,835 \\
131,931 \\
81,445 \\
315,218 \\
7,843,200\end{array}$ & $\begin{array}{r}509 \\
145 \\
722 \\
1 \\
2,217 \\
160,070\end{array}$ & $\begin{array}{r}282 \\
52,709 \\
223,417 \\
554,196 \\
898,940 \\
\mathbf{5 , 8 1 4 , 0 4 7}\end{array}$ & $\begin{array}{r}0 \\
0 \\
9,754 \\
-3 \\
9,750 \\
252,704\end{array}$ & $\begin{array}{r}0 \\
1,662 \\
23,519 \\
179,868 \\
217,746 \\
2,514,029\end{array}$ & $\begin{array}{r}0 \\
23,262 \\
92,826 \\
768,582 \\
\mathbf{9 0 2 , 1 7 0} \\
\mathbf{4 , 1 2 4 , 1 2 5}\end{array}$ \\
\hline
\end{tabular}

See endnotes at end of an individual electric utility. 
Table 38. Balance Sheet by Major U.S. Investor-Owned Electric Utility Within State on Decomber 31, 1992 (Continued)

(Thousand Dollars)

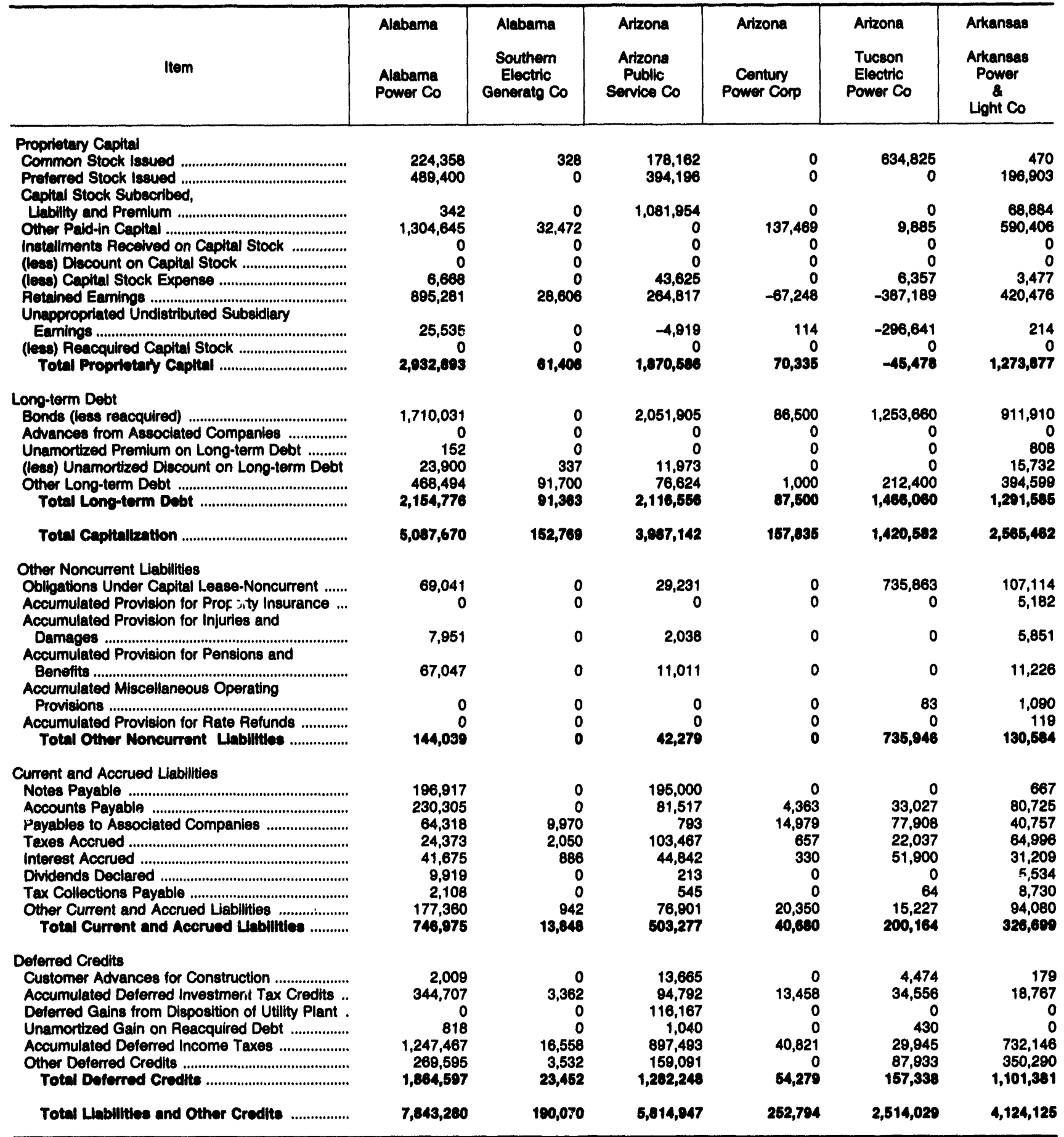

Note: Totals may not equal sum of components because of independent rounding. Summary data are provided in Table 8.

Source: Federal Energy Regulatory Commission, FERC Form 1, "Annual Report of Major Electric Utilities, Licensees and Others." 
Tabie 38. Balance Sheot by Major U.8. Inveator-Owned Electric Utility Within State on Decombor 31, 1092 (Continuod) (Thousand Dollars)

\begin{tabular}{|c|c|c|c|c|c|c|}
\hline ltem & $\begin{array}{c}\text { Callormia } \\
\text { Pacille } \\
\text { Cass } \\
2 \\
\text { Electrio Co }\end{array}$ & $\begin{array}{l}\text { Calfornia } \\
\text { San Diego } \\
\text { Cas } \\
\text { Electric Co }\end{array}$ & $\begin{array}{l}\text { Calliomia } \\
\text { Southern } \\
\text { Calfornia } \\
\text { Edicon Co }\end{array}$ & $\begin{array}{c}\text { Colorado } \\
\text { Publle } \\
\text { Service } \\
\text { Co } \\
\text { of Colorado }\end{array}$ & $\begin{array}{l}\text { Connectiout } \\
\text { Cittzens } \\
\text { Utilltes Co }\end{array}$ & $\begin{array}{l}\text { Connectlout } \\
\text { Connectlout } \\
\text { Light } \\
\text { Power Co }\end{array}$ \\
\hline 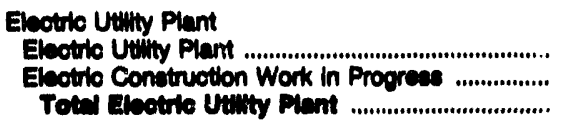 & $\begin{array}{r}20,518,540 \\
310,376 \\
20,02,922\end{array}$ & $\begin{array}{r}3,868,079 \\
100,221 \\
3,009,800\end{array}$ & $\begin{array}{r}17,706,212 \\
723,101 \\
18,810,313\end{array}$ & $\begin{array}{r}3,320,708 \\
135,575 \\
3,468,243\end{array}$ & $\begin{array}{r}393,411 \\
12,572 \\
406,003\end{array}$ & $\begin{array}{r}5,822,783 \\
110,081 \\
6,032,804\end{array}$ \\
\hline 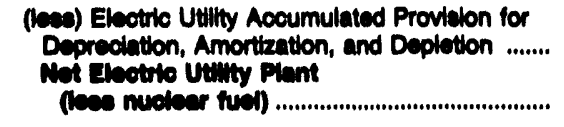 & $\begin{array}{r}7,304,736 \\
13,824,186\end{array}$ & $\begin{array}{l}1,494,131 \\
2,400,180\end{array}$ & $\begin{array}{r}6,711,507 \\
11,607,800\end{array}$ & $\begin{array}{l}1,246,130 \\
2,210,163\end{array}$ & $\begin{array}{r}96,818 \\
309,185\end{array}$ & $\begin{array}{l}1,827,024 \\
4,108,041\end{array}$ \\
\hline 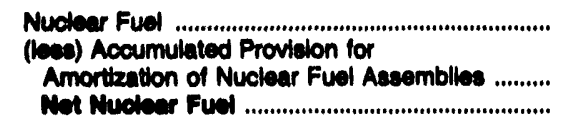 & $\begin{array}{l}502,443 \\
467,272 \\
138,171\end{array}$ & $\begin{array}{r}22,577 \\
0 \\
22,677\end{array}$ & $\begin{array}{l}278,332 \\
154,723 \\
123,610\end{array}$ & $\begin{array}{l}0 \\
0 \\
0\end{array}$ & $\begin{array}{l}0 \\
0\end{array}$ & $\begin{array}{r}738,414 \\
689,942 \\
46,472\end{array}$ \\
\hline 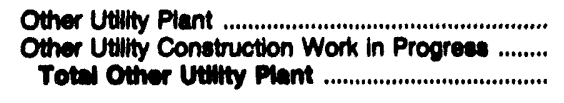 & $\begin{array}{r}6,692,348 \\
687,146 \\
7,370,408\end{array}$ & $\begin{array}{r}763,899 \\
38,106 \\
602,006\end{array}$ & $\begin{array}{r}8,410 \\
663 \\
9,003\end{array}$ & $\begin{array}{r}785,957 \\
83,811 \\
800,700\end{array}$ & $\begin{array}{r}336,206 \\
3,130 \\
339,330\end{array}$ & $\begin{array}{l}0 \\
0\end{array}$ \\
\hline 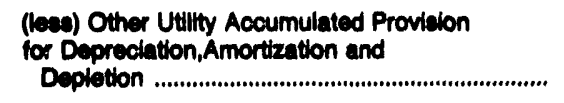 & $2,883,466$ & 316,068 & 3,189 & 323,163 & 102,356 & 0 \\
\hline Met Other Utithy Plamt ......................................... & $4,406,030$ & 496,047 & 5,008 & 840,016 & 238,200 & 0 \\
\hline 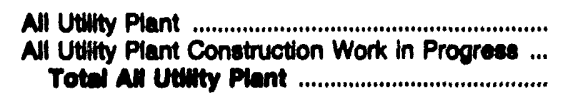 & $\begin{array}{r}27,803,338 \\
997,622 \\
28,000,060\end{array}$ & $\begin{array}{r}4,649,554 \\
138,328 \\
4,767,002\end{array}$ & $\begin{array}{r}18,082,963 \\
723,765 \\
18,806,728\end{array}$ & $\begin{array}{r}4,106,685 \\
219,386 \\
4,326,051\end{array}$ & $\begin{array}{r}729,617 \\
15,702 \\
748,310\end{array}$ & $\begin{array}{r}6,661,197 \\
110,081 \\
6,671,270\end{array}$ \\
\hline $\begin{array}{l}\text { (leas) All Utilly Accumulated Provision for } \\
\text { Depreciation, Amortization and Depletion ........... } \\
\text { Wot All Utility Plant ......................................... }\end{array}$ & $\begin{array}{l}10,645,465 \\
16,165,305\end{array}$ & $\begin{array}{l}1,809,189 \\
2,078,602\end{array}$ & $\begin{array}{r}6,868,410 \\
11,937,300\end{array}$ & $\begin{array}{l}1,569,283 \\
2,766,760\end{array}$ & $\begin{array}{l}199,174 \\
646,144\end{array}$ & $\begin{array}{r}2,516,966 \\
4,164,312\end{array}$ \\
\hline 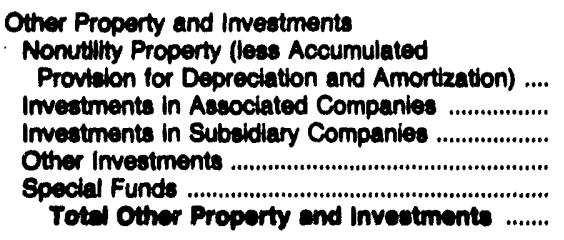 & $\begin{array}{r}25,156 \\
0 \\
1,339,608 \\
68,106 \\
480,681 \\
1,911,627\end{array}$ & $\begin{array}{r}13,675 \\
0 \\
109,264 \\
10,046 \\
147,670 \\
280,086\end{array}$ & $\begin{array}{r}17,861 \\
0 \\
12,211 \\
13,476 \\
653,478 \\
697,027\end{array}$ & $\begin{array}{r}1,662 \\
0 \\
139,108 \\
1,584 \\
9,196 \\
151,650\end{array}$ & $\begin{array}{r}0 \\
0 \\
558,916 \\
20,557 \\
0 \\
579,473\end{array}$ & $\begin{array}{r}14,077 \\
0 \\
53,718 \\
122,008 \\
0 \\
180,803\end{array}$ \\
\hline 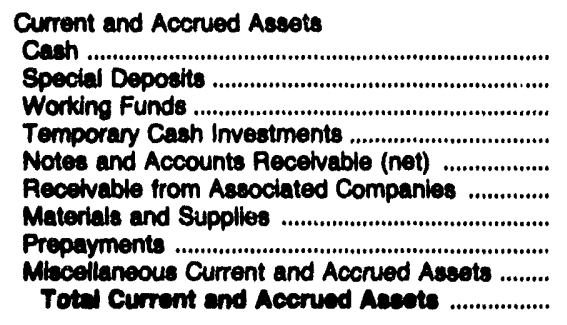 & $\begin{array}{r}0 \\
27,210 \\
1,441 \\
15,000 \\
954,910 \\
24,942 \\
374,058 \\
32,502 \\
1,301,188 \\
2,731,251\end{array}$ & $\begin{array}{r}3,241 \\
248,619 \\
126 \\
0 \\
130,544 \\
8,322 \\
63,813 \\
8,684 \\
133,923 \\
898,363\end{array}$ & $\begin{array}{r}0 \\
0 \\
4,879 \\
256,176 \\
543,176 \\
5,417 \\
218,114 \\
15,660 \\
459,850 \\
1,602,272\end{array}$ & $\begin{array}{r}5,350 \\
5,234 \\
306 \\
24,416 \\
6,021 \\
48,656 \\
110,476 \\
18,509 \\
73,940 \\
202,007\end{array}$ & $\begin{array}{r}4,775 \\
35 \\
131 \\
3,386 \\
55,172 \\
507,567 \\
6,711 \\
3,472 \\
514 \\
561,763\end{array}$ & $\begin{array}{r}91 \\
11,016 \\
101 \\
0 \\
231,066 \\
5,352 \\
72,198 \\
31,752 \\
174,021 \\
525,607\end{array}$ \\
\hline 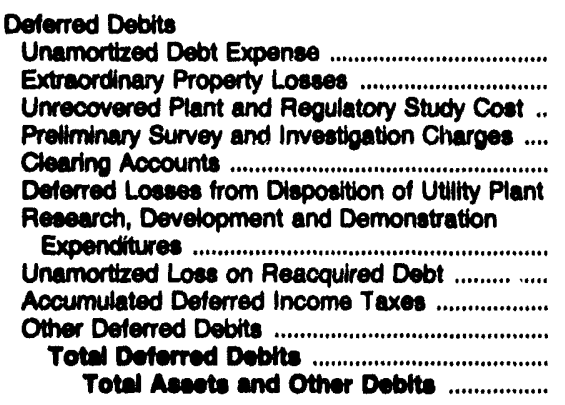 & $\begin{array}{r}18,572 \\
0 \\
41,616 \\
22,748 \\
15,315 \\
0 \\
0 \\
0 \\
300,206 \\
379,051 \\
591,450 \\
1,396,067 \\
24,167,131\end{array}$ & $\begin{array}{r}0 \\
50,049 \\
75,780 \\
45,825 \\
274,025 \\
4,129,628\end{array}$ & $\begin{array}{r}36,481 \\
0 \\
18,977 \\
0 \\
0 \\
0 \\
0 \\
0 \\
264,134 \\
524,058 \\
1,136,252 \\
1,070,902 \\
16,116,510\end{array}$ & $\begin{array}{r}8,069 \\
0 \\
0 \\
805 \\
1,698 \\
0 \\
0 \\
10,860 \\
42,787 \\
213,604 \\
277,024 \\
3,470,050\end{array}$ & $\begin{array}{r}13,197 \\
0 \\
0 \\
1,007 \\
0 \\
0 \\
0 \\
54 \\
5,300 \\
31,601 \\
54,150 \\
1,761,540\end{array}$ & $\begin{array}{r}0 \\
17,744 \\
62,641 \\
560,332 \\
680,043 \\
5,620,756\end{array}$ \\
\hline
\end{tabular}

See endnotes at end of an individual electric utility. 
Table 38. Balance Sheet by Major U.S. Inveetor-Owned Electric Utility Within State on December 31, 1982 (Continued) (Thousand Dollars)

\begin{tabular}{|c|c|c|c|c|c|c|}
\hline Item & $\begin{array}{l}\text { Calliomia } \\
\text { Pacitic } \\
\text { Gas } \\
\mathbf{2} \\
\text { Electrio Co }\end{array}$ & $\begin{array}{l}\text { Calliomia } \\
\text { San Diego } \\
\text { Gas } \\
\text { Electric Co }\end{array}$ & $\begin{array}{l}\text { Calliomia } \\
\text { Southem } \\
\text { California } \\
\text { Edleon Co }\end{array}$ & $\begin{array}{l}\text { Colorado } \\
\text { Publle } \\
\text { Service } \\
\text { Co } \\
\text { of Colorado }\end{array}$ & $\begin{array}{l}\text { Connecticut } \\
\text { Cltizens } \\
\text { Utilties Co }\end{array}$ & $\begin{array}{l}\text { Connecticut } \\
\text { Connecticut } \\
\text { Light } \\
\& \\
\text { Power Co }\end{array}$ \\
\hline 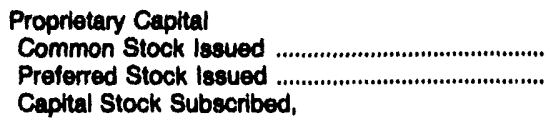 & $\begin{array}{r}2,134,228 \\
050,301\end{array}$ & $\begin{array}{l}287,685 \\
130,883\end{array}$ & $\begin{array}{l}808,017 \\
842,643\end{array}$ & $\begin{array}{l}292,384 \\
185,665\end{array}$ & $\begin{array}{r}21,690 \\
0\end{array}$ & $\begin{array}{l}122,229 \\
431,196\end{array}$ \\
\hline 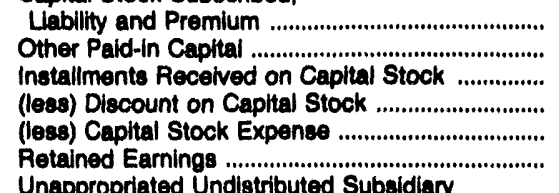 & $\begin{array}{r}3,680,432 \\
4,341 \\
0 \\
0 \\
12,153 \\
55,558 \\
2,663,880\end{array}$ & $\begin{array}{r}556,495 \\
0 \\
0 \\
0 \\
25,999 \\
575,249\end{array}$ & $\begin{array}{r}1,237,602 \\
207,288 \\
0 \\
0 \\
5,153 \\
2,430,860\end{array}$ & $\begin{array}{r}580,845 \\
0 \\
0 \\
0 \\
0 \\
231,582\end{array}$ & $\begin{array}{r}558,097 \\
24,170 \\
0 \\
0 \\
60 \\
-125,875\end{array}$ & $\begin{array}{r}38,093 \\
611,855 \\
0 \\
0 \\
15,097 \\
725,081\end{array}$ \\
\hline 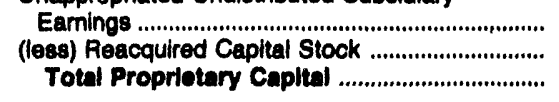 & $\begin{array}{r}67,858 \\
0 \\
0,283,480\end{array}$ & $\begin{array}{r}58,811 \\
0 \\
1,579,904\end{array}$ & $\begin{array}{r}-1,815 \\
0 \\
6,417,321\end{array}$ & $\begin{array}{r}16,628 \\
0 \\
1,287,192\end{array}$ & $\begin{array}{r}359,258 \\
0 \\
897,180\end{array}$ & $\begin{array}{r}23,736 \\
0 \\
1,937,004\end{array}$ \\
\hline 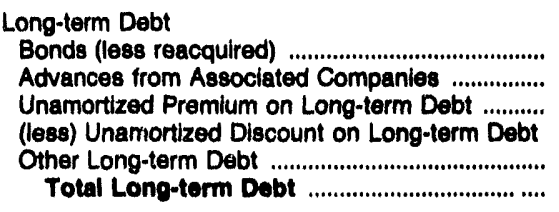 & $\begin{array}{r}6,646,364 \\
0 \\
324 \\
107,320 \\
1,798,416 \\
8,637,705\end{array}$ & $\begin{array}{r}1,410,082 \\
0 \\
724 \\
14,888 \\
17,991 \\
1,413,021\end{array}$ & $\begin{array}{r}4,713,421 \\
350,000 \\
258 \\
61,384 \\
288,883 \\
5,201,178\end{array}$ & $\begin{array}{r}860,250 \\
1,770 \\
485 \\
2,136 \\
179,167 \\
1,139,588\end{array}$ & $\begin{array}{r}421,718 \\
0 \\
0 \\
4,358 \\
62,680 \\
480,040\end{array}$ & $\begin{array}{r}1,547,000 \\
0 \\
90 \\
4,960 \\
426,461 \\
1,988,592\end{array}$ \\
\hline Total Capltalization ............................................... & $17,771,224$ & $2,008,015$ & $10,708,600$ & $2,486,728$ & $1,317,220$ & $3,906,685$ \\
\hline $\begin{array}{l}\text { Other Noncurrent Liabilities } \\
\text { Obligations Under Capltal Lease-Noncurrent ...... } \\
\text { Accumulated Provision for Property Insurance ... } \\
\text { Accumulated Provision for Injuries and }\end{array}$ & $\begin{array}{r}148,915 \\
0\end{array}$ & $\begin{array}{r}104,763 \\
0\end{array}$ & $\begin{array}{r}0 \\
4,127\end{array}$ & $\begin{array}{r}982 \\
0\end{array}$ & $\begin{array}{l}0 \\
0\end{array}$ & $\begin{array}{r}136,800 \\
0\end{array}$ \\
\hline $\begin{array}{l}\text { Damages ... Accumulated Provision for Pensions and } \\
\text { Acion }\end{array}$ & 238,635 & 12,448 & 59,892 & 0 & 1,871 & 8,358 \\
\hline Becurnulated Miscellaneous Operating & 37,300 & 3,871 & 111,139 & 6,139 & 0 & 4,444 \\
\hline $\begin{array}{l}\text { Provisions . Accumulated Provision for Rate Refunds ............. } \\
\text { Total Other Noncurrent Lablittios ............... }\end{array}$ & $\begin{array}{r}80,342 \\
35,472 \\
540,684\end{array}$ & $\begin{array}{r}0 \\
0 \\
121,081\end{array}$ & $\begin{array}{r}113,380 \\
0 \\
289,688\end{array}$ & $\begin{array}{r}0 \\
0 \\
7,121\end{array}$ & $\begin{array}{r}0 \\
0 \\
1,871\end{array}$ & $\begin{array}{r}-12,719 \\
5,408 \\
142,291\end{array}$ \\
\hline 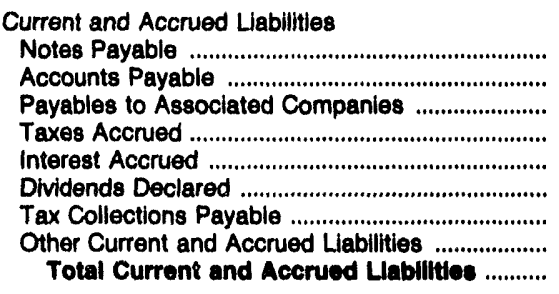 & $\begin{array}{r}921,080 \\
747,072 \\
114,495 \\
217,623 \\
88,866 \\
187,721 \\
16,508 \\
253,349 \\
2,546,715\end{array}$ & $\begin{array}{r}68,600 \\
147,796 \\
2,276 \\
65,627 \\
24,250 \\
43,298 \\
2,556 \\
168,277 \\
522,090\end{array}$ & $\begin{array}{r}607,647 \\
385,719 \\
2,134 \\
338,183 \\
108,247 \\
161,343 \\
8,620 \\
726,803 \\
2,318,606\end{array}$ & $\begin{array}{r}0 \\
138,171 \\
67,314 \\
80,697 \\
29,722 \\
32,248 \\
9,694 \\
74,881 \\
432,707\end{array}$ & $\begin{array}{r}0 \\
68,168 \\
174,095 \\
39,901 \\
15,674 \\
0 \\
4,425 \\
23,361 \\
325,623\end{array}$ & $\begin{array}{r}205,740 \\
87,168 \\
67,437 \\
85,621 \\
32,829 \\
3,693 \\
2,738 \\
74,990 \\
570,216\end{array}$ \\
\hline Deferred Credits & & & & & & \\
\hline 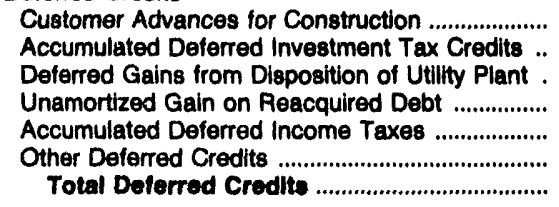 & $\begin{array}{r}175,451 \\
473,412 \\
0 \\
10,720 \\
2,453,022 \\
195,923 \\
3,308,520\end{array}$ & $\begin{array}{r}38,024 \\
119,258 \\
0 \\
271 \\
268,402 \\
64,795 \\
401,750\end{array}$ & $\begin{array}{r}66,201 \\
426,155 \\
0 \\
0 \\
2,015,288 \\
203,133 \\
2,800,777\end{array}$ & $\begin{array}{r}59,311 \\
121,980 \\
0 \\
0 \\
280,763 \\
150,431 \\
612,404\end{array}$ & $\begin{array}{r}47,053 \\
10,767 \\
0 \\
0 \\
38,267 \\
20,739 \\
116,826\end{array}$ & $\begin{array}{r}3,017 \\
165,710 \\
0 \\
589 \\
570,507 \\
171,740 \\
911,562\end{array}$ \\
\hline Total Labilities and Other Credits ................ & $24,167,131$ & $4,129,626$ & $16,116,510$ & $3,470,050$ & $1,761,540$ & $5,529,756$ \\
\hline
\end{tabular}

Note: Totals may not equal sum of components because of independent rounding. Summary data are provided in Table 8 .

Source: Federal Energy Regulatory Commission, FERC Form 1, "Annual Report of Major Electric Utilities, Licensees and Others." 
Table 38. Balance Sheot by Major U.S. Investor-Owned Electric Utillty Within State on December 31, 1992 (Continued)

(Thousand Dollars)

\begin{tabular}{|c|c|c|c|c|c|c|}
\hline Item & $\begin{array}{l}\text { Connecticut } \\
\text { Connecticut } \\
\text { Yankee } \\
\text { Atom } \\
\text { Pwr Co }\end{array}$ & $\begin{array}{l}\text { Connectlout } \\
\text { United } \\
\text { Illuminating } \\
\text { Co }\end{array}$ & $\begin{array}{c}\text { Delaware } \\
\text { Delmarva } \\
\text { Power } \\
\& \\
\text { Light Co }\end{array}$ & $\begin{array}{l}\text { District of } \\
\text { Columbia } \\
\text { Potomac } \\
\text { Electric } \\
\text { Power Co }\end{array}$ & $\begin{array}{c}\text { Florida } \\
\text { Florida } \\
\text { Power } \\
\& \\
\text { Lught Co }\end{array}$ & $\begin{array}{l}\text { Florida } \\
\text { Fiorida } \\
\text { Power Corp }\end{array}$ \\
\hline 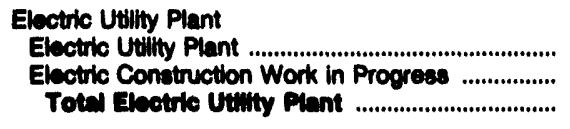 & $\begin{array}{r}349,693 \\
7,737 \\
357,330\end{array}$ & $\begin{array}{r}1,631,786 \\
59,809 \\
1,601,500\end{array}$ & $\begin{array}{r}2,345,697 \\
174,395 \\
2,620,002\end{array}$ & $\begin{array}{r}5,049,047 \\
314,855 \\
5,393,002\end{array}$ & $\begin{array}{r}13,256,988 \\
1,158,68 d \\
14,415,676\end{array}$ & $\begin{array}{r}4,853,851 \\
333,784 \\
5,187,686\end{array}$ \\
\hline 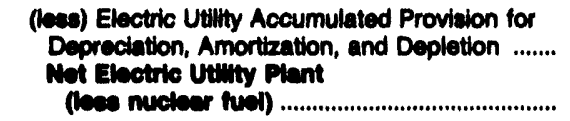 & $\begin{array}{l}241,782 \\
116,640\end{array}$ & $\begin{array}{r}407,728 \\
1,203,807\end{array}$ & $\begin{array}{r}818,066 \\
1,701,026\end{array}$ & $\begin{array}{l}1,435,853 \\
3,027,040\end{array}$ & $\begin{array}{l}5,058,241 \\
9,357,435\end{array}$ & $\begin{array}{l}1,809,853 \\
3,377,703\end{array}$ \\
\hline 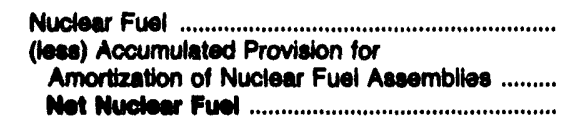 & $\begin{array}{r}429,183 \\
390,371 \\
38,811\end{array}$ & $\begin{array}{r}111,237 \\
59,083 \\
62,144\end{array}$ & $\begin{array}{r}45,071 \\
8,289 \\
36,762\end{array}$ & $\begin{array}{l}0 \\
0 \\
0\end{array}$ & $\begin{array}{r}277,803 \\
0 \\
277,803\end{array}$ & $\begin{array}{r}337,773 \\
273,643 \\
64,120\end{array}$ \\
\hline 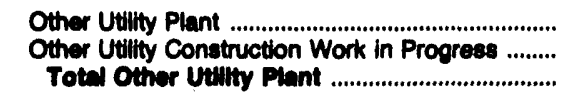 & $\begin{array}{l}0 \\
0 \\
0\end{array}$ & $\begin{array}{l}0 \\
0 \\
0\end{array}$ & $\begin{array}{r}288,868 \\
13,449 \\
302,415\end{array}$ & $\begin{array}{l}0 \\
0 \\
0\end{array}$ & $\begin{array}{l}0 \\
0 \\
0\end{array}$ & \\
\hline 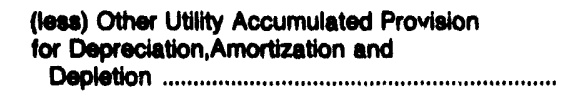 & 0 & 0 & 108,606 & 0 & 0 & 0 \\
\hline Not Other Uallty Plant .......................................... & $\mathbf{0}$ & 0 & 198,608 & $\mathbf{0}$ & o & $\mathbf{0}$ \\
\hline 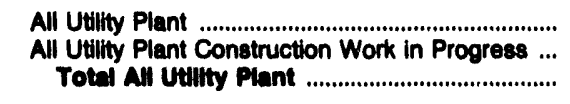 & $\begin{array}{r}778,776 \\
7,737 \\
786,613\end{array}$ & $\begin{array}{r}1,743,023 \\
58,809 \\
1,802,833\end{array}$ & $\begin{array}{r}2,679,735 \\
187,844 \\
2,807,570\end{array}$ & $\begin{array}{r}5,048,047 \\
314,855 \\
5,303,902\end{array}$ & $\begin{array}{r}13,534,791 \\
1,158,688 \\
14,603,470\end{array}$ & $\begin{array}{r}5,191,624 \\
333,784 \\
5,625,400\end{array}$ \\
\hline 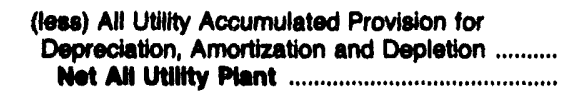 & $\begin{array}{r}632,154 \\
154,350\end{array}$ & $\begin{array}{r}466,822 \\
1,338,011\end{array}$ & $\begin{array}{r}935,962 \\
1,931,617\end{array}$ & $\begin{array}{l}1,435,953 \\
3,027,040\end{array}$ & $\begin{array}{l}5,058,241 \\
8,835,236\end{array}$ & $\begin{array}{l}2,083,496 \\
3,441,012\end{array}$ \\
\hline 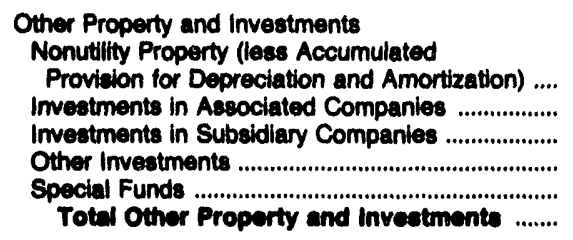 & $\begin{array}{r}0 \\
0 \\
0 \\
106,054 \\
67,892 \\
174,046\end{array}$ & $\begin{array}{r}2,178 \\
0 \\
9,359 \\
96,168 \\
0 \\
107,708\end{array}$ & $\begin{array}{r}6,781 \\
0 \\
46,597 \\
128 \\
14,114 \\
67,620\end{array}$ & $\begin{array}{r}3,308 \\
0 \\
280,474 \\
238 \\
824 \\
284,845\end{array}$ & $\begin{array}{r}5,530 \\
0 \\
0 \\
1,887 \\
319,533 \\
328,950\end{array}$ & $\begin{array}{r}5,219 \\
0 \\
0 \\
3 \\
92,630 \\
97,052\end{array}$ \\
\hline 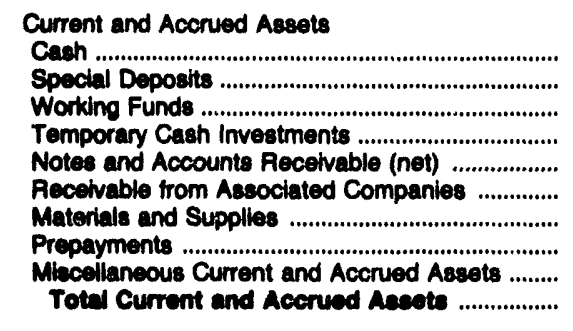 & $\begin{array}{r}37 \\
0 \\
7 \\
0 \\
1,642 \\
20,312 \\
18,139 \\
4,822 \\
0 \\
44,080\end{array}$ & $\begin{array}{r}1,420 \\
205 \\
9,220 \\
257 \\
87,355 \\
0 \\
20,540 \\
3,130 \\
31,298 \\
163,426\end{array}$ & $\begin{array}{r}4,040 \\
6,440 \\
13,846 \\
22 \\
76,255 \\
177 \\
68,406 \\
7,641 \\
28,783 \\
105,600\end{array}$ & $\begin{array}{r}2,611 \\
67 \\
628 \\
1,635 \\
122,989 \\
890 \\
176,744 \\
32,223 \\
67,388 \\
405,176\end{array}$ & $\begin{array}{r}0 \\
239 \\
2,763 \\
0 \\
376,233 \\
1,032 \\
363,120 \\
35,892 \\
129,267 \\
908,646\end{array}$ & $\begin{array}{r}-10,296 \\
2,600 \\
532 \\
0 \\
04,800 \\
308 \\
181,196 \\
5,852 \\
52,746 \\
927,830\end{array}$ \\
\hline $\begin{array}{l}\text { Deferred Debits } \\
\text { Unamortized Debt Expense .................................... } \\
\text { Extraordinary Property Losses ..................... } \\
\text { Unrecovered Plant and Regulatory Sturdy Cost ... } \\
\text { Prelliminary Survey and Investigation Charges .... } \\
\text { Clearing Accounte ............................................ } \\
\text { Deferred Losses from Disposition of Utilty Plant } \\
\text { Research, Development and Demonstration }\end{array}$ & $\begin{array}{r}2,189 \\
0 \\
0 \\
0 \\
1 \\
0\end{array}$ & $\begin{array}{r}6,474 \\
0 \\
18,845 \\
0 \\
0 \\
0\end{array}$ & $\begin{array}{r}10,617 \\
0 \\
15,019 \\
3,177 \\
444 \\
0\end{array}$ & $\begin{array}{r}7,482 \\
0 \\
3,313 \\
15,896 \\
1,313 \\
0\end{array}$ & $\begin{array}{r}14,486 \\
0 \\
0 \\
1,663 \\
-3,060 \\
0\end{array}$ & $\begin{array}{r}6,477 \\
0 \\
0 \\
797 \\
276 \\
0\end{array}$ \\
\hline 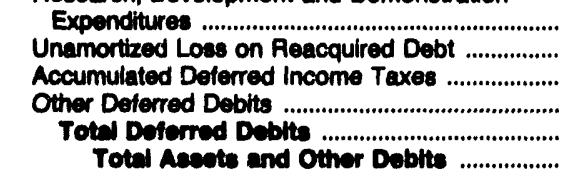 & $\begin{array}{r}0 \\
398 \\
19,528 \\
46,805 \\
68,920 \\
442,284\end{array}$ & $\begin{array}{r}0 \\
25,590 \\
144,667 \\
685,189 \\
880,785 \\
2,477,003\end{array}$ & $\begin{array}{r}9 \\
22,510 \\
29,600 \\
28,316 \\
100,692 \\
2,304,539\end{array}$ & $\begin{array}{r}0 \\
25,791 \\
31,977 \\
87,206 \\
173,098 \\
4,701,058\end{array}$ & $\begin{array}{r}i, 126 \\
175,1120 \\
248,1) 50 \\
288,258 \\
725,843 \\
11,688,676\end{array}$ & $\begin{array}{r}-10 \\
14,581 \\
100,984 \\
75,530 \\
108,638 \\
4,068,230\end{array}$ \\
\hline
\end{tabular}

See endnotes at end of an indlidual electric utillty. 
Table 38. Balance Sheet by Major U.S. Inveotor-Owned Electric Utillity Within State on Decomber 31, 1992 (Continued) (Thousand Dollars)

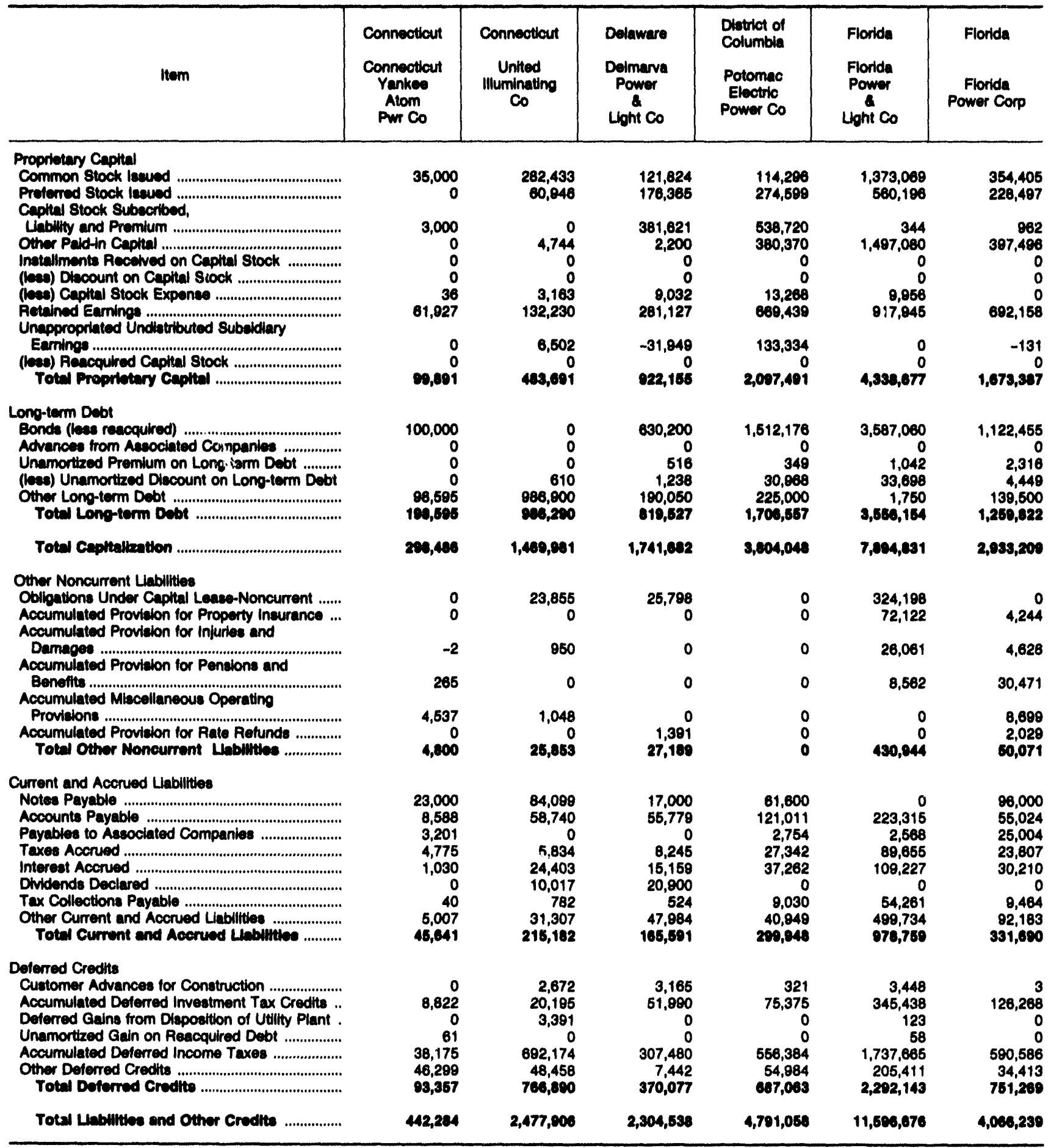

Note: Totals may not equal sum of components because of independent rounding. Summary data are provided in Table 8.

Source: Federal Energy Regulatory Commiseion, FERC Form 1, "Annual Report of Major Electric Utilities, Licensees and Others." 
Table 38. Balance Sheet by Major U.S. Investor-Owned Electrlc Utillty Within State on December 31, 1992 (Continued)

(Thousand Dollars)

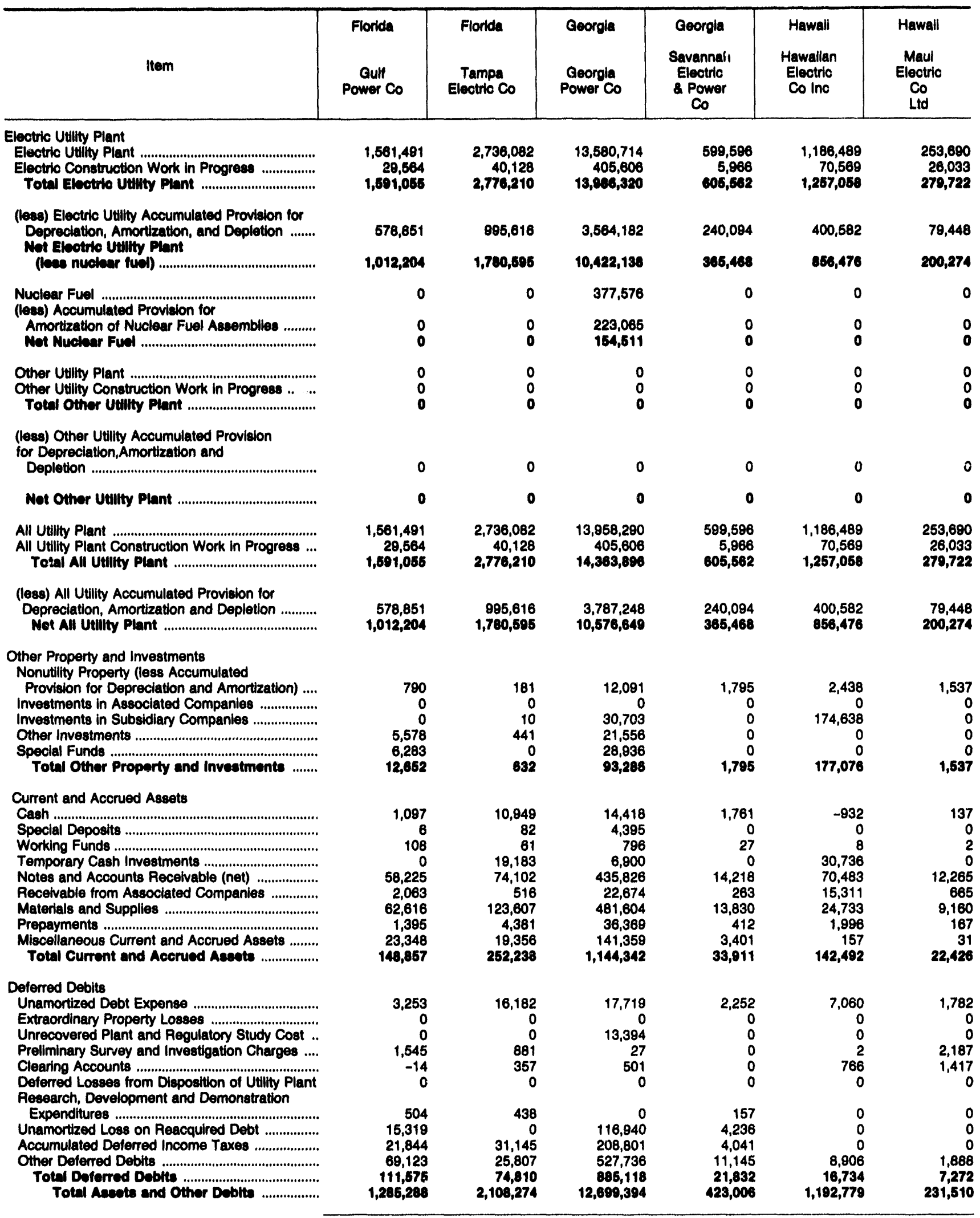

See endnotes at end of an individual electric utility. 
Table 38. Balance 8heot by Major U.8. Inveotor-Owned Electrlo Utillty Within state on Decombor 31, 1902 (Continued)

(Thousand Dollars)

\begin{tabular}{|c|c|c|c|c|c|c|}
\hline Item & $\begin{array}{l}\text { Florida } \\
\text { Qulf } \\
\text { Power co }\end{array}$ & $\begin{array}{l}\text { Florida } \\
\text { Tampe } \\
\text { Elcotrio co }\end{array}$ & $\begin{array}{l}\text { Georgla } \\
\text { Georgla } \\
\text { Power Co }\end{array}$ & $\begin{array}{l}\text { Georgla } \\
\text { 8avannah } \\
\text { Electric } \\
\text { a Power } \\
\text { Co }\end{array}$ & $\begin{array}{l}\text { Hawall } \\
\text { Hawallan } \\
\text { Eleotrlo } \\
\text { Co Ino }\end{array}$ & $\begin{array}{l}\text { Hawall } \\
\text { Maul } \\
\text { Eleotrio } \\
\text { Co } \\
\text { Lid } \\
\end{array}$ \\
\hline 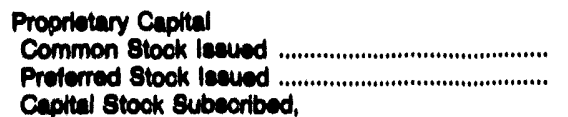 & $\begin{array}{l}38,060 \\
77,668\end{array}$ & $\begin{array}{r}110,697 \\
64,060\end{array}$ & $\begin{array}{l}344,250 \\
762,702\end{array}$ & $\begin{array}{l}64,223 \\
20,000\end{array}$ & $\begin{array}{l}69,081 \\
62,243\end{array}$ & $\begin{array}{l}10,943 \\
10,725\end{array}$ \\
\hline 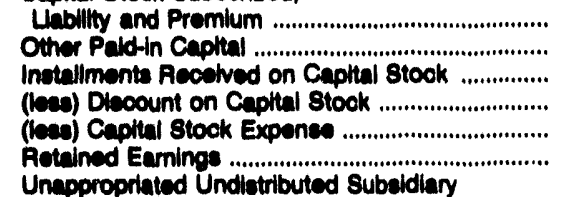 & $\begin{array}{r}88 \\
216,271 \\
0 \\
0 \\
1,509 \\
148,280\end{array}$ & $\begin{array}{r}10 \\
600,607 \\
0 \\
0 \\
1,602 \\
182,273\end{array}$ & $\begin{array}{r}467 \\
2,384,140 \\
0 \\
0 \\
0 \\
1,145,077\end{array}$ & $\begin{array}{r}8,608 \\
333 \\
0 \\
0 \\
3,280 \\
88,436\end{array}$ & $\begin{array}{r}186,441 \\
-27 \\
0 \\
0 \\
6,184 \\
180,168\end{array}$ & $\begin{array}{r}38,128 \\
0 \\
0 \\
0 \\
325 \\
38,480\end{array}$ \\
\hline 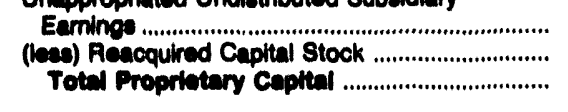 & $\begin{array}{r}0 \\
0 \\
40,988\end{array}$ & $\begin{array}{r}0 \\
0 \\
\operatorname{ran}, 1 \times 0\end{array}$ & $\begin{array}{r}14,303 \\
0 \\
4,881,020\end{array}$ & $\begin{array}{r}0 \\
18 \\
170,987\end{array}$ & $\begin{array}{r}69,427 \\
0 \\
892,197\end{array}$ & $\begin{array}{r}0 \\
0 \\
97,981\end{array}$ \\
\hline 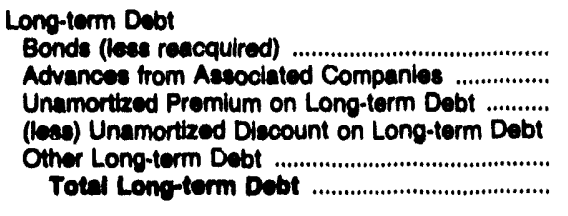 & $\begin{array}{r}215,345 \\
0 \\
29 \\
1,843 \\
182,338 \\
308,086\end{array}$ & $\begin{array}{r}644,675 \\
0 \\
182 \\
0 \\
0 \\
044,897\end{array}$ & $\begin{array}{r}2,482,538 \\
0 \\
96 \\
34,428 \\
1,681,690 \\
4,129,708\end{array}$ & $\begin{array}{r}111,670 \\
0 \\
1 \\
0 \\
0 \\
111,671\end{array}$ & $\begin{array}{r}100,000 \\
0 \\
0 \\
0 \\
132,413 \\
232,413\end{array}$ & $\begin{array}{r}22,500 \\
0 \\
0 \\
0 \\
46,146 \\
67,640\end{array}$ \\
\hline Total Capltallzation & $\mathbf{8 7 6 , 7 1 0}$ & $1,600,727$ & $0,780,025$ & 290,020 & 794,680 & 105,607 \\
\hline $\begin{array}{l}\text { Other Nonourrent Llablilities } \\
\text { Obllaations Under Capltal Lease-Noncurrent ...... } \\
\text { Acoumulated Provision for Property Inaurance ... } \\
\text { Accumulated Provilion for Injuries and }\end{array}$ & $\begin{array}{r}0 \\
8,692\end{array}$ & $\begin{array}{l}0 \\
0\end{array}$ & $\begin{array}{r}96,136 \\
4,308\end{array}$ & $\begin{array}{r}2,668 \\
300\end{array}$ & $\begin{array}{l}0 \\
0\end{array}$ & $\begin{array}{l}0 \\
0\end{array}$ \\
\hline $\begin{array}{l}\text { Damages } \\
\text { Acoumulated Provision for Pensiona and }\end{array}$ & 2,484 & 5,768 & 0 & 495 & 0 & 0 \\
\hline $\begin{array}{c}\text { Boneffts ...ed Miscollaneous Operating } \\
\text { Accumulated }\end{array}$ & 0 & 1,290 & 0 & 0 & 0 & 0 \\
\hline 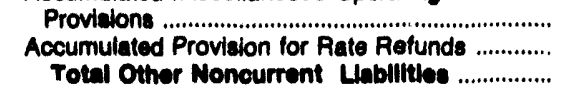 & $\begin{array}{r}0 \\
0 \\
12,178\end{array}$ & $\begin{array}{r}0 \\
0 \\
7,068\end{array}$ & $\begin{array}{r}0 \\
0 \\
100,444\end{array}$ & $\begin{array}{r}0 \\
0 \\
3,482\end{array}$ & $\begin{array}{l}0 \\
0 \\
0\end{array}$ & $\begin{array}{l}0 \\
0 \\
0\end{array}$ \\
\hline 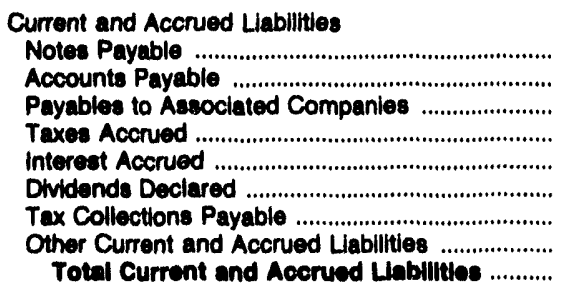 & $\begin{array}{r}44,000 \\
24,829 \\
5,323 \\
8,862 \\
6,370 \\
1,415 \\
962 \\
19,362 \\
111,124\end{array}$ & $\begin{array}{r}29,200 \\
42,499 \\
24,044 \\
4,030 \\
11,571 \\
0 \\
3,097 \\
53,231 \\
107,672\end{array}$ & $\begin{array}{r}533,671 \\
264,639 \\
33,258 \\
138,289 \\
132,319 \\
13,922 \\
19,564 \\
168,697 \\
1,304,240\end{array}$ & $\begin{array}{r}7,500 \\
5,880 \\
4,672 \\
3,016 \\
5,733 \\
475 \\
527 \\
10,387 \\
38,200\end{array}$ & $\begin{array}{r}122,176 \\
28,879 \\
415 \\
19,779 \\
5,483 \\
936 \\
616 \\
6,127 \\
187,411\end{array}$ & $\begin{array}{r}0 \\
10,323 \\
2,773 \\
5,821 \\
1,108 \\
209 \\
78 \\
3,342 \\
23,084\end{array}$ \\
\hline 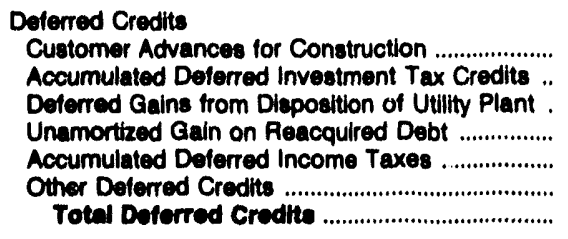 & $\begin{array}{r}0 \\
43,117 \\
0 \\
0 \\
225,145 \\
17,007 \\
205,260\end{array}$ & $\begin{array}{r}0 \\
70,846 \\
12 \\
0 \\
337,722 \\
15,138 \\
423,817\end{array}$ & $\begin{array}{r}0 \\
515,539 \\
0 \\
734 \\
1,734,952 \\
262,650 \\
2,613,076\end{array}$ & $\begin{array}{r}1,862 \\
15,965 \\
0 \\
0 \\
68,579 \\
4,821 \\
01,226\end{array}$ & $\begin{array}{r}3,054 \\
26,101 \\
0 \\
0 \\
85,525 \\
86,138 \\
210,018\end{array}$ & $\begin{array}{r}5,630 \\
7,229 \\
0 \\
0 \\
14,118 \\
15,281 \\
42,260\end{array}$ \\
\hline Total Labullties and Other Credits ................. & $1,285,288$ & $2,100,274$ & $12,609,394$ & 423,006 & $1,192,779$ & 231,610 \\
\hline
\end{tabular}

Note: Totals may not equal sum of components because of independent rounding. Summary data are provided in Table 8.

Source: Federal Energy Regulatory Commiesion, FEAC Form 1, "Annual Report of Major Electric Utilties, Llcensees and Others." 
Table 38. Balance Sheot by Major U.8. Invwotor-Owned Eloctric Utility Within state on December 31, 1992 (Continued) (Thousand Dollars)

\begin{tabular}{|c|c|c|c|c|c|c|}
\hline Item & $\begin{array}{l}\text { Idaho } \\
\text { Idaho } \\
\text { Power Co }\end{array}$ & $\begin{array}{l}\text { Illinois } \\
\text { Contral } \\
\text { Illinois } \\
\text { Light Co }\end{array}$ & $\begin{array}{l}\text { Illinols } \\
\text { Central } \\
\text { lilinols } \\
\text { Pub } \\
\text { Serv Co }\end{array}$ & $\begin{array}{l}\text { Illinols } \\
\text { Commonwealth } \\
\text { Edison Co }\end{array}$ & $\begin{array}{l}\text { Illinole } \\
\text { Eleotric } \\
\text { Energy Ino }\end{array}$ & $\begin{array}{c}\text { Iliinols } \\
\text { IIInols } \\
\text { Power Co }\end{array}$ \\
\hline 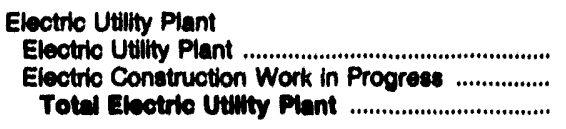 & $\begin{array}{r}2,201,881 \\
46,099 \\
2,247,030\end{array}$ & $\begin{array}{r}1,036,250 \\
19,046 \\
1,086,206\end{array}$ & $\begin{array}{r}2,116,322 \\
41,569 \\
2,167,041\end{array}$ & $\begin{array}{r}24,061,600 \\
1,163,043 \\
28,214,050\end{array}$ & $\begin{array}{r}267,738 \\
6,939 \\
224,677\end{array}$ & $\begin{array}{r}5,368,166 \\
176,686 \\
8,843,041\end{array}$ \\
\hline 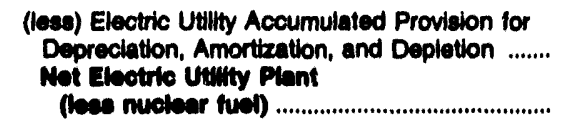 & $\begin{array}{r}683,332 \\
1,894,697\end{array}$ & $\begin{array}{l}449,446 \\
008,061\end{array}$ & $\begin{array}{r}882,240 \\
1,278,842\end{array}$ & $\begin{array}{r}8,025,979 \\
17,189,671\end{array}$ & $\begin{array}{r}204,676 \\
00,001\end{array}$ & $\begin{array}{l}1,601,272 \\
3,941,700\end{array}$ \\
\hline 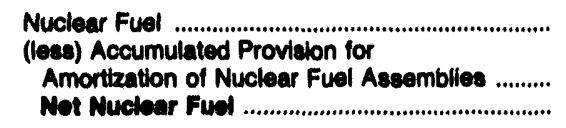 & $\begin{array}{l}0 \\
0\end{array}$ & $\begin{array}{l}0 \\
0\end{array}$ & $\begin{array}{l}0 \\
0\end{array}$ & $\begin{array}{r}1,205,755 \\
582,384 \\
613,372\end{array}$ & $\begin{array}{l}0 \\
0\end{array}$ & $\begin{array}{r}151,777 \\
0 \\
151,777\end{array}$ \\
\hline 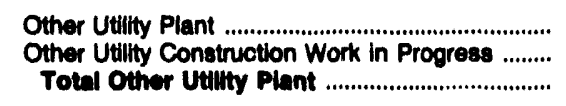 & $\begin{array}{l}0 \\
0 \\
0\end{array}$ & $\begin{array}{r}351,413 \\
6,432 \\
367,045\end{array}$ & $\begin{array}{r}195,709 \\
3,660 \\
100,380\end{array}$ & $\begin{array}{l}0 \\
0 \\
0\end{array}$ & $\begin{array}{l}0 \\
0 \\
0\end{array}$ & $\begin{array}{r}480,916 \\
31,898 \\
822,811\end{array}$ \\
\hline 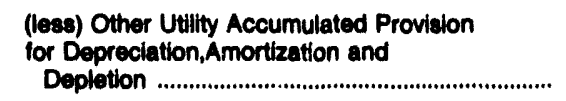 & 0 & 157,047 & 79,180 & 0 & 0 & 207,503 \\
\hline Not Other Utilty Plant ................................................ & $\mathbf{0}$ & 200,700 & 120,190 & $\mathbf{0}$ & $\mathbf{0}$ & 316,109 \\
\hline 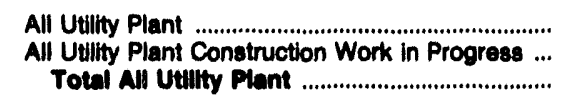 & $\begin{array}{r}2,201,831 \\
46,099 \\
2,247,030\end{array}$ & $\begin{array}{r}1,387,664 \\
25,477 \\
1,413,141\end{array}$ & $\begin{array}{r}2,312,031 \\
45,219 \\
2,357,261\end{array}$ & $\begin{array}{r}25,267,362 \\
1,163,043 \\
26,420,406\end{array}$ & $\begin{array}{r}257,738 \\
6,939 \\
264,677\end{array}$ & $\begin{array}{r}6,008,848 \\
208,582 \\
6,217,430\end{array}$ \\
\hline $\begin{array}{l}\text { (less) All Utility Accumulated Provision for } \\
\text { Depreciation, Amortization and Depletion ........... } \\
\text { Net All Utility Plant ........................................... }\end{array}$ & $\begin{array}{r}683,332 \\
1,604,697\end{array}$ & $\begin{array}{l}606,491 \\
004,650\end{array}$ & $\begin{array}{r}961,418 \\
1,395,031\end{array}$ & $\begin{array}{r}8,618,363 \\
17,002,042\end{array}$ & $\begin{array}{r}204,676 \\
60,001\end{array}$ & $\begin{array}{l}1,808,775 \\
4,408,684\end{array}$ \\
\hline 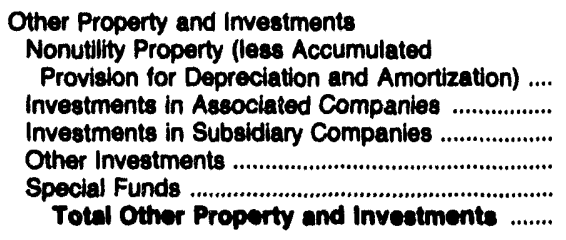 & $\begin{array}{r}3,927 \\
0 \\
21,370 \\
1,352 \\
2 \\
24,851\end{array}$ & $\begin{array}{r}896 \\
0 \\
531 \\
10,753 \\
69 \\
12,240\end{array}$ & $\begin{array}{r}164 \\
25 \\
2,116 \\
7,540 \\
0 \\
9,844\end{array}$ & $\begin{array}{r}119,762 \\
0 \\
180,676 \\
2,297 \\
534,739 \\
837,463\end{array}$ & $\begin{array}{r}0 \\
0 \\
100 \\
0 \\
0 \\
100\end{array}$ & $\begin{array}{r}2,837 \\
0 \\
2,681 \\
19,514 \\
43,804 \\
98,716\end{array}$ \\
\hline 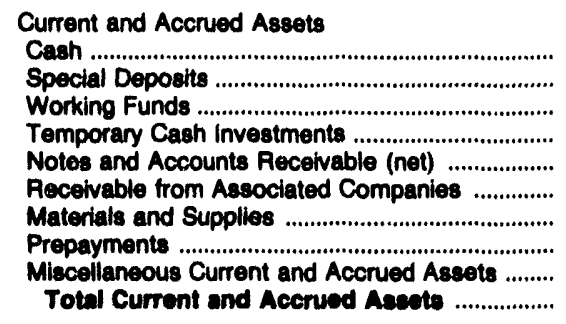 & $\begin{array}{r}768 \\
1,686 \\
71 \\
0 \\
35,815 \\
35 \\
40,044 \\
20,455 \\
27,210 \\
128,094\end{array}$ & $\begin{array}{r}0 \\
0 \\
49 \\
1,200 \\
36,279 \\
424 \\
27,115 \\
8,668 \\
42,190 \\
114,924\end{array}$ & $\begin{array}{r}383 \\
1,104 \\
87 \\
0 \\
43,383 \\
481 \\
73,055 \\
5,997 \\
53,267 \\
177,768\end{array}$ & $\begin{array}{r}0 \\
260,898 \\
1,683 \\
158,192 \\
501,341 \\
5,431 \\
705,782 \\
34,705 \\
11,863 \\
1,679,898\end{array}$ & $\begin{array}{r}173 \\
203 \\
24 \\
0 \\
22,469 \\
12,878 \\
11,600 \\
1,215 \\
0 \\
48,683\end{array}$ & $\begin{array}{r}8,413 \\
303 \\
155 \\
4 \\
98,138 \\
2,478 \\
116,694 \\
11,455 \\
113,774 \\
351,413\end{array}$ \\
\hline $\begin{array}{l}\text { Deferred Deblts } \\
\text { Unamortized Debt Expense ................................... } \\
\text { Extreordinary Property Losses ............................. } \\
\text { Unrecovered Plant and Regulatory Study Cost .. } \\
\text { Prellminary Survey and Investigation Charges .... } \\
\text { Clearing Accounts ............................................... } \\
\text { Deferred Losees from Dieposition of Utility Plant } \\
\text { Research, Development and Demonstration }\end{array}$ & $\begin{array}{r}6,635 \\
0 \\
0 \\
643 \\
720 \\
0\end{array}$ & $\begin{array}{r}1,769 \\
0 \\
0 \\
494 \\
140 \\
0\end{array}$ & $\begin{array}{r}1,210 \\
0 \\
0 \\
430 \\
-302 \\
0\end{array}$ & $\begin{array}{r}10,410 \\
0 \\
0 \\
57 \\
11,198 \\
0\end{array}$ & $\begin{array}{r}369 \\
0 \\
0 \\
0 \\
0 \\
0\end{array}$ & $\begin{array}{r}13,013 \\
0 \\
0 \\
1,788 \\
210 \\
0\end{array}$ \\
\hline 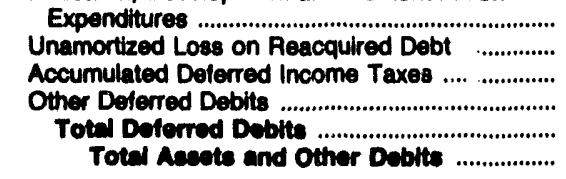 & $\begin{array}{r}0 \\
4,886 \\
10,170 \\
121,346 \\
144,600 \\
1,801,842\end{array}$ & $\begin{array}{r}0 \\
5,608 \\
\mathbf{6 , 9 3 1} \\
23,858 \\
\mathbf{3 8 , 7 9 0} \\
\mathbf{9 7 2 , 8 2 2}\end{array}$ & $\begin{array}{r}0 \\
12,874 \\
14,755 \\
40,249 \\
69,215 \\
1,852,658\end{array}$ & $\begin{array}{r}0 \\
100,891 \\
552,409 \\
126,993 \\
801,958 \\
21,121,360\end{array}$ & $\begin{array}{r}0 \\
0 \\
5,793 \\
4,503 \\
10,668 \\
110,330\end{array}$ & $\begin{array}{r}3,177 \\
64,629 \\
310,232 \\
435,644 \\
828,602 \\
\mathbf{5 , 6 5 7 , 4 7 5}\end{array}$ \\
\hline
\end{tabular}

See endnotes at end of an individual electric utility. 
Tablo 38. Balance Shoot by Major U.8. Investor-Owned Electrle Utillty Within state on Docomber 31, 1902 (Continuod)

(Thousand Dollars)

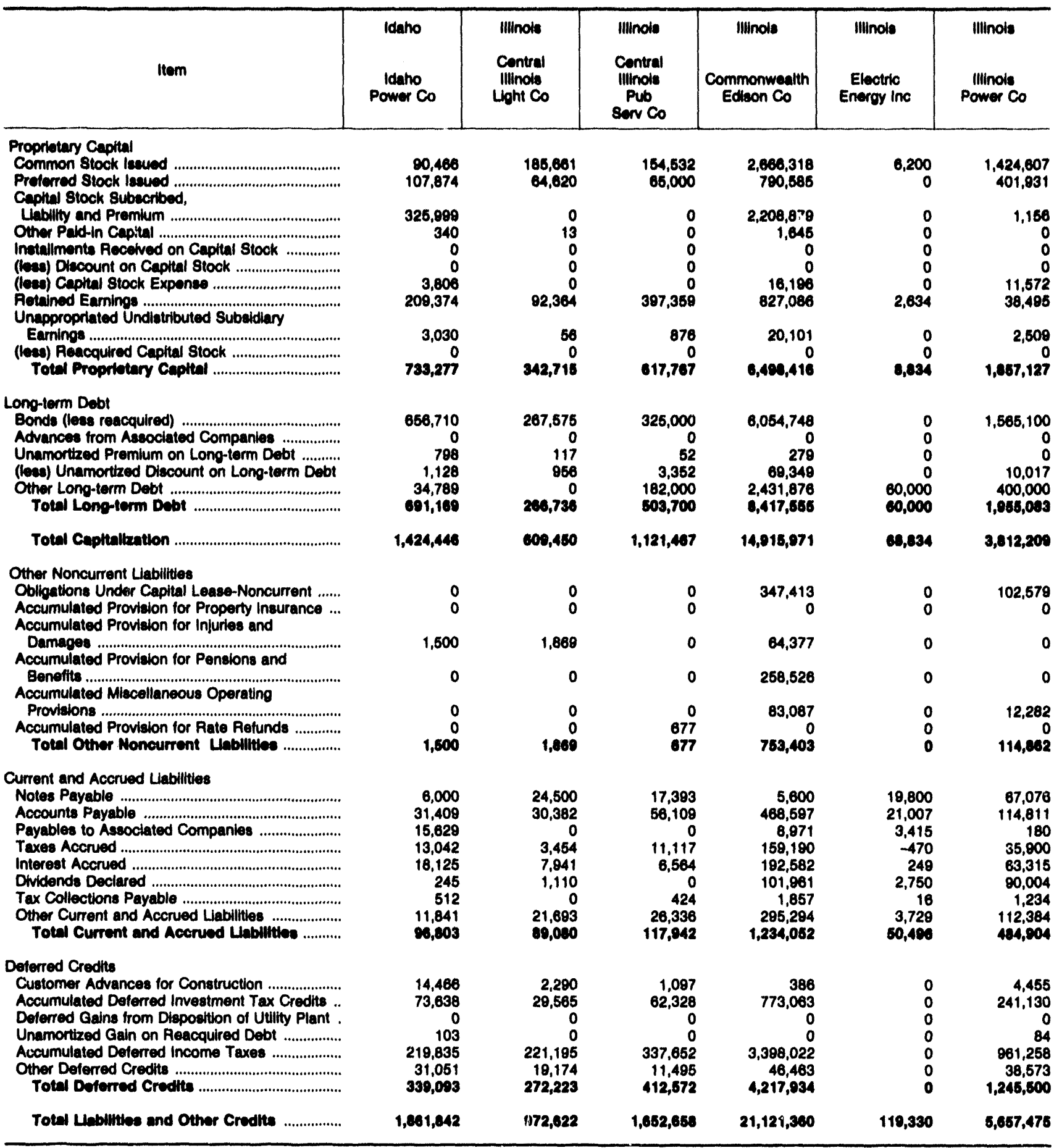

Note: Totals may not equal sum of components because of independent rounding. Summary data are provided in Table 8.

Source: Federal Energy Regulatory Commission, FERC Form 1. "Annual Report of Major Electric Utilities, Licensees and Others. " 
Table 38. Balance sheot by Major U.8. Inveotor-Owned Eleotrle Utillty Within state on Decomber 31, 1092 (Continued) (Thousand Dollars)

\begin{tabular}{|c|c|c|c|c|c|c|}
\hline Hem & $\begin{array}{l}\text { Ilitinols } \\
\text { Mit } \\
\text { Carmol } \\
\text { Publls } \\
\text { Uullyy Co }\end{array}$ & $\begin{array}{l}\text { Indiana } \\
\text { Aloo: } \\
\text { cenerating } \\
\text { Corp }\end{array}$ & $\begin{array}{l}\text { Indinn } \\
\text { AEP } \\
\text { Cenerating } \\
\text { Co }\end{array}$ & $\begin{array}{l}\text { Indiann } \\
\text { Commonwealth } \\
\text { Edbon } \\
\text { Co } \\
\text { IN Ino }\end{array}$ & $\begin{array}{l}\text { Indiane } \\
\text { Indiana } \\
\text { Mlohigan } \\
\text { Power Co }\end{array}$ & $\begin{array}{l}\text { Indien } \\
\text { Indianupolis } \\
\text { Power } \\
\text { Woht Co }\end{array}$ \\
\hline 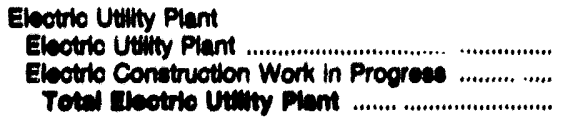 & $\begin{array}{r}11,083 \\
3,380 \\
18,019\end{array}$ & $\begin{array}{r}163,462 \\
8,670 \\
100,041\end{array}$ & $\begin{array}{r}622,683 \\
3,933 \\
92,010\end{array}$ & $\begin{array}{r}174,028 \\
12,100 \\
10,172\end{array}$ & $\begin{array}{r}4,033,326 \\
118,346 \\
4,181,070\end{array}$ & $\begin{array}{r}2,143,030 \\
109,882 \\
2,209,880\end{array}$ \\
\hline 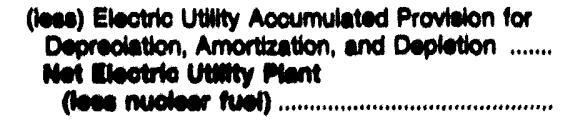 & $\begin{array}{l}6,182 \\
6,907\end{array}$ & $\begin{array}{r}103,886 \\
0,885\end{array}$ & $\begin{array}{l}160,200 \\
47,280\end{array}$ & $\begin{array}{r}120,407 \\
08,709\end{array}$ & $\begin{array}{l}1,600,808 \\
2,600,992\end{array}$ & $\begin{array}{r}787,486 \\
1,499,096\end{array}$ \\
\hline 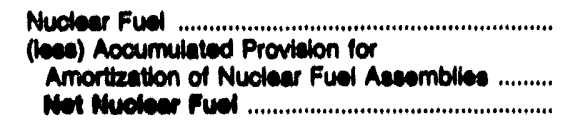 & $\begin{array}{l}0 \\
0\end{array}$ & $\begin{array}{l}0 \\
0\end{array}$ & $\begin{array}{l}0 \\
0\end{array}$ & $\begin{array}{l}0 \\
0\end{array}$ & $\begin{array}{r}85,464 \\
1,284 \\
24,181\end{array}$ & $\begin{array}{l}0 \\
0 \\
0\end{array}$ \\
\hline 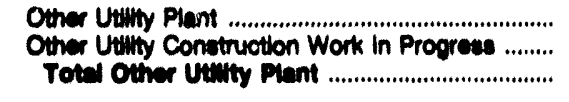 & $\begin{array}{r}3,004 \\
0 \\
2,004\end{array}$ & $\begin{array}{l}0 \\
0 \\
0\end{array}$ & $\begin{array}{l}0 \\
0 \\
0\end{array}$ & $\begin{array}{l}0 \\
0 \\
0\end{array}$ & $\begin{array}{l}0 \\
0 \\
0\end{array}$ & $\begin{array}{r}86,838 \\
6,391 \\
103,200\end{array}$ \\
\hline \multicolumn{7}{|l|}{$\begin{array}{l}\text { (bed) Other Utilly Acoumulated Provision } \\
\text { for Depreciation,Amortization and }\end{array}$} \\
\hline 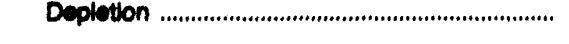 & 1,916 & 0 & 0 & 0 & 0 & 30,884 \\
\hline Net Other Utiuty Plant .......................................... & 1,000 & 0 & 0 & 0 & $\mathbf{0}$ & $72,3 e s$ \\
\hline 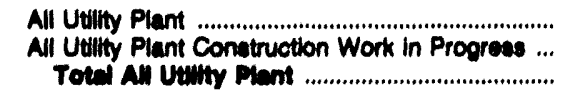 & $\begin{array}{r}14,687 \\
3,380 \\
10,070\end{array}$ & $\begin{array}{r}153,462 \\
6,679 \\
100,041\end{array}$ & $\begin{array}{r}622,683 \\
3,033 \\
28,010\end{array}$ & $\begin{array}{r}174,083 \\
12,109 \\
104,172\end{array}$ & $\begin{array}{r}4,118,789 \\
118,346 \\
4,237,134\end{array}$ & $\begin{array}{r}2,240,777 \\
116,073 \\
2,893,780\end{array}$ \\
\hline 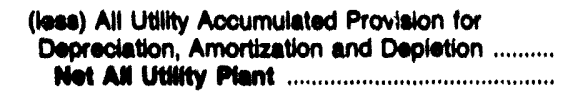 & $\begin{array}{l}6.098 \\
0,978\end{array}$ & $\begin{array}{r}103,689 \\
89,288\end{array}$ & $\begin{array}{l}159,293 \\
47,828\end{array}$ & $\begin{array}{r}120,467 \\
88,705\end{array}$ & $\begin{array}{l}1,602,092 \\
2,688,042\end{array}$ & $\begin{array}{r}818,320 \\
1,896,431\end{array}$ \\
\hline \multicolumn{7}{|l|}{$\begin{array}{l}\text { Other Property and Inveatments } \\
\text { Nonutility Property (leses Accumulated }\end{array}$} \\
\hline 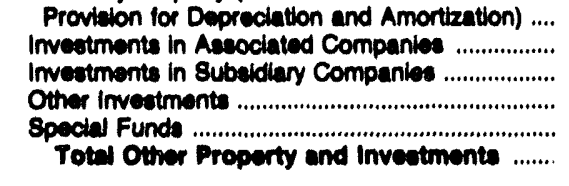 & $\begin{array}{r}0 \\
0 \\
0 \\
103 \\
0 \\
103\end{array}$ & $\begin{array}{r}2,099 \\
0 \\
0 \\
0 \\
0 \\
2,000\end{array}$ & $\begin{array}{l}0 \\
0 \\
0 \\
0 \\
6 \\
6\end{array}$ & $\begin{array}{l}0 \\
0 \\
0 \\
0 \\
0 \\
0\end{array}$ & $\begin{array}{r}9,937 \\
0 \\
114,344 \\
28,343 \\
282,807 \\
416,432\end{array}$ & $\begin{array}{r}1,048 \\
0 \\
41 \\
424 \\
0 \\
1,818\end{array}$ \\
\hline 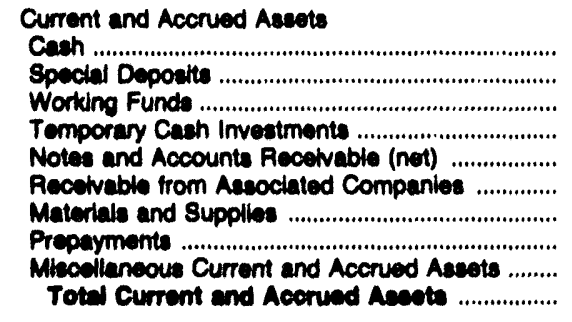 & $\begin{array}{r}73 \\
0 \\
1 \\
47 \\
547 \\
0 \\
285 \\
83 \\
154 \\
1,200\end{array}$ & $\begin{array}{r}0 \\
0 \\
0 \\
0 \\
96 \\
10,992 \\
14,746 \\
83 \\
0 \\
28,918\end{array}$ & $\begin{array}{r}37 \\
0 \\
-2,188 \\
30,126 \\
68 \\
21,678 \\
21,660 \\
626 \\
33 \\
71,010\end{array}$ & $\begin{array}{r}0 \\
0 \\
108 \\
0,784 \\
48 \\
7,428 \\
26,800 \\
921 \\
0 \\
44,184\end{array}$ & $\begin{array}{r}2,501 \\
2,187 \\
2,549 \\
0 \\
70,186 \\
41,180 \\
107,214 \\
10,858 \\
86,488 \\
323,171\end{array}$ & $\begin{array}{r}5,988 \\
106 \\
116 \\
4,500 \\
48,843 \\
442 \\
100,694 \\
1,469 \\
888 \\
182,910\end{array}$ \\
\hline 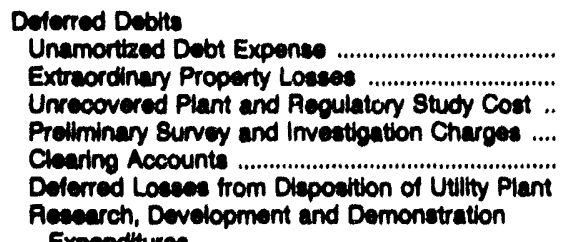 & $\begin{array}{r}16 \\
0 \\
0 \\
0 \\
0 \\
0\end{array}$ & $\begin{array}{l}0 \\
0 \\
0 \\
0 \\
0 \\
0\end{array}$ & $\begin{array}{r}2,634 \\
0 \\
0 \\
0 \\
0 \\
0\end{array}$ & $\begin{array}{r}76 \\
0 \\
0 \\
0 \\
174 \\
0\end{array}$ & $\begin{array}{r}4,539 \\
0 \\
0 \\
0 \\
477 \\
0\end{array}$ & $\begin{array}{r}6,584 \\
0 \\
0 \\
680 \\
115 \\
0\end{array}$ \\
\hline 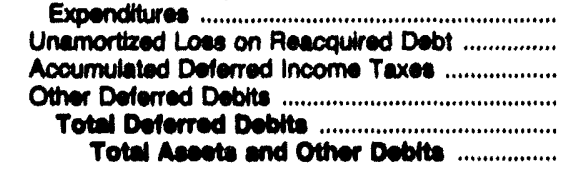 & $\begin{array}{r}0 \\
0 \\
208 \\
87 \\
300 \\
11,808\end{array}$ & $\begin{array}{r}0 \\
0 \\
0 \\
77 \\
77 \\
4.44\end{array}$ & $\begin{array}{r}0 \\
0 \\
119,532 \\
10,413 \\
132,470 \\
671,724\end{array}$ & $\begin{array}{r}0 \\
0 \\
-10 \\
45 \\
208 \\
110,176\end{array}$ & $\begin{array}{r}0 \\
13,670 \\
186,321 \\
184,236 \\
390,143 \\
3,772,703\end{array}$ & $\begin{array}{r}2,633 \\
17,290 \\
32,483 \\
33,253 \\
92,093 \\
1,798,720\end{array}$ \\
\hline
\end{tabular}

See endnotes at end of an individual electric utillty. 
Table 38. Balance sheot by Major U.8. Invector-Owned Electrle Utility Within 8tate on Decomber 31, 1902 (Continued)

(Thousand Dollars)

\begin{tabular}{|c|c|c|c|c|c|c|}
\hline Item & $\begin{array}{l}\text { Illinole } \\
\text { Mit } \\
\text { Carmel } \\
\text { Publlo } \\
\text { Utilty Co }\end{array}$ & $\begin{array}{l}\text { Indiana } \\
\text { Alooe } \\
\text { Cenerating } \\
\text { Corp }\end{array}$ & $\begin{array}{l}\text { Indiana } \\
\text { AEP } \\
\text { Genorating } \\
\text { Co }\end{array}$ & $\begin{array}{l}\text { Indlana } \\
\text { Commonweatth } \\
\text { Edicon } \\
\text { Co } \\
\text { IN ino }\end{array}$ & $\begin{array}{l}\text { Indlana } \\
\text { Indiana } \\
\text { Michigan } \\
\text { Power Co }\end{array}$ & $\begin{array}{l}\text { Indiana } \\
\text { Indianapolls } \\
\text { Power } \\
\text { Lught Co }\end{array}$ \\
\hline 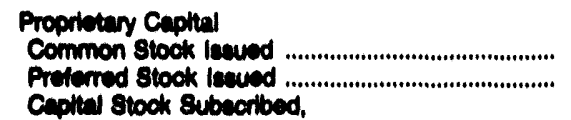 & $\begin{array}{r}2,000 \\
0\end{array}$ & $\begin{array}{r}1,000 \\
0\end{array}$ & $\begin{array}{r}1,000 \\
0\end{array}$ & $\begin{array}{l}27,000 \\
20,000\end{array}$ & $\begin{array}{r}56,584 \\
197,000\end{array}$ & $\begin{array}{r}324,637 \\
51,889\end{array}$ \\
\hline 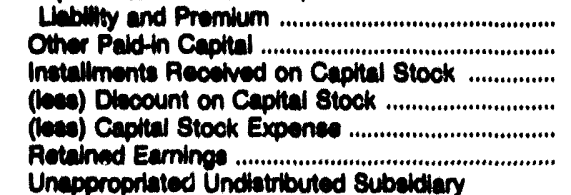 & $\begin{array}{r}0 \\
0 \\
0 \\
0 \\
0 \\
4,790\end{array}$ & $\begin{array}{r}61,890 \\
0 \\
0 \\
0 \\
6,803\end{array}$ & $\begin{array}{r}0 \\
66,736 \\
0 \\
0 \\
0 \\
23,173\end{array}$ & $\begin{array}{r}0 \\
0 \\
0 \\
0 \\
0 \\
20,777\end{array}$ & $\begin{array}{r}4,616 \\
721,541 \\
0 \\
0 \\
0 \\
154,815\end{array}$ & $\begin{array}{r}1,363 \\
0 \\
0 \\
0 \\
0 \\
356,505\end{array}$ \\
\hline 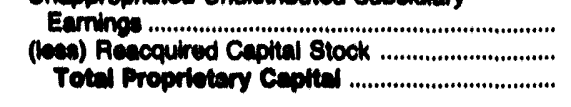 & $\begin{array}{r}0 \\
0 \\
0,780\end{array}$ & $\begin{array}{r}0 \\
0 \\
00,703\end{array}$ & $\begin{array}{r}0 \\
0 \\
70,008\end{array}$ & $\begin{array}{r}0 \\
0 \\
67,777\end{array}$ & $\begin{array}{r}21,268 \\
0 \\
1,155,024\end{array}$ & $\begin{array}{r}8 \\
0 \\
734,311\end{array}$ \\
\hline 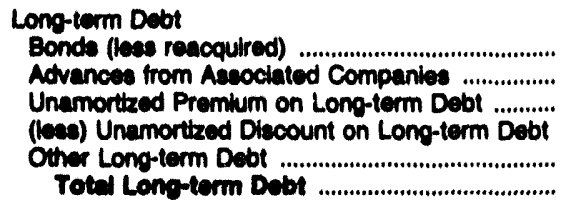 & $\begin{array}{r}0 \\
0 \\
0 \\
0 \\
2,633 \\
2,699\end{array}$ & $\begin{array}{l}0 \\
0 \\
0 \\
0 \\
0 \\
0\end{array}$ & $\begin{array}{r}0 \\
0 \\
0 \\
2,220 \\
165,000 \\
162,760\end{array}$ & $\begin{array}{r}0 \\
0 \\
0 \\
308 \\
20,000 \\
10,092\end{array}$ & $\begin{array}{r}722,889 \\
0 \\
85 \\
6,773 \\
495,322 \\
1,211,623\end{array}$ & $\begin{array}{r}541,129 \\
0 \\
-488 \\
0 \\
0 \\
040,641\end{array}$ \\
\hline 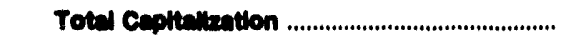 & 9,423 & $60,7 \in 3$ & 242,687 & 87,468 & $2,307,448$ & $1,274,052$ \\
\hline 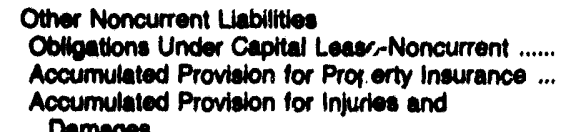 & $\begin{array}{l}0 \\
0\end{array}$ & $\begin{array}{l}0 \\
0\end{array}$ & $\begin{array}{r}1,015 \\
0\end{array}$ & $\begin{array}{l}0 \\
0\end{array}$ & $\begin{array}{r}93,944 \\
0\end{array}$ & $\begin{array}{l}0 \\
0\end{array}$ \\
\hline 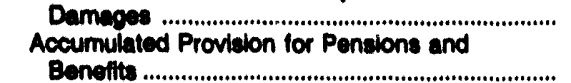 & 0 & 0 & 0 & 135 & 5,817 & 0 \\
\hline 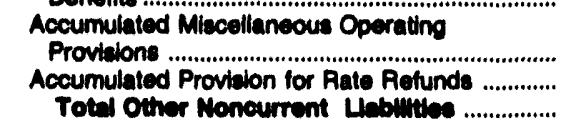 & $\begin{array}{r}0 \\
0 \\
71\end{array}$ & $\begin{array}{l}0 \\
0 \\
0\end{array}$ & $\begin{array}{r}0 \\
0 \\
1,016\end{array}$ & $\begin{array}{r}0 \\
0 \\
153\end{array}$ & $\begin{array}{r}152,125 \\
70 \\
251,976\end{array}$ & $\begin{array}{l}0 \\
0 \\
0\end{array}$ \\
\hline 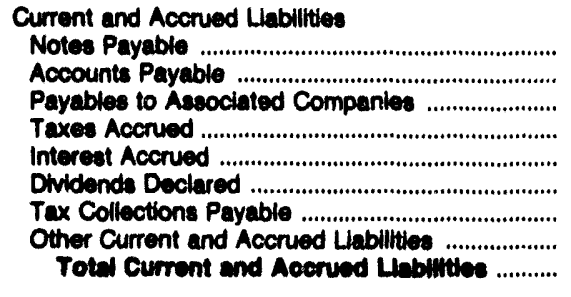 & $\begin{array}{r}395 \\
687 \\
0 \\
143 \\
67 \\
0 \\
3 \\
110 \\
1,408\end{array}$ & $\begin{array}{r}0 \\
5,258 \\
2,213 \\
1,218 \\
0 \\
0 \\
0 \\
3 \\
8,602\end{array}$ & $\begin{array}{r}0 \\
3,962 \\
906 \\
-5,974 \\
3,098 \\
0 \\
0 \\
0,468 \\
8,439\end{array}$ & $\begin{array}{r}0 \\
1,300 \\
2,243 \\
6,573 \\
76 \\
275 \\
21 \\
1,057 \\
11,546\end{array}$ & $\begin{array}{r}44,200 \\
35,706 \\
14,938 \\
15,478 \\
22,759 \\
3,854 \\
3,644 \\
94,690 \\
236,280\end{array}$ & $\begin{array}{r}40,000 \\
46,633 \\
0 \\
23,572 \\
11,474 \\
19,244 \\
2,758 \\
31,148 \\
174,629\end{array}$ \\
\hline 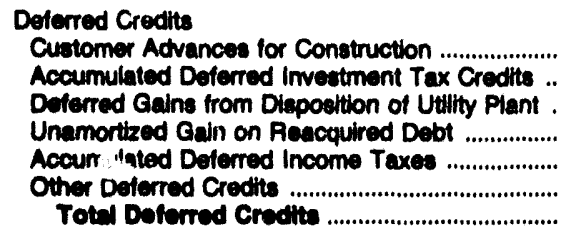 & $\begin{array}{r}0 \\
188 \\
0 \\
0 \\
498 \\
0 \\
07\end{array}$ & $\begin{array}{r}0 \\
1,876 \\
0 \\
0 \\
3,720 \\
375 \\
5,972\end{array}$ & $\begin{array}{r}87,380 \\
0 \\
0 \\
105,991 \\
226,203 \\
419,804\end{array}$ & $\begin{array}{r}0 \\
2,870 \\
0 \\
0 \\
0 \\
8,137 \\
0 \\
11,007\end{array}$ & $\begin{array}{r}2,115 \\
195,043 \\
0 \\
0 \\
488,088 \\
232,840 \\
918,086\end{array}$ & $\begin{array}{r}3 \\
60,297 \\
0 \\
0 \\
284,738 \\
912 \\
345,948\end{array}$ \\
\hline Totel Lebuinties and Other Crectite ................. & 11,606 & 84,446 & 671,724 & 110,175 & $3,772,768$ & $1,798,720$ \\
\hline
\end{tabular}

Note: Totale may not equal aum of componenta because of independent rounding. Summary data are provided in Table 8.

Source: Federal Energy Regulatory Commiselon, FERC Form 1, "Annual Report of Malor Electric Utillites, Llcensees and Others." 
Table 38. Balance sheot by Major U.8. Inveotor-Owned Electric Utility Within 8tate on Decomber 31, 1902 (Continued)

(Thousand Dollars)

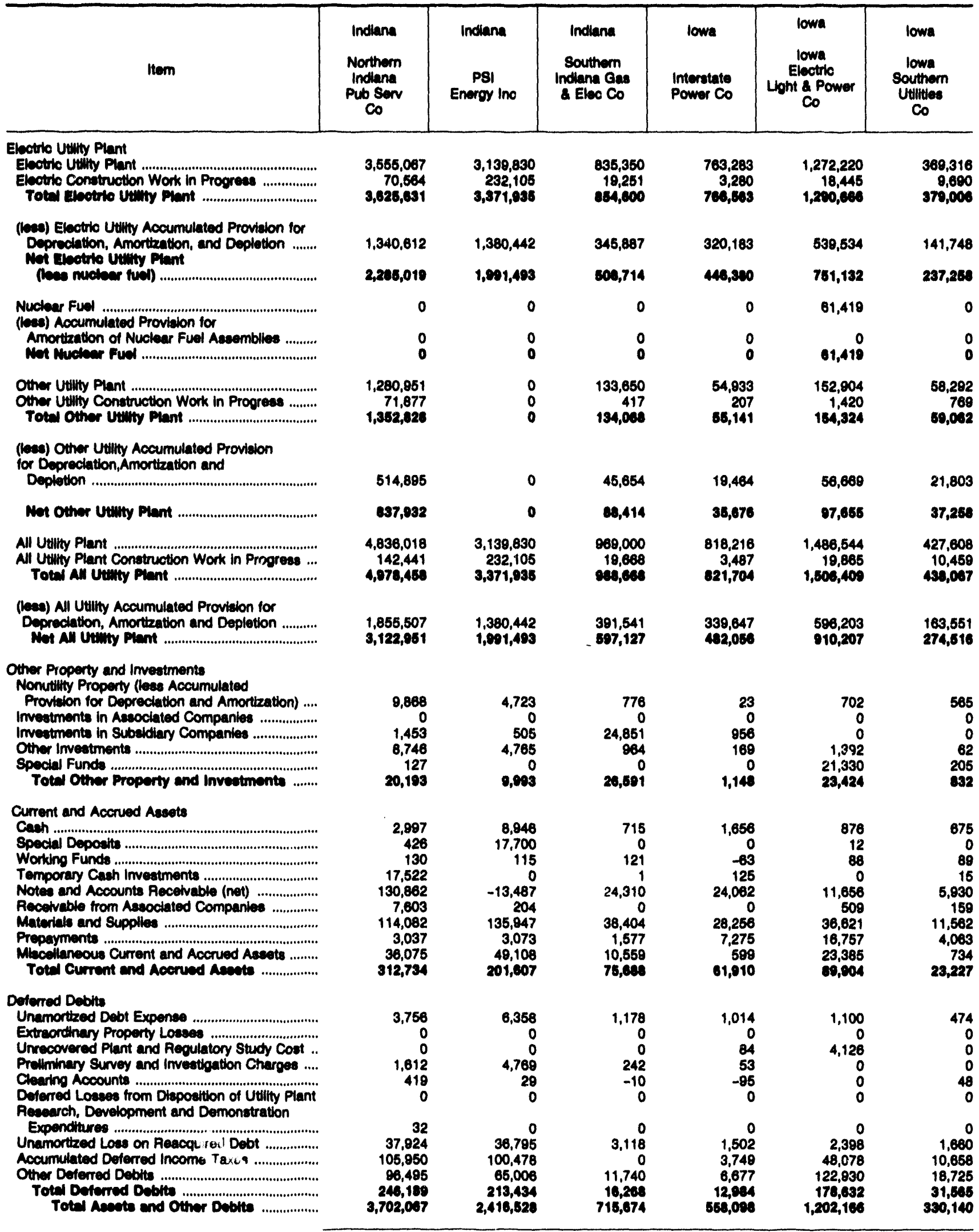

See endnotes at end of an individual electric utility. 
Table 38. Balance Sheot by Major U.8. Investor-Owned Electrle Utility Within state on Decomber 31, 1992 (Continued)

(Thousand Dollars)

\begin{tabular}{|c|c|c|c|c|c|c|}
\hline Item & $\begin{array}{l}\text { Indlana } \\
\text { Northem } \\
\text { Indlana } \\
\text { Pub Serv } \\
\text { Co }\end{array}$ & $\begin{array}{l}\text { Indlana } \\
\text { PSI } \\
\text { Energy Inc }\end{array}$ & $\begin{array}{l}\text { Indiana } \\
\text { Southem } \\
\text { Indiena Gas } \\
\text { \& Elec Co }\end{array}$ & $\begin{array}{l}\text { lowa } \\
\text { Interstate } \\
\text { Power Co }\end{array}$ & $\begin{array}{c}\text { lowa } \\
\text { lowa } \\
\text { Electrio } \\
\text { Light \& Power } \\
\text { Co }\end{array}$ & $\begin{array}{l}\text { lowa } \\
\text { lowa } \\
\text { Southem } \\
\text { Utilltes } \\
\text { Co }\end{array}$ \\
\hline 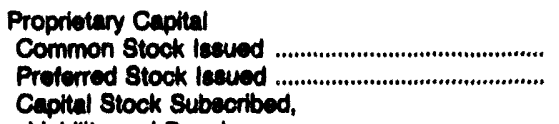 & $\begin{array}{l}859,488 \\
169,968\end{array}$ & $\begin{array}{r}539 \\
87,074\end{array}$ & $\begin{array}{r}102,691 \\
19,605\end{array}$ & $\begin{array}{l}32,542 \\
26,601\end{array}$ & $\begin{array}{l}33,427 \\
18,320\end{array}$ & $\begin{array}{r}28,749 \\
0\end{array}$ \\
\hline 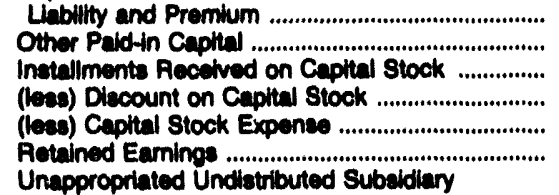 & $\begin{array}{r}264 \\
10,199 \\
0 \\
0 \\
5399 \\
143,842\end{array}$ & $\begin{array}{r}856 \\
220,958 \\
0 \\
0 \\
0 \\
432,746\end{array}$ & $\begin{array}{r}0 \\
0 \\
0 \\
0 \\
0 \\
181,145\end{array}$ & $\begin{array}{r}102,068 \\
4,768 \\
0 \\
0 \\
0 \\
60,460\end{array}$ & $\begin{array}{r}139,703 \\
46,473 \\
0 \\
0 \\
0 \\
90,450\end{array}$ & $\begin{array}{r}15,124 \\
0 \\
0 \\
0 \\
0 \\
62,657\end{array}$ \\
\hline 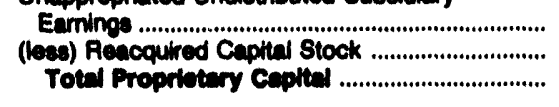 & $\begin{array}{r}4,258 \\
0 \\
1,107,440\end{array}$ & $\begin{array}{r}0 \\
0 \\
742,171\end{array}$ & $\begin{array}{r}9,651 \\
24,640 \\
200,681\end{array}$ & $\begin{array}{r}199 \\
0 \\
226,617\end{array}$ & $\begin{array}{r}0 \\
0 \\
327,373\end{array}$ & $\begin{array}{r}0 \\
0 \\
100,623\end{array}$ \\
\hline 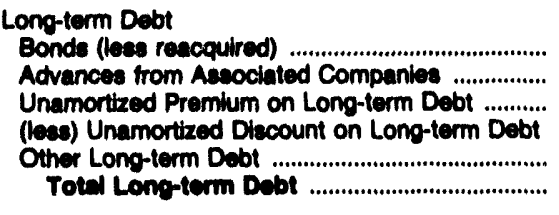 & $\begin{array}{r}645,282 \\
0 \\
436 \\
3,592 \\
460,000 \\
1,102,126\end{array}$ & $\begin{array}{r}391,630 \\
0 \\
180 \\
887 \\
386,384 \\
777,300\end{array}$ & $\begin{array}{r}245,815 \\
0 \\
82 \\
1,089 \\
1,000 \\
245,000\end{array}$ & $\begin{array}{r}189,625 \\
0 \\
0 \\
1,779 \\
1,648 \\
189,304\end{array}$ & $\begin{array}{r}342,100 \\
0 \\
4 \\
876 \\
0 \\
341,228\end{array}$ & $\begin{array}{r}88,144 \\
0 \\
0 \\
1,028 \\
3,400 \\
100,810\end{array}$ \\
\hline Total Cespltalleation & $2,209,600$ & $1,510,470$ & 534,360 & 428,010 & 668,601 & 207,041 \\
\hline $\begin{array}{l}\text { Other Noncurrent Liabilities } \\
\text { Obligations Under Capital Lease-Noncurrent ...... } \\
\text { Accumulated Provision for Property Insurance ... } \\
\text { Accumulated Provieion for Injurles and }\end{array}$ & $\begin{array}{l}0 \\
0\end{array}$ & $\begin{array}{l}0 \\
0\end{array}$ & $\begin{array}{l}0 \\
0\end{array}$ & $\begin{array}{r}138 \\
0\end{array}$ & $\begin{array}{r}35,294 \\
0\end{array}$ & o \\
\hline $\begin{array}{l}\text { Damages } \\
\text { Accumulated Provision for Pensions and } \\
\text { Benefits ............................................................... } \\
\text { Accumulated Miscollaneous Operating }\end{array}$ & 4,367 & $\begin{array}{r}4,134 \\
14,854\end{array}$ & 334 & $\begin{array}{l}923 \\
583\end{array}$ & $\begin{array}{r}374 \\
0\end{array}$ & 648 \\
\hline 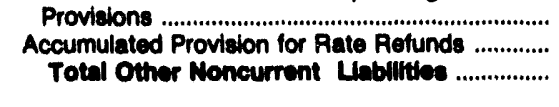 & $\begin{array}{r}2,860 \\
21 \\
7,240\end{array}$ & $\begin{array}{r}4,078 \\
0 \\
23,004\end{array}$ & $\begin{array}{r}0 \\
0 \\
334\end{array}$ & $\begin{array}{r}0 \\
0 \\
1,644\end{array}$ & $\begin{array}{r}0 \\
8,951 \\
44,619\end{array}$ & $\begin{array}{r}3,127 \\
69 \\
3,946\end{array}$ \\
\hline 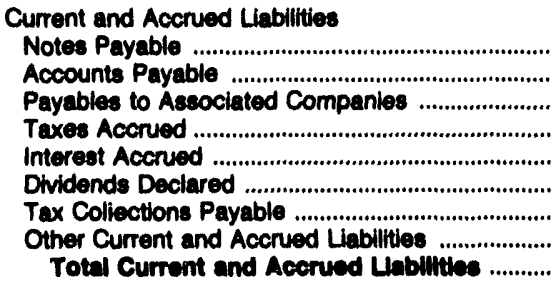 & $\begin{array}{r}225,201 \\
139,152 \\
6,325 \\
60,200 \\
15,664 \\
35,672 \\
5,860 \\
26,485 \\
514,660\end{array}$ & $\begin{array}{r}120,802 \\
161,168 \\
0 \\
46,396 \\
21,505 \\
0 \\
0 \\
3,018 \\
169,923 \\
512,012\end{array}$ & $\begin{array}{r}5,000 \\
33,820 \\
0 \\
10,896 \\
5,111 \\
135 \\
846 \\
7,839 \\
63,746\end{array}$ & $\begin{array}{r}9,000 \\
14,050 \\
1 \\
17,781 \\
4,151 \\
729 \\
1,378 \\
9,616 \\
60,704\end{array}$ & $\begin{array}{r}86,700 \\
35,049 \\
621 \\
30,468 \\
5,852 \\
229 \\
2,077 \\
33,093 \\
194,000\end{array}$ & $\begin{array}{r}5,300 \\
13,518 \\
902 \\
11,579 \\
3,396 \\
0 \\
290 \\
2,421 \\
37,414\end{array}$ \\
\hline 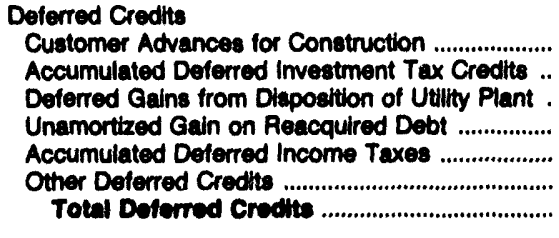 & $\begin{array}{r}10,208 \\
135,602 \\
0 \\
0 \\
701,123 \\
43,742 \\
800,673\end{array}$ & $\begin{array}{r}1,526 \\
68,965 \\
0 \\
102 \\
288,730 \\
1,851 \\
381,173\end{array}$ & $\begin{array}{r}617 \\
28,416 \\
0 \\
0 \\
0 \\
88,025 \\
176 \\
117,235\end{array}$ & $\begin{array}{r}957 \\
21,126 \\
0 \\
0 \\
47,311 \\
4,346 \\
73,740\end{array}$ & $\begin{array}{r}1,307 \\
35,687 \\
0 \\
0 \\
197,888 \\
59,875 \\
204,850\end{array}$ & $\begin{array}{r}387 \\
11,620 \\
0 \\
0 \\
0 \\
66,947 \\
2,885 \\
81,840\end{array}$ \\
\hline Total Lleblitties and Other Credits & $3,702,067$ & $2,416,528$ & 716,674 & 858,000 & $1,202,168$ & 330,140 \\
\hline
\end{tabular}

Note: Totals may not equal sum of components because of independent rounding. Summary data are provided in Table 8 .

Source: Federal Energy Regulatory Commiselon, FERC Form 1, "Annual Report of Major El butric Utilities, Licensees and Others." 
Table 38. Balance Sheet by Major U.S. Investor-Owned Electrlc Utility Within State on December 31, 1982 (Continued)

(Thousand Dollars)

\begin{tabular}{|c|c|c|c|c|c|c|}
\hline Item & $\begin{array}{c}\text { lowa } \\
\text { lowa- } \\
\text { Illinols } \\
\text { Gaedelectric } \\
\text { Co }\end{array}$ & $\begin{array}{l}\text { lowa } \\
\text { Milweed } \\
\text { Power } \\
\text { Syctems } \\
\text { Inc }\end{array}$ & $\begin{array}{c}\text { Kaneas } \\
\text { Kanaas } \\
\text { Gas } \\
\& \\
\text { Electric Co }\end{array}$ & $\begin{array}{l}\text { Kaneas } \\
\text { Woetem } \\
\text { Recources } \\
\text { Inc }\end{array}$ & $\begin{array}{l}\text { Kentucky } \\
\text { Kentucky } \\
\text { Power Co }\end{array}$ & $\begin{array}{l}\text { Kentucky } \\
\text { Kentucky } \\
\text { Utilltes Co }\end{array}$ \\
\hline 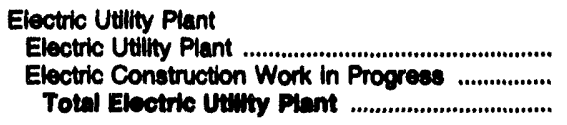 & $\begin{array}{r}1,208,679 \\
28,236 \\
1,231,016\end{array}$ & $\begin{array}{r}2,154,811 \\
28,283 \\
2,109,004\end{array}$ & $\begin{array}{r}3,293,362 \\
20,697 \\
2,322,600\end{array}$ & $\begin{array}{r}1,713,628 \\
19,484 \\
1,739,2492\end{array}$ & $\begin{array}{r}768,835 \\
10,406 \\
777,240\end{array}$ & $\begin{array}{r}1,055,164 \\
37,422 \\
1,092,600\end{array}$ \\
\hline $\begin{array}{l}\text { (less) Electric Utility Accumulated Proviston for } \\
\text { Depreciation, Amortization, and Depletion ....... } \\
\text { Net Electric Uttity Plam } \\
\text { (lose nuctear fuel) .............................................. }\end{array}$ & $\begin{array}{l}440,227 \\
701,000\end{array}$ & $\begin{array}{r}873,183 \\
1,300,001\end{array}$ & $\begin{array}{r}724,188 \\
2,600,810\end{array}$ & $\begin{array}{r}637,726 \\
1,005,697\end{array}$ & $\begin{array}{l}234,726 \\
542,514\end{array}$ & $\begin{array}{r}828,502 \\
1,169,084\end{array}$ \\
\hline 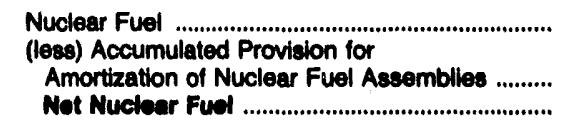 & $\begin{array}{r}174,409 \\
136,295 \\
38,114\end{array}$ & $\begin{array}{l}0 \\
0 \\
0\end{array}$ & $\begin{array}{r}112,898 \\
79,586 \\
33,312\end{array}$ & $\begin{array}{l}0 \\
0 \\
0\end{array}$ & $\begin{array}{l}0 \\
0 \\
0\end{array}$ & $\begin{array}{l}0 \\
0\end{array}$ \\
\hline 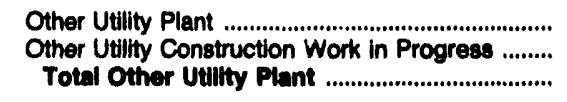 & $\begin{array}{r}292,559 \\
4,305 \\
266,0065\end{array}$ & $\begin{array}{r}415,731 \\
5,133 \\
420,064\end{array}$ & $\begin{array}{l}0 \\
0 \\
0\end{array}$ & $\begin{array}{r}1,022,862 \\
18,973 \\
1,041,036\end{array}$ & $\begin{array}{l}0 \\
0 \\
0\end{array}$ & $\begin{array}{l}0 \\
0 \\
0\end{array}$ \\
\hline $\begin{array}{l}\text { (less) Other Utility Accumulated Proviaion } \\
\text { for Depreciation,Amortization and } \\
\text { Depletion }\end{array}$ & 128,876 & 151,986 & 0 & 329,710 & 0 & 0 \\
\hline 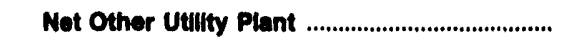 & 107,000 & 200,078 & 0 & 712,126 & o & 0 \\
\hline 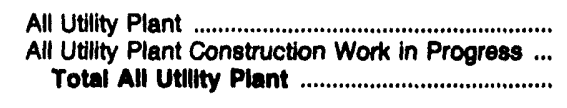 & $\begin{array}{r}1,670,648 \\
32,541 \\
1,703,180\end{array}$ & $\begin{array}{r}2,570,542 \\
33,416 \\
2,603,056\end{array}$ & $\begin{array}{r}3,406,260 \\
29,637 \\
3,436,006\end{array}$ & $\begin{array}{r}2,736,690 \\
38,407 \\
2,775,007\end{array}$ & $\begin{array}{r}766,835 \\
10,406 \\
777,240\end{array}$ & $\begin{array}{r}1,955,164 \\
37,422 \\
1,002,606\end{array}$ \\
\hline 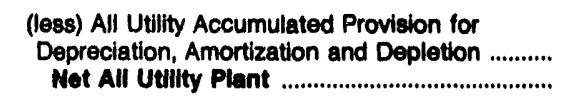 & $\begin{array}{l}705,399 \\
907,791\end{array}$ & $\begin{array}{l}1,025,179 \\
1,570,770\end{array}$ & $\begin{array}{r}803,774 \\
2,632,122\end{array}$ & $\begin{array}{r}967,436 \\
1,807,681\end{array}$ & $\begin{array}{l}234,726 \\
542,614\end{array}$ & $\begin{array}{r}823,502 \\
1,169,094\end{array}$ \\
\hline 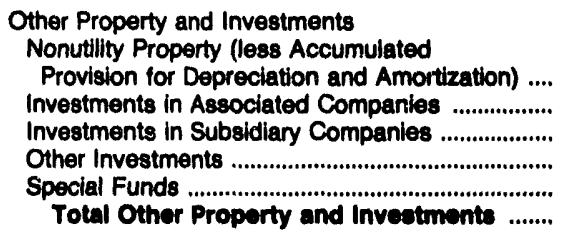 & $\begin{array}{r}1,638 \\
0 \\
132,600 \\
11,500 \\
30,127 \\
175,064\end{array}$ & $\begin{array}{r}1,809 \\
0 \\
284 \\
274,760 \\
0 \\
276,893\end{array}$ & $\begin{array}{r}529 \\
0 \\
0 \\
5,146 \\
13,437 \\
19,112\end{array}$ & $\begin{array}{r}12 \\
0 \\
1,157,643 \\
3,191 \\
0 \\
1,160,846\end{array}$ & $\begin{array}{r}889 \\
0 \\
0 \\
7,113 \\
9 \\
8,020\end{array}$ & $\begin{array}{r}493 \\
0 \\
2,167 \\
1,246 \\
5,740 \\
9,446\end{array}$ \\
\hline 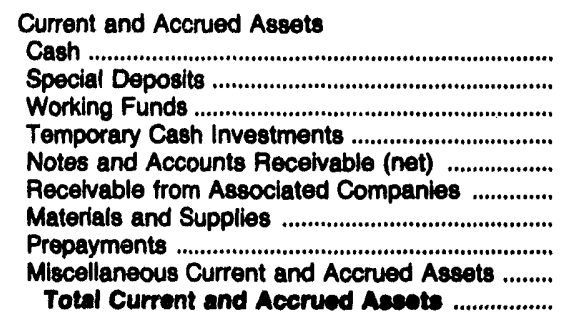 & $\begin{array}{r}5,741 \\
26 \\
5,311 \\
0 \\
0 \\
45,823 \\
392 \\
26,295 \\
16,679 \\
30,418 \\
130,684\end{array}$ & $\begin{array}{r}3,405 \\
0 \\
808 \\
0 \\
87,050 \\
37,895 \\
40,465 \\
8,256 \\
62,918 \\
240,787\end{array}$ & $\begin{array}{r}-15 \\
4,015 \\
807 \\
0 \\
11,181 \\
74,217 \\
47,554 \\
7,682 \\
169 \\
145,711\end{array}$ & $\begin{array}{r}-234 \\
1,595 \\
167 \\
0 \\
191,560 \\
35,574 \\
60,810 \\
5,477 \\
14,646 \\
300,506\end{array}$ & $\begin{array}{r}829 \\
119 \\
22 \\
0 \\
18,605 \\
3,232 \\
17,658 \\
1,340 \\
13,062 \\
54,000\end{array}$ & $\begin{array}{r}-6,862 \\
1,769 \\
77 \\
99,314 \\
31,335 \\
42 \\
50,699 \\
1,946 \\
24,156 \\
202,476\end{array}$ \\
\hline 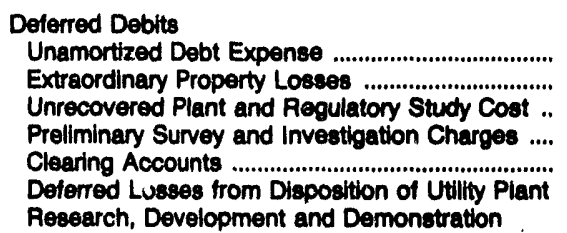 & $\begin{array}{r}1,157 \\
0 \\
0 \\
506 \\
-148 \\
0\end{array}$ & $\begin{array}{r}3,685 \\
0 \\
6,013 \\
4,228 \\
468 \\
0\end{array}$ & $\begin{array}{r}10,040 \\
0 \\
0 \\
20 \\
41 \\
0\end{array}$ & $\begin{array}{r}9,007 \\
0 \\
13,563 \\
0 \\
-404 \\
0\end{array}$ & $\begin{array}{r}557 \\
0 \\
0 \\
4,324 \\
64 \\
0\end{array}$ & $\begin{array}{r}3,892 \\
0 \\
0 \\
27 \\
-723 \\
0\end{array}$ \\
\hline 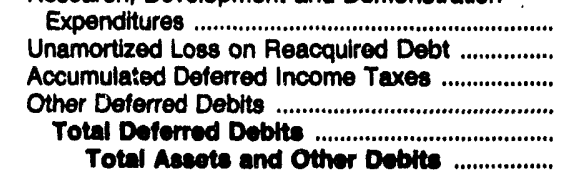 & $\begin{array}{r}0 \\
5,863 \\
13,386 \\
14,320 \\
35,274 \\
1,330,613\end{array}$ & $\begin{array}{r}-150 \\
7,649 \\
5,081 \\
52,787 \\
79,751 \\
2,178,179\end{array}$ & $\begin{array}{r}0 \\
12,860 \\
166,109 \\
1,035,760 \\
1,224,031 \\
4,021,776\end{array}$ & $\begin{array}{r}0 \\
3,758 \\
6,884 \\
193,898 \\
228,700 \\
3,504,000\end{array}$ & $\begin{array}{r}0 \\
0 \\
6,225 \\
6,252 \\
17,423 \\
922,025\end{array}$ & $\begin{array}{r}0 \\
8,613 \\
15,842 \\
15,436 \\
43,097 \\
1,424,296\end{array}$ \\
\hline
\end{tabular}

See endnotes at end of an indwidual olectric utillity. 
Table 38. Balance Sheet by Major U.S. Inveator-Owned Electric Utillty Within State on December 31, 1992 (Continued) (Thousand Dollars)

\begin{tabular}{|c|c|c|c|c|c|c|}
\hline Item & $\begin{array}{c}\text { lowa } \\
\text { lown- } \\
\text { IIInols } \\
\text { GasdEleotric } \\
\text { Co }\end{array}$ & $\begin{array}{l}\text { lowa } \\
\text { Micweat } \\
\text { Power } \\
\text { Syctems } \\
\text { Inc }\end{array}$ & $\begin{array}{c}\text { Kanses } \\
\text { Kanaes } \\
\text { Gase } \\
\mathbf{8} \\
\text { Electric Co }\end{array}$ & $\begin{array}{c}\text { Kaneas } \\
\text { Weatem } \\
\text { Resources } \\
\text { Inc }\end{array}$ & $\begin{array}{l}\text { Kentucky } \\
\text { Kentucky } \\
\text { Power Co }\end{array}$ & $\begin{array}{l}\text { Kentuoky } \\
\text { Kentucky } \\
\text { Utilites Co }\end{array}$ \\
\hline 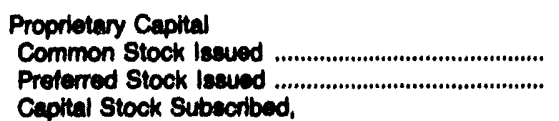 & $\begin{array}{r}284,466 \\
60,029\end{array}$ & $\begin{array}{l}76,806 \\
54,413\end{array}$ & $\begin{array}{r}1,085,684 \\
0\end{array}$ & $\begin{array}{l}200,228 \\
189,288\end{array}$ & $\begin{array}{r}60,460 \\
0\end{array}$ & $\begin{array}{r}308,140 \\
40,000\end{array}$ \\
\hline 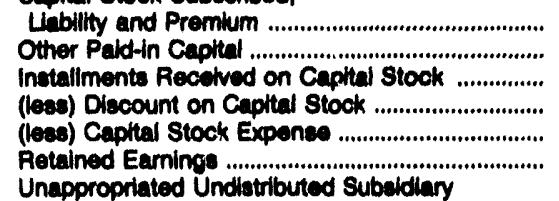 & $\begin{array}{r}32 \\
18,388 \\
0 \\
2,465 \\
248 \\
183,482\end{array}$ & $\begin{array}{r}174,274 \\
212,135 \\
0 \\
0 \\
0 \\
183,595\end{array}$ & $\begin{array}{r}0 \\
0 \\
0 \\
0 \\
0 \\
71,841\end{array}$ & $\begin{array}{r}88,280 \\
473,413 \\
0 \\
0 \\
2,058 \\
325,045\end{array}$ & $\begin{array}{r}0 \\
58,750 \\
0 \\
0 \\
0 \\
89,957\end{array}$ & $\begin{array}{r}44 \\
0 \\
0 \\
0 \\
321 \\
225,340\end{array}$ \\
\hline 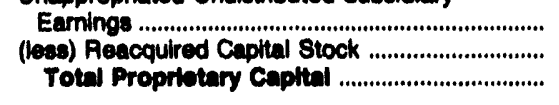 & $\begin{array}{r}32,600 \\
87 \\
398,107\end{array}$ & $\begin{array}{r}781 \\
0 \\
701,049\end{array}$ & $\begin{array}{r}0 \\
0 \\
1,197,678\end{array}$ & $\begin{array}{r}73,468 \\
12,060 \\
1,424,600\end{array}$ & $\begin{array}{r}0 \\
0 \\
100,187\end{array}$ & $\begin{array}{r}870 \\
0 \\
674,078\end{array}$ \\
\hline 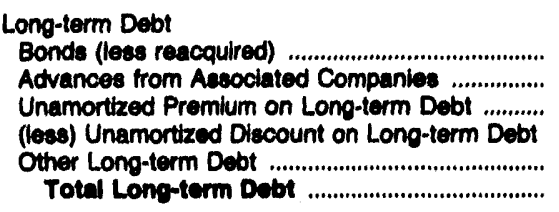 & $\begin{array}{r}336,820 \\
0 \\
5 \\
2,084 \\
0 \\
393,040\end{array}$ & $\begin{array}{r}677,382 \\
0 \\
48 \\
1,937 \\
197,658 \\
878,060\end{array}$ & $\begin{array}{r}684,985 \\
0 \\
295 \\
4,200 \\
293,688 \\
984,610\end{array}$ & $\begin{array}{r}827,189 \\
0 \\
63 \\
2,889 \\
230,000 \\
1,054,373\end{array}$ & $\begin{array}{r}199,436 \\
0 \\
181 \\
520 \\
56,000 \\
284,007\end{array}$ & $\begin{array}{r}443,380 \\
0 \\
519 \\
0 \\
149 \\
48,000\end{array}$ \\
\hline Total Capitallation ............................................. & 800,080 & $1,674,003$ & $2,002,109$ & $2,470,081$ & 463,244 & $1,018,071$ \\
\hline $\begin{array}{l}\text { Other Noncurrent Liabllities } \\
\text { Obligations Under Capltal Lease-Noncurrent ...... } \\
\text { Accumulated Provision for Property Ineurance ... } \\
\text { Accumulated Provilion for Injuries and }\end{array}$ & $\begin{array}{r}10,600 \\
2,426\end{array}$ & $\begin{array}{r}4,720 \\
0\end{array}$ & $\begin{array}{r}0 \\
-233\end{array}$ & $\begin{array}{r}0 \\
595\end{array}$ & $\begin{array}{r}4,409 \\
0\end{array}$ & $\begin{array}{l}0 \\
0\end{array}$ \\
\hline 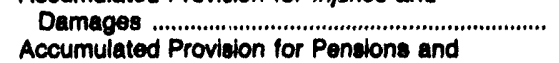 & 742 & 291 & 1,880 & -800 & 1,805 & 0 \\
\hline 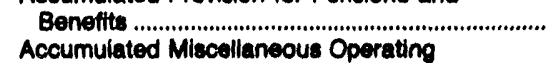 & 8,876 & 291 & 0 & 541 & 118 & 0 \\
\hline 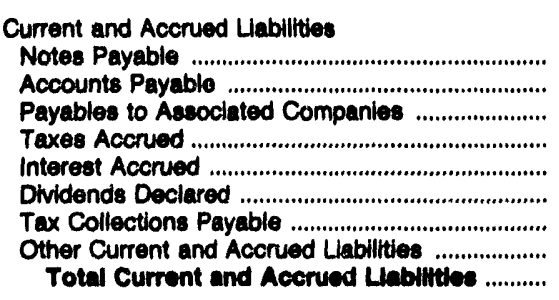 & $\begin{array}{r}52,500 \\
37,287 \\
-2,229 \\
27,566 \\
7,064 \\
1,268 \\
2,292 \\
21,924 \\
147,061\end{array}$ & $\begin{array}{r}58,100 \\
68,071 \\
5,126 \\
65,666 \\
16,475 \\
0 \\
3,100 \\
22,801 \\
237,330\end{array}$ & $\begin{array}{r}93,723 \\
44,803 \\
16,803 \\
17,684 \\
10,835 \\
0 \\
3,179 \\
29,125 \\
218,161\end{array}$ & $\begin{array}{r}131,768 \\
139,390 \\
74,291 \\
19,498 \\
29,538 \\
31,031 \\
6,002 \\
34,542 \\
446,062\end{array}$ & $\begin{array}{r}16,000 \\
9,330 \\
7,126 \\
8,483 \\
4,383 \\
0 \\
1,285 \\
13,381 \\
60,090\end{array}$ & $\begin{array}{r}0 \\
21,206 \\
34 \\
4,029 \\
10,621 \\
210 \\
2,084 \\
21,084 \\
50,246\end{array}$ \\
\hline 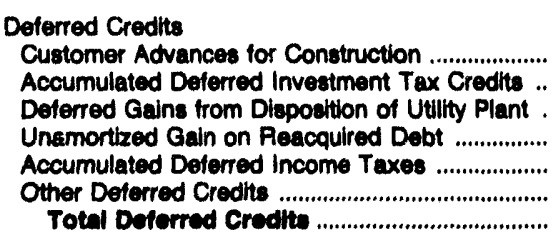 & $\begin{array}{r}2,394 \\
43,563 \\
0 \\
85 \\
172,458 \\
47,138 \\
285,680\end{array}$ & $\begin{array}{r}4,591 \\
70,283 \\
0 \\
372 \\
248,329 \\
35,654 \\
360,120\end{array}$ & $\begin{array}{r}-76 \\
73,938 \\
0 \\
0 \\
809,953 \\
727,970 \\
1,711,706\end{array}$ & $\begin{array}{r}7,914 \\
76,008 \\
0 \\
0 \\
325,843 \\
142,823 \\
680,300\end{array}$ & $\begin{array}{r}492 \\
17,696 \\
0 \\
0 \\
77,508 \\
6,708 \\
102,401\end{array}$ & $\begin{array}{r}1,811 \\
46,616 \\
0 \\
0 \\
280,631 \\
17,020 \\
346,070\end{array}$ \\
\hline Told Lubilites and Other Credtie ................ & $1,388,613$ & $2,178,170$ & $4,021,776$ & $8,604,000$ & 922,928 & $1,424,265$ \\
\hline
\end{tabular}

Note: Totale may not equal sum of components because of independent rounding. Summary date are provided in Table 8.

Source: Federal Energy Regulatory Commiselon, FERC Form 1. "Annual Report of Major Electric Utilities, Licensees and Others." 
Table 38. Balance Sheet by Major U.S. Investor-Owned Electric Utility Within State on December 31, 1992 (Continued) (Thousand Dollars)

\begin{tabular}{|c|c|c|c|c|c|c|}
\hline Item & $\begin{array}{c}\text { Kentucky } \\
\text { Louleville } \\
\text { Gas } \\
\text { Electric Co }\end{array}$ & $\begin{array}{l}\text { Kentucky } \\
\text { Union Light } \\
\text { Heat \& Power } \\
\text { Co }\end{array}$ & $\begin{array}{l}\text { Louleiana } \\
\text { Central } \\
\text { Loulaiana } \\
\text { Elec } \\
\text { Co ino }\end{array}$ & $\begin{array}{c}\text { Loulaiana } \\
\text { Loulaiana } \\
\text { Power } \\
8 \\
\text { Light Co }\end{array}$ & $\begin{array}{l}\text { Louisiana } \\
\text { New Orleans } \\
\text { Public } \\
\text { Service Inc }\end{array}$ & $\begin{array}{l}\text { Loulaiana } \\
\text { Southweatern } \\
\text { Electric } \\
\text { Power Co }\end{array}$ \\
\hline 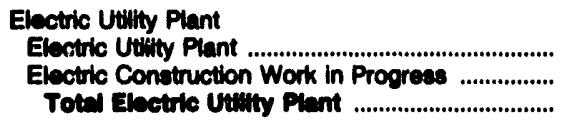 & $\begin{array}{r}1,976,206 \\
30,948 \\
2,007,184\end{array}$ & $\begin{array}{r}158,317 \\
6,688 \\
166,008\end{array}$ & $\begin{array}{r}1,177,723 \\
55,492 \\
1,233,216\end{array}$ & $\begin{array}{r}4,802,483 \\
67,535 \\
4,870,026\end{array}$ & $\begin{array}{r}468,319 \\
5,969 \\
472,209\end{array}$ & $\begin{array}{r}2,505,298 \\
73,421 \\
2,578,718\end{array}$ \\
\hline 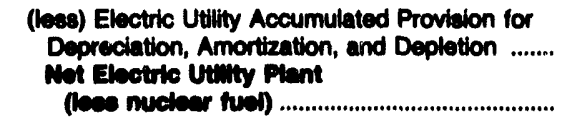 & $\begin{array}{r}634,147 \\
1,373,003\end{array}$ & $\begin{array}{r}53,302 \\
111,704\end{array}$ & $\begin{array}{l}368,580 \\
870,095\end{array}$ & $\begin{array}{l}1,380,282 \\
3,499,748\end{array}$ & $\begin{array}{l}265,886 \\
200,402\end{array}$ & $\begin{array}{r}875,888 \\
1,702,830\end{array}$ \\
\hline 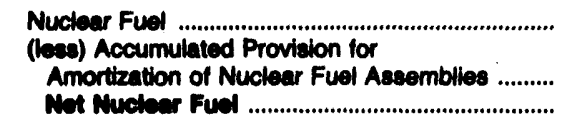 & $\begin{array}{l}\mathbf{0} \\
\mathbf{0}\end{array}$ & $\begin{array}{l}0 \\
\mathbf{0}\end{array}$ & $\begin{array}{l}0 \\
\mathbf{0}\end{array}$ & $\begin{array}{r}66,627 \\
0 \\
68,627\end{array}$ & $\begin{array}{l}0 \\
\mathbf{0}\end{array}$ & $\begin{array}{l}0 \\
\mathbf{0}\end{array}$ \\
\hline $\begin{array}{l}\text { Other Utilty Plant ................................................ } \\
\text { Other Utilly Construction Work in Progress ........ } \\
\text { Totel Other Utilty Piant ..................................... }\end{array}$ & $\begin{array}{r}359,782 \\
4,418 \\
384,201\end{array}$ & $\begin{array}{r}130,823 \\
7,648 \\
130,471\end{array}$ & $\begin{array}{l}0 \\
0 \\
0\end{array}$ & $\begin{array}{l}0 \\
0 \\
0\end{array}$ & $\begin{array}{r}110,399 \\
937 \\
111,338\end{array}$ & $\begin{array}{l}0 \\
0 \\
0\end{array}$ \\
\hline \multicolumn{7}{|l|}{$\begin{array}{l}\text { (leas) Other Utility Accumulated Proviaion } \\
\text { for Depreclation,Amortization and }\end{array}$} \\
\hline Depletion & 120,282 & 35,830 & 0 & 0 & 49,553 & 0 \\
\hline 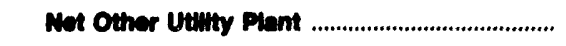 & 243,910 & 102,041 & $\mathbf{0}$ & $\mathbf{0}$ & 61,703 & $\mathbf{0}$ \\
\hline 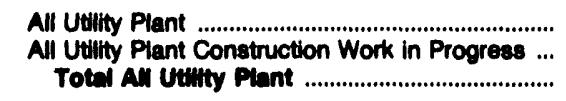 & $\begin{array}{r}2,335,889 \\
35,367 \\
2,371,355\end{array}$ & $\begin{array}{r}289,140 \\
14,336 \\
308,478\end{array}$ & $\begin{array}{r}1,177,723 \\
55,492 \\
1,233,215\end{array}$ & $\begin{array}{r}4,869,120 \\
67,535 \\
4,038,655\end{array}$ & $\begin{array}{r}576,717 \\
6,907 \\
583,624\end{array}$ & $\begin{array}{r}2,505,298 \\
73,421 \\
2,578,718\end{array}$ \\
\hline 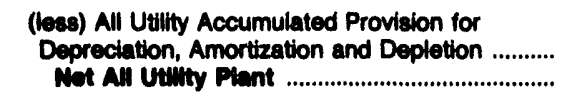 & $\begin{array}{r}754,429 \\
1,616,027\end{array}$ & $\begin{array}{r}89,132 \\
214,344\end{array}$ & $\begin{array}{l}356,580 \\
678,635\end{array}$ & $\begin{array}{l}1,380,282 \\
3,558,373\end{array}$ & $\begin{array}{l}315,439 \\
289,185\end{array}$ & $\begin{array}{r}875,888 \\
1,702,080\end{array}$ \\
\hline 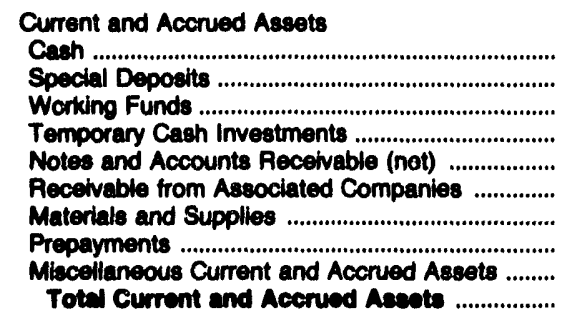 & $\begin{array}{r}939 \\
0 \\
89 \\
7 \\
63,735 \\
511 \\
62,394 \\
467 \\
62,463 \\
190,605\end{array}$ & $\begin{array}{r}1,785 \\
0 \\
4 \\
0 \\
36,834 \\
316 \\
3,732 \\
1,323 \\
3,349 \\
47,342\end{array}$ & $\begin{array}{r}1,689 \\
6 \\
110 \\
0 \\
8,046 \\
0 \\
20,710 \\
9,199 \\
-2,183 \\
37,577\end{array}$ & $\begin{array}{r}0 \\
4,080 \\
467 \\
15,092 \\
73,658 \\
16,553 \\
87,856 \\
11,692 \\
85,706 \\
205,104\end{array}$ & $\begin{array}{r}0 \\
21 \\
148 \\
490 \\
31,943 \\
47,812 \\
9,890 \\
678 \\
4,566 \\
95,547\end{array}$ & $\begin{array}{r}874 \\
39 \\
114 \\
71 \\
17,036 \\
3,442 \\
94,899 \\
14,212 \\
333 \\
131,020\end{array}$ \\
\hline 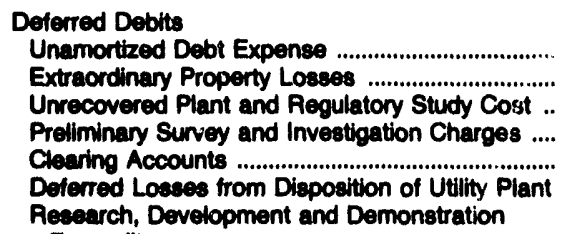 & $\begin{array}{r}7,953 \\
15,302 \\
0 \\
4,486 \\
194 \\
0\end{array}$ & $\begin{array}{r}386 \\
216 \\
0 \\
0 \\
118 \\
0\end{array}$ & $\begin{array}{r}2,584 \\
0 \\
0 \\
110 \\
71 \\
0\end{array}$ & $\begin{array}{r}11,387 \\
0 \\
8,410 \\
344 \\
50 \\
0\end{array}$ & $\begin{array}{r}1,078 \\
0 \\
0 \\
47 \\
22 \\
0\end{array}$ & $\begin{array}{r}1,821 \\
0 \\
0 \\
57 \\
0 \\
0\end{array}$ \\
\hline 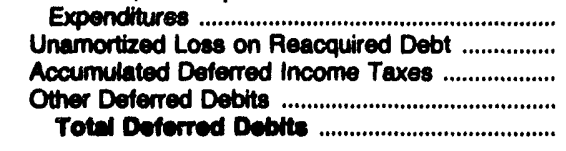 & $\begin{array}{r}0 \\
9,329 \\
12,179 \\
15,092 \\
\mathbf{4 , 6 8 5}\end{array}$ & $\begin{array}{r}0 \\
0 \\
2,559 \\
-63 \\
3,216\end{array}$ & $\begin{array}{r}0 \\
9,701 \\
4,744 \\
19,100 \\
38,320\end{array}$ & $\begin{array}{r}0 \\
49,617 \\
233,141 \\
130,614 \\
433,583\end{array}$ & $\begin{array}{r}0 \\
873 \\
45,099 \\
248,114 \\
295,233\end{array}$ & $\begin{array}{r}0 \\
39,063 \\
24,174 \\
36,561 \\
101,670\end{array}$ \\
\hline 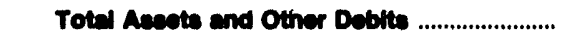 & $1,973,030$ & 294,000 & 074,774 & $4,337,374$ & 682,224 & $1,900,076$ \\
\hline
\end{tabular}

See endnotes at end of an individual electric utility. 
Table 38. Balance Sheet by Major U.S. Investor-Owned Electric Utility Within State on December 31, 1992 (Continued) (Thousand Dollars)

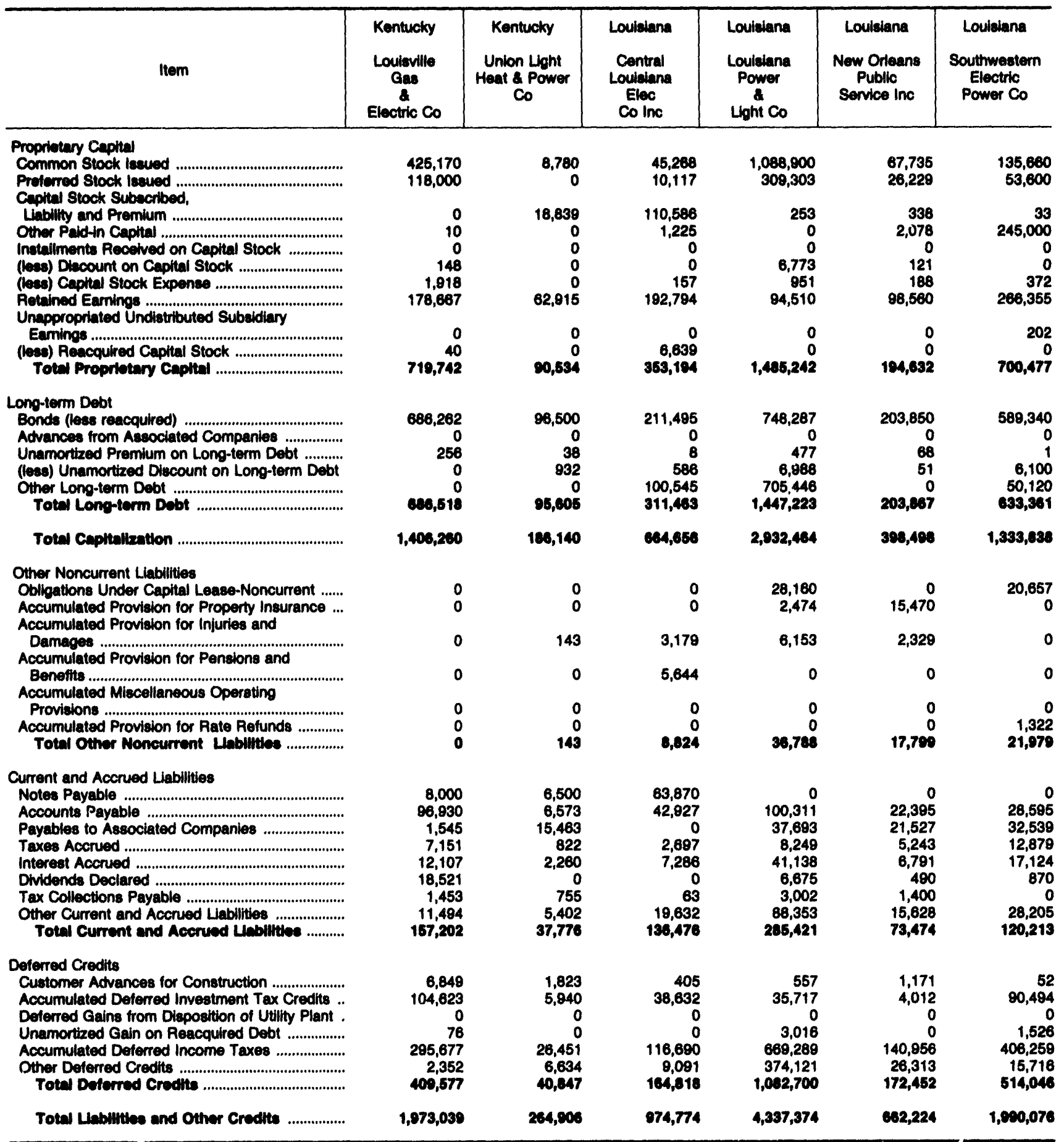

Note: Totals may not equal sum of components because of independent rounding. Summary data are provided in Table 8.

Source: Federal Energy Regulatory Commission, FERC Form 1, "Annual Report of Malor Electric Utilities, Licensees and Others." 
Table 38. Balance Sheot by Major U.S. Invector-Owned Electric Utility Within State on Decomber 31, 1992 (Continued) (Thousand Dollars)

\begin{tabular}{|c|c|c|c|c|c|c|}
\hline ftem & $\begin{array}{l}\text { Maine } \\
\text { Bangor } \\
\text { Hydro- } \\
\text { Electric } \\
\text { Co }\end{array}$ & $\begin{array}{l}\text { Maine } \\
\text { Central } \\
\text { Maine } \\
\text { Power } \\
\text { Co } \\
\end{array}$ & $\begin{array}{l}\text { Maine } \\
\text { Maine } \\
\text { Electric } \\
\text { Power } \\
\text { Co Inc } \\
\end{array}$ & $\begin{array}{c}\text { Maine } \\
\text { Maine } \\
\text { Public } \\
\text { Service } \\
\text { Co } \\
\end{array}$ & $\begin{array}{c}\text { Maine } \\
\text { Maine } \\
\text { Yankee } \\
\text { Atomic } \\
\text { Power Co } \\
\end{array}$ & $\begin{array}{c}\text { Maryland } \\
\text { Baltimore } \\
\text { Gas } \\
\& \\
\text { Electrlc Co }\end{array}$ \\
\hline 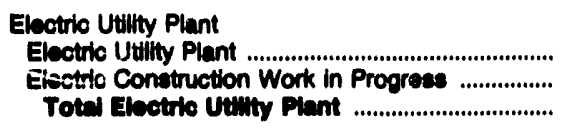 & $\begin{array}{r}227,605 \\
16,391 \\
242,006\end{array}$ & $\begin{array}{r}1,493,716 \\
34,356 \\
1,628,071\end{array}$ & $\begin{array}{r}22,916 \\
196 \\
23,110\end{array}$ & $\begin{array}{r}74,290 \\
1,332 \\
75,623\end{array}$ & $\begin{array}{r}384,664 \\
3,705 \\
386,388\end{array}$ & $\begin{array}{r}5,494,333 \\
273,140 \\
5,767,474\end{array}$ \\
\hline 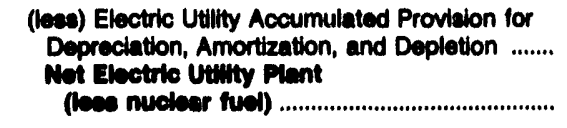 & $\begin{array}{r}67,645 \\
176,351\end{array}$ & $\begin{array}{r}466,145 \\
1,071,026\end{array}$ & $\begin{array}{r}17,891 \\
6,210\end{array}$ & $\begin{array}{l}32,073 \\
43,560\end{array}$ & $\begin{array}{l}163,887 \\
224,482\end{array}$ & $\begin{array}{l}1,713,673 \\
4,053,800\end{array}$ \\
\hline 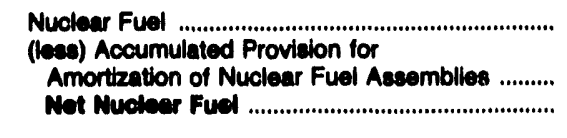 & $\begin{array}{l}0 \\
0 \\
0\end{array}$ & $\begin{array}{l}8,443 \\
6,544 \\
1,800\end{array}$ & $\begin{array}{l}0 \\
0 \\
0\end{array}$ & $\begin{array}{l}0 \\
0 \\
0\end{array}$ & $\begin{array}{r}476,225 \\
401,562 \\
74,673\end{array}$ & $\begin{array}{l}607,071 \\
659,697 \\
147,374\end{array}$ \\
\hline 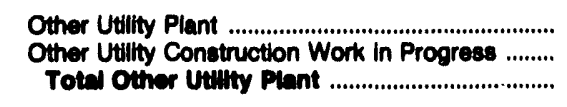 & $\begin{array}{l}0 \\
0 \\
0\end{array}$ & $\begin{array}{l}0 \\
0 \\
0\end{array}$ & $\begin{array}{l}0 \\
0 \\
0\end{array}$ & $\begin{array}{l}0 \\
0 \\
0\end{array}$ & $\begin{array}{l}0 \\
0 \\
0\end{array}$ & $\begin{array}{r}996,065 \\
35,768 \\
1,031,832\end{array}$ \\
\hline 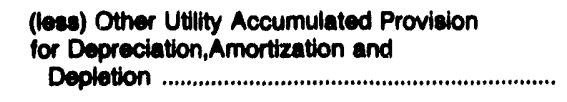 & 0 & 0 & 0 & 0 & 0 & 266,688 \\
\hline Not Other Utulty Plant ........................................... & 0 & 0 & o & o & 0 & 785,144 \\
\hline 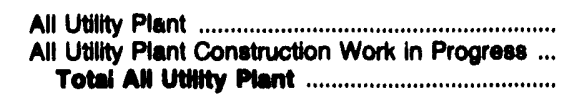 & $\begin{array}{r}227,605 \\
15,391 \\
242,000\end{array}$ & $\begin{array}{r}1,502,158 \\
34,355 \\
1,536,513\end{array}$ & $\begin{array}{r}22,916 \\
195 \\
23,110\end{array}$ & $\begin{array}{r}74,290 \\
1,332 \\
75,623\end{array}$ & $\begin{array}{r}860,889 \\
3,705 \\
864,604\end{array}$ & $\begin{array}{r}7,297,469 \\
308,908 \\
7,606,377\end{array}$ \\
\hline 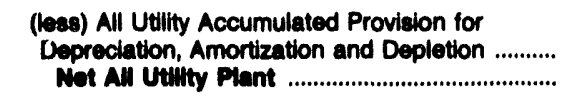 & $\begin{array}{r}67,645 \\
175,361\end{array}$ & $\begin{array}{r}462,688 \\
1,073,825\end{array}$ & $\begin{array}{r}17,891 \\
6,210\end{array}$ & $\begin{array}{l}32,073 \\
43,550\end{array}$ & $\begin{array}{l}565,439 \\
209,155\end{array}$ & $\begin{array}{l}2,640,059 \\
4,866,319\end{array}$ \\
\hline 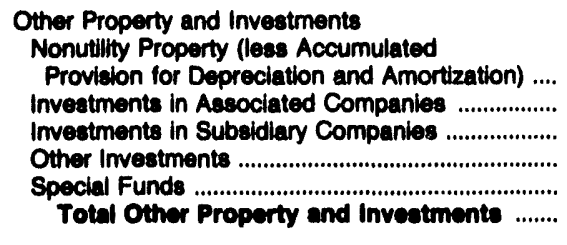 & $\begin{array}{r}465 \\
0 \\
6,671 \\
262 \\
0 \\
7,300\end{array}$ & $\begin{array}{r}3,802 \\
0 \\
48,261 \\
195 \\
0 \\
0 \\
52,250\end{array}$ & $\begin{array}{l}0 \\
0 \\
0 \\
0 \\
0 \\
0\end{array}$ & $\begin{array}{r}287 \\
0 \\
8,834 \\
2 \\
3,310 \\
12,542\end{array}$ & $\begin{array}{r}0 \\
0 \\
0 \\
0 \\
161,932 \\
161,932\end{array}$ & $\begin{array}{r}10,056 \\
0 \\
335,435 \\
7,860 \\
48,837 \\
403,180\end{array}$ \\
\hline 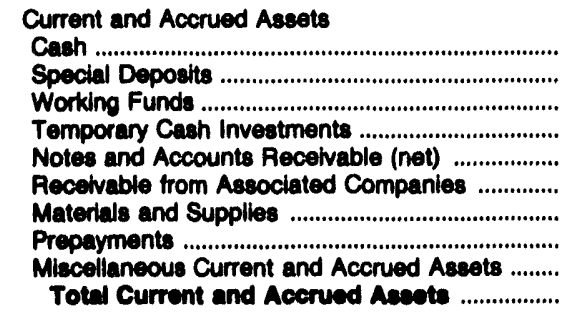 & $\begin{array}{r}1,431 \\
839 \\
60 \\
-3 \\
20,750 \\
71 \\
4,044 \\
2,314 \\
7,389 \\
37,006\end{array}$ & $\begin{array}{r}654 \\
64,533 \\
131 \\
0 \\
85,165 \\
1,639 \\
24,206 \\
6,813 \\
149,059 \\
332,100\end{array}$ & $\begin{array}{r}6 \\
0 \\
0 \\
150 \\
182 \\
189 \\
0 \\
59 \\
0 \\
685\end{array}$ & $\begin{array}{r}528 \\
939 \\
7 \\
0 \\
6,041 \\
107 \\
1,243 \\
230 \\
1,683 \\
10,770\end{array}$ & $\begin{array}{r}-911 \\
0 \\
13 \\
0 \\
3,968 \\
18,565 \\
13,067 \\
5,119 \\
65 \\
30,887\end{array}$ & $\begin{array}{r}3,781 \\
642 \\
1,068 \\
8,701 \\
294,650 \\
989 \\
211,273 \\
71,590 \\
86,289 \\
678,883\end{array}$ \\
\hline 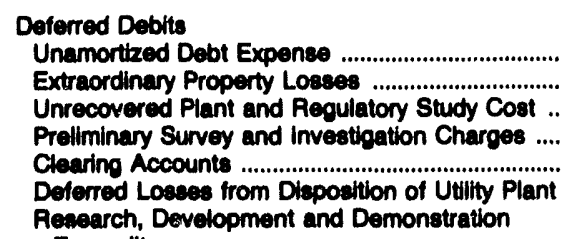 & $\begin{array}{r}950 \\
0 \\
38,863 \\
4,210 \\
4,175 \\
0\end{array}$ & $\begin{array}{r}3,710 \\
0 \\
124,591 \\
1,229 \\
0 \\
0\end{array}$ & $\begin{array}{r}39 \\
0 \\
0 \\
19 \\
0 \\
0\end{array}$ & $\begin{array}{r}678 \\
0 \\
40,511 \\
322 \\
75 \\
0\end{array}$ & $\begin{array}{r}528 \\
0 \\
3,747 \\
540 \\
0 \\
0\end{array}$ & $\begin{array}{r}4,818 \\
0 \\
0 \\
409 \\
327 \\
0\end{array}$ \\
\hline 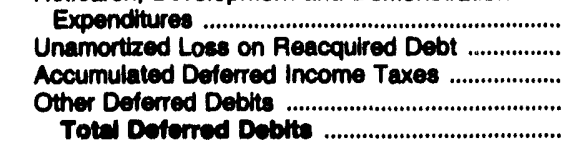 & $\begin{array}{r}0 \\
728 \\
4,216 \\
17,622 \\
70,663\end{array}$ & $\begin{array}{r}151 \\
15,114 \\
18,821 \\
150,759 \\
\mathbf{3 1 4 , 3 7 5}\end{array}$ & $\begin{array}{r}0 \\
3 \\
113 \\
546 \\
720\end{array}$ & $\begin{array}{r}0 \\
786 \\
0 \\
0 \\
1,719 \\
44,091\end{array}$ & $\begin{array}{r}0 \\
168 \\
11,533 \\
2,779 \\
19,203\end{array}$ & $\begin{array}{r}5,825 \\
4,557 \\
108,181 \\
626,223 \\
748,340\end{array}$ \\
\hline Total Asects and Other Deblts ........................... & 290,400 & $1,772,658$ & 6,524 & 110,962 & 520,287 & $6,796,830$ \\
\hline
\end{tabular}

See endnotes at end of an individual electric utility. 
Table 38. Balance Sheot by Major U.S. Investor-Owned Electric Utillty Within State on December 31, 1992 (Continued) (Thousand Dollars)

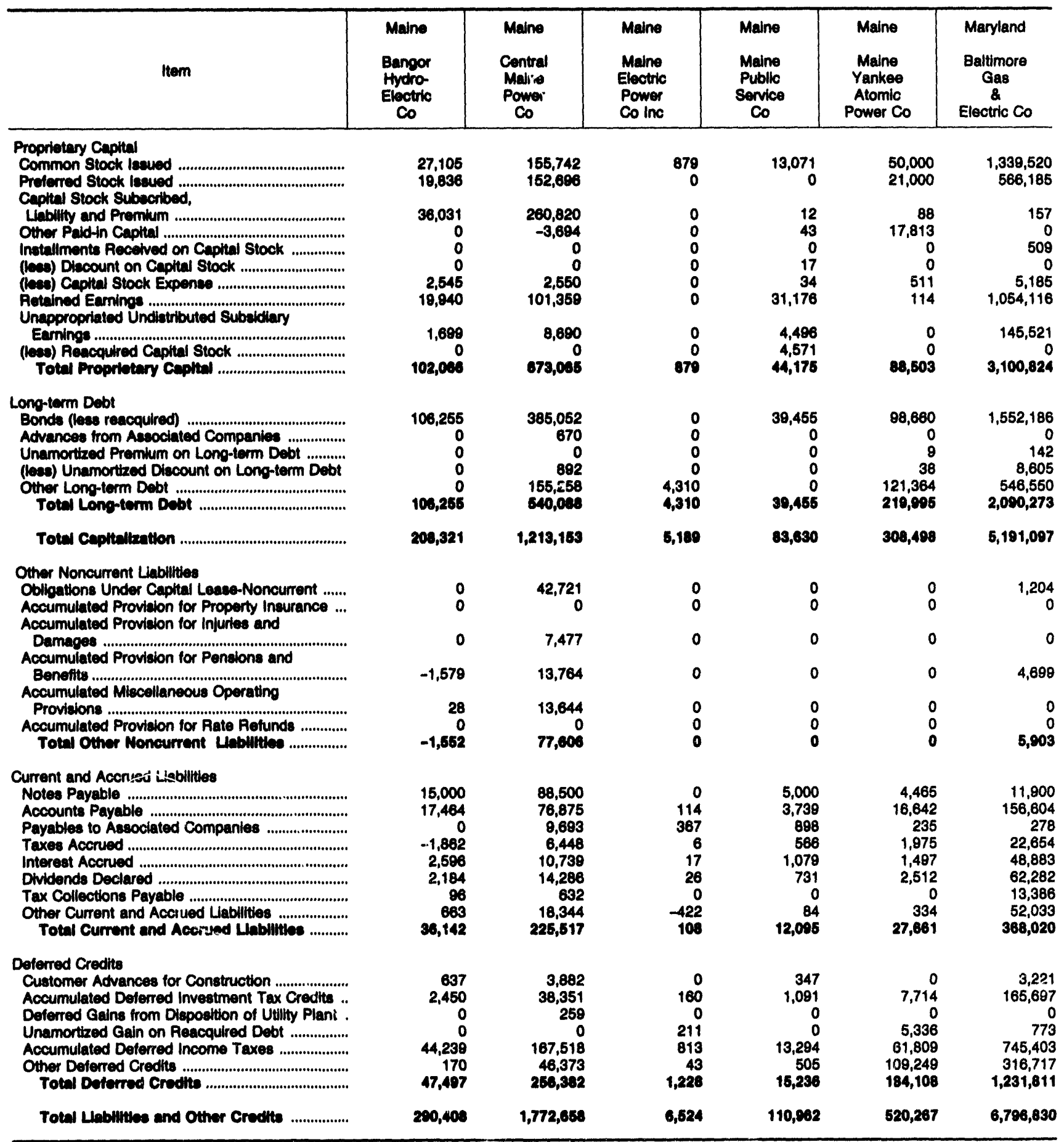

Note: Totals may not equal sum of components because of independent rounding. Summary data are provided in Table 8.

Source: Federal Energy Regulatory Commission, FERC Form 1, "Annual Report of Major Electric Utilities, Licensees and Others." 
Table 38. Balance Sheet by Major U.S. Investor-Owned Electric Utility Within State on December 31, 1992 (Continued) (Thousand Dollars)

\begin{tabular}{|c|c|c|c|c|c|c|}
\hline Item & $\begin{array}{l}\text { Maryland } \\
\text { Potomac } \\
\text { Edison Co }\end{array}$ & $\begin{array}{l}\text { Maseachusetts } \\
\text { Boston } \\
\text { Edison Co }\end{array}$ & $\begin{array}{l}\text { Maseachusetts } \\
\text { Cambridge } \\
\text { Electric } \\
\text { Light Co }\end{array}$ & $\begin{array}{l}\text { Massachusetts } \\
\text { Canal } \\
\text { Electric Co }\end{array}$ & $\begin{array}{l}\text { Maseachusetts } \\
\text { Commonwealth } \\
\text { Electric Co }\end{array}$ & $\begin{array}{l}\text { Massachusetts } \\
\text { Eastern } \\
\text { Edison Co }\end{array}$ \\
\hline 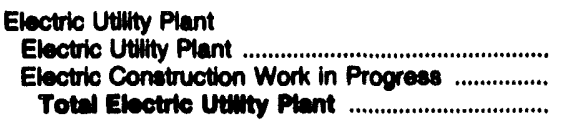 & $\begin{array}{r}1,653,645 \\
141,611 \\
1,695,266\end{array}$ & $\begin{array}{r}3,590,210 \\
178,125 \\
3,760,395\end{array}$ & $\begin{array}{r}137,222 \\
96 \\
137,318\end{array}$ & $\begin{array}{r}400,535 \\
1,625 \\
402,160\end{array}$ & $\begin{array}{r}475,180 \\
4,794 \\
470,074\end{array}$ & $\begin{array}{r}208,837 \\
965 \\
207,802\end{array}$ \\
\hline 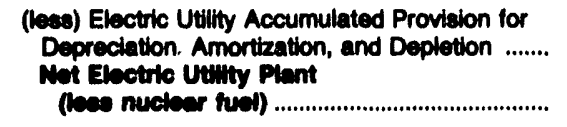 & $\begin{array}{r}591,258 \\
1,103, \infty e 8\end{array}$ & $\begin{array}{l}1,174,860 \\
2,603,375\end{array}$ & $\begin{array}{l}45,586 \\
91,733\end{array}$ & $\begin{array}{l}114,285 \\
207,075\end{array}$ & $\begin{array}{l}135,682 \\
344,292\end{array}$ & $\begin{array}{r}62,147 \\
146,065\end{array}$ \\
\hline 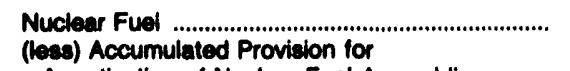 & 0 & 287,070 & 0 & 17,083 & 0 & 0 \\
\hline 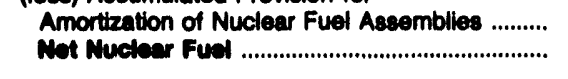 & $\begin{array}{l}0 \\
0\end{array}$ & $\begin{array}{r}201,878 \\
85,002\end{array}$ & $\begin{array}{l}0 \\
0\end{array}$ & $\begin{array}{l}9,777 \\
7,306\end{array}$ & $\begin{array}{l}0 \\
0\end{array}$ & $\begin{array}{l}0 \\
0\end{array}$ \\
\hline 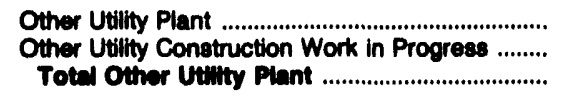 & $\begin{array}{l}0 \\
0 \\
0\end{array}$ & $\begin{array}{l}0 \\
0 \\
0\end{array}$ & $\begin{array}{l}0 \\
0 \\
0\end{array}$ & $\begin{array}{l}0 \\
0 \\
0\end{array}$ & $\begin{array}{l}0 \\
0 \\
0\end{array}$ & $\begin{array}{l}0 \\
0 \\
0\end{array}$ \\
\hline 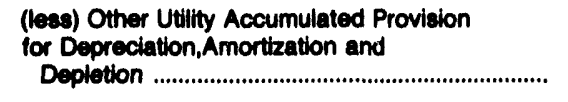 & 0 & 0 & 0 & 0 & 0 & 0 \\
\hline 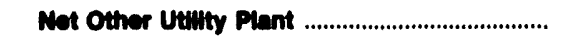 & 0 & $\mathbf{0}$ & 0 & 0 & $\mathbf{0}$ & $\mathbf{0}$ \\
\hline 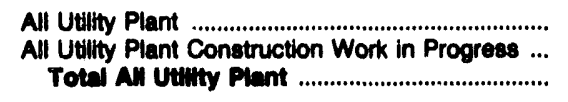 & $\begin{array}{r}1,553,645 \\
141,611 \\
1,606,266\end{array}$ & $\begin{array}{r}3,877,280 \\
178,125 \\
4,055,405\end{array}$ & $\begin{array}{r}137,222 \\
96 \\
137,310\end{array}$ & $\begin{array}{r}417,618 \\
1,625 \\
410,242\end{array}$ & $\begin{array}{r}475,180 \\
4,794 \\
470,974\end{array}$ & $\begin{array}{r}206,837 \\
965 \\
207,002\end{array}$ \\
\hline 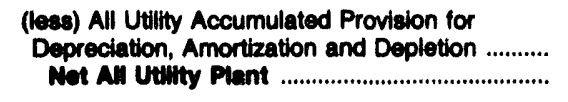 & $\begin{array}{r}591,258 \\
1,103,086\end{array}$ & $\begin{array}{l}1,376,838 \\
2,678,467\end{array}$ & $\begin{array}{l}45,586 \\
91,733\end{array}$ & $\begin{array}{l}124,062 \\
205,181\end{array}$ & $\begin{array}{l}135,682 \\
344,292\end{array}$ & $\begin{array}{r}62,147 \\
145,655\end{array}$ \\
\hline 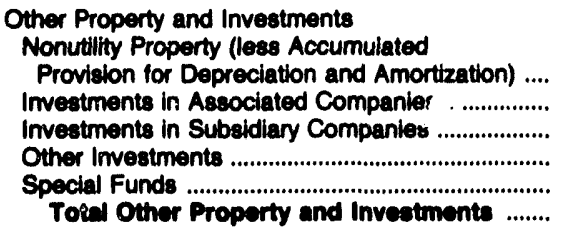 & $\begin{array}{r}3,336 \\
0 \\
66,741 \\
75 \\
271 \\
70,424\end{array}$ & $\begin{array}{r}856 \\
0 \\
30,562 \\
40 \\
50,872 \\
82,431\end{array}$ & $\begin{array}{r}1,158 \\
0 \\
9,089 \\
73 \\
0 \\
10,380\end{array}$ & $\begin{array}{r}0 \\
0 \\
4,170 \\
80 \\
0 \\
4,280\end{array}$ & $\begin{array}{r}1,657 \\
0 \\
601 \\
164 \\
0 \\
2,421\end{array}$ & $\begin{array}{r}96 \\
0 \\
369,965 \\
50 \\
0 \\
370,111\end{array}$ \\
\hline 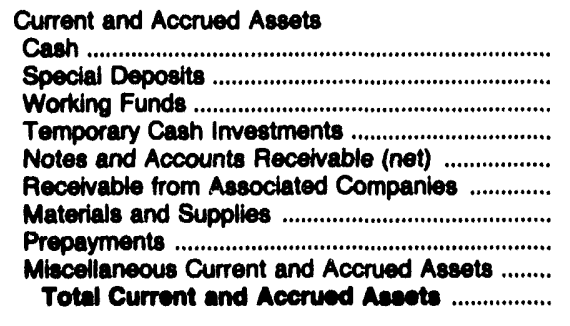 & $\begin{array}{r}1,684 \\
2,607 \\
87 \\
0 \\
39,293 \\
40,649 \\
58,719 \\
5,553 \\
10,905 \\
160,608\end{array}$ & $\begin{array}{r}531 \\
16 \\
152 \\
0 \\
176,821 \\
0 \\
83,930 \\
5,204 \\
38,138 \\
314,091\end{array}$ & $\begin{array}{r}0 \\
0 \\
2 \\
0 \\
8,763 \\
1,253 \\
1,553 \\
1,078 \\
3,736 \\
16,386\end{array}$ & $\begin{array}{r}445 \\
0 \\
1 \\
0 \\
9,497 \\
11,754 \\
3,856 \\
1,104 \\
1,755 \\
28,512\end{array}$ & $\begin{array}{r}493 \\
0 \\
14 \\
0 \\
36,366 \\
3,906 \\
6,525 \\
2,113 \\
17,887 \\
67,304\end{array}$ & $\begin{array}{r}769 \\
0 \\
18 \\
2,400 \\
25,445 \\
6,774 \\
1,680 \\
3,544 \\
8,669 \\
49,198\end{array}$ \\
\hline 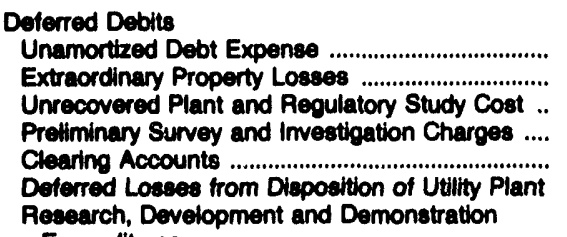 & $\begin{array}{r}1,689 \\
0 \\
0 \\
7,071 \\
245 \\
0\end{array}$ & $\begin{array}{r}5,474 \\
18,785 \\
310 \\
31 \\
0 \\
0\end{array}$ & $\begin{array}{r}199 \\
0 \\
0 \\
368 \\
0 \\
0\end{array}$ & $\begin{array}{r}2,709 \\
0 \\
8,792 \\
92 \\
36 \\
0\end{array}$ & $\begin{array}{r}278 \\
0 \\
0 \\
932 \\
0 \\
0\end{array}$ & $\begin{array}{r}7,404 \\
0 \\
0 \\
0 \\
0 \\
0\end{array}$ \\
\hline 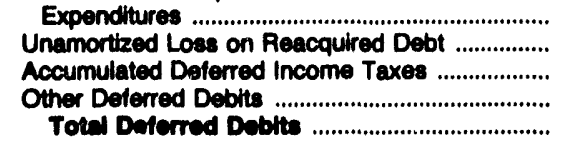 & $\begin{array}{r}0 \\
5,897 \\
32,711 \\
8,560 \\
88,173\end{array}$ & $\begin{array}{r}0 \\
32,617 \\
48,799 \\
142,508 \\
248,524\end{array}$ & $\begin{array}{r}0 \\
68 \\
3,513 \\
8,601 \\
12,751\end{array}$ & $\begin{array}{r}0 \\
0 \\
2,182 \\
18,448 \\
32,268\end{array}$ & $\begin{array}{r}0 \\
420 \\
7,607 \\
23,520 \\
32,750\end{array}$ & $\begin{array}{r}0 \\
5,255 \\
2,881 \\
8,916 \\
24,456\end{array}$ \\
\hline 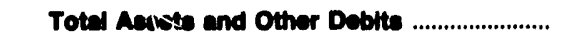 & $1,390,102$ & $3,324,314$ & 131,180 & 360,210 & 446,774 & 600,421 \\
\hline
\end{tabular}

See endnotes at end of an individual eleciric utility. 
Table 38. Balance Sheet by Major U.S. Investor-Owned Electric Utility Within State on December 31, 1982 (Continued) (Thousand Dollars)

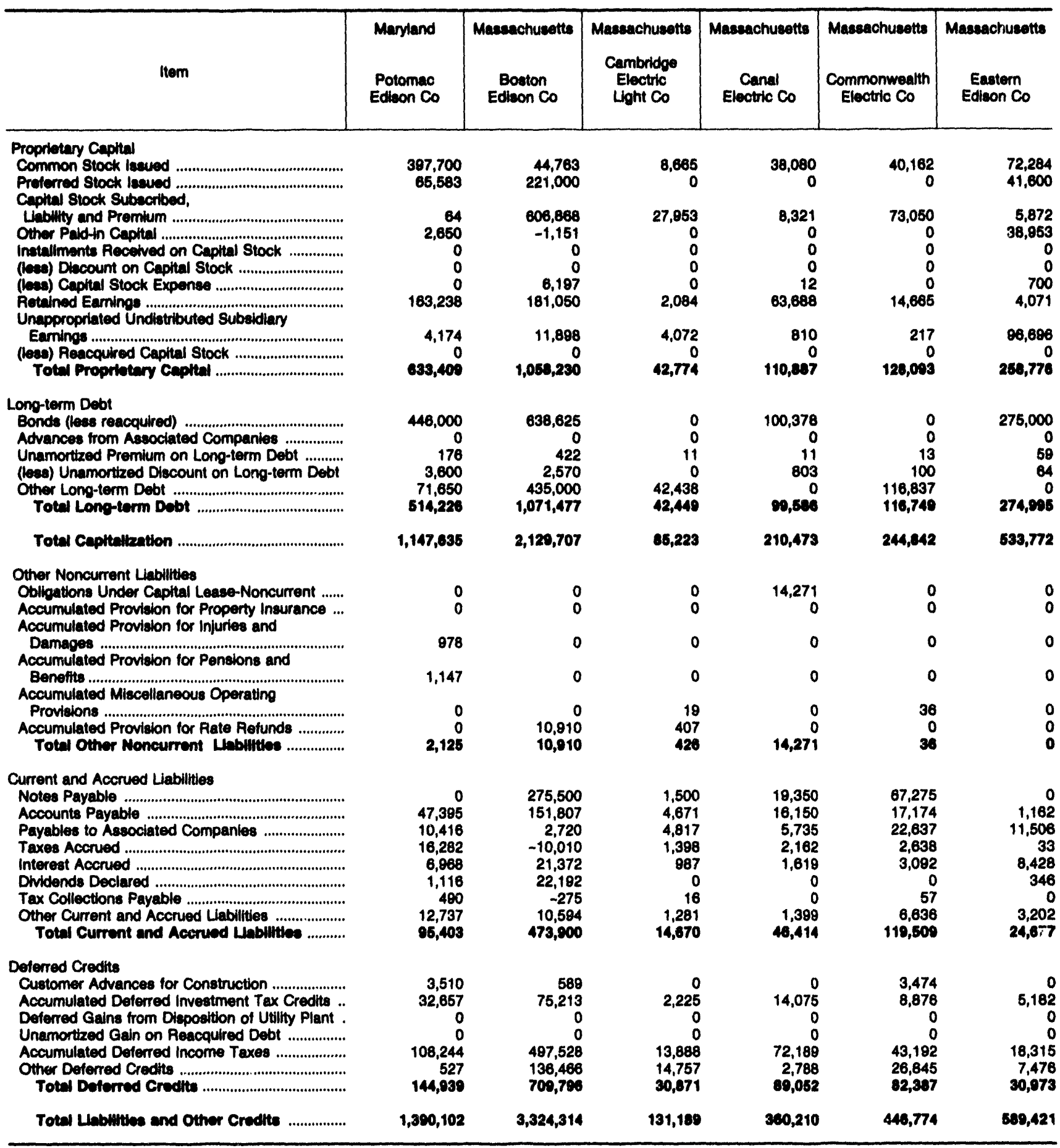

Note: Totals may not equal sum of components because of independent rounding. Summary data are provided in Table 8.

Source: Federal Energy Regulatory Commission, FERC Form 1, "Annual Report of Major Electric Utilties, Licensees and Others." 
Table 38. Balance Sheot by Major U.8. Investor-Owned Electrle Utility Within State on December 31, 1992 (Continued)

(Thousand Dollars)

\begin{tabular}{|c|c|c|c|c|c|c|}
\hline Item & $\begin{array}{l}\text { Masasechusetts } \\
\text { Fitchburg } \\
\text { Gas \& } \\
\text { Elec Light Co }\end{array}$ & $\begin{array}{c}\text { Masaachusetts } \\
\text { Holyoke } \\
\text { Power } \\
\text { Electric co }\end{array}$ & $\begin{array}{l}\text { Maseachusette } \\
\text { Hotyoke } \\
\text { Water } \\
\text { Power } \\
\text { Co }\end{array}$ & $\begin{array}{l}\text { Masaachusetts } \\
\text { Maseachusetts } \\
\text { Electric Co }\end{array}$ & $\begin{array}{l}\text { Maseachusetts } \\
\text { Montaup } \\
\text { Eiectric Co }\end{array}$ & $\begin{array}{c}\text { Maseachusetto } \\
\text { New England } \\
\text { Hydro- } \\
\text { Tran } \\
\text { Elec Co }\end{array}$ \\
\hline 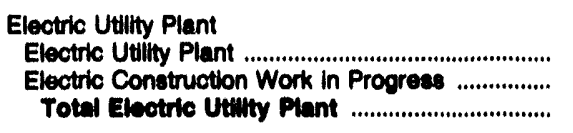 & $\begin{array}{r}67,131 \\
67,-60 \\
67,071\end{array}$ & $\begin{array}{r}1,433 \\
4 \\
1,497\end{array}$ & $\begin{array}{r}85,807 \\
3,512 \\
60,310\end{array}$ & $\begin{array}{r}1,223,108 \\
14,376 \\
1,237,402\end{array}$ & $\begin{array}{r}549,022 \\
2,210 \\
861,232\end{array}$ & $\begin{array}{r}212,228 \\
0 \\
212,230\end{array}$ \\
\hline 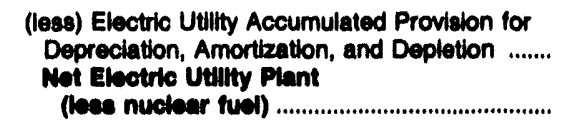 & $\begin{array}{l}10,233 \\
37,035\end{array}$ & $\begin{array}{l}791 \\
640\end{array}$ & $\begin{array}{l}36,003 \\
63,916\end{array}$ & $\begin{array}{l}331,942 \\
605,541\end{array}$ & $\begin{array}{l}137,477 \\
413,756\end{array}$ & $\begin{array}{r}17,868 \\
194,262\end{array}$ \\
\hline $\begin{array}{l}\text { Nuclear Fuel ... } \\
\text { (lese) Accumulated Proviaion for }\end{array}$ & 282 & 0 & 0 & 0 & 21,261 & 0 \\
\hline 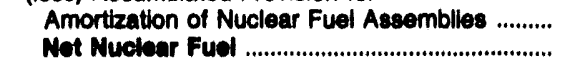 & $\begin{array}{l}118 \\
184\end{array}$ & $\begin{array}{l}0 \\
0\end{array}$ & $\begin{array}{l}0 \\
0\end{array}$ & $\begin{array}{l}0 \\
0\end{array}$ & $\begin{array}{r}9,760 \\
11,611\end{array}$ & $\begin{array}{l}0 \\
0\end{array}$ \\
\hline 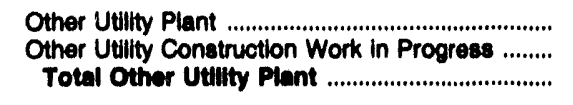 & $\begin{array}{r}26,932 \\
675 \\
27,600\end{array}$ & $\begin{array}{l}0 \\
0 \\
0\end{array}$ & $\begin{array}{l}0 \\
0 \\
0\end{array}$ & $\begin{array}{l}0 \\
0 \\
0\end{array}$ & $\begin{array}{l}0 \\
0 \\
0\end{array}$ & $\begin{array}{l}0 \\
0 \\
0\end{array}$ \\
\hline 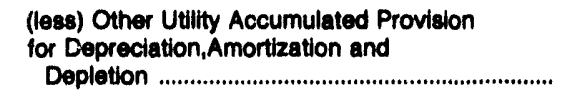 & 5,214 & 0 & 0 & 0 & 0 & 0 \\
\hline 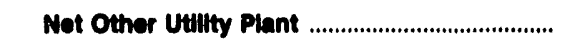 & 22,304 & 0 & 0 & 0 & 0 & 0 \\
\hline 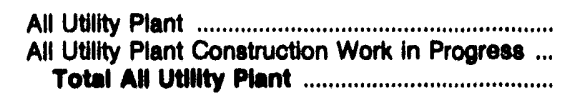 & $\begin{array}{r}84,344 \\
616 \\
84,680\end{array}$ & $\begin{array}{r}1,433 \\
4 \\
1,437\end{array}$ & $\begin{array}{r}85,807 \\
3,612 \\
80,318\end{array}$ & $\begin{array}{r}1,223,106 \\
14,376 \\
1,237,402\end{array}$ & $\begin{array}{r}570,283 \\
2,210 \\
672,403\end{array}$ & $\begin{array}{r}212,228 \\
0 \\
212,228\end{array}$ \\
\hline 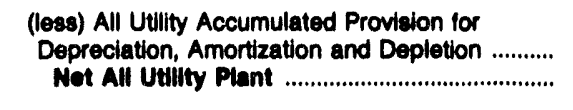 & $\begin{array}{l}24,565 \\
60,396\end{array}$ & $\begin{array}{l}791 \\
646\end{array}$ & $\begin{array}{l}36,003 \\
63,316\end{array}$ & $\begin{array}{l}331,942 \\
\mathbf{0 0 5 , 5 4 1}\end{array}$ & $\begin{array}{l}147,227 \\
428,266\end{array}$ & $\begin{array}{r}17,866 \\
104,202\end{array}$ \\
\hline 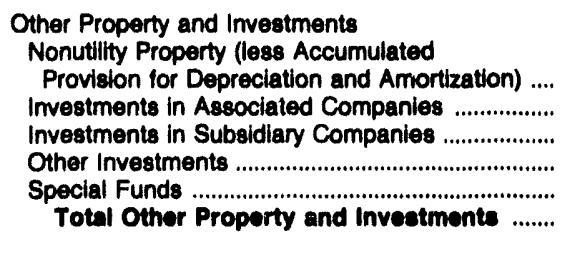 & $\begin{array}{r}14 \\
0 \\
351 \\
11 \\
0 \\
377\end{array}$ & $\begin{array}{l}0 \\
0 \\
0 \\
0 \\
0 \\
0\end{array}$ & $\begin{array}{r}3,481 \\
0 \\
673 \\
3 \\
0 \\
4,167\end{array}$ & $\begin{array}{r}1,547 \\
0 \\
0 \\
75 \\
0 \\
1,622\end{array}$ & $\begin{array}{r}2,610 \\
0 \\
13,696 \\
0 \\
0 \\
16,205\end{array}$ & $\begin{array}{l}0 \\
0 \\
5 \\
0 \\
0 \\
5\end{array}$ \\
\hline 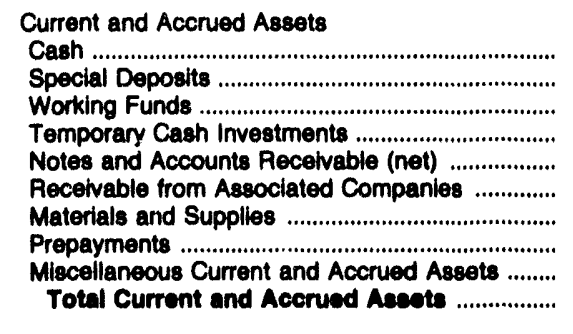 & $\begin{array}{r}684 \\
0 \\
4 \\
0 \\
6,787 \\
0 \\
2,185 \\
3,280 \\
2,271 \\
16,212\end{array}$ & $\begin{array}{r}1,549 \\
0 \\
0 \\
0 \\
1,933 \\
1,956 \\
0 \\
0 \\
0 \\
\mathbf{5 , 4 3 8}\end{array}$ & $\begin{array}{r}34 \\
15,000 \\
2 \\
0 \\
2,792 \\
6,176 \\
7,365 \\
98 \\
5 \\
31,472\end{array}$ & $\begin{array}{r}655 \\
343 \\
83 \\
0 \\
149,874 \\
1,483 \\
9,910 \\
25,877 \\
387 \\
188,721\end{array}$ & $\begin{array}{r}-991 \\
0 \\
6 \\
23,318 \\
2,491 \\
22,402 \\
9,056 \\
6,307 \\
3,738 \\
68,328\end{array}$ & $\begin{array}{r}22 \\
0 \\
0 \\
0 \\
55 \\
10,075 \\
0 \\
221 \\
39 \\
10,413\end{array}$ \\
\hline 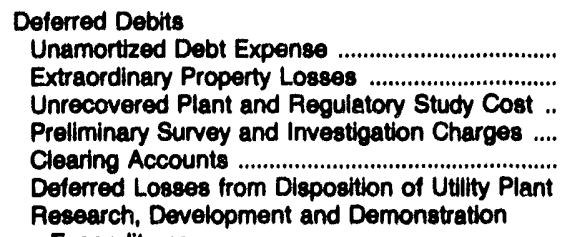 & $\begin{array}{r}153 \\
0 \\
13,778 \\
0 \\
33 \\
0\end{array}$ & $\begin{array}{l}0 \\
0 \\
0 \\
0 \\
0 \\
0\end{array}$ & $\begin{array}{r}977 \\
0 \\
0 \\
0 \\
-19 \\
0\end{array}$ & $\begin{array}{r}876 \\
0 \\
0 \\
752 \\
0 \\
0\end{array}$ & $\begin{array}{r}35 \\
0 \\
22,683 \\
144 \\
0 \\
0\end{array}$ & $\begin{array}{r}977 \\
0 \\
0 \\
0 \\
0 \\
0\end{array}$ \\
\hline 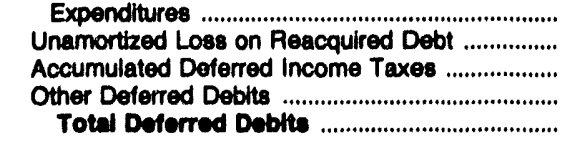 & $\begin{array}{r}0 \\
0 \\
247 \\
5,610 \\
10,821\end{array}$ & $\begin{array}{r}0 \\
0 \\
0 \\
18 \\
18\end{array}$ & $\begin{array}{r}0 \\
0 \\
194 \\
737 \\
1,808\end{array}$ & $\begin{array}{r}0 \\
2,259 \\
48,496 \\
4,915 \\
57,290\end{array}$ & $\begin{array}{r}0 \\
0 \\
972 \\
42,322 \\
66,136\end{array}$ & $\begin{array}{r}0 \\
0 \\
662 \\
2,417 \\
3,068\end{array}$ \\
\hline Total Aesets and Other Deblts ......................... & 95,805 & 6,102 & 90,033 & $1,183,183$ & 673,937 & 208,638 \\
\hline
\end{tabular}

See endnotes at end of an indlvidual electric utility. 
Table 38. Balance 8heot by Major U.S. Inveator-Owned Electrlc Utility Within state on Decomber 31, 1902 (Continued) (Thousand Dollars)

\begin{tabular}{|c|c|c|c|c|c|c|}
\hline ltom & $\begin{array}{l}\text { Masasohusetts } \\
\text { Fitchburg } \\
\text { Gas \& } \\
\text { Eleo Light Co }\end{array}$ & $\begin{array}{l}\text { Masanchusotts } \\
\text { Holyoke } \\
\text { Power } \\
2 \\
\text { Electric Co }\end{array}$ & $\begin{array}{l}\text { Masanohuestts } \\
\text { Holyoke } \\
\text { Water } \\
\text { Power } \\
\text { Co }\end{array}$ & $\begin{array}{l}\text { Maenachusotts } \\
\text { Masenchusotts } \\
\text { Electric Co }\end{array}$ & $\begin{array}{l}\text { Maseachusetts } \\
\text { Montaup } \\
\text { Electric Co }\end{array}$ & $\begin{array}{c}\text { Meseachusetts } \\
\text { Now England } \\
\text { Hydro- } \\
\text { Tran } \\
\text { Eleo Co }\end{array}$ \\
\hline 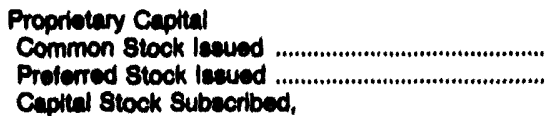 & $\begin{array}{r}12,446 \\
2,732\end{array}$ & $\begin{array}{r}486 \\
0\end{array}$ & $\begin{array}{r}2,400 \\
0\end{array}$ & $\begin{array}{l}59,853 \\
50,000\end{array}$ & $\begin{array}{r}68,600 \\
1,500\end{array}$ & $\begin{array}{r}4,000 \\
0\end{array}$ \\
\hline 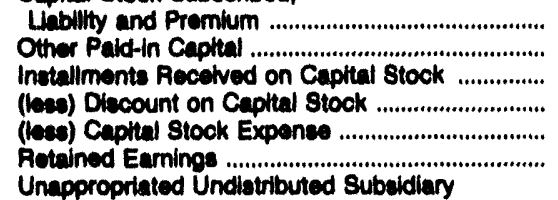 & $\begin{array}{r}10,183 \\
-2 \\
0 \\
0 \\
1,652 \\
8,652\end{array}$ & $\begin{array}{r}0 \\
0 \\
0 \\
0 \\
0 \\
-236\end{array}$ & $\begin{array}{r}0 \\
6,000 \\
0 \\
0 \\
0 \\
11,480\end{array}$ & $\begin{array}{r}46,091 \\
90,737 \\
0 \\
0 \\
0 \\
134,670\end{array}$ & $\begin{array}{r}0 \\
29,528 \\
0 \\
0 \\
0 \\
92,697\end{array}$ & $\begin{array}{r}36,000 \\
16,385 \\
0 \\
0 \\
0 \\
18,116\end{array}$ \\
\hline 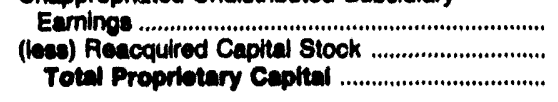 & $\begin{array}{r}0 \\
0 \\
32,469\end{array}$ & $\begin{array}{r}0 \\
0 \\
240\end{array}$ & $\begin{array}{r}-243 \\
0 \\
19,897\end{array}$ & $\begin{array}{r}0 \\
0 \\
391,462\end{array}$ & $\begin{array}{r}3,898 \\
0 \\
102,324\end{array}$ & $\begin{array}{r}0 \\
0 \\
76,601\end{array}$ \\
\hline 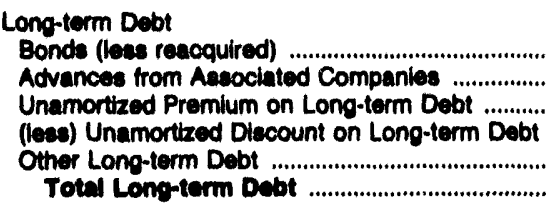 & $\begin{array}{r}0 \\
0 \\
0 \\
0 \\
36,680 \\
34,600\end{array}$ & $\begin{array}{r}0 \\
424 \\
0 \\
0 \\
0 \\
424\end{array}$ & $\begin{array}{r}0 \\
0 \\
0 \\
0 \\
53,300 \\
53,300\end{array}$ & $\begin{array}{r}267,000 \\
0 \\
73 \\
1,495 \\
0 \\
265,674\end{array}$ & $\begin{array}{r}173,640 \\
0 \\
0 \\
0 \\
0 \\
173,640\end{array}$ & $\begin{array}{r}0 \\
118,370 \\
0 \\
0 \\
0 \\
119,370\end{array}$ \\
\hline Total Ceppitaltzation ............................................... & 69,030 & 973 & 72,937 & 647,020 & 399,908 & 124,871 \\
\hline $\begin{array}{l}\text { Other Noncurrent Liabillties } \\
\text { Obligatione Under Capltal Lease-Noncurrent ...... } \\
\text { Accumulated Provision for Property Insurance ... } \\
\text { Accumulated Provision for Injurles and }\end{array}$ & $\begin{array}{r}3,785 \\
0\end{array}$ & $\begin{array}{l}0 \\
0\end{array}$ & $\begin{array}{l}0 \\
0\end{array}$ & $\begin{array}{r}1,509 \\
0\end{array}$ & $\begin{array}{l}0 \\
0\end{array}$ & $\begin{array}{l}0 \\
0\end{array}$ \\
\hline 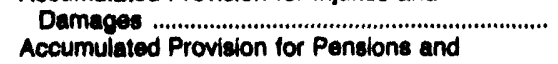 & 0 & 0 & 738 & 0 & 0 & 0 \\
\hline 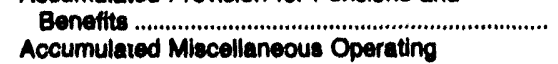 & 0 & 0 & 218 & 0 & 0 & 0 \\
\hline 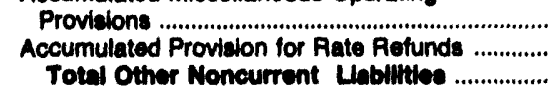 & $\begin{array}{r}0 \\
0 \\
3,796\end{array}$ & $\begin{array}{l}0 \\
0 \\
0\end{array}$ & $\begin{array}{r}0 \\
0 \\
984\end{array}$ & $\begin{array}{r}0 \\
0 \\
1,800\end{array}$ & $\begin{array}{r}0 \\
3,133 \\
3,133\end{array}$ & $\begin{array}{l}0 \\
0 \\
0\end{array}$ \\
\hline 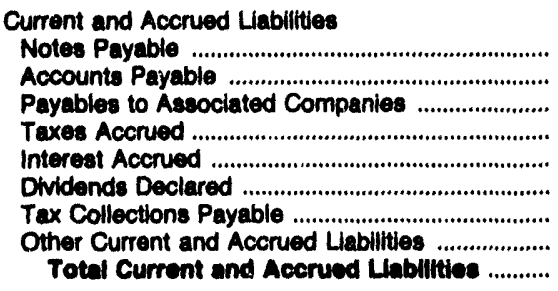 & $\begin{array}{r}3,868 \\
4,130 \\
362 \\
509 \\
601 \\
843 \\
20 \\
614 \\
11,047\end{array}$ & $\begin{array}{r}0 \\
0 \\
4,682 \\
673 \\
0 \\
0 \\
0 \\
10 \\
6,346\end{array}$ & $\begin{array}{r}0 \\
1,738 \\
2,003 \\
308 \\
174 \\
0 \\
12 \\
552 \\
4,708\end{array}$ & $\begin{array}{r}34,800 \\
17,864 \\
180,615 \\
856 \\
6,175 \\
6,253 \\
-360 \\
36,443 \\
282,657\end{array}$ & $\begin{array}{r}0 \\
23,587 \\
3,121 \\
3,358 \\
5,980 \\
0 \\
0 \\
9,649 \\
45,604\end{array}$ & $\begin{array}{r}0 \\
361 \\
409 \\
27 \\
452 \\
0 \\
0 \\
175 \\
1,424\end{array}$ \\
\hline 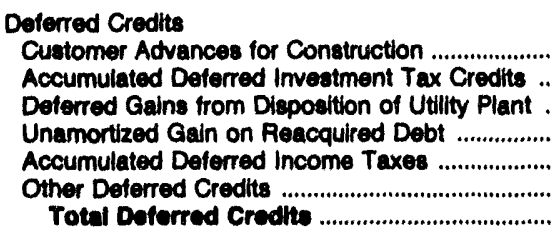 & $\begin{array}{r}431 \\
1,370 \\
0 \\
0 \\
10,134 \\
0 \\
11,934\end{array}$ & $\begin{array}{r}0 \\
43 \\
0 \\
0 \\
41 \\
0 \\
84\end{array}$ & $\begin{array}{r}0 \\
4,379 \\
0 \\
0 \\
7,812 \\
163 \\
12,164\end{array}$ & $\begin{array}{r}10,071 \\
21,272 \\
0 \\
4 \\
182,473 \\
8,171 \\
221,901\end{array}$ & $\begin{array}{r}0 \\
14,967 \\
0 \\
0 \\
96,854 \\
43,223 \\
166,144\end{array}$ & $\begin{array}{r}0 \\
2,039 \\
0 \\
0 \\
10,303 \\
0 \\
12,342\end{array}$ \\
\hline Total Labilltes and Other Credits ................ & 05,806 & 6,102 & 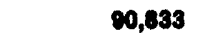 & $1,153,183$ & 673,037 & 208,030 \\
\hline
\end{tabular}

Note: Totals may not equal sum of components because of independent rounding. Summary data are provided in Table 8.

Source: Federal Energy Regulatory Commiselon, FEAC Form 1, "Annual Report of Major Electric Utilities, Licensees and Others." 
Table 38. Balance Sheot by Major U.8. Inveotor-Owned Electric Utility Within 8tate on Decomber 31, 1992 (Continued)

(Thousand Dollars)

\begin{tabular}{|c|c|c|c|c|c|c|}
\hline Item & $\begin{array}{l}\text { Mereachusetts } \\
\text { New England } \\
\text { Power Co }\end{array}$ & $\begin{array}{l}\text { Masenchusetts } \\
\text { Western } \\
\text { Massachusetts } \\
\text { Elec Co }\end{array}$ & $\begin{array}{l}\text { Michigan } \\
\text { Consumers } \\
\text { Power Co }\end{array}$ & $\begin{array}{c}\text { Michigan } \\
\text { Detroit } \\
\text { Edison Co }\end{array}$ & $\begin{array}{c}\text { Michigan } \\
\text { Edison } \\
\text { Sault } \\
\text { Electric } \\
\text { Co }\end{array}$ & $\begin{array}{l}\text { Michigan } \\
\text { Upper } \\
\text { Peninaula } \\
\text { Power Co }\end{array}$ \\
\hline 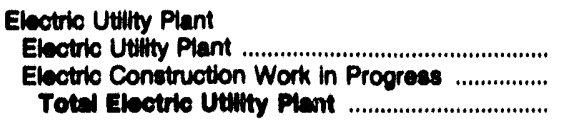 & $\begin{array}{r}2,686,029 \\
74,640 \\
2,780,694\end{array}$ & $\begin{array}{r}1,168,160 \\
18,522 \\
1,176,642\end{array}$ & $\begin{array}{r}4,716,196 \\
182,823 \\
4,090,110\end{array}$ & $\begin{array}{r}12,408,368 \\
130,602 \\
12,638,970\end{array}$ & $\begin{array}{r}80,980 \\
0 \\
00,810\end{array}$ & $\begin{array}{r}147,465 \\
4,539 \\
182,004\end{array}$ \\
\hline 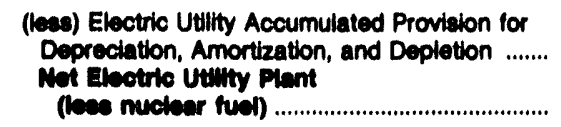 & $\begin{array}{l}1,032,869 \\
1,727,689\end{array}$ & $\begin{array}{l}384,702 \\
811,900\end{array}$ & $\begin{array}{l}1,975,275 \\
2,023,043\end{array}$ & $\begin{array}{l}3,736,362 \\
8,002,608\end{array}$ & 21,628 & $\begin{array}{l}57,598 \\
94,400\end{array}$ \\
\hline 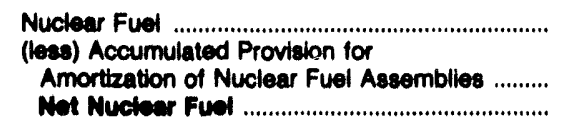 & $\begin{array}{l}46,582 \\
31,544 \\
14,048\end{array}$ & $\begin{array}{r}168,552 \\
160,381 \\
8,171\end{array}$ & $\begin{array}{r}236,591 \\
228,866 \\
7,725\end{array}$ & $\begin{array}{r}141,646 \\
0 \\
141,646\end{array}$ & $\begin{array}{l}0 \\
0\end{array}$ & $\begin{array}{l}0 \\
0\end{array}$ \\
\hline 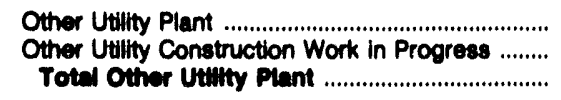 & $\begin{array}{l}0 \\
0 \\
0\end{array}$ & $\begin{array}{l}0 \\
0 \\
0\end{array}$ & $\begin{array}{r}1,820,182 \\
61,299 \\
1,881,491\end{array}$ & $\begin{array}{r}68,226 \\
0 \\
69,228\end{array}$ & $\begin{array}{l}0 \\
0 \\
0\end{array}$ & $\begin{array}{l}0 \\
0 \\
0\end{array}$ \\
\hline 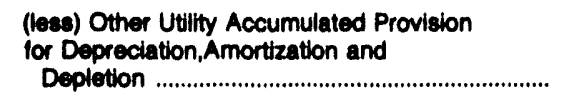 & 0 & 0 & 954,648 & 28,243 & 0 & 0 \\
\hline Net Other Utulty Piant .......................................... & $\mathbf{0}$ & 0 & 928,843 & 30,993 & 0 & $\mathbf{0}$ \\
\hline 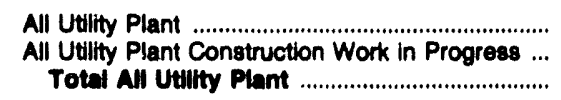 & $\begin{array}{r}2,731,621 \\
74,640 \\
2,000,280\end{array}$ & $\begin{array}{r}1,326,712 \\
18,522 \\
1,346,284\end{array}$ & $\begin{array}{r}6,772,979 \\
244,222 \\
7,017,201\end{array}$ & $\begin{array}{r}12,618,240 \\
130,602 \\
12,749,842\end{array}$ & $\begin{array}{r}60,880 \\
0 \\
60,980\end{array}$ & $\begin{array}{r}147,465 \\
4,539 \\
152,004\end{array}$ \\
\hline 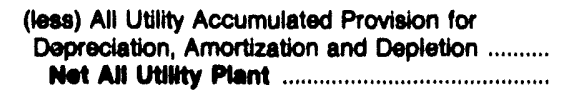 & $\begin{array}{l}1,064,513 \\
1,741,747\end{array}$ & $\begin{array}{l}525,083 \\
820,151\end{array}$ & $\begin{array}{l}3,158,789 \\
3,058,411\end{array}$ & $\begin{array}{l}3,764,605 \\
8,944,237\end{array}$ & $\begin{array}{l}21,628 \\
39,352\end{array}$ & $\begin{array}{l}57,588 \\
94,406\end{array}$ \\
\hline 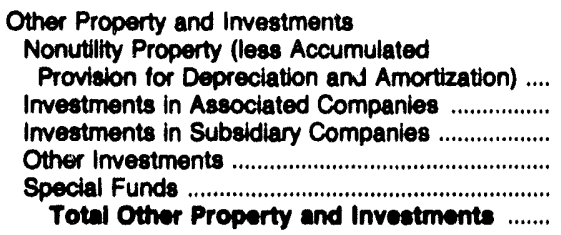 & $\begin{array}{r}7,040 \\
0 \\
45,798 \\
20 \\
10,481 \\
83,340\end{array}$ & $\begin{array}{r}3,619 \\
0 \\
14,567 \\
42,209 \\
0 \\
60,396\end{array}$ & $\begin{array}{r}24,854 \\
301,245 \\
265,972 \\
4,167 \\
125,824 \\
722,062\end{array}$ & $\begin{array}{r}7,679 \\
0 \\
7,403 \\
1,801 \\
35,479 \\
\mathbf{5 2 , 4 6 2}\end{array}$ & $\begin{array}{r}14 \\
0 \\
0 \\
273 \\
25 \\
312\end{array}$ & $\begin{array}{r}310 \\
0 \\
0 \\
0 \\
0 \\
310\end{array}$ \\
\hline 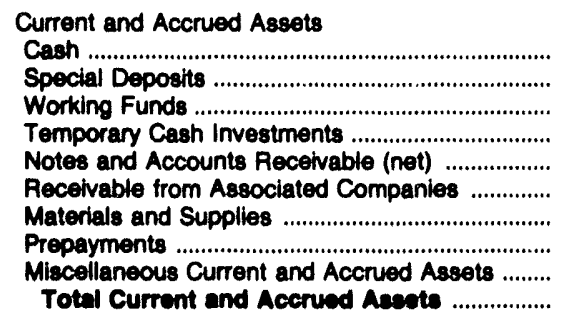 & $\begin{array}{r}527 \\
1,017 \\
125 \\
0 \\
70,414 \\
218,180 \\
72,857 \\
20,529 \\
1,974 \\
38,683\end{array}$ & $\begin{array}{r}76 \\
31 \\
59 \\
0 \\
36,417 \\
2,998 \\
9,001 \\
5,285 \\
18,309 \\
72,177\end{array}$ & $\begin{array}{r}10,789 \\
1 \\
505 \\
55,912 \\
-33,263 \\
349,361 \\
106,606 \\
8,764 \\
541,471 \\
1,040,146\end{array}$ & $\begin{array}{r}4,386 \\
2,024 \\
222 \\
0 \\
151,781 \\
0 \\
335,183 \\
9,413 \\
77,576 \\
580,606\end{array}$ & $\begin{array}{r}387 \\
0 \\
2 \\
0 \\
2,375 \\
22 \\
1,186 \\
14 \\
1,155 \\
6,141\end{array}$ & $\begin{array}{r}998 \\
0 \\
30 \\
0 \\
5,860 \\
18 \\
4,101 \\
283 \\
3,424 \\
14,734\end{array}$ \\
\hline $\begin{array}{l}\text { Deferred Debits } \\
\text { Unamortized Debt Expense .................................. } \\
\text { Extraordinary Property Losses .............................. } \\
\text { Unrecovered Plant and Regulatory Study Cost ... } \\
\text { Preliminary Survey and Investigation Charges .... } \\
\text { Clearing Accounts ............................................... } \\
\text { Deferred Loseses from Disposition of Utility Plant } \\
\text { Research, Development and Demonstration }\end{array}$ & $\begin{array}{r}4,141 \\
0 \\
18,233 \\
3,138 \\
0 \\
0\end{array}$ & $\begin{array}{r}2,141 \\
0 \\
39,201 \\
0 \\
-15 \\
0\end{array}$ & $\begin{array}{r}2,973 \\
0 \\
175,196 \\
2,419 \\
121 \\
0\end{array}$ & $\begin{array}{r}47,129 \\
0 \\
1,758 \\
604 \\
480 \\
0\end{array}$ & $\begin{array}{r}73 \\
0 \\
0 \\
0 \\
0 \\
0\end{array}$ & $\begin{array}{r}380 \\
0 \\
0 \\
17 \\
3 \\
0\end{array}$ \\
\hline 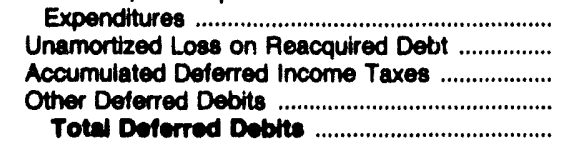 & $\begin{array}{r}0 \\
33,394 \\
103,614 \\
136,610 \\
29,130\end{array}$ & $\begin{array}{r}0 \\
11,684 \\
9,195 \\
95,813 \\
180,010\end{array}$ & $\begin{array}{r}0 \\
2,589 \\
707,487 \\
840,910 \\
1,731,690\end{array}$ & $\begin{array}{r}0 \\
29,840 \\
136,792 \\
575,405 \\
792,008\end{array}$ & $\begin{array}{r}0 \\
0 \\
382 \\
1,541 \\
1,908\end{array}$ & $\begin{array}{r}0 \\
78 \\
3,964 \\
212 \\
4,653\end{array}$ \\
\hline Totel Aesets and Other Debits. & $2,490,850$ & $1,110,742$ & $7,352,316$ & $10,400,313$ & 46,801 & 114,104 \\
\hline
\end{tabular}

See endnotes at end of an individual electric utility. 
Table 38. Balance Sheot by Major U.8. Investor-Owned Electric Utility Within state on December 31, 1992 (Continued) (Thousand Dollars)

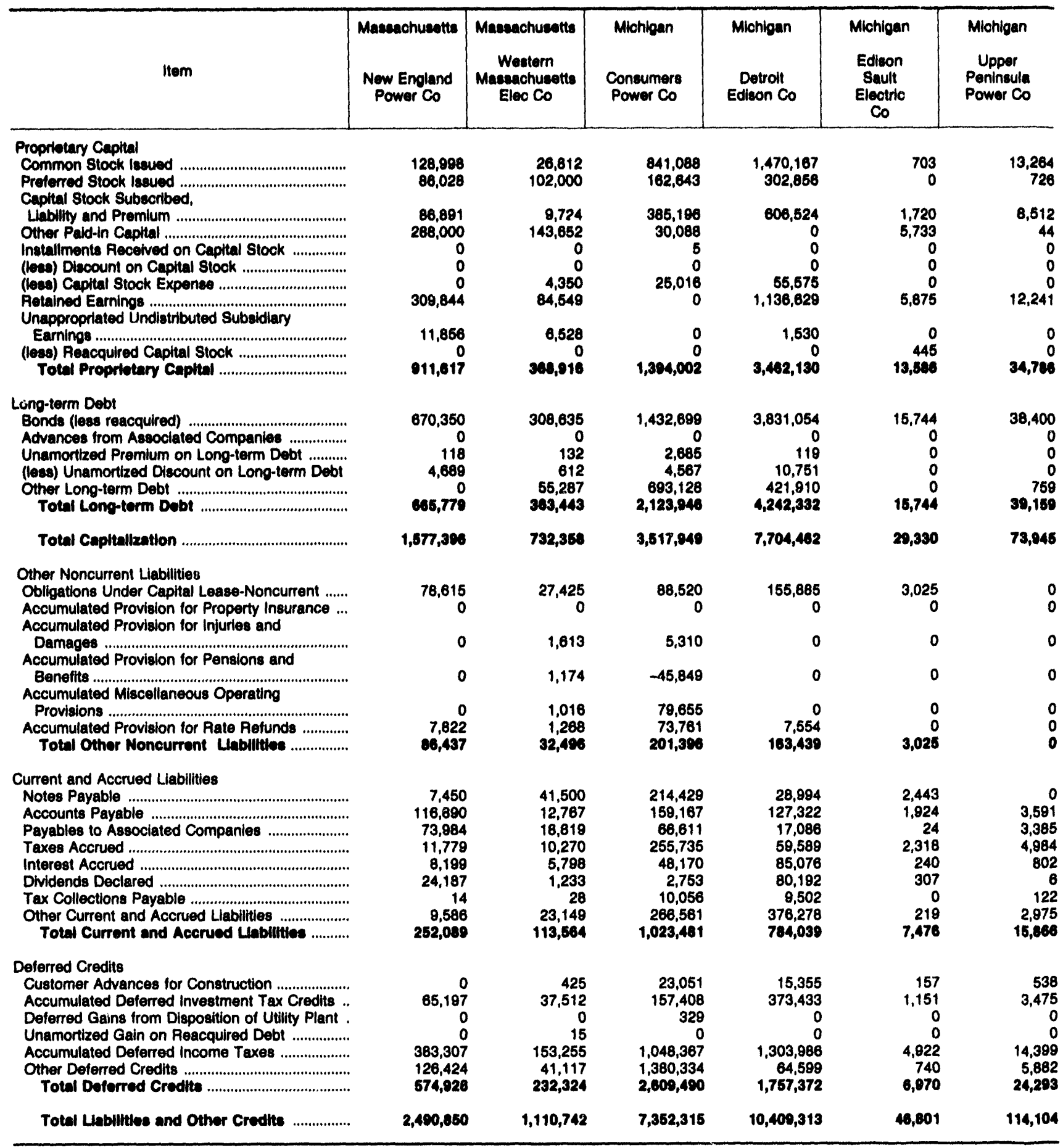

Note: Totals may not equal sum of components because of independent rounding. Summary data are provided in Table 8.

Source: Federal Energy Regulatory Commission, FERC Form 1, "Annual Report of Major Electric Utilties, Licensees and Others." 
Table 38. Balance 8heot by Major U.8. Inveotor-Owned Eloctrle Utillty Within state on Decomber 31, 1902 (Continued)

(Thousand Dollars)

\begin{tabular}{|c|c|c|c|c|c|c|}
\hline Item & $\begin{array}{l}\text { Minnesota } \\
\text { Minnesota } \\
\text { Power } \\
\text { Light Co }\end{array}$ & $\begin{array}{l}\text { Minneseta } \\
\text { Northern } \\
\text { States } \\
\text { Power Co }\end{array}$ & $\begin{array}{c}\text { Minnesota } \\
\text { Otter } \\
\text { Tall } \\
\text { Power } \\
\text { Co }\end{array}$ & $\begin{array}{l}\text { Miasisalppl } \\
\text { Misalsaippl } \\
\text { Power } \\
\text { Light Co }\end{array}$ & $\begin{array}{l}\text { Misedesippl } \\
\text { Miseiselppi } \\
\text { Power Co }\end{array}$ & $\begin{array}{l}\text { Misalealppl } \\
\text { Syatem } \\
\text { Energy } \\
\text { Resources } \\
\text { Inc }\end{array}$ \\
\hline 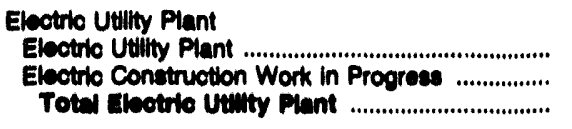 & $\begin{array}{r}1,106,637 \\
19,623 \\
1,126,061\end{array}$ & $\begin{array}{r}5,042,100 \\
133,191 \\
5,178,201\end{array}$ & $\begin{array}{r}682,055 \\
6,812 \\
608,807\end{array}$ & $\begin{array}{r}1,364,464 \\
25,879 \\
1,390,343\end{array}$ & $\begin{array}{r}1,180,505 \\
41,692 \\
1,222,107\end{array}$ & $\begin{array}{r}3,456,568 \\
30,689 \\
3,407,216\end{array}$ \\
\hline 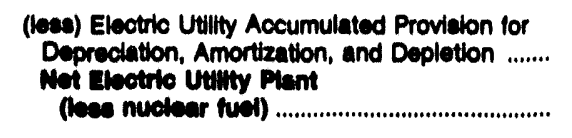 & $\begin{array}{l}389,672 \\
726,400\end{array}$ & $\begin{array}{l}2,050,816 \\
3,124,476\end{array}$ & $\begin{array}{l}248,256 \\
420,611\end{array}$ & $\begin{array}{l}649,160 \\
841,103\end{array}$ & $\begin{array}{l}440,777 \\
701,420\end{array}$ & $\begin{array}{r}572,303 \\
2,014,014\end{array}$ \\
\hline 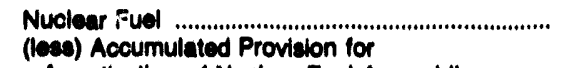 & 0 & 711,517 & 0 & 0 & 0 & 67,891 \\
\hline 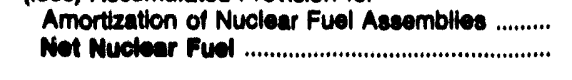 & : & $\begin{array}{r}630,549 \\
60,000\end{array}$ & $\begin{array}{l}0 \\
0\end{array}$ & $\begin{array}{l}0 \\
0\end{array}$ & $\begin{array}{l}0 \\
0\end{array}$ & 07,001 \\
\hline 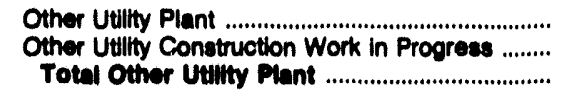 & $\begin{array}{l}0 \\
0 \\
0\end{array}$ & $\begin{array}{r}583,007 \\
14,248 \\
577,254\end{array}$ & $\begin{array}{l}0 \\
0 \\
0\end{array}$ & $\begin{array}{l}0 \\
0 \\
0\end{array}$ & $\begin{array}{l}0 \\
0 \\
0\end{array}$ & $\begin{array}{l}0 \\
0 \\
0\end{array}$ \\
\hline 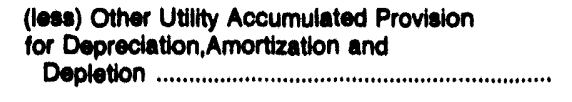 & 0 & 242,003 & 0 & 0 & 0 & 0 \\
\hline 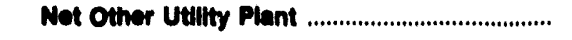 & $\mathbf{0}$ & 335,252 & 0 & 0 & $\mathbf{0}$ & $\mathbf{0}$ \\
\hline 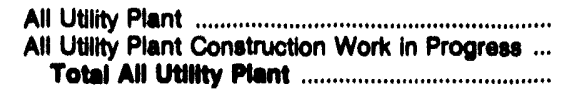 & $\begin{array}{r}1,106,537 \\
19,523 \\
1,120,061\end{array}$ & $\begin{array}{r}6,316,624 \\
147,439 \\
0,464,003\end{array}$ & $\begin{array}{r}662,055 \\
6,812 \\
668,867\end{array}$ & $\begin{array}{r}1,364,464 \\
25,879 \\
1,300,343\end{array}$ & $\begin{array}{r}1,180,505 \\
41,692 \\
1,222,197\end{array}$ & $\begin{array}{r}3,524,549 \\
30,659 \\
3,565,207\end{array}$ \\
\hline 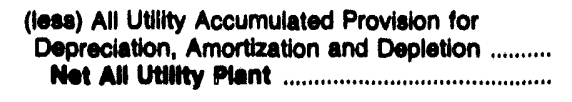 & $\begin{array}{l}389,572 \\
726,480\end{array}$ & $\begin{array}{l}2,923,367 \\
3,640,695\end{array}$ & $\begin{array}{l}248,255 \\
420,611\end{array}$ & $\begin{array}{l}549,160 \\
841,193\end{array}$ & $\begin{array}{l}440,777 \\
781,480\end{array}$ & $\begin{array}{r}572,303 \\
2,092,006\end{array}$ \\
\hline 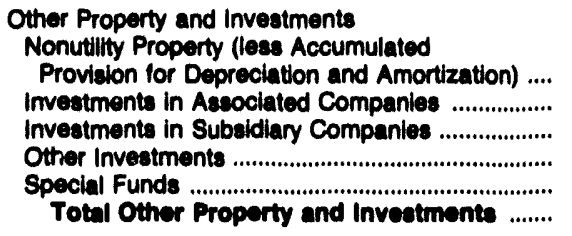 & $\begin{array}{r}7,105 \\
54,551 \\
196,691 \\
198,547 \\
486 \\
485,370\end{array}$ & $\begin{array}{r}51,740 \\
0 \\
340,728 \\
19,016 \\
68,802 \\
440,286\end{array}$ & $\begin{array}{r}950 \\
0 \\
15,206 \\
i 1,069 \\
6,933 \\
34,160\end{array}$ & $\begin{array}{r}4,362 \\
0 \\
5,531 \\
20 \\
0 \\
9,913\end{array}$ & $\begin{array}{r}3,446 \\
0 \\
0 \\
979 \\
282 \\
4,707\end{array}$ & $\begin{array}{r}0 \\
0 \\
0 \\
0 \\
19,127 \\
19,127\end{array}$ \\
\hline 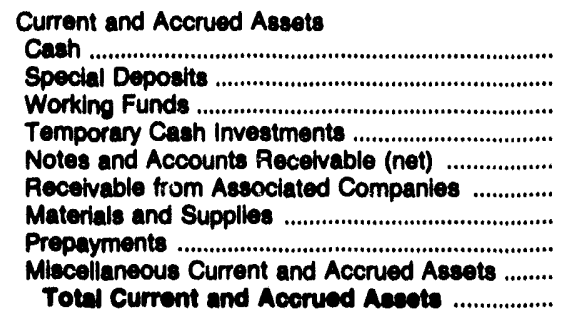 & $\begin{array}{r}108 \\
1,489 \\
170 \\
4,827 \\
28,767 \\
53,651 \\
21,070 \\
7,650 \\
11,807 \\
129,683\end{array}$ & $\begin{array}{r}7,059 \\
0 \\
301 \\
3,843 \\
202,409 \\
42,764 \\
133,011 \\
8,953 \\
99,794 \\
498,134\end{array}$ & $\begin{array}{r}469 \\
0 \\
46 \\
15,500 \\
12,768 \\
98 \\
11,823 \\
469 \\
114 \\
41,208\end{array}$ & $\begin{array}{r}-3,683 \\
7,121 \\
90 \\
0 \\
55,878 \\
34,175 \\
28,797 \\
1,026 \\
79,076 \\
202,479\end{array}$ & $\begin{array}{r}2,353 \\
135 \\
114 \\
4,951 \\
24,404 \\
3,532 \\
43,449 \\
1,651 \\
22,020 \\
102,610\end{array}$ & $\begin{array}{r}-278 \\
0 \\
183 \\
180,795 \\
4,871 \\
60,602 \\
71,680 \\
2,120 \\
924 \\
320,377\end{array}$ \\
\hline $\begin{array}{l}\text { Deferred Deblts } \\
\text { Unamortized Debt Expense ................................... } \\
\text { Extraordinary Property Losese .......................... } \\
\text { Unrecovered Plant and Regulatory Study Cost ... } \\
\text { Preliminary Survey and Investigation Charges .... } \\
\text { Clearing Accounts ............................................. } \\
\text { Deferred Losees trom Dieposition of Utility Plant } \\
\text { Research, Development and Demonstration }\end{array}$ & $\begin{array}{r}4,847 \\
0 \\
0 \\
2,246 \\
204 \\
0\end{array}$ & $\begin{array}{r}8,445 \\
0 \\
0 \\
-17 \\
2,397 \\
0\end{array}$ & $\begin{array}{r}1,611 \\
0 \\
592 \\
40 \\
234 \\
0\end{array}$ & $\begin{array}{r}1,977 \\
0 \\
0 \\
0 \\
-641 \\
0\end{array}$ & $\begin{array}{r}804 \\
0 \\
0 \\
307 \\
11 \\
0\end{array}$ & $\begin{array}{r}17,371 \\
0 \\
0 \\
0 \\
-492 \\
0\end{array}$ \\
\hline 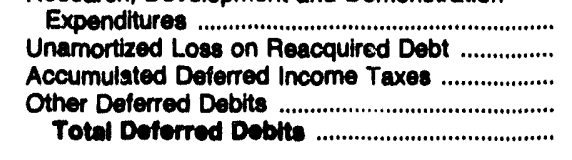 & $\begin{array}{r}0 \\
7,753 \\
29,954 \\
40,930 \\
85,935\end{array}$ & $\begin{array}{r}0 \\
28,148 \\
143,568 \\
228,031 \\
410,570\end{array}$ & $\begin{array}{r}0 \\
4,279 \\
8,593 \\
2,046 \\
17,396\end{array}$ & $\begin{array}{r}0 \\
3,351 \\
52,228 \\
607,206 \\
664,122\end{array}$ & $\begin{array}{r}901 \\
10,102 \\
19,966 \\
28,581 \\
80,071\end{array}$ & $\begin{array}{r}0 \\
14,723 \\
183,278 \\
302,248 \\
517,127\end{array}$ \\
\hline Total Asects and Other Deblte . & $1,307,441$ & $4,029,695$ & 513,452 & $1,717,708$ & 949,407 & $3,840,038$ \\
\hline
\end{tabular}

See endnotes at end of an individual electric utility. 
Table 38. Balance Sheot by Major U.8. Investor-Owned Electric Utillty Within State on December 31, 1992 (Continued) (Thousand Dollars)

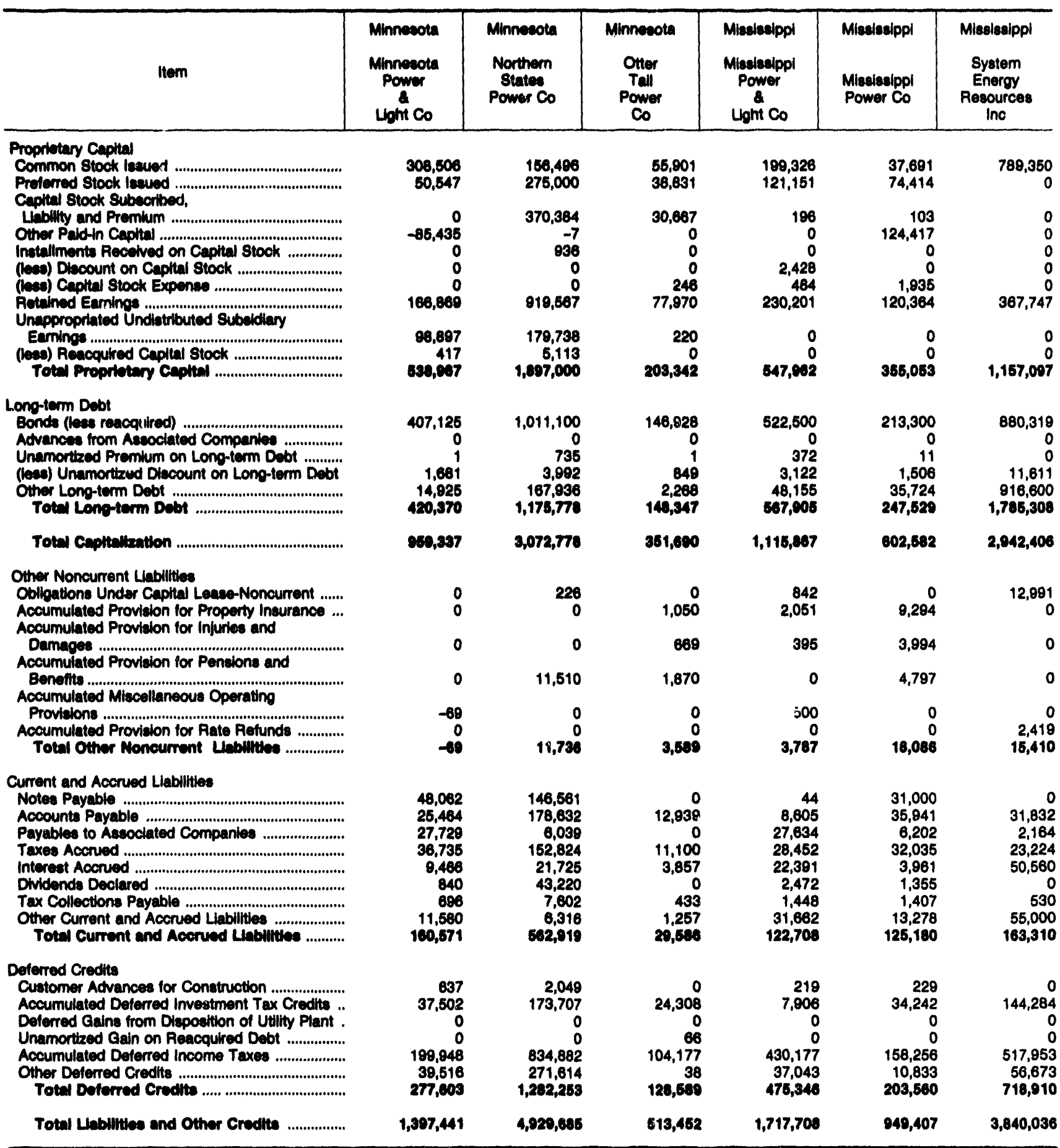

Note: Totals may not equal sum of components because of independent rounding. Summary data are provided in Table 8.

Source: Federal Energy Requlatory Commiecion, FERC Form 1, "Annual Report of Major Electric Utilities, Llcensees and Others." 
Table 38. Balance Sheet by Major U.S. Investor-Owned Electric Utillty Within State on December 31, 1992 (Continued) (Thousand Dollars)

\begin{tabular}{|c|c|c|c|c|c|c|}
\hline Item & $\begin{array}{l}\text { Mlesouri } \\
\text { Emplre } \\
\text { Dlatrict } \\
\text { Electric Co }\end{array}$ & $\begin{array}{c}\text { Milesouri } \\
\text { Kansas City } \\
\text { Power \& Light } \\
\text { Co }\end{array}$ & $\begin{array}{l}\text { Miseourt } \\
\text { St Joseph } \\
\text { Light } \\
\& \\
\text { Power Co }\end{array}$ & $\begin{array}{l}\text { Miseourt } \\
\text { Union } \\
\text { Electric Co }\end{array}$ & $\begin{array}{l}\text { Miseourt } \\
\text { Utilicorp } \\
\text { United Inc }\end{array}$ & $\begin{array}{l}\text { Moniana } \\
\text { Montana } \\
\text { Power Co }\end{array}$ \\
\hline 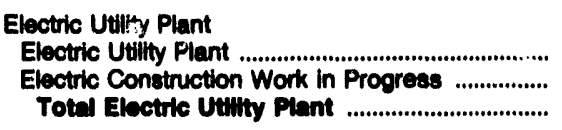 & $\begin{array}{r}538,990 \\
3,366 \\
542,368\end{array}$ & $\begin{array}{r}3,133,059 \\
65,866 \\
3,190,024\end{array}$ & $\begin{array}{r}255,658 \\
1,964 \\
257,022\end{array}$ & $\begin{array}{r}7,137,489 \\
131,581 \\
7,200,070\end{array}$ & $\begin{array}{l}1,136,2 \\
1,1^{35}\end{array}$ & $\therefore$ \\
\hline 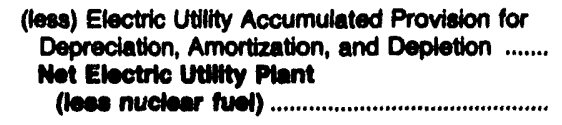 & $\begin{array}{l}177,883 \\
364,473\end{array}$ & $\begin{array}{r}948,266 \\
2,260,788\end{array}$ & $\begin{array}{l}119,756 \\
137,806\end{array}$ & $\begin{array}{l}2,329,363 \\
4,939,707\end{array}$ & $\begin{array}{l}\text { 415, } \\
760,01:\end{array}$ & 12. 358 \\
\hline 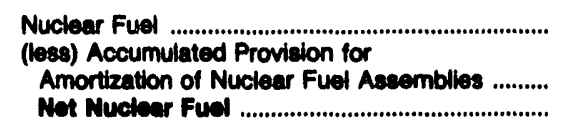 & $\begin{array}{l}0 \\
0 \\
0\end{array}$ & $\begin{array}{r}112,945 \\
78,736 \\
34,210\end{array}$ & $\begin{array}{l}0 \\
0 \\
0\end{array}$ & $\begin{array}{l}557,360 \\
395,886 \\
161,474\end{array}$ & $\begin{array}{l}0 \\
0 \\
0\end{array}$ & $\begin{array}{l}0 \\
0 \\
0\end{array}$ \\
\hline 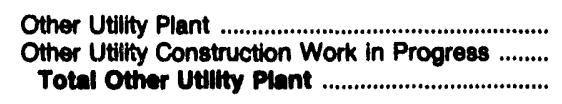 & $\begin{array}{r}4,333 \\
0 \\
4,333\end{array}$ & $\begin{array}{l}0 \\
0 \\
0\end{array}$ & $\begin{array}{r}9,412 \\
51 \\
9,463\end{array}$ & $\begin{array}{r}139,805 \\
1,555 \\
141,300\end{array}$ & $\begin{array}{r}811,300 \\
8,382 \\
819,682\end{array}$ & $\begin{array}{r}365,454 \\
1,167 \\
368,621\end{array}$ \\
\hline 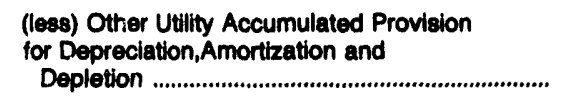 & 1,369 & 0 & 3,948 & 42,684 & 290,067 & 127,718 \\
\hline 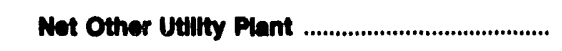 & 2,064 & $\mathbf{0}$ & 6,514 & 88,678 & 529,616 & 238,003 \\
\hline 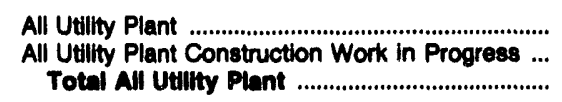 & $\begin{array}{r}543,323 \\
3,366 \\
546,680\end{array}$ & $\begin{array}{r}3,246,004 \\
65,968 \\
3,311,970\end{array}$ & $\begin{array}{r}265,071 \\
2,014 \\
287,085\end{array}$ & $\begin{array}{r}7,834,654 \\
133,136 \\
7,267,700\end{array}$ & $\begin{array}{r}1,947,645 \\
44,096 \\
1,001,741\end{array}$ & $\begin{array}{r}1,761,838 \\
20,900 \\
1,72,730\end{array}$ \\
\hline 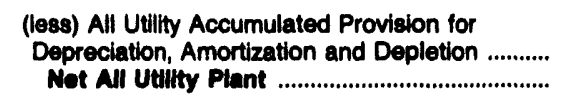 & $\begin{array}{l}179,252 \\
367,437\end{array}$ & $\begin{array}{l}1,027,002 \\
2,284,96\end{array}$ & $\begin{array}{l}123,704 \\
143,381\end{array}$ & $\begin{array}{l}2,767,934 \\
5,190,856\end{array}$ & $\begin{array}{r}705.314 \\
1,286,426\end{array}$ & $\begin{array}{r}524,980 \\
1,257,758\end{array}$ \\
\hline 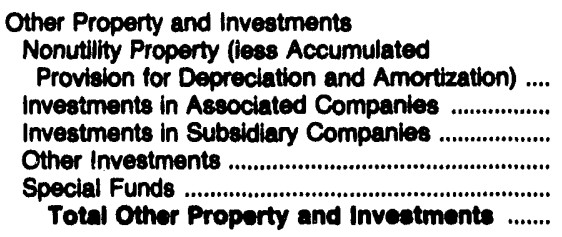 & $\begin{array}{r}8 \\
0 \\
0 \\
234 \\
0 \\
241\end{array}$ & $\begin{array}{r}4,: \\
u \\
2,256 \\
6,390 \\
14,774 \\
27,560\end{array}$ & $\begin{array}{r}44 \\
0 \\
0 \\
258 \\
0 \\
302\end{array}$ & $\begin{array}{r}1,518 \\
0 \\
1,482 \\
2,104 \\
42,387 \\
47,491\end{array}$ & $\begin{array}{r}1,642 \\
0 \\
236,748 \\
28,552 \\
0 \\
287,941\end{array}$ & $\begin{array}{r}1,280 \\
0 \\
299,066 \\
60,210 \\
2,780 \\
303,336\end{array}$ \\
\hline 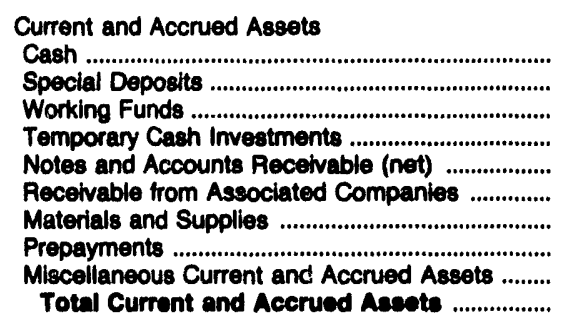 & $\begin{array}{r}550 \\
21 \\
256 \\
2,800 \\
10,475 \\
0 \\
11,182 \\
419 \\
5,386 \\
31,008\end{array}$ & $\begin{array}{r}0 \\
0 \\
128 \\
0 \\
11,419 \\
0 \\
65,887 \\
12,968 \\
26,996 \\
117,390\end{array}$ & $\begin{array}{r}42 \\
0 \\
238 \\
4,226 \\
10,170 \\
0 \\
9,909 \\
428 \\
4 \\
25,017\end{array}$ & $\begin{array}{r}1,820 \\
47,826 \\
437 \\
0 \\
162,425 \\
9,391 \\
187,634 \\
11,883 \\
82,370 \\
603,786\end{array}$ & $\begin{array}{r}-7,777 \\
65 \\
892 \\
10,000 \\
11,573 \\
38,895 \\
45,141 \\
12,297 \\
96,451 \\
207,630\end{array}$ & $\begin{array}{r}648 \\
6 \\
167 \\
0 \\
64,127 \\
49,338 \\
23,162 \\
6,617 \\
21,840 \\
165,008\end{array}$ \\
\hline $\begin{array}{l}\text { Deferred Deblts } \\
\text { Unamortized Debt Expense .................................. } \\
\text { Extraordinary Property Losses .......................... } \\
\text { Unrecovered Plant and Regulatory Study Cost .. } \\
\text { Preliminary Survey and Investigation Charges .... } \\
\text { Clearing Accounts ............................................... } \\
\text { Deferred Losses trom Disposition of Utility Plant } \\
\text { Research, Development and Demonstration }\end{array}$ & $\begin{array}{r}3,814 \\
0 \\
0 \\
155 \\
28 \\
0\end{array}$ & $\begin{array}{r}3,990 \\
0 \\
0 \\
19 \\
141 \\
0\end{array}$ & $\begin{array}{r}276 \\
0 \\
0 \\
177 \\
79 \\
0\end{array}$ & $\begin{array}{r}9,188 \\
0 \\
1,671 \\
0 \\
1,569 \\
0\end{array}$ & $\begin{array}{r}9,802 \\
0 \\
312 \\
934 \\
-93 \\
0\end{array}$ & $\begin{array}{r}2,112 \\
0 \\
0 \\
743 \\
283 \\
0\end{array}$ \\
\hline 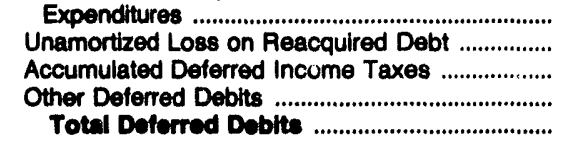 & $\begin{array}{r}0 \\
2,737 \\
510 \\
1,430 \\
8,476\end{array}$ & $\begin{array}{r}85 \\
8,593 \\
5,553 \\
198,605 \\
216,286\end{array}$ & $\begin{array}{r}0 \\
532 \\
990 \\
8,597 \\
10,850\end{array}$ & $\begin{array}{r}0 \\
27,410 \\
23,678 \\
6,392 \\
00,908\end{array}$ & $\begin{array}{r}33 \\
11,358 \\
2,671 \\
27,156 \\
52,473\end{array}$ & $\begin{array}{r}0 \\
8,604 \\
29,402 \\
263,018 \\
304,162\end{array}$ \\
\hline Total Aceots and Other Doblte .......................... & 407,240 & $2,646,023$ & 179,350 & $5,621,041$ & $1,814,478$ & $2,001,161$ \\
\hline
\end{tabular}

See endnotes at end of an individual electric utility. 
Table 38. Balance Sheet by Major U.S. Investor-Owned Electric Utility Within State on December 31, 1982 (Continued)

(Thousand Dollars)

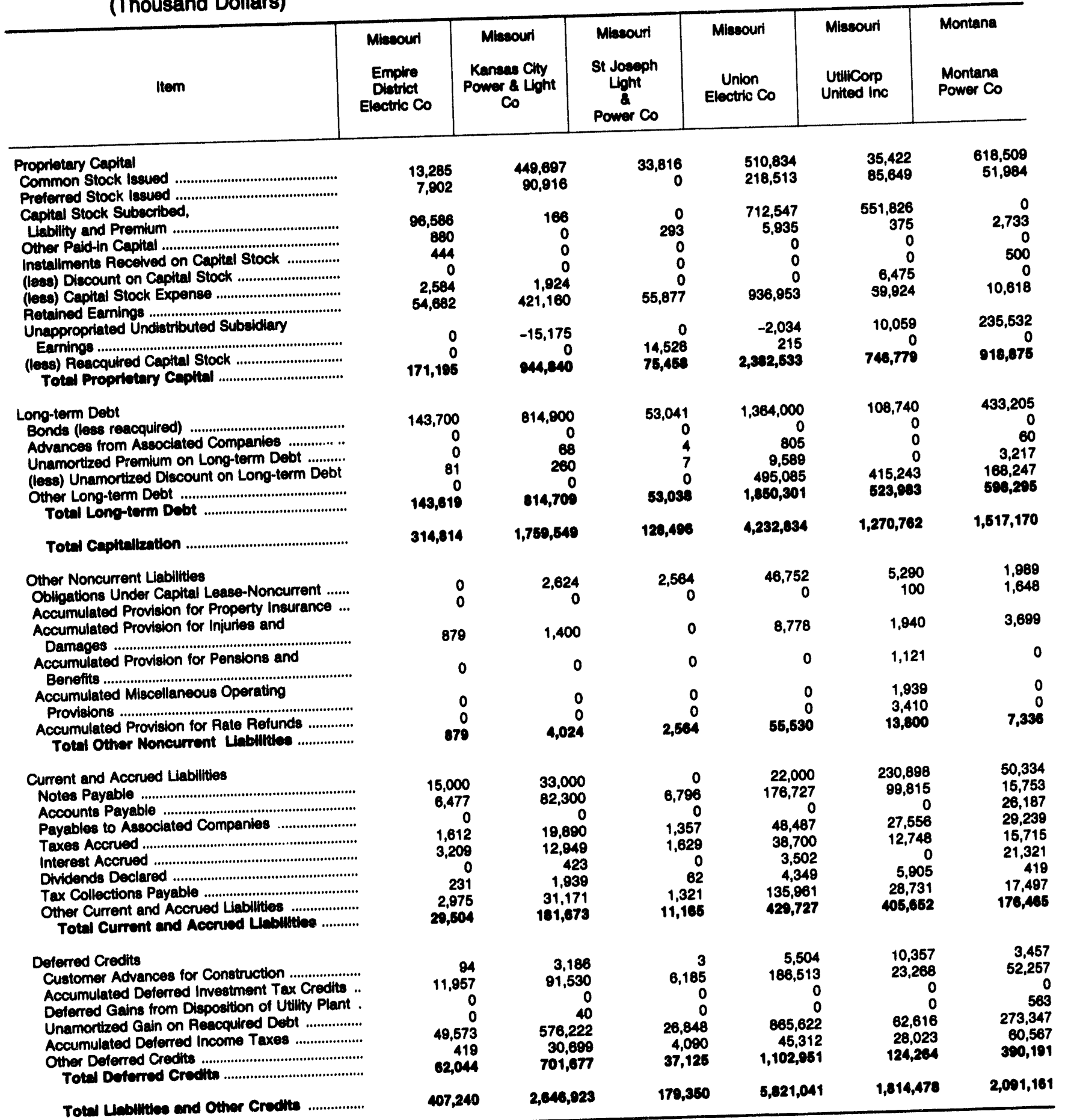

Totel unbilites and other Crodits

Note: Totals may not equal sum of components because of independent rounding. Summary data are provided in Table 8.

sum of components because of independent rounding. Summary data are provided in Tables

Source: Federal Energy Regulatory Commiseion, FERC Form 1, "Annual Report of Mapr Electrio Uthties, Licensees and Others." 
Table 38. Balance Sheet by Major U.S. Investor-Owned Electric Utility Within State on December 31, 1992 (Continued)

(Thousand Dollars)

\begin{tabular}{|c|c|c|c|c|c|c|}
\hline Item & $\begin{array}{l}\text { Novada } \\
\text { Nevada } \\
\text { Power Co }\end{array}$ & $\begin{array}{l}\text { Nevada } \\
\text { Slerra } \\
\text { Pactilic } \\
\text { Power Co }\end{array}$ & \begin{tabular}{|c|} 
Now Hampehire \\
Great \\
Bay \\
Power \\
Corp \\
\end{tabular} & $\begin{array}{c}\text { Now Hampshire } \\
\text { Now England } \\
\text { Elec } \\
\text { Tranemn } \\
\text { Corp }\end{array}$ & $\begin{array}{c}\text { Now Hampshire } \\
\text { Now England } \\
\text { Hydro- } \\
\text { Trans } \\
\text { Corp }\end{array}$ & $\begin{array}{l}\text { Now Hampshire } \\
\text { North } \\
\text { Atlantic } \\
\text { Energy Corp }\end{array}$ \\
\hline 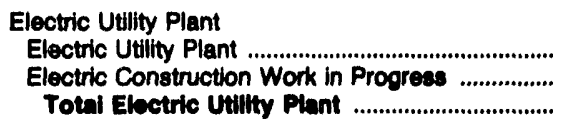 & $\begin{array}{r}1,587,541 \\
172,092 \\
1,730,633\end{array}$ & $\begin{array}{r}1,189,063 \\
20,931 \\
1,210,004\end{array}$ & $\begin{array}{r}611,816 \\
1,876 \\
613,792\end{array}$ & $\begin{array}{r}91,178 \\
0 \\
91,178\end{array}$ & $\begin{array}{r}171,101 \\
0 \\
171,101\end{array}$ & $\begin{array}{r}673,025 \\
4,775 \\
677,000\end{array}$ \\
\hline $\begin{array}{l}\text { (less) Electric Utility Accumulated Provision for } \\
\text { Depreciation, Amortization, and Depletion ........ } \\
\text { Not Electric Utilty Plant } \\
\text { (loes nuclear fuel) ............................................ }\end{array}$ & $\begin{array}{r}410,963 \\
1,326,670\end{array}$ & $\begin{array}{l}345,844 \\
874,160\end{array}$ & $\begin{array}{l}209,187 \\
304,605\end{array}$ & $\begin{array}{l}28,659 \\
02,520\end{array}$ & $\begin{array}{r}11,914 \\
150,186\end{array}$ & $\begin{array}{r}36,327 \\
641,474\end{array}$ \\
\hline 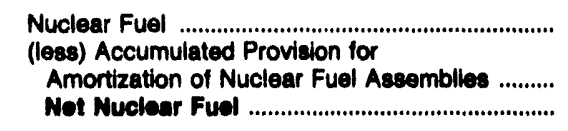 & $\begin{array}{l}0 \\
0 \\
0\end{array}$ & $\begin{array}{l}0 \\
0\end{array}$ & $\begin{array}{r}22,828 \\
8,444 \\
14,306\end{array}$ & $\begin{array}{l}0 \\
0\end{array}$ & $\begin{array}{l}0 \\
0\end{array}$ & $\begin{array}{r}13,811 \\
573 \\
13,389\end{array}$ \\
\hline 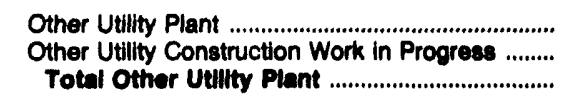 & $\begin{array}{l}0 \\
0 \\
0\end{array}$ & $\begin{array}{r}321,994 \\
43,864 \\
305,040\end{array}$ & $\begin{array}{l}0 \\
0 \\
0\end{array}$ & $\begin{array}{l}0 \\
0 \\
0\end{array}$ & $\begin{array}{l}0 \\
0 \\
0\end{array}$ & $\begin{array}{l}0 \\
0 \\
0\end{array}$ \\
\hline 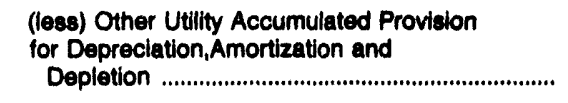 & 0 & 80,057 & 0 & 0 & 0 & 0 \\
\hline 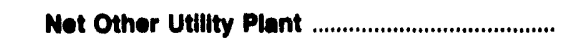 & 0 & 286,701 & 0 & 0 & 0 & 0 \\
\hline 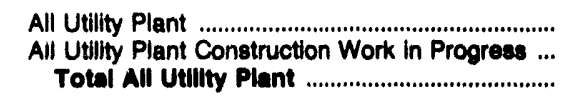 & $\begin{array}{r}1,567,541 \\
172,092 \\
1,739,638\end{array}$ & $\begin{array}{r}1,621,057 \\
64,785 \\
1,685,842\end{array}$ & $\begin{array}{r}534,644 \\
1,976 \\
538,620\end{array}$ & $\begin{array}{r}91,178 \\
0 \\
01,178\end{array}$ & $\begin{array}{r}171,101 \\
0 \\
171,101\end{array}$ & $\begin{array}{r}686,936 \\
4,775 \\
601,712\end{array}$ \\
\hline 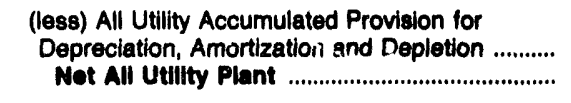 & $\begin{array}{r}410,963 \\
1,328,670\end{array}$ & $\begin{array}{r}425,801 \\
1,150,041\end{array}$ & $\begin{array}{l}217,631 \\
318,989\end{array}$ & $\begin{array}{l}28,659 \\
62,520\end{array}$ & $\begin{array}{r}11,914 \\
150,186\end{array}$ & $\begin{array}{r}36,900 \\
654,812\end{array}$ \\
\hline 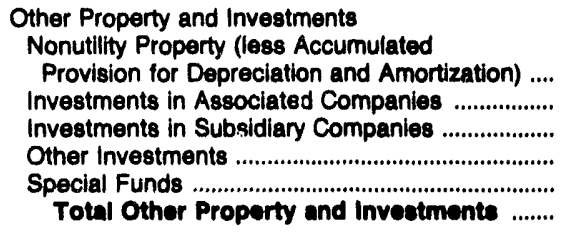 & $\begin{array}{r}206 \\
0 \\
13,135 \\
5,824 \\
0 \\
10,184\end{array}$ & $\begin{array}{r}1,898 \\
0 \\
0 \\
6 \\
0 \\
1,904\end{array}$ & $\begin{array}{l}0 \\
0 \\
0 \\
0 \\
0 \\
0\end{array}$ & $\begin{array}{l}0 \\
0 \\
0 \\
0 \\
0 \\
0\end{array}$ & $\begin{array}{l}0 \\
0 \\
5 \\
0 \\
0 \\
5\end{array}$ & $\begin{array}{r}0 \\
0 \\
0 \\
88,818 \\
0 \\
88,818\end{array}$ \\
\hline 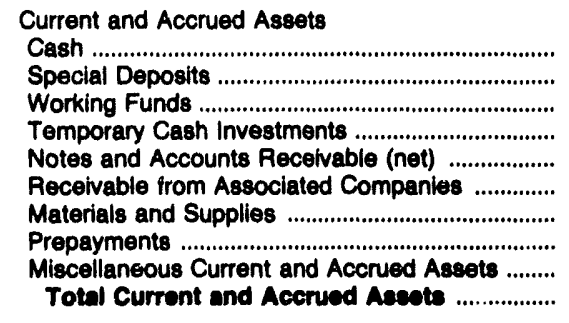 & $\begin{array}{r}-16,335 \\
174 \\
35 \\
0 \\
40,324 \\
0 \\
45,816 \\
9,151 \\
10,361 \\
80,526\end{array}$ & $\begin{array}{r}-5,057 \\
0 \\
24 \\
15,000 \\
36,585 \\
468 \\
28,544 \\
116 \\
16,233 \\
91,920\end{array}$ & $\begin{array}{r}26 \\
1 \\
0 \\
4,790 \\
2,373 \\
0 \\
0 \\
2,510 \\
0 \\
9,700\end{array}$ & $\begin{array}{r}5 \\
0 \\
0 \\
0 \\
0 \\
0 \\
1,457 \\
78 \\
0 \\
1,641\end{array}$ & $\begin{array}{r}22 \\
0 \\
0 \\
0 \\
15 \\
1,809 \\
0 \\
167 \\
40 \\
2,023\end{array}$ & $\begin{array}{r}251 \\
0 \\
0 \\
0 \\
0 \\
22,842 \\
5,361 \\
8,209 \\
0 \\
36,664\end{array}$ \\
\hline 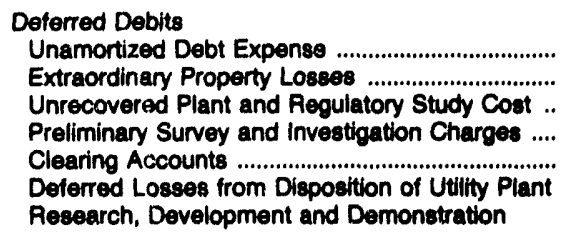 & $\begin{array}{r}13,239 \\
0 \\
832 \\
8,417 \\
2,250 \\
0\end{array}$ & $\begin{array}{r}8,712 \\
0 \\
1,732 \\
0 \\
-323 \\
0\end{array}$ & $\begin{array}{r}5,060 \\
0 \\
0 \\
0 \\
0 \\
0\end{array}$ & $\begin{array}{r}546 \\
0 \\
0 \\
0 \\
0 \\
0\end{array}$ & $\begin{array}{r}650 \\
0 \\
0 \\
0 \\
0 \\
0\end{array}$ & $\begin{array}{r}6,179 \\
0 \\
0 \\
0 \\
-45 \\
0\end{array}$ \\
\hline 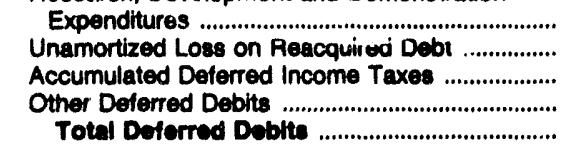 & $\begin{array}{r}0 \\
12,264 \\
21,825 \\
44,382 \\
103,219\end{array}$ & $\begin{array}{r}0 \\
8,989 \\
20,009 \\
101,291 \\
140,400\end{array}$ & $\begin{array}{r}0 \\
0 \\
12,379 \\
0 \\
17,448\end{array}$ & $\begin{array}{r}0 \\
0 \\
351 \\
0 \\
897\end{array}$ & $\begin{array}{r}0 \\
0 \\
32 \\
1,287 \\
1,970\end{array}$ & $\begin{array}{r}0 \\
0 \\
7,751 \\
29,385 \\
43,270\end{array}$ \\
\hline Total Acecte and Other Debits ......................... & $1,540,680$ & $1,304,174$ & 348,137 & 64,058 & 163,184 & 823,664 \\
\hline
\end{tabular}

See endnotes at end of an individual electric utility. 
Table 38. Balance Sheet by Major U.S. Inveotor-Owned Electric Utility Within State on Decomber 31, 1992 (Continued) (Thousand Dollars)

\begin{tabular}{|c|c|c|c|c|c|c|}
\hline Item & $\begin{array}{l}\text { Nevada } \\
\text { Nevada } \\
\text { Power Co }\end{array}$ & $\begin{array}{c}\text { Neveda } \\
\text { Slerra } \\
\text { Pacific } \\
\text { Power Co }\end{array}$ & $\begin{array}{c}\text { New Hampehire } \\
\text { Great } \\
\text { Bay } \\
\text { Power } \\
\text { Corp }\end{array}$ & $\begin{array}{c}\text { New Hampehire } \\
\text { New England } \\
\text { Eloc } \\
\text { Transmn } \\
\text { Corp }\end{array}$ & $\begin{array}{c}\text { Now Hampenire } \\
\text { New England } \\
\text { Hydro- } \\
\text { Trans } \\
\text { Corp }\end{array}$ & $\begin{array}{c}\text { Now Hampahire } \\
\text { North } \\
\text { Atlantic } \\
\text { Energy Corp }\end{array}$ \\
\hline 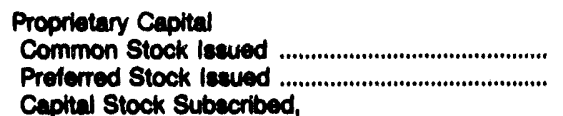 & $\begin{array}{l}40,337 \\
42,464\end{array}$ & $\begin{array}{r}4 \\
107,115\end{array}$ & $\begin{array}{r}0 \\
68,080\end{array}$ & $\begin{array}{l}1 \\
0\end{array}$ & $\begin{array}{r}115 \\
0\end{array}$ & $\begin{array}{l}1 \\
0\end{array}$ \\
\hline 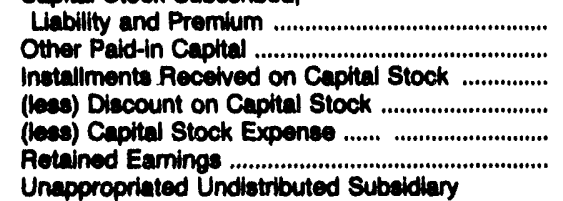 & $\begin{array}{r}393,396 \\
5 \\
0 \\
0 \\
3,757 \\
113,416\end{array}$ & $\begin{array}{r}180,491 \\
139,982 \\
0 \\
0 \\
0 \\
98,021\end{array}$ & $\begin{array}{r}10 \\
63,100 \\
0 \\
0 \\
0 \\
-130,381\end{array}$ & $\begin{array}{r}184 \\
4,680 \\
0 \\
0 \\
0 \\
248\end{array}$ & $\begin{array}{r}22,885 \\
18,949 \\
0 \\
0 \\
0 \\
4,864\end{array}$ & $\begin{array}{r}160,899 \\
0 \\
0 \\
0 \\
0 \\
12,703\end{array}$ \\
\hline 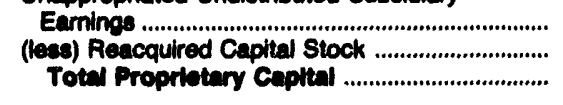 & $\begin{array}{r}-10,823 \\
0 \\
674,088\end{array}$ & $\begin{array}{r}0 \\
0 \\
638,612\end{array}$ & $\begin{array}{r}0 \\
68,100 \\
-67,281\end{array}$ & $\begin{array}{r}0 \\
0 \\
6,123\end{array}$ & $\begin{array}{r}0 \\
0 \\
4,913\end{array}$ & $\begin{array}{r}0 \\
0 \\
173,708\end{array}$ \\
\hline 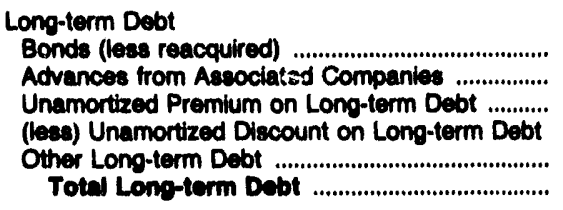 & $\begin{array}{r}435,445 \\
0 \\
14 \\
80 \\
171,115 \\
608,404\end{array}$ & $\begin{array}{r}239,800 \\
0 \\
234 \\
1,616 \\
284,763 \\
603,182\end{array}$ & $\begin{array}{r}180,000 \\
0 \\
0 \\
0 \\
0 \\
180,000\end{array}$ & $\begin{array}{r}0 \\
0 \\
0 \\
0 \\
43,392 \\
43,302\end{array}$ & $\begin{array}{r}0 \\
74,720 \\
0 \\
0 \\
0 \\
74,720\end{array}$ & $\begin{array}{r}355,000 \\
0 \\
0 \\
0 \\
205,000 \\
860,000\end{array}$ \\
\hline Total Ceppitallention ................................................. & $1,181,432$ & $1,086,705$ & 112,730 & 4,615 & 121,638 & 733,703 \\
\hline $\begin{array}{l}\text { Other Noncurrent Llabillites } \\
\text { Obligations Under Capltal Lease-Noncurrent ...... } \\
\text { Accumulated Provision for Property Insurance ... } \\
\text { Accumulated Provision for Injurles and }\end{array}$ & $\begin{array}{r}108,956 \\
0\end{array}$ & $\begin{array}{l}0 \\
0\end{array}$ & $\begin{array}{l}0 \\
0\end{array}$ & $\begin{array}{l}0 \\
0\end{array}$ & $\begin{array}{r}30,826 \\
0\end{array}$ & $\begin{array}{l}0 \\
0\end{array}$ \\
\hline $\begin{array}{l}\text { Damages ... Accumulated Provision for Pensions and } \\
\text { Ac...... }\end{array}$ & 0 & 1,537 & 0 & 0 & 0 & 0 \\
\hline $\begin{array}{l}\text { Benefits .... } \\
\text { Accumulated Miscellaneous Operating }\end{array}$ & 0 & 868 & 0 & 0 & 0 & 0 \\
\hline 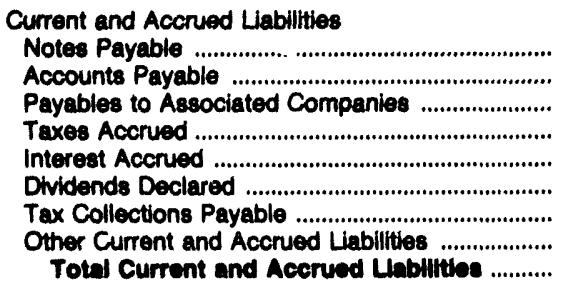 & $\begin{array}{r}0 \\
27,368 \\
0 \\
1,375 \\
7,178 \\
1,444 \\
-5 \\
34,967 \\
72,327\end{array}$ & $\begin{array}{r}0 \\
30,084 \\
555 \\
1,027 \\
8,208 \\
0 \\
1,680 \\
8,767 \\
80,301\end{array}$ & $\begin{array}{r}0 \\
318 \\
36 \\
442 \\
14,126 \\
0 \\
0 \\
100,084 \\
114,986\end{array}$ & $\begin{array}{r}0 \\
97 \\
697 \\
127 \\
160 \\
234 \\
0 \\
49 \\
1,384\end{array}$ & $\begin{array}{r}0 \\
178 \\
321 \\
434 \\
282 \\
0 \\
0 \\
2,387 \\
3,683\end{array}$ & $\begin{array}{r}0 \\
760 \\
19,102 \\
-2,309 \\
18,288 \\
0 \\
0 \\
0 \\
38,841\end{array}$ \\
\hline 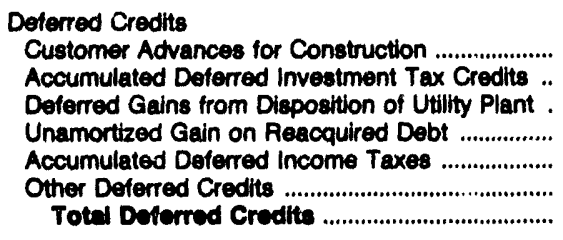 & $\begin{array}{r}26,803 \\
36,687 \\
0 \\
42 \\
91,380 \\
22,872 \\
177,865\end{array}$ & $\begin{array}{r}37,749 \\
49,592 \\
0 \\
0 \\
155,821 \\
61,414 \\
304,576\end{array}$ & $\begin{array}{r}0 \\
7,412 \\
0 \\
0 \\
66,823 \\
44,178 \\
118,412\end{array}$ & $\begin{array}{r}0 \\
5,419 \\
0 \\
0 \\
\theta, 680 \\
0 \\
16,070\end{array}$ & $\begin{array}{r}0 \\
1,283 \\
0 \\
0 \\
5,958 \\
0 \\
7,242\end{array}$ & $\begin{array}{r}0 \\
0 \\
0 \\
0 \\
16,146 \\
37,874 \\
54,020\end{array}$ \\
\hline Totai Unbilities and Other Credits ................. & $1,540,580$ & $1,394,174$ & 346,137 & 94,058 & 163,184 & 828,684 \\
\hline
\end{tabular}

Note: Totals may not equal sum of components because of independent rounding. Summary data are provided in Table 8.

Source: Federal Energy Regulatory Commission, FERC Form 1, "Annual Report of Major Electric Utilities, Lloensees and Others." 
Table 38. Balance Sheet by Major U.S. Investor-Owned Electric USIllty Within State on December 31, 1992 (Continued)

(Thousand Dollars)

\begin{tabular}{|c|c|c|c|c|c|c|}
\hline Item & $\begin{array}{c}\text { New Hempehire } \\
\text { Public } \\
\text { Service } \\
\text { Co } \\
\text { of NH }\end{array}$ & $\begin{array}{l}\text { Now Jersey } \\
\text { Atlantic } \\
\text { City } \\
\text { Electric } \\
\text { Co }\end{array}$ & $\begin{array}{l}\text { Now Jersey } \\
\text { Jersey } \\
\text { Central } \\
\text { Power\&Light } \\
\text { Co }\end{array}$ & $\begin{array}{l}\text { New Jersey } \\
\text { Public } \\
\text { Service } \\
\text { Electric\&Gas } \\
\text { Co }\end{array}$ & $\begin{array}{l}\text { Now Jersey } \\
\text { Rockland } \\
\text { Electric Co }\end{array}$ & $\begin{array}{c}\text { Now Mexico } \\
\text { Public } \\
\text { Sorvice } \\
\text { Co } \\
\text { of NM }\end{array}$ \\
\hline 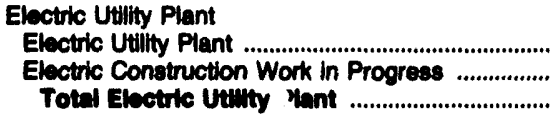 & $\begin{array}{r}1,887,722 \\
4,363 \\
1,002,005\end{array}$ & $\begin{array}{r}2,106,529 \\
130,685 \\
2,237,214\end{array}$ & $\begin{array}{r}3,715,332 \\
178,903 \\
3,094,235\end{array}$ & $\begin{array}{r}11,643,863 \\
407,680 \\
11,951,543\end{array}$ & $\begin{array}{r}134,365 \\
3,616 \\
137,981\end{array}$ & $\begin{array}{r}1,886,333 \\
64,080 \\
2,051,314\end{array}$ \\
\hline 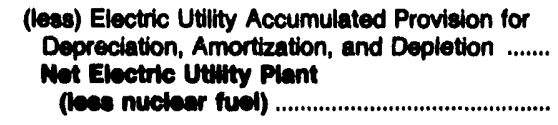 & $\begin{array}{r}410,089 \\
1,481,080\end{array}$ & $\begin{array}{r}598,100 \\
1,638,114\end{array}$ & $\begin{array}{l}1,262,562 \\
2,031,673\end{array}$ & $\begin{array}{l}3,438,650 \\
8,512,893\end{array}$ & $\begin{array}{r}34,530 \\
103,451\end{array}$ & $\begin{array}{r}606,578 \\
1,444,738\end{array}$ \\
\hline 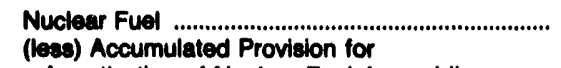 & 9,766 & 43,830 & 134,217 & 772,243 & 0 & 69,306 \\
\hline 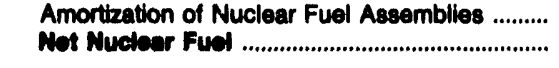 & $\begin{array}{l}7,430 \\
2,336\end{array}$ & $\begin{array}{r}0 \\
43,830\end{array}$ & $\begin{array}{r}0 \\
134,217\end{array}$ & $\begin{array}{l}569,458 \\
202,786\end{array}$ & $\begin{array}{l}0 \\
0\end{array}$ & $\begin{array}{l}25,476 \\
37,030\end{array}$ \\
\hline 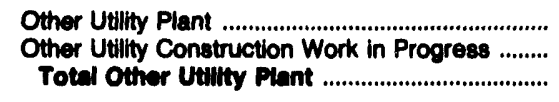 & $\begin{array}{l}0 \\
0 \\
0\end{array}$ & $\begin{array}{l}0 \\
0 \\
0\end{array}$ & $\begin{array}{l}0 \\
0 \\
0\end{array}$ & $\begin{array}{r}2,524,916 \\
16,444 \\
2,541,361\end{array}$ & $\begin{array}{l}0 \\
0 \\
0\end{array}$ & $\begin{array}{r}523,102 \\
21,749 \\
544,851\end{array}$ \\
\hline 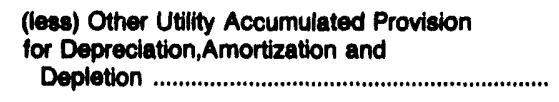 & 0 & 0 & 0 & 976,713 & 0 & 183,186 \\
\hline 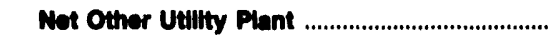 & 0 & $\mathbf{0}$ & 0 & $1,664,648$ & D & 301,685 \\
\hline 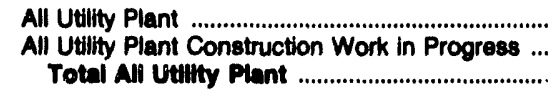 & $\begin{array}{r}1,897,489 \\
4,363 \\
1,001,852\end{array}$ & $\begin{array}{r}2,150,360 \\
130,685 \\
2,281,045\end{array}$ & $\begin{array}{r}3,849,549 \\
178,903 \\
4,028,452\end{array}$ & $\begin{array}{r}14,841,022 \\
424,125 \\
15,265,147\end{array}$ & $\begin{array}{r}134,365 \\
3,616 \\
137,981\end{array}$ & $\begin{array}{r}2,572,742 \\
86,729 \\
2,659,471\end{array}$ \\
\hline 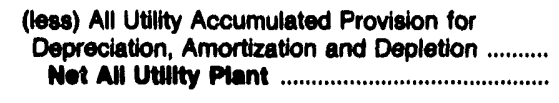 & $\begin{array}{r}417,519 \\
1,484,333\end{array}$ & $\begin{array}{r}589,100 \\
1,681,945\end{array}$ & $\begin{array}{l}1,262,562 \\
2,765,800\end{array}$ & $\begin{array}{r}4,984,820 \\
10,280,327\end{array}$ & $\begin{array}{r}34,530 \\
103,451\end{array}$ & $\begin{array}{r}815,240 \\
1,844,231\end{array}$ \\
\hline 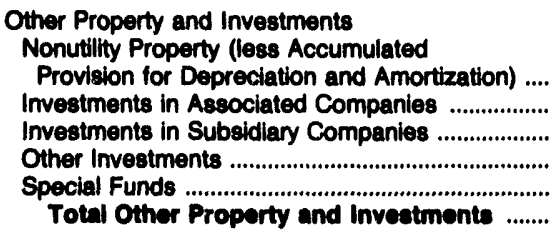 & $\begin{array}{r}278 \\
0 \\
19,917 \\
144 \\
1,148 \\
21,486\end{array}$ & $\begin{array}{r}1,286 \\
0 \\
3,620 \\
10 \\
34,929 \\
30,845\end{array}$ & $\begin{array}{r}746 \\
0 \\
0 \\
4,473 \\
114,657 \\
119,876\end{array}$ & $\begin{array}{r}19,829 \\
0 \\
6,831 \\
70,514 \\
134,524 \\
231,698\end{array}$ & $\begin{array}{r}17 \\
0 \\
6,488 \\
0 \\
0 \\
6,505\end{array}$ & $\begin{array}{r}6,670 \\
0 \\
0 \\
24,829 \\
3,831 \\
27,122 \\
62,853\end{array}$ \\
\hline 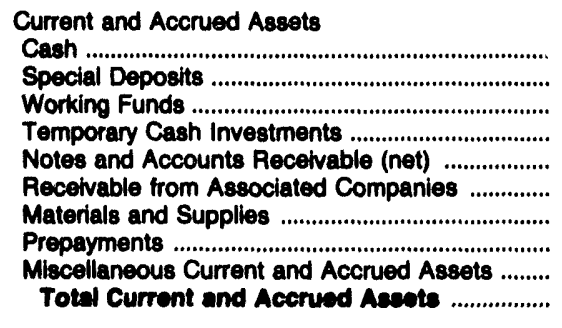 & $\begin{array}{r}1,876 \\
436 \\
15 \\
0 \\
73,585 \\
2,827 \\
45,123 \\
7,566 \\
33,810 \\
165,230\end{array}$ & $\begin{array}{r}3,173 \\
2 \\
15,415 \\
27,600 \\
55,629 \\
905 \\
42,207 \\
9,848 \\
49,823 \\
204,602\end{array}$ & $\begin{array}{r}0 \\
84,989 \\
140 \\
0 \\
139,789 \\
85 \\
124,763 \\
30,450 \\
57,871 \\
438,087\end{array}$ & $\begin{array}{r}340 \\
4,381 \\
12,577 \\
0 \\
495,564 \\
3,705 \\
273,429 \\
23,443 \\
462,603 \\
1,268,041\end{array}$ & $\begin{array}{r}899 \\
6 \\
0 \\
8,588 \\
11,232 \\
478 \\
7,758 \\
1,658 \\
3,108 \\
33,728\end{array}$ & $\begin{array}{r}16,213 \\
2,474 \\
2,259 \\
0 \\
106,758 \\
15,232 \\
49,470 \\
6,576 \\
10,074 \\
209,057\end{array}$ \\
\hline 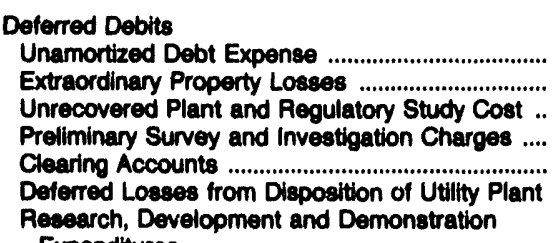 & $\begin{array}{r}22,494 \\
0 \\
0 \\
172 \\
454 \\
0\end{array}$ & $\begin{array}{r}5,002 \\
0 \\
10,297 \\
2,922 \\
-1,711 \\
0\end{array}$ & $\begin{array}{r}6,797 \\
97,851 \\
101,442 \\
5,686 \\
0 \\
0\end{array}$ & $\begin{array}{r}6,372 \\
0 \\
196,892 \\
17,300 \\
0 \\
0\end{array}$ & $\begin{array}{r}1 \\
425 \\
4,630 \\
0 \\
14 \\
0 \\
0\end{array}$ & $\begin{array}{r}7,382 \\
0 \\
0 \\
169 \\
342 \\
0\end{array}$ \\
\hline 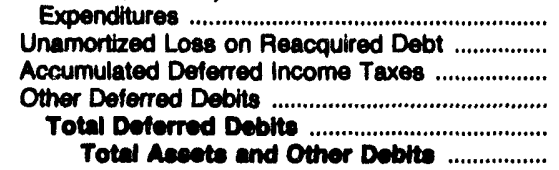 & $\begin{array}{r}0 \\
1,658 \\
0 \\
1,112,687 \\
1,137,386 \\
2,008,424\end{array}$ & $\begin{array}{r}0 \\
15,550 \\
22,529 \\
145,310 \\
190,890 \\
2,126,291\end{array}$ & $\begin{array}{r}0 \\
15,225 \\
116,518 \\
210,484 \\
554,003 \\
3,877,857\end{array}$ & $\begin{array}{r}0 \\
52,552 \\
61,407 \\
216,868 \\
551,390 \\
12,320,456\end{array}$ & $\begin{array}{r}188 \\
0 \\
3,449 \\
3,984 \\
12,691 \\
158,376\end{array}$ & $\begin{array}{r}0 \\
19,208 \\
243,717 \\
211,487 \\
482,304 \\
2,508,245\end{array}$ \\
\hline
\end{tabular}

See endnotes at end of an individual electric utility. 
Table 38. Balance Sheot by Major U.S. Investor-Owned Electric Utility Within State on December 31, 1992 (Continued)

(Thousand Dollars)

\begin{tabular}{|c|c|c|c|c|c|c|}
\hline Item & $\begin{array}{c}\text { Now Hampshire } \\
\text { Public } \\
\text { Service } \\
\text { Co } \\
\text { of } \mathrm{NH}\end{array}$ & $\begin{array}{l}\text { New Jersey } \\
\text { Attantic } \\
\text { City } \\
\text { Electric } \\
\text { Co }\end{array}$ & $\begin{array}{l}\text { Now Jersey } \\
\text { Jersey } \\
\text { Contral } \\
\text { Power\&Light } \\
\text { Co }\end{array}$ & $\begin{array}{l}\text { Now Jersey } \\
\text { Public } \\
\text { Service } \\
\text { Electric\&ags } \\
\text { Co }\end{array}$ & $\begin{array}{l}\text { Now Jersey } \\
\text { Rockland } \\
\text { Electric Co }\end{array}$ & $\begin{array}{l}\text { Now Mexico } \\
\text { Public } \\
\text { Service } \\
\text { Co } \\
\text { of NM }\end{array}$ \\
\hline $\begin{array}{l}\text { Proprotary Capltal } \\
\text { Common Stock lseued ............................................ } \\
\text { Preferred Stock lasued ....................................... } \\
\text { Capital Stock Subecribed, }\end{array}$ & 125,000 & $\begin{array}{r}54,863 \\
231,300\end{array}$ & $\begin{array}{l}153,713 \\
237,500\end{array}$ & $\begin{array}{r}2,536,381 \\
504,894\end{array}$ & $\begin{array}{r}11,200 \\
0\end{array}$ & $\begin{array}{r}208,870 \\
85,286\end{array}$ \\
\hline 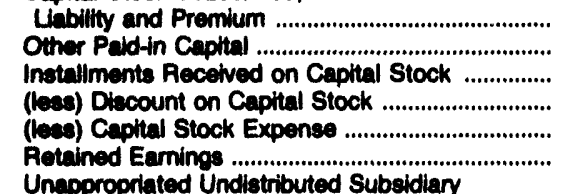 & $\begin{array}{r}0 \\
424,899 \\
0 \\
0 \\
4,237 \\
20,875\end{array}$ & $\begin{array}{r}231,081 \\
216,489 \\
0 \\
0 \\
2,497 \\
246,883\end{array}$ & $\begin{array}{r}378 \\
435,715 \\
0 \\
0 \\
0 \\
644,899\end{array}$ & $\begin{array}{r}557 \\
385,790 \\
0 \\
0 \\
0 \\
1,098,360\end{array}$ & $\begin{array}{r}0 \\
0 \\
0 \\
0 \\
20 \\
74,688\end{array}$ & $\begin{array}{r}711,384 \\
-220,209 \\
0 \\
0 \\
21,025 \\
-57,593\end{array}$ \\
\hline 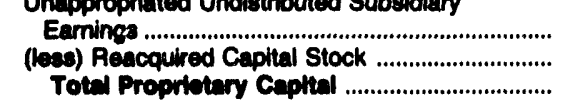 & $\begin{array}{r}978 \\
0 \\
567,616\end{array}$ & $\begin{array}{r}0 \\
0 \\
978,219\end{array}$ & $\begin{array}{r}0 \\
0 \\
1,472,204\end{array}$ & $\begin{array}{r}-626 \\
0 \\
4,526,486\end{array}$ & $\begin{array}{r}-512 \\
0 \\
85,387\end{array}$ & $\begin{array}{r}5,060 \\
0 \\
711,772\end{array}$ \\
\hline 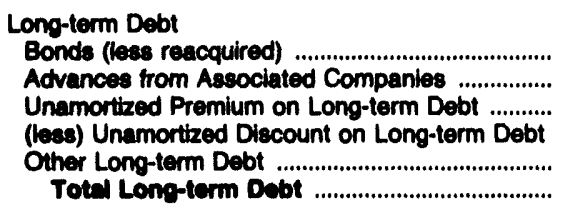 & $\begin{array}{r}342,500 \\
0 \\
0 \\
0 \\
845,485 \\
1,187,905\end{array}$ & $\begin{array}{r}629,847 \\
0 \\
329 \\
4,368 \\
0 \\
025,800\end{array}$ & $\begin{array}{r}1,130,215 \\
0 \\
233 \\
2,125 \\
109,551 \\
1,237,074\end{array}$ & $\begin{array}{r}4,194,800 \\
0 \\
449 \\
25,410 \\
0 \\
4,169,838\end{array}$ & $\begin{array}{r}38,350 \\
0 \\
0 \\
0 \\
0 \\
38,350\end{array}$ & $\begin{array}{r}925,785 \\
0 \\
33 \\
1,156 \\
0 \\
924,862\end{array}$ \\
\hline Total Caphallization . & $1,755,601$ & $1,604,027$ & $2,710,070$ & $8,605,204$ & 123,717 & $1,636,434$ \\
\hline $\begin{array}{l}\text { Other Noncurrent Liabillties } \\
\text { Obligations Under Capital Lease-Noncurrent ...... } \\
\text { Accumulated Provision for Property insurance ... } \\
\text { Accumulated Provision for Injuries and }\end{array}$ & $\begin{array}{r}752,866 \\
0\end{array}$ & $\begin{array}{r}48,505 \\
450\end{array}$ & $\begin{array}{l}4,645 \\
1,000\end{array}$ & $\begin{array}{r}53,104 \\
0\end{array}$ & $\begin{array}{l}0 \\
0\end{array}$ & $\begin{array}{l}0 \\
0\end{array}$ \\
\hline 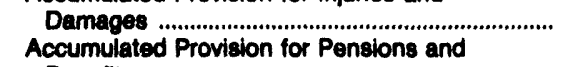 & 2,771 & 1,008 & 8,164 & 0 & 224 & 0 \\
\hline $\begin{array}{l}\text { Benefits .... Wiscellaneous Operating } \\
\text { Accumulated }\end{array}$ & 0 & 0 & 1,830 & 0 & 0 & 0 \\
\hline 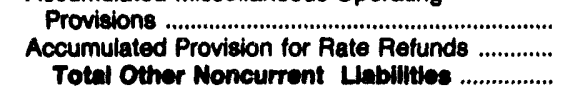 & $\begin{array}{r}338 \\
0 \\
755,975\end{array}$ & $\begin{array}{r}0 \\
0 \\
49,263\end{array}$ & $\begin{array}{r}132 \\
392 \\
17,162\end{array}$ & $\begin{array}{r}0 \\
12,516 \\
65,620\end{array}$ & $\begin{array}{r}0 \\
0 \\
224\end{array}$ & $\begin{array}{l}0 \\
0 \\
0\end{array}$ \\
\hline 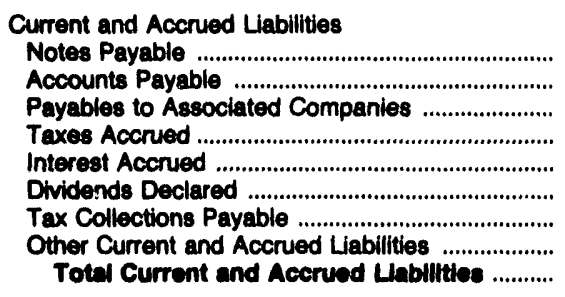 & $\begin{array}{r}35,000 \\
24,843 \\
31,245 \\
1,515 \\
10,639 \\
0 \\
0 \\
116 \\
93,891 \\
197,250\end{array}$ & $\begin{array}{r}14,600 \\
19,045 \\
7,706 \\
5,669 \\
14,555 \\
24,275 \\
323 \\
74,639 \\
160,613\end{array}$ & $\begin{array}{r}5,700 \\
99,053 \\
54,618 \\
127,406 \\
33,294 \\
4,706 \\
613 \\
156,591 \\
401,902\end{array}$ & $\begin{array}{r}135,000 \\
252,092 \\
17,051 \\
591,448 \\
103,988 \\
1,178 \\
7,234 \\
283,654 \\
1,391,644\end{array}$ & $\begin{array}{r}0 \\
23 \\
10,116 \\
3,005 \\
1,461 \\
0 \\
0 \\
3,446 \\
18,051\end{array}$ & $\begin{array}{r}51,550 \\
157,779 \\
19,596 \\
5,424 \\
13,971 \\
1,720 \\
844 \\
33,043 \\
283,026\end{array}$ \\
\hline 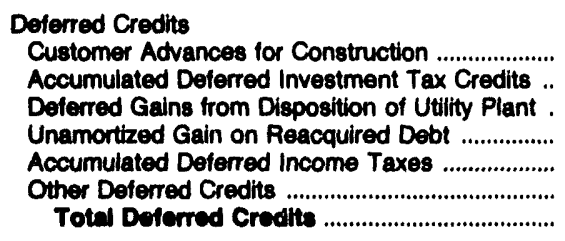 & $\begin{array}{r}226 \\
6,740 \\
0 \\
0 \\
14,866 \\
77,765 \\
00,508\end{array}$ & $\begin{array}{r}2,001 \\
56,715 \\
0 \\
0 \\
247,832 \\
4,840 \\
311,460\end{array}$ & $\begin{array}{r}5,888 \\
86,021 \\
0 \\
2,258 \\
417,367 \\
157,091 \\
868,634\end{array}$ & $\begin{array}{r}1,802 \\
427,337 \\
0 \\
0 \\
1,464,350 \\
283,408 \\
2,176,097\end{array}$ & $\begin{array}{r}77 \\
2,709 \\
0 \\
0 \\
11,561 \\
38 \\
14,385\end{array}$ & $\begin{array}{r}20,698 \\
86,783 \\
0 \\
2,055 \\
329,712 \\
238,636 \\
677,685\end{array}$ \\
\hline Total Lablltites and Other Credlts ................ & $2,008,424$ & $2,126,291$ & $3,877,867$ & $12,329,456$ & 166,376 & $2,508,245$ \\
\hline
\end{tabular}

Note: Totals may not equal sum of components because of independent rounding. Summary data are provided in Table 8 .

Source: Federal Energy Regulatory Commission, FERC Form 1, "Annual Report of Major Electric Utilities, Licensees and Others." 
Table 38. Balance Sheot by Major U.8. Investor-Owned Electric Utility Within siate on Decomber 31, 1902 (Continued)

(Thousand Dollars)

\begin{tabular}{|c|c|c|c|c|c|c|}
\hline Itom & $\begin{array}{l}\text { Now York } \\
\text { Contral } \\
\text { Hudion Gas } \\
2 \text { Elec Corp }\end{array}$ & $\begin{array}{l}\text { Now York } \\
\text { Coneolldated } \\
\text { Edleon } \\
\text { Co- } \\
\text { NY Ino }\end{array}$ & $\begin{array}{c}\text { New York } \\
\text { Long } \\
\text { ialand } \\
\text { Lighting } \\
\text { Co }\end{array}$ & $\begin{array}{l}\text { New York } \\
\text { Long } \\
\text { Sault inc }\end{array}$ & $\begin{array}{l}\text { Now York } \\
\text { Now York } \\
\text { State Eloc } \\
\text { \& Gas Corp }\end{array}$ & $\begin{array}{l}\text { New York } \\
\text { Nlagara } \\
\text { Mohawk } \\
\text { Power Corp }\end{array}$ \\
\hline 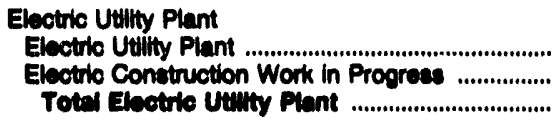 & $\begin{array}{r}1,080,628 \\
26,528 \\
1,007,034\end{array}$ & $\begin{array}{r}10,172,606 \\
263,431 \\
10,436,007\end{array}$ & $\begin{array}{r}3,429,803 \\
24,977 \\
3,824,770\end{array}$ & $\begin{array}{r}9,042 \\
190 \\
9,232\end{array}$ & $\begin{array}{r}4,526,414 \\
118,753 \\
4,846,107\end{array}$ & $\begin{array}{r}7,658,633 \\
487,560 \\
\mathbf{8 , 0 4 6 , 1 8 4}\end{array}$ \\
\hline 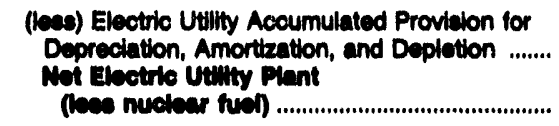 & $\begin{array}{l}341,337 \\
746,710\end{array}$ & $\begin{array}{l}2,889,359 \\
7,840,788\end{array}$ & $\begin{array}{l}1,139,339 \\
2,396,441\end{array}$ & $\begin{array}{l}7,237 \\
1,006\end{array}$ & $\begin{array}{l}1,264,148 \\
3,381,020\end{array}$ & $\begin{array}{l}2,348,913 \\
5,896,281\end{array}$ \\
\hline $\begin{array}{l}\text { Nuclear Fuel } \\
\text { (leas) Accumulated Provialon for }\end{array}$ & 26,889 & 445,373 & 10,216 & 0 & 48,808 & 444,400 \\
\hline $\begin{array}{l}\text { Amorttention of Nuclear Fuel Ascemblios } \\
\text { Net Muci.......... }\end{array}$ & $\begin{array}{r}17,872 \\
8,117\end{array}$ & $\begin{array}{r}368,640 \\
76,732\end{array}$ & $\begin{array}{r}3,430 \\
18,708\end{array}$ & $\begin{array}{l}0 \\
0\end{array}$ & $\begin{array}{l}38,158 \\
18,740\end{array}$ & $\begin{array}{l}334,631 \\
100,780\end{array}$ \\
\hline 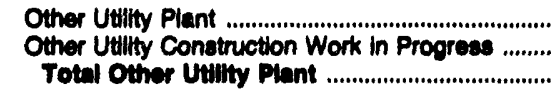 & $\begin{array}{r}198,891 \\
8,404 \\
207,206\end{array}$ & $\begin{array}{r}2,602,915 \\
163,236 \\
2,606,160\end{array}$ & $\begin{array}{r}932,584 \\
66,686 \\
900,270\end{array}$ & $\begin{array}{r}1,839 \\
0 \\
1,039\end{array}$ & $\begin{array}{r}510,038 \\
56,937 \\
566,076\end{array}$ & $\begin{array}{r}1,004,504 \\
98,878 \\
1,103,302\end{array}$ \\
\hline 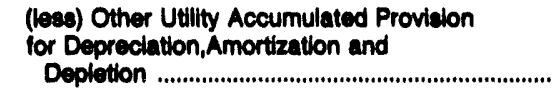 & 56,555 & $571,59 \theta$ & 240,103 & 1,360 & 130,488 & 271,265 \\
\hline 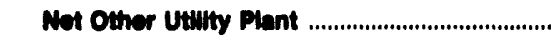 & 160,740 & $2,004,651$ & 750,167 & 400 & 486,408 & 832,117 \\
\hline $\begin{array}{l}\text { All Utllty Plant } \\
\text { All Utllity Plant Conatruction Work in Progrese } \\
\text { Total All Utallty Plant }\end{array}$ & $\begin{array}{r}1,285,408 \\
34,930 \\
1,320,338\end{array}$ & $\begin{array}{r}13,120,054 \\
426,867 \\
13,847,020\end{array}$ & $\begin{array}{r}4,381,602 \\
161,663 \\
4,643,286\end{array}$ & $\begin{array}{r}10,881 \\
190 \\
11,071\end{array}$ & $\begin{array}{r}5,085,358 \\
175,690 \\
5,261,046\end{array}$ & $\begin{array}{r}9,007,537 \\
586,438 \\
9,503,976\end{array}$ \\
\hline 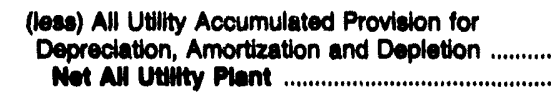 & $\begin{array}{l}415,765 \\
604,673\end{array}$ & $\begin{array}{l}3,829,599 \\
0,718,021\end{array}$ & $\begin{array}{l}1,382,871 \\
3,160,394\end{array}$ & $\begin{array}{l}8,687 \\
2,404\end{array}$ & $\begin{array}{l}1,427,793 \\
3,833,265\end{array}$ & $\begin{array}{r}2,955,809 \\
6,038,167\end{array}$ \\
\hline 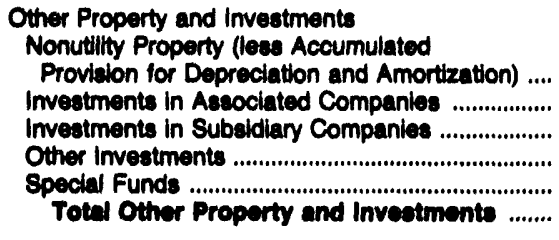 & $\begin{array}{r}957 \\
0 \\
9,274 \\
2,492 \\
2,685 \\
16,308\end{array}$ & $\begin{array}{r}1,238 \\
0 \\
11,151 \\
10,555 \\
68,523 \\
91,480\end{array}$ & $\begin{array}{r}3,713 \\
0 \\
1,459 \\
1,149 \\
15,163 \\
21,408\end{array}$ & $\begin{array}{r}76 \\
0 \\
0 \\
0 \\
0 \\
76\end{array}$ & $\begin{array}{r}8,314 \\
0 \\
3,999 \\
15 \\
5,161 \\
17,480\end{array}$ & $\begin{array}{r}20,031 \\
0 \\
175,891 \\
123 \\
59,224 \\
255,260\end{array}$ \\
\hline 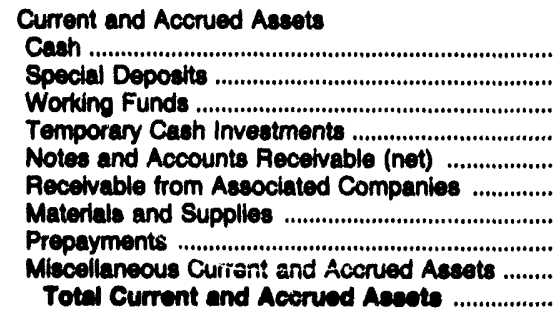 & $\begin{array}{r}3,487 \\
671 \\
445 \\
4,176 \\
48,037 \\
537 \\
32,645 \\
10,572 \\
21,341 \\
122,110\end{array}$ & $\begin{array}{r}14,065 \\
4,296 \\
2,523 \\
265,772 \\
479,536 \\
0 \\
363,614 \\
51,829 \\
46,249 \\
1,227,005\end{array}$ & $\begin{array}{r}-1,858 \\
23,683 \\
550 \\
310,893 \\
210,795 \\
1,169 \\
138,184 \\
5,421 \\
228,186 \\
918,914\end{array}$ & $\begin{array}{r}0 \\
0 \\
0 \\
0 \\
19 \\
165 \\
0 \\
5 \\
0 \\
180\end{array}$ & $\begin{array}{r}-91,110 \\
96,432 \\
1,088 \\
93,672 \\
109,221 \\
-275 \\
110,039 \\
31,933 \\
77,417 \\
128,617\end{array}$ & $\begin{array}{r}16,767 \\
200 \\
1,429 \\
4,121 \\
210,404 \\
3,982 \\
260,282 \\
70,039 \\
210,550 \\
767,774\end{array}$ \\
\hline 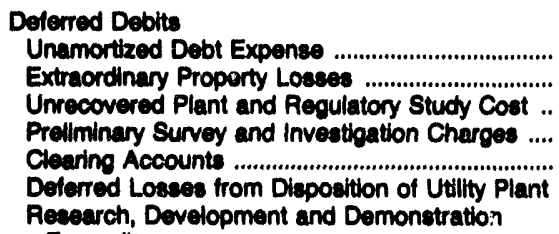 & $\begin{array}{r}6,858 \\
0 \\
0 \\
459 \\
248 \\
0\end{array}$ & $\begin{array}{r}55,072 \\
0 \\
23,880 \\
4,507 \\
2,736 \\
0\end{array}$ & $\begin{array}{r}302,828 \\
0 \\
3,685,432 \\
812 \\
0 \\
0\end{array}$ & $\begin{array}{l}0 \\
0 \\
0 \\
0 \\
0 \\
0\end{array}$ & $\begin{array}{r}24,127 \\
0 \\
39,826 \\
9,693 \\
1,225 \\
0\end{array}$ & $\begin{array}{r}140,803 \\
0 \\
8,033 \\
18,085 \\
17 \\
0\end{array}$ \\
\hline 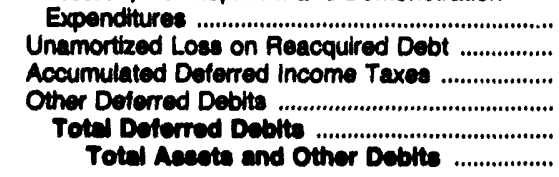 & $\begin{array}{r}232 \\
6,566 \\
44,152 \\
104,169 \\
162,704 \\
1,204,055\end{array}$ & $\begin{array}{r}1,495 \\
0 \\
188,947 \\
472,529 \\
769,168 \\
11,768,680\end{array}$ & $\begin{array}{r}2,198 \\
0 \\
1,027,733 \\
1,646,685 \\
6,685,686 \\
10,764,460\end{array}$ & $\begin{array}{r}0 \\
0 \\
0 \\
0 \\
0 \\
2,740\end{array}$ & $\begin{array}{r}1,802 \\
72,251 \\
122,725 \\
673,095 \\
944,744 \\
6,224,104\end{array}$ & $\begin{array}{r}-4,023 \\
199 \\
288,284 \\
665,622 \\
1,117,221 \\
8,778,430\end{array}$ \\
\hline
\end{tabular}

See endnotes at end of an indwidual electric utility. 
Table 38. Balance Sheet by Major U.S. Investor-Owned Electric Utillty Within State on December 31, 1992 (Continued) (Thousand Dollars)

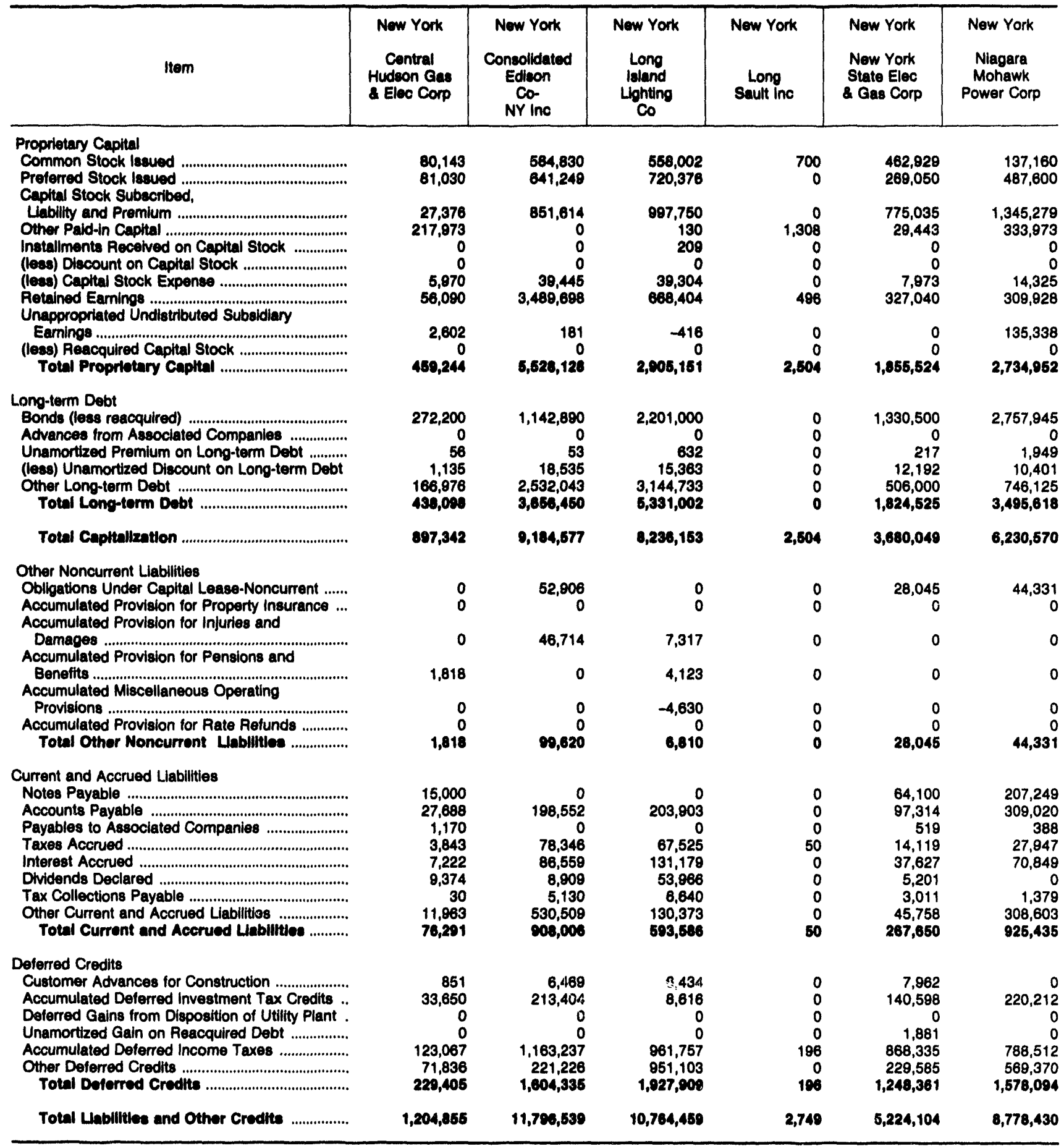

Note: Totals may not equal sum of components because of independent rounding. Summary data are provided in Table 8.

Source: Federal Energy Regulatory Commiseion, FERC Form 1, "Annual Report of Major Electric Utilities, Licensees and Others." 
Table 38. Balance Sheot by Major U.8. Investor-Owned Electric Utility Within State on Decomber 31, 1992 (Continued)

(Thousand Dollars)

\begin{tabular}{|c|c|c|c|c|c|c|}
\hline Item & $\begin{array}{l}\text { New York } \\
\text { Orenge a } \\
\text { Rockiand } \\
\text { Utils } \\
\text { Inc }\end{array}$ & $\begin{array}{l}\text { Now York } \\
\text { Rocheoter } \\
\text { Gas } \\
\text { Electric Corp }\end{array}$ & $\begin{array}{c}\text { North Carolina } \\
\text { Carolina } \\
\text { Power } \\
\text { L } \\
\text { Light Co }\end{array}$ & $\begin{array}{l}\text { North Carolina } \\
\text { Duke } \\
\text { Power Co }\end{array}$ & $\begin{array}{c}\text { North Carolina } \\
\text { Nantahala } \\
\text { Power } \\
8 \\
\text { Light Co }\end{array}$ & $\begin{array}{l}\text { North Carolina } \\
\text { Yadkin } \\
\text { inc }\end{array}$ \\
\hline 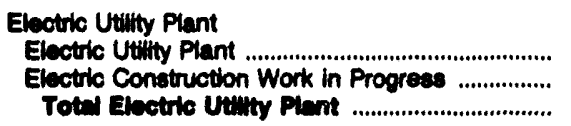 & $\begin{array}{r}768,340 \\
15,848 \\
704,186\end{array}$ & $\begin{array}{r}2,175,254 \\
70,516 \\
2,245,770\end{array}$ & $\begin{array}{r}8,591,839 \\
251,238 \\
\mathbf{2}, 243,076\end{array}$ & $\begin{array}{r}12,193,888 \\
341,463 \\
12,595,351\end{array}$ & $\begin{array}{r}131,412 \\
7,776 \\
139,186\end{array}$ & $\begin{array}{r}52,689 \\
5,832 \\
68,600\end{array}$ \\
\hline 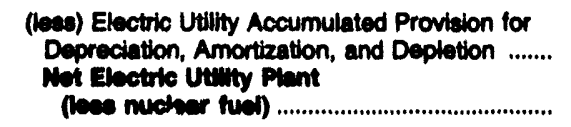 & $\begin{array}{l}231,111 \\
863,077\end{array}$ & $\begin{array}{r}800,215 \\
1,245,685\end{array}$ & $\begin{array}{l}2,632,577 \\
0,210,400\end{array}$ & $\begin{array}{l}4,197,605 \\
8,337,845\end{array}$ & $\begin{array}{l}68,102 \\
73,096\end{array}$ & $\begin{array}{l}36,297 \\
22,203\end{array}$ \\
\hline 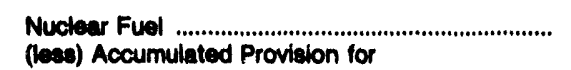 & 0 & 158,405 & 410,824 & $2,417,893$ & 0 & 0 \\
\hline 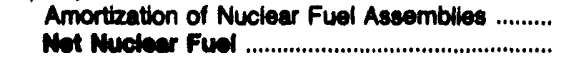 & $\begin{array}{l}0 \\
0\end{array}$ & $\begin{array}{l}183,182 \\
-34,777\end{array}$ & $\begin{array}{l}195,644 \\
215,079\end{array}$ & $\begin{array}{r}1,873,830 \\
544,033\end{array}$ & $\begin{array}{l}0 \\
0\end{array}$ & $\begin{array}{l}\mathbf{0} \\
\mathbf{0}\end{array}$ \\
\hline 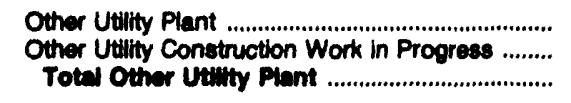 & $\begin{array}{r}227,171 \\
7,246 \\
234,417\end{array}$ & $\begin{array}{r}464,500 \\
13,316 \\
477,816\end{array}$ & $\begin{array}{l}0 \\
0 \\
0\end{array}$ & $\begin{array}{r}35,652 \\
2 \\
36,654\end{array}$ & $\begin{array}{l}0 \\
0 \\
0\end{array}$ & $\begin{array}{l}0 \\
0 \\
0\end{array}$ \\
\hline $\begin{array}{l}\text { (leas) Other Utlity Accumulated Provision } \\
\text { for Depreciation,Amortization and } \\
\text { Depletion }\end{array}$ & 81,138 & 165,287 & 0 & 8,586 & 0 & 0 \\
\hline 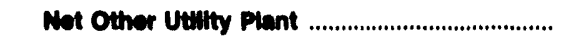 & 163,278 & 312,528 & 0 & 27,060 & 0 & 0 \\
\hline 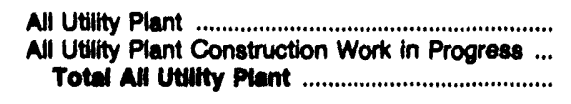 & $\begin{array}{r}995,511 \\
23,094 \\
1,016,605\end{array}$ & $\begin{array}{r}2,798,160 \\
83,832 \\
2,001,902\end{array}$ & $\begin{array}{r}9,002,762 \\
251,238 \\
0,254,000\end{array}$ & $\begin{array}{r}14,647,432 \\
341,465 \\
14,000,007\end{array}$ & $\begin{array}{r}131,412 \\
7,776 \\
130,186\end{array}$ & $\begin{array}{r}52,669 \\
5,832 \\
68,500\end{array}$ \\
\hline 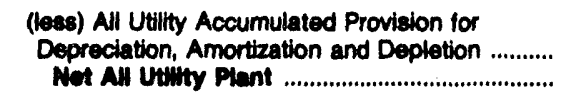 & $\begin{array}{l}312,249 \\
706,360\end{array}$ & $\begin{array}{l}1,318,684 \\
1,683,307\end{array}$ & $\begin{array}{l}2,828,422 \\
6,425,578\end{array}$ & $\begin{array}{l}\text { 6,079,921 } \\
8,008,976\end{array}$ & $\begin{array}{l}68,102 \\
73,086\end{array}$ & $\begin{array}{l}36,297 \\
22,203\end{array}$ \\
\hline 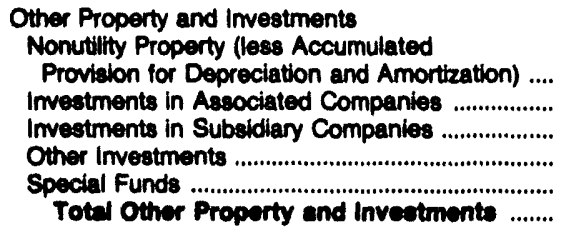 & $\begin{array}{r}72 \\
0 \\
102,286 \\
2 \\
0 \\
102,390\end{array}$ & $\begin{array}{r}27 \\
0 \\
1,017 \\
841 \\
29,549 \\
31,434\end{array}$ & $\begin{array}{r}14,687 \\
0 \\
77 \\
300,763 \\
98,552 \\
414,070\end{array}$ & $\begin{array}{r}16,41 \theta \\
0 \\
062,699 \\
62,259 \\
95,124 \\
536,600\end{array}$ & $\begin{array}{r}1,010 \\
0 \\
0 \\
8 \\
987 \\
2,014\end{array}$ & $\begin{array}{l}0 \\
0 \\
0 \\
0 \\
0 \\
0\end{array}$ \\
\hline 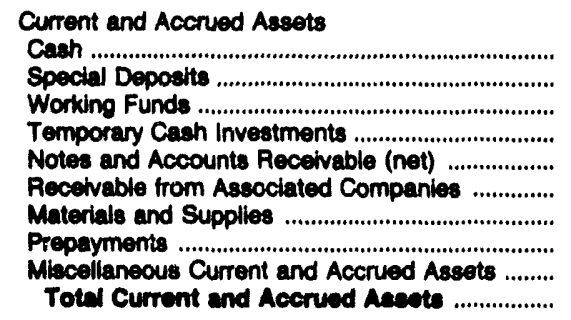 & $\begin{array}{r}2,119 \\
1 \\
88 \\
0 \\
50,921 \\
10,680 \\
19,517 \\
18,912 \\
47,136 \\
140,374\end{array}$ & $\begin{array}{r}1,294 \\
231 \\
234 \\
0 \\
82,034 \\
0 \\
25,403 \\
19,885 \\
70,440 \\
200,821\end{array}$ & $\begin{array}{r}10,718 \\
22 \\
83 \\
0 \\
312,493 \\
0 \\
209,072 \\
17,934 \\
56,375 \\
606,600\end{array}$ & $\begin{array}{r}6,632 \\
111 \\
2,550 \\
0 \\
328,952 \\
21,638 \\
321,762 \\
11,610 \\
167,692 \\
858,846\end{array}$ & $\begin{array}{r}1,547 \\
0 \\
45 \\
0 \\
4,871 \\
1,070 \\
2,107 \\
192 \\
3 \\
9,835\end{array}$ & $\begin{array}{r}0 \\
0 \\
0 \\
0 \\
0 \\
0 \\
0 \\
70 \\
0 \\
70\end{array}$ \\
\hline 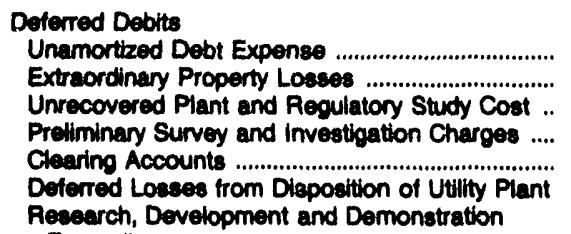 & $\begin{array}{r}6,501 \\
15,249 \\
0 \\
884 \\
0 \\
0\end{array}$ & $\begin{array}{r}13,553 \\
0 \\
0 \\
2,493 \\
0 \\
0\end{array}$ & $\begin{array}{r}6,954 \\
0 \\
225,924 \\
0 \\
852 \\
0\end{array}$ & $\begin{array}{r}5,772 \\
7,466 \\
49,910 \\
3,364 \\
1,103 \\
0\end{array}$ & $\begin{array}{r}232 \\
0 \\
0 \\
98 \\
0 \\
0\end{array}$ & $\begin{array}{l}0 \\
0 \\
0 \\
0 \\
0 \\
0\end{array}$ \\
\hline 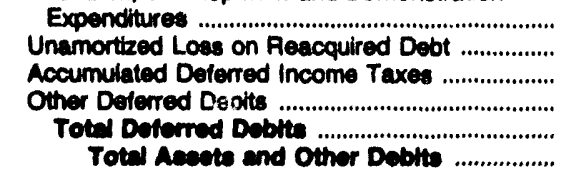 & $\begin{array}{r}257 \\
0 \\
11,487 \\
40,340 \\
74,719 \\
1,032,010\end{array}$ & $\begin{array}{r}1,375 \\
0 \\
38,648 \\
155,827 \\
211,606 \\
2,018,260\end{array}$ & $\begin{array}{r}0 \\
42,649 \\
253,519 \\
220,722 \\
760,721 \\
0,197,078\end{array}$ & $\begin{array}{r}-1,599 \\
109,684 \\
159,699 \\
705,264 \\
1,040,642 \\
11,344,648\end{array}$ & $\begin{array}{r}0 \\
55 \\
1,496 \\
8,907 \\
10,786 \\
85,722\end{array}$ & $\begin{array}{r}0 \\
0 \\
34 \\
0 \\
34 \\
22,307\end{array}$ \\
\hline
\end{tabular}

See endnotes at end of an individual electric utility. 
Table 38. Balance Sheot by Major U.S. Investor-Owned Electric Utility Within State on December 31, 1982 (Continued) (Thousand Dollars)

\begin{tabular}{|c|c|c|c|c|c|c|}
\hline Item & $\begin{array}{l}\text { Now York } \\
\text { Orange } 8 \\
\text { Rockland } \\
\text { Utlls } \\
\text { Inc }\end{array}$ & $\begin{array}{l}\text { Now York } \\
\text { Rochester } \\
\text { Gas } \\
\text { Electrio Corp }\end{array}$ & $\begin{array}{c}\text { North Carolina } \\
\text { Carolina } \\
\text { Power } \\
\text { L } \\
\text { Light Co }\end{array}$ & $\begin{array}{l}\text { North Carolina } \\
\text { Duke } \\
\text { Power Co }\end{array}$ & $\begin{array}{l}\text { North Carolina } \\
\text { Nantahala } \\
\text { Power } \\
\mathbf{8} \\
\text { Light Co }\end{array}$ & $\begin{array}{l}\text { North Carolina } \\
\text { Yadkin } \\
\text { Inc }\end{array}$ \\
\hline 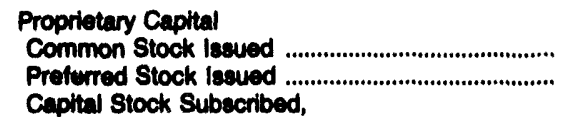 & $\begin{array}{l}67,656 \\
50,233\end{array}$ & $\begin{array}{l}173,983 \\
127,000\end{array}$ & $\begin{array}{r}1,622,277 \\
143,801\end{array}$ & $\begin{array}{r}1,926,800 \\
782,500\end{array}$ & $\begin{array}{r}382 \\
0\end{array}$ & $\begin{array}{r}100 \\
0\end{array}$ \\
\hline 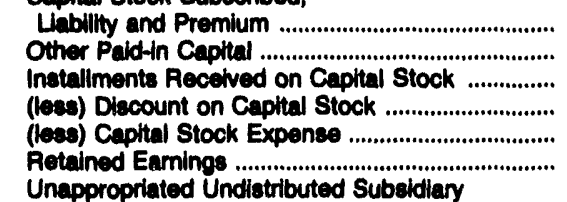 & $\begin{array}{r}130,288 \\
0 \\
0 \\
0 \\
6,030 \\
103,239\end{array}$ & $\begin{array}{r}434,655 \\
71 \\
0 \\
0 \\
17,077 \\
69,093\end{array}$ & $\begin{array}{r}0 \\
-334 \\
0 \\
0 \\
0 \\
1,153,647\end{array}$ & $\begin{array}{r}0 \\
-7,944 \\
0 \\
0 \\
0 \\
1,988,172\end{array}$ & $\begin{array}{r}0 \\
2,237 \\
0 \\
0 \\
0 \\
40,291\end{array}$ & $\begin{array}{r}0 \\
14,561 \\
0 \\
0 \\
0 \\
5,448\end{array}$ \\
\hline 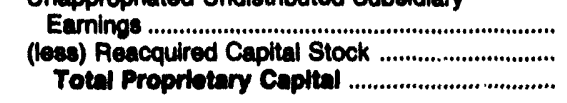 & $\begin{array}{r}73,182 \\
0 \\
418,579\end{array}$ & $\begin{array}{r}-2,125 \\
0 \\
785,500\end{array}$ & $\begin{array}{r}8 \\
0 \\
2,919,390\end{array}$ & $\begin{array}{r}243,489 \\
1,481 \\
4,031,646\end{array}$ & $\begin{array}{r}0 \\
0 \\
42,011\end{array}$ & $\begin{array}{r}0 \\
0 \\
20,109\end{array}$ \\
\hline 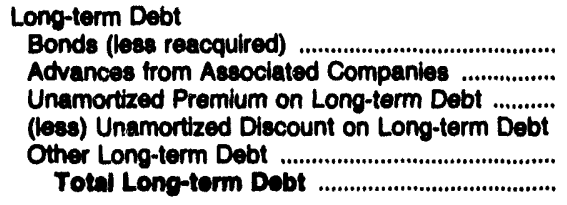 & $\begin{array}{r}98,000 \\
0 \\
196 \\
992 \\
234,068 \\
331,272 \\
\end{array}$ & $\begin{array}{r}678,000 \\
0 \\
146 \\
916 \\
91,900 \\
789,130\end{array}$ & $\begin{array}{r}2,416,195 \\
0 \\
128 \\
16,330 \\
499,830 \\
2,890,823\end{array}$ & $\begin{array}{r}2,889,348 \\
0 \\
933 \\
36,874 \\
302,000 \\
3,158,407\end{array}$ & $\begin{array}{r}0 \\
0 \\
0 \\
0 \\
33,560 \\
33,560\end{array}$ & $\begin{array}{l}0 \\
0 \\
0 \\
0\end{array}$ \\
\hline 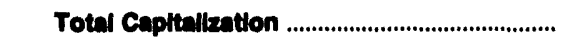 & 740,851 & $1,564,630$ & $5,810,222$ & $8,087,054$ & 76,471 & 20,100 \\
\hline $\begin{array}{l}\text { Other Noncurrent Liabilitites } \\
\text { Obllgationa Under Capital Lease-Noncurrent ...... } \\
\text { Accumulated Provision for Property Insurance ... } \\
\text { Accumulated Provision for Injuries and }\end{array}$ & $\begin{array}{r}1,272 \\
0\end{array}$ & $\begin{array}{r}0 \\
1.081\end{array}$ & $\begin{array}{l}43,754 \\
23,218\end{array}$ & $\begin{array}{l}47,030 \\
58,187\end{array}$ & 0 & 0 \\
\hline 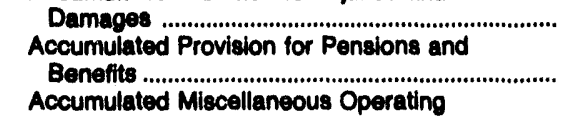 & 3,297 & 0 & 2,046 & $\begin{array}{r}16,976 \\
5,549\end{array}$ & 0 & 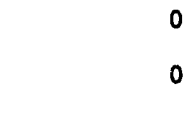 \\
\hline 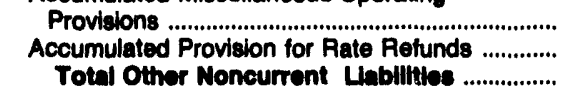 & $\begin{array}{r}-2,532 \\
40 \\
2,077\end{array}$ & $\begin{array}{r}0 \\
0 \\
1,0,1\end{array}$ & $\begin{array}{r}55,983 \\
0 \\
125,001\end{array}$ & $\begin{array}{r}4,813 \\
5,553 \\
138,117\end{array}$ & $\begin{array}{l}0 \\
0 \\
0\end{array}$ & \\
\hline 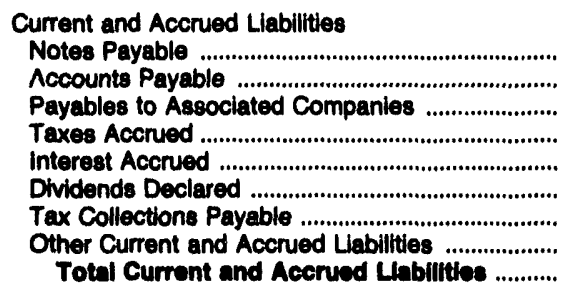 & $\begin{array}{r}46,600 \\
68,390 \\
115 \\
3,188 \\
7,516 \\
780 \\
291 \\
29,936 \\
165,016\end{array}$ & $\begin{array}{r}50,800 \\
89,014 \\
0 \\
13,743 \\
15,461 \\
17,035 \\
456 \\
11,930 \\
189,439\end{array}$ & $\begin{array}{r}46,800 \\
309,930 \\
0 \\
23,344 \\
61,115 \\
70,706 \\
10,502 \\
48,971 \\
571,368\end{array}$ & $\begin{array}{r}126,045 \\
37,027 \\
14,793 \\
38,182 \\
68,078 \\
106 \\
15,670 \\
83,115 \\
722,016\end{array}$ & $\begin{array}{r}0 \\
1,286 \\
3,011 \\
257 \\
564 \\
0 \\
5 \\
387 \\
5,500\end{array}$ & $\begin{array}{r}1,035 \\
915 \\
70 \\
0 \\
0 \\
21 \\
404 \\
2,446\end{array}$ \\
\hline 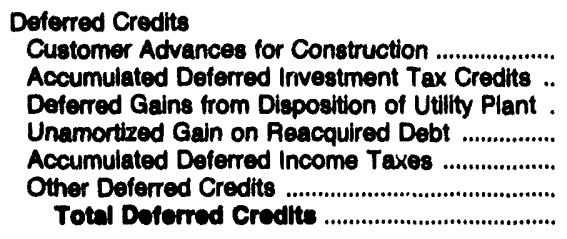 & $\begin{array}{r}1,003 \\
16,154 \\
0 \\
0 \\
0 \\
100,646 \\
7,261 \\
125,064\end{array}$ & $\begin{array}{r}0 \\
55,208 \\
0 \\
0 \\
155,115 \\
51,808 \\
262,129\end{array}$ & $\begin{array}{r}3,179 \\
276,394 \\
0 \\
0 \\
0 \\
1,328,922 \\
72,991 \\
1,681,486\end{array}$ & $\begin{array}{r}0 \\
296,165 \\
0 \\
0 \\
0 \\
1,812,520 \\
288,192 \\
2,396,878\end{array}$ & $\begin{array}{r}0 \\
1,589 \\
0 \\
0 \\
0,620 \\
2,534 \\
13,742\end{array}$ & $\begin{array}{r}0 \\
432 \\
0 \\
0 \\
-680 \\
0 \\
0 \\
-248\end{array}$ \\
\hline Total Llablitise and Other Credits & $1,032,810$ & $2,016,260$ & $8,197,076$ & $11,344,906$ & 95,722 & 22,307 \\
\hline
\end{tabular}

Note: Totals may not equal sum of components because of independent rounding. Summary data are provided in Table 8. Source: Federal Energy Regulatory Commiseion, FERC Form 1, "Annual Report of Major Electric Utilities, Licensees and Others." 
Table 38. Balance Sheet by Major U.8. Inveator-Owned Eloctric Utilit Within State on December 31, 1992 (Continued)

(Thousand Dollars)

\begin{tabular}{|c|c|c|c|c|c|c|}
\hline Item & $\begin{array}{c}\text { North Dakota } \\
\text { MDU } \\
\text { Resources } \\
\text { Group } \\
\text { Ino }\end{array}$ & $\begin{array}{c}\text { Ohio } \\
\text { Cincinnat } \\
\text { Gas } \\
a \\
\text { Electrio Co }\end{array}$ & $\begin{array}{l}\text { Ohio } \\
\text { Cleveland } \\
\text { Electric } \\
\text { Illum Co }\end{array}$ & $\begin{array}{l}\text { Ohlo } \\
\text { Columbus } \\
\text { Southern } \\
\text { Power Co }\end{array}$ & $\begin{array}{c}\text { Ohio } \\
\text { Dayton } \\
\text { Power } \\
\& \\
\text { Loht Co }\end{array}$ & $\begin{array}{l}\text { Onio } \\
\text { Indiana- } \\
\text { Kentucky } \\
\text { Electric } \\
\text { Corp }\end{array}$ \\
\hline 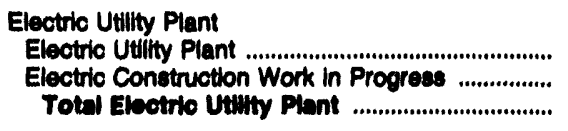 & $\begin{array}{r}462,897 \\
3,968 \\
466,868\end{array}$ & $\begin{array}{r}4,310,088 \\
84,822 \\
4,384,710\end{array}$ & $\begin{array}{r}7,107,620 \\
119,899 \\
7,227,410\end{array}$ & $\begin{array}{r}2,679,645 \\
31,447 \\
2,710,982\end{array}$ & $\begin{array}{r}2,865,836 \\
33,606 \\
2,090,342\end{array}$ & $\begin{array}{r}301,667 \\
12,211 \\
313,070\end{array}$ \\
\hline 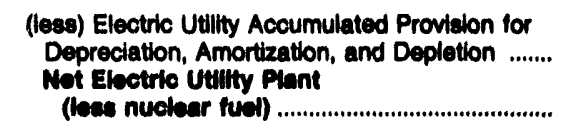 & $\begin{array}{l}207,704 \\
260,101\end{array}$ & $\begin{array}{l}1,135,259 \\
3,260,461\end{array}$ & $\begin{array}{l}1,738,142 \\
5,400,276\end{array}$ & $\begin{array}{r}742,617 \\
1,993,375\end{array}$ & $\begin{array}{r}754,274 \\
2,146,060\end{array}$ & $\begin{array}{r}300,227 \\
13,661\end{array}$ \\
\hline 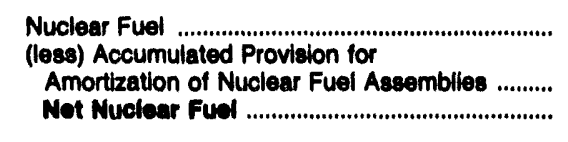 & $\begin{array}{l}0 \\
0 \\
0\end{array}$ & $\begin{array}{l}0 \\
0 \\
0\end{array}$ & $\begin{array}{r}223,518 \\
0 \\
223,610\end{array}$ & $\begin{array}{l}0 \\
0 \\
0\end{array}$ & $\begin{array}{l}0 \\
0 \\
0\end{array}$ & $\begin{array}{l}0 \\
0 \\
0\end{array}$ \\
\hline 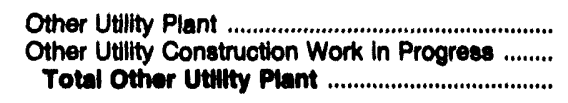 & $\begin{array}{r}148,716 \\
1,677 \\
150,303\end{array}$ & $\begin{array}{r}651,268 \\
45,793 \\
607,051\end{array}$ & $\begin{array}{l}0 \\
0 \\
0\end{array}$ & $\begin{array}{l}0 \\
0 \\
0\end{array}$ & $\begin{array}{r}238,075 \\
9,214 \\
247,280\end{array}$ & $\begin{array}{l}0 \\
0 \\
0\end{array}$ \\
\hline 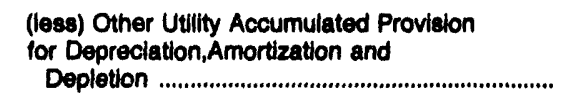 & 75,063 & 134,680 & 0 & 0 & 99,161 & 0 \\
\hline 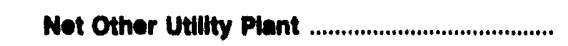 & 75,330 & 402,361 & $\mathbf{0}$ & 0 & 148,128 & 0 \\
\hline 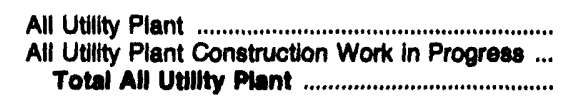 & $\begin{array}{r}611,613 \\
5,644 \\
617,250\end{array}$ & $\begin{array}{r}4,861,346 \\
130,415 \\
4,001,761\end{array}$ & $\begin{array}{r}7,331,038 \\
119,899 \\
7,460,037\end{array}$ & $\begin{array}{r}2,679,545 \\
31,447 \\
2,710,902\end{array}$ & $\begin{array}{r}3,103,911 \\
42,720 \\
3,146,630\end{array}$ & $\begin{array}{r}301,687 \\
12,211 \\
313,676\end{array}$ \\
\hline 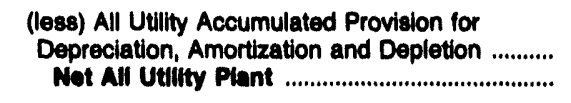 & $\begin{array}{l}282,767 \\
334,480\end{array}$ & $\begin{array}{l}1,269,949 \\
\mathbf{3 , 7 2 1 , 0 1 3}\end{array}$ & $\begin{array}{l}1,738,142 \\
5,712,705\end{array}$ & $\begin{array}{r}742,617 \\
1,008,375\end{array}$ & $\begin{array}{r}853,495 \\
2,203,196\end{array}$ & $\begin{array}{r}300,227 \\
13,061\end{array}$ \\
\hline 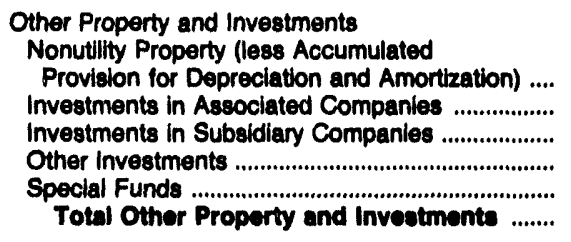 & $\begin{array}{r}224 \\
0 \\
268,188 \\
4,774 \\
2,409 \\
273,805\end{array}$ & $\begin{array}{r}2,553 \\
0 \\
108,863 \\
1,488 \\
0 \\
112,913\end{array}$ & $\begin{array}{r}13,530 \\
0 \\
22,511 \\
0 \\
23,699 \\
50,740\end{array}$ & $\begin{array}{r}15,350 \\
0 \\
4,999 \\
13,690 \\
28 \\
34,066\end{array}$ & $\begin{array}{r}1,436 \\
3,387 \\
402 \\
531 \\
246 \\
6,001\end{array}$ & $\begin{array}{l}0 \\
0 \\
0 \\
0 \\
0 \\
0\end{array}$ \\
\hline 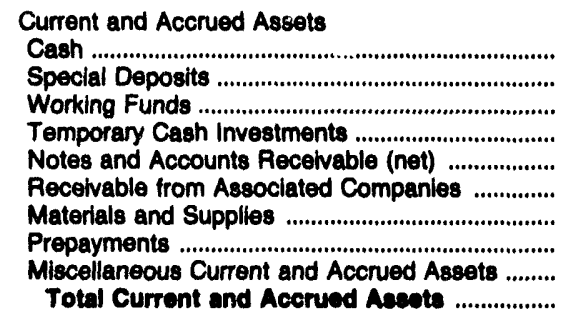 & $\begin{array}{r}2,391 \\
271 \\
21 \\
2,000 \\
27,203 \\
6,600 \\
9,702 \\
5,686 \\
9,300 \\
63,174\end{array}$ & $\begin{array}{r}5,465 \\
242 \\
-5,095 \\
0 \\
236,194 \\
17,831 \\
132,096 \\
27,894 \\
119,211 \\
833,828\end{array}$ & $\begin{array}{r}4,190 \\
-58 \\
170 \\
20,571 \\
158,226 \\
10,022 \\
129,455 \\
57,435 \\
216,001 \\
586,012\end{array}$ & $\begin{array}{r}3,689 \\
1,473 \\
3,995 \\
0 \\
42,045 \\
1,010 \\
58,430 \\
28,703 \\
20,614 \\
150,968\end{array}$ & $\begin{array}{r}-2,300 \\
82 \\
5,338 \\
1 \\
95,750 \\
2,407 \\
76,856 \\
52,697 \\
36,793 \\
207,624\end{array}$ & $\begin{array}{r}122 \\
1 \\
8 \\
0 \\
22 \\
-6,619 \\
22,804 \\
375 \\
468 \\
17,182 \\
\end{array}$ \\
\hline 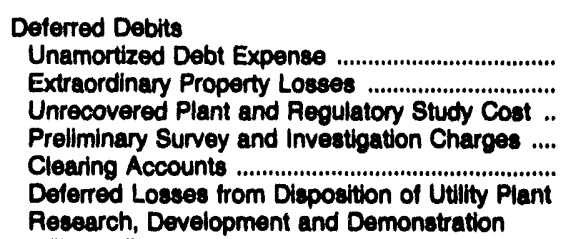 & $\begin{array}{r}2,744 \\
0 \\
0 \\
0 \\
828 \\
0\end{array}$ & $\begin{array}{r}2,796 \\
0 \\
0 \\
329 \\
-317 \\
0\end{array}$ & $\begin{array}{r}23,800 \\
0 \\
0 \\
18,876 \\
1,323 \\
0\end{array}$ & $\begin{array}{r}3,319 \\
0 \\
0 \\
0 \\
45 \\
0\end{array}$ & $\begin{array}{r}9,716 \\
0 \\
0 \\
0 \\
1,294 \\
0\end{array}$ & $\begin{array}{l}0 \\
0 \\
0 \\
0 \\
0 \\
0\end{array}$ \\
\hline 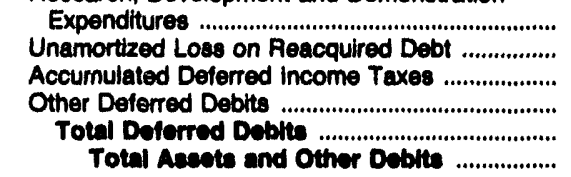 & $\begin{array}{r}0 \\
14,809 \\
11,703 \\
9,396 \\
30,479 \\
710,730\end{array}$ & $\begin{array}{r}0 \\
20,080 \\
23,616 \\
186,837 \\
233,352 \\
4,601,908\end{array}$ & $\begin{array}{r}0 \\
63,995 \\
312,086 \\
1,710,430 \\
2,131,490 \\
8,600,037\end{array}$ & $\begin{array}{r}0 \\
26,920 \\
19,972 \\
177,428 \\
227,894 \\
2,300,024\end{array}$ & $\begin{array}{r}0 \\
14,552 \\
35,172 \\
239,980 \\
300,713 \\
2,837,634\end{array}$ & $\begin{array}{r}0 \\
0 \\
0 \\
5 \\
5 \\
30,830\end{array}$ \\
\hline
\end{tabular}

See endnotes at end of an indluidual electric utility. 
Table 38. Balance Sheot by Major U.8. Inveator-Owned Electric Utility Within State on Decembor 31, 1902 (Continued)

(Thousand Dollars)

\begin{tabular}{|c|c|c|c|c|c|c|}
\hline itom & $\begin{array}{l}\text { North Dakota } \\
\text { Mou } \\
\text { Rosources } \\
\text { Group } \\
\text { Inc }\end{array}$ & $\begin{array}{l}\text { Ohlo } \\
\text { Cincinnatl } \\
\text { Gas } \\
\& \\
\text { Electrio Co }\end{array}$ & $\begin{array}{l}\text { Ohio } \\
\text { Cloveland } \\
\text { Electric } \\
\text { Illum Co }\end{array}$ & $\begin{array}{l}\text { Ohio } \\
\text { Columbus } \\
\text { Southern } \\
\text { Power Co }\end{array}$ & $\begin{array}{l}\text { Ohio } \\
\text { Dayton } \\
\text { Power } \\
\text { Light Co }\end{array}$ & $\begin{array}{l}\text { Onio } \\
\text { Indiana- } \\
\text { Kentucky } \\
\text { Electric } \\
\text { Corp }\end{array}$ \\
\hline $\begin{array}{l}\text { Propribtary Capltal } \\
\text { Common Stock leaved ............................................. } \\
\text { Proterred Stock leaued ........................................ } \\
\text { Captital Stook Subecrlbed, }\end{array}$ & $\begin{array}{l}94,023 \\
17,300\end{array}$ & $\begin{array}{l}734,307 \\
330,000\end{array}$ & $\begin{array}{r}1,243,104 \\
498,121\end{array}$ & $\begin{array}{r}41,026 \\
126,000\end{array}$ & $\begin{array}{r}412 \\
125,600\end{array}$ & $\begin{array}{r}3,400 \\
0\end{array}$ \\
\hline 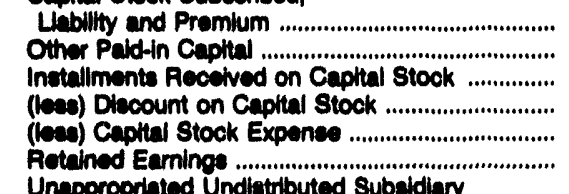 & $\begin{array}{r}66,460 \\
0 \\
0 \\
0 \\
2,250 \\
23,844\end{array}$ & $\begin{array}{r}309,650 \\
0 \\
0 \\
0 \\
25,084 \\
589,717\end{array}$ & $\begin{array}{r}0 \\
78,625 \\
0 \\
0 \\
1,864 \\
537,525\end{array}$ & $\begin{array}{r}267,892 \\
308,164 \\
0 \\
0 \\
0 \\
125,342\end{array}$ & $\begin{array}{r}301,186 \\
391,507 \\
0 \\
0 \\
17,704 \\
360,532\end{array}$ & $\begin{array}{l}0 \\
0 \\
0 \\
0 \\
0 \\
0\end{array}$ \\
\hline 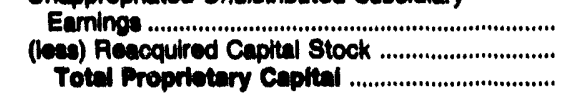 & $\begin{array}{r}120,374 \\
0 \\
320,761\end{array}$ & $\begin{array}{r}66,620 \\
0 \\
1,205,120\end{array}$ & $\begin{array}{r}7,597 \\
0 \\
2,391,100\end{array}$ & $\begin{array}{r}2,220 \\
0 \\
850,634\end{array}$ & $\begin{array}{r}-2,425 \\
0 \\
1,140,108\end{array}$ & $\begin{array}{r}0 \\
0 \\
3,400\end{array}$ \\
\hline 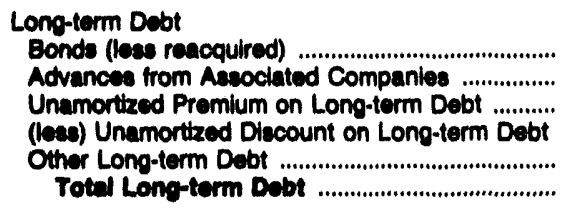 & $\begin{array}{r}195,850 \\
0 \\
0 \\
205 \\
35,000 \\
230,845\end{array}$ & $\begin{array}{r}1,656,700 \\
0 \\
716 \\
12,868 \\
175,746 \\
1,719,290\end{array}$ & $\begin{array}{r}1,867,614 \\
0 \\
574 \\
6,271 \\
924,950 \\
2,779,007\end{array}$ & $\begin{array}{r}839,140 \\
0 \\
40 \\
4,800 \\
143,650 \\
977,021\end{array}$ & $\begin{array}{r}1,005,609 \\
0 \\
194 \\
6,692 \\
0 \\
900,112\end{array}$ & $\begin{array}{l}0 \\
0 \\
0 \\
0 \\
0 \\
0\end{array}$ \\
\hline 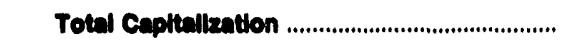 & 851,390 & $3,704,425$ & $6,137,076$ & $1,097,658$ & $2,140,220$ & 3,400 \\
\hline $\begin{array}{l}\text { Other Noncurrent Llabillities } \\
\text { Oblloations Under Capital Lease-Nonourrent ...... } \\
\text { Accumulated Provilion for Property Insurance ... } \\
\text { Accumulated Provision for Injuries and }\end{array}$ & $\begin{array}{l}0 \\
0\end{array}$ & $\begin{array}{l}0 \\
0\end{array}$ & $\begin{array}{r}185,146 \\
0\end{array}$ & $\begin{array}{r}7,082 \\
0\end{array}$ & $\begin{array}{l}j \\
0\end{array}$ & $\begin{array}{l}0 \\
0\end{array}$ \\
\hline $\begin{array}{l}\text { Damages } \\
\text { Accumulated Provision for Pensions and }\end{array}$ & 842 & 835 & 0 & 3,173 & 7,687 & 0 \\
\hline $\begin{array}{l}\text { Beneffits . } \\
\text { Accumulated Miscellaneous Operating }\end{array}$ & 0 & 0 & 0 & 0 & 0 & 0 \\
\hline 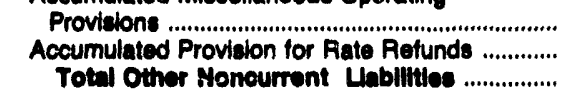 & $\begin{array}{r}0 \\
0 \\
842\end{array}$ & $\begin{array}{r}0 \\
0 \\
938\end{array}$ & $\begin{array}{r}17,700 \\
0 \\
202,846\end{array}$ & $\begin{array}{r}4 \\
0 \\
10,280\end{array}$ & $\begin{array}{r}0 \\
0 \\
7,667\end{array}$ & \\
\hline 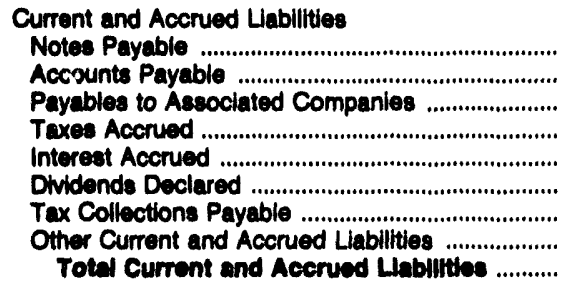 & $\begin{array}{r}4,000 \\
8,305 \\
14,221 \\
8,202 \\
3,293 \\
7,226 \\
1,347 \\
7,837 \\
64,631\end{array}$ & $\begin{array}{r}40,000 \\
109,785 \\
311 \\
208,497 \\
26,143 \\
8,290 \\
432 \\
23,329 \\
412,787\end{array}$ & $\begin{array}{r}10,000 \\
103,635 \\
50,787 \\
290,306 \\
55,408 \\
14,185 \\
-903 \\
90,609 \\
614,027\end{array}$ & $\begin{array}{r}53,819 \\
33,372 \\
15,801 \\
118,434 \\
26,047 \\
2,768 \\
717 \\
15,767 \\
268,723\end{array}$ & $\begin{array}{r}62,000 \\
9,114 \\
1,028 \\
104,286 \\
12,348 \\
0 \\
556 \\
46,101 \\
316,433\end{array}$ & $\begin{array}{r}0 \\
19,880 \\
154 \\
1,815 \\
0 \\
0 \\
57 \\
169 \\
21,874\end{array}$ \\
\hline 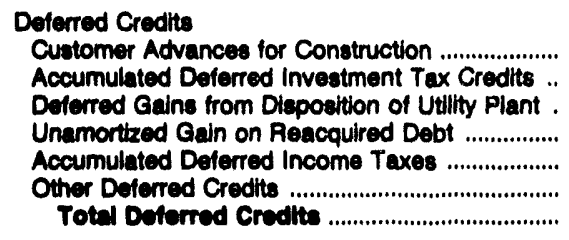 & $\begin{array}{r}451 \\
12,645 \\
0 \\
0 \\
0 \\
85,050 \\
5,823 \\
103,860\end{array}$ & $\begin{array}{r}8,027 \\
141,436 \\
0 \\
0 \\
268,438 \\
65,857 \\
403,768\end{array}$ & $\begin{array}{r}0 \\
263,080 \\
0 \\
7,580 \\
1,711,416 \\
663,111 \\
2,646,100\end{array}$ & $\begin{array}{r}726 \\
73,846 \\
0 \\
1,180 \\
194,238 \\
5,478 \\
276,607\end{array}$ & $\begin{array}{r}3,615 \\
87,369 \\
0 \\
0 \\
0 \\
267,801 \\
36,430 \\
306,216\end{array}$ & $\begin{array}{r}2,970 \\
0 \\
0 \\
0 \\
0 \\
2,594 \\
\mathbf{5 , 6 0 4}\end{array}$ \\
\hline Total Lebullties and Other Credth ................ & 710,730 & $4,601,405$ & $8,600,037$ & $2,300,004$ & $2,007,634$ & 30,898 \\
\hline
\end{tabular}

Note: Totale may not equal sum of components because of independent rounding. Summary data are provided in Table 8. Source: Federal Energy Regulatory Commission, FERC Form 1, "Annual Report of Major Electric Utilties, Llcensees and Others." 
Table 38. Balance Shoot by Major U.S. Investor-Owned Electrle Utillity Within state on December 31, 1992 (Continued) (Thousand Dollars)

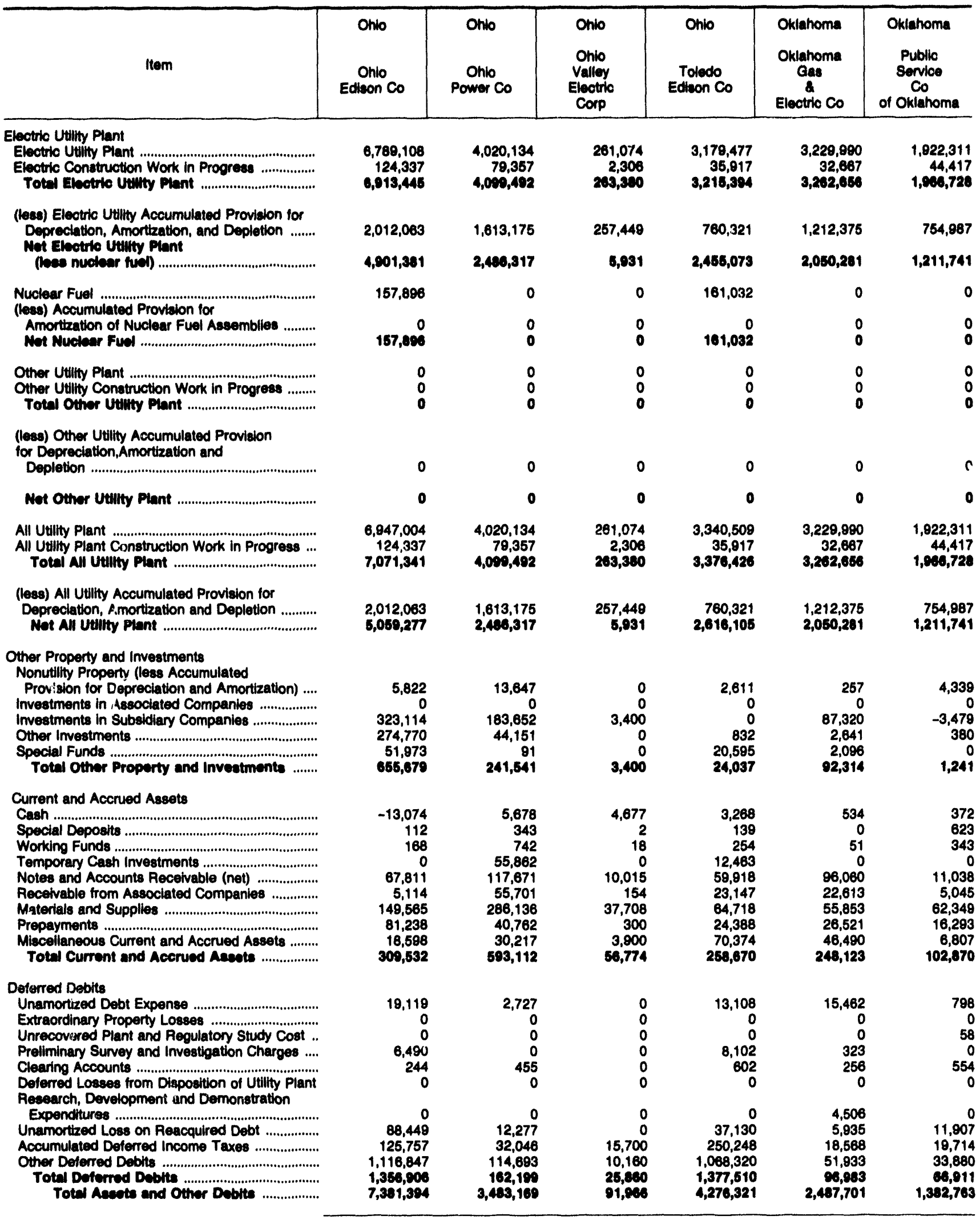

Ses endnotes at end of an individual electric utility. 
Table 38. Balance Sheot by Major U.8. Investor-Owned Electric Utility Within state on Decomber 31, 1992 (Continued) (Thousand Dollars)

\begin{tabular}{|c|c|c|c|c|c|c|}
\hline Item & $\begin{array}{c}\text { Ohio } \\
\text { Ohio } \\
\text { Edison Co }\end{array}$ & $\begin{array}{c}\text { Ohio } \\
\text { Ohio } \\
\text { Power Co }\end{array}$ & $\begin{array}{l}\text { Ohio } \\
\text { Onio } \\
\text { Valley } \\
\text { Electric } \\
\text { Corp }\end{array}$ & $\begin{array}{c}\text { Onio } \\
\text { Toledo } \\
\text { Edieon Co }\end{array}$ & $\begin{array}{c}\text { Oklahoma } \\
\text { Oklahoma } \\
\text { Gas } \\
8 \\
\text { Electric Co }\end{array}$ & $\begin{array}{c}\text { Oklahoma } \\
\text { I ublio } \\
\text { Senvice } \\
\text { Co } \\
\text { of Okiahoma }\end{array}$ \\
\hline 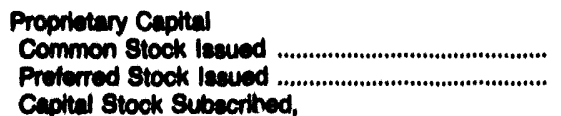 & $\begin{array}{r}1,373,125 \\
342,735\end{array}$ & $\begin{array}{l}321,201 \\
232,978\end{array}$ & $\begin{array}{r}10,000 \\
0\end{array}$ & $\begin{array}{l}196,687 \\
271,680\end{array}$ & $\begin{array}{r}116,177 \\
49,973\end{array}$ & $\begin{array}{r}157,230 \\
18,760\end{array}$ \\
\hline 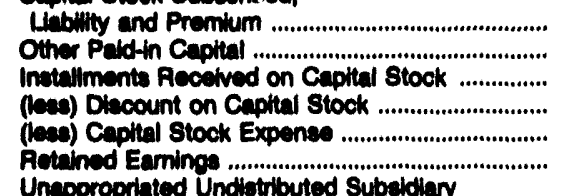 & $\begin{array}{r}736,178 \\
-4,427 \\
0 \\
0 \\
274 \\
401,760\end{array}$ & $\begin{array}{r}2,161 \\
462,725 \\
0 \\
0 \\
0 \\
411,802\end{array}$ & $\begin{array}{r}0 \\
0 \\
0 \\
0 \\
0 \\
57\end{array}$ & $\begin{array}{r}496,940 \\
117,837 \\
0 \\
0 \\
12,681 \\
138,586\end{array}$ & $\begin{array}{r}606,305 \\
1,869 \\
0 \\
0 \\
0 \\
386,863\end{array}$ & $\begin{array}{r}36 \\
180,000 \\
0 \\
0 \\
0 \\
99,233\end{array}$ \\
\hline 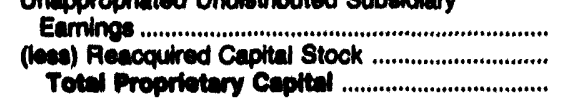 & $\begin{array}{r}88,814 \\
0 \\
2,997,001\end{array}$ & $\begin{array}{r}34,164 \\
0 \\
1,498,042\end{array}$ & $\begin{array}{r}0 \\
0 \\
10,067\end{array}$ & $\begin{array}{r}0 \\
0 \\
1,209,000\end{array}$ & $\begin{array}{r}2,635 \\
213,883 \\
99,989\end{array}$ & $\begin{array}{r}-7,318 \\
0 \\
49,072\end{array}$ \\
\hline 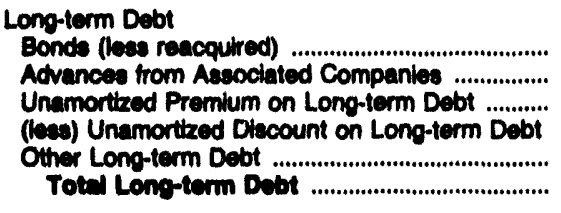 & $\begin{array}{r}1,492,483 \\
0 \\
465 \\
7,604 \\
1,316,464 \\
2,801,000\end{array}$ & $\begin{array}{r}1,218,085 \\
0 \\
675 \\
4,452 \\
235,000 \\
1,240,300\end{array}$ & $\begin{array}{r}0 \\
0 \\
0 \\
0 \\
10,000 \\
10,000\end{array}$ & $\begin{array}{r}585,126 \\
0 \\
0 \\
2,434 \\
641,868 \\
1,224,680\end{array}$ & $\begin{array}{r}773,200 \\
0 \\
808 \\
10,064 \\
0 \\
783,084\end{array}$ & $\begin{array}{r}433,060 \\
0 \\
0 \\
0 \\
2,752 \\
0 \\
480,300\end{array}$ \\
\hline Total Cespitalimation ............................................. & $8,739,700$ & $2,714,350$ & 20,087 & $2,480,628$ & $1,713,892$ & 870,200 \\
\hline $\begin{array}{l}\text { Other Noncurrent Liablitiles } \\
\text { Obllgations Under Capltal Lease-Noncurrent ...... } \\
\text { Accumulated Proviaion for Property Ineurance ... } \\
\text { Accumulated Provision for Injurles and }\end{array}$ & $\begin{array}{r}153,222 \\
0\end{array}$ & $\begin{array}{r}17,291 \\
0\end{array}$ & $\begin{array}{l}0 \\
0\end{array}$ & $\begin{array}{r}125,592 \\
0\end{array}$ & $\begin{array}{r}5,809 \\
0\end{array}$ & $\begin{array}{l}0 \\
0\end{array}$ \\
\hline 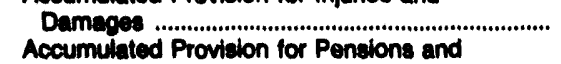 & 3,884 & 6,477 & 0 & 0 & 0 & 0 \\
\hline $\begin{array}{l}\text { Beneftits ................................................... } \\
\text { Accumulated Miscellaneous Operating }\end{array}$ & 20,456 & 484 & 0 & 0 & 6,620 & 0 \\
\hline 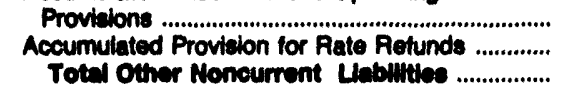 & $\begin{array}{r}17,000 \\
0 \\
184,083\end{array}$ & $\begin{array}{r}5,861 \\
0 \\
30,213\end{array}$ & $\begin{array}{l}0 \\
0 \\
0\end{array}$ & $\begin{array}{r}16,102 \\
0 \\
141,695\end{array}$ & $\begin{array}{r}0 \\
18,000 \\
29,420\end{array}$ & $\begin{array}{l}0 \\
0 \\
0\end{array}$ \\
\hline 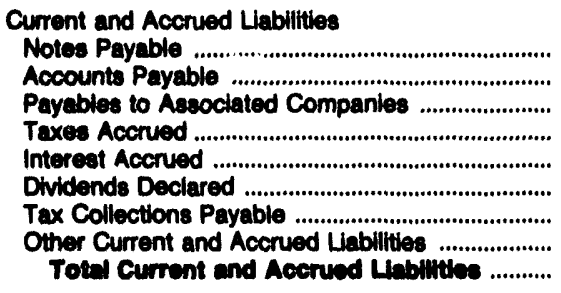 & $\begin{array}{r}35,700 \\
86,619 \\
39,980 \\
125,250 \\
61,630 \\
633 \\
371 \\
117,376 \\
497,600\end{array}$ & $\begin{array}{r}0 \\
61,801 \\
34,536 \\
167,324 \\
22,229 \\
0 \\
899 \\
47,500 \\
334,200\end{array}$ & $\begin{array}{r}16,00 C \\
21,642 \\
-6,619 \\
5,758 \\
94 \\
0 \\
0 \\
295 \\
37,160\end{array}$ & $\begin{array}{r}39,502 \\
47,844 \\
15,938 \\
78,363 \\
28,465 \\
3 \\
552 \\
64,860 \\
275,627\end{array}$ & $\begin{array}{r}26,000 \\
62,125 \\
9,332 \\
25,860 \\
26,863 \\
27,397 \\
7,078 \\
64,112 \\
248,868\end{array}$ & $\begin{array}{r}0 \\
45,597 \\
20,330 \\
5,571 \\
8,579 \\
184 \\
4,686 \\
21,499 \\
100,486\end{array}$ \\
\hline 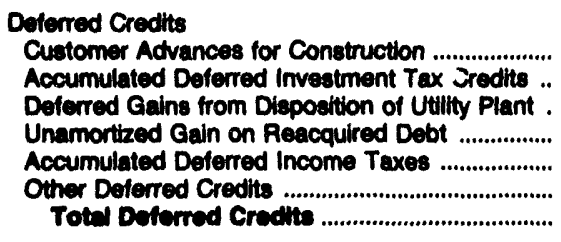 & $\begin{array}{r}2,112 \\
205,287 \\
0 \\
131 \\
644,204 \\
127,720 \\
979,464\end{array}$ & $\begin{array}{r}996 \\
49,354 \\
0 \\
0 \\
324,331 \\
29,636 \\
404,317\end{array}$ & $\begin{array}{r}1,446 \\
10,610 \\
0 \\
0 \\
11,023 \\
11,680 \\
34,740\end{array}$ & $\begin{array}{r}536 \\
112,857 \\
0 \\
4,790 \\
880,019 \\
420,270 \\
1,428,472\end{array}$ & $\begin{array}{r}63 \\
88,627 \\
0 \\
0 \\
396,033 \\
791 \\
495,614\end{array}$ & $\begin{array}{r}919 \\
54,638 \\
0 \\
331 \\
296,436 \\
44,733 \\
397,050\end{array}$ \\
\hline Total Lablities and Other Crealts ................ & $7,381,394$ & $3,403,189$ & 91,868 & $4,276,321$ & $2,487,701$ & $1,392,798$ \\
\hline
\end{tabular}

Note: Totals may not equal sum of components because of independent rounding. Summary data are provided in Table 8.

Source: Federal Energy Regulatory Commission, FERC Form 1, "Annual Report of Major Electric Utilities, Licensees and Others." 


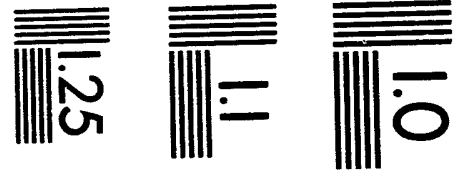

$$
\begin{aligned}
& \text { 咅咅 }
\end{aligned}
$$

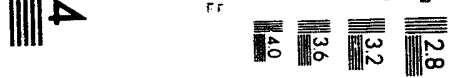

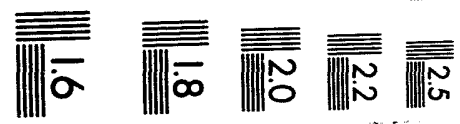



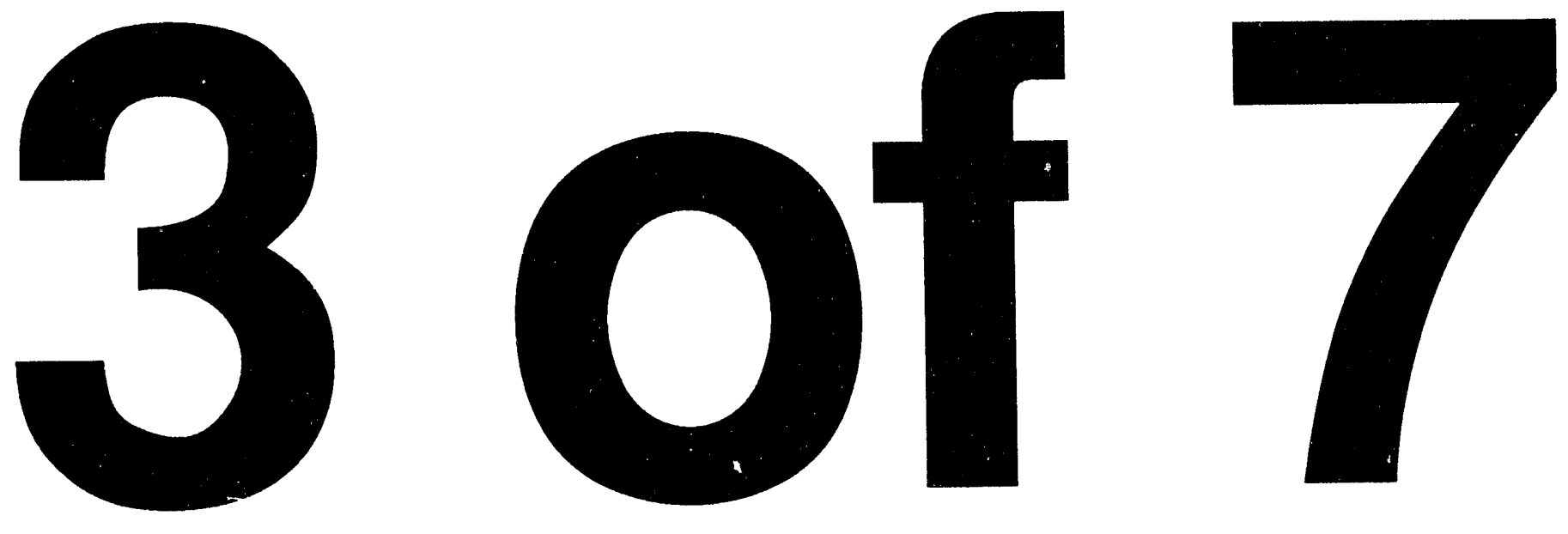
Table 38. Balance Sheet by Major U.S. Investor-Owned Electric Utility Within State on December 31, 1992 (Continued) (Thousand Dollars)

\begin{tabular}{|c|c|c|c|c|c|c|}
\hline Item & $\begin{array}{l}\text { Oregon } \\
\text { Pacticorp }\end{array}$ & $\begin{array}{l}\text { Oregon } \\
\text { Portind } \\
\text { General } \\
\text { Electric Co }\end{array}$ & $\begin{array}{l}\text { Pennoytvania } \\
\text { Duquesne } \\
\text { Light Co }\end{array}$ & $\begin{array}{c}\text { Pennoytvania } \\
\text { Metropolitan } \\
\text { Edison Co }\end{array}$ & $\begin{array}{l}\text { Pennoytvania } \\
\text { Penneytvania } \\
\text { Electric Co }\end{array}$ & $\begin{array}{c}\text { Penneytvenia } \\
\text { Penneytvania } \\
\text { Power } \\
\mathbf{a} \\
\text { Loht Co }\end{array}$ \\
\hline 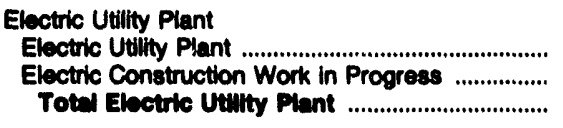 & $\begin{array}{r}9,193,763 \\
288,278 \\
9,462,041\end{array}$ & $\begin{array}{r}2,386,240 \\
12,308 \\
2,408,646\end{array}$ & $\begin{array}{r}4,110,028 \\
67,435 \\
4,177,463\end{array}$ & $\begin{array}{r}1,873,453 \\
80,134 \\
1,053,697\end{array}$ & $\begin{array}{r}2,321,346 \\
54,255 \\
2,376,601\end{array}$ & $\begin{array}{r}8,668,518 \\
211,534 \\
\mathbf{0 , 9 8 0 , 0 5 2}\end{array}$ \\
\hline 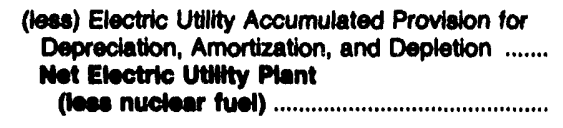 & $\begin{array}{l}2,684,568 \\
0,777,473\end{array}$ & $\begin{array}{r}876,369 \\
1,532,179\end{array}$ & $\begin{array}{l}1,252,294 \\
2,926,169\end{array}$ & $\begin{array}{r}586,076 \\
1,397,512\end{array}$ & $\begin{array}{r}836,339 \\
1,630,292\end{array}$ & $\begin{array}{l}2,199,687 \\
8,890,398\end{array}$ \\
\hline 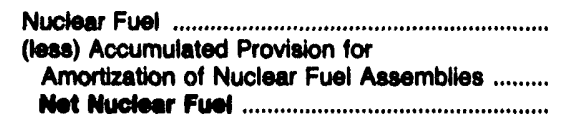 & $\begin{array}{r}0 \\
80\end{array}$ & $\begin{array}{l}0 \\
0\end{array}$ & $\begin{array}{r}77,217 \\
0 \\
77,217\end{array}$ & $\begin{array}{r}53,382 \\
0 \\
53,392\end{array}$ & $\begin{array}{r}26,645 \\
0 \\
28,645\end{array}$ & $\begin{array}{r}174,368 \\
0 \\
174,398\end{array}$ \\
\hline 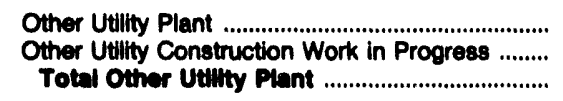 & $\begin{array}{r}1,520 \\
0 \\
1,520\end{array}$ & $\begin{array}{l}0 \\
0 \\
0\end{array}$ & $\begin{array}{l}0 \\
0 \\
0\end{array}$ & $\begin{array}{l}0 \\
0 \\
0\end{array}$ & $\begin{array}{l}0 \\
0 \\
0\end{array}$ & $\begin{array}{l}0 \\
0 \\
0\end{array}$ \\
\hline 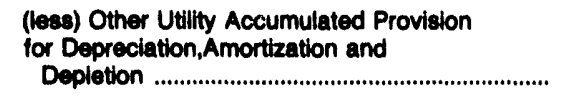 & 313 & 0 & 0 & 0 & 0 & 0 \\
\hline 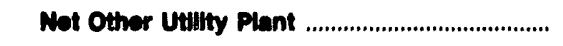 & 1,206 & $\mathbf{0}$ & $\mathbf{0}$ & $\mathbf{0}$ & $\mathbf{0}$ & $\mathbf{0}$ \\
\hline 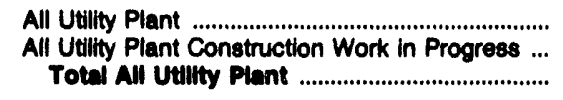 & $\begin{array}{r}9,195,363 \\
268,278 \\
9,463,641\end{array}$ & $\begin{array}{r}2,396,240 \\
12,308 \\
2,400,546\end{array}$ & $\begin{array}{r}4,187,246 \\
67,435 \\
4,264,600\end{array}$ & $\begin{array}{r}1,826,834 \\
80,134 \\
2,000,630\end{array}$ & $\begin{array}{r}2,347,891 \\
54,255 \\
2,402,246\end{array}$ & $\begin{array}{r}8,842,886 \\
211,534 \\
9,064,480\end{array}$ \\
\hline 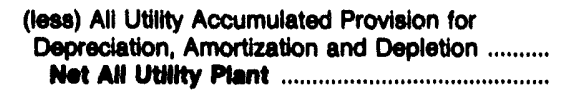 & $\begin{array}{l}2,684,882 \\
6,778,750\end{array}$ & $\begin{array}{r}876,369 \\
1,632,170\end{array}$ & $\begin{array}{l}1,252,294 \\
3,002,396\end{array}$ & $\begin{array}{r}586,076 \\
1,420,603\end{array}$ & $\begin{array}{r}836,339 \\
1,685,007\end{array}$ & $\begin{array}{r}2,198,687 \\
8,064,733\end{array}$ \\
\hline 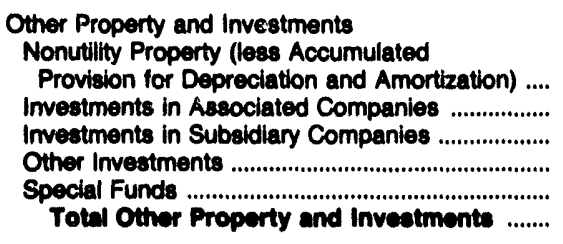 & $\begin{array}{r}6,690 \\
6,108 \\
784,661 \\
18,632 \\
77,560 \\
898,641\end{array}$ & $\begin{array}{r}10,376 \\
0 \\
3,154 \\
17,536 \\
85,157 \\
118,222\end{array}$ & $\begin{array}{r}2,300 \\
0 \\
707 \\
33,553 \\
14,744 \\
61,004\end{array}$ & $\begin{array}{r}4,521 \\
0 \\
9,002 \\
2,825 \\
8,687 \\
26,114\end{array}$ & $\begin{array}{r}1,569 \\
0 \\
1,442 \\
1,623 \\
4,350 \\
0,005\end{array}$ & $\begin{array}{r}3,118 \\
0 \\
39,841 \\
20,385 \\
92,181 \\
165,604\end{array}$ \\
\hline 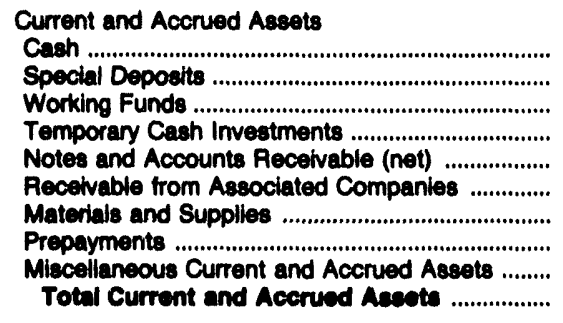 & $\begin{array}{r}-40,297 \\
868 \\
1,406 \\
25,600 \\
243,413 \\
2,548 \\
195,478 \\
41,884 \\
135,816 \\
608,716\end{array}$ & $\begin{array}{r}3,234 \\
19 \\
82 \\
0 \\
79,880 \\
3,433 \\
61,550 \\
20,899 \\
81,155 \\
250,352\end{array}$ & $\begin{array}{r}929 \\
101 \\
121 \\
5,000 \\
51,078 \\
983 \\
105,313 \\
5,276 \\
6,509 \\
175,310\end{array}$ & $\begin{array}{r}0 \\
1,233 \\
523 \\
0 \\
67,767 \\
883 \\
53,548 \\
4,862 \\
28,579 \\
167,348\end{array}$ & $\begin{array}{r}0 \\
3,465 \\
88 \\
0 \\
85,678 \\
0 \\
81,249 \\
4,810 \\
30,158 \\
185,485\end{array}$ & $\begin{array}{r}2,673 \\
371 \\
851 \\
7,000 \\
189,971 \\
53,550 \\
280,740 \\
6,843 \\
134,187 \\
88,187\end{array}$ \\
\hline $\begin{array}{l}\text { Deferred Debits } \\
\text { Unamortzed Debt Expense ..................................... } \\
\text { Extraordinary Property Losses ............................ } \\
\text { Unrecovered Plant and Regulatory Study Cost ... } \\
\text { Prellminary Survey and Investigation Charges .... } \\
\text { Clearing Accounts ...................................................... } \\
\text { Deferred Losees from Disposition of Utility Plant } \\
\text { Research, Development and Demonstration }\end{array}$ & $\begin{array}{r}15,216 \\
3,800 \\
29,938 \\
4,517 \\
0 \\
0\end{array}$ & $\begin{array}{r}6,234 \\
0 \\
671,221 \\
499 \\
10 \\
0\end{array}$ & $\begin{array}{r}10,419 \\
0 \\
46,447 \\
19,569 \\
1,253 \\
0\end{array}$ & $\begin{array}{r}2,175 \\
20,800 \\
2,888 \\
238 \\
441 \\
0\end{array}$ & $\begin{array}{r}3,145 \\
19,978 \\
1,343 \\
40 \\
-330 \\
0\end{array}$ & $\begin{array}{r}5,082 \\
0 \\
0 \\
680 \\
1,408 \\
0\end{array}$ \\
\hline 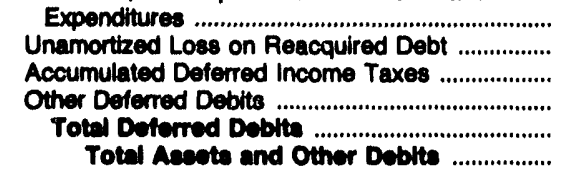 & $\begin{array}{r}0 \\
70,377 \\
42,523 \\
262,304 \\
428,773 \\
8,707,800\end{array}$ & $\begin{array}{r}0 \\
22,635 \\
86,079 \\
345,007 \\
1,131,698 \\
3,030,439\end{array}$ & $\begin{array}{r}981 \\
70,325 \\
41,642 \\
418,577 \\
600,211 \\
3,838,211\end{array}$ & $\begin{array}{r}0 \\
0 \\
51,488 \\
85,540 \\
173,490 \\
1,778,809\end{array}$ & $\begin{array}{r}0 \\
10,287 \\
32,248 \\
65,693 \\
132,254 \\
1,892,601\end{array}$ & $\begin{array}{r}0 \\
78,917 \\
125,430 \\
251,311 \\
462,039 \\
8,160,243\end{array}$ \\
\hline
\end{tabular}

See endnotes at end of an individual electric utility. 
Table 38. Balance Sheot by Major U.S. Inveator-Owned Electric Utility Within State on December 31, 1992 (Continued)

(Thousand Dollars)

\begin{tabular}{|c|c|c|c|c|c|c|}
\hline Item & $\begin{array}{l}\text { Oregon } \\
\text { Pacificorp }\end{array}$ & $\begin{array}{l}\text { Oregon } \\
\text { Portiand } \\
\text { General } \\
\text { Electric Co }\end{array}$ & $\begin{array}{l}\text { Penneytvania } \\
\text { Duquesne } \\
\text { Light Co }\end{array}$ & $\begin{array}{l}\text { Pennsytvania } \\
\text { Metropolitan } \\
\text { Edison Co }\end{array}$ & $\begin{array}{l}\text { Pennsylvania } \\
\text { Penn :ania } \\
\text { Electri: Co }\end{array}$ & $\begin{array}{l}\text { Penneytvania } \\
\text { Pennsytvania } \\
\text { Power } \\
8 \\
\text { Light Co }\end{array}$ \\
\hline 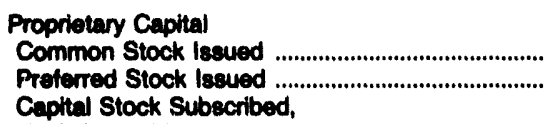 & $\begin{array}{r}2,817,116 \\
636,360\end{array}$ & $\begin{array}{l}151,721 \\
153,304\end{array}$ & $\begin{array}{r}0 \\
77,732\end{array}$ & $\begin{array}{r}68,273 \\
139,391\end{array}$ & $\begin{array}{r}105,812 \\
86,500\end{array}$ & $\begin{array}{r}1,364,148 \\
549,212\end{array}$ \\
\hline 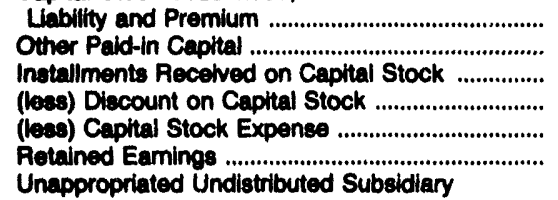 & $\begin{array}{r}0 \\
0 \\
202 \\
0 \\
40,944 \\
-139,240\end{array}$ & $\begin{array}{r}443,720 \\
1,202 \\
0 \\
0 \\
2,653 \\
141,724\end{array}$ & $\begin{array}{r}54,276 \\
808,706 \\
0 \\
0 \\
1,839 \\
300,529\end{array}$ & $\begin{array}{r}483 \\
295,524 \\
0 \\
0 \\
0 \\
176,422\end{array}$ & $\begin{array}{r}422 \\
265,486 \\
0 \\
0 \\
0 \\
278,418\end{array}$ & $\begin{array}{r}87 \\
0 \\
0 \\
0 \\
12,055 \\
1,003,987\end{array}$ \\
\hline 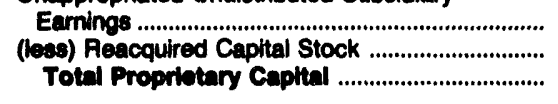 & $\begin{array}{r}339,872 \\
280 \\
3,613,186\end{array}$ & $\begin{array}{r}958 \\
0 \\
899,976\end{array}$ & $\begin{array}{r}-781 \\
0 \\
1,238,625\end{array}$ & $\begin{array}{r}6,147 \\
0 \\
684,240\end{array}$ & $\begin{array}{r}65 \\
0 \\
738,703\end{array}$ & $\begin{array}{r}10,773 \\
0 \\
2,916,151\end{array}$ \\
\hline 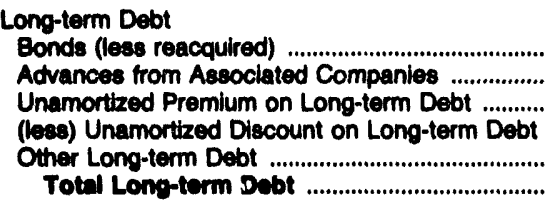 & $\begin{array}{r}3,017,509 \\
0 \\
14,392 \\
3,408 \\
0 \\
0 \\
3,028,498\end{array}$ & $\begin{array}{r}782,127 \\
0 \\
0 \\
934 \\
69,736 \\
850,920\end{array}$ & $\begin{array}{r}1,034,780 \\
0 \\
25 \\
4,037 \\
393,624 \\
1,424,402\end{array}$ & $\begin{array}{r}491,200 \\
0 \\
133 \\
1,081 \\
30,231 \\
520,603\end{array}$ & $\begin{array}{r}580,420 \\
0 \\
294 \\
1,151 \\
15,116 \\
594,679\end{array}$ & $\begin{array}{r}2,628,750 \\
0 \\
168 \\
19,474 \\
116 \\
2,600,650\end{array}$ \\
\hline 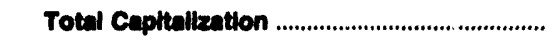 & $6,641,679$ & $1,740,905$ & $2,683,028$ & $1,204,744$ & $1,331,382$ & $5,525,710$ \\
\hline $\begin{array}{l}\text { Other Noncurrent Liabilities } \\
\text { Obligations Under Capital Lease-Noncurrent ...... } \\
\text { Accumulated Provision for Property Insurance ... } \\
\text { Accumulated Provision for Injurles and }\end{array}$ & $\begin{array}{r}17,972 \\
3,880\end{array}$ & $\begin{array}{r}13,817 \\
0\end{array}$ & $\begin{array}{r}71,876 \\
0\end{array}$ & $\begin{array}{l}2,643 \\
1,569\end{array}$ & $\begin{array}{r}7,691 \\
0\end{array}$ & $\begin{array}{r}162,891 \\
0\end{array}$ \\
\hline $\begin{array}{l}\text { Damages ..................................................... } \\
\text { Accumulated Provision tor Pensions and }\end{array}$ & 3,680 & 1,656 & 11,753 & 4,537 & 5,151 & 0 \\
\hline 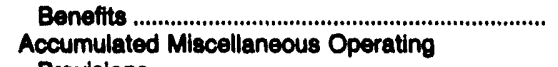 & 0 & 18,167 & 0 & 1,464 & 2,356 & $\mathrm{C}$ \\
\hline Current and Accrued Liabilities & & & & & & \\
\hline 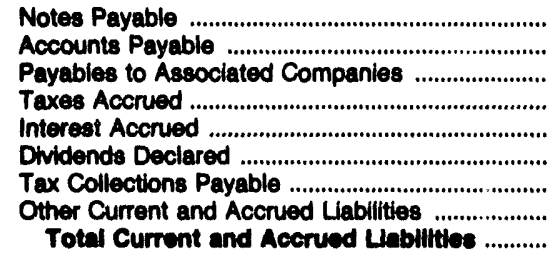 & $\begin{array}{r}362,623 \\
201,375 \\
29,614 \\
61,047 \\
78,598 \\
114,201 \\
7,075 \\
88,580 \\
944,113\end{array}$ & $\begin{array}{r}100,065 \\
110,620 \\
5,275 \\
41,503 \\
23,416 \\
21,568 \\
2,234 \\
6,454 \\
311,133\end{array}$ & $\begin{array}{r}0 \\
109,237 \\
830 \\
99,517 \\
28,258 \\
35,109 \\
2,789 \\
59,011 \\
334,052\end{array}$ & $\begin{array}{r}11,800 \\
52,807 \\
14,328 \\
18,762 \\
18,046 \\
2,572 \\
1,803 \\
64,721 \\
184,830\end{array}$ & $\begin{array}{r}48,300 \\
58,993 \\
10,826 \\
9,133 \\
12,985 \\
0 \\
2,222 \\
41,621 \\
184,079\end{array}$ & $\begin{array}{r}67,000 \\
138,359 \\
1,722 \\
62,241 \\
58,908 \\
70,556 \\
4,437 \\
175,616 \\
578,028\end{array}$ \\
\hline Deferred Credits & & & & & & \\
\hline 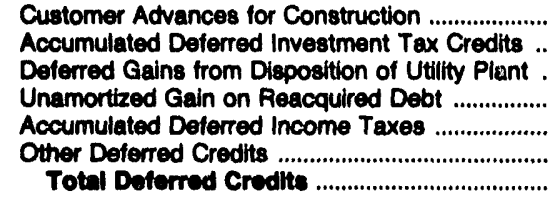 & $\begin{array}{r}13,918 \\
191,598 \\
0 \\
4,824 \\
643,625 \\
89,294 \\
943,259\end{array}$ & $\begin{array}{r}3,016 \\
64,781 \\
0 \\
60 \\
323,312 \\
134,051 \\
525,220\end{array}$ & $\begin{array}{r}402 \\
135,580 \\
0 \\
1,724 \\
546,523 \\
71,199 \\
765,428\end{array}$ & $\begin{array}{r}1,318 \\
40,936 \\
0 \\
698 \\
140,649 \\
193,230 \\
378,832\end{array}$ & $\begin{array}{r}1,289 \\
55,469 \\
0 \\
551 \\
212,754 \\
91,878 \\
361,942\end{array}$ & $\begin{array}{r}34 \\
253,310 \\
0 \\
0 \\
0 \\
1,192,597 \\
445,792 \\
1,891,734\end{array}$ \\
\hline Total Lublittes and Other Credits & $8,707,889$ & $3,080,430$ & $3,838,211$ & $1,776,883$ & $1,892,601$ & $8,150,263$ \\
\hline
\end{tabular}

Note: Totals may not equal sum of components because of independent rounding. Summary data are provided in Table 8.

Source: Federal Energy Regulatory Commiseion, FERC Form 1. "Annual Report of Major Electric Utilities, Licensees and Others." 
Table 38. Balance Sheet by Major U.S. Investor-Owned Electric Utility Within State on December 31, 1992 (Continued) (Thousand Dollars)

\begin{tabular}{|c|c|c|c|c|c|c|}
\hline Item & $\begin{array}{l}\text { Pennsylvania } \\
\text { Pennsylvania } \\
\text { Power Co }\end{array}$ & $\begin{array}{l}\text { Pennsytvania } \\
\text { Philadelphia } \\
\text { Electric Co }\end{array}$ & $\begin{array}{c}\text { Pennsytvania } \\
\text { Sate } \\
\text { Harbor } \\
\text { Water } \\
\text { Power Corp }\end{array}$ & $\begin{array}{l}\text { Pennsylvania } \\
\text { Susquehanna } \\
\text { Electric Co }\end{array}$ & $\begin{array}{c}\text { Pennsylvania } \\
\text { West } \\
\text { Penn } \\
\text { Power } \\
\text { Co }\end{array}$ & $\begin{array}{c}\text { Pennsylvania } \\
\text { York } \\
\text { Haven } \\
\text { Power } \\
\text { Co }\end{array}$ \\
\hline 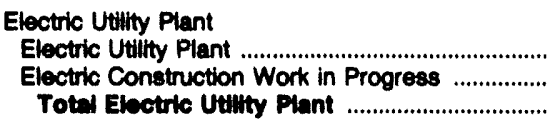 & $\begin{array}{r}1,135,361 \\
11,946 \\
1,147,307\end{array}$ & $\begin{array}{r}12,575,175 \\
291,834 \\
12,867,009\end{array}$ & $\begin{array}{r}161,257 \\
143 \\
161,400\end{array}$ & $\begin{array}{l}1 \\
0 \\
1\end{array}$ & $\begin{array}{r}2,405,337 \\
170,844 \\
2,576,181\end{array}$ & $\begin{array}{r}12,528 \\
1,464 \\
13,992\end{array}$ \\
\hline 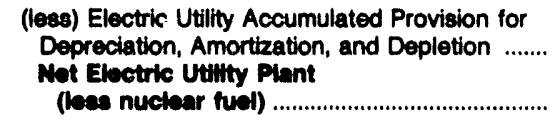 & $\begin{array}{l}333,330 \\
813,977\end{array}$ & $\begin{array}{l}3,265,052 \\
9,601,958\end{array}$ & $\begin{array}{r}44,014 \\
117,386\end{array}$ & 0 & $\begin{array}{r}904,499 \\
1,671,682\end{array}$ & $\begin{array}{l}4,489 \\
9,503\end{array}$ \\
\hline 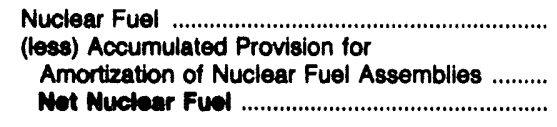 & $\begin{array}{r}31,670 \\
0 \\
31,670\end{array}$ & $\begin{array}{l}820,285 \\
422,915 \\
397,370\end{array}$ & $\begin{array}{l}0 \\
0\end{array}$ & $\begin{array}{l}0 \\
0\end{array}$ & $\begin{array}{l}0 \\
0\end{array}$ & $\begin{array}{l}0 \\
0\end{array}$ \\
\hline 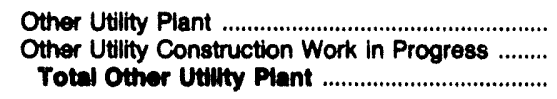 & $\begin{array}{l}0 \\
0 \\
0\end{array}$ & $\begin{array}{r}943,769 \\
53,653 \\
997,422\end{array}$ & $\begin{array}{l}0 \\
0 \\
0\end{array}$ & $\begin{array}{l}0 \\
0 \\
0\end{array}$ & $\begin{array}{l}0 \\
0 \\
0\end{array}$ & $\begin{array}{l}0 \\
0 \\
\mathbf{0}\end{array}$ \\
\hline 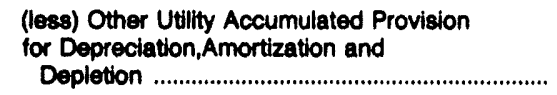 & 0 & 254,131 & 0 & 0 & 0 & 0 \\
\hline 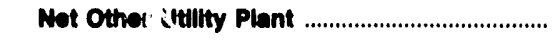 & $\mathbf{0}$ & 743,291 & 0 & $\mathbf{0}$ & 0 & 0 \\
\hline 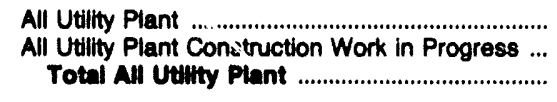 & $\begin{array}{r}1,167,030 \\
11,946 \\
1,178,876\end{array}$ & $\begin{array}{r}14,339,229 \\
345,487 \\
14,684,716\end{array}$ & $\begin{array}{r}161,257 \\
143 \\
161,400\end{array}$ & $\begin{array}{l}1 \\
0 \\
1\end{array}$ & $\begin{array}{r}2,405,337 \\
170,844 \\
2,576,181\end{array}$ & $\begin{array}{r}12,528 \\
1,464 \\
13,992\end{array}$ \\
\hline 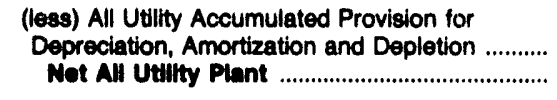 & $\begin{array}{l}333,330 \\
845,847\end{array}$ & $\begin{array}{r}3,942,097 \\
10,742,619\end{array}$ & $\begin{array}{r}44,014 \\
117,386\end{array}$ & $\begin{array}{l}0 \\
1\end{array}$ & $\begin{array}{r}904,499 \\
1,671,682\end{array}$ & $\begin{array}{l}4,489 \\
9,503\end{array}$ \\
\hline 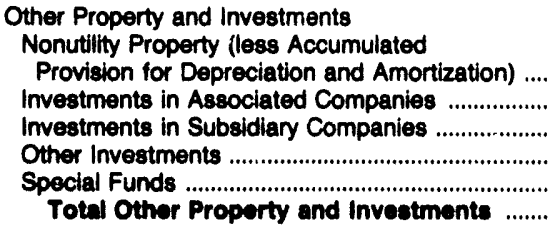 & $\begin{array}{r}524 \\
0 \\
0 \\
7,590 \\
8,136 \\
16,250\end{array}$ & $\begin{array}{r}21,562 \\
60 \\
187,813 \\
279 \\
127,459 \\
337,172\end{array}$ & $\begin{array}{l}1 \\
0 \\
0 \\
0 \\
0 \\
1\end{array}$ & $\begin{array}{l}0 \\
0 \\
0 \\
0 \\
0 \\
0\end{array}$ & $\begin{array}{r}2,702 \\
0 \\
110,086 \\
83 \\
535 \\
113,405\end{array}$ & $\begin{array}{l}0 \\
0 \\
0 \\
0 \\
0 \\
0\end{array}$ \\
\hline 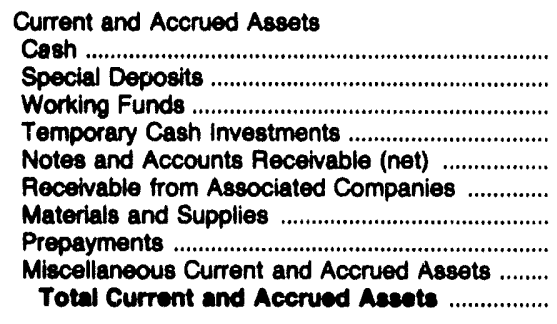 & $\begin{array}{r}3,621 \\
15 \\
28 \\
0 \\
35,292 \\
15,170 \\
21,104 \\
2,528 \\
63 \\
77,821\end{array}$ & $\begin{array}{r}7,748 \\
1,841 \\
35,335 \\
3 \\
84,217 \\
15,903 \\
191,523 \\
15,489 \\
83,114 \\
435,174\end{array}$ & $\begin{array}{r}156 \\
0 \\
1 \\
8,800 \\
2,402 \\
0 \\
586 \\
193 \\
50 \\
12,188\end{array}$ & $\begin{array}{r}528 \\
0 \\
1 \\
0 \\
313 \\
7,602 \\
540 \\
28 \\
81 \\
9,093\end{array}$ & $\begin{array}{r}0 \\
3,393 \\
271 \\
13,700 \\
91,874 \\
38,369 \\
95,810 \\
6,342 \\
15,262 \\
265,021\end{array}$ & $\begin{array}{r}20 \\
0 \\
0 \\
42 \\
0 \\
236 \\
0 \\
0 \\
0 \\
298\end{array}$ \\
\hline 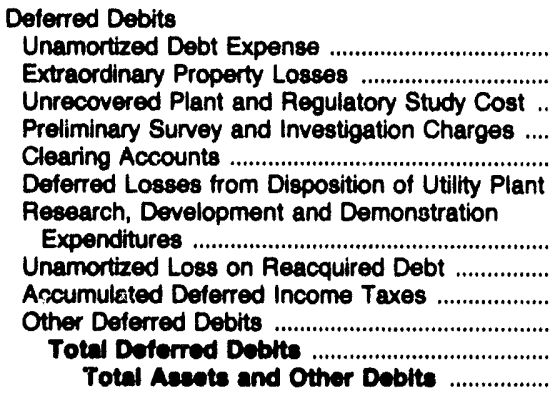 & $\begin{array}{r}0 \\
5,804 \\
22,455 \\
33,615 \\
66,565 \\
1,006,282\end{array}$ & $\begin{array}{r}16,268 \\
0 \\
26,009 \\
18,505 \\
17 \\
0 \\
\\
-78 \\
273,120 \\
477,229 \\
600,085 \\
1,411,156 \\
12,926,120\end{array}$ & $\begin{array}{r}0 \\
0 \\
383 \\
0 \\
481 \\
130,057\end{array}$ & $\begin{array}{r}2 \\
0 \\
477 \\
106 \\
844 \\
9,938\end{array}$ & $\begin{array}{r}0 \\
6,710 \\
43,434 \\
7,837 \\
77,407 \\
2,127,516\end{array}$ & $\begin{array}{r}0 \\
0 \\
0 \\
0 \\
0 \\
9,801\end{array}$ \\
\hline
\end{tabular}

See endnotes at end of an individual electric utility. 
Table 38. Balance Sheet by Major U.S. Investor-Owned Electric Utility Within State on December 31, 1992 (Continued) (Thousand Dollars)

\begin{tabular}{|c|c|c|c|c|c|c|}
\hline ltem & $\begin{array}{l}\text { Pennsylvania } \\
\text { Pennsylvania } \\
\text { Power Co }\end{array}$ & $\begin{array}{l}\text { Pennsyivania } \\
\text { Philadelphia } \\
\text { Electric Co }\end{array}$ & $\begin{array}{c}\text { Pennsylvania } \\
\text { Safe } \\
\text { Harbor } \\
\text { Water } \\
\text { Power Corp }\end{array}$ & $\begin{array}{l}\text { Pennsylvania } \\
\text { Susquehanna } \\
\text { Electric Co }\end{array}$ & $\begin{array}{c}\text { Pennsylvania } \\
\text { West } \\
\text { Penn } \\
\text { Power } \\
\text { Co }\end{array}$ & $\begin{array}{c}\text { Pennsylvania } \\
\text { York } \\
\text { Haven } \\
\text { Power } \\
\text { Co }\end{array}$ \\
\hline $\begin{array}{l}\text { Proprietary Capital } \\
\text { Common Stock lesued .............................................. } \\
\text { Preferred Stock lssued ....................................... } \\
\text { Capital Stock Subscribed, }\end{array}$ & $\begin{array}{r}188,700 \\
75,567\end{array}$ & $\begin{array}{r}3,459,131 \\
868,102\end{array}$ & $\begin{array}{r}9,000 \\
0\end{array}$ & $\begin{array}{r}10 \\
0\end{array}$ & $\begin{array}{l}325,994 \\
149,708\end{array}$ & $\begin{array}{r}1,163 \\
0\end{array}$ \\
\hline 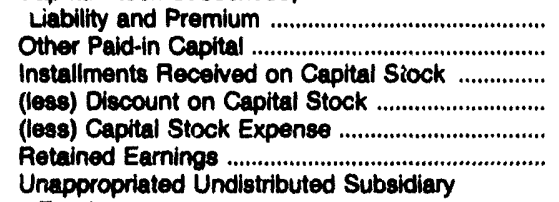 & $\begin{array}{r}41 \\
0 \\
0 \\
0 \\
187 \\
72,777\end{array}$ & $\begin{array}{r}1,214 \\
0 \\
0 \\
0 \\
0 \\
512,098\end{array}$ & $\begin{array}{r}0 \\
18,000 \\
0 \\
0 \\
0 \\
24,265\end{array}$ & $\begin{array}{r}0 \\
0 \\
0 \\
0 \\
0 \\
-40\end{array}$ & $\begin{array}{r}835 \\
54,997 \\
0 \\
0 \\
0 \\
394,713\end{array}$ & $\begin{array}{r}0 \\
1,500 \\
0 \\
0 \\
0 \\
6,338\end{array}$ \\
\hline 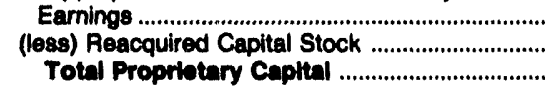 & $\begin{array}{r}0 \\
0 \\
338,898\end{array}$ & $\begin{array}{r}49,725 \\
214,500 \\
4,675,771\end{array}$ & $\begin{array}{r}0 \\
0 \\
51,285\end{array}$ & $\begin{array}{r}0 \\
0 \\
-30\end{array}$ & $\begin{array}{r}5,802 \\
0 \\
932,048\end{array}$ & $\begin{array}{r}0 \\
0 \\
9,002\end{array}$ \\
\hline 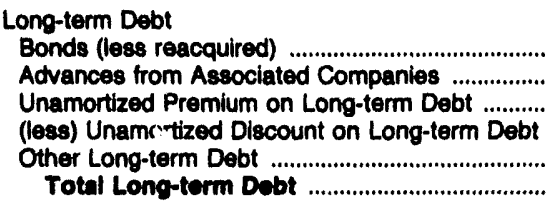 & $\begin{array}{r}230,000 \\
0 \\
91 \\
898 \\
166,887 \\
398,180\end{array}$ & $\begin{array}{r}4,099,868 \\
0 \\
150 \\
29,102 \\
1,220,696 \\
5,291,612\end{array}$ & $\begin{array}{r}0 \\
0 \\
0 \\
0 \\
45,000 \\
45,000\end{array}$ & $\begin{array}{r}0 \\
60 \\
0 \\
0 \\
0 \\
60\end{array}$ & $\begin{array}{r}584,000 \\
0 \\
273 \\
6,171 \\
184,035 \\
762,137\end{array}$ & $\begin{array}{l}0 \\
0 \\
0 \\
0 \\
0 \\
0\end{array}$ \\
\hline 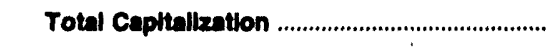 & 733,078 & $9,987,382$ & 89,286 & 30 & $1,694,185$ & 8,002 \\
\hline $\begin{array}{l}\text { Other Noncurrent Liabilities } \\
\text { Obligations Under Capital Lease-Noncurrent ...... } \\
\text { Accumulated Provision for Property Insurance ... } \\
\text { Accumulated Provision for Injuries and }\end{array}$ & $\begin{array}{r}29,869 \\
0\end{array}$ & $\begin{array}{r}150,997 \\
0\end{array}$ & $\begin{array}{l}0 \\
0\end{array}$ & $\begin{array}{l}0 \\
0\end{array}$ & $\begin{array}{r}3,696 \\
0\end{array}$ & $\begin{array}{l}0 \\
0\end{array}$ \\
\hline $\begin{array}{l}\text { Damages ............................................... } \\
\text { Accumulated Provision for }\end{array}$ & 949 & 0 & 0 & 0 & 931 & 0 \\
\hline Benefits & 1,985 & 0 & 0 & 0 & 1,359 & 0 \\
\hline 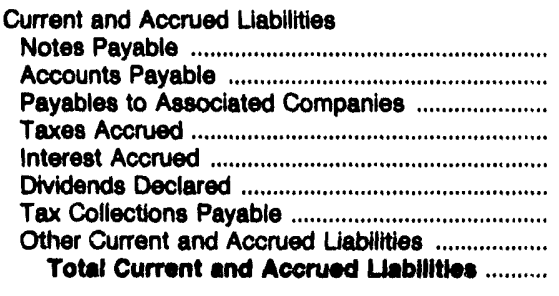 & $\begin{array}{r}15,000 \\
25,480 \\
8,329 \\
9,548 \\
8,971 \\
1,368 \\
478 \\
25,911 \\
95,085\end{array}$ & $\begin{array}{r}110,275 \\
355,992 \\
3,538 \\
22,879 \\
115,741 \\
19,459 \\
9,656 \\
158,842 \\
796,382\end{array}$ & $\begin{array}{r}0 \\
78 \\
0 \\
75 \\
877 \\
1,620 \\
15 \\
595 \\
3,260\end{array}$ & $\begin{array}{r}0 \\
1,739 \\
7,048 \\
356 \\
0 \\
0 \\
23 \\
494 \\
9,660\end{array}$ & $\begin{array}{r}0 \\
107,874 \\
7,652 \\
25,133 \\
19,001 \\
1,979 \\
1,151 \\
13,120 \\
175,911\end{array}$ & $\begin{array}{r}0 \\
0 \\
0 \\
164 \\
0 \\
0 \\
0 \\
0 \\
164\end{array}$ \\
\hline 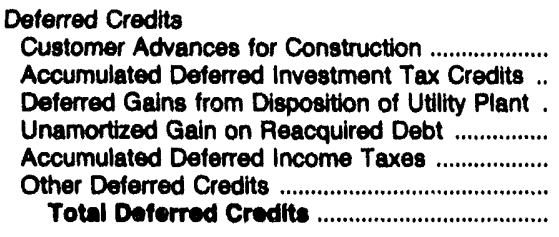 & $\begin{array}{r}300 \\
34,921 \\
0 \\
0 \\
96,791 \\
9,703 \\
141,715\end{array}$ & $\begin{array}{r}2,179 \\
300,220 \\
0 \\
6,684 \\
1,405,819 \\
296,457 \\
2,011,360\end{array}$ & $\begin{array}{r}0 \\
8,427 \\
0 \\
0 \\
22,101 \\
3 \\
30,532\end{array}$ & $\begin{array}{r}0 \\
0 \\
0 \\
0 \\
245 \\
3 \\
248\end{array}$ & $\begin{array}{r}3,267 \\
58,116 \\
0 \\
0 \\
187,582 \\
2,470 \\
251,434\end{array}$ & $\begin{array}{r}0 \\
59 \\
0 \\
0 \\
577 \\
0 \\
636\end{array}$ \\
\hline Total Lablittes and Other Credits ................ & $1,008,282$ & $12,926,120$ & 130,057 & 9,938 & $2,127,546$ & 8,801 \\
\hline
\end{tabular}

Note: Totals may not equal sum of components because of independent rounding. Summary data are provided in Table 8 .

Source: Federal Energy Regulatory Commission, FERC Form 1, "Annual Report of Major Electric Utilities, Licensees and Others." 
Table 38. Balance Sheet by Major U.S. Investor-Owned Electric Utility Within State on December 31, 1992 (Continued)

(Thousand Dollars)

\begin{tabular}{|c|c|c|c|c|c|c|}
\hline Item & $\begin{array}{l}\text { Rhode Island } \\
\text { Blackstone } \\
\text { Valley } \\
\text { Electric Co }\end{array}$ & $\begin{array}{l}\text { Rhode Island } \\
\text { Narragansett } \\
\text { Electric Co }\end{array}$ & $\begin{array}{l}\text { Rhode Island } \\
\text { Nowport } \\
\text { Electric } \\
\text { Corp }\end{array}$ & $\begin{array}{l}\text { South Carolina } \\
\text { Lockhart } \\
\text { Power Co }\end{array}$ & $\begin{array}{c}\text { South Carolina } \\
\text { South } \\
\text { Carolina } \\
\text { Electric\&Gas } \\
\text { Co }\end{array}$ & $\begin{array}{l}\text { South Carolina } \\
\text { South } \\
\text { Carolina } \\
\text { Genertg } \\
\text { Co Inc }\end{array}$ \\
\hline 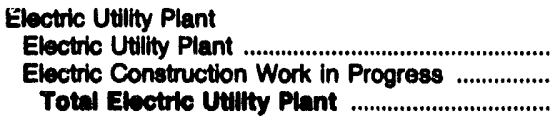 & $\begin{array}{r}125,492 \\
375 \\
125,868\end{array}$ & $\begin{array}{r}508,731 \\
16,073 \\
524,804\end{array}$ & $\begin{array}{r}69,805 \\
1,233 \\
71,038\end{array}$ & $\begin{array}{r}20,386 \\
188 \\
20,674\end{array}$ & $\begin{array}{r}2,943,097 \\
203,255 \\
3,146,353\end{array}$ & $\begin{array}{r}249,786 \\
11,429 \\
281,215\end{array}$ \\
\hline 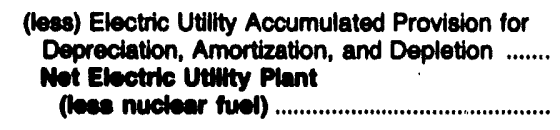 & $\begin{array}{l}37,552 \\
88,316\end{array}$ & $\begin{array}{l}150,372 \\
374,432\end{array}$ & $\begin{array}{l}19,053 \\
51,984\end{array}$ & $\begin{array}{r}9,132 \\
11,442\end{array}$ & $\begin{array}{r}926,091 \\
2,220,262\end{array}$ & $\begin{array}{r}76,419 \\
184,796\end{array}$ \\
\hline 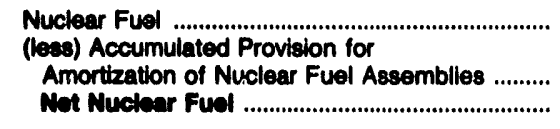 & $\begin{array}{l}0 \\
0\end{array}$ & $\begin{array}{l}0 \\
0\end{array}$ & $\begin{array}{l}0 \\
0\end{array}$ & $\begin{array}{l}0 \\
0\end{array}$ & $\begin{array}{r}248,524 \\
208,608 \\
38,816\end{array}$ & $\begin{array}{l}0 \\
0\end{array}$ \\
\hline 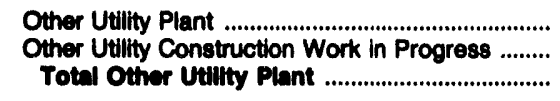 & $\begin{array}{l}0 \\
0 \\
0\end{array}$ & $\begin{array}{l}0 \\
0 \\
0\end{array}$ & $\begin{array}{l}0 \\
0 \\
0\end{array}$ & $\begin{array}{r}257 \\
0 \\
257\end{array}$ & $\begin{array}{r}332,086 \\
13,819 \\
345,905\end{array}$ & $\begin{array}{l}0 \\
0 \\
0\end{array}$ \\
\hline 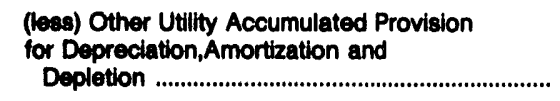 & 0 & 0 & 0 & 95 & 114,599 & 0 \\
\hline Not Other Utllty Plant ............................................... & $\mathbf{0}$ & $\mathbf{0}$ & $\mathbf{0}$ & 162 & 231,306 & 0 \\
\hline 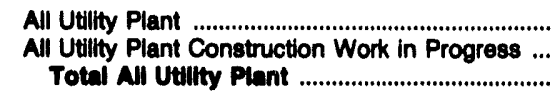 & $\begin{array}{r}125,492 \\
375 \\
125,868\end{array}$ & $\begin{array}{r}508,731 \\
16,073 \\
524,804\end{array}$ & $\begin{array}{r}69,805 \\
1,233 \\
71,038\end{array}$ & $\begin{array}{r}20,643 \\
188 \\
20,831\end{array}$ & $\begin{array}{r}3,523,708 \\
217,074 \\
3,740,782\end{array}$ & $\begin{array}{r}249,786 \\
11,429 \\
261,215\end{array}$ \\
\hline 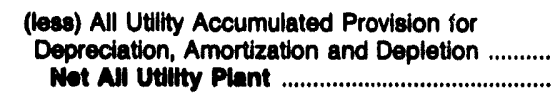 & $\begin{array}{l}37,552 \\
88,316\end{array}$ & $\begin{array}{l}150,372 \\
374,432\end{array}$ & $\begin{array}{l}19,053 \\
51,064\end{array}$ & $\begin{array}{r}9,227 \\
11,605\end{array}$ & $\begin{array}{l}1,249,298 \\
2,491,484\end{array}$ & $\begin{array}{r}76,419 \\
184,706\end{array}$ \\
\hline 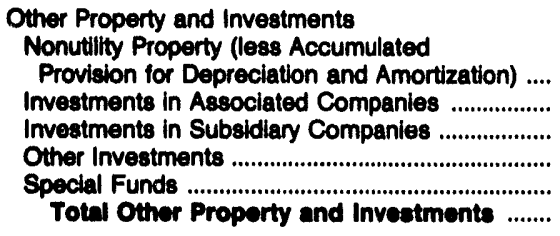 & $\begin{array}{r}50 \\
0 \\
0 \\
0 \\
0 \\
50\end{array}$ & $\begin{array}{r}2,375 \\
0 \\
0 \\
25 \\
0 \\
2,400\end{array}$ & $\begin{array}{l}0 \\
0 \\
0 \\
0 \\
0 \\
0\end{array}$ & $\begin{array}{r}309 \\
0 \\
0 \\
0 \\
0 \\
309\end{array}$ & $\begin{array}{r}12,542 \\
0 \\
0 \\
62 \\
0 \\
12,604\end{array}$ & $\begin{array}{l}0 \\
0 \\
0 \\
0 \\
0 \\
0\end{array}$ \\
\hline 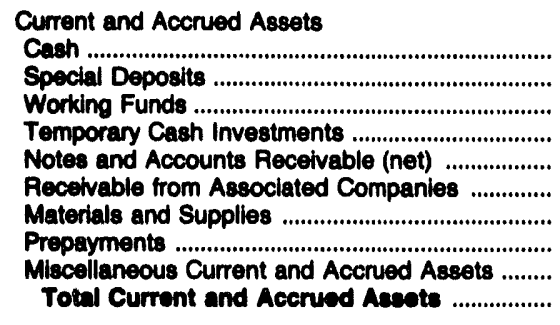 & $\begin{array}{r}147 \\
698 \\
14 \\
0 \\
13,057 \\
995 \\
864 \\
2,596 \\
1,584 \\
19,056\end{array}$ & $\begin{array}{r}798 \\
155 \\
32 \\
0 \\
58,014 \\
1,833 \\
5,001 \\
13,720 \\
1,666 \\
81,218\end{array}$ & $\begin{array}{r}-106 \\
1 \\
6 \\
305 \\
7,994 \\
483 \\
1,039 \\
617 \\
580 \\
10,930\end{array}$ & $\begin{array}{r}680 \\
0 \\
0 \\
0 \\
786 \\
294 \\
198 \\
3 \\
0 \\
1,861\end{array}$ & $\begin{array}{r}-10,331 \\
382 \\
160 \\
34,752 \\
91,277 \\
341 \\
75,965 \\
11,797 \\
1 \\
204,345\end{array}$ & $\begin{array}{r}5,307 \\
0 \\
0 \\
0 \\
13 \\
4,654 \\
14,282 \\
313 \\
0 \\
24,680\end{array}$ \\
\hline 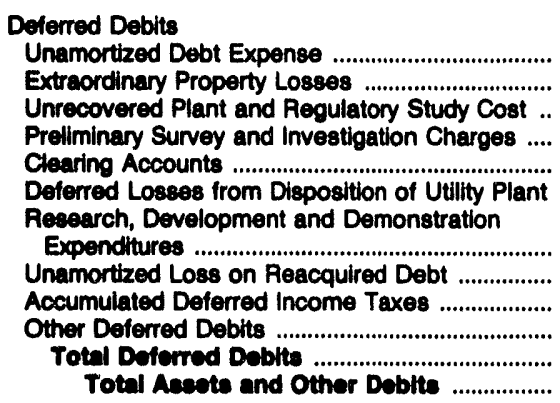 & $\begin{array}{r}847 \\
0 \\
0 \\
0 \\
0 \\
0 \\
0 \\
547 \\
814 \\
5,169 \\
7,376 \\
115,698\end{array}$ & $\begin{array}{r}733 \\
0 \\
0 \\
778 \\
0 \\
0 \\
0 \\
13,501 \\
9,482 \\
5,902 \\
30,396 \\
488,446\end{array}$ & $\begin{array}{r}551 \\
0 \\
0 \\
0 \\
0 \\
0 \\
0 \\
0 \\
73 \\
1,347 \\
3,177 \\
5,148 \\
68,063\end{array}$ & $\begin{array}{r}0 \\
0 \\
0 \\
22 \\
0 \\
0 \\
0 \\
0 \\
0 \\
0 \\
54 \\
76 \\
13,961\end{array}$ & $\begin{array}{r}8,354 \\
0 \\
0 \\
1,654 \\
1,373 \\
0 \\
5 \\
5 \\
2,457 \\
41,217 \\
127,450 \\
182,510 \\
2,890,943\end{array}$ & $\begin{array}{r}980 \\
0 \\
0 \\
0 \\
0 \\
0 \\
0 \\
0 \\
278 \\
0 \\
144 \\
1,402 \\
210,767\end{array}$ \\
\hline
\end{tabular}

See endnotes at end of an individual electric utility. 
Table 38. Balance Sheet by Major U.S. Investor-Owned Electric Utility Within State on December 31, 1982 (Continued) (Thousand Dollars)

\begin{tabular}{|c|c|c|c|c|c|c|}
\hline Item & $\begin{array}{l}\text { Ahode Island } \\
\text { Blackstone } \\
\text { Valley } \\
\text { Electric Co }\end{array}$ & $\begin{array}{l}\text { Rhode isiand } \\
\text { Narragansett } \\
\text { Electric Co }\end{array}$ & $\begin{array}{l}\text { Rhode leland } \\
\text { Newport } \\
\text { Electric } \\
\text { Corp }\end{array}$ & $\begin{array}{l}\text { South Carolina } \\
\text { Lockhart } \\
\text { Power Co }\end{array}$ & $\begin{array}{c}\text { South Carolina } \\
\text { South } \\
\text { Carolina } \\
\text { Electric\&as } \\
\text { Co }\end{array}$ & $\begin{array}{l}\text { South Carolina } \\
\text { South } \\
\text { Carollina } \\
\text { Genertg } \\
\text { Co Inc }\end{array}$ \\
\hline 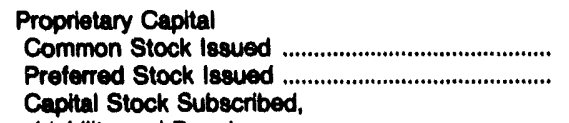 & $\begin{array}{l}8,203 \\
6,000\end{array}$ & $\begin{array}{l}56,624 \\
26,500\end{array}$ & $\begin{array}{r}11,369 \\
1,159\end{array}$ & $\begin{array}{r}300 \\
0\end{array}$ & $\begin{array}{r}181,333 \\
84,667\end{array}$ & $\begin{array}{r}20,000 \\
0\end{array}$ \\
\hline 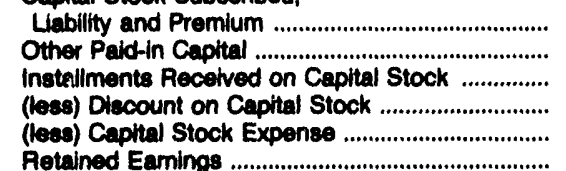 & $\begin{array}{r}737 \\
17,300 \\
0 \\
0 \\
0 \\
7,440\end{array}$ & $\begin{array}{r}376 \\
45,000 \\
0 \\
0 \\
0 \\
74,207\end{array}$ & $\begin{array}{r}0 \\
9,002 \\
0 \\
0 \\
756 \\
972\end{array}$ & $\begin{array}{r}0 \\
0 \\
0 \\
0 \\
0 \\
10,605\end{array}$ & $\begin{array}{r}395,072 \\
130,624 \\
0 \\
0 \\
5,550 \\
262,282\end{array}$ & $\begin{array}{r}0 \\
0 \\
0 \\
0 \\
0 \\
4,460\end{array}$ \\
\hline 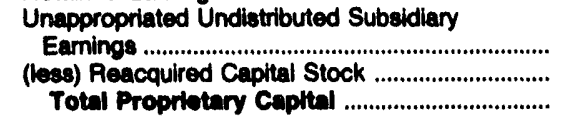 & $\begin{array}{r}0 \\
0 \\
40,681\end{array}$ & $\begin{array}{r}0 \\
0 \\
202,707\end{array}$ & $\begin{array}{r}0 \\
0 \\
21,746\end{array}$ & $\begin{array}{r}0 \\
0 \\
10,205\end{array}$ & $\begin{array}{r}0 \\
0 \\
1,048,408\end{array}$ & $\begin{array}{r}0 \\
0 \\
24,460\end{array}$ \\
\hline 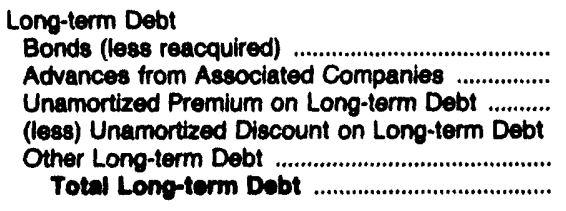 & $\begin{array}{r}39,500 \\
0 \\
0 \\
0 \\
0 \\
39,500\end{array}$ & $\begin{array}{r}144,600 \\
0 \\
20 \\
1,178 \\
0 \\
143,442\end{array}$ & $\begin{array}{r}27,228 \\
0 \\
0 \\
0 \\
0 \\
27,228\end{array}$ & $\begin{array}{l}0 \\
0 \\
0 \\
0 \\
0 \\
0\end{array}$ & $\begin{array}{r}800,340 \\
1,547 \\
0 \\
3,743 \\
55,823 \\
953,967\end{array}$ & $\begin{array}{r}35,850 \\
0 \\
0 \\
0 \\
74,800 \\
110,650\end{array}$ \\
\hline Total Capitallation & 60,181 & 346,160 & 48,974 & 10,805 & $2,002,376$ & 135,110 \\
\hline $\begin{array}{l}\text { Other Noncurrent Liabilltites } \\
\text { Obligations Under Capital Lesse-Noncurrent ...... } \\
\text { Accumulated Provision for Property Insurance ... } \\
\text { Accumulated Provision for Injuries and }\end{array}$ & $\begin{array}{r}0 \\
698\end{array}$ & $\begin{array}{l}0 \\
0\end{array}$ & $\begin{array}{l}0 \\
0\end{array}$ & $\begin{array}{l}0 \\
0\end{array}$ & $\begin{array}{r}2,985 \\
0\end{array}$ & $\begin{array}{l}0 \\
0\end{array}$ \\
\hline $\begin{array}{c}\text { Damages } \\
\text { Accumulated Provision for Pensions and }\end{array}$ & 0 & 0 & 0 & 0 & 2,142 & 62 \\
\hline $\begin{array}{l}\text { Benefitts } \\
\text { Accumulated Miscollaneous Operating }\end{array}$ & 0 & 0 & 0 & 0 & 1,673 & 0 \\
\hline 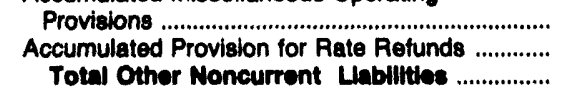 & $\begin{array}{r}0 \\
0 \\
608\end{array}$ & $\begin{array}{l}0 \\
0 \\
0\end{array}$ & $\begin{array}{r}-1,065 \\
0 \\
-1,065\end{array}$ & $\begin{array}{r}23 \\
0 \\
23\end{array}$ & $\begin{array}{r}0 \\
0 \\
6,800\end{array}$ & $\begin{array}{r}0 \\
0 \\
82\end{array}$ \\
\hline 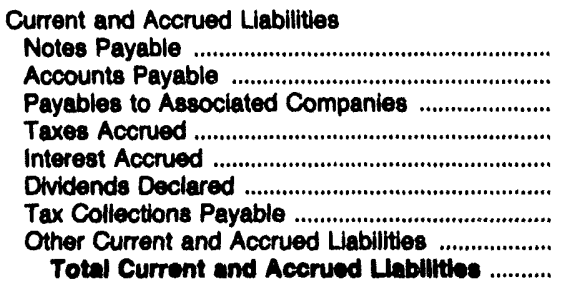 & $\begin{array}{r}0 \\
806 \\
10,221 \\
5,784 \\
1,138 \\
72 \\
178 \\
2,973 \\
21,171\end{array}$ & $\begin{array}{r}0 \\
5,028 \\
51,087 \\
1,761 \\
4,313 \\
2,087 \\
846 \\
12,987 \\
79,006\end{array}$ & $\begin{array}{r}0 \\
3,260 \\
2,630 \\
480 \\
1,141 \\
17 \\
110 \\
3,116 \\
10,763\end{array}$ & $\begin{array}{r}0 \\
870 \\
41 \\
565 \\
0 \\
0 \\
12 \\
310 \\
1,700\end{array}$ & $\begin{array}{r}33 \\
49,749 \\
32,222 \\
51,126 \\
26,433 \\
28,343 \\
2,207 \\
38,473 \\
228,586\end{array}$ & $\begin{array}{r}0 \\
3,783 \\
4,947 \\
1,531 \\
617 \\
0 \\
14 \\
38 \\
10,930\end{array}$ \\
\hline 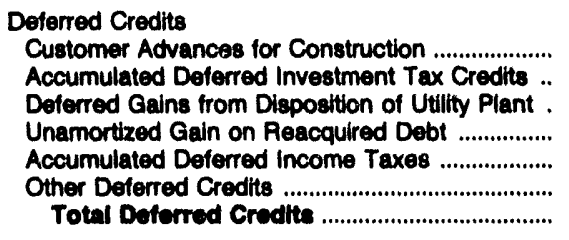 & $\begin{array}{r}0 \\
2,850 \\
0 \\
0 \\
0 \\
7,063 \\
3,736 \\
13,648\end{array}$ & $\begin{array}{r}2,351 \\
8,534 \\
0 \\
0 \\
46,608 \\
4,796 \\
63,206\end{array}$ & $\begin{array}{r}0 \\
1,554 \\
1,351 \\
0 \\
5,584 \\
911 \\
0,401\end{array}$ & $\begin{array}{r}0 \\
276 \\
0 \\
0 \\
0 \\
948 \\
0 \\
1,224\end{array}$ & $\begin{array}{r}0 \\
87,682 \\
0 \\
126 \\
451,046 \\
116,317 \\
665,181\end{array}$ & $\begin{array}{r}0 \\
8,778 \\
0 \\
0 \\
55,702 \\
185 \\
64,686\end{array}$ \\
\hline Total Uabllitice and Other Credits ................. & 115,608 & 488,446 & 68,063 & 13,051 & $2,890,843$ & 210.787 \\
\hline
\end{tabular}

Note: Totals may not equal sum of components because of independent rounding. Summery data are provided in Table 8. Source: Federal Energy Regulatory Commiseion, FERC Form 1, "Annual Report of Major Electric Utillites, Licensees and Others." 
Table 38. Balance Sheet by Major U.S. Investor-Owned Electric Utility Within State on December 31, 1992 (Continued) (Thousand Dollars)

\begin{tabular}{|c|c|c|c|c|c|c|}
\hline Item & $\begin{array}{l}\text { South Dakota } \\
\text { Black } \\
\text { Hills Corp }\end{array}$ & $\begin{array}{l}\text { South Dakota } \\
\text { Northwestern } \\
\text { Publlc } \\
\text { Service Co }\end{array}$ & $\begin{array}{l}\text { Tennesser } \\
\text { Kingsport } \\
\text { Power Co }\end{array}$ & $\begin{array}{l}\text { Tennessee } \\
\text { Tapoco } \\
\text { Inc }\end{array}$ & $\begin{array}{c}\text { Texas } \\
\text { Central } \\
\text { Power } \\
\& \\
\text { Light Co }\end{array}$ & $\begin{array}{c}\text { Texas } \\
\text { EI } \\
\text { Paso } \\
\text { Electric } \\
\text { Co }\end{array}$ \\
\hline 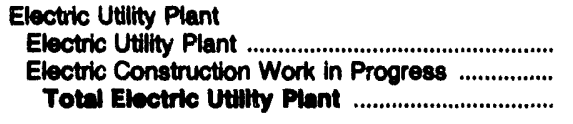 & $\begin{array}{r}313,462 \\
9,829 \\
323,201\end{array}$ & $\begin{array}{r}284,656 \\
3,542 \\
286,100\end{array}$ & $\begin{array}{r}60,153 \\
416 \\
60,606\end{array}$ & $\begin{array}{r}68,399 \\
2,304 \\
70,702\end{array}$ & $\begin{array}{r}4,307,206 \\
94,736 \\
4,401,942\end{array}$ & $\begin{array}{r}1,532,477 \\
40,843 \\
1,673,320\end{array}$ \\
\hline 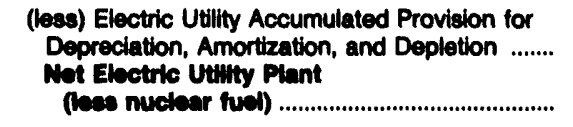 & $\begin{array}{l}109,604 \\
213,607\end{array}$ & $\begin{array}{l}105,012 \\
183,186\end{array}$ & $\begin{array}{l}21,114 \\
39,464\end{array}$ & $\begin{array}{l}53,609 \\
17,003\end{array}$ & $\begin{array}{l}1,076,395 \\
3,325,547\end{array}$ & $\begin{array}{r}378,828 \\
1,194,492\end{array}$ \\
\hline 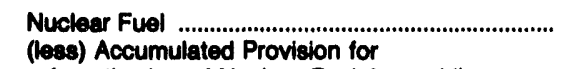 & 0 & 0 & 0 & 0 & 152,494 & 101,078 \\
\hline 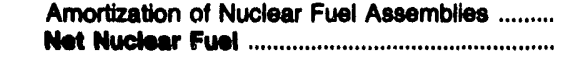 & $\begin{array}{l}0 \\
0\end{array}$ & $\begin{array}{l}0 \\
0\end{array}$ & $\begin{array}{l}0 \\
0\end{array}$ & $\begin{array}{l}0 \\
0\end{array}$ & $\begin{array}{l}71,953 \\
80,541\end{array}$ & $\begin{array}{l}44,535 \\
66,544\end{array}$ \\
\hline 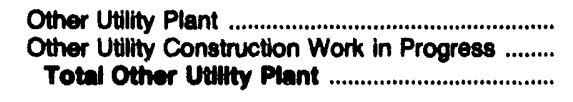 & $\begin{array}{l}0 \\
0 \\
0\end{array}$ & $\begin{array}{r}61,537 \\
2,082 \\
83,620\end{array}$ & $\begin{array}{l}0 \\
0 \\
0\end{array}$ & $\begin{array}{l}0 \\
0 \\
0\end{array}$ & $\begin{array}{l}0 \\
0 \\
0\end{array}$ & $\begin{array}{l}0 \\
0 \\
0\end{array}$ \\
\hline 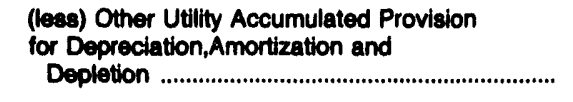 & 0 & 23,338 & 0 & 0 & 0 & 0 \\
\hline 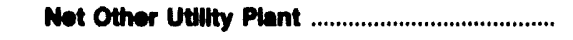 & $\mathbf{0}$ & 40,282 & $\mathbf{0}$ & $\mathbf{0}$ & $\mathbf{0}$ & 0 \\
\hline 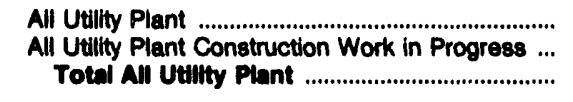 & $\begin{array}{r}313,462 \\
9,829 \\
323,291\end{array}$ & $\begin{array}{r}346,193 \\
5,625 \\
351,818\end{array}$ & $\begin{array}{r}60,153 \\
416 \\
60,668\end{array}$ & $\begin{array}{r}68,399 \\
2,304 \\
70,702\end{array}$ & $\begin{array}{r}4,459,700 \\
94,736 \\
4,554,438\end{array}$ & $\begin{array}{r}1,633,555 \\
40,643 \\
1,674,390\end{array}$ \\
\hline 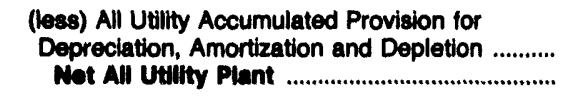 & $\begin{array}{l}109,604 \\
213,687\end{array}$ & $\begin{array}{l}128,350 \\
223,468\end{array}$ & $\begin{array}{l}21,114 \\
39,454\end{array}$ & $\begin{array}{l}53,609 \\
17,003\end{array}$ & $\begin{array}{l}1,148,348 \\
3,408,087\end{array}$ & $\begin{array}{r}423,363 \\
1,251,038\end{array}$ \\
\hline 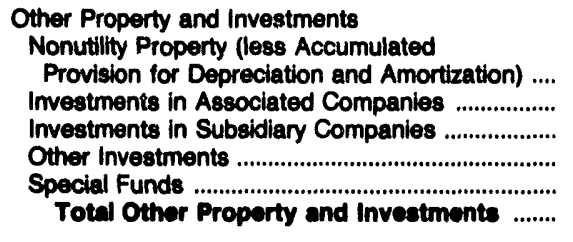 & $\begin{array}{r}2 \\
0 \\
62,536 \\
540 \\
871 \\
63,040\end{array}$ & $\begin{array}{r}0 \\
0 \\
26,385 \\
16,373 \\
0 \\
42,757\end{array}$ & $\begin{array}{r}105 \\
0 \\
0 \\
376 \\
1 \\
481\end{array}$ & $\begin{array}{r}481 \\
0 \\
0 \\
0 \\
0 \\
481\end{array}$ & $\begin{array}{r}2,171 \\
0 \\
0 \\
288 \\
0 \\
2,459\end{array}$ & $\begin{array}{r}441 \\
0 \\
0 \\
12,342 \\
21,300 \\
34,003\end{array}$ \\
\hline 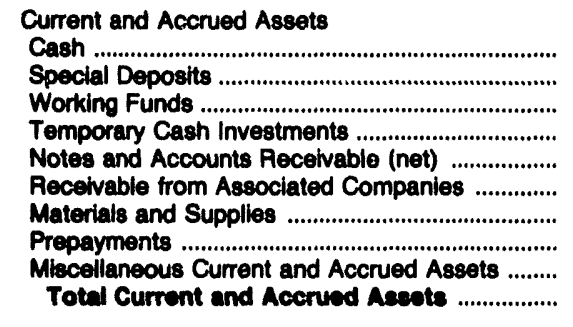 & $\begin{array}{r}361 \\
0 \\
3 \\
2 \\
2 \\
9,733 \\
117 \\
5,851 \\
1,538 \\
0 \\
17,806\end{array}$ & $\begin{array}{r}1,025 \\
0 \\
118 \\
2,200 \\
7,980 \\
68 \\
7,186 \\
1,220 \\
7,540 \\
27,337\end{array}$ & $\begin{array}{r}545 \\
10 \\
5 \\
0 \\
5,585 \\
422 \\
566 \\
1,057 \\
3,485 \\
11,875\end{array}$ & $\begin{array}{r}1 \\
0 \\
0 \\
0 \\
23 \\
2,614 \\
0 \\
105 \\
0 \\
2,743\end{array}$ & $\begin{array}{r}3,368 \\
151,589 \\
298 \\
0 \\
19,613 \\
683 \\
88,099 \\
2,198 \\
0 \\
265,847\end{array}$ & $\begin{array}{r}272 \\
16 \\
4,293 \\
162,270 \\
43,523 \\
0 \\
36,578 \\
6,817 \\
13,560 \\
267,330\end{array}$ \\
\hline 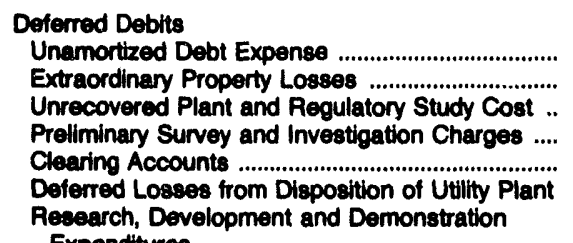 & $\begin{array}{r}1,130 \\
0 \\
0 \\
2,251 \\
272 \\
0\end{array}$ & $\begin{array}{r}764 \\
0 \\
0 \\
113 \\
102 \\
0\end{array}$ & $\begin{array}{l}0 \\
0 \\
0 \\
0 \\
1 \\
0\end{array}$ & $\begin{array}{l}0 \\
0 \\
0 \\
0 \\
0 \\
0\end{array}$ & $\begin{array}{r}9,147 \\
0 \\
0 \\
71 \\
1 \\
0\end{array}$ & $\begin{array}{r}11,782 \\
0 \\
0 \\
10 \\
7 \\
0\end{array}$ \\
\hline 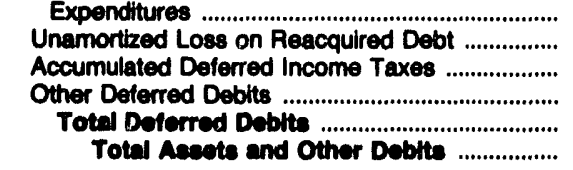 & $\begin{array}{r}0 \\
493 \\
1,310 \\
334 \\
5,791 \\
301,031\end{array}$ & $\begin{array}{r}0 \\
680 \\
5,258 \\
1,231 \\
8,149 \\
301,711\end{array}$ & $\begin{array}{r}0 \\
0 \\
950 \\
22 \\
\mathbf{9 7 3} \\
52,584\end{array}$ & $\begin{array}{r}0 \\
0 \\
120 \\
0 \\
120 \\
20,437\end{array}$ & $\begin{array}{r}0 \\
50,598 \\
90,916 \\
864,331 \\
1,015,084 \\
4,689,457\end{array}$ & $\begin{array}{r}0 \\
473 \\
498,112 \\
742,281 \\
1,252,684 \\
2,005,113\end{array}$ \\
\hline
\end{tabular}

See endnotes at end of an indlvidual electric utility. 
Table 38. Balance Sheet by Major U.S. Investor-Owned Electric Utility Within State on December 31, 1992 (Continued) (Thousand Dollars)

\begin{tabular}{|c|c|c|c|c|c|c|}
\hline Item & $\begin{array}{l}\text { South Dakota } \\
\text { Black } \\
\text { Hills Corp }\end{array}$ & $\begin{array}{l}\text { South Dakota } \\
\text { Northwestern } \\
\text { Public } \\
\text { Service Co }\end{array}$ & $\begin{array}{l}\text { Tennessee } \\
\text { Kingsport } \\
\text { Power Co }\end{array}$ & $\begin{array}{l}\text { Tennessee } \\
\text { Tapoco } \\
\text { Inc }\end{array}$ & $\begin{array}{l}\text { Texas } \\
\text { Central } \\
\text { Power } \\
8 \\
\text { Light Co }\end{array}$ & $\begin{array}{l}\text { Texas } \\
\text { El } \\
\text { Paso } \\
\text { Electric } \\
\text { Co }\end{array}$ \\
\hline 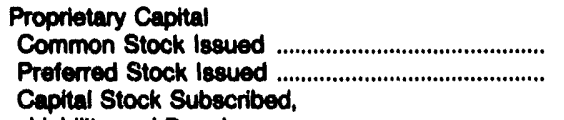 & $\begin{array}{r}13,701 \\
0\end{array}$ & $\begin{array}{r}26,870 \\
2,700\end{array}$ & $\begin{array}{r}4,100 \\
0\end{array}$ & $\begin{array}{r}150 \\
0\end{array}$ & $\begin{array}{l}168,888 \\
285,875\end{array}$ & $\begin{array}{r}339,077 \\
88,077\end{array}$ \\
\hline 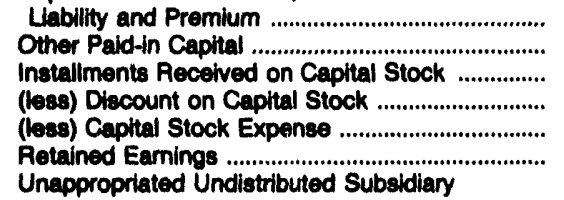 & $\begin{array}{r}32,099 \\
0 \\
0 \\
0 \\
1,815 \\
42,687\end{array}$ & $\begin{array}{r}29,923 \\
0 \\
0 \\
0 \\
0 \\
50,806\end{array}$ & $\begin{array}{r}0 \\
5,800 \\
0 \\
0 \\
0 \\
4,467\end{array}$ & $\begin{array}{r}0 \\
23,727 \\
0 \\
0 \\
0 \\
-4,907\end{array}$ & $\begin{array}{r}69 \\
405,000 \\
0 \\
0 \\
3,731 \\
863,988\end{array}$ & $\begin{array}{r}0 \\
0 \\
0 \\
0 \\
0 \\
-26,011\end{array}$ \\
\hline 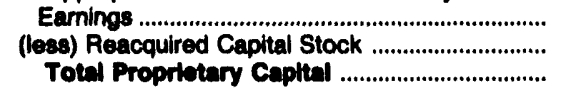 & $\begin{array}{r}62,486 \\
0 \\
149,168\end{array}$ & $\begin{array}{r}-552 \\
0 \\
100,747\end{array}$ & $\begin{array}{r}0 \\
0 \\
14,387\end{array}$ & $\begin{array}{r}0 \\
0 \\
18,971\end{array}$ & $\begin{array}{r}0 \\
0 \\
1,720,089\end{array}$ & $\begin{array}{r}0 \\
0 \\
401,143\end{array}$ \\
\hline 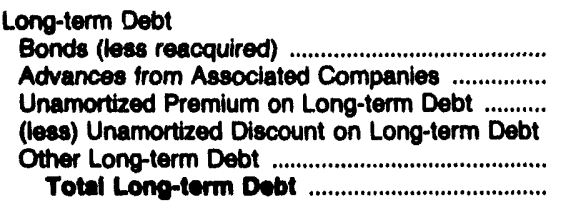 & $\begin{array}{r}65,577 \\
0 \\
0 \\
0 \\
24,500 \\
90,077\end{array}$ & $\begin{array}{r}84,000 \\
0 \\
0 \\
0 \\
21,500 \\
105,500\end{array}$ & $\begin{array}{r}0 \\
0 \\
0 \\
0 \\
17,000 \\
17,000\end{array}$ & $\begin{array}{l}0 \\
0 \\
0 \\
0 \\
0 \\
0\end{array}$ & $\begin{array}{r}1,306,400 \\
0 \\
326 \\
18,250 \\
249,803 \\
1,538,270\end{array}$ & $\begin{array}{l}0 \\
0 \\
0 \\
0 \\
0 \\
0\end{array}$ \\
\hline Total Coptrallention .............................................. & 230,235 & 215,247 & 31,367 & 18,971 & $3,258,368$ & 401,143 \\
\hline $\begin{array}{l}\text { Other Noncurrent Liabilities } \\
\text { Obligations Under Capital Lease-Noncurrent ...... } \\
\text { Accumulated Provision for Property Insurance ... } \\
\text { Accumulated Provision for Injuries and }\end{array}$ & $\begin{array}{l}0 \\
0\end{array}$ & $\begin{array}{l}0 \\
0\end{array}$ & $\begin{array}{r}216 \\
0\end{array}$ & $\begin{array}{l}0 \\
0\end{array}$ & $\begin{array}{r}162 \\
5,354\end{array}$ & $\begin{array}{r}8,206 \\
0\end{array}$ \\
\hline Accumulated Provision for Pensions and & 0 & 200 & 37 & 0 & 0 & 100 \\
\hline Accumulated Miscellanoous Operating & 0 & 421 & 0 & 0 & 0 & 0 \\
\hline 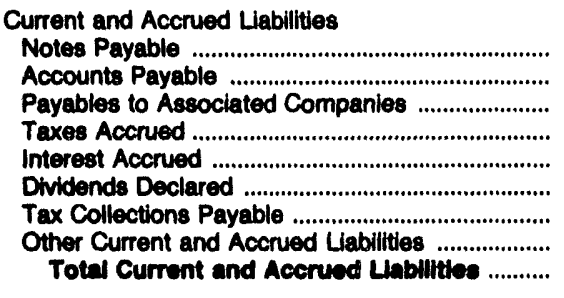 & $\begin{array}{r}6,184 \\
3,736 \\
40 \\
2,621 \\
1,483 \\
0 \\
437 \\
6,461 \\
20,863\end{array}$ & $\begin{array}{r}428 \\
11,438 \\
34 \\
5,729 \\
2,751 \\
0 \\
962 \\
1,957 \\
23,290\end{array}$ & $\begin{array}{r}4,250 \\
275 \\
6,531 \\
2,010 \\
238 \\
0 \\
120 \\
2,350 \\
15,774\end{array}$ & $\begin{array}{r}0 \\
654 \\
0 \\
513 \\
0 \\
0 \\
49 \\
769 \\
1,085\end{array}$ & $\begin{array}{r}0 \\
54,494 \\
97,923 \\
27,224 \\
25,470 \\
2,140 \\
3,140 \\
12,017 \\
222,408\end{array}$ & $\begin{array}{r}438,416 \\
49,329 \\
0 \\
36,641 \\
34,117 \\
0 \\
592 \\
922,029 \\
1,461,124\end{array}$ \\
\hline 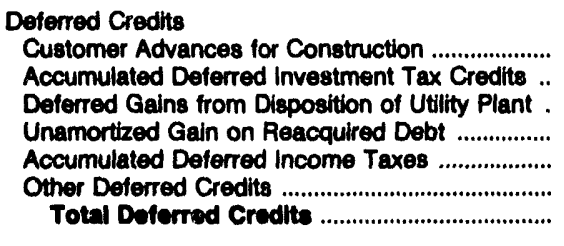 & $\begin{array}{r}491 \\
6,532 \\
0 \\
0 \\
31,870 \\
1,940 \\
29,833\end{array}$ & $\begin{array}{r}0 \\
11,716 \\
0 \\
0 \\
42,313 \\
8,515 \\
82,544\end{array}$ & $\begin{array}{r}4 \\
1,394 \\
0 \\
0 \\
3,363 \\
240 \\
5,001\end{array}$ & $\begin{array}{r}0 \\
474 \\
0 \\
0 \\
-993 \\
0 \\
-510\end{array}$ & $\begin{array}{r}0 \\
170,128 \\
0 \\
637 \\
787,580 \\
244,820 \\
1,203,165\end{array}$ & $\begin{array}{r}1,112 \\
74,455 \\
0 \\
0 \\
542,566 \\
296,407 \\
914,540\end{array}$ \\
\hline Total Labilltes and Other Credits ................ & 301,031 & 301,711 & 52,584 & 20,437 & $4,689,457$ & $2,805,113$ \\
\hline
\end{tabular}

Note: Totals may not equal sum of components because of independent rounding. Summary data are provided in Table 8.

Source: Federal Energy Regulatory Commission, FERC Form 1, "Annual Report of Major Electric Utilities, Licensees and Others." 
Table 38. Balance Sheot by Major U.S. Investor-Owned Electrlc Utillty Within State on December 31, 1992 (Continued)

(Thousand Dollars)

\begin{tabular}{|c|c|c|c|c|c|c|}
\hline Item & $\begin{array}{c}\text { Texas } \\
\text { Gulf } \\
\text { States } \\
\text { Utilities } \\
\text { Co }\end{array}$ & $\begin{array}{l}\text { Toxas } \\
\text { Houston } \\
\text { Lohting } \\
\text { Power Co }\end{array}$ & $\begin{array}{l}\text { Texas } \\
\text { Southwestern } \\
\text { Electric } \\
\text { Serv Co }\end{array}$ & $\begin{array}{l}\text { Texas } \\
\text { Southwestern } \\
\text { Public } \\
\text { Service Co }\end{array}$ & $\begin{array}{l}\text { Texas } \\
\text { Texas } \\
\text { Utilities } \\
\text { Electric Co }\end{array}$ & $\begin{array}{l}\text { Toxas } \\
\text { Texas- } \\
\text { Now Mexico } \\
\text { Power Co }\end{array}$ \\
\hline 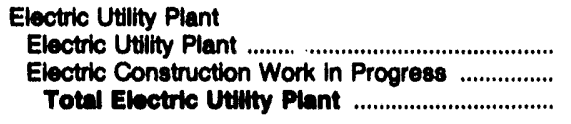 & $\begin{array}{r}6,857,231 \\
28,579 \\
6,085,800\end{array}$ & $\begin{array}{r}11,007,779 \\
201,165 \\
11,208,044\end{array}$ & $\begin{array}{r}86,379 \\
243 \\
86,622\end{array}$ & $\begin{array}{r}2,121,537 \\
59,103 \\
2,180,641\end{array}$ & $\begin{array}{r}16,021,766 \\
5,528,222 \\
21,549,988\end{array}$ & $\begin{array}{r}1,184,634 \\
3,922 \\
1,188,657\end{array}$ \\
\hline $\begin{array}{l}\text { (leses) Electric Utility Accumulated Provision for } \\
\text { Depreciation, Amortization, and Depletion ....... } \\
\text { Not Eloctrle Utulty Plant } \\
\text { (1eae nuctear fuel) ............................................. }\end{array}$ & $\begin{array}{l}2,096,115 \\
4,709,605\end{array}$ & $\begin{array}{l}2,676,786 \\
8,532,148\end{array}$ & $\begin{array}{l}32,408 \\
54,214\end{array}$ & $\begin{array}{r}716,121 \\
1,484,520\end{array}$ & $\begin{array}{r}3,741,020 \\
17,908,968\end{array}$ & $\begin{array}{r}172,848 \\
1,015,700\end{array}$ \\
\hline $\begin{array}{l}\text { Nuciear Fuel . } \\
\text { (lese) Accumulated Provision for }\end{array}$ & 255,621 & 202,013 & 0 & 0 & 407,693 & 0 \\
\hline 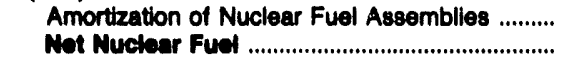 & $\begin{array}{l}149,056 \\
108,565\end{array}$ & $\begin{array}{r}90,259 \\
111,754\end{array}$ & $\begin{array}{l}0 \\
0\end{array}$ & $\begin{array}{l}0 \\
0\end{array}$ & $\begin{array}{r}49,606 \\
358,087\end{array}$ & $\begin{array}{l}0 \\
0\end{array}$ \\
\hline 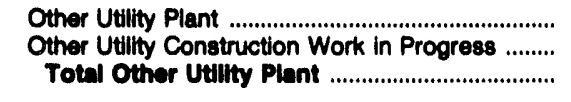 & $\begin{array}{r}113,453 \\
3,727 \\
117,170\end{array}$ & $\begin{array}{l}0 \\
0 \\
0\end{array}$ & $\begin{array}{l}0 \\
0 \\
0\end{array}$ & $\begin{array}{l}0 \\
0 \\
0\end{array}$ & $\begin{array}{l}0 \\
0 \\
0\end{array}$ & $\begin{array}{l}0 \\
0 \\
0\end{array}$ \\
\hline 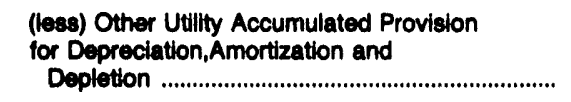 & 76,604 & 0 & 0 & 0 & 0 & 0 \\
\hline Not Other Utilty Plant ................................................ & 40,576 & 0 & 0 & $\mathbf{0}$ & 0 & $\mathbf{0}$ \\
\hline 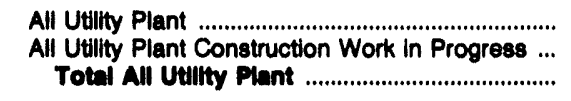 & $\begin{array}{r}7,226,304 \\
32,305 \\
7,268,610\end{array}$ & $\begin{array}{r}11,209,792 \\
201,165 \\
11,410,967\end{array}$ & $\begin{array}{r}86,379 \\
243 \\
86,622\end{array}$ & $\begin{array}{r}2,121,537 \\
59,103 \\
2,180,641\end{array}$ & $\begin{array}{r}16,429,460 \\
5,528,222 \\
21,057,682\end{array}$ & $\begin{array}{r}1,184,634 \\
3,922 \\
1,188,557\end{array}$ \\
\hline $\begin{array}{l}\text { (less) All Utility Accumulated Provision for } \\
\text { Depreciation, Amortization and Depletion ............ } \\
\text { Not All Utilty Plant ............................................ }\end{array}$ & $\begin{array}{l}2,321,775 \\
4,036,834\end{array}$ & $\begin{array}{l}2,767,055 \\
8,643,003\end{array}$ & $\begin{array}{l}32,408 \\
54,214\end{array}$ & $\begin{array}{r}716,121 \\
1,464,620\end{array}$ & $\begin{array}{r}3,790,626 \\
18,167,055\end{array}$ & $\begin{array}{r}172,848 \\
1,015,700\end{array}$ \\
\hline 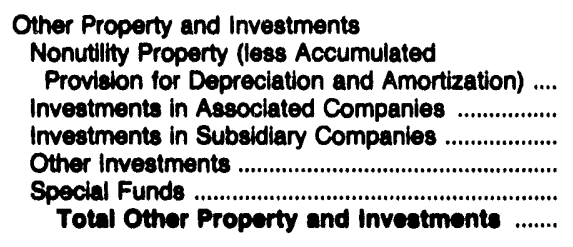 & $\begin{array}{r}8,993 \\
0 \\
14,241 \\
6,480 \\
28,928 \\
58,642\end{array}$ & $\begin{array}{r}0 \\
0 \\
0 \\
30 \\
11,941 \\
11,971\end{array}$ & $\begin{array}{r}32 \\
0 \\
0 \\
0 \\
16 \\
4\end{array}$ & $\begin{array}{r}101 \\
0 \\
43,389 \\
4,466 \\
2 \\
47,968\end{array}$ & $\begin{array}{r}4,373 \\
0 \\
0 \\
-1,295,930 \\
21,795 \\
-1,269,762\end{array}$ & $\begin{array}{r}183 \\
0 \\
0 \\
0 \\
0 \\
183\end{array}$ \\
\hline 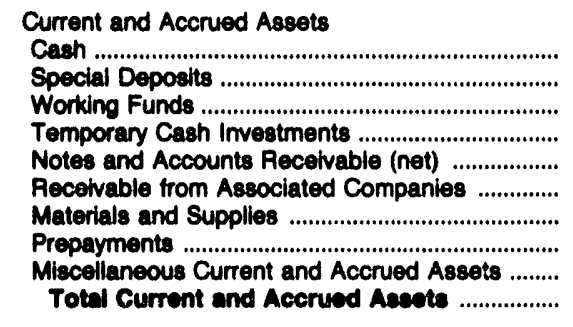 & $\begin{array}{r}86 \\
37 \\
275 \\
190,000 \\
333,360 \\
1,407 \\
107,454 \\
31,893 \\
6,341 \\
670,852\end{array}$ & $\begin{array}{r}251 \\
2,071 \\
428 \\
0 \\
7,380 \\
2,111 \\
188,130 \\
8,850 \\
225,116 \\
434,336\end{array}$ & $\begin{array}{r}187 \\
0 \\
33 \\
0 \\
7,032 \\
0 \\
492 \\
315 \\
0 \\
8,058\end{array}$ & $\begin{array}{r}398 \\
128 \\
85 \\
22,100 \\
41,007 \\
558 \\
16,345 \\
3,588 \\
15,220 \\
90,430\end{array}$ & $\begin{array}{r}5,686 \\
7,510 \\
3,628 \\
0 \\
-18,989 \\
508 \\
278,836 \\
27,931 \\
157,153 \\
462,263\end{array}$ & $\begin{array}{r}1,399 \\
0 \\
42 \\
62,402 \\
3,078 \\
23 \\
8,431 \\
676 \\
17,934 \\
93,986\end{array}$ \\
\hline 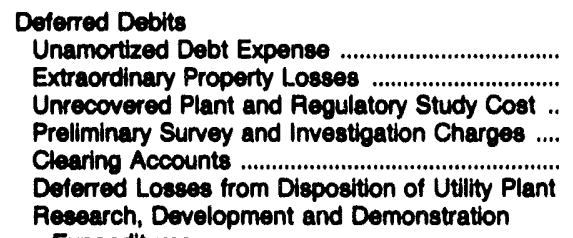 & $\begin{array}{r}21,909 \\
0 \\
37,348 \\
5,706 \\
0 \\
0\end{array}$ & $\begin{array}{r}39,805 \\
130,035 \\
0 \\
177,426 \\
0 \\
0\end{array}$ & $\begin{array}{r}150 \\
0 \\
0 \\
0 \\
0 \\
0\end{array}$ & $\begin{array}{r}3,311 \\
0 \\
889 \\
261 \\
2,239 \\
0\end{array}$ & $\begin{array}{r}27,848 \\
0 \\
23,189 \\
0 \\
-1,922 \\
0\end{array}$ & $\begin{array}{r}9,504 \\
0 \\
0 \\
0 \\
529 \\
0\end{array}$ \\
\hline 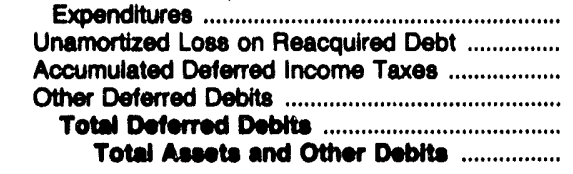 & $\begin{array}{r}0 \\
68,975 \\
179,885 \\
880,799 \\
1,192,723 \\
8,850,052\end{array}$ & $\begin{array}{r}0 \\
15 \\
80,556 \\
1,111,044 \\
1,648,901 \\
10,830,180\end{array}$ & $\begin{array}{r}0 \\
325 \\
0 \\
188 \\
682 \\
\mathbf{6 2 , 9 2 8}\end{array}$ & $\begin{array}{r}7,039 \\
25,273 \\
13,282 \\
21,045 \\
73,339 \\
1,685,247\end{array}$ & $\begin{array}{r}0 \\
214,245 \\
701,154 \\
339,129 \\
1,303,743 \\
18,603,290\end{array}$ & $\begin{array}{r}0 \\
5,482 \\
17,529 \\
13,645 \\
\mathbf{4 6 , 6 8 9} \\
1,156,687\end{array}$ \\
\hline
\end{tabular}

See endnotes at end of an individual electric utility. 
Table 38. Balance Sheet by Major U.S. Investor-Owned Electric Utillty Within State on December 31, 1992 (Continued)

(Thousand Dollars)

\begin{tabular}{|c|c|c|c|c|c|c|}
\hline Item & $\begin{array}{l}\text { Texas } \\
\text { Gulf } \\
\text { States } \\
\text { Utilities } \\
\text { Co } \\
\end{array}$ & $\begin{array}{l}\text { Texas } \\
\text { Houston } \\
\text { Lighting } \\
\& \\
\text { Power Co }\end{array}$ & $\begin{array}{l}\text { Texas } \\
\text { Southwestern } \\
\text { Electric } \\
\text { Serv Co }\end{array}$ & $\begin{array}{l}\text { Texas } \\
\text { Southwestern } \\
\text { Public } \\
\text { Service Co }\end{array}$ & $\begin{array}{l}\text { Texas } \\
\text { Texas } \\
\text { Utilities } \\
\text { Electric Co }\end{array}$ & $\begin{array}{l}\text { Texas } \\
\text { Texas- } \\
\text { Now Mexico } \\
\text { Power Co }\end{array}$ \\
\hline 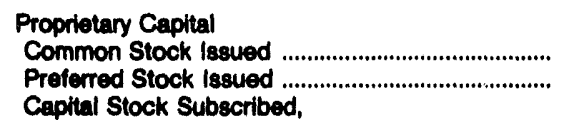 & $\begin{array}{r}1,200,923 \\
405,831\end{array}$ & $\begin{array}{r}1,602,098 \\
563,678\end{array}$ & $\begin{array}{r}660 \\
1,683\end{array}$ & $\begin{array}{l}40,918 \\
72,680\end{array}$ & $\begin{array}{l}4,717,625 \\
1,328,312\end{array}$ & $\begin{array}{r}107 \\
10,440\end{array}$ \\
\hline 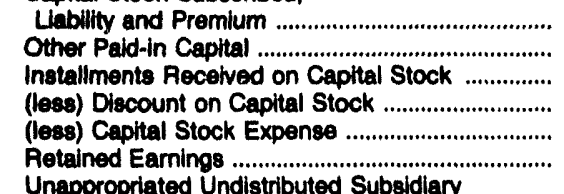 & $\begin{array}{r}406 \\
77,861 \\
0 \\
0 \\
10,940 \\
771,810\end{array}$ & $\begin{array}{r}0 \\
0 \\
0 \\
0 \\
5,490 \\
1,872,605\end{array}$ & $\begin{array}{r}6,051 \\
0 \\
0 \\
0 \\
380 \\
26,010\end{array}$ & $\begin{array}{r}317,065 \\
0 \\
0 \\
0 \\
10,688 \\
321,574\end{array}$ & $\begin{array}{r}0 \\
0 \\
0 \\
0 \\
0 \\
1,480,583\end{array}$ & $\begin{array}{r}66,225 \\
93,861 \\
0 \\
0 \\
0 \\
45,683\end{array}$ \\
\hline 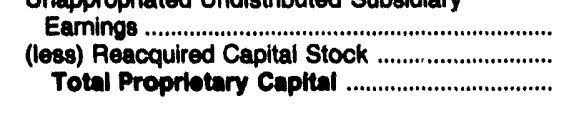 & $\begin{array}{r}-67,176 \\
0 \\
0 \\
2,378,708\end{array}$ & $\begin{array}{r}0 \\
0 \\
4,032,891\end{array}$ & $\begin{array}{r}0 \\
0 \\
34,024\end{array}$ & $\begin{array}{r}17,208 \\
0 \\
758,757\end{array}$ & $\begin{array}{r}0 \\
0 \\
7,526,520\end{array}$ & $\begin{array}{r}0 \\
0 \\
216,316\end{array}$ \\
\hline 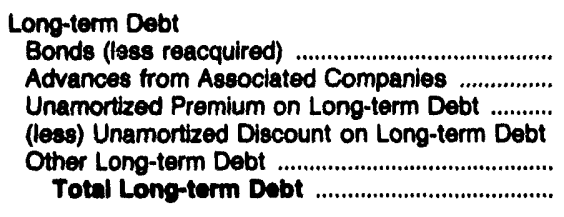 & $\begin{array}{r}2,378,310 \\
0 \\
176 \\
6,321 \\
162,718 \\
2,534,682\end{array}$ & $\begin{array}{r}3,064,151 \\
0 \\
895 \\
13,013 \\
257,681 \\
3,309,714\end{array}$ & $\begin{array}{r}12,830 \\
0 \\
0 \\
0 \\
217 \\
13,047\end{array}$ & $\begin{array}{r}561,680 \\
0 \\
8 \\
1,726 \\
1,764 \\
561,707\end{array}$ & $\begin{array}{r}7,065,214 \\
0 \\
565 \\
59,198 \\
437,773 \\
7,444,356\end{array}$ & $\begin{array}{r}263,598 \\
0 \\
6 \\
729 \\
489,500 \\
762,375\end{array}$ \\
\hline 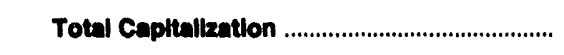 & $4,913,588$ & $7,342,605$ & 47,071 & $1,320,464$ & $14,970,875$ & 968,601 \\
\hline $\begin{array}{l}\text { Other Noncurrent Liabilities } \\
\text { Obligations Under Capital Lease-Noncurrent ...... } \\
\text { Accumulated Provision for Property Insurance ... } \\
\text { Accumulated Provision for Injurles and }\end{array}$ & $\begin{array}{r}154,923 \\
8,397\end{array}$ & $\begin{array}{r}1,673 \\
-2,821\end{array}$ & $\begin{array}{l}0 \\
0\end{array}$ & $\begin{array}{l}0 \\
0\end{array}$ & $\begin{array}{r}0 \\
-3,880\end{array}$ & $\begin{array}{l}0 \\
0\end{array}$ \\
\hline $\begin{array}{l}\text { Damages . } \\
\text { Accumulated Provision for Pensions and } \\
\text { Benefits ................................................................. } \\
\text { Accumulated Miscellaneous Operating }\end{array}$ & $\begin{array}{r}6,594 \\
0\end{array}$ & $\begin{array}{r}3,911 \\
0\end{array}$ & 0 & 0 & $\begin{array}{r}0 \\
391\end{array}$ & $\begin{array}{l}0 \\
0\end{array}$ \\
\hline 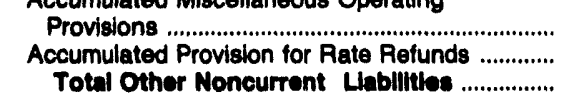 & $\begin{array}{r}2,873 \\
0 \\
173,788\end{array}$ & $\begin{array}{r}0 \\
0 \\
2,763\end{array}$ & $\begin{array}{l}0 \\
0 \\
0\end{array}$ & $\begin{array}{l}0 \\
0 \\
0\end{array}$ & $\begin{array}{r}0 \\
0 \\
-3,489\end{array}$ & $\begin{array}{l}0 \\
0 \\
0\end{array}$ \\
\hline 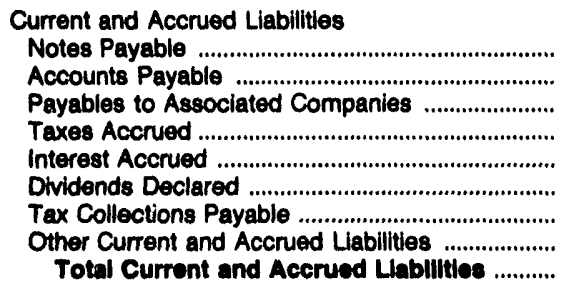 & $\begin{array}{r}0 \\
103,648 \\
807 \\
18,088 \\
62,013 \\
1,905 \\
4,476 \\
138,403 \\
330,340\end{array}$ & $\begin{array}{r}159,224 \\
129,845 \\
29,697 \\
186,812 \\
79,624 \\
7,992 \\
510 \\
295,950 \\
889,654\end{array}$ & $\begin{array}{r}0 \\
4,982 \\
0 \\
1,341 \\
202 \\
14 \\
0 \\
948 \\
7,487\end{array}$ & $\begin{array}{r}0 \\
8,789 \\
1,243 \\
18,368 \\
10,744 \\
813 \\
1,311 \\
52,177 \\
91,442\end{array}$ & $\begin{array}{r}250,281 \\
68,257 \\
190,844 \\
257,384 \\
181,415 \\
27,795 \\
3,549 \\
192,854 \\
1,172,380\end{array}$ & $\begin{array}{r}0 \\
25,809 \\
0 \\
18,795 \\
9,822 \\
0 \\
451 \\
27,522 \\
82,490\end{array}$ \\
\hline 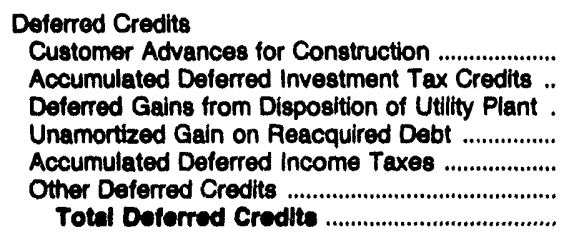 & $\begin{array}{r}346 \\
94,690 \\
0 \\
0 \\
0 \\
852,302 \\
493,999 \\
1,441,336\end{array}$ & $\begin{array}{r}3,609 \\
433,118 \\
0 \\
0 \\
0 \\
1,703,840 \\
263,601 \\
2,404,168\end{array}$ & $\begin{array}{r}0 \\
1,887 \\
0 \\
0 \\
6,539 \\
-2 \\
8,424\end{array}$ & $\begin{array}{r}339 \\
6,721 \\
0 \\
0 \\
255,939 \\
10,342 \\
273,341\end{array}$ & $\begin{array}{r}0 \\
707,358 \\
0 \\
0 \\
1,590,730 \\
225,445 \\
2,523,533\end{array}$ & $\begin{array}{r}311 \\
18,152 \\
0 \\
0 \\
85,807 \\
1,107 \\
106,377\end{array}$ \\
\hline Total Llablitites and Other Credite ................ & $6,859,052$ & $10,639,190$ & 62,982 & $1,605,247$ & $18,663,299$ & $1,158,507$ \\
\hline
\end{tabular}

Note: Totals may not equal sum of components because of independent rounding. Summary data are provided in Table 8.

Source: Federal Energy Regulatory Commission, FERC Form 1, "Annual Report of Major Electric Utillities, Licensees and Others." 
Table 38. Balance Sheet by Major U.S. Investor-Owned Electric Utility Within State on December 31, 1992 (Continued)

(Thousand Dollars)

\begin{tabular}{|c|c|c|c|c|c|c|}
\hline Item & $\begin{array}{l}\text { Texas } \\
\text { West } \\
\text { Texas } \\
\text { Utilities } \\
\text { Co }\end{array}$ & $\begin{array}{l}\text { Vermont } \\
\text { Central } \\
\text { Vermont } \\
\text { Pub } \\
\text { Serv Corp }\end{array}$ & $\begin{array}{l}\text { Vermont } \\
\text { Green } \\
\text { Mountain } \\
\text { Power Corp }\end{array}$ & $\begin{array}{l}\text { Vermont } \\
\text { Vermont } \\
\text { Electric } \\
\text { Power } \\
\text { Co inc }\end{array}$ & $\begin{array}{l}\text { Vermont } \\
\text { Vermont } \\
\text { Electric } \\
\text { Trans } \\
\text { Co Inc }\end{array}$ & $\begin{array}{l}\text { Vermont } \\
\text { Vermont } \\
\text { Yankee } \\
\text { Nucl } \\
\text { Pwr Corp }\end{array}$ \\
\hline 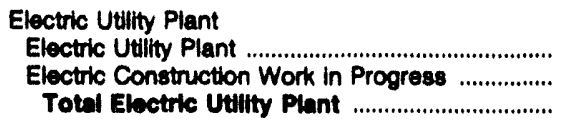 & $\begin{array}{r}951,694 \\
13,193 \\
924,987\end{array}$ & $\begin{array}{r}396,877 \\
10,376 \\
407,263\end{array}$ & $\begin{array}{r}213,592 \\
9,647 \\
223,239\end{array}$ & $\begin{array}{r}89,428 \\
1,041 \\
00,489\end{array}$ & $\begin{array}{r}47,877 \\
0 \\
47,877\end{array}$ & $\begin{array}{r}362,278 \\
6,408 \\
38,898\end{array}$ \\
\hline $\begin{array}{l}\text { (less) Electric Utility Accumulated Provision for } \\
\text { Depreciation, Amortization, and Depletion ....... } \\
\text { Not Eloctric Utilty Plant } \\
\text { (leas nuclear fuel) }\end{array}$ & $\begin{array}{l}313,666 \\
651,221\end{array}$ & $\begin{array}{r}99,107 \\
309,148\end{array}$ & $\begin{array}{r}58,516 \\
184,723\end{array}$ & $\begin{array}{l}39,141 \\
51,320\end{array}$ & $\begin{array}{l}15,440 \\
32,437\end{array}$ & $\begin{array}{l}185,283 \\
183,423\end{array}$ \\
\hline $\begin{array}{l}\text { Nuclear Fuel ................................................ } \\
\text { (less) Accumuled Provision for }\end{array}$ & 0 & 5,882 & 0 & 0 & 0 & 338,480 \\
\hline 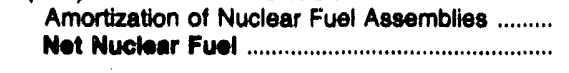 & $\begin{array}{l}0 \\
0\end{array}$ & $\begin{array}{l}4,385 \\
1,497\end{array}$ & $\begin{array}{l}0 \\
\mathbf{0}\end{array}$ & $\begin{array}{l}0 \\
0\end{array}$ & $\begin{array}{l}0 \\
0\end{array}$ & $\begin{array}{r}348,133 \\
-9,673\end{array}$ \\
\hline 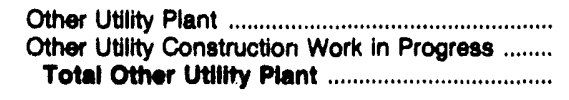 & $\begin{array}{l}0 \\
0 \\
0\end{array}$ & $\begin{array}{l}0 \\
0 \\
0\end{array}$ & $\begin{array}{l}0 \\
0 \\
0\end{array}$ & $\begin{array}{l}0 \\
0 \\
0\end{array}$ & $\begin{array}{l}0 \\
0 \\
0\end{array}$ & $\begin{array}{l}0 \\
0 \\
0\end{array}$ \\
\hline \multicolumn{7}{|l|}{$\begin{array}{l}\text { (less) Other Utility Accumulated Provision } \\
\text { for Depreciation,Amortization and }\end{array}$} \\
\hline 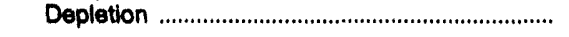 & 0 & 0 & 0 & 0 & 0 & 0 \\
\hline Not Other Utility Piant ............................................ & 0 & $\mathbf{0}$ & $\mathbf{0}$ & $\mathbf{0}$ & 0 & $\mathbf{0}$ \\
\hline 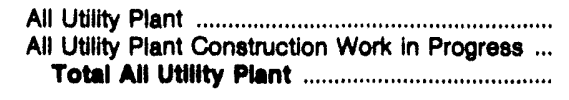 & $\begin{array}{r}951,694 \\
13,193 \\
984,887\end{array}$ & $\begin{array}{r}402,759 \\
10,376 \\
413,135\end{array}$ & $\begin{array}{r}213,592 \\
9,647 \\
223,239\end{array}$ & $\begin{array}{r}89,428 \\
1,041 \\
90,489\end{array}$ & $\begin{array}{r}47,877 \\
0 \\
47,877\end{array}$ & $\begin{array}{r}700,739 \\
6,408 \\
707,148\end{array}$ \\
\hline 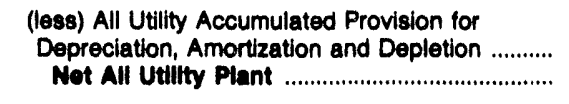 & $\begin{array}{l}313,666 \\
651,221\end{array}$ & $\begin{array}{l}103,492 \\
309,643\end{array}$ & $\begin{array}{r}58,516 \\
184,723\end{array}$ & $\begin{array}{l}39,141 \\
51,329\end{array}$ & $\begin{array}{l}15,440 \\
32,437\end{array}$ & $\begin{array}{l}533,396 \\
173,750\end{array}$ \\
\hline \multicolumn{7}{|l|}{$\begin{array}{l}\text { Other Property and Investments } \\
\text { Nonutlity Property (less Accumulated }\end{array}$} \\
\hline 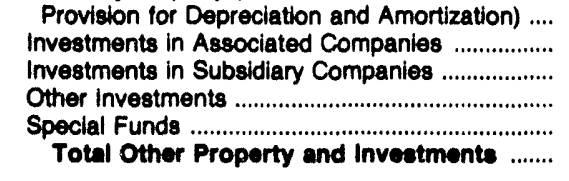 & $\begin{array}{r}443 \\
0 \\
0 \\
392 \\
0 \\
836\end{array}$ & $\begin{array}{r}2,627 \\
0 \\
53,129 \\
363 \\
0 \\
56,119\end{array}$ & $\begin{array}{r}1,018 \\
0 \\
27,805 \\
3,040 \\
1,520 \\
33,385\end{array}$ & $\begin{array}{r}0 \\
0 \\
5,807 \\
0 \\
387 \\
6,194\end{array}$ & $\begin{array}{l}0 \\
0 \\
0 \\
0 \\
0 \\
0\end{array}$ & $\begin{array}{r}598 \\
0 \\
0 \\
0 \\
42,215 \\
42,813\end{array}$ \\
\hline 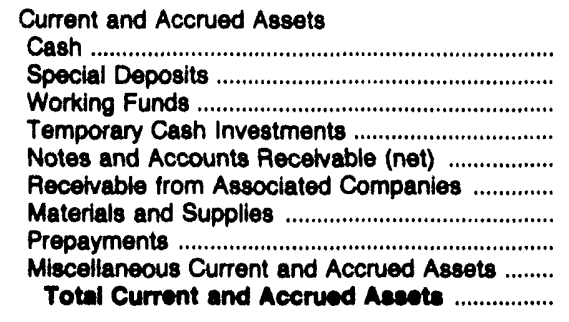 & $\begin{array}{r}1,635 \\
208 \\
109 \\
0 \\
19,762 \\
1,575 \\
27,733 \\
209 \\
0 \\
51,232\end{array}$ & $\begin{array}{r}1,211 \\
374 \\
44 \\
259 \\
16,099 \\
3,004 \\
4,201 \\
4,012 \\
15,270 \\
44,474\end{array}$ & $\begin{array}{r}185 \\
0 \\
16 \\
0 \\
17,042 \\
3,615 \\
2,894 \\
1,866 \\
6,065 \\
31,883\end{array}$ & $\begin{array}{r}285 \\
410 \\
2 \\
0 \\
2,738 \\
6,489 \\
1,234 \\
350 \\
781 \\
12,288\end{array}$ & $\begin{array}{r}30 \\
0 \\
0 \\
0 \\
0 \\
2 \\
124 \\
407 \\
0 \\
683\end{array}$ & $\begin{array}{r}84 \\
0 \\
1 \\
1,837 \\
2,715 \\
15,407 \\
16,862 \\
4,381 \\
-1 \\
41,287\end{array}$ \\
\hline $\begin{array}{l}\text { Deferred Debits } \\
\text { Unamortized Debt Expense ................................... } \\
\text { Extraordinary Property Losses .............................. } \\
\text { Unrecovered Plant and Regulatory Study Cost ... } \\
\text { Preliminary Survey and Investigation Charges .... } \\
\text { Clearing Accounts ................................................ } \\
\text { Deferred Losses from Disposition of Usilty Plant } \\
\text { Research, Development and Demonstration }\end{array}$ & $\begin{array}{r}1,647 \\
0 \\
0 \\
186 \\
40 \\
0\end{array}$ & $\begin{array}{r}1,150 \\
0 \\
4,585 \\
881 \\
11 \\
0\end{array}$ & $\begin{array}{r}927 \\
0 \\
0 \\
2,015 \\
91 \\
0\end{array}$ & $\begin{array}{r}158 \\
0 \\
0 \\
0 \\
5 \\
0\end{array}$ & $\begin{array}{r}261 \\
0 \\
0 \\
0 \\
0 \\
0\end{array}$ & $\begin{array}{r}787 \\
0 \\
0 \\
272 \\
0 \\
0\end{array}$ \\
\hline 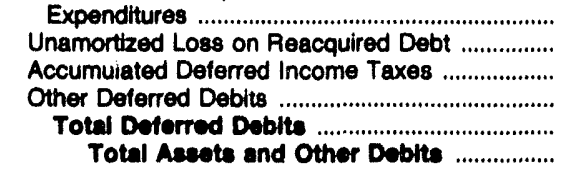 & $\begin{array}{r}0 \\
30,804 \\
8,802 \\
39,668 \\
81,147 \\
784,435\end{array}$ & $\begin{array}{r}0 \\
775 \\
14,148 \\
26,192 \\
47,721 \\
467,057\end{array}$ & $\begin{array}{r}0 \\
64 \\
10,012 \\
15,915 \\
29,023 \\
258,014\end{array}$ & $\begin{array}{r}0 \\
0 \\
0 \\
848 \\
1,011 \\
70,821\end{array}$ & $\begin{array}{r}0 \\
0 \\
231 \\
0 \\
492 \\
33,492\end{array}$ & $\begin{array}{r}0 \\
622 \\
10,377 \\
137,854 \\
160,013 \\
407,803\end{array}$ \\
\hline
\end{tabular}

See endnotes at end of an individual electric utility. 
Table 38. Balance Sheet by Major U.S. Investor-Owned Electric Utility Within State on December 31, 1992 (Continued) (Thousand Dollars)

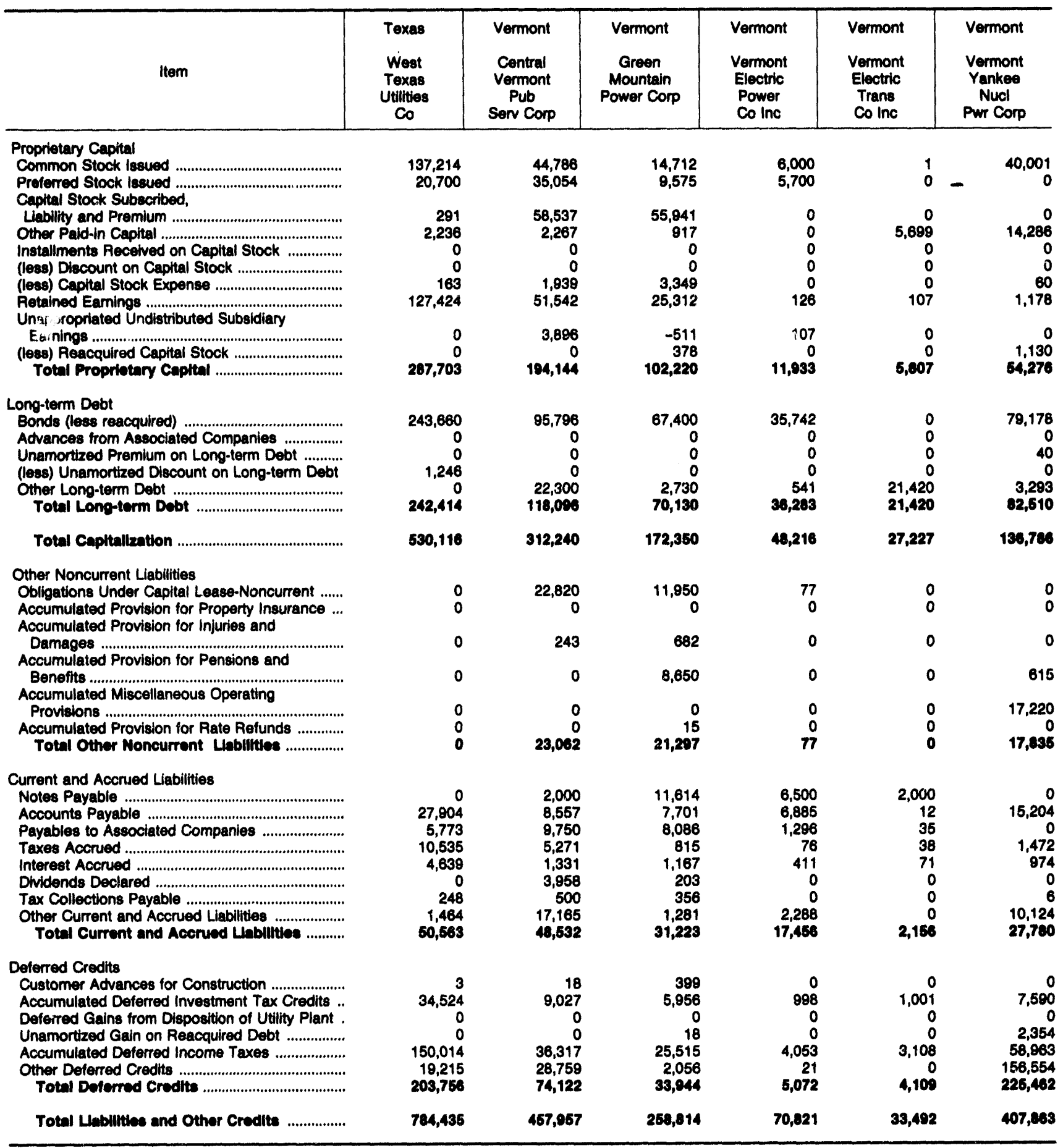

Note: Totals may not equal sum of components because of independent rounding. Summary data are provided in Table 8.

Source: Federal Energy Regulatory Commission, FERC Form 1, "Annual Report of Major Electric Utilities, Licensees and Others." 
Table 38. Balance Sheet by Major U.S. Investor-Owned Electric Utility Within State on December 31, 1992 (Continued)

(Thousand Dollars)

\begin{tabular}{|c|c|c|c|c|c|c|}
\hline Item & $\begin{array}{l}\text { Virginia } \\
\text { Appalachlan } \\
\text { Power Co }\end{array}$ & $\begin{array}{l}\text { Virginia } \\
\text { Virginia } \\
\text { Electric } \\
\text { \& Power } \\
\text { Co }\end{array}$ & $\begin{array}{l}\text { Weshington } \\
\text { Puget Sound } \\
\text { Power \& Light } \\
\text { Co }\end{array}$ & $\begin{array}{l}\text { Washington } \\
\text { Washington } \\
\text { Water } \\
\text { Power Co }\end{array}$ & $\begin{array}{c}\text { West Virginia } \\
\text { Kanawha } \\
\text { Valley } \\
\text { Power Co }\end{array}$ & $\begin{array}{l}\text { Weat Virginia } \\
\text { Monongahela } \\
\text { Power Co }\end{array}$ \\
\hline 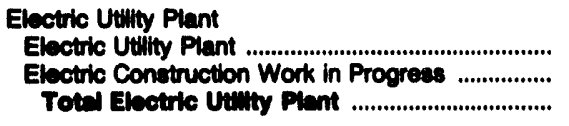 & $\begin{array}{r}3,958,812 \\
45,272 \\
4,004,004\end{array}$ & $\begin{array}{r}12,138,195 \\
840,941 \\
12,077,183\end{array}$ & $\begin{array}{r}2,919,591 \\
80,042 \\
3,009,639\end{array}$ & $\begin{array}{r}1,338,231 \\
27,296 \\
1,386,627\end{array}$ & $\begin{array}{r}14,484 \\
133 \\
14,817\end{array}$ & $\begin{array}{r}1,467,212 \\
99,177 \\
1,683,890\end{array}$ \\
\hline 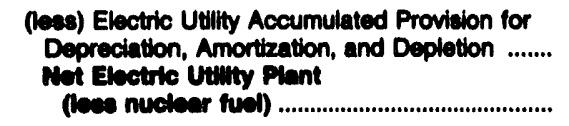 & $\begin{array}{l}1,452,621 \\
2,851,403\end{array}$ & $\begin{array}{l}3,852,508 \\
9,124,829\end{array}$ & $\begin{array}{r}809,688 \\
2,090,097\end{array}$ & $\begin{array}{r}352,612 \\
1,012,016\end{array}$ & $\begin{array}{r}4,423 \\
10,184\end{array}$ & $\begin{array}{l}628,501 \\
897,098\end{array}$ \\
\hline 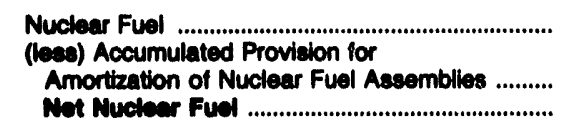 & $\begin{array}{l}0 \\
0 \\
0\end{array}$ & $\begin{array}{r}1,012,881 \\
851,227 \\
181,054\end{array}$ & $\begin{array}{l}0 \\
0\end{array}$ & $\begin{array}{l}0 \\
0\end{array}$ & $\begin{array}{l}0 \\
0\end{array}$ & $\begin{array}{l}0 \\
0\end{array}$ \\
\hline 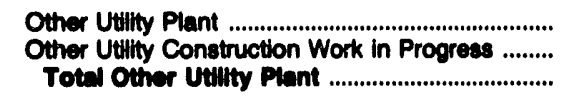 & $\begin{array}{l}0 \\
0 \\
0\end{array}$ & $\begin{array}{l}0 \\
0 \\
0\end{array}$ & $\begin{array}{l}0 \\
0 \\
0\end{array}$ & $\begin{array}{r}250,530 \\
5,443 \\
256,074\end{array}$ & $\begin{array}{l}0 \\
0 \\
0\end{array}$ & $\begin{array}{l}0 \\
0 \\
0\end{array}$ \\
\hline 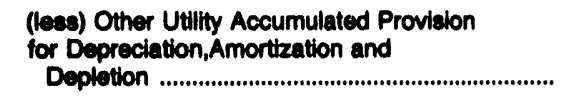 & 0 & 0 & 0 & 77,736 & 0 & 0 \\
\hline Net Other Utilly Plant ......................................... & $\mathbf{0}$ & $\mathbf{0}$ & $\mathbf{0}$ & 178,288 & 0 & 0 \\
\hline 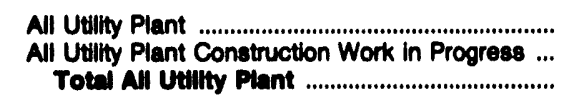 & $\begin{array}{r}3,958,812 \\
45,272 \\
4,004,084\end{array}$ & $\begin{array}{r}13,149,076 \\
840,941 \\
13,900,017\end{array}$ & $\begin{array}{r}2,919,591 \\
90,042 \\
3,000,633\end{array}$ & $\begin{array}{r}1,588,762 \\
32,739 \\
1,621,601\end{array}$ & $\begin{array}{r}14,484 \\
133 \\
14,617\end{array}$ & $\begin{array}{r}1,467,212 \\
99,177 \\
1,689,390\end{array}$ \\
\hline 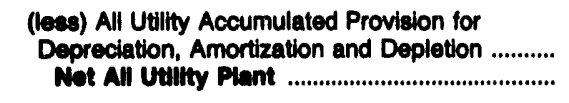 & $\begin{array}{l}1,452,621 \\
2,651,403\end{array}$ & $\begin{array}{l}4,703,734 \\
0,206,283\end{array}$ & $\begin{array}{r}909,686 \\
2,000,037\end{array}$ & $\begin{array}{r}430,348 \\
1,191,163\end{array}$ & $\begin{array}{r}4,423 \\
10,184\end{array}$ & $\begin{array}{l}628,501 \\
037,09\end{array}$ \\
\hline 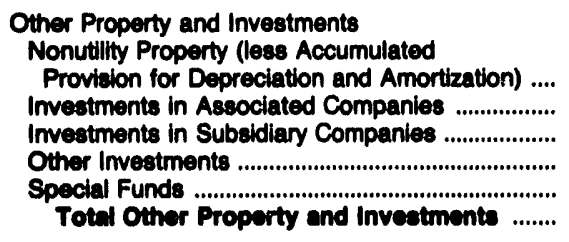 & $\begin{array}{r}16,520 \\
0 \\
33,189 \\
24,954 \\
42 \\
74,705\end{array}$ & $\begin{array}{r}9,454 \\
0 \\
0 \\
12,343 \\
246,840 \\
298,637\end{array}$ & $\begin{array}{r}2,219 \\
0 \\
76,181 \\
9,191 \\
0 \\
97,601\end{array}$ & $\begin{array}{r}2,108 \\
0 \\
79,616 \\
117,976 \\
6,711 \\
208,410\end{array}$ & $\begin{array}{l}0 \\
0 \\
0 \\
3 \\
0 \\
3\end{array}$ & $\begin{array}{r}768 \\
0 \\
64,264 \\
0 \\
301 \\
65,339\end{array}$ \\
\hline 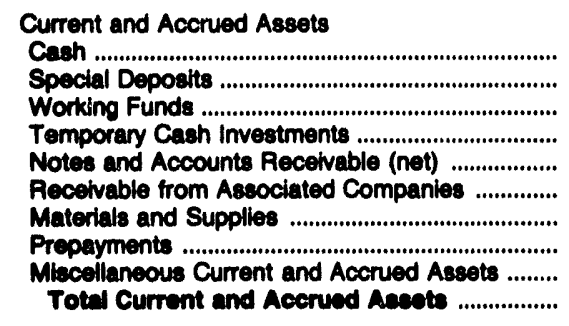 & $\begin{array}{r}7,310 \\
928 \\
337 \\
0 \\
112,963 \\
14,640 \\
152,695 \\
7,297 \\
47,584 \\
343,751\end{array}$ & $\begin{array}{r}23,068 \\
0 \\
68 \\
42,008 \\
205,248 \\
21 \\
330,468 \\
28,208 \\
104,070 \\
733,354\end{array}$ & $\begin{array}{r}-9,060 \\
82 \\
1,893 \\
128,192 \\
74,321 \\
92 \\
53,437 \\
3,408 \\
77,873 \\
330,235\end{array}$ & $\begin{array}{r}60 \\
0 \\
104 \\
0 \\
24,687 \\
3,770 \\
14,530 \\
2,063 \\
7,061 \\
52,274\end{array}$ & $\begin{array}{r}5 \\
0 \\
0 \\
0 \\
0 \\
317 \\
146 \\
24 \\
5 \\
408\end{array}$ & $\begin{array}{r}0 \\
2,179 \\
115 \\
0 \\
34,671 \\
9,386 \\
55,214 \\
4,839 \\
34,261 \\
140,675\end{array}$ \\
\hline 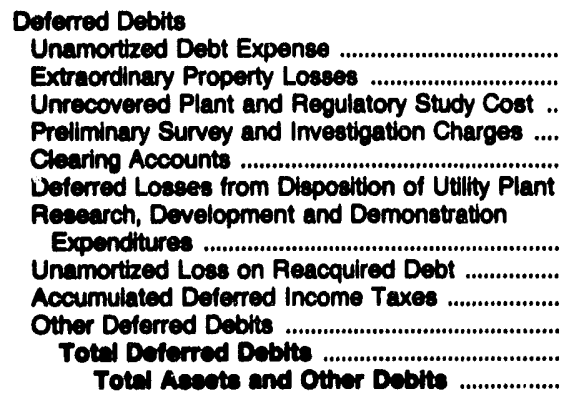 & $\begin{array}{r}3,695 \\
0 \\
0 \\
3,645 \\
887 \\
0 \\
0 \\
22,614 \\
25,860 \\
87,664 \\
144,386 \\
3,114,286\end{array}$ & $\begin{array}{r}24,970 \\
178,605 \\
37,628 \\
560 \\
1 \\
0 \\
0 \\
0 \\
61,725 \\
0 \\
724,895 \\
1,029,303 \\
11,316,857\end{array}$ & $\begin{array}{r}9,808 \\
27,316 \\
24,353 \\
78 \\
0 \\
70 \\
0 \\
0 \\
10,968 \\
36,477 \\
400,238 \\
600,407 \\
3,027,170\end{array}$ & $\begin{array}{r}4,720 \\
0 \\
7,477 \\
9,773 \\
-851 \\
0 \\
0 \\
6 \\
17,182 \\
26,259 \\
30,277 \\
24,863 \\
1,644,689\end{array}$ & $\begin{array}{r}0 \\
0 \\
0 \\
0 \\
0 \\
0 \\
0 \\
0 \\
0 \\
71 \\
210 \\
281 \\
10,977\end{array}$ & $\begin{array}{r}0 \\
11,383 \\
12,756 \\
3,511 \\
30,875 \\
1,100,772\end{array}$ \\
\hline
\end{tabular}

See endnotes at end of an individual electric utility. 
Table 38. Balance Sheot by Major U.S. Inveator-Owned Electric Utility Within state on Decomber 31, 1992 (Continued)

(Thousand Dollars)

\begin{tabular}{|c|c|c|c|c|c|c|}
\hline $1 \mathrm{tem}$ & $\begin{array}{l}\text { Virginia } \\
\text { Appalachian } \\
\text { Power Co }\end{array}$ & $\begin{array}{l}\text { Virginia } \\
\text { Virginia } \\
\text { Electric } \\
\text { a Power } \\
\text { Co } \\
\end{array}$ & $\begin{array}{l}\text { Waehington } \\
\text { Puget Sound } \\
\text { Power \& Light } \\
\text { Co }\end{array}$ & $\begin{array}{l}\text { Washington } \\
\text { Washington } \\
\text { Water } \\
\text { Power Co }\end{array}$ & $\begin{array}{l}\text { Woat Virginia } \\
\text { Kanawha } \\
\text { Valley } \\
\text { Power Co }\end{array}$ & $\begin{array}{l}\text { West Virginla } \\
\text { Monongahela } \\
\text { Power Co }\end{array}$ \\
\hline 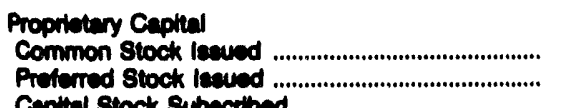 & $\begin{array}{l}280,458 \\
213,610\end{array}$ & $\begin{array}{r}2,612,428 \\
845,556\end{array}$ & $\begin{array}{l}585,746 \\
258,822\end{array}$ & $\begin{array}{l}508,203 \\
135,000\end{array}$ & $\begin{array}{l}1 \\
0\end{array}$ & $\begin{array}{r}294,550 \\
64,000\end{array}$ \\
\hline 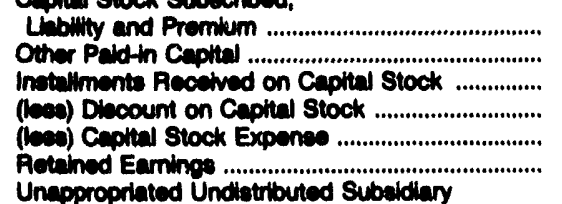 & $\begin{array}{r}1,475 \\
470,576 \\
0 \\
0 \\
0 \\
225,074\end{array}$ & $\begin{array}{r}0 \\
22,032 \\
0 \\
0 \\
13,282 \\
1,195,813\end{array}$ & $\begin{array}{r}248,814 \\
216 \\
0 \\
0 \\
6,157 \\
208,891\end{array}$ & $\begin{array}{r}0 \\
0 \\
0 \\
0 \\
9,623 \\
45,048\end{array}$ & $\begin{array}{r}0 \\
2,396 \\
0 \\
0 \\
0 \\
2,225\end{array}$ & $\begin{array}{r}2,662 \\
332 \\
0 \\
0 \\
0 \\
174,168\end{array}$ \\
\hline 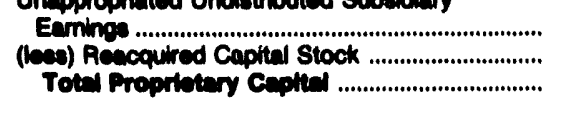 & $\begin{array}{r}4,840 \\
0 \\
1,184,930\end{array}$ & $\begin{array}{r}0 \\
0 \\
4,602,600\end{array}$ & $\begin{array}{r}1,653 \\
0 \\
1,206,006\end{array}$ & $\begin{array}{r}56,586 \\
0 \\
736,224\end{array}$ & $\begin{array}{r}0 \\
0 \\
4,622\end{array}$ & $\begin{array}{r}3,918 \\
0 \\
639,628\end{array}$ \\
\hline 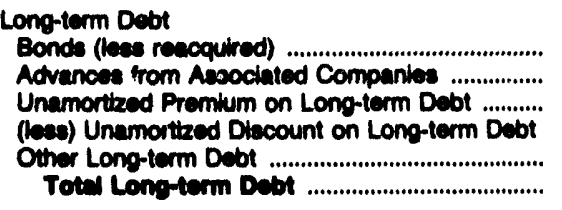 & $\begin{array}{r}871,381 \\
0 \\
505 \\
8,685 \\
237,101 \\
1,200,272\end{array}$ & $\begin{array}{r}2,858,625 \\
0 \\
2,061 \\
15,491 \\
1,291,730 \\
3,936,025\end{array}$ & $\begin{array}{r}1,207,660 \\
0 \\
112 \\
1,030 \\
50 \\
1,206,902\end{array}$ & $\begin{array}{r}297,600 \\
0 \\
103 \\
1,624 \\
299,280 \\
595,660\end{array}$ & $\begin{array}{l}0 \\
0 \\
0 \\
0 \\
0 \\
0\end{array}$ & $\begin{array}{r}368,000 \\
0 \\
62 \\
2,914 \\
81,210 \\
446,360\end{array}$ \\
\hline 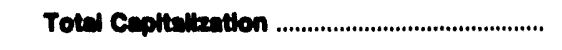 & $2,305,210$ & $0,600,694$ & $2,605,078$ & $1,330,783$ & 4,022 & 985,060 \\
\hline $\begin{array}{l}\text { Other Noncurrent Liabilitites } \\
\text { Obligations Under Capttal Lease-Noncurrent ...... } \\
\text { Accumulated Provialon for Property Ineurance ... } \\
\text { Accumulated Provialon for Infuries and }\end{array}$ & $\begin{array}{r}19,551 \\
0\end{array}$ & $\begin{array}{r}29,108 \\
0\end{array}$ & $\begin{array}{l}0 \\
0\end{array}$ & $\begin{array}{r}936 \\
0\end{array}$ & $\begin{array}{l}0 \\
0\end{array}$ & $\begin{array}{r}810 \\
0\end{array}$ \\
\hline $\begin{array}{l}\text { Damages } \\
\text { Acoumulated Provition for Pencions and }\end{array}$ & 9,028 & 0 & 87 & 1,438 & 12 & 349 \\
\hline $\begin{array}{l}\text { Benefita .... } \\
\text { Accumulated Miscellaneous Operating }\end{array}$ & 122 & 0 & 0 & 0 & 0 & 933 \\
\hline 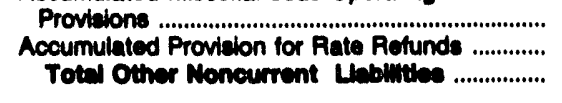 & $\begin{array}{r}0 \\
945 \\
20,644\end{array}$ & $\begin{array}{r}0 \\
189,280 \\
218,380\end{array}$ & $\begin{array}{r}0 \\
0 \\
87\end{array}$ & $\begin{array}{r}0 \\
0 \\
2,374\end{array}$ & $\begin{array}{c}0 \\
0 \\
12\end{array}$ & $\begin{array}{r}0 \\
0 \\
2,191\end{array}$ \\
\hline 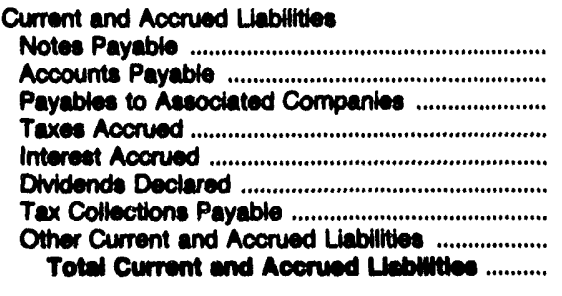 & $\begin{array}{r}76,550 \\
46,629 \\
41,742 \\
43,391 \\
22,806 \\
4,122 \\
4,587 \\
50,786 \\
209,604\end{array}$ & $\begin{array}{r}49,500 \\
274,177 \\
1,405 \\
-10,216 \\
108,180 \\
1,306 \\
18,858 \\
155,020 \\
506,230\end{array}$ & $\begin{array}{r}90,452 \\
68,575 \\
227 \\
21,464 \\
19,348 \\
0 \\
25 \\
10,121 \\
210,211\end{array}$ & $\begin{array}{r}0 \\
27,525 \\
0 \\
17,656 \\
12,769 \\
285 \\
572 \\
14,032 \\
72,039\end{array}$ & $\begin{array}{r}4,300 \\
39 \\
47 \\
432 \\
8 \\
0 \\
0 \\
6 \\
662 \\
5,404\end{array}$ & $\begin{array}{r}0 \\
36,218 \\
14,971 \\
26,935 \\
10,351 \\
1,115 \\
679 \\
9,213 \\
09,401\end{array}$ \\
\hline 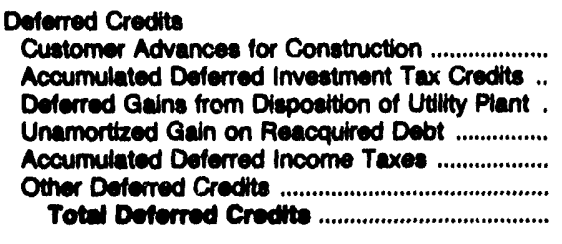 & $\begin{array}{r}166 \\
88,061 \\
0 \\
3 \\
388,825 \\
32,783 \\
409,837\end{array}$ & $\begin{array}{r}674 \\
325,472 \\
842 \\
40 \\
1,382,666 \\
190,772 \\
1,000,465\end{array}$ & $\begin{array}{r}19,483 \\
3,259 \\
2,440 \\
225 \\
252,236 \\
33,251 \\
310,006\end{array}$ & $\begin{array}{r}3,426 \\
2,554 \\
0 \\
0 \\
0 \\
119,418 \\
13,294 \\
138,603\end{array}$ & $\begin{array}{r}0 \\
25 \\
0 \\
0 \\
824 \\
0 \\
840\end{array}$ & $\begin{array}{r}3,484 \\
28,048 \\
0 \\
0 \\
59,839 \\
642 \\
93,113\end{array}$ \\
\hline Total Labintibe and Other Crodits ................. & $3,114,200$ & $11,316,667$ & $3,027,170$ & $1,844,600$ & 10,977 & $1,160,772$ \\
\hline
\end{tabular}

Note: Totals may not equal sum of components because of independent rounding. Summary data are provided in Table 8.

Source: Federcl Energy Requlatory Commiacion, FERC Form 1, "Annual Report of Major Electric Utilities, Licensees and Others." 
Table 38. Balance Sheet by Major U.S. Investor-Owned Electrle Utility Within State on December 31, 1992 (Continued)

(Thousand Dollars)

\begin{tabular}{|c|c|c|c|c|c|c|}
\hline Item & $\begin{array}{l}\text { Weat Virginia } \\
\text { Wheeling } \\
\text { Power Co }\end{array}$ & $\begin{array}{l}\text { Wisconain } \\
\text { Consolldated } \\
\text { Water } \\
\text { Power Co }\end{array}$ & $\begin{array}{l}\text { Wisconain } \\
\text { Madison } \\
\text { Gas } \\
\$ \\
\text { Electric Co }\end{array}$ & $\begin{array}{l}\text { Wisconsin } \\
\text { Northern } \\
\text { States } \\
\text { Power Co }\end{array}$ & $\begin{array}{l}\text { Wisconsin } \\
\text { Northwestem } \\
\text { Wisconsin } \\
\text { Elec Co }\end{array}$ & $\begin{array}{c}\text { Wisconsin } \\
\text { Ploneer } \\
\text { Power } \\
\& \\
\text { Light co }\end{array}$ \\
\hline 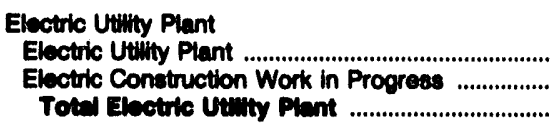 & $\begin{array}{r}77,800 \\
1,060 \\
78,081\end{array}$ & $\begin{array}{r}31,980 \\
408 \\
32,386\end{array}$ & $\begin{array}{r}437,201 \\
5,215 \\
442,416\end{array}$ & $\begin{array}{r}767,003 \\
14,571 \\
781,674\end{array}$ & $\begin{array}{r}20,182 \\
450 \\
20,632\end{array}$ & $\begin{array}{r}2,026 \\
0 \\
2,026\end{array}$ \\
\hline 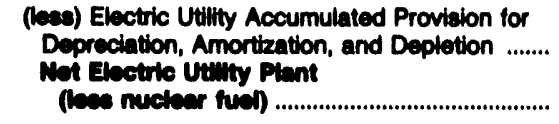 & $\begin{array}{l}30,473 \\
48,408\end{array}$ & $\begin{array}{l}11,759 \\
20,620\end{array}$ & $\begin{array}{l}203,518 \\
238,896\end{array}$ & $\begin{array}{l}263,193 \\
518,391\end{array}$ & $\begin{array}{l}10,017 \\
10,616\end{array}$ & $\begin{array}{r}1,108 \\
017\end{array}$ \\
\hline 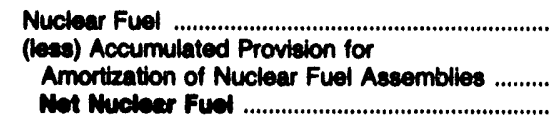 & $\begin{array}{l}0 \\
0\end{array}$ & $\begin{array}{l}0 \\
0\end{array}$ & $\begin{array}{l}0 \\
0\end{array}$ & $\begin{array}{l}0 \\
0\end{array}$ & $\begin{array}{l}0 \\
0\end{array}$ & $\begin{array}{l}0 \\
0 \\
0\end{array}$ \\
\hline 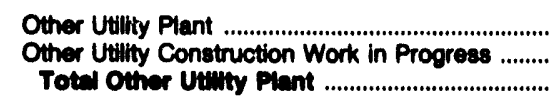 & $\begin{array}{l}0 \\
0 \\
0\end{array}$ & $\begin{array}{l}0 \\
0 \\
0\end{array}$ & $\begin{array}{r}175,718 \\
1,509 \\
177,227\end{array}$ & $\begin{array}{r}93,831 \\
9,984 \\
103,816\end{array}$ & $\begin{array}{l}0 \\
0 \\
0\end{array}$ & $\begin{array}{l}0 \\
0 \\
0\end{array}$ \\
\hline 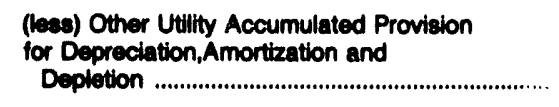 & 0 & 0 & 79,071 & 37,201 & 0 & 0 \\
\hline Net Other Ututhy Plant ............................................... & $\mathbf{0}$ & 0 & 90,157 & 86,614 & $\mathbf{0}$ & $\mathbf{0}$ \\
\hline 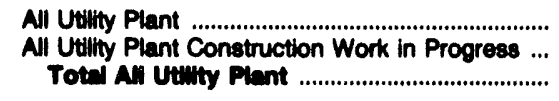 & $\begin{array}{r}77,900 \\
1,060 \\
70,981\end{array}$ & $\begin{array}{r}31,880 \\
408 \\
32,380\end{array}$ & $\begin{array}{r}612,919 \\
6,724 \\
619,643\end{array}$ & $\begin{array}{r}860,833 \\
24,555 \\
205,340\end{array}$ & $\begin{array}{r}20,182 \\
450 \\
20,632\end{array}$ & $\begin{array}{r}2,028 \\
0 \\
2,026\end{array}$ \\
\hline 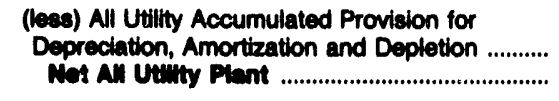 & $\begin{array}{l}30,473 \\
48,468\end{array}$ & $\begin{array}{l}11,759 \\
20,620\end{array}$ & $\begin{array}{l}282,568 \\
337,064\end{array}$ & $\begin{array}{l}300,394 \\
584,905\end{array}$ & $\begin{array}{l}10,017 \\
10,616\end{array}$ & $\begin{array}{r}1,108 \\
917\end{array}$ \\
\hline 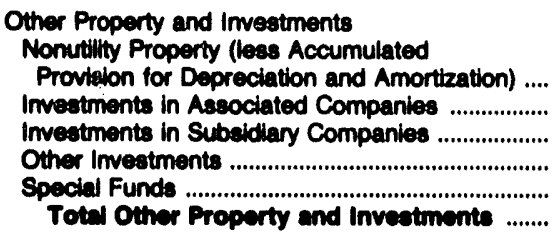 & $\begin{array}{r}1,215 \\
0 \\
0 \\
1,157 \\
8 \\
8,380 \\
2,30\end{array}$ & $\begin{array}{r}0 \\
373 \\
4,830 \\
0 \\
0 \\
5,202\end{array}$ & $\begin{array}{r}949 \\
0 \\
3,781 \\
4,167 \\
23,100 \\
31,907\end{array}$ & $\begin{array}{r}2,757 \\
0 \\
1,090 \\
2,571 \\
0 \\
6,417\end{array}$ & $\begin{array}{l}0 \\
0 \\
0 \\
2 \\
0 \\
2\end{array}$ & $\begin{array}{r}0 \\
0 \\
0 \\
1 \\
34 \\
35\end{array}$ \\
\hline 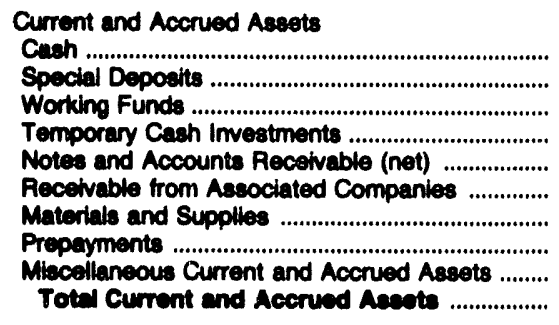 & $\begin{array}{r}269 \\
15,036 \\
6 \\
0 \\
6,431 \\
409 \\
351 \\
238 \\
2,175 \\
24,916\end{array}$ & $\begin{array}{r}0 \\
0 \\
0 \\
0 \\
0 \\
10 \\
0 \\
359 \\
0 \\
369\end{array}$ & $\begin{array}{r}1,431 \\
2,466 \\
4 \\
26,015 \\
9,533 \\
6,596 \\
11,722 \\
6,665 \\
17,894 \\
82,326\end{array}$ & $\begin{array}{r}881 \\
0 \\
42 \\
0 \\
36,050 \\
5,768 \\
7,745 \\
9,888 \\
18,808 \\
79,182\end{array}$ & $\begin{array}{r}136 \\
0 \\
1 \\
0 \\
754 \\
0 \\
427 \\
226 \\
452 \\
1,005\end{array}$ & $\begin{array}{r}29 \\
0 \\
0 \\
0 \\
90 \\
51 \\
54 \\
8 \\
0 \\
232\end{array}$ \\
\hline 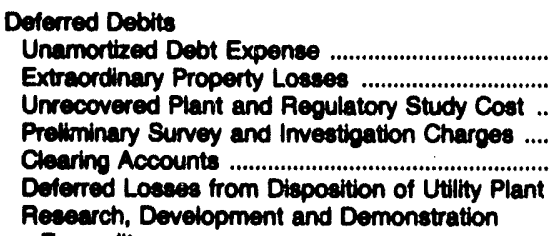 & $\begin{array}{l}0 \\
0 \\
0 \\
0 \\
4 \\
0\end{array}$ & $\begin{array}{l}0 \\
0 \\
0 \\
0 \\
0 \\
0\end{array}$ & $\begin{array}{r}5,043 \\
0 \\
0 \\
434 \\
639 \\
0\end{array}$ & $\begin{array}{r}3,031 \\
0 \\
0 \\
307 \\
1,032 \\
0\end{array}$ & $\begin{array}{r}49 \\
0 \\
0 \\
42 \\
0 \\
34\end{array}$ & $\begin{array}{l}0 \\
0 \\
0 \\
0 \\
0 \\
0\end{array}$ \\
\hline 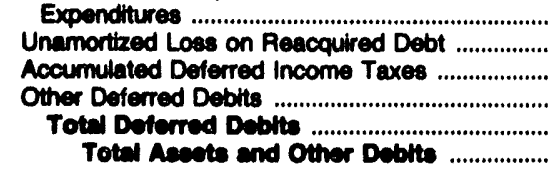 & $\begin{array}{r}0 \\
0 \\
10,191 \\
9,239 \\
19,435 \\
95,210\end{array}$ & $\begin{array}{r}0 \\
0 \\
0 \\
40 \\
40 \\
26,240\end{array}$ & $\begin{array}{r}0 \\
0 \\
6,800 \\
20,425 \\
33,342 \\
484,718\end{array}$ & $\begin{array}{r}0 \\
5,037 \\
4,975 \\
8,735 \\
23,117 \\
803,711\end{array}$ & $\begin{array}{r}0 \\
4 \\
34 \\
85 \\
240 \\
12,860\end{array}$ & $\begin{array}{r}0 \\
0 \\
0 \\
0 \\
0 \\
1,184\end{array}$ \\
\hline
\end{tabular}

See endinotes at end of an individual electric utility. 
Table 38. Balance Sheot by Major U.S. Investor-Owned Electric Utility Within State on Decomber 31, 1992 (Continued) (Thousand Dollars)

\begin{tabular}{|c|c|c|c|c|c|c|}
\hline Item & $\begin{array}{l}\text { Weat Virginia } \\
\text { Wheeling } \\
\text { Power Co }\end{array}$ & $\begin{array}{l}\text { Whaconsin } \\
\text { Consolidated } \\
\text { Water } \\
\text { Power Co }\end{array}$ & $\begin{array}{l}\text { Wieconsin } \\
\text { Madieon } \\
\text { Gas } \\
\text { Electric Co }\end{array}$ & $\begin{array}{l}\text { Wieconsin } \\
\text { Northern } \\
\text { States } \\
\text { Power Co }\end{array}$ & $\begin{array}{l}\text { Wisconsin } \\
\text { Northwestern } \\
\text { Wisconsin } \\
\text { Eleo So }\end{array}$ & $\begin{array}{l}\text { Wieconein } \\
\text { Ploneer } \\
\text { Power } \\
\& \\
\text { Light Co }\end{array}$ \\
\hline $\begin{array}{l}\text { Propriotany Capltal } \\
\text { Common Siock leeved .............................................. } \\
\text { Profered Stock leaved ......................................... } \\
\text { Ceapltal Stock Subecritbed, }\end{array}$ & $\begin{array}{r}2,428 \\
0\end{array}$ & $\begin{array}{r}1,000 \\
0\end{array}$ & $\begin{array}{r}85,678 \\
5,700\end{array}$ & $\begin{array}{r}86,200 \\
0\end{array}$ & $\begin{array}{r}4,030 \\
0\end{array}$ & $\begin{array}{r}20 \\
0\end{array}$ \\
\hline 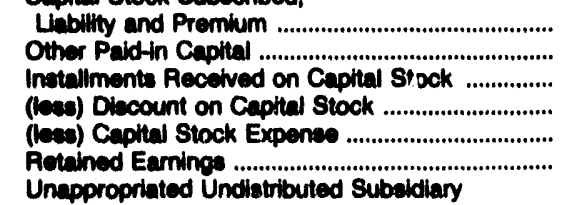 & $\begin{array}{r}0 \\
12,586 \\
0 \\
0 \\
0 \\
5,692\end{array}$ & $\begin{array}{r}0 \\
0 \\
0 \\
0 \\
0 \\
13,478\end{array}$ & $\begin{array}{r}26,409 \\
0 \\
0 \\
0 \\
0 \\
69,731\end{array}$ & $\begin{array}{r}10,461 \\
0 \\
0 \\
0 \\
0 \\
182,375\end{array}$ & $\begin{array}{r}0 \\
0 \\
0 \\
0 \\
0 \\
821\end{array}$ & $\begin{array}{r}0 \\
0 \\
0 \\
0 \\
0 \\
1,253\end{array}$ \\
\hline 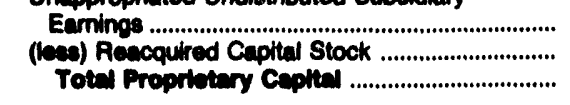 & $\begin{array}{r}0 \\
0 \\
20,016\end{array}$ & $\begin{array}{r}1,836 \\
0 \\
16,314\end{array}$ & $\begin{array}{r}-1,351 \\
0 \\
166,007\end{array}$ & $\begin{array}{r}441 \\
0 \\
200,477\end{array}$ & $\begin{array}{r}0 \\
0 \\
5,001\end{array}$ & $\begin{array}{r}0 \\
392 \\
081\end{array}$ \\
\hline 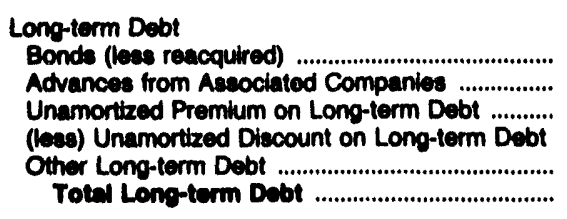 & $\begin{array}{r}0 \\
0 \\
0 \\
0 \\
28,000 \\
20,000\end{array}$ & $\begin{array}{l}0 \\
0 \\
0 \\
0 \\
0 \\
0\end{array}$ & $\begin{array}{r}149,350 \\
0 \\
10 \\
1,072 \\
0 \\
149,200\end{array}$ & $\begin{array}{r}178,708 \\
0 \\
37 \\
0 \\
18,600 \\
197,345\end{array}$ & $\begin{array}{r}4,790 \\
0 \\
0 \\
0 \\
0 \\
4,7 \% 0\end{array}$ & $\begin{array}{r}0 \\
0 \\
0 \\
0 \\
160 \\
160\end{array}$ \\
\hline 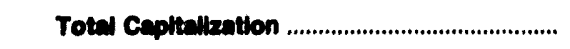 & 40,016 & 16,314 & 334,368 & 406,822 & 9,791 & 1,041 \\
\hline $\begin{array}{l}\text { Other Noncurrent Liabillties } \\
\text { Obllgations Under Capital Lease-Noncurrent ...... } \\
\text { Accumulated Provision for Property Insurance ... } \\
\text { Accumulated Provision for Injuries and }\end{array}$ & $\begin{array}{r}215 \\
0\end{array}$ & $\begin{array}{l}0 \\
0\end{array}$ & $\begin{array}{l}0 \\
0\end{array}$ & $\begin{array}{r}742 \\
0\end{array}$ & $\begin{array}{l}0 \\
0\end{array}$ & 0 \\
\hline 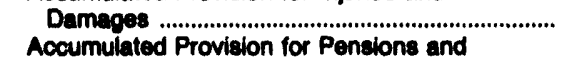 & 546 & 0 & 0 & 0 & 0 & \\
\hline 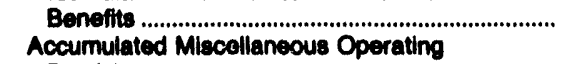 & 0 & 0 & 0 & 0 & 88 & \\
\hline 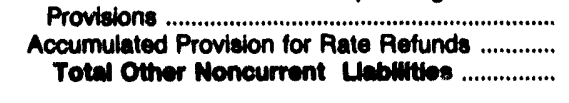 & $\begin{array}{r}0 \\
0 \\
761\end{array}$ & $\begin{array}{l}0 \\
0 \\
0\end{array}$ & $\begin{array}{l}0 \\
0 \\
0\end{array}$ & $\begin{array}{r}0 \\
0 \\
742\end{array}$ & $\begin{array}{r}0 \\
0 \\
8\end{array}$ & \\
\hline 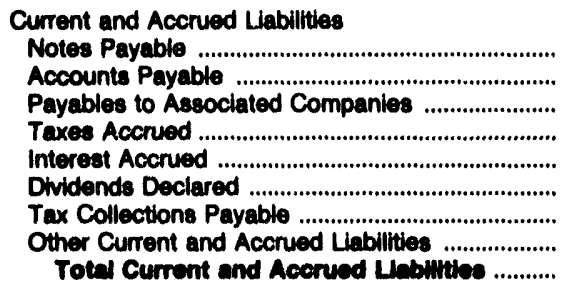 & $\begin{array}{r}6,350 \\
479 \\
28,686 \\
2,496 \\
368 \\
0 \\
69 \\
1,173 \\
39,692\end{array}$ & $\begin{array}{r}0 \\
0 \\
6,849 \\
-2 \\
0 \\
0 \\
130 \\
158 \\
7,135\end{array}$ & $\begin{array}{r}17,000 \\
13,639 \\
0 \\
3,347 \\
2,890 \\
0 \\
429 \\
10,311 \\
47,616\end{array}$ & $\begin{array}{r}0 \\
15,254 \\
41,577 \\
6,860 \\
5,934 \\
0 \\
1,280 \\
972 \\
71,877\end{array}$ & $\begin{array}{r}1,736 \\
507 \\
0 \\
36 \\
119 \\
0 \\
22 \\
210 \\
2,620\end{array}$ & $\begin{array}{r}23 \\
81 \\
0 \\
-14 \\
1 \\
0 \\
0 \\
9 \\
100\end{array}$ \\
\hline 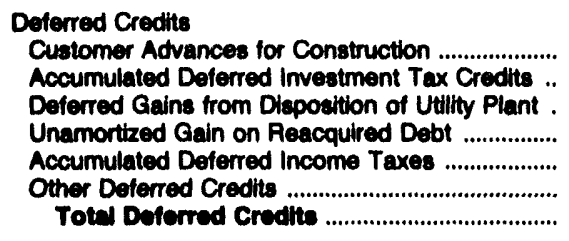 & $\begin{array}{r}0 \\
812 \\
0 \\
0 \\
5,956 \\
1,181 \\
7,940\end{array}$ & $\begin{array}{r}0 \\
786 \\
0 \\
0 \\
0,005 \\
0 \\
2,701\end{array}$ & $\begin{array}{r}2,853 \\
14,854 \\
0 \\
0 \\
0 \\
81,864 \\
3,078 \\
102,740\end{array}$ & $\begin{array}{r}5,088 \\
24,886 \\
0 \\
0 \\
0 \\
77,429 \\
26,869 \\
134,270\end{array}$ & $\begin{array}{r}6 \\
345 \\
0 \\
0 \\
0 \\
0 \\
351\end{array}$ & $\begin{array}{r}0 \\
36 \\
0 \\
0 \\
7 \\
0 \\
43\end{array}$ \\
\hline Totel Lablitties and Other Credits ................. & 95,210 & 28,240 & 404,718 & 693,711 & 12,960 & 1,184 \\
\hline
\end{tabular}

Note: Totals may not equal sum of components beceuse of independent rounding. Summary data are provided in Table 8 . Source: Federal Energy Regulatory Commision, FERC Form 1, "Annisal Report of Major Electric Utilties, Licensees and Others." 
Table 38. Balance Sheot by Major U.S. Inveotor-Owned Electric Utility Within State on December 31, 1992 (Continued) (Thousand Dollars)

\begin{tabular}{|c|c|c|c|c|c|c|}
\hline Item & $\begin{array}{c}\text { Wleconsin } \\
\text { South } \\
\text { Belolt } \\
\text { Water } \\
\text { Gasselec Co }\end{array}$ & $\begin{array}{c}\text { Weconain } \\
\text { Superior } \\
\text { Water } \\
\text { Light\&Power } \\
\text { Co }\end{array}$ & $\begin{array}{l}\text { Wleconsin } \\
\text { Wleconsin } \\
\text { Electric } \\
\text { Power Co }\end{array}$ & $\begin{array}{l}\text { Wisconsin } \\
\text { Wisconsin } \\
\text { Power } \\
\text { Light Co }\end{array}$ & $\begin{array}{l}\text { Wisconsin } \\
\text { Wisconsin } \\
\text { Public } \\
\text { Service Corp }\end{array}$ & $\begin{array}{l}\text { Wisconsin } \\
\text { Wieconsin } \\
\text { Rlver } \\
\text { Power Co }\end{array}$ \\
\hline 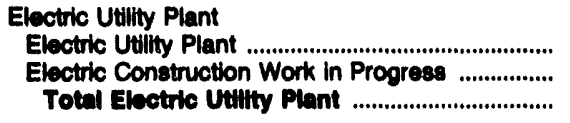 & $\begin{array}{r}8,502 \\
0 \\
0,602\end{array}$ & $\begin{array}{r}27,289 \\
0 \\
27,290\end{array}$ & $\begin{array}{r}3,821,480 \\
180,413 \\
4,001,603\end{array}$ & $\begin{array}{r}1,434,842 \\
54,316 \\
1,460,150\end{array}$ & $\begin{array}{r}1,241,044 \\
25,970 \\
1,2287,013\end{array}$ & $\begin{array}{r}24,658 \\
102 \\
24,700\end{array}$ \\
\hline $\begin{array}{l}\text { (lese) Electric Utility Accumulated Proviaion for } \\
\text { Depreclation, Amortzzation, and Depletion ....... } \\
\text { Not Electirle Utilty Piant } \\
\text { (leas nuclear fuel) ........................................ }\end{array}$ & $\begin{array}{l}3,127 \\
6,376\end{array}$ & $\begin{array}{l}12,041 \\
16,220\end{array}$ & $\begin{array}{l}1,653,080 \\
2,349,812\end{array}$ & $\begin{array}{l}607,229 \\
031,020\end{array}$ & $\begin{array}{l}619,496 \\
647,518\end{array}$ & $\begin{array}{l}12,937 \\
11,028\end{array}$ \\
\hline 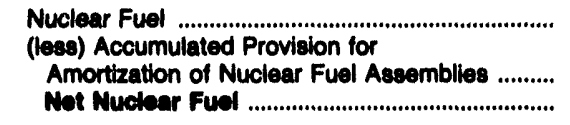 & $\begin{array}{l}0 \\
0\end{array}$ & $\begin{array}{l}0 \\
0 \\
0\end{array}$ & $\begin{array}{r}108,586 \\
54,786 \\
68,800\end{array}$ & $\begin{array}{r}140,652 \\
123,729 \\
18,028\end{array}$ & $\begin{array}{r}141,274 \\
124,394 \\
18,010\end{array}$ & $\begin{array}{l}0 \\
0\end{array}$ \\
\hline 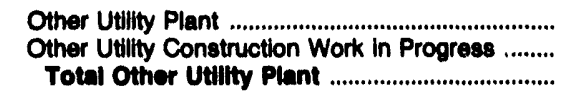 & $\begin{array}{r}8,598 \\
0 \\
0,500\end{array}$ & $\begin{array}{r}26,745 \\
0 \\
28,746\end{array}$ & $\begin{array}{r}33,177 \\
1,039 \\
34,216\end{array}$ & $\begin{array}{r}284,650 \\
4,657 \\
200,307\end{array}$ & $\begin{array}{r}259,683 \\
895 \\
240,678\end{array}$ & $\begin{array}{l}0 \\
0 \\
0\end{array}$ \\
\hline 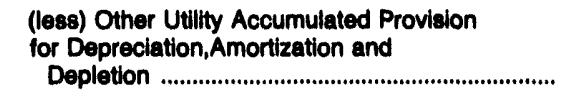 & 2,892 & 9,263 & 16,174 & 106,739 & 128,932 & 0 \\
\hline Net Other Utility Piant ,............................................... & 5,708 & 17,492 & 19,041 & 192,698 & 131,646 & $\mathbf{0}$ \\
\hline 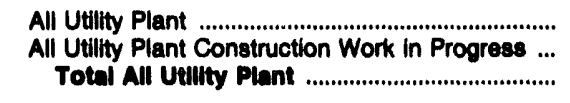 & $\begin{array}{r}17,100 \\
0 \\
17,100\end{array}$ & $\begin{array}{r}54,014 \\
0 \\
64,014\end{array}$ & $\begin{array}{r}3,963,252 \\
181,451 \\
4,144,704\end{array}$ & $\begin{array}{r}1,860,144 \\
58,974 \\
1,910,117\end{array}$ & $\begin{array}{r}1,642,001 \\
26,864 \\
1,688,898\end{array}$ & $\begin{array}{r}24,658 \\
102 \\
24,700\end{array}$ \\
\hline 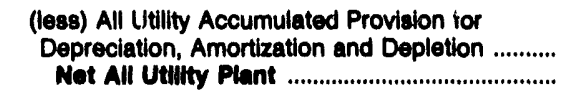 & $\begin{array}{r}6,019 \\
11,051\end{array}$ & $\begin{array}{l}21,304 \\
32,710\end{array}$ & $\begin{array}{l}1,723,050 \\
2,421,054\end{array}$ & $\begin{array}{r}837,687 \\
1,031,420\end{array}$ & $\begin{array}{l}872,822 \\
793,044\end{array}$ & $\begin{array}{l}12,037 \\
11,028\end{array}$ \\
\hline 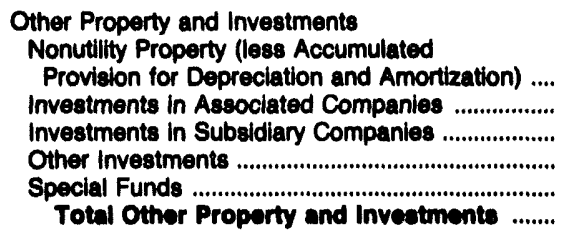 & $\begin{array}{l}4 \\
0 \\
0 \\
0 \\
0 \\
4\end{array}$ & $\begin{array}{r}42 \\
0 \\
0 \\
12 \\
17 \\
71\end{array}$ & $\begin{array}{r}2,843 \\
0 \\
0 \\
118,590 \\
228,621 \\
349,063\end{array}$ & $\begin{array}{r}462 \\
5,314 \\
4,036 \\
8,013 \\
40,628 \\
68,463\end{array}$ & $\begin{array}{r}2,133 \\
0 \\
6,872 \\
7,563 \\
51,023 \\
67,602\end{array}$ & $\begin{array}{r}3,687 \\
213 \\
125 \\
56 \\
0 \\
4,090\end{array}$ \\
\hline 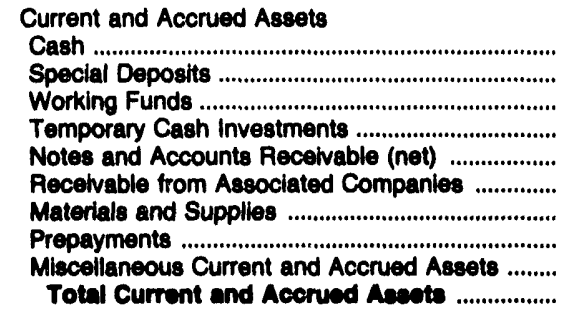 & $\begin{array}{r}0 \\
0 \\
0 \\
0 \\
1,718 \\
0 \\
-2 \\
0 \\
689 \\
2,416\end{array}$ & $\begin{array}{r}132 \\
0 \\
8 \\
1,000 \\
3,136 \\
1 \\
523 \\
865 \\
2,160 \\
7,025\end{array}$ & $\begin{array}{r}26,829 \\
2,548 \\
200 \\
25,000 \\
73,449 \\
58 \\
142,498 \\
47,117 \\
88,046 \\
416,730\end{array}$ & $\begin{array}{r}0 \\
16 \\
384 \\
0 \\
-3,757 \\
14,225 \\
40,661 \\
21,294 \\
37,209 \\
110,013\end{array}$ & $\begin{array}{r}0 \\
87 \\
91 \\
0 \\
62,573 \\
0 \\
31,629 \\
19,929 \\
46,021 \\
160,381\end{array}$ & $\begin{array}{r}16 \\
0 \\
0 \\
425 \\
111 \\
850 \\
68 \\
33 \\
0 \\
1,501\end{array}$ \\
\hline 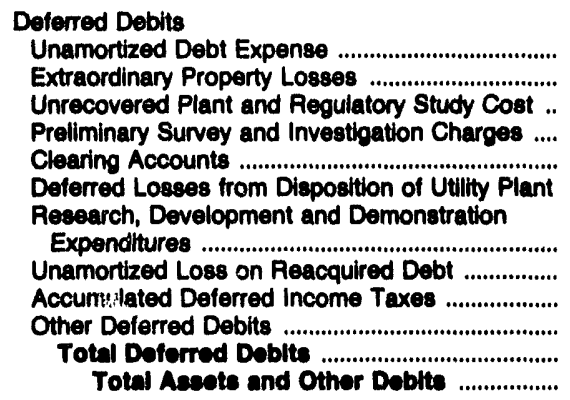 & $\begin{array}{r}0 \\
0 \\
0 \\
298 \\
290 \\
13,700\end{array}$ & $\begin{array}{r}11 \\
0 \\
0 \\
627 \\
41 \\
41,497\end{array}$ & $\begin{array}{r}1,504 \\
0 \\
0 \\
0 \\
1,435 \\
0 \\
0 \\
0 \\
22,764 \\
61,785 \\
13,300 \\
100,700 \\
3,286,245\end{array}$ & $\begin{array}{r}0 \\
0 \\
8,522 \\
182,161 \\
208,180 \\
1,486,046\end{array}$ & $\begin{array}{r}0 \\
4,053 \\
25,905 \\
115,434 \\
147,498 \\
1,171,456\end{array}$ & $\begin{array}{r}0 \\
0 \\
0 \\
243 \\
243 \\
17,047\end{array}$ \\
\hline
\end{tabular}

See endnotes at end of an indlvidual electric utility. 
Table 38. Balance Sheot by Major U.S. Investor-Owned Electric Utility Within State on December 31, 1992 (Continued)

(Thousand Dollars)

\begin{tabular}{|c|c|c|c|c|c|c|}
\hline Item & $\begin{array}{l}\text { Wisconsin } \\
\text { South } \\
\text { Boloit } \\
\text { Water } \\
\text { Gas\&Elec co }\end{array}$ & $\begin{array}{c}\text { Wisconsin } \\
\text { Superior } \\
\text { Water } \\
\text { LightaPower } \\
\text { Co }\end{array}$ & $\begin{array}{l}\text { Weconain } \\
\text { Weconsin } \\
\text { Electric } \\
\text { Power Co }\end{array}$ & $\begin{array}{l}\text { Wisconsin } \\
\text { Wisconsin } \\
\text { Power } \\
2 \\
\text { Light Co }\end{array}$ & $\begin{array}{l}\text { Wisconsin } \\
\text { Wisconsin } \\
\text { Public } \\
\text { Service Corp }\end{array}$ & $\begin{array}{l}\text { Wisconsin } \\
\text { Wisconsin } \\
\text { Rlver } \\
\text { Power Co }\end{array}$ \\
\hline $\begin{array}{l}\text { Proprietary Capital } \\
\text { Common Stock lasued .............................................. } \\
\text { Proferred Stock lesued .......................................... } \\
\text { Ceppltul Stock Subecribed, }\end{array}$ & $\begin{array}{r}2,440 \\
0\end{array}$ & $\begin{array}{r}5,200 \\
0\end{array}$ & $\begin{array}{r}332,893 \\
88,351\end{array}$ & $\begin{array}{l}68,183 \\
59,863\end{array}$ & $\begin{array}{l}95,385 \\
51,200\end{array}$ & $\begin{array}{r}9,360 \\
0\end{array}$ \\
\hline 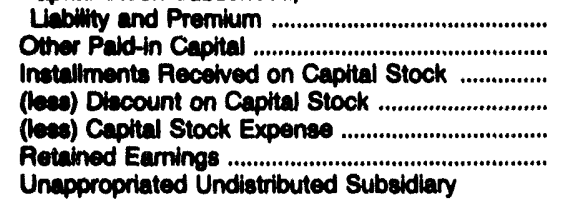 & $\begin{array}{r}0 \\
0 \\
0 \\
0 \\
0 \\
1,441\end{array}$ & $\begin{array}{r}0 \\
600 \\
0 \\
0 \\
0 \\
10,043\end{array}$ & $\begin{array}{r}92,074 \\
50,453 \\
0 \\
0 \\
0 \\
818,678\end{array}$ & $\begin{array}{r}111,051 \\
17,070 \\
0 \\
0 \\
0 \\
261,869\end{array}$ & $\begin{array}{r}73,227 \\
128 \\
0 \\
0 \\
1,035 \\
248,528\end{array}$ & $\begin{array}{r}0 \\
0 \\
0 \\
0 \\
0 \\
6,346\end{array}$ \\
\hline 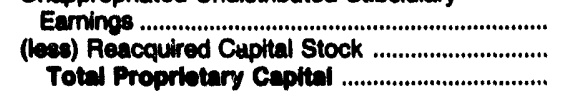 & $\begin{array}{r}0 \\
0 \\
3,881\end{array}$ & $\begin{array}{r}0 \\
0 \\
16,849\end{array}$ & $\begin{array}{r}0 \\
0 \\
1,392,480\end{array}$ & $\begin{array}{r}364 \\
0 \\
518,500\end{array}$ & $\begin{array}{r}-3,006 \\
0 \\
484,428\end{array}$ & $\begin{array}{r}0 \\
0 \\
15,709\end{array}$ \\
\hline Long-term Debt & & & & & & \\
\hline 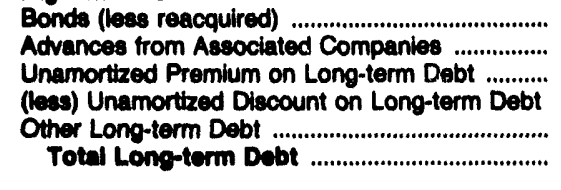 & $\begin{array}{l}0 \\
0 \\
0 \\
0 \\
0 \\
0\end{array}$ & $\begin{array}{r}6,350 \\
0 \\
0 \\
0 \\
7,350 \\
12,700\end{array}$ & $\begin{array}{r}1,056,076 \\
0 \\
52 \\
18,780 \\
67,000 \\
1,104,330\end{array}$ & $\begin{array}{r}337,899 \\
0 \\
0 \\
1,483 \\
0 \\
389,416\end{array}$ & $\begin{array}{r}304,286 \\
0 \\
0 \\
1,037 \\
26,996 \\
330,224\end{array}$ & $\begin{array}{l}0 \\
0 \\
0 \\
0 \\
0 \\
0\end{array}$ \\
\hline Totel Capitallantion ............................................. & 3,801 & 20,543 & $2,496,798$ & 852,917 & 784,850 & 15,708 \\
\hline $\begin{array}{l}\text { Other Noncurrent Liabilities } \\
\text { Obligations Under Capital Lease-Noncurrent ...... } \\
\text { Accumulated Provision for Property Insurance ... } \\
\text { Accumulated Provision for Injuries and }\end{array}$ & $\begin{array}{l}0 \\
0\end{array}$ & 0 & $\begin{array}{r}22,971 \\
0\end{array}$ & $\begin{array}{l}0 \\
0\end{array}$ & $\begin{array}{l}0 \\
0\end{array}$ & $\begin{array}{l}0 \\
0\end{array}$ \\
\hline Accumulated Provision for Pensions and & 0 & 0 & 1,381 & 0 & 0 & 0 \\
\hline Accumulated Miscellaneous Operating & 0 & 0 & 4,885 & 15 & 0 & 0 \\
\hline 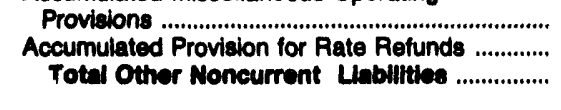 & $\begin{array}{l}0 \\
0 \\
0\end{array}$ & $\begin{array}{l}0 \\
0 \\
0\end{array}$ & $\begin{array}{r}0 \\
0 \\
29,287\end{array}$ & $\begin{array}{r}9 \\
0 \\
24\end{array}$ & $\begin{array}{l}0 \\
0 \\
0\end{array}$ & $\begin{array}{l}0 \\
0 \\
0\end{array}$ \\
\hline 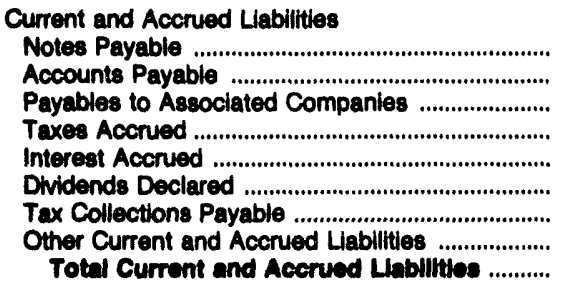 & $\begin{array}{r}0 \\
22 \\
8,991 \\
-120 \\
2 \\
0 \\
23 \\
34 \\
8,052\end{array}$ & $\begin{array}{r}0 \\
1,317 \\
2,012 \\
1 \\
204 \\
0 \\
188 \\
1,050 \\
4,772\end{array}$ & $\begin{array}{r}73,724 \\
66,469 \\
69 \\
11,659 \\
17,023 \\
67 \\
3,472 \\
50,397 \\
222,081\end{array}$ & $\begin{array}{r}51,000 \\
70,810 \\
-52 \\
1,461 \\
7,664 \\
0 \\
1,825 \\
67,822 \\
200,531\end{array}$ & $\begin{array}{r}20,000 \\
51,990 \\
0 \\
1,234 \\
7,204 \\
0 \\
3,310 \\
10,207 \\
98,945\end{array}$ & $\begin{array}{r}0 \\
21 \\
210 \\
1,232 \\
0 \\
0 \\
3 \\
369 \\
1,835\end{array}$ \\
\hline Deferred Credits & & & & & & \\
\hline 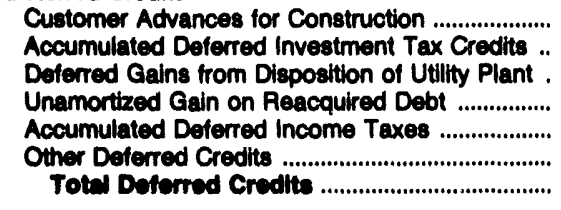 & $\begin{array}{r}459 \\
337 \\
0 \\
0 \\
168 \\
1 \\
985\end{array}$ & $\begin{array}{r}1,486 \\
1,170 \\
0 \\
0 \\
3,768 \\
748 \\
7,172\end{array}$ & $\begin{array}{r}14,005 \\
96,233 \\
0 \\
0 \\
415,522 \\
11,579 \\
587,339\end{array}$ & $\begin{array}{r}18,914 \\
44,314 \\
0 \\
0 \\
214,150 \\
125,185 \\
402,574\end{array}$ & $\begin{array}{r}14,489 \\
36,071 \\
0 \\
0 \\
194,916 \\
37,384 \\
282,860\end{array}$ & $\begin{array}{r}0 \\
48 \\
0 \\
0 \\
58 \\
0 \\
106\end{array}$ \\
\hline Total Labilluee end Other Credite ................ & 13,798 & 41,497 & $3,286,245$ & $1,456,045$ & $1,171,455$ & 17,647 \\
\hline
\end{tabular}

Note: Totals may not equal sum of components because of independent rounding. Summary data are provided in Table 8 .

Source: Federal Energy Regulatory Commission, FERC Form 1, "Annual Report of Major Electric Utilities, Licensees and Others." 
Table 39. Statement of Cash Flows by Major U.S. Investor-Owned Electric Utility Within State, 1992

(Thousand Dollars)

\begin{tabular}{|c|c|c|c|c|c|c|}
\hline Item & $\begin{array}{l}\text { Alabama } \\
\text { Alabama } \\
\text { Power Co }\end{array}$ & $\begin{array}{c}\text { Alabama } \\
\text { Southern } \\
\text { Electric } \\
\text { Generato Co }\end{array}$ & $\begin{array}{l}\text { Arizona } \\
\text { Arizona } \\
\text { Public } \\
\text { Service Co }\end{array}$ & $\begin{array}{l}\text { Arizona } \\
\text { Century } \\
\text { Power Corp }\end{array}$ & $\begin{array}{l}\text { Arizona } \\
\text { Tucson } \\
\text { Electric } \\
\text { Power Co }\end{array}$ & $\begin{array}{c}\text { Arkansas } \\
\text { Arkansas } \\
\text { Power } \\
\& \\
\text { Light Co }\end{array}$ \\
\hline \multicolumn{7}{|l|}{ Net Cash Flow from Operating Acthities: } \\
\hline 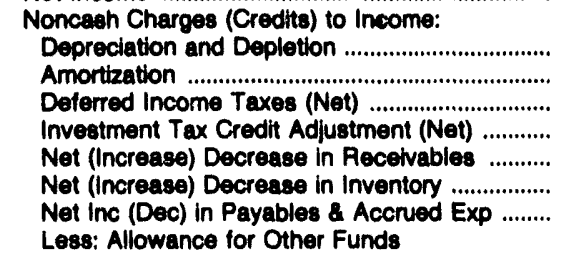 & $\begin{array}{r}304,915 \\
51,471 \\
23,514 \\
-17,865 \\
34,498 \\
12,705 \\
-26,575\end{array}$ & $\begin{array}{r}9,827 \\
-468 \\
-413 \\
0 \\
6,661 \\
0 \\
4,174\end{array}$ & $\begin{array}{r}188,216 \\
67,508 \\
84,097 \\
-6,804 \\
-33,985 \\
5,095 \\
8,325\end{array}$ & $\begin{array}{r}8,5^{\prime} 4 \\
2,216 \\
2,388 \\
-877 \\
440 \\
358 \\
-1,833\end{array}$ & $\begin{array}{r}69,445 \\
-7,948 \\
-5,449 \\
-5,745 \\
-833 \\
2,360 \\
5,618\end{array}$ & $\begin{array}{r}132,459 \\
1,359 \\
7,452 \\
-8,272 \\
-22,281 \\
13,291 \\
-36,925\end{array}$ \\
\hline 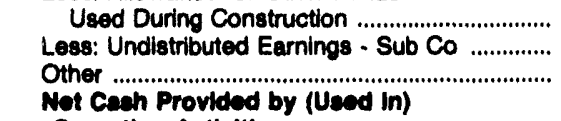 & $\begin{array}{r}2,071 \\
1,462 \\
16,408\end{array}$ & $\begin{array}{r}617 \\
0 \\
-1,080\end{array}$ & $\begin{array}{r}3,103 \\
1,879 \\
-89,037\end{array}$ & $\begin{array}{r}-8 \\
-2 \\
-53,827\end{array}$ & $\begin{array}{r}0 \\
1,241 \\
140,540\end{array}$ & $\begin{array}{r}4,173 \\
2 \\
10,193\end{array}$ \\
\hline 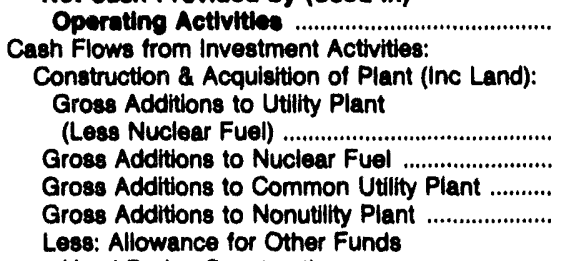 & $\begin{array}{r}-327,110 \\
-40,353 \\
0 \\
-3,668\end{array}$ & $\begin{array}{r}-35,900 \\
0 \\
0 \\
0\end{array}$ & $\begin{array}{r}-176,000 \\
-50,916 \\
0 \\
0\end{array}$ & $\begin{array}{r}-863 \\
0 \\
0 \\
0\end{array}$ & $\begin{array}{r}-34,154 \\
0 \\
0 \\
0\end{array}$ & $\begin{array}{r}-178,675 \\
0 \\
0 \\
0\end{array}$ \\
\hline 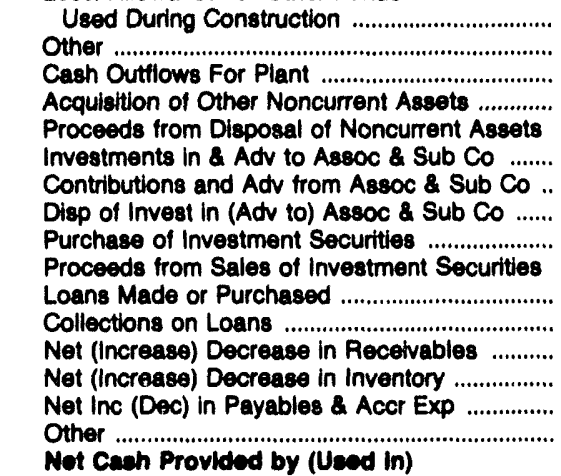 & $\begin{array}{r}-2,071 \\
32,533 \\
-336,525 \\
0 \\
0 \\
0 \\
0 \\
0 \\
0 \\
0 \\
0 \\
0 \\
0 \\
0 \\
-760 \\
0\end{array}$ & $\begin{array}{r}-617 \\
0 \\
-35,291 \\
0 \\
0 \\
0 \\
0 \\
0 \\
0 \\
0 \\
0 \\
0 \\
0 \\
0 \\
-2,064 \\
23,618\end{array}$ & $\begin{array}{r}-3,103 \\
0 \\
-224,702 \\
0 \\
0 \\
-1,481 \\
0 \\
0 \\
0 \\
1,000 \\
0 \\
0 \\
0 \\
0 \\
3,386 \\
-1,739\end{array}$ & $\begin{array}{r}0 \\
0 \\
-863 \\
0 \\
0 \\
0 \\
0 \\
0 \\
0 \\
1,200 \\
0 \\
0 \\
0 \\
0 \\
0 \\
0\end{array}$ & $\begin{array}{r}0 \\
0 \\
-34,154 \\
0 \\
0 \\
0 \\
44,529 \\
0 \\
66,825 \\
0 \\
0 \\
0 \\
0 \\
0 \\
0 \\
0\end{array}$ & $\begin{array}{r}-4,173 \\
68,536 \\
-105,966 \\
0 \\
0 \\
0 \\
0 \\
0 \\
0 \\
0 \\
0 \\
0 \\
0 \\
0 \\
-645 \\
0\end{array}$ \\
\hline $\begin{array}{l}\text { Inveoting Activities ................................... } \\
\text { Cash Flows from Financing Activites: } \\
\text { Proceeds from lesuance of: }\end{array}$ & $-337,285$ & $-13,738$ & $-223,537$ & 337 & $-56,551$ & $-106,611$ \\
\hline 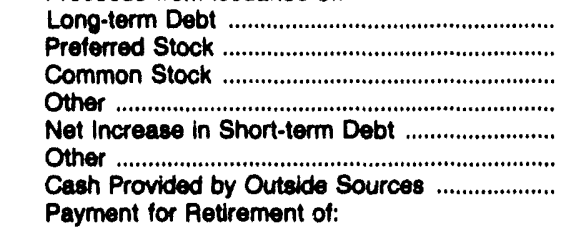 & $\begin{array}{r}793,382 \\
150,000 \\
0 \\
116,338 \\
0 \\
0 \\
1,059,722\end{array}$ & $\begin{array}{r}-1,000 \\
0 \\
0 \\
0 \\
0 \\
0 \\
-1,000\end{array}$ & $\begin{array}{r}243,381 \\
24,781 \\
0 \\
0 \\
195,000 \\
0 \\
863,142\end{array}$ & $\begin{array}{l}0 \\
0 \\
0 \\
0 \\
0 \\
0 \\
0\end{array}$ & $\begin{array}{r}16,732 \\
0 \\
0 \\
-2,394 \\
0 \\
2,181 \\
16,518\end{array}$ & $\begin{array}{r}148,580 \\
14,222 \\
0 \\
0 \\
4,000 \\
3,507 \\
170,309\end{array}$ \\
\hline 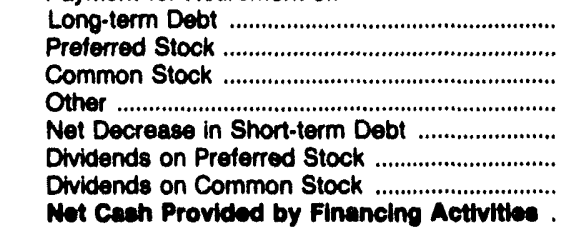 & $\begin{array}{r}986,019 \\
145,000 \\
0 \\
49,119 \\
0 \\
35,704 \\
273,300 \\
-429,421\end{array}$ & $\begin{array}{r}681 \\
0 \\
0 \\
0 \\
0 \\
0 \\
12,002 \\
-13,663\end{array}$ & $\begin{array}{r}1,013,372 \\
27,850 \\
0 \\
0 \\
0 \\
32,574 \\
170,000 \\
-380,654\end{array}$ & $\begin{array}{l}0 \\
0 \\
0 \\
0 \\
0 \\
0 \\
0 \\
0\end{array}$ & $\begin{array}{r}31,855 \\
64 \\
0 \\
-89 \\
0 \\
0 \\
0 \\
-15,312\end{array}$ & $\begin{array}{r}330,244 \\
34,388 \\
0 \\
32 \\
0 \\
23,730 \\
75,000 \\
-293,086\end{array}$ \\
\hline $\begin{array}{l}\text { Net Increase (Decrease) in Cash and } \\
\text { Cash Equivalents ......................................... } \\
\text { Cach and Cach Equivalents at }\end{array}$ & 2,469 & -45 & $-137,033$ & $-13,882$ & -645 & $-176,068$ \\
\hline $\begin{array}{l}\text { Besinning of Year ................................... } \\
\text { Cash and Cach Equhalents at End of Year .. }\end{array}$ & $\begin{array}{l}11,160 \\
13,629\end{array}$ & $\begin{array}{l}167 \\
112\end{array}$ & $\begin{array}{r}130,085 \\
1,162\end{array}$ & $\begin{array}{l}27,416 \\
13,634\end{array}$ & $\begin{array}{l}2,009 \\
1,465\end{array}$ & $\begin{array}{r}176,088 \\
0\end{array}$ \\
\hline
\end{tabular}

Note: Totals may not equal sum of components because of independent rounding. Summary data are provided in Table 10.

Source: Federal Energy Regulatory Commission, FERC Form 1, "Annual Report of Major Electric Utilties, Licensees and Others." 
Table 39. Statement of Cash Flows by Major U.S. Investor-Owned Electric Utility Within State, 1992 (Continued) (Thousand Dollars)

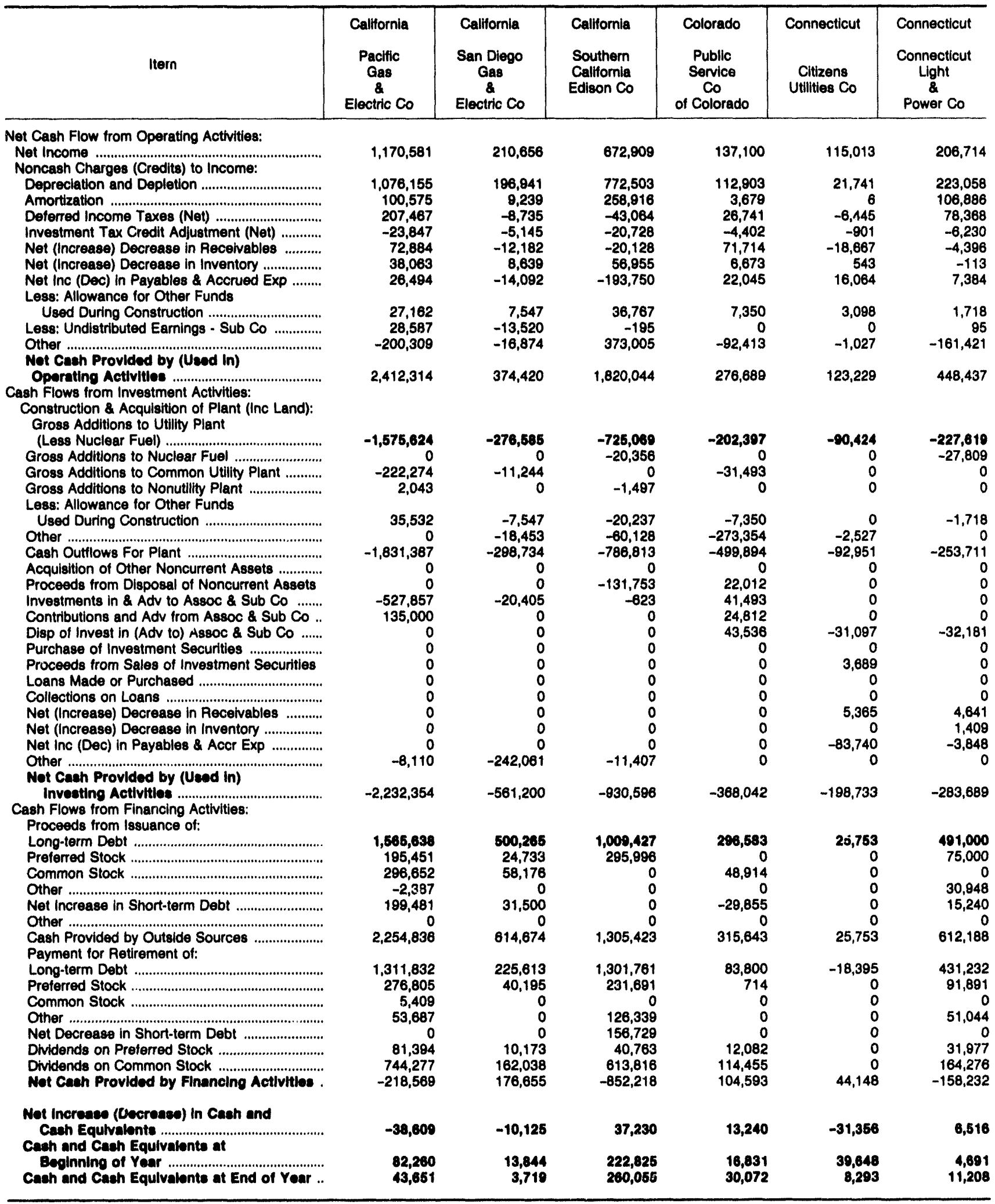

Note: Totals may not equal sum of components because of independent rounding. Summary data are provided in Table 10.

Source: Federal Energy Regulatory Commission, FERC Form 1, "Annual Report of Major Electric Utilities, Licensees and Others." 
Table 39. Statement of Cash Flows by Major U.S. Investor-Owned Electric Utility Within State, 1992 (Continued)

(Thousand Dollars)

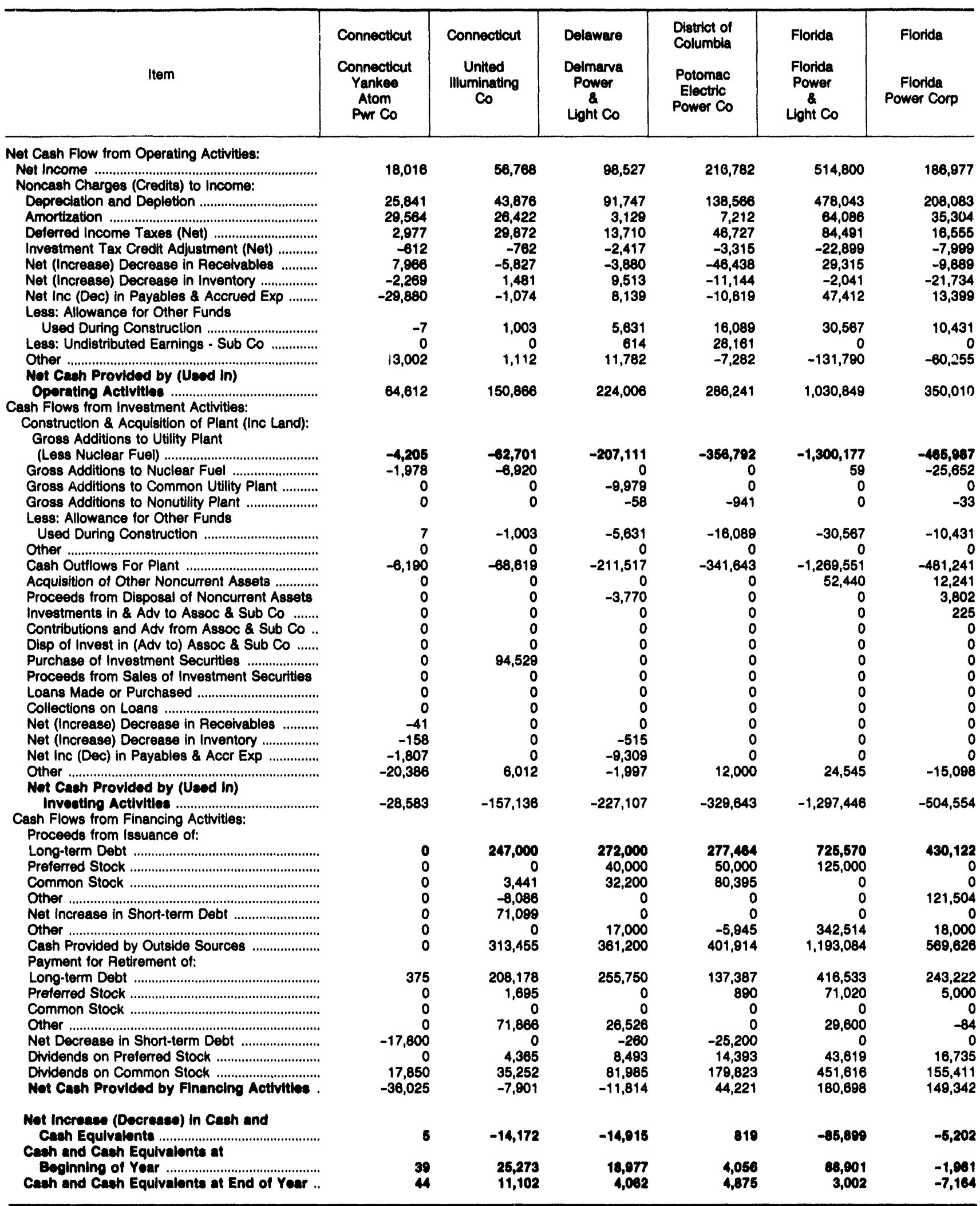

Note: Totals may not equal sum of components because of independent rounding. Summary data are provided in Table 10.

Source: Federal Energy Regulatory Commission, FERC Form 1, "Annual Report of Major Electric Utillies, Licensees and Others." 
Table 39. Statement of Cash Flows by Major U.S. Investor-Owned Electric Utility Within State, 1992 (Continued) (Thousand Dollars)

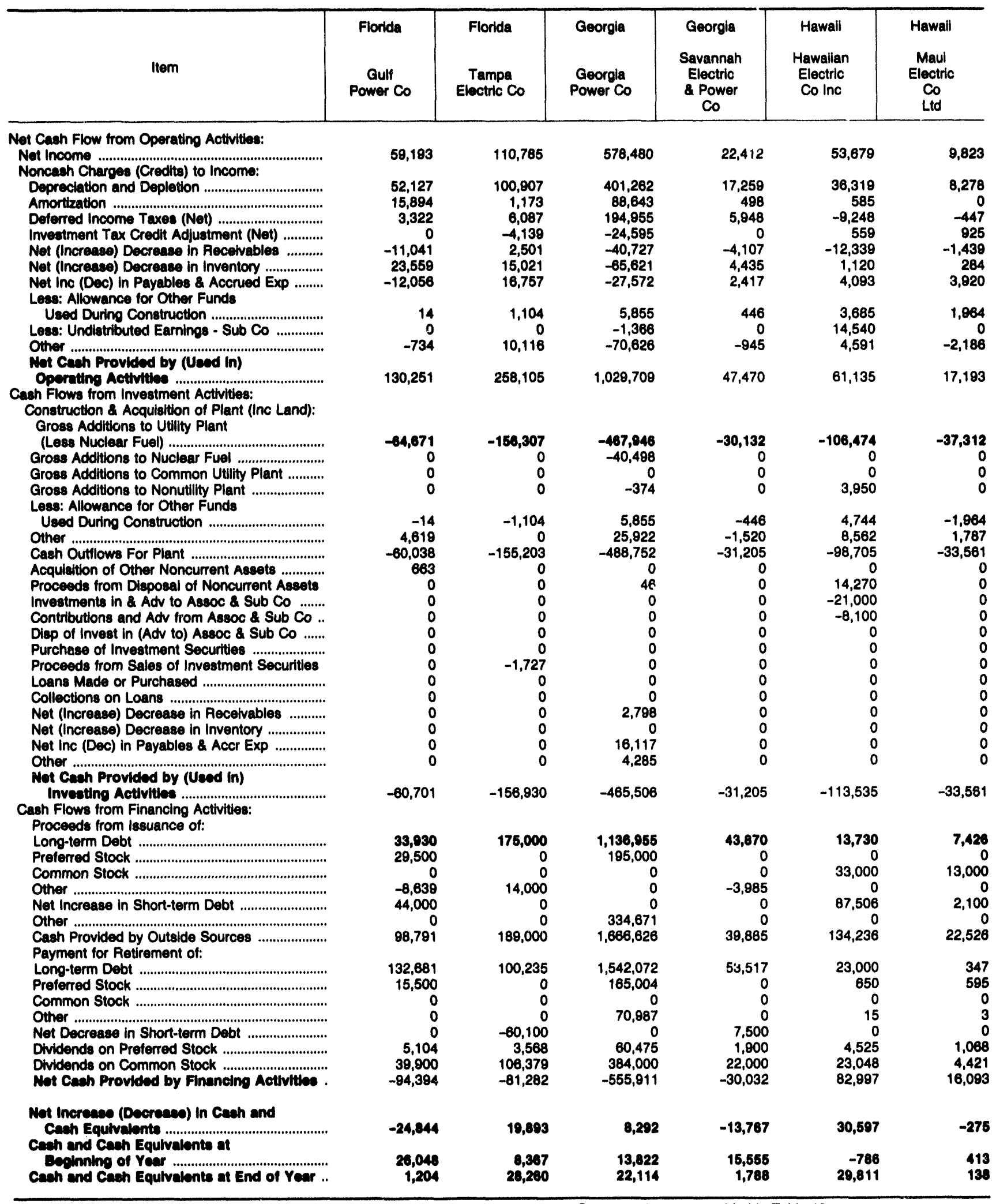

Note: Totale may not equal sum of components because of independent rounding. Summary data are provided in Table 10.

Source: Federal Energy Regulatory Commission, FEAC Form 1, "Annual Report of Major Electric Utilities, Licensees and Others." 
Table 39. Statement of Cash Flows by Major U.S. Investor-Owned Electrlc Utility Within State, 1992 (Continued)

(Thousand Dollars)

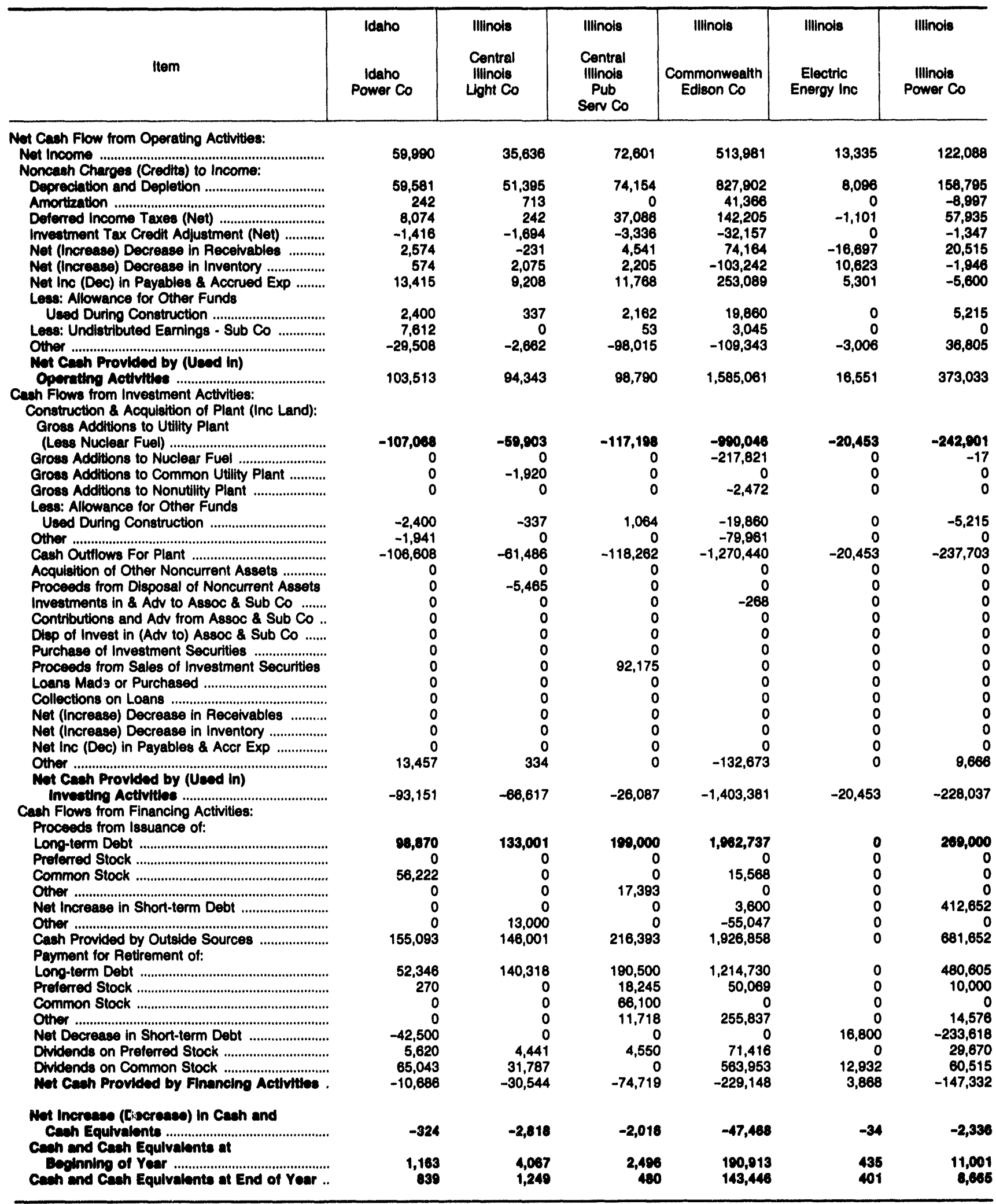

Note: Totals may not equal sum of components because of independent rounding. Summary data are provided in Table 10.

Source: Federal Energy Regulatory Commission, FERC Form 1, "Annual Report of Major Electric Utilities, Licensees and Others." 
Table 39. Statement of Cash Flows by Major U.S. Investor-Owned Electric Utility Within State, 1992 (Continued)

(Thousand Dollars)

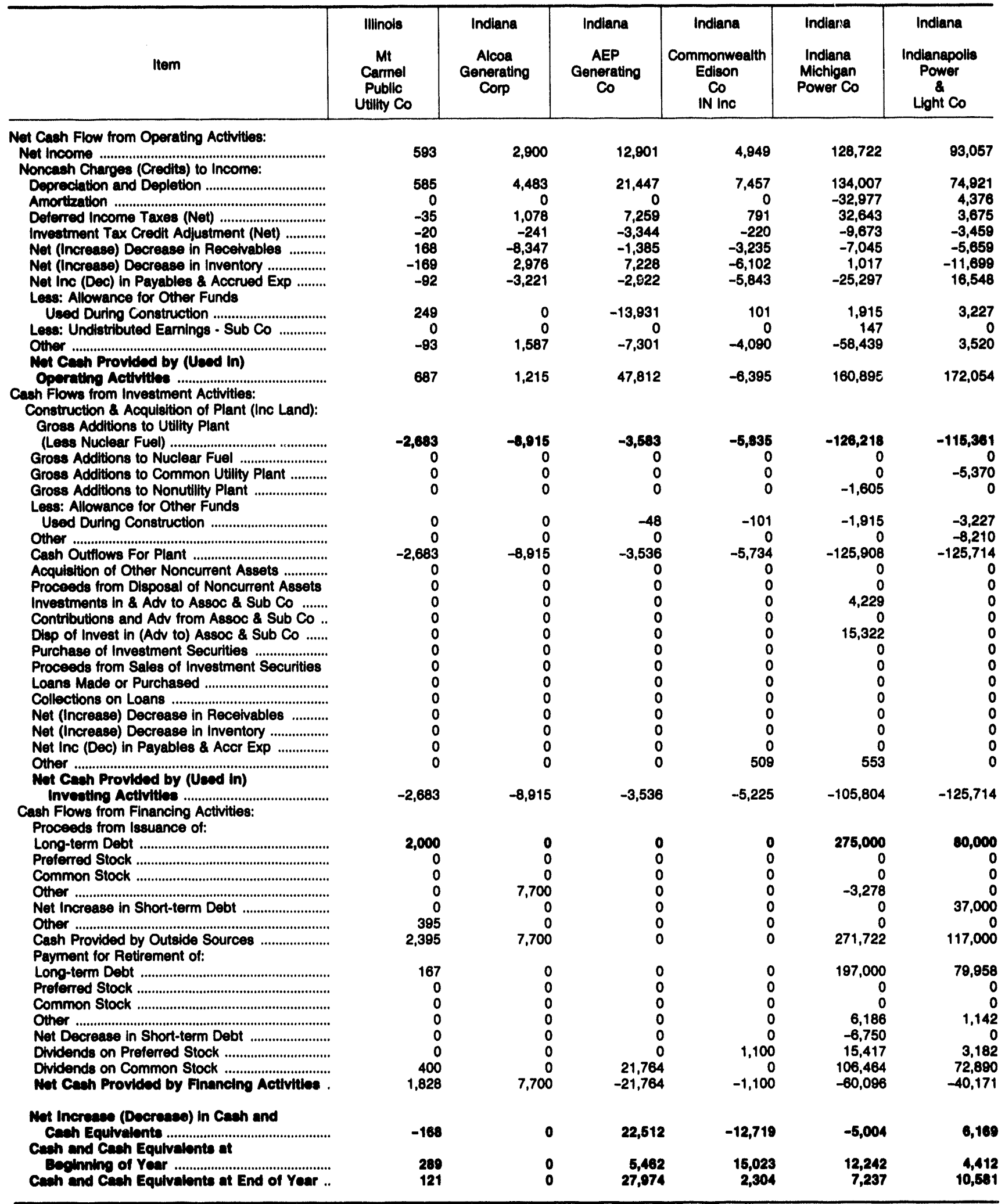

Note: Totals may not equal sum of components because of independent rounding. Summary data are provided in Table 10. Source: Federal Energy Regulatory Commission, FERC Form 1. "Annual Report of Major Electric Utilities, Licensees and Others." 
Table 39. Statement of Cash Flows by Major U.S. Investor-Owned Electric Utility Within State, 1992 (Continued) (Thousand Dollars)

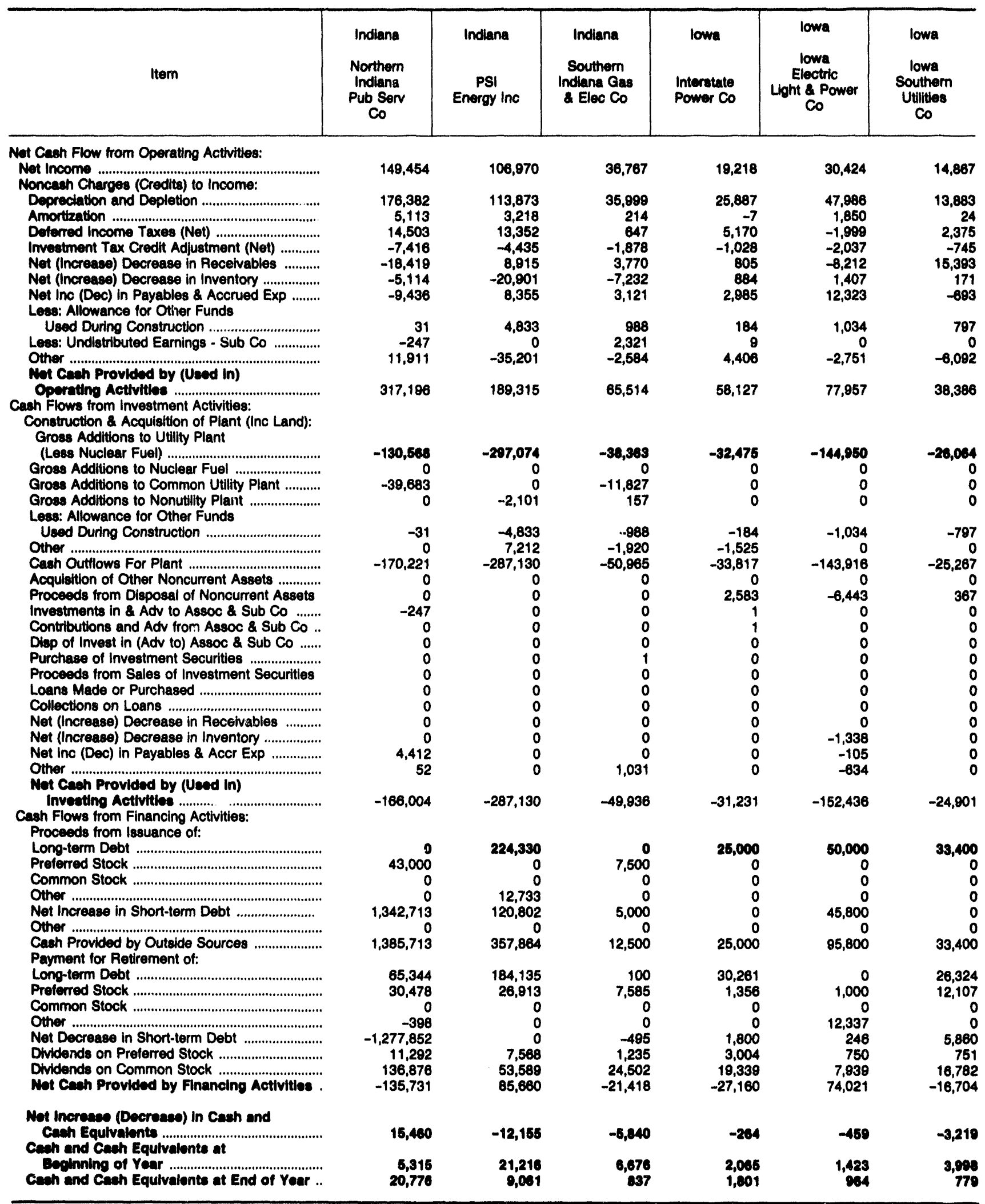

Note: Totals may not equal sum of components because of independent rounding. Summary data are provided in Table 10.

Source: Federal Energy Regulatory Commission, FERC Form 1, "Annual Report of Major Electric Utilties, Licensees and Others." 
Table 39. Statement of Cash Flows by Major U.S. Investor-Owned Electric Utility Within State, 1992 (Continued) (Thousand Dollars)

\begin{tabular}{|c|c|c|c|c|c|c|}
\hline Item & $\begin{array}{c}\text { lowe } \\
\text { lowa- } \\
\text { llinols } \\
\text { GasdElectric } \\
\text { Co }\end{array}$ & $\begin{array}{l}\text { Lowa } \\
\text { Midweest } \\
\text { Power } \\
\text { Systems } \\
\text { Inc }\end{array}$ & $\begin{array}{c}\text { Kansas } \\
\text { Kansas } \\
\text { Gas } \\
8 \\
\text { Electric: Co }\end{array}$ & $\begin{array}{l}\text { Kansas } \\
\text { Western } \\
\text { Resources } \\
\text { Inc }\end{array}$ & $\begin{array}{l}\text { Kentucky } \\
\text { Kentucky } \\
\text { Power Co }\end{array}$ & $\begin{array}{l}\text { Kentucky } \\
\text { Kentucky } \\
\text { Utilities Co }\end{array}$ \\
\hline \multirow{4}{*}{ 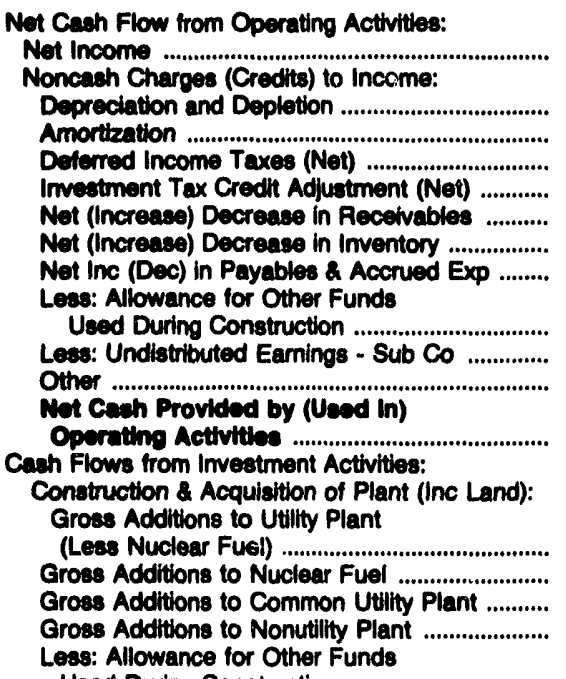 } & 45,433 & 50,650 & 77,882 & 127,884 & 26,537 & 76,298 \\
\hline & $\begin{array}{r}53,423 \\
12,892 \\
2,082 \\
-2,326 \\
-2,824 \\
-350 \\
-9,529\end{array}$ & $\begin{array}{r}83,868 \\
5,566 \\
6,408 \\
-3,817 \\
8,640 \\
-6,248 \\
-6,018\end{array}$ & $\begin{array}{r}68,378 \\
3,450 \\
8,706 \\
-2,232 \\
6,264 \\
-2,462 \\
5,438\end{array}$ & $\begin{array}{r}83,215 \\
5,252 \\
20,255 \\
-3,463 \\
-1,713 \\
4,274 \\
94,914 \\
\end{array}$ & $\begin{array}{r}21,667 \\
572 \\
-3,140 \\
-1,331 \\
556 \\
8,857 \\
-735\end{array}$ & $\begin{array}{r}58,816 \\
34 \\
3,974 \\
-4,150 \\
7,338 \\
-502 \\
-4,744\end{array}$ \\
\hline & $\begin{array}{r}0 \\
0,476 \\
-6,241\end{array}$ & $\begin{array}{r}804 \\
0 \\
23,958\end{array}$ & $\begin{array}{r}0 \\
0 \\
-69,724\end{array}$ & $\begin{array}{r}0 \\
73,818 \\
-2,215\end{array}$ & $\begin{array}{r}130 \\
0 \\
879\end{array}$ & $\begin{array}{r}169 \\
53 \\
-1,041\end{array}$ \\
\hline & $\begin{array}{r}-66,947 \\
-9,313 \\
-7,438 \\
-1,140\end{array}$ & $\begin{array}{r}-101,079 \\
0 \\
0 \\
0\end{array}$ & $\begin{array}{r}-19,072 \\
-16,563 \\
0 \\
0\end{array}$ & $\begin{array}{r}-149,354 \\
0 \\
0 \\
0\end{array}$ & $\begin{array}{r}-31,814 \\
0 \\
0 \\
0\end{array}$ & $\begin{array}{r}-86,246 \\
0 \\
0 \\
0\end{array}$ \\
\hline 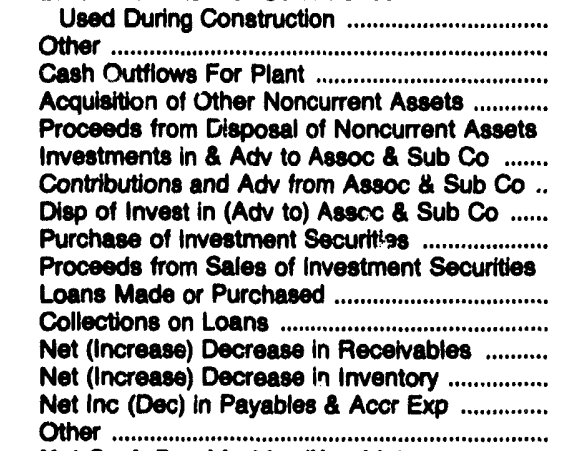 & $\begin{array}{r}0 \\
0 \\
-74,837 \\
2,543 \\
-8,344 \\
-5,000 \\
0 \\
0 \\
0 \\
0 \\
0 \\
0 \\
0 \\
0 \\
0 \\
-14\end{array}$ & $\begin{array}{r}-804 \\
-6,778 \\
-107,053 \\
0 \\
0 \\
-125 \\
0 \\
0 \\
112 \\
2,205 \\
0 \\
0 \\
0 \\
0 \\
0 \\
-10,028\end{array}$ & $\begin{array}{r}0 \\
0 \\
-64,635 \\
0 \\
0 \\
0 \\
0 \\
0 \\
0 \\
0 \\
0 \\
0 \\
0 \\
0 \\
0 \\
-471,954\end{array}$ & $\begin{array}{r}0 \\
0 \\
-149,354 \\
0 \\
0 \\
-1,060,010 \\
0 \\
0 \\
0 \\
0 \\
0 \\
0 \\
-35,563 \\
0 \\
0 \\
0\end{array}$ & $\begin{array}{r}-130 \\
0 \\
-31,684 \\
-1,567 \\
0 \\
0 \\
0 \\
0 \\
0 \\
0 \\
0 \\
0 \\
0 \\
0 \\
0 \\
0\end{array}$ & $\begin{array}{r}-169 \\
0 \\
-86,077 \\
0 \\
801 \\
0 \\
0 \\
0 \\
0 \\
0 \\
0 \\
0 \\
0 \\
0 \\
0 \\
0\end{array}$ \\
\hline 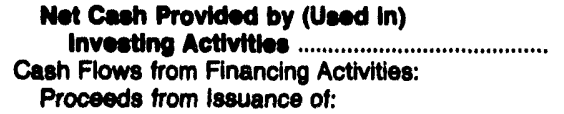 & $-80,739$ & $-115,112$ & $-536,589$ & $-1,244,926$ & $-30,116$ & $-65,277$ \\
\hline 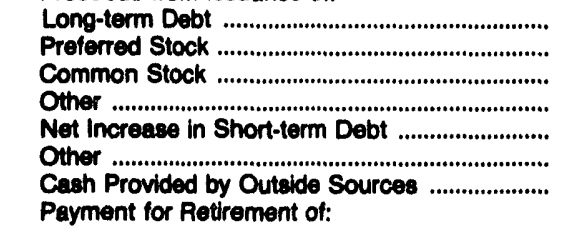 & $\begin{array}{r}60,000 \\
0 \\
61,563 \\
-2,700 \\
0 \\
0 \\
0 \\
118,863\end{array}$ & $\begin{array}{r}0 \\
0 \\
0 \\
0 \\
0 \\
58,100 \\
58,100\end{array}$ & $\begin{array}{r}180,762 \\
0 \\
453,670 \\
3,680 \\
-6.434 \\
-18,589 \\
622,099\end{array}$ & $\begin{array}{r}580,000 \\
50,000 \\
589,919 \\
0 \\
0 \\
0 \\
1,219,919\end{array}$ & $\begin{array}{r}35,000 \\
0 \\
0 \\
0 \\
0 \\
-473 \\
34,527\end{array}$ & $\begin{array}{r}219,930 \\
0 \\
0 \\
0 \\
0 \\
528 \\
220,458\end{array}$ \\
\hline 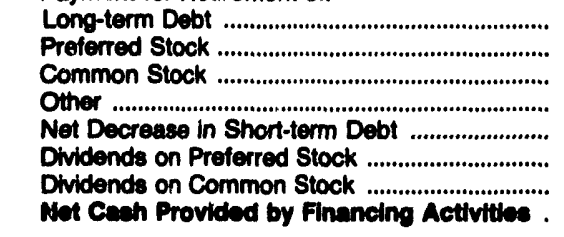 & $\begin{array}{r}60,232 \\
575 \\
0 \\
0 \\
2,394 \\
0 \\
5,037 \\
48,592 \\
2,032\end{array}$ & $\begin{array}{r}1,278 \\
30,036 \\
0 \\
0 \\
0 \\
3,706 \\
73,944 \\
-50,864\end{array}$ & $\begin{array}{r}169,074 \\
0 \\
0 \\
0 \\
0 \\
205 \\
13,330 \\
439,489\end{array}$ & $\begin{array}{r}111,966 \\
2,600 \\
0 \\
0 \\
-7,075 \\
12,751 \\
99,134 \\
886,383\end{array}$ & $\begin{array}{r}35,000 \\
0 \\
0 \\
0 \\
-1,600 \\
0 \\
21,350 \\
-23,424\end{array}$ & $\begin{array}{r}190,756 \\
0 \\
0 \\
0 \\
0 \\
2,518 \\
108,996 \\
-81,812\end{array}$ \\
\hline $\begin{array}{l}\text { Mot Increase (Decrease) in Cach and } \\
\text { Caen Equivalente..................................... } \\
\text { Ceech and Cach Equivalonts af }\end{array}$ & $-5,723$ & $-3,771$ & $-1,290$ & $-3,940$ & 181 & $-31,280$ \\
\hline 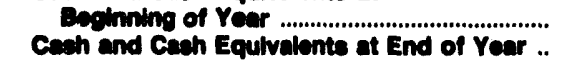 & $\begin{array}{l}16,601 \\
11,078\end{array}$ & $\begin{array}{l}7,084 \\
4,213\end{array}$ & $\begin{array}{r}2,101 \\
892\end{array}$ & $\begin{array}{l}5,477 \\
1,528\end{array}$ & $\begin{array}{r}880 \\
1,070\end{array}$ & $\begin{array}{r}125,506 \\
94,200\end{array}$ \\
\hline
\end{tabular}

Note: Totals may not equal sum of components because of independent rounding. Summary data are provided in Table 10.

Source: Federal Energy Regulatory Commiseion, FERC Form 1, "Annual Report of Major Electric Utillities, Licensees and Others." 
Table 39. Statement of Cash Flows by Major U.S. Investor-Owned Electric Utility Within State, 1992 (Continued)

(Thousand Dollars)

\begin{tabular}{|c|c|c|c|c|c|c|}
\hline Item & $\begin{array}{c}\text { Kentucky } \\
\text { Louieville } \\
\text { Gass } \\
\& \\
\text { Electric Co }\end{array}$ & $\begin{array}{l}\text { Kentucky } \\
\text { Union Light } \\
\text { Heat \& Power } \\
\text { Co }\end{array}$ & $\begin{array}{l}\text { Louleiana } \\
\text { Contral } \\
\text { Loulaiana } \\
\text { Elec } \\
\text { Co inc }\end{array}$ & $\begin{array}{l}\text { Loulaiana } \\
\text { Louisiana } \\
\text { Power } \\
\text { Lught Co }\end{array}$ & $\begin{array}{l}\text { Louisiana } \\
\text { Now Orleans } \\
\text { Public } \\
\text { Service Inc }\end{array}$ & $\begin{array}{l}\text { Louisiana } \\
\text { Southwestern } \\
\text { Electric } \\
\text { Power Co }\end{array}$ \\
\hline \multirow{10}{*}{ 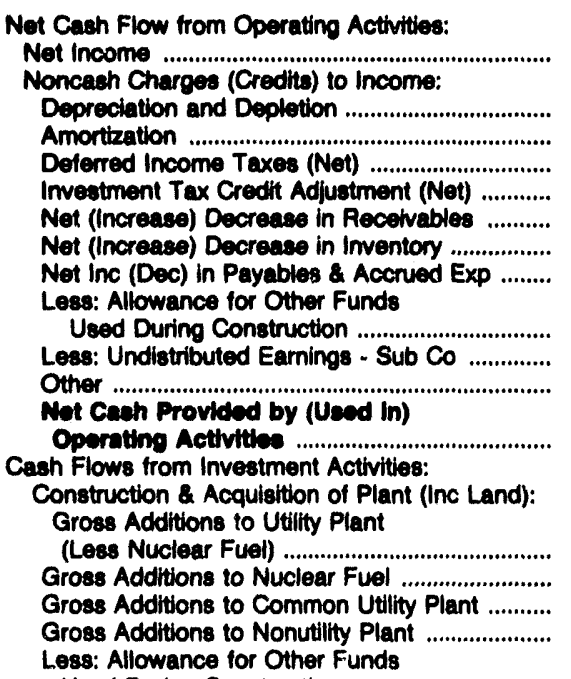 } & 73,783 & 1,102 & 46,158 & 182,989 & 26,424 & 04,883 \\
\hline & $\begin{array}{r}75,203 \\
4,484 \\
28,911 \\
-5,033 \\
-7,494 \\
-8,014 \\
13,883\end{array}$ & $\begin{array}{r}8,316 \\
57 \\
1,815 \\
-289 \\
-6,174 \\
-1,845 \\
3,890\end{array}$ & $\begin{array}{r}35,017 \\
1,282 \\
10,826 \\
-1,830 \\
-4,076 \\
-409 \\
283\end{array}$ & $\begin{array}{r}138,290 \\
32,862 \\
51,889 \\
-8,894 \\
-5,133 \\
-111 \\
16,652\end{array}$ & $\begin{array}{r}16,619 \\
0 \\
-340 \\
-524 \\
1,570 \\
-816 \\
-1,669\end{array}$ & $\begin{array}{r}80,784 \\
341 \\
10,257 \\
-6,864 \\
-9,981 \\
11,288 \\
3,250\end{array}$ \\
\hline & 0 & -46 & 734 & 1,714 & 119 & 133 \\
\hline & 0 & 0 & & & 0 & \\
\hline & $-16,115$ & -31 & $-6,014$ & $-83,410$ & $-18,748$ & $-15,022$ \\
\hline & 159,619 & 6,887 & 80,602 & 313,421 & 22,387 & 168,803 \\
\hline & $-81,158$ & $-23,530$ & $-64,426$ & $-160,527$ & $-21,043$ & \\
\hline & & & & & & $-96,609$ \\
\hline & $-20,019$ & $-1,023$ & 0 & 0 & 0 & \\
\hline & & & 0 & 0 & 0 & \\
\hline Used During Construction ................................... & 0 & 46 & -734 & $-1,714$ & -119 & \\
\hline 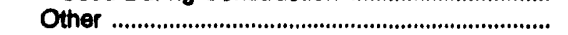 & 0 & 489 & & & 0 & 133 \\
\hline Cash Outtlows For Plant ........................................... & $-101,175$ & $-24,119$ & $-63,682$ & $-148,813$ & $-20,924$ & $-96,676$ \\
\hline Acquisition of Other Noncurrent Assets ............. & & & & & & \\
\hline Procesds from Disposal of Noncurrent Assets & 13 & 1,351 & 673 & 0 & 0 & $-2,339$ \\
\hline investments in \& Adv to Assoc \& Sub Co ....... & $\begin{array}{l}0 \\
0 \\
0\end{array}$ & $\begin{array}{l}0 \\
0\end{array}$ & $\begin{array}{l}0 \\
0\end{array}$ & 0 & 0 & \\
\hline $\begin{array}{l}\text { Contributions and Adv from Assoc \& Sub Co .. } \\
\text { Disp of imvest in (Adv to) Assoc \& Sub Co ...... }\end{array}$ & $\begin{array}{l}0 \\
0\end{array}$ & $\begin{array}{l}0 \\
0\end{array}$ & $\begin{array}{l}0 \\
0\end{array}$ & $\begin{array}{l}0 \\
0\end{array}$ & 0 & \\
\hline 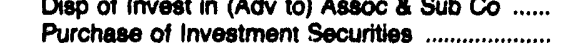 & 10,441 & $\begin{array}{l}0 \\
0\end{array}$ & 10,774 & 0 & $\begin{array}{l}0 \\
0\end{array}$ & \\
\hline of investment Securties & 0 & 0 & 8,808 & 0 & 0 & \\
\hline 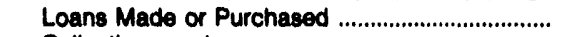 & 0 & 0 & 0 & 0 & 0 & \\
\hline Collections on & 0 & 0 & & 0 & 0 & \\
\hline Net (Increase) Decrease in Recelvables ........... & 0 & 0 & $-2,755$ & 0 & 0 & \\
\hline Net (increase) Decrease in inventory ................. & 0 & 0 & 0 & 0 & 0 & \\
\hline Net inc (Dec) in Payables \& Accr Exp ................. & 0 & 0 & 0 & 0 & 0 & \\
\hline Not Cach Provided by (Uead in) & & 0 & 0 & 0 & 0 & \\
\hline $\begin{array}{l}\text { Inveeting Acttvittios ..................................... } \\
\text { Cash Flows from Financing Acthuties: }\end{array}$ & $-111,604$ & $-22,768$ & $-86,741$ & $-148,813$ & $-20,824$ & $-89,016$ \\
\hline Proceeds from lssuance of: & & & & & & \\
\hline 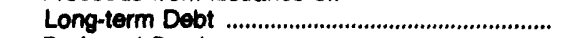 & 80,461 & 10,611 & 75,000 & 313,004 & $\mathbf{0}$ & 221,067 \\
\hline $\begin{array}{l}\text { Preferred Stock } \\
\text { Common Stock }\end{array}$ & 49,099 & & & 87,000 & 0 & \\
\hline & & 15,000 & 786 & & 0 & \\
\hline $\begin{array}{l}\text { Other } \\
\text { Net Increase in Short-term Debt }\end{array}$ & $\begin{array}{l}0 \\
0\end{array}$ & $\begin{array}{l}0 \\
0\end{array}$ & $\begin{array}{r}0 \\
38,808\end{array}$ & & $\begin{array}{l}0 \\
0\end{array}$ & $\begin{array}{r}-53,500 \\
28,150\end{array}$ \\
\hline 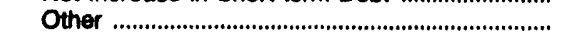 & 0 & 0 & & & 0 & \\
\hline Cash Provided by Outside Sources ..................... & 137,561 & 34,611 & 114,601 & 400,094 & 0 & 185,717 \\
\hline Long-term Debt ................................................... & 82,400 & & 136,489 & 305,182 & 28,000 & 179,863 \\
\hline 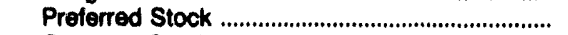 & 51,443 & 0 & 5,800 & 62,379 & 1,500 & 1,190 \\
\hline Common Stock & & & & & & \\
\hline & & & 81 & 39,390 & & \\
\hline 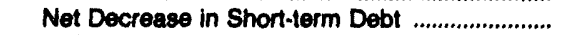 & $-4,000$ & $-18,500$ & & & 0 & \\
\hline Dividends on Preferred Stock ...................................... & 8,017 & & 2,539 & 28,845 & & 3,443 \\
\hline Dividends on common Stock ................................. & 66,500 & & 30,526 & 174,600 & 32,154 & 90,000 \\
\hline Not Cach Provlded by Financing Activities. & a 700 & 16,111 & & & & \\
\hline Not Increase (Decreace) in Cach and & & & & & & \\
\hline Caen Equivalents & $-36,784$ & 229 & $-46,073$ & $-45,694$ & $-62,238$ & $-9,091$ \\
\hline 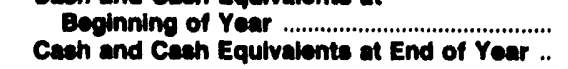 & $\begin{array}{r}37,730 \\
846\end{array}$ & $\begin{array}{l}1,659 \\
1,788\end{array}$ & $\begin{array}{r}47,672 \\
1,790\end{array}$ & $\begin{array}{l}68,475 \\
22,782\end{array}$ & $\begin{array}{r}108,308 \\
46,070\end{array}$ & $\begin{array}{r}10,150 \\
1,068\end{array}$ \\
\hline
\end{tabular}

Note: Totals may not equal sum of components because of independent rounding. Summary date are provided in Table 10.

Source: Federal Energy Regulatory Commiseion, FERC Form 1, "Annual Report of Major Electric Utilities, Licensees and Others." 
Table 39. Statement of Cach Flowe by Major U.S. Inveotor-Owned Electric Utility Within State, 1992 (Continued) (Thousand Dollars)

\begin{tabular}{|c|c|c|c|c|c|c|}
\hline Item & $\begin{array}{l}\text { Maine } \\
\text { Bangor } \\
\text { Hydro- } \\
\text { Electric } \\
\text { Co }\end{array}$ & $\begin{array}{l}\text { Maine } \\
\text { Central } \\
\text { Maine } \\
\text { Power } \\
\text { Co }\end{array}$ & $\begin{array}{l}\text { Maine } \\
\text { Maine } \\
\text { Electric } \\
\text { Power } \\
\text { Co Inc }\end{array}$ & $\begin{array}{l}\text { Maine } \\
\text { Maine } \\
\text { Public } \\
\text { Service } \\
\text { Co }\end{array}$ & $\begin{array}{c}\text { Maine } \\
\text { Maine } \\
\text { Yankee } \\
\text { Atomic } \\
\text { Power Co }\end{array}$ & $\begin{array}{l}\text { Maryland } \\
\text { Baltimore } \\
\text { Gas } \\
8 \\
\text { Electric Co }\end{array}$ \\
\hline $\begin{array}{l}\text { Net Cash Flow from Operating Acthities: } \\
\text { Net Income ................................................................. } \\
\text { Noncash Charges (Credite) to Income: }\end{array}$ & 10,256 & 63,585 & 105 & 4,865 & 9,173 & 264,347 \\
\hline 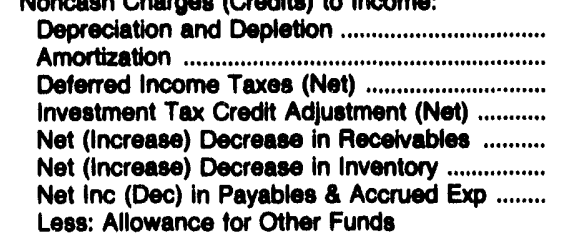 & $\begin{array}{r}4,122 \\
2,667 \\
1,670 \\
673 \\
1,733 \\
317 \\
2,145\end{array}$ & $\begin{array}{r}38,076 \\
21,051 \\
3,485 \\
-1,650 \\
-28,633 \\
1,167 \\
-8,813\end{array}$ & $\begin{array}{r}1,143 \\
107 \\
-284 \\
-40 \\
1,946 \\
0 \\
-2,211\end{array}$ & $\begin{array}{r}2,033 \\
1,355 \\
1,217 \\
-77 \\
-426 \\
210 \\
369\end{array}$ & $\begin{array}{r}23,993 \\
21,264 \\
-4,933 \\
-538 \\
1,215 \\
-190 \\
-5,700\end{array}$ & $\begin{array}{r}253,017 \\
10,165 \\
8,062 \\
-8,744 \\
5,699 \\
-14,597 \\
-8,896\end{array}$ \\
\hline $\begin{array}{l}\text { Used During Construction ............................ } \\
\text { Less: Undistributed Earnings - Sub Co ............ } \\
\text { Other ...................................................................... } \\
\text { Net Cech Provided by (Used in) }\end{array}$ & $\begin{array}{r}1,295 \\
292 \\
3,545\end{array}$ & $\begin{array}{r}1,630 \\
133 \\
-30,204\end{array}$ & $\begin{array}{r}4 \\
0 \\
-193\end{array}$ & $\begin{array}{r}98 \\
0 \\
-2,790\end{array}$ & $\begin{array}{r}57 \\
0 \\
2,340\end{array}$ & $\begin{array}{l}10,028 \\
19,862 \\
82,865\end{array}$ \\
\hline $\begin{array}{l}\text { Cash Flows from Investment Activities: } \\
\text { Construction \& Acquisition of Plant (Inc Land): } \\
\text { Gross Additions to Utility Plant }\end{array}$ & 25,540 & 56,401 & 571 & 6,666 & 46,588 & 561,929 \\
\hline $\begin{array}{l}\text { (Less Nuclear Fuel) } \\
\text { Gross Additions to Nuclear Fuel ......................... } \\
\text { Gross Additions to Common Utilty Plant .......... } \\
\text { Gross Additions to Nonutility Plant ..................... } \\
\text { Less: Allowance for Other Funds }\end{array}$ & $\begin{array}{r}-26,363 \\
0 \\
0 \\
0\end{array}$ & $\begin{array}{r}0 \\
-73,155 \\
-468 \\
0\end{array}$ & $\begin{array}{r}-318 \\
0 \\
0 \\
0\end{array}$ & $\begin{array}{r}-3,837 \\
0 \\
0 \\
0\end{array}$ & $\begin{array}{r}-6,715 \\
-17,815 \\
0 \\
0\end{array}$ & $\begin{array}{r}-349,277 \\
-39,466 \\
-39,557 \\
-582\end{array}$ \\
\hline 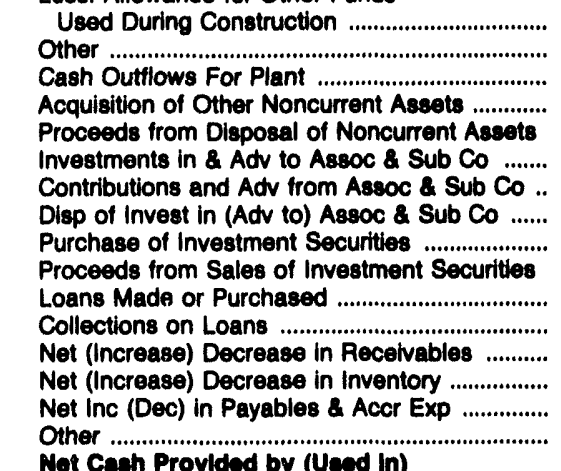 & $\begin{array}{r}-1,295 \\
-1,297 \\
-25,355 \\
0 \\
0 \\
67 \\
0 \\
0 \\
0 \\
0 \\
0 \\
0 \\
0 \\
0 \\
0 \\
0\end{array}$ & $\begin{array}{r}0 \\
1,630 \\
-71,993 \\
0 \\
0 \\
-885 \\
0 \\
0 \\
0 \\
0 \\
0 \\
0 \\
0 \\
0 \\
-1,932 \\
0\end{array}$ & $\begin{array}{r}-4 \\
1 \\
-314 \\
0 \\
0 \\
0 \\
0 \\
0 \\
0 \\
0 \\
0 \\
0 \\
0 \\
0 \\
0 \\
0\end{array}$ & $\begin{array}{r}0 \\
0 \\
-3,837 \\
0 \\
0 \\
0 \\
0 \\
0 \\
0 \\
0 \\
0 \\
0 \\
0 \\
0 \\
0 \\
-15\end{array}$ & $\begin{array}{r}-57 \\
0 \\
-24,474 \\
0 \\
0 \\
0 \\
0 \\
0 \\
0 \\
0 \\
0 \\
4,542 \\
0 \\
0 \\
2,652 \\
-23,138\end{array}$ & $\begin{array}{r}-10,026 \\
-36,500 \\
-455,377 \\
0 \\
0 \\
0 \\
0 \\
0 \\
0 \\
0 \\
0 \\
0 \\
0 \\
0 \\
0 \\
0\end{array}$ \\
\hline $\begin{array}{l}\text { Inveeting Activities ................................... } \\
\text { Cash Flows from Financing Acthities: } \\
\text { Proceeds from Issuance of: }\end{array}$ & $-25,289$ & $-74,810$ & -314 & $-3,852$ & $-40,417$ & $-455,377$ \\
\hline 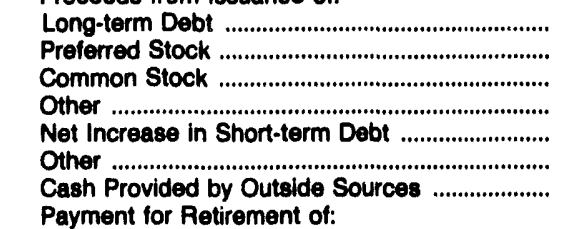 & $\begin{array}{r}40,000 \\
0 \\
914 \\
0 \\
0 \\
0 \\
40,914\end{array}$ & $\begin{array}{r}75,000 \\
75,000 \\
24,180 \\
70,000 \\
5,000 \\
0 \\
249,180\end{array}$ & $\begin{array}{l}0 \\
0 \\
0 \\
0 \\
0 \\
0 \\
0\end{array}$ & $\begin{array}{r}0 \\
0 \\
0 \\
2,217 \\
2,100 \\
0 \\
4,317\end{array}$ & $\begin{array}{r}0 \\
15,000 \\
0 \\
0 \\
2,025 \\
0 \\
17,025\end{array}$ & $\begin{array}{r}445,129 \\
0 \\
356,758 \\
0 \\
0 \\
0 \\
800,881\end{array}$ \\
\hline 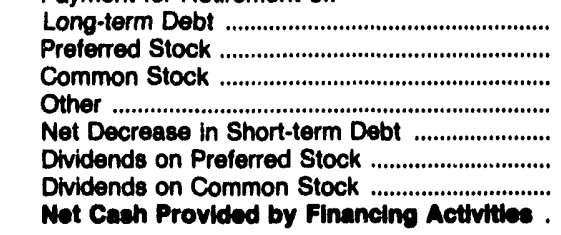 & $\begin{array}{r}19,860 \\
0 \\
0 \\
0 \\
-13,500 \\
1,580 \\
7,108 \\
-1,131\end{array}$ & $\begin{array}{r}135,015 \\
2,750 \\
0 \\
40,712 \\
0 \\
6,115 \\
47,543 \\
17,045\end{array}$ & $\begin{array}{r}860 \\
0 \\
0 \\
0 \\
0 \\
0 \\
105 \\
-985\end{array}$ & $\begin{array}{r}5,290 \\
0 \\
0 \\
0 \\
0 \\
0 \\
2,922 \\
-3,895\end{array}$ & $\begin{array}{r}14,258 \\
600 \\
0 \\
0 \\
0 \\
480 \\
8,375 \\
-6,698\end{array}$ & $\begin{array}{r}336,063 \\
2,924 \\
0 \\
0 \\
-322,600 \\
42,246 \\
186,601 \\
-98,554\end{array}$ \\
\hline $\begin{array}{l}\text { Not Increase (Decreseo) in Cach and } \\
\text { Cash Equlvalents ............................................ } \\
\text { Cach and Cash Equivalente of }\end{array}$ & - & $-1,304$ & -700 & $-1,081$ & -547 & 6,000 \\
\hline $\begin{array}{l}\text { Beginning of Year .............................. } \\
\text { Cash and Cash Equivalente at End of Year .. }\end{array}$ & $\begin{array}{l}2,398 \\
1,498\end{array}$ & $\begin{array}{r}2,018 \\
684\end{array}$ & $\begin{array}{l}864 \\
186\end{array}$ & $\begin{array}{r}1,617 \\
686\end{array}$ & $\begin{array}{l}-350 \\
-997\end{array}$ & $\begin{array}{r}7,194 \\
14,192\end{array}$ \\
\hline
\end{tabular}

Note: Totals may not equal sum of components because of independent rounding. Summary data are provided in Table 10.

Source: Federal Energy Regulatory Commission, FERC Form 1. "Annual Report of Major Electric Utilities, Licensees and Others." 
Table 39. Statement of Cach Flows by Major U.S. Invector-Owned Electric Utility Within State, 1992 (Continuod)

(Thousand Dollars)

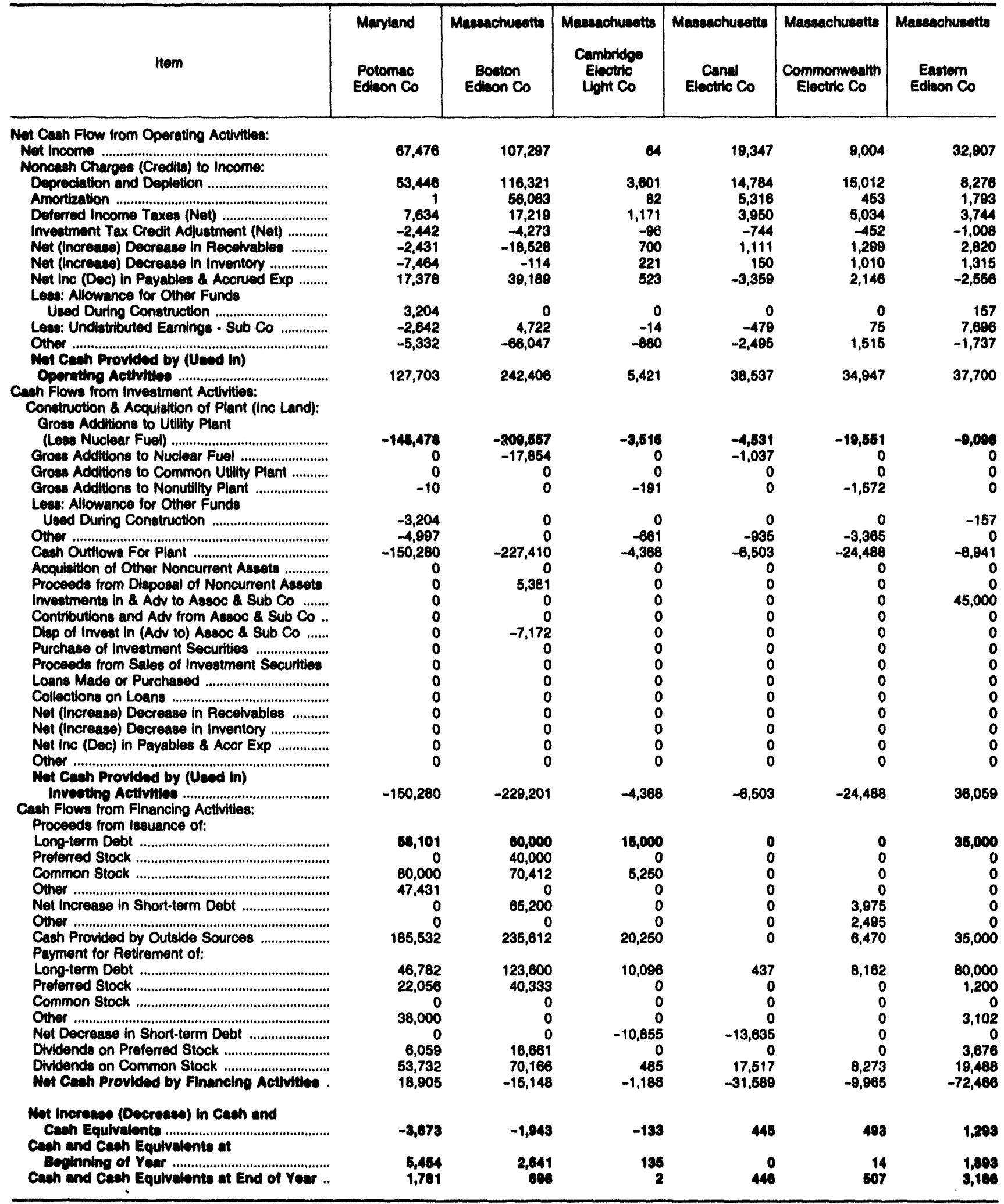

Note: Totals may not equal sum of components because of independent rounding. Summary data are provided in Table 10.

Source: Federal Energy Regulatory Commiseion, FERC Form 1, "Annual Report of Malor Electric Utilities, Licensees and Others." 
Table 39. Statement of Cach Flowe by Major U.S. Inveator-Owned Electrlc Utility Within state, 1902 (Continued)

(Thousand Dollars)

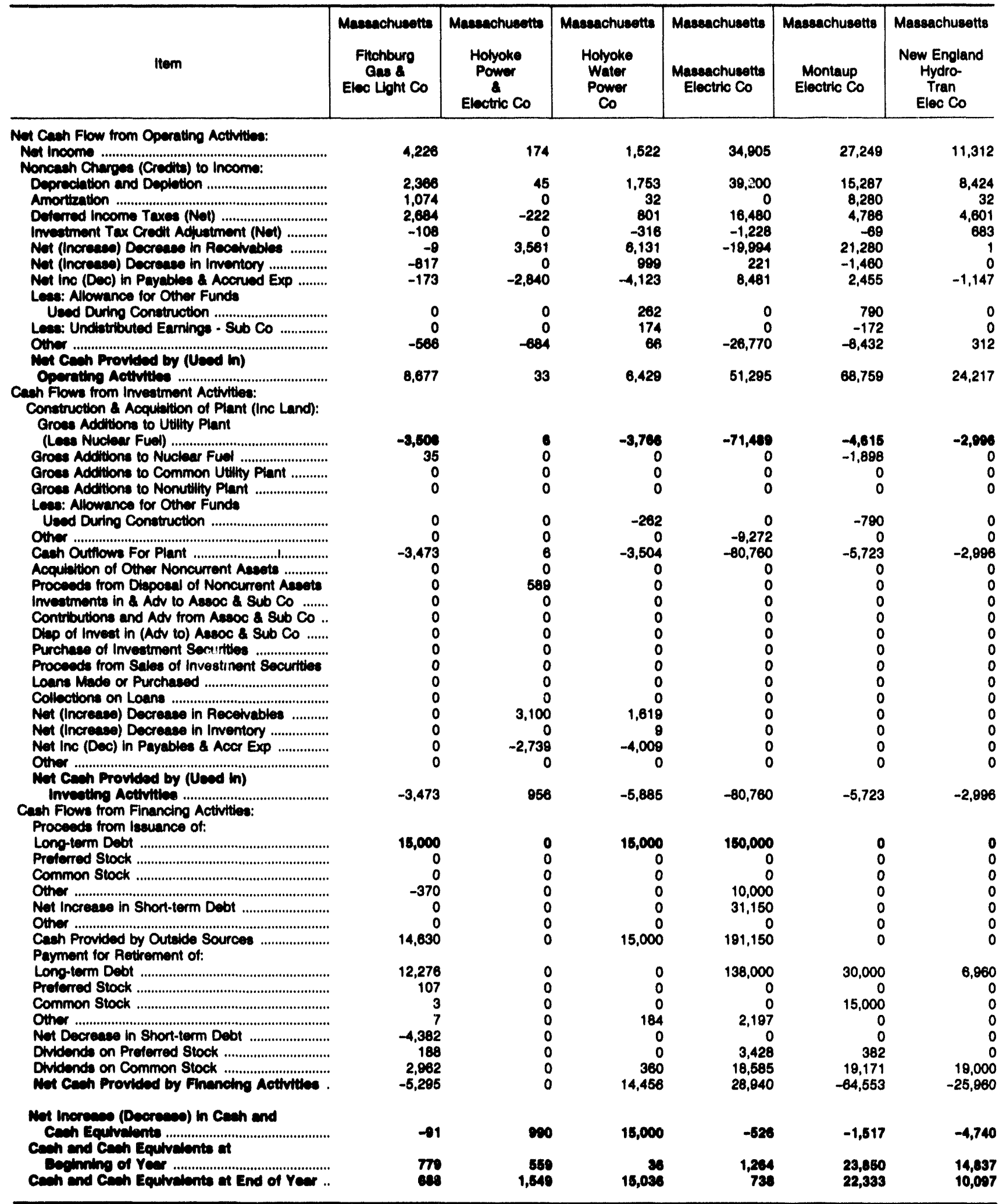

Note: Totals may not equal eum of components because of independent rounding. Summary data are provided in Table 10.

8ource: Federal Eneroy Regulatory Commiacion, FERC Form 1, "Annual Report of Malor Electric Utilities, Licenseess and Others." 
Table 39. Stotement of Cach Flows by Major U.S. Invector-Owned Electric Uilility Within Stato, 1992 (Continued)

(Thousand Dollars)

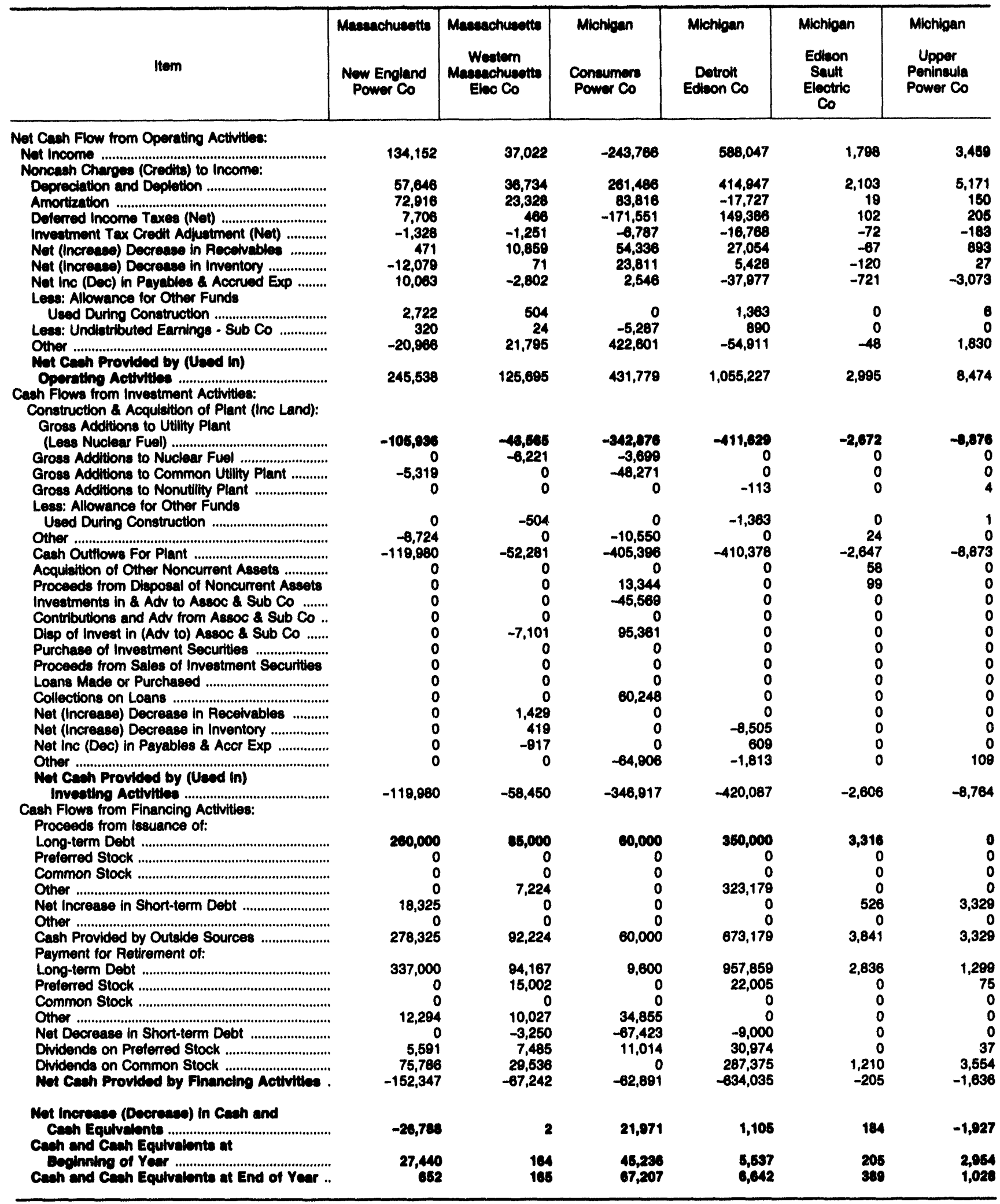

Note: Totals may not equal sum of components because of independent rounding. Summary data are provided in Table 10.

Source: Federal Energy Regulatory Commiseion, FERC Form 1, "Annual Report of Major Electric Utilties, Licensees and Others." 
Table 39. Statement of Cash Flows by Major U.S. Investor-Owned Electric Utility Within State, 1992 (Continued)

(Thousand Dollars)

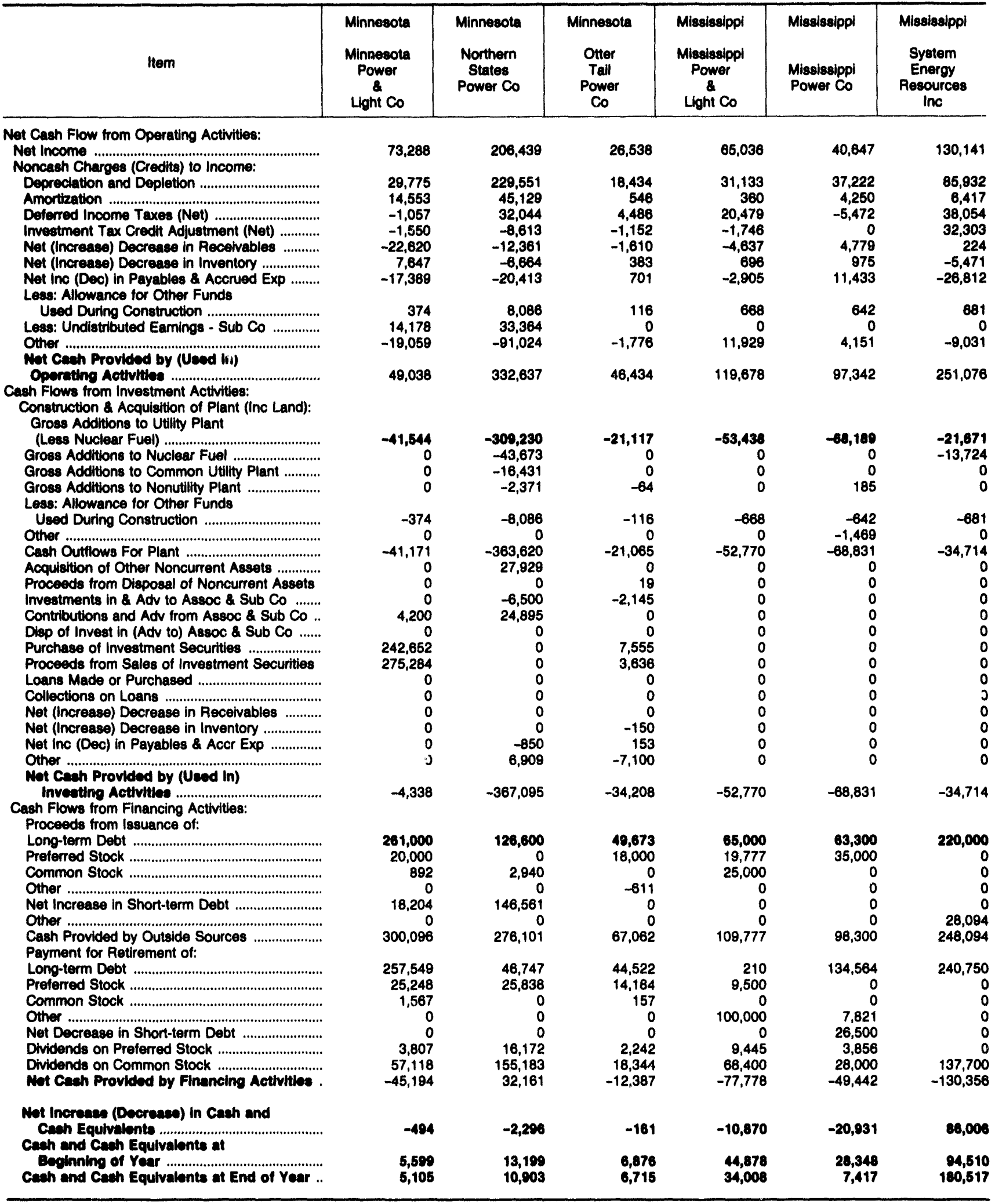

Note: Totals may not equal sum of components because of independent rounding. Summary data are provided in Table 10.

Source: Federal Energy Regulatory Commission, FERC Form 1, "Annual Report of Major Electric Utilities, Licensees and Others." 
Table 39. Statomont of Cach Flowe by Major U.8. Inveator-Owned Electric Utility Within 8tate, 1902 (Continued)

(Thousand Dollars)

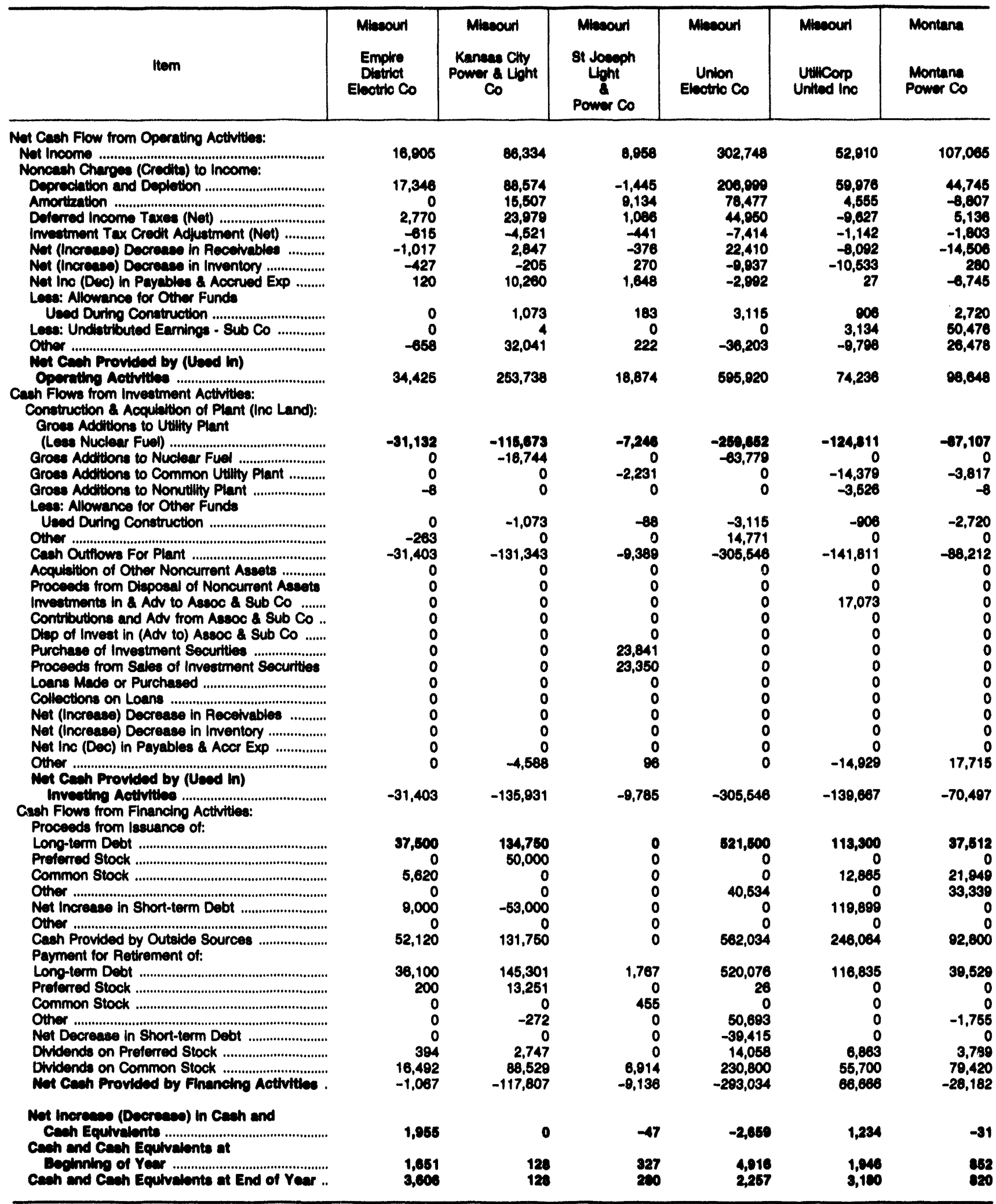

Note: Totals may not equal sum of components because of independent rounding. Summary data are provided in Table 10. Source: Federal Energy Regulatory Commiselon, FERC Form 1, "Annual Report of Major Electric Utilities, Licensees and Othere." 
Table 39. Statement of Cash Flowe by Major U.S. Inveator-Owned Electric Utility Within State, 1992 (Continued)

(Thousand Dollars)

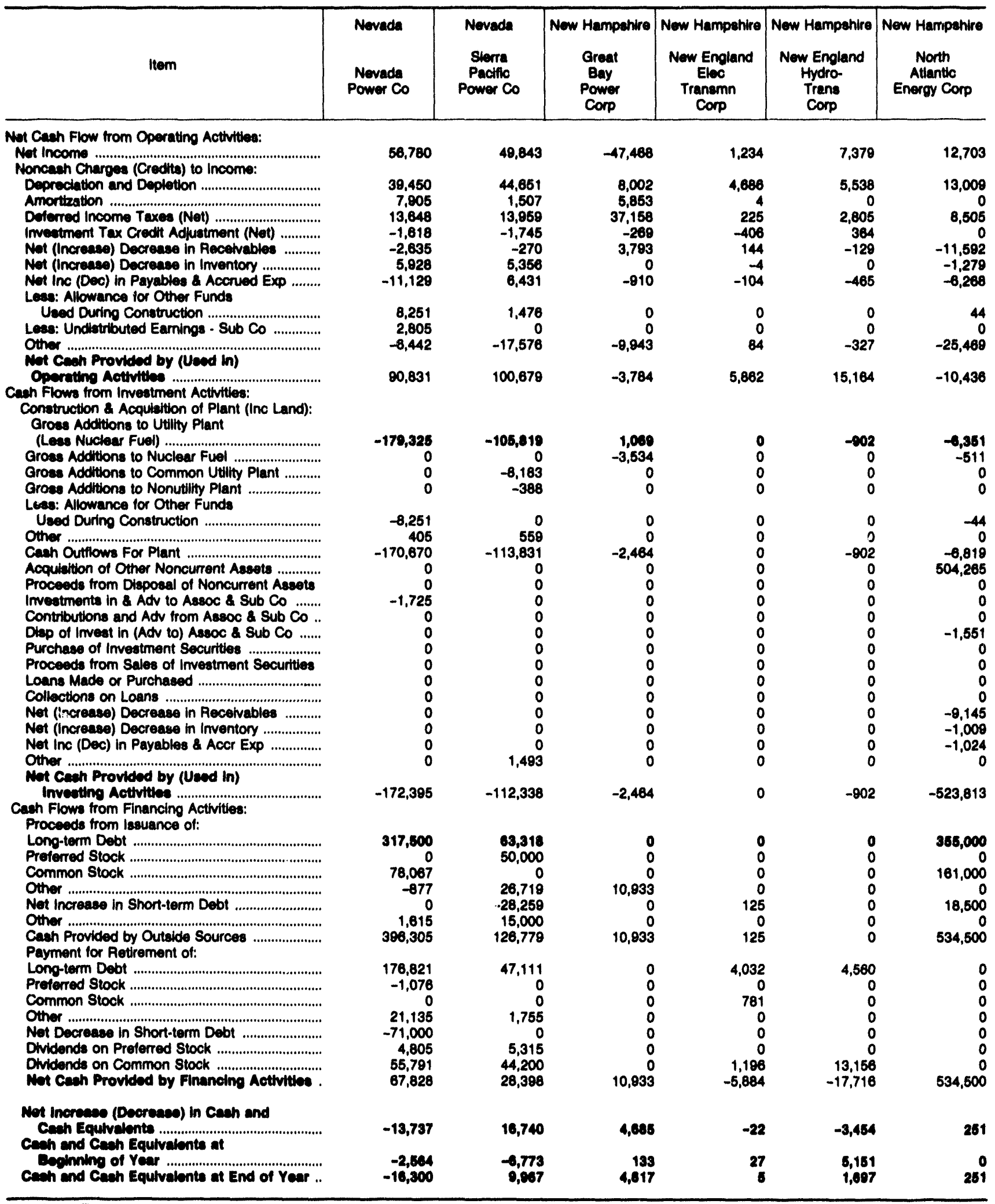

Note: Totals may not equal sum of components because of independent rounding. Summary data are provided in Table 10.

Source: Federal Energy Regulatory Commiedion, FERC Form 1, "Annual Report of Major Electric Utilties, Llcensees and Others." 
Table 39. Statement of Cash Flows by Major U.S. Investor-Owned Eleotric Uility Within State, 1992 (Continued)

(Thousand Dollars)

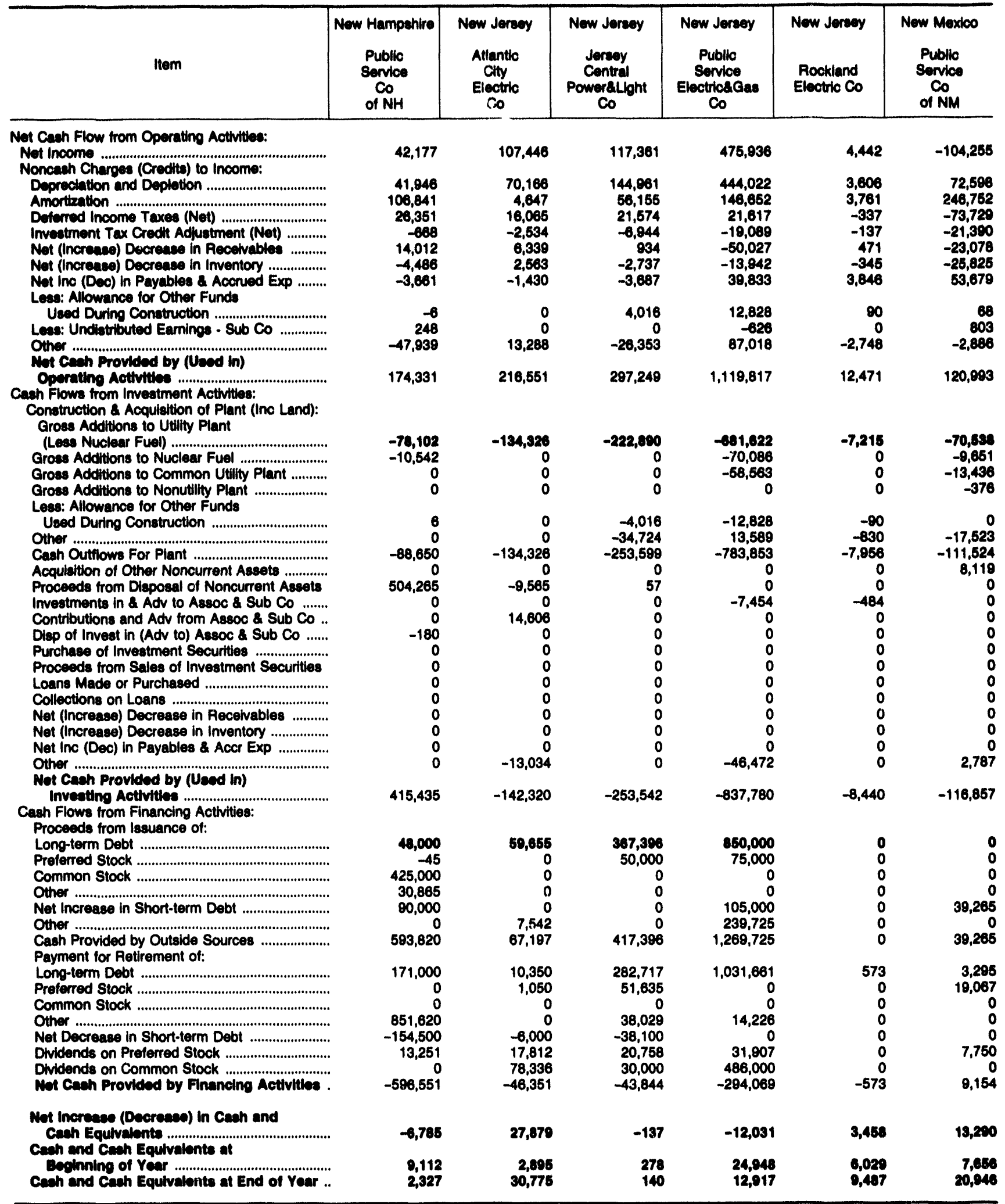

Note: Totals may not equal sum of components because of independent rounding. Summary data are provided in Table 10.

Source: Federal Energy Regulatory Commiseion, FERC Form 1, "Annual Report of Major Electric Utilities, Licensees and Others." 
Tablo 39. Statement of Cash Flows by Major U.S. Investor-Owned Eloctrlc Utility Within State, 1992 (Continued)

(Thousand Dollars)

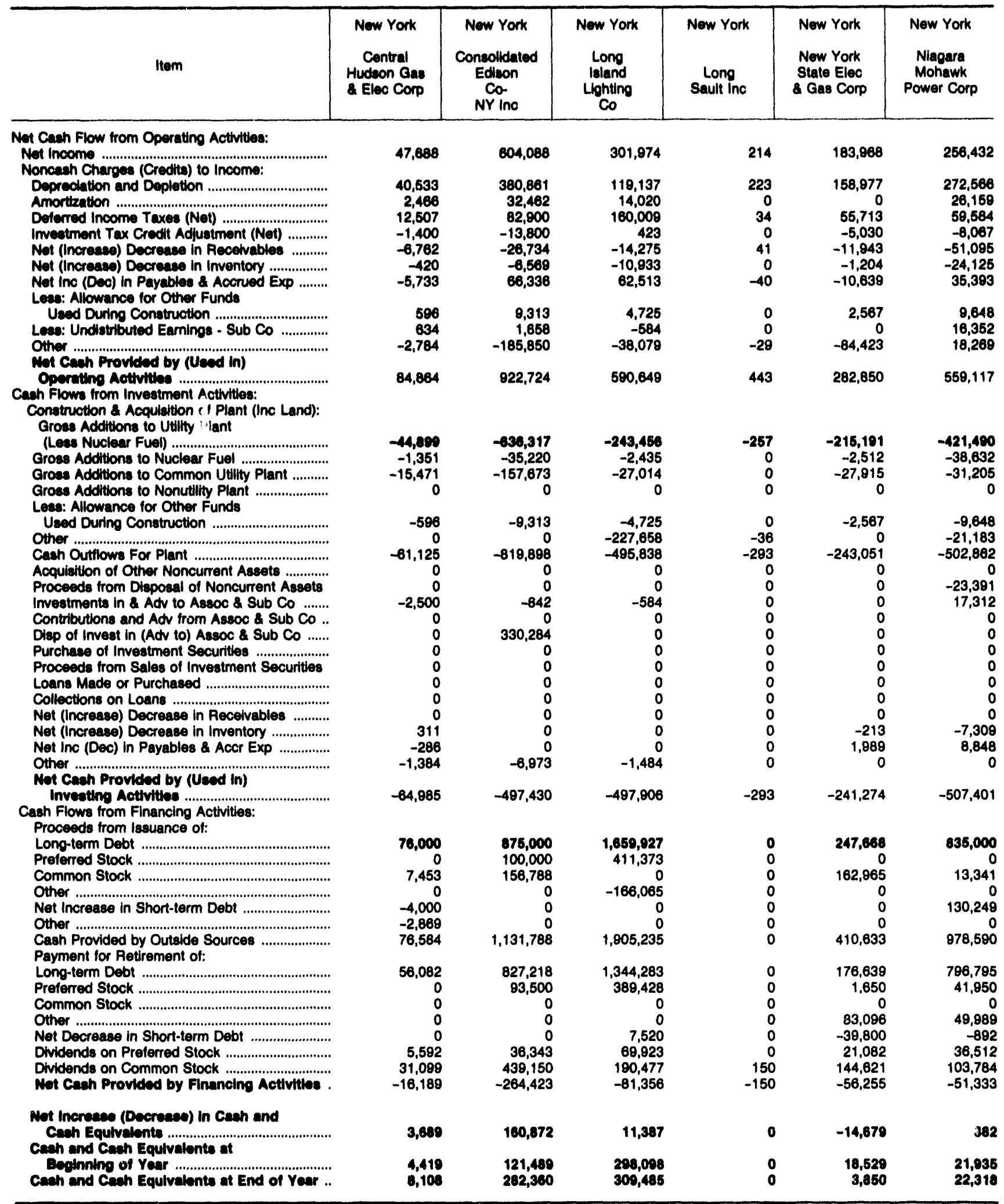

Note: Totale may not equal sum of components because of independent rounding. Summary data are provided in Table 10.

Source: Federal Energy Regulatory Commission, FERC Form 1, "Annual Report of Major Electric Utilities, Licensees and Others." 
Table 39. Statement of Cach Flows by Major U.S. Investor-Owned Electrlc Utility Within State, 1902 (Continued)

(Thousand Dollars)

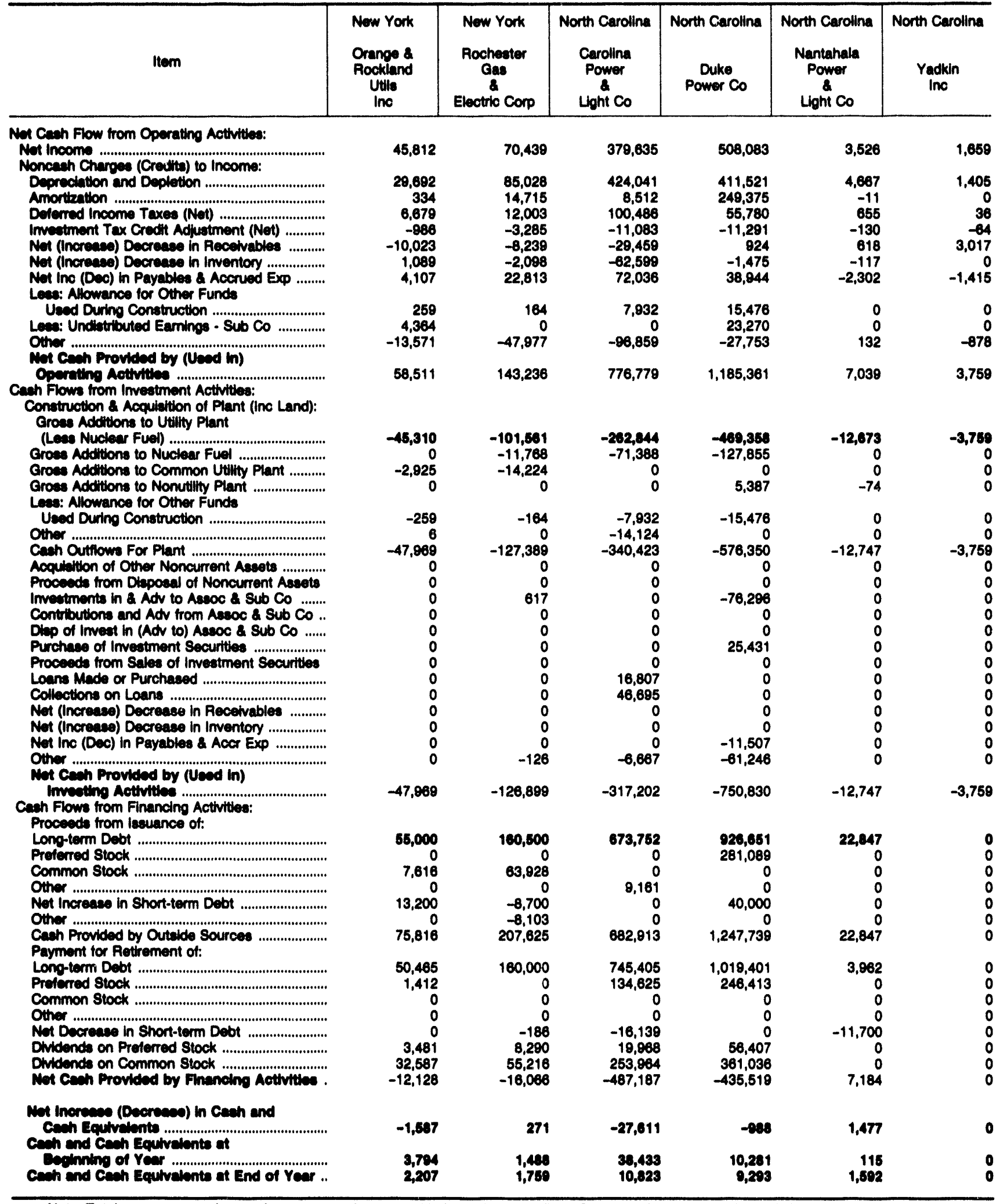

Note: Totals may not equal sum of components because of independent rounding. Summary data are provided in Table 10.

Source: Federal Eneroy Regulatory Commiselon, FERC Form 1, "Annual Report of Major Electric IJtilties, Licensees and Others." 
Table 39. Statement of Cach Flows by Major U.8. Investor-Owned Electric Utility Within 8tate, 1992 (Continued)

(Thousand Dollars)

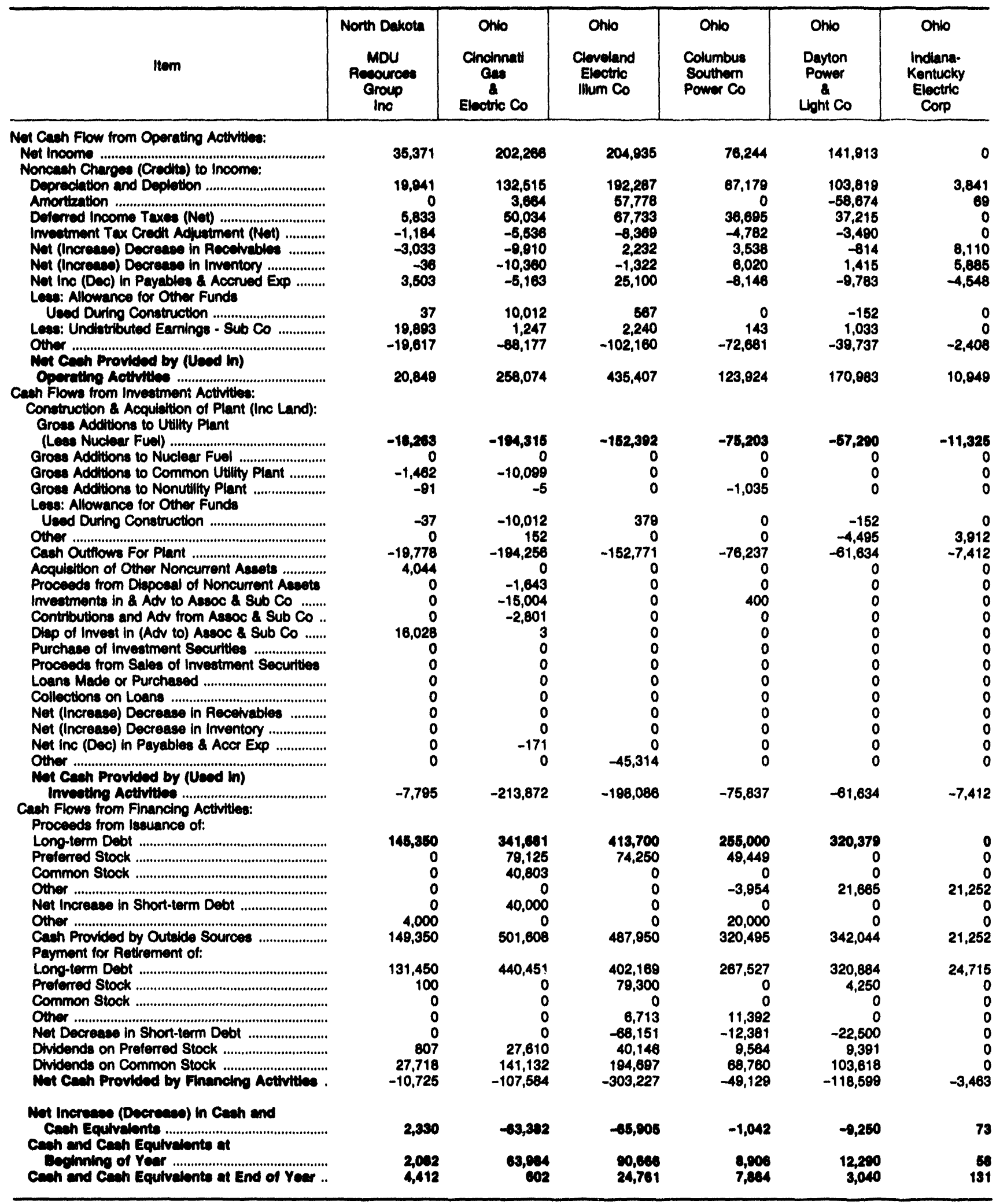

Note: Totals may not equal sum of components because of independent rounding. Summary data are provided in Table 10.

Source: Federal Energy Regulatory Commiscion, FERC Form 1, "Annual Report of Malor Electric Utillities, Licensees and Others." 
Table 39. Statement of Cash Flowe by Major U.S. Investor-Owned Electric Utility Within State, 1992 (Continued)

(Thousand Dollars)

\begin{tabular}{|c|c|c|c|c|c|c|}
\hline Item & $\begin{array}{l}\text { Ohio } \\
\text { Ohio } \\
\text { Edison Co }\end{array}$ & $\begin{array}{l}\text { Ohio } \\
\text { Ohio } \\
\text { Power Co }\end{array}$ & $\begin{array}{l}\text { Ohio } \\
\text { Ohio } \\
\text { Valley } \\
\text { Electric } \\
\text { Corp }\end{array}$ & $\begin{array}{l}\text { Toledo } \\
\text { Edieon Co }\end{array}$ & $\begin{array}{c}\text { Oklahoma } \\
\text { Oklahoma } \\
\text { Gas } \\
\text { Electric Co }\end{array}$ & $\begin{array}{c}\text { Oklahoma } \\
\text { Public } \\
\text { Service } \\
\text { Co } \\
\text { of Oklahoma }\end{array}$ \\
\hline \multicolumn{7}{|l|}{$\begin{array}{l}\text { Net Cach Flow from Operating Actwities: } \\
\text { Not Income } \\
\text { Noncach Charges (Credite) to Income: }\end{array}$} \\
\hline 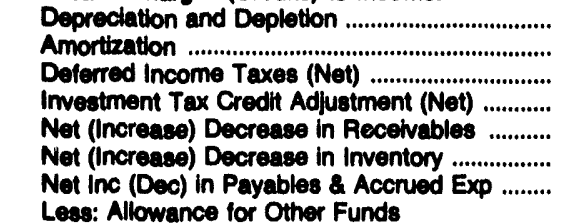 & $\begin{array}{r}191,732 \\
77,441 \\
20,134 \\
-16,898 \\
-7,101 \\
-11,018 \\
-26,375\end{array}$ & $\begin{array}{r}125,050 \\
7,107 \\
13,501 \\
-4,137 \\
-62,463 \\
44,772 \\
8,394\end{array}$ & $\begin{array}{r}108 \\
52 \\
5,540 \\
-1,449 \\
1,155 \\
-8,080 \\
-8,769\end{array}$ & $\begin{array}{r}85,010 \\
71,132 \\
28,008 \\
-5,303 \\
-1,362 \\
-9,339 \\
4,791\end{array}$ & $\begin{array}{r}99,194 \\
19,337 \\
2,784 \\
-5,465 \\
-15,050 \\
6,321 \\
3,199\end{array}$ & $\begin{array}{r}64,719 \\
-2,260 \\
21,157 \\
-2,710 \\
-2,173 \\
-5,744 \\
4,759\end{array}$ \\
\hline 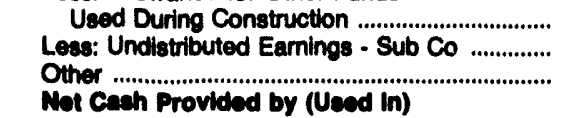 & $\begin{array}{r}2,911 \\
-1,289 \\
15,034\end{array}$ & $\begin{array}{r}1,480 \\
-1,044 \\
4,584\end{array}$ & $\begin{array}{r}0 \\
0 \\
-617\end{array}$ & $\begin{array}{r}1,048 \\
0 \\
-65,867\end{array}$ & $\begin{array}{r}0 \\
-241 \\
-2,505\end{array}$ & $\begin{array}{r}348 \\
-200 \\
-24,692\end{array}$ \\
\hline 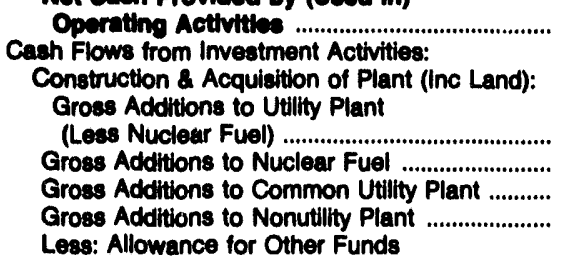 & $\begin{array}{r}-192,398 \\
0 \\
0 \\
4,661\end{array}$ & $\begin{array}{r}-159,992 \\
0 \\
0 \\
-19,778\end{array}$ & $\begin{array}{r}-1,174 \\
0 \\
0 \\
0\end{array}$ & $\begin{array}{r}-47,548 \\
0 \\
0 \\
0\end{array}$ & $\begin{array}{r}-111,335 \\
0 \\
0 \\
0\end{array}$ & $\begin{array}{r}-\infty, 818 \\
0 \\
0 \\
0\end{array}$ \\
\hline 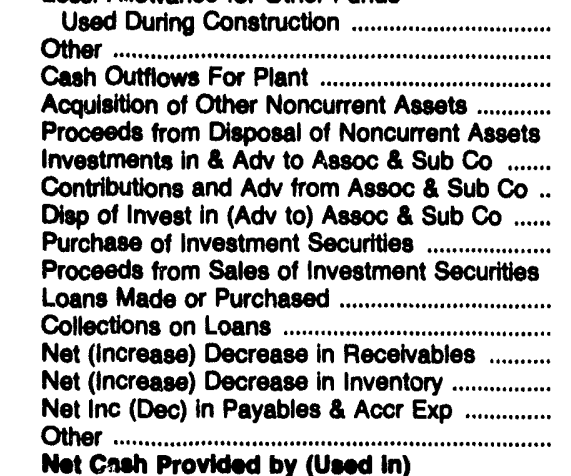 & $\begin{array}{r}2,911 \\
0 \\
-190,616 \\
0 \\
0 \\
0 \\
0 \\
0 \\
5,466 \\
0 \\
0 \\
8,000 \\
0 \\
0 \\
0 \\
-45,589\end{array}$ & $\begin{array}{r}-1,480 \\
0 \\
-178,290 \\
0 \\
42,837 \\
33,957 \\
0 \\
0 \\
0 \\
0 \\
0 \\
0 \\
0 \\
0 \\
0 \\
0\end{array}$ & $\begin{array}{r}0 \\
2,217 \\
1,044 \\
0 \\
0 \\
0 \\
0 \\
0 \\
0 \\
0 \\
0 \\
0 \\
0 \\
0 \\
0 \\
0\end{array}$ & $\begin{array}{r}718 \\
-31,150 \\
-79,416 \\
0 \\
0 \\
0 \\
0 \\
0 \\
0 \\
0 \\
0 \\
0 \\
0 \\
0 \\
0 \\
-14,435\end{array}$ & $\begin{array}{r}0 \\
0 \\
-111,335 \\
0 \\
0 \\
0 \\
0 \\
0 \\
0 \\
0 \\
0 \\
0 \\
0 \\
0 \\
0 \\
0\end{array}$ & $\begin{array}{r}-348 \\
-2,418 \\
-101,888 \\
0 \\
0 \\
0 \\
0 \\
0 \\
0 \\
0 \\
0 \\
0 \\
0 \\
0 \\
0 \\
0\end{array}$ \\
\hline $\begin{array}{l}\text { Inveating Activities ................................... } \\
\text { Cash Flows from Financing Activities: } \\
\text { Proceeds from lssuance of: }\end{array}$ & $-239,671$ & $-101,496$ & 1,044 & $-93,851$ & $-111,335$ & $-101,888$ \\
\hline 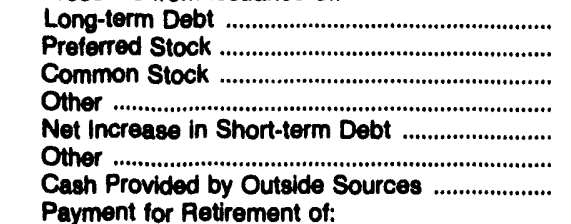 & $\begin{array}{r}645,778 \\
0 \\
0 \\
0 \\
35,700 \\
-1,646 \\
679,832\end{array}$ & $\begin{array}{r}250,000 \\
0 \\
0 \\
-2,823 \\
0 \\
0 \\
0 \\
247,177\end{array}$ & $\begin{array}{r}0 \\
0 \\
0 \\
18,306 \\
0 \\
11,000 \\
29,306\end{array}$ & $\begin{array}{r}458,750 \\
0 \\
0 \\
0 \\
0 \\
0 \\
458,750\end{array}$ & $\begin{array}{r}0 \\
0 \\
0 \\
0 \\
13,500 \\
0 \\
13,500\end{array}$ & $\begin{array}{r}113,898 \\
0 \\
0 \\
0 \\
0 \\
0 \\
113,888\end{array}$ \\
\hline 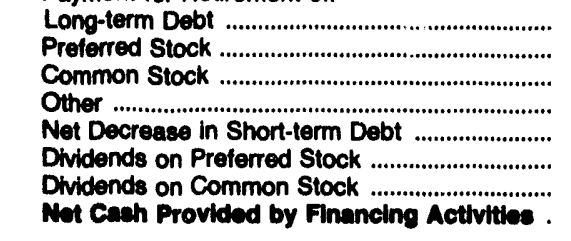 & $\begin{array}{r}757,995 \\
1,800 \\
0 \\
0 \\
0 \\
23,786 \\
234,188 \\
-337,936\end{array}$ & $\begin{array}{r}104,500 \\
0 \\
0 \\
609 \\
-132,325 \\
17,115 \\
134,172 \\
-141,543\end{array}$ & $\begin{array}{r}16,275 \\
0 \\
0 \\
0 \\
0 \\
0 \\
1,525 \\
11,506\end{array}$ & $\begin{array}{r}526,989 \\
4,173 \\
0 \\
7,347 \\
-42,632 \\
24,018 \\
0 \\
-146,409\end{array}$ & $\begin{array}{r}300 \\
0 \\
0 \\
0 \\
0 \\
2,317 \\
107,237 \\
-96,354\end{array}$ & $\begin{array}{r}63,833 \\
0 \\
0 \\
0 \\
-11,575 \\
817 \\
35,000 \\
2,561\end{array}$ \\
\hline $\begin{array}{l}\text { Not Increase (Decrease) In Cach and } \\
\text { Cach Equlvalente....................................... } \\
\text { Cach and Cach Equlvalents at }\end{array}$ & $-52,295$ & 53,905 & 2,040 & 558 & 80 & -800 \\
\hline 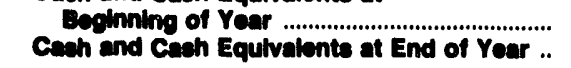 & $\begin{array}{r}39,602 \\
-12,793\end{array}$ & $\begin{array}{r}8,721 \\
62,625\end{array}$ & $\begin{array}{l}2,657 \\
4,698\end{array}$ & $\begin{array}{l}79,289 \\
16,731\end{array}$ & $\begin{array}{l}506 \\
585\end{array}$ & $\begin{array}{r}1,575 \\
716\end{array}$ \\
\hline
\end{tabular}

Note: Totals may not equal sum of components because of independent rounding. Summary data are provided in Table 10.

Source: Federal Energy Regulatory Commission, FERC Form 1, "Annual Report of Major Electric Utilities, Licensees and Others." 
Table 39. Statement of Cash Flows by Major U.S. Investor-Owned Electric Utility Within State, 1992 (Continued)

(Thousand Dollars)

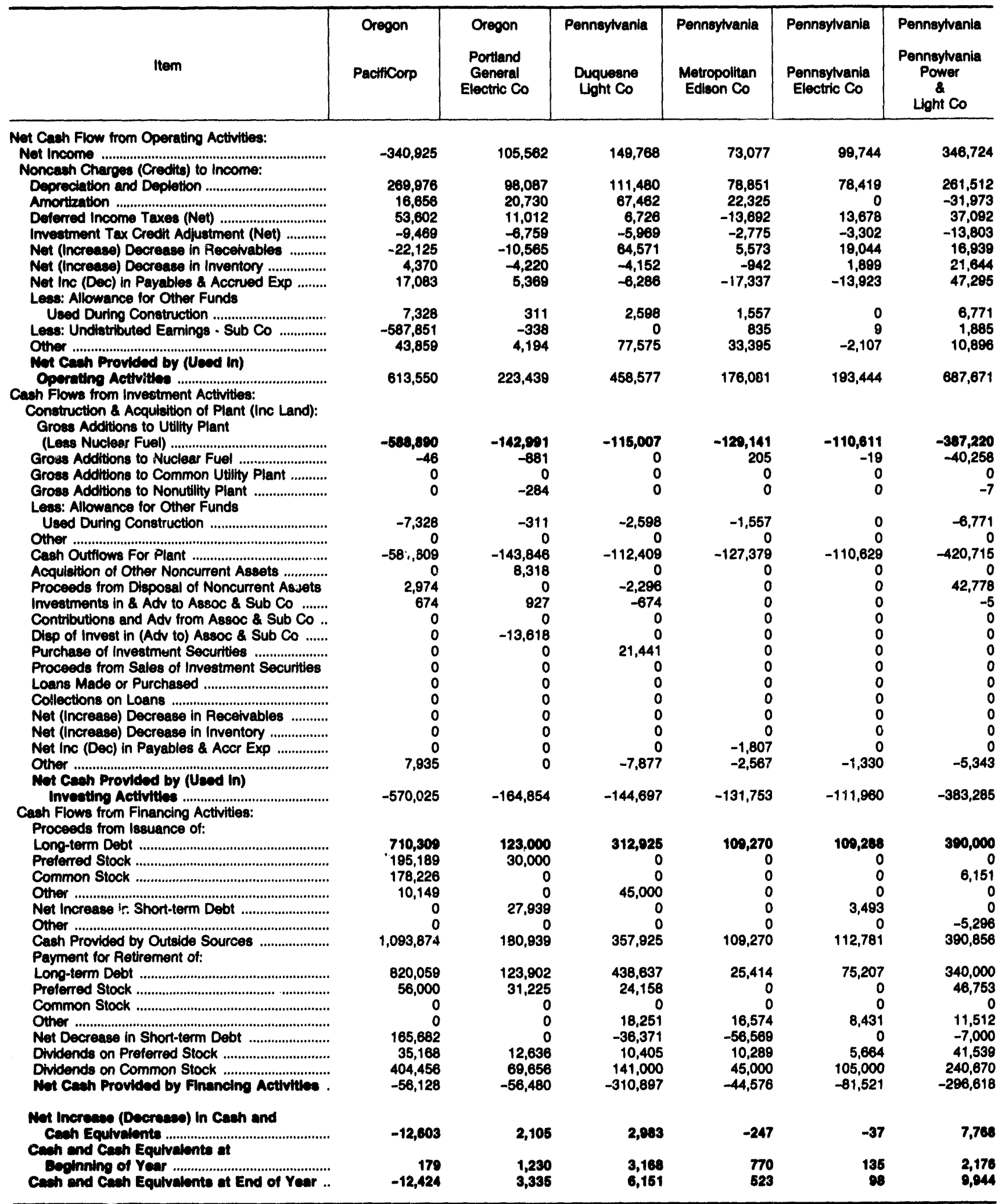

Note: Thtals may not equal sum of components because of independent rounding. Summary data are provided in Table 10.

Source: Federal Energy Regulatory Commission, FERC Form 1, "Annual Report of Major Electric Utilities, Licensees and Others." 
Table 30. Statoment of Cash Flows by Major U.S. Investor-Owned Electric Utility Within State, 1992 (Continued) (Thousand Dollars)

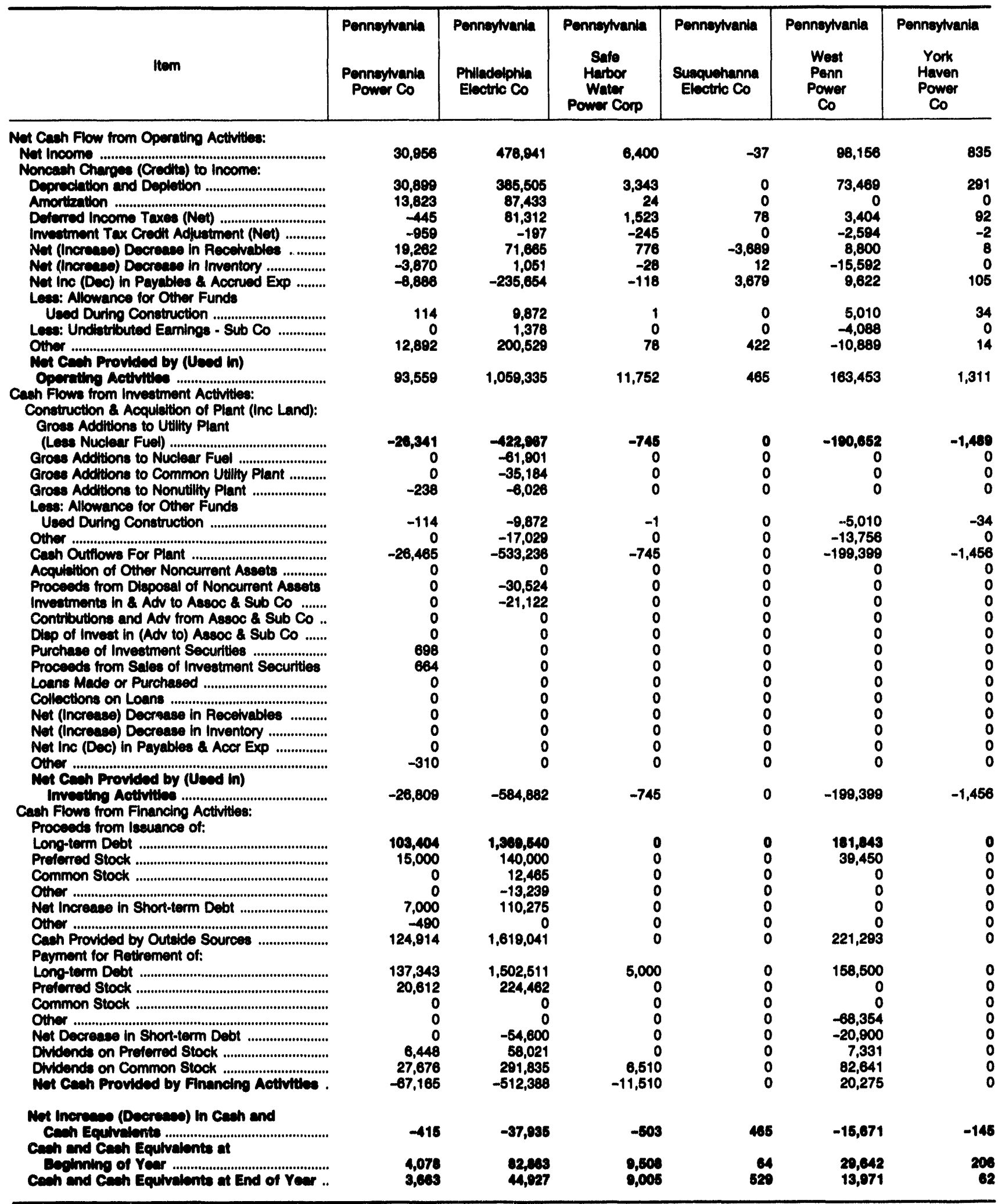

Note: Totals may not equal sum of components because of independent rounding. Summary data are provided in Table 10.

Source: Federal Energy Regulatory Commission, FERC Form 1, "Annual Report of Major Electric Uullities, Licensees and Others." 
Table 39. Statement of Cash Flows by Major U.S. Investor-Owned Electric Utility Within State, 1992 (Continued) (Thousand Dollars)

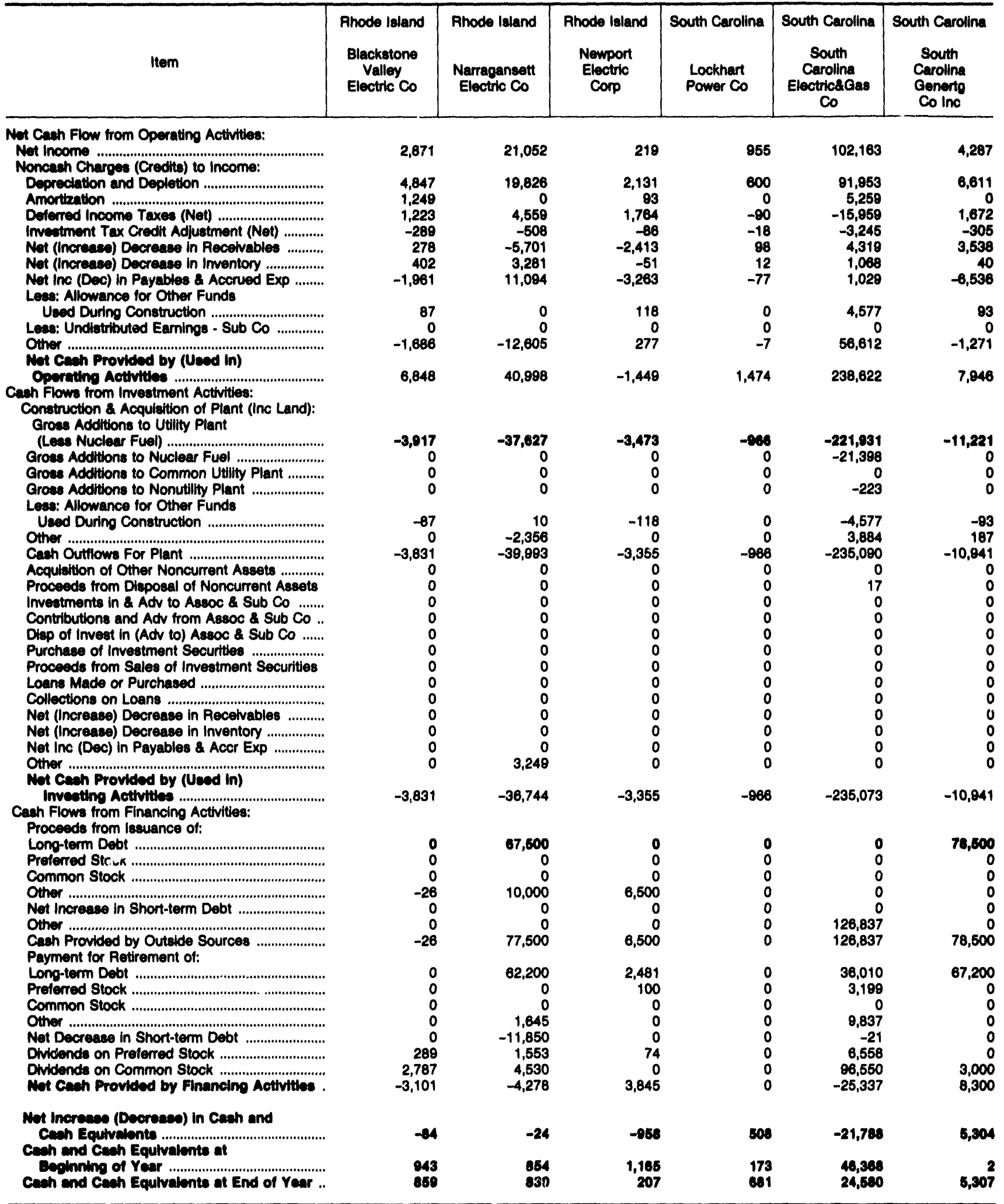

Note: Totals may not equal sum of components because of independent rounding. Summary data are provided in Table 10.

Source: Federal Energy Regulatory Commiasion, FERC Form 1, "Annual Report of Major Electric Utillies, Licensees and Others." 
Table 39. Statement of Cash Flows by Major U.S. Investor-Owned Electrlc Utility Within State, 1902 (Continued) (Thousand Dollars)

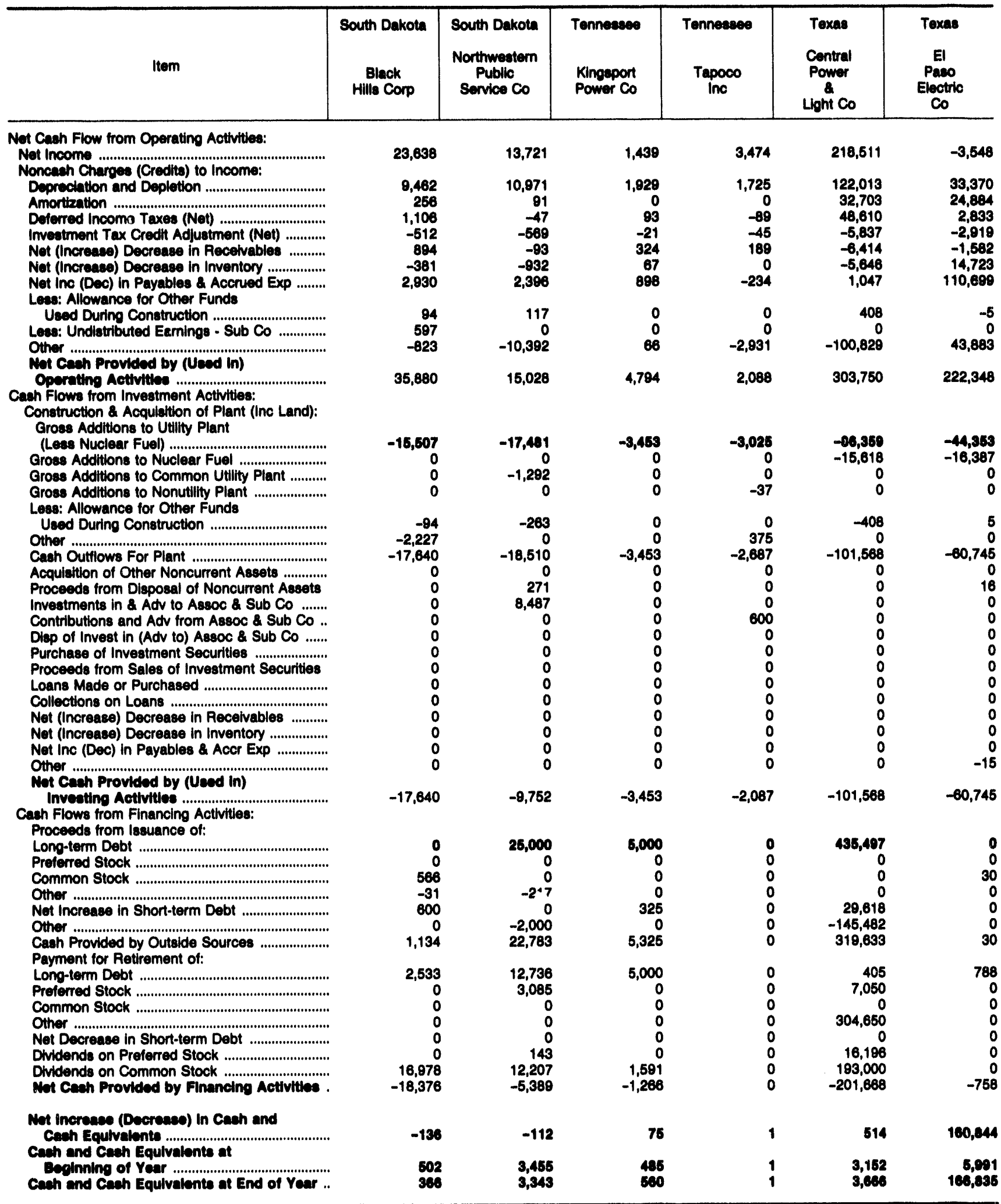

Note: Totals may not equal sum of components because of independent rounding. Summary data are provided in Table 10.

Source: Federal Energy Regulatory Commission, FERC Form 1, "Annual Report of Major Electric Utilties, Licensees and Others." 
Table 39. Statement of Cach Flows by Major U.S. Investor-Owned Electric Utility Within State, 1982 (Continued) (Thousand Dollars)

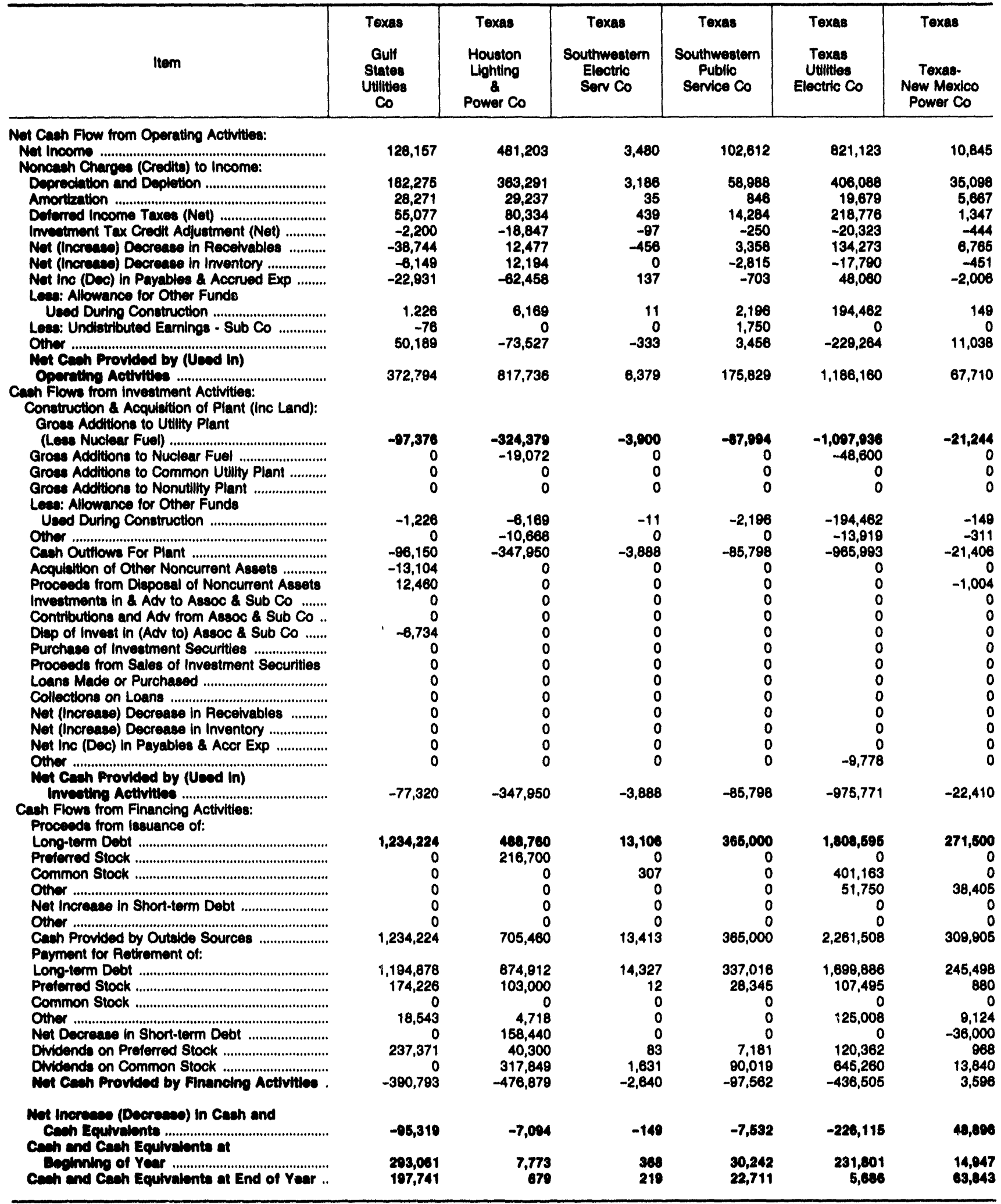

Note: Totale may not equal sum of components because of independent rounding. Summary data are provided in Table 10.

Source: Federal Energy Regulatory Commiseion, FERC Form 1, "Annual Report of Major Electrle Utillties, Licensees and Others." 
Table 39. Statement of Cach Flows by Major U.S. Investor-Owned Electric Utility Within State, 1982 (Continued)

(Thousand Dollars)

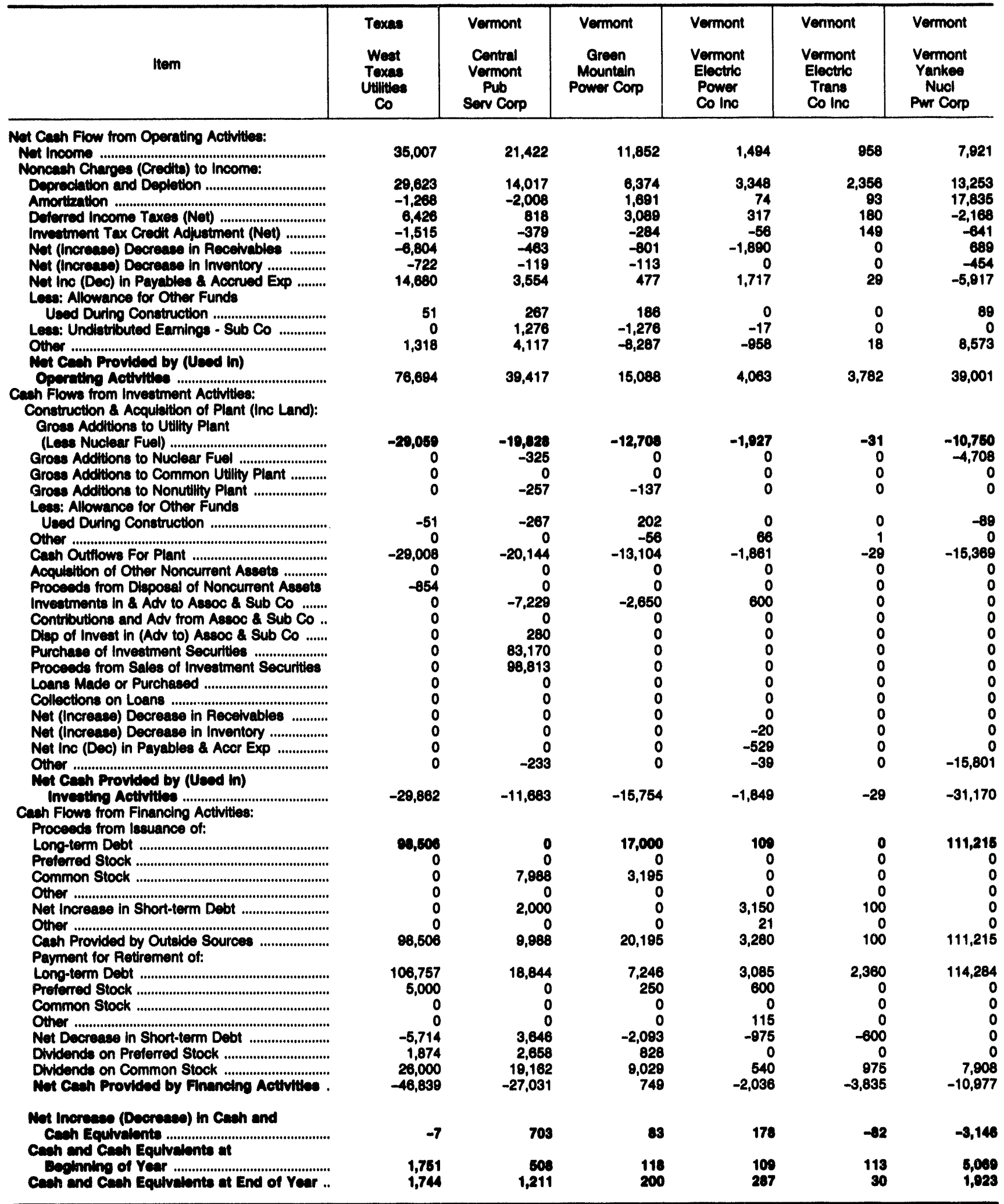

Note: Totals may not equal sum of components because of independent rounding. Summary data are provided in Table 10.

Source: Federal Energy Regulatory Commiasion, FERC Form 1, "Annual Report of Major Electric Utilties, Licensees and Others." 
Table 30. 8tatemont of Cach Flowe by Major U.8. Investor-Owned Electric Utility Within state, 1902 (Continued)

(Thousand Dollars)

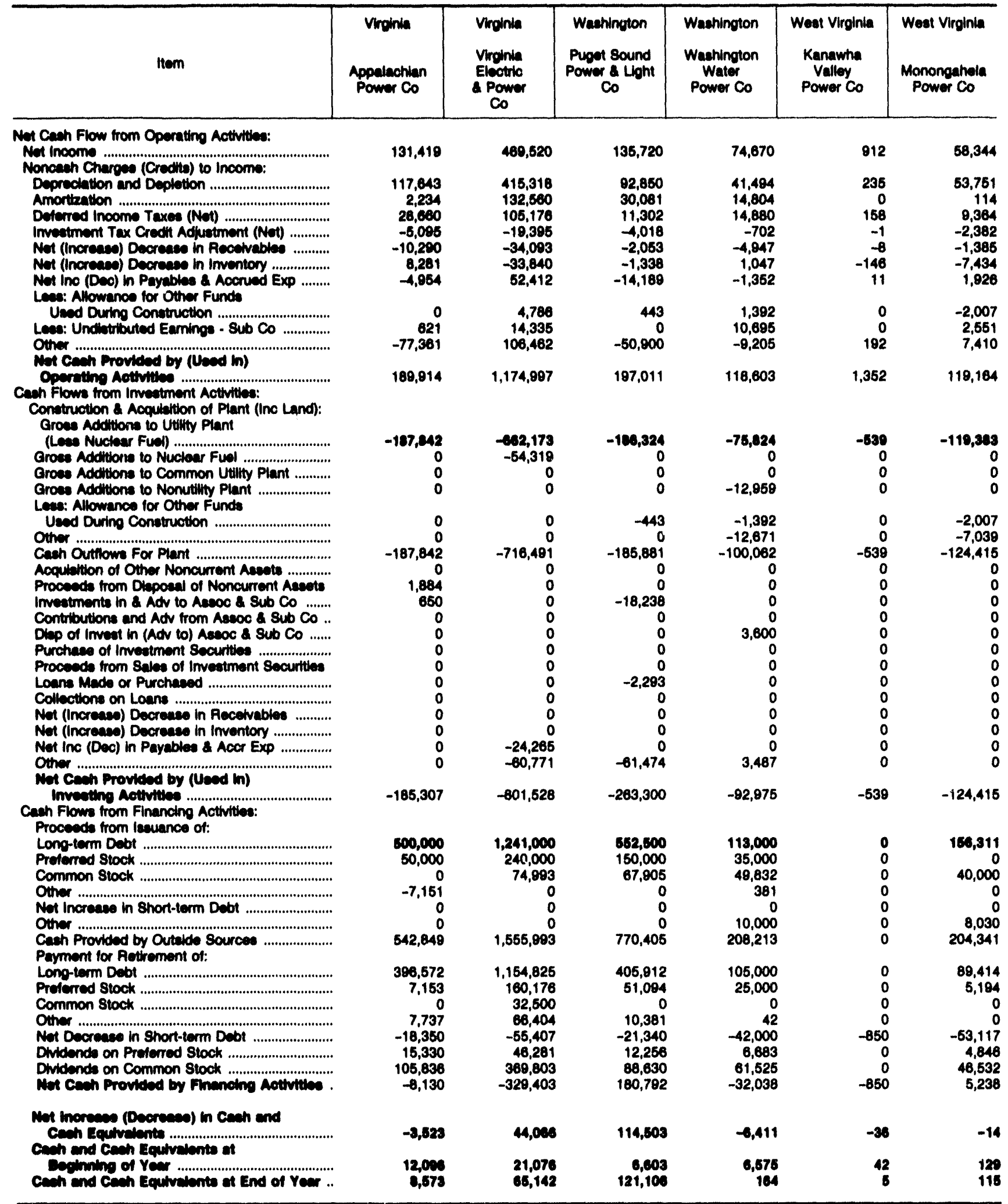

Note: Totals may not equal eum of components becasues of independent rounding. Summary data are provided in Table 10.

Source: Federal Eneroy Requlatory Commiacion, FERC Form 1, "Annual Report of Major Electric Utilities, Licensees and Others." 
Table 39. Statement of Caoh Flows by Major U.S. Investor-Owned Electric Utility Within Stato, 1992 (Continued)

(Thousand Dollars)

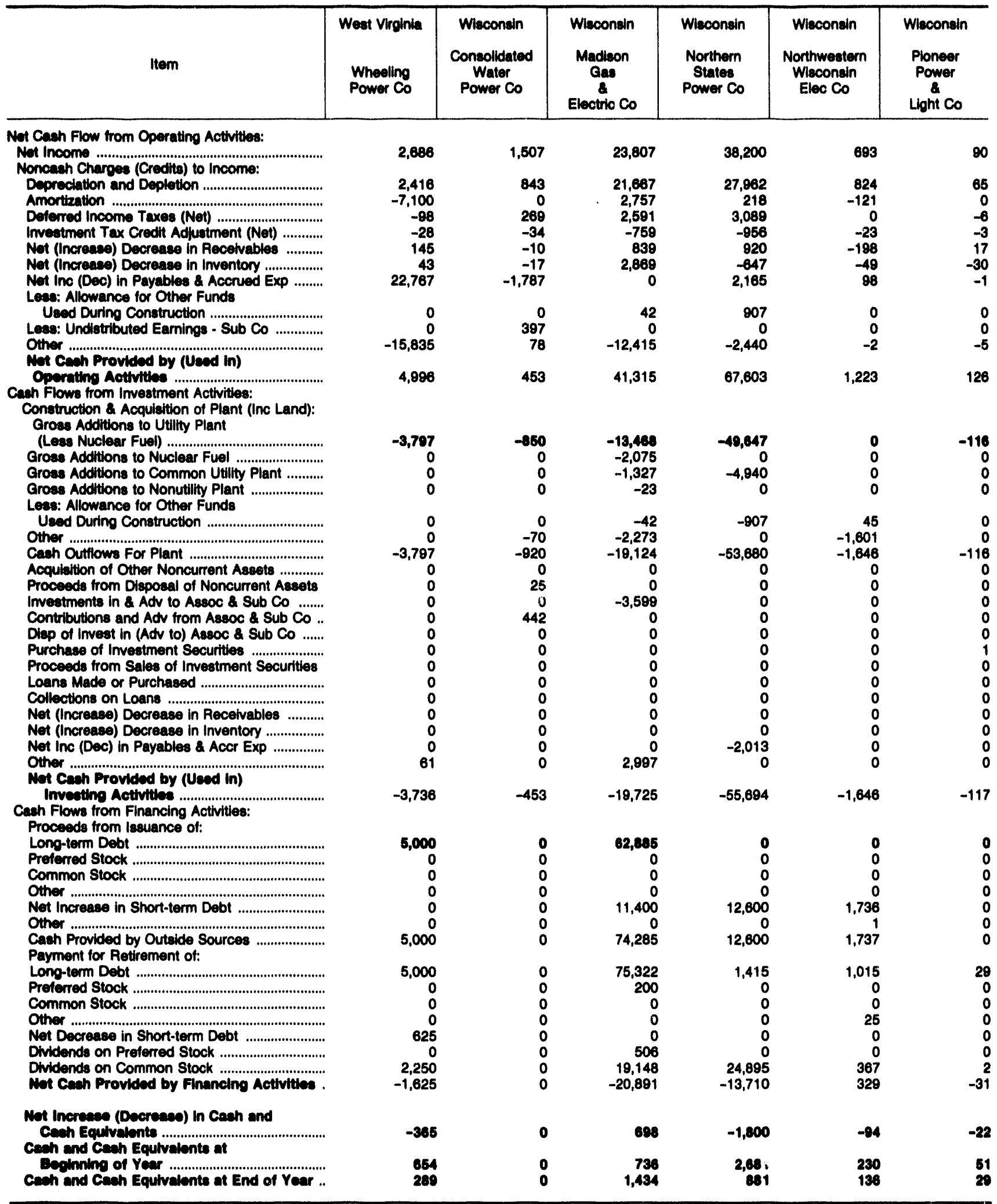

Note: Totals may not equal sum of components because of independent rounding. Summary data are provided in Table 10.

Source: Federal Energy Regulatory Commission, FERC Form 1, "Annual Report of Major Electric Utilities, Licensees and Others." 
Table 39. Statement of Cach Flows by Major U.8. Investor-Owned Eloctric Utility Within State, 1992 (Continuod)

(Thousand Dollars)

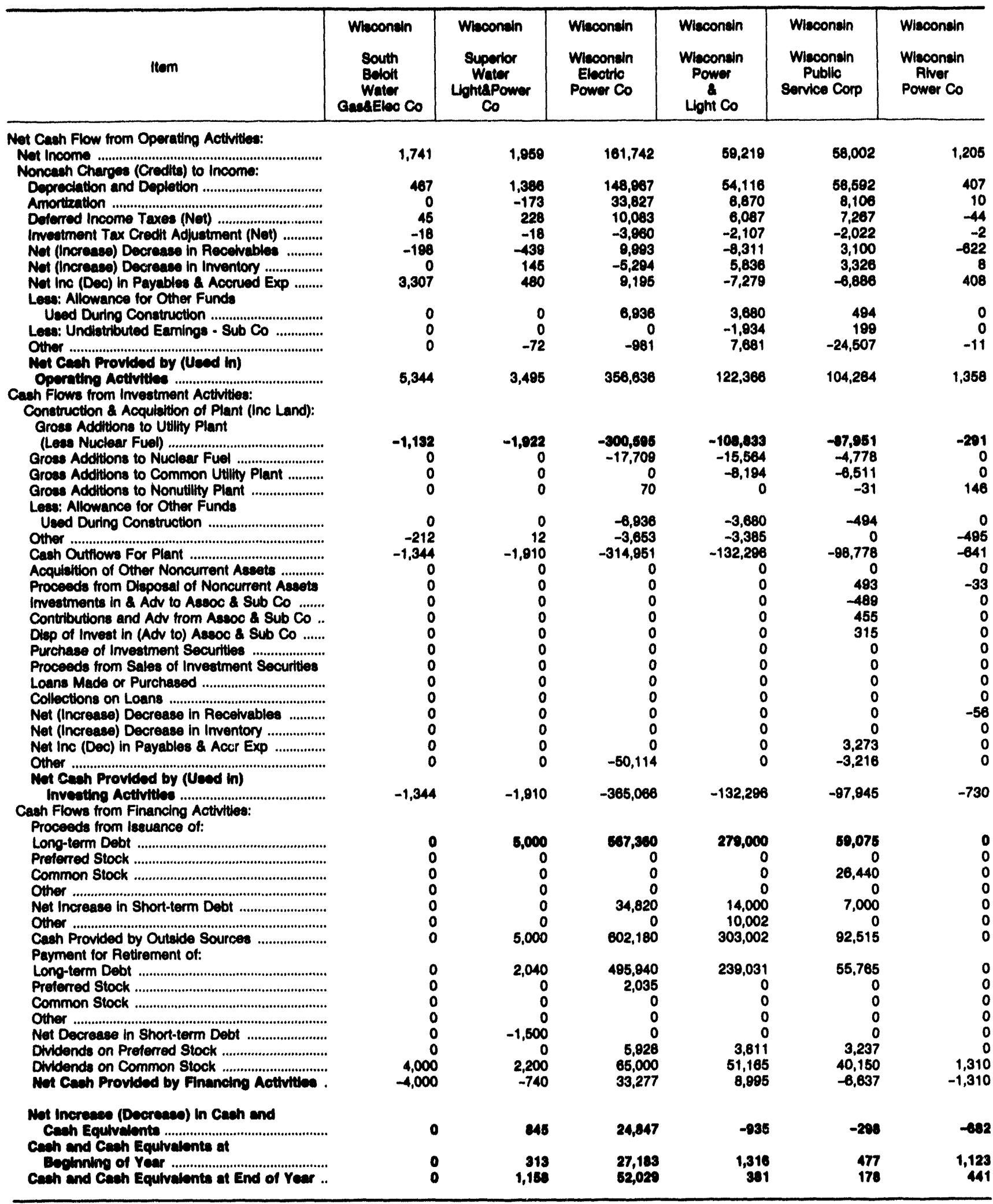

Note: Totale may not equal sum of components because of independent rounding. Summary data are provided in Table 10.

Source: Federal Energy Regulatory Commiseion, FERC Form 1, "Annual Report of Major Electric Utilities, Llcensees and Others." 
Table 40. Number of Coneumors, 8alea, and Oporating Rovenue by Major U.8. Investor-Owned Electric Utility Within 8tate, 1902

\begin{tabular}{|c|c|c|c|c|c|c|}
\hline Item & $\begin{array}{l}\text { Alabama } \\
\text { Alabama } \\
\text { Power Co }\end{array}$ & $\begin{array}{l}\text { Alobama } \\
\text { Southem } \\
\text { Eloctito } \\
\text { Cenerate Co }\end{array}$ & $\begin{array}{l}\text { Artaon } \\
\text { Artaon } \\
\text { Publio } \\
\text { service Co }\end{array}$ & $\begin{array}{l}\text { Artaon } \\
\text { Centiny } \\
\text { Power Corp }\end{array}$ & $\begin{array}{l}\text { Artzona } \\
\text { Tuceon } \\
\text { Electule } \\
\text { Power Co }\end{array}$ & $\begin{array}{l}\text { Arkanase } \\
\text { Adkanase } \\
\text { Pown } \\
\text { Lom Co }\end{array}$ \\
\hline 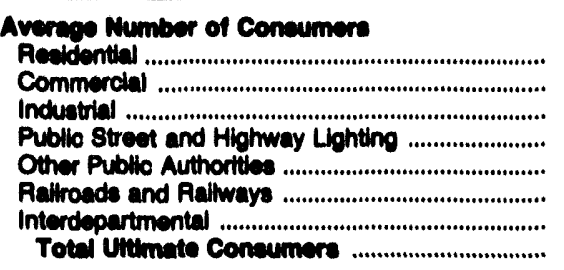 & $\begin{array}{r}1,004,343 \\
150,628 \\
5,443 \\
688 \\
0 \\
0 \\
1 \\
1,100,091\end{array}$ & $\begin{array}{l}0 \\
0 \\
0 \\
0 \\
0 \\
0 \\
0 \\
0\end{array}$ & $\begin{array}{r}649,778 \\
68,800 \\
3,022 \\
483 \\
207 \\
0 \\
0 \\
029,100\end{array}$ & $\begin{array}{l}0 \\
0 \\
0 \\
0 \\
0 \\
0 \\
0 \\
0\end{array}$ & $\begin{array}{r}248,693 \\
28,272 \\
624 \\
28 \\
33 \\
0 \\
0 \\
276,419\end{array}$ & $\begin{array}{r}608,741 \\
68,008 \\
20,980 \\
426 \\
18 \\
0 \\
0 \\
69101\end{array}$ \\
\hline Sales for Resale & 33 & 2 & 43 & 8 & 18 & 17 \\
\hline Total Number of Concumers ............................. & $1,181,014$ & 2 & 928,149 & 6 & 278,600 & coneses \\
\hline 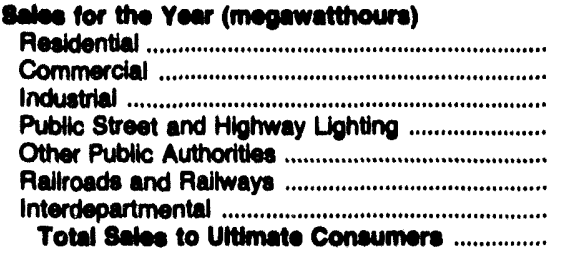 & $\begin{array}{r}12,069,268 \\
8,629,869 \\
18,260,274 \\
174,121 \\
0 \\
0 \\
2,677 \\
39,139,200\end{array}$ & $\begin{array}{l}0 \\
0 \\
0 \\
0 \\
0 \\
0 \\
0 \\
0\end{array}$ & $\begin{array}{r}6,068,830 \\
6,004,072 \\
2,089,970 \\
68,984 \\
4,889 \\
0 \\
0 \\
19,094,791\end{array}$ & $\begin{array}{l}0 \\
0 \\
0 \\
0 \\
0 \\
0 \\
0 \\
0\end{array}$ & $\begin{array}{r}2,146,268 \\
1,216,179 \\
2,863,728 \\
28,324 \\
137,698 \\
0 \\
0 \\
0,391,007\end{array}$ & $\begin{array}{r}5,102,300 \\
3,840,370 \\
5,508,714 \\
63,824 \\
184,684 \\
0 \\
0 \\
14,400,402\end{array}$ \\
\hline 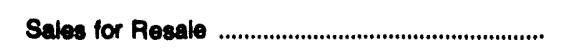 & $15,593,268$ & $5,328,171$ & $4,528,172$ & $3,079,702$ & $2,121,245$ & $15,413,398$ \\
\hline 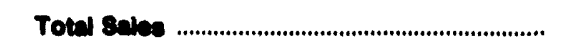 & $84,720,477$ & $6,329,171$ & $20,692,000$ & $3,079,702$ & $0,002,942$ & $30,113,000$ \\
\hline 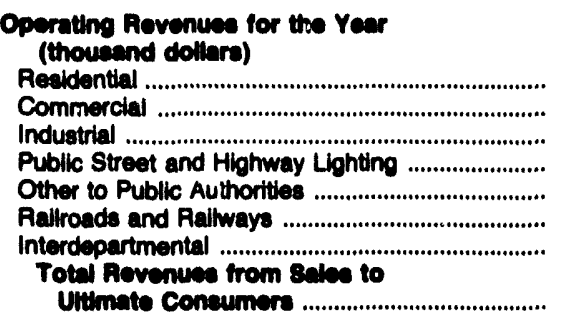 & $\begin{array}{r}845,680 \\
589,816 \\
800,311 \\
12,574 \\
0 \\
0 \\
160 \\
\\
2,249,621\end{array}$ & $\begin{array}{l}0 \\
0 \\
0 \\
0 \\
0 \\
0 \\
0 \\
0\end{array}$ & $\begin{array}{r}648,587 \\
681,797 \\
188,879 \\
12,602 \\
209 \\
0 \\
0\end{array}$ & $\begin{array}{l}0 \\
0 \\
0 \\
0 \\
0 \\
0 \\
0\end{array}$ & $\begin{array}{r}204,220 \\
136,849 \\
186,716 \\
2,410 \\
10,344 \\
0 \\
0 \\
\\
040,890\end{array}$ & $\begin{array}{r}476,086 \\
291,443 \\
328,587 \\
7,324 \\
10,376 \\
0 \\
0 \\
1,111,705\end{array}$ \\
\hline 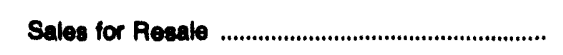 & 565,878 & 146,546 & 138,110 & 179,167 & 68,912 & 384,170 \\
\hline 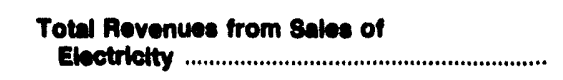 & $2,814,400$ & 146,646 & $1,618,163$ & 178,187 & 818,452 & $1,4 \times 8,098$ \\
\hline (less) Provision for Rate Refunds ......................... & 0 & 0 & 0 & 0 & $-6,378$ & 211 \\
\hline Net Rovenuse from sales of Electuletty ....... & $2,014,400$ & 140,846 & $1,612,183$ & 170,107 & 124,.227 & $1,486,784$ \\
\hline 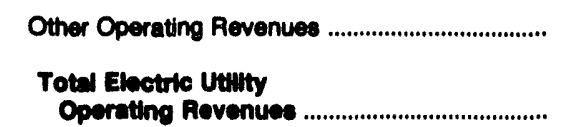 & $2,846,840$ & 140,890 & $1,090,670$ & 170,107 & 827,477 & $1,521,120$ \\
\hline
\end{tabular}

Note: Totals may not equal sum of components because of independent rounding. Summary data are provided in Table 15.

Source: Federal Energy Regulatory Commiseion, FERC Form 1, "Annual Report of Major Electrite Utilities, Licenseces and Others." 
Table 40. Number of Consumere, 8ales, and Oporating Revenue by Major U.8. Investor-Owned Electrle Utility Within State, 1992 (Continued)

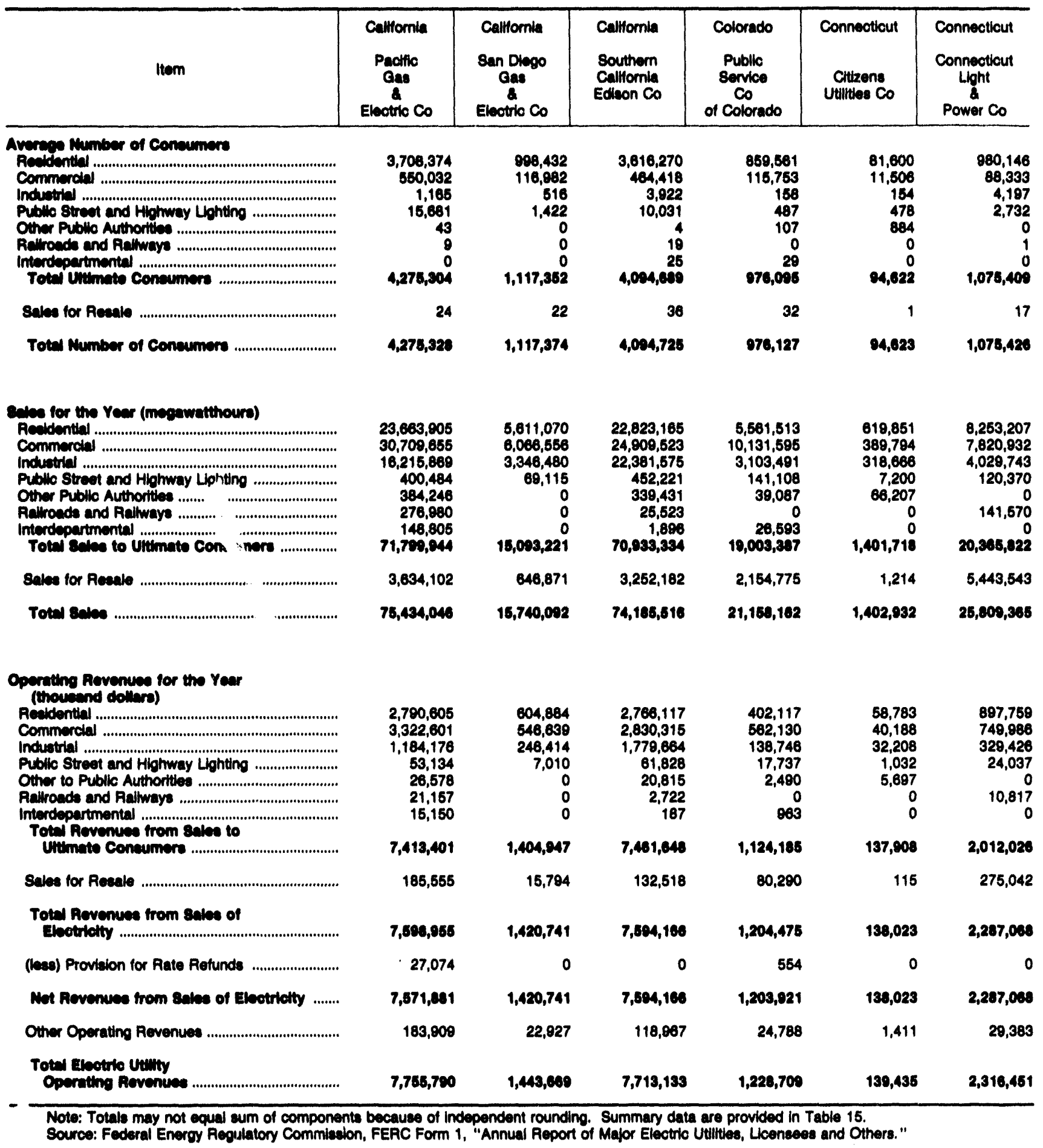


Table 40. Number of Consumers, 8ales, and Operating Rovenue by Major U.8. Investor-Owned Eleotrlo Utility Within 8tate, 1902 (Continued)

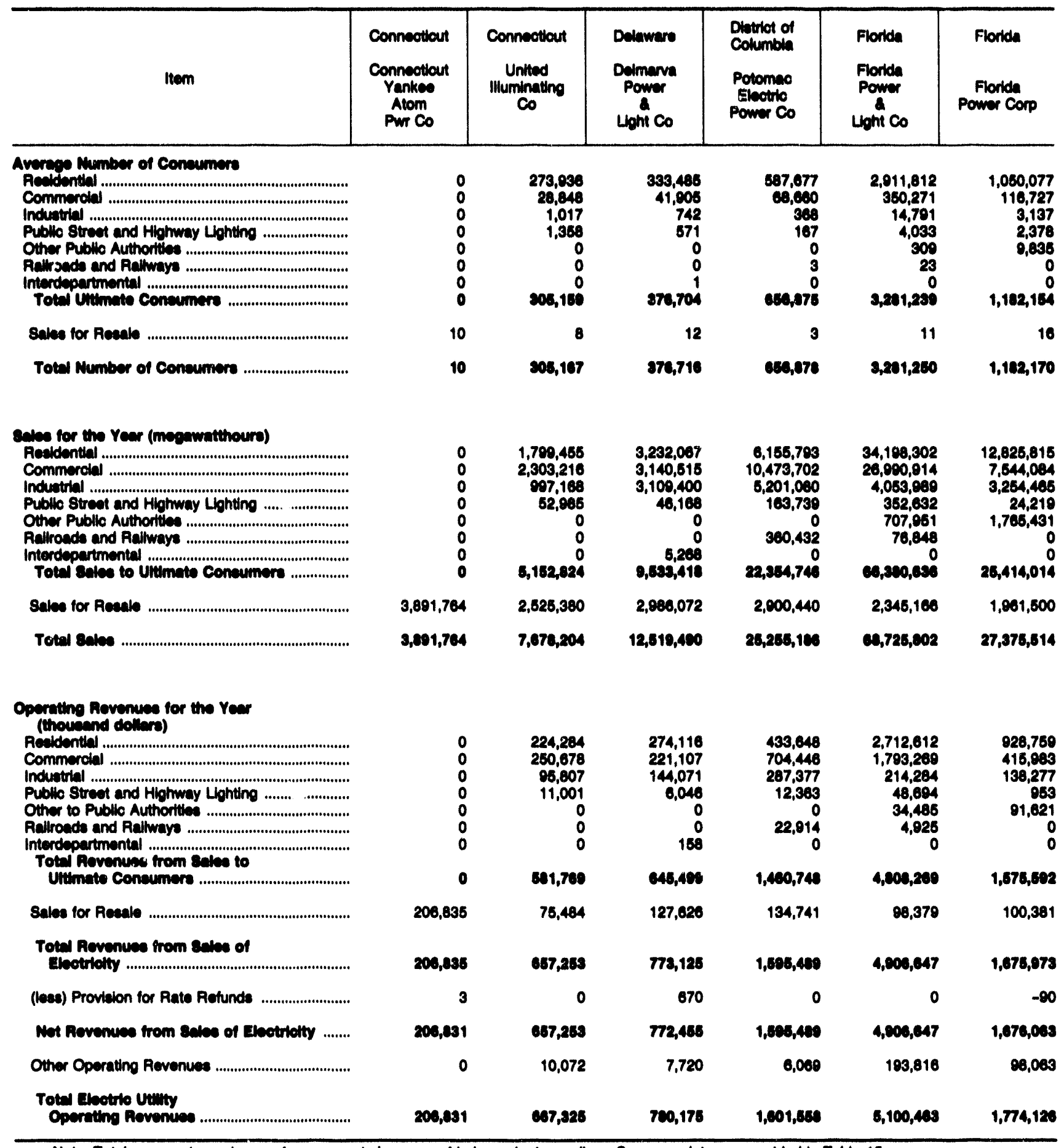

Note: Totals may not equal eum of components becauee of independent rounding. Summary data are provided in Table 15. Source: Federal Energy Regulatory Commledion, FERC Form 1. "Annual Report of Major Electric Utilties, Lleeneses and Othere." 
Table 40. Number of Consumore, sales, and Operating Rovenue by Major U.S. Inveotor-Owned Eloctric Utility Within State, 1992 (Continued)

\begin{tabular}{|c|c|c|c|c|c|c|}
\hline Item & $\begin{array}{l}\text { Florida } \\
\text { Gulf } \\
\text { Power Co }\end{array}$ & $\begin{array}{l}\text { Florida } \\
\text { Tampa } \\
\text { Electric Co }\end{array}$ & $\begin{array}{l}\text { Georgla } \\
\text { Georgla } \\
\text { Power Co }\end{array}$ & $\begin{array}{l}\text { Georgla } \\
\text { Savannah } \\
\text { Electrio } \\
\text { Power } \\
\text { Co }\end{array}$ & $\begin{array}{l}\text { Hawali } \\
\text { Hawallan } \\
\text { Electric } \\
\text { Co Inc }\end{array}$ & $\begin{array}{l}\text { Hawall } \\
\text { Maul } \\
\text { Electric } \\
\text { Co } \\
\text { Lid }\end{array}$ \\
\hline 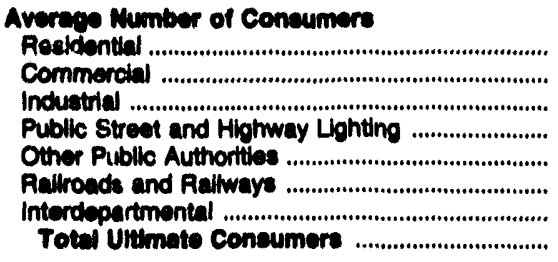 & $\begin{array}{r}266,374 \\
36,009 \\
262 \\
68 \\
0 \\
0 \\
0 \\
301,713\end{array}$ & $\begin{array}{r}412,070 \\
61,727 \\
609 \\
117 \\
3,673 \\
0 \\
0 \\
408,000\end{array}$ & $\begin{array}{r}1,408,963 \\
181,906 \\
11,636 \\
2,226 \\
0 \\
1 \\
0 \\
1,004,811\end{array}$ & $\begin{array}{r}98,389 \\
12,268 \\
73 \\
189 \\
730 \\
0 \\
0 \\
111,840\end{array}$ & $\begin{array}{r}224,418 \\
30,320 \\
478 \\
1,085 \\
0 \\
0 \\
0 \\
260,271\end{array}$ & $\begin{array}{r}42,238 \\
6,833 \\
101 \\
384 \\
0 \\
0 \\
0 \\
49,860\end{array}$ \\
\hline Sales for Resale & 6 & 0 & 4 & 0 & 0 & 0 \\
\hline Total Number of Coneumers ............................. & 301,710 & 400,060 & $1,604,816$ & 111,040 & 268,271 & 49,860 \\
\hline 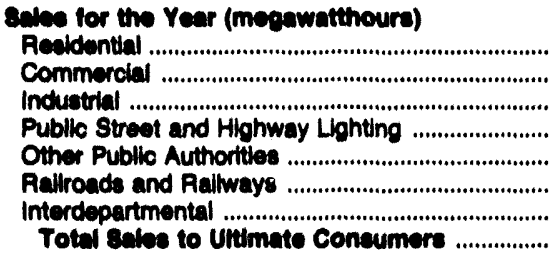 & $\begin{array}{r}3,596,515 \\
2,389,286 \\
2,179,435 \\
15,791 \\
0 \\
0 \\
868 \\
8,181,038\end{array}$ & $\begin{array}{r}5,659,833 \\
4,332,572 \\
2,625,364 \\
42,781 \\
991,218 \\
0 \\
0 \\
13,561,788\end{array}$ & $\begin{array}{r}14,939,172 \\
17,260,614 \\
22,978,312 \\
288,892 \\
0 \\
147,252 \\
0 \\
85,014,242\end{array}$ & $\begin{array}{r}1,216,993 \\
953,840 \\
861,121 \\
18,605 \\
91,665 \\
0 \\
0 \\
3,142,224\end{array}$ & $\begin{array}{r}1,730,537 \\
1,698,076 \\
3,174,873 \\
46,863 \\
0 \\
0 \\
0 \\
8,050,440\end{array}$ & $\begin{array}{r}295,148 \\
286,284 \\
304,174 \\
5,075 \\
0 \\
0 \\
0 \\
0900,601\end{array}$ \\
\hline Sales for Resale & $2,639,679$ & $2,710,038$ & $19,180,283$ & 404,688 & 0 & 0 \\
\hline 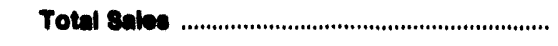 & $10,601,614$ & $16,261,796$ & $74,004,626$ & $3,840,022$ & $0,050,448$ & 890,681 \\
\hline 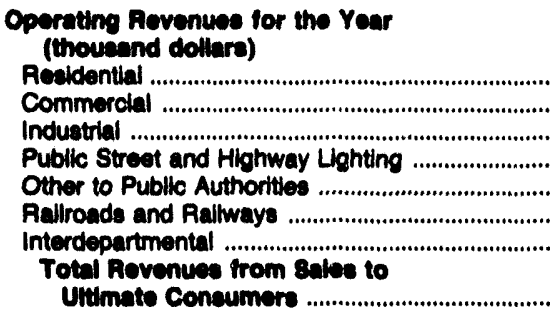 & $\begin{array}{r}235,286 \\
133,071 \\
91,320 \\
1,742 \\
0 \\
0 \\
43 \\
\\
401,471\end{array}$ & $\begin{array}{r}444,961 \\
287,422 \\
116,672 \\
7,969 \\
63,949 \\
0 \\
0 \\
\\
920,973\end{array}$ & $\begin{array}{r}1,128,396 \\
1,285,681 \\
1,083,856 \\
32,378 \\
0 \\
7,126 \\
0 \\
0 \\
3,637,437\end{array}$ & $\begin{array}{r}80,471 \\
62,965 \\
31,870 \\
2,202 \\
4,686 \\
0 \\
0 \\
\\
182,198\end{array}$ & $\begin{array}{r}171,756 \\
159,034 \\
229,609 \\
4,176 \\
0 \\
0 \\
0 \\
\\
564,574\end{array}$ & $\begin{array}{r}36,268 \\
36,836 \\
30,496 \\
549 \\
0 \\
0 \\
0 \\
104,149\end{array}$ \\
\hline Sales for Resale & 84,153 & 72,967 & 708,447 & 9,326 & 0 & 0 \\
\hline $\begin{array}{l}\text { Total Revenues from sales of } \\
\text { Eleotrletty }\end{array}$ & 685,624 & $\infty 98,020$ & $4,245,824$ & 191,621 & 684,674 & 104,140 \\
\hline 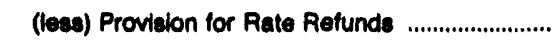 & 0 & 360 & 1,009 & 0 & 0 & 0 \\
\hline Not Rovenuse from sales of Electrletty ........ & 888,024 & 903,600 & $4,244,076$ & 191,621 & 864,674 & 104,149 \\
\hline 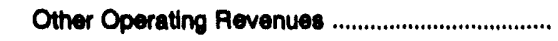 & 15,277 & 12,212 & 52,581 & 743 & 2,108 & 1,194 \\
\hline 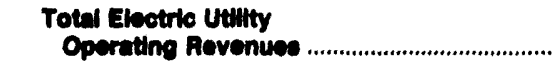 & $570, \infty 02$ & $1,005,702$ & $4,207,436$ & 192,264 & 566,602 & 105,343 \\
\hline
\end{tabular}

Note: Totale may not equal eum of components because of independent rounding. Summary data are provided in Table 15.

Source: Federal Energy Regulatory Commiseion, FERC Form 1, "Annual Report of Major Electric Utilties, Licensees and Others. " 
Table 40. Number of Consumers, Sales, and Operating Rovenue by Major U.S. Investor-Owned Electrlc Utility Within State, 1992 (Continued)

\begin{tabular}{|c|c|c|c|c|c|c|}
\hline Item & $\begin{array}{l}\text { Idaho } \\
\text { Idaho } \\
\text { Power Co }\end{array}$ & $\begin{array}{l}\text { Illinols } \\
\text { Central } \\
\text { llitinols } \\
\text { Light Co }\end{array}$ & $\begin{array}{l}\text { Illinols } \\
\text { Central } \\
\text { Illinols } \\
\text { Pub } \\
\text { Senv Co }\end{array}$ & $\begin{array}{c}\text { Illinols } \\
\text { Commonwealth } \\
\text { Edison Co }\end{array}$ & $\begin{array}{l}\text { Illinols } \\
\text { Electic } \\
\text { Energy inc }\end{array}$ & $\begin{array}{c}\text { Illinols } \\
\text { Illinols } \\
\text { Power Co }\end{array}$ \\
\hline 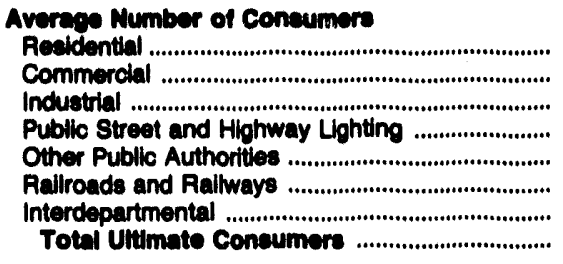 & $\begin{array}{r}250,761 \\
51,783 \\
145 \\
155 \\
0 \\
0 \\
0 \\
302,034\end{array}$ & $\begin{array}{r}167,447 \\
20,026 \\
230 \\
150 \\
80 \\
0 \\
0 \\
187,938\end{array}$ & $\begin{array}{r}286,498 \\
37,868 \\
3,628 \\
388 \\
381 \\
0 \\
1 \\
809,782\end{array}$ & $\begin{array}{r}2,885,652 \\
280,451 \\
1,518 \\
1,644 \\
10,310 \\
2 \\
0 \\
3,230,577\end{array}$ & $\begin{array}{l}0 \\
0 \\
1 \\
0 \\
0 \\
0 \\
0 \\
1\end{array}$ & $\begin{array}{r}495,948 \\
56,800 \\
421 \\
368 \\
344 \\
0 \\
0 \\
683,081\end{array}$ \\
\hline 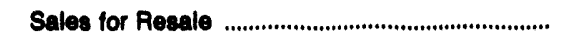 & 13 & 5 & 29 & 16 & 4 & 14 \\
\hline Total Number of Consumere .............................. & 302,047 & 187,098 & 309,701 & $3,260,698$ & 5 & 669,805 \\
\hline 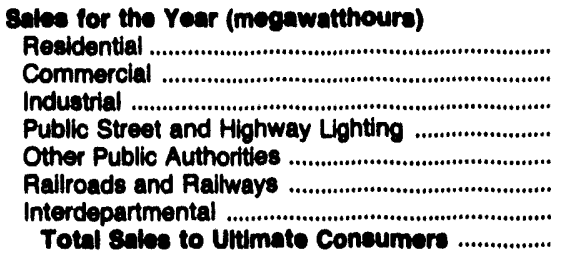 & $\begin{array}{r}3,474,325 \\
4,147,842 \\
3,864,200 \\
19,881 \\
0 \\
0 \\
0 \\
11,604,284\end{array}$ & $\begin{array}{r}1,507,811 \\
1,310,638 \\
2,119,615 \\
15,075 \\
16,752 \\
0 \\
2,375 \\
4,972,34\end{array}$ & $\begin{array}{r}2,413,202 \\
959,180 \\
3,792,800 \\
45,546 \\
115,983 \\
0 \\
1,063 \\
7,327,000\end{array}$ & $\begin{array}{r}19,269,209 \\
22,681,865 \\
22,162,859 \\
557,871 \\
6,008,762 \\
410,450 \\
0 \\
71,096,816\end{array}$ & $\begin{array}{r}0 \\
0 \\
13,583,703 \\
0 \\
0 \\
0 \\
0 \\
13,683,708\end{array}$ & $\begin{array}{r}4,137,858 \\
3,055,345 \\
8,082,700 \\
58,971 \\
251,923 \\
0 \\
0 \\
18,601,707\end{array}$ \\
\hline Sales for Resale & $1,621,469$ & 442,348 & $3,018,396$ & $4,613,825$ & $1,297,056$ & $2,868,814$ \\
\hline 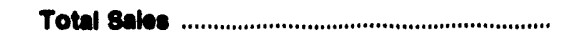 & $13,227,723$ & $8,414,714$ & $10,349,208$ & $76,670,041$ & $14,090,780$ & $18,446,611$ \\
\hline 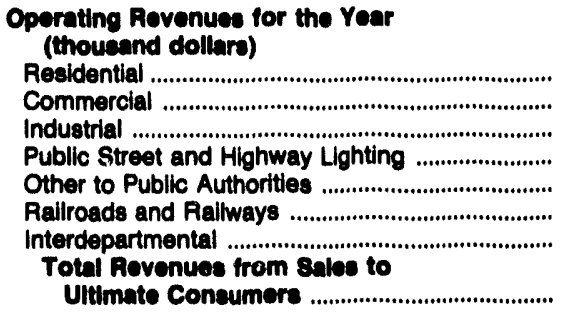 & $\begin{array}{r}168,745 \\
162,524 \\
100,490 \\
2,058 \\
0 \\
0 \\
0 \\
491,010\end{array}$ & $\begin{array}{r}108,562 \\
88,747 \\
82,122 \\
1,002 \\
1,032 \\
0 \\
187 \\
279,681\end{array}$ & $\begin{array}{r}196,423 \\
80,817 \\
197,267 \\
2,801 \\
6,788 \\
0 \\
30 \\
\\
44,225\end{array}$ & $\begin{array}{r}2,146,523 \\
1,874,393 \\
1,373,939 \\
36,641 \\
415,867 \\
27,683 \\
0 \\
\\
5,074,008\end{array}$ & $\begin{array}{r}0 \\
0 \\
244,277 \\
0 \\
0 \\
0 \\
0 \\
244,277\end{array}$ & $\begin{array}{r}434,617 \\
262,978 \\
381,358 \\
7,164 \\
17,548 \\
0 \\
0 \\
\\
1,103,686\end{array}$ \\
\hline Sales for Resale & 42,000 & 8,433 & 93,603 & 113,603 & 30,227 & 79,279 \\
\hline 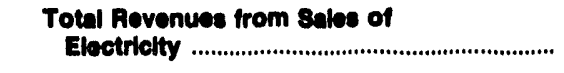 & 473,818 & 289,094 & $\mathbf{5 7 7 , 0 2 8}$ & $5, \oplus 98,690$ & 274,504 & $1,182,944$ \\
\hline 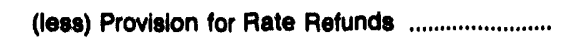 & 3,323 & 0 & $-1,646$ & 18,372 & 0 & 0 \\
\hline Net Rovenues from sales of Electilctly ....... & 470,495 & 288,044 & 679,474 & $5,970,227$ & 274,604 & $1,182,944$ \\
\hline 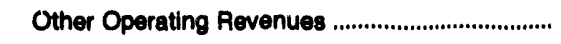 & 27,597 & 915 & 16,167 & 58,083 & 0 & 7,888 \\
\hline 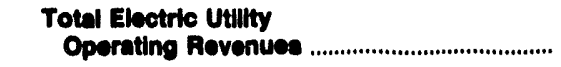 & 409,002 & 200,900 & 505,042 & $6,026,320$ & 274,604 & $1,190,832$ \\
\hline
\end{tabular}

Note: Totals may not equal sum of components because of independent rounding. Summary data are provided in Table 15.

Source: Federal Energy Regulatory Commission, FERC form 1, "Annual Report of Major Electric Utilities, Llcensees and Othere." 
Table 40. Number of Consumers, sales, and Oporating Revenue by Major U.S. Inveator-Owned Electric Utility Within State, 1992 (Continued)

\begin{tabular}{|c|c|c|c|c|c|c|}
\hline Hem & $\begin{array}{l}\text { Illinols } \\
\text { Mit } \\
\text { Carmel } \\
\text { Public } \\
\text { Utility Co }\end{array}$ & $\begin{array}{l}\text { Indiana } \\
\text { Alooa } \\
\text { Generating } \\
\text { Corp }\end{array}$ & $\begin{array}{c}\text { Indiana } \\
\text { AEP } \\
\text { Generating } \\
\text { Co }\end{array}$ & $\begin{array}{c}\text { Indiana } \\
\text { Commomwealth } \\
\text { Edison } \\
\text { Co } \\
\text { IN Inc }\end{array}$ & $\begin{array}{l}\text { Indiana } \\
\text { Indiana } \\
\text { Michigan } \\
\text { Power Co }\end{array}$ & $\begin{array}{l}\text { Indlana } \\
\text { Indianapolis } \\
\text { Power } \\
\& \\
\text { Light Co }\end{array}$ \\
\hline 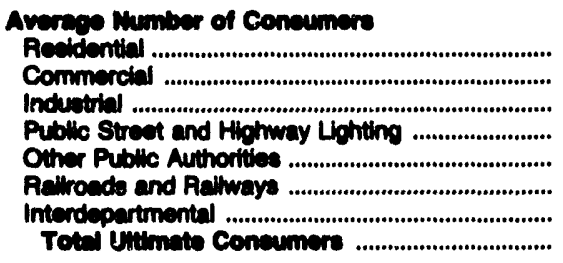 & $\begin{array}{r}4,557 \\
857 \\
137 \\
0 \\
1 \\
0 \\
0 \\
6,662\end{array}$ & $\begin{array}{l}0 \\
0 \\
1 \\
0 \\
0 \\
0 \\
0 \\
1\end{array}$ & $\begin{array}{l}0 \\
0 \\
0 \\
0 \\
0 \\
0 \\
0 \\
0\end{array}$ & $\begin{array}{l}0 \\
0 \\
0 \\
0 \\
0 \\
0 \\
0 \\
0\end{array}$ & $\begin{array}{r}458,470 \\
51,845 \\
4,859 \\
1,731 \\
386 \\
0 \\
0 \\
517,301\end{array}$ & $\begin{array}{r}349,539 \\
38,068 \\
3,069 \\
235 \\
10 \\
0 \\
0 \\
380,010\end{array}$ \\
\hline Sales for Resale & 1 & 0 & 3 & 1 & 54 & 6 \\
\hline Total Number of Coneumere .................................. & 5,653 & 1 & 3 & 1 & 517,445 & 390,025 \\
\hline 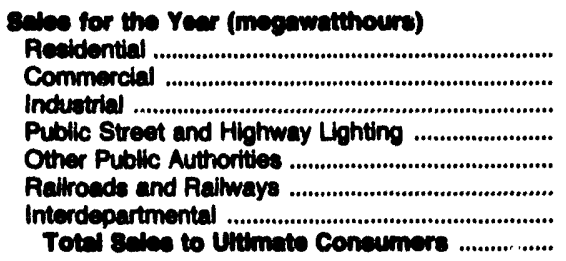 & $\begin{array}{r}43,979 \\
12,474 \\
82,977 \\
0 \\
646 \\
0 \\
0 \\
140,076\end{array}$ & $\begin{array}{r}0 \\
0 \\
5,165,612 \\
0 \\
0 \\
0 \\
0 \\
5,108,812\end{array}$ & $\begin{array}{l}0 \\
0 \\
0 \\
0 \\
0 \\
0 \\
0 \\
0\end{array}$ & $\begin{array}{l}0 \\
0 \\
0 \\
0 \\
0 \\
0 \\
0 \\
0\end{array}$ & $\begin{array}{r}4,639,779 \\
3,747,194 \\
5,684,858 \\
81,786 \\
112,332 \\
0 \\
0 \\
14,269,940\end{array}$ & $\begin{array}{r}3,675,431 \\
2,158,752 \\
5,842,684 \\
63,556 \\
12,038 \\
0 \\
0 \\
11,752,441\end{array}$ \\
\hline 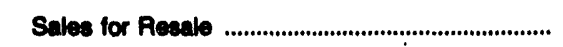 & 2,882 & 0 & $8,595,767$ & 610,165 & $11,731,440$ & 182,310 \\
\hline 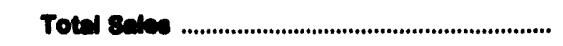 & 152,058 & $5,165,612$ & $8,595,767$ & 610,165 & $25,001,390$ & $11,044,751$ \\
\hline 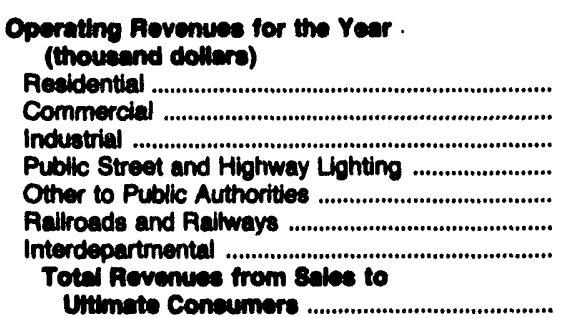 & $\begin{array}{r}2,956 \\
982 \\
5,016 \\
0 \\
31 \\
0 \\
0 \\
\\
8,994\end{array}$ & $\begin{array}{r}0 \\
0 \\
103,109 \\
0 \\
0 \\
0 \\
0 \\
103,109\end{array}$ & $\begin{array}{l}0 \\
0 \\
0 \\
0 \\
0 \\
0 \\
0 \\
0\end{array}$ & $\begin{array}{l}0 \\
0 \\
0 \\
0 \\
0 \\
0 \\
0 \\
0\end{array}$ & $\begin{array}{r}308,235 \\
228,285 \\
267,643 \\
5,911 \\
5,097 \\
0 \\
0 \\
\\
815,175\end{array}$ & $\begin{array}{r}212,757 \\
125,844 \\
243,447 \\
7,133 \\
745 \\
0 \\
0 \\
\\
689,025\end{array}$ \\
\hline Sales for Resale & 115 & 0 & 239,167 & 69,549 & 369,379 & 3,261 \\
\hline 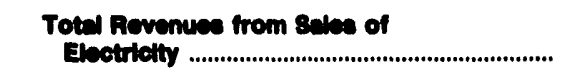 & 9,000 & 103,100 & 230,167 & 60,540 & $1,184,554$ & 593,186 \\
\hline (leas) Provision for Rate Refunds ......................... & 0 & 0 & 0 & 0 & 4,038 & 0 \\
\hline Net Rovenuse from selee of Electrictly ....... & 0,000 & 103,100 & 239,167 & 69,540 & $1,180,516$ & 503,180 \\
\hline 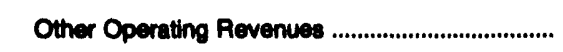 & -34 & 511 & 65 & 303 & 16,239 & 6,018 \\
\hline $\begin{array}{l}\text { Total Electric Utinty } \\
\text { Operating Rovenue .......................................... }\end{array}$ & 9,006 & 103,620 & 239,232 & 60,052 & $1,196,755$ & 500,204 \\
\hline
\end{tabular}

Note: Totals may not equal eum of components because of independent rounding. Summary data are provided in Table 15.

Source: Federal Energy Regulatory Commiseion, FERC Form 1, "Annual Report of Major Electric Utiltites, Licensees and Others." 
Table 40. Number of Consumere, Sales, and Operating Revenue by Major U.S. Investor-Owned Electric Utility Within State, 1992 (Continued)

\begin{tabular}{|c|c|c|c|c|c|c|}
\hline Item & $\begin{array}{l}\text { Indiana } \\
\text { Northern } \\
\text { Indiana } \\
\text { Pub Sern } \\
\text { Co }\end{array}$ & $\begin{array}{c}\text { Indiana } \\
\text { PSI } \\
\text { Energy inc }\end{array}$ & $\begin{array}{l}\text { Indians } \\
\text { Southern } \\
\text { Indiana Gas } \\
\& \text { Elec Co }\end{array}$ & $\begin{array}{c}\text { lowa } \\
\text { Interstate } \\
\text { Power Co }\end{array}$ & $\begin{array}{c}\text { lowa } \\
\text { lowa } \\
\text { Electric } \\
\text { Light \& Power } \\
\text { Co }\end{array}$ & $\begin{array}{l}\text { lowa } \\
\text { lowa } \\
\text { Southem } \\
\text { Utillies } \\
\text { Co }\end{array}$ \\
\hline 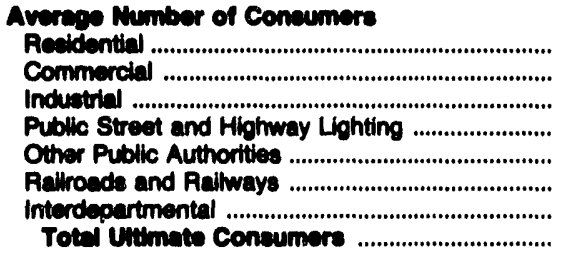 & $\begin{array}{r}344,861 \\
40,034 \\
2,513 \\
280 \\
534 \\
1 \\
0 \\
300,223\end{array}$ & $\begin{array}{r}530,920 \\
72,274 \\
2,990 \\
1,214 \\
75 \\
0 \\
0 \\
607,473\end{array}$ & $\begin{array}{r}101,547 \\
14,316 \\
183 \\
19 \\
0 \\
0 \\
0 \\
116,085\end{array}$ & $\begin{array}{r}126,936 \\
30,608 \\
627 \\
270 \\
642 \\
0 \\
0 \\
160,292\end{array}$ & $\begin{array}{r}180,771 \\
30,608 \\
399 \\
280 \\
2 \\
0 \\
0 \\
212,070\end{array}$ & $\begin{array}{r}81,656 \\
12,685 \\
386 \\
126 \\
0 \\
0 \\
0 \\
94,863\end{array}$ \\
\hline 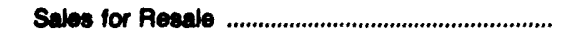 & 14 & 30 & 4 & 34 & 42 & 8 \\
\hline Total Number of Coneumere .................................. & 368,237 & 607,503 & 116,069 & 150,316 & 212,112 & 94,871 \\
\hline 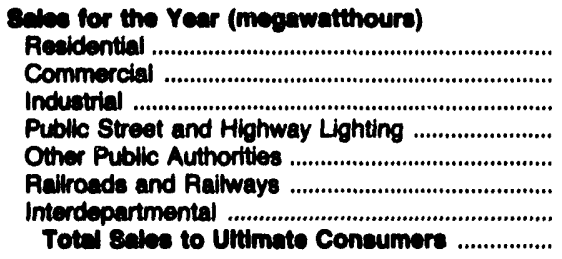 & $\begin{array}{r}2,343,303 \\
2,608,614 \\
8,188,605 \\
52,609 \\
26,252 \\
12,785 \\
38,838 \\
13,271,106\end{array}$ & $\begin{array}{r}5,942,542 \\
5,121,009 \\
8,337,995 \\
59,038 \\
179 \\
0 \\
0 \\
19,460,853\end{array}$ & $\begin{array}{r}1,119,517 \\
1,044,824 \\
1,768,194 \\
18,587 \\
0 \\
0 \\
2,055 \\
3,063,100\end{array}$ & $\begin{array}{r}831,848 \\
776,522 \\
2,766,359 \\
20,177 \\
39,508 \\
0 \\
475 \\
4,534,839\end{array}$ & $\begin{array}{r}1,434,268 \\
1,342,627 \\
1,452,328 \\
35,873 \\
8,835 \\
0 \\
0 \\
4,274,032\end{array}$ & $\begin{array}{r}734,242 \\
433,998 \\
1,171,577 \\
15,435 \\
0 \\
0 \\
5,909 \\
2,381,182\end{array}$ \\
\hline Sales for Resule & $1,162,005$ & $6,290,210$ & $1,265,296$ & 269,417 & $1,397,746$ & 170,585 \\
\hline 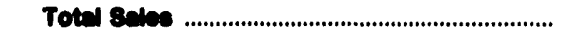 & $14,433,111$ & $25,751,083$ & $5,218,476$ & $4,804,256$ & $5,672,677$ & $2,631,747$ \\
\hline 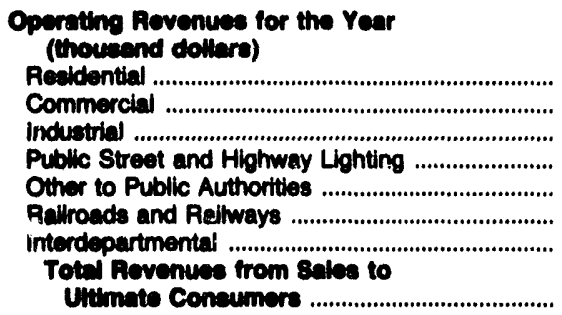 & $\begin{array}{r}240,680 \\
227,707 \\
397,859 \\
8,085 \\
2,297 \\
1,130 \\
2,634 \\
800,392\end{array}$ & $\begin{array}{r}354,975 \\
238,668 \\
293,688 \\
7,248 \\
22 \\
0 \\
0 \\
\\
894,602\end{array}$ & $\begin{array}{r}73,739 \\
58,098 \\
69,191 \\
1,867 \\
0 \\
0 \\
115 \\
203,008\end{array}$ & $\begin{array}{r}66,711 \\
50,012 \\
106,485 \\
2,578 \\
1,850 \\
0 \\
31 \\
227,687\end{array}$ & $\begin{array}{r}145,150 \\
106,458 \\
68,476 \\
3,920 \\
452 \\
0 \\
0 \\
324,468\end{array}$ & $\begin{array}{r}38,022 \\
22,200 \\
38,759 \\
1,151 \\
0 \\
0 \\
41 \\
100,174\end{array}$ \\
\hline Sales for Resele & 29,697 & 146,507 & 40,916 & 9,828 & 28,014 & 18,063 \\
\hline $\begin{array}{l}\text { Total Rovenues from sales of } \\
\text { Ebetrletty }\end{array}$ & 910,089 & $1,041,100$ & 243,024 & 237,495 & 352,471 & 110,137 \\
\hline 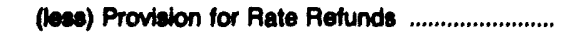 & 0 & $-6,776$ & 1,812 & 3,835 & 8,218 & 4,046 \\
\hline Not Revenues from sales of Ebetriletty ........ & 910,009 & $1,047,895$ & 242,012 & 233,660 & 344,252 & 116,001 \\
\hline 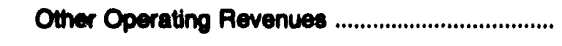 & 6,046 & 24,298 & 1,085 & 5,533 & 1,039 & 2,617 \\
\hline $\begin{array}{l}\text { Totwl Electrle Utilty } \\
\text { Operating Rovenues .......................................... }\end{array}$ & 916,135 & $1,072,183$ & 243,077 & 230,193 & 345,201 & 117,708 \\
\hline
\end{tabular}

Note: Totals may not equal sum of components because of independent rounding. Summary data are provided in Table 15.

Source: Federal Energy Regulatory Commission, FERC Form 1, "Annual Report of Major Electric Utilties, Licensees and Others." 
Table 40. Number of Consumers, Sales, and Operating Revenue by Major U.S. Investor-Owned Electric Utility Within State, 1992 (Continued)

\begin{tabular}{|c|c|c|c|c|c|c|}
\hline Item & $\begin{array}{c}\text { lowa } \\
\text { lowa- } \\
\text { Illinois } \\
\text { GaseElectric } \\
\text { Co }\end{array}$ & $\begin{array}{l}\text { Lowa } \\
\text { Midwest } \\
\text { Power } \\
\text { Systems } \\
\text { Inc }\end{array}$ & $\begin{array}{c}\text { Kansas } \\
\text { Kansas } \\
\text { Gas } \\
\& \\
\text { Electric Co }\end{array}$ & $\begin{array}{c}\text { Kansas } \\
\text { Weatern } \\
\text { Resources } \\
\text { Inc }\end{array}$ & $\begin{array}{l}\text { Kentucky } \\
\text { Kentucky } \\
\text { Power Co }\end{array}$ & $\begin{array}{l}\text { Kentucky } \\
\text { Kentucky } \\
\text { Utilities Co }\end{array}$ \\
\hline 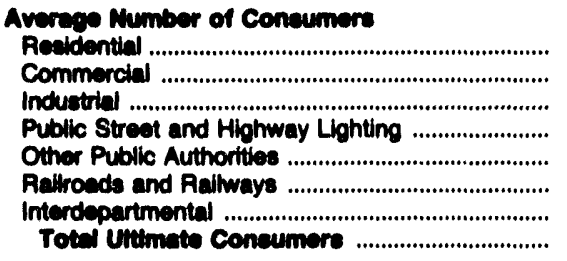 & $\begin{array}{r}175,591 \\
20,257 \\
75 \\
75 \\
626 \\
0 \\
0 \\
196,624\end{array}$ & $\begin{array}{r}358,018 \\
51,231 \\
758 \\
338 \\
4,168 \\
0 \\
0 \\
414,613\end{array}$ & $\begin{array}{r}238,286 \\
22,840 \\
4,149 \\
0 \\
0 \\
0 \\
0 \\
285,275\end{array}$ & $\begin{array}{r}272,342 \\
38,490 \\
1,811 \\
0 \\
0 \\
0 \\
0 \\
312,643\end{array}$ & $\begin{array}{r}133,640 \\
21,136 \\
1,732 \\
408 \\
0 \\
0 \\
0 \\
187,116\end{array}$ & $\begin{array}{r}356,287 \\
58,685 \\
2,068 \\
1,327 \\
6,010 \\
0 \\
0 \\
426,377\end{array}$ \\
\hline Sales for Resale & 33 & 75 & 39 & 46 & 25 & 26 \\
\hline 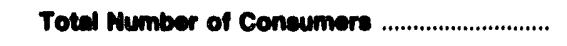 & 194,657 & 914,680 & 286,314 & 312,600 & 167,141 & 425,403 \\
\hline 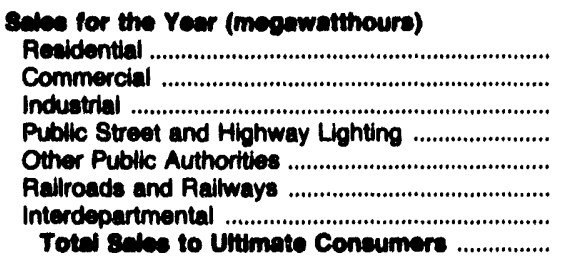 & $\begin{array}{r}1,142,078 \\
1,268,117 \\
2,056,172 \\
28,377 \\
94,696 \\
0 \\
0 \\
4,680,440\end{array}$ & $\begin{array}{r}2,856,489 \\
2,617,781 \\
2,837,041 \\
70,791 \\
256,140 \\
0 \\
20,440 \\
8,858,692\end{array}$ & $\begin{array}{r}2,101,531 \\
1,892,382 \\
3,217,968 \\
45,399 \\
0 \\
0 \\
0 \\
7,207,270\end{array}$ & $\begin{array}{r}2,239,172 \\
3,008,341 \\
1,967,969 \\
57,172 \\
0 \\
0 \\
115 \\
7,270,201\end{array}$ & $\begin{array}{r}1,888,021 \\
991,361 \\
2,819,176 \\
9,185 \\
0 \\
0 \\
0 \\
5,705,743\end{array}$ & $\begin{array}{r}4,278,086 \\
3,080,045 \\
4,070,145 \\
62,751 \\
1,060,743 \\
0 \\
0 \\
12,681,702\end{array}$ \\
\hline$x_{1}$ & $1,301,449$ & $5,085,036$ & $1,249,113$ & $2,037,431$ & $4,104,779$ & $2,307,172$ \\
\hline Total sales & $5,890,880$ & $13,943,718$ & $8,636,391$ & $0,307,722$ & $9,810,522$ & $14,860,084$ \\
\hline 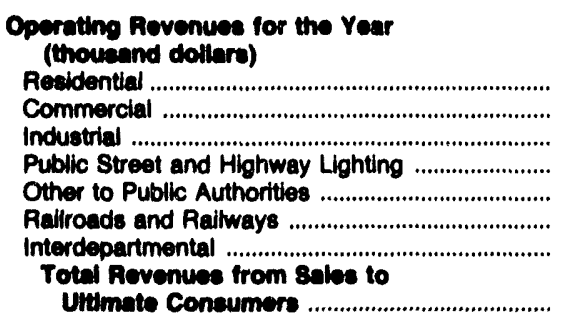 & $\begin{array}{r}99,547 \\
85,973 \\
87,582 \\
2,598 \\
5,554 \\
0 \\
0 \\
\\
281,255\end{array}$ & $\begin{array}{r}246,081 \\
151,846 \\
112,909 \\
9,019 \\
13,100 \\
0 \\
1,000 \\
\\
533,964\end{array}$ & $\begin{array}{r}194,142 \\
154,005 \\
174,226 \\
5,835 \\
0 \\
0 \\
0 \\
\\
528,207\end{array}$ & $\begin{array}{r}144,434 \\
152,079 \\
81,330 \\
3,959 \\
0 \\
0 \\
9 \\
301,811\end{array}$ & $\begin{array}{r}96,657 \\
53,647 \\
97,917 \\
799 \\
0 \\
0 \\
0 \\
\\
240,921\end{array}$ & $\begin{array}{r}194,817 \\
133,519 \\
139,503 \\
4,801 \\
40,769 \\
0 \\
0 \\
813,410\end{array}$ \\
\hline Sales for Resale & 20,748 & 86,232 & 28,198 & 75,382 & 61,360 & 58,978 \\
\hline 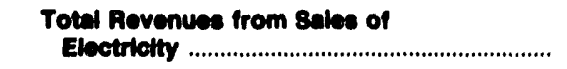 & 302,004 & 620,196 & 568,408 & 467,193 & 310,281 & 572,300 \\
\hline 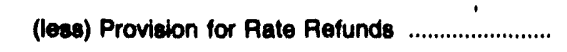 & 0 & 4,948 & 0 & 0 & 0 & 143 \\
\hline Not Rovenues from sales of Electrictly ....... & 302,004 & 615,247 & 566,408 & 467,103 & 310,281 & 572,240 \\
\hline 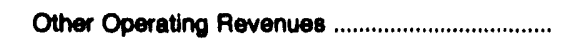 & 10,683 & 8,113 & $-4,160$ & 1,488 & 2,935 & 3,676 \\
\hline 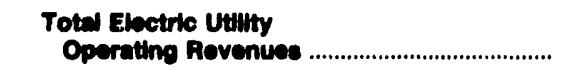 & 312,687 & 623,380 & 652,246 & 464,602 & 313,216 & 676,021 \\
\hline
\end{tabular}

Note: Totals may not equal sum of components because of independent rounding. Summary data are provided in Table 15. Source: Federal Energy Regulatory Commission, FERC Form 1, "Annual Report of Major Electric Utilities, Licensees and Others." 
Table 40. Number of Consumere, Sales, and Operating Rovenue by Major U.S. Investor-Owned Electric Utility Within State, 1992 (Continued)

\begin{tabular}{|c|c|c|c|c|c|c|}
\hline Itom & $\begin{array}{l}\text { Kentucky } \\
\text { Louteville } \\
\text { Gas } \\
\text { Electric Co }\end{array}$ & $\begin{array}{l}\text { Kentucky } \\
\text { Union Loht } \\
\text { Heat \& Power } \\
\text { Co }\end{array}$ & $\begin{array}{l}\text { Louldiana } \\
\text { Contral } \\
\text { Louidiana } \\
\text { Elec } \\
\text { Co Inc }\end{array}$ & $\begin{array}{c}\text { Loulaiana } \\
\text { Loulalana } \\
\text { Power } \\
\text { Light Co }\end{array}$ & $\begin{array}{l}\text { Loulalane } \\
\text { New Orleans } \\
\text { Publle } \\
\text { Service Inc }\end{array}$ & $\begin{array}{l}\text { Louldiana } \\
\text { Southweatern } \\
\text { Electric } \\
\text { Power Co }\end{array}$ \\
\hline 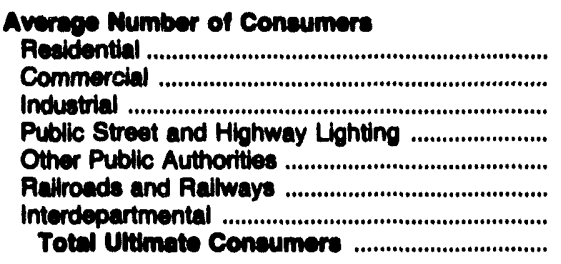 & $\begin{array}{r}292,084 \\
33,474 \\
340 \\
3,244 \\
2,014 \\
0 \\
0 \\
391,180\end{array}$ & $\begin{array}{r}96,723 \\
10,110 \\
412 \\
101 \\
781 \\
0 \\
0 \\
108,127\end{array}$ & $\begin{array}{r}178,981 \\
23,648 \\
761 \\
97 \\
4,848 \\
0 \\
0 \\
208,336\end{array}$ & $\begin{array}{r}522,641 \\
60,145 \\
6,168 \\
1,492 \\
2,853 \\
0 \\
0 \\
698,297\end{array}$ & $\begin{array}{r}170,621 \\
16,682 \\
814 \\
404 \\
1,181 \\
0 \\
0 \\
189,082\end{array}$ & $\begin{array}{r}323,477 \\
44,907 \\
5,681 \\
202 \\
2,426 \\
0 \\
0 \\
376,603\end{array}$ \\
\hline 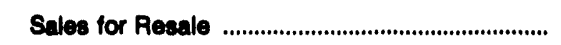 & 12 & 1 & 11 & 2 & 1 & 20 \\
\hline Total Number of Conoumere .............................. & 331,168 & 108,128 & 200,346 & 608,200 & 189,003 & 376,713 \\
\hline 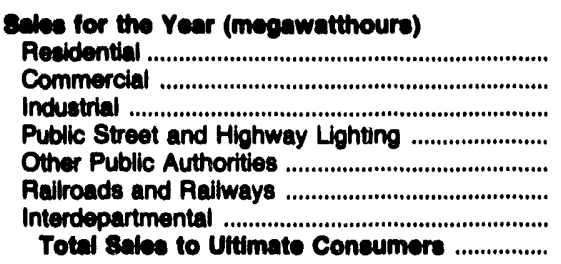 & $\begin{array}{r}2,923,517 \\
2,635,271 \\
2,671,212 \\
63,613 \\
941,298 \\
0 \\
0 \\
9,294,911\end{array}$ & $\begin{array}{r}1,028,082 \\
730,497 \\
769,507 \\
13,805 \\
264,284 \\
0 \\
906 \\
2,007,171\end{array}$ & $\begin{array}{r}2,353,449 \\
1,061,478 \\
1,971,698 \\
24,778 \\
451,809 \\
0 \\
0 \\
5,803,212\end{array}$ & $\begin{array}{r}6,986,327 \\
4,307,236 \\
15,012,465 \\
111,036 \\
274,288 \\
0 \\
0 \\
29,701,341\end{array}$ & $\begin{array}{r}1,805,611 \\
1,876,686 \\
457,309 \\
54,113 \\
833,451 \\
0 \\
2,552 \\
5,129,022\end{array}$ & $\begin{array}{r}3,702,277 \\
3,039,055 \\
5,861,740 \\
143,405 \\
229,693 \\
0 \\
0 \\
12,070,170\end{array}$ \\
\hline 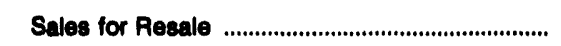 & $3,234,758$ & 49,108 & 234,588 & $1,305,067$ & 404,823 & $3,854,183$ \\
\hline 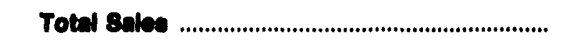 & $12,469,600$ & $2,050,279$ & $6,007,810$ & $20,006,400$ & $5,534,446$ & $16,030,363$ \\
\hline 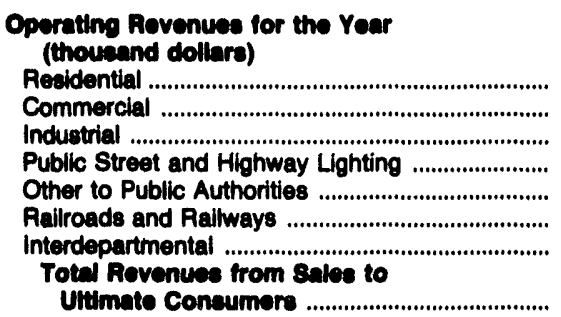 & $\begin{array}{r}174,559 \\
146,224 \\
101,699 \\
5,495 \\
44,104 \\
0 \\
0 \\
\\
472,082\end{array}$ & $\begin{array}{r}64,000 \\
43,475 \\
34,650 \\
1,065 \\
13,684 \\
0 \\
43 \\
168,916\end{array}$ & $\begin{array}{r}156,078 \\
65,551 \\
80,346 \\
1,373 \\
26,004 \\
0 \\
0 \\
\\
320,352\end{array}$ & $\begin{array}{r}518,255 \\
320,687 \\
578,741 \\
11,476 \\
16,304 \\
0 \\
0 \\
1,446,464\end{array}$ & $\begin{array}{r}137,668 \\
160,229 \\
23,860 \\
4,444 \\
51,579 \\
0 \\
129 \\
\\
377,000\end{array}$ & $\begin{array}{r}249,182 \\
165,836 \\
243,508 \\
11,860 \\
11,136 \\
0 \\
0 \\
\\
691,622\end{array}$ \\
\hline 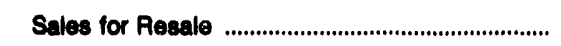 & 46,698 & 1,636 & 5,364 & 38,632 & 10,320 & 79,390 \\
\hline 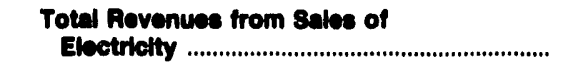 & 517,780 & 168,562 & 334,716 & $1,494,008$ & 389,229 & 760,012 \\
\hline (less) Provision for Rate Refunds ........................ & 0 & 0 & 0 & 0 & 0 & 576 \\
\hline Not Rovenuse from sales of Ebetricity ....... & $, 517,780$ & 168,562 & 334,716 & $1,404,008$ & 328,220 & 760,336 \\
\hline 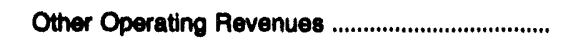 & 3,889 & 1,137 & 16,897 & 69,649 & 3,992 & 18,102 \\
\hline $\begin{array}{l}\text { Total Electric Utility } \\
\text { Operating Rovenued ....................................... }\end{array}$ & 521,670 & 159,800 & 351,613 & $1,653,745$ & 392,221 & 778,430 \\
\hline
\end{tabular}

Note: Totals may not equal sum of components because of independent rounding. Summary data are provided in Table 15.

Source: Federal Energy Regulatory Commiselon, FERC Form 1, "Annual Report of Major Electric Utilities, Licensees and Others." 
Table 40. Number of Consumere, Sales, and Operating Revenue by Major U.S. Inveator-Owned Electrlc Utility Within State, 1992 (Continued)

\begin{tabular}{|c|c|c|c|c|c|c|}
\hline Item & $\begin{array}{l}\text { Maino } \\
\text { Bangor } \\
\text { Hydro- } \\
\text { Electric } \\
\text { Co }\end{array}$ & $\begin{array}{l}\text { Maine } \\
\text { Contral } \\
\text { Maine } \\
\text { Power } \\
\text { Co }\end{array}$ & $\begin{array}{l}\text { Maine } \\
\text { Maine } \\
\text { Electric } \\
\text { Power } \\
\text { Co Inc }\end{array}$ & $\begin{array}{l}\text { Maine } \\
\text { Maine } \\
\text { Publlc } \\
\text { Service } \\
\text { Co }\end{array}$ & $\begin{array}{c}\text { Maine } \\
\text { Maine } \\
\text { Yankee } \\
\text { Alomic } \\
\text { Power Co }\end{array}$ & $\begin{array}{c}\text { Maryland } \\
\text { Baltimore } \\
\text { Gas } \\
\& \\
\text { Electric Co }\end{array}$ \\
\hline 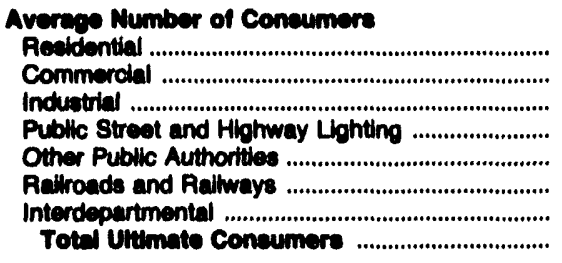 & $\begin{array}{r}85,613 \\
12,421 \\
1,199 \\
16,108 \\
95 \\
0 \\
0 \\
116,434\end{array}$ & $\begin{array}{r}446,698 \\
49,405 \\
124 \\
441 \\
0 \\
0 \\
0 \\
409,948\end{array}$ & $\begin{array}{l}0 \\
0 \\
0 \\
0 \\
0 \\
0 \\
0 \\
0\end{array}$ & $\begin{array}{r}28,102 \\
5,261 \\
15 \\
1,113 \\
8 \\
0 \\
0 \\
34,400\end{array}$ & $\begin{array}{l}0 \\
0 \\
0 \\
0 \\
0 \\
0 \\
0 \\
0\end{array}$ & $\begin{array}{r}949,268 \\
94,862 \\
7,866 \\
101 \\
0 \\
1 \\
0 \\
1,052,009\end{array}$ \\
\hline Sales for Resale & 16 & 6 & 3 & 7 & 38 & 0 \\
\hline 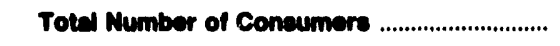 & 115,440 & 408,672 & 3 & 34,600 & 39 & $1,052,098$ \\
\hline 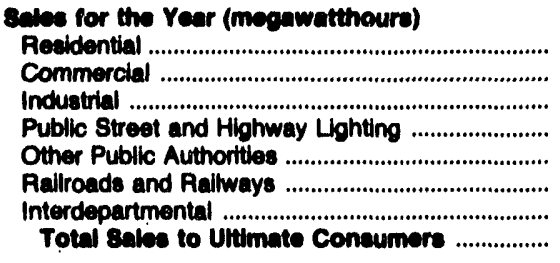 & $\begin{array}{r}515,381 \\
143,800 \\
849,004 \\
9,768 \\
56,585 \\
0 \\
0 \\
1,674,628\end{array}$ & $\begin{array}{r}2,989,402 \\
2,365,898 \\
3,672,096 \\
35,682 \\
0 \\
0 \\
0 \\
9,002,976\end{array}$ & $\begin{array}{l}0 \\
0 \\
0 \\
0 \\
0 \\
0 \\
0 \\
0\end{array}$ & $\begin{array}{r}176,814 \\
155,267 \\
129,981 \\
3,402 \\
58,388 \\
0 \\
0 \\
523,852\end{array}$ & $\begin{array}{l}0 \\
0 \\
0 \\
0 \\
0 \\
0 \\
0 \\
0\end{array}$ & $\begin{array}{r}9,677,272 \\
2,500,060 \\
12,787,877 \\
157,270 \\
0 \\
110,608 \\
74,345 \\
25,307,432\end{array}$ \\
\hline Sales for Resale & 122,887 & 438,171 & 341,711 & 132,902 & $5,342,773$ & $3,179,408$ \\
\hline 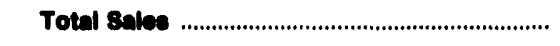 & $1,097,416$ & $0,001,140$ & 341,711 & 659,754 & $6,342,773$ & $28,486,040$ \\
\hline 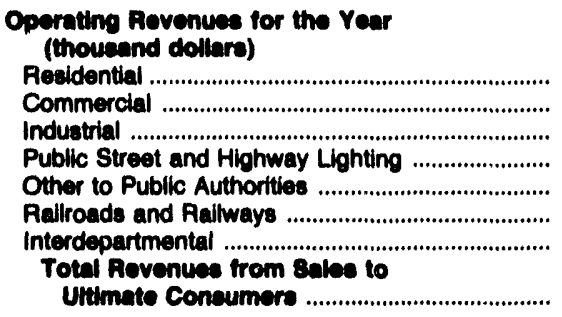 & $\begin{array}{r}65,934 \\
17,539 \\
69,633 \\
1,022 \\
5,616 \\
0 \\
0 \\
180,544\end{array}$ & $\begin{array}{r}335,152 \\
216,460 \\
241,928 \\
9,312 \\
0 \\
0 \\
0\end{array}$ & $\begin{array}{l}0 \\
0 \\
0 \\
0 \\
0 \\
0 \\
0\end{array}$ & $\begin{array}{r}18,705 \\
13,788 \\
8,891 \\
762 \\
3,762 \\
0 \\
0\end{array}$ & $\begin{array}{l}0 \\
0 \\
0 \\
0 \\
0 \\
0 \\
0\end{array}$ & $\begin{array}{r}837,350 \\
215,108 \\
788,643 \\
26,908 \\
0 \\
6,833 \\
2,394 \\
\\
1,077,236\end{array}$ \\
\hline 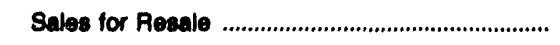 & 14,762 & 10,426 & 8,411 & 7,655 & 187,259 & 64,323 \\
\hline $\begin{array}{l}\text { Total Rovenues from sales of } \\
\text { Eleotriclty }\end{array}$ & 176,29 & 821,280 & 8,411 & 63,662 & 187,280 & $1,041,660$ \\
\hline 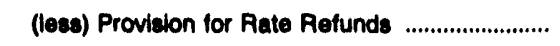 & 0 & $-2,417$ & 0 & 0 & 0 & 0 \\
\hline Net Rovenues from salee of Elsotriclty ....... & 176,296 & $\mathbf{8 2 3 , 6 8 0}$ & 8,411 & 63,862 & 197,260 & $1,041,650$ \\
\hline 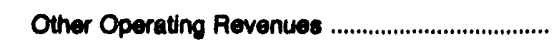 & 2,017 & 48,717 & 3,197 & 2,893 & 0 & 26,364 \\
\hline $\begin{array}{l}\text { Total Eleotrle Utilly } \\
\text { Opernitung Rovenues }\end{array}$ & 177,313 & 872,403 & 11,605 & $\mathbf{6 9 , 4 6 5}$ & 187,260 & $1,987,923$ \\
\hline
\end{tabular}

Note: Totals may not equal sum of components because of independent rounding. Summary data are provided in Table 15. Source: Federal Energy Regulatory Commisaion, FERC Form 1. "Annual Report of Major Electric Utillties, Llcensees and Others." 
Table 40. Number of Consumers, Sales, and Operating Rovenue by Major U.S. Investor-Owned Electric Utility Within State, 1992 (Continued)

\begin{tabular}{|c|c|c|c|c|c|c|}
\hline Item & $\begin{array}{l}\text { Maryland } \\
\text { Potomac } \\
\text { Edieon Co }\end{array}$ & $\begin{array}{l}\text { Massachusetts } \\
\text { Boston } \\
\text { Edileon Co }\end{array}$ & $\begin{array}{c}\text { Masaschusetts } \\
\text { Cambridge } \\
\text { Electric } \\
\text { Light Co }\end{array}$ & $\begin{array}{c}\text { Maseachusetts } \\
\text { Canal } \\
\text { Electric Co }\end{array}$ & $\begin{array}{c}\text { Massachusetts } \\
\text { Commonwealth } \\
\text { Eloctric Co }\end{array}$ & $\begin{array}{l}\text { Massachusetts } \\
\text { Eastorn } \\
\text { Edison Co }\end{array}$ \\
\hline 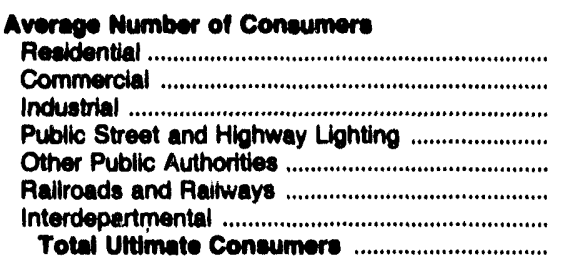 & $\begin{array}{r}299,415 \\
38,939 \\
4,352 \\
483 \\
0 \\
0 \\
0 \\
343,180\end{array}$ & $\begin{array}{r}661,838 \\
80,605 \\
1,720 \\
2,816 \\
0 \\
1 \\
0 \\
867,000\end{array}$ & $\begin{array}{r}37,450 \\
6,513 \\
120 \\
276 \\
355 \\
0 \\
0 \\
44,714\end{array}$ & $\begin{array}{l}0 \\
0 \\
0 \\
0 \\
0 \\
0 \\
0 \\
0\end{array}$ & $\begin{array}{r}266,513 \\
34,348 \\
322 \\
830 \\
2,367 \\
0 \\
0 \\
304,300\end{array}$ & $\begin{array}{r}154,280 \\
20,036 \\
627 \\
23 \\
0 \\
0 \\
0 \\
174,206\end{array}$ \\
\hline 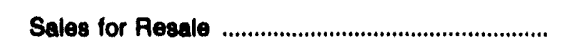 & 29 & 26 & 2 & 6 & 3 & 0 \\
\hline Total Mumber of Consumers .............................. & 343,210 & 857,106 & 44,716 & 6 & 304,303 & 174,696 \\
\hline 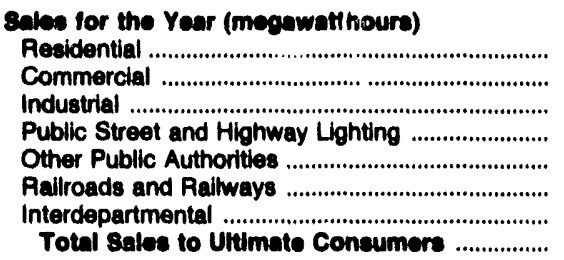 & $\begin{array}{r}3,822,387 \\
1,854,025 \\
4,979,219 \\
22,118 \\
0 \\
0 \\
0 \\
10,777,740\end{array}$ & $\begin{array}{r}3,424,275 \\
7,202,580 \\
1,678,242 \\
133,052 \\
0 \\
159,458 \\
0 \\
12,507,607\end{array}$ & $\begin{array}{r}146,176 \\
860,041 \\
89,021 \\
8,262 \\
94,813 \\
0 \\
0 \\
1,294,313\end{array}$ & $\begin{array}{l}0 \\
0 \\
0 \\
0 \\
0 \\
0 \\
0 \\
0\end{array}$ & $\begin{array}{r}1,584,219 \\
1,021,038 \\
326,077 \\
14,842 \\
259,860 \\
0 \\
0 \\
3,206,086\end{array}$ & $\begin{array}{r}1,023,542 \\
1,114,702 \\
304,850 \\
15,399 \\
0 \\
0 \\
0 \\
2,468,593\end{array}$ \\
\hline Sales for Resale & $5,988,599$ & $4,415,306$ & 254,348 & $5,49 \theta, 090$ & 891,954 & 0 \\
\hline Total Sales & $16,766,340$ & $17,012,013$ & $1,652,681$ & $5,400,000$ & $4,197,090$ & $2,468,693$ \\
\hline 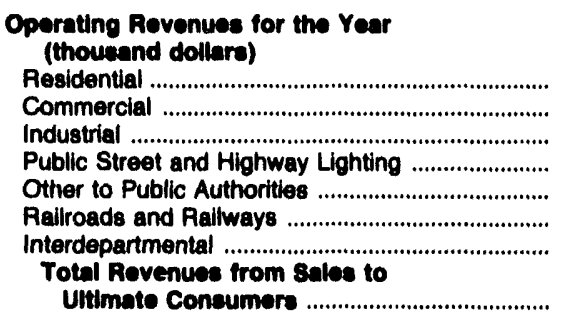 & $\begin{array}{r}243,412 \\
111,506 \\
157,304 \\
3,021 \\
0 \\
0 \\
0 \\
\\
515,243\end{array}$ & $\begin{array}{r}371,098 \\
658,060 \\
137,023 \\
21,870 \\
0 \\
10,971 \\
0 \\
0 \\
1,199,023\end{array}$ & $\begin{array}{r}16,149 \\
71,181 \\
6,420 \\
1,408 \\
7,065 \\
0 \\
0 \\
102,224\end{array}$ & $\begin{array}{l}0 \\
0 \\
0 \\
0 \\
0 \\
0 \\
0\end{array}$ & $\begin{array}{r}208,667 \\
113,626 \\
29,606 \\
3,786 \\
26,343 \\
0 \\
0 \\
301,928\end{array}$ & $\begin{array}{r}112,789 \\
105,867 \\
29,081 \\
2,883 \\
0 \\
0 \\
0 \\
250,710\end{array}$ \\
\hline Sales for Resale . & 163,141 & 182,584 & 8,852 & 216,932 & 22,252 & 0 \\
\hline $\begin{array}{l}\text { Total Revenues from 8ales of } \\
\text { Electrictiy }\end{array}$ & 670,384 & $1,361,607$ & 111,078 & 216,032 & 404,180 & 250,719 \\
\hline 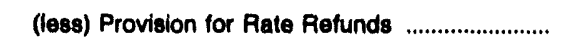 & 8 & 2,743 & 1,083 & 3,793 & 0 & 0 \\
\hline Not Rovenues from salos of Electrictty ....... & 678,376 & $1,378,864$ & 109,903 & 213,130 & 404,180 & 250,710 \\
\hline 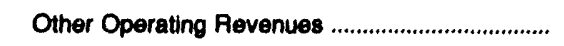 & 8,510 & 27,606 & 2,966 & 8,528 & 5,313 & 2,295 \\
\hline $\begin{array}{l}\text { Total Electric Utility } \\
\text { Operating Rovenues }\end{array}$ & 607,086 & $1,406,680$ & 112,948 & 221,085 & 400,493 & 263,014 \\
\hline
\end{tabular}

Note: Totals may not equal sum of components because of independent rounding. Summary data are provided in Table 15. Source; Federal Energy Regulatory Commisston, FERC Form 1. "Annual Report of Major Electric Utilities, Licensees and Others." 
Table 40. Number of Consumera, 8alos, and Operating Rovenue by Major U.8. Inveator-Owned Electric Utility Within state, 1992 (Continued)

\begin{tabular}{|c|c|c|c|c|c|c|}
\hline Item & $\begin{array}{c}\text { Macesohusetto } \\
\text { Fltohburg } \\
\text { Gas \& } \\
\text { Elec Light Co }\end{array}$ & $\begin{array}{c}\text { Musesachuectte } \\
\text { Holyoke } \\
\text { Power } \\
\text { E } \\
\text { Electrile Co }\end{array}$ & $\begin{array}{l}\text { Maseachusetts } \\
\text { Holyoke } \\
\text { Water } \\
\text { Power } \\
\text { Co }\end{array}$ & $\begin{array}{l}\text { Massechusetts } \\
\text { Masesachusetts } \\
\text { Eleotrio Co }\end{array}$ & $\begin{array}{c}\text { Masesohusett } \\
\text { Montaup } \\
\text { Electric Co }\end{array}$ & $\begin{array}{l}\text { Maseachusetts } \\
\text { Now Engiand } \\
\text { Hydro- } \\
\text { Tran } \\
\text { Elec Co }\end{array}$ \\
\hline 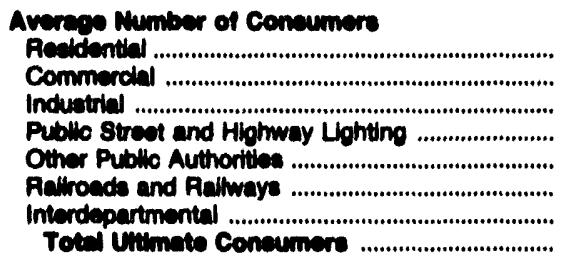 & $\begin{array}{r}22,766 \\
2,768 \\
34 \\
2 \\
3 \\
0 \\
0 \\
26,573\end{array}$ & $\begin{array}{l}0 \\
0 \\
0 \\
0 \\
0 \\
0 \\
0 \\
0\end{array}$ & $\begin{array}{r}0 \\
0 \\
53 \\
0 \\
0 \\
0 \\
0 \\
\mathbf{5 3}\end{array}$ & $\begin{array}{r}819,782 \\
83,231 \\
4,618 \\
975 \\
0 \\
0 \\
0 \\
009,600\end{array}$ & $\begin{array}{l}0 \\
0 \\
0 \\
0 \\
0 \\
0 \\
0 \\
0\end{array}$ & $\begin{array}{l}0 \\
0 \\
0 \\
0 \\
0 \\
0 \\
0 \\
0\end{array}$ \\
\hline Sales for Resale & 0 & 4 & 4 & 22 & 14 & \\
\hline Total Number of Coneumere ................................ & 25,573 & 4 & 87 & 800,028 & 14 & \\
\hline 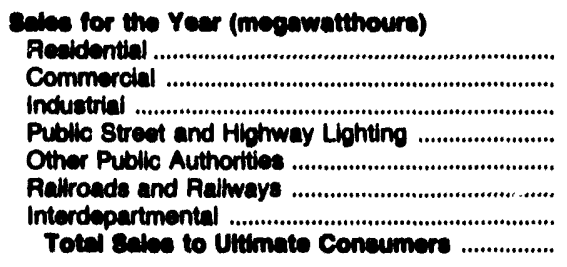 & $\begin{array}{r}127,371 \\
28,860 \\
146,801 \\
2,009 \\
3,413 \\
0 \\
0 \\
370,174\end{array}$ & $\begin{array}{l}0 \\
0 \\
0 \\
0 \\
0 \\
0 \\
0 \\
0\end{array}$ & $\begin{array}{r}0 \\
0 \\
112,823 \\
0 \\
0 \\
0 \\
0 \\
112,823\end{array}$ & $\begin{array}{r}5,645,350 \\
5,645,867 \\
3,907,040 \\
105,842 \\
0 \\
0 \\
0 \\
0 \\
18,304,000\end{array}$ & $\begin{array}{l}0 \\
0 \\
0 \\
0 \\
0 \\
0 \\
0 \\
0\end{array}$ & $\begin{array}{l}0 \\
0 \\
0 \\
0 \\
0 \\
0\end{array}$ \\
\hline Salee for Reeale & 13,872 & $1,048,515$ & $1,854,017$ & 3,747 & $6,118,288$ & \\
\hline 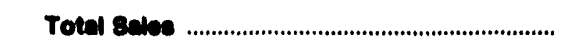 & 303,140 & $1,040,816$ & $1,060,840$ & $16,307,840$ & & \\
\hline
\end{tabular}

\begin{tabular}{|c|c|c|c|c|c|c|}
\hline 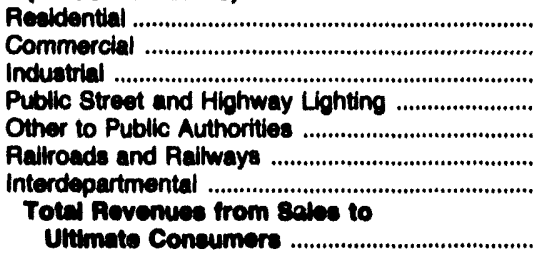 & $\begin{array}{r}14,618 \\
10,993 \\
12,199 \\
687 \\
400 \\
0 \\
0\end{array}$ & $\begin{array}{l}0 \\
0 \\
0 \\
0 \\
0 \\
0 \\
0\end{array}$ & $\begin{array}{r}0 \\
0 \\
9,148 \\
0 \\
0 \\
0 \\
0\end{array}$ & $\begin{array}{r}549,884 \\
510,638 \\
319,806 \\
17,488 \\
0 \\
0 \\
0\end{array}$ & $\begin{array}{l}0 \\
0 \\
0 \\
0 \\
0 \\
0 \\
0\end{array}$ & $\begin{array}{l}0 \\
0 \\
0 \\
0 \\
0 \\
0 \\
0\end{array}$ \\
\hline Sales for Resale & 389 & 27,280 & 44,807 & 278 & 365,626 & 0 \\
\hline 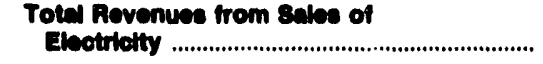 & 30,207 & $27,2+0$ & 63,057 & $1,309,184$ & 365,028 & $\mathbf{0}$ \\
\hline (lese) Proviaion for Rate Refunds ............................. & 0 & 266 & 0 & 0 & 2,792 & 446 \\
\hline Net Rovenuses from sabes of Electulctly ........ & 80,207 & 27,028 & 88,967 & $1,300,194$ & 382,034 & -446 \\
\hline 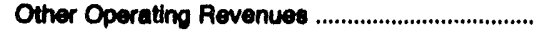 & 208 & 3 & 472 & 14,764 & 3,224 & 45,025 \\
\hline $\begin{array}{l}\text { Total Electric Vtully } \\
\text { Operntine Rovenue }\end{array}$ & 30,493 & 27,024 & 84,489 & $1,412,049$ & 388,080 & 44,670 \\
\hline
\end{tabular}

Note: Totals may not equal sum of components because of independent rounding. Summary date are provided in Table 16.

Source: Federal Eneroy Regulatory Commiseion, FERC Form 1, "Annual Report of Major Electric Utilities, Lloensees and Others." 
Table 40. Number of Consumers, 8ales, and Oporating Rovenue by Major U.8. Investor-Owned Electric Utility Within State, 1992 (Continued)

\begin{tabular}{|c|c|c|c|c|c|c|}
\hline Item & $\begin{array}{l}\text { Marenohusetts } \\
\text { New England } \\
\text { Power Co }\end{array}$ & $\begin{array}{l}\text { Mananchusetis } \\
\text { Weatem } \\
\text { Mnenchusetis } \\
\text { Elec Co }\end{array}$ & $\begin{array}{l}\text { Mlohionn } \\
\text { Consumers } \\
\text { Powror Co }\end{array}$ & $\begin{array}{l}\text { Mohigan } \\
\text { Dotrolt } \\
\text { Edison Co }\end{array}$ & $\begin{array}{l}\text { Mlohigan } \\
\text { Edison } \\
\text { Sault } \\
\text { Electrio } \\
\text { Co }\end{array}$ & $\begin{array}{l}\text { Miohioan } \\
\text { Upper } \\
\text { Penineula } \\
\text { Power Co }\end{array}$ \\
\hline 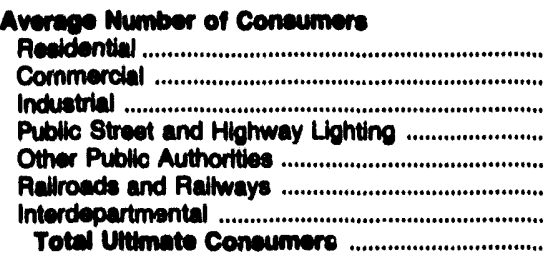 & $\begin{array}{l}0 \\
4 \\
4 \\
0 \\
0 \\
0 \\
0 \\
0\end{array}$ & $\begin{array}{r}175,673 \\
14,865 \\
810 \\
584 \\
0 \\
0 \\
0 \\
101,912\end{array}$ & $\begin{array}{r}1,327,681 \\
168,517 \\
9,191 \\
1,684 \\
0 \\
0 \\
0 \\
1,497,028\end{array}$ & $\begin{array}{r}1,774,085 \\
168,798 \\
2,768 \\
788 \\
1,187 \\
0 \\
0 \\
1,048,924\end{array}$ & $\begin{array}{r}16,919 \\
2,894 \\
4 \\
37 \\
4 \\
0 \\
0 \\
19,020\end{array}$ & $\begin{array}{r}54,895 \\
6,281 \\
16 \\
76 \\
84 \\
0 \\
0 \\
81,891\end{array}$ \\
\hline Sales for Resale & 24 & 8 & 27 & 14 & 2 & 24 \\
\hline Total Number of Coneumere .............................. & 32 & 191,920 & $1,497,050$ & $1,048,638$ & 10,090 & 61,986 \\
\hline 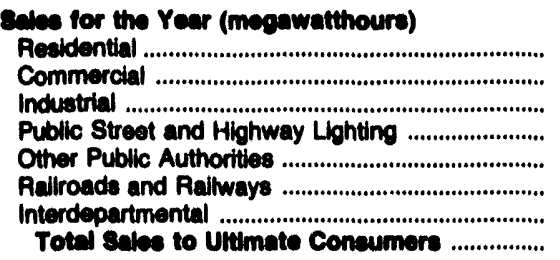 & $\begin{array}{r}0 \\
12,659 \\
6,535 \\
0 \\
0 \\
0 \\
0 \\
10,184\end{array}$ & $\begin{array}{r}1,358,845 \\
1,238,578 \\
974,634 \\
27,830 \\
0 \\
0 \\
0 \\
8,600,047\end{array}$ & $\begin{array}{r}9,732,628 \\
8,651,776 \\
10,831,382 \\
168,089 \\
0 \\
0 \\
44,052 \\
29,427,707\end{array}$ & $\begin{array}{r}11,378,480 \\
8,668,326 \\
18,543,334 \\
244,768 \\
541,098 \\
0 \\
809 \\
98,978,819\end{array}$ & $\begin{array}{r}144,203 \\
173,141 \\
180,004 \\
2,646 \\
47,481 \\
0 \\
0 \\
687,978\end{array}$ & $\begin{array}{r}253,690 \\
188,094 \\
281,114 \\
5,382 \\
3,403 \\
0 \\
0 \\
070,093\end{array}$ \\
\hline Sales for Resale & $\begin{array}{l}23,535,480 \\
28,664,084\end{array}$ & $\begin{array}{r}653,670 \\
4,154,657\end{array}$ & $\begin{array}{r}2,173,307 \\
91,001,004\end{array}$ & $\begin{array}{r}4,524,308 \\
48,001,121\end{array}$ & $\begin{array}{l}127,354 \\
94,720\end{array}$ & $\begin{array}{l}127,428 \\
007,100\end{array}$ \\
\hline 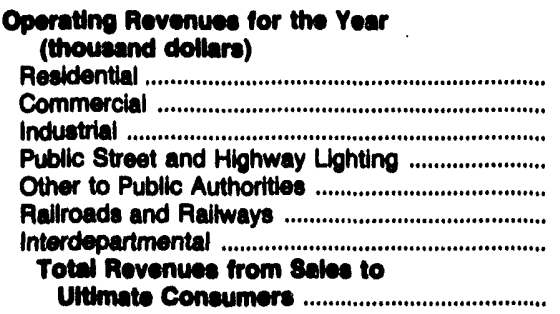 & $\begin{array}{r}0 \\
822 \\
578 \\
0 \\
0 \\
0 \\
0 \\
1,300\end{array}$ & $\begin{array}{r}165,098 \\
128,602 \\
86,688 \\
5,460 \\
0 \\
0 \\
0\end{array}$ & $\begin{array}{r}645,105 \\
562,074 \\
551,683 \\
15,805 \\
0 \\
0 \\
2,522 \\
\\
1,777,000\end{array}$ & $\begin{array}{r}1,098,027 \\
925,613 \\
1,201,885 \\
38,368 \\
41,448 \\
0 \\
87 \\
\\
3,396,416\end{array}$ & $\begin{array}{r}8,310 \\
10,764 \\
6,875 \\
250 \\
653 \\
0 \\
0\end{array}$ & $\begin{array}{r}22,843 \\
15,614 \\
12,686 \\
727 \\
296 \\
0 \\
0\end{array}$ \\
\hline Sales for Resale & $1,501,892$ & 20,008 & 66,052 & 118,883 & 3,179 & 6,249 \\
\hline $\begin{array}{l}\text { Total Rovenues from sales of } \\
\text { Electrictly }\end{array}$ & $1,603,302$ & 406,707 & $1,048,142$ & $3,492,300$ & 80,081 & 63,418 \\
\hline (leas) Provision for Rate Refunds ........................ & 7.722 & 0 & 1,788 & 3,180 & 0 & -34 \\
\hline Not Rovenues from 8ales of Electricty ....... & $1,495,680$ & 405,707 & $1,841,964$ & $3,479,120$ & 30,031 & 80,440 \\
\hline 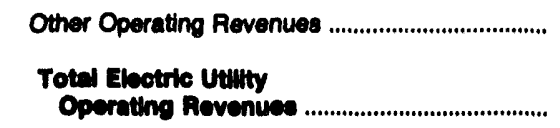 & $1,880,675$ & 410,720 & $1,892,720$ & $3,628,820$ & 30,210 & 91,69 \\
\hline
\end{tabular}

Note: Totals may not equal sum of components because of independent rounding. Summary data are provided in Table 15 . Source: Federal Eneroy Regulatory Commiseion, FERC Form 1, "Annual Report of Major Electric Utilities, Licensees and Others." 
Table 40. Number of Concumors, 8alos, and Oporating Rovonus by Major U.8. Investor-Owned Electric Utility Within state, 1902 (Continued)

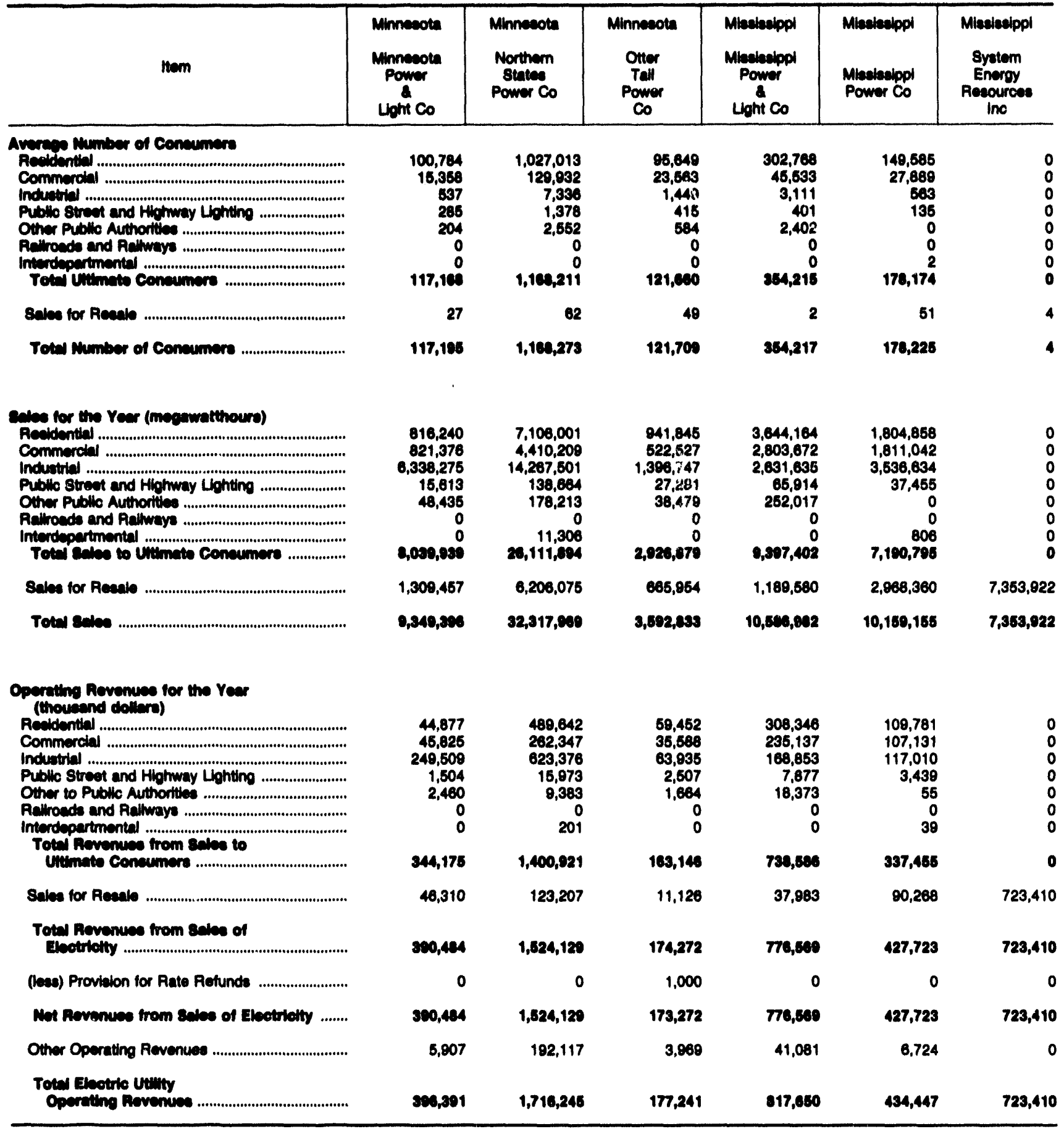

Nole: Totale may not equal sum of components because of independent rounding. Summary date are provided in Table 15.

Source: Federal Energy Reculatory Commiecion, FERC Form 1, "Annual Report of Major Electric Utilties, Llcensees and Others." 
Table 40. Number of Consumore, 8alos, and Oporating Rovenue by Major U.8. Investor-Owned Electrle Utility Within 8tate, 1902 (Continued)

\begin{tabular}{|c|c|c|c|c|c|c|}
\hline Item & $\begin{array}{l}\text { Miseourt } \\
\text { Empire } \\
\text { Distriot } \\
\text { Electrio Co }\end{array}$ & $\begin{array}{c}\text { Mrasourl } \\
\text { Kaneas City } \\
\text { Powir \& Light } \\
\text { Co }\end{array}$ & $\begin{array}{l}\text { Mineourt } \\
\text { St Joenph } \\
\text { Uoht } \\
\text { Powner co }\end{array}$ & $\begin{array}{c}\text { Mhosourl } \\
\text { Union } \\
\text { Eleotric Co }\end{array}$ & $\begin{array}{l}\text { Missourt } \\
\text { UtillCorp } \\
\text { United Inc }\end{array}$ & $\begin{array}{l}\text { Montana } \\
\text { Montana } \\
\text { Power Co }\end{array}$ \\
\hline \multicolumn{7}{|l|}{ Avertes Number of Coneumsers } \\
\hline 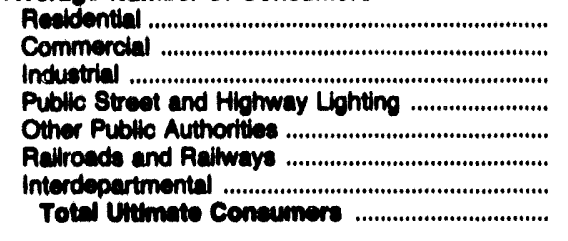 & $\begin{array}{r}101,943 \\
17,788 \\
287 \\
540 \\
927 \\
0 \\
9 \\
121,492\end{array}$ & $\begin{array}{r}385,089 \\
49,622 \\
2,328 \\
122 \\
11 \\
0 \\
0 \\
410,082\end{array}$ & $\begin{array}{r}88,037 \\
6,434 \\
108 \\
105 \\
67 \\
0 \\
0 \\
8.751\end{array}$ & $\begin{array}{r}892,398 \\
125,147 \\
7,646 \\
1,610 \\
1 \\
0 \\
0 \\
1,119,870\end{array}$ & $\begin{array}{r}286,108 \\
44,808 \\
264 \\
278 \\
3,088 \\
0 \\
29 \\
394,678\end{array}$ & $\begin{array}{r}210,483 \\
38,077 \\
3,389 \\
2,876 \\
200 \\
0 \\
200 \\
268,283\end{array}$ \\
\hline 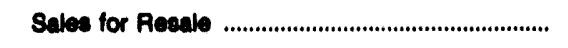 & 12 & 36 & 8 & 40 & 46 & 69 \\
\hline Total Number of Consumere .............................. & 121,494 & 418,015 & 60,760 & $1,110,718$ & 394,820 & 285,302 \\
\hline \multicolumn{7}{|l|}{ Eales for the Yeer (megmmatthours) } \\
\hline 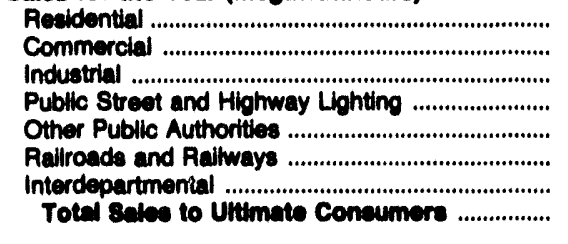 & $\begin{array}{r}1,088,695 \\
860,829 \\
695,271 \\
20,367 \\
57,693 \\
0 \\
1,385 \\
2,604,120\end{array}$ & $\begin{array}{r}3,172,811 \\
4,884,285 \\
2,429,883 \\
70,541 \\
1,688 \\
0 \\
0 \\
10,089,005\end{array}$ & $\begin{array}{r}505,047 \\
387,013 \\
438,280 \\
9,625 \\
3,482 \\
0 \\
0 \\
1,349,297\end{array}$ & $\begin{array}{r}9,690,260 \\
10,653,257 \\
9,029,999 \\
144,308 \\
415 \\
0 \\
0 \\
29,410,290\end{array}$ & $\begin{array}{r}2,329,755 \\
1,986,076 \\
1,376,868 \\
41,579 \\
371,535 \\
0 \\
605 \\
6,108,416\end{array}$ & $\begin{array}{r}1,738,089 \\
2,018,319 \\
3,088,557 \\
33,890 \\
69,073 \\
0 \\
19,083 \\
6,073,801\end{array}$ \\
\hline 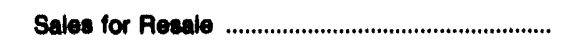 & 581,167 & $3,043,876$ & 27,356 & $6,327,968$ & 508,008 & $4,454,730$ \\
\hline Totel 8 alde & $3,276,207$ & $13,702,704$ & $1,370,089$ & $35,740,207$ & $8,614,428$ & $11,428,881$ \\
\hline \multicolumn{7}{|l|}{$\begin{array}{l}\text { Opernting Rovenues for the Year } \\
\text { (thousand dollers) }\end{array}$} \\
\hline 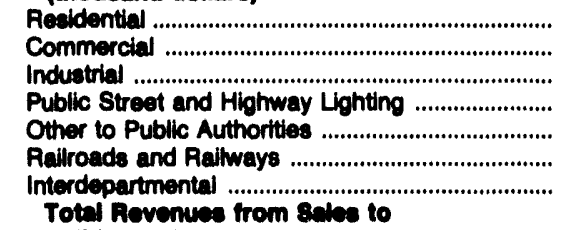 & $\begin{array}{r}69,646 \\
45,264 \\
26,598 \\
1,037 \\
2,140 \\
0 \\
68\end{array}$ & $\begin{array}{r}268,124 \\
351,025 \\
118,389 \\
14,213 \\
103 \\
0 \\
0\end{array}$ & $\begin{array}{r}28,334 \\
22,268 \\
18,312 \\
529 \\
170 \\
0 \\
0\end{array}$ & $\begin{array}{r}754,667 \\
676,761 \\
410,370 \\
13,505 \\
57 \\
0 \\
0\end{array}$ & $\begin{array}{r}182,459 \\
131,083 \\
62,420 \\
5,542 \\
21,277 \\
0 \\
17\end{array}$ & $\begin{array}{r}99,973 \\
102,318 \\
113,378 \\
5,173 \\
3,174 \\
0 \\
886\end{array}$ \\
\hline 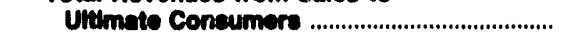 & 134,749 & 741,089 & 60,011 & $1,086,2 \times 0$ & 402,700 & 324,013 \\
\hline 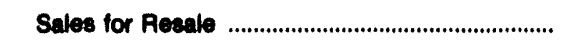 & 12,834 & 52,377 & 412 & 142,130 & 17,775 & 146,294 \\
\hline 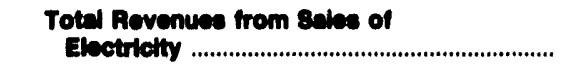 & 147,691 & 794,280 & 70,023 & $1, \infty 07,490$ & 420,673 & 471,207 \\
\hline 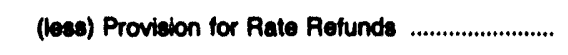 & 0 & 0 & 0 & 0 & 0 & 0 \\
\hline Net Revenuce from seles of Electrictily ....... & 147,601 & 794,280 & 70,023 & $1,007,400$ & 420,673 & 471,207 \\
\hline 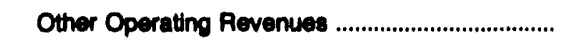 & 1,809 & 8,437 & 688 & 18,882 & 6,035 & 14,673 \\
\hline $\begin{array}{l}\text { Totel Eloctrie Uinity } \\
\text { Opereting Revenuwe }\end{array}$ & 149,401 & 602,690 & 70,711 & $2,014,372$ & 428,000 & 498,870 \\
\hline
\end{tabular}

Note: Totals may not equal sum of components because of independent rounding. Summary data are provided in Table 15.

Source: Federal Energy Regulatory Commiseion, FERC Form 1, "Annual Report of Major Electrlc Utilities, Licensees and Others." 
Table 40. Number of Consumors, salos, and Oporating Rovenue by Major U.8. Inveotor-Owned Eleotrle Uilility Within state, 1902 (Continuad)

\begin{tabular}{|c|c|c|c|c|c|c|}
\hline Item & $\begin{array}{l}\text { Nevada } \\
\text { Nevada } \\
\text { Power Co }\end{array}$ & $\begin{array}{l}\text { Noveda } \\
\text { Sierra } \\
\text { Pactilo } \\
\text { Power Co }\end{array}$ & $\begin{array}{c}\text { Now Hampahire } \\
\text { Great } \\
\text { Bay } \\
\text { Power } \\
\text { Corp }\end{array}$ & $\begin{array}{c}\text { Now Hampanire } \\
\text { Now England } \\
\text { Eloo } \\
\text { Tranemn } \\
\text { Corp }\end{array}$ & $\begin{array}{c}\text { Now Hampenire } \\
\text { New England } \\
\text { Hydro- } \\
\text { Trane } \\
\text { Corp }\end{array}$ & $\begin{array}{c}\text { Now Hampehire } \\
\text { North } \\
\text { Atlantic } \\
\text { Energy Corp }\end{array}$ \\
\hline 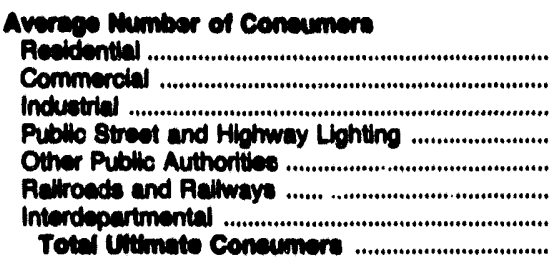 & $\begin{array}{r}328,388 \\
46,244 \\
683 \\
5 \\
27 \\
0 \\
0 \\
374,317\end{array}$ & $\begin{array}{r}214,530 \\
33,169 \\
121 \\
117 \\
0 \\
0 \\
0 \\
247,027\end{array}$ & $\begin{array}{l}0 \\
0 \\
0 \\
0 \\
0 \\
0 \\
0 \\
0\end{array}$ & $\begin{array}{l}0 \\
0 \\
0 \\
0 \\
0 \\
0 \\
0 \\
0\end{array}$ & $\begin{array}{l}0 \\
0 \\
0 \\
0 \\
0 \\
0 \\
0 \\
0\end{array}$ & $\begin{array}{l}0 \\
0 \\
0 \\
0 \\
0 \\
0 \\
0 \\
0\end{array}$ \\
\hline 8ales for Reals & 5 & 4 & 6 & 0 & 0 & 1 \\
\hline Totw Number of Coneunners ............................... & 374,322 & 247,031 & 6 & o & 0 & 1 \\
\hline 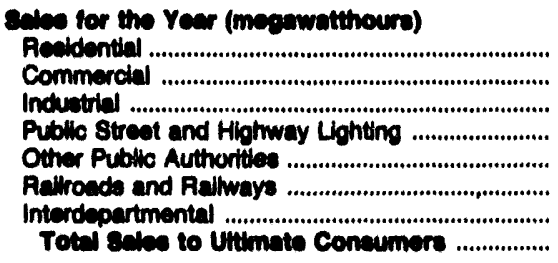 & $\begin{array}{r}4,372,048 \\
1,968,639 \\
3,181,275 \\
89,232 \\
460,911 \\
0 \\
0 \\
10,097,005\end{array}$ & $\begin{array}{r}1,671,360 \\
2,077,867 \\
2,352,263 \\
10,936 \\
0 \\
0 \\
0 \\
6,012,406\end{array}$ & $\begin{array}{l}0 \\
0 \\
0 \\
0 \\
0 \\
0 \\
0 \\
0\end{array}$ & $\begin{array}{l}0 \\
0 \\
0 \\
0 \\
0 \\
0 \\
0 \\
0\end{array}$ & $\begin{array}{l}0 \\
0 \\
0 \\
0 \\
0 \\
0 \\
0 \\
0\end{array}$ & $\begin{array}{l}0 \\
0 \\
0 \\
0 \\
0 \\
0 \\
0 \\
0\end{array}$ \\
\hline Sales for Resale & 473,300 & 228,831 & 057,514 & 0 & 0 & $1,288,123$ \\
\hline 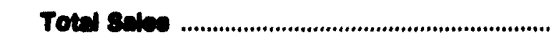 & $10,641,208$ & $6,241,237$ & 057,614 & o & $\mathbf{0}$ & $1,240,123$ \\
\hline 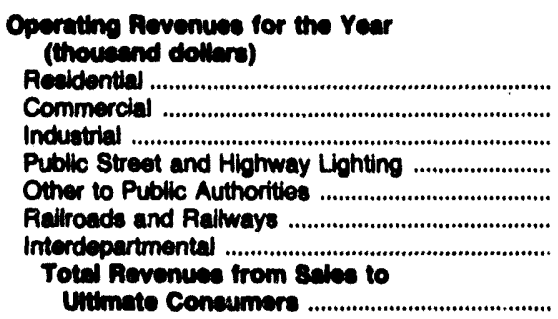 & $\begin{array}{r}245,160 \\
122,198 \\
183,508 \\
4,368 \\
22,059 \\
0 \\
0 \\
677,293\end{array}$ & $\begin{array}{r}130,398 \\
136,998 \\
117,376 \\
2,180 \\
0 \\
0 \\
0 \\
396,962\end{array}$ & $\begin{array}{l}0 \\
0 \\
0 \\
0 \\
0 \\
0 \\
0 \\
0\end{array}$ & $\begin{array}{l}0 \\
0 \\
0 \\
0 \\
0 \\
0 \\
0\end{array}$ & $\begin{array}{l}0 \\
0 \\
0 \\
0 \\
0 \\
0 \\
0\end{array}$ & $\begin{array}{l}0 \\
0 \\
0 \\
0 \\
0 \\
0 \\
0\end{array}$ \\
\hline Sales for Resale & 15,583 & 10,858 & 22,953 & 0 & 0 & 78,444 \\
\hline $\begin{array}{l}\text { Total Revenese from 8dee of } \\
\text { Ebetricty }\end{array}$ & 802,086 & 397,607 & 22,053 & 0 & 0 & 70,444 \\
\hline (leas) Provision for Rate Refunds .......................... & 0 & 1,409 & 0 & 0 & 1,228 & 0 \\
\hline Net Rovenuee from salee of Eloctrictly ....... & 602,8106 & 390,190 & 22,953 & 0 & $-1,228$ & 70,444 \\
\hline 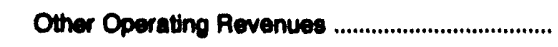 & 8,037 & 5,653 & 74 & 12,708 & . 36,784 & 0 \\
\hline $\begin{array}{l}\text { Total Eicetric Utilty } \\
\text { Opereting Rovernues .......................................... }\end{array}$ & 600,023 & 401,851 & 23,027 & 12,700 & 35,860 & 78,444 \\
\hline
\end{tabular}

Note: Totals may nol equal aum of components because of independent rounding. Summary data are provided in Table 15.

Source: Federal Energy Regulatory Commiseion, FERC Form 1, "Annual Report of Major Electric Utilities, Licensees and Others." 
Table 40. Number of Consumore, sales, and Operating Rovenue by Major U.8. Inveator-Owned Electrie Utility Whin 8tate, 1992 (Continued)

\begin{tabular}{|c|c|c|c|c|c|c|}
\hline $\mathrm{kmom}$ & $\begin{array}{c}\text { New Hemperire } \\
\text { Publio } \\
\text { gervice } \\
\text { Co } \\
\text { of NH }\end{array}$ & $\begin{array}{c}\text { Now Jareey } \\
\text { Atiantio } \\
\text { Clyy } \\
\text { Eloctio } \\
\text { Co }\end{array}$ & 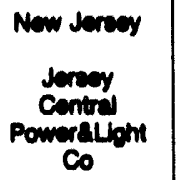 & $\begin{array}{l}\text { Now Jerey } \\
\text { Publo } \\
\text { 8envioe } \\
\text { Electriales } \\
\text { Co }\end{array}$ & $\begin{array}{l}\text { Now Jerecy } \\
\text { Rockland } \\
\text { Electitic Co }\end{array}$ & $\begin{array}{l}\text { Now Moxico } \\
\text { Publlo } \\
\text { senvios } \\
\text { Co } \\
\text { of NM }\end{array}$ \\
\hline 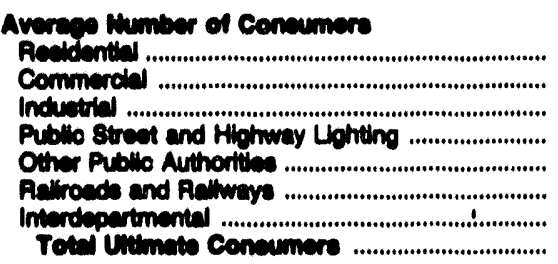 & $\begin{array}{r}344,400 \\
82,060 \\
1,284 \\
404 \\
0 \\
0 \\
0 \\
2 m, 189\end{array}$ & $\begin{array}{r}402,080 \\
81,000 \\
000 \\
628 \\
0 \\
1 \\
0 \\
49,400\end{array}$ & $\begin{array}{r}7 \% 4,778 \\
93,015 \\
3,202 \\
1,462 \\
0 \\
0 \\
0 \\
02,126\end{array}$ & $\begin{array}{r}1,020,300 \\
213,344 \\
0,203 \\
7,374 \\
0 \\
0 \\
1 \\
1,292,29\end{array}$ & $\begin{array}{r}68,409 \\
7,040 \\
200 \\
20 \\
0 \\
0 \\
0 \\
62,711\end{array}$ & $\begin{array}{r}207,640 \\
32,046 \\
302 \\
343 \\
136 \\
0 \\
0 \\
41 \\
200,402\end{array}$ \\
\hline Sales tor Reade & 44 & 0 & $\bullet$ & 4 & 0 & 30 \\
\hline Toud Mumber of Consumere .............................. & 200,197 & 463,400 & Cas,1si & 1,048,402 & 02,701 & 200,531 \\
\hline 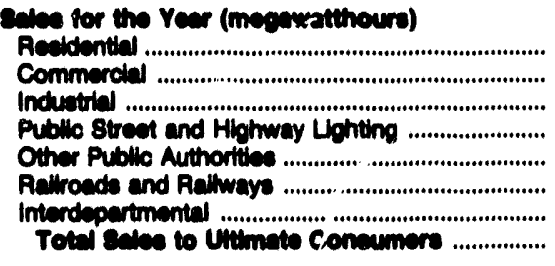 & $\begin{array}{r}2,342,789 \\
1,224,080 \\
2,640,641 \\
22,373 \\
0 \\
0 \\
0 \\
6,229,709\end{array}$ & $\begin{array}{r}3,289,492 \\
3,100,133 \\
1,229,211 \\
43,704 \\
0 \\
5,760 \\
0 \\
7, \times 1,000\end{array}$ & $\begin{array}{r}6,607,067 \\
6,207,321 \\
3,723,630 \\
76,684 \\
0 \\
0 \\
0 \\
14,674,401\end{array}$ & 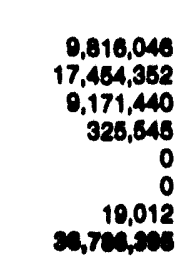 & $\begin{array}{r}474,697 \\
300,290 \\
364,834 \\
6,610 \\
0 \\
0 \\
0 \\
1,141,101\end{array}$ & $\begin{array}{r}1,071,600 \\
2,375,700 \\
1,000,210 \\
44,302 \\
140,000 \\
0 \\
10,220 \\
6,294,240\end{array}$ \\
\hline 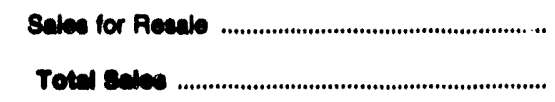 & $\begin{array}{r}6,008,842 \\
12,203,028\end{array}$ & $\begin{array}{l}1,055,081 \\
\mathbf{2 , 7 2 1 , 2 0 1}\end{array}$ & $\begin{array}{r}2,311,610 \\
10,201,011\end{array}$ & $\begin{array}{r}2,262,023 \\
20,028,410\end{array}$ & $\begin{array}{r}0 \\
1,140,101\end{array}$ & $\begin{array}{l}3,006,418 \\
\text { 0,045esen }\end{array}$ \\
\hline 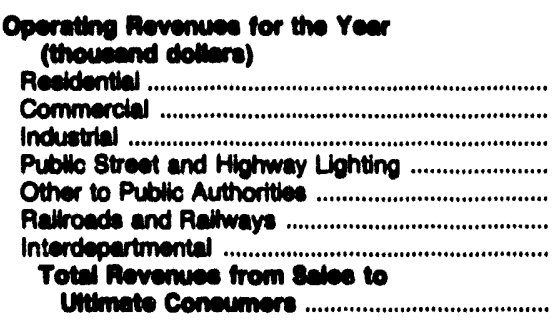 & $\begin{array}{r}282,219 \\
134,160 \\
229,375 \\
5,047 \\
0 \\
0 \\
0 \\
\\
060,600\end{array}$ & $\begin{array}{r}364,232 \\
200,860 \\
95,976 \\
10,114 \\
0 \\
434 \\
0 \\
770,092\end{array}$ & $\begin{array}{r}732,177 \\
625,042 \\
305,217 \\
10,368 \\
0 \\
0 \\
0 \\
1,022,002\end{array}$ & $\begin{array}{r}1,041,320 \\
1,602,460 \\
670,741 \\
47,720 \\
0 \\
0 \\
1,544 \\
2,992,002\end{array}$ & $\begin{array}{r}53,161 \\
39,520 \\
32,047 \\
1,063 \\
0 \\
0 \\
0 \\
124, e 01\end{array}$ & $\begin{array}{r}169,100 \\
211,881 \\
60,870 \\
4,739 \\
8,460 \\
0 \\
1,328 \\
486,997\end{array}$ \\
\hline 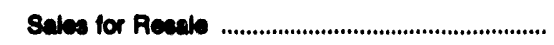 & 185,716 & 35,884 & 74,149 & 69,318 & 0 & 123,201 \\
\hline 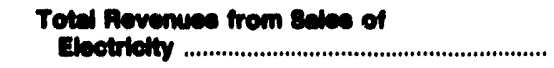 & 896,610 & $\cos , 600$ & $1,7: 0, M 1$ & $2,292,120$ & 124,91 & s79,670 \\
\hline (less) Providion for Rate Retunds ........................ & $-15,863$ & 0 & 392 & 16,720 & 0 & 0 \\
\hline Net Revenues from sales of Electriotly ........ & 062,370 & 600,500 & $1,794,440$ & $2,374,292$ & 129,601 & s7m,970 \\
\hline 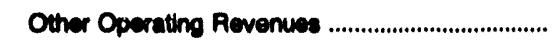 & 21,850 & 10,425 & 17,623 & 31,427 & 76 & 17,644 \\
\hline timty & 974,329 & 018,032 & $1,774,071$ & $2,407,010$ & 184,767 & cen,sea \\
\hline
\end{tabular}

Note: Totale may not equal eum of components because of independent rounding. Summary data ere provided in Table 15. Source: Federal Energy Regulatory Commiselon, FERC Form 1, "Annual Report of Major Electric Utiltibes, Liceneces and Othere." 
Table 40. Number of Consumore, sales, and Operating Rovenue by Major U.8. Investor-Owned Electric Uttlity Within State, 1092 (Continued)

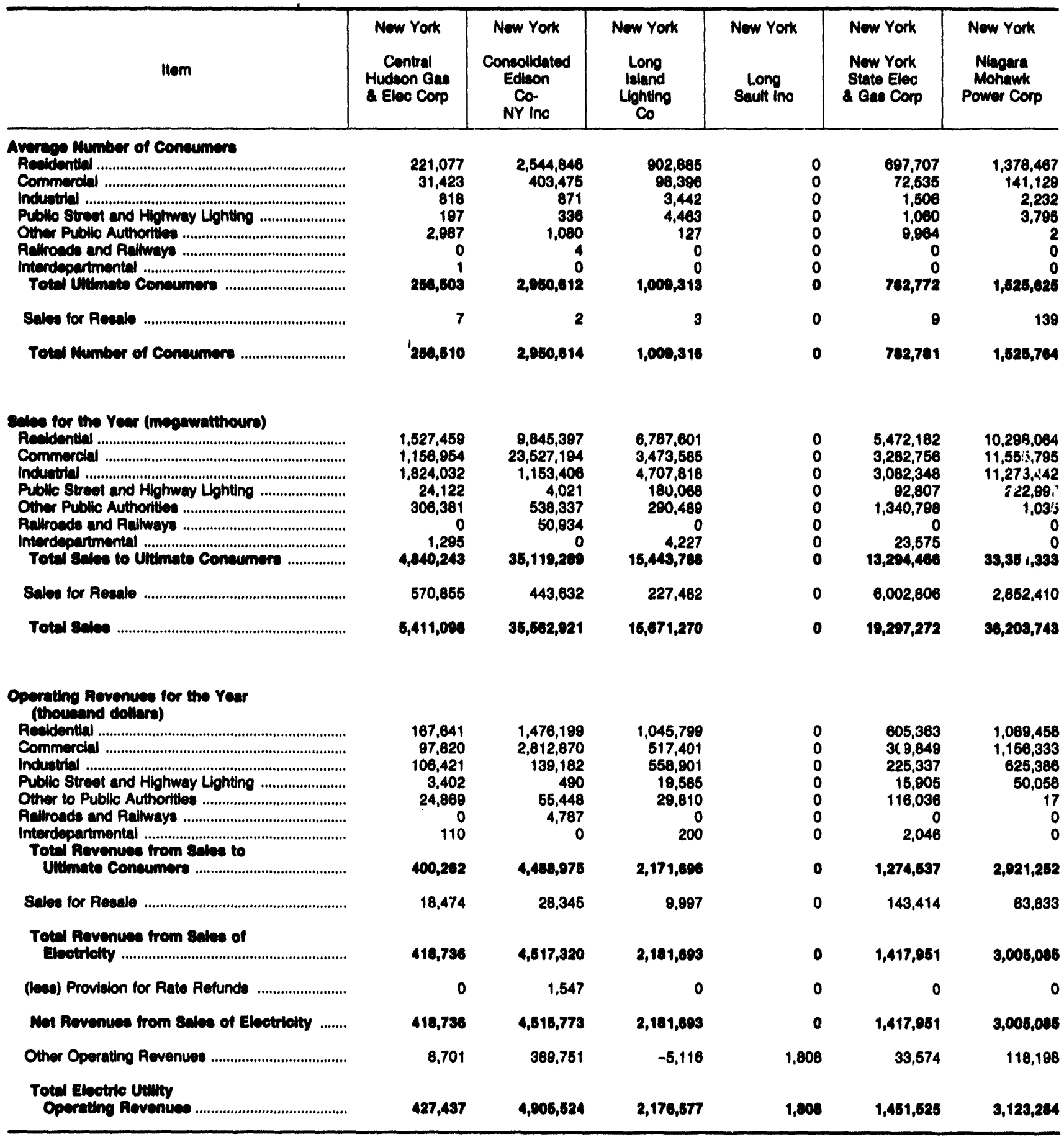

Note: Totale may not equal sum of components because of independent rounding. Summary data are provided in Table 15.

Source: Federal Energy Regulatory Commiselon, FERC Form 1, "Annual Report of Major Electric Utilties, Licensees and Others." 
Table 40. Number of Consumers, Sales, and Oporating Rovenue by Major U.8. Investor-Owned Electrlc Utility Within state, 1992 (Continued)

\begin{tabular}{|c|c|c|c|c|c|c|}
\hline Item & $\begin{array}{l}\text { New York } \\
\text { Orange \& } \\
\text { Rockland } \\
\text { Utlls } \\
\text { Inc }\end{array}$ & $\begin{array}{c}\text { New York } \\
\text { Rochester } \\
\text { Gas } \\
\& \\
\text { Electric Corp }\end{array}$ & $\begin{array}{c}\text { North Carollna } \\
\text { Carolina } \\
\text { Power } \\
\text { Light Co }\end{array}$ & $\begin{array}{c}\text { North Carolina } \\
\text { Duke } \\
\text { Power Co }\end{array}$ & $\begin{array}{c}\text { North Carolina } \\
\text { Nantahala } \\
\text { Power } \\
\text { Light Co }\end{array}$ & $\begin{array}{l}\text { North Carollna } \\
\text { Yadkin } \\
\text { Inc }\end{array}$ \\
\hline 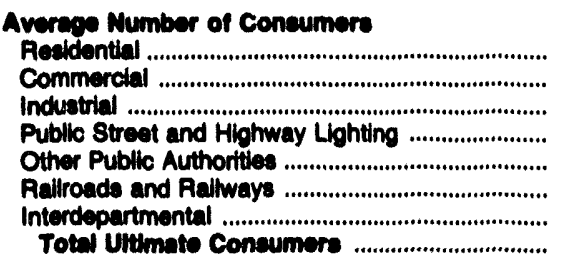 & $\begin{array}{r}162,641 \\
23,116 \\
328 \\
473 \\
1 \\
0 \\
1 \\
180,680\end{array}$ & $\begin{array}{r}299,327 \\
29,256 \\
1,387 \\
386 \\
2,199 \\
0 \\
0 \\
332,686\end{array}$ & $\begin{array}{r}846,232 \\
146,868 \\
4,727 \\
2,241 \\
5 \\
0 \\
0 \\
909,003\end{array}$ & $\begin{array}{r}1,431,403 \\
226,245 \\
6,660 \\
7,626 \\
0 \\
0 \\
36 \\
1,672,970\end{array}$ & $\begin{array}{r}44,699 \\
5,624 \\
8 \\
11 \\
0 \\
0 \\
0 \\
50,342\end{array}$ & $\begin{array}{l}0 \\
0 \\
1 \\
0 \\
0 \\
0 \\
0 \\
1\end{array}$ \\
\hline 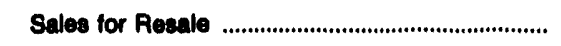 & 6 & 8 & 27 & 34 & 10 & 0 \\
\hline 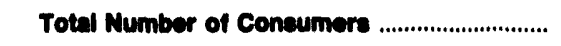 & 180,500 & 332,673 & 900,000 & $1,073,004$ & 50,362 & 1 \\
\hline 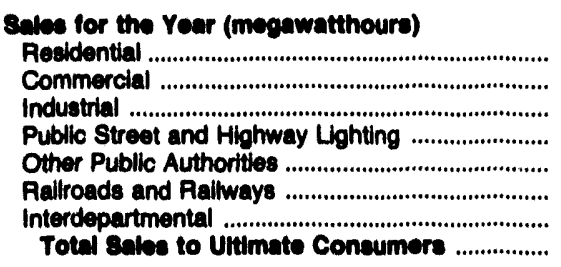 & $\begin{array}{r}1,034,849 \\
695,834 \\
1,148,326 \\
20,834 \\
70,257 \\
0 \\
2,908 \\
2,973,008\end{array}$ & $\begin{array}{r}2,084,934 \\
1,949,750 \\
1,916,695 \\
49,241 \\
455,366 \\
0 \\
0 \\
6,455,986\end{array}$ & $\begin{array}{r}10,490,030 \\
8,080,282 \\
13,133,543 \\
97,267 \\
1,115,495 \\
0 \\
0 \\
0 \\
32,896,617\end{array}$ & $\begin{array}{r}17,827,792 \\
15,812,145 \\
27,069,048 \\
207,350 \\
0 \\
0 \\
18,853 \\
60,938,180\end{array}$ & $\begin{array}{r}415,117 \\
248,293 \\
117,593 \\
1,597 \\
0 \\
0 \\
0 \\
782,600\end{array}$ & $\begin{array}{r}0 \\
0 \\
1,793,870 \\
0 \\
0 \\
0 \\
0 \\
1,793,870\end{array}$ \\
\hline Sales for Resale & $1,581,955$ & $1,062,738$ & $9,932,456$ & $10,106,606$ & 218,225 & 0 \\
\hline Total Sabe & $4,554,963$ & $7,618,724$ & $42,020,073$ & $71,041,794$ & $1,000,825$ & $1,793,070$ \\
\hline \multicolumn{7}{|l|}{$\begin{array}{l}\text { Operating Rovenuwe for the Year } \\
\text { (thougand dollare) }\end{array}$} \\
\hline 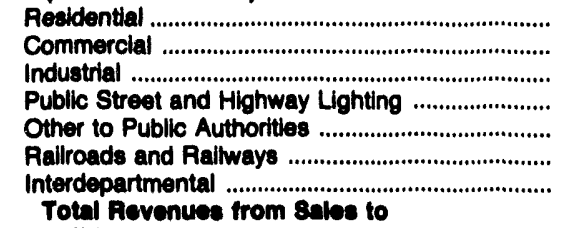 & $\begin{array}{r}137,711 \\
83,519 \\
91,653 \\
3,790 \\
4,212 \\
0 \\
131\end{array}$ & $\begin{array}{r}222,510 \\
187,261 \\
141,208 \\
11,941 \\
41,218 \\
0 \\
0\end{array}$ & $\begin{array}{r}871,469 \\
560,560 \\
720,413 \\
13,561 \\
63,277 \\
0 \\
0\end{array}$ & $\begin{array}{r}1,294,025 \\
961,027 \\
1,201,726 \\
17,828 \\
0 \\
0 \\
877\end{array}$ & $\begin{array}{r}25,686 \\
13,366 \\
4,675 \\
185 \\
0 \\
0 \\
0\end{array}$ & $\begin{array}{r}0 \\
0 \\
24,129 \\
0 \\
0 \\
0 \\
0\end{array}$ \\
\hline 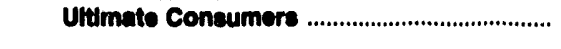 & 321,016 & 604,130 & $2,229,280$ & $3,475,463$ & 43,091 & 24,120 \\
\hline Sales for Resale & 75,228 & 25,542 & 497,950 & 443,012 & 15,589 & 0 \\
\hline $\begin{array}{l}\text { Total Rovenues from Salee of } \\
\text { Ebetriclty }\end{array}$ & 396,244 & 629,681 & $2,727,230$ & $3,018,405$ & 50,400 & 24,120 \\
\hline (lese) Provision for Rate Refunds ........................ & -228 & 0 & 0 & 71,623 & 0 & 0 \\
\hline Not Rovenuse from sales of Electrielty ....... & 398,472 & 629,681 & $2,727,230$ & $3,846,871$ & 50,400 & 24,120 \\
\hline Other Operating Revenues & 6,653 & 6,671 & 39,591 & 114,612 & 703 & 1,318 \\
\hline $\begin{array}{l}\text { Total Electric Utillty } \\
\text { Oporating Rovenues }\end{array}$ & 403,126 & 636,352 & $2,768,821$ & $3,901,484$ & 60,183 & 26,448 \\
\hline
\end{tabular}

Note: Totals may not equal sum of components because of independent rounding. Summary data are provided in Table 15. Source: Federal Energy Regulatory Commission, FERC Form 1. "Annual Report of Major Electric Utilities, Licensees and Others." 
Table 40. Number of Consumers, Sales, and Operating Revenue by Major U.S. Investor-Owned Electric Utility Within State, 1992 (Continued)

\begin{tabular}{|c|c|c|c|c|c|c|}
\hline Item & $\begin{array}{l}\text { North Dakota } \\
\text { MDU } \\
\text { Resources } \\
\text { Group } \\
\text { Inc }\end{array}$ & $\begin{array}{c}\text { Onio } \\
\text { Cincinnati } \\
\text { Gas } \\
8 \\
\text { Electric Co }\end{array}$ & $\begin{array}{l}\text { Ohio } \\
\text { Cleveland } \\
\text { Electric } \\
\text { Illum Co }\end{array}$ & $\begin{array}{l}\text { Ohio } \\
\text { Columbus } \\
\text { Southern } \\
\text { Power Co }\end{array}$ & $\begin{array}{c}\text { Ohio } \\
\text { Dayton } \\
\text { Power } \\
8 \\
\text { Light Co }\end{array}$ & $\begin{array}{l}\text { Ohio } \\
\text { Indlana- } \\
\text { Kentucky } \\
\text { Electric } \\
\text { Corp }\end{array}$ \\
\hline 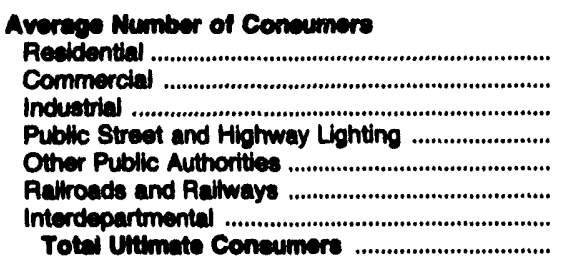 & $\begin{array}{r}92,717 \\
16,378 \\
427 \\
169 \\
142 \\
0 \\
1 \\
109,034\end{array}$ & $\begin{array}{r}520,026 \\
58,384 \\
2,761 \\
384 \\
3,126 \\
0 \\
0 \\
584,601\end{array}$ & $\begin{array}{r}868,136 \\
70,655 \\
7,971 \\
270 \\
135 \\
1 \\
0 \\
747,160\end{array}$ & $\begin{array}{r}509,485 \\
51,581 \\
3,026 \\
311 \\
2 \\
0 \\
0 \\
584,425\end{array}$ & $\begin{array}{r}411,254 \\
39,401 \\
2,417 \\
1,425 \\
3,674 \\
1 \\
16 \\
480,180\end{array}$ & $\begin{array}{l}0 \\
0 \\
0 \\
0 \\
0 \\
0 \\
0 \\
0\end{array}$ \\
\hline 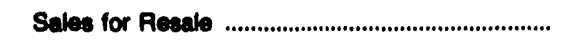 & 0 & 13 & 9 & 30 & 16 & 1 \\
\hline Toted Number of Coneumere ............................... & 100,834 & 584,704 & 747,177 & 664,465 & 260,204 & 1 \\
\hline 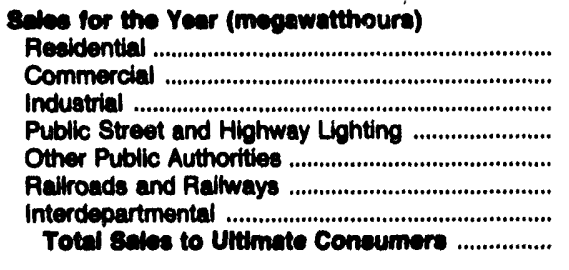 & $\begin{array}{r}696,717 \\
771,682 \\
288,650 \\
32,303 \\
41,011 \\
0 \\
560 \\
1,829,983\end{array}$ & $\begin{array}{r}5,552,285 \\
4,456,160 \\
5,155,796 \\
82,144 \\
1,180,721 \\
0 \\
8,934 \\
16,436,040\end{array}$ & $\begin{array}{r}4,724,986 \\
5,466,615 \\
7,988,153 \\
165,901 \\
319,087 \\
48,062 \\
0 \\
18,712,814\end{array}$ & $\begin{array}{r}4,859,226 \\
5,151,327 \\
2,900,747 \\
31,926 \\
321,116 \\
0 \\
0 \\
13,264,342\end{array}$ & $\begin{array}{r}4,259,572 \\
2,896,081 \\
3,938,346 \\
73,632 \\
1,234,213 \\
3,552 \\
3,126 \\
12,408,6212\end{array}$ & $\begin{array}{l}0 \\
0 \\
0 \\
0 \\
0 \\
0 \\
0 \\
0\end{array}$ \\
\hline 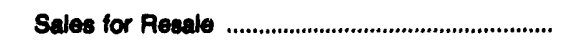 & 352,550 & $4,885,853$ & $1,888,646$ & $2,707,888$ & $1,648,818$ & $9,185,404$ \\
\hline 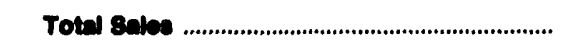 & $2,182,403$ & $21,321,093$ & $20,701,460$ & $15,972,230$ & $14,067,340$ & $9,105,404$ \\
\hline 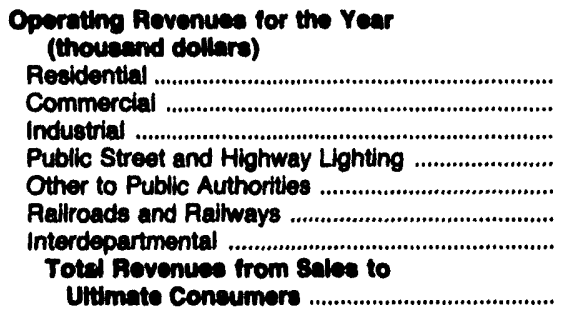 & $\begin{array}{r}50,049 \\
48,358 \\
14,168 \\
1,922 \\
2,027 \\
0 \\
64 \\
116,580\end{array}$ & $\begin{array}{r}372,238 \\
281,723 \\
228,527 \\
4,755 \\
64,608 \\
0 \\
418 \\
962,269\end{array}$ & $\begin{array}{r}516,974 \\
530,616 \\
529,975 \\
17,676 \\
20,763 \\
4,514 \\
0 \\
\\
1,620,517\end{array}$ & $\begin{array}{r}330,312 \\
285,487 \\
128,427 \\
3,003 \\
10,946 \\
0 \\
0 \\
768,177\end{array}$ & $\begin{array}{r}326,547 \\
180,890 \\
189,720 \\
3,772 \\
63,573 \\
250 \\
186 \\
\\
764,939\end{array}$ & $\begin{array}{l}0 \\
0 \\
0 \\
0 \\
0 \\
0 \\
0 \\
0\end{array}$ \\
\hline 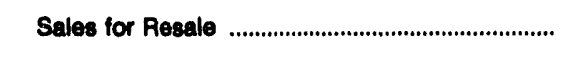 & 5,601 & 165,520 & 68,508 & 64,594 & 35,174 & 140,704 \\
\hline 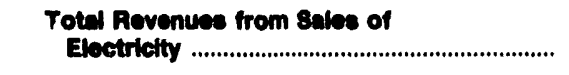 & 122,189 & $1,117,789$ & $1,684,026$ & 832,771 & 800,113 & 140,704 \\
\hline (leses) Provision for Rate Retunds ............................ & 413 & 0 & 0 & 0 & 0 & 0 \\
\hline Net Revenuse from sales of Electricity ........ & 121,777 & $1,117,780$ & $1,684,026$ & 832,771 & 800,113 & 140,704 \\
\hline 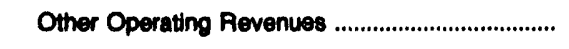 & 2,131 & 10,327 & 59,143 & 11,225 & 12,999 & 12 \\
\hline $\begin{array}{l}\text { Totel Electrle Utilty } \\
\text { Operating Rovenues ......................................... }\end{array}$ & 123,800 & $1,120,116$ & $1,743,168$ & 843,906 & 613,112 & 140,716 \\
\hline
\end{tabular}

Note: Totals may not equal sum of components because of independent rounding. Summary data are provided in Table 15.

Source: Federal Energy Regulatory Commission, FERC Form 1, "Annual Report of Major Electric Utilities, Licensees and Others." 
Table 40. Number of Consumers, Sales, and Operating Rovenue by Major U.S. Investor-Owned Elostric UtIIIty Within State, 1982 (Continued)

\begin{tabular}{|c|c|c|c|c|c|c|}
\hline Item & $\begin{array}{c}\text { Ohio } \\
\text { Ohio } \\
\text { Edison co }\end{array}$ & $\begin{array}{l}\text { Ohio } \\
\text { Ohio } \\
\text { Power Co }\end{array}$ & $\begin{array}{l}\text { Ohio } \\
\text { Ohio } \\
\text { Valley } \\
\text { Electric } \\
\text { Corp }\end{array}$ & $\begin{array}{c}\text { Ohio } \\
\text { Toledo } \\
\text { Edison Co }\end{array}$ & $\begin{array}{c}\text { Oklahoma } \\
\text { Oklahoma } \\
\text { Gas } \\
\& \\
\text { Electric Co }\end{array}$ & $\begin{array}{c}\text { Oklahoma } \\
\text { Public } \\
\text { Service } \\
\text { Co } \\
\text { of Oklahom }\end{array}$ \\
\hline 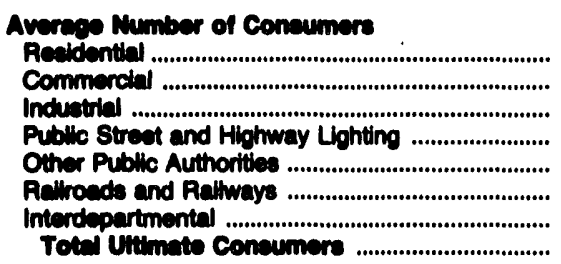 & $\begin{array}{r}818,038 \\
90,210 \\
3,186 \\
1,019 \\
0 \\
0 \\
0 \\
912,463\end{array}$ & $\begin{array}{r}565,020 \\
72,860 \\
7,924 \\
2,497 \\
57 \\
0 \\
0 \\
046,360\end{array}$ & $\begin{array}{l}0 \\
0 \\
1 \\
0 \\
0 \\
0 \\
0 \\
1\end{array}$ & $\begin{array}{r}254,268 \\
26,008 \\
1,893 \\
251 \\
2,282 \\
0 \\
0 \\
224,700\end{array}$ & $\begin{array}{r}560,801 \\
68,421 \\
10,098 \\
248 \\
9,823 \\
0 \\
0 \\
640,301\end{array}$ & $\begin{array}{r}402,010 \\
51,837 \\
5,162 \\
841 \\
167 \\
0 \\
0 \\
460,117\end{array}$ \\
\hline 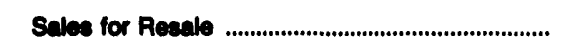 & 10 & 45 & 15 & 8 & 36 & 12 \\
\hline Toted Number of Conoumere ............................ & 912,403 & 646,403 & 16 & 284,708 & 640,427 & 400,120 \\
\hline 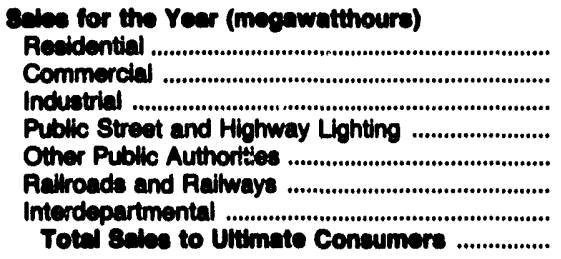 & $\begin{array}{r}6,634,111 \\
5,697,850 \\
8,075,383 \\
138,132 \\
0 \\
0 \\
0 \\
20,546,476\end{array}$ & $\begin{array}{r}5,728,601 \\
4,176,841 \\
18,931,450 \\
83,440 \\
28,288 \\
0 \\
0 \\
0 \\
28,948,020\end{array}$ & $\begin{array}{r}0 \\
0 \\
14,602,458 \\
0 \\
0 \\
0 \\
0 \\
14,602,450\end{array}$ & $\begin{array}{r}1,940,661 \\
1,619,478 \\
3,562,824 \\
60,457 \\
417,635 \\
0 \\
0 \\
7,601,056\end{array}$ & $\begin{array}{r}5,880,308 \\
4,327,325 \\
6,013,455 \\
62,684 \\
1,932,478 \\
0 \\
0 \\
18,316,230\end{array}$ & $\begin{array}{r}4,139,572 \\
4,091,944 \\
4,419,666 \\
46,704 \\
38,246 \\
0 \\
0 \\
12,738,132\end{array}$ \\
\hline Sales for Resale & $7,850,252$ & $16,275,872$ & $2,607,018$ & $2,752,832$ & $5,061,697$ & 684,823 \\
\hline 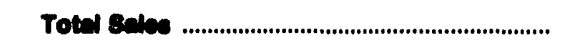 & $28,305,728$ & $45,224,492$ & $17,200,476$ & $10,363,097$ & $28,377,027$ & $13,400,856$ \\
\hline 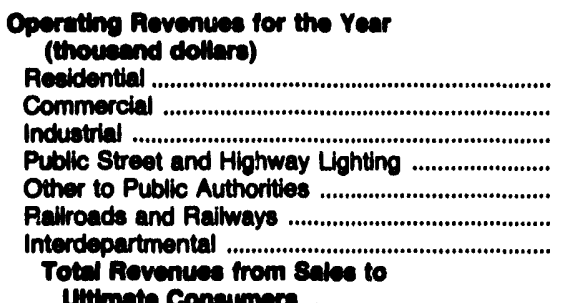 & $\begin{array}{r}716,554 \\
553,707 \\
524,664 \\
12,454 \\
0 \\
0 \\
0\end{array}$ & $\begin{array}{r}369,972 \\
231,985 \\
605,494 \\
8,110 \\
1,403 \\
0 \\
0\end{array}$ & $\begin{array}{r}0 \\
0 \\
254,571 \\
0 \\
0 \\
0 \\
0\end{array}$ & $\begin{array}{r}215,121 \\
175,349 \\
235,979 \\
7,143 \\
36,371 \\
0 \\
0\end{array}$ & $\begin{array}{r}436,984 \\
282,579 \\
268,158 \\
9,134 \\
101,434 \\
0 \\
0\end{array}$ & $\begin{array}{r}258,259 \\
203,176 \\
122,180 \\
4,144 \\
1,872 \\
0 \\
0 \\
\end{array}$ \\
\hline Sales for Resale & 220,476 & 464,351 & 29,434 & 157,575 & 95,629 & 17,782 \\
\hline 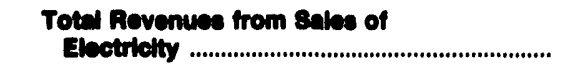 & $2,027,865$ & $1,681,315$ & 284,005 & 827,538 & $1,193,810$ & 607,413 \\
\hline 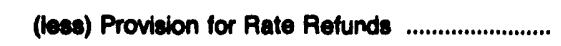 & 0 & 0 & 0 & 0 & 18,000 & $-1,640$ \\
\hline Net Rovenuse from salee of Electrictly ........ & $2,027,855$ & $1,681,315$ & 284,005 & 827,538 & $1,175,819$ & 609,053 \\
\hline 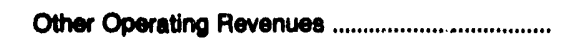 & 30,648 & 21,115 & 0 & 17,117 & 18,173 & 13,039 \\
\hline $\begin{array}{l}\text { Total Electric Utitity } \\
\text { Opernating Rovenued .......................................... }\end{array}$ & $2,058,603$ & $1,702,430$ & 284,005 & 844,655 & $1,193,903$ & 622,002 \\
\hline
\end{tabular}

Note: Totals may not equal sum of components because of independent rounding. Summary data are provided in Table 15. Source: Federal Energy Regulatory Commiseion, FERC Form 1, "Annual Report of Major Electrlc Utilities, Licensees and Others." 
Table 40. Number of Consumors, Sales, and Oporating Revenue by Major U.S. Investor-Owned Electric Utillty Within State, 1992 (Continued)

\begin{tabular}{|c|c|c|c|c|c|c|}
\hline Item & $\begin{array}{l}\text { Orecon } \\
\text { Proificorp }\end{array}$ & $\begin{array}{l}\text { Oregon } \\
\text { Portiand } \\
\text { Ceneral } \\
\text { Electric Co }\end{array}$ & $\begin{array}{l}\text { Pennoytvania } \\
\text { Duqueane } \\
\text { Light Co }\end{array}$ & $\begin{array}{l}\text { Pennoytrania } \\
\text { Metropolitan } \\
\text { Edison Co }\end{array}$ & $\begin{array}{l}\text { Pennoylvania } \\
\text { Pennoytvania } \\
\text { Electric Co }\end{array}$ & $\begin{array}{l}\text { Pennoytvania } \\
\text { Pennoytvania } \\
\text { Power } \\
\text { Light Co }\end{array}$ \\
\hline \multicolumn{7}{|l|}{ Averege Number of Consumers } \\
\hline 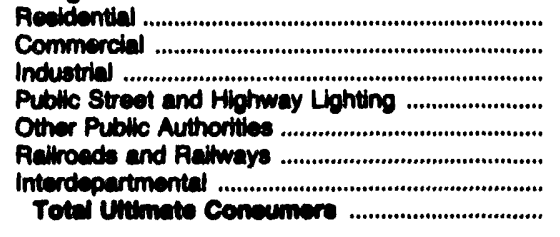 & $\begin{array}{r}1,102,707 \\
147,289 \\
25,865 \\
3,083 \\
28 \\
0 \\
5 \\
1,270,117\end{array}$ & $\begin{array}{r}582,104 \\
74,002 \\
188 \\
609 \\
0 \\
0 \\
0 \\
607,051\end{array}$ & $\begin{array}{r}520,077 \\
52,685 \\
1,983 \\
1,851 \\
0 \\
0 \\
0 \\
670,816\end{array}$ & $\begin{array}{r}390,339 \\
46,615 \\
2,229 \\
760 \\
362 \\
0 \\
0 \\
440,205\end{array}$ & $\begin{array}{r}485,699 \\
65,681 \\
3,242 \\
1,069 \\
0 \\
0 \\
0 \\
68,841\end{array}$ & $\begin{array}{r}1,038,680 \\
133,622 \\
5,428 \\
1,189 \\
17 \\
1 \\
0 \\
1,179,137\end{array}$ \\
\hline Sales for Reale ...................................................... & 47 & 12 & 1 & 8 & 25 & 55 \\
\hline Totel Nember of Consumers ................................ & $1,270,14$ & 607,003 & 679,617 & 440,303 & 869,696 & $1,170,192$ \\
\hline \multicolumn{7}{|l|}{ Sales for the Year (moempetthours) } \\
\hline 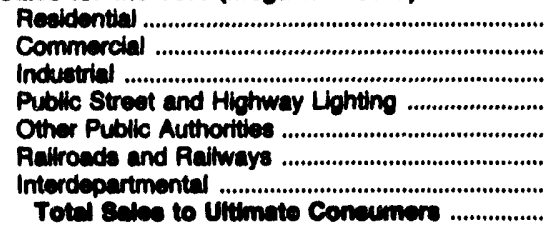 & $\begin{array}{r}11,230,320 \\
9,732,745 \\
19,842,500 \\
104,717 \\
486,889 \\
0 \\
14,037 \\
41,811,900\end{array}$ & $\begin{array}{r}6,225,986 \\
5,717,035 \\
3,602,161 \\
98,726 \\
0 \\
0 \\
0 \\
16,949,05\end{array}$ & $\begin{array}{r}3,069,087 \\
5,368,492 \\
3,058,651 \\
70,886 \\
0 \\
0 \\
0 \\
11,657,195\end{array}$ & $\begin{array}{r}3,567,292 \\
2,637,650 \\
3,589,094 \\
34,035 \\
105,440 \\
0 \\
0 \\
9,984,411\end{array}$ & $\begin{array}{r}3,580,161 \\
3,488,165 \\
4,588,552 \\
44,024 \\
0 \\
0 \\
0 \\
11,710,002\end{array}$ & $\begin{array}{r}10,614,208 \\
9,031,604 \\
8,743,055 \\
78,820 \\
607 \\
8,835 \\
0 \\
28,477,120\end{array}$ \\
\hline Sales for Resale & $13,418,912$ & $2,739,212$ & $4,071,769$ & $2,571,794$ & $3,319,791$ & $13,764,589$ \\
\hline 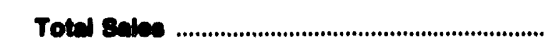 & $64,091,220$ & $10,899,070$ & $18,624,90 s$ & $12,600,205$ & $16,080,698$ & $42,241,727$ \\
\hline \multicolumn{7}{|l|}{$\begin{array}{l}\text { Opernting Rovenues for the Year } \\
\text { (thousind dolines) }\end{array}$} \\
\hline 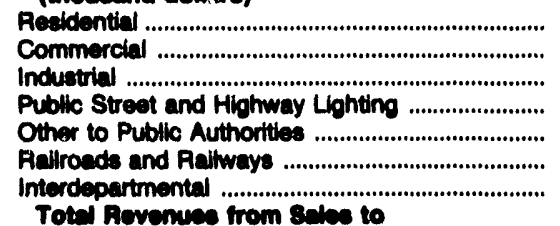 & $\begin{array}{r}649,817 \\
528,853 \\
695,684 \\
10,800 \\
18,478 \\
0 \\
588\end{array}$ & $\begin{array}{r}307,783 \\
291,588 \\
137,590 \\
10,821 \\
0 \\
0 \\
0\end{array}$ & $\begin{array}{r}392,642 \\
476,8986 \\
185,701 \\
17,276 \\
0 \\
0 \\
0\end{array}$ & $\begin{array}{r}308,802 \\
201,109 \\
213,683 \\
4,898 \\
8,888 \\
0 \\
0\end{array}$ & $\begin{array}{r}296,899 \\
247,887 \\
233,272 \\
5,922 \\
0 \\
0 \\
0\end{array}$ & $\begin{array}{r}875,508 \\
711,722 \\
522,174 \\
18,297 \\
52 \\
686 \\
0\end{array}$ \\
\hline Unimate Concumere ........................................... & $1,002,250$ & 747,281 & $1,002,245$ & 735,677 & 784,031 & $2,124,480$ \\
\hline Sales for Resale & 430,053 & 108,793 & 73,235 & 70,837 & 83,303 & 509,974 \\
\hline 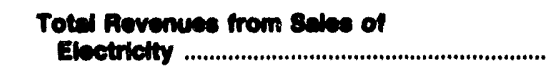 & $2,332,304$ & 968,674 & $1,168,400$ & 000,614 & $\mathbf{0 7 , 3 9 4}$ & $2,898,414$ \\
\hline (leas) Provieion for Rate Refunds ......................... & 3,381 & $-6,887$ & 0 & 0 & 0 & 0 \\
\hline Net Rovenuse from sales of Electuletty ....... & $2,322,049$ & $\mathbf{c o s , c e r}$ & $1,165,490$ & $\cos , 614$ & 687,334 & $2,058,414$ \\
\hline Other Operating Revenues ......................................... & 32,565 & 17,411 & 31,809 & 15,220 & 29,003 & 105,203 \\
\hline $\begin{array}{l}\text { Toted Ebetric Utilty } \\
\text { Operating Revenuse }\end{array}$ & $2,831,483$ & S1,072 & $1,187,300$ & 921,734 & 006,337 & $2,741,816$ \\
\hline
\end{tabular}

Note: Totale may not equal sum of components because of independent rounding. Summary data are provided in Table 15.

Source: Federal Energy Regulatory Cornmiseion, FERC Form 1, "Annual Peport of Melor Electric Utilities, Licensees and Othere." 
Table 40. Number of Consumers, 8ales, and Operating Rovenue by Major U.S. Invoator-Owned Electric Utility Within State, 1992 (Continued)

\begin{tabular}{|c|c|c|c|c|c|c|}
\hline Item & $\begin{array}{l}\text { Pennoylvenia } \\
\text { Pennoylvania } \\
\text { Power Co }\end{array}$ & $\begin{array}{l}\text { Pennoytvania } \\
\text { Philedelphia } \\
\text { Electric Co }\end{array}$ & $\begin{array}{l}\text { Penneytrania } \\
\text { Sale } \\
\text { Hartor } \\
\text { Water } \\
\text { Power Corp }\end{array}$ & $\begin{array}{l}\text { Pennoytvania } \\
\text { Suequehanna } \\
\text { Electric Co }\end{array}$ & $\begin{array}{c}\text { Pennoytvania } \\
\text { Weat } \\
\text { Penn } \\
\text { Power } \\
\text { Co }\end{array}$ & $\begin{array}{c}\text { Pennoytuania } \\
\text { York } \\
\text { Haven } \\
\text { Power } \\
\text { Co }\end{array}$ \\
\hline 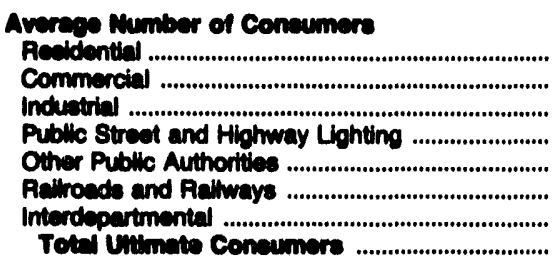 & $\begin{array}{r}121,147 \\
15,287 \\
237 \\
89 \\
0 \\
0 \\
0 \\
189,700\end{array}$ & $\begin{array}{r}1,297,917 \\
137,833 \\
3,880 \\
804 \\
0 \\
3 \\
0 \\
1,440,637\end{array}$ & $\begin{array}{l}0 \\
0 \\
0 \\
0 \\
0 \\
0 \\
0 \\
0\end{array}$ & $\begin{array}{l}0 \\
0 \\
0 \\
0 \\
0 \\
0 \\
0 \\
0\end{array}$ & $\begin{array}{r}561,659 \\
68,368 \\
10,979 \\
623 \\
0 \\
0 \\
0 \\
683,620\end{array}$ & $\begin{array}{l}0 \\
0 \\
0 \\
0 \\
0 \\
0 \\
0 \\
0\end{array}$ \\
\hline Selee for Reade & 14 & 13 & 2 & 2 & 46 & 1 \\
\hline Total Mumber of Coneumere ............................... & 136,771 & $1,440,650$ & 2 & 2 & 689,674 & 1 \\
\hline 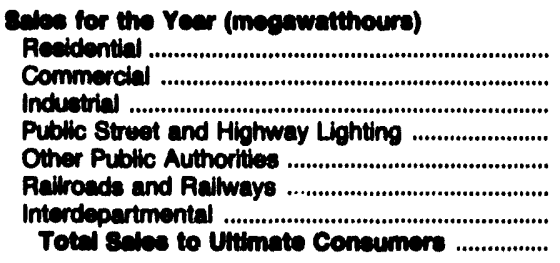 & $\begin{array}{r}1,050,601 \\
781,630 \\
1,674,510 \\
6,380 \\
0 \\
0 \\
0 \\
3,513,321\end{array}$ & $\begin{array}{r}9,522,301 \\
5,222,052 \\
15,568,786 \\
207,331 \\
0 \\
674,157 \\
79,863 \\
31,294,490\end{array}$ & $\begin{array}{l}0 \\
0 \\
0 \\
0 \\
0 \\
0 \\
0 \\
0\end{array}$ & $\begin{array}{l}0 \\
0 \\
0 \\
0 \\
0 \\
0 \\
0 \\
0\end{array}$ & $\begin{array}{r}5,396,533 \\
3,374,355 \\
7,058,895 \\
52,918 \\
0 \\
0 \\
0 \\
15,292,702\end{array}$ & $\begin{array}{l}0 \\
0 \\
0 \\
0 \\
0 \\
0 \\
0 \\
0\end{array}$ \\
\hline Sales for Resale & $1,822,957$ & $8,658,707$ & $1,084,380$ & $1,788,123$ & $8,975,679$ & 141,544 \\
\hline 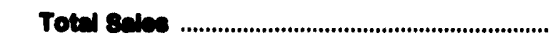 & $8,336,276$ & $39,024,197$ & $1,004,300$ & $1,7 e 4,123$ & $25,060,281$ & 141,844 \\
\hline $\begin{array}{l}\text { Operating Revenuse for the Year } \\
\text { (thouvend dollars) }\end{array}$ & & & & & & \\
\hline 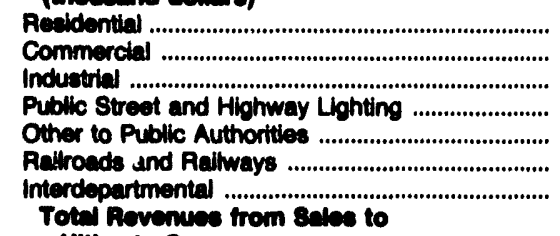 & $\begin{array}{r}104,133 \\
62,554 \\
82,145 \\
1,583 \\
0 \\
0 \\
0\end{array}$ & $\begin{array}{r}1,265,943 \\
653,476 \\
1,207,256 \\
36,167 \\
0 \\
0 \\
51,451 \\
6,829\end{array}$ & $\begin{array}{l}0 \\
0 \\
0 \\
0 \\
0 \\
0 \\
0\end{array}$ & $\begin{array}{l}0 \\
0 \\
0 \\
0 \\
0 \\
0 \\
0\end{array}$ & $\begin{array}{r}321,871 \\
177,697 \\
293,910 \\
6,159 \\
0 \\
0 \\
0\end{array}$ & $\begin{array}{l}0 \\
0 \\
0 \\
0 \\
0 \\
0 \\
0\end{array}$ \\
\hline Ulitinate Conseumere ........................................... & 260,416 & $3,221,222$ & $\mathbf{0}$ & $\mathbf{0}$ & 709,638 & $\mathbf{0}$ \\
\hline Sales for Resale & 48,433 & 274,872 & 28,245 & 27,010 & 255,835 & 4,336 \\
\hline 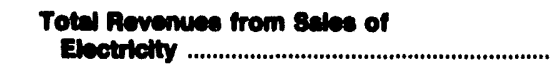 & 203,840 & $3,490,194$ & 28,245 & 27,010 & $1,055,473$ & 4,830 \\
\hline (leces) Provision for Rate Refunds ............................ & 0 & 0 & 0 & 0 & 0 & 0 \\
\hline Net Rovenuse from Eales of Electrictly ........ & 298,840 & $3,486,104$ & 28,245 & 27,010 & $1,055,473$ & 4,398 \\
\hline 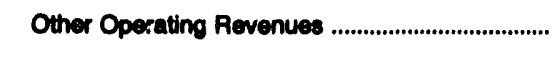 & 16,610 & 71,889 & 122 & 430 & 21,368 & 89 \\
\hline $\begin{array}{l}\text { Yotal Electule Utivity } \\
\text { Operathing Revenued ........................................ }\end{array}$ & 315,460 & $3,603,003$ & 28,307 & 27,440 & $1,076,041$ & 4,426 \\
\hline
\end{tabular}

Note: Totals may not equal sum of components because of independent rounding. Summary data are provided in Table 15. Source: Federal Energy Regulatory Commisaion, FERC Form 1, "Annual Report of Malor Electric Utillties, Licensees and Others." 
Table 40. Number of Consumors, Sales, and Operating Rovenue by Major U.S. Inveator-Owned Electric Utility Within State, 1992 (Continued)

\begin{tabular}{|c|c|c|c|c|c|c|}
\hline $1 \mathrm{tem}$ & $\begin{array}{l}\text { Ahode leland } \\
\text { Blacketone } \\
\text { Valley } \\
\text { Electric Co }\end{array}$ & $\begin{array}{l}\text { Rhode leland } \\
\text { Narraganeett } \\
\text { Electric Co }\end{array}$ & $\begin{array}{l}\text { Rhode letand } \\
\text { Nemport } \\
\text { Electric } \\
\text { Corp }\end{array}$ & $\begin{array}{l}\text { South Carolina } \\
\text { Lockhart } \\
\text { Power Co }\end{array}$ & $\begin{array}{c}\text { South Carolina } \\
\text { South } \\
\text { Carolina } \\
\text { Electric\&Gas } \\
\text { Co }\end{array}$ & $\begin{array}{l}\text { South Carollna } \\
\text { South } \\
\text { Carolina } \\
\text { Generts } \\
\text { Co Inc }\end{array}$ \\
\hline 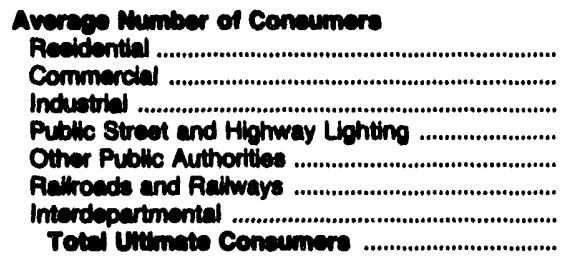 & $\begin{array}{r}74,541 \\
8,572 \\
550 \\
7 \\
0 \\
0 \\
0 \\
68,670\end{array}$ & $\begin{array}{r}284,711 \\
31,417 \\
1,835 \\
841 \\
0 \\
0 \\
0 \\
310,004\end{array}$ & $\begin{array}{r}27,249 \\
4,230 \\
10 \\
6 \\
1 \\
0 \\
0 \\
31,400\end{array}$ & $\begin{array}{r}4,138 \\
741 \\
12 \\
5 \\
0 \\
0 \\
0 \\
4,000\end{array}$ & $\begin{array}{r}395,471 \\
59,413 \\
705 \\
723 \\
1,893 \\
0 \\
0 \\
460,208\end{array}$ & $\begin{array}{l}0 \\
0 \\
0 \\
0 \\
0 \\
0 \\
0 \\
0\end{array}$ \\
\hline Sales for Resale & 0 & 2 & 1 & 1 & 12 & 1 \\
\hline Toted Number of Conaumere .............................. & $\mathbf{8 3 , 6 7 0}$ & 310,000 & 31,401 & 4,007 & 460,217 & 1 \\
\hline 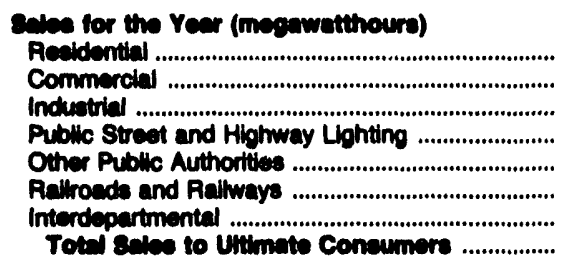 & $\begin{array}{r}364,430 \\
395,907 \\
454,101 \\
12,500 \\
0 \\
0 \\
0 \\
1,228,988\end{array}$ & $\begin{array}{r}1,783,754 \\
1,877,738 \\
869,062 \\
55,476 \\
0 \\
0 \\
0 \\
4,686,030\end{array}$ & $\begin{array}{r}192,652 \\
199,383 \\
27,898 \\
3,604 \\
116,870 \\
0 \\
0 \\
540,395\end{array}$ & $\begin{array}{r}53,138 \\
14,385 \\
123,538 \\
283 \\
0 \\
0 \\
0 \\
101,350\end{array}$ & $\begin{array}{r}5,155,886 \\
4,538,862 \\
4,684,072 \\
50,818 \\
425,146 \\
0 \\
0 \\
14,854,804\end{array}$ & $\begin{array}{l}0 \\
0 \\
0 \\
0 \\
0 \\
0 \\
0 \\
0\end{array}$ \\
\hline Sales for Resale & 0 & 590 & 91,606 & 121,437 & $1,023,403$ & $2,772,738$ \\
\hline 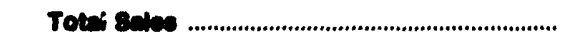 & $1,228,030$ & $4,586,020$ & 631,001 & 312,786 & $15,070,287$ & $2,772,730$ \\
\hline 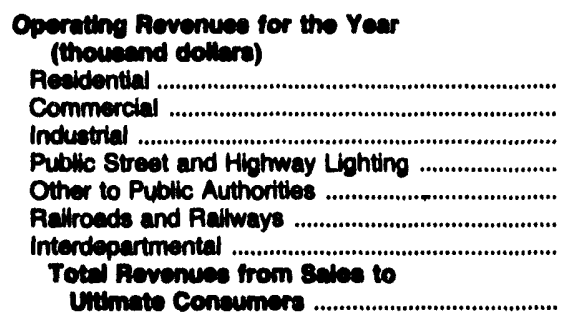 & $\begin{array}{r}42,968 \\
42,451 \\
45,375 \\
1,937 \\
0 \\
0 \\
0 \\
132,731\end{array}$ & $\begin{array}{r}196,983 \\
183,702 \\
76,275 \\
6,587 \\
0 \\
0 \\
0 \\
\\
463,647\end{array}$ & $\begin{array}{r}20,831 \\
21,742 \\
2,664 \\
466 \\
10,325 \\
0 \\
0 \\
\\
56,028\end{array}$ & $\begin{array}{r}3,824 \\
1,156 \\
5,221 \\
32 \\
0 \\
0 \\
0 \\
\\
10,233\end{array}$ & $\begin{array}{r}353,656 \\
248,358 \\
178,335 \\
4,231 \\
18,624 \\
0 \\
0 \\
808,204\end{array}$ & $\begin{array}{l}0 \\
0 \\
0 \\
0 \\
0 \\
0 \\
0\end{array}$ \\
\hline Sales for Resale & 0 & 68 & 3,069 & 5,555 & 36,263 & 73,108 \\
\hline 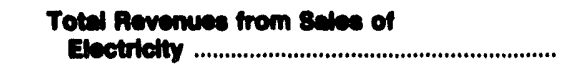 & 132,731 & 403,615 & 80,007 & 15,798 & 830,467 & 73,103 \\
\hline (lese) Provision for Rate Retunds ........................... & 0 & 0 & 0 & 0 & 14,588 & 0 \\
\hline Not Rovenues from sales of Ebetrictly ....... & 1332,731 & 403,616 & 60,097 & 15,788 & 824,879 & 73,100 \\
\hline 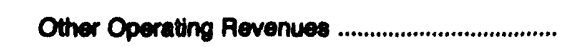 & 5,873 & 4,637 & 446 & 22 & 5,059 & 0 \\
\hline 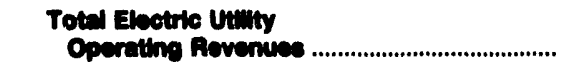 & 130,604 & 468,252 & 60,543 & 16,810 & 820,938 & 73,103 \\
\hline
\end{tabular}

Note: Totals may not equal sum of components because of independent rounding. Summary data are provided in Table 15. Source: Federal Energy Regulatory Commiseion, FERC Form 1, "Annual Report of Major Electric Utilties, Licensees and Others." 
Table 40. Number of Consumers, 8alee, and Operating Revenue by Major U.S. Investor-Owned Electric Utility Within State, 1092 (Continued)

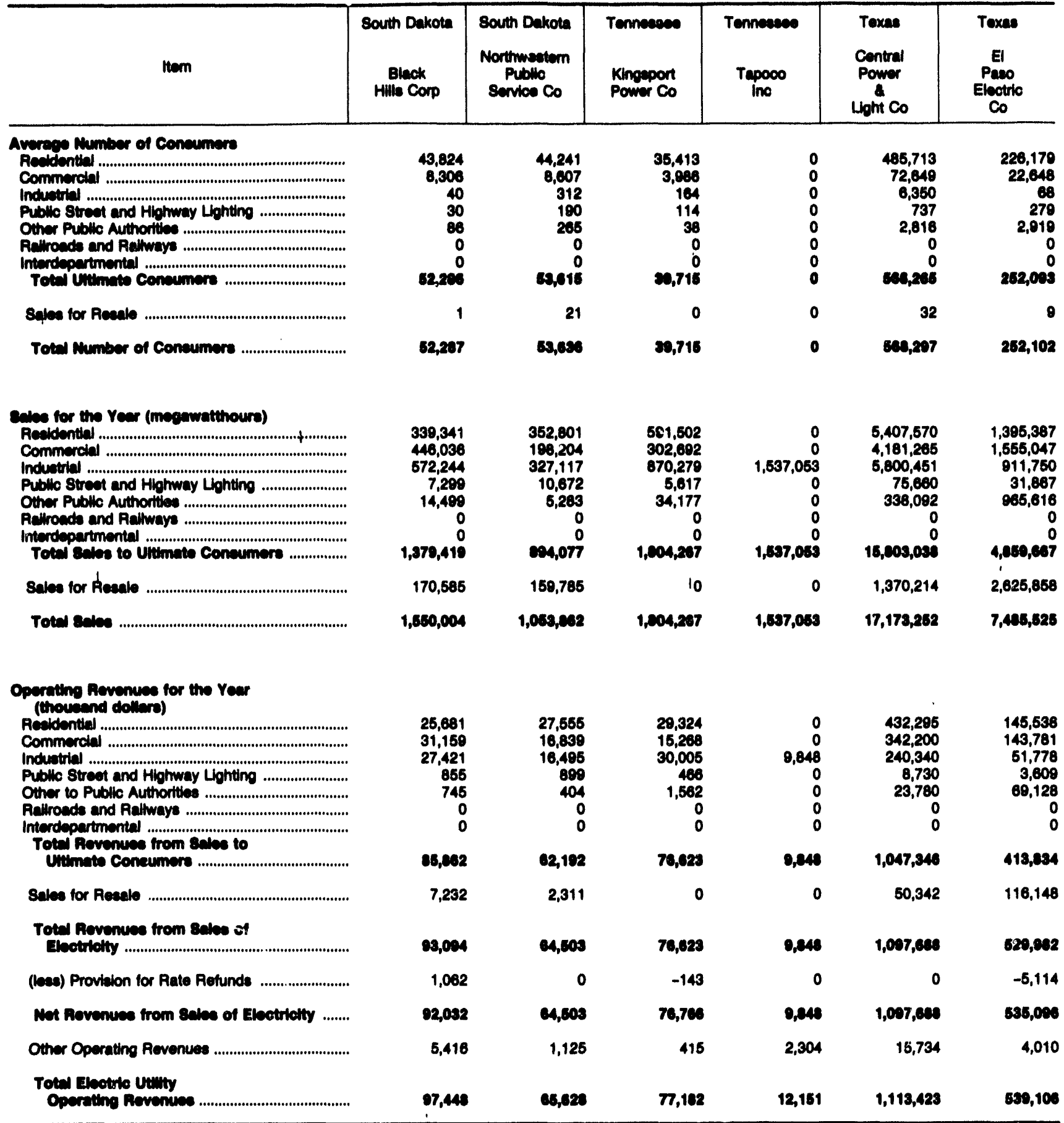

Note: Totale may not equal sum of components because of independent roundino. Summary data are provided in Table 15.

Source: Federal Energy Regulatory Commiseion, FERC Form 1. "Annual Report of Malor Electric Utilties, Llcensees and Othere." 
Table 40. Number of Consumers, Sales, and Operating Revenue by Major U.S. Investor-Owned Electric Utility Within State, 1992 (Continued)

\begin{tabular}{|c|c|c|c|c|c|c|}
\hline Item & $\begin{array}{l}\text { Texas } \\
\text { Gulf } \\
\text { States } \\
\text { Utilties } \\
\text { Co }\end{array}$ & $\begin{array}{c}\text { Texas } \\
\text { Houston } \\
\text { Lighting } \\
\text { Power Co }\end{array}$ & $\begin{array}{l}\text { Texas } \\
\text { Southwestern } \\
\text { Electric } \\
\text { Serv Co }\end{array}$ & $\begin{array}{l}\text { Texas } \\
\text { Southwestern } \\
\text { Public } \\
\text { Sorvice Co }\end{array}$ & $\begin{array}{c}\text { Texas } \\
\text { Texes } \\
\text { Utilities } \\
\text { Electric Co }\end{array}$ & $\begin{array}{l}\text { Texas } \\
\text { Texas- } \\
\text { New Mexico } \\
\text { Power Co }\end{array}$ \\
\hline 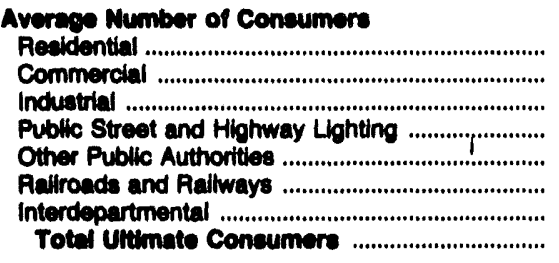 & $\begin{array}{r}510,003 \\
64,000 \\
6,923 \\
940 \\
1,900 \\
0 \\
0 \\
623,706\end{array}$ & $\begin{array}{r}1,250,888 \\
164,051 \\
1,765 \\
82 \\
0 \\
0 \\
0 \\
1,416,786\end{array}$ & $\begin{array}{r}33,344 \\
5,743 \\
243 \\
26 \\
439 \\
0 \\
0 \\
30,794\end{array}$ & $\begin{array}{r}292,283 \\
51,773 \\
10,730 \\
106 \\
488 \\
0 \\
0 \\
365,300\end{array}$ & $\begin{array}{r}1,936,787 \\
208,361 \\
22,022 \\
5,340 \\
22,641 \\
0 \\
0 \\
2,105,151\end{array}$ & $\begin{array}{r}176,089 \\
30,503 \\
156 \\
106 \\
122 \\
0 \\
0 \\
207,006\end{array}$ \\
\hline 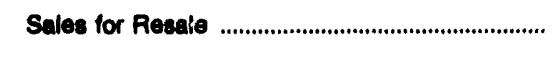 & 30 & 10 & 2 & 112 & 247 & 12 \\
\hline 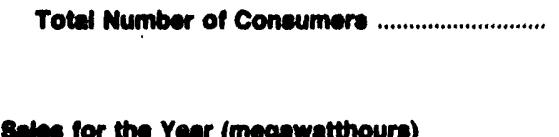 & 583,796 & $1,416,706$ & 30,796 & 355,602 & $2,105,300$ & 207,207 \\
\hline 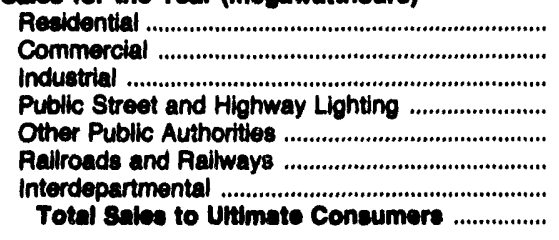 & $\begin{array}{r}6,824,670 \\
5,474,432 \\
14,412,451 \\
82,441 \\
218,307 \\
0 \\
423,517 \\
27,438,818\end{array}$ & $\begin{array}{r}16,375,400 \\
12,541,636 \\
30,348,487 \\
110,896 \\
0 \\
0 \\
0 \\
50,376,410\end{array}$ & $\begin{array}{r}364,906 \\
244,298 \\
163,130 \\
6,100 \\
99,096 \\
0 \\
0 \\
677,680\end{array}$ & $\begin{array}{r}2,427,639 \\
2,481,384 \\
7,370,980 \\
48,752 \\
445,485 \\
0 \\
0 \\
12,774,460\end{array}$ & $\begin{array}{r}27,266,411 \\
22,859,464 \\
21,108,894 \\
364,842 \\
4,667,938 \\
0 \\
0 \\
76,367,640\end{array}$ & $\begin{array}{r}1,947,593 \\
1,499,927 \\
2,508,837 \\
37,848 \\
68,932 \\
0 \\
0 \\
6,003,137\end{array}$ \\
\hline 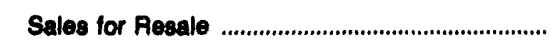 & 540,286 & 565,869 & 94,448 & $5,791,850$ & $4,006,325$ & 3,174 \\
\hline Total sales & $27,077,104$ & $59,042,388$ & 971,078 & $18,586,300$ & $60,373,874$ & $6,006,311$ \\
\hline \multicolumn{7}{|l|}{$\begin{array}{l}\text { Operating Rovenuses for the Yoar } \\
\text { (thousend dollare) }\end{array}$} \\
\hline 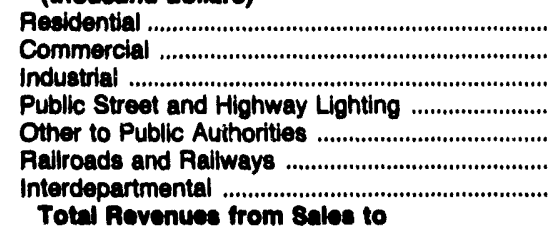 & $\begin{array}{r}560,552 \\
400,804 \\
642,287 \\
11,615 \\
14,580 \\
0 \\
25,725\end{array}$ & $\begin{array}{r}1,465,627 \\
926,157 \\
1,261,643 \\
23,148 \\
0 \\
0 \\
0\end{array}$ & $\begin{array}{r}29,640 \\
17,916 \\
9,160 \\
663 \\
6,106 \\
0 \\
0\end{array}$ & $\begin{array}{r}149,303 \\
137,012 \\
262,197 \\
3,785 \\
21,802 \\
0 \\
0\end{array}$ & $\begin{array}{r}1,995,767 \\
1,405,546 \\
849,365 \\
36,003 \\
268,283 \\
0 \\
0\end{array}$ & $\begin{array}{r}175,885 \\
128,650 \\
121,027 \\
2,599 \\
5,426 \\
0 \\
0\end{array}$ \\
\hline 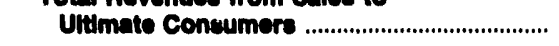 & $1,656,673$ & $3,676,575$ & 63,405 & 574,098 & $4,554,964$ & 433,407 \\
\hline Sales for Resale & 24,485 & 33,198 & 4,561 & 178,373 & 209,170 & 245 \\
\hline $\begin{array}{l}\text { Total Aovenues from 8ales of } \\
\text { Ebetrielty }\end{array}$ & $1,680,058$ & $3,709,773$ & 68,046 & 763,471 & $4,764,135$ & 433,732 \\
\hline (less) Provision for Rate Refunds ........................... & 0 & 0 & 0 & 0 & 0 & 0 \\
\hline Net Revenues from sales of Eloctrielty ....... & $1,680,058$ & $3,700,773$ & 68,046 & 763,471 & $4,784,135$ & 433,732 \\
\hline 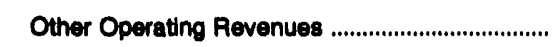 & 40,372 & 117,068 & 390 & 3,762 & 285,147 & 10,095 \\
\hline $\begin{array}{l}\text { Total Eloctric Utilty } \\
\text { Operating Rovenues .......................................... }\end{array}$ & $1,720,430$ & $3,826,841$ & 68,436 & 767,233 & $5,020,281$ & 443,027 \\
\hline
\end{tabular}

Note: Totals may not equal sum of components because of independent rounding. Summary data are provided in Table 15.

Source: Federal Energy Regulatory Commission, FERC Form 1, "Annual Report of Major Electric Utilities, Licensees and Others." 
Table 40. Number of Consumers, Sales, and Operating Rovenue by Major U.S. Investor-Owned Electric Utility Within state, 1992 (Continued)

\begin{tabular}{|c|c|c|c|c|c|c|c|}
\hline Item & $\begin{array}{c}\text { Texas } \\
\text { Wost } \\
\text { Toxas } \\
\text { Utilties } \\
\text { Co }\end{array}$ & $\begin{array}{l}\text { Vermont } \\
\text { Central } \\
\text { Vermont } \\
\text { Pub } \\
\text { Serv Corp }\end{array}$ & $\begin{array}{c}\text { Vermont } \\
\text { Green } \\
\text { Mountain } \\
\text { Power Corp }\end{array}$ & $\begin{array}{l}\text { Vermont } \\
\text { Vermont } \\
\text { Electite } \\
\text { Power } \\
\text { Co Inc }\end{array}$ & $\begin{array}{l}\text { Vermont } \\
\text { Vermont } \\
\text { Electile } \\
\text { Trant } \\
\text { Co Inc }\end{array}$ & & $\begin{array}{l}\text { Vermont } \\
\text { Vermont } \\
\text { Yankee } \\
\text { Nycl } \\
\text { 'Pwr Corp }\end{array}$ \\
\hline 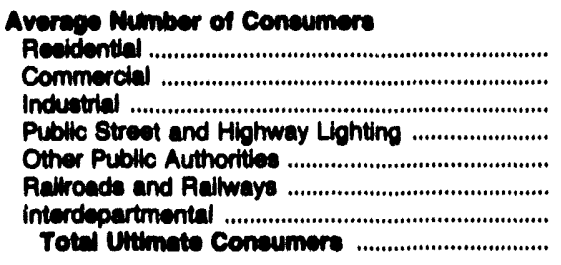 & $\begin{array}{r}141,681 \\
25,438 \\
7,376 \\
128 \\
4,050 \\
0 \\
0 \\
179,673\end{array}$ & $\begin{array}{r}118,289 \\
16,205 \\
37 \\
179 \\
1 \\
0 \\
0 \\
124,681\end{array}$ & $\begin{array}{r}67,201 \\
11,245 \\
24 \\
56 \\
1 \\
0 \\
0 \\
70,626\end{array}$ & $\begin{array}{l}0 \\
0 \\
0 \\
0 \\
0 \\
0 \\
0 \\
0\end{array}$ & & $\begin{array}{l}0 \\
0 \\
0 \\
0 \\
0 \\
0 \\
0 \\
0\end{array}$ & $\begin{array}{l}0 \\
0 \\
0 \\
0 \\
0 \\
0 \\
0 \\
0\end{array}$ \\
\hline Sales for Reale & 121 & 28 & 17 & 21 & & 0 & $\theta$ \\
\hline Totel Number of Consumere ................................ & 1779,604 & 134,090 & 70,649 & 21 & & $\mathbf{0}$ & e \\
\hline 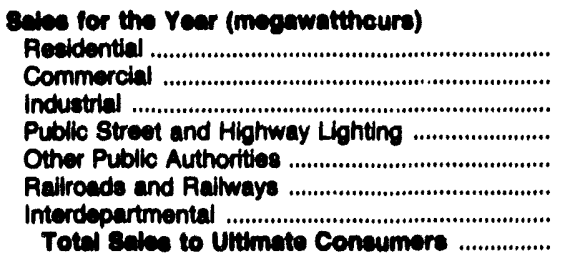 & $\begin{array}{r}1,343,774 \\
1,057,669 \\
1,175,312 \\
28,372 \\
464,325 \\
0 \\
0 \\
4,037,362\end{array}$ & $\begin{array}{r}813,279 \\
775,031 \\
383,300 \\
6,721 \\
12 \\
0 \\
0 \\
1,970,397\end{array}$ & $\begin{array}{r}563,608 \\
584,063 \\
539,665 \\
4,809 \\
44 \\
0 \\
0 \\
1,002,170\end{array}$ & $\begin{array}{l}0 \\
0 \\
0 \\
0 \\
0 \\
0 \\
0 \\
0\end{array}$ & & $\begin{array}{l}0 \\
0 \\
0 \\
0 \\
0 \\
0 \\
0 \\
0\end{array}$ & $\begin{array}{l}0 \\
0 \\
0 \\
0 \\
0 \\
0 \\
0\end{array}$ \\
\hline 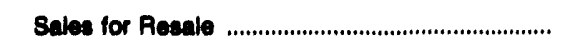 & $1,850,885$ & $1,597,623$ & 376,894 & 858,517 & & 0 & $3,734,598$ \\
\hline 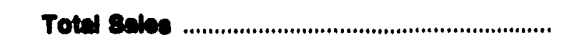 & $6,018,337$ & $3,676,000$ & $2,008,073$ & 068,617 & & 0 & $3,734,698$ \\
\hline
\end{tabular}

\section{Operating Rovenues for the Year}

\section{(thouend dollare)}

Pecidential

Commerclal

Publis Street and Highway Lighting

Other to Public Authorities

Pallionds and Raihways

Total Rovenuses from sabes to

Uhinate Consumers .

Salea for Resale

\begin{tabular}{|c|c|c|c|c|c|}
\hline $\begin{array}{r}106,497 \\
62,244 \\
52,651 \\
3,220 \\
25,233 \\
0 \\
0\end{array}$ & $\begin{array}{r}87,518 \\
80,077 \\
29,111 \\
1,542 \\
2 \\
0 \\
0\end{array}$ & $\begin{array}{r}46,658 \\
45,552 \\
31,775 \\
821 \\
1 \\
0 \\
0\end{array}$ & $\begin{array}{l}0 \\
0 \\
0 \\
0 \\
0 \\
0 \\
0\end{array}$ & $\begin{array}{l}0 \\
0 \\
0 \\
0 \\
0 \\
0 \\
0\end{array}$ & $\begin{array}{l}0 \\
0 \\
0 \\
0 \\
0 \\
0 \\
0\end{array}$ \\
\hline 249,044 & 199,250 & 128,008 & 0 & 0 & 0 \\
\hline 60,833 & 63,421 & 17,186 & 30,342 & 0 & 175,818 \\
\hline 310,677 & 281,670 & 141,002 & 30,342 & 0 & 176,010 \\
\hline 0 & 0 & -62 & 0 & 0 & 0 \\
\hline 310,677 & 281,670 & 141,034 & 30,342 & 0 & 175,013 \\
\hline 4,693 & 6,282 & 4,176 & 16,722 & 7,015 & 0 \\
\hline 315,370 & 207,053 & 146,240 & $47,0 \times 4$ & 7,016 & 175,010 \\
\hline
\end{tabular}

Totel Rovenuse from sales of

Ehotuletly

(leas) Provision for Rate Refunds

Not Rovenuse from 8abes of Electrictly .......

Other Operating Revenues

5.

Source: Federal Energy Regulatory Commiselon, FERC Form 1, "Annual Report of Major Electric Utilties, Licensees and Others." 
Table 40. Number of Consumere, Sales, and Operating Rovenue , by Major U.S. Inveator-Owned Electric Utility Within State, 1992 (Continued)

\begin{tabular}{|c|c|c|c|c|c|c|}
\hline Item & $\begin{array}{l}\text { Virginia } \\
\text { Appalachian } \\
\text { Power Co }\end{array}$ & $\begin{array}{l}\text { Virginia } \\
\text { Virginia } \\
\text { Electric } \\
\text { \& Power } \\
\text { Co }\end{array}$ & $\begin{array}{l}\text { Washington } \\
\text { Puget Sound } \\
\text { Power \& Light } \\
\text { Co }\end{array}$ & $\begin{array}{l}\text { Washington } \\
\text { Washington } \\
\text { Water } \\
\text { Power Co }\end{array}$ & $\begin{array}{l}\text { West Virginia } \\
\text { Kanawha } \\
\text { Valley } \\
\text { Power Co }\end{array}$ & $\begin{array}{l}\text { West Virginia } \\
\text { Monongahela } \\
\text { Power Co }\end{array}$ \\
\hline 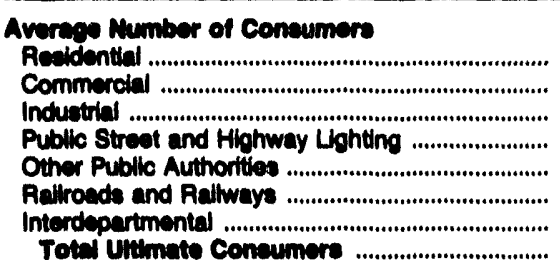 & $\begin{array}{r}717,154 \\
94,672 \\
3,761 \\
1,551 \\
3,735 \\
0 \\
0 \\
090,779\end{array}$ & $\begin{array}{r}1,617,743 \\
175,653 \\
840 \\
1,463 \\
23,365 \\
0 \\
0 \\
1,010,054\end{array}$ & $\begin{array}{r}692,100 \\
80,863 \\
3,659 \\
1,245 \\
0 \\
0 \\
0 \\
777,907\end{array}$ & $\begin{array}{r}227,576 \\
27,781 \\
974 \\
302 \\
0 \\
0 \\
42 \\
258,075\end{array}$ & $\begin{array}{l}0 \\
0 \\
0 \\
0 \\
0 \\
0 \\
0 \\
0\end{array}$ & $\begin{array}{r}292,646 \\
33,749 \\
8,004 \\
144 \\
0 \\
0 \\
0 \\
334,643\end{array}$ \\
\hline Sales for Resale & 56 & 13 & 18 & 26 & 1 & 29 \\
\hline Toted Number of Conoumere ................................ & 820,020 & $1,810,067$ & 777,005 & 280,701 & 1 & 334,672 \\
\hline 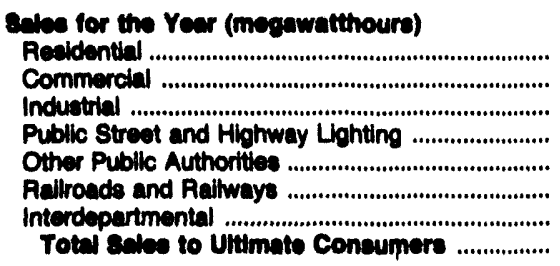 & $\begin{array}{r}8,944,292 \\
4,855,878 \\
9,306,650 \\
67,771 \\
466,428 \\
0 \\
0 \\
28,761,020\end{array}$ & $\begin{array}{r}19,884,489 \\
17,692,997 \\
9,419,449 \\
252,348 \\
7,315,451 \\
0 \\
0 \\
54,604,734\end{array}$ & $\begin{array}{r}8,441,893 \\
5,996,355 \\
3,718,344 \\
67,903 \\
0 \\
0 \\
0 \\
18,224,495\end{array}$ & $\begin{array}{r}3,023,854 \\
2,298,515 \\
1,562,549 \\
20,538 \\
0 \\
0 \\
15,376 \\
8,920,832\end{array}$ & $\begin{array}{l}0 \\
0 \\
0 \\
0 \\
0 \\
0 \\
0 \\
0\end{array}$ & $\begin{array}{r}2,527,247 \\
1,742,489 \\
4,672,126 \\
25,699 \\
0 \\
0 \\
0 \\
0,167,641\end{array}$ \\
\hline Sales for Resale & $8,800,582$ & $4,652,405$ & $1,283,545$ & $3,162,447$ & 276,073 & $5,376,881$ \\
\hline 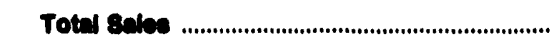 & $32,601,602$ & $50,317,130$ & $10,508,040$ & $10,003,279$ & 278,073 & $14,544,422$ \\
\hline 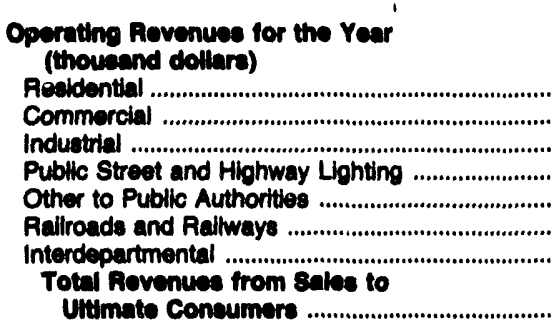 & $\begin{array}{r}505,248 \\
25,994 \\
351,810 \\
5,476 \\
23,911 \\
0 \\
0 \\
1,141,500\end{array}$ & $\begin{array}{r}1,630,316 \\
1,122,898 \\
427,420 \\
36,477 \\
38,, 520 \\
0 \\
0 \\
\\
3,604,731\end{array}$ & $\begin{array}{r}453,896 \\
327,439 \\
139,416 \\
8,803 \\
0 \\
0 \\
0 \\
\\
929,653\end{array}$ & $\begin{array}{r}146,073 \\
121,277 \\
50,934 \\
2,891 \\
0 \\
0 \\
711 \\
\\
321,896\end{array}$ & $\begin{array}{l}0 \\
0 \\
0 \\
0 \\
0 \\
0 \\
0\end{array}$ & $\begin{array}{r}160,590 \\
102,709 \\
188,442 \\
2,686 \\
0 \\
0 \\
0 \\
401,428\end{array}$ \\
\hline Sales for Resale & 253,111 & 187,767 & 30,092 & 91,791 & 4,273 & 155,714 \\
\hline 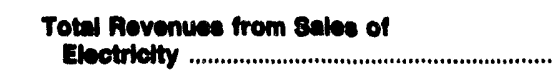 & $1,394,611$ & $3,702,400$ & 969,645 & 413,676 & 4,273 & 617,140 \\
\hline (tese) Provlaion for Rate Retunds ......................... & -41 & 161,915 & 0 & 0 & 0 & 0 \\
\hline Not Rovenuse from sales of Electriclity ........ & $1,394,652$ & $3,630,683$ & 969,646 & 413,675 & 4,273 & 617,140 \\
\hline 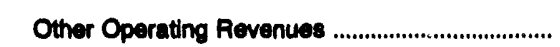 & 16,162 & 49,038 & 65,325 & 10,737 & 0 & 14,824 \\
\hline$\ldots$ & $1,410,813$ & $3,679,621$ & $1,024,970$ & 424,413 & 4,273 & 631,004 \\
\hline
\end{tabular}

Note: Totale may not equal sum of components because of independent rounding. Summary data are provided in Table 15. Source: Federal Energy Regulatory Commiselon, FERC Form 1, "Annual Report of Major Electric Utilities, Licensees and Others." 
Table 40. Number of Conoumere, 8ales, and Operating Rovenue by Major U.8. Investor-Owned Eloctric Utility Within State, 1902 (Continued)

\begin{tabular}{|c|c|c|c|c|c|c|}
\hline Itom & $\begin{array}{l}\text { Weot Virginia } \\
\text { Wheeling } \\
\text { Power Co }\end{array}$ & $\begin{array}{l}\text { Wheconeln } \\
\text { Coneollidated } \\
\text { Water } \\
\text { Power co }\end{array}$ & $\begin{array}{l}\text { Weconain } \\
\text { Madieon } \\
\text { Cass } \\
\text { Electrite Co }\end{array}$ & $\begin{array}{l}\text { Wheoonain } \\
\text { Northern } \\
\text { States } \\
\text { Power Co }\end{array}$ & $\begin{array}{l}\text { Whaconein } \\
\text { Northweotern } \\
\text { Whecondin } \\
\text { Elec Co }\end{array}$ & $\begin{array}{l}\text { Wisconein } \\
\text { Pioneer } \\
\text { Power } \\
\text { Light Co }\end{array}$ \\
\hline 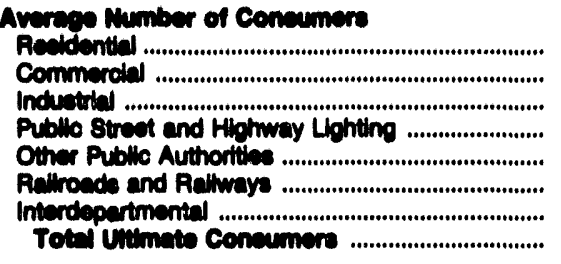 & $\begin{array}{r}35,889 \\
4,674 \\
290 \\
167 \\
0 \\
0 \\
0 \\
40,020\end{array}$ & $\begin{array}{r}847 \\
144 \\
1 \\
5 \\
15 \\
0 \\
0 \\
1,012\end{array}$ & $\begin{array}{r}90,244 \\
14,840 \\
80 \\
48 \\
2 \\
0 \\
1 \\
114,216\end{array}$ & $\begin{array}{r}172,802 \\
28,405 \\
1,141 \\
685 \\
434 \\
0 \\
0 \\
201,247\end{array}$ & $\begin{array}{r}10,204 \\
1,468 \\
21 \\
51 \\
0 \\
0 \\
0 \\
11,784\end{array}$ & $\begin{array}{r}103 \\
68 \\
20 \\
13 \\
1,365 \\
0 \\
0 \\
1,860\end{array}$ \\
\hline 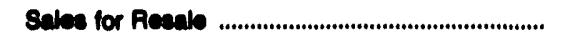 & 0 & 1 & 3 & 10 & 1 & 1 \\
\hline Total Number of Conoumere ................................ & 40,020 & 1,013 & 114,219 & 201,367 & 11,786 & 1,000 \\
\hline 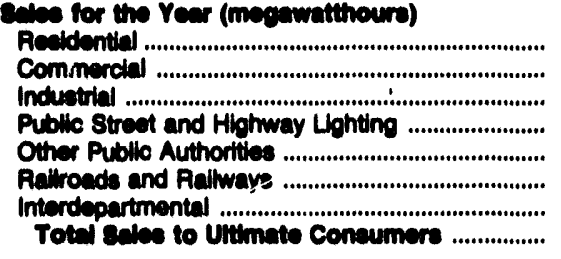 & $\begin{array}{r}354,960 \\
335,448 \\
1,129,127 \\
6,446 \\
0 \\
0 \\
0 \\
1,028,070\end{array}$ & $\begin{array}{r}7,380 \\
4,646 \\
1,127,810 \\
267 \\
169 \\
0 \\
0 \\
1,140,282\end{array}$ & $\begin{array}{r}625,231 \\
1,346,730 \\
168,807 \\
8,942 \\
157,477 \\
0 \\
5,831 \\
2,310,018\end{array}$ & $\begin{array}{r}1,674,622 \\
811,865 \\
2,009,780 \\
23,764 \\
17,140 \\
0 \\
2,622 \\
4,620,703\end{array}$ & $\begin{array}{r}57,859 \\
38,411 \\
17,038 \\
1,000 \\
0 \\
0 \\
0 \\
114,400\end{array}$ & $\begin{array}{r}7,371 \\
1,080 \\
2,685 \\
197 \\
0 \\
0 \\
0 \\
0 \\
11,289\end{array}$ \\
\hline 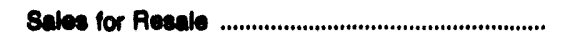 & 0 & 1,108 & 30,765 & 383,810 & 4,483 & 9,578 \\
\hline Total 8abes .......................................................... & $1,026,970$ & $1,141,358$ & $2,340,703$ & $4,023,603$ & 118,001 & 20,811 \\
\hline 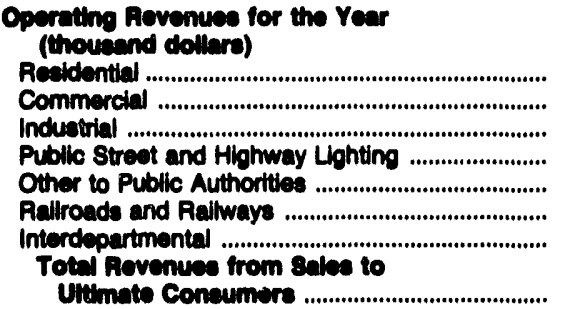 & $\begin{array}{r}23,700 \\
18,069 \\
38,141 \\
817 \\
0 \\
0 \\
0 \\
\\
00,726\end{array}$ & $\begin{array}{r}362 \\
219 \\
32,962 \\
12 \\
9 \\
0 \\
0 \\
33,544\end{array}$ & $\begin{array}{r}49,479 \\
76,042 \\
7,930 \\
632 \\
7,060 \\
0 \\
382 \\
\\
141,580\end{array}$ & $\begin{array}{r}108,410 \\
49,629 \\
95,941 \\
2,938 \\
1,131 \\
0 \\
138 \\
\\
268,187\end{array}$ & $\begin{array}{r}4,281 \\
2,576 \\
823 \\
92 \\
0 \\
0 \\
0 \\
7,773\end{array}$ & $\begin{array}{r}588 \\
83 \\
188 \\
18 \\
0 \\
0 \\
0 \\
077\end{array}$ \\
\hline 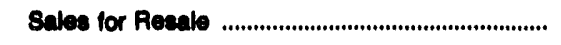 & 0 & 7 & 602 & 14,756 & 195 & 375 \\
\hline 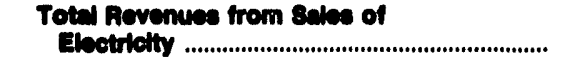 & 80,726 & 33,651 & 142,126 & 272,942 & 7,900 & 1,252 \\
\hline 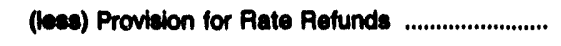 & 0 & 0 & 0 & $\mathbf{0}$ & $\mathbf{0}$ & 62 \\
\hline Not Rovemuse from seles of Electrlotty ........ & 60,720 & 33,651 & 142,128 & 272,042 & 7,900 & 1,180 \\
\hline 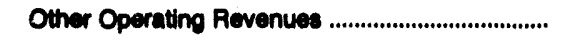 & 1,880 & 1,176 & 871 & 72,347 & 111 & 16 \\
\hline $\begin{array}{l}\text { Totel Electric Uitity } \\
\text { Operating Rovenues }\end{array}$ & 02,706 & 34,727 & 142,000 & 346,200 & 8,070 & 1,208 \\
\hline
\end{tabular}

Note: Totals may not equal sum of components because of independent rounding. Summ, data are provided in Table 15 . Source: Federal Energy Regulatory Commiedion, FERC Form 1, "Annual Report of Major Elex 's Utillties, Licensees and Others." 
Table 40. Number of Consumore, 8ales, and Operating Rovenus

by Major U.8. Invector-Owned Electrle Utilly Within state, 1902 (Continued)

\begin{tabular}{|c|c|c|c|c|c|c|}
\hline mam & $\begin{array}{l}\text { Whoonaln } \\
\text { Eouth } \\
\text { Belott } \\
\text { Water } \\
\text { castere co }\end{array}$ & $\begin{array}{l}\text { Whooncin } \\
\text { Experior } \\
\text { Woter } \\
\text { UghtsPower } \\
\text { Co }\end{array}$ & $\begin{array}{l}\text { Whoonsin } \\
\text { Whooncin } \\
\text { Electilo } \\
\text { Powre Co }\end{array}$ & $\begin{array}{l}\text { Weconsin } \\
\text { Whoconain } \\
\text { Power } \\
\text { Loht co }\end{array}$ & $\begin{array}{l}\text { Wheondin } \\
\text { Wecondin } \\
\text { Publito } \\
\text { Senvico Corp }\end{array}$ & $\begin{array}{l}\text { Whaconsin } \\
\text { Wieconsin } \\
\text { Alver } \\
\text { Power Co }\end{array}$ \\
\hline 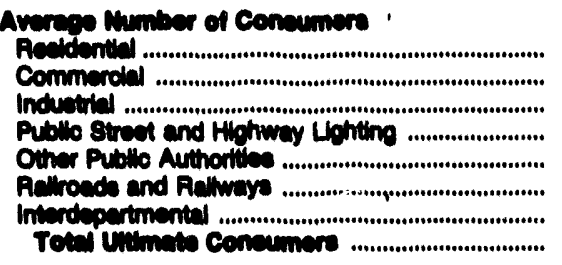 & $\begin{array}{r}6,492 \\
711 \\
20 \\
11 \\
10 \\
0 \\
0 \\
0\end{array}$ & $\begin{array}{r}11,747 \\
1,882 \\
72 \\
3 \\
0 \\
0 \\
25 \\
11,400\end{array}$ & $\begin{array}{r}824,644 \\
86,090 \\
670 \\
1,861 \\
68 \\
0 \\
0 \\
912,120\end{array}$ & $\begin{array}{r}302,395 \\
40,801 \\
682 \\
1,028 \\
138 \\
0 \\
0 \\
34,124\end{array}$ & $\begin{array}{r}300,973 \\
34,368 \\
127 \\
811 \\
0 \\
0 \\
1 \\
12,219\end{array}$ & $\begin{array}{l}0 \\
0 \\
0 \\
0 \\
0 \\
0 \\
0 \\
0\end{array}$ \\
\hline 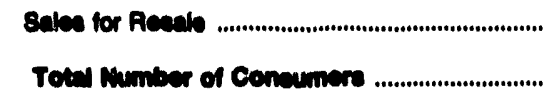 & 1 & 0 & 28 & 39 & 92 & 3 \\
\hline 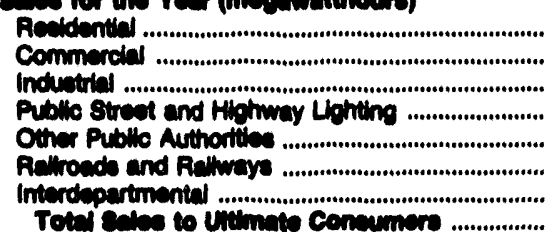 & $\begin{array}{r}49,198 \\
27,270 \\
04,507 \\
607 \\
0 \\
0 \\
25 \\
148,005\end{array}$ & $\begin{array}{r}71,644 \\
80,798 \\
380,012 \\
2,701 \\
0 \\
0 \\
1,928 \\
192,070\end{array}$ & $\begin{array}{r}6,230,138 \\
6,164,680 \\
9,702,303 \\
204,843 \\
11,739 \\
0 \\
0 \\
22,209,861\end{array}$ & $\begin{array}{r}2,671,242 \\
1,524,543 \\
3,282,686 \\
33,329 \\
0 \\
0 \\
21,389 \\
7,489,010\end{array}$ & $\begin{array}{r}2,288,685 \\
2,384,098 \\
3,016,329 \\
29,655 \\
0 \\
0 \\
3,409 \\
7,702,170\end{array}$ & $\begin{array}{l}0 \\
0 \\
0 \\
0 \\
0 \\
0 \\
0 \\
0\end{array}$ \\
\hline Saled for Reads ........................................................ & 6,682 & 0 & $2,444,030$ & $2,375,620$ & $2,044,898$ & 229,290 \\
\hline 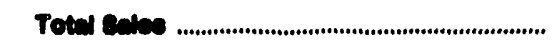 & 172,120 & 824, 978 & $24,747,891$ & $9,004,047$ & $0,747,160$ & 220,200 \\
\hline 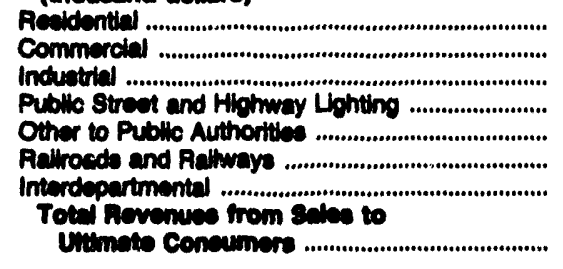 & $\begin{array}{r}2,804 \\
1,685 \\
4,018 \\
52 \\
0 \\
0 \\
1 \\
0,440\end{array}$ & $\begin{array}{r}4,532 \\
4,090 \\
14,481 \\
202 \\
0 \\
0 \\
87 \\
28,402\end{array}$ & $\begin{array}{r}441,239 \\
372,213 \\
381,083 \\
14,491 \\
754 \\
0 \\
0 \\
1,200,701\end{array}$ & $\begin{array}{r}189,083 \\
00,143 \\
124,448 \\
3,581 \\
6 \\
0 \\
1,043 \\
39,309\end{array}$ & $\begin{array}{r}168,659 \\
136,164 \\
115,147 \\
4,045 \\
0 \\
0 \\
207 \\
412,223\end{array}$ & $\begin{array}{l}0 \\
0 \\
0 \\
0\end{array}$ \\
\hline Sales for Reade ......................................................... & 134 & 0 & 80,867 & 81,125 & 61,872 & 5,615 \\
\hline 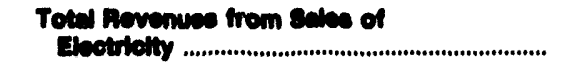 & 0,674 & 23,402 & $1,290,040$ & 499,420 & 474,095 & 8,816 \\
\hline (leas) Provialon for Rate Rotunds ........................... & 0 & 0 & 0 & 0 & 0 & 0 \\
\hline 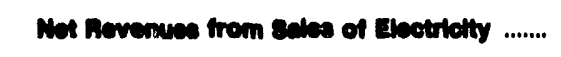 & 8,674 & 28,402 & $1,290,840$ & 409,429 & 474,005 & 6,816 \\
\hline 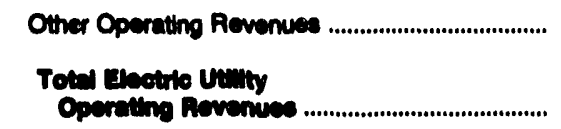 & 0.408 & 24,914 & 8,075 & $\begin{array}{r}4,3: 6 \\
473,744\end{array}$ & $\begin{array}{r}3,531 \\
477,025\end{array}$ & b.era \\
\hline
\end{tabular}

Nots: Totale may not equal sum of components because of independent isunding. Summary data are provided in Table 15.

Source: Federal Eneroy Reoulatory Commiteion, FERC Form 1, "Annuad Report of Major Electric Utillites, Licenseees and Others." 
Table 41. Electric Operation and Maintenance Expenses by Major U.8. Investor-Owned Eloctrlo Utility Within State, 1902 (Thousand Dollars)

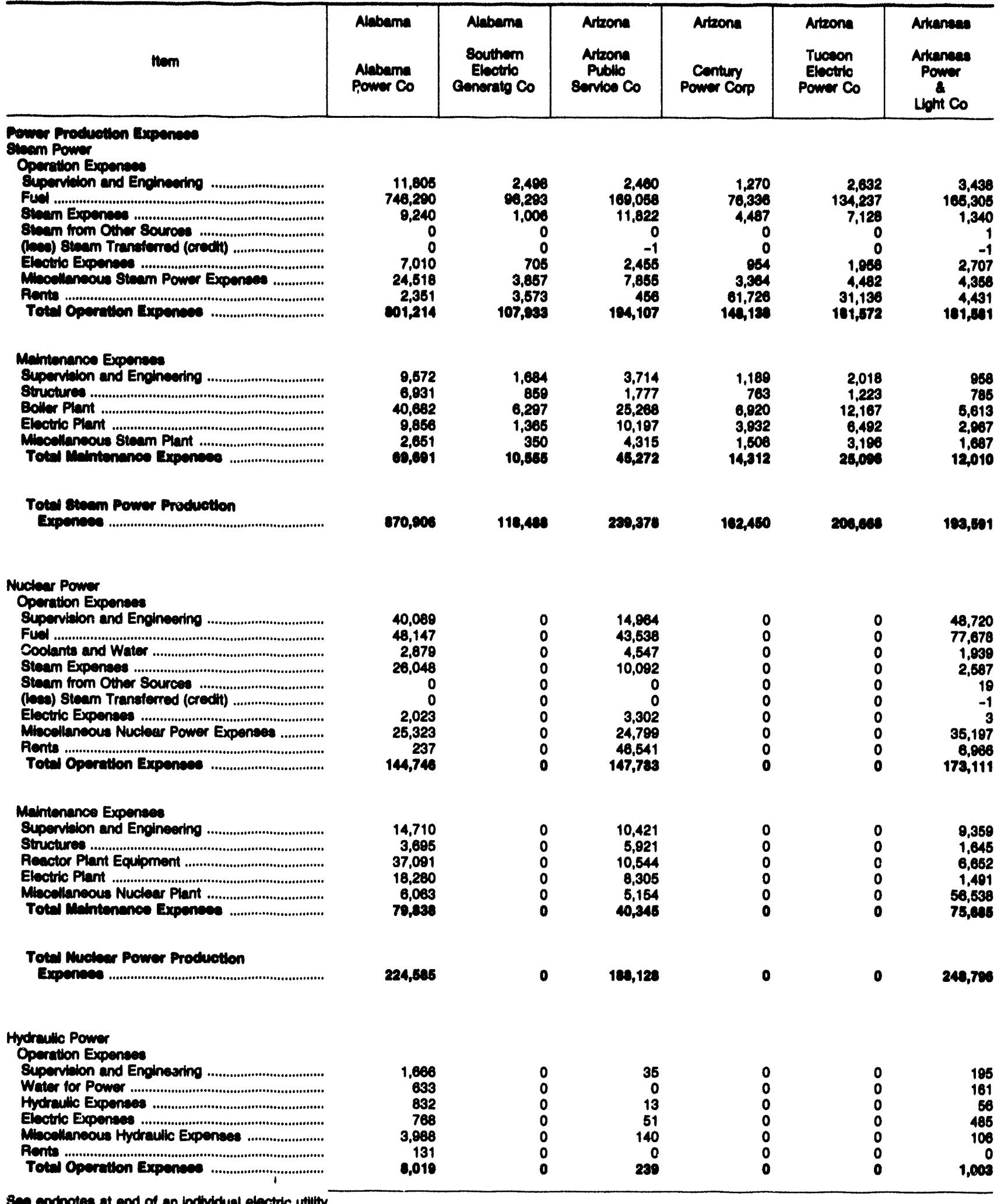

sec endnotes at end of an individual olectric utility. 
Table 41. Eleotrle Operatton and Malintenanos Expenees by Major U.8. Investor-Owned Eloctric Utilly Whthin 8tate, 1992 (Continued) (Thousand Dollars)

\begin{tabular}{|c|c|c|c|c|c|c|}
\hline hom & $\begin{array}{l}\text { Arbesm } \\
\text { Arbenm } \\
\text { Power Co }\end{array}$ & $\begin{array}{l}\text { Alubem } \\
\text { Eouthem } \\
\text { Eleotilo } \\
\text { cencrato Co }\end{array}$ & $\begin{array}{l}\text { Arteon } \\
\text { Atron } \\
\text { Publis } \\
\text { Eenvice Co }\end{array}$ & $\begin{array}{l}\text { Artzon } \\
\text { Centiry } \\
\text { Power Corp }\end{array}$ & $\begin{array}{l}\text { Artaon } \\
\text { Tuceson } \\
\text { Eleotilo } \\
\text { Power Co }\end{array}$ & $\begin{array}{c}\text { Arkensas } \\
\text { Arkansas } \\
\text { Pown } \\
\text { Loht Co }\end{array}$ \\
\hline
\end{tabular}

Meintonanos Expenece

Eupervition end Encinering

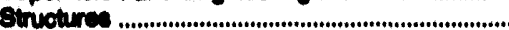

Reservoin, Dame and Waternmys ........................

Electib Piant

Mincellanicous Hyctractio Pient

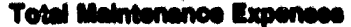

Toted Hyduring Powner

Froduction Exponese

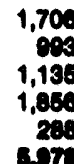

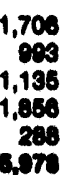

12,97

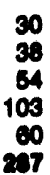

528

30
88
64
03
60
797
0

Other Power

Opention Expenses

Supervition and Engincering

Fuel.

Conertion Expenses

Pento

Total Operation Expenses

Soe endrotes at end of an individual electric uitity.

Mintenence Expenses

Supenvition and Engineering .

Structures ....... Electro Plant

Generating and Electric Plant

Mhocllaneous Other Power Plant

Toty Merrienemoe Expenses

Toty Other Power Prodwetion

Expenese

Other Power Supply Expenses

Pyrchased Power ...................................................

Other Expenses

Totel Other Power Supphy Expenase ............

Fotal Power Production Expenses

(1)

$1,207,267$

6,112

0

688
3
0

2,258

1,085

13,189

Pents

Toted Operation Expensese

Operation Expenees

Supenvition and Engineering ................................

Station Expente

Overhoed Line Expensee ........................................

Tranamiacion of Electricty by Othere ..................

.

21,490

57,007
858
446

B.,911

07,70

102,014

343,048

977,025

128,886

871
7,030

184,893

417,100

3,211

111,232

631,642

91
Maintenance Expenses

Supervicion and Enoineering

Sinchures

Stution Equipmen

Overhaed Lines

Underground Line:
090

4,708

10,182
0

89

$$
2
$$

Underground Line Expenses ....................................

ning (......................................

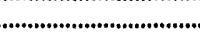

(n......

44

$\begin{array}{rr}23 & 3,342 \\ 0 & 1,293 \\ 87 & 255 \\ 3 & 270 \\ 0 & 0 \\ 0 & 3,389 \\ 0 & 772 \\ 329 & 508 \\ 492 & 0,490 \\ & 1\end{array}$

0
0
0
0
0
121
0
0

$\begin{array}{rr}376 & 2,991 \\ 682 & 352 \\ 43 & 376 \\ 60 & 319 \\ 0 & 0 \\ 2,332 & 160 \\ 129 & 1,062 \\ 216 & 210\end{array}$

$3,810 \quad 6,471$ 10 74 19

716 32

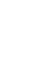

.


Table 41. Electric Oporation and Maintenance Expences by Major U.8. Inveotor-Owned Eloctric Utility Within 8tate, 1902 (Continued) (Thousand Dollars)

\begin{tabular}{|c|c|c|c|c|c|c|}
\hline Itom & $\begin{array}{l}\text { Alebama } \\
\text { Alabama } \\
\text { Power Co }\end{array}$ & $\begin{array}{l}\text { Alebama } \\
\text { Southem } \\
\text { Electric } \\
\text { cencrats Co }\end{array}$ & $\begin{array}{l}\text { Artzona } \\
\text { Antzona } \\
\text { Publlo } \\
\text { Sarvice Co }\end{array}$ & $\begin{array}{l}\text { Artzone } \\
\text { Century } \\
\text { Power Corp }\end{array}$ & $\begin{array}{l}\text { Artzona } \\
\text { Tucion } \\
\text { Eleotilo } \\
\text { Power Co }\end{array}$ & $\begin{array}{l}\text { Arkanses } \\
\text { Arkanase } \\
\text { Powrer } \\
\text { Loht Co }\end{array}$ \\
\hline
\end{tabular}

Mentenenos Expences

Mecellencous Tranemiacion Plant

Totel Meritienenes Expenese

148

18,78

expes

Totel Trumingaton Expenses

Dintibution

Operation Expenese

Suparviabon and Encinosing

Loed Dlapatohiny

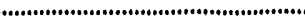

Orechend

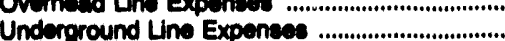

Street Lughting and Sional System Expenses ...

Meter Expenses .

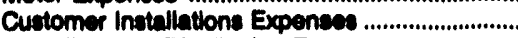

Miscollaneous Distribution Expenses

Aenth

Totel Operation Expentese

$m$

13,012

121

8,600

0,417

Maintenance Expenses

Structures.

Station Equipment

Overhead Lines

4,684

0

1,000

2,507

434

1,381

6,277

2,048

6,120

200

20,201

2,014

1,072

465

1,736

2,021

1,132

3,524

679

3,878

1,300

10,418

1,117

680

607

3,218

465

6,208

1,400

2,810

120

16,12

Underground Lines

Une Trentomere

Gtreat Lohting and Sione

Metere

Macellaneous Distribution Plent

Totel Melntenence Expennes

\section{Customer Accounts Expenses}

Supervition ...................................................................

Meter Reading Expenses ...............................

Uncollectible Accounts .............................................

Miscellaneous Customer Accounts Expenses ...

Totel Cuntemer Acoounte Enponese

Customer Service and Information Expenses

Superviton ...............................................................

Sales Expenses

Supervition .................................................................... 142

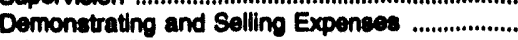

Advertieing Expenses ..................................................

Milcellaneous Sales Expenses ..............................

Total selee Exponaces

See endnotes at end of an individual electrlc utility. 
Table 41. Electrlc Oporation and Malntenance Expenses by Major U.S. Inveator-Owned Electric Utility Within State, 1992 (Continued) (Thousand Dollars)

\begin{tabular}{|c|c|c|c|c|c|c|}
\hline Item & $\begin{array}{l}\text { Alabama } \\
\text { Alabama } \\
\text { Power Co }\end{array}$ & $\begin{array}{l}\text { Alabama } \\
\text { Southem } \\
\text { Electric } \\
\text { Cenerate Co }\end{array}$ & $\begin{array}{l}\text { Artzona } \\
\text { Artzona } \\
\text { Public } \\
\text { Service Co }\end{array}$ & $\begin{array}{l}\text { Arizona } \\
\text { Century } \\
\text { Power Corp }\end{array}$ & $\begin{array}{l}\text { Artzona } \\
\text { Tucson } \\
\text { Electric } \\
\text { Power Co }\end{array}$ & $\begin{array}{c}\text { Arkansas } \\
\text { Arkansas } \\
\text { Power } \\
8 \\
\text { Light Co }\end{array}$ \\
\hline \multicolumn{7}{|l|}{$\begin{array}{l}\text { Adminivtrative and General Expenses } \\
\text { Opieration Expenses }\end{array}$} \\
\hline Adminietrative and Ceneral Salarios ..................... & $\begin{array}{l}38,793 \\
18,685\end{array}$ & $\begin{array}{r}853 \\
60\end{array}$ & $\begin{array}{l}27,474 \\
14,707\end{array}$ & $\begin{array}{l}897 \\
246\end{array}$ & $\begin{array}{r}12,524 \\
9,186\end{array}$ & $\therefore$ \\
\hline 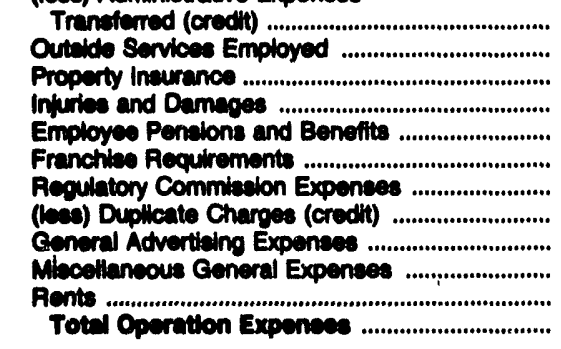 & $\begin{array}{r}3,415 \\
55,419 \\
4,784 \\
12,525 \\
42,024 \\
143 \\
6,013 \\
248 \\
2,513 \\
12,235 \\
1,700 \\
101,032\end{array}$ & $\begin{array}{r}554 \\
202 \\
204 \\
21 \\
1,272 \\
0 \\
426 \\
0 \\
0 \\
50 \\
108 \\
2,472\end{array}$ & $\begin{array}{r}11,832 \\
8,384 \\
5,099 \\
7,680 \\
22,613 \\
19,602 \\
3,184 \\
7,889 \\
104 \\
-23,884 \\
8,662 \\
73,060\end{array}$ & $\begin{array}{r}772 \\
1,143 \\
407 \\
656 \\
1,952 \\
0 \\
140 \\
0 \\
0 \\
0 \\
103 \\
4,772\end{array}$ & $\begin{array}{r}2,341 \\
30,720 \\
1,014 \\
4,662 \\
\varepsilon, 774 \\
0 \\
759 \\
1,075 \\
28 \\
1,645 \\
1,604 \\
67,600\end{array}$ & $\begin{array}{r}10,310 \\
7,120 \\
15,440 \\
0 \\
307 \\
7 \\
774 \\
5,319 \\
5,507 \\
116,890\end{array}$ \\
\hline \multirow{2}{*}{ 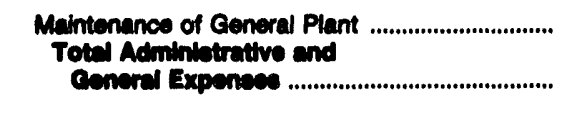 } & 8,015 & 0 & 6,584 & 6 & 626 & $2,27 \theta$ \\
\hline & 100,010 & 2,472 & 00,498 & 4,778 & 69,128 & 119,110 \\
\hline Melintenanee Expensese .................................... & $1,600,469$ & 122,225 & 697,331 & 167,612 & $\mathbf{4 1 , 8 1 4}$ & $1,578,130$ \\
\hline \multicolumn{7}{|l|}{$\begin{array}{l}\text { Diotribution of Salaries and } \\
\text { Weges Charged to Electric } \\
\text { Operation and Maintenance }\end{array}$} \\
\hline 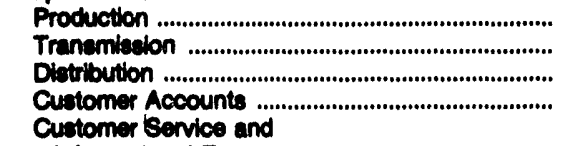 & $\begin{array}{l}73,602 \\
10,911 \\
25,431 \\
23,730\end{array}$ & $\begin{array}{l}0 \\
0 \\
0 \\
0\end{array}$ & $\int_{1}^{3}$ & $\begin{array}{r}4,819 \\
0 \\
0 \\
0\end{array}$ & $\begin{array}{l}3,417 \\
2,213 \\
6,132 \\
4,608\end{array}$ & $\begin{array}{r}13,181 \\
2,900 \\
18,948 \\
11,375\end{array}$ \\
\hline 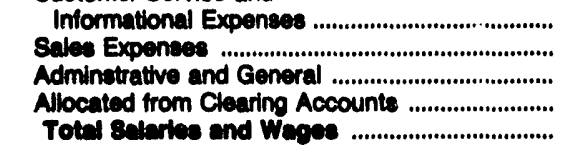 & $\begin{array}{r}12,486 \\
1,631 \\
39,002 \\
35,686 \\
229,290\end{array}$ & $\begin{array}{l}0 \\
0 \\
0 \\
0 \\
0\end{array}$ & $\begin{array}{r}3,577 \\
2,897 \\
23,577 \\
12,008 \\
179,807\end{array}$ & $\begin{array}{r}0 \\
0 \\
441 \\
860 \\
6,220\end{array}$ & $\begin{array}{r}126 \\
0 \\
10,342 \\
5,687 \\
32,436\end{array}$ & $\begin{array}{r}2,858 \\
2,776 \\
17,273 \\
0 \\
69,311\end{array}$ \\
\hline $\begin{array}{l}\text { Number of Electric Depertment Employees } \\
\text { Recular Full-time Employees .................................. } \\
\text { Part-time and Temporary Employees .................. }\end{array}$ & $\begin{array}{r}7,872 \\
227\end{array}$ & $\begin{array}{l}0 \\
0\end{array}$ & $\begin{array}{r}6,998 \\
100\end{array}$ & $\begin{array}{r}236 \\
0\end{array}$ & $\begin{array}{r}1,314 \\
12\end{array}$ & $\begin{array}{r}2,836 \\
58\end{array}$ \\
\hline Totel Elocture Depertinent Employeec .......... & 8,000 & $\mathbf{0}$ & 7,000 & 288 & 1,324 & $2, \infty 2$ \\
\hline
\end{tabular}

Note: Totals may not equal sum of components because of independent rounding. Summary data are provided in Table 11.

Source: Federal Eneroy Regulatory Commisuion, FERC Form 1, "Annual Report of Major Electric Utilties, Llcensees and Others." 
Table 41. Electric Operation and Maintenance Expenses by Major U.S. Investor-Owned Electric Utility Within State, 1992 (Continued) (Thousand Dollars)

\begin{tabular}{|c|c|c|c|c|c|c|}
\hline Item & $\begin{array}{l}\text { Calliomia } \\
\text { Pactific } \\
\text { Gas } \\
\& \\
\text { Electric Co }\end{array}$ & $\begin{array}{l}\text { Califomia } \\
\text { San Diego } \\
\text { Gas } \\
\text { Electric Co }\end{array}$ & $\begin{array}{l}\text { Callfornia } \\
\text { Southern } \\
\text { California } \\
\text { Edison Co }\end{array}$ & $\begin{array}{l}\text { Colorado } \\
\text { Public } \\
\text { Service } \\
\text { Co } \\
\text { of Colorado }\end{array}$ & $\begin{array}{l}\text { Connecticut } \\
\text { Cltizens } \\
\text { Utilltes Co }\end{array}$ & $\begin{array}{l}\text { Connecticut } \\
\text { Connecticut } \\
\text { Light } \\
\& \\
\text { Power Co }\end{array}$ \\
\hline 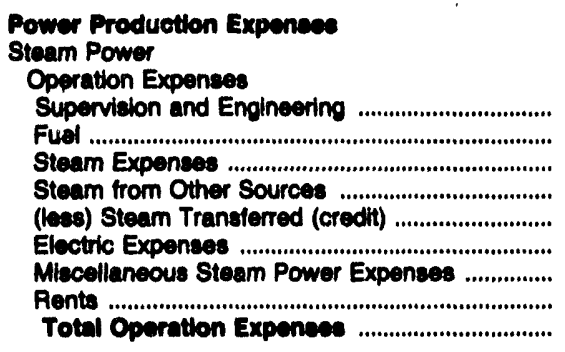 & $\begin{array}{r}13,060 \\
694,348 \\
14,205 \\
102,035 \\
0 \\
24,350 \\
32,094 \\
1,673 \\
12,606\end{array}$ & $\begin{array}{r}2,872 \\
14,289 \\
4,024 \\
0 \\
0 \\
4,211 \\
1,245 \\
9,468 \\
107,100\end{array}$ & $\begin{array}{r}11,280 \\
688,133 \\
17,378 \\
0 \\
0 \\
8,787 \\
20,368 \\
351 \\
726,307\end{array}$ & $\begin{array}{r}6,818 \\
181,637 \\
7,536 \\
0 \\
0 \\
8,069 \\
9,974 \\
5 \\
214,040\end{array}$ & $\begin{array}{r}198 \\
592 \\
197 \\
0 \\
0 \\
58 \\
83 \\
0 \\
1,128\end{array}$ & $\begin{array}{r}5,350 \\
50,416 \\
4,898 \\
0 \\
0 \\
3,475 \\
9,956 \\
10 \\
74,104\end{array}$ \\
\hline 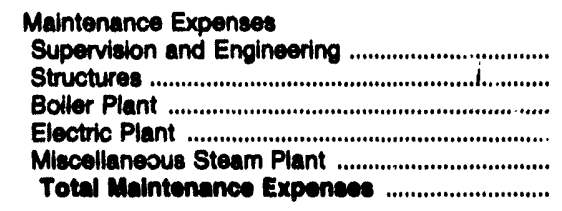 & $\begin{array}{r}9,858 \\
2,703 \\
40,576 \\
52,770 \\
18,371 \\
124,276\end{array}$ & $\begin{array}{r}686 \\
5,042 \\
4,377 \\
3,231 \\
682 \\
14,160\end{array}$ & $\begin{array}{r}21,213 \\
5,946 \\
41,496 \\
16,745 \\
20,195 \\
105,604\end{array}$ & $\begin{array}{r}8,731 \\
3,225 \\
17,157 \\
4,874 \\
4,707 \\
30,604\end{array}$ & $\begin{array}{r}79 \\
62 \\
369 \\
61 \\
0 \\
670\end{array}$ & $\begin{array}{r}2,421 \\
3,249 \\
13,241 \\
5,568 \\
4,290 \\
28,760\end{array}$ \\
\hline $\begin{array}{l}\text { Total Steam Power Production } \\
\text { Expenese }\end{array}$ & $1,000,042$ & 181,200 & 891,001 & 252,734 & 1,608 & 102,063 \\
\hline 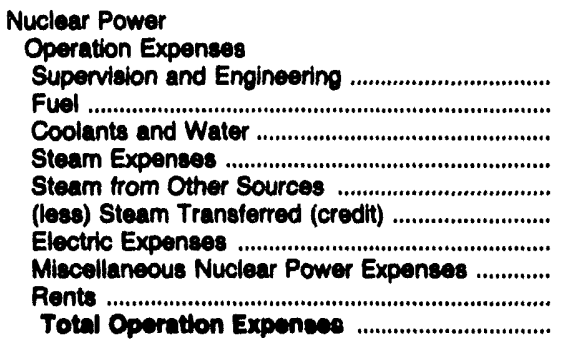 & $\begin{array}{r}68,918 \\
69,552 \\
9,123 \\
14,066 \\
0 \\
0 \\
0 \\
3,797 \\
24,713 \\
0 \\
100,160\end{array}$ & $\begin{array}{r}18,180 \\
28,573 \\
1,701 \\
5,803 \\
0 \\
0 \\
800 \\
17,391 \\
216 \\
72,604\end{array}$ & $\begin{array}{r}65,731 \\
128,791 \\
7,684 \\
22,850 \\
0 \\
0 \\
3,766 \\
68,863 \\
932 \\
206,617\end{array}$ & $\begin{array}{r}0 \\
0 \\
0 \\
0 \\
0 \\
0 \\
0 \\
0 \\
-1,350 \\
0 \\
-1,360\end{array}$ & $\begin{array}{l}0 \\
0 \\
0 \\
0 \\
0 \\
0 \\
0 \\
0 \\
0 \\
0\end{array}$ & $\begin{array}{r}44,073 \\
86,325 \\
5,543 \\
18,984 \\
0 \\
0 \\
4,361 \\
64,128 \\
5,054 \\
226,400\end{array}$ \\
\hline 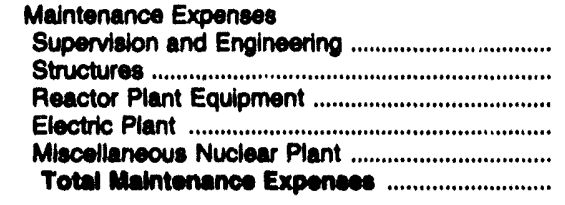 & $\begin{array}{r}8,128 \\
5,819 \\
24,861 \\
6,780 \\
60,882 \\
106,670\end{array}$ & $\begin{array}{r}9,251 \\
1,843 \\
5,406 \\
3,846 \\
8,633 \\
20,070\end{array}$ & $\begin{array}{r}29,388 \\
12,818 \\
19,281 \\
15,332 \\
27,699 \\
104,619\end{array}$ & $\begin{array}{l}0 \\
0 \\
0 \\
0 \\
0 \\
0\end{array}$ & $\begin{array}{l}0 \\
0 \\
0 \\
0 \\
0 \\
0\end{array}$ & $\begin{array}{r}13,017 \\
13,809 \\
35,64 \\
25,815 \\
1,417 \\
89,090\end{array}$ \\
\hline $\begin{array}{l}\text { Total Nuclear Power Production } \\
\text { Expenees }\end{array}$ & 206,747 & 101,749 & 403,006 & $-1,360$ & 0 & 318,300 \\
\hline 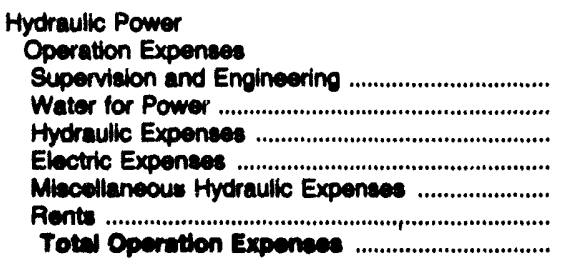 & $\begin{array}{r}2,378 \\
5,360 \\
5,360 \\
6,352 \\
4,886 \\
5,150 \\
20,466\end{array}$ & $\begin{array}{l}0 \\
0 \\
0 \\
0 \\
0 \\
0 \\
0\end{array}$ & $\begin{array}{r}2,203 \\
1,609 \\
1,801 \\
1,899 \\
2,357 \\
810 \\
10,670\end{array}$ & $\begin{array}{r}397 \\
36 \\
168 \\
553 \\
207 \\
231 \\
1,502\end{array}$ & $\begin{array}{r}135 \\
0 \\
0 \\
194 \\
104 \\
0 \\
433\end{array}$ & $\begin{array}{r}2,383 \\
6 \\
2,666 \\
1,303 \\
708 \\
1,567 \\
8,612\end{array}$ \\
\hline
\end{tabular}


Table 41. Electric Operatidn and Maintenance Expenses by Major U.S. Inveotor-Owned Electric Utility Within State, 1992 (Continued) (Thousand Dollars)

\begin{tabular}{|c|c|c|c|c|c|c|}
\hline Item & $\begin{array}{c}\text { California } \\
\text { Pacific } \\
\text { Gas } \\
\mathbf{\alpha} \\
\text { Electric Co }\end{array}$ & $\begin{array}{c}\text { California } \\
\text { San Diego } \\
\text { Gas } \\
\& \\
\text { Electric Co }\end{array}$ & $\begin{array}{l}\text { Callifornia } \\
\text { Southern } \\
\text { Calfornia } \\
\text { Edison co }\end{array}$ & $\begin{array}{l}\text { Colorado } \\
\text { Publle } \\
\text { Service } \\
\text { Co } \\
\text { of Colorado }\end{array}$ & $\begin{array}{l}\text { Connectiout } \\
\text { Cltizens } \\
\text { Utilities Co }\end{array}$ & $\begin{array}{c}\text { Connecticut } \\
\text { Connecticut } \\
\text { Light } \\
8 \\
\text { Power Co }\end{array}$ \\
\hline
\end{tabular}

Maintenance Expenses

Supervicion and Engineering ...............................

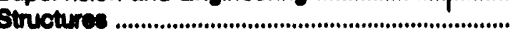

Rceervoirs, Dams and Waterways

Electio Pient

Mboollaneous Hydraulic Plant

Toted Meintenanes Expenses

Totel Hydreulle Power

Production Expenese

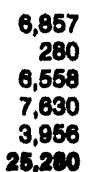

64,783

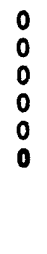

0

21,040

1,565

1,586

3,105

3,673

11,292
34

1,334

518

62
0

1,046

Total Operation Expenses

Operation Expenses

Supervition and Engineering .................................

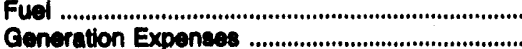

Miscellaneous Other Power Expenses

46,163
Maintenance Expenses

Supervision and Engineering

Structures .......................................

Miscellaneous Other Power Plant .........................

Total Malntenance Expenses

Totel Other Power Production

Expensese

Other Power Supply Expenses

Purchaeed Power ........................................................

System Control and Load Dispatching ................

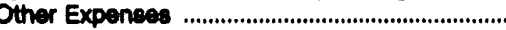

Total Other Power supply Expenese

Totel Power Production Expences
$3,072,396$

116

310

449

84

2,839

$1,709,526$
0
1,521
$1,711,047$

311,046
1,781
1,659
314,497

$2,249,480$
8,337
374,587
$2,832,406$

343,616
3,027
176
348,810

602,045

600,682

$3,944,104$

1,376

813

1,780

8,768

84,022

1,022

280
126
237
185
81
020

2,621

46

1,300

15
20

1,302

Tranemiacion
14,698

2,478

$\begin{array}{rr}248 & 80 \\ 11,623 & 744 \\ 754 & 89 \\ 235 & 552 \\ 0 & 0 \\ 12,060 & 1,406\end{array}$

88
0

1,641

1,720

10
6
947
50

1,012

617,567

5,831

2,683
623,001
$1,003,016$
Operation Expenees

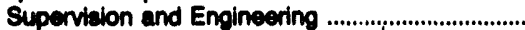

Load Olepatching

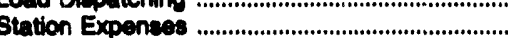

Overtead Line Expanses

Underoround Line Expenees

Tranemiseion of Electricty by Others

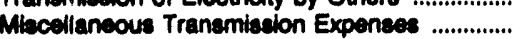

Rents

Totel Operation Expenses
4,643

7,361

8,038

3,783

149

6,813

3,823

204

34,910

680

11,708

0,533
304
923

1,312

301

0

8,837

1,622

334

19,693

8,100

50

1,120

8,654

827

654
Maintenance Expenses

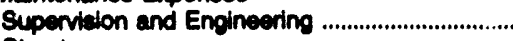

Structures ..................

188
4
1,710
2,310

4,050

1,828

8,829

10,087

80

1,304
1
725
716
0
3,242
842
113

7,042

77,924

Underground Lines

See endnotes at end of an individual electric utilty. 
Table 41. Electric Operation and Maintenance Expenses by Major U.S. Investor-Owned Electric Utility Within State, 1992 (Continued) (Thousand Dollars),

\begin{tabular}{|c|c|c|c|c|c|c|}
\hline Item & $\begin{array}{c}\text { Calisornia } \\
\text { Pacific } \\
\text { Gas } \\
2 \\
\text { Electric Co }\end{array}$ & $\begin{array}{c}\text { California } \\
\text { San Diego } \\
\text { Gas } \\
\mathbf{a} \\
\text { Electric Co }\end{array}$ & $\begin{array}{l}\text { California } \\
\text { Southern } \\
\text { Callomia } \\
\text { Edison Co }\end{array}$ & $\begin{array}{c}\text { Colorado } \\
\text { Public } \\
\text { Senvice } \\
\text { Co } \\
\text { of Colorado }\end{array}$ & $\begin{array}{l}\text { Connecticut } \\
\text { Clitizens } \\
\text { Utilites Co }\end{array}$ & $\begin{array}{l}\text { Connecticut } \\
\text { Connecticut } \\
\text { Light } \\
\text { Power Co }\end{array}$ \\
\hline
\end{tabular}

Maintenance Expenses

Miscellaneous Tranemiseion Plant

Total Melntenance Expenses

421

6,642

Total Tranemiaslon Expenses

Distribution

Operation Expenses

Supervision and Engineering

Load Diepatching

Station Expenees

Overhead Line Expenses ..................

Underground Line Expentus

Street Lighting and Signal System Expenses ....

Meter Expenses ...........................................................

Customer Installations Expenses

Miecellaneous Diatribution Expenses

Rents

Total Operation Expensese

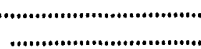

Maintenance Expenses

Supervision and Engineering

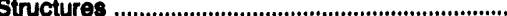

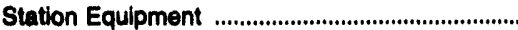

Overhead Lines

Underground Lines

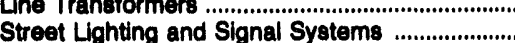

Meters

Miscellaneous Distribution Plant 1

Totel Malntenance Expeneso

(n)

Total Distribution Expenese

$\begin{array}{rr}18,445 & 2,588 \\ 0 & 829 \\ 8,516 & 2,573 \\ 21,978 & 1,559 \\ 5,076 & 1,201 \\ 1,825 & 236 \\ 24,283 & 3,817 \\ 14,627 & 2,230 \\ 35,340 & 3,651 \\ 123 & 161 \\ 130,213 & 18,846\end{array}$

23,446

0
10,589

6,442

3,084

848

15,840

13,101

14,817

2,384

0,652

13,437

1,102

7,474

75,093

9,845

7,814

1,621

806

17

117,300

247,522

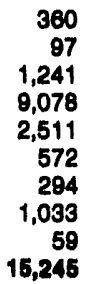

11,301

2,589

5,838

28,068

8,162

2,420

2,227

1,622

21,812

84,046

34,091

174,697

5,842

21,546

63,036

25,482

7,268

128,172

Miscellaneous Customer Accounts Expenses ...

Total Customer Accounts Exponses .............

Customer Service and Information Expenses

Supervision

Customer Assigtance Expenses

Informational and Instructional Expenses ............

Miscelianeous Customer Service

and Intormational Expenses

Totil Customer Eervices and

Informational Expensea

....................................

Sales Expenses

Supervision ...

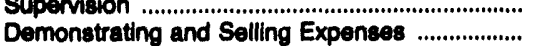

Advertising Expenses ...............................................

Miscellaneous Sales Expenses ...............................

Total sales Expensese.

e........................................

30,398

114,529

1,585

31,865

3,989
104,283

$\mathbf{5 , 5 6 5}$

6,699

1,698

12,095

35,287

126,921

8,282
27,128
87,987
22,810
3,361
149,668

163,191

462

6,629
15

402
7,608

$\begin{array}{r}421 \\ \hline 510\end{array}$

2,510

0
405

6,970

0,663

Qs)

35,200

See endnotes at end of an individual electric utility. 
Table 41. Electric Oporation and Malntenance Exponses by Major' U.S. Inveotor-Owned Electric Utility Within State, 1902 (Continued) (Thousand Dollars)

\begin{tabular}{|c|c|c|c|c|c|c|}
\hline Item & $\begin{array}{c}\text { Callfomia } \\
\text { Pacific } \\
\text { Cas } \\
\text { Electrip Co }\end{array}$ & $\begin{array}{c}\text { Calfornia } \\
\text { San Diego } \\
\text { Gas } \\
2 \\
\text { Electric Co }\end{array}$ & $\begin{array}{l}\text { Calliomia } \\
\text { Southern } \\
\text { Calfornia } \\
\text { Edison Co }\end{array}$ & $\begin{array}{l}\text { Colorado } \\
\text { Public } \\
\text { Service } \\
\text { Co } \\
\text { of Colorado }\end{array}$ & $\begin{array}{l}\text { Conneoticut } \\
\text { Clizens } \\
\text { Utilties Co }\end{array}$ & $\begin{array}{c}\text { Connecticut } \\
\text { Connecticut } \\
\text { Light } \\
\text { Power co }\end{array}$ \\
\hline
\end{tabular}

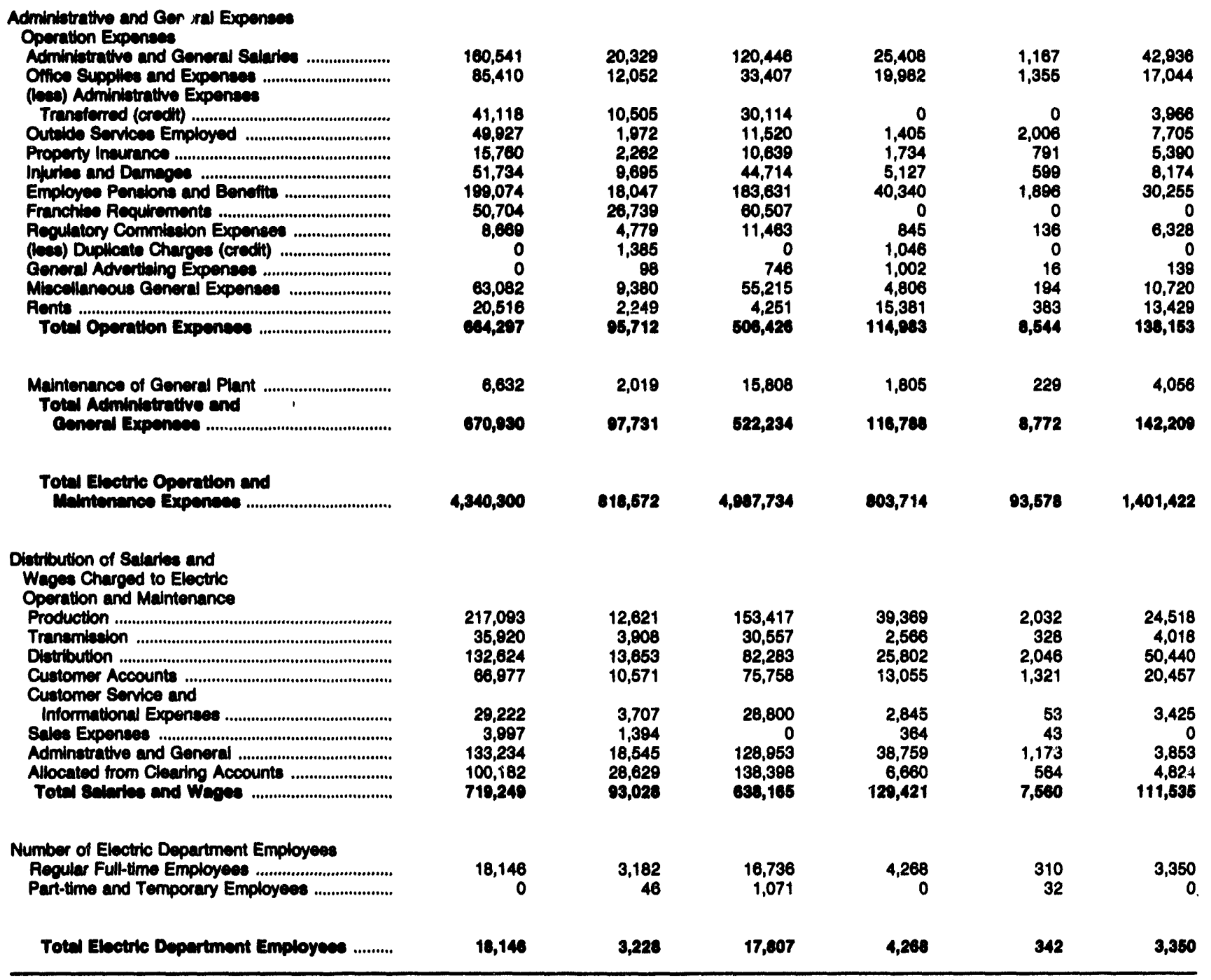

Note: Totals may not equal sum of components because of independent rounding. Summary data are provided in Table 11. Source: Federal Eneroy Requlatory Commiseion, FERC Form 1, "Annual Report of Major Electric Utillies, Liceneees and Others." 
Table 41. Electrle Operation and Maintenance Exponses by Major U.S. Investor-Owned Electric Utility Within State, 1902 (Continued) (Thousand Dollars)

\begin{tabular}{|c|c|c|c|c|c|c|}
\hline Item & $\begin{array}{l}\text { Connecticut } \\
\text { Connecticut } \\
\text { Yankee } \\
\text { Atom } \\
P w \text { Co }\end{array}$ & $\begin{array}{l}\text { Connecticut } \\
\text { United } \\
\text { Iltuminating } \\
\text { Co }\end{array}$ & $\begin{array}{l}\text { Delaware } \\
\text { Delmana } \\
\text { Power } \\
\text { Light Co }\end{array}$ & $\begin{array}{l}\text { District of } \\
\text { Columbia } \\
\text { Potomac } \\
\text { Electric } \\
\text { Power Co }\end{array}$ & $\begin{array}{l}\text { Florida } \\
\text { Florida } \\
\text { Power } \\
\text { \& } \\
\text { Light Co }\end{array}$ & $\begin{array}{l}\text { Florida } \\
\text { Florida } \\
\text { Power Corp }\end{array}$ \\
\hline 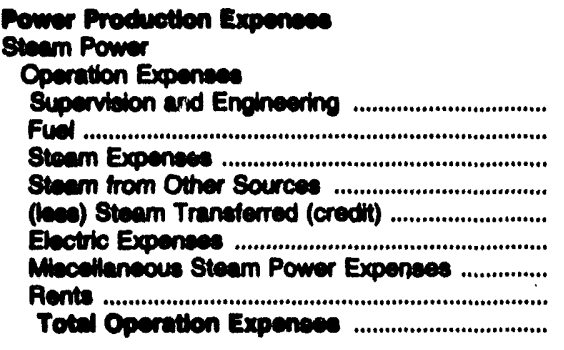 & $\begin{array}{l}0 \\
0 \\
0 \\
0 \\
0 \\
0 \\
0 \\
0 \\
0\end{array}$ & $\begin{array}{r}2,940 \\
105,696 \\
4,655 \\
0 \\
0 \\
1,406 \\
3,584 \\
0 \\
118,262\end{array}$ & $\begin{array}{r}4,264 \\
136,024 \\
8,920 \\
0 \\
38 \\
3,568 \\
10,217 \\
38 \\
102,903\end{array}$ & $\begin{array}{r}4,023 \\
337,304 \\
12,808 \\
0 \\
0 \\
6,734 \\
12,210 \\
39 \\
373,217\end{array}$ & $\begin{array}{r}16,418 \\
735,889 \\
11,644 \\
0 \\
0 \\
2,234 \\
32,190 \\
334 \\
796,706\end{array}$ & $\begin{array}{r}3,591 \\
420,818 \\
7,268 \\
0 \\
284 \\
5,129 \\
15,828 \\
32 \\
462,402\end{array}$ \\
\hline 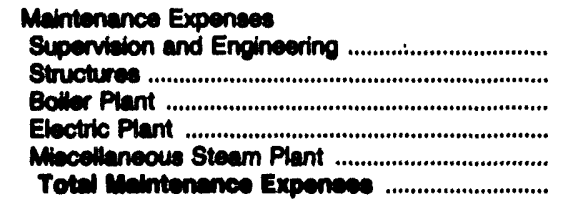 & $\begin{array}{l}0 \\
0 \\
0 \\
0 \\
0 \\
0\end{array}$ & $\begin{array}{r}132 \\
1,402 \\
12,421 \\
3,215 \\
137 \\
17,307\end{array}$ & $\begin{array}{r}1,431 \\
1,929 \\
18,802 \\
6,746 \\
2,507 \\
31,417\end{array}$ & $\begin{array}{r}11,388 \\
3,546 \\
26,756 \\
9,216 \\
3,627 \\
\mathbf{6 4 , 5 3 3}\end{array}$ & $\begin{array}{r}16,767 \\
9,599 \\
32,294 \\
16,939 \\
8,765 \\
\mathbf{4 , 3 6 3}\end{array}$ & $\begin{array}{r}8,084 \\
2,688 \\
22,828 \\
11,108 \\
4,440 \\
40,128\end{array}$ \\
\hline Toted Btaem Power Production & 0 & 135,500 & 194,410 & 427,750 & ex3,071 & 801,600 \\
\hline 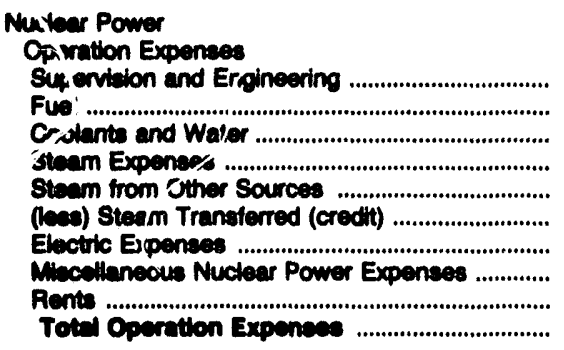 & $\begin{array}{r}18,156 \\
31,366 \\
1,934 \\
5,002 \\
0 \\
0 \\
-40 \\
24,281 \\
1,184 \\
81,844\end{array}$ & $\begin{array}{r}4,104 \\
23,596 \\
202 \\
2,881 \\
0 \\
0 \\
141 \\
8,732 \\
68 \\
30,724\end{array}$ & $\begin{array}{r}9,880 \\
11,358 \\
21 \\
4,625 \\
0 \\
0 \\
780 \\
8,717 \\
277 \\
35,060\end{array}$ & $\begin{array}{l}0 \\
0 \\
0 \\
0 \\
0 \\
0 \\
0 \\
0 \\
0 \\
0\end{array}$ & $\begin{array}{r}69,348 \\
134,462 \\
4,916 \\
21,519 \\
0 \\
0 \\
51 \\
52,022 \\
289 \\
323,507\end{array}$ & $\begin{array}{r}26,885 \\
28,508 \\
0 \\
208 \\
49 \\
0 \\
0 \\
21,808 \\
0 \\
77,550\end{array}$ \\
\hline 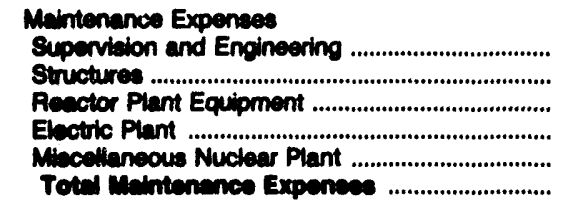 & $\begin{array}{r}4,763 \\
3,545 \\
10,278 \\
8,401 \\
1,284 \\
20,271\end{array}$ & $\begin{array}{l}1,437 \\
1,014 \\
2,008 \\
1,654 \\
1,613 \\
7,726\end{array}$ & $\begin{array}{r}2,879 \\
1,781 \\
6,819 \\
2,669 \\
1,283 \\
15,432\end{array}$ & $\begin{array}{l}0 \\
0 \\
0 \\
0 \\
0 \\
0\end{array}$ & $\begin{array}{r}44,925 \\
3,752 \\
29,016 \\
13,867 \\
16,513 \\
103,073\end{array}$ & $\begin{array}{r}32,497 \\
2,089 \\
13,434 \\
1,374 \\
1,926 \\
51,320\end{array}$ \\
\hline Total Nuclaer Power Production & 110,135 & 47,460 & 51,000 & 0 & 431,600 & 120,078 \\
\hline 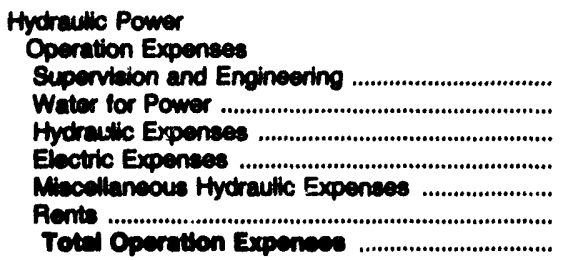 & $\begin{array}{l}0 \\
0 \\
0 \\
0 \\
0 \\
0 \\
0\end{array}$ & $\begin{array}{l}0 \\
0 \\
0 \\
0 \\
0 \\
0 \\
0\end{array}$ & $\begin{array}{l}0 \\
0 \\
0 \\
0 \\
0 \\
0 \\
0\end{array}$ & $\begin{array}{l}0 \\
0 \\
0 \\
0 \\
0 \\
0 \\
0\end{array}$ & $\begin{array}{l}0 \\
0 \\
0 \\
0 \\
0 \\
0 \\
0\end{array}$ & $\begin{array}{l}0 \\
0 \\
0 \\
0 \\
0 \\
0 \\
0\end{array}$ \\
\hline
\end{tabular}

see endinotes at end of an individual electric utility. 
Table 41. Electric Operation and Maintenance Expences by Major U.S. Investor-Owned Electric Utility Within State, 1992 (Continued) (Thousand Dollars)

\begin{tabular}{|c|c|c|c|c|c|c|}
\hline Item & $\begin{array}{l}\text { Connecticut } \\
\text { Connectlout } \\
\text { Yankee } \\
\text { Atom } \\
\text { Pwr Co }\end{array}$ & $\begin{array}{l}\text { Connecticut } \\
\text { United } \\
\text { Illuminating } \\
\text { Co }\end{array}$ & $\begin{array}{c}\text { Delaware } \\
\text { Delmarva } \\
\text { Power } \\
\text { a } \\
\text { Loht Co }\end{array}$ & $\begin{array}{l}\text { Dietrict of } \\
\text { Columbia } \\
\text { Potomac } \\
\text { Electric } \\
\text { Power Co }\end{array}$ & $\begin{array}{c}\text { Florida } \\
\text { Florida } \\
\text { Power } \\
\& \\
\text { Light Co }\end{array}$ & $\begin{array}{l}\text { Florida } \\
\text { Florida } \\
\text { Power Corp }\end{array}$ \\
\hline
\end{tabular}

Maintenunce Expenses

Supervition and Engineering

Structurea and Engineoring ines.

Reservoirs, Dams and Waterways

Electric Plant

Miscellaneous Hyctraulic Plant

Toted Meintenenes Expensese

Toted Hydratis Power

Production Expentes

Other Power

Operation Expenses

Supervision and Engineering

Fund

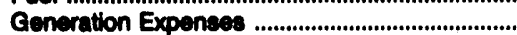

Miscellaneous Other Power Expenses

Rents

Totel Operation Expensese
Maintenance Expenses

Supervition and Engineering

Structures ...................................

Generating and Electric Plant ................................

Mlecellaneous Other Power Plant

Totel Melintenence Expenses

Totel Other Power Production

Expensese

Other Power Supply Expenses

Purchased Power

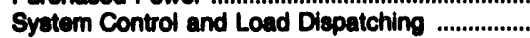

Other Expenses

Totel Other Power Supply Expensed

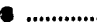

Total Power Production Expenses

0
0
0
0
0
0

0

$\mathbf{0}$
336
9,783
273
85
0

10,477

161

2,465

200

2,980

18,403

10,309

79,54

20,025

re, 916

Tranemiscion

Operation Expenses

Superviaion and Engineering

Load Dispatching

Sthtion Expenses

Overhead Line Expenses

Underground Line Expenses

Tranemiesion of Electricity by Othere

Miscellaneous Transmiseion Expenser

Rents

Totel Operation Expenese

$\begin{array}{rr}2,148 & 924 \\ 0 & 1,051 \\ 456 & 1,057 \\ 1 & 38 \\ 27 & 0 \\ 10,215 & -116 \\ 7 & 1,130 \\ 1,535 & 1,700 \\ 14,398 & 5,703\end{array}$

See endnotes at end of an individual electric utility. 
Table 41. Electric Operation and Malntenance Expenses by Major U.S. Investor-Owned Electric Utility Within State, 1902 (Continued) (Thousand Dollars)

\begin{tabular}{|c|c|c|c|c|c|c|}
\hline litem & $\begin{array}{l}\text { Connecticut } \\
\text { Connecticut } \\
\text { Yankee } \\
\text { Atom } \\
\text { Pwr Co }\end{array}$ & $\begin{array}{l}\text { Connecticut } \\
\text { Unted } \\
\text { Illuminnting } \\
\text { Co }\end{array}$ & $\begin{array}{c}\text { Delaware } \\
\text { Delmarva } \\
\text { Power } \\
\text { Loht Co }\end{array}$ & $\begin{array}{l}\text { Eivinict of } \\
\text { Columbla } \\
\text { Potomac } \\
\text { Electric } \\
\text { Power Co }\end{array}$ & $\begin{array}{l}\text { Florida } \\
\text { Fionida } \\
\text { Power } \\
\text { Light Co }\end{array}$ & $\begin{array}{l}\text { Florida } \\
\text { Florida } \\
\text { Power Corp }\end{array}$ \\
\hline
\end{tabular}

Maintenance Expenses

Supervision and Engineering

Structures

Sthtion Equipment

Overheed Lines

Underground Lines

transmiseion Plant

Totel Melntenence Expenses

Total Tranemiecion Expenses

Diatribution

Operation Expenses

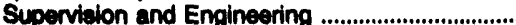

Load Dispatching .

Station Expenses

Overhead Line Expenses

Underoround Line Expenses

Street Lighting and Signal System Expenses ....

Meter Expenses

Customer Installations Expenses

Miecellaneous Distribution Exp

Rents

Maintenance Expenses

Supervision and Engineering

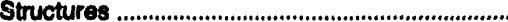

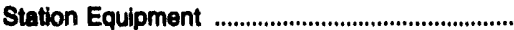

Overhead Lines.

Underground Lines

Une Trenstormers

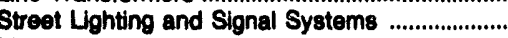

Meters .

Miscellaneous Distribution Plant

Total Meintenence Expences

Total Distribution Expenses

$\begin{array}{ll}0 & \\ 0 & \\ 0 & 1 \\ 0 & \\ 0 & \\ 0 & \\ 0 & 1\end{array}$

121

18,110

243
0
1,535
1,095
2
31
2,000

29
170
2,681
1,221
78
3,040
7,190

8,000

0,180

42,200
147

318

1,684

6

5,020

11,014
Total Operation Expences
6,370

0
2,127

2,82

1,550

183

3,194

580

831

1,305

17,003

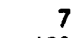

120

567
7,904

1,385

164

267

495

10,000

28,073
2,789

838

762

869

679

309
3,085

6,302

1,168

17,305

2,099

1,801

1,801
10,687

2,428

375

480

98

18,294

36,809

1,038

2,535

9,288

1,195

14,120

89
19,700

Miscellaneous Customer Accounts Expenses

Totel Customer Accounts Expenses .............

Customer Service and Information Expenses

Supervision .............................................................

Informational and Instructional Expenses

Miscellaneous Customer Service

and Informational Expenses .................................

Total Customer service and

Informationsl Expenses

Customer Accounts Expenses

Meter Reading Expenses

See endnotes at end of an individual electric utility.

5,123

0
1,127

2,410

1,147

82

4,265

1,334

8,203

.44

25,148

28,078

42.424

210,097

0,295 
Table 41. Electrlc Operation and Malntenance Expenses by Major U.S. Investor-Owned Electric Utility Within State, 1992 (Continued) (Thousand Dollars)

\begin{tabular}{|c|c|c|c|c|c|c|}
\hline Item & $\begin{array}{l}\text { Connecticut } \\
\text { Connecticut } \\
\text { Yankee } \\
\text { Atom } \\
\text { Pwr Co }\end{array}$ & $\begin{array}{c}\text { Connecticut } \\
\text { United } \\
\text { Illuminating } \\
\text { Co }\end{array}$ & $\begin{array}{c}\text { Delaware } \\
\text { Delmarva } \\
\text { Power } \\
\text { Light Co }\end{array}$ & $\begin{array}{l}\text { Diatrict of } \\
\text { Columbla } \\
\text { Potomac } \\
\text { Electric } \\
\text { Power Co }\end{array}$ & $\begin{array}{c}\text { Florida } \\
\text { Florida } \\
\text { Power } \\
8 \\
\text { Light Co }\end{array}$ & $\begin{array}{l}\text { Florida } \\
\text { Florida } \\
\text { Power Corp }\end{array}$ \\
\hline
\end{tabular}

\section{Sales Expenses}

Demonetrating and Sollir

Miscellaneous Sales Expenses

Totel sales Exponece
Advertiaing Expenses

Administrattve and General Expenees

Operation Expenses

Ofitice Supplles and Expenses

(less) Administrative Expenses

Tranoferred (credii)

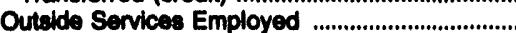

Property Ineurance

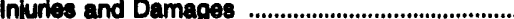

Employee Penaions and Benefite

Franchise Requirements

Aequiatory Commission Expenses

(lese) Duplicate Charges (credit)

General Advertising Expenses

Miscellaneous General Expenses

Rents

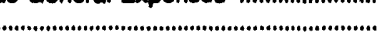

Totel Operation Expenses

Maintenance of General Plant

Totel Adminiotrattve and

Ceneral Exponses

Total Ekctivic Operation and

Malntensence Expenses
127,296

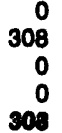

$\begin{array}{rr}0 & 13,568 \\ -212 & 10,584\end{array}$

18,800

10,355

5,700

2,786

1,267

10,548

0
1,185

1,811

1,811

6,112

1,384

47,030

232

48,071

479,617

908,874

12,769

4,981

6,914

4,765

8,440

34,631

0
2,190

0

285

9,198

3,790

104,173

1,383

105,657
1
168
0
0
170

68,194

45,606

22,859

676
7,954

7,954
$\mathbf{9}, 542$

42,219

68,810

0
3,236

671

22,856

14,790

281,981

5,132

3,217

87,070

78

2,615
4,946

5,398

24,861
0

809

3,650

126
18,505

1,167

$\mathbf{0 3 , 8 5 3}$

$3,033,460$

1,069,175

Distribution of Salaries and

Wages Charged to Electric

Operation and Maintenance

Production

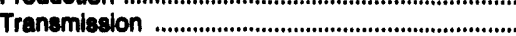

Distribution .

Customer Accounts

Customer Service and

informational Expenses

Sales Expenses

.

Adminstrathe and General

Allocated from Clearing Accounts

Total selaries and Weres

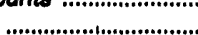

Number of Electric Department Employees,

Regular Full-time Employees .................................

Part-time and Temporary Employees

(.....................

Totel Electric Departument Employese .........

$\begin{array}{rr}16,955 & 17,298 \\ 0 & 2,540 \\ 0 & 16,133 \\ 0 & 7,475 \\ & \\ 0 & 3,622 \\ 0 & 76 \\ 0 & 13,780 \\ 625 & 848 \\ 17,480 & 61,773\end{array}$

24,247

5,683

25,518

8,324

3,644

236

19,763

5,646

93,081

58,868

4,818

23,423

20,123

204,800
16,80

113,221

70,352

2,043

88

28,746
10,470

148,57 .

21,603

147

64,973

10,473

502,471

2,573

21

5,035

14,04

5,823

431
1,584

2,594

5,036

14,042

6,254

Note: Totals may not equal sum of components because of independent rounding. Summary data are provided in Table 11.

Source; Federal Energy Regulatory Commiseion, FERC Form 1, "Annual Report of Major Electric Utilities, Licensees and Others." 
Table 41. Electric Operation and Malntonance Expenses by Major U.S. Inveotor-Owned Electric Utility Within State, 1992 (Continued) (Thousand Dollars)

\begin{tabular}{|c|c|c|c|c|c|c|}
\hline Item & $\begin{array}{l}\text { Florida } \\
\text { Gulf } \\
\text { Power Co }\end{array}$ & $\begin{array}{l}\text { Florida } \\
\text { Tampa } \\
\text { Electric Co }\end{array}$ & $\begin{array}{l}\text { Georgla } \\
\text { Georgla } \\
\text { Power Co }\end{array}$ & $\begin{array}{l}\text { Georgia } \\
\text { Savannah } \\
\text { Electric } \\
\text { \& Power } \\
\text { Co }\end{array}$ & $\begin{array}{l}\text { Hawall } \\
\text { Hawallan } \\
\text { Electric } \\
\text { Co inc }\end{array}$ & $\begin{array}{l}\text { Hawall } \\
\text { Maul } \\
\text { Electric } \\
\text { Co } \\
\text { Ltd }\end{array}$ \\
\hline 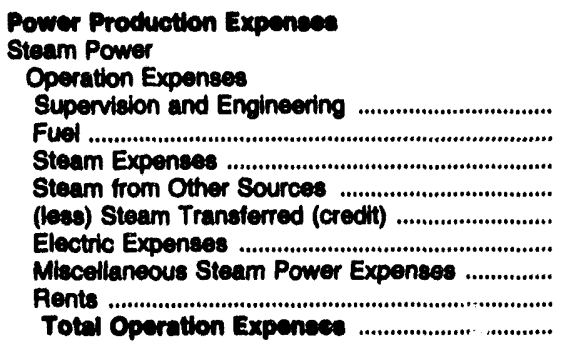 & $\begin{array}{r}4,163 \\
182,674 \\
3,716 \\
0 \\
0 \\
3,928 \\
18,404 \\
21 \\
212,907\end{array}$ & $\begin{array}{r}3,165 \\
369,595 \\
11,070 \\
0 \\
0 \\
4,612 \\
10,001 \\
17 \\
390,480\end{array}$ & $\begin{array}{r}14,070 \\
842,892 \\
17,574 \\
0 \\
0 \\
9,265 \\
38,117 \\
378 \\
922,290\end{array}$ & $\begin{array}{r}1,010 \\
8,611 \\
1,834 \\
0 \\
0 \\
1,557 \\
2,445 \\
0 \\
15,358\end{array}$ & $\begin{array}{r}1,215 \\
156,947 \\
4,243 \\
0 \\
0 \\
4,040 \\
2,216 \\
9 \\
187,071\end{array}$ & $\begin{array}{r}133 \\
8,798 \\
562 \\
0 \\
0 \\
533 \\
190 \\
4 \\
10,220\end{array}$ \\
\hline 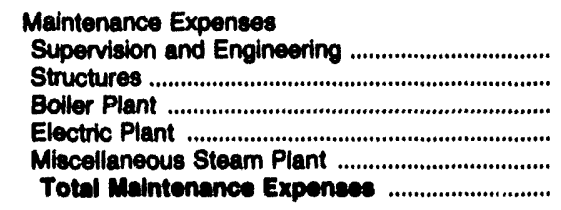 & $\begin{array}{r}3,488 \\
2,509 \\
13,490 \\
5,307 \\
2,126 \\
28,020\end{array}$ & $\begin{array}{r}763 \\
5,347 \\
30,633 \\
7,260 \\
1,676 \\
45,679\end{array}$ & $\begin{array}{r}15,271 \\
9,782 \\
76,304 \\
23,002 \\
-47,889 \\
78,470\end{array}$ & $\begin{array}{r}551 \\
1,221 \\
3,567 \\
1,612 \\
1,135 \\
8,085\end{array}$ & $\begin{array}{r}2,688 \\
1,071 \\
8,284 \\
5,535 \\
520 \\
18,007\end{array}$ & $\begin{array}{r}182 \\
34 \\
896 \\
256 \\
-7 \\
1,380\end{array}$ \\
\hline $\begin{array}{l}\text { Total 8team Power Production } \\
\text { Expentes }\end{array}$ & 289,027 & 44,120 & 988,787 & 23,443 & 185,767 & 11,580 \\
\hline 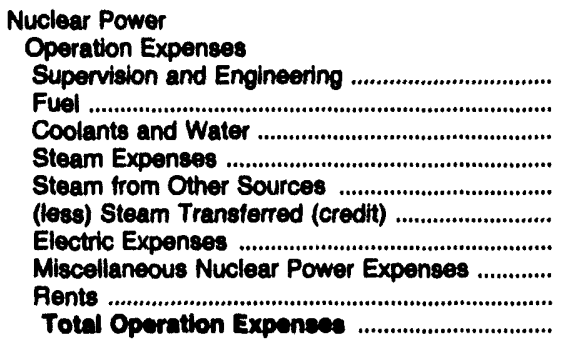 & $\begin{array}{l}0 \\
0 \\
0 \\
0 \\
0 \\
0 \\
0 \\
0 \\
0 \\
0\end{array}$ & $\begin{array}{l}0 \\
0 \\
0 \\
0 \\
0 \\
0 \\
0 \\
0 \\
0 \\
0\end{array}$ & $\begin{array}{r}24,686 \\
84,228 \\
806 \\
18,891 \\
0 \\
0 \\
139 \\
34,891 \\
1 \\
163,689\end{array}$ & $\begin{array}{l}0 \\
0 \\
0 \\
0 \\
0 \\
0 \\
0 \\
0 \\
0 \\
0\end{array}$ & $\begin{array}{l}0 \\
0 \\
0 \\
0 \\
0 \\
0 \\
0 \\
0 \\
0 \\
0\end{array}$ & $\begin{array}{l}0 \\
0 \\
0 \\
0 \\
0 \\
0 \\
0 \\
0 \\
0 \\
0\end{array}$ \\
\hline 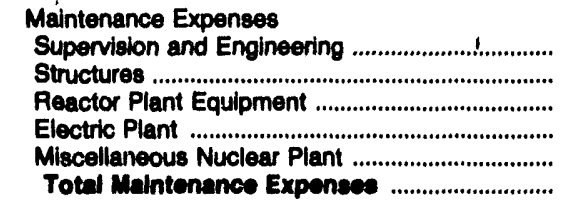 & $\begin{array}{l}0 \\
0 \\
0 \\
0 \\
0 \\
0\end{array}$ & $\begin{array}{l}0 \\
0 \\
0 \\
0 \\
0 \\
0\end{array}$ & $\begin{array}{r}18,624 \\
3,792 \\
25,832 \\
9,941 \\
6,499 \\
84,688\end{array}$ & $\begin{array}{l}0 \\
0 \\
0 \\
0 \\
0 \\
0\end{array}$ & $\begin{array}{l}0 \\
0 \\
0 \\
0 \\
0 \\
0\end{array}$ & $\begin{array}{l}0 \\
0 \\
0 \\
0 \\
0 \\
0\end{array}$ \\
\hline 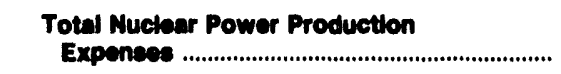 & 0 & 0 & 228,327 & 0 & 0 & 0 \\
\hline 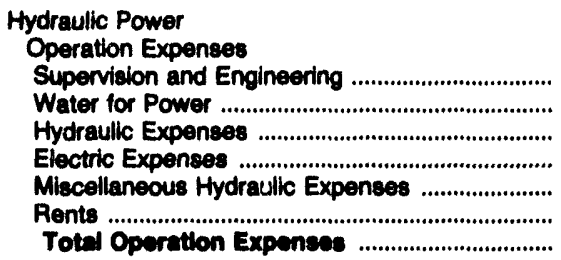 & $\begin{array}{l}0 \\
0 \\
0 \\
0 \\
0 \\
0 \\
0\end{array}$ & $\begin{array}{l}0 \\
0 \\
0 \\
0 \\
0 \\
0 \\
0\end{array}$ & $\begin{array}{r}1,204 \\
411 \\
1,878 \\
1,865 \\
1,978 \\
146 \\
7,582\end{array}$ & $\begin{array}{l}0 \\
0 \\
0 \\
0 \\
0 \\
0 \\
0\end{array}$ & $\begin{array}{l}0 \\
0 \\
0 \\
0 \\
0 \\
0 \\
0\end{array}$ & $\begin{array}{l}0 \\
0 \\
0 \\
0 \\
0 \\
0 \\
0\end{array}$ \\
\hline
\end{tabular}


Table 41. Electric Operation and Maintenance Expenses by Major

U.S. Inveotor-Owned Electric Utility Within State, 1992 (Continued)

(Thousand Dollars)

\begin{tabular}{|c|c|c|c|c|c|c|}
\hline Item & $\begin{array}{l}\text { Florida } \\
\text { Gulf } \\
\text { Power co }\end{array}$ & $\begin{array}{l}\text { Fiorida } \\
\text { Tampa } \\
\text { Electric Co }\end{array}$ & $\begin{array}{l}\text { Georgla } \\
\text { Georgla } \\
\text { Power Co }\end{array}$ & $\begin{array}{l}\text { Georola } \\
\text { Savannah } \\
\text { Electric } \\
\& \text { Power } \\
\text { Co }\end{array}$ & $\begin{array}{l}\text { Hawall } \\
\text { Hawallan } \\
\text { Electric } \\
\text { Co inc }\end{array}$ & $\begin{array}{l}\text { Hawall } \\
\text { Maul } \\
\text { Electric } \\
\text { Co } \\
\text { Ltd }\end{array}$ \\
\hline
\end{tabular}

Maintenance Expenses

Superviaion and Engineering

Structures

Recervoirs, Dams and Waienways

Electric Plant

Miecellaneous Hydraulio Plant

Totel Melntenance Expenees

Totel Hydreulle Power

Other Power

Operation Expenses

Supervilion and Engineering

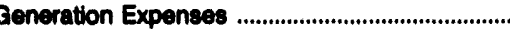

Miscellaneous Other Power Expenses

Rents

Totel Operation Expenses
Production Expenees

Fuel ..................................

0
0
0
0
0
0

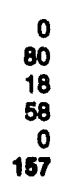

157

0
2
-7
3
-2

155

4,400

28,182

920

29,285

289,286

Total Power Production Expences

(.................

Maintenance Expenses

Structures

Generating and Electric Plant

Miscellaneous Other Power Plant

Total Other Power Production

Other Power Supply Expenses

System Control and Laed Dispatchir

Other Expenses

Total Other Power Supply Expences

..............

Operation Expenses

Supervision and Engineering

Load Diepatching

Station Expenses

Overhaad Line Expenses

Und Line Expenses

Tranamiacion of Electricity by Others

Miscellaneous Tranemission Expenses ...............

Pents

Total Operation Expenses

$\begin{array}{rr}19,671 & 595,140 \\ 0 & 8,767 \\ 5,949 & 7,093 \\ 25,620 & 610,901\end{array}$

489
105
2,621
$-2,124$
1,001

41
0
93
5
139

56,986
805
0
57,891

$\begin{array}{rrr}555 & 1,080 & 2,709 \\ 564 & 1,277 & 2,396 \\ 277 & 804 & 2,472 \\ 309 & 140 & 637 \\ 3 & 0 & 28 \\ 0 & 14 & 0 \\ 297 & 329 & 2,145 \\ 2,547 & 22 & 23,973\end{array}$

158
187
177
15
0
0
33
6

$\begin{array}{rr}1,055 & 55 \\ 993 & 156 \\ 410 & 40 \\ 549 & 39 \\ 52 & 0 \\ 0 & 0 \\ 226 & 26 \\ 27 & 86 \\ 3,313 & 402\end{array}$

Maintenance Expenses

Supervision and Engineering .................................. Siructures.

Station Equipment

Overhead Lines ....

Underground Lines

34,360

$\mathbf{5 7 6}$

3,007
71
6,261
7,896
1

0
17
1,880
1,777
0

42
19
509
286

388
27
808
2,161
42

See endnotes at end of an individual electric utility. 
Table 41. Electrlc Oporation and Malntenance Exponses by Major U.S. Investor-Owned Electric Utility Within State, 1992 (Continued) (Thousand Dollars)

\begin{tabular}{|c|c|c|c|c|c|c|}
\hline Item & $\begin{array}{l}\text { Florida } \\
\text { Gulf } \\
\text { Power co }\end{array}$ & $\begin{array}{l}\text { Fiorida } \\
\text { Tampa } \\
\text { Electrio co }\end{array}$ & $\begin{array}{l}\text { Ceorgia } \\
\text { Georgla } \\
\text { Power Co }\end{array}$ & $\begin{array}{l}\text { Ceorgia } \\
\text { Savannah } \\
\text { Electric } \\
\text { \& Power } \\
\text { Co }\end{array}$ & $\begin{array}{l}\text { Hewall } \\
\text { Hawallan } \\
\text { Electrio } \\
\text { Co Inc }\end{array}$ & $\begin{array}{l}\text { Hawall } \\
\text { Maul } \\
\text { Electric } \\
\text { Co } \\
\text { Lid }\end{array}$ \\
\hline
\end{tabular}

Maintenance Expenses

Mecellaneous Tranamiacion Plant ....

Totel Melmitenence Expeneos

Toted Trenomiedion Exponsere

\section{Dietribution}

Operation Expenses

Supervialon and Engineering

Load Diapatching .

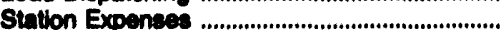

Overhead Line Expenses

Underground Line Expenses ..................................

Street Llohting and Signal System Expenses ....

Meter Expenses

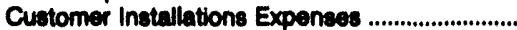

Miscellaneous Diatribution Expenses ...................

Rents

Totel Operation Exponese

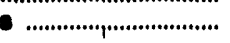

Maintenance Expenses

Supervision and Engineering

Structures

Station Equipment

Overhead Lines

Underground

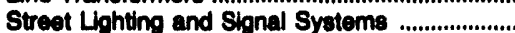

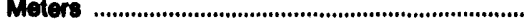

Mecellaneous Distribution Plant

Total Meintenanos Exponese

Total Diotribution Expenese

Customer Accounts Expenses

Supervision

Meter Reading Expenses ..........................................

Customer Records and Collection Expenses ....

Uncollectible Accounts .............................................

Mlecellaneous Customer Accounts Expenses ....

Total Customer Accounts Expenses

74
9,002

0.415

0
3,075

5
17,941

61,700

7,41

1,287

1,079

197

1,184

1,184
273

524

1,500

482

981
6

6,770

898

468
748

7,134

993

788

371

118

187

11,704

18,49

440

1,622

5,882

146
62

0,251

$$
\begin{array}{r}
0 \\
800 \\
556 \\
242 \\
583 \\
2,384 \\
1,408 \\
4,358 \\
27 \\
11,632
\end{array}
$$

7,338

1,163

2,607

4,007

2,679

2,256

13,378

4,826

6,108

1,172

48,681

887

218

185

9,051

731

328

1,323

458

14,181

26,914

7,708

82
6,008

6,008
27,879

6,468

5,460

2,640

1,030

341
67,000

109,130

528
2,103

13,470

1,738

17,097

829
4,538

929

316

16,822

16,822
679

19,116

1,863

6,534

0,811

17,801

34,039

5,168
10,828

39,569

11,475

2,854

540

2,923

454
17

3,034

167
5
355
3,600
124
204
213
16
83
4,44

713

331
434

3.471

1,988

643

15

10
7,085

10,841

14,871

$\begin{array}{rr}136 & 224 \\ 1,492 & 355 \\ 5,115 & 1,042 \\ 676 & 108 \\ 0 & 0 \\ 7,410 & 1,700\end{array}$

and Informational Expennes

Total Customor sorvice and

informationel Expenices

Sales Expenses

Supervision

Demonstrating and Selling Expenses ..................

Advertiding Expenses

Miscollaneous Sales Expenses

Totel Eales Exponses

21
142
78
0
241

0
13,005
384
0
14,200

120
457
335
838
1,760

47
439
25

0

:

3

0

188

0

183

600

o

103

See endnctes at end of an incividual olectric utilty. 
Table 41. Elective Oporation and Malntenanos Expenses by Major U.8. Investor-Owned Eleotrle Utillty Whthin 8tate, 1902 (Continued) (Thousand Dollars)

\begin{tabular}{|c|c|c|c|c|c|c|}
\hline Hem & $\begin{array}{l}\text { Florida } \\
\text { Qulf } \\
\text { Power co }\end{array}$ & $\begin{array}{l}\text { Florida } \\
\text { Tampa } \\
\text { Electrio Co }\end{array}$ & $\begin{array}{l}\text { Georgla } \\
\text { Georgia } \\
\text { Power co }\end{array}$ & $\begin{array}{l}\text { Georgia } \\
\text { Savannah } \\
\text { Elcotic } \\
\text { \& Power } \\
\text { Co }\end{array}$ & $\begin{array}{l}\text { Hawall } \\
\text { Hawallan } \\
\text { Electric } \\
\text { Co inc }\end{array}$ & $\begin{array}{l}\text { Hawall } \\
\text { Maul } \\
\text { Eleotric } \\
\text { Co } \\
\text { Lid }\end{array}$ \\
\hline
\end{tabular}

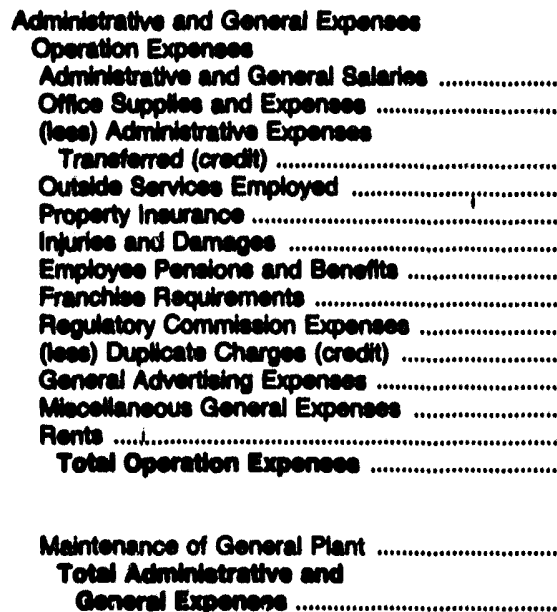

escrert Expenese

Totel Enotits Opermiton and

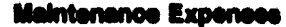

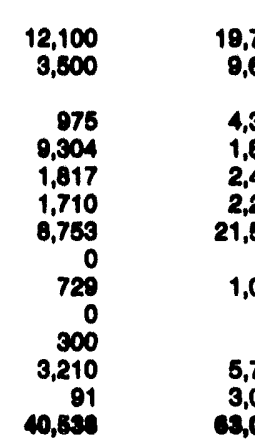

40,60

1,468

42,002

351,119

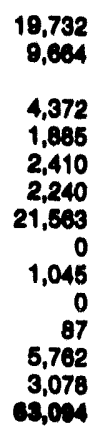

3,984

67,07

610,031

$2,908,451$

116,768
404,383

1,416

470

433

1,987

165

846
2,568

20
0

2

531
0

7,681

18,600

292

248

78

7,840

70,449

Dictibution of Saleree and

Wores Charead to Electrio

Operation and Meintenance

Production...

Trenemiacion .

Dhtitioution

Customer Service and

Informational Expenses

Sales Expenses

Alocated from Clating Account

Total entertos and Werese

$\begin{array}{rrr}15,558 & 42,454 & 173,657 \\ 1,354 & 4,641 & 17,834 \\ 7,481 & 13,012 & 63,354 \\ 4,706 & 9,243 & 39,656 \\ & & \\ 3,597 & 3,780 & 21,569 \\ 0 & 165 & 8,532 \\ 11,440 & 20,248 & 68,290 \\ 2,760 & 10,800 & 12,836 \\ 4,, 005 & 104,354 & 403,020\end{array}$

$8,6 \times 3$
8,4
5,379

5,379
2,268

$\begin{array}{rr}15,682 & 5,165 \\ 3,389 & 249 \\ 6,627 & 1,255 \\ 3,682 & 832 \\ & \\ 1,205 & 119 \\ 0 & 0 \\ 11,663 & 1,433 \\ 0 & 1,746 \\ 42,400 & 10,793\end{array}$

Number of Electric Department Employees

Regular Fult-time Employees

Part-time and Temporary Employese

1,568

3,186

37

12,588
12

540
461
4,452

22, 224

10,790

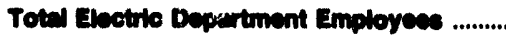

1,606

3,295

12,000

649

1,523

285

40

21

24

0

Note: Totals may not equal sum of components because of independent rounding. Summary data are provided in Table 11.

Source: Federal Energy Regulatory Commiselon, FERC Form 1, "Annual Report of Major Electric Utilities, Licensees and Others." 
Table 41. Electrie Oporation and Malntenance Expences by Mulor

U.8. Inveotor-Owned Ekotrle Utility Whinln Etarte, 1902 (Continued)

(Thousand Dollars)

\begin{tabular}{|c|c|c|c|c|c|c|}
\hline item & $\begin{array}{l}\text { Idaho } \\
\text { Idano } \\
\text { Powner co }\end{array}$ & 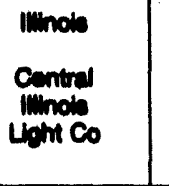 & 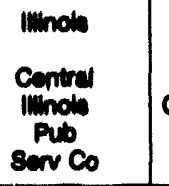 & $\begin{array}{c}\text { Ilinno: } \\
\text { Commonmealth } \\
\text { Edison } \mathrm{Co}^{-}\end{array}$ & $\begin{array}{l}\text { Illinole } \\
\text { Electio } \\
\text { Energy Ino }\end{array}$ & $\begin{array}{l}\text { Illinole } \\
\text { Iilinols } \\
\text { Power co }\end{array}$ \\
\hline 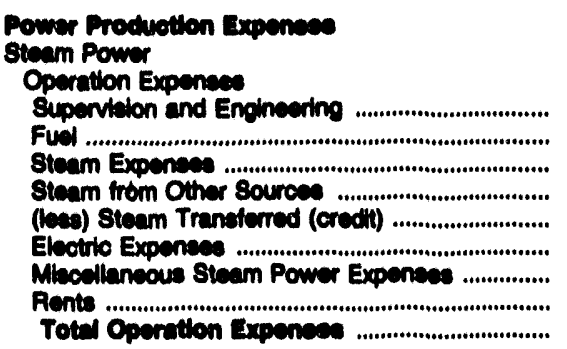 & $\begin{array}{r}2,380 \\
00,677 \\
5,680 \\
0 \\
0 \\
2,678 \\
3,712 \\
410 \\
111,974\end{array}$ & $\begin{array}{r}997 \\
9,700 \\
8,496 \\
0 \\
0 \\
1,104 \\
1,818 \\
0 \\
102,109\end{array}$ & $\begin{array}{r}4,026 \\
107,094 \\
18,717 \\
10 \\
0 \\
4,000 \\
6,770 \\
0 \\
107,000\end{array}$ & $\begin{array}{r}27,314 \\
462,004 \\
10,755 \\
0 \\
0 \\
13,685 \\
24,776 \\
0 \\
894,468\end{array}$ & $\begin{array}{r}739 \\
86,220 \\
3,467 \\
0 \\
0 \\
844 \\
1,477 \\
14 \\
02,769\end{array}$ & $\begin{array}{r}3,439 \\
202,449 \\
7,734 \\
0 \\
0 \\
4,007 \\
7,143 \\
100 \\
228,900\end{array}$ \\
\hline 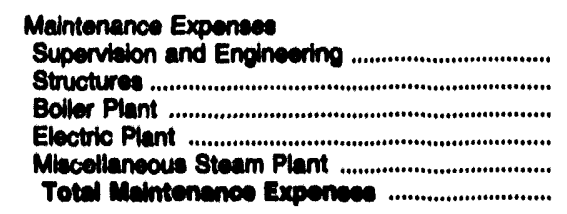 & $\begin{array}{r}1,472 \\
1,280 \\
8,289 \\
1,476 \\
1,438 \\
14,98\end{array}$ & $\begin{array}{r}1,181 \\
1,100 \\
10,000 \\
2,417 \\
097 \\
110917\end{array}$ & $\begin{array}{r}4,627 \\
3,680 \\
24,206 \\
4,190 \\
1,602 \\
\mathbf{2 a , 1 0 0}\end{array}$ & $\begin{array}{r}7,270 \\
19,211 \\
69,704 \\
18,092 \\
12,700 \\
121,077\end{array}$ & $\begin{array}{r}374 \\
946 \\
10,049 \\
3,401 \\
979 \\
18,743\end{array}$ & $\begin{array}{r}3,678 \\
1,697 \\
18,787 \\
4,868 \\
1,481 \\
30,460\end{array}$ \\
\hline $\begin{array}{l}\text { Total steam Power Production } \\
\text { Exponece }\end{array}$ & 124,700 & 117,07 & 298,731 & 008,491 & 100,600 & 260,040 \\
\hline 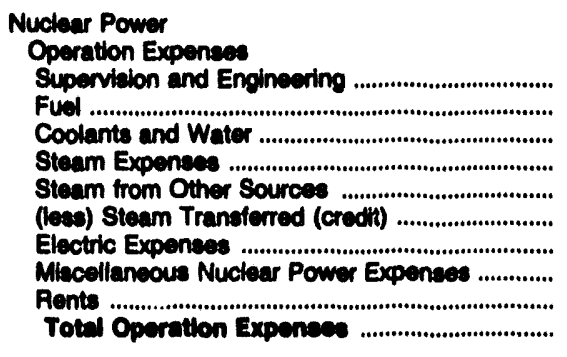 & $\begin{array}{l}0 \\
0 \\
0 \\
0 \\
0 \\
0 \\
0 \\
0 \\
0 \\
0\end{array}$ & $\begin{array}{l}0 \\
0 \\
0 \\
0 \\
0 \\
0 \\
0 \\
0 \\
0 \\
0\end{array}$ & $\begin{array}{l}0 \\
0 \\
0 \\
0 \\
0 \\
0 \\
0 \\
0 \\
0 \\
0\end{array}$ & $\begin{array}{r}300,260 \\
347,150 \\
23,095 \\
131,323 \\
0 \\
0 \\
0 \\
18,148 \\
189,895 \\
0 \\
1,027,000\end{array}$ & $\begin{array}{l}0 \\
0 \\
0 \\
0 \\
0 \\
0 \\
0 \\
0 \\
0 \\
0\end{array}$ & $\begin{array}{r}16,822 \\
46,898 \\
1,383 \\
21,185 \\
0 \\
0 \\
0 \\
1,898 \\
15,832 \\
0 \\
109,013\end{array}$ \\
\hline 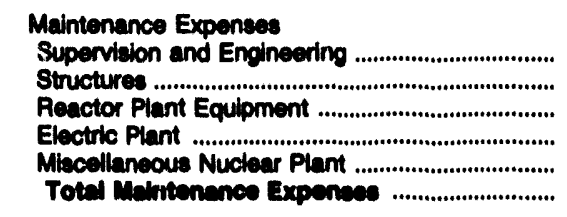 & $\begin{array}{l}0 \\
0 \\
0 \\
0 \\
0 \\
0\end{array}$ & $\begin{array}{l}0 \\
0 \\
0 \\
0 \\
0 \\
0\end{array}$ & $\begin{array}{l}0 \\
0 \\
0 \\
0 \\
0 \\
0\end{array}$ & $\begin{array}{r}83,363 \\
28,273 \\
88,128 \\
45,093 \\
36,630 \\
279,307\end{array}$ & $\begin{array}{l}0 \\
0 \\
0 \\
0 \\
0 \\
0\end{array}$ & $\begin{array}{r}9,826 \\
3,342 \\
9,206 \\
2,688 \\
1,383 \\
28,274\end{array}$ \\
\hline 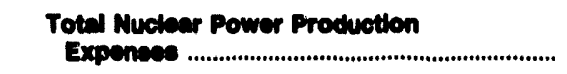 & 0 & 0 & 0 & $1,207,240$ & 0 & 120,237 \\
\hline 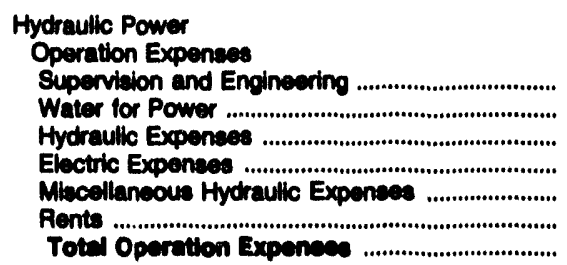 & $\begin{array}{r}1,175 \\
3,080 \\
1,788 \\
2,686 \\
2,427 \\
307 \\
11,493\end{array}$ & $\begin{array}{l}0 \\
0 \\
0 \\
0 \\
0 \\
0 \\
0\end{array}$ & $\begin{array}{l}0 \\
0 \\
0 \\
0 \\
0 \\
0 \\
0\end{array}$ & $\begin{array}{r}0 \\
0 \\
0 \\
35 \\
0 \\
0 \\
36\end{array}$ & $\begin{array}{l}0 \\
0 \\
0 \\
0 \\
0 \\
0 \\
0\end{array}$ & $\begin{array}{l}0 \\
0 \\
0 \\
0 \\
0 \\
0 \\
0\end{array}$ \\
\hline
\end{tabular}

See endinotes at end of an individual electric utilly. 


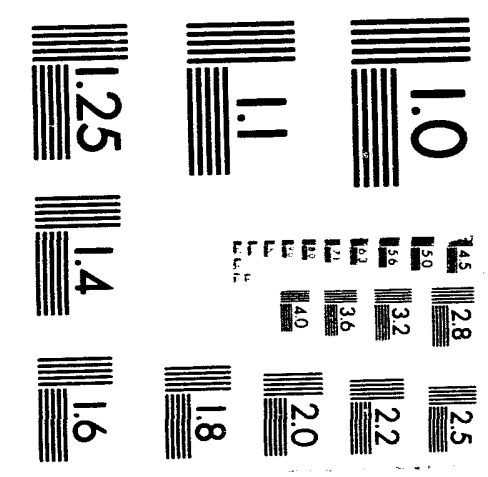



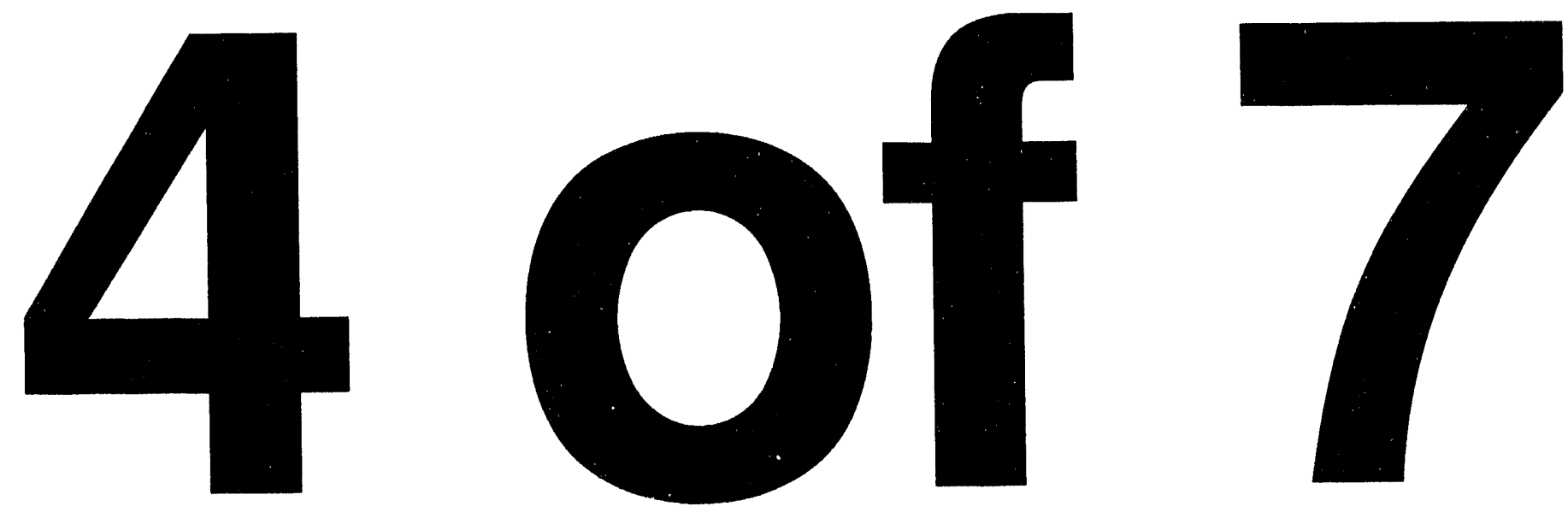
Table 41. Electric Operation and Malntenance Expenses by Major U.S. Investor-Owned Electric Utility Within State, 1992 (Continued) (Thousand Dollars)

\begin{tabular}{|c|c|c|c|c|c|c|}
\hline Item & $\begin{array}{l}\text { Idaho } \\
\text { Idaho } \\
\text { Power Co }\end{array}$ & $\begin{array}{l}\text { Illinols } \\
\text { Central } \\
\text { Illinois } \\
\text { Light Co }\end{array}$ & $\begin{array}{l}\text { Illinols } \\
\text { Central } \\
\text { Illinols } \\
\text { Pub } \\
\text { Serv Co }\end{array}$ & $\begin{array}{c}\text { Illinois } \\
\text { Commonwealth } \\
\text { Edison Co }\end{array}$ & $\begin{array}{l}\text { Illinois } \\
\text { Electric } \\
\text { Energy Inc }\end{array}$ & $\begin{array}{l}\text { Illinois } \\
\text { Illinols } \\
\text { Power Co }\end{array}$ \\
\hline
\end{tabular}

Maintenance Expenses

Superviaton and Engineering

Structures

Resenvoirs, Dams and Watenways

Electric Plant

Miscellaneous Hydraulic Plant

Total Meintenence Expenese.

Totel Hydreulle Power

Production Expensese

Other Power

Operation Expenses

Supervition and Enginearing

Fuel

Generation Expenses

Mecellaneous Other Pomer Expenses

Rents

Total Operntion Expences.

Maintenance Expenses

Superviaion and Engineering

Structures .....................................

Generating and Electric Plant ....
Miscellaneous Other Power Plant

Total Meintenence Expenses

Total Other Power Production

Expenses

Other Power Supply Expenses

Purchased Power

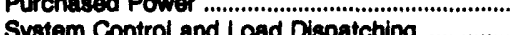

Total Other Power Supply Expences

(n...........

Total Power Production Expences

Transmission

Operation Expenses

Supenvion and Engineering

Loed Din

Station Expenses

Overhead Line Expenses

Underground Line Expenees

Tranambeion of Electricity by Others

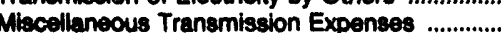

Rents

Totel Operration Exponses

0
0
34
3
37

78

58,496

373

$-5,150$

53,710

105,493

967

1,164

256

200

2,085

209

808
15,905

729

1,264

53

1254

754

4,632

$\mathbf{0}$
0
41
0
0
0
41

123,479

282,900

5,689

201
218
192
22
0
0
57
9

699

538
1
1,403
1,037
0
$2,076,597$

280,028

410,010

0
1,012

631

594

2,244

188
553

11,414

0
12,155

14,390

115,129

4,239

$-30,249$

80,110

122,422
0
122,422

24,002

890

351
25,249

4,533

7,200

4,611

4,137

17,629

553

439

302

1,315

29,700

3,712

131

1,407

16,459

$\mathbf{3 , 7 2 3}$

2,454

690
51
2,040
2,267
0

0
0
61
88
0

255
56
2,495
1,501
0

51
28
344
448
0

Maintenance Expenses

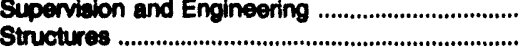

Station Equipment

Undereround Lines

See endnotes at end of an indhidual electric utility. 
Table 41. Electrlc Operation and Maintenance Expenese by Major

U.S. Investor-Owned Electric Utility Within State, 1992 (Continued) (Thousand Dollars)

\begin{tabular}{|c|c|c|c|c|c|c|}
\hline Item & $\begin{array}{l}\text { Idaho } \\
\text { Idano } \\
\text { Power co }\end{array}$ & $\begin{array}{l}\text { Illinols } \\
\text { Contral } \\
\text { Illinois } \\
\text { Light Co }\end{array}$ & $\begin{array}{l}\text { Ilinole } \\
\text { Central } \\
\text { Illinole } \\
\text { Pub } \\
\text { Sen Co }\end{array}$ & $\begin{array}{c}\text { Ininole } \\
\text { Commonmmealth } \\
\text { Edison Co }\end{array}$ & $\begin{array}{l}\text { Illinois } \\
\text { Encioy inc }\end{array}$ & 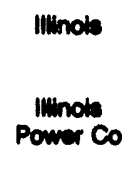 \\
\hline
\end{tabular}

Muntenance Expenese

Mibcollaneous Tranamisalon Plant

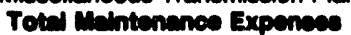

Toty Trensminelon Exponsese

Dintibution

Operation Expenses

Supervition and Enoineering

Loed Dientching

Station Expeneas

Overthe

Underoround Line Expenses ....................................

Street Lughting and Signal System Expenses ....

Meter Expensea

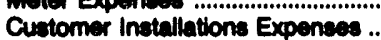

Miscellaneous Distribution Expenses

Rents

Totel Operation Expensese
20

8,000

9,89

1,483

1,278

1,239

1,797

771

128

2,890

545

805

1,039

Maintenance Expenses

Supenvilon and Engineering

Structures ................

Overhead Lines

Underground Lines

Line Transformers .

Street Lighting and

Moters .

stribution Plant

Total Distribution Exponese

Customer Accounts Expenses

Superviaion

Meter Reading Expenses ............................................

Customer Records and Collection Expenses .....

Uncollectible Accounts

Miecellaneous Customer Accounts Expenses ...

Totil Customer Aocount Expeness ..............

Customer Service and Information Expenses

Supervision .

Customer Aceiotance Expenses ........................

Informational and Instructional Expenses .............

Miscellaneous Customer Service

and Informational Expenses

Totel Cuxtomer gervioe end

Informationel Expensese

Sales Expenses

Supervidion

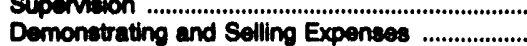

Advertiaing Expenses

Mibceltaneous Sales Expenses

Toul Eales Expennes

See endnotes at end of an individual electric utility.

1,628

43

2,022

5,782

1,284

1,788

+ 81

176

(2)

28,9s
188

2,414

7,880

1,225

11,703

323

2,830
186

108

3,654

$\begin{array}{rrrr}5,627 & 24,174 & 0 & 0 \\ 0,200 & 64,074 & 140 & 4,207\end{array}$

803
312
513
680
683
483
1,331
484
1,500
257
6,084

1,853
180
698
1,713
548
208
1,805
491
1,192
68
6,948

10,425

2,202

$\mathbf{9 , 2 4 0}$

15,814

5,268

445

11,287

15,180

7,687

468

77.00

$\begin{array}{rr}887 & 1,220 \\ 10 & 521 \\ 1,680 & 7,921 \\ 8,689 & 78,006 \\ 684 & 38,089 \\ 422 & 3,328 \\ 438 & 1,300 \\ 373 & 1,233 \\ 243 & 421 \\ 18,306 & 124,127\end{array}$

2,451

2,451
110
2,251
0,280
1,168
1,534
1,131
360
0
0,244
0,697

2,261

20,280

1,168

1,634

1,131

2,451
110
2,251
, 2000
, 168
, 634
1,131
360
0
, 244

2.,24

7,304

22,240

204,107

49,eer
722

2,355

5,362

1,318

319
10,094

78
5,390

90
711

462

43

1,300
380

22,481

89,187

38,703

is.725
70
1,854
0

1,388

1,742
652

382

3,162
462

2,116

1,763

2,020

2,967

7,281

2,242

738

18,107

147

841
785

173

1,99

18,600

o

128

3,148

3,148
221
748

743
4,203 
Table 41. Electric Operation and Malntenance Expenses by Major U.S. Investor-Owned Electric Utility Within State, 1992 (Continued) (Thousand Dollars)

\begin{tabular}{|c|c|c|c|c|c|c|}
\hline Item & $\begin{array}{l}\text { Idaho } \\
\text { Idaho } \\
\text { Power Co }\end{array}$ & $\begin{array}{l}\text { Illinois } \\
\text { Central } \\
\text { Illinois } \\
\text { Light Co }\end{array}$ & $\begin{array}{l}\text { Illinols } \\
\text { Central } \\
\text { Illinols } \\
\text { Pub } \\
\text { Serv Co }\end{array}$ & $\begin{array}{c}\text { Illinoils } \\
\text { Commonwealth } \\
\text { Editon Co }\end{array}$ & $\begin{array}{l}\text { Illinoie } \\
\text { Electric } \\
\text { Energy Inc }\end{array}$ & $\begin{array}{l}\text { Illinols } \\
\text { IIIinols } \\
\text { Power Co }\end{array}$ \\
\hline
\end{tabular}

Adminietrative and Ceneral Expenses

Operation Expentes

Adminintratuve and General Salarios

Otice Supplies and Expenses

(kes) Administrative Expenses

Transferred (ared"t)

Outeids Servican Emplo.........................................

Property Incurance

In'uries and Dameges

Frenchise Requirements

Reoulatory Commiseion Expenses

(kei) Duplicate Charges (credt)

Cenerd Advertiaing Expenses

Miscollan

Rents

Totil Operation Expenses

Maintenance of General Plant

Total Adminlotrative and

Cenerd Expenses

Totel Elective Operation end

Mintenance Expensen

Distribution of Salaries and

Weges Charged to Electric

Operation and Malntenance

Production

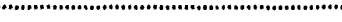

Diatribution

Customer Accounts

Customer Service and

Informational Expenses

Sales Expenses

Adminatrattve and General .....................................

Alocated from Clearing Accounts

Total Eelaries and Waces
16,58

5,315

489

1,725

1,608

3,613

13,747

2,254

91

338

3,546

147

46,300

1,168

40,477

202,753

170,828

$\begin{array}{rr}8,264 & 93,288 \\ 2,190 & 25,549 \\ & \\ 5 & 8,907 \\ 2,335 & 19,885 \\ 2,566 & 10,184 \\ 4,628 & 30,675 \\ 22,775 & 250,483 \\ 81 & 20,387 \\ 1,595 & 7,619 \\ 364 & 20,484 \\ 0 & 3,181 \\ 3,073 & 45,527 \\ 2,218 & 6,894 \\ 60,355 & 484,281\end{array}$

4,314

498,695

53,494

381,558

2,998,877

239,738

591,545
Number of Electric Department Employees

Recular Full-time Employees

Part-time and Temporary Employees ....................

Total Electris Department Employees ..........

$\begin{array}{rr}5,823 & 14,570 \\ 2,393 & 735 \\ 12,796 & 7,832 \\ 6,992 & 3,675 \\ & \\ 1,961 & 787 \\ 0 & 304 \\ 16,725 & 5,677 \\ 4,885 & 3,287 \\ 51,575 & 38,89\end{array}$

$\begin{array}{rr}35,967 & 452,979 \\ 2,474 & 27,114 \\ 10,780 & 87,155 \\ 5,561 & 86,028 \\ 1,770 & \\ 0 & 7,231 \\ 10,211 & 4,755 \\ 4,587 & 77,649 \\ 71,340 & 105,563 \\ 7,040,475\end{array}$

$\begin{array}{rr}12,371 & 68,593 \\ 460 & 1,568 \\ 10 & 11,800 \\ 0 & 6,531 \\ & \\ 0 & 668 \\ 0 & 2,472 \\ 1,524 & 31,894 \\ 0 & 29,977 \\ 14,384 & 163,400\end{array}$

1,638

1,028

2,662

19,637

312

2,333

1,703

1,067

2,760

19,637

340

3,846

Note: Totals may not equal sum of components because of independent rounding. Summary data are provided in Table 11

Source: Federal Energy Regulatory Commisalon, FERC Form 1, "Annual Report of Major Electric Utilities, Licensees and Others." 
Table 41. Electric Operation and Malntenance Expenses by Major U.S. Investor-Owned Electric Utility Within State, 1992 (Continued) (Thousand Dollars)

\begin{tabular}{|c|c|c|c|c|c|c|}
\hline Item & $\begin{array}{c}\text { Illinois } \\
\text { Mt } \\
\text { Carmel } \\
\text { Pubilc } \\
\text { Utility Co }\end{array}$ & $\begin{array}{l}\text { Indiana } \\
\text { Alcos } \\
\text { Generating } \\
\text { Corp }\end{array}$ & $\begin{array}{c}\text { Indiana } \\
\text { AEP } \\
\text { Generating } \\
\text { Co }\end{array}$ & $\begin{array}{c}\text { Indiana } \\
\text { Commonwealth } \\
\text { Edison } \\
\text { Co } \\
\text { IN Inc }\end{array}$ & $\begin{array}{l}\text { Indiana } \\
\text { Indiana } \\
\text { Michigan } \\
\text { Power Co }\end{array}$ & $\begin{array}{c}\text { Indiana } \\
\text { Indianapolts } \\
\text { Power } \\
8 \\
\text { Light Co }\end{array}$ \\
\hline
\end{tabular}

Power Production Expenses

Steam Power

Oparation Expenses

Superviaion and Engineering

Fubl

Steam Expenses ........................................................

Steam from Other Sources

(less) Steam Transferred (credit)

Electric Expenses .....................

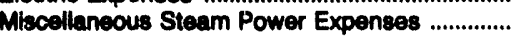

Rents

Totel Opartion Exponsen

$\begin{array}{rr}2,101 & 1,809 \\ 60,771 & 102,437 \\ 2,100 & 843 \\ 0 & 0 \\ 3,599 & 0 \\ 826 & 623 \\ 948 & 1,858 \\ 0 & 65,937 \\ 89,147 & 173,807\end{array}$

2,186

20,493

2,183
0

0

1,887

2,262

11

173,607

29,142

1,045

2,351

6,072

1,832

801

12,101

11,584

Miscellaneous Steam Plant ........
Total Maintenance Expensees

Total steam Power Production

Expenses $\mathbf{7 4 , 7 3 1}$

183,629
41,243

6,269
1,373

10,122

$\begin{array}{rr}4,447 & 3,457 \\ 154,985 & 144,684 \\ 3,673 & 4,015 \\ 0 & 0 \\ 0 & 0 \\ 1,897 & 4,027 \\ 4,858 & 7,684 \\ 68,203 & 18 \\ 286,113 & 108,084\end{array}$

1,986

2,451

17,70

4,243

2,783

2,177

205,290

197,016

Nuclear Power

Operation Expenses

Supervision and Engineering

Fuel .

Coolants and Water

Steam Expenses

Steam from Other Sources

Stean Transterred (credit)

Rente

Tothl Operntion Expenses

Maintenance Expenses

Supervision and Engineering

Structures .

Reactor Plant Equipment ...

Electric Plant

Miscellaneous Nuclear Plant

Total Maintenance Expensea

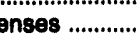

Total Nuclear Power Production

Exponees

Hydraulic Power

Operation Expenses

Supervision and Engineering

Water for Power...

uxpenses

Electric Expenses

Miscellaneous Hydraulic Expenses

Rents

Total Operation Expenses

See endnotes at end of an individual electric utility.

$\begin{array}{rl}112 & 0 \\ 0 & 0 \\ 249 & 0 \\ 18 & 0 \\ 280 & 0 \\ 2 & 0 \\ 662 & 0\end{array}$


Table 41. Electric Operation and Malntenance Expenses by Major U.S. Investor-Owned Electric Utility Within State, 1992 (Continued) (Thousand Dollars)

\begin{tabular}{|c|c|c|c|c|c|c|}
\hline Item & $\begin{array}{l}\text { Illinols } \\
\text { Mit } \\
\text { Carmel } \\
\text { Public } \\
\text { Utility Co }\end{array}$ & $\begin{array}{l}\text { Indiana } \\
\text { Alcoa } \\
\text { Generating } \\
\text { Corp }\end{array}$ & $\begin{array}{l}\text { Indiana } \\
\text { AEP } \\
\text { Generating } \\
\text { Co }\end{array}$ & $\begin{array}{c}\text { Indlana } \\
\text { Commonwealth } \\
\text { Edison } \\
\text { Co } \\
\text { IN Inc }\end{array}$ & $\begin{array}{l}\text { Indiana } \\
\text { Indiana } \\
\text { Michigan } \\
\text { Power Co }\end{array}$ & $\begin{array}{l}\text { Indlana } \\
\text { Indlanapolis } \\
\text { Power } \\
\& \\
\text { Light Co }\end{array}$ \\
\hline
\end{tabular}

\footnotetext{
Mintenance Expenses

Supenvilon and Engineering

Structures

Resenvoirs, Dams and Waterways

Electric Plant .

Mbcellaneous Hydreulic Piant

Totel Maintenence Expenses

Totel Hydrenclic Power

Production Expensea

Other Power

Operation Expensess

Supervision and Engineering

Fued...

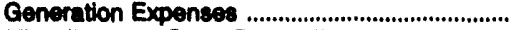

Miscellaneous Other Power Expenses

Rents

Totel Opertition Expenses.
}

0
0
0
0
0
0

0
0
0
0
0
0

$\mathbf{0}$

0

0

0
1,728

$\begin{array}{rr}30 & 0 \\ 48 & 0 \\ 438 & 0 \\ 480 & 0 \\ 71 & 0 \\ 1,068 & 0\end{array}$

$\mathbf{0}$

Maintenance Expenses

Supervision and Engineering

Structures .

Generating and Electric Plant

Miscellaneous Other Power Plant

Total Maintenance Expenses

Totel Other Power Production

Expenese .

0

o

o

452

128

Other Power Supply Expenses

Purchased Power

System Control and Load Dispatching

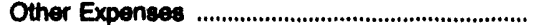

Total Other Power 8upply Expenses.

...............

5,793

18,579
0
0

18,670

1
309
11

180,365

1,793

182,170

7,804

221

6,793

321

8,026

Total Power Production Expences

5,801

93,300

183,051

41,243

700,219

205,160

Transmission

Operation Expenses

Supervision and Engineering

Load Dispatching

Station Expe

Overhead Une Expenses

Underground Line Expenses

Tranamiseion of Electricity by Others

Miscelianeous Transmiseion Expenses ...............

Rents

Total Operatton Expenses

0

Maintenance Expenses

Superviaion and Engineoring

Structures .

0

Station Equipment

Overhead Lines.

Underground Lines

3
0
0
0
0

$\begin{array}{rrr}0 & 2,006 & 575 \\ 0 & 337 & 31 \\ 172 & 4,410 & 2,628 \\ 3 & 3,486 & 921 \\ 0 & 22 & 20\end{array}$

See endnotes at end of an individual electric utility. 
Table 41. Electric Operation and Maintenance Expenses by Major U.S. Investor-Owned Electric Utillty Within State, 1992 (Continued) (Thousand Dollars)

\begin{tabular}{|c|c|c|c|c|c|c|}
\hline Item & $\begin{array}{l}\text { Illinols } \\
\text { Mit } \\
\text { Carmel } \\
\text { Public } \\
\text { Utility Co }\end{array}$ & $\begin{array}{l}\text { Indiana } \\
\text { Alcoa } \\
\text { Generating } \\
\text { Corp }\end{array}$ & $\begin{array}{c}\text { Indiana } \\
\text { AEP } \\
\text { Generating } \\
\text { Co }\end{array}$ & $\begin{array}{c}\text { Indiana } \\
\text { Commonwealth } \\
\text { Edison } \\
\text { Co } \\
\text { IN Inc }\end{array}$ & $\begin{array}{l}\text { Indlana } \\
\text { Indiana } \\
\text { Michlgan } \\
\text { Power Co }\end{array}$ & $\begin{array}{l}\text { Indiana } \\
\text { Indianapolis } \\
\text { Power } \\
\mathbf{8} \\
\text { Light Co }\end{array}$ \\
\hline
\end{tabular}

Mintenance Expenses

Mincellaneous Tranemiseion Plant

Totel Melotenanes Expenses

Totel Tranembelen Expenses

Dintribution

Operation Expenses

Supenvion and Engineering

Loed Diepatching

Station Expenses

Overheed Line Expenses

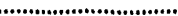

Expenses

Street Lighting and Signal System Expenses ...

Meter Expenses

Cutcomer Installations Expenses

Miscollaneous Distritbution Expen

Rents

Totil Operation Expenses

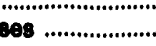

Maintenance Expenses

Supervition and Engineering

Structures

Station Equipment

Overhead Lines.

Underoround Lines

Line Tranoiom

Street Lighting and Signal Syotems

Meters ................................................

Miscollanoous Distritution Plant

Total Meintenence Expenses

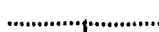

Totel Dietribution Expenses

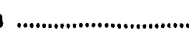

Customer Accounts Expenses

Supervialon .............................................................

Meter Reading Expenses ..................................

Uncollectible Accounts ..........................................

Miscellaneous Customer Accounts Expenses ...
Total Customer Accounts Expenses ............

Customer Service and Information Expenses

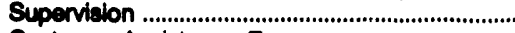

Customer Aselstance Expenses .............................

Informational and Instructional Expenses

Miscellaneous Customer Service

and Informational Expenses

Total Customer service and

informational Expenses .

Sales Expenses

Supervition

Demonstrating and Selling Expenses

Advertieing Expenses

Miscellaneous Sales Expenses

Totid Eales Expenues
2

28
109
3
46
40
0
1
68
12
14
0
292

161

161

0
1
22

247

539

\section{0}

12

0

0

579

$-28,496$
32
4,207

6,523

0
0
0
0
0
0
0
0
0
0
0

3,627

418
1,113

741

340

2,161

1,130

5,883

2,841

18,797

483

478

340

356

1,222

303

2,297

2,305

409

34

8,228

3,220

184

1,347

9,745

2,473

2,022

377

738

543

20,650

982

7
373

11,399

2,367

1,028

1,126

857

533

18,773

39,468

27,000

1,428

3,294

10,012

1,725

679

17,138

388
2,711

6,692

1,631

887

12,300

See endnotes at end of an individual electric utility. 
Table 41. Electric Operation and Maintenance Expenses by Major

U.S. Inveotor-Owned Electiric Utility Within State, 1992 (Continued)

(Thousand Dollars)

\begin{tabular}{|c|c|c|c|c|c|c|}
\hline litem & $\begin{array}{l}\text { Mlinois } \\
\text { Mt } \\
\text { Carmel } \\
\text { Public } \\
\text { Utilly Co }\end{array}$ & $\begin{array}{l}\text { Indiana } \\
\text { Alcon } \\
\text { Generating } \\
\text { Corp }\end{array}$ & $\begin{array}{c}\text { Indlana } \\
\text { AEP } \\
\text { Generating } \\
\text { Co }\end{array}$ & $\begin{array}{c}\text { Indlans } \\
\text { Commonwealth } \\
\text { Eolleon } \\
\text { Co } \\
\text { IN Inc }\end{array}$ & $\begin{array}{l}\text { Indiana } \\
\text { Indiane } \\
\text { Mlchigan } \\
\text { Power Co }\end{array}$ & $\begin{array}{l}\text { Indiana } \\
\text { Indianapolis } \\
\text { Power } \\
8 \\
\text { Light Co }\end{array}$ \\
\hline
\end{tabular}

Administrative and General Expenses

Operation Expenses

Administratwe and General Salaries

Office Supplies and Expenses ..................................

(bes) Adminiatrative Expenses

Tranoferred (credit)

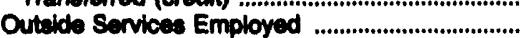

Property Ineurance.

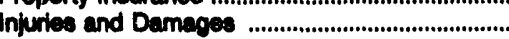

Employes Pensions and Beneftes

Franchise Requirements

Regulatory Commiseion Expenses

(leas) Dupllcate Charges (credit)

General Advertising Expenses ...

Mbcellaneous General Expenses

Rents

Totil Operation Expensece

Maintenance of General Plant .............................

Totel Adminiatrathe and

Ceneral Expenses .....

$\begin{array}{rr}247 & \\ 44 & \\ 0 & \\ 30 & \\ 31 & 1,0 \\ 140 & \\ 350 & \\ 5 & \\ 0 & \\ 0 & \\ 0 & \\ 21 & \\ 0 & \\ 200 & \end{array}$

$232 \quad 1,005$

48

840

1,045

11,895

6,161

12,289

$0 \quad 57$

015182

$153 \quad 373$

373
279

1,354

0

434

78

76
168
4,850

$\begin{array}{lll}37 & 0 & 146\end{array}$

$\cos$

1,649

4,005

7,431

e4,004

189,758

47,208

811,070

303,948

Distribution of Salaries and

Weges Charged to Electric

Operation and Maintenance

Production .

Tranemiseion

Distribution

Customer Accounts

Cuatomer Service and

Informational Expenses

Sales Expenses

Adminatrative and Generel

Total Enlaries and Wares

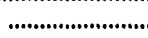

Number of Electric Department Employees

Regular Full-time Employees ..................................

Part-time and Temporary Employees ....................

Total Electrle Departinemt Employees ..........

7
18
443
102
0
0
276
11
28

10,298
352
0
0
0
0
6
1,628

67,154

8,618

19,787

75,924

7,813

2,407

17
12,342

7,891

128,128

75,02

18

18
24

0
0

0
0

268

3,613

2,173

42

o

0

298

3,697

2,187

Note: Totals may not equal sum of components because of independent rounding. Summary data are provided in Table 11.

Source: Federal Energy Regulatory Commission, FERC Form 1, "Annual Report of Major Electric Utilites, Licensees and Others." 
Table 41. Electric Operation and Maintenance Expenses by Major U.S. Investor-Owned Electric Utility Within State, 1992 (Continued) (Thousand Dollars)

\begin{tabular}{|c|c|c|c|c|c|c|}
\hline Item & $\begin{array}{l}\text { Indiana } \\
\text { Northem } \\
\text { Indiana } \\
\text { Pub Serv } \\
\text { Co }\end{array}$ & $\begin{array}{c}\text { Indtana } \\
\text { PSI } \\
\text { Energy Inc }\end{array}$ & $\begin{array}{l}\text { Indiana } \\
\text { Southem } \\
\text { Indiana Gas } \\
\text { \& Elec Co }\end{array}$ & $\begin{array}{c}\text { Iowa } \\
\text { Interstate } \\
\text { Power Co }\end{array}$ & $\begin{array}{c}\text { lowa } \\
\text { lowa } \\
\text { Electric } \\
\text { Llght \& Power } \\
\text { Co }\end{array}$ & $\begin{array}{l}\text { lowa } \\
\text { lowa } \\
\text { Southem } \\
\text { Utilities } \\
\text { Co }\end{array}$ \\
\hline
\end{tabular}

\section{Power Production Expense:}

Steam Power

Operation Expenses

Steam Expenses ...............n.

Steam from Other Sources ...

(tess) Steam Transferred (credit)

Electric Expenses ...............................

Mibcellaneous Steam Power Expenses ................

Rents

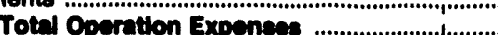

Supervision and Engineering

Structures

Boller Plant

Electric Plant

Miscellaneous Steam Plant

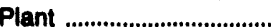

Total Maintenance Expenses

$\begin{array}{rr}2,888 & 11,015 \\ 242,136 & 392,193 \\ 23,328 & 11,560 \\ 0 & 0 \\ 0 & 540 \\ 5,220 & 5,245 \\ 9,231 & 5,787 \\ 0 & 0 \\ 282,202 & 425,250\end{array}$

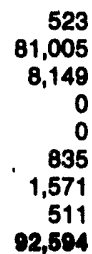

726
58,034

531
30200

1,724

2,595

0
11

1,453

1,145

31

68,103

2,595
0
5,472
1,464

1,468

3
30,709

Total 8team Power Production

Expensees

333,572

477,010

105,254

70,422

30,009

36,749

Nuclear Power

Operation Expenses

Supervision and Engineering

Fuel

Coolants and Water

Steam Expenses

Steam from Other Sources

(leas) Steam Transferred (credil)

Electric Expenses

Totel Operatton Expensese

Maintenance Expenses

Supervision and Engineering

Structures

Electric Plant

Miscellaneous Nuclear Plant

Total Malntenance Expensese

Total Nuclear Power Production

Expensese

Hydraulic Power

Operation Expenses

Supervision and Engineering

Water for Power

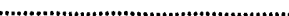

Hydraulic Expenses

Electric Expenses

Rents

Total Operation Expenses

8 ........................

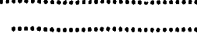

See endnotes at end of an individual electric utility.

$\begin{array}{rr}37 & \\ 0 & 5 \\ 65 & 7 \\ 72 & 5 \\ 65 & 143 \\ 0 & 57 \\ 280 & 38\end{array}$

0
52
78
58
143
57
388

0
0
0
0
0
0
0

0
0
0
0
0
0
0

6
0
12
69
47
0
134


Table 41. Electric Operation and Malntenance Expenses by Major U.S. Inveator-Owned Electric Utility Within State, 1992 (Continued) (Thousand Dollars)

\begin{tabular}{|c|c|c|c|c|c|c|}
\hline Item & $\begin{array}{l}\text { Indiana } \\
\text { Northern } \\
\text { Indiana } \\
\text { Pub Sen } \\
\text { Co }\end{array}$ & $\begin{array}{c}\text { Indiana } \\
\text { PSI } \\
\text { Energy Inc }\end{array}$ & $\begin{array}{l}\text { Indiana } \\
\text { Southem } \\
\text { Indlana Gas } \\
\text { Elec Co }\end{array}$ & $\begin{array}{c}\text { lowa } \\
\text { Interstate } \\
\text { Power Co }\end{array}$ & $\begin{array}{c}\text { Lowa } \\
\text { lowa } \\
\text { Electric } \\
\text { Light \& Power } \\
\text { Co }\end{array}$ & $\begin{array}{l}\text { lowa } \\
\text { lowa } \\
\text { Southern } \\
\text { Utlities } \\
\text { Co }\end{array}$ \\
\hline
\end{tabular}

Maintenance Expenses

Supervision and Engineering

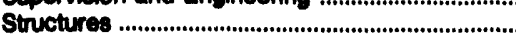

Reservoirs, Dams and Weterways

Electric Plant

Miecellaneous

Total Malitienance Expenses

Totel Hydreulic Power

Production Expenses.

Other Power

Operation Expenses

Supervition and Engineering

Generation Expenses ............................................

Mlecellaneous Other Power Expenses

Rents

Total Operation Expences

Maintenance Expenses

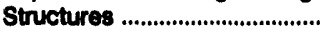

Generating and Electric Plant

Miscellaneous Other Power Plant

Total Maintenance Expenees

Total Other Power Production

Expensese

413

658

30
17
340
4
392

1
1
201
5
208

0
2
168
3
173

7
1
19
1
28

Other Power Supply Expenses

Purchased Power

Syetem Control and L...........................................

Other Expenses ..........................................................

Totw Other Power supply Expenses.

.............

Total Power Production Expenses

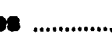

346,454

492,352

100,005

116,749

158,897

40,051

Transmiseion

Operation Expenses

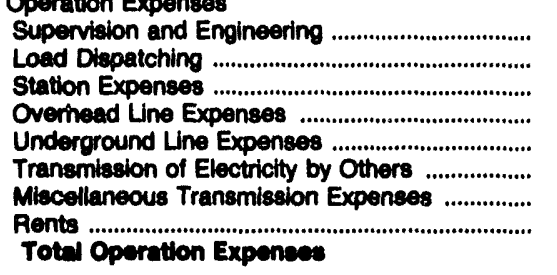

4,270

$\begin{array}{rr}53 & 410 \\ 115 & 311 \\ 19 & 488 \\ 14 & 81 \\ 1 & \\ 7 & 1,338 \\ 42 & 59 \\ 10 & 53\end{array}$

410
311
486
91
0
1,338
59
53
2,740

See endnotes at end of an indlividual electric utility. 
Table 41. Electric Operation and Maintenance Expenses by Major U.S. Investor-Ownod Electric Utility Within State, 1992 (Continued)

(Thousand Dollars)

\begin{tabular}{|c|c|c|c|c|c|c|}
\hline Item & $\begin{array}{l}\text { Indiana } \\
\text { Northern } \\
\text { Indlana } \\
\text { Pub Sen } \\
\text { Co }\end{array}$ & $\begin{array}{c}\text { Indlana } \\
\text { PSI } \\
\text { Enorgy Inc }\end{array}$ & $\begin{array}{l}\text { Indiana } \\
\text { Southern } \\
\text { Indiana Gas } \\
\text { \& Elec Co }\end{array}$ & $\begin{array}{c}\text { Iowa } \\
\text { Interstate } \\
\text { Power Co }\end{array}$ & $\begin{array}{c}\text { lowa } \\
\text { lowa } \\
\text { Electric } \\
\text { Light \& Power } \\
\text { Co }\end{array}$ & $\begin{array}{l}\text { lowa } \\
\text { lowa } \\
\text { Southern } \\
\text { Utilltes } \\
\text { Co }\end{array}$ \\
\hline
\end{tabular}

Maintenance Expenses

Supervision and Engineering

(n)

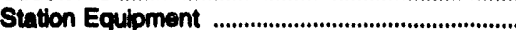

Orecthed

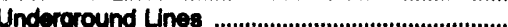

Mlecellaneous Transmiseion Plant

Toted Melntenance Expensee

(.......................

Totol Tranemiecten Expensese

Total Tranemiesion Expenses

Dietribution

Operation Expenses

Superviaion and Engineering .................................

Load Diepatching

Station Expenses .........................................................

Overhead Line Expenses

Underground Line Expenses .....................................

Street Llohting and Signal System Expenses ....

Meter Expenses .........................................................

Customer Installations Expenses ..........................

Miscellaneous Distribution Expenses

Rents

Total Opention Expences
1,388

108

2,131

1,471

227

8,305

11,724

2,440

50

1,648

819

192

2,296

862
2,804

72

12,963

1,092

Maintenance Expenses

Supervision and Engineering ..................................

Structures

Overhead Unes .

Underground Lines

Line Transformers

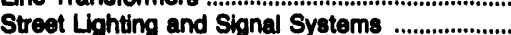

Meters

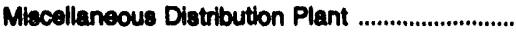

Totel Malntenance Expenese

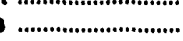

Total Diotribution Expences

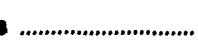

Customer Accounts Expenses

Supervision .............................................................

Customer Records and Collection Expenses ....

Uncollectible Accounts

Miscellaneous Customer Accounts Expenses ...

Total Cuotomer Accounts Exponses

Customer Service and Information Expenses

Superviaion.

Customer Aseigtance Expenses

Informational and Instructional Expenses .............

Miscellaneous Customer Service

and Informational Expenses ...

Tothl Customer service and

Informational Expenses

1,089

8,005

508

228

374

295

12,650

24,915

541

1,954

9,335

2,434

1,343

15,607

389
84
2,029
2,525
0
82
5,110

9,397

61
0
374
654
1
8
1,007

1,36

4,090

224
11
535
569
0
0
1,340
4,090

325

762

1,313

0

2,419

6,522

1,174

$$
\begin{array}{r}
4,779 \\
0 \\
1,329 \\
483 \\
-1 \\
408 \\
2,013 \\
838 \\
1,462 \\
141 \\
11,484
\end{array}
$$

3,203

69
1,678

13,855

2,262

1,288

482

236

23,692

84,009

113
4
176
283
177
121
491
31
244
1
1.90

980
1
419
836
244
112
1,000
345
1,803
48
8,706

1,211
0

294

586

270
87

1,026

1,028
-116

1,551

41

4,949

176
16
224
4,104
292
134
108
38
72
5,181

489

1,360

268

912

4,253

188

459

198
70

70

509
8,227

6,781

11,300

13,175

4,743
445

1,181
2,266

2,200

64
4,071

See endnotes at end of an individual electric uullity.

\begin{tabular}{rrrrrr}
33 & 254 & 56 & 74 & 3 & 117 \\
243 & 240 & 115 & 1,008 & 17 & 283 \\
774 & 290 & 15 & 19 & 2 & 92 \\
202 & 846 & 29 & 119 & 0 & 61 \\
1,252 & 1,030 & 216 & 1,220 & 22 & 562 \\
\hline
\end{tabular}


Table 41. Electric Operation and Malntenance Expenses by Major

U.S. Investor-Owned Electric Utility Within State, 1992 (Continued)

(Thousand Dollars)

\begin{tabular}{|c|c|c|c|c|c|c|}
\hline Item & $\begin{array}{l}\text { Indlana } \\
\text { Northem } \\
\text { Indland } \\
\text { Pub Ser } \\
\text { Co }\end{array}$ & $\begin{array}{c}\text { Indiana } \\
\text { PSI } \\
\text { Energy Inc }\end{array}$ & $\begin{array}{l}\text { Indiana } \\
\text { Southern } \\
\text { Indlana Gas } \\
\text { \& Elec Co }\end{array}$ & $\begin{array}{c}\text { lowa } \\
\text { Interstate } \\
\text { Power Co }\end{array}$ & $\begin{array}{c}\text { lowa } \\
\text { lowa } \\
\text { Electric } \\
\text { Lught \& Power } \\
\text { Co }\end{array}$ & $\begin{array}{l}\text { lowa } \\
\text { lowa } \\
\text { Southem } \\
\text { Utillties } \\
\text { Co }\end{array}$ \\
\hline
\end{tabular}

Sales Expenses

Supervision

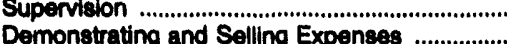

Advertising Expenses

Miscellaneous Sales Expenses

Total Soles Expenses

Administrative and General Expenses

Operation Expenses

Adminiotratho and General Salar

(less) Administrative Expenses

Transferred (credit)

Property Insurance

Injuries and Damages

Employee Pensions and Benefits

Franchise Requirements

Commiason Expenses

(les8) Duplicate Charges (credit)

General Advertising Expenses ...

Miscellaneous General Expenses

Rents

Total Operation Expenses

Maintenance of General Plant

Total Administrattre and

Coneral Expensee

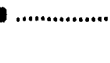

Total Electric Operation and

Malntenance Expenses .

Distribution of Salaries and

Wages Charged to Electric

Operation and Maintenance

Production

Production ..................................................................

Distribution

Customer Accounts

Customer Service and

Informational Expenses

Sales Expenses

Adminstrative and General ....................................

Total salaries and Woges

\section{1,0}

1,353

33

855

2,341

23,989

17,791

10,329

4,480

1,477

3,054

32,401

0
60

989

186

5,779

1,136

79,048

653

79,690

481,902

677,022

37,344

14,391

733

5,374

2,009
4,703

27,222

0
1,770

1,123

131

7,330

5,116

103,585

5,085

108,619

2,765

1,176

1,059

1,470

585

646

3,129

0
80

0
0

1,782

441

11,025

751

11,778

132,168

5

54
Office Supplies and Expenses

Allocated from Clearing Accounts

\section{6,123
6,865 \\ 8,865
14,318}

7,551

45,880
4,541
19,632

19,632
11,628

8,912
562

562
3,195

1,288

243

228
588
28,349

14,032

118,034

1,224
37,765

7,562

128,575

2,884

23

4,068

188

2,007

4,254

144
94

3,051

353

17,600

$\begin{array}{rrr}6,047 & 27,094 & 3,468 \\ 1,498 & 1,258 & 354 \\ 7,379 & 6,366 & 2,724 \\ 2,989 & 2,850 & 1,126 \\ 637 & & \\ 0 & 13 & 340 \\ 4,295 & 11 & 0 \\ 313 & 7,165 & 2,806 \\ 23,168 & 4,036 & 1,625 \\ & 48,792 & 12,843\end{array}$

834

15,576

8,243

1,150

2,945

4,390
1,054

2,594

1,852

3,332

1,896

6,790

5,481

3
848

496
6

1,808

108

14,741

3,568

397

0
2,208

3,446

29,404

166

20,620

0,952

Rumber of Electric Department Employees

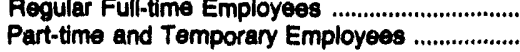

Total Electric Department Employees .........

Note: Totals may not equal sum of components because of independent rounding. Summary data are provided in Table 11.

Source: Federal Energy Regulatory Commission, FERC Form 1, "Annual Report of Major Electric Utilties, Licensees and Others." 
Table 41. Electrlc Operation and Maintenance Expenses by Major

U.S. Investor-Owned Electric Utility Within State, 1992 (Continued) (Thousand Dollars)

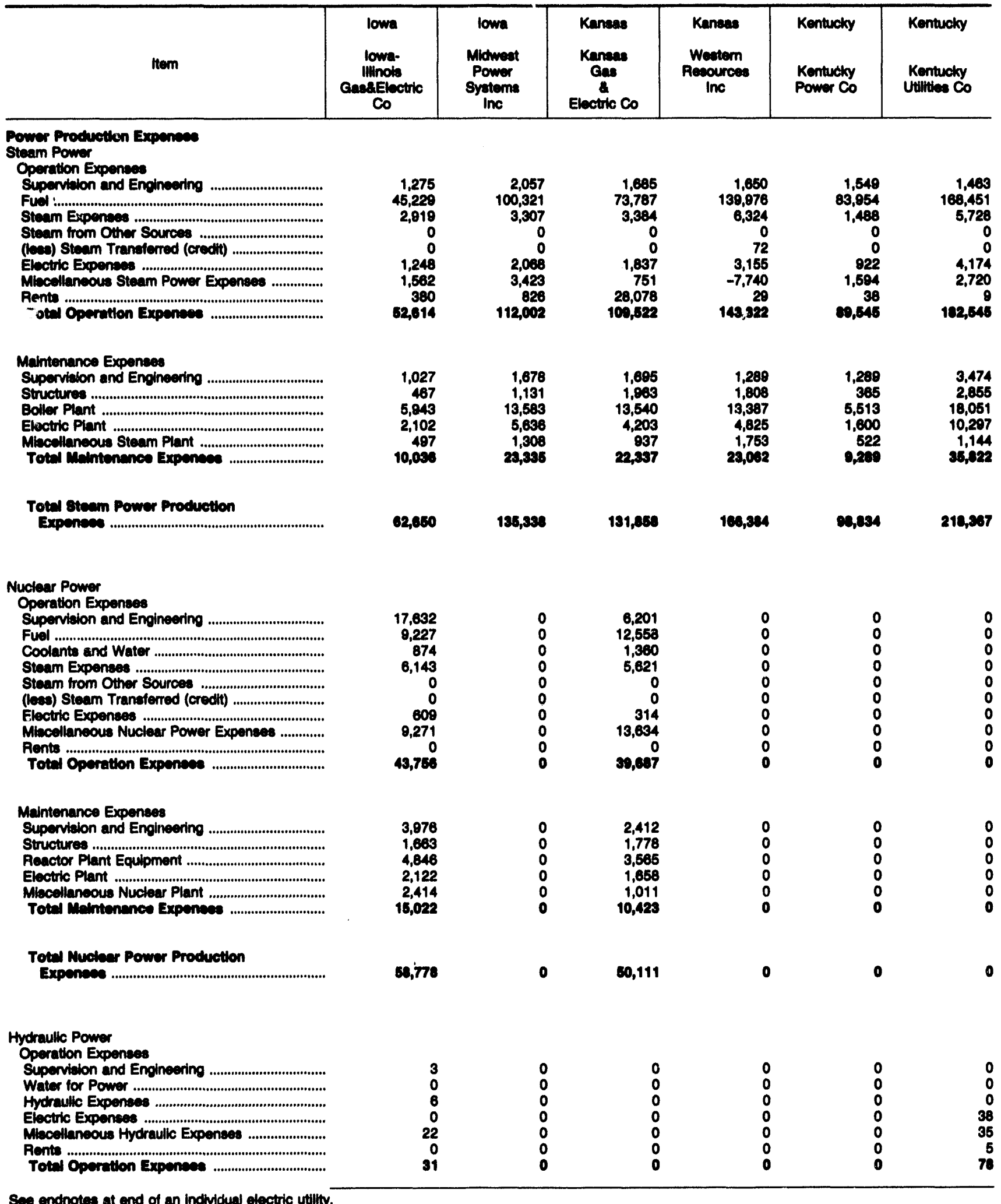


Table 41. Electrlc Operation and Malntenance Expenses by Major U.S. Investor-Owned Electric Utility Within State, 1992 (Continued) (Thousand Dollars)

\begin{tabular}{|c|c|c|c|c|c|c|}
\hline them & $\begin{array}{c}\text { lowe } \\
\text { lown- } \\
\text { Ilinole } \\
\text { GasaElectic } \\
\text { Co }\end{array}$ & $\begin{array}{l}\text { lown } \\
\text { Milweet } \\
\text { Power } \\
\text { Syetems } \\
\text { Inc }\end{array}$ & $\begin{array}{c}\text { Kaneas } \\
\text { Kansas } \\
\text { Gas } \\
\mathbf{2} \\
\text { Electric Co }\end{array}$ & $\begin{array}{c}\text { Kunsas } \\
\text { Westem } \\
\text { Resources } \\
\text { Inc }\end{array}$ & $\begin{array}{l}\text { Kentucky } \\
\text { Kentucky } \\
\text { Power Co }\end{array}$ & $\begin{array}{c}\text { Kentucky } \\
\text { Kentucky } \\
\text { Utilties Co }\end{array}$ \\
\hline
\end{tabular}

Mintenance Expenses:

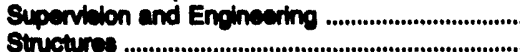

Recenvime, Dams and Waterways ...........................

Electric Piant

...................................

Hychous Piant...

Total Irrinums Power

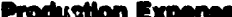

$\begin{array}{rr}0 & \\ 0 & 8 \\ 57 & 0 \\ 0 & \\ 6 & \end{array}$

0
0
0
0
0

75
16
99
103
188
190

Other Power

Operation Expensese

Supervivion and Encineering ....................................

Furl

Generation Expentese .................................................

Milcollensous Other Power Expenses

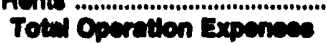

.............

Maintenence Expenses

Supenvion and Engineering

Structures

Cenerating and Electric Piant

Miscettinneous Other Power Plant

Totel Meintenanes Exponises

Totel Other Power Production

Expenses

2,858

40
1,146
80
121
0
1,307

0

680

83

780

19

37

0

74

$\begin{array}{rr}1 & 61 \\ 1 & 37 \\ 362 & 1,346 \\ 0 & 17 \\ 204 & 1,461\end{array}$

0
0
711
3

12
9

3

17

714

26

Other Power Supply Expenses

Purchened Power

Syotem Control and Load Diepatohing ................

Other Expeneas and Load Dlepatohing

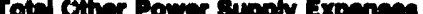

124,451

104

Totel Power Production Expenses

129,481

202,047

189,060

Tranamiacion

Operation Expenses

Supervision and Engineering .....................................

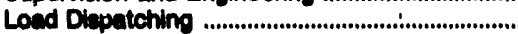

Station Expence

Overhend Line Expences ..........................................

Undereround line Expenses

Tranemiendon of Electriaty by Othare.

Miscellaneous Tranemisaion Expenses ................

Rent

Total Operation Expenses:

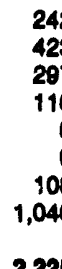

242

423
297

110

0

108
, 046

2,226

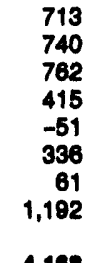

4,163

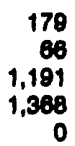

8,850
$-2,885$
95
6,040

149,280

191,800

269,780

237
210
278
29
0
-765
1,372
794

229
0
466
53
0
1,812
12
3

583

303

299
405

0

$-4,094$

527

107

32,758

1,971

$\mathbf{3 4 , 7 4 7}$

2,166

2,698

$-1,007$

251
10
1,438
1,087
1

$\begin{array}{rr}268 & 251 \\ 4 & 10 \\ 1,329 & 1,438 \\ 249 & 1,037 \\ 35 & 1\end{array}$

$\begin{array}{rr}334 & 328 \\ 61 & 206 \\ 647 & 2,311 \\ 614 & 3,340 \\ 0 & 0\end{array}$

See endnotes at end of an individual electric utility. 
Table 41. Electric Operation and Malntenance Expenses by Major

U.S. Investor-Owned Electric Utility Within State, 1902 (Continusd)

(Thousand Dollars)

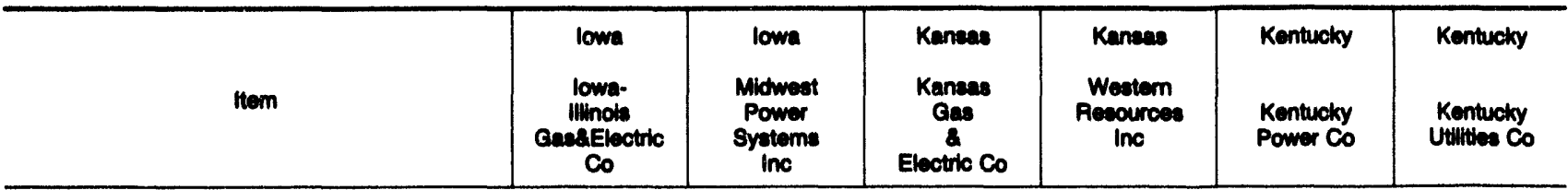

Melitienance Expensea

Mucollaneous Tranemisalon Pient

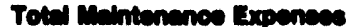

Totel Trencmiesion Exponew

Dinturution

Operation Expense:

Supention and Encineering ..................................

Loed Dispatching

Station Expentes. ...

expensen

Street Lighting and Sional Sytem Expenses ....

Meter Expenses ...............................................................

Cuntomer Inethllations Expenses

Miscellaneous Distribution Expenses

Pente

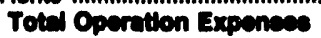

...................................

Muintenance Expences

Supemvion and Enoineering

Structures

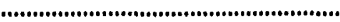

Overthend Lines

Underground Lines

Une Transformers

Street Lighting and Sional Systems .....................

Motere

Dletribution Plant

Totel Melentennon Expentese

Total Dotutiution Exponece

(a)

Customer Accounts Expenses

Evpention

Meter Reading Expenses

Customer Records and Collection Expehses ....

Uncollectible Account .............................................

Mincellaneous Customer Accounts Expenises

Totel Cuntemer Acoounts Expenses ..............

$\begin{array}{rr}0 & 45 \\ 024 & 2,890 \\ 3,050 & 7,018 \\ & \\ & \\ 1,172 & 2,516 \\ 338 & 387 \\ 658 & 1,229 \\ 1,011 & 823 \\ 315 & 1,251 \\ 208 & 327 \\ 1,022 & 1,920 \\ 221 & 838 \\ 1,424 & 3,268 \\ 7 & 315 \\ 6,377 & 12,984\end{array}$

289

2,184

5
2,749

27

11
0,16

4,320

5,800

$-303$

2,000

37

2,984

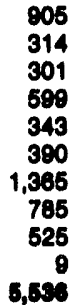

602

0
738

301

234

149
2,289

498

1,293

53

6,160

1,420

125

1,406

12,792

1,647

274

670

287

793

10,416

7.916

32.370

14,109

32,370

18,240

868
8
630
6,039

6,039
612

751

228

255

224

0,713

368
2

736

7,042

648

113

277

227

130

0,697

16,007

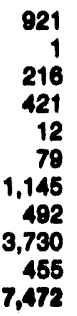

1,917

0
628

1,851

76

687

3,300

1,875

20
10,818

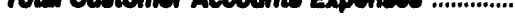

Cutcomer Service and Information Expenees

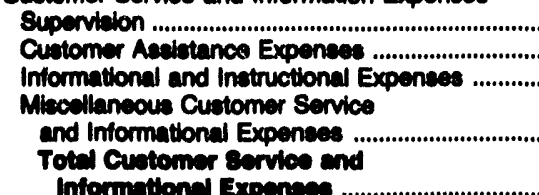

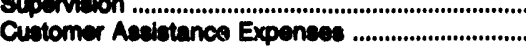

Informationd and Intructional Expenees .............

Mccilaneas Cuntomer Service

Totel Gustomer Eervioe and

informationd Exponices

\section{8nies Expenses}

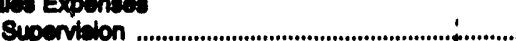

Demonatrating and Selling Expences ...................

Advertising Expenses

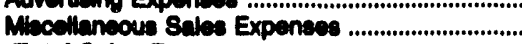

Toted secen Expenese

$\begin{array}{rr}295 & 1,388 \\ 814 & 2,818 \\ 2,889 & 11,542 \\ 504 & 846 \\ 9 & 517 \\ 4,810 & 17,200\end{array}$

467
2,062
4,590
3,980
-123
10,908

710
2,429
4,491
1,829
62
0,622

378
1,602
2,683
630
958
8,231

2,104

3,182

$\mathbf{0 , 6 1 8}$

611

1,152

10,497

see endnotes at end of an individual electric utility.

$\begin{array}{rrrrrr}83 & 541 & 196 & 36 & 404 & 627 \\ 1,101 & 4,047 & 687 & 274 & 601 & 2,250 \\ 168 & 470 & 128 & 62 & 163 & 514 \\ 95 & 468 & 228 & 3 & 169 & 247 \\ 1,436 & 6,433 & 1,238 & 396 & 1,627 & 3,690\end{array}$

$\begin{array}{rrrrrr}8 & 408 & 125 & 95 & 0 & 224 \\ 137 & 1,852 & 1,393 & 227 & 46 & 1,006 \\ 25 & 158 & 2 & 1 & 234 & 46 \\ 0 & 725 & 110 & 201 & 538 & 9 \\ 170 & 3,143 & 1,630 & 528 & 010 & 1,376\end{array}$


Tablo 41. Electric Operation and Malntenance Expenses by Major U.8. Investor-Owned Electric Utility Within State, 1992 (Continued) (Thousand Dollars)

\begin{tabular}{|c|c|c|c|c|c|c|}
\hline hem & $\begin{array}{c}\text { lown } \\
\text { lowe- } \\
\text { Illinois } \\
\text { Canseloctric } \\
\text { Co }\end{array}$ & $\begin{array}{l}\text { lown } \\
\text { Midweat } \\
\text { Powner } \\
\text { Syctems } \\
\text { Inc }\end{array}$ & $\begin{array}{c}\text { Kanaas } \\
\text { Kanaas } \\
\text { Cas } \\
\mathbf{a} \\
\text { Electric Co }\end{array}$ & $\begin{array}{c}\text { Kansas } \\
\text { Westem } \\
\text { Resources } \\
\text { Inc }\end{array}$ & $\begin{array}{l}\text { Kentucky } \\
\text { Kentucky } \\
\text { Power Co }\end{array}$ & $\begin{array}{c}\text { Kentucky } \\
\text { Kentucky } \\
\text { Utilties Co }\end{array}$ \\
\hline
\end{tabular}

Adiminietrative and Ceneral Expenese

Operation Expenes

Orilos Eupothes and Expenses

(Nee) Adininistrative Expenices

Trentered (credit)

Orterdes Sondane Emplound

Property incurance.

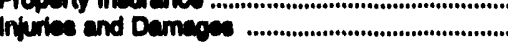

Emploses Pencions and Benufits

Frenchies Recuirements

Regulatory Commiscion Expensece........................

(kes) Duplloato Charges (credt)

Cenerd Advetining Exponses.

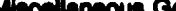

Remest

Tot Operntion Expones

.............................

Meintenance of Cenerd Plant

Tous Adiniminterative and

Conerd Expenises

..............................

esmera Expenises

Tound Ebotite Operwiten end

Mmintenence Expersese .

96,657

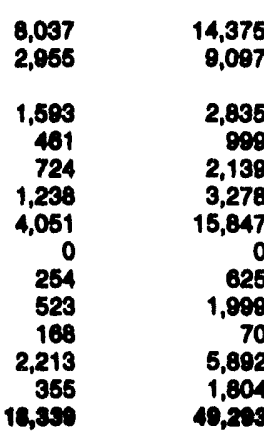

14,605
6,721
121
3,608
2,681
3,413
13,431
0
678
0
142
1,467
512
47,328

8,221
5,898
717
880
960
1,267
14,249
0
586
195
476
3,179
3,705
38,505

4,076

11,055

1,864

5,608

885

899

2,139
3,278

15,847

625

1,899
70

5,892

$4,2.98$

47,325

38,605

$519 \quad 1,038$

2,074

868

188

238

$555 \quad 2,028$

232

2,480

1,839

3,650

14,701

114

135
0

552

161

49
16,000

385

385
3
6

4,104

470
43,705

14,050

40,401

89,471

1,078

919

4,625

atribution of Selnies and

Whoes Chared to Elsctilc

Operation and Maintenance

Production

Tranemiasion

Dlotribution ....u.

Customer Account

Customer Service and

Informationd Expenses

Sales Expenses

Allocated from Clearing Accounts

Totel selwites and Wores

370,147

270,974

254,116

283,501

359,253

Number of Electric Depertment Employeea

Recular Futh-time Employees .................................

Part-time and Temporany Employees ....................

Totel Electuls Depertinomt Empiovece ..........

\begin{tabular}{rr}
7,028 & 16,687 \\
888 & 2,284 \\
7,020 & 17,104 \\
2,382 & 10,411 \\
709 & \\
82 & 1,601 \\
7,685 & 1,383 \\
8,085 & 15,103 \\
31,744 & 7,563 \\
\hline 2,107
\end{tabular}

$$
\begin{array}{r}
5,887 \\
1,675 \\
7,759 \\
5,333 \\
1,049 \\
687 \\
12,837 \\
3,045
\end{array}
$$

19,320
1,424

7,882

7,336
1,535

7,545

21,836
2,320

12,330

4,733

2,832

9,278

$871 \quad 1,865$

257

8,788

6,409

4,264

2,516

27,002

0,569

8,784

8,784

870

2,132

51

848

1,620

3,518

858

2,071

$022 \quad 2,113$

84

6,183

90

2,197

Note: Totale may not equal eum of components because of independent rounding. Summary data are provided in Table 11.

Source: Federel Eneroy Reculationy Commiedion, FERC Form 1. "Annual Report of Major Electric Utillties, Licensees and Others." 
Table 41. Electrlc Operation and Maintenance Expenses by Major U.S. Investor-Owned Electric Utility Within State, 1992 (Continued) (Thousand Dollars)

\begin{tabular}{|c|c|c|c|c|c|c|}
\hline Item & $\begin{array}{c}\text { Kentucky } \\
\text { Louleville } \\
\text { Ces } \\
8 \\
\text { Electiric Co }\end{array}$ & $\begin{array}{l}\text { Kentucky } \\
\text { Union Light } \\
\text { Heat \& Power } \\
\text { Co }\end{array}$ & $\begin{array}{l}\text { Louliana } \\
\text { Central } \\
\text { Louisiana } \\
\text { Elec } \\
\text { Co inc }\end{array}$ & $\begin{array}{c}\text { Loulaiana } \\
\text { Loulaiana } \\
\text { Power } \\
8 \\
\text { Light Co }\end{array}$ & $\begin{array}{l}\text { Louisiana } \\
\text { New Orleans } \\
\text { Public } \\
\text { Service Inc }\end{array}$ & $\begin{array}{l}\text { Loulaiana } \\
\text { Southwestern } \\
\text { Electric } \\
\text { Power Co }\end{array}$ \\
\hline
\end{tabular}

Power Production Expensea

Stearn Power

Operation Expenses

Supervition and Engineering .............................. $\quad 3,620$

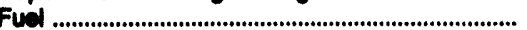

Steam Expenees ..................................................... 20,644

Steam from Other Sources ...................................

(kes) Steam Transterred (credit) ...........................

Electric Expenses .....................................................

Mincellaneous Steam Power Expenses

Pents

Totel Cperration Expenses.

1,295

114,940

1,852

0

927

1,485

120,600

5,016
219,785
2,742
0
0
2,308
5,657
0
285,400

1,221
48,678

658

0

795

1,286

52,850

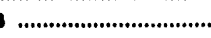

Maintenance Expenses

Supenvition and Engineering

Structures

Boller Plant

Electric Plant

ter

Totel Etean Power Production

Expenen

128,539

58,305

388,540

Nuclear Power

Operation Expenses

Supervision and Engineering

Funel

Coolants and Water

Cream Expenses

Steam from Other Sources

(less) Steam Transferred (credit)

Electric Expenses

Expenses

Rents

Total Operation Expenses:

2,216

3,880

14,802

2,646

27,275

102,542
711
241
4,683
1,527
782
7,024

1,170

1,217

6,992

$\begin{array}{rr}403 & 656 \\ 776 & 1,675 \\ 1,800 & 12,488 \\ 2,376 & 3,075 \\ 371 & 547 \\ 6,726 & 18,441\end{array}$

334,972

6,120

3,751

4,408

350,100

488

547

8,441

30,284

44,281

1,882

7,626

0
38

13,931

446

98,697

26,077

1,280

10,135

5,003

1,028

Miscellarneous Nuclear Plant

Totel Maintenance Expensese

Totel Muclear Power Production

Expeneses

142,000

Hydraulic Power

Operation Expenses

Supervilon and Engineering

Water for Power...

Hydruulic Expenses

Electric Expenees

Miscellaneous Hydraullc Expenses

Rents

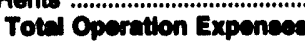

See endnotes at end of an individual electric utility.

$\begin{array}{rlllll}68 & 0 & 0 & 0 & 0 & 0 \\ 56 & 0 & 0 & 0 & 0 & 0 \\ 3 & 0 & 0 & 0 & 0 & 0 \\ 418 & 0 & 0 & 0 & 0 & 0 \\ 52 & 0 & 0 & 0 & 0 & 0 \\ 898 & 0 & 0 & 0 & 0 & 0 \\ 1,495 & 0 & 0 & 0 & 0 & 0\end{array}$


Table 41. Electric Operation and Malntenance Expenses by Major U.S. Investor-Owned Electric Utility Within State, 1992 (Continued) (Thousand Dollars)

\begin{tabular}{|c|c|c|c|c|c|c|}
\hline Item & $\begin{array}{c}\text { Kentucky } \\
\text { Loulovilie } \\
\text { Gas } \\
\& \\
\text { Electic Co }\end{array}$ & $\begin{array}{l}\text { Kentucky } \\
\text { Union Lloht } \\
\text { Heat \& Power } \\
\text { Co }\end{array}$ & $\begin{array}{l}\text { Loulaiana } \\
\text { Contral } \\
\text { Loulaiana } \\
\text { Elec } \\
\text { Co Inc }\end{array}$ & $\begin{array}{c}\text { Louialana } \\
\text { Loulaiana } \\
\text { Power } \\
\text { Lught Co }\end{array}$ & $\begin{array}{l}\text { Loulsiana } \\
\text { Now Orleans } \\
\text { Public } \\
\text { Sorvice Inc }\end{array}$ & $\begin{array}{l}\text { Louleiana } \\
\text { Southweatern } \\
\text { Electric } \\
\text { Power Co }\end{array}$ \\
\hline
\end{tabular}

\section{Maintenance Expense:}

Supervicion and Encineering

Reservoirs, Dams and Waterwaye .........................

Electrilo Pint

Mincellaneous Hydraulle Plant

Toted Melintenence Expensece

Totel thdreule Powe

Production Expences

Other Power

Operation Expenses

Supervition and Enoineering

Fund

Coneratlon Expenes

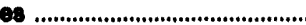

Miscellaneous Other Power Expenses

Rents

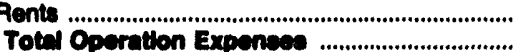

40
20
50
46
575
731

2,223

0
0
0
0
0
0

0
0
0
0
0
0

0
0
0
0
0
0

0
0
0
0
0
0

Maintenance Expenses

Superviaion and Engineering

Structures ...

Generating and Electric Plant

Miscellaneous Other Power Plant

Total Melntenance Expensese

Pourer Production

Explinos.

Other Power Supply Expenses

Purchaeed Power .......................................................

Syetem Control and Load Dlepatching

Other Expenses .........................................................

Total Other Power Supply

Expentes .

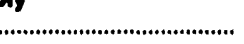

Totel Power Production Expenses

127,188

730,911

229,209

378,002

Tranemiscion

Operation Expenses

Buperision and Engineering

Loed Dinpatching

Station Expenses .

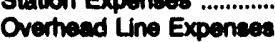

Underground Line Expenees

Transmiselon of Electrictly by Other ..................

Miecellaneous Tranamiacion Expenses

Rents

Totel Operation Expenses

$\begin{array}{rr}701 \\ 424 \\ 1,644 \\ 103 & 14 \\ 0 & \\ 6 & \\ 351 & \\ 88 & \end{array}$

80
141
24
32
0
0
33
27

576
742
143
7
0
0
46
0
1,919
613
35
60
0
14,080
179
48

1,612

18,934

$\begin{array}{rr}317 & 57 \\ 401 & 670 \\ 21 & 926 \\ 4 & 202 \\ 0 & 0 \\ 6,414 & 4,285 \\ 83 & 387 \\ 81 & 114 \\ 7,321 & 6,601\end{array}$

See endnotes at end of an individual electric utility.

937

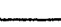

$\begin{array}{rr}0 & 0 \\ 53 & 0 \\ 0 & 0 \\ 0 & 0 \\ 0 & 0 \\ \mathbf{5 3} & 0\end{array}$

$\begin{array}{ll}0 & 0 \\ 0 & 0 \\ 0 & 0 \\ 0 & 0 \\ 0 & 0\end{array}$

530

$\begin{array}{rr}170,703 & 6,620 \\ 820 & 1,191 \\ -691 & 622\end{array}$

3,434

670 928 0 285 114 , 601 
Table 41. Electric Operation and Malntenance Expenses by Major U.S. Investor-Owned Electric Utillty Within State, 1992 (Continued) (Thousand Dollars)

\begin{tabular}{|c|c|c|c|c|c|c|}
\hline Item & $\begin{array}{c}\text { Kentucky } \\
\text { Louloville } \\
\text { Gas } \\
\text { Electric Co }\end{array}$ & $\begin{array}{l}\text { Kentucky } \\
\text { Union Loght } \\
\text { Heat \& Power } \\
\text { Co }\end{array}$ & $\begin{array}{l}\text { Louisiana } \\
\text { Contral } \\
\text { Louisiana } \\
\text { Elec } \\
\text { Co Inc }\end{array}$ & $\begin{array}{l}\text { Louldiana } \\
\text { Louleiana } \\
\text { Power } \\
\mathbf{8} \\
\text { Light Co }\end{array}$ & $\begin{array}{l}\text { Loulalana } \\
\text { New Orleans } \\
\text { Public } \\
\text { Service Inc }\end{array}$ & $\begin{array}{l}\text { Louialana } \\
\text { Southwestem } \\
\text { Electric } \\
\text { Power Co }\end{array}$ \\
\hline
\end{tabular}

Maintenance Expenses

Supervision and Engineering

Structures ......................

Station Equipment

Overhead Lines ....

Underground Lines

Total Tranemiseion Exponses

................................

Distribution

Supervision and Engineering

Load Dispatching

Station Expeng

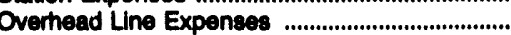

Underground Line Expenses .................................

Street Lighting and Signal System Expenses ...

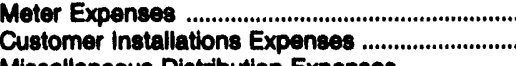

Miscellaneous Distribution Expenses ...................

Rents

Total Operation Expenses

Supervision and Engineering .................................

Structures .....................................................................

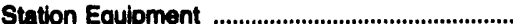

Overhead Lines

Underground Lines

ine Tranoformere

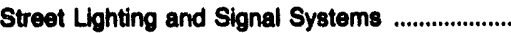

Meters

Miscellaneous Distribution Plant

Total Maintenance Expenses

Totel Diatribution Expenses
Operation Expenses

Mainienance Expenses

52

252

0
5

1,330

4,653

1,204
0

1,485

3,492

1,870

298

1,364

219

3,125

186

13,303

114

421

608

6,081

577

582

586

303

22,092

604

2,014

3,033

1,640

7,204

Miecellaneous Customer Accounts Expenses ...

Total Customer Accounts Expenses

Customer Service and Information Expenses

Supenvision ............................................................

Customer Assistance Expenses ..............................

Informational and Instructional Expenses ............

Miscellaneous Customer Service

and Informational Expenses

Total Customer servlos and

Informational Expenses.

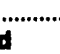

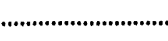$$
397
$$

40

750

24
1
38
40
0
1
102
430

224
21
1,417
779
4
1,129
3,573
5,005

283
87
305
2,282
1
29
2,096

19,002

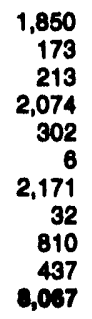

1,291
387
889
1,384
74
383
3,554
380
2,083
1,382
11,878

1,242
14

13,945

3,091

7,850

22,012

10,00

$\begin{array}{rr}106 & 80 \\ 1 & 25 \\ 108 & 1,982 \\ 193 & 1,957 \\ 0 & 0 \\ 9 & 16 \\ 417 & 4,090 \\ 7,730 & 10,491\end{array}$

$\begin{array}{rr}486 & 318 \\ 42 & 439 \\ 180 & 684 \\ 585 & 1,067 \\ 183 & 277 \\ 218 & 461 \\ 782 & 3,716 \\ 326 & 509 \\ 893 & 2,180 \\ 104 & 485 \\ 3,000 & 10,122\end{array}$

485

$\begin{array}{rr}180 & 302 \\ 7 & 39 \\ 925 & 945 \\ 2,102 & 12,688 \\ 1,184 & 807 \\ 280 & 684 \\ 1,151 & 488 \\ 145 & 465 \\ 17 & 380 \\ 5, \infty 1 & 18,703\end{array}$

9,800

24,010

57
865

855
51

178

670

1,128

6,474

2,204

187
584

838

374

885

320

8

1,620

e,eer

3,261

1,705

\begin{tabular}{rrrrrr}
133 & 18 & 136 & 1,363 & 488 & 332 \\
680 & 179 & 913 & 599 & 149 & 2,422 \\
175 & 11 & 458 & 951 & 161 & 0 \\
0 & 0 & 6 & 982 & 265 & 260 \\
090 & 200 & 1,512 & 3,005 & 1,002 & 3,014 \\
\hline
\end{tabular}

See endnotes at end of an individual electric uttlity. 
Table 41. Electrle Operation and Maintenance Expenses by Major U.S. Inveotor-Owned Eloctric Utility Within State, 1992 (Continued) (Thousand Dollars)

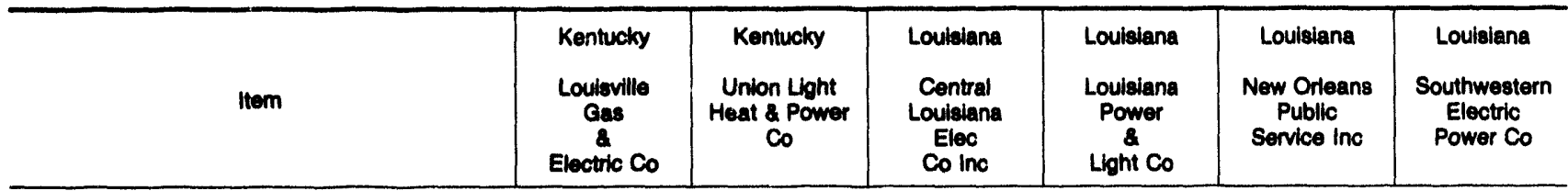

Adminiotruttre and General Expenses
Operation Expeneses

Adrinitrattve and General Salartes

Orice Suppline and Expenass

(kes) Adminiatrative Expenses

Transferred (credti)

Outalde Somicen Employed

Property Insurance.

iniuites And Damages

Employee Penaions And Benefite

Franchies Requirements

Regulatory Commiscion Expenses

(beo)Dupliante Cherges (credit)

General Advertiaing Expenses ....

Mincellaneous General Expenses

Rents

Toted Operation Expenses

Maintenance of General Plant ..

Tosil Adminlatertive and

Eenersl Expences ....

$$
\begin{array}{r}
14,494 \\
3,801
\end{array}
$$

3,829

2,897

860

4,086

10,472

13

767
174

62

2,958

4,555

41,173

1,893

48,008

287,17

149,049

Totil Elective Operation and

Mentenenes Expenees

\section{Dotribution of Salaries and}

Weges Charged to Electric

Operation and Maintenance

Production ...

Distribution

Customer Accounts

Customer Service and

Informational Expenses

Sales Expenses

Adminotrative and Geners

Alocated from Clearing Accounts

Tot

$\begin{array}{rr}1,889 & 8,271 \\ 574 & 3,792 \\ & \\ 343 & 1,340 \\ 67 & 1,658 \\ 35 & 752 \\ 867 & 1,800 \\ 1,571 & 5,899 \\ 0 & 224 \\ 86 & 77 \\ 152 & 2,545 \\ 50 & 40 \\ 800 & 3,621 \\ 1,337 & 194 \\ 8,700 & 22,444\end{array}$

17,063
10,520

383
43,815
10,568
7,680
14,568
0
807
0
545
7,545
3,405
116,132

5,060

2,632

3,165 4,292

$-67$

7,615

1,724

$\begin{array}{rr}1,771 & 2,119 \\ 7,757 & 8,123 \\ 0 & 8\end{array}$

$\begin{array}{rr}1,771 & 2,119 \\ 7,757 & 8,123 \\ 0 & 8\end{array}$

3,580

0
93

$-275$

217

29,217

3,085

879

320
8

151

5,248

1,579

44,302

768

23,210

119,217

30,098

2,903

47,294

935,202

288,751

481,072

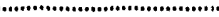

(..........................

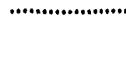

Number of Electric Department Employees

Regular Full-time Employees .................................

Part-time and Temporany Employees

Totel Electrle Depertment Employee .........
31,959

2,709

12,246

3,823

355

483
12,277

10,877

74,737

0
280
3,494

3,008

0
875
2,054

289

9,978

2,480

22

2,512

11,096
1,592
9,911
5,614

14,238
1,051
15,161

15,161
10,305

$\begin{array}{rr}3,383 & 19,723 \\ 683 & 2,520 \\ 4,920 & 13,064 \\ 3,562 & 8,279 \\ & \\ 1,495 & 671 \\ 101 & 1,297 \\ 5,195 & 9,819 \\ 358 & 1,278 \\ 19,686 & 66,651\end{array}$

30,247
4,977
259
28,214
1,015

19,689

66,651

Noto: Totals may not equal sum of components because of independent rounding. Summary data are provided in Table 11

Source: Federal Energy Regulatory Commiselon, FERC Form 1, "Annual Report of Major Electric Utilities, Licensees and Others." 
Table 41. Electric Operation and Maintenance Expenses by Major U.S. Investor-Owned Electric Utility Within State, 1992 (Continued) (Thousand Dollars)

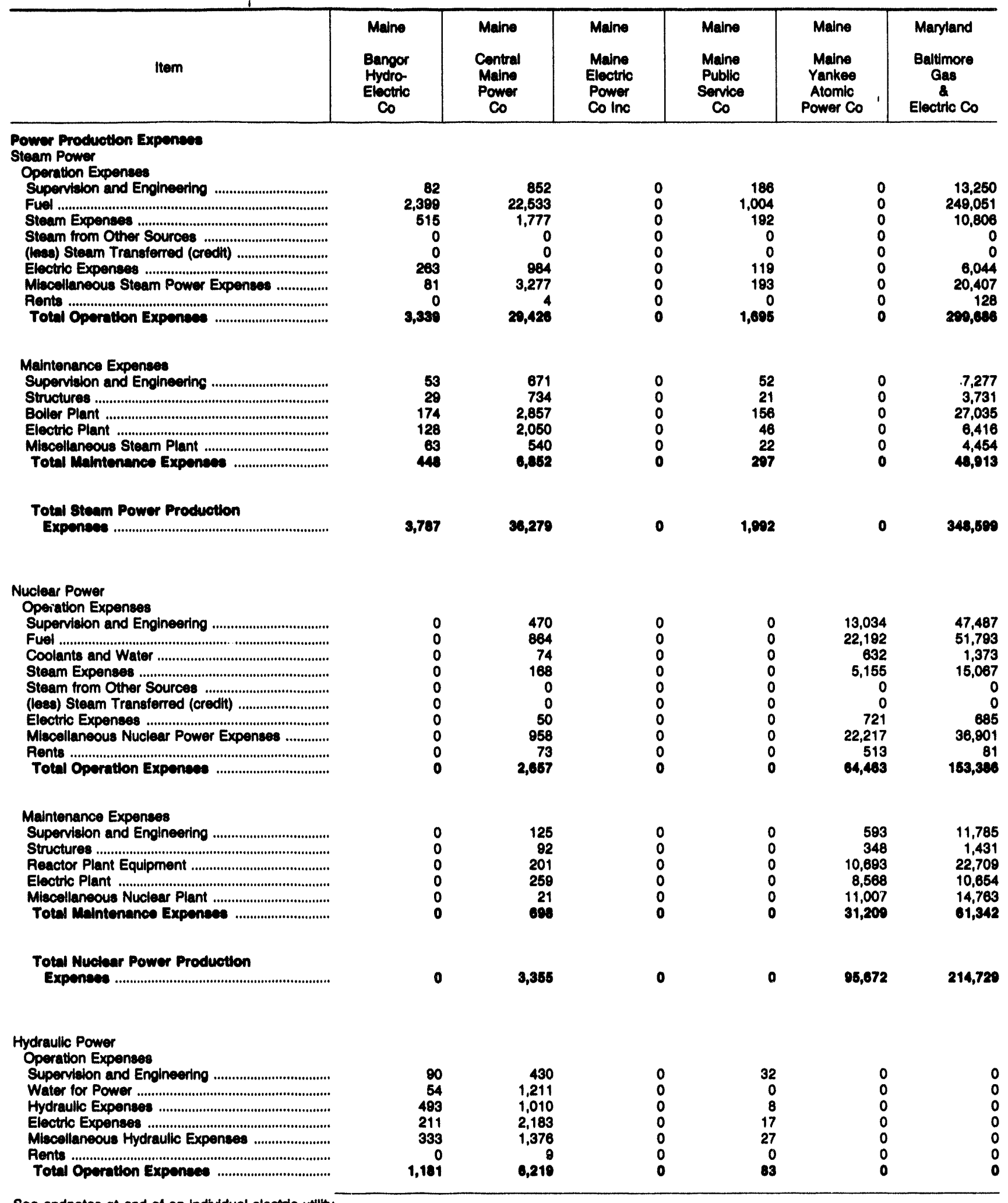

See endnotes at end of an individual electric utility. 
Table 41. Electric Operation and Malntenance Expenses by Major U.S. Investor-Owned Electric Utility Within State, 1992 (Continued) (Thousand Dollars)

\begin{tabular}{|c|c|c|c|c|c|c|}
\hline ltem & $\begin{array}{l}\text { Malne } \\
\text { Bangor } \\
\text { Hydro- } \\
\text { Electric } \\
\text { Co }\end{array}$ & $\begin{array}{l}\text { Maine } \\
\text { Central } \\
\text { Maine } \\
\text { Power } \\
\text { Co }\end{array}$ & $\begin{array}{l}\text { Maine } \\
\text { Maine } \\
\text { Electric } \\
\text { Power } \\
\text { Co Inc }\end{array}$ & $\begin{array}{c}\text { Maine } \\
\text { Maine } \\
\text { Public } \\
\text { Service } \\
\text { Co }\end{array}$ & $\begin{array}{c}\text { Maine } \\
\text { Maine } \\
\text { Yankee } \\
\text { Atomic } \\
\text { Power Co }\end{array}$ & $\begin{array}{l}\text { Maryland } \\
\text { Baltimore } \\
\text { Gas } \\
\text { Electric Co }\end{array}$ \\
\hline
\end{tabular}

Maintenance Expenses

Superviaion and Engineering

Structurea ...........................................

Rescervoirs, Dams and Waterways

Miscetlaneous Hydraulic Plant

Totel Meintenence Expensen

Totel Hydractio Power

Production Expenses

Other Power

Operation Expenses

Superviaion and Engineering ...............................

Fue!

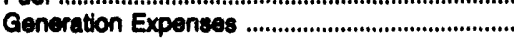

Miscellaneous Other Power Expenses

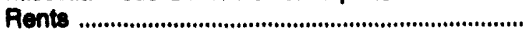

Total Operation Exponses

$\begin{array}{rr}4 & 575 \\ 44 & 829 \\ 55 & 2,68 \\ 149 & 2,168 \\ 35 & 169 \\ 207 & 6,410\end{array}$

1,467

12,685

Maintenance Expenses

Supervision and Engineering

Structures ...............................

Generating and Electric Plant .....

Totel Melntenance Expenses

Total Other Power Production

Expenses

Supply Expenses

Other Power Supply

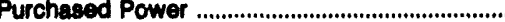

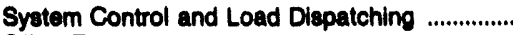

Other Expenses

Total Other Power Supphy

Expences

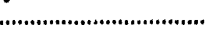

Total Power Production Expenses

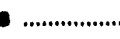

Transmission

Operation Expenses

Supervision and Engineering .................................

Load Dispatching

Station Expenses

Overhead Line Expenses

Underground Line Expenses

.

Miecelianeous Transmiseion Expanso

Pente

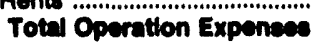

190

152

109,812

405,944

1,415

611

8,411

0
0

29,121

156

$-2,033$

8,411

27,245

8,411

29,681

95,072

834,296

118,205

520,300

$\begin{array}{rr}-163 & 1,024 \\ 487 & 686 \\ 17 & 1,014 \\ 78 & 209 \\ 1 & 0 \\ 3,282 & 1,489 \\ 28 & 3,652 \\ 0 & 1,672\end{array}$

5
317
47
1
0
0
12
0

76
52
35
11
0
1,858
50
32

3,741

$\mathbf{9 , 7 4 7}$

392

2,214

See endnotes at end of an individual electric utility. 
Table 41. Electrlc Operation and Maintenance Expenses by Major U.S. Investor-Owned Electric Utility Within State, 1992 (Continued) (Thousand Dollars)

\begin{tabular}{|c|c|c|c|c|c|c|}
\hline Item & $\begin{array}{c}\text { Maine } \\
\text { Bangor } \\
\text { Hydro- } \\
\text { Electric } \\
\text { Co }\end{array}$ & $\begin{array}{l}\text { Maine } \\
\text { Central } \\
\text { Maine } \\
\text { Power } \\
\text { Co }\end{array}$ & $\begin{array}{l}\text { Maine } \\
\text { Maine } \\
\text { Electric } \\
\text { Power } \\
\text { Co Inc }\end{array}$ & $\begin{array}{l}\text { Maine } \\
\text { Maine } \\
\text { Public } \\
\text { Service } \\
\text { Co }\end{array}$ & $\begin{array}{l}\text { Maine } \\
\text { Maine } \\
\text { Yankee } \\
\text { Atomic } \\
\text { Power Co }\end{array}$ & $\begin{array}{l}\text { Maryland } \\
\text { Baltimole } \\
\text { Gas } \\
\& \\
\text { Electric Co }\end{array}$ \\
\hline
\end{tabular}

Maintenance Expenses

Supervision and Engineering

Structures .

Station Equipment

Overhead Lines.

Underground Lines

Total Malntenance Expenses

Total Transmieston Expenese

.

Distribution

Operation Expenses

Superviston and Engineering

Load Dispatching

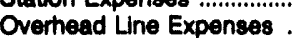

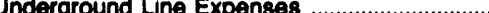

Street Lighting and Signal System Expenses ....

Meter Expenses

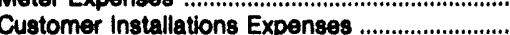

Miscellaneous Distribution Expenses

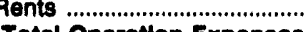

Total Operntion Expenses

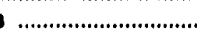

Maintenance Expenses

Supervision and Engineering

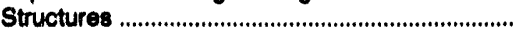

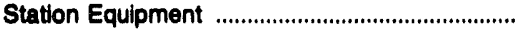

Overhead Lines.

Underground Lines

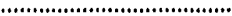

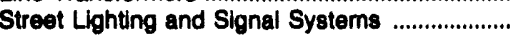

Meters .

Miscellaneous Distribution Plant

Total Maintenance Exponses:

$\begin{array}{rr}66 & 50 \\ 1 & 100 \\ 263 & 1,500 \\ 995 & 2,287 \\ 1 & 0 \\ 28 & -68 \\ 1,353 & 4,33\end{array}$

501
100
, 506
2,297
0
-68
1,330

14,096

6,004

3,341

162

1,221

1,940

112

337

5,385

1,757

6,524

2,316

23,004

$302 \quad 1,227$

$42 \quad 75$

$412 \quad 1,232$

2,033

151

121

103

46

3,213

5,200

15,668

141

370

282

385

19,419

Total Distribution Expenses

.................................

Customer Accounts Expenses

Supervision

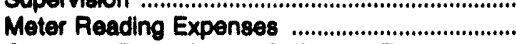

Customer Records and Collection Expenses ...

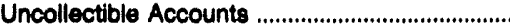

Miscellaneous Customer Accounts Expenses ...

Total Customer Accounte Expenses

Customer Service and Information Expenses

Superviston

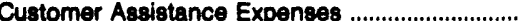

Informational and Instructional Expenses ............

Miscellaneous Customer Service

and Informational Expenses .

Total Customer sorvice and

Informattonal Expenses

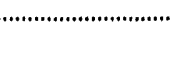

Sales Expenses

Supervision

Demonstrating and Selling Expenses

Advertising Expenses

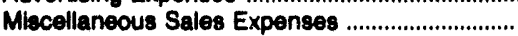

Total sales Expenses

42,514

$\begin{array}{rr}1 & 424 \\ 953 & 11,904 \\ 430 & 1,211 \\ 1 & 494 \\ 1,384 & 14,032\end{array}$

0
0
0
0
0

See endnotes at end of an individual electric utility.

0
22
381
238
0
0
641

62
1
42
87
0
0
198

220

1,240

3,505

89

5.297

1,024

2,407

11,024

18,968

2,032

4,953

2,866

2,180

2,726

0
13,507

1,896

1,896
40,216

2,400

15,749

3,857

1,224

1,813

1,000

1,202

30,151

1,401

79,397

0
0
0
0
0

0
0
0
0
0


Table 41. Electric Operation and Maintenance Expenses by Major

U.S. Investor-Owned Electric Utility Within Stato, 1992 (Continued)

(Thousand Dollars)

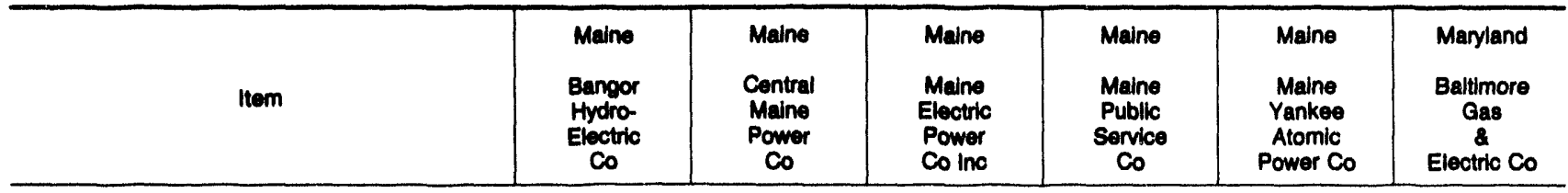

Adminietrative and General Expencese

Operation Expenses

Adminintrative and General Selaries

Oficos Supplies and Expenses

(lose) Adminiatrattve Expenses

Transferred (credt)

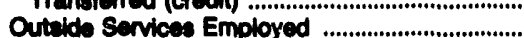

Property Ineurance...

Injuries And Damages

Employes Pencions And Benofits

Franchise Requirements

Regulatory Commision Expenses

(bess) Duplicate Charges (credit)

Generd Advertiding Expenses .

Miscellaneous Genoral Expenses

Rents

.

Maintenance of General Plant ..

Totel Adminiotrattve and

Ceneral Expenees

$\begin{array}{rr}5,801 & 31,020 \\ 1,610 & 11,253 \\ 3,080 & 731 \\ 834 & 1,533 \\ 28 & 719 \\ 1,409 & 1,801 \\ 2,860 & 329 \\ 0 & 0 \\ 498 & 1,731 \\ 0 & 0 \\ 2 & 71 \\ 317 & 4,587 \\ 270 & 1,682 \\ 10,937 & 54,074\end{array}$

0

54,68

10

364

64,682
20,443

631

719

,731

0

4,567

54,074

0
182
18

0
307

307
57

537

901

0
841

15
6

276

0
4,452

$\begin{array}{rr}871 & 20,443 \\ 0 & 0 \\ 12,716 & 3,506\end{array}$

$\begin{array}{rr}12,716 & 3,506 \\ 5,608 & 7,082\end{array}$

$284 \quad 7,346$

$3,459 \quad 70,887$

$\begin{array}{rr}0 & 0 \\ 7,510 & 7,326\end{array}$

0

$1,096 \quad 317$

$1,140 \quad 9,848$

$227 \quad 3,655$

$\begin{array}{rrrr}3 & 0 & 227 & 3,655 \\ 373 & 4,452 & 38,144 & 185,072\end{array}$

$316 \quad 2,260$

165

11,350

10,093

$\mathbf{6 9 , 3 9 4}$

4,817

38,144

190,422

Total Electrite Operatten and

Malntenenos Expenses

142,60

673,245

9,849

39,604

133,815

$1,178,647$

Distribution of Salaries and

Wages Charged to Electric

Operation and Maintenance

Production

Tranemiagion ..........................................................

Distribution

Customer Rocounts

Customer Service and

Intormational Expenses

Sales Expenses

Adminstrative and Genere

Allocated from Clearing Accounts

Totel gelartes and Weres

$\begin{array}{rr}1,688 & 8,901 \\ 713 & 2,013 \\ 3,449 & 14,069 \\ 2,476 & 8,171 \\ & \\ 115 & 3,388 \\ 22 & 0 \\ 6,845 & 21,029 \\ 0 & 10,710 \\ 15,307 & 68,281\end{array}$

830
253
883
729

240
0
1,415
316
4,867

56,131
28,414

$\begin{array}{rr}0 & 4,246 \\ 0 & 0 \\ 3,781 & 59,854\end{array}$

2,664

$25,346 \quad 297,702$

Number of Electric Department Employees

Regular Full-time Employees ..................................

Part-time and Temporary Employees

$47 \quad 233$

193

460

7,220

Total Electute Depertment Employees .........

671

2,378

197

503

7,222

Note: Totals may not equal sum of components because of independent rounding. Summary data are provided in Table 11.

Source: Federal Energy Regulatory Commlesion, FERC Form 1, "Annual Report of Major Electric Utilities, Licensees and Others." 
Table 41. Electric Operation and Maintenance Expenses by Major U.S. Investor-Owned Electric Utility Within State, 1992 (Continued) (Thousand Dollars)

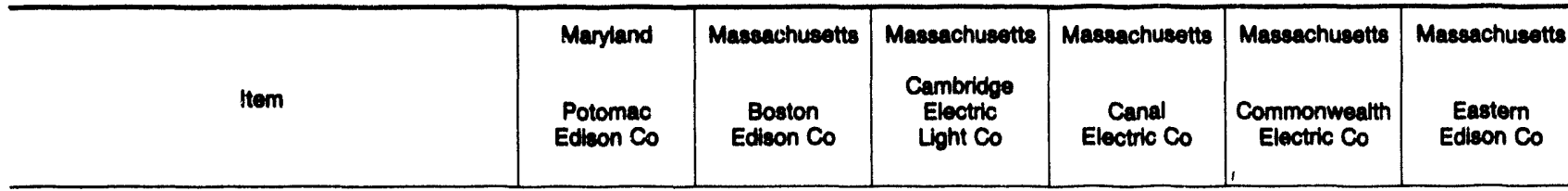

\section{Pomer Produstion Expenace}

Steam Power

Operation Expenses

Supervition and Encineering

Firel

Steam Expenaes

Steam trom Other Sources

(bee) Steam Transferred (credit)

Electivo Expenseg

Mhoellaneous Steam Power Expenses

Rents

Tot-1 Operation Expenses

$\begin{array}{rr}2,762 & 3,118 \\ 150,218 & 170,340 \\ 3,167 & 7,967 \\ 0 & 0 \\ 0 & 0 \\ 1,311 & 2,161 \\ 2,585 & 5,931 \\ 16 & 7\end{array}$

950
6,484
1,062
0
3,902
478
421
0
6,424

$$
\begin{array}{r}
1,980 \\
91,986 \\
2,082 \\
0 \\
86 \\
3,836 \\
1,920 \\
682 \\
102,400
\end{array}
$$

$\begin{array}{rr}1,100 & 0 \\ 1,007 & 0 \\ 425 & 0 \\ 0 & 0 \\ 53 & 0 \\ 142 & 0 \\ 308 & 0 \\ 0 & 0 \\ 2,990 & 0\end{array}$

Maintenance Expenses

Supervision and Enginoering

2,287

2,119

3,328

1,528

$\begin{array}{rr}19,568 & 17,469 \\ 5,789 & 6,398\end{array}$

Bover Plant

Electric Plant

Miscolleneous Steam Piant

$1,345 \quad 2,388$

Total Mointenance Expenses

31,096

31,108

101,145

220,633

113,990

Nuclear Power

Operation Expenses

Supervision and Engineering

Fuel

Coolants and Water

Steam Expenses

Steam trom Other Sources

(leas) Steam Transferred (credti)

Miscollaneous Nuclear Power Expenses .............

Rente

Totel Operation Exponese

Maintenance Expenses

Supervision and Engineering

Structures

Reactor Plant Equipment

Electric Piant

Macellaneous Nuclear Plant

Total Meintenence Expenees

Totel Nuclens Power Production

Expensees

Hydraulic Power

Operation Expenses

Supervidion and Engineering ................................... Water for Power

Hydraulic Expenses

Electric Expenses ....

Miecellaneous Hydraulic Expenses ........................

Rento

Total Operation Expenace

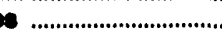

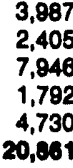

7,846

4,730

20,081

120,805

0

7,842

269

185

378

1,501

$\begin{array}{rl}200 & 0 \\ 13 & 0 \\ 232 & 0 \\ 82 & 0 \\ 144 & 0 \\ 0 & 0 \\ 672 & 0\end{array}$

$\begin{array}{ll}0 & 0 \\ 0 & 0 \\ 0 & 0 \\ 0 & 0 \\ 0 & 0 \\ 0 & 0 \\ 0 & 0\end{array}$

See endnotes at end of an individual electric utility. 
Table 41. Electric Operation and Maintenance Expenses by Major U.S. Investor-Owned Electric Utility Within State, 1992 (Continued) (Thousand Dollars)

\begin{tabular}{|c|c|c|c|c|c|c|}
\hline Itom & $\begin{array}{l}\text { Maryland } \\
\text { Potomac } \\
\text { Edison Co }\end{array}$ & $\begin{array}{l}\text { Massachusetts } \\
\text { Boston } \\
\text { Edison Co }\end{array}$ & $\begin{array}{c}\text { Massachusetts } \\
\text { Cambridge } \\
\text { Electric } \\
\text { Light Co }\end{array}$ & $\begin{array}{c}\text { Massachusetts } \\
\text { Canal } \\
\text { Electric Co }\end{array}$ & $\begin{array}{c}\text { Massachusetts } \\
\text { Commonwealth } \\
\text { Electric Co }\end{array}$ & $\begin{array}{l}\text { Massachusette } \\
\text { Eastorn } \\
\text { Edison Co }\end{array}$ \\
\hline
\end{tabular}

\section{Maintenance Expenses}

Supervicion and Engineering

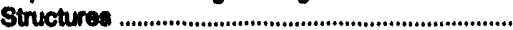

Reservoirs, Dams and Waterways

Elvictulc Plant

Miscellaneous Hydraulic Plant

Totel Meintenence Expenses

Total Hydralle Power

Production Exponee:

Other Power

Operation Expenses

Supervision and Engineering

Fuel

Generation Expenseg

Miscellaneous Other Power Expenses

Rents

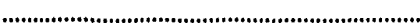

Total Operation Expenses

Maintenance Expenses

Supervilion and Engineering

Structures ...............................................

Miscollaneous Other Power Plant

Total Maintenance Expenses

Total Other Power Production

Expences

Other Power Supply Expenses

Purchased Power

Syatem Control and Load Di.................................

Other Expenses

Totel Other Power Supph

Expenses

Total Power Production Expenses

Tranemiasion

Operation Expenses

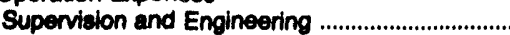

Load Diapatching

Station Expenses ....

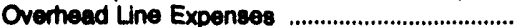

Undercround Line Expenses

Tranemiselon of Electricity by Others

Miscellaneous Tranamiasion Expenses

Rents

Totel Operotion Expenese

156
36
5
209
65
472

1,144

56
36
5
65
72

0
0
0
0
0
0

$\mathbf{0}$

0
0
0
0
0
0

$\mathbf{0}$

0
4
14
0
275
293

$\begin{array}{rl}0 & 0 \\ 11 & 0 \\ 2 & 0 \\ 36 & 0 \\ 0 & 0 \\ 40 & 0\end{array}$

974

182
601
918
23
1,726

2,690

201,220

2,672

$-3,041$

331,507
3,079
5,977

64,132
626
0

26,512
211
0

253,831
1,685

186,102

200,851

340,583

64,757.

28,723

$255,3 \bullet 6$

189,110

393,140

694,789

71,734

148,648

250,057

188,110

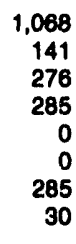

2,085

761
0
806
112
475
3,337
110
16,111

26
67
1
0
0
7,922
5
1

21,711

0
0
0
0
0
5,791
0
0

253
202
282
33
0
5,225
115
29

6,130

6,791

-

See endnotes at end of an indlvidual electric utility. 
Table 41. Electric Operation and Maintenance Expenses by Major U.S. Investor-Owned Electric Utility Within State, 1992 (Continued) (Thousand Dollars)

\begin{tabular}{|c|c|c|c|c|c|c|}
\hline Item & $\begin{array}{l}\text { Maryland } \\
\text { Potomac } \\
\text { Edibon Co }\end{array}$ & $\begin{array}{l}\text { Masaachusetts } \\
\text { Boston } \\
\text { Edicon Co }\end{array}$ & $\begin{array}{l}\text { Mesasechusetts } \\
\text { Cambridoe } \\
\text { Electric } \\
\text { Light Co }\end{array}$ & $\begin{array}{l}\text { Macaschusetts } \\
\text { Canal } \\
\text { Enectric Co }\end{array}$ & $\begin{array}{l}\text { Masaachusetts } \\
\text { Commonwiealth } \\
\text { Electric Co }\end{array}$ & $\begin{array}{l}\text { Maseachusetts } \\
\text { Eastern } \\
\text { Edivon Co }\end{array}$ \\
\hline
\end{tabular}

Muintenance Expenses

Supervition and Engineering

Structures ...

Overhead Lines

Underground Lines

Tranemiasion Plant

Totel Meintenance Expenses

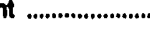

Totel Tranambalon Expenses

..........................

Diatribution

Operation Expenses

Supervision and Engineering .................................

Loed Diepatching

Station Expenses

Overhead Line Expenses

Underground Line Expenses ....................................

Street Lighting and Signal Syatem Expenses ....

Meter Expenses ...........................................................

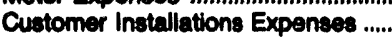

Miscellanecus Distribution Expenses

Rente

Totel Operathon Exponses.

Supervision and Engineering

Structures.

Underground Lines

Line Transformers

Street Lighting and Signal Systems

Meters ...............

Miscellaneous Distribution Plant

Totel Malntenance Expenses

Total Diotribution Exponses

..................................

Customer Accounts Expenses

Supervition

Customer Records and Collection Expenses ....

Uncollectible Accounts .............................................

Miscellaneous Customer Accounts Expenses ...

Total Customer Acoounts Expenses.

Customer Senvice and Intormation Expenses

Supervision .....................................................................

Customer Aseistance Expenses ............................

Miecellaneous Customer Service

and Informational Expenees

Total Customer service and

Informattonal Expones.

Sales Expenses

Supervision .

Demonstrating and Selling Expenses

Advertieing Expene

Miscellaneous Sales Expenses

Totel seles Expenses
Sthtion Equipment

Maintenance Expenses

Overhead Lines

Meter Reading Expenses

$\begin{array}{rr}329 & 0 \\ 9 & 78 \\ 1,068 & 268 \\ 1,321 & 740 \\ 0 & 267 \\ 20 & 3 \\ 2,768 & 1,367\end{array}$

4,941

28,009

2,211

1,082

518

1,268

642

213

601

647
2,334

231

9,746

8,249

3,464

4,699

4,240

7,555

785

4,512

5,338

698

378
00,800

0
4
104
0
0
17
128

8,140

\section{8}

488
0
94
502
160
97
107
122
311
2
1,992

1,110

11
1,088

1,088
13,138

13,136
1,013

1,013
416

250

204

348
17,573

27,318

60,802

3,625

483
3,532

0,858

$\mathbf{0 , 6 8 8}$

389

1,827

613
0

2.,919

588
2,167

5,351

1,325

187

9,600

1,644
6,145
15,880
17,079
0
40,840

81
467

1,725

1,725
$801 ।$

75

3,160

809

2,324

212

382

3,727

24
9,338

164

362

e,ps

0
4,469
5

4

4,477

19
658
0
1,649
2,328

1
185
2
121
320
0
0
7
0
0
0
7

$\begin{array}{rr}122 & 1 \\ 8 & 0 \\ 475 & 3 \\ 170 & 86 \\ 0 & 0 \\ 33 & 0 \\ 008 & 01 \\ 6,047 & 428\end{array}$

8,79

c.

428

$\begin{array}{rr}1,619 & 1,141 \\ 0 & 839 \\ 488 & 838 \\ 860 & 1,567 \\ 277 & 685 \\ 1,005 & 77 \\ 1,174 & 1,128 \\ 1,229 & 580 \\ 1,893 & 1,849 \\ 141 & 288 \\ 0,935 & 9,002\end{array}$

1,301

1,301
038

5,332

5,332
758

333

242

68

229
8,440

17,311

12,92

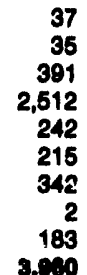

183
.00

65

2,588

10,832

$\mathbf{5 , 2 1 6}$

559

1,119

5,022

1,953

8,180

See endnotes at end of an individual electric utility. 
Table 41. Electric Operation and Malntenance Expenses by Major U.S. Investor-Owned Electric Utility Within State, 1992 (Continued) (Thousand Dollars)

\begin{tabular}{|c|c|c|c|c|c|c|}
\hline Item & $\begin{array}{l}\text { Maryland } \\
\text { Potomac } \\
\text { Edleon Co }\end{array}$ & $\begin{array}{l}\text { Masachusetts } \\
\text { Boston } \\
\text { Edison Co }\end{array}$ & $\begin{array}{l}\text { Masachusetts } \\
\text { Cambridge } \\
\text { Electric } \\
\text { Light Co }\end{array}$ & $\begin{array}{c}\text { Maseachusetts } \\
\text { Canal } \\
\text { Electic Co }\end{array}$ & $\begin{array}{l}\text { Messachusetts } \\
\text { Commonwealth } \\
\text { Electric Co }\end{array}$ & $\begin{array}{c}\text { Massachusetts } \\
\text { Eastern } \\
\text { Edison Co }\end{array}$ \\
\hline
\end{tabular}

Adminiatrattve and General Expenses

\section{Operation Expenses}

Administrative and General Salaries

Olice Supplies and Expenses.

(Na) Administrettve Expenses

Tranoferred (credit) ...

Outaide Services Employed

Property Ineurance

Injuries And Damages

Franchise Requirements

Peouthtory Commiscion Expenses

(ees)Duplcate Charges (crectit)

General Advertising Expenses

Miscellaneous General Expenses

Rente

.

Totw Operation Experises

.................................

Maintenance of General Plant

Totel Adminiotrathe and

Conerd Expensese

Tot'l Electile Operation and

Melntenence Expenses .

Dietribution of Salaries and

Wages Charged to Electric

Operation and Mainterance

Production

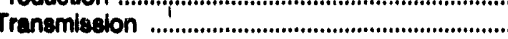

Distribution

Customer Accounts

Customer Service and

Informational Expenses

Sales Expenses

Admingtrative and General

Allocated from Clearing Accounts

Total Salaries and Weoes

Number of Electric Department Employees

Regular Full-time Employees ...................

14,762

1,556

12,440

4,627

78,076

1,595
48,084

19,612

2,510
127
1,113
461

194
120
1,886
2,400
8,813

3,838

2,300

6,017

1,315

43,018

1,043
406
33,271
8,200
180,208

1,386

4,553

21

4,574

1,390

3,145

813

1,470
2,234

0
461

461
0

14
620

360

10,167

286

11,060

102,748

10,167

Totel Electrie Department Employese .........

7,842

10,590

0
2,615

529

1,328

12,351

350,175

224,330

1,466

408

40,540

16,187

Note: Totals may not equal sum of components because of independent rounding. Summary data are provided in Table 11

Source: Federal Energy Regulatory Commiselon, FERC Form 1. "Annual Report of Major Electric Utilties, Licensees and Others." 
Table 41. Electric Operation and Malntenance Expences by Major U.S. Inveator-Owned Electric Utility Whthin State, 1902 (Continued) (Thousand Dollars)

\begin{tabular}{|c|c|c|c|c|c|c|}
\hline Item & $\begin{array}{l}\text { Masechuestis } \\
\text { Fitchburs } \\
\text { Cas } 8 \\
\text { Elec Light Co }\end{array}$ & $\begin{array}{l}\text { Masanchusetts } \\
\text { Holyoke } \\
\text { Power } \\
\text { Electric Co }\end{array}$ & $\begin{array}{l}\text { Masenchusetts } \\
\text { Holyoke } \\
\text { Water } \\
\text { Power } \\
\text { Co }\end{array}$ & $\begin{array}{l}\text { Masenchusetts } \\
\text { Masenchusette } \\
\text { Electric Co }\end{array}$ & $\begin{array}{l}\text { Maseschusetts } \\
\text { Montaup } \\
\text { Electilo Co }\end{array}$ & $\begin{array}{l}\text { Massachusetts } \\
\text { Now England } \\
\text { Hydro- } \\
\text { Tran } \\
\text { Elec Co }\end{array}$ \\
\hline
\end{tabular}

Power Production Expenses

Steam Power

Operation Expenses

Superviaion and Engineering

Fual

Stoam Expenser

Steam from Other Sources

(leas) Steam Tranaferred (crediil)

Electric Expenees

(a)

Totid Operriten Exponeses

Maintenance Expenses

Supervision and Engineering

Structures.

Boiler Plant

Electric Plant

Miecellaneous Stoam Piant

Toth Meintennes Exponses

5
11
169
77
0
282

Nuclear Power

Operation Expenses

Supervision and Engineering

Fuel ...........................

Coolants and Water

Steam Expenses

Steam from Other Sources

(less) Steam Transferred (credit)

Miscellaneous Nuclear Power Expenses ..............

Rents

Total Operatton Expensece

Maintenance Expenses

Supervision and Engineering

Structures .............................

Electric Plant

Miscellaneous Nuclear Plant

Total Malntonance Expenees

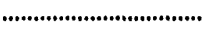

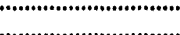

.............................

Total Nuclear Power Production

Expenese

79

$\begin{array}{rl}41 & 0 \\ 81 & 0 \\ 6 & 0 \\ 15 & 0 \\ 0 & 0 \\ 0 & 0 \\ 4 & 0 \\ 68 & 0 \\ 4 & 0 \\ 210 & 0\end{array}$

1,319
5,456
134
706
0
0
92
2,551
74
10,331

10
9
17
23
1
00

0
0
0
0
0
0

$$
\begin{aligned}
& 0 \\
& 0 \\
& 0 \\
& 0 \\
& 0 \\
& 0
\end{aligned}
$$

407

293
608

626

2,218

12,647

o

Hydraulic Power

Operation Expenses

Supervision and Engineering

Water for Power ........

Hydraulic Expenses

Electric Expenses ....u.

Miscellaneous Hydraulic Expenses

Rents

Total Operntion Expensese

.........................

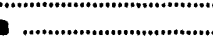

See endnotes at end of an individual electric utility. 
Table 41. Electric Operation and Malntenance Expences by Major U.S. Investor-Owned Electrlc Utility Withiri State, 1992 (Continued) (Thousand Dollars)

\begin{tabular}{|c|c|c|c|c|c|c|}
\hline Item & $\begin{array}{c}\text { Maseachueotte } \\
\text { Fitchburg } \\
\text { Gas a } \\
\text { - Elec Light Co }\end{array}$ & $\begin{array}{c}\text { Maseachusetts } \\
\text { Hohyoke } \\
\text { Power } \\
\text { Electric Co }\end{array}$ & $\begin{array}{l}\text { Massachusetts } \\
\text { Holyoke } \\
\text { Water } \\
\text { Power } \\
\text { Co }\end{array}$ & $\begin{array}{c}\text { Masanchusetts } \\
\text { Meseachusetts } \\
\text { Electrio Co }\end{array}$ & $\begin{array}{l}\text { Masaschusette } \\
\text { Montaup } \\
\text { Electric Co }\end{array}$ & $\begin{array}{c}\text { Massachusetts } \\
\text { New England } \\
\text { Hydro- } \\
\text { Tran } \\
\text { Elec Co }\end{array}$ \\
\hline
\end{tabular}

Maintenance Expenses

Superviaion and Engineering

Structurea

Recervolrs, Dams and Watenways

Electric Plant

Miscellaneous Hyoraullo Plant

Totel Melntienance Expenses:

Totel Hydreulle Power

Production Expenece

Other Power

Operation Expenses

Superviaion and Engineering

Fuel .............................

Generation Expenses ................................................

Miscellaneous Other Power Expenses

Rents

Total Operation Exponses

Maintenance Expenses

Supervision and Engineering

Structures ......................................

Miscelleneous Other Power Plant

Total Malntenance Expences

Totel Other Power Production

Expenses .

Other Power Supply Expenses

Purchased Power

Syatem Control and Load

Other Expenses

Total Other Power Supply

Expenese

.............................

Transmisaion

Operation Expenses

Supervision and Engineering ................................

Load Dispatching

Station Expenses

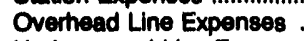

Underground Line Expenses

Transmission of Electricity by Others

Miscellaneous Transmission Expenses

Pents

$\mathbf{0}$

489

203

273

141
1,044

4,200

$\begin{array}{rr}0 & 0 \\ 132 & 0 \\ 0 & 0 \\ 7 & 0 \\ 398 & 0 \\ 587 & 0\end{array}$

9
1
49
1
81

508

0

15,647

205

364

16,215

$$
27,189
$$

0
0

27,180

70

$1,065,189$

0

17,444

$1,065,213$

4,434

$1,086,213$

252,080

162,994
2,180
8,984
174,197

0

18,087

27,180

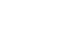

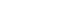

0

Totil Operation Expenses

0
0
26
1
1
1,491
5
2

1,526

17
0
0
0
0
317
47
0

391
124
4
117
38
2
0
4
41
330

191
336
380
238
0
1,777
63
8,536
11,621

See endnotes at end of an individual electric utility. 
Table 41. Electric Operation and Malntenance Expenses by Major U.S. Investor-Owned Electric Utility Within State, 1902 (Continued) (Thousand Dollars)

\begin{tabular}{|c|c|c|c|c|c|c|}
\hline Item & $\begin{array}{l}\text { Maseachusetts } \\
\text { Fltchburg } \\
\text { Cas } 8 \\
\text { Elec Light Co }\end{array}$ & $\begin{array}{l}\text { Mansachuestis } \\
\text { Hohyoke } \\
\text { Power } \\
\mathbf{a} \\
\text { Electio Co }\end{array}$ & $\begin{array}{l}\text { Mesenchusetts } \\
\text { Hohyoke } \\
\text { Water } \\
\text { Power } \\
\text { Co }\end{array}$ & $\begin{array}{l}\text { Masaschusetts } \\
\text { Maseschusotts } \\
\text { Electrio Co }\end{array}$ & $\begin{array}{l}\text { Masenchusetts } \\
\text { Montwup } \\
\text { Electio Co }\end{array}$ & $\begin{array}{l}\text { Mascachusetts } \\
\text { New Enoland } \\
\text { Hyctro- } \\
\text { Tran } \\
\text { Elec Co }\end{array}$ \\
\hline
\end{tabular}

Maintenance Expenses

Supenvioion and Engineering

Structures

Station Equipmen

Overhead Lines ...

Underaround Lines

Totel Tranamiacton Expenese

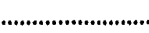

Tot:l Transmiedien Expensec

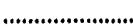

Distribution

Operation Expenses

Supervision and Engineering

Load Dispatching

Station Expenses

Overhead Une Expenses

Underground Line Expenses ...................................

Streot Lighting and Signal System Expenses ....

Meter Expenses ........................................................

Customer Installations Expenses ........

Miecellaneous Diatribution Expenses

Pents

Total Operntion Expenses
31

0

74

0

10

1,032

Maintenance Expenses

Supervision and Engineering

Structures

Station Equipment

Overhead Lines ....

Underground Lit

Line Transformers

Street Lighting and Signal Systems

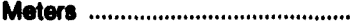

Miscellaneous Distribution Plant

Total Dietribution Expenses

Gentomer Accounts Expenses

Supervition

Meter Reading Expenses ........................................

Customer Records and Collection Expenses ....

Uncollectble Accounts ............................................

Miscellaneous Customer Accounts Expenses ...

Totel Customer Acoounts Expenses

Customer Service and Information Expenses

Supervition ..................................................................

Customer Aadatance Expenses ............................

Miscellaneous Customer Service

and Informational Expenses

Totel Customer gervice and

informational Exponces.

Seles Expenees

Supervition

Demonstrating and Selling Expenses

Advertiaing Expenses .............................................

Mhcellaneous Sales Expenser

Totel 8ales Expenses

.

see endnotes at end of an individual electric utility.

873

700

1,381

891

$\begin{array}{rrrr}4 & 47 & 6 & 27 \\ 0 & 2 & 1 & 0 \\ 3 & 98 & 214 & 678 \\ 0 & 147 & 180 & 20 \\ 0 & 20 & 0 & 0 \\ 0 & 16 & 138 & 0 \\ 7 & 390 & 540 & 722 \\ 300 & 650 & 12,060 & 2,104\end{array}$

4,271

2,680

5,180

1,714

2,394

3.781

3,064

8,341

530

32,015

210

1,587

213
4,452

21,381

2,550

1,784

274

164
32,096

08,090

0

$\begin{array}{rr}0 & 0 \\ 206 & 2 \\ 530 & 0 \\ 432 & 0 \\ 15 & 0 \\ 1,184 & 2\end{array}$

1,810

7,053

16,789

13,345

95,000

101

893

47,411

2,182

3,281

69,727

o

17

$\begin{array}{rr}3 & 0 \\ 16 & 0 \\ 0 & 0 \\ 134 & 0 \\ 161 & 0\end{array}$


Table 41. Eloctric Operation and Maintenance Expeneos by Major U.8. Inveotor-Owned Electric Utility Within 8tato, 1992 (Continued) (Thousand Dollars)

\begin{tabular}{|c|c|c|c|c|c|c|}
\hline liem & $\begin{array}{c}\text { Menesohuseti } \\
\text { Fliohburg } \\
\text { Cos } 8 \\
\text { Eleo Light Co }\end{array}$ & $\begin{array}{c}\text { Masanchusetts } \\
\text { Holyoke } \\
\text { Powrer } \\
\text { Enotilo Co }\end{array}$ & $\begin{array}{l}\text { Manenchusetts } \\
\text { Holyoke } \\
\text { Water } \\
\text { Power } \\
\text { Co }\end{array}$ & $\begin{array}{l}\text { Maresechuesti } \\
\text { Mencohusetti } \\
\text { Electro Co }\end{array}$ & $\begin{array}{c}\text { Morenchuests } \\
\text { Montaup } \\
\text { Electric Co }\end{array}$ & $\begin{array}{l}\text { Maseachusetts } \\
\text { New England } \\
\text { Hydro- } \\
\text { Tran } \\
\text { Eleo Co }\end{array}$ \\
\hline
\end{tabular}

Adrinictrattwe and Ceneral Expensese

Operation Expensers

Adminimtrative and Ceneral Salertes

Oilios Supoline and Expentes

(ieco) Adminietrattwe Expenses

Traneferred (oreati) .

Eenvioes Employed

210
1,189

Property Incurence ....................................................

In'ustes And Dameges ............................................

Employes Penclone And Benefite

Franchise Recuirements ..........................................

Reculatory Commiadion Expenses ........................

(emplomplo

Corges (credil)

Eenord Advertiang Expenses ..................................

Mincelleneous General Expensese

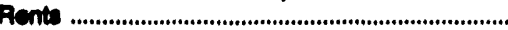

Totel Operration Expenese

..................................

Maintenance of Generd Plant ...............................

Totel Actuminetrattwe and

esnerd Expenses ...

$\begin{array}{rr}420 \\ 233 \\ 210 \\ 1,189 \\ 42 & \\ 197 & \\ 542 & \\ 0 & \\ 25 & \\ 65 & \\ 9 & \\ 137 & \\ -189 & \\ 2,381 & \end{array}$

$\begin{array}{rr}4 & 1,0 \\ 6 & 230 \\ 0 & \\ 1 & 1 \\ 0 & \\ 0 & 240 \\ 1 & 1,457 \\ 0 & \\ 48 & 1 \\ 0 & \\ 0 & \\ 3 & 1 \\ 0 & 157 \\ 8 & 3,648\end{array}$

$\begin{array}{rr}1,050 & 9,5 \\ 238 & 7,324 \\ 10 & 778 \\ 127 & 489 \\ 80 & 414 \\ 246 & 3,621 \\ 1,467 & 18,380 \\ 0 & \\ 147 & 2,85 \\ 0 & 284 \\ 1 & 1,94 \\ 157 & 2,01 \\ 158 & 48,091 \\ 3,042 & \end{array}$

$\mathbf{9 , 5 4 3}$

7,324

3,761

210

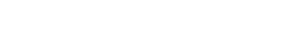

Totel Esotits Operntion and

Melmitenenes Expenten.

84

778
488

414

3,621

18,398

2,858

234

1,243

2,019

8,681

80
2,844

2,844
813

1,823

2,248

703

14

2,184

200

16,180

970

27

40,602

16,109

1,364

27,211

27,272

49,065

$1,270,481$

200,144

4,847

Ditulbution of Salaries and

Weoes Chereed to Electrle

Operation and Maintenance

Production

Tranamiasion ...............................................................

Dintributior

Customer Acoounts .................................................

Customer Service and

Informationd Expenses

Sales Expense:

Adminatrattve and General

Allocated from Chearing Accounts

Total selestes end Weces ..................................

Number of Electric Department Employees

Regular Full-time Employece ................................

Part-time and Temporary Employees

Toted Ebotrlo Depertimemt Employee .........

$\begin{array}{rr}140 & 0 \\ 36 & 0 \\ 742 & 0 \\ 564 & 0 \\ 0 & \\ 03 & 0 \\ 488 & 0 \\ 0 & 0 \\ 2,002 & 0\end{array}$

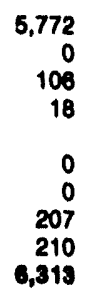

62
0

82

$\begin{array}{ll}32 & 0 \\ 0 & 10\end{array}$

0
136
0

183

$$
\begin{array}{r}
0 \\
85 \\
31,571 \\
13,428 \\
4,326 \\
0 \\
4,093 \\
1,490 \\
44,903
\end{array}
$$

5,018

386

1,892

30

1,022

151

o

Note: Totals may not equal sum of components because of independent rounding. Summary data are provided in Table 11.

Source: Federal Energy Reculatory Commisalon, FERC Form 1, "Annual Report of Major Electric Utilities, Licensees and Others." 
Table 41. Electric Oporation and Malntenance Exponees by Major U.S. Inveotor-Owned Eloctric Utility Whthin State, 1902 (Continued) (Thousand Dollars)

\begin{tabular}{|c|c|c|c|c|c|c|}
\hline Item & $\begin{array}{l}\text { Maseachusetts } \\
\text { Now England } \\
\text { Power Co }\end{array}$ & $\begin{array}{l}\text { Masesechuectis } \\
\text { Westem } \\
\text { Masesechusetts } \\
\text { Elec Co }\end{array}$ & $\begin{array}{l}\text { Muchioan } \\
\text { Consumere } \\
\text { Power Co }\end{array}$ & $\begin{array}{l}\text { Milohioan } \\
\text { Dotrot } \\
\text { Edison Co }\end{array}$ & $\begin{array}{c}\text { Michioan } \\
\text { Edison } \\
\text { Sault } \\
\text { Electric } \\
\text { Co }\end{array}$ & $\begin{array}{l}\text { Milchigan } \\
\text { Upper } \\
\text { Peninaula } \\
\text { Power Co }\end{array}$ \\
\hline
\end{tabular}

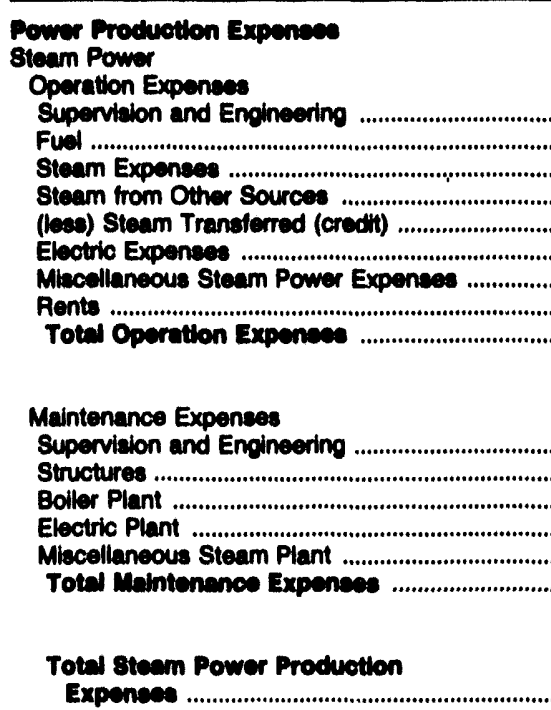

Nuclear Power

Operation Expenses

Suparviaion and Engineering

$\begin{array}{rr}4,237 & 9,331 \\ 5,859 & 16,538 \\ 413 & 1,302 \\ 2,320 & 4,005 \\ 0 & 0 \\ 0 & 0 \\ 283 & 843 \\ 6,764 & 17,672 \\ 2225 & 1,234 \\ 20,102 & 80,028\end{array}$

10,578

21,620

9,704

2,948

282,421

7,222

1,089

281,040

8,388

5,589

12,541

310,907

0
691
947
1
21,200

6,131

8,697

314,

620,010

24,092

0
0
3,054

30,154

13

8,505

8,424

5,380

51,747

23,738

1,142

06,405

378
449
1,096
481
70

6,562

23,739

$\mathbf{9 , 9 8 0}$

2,186

63,784

20,437

15,038

120,293

307,103

28,992

893,00

017,031

4,103

Coolants and Water

Steam Expenses

Steam from Other Sources

(less) Steam Transferred (credit)

Electric Expenses

Rents

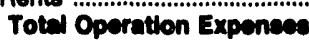

80,020

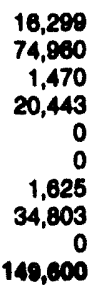

127

2,627

478

0

147

8,407

Maintenance Expenses

Supervision and Engineering

Structures ...

Reactor Plant Equipment

Electric Plant

Miscellaneous Nuclear Plant

Total Malntenance Expenace

1,321

2,772

1,736

8,637

1,954

1,964
1,889

885

5,470

247

2,753
11,390

11,389

0
1,616

29,475

507

77,916

149,600

78
14
320
278
10
701

Total Nuctear Power Production

Expenaes

27,281

00,890

8,301

1,800

18,088

6,628

1,898

852

7,254

4,478

8,281

$\mathbf{3 4} 8 \mathbf{8 1}$

Hydraulic Power

Operation Expenses

Supervision and Engineering

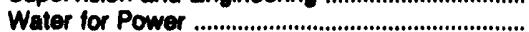

Hydraullo Expenses.

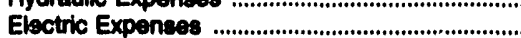

Miscellaneous Hydraulic Expenses

Rent

Total Operetion Expenses

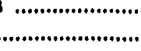

See endnotes at end of an individual electric utility.

\begin{tabular}{|c|c|c|c|c|c|}
\hline $\begin{array}{r}935 \\
286 \\
761 \\
1,797 \\
1,914 \\
38 \\
5,740\end{array}$ & $\begin{array}{r}923 \\
31 \\
759 \\
465 \\
351 \\
811 \\
3,841\end{array}$ & $\begin{array}{r}508 \\
781 \\
0 \\
1,114 \\
1,110 \\
2 \\
3,516\end{array}$ & $\begin{array}{r}110 \\
0 \\
0 \\
303 \\
686 \\
-3 \\
1,007\end{array}$ & $\begin{array}{r}13 \\
720 \\
241 \\
287 \\
86 \\
0 \\
1,389\end{array}$ & $\begin{array}{r}218 \\
0 \\
139 \\
161 \\
71 \\
80 \\
680\end{array}$ \\
\hline
\end{tabular}


Table 41. Electrle Operation and Malntonance Expenses by Major

U.S. Investor-Owned Eloctric Utility Within State, 1992 (Continued)

(Thousand Dollars)

\begin{tabular}{|c|c|c|c|c|c|c|}
\hline Item & $\begin{array}{l}\text { Massachusetts } \\
\text { New England } \\
\text { Power Co }\end{array}$ & $\begin{array}{l}\text { Massachusetto } \\
\text { Western } \\
\text { Masasachusetts } \\
\text { Elec Co }\end{array}$ & $\begin{array}{l}\text { Michigan } \\
\text { Consumers } \\
\text { Power Co }\end{array}$ & $\begin{array}{l}\text { Michigan } \\
\text { Dotroit } \\
\text { Edison Co }\end{array}$ & $\begin{array}{c}\text { Michigan } \\
\text { Edison } \\
\text { Sault } \\
\text { Electric } \\
\text { Co }\end{array}$ & $\begin{array}{c}\text { Mlohigan } \\
\text { Upper } \\
\text { Poninaula } \\
\text { Power Co }\end{array}$ \\
\hline
\end{tabular}

Maintenance Expenses

$$
\begin{array}{r}
914 \\
1,086 \\
775 \\
3,626 \\
422
\end{array}
$$

6,823

12,863

6,189
Superviaion and Engineering

Structures

Reservoirs, Dams and Waterways

Electric Plant

Miscellaneous Hydraulic Piant

Tot't Melntenenos Expense

(n)........

Total Hydraulle Power

Production Expenses
438

482

4,203

3,031

3,389

11,879

171
124
2,860
3,058
158
0,471

7,628

40
298
124
218
28

703

2,042

1,120

Other Power

Operation Expenses

Supervision and Engineering

Fuel.

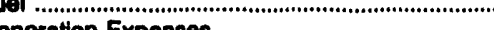

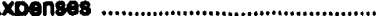

Milacellaneous Other Power Expenses

Rents

Total Opuration Expenses

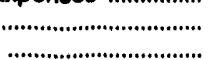

1
12
9
14
0
37
Meintenance Expenses

Supervision and Engineering

Structures ...

Generating and Electric Plant

Miscellaneous Other Power Plant

Total Malntenance Expenses

(n)

Total Malntenance Expenses

Total Other Power Production

Expenses

524

3,151

1,570

74
297
157
8
0
538

14
135
21
12
0
182

Other Power Supply Expenses

Purchased Power.

Total Other Power Supply

Expensese

............................................................

507,354
4,157

67,693
976

976
237

571,952
7,935

7,935

104,822
3,737

1,727

328
13

677

19

1,034

516,809

88,008

500,304

110,288

14,77

14,771

Total Power Production Expenses

965,324

168,370

$1,074,124$

$1,120,440$

16,092

25,813

Transmission

Operation Exponses

Supervision and Engineering

Load Diepatching .

Station Expenses

Overhead Line Expenses

Underground Line Expenses

Transmission of Electricity by Others

Miscellaneous Transmission Expenses

Rents

Total Operation Expenses

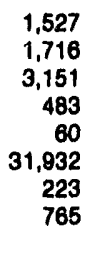
435
353
19
5
5,376
5,376
469
88

6,744

39,858
6,035
1,067
3,474
708
444
2,875
2,003
571

$\begin{array}{rr}25 & 356 \\ 212 & 0 \\ 22 & 160 \\ 8 & 101 \\ 10 & 0 \\ 0 & 0 \\ 2 & 90 \\ 0 & 8\end{array}$

17,178

See endnotes at end of an individual electric utility. 
Table 41. Electric Oporation and Malntenance Expenses by Major U.S. Inveator-Owned Electric Utility Within State, 1992 (Continued) (Thousand Dollars)

\begin{tabular}{|c|c|c|c|c|c|c|}
\hline Item & $\begin{array}{l}\text { Mnseachusetis } \\
\text { New England } \\
\text { Power Co }\end{array}$ & $\begin{array}{l}\text { Maseschusetts } \\
\text { Westem } \\
\text { Maseschusctis } \\
\text { Elec Co }\end{array}$ & $\begin{array}{l}\text { Michigan } \\
\text { Consumers } \\
\text { Powm Co }\end{array}$ & $\begin{array}{l}\text { Moniean } \\
\text { Dotroit } \\
\text { Edimon Co }\end{array}$ & $\begin{array}{l}\text { Miohigen } \\
\text { Ection } \\
\text { Seult } \\
\text { Elootio } \\
\text { Co }\end{array}$ & $\begin{array}{l}\text { Michigen } \\
\text { Upoer } \\
\text { Peninsula } \\
\text { Powner Co }\end{array}$ \\
\hline
\end{tabular}

Meintenance Expensea

Supervision and Engineering

Structurea

Stintion Equ'sment

Overteed Line $\quad 3,852$

Undereround Lines .....................................................

Miscellaneous Tranamiacion Plent

Totel Melntenenos Expenese

Total Trunomiselen Expenees

82,101

Fents ......................................

Muintenance Expense:

Supervilon and Engineering

Structures

Overhead Lines ...

Underoround Lines

Une Trantormers

Street Lighting and Signal Sy

Meters

Miscollaneous Distribution Plant

Total Malntenanes Expences

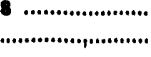

Total Distribution Expensese

..............................

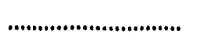

Customer Accounts Expenses

Supervision

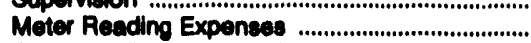

Customer Records and Collection Expenses ....

Uncollectible Accounts ...........................................

Misceliancous Customer Accounts Expenses ....

Total Customer Accoumts Expenses

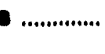

Customer Service and Information Expenses

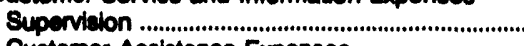

Customer Ascibtance Expenses ..............................

Informational and Instructional Expenses ..............

Miscellaneous Customer Service

and Informational Expenses ...

Total Customer 8avioes and

Informational Expenses

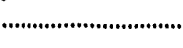

......................................

Sales Expenses

Supervision ...

Demonstrating and Selling Expenses

Advertising Expenses

Miscellaneous Sales Expenses

Total Eales Expenese

Sea endnotes at end of an individual electric utility.
630

52

5,481

3,862
2,216

71

12,809

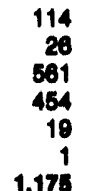

1,175

7,020

$\begin{array}{rr}491 & 1,648 \\ 0 & 704 \\ 52 & 734 \\ 3 & 668 \\ 1 & 683 \\ 0 & 167 \\ 241 & 884 \\ 6 & 471 \\ 242 & 730 \\ 103 & 79 \\ 1,140 & 6,934\end{array}$

8,830

2,364

$\mathbf{5 , 6 7 7}$

2,836

471
3,492

3,482
2,388

11,350

2,246

20,158

35
2
118
71
2
0
0
291
3
192

10,058

$\begin{array}{rr}14 & 169 \\ 288 & 648 \\ 409 & 781 \\ 58 & 132 \\ 47 & 92 \\ 014 & 1,920\end{array}$

0,440

16,000

$\begin{array}{rr}1,076 & 1,324 \\ 1,105 & 6,389 \\ 1 & 41 \\ 0 & 3,709 \\ 2,273 & 11,483\end{array}$


Table 41. Electric Operation and Maintenance Expenses by Major U.S. Inveotor-Owned Electric Utility Within State, 1992 (Continued) (Thousand Dollars)

\begin{tabular}{|c|c|c|c|c|c|c|}
\hline Item & $\begin{array}{l}\text { Maseachusetts } \\
\text { New England } \\
\text { Power Co }\end{array}$ & $\begin{array}{l}\text { Masaschusotts } \\
\text { Western } \\
\text { Massachusetts } \\
\text { Elec Co }\end{array}$ & $\begin{array}{l}\text { Mlchigan } \\
\text { Consumers } \\
\text { Power Co }\end{array}$ & $\begin{array}{c}\text { Miohigan } \\
\text { Dotroit } \\
\text { Edison Co }\end{array}$ & $\begin{array}{l}\text { Michigan } \\
\text { Edison } \\
\text { Sault } \\
\text { Electric } \\
\text { Co }\end{array}$ & $\begin{array}{l}\text { Michigan } \\
\text { Upper } \\
\text { Peninsula } \\
\text { Power Co }\end{array}$ \\
\hline
\end{tabular}

Adminiotrative and General Expenses

\begin{tabular}{|c|c|c|c|c|c|c|}
\hline $\begin{array}{l}\text { Administrathe and General Salaries } \\
\text { Office Supplles and Expenses } \\
\text { (lese) Adminiatrative Expenses }\end{array}$ & $\begin{array}{r}10,842 \\
5,870\end{array}$ & $\begin{array}{l}9,738 \\
3,553\end{array}$ & $\begin{array}{r}18,929 \\
7,972\end{array}$ & $\begin{array}{l}63,197 \\
26,987\end{array}$ & $\begin{array}{l}962 \\
229\end{array}$ & $\begin{array}{r}2,442 \\
372\end{array}$ \\
\hline 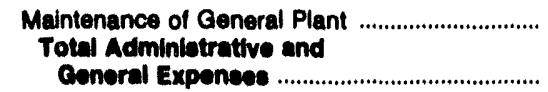 & 86,467 & 1,399 & 110,501 & 6,574 & 2,437 & $\begin{array}{r}145 \\
9,038\end{array}$ \\
\hline $\begin{array}{l}\text { Total Electric Operation and } \\
\text { Malntenance Expenese }\end{array}$ & $1,072,665$ & 251,718 & $1,353,908$ & $1,608,080$ & 22,299 & 42,648 \\
\hline $\begin{array}{l}\text { Distribution of Salarles and } \\
\text { Wages Charged to Electric } \\
\text { Operation and Maintenance }\end{array}$ & & & & & & \\
\hline 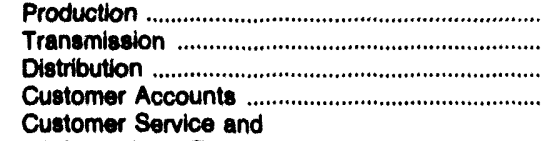 & $\begin{array}{r}41,864 \\
4,023 \\
31 \\
3\end{array}$ & $\begin{array}{r}8,398 \\
690 \\
10,086 \\
4,269\end{array}$ & $\begin{array}{r}54,486 \\
3,224 \\
30,584 \\
14,983\end{array}$ & $\begin{array}{r}183,950 \\
18,970 \\
67,239 \\
29,063\end{array}$ & $\begin{array}{r}658 \\
296 \\
1,084 \\
514\end{array}$ & $\begin{array}{r}2,077 \\
920 \\
3,052 \\
1,192\end{array}$ \\
\hline 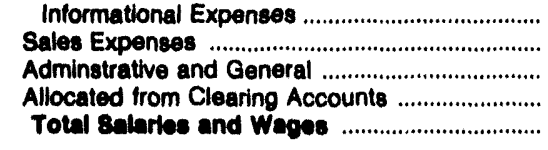 & $\begin{array}{r}0 \\
0 \\
285 \\
618 \\
48,824\end{array}$ & $\begin{array}{r}820 \\
0 \\
1,287 \\
1,029 \\
28,579\end{array}$ & $\begin{array}{r}4,531 \\
966 \\
22,333 \\
82,359 \\
213,476\end{array}$ & $\begin{array}{r}6,401 \\
6,170 \\
67,323 \\
13,584 \\
402,701\end{array}$ & $\begin{array}{r}33 \\
0 \\
1,247 \\
303 \\
4,135\end{array}$ & $\begin{array}{r}146 \\
23 \\
2,490 \\
134 \\
10,034\end{array}$ \\
\hline $\begin{array}{l}\text { Number of Electric Department Employees } \\
\text { Regular Full-time Employees ............................... } \\
\text { Part-time and Temporary Employees .................. }\end{array}$ & $\begin{array}{r}951 \\
18\end{array}$ & $\begin{array}{r}725 \\
14\end{array}$ & $\begin{array}{r}6,113 \\
174\end{array}$ & $\begin{array}{r}8,985 \\
42\end{array}$ & $\begin{array}{r}93 \\
3\end{array}$ & $\begin{array}{r}574 \\
8\end{array}$ \\
\hline Total Electric Dopartment & 899 & 739 & 6,287 & 9,007 & $\boldsymbol{\infty}$ & 582 \\
\hline
\end{tabular}

Note: Totals may not equal sum of components because of independent rounding. Summary data are provided in Table 11.

Source: Federal Energy Regulatory Commission, FERC Form 1, "Annual Report of Major Electric Utilities, Licensees and Others." 
Tablo 41. Electric Operation and Maintenance Expenses by Major U.8. Investor-Owned Electric Utility Within State, 1992 (Continued) (Thousand Dollars)

\begin{tabular}{|c|c|c|c|c|c|c|}
\hline Item & $\begin{array}{l}\text { Minnesota } \\
\text { Minnesota } \\
\text { Power } \\
\text { Light Co }\end{array}$ & $\begin{array}{l}\text { Minnesota } \\
\text { Northern } \\
\text { States } \\
\text { Power Co }\end{array}$ & $\begin{array}{l}\text { Minnesota } \\
\text { Otter } \\
\text { Tall } \\
\text { Power } \\
\text { Co }\end{array}$ & $\begin{array}{l}\text { Mlectosippl } \\
\text { Mlselselppi } \\
\text { Power } \\
\text { Light Co }\end{array}$ & $\begin{array}{l}\text { Miselasippl } \\
\text { Mbalasippi } \\
\text { Power Co }\end{array}$ & $\begin{array}{l}\text { Miselualpol } \\
\text { Syetem } \\
\text { Energy } \\
\text { Resources } \\
\text { inc }\end{array}$ \\
\hline 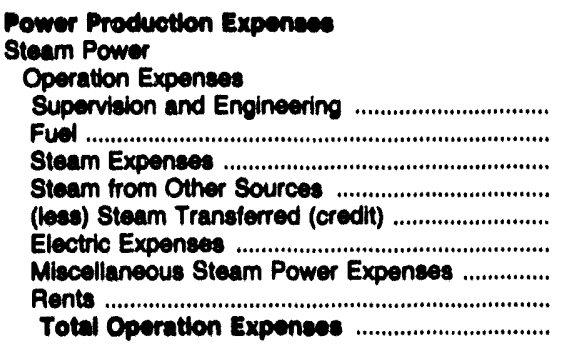 & $\begin{array}{r}1,639 \\
83,123 \\
3,687 \\
0 \\
0 \\
1,586 \\
1,752 \\
0 \\
91,698\end{array}$ & $\begin{array}{r}9,418 \\
244,404 \\
15,788 \\
0 \\
0 \\
4,659 \\
18,453 \\
6 \\
202,730\end{array}$ & $\begin{array}{r}826 \\
28,885 \\
2,033 \\
0 \\
0 \\
987 \\
921 \\
1 \\
33,084\end{array}$ & $\begin{array}{r}4,692 \\
112,032 \\
2,127 \\
0 \\
0 \\
2,432 \\
4,136 \\
0 \\
125,310\end{array}$ & $\begin{array}{r}4,091 \\
86,679 \\
3,340 \\
0 \\
0 \\
2,153 \\
11,715 \\
55 \\
118,033\end{array}$ & $\begin{array}{l}0 \\
0 \\
0 \\
0 \\
0 \\
0 \\
0 \\
0 \\
0\end{array}$ \\
\hline 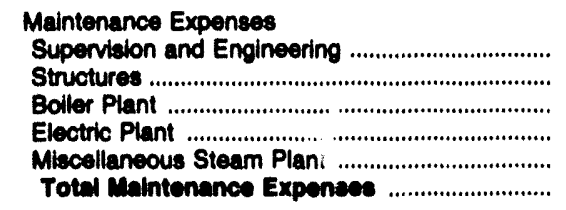 & $\begin{array}{r}1,391 \\
636 \\
3,887 \\
871 \\
1,892 \\
8,677\end{array}$ & $\begin{array}{r}6,043 \\
3,307 \\
27,622 \\
7,783 \\
3,769 \\
49,624\end{array}$ & $\begin{array}{r}489 \\
299 \\
2,798 \\
456 \\
324 \\
4,386\end{array}$ & $\begin{array}{r}1,404 \\
826 \\
7,181 \\
4,721 \\
1,182 \\
16,205\end{array}$ & $\begin{array}{r}3,693 \\
2,627 \\
12,161 \\
5,129 \\
1,378 \\
24,29\end{array}$ & $\begin{array}{l}0 \\
0 \\
0 \\
0 \\
0 \\
0\end{array}$ \\
\hline $\begin{array}{l}\text { Total Steam Power Production } \\
\text { Expenees }\end{array}$ & 100,375 & 341,254 & 38,020 & 140,614 & 143,020 & 0 \\
\hline 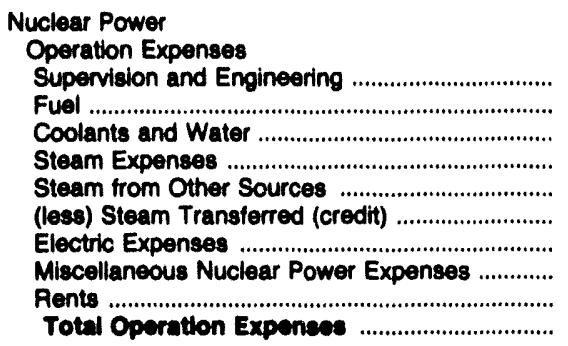 & $\begin{array}{l}0 \\
0 \\
0 \\
0 \\
0 \\
0 \\
0 \\
0 \\
0 \\
0\end{array}$ & $\begin{array}{r}39,444 \\
51,956 \\
199 \\
18,417 \\
0 \\
0 \\
4,822 \\
46,295 \\
0 \\
181,133\end{array}$ & $\begin{array}{l}0 \\
0 \\
0 \\
0 \\
0 \\
0 \\
0 \\
0 \\
0 \\
0\end{array}$ & $\begin{array}{l}0 \\
0 \\
0 \\
0 \\
0 \\
0 \\
0 \\
0 \\
0 \\
0\end{array}$ & $\begin{array}{l}0 \\
0 \\
0 \\
0 \\
0 \\
0 \\
0 \\
0 \\
0 \\
0\end{array}$ & $\begin{array}{r}18,063 \\
55,110 \\
545 \\
8,192 \\
0 \\
0 \\
3,481 \\
41,871 \\
1,107 \\
129,389\end{array}$ \\
\hline 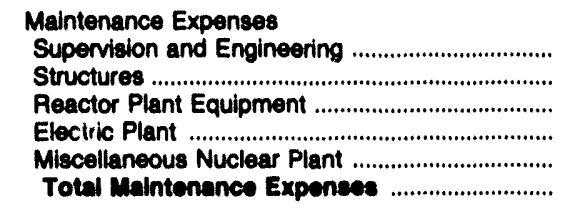 & $\begin{array}{l}0 \\
0 \\
0 \\
0 \\
0 \\
0\end{array}$ & $\begin{array}{r}10,444 \\
1,444 \\
11,107 \\
7,491 \\
7,350 \\
37,838\end{array}$ & $\begin{array}{l}0 \\
0 \\
0 \\
0 \\
0 \\
0\end{array}$ & $\begin{array}{l}0 \\
0 \\
0 \\
0 \\
0 \\
0\end{array}$ & $\begin{array}{l}0 \\
0 \\
0 \\
0 \\
0 \\
0\end{array}$ & $\begin{array}{r}7,958 \\
778 \\
8,784 \\
5,164 \\
6,676 \\
29,370\end{array}$ \\
\hline $\begin{array}{l}\text { Total Nuclear Power Production } \\
\text { Expences }\end{array}$ & 0 & 199,988 & 0 & 0 & 0 & 189,738 \\
\hline 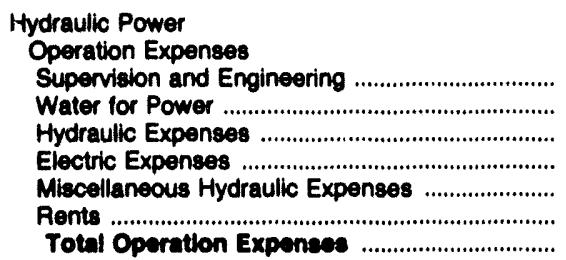 & $\begin{array}{r}402 \\
0 \\
268 \\
671 \\
283 \\
0 \\
1,623\end{array}$ & $\begin{array}{r}400 \\
84 \\
38 \\
55 \\
176 \\
2 \\
756\end{array}$ & $\begin{array}{r}5 \\
0 \\
0 \\
0 \\
67 \\
0 \\
72\end{array}$ & $\begin{array}{l}0 \\
0 \\
0 \\
0 \\
0 \\
0 \\
0\end{array}$ & $\begin{array}{l}0 \\
0 \\
0 \\
0 \\
0 \\
0 \\
0\end{array}$ & $\begin{array}{l}0 \\
0 \\
0 \\
0 \\
0 \\
0 \\
0\end{array}$ \\
\hline
\end{tabular}


Table 41. Electrlc Operation and Malntenance Expenses by Major U.8. Inveator-Owned Electric Utility Within State, 1992 (Continued) (Thousand Dollars)

\begin{tabular}{|c|c|c|c|c|c|c|}
\hline Hitm & $\begin{array}{l}\text { Minnesota } \\
\text { Minnesota } \\
\text { Power } \\
\text { Light Co }\end{array}$ & $\begin{array}{l}\text { Minnesota } \\
\text { Northern } \\
\text { States } \\
\text { Power Co }\end{array}$ & $\begin{array}{c}\text { Minnesota } \\
\text { Onter } \\
\text { Tall } \\
\text { Power } \\
\text { Co }\end{array}$ & $\begin{array}{l}\text { Mississippl } \\
\text { Miseiselppl } \\
\text { Power } \\
\text { L } \\
\text { Light Co }\end{array}$ & $\begin{array}{l}\text { Misciselppi } \\
\text { Mississippi } \\
\text { Power Co }\end{array}$ & $\begin{array}{c}\text { Miselseipp } \\
\text { System } \\
\text { Energy } \\
\text { Pesources } \\
\text { Inc }\end{array}$ \\
\hline
\end{tabular}

Maintenance Expenses

Supervision and Engineering

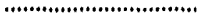

Aearvoirs, Dams and $w$

Electric Plant

Miecelleneous Hydraulic Plent

Total Hydruthe Power

Production Expences

2,806

210
114
132
288

Other Power

Operation Expenses

Supervision and Engineering

Fuel

Gencration Expenses

Miscollaneous Other Power Expenses ...............

Rents

Total Operation Expenses

957

113

0

0

Maintenance Expenses

Supervision and Engineering

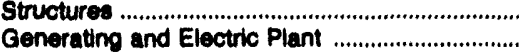

Miscellaneous Other Power Plant

Totel Meintenance Expenses

Total Other Power Production

Expensese

0

2,894

1,728

0

Other Power Supply Expenses

Purchased Power

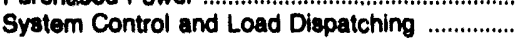

Other Expenses

Totwl Other Power supply

Expenese

85,360

1,885

100,000

749,861

154,875

2,394

48,519

205,789

Total Power Production Expenese

Tranemission

Operation Expenses

Supervision and Engineering

Losd Dispatching

Station Expon

Overhead Line Expenses

Underground Line Expenses

Transmission of Electricity by Others

Miscollaneous Transmisabn Expenses

Pents

Total Operation Expenses

$\begin{array}{rr}182 & 1,581 \\ 0 & 3,516 \\ 180 & 263 \\ 34 & 604 \\ 0 & 62 \\ 0 & 2,439 \\ 101 & 26,038 \\ 896 & 501 \\ 1,494 & 35,004\end{array}$

340,492
1,807
58

62,026

1,175

33,217

207,266

168,739 
Table 41. Eloctric Operation and Maintenance Expenses by Major U.S. Investor-Owned Electric Utillity Within State, 1992 (Continued) (Thousand Dollars)

\begin{tabular}{|c|c|c|c|c|c|c|}
\hline Item & $\begin{array}{l}\text { Minnesota } \\
\text { Minnesota } \\
\text { Power } \\
\text { \& } \\
\text { Light Co }\end{array}$ & $\begin{array}{l}\text { Minnesota } \\
\text { Northern } \\
\text { States } \\
\text { Power Co }\end{array}$ & $\begin{array}{c}\text { Minnesota } \\
\text { Otter } \\
\text { Tail } \\
\text { Power } \\
\text { Co }\end{array}$ & $\begin{array}{l}\text { Miseissippi } \\
\text { Miseissippi } \\
\text { Power } \\
\text { \& } \\
\text { Lught Co }\end{array}$ & $\begin{array}{l}\text { Miselesippl } \\
\text { Misaissippl } \\
\text { Power Co }\end{array}$ & $\begin{array}{l}\text { Miselesippl } \\
\text { Syatem } \\
\text { Energy } \\
\text { Resources } \\
\text { Inc }\end{array}$ \\
\hline
\end{tabular}

Maintenance Expenses

Supervblon and Engineering

Structures

Station Equipment

Overhead Lines.

Underground Lines

Total Tranambelon Exponese

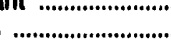

Tolatribution Tran

Operation Expenses

Superviaion and Engineering

Load Dispatching

Station Expenses .

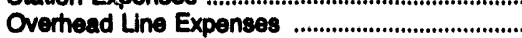

Underground Line Expenses ....................................

Street Lighting and Signal System Expenses ...

Meter Expenses ...

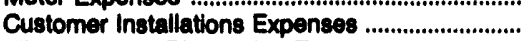

Miscellaneous Distribution Expenses

Rents

Maintenance Expenses

Supervision and Engineering

Structures

Station Equipment

Overhead Lines

Underground Lines

Line Transformers

Street Lighting and Signal Systems

Meters ...

Miscellaneous Distribution Plant

Total Maintenance Expenses

Total Distribution Expenses

Customer Accounts Expenses

Supervision

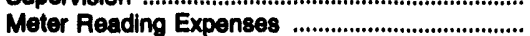

Customer Records and Collection Expenses .....

Uncollectible Accounts

Miscellaneous Customer Accounts Expenses

Tothl Cuntomer Accounts Expenesd

Customer Service and Information Expenses

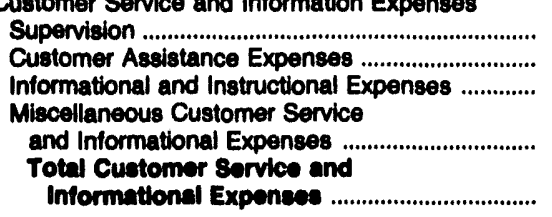

Supervision .............................................................

Informational and Instructional Expenses

Miscellaneous Customer Service

Total Customer Sorvice and

Informational Expenses

Sales Expenses

Supervision

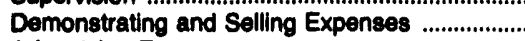

Advertising Expenses

Miscellaneous Sales Expenses

Total sake Expenese
231

56

411

881

0
1,579

3,073

624
0

353

1,112

295

43
943

943
38

1,828

124

5,350

720

92

1,110

3,424

287

153
72

72
280

1
6,139

11,498

86,076

2,071

8,316

13,103

4,859

4,522

32,871

2
4,017

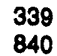

840
70

135

2,166

1,759

557

9,722

1,808

13,782

0
265
87
21
373
517
0
540
464
1
0
1,522

3,270

832

311

869

362

201

354

245

546

114

3,833

1,306
57

670

1,252

203

2,317

110

4,349

257
11,188

745

0
349

349
1,834

1,834
341

124

192

435
6

4,026

7,859

1,058
56

1,358

17,880

1,328

769

693

231

23,427

34,615

426

1,436

3,264

134

67
5,327

316

2,485

10,307

1,252

14,360

159

1,134
149

380

1,793

103

495

2,771

1,463

786

2,144

294

654

3,877

$\begin{array}{rr}858 & 0 \\ -3 & 0 \\ 1,182 & 0 \\ 2,701 & 0 \\ 0 & 0 \\ 79 & 0 \\ 4,818 & 0 \\ 0,650 & 7\end{array}$

$\begin{array}{rl}1,994 & 0 \\ 347 & 0 \\ 280 & 0 \\ 1,323 & 0 \\ 242 & 0 \\ 201 & 0 \\ 941 & 0 \\ 37 & 0 \\ 1,314 & 0 \\ 170 & 0 \\ 6,840 & 0\end{array}$

See endnotes at end of an indlvidual electric utility.

$\begin{array}{rr}1,639 & 0 \\ 201 & 0 \\ 1,253 & 0 \\ 5,528 & 0 \\ 713 & 0 \\ 365 & 0 \\ 140 & 0 \\ 281 & 0 \\ 501 & 0 \\ 10,621 & 0\end{array}$

17,470 
Table 41. Electrlc Operation and Maintenance Expenses by Major U.S. Investor-Owned Electric Utility Within State, 1992 (Continued) (Thousand Dollars)

\begin{tabular}{|c|c|c|c|c|c|c|}
\hline Item & $\begin{array}{c}\text { Minnesota } \\
\text { Minnesota } \\
\text { Power } \\
\text { Lught Co }\end{array}$ & $\begin{array}{l}\text { Minnesota } \\
\text { Northem } \\
\text { States } \\
\text { Power Co }\end{array}$ & $\begin{array}{c}\text { Minnesota } \\
\text { Otter } \\
\text { Tall } \\
\text { Power } \\
\text { Co }\end{array}$ & $\begin{array}{l}\text { Misclesippl } \\
\text { Miselselppi } \\
\text { Power } \\
\text { Light Co }\end{array}$ & $\begin{array}{l}\text { Miselesippl } \\
\text { Mlaclesippl } \\
\text { Power Co }\end{array}$ & $\begin{array}{l}\text { Misalasippl } \\
\text { System } \\
\text { Energy } \\
\text { Resources } \\
\text { inc }\end{array}$ \\
\hline
\end{tabular}

Adminiatrative and General Expenses

Operation Expenses

Adminiatrattve and General Salarios

Orfice supplies and Expor

(18as) Administrathe Expenses

Transterred (credit)

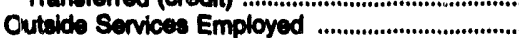

Property Insurance

Irtures And Dameas

Employes Pentions And

Franchise Requirements

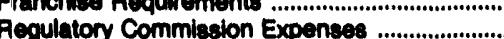

(kesa)Duplicate Charges (credit)

General Advertising Expenses ....

Milecellaneous General Expenses ..........................

Rents

Totel Operetion Expensese

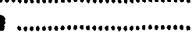

Maintenance of General Plant

Totel Admintetratwe and

Ceneral Expences

18,810

4,491

744

1,118

1,127

829

6,397

704
1,253

1,253

243

3,471

$-108$

37,006

2,624

40,820

Total Eloctric Operation and

Maintenance Expenses

Distribution of Salaries and

Wages Charged to Electric

Operation and Maintenance

Production

Transmission .

Distribution ........................................................................

Customer Accounts

Customer Service and

Informational Expenses

Sales Expenses

Adminstrattve and Genera

Allocated from Clearing Accounts

Total salarte and Weges

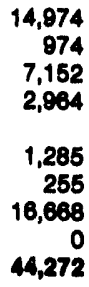

$$
\begin{array}{r}
130,419 \\
4,724 \\
36,679 \\
17,868 \\
\\
5,797 \\
345 \\
38,581 \\
6,398 \\
240,011
\end{array}
$$

\section{6,791}

2,480

6,122

4,359

8,398
1,699

16,276

7,202

20,813
2,036

2,036
7,054

4,676

40,068

704
336

11,220

618

32,030

1,839

829

11,104

3,582

$\mathbf{8 0 , 0 2 0}$

1,051

3,131

13,955

884

63,601

1,438

32

1,521

98

1,278

152

865

784
60

1,470

1,610

1,270

Total Elsctris Departmont Employees ..........

1,677

6,374

894

Note: Totals may not equal sum of cnmponents because of independent rounding. Summery data are provided in Table 11.

Source: Federal Energy Regulatory Commiselon, FERC Form 1, "Annual Report of Major Electric Utillibe, Licensees and Others." 
Table 41. Electric Operation and Maintenance Expenses by Major U.S. Investor-Owned Electric Utility Within State, 1992 (Continued) (Thousand Dollars)

\begin{tabular}{|c|c|c|c|c|c|c|}
\hline Item & $\begin{array}{l}\text { Mitseouri } \\
\text { Empire } \\
\text { Diatrict } \\
\text { Electric Co }\end{array}$ & $\begin{array}{c}\text { Miseouri } \\
\text { Kaneas Clty } \\
\text { Power \& Light } \\
\text { Co }\end{array}$ & $\begin{array}{l}\text { Miasount } \\
\text { St Joseph } \\
\text { Light } \\
\text { Power Co }\end{array}$ & $\begin{array}{l}\text { Miseouri } \\
\text { Union } \\
\text { Electric Co }\end{array}$ & $\begin{array}{l}\text { Mlseourl } \\
\text { UtillCorp } \\
\text { United Inc }\end{array}$ & $\begin{array}{l}\text { Montana } \\
\text { Montana } \\
\text { Power Co }\end{array}$ \\
\hline 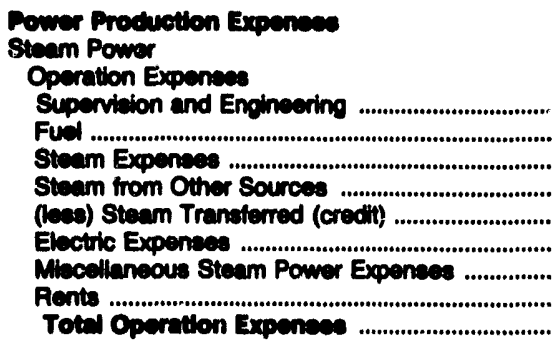 & $\begin{array}{r}1,157 \\
26,255 \\
1,110 \\
0 \\
0 \\
753 \\
561 \\
21 \\
20,067\end{array}$ & $\begin{array}{r}3,049 \\
116,895 \\
5,680 \\
1,138 \\
0 \\
2,282 \\
7,289 \\
297 \\
136,041\end{array}$ & $\begin{array}{r}645 \\
14,893 \\
932 \\
0 \\
5,332 \\
532 \\
1,089 \\
16 \\
12,775\end{array}$ & $\begin{array}{r}4,945 \\
332,524 \\
9,283 \\
0 \\
0 \\
2,048 \\
12,236 \\
95 \\
331,131\end{array}$ & $\begin{array}{r}1,603 \\
72,915 \\
2,826 \\
0 \\
0 \\
1,726 \\
2,017 \\
10,280 \\
91,306\end{array}$ & $\begin{array}{r}1,471 \\
51,894 \\
3,783 \\
1 \\
0 \\
2,188 \\
3,681 \\
37,465 \\
100,366\end{array}$ \\
\hline 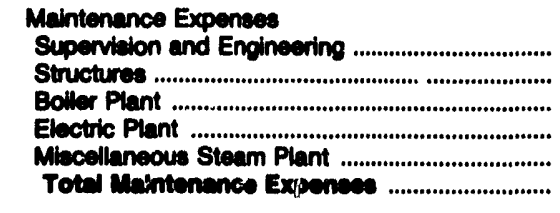 & $\begin{array}{r}395 \\
278 \\
2,171 \\
1,033 \\
184 \\
4,071\end{array}$ & $\begin{array}{r}2,627 \\
4,245 \\
26,222 \\
7,720 \\
2,185 \\
42,000\end{array}$ & $\begin{array}{r}318 \\
293 \\
2,934 \\
943 \\
171 \\
4,650\end{array}$ & $\begin{array}{r}6,675 \\
4,251 \\
43,800 \\
14,523 \\
8,111 \\
77,481\end{array}$ & $\begin{array}{r}1,152 \\
378 \\
5,580 \\
1,937 \\
807 \\
0,854\end{array}$ & $\begin{array}{r}1,401 \\
1,460 \\
9,961 \\
3,141 \\
1,442 \\
17,306\end{array}$ \\
\hline $\begin{array}{l}\text { Total Steam Power Production } \\
\text { Expenees }\end{array}$ & 33,928 & 170,041 & 17,434 & 439,598 & 101,220 & 117,750 \\
\hline 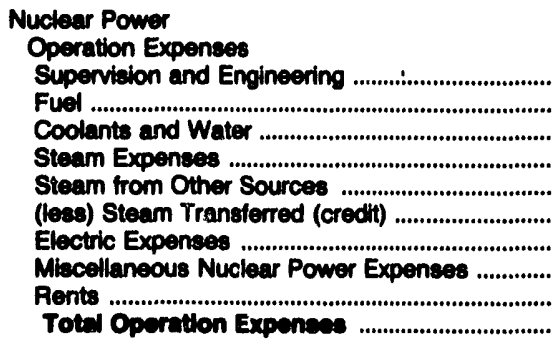 & $\begin{array}{l}0 \\
0 \\
0 \\
0 \\
0 \\
0 \\
0 \\
0 \\
0 \\
0\end{array}$ & $\begin{array}{r}6,250 \\
13,020 \\
1,360 \\
5,621 \\
0 \\
0 \\
314 \\
15,661 \\
0 \\
42,226\end{array}$ & $\begin{array}{l}0 \\
0 \\
0 \\
0 \\
0 \\
0 \\
0 \\
0 \\
0 \\
0\end{array}$ & $\begin{array}{r}13,549 \\
49,689 \\
2,421 \\
3,294 \\
0 \\
0 \\
0 \\
5,013 \\
28,465 \\
18 \\
102,448\end{array}$ & $\begin{array}{l}0 \\
0 \\
0 \\
0 \\
0 \\
0 \\
0 \\
0 \\
0 \\
0\end{array}$ & $\begin{array}{l}0 \\
0 \\
0 \\
0 \\
0 \\
0 \\
0 \\
0 \\
0 \\
0\end{array}$ \\
\hline 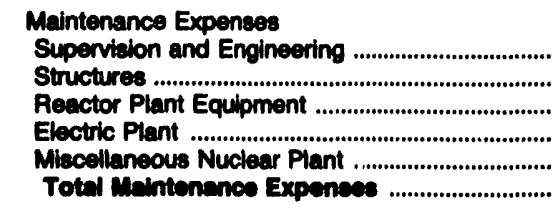 & $\begin{array}{l}0 \\
0 \\
0 \\
0 \\
0 \\
0\end{array}$ & $\begin{array}{r}2,624 \\
1,778 \\
7,525 \\
1,658 \\
1,056 \\
14,641\end{array}$ & $\begin{array}{l}0 \\
0 \\
0 \\
0 \\
0 \\
0\end{array}$ & $\begin{array}{r}6,305 \\
4,699 \\
16,977 \\
6,511 \\
6,008 \\
40,600\end{array}$ & $\begin{array}{l}0 \\
0 \\
0 \\
0 \\
0 \\
0\end{array}$ & $\begin{array}{l}0 \\
0 \\
0 \\
0 \\
0 \\
0\end{array}$ \\
\hline 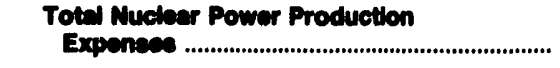 & 0 & 85,e67 & 0 & 142,040 & 0 & 0 \\
\hline 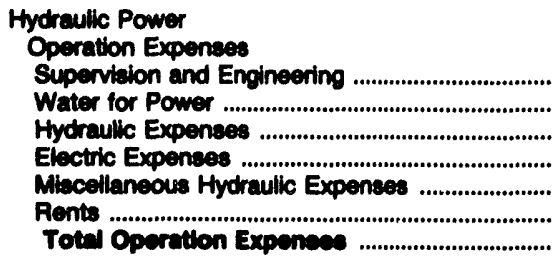 & $\begin{array}{r}40 \\
110 \\
16 \\
194 \\
103 \\
0 \\
403\end{array}$ & $\begin{array}{l}0 \\
0 \\
0 \\
0 \\
0 \\
0 \\
0\end{array}$ & $\begin{array}{l}0 \\
0 \\
0 \\
0 \\
0 \\
0 \\
0\end{array}$ & $\begin{array}{r}402 \\
274 \\
287 \\
2,031 \\
1,011 \\
1 \\
4,006\end{array}$ & $\begin{array}{l}0 \\
0 \\
0 \\
0 \\
0 \\
0 \\
0\end{array}$ & $\begin{array}{r}981 \\
599 \\
318 \\
1,028 \\
472 \\
11,910 \\
15,307\end{array}$ \\
\hline
\end{tabular}

See endinotes at end of an individual electric utillty. 
Table 41. Electric Operation and Maintenance Expenses by Major U.S. Investor-Owned Electric Utility Within State, 1992 (Continued)

(Thousand Dollars)

\begin{tabular}{|c|c|c|c|c|c|c|}
\hline Item & $\begin{array}{l}\text { Mlasouri } \\
\text { Empire } \\
\text { District } \\
\text { Electric Co }\end{array}$ & $\begin{array}{c}\text { Missouri } \\
\text { Kansas City } \\
\text { Power \& Light } \\
\text { Co }\end{array}$ & $\begin{array}{l}\text { Mlasouri } \\
\text { St Joseph } \\
\text { Light } \\
\text { Power Co }\end{array}$ & $\begin{array}{l}\text { Miseouri } \\
\text { Union } \\
\text { Electric Co }\end{array}$ & $\begin{array}{l}\text { Mlasourt } \\
\text { Utilcorp } \\
\text { United Inc }\end{array}$ & $\begin{array}{l}\text { Montana } \\
\text { Montana } \\
\text { Power Co }\end{array}$ \\
\hline
\end{tabular}

Mosintenance Expenses

Supervition and Enoineering

Brnctures

Reacrvoin, Dams and Watenueys

Electric Plant

Miscellaneous Hydraulic Piant

Tot- in rintenenos Expenses

Totel Ifydrestie Power

Production Expense.

580

49

24

11

28

17

Other Power

Operation Expenses

Supervision and Engineering

Fuel

Genoration Expenses

Misceltaneous Other Power Expenses

Rents .........................................

Tetal Cperation Expenses ................................

Maintenance Expenses

Supervition and Enoineering

Structures ......................

Generating and Electric Plant

Mlscellaneous Other Power Plant

Total Melntenence Expenses

Total Other Power Production

Expeneece.

Other Power Supply Expenses

Purchased Power

Syatem Control and

Other Expenses

Totel Other Power supply

Expenese

Totel Power Production Expenees

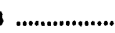

Transmisalon

Operation Expenses

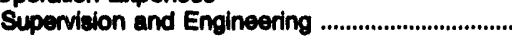

Load Diapatching

Station Expenses

Overhead Line Expenses

Undercround Line Expenses ...................................

Transmiseion of Electricity by Others

Miscollaneous Tranemiseion Expenees

Rents

Totw Operration Expenses

658

44
243
126
34
2
440

64

117
119

28

0
349

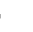

0

7,002

479
363
1,175
528
582
$\mathbf{3}, 076$

0
0
0
0
0
0

172

1,112

103
2,077

49

340

$\begin{array}{rr}62 & 84 \\ 0 & 41 \\ 135 & 286 \\ 10 & 0 \\ 208 & 412\end{array}$

6
0
82
4
102

11

38

957

1,013

760

416

1,610

4,700

01

$\begin{array}{rr}22,533 & 21,868 \\ 510 & 1,496 \\ 29 & 2,799\end{array}$

7,863

125

119,310

1,955

5,628

92,461
938

85,332

a., 189

8,002

128,003

89,402

07,260

69,287

203,430

25,942

717,028

190,411

222,419

$\begin{array}{rrrrrr}319 & 730 & 206 & 57 & 147 & 1,136 \\ 277 & 607 & 134 & 1,608 & 667 & 410 \\ 301 & 152 & 96 & 647 & 395 & 199 \\ 46 & 69 & 12 & 52 & 143 & 442 \\ 0 & 22 & 0 & 0 & 1 & 0 \\ 1,285 & 277 & 38 & 581 & 1,733 & 8,748 \\ 6 & -84 & 55 & 382 & 66 & 41 \\ 53 & 2,391 & 239 & 858 & 75 & 4,941 \\ 2,206 & 4,194 & 779 & 4,186 & 3,227 & 15,017\end{array}$

See endnotes at end of an indlividual electric utility. 
Table 41. Electric Operation and Maintenance Expences by Major

U.S. Investor-Owned Electrlc Utility Within State, 1902 (Continued) (Thousand Dollars)

\begin{tabular}{|c|c|c|c|c|c|c|}
\hline Item & $\begin{array}{l}\text { Mbecourt } \\
\text { Empire } \\
\text { Diotrict } \\
\text { Electric Co }\end{array}$ & $\begin{array}{c}\text { Milacouri } \\
\text { Kaneas City } \\
\text { Pawer \& Light } \\
\text { Co }\end{array}$ & $\begin{array}{l}\text { Missount } \\
\text { St Joeseph } \\
\text { Loht } \\
\text { Power Co }\end{array}$ & $\begin{array}{l}\text { Miseourt } \\
\text { Union } \\
\text { Electric Co }\end{array}$ & $\begin{array}{l}\text { Miseourl } \\
\text { Utillcorp } \\
\text { United inc }\end{array}$ & $\begin{array}{l}\text { Montana } \\
\text { Montana } \\
\text { Power Co }\end{array}$ \\
\hline
\end{tabular}

Meintenance Expenses

Supervition and Encineering

Sinctures

Overhead Lineo ....

Totel Meloutenes Tranemision Plant.

Totel Trancmiacion Expences .........................

Diatribution

Operation Expenses

Supervition and Engineering .................................

Loed Diepatching

Stution Expenses

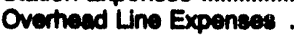

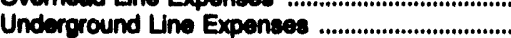

Street Liphting and Signal Syatem Expenses ...

Meter Expenses .......................................................

Miscellaneous Distribution Expenses

Rents

Totw Operation Exponses
Station Equipment

Underground Line:

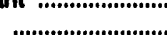

$\begin{array}{rr}246 & 88 \\ 5 & 2 \\ 375 & 803 \\ 214 & 1,250 \\ 0 & 107 \\ 0 & 0 \\ 240 & 2,280\end{array}$

3,120

6,422

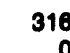

0
275
172

1,172
140

140
89

1,124

143

430

3,698

Maintenance Expenses

Supervision and Engineering

Structures

Station Equipment

Overhead Lines

Underground Lines

Une Transtormers

Metere

Miecellaneous Diatribution Plant

Total Malntenanes Expenses

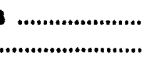

(n)

Toty Dietribution Expenace

Customer Accounts Expenses

Supervision ...

Meter Reading lixpenses ..........................................

Customer Records and Collection Expenses ...

Uncollectlble Accounts

Miscellaneous Customer Accounts Expenses ..

Totel Customer Acoounts Expenese .............

Customer Service and Information Expenses

Supervision

Customer Asciatance Expenses

Informational and Instructional Expenses ............

Mhocellaneous Customer Service

and Informational Expenses

Totel Customer senioe and

informationd Expences

(n).....

Sales Expenser

Supenvidion ...........................................................

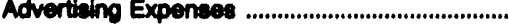

Miecellaneous Sales Expenses

Totel Eates Expensece

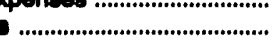

272
287

755

2,717

163

129

4,031

$\begin{array}{rr}247 & 541 \\ 627 & 3,417 \\ 170 & 1,134 \\ 11 & 0 \\ 1,056 & 5,091 \\ & \\ 120 & 191 \\ 449 & 198 \\ 0 & 170 \\ 81 & 1,110 \\ 440 & 1,694\end{array}$

207

3,111

10,378

2,464

16,100

49
0
587
92
0
9
797

148

49
1,673

2,560

1
4.490

0,615

156
18
558
1,184
0
7
1,932

268

708

1,875

0
0

2,051

8,180

18,708

2,918

465

4,709

4,708

1,125

760

3,174

2,044

5,300

148

26,42

$\begin{array}{rr}1,340 & 1,635 \\ 2 & 0 \\ 319 & 366 \\ 869 & 1,677 \\ 647 & 603 \\ 373 & 414 \\ 1,845 & 1,099 \\ 401 & 1,604 \\ 1,341 & 1,085 \\ 161 & 84 \\ 7,309 & 0,437\end{array}$

3,424

450

8,003

32,214

4,191

1,744

1,680

657

108

62,400

891

104
1,101

1,101
7,463

7,463
487

285

305

297

182

11,126

77,00

18,524

18,000

8,641

21,111

10,636

888

42,397

1,273

2,700

6,388

768

608
11,708

491

2,259

2,155

414

6,320

40

551

2,685

53

163
3,462
172

2,105

4,688

780

51
7,800

185
1,413

1,413

14

1,808

See endnotes at end of an individual electric utility. 
Table 41. Electrlc Operation and Malntenance Expenses by Major U.S. Investor-Owned Eloctric Utillty Within State, 1992 (Continued) (Thousand Dollars)

\begin{tabular}{|c|c|c|c|c|c|c|}
\hline ltem & $\begin{array}{l}\text { Missouri } \\
\text { Empire } \\
\text { District } \\
\text { Electric Co }\end{array}$ & $\begin{array}{l}\text { Miseourl } \\
\text { Kansas City } \\
\text { Power } 8 \text { Light } \\
\text { Co }\end{array}$ & $\begin{array}{l}\text { Miseour } \\
\text { St Joseph } \\
\text { Light } \\
\text { Power Co }\end{array}$ & $\begin{array}{l}\text { Miseouri } \\
\text { Union } \\
\text { Electiric Co }\end{array}$ & $\begin{array}{l}\text { Mlesouri } \\
\text { UtilCorp } \\
\text { United Inc }\end{array}$ & $\begin{array}{l}\text { Montana } \\
\text { Montana } \\
\text { Power Co }\end{array}$ \\
\hline
\end{tabular}

\begin{tabular}{|c|c|c|c|c|c|c|}
\hline 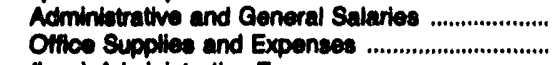 & $\begin{array}{l}2,808 \\
1,323\end{array}$ & $\begin{array}{r}25,094 \\
6,827\end{array}$ & $\begin{array}{r}2,668 \\
799\end{array}$ & $\begin{array}{l}26,349 \\
10,811\end{array}$ & $\begin{array}{r}13,475 \\
4,241\end{array}$ & $\begin{array}{r}12,332 \\
3,280\end{array}$ \\
\hline 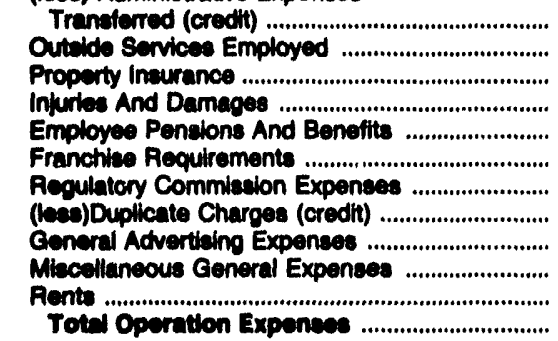 & $\begin{array}{r}386 \\
885 \\
453 \\
408 \\
2,911 \\
2,275 \\
268 \\
2,364 \\
27 \\
1,600 \\
147 \\
10,318\end{array}$ & $\begin{array}{r}1,936 \\
4,034 \\
3,175 \\
3,883 \\
18,871 \\
0 \\
1,104 \\
0 \\
181 \\
6,787 \\
6,846 \\
74,807\end{array}$ & $\begin{array}{r}160 \\
322 \\
391 \\
649 \\
891 \\
0 \\
87 \\
127 \\
6 \\
806 \\
228 \\
6,465\end{array}$ & $\begin{array}{r}168 \\
2,807 \\
9,138 \\
8,257 \\
52,528 \\
11 \\
8,932 \\
46 \\
462 \\
12,752 \\
462 \\
130,305\end{array}$ & $\begin{array}{r}2,644 \\
2,911 \\
508 \\
848 \\
7,379 \\
9 \\
1,166 \\
379 \\
191 \\
4,043 \\
1,528 \\
33,276\end{array}$ & $\begin{array}{r}6,207 \\
914 \\
640 \\
3,632 \\
10,040 \\
0 \\
1,043 \\
0 \\
3 \\
3,809 \\
349 \\
29,814\end{array}$ \\
\hline 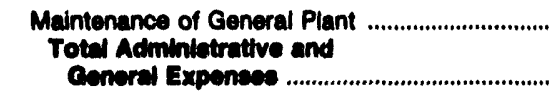 & $\begin{array}{r}278 \\
10,598\end{array}$ & $\begin{array}{r}3,099 \\
77,908\end{array}$ & $\begin{array}{r}361 \\
6,806\end{array}$ & $\begin{array}{r}4,889 \\
136,294\end{array}$ & $\begin{array}{r}1,889 \\
36,186\end{array}$ & $\begin{array}{r}1,824 \\
31,730\end{array}$ \\
\hline $\begin{array}{l}\text { Totel Electite Operatton and } \\
\text { Melntenance Expenese }\end{array}$ & 80,010 & 400,032 & 40,404 & 900,901 & 271,502 & 300,700 \\
\hline \multicolumn{7}{|l|}{$\begin{array}{l}\text { Distribution of Salaries and } \\
\text { Wages Charged to Electric } \\
\text { Operation and Maintenance }\end{array}$} \\
\hline 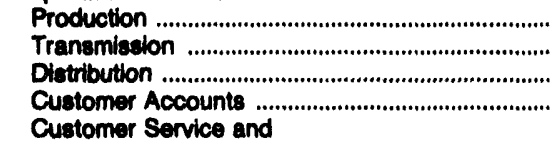 & $\begin{array}{l}6,273 \\
1,377 \\
4,645 \\
2,315\end{array}$ & $\begin{array}{r}53,319 \\
1,441 \\
17,531 \\
8,170\end{array}$ & $\begin{array}{r}4,340 \\
588 \\
2,121 \\
843\end{array}$ & $\begin{array}{r}126,180 \\
3,863 \\
45,587 \\
24,623\end{array}$ & $\begin{array}{l}8,034 \\
1,318 \\
9,542 \\
7,558\end{array}$ & $\begin{array}{r}17,655 \\
2,655 \\
8,492 \\
4,832\end{array}$ \\
\hline 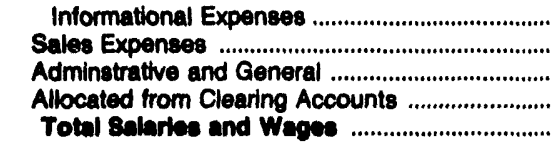 & $\begin{array}{r}663 \\
471 \\
3,052 \\
1,577 \\
20,374\end{array}$ & $\begin{array}{r}2,011 \\
655 \\
26,230 \\
7,489 \\
116,847\end{array}$ & $\begin{array}{r}396 \\
98 \\
2,701 \\
498 \\
11,685\end{array}$ & $\begin{array}{r}2,608 \\
2,798 \\
33,368 \\
9,325 \\
249,482\end{array}$ & $\begin{array}{r}414 \\
344 \\
9,686 \\
5,978 \\
42,974\end{array}$ & $\begin{array}{r}1,364 \\
837 \\
14,886 \\
1,131 \\
52,853\end{array}$ \\
\hline $\begin{array}{l}\text { Number of Electric Department Employees } \\
\text { Regular Full-time Employees ............................... } \\
\text { Part-time and Temporary Employees .................. }\end{array}$ & $\begin{array}{r}651 \\
29\end{array}$ & $\begin{array}{r}3,149 \\
32\end{array}$ & $\begin{array}{r}341 \\
5\end{array}$ & $\begin{array}{r}6,245 \\
20\end{array}$ & $\begin{array}{r}1,485 \\
26\end{array}$ & $\begin{array}{r}1,821 \\
0\end{array}$ \\
\hline Total Electric Departiment Employeee .......... & 680 & 3,181 & 348 & 6,285 & 1,511 & 1,021 \\
\hline
\end{tabular}

Note: Totals may not equal sum of componente because of independent rounding. Summary data are provided in Table 11.

Source: Federal Energy Regulatory Commission, FERC Form 1, "Annual Report of Major Electric Utilities, Licensees and Others." 
Table 41. Electric Operation and Malntenance Expenses by Major U.S. Investor-Owned Electric Utility Within State, 1992 (Continued) (Thousand Dollars)

\begin{tabular}{|c|c|c|c|c|c|c|}
\hline Item & $\begin{array}{l}\text { Nevada } \\
\text { Nevada } \\
\text { Power Co }\end{array}$ & $\begin{array}{c}\text { Nevada } \\
\text { Slerra } \\
\text { Paclfic } \\
\text { Power Co }\end{array}$ & \begin{tabular}{|c|} 
Now Hampshire \\
Great \\
Bay \\
Power \\
Corp
\end{tabular} & $\begin{array}{c}\text { New Hampshire } \\
\text { New England } \\
\text { Elec } \\
\text { Transmn } \\
\text { Corp }\end{array}$ & \begin{tabular}{|c|} 
New Hampshire \\
Now England \\
Hydro- \\
Trans \\
Corp
\end{tabular} & $\begin{array}{c}\text { Now Hampehire } \\
\text { North } \\
\text { Atlantic } \\
\text { Energy Corp }\end{array}$ \\
\hline
\end{tabular}

Power Production Expenses

Steam Power

Operation Expenses

Supervision and Engineering

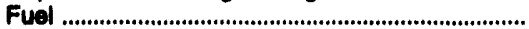

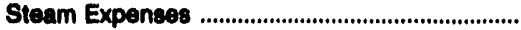

Steam from Other Sources

(leas) Steam Transterred (credit)

Electric Expenseg

Miscellaneous Steam Power Expenses ...............

Rente

Total Operation Expenses

$\begin{array}{rr}2,210 & 886 \\ 91,910 & 78,043 \\ 5,291 & 3,186 \\ 0 & 0 \\ 0 & 0 \\ 5,625 & 2,537 \\ 3,856 & 2,138 \\ 59 & 29 \\ 100,050 & 89,031\end{array}$

Maintenance Expenses

Supervision and Engineering

Structures .

Boiler Plant .

Electric Piant ..........

Miscellaneous Steam Plant

Total Maintenance Expenses

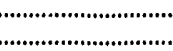

Total steam Power Production

Exponese

$\bullet 2,390$

225

322

3,318

1,285

408

4,857

2,929
28,390

5,560

0

Nuclear Power

Operation Expenses

Supervision and Engineering

Fuel

Coolants and Water

Steam Expenses

Steam from Other Sources

(lese) Steam Transferred (credit)

Electric Expenses

Miscellaneous Nuclear Power Expenses ............

Rents

Total Operation Expenese

Maintenance Expenses

Supervision and Engineering

Structures

Reactor Plant Equipment .

Electric Plant

Miscellaneous Nuclear Plant

Total Malntenance Expenses

Total Nuclear Power Production

Exponces

2,365
6,735
65
1,825
0
0
47
4,830
0
15,868

4,435

1,688

117

3,690

0
0
78

7,807

0
7,815

0

0

869

608

1,187

882

1,106

4,653

1,578

1,130

2,864

1,670

2,131

9,373

Hydraulic Power

Operation Expenses

Supervision and Engineering

Water for Power

Hydraulic Expenses

Electric Expenses

Rents

Total Operation Exponese

88

20,519

0

27,188

See endnotes at end of an individual electric utility. 
Table 41. Electric Operatlon and Maintenance Expenses by Major

U.S. Investor-Owned Electric Utility Within State, 1992 (Continued)

(Thousand Dollars)

\begin{tabular}{|c|c|c|c|c|c|c|}
\hline Item & $\begin{array}{l}\text { Nevada } \\
\text { Nevada } \\
\text { Power Co }\end{array}$ & $\begin{array}{l}\text { Nevada } \\
\text { Slerra } \\
\text { Paciflo } \\
\text { Power Co }\end{array}$ & \begin{tabular}{|c|} 
Now Hampenire \\
Great \\
Bay \\
Power \\
Corp
\end{tabular} & $\begin{array}{c}\text { New Hampehire } \\
\text { New England } \\
\text { Elec } \\
\text { Transmn } \\
\text { Corp }\end{array}$ & $\begin{array}{l}\text { Now Hampehire } \\
\text { Now England } \\
\text { Hydro- } \\
\text { Trans } \\
\text { Corp }\end{array}$ & $\begin{array}{c}\text { Now Hampshire } \\
\text { North } \\
\text { Atlantlo } \\
\text { Energy Corp }\end{array}$ \\
\hline
\end{tabular}

Maintenance Expenses

Supervition and Engineering

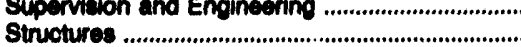

Pecervoirs, Dams and Waterways

Electric Plant

Miscollaneous Hydraulic Plant

Toted Maintenance Expenses

Totel Hydreullo Power

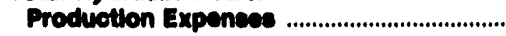

33
30
97
263
1
424

0
0
0
0
0
0

$\begin{array}{ll}0 & 0 \\ 0 & 0 \\ 0 & 0 \\ 0 & 0 \\ 0 & 0 \\ 0 & 0\end{array}$

$\mathbf{0}$

680

$\mathbf{0}$

0

$\mathbf{0}$

Other Power

Operation Expenses

Supervition and Engineering .................................

Fuel

140

4,653

324

Generation Expenses

Miscellarieous Other Power Expenses .................

Rents

Totel Operation Expenses

.

0
5,206

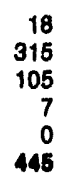

138
6
1,305

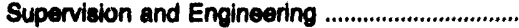

Structures

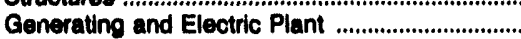

Miscellaneous Other Power Plant

Total Malntenance Exponses

1,305
0

1,460

0
303

1

334

6,686

779

200,353

Purchased Power

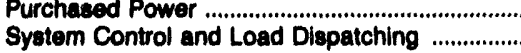

Other Expenses

Total Other Power 8upply

Expenses

ply

0
$-12,834$

100,783

1,942

187,618

80,095

329,405

183,835

20,535

0

o

27,188

Transmission

Operation Expenses

Supervision and Engineering .................................

Load Dispatching

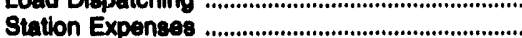

Overhead Line Expenses ..........................

Underground Line Expenses

of Electricty by Others

Miscellaneous Tranamiseion Expenses ................

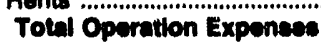

\begin{tabular}{|c|c|c|c|c|c|}
\hline $\begin{array}{r}564 \\
971 \\
733 \\
38 \\
0 \\
1,273 \\
117 \\
160\end{array}$ & $\begin{array}{r}318 \\
146 \\
446 \\
132 \\
0 \\
1,952 \\
97 \\
63\end{array}$ & $\begin{array}{r}0 \\
0 \\
0 \\
0 \\
0 \\
-40 \\
0 \\
926\end{array}$ & $\begin{array}{r}3 \\
0 \\
462 \\
28 \\
0 \\
0 \\
33 \\
43\end{array}$ & $\begin{array}{r}7 \\
0 \\
19 \\
5,327 \\
0 \\
0 \\
14 \\
3,863\end{array}$ & $\begin{array}{r}0 \\
0 \\
0 \\
0 \\
0 \\
1,686 \\
0 \\
0\end{array}$ \\
\hline 3,858 & 3,155 & 896 & 560 & 9,230 & 1,698 \\
\hline
\end{tabular}

Soe endnotes at end of an indlvidual electric utility. 
Table 41. Electric Operation and Maintenance Expenses by Major U.S. Investor-Owned Electrlc Utility Within State, 1992 (Continued) (Thousand Dollars)

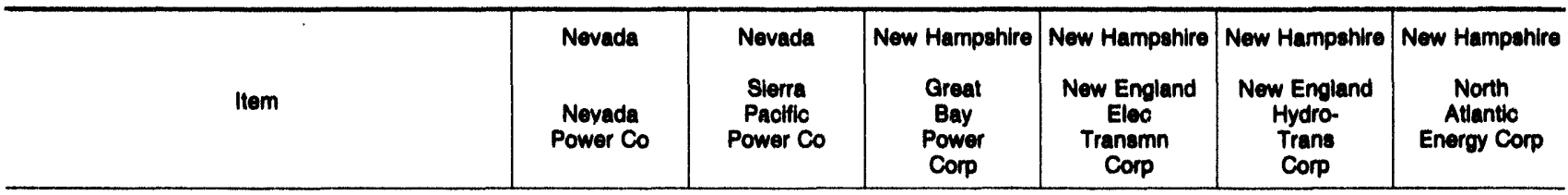

Maintenance Expenses

Supervision and Engineering

Structures

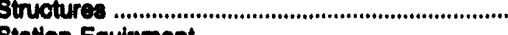

Overhead Lines

Underoround Lines ..............

Miscellaneous Transmiseion Piant

Total Melntenance Expenses ............................

Total Tranemiacion Expenses

\section{9}

188

909

381

15

1,712

5,568

Distribution

Operation Expenses

Supervision and Engineering

Load Dlepatching

Station Expenses

Overhead Line Expenses

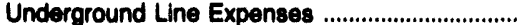

Street Lighting and Signal System Expenses ....

Meter Expenses

Customer Installations Expenses ........................

Miacellaneous Distribution Expenses ....................

Rents .

Total Operation Expensese

438

804

173

779

608

2,851

1,040

1,210

23

8,031

Maintenance Expenses

Supervision and Engineering

Structures

Station Equipment

Overhead Lines

Underground Lines

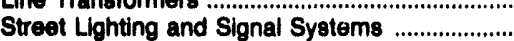

Moters

Miacellaneous Distribution Plant

Total Malntenance Expenees

Total Distribution Expenees

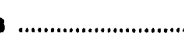

Customer Accounts Expenses

Supervision

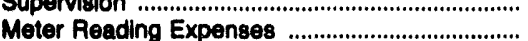

Customer Records and Collection Expenses ....

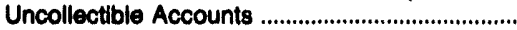

Miscellaneous Customer Accounts Expenses ...

Total Customer Accounte Expenses

Customer Service and Information Expenses

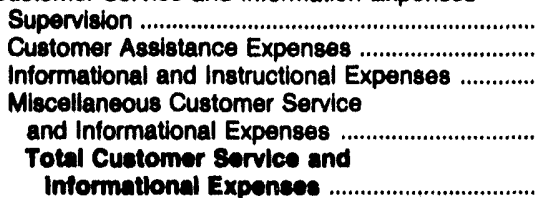

Informational Expenese

Sales Expenses

Supervision

Demonstrating and Selling Expenses

Advertising Expenses

Miscellaneous Sales Expenses

Total 8ales Expenese

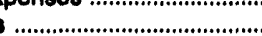

See endnotes at end of an individual electric utility.

15
0
630
822
0
0
1,487

4,822

1,979

0
1,132

1,585

1,284

97

1,208

548

2,022

414

10,280

316

868

2,130

1,722

525

21

382

24
6,087

14,118

501

0
362

2,739

836

220

119

106

128

5,008

15,278

111

1,658

11,152

2,068

0
14,989

750

1,899

5,448

879

8,078

$\begin{array}{rr}0 & 2,603 \\ 2,225 & 1,340 \\ 765 & 220\end{array}$

358

125

3,348

4,289

0
1,118
0
0
1,118
32
0
346
29
0
0
407

976

$\begin{array}{rr}0 & 0 \\ 0 & 0 \\ 42 & 38 \\ 29 & 0 \\ 0 & 0 \\ 0 & 0 \\ 72 & 3\end{array}$

9,802

1,735 
Table 41. Electrle Oporation and Malntenance Exponses by Major U.8. Investor-Owned Eloctric Utility Within 8tate, 1092 (Continued) (Thousand Dollars)

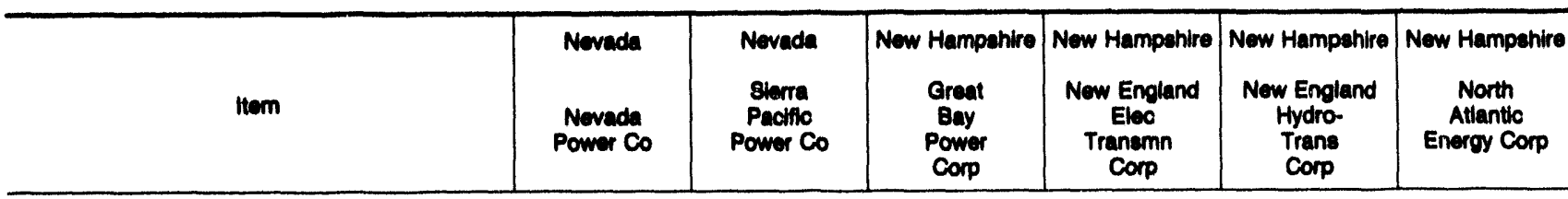

Adminibtrative and Ceneral Expenses

Operation Expeneev

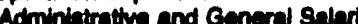

Olive Suppines and Expentses

(bee) Administrative Expenseses

Tranterned (credili) ...........

Outeide Services Employed

Property inverences

In'viles And Damese.

Employec Pendions And Benefits

Franchise Requirements

Reculatory Commiasion Expenses

(isas)Duplicate Charges (crecili)

General Advertieing Expenese ................................

Miscellancous Ceneral Expenses

Pent ....u.

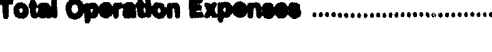

Maintenance of General Plant

Totel Adininiatrattre and

Cenerd Expenses

$\begin{array}{rr}12,173 & 11,079 \\ 6,930 & 2,162 \\ 1,864 & 4,424 \\ 1,655 & 825 \\ 1,099 & 737 \\ 3,511 & 3,249 \\ 13,042 & 8,868 \\ 0 & 0 \\ 374 & 1,631 \\ 1,104 & 0 \\ 12 & 0 \\ 3,794 & 5,569 \\ 3,740 & 5,239 \\ 1,181 & 28,059\end{array}$

837
329
49
2,257
691
602
1,484
0
682
0
48
217
0
7,077

0
100
-40
71
57
86
71
0
21
0
0
0
10
405

$\begin{array}{rr}104 & 1,004 \\ 49 & 608 \\ & \\ 0 & 6 \\ 20 & 535 \\ 1 & 1,263 \\ 184 & 583 \\ 39 & 2,658 \\ 1 & 0 \\ 57 & 1,191 \\ 0 & 0 \\ 0 & 82 \\ 17 & 169 \\ 9 & 3 \\ 481 & 7,090\end{array}$

Total Enetrite Operation end

Mrinticnence Expences

2,302

2,097

49,493

37,169

0

0

7,070

485

0

1

900

284,185

29,522

1,441

9,702

88,912

Distribution of Salaries and

Weges Charged to Electric

Operation and Maintenance

Production

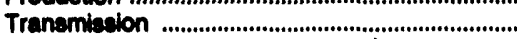

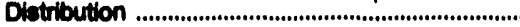

Customer Accounts

Customer Service and

informational Expenses .........................................

Sales Expenses

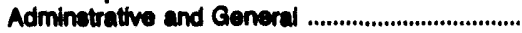

Allocated from Clearing Account .......................

Totel enterios end Wares

17,358

1,800

7,523

5,682

1,022

0
12,097

12,542

60,035

\section{0,378}

1,418

7,744

5,103

2,315

6,670

$\mathbf{4 , 6 5 4}$

1,734

1,409

1,461

1,706

Total Electrie Depertinent Employees .........

Note: Totals may not equal sum of components because of independent rounding. Summary data are provided in Table 11.

Source: Federal Energy Regulatory Commission, FERC Form 1. "Annual Report of Major Electric Utilties, Licensees and Others." 
Table 41. Eleotric Operation and Malntenance Exponses by Major

U.8. Investor-Owned Electric Utility Within 8tate, 1992 (Continued) (Thousand Dollars)

\begin{tabular}{|c|c|c|c|c|c|c|}
\hline Item & $\begin{array}{c}\text { New Hampenire } \\
\text { Public } \\
\text { Service } \\
\text { Co } \\
\text { of NH }\end{array}$ & $\begin{array}{l}\text { New Jereey } \\
\text { Atlantic } \\
\text { City } \\
\text { Electric } \\
\text { Co }\end{array}$ & $\begin{array}{l}\text { Now Jereoy } \\
\text { Jersey } \\
\text { Contral } \\
\text { Powerdulght } \\
\text { Co }\end{array}$ & $\begin{array}{l}\text { Now Jereoy } \\
\text { Publle } \\
\text { Service } \\
\text { Electricalas } \\
\text { Co }\end{array}$ & $\begin{array}{l}\text { New Jarsey } \\
\text { Rockland } \\
\text { Electric Co }\end{array}$ & $\begin{array}{l}\text { Now Moxico } \\
\text { Publlic } \\
\text { Sorvice } \\
\text { Co } \\
\text { of NM }\end{array}$ \\
\hline \multicolumn{7}{|l|}{$\begin{array}{l}\text { Pown Production Expences } \\
\text { Steam Power } \\
\text { Operation Expeneses }\end{array}$} \\
\hline 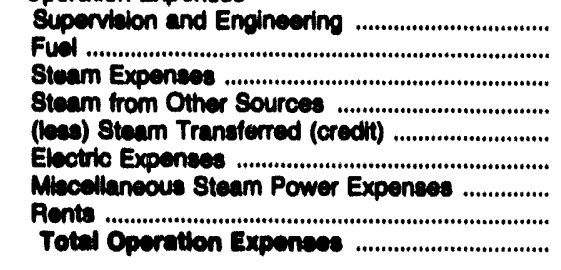 & $\begin{array}{r}3,113 \\
90,205 \\
2,427 \\
0 \\
0 \\
289 \\
3,347 \\
2 \\
20,303\end{array}$ & $\begin{array}{r}6,371 \\
45,101 \\
4,199 \\
0 \\
0 \\
978 \\
5,234 \\
25 \\
61,000\end{array}$ & $\begin{array}{r}1,687 \\
33,860 \\
2,696 \\
0 \\
0 \\
2,074 \\
9,464 \\
68 \\
49,830\end{array}$ & $\begin{array}{r}17,094 \\
270,529 \\
8,982 \\
0 \\
0 \\
4,586 \\
37,762 \\
300 \\
330,252 \\
\end{array}$ & $\begin{array}{l}0 \\
0 \\
0 \\
0 \\
0 \\
0 \\
0 \\
0 \\
0\end{array}$ & $\begin{array}{r}2,278 \\
110,248 \\
4,860 \\
0 \\
0 \\
2,601 \\
2,870 \\
89 \\
122,041\end{array}$ \\
\hline 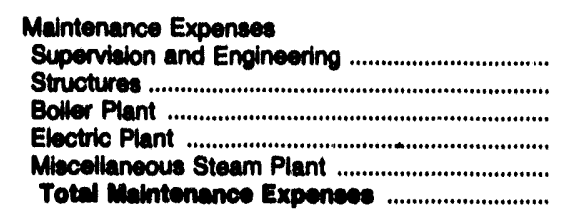 & $\begin{array}{r}2,879 \\
946 \\
9,682 \\
5,973 \\
2,310 \\
21,790\end{array}$ & $\begin{array}{r}1,019 \\
2,444 \\
10,343 \\
4,882 \\
1,132 \\
10,020\end{array}$ & $\begin{array}{r}1,802 \\
1,434 \\
5,170 \\
1,273 \\
1,452 \\
11,130\end{array}$ & $\begin{array}{r}15,955 \\
7,962 \\
53,249 \\
10,404 \\
6,332 \\
93,902\end{array}$ & $\begin{array}{l}0 \\
0 \\
0 \\
0 \\
0 \\
0\end{array}$ & $\begin{array}{r}2,039 \\
1,008 \\
13,152 \\
2,132 \\
2,281 \\
20,612\end{array}$ \\
\hline \multicolumn{5}{|l|}{ Total Steam Power Production } & 0 & 143,463 \\
\hline $\begin{array}{l}\text { Nuclear Power } \\
\text { Operation Expenses }\end{array}$ & & & & & & \\
\hline 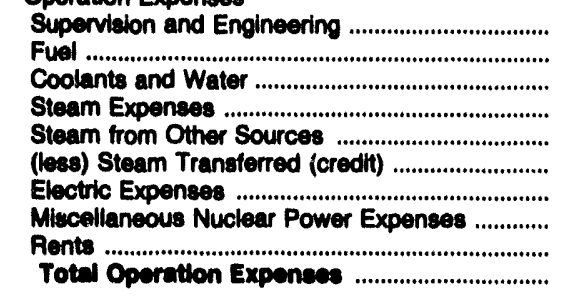 & $\begin{array}{r}3,064 \\
2,493 \\
167 \\
1,713 \\
0 \\
0 \\
112 \\
5,427 \\
54 \\
13,020\end{array}$ & $\begin{array}{r}10,082 \\
14,913 \\
23 \\
3,880 \\
0 \\
0 \\
1,013 \\
17,488 \\
277 \\
47,675\end{array}$ & $\begin{array}{r}26,150 \\
40,581 \\
1,147 \\
31,051 \\
0 \\
0 \\
1,494 \\
20,393 \\
0 \\
120,817\end{array}$ & $\begin{array}{r}53,617 \\
107,265 \\
289 \\
27,928 \\
0 \\
0 \\
7,659 \\
91,055 \\
1,299 \\
289,113\end{array}$ & $\begin{array}{l}0 \\
0 \\
0 \\
0 \\
0 \\
0 \\
0 \\
0 \\
0 \\
0\end{array}$ & $\begin{array}{r}5,462 \\
16,290 \\
1,607 \\
3,656 \\
0 \\
0 \\
1,157 \\
11,977 \\
88,913 \\
128,962\end{array}$ \\
\hline 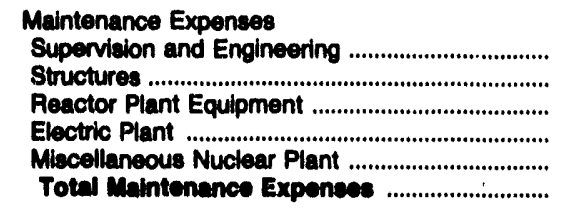 & $\begin{array}{r}\mathbf{9 7 9} \\
\mathbf{6 0 9} \\
\mathbf{3 7 5} \\
\mathbf{6 7 0} \\
\mathbf{6 7 2} \\
\mathbf{3 , 3 0 4}\end{array}$ & $\begin{array}{r}3,490 \\
1,923 \\
7,449 \\
2,669 \\
1,542 \\
17,074\end{array}$ & $\begin{array}{r}8,231 \\
3,150 \\
42,056 \\
10,708 \\
5,079 \\
68,224\end{array}$ & $\begin{array}{r}20,822 \\
13,309 \\
52,776 \\
18,783 \\
9,278 \\
114,968\end{array}$ & $\begin{array}{l}0 \\
0 \\
0 \\
0 \\
0 \\
0\end{array}$ & $\begin{array}{r}3,650 \\
2,078 \\
3,713 \\
2,350 \\
1,827 \\
13,617\end{array}$ \\
\hline 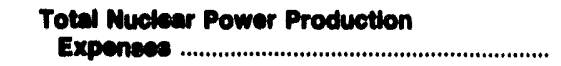 & 16,324 & 64,740 & 190,041 & 404,081 & 0 & 142,579 \\
\hline
\end{tabular}

Hydraulic Power

Operation Expenses

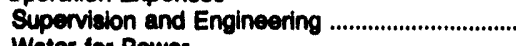

Water for Power.

Hydraulic Expenses

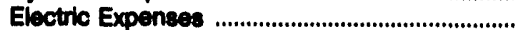

Miscellaneous Hydraullc Expenses

Rents

Total Operation Expenses

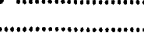

See endnotes at end of an individual electric utility

$\begin{array}{rrrrll}153 & 0 & 40 & 47 & 0 & 0 \\ 122 & 0 & 0 & 0 & 0 & 0 \\ 102 & 0 & 17 & 22 & 0 & 0 \\ 132 & 0 & 5 & 6 & 0 & 0 \\ 937 & 0 & 138 & 178 & 0 & 0 \\ 0 & 0 & 0 & 14 & 0 & 0 \\ 1,446 & 0 & 200 & 287 & 0 & 0\end{array}$


Table 41. Electric Operation and Maintenance Expenses by Major

U.8. Investor-Owned Electric Utility Within 8tate, 1992 (Continued)

(Thousand Dollars)

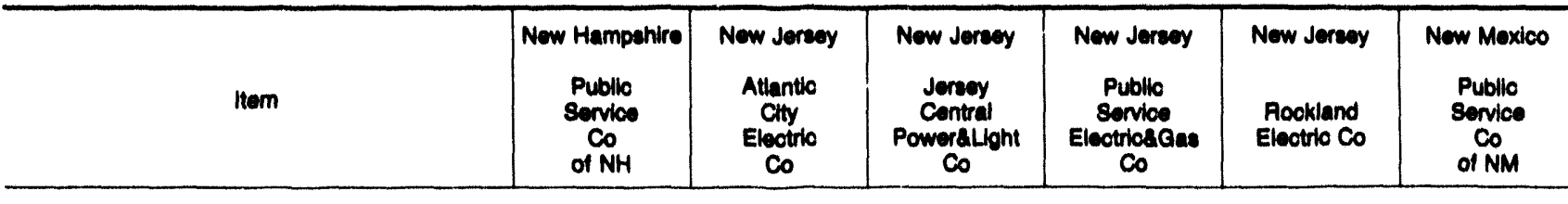

Maintenance Expenses

Supervition and Engineering

Structures

Reservoirs, Dams and Waterways

Electric Plant

Miscellinneous Hyorraulic Piant

Total Melntenanos Expenses

Totel Hydraulic Power

Production Exponses

Other Power

Operation Expenses

Supervision and Engineering

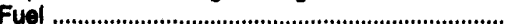

Generation Expenses ..............................................

Miscellaneous Other Power Expenses

Rents

Total Operation Expenses
164

210

193

344

1,201

2,737

0

413

10,410

1,822

2,542

2,800

17,900

82

7
36
457

82

94

4$$
17.92
$$

498

1,392

4,834

609
7,432

20
1,208

13,694

25,429

30,147

553
12,157

2,157

13,18 .

374

270,263
2,401
258
272,921

193,579

1,329

$-3,618$

191,280

640,699

5,725

387,042

8,532

2,303

849,850

397,077

$1,268,134$

67,069

338,131
351,400

$\bullet 2 ., 043$

$\begin{array}{ll}0 & 0 \\ 0 & 0 \\ 0 & 0 \\ 0 & 0 \\ 0 & 0 \\ 0 & 0\end{array}$

o

$\begin{array}{rr}67,069 & 50,774 \\ 0 & 1,289 \\ 0 & 0 \\ 67,000 & 52,063\end{array}$

....................

Transmisaion

Operation Expenses

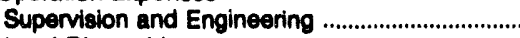

Load Dispatching

Station Expenses

Overhead Line Expenses.

Underground Line Expenses

of Eleciricity by Others

Miecelleneous Transmiseion Expenses

Rents

Total Operation Expenses

\begin{tabular}{|c|c|c|c|}
\hline $\begin{array}{r}357 \\
0 \\
405 \\
212 \\
1 \\
927 \\
216 \\
14,496\end{array}$ & $\begin{array}{r}1,645 \\
2,488 \\
1,049 \\
122 \\
0 \\
1,869 \\
863 \\
151\end{array}$ & $\begin{array}{r}1,099 \\
2,921 \\
1,997 \\
567 \\
5 \\
4,418 \\
2,717 \\
8,074\end{array}$ & $\begin{array}{r}4,024 \\
18 \\
2,164 \\
275 \\
22 \\
2,377 \\
654 \\
2,055\end{array}$ \\
\hline 18,613 & 8,287 & 21,700 & 11,680 \\
\hline
\end{tabular}

See endnotes at end of an individual electric utility. 
Table 41. Electrlc Oporation and Malntenance Expenses by Major

U.8. Inveator-Owned Electric Utility Within Stato, 1902 (Continued) (Thousand Dollars)

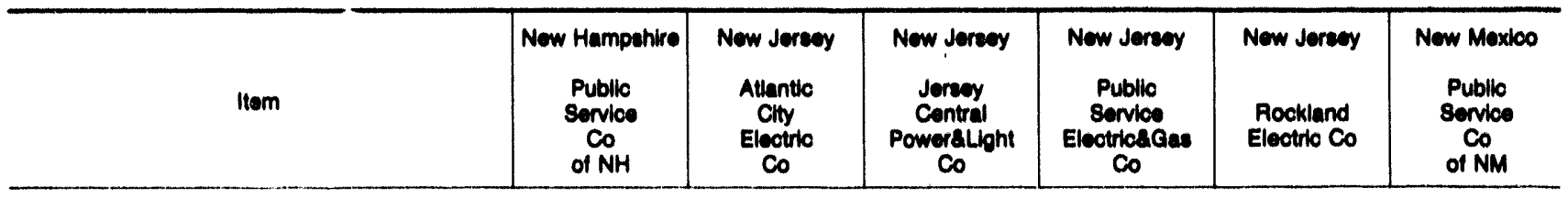

Maintenance Expenses

Supervision and Engineering

Structures

Station Equipment

Overhead Lines ........

Underground Lines

Totel Melntentanes Expenses

Total Tranemlealon Exponees

....................................

Total Tran

Operation Expenses

Supervision and Engineering

Load Dispatching

Station Expenses

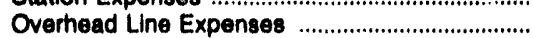

Underground Line Expenses

Street Lighting and Signal System Exr nses ....

Meter Expenses .................................. ...........

Customer Installations Expenses ......... .........

Miscellaneous Distribution Expenses .... .........

Rents

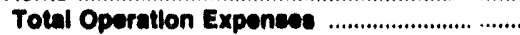

P raintenance Expenses

Supervision and Engineering .............................

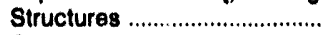

Station Equipment

Overhead Lines

Underground Lines

Line Transformers

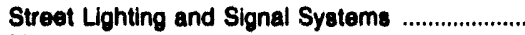

Meters

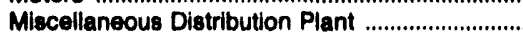

Total Malntenance Exponses

Total Distribution Expenses

..........................

Total Distribution Exponses

Customer Accounts Expenses

Supervision

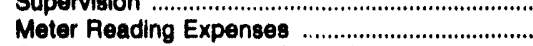

Customer Records and Collection Expenses ....

Uncollectible Accounts ..........................................

Miscellaneous Customer Accounts Expenses ...

Total Customer Accoun is Expenese

808

Customer Service and Information Expenses

Supervision ...

Customer Assistance Expenses .............................

Informational and Instructional Expenses ............

Miscellaneous Customer Service

and informational Expenses .......

Total Customor Eorvice and

Informational Exponses

.

Sales Expense8

Supervision .......

Demonstrating and Selling Expenses

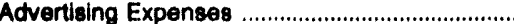

Miecellaneous Sales Expenses ............................

Total Sales Expenese

See endnotes at end of an individual electric utility.

$\begin{array}{rr}414 & 390 \\ 0 & 37 \\ 1,340 & 1,502 \\ 2,342 & 542 \\ 15 & 123 \\ 5 & 64 \\ 4,127 & 2,694\end{array}$

$\begin{array}{rr}274 & 1,368 \\ 2 & 322 \\ 3,977 & 3,463 \\ 1,488 & 2,893 \\ 12 & 27 \\ 5 & 1,040 \\ 8,785 & 9,173\end{array}$

10,082

27,668

20,781

1,137

1,763

2,654

1,384

1,861

1,895

3,681

7,646

4,538

28,690

10,337

3,089

13,043

6,693
3,970
4,744
5,269
2,190
1,166
4,627
2,690
6,796
4,271
42,169

1,081
0

2,785

17,098

4,837

184

340

593

831

27,727

10,712

21,040

20,177

84,287

92,968

7,213
5,012

18,879

6,427

80,670

0
0
468
148
1
0
617

146

1,617

623

3

2,499

16,184

1,411

$\begin{array}{rr}179 & 887 \\ 48 & 0 \\ 80 & 168 \\ 200 & 423 \\ 49 & 382 \\ 1 & 119 \\ 408 & 1,460 \\ 50 & 87 \\ 361 & 2,087 \\ 822 & 149 \\ 2,100 & 6,740\end{array}$

8,740

778

2,409

6,839

3,198

1,162

14,386

0
2,448

2,448
101

23

2,673

611

305

229

1,108
437

0,488

15,697

5,745

1,653

29,009

2,365

13,180

24,304

16,739

1,290

67,004

5,478

5,667

2,989
13,080

13,080

1,325

2,837

14,410

20,811

0,286

.

\section{0}

308
284

55

24

236
0
0
0
238
4,384

4,403
952

1.219

2,181

$\begin{array}{rr}11 & 36 \\ 0 & 22 \\ 328 & 701 \\ 3,843 & 3,073 \\ 398 & 1,262 \\ 1 & 167 \\ 98 & 420 \\ 25 & 335 \\ 0 & 80 \\ 4,600 & 6,097\end{array}$

6,808

11,035

$\begin{array}{rr}122 & 488 \\ 580 & 1,857 \\ 1,785 & 7,320 \\ 252 & 803 \\ 0 & 86 \\ 2,740 & 10,285\end{array}$

86
0,885

221
2,586

16

488

3,20

811

0
83
7
0
80

0
1,729
461
0
2,100 
Table 41. Electrlc Operation and Maintenance Expenses by Major U.8. Invector-Owned Electrlc Utility Within State, 1992 (Continued) (Thousand Dollars)

\begin{tabular}{|c|c|c|c|c|c|c|}
\hline ltem & $\begin{array}{c}\text { Now Hempehire } \\
\text { Public } \\
\text { Servlce } \\
\text { Co } \\
\text { of } \mathrm{NH}\end{array}$ & $\begin{array}{c}\text { Now Jereey } \\
\text { Atiantic } \\
\text { Clty } \\
\text { Electric } \\
\text { Co }\end{array}$ & $\begin{array}{c}\text { New Jersey } \\
\text { Jersey } \\
\text { Central } \\
\text { PowerdLight } \\
\text { Co }\end{array}$ & $\begin{array}{c}\text { New Jersey } \\
\text { Public } \\
\text { Service } \\
\text { ElectricsGas } \\
\text { Co }\end{array}$ & $\begin{array}{l}\text { Now Jersey } \\
\text { Rockland } \\
\text { Electric Co }\end{array}$ & $\begin{array}{c}\text { New Mexico } \\
\text { Public } \\
\text { Service } \\
\text { Co } \\
\text { of NM }\end{array}$ \\
\hline
\end{tabular}

Adminiatrattve and Ceneral Expences

Operation Expenses

Adminiatrative and Ceneral Salarles

Orifoe Supolles and Expenses.

(leas) Adminiatrattve Expenses

Transierred (credit) ...

Outelde Services Employed

Property Inaurance

Reoulatory Commiselon Expenses

(lees)Duplicate Charges (credit)

General Advertiaing Expenses

Maintenance of General Plant
Eranchions And Benefit

eneral Exponses

Total Operation Expensese

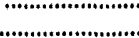

(n)

Total Adminletrattve and

Coneral Expenese

$$
\begin{array}{r}
20,862 \\
4,960 \\
1,247 \\
5,781 \\
1,921 \\
3,675 \\
28,809 \\
81 \\
2,460 \\
656 \\
67 \\
2,092 \\
7,905 \\
77,010
\end{array}
$$

4,860

1,821

656
67

2,092

7,805

1,633

7,643

652,114

Total Ebetrio Operation and

Malntenanos Expenese

16,122
6,606
0
2,975
1,504
3,612
17,779
0
830
974
0
3,485
0
51,941

10,443
11,269
0
0
38,463
5,096
5,768
16,158
0
1,477
0
854
7,572
400
97,498

43,187

29,378

0
1,868

0,831

14,620

80,918

0

4,988

368

$-1,134$

12,838

205,920

2,800

7,126

100,208

213,046

63,100

483,837

$1,164,087$

$1,671,747$

96,157

419,784

Dlstribution of Salaries and

Wages Charged to Electric

Operation and Maintenance

Producth

Transmission

Diatribution

Customer Accoun

Customer Service and

Intormational Expenses

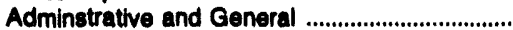

Allocated from Clearing Accounts

Total Ealaries and Woges

Number of Electric Department Employees

Regular Full-time Employees ..................................

Part-time and Temporary Employees ...................

Total Electrle Department Employees .........

$\begin{array}{rr}16,249 & 15,936 \\ 2,097 & 5,203 \\ 13,804 & 12,665 \\ 8,631 & 7,914 \\ & \\ 625 & 2,085 \\ 1,080 & 0 \\ 20,154 & 18,268 \\ 5,832 & 6,572 \\ 88,374 & 68,030\end{array}$

17,521
6,468
28,258
13,811

2,467
181
11,858
5,241
85,804

$$
\begin{array}{r}
204,118 \\
13,146 \\
65,421 \\
34,250 \\
6,182 \\
149 \\
52,502 \\
0 \\
375,748
\end{array}
$$

3,434
9,102
55

9,167

3,452

2,023

1,680

Source: Federal Energy Regulatory Commission, FERC Form 1, "Annual Report of Major Electric Utilities, Licensees and Others." 
Table 41. Electrle Operation and Malntenance Expenees by Major U.S. Inveotor-Owned Eloctric Utility Within State, 1992 (Continued) (Thousand Dollars)

\begin{tabular}{|c|c|c|c|c|c|c|}
\hline Item & $\begin{array}{l}\text { Now York } \\
\text { Contral } \\
\text { Hudson Gas } \\
\text { \& Elec Corp }\end{array}$ & $\begin{array}{l}\text { Now York } \\
\text { Consolldated } \\
\text { Edicon } \\
\text { Co- } \\
\text { NY Ino }\end{array}$ & $\begin{array}{l}\text { Now York } \\
\text { Long } \\
\text { laland } \\
\text { Lighting } \\
\text { Co }\end{array}$ & $\begin{array}{l}\text { Now York } \\
\text { Long } \\
\text { Sault Inc }\end{array}$ & $\begin{array}{l}\text { New York } \\
\text { New York } \\
\text { State Elec } \\
\text { \& Gas Corp }\end{array}$ & $\begin{array}{l}\text { Now York } \\
\text { Nlagara } \\
\text { Mohawk } \\
\text { Power Corp }\end{array}$ \\
\hline 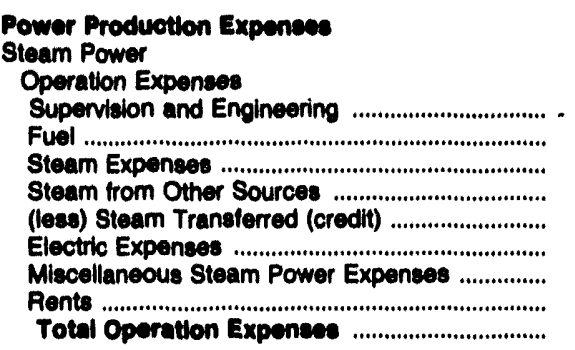 & $\begin{array}{r}1,391 \\
103,644 \\
2,799 \\
0 \\
0 \\
1,017 \\
3,423 \\
1,362 \\
113,037\end{array}$ & $\begin{array}{r}27,870 \\
516,140 \\
25,824 \\
0 \\
8,102 \\
9,098 \\
28,675 \\
2,985 \\
603,260\end{array}$ & $\begin{array}{r}6,662 \\
263,513 \\
8,603 \\
0 \\
0 \\
3,807 \\
15,354 \\
29 \\
207,260\end{array}$ & $\begin{array}{l}0 \\
0 \\
0 \\
0 \\
0 \\
0 \\
0 \\
0 \\
0\end{array}$ & $\begin{array}{r}11,009 \\
267,568 \\
7,666 \\
0 \\
0 \\
4,529 \\
15,957 \\
199 \\
208,028\end{array}$ & $\begin{array}{r}681 \\
286,044 \\
10,052 \\
0 \\
0 \\
6,685 \\
9,784 \\
788 \\
314,014\end{array}$ \\
\hline 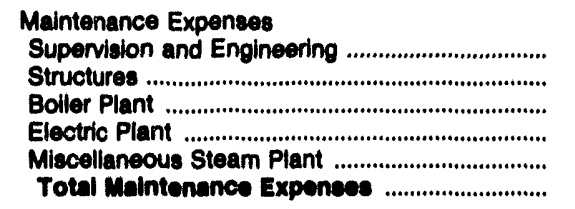 & $\begin{array}{r}800 \\
571 \\
10,557 \\
3,007 \\
428 \\
18,302\end{array}$ & $\begin{array}{r}15,961 \\
18,633 \\
70,270 \\
50,465 \\
9,193 \\
164,622\end{array}$ & $\begin{array}{r}6,473 \\
2,680 \\
9,878 \\
9,194 \\
2,143 \\
30,307\end{array}$ & $\begin{array}{l}0 \\
0 \\
0 \\
0 \\
0 \\
0\end{array}$ & $\begin{array}{r}7,012 \\
2,485 \\
20,174 \\
4,564 \\
2,523 \\
36,758\end{array}$ & $\begin{array}{r}883 \\
2,947 \\
30,212 \\
11,054 \\
2,268 \\
47,384\end{array}$ \\
\hline 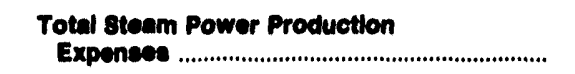 & 128,090 & 767,012 & 326,336 & 0 & 333,686 & 361,378 \\
\hline 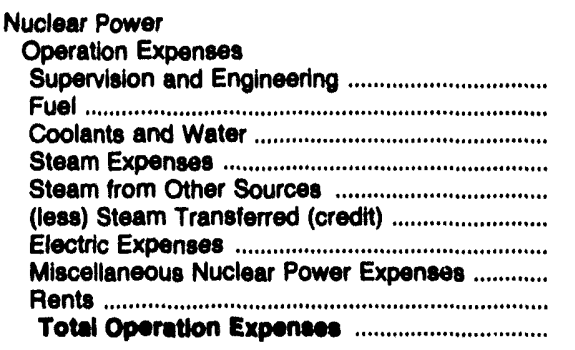 & $\begin{array}{r}2,510 \\
2,081 \\
22 \\
1,688 \\
0 \\
0 \\
91 \\
4,060 \\
280 \\
11,612\end{array}$ & $\begin{array}{r}14,524 \\
37,896 \\
1,038 \\
809 \\
0 \\
0 \\
886 \\
41,576 \\
128 \\
98,858\end{array}$ & $\begin{array}{r}4,526 \\
5,156 \\
44 \\
4,826 \\
0 \\
0 \\
183 \\
4,042 \\
520 \\
19,297\end{array}$ & $\begin{array}{l}0 \\
0 \\
0 \\
0 \\
0 \\
0 \\
0 \\
0 \\
0 \\
0\end{array}$ & $\begin{array}{r}5,686 \\
5,110 \\
44 \\
4,748 \\
0 \\
0 \\
183 \\
11,856 \\
520 \\
28,148\end{array}$ & $\begin{array}{r}28,855 \\
37,096 \\
159 \\
25,268 \\
0 \\
0 \\
0 \\
1,036 \\
33,681 \\
3,588 \\
129,683\end{array}$ \\
\hline 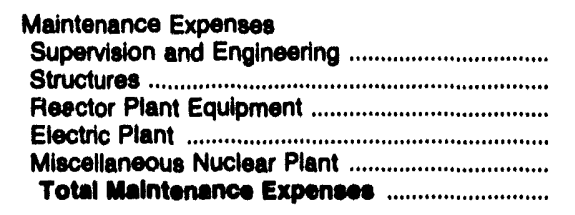 & $\begin{array}{r}120 \\
58 \\
844 \\
84 \\
1,574 \\
2,680\end{array}$ & $\begin{array}{r}15,012 \\
666 \\
8,831 \\
757 \\
3,845 \\
29,100\end{array}$ & $\begin{array}{r}215 \\
115 \\
2,759 \\
1,136 \\
2,934 \\
7,150\end{array}$ & $\begin{array}{l}0 \\
0 \\
0 \\
0 \\
0 \\
0\end{array}$ & $\begin{array}{r}224 \\
115 \\
2,816 \\
1,201 \\
2,844 \\
7,200\end{array}$ & $\begin{array}{r}1,117 \\
663 \\
13,198 \\
4,680 \\
12,236 \\
31,896\end{array}$ \\
\hline $\begin{array}{l}\text { Total Nuclear Power Production } \\
\text { Expensese }\end{array}$ & 14,202 & 126,066 & 26,457 & 0 & 35,348 & 161,550 \\
\hline 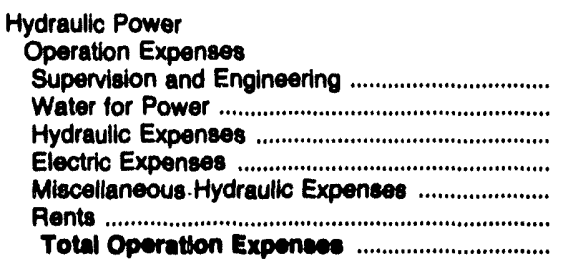 & $\begin{array}{r}72 \\
214 \\
12 \\
169 \\
15 \\
0 \\
403\end{array}$ & $\begin{array}{l}0 \\
0 \\
0 \\
0 \\
0 \\
0 \\
0\end{array}$ & $\begin{array}{l}0 \\
0 \\
0 \\
0 \\
0 \\
0 \\
0\end{array}$ & $\begin{array}{l}0 \\
0 \\
0 \\
0 \\
0 \\
0 \\
0\end{array}$ & $\begin{array}{r}360 \\
1 \\
61 \\
174 \\
163 \\
0 \\
760\end{array}$ & $\begin{array}{r}30 \\
2,430 \\
723 \\
2,155 \\
613 \\
419 \\
6,370\end{array}$ \\
\hline
\end{tabular}

See endnotes at end of an individual electric utility. 
Table 41. Electrlc Operation and Maintenance Expenses by Major U.S. Investor-Owned Electric Utility Within State, 1992 (Continued) (Thousand Dollars)

\begin{tabular}{|c|c|c|c|c|c|c|}
\hline Item & $\begin{array}{c}\text { New York } \\
\text { Central } \\
\text { Hudson Gas } \\
\text { Elec Corp }\end{array}$ & $\begin{array}{l}\text { New York } \\
\text { Consolidated } \\
\text { Edison } \\
\text { Co- } \\
\text { NY Inc }\end{array}$ & $\begin{array}{c}\text { New York } \\
\text { Long } \\
\text { loland } \\
\text { Lighting } \\
\text { Co }\end{array}$ & $\begin{array}{c}\text { Now York } \\
\text { Long } \\
\text { Sault inc }\end{array}$ & $\begin{array}{l}\text { New York } \\
\text { New York } \\
\text { State Elec } \\
\text { \& Gas Corp }\end{array}$ & $\begin{array}{c}\text { Now York } \\
\text { Niagara } \\
\text { Mohawk } \\
\text { Power Corp }\end{array}$ \\
\hline
\end{tabular}

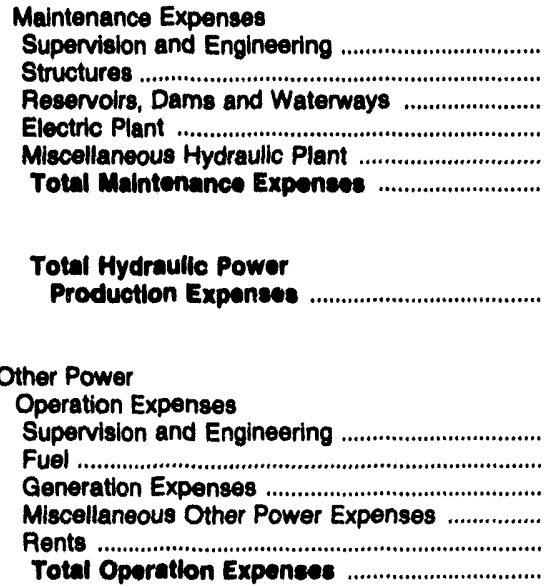

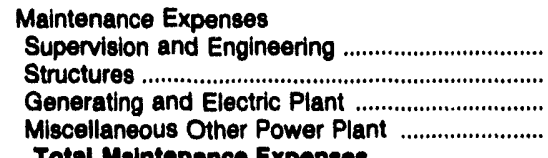

Total Malntenance Expenses

Total Other Power Production

Exponses

Other Power Supply Expenses

Purchased Power

System Control and

Other Expenses

Total Other Powor Supply

Expenses

Total Power Production Expenees

Transmission

Operation Expenses

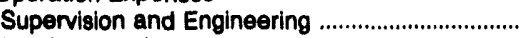

Load Dispatching

Station Expenses .............u.u.u.

Overhead Line Expenses

Underground Line Expenses

Le Electricity by Others

Miscellaneous Transmission Expenses

Rents

Total Operation Exponses

16
47
100
307
49
520

1,002
952

9,313

3,801

209

37
14,411

183

2,092

3,515

12,280

2,131

20,018

254

34,429

12,859

240,602

$-74$

2,911

243,438

618,218

$1,546,416$

611,090

171,022

1,243

7,592

12,909

402

789

3,627

20,689

47,252

2,164

227
1,446

$\mathbf{5 , 7 7 7}$

53,952
0
0
0
0
0
0

0

804

4,304
1,568

843

7,517

1,377
267
3,466
232
5,342

0

0

0

0

1,687

11,218
212

769

2,394

1,017

4,848

0
97
47
3
0
147

490

657,390

$99,563 \quad 657,390$

604
2,566
2,064
520
19
17,932
547
223

365

3,436

5,405

726

362
3,885

1,668

21,409

252

24,475

37,255

See endnotes at end of an individual electric utility. 
Table 41. Electrlc Operation and Maintenance Expenses by Major

U.S. Investor-Owned Electric Utility Within State, 1992 (Continued)

(Thousand Dollars)

\begin{tabular}{|c|c|c|c|c|c|c|}
\hline Item & $\begin{array}{l}\text { Now York } \\
\text { Contral } \\
\text { Hudson Gas } \\
\text { \& Elec Corp }\end{array}$ & $\begin{array}{l}\text { New York } \\
\text { Consolidated } \\
\text { Edison } \\
\text { Co- } \\
\text { NY inc }\end{array}$ & $\begin{array}{c}\text { New York } \\
\text { Long } \\
\text { laland } \\
\text { Lighting } \\
\text { Co }\end{array}$ & $\begin{array}{l}\text { Now York } \\
\text { Long } \\
\text { Sault Inc }\end{array}$ & $\begin{array}{l}\text { Now York } \\
\text { Now York } \\
\text { State Elec } \\
\text { Ges Corp }\end{array}$ & $\begin{array}{l}\text { Now York } \\
\text { Niagara } \\
\text { Mohawk } \\
\text { Power Corp }\end{array}$ \\
\hline
\end{tabular}

Station Equipment
Maintenance Expentes

Supervision and Engineering

Structures

Overhead Lines ......

Miscellaneous Tranemiscion Plant

Totel Melntenence Expenses

Total Tranamielon Exponses

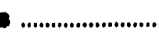

Distribution

Supervision and Engineering ..................................

Load Dispatching

Station Expenses

Overhead Line Expenses

Street Lighting and Signal System Expenses ....

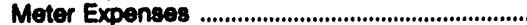

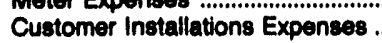

Miscellaneous Distribution Expenses

Rents

Total Operation Expenses
Underground Unes ...................................................

Operation " xpenees

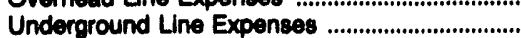

Maintenance Expenses

Supervision and Engineering

Structures ...................

Overhead Lines

Overhead Lines ........

Line Transformers

Street Llght

Meters

Miscellaneous Distribution Plent

Total Malntonance Expeness

(1)

Total Distribution Expences

Customer Accounts Expenses

Supervision

Meter Reading Expenses .......................................

Customer Records and Collection Expenses ...

Uncollectible Accounts

Totel Customer Accounts Exponses .............

Customer Service and Information Expenses

Supervision

Informational and Instructional Expenses ............

Miscellaneous Customer Service

and Informational Expenses

Total Cutomor service and

Informational Expensese

4,585

4,978
Miscellaneous Customer Accounts Expenses ...

Customer Adsistance Expenses

$\begin{array}{rr}288 & 1,896 \\ 8 & 5,346 \\ 659 & 24,316 \\ 623 & 1,740 \\ 1 & 11,972 \\ 0 & 0 \\ 1,687 & 45,300 \\ 7,384 & 92,621\end{array}$

1,513

205

788

873

285

432

1,122

501

1,833

246

7,203

568

6,867

3,194

16,447

8,591

28,059

3,835

13,836
10,846

10,535

20,401

110,024

11,275

$3,38:$

11,165

25,697

77,103

24,950

1,893

2,985

3,513

162,102

10,188

17,005

281,128

4,598

25,018

87,586

23,522

9,454

150,168
1,360

21
1,808

1,088

297

430
5004

ce,ess

8,447

1,838

7,774
1,554

471

2,258

82
1,687

70

24,170

8,642

2755

37,314

4,910

869

442

33
79

56,171

79,349

5,229

6,239

20,437

13,802

2,321

4,027

$\begin{array}{rrr}165 & 445 & 165 \\ 0 & 4 & 449 \\ 281 & 2,741 & 7,991 \\ 336 & 3,954 & 7,242 \\ 0 & 5 & 348 \\ 0 & 0 & 30 \\ 703 & 7,146 & 16,215 \\ 1,035 & 31,828 & 63,470\end{array}$

2,736

8
4,756

4,70

4,70
+12

86

5,337

419

4,255

23,343

3,760

16
2.149

2,149

29,776

913
1,733

1,733

1,408
535

795

41,005

64,428

128,973

3,459

1,200

4,584

14,838

$\begin{array}{r}8,978 \\ \hline\end{array}$

1,668

31,180

7,519

28,475

19,204

2,260

00,017

496
1,147

1,147

0
24,715
1,845

1,542

27,337

2,021

32,430

4,846

1,770

1,293

51,618

26,690

30,693

40,500

Sales Expenses

Supenvision

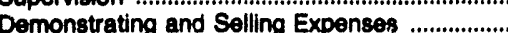

Advertising Expenses

Miscellaneous Sales Expenses ..............................

Total 8ales Exponese

53,790

o

486
108
7
121
730

See endnotes at end of an individual electric utility. 
Table 41. Electric Operation and Maintenance Expenses by Major

U.S. Inveotor-Owned Electric Utility Within State, 1992 (Continued)

(Thousand Dollars)

\begin{tabular}{|c|c|c|c|c|c|c|}
\hline Itom & $\begin{array}{l}\text { Now York } \\
\text { Central } \\
\text { Hudeon Gas } \\
\text { Elec Corp }\end{array}$ & $\begin{array}{l}\text { New York } \\
\text { Consolidated } \\
\text { Edison } \\
\text { Co- } \\
\text { NY Inc }\end{array}$ & $\begin{array}{c}\text { New York } \\
\text { Long } \\
\text { Island } \\
\text { Lighting } \\
\text { Co }\end{array}$ & $\begin{array}{c}\text { Now York } \\
\text { - } \\
\text { Long } \\
\text { Sault Inc }\end{array}$ & $\begin{array}{l}\text { Now York } \\
\text { Now York } \\
\text { State Elec } \\
\text { \& Gas Corp }\end{array}$ & $\begin{array}{c}\text { New York } \\
\text { Niagara } \\
\text { Mohawk } \\
\text { Power Corp }\end{array}$ \\
\hline
\end{tabular}

Adminiatrative and General Expenses

Operation Expeneses

Office Supplios and Expense

(lees) Adminietrathe Expenses

Transferred (credit)

Outide Services Employed .....................................

Property incurance ....

Iniuries And Dameras

Employee Pensions And Benefits

Franchiee Requirements

Reoulatory Commiscion Expenses

(lese) Duplicate Charoes (credit)

General Advertising Expenses ....

Miscellanecus General Expenses

Rents

Totwl Operation Expenses

Maintenance of General Piant

Total Adminlotratwe and

Cenerd Expenses

\section{t...................}

Toted Elective Operation end

Meintenance Expenses.

Distribution of Salaries and

Wages Charged to Electric

Operation and Maintenance

Production

Transmiseion

Distribution ............

Customer Accounts

Customer Service and

Informational Expenses ...

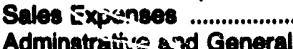

Acongts

Allocated from Clearing Accounts

Total estaries and Weoses

.....................................

Number of Electric Department Employees

Regular Full-time Employees .................

Pert-time and Temporary Employees

Totel Elocticle Departiment Employees

$\begin{array}{rrr}9,857 & 101,593 & 26,764 \\ 2,484 & 42,840 & 14,021 \\ 0 & 42,309 & \\ 2,587 & 2,283 & 284 \\ 817 & 7,796 & 4,063 \\ 3,824 & 44,775 & 7,121 \\ 9,333 & 171,641 & 10,298 \\ 0 & 9 & 40,000 \\ 1,951 & 15,138 & 14 \\ 0 & 9,477 & 6,912 \\ 0 & 0 & 3,770 \\ 3,342 & 38,795 & 1,411 \\ 565 & 0 & 22,227 \\ 34,761 & 373,086 & 4,876 \\ & & 133,652\end{array}$

1,186

35,058

248,018

$2,490,191$

$\mathbf{9 0 , 0 8 3}$

2,299

135,950

373,098

11,079

1,806

10,220

5,138

107,021

481
8,668

8,006
86,377

36,270

5,730

27,110

21,627

777
0
11,382
1,480
41,982

477
0
93,040
289,608

$\mathbf{5 8 6 , 6 7 0}$

608
0
34,171
58,111
188,627

1,167

15,340

122

4,891

0
0

3,452

10,281

7,109

15,482

4,091

o

3,622

10,508

Note: Totals may not equal sum of components because of independent rounding. Summary data are provided in Table 11.

Source: Federal Energy Regulatory Commiseion, FERC Form 1, "Annual Report of Major Electric Utilities, Licensees and Others." 
Table 41. Electric Operation and Malntenance Expenses by Major U.S. Investor-Owned Electric Utility Within State, 1992 (Continued) (Thousand Dollars)

\begin{tabular}{|c|c|c|c|c|c|c|}
\hline Item & $\begin{array}{l}\text { Now York } \\
\text { Orange a } \\
\text { Rockland } \\
\text { Utils } \\
\text { Inc }\end{array}$ & $\begin{array}{c}\text { New York } \\
\text { Rochester } \\
\text { Gas } \\
\text { Electric Corp }\end{array}$ & $\begin{array}{c}\text { North Carolina } \\
\text { Carolina } \\
\text { Power } \\
\text { Light co }\end{array}$ & $\begin{array}{c}\text { North Carolina } \\
\text { Duke } \\
\text { Power Co }\end{array}$ & $\begin{array}{c}\text { North Carolina } \\
\text { Nantahala } \\
\text { Power } \\
\text { Loht Co }\end{array}$ & $\begin{array}{l}\text { North Carolina } \\
\text { Yadkin } \\
\text { Inc }\end{array}$ \\
\hline
\end{tabular}

Power Procuction Expences

Stanem Power

Operation Expenses

Supervition and Engineering

Fud

Steam Expense:

Steam from Other Sources

(leas) Steam Tranaterred (credit)

Electuc Expensea

Miscellaneous Steam Power Expenses ...............

Rents

Totel Operation Expenses

$\begin{array}{rr}1,482 & 1,671 \\ 82,780 & 43,531 \\ 2,472 & 2,989 \\ 0 & 0 \\ 0 & 0 \\ 1,238 & 1,844 \\ 3,180 & 1,751 \\ 1 & 382 \\ 91,180 & 62,188\end{array}$

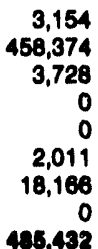

6,394

485,238

18,914

0
8,718

13,145

62,168

495,492

832,400

Maintenance Expenses

Supervision and Engineering

Structures

Boller Plant

Electric Plant

Miscollaneous Steam Piant

Piant ....................................

Totel Maintenance Expenses

488

$\mathbf{6 4 , 4 1 0}$

$$
\begin{array}{r}
10,974 \\
3,177 \\
37,582 \\
21,868 \\
5,427 \\
79,017
\end{array}
$$

Totel Bteam Power Production

Expeneen

104,102

02,810

699,850

811,428

$\begin{array}{rr}30,797 & 6,589 \\ 54,613 & 180,975 \\ 3,768 & 8,138 \\ 35,071 & 43,214 \\ 0 & 0 \\ 0 & 0 \\ 3,442 & 23,603 \\ 115,742 & 71,685 \\ 0 & 0 \\ 243,434 & 334,201\end{array}$

18,321
17,671
815
9,132
0
0
281
25,774
405
72,407

8,589

8,136

3,214

Coolants and Water

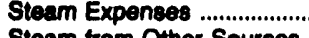

(lese) Steam Transferred (credit)

Electric Expenses

Miscellaneous Nuclear Power Expenses

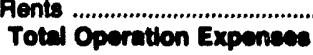

Maintenance Expenses

Supervision and Engineering

Structures ..................................

Electric Plant

Miscellaneous Nuclear Plant

Total Meintenance Expenseses

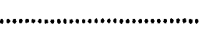

Totel Nucluer Power Production

Expenoen

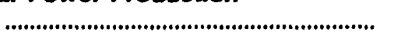

$\begin{array}{rr}871 & 21,76 \\ 110 & 56,217 \\ 13,769 & 27,19 \\ 4,470 & 20,57 \\ 2,667 & 5,537 \\ 21,897 & 131,29\end{array}$

21,768
56,217
27,199
20,574
5,537
131,29

33,496

16,606

68,489

28,612

70,342

215,645

374,729

649,747

0

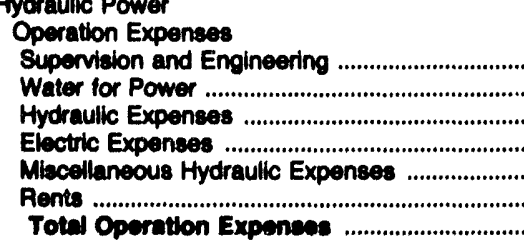

See endnotes at end of an individual electric utility.

\begin{tabular}{rrrrrr}
52 & 93 & 159 & 684 & 77 & 0 \\
722 & 267 & 63 & 0 & 0 & 0 \\
154 & 332 & 108 & 1,812 & 190 & 271 \\
208 & 14 & 393 & 7,063 & 571 & 85 \\
200 & 181 & 1,184 & 4,105 & 245 & 55 \\
0 & 0 & 0 & 255 & 0 & 0 \\
1,337 & 887 & 1,008 & 13,090 & 1,093 & 411 \\
\hline
\end{tabular}


Table 41. Electrlc Operation and Maintenance Expenses by Major

U.S. Investor-Owned Electric Utility Within State, 1992 (Continued)

(Thousand Dollars)

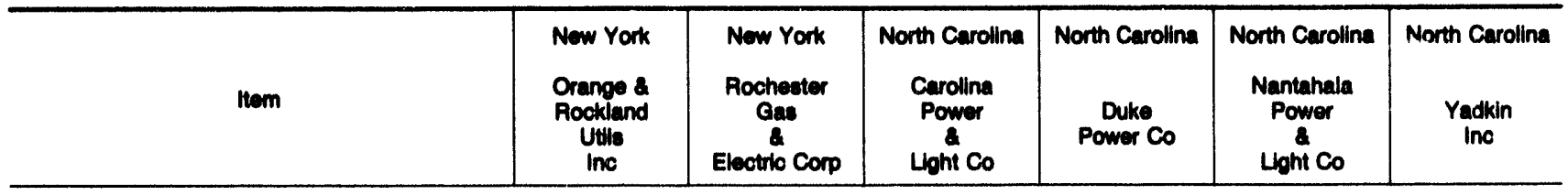

Muintenanos Expenses

\section{7}

30

101

375

685

2,002

16

504

126

563

1,200
Supervilion and Enoineering

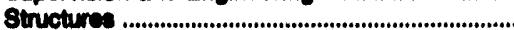

Acrenoine, Dame and Watonways

Electirc Piant

Mibcelleneous Hydraulic Ptant

Toted Malntenanes Exponses

(................................

Tot Hydrestlo Power

Prodistion Expenes.

Other Power

Operation Expense:

Superviaion and Engineering

Find

Ceneration Expenses

Power Expenses

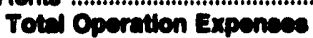

38
76
61
287
68
615

1,402

0
1,425
0
289
0
1,684

1,684

Maintenunce Expenses

Supervision and Encineering

Structures ....................................

Miecellaneous Other Power Plant

Totel Melntenance Expences

Total Other Power Production

Expenives

Other Power Supply Expenses

Purchased Power

Syetem Control and Load Dier

Total Other Power supphy

Expensese

Totel Power Production Expenses

Tranemiacion

Operation Expenses

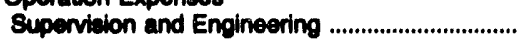

Load Dispatching

Station Expenses

Underground Line Expenses

Tranemiscion of Electrictly by Others

Miscellaneous Tranamiseion Expenses

Pente

Tot Operition Expenees

32
22
622
2
670

7
5

187

203

1,887

1,008

$\begin{array}{rr}48,869 & 29,481 \\ 1,617 & 2,250 \\ 4 & -9,717\end{array}$

60,600

22,013

168,082

182,305

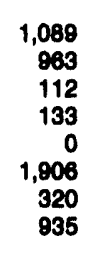

617
1,045
225
182
31
14,307
173
143
Other Expenses

Overhead Line Expences

$\begin{array}{rr}143 & 1,448 \\ 188 & 289 \\ 334 & 1,289 \\ 641 & 9,883 \\ 89 & 1,081\end{array}$

3,200

27,070

1,045

$\begin{array}{rr}1,89 & 1,081 \\ 1,802 & 19,971\end{array}$

3,612

173

1,740

141

737

3,101

782

182
826
168
220
0
1,404

$\begin{array}{ll}0 & 0 \\ 0 & 0 \\ 0 & 0 \\ 0 & 0 \\ 0 & 0 \\ 0 & 0\end{array}$

463

2,267

206

3,246

378
-420

-420
1,807

182

182
1,847

18,030

3,441

0

340,241

1,344

$-82,792$

559,690

0
1,023

33,185

23
0

16,389

289,794

600,712

33,200

16,300

$1,180,412$

$1,753,1 \oplus 6$

35,054

18,800

144
1,902
2,044
521
0
3,884
694
482

1,033

4,879

7,258

848
0

807

5,143

19,722

0,771

19,074

$\begin{array}{rr}22 & 163 \\ 0 & 226 \\ 134 & 40 \\ 0 & 0 \\ 0 & 0 \\ 0 & 0 \\ 1 & 0 \\ 10 & 0 \\ 168 & 420\end{array}$

See endnotes at end of an individual electric utility. 
Tabis 41. Electric Operation and Maintenance Expenses by Major U.S. Investor-Owned Electric Utility Within State, 1992 (Continued) (Thousand Dollars)

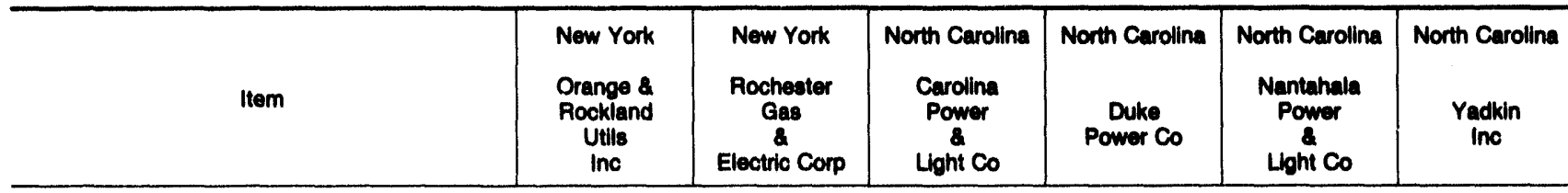

Maintenance Expenses

Supervision and Engineering

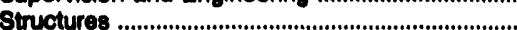

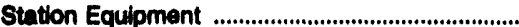

Overhead Lines.

Underground Lines

chemission Plant

Total Malntenance Expenese

Total Tranamiadon Expenses

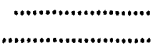

Operation Expenses

Supervision and Engineering

Load Dianatchin

Station Expenses

xenses

Street Lighting and Signal System Expences ...

Meter Expenses

Customer Installations Expenses

Miscellaneous Distribution Expenses

Rents

Total Operation Expenses

$\begin{array}{rr}2 & 331 \\ 0 & 54 \\ 2,286 & 1,110 \\ 1,082 & 779 \\ 14 & 487 \\ 0 & 7 \\ 8,385 & 2,709 \\ 8,844 & 19,491 \\ & \\ & \\ 427 & 2,433 \\ 138 & 0 \\ 621 & 684 \\ 630 & 1,240 \\ 328 & 495 \\ 6 & 286 \\ 1,821 & 1,720 \\ 275 & 877 \\ 655 & 4,413 \\ 19 & 32 \\ 4,920 & 12,180\end{array}$

Maintenance Expenses

Superviston and Engineering .

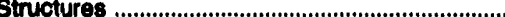

Station Equipment ......................................................

Overhead Lines

Underground Lines

Line Transformers

Street Lighting and Signal Systems .......................

Meters

Miscellaneous Distribution Plant

Totel Maintenence Expenese

...............................

Total Dibtribution Expenees

Customer Accounts Expenses

Supervision

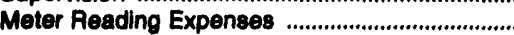

Customer Records and Collection Expenses ...

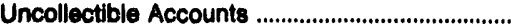

Miscelianeous Customer Accounts Expenses ...

Total Customer Accounts Expeness ..............

18

11,067

1,509

14,357

19,270

76
86
757
07
4
4

0
19

7,201

11,688

667

10,487

30,492



$\begin{array}{rr}27 & 14 \\ 0 & 13 \\ 163 & 264 \\ 92 & 3 \\ 0 & 0 \\ 0 & 0 \\ 202 & 204 \\ 440 & 723\end{array}$

1,627

0
11,414

3,267

4,468

597

9,066

4,707

7,066

147

42,800

$\begin{array}{rr}110 & 0 \\ 0 & 0 \\ 7 & 0 \\ 4 & 0 \\ 0 & 0 \\ 16 & 0 \\ 309 & 0 \\ 4 & 0 \\ 165 & 0 \\ 136 & 0 \\ 761 & 0\end{array}$

Customer Service and Information Expenses

Supervision.

Customer Aseistance Expenses

Informational and Instructional Expenses .............

Miscellaneous Customer Service

and Informational Expenses

Total Customer service and

Informational Expenses .

..................

.............

Sales Expenses

Supervid

Demonstrating and Selling Expenses ..................

Advertiging Expenses

Miscellaneous Sales Expense8 ...............................

Total 8aves Exponses ...

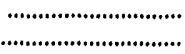

See endnotes at end of an indlvidual electric utility.
1,109

59

454
143

0

1,201
1,169
1,562
6,748
1,817
815
639
300
1
14,260

2,316

121

2,418

29,933

3,405

1,854

471

1,306

739

42,582

28,480

09,420

$\begin{array}{rrr}1,009 & 148 & 0 \\ 73 & 0 & 0 \\ 4,056 & 24 & 0 \\ 35,624 & 3,360 & 0 \\ 6,449 & 34 & 0 \\ 3,308 & 82 & 0 \\ 1,561 & 0 & 0 \\ 1,295 & 1 & 0 \\ 638 & 25 & 0 \\ 64,010 & 3,672 & 0\end{array}$

es,370

4,423

o

1,294

13,196

41,808

4,380

25,814

3,723

222

39,070

647
81,398

$\begin{array}{rr}165 & 0 \\ 407 & 0 \\ 778 & 0 \\ 92 & 0 \\ 1 & 0 \\ 1,449 & 0\end{array}$

$\begin{array}{rr}127 & 105 \\ 844 & 14,945 \\ 318 & 285 \\ 14 & 272 \\ \end{array}$

$$
\begin{array}{r}
890 \\
7,893
\end{array}
$$

2,577

1,238

32,688

$342 \quad 2,985$

41,800

11,802

41,000

$\begin{array}{rr}262 & 0 \\ 3,421 & 175 \\ 0 & 0 \\ 17 & 64 \\ 3,700 & 240\end{array}$

$\begin{array}{rrr}0 & 55 & 262 \\ 285 & 258 & 3,421 \\ 27 & 6 & 0 \\ 0 & 0 & 17 \\ 311 & 320 & 3,700\end{array}$

0
175
0
64
240

$\begin{array}{ll}0 & 0 \\ 0 & 0 \\ 0 & 0 \\ 0 & 0 \\ 0 & 0\end{array}$

保


Table 41. Electric Operation and Maintenance Expenses by Major U.S. Investor-Owned Electric Utility Within State, 1992 (Continued) (Thousand Dollars)

\begin{tabular}{|c|c|c|c|c|c|c|}
\hline liem & $\begin{array}{l}\text { Now York } \\
\text { Orange } 8 \\
\text { Rockland } \\
\text { Utlis } \\
\text { Inc }\end{array}$ & $\begin{array}{c}\text { Now York } \\
\text { Rochester } \\
\text { Gas } \\
8 \\
\text { Electric Corp }\end{array}$ & $\begin{array}{c}\text { North Carolina } \\
\text { Carolina } \\
\text { Power } \\
\text { Light Co }\end{array}$ & $\begin{array}{c}\text { North Carolina } \\
\text { Duke } \\
\text { Power Co }\end{array}$ & $\begin{array}{c}\text { North Carolina } \\
\text { Nantahala } \\
\text { Power } \\
8 \\
\text { Light Co }\end{array}$ & $\begin{array}{l}\text { North Carolina } \\
\text { Yadkin } \\
\text { Inc }\end{array}$ \\
\hline
\end{tabular}

\section{Adminictrative and General Expenses}

Operation Expenses

(lese) Adminiatrative Expenses

Tranoferred (credt)

Outuide Senvices En

Property Inaurance

Inturies And Damages

Denefits

Franchise Requirements

Reculatory Commiseion Expenses

(bes)Duplicate Charges (credit)

Generd Advertising Expenses ....

Miscellaneous General Expenses

Rents

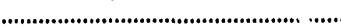

Muintenance of General Plant

Totel Adminiotrattve and

Coneral Exponses

$\begin{array}{rr}11,785 & 13,250 \\ 3,388 & 4,923 \\ & \\ 3,501 & 0 \\ 1,777 & 2,301 \\ 363 & 5,883 \\ 2,493 & 2,753 \\ 9,712 & 19,440 \\ 0 & 0 \\ 1,279 & 7,483 \\ 554 & 28 \\ 8 & 59 \\ 17,388 & -2,533 \\ 1,462 & 2,001 \\ \mathbf{4 5 , 6 1 0} & 55,533\end{array}$

35,391

68,316

$\begin{array}{rr}30,779 & 15,267 \\ 0 & 35,732\end{array}$

1,069

221

542

$\begin{array}{rr}0 & 35,732 \\ 12,271 & 9,983\end{array}$

$4,870 \quad 17,486$

$3,862 \quad 25,589$

$44,201 \quad 104,466$

04,466
0

3,887

1,488

131

8,712

4,739

10,518

54

44,676

4,855

147,564

247,407

0
338

338
179

128

1,392

0
300

0

0
43

22

3,692

178

3,437

4,749

19,214

150

289

45,707

59,970

152,304

208,710

3,842

Total Electite Operatton and

Melntenence Expences

244,243

313,457

$1,494,679$

$2,250,173$

45,231

22,027

Distribution of Salaries and

Weges Charged to Electric

Operation and Maintenance

Production .

Transmiseion

Distribution

Customer Accounts

Customer Service and

Informational Expenses

Sales Expenses

Adminstrative and General

Total selarise and Wages

ounts .........................

Regular Full-time Employees

Part-time and Temporary Employees

$\begin{array}{rr}13,063 & 46,450 \\ 3,085 & 2,607 \\ 12,128 & 15,504 \\ 5,565 & 5,226 \\ & \\ 689 & 1,124 \\ 148 & 286 \\ 13,594 & 15,680 \\ 0 & 3,941 \\ 49,273 & 90,846\end{array}$

154,718

5,936

30,436

17,920

6,075

2,144

36,879

9,497

283,606

1,433

2,023

8,089

17,066

1,218

253

2,239

1,080

441

143
0

205

733

0

5

2,398

36

104

Totel Electrlc Department Employees .

1,493

2,096

8,354

18,340

15
0
1,142
0
5,058

0

546

546
0

1,913

Note: Totals may not equal sum of components because of independent rounding. Summary data are provided in Table 11.

Source: Federal Energy Regulatory Commission, FERC Form 1, "Annual Report of Major Electric Utilities, Licensees and Others." 
Table 41. Electrlc Operation and Maintenance Expenses by Major

U.S. Investor-Owned Electric Utility Within State, 1992 (Continued)

(Thousand Dollars)

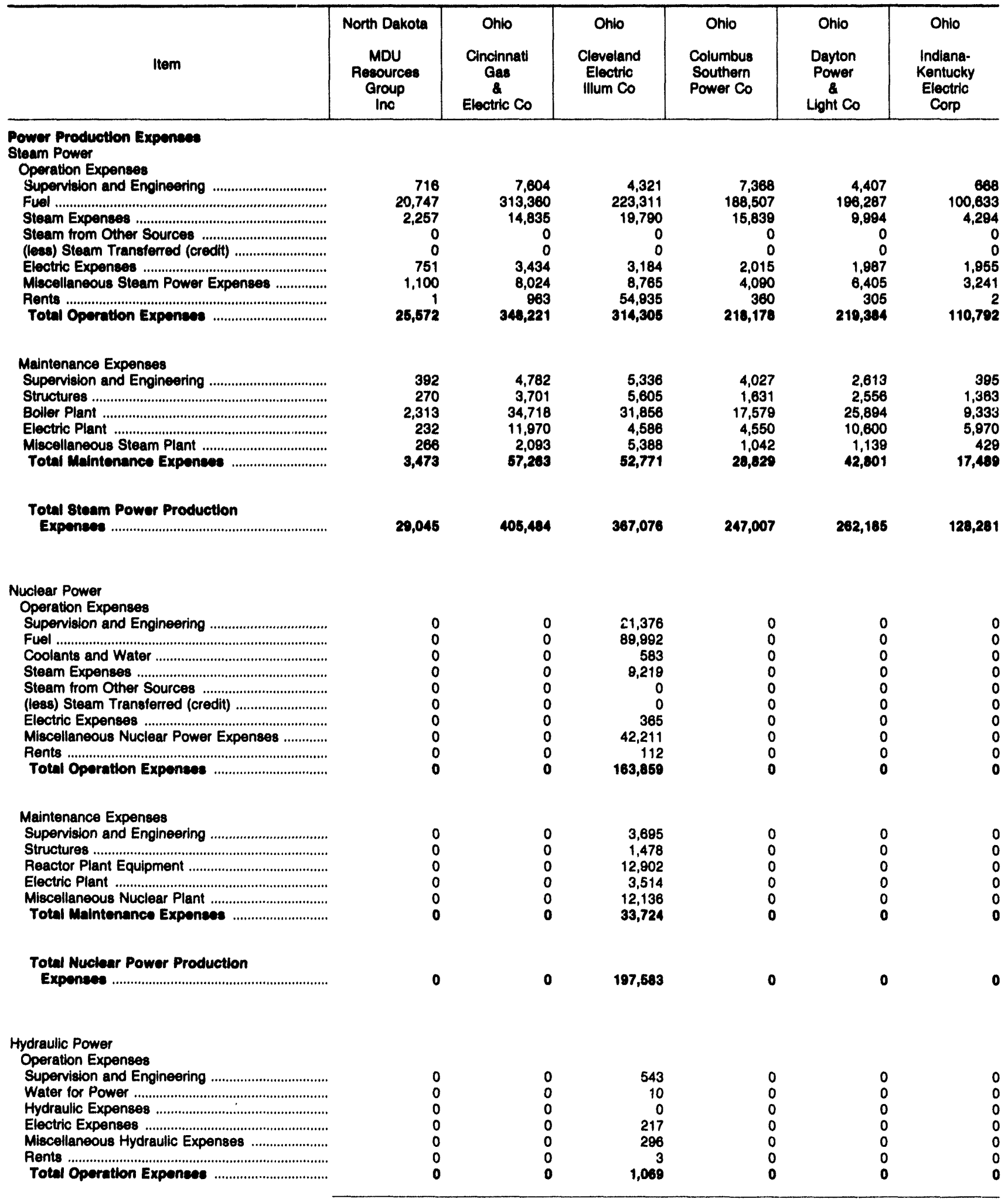

See endnotes at end of an individual electric utility. 
Table 41. Electric Operation and Malntenance Expenses by Major U.S. Investor-Owned Electric Utility Within State, 1992 (Continued) (Thousand Dollars)

\begin{tabular}{|c|c|c|c|c|c|c|}
\hline Item & $\begin{array}{c}\text { North Dakota } \\
\text { MDU } \\
\text { Resources } \\
\text { Group } \\
\text { Ino }\end{array}$ & $\begin{array}{c}\text { Ohio } \\
\text { Cincinnat } \\
\text { Gas } \\
\text { Electric Co }\end{array}$ & $\begin{array}{c}\text { Ohio } \\
\text { Cleveland } \\
\text { Electrlc } \\
\text { Illum Co }\end{array}$ & $\begin{array}{l}\text { Ohlo } \\
\text { Columbus } \\
\text { Southern } \\
\text { Power Co }\end{array}$ & $\begin{array}{l}\text { Ohio } \\
\text { Dayton } \\
\text { Power } \\
\& \\
\text { Light Co }\end{array}$ & $\begin{array}{l}\text { Ohio } \\
\text { Indiana- } \\
\text { Kentucky } \\
\text { Electric } \\
\text { Corp }\end{array}$ \\
\hline
\end{tabular}

Maintenance Expenses

Supervision and Engineering

Structures

Reservolre, Dame and Waterway

Electric Plant

Miscellaneous Hydraulic Plant

Total Mantenance Expenses

Total Hydraulle Power

Production Expences

1,059

76
22
283
424
30

0
0
0
0
0
0

o

0

0

Other Power

Operation Expenses

Supervision and Engineering

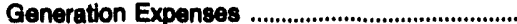

Miscellaneous Other Power Expenses

Rents

Total Operation Expenses

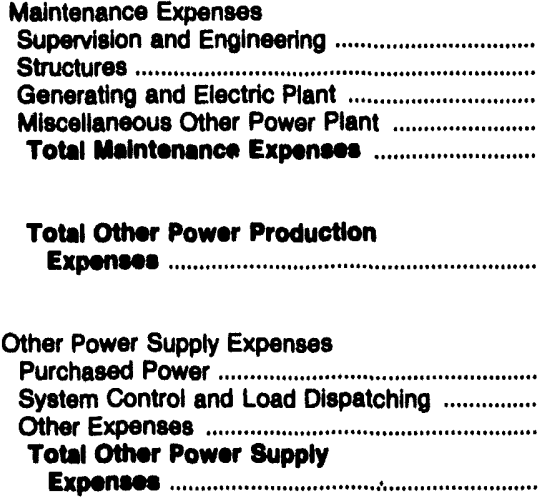

Total Power Production Exponses
32
266
5
32
0
325

368

571

428

0

1,037

326

29
1,001

1,001
150

1,607

480

3,344

$16,889 \quad 22,116$

771

1,114

6,846

17,660

30,076

47,165

489,804

722,980

397,040

291,922

128,281

$\begin{array}{rl}27,081 & 0 \\ 644 & 0 \\ 777 & 0\end{array}$

20,603

0

Transmission

Operation Expenses

Supervision and Engineering ................................

Load Dispatching

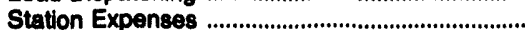

Overhead Line Expenses

Underground Line Expenses

Transmiseion of Electricity by Others

Miscellaneous Transmission Expenses

Rents

$\begin{array}{rr}507 & 1,010 \\ 284 & 516 \\ 226 & 1,284 \\ 86 & 346 \\ 0 & 41 \\ 370 & 0 \\ 36 & 589 \\ 259 & 100\end{array}$

1,771
824
1,982
333
144
7,033
78
97

2,634

3,888

12,281

33,714

See endnotes at end of an individual electric utility. 
Table 41. Electrle Operation and Maintenance Expenses by Major U.S. Investor-Owned Eloctric Utility Within State, 1992 (Continued) (Thousand Dollars)

\begin{tabular}{|c|c|c|c|c|c|c|}
\hline Item & $\begin{array}{c}\text { North Dakota } \\
\text { MDU } \\
\text { Pesources } \\
\text { Group } \\
\text { Inc }\end{array}$ & $\begin{array}{c}\text { Ohio } \\
\text { Cincinnati } \\
\text { Gas } \\
\text { Electrio Co }\end{array}$ & $\begin{array}{l}\text { Ohio } \\
\text { Cleveland } \\
\text { Electric } \\
\text { Illum Co }\end{array}$ & $\begin{array}{c}\text { Onio } \\
\text { Columbus } \\
\text { Southern } \\
\text { Power Co }\end{array}$ & $\begin{array}{l}\text { Ohio } \\
\text { Dayton } \\
\text { Power } \\
\text { Light Co }\end{array}$ & $\begin{array}{l}\text { Onio } \\
\text { Indiana- } \\
\text { Kentucky } \\
\text { Electric } \\
\text { Corp }\end{array}$ \\
\hline
\end{tabular}

Maintenance Expenees

Supervision and Engineering

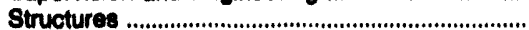

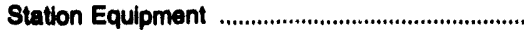

Overhead Lines

Underground Lines

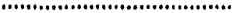

smission Plant

Total Maintenance Exponses

............................

Total Tranamiaslon Expenses

Distribution

Operation Expenses

Supervision and Engineering

Load Dispatching

Station Expenses

Overhead Line Expenses

Underground Line Expenses

Street Lighting and Signal System Expenees ....

Meter Expenses

Customer Installations Expenses

Miscellaneous Distribution Expenses ...................

Rents
Total Operation Expenses

$\begin{array}{rr}219 & 397 \\ 0 & 131 \\ 417 & 955 \\ 564 & 1,830 \\ 0 & 19 \\ 1 & 6 \\ 1,202 & 3,437 \\ 2,969 & 7,323\end{array}$

17,342

3,956

647

2,081

1,857

1,323

481

1,716

2,294

6,354

61

45
3,577

20,071

1,777

234

2,537

13,83

2,721

1,822

862

695

24,479

Miscellaneous Distribution Plant

Total Maintenance Expenses

.............................

Total Diotribution Expeneas

.................................

6,208

45,350

27,705

44,308

688

5,512

14,918

10,256

85

31,441

30,688
889

23

1,648
1,335

158

1,027

5,001

5,751

4,013

23
1,541

8,484

1,206

177

68
465

885

3,072
7,642

16,358

2,627

889
20
1,878
1,185
9
0
3,000

37,095

$\mathbf{6 , 8 3 0}$

0
1,217

1,362

998

56
2,541

922

4,190

1,466

18,501

2,085

83

2,009

$\mathbf{9}, \mathbf{8 7 0}$

1,869

1,869
1,461

399

653

218

18,648

39,228

2,472

17
1,303

1,303
13,811

2,184

633

2
167

146

20,736

31,000

0

1,384

3,186

11,517

5,708

156

21,050

0

3,220
10,517

6,703

20,440

$\begin{array}{rr}4,847 & 1,405 \\ 224 & 2,918 \\ 1,876 & 1,533 \\ & \\ 4 & 220 \\ 6,950 & 6,076\end{array}$

6,866

133

0

7,000

$\begin{array}{rr}0 & 0 \\ 1,095 & 313 \\ 0 & 1,073 \\ 0 & 1,438 \\ 1,005 & 2,824\end{array}$

24

21

271

0

418

827
0
313
, 073
, 438
.824

$\begin{array}{ll}0 & 0 \\ 0 & 0 \\ 0 & 0 \\ 0 & 0 \\ 0 & 0\end{array}$

Customer Service and Information Expenses

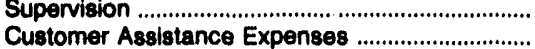

Informational and instructional Expenses .............

Miscellaneous Customer Service

and Informational Expenses

Informational Expenses

6,014

245

493

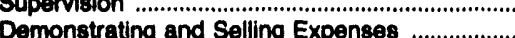

Advertising Expenses

Miecellaneous Sales Expenses .............................

Total 8aks Exponses

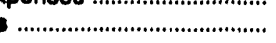

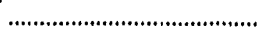

896

114
684
59
0
857

See endnotes at end of an individual electric utility. 
Table 41. Electrle Operation and Maintenance Expenees by Major U.8. Inveotor-Owned Electrle Utility Within state, 1992 (Continued) (Thousand Dollars)

\begin{tabular}{|c|c|c|c|c|c|c|}
\hline Item & $\begin{array}{c}\text { North Dakotu } \\
\text { MDU } \\
\text { Resouroes } \\
\text { Group } \\
\text { Ino }\end{array}$ & $\begin{array}{c}\text { Ohlo } \\
\text { Cincinnat } \\
\text { Gas } \\
\text { Electrilo co }\end{array}$ & $\begin{array}{l}\text { Ohio } \\
\text { Cleveland } \\
\text { Electic } \\
\text { Illum Co }\end{array}$ & $\begin{array}{c}\text { Onlo } \\
\text { Columbus } \\
\text { Southern } \\
\text { Power Co }\end{array}$ & $\begin{array}{l}\text { Ohio } \\
\text { Dayton } \\
\text { Power } \\
\text { \& } \\
\text { Light Co }\end{array}$ & $\begin{array}{l}\text { Ohio } \\
\text { Indlana- } \\
\text { Kentuoky } \\
\text { Electric } \\
\text { Corp }\end{array}$ \\
\hline
\end{tabular}

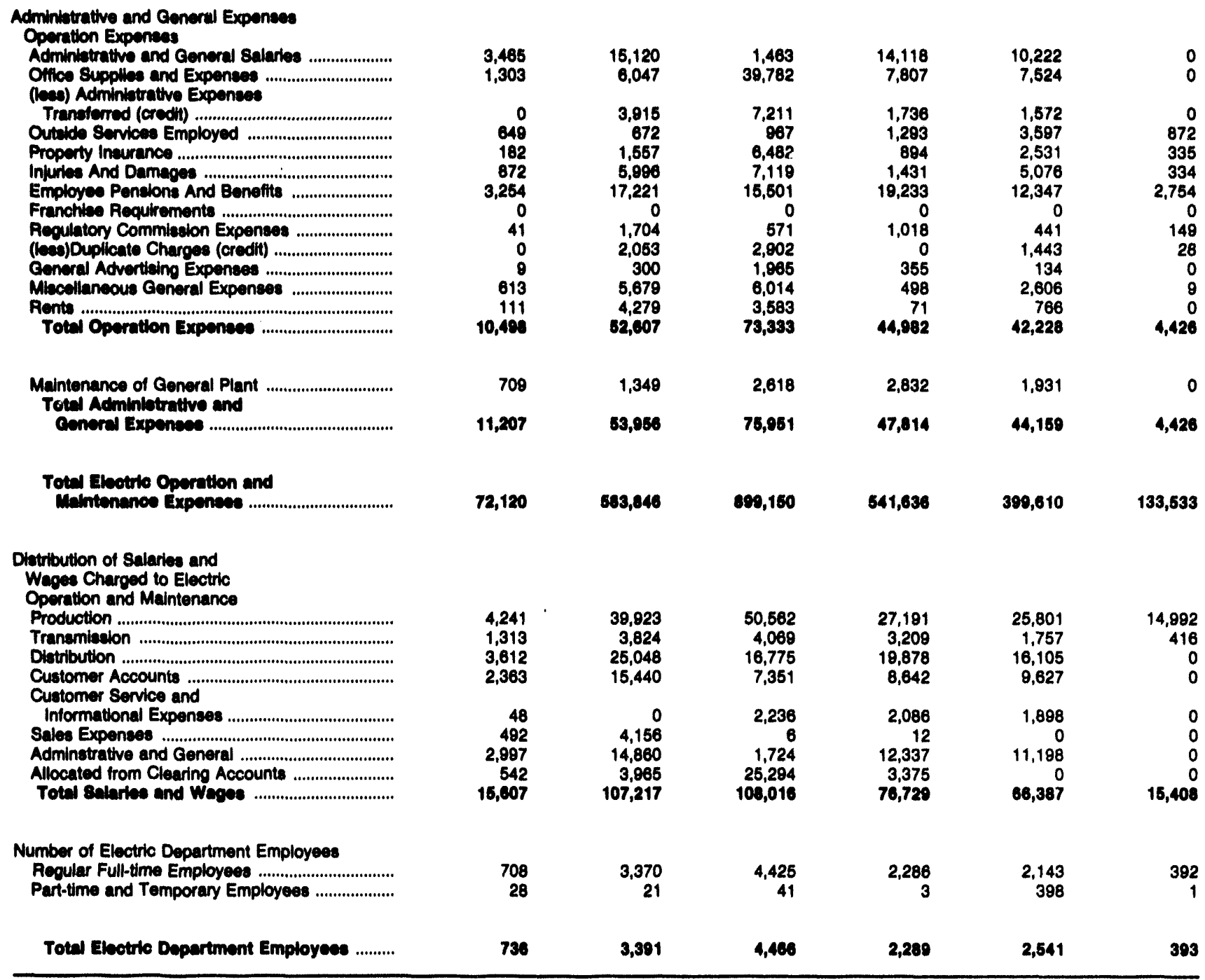

Note: Totals may not equal sum of components because of independent rounding. Summary data are provided in Table 11.

Source: Federal Energy Regulatory Commiseion, FERC Form 1, "Annual Report of Major Electric Utilties, Licensees and Others." 
Table 41. Electric Oporation and Maintenance Expenses by Major U.8. Investor-Owned Eleotric Utility Within 8tate, 1992 (Continued) (Thousand Dollars)

\begin{tabular}{|c|c|c|c|c|c|c|}
\hline $\mathrm{Hem}$ & $\begin{array}{l}\text { Ohlo } \\
\text { Ohio } \\
\text { Eotion Co }\end{array}$ & $\begin{array}{l}\text { Ohlo } \\
\text { Ohlo } \\
\text { Power co }\end{array}$ & $\begin{array}{l}\text { Onio } \\
\text { Onio } \\
\text { Valley } \\
\text { Electrio } \\
\text { Corp }\end{array}$ & $\begin{array}{c}\text { Onio } \\
\text { Toledo } \\
\text { Edison Co }\end{array}$ & $\begin{array}{c}\text { Oklahoma } \\
\text { Oklahoma } \\
\text { Gas } \\
a \\
\text { Electric Co }\end{array}$ & $\begin{array}{c}\text { Oklahoma } \\
\text { Publlo } \\
\text { service } \\
\text { Co } \\
\text { of Oklahoma }\end{array}$ \\
\hline
\end{tabular}

Power Produotion Expances

Steam Power

Operation Expense:

Supervision and Enoineering

Fue

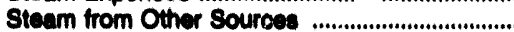

(leas) Steam Trangterred (credti)

Electric Expenses

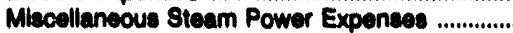

Fents.

Total Operation Expenses

$\begin{array}{rr}10,543 & 12,233 \\ 318,757 & 702,514 \\ 28,667 & 10,84 \\ 0 & \\ 0 & \\ 6,116 & 4,419 \\ 18,055 & 37,878 \\ 39 & 277 \\ 390,177 & 709,104\end{array}$

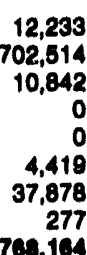

708,104

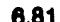

4,612

49,146

13,450

4,463

78,402

485,089

7,968

5,770

68,081

16,175

5,182

103,174

Total steam Power Production

Expenses

Nuclear Power

Operation Expenses

628
97,999
2,743
0
0
1,681
2,634
0
108,858

2,990
90,349
8,205
0
0
1,191
4,183
35,902

4,802
415,648
6,380
0
0
4,713
6,466
2
480,920

2,470

244,289

3,246

5,793

2,378

19,357

4,625

898

5,452

473

14,708

39,049

1,621
18,043

120,360

189,884

469,999

289,241

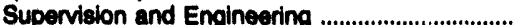

Furel

Coolants and Water

Steam Expenses

Steam from Other

(less) Steam Transferred (credt)

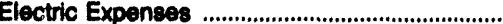

Miscellaneous Nuclear Power Expenses ............

Rents

Total Operation Expences
4,311

2,332

10,251

4,078

12,668

33,539

304,017

$$
\begin{array}{r}
17,054 \\
71,683 \\
412 \\
7,158 \\
0 \\
0 \\
329 \\
35,111 \\
70,163 \\
201,921
\end{array}
$$

2,962

1,101

11,040

2,794

9,738

27,038

229,560

Hydraullo Power

Operation Expenses

Supervision and Engineering

Water for Power

Hydraulic Expen

Electric Expenses

Miscellaneous Hydraulic Expenses

Rents

Total Operation Expenses

0

0
2,309
888
13,655
5,326
1,603
23,781

See endnotes at end of an individual electric utility. 
Table 41. Electric Operation and Maintenance Expeneses by Major U.8. Inveotor-Owned Electric Utility Within State, 1902 (Continued) (Thousand Dollars)

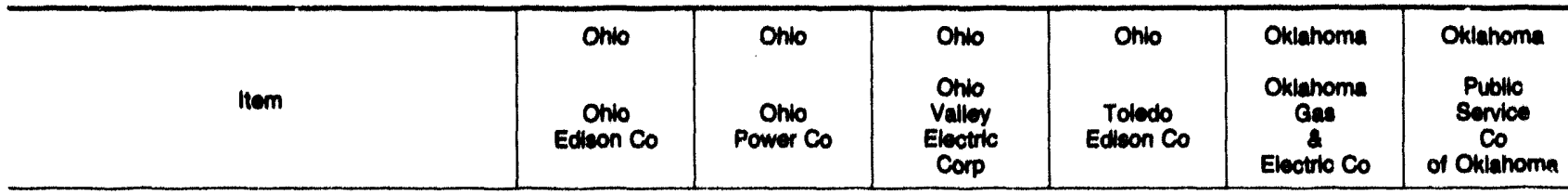

Malmenance Expensece

Eupervition and Encinearing

Struotures

Acearvolve, Dame and Water

Electric Piant

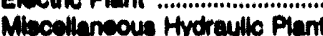

Totel Merntenance Expenece.

\section{Tot'l Hydrewile Power}

Production Expenses

980

Other Power

Operation Expenses

Supervision and Engineering .................................

Fuel

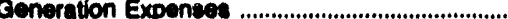

Miscellaneous Other Power Expenses ................

Rents

Totel Opertition Expensese

Maintenence Expenses

Supervision and Engineering

Structures

Generating and Electric Plant

Miscellaneous Other Power Plant

Total Malntenanos Expenses

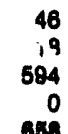

898

Total Other Power Production

$$
\text { Expones }
$$

Other Power Supply Expenses

Purchased P

System Control and Load Diepatching

Other Expenses

Totd Other Power 8upply

Expones

....... Eupply

Total Power Production Expensece

Load Dise *hing

Station Expense:

Overhead Une Expenses

Underaround Line Expenses

Tranemiasion of Electricity by Others

Miscellaneous Tranemiasion Expenses

Rents

08,631

0
110
0
0
0
110

33
16,977
324
20
0
17,389

1
134
54
64
0
244

Tots Oparation Expenses

$$
\begin{array}{r}
3,188 \\
1,595 \\
1,439 \\
533 \\
1 \\
15,680 \\
2,316 \\
121
\end{array}
$$

12,777

24,074

202,698

416,094

671,19

317,320

See endnotes at end of an individual electric utility. 
Table 41. Electrlc Operation and Malntenance Expenses by Major U.8. Invector-Owned Electrle Utility Withlis State, 1992 (Continued) (Thousand Dollars)

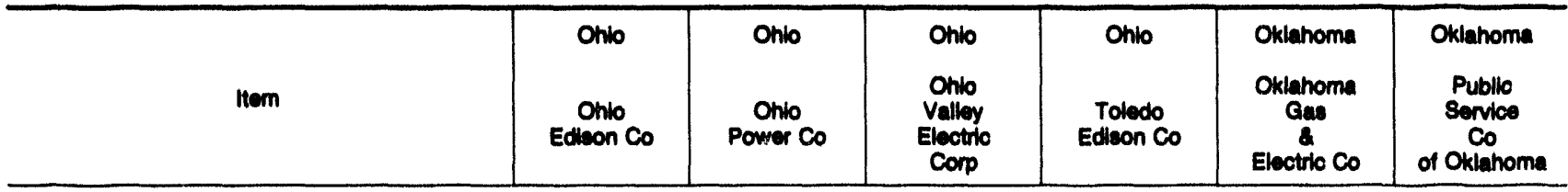

Malntenance Expenses

Supervition and Engineering

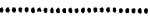

Station Equipmon

Orentend Unes

Underoround Lines

Tranemiacion Plant

Toted Melettenence Expenees ..............................

Totel Tranemiselon Expenees

istribution

Operntion Expense:

Supervilion and Enginearing

Loed Diepatching

Station Expenses

Overhesd Line Expenses

Underground line Expenses

Street Lighting and Signal System Expenses ...

Moter Expenses .

Cuntomer Ingtallations Expenses

Miscolianeous Distribution Expenses

Rents

Totel Operrition Expences

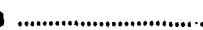

Maintenance Expenses

Supervition and Engineering

Structures

Station Equipment

Overhasd Lines.

Underground Lines

Une Trangformers

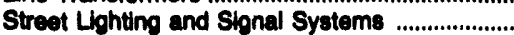

Meters

Miecelleneous Distribution Plant

Totel Melntenanes Expenses

Total Diatibution Expenses

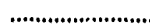

Customer Accounts Expenses

Superviaion

Meter Reading Expenses .......................................

Customer Records and Collection Expenses ...

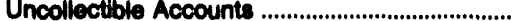

Miscelianeous Customer Accounts Expenses ...

Toted Customer Acoounto Expenses .............

Customer Senvice and Information Expenses

Supenvition

Cutomer Aestatance Expenses

Informational and Instructional Expenses ............

Miscellaneous Customer Service

and Informational Expenses

Tot-1 Customer Eenvlos and

Informationd Expenses

Sales Expenses

Supervilion .................................

Advertiving Expenses

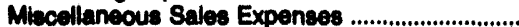

Totel 8ales Expenses

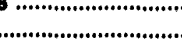

\section{4}

244

3,088

6,144

84
29

10,518

28,203

2,768

628

1,888

5,134

688

1,156

2,606

3,892

4,477

272

23,686

2,391

155

2,611

27,676

1,955

1,269

805

526

37,427

0,092

1,722

4,530

4,847

28,525

7,885

400

42,49

0,237

744
20,057

1,888

12,325

1,011

1,539

2,228

43

16,293
39
20
295
291
0
26
071

389

0

308

87

1,042

0,051

1.774

2,675
752
612
-116
161
282
809
1,672
184
9
7,141

2,931

2,271

4,601

2,289

220

1,800

765

7,375

468

22,031

2,281

8

968

6,564

465

137
293

151

4.173

16,042

22,183

1,322

3
2,572

15,637

1,804

773

1,058

1,238

25,738

4,657

486

1,188

3,880

3,314

0

s.ees

448

3,525

17,836

6,256

$20,0.5$

2,562

2,713

8,685

2,779

2,779
17,819

180
3865

3,665

1,205

9,891

2,564

2,084

5,422

2,048

578

16,709

0,407

See endnotes at end of an individual electric utility.

$\begin{array}{rr}0 & 0 \\ 819 & 156 \\ 684 & 587 \\ 0 & 815 \\ 1,603 & 1,638\end{array}$

833
76
0
0
800

0
0
0
0
0 
Table 41. Electric Operation and Malntenance Expences by Major U.8. Investor-Owned Electric Utility Within 8tato, 1992 (Continued) (Thousand Dollars)

\begin{tabular}{|c|c|c|c|c|c|c|}
\hline Item & $\begin{array}{l}\text { Onio } \\
\text { Onio } \\
\text { Edivon co }\end{array}$ & $\begin{array}{l}\text { Ohlo } \\
\text { Ohlo } \\
\text { Power co }\end{array}$ & $\begin{array}{c}\text { Onio } \\
\text { Ohio } \\
\text { Valley } \\
\text { Eleotric } \\
\text { Corp }\end{array}$ & $\begin{array}{l}\text { Onlo } \\
\text { Toledo } \\
\text { Edison Co }\end{array}$ & $\begin{array}{c}\text { Oklahoma } \\
\text { Oklahoma } \\
\text { Gas } \\
a \\
\text { Electric Co }\end{array}$ & $\begin{array}{c}\text { Oklahoma } \\
\text { Public } \\
\text { Service } \\
\text { Co } \\
\text { of Oklahoma }\end{array}$ \\
\hline
\end{tabular}

Administrative and Ceneral Expenses

Operation Expenses

(loes) Administrative Expenses

Tranaterred (credit)

Outaide Servae Employed ....................................

Property Insurance

Iniviea And Damnoes ......

Employes Penslone And Bendith

Frenchice Requirements

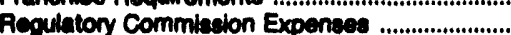

(ben) Dupltoete Charges (credit)

General Advertiang Expenses

Mbcellaneous General Expenses

Pente

Totel Operation Expenses

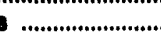

Maintenance of General Plant

Totel Administrattve and

Eenerd Expenses

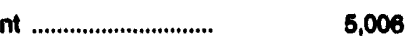

21,209

13,270

4,132

3,067

8,689

4,852

18,878

2,494

1,289

43,151

4,926

118,711

120,717

$1,073,189$

$1,120,223$

272,302

1,622

396

42

1,893

280

335

2,689

6,184

30,100

870

870
782
1,399

1,369

2,687

648

$\mathbf{6 3 , 3 0 0}$

3,008

09,403

112

7,900

810,845

2,186

22,892

4,847

686
4,882

2,106

17,748

1
351

1,578

505

4,453

124

49,600

755

60,496

tion end

Diatribution of Salaries and

Wages Charged to Electric

Operation and Maintenance

Production

Tranemingion

Diotribution

Customer Accounts

Customer Service and

Informational Expenses

Sales Expense:

Adminatrathe and General

Allocated from Clearing Accounts

Totel ederites and Weees

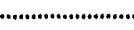

Employees

Regular Full-time Employees ..................................

Part-time and Temporary Employees

Total Electric Departmont Employees .........

\section{1,168}

8,044

32,656

11,518

8,444

0
21,801

16,282

140,001

4,769

79

4,048
12,895
1,691
0
0
24,009
1,058

1,058
6,877

3,251

1,373

2,591

23,010

23,010
02,107

19,200

4,429

24

4,483

401

399

2,337

86

3,450

10

2,005

2

2,422

3,460

2,088

Note: Totals may not equal sum of components because of independent rounding. Summany date are provided in Table 11.

Source: Federal Energy Requlatory Commiselon, FERC Form 1, "Annual Report of Major Electric Utillties, Licensees and Others." 
Table 41. Electric Operation and Maintenance Expenses by Major U.S. Investor-Owned Electric Utility Within State, 1992 (Continued) (Thousand Dollars)

\begin{tabular}{|c|c|c|c|c|c|c|}
\hline Item & $\begin{array}{l}\text { Oregon } \\
\text { Pacticorp }\end{array}$ & $\begin{array}{l}\text { Oregon } \\
\text { Portiand } \\
\text { General } \\
\text { Electric Co }\end{array}$ & $\begin{array}{l}\text { Penneytvania } \\
\text { Duquesne } \\
\text { Light Co }\end{array}$ & $\begin{array}{l}\text { Pennoytvania } \\
\text { Metropolitan } \\
\text { Edison Co }\end{array}$ & $\begin{array}{c}\text { Pennoylvania } \\
\text { Pennsylvania } \\
\text { Electric Co }\end{array}$ & $\begin{array}{c}\text { Pennayivania } \\
\text { Pennaytvania } \\
\text { Power } \\
\& \\
\text { Light Co }\end{array}$ \\
\hline
\end{tabular}

Power Production Expenses:

Steam Power

Cjeration Expenses

Supervision and Engineering

Fuld

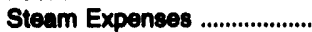

Steam from Other Sources..........................

(less) Steam Transferred (credit)

Electric Expenses ..............................................

Rents

Tothl Operation Expenses

(..................................

$\begin{array}{rr}12,941 & 1,367 \\ 498,011 & 52,962 \\ 26,597 & 3,000 \\ 3,826 & -1 \\ 0 & 0 \\ 13,206 & 995 \\ 28,575 & 2,196 \\ 91 & 2,333 \\ 593,248 & 62,950\end{array}$

3,888
182,726
8,387
0
0
2,220
7,765
672

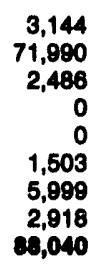

5,709

168,076

4,717

0
0

1,868

6,889

404

187,001

652,058

Maintenance Expenses

Supervision and Engineering

Structures

Boiler Plant

7,595

48,143

12,750

Miscellaneous Steam Plant

21,046

Total Maintenance Expenses

105,351

1,127
1,357
6,016
2,157
1,183
11,041

2,257

2,254
15,879

15,879

5,394

5,384
29,224

2,123

1,077

8,468

3,411

1,767

18,846

3,471

2,092

20,508

5,343

2,123

33,584

698,690

74,698

234,882

104,088

221,105

894,403

Nuclear Power

Operation Expenses

Supervision and Engineering

Fuel

Coolants and Water

Steam Expene

Steam from Other Sources

(less) Steam Transferred (credit)

Electric Expenses

Miscellaneous Nuclear Power Expenses ............

Rents

Total Oparation Expenses

Maintenance Expenses

Supervision and Engineering

Structures

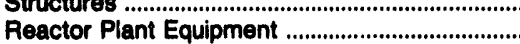

Electric Plant

Miscell.2neous Nuclear Plant

Total Malntenance Expenses

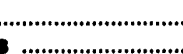

Totel Nuclear Powor Production

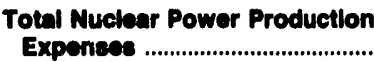

3,716

13,742

46,725

11,511

19,393

477

13,203

930
2,987

7,124

240
0

0

1,601

0
3,338

0
1,097

18,140
0

0

164

22,805

54,282

0
1,354

669
0

48,607

5,687

6,466

55,441

17,678

$-3,678$

81,649

63,465

145,451

$\begin{array}{rr}422 & 13,174 \\ 97 & 2,424 \\ -347 & 4,858 \\ 26 & 734 \\ 180 & 8,680 \\ 377 & 29,870\end{array}$

2,541

1,646

5,925

3,469

6,899

20,479

3,785
728
8,324
1,391
1,553
15,781

1,849

364

4,164

4,990

17,249

0,358

$-7,108$

776

40,204

165,080

62,387

31,300

280,000

Hydraulic Power

Operation Expenses

Supervision and Engineering .................................

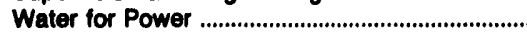

Hydraulic Expenses

Electric Expenses

Miscellaneous Hydraulic Expenses

Rents

Total Operntion Expenese

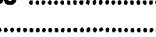

....

See endnotes at end of an individual electric utility.

$\begin{array}{rr}580 & 969 \\ 64 & 325 \\ 2,050 & 865 \\ 2,771 & 1,400 \\ 3,093 & 1,146 \\ 17 & 7,781 \\ 8,576 & 12,495\end{array}$

$\begin{array}{ll}0 & 0 \\ 0 & 0 \\ 0 & 0 \\ 0 & 0 \\ 0 & 0 \\ 0 & 0 \\ 0 & 0\end{array}$

265
164
42
461
177
67
1,178

480

179

876

938

688

3,103 
Table 41. Electric Operation and Malntenance Expenses by Major U.S. Investor-Owned Electric Ut!lity Within Stato, 1992 (Continued) (Thousand Dollars)

\begin{tabular}{|c|c|c|c|c|c|c|}
\hline Item & $\begin{array}{l}\text { Oregon } \\
\text { Pacticorp }\end{array}$ & $\begin{array}{c}\text { Oregon } \\
\text { Portiand } \\
\text { General } \\
\text { Electric Co }\end{array}$ & $\begin{array}{l}\text { Pennaytvania } \\
\text { Duquesne } \\
\text { Light Co }\end{array}$ & $\begin{array}{l}\text { Pennayivania } \\
\text { Metropolttan } \\
\text { Edison Co }\end{array}$ & $\begin{array}{l}\text { Pennsylvania } \\
\text { Pennsylvania } \\
\text { Electric Co }\end{array}$ & $\begin{array}{c}\text { Pennaytvania } \\
\text { Pennaytvania } \\
\text { Power } \\
\text { Light Co }\end{array}$ \\
\hline
\end{tabular}

Maintenance Expenses

Superviaion and Engineering

Structurat

Reservolrs, Dams and Waterways

Electric Plant

Miscellaneous Hydraulic Plant

Total Meintenance Expeneses

Totel Hydraulle Power

Production Expences

Other Power

Operation Expenses

Supervision and Engineering

Fuel

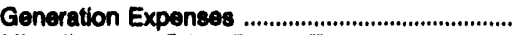

Miscellaneous Other Power Expenses

Rents

Total Operation Expenses

Maintenance Expenses

Supervision and Engineering

Structures ...

Generating and Electric Plant

Miscellaneous Other Power Plant

Total Malntenance Expenese

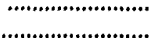

Total Other Power Production

Expenees

2,000

41
2,227
247
122
0
2,637

638

29,121

1,187

793

3,048

2,037

34,788

$\begin{array}{rr}41 & 469 \\ 0 & 138 \\ 242 & 3,697 \\ 71 & 87 \\ 354 & 4,390\end{array}$

39,178

675

1,929

Other Power Supply Expenses

Purchased Power

System Control and Loed Diepatching

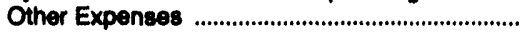

Total Other Power Supply

Expenses

108,658

881

981
1,648

9,474

583

187,144

3,198

36,473

128,41

3,917

111,287

37,098

228,815

133,423

Total Power Production Expensee

947,436

323,536

438,565

$3 \bullet 8,018$

388,551

$1,160,774$

Transmission

Operation Expenses

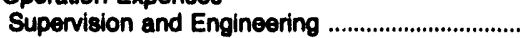

Load Dispatching .

660

3,534

3,421

1,609

Overhead Line Expenses

50

42,791

656

Transmission of Electricity by Others

Rents

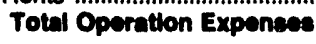

640

53,281

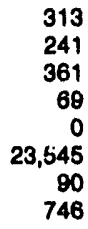

25,396

186
961
631
28
55
7,972
76
680

10,590

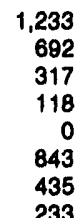

1,745

1,198

346

154
0

2,261

517

325

3,871

6,547

1,476

2,068

441

162

928

463

42

See endnotes at and of an individual electric utility. 
Table 41. Electric Operation and Maintenance Expenses by Major U.S. Investor-Owned Electric Ut!lty Within State, 1992 (Continued) (Thousand Dollars)

\begin{tabular}{|c|c|c|c|c|c|c|}
\hline Item & $\begin{array}{l}\text { Oregon } \\
\text { Pacificorp }\end{array}$ & $\begin{array}{l}\text { Oregon } \\
\text { Portiand } \\
\text { General } \\
\text { Electric Co }\end{array}$ & $\begin{array}{l}\text { Penneytvania } \\
\text { Duquesne } \\
\text { Light Co }\end{array}$ & $\begin{array}{l}\text { Pennoytvania } \\
\text { Metropolitan } \\
\text { Edison Co }\end{array}$ & $\begin{array}{l}\text { Pennoylvania } \\
\text { Pennoytvania } \\
\text { Electric Co }\end{array}$ & $\begin{array}{c}\text { Penneytvanie } \\
\text { Penneytvanic } \\
\text { Power } \\
\text { Loht Co }\end{array}$ \\
\hline
\end{tabular}

Maintenance Expenses

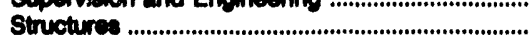

Station Eculpment

Overhead Lines.

Underoround Lines

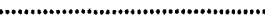

Miecellenoou Tranamiasion Plant .....................

Totel Meintenenes Expeneses

..........................

Totel Trunemiadon Expenses

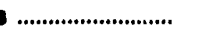

Distribution

Operation Expenses

Loed Diepatching

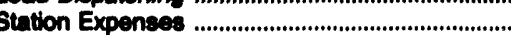

Overteed Uine Expenses

Underground Line Expenses

Street Lighting and Signal System Expenses ....

Meter Expenses.

Customer Intrallations Expenses........

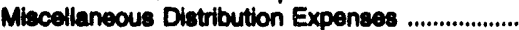

Pents

Totel Operation Expense
Supentaion and Enoineering

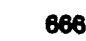

64,394

Total Distribution Expenses

Customer Accounts Expenses

Superviaion

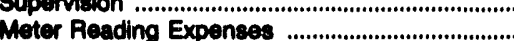

Curtomer Records and Collection Expenses ....

Uncollectible Accounts .........................................

Miscellaneous Customer Accounts Expenses ...

Total Customer Accounts Expeness

Customer Senvice and Intormation Expenses

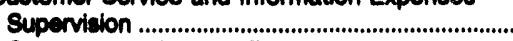

Customer Aseistance Expenses ...............................

Informational and Instructional Expenses

Miscellaneous Customer Service

and Informational Expenses

Totel Customer Eervice and

informationd Expenses

Sales Expenses

Supervision

Demonetrating and

Adverthing

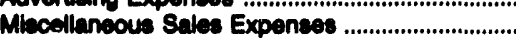

Totel 8ale Expenow
188

4,258

3,410

2,578

11,102

2,756

2,508

3,468

8,114

2,606

826

7,132

1,965

7,809

1,003

38,184

1,580

613
3,103

24,294

3,897

1,543

1,005

820

2,680

30,525

77,700

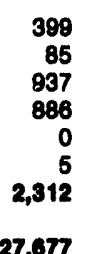

27,677

3,918

436
1.418

479

1,229

748

593

998

4,352

1,400

15,672

184

205
1,244

12,884

2,887

930

282

94

19,786

34,328

3,345

11,387

30,903

6,186

625
52.455

\section{1,002}

10,668

495

775

12,940

782
4,341

4,341

1,288

1,288
7,274

6,327

18,698

492

4,540

3,002

544

8,670

0
28
0
634
682

117
9
691
959
20
34
1,020
12498

1,618

4,126

3,671

804

411

1,548

2,182

3,368

2,242

0
10,009

19,000

23,493

43,402

16,581
18

1,691

1,216

0
0

2,925

6,707

2,414
1,108

1,108
620

922

660

338

1,658

569

$\mathbf{5 , 7 8 1}$

1,306
15,380

15,390

68

3
1,358

11,846

1,595

698

389

502

16
16,571

31,041

1,056

1,307

2,393

325

617

2,087

1,671

0,397

2,129

27,192

\section{0}

691

473
0

2,868

8,008

$$
\begin{array}{r}
8 \\
83 \\
1,65 \\
18,84 \\
1,118 \\
48
\end{array}
$$

1,655

18,846

1,118

488
6

652

23,630

80,722

See endnotes at end of an individual electric utility.

682

2,605

15,335

781

287

728

860

7,270

10,800

201

0
34,952

1,885

8,486

18,881

16,162

1,270

6,581

864

20,021

3,018

53

47,708

70

9,793
1,837

825

103

789

3,435

12,466

1,305

5,882

7,200

2,000

338
1,711
150
153
2,352

136
899
122
1
1,165


Table 41. Electric Operation and Malntenance Expenees by Major

U.S. Investor-Owned Electric Utility Within State, 1902 (Continued)

(Thousand Dollars)

\begin{tabular}{|c|c|c|c|c|c|c|}
\hline Item & $\begin{array}{l}\text { Orecon } \\
\text { Pacticonp }\end{array}$ & $\begin{array}{l}\text { Oregon } \\
\text { Portland } \\
\text { General } \\
\text { Electric Co }\end{array}$ & $\begin{array}{l}\text { Penneyivania } \\
\text { Duqueene } \\
\text { Light Co }\end{array}$ & $\begin{array}{l}\text { Penneylvania } \\
\text { Metropolitan } \\
\text { Edieon Co }\end{array}$ & $\begin{array}{l}\text { Pennoyivania } \\
\text { Penneytvania } \\
\text { Electric Co }\end{array}$ & $\begin{array}{c}\text { Pennoytvania } \\
\text { Pennoytvania } \\
\text { Power } \\
\& \\
\text { Light Co }\end{array}$ \\
\hline
\end{tabular}

Administrattve and General Expenses

Operation Expenses

Adminimtrathe and General Salaries

Orice Supolies and Expenes

(bei) Adminiotrattve Expenses

Trenstemed (credit) .

Property Incurance

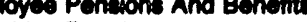

Acoulatory Commiecion Expenses

(leas) Duplicate Charges (credit)

General Advertiding Expenses....

Rents

Totyl Operration Expensese.

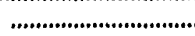

Maintenance of General Plant

Totel Adminiotrattre and

cenerd Expenese

68,498
26,868
0
10,747
9,543
9,016
84,878
14
1,824
100,713
115
17,328
8,317
144,592

\section{8,529}

27,132

28,810

8,863

2,431

4,168

5,688

4,427

13,125
0

6,123

1,705

68
4587

4,587

70,720

6,233

740

160,768

0,000

$1,312,042$

408,088

628,60

522,001

533,074

$1,472,697$

Distribution of Salaries and

Wegea Charged to Electric

Operation and Maintenance

Production

Transmiseion

Dietribution ...e.

Customer Accounts

Customer Service and

Informational Expenses

Adminetrathve and General

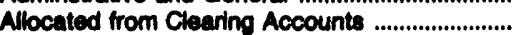

Total selaries and Wages

....................................

Number of Electric Department Employees

Regular Full-time Employees .......................................

Part-time and Temporary Employees

87,743
8,893
35,891
24,857

3,688
4,456
53,084
7,134
225,865

43,597

1,491

15,498

37,060

2,101

22,842

14,898

2,556

17,142

7,690

26,739

15,120

1,516

2,331

15

$\begin{array}{r}557 \\ \hline\end{array}$

7,931

22,448

09,108

128,600

9,823

4,403

$\mathbf{6 8 , 0 2 8}$

4,151

1,931
36

3,551

7,882
89

9,007
148

3,048
217

3,263

4,151

1,097

3,600

7,981

Note: Totals may not equal sum of components because of independent rounding. Summary data are provided in Table 11.

Source: Federal Energy Regulatory Commiseion, FERC Form 1, "Annual Report of Major Electric Utilities, Licensees and Others." 
Table 41. Electric Operation and Malntenance Expenses by Major

U.S. Investor-Owned Electric Utility Within State, 1992 (Continued)

(Thousand Dollars)

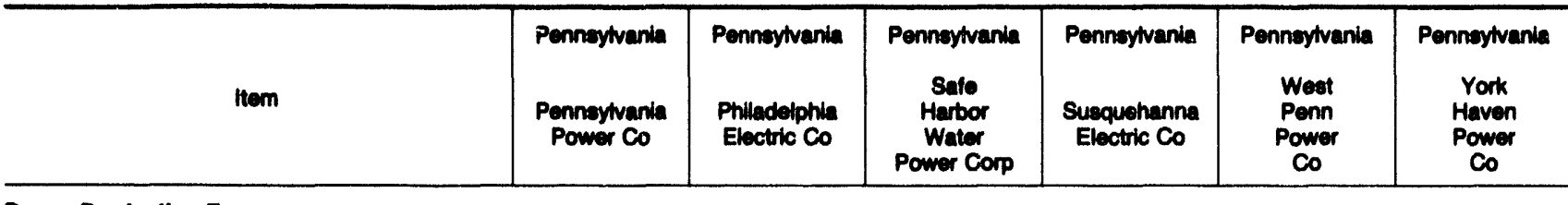

Power Production Expencece

Steam Power

Operation Expenaes

Supervition and Enginearing

$1,461 \quad 13,458$

47.801

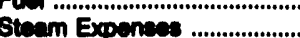

Steam from Other Sources

(kes) Steam Transferred (cred't)

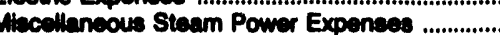

Rents

47,801
4,849

143,418
25,434

$\begin{array}{rr}0 & 0 \\ 0 & 0\end{array}$

$1,121 \quad 5,050$

$2,364 \quad 20,890$

$7 \quad 19,28$

Totel Operefion Exponsen

227,034

Maintenance Expenses

Supenvition and Engineering

Structures

Boller Plant

Electric Plent

Mbcellaneous Steam Plant...

Toted Melntienimes Expences

Toted Etean Power Production

Expensese

301,016

6,440

6,758

41,844

6,217

73,381

$\begin{array}{rr}4,054 & 86,951 \\ 16,329 & 141,491 \\ 188 & 12,050 \\ 1,707 & 34,727 \\ 0 & 0 \\ 0 & 0 \\ 48 & 5,263 \\ 7,768 & 80,073 \\ 18 & 20,382 \\ 30,111 & 300,989\end{array}$

Nuclear Power

Operation Expenees

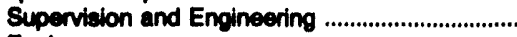

Fuel

Coolants and Water

Steam Expenses

Steam from Other Sources

(lese) Steam Transferred (credit)

Electric Expenses ...........

Miscellaneous Nuclear Power Expenses ............

Rente

Toted Operation Expenses

30,11

300,038

Maintenance Expenses

Supervition and Engineering

Structures ......

Reactor Plant Equipment

Electric Plant

Miscellaneous Nuclear Plant

Toted Malntensence Expenseses

(.............................

Totel Muclene Power Producthon

Expenses

5,085

23,701

14,638

66,159

33,566

25,497

$\begin{array}{rr}2,731 & 25,487 \\ 5,027 & 163,652\end{array}$

$\mathbf{0}$

3,189

4,039

34,306

8,401

1,834

82,780

4,565

98,395
5,488

0
0

1,934
4,776

580

295,763

393,526

Hydreulic Power

Operation Expenses

Supervition and Engineering .................................

Water for Power

Hydreulic Expenses

Electric Expenses

Macellaneous thydraulio Expenses

Rents

Totet Operation Expenses

88

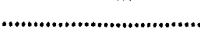

....

See endnotes at end of an individual electric utility.

$\begin{array}{rrrrr}492 & 331 & 539 & 117 & 241 \\ 865 & 0 & 685 & 50 & 26 \\ 1,144 & 296 & 497 & 86 & 214 \\ 646 & 904 & 880 & 168 & 436 \\ 398 & 1,658 & 1,216 & 411 & 254 \\ -648 & 0 & 13,100 & 0 & 0 \\ 2,097 & 3,168 & 17,125 & 843 & 1,171\end{array}$


Table 41. Electric Operation and Maintenance Expensese by Major

U.8. Investor-Owned Electric Utility Within Stato, 1902 (Continued) (Thousand Dollars)

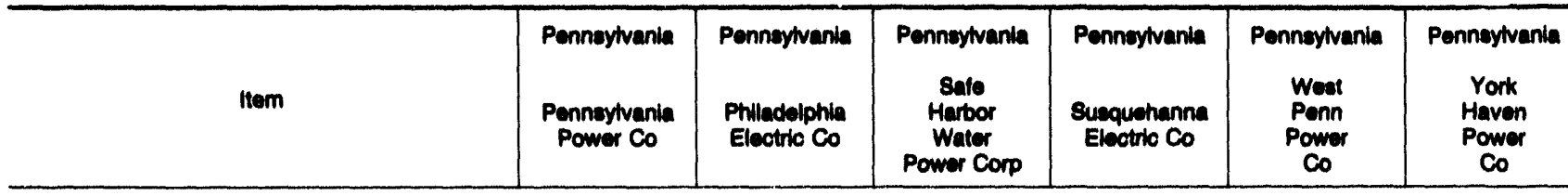

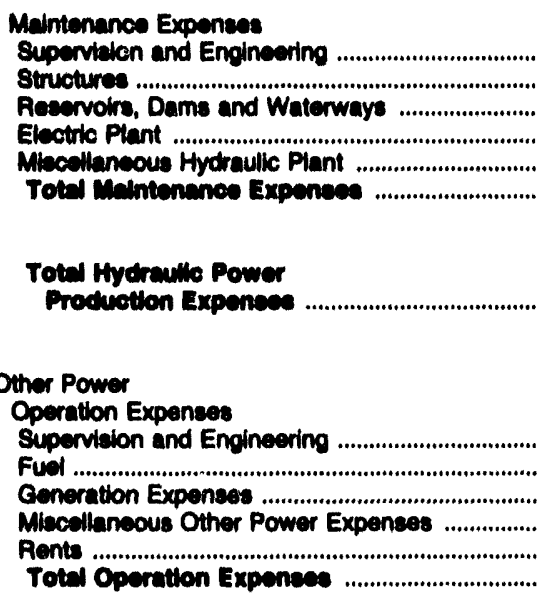

Maintenance Expenses

Supentilon and Engineering

Structures ..................................

Miecellaneous Other Power Plant

Totel Malmenanos Expenses

Totel Other Power Production

Expense?

Other Power Supply Expenses

Purchened Power

System Control and Load Dispatching .................

Other Expenses

Totel Other Power supply

Expenees

..............................................................

Totel Power Production Expenses

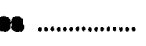

$1,157,504$

662

1,116

4,237

41

104

6,057

249

12,310

14,242

625
1,467

218,778

7,803

18,324

208,817

Tranamisesion

Operation Expenses

Supenteion and Engineering

Load Dispatching

Overtead Line Expenses

Underground Line Expenses

Tranemiselon of Electricity by Others

Miscellaneous Tranemiseion Expenses

Rents

Totel Opertiton Expenese

189
178
230
1,717
742
3,060

93

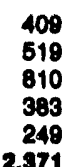

161

1,360

1,554

2,808

812

2,371

0,032

28,977

1,000

$\begin{array}{rr}4 & 66 \\ 87 & 51 \\ 81 & 60 \\ 187 & 506 \\ 58 & 60 \\ 417 & 70\end{array}$

1,290

see endnotes at end of an indhidual electric utility.

36
51
60
106


Table 41. Electric Operation and Maintenance Exponses by Major

U.S. Investor-Owned Elcotric Utility Within State, 1902 (Continued)

(Thousand Dollars)

\begin{tabular}{|c|c|c|c|c|c|c|}
\hline Item & $\begin{array}{l}\text { Pennoytuania } \\
\text { Pennoytvania } \\
\text { Power Co }\end{array}$ & $\begin{array}{l}\text { Pennoytvania } \\
\text { Philadelphila } \\
\text { Electric Co }\end{array}$ & $\begin{array}{c}\text { Penneytrania } \\
\text { Safo } \\
\text { Harbor } \\
\text { Water } \\
\text { Power Corp }\end{array}$ & $\begin{array}{l}\text { Pennaytvania } \\
\text { Susquehanna } \\
\text { Electrio Co }\end{array}$ & $\begin{array}{c}\text { Pennoytvania } \\
\text { Woot } \\
\text { Ponn } \\
\text { Power } \\
\text { Co }\end{array}$ & $\begin{array}{c}\text { Penneytvania } \\
\text { York } \\
\text { Haven } \\
\text { Power } \\
\text { Co }\end{array}$ \\
\hline
\end{tabular}

Maintenance Expenses

Supervition and Engineering

Structures

Station Equipment

Overhead Lines....

Underground Lines .

Miscollaneous Tranemiacion Plant

Totel Melentenanoe Expenses

Totel Tranembelon Expenese

Distribution

Operation Expenses

Supervicion and Engineering

Load Dlepatching

Station Expenses

Oreitiond Line Expe

Underground Line Expenses ...................................

Street Lighting and Signal Syatem Expenses ....

Moter Expences

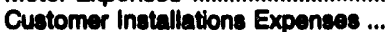

Rents

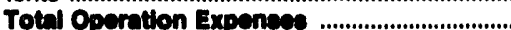

Maintenance Expenses

Supervision and Engineering

Structures .

Sthtion Equipment

Overhead Lines

Underground Lines

Une Transformers

Street Llahting and Signal Systems

Miscellaneous Distribution Plant

Total Maintenance Expenses

Total Diatribution Expenses

180,351

Customer Accounts Expenses

Supervision

Meter Reading Expenses ..................................

Customer Records and Collection Expenses ....

Uncollectible Accounts

Miscellaneous Customer Accounts Expenses

Total Customer Acoounte Expenes:

$\begin{array}{rr}131 & 461 \\ 54 & 424 \\ 732 & 8,795 \\ 183 & 4,696 \\ 0 & 1,250 \\ 6 & 87 \\ 1,100 & 16,712 \\ 4,090 & 20,063\end{array}$

461

796

87

20,063

39

177

1,373

116
64

630

146

780

3,073

170

48
877

4,946

233
43
23

135

28

0,409

10,471

230

875

2,575

14,548

156

18,494

4,745

2,689

5,381

9.448

3,173

768

4,464

4,090

25,654

5,357

86,051

2,367

1,358

8,732

82,830

11,687

2,000

1,761

2,098

1,871

64,70

2,731

11,358

41,273

05,059

102

160,523

$218 \quad 1,080$

2,473

422

6,629
1,894

31

1,269

3,144

10,081

Total Customer service and

Informational Expenese

Sales Expenses

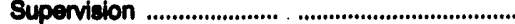

Demonatrating and Sellin, Expenses

Advertising Expenses

Miscellaneous Sales Expersees

Totil sales Expences
................................

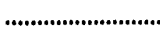

0

0

0
38

0

0

9

41

114
0
455
55
0
0
024
1,520

$\begin{array}{rr}291 & 0 \\ 63 & 0 \\ 1,871 & 0 \\ 2,386 & 0 \\ 0 & 0 \\ 2 & 0 \\ 4,612 & 0 \\ 10,065 & 0\end{array}$

3,172

1,558

1,791

2,104

256

289

1,082

910

4,599

179

16,910

1,389

236
2,859

2,869
24,343

836

836
387

381

427

65

30,928

4, 042

0

See endnotes at end of an individual electric utility.

$\begin{array}{rllll}680 & 0 & 0 & 0 & 0 \\ 4,791 & 0 & 0 & 0 & 0 \\ 720 & 0 & 0 & 0 & 0 \\ 8 & 0 & 0 & 0 & 0 \\ 8,200 & 0 & 0 & 0 & 0\end{array}$


Table 41. Electric Operation and Maintenance Expenese by Major

U.8. Investor-Owned Electric Utility Within State, 1992 (Continued)

(Thousand Dollars)

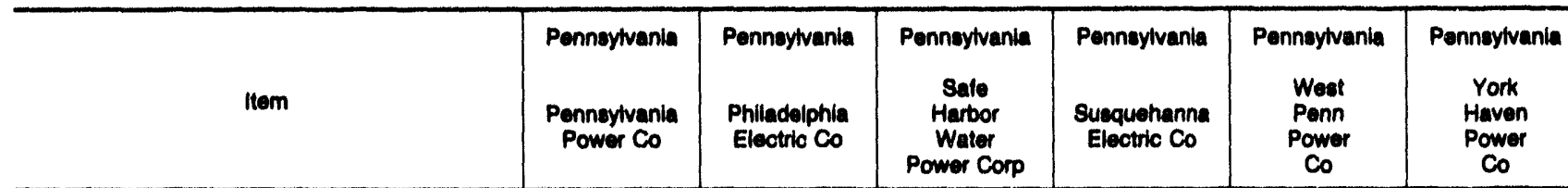

Adminiatrative and General Expenees

Operation Expenes

Adminietrattve and General Solaries

(lese) Adminiotrative Expenses

Transterted (credii) .

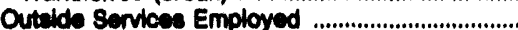

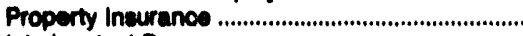

Injurke And Damages

Employee Pencions And Beneffts

Franchtee Requirements

Requilatory Commiscion Expences

(bis)Dupllcate Charges (credil)

Ceneral Advertiaing Expenses ...

vilecellanasu $\mathbf{G}$ on

Rents

Total Opertition Expenese ...............................

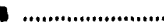

Maintenance of General Plant .............................

Totel Adminietrattve and

Cenerd Expensees.

$\begin{array}{rr}4,070 & 87,310 \\ 3,719 & 32,414 \\ 876 & 0 \\ 435 & 14,274 \\ 1,196 & 13,267 \\ 1,357 & 20,560 \\ -1,268 & 64,831 \\ 0 & 0 \\ 443 & 4,928 \\ 0 & 2,846 \\ 14 & 292 \\ 7,134 & 8,883 \\ 407 & 0 \\ 16,830 & 244,193\end{array}$

688

122

0
169

169
280

53

1,004

503

0

481

3,210

$389 \quad 621$

17,010

244,814

172,469

$1,720,810$

0,001

20,410

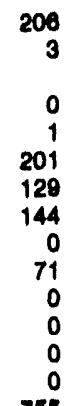

788

15

3,276

147

902

49,496

Totel Electris Operation and

Melntenanes Expenese

Diatribution of Salaries and

Wages Charged to Electric

Operation and Maintenance

Production

Tranemiselon ..........................................................

Ditiribution

Customer Accounts .................................................

Customer Senvice and

Informational Expenses

Selea Expenses

Adminotrattve and General

Clearing Accounts

Total ealartes and Wages

Employege

Number of Electric Department Employees

Regular Full-time Employees ..................................

Part-time and Temporary Employees

Total Eleotive Departmont Employee ........

$\begin{array}{rr}33,737 & 160,096 \\ 1,228 & 7,450 \\ 5,098 & 58,315 \\ 2,367 & 34,839 \\ & \\ 1,523 & 5,589 \\ 0 & 3,720 \\ 4,152 & 58,580 \\ -23,436 & 13,860 \\ 24,697 & 343,564\end{array}$

3,870
33
0
0
0
0
708
4
4,816

2,858
188
0
0
0
0
10
302
3,368

24,833

1,775

22,617

8,613

2,770

8,408

2,124

71,140

$$
1,411
$$

8,817

0

1,482

8,817
108

111
76

76
2,172

21

2,193

0

Note: Totale may not equal eum of components because of independent rounding. Summary data are provided in Table 11.

Source: Federal Energy Regulatory Commiseion, FERC Form 1, "Annual Report of Major Electric Utilities, Licensees and Others." 
Table 41. Electric Operation and Malntenance Expensees by Major U.S. Investor-Owned Electric Utility Within State, 1902 (Continued) (Thousand Dollars)

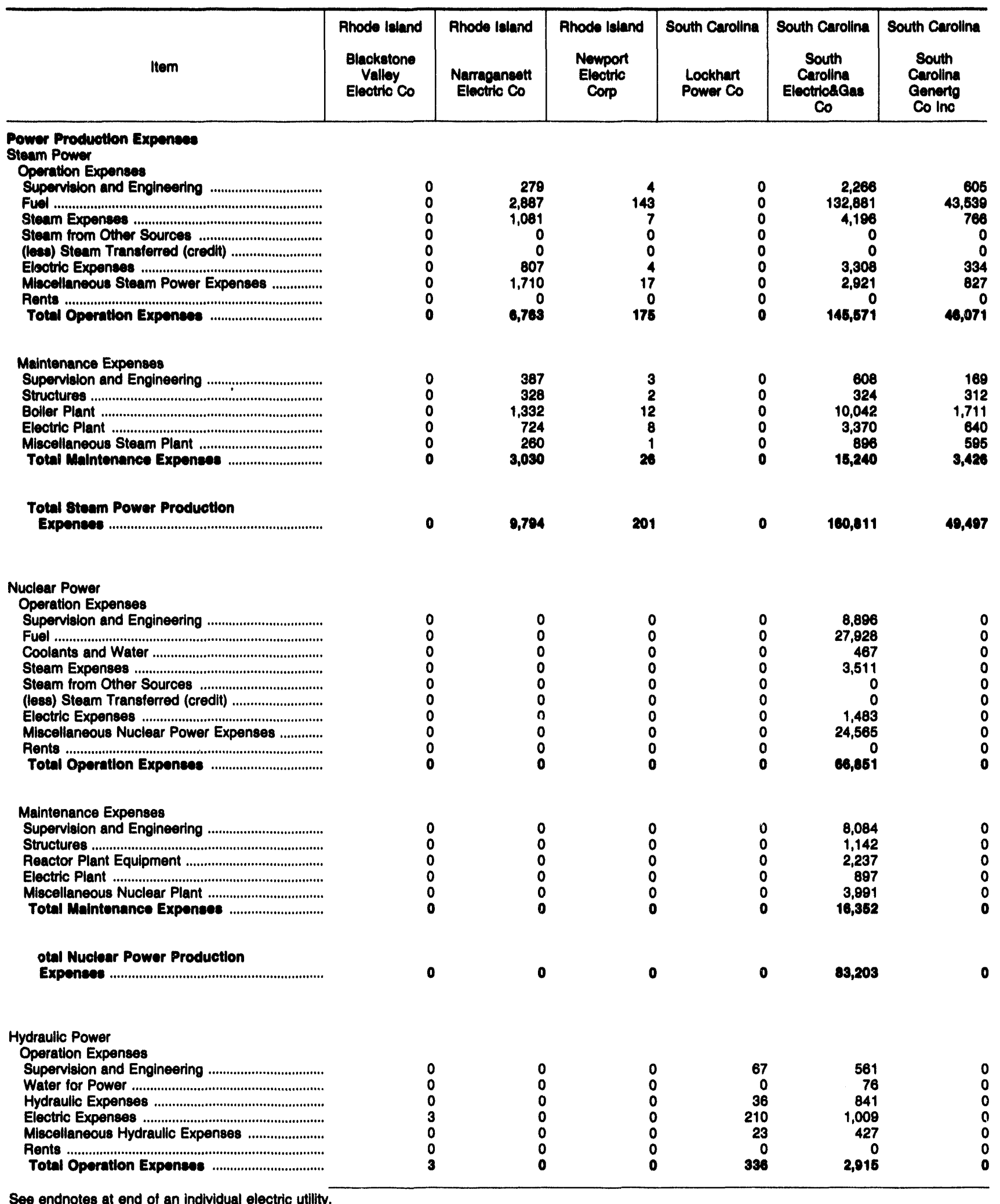


Table 41. Electrle Operation and Maintenance Expenses by Major

U.8. Investor-Owned Electric Utility Within 8tate, 1992 (Continued)

(Thousand Dollars)

\begin{tabular}{|c|c|c|c|c|c|c|}
\hline Itom & $\begin{array}{l}\text { Rhode laland } \\
\text { Blackatone } \\
\text { Valley } \\
\text { Electric Co }\end{array}$ & $\begin{array}{l}\text { Fhode laland } \\
\text { Narraganeett } \\
\text { Electric Co }\end{array}$ & $\begin{array}{l}\text { Phode laland } \\
\text { Newport } \\
\text { Eleotric } \\
\text { Corp }\end{array}$ & $\begin{array}{l}\text { South Carolina } \\
\text { Lockhart } \\
\text { Power Co }\end{array}$ & $\begin{array}{c}\text { South Carolina } \\
\text { South } \\
\text { Carollna } \\
\text { Electriodaas } \\
\text { Co }\end{array}$ & $\begin{array}{l}\text { South Carolina } \\
\text { South } \\
\text { Carolina } \\
\text { Generto } \\
\text { Co Ino }\end{array}$ \\
\hline
\end{tabular}

Malntenance Expenses

Supenviaton and Engineering

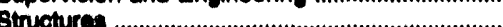

Reanvirs, Dame and Watemuye

Electric Plant

Miscelleneous Hyoraulio Plant

Total Meintenenos Exponsese

Totel Hydraulle Power

Production Expenses

11
5
1
101
0
118

0
0
0
0
0
0

28

54

75

178

381

168

595

1,443

324
2,001

-

6,017

Other Power

Operation Expences

Supervicion and Engineering .................................

Fuel ......................................................................

Generation Expenses ............................................

Miscellaneous Other Power Expenses

Rente

Total Opernition Exponses

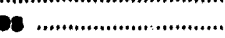

Maintenance Expenses

Supervilion and Engineering

Structures

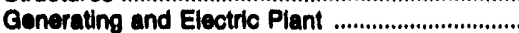

Miscellaneous Other Power Plant

Total Maintenanos Expences

Total Other Power Production

Exponsese

Other Power Supply Expenses

Purchased Power ........................................................

System Control and Load Dispatching ................

Other Expenses

Total Other Power supply

Expensese

...........................................................

Total Power Production Exponees

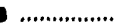

95,073
7
0

95,000

95,201

20,491

42,620

41,685
452
0

42,138

11,493

12,006

334,050

49,841

Transmiselon

Operation Expenses

Supervilion and Engineering

Load Diapatching ...

Overhead Line Expenses

Underground Line Expenses

Tranamiseion of Electricity by Others

Miscellaneous Tranemiseion lExpenses

Rente

Total Operation Expenses

$\begin{array}{rrr}66 & 148 \\ 45 & 889 \\ 122 & 428 \\ 11 & 25 \\ 0 & 0 \\ 0 & 1,307 \\ 47 & 1 & 57 \\ 2 & 5 & \end{array}$

203

2,011

132

See endnotes at end of an individual electric utlity. 
Table 41. Electrle Oporation and Malntenance Expenses by Major U.8. Investor-Owned Electrle Utillty Whiln state, 1992 (Continued) (Thousand Dollars)

\begin{tabular}{|c|c|c|c|c|c|c|}
\hline $1 \mathrm{tem}$ & $\begin{array}{l}\text { Ahode Ieland } \\
\text { Elecketons } \\
\text { Valley } \\
\text { Electric Co }\end{array}$ & $\begin{array}{l}\text { Rhods Ieland } \\
\text { Narreganeett } \\
\text { Electrio Co }\end{array}$ & $\begin{array}{l}\text { Ahods Idland } \\
\text { Nomport } \\
\text { Eleotrlo } \\
\text { Corp }\end{array}$ & $\begin{array}{l}\text { South Carollna } \\
\text { Lockhart } \\
\text { Power Co }\end{array}$ & $\begin{array}{c}\text { South Carolina } \\
\text { Bouth } \\
\text { Caroltha } \\
\text { Electriodeas } \\
\text { Co }\end{array}$ & $\begin{array}{l}\text { Eouth Carolina } \\
\text { South } \\
\text { Carolina } \\
\text { Conerto } \\
\text { Co ino }\end{array}$ \\
\hline
\end{tabular}

\section{Malntenances Expenees}

Supervilon and Engineering

Struotures

Btation Equipment

Overtend Lines

Underground Line:

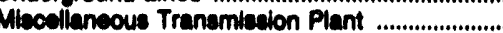

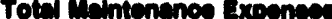

Totel Tranemisolon Expenese

(1)

Dietribution

Operation Expences

Supervision and Engineering ................................

Loend Diepatching

Station Expenses

Overtead Une Expences

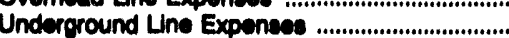

Btreot Lohting and Signal Byatem Expenees ...

Meter Expense

Cuatomer Intallations Expenese .............................

Miscollaneous Distribution Expenses.

Rent

$\begin{array}{rr}0 & 2 \\ 1 & \\ 182 & 31 \\ 92 & 20 \\ 0 & 28 \\ 0 & 77 \\ 278 & 77\end{array}$

s,e0

1,000

888

1,237

608

467

1,480

678
2.517

0,292

28
0
311
207
284
0
770
200

10
0
26
7
0
3
48

21
0
30
30
0
0
100

30

1,142

2,184

0
-8

3,840

17

117

8,021

$\begin{array}{rrrr}381 & 2 & 810 & 0 \\ 6 & 0 & 82 & 0 \\ 81 & 6 & 244 & 0 \\ 132 & 1 & 1,238 & 0 \\ 38 & 0 & 238 & 0 \\ 0 & 0 & 816 & 0 \\ 237 & 21 & 1,728 & 0 \\ 8 & 7 & 402 & 0 \\ 492 & 10 & 2,758 & 0 \\ 20 & 0 & 102 & 0 \\ 1,378 & 47 & 0,000 & 0\end{array}$

Muintenance Expenses

Bupervision and Engineering .................................

Btruotures .....................................

Station Equipment

Underground Lines

Line Tranglormers

Street Lohting and Signal Syatems ......................

Motere

Mlecollaneous Distribution Piant

Total Maintenenes Expensese

$\begin{array}{rr}49 & 137 \\ 68 & 0 \\ 488 & 1,407 \\ 1,640 & 6,070 \\ 72 & 528 \\ 04 & -538 \\ 48 & 38 \\ 0 & 84 \\ 84 & 8 \\ 2,440 & 7,738\end{array}$

137
0
1,407
6,070
528
-538
33
84
9
7,732

-42
0
180
873
93
13
100
0
28
1,240

212

39

21

174

1
2

29

5

29

1,149

1,149
8,492

1,091

767

1,098

68

61

12,053

8,050

17,114

2.814

32

21,928

Customer Accounts Expenses

Suporvision

Meter Reading Expenees .........................................

Customer Records and Collection Expenses ....

Uncollectible Accounts.

Miscellansous Customer Accounts Expences ...

Totil Customer Acoounts Expentes

894
2,601
6,094
4,942
16
14,447

1
278
013
427
0
1,010

047

2,468

10,130

1,844

670

18,78

178

361
6,108

1,000

12,881

52
194
46

0

3

30

228

7,704

18,09

322

8

320
1,803
107
680
2,080

Totel Customer serviee and

Sales Expenses

Eupenvilon

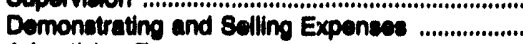

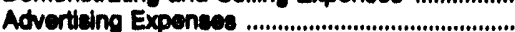

Miscollancous 8ales Expences

Totel seles Expenses .............................................

890 endnotes at end of en individual electric utility. 
Table 41. Electric Operation and Maintenance Expenase by Major U.8. Inveotor-Owned Electric Utility Within State, 1992 (Continued) (Thousand Dollars)

\begin{tabular}{|c|c|c|c|c|c|c|}
\hline litem & $\begin{array}{l}\text { Ahode laland } \\
\text { Blackatone } \\
\text { Valley } \\
\text { Electric Co }\end{array}$ & $\begin{array}{l}\text { Fhode Ilaland } \\
\text { Nerraganeott } \\
\text { Electrlo Co }\end{array}$ & $\begin{array}{l}\text { Phode Iland } \\
\text { Newport } \\
\text { Electilo } \\
\text { Corp }\end{array}$ & $\begin{array}{l}\text { South Carolina } \\
\text { Lockhert } \\
\text { Power Co }\end{array}$ & $\begin{array}{l}\text { South Carolina } \\
\text { South } \\
\text { Carollina } \\
\text { Electricaces } \\
\text { Co }\end{array}$ & $\begin{array}{l}\text { South Carolina } \\
\text { South } \\
\text { Carolina } \\
\text { Cenerts } \\
\text { Co Ino }\end{array}$ \\
\hline
\end{tabular}

Adminiatrative and Coneral Expenees

Operation Expenses

Adminiatrative and General Salaries

(1eap) Adminiatrathve Exponses

Traneterred (oredit) ............

Outalde Services Employed

Property Invurance

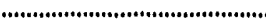

Injuries And Damages

Employee Penclons And Benefits

Franchice Requirements

Reoulatory Commistion Expenses

(lese)Duplicate Charges (crodil)

General Advertieing Expenses ....

Miscellaneous General Expenses

Rente

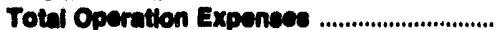

Maintenance of General Plant

Total Adminiotrotive and

Ceneral Expenses

$\begin{array}{rr}3,099 & 4,905 \\ 442 & 3,264 \\ 87 & 362 \\ 689 & 119 \\ 208 & 1,098 \\ 928 & 1,725 \\ 1,081 & 8,299 \\ 0 & 0 \\ 760 & 1,307 \\ 319 & 0 \\ 18 & 51 \\ 2,502 & 892 \\ 143 & 729 \\ 9,302 & 22,028\end{array}$

1,688
108
81
174
46
365
830
0
131
0
4
1,121
47
4.839

197
32

$20,483 \quad 288$

90

4,633

9,466

32

$88 \quad 721 \quad 178$

9,400

22,740

4,711

7

0
7,768

4,001

2,890

18,840

280

2,685

2,809

48

5,008

3,808

72,890

0
363
283
172
700
0
133
0
0
87
101
2,000

Total Electrite Operation and

Malntenanos Expenses

116,818

39,372

51,932

493,089

81,046

Diatribution of Salaries and

Wages Charged to Electric

Operation and Maintenance

Production

Tranemiseion

Distribution

Customer Accounts

Cuatomer Service and

Sales Expenses

Adminatrative and General

Allocated from Clearing Accounts .........................

Total Salarise and Woeses

....................................

Number of Electric Department Employees

Regular Full-time Employees ................................

Part-time and Temporary Employees

Total Eloctric Department Employees ..........

$\begin{array}{rr}71 & 4,493 \\ 10 & 1,139 \\ 3,266 & 8,250 \\ 986 & 5,090 \\ 779 & 1,450 \\ 0 & 0 \\ 689 & 2,235 \\ 192 & 718 \\ 6,002 & 24,885\end{array}$

350
70
1,583
463

281
0
461
122
3,200

406
56
135
86
0
0
0
304
20
1,007

42,676
2,295
10,482
8,968

2,125
2,087
17,586
6,303
91,523

3,354

0

0
0

156

3,600

Note: Totals may not equal sum of components because of independent rounding. Summary data are provided in Table 11.

Source: Federal Energy Regulatory Commission, FERC Form 1, "Annual Report of Major Electric Utillies, Licensees and Others." 
Tablo 41. Electrle Oporation and Malntenance Exponece by Major U.8. Inveotor-Owned Eleotric Utllity Within State, 1902 (Continued) (Thousand Dollars)

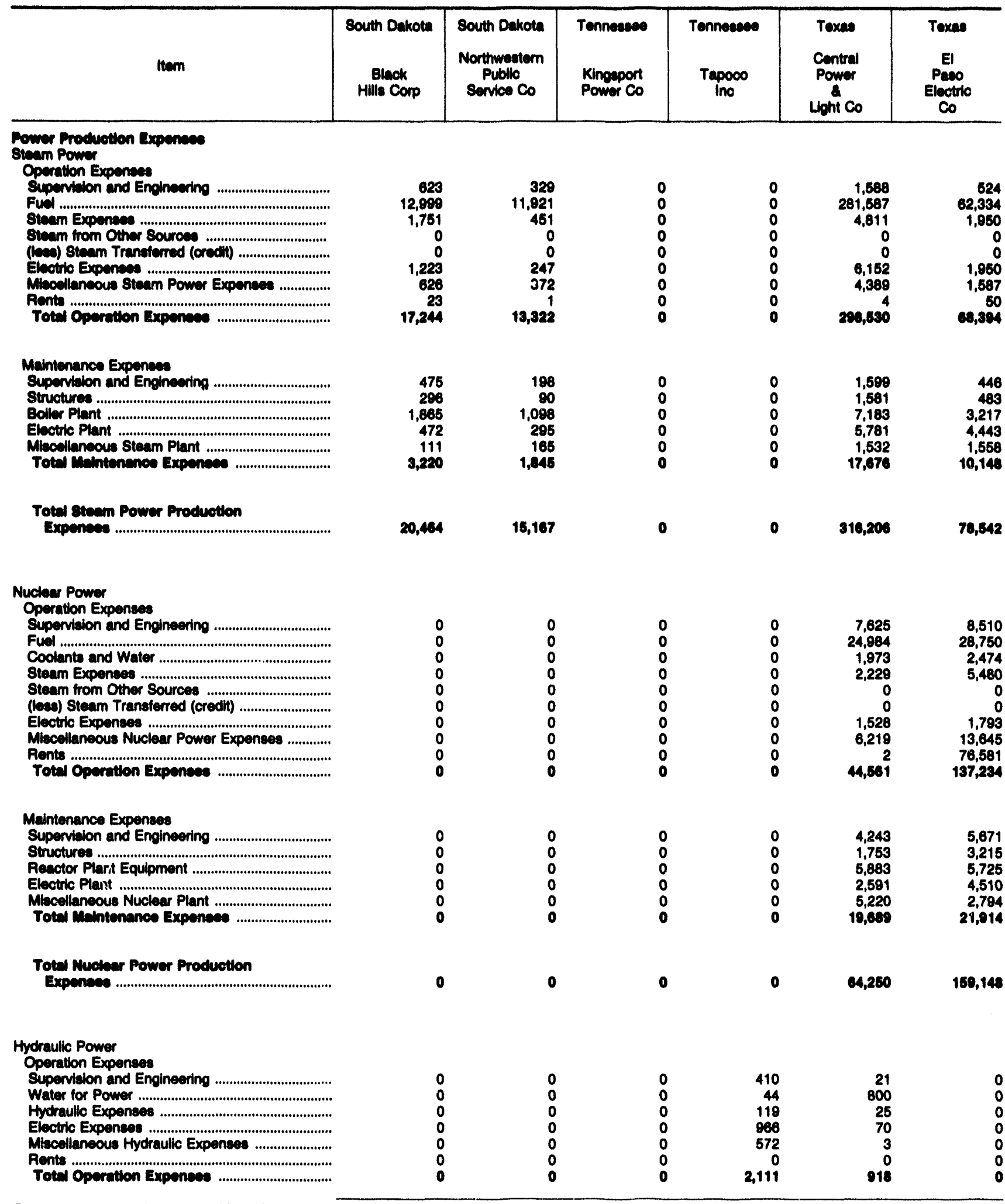

See endnotes at end of an individual electric utility. 
Table 41. Electric Oporation and Malntenanee Expenses by Major

U.8. Investor-Owned Electric Utility Within State, 1902 (Continued) (Thousand Dollars)

\begin{tabular}{|c|c|c|c|c|c|c|}
\hline liem & $\begin{array}{l}\text { South Dakota } \\
\text { Blaok } \\
\text { Hills Corp }\end{array}$ & $\begin{array}{l}\text { South Dakota } \\
\text { Northweatern } \\
\text { Publlo } \\
\text { Service Co }\end{array}$ & $\begin{array}{l}\text { Tenneasece } \\
\text { Kingeport } \\
\text { Power Co }\end{array}$ & $\begin{array}{l}\text { Tennesecee } \\
\text { Tapoco } \\
\text { inc }\end{array}$ & $\begin{array}{l}\text { Texas } \\
\text { Contral } \\
\text { Power } \\
\text { Laht co }\end{array}$ & $\begin{array}{c}\text { Texas } \\
\text { El } \\
\text { Paso } \\
\text { Electric } \\
\text { Co }\end{array}$ \\
\hline
\end{tabular}

Maintenance Expenses

Supervilon and Encineering

Structures

Reservolrs, Dams and Waterways

Electric Plant

Mbcellaneous Hydraulic Plant

Total Meintenance Expenses.

Totw Hydroulle Power

Production Exponses

Other Power

Operation Expense:

Supervision and Engineering

Fuel ....

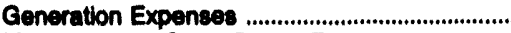

Miscellaneous Other Power Expensed

Rents

Total Operration Expenses

$\begin{array}{ll}0 & 0 \\ 0 & 0 \\ 0 & 0 \\ 0 & 0 \\ 0 & 0 \\ 0 & 0\end{array}$

$\mathbf{0}$

50
1,087
164
15
0
1,325

54
115
118
79
0
387

Maintenance Expenses

Supervision and Engineering

Structures .

Generating and Electric Plant

Miscellaneous Other Power Plant

Toted Melntenance Expeness

Total Other Power Production

Expences

Purchased Power

System Control and Load Dispatching ................

Other Expenses

Total Other Power supply

Exponses

Total Power Production Expenses

0

0

0

0

4,000

314
419
886
764
312
2,008

$\begin{array}{rr}2 & 0 \\ 46 & 0 \\ 26 & 0 \\ 26 & 0 \\ 9 & 0 \\ 100 & 0\end{array}$

1,028

0

Transmiseion

Operation Expenses

Supervision and Engineering

Load Dispatching .

Station Expenees

Overhead Line Expenses

Underground Line Expenses

Transmiseion of Electrictly by Others

Miscellaneous Transmisaion Expenses

Rents

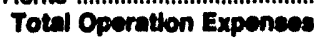

46,108

16,916

5,131

401,172

289,370

See endnotes at end of an indlvidual electric utility. 
Table 41. Electrlc Operation and Maintenance Expenses by Major U.S. Investor-Owned Electric Utillty Within State, 1992 (Continued) (Thousand Dollars)

\begin{tabular}{|c|c|c|c|c|c|c|}
\hline Item & $\begin{array}{l}\text { South Dakota } \\
\text { Black } \\
\text { Hills Corp }\end{array}$ & $\begin{array}{l}\text { South Dakota } \\
\text { Northwestern } \\
\text { Public } \\
\text { Service Co }\end{array}$ & $\begin{array}{l}\text { Tenneseses } \\
\text { Kingeport } \\
\text { Power Co }\end{array}$ & $\begin{array}{l}\text { Tennessee } \\
\text { Tapoco } \\
\text { Inc }\end{array}$ & $\begin{array}{c}\text { Texas } \\
\text { Central } \\
\text { Power } \\
\mathbf{a} \\
\text { Luht Co }\end{array}$ & $\begin{array}{c}\text { Texas } \\
\text { El } \\
\text { Peso } \\
\text { Electric } \\
\text { Co }\end{array}$ \\
\hline
\end{tabular}

Maintenance Expenses

Supervision and Engineering

Structures .................

Overhead Lines .

Underground Lines

Miscellaneous Transmission Plant

Totel Maintenance Expenses

................................

Total Tranamieden Expences

...........................

Distribution

Operation Expenses

Supervision and Engineering

Load Dispatching

Station Expenses

Overhead Line Expenses

Underground Line Expenses ..........

Street Lighting and Signal System Expenses ...

Meter Expenseg

Customer Installations Expenses ...........................

Miscellaneous Distribution Expenses

Rents

Total Operation Expenses

......................................

Maintenance Expenses

Supervision and Engineering ..................................

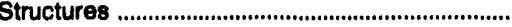

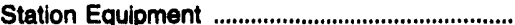

Overhead Lines

Underground Lines

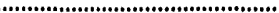

Street Lighting and Signal Systems .....................

Meters

Miscellaneous Distribution Plant

Total Malntonance Expenses

Total Dlatribution Expenses

$\begin{array}{rr}62 & 88 \\ 0 & 0 \\ 368 & 168 \\ 152 & 249 \\ 0 & 0 \\ 2 & 0 \\ 570 & 601\end{array}$

55
8
97
230
0
10
400

313
81
761
171
0
1
1,827

363

1,263

1,642

780

1,710

1,458

2,729

1
09

4,001

14,305

74

6,424

334
73

73

41
736

59

362

13

178

44
1,030

229

318

0

58

111

175
186

39

355

101

1,790

$\begin{array}{rr}1,651 & 747 \\ 650 & 223 \\ 850 & 793 \\ 2,358 & 681 \\ 368 & 360 \\ 450 & 8 \\ 3,318 & 1,171 \\ 1,720 & 519 \\ 4,278 & 2,738 \\ 15 & 144 \\ 16,654 & 7,385\end{array}$

245

129

156

156
918

108

71

93

13

1,692

60
1,304
186
145
57
61
52
2,004

245
18
163
1,380
6

1,057

36

1,426
7,899

7,899
476

1,183

708

1,055

657

2,120

14,492

Customer Accounts Expenses

Supervision

Meter Reading Expenses ....................................

Customer Records and Collection Expenses ....

Uncollectible Accounts ...

Miscellaneous Customer Accounts Expenses

Total Customer Accounts Expenses

3,531

3,799

30,048

11,767

302

611

1,336

198

261

2,703

3,803

77

333

764

45

1,222

123
256
704
63
30
1,176

1,860

3,246

10,868

1746

17,721

1,073

1,073
4,952

4,227

168

$10,7.0$

Customer Service and Information Expenses

Supervision ...............................................................

Customer Assistance Expenses ..........................

Informational and Instructional Expenses ............

Miscellaneous Customer Service

and Informational Expenses ...

Intormatlonal Expenees
53

637

132

8

831
245

1,326

1,158

256

2,094
14

155
38

40

248

162

154

109

49

Sales Expenses

Supervision ..........................................

Advertising Expenses .....................

Miscellaneous Sales Expenses

Total Sales Expenees

$\begin{array}{rr}0 & 162 \\ 0 & 154 \\ 0 & 109 \\ 0 & 0 \\ 0 & 428\end{array}$

0
6
0
1
7

See endnotes at end of an individual electric utility. 
Table 41. Electric Operation and Malntenance Exponees by Major U.S. Inveotor-Owned Electric Utility Within State, 1992 (Continued) (Thousand Dollars)

\begin{tabular}{|c|c|c|c|c|c|c|}
\hline Item & $\begin{array}{l}\text { South Dakota } \\
\text { Black } \\
\text { Hills Corp }\end{array}$ & $\begin{array}{l}\text { South Dakota } \\
\text { Nortmwestern } \\
\text { Public } \\
\text { Service Co }\end{array}$ & $\begin{array}{l}\text { Tennesesee } \\
\text { Kingeport } \\
\text { Power Co }\end{array}$ & $\begin{array}{l}\text { Tennescese } \\
\text { Tapoco } \\
\text { Inc }\end{array}$ & $\begin{array}{c}\text { Texas } \\
\text { Central } \\
\text { Power } \\
\text { Light Co }\end{array}$ & $\begin{array}{c}\text { Texas } \\
\text { El } \\
\text { Paso } \\
\text { Electric } \\
\text { Co }\end{array}$ \\
\hline
\end{tabular}

\section{Adminibtrative and Ceneral Expensea}

Operation Expenses

Admintotrative and General Salaries

Orince supplies and Expenses

Tranaferred (creciti)

Outelde Services Employed .......................................

Property Invurance ....

In'uries And Dameges

Frenchice Requirements

Expenses

(kes) Duplloate Charges (credit)

Generd Advertising Expenses

Miscellansous General Expenses ...........................

Rents

Totel Operrition Expences

Maintenance of General Plant

Totel Adininiotrattwe end

Cenerel Exponeso

...........

Totel Ebetule Operntion and

Meintenenes Expenises.

(n)

Distribution of Salaries and

Weoes Charged to Electric

Operation and Maintenance

Production .

Distribution .

Accounts

Cutomer Service and

Informational Expensen

Sales Expenses

Adminutrative and General ....

Alocated from Clearing Account

Totel selation and Wegen

Number of Electric Depertment Employees

Regular Full-time Employees ..................................

Part-time and Temporary Employees

Totel Eloctils Depertinent Empioyees .........

$\begin{array}{rr}1,141 & 1,921 \\ 308 & 658 \\ 0 & 371 \\ 572 & 381 \\ 186 & 183 \\ 688 & 687 \\ 2,287 & 1,454 \\ 0 & 0 \\ 38 & 6 \\ 0 & 0 \\ 12 & 64 \\ 655 & 618 \\ 18 & 52 \\ 5,89: & 6,446\end{array}$

839

440

111

478

24,568

20,097

11,450

3,883

3,680

5,040

2,898

4,449

16,139

0
491

0

1,121

8,482

4,341

$\mathbf{8 4 , 1 4 7}$

4,465

1,410

174

442

119

144

0,012

84,914

6,088

$0,0.7$

2,440

1,937

8,720

889,600

364,043

09,491

80,242

97,000

0
10,436
2,088

2,088
5,489

13,509

0
4,573

4,573
0
19

18
5,742

6,316

63,604

$\begin{array}{rr}3,749 & 528 \\ 582 & 633 \\ 2,640 & 2,505 \\ 1,800 & 853 \\ 680 & 183 \\ 0 & 278 \\ 2,071 & 2,152 \\ 0 & 1,057 \\ 11,622 & 0,297\end{array}$

0
87
1,485
555
112
0
511
141
2,801

3,228
957
0
0
0
0
709
0
4,004

19,632
3,873
16,540
10,351

6,772

1,082

7,644

4,817

1,281

1,710

14,481

1,295

00,172

1,660

0
13,460

605

36,030

$\begin{array}{rrrrrr}332 & 280 & 104 & 91 & 2,308 & 1,104 \\ 10 & 28 & 0 & 0 & 23 & 25\end{array}$

861

30

104

91

2,331

1,120

Note: Totals may not cqual sum of components because of independent rounding. Summary data cre provided in Table 11.

Source: Federal Energy Regulatory Commialion, FERC Form 1, "Annual Report of Malor Electric Utilites, Liceneses and Others." 
Table 41. Electric Operation and Maintenance Expences by Major U.S. Investor-Owned Electric Utility Within State, 1992 (Continued) (Thousand Dollars)

\begin{tabular}{|c|c|c|c|c|c|c|}
\hline Item & $\begin{array}{l}\text { Toxas } \\
\text { Gulf } \\
\text { States } \\
\text { Utillibs } \\
\text { Co }\end{array}$ & $\begin{array}{l}\text { Toxes } \\
\text { Houston } \\
\text { Lohting } \\
\text { Power Co }\end{array}$ & $\begin{array}{l}\text { Texas } \\
\text { Southweatern } \\
\text { Electric } \\
\text { Serv Co }\end{array}$ & $\begin{array}{l}\text { Texas } \\
\text { Southwestern } \\
\text { Public } \\
\text { Service Co }\end{array}$ & $\begin{array}{c}\text { Texas } \\
\text { Texas } \\
\text { Utillties } \\
\text { Electric Co }\end{array}$ & $\begin{array}{l}\text { Texas } \\
\text { Texas- } \\
\text { New Moxico } \\
\text { Power Co }\end{array}$ \\
\hline 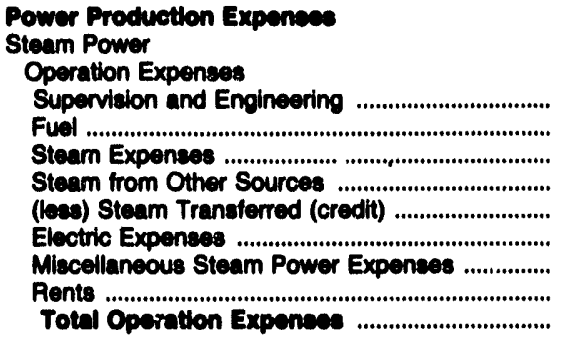 & $\begin{array}{r}2,973 \\
440,238 \\
5,862 \\
0 \\
0 \\
4,783 \\
8,389 \\
0 \\
402,246\end{array}$ & $\begin{array}{r}9,818 \\
925,570 \\
22,098 \\
0 \\
0 \\
98,165 \\
14,323 \\
0 \\
1,000,074\end{array}$ & $\begin{array}{l}0 \\
0 \\
0 \\
0 \\
0 \\
0 \\
0 \\
0 \\
0\end{array}$ & $\begin{array}{r}851 \\
337,897 \\
4,662 \\
2,683 \\
0 \\
6,763 \\
5,744 \\
8 \\
368,306\end{array}$ & $\begin{array}{r}25,032 \\
1,237,447 \\
34,465 \\
0 \\
0 \\
11,689 \\
20,163 \\
1,778 \\
1,330,574\end{array}$ & $\begin{array}{r}559 \\
44,977 \\
885 \\
0 \\
0 \\
827 \\
1,068 \\
0 \\
46,316\end{array}$ \\
\hline 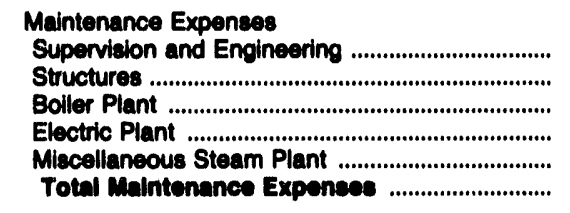 & $\begin{array}{r}3,136 \\
4,691 \\
21,387 \\
10,694 \\
1,688 \\
41,496\end{array}$ & $\begin{array}{r}21,838 \\
10,503 \\
72,183 \\
33,615 \\
7,278 \\
145,417\end{array}$ & $\begin{array}{l}0 \\
0 \\
0 \\
0 \\
0 \\
0\end{array}$ & $\begin{array}{r}1,709 \\
1,385 \\
8,173 \\
3,613 \\
1,239 \\
16,120\end{array}$ & $\begin{array}{r}23,042 \\
10,012 \\
90,204 \\
42,016 \\
1,701 \\
168,974\end{array}$ & $\begin{array}{r}165 \\
129 \\
2,516 \\
281 \\
725 \\
3,017\end{array}$ \\
\hline $\begin{array}{c}\text { Total Steam Power Production } \\
\text { Expenees }\end{array}$ & 503,741 & $1,215,301$ & 0 & 374,428 & $1,497,540$ & 52,133 \\
\hline 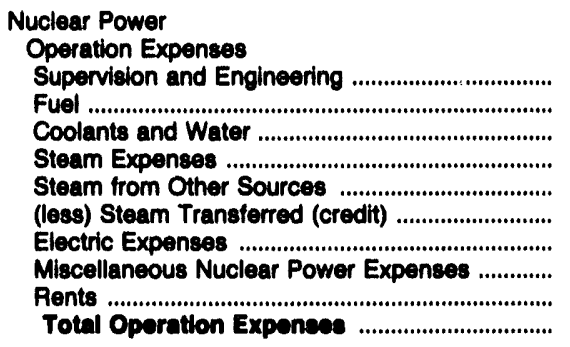 & $\begin{array}{r}13,977 \\
31,635 \\
1,573 \\
6,215 \\
0 \\
0 \\
1,442 \\
24,130 \\
1,572 \\
80,644\end{array}$ & $\begin{array}{r}9,283 \\
33,984 \\
2,394 \\
2,724 \\
0 \\
0 \\
0 \\
1,851 \\
7,659 \\
2 \\
67,007\end{array}$ & $\begin{array}{l}0 \\
0 \\
0 \\
0 \\
0 \\
0 \\
0 \\
0 \\
0 \\
0\end{array}$ & $\begin{array}{l}0 \\
0 \\
0 \\
0 \\
0 \\
0 \\
0 \\
0 \\
0 \\
0\end{array}$ & $\begin{array}{r}21,747 \\
30,317 \\
2,583 \\
9,954 \\
0 \\
0 \\
1,870 \\
31,589 \\
288 \\
98,340\end{array}$ & $\begin{array}{l}0 \\
0 \\
0 \\
0 \\
0 \\
0 \\
0 \\
0 \\
0 \\
0\end{array}$ \\
\hline 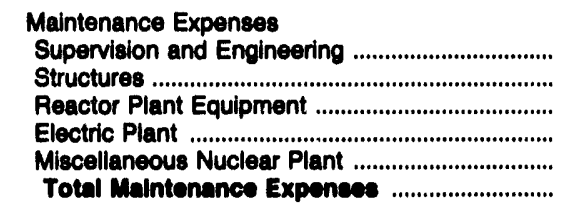 & $\begin{array}{r}14,031 \\
16,603 \\
22,139 \\
9,296 \\
5,533 \\
67,602\end{array}$ & $\begin{array}{r}5,196 \\
2,135 \\
7,139 \\
3,056 \\
6,324 \\
23,050\end{array}$ & $\begin{array}{l}0 \\
0 \\
0 \\
0 \\
0 \\
0\end{array}$ & $\begin{array}{l}0 \\
0 \\
0 \\
0 \\
0 \\
0\end{array}$ & $\begin{array}{r}9,773 \\
6,620 \\
13,376 \\
8,880 \\
5,220 \\
43,869\end{array}$ & $\begin{array}{l}0 \\
0 \\
0 \\
0 \\
0 \\
0\end{array}$ \\
\hline $\begin{array}{c}\text { Total Muclear Power Production } \\
\text { Expenese }\end{array}$ & 146,146 & 01,747 & 0 & 0 & 142,218 & 0 \\
\hline 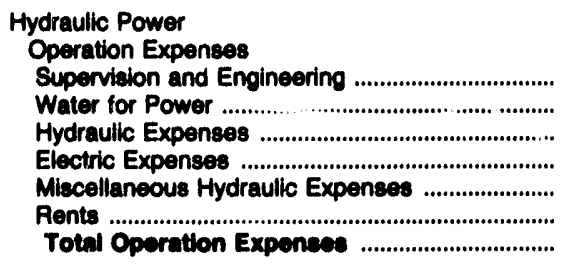 & $\begin{array}{l}0 \\
0 \\
0 \\
0 \\
0 \\
0 \\
0\end{array}$ & $\begin{array}{l}0 \\
0 \\
0 \\
0 \\
0 \\
0 \\
0\end{array}$ & $\begin{array}{l}0 \\
0 \\
0 \\
0 \\
0 \\
0 \\
0\end{array}$ & $\begin{array}{l}0 \\
0 \\
0 \\
0 \\
0 \\
0 \\
0\end{array}$ & $\begin{array}{l}0 \\
0 \\
0 \\
0 \\
0 \\
0 \\
0\end{array}$ & $\begin{array}{l}0 \\
0 \\
0 \\
0 \\
0 \\
0 \\
0\end{array}$ \\
\hline
\end{tabular}

See endnotes at end of an individual electric utillty. 
Table 41. Electrlc Operation and Maintenance Expenses by Major U.S. Investor-Owned Electric Utility Within State, 1992 (Continued) (Thousand Dollars)

\begin{tabular}{|c|c|c|c|c|c|c|}
\hline Item & $\begin{array}{c}\text { Texas } \\
\text { Gulf } \\
\text { States } \\
\text { Utilities } \\
\text { Co }\end{array}$ & $\begin{array}{l}\text { Texas } \\
\text { Houston } \\
\text { Lighting } \\
\text { Power Co }\end{array}$ & $\begin{array}{l}\text { Texas } \\
\text { Southwestem } \\
\text { Electric } \\
\text { Serv Co }\end{array}$ & $\begin{array}{c}\text { Texas } \\
\text { Southwestern } \\
\text { Public } \\
\text { Sorvice Co }\end{array}$ & $\begin{array}{c}\text { Texas } \\
\text { Texas } \\
\text { Utilities } \\
\text { Electric Co }\end{array}$ & $\begin{array}{c}\text { Texas } \\
\text { Texas- } \\
\text { Now Mexico } \\
\text { Power Co }\end{array}$ \\
\hline
\end{tabular}

Maintenance Expenses

Supervision and Engineering

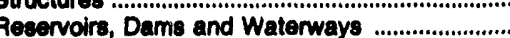

Electric Plant

Miecellaneous Hydraulic Plant

Total Malntenence Expenese

Total Hydraulle Power

Production Expenses

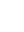

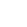

0
0
0
0
0
0

0
0
0
0
0
0

0
0
0
0
0
0

0
0
0
0
0
0

Other Power

Operation Expenses

Supervision and Engineering

Fuol ................u.u.u.u.

Generation Expenses ............................................

Miscellaneous Other Power Expenses

Rents

Totel Operation Expenese.

Maintenance Expenses

Supervision and Engineering

Structures ...

Generating and Electric Plant

Total Malntonenco Exponees

Total Other Power Production

Exponces

271
28,364
1,396
80
0
30,112

$\begin{array}{rr}71 & 281 \\ 837 & 11,370 \\ 45 & 528 \\ 37 & 72 \\ 0 & 37,777 \\ 000 & 80,037\end{array}$

0
0
0
0
0
0

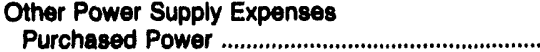

System Control and Load Dispatching

Other Expenses

Total Other Power supply

Expenses

Total Power Production Expenses

789,936

$1,827,456$

47,292

381,234

$2,204,067$

235,794

Transmission

Operation Expenses

Supervision and Engineering ..............................

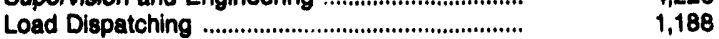

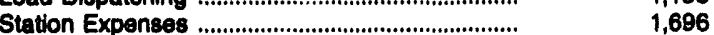

Overhead Line Expenses

Underground Line Expenses

Transmission of Electricity by Others

Transmision Expenses

Total Operation Expenses

218
698
702
665
0
178
332
164

126
0
38
4
0
0
47
0

735

1,069

706

202
0

87

303
15

496,752
1,901

174,257

61

14,174

189,661

2,057

214

3,177

1,298
4,949
3,129
1,060
39
3,419
6,324
712

272

599

110
66

005

8,005

294
13

9,350

See endnotes at end of an individual electric utility. 
Table 41. Electric Operation and Malntenance Expenses by Major U.S. Investor-Owned Electric Utility Within State, 1992 (Continued) (Thousand Dollars)

\begin{tabular}{|c|c|c|c|c|c|c|}
\hline Item & $\begin{array}{c}\text { Texas } \\
\text { Gulf } \\
\text { States } \\
\text { Utillies } \\
\text { Co }\end{array}$ & $\begin{array}{l}\text { Texas } \\
\text { Houston } \\
\text { Lighting } \\
\text { Power Co }\end{array}$ & $\begin{array}{l}\text { Texas } \\
\text { Souttwwestern } \\
\text { Electric } \\
\text { Serv Co }\end{array}$ & $\begin{array}{c}\text { Texas } \\
\text { Southwestem } \\
\text { Public } \\
\text { Service Co }\end{array}$ & $\begin{array}{c}\text { Texas } \\
\text { Texas } \\
\text { Utillies } \\
\text { Electric Co }\end{array}$ & $\begin{array}{c}\text { Texas } \\
\text { Texas- } \\
\text { New Mexico } \\
\text { Power Co }\end{array}$ \\
\hline
\end{tabular}

Maintenance Expenses

Supervision and Engineering

Structures

Station Equip..............................................................

Overhead Lines

Underground Lines

Totel Tranemiaton Exponese

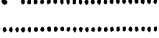

Diatribution

Operation Expenses

Supervision and Engineering

Load Dispatching

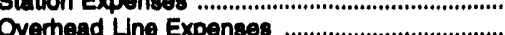

Underground Line Expenses ..................................

Street Lighting and Signal System Expenses ....

Meter Expenses

Customer Installations Expenses

Miscellaneous Distribution Expenses .....................

Rents .

Total Operation Expences

2,813

41

6,319

5,175

14

14,969

28,188

3,124

3,124
970

1,394

2,404

1,407

1,248

2,374

1,913

2,958

1,008

18,101

4,300

2
2,287

14,802

1,835

1,675

659

736

275

28,671

48,872

Totel Dlotribution Expenses

Miscellaneous Distribution Plant

Total Malntenance Expences

......................................

Customer Accounts Expenses

Supervision

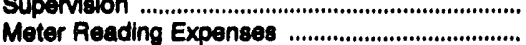

Customer Records and Collection Expenses ...

Uncollectible Accounts ...........................................

Miscellaneous Customer Accounts Expenses ...

Total Customor Accounts Expenses ..............

Customer Service and Information Expenses

Supervision ................................................................

Informational and Instructional Expenses ..............

Miscellaneous Customer Service

and Informational Expenses

Total Cuotomer sorvices and

Informational Expenees ...

Sales Expenses

Supervision

Demonstrating and Selling Expenses ...................

Advertiaing Expenses ............................................

Miscellaneous Sales Expenses

Total 8ales Expensece

See endnotes at end of an individual electric utility.

852

3,173
13,428

2,224

73
19,761

6,091

542
77
2,861
5,173
124
82
8,890

78
0
60
10
0
1
149

111
3
1,507
514
1
28

1,471

222
6,410

6,893

41

1,831

2,105

18,96

11,027

303

5,341

37,707

9,003

$$
\begin{array}{r}
4,688 \\
646 \\
2,014 \\
4,612 \\
2,240 \\
1,147 \\
9,488 \\
5,914 \\
11,656 \\
-1 \\
42,203
\end{array}
$$

210
0
189
188
1
30
383
19
70
24
1,133

668

271

686
1,610

1,610
173

172

3,081

723

1,847

285

0,300

5,539

2,469

3,793

4,613

3,273

820
7.728

$\mathbf{2 , 7 4 0}$

20,661

1,035

s2,6s1

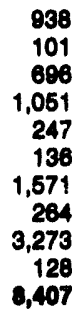

3,331

223
7,884

26,655

6,673

1,105

3,377

978

248

60,678

498

0
1,144

3,431

130

603

371

447

131
0,768

5,449

276

5,820

31,268

6,847

5,914

2,813

2,346

2,738

08,471

18,182

116,131

16,269

$\bullet 2,776$

2,703

1,925

6,063

41,381

8,028

78
67,478

401
2,500

8,468

8,468
839

191

12,900

2,519

12,414

80,701

4,102

880

100,818

112
1,767

6,308

970

384

0,510

$\begin{array}{rr}1,024 & 1,931 \\ 2,800 & 8,780 \\ 745 & 2,857 \\ 1,391 & 332\end{array}$

14,010

291
3980

3,860
1,186

1,055

22,442

1,707

188

742

202

1,503

290

202

27,000

1,421
61
729
135
2,070
2,008
0
0
27
0
27

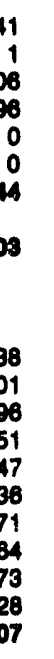

89
52
848
.511
461
175
318
275
6
946

40

19

6,689

$\begin{array}{rrrrr}94 & 0 & 61 & 0 & 0 \\ 326 & 0 & 729 & 0 & 0 \\ 0 & 0 & 135 & 27 & 38 \\ 14 & 0 & 2,070 & 0 & 0 \\ 495 & 0 & 2,000 & 27 & 38\end{array}$


Table 41. Eloctric Operation and Maintenance Expenees by Major U.S. Investor-Owned Eloctric Utility Within State, 1992 (Continued) (Thousand Dollars)

\begin{tabular}{|c|c|c|c|c|c|c|}
\hline Hem & $\begin{array}{l}\text { Toxas } \\
\text { Culf } \\
\text { States } \\
\text { Utilibes } \\
\text { Co }\end{array}$ & $\begin{array}{l}\text { Toxas } \\
\text { Houston } \\
\text { Lighting } \\
\text { Power Co }\end{array}$ & $\begin{array}{l}\text { Toxas } \\
\text { Southweotern } \\
\text { Electric } \\
\text { Serv Co }\end{array}$ & $\begin{array}{l}\text { Toxas } \\
\text { Soutmwestern } \\
\text { Public } \\
\text { Service Co }\end{array}$ & $\begin{array}{l}\text { Toxas } \\
\text { Toxas } \\
\text { Utilities } \\
\text { Electric Co }\end{array}$ & $\begin{array}{l}\text { Texas } \\
\text { Texas- } \\
\text { New Mexico } \\
\text { Power Co }\end{array}$ \\
\hline \multirow{3}{*}{ 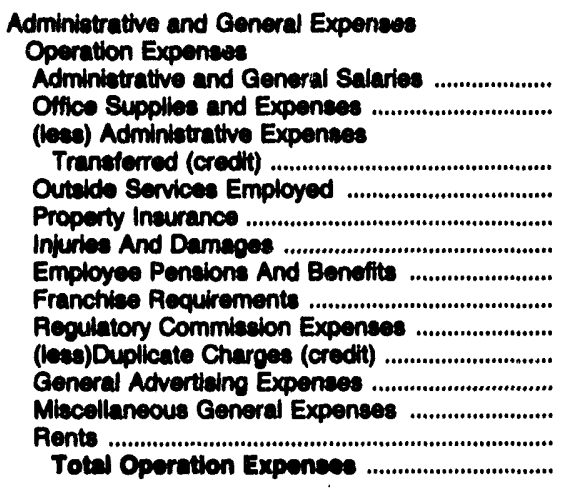 } & & & & & & \\
\hline & $\begin{array}{l}38,247 \\
12,429\end{array}$ & $\begin{array}{l}45,878 \\
23,251\end{array}$ & $\begin{array}{r}1,075 \\
287\end{array}$ & $\begin{array}{r}12,376 \\
6,863\end{array}$ & $\begin{array}{l}64,650 \\
12,705\end{array}$ & $\begin{array}{l}9,200 \\
2,145\end{array}$ \\
\hline & $\begin{array}{r}7,442 \\
10,388 \\
9,488 \\
11,200 \\
30,162 \\
0 \\
4,010 \\
0 \\
370 \\
20,323 \\
6,682 \\
138,836\end{array}$ & $\begin{array}{r}6,075 \\
41,497 \\
8,686 \\
15,006 \\
84,450 \\
89,868 \\
3,608 \\
0 \\
659 \\
24,708 \\
9,158 \\
341,401\end{array}$ & $\begin{array}{r}548 \\
282 \\
26 \\
485 \\
1,308 \\
0 \\
28 \\
0 \\
28 \\
207 \\
86 \\
3,240\end{array}$ & $\begin{array}{r}0 \\
4,162 \\
1,300 \\
2,835 \\
10,410 \\
0 \\
1,733 \\
0 \\
335 \\
2,455 \\
1,391 \\
43,940\end{array}$ & $\begin{array}{r}0 \\
49,682 \\
14,812 \\
12,080 \\
76,151 \\
0 \\
2,579 \\
0 \\
1,056 \\
25,040 \\
7,699 \\
268,353\end{array}$ & $\begin{array}{r}0 \\
1,915 \\
719 \\
985 \\
7,292 \\
0 \\
2,870 \\
0 \\
126 \\
737 \\
1,096 \\
27,006\end{array}$ \\
\hline $\begin{array}{l}\text { Maintenance of General Piant ................................ } \\
\text { Total Adinlaletrattve end }\end{array}$ & 5,544 & 17,487 & 73 & 1,064 & 4,461 & 235 \\
\hline Cenerd Expenros ............................................. & 130,320 & 350,978 & 3,393 & 45,024 & 270,814 & 27,381 \\
\hline $\begin{array}{l}\text { Total Electirl Operatton and } \\
\text { Melntenana Expensees ................................... }\end{array}$ & $1,027,639$ & $2,392,057$ & 86,616 & 489,770 & $2,757,050$ & 290,160 \\
\hline \multicolumn{7}{|l|}{$\begin{array}{l}\text { Distribution of Salaries and } \\
\text { Weges Charged to Electric } \\
\text { Operation and Maintenance }\end{array}$} \\
\hline 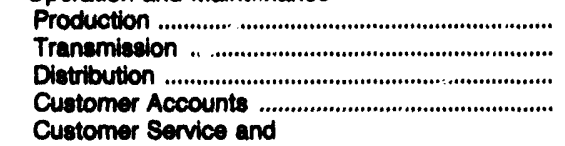 & $\begin{array}{l}82,704 \\
13,082 \\
22,910 \\
12,678\end{array}$ & $\begin{array}{r}110,018 \\
3,903 \\
45,537 \\
26,352\end{array}$ & $\begin{array}{r}0 \\
322 \\
1,701 \\
1,104\end{array}$ & $\begin{array}{r}19,664 \\
3,399 \\
10,840 \\
7,098\end{array}$ & $\begin{array}{r}157,333 \\
18,293 \\
64,384 \\
41,879\end{array}$ & $\begin{array}{r}5,005 \\
822 \\
10,709 \\
4,709\end{array}$ \\
\hline 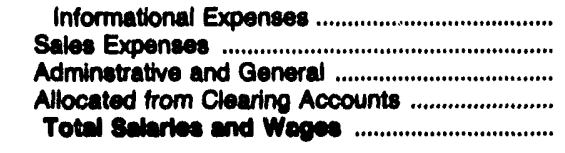 & $\begin{array}{r}3,663 \\
2,516 \\
41,265 \\
4,235 \\
108,038\end{array}$ & $\begin{array}{r}5,467 \\
381 \\
69,464 \\
51,525 \\
312,627\end{array}$ & $\begin{array}{r}24 \\
0 \\
1,183 \\
13 \\
4,846\end{array}$ & $\begin{array}{r}2,337 \\
523 \\
14,277 \\
6,757 \\
\mathbf{6 4 , 8 9 8}\end{array}$ & $\begin{array}{r}15,979 \\
0 \\
70,770 \\
0 \\
099,689\end{array}$ & $\begin{array}{r}757 \\
0 \\
2,409 \\
7,439 \\
31,800\end{array}$ \\
\hline $\begin{array}{l}\text { Number of Electric Department Employees } \\
\text { Regular Full-time Employees .................................. } \\
\text { Part-time and Temporany Employees ................... }\end{array}$ & $\begin{array}{r}4,550 \\
38\end{array}$ & $\begin{array}{r}9,376 \\
53\end{array}$ & $\begin{array}{r}144 \\
9\end{array}$ & $\begin{array}{r}2,043 \\
5\end{array}$ & $\begin{array}{r}7,492 \\
108\end{array}$ & $\begin{array}{r}1,088 \\
13\end{array}$ \\
\hline Total Electric Depertment Employee .......... & 4,888 & 0,420 & 163 & 2,048 & 7,000 & 1,081 \\
\hline
\end{tabular}

Note: Totals may not equal sum of components because of independent rounding. Summary data are provided in Table 11. Source: Federal Energy Regulatory Commiselon, FERC Form 1, "Annual Report of Major Electric Utilities, Licensees and Others." 
Table 41. Electric Operation and Malntenance Expenses by Major U.S. Investor-Owned Electric Utillty Within State, 1902 (Continued) (Thousand Dollars)

\begin{tabular}{|c|c|c|c|c|c|c|}
\hline Itom & $\begin{array}{c}\text { Texas } \\
\text { Woat } \\
\text { Texas } \\
\text { Utillies } \\
\text { Co }\end{array}$ & $\begin{array}{l}\text { Vermont } \\
\text { Central } \\
\text { Vermont } \\
\text { Pub } \\
\text { Serv Corp }\end{array}$ & $\begin{array}{l}\text { Vermont } \\
\text { Green } \\
\text { Mountain } \\
\text { Power Corp }\end{array}$ & $\begin{array}{l}\text { Vermont } \\
\text { Vermont } \\
\text { Electrio } \\
\text { Power } \\
\text { Co Inc }\end{array}$ & $\begin{array}{l}\text { Vermont } \\
\text { Vermont } \\
\text { Electric } \\
\text { Trans } \\
\text { Co Inc }\end{array}$ & $\begin{array}{c}\text { Vermont } \\
\text { Vermont } \\
\text { Yankee } \\
\text { Nucl } \\
\text { Pwr Corp }\end{array}$ \\
\hline
\end{tabular}

Power Production Expenses

Steam Power

Operation Expenses

Supenvision and Engineering

Steam Expensea

Steam from Other Sources

(leas) Steam Tranaterred (credit) ............................

Electric Expenses ...u.u.u.u.u.u.............................

Mreellaneous Steam Power Expenses ...............

Rents

Toted Operatton Expenses

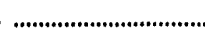

1,183
112,889
888
0
0
3,785
2,432
10
120,278

Maintenance Expenses

Supervision and Engineering

Structures

Boiler Piant

Electric Plant

Miscellaneous Steam Plant

Total Maintenance Expenses.

Total steam Power Production

Expences.

Nuclear Power

Operation Expenses

Supervision and Engineering

Fuel

Coolants and Water

Steam Expenses

Steam from Other Sources

(less) Steam Transferred (credit)

Electric Expenses

Miscollaneous Nuclear Power Expenses .

Rents

Total Operation Expenses

\section{Maintenance Expenses}

Supervision and Engineering

Structures

Reactor Plant Equipment

Electric Plant

Miscellaneous Nuclear Plant

Totel Nuchear Power Production

Exponses

Hydraulic Power

Operation Expenses

Supervision and Engineering ................................

Water for Power...

Hydraulic Expenses

Electric Expenses

Rents

Total Operation Expenses

See endnotes at end of an individual electric utility.

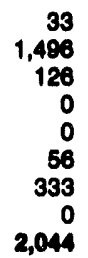

15
887
74
123
0
31
33
0
1,184

834

657

1,925

883

6,320

34
15
320
76
6
451

17

5

74
74

4

175

133,607

2,495

1,330

$\mathbf{0}$

0 
Table 41. Electric Operation and Malntenance Expenees by Major

U.S. Investor-Owned Electric Utility Within State, 1992 (Continued)

(Thousand Dollars)

\begin{tabular}{|c|c|c|c|c|c|c|}
\hline Item & $\begin{array}{c}\text { Texas } \\
\text { Weat } \\
\text { Texas } \\
\text { Utillies } \\
\text { Co }\end{array}$ & $\begin{array}{l}\text { Vermont } \\
\text { Central } \\
\text { Vermont } \\
\text { Pub } \\
\text { Serv Corp }\end{array}$ & $\begin{array}{c}\text { Vermont } \\
\text { Green } \\
\text { Mountain } \\
\text { Power Corp }\end{array}$ & $\begin{array}{l}\text { Vermont } \\
\text { Vermont } \\
\text { Electric } \\
\text { Power } \\
\text { Co Inc }\end{array}$ & $\begin{array}{l}\text { Vermont } \\
\text { Vermont } \\
\text { Electric } \\
\text { Trans } \\
\text { Co Inc }\end{array}$ & $\begin{array}{c}\text { Vermont } \\
\text { Vermont } \\
\text { Yankee } \\
\text { Nucl } \\
\text { Pwr Corp }\end{array}$ \\
\hline
\end{tabular}

\section{Muintenance Expenses}

Supenvition and Engineering

Structures

Reservoine, Dams and Waterways

Elactrio Plant

Miscellaneous Hydraulic Plant

Total Melntenenos Expences

Totel Aydravile Power

Production Expeniear.

Other Power

Operation Expenees

Supervition and Engineering

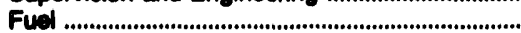

Generation Expenses ................................................

Miscellaneous Other Power Expenses

Rents

Total Operation Expenses

Maintenance Expenses

Supervition and Engineering

Structures .

Generating and Electric Plant

Miscellaneous Other Power Plant

Total Meintenence Exponees

............................

Toul Ower Power Production

Expensese .

$30,3+2$

Transmission

Operation Expenses

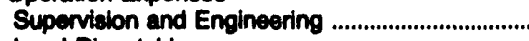
Load Diepatching

Station Expenses

Overhead Line Expenses

Underground Line Expenses ....

Tranamiseion of Electricty by Others

Miscellaneous Transmiseion Expenses

Rents

...................

Totil Operation Expenses

\begin{tabular}{|c|c|c|c|c|}
\hline $\begin{array}{r}135 \\
319 \\
268 \\
50 \\
0 \\
504 \\
1,144 \\
15\end{array}$ & $\begin{array}{r}78 \\
198 \\
34 \\
47 \\
0 \\
13,517 \\
67 \\
8\end{array}$ & $\begin{array}{r}79 \\
127 \\
58 \\
22 \\
0 \\
10,444 \\
3 \\
179\end{array}$ & $\begin{array}{r}189 \\
943 \\
140 \\
30 \\
3 \\
0 \\
0 \\
114\end{array}$ & $\begin{array}{l}7 \\
0 \\
0 \\
6 \\
0 \\
0 \\
0 \\
1\end{array}$ \\
\hline 2,480 & 13,950 & 10,910 & 1,420 & 13 \\
\hline
\end{tabular}

See endnotes at end of an individual electric utility. 
Table 41. Electric Operation and Maintenance Expenses by Major U.S. Investor-Owned Electric Utility Whthin State, 1902 (Continued) (Thousand Dollars)

\begin{tabular}{|c|c|c|c|c|c|c|}
\hline Item & $\begin{array}{c}\text { Texes } \\
\text { Weat } \\
\text { Texas } \\
\text { Utilities } \\
\text { Co }\end{array}$ & $\begin{array}{l}\text { Vermont } \\
\text { Central } \\
\text { Vermont } \\
\text { Pub } \\
\text { Serv Corp }\end{array}$ & $\begin{array}{l}\text { Vermont } \\
\text { Green } \\
\text { Mountain } \\
\text { Power Corp }\end{array}$ & $\begin{array}{l}\text { Vermont } \\
\text { Vermont } \\
\text { Electic } \\
\text { Power } \\
\text { Co Inc }\end{array}$ & $\begin{array}{l}\text { Vermont } \\
\text { Vermont } \\
\text { Electric } \\
\text { Trans } \\
\text { Co Ine }\end{array}$ & $\begin{array}{l}\text { Vermont } \\
\text { Vermont } \\
\text { Yankee } \\
\text { Nucl } \\
\text { Pwr Corp }\end{array}$ \\
\hline
\end{tabular}

Muintenance Expenses

Supenvilon and Encineering

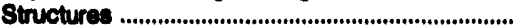

Stution Equipment

Overheed Lines .

Undercround Lines

.

Miecellaneous Tranamiseion Plant .......................

Totw Meintenenos Expenses...

Total Tranemleslon Expensese

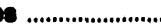

Datribution

Operation Expenses

Supervision and Engineering ....................................

Load Dispatching ...........................................................

Station Expenses

Overhead Line Expenses

Underground Iine Expo

Street Lighting and Signal System Expenses ....

Moter Expenses

Customer Installations Expenses

Miecellaneous Distribution Expenses ...................

Rents

Total Operation Expenses

$\begin{array}{rr}59 & 74 \\ 0 & 2 \\ 435 & 378 \\ 521 & 882 \\ 0 & 0 \\ 1 & 2 \\ 1,016 & 1,490 \\ 3,459 & 15,997\end{array}$

37
0
93
62
0
1
103

68
28
444
801
0
0
1,441
291

0
0
0
128
0
0
130
149

0
0
497
0
0
0
497
497

589

112

152

704

50

208

1,880

383

2,805

81
7,092

11,103

2,001

140

Maintenance Expenses

Supervision and Engineering

Structures

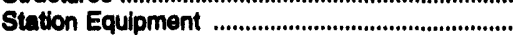

Overhead Lines ....

Underoround Lines

Street Lighting and Signal Syatems ...................

Meters ..........................................................................

Miscellaneous Distribution Plant

Totel Maintenance Expenses

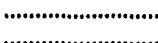

Total Diotribution Exponses

(a)

Customer Accounts Expenses

Supervision

Meter Reading Expenses ........................................

Customer Records and Collection Expenses ....

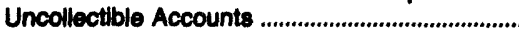

Miscellaneous Customer Accounts Expenses ...

Totil Customer Accounts Expensese

418

531

2,411

114

463

188

272

124

4,631

377
378
127
686
13
61
898
82
764
1,089
4,464

158

38
59

365

99

35
318

80

124

1,286

11,802

286
61
432
6,439
38
123
102
45
3
7,630

86

300

1,350

85

109

49
129

22

2,131

11,939

3,417

0
0
0
0
0
0
0
0
0
0
0

$$
\begin{aligned}
& 0 \\
& 0 \\
& 0 \\
& 0 \\
& 0 \\
& 0 \\
& 0 \\
& 0 \\
& 0 \\
& 0 \\
& 0
\end{aligned}
$$

1,434
3,887

956

6,508

396
1,327
2,368
861
35
$\mathbf{5 , 0 9 6}$

262
413
1,347
435
82
2,690

\begin{tabular}{rr}
96 & 327 \\
1,630 & 3,617 \\
624 & 465 \\
111 & 97 \\
& \\
\hline & 490
\end{tabular}

67

128
5

14

214

4,500

$\begin{array}{rl}102 & 0 \\ 299 & 0 \\ 135 & 0 \\ 0 & 0 \\ 637 & 0\end{array}$

$\begin{array}{llll}0 & 0 & 0 & 0 \\ 0 & 0 & 0 & 0 \\ 0 & 0 & 0 & 0 \\ 3 & 0 & 0 & 0 \\ 3 & 0 & 0 & 0\end{array}$

See endnotes at end of an individual electric utility. 
Table 41. Electric Operation and Maintenance Expenses by Major U.S. Inveotor-Owned Electric Utility Within State, 1992 (Continued) (Thousand Dollars)

\begin{tabular}{|c|c|c|c|c|c|c|}
\hline liem & $\begin{array}{c}\text { Texas } \\
\text { West } \\
\text { Texas } \\
\text { Utilities } \\
\text { Co }\end{array}$ & $\begin{array}{l}\text { Vermont } \\
\text { Central } \\
\text { Vermont } \\
\text { Pub } \\
\text { Serv Corp }\end{array}$ & $\begin{array}{c}\text { Vermont } \\
\text { Green } \\
\text { Mountain } \\
\text { Power Corp }\end{array}$ & $\begin{array}{l}\text { Vermont } \\
\text { Vermont } \\
\text { Electric } \\
\text { Power } \\
\text { Co Inc }\end{array}$ & $\begin{array}{l}\text { Vermont } \\
\text { Vermont } \\
\text { Electric } \\
\text { Trans } \\
\text { Co Inc }\end{array}$ & $\begin{array}{c}\text { Vermont } \\
\text { Vermont } \\
\text { Yankee } \\
\text { Nud } \\
\text { Pwr Corp }\end{array}$ \\
\hline
\end{tabular}

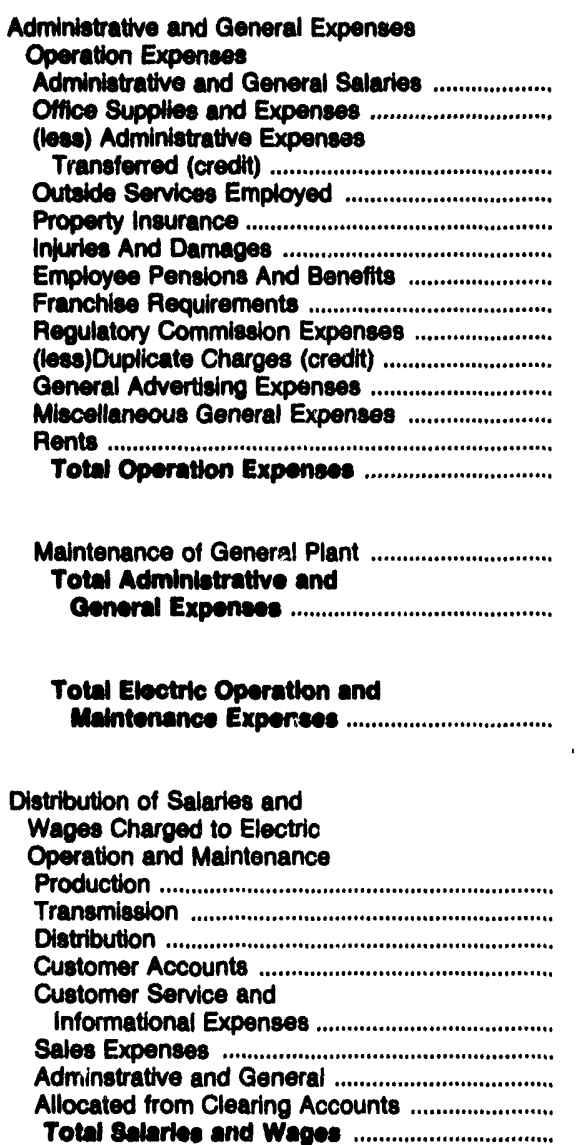

Number of Electric Department Employees

Regular Full-time Employees .................................

Part-time and Temporary Employees ...................

Total Electrle Department Employees .........

9,708
3,593

997
3,184
539
1,421
5,549
1
345
0
193
2,795
1,583
27,911

7,367
2,172
0
6,546
282
1,311
3,906
0
266
0
43
781
642
23,325

867

28,078

190,656

5,891
1,302
2,425
826
144
736
3,142
0
568
159
28
1,225
1,096
12,473

695

28,020

205,249

107,048

984

13,457

1,385
533
0
123
76
140
690
0
123
0
0
211
2
3,283

11,927

2,013

7,799

4,986

1,446

318

8,376

197

37,031

1,135
16

1,161

1,904
493
4,775
2,770
2,220
0
7,603
706
20,471

$$
\begin{array}{r}
1,389 \\
280 \\
2,032 \\
1,600 \\
\\
195 \\
0 \\
6,068 \\
515 \\
12,080
\end{array}
$$

739
65

$$
\begin{array}{r}
384 \\
9
\end{array}
$$

393

804

0
1,380
0
0
0
0
1,430
0
2,811

294

$\mathbf{3 , 6 7 8}$

39,780

322

122,085

Note: Totals may not equal sum of components because of independent rounding. Summary data are provided in Table 11. Source: Federal Energy Regulatory Commission, FERC Form 1, "Annual Report of Major Electrlc Utilities, Licensees and Others." 
Table 41. Electric Operation and Maintenance Expenses by Major U.S. Investor-Owned Electric Utility Within State, 1992 (Continued) (Thousand Dollars)

\begin{tabular}{|c|c|c|c|c|c|c|}
\hline Item & $\begin{array}{l}\text { Virginia } \\
\text { Appalachian } \\
\text { Power Co }\end{array}$ & $\begin{array}{l}\text { Virginia } \\
\text { Virginia } \\
\text { Electrio } \\
\text { \& Power } \\
\text { Co }\end{array}$ & $\begin{array}{l}\text { Washington } \\
\text { Puget Sound } \\
\text { Power \& Light } \\
\text { Co }\end{array}$ & $\begin{array}{l}\text { Washington } \\
\text { Washington } \\
\text { Water } \\
\text { Power Co }\end{array}$ & $\begin{array}{c}\text { West Virginia } \\
\text { Kanawha } \\
\text { Valley } \\
\text { Power Co }\end{array}$ & $\begin{array}{l}\text { West Virginia } \\
\text { Monongahela } \\
\text { Power Co }\end{array}$ \\
\hline 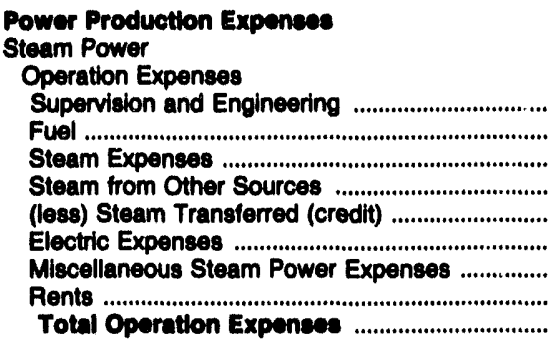 & $\begin{array}{r}10,102 \\
351,749 \\
5,378 \\
0 \\
0 \\
2,444 \\
7,924 \\
400 \\
377,907\end{array}$ & $\begin{array}{r}12,761 \\
423,769 \\
9,292 \\
0 \\
0 \\
5,004 \\
17,312 \\
145 \\
469,282\end{array}$ & $\begin{array}{r}1,521 \\
47,367 \\
3,719 \\
1 \\
0 \\
2,183 \\
5,268 \\
120 \\
60,178\end{array}$ & $\begin{array}{r}952 \\
36,805 \\
1,898 \\
0 \\
0 \\
1,032 \\
2,218 \\
3 \\
42,909\end{array}$ & $\begin{array}{l}0 \\
0 \\
0 \\
0 \\
0 \\
0 \\
0 \\
0 \\
0\end{array}$ & $\begin{array}{r}3,354 \\
149,219 \\
3,847 \\
0 \\
0 \\
1,522 \\
3,270 \\
79 \\
161,292\end{array}$ \\
\hline 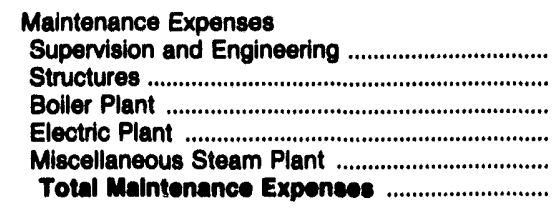 & $\begin{array}{r}3,973 \\
3,381 \\
25,098 \\
7,565 \\
3,694 \\
43,710\end{array}$ & $\begin{array}{r}12,446 \\
4,437 \\
37,048 \\
14,844 \\
15,718 \\
84,493\end{array}$ & $\begin{array}{r}1,861 \\
1,795 \\
10,349 \\
3,778 \\
1,665 \\
19,449\end{array}$ & $\begin{array}{r}990 \\
599 \\
3,768 \\
1,347 \\
701 \\
7,404\end{array}$ & $\begin{array}{l}0 \\
0 \\
0 \\
0 \\
0 \\
0\end{array}$ & $\begin{array}{r}2,665 \\
2,416 \\
21,712 \\
5,567 \\
1,446 \\
33,806\end{array}$ \\
\hline Total Steam Power Production & 421,707 & 552,774 & 79,627 & 50,313 & 0 & 195,098 \\
\hline 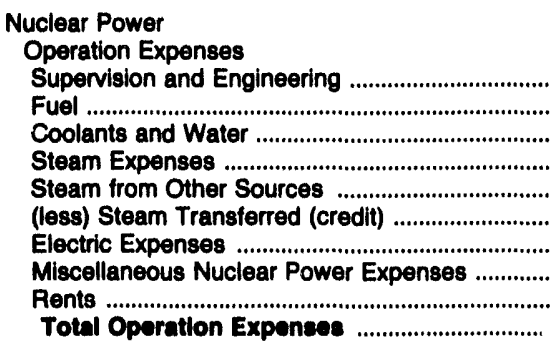 & $\begin{array}{l}0 \\
0 \\
0 \\
0 \\
0 \\
0 \\
0 \\
0 \\
0 \\
0\end{array}$ & $\begin{array}{r}28,882 \\
102,559 \\
1,332 \\
23,604 \\
0 \\
0 \\
165 \\
46,704 \\
293 \\
208,540\end{array}$ & $\begin{array}{l}0 \\
0 \\
0 \\
0 \\
0 \\
0 \\
0 \\
0 \\
0 \\
0\end{array}$ & $\begin{array}{l}0 \\
0 \\
0 \\
0 \\
0 \\
0 \\
0 \\
0 \\
0 \\
0\end{array}$ & $\begin{array}{l}0 \\
0 \\
0 \\
0 \\
0 \\
0 \\
0 \\
0 \\
0 \\
0\end{array}$ & $\begin{array}{l}0 \\
0 \\
0 \\
0 \\
0 \\
0 \\
0 \\
0 \\
0 \\
0\end{array}$ \\
\hline 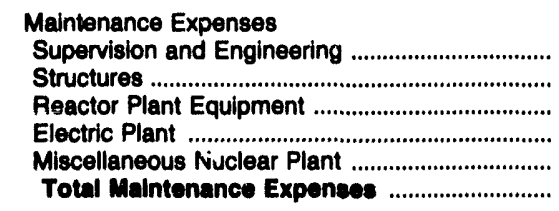 & $\begin{array}{l}0 \\
0 \\
0 \\
0 \\
0 \\
0\end{array}$ & $\begin{array}{r}34,489 \\
4,935 \\
32,789 \\
20,279 \\
15,396 \\
107,898\end{array}$ & $\begin{array}{l}0 \\
0 \\
0 \\
0 \\
0 \\
0\end{array}$ & $\begin{array}{l}0 \\
0 \\
0 \\
0 \\
0 \\
0\end{array}$ & $\begin{array}{l}0 \\
0 \\
0 \\
0 \\
0 \\
0\end{array}$ & $\begin{array}{l}0 \\
0 \\
0 \\
0 \\
0 \\
0\end{array}$ \\
\hline $\begin{array}{l}\text { Total Nuclear Power Production } \\
\text { Expenees }\end{array}$ & 0 & 311,437 & 0 & 0 & 0 & 0 \\
\hline 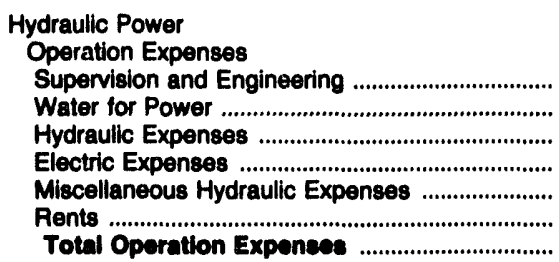 & $\begin{array}{r}606 \\
0 \\
467 \\
159 \\
660 \\
0 \\
1,803\end{array}$ & $\begin{array}{r}1,138 \\
427 \\
352 \\
1,437 \\
1,368 \\
0 \\
4,722\end{array}$ & $\begin{array}{r}559 \\
7 \\
1,315 \\
687 \\
835 \\
0 \\
3,403\end{array}$ & $\begin{array}{r}1,898 \\
91 \\
370 \\
2,452 \\
651 \\
78 \\
5,540\end{array}$ & $\begin{array}{r}75 \\
7 \\
95 \\
222 \\
211 \\
427 \\
1,037\end{array}$ & $\begin{array}{l}0 \\
0 \\
0 \\
0 \\
0 \\
0 \\
0\end{array}$ \\
\hline
\end{tabular}

See endnotes at end of an individual electric utility. 
Table 41. Electric Operation and Maintenance Expenses by Major U.S. Investor-Owned Electric Utility Within State, 1902 (Continued) (Thousand Dollars)

\begin{tabular}{|c|c|c|c|c|c|c|}
\hline Item & $\begin{array}{c}\text { Virginia } \\
\text { ' Appalachian } \\
\text { Power Co }\end{array}$ & $\begin{array}{l}\text { Virginia } \\
\text { Virginia } \\
\text { Electric } \\
\text { a Power } \\
\text { Co }\end{array}$ & $\begin{array}{c}\text { Washington } \\
\text { Puget Sound } \\
\text { Power \& Light } \\
\text { Co }\end{array}$ & $\begin{array}{l}\text { Washington } \\
\text { Washington } \\
\text { Water } \\
\text { Power Co }\end{array}$ & $\begin{array}{l}\text { Weat Virginia } \\
\text { Kanawha } \\
\text { Valley } \\
\text { Power Co }\end{array}$ & $\begin{array}{c}\text { West Virginia } \\
\text { Monongahela } \\
\text { Power Co }\end{array}$ \\
\hline
\end{tabular}

Maintenance Expenses

Supervision and Engineering

Structures.

Reservoirs, Dams and Waterways

Electric Piant

Miscellaneous Hydraulic Plant

Total Maintenanes Expences.

.

Total Hydraulic Power

Production Expenaes

Other Power

Operation Expenses

Supervision and Engineering

Fuel

Generation Expenses

Rents

Totil Operation Expensese

Maintenance Expenses

Supervision and Engineering

Structures ..........................................

Miscellaneous Other Power Plant

Total Maintenance Expenses

Total Other Power Production

Expenses

Other Power Supply Expenses

Purchased Power

System Control and Load D

Other Expenses

Total Other Power Supply

Expences

Total Power Production Expenees

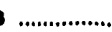

Transmission

Operation Expenses

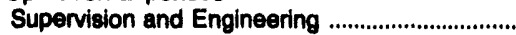

Load Dispatching .

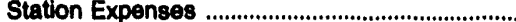

Overhead Line Expenses

Underground Line Expenses

Transmission of Electricity by Others

Rents

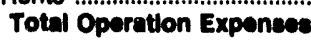

224
95
320
951
284
1,064

813
757
383
1,694
765
4,413

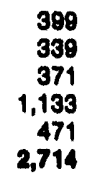

$\mathbf{3 , 7 4 7}$

9,135

6,117

0,111

1,320

$\begin{array}{rr}143 & 43 \\ 200 & 46 \\ 514 & 45 \\ 1,620 & 105 \\ 95 & 54 \\ 2,871 & 292\end{array}$

1,101

31,869

678

775

2,042
38,494

345

9,846

218

363

3,337
13,000

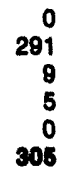

0
0
0
0
0
0

0
0
0
0
0
0

163

227

2,082

611
3,093

14

41

468
9

520

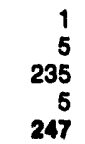

14,438

562

$\mathbf{0}$

286,439

3,387

765,978

829

$-57,477$

235,525

866
654

91,708

807

$-3,358$

80,168

33,272

2,183

6,118

237,046

161,573

$7+5,313$

1,622,224

337,227

149,134

1,320

366,671

3,515

1,707

2,243

794

7,800

2,213

155

18,427
2.773

1,466

3,929

992

0
12

1,007

749

10,028

1,728
537
546
57
8
26,940
$6^{\circ} 8$
18

30,470

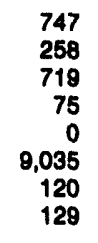

$\cdot 11,098$
761
425
294
294
0
0
205
14
1,002

See endnotes at end of an individual electric utility. 
Table 41. Eleotrle Operation and Malntenance Expenees by Major

U.8. Investor-Owned Electric Utility Within 8tate, 1902 (Continued) (Thousand Dollars)

\begin{tabular}{|c|c|c|c|c|c|c|}
\hline Item & $\begin{array}{l}\text { Vroinia } \\
\text { Appalechilan } \\
\text { Power Co }\end{array}$ & $\begin{array}{l}\text { Viroinia } \\
\text { Virginia } \\
\text { Elcotilo } \\
\text { a Power }\end{array}$ & $\begin{array}{l}\text { Waehington } \\
\text { Puget Sound } \\
\text { Power \& Light } \\
\text { co }\end{array}$ & $\begin{array}{l}\text { Washington } \\
\text { Washington } \\
\text { Water } \\
\text { Power Co }\end{array}$ & $\begin{array}{l}\text { Weat Virginia } \\
\text { Kanawha } \\
\text { Valley } \\
\text { Power Co }\end{array}$ & $\begin{array}{l}\text { Weat Virginia } \\
\text { Monongahela } \\
\text { Power Co }\end{array}$ \\
\hline
\end{tabular}

Maintenance Expenses

Structures $\ldots$.............

Underground Line Expenses ...................................

Meter Expenses ......................................................
Supervibion and Engineering

Station Equipment

Overhead Lines ...

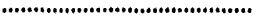

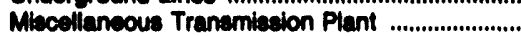

Total Melmtenance Expeneses

Total Transmbelon Exponses

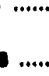

Diatribution

Operation Expenses

Supervition and Engineering

Load Diepatching

Station Expenses

Overhead Ine Expenses

Street Lighting and Signal System Expenses .....

Customer Installations Expenses ...........

Miscellaneous Distribution Expenses .......................

Rents

Total Operation Expences

1,392

340

5,510

4,814

23
212

12,201

80,718

5,442

16
1,200

1,200

1,686
421

164

4,308

1,743

8,210

820

24,110

Maintenance Expenses

Supervision and Engineering

Structures

Station Equipment

Overhead Lines.

Underground Lines

Line Transtormers

Street Lighting and Signal Systems

Meters

Miscellaneous Distribution Piant

Total Maintenence Expensese

Totel Dietribution Expences

...........................

Customer Accounts Expenses

Superviaion

Meter Reading Expenses ...................eg .....................

Customer Records and Collection Expenses ....

Uncollectible Accounts .............................................

Miscellaneous Customer Accounte Expenses ....

Total Customer Acosunts Expenses .............

Cutomer Senvice and Information Expenses

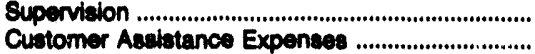

Informational and Inatructional Expenses ...............

Miscellaneous Customer Senvice

and Informational Expenses ...

Totel Customer Eervice and

Informational Exponsese

Sales Expenses

Supervision .

Demonetrating and Seling/ Expensea ...................

Advertiaing Expenses .............................................

Miscellaneous Sales Exprenses

Toted seles Expenses

3,349

378
2,845

28,647

2,520

3,207

525

808
615

42,003

00,020

1,793
7,569
15,116
1,810
870
27,169

639
7,114

1,660
49
2,815
7,247
38
327
12,136

182
9
824
1,663
28
0
2,697

217
24
486
699
2
16
1,424

0
0
39
0
0
0
30

430
21
1,351
2,653
0
32
4,405
6,497

12,507

10,162

2,432

$\mathbf{8 , 2 1 0}$

273
4,088

1,082

3,608

2,670

19,710

975

3,167

(1)

2,824

2,012

1,084

105
2,538

165

1,213

2,014

4,511

16,293

501
184
659
879
699
85
478
480
889
260
$\mathbf{8}, 114$

975
617

679

1,475

23

120

888

1,167

1,413

131

5,600

45
3,613

30,547

13,284

1,188

2,120

$-457$

612

6.,851

107,068

572
16
1,884

15,859

6,893

328

804

12
258

2.800

7,49

42,700

672
39
530
3,889
1,200
668
324
162
44
7,618

733
27

1,461

19,618

138

423

273

258

571
28,899

12,090

sopes

3,743
11,789

11,788

28,959

6,289

0
0,793

1,781

13,280

1,880
1,880

593

20,620

453
1,540

5,013

846

489

$\mathbf{0 , 4 1 1}$

417
1878

1,878

5,405
1,281

173

0,108

$\begin{array}{ll}1,572 & 1,811 \\ 3,207 & 8,227\end{array}$

$\begin{array}{ll}3,207 & 8,227 \\ 1,698 & 3,838\end{array}$

288

20,781

168

6
3,816

201

650

6

844

21,005

4,028

688

1,913
625

160

14,720

8,840

See endnotes at end of in individual electric utillty.

$\begin{array}{rl}0 & 0 \\ 60 & 0 \\ 0 & 0 \\ 0 & 0 \\ 60 & 0\end{array}$

0
0
0
0
0

0
0
0
0
0

0
922
0
0
922


Table 41. Electrlc Oporation and Malntenance Expenses by Major

U.8. Investor-Owned Electrle Utility Within State, 1902 (Cointinued) (Thousand Dollars)

\begin{tabular}{|c|c|c|c|c|c|c|}
\hline Itom & $\begin{array}{l}\text { Virginila } \\
\text { Appalachian } \\
\text { Power Co }\end{array}$ & $\begin{array}{c}\text { Virginla } \\
\text { Virginla } \\
\text { Electric } \\
\text { \& Power } \\
\text { Co }\end{array}$ & $\begin{array}{l}\text { Washington } \\
\text { Puget Sound } \\
\text { Power \& Light } \\
\text { Co }\end{array}$ & $\begin{array}{l}\text { Washington } \\
\text { Washington } \\
\text { Water } \\
\text { Power Co }\end{array}$ & $\begin{array}{l}\text { Weat Virginiel } \\
\text { Kanawha } \\
\text { Valley } \\
\text { Power Co }\end{array}$ & $\begin{array}{l}\text { Weat Virginia } \\
\text { Monongahela } \\
\text { Power Co }\end{array}$ \\
\hline
\end{tabular}

Administrative and Ceneral Expenses

Operation Expenses

Adminiatrathe and Genaral Salaries

(lea) Adininitrative Expenses

Transferred (credit)

Outaide Services Employed

Property Incurance.

Inivies And Damages

Emploves Pensions And Benefits

Franchise Requirements

Reoulatory Commiselon Expenses

(less)Duplicate Charges (credtt)

Ceneral Advertleing Expens

Miscellaneous General Expenses

Rents

Total Operation Expenese

Malntenance of General Plant

Total Adminlotututwe and

Coneral Exponses

Totel Eleotits Operation and

Mointenance Expeneses.

Wages Charged to Electric

Operation and Maintenance

Transmiselon

Distribution ................

Customer Accounts

Customer Service and

Informational Expenses

Sales Expenses .......................

Allocsted from Clearing Accounts

Totas selarkes and Weges

..........................

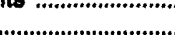

Number of Electric Department Employees

Regular Full-time Employees .......................

36,521

12,024

33,618

185,493

11,989

14,590

33,308

3,240

0
12,150

12,150
14,055

128,190

8,306
0
85,096
9,268
409,536

4,590

12,034

88

2,650

5,511

3,065

19,849

12,856

1,615

25,348

1,326

69,569

$$
\begin{array}{r}
6,886 \\
1,617 \\
6,627 \\
3,681 \\
\\
304 \\
401 \\
8,298 \\
932 \\
28,745
\end{array}
$$

8,025
3,490

0

2,941
417

2,638

1,807
626

2,512

4

2,333

28,498

1,689

28,055

180

28,300

1,210

Part-time and Temporary Employees ...................

Total Eloctric Department Employees

4,648

12,122

2,844

448

58

12

1,534

508

12

1,548

Note: Totals may not equal sum of components because of independent rounding. Summary data are provided in Table 11.

Source: Federal Energy Regulatory Commission, FERC Form 1, "Annual Report of Major Electric Utilities, Licensees and Others." 


$$
\begin{aligned}
& \text { 震 }
\end{aligned}
$$

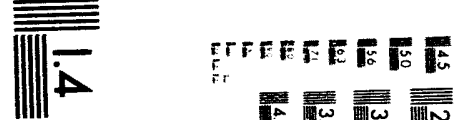

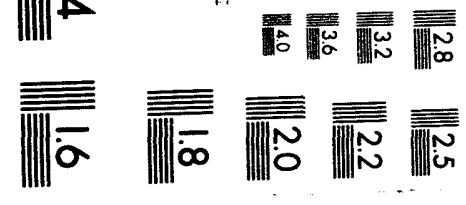



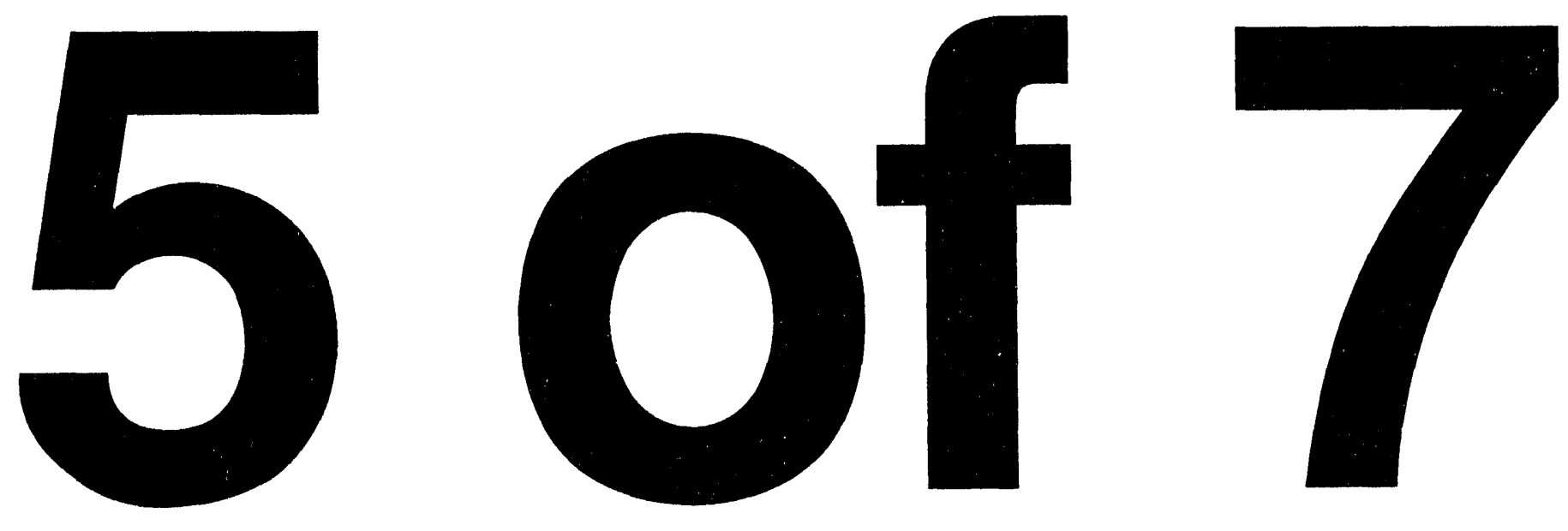
Table 41. Electric Operation and Malntenance Expenses by Major U.S. Investor-Owned Electric Utility Within State, 1992 (Continued) (Thousand Dollars)

\begin{tabular}{|c|c|c|c|c|c|c|}
\hline Item & $\begin{array}{l}\text { Weat Virginia } \\
\text { Wheeling } \\
\text { Power Co }\end{array}$ & $\begin{array}{l}\text { Wisconsin } \\
\text { Consolidated } \\
\text { Water } \\
\text { Power Co }\end{array}$ & $\begin{array}{c}\text { Wisconsin } \\
\text { Madison } \\
\text { Gas } \\
\& \\
\text { Electric Co }\end{array}$ & $\begin{array}{l}\text { Wisconsin } \\
\text { Northern } \\
\text { States } \\
\text { Power Co }\end{array}$ & $\begin{array}{l}\text { Wisconsin } \\
\text { Northwestern } \\
\text { Wisconsin } \\
\text { Elec Co }\end{array}$ & $\begin{array}{c}\text { Wisconsin } \\
\text { Pioneer } \\
\text { Power } \\
\text { Light Co }\end{array}$ \\
\hline
\end{tabular}

Power Production Expenace

Steam Power

Operation Expenses

Supervision and Enoineering

Fuel

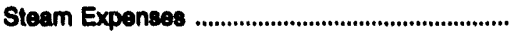

Steam from Other Sources

(leso) Steam Transterred (credit)

Electric Expenees

Miscellaneous Steam Power Expenses

Rents

.

Total Operntion Expenses

Maintenance Expenses

Supervision and Engineering

Structures

Boller Plant

Electric Plant

Total Maintenence Expeneet

Total Steam Power Production

Expenaes

Nuclear Power

Operation Expenses

Supervision and Engineering

Fuel

Coolants and Water

Steam Expenses

Steam from Otho

(less) Steam Transferred (cred

Electric Expenses

Rents

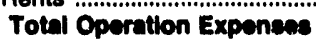

Maintenance Expenses

Supervision and Engineering

Structures

Reactor Plant Equipment

Electric Plant

Miscellaneous Nuclear Plant

Totel Malntenance Expenses

Total Nuclear Power Production

Exponeses
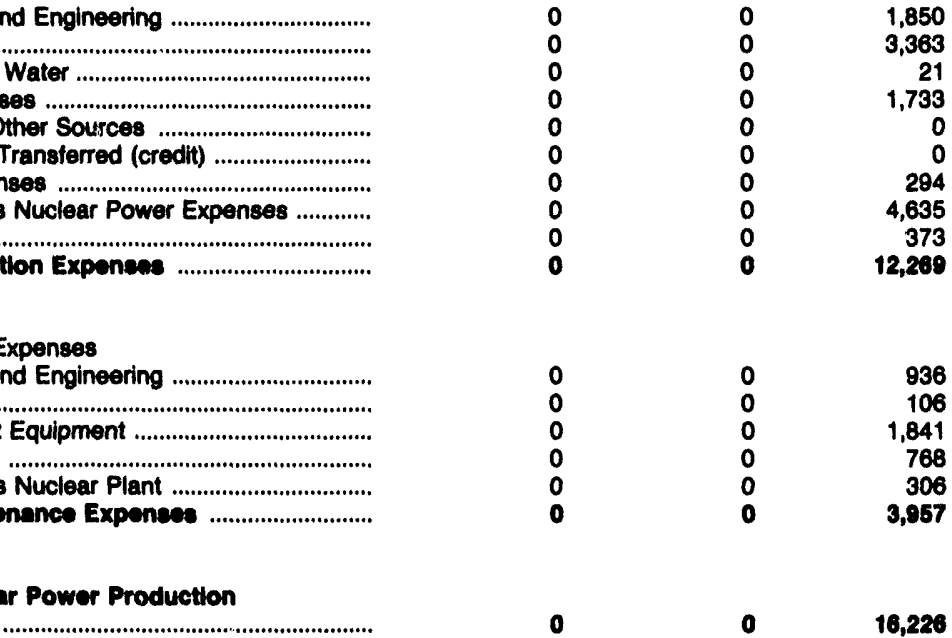

$\begin{array}{rr}292 & 187 \\ 272 & 95 \\ 2,029 & 1,682 \\ 711 & 1,210 \\ 236 & 74 \\ 3,530 & 3,249\end{array}$

32,391

6,833

Hydraulic Power

Operation Expenses

Supervision and Engineering ..................................

Water for Power ...

Hydraulic Expenses

Electric Expenses

Miscellaneous Hydraulic Expenses

Tonts ..........................................

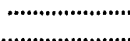

Total Operation Expenees

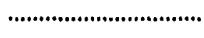

See endnotes at end of an individual electric utility. 
Table 41. Electric O'peration and Maintenance Expenses by Major U.S. Investor-Owned Electric Utility Within State, 1992 (Continued) (Thousand Dollars)

\begin{tabular}{|c|c|c|c|c|c|c|}
\hline Item & $\begin{array}{l}\text { West Virginia } \\
\text { Wheeling } \\
\text { Power Co }\end{array}$ & $\begin{array}{l}\text { Wieconsin } \\
\text { Consollidated } \\
\text { Water } \\
\text { Power Co }\end{array}$ & $\begin{array}{c}\text { Wisconein } \\
\text { Madison } \\
\text { Gas } \\
\mathbf{8} \\
\text { Electric Co }\end{array}$ & $\begin{array}{l}\text { Wlsconsin } \\
\text { Northern } \\
\text { States } \\
\text { Power Co }\end{array}$ & $\begin{array}{l}\text { Wisconsin } \\
\text { Northw: tern } \\
\text { Whiscors in } \\
\text { Elec Co }\end{array}$ & $\begin{array}{c}\text { Wisconsin } \\
\text { Pioneer } \\
\text { Power } \\
\text { Light Co }\end{array}$ \\
\hline
\end{tabular}

Maintenance Expenses

Supervision and Engineering

Structure:

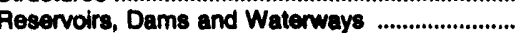

Electric Plant

Miscellaneous Hydraulic Plant

Total Maintenance Expenses

Total Hydralle Power

Production Expensea

Ther Power

Operation Expenses

Supervision and Engineering

Fuel .

.

.

Miscellaneous Other Power Expenses

Rents

Total Operation Expenses.

Maintenance Expenses

Supervision and Engineering

Structures

Generating and Electric Plant

Miscellaneous Other Power Plent

Total Malntenance Expenese

Total Other Power Production

Expenses

Other Power Supply Expenses

Purchased Power ...................................................

System Control and Load Dispatching

Other Expenses

Total Other Power Supply

Exponesen

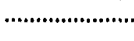

Total Power Production Expenses

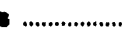

Transmission

Operation Expenses

Supervision and Engineering .................................

Losd Dispatching

Station Expenses

Overhead Line Expenses

Underground Line Expenses

Miscellaneous Transmission Expenses ..........

Rents

Total Operation Expenses

See endnotes at end of an individual electric utility.

$\begin{array}{lr}0 & 17 \\ 0 & 47 \\ 0 & 610 \\ 0 & 14 \\ 0 & 1,11\end{array}$

o

1,097

0
17
474
610
14
115

0
0
0
0
0
0

473
136
2,638
1,263
124
4,634

$\begin{array}{rl}8 & 0 \\ 1 & 0 \\ 9 & 0 \\ 5 & 0 \\ 0 & 0 \\ 23 & 0\end{array}$

8,538

128

0

$\begin{array}{rr}2 & 37 \\ 94 & 223 \\ 20 & 28 \\ 140 & 244 \\ 481 & 2 \\ 747 & 533\end{array}$

$\begin{array}{rl}1 & 0 \\ 6 & 0 \\ 30 & 0 \\ 30 & 0 \\ 0 & 0 \\ 67 & 0\end{array}$

1,083

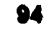

0

58,066
77

066
77
0

6,348

562
368

3,392

0
366
156,586

721

68,143

27,518

7,279

156,952

721

58,149

29,494

56,730

173,405

3,632

721

$\begin{array}{rrrrrr}115 & 0 & 142 & 556 & 10 & 0 \\ 132 & 248 & 89 & 583 & 0 & 0 \\ 39 & 0 & 114 & 1,032 & 7 & 0 \\ 6 & 4 & 19 & 147 & 4 & 0 \\ 0 & 0 & 4 & 0 & 0 & 0 \\ 0 & 0 & 426 & 0 & 0 & 0 \\ 34 & 0 & 158 & 11,926 & 0 & 0 \\ 0 & 2 & 146 & 699 & 0 & 0 \\ 325 & 254 & 1,098 & 14,943 & 22 & 0\end{array}$


Table 41. Electric Operation and Maintenance Expenses by Major U.S. Investor-Owned Electric Utility Within State, 1992 (Continued) (Thousand Dollars)

\begin{tabular}{|c|c|c|c|c|c|c|}
\hline Item & $\begin{array}{l}\text { West Virginia } \\
\text { Wheeling } \\
\text { Power Co }\end{array}$ & $\begin{array}{c}\text { Wisconsin } \\
\text { Consolidated } \\
\text { Water } \\
\text { Power Co }\end{array}$ & $\begin{array}{c}\text { Wisconsin } \\
\text { Madison } \\
\text { Gas } \\
\& \\
\text { Electric Co }\end{array}$ & $\begin{array}{l}\text { Wisconsin } \\
\text { Northern } \\
\text { States } \\
\text { Power Co }\end{array}$ & $\begin{array}{l}\text { Wisconsin } \\
\text { Northwestern } \\
\text { Wisconsin } \\
\text { Elec Co }\end{array}$ & $\begin{array}{c}\text { Wisconsin } \\
\text { Ploneer } \\
\text { Power } \\
8 \\
\text { Light Co }\end{array}$ \\
\hline
\end{tabular}

Maintenance Expenses

Supervision and Engineering

Structures

Station Equipment

Overhead Lines

Underground Lines

Miscollaneous Transmission Plant

Totel Maintenence Expenses.

Total Transmiaton Exponees

$\begin{array}{rr}104 & 37 \\ 51 & 0 \\ 225 & 98 \\ 254 & 28 \\ 0 & 0 \\ 0 & 0 \\ 635 & 165\end{array}$

60

524

374

2
1

989

2,002

$\begin{array}{rrr}462 & 5 & 0 \\ 0 & 0 & 0 \\ 550 & 8 & 0 \\ 1,987 & 5 & 0 \\ 0 & 0 & 0 \\ 0 & 0 & 0 \\ 2,009 & 18 & 0\end{array}$

980

410

17,043

40

o

Distribution

Operation Expenses

Supervision and Engineering

Loed Dispatching

Station Expenses

Overhead Line Expenses

Underground Line Expenses

Street Lighting and Signal System Expenses ....

Meter Expenses

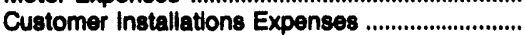

Miscellaneous Distribution Expenses

Rents

Total Operation Exponese

$\begin{array}{rr}410 & 0 \\ 0 & 0 \\ 74 & 0 \\ 5 & 20 \\ 23 & 0 \\ 15 & 2 \\ 326 & 2 \\ 61 & 13 \\ 470 & 0 \\ 18 & 0 \\ 1,402 & 37\end{array}$

$\begin{array}{rr}441 & 716 \\ 40 & 458 \\ 42 & 452 \\ 259 & 2,145 \\ 129 & 748 \\ 75 & 83 \\ 468 & 867 \\ 126 & 117 \\ 1,945 & 1,942 \\ 195 & 187 \\ 3,717 & 7,716\end{array}$

Maintenance Expenses

Supervision and Engineering

Structures

458

14

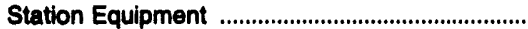

Overhead Lines ...

Underground Lines .

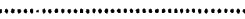

Street Lighting and Signal Systems

Meters

Miscellaneous Distribution Plant

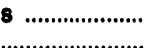

Total Malntenance Expenees

............................

Toth Malntonance Exponses

Total Diatribution Expenses

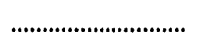

3,761

227
5
77
1,583
243
120
26
26
60
2,366

719
1
655
6,131
625
243
223
67
54
8,718

6,093

18,435

$\begin{array}{rr}20 & 18 \\ 0 & 0 \\ 2 & 1 \\ 280 & 0 \\ 55 & 0 \\ 10 & 3 \\ 43 & 1 \\ 1 & 1 \\ 72 & 0 \\ 0 & 0 \\ 482 & 23\end{array}$

Customer Accounts Expenses

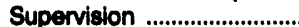

Meter Reading Expenses ......................................

Customer Records and Collection Expenses ....

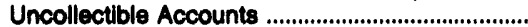

Miscellaneous Customer Accounts Expenses ...

Total Customer Accounts Expenses

1,377

87

100
29

104

2,359

389

716

452

2,145

83

117

187

7,716

Customer Service and Information Expenses

Supervision

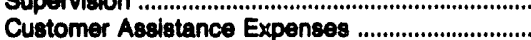

Informational and Instructional Expenses ..............

Miscellaneous Customer Service

and Informational Expenses ...

Total Cuotomer Service and

Informational Expences

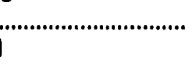

Sales Expenses

Supervision ...

Demonstrating and Selling Expenses

Advertising Expenses

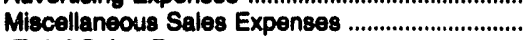

Total salee Exponses

$\begin{array}{rr}88 & 0 \\ 313 & 15 \\ 682 & 0 \\ -27 & 4 \\ 73 & 0 \\ 1,129 & 18\end{array}$

$\begin{array}{rr}52 & 564 \\ 616 & 1,868 \\ 1,998 & 2,844 \\ 913 & 933 \\ 81 & 374 \\ 3,680 & 6,582\end{array}$

$\begin{array}{rr}5 & 0 \\ 121 & 21 \\ 181 & 35 \\ 18 & 6 \\ 0 & 6 \\ 325 & 68\end{array}$

See endnotes at end of an individual electric utility. 
Table 41. Electrlc Operation and Maintenance Expenses by Major U.S. Inveator-Owned Electric Utility Within State, 1992 (Continued) (Thousand Dollars)

\begin{tabular}{|c|c|c|c|c|c|c|}
\hline Item & $\begin{array}{l}\text { West Virginia } \\
\text { Wheeling } \\
\text { Power Co }\end{array}$ & $\begin{array}{l}\text { Wisconain } \\
\text { Consolidated } \\
\text { Water } \\
\text { Power Co }\end{array}$ & $\begin{array}{l}\text { Wisconsin } \\
\text { Madison } \\
\text { Gas } \\
\text { Electric Co }\end{array}$ & $\begin{array}{l}\text { Wisconsin } \\
\text { Northern } \\
\text { States } \\
\text { Power Co }\end{array}$ & $\begin{array}{l}\text { Wisconsin } \\
\text { Northwestern } \\
\text { Wisconsin } \\
\text { Elec Co }\end{array}$ & $\begin{array}{c}\text { Wisconsin } \\
\text { Pioneer } \\
\text { Power } \\
\& \\
\text { Light Co }\end{array}$ \\
\hline
\end{tabular}

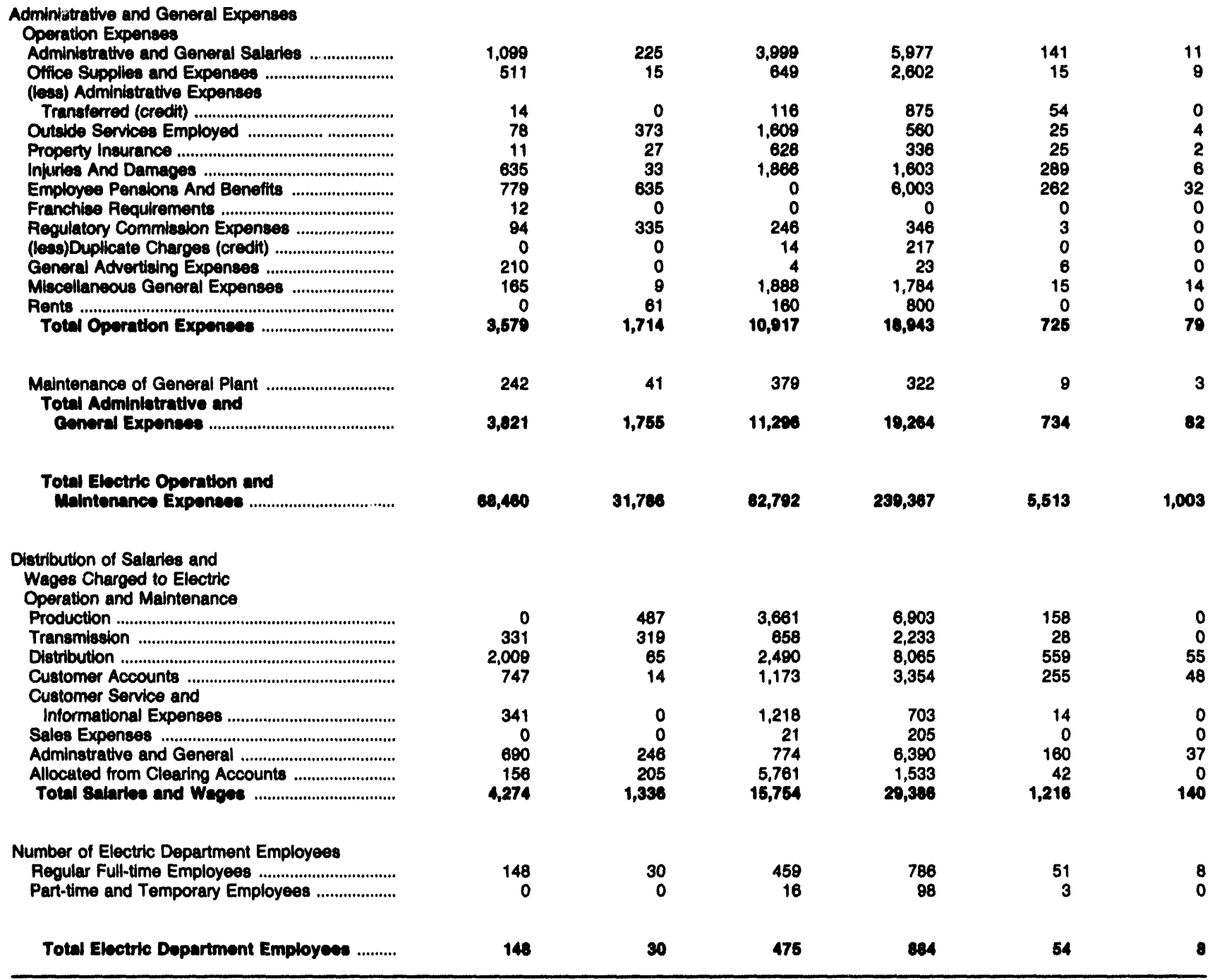

Note: Totals may not equal sum of components because of independent rounding. Summary data are provided in Table 11.

Source: Federal Energy Regulatory Commission, FERC Form 1, "Annual Report of Major Electric Utilities, Licensees and Others." 
Table 41. Electric Operation and Maintenance Expenses by Major

U.S. Investor-Owned Electric Utility Within State, 1992 (Continued)

(Thousand Dollars)

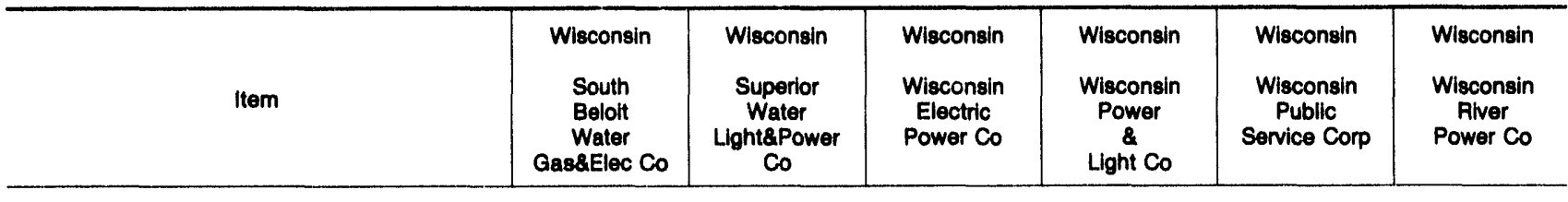

Power Production Expenses

Steam Power

Operation Expenses

Supervision and Engineering

Steam from Other Sources

(less) Steam Transferred (credit)

Electric Expenses ....

Miscellaneous Steam Power Expenses

Pents

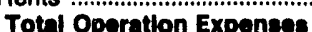

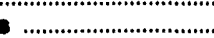

0
0
0
0
0
0
0

3,839
236,245
11,986
0
5,911
5,405
18,472
0
270,036

1,228

115,241

4,431

3,582

116,592

5,212

0

2,385

3,345

126,631

Maintenance Expenses

Supervision and Engineering

Structures

Boller Plant

Electric Plant

Miscellaneous Steam Plant

Total Malntenance Expenees

Total Steam Power Production

Expenses

Operation Expenses

Supervision and Engineering

Fuel.

Coolants and Water

Steam Expenses

Steam from Other Sources

(less) Steam Transferred (credit)

Electric Expenses

Miscellaneous Nuclear Power Expenses ...........

Rents

Total Operation Expeneos

Maintenance Expenses

Supervision and Engineering

Structures

Reactor Plant Equipment

Electric Plant

Miscellaneous Nuclear Plant

Total Maintenance Expenses

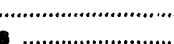

Total Nuclear Power Production

Expenses

80,039

Hydraulic Power

Operation Expenses

Supervision and Engineering ..................................

Water for Power

Hydraulic Expenses

Electric Expenses

Miscellaneous Hydraulic Expenses

Rents

Total Operation Expenses

1
14
2
6
17
7
47

484
0
100
380
1,548
2
2,514

134
468
21
285
199
0
1,109

383
491
202
147
448
0
1,671

See endnotes at end of an individual electric utility. 
Table 41. Electric Operation and Maintenance Expenses by Major

U.S. Investor-Owned Electric Utility Within State, 1992 (Continued)

(Thousand Dollars)

\begin{tabular}{c|c|c|c|c|c|c}
\hline & Wisconsin & Wisconsin & Wisconsin & Wisconsin & Wisconsin & Wisconsin \\
Item & $\begin{array}{c}\text { South } \\
\text { Beloit } \\
\text { Water } \\
\text { Gas\&Elec Co }\end{array}$ & $\begin{array}{c}\text { Superior } \\
\text { Water } \\
\text { Light\&Power } \\
\text { Co }\end{array}$ & $\begin{array}{c}\text { Wisconsin } \\
\text { Electric } \\
\text { Power Co }\end{array}$ & $\begin{array}{c}\text { Wisconsin } \\
\text { Power } \\
\text { \& } \\
\text { Light Co }\end{array}$ & $\begin{array}{c}\text { Wisconsin } \\
\text { Public } \\
\text { Service Corp }\end{array}$ & $\begin{array}{c}\text { Wisconsin } \\
\text { River } \\
\text { Power Co }\end{array}$ \\
\hline
\end{tabular}

Maintenance Expenses

Supervision and Engineering

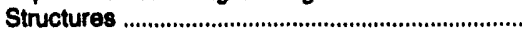

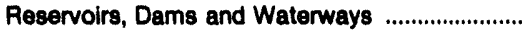

Electric Plant

Miscellaneous Hydraulic Plant

Total Maintenance Expenese

Total Hydraulic Power

Production Expenses

139

1
3
79
9
1
92

0
0
0
0
0

286

187

658

865

248

$$
\begin{array}{r}
135 \\
77 \\
250 \\
162 \\
111 \\
735
\end{array}
$$

$\begin{array}{rr}183 & 0 \\ 61 & 2 \\ 583 & 115 \\ 330 & 124 \\ 68 & 135 \\ 1,224 & 375\end{array}$

2,894

792

Other Power

Operation Expenses

Supervision and Engineering

Fuel

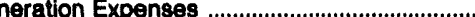

Miscellaneous Other Power Expenses

Rents

Total Operation Expenses

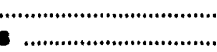

Maintenance Expenses

Supervision and Engineering

Generating and Electric Plan

Generating and Electric Plant ...

Miscellaneous Other Power Plan

Total Other Power Production

Expanses

Other Power Supply Expenses

Purchased Power

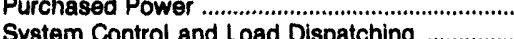

Other Expenses

Total Other Power Supply

Expenses

Total Power Production Expences

.....................
4,299

3,640
0
0

17,859

13
0

63,745

866

2,112

3,640

17,873

66,722

17,925

525,578

205,486

215,936

792

Transmission

Operation Expenses

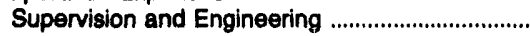

Load Dispatching

Station Expenses

Overhead Line Expenses

Underground Line Expenses

Transmission of Electricity by Others

Total Operation Expences

0
0
0
0
0
0
0
54

154

1,222
2,204
328
288
7
719
344
26
5,138

See endnotes at end of an individual electric utility.

5,138

3,502

598
81
253
209
0
39
1,308
2,488
4,976


Table 41. Electrlc Operation and Malntenance Expenses by Major U.S. Investor-Owned Electric Utility Within State, 1992 (Continued) (Thousand Dollars)

\begin{tabular}{c|c|c|c|c|c|c}
\hline & Wisconsin & Wisconsin & Wisconsin & Wisconsin & Wisconsin & Wisconsin \\
Item & $\begin{array}{c}\text { South } \\
\text { Beloit } \\
\text { Water } \\
\text { GasbElec Co }\end{array}$ & $\begin{array}{c}\text { Superior } \\
\text { Water } \\
\text { Light\&Power } \\
\text { Co }\end{array}$ & $\begin{array}{c}\text { Wisconsin } \\
\text { Electric } \\
\text { Power Co }\end{array}$ & $\begin{array}{c}\text { Wisconsin } \\
\text { Power } \\
8 \\
\text { Light Co }\end{array}$ & $\begin{array}{c}\text { Wisconsin } \\
\text { Public } \\
\text { Service Corp }\end{array}$ & $\begin{array}{c}\text { Wisconsin } \\
\text { Alver } \\
\text { Power Co }\end{array}$ \\
\hline
\end{tabular}

Maintenance Expenses

Supervision and Engineering

Structures

Station Equipm

Overhead Lines

Underoround Lines

.

Miscellaneous Transmiseion Plant

Totel Maintenance Expenses

Total Tranemiesion Expenses

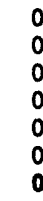

154

Distribution

Operation Expenses

Supervision and Engineering

Load Dispatching

Station Expenses

Overhead Line Expenses

Underground Line Exp

Street Lighting and Signal System Expenses ...

Meter Expenses

Customer Installatlone Expenses

Miscollaneous Distribution Expenses

Rents

Total Operation Expenses
Maintenance Expenses

Supervision and Engineering

Structures

Station Equipment

Overhead Lines

Underground Lines

Line Transiormers

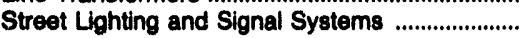

Meters

Miscellaneous Distribution Plant

Total Malntenance Exponese

Total Distribution Expenses

............................

Customer Accounts Expenses

Supervision

Meter Reading Expenses

Customer Records and Collection Expenses ....

Uncollectible Accounts

Miscellaneous Customer Accounts Expenses ...

Customer Service and Information Expenses

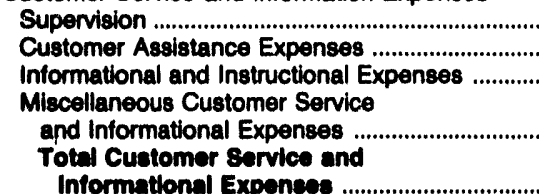

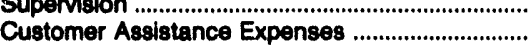

Informational and Instructional Expenses ............

Miscellaneous Customer Service

Total Customer Eervice and

Intormational Expentes .

Sales Expenses

Supervision

Demonstrating and Selling Expens.......................

Advertising Expenses

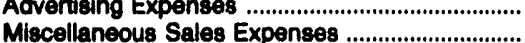

Total salee Expenses

See endnotes at end of an individual electric utility.

\section{0}

0

88

0
0
22
38
0
0
59
68

732

276

2,450

1,644

218

571

6,880

11,028

8,733

4,590

2,526

4,025

5,296

681

3,405

1,948

12,134

174

43,513

480

$\begin{array}{rrr}197 & 315 & 0 \\ 13 & 0 & 0 \\ 142 & 1,257 & 4 \\ 2,348 & 640 & 0 \\ 10 & 0 & 0 \\ 230 & 228 & 0 \\ 2,040 & 2,440 & 4 \\ 6,442 & 7,417 & 4\end{array}$

1,118

206

422

1,179

404
0

1,163

556

4,842

123

10,013

2,590

138

215
1,672

736
148

148
1,130

294

3,593

272

10,788

2,656

535

3,493

22,036

4,774

349

239

289

2,152

30,524

574

324
9,134

546

150

265

51

730
11,783

80,038

21,795

1,059

-2
471

471
11,728

865

297

168

131

144
14,861

347

649

25,649

444
2,365

2,365
4,657

4,657
1,007

1,007
53

8,526

341
2,53

2,453

7,019

1,076

11,004

27,390

1,132

43,818

2,218

0
13,655

78

1,033

6,718

1,410

395

755

14,128

9,916

47,424

$$
\begin{array}{r}
0 \\
270 \\
0 \\
0 \\
270
\end{array}
$$

51
90
141
23
305

305



0

0
0
0
0
0
0
0
0
0
0
0
0
0
0
0
0
0


Table 41. Electric Operation and Maintenance Expenses by Major U.S. Investor-Owned Electric Utility Within State, 1992 (Continued) (Thousand Dollars)

\begin{tabular}{|c|c|c|c|c|c|c|}
\hline Item & $\begin{array}{c}\text { Wisconsin } \\
\text { South } \\
\text { Beloit } \\
\text { Water } \\
\text { Gas\&Elec Co }\end{array}$ & $\begin{array}{l}\text { Wisconsin } \\
\text { Superior } \\
\text { Water } \\
\text { Light\&Power } \\
\text { Co }\end{array}$ & $\begin{array}{l}\text { Wisconsin } \\
\text { Wisconsin } \\
\text { Electric } \\
\text { Power Co }\end{array}$ & $\begin{array}{l}\text { Wisconsin } \\
\text { Wisconsin } \\
\text { Power } \\
\& \\
\text { Light Co }\end{array}$ & $\begin{array}{l}\text { Wisconsin } \\
\text { Wisconsin } \\
\text { Publlc } \\
\text { Service Corp }\end{array}$ & $\begin{array}{l}\text { Wisconsin } \\
\text { Wisconsin } \\
\text { River } \\
\text { Power Co }\end{array}$ \\
\hline
\end{tabular}

Administrative and General Expenses

Operation Expenses

Administrathe and General Salaries

Otice Supolies and Expenses

(less) Administrattve Expenses

Transferred (credit) ...

Outside Services Employed

Property Insurance

Injuries And Dar

Franchise Requirements

Regulatory Commiseion Expenses

(less)Duplicate Charges (credit)

General Advertising Expenses ....

Miscelianeous General Expenses

Rents

Tothl Opprathon Exponses

Maintenance of General Plant

Total Adminiotrative and

Coneral Exponses

Total Electric Operation and

Malntenance Exponees ..

$\begin{array}{rr}16 & \\ 0 & \\ 0 & \\ 0 & \\ 0 & \\ 0 & \\ 0 & \\ 0 & \\ 2 & \\ 0 & \\ 0 & \\ 688 & \\ 0 & \\ 708 & 1,78\end{array}$

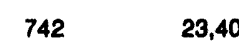

23,403
13,441

18,205

4,282

294

4,586

2,143

5,304

28,766

0
2,422

2,715

2,715
169

169
10,447

25

$87,8 \bullet$

4,040

81,736

1,780

708

6

6,149

21,089

783,376

280,532

302,634

2,003

Distribution of Salaries and

Wages Charged to Electric

Operation and Maintenance

Production

Transmission

Distribution ...............

Customer Service and

Informational Expenses

Sales Expenses

Adminstrative and General

Allocated from Clearing Accounts

Total Salartes and Wages

Number of Electric Department Employees

Regular Full-time Employees ...............................

Part-time and Temporary Employees

Total Electric Department Employese .........

33
7
467
237
119
0
818
93
1,773

72,762

2,880

34,974

12,632

11,387

21

25,562

28,801

180,119
37,033

2,518

$\begin{array}{rr}13,034 & 10,197 \\ 4,750 & 5,476\end{array}$

138

3,935

$\begin{array}{rr}2,011 & 3,935 \\ 165 & 103\end{array}$

8,293

$5,297 \quad 3,864$

$70,684 \quad 71,418$

0
8

0
505

29

107

407
0

230

0

0

1,201

6

207

Note: Totals may not equal sum of components because of independent rounding. Summary data are provided in Table 11

Source: Federal Energy Regulatory Commission, FERC Form 1, "Annual Report of Major Electric Utilities, Licensees and Others." 
Table 42. UtIIIty Plant by Major U.S. Investor-Owned Electric Utility Within State on December 31, 1992

(Thousand Dollars)

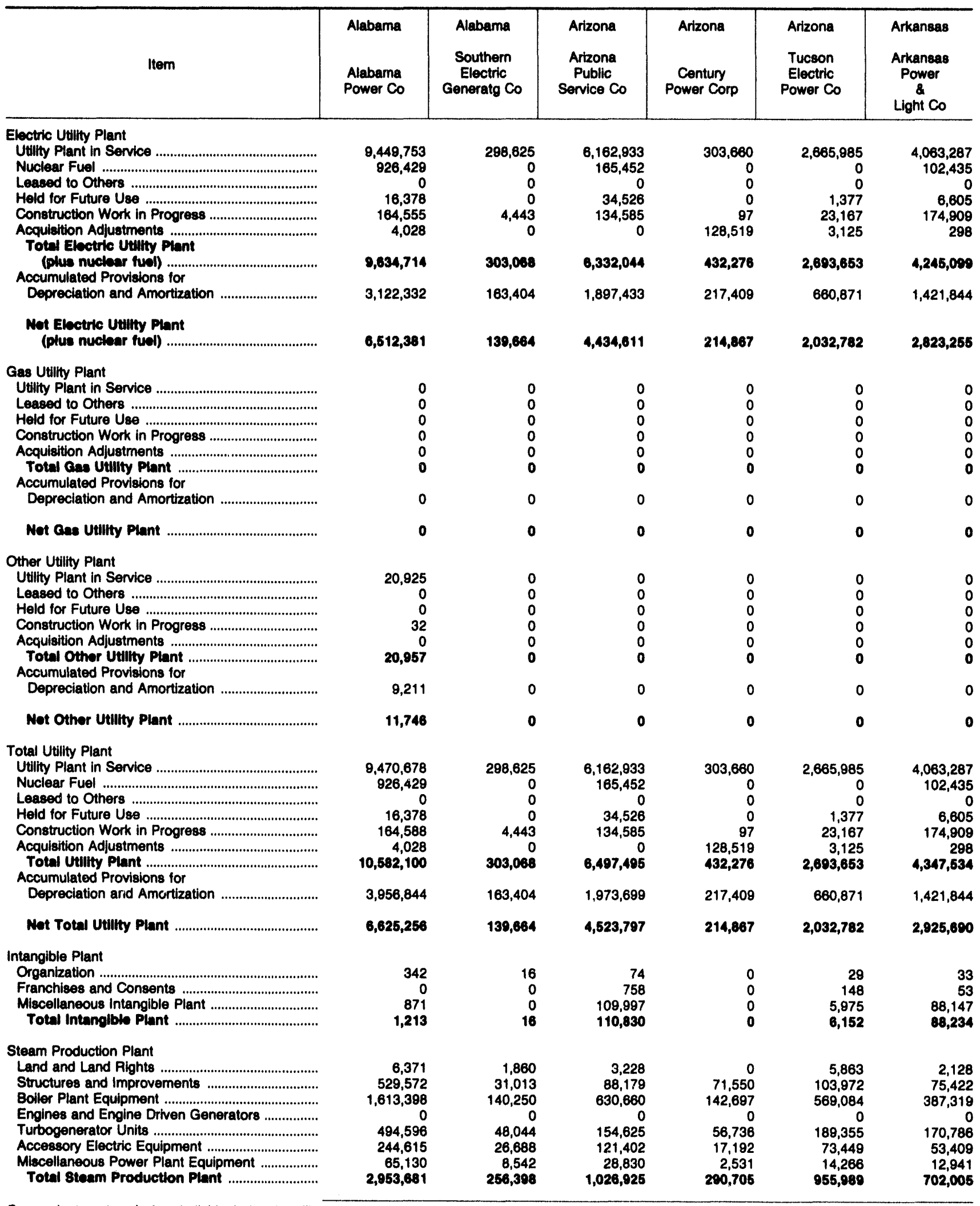

See endnotes at end of an individual electric utility. 
Table 42. Utility Plant by Major U.S. Investor-Owned Electric Utility Within State on December 31, 1992 (Continued) (Thousand Dollars)

\begin{tabular}{|c|c|c|c|c|c|c|}
\hline Item & $\begin{array}{l}\text { Alabama } \\
\text { Alabama } \\
\text { Power Co }\end{array}$ & $\begin{array}{l}\text { Alabama } \\
\text { Southern } \\
\text { Electric } \\
\text { Generatg Co }\end{array}$ & $\begin{array}{l}\text { Arizona } \\
\text { Arizona } \\
\text { Public } \\
\text { Service Co }\end{array}$ & $\begin{array}{l}\text { Arizona } \\
\text { Century } \\
\text { Power Corp }\end{array}$ & $\begin{array}{l}\text { Arizona } \\
\text { Tucson } \\
\text { Electric } \\
\text { Power Co }\end{array}$ & $\begin{array}{c}\text { Arkansas } \\
\text { Arkansas } \\
\text { Power } \\
\& \\
\text { Light Co }\end{array}$ \\
\hline 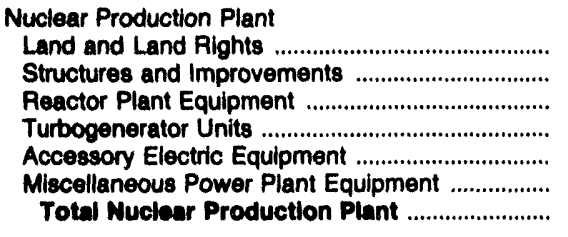 & $\begin{array}{r}1,454 \\
462,045 \\
790,125 \\
317,682 \\
214,026 \\
75,500 \\
1,860,833\end{array}$ & $\begin{array}{l}0 \\
0 \\
0 \\
0 \\
0 \\
0 \\
0\end{array}$ & $\begin{array}{r}3,400 \\
614,390 \\
861,253 \\
332,563 \\
264,174 \\
129,965 \\
2,305,745\end{array}$ & $\begin{array}{l}0 \\
0 \\
0 \\
0 \\
0 \\
0 \\
0\end{array}$ & $\begin{array}{l}0 \\
0 \\
0 \\
0 \\
0 \\
0 \\
0\end{array}$ & $\begin{array}{r}1,050 \\
290,919 \\
578,494 \\
191,680 \\
192,310 \\
104,840 \\
1,359,294\end{array}$ \\
\hline 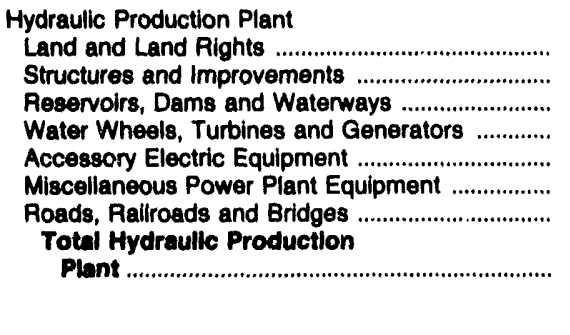 & $\begin{array}{r}103,062 \\
101,413 \\
393,275 \\
158,843 \\
33,110 \\
23,825 \\
4,737 \\
818,364\end{array}$ & $\begin{array}{l}0 \\
0 \\
0 \\
0 \\
0 \\
0 \\
0 \\
0\end{array}$ & $\begin{array}{r}65 \\
75 \\
992 \\
157 \\
377 \\
109 \\
49 \\
1,824\end{array}$ & $\begin{array}{l}0 \\
0 \\
0 \\
0 \\
0 \\
0 \\
0\end{array}$ & $\begin{array}{l}0 \\
0 \\
0 \\
0 \\
0 \\
0 \\
0 \\
0\end{array}$ & $\begin{array}{r}1,156 \\
1,540 \\
6,670 \\
1,773 \\
484 \\
373 \\
0 \\
12,196\end{array}$ \\
\hline 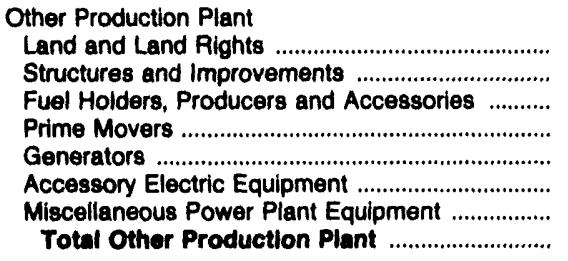 & $\begin{array}{l}2 \\
0 \\
0 \\
0 \\
0 \\
0 \\
0 \\
2\end{array}$ & $\begin{array}{r}0 \\
28 \\
126 \\
0 \\
1,502 \\
16 \\
1 \\
1,674\end{array}$ & $\begin{array}{r}28 \\
4,946 \\
18,381 \\
31,932 \\
64,472 \\
13,100 \\
2,695 \\
135,554\end{array}$ & $\begin{array}{l}0 \\
0 \\
0 \\
0 \\
0 \\
0 \\
0 \\
0\end{array}$ & $\begin{array}{r}402 \\
524 \\
80 \\
456 \\
18,386 \\
3,378 \\
518 \\
23,743\end{array}$ & $\begin{array}{r}107 \\
1,519 \\
310 \\
6,041 \\
2,157 \\
830 \\
37 \\
11,002\end{array}$ \\
\hline 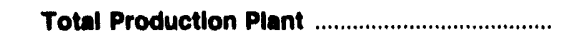 & $5,632,880$ & 258,072 & $3,470,047$ & 290,705 & 979,732 & $2,084,498$ \\
\hline 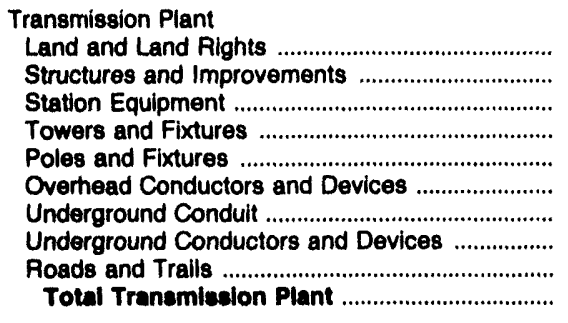 & $\begin{array}{r}74,326 \\
18,240 \\
318,119 \\
133,369 \\
225,959 \\
241,229 \\
1,100 \\
1,127 \\
0 \\
1,013,464\end{array}$ & $\begin{array}{r}627 \\
0 \\
7,586 \\
4,990 \\
0 \\
4,085 \\
0 \\
0 \\
0 \\
17,288\end{array}$ & $\begin{array}{r}32,354 \\
18,557 \\
272,907 \\
83,263 \\
110,239 \\
168,881 \\
5,160 \\
12,539 \\
0 \\
703,001\end{array}$ & $\begin{array}{l}0 \\
0 \\
0 \\
0 \\
0 \\
0 \\
0 \\
0 \\
0 \\
0\end{array}$ & $\begin{array}{r}19,771 \\
13,166 \\
176,131 \\
153,952 \\
11,395 \\
76,785 \\
0 \\
0 \\
4,486 \\
455,685\end{array}$ & $\begin{array}{r}42,714 \\
17,083 \\
202,123 \\
128,759 \\
78,903 \\
174,705 \\
0 \\
0 \\
33 \\
644,321\end{array}$ \\
\hline 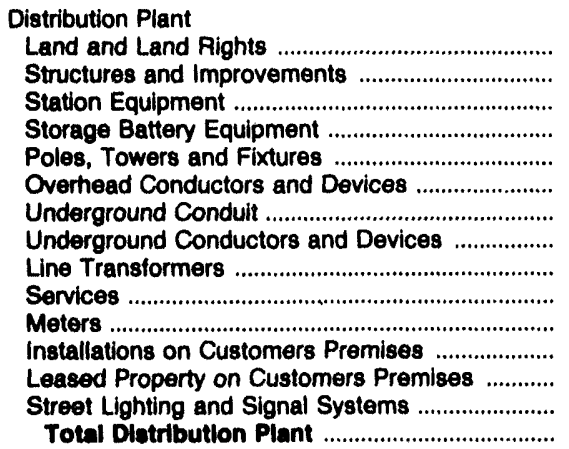 & $\begin{array}{r}11,575 \\
17,767 \\
258,989 \\
0 \\
456,609 \\
379,448 \\
12,579 \\
88,894 \\
460,941 \\
194,131 \\
113,158 \\
0 \\
0 \\
78,073 \\
2,072,163\end{array}$ & $\begin{array}{l}0 \\
0 \\
0 \\
0 \\
0 \\
0 \\
0 \\
0 \\
0 \\
0 \\
0 \\
0 \\
0 \\
0 \\
0\end{array}$ & $\begin{array}{r}12,429 \\
14,025 \\
102,805 \\
0 \\
209,184 \\
133,203 \\
77,806 \\
423,659 \\
296,277 \\
111,989 \\
96,713 \\
11,317 \\
0 \\
41,012 \\
1,580,420\end{array}$ & $\begin{array}{l}0 \\
0 \\
0 \\
0 \\
0 \\
0 \\
0 \\
0 \\
0 \\
0 \\
0 \\
0 \\
0 \\
0 \\
0\end{array}$ & $\begin{array}{r}5,326 \\
2,627 \\
49,287 \\
0 \\
54,059 \\
66,805 \\
28,303 \\
88,626 \\
90,080 \\
38,258 \\
22,101 \\
0 \\
0 \\
4,853 \\
450,327\end{array}$ & $\begin{array}{r}3,804 \\
7,366 \\
124,523 \\
0 \\
252,671 \\
168,282 \\
23,444 \\
50,582 \\
219,881 \\
83,986 \\
94,336 \\
12,972 \\
0 \\
40,005 \\
1,081,852\end{array}$ \\
\hline
\end{tabular}

See endnotes at end of an individual electric utility. 
Table 42. Utility Plant by Major U.S. Investor-Owned Electric Utility Within State on December 31, 1992 (Continued) (Thousand Dollars)

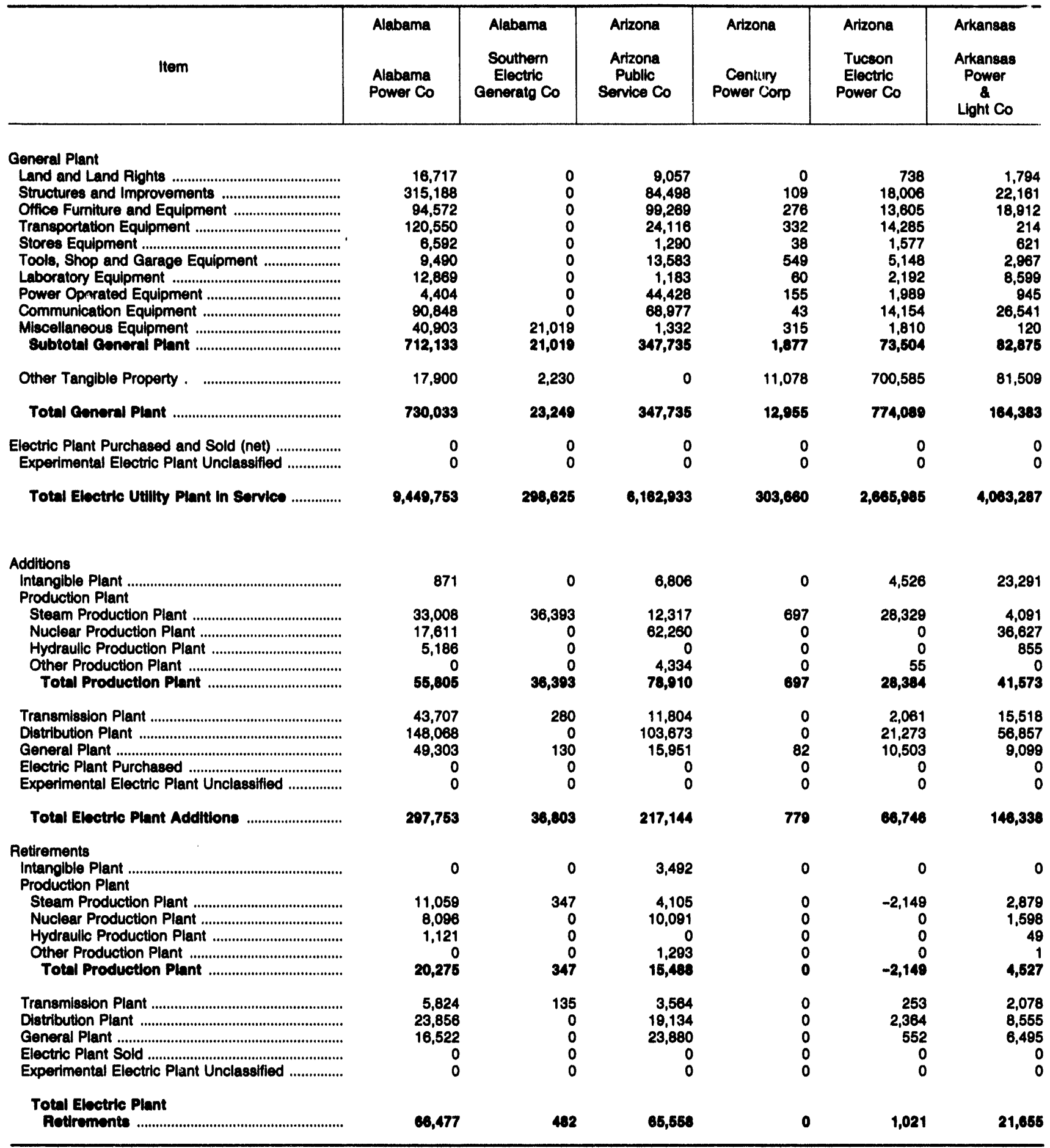

Note: Totals may not equal sum of components because of independent rounding. Summary data are provided in Table 28.

Source: Federal Energy Regulatory Commission, FERC Form 1, "Annual Report of Major Electric Utilities, Licensees and Others." 
Table 42. Utility Plant by Major U.S. Investor-Owned Electric Utillty Within State on December 31, 1992 (Continued)

(Thousand Dollars)

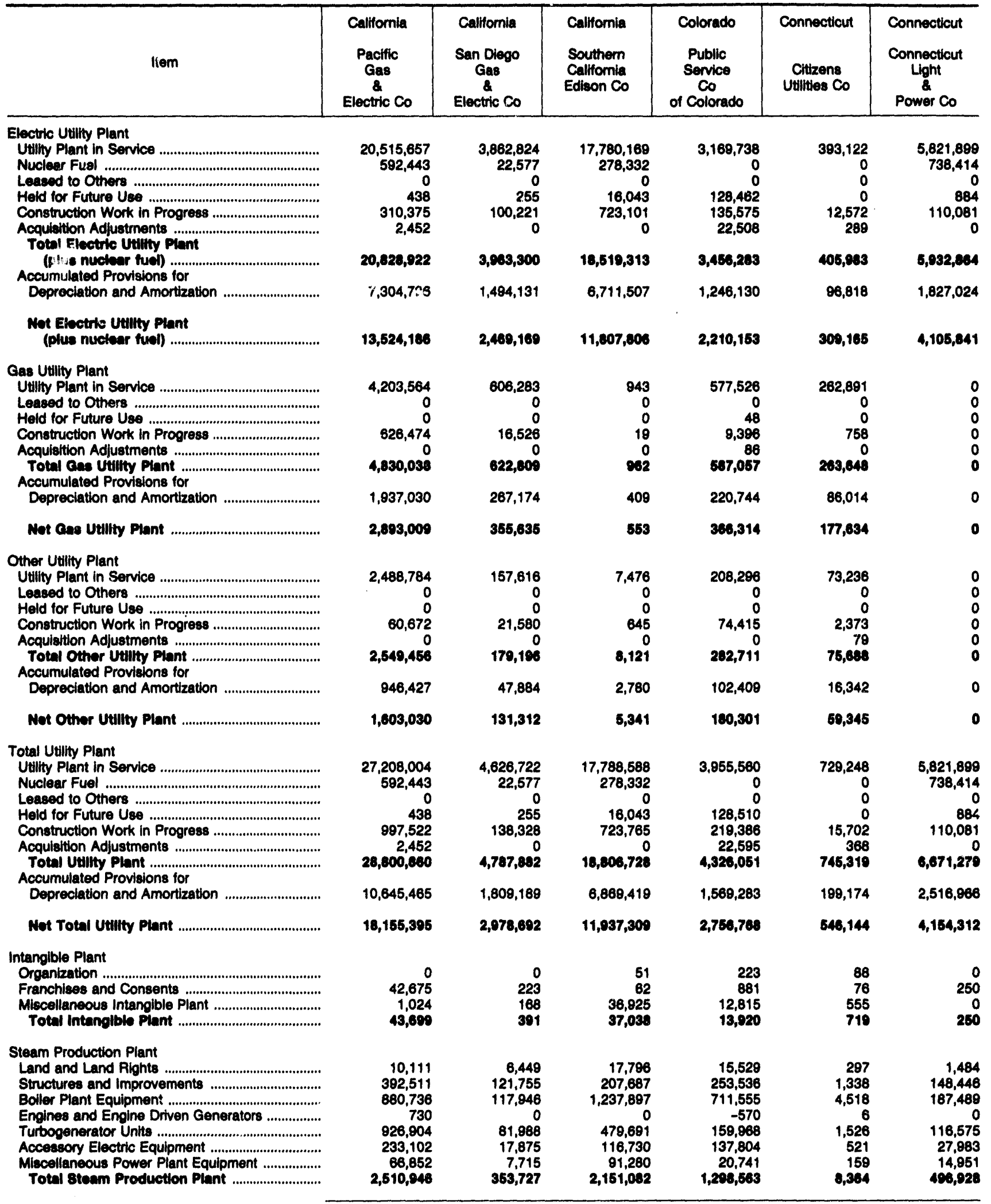

See endnotes at end of an individual electric utility. 
Table 42. Utility Plant by Major U.S. Investor-Owned Electric Utility Within State on December 31, 1992 (Continued)

(Thousand Dollars)

\begin{tabular}{|c|c|c|c|c|c|c|}
\hline Item & $\begin{array}{c}\text { California } \\
\text { Pacific } \\
\text { Gas } \\
\& \\
\text { Electric Co }\end{array}$ & $\begin{array}{c}\text { California } \\
\text { San Diego } \\
\text { Gas } \\
\& \\
\text { Electric Co }\end{array}$ & $\begin{array}{l}\text { California } \\
\text { Southern } \\
\text { California } \\
\text { Edison Co }\end{array}$ & $\begin{array}{l}\text { Colorado } \\
\text { Public } \\
\text { Service } \\
\text { Co } \\
\text { of Colorado }\end{array}$ & $\begin{array}{l}\text { Conriecticut } \\
\text { Citizens } \\
\text { Utilities Co }\end{array}$ & $\begin{array}{l}\text { Connecticut } \\
\text { Connecticut } \\
\text { Light } \\
\& \\
\text { Power Co }\end{array}$ \\
\hline 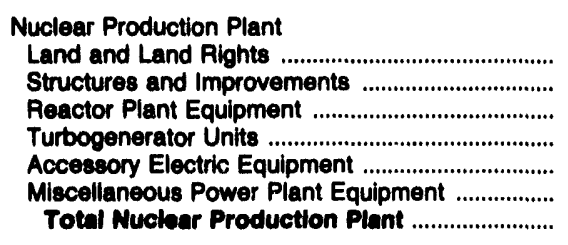 & $\begin{array}{r}16,408 \\
935,534 \\
2,684,360 \\
1,007,681 \\
704,719 \\
474,646 \\
5,823,340\end{array}$ & $\begin{array}{r}1,459 \\
246,446 \\
367,634 \\
131,146 \\
152,330 \\
136,028 \\
1,035,043\end{array}$ & $\begin{array}{r}2,304 \\
1,440,185 \\
2,083,677 \\
714,434 \\
802,394 \\
337,463 \\
\mathbf{5 , 3 8 0 , 4 5 7}\end{array}$ & $\begin{array}{l}0 \\
0 \\
0 \\
0 \\
0 \\
0 \\
0\end{array}$ & $\begin{array}{l}0 \\
0 \\
0 \\
0 \\
0 \\
0 \\
0\end{array}$ & $\begin{array}{r}2,675 \\
794,821 \\
1,538,498 \\
370,391 \\
259,477 \\
47,564 \\
3,013,425\end{array}$ \\
\hline 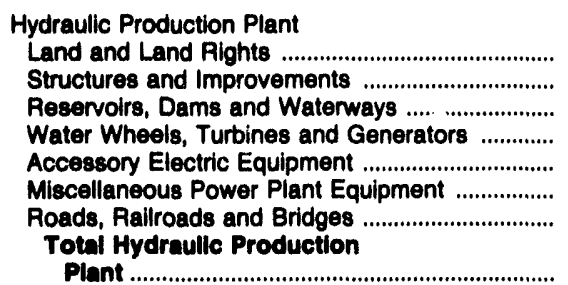 & $\begin{array}{r}26,975 \\
303,691 \\
1,300,969 \\
368,324 \\
119,585 \\
26,097 \\
36,089 \\
2,181,730\end{array}$ & $\begin{array}{l}0 \\
0 \\
0 \\
0 \\
0 \\
0 \\
0\end{array}$ & $\begin{array}{r}5,115 \\
83,892 \\
339,096 \\
87,756 \\
42,471 \\
9,516 \\
4,012\end{array}$ & $\begin{array}{r}1,309 \\
8,465 \\
33,882 \\
14,198 \\
4,031 \\
734 \\
749\end{array}$ & $\begin{array}{r}334 \\
174 \\
2,812 \\
866 \\
72 \\
10 \\
21\end{array}$ & $\begin{array}{r}9,159 \\
23,377 \\
79,357 \\
41,615 \\
10,829 \\
4,212 \\
3,960 \\
172,508\end{array}$ \\
\hline 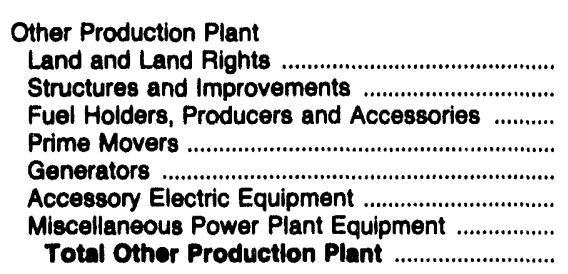 & $\begin{array}{r}15 \\
5,842 \\
5,360 \\
3,800 \\
55,599 \\
3,379 \\
568 \\
74,563\end{array}$ & $\begin{array}{r}188 \\
1,830 \\
3,159 \\
0 \\
37,405 \\
966 \\
0 \\
43,648\end{array}$ & $\begin{array}{r}4,892 \\
39,427 \\
16,913 \\
174,802 \\
97,684 \\
43,787 \\
18,592 \\
396,005\end{array}$ & $\begin{array}{r}49 \\
369 \\
3,183 \\
0 \\
17,438 \\
635 \\
24 \\
21,690\end{array}$ & $\begin{array}{r}7,404 \\
6,409 \\
1,016 \\
39,875 \\
2,227 \\
5,934 \\
535 \\
63,400\end{array}$ & $\begin{array}{r}22 \\
4,496 \\
1,721 \\
18,570 \\
6,705 \\
3,703 \\
76 \\
35,293\end{array}$ \\
\hline Total Production Plant & $10,590,587$ & $1,432,318$ & $8,499,492$ & $1,383,630$ & 76,051 & $3,718,165$ \\
\hline 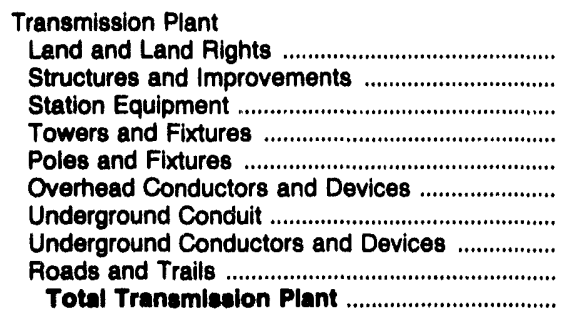 & $\begin{array}{r}113,107 \\
55,931 \\
921,914 \\
304,365 \\
151,505 \\
410,747 \\
37,336 \\
29,030 \\
7,110 \\
2,031,045\end{array}$ & $\begin{array}{r}47,441 \\
33,771 \\
198,919 \\
89,697 \\
48,401 \\
105,271 \\
11,038 \\
13,621 \\
8,130 \\
656,289\end{array}$ & $\begin{array}{r}183,097 \\
110,858 \\
1,186,883 \\
398,342 \\
167,775 \\
420,389 \\
19,610 \\
60,676 \\
20,769 \\
2,568,300\end{array}$ & $\begin{array}{r}27,189 \\
8,226 \\
146,039 \\
90,897 \\
73,583 \\
96,457 \\
7,540 \\
13,923 \\
3,998 \\
467,864\end{array}$ & $\begin{array}{r}752 \\
411 \\
24,013 \\
121 \\
23,779 \\
21,520 \\
0 \\
14 \\
162 \\
70,772\end{array}$ & $\begin{array}{r}40,892 \\
11,923 \\
217,955 \\
27,569 \\
96,176 \\
83,641 \\
2,304 \\
14,552 \\
6,633 \\
501,645\end{array}$ \\
\hline 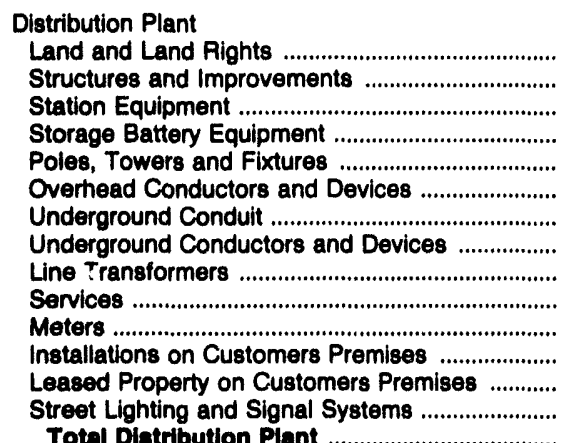 & $\begin{array}{r}105,922 \\
81,130 \\
641,857 \\
323 \\
998,178 \\
606,984 \\
789,903 \\
1,282,538 \\
1,232,238 \\
1,193,808 \\
332,733 \\
25,519 \\
1,134 \\
126,738 \\
719,006\end{array}$ & $\begin{array}{r}47,360 \\
2,731 \\
106,882 \\
0 \\
176,959 \\
132,589 \\
349,055 \\
381,609 \\
214,257 \\
168,440 \\
79,060 \\
4,347 \\
0 \\
20,458 \\
\end{array}$ & $\begin{array}{r}76,645 \\
217,278 \\
574,925 \\
0 \\
470,423 \\
512,236 \\
533,483 \\
1,072,498 \\
1,093,708 \\
457,182 \\
289,442 \\
0 \\
0 \\
300,414\end{array}$ & $\begin{array}{r}8,813 \\
13,415 \\
154,935 \\
0 \\
118,949 \\
110,505 \\
58,208 \\
309,689 \\
194,877 \\
131,807 \\
86,422 \\
5,669 \\
0 \\
79,764 \\
1273,052\end{array}$ & $\begin{array}{r}467 \\
465 \\
16,381 \\
0 \\
44,255 \\
38,862 \\
7,037 \\
15,652 \\
33,281 \\
10,456 \\
8,385 \\
11 \\
0 \\
3,380 \\
178,631\end{array}$ & $\begin{array}{r}8,549 \\
9,609 \\
160,096 \\
0 \\
172,107 \\
274,068 \\
96,563 \\
218,113 \\
28,484 \\
119,4839 \\
72,558 \\
6,625 \\
0 \\
28,019 \\
150,620\end{array}$ \\
\hline
\end{tabular}

See endnotes at end of an individual electric utility. 
Table 42. Utility Plant by Major U.S. Investor-Owned Electrlc Utility Within State on December 31, 1992 (Continued) (Thousand Dollars)

\begin{tabular}{|c|c|c|c|c|c|c|}
\hline Item & $\begin{array}{c}\text { California } \\
\text { Pacific } \\
\text { Gas } \\
\& \\
\text { Electric Co }\end{array}$ & $\begin{array}{c}\text { California } \\
\text { San Diego } \\
\text { Gas } \\
\& \\
\text { Electric Co }\end{array}$ & $\begin{array}{l}\text { Callfornia } \\
\text { Southern } \\
\text { Callfornia } \\
\text { Edison Co }\end{array}$ & $\begin{array}{c}\text { Colorado } \\
\text { Public } \\
\text { Service } \\
\text { Co } \\
\text { of Colorado }\end{array}$ & $\begin{array}{l}\text { Connecticut } \\
\text { Citizens } \\
\text { Utillties Co }\end{array}$ & $\begin{array}{l}\text { Connecticut } \\
\text { Connecticut } \\
\text { Light } \\
\& \\
\text { Power Co }\end{array}$ \\
\hline 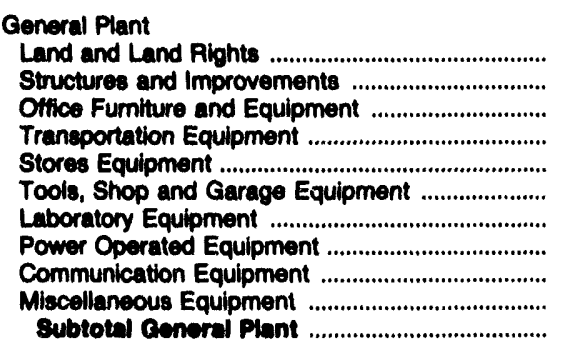 & $\begin{array}{r}364 \\
5,571 \\
7,165 \\
0 \\
0 \\
43,650 \\
9,502 \\
205 \\
13,487 \\
54,142 \\
134,084\end{array}$ & $\begin{array}{r}417 \\
10,424 \\
5 \\
382 \\
103 \\
5,191 \\
1,037 \\
120 \\
45,148 \\
436 \\
63,257\end{array}$ & $\begin{array}{r}20,941 \\
314,781 \\
312,096 \\
12,383 \\
7,342 \\
24,994 \\
34,925 \\
5,193 \\
296,031 \\
6,046 \\
1,035,633\end{array}$ & $\begin{array}{r}778 \\
7,693 \\
1,383 \\
0 \\
161 \\
4,043 \\
3,716 \\
0 \\
13,237 \\
107 \\
31,117\end{array}$ & $\begin{array}{r}1,719 \\
9,481 \\
17,161 \\
5,810 \\
296 \\
1,203 \\
681 \\
333 \\
1,143 \\
444 \\
38,271\end{array}$ & $\begin{array}{r}2,400 \\
70,658 \\
13,128 \\
5,377 \\
5,062 \\
8,939 \\
5,261 \\
1,034 \\
17,274 \\
1,018 \\
130,152 \\
\end{array}$ \\
\hline 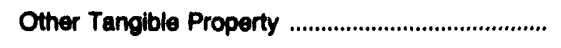 & 0 & 126,803 & 0 & 0 & 0 & 21,068 \\
\hline 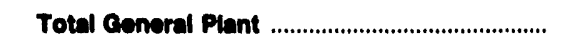 & 134,084 & 190,061 & $1,035,633$ & 31,117 & 38,271 & 151,220 \\
\hline $\begin{array}{l}\text { Electric Plant Purchased and Sold (net) .................... } \\
\text { Experimental Electric Plant Unclassified ................ }\end{array}$ & $\begin{array}{r}-2,764 \\
0\end{array}$ & $\begin{array}{r}18 \\
0\end{array}$ & $\begin{array}{r}0 \\
31,381\end{array}$ & $\begin{array}{r}146 \\
0\end{array}$ & $\begin{array}{r}0 \\
28,677\end{array}$ & $\begin{array}{l}0 \\
0\end{array}$ \\
\hline Total Electric Utility Plant in Sorvice ............... & $20,515,657$ & $3,862,824$ & $17,780,160$ & $3,169,738$ & 393,122 & $5,821,899$ \\
\hline $\begin{array}{l}\text { Additions } \\
\text { Intangible Plant } \\
\text { Production Plant }\end{array}$ & $-4,469$ & 10 & 36,925 & 8,306 & 544 & \\
\hline 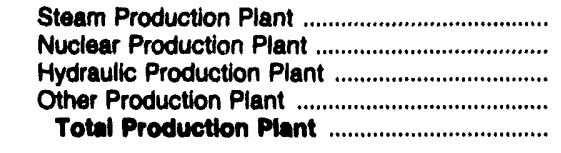 & $\begin{array}{r}85,381 \\
115,446 \\
23,526 \\
3,016 \\
227,369\end{array}$ & $\begin{array}{r}10,217 \\
18,009 \\
0 \\
324 \\
28,550\end{array}$ & $\begin{array}{r}96,120 \\
70,661 \\
3,519 \\
5,595 \\
175,896\end{array}$ & $\begin{array}{r}189,717 \\
0 \\
6,799 \\
121 \\
196,637\end{array}$ & $\begin{array}{r}811 \\
0 \\
360 \\
5,349 \\
6,520\end{array}$ & $\begin{array}{r}9,451 \\
155,425 \\
543 \\
-353 \\
185,066\end{array}$ \\
\hline 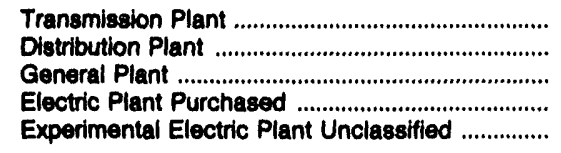 & $\begin{array}{r}94,008 \\
515,574 \\
-3,350 \\
0 \\
0\end{array}$ & $\begin{array}{r}15,934 \\
134,613 \\
3,562 \\
0 \\
0\end{array}$ & $\begin{array}{r}106,779 \\
376,132 \\
88,761 \\
0 \\
262\end{array}$ & $\begin{array}{r}141,930 \\
80,838 \\
11,231 \\
0 \\
0\end{array}$ & $\begin{array}{r}11,102 \\
12,874 \\
5,942 \\
0 \\
35,110\end{array}$ & $\begin{array}{r}14,889 \\
60,269 \\
8,818 \\
0\end{array}$ \\
\hline Total Electric Plant Additions .............................. & 829,283 & 182,687 & 784,755 & 439,088 & 72,092 & 249,042 \\
\hline $\begin{array}{l}\text { Petrements } \\
\text { Intangible Plant } \\
\text { Production Plant }\end{array}$ & 0 & -136 & 0 & 0 & 16 & \\
\hline 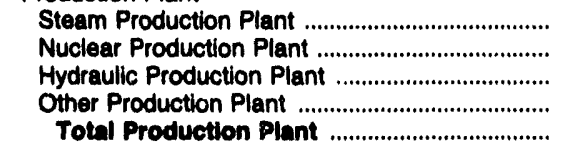 & $\begin{array}{r}36,219 \\
7,413 \\
1,314 \\
0 \\
44,045\end{array}$ & $\begin{array}{r}3,783 \\
161,608 \\
0 \\
87 \\
165,470\end{array}$ & $\begin{array}{r}15,578 \\
606,076 \\
982 \\
4,135 \\
626,771\end{array}$ & $\begin{array}{r}4,068 \\
0 \\
153 \\
0 \\
4,221\end{array}$ & $\begin{array}{l}0 \\
0 \\
0 \\
0 \\
0\end{array}$ & $\begin{array}{r}354 \\
69,894 \\
37 \\
1,201 \\
71,466\end{array}$ \\
\hline 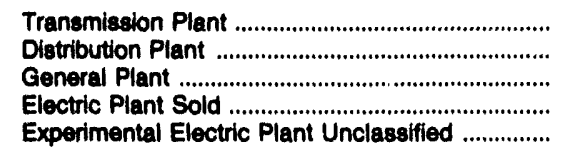 & $\begin{array}{r}4,938 \\
35,778 \\
14 \\
1,105 \\
0\end{array}$ & $\begin{array}{r}1,246 \\
11,636 \\
6,028 \\
0 \\
0\end{array}$ & $\begin{array}{r}7,491 \\
59,809 \\
48,290 \\
0 \\
5,839\end{array}$ & $\begin{array}{r}1,104 \\
7,919 \\
279 \\
0 \\
0\end{array}$ & $\begin{array}{r}125 \\
2,799 \\
434 \\
0 \\
1,933\end{array}$ & $\begin{array}{r}1,480 \\
13,801 \\
360 \\
0\end{array}$ \\
\hline $\begin{array}{l}\text { Total Ebetric Plant } \\
\text { Rottrements }\end{array}$ & 84,568 & 184,252 & 746,301 & 13,523 & 5,306 & 87,127 \\
\hline
\end{tabular}

Note: Totals may not equal sum of components because of independent rounding. Summary data are provided in Table 28. Source: Federal Energy Regulatory Commission, FERC Form 1, "Annual Report of Major Electric Utilities, Licensees and Others." 
Table 42. Utility Plant by Major U.S. Investor-Owned Electric Utility Within State on December 31, 1992 (Continued)

(Thousand Dollars)

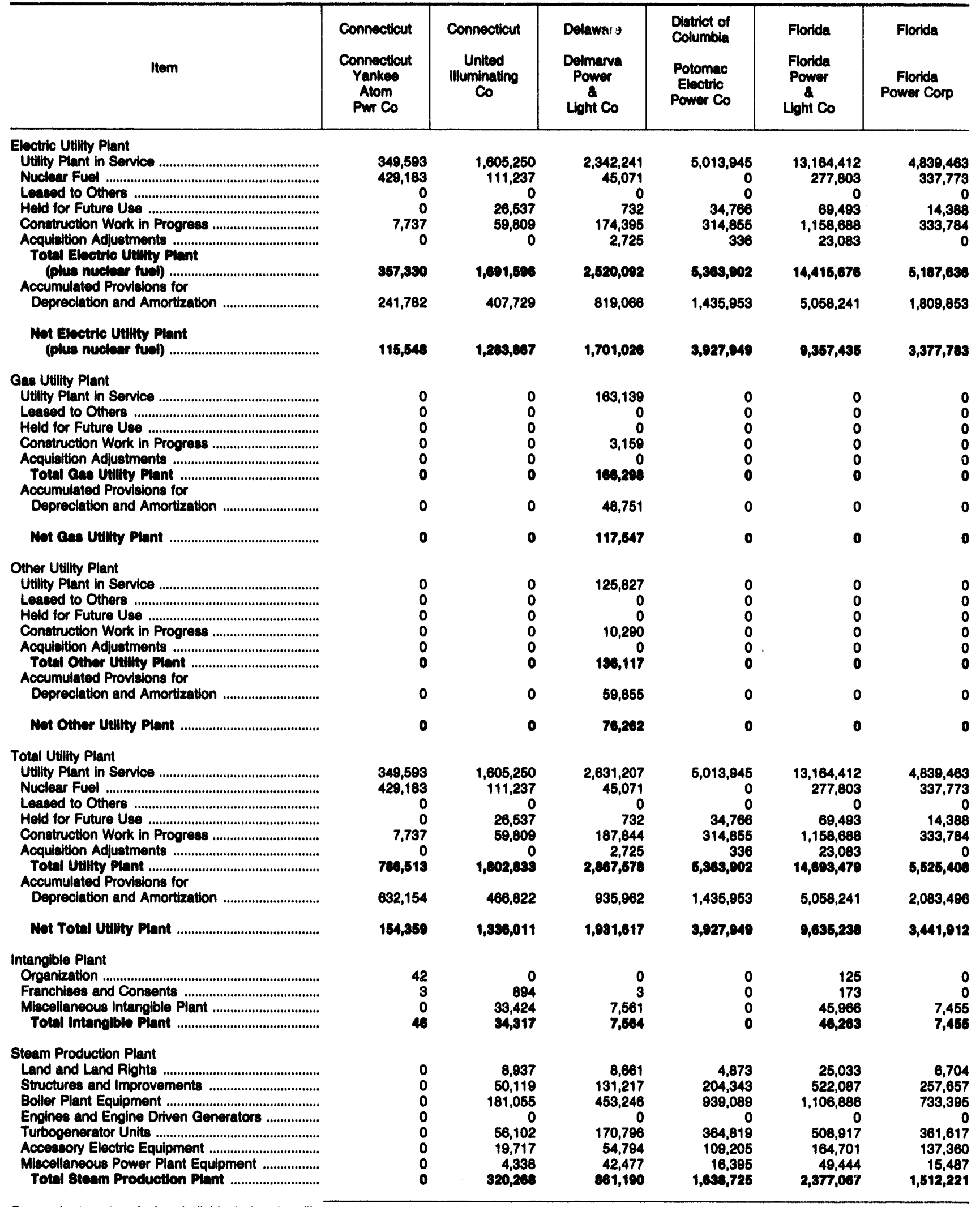

See endnotes at end of an individual electric utility. 
Table 42. UtIlity Plant by Major U.S. Investor-Owned Electric UtIlity Within State on December 31, 1992 (Continued)

(Thousand Dollars)

\begin{tabular}{|c|c|c|c|c|c|c|}
\hline Item & $\begin{array}{l}\text { Connecticut } \\
\text { Connecticut } \\
\text { Yankee } \\
\text { Atom } \\
\text { Pwr Co }\end{array}$ & $\begin{array}{l}\text { Connecticut } \\
\text { United } \\
\text { Illuminating } \\
\text { Co }\end{array}$ & $\begin{array}{c}\text { Delaware } \\
\text { Delmarva } \\
\text { Power } \\
\& \\
\text { Light Co }\end{array}$ & $\begin{array}{l}\text { District of } \\
\text { Columbia } \\
\text { Potomac } \\
\text { Electric } \\
\text { Power Co }\end{array}$ & $\begin{array}{c}\text { Florida } \\
\text { Florida } \\
\text { Power } \\
8 \\
\text { Light Co }\end{array}$ & $\begin{array}{c}\text { Florida } \\
\text { Florida } \\
\text { Power Corp }\end{array}$ \\
\hline 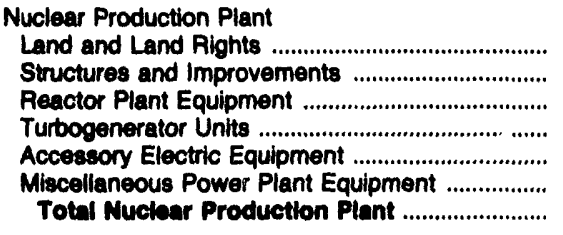 & $\begin{array}{r}562 \\
67,341 \\
157,064 \\
52,351 \\
33,912 \\
27,848 \\
330,077\end{array}$ & $\begin{array}{r}157 \\
249,713 \\
335,117 \\
65,362 \\
82,236 \\
25,160 \\
757,745\end{array}$ & $\begin{array}{r}22 \\
69,442 \\
141,236 \\
46,185 \\
40,966 \\
11,642 \\
300,492\end{array}$ & $\begin{array}{l}0 \\
0 \\
0 \\
0 \\
0 \\
0 \\
0\end{array}$ & $\begin{array}{r}15,914 \\
984,494 \\
1,322,508 \\
392,048 \\
524,605 \\
125,676 \\
3,365,245\end{array}$ & $\begin{array}{r}41 \\
160,186 \\
196,644 \\
90,534 \\
141,047 \\
18,186 \\
600,637\end{array}$ \\
\hline 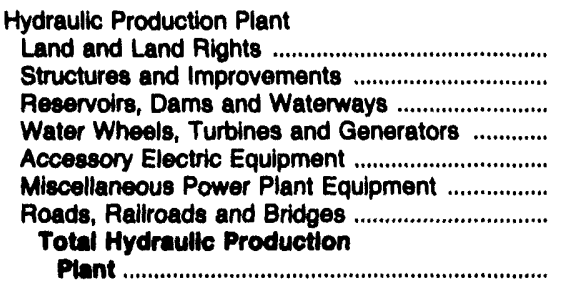 & $\begin{array}{l}0 \\
0 \\
0 \\
0 \\
0 \\
0 \\
0\end{array}$ & $\begin{array}{l}0 \\
0 \\
0 \\
0 \\
0 \\
0 \\
0\end{array}$ & $\begin{array}{l}0 \\
0 \\
0 \\
0 \\
0 \\
0 \\
0\end{array}$ & $\begin{array}{l}0 \\
0 \\
0 \\
0 \\
0 \\
0 \\
0 \\
0\end{array}$ & $\begin{array}{l}0 \\
0 \\
0 \\
0 \\
0 \\
0 \\
0\end{array}$ & $\begin{array}{l}0 \\
0 \\
0 \\
0 \\
0 \\
0 \\
0\end{array}$ \\
\hline 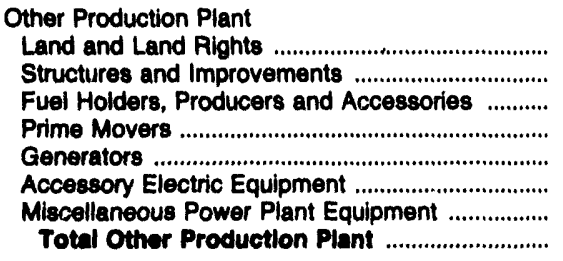 & $\begin{array}{l}0 \\
0 \\
0 \\
0 \\
0 \\
0 \\
0 \\
0\end{array}$ & $\begin{array}{r}0 \\
14 \\
160 \\
1,036 \\
302 \\
331 \\
1 \\
1,845\end{array}$ & $\begin{array}{r}1,412 \\
11,054 \\
16,553 \\
53,977 \\
31,420 \\
8,259 \\
2,606 \\
125,281\end{array}$ & $\begin{array}{r}1,515 \\
2,240 \\
3,272 \\
0 \\
354,574 \\
9,932 \\
139 \\
371,670\end{array}$ & $\begin{array}{r}38 \\
41,591 \\
22,093 \\
157,608 \\
79,647 \\
31,899 \\
5,735 \\
338,611\end{array}$ & $\begin{array}{r}2,157 \\
11,994 \\
19,537 \\
190,989 \\
36,207 \\
24,547 \\
1,051 \\
285,492\end{array}$ \\
\hline 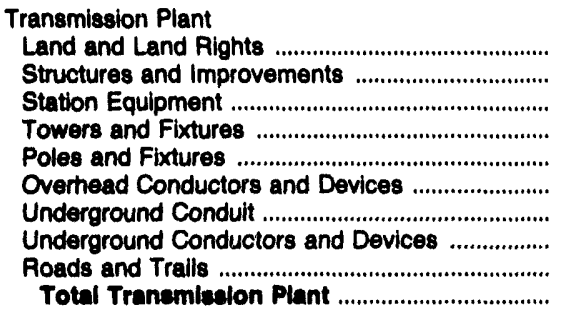 & $\begin{array}{r}5 \\
270 \\
8,949 \\
0 \\
0 \\
0 \\
0 \\
0 \\
0 \\
9,224\end{array}$ & $\begin{array}{r}5,171 \\
2,038 \\
75,816 \\
6,218 \\
11,264 \\
10,513 \\
4,746 \\
10,443 \\
0 \\
128,210\end{array}$ & $\begin{array}{r}38,944 \\
5,990 \\
124,802 \\
63,971 \\
37,487 \\
50,765 \\
59 \\
6,274 \\
738 \\
329,029\end{array}$ & $\begin{array}{r}20,480 \\
11,529 \\
284,371 \\
72,527 \\
913 \\
32,982 \\
45,074 \\
42,829 \\
4,393 \\
515,007\end{array}$ & $\begin{array}{r}117,478 \\
29,044 \\
602,794 \\
217,829 \\
285,432 \\
324,643 \\
24,918 \\
29,497 \\
42,787 \\
1,674,424\end{array}$ & $\begin{array}{r}36,762 \\
13,598 \\
268,435 \\
67,761 \\
125,519 \\
136,394 \\
6,894 \\
9,055 \\
1,679 \\
684,008\end{array}$ \\
\hline 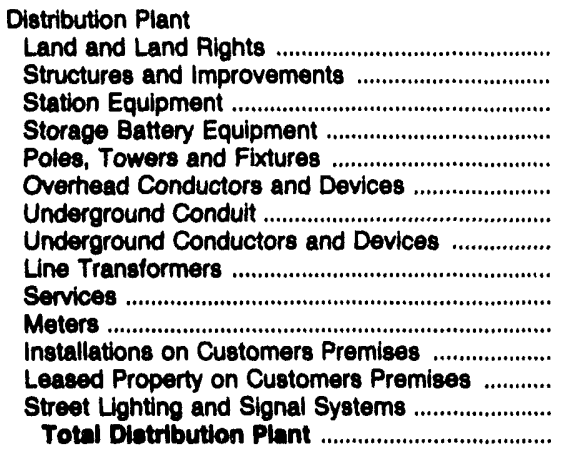 & $\begin{array}{l}0 \\
0 \\
0 \\
0 \\
0 \\
0 \\
0 \\
0 \\
0 \\
0 \\
0 \\
0 \\
0 \\
0 \\
0\end{array}$ & $\begin{array}{r}2,623 \\
7,342 \\
24,099 \\
0 \\
38,562 \\
60,808 \\
25,870 \\
33,944 \\
63,801 \\
12,858 \\
26,265 \\
1,389 \\
6,196 \\
13,293 \\
317,010\end{array}$ & $\begin{array}{r}7,674 \\
6,991 \\
98,148 \\
0 \\
63,997 \\
77,735 \\
12,817 \\
121,922 \\
116,017 \\
63,274 \\
40,330 \\
15,925 \\
0 \\
28,108 \\
852,937\end{array}$ & $\begin{array}{r}14,618 \\
79,605 \\
294,816 \\
0 \\
99,332 \\
123,480 \\
472,903 \\
415,973 \\
334,761 \\
222,741 \\
87,664 \\
3,129 \\
0 \\
22,192 \\
2,171,213\end{array}$ & $\begin{array}{r}17,201 \\
42,688 \\
662,414 \\
0 \\
382,274 \\
603,685 \\
344,184 \\
728,444 \\
828,793 \\
323,061 \\
285,223 \\
118,645 \\
0 \\
167,657 \\
4,604,269\end{array}$ & $\begin{array}{r}8,749 \\
12,052 \\
220,445 \\
0 \\
213,048 \\
240,514 \\
53,981 \\
140,880 \\
249,714 \\
184,438 \\
94,289 \\
3,478 \\
0 \\
83,958 \\
1,505,546\end{array}$ \\
\hline
\end{tabular}

See endnotes at end of an individual electric utility. 
Table 42. Utility Plant by Major U.S. Investor-Owned Electric Utility Within State on December 31, 1982 (Continued) (Thousand Dollars)

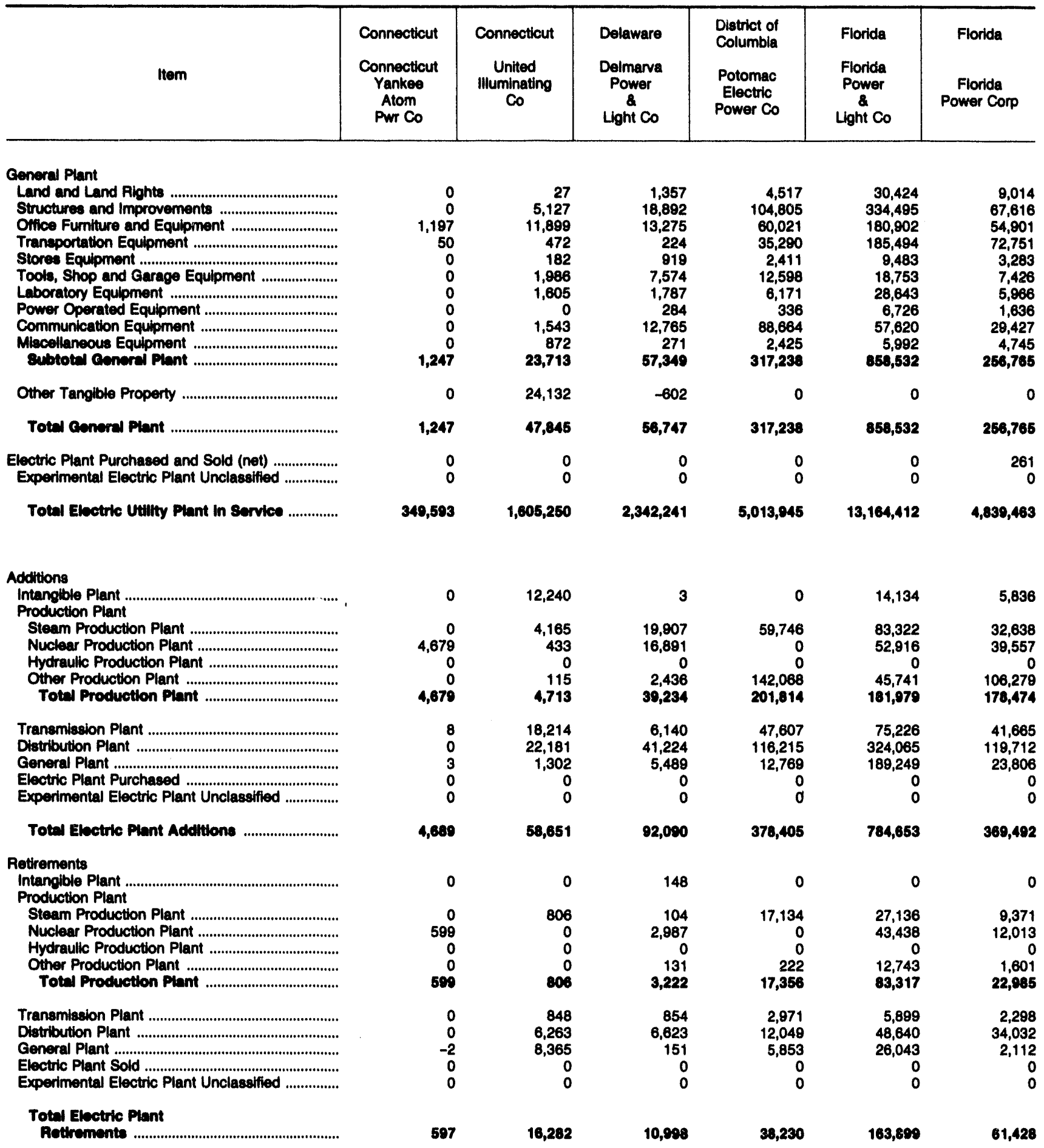

Note: Totals may not equal sum of components because of independent rounding. Summary data are provided in Table 28. Source: Federal Energy Regulatory Commission, FERC Form 1, "Annual Report of Major Electric Utilities, Licensees and Others." 
Table 42. Utility Plant by Mafor U.S. Investor-Owned Electric Utility Within State on December 31, 1992 (Continued) (Thousand Dollars)

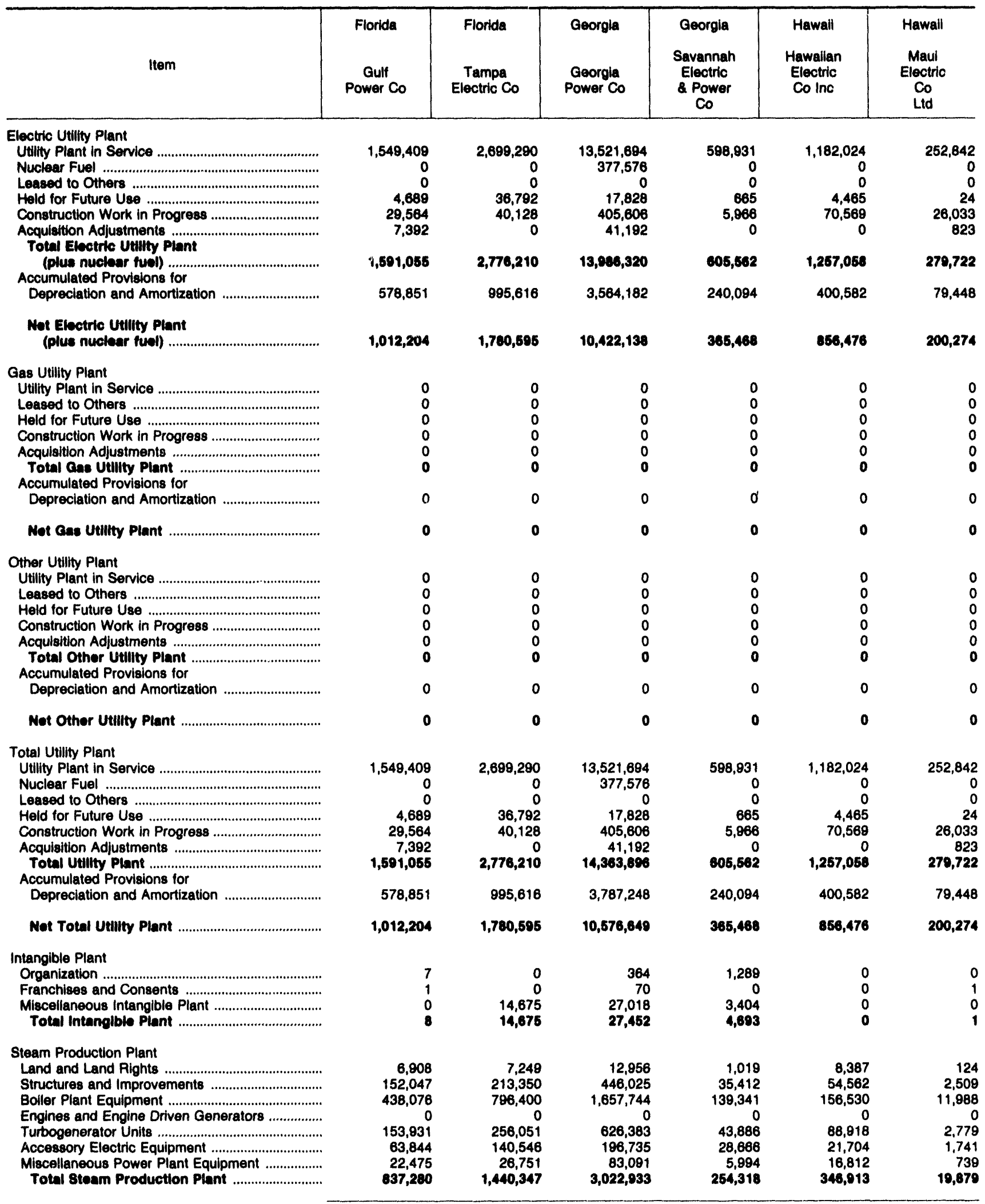

See endnotes at end of an Individual electric utility. 
Table 42. Utility Plant by Major U.S. Investor-Owned Electric Utility Within State on December 31, 1992 (Continued) (Thousand Dollars)

\begin{tabular}{|c|c|c|c|c|c|c|}
\hline Item & $\begin{array}{c}\text { Florida } \\
\text { Gulf } \\
\text { Power Co }\end{array}$ & $\begin{array}{c}\text { Florida } \\
\text { Tampa } \\
\text { Electric Co }\end{array}$ & $\begin{array}{l}\text { Georgla } \\
\text { Goorgla } \\
\text { Power Co }\end{array}$ & $\begin{array}{l}\text { Georgia } \\
\text { Savannah } \\
\text { Electric } \\
\text { \& Power } \\
\text { Co }\end{array}$ & $\begin{array}{l}\text { Hawail } \\
\text { Hawailan } \\
\text { Electric } \\
\text { Co Inc }\end{array}$ & $\begin{array}{l}\text { Hawall } \\
\text { Maui } \\
\text { Electric } \\
\text { Co } \\
\text { Lid }\end{array}$ \\
\hline 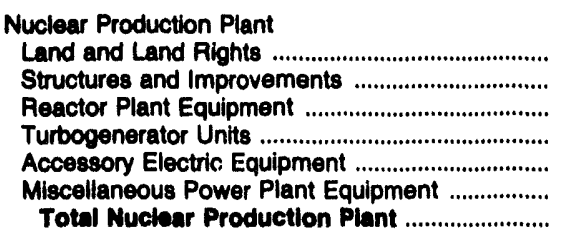 & $\begin{array}{l}0 \\
0 \\
0 \\
0 \\
0 \\
0 \\
0\end{array}$ & $\begin{array}{l}0 \\
0 \\
0 \\
0 \\
0 \\
0 \\
0\end{array}$ & $\begin{array}{r}1,176 \\
1,258,383 \\
1,794,524 \\
506,765 \\
360,689 \\
131,482 \\
4,051,020\end{array}$ & $\begin{array}{l}0 \\
0 \\
0 \\
0 \\
0 \\
0 \\
0\end{array}$ & $\begin{array}{l}0 \\
0 \\
0 \\
0 \\
0 \\
0 \\
0\end{array}$ & $\begin{array}{l}0 \\
0 \\
0 \\
0 \\
0 \\
0 \\
0\end{array}$ \\
\hline 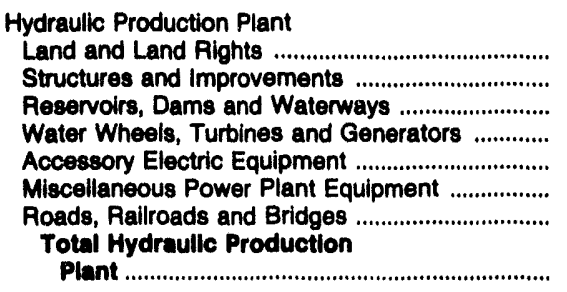 & $\begin{array}{l}0 \\
0 \\
0 \\
0 \\
0 \\
0 \\
0 \\
0\end{array}$ & $\begin{array}{l}0 \\
0 \\
0 \\
0 \\
0 \\
0 \\
0 \\
0\end{array}$ & $\begin{array}{r}33,597 \\
65,916 \\
187,923 \\
112,375 \\
18,759 \\
13,801 \\
1,970 \\
434,342\end{array}$ & $\begin{array}{l}0 \\
0 \\
0 \\
0 \\
0 \\
0 \\
0 \\
0\end{array}$ & $\begin{array}{l}0 \\
0 \\
0 \\
0 \\
0 \\
0 \\
0\end{array}$ & $\begin{array}{l}0 \\
0 \\
0 \\
0 \\
0 \\
0 \\
0\end{array}$ \\
\hline 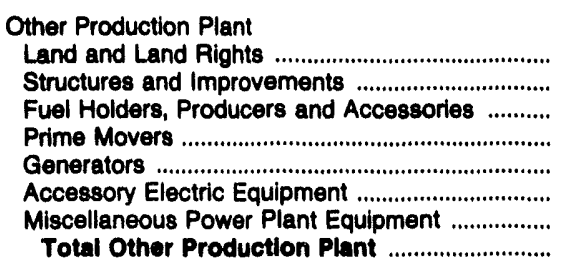 & $\begin{array}{r}0 \\
697 \\
241 \\
77 \\
3,063 \\
127 \\
4 \\
4,209\end{array}$ & $\begin{array}{r}1,014 \\
1,587 \\
1,151 \\
0 \\
78,008 \\
2,885 \\
22 \\
84,687\end{array}$ & $\begin{array}{r}38 \\
3,780 \\
9,538 \\
67,445 \\
23,627 \\
10,998 \\
886 \\
116,311\end{array}$ & $\begin{array}{r}0 \\
132 \\
170 \\
3,312 \\
432 \\
165 \\
10 \\
4,222\end{array}$ & $\begin{array}{r}38 \\
696 \\
1,004 \\
7,176 \\
4,213 \\
2,227 \\
391 \\
15,745\end{array}$ & $\begin{array}{r}401 \\
12,879 \\
1,246 \\
32,207 \\
29,750 \\
6,652 \\
6,233 \\
89,368\end{array}$ \\
\hline 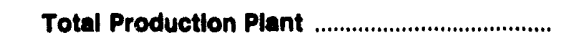 & 841,488 & $1,525,014$ & $7,624,606$ & 258,540 & 362,658 & 100,246 \\
\hline 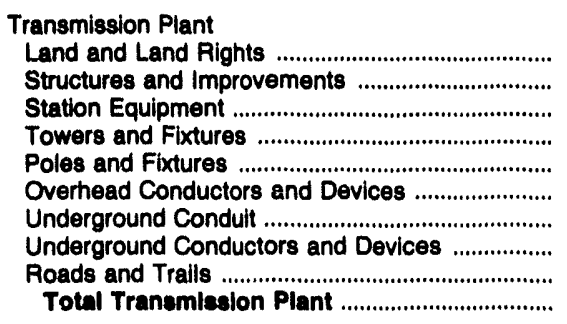 & $\begin{array}{r}9,910 \\
4,077 \\
48,026 \\
22,007 \\
26,383 \\
24,754 \\
0 \\
13,613 \\
52 \\
148,822\end{array}$ & $\begin{array}{r}9,971 \\
1,109 \\
88,168 \\
4,339 \\
48,195 \\
52,812 \\
695 \\
917 \\
2,062 \\
209,268\end{array}$ & $\begin{array}{r}125,648 \\
40,164 \\
575,408 \\
343,301 \\
208,277 \\
349,248 \\
3,175 \\
1,449 \\
234 \\
1,646,905\end{array}$ & $\begin{array}{r}932 \\
1,600 \\
46,189 \\
5,966 \\
22,828 \\
14,589 \\
523 \\
454 \\
0 \\
93,181\end{array}$ & $\begin{array}{r}5,412 \\
18,023 \\
95,195 \\
13,997 \\
59,255 \\
37,201 \\
25,538 \\
20,649 \\
1,553 \\
278,821\end{array}$ & $\begin{array}{r}373 \\
552 \\
8,486 \\
0 \\
6,462 \\
5,201 \\
3 \\
14 \\
0 \\
21,001\end{array}$ \\
\hline 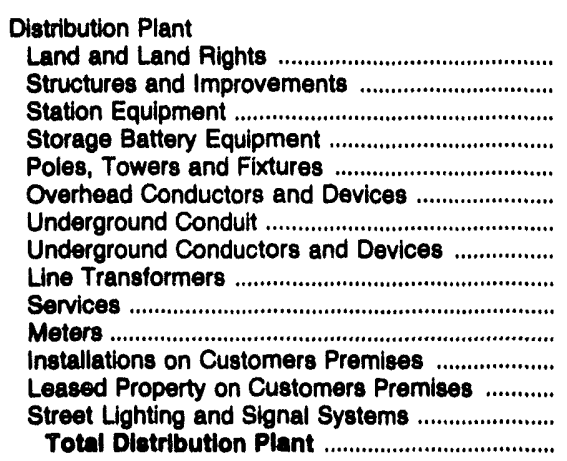 & $\begin{array}{r}1,380 \\
9,493 \\
87,313 \\
0 \\
0 \\
58,498 \\
74,834 \\
1,088 \\
24,178 \\
99,430 \\
47,886 \\
21,016 \\
0 \\
0 \\
18,238 \\
443,352\end{array}$ & $\begin{array}{r}4,650 \\
561 \\
87,523 \\
0 \\
90 \\
90,925 \\
117,624 \\
52,143 \\
65,980 \\
168,254 \\
68,407 \\
35,331 \\
0 \\
0 \\
48,061 \\
737,458\end{array}$ & $\begin{array}{r}26,540 \\
36,325 \\
442,757 \\
0 \\
409,565 \\
410,426 \\
170,366 \\
483,754 \\
725,141 \\
383,548 \\
178,712 \\
358 \\
1,971 \\
144,216 \\
3,413,681\end{array}$ & $\begin{array}{r}3,155 \\
460 \\
26,263 \\
0 \\
0 \\
35,674 \\
46,085 \\
9,348 \\
27,271 \\
32,597 \\
14,017 \\
13,378 \\
0 \\
0 \\
13,776 \\
222,023\end{array}$ & $\begin{array}{r}7,262 \\
10,430 \\
54,480 \\
0 \\
49,538 \\
48,272 \\
56,273 \\
101,216 \\
67,585 \\
60,831 \\
16,478 \\
0 \\
0 \\
0 \\
472,936\end{array}$ & $\begin{array}{r}405 \\
869 \\
13,113 \\
0 \\
12,348 \\
14,138 \\
1,841 \\
18,336 \\
15,784 \\
7,238 \\
4,039 \\
0 \\
0 \\
5,123 \\
93,234\end{array}$ \\
\hline
\end{tabular}

See endnotes at end of an indlividual electric utility. 
Table 42. Utilly Plant by Major U.S. Inveator-Owned Electric Utility Within State on December 31, 1992 (Continued) (Thousand Dollars)

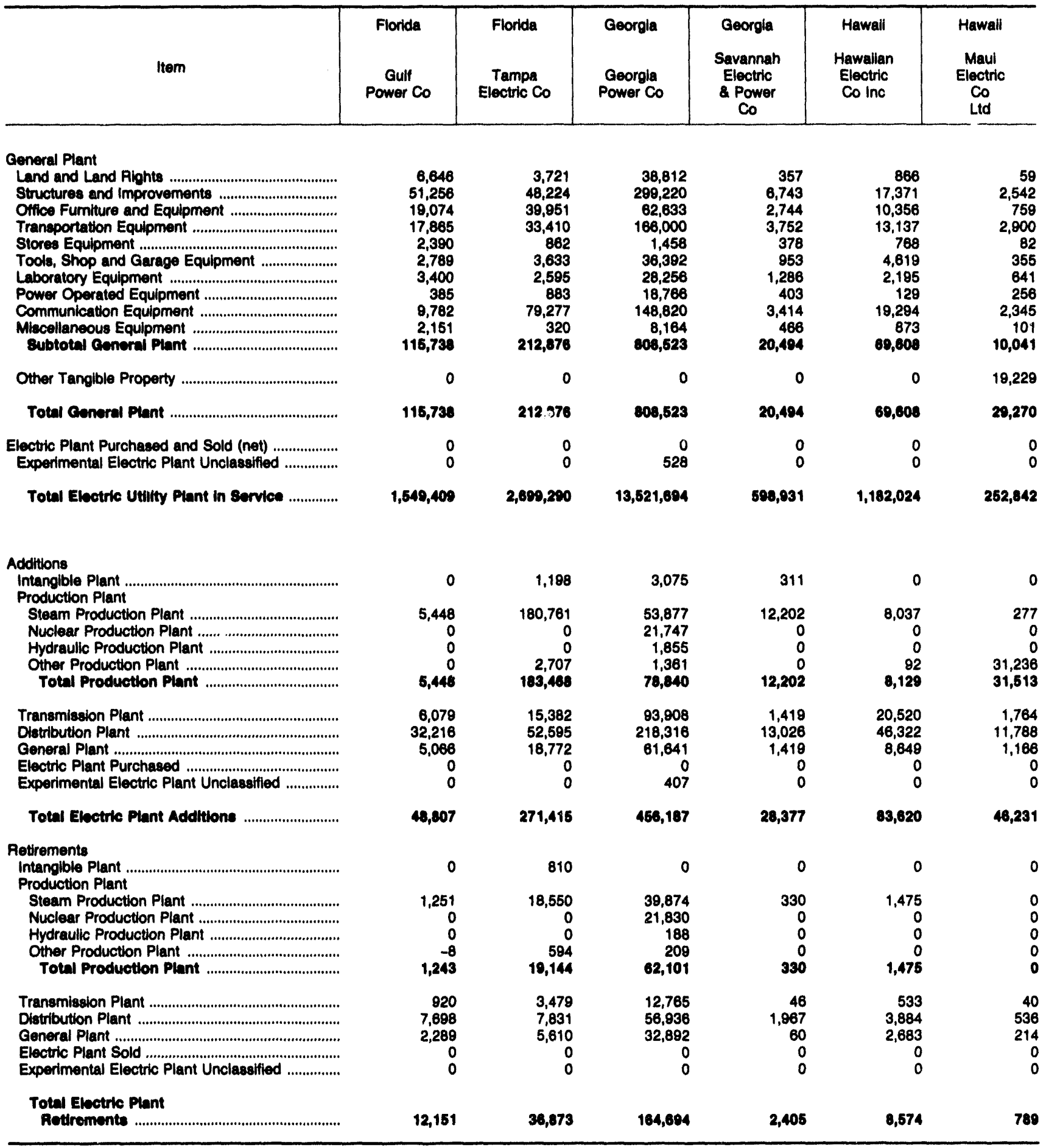

Note: Totals may not equal sum of components because of independent rounding. Summary data are provided in Table 28. Source: Federal Energy Regulatory Commission, FERC Form 1, "Annual Report of Major Electric Utilities, Licensees and Others." 
Table 42. Utility Plant by Major U.S. Investor-Owned Electric Utility Within State on December 31, 1992 (Continued)

(Thousand Dollars)

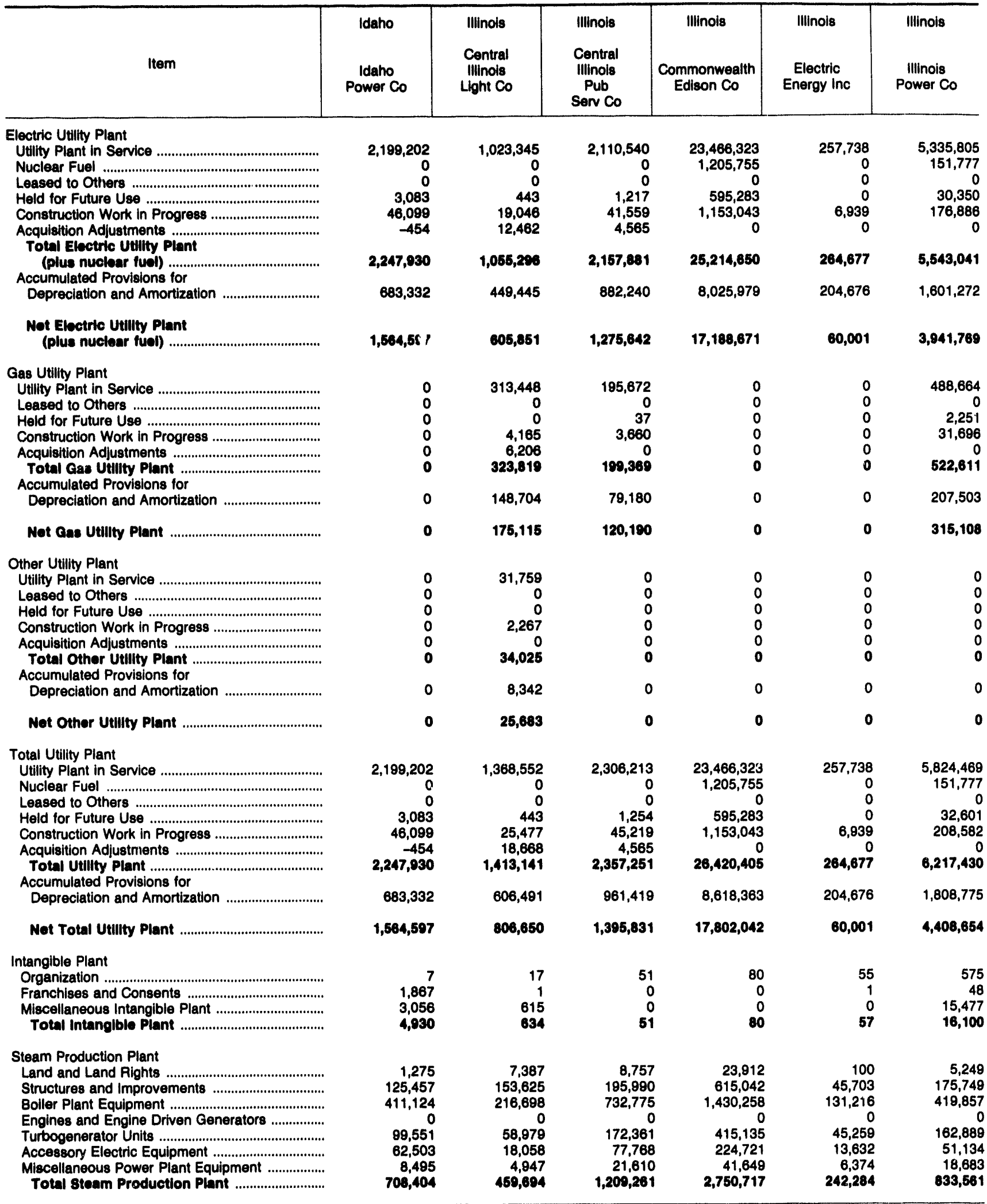

See endnotes at end of an individual electric utility. 
Table 42. UtIlity Plant by Major U.S. Investor-Owned Electric Utility Within State on December 31, 1992 (Continued) (Thousand Dollars)

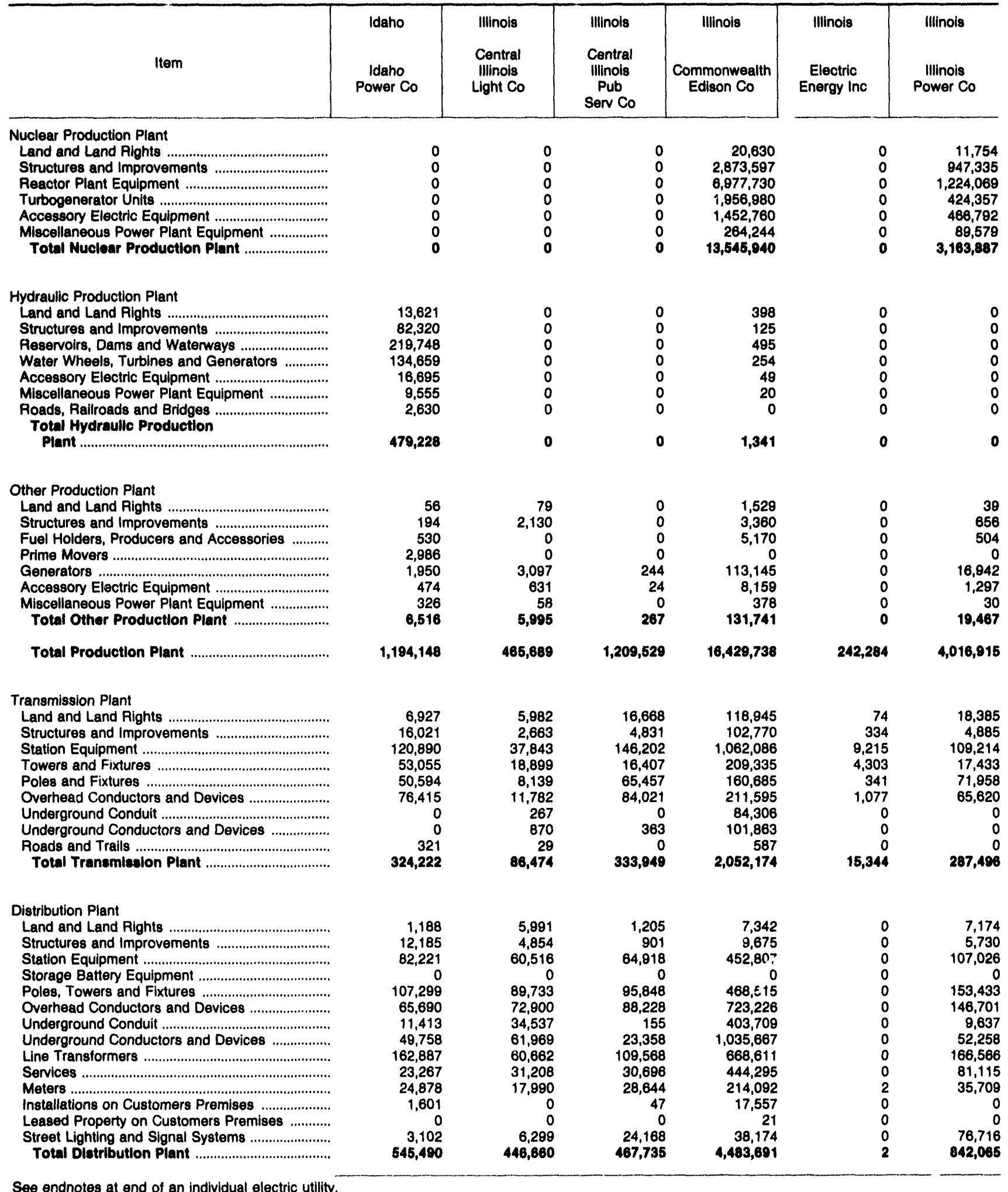


Table 42. Utility Plant by Major U.S. Investor-Owned Electric Utility Within State on December 31, 1992 (Continued) (Thousand Dollars)

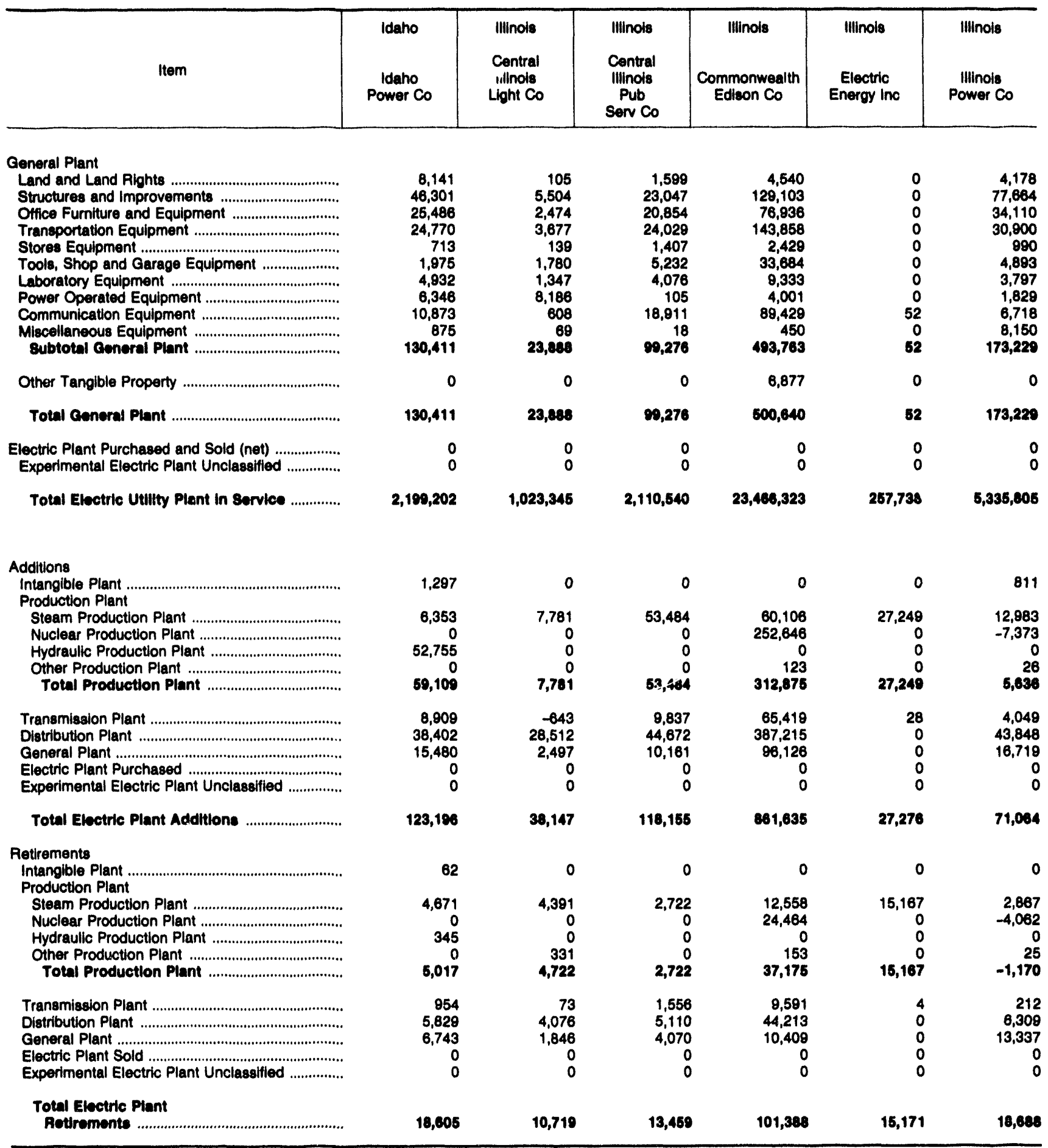

Note: Totals may not equal sum of components because of independent rounding. Summary data are provided in Table 28. Source: Federal Energy Regulatory Commission, FERC Form 1, "Annual Report of Major Electric Utilities, Licensees and Others." 
Table 42. Utility Plant by Major U.S. Investor-Owned Electric Utility Within State on December 31, 1992 (Continued)

(Thousand Dollars)

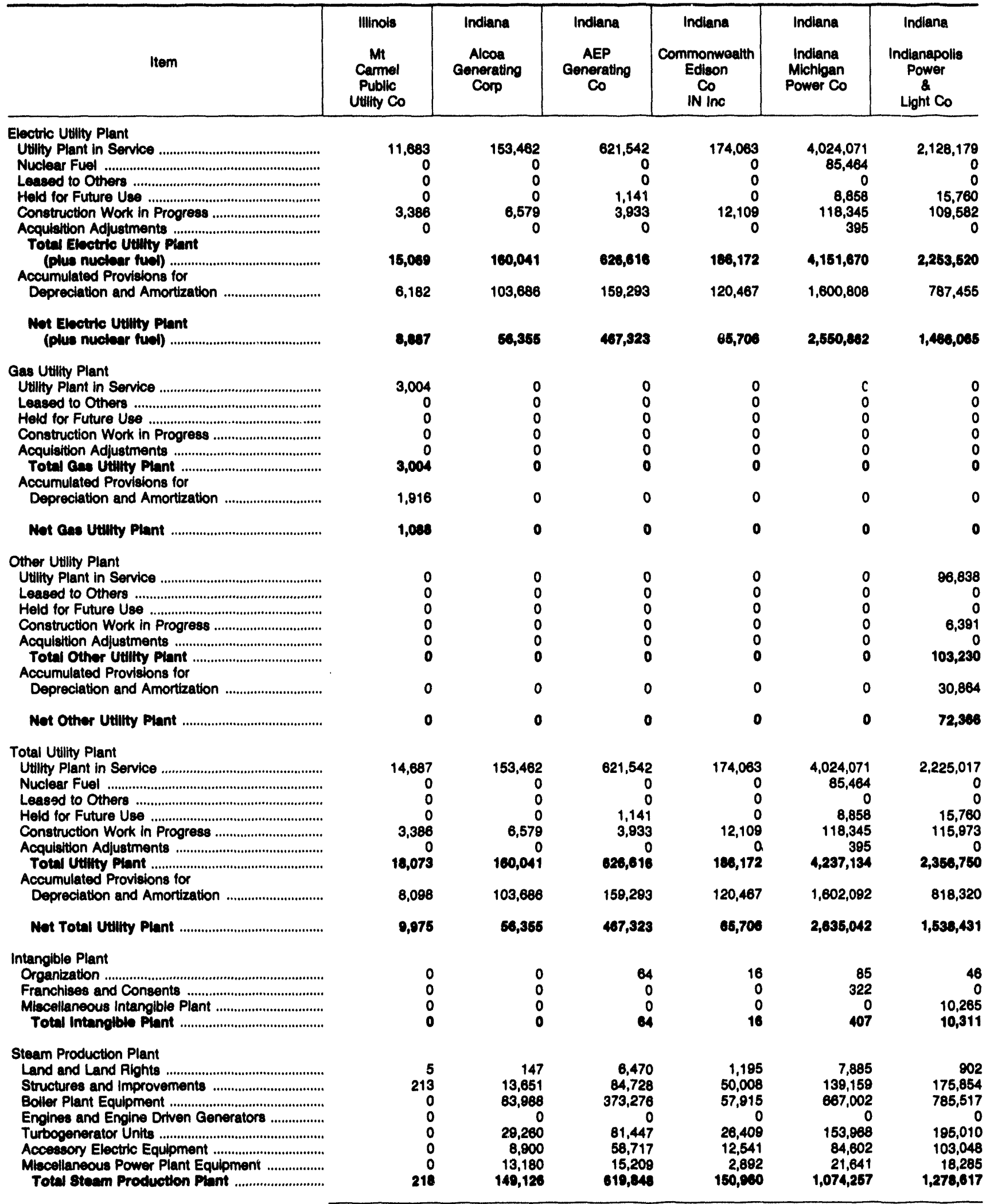

See endnotes at end of an individual electric utillty. 
Table 42. Utility Plant by Major U.S. Investor-Owned Electric Utility Within State on Decomber 31, 1992 (Continued) (Thousand Dollars)

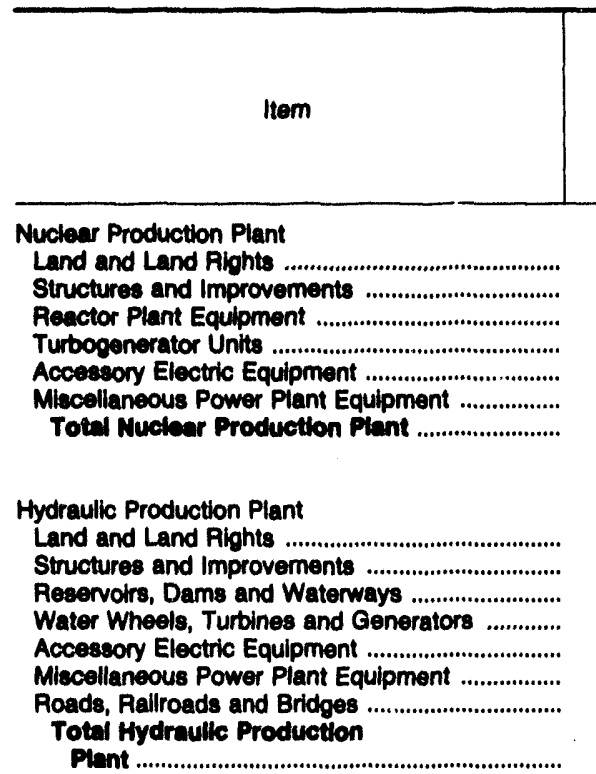

Other Production Plant

Land and Land Rights

Structures and Improvements ..................................

Fuel Holders, Producers and Accessorles

Prime Movers

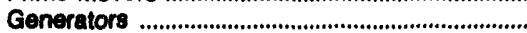

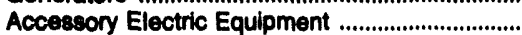

Miscellaneous Power Plant Equipment

Total Other Production Plant

Total Production Plant

............................

\begin{tabular}{|c|c|c|c|c|c|}
\hline Illinols & Indiana & Indlana & Indiana & Indlana & Indlana \\
\hline $\begin{array}{l}\text { Mt } \\
\text { Carmel } \\
\text { Public } \\
\text { Utilty Co }\end{array}$ & $\begin{array}{l}\text { Alcoa } \\
\text { Generating } \\
\text { Corp }\end{array}$ & $\begin{array}{c}\text { AEP } \\
\text { Generating } \\
\text { Co }\end{array}$ & $\begin{array}{c}\text { Commonwealth } \\
\text { Edleon } \\
\text { Co } \\
\text { in inc }\end{array}$ & $\begin{array}{l}\text { Indlana } \\
\text { Michigan } \\
\text { Power Co }\end{array}$ & $\begin{array}{c}\text { Indlanapolis } \\
\text { Power } \\
\text { Light Co }\end{array}$ \\
\hline
\end{tabular}

Transmission Plant

Land and Land Rights ....

Structures and Improvements

Station Equipment .

Towers and Fixtures

Poles and Fixtures

Overhead Conductors and Devices

Underground Conduit ................................................

Underground Conductors and $\mathrm{C}$ ivices

Roads and Trails

Total Tranemieslon Plant

$\begin{array}{ll}0 & 0 \\ 0 & 0 \\ 0 & 0 \\ 0 & 0 \\ 0 & 0 \\ 0 & 0 \\ 0 & 0\end{array}$

0
0
0
0
0
0
0

1,813

288,169

733,726

227,334

127,408

70,771

$1,440,220$

0
0
0
0
0
0
0
0

655

1,058

12,451

5,675

4,240

877

24,054

$\begin{array}{ll}0 & 0 \\ 0 & 0 \\ 0 & 0 \\ 0 & 0 \\ 0 & 0 \\ 0 & 0 \\ 0 & 0 \\ 0 & 0\end{array}$

$\begin{array}{rr}0 & 0 \\ 2 & 0 \\ 0 & 0 \\ 0 & 0 \\ 158 & 7,808 \\ 8 & 0 \\ 0 & 0 \\ 167 & 7,000\end{array}$

218

149,128

160,990

$2,549,498$

$1,296,423$

$\begin{array}{rr}304 & 0 \\ 190 & 0 \\ 840 & 2,288 \\ 0 & 302 \\ 632 & 0 \\ 506 & 1,746 \\ 0 & 0 \\ 0 & 0 \\ 0 & 0 \\ 2,490 & 4,337\end{array}$

842
598
16,036
2,152
615
1,422
288
370
0
22,394

55,246
14,492
329,660
216,778
30,481
177,392
1,469
3,981
8
829,507

18,147

3,303

91,622

38,448

16,396

40,140

1,256

1,387

210,600

Distribution Plant

Land and Land Aights

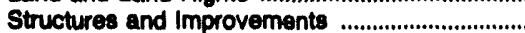

Station Equipment

Storage Battery Equipment

14
0
972
0
1,888
1,801
1
31
1,364
419
473
58
0
123
7,243

0
0
0
0
0
0
0
0
0
0
0
0
0
0
0

$\begin{array}{rr}4,443 & 2,724 \\ 3,535 & 5,135 \\ 56,629 & 85,586 \\ 0 & 0 \\ 92,708 & 49,338 \\ 76,051 & 59,188 \\ 17,628 & 31,420 \\ 47,339 & 70,980 \\ 128,959 & 95,861 \\ 64,037 & 42,589 \\ 46,828 & 37,426 \\ 0,401 & 16,016 \\ 0 & 0 \\ 14,054 & 31,069 \\ 581,607 & 528,233\end{array}$

See endnotes at end of an individual electric utility. 
Tablo 42. Utility Plant by Major U.S. Investor-Owned Electric Utility Within State on December 31, 1992 (Continued) (Thousand Dollars)

\begin{tabular}{|c|c|c|c|c|c|c|}
\hline Item & $\begin{array}{c}\text { Illinols } \\
\text { Mit } \\
\text { Carmel } \\
\text { Publle } \\
\text { Utilty Co }\end{array}$ & $\begin{array}{l}\text { Indiana } \\
\text { Alcoa } \\
\text { Generating } \\
\text { Corp }\end{array}$ & $\begin{array}{l}\text { Indiana } \\
\text { AEP } \\
\text { Generating } \\
\text { Co }\end{array}$ & $\begin{array}{l}\text { Indiana } \\
\text { Commonmeatth } \\
\text { Edicon } \\
\text { Co } \\
\text { iN inc }\end{array}$ & $\begin{array}{l}\text { Indiana } \\
\text { Indiana } \\
\text { Michigan } \\
\text { Power Co }\end{array}$ & $\begin{array}{c}\text { Indiana } \\
\text { Indianapolis } \\
\text { Power } \\
\& \\
\text { Light Co }\end{array}$ \\
\hline 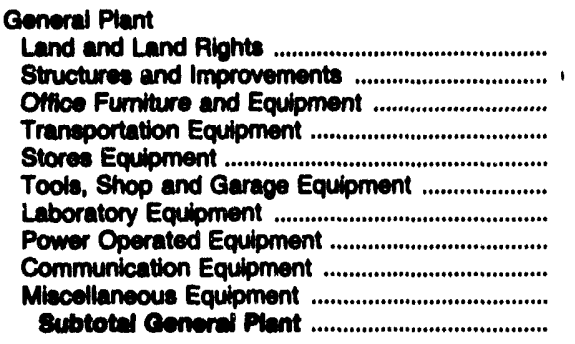 & $\begin{array}{r}2 \\
356 \\
411 \\
726 \\
0 \\
51 \\
30 \\
95 \\
57 \\
11 \\
1,742\end{array}$ & $\begin{array}{l}0 \\
0 \\
0 \\
0 \\
0 \\
0 \\
0 \\
0 \\
0 \\
0 \\
0\end{array}$ & $\begin{array}{r}0 \\
0 \\
159 \\
0 \\
0 \\
0 \\
0 \\
0 \\
176 \\
0 \\
336\end{array}$ & $\begin{array}{r}0 \\
0 \\
174 \\
0 \\
0 \\
0 \\
0 \\
0 \\
579 \\
0 \\
753\end{array}$ & $\begin{array}{r}1,159 \\
17,856 \\
3,068 \\
97 \\
326 \\
2,838 \\
2,329 \\
51 \\
13,168 \\
815 \\
41,705\end{array}$ & $\begin{array}{r}3,032 \\
38,106 \\
15,638 \\
15,136 \\
953 \\
8,013 \\
4,213 \\
2,088 \\
4,126 \\
1,208 \\
92,512\end{array}$ \\
\hline 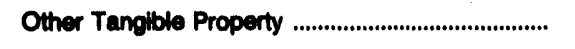 & 0 & 0 & 1,294 & 0 & 41,973 & 0 \\
\hline 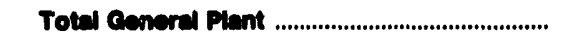 & 1,742 & $\mathbf{0}$ & 1,020 & 753 & 83,678 & 92,512 \\
\hline $\begin{array}{l}\text { Electric Plant Purchased and Sold (net) ..................... } \\
\text { Experimental Electric Plant Unclaselfied ............... }\end{array}$ & $\begin{array}{l}0 \\
0\end{array}$ & $\begin{array}{l}0 \\
0\end{array}$ & $\begin{array}{l}0 \\
0\end{array}$ & $\begin{array}{l}0 \\
0\end{array}$ & $\begin{array}{r}0 \\
374\end{array}$ & $\begin{array}{l}0 \\
0\end{array}$ \\
\hline Totad Electric Utilty Piant in service ............... & 11,603 & 163,462 & 821,642 & 174,063 & $4,024,071$ & $2,128,170$ \\
\hline 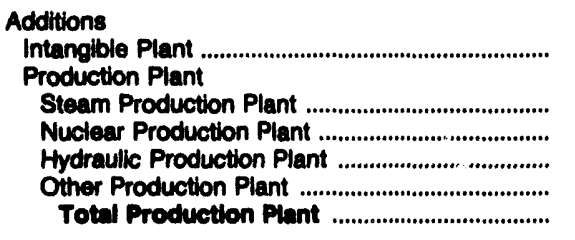 & $\begin{array}{l}0 \\
3 \\
0 \\
0 \\
0 \\
3\end{array}$ & $\begin{array}{r}0 \\
13,423 \\
0 \\
0 \\
0 \\
13,423\end{array}$ & $\begin{array}{r}0 \\
3,411 \\
0 \\
0 \\
0 \\
3,411\end{array}$ & $\begin{array}{r}0 \\
1,622 \\
0 \\
0 \\
0 \\
1,022\end{array}$ & $\begin{array}{r}31 \\
25,011 \\
12,990 \\
3,797 \\
0 \\
41,708\end{array}$ & $\begin{array}{r}3,750 \\
21,788 \\
0 \\
0 \\
0 \\
21,780\end{array}$ \\
\hline 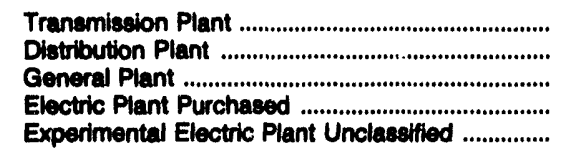 & $\begin{array}{r}2,103 \\
356 \\
221 \\
0 \\
0\end{array}$ & $\begin{array}{l}0 \\
0 \\
0 \\
0 \\
0\end{array}$ & $\begin{array}{l}0 \\
0 \\
1 \\
0 \\
0\end{array}$ & $\begin{array}{r}2,045 \\
0 \\
90 \\
0 \\
0\end{array}$ & $\begin{array}{r}13,876 \\
34,747 \\
874 \\
0 \\
0\end{array}$ & $\begin{array}{r}6,643 \\
32,230 \\
9,100 \\
0 \\
0\end{array}$ \\
\hline Total Electrle Plant Additions ................................ & 2,603 & 13,423 & 3,412 & 3,757 & 91,327 & 73,571 \\
\hline 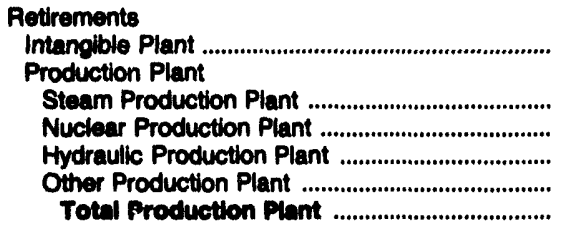 & $\begin{array}{l}0 \\
0 \\
0 \\
0 \\
0 \\
0\end{array}$ & $\begin{array}{r}0 \\
3,078 \\
0 \\
0 \\
0 \\
3,078\end{array}$ & $\begin{array}{r}0 \\
1,778 \\
0 \\
0 \\
0 \\
1,778\end{array}$ & $\begin{array}{r}0 \\
300 \\
0 \\
0 \\
0 \\
300\end{array}$ & $\begin{array}{r}8 \\
8,718 \\
2,023 \\
220 \\
0 \\
10,861\end{array}$ & $\begin{array}{r}0 \\
984 \\
0 \\
0 \\
0 \\
984\end{array}$ \\
\hline 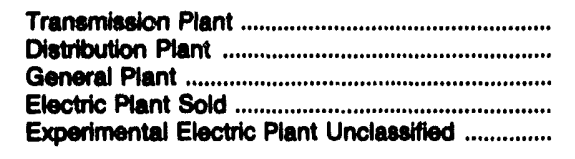 & $\begin{array}{r}3 \\
50 \\
0 \\
0 \\
0\end{array}$ & $\begin{array}{l}0 \\
0 \\
0 \\
0 \\
0\end{array}$ & $\begin{array}{l}0 \\
0 \\
2 \\
0 \\
0\end{array}$ & $\begin{array}{r}144 \\
0 \\
3 \\
0 \\
0\end{array}$ & $\begin{array}{r}211 \\
9,357 \\
348 \\
0 \\
0\end{array}$ & $\begin{array}{r}961 \\
3,169 \\
1,327 \\
0 \\
0\end{array}$ \\
\hline 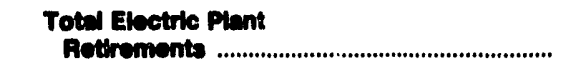 & 53 & 3,078 & 1,700 & 447 & 20,894 & 6,442 \\
\hline
\end{tabular}

Note: Totals may not equal sum of components because of independent rounding. Summary data are provided in Table 28. Source: Federal Energy Regulatory Commiselon, FERC Form 1, "Annual Report of Major Electric Utillties, Lcensees and Oihers." 
Table 42. Utility Plant by Major U.S. Investor-Owned Electrlc Utility Within State on December 31, 1992 (Continued) (Thousand Dollars)

\begin{tabular}{|c|c|c|c|c|c|c|}
\hline Item & $\begin{array}{l}\text { Indiana } \\
\text { Northern } \\
\text { Indiana } \\
\text { Pub Serv } \\
\text { Co }\end{array}$ & $\begin{array}{c}\text { Indiana } \\
\text { PSI } \\
\text { Energy inc }\end{array}$ & $\begin{array}{l}\text { Indiana } \\
\text { Southern } \\
\text { Ind'ina Gas } \\
\text { a Elec Co }\end{array}$ & $\begin{array}{c}\text { lowa } \\
\text { Interstate } \\
\text { Power Co }\end{array}$ & $\begin{array}{l}\text { lowa } \\
\text { lowa } \\
\text { Electric } \\
\text { Light \& Power } \\
\text { Co }\end{array}$ & $\begin{array}{l}\text { lowa } \\
\text { lowa } \\
\text { Southern } \\
\text { Utillies } \\
\text { Co }\end{array}$ \\
\hline 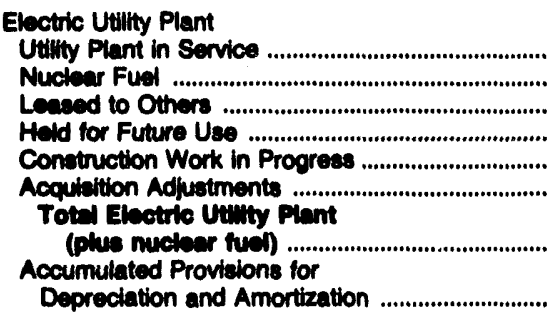 & $\begin{array}{r}3,560,327 \\
0 \\
0 \\
4,740 \\
70,564 \\
0 \\
3,625,631 \\
1,340,612\end{array}$ & $\begin{array}{r}3,137,360 \\
0 \\
0 \\
2,480 \\
232,105 \\
0 \\
3,371,935 \\
1,380,442\end{array}$ & $\begin{array}{r}832,768 \\
0 \\
0 \\
2,581 \\
19,251 \\
0 \\
864,600 \\
345,887\end{array}$ & $\begin{array}{r}759,255 \\
0 \\
0 \\
587 \\
3,280 \\
3,441 \\
769,869 \\
320,183\end{array}$ & $\begin{array}{r}1,237,438 \\
61,419 \\
0 \\
1,858 \\
18,445 \\
32,924 \\
1,290,686 \\
539,534\end{array}$ & $\begin{array}{r}369,100 \\
0 \\
0 \\
0 \\
9,680 \\
216 \\
379,000 \\
141,748\end{array}$ \\
\hline 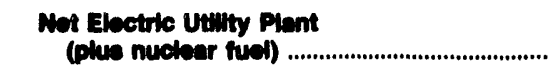 & $2,285,010$ & $1,001,403$ & $\cos , 714$ & 446,340 & 751,132 & 237,250 \\
\hline 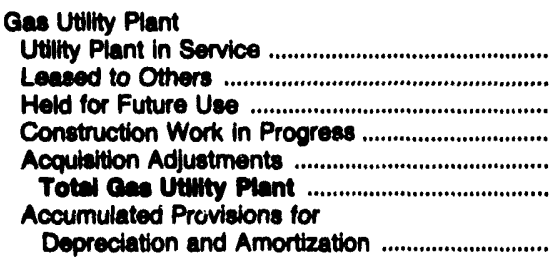 & $\begin{array}{r}1,004,156 \\
0 \\
151 \\
18,722 \\
0 \\
1,023,090 \\
435,680\end{array}$ & $\begin{array}{l}0 \\
0 \\
0 \\
0 \\
0 \\
0\end{array}$ & $\begin{array}{r}97,328 \\
0 \\
0 \\
242 \\
0 \\
97,608 \\
38,796\end{array}$ & $\begin{array}{r}54,883 \\
0 \\
0 \\
207 \\
0 \\
55,141 \\
19,464\end{array}$ & $\begin{array}{r}107,433 \\
0 \\
0 \\
353 \\
0 \\
107,785\end{array}$ & $\begin{array}{r}29,613 \\
0 \\
0 \\
118 \\
181 \\
29,912\end{array}$ \\
\hline 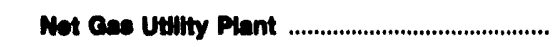 & 887,380 & $\mathbf{0}$ & 50,772 & 35,678 & 73,170 & 21,460 \\
\hline 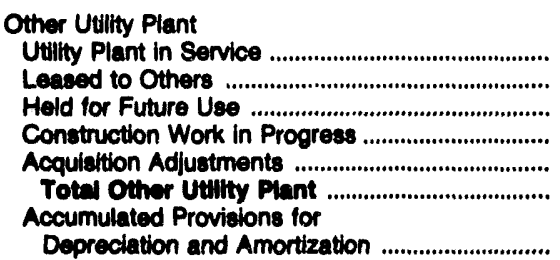 & $\begin{array}{r}276,615 \\
0 \\
28 \\
53,155 \\
0 \\
329,709 \\
79,216\end{array}$ & $\begin{array}{l}0 \\
0 \\
0 \\
0 \\
0 \\
0\end{array}$ & $\begin{array}{r}36,325 \\
0 \\
0 \\
175 \\
0 \\
38,490 \\
6,858\end{array}$ & $\begin{array}{l}0 \\
0 \\
0 \\
0 \\
0 \\
0\end{array}$ & $\begin{array}{r}45,472 \\
0 \\
0 \\
1,087 \\
0 \\
46,580 \\
22,063\end{array}$ & $\begin{array}{r}28,498 \\
0 \\
0 \\
652 \\
0 \\
20,140 \\
13,360\end{array}$ \\
\hline Net Other Utitly Piant ........................................ & 260,602 & $\mathbf{0}$ & 29,042 & $\mathbf{0}$ & 24,476 & 16,780 \\
\hline 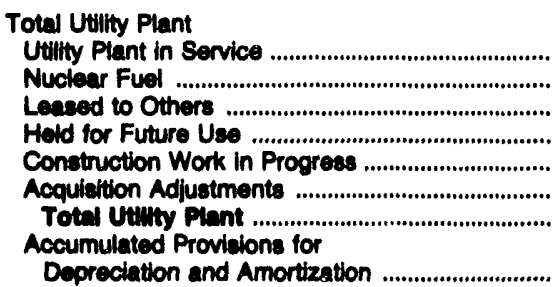 & $\begin{array}{r}4,831,098 \\
0 \\
0 \\
4,919 \\
142,441 \\
0 \\
4,970,460 \\
\\
1,855,507\end{array}$ & $\begin{array}{r}3,137,350 \\
0 \\
0 \\
2,480 \\
232,105 \\
0 \\
3,371,935\end{array}$ & $\begin{array}{r}966,419 \\
0 \\
0 \\
2,581 \\
19,688 \\
0 \\
998,988 \\
\\
391,541\end{array}$ & $\begin{array}{r}814,189 \\
0 \\
0 \\
587 \\
3,487 \\
3,441 \\
821,704 \\
339,647\end{array}$ & $\begin{array}{r}1,390,342 \\
61,419 \\
0 \\
1,858 \\
19,865 \\
32,824 \\
1,600,400 \\
586,203\end{array}$ & $\begin{array}{r}427,210 \\
0 \\
0 \\
0 \\
10,459 \\
388 \\
439,067 \\
163,551\end{array}$ \\
\hline Not Total Uumty Piant ........................................... & $3,122,051$ & $1,001,403$ & 807,127 & 492,058 & 910,207 & 274,616 \\
\hline 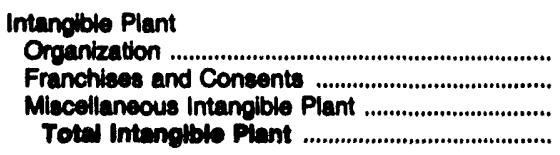 & $\begin{array}{l}0 \\
1 \\
0 \\
1\end{array}$ & $\begin{array}{r}226 \\
0 \\
14,358 \\
14,884\end{array}$ & $\begin{array}{r}12 \\
0 \\
0 \\
12\end{array}$ & $\begin{array}{r}34 \\
337 \\
5,849 \\
6,221\end{array}$ & $\begin{array}{r}0 \\
250 \\
6,024 \\
8,274\end{array}$ & $\begin{array}{r}0 \\
263 \\
0 \\
203\end{array}$ \\
\hline 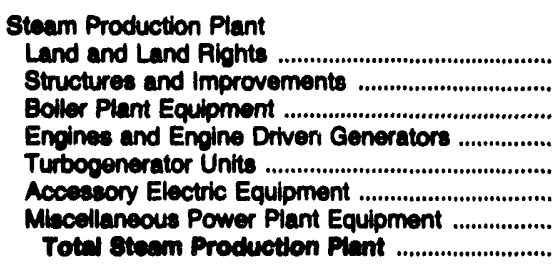 & $\begin{array}{r}5,718 \\
460,264 \\
1,108,820 \\
0 \\
380,808 \\
202,303 \\
27,288 \\
2,175,180\end{array}$ & $\begin{array}{r}5,246 \\
318,329 \\
816,891 \\
0 \\
252,883 \\
100,656 \\
23,812 \\
1,510,016\end{array}$ & $\begin{array}{r}2,734 \\
51,612 \\
320,684 \\
0 \\
103,263 \\
34,136 \\
6,109 \\
618,418\end{array}$ & $\begin{array}{r}533 \\
54,601 \\
191,122 \\
0 \\
54,222 \\
28,711 \\
3,219 \\
390,403\end{array}$ & $\begin{array}{r}672 \\
32,309 \\
102,485 \\
0 \\
32,637 \\
16,523 \\
3,541 \\
189,168\end{array}$ & $\begin{array}{r}587 \\
32,957 \\
110,029 \\
0 \\
33,228 \\
14,261 \\
3,805 \\
105,027\end{array}$ \\
\hline
\end{tabular}

See endnotes at end of an individual electric utility. 
Table 42. Utility Plant by Major U.S. Investor-Owned Electric Utility Within State on December 31, 1992 (Continued) (Thousand Dollars)

\begin{tabular}{|c|c|c|c|c|c|c|}
\hline Item & $\begin{array}{l}\text { Indiana } \\
\text { Northern } \\
\text { Indtana } \\
\text { Pub Serv } \\
\text { Co }\end{array}$ & $\begin{array}{c}\text { Indiana } \\
\text { PSI } \\
\text { Energy Inc }\end{array}$ & $\begin{array}{l}\text { Indlana } \\
\text { Southem } \\
\text { Indlana Gas } \\
\text { \& Elec Co }\end{array}$ & $\begin{array}{c}\text { lowe } \\
\text { Interstate } \\
\text { Power Co }\end{array}$ & $\begin{array}{c}\text { lowa } \\
\text { lowa } \\
\text { Electric } \\
\text { Light \& Power } \\
\text { Co }\end{array}$ & $\begin{array}{l}\text { lowa } \\
\text { lowa } \\
\text { Southern } \\
\text { Utilities } \\
\text { Co }\end{array}$ \\
\hline 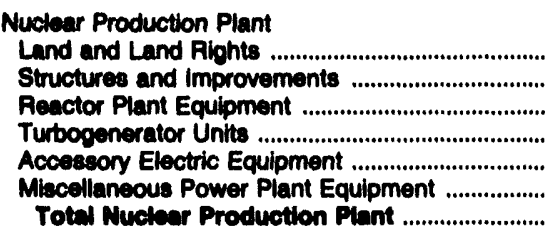 & $\begin{array}{l}0 \\
0 \\
0 \\
0 \\
0 \\
0 \\
0\end{array}$ & $\begin{array}{l}0 \\
0 \\
0 \\
0 \\
0 \\
0 \\
0\end{array}$ & $\begin{array}{l}0 \\
0 \\
0 \\
0 \\
0 \\
0 \\
0\end{array}$ & $\begin{array}{l}0 \\
0 \\
0 \\
0 \\
0 \\
0 \\
0\end{array}$ & $\begin{array}{r}1,308 \\
86,141 \\
208,578 \\
58,454 \\
57,481 \\
39,427 \\
461,389\end{array}$ & $\begin{array}{l}0 \\
0 \\
0 \\
0 \\
0 \\
0 \\
0\end{array}$ \\
\hline 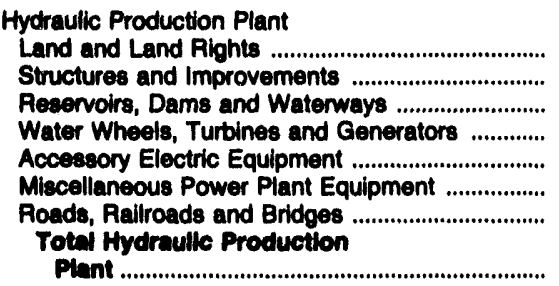 & $\begin{array}{r}835 \\
927 \\
4,287 \\
3,853 \\
241 \\
131 \\
0 \\
10,274\end{array}$ & $\begin{array}{r}0 \\
2,415 \\
11,259 \\
6,018 \\
699 \\
188 \\
0\end{array}$ & $\begin{array}{l}0 \\
0 \\
0 \\
0 \\
0 \\
0 \\
0\end{array}$ & $\begin{array}{l}0 \\
0 \\
0 \\
0 \\
0 \\
0 \\
0\end{array}$ & $\begin{array}{r}158 \\
281 \\
489 \\
837 \\
237 \\
11 \\
0\end{array}$ & $\begin{array}{l}0 \\
0 \\
0 \\
0 \\
0 \\
0 \\
0\end{array}$ \\
\hline 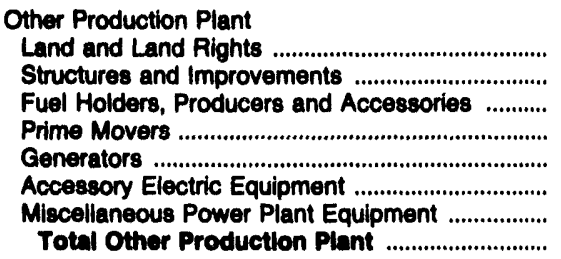 & $\begin{array}{r}9 \\
2,109 \\
9,086 \\
23,808 \\
5,663 \\
1,813 \\
337 \\
42,828\end{array}$ & $\begin{array}{r}0 \\
197 \\
489 \\
8,694 \\
6,525 \\
1,879 \\
39 \\
17,824\end{array}$ & $\begin{array}{r}79 \\
836 \\
2,771 \\
27,220 \\
11,173 \\
1,772 \\
19 \\
43,070\end{array}$ & $\begin{array}{r}18 \\
2,187 \\
1,129 \\
14,173 \\
10,550 \\
1,042 \\
57 \\
29,157\end{array}$ & $\begin{array}{r}21 \\
471 \\
759 \\
1,047 \\
21,355 \\
113 \\
14 \\
23,779\end{array}$ & $\begin{array}{r}25 \\
208 \\
131 \\
0 \\
4,503 \\
623 \\
17 \\
5,506\end{array}$ \\
\hline Total Production Piant ......................................... & $2,228,200$ & $1,557,419$ & 562,289 & 350,585 & 675,348 & 200,533 \\
\hline 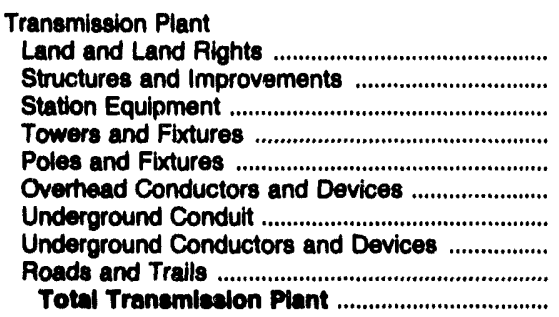 & $\begin{array}{r}28,159 \\
15,295 \\
292,203 \\
86,901 \\
50,682 \\
105,636 \\
643 \\
421 \\
70 \\
580,010\end{array}$ & $\begin{array}{r}27,234 \\
9,572 \\
223,323 \\
71,973 \\
67,081 \\
110,273 \\
0 \\
0 \\
0 \\
500,457\end{array}$ & $\begin{array}{r}4,672 \\
1,411 \\
44,767 \\
4,052 \\
18,303 \\
18,409 \\
1,105 \\
721 \\
0 \\
93,438\end{array}$ & $\begin{array}{r}9,541 \\
2,126 \\
62,110 \\
9,961 \\
44,635 \\
39,031 \\
0 \\
22 \\
0 \\
167,425\end{array}$ & $\begin{array}{r}3,375 \\
3,056 \\
70,863 \\
2,020 \\
36,955 \\
53,115 \\
0 \\
0 \\
0 \\
169,385\end{array}$ & $\begin{array}{r}4,629 \\
228 \\
14,949 \\
1,347 \\
15,599 \\
20,175 \\
74 \\
137 \\
0 \\
57,138\end{array}$ \\
\hline 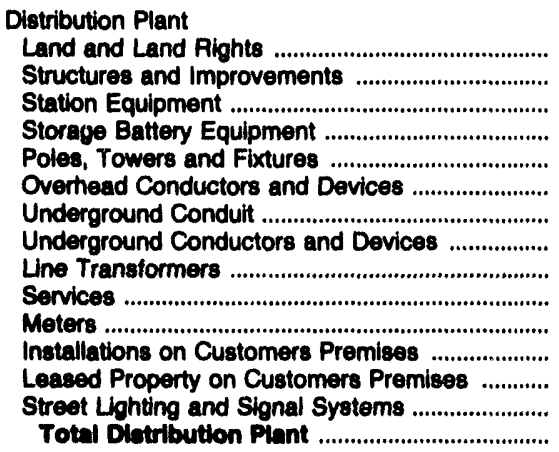 & $\begin{array}{r}1,512 \\
7,381 \\
109,079 \\
0 \\
117,596 \\
97,265 \\
2,558 \\
60,402 \\
120,558 \\
68,077 \\
44,525 \\
2,847 \\
0 \\
24,615 \\
656,415\end{array}$ & $\begin{array}{r}4,168 \\
8,161 \\
134,136 \\
0 \\
174,296 \\
109,550 \\
5,733 \\
101,774 \\
187,089 \\
90,180 \\
76,454 \\
10,282 \\
0 \\
18,343 \\
920,187\end{array}$ & $\begin{array}{r}601 \\
571 \\
25,269 \\
0 \\
22,205 \\
27,356 \\
5,507 \\
16,224 \\
33,946 \\
16,206 \\
10,509 \\
1,448 \\
0 \\
7,222 \\
167,003\end{array}$ & $\begin{array}{r}645 \\
788 \\
26,728 \\
0 \\
50,024 \\
40,370 \\
2,699 \\
14,850 \\
28,467 \\
10,496 \\
13,189 \\
3 \\
0 \\
3,172 \\
191,432\end{array}$ & $\begin{array}{r}1,275 \\
2,765 \\
54,227 \\
0 \\
70,588 \\
79,095 \\
8,785 \\
35,533 \\
61,657 \\
0 \\
27,712 \\
3,581 \\
0 \\
11,155 \\
356,372\end{array}$ & $\begin{array}{r}238 \\
746 \\
15,626 \\
0 \\
21,581 \\
23,620 \\
1,419 \\
7,388 \\
22,685 \\
6,128 \\
7,201 \\
2,288 \\
0 \\
2,245 \\
111,165\end{array}$ \\
\hline
\end{tabular}

See endnotes at end of an individuel electric utlity. 
Table 42. Utillty Plant by Major U.S. Inveator-Owned Electric Utillty Within State on December 31, 1992 (Continued) (Thousand Dollars)

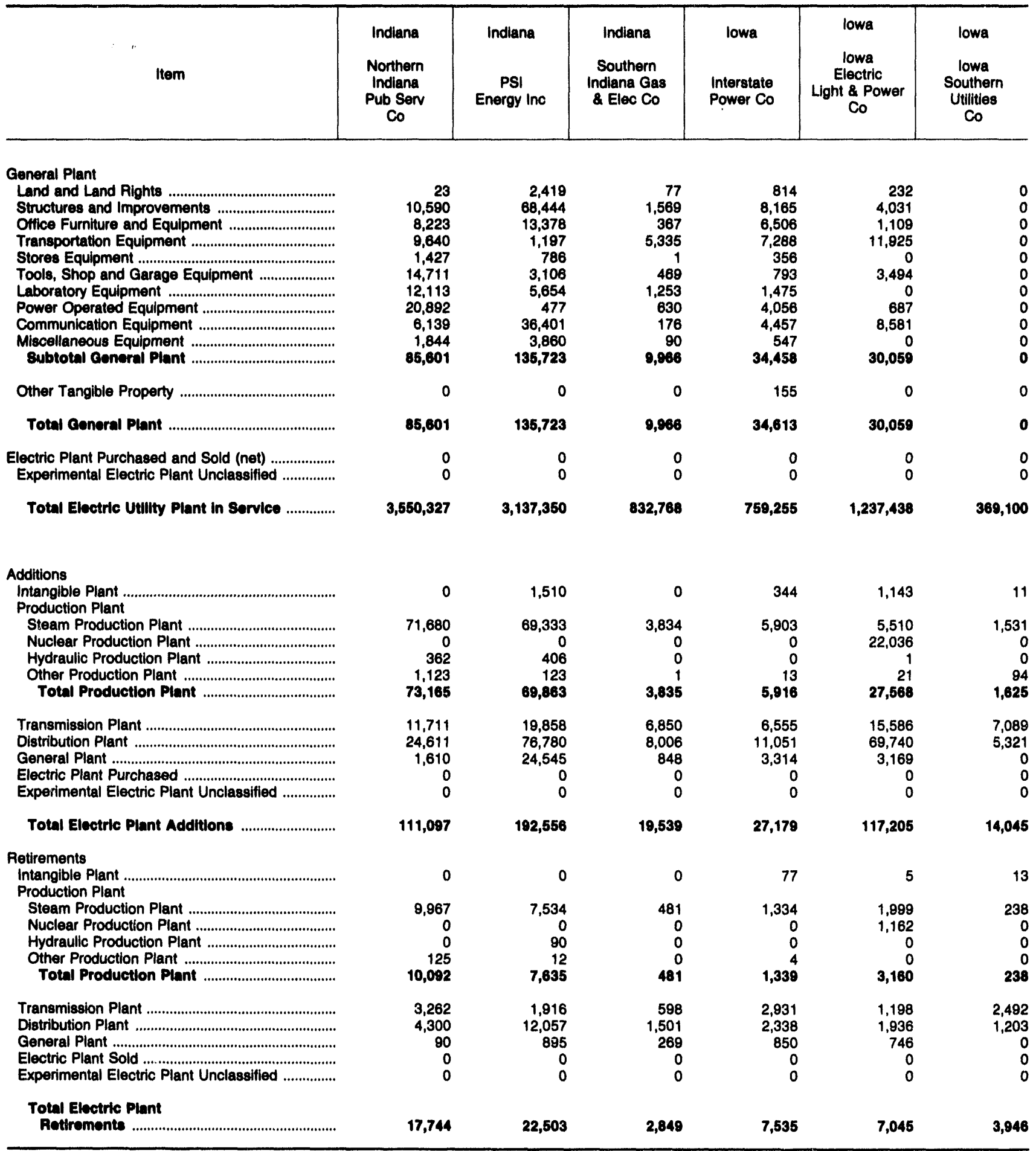

Note: Totals may not equal sum of components because of independent rounding. Summary data are provided in Table 28. Source: Federal Energy Regulatory Commission, FERC Form 1, "Annual Report of Major Electric Utilities, Licensees and Others." 
Table 42. Utility Plant by Major U.S. Inveator-Owned Electric Utility Within State on Decomber 31, 1992 (Continued)

(Thousand Dollars)

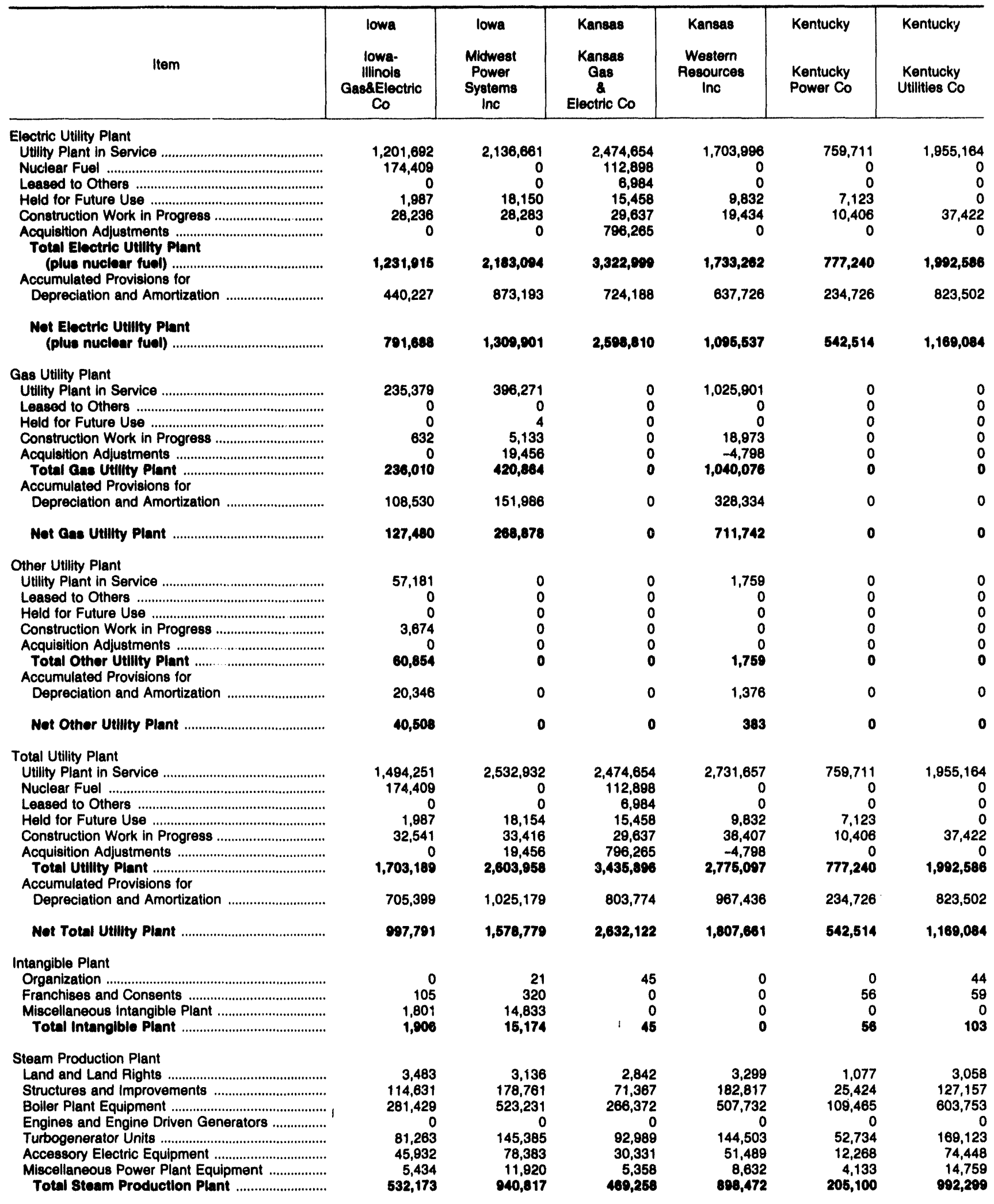

See endnotes at end of an individual electric utility. 
Table 42. Utility Plant by Major U.S. Inveator-Owned Electric Utility Within State on December 31, 1992 (Continued)

(Thousand Dollars)

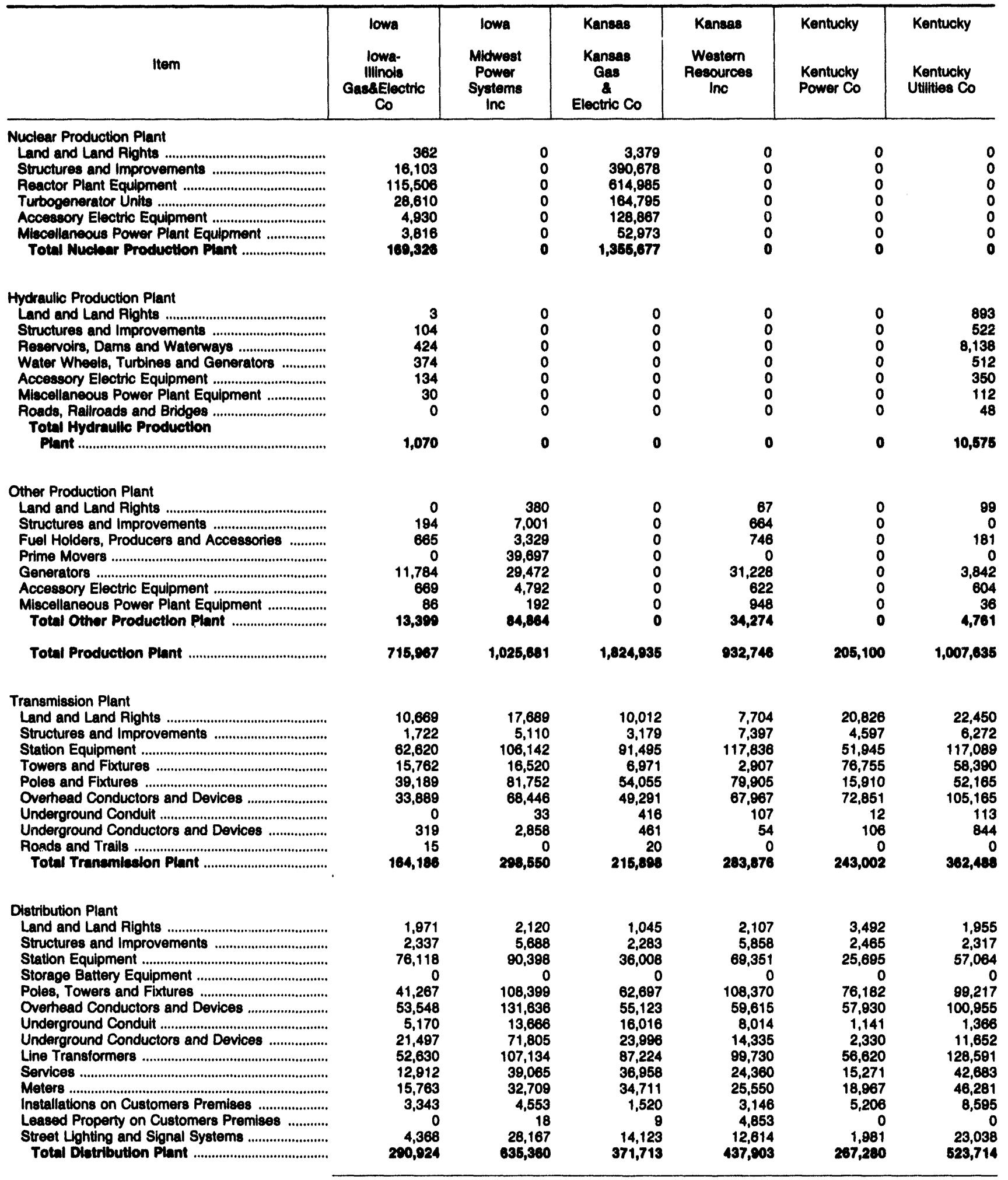

See endnotes at end of an individual electric utility. 
Table 42. Utility Plant by Major U.S. Investor-Owned Electric Utility Within State on December 31, 1992 (Continued) (Thousand Dollars)

\begin{tabular}{|c|c|c|c|c|c|c|}
\hline Item & $\begin{array}{c}\text { lowa } \\
\text { lowa- } \\
\text { Illinois } \\
\text { GasdElectric } \\
\text { Co }\end{array}$ & $\begin{array}{l}\text { lowa } \\
\text { Midwest } \\
\text { Power } \\
\text { Systems } \\
\text { Inc }\end{array}$ & $\begin{array}{c}\text { Kansas } \\
\text { Kansas } \\
\text { Gas } \\
8 \\
\text { Electric Co }\end{array}$ & $\begin{array}{c}\text { Kansas } \\
\text { Western } \\
\text { Resources } \\
\text { Inc }\end{array}$ & $\begin{array}{l}\text { Kentucky } \\
\text { Kentucky } \\
\text { Power Co }\end{array}$ & $\begin{array}{l}\text { Kentucky } \\
\text { Kentucky } \\
\text { Utillties Co }\end{array}$ \\
\hline
\end{tabular}

\section{General Plant}

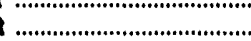

Land and Land Rights

Structures and Improvements

Office Furniture and Equipment

Traneportation Equipment

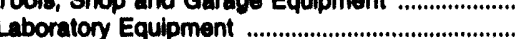

Power Operated Equipment

Communication Equipment

Miscellaneous Equipment

subtotal cemeral Piant

Other Tangible Property

Total Ceneral Piant

Electric Plant Purchased and Sold (net)

Experimental Electric Plant Unclaseified

Total Eloctric Utilty Piant In service
87

1,180

611

19,294

1,008

1,769

2,120

673

1,750

220

28,70!

0

28,70

3,860

54,442

37,861

33,692

1,337

4,425

4,261

4,746

15,744

1,274

181,844

0

181,844

0
53

$1,201,692$

$2,138,681$

\section{2}

14,923

14,750

8,180

308

1,105

1,743

1,203

18,862

147

82,083

0

62,033

0
0

$2,474,654$
2,121

22,806

4,889

2,173

1,897

4,388

1,920

702

8,480

95
49,472

0

49,472

0
0

$1,703,906$
2,288

28,685

901

829

107

872

394

3,801
460

38,339

5,835

$44,274^{\prime}$

0
0

759,711

$1,955,164$

\section{Additions}

Intanglble Plant

Production Plant

Steam Production Plant

Nuclear Production Plant

Hydraulic Production Plant

Other Production Plant

Total Production Plant

752

0

0
7,569
0
0
106

0

4,048

8,421
4,282

2,604
5,412

0

8,020

0
0
28
7.877

0
0

0
0
0
4,048

7,777

2,328

15,763

1,931
0

25,105

3,780

1,888

33,744

18,626

Electric Plant Purchased

Experimental Electric Plant Unclassified

0

0

32,728

2,506

23,100

8,643

18,580

441

1,563

1,944

3,798

498

61,224

0

31,816

02,450

5,553
18,330

1,828

1,828
0
0

9,861

Retirements

Intangible Plant

Production Plant

Steam Production Plant

Nuclear Production Plant ....

Hydraullc Production Plant

Other Production Plant

Totel Production Pint

Tranemisaion Plant

Distribution Plant

General Plant .

Electric Plant Sold

Experimental Electric Plant Unclassified

.................

Total Electrite Plant

Rotiremente

9,779

0
2,354
7,034
0
0
0,388

358
1,536
763
0
0

12,044

0
1,179
0
0
1
1,180
715
3,303
83
0
0

5,281
0
2,618
0
0
0
2,618
1,684
5,200
748
0
0

10,252

10,748

Note: Totals may not equal sum of components because of independent rounding. Summary data are provided in Table 28.

Source: Federal Energy Regulatory Commiseion, FERC Form 1, "Annual Report of Major Electric Utilities, Licensees and Others." 
Table 42. Utility Plant by Major U.S. Inveator-Owned Electric Utility Within State on December 31, 1992 (Continued) (Thousand Dollars)

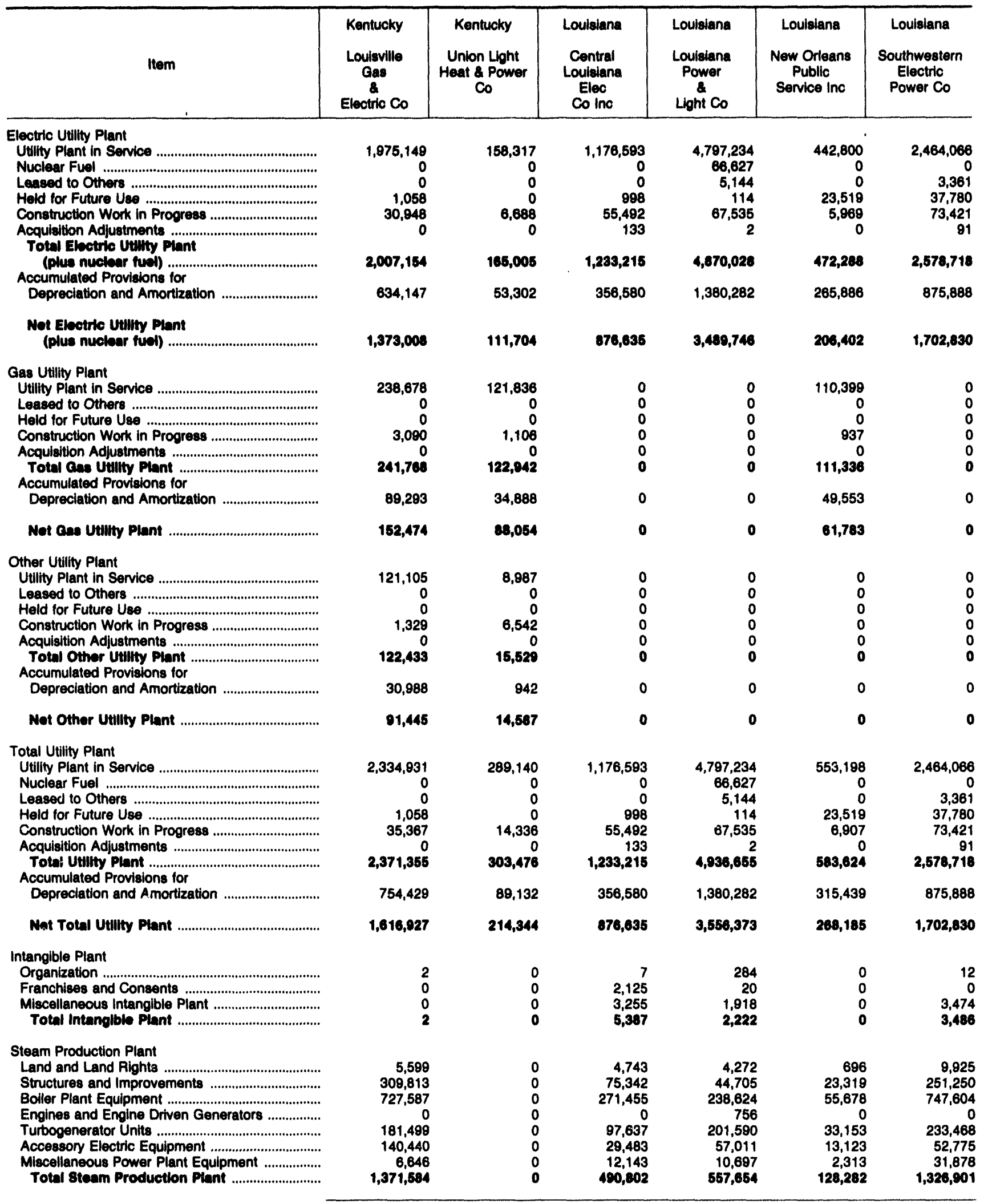

See endnotes at end of an individual electric utility. 
Table 42. Utility Plant by Major U.S. Investor-Owned Eloctric Utility Within State on Decomber 31, 1992 (Continued)

(Thousand Dollars)

\begin{tabular}{|c|c|c|c|c|c|c|}
\hline Item & $\begin{array}{c}\text { Kentucky } \\
\text { Loulevilk } \\
\text { Cas } \\
8 \\
\text { Electric Co }\end{array}$ & $\begin{array}{l}\text { Kentucky } \\
\text { Unlon Light } \\
\text { Heat \& Power } \\
\text { Co }\end{array}$ & $\begin{array}{l}\text { Loulaiana } \\
\text { Central } \\
\text { Louisiana } \\
\text { Elec } \\
\text { Co inc }\end{array}$ & $\begin{array}{c}\text { Loulaiana } \\
\text { Loulaiana } \\
\text { Power } \\
8 \\
\text { Light co }\end{array}$ & $\begin{array}{l}\text { Louisiana } \\
\text { New Orleans } \\
\text { Public } \\
\text { Service inc }\end{array}$ & $\begin{array}{l}\text { Louiaiana } \\
\text { Southwestern } \\
\text { Electric } \\
\text { Power Co }\end{array}$ \\
\hline 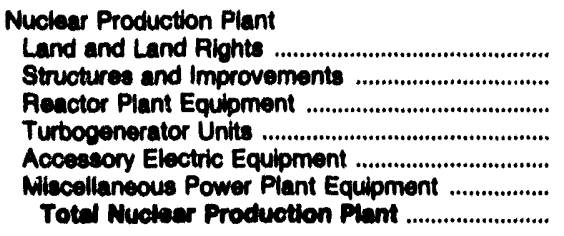 & $\begin{array}{l}0 \\
0 \\
0 \\
0 \\
0 \\
0 \\
0\end{array}$ & $\begin{array}{l}0 \\
0 \\
0 \\
0 \\
0 \\
0 \\
0\end{array}$ & $\begin{array}{l}0 \\
0 \\
0 \\
0 \\
0 \\
0 \\
0\end{array}$ & $\begin{array}{r}888 \\
703,691 \\
889,682 \\
229,537 \\
511,682 \\
108,041 \\
2,448,410\end{array}$ & $\begin{array}{l}0 \\
0 \\
0 \\
0 \\
0 \\
0 \\
0\end{array}$ & $\begin{array}{l}0 \\
0\end{array}$ \\
\hline 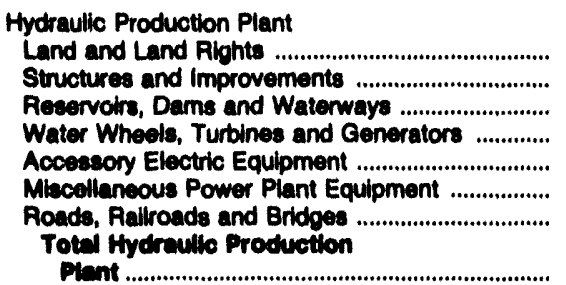 & $\begin{array}{r}0 \\
4,684 \\
157 \\
2,223 \\
838 \\
135 \\
186\end{array}$ & $\begin{array}{l}0 \\
0 \\
0 \\
0 \\
0 \\
0 \\
0\end{array}$ & $\begin{array}{l}0 \\
0 \\
0 \\
0 \\
0 \\
0 \\
0\end{array}$ & $\begin{array}{l}0 \\
0 \\
0 \\
0 \\
0 \\
0 \\
0\end{array}$ & $\begin{array}{l}0 \\
0 \\
0 \\
0 \\
0 \\
0 \\
0\end{array}$ & \\
\hline 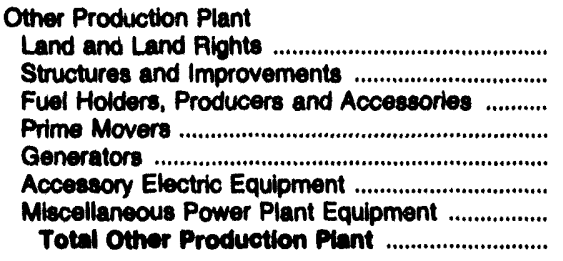 & $\begin{array}{r}41 \\
532 \\
251 \\
2,307 \\
7,5 \% 7 \\
429 \\
27 \\
11,46\end{array}$ & $\begin{array}{l}0 \\
0 \\
0 \\
0 \\
0 \\
0 \\
0 \\
0\end{array}$ & $\begin{array}{r}68 \\
30 \\
61 \\
48 \\
1,237 \\
6 \\
53 \\
1,604\end{array}$ & $\begin{array}{r}60 \\
1,823 \\
21 \\
1,503 \\
331 \\
18 \\
18 \\
3,876\end{array}$ & $\begin{array}{l}0 \\
0 \\
0 \\
0 \\
0 \\
0 \\
0 \\
0\end{array}$ & \\
\hline 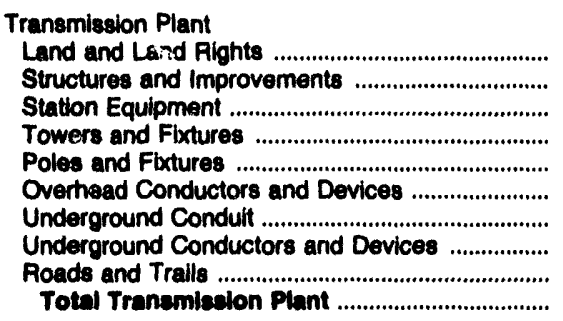 & $\begin{array}{r}1,387 \\
i, 009 \\
91,234 \\
23,530 \\
18,593 \\
24,097 \\
173 \\
580 \\
3 \\
163,408\end{array}$ & $\begin{array}{r}1,425 \\
454 \\
4,032 \\
0 \\
3,085 \\
3,095 \\
0 \\
0 \\
0 \\
1,2,071\end{array}$ & $\begin{array}{r}19,016 \\
307 \\
123,625 \\
10,855 \\
34,980 \\
37,728 \\
0 \\
129 \\
56 \\
229,897\end{array}$ & $\begin{array}{r}21,402 \\
3,994 \\
98,380 \\
54,881 \\
100,853 \\
86,838 \\
0 \\
1,301 \\
136 \\
367,794\end{array}$ & $\begin{array}{r}1,325 \\
760 \\
21,283 \\
6,418 \\
11,651 \\
5,860 \\
461 \\
610 \\
0 \\
60,490\end{array}$ & $\begin{array}{r}21,626 \\
4,869 \\
127,838 \\
29,701 \\
61,343 \\
99,808 \\
0 \\
0 \\
0 \\
345,183\end{array}$ \\
\hline 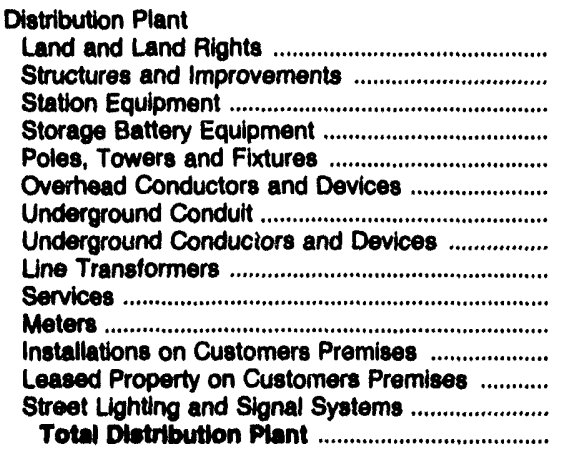 & $\begin{array}{r}1,850 \\
4,928 \\
54,909 \\
0 \\
62,255 \\
78,034 \\
24,160 \\
40,216 \\
69,964 \\
16,830 \\
24,170 \\
0 \\
0 \\
27,674 \\
404,990\end{array}$ & $\begin{array}{r}4,: 114 \\
175 \\
18,248 \\
0 \\
24,581 \\
28,352 \\
2,307 \\
14,831 \\
28,558 \\
6,885 \\
9,163 \\
0 \\
0 \\
4,004 \\
141,418\end{array}$ & $\begin{array}{r}6,883 \\
60 \\
28,369 \\
0 \\
77,304 \\
97,362 \\
14,518 \\
17,933 \\
87,221 \\
34,880 \\
18,890 \\
0 \\
0 \\
8,771 \\
392,301\end{array}$ & $\begin{array}{r}17,681 \\
8,423 \\
226,672 \\
0 \\
132,494 \\
218,344 \\
12,657 \\
28,920 \\
262,397 \\
87,600 \\
72,388 \\
0 \\
0 \\
37,775 \\
1,105,360\end{array}$ & $\begin{array}{r}1,800 \\
4,381 \\
36,472 \\
0 \\
21,308 \\
17,082 \\
31,074 \\
36,743 \\
44,789 \\
18,620 \\
15,371 \\
0 \\
0 \\
3,586 \\
231,208\end{array}$ & $\begin{array}{r}2,964 \\
2,488 \\
71,848 \\
0 \\
118,200 \\
114,562 \\
9,334 \\
44,054 \\
141,064 \\
18,293 \\
39,846 \\
15,698 \\
0 \\
17,248 \\
505,690\end{array}$ \\
\hline
\end{tabular}

See endnotes at end of an indlvidual electric utility. 
Table 42. Utility Plant by Major U.8. Inveotor-Owned Eleotric Utility Within state on Decomber 31, 1902 (Continued)

(Thousand Dollars)

\begin{tabular}{|c|c|c|c|c|c|c|}
\hline Item & $\begin{array}{c}\text { Kentucky } \\
\text { Louloville } \\
\text { Gas } \\
\text { Electrio Co }\end{array}$ & $\begin{array}{l}\text { Kentucky } \\
\text { Union Lught } \\
\text { Heat \& Power } \\
\text { Co }\end{array}$ & $\begin{array}{l}\text { Loulaiana } \\
\text { Contral } \\
\text { Loulaiana } \\
\text { Elec } \\
\text { Co Inc }\end{array}$ & $\begin{array}{l}\text { Louidana } \\
\text { Loulalana } \\
\text { Power } \\
\text { Light Co }\end{array}$ & $\begin{array}{l}\text { Louldelana } \\
\text { Now Orleans } \\
\text { Publlo } \\
\text { Sorvice inc }\end{array}$ & $\begin{array}{l}\text { Louldiana } \\
\text { Southweutern } \\
\text { Electric } \\
\text { Power Co }\end{array}$ \\
\hline 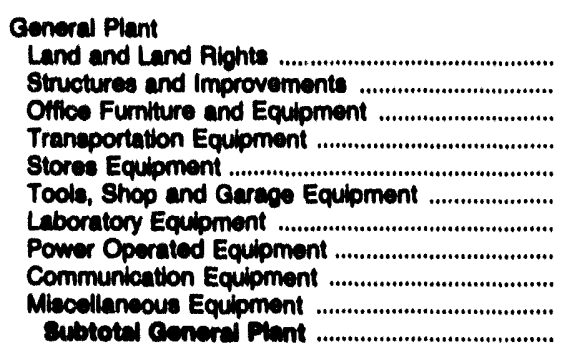 & $\begin{array}{r}0 \\
0 \\
0 \\
11,249 \\
0 \\
929 \\
1,423 \\
2,114 \\
84 \\
0 \\
16,700\end{array}$ & $\begin{array}{r}0 \\
16 \\
58 \\
4,249 \\
1 \\
294 \\
4 \\
212 \\
0 \\
1 \\
1 \\
4,028\end{array}$ & $\begin{array}{r}1,670 \\
18,688 \\
11,276 \\
1,096 \\
668 \\
2,081 \\
1,869 \\
1,181 \\
7,209 \\
304 \\
40,116\end{array}$ & $\begin{array}{r}782 \\
15,028 \\
17,604 \\
13,361 \\
531 \\
3,778 \\
3,445 \\
0 \\
34,623 \\
145 \\
10,006\end{array}$ & $\begin{array}{r}1,054 \\
11,858 \\
3,442 \\
1,602 \\
369 \\
1,340 \\
837 \\
2,324 \\
9,877 \\
151 \\
32,043\end{array}$ & $\begin{array}{r}3,969 \\
34,980 \\
17,704 \\
21,061 \\
437 \\
4,129 \\
2,999 \\
806 \\
6,161 \\
680 \\
98,037\end{array}$ \\
\hline 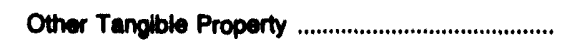 & 0 & 0 & 13,780 & 1.747 & 0 & 99,870 \\
\hline 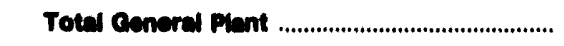 & 18,790 & 4,028 & 80,002 & 81,034 & 32,043 & 102,000 \\
\hline $\begin{array}{l}\text { Electric Plant Purchased and Sold (net) .................... } \\
\text { Experimental Electric Plant Unclaedified ............... }\end{array}$ & $\begin{array}{l}0 \\
0\end{array}$ & $\begin{array}{l}0 \\
0\end{array}$ & $\begin{array}{l}0 \\
0\end{array}$ & $\begin{array}{r}225,083 \\
0\end{array}$ & $\begin{array}{l}0 \\
0\end{array}$ & $\begin{array}{l}0 \\
0\end{array}$ \\
\hline Total Elcetric Utility Plant in Bervioe .............. & $1,076,140$ & 160,317 & $1,176,593$ & $4,797,234$ & 442,600 & $2,404,000$ \\
\hline 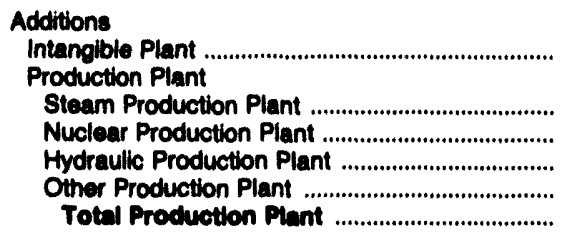 & $\begin{array}{r}8,224 \\
0 \\
17 \\
0 \\
8,242\end{array}$ & $\begin{array}{l}0 \\
0 \\
0 \\
0 \\
0\end{array}$ & $\begin{array}{r}0 \\
1,029 \\
0 \\
0 \\
0 \\
1,020\end{array}$ & $\begin{array}{r}1,050 \\
36,718 \\
21,813 \\
0 \\
312 \\
68,843\end{array}$ & $\begin{array}{r}0 \\
2,650 \\
0 \\
0 \\
0 \\
2,650\end{array}$ & $\begin{array}{r}0 \\
7,658 \\
0 \\
0 \\
0 \\
7,958\end{array}$ \\
\hline 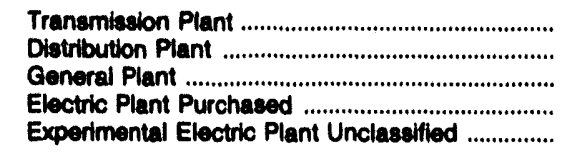 & $\begin{array}{r}2,957 \\
29,804 \\
3,729 \\
0 \\
0\end{array}$ & $\begin{array}{r}1,046 \\
13,147 \\
1,054 \\
0 \\
0\end{array}$ & $\begin{array}{r}5,548 \\
24,292 \\
2,348 \\
0 \\
0\end{array}$ & $\begin{array}{r}19,233 \\
70,204 \\
26,153 \\
0 \\
0\end{array}$ & $\begin{array}{r}739 \\
10,538 \\
8,284 \\
0 \\
0\end{array}$ & $\begin{array}{r}12,755 \\
29,147 \\
15,748 \\
0 \\
0\end{array}$ \\
\hline Total Elcotric Plant Additions ......................... & 44,731 & 16,240 & $\mathbf{3 3 , 2 1 7}$ & 175,403 & 22,210 & 85,300 \\
\hline 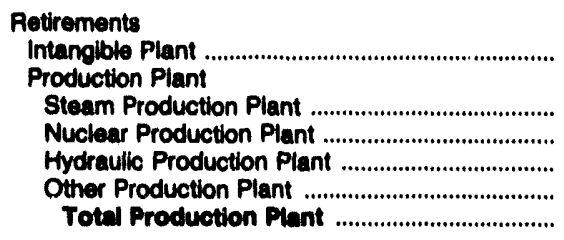 & $\begin{array}{r}1,000 \\
0 \\
0 \\
0 \\
1,000\end{array}$ & $\begin{array}{l}0 \\
0 \\
0 \\
0 \\
0\end{array}$ & $\begin{array}{r}190 \\
0 \\
0 \\
0 \\
100\end{array}$ & $\begin{array}{r}-240 \\
\\
2,752 \\
7,117 \\
0 \\
115 \\
9,804\end{array}$ & $\begin{array}{r}73 \\
0 \\
0 \\
0 \\
73\end{array}$ & $\begin{array}{r}0 \\
1,616 \\
0 \\
0 \\
0 \\
1,616\end{array}$ \\
\hline 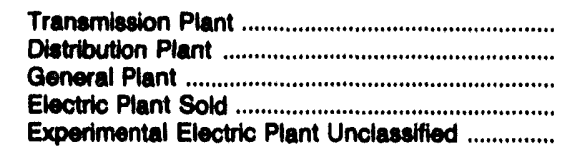 & $\begin{array}{r}420 \\
2,386 \\
1,532 \\
0 \\
0\end{array}$ & $\begin{array}{r}19 \\
2,337 \\
792 \\
0 \\
0\end{array}$ & $\begin{array}{r}334 \\
2,659 \\
126 \\
0 \\
0\end{array}$ & $\begin{array}{r}657 \\
9,458 \\
7,859 \\
0 \\
0\end{array}$ & $\begin{array}{r}42 \\
1,533 \\
53 \% \\
0 \\
0\end{array}$ & $\begin{array}{r}1,038 \\
5,243 \\
3,140 \\
0 \\
0\end{array}$ \\
\hline $\begin{array}{l}\text { Total Ebctive Plant } \\
\text { Rotinements }\end{array}$ & 5,337 & 3,147 & 3,309 & 27,718 & 2,185 & 11,037 \\
\hline
\end{tabular}

Note: Totals may not equal sum of components because of independent rounding. Summary data are provided in Table 28.

Source: Federal Energy Regulatory Commission, FERC Form 1. "Annual Report of Major Electric Utilities, Licensees and Others." 
Table 42. Utility Plant by Major U.8. Inveator-Owned Electric Utillity Within state on Decomber 31, 1992 (Continued)

(Thousand Dollars)

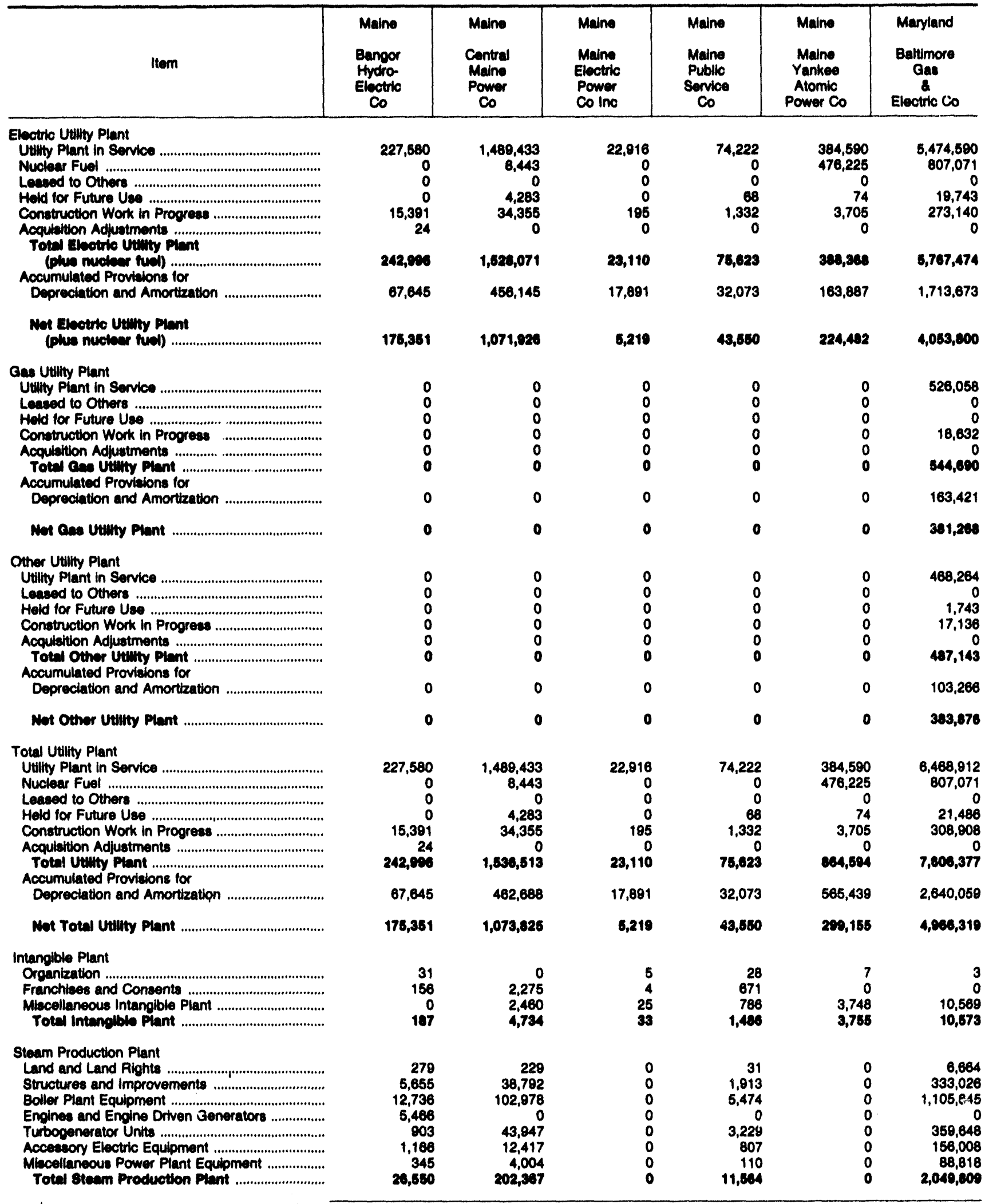

See endnotes at end of an individual electric utillty. 
Table 42. Utility Plant by Major U.S. Investor-Owned Electric Utility Within State on Decomber 31, 1992 (Continued) (Thousand Dollars)

\begin{tabular}{|c|c|c|c|c|c|c|}
\hline Item & $\begin{array}{c}\text { Maine } \\
\text { Bangor } \\
\text { Hydro- } \\
\text { Electric } \\
\text { Co }\end{array}$ & $\begin{array}{l}\text { Maine } \\
\text { Contral } \\
\text { Maine } \\
\text { Power } \\
\text { Co }\end{array}$ & $\begin{array}{l}\text { Maine } \\
\text { Maine } \\
\text { Electric } \\
\text { Power } \\
\text { Co Inc }\end{array}$ & $\begin{array}{l}\text { Maine } \\
\text { Maine } \\
\text { Publlc } \\
\text { Service } \\
\text { Co }\end{array}$ & $\begin{array}{c}\text { Maine } \\
\text { Maine } \\
\text { Yankee } \\
\text { Atomic } \\
\text { Power Co }\end{array}$ & $\begin{array}{c}\text { Maryland } \\
\text { Baltimore } \\
\text { Gas } \\
2 \\
\text { Electric Co }\end{array}$ \\
\hline 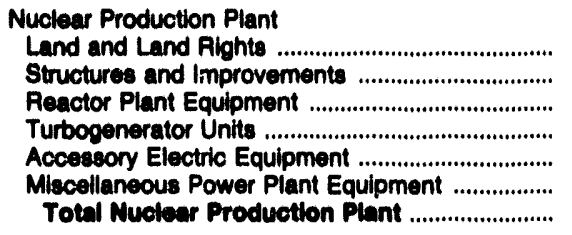 & $\begin{array}{l}0 \\
0 \\
0 \\
0 \\
0 \\
0 \\
0\end{array}$ & $\begin{array}{r}12 \\
39,630 \\
33,600 \\
12,999 \\
9,150 \\
2,360 \\
97,751\end{array}$ & $\begin{array}{l}0 \\
0 \\
0 \\
0 \\
0 \\
0 \\
0\end{array}$ & $\begin{array}{l}0 \\
0 \\
0 \\
0 \\
0 \\
0 \\
0\end{array}$ & $\begin{array}{r}468 \\
42,092 \\
185,689 \\
108,200 \\
21,359 \\
18,239 \\
376,049\end{array}$ & $\begin{array}{r}4,628 \\
285,391 \\
491,547 \\
214,681 \\
125,698 \\
73,880 \\
1,175,836\end{array}$ \\
\hline 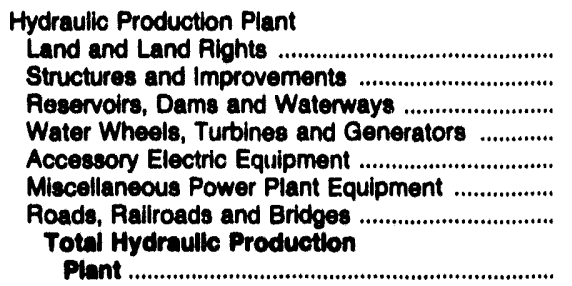 & $\begin{array}{r}1,321 \\
3,744 \\
9,810 \\
4,789 \\
824 \\
139 \\
16 \\
20,644\end{array}$ & $\begin{array}{r}12,946 \\
51,819 \\
74,679 \\
42,392 \\
10,802 \\
3,165 \\
1,010 \\
199,813\end{array}$ & $\begin{array}{l}0 \\
0 \\
0 \\
0 \\
0 \\
0 \\
0\end{array}$ & $\begin{array}{r}92 \\
117 \\
3,126 \\
230 \\
0 \\
29 \\
44 \\
3,638\end{array}$ & $\begin{array}{l}0 \\
0 \\
0 \\
0 \\
0 \\
0 \\
0\end{array}$ & 0 \\
\hline 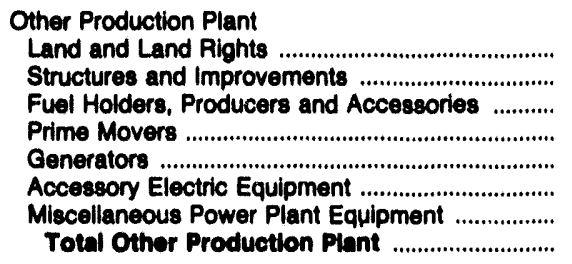 & $\begin{array}{r}2 \\
95 \\
419 \\
1,720 \\
925 \\
0 \\
1 \\
3,182\end{array}$ & $\begin{array}{r}33 \\
422 \\
329 \\
4 \\
3,196 \\
58 \\
38 \\
4,080\end{array}$ & $\begin{array}{l}0 \\
0 \\
0 \\
0 \\
0 \\
0 \\
0 \\
0\end{array}$ & $\begin{array}{r}0 \\
465 \\
58 \\
1,371 \\
332 \\
41 \\
61 \\
2,329\end{array}$ & $\begin{array}{l}0 \\
0 \\
0 \\
0 \\
0 \\
0 \\
0 \\
0\end{array}$ & $\begin{array}{r}219 \\
4,186 \\
3,974 \\
16,775 \\
50,584 \\
5,855 \\
216 \\
81,800\end{array}$ \\
\hline 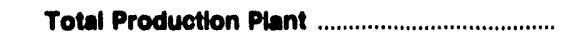 & 50,356 & 501,011 & $\mathbf{0}$ & 17,531 & 376,049 & $3,307,453$ \\
\hline 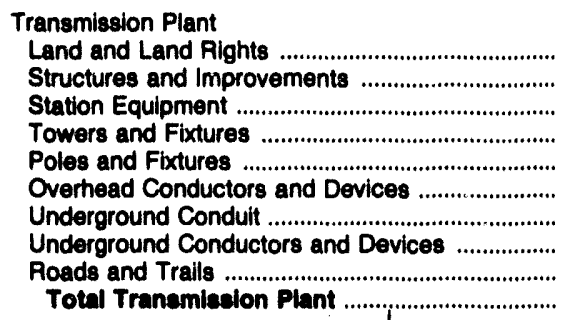 & $\begin{array}{r}1,214 \\
0 \\
14,494 \\
25 \\
7,370 \\
9,178 \\
3 \\
342 \\
2 \\
32,620\end{array}$ & $\begin{array}{r}10,857 \\
6,079 \\
76,815 \\
11,422 \\
96,690 \\
41,308 \\
1,272 \\
1,465 \\
100 \\
246,000\end{array}$ & $\begin{array}{r}839 \\
419 \\
5,875 \\
615 \\
9,007 \\
4,554 \\
0 \\
0 \\
3 \\
21,413\end{array}$ & $\begin{array}{r}828 \\
68 \\
3,716 \\
0 \\
4,240 \\
2,452 \\
0 \\
0 \\
0 \\
11,303\end{array}$ & $\begin{array}{r}0 \\
0 \\
4,786 \\
0 \\
0 \\
0 \\
0 \\
0 \\
0 \\
4,786\end{array}$ & $\begin{array}{r}34,529 \\
13,843 \\
169,014 \\
36,670 \\
35,244 \\
70,341 \\
28,394 \\
23,799 \\
55 \\
411,891\end{array}$ \\
\hline 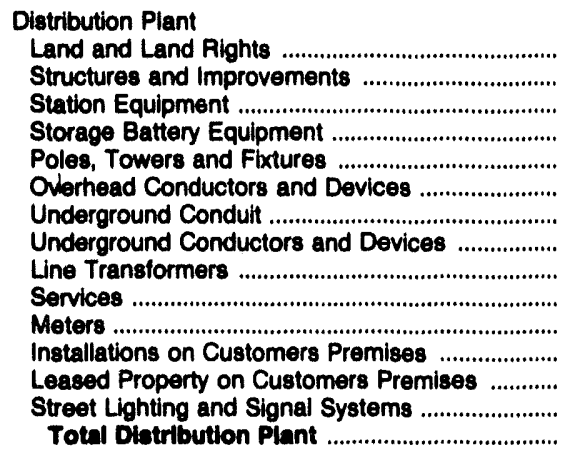 & $\begin{array}{r}3,301 \\
95 \\
11,306 \\
0 \\
33,334 \\
30,926 \\
978 \\
2,398 \\
23,780 \\
9,811 \\
6,757 \\
0 \\
0 \\
2,431 \\
125,117\end{array}$ & $\begin{array}{r}944 \\
4,968 \\
45,781 \\
0 \\
0 \\
164,333 \\
134,901 \\
7,517 \\
21,799 \\
126,438 \\
39,343 \\
41,306 \\
0 \\
0 \\
12,764 \\
600,094\end{array}$ & $\begin{array}{l}0 \\
0 \\
0 \\
0 \\
0 \\
0 \\
0 \\
0 \\
0 \\
0 \\
0 \\
0 \\
0 \\
0 \\
0\end{array}$ & $\begin{array}{r}145 \\
46 \\
3,655 \\
0 \\
0 \\
10,385 \\
9,321 \\
11 \\
145 \\
4,970 \\
3,259 \\
2,066 \\
582 \\
0 \\
829 \\
35,415\end{array}$ & $\begin{array}{l}0 \\
0 \\
0 \\
0 \\
0 \\
0 \\
0 \\
0 \\
0 \\
0 \\
0 \\
0 \\
0 \\
0 \\
0\end{array}$ & $\begin{array}{r}14,418 \\
36,843 \\
237,511 \\
0 \\
134,678 \\
176,249 \\
32,988 \\
440,016 \\
244,583 \\
120,571 \\
144,420 \\
12,224 \\
0 \\
39,856 \\
1,034,357\end{array}$ \\
\hline
\end{tabular}

See endnotes at end of an individual electric utility. 
Table 42. Utility Plant by Major U.S. Investor-Owned Electric UtIIIty Within State on December 31, 1992 (Continued) (Thousand Dollars)

\begin{tabular}{|c|c|c|c|c|c|c|}
\hline Item & $\begin{array}{l}\text { Maine } \\
\text { Bangor } \\
\text { Hydro- } \\
\text { Electric } \\
\text { Co }\end{array}$ & $\begin{array}{l}\text { Maine } \\
\text { Central } \\
\text { Maine } \\
\text { Power } \\
\text { Co }\end{array}$ & $\begin{array}{l}\text { Maine } \\
\text { Maine } \\
\text { Electric } \\
\text { Power } \\
\text { Co Inc }\end{array}$ & $\begin{array}{l}\text { Maine } \\
\text { Maine } \\
\text { Public } \\
\text { Service } \\
\text { Co }\end{array}$ & $\begin{array}{l}\text { Maine } \\
\text { Maine } \\
\text { Yankee } \\
\text { Atomic } \\
\text { Power Co }\end{array}$ & $\begin{array}{l}\text { Maryland } \\
\text { Baltimore } \\
\text { Gas } \\
\& \\
\text { Electric Co }\end{array}$ \\
\hline 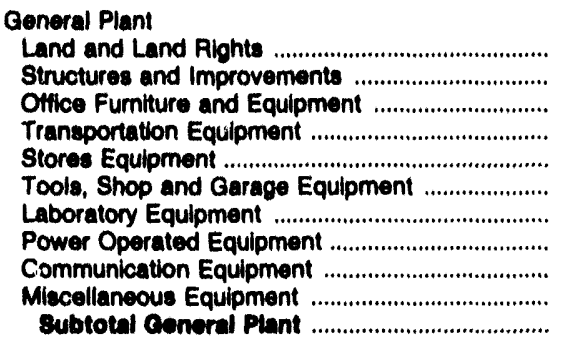 & $\begin{array}{r}427 \\
6,631 \\
4,235 \\
748 \\
274 \\
196 \\
784 \\
2,824 \\
1,840 \\
1,333 \\
19,202\end{array}$ & $\begin{array}{r}1,527 \\
52,664 \\
28,395 \\
26,194 \\
1,264 \\
2,807 \\
5,515 \\
28 \\
11,614 \\
7,577 \\
137,686\end{array}$ & $\begin{array}{r}5 \\
139 \\
13 \\
0 \\
0 \\
23 \\
0 \\
0 \\
1,261 \\
28 \\
1,469\end{array}$ & $\begin{array}{r}109 \\
3,154 \\
1,637 \\
716 \\
76 \\
245 \\
314 \\
1,465 \\
691 \\
180 \\
8,408\end{array}$ & $\begin{array}{l}0 \\
0 \\
0 \\
0 \\
0 \\
0 \\
0 \\
0 \\
0 \\
0 \\
0\end{array}$ & $\begin{array}{r}394 \\
44,564 \\
0 \\
0 \\
686 \\
7,523 \\
6,245 \\
0 \\
26,302 \\
24,601 \\
110,316\end{array}$ \\
\hline Other Tanglble Property & 0 & 0 & 0 & 0 & 0 & 0 \\
\hline Total Coneral Ptant ................................................ & 19,292 & 137,586 & 1,469 & 8,488 & $\mathbf{0}$ & 110,316 \\
\hline $\begin{array}{l}\text { Electric Plant Purchaeed and Sold (net) ..................... } \\
\text { Experimental Electric Plant Unclassfied ............... }\end{array}$ & $\begin{array}{l}0 \\
0\end{array}$ & $\begin{array}{l}0 \\
0\end{array}$ & $\begin{array}{l}0 \\
0\end{array}$ & $\begin{array}{l}0 \\
0\end{array}$ & $\begin{array}{l}0 \\
0\end{array}$ & $\begin{array}{l}0 \\
0\end{array}$ \\
\hline Total Electric Utilty Plant In Eorvice .............. & 227,680 & $1,480,433$ & 22,016 & 74,222 & 384,680 & $5,474,690$ \\
\hline \multicolumn{7}{|l|}{ Additions } \\
\hline $\begin{array}{l}\text { Intanglble Plant } \\
\text { Production Plant }\end{array}$ & 60 & 379 & 0 & 94 & 99 & 1,818 \\
\hline 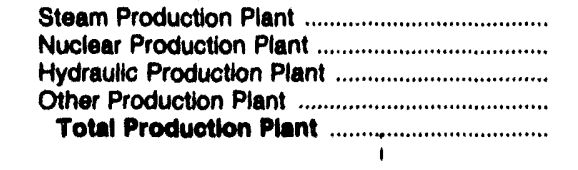 & $\begin{array}{r}118 \\
0 \\
614 \\
5 \\
736\end{array}$ & $\begin{array}{r}3,324 \\
185 \\
5,941 \\
0 \\
9,460\end{array}$ & $\begin{array}{l}0 \\
0 \\
0 \\
0 \\
0\end{array}$ & $\begin{array}{r}483 \\
0 \\
34 \\
12 \\
528\end{array}$ & $\begin{array}{r}0 \\
16,522 \\
0 \\
0 \\
16,522\end{array}$ & $\begin{array}{r}73,431 \\
44,960 \\
0 \\
1,380 \\
119,761\end{array}$ \\
\hline 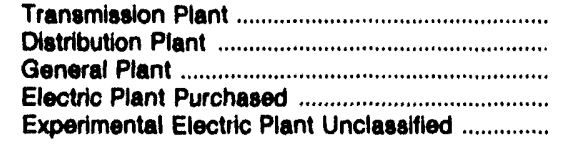 & $\begin{array}{r}6,742 \\
13,183 \\
2,796 \\
0 \\
0\end{array}$ & $\begin{array}{r}10,579 \\
32,965 \\
10,589 \\
0 \\
0\end{array}$ & $\begin{array}{r}243 \\
0 \\
28 \\
0 \\
0\end{array}$ & $\begin{array}{r}300 \\
2,324 \\
591 \\
0 \\
0\end{array}$ & $\begin{array}{l}0 \\
0 \\
0 \\
0 \\
0\end{array}$ & $\begin{array}{r}30,440 \\
140,657 \\
9,669 \\
0 \\
0\end{array}$ \\
\hline Total Electric Plant Additions .............................. & 23,516 & 63,971 & 271 & 3,837 & 16,621 & 302,336 \\
\hline 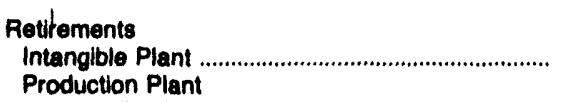 & 0 & 0 & 0 & 0 & 0 & 1,486 \\
\hline 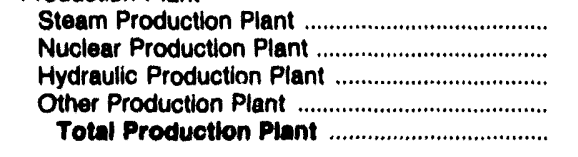 & $\begin{array}{r}1,562 \\
0 \\
42 \\
0 \\
1,6 n 3\end{array}$ & $\begin{array}{r}1,380 \\
0 \\
314 \\
0 \\
1,694\end{array}$ & $\begin{array}{l}0 \\
0 \\
0 \\
0 \\
0\end{array}$ & $\begin{array}{r}13 \\
0 \\
0 \\
0 \\
13\end{array}$ & $\begin{array}{r}0 \\
909 \\
0 \\
0 \\
900\end{array}$ & $\begin{array}{r}26,404 \\
2,687 \\
0 \\
371 \\
29,463\end{array}$ \\
\hline 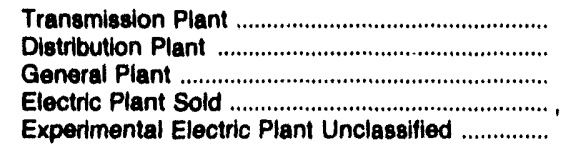 & $\begin{array}{r}136 \\
581 \\
674 \\
0 \\
0\end{array}$ & $\begin{array}{r}1,695 \\
8,478 \\
4,568 \\
0 \\
0\end{array}$ & $\begin{array}{r}111 \\
0 \\
19 \\
0 \\
0\end{array}$ & $\begin{array}{r}78 \\
517 \\
167 \\
0 \\
0\end{array}$ & $\begin{array}{l}0 \\
0 \\
0 \\
0 \\
0\end{array}$ & $\begin{array}{r}735 \\
10,385 \\
1,387 \\
0 \\
0\end{array}$ \\
\hline $\begin{array}{l}\text { Total Electric Plant } \\
\text { Rotirements }\end{array}$ & 2,095 & 16,435 & 130 & 776 & 800 & 43,456 \\
\hline
\end{tabular}

Note: Totals may not equal sum of components because of independent rounding. Summary data are provided in Table 28.

Source: Federal Energy Pegulatory Commission, FERC Form 1, "Annual Report of Major Electric Utilities, Licensees and Others." 
Table 42. Utility Plant by Major U.S. Investor-Owned Electric Utillty Within State on December 31, 1992 (Continued)

(Thousand Dollars)

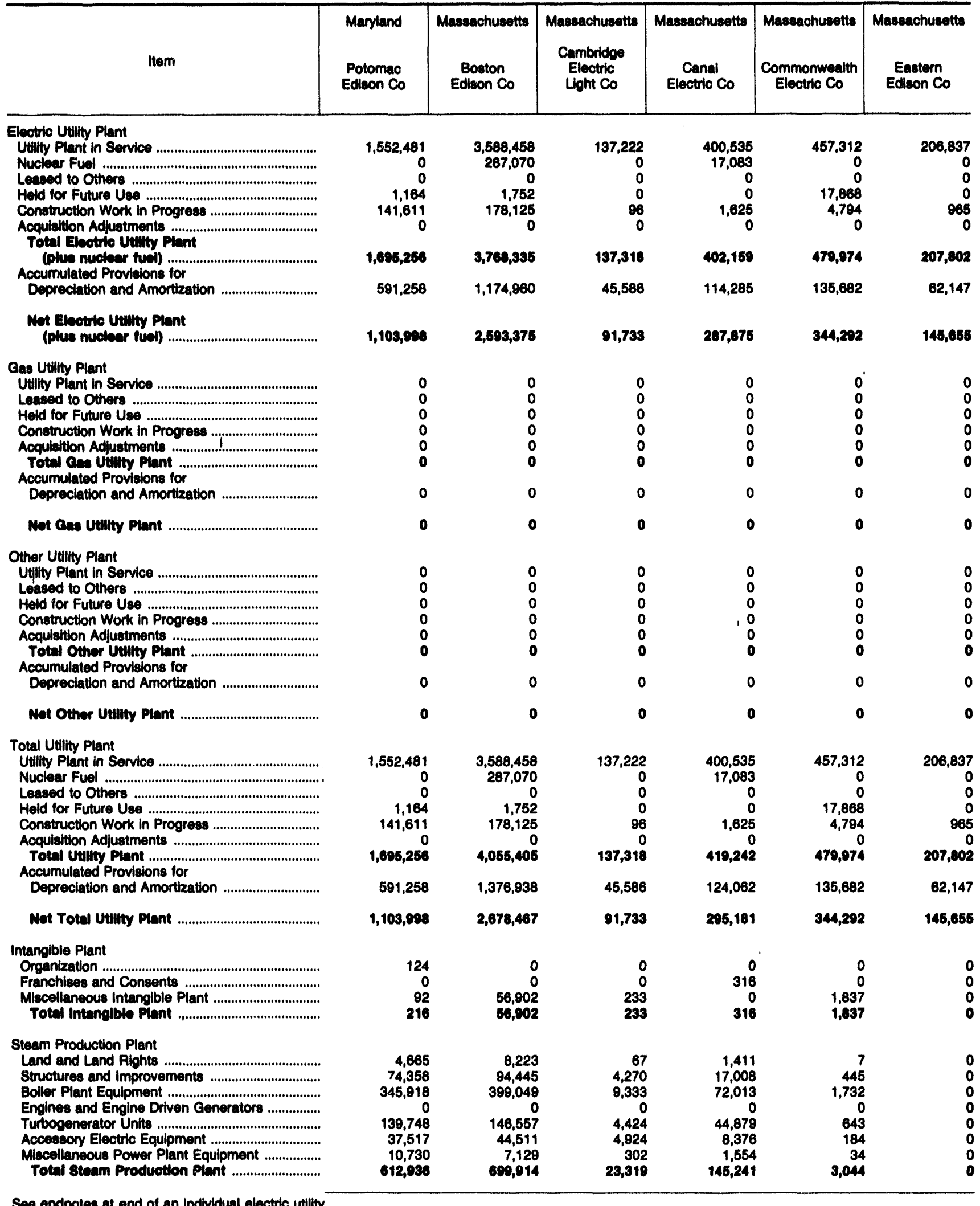


Table 42. Utility Plant by Major U.S. Inveator-Owned Electric Utility Within State on December 31, 1992 (Continued)

(Thousand Dollars)

\begin{tabular}{|c|c|c|c|c|c|c|}
\hline Item & $\begin{array}{l}\text { Maryland } \\
\text { Potomec } \\
\text { Edteon Co }\end{array}$ & $\begin{array}{l}\text { Masasechusetts } \\
\text { Boston } \\
\text { Edison Co }\end{array}$ & $\begin{array}{c}\text { Masenchusetts } \\
\text { Cambridge } \\
\text { Electric } \\
\text { Uoht Co }\end{array}$ & $\begin{array}{c}\text { Maseachusetts } \\
\text { Canal } \\
\text { Electric Co }\end{array}$ & $\begin{array}{c}\text { Massachusetts } \\
\text { Commonwealth } \\
\text { Electric Co }\end{array}$ & $\begin{array}{l}\text { Masaachusetts } \\
\text { Eastom } \\
\text { Edison Co }\end{array}$ \\
\hline 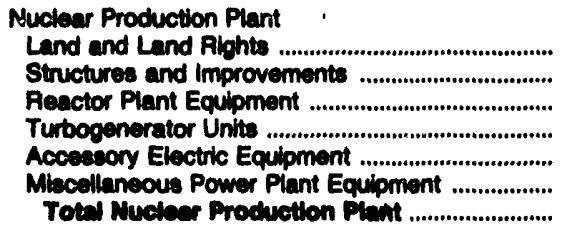 & $\begin{array}{l}0 \\
0 \\
0 \\
0 \\
0 \\
0 \\
0\end{array}$ & $\begin{array}{r}6,707 \\
211,050 \\
658,173 \\
82,686 \\
81,510 \\
135,500 \\
1,070,613\end{array}$ & $\begin{array}{l}0 \\
0 \\
0 \\
0 \\
0 \\
0 \\
0\end{array}$ & $\begin{array}{r}58 \\
74,344 \\
103,497 \\
16,841 \\
24,920 \\
7,835 \\
227,504\end{array}$ & $\begin{array}{l}0 . \\
0 \\
0 \\
0 \\
0 \\
0 \\
0\end{array}$ & $\begin{array}{l}0 \\
0 \\
0 \\
0 \\
0 \\
0 \\
0\end{array}$ \\
\hline 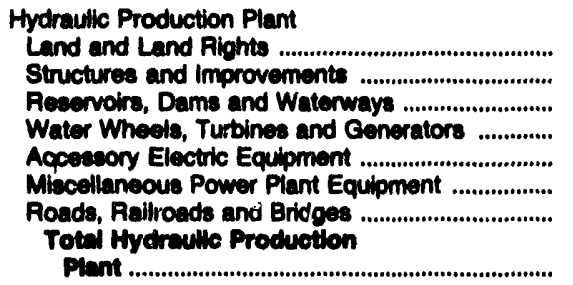 & $\begin{array}{r}121 \\
3,180 \\
4,475 \\
2,284 \\
615 \\
178 \\
0 \\
10,812\end{array}$ & $\begin{array}{l}0 \\
0 \\
0 \\
0 \\
0 \\
0 \\
0\end{array}$ & $\begin{array}{l}0 \\
0 \\
0 \\
0 \\
0 \\
0 \\
0\end{array}$ & $\begin{array}{l}0 \\
0 \\
0 \\
0 \\
0 \\
0 \\
0 \\
0\end{array}$ & $\begin{array}{l}0 \\
0 \\
0 \\
0 \\
0 \\
0 \\
0\end{array}$ & $\begin{array}{l}0 \\
0 \\
0 \\
0 \\
0 \\
0 \\
0\end{array}$ \\
\hline 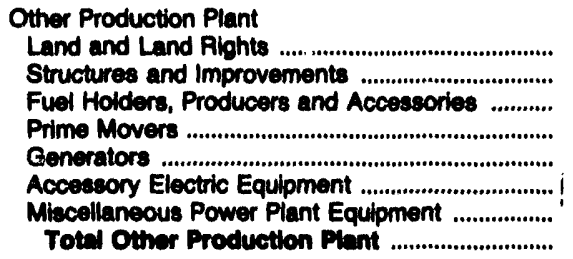 & $\begin{array}{l}0 \\
0 \\
0 \\
0 \\
0 \\
0 \\
0 \\
0\end{array}$ & $\begin{array}{r}37 \\
2,695 \\
1,237 \\
24,590 \\
4,911 \\
4,979 \\
1,092 \\
30,541\end{array}$ & $\begin{array}{r}29 \\
73 \\
148 \\
2,121 \\
1,684 \\
215 \\
13 \\
4,243\end{array}$ & $\begin{array}{l}0 \\
0 \\
0 \\
0 \\
0 \\
0 \\
0 \\
0\end{array}$ & $\begin{array}{r}0 \\
33 \\
147 \\
1,014 \\
382 \\
75 \\
15 \\
1,086\end{array}$ & $\begin{array}{l}0 \\
0 \\
0 \\
0 \\
0 \\
0 \\
0 \\
0\end{array}$ \\
\hline Total Producten Piant .......................................... & 628,740 & $1,810,068$ & 27,692 & 372,835 & 4,710 & $\mathbf{0}$ \\
\hline 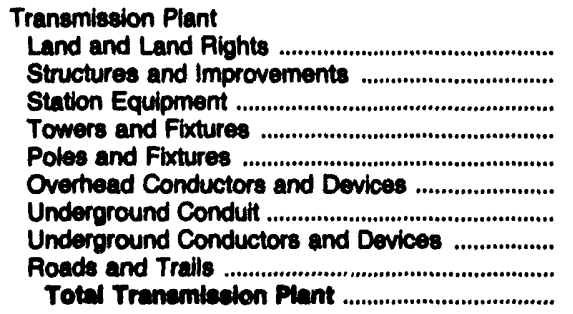 & $\begin{array}{r}27,570 \\
3,693 \\
111,646 \\
17,470 \\
39,947 \\
50,746 \\
0 \\
0 \\
0 \\
251,070\end{array}$ & $\begin{array}{r}11,819 \\
37,889 \\
132,890 \\
29,462 \\
8,282 \\
20,622 \\
8,203 \\
128,809 \\
870 \\
378,039\end{array}$ & $\begin{array}{r}315 \\
4,927 \\
6,143 \\
0 \\
37 \\
0 \\
6,154 \\
5,463 \\
0 \\
28,089\end{array}$ & $\begin{array}{r}7 \\
210 \\
0,123 \\
0 \\
0 \\
0 \\
0 \\
0 \\
0 \\
0,340\end{array}$ & $\begin{array}{r}4,260 \\
1,461 \\
48,413 \\
3,911 \\
20,151 \\
13,199 \\
559 \\
509 \\
899 \\
08,481\end{array}$ & $\begin{array}{r}381 \\
136 \\
6,301 \\
221 \\
3,210 \\
2,255 \\
0 \\
0 \\
101 \\
12,604\end{array}$ \\
\hline 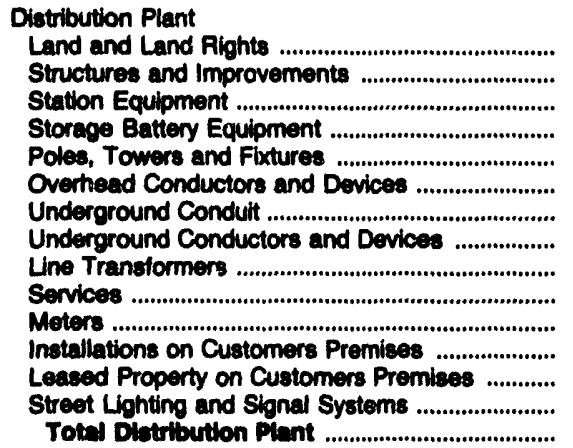 & $\begin{array}{r}7,337 \\
2,893 \\
95,163 \\
0 \\
106,463 \\
101,843 \\
21,544 \\
67,301 \\
127,803 \\
45,829 \\
30,045 \\
0 \\
0 \\
9,115 \\
814,980\end{array}$ & $\begin{array}{r}8,773 \\
34,542 \\
174,819 \\
0 \\
53,408 \\
155,858 \\
101,393 \\
355,481 \\
170,003 \\
81,322 \\
53,119 \\
0 \\
0 \\
39,636 \\
1,220,363\end{array}$ & $\begin{array}{r}257 \\
2,585 \\
24,111 \\
0 \\
1,687 \\
4,284 \\
14,206 \\
24,042 \\
2,589 \\
3,334 \\
4,447 \\
0 \\
0 \\
2,984 \\
84,468\end{array}$ & $\begin{array}{l}0 \\
0 \\
0 \\
0 \\
0 \\
0 \\
0 \\
0 \\
0 \\
0 \\
0 \\
0 \\
0 \\
0 \\
0\end{array}$ & $\begin{array}{r}2,359 \\
294 \\
9,168 \\
0 \\
58,494 \\
76,172 \\
15,996 \\
45,505 \\
56,394 \\
30,513 \\
22,193 \\
0 \\
0 \\
10,007 \\
327,003\end{array}$ & $\begin{array}{r}2,038 \\
1,453 \\
17,461 \\
0 \\
30,340 \\
34,330 \\
8,464 \\
20,921 \\
33,731 \\
12,727 \\
11,588 \\
0 \\
0 \\
8,038 \\
181,030\end{array}$ \\
\hline
\end{tabular}


Table 42. Utility Plant by Major U.S. Inveator-Owned Electric Utility Within State on Decombor 31, 1902 (Continued) (Thousand Dollars)

\begin{tabular}{|c|c|c|c|c|c|c|}
\hline Item & $\begin{array}{l}\text { Maryland } \\
\text { Potomac } \\
\text { Edison Co }\end{array}$ & $\begin{array}{l}\text { Masanchusetts } \\
\text { Boston } \\
\text { Edison Co }\end{array}$ & Maseachusetts & $\begin{array}{l}\text { Massachusetts } \\
\text { Canal } \\
\text { Electric Co }\end{array}$ & $\begin{array}{l}\text { Massachusetts } \\
\text { Commonwealth } \\
\text { Electric Co }\end{array}$ & $\begin{array}{l}\text { Massachusetts } \\
\text { Eastern } \\
\text { Edison Co }\end{array}$ \\
\hline 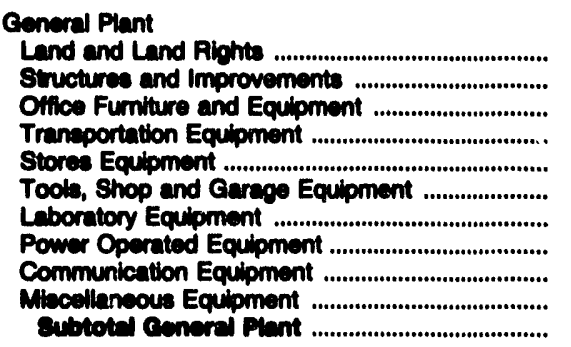 & $\begin{array}{r}1,753 \\
30,771 \\
7,024 \\
7,863 \\
1,014 \\
2,573 \\
1,845 \\
589 \\
9,013 \\
68 \\
62,512\end{array}$ & $\begin{array}{r}1,179 \\
46,091 \\
41,032 \\
1 \\
1,861 \\
7,587 \\
8,380 \\
0 \\
9,217 \\
259 \\
116,006\end{array}$ & $\begin{array}{r}64 \\
806 \\
195 \\
22 \\
18 \\
413 \\
123 \\
0 \\
97 \\
65 \\
1,004\end{array}$ & $\begin{array}{r}0 \\
998 \\
1,833 \\
108 \\
15 \\
0 \\
12 \\
75 \\
5 \\
130 \\
3,166\end{array}$ & $\begin{array}{r}1,259 \\
22,615 \\
1,249 \\
15 \\
315 \\
3,072 \\
481 \\
43 \\
616 \\
646 \\
30,211\end{array}$ & $\begin{array}{r}998 \\
8,858 \\
856 \\
11 \\
151 \\
744 \\
434 \\
11 \\
647 \\
504 \\
13,102\end{array}$ \\
\hline 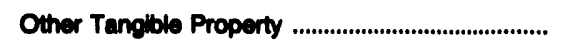 & 0 & $-2,508$ & 0 & 14,868 & 0 & 42 \\
\hline Toted Conerel Plant ..............................................' & 82,612 & 114,008 & 1,004 & 18,034 & 30,211 & 13,144 \\
\hline $\begin{array}{l}\text { Electric Plant Purchased and Sold (net) ................... } \\
\text { Experimental Electric Plant Unclaesified ................ }\end{array}$ & $\begin{array}{l}0 \\
0\end{array}$ & $\begin{array}{l}0 \\
0\end{array}$ & $\begin{array}{l}0 \\
0\end{array}$ & $\begin{array}{l}0 \\
0\end{array}$ & $\begin{array}{l}0 \\
0\end{array}$ & $\begin{array}{l}\mathbf{0} \\
0\end{array}$ \\
\hline Total Electric Utinty Plant in Servico ............... & $1,552,401$ & $3,680,468$ & 137,222 & 400,535 & 457,312 & 206,037 \\
\hline 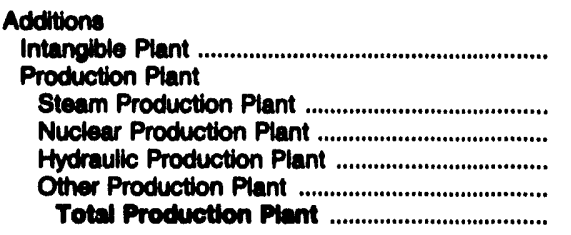 & $\begin{array}{r}18,568 \\
0 \\
1,381 \\
0 \\
19,980\end{array}$ & $\begin{array}{r}2,487 \\
\\
19,560 \\
17,450 \\
0 \\
747 \\
37,768\end{array}$ & $\begin{array}{r}584 \\
0 \\
0 \\
127 \\
712\end{array}$ & $\begin{array}{r}0 \\
4,069 \\
470 \\
0 \\
0 \\
4,530\end{array}$ & $\begin{array}{r}0 \\
72 \\
0 \\
0 \\
0 \\
72\end{array}$ & $\begin{array}{l}0 \\
0 \\
0 \\
0 \\
0\end{array}$ \\
\hline 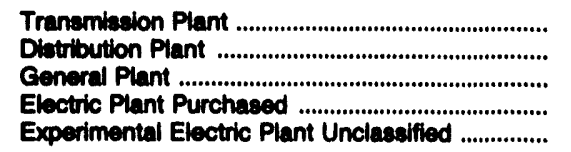 & $\begin{array}{r}5,882 \\
46,316 \\
8,071 \\
0 \\
0\end{array}$ & $\begin{array}{r}2,915 \\
66,897 \\
9,221 \\
0 \\
0\end{array}$ & $\begin{array}{r}0 \\
3,399 \\
36 \\
0 \\
0\end{array}$ & $\begin{array}{r}188 \\
0 \\
20 \\
0 \\
0\end{array}$ & $\begin{array}{r}9,477 \\
17,109 \\
353 \\
0 \\
0\end{array}$ & $\begin{array}{r}181 \\
9,000 \\
89 \\
0 \\
0\end{array}$ \\
\hline Total Electric Plant Additions ............................... & 80,210 & 110,287 & 4,147 & 4,747 & 27,011 & 9,271 \\
\hline 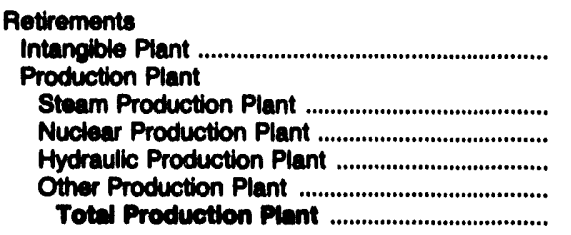 & $\begin{array}{r}2,988 \\
0 \\
4 \\
0 \\
2,902\end{array}$ & $\begin{array}{r}2,411 \\
12,140 \\
1,199 \\
0 \\
1,576 \\
14,914\end{array}$ & $\begin{array}{r}136 \\
0 \\
0 \\
30 \\
168\end{array}$ & $\begin{array}{r}0 \\
1,544 \\
150 \\
0 \\
0 \\
1,003\end{array}$ & $\begin{array}{l}0 \\
1 \\
0 \\
0 \\
0 \\
1\end{array}$ & $\begin{array}{l}0 \\
0 \\
0 \\
0 \\
0\end{array}$ \\
\hline 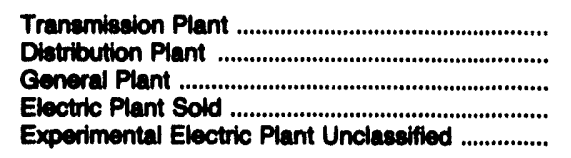 & $\begin{array}{r}341 \\
3,741 \\
122 \\
0 \\
0\end{array}$ & $\begin{array}{r}256 \\
15,143 \\
1,313 \\
0 \\
0\end{array}$ & $\begin{array}{r}0 \\
742 \\
6 \\
0 \\
0\end{array}$ & $\begin{array}{r}30 \\
0 \\
1 \\
0 \\
0\end{array}$ & $\begin{array}{r}1,048 \\
3,495 \\
91 \\
0 \\
0\end{array}$ & $\begin{array}{r}8 \\
6,270 \\
12 \\
0 \\
0\end{array}$ \\
\hline 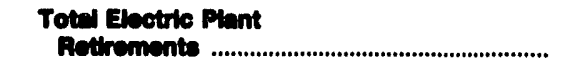 & 7,106 & 34,036 & 913 & 1,724 & 4,635 & 6,240 \\
\hline
\end{tabular}

Note: Totals may not equal sum of components because of independent rounding. Summary data are provided in Table 28. Source: Federal Energy Regulatory Commiselon, FERC Form 1, "Annual Report of Major Electric Utilities, Llcensees and Others." 
Table 42. Utility Plant by Major U.S. Inveator-Owned Electric Utillity Within State on December 31, 1992 (Continued)

(Thousand Dollars)

\begin{tabular}{|c|c|c|c|c|c|c|}
\hline Item & $\begin{array}{l}\text { Masasachusetts } \\
\text { Fitchburg } \\
\text { Gas \& } \\
\text { Elec Light Co }\end{array}$ & $\begin{array}{c}\text { Maseachusetts } \\
\text { Holyoke } \\
\text { Power } \\
\& \\
\text { Electric Co }\end{array}$ & $\begin{array}{l}\text { Maseachusetts } \\
\text { Holyoke } \\
\text { Water } \\
\text { Power } \\
\text { Co }\end{array}$ & $\begin{array}{l}\text { Massachusetts } \\
\text { Massachusetts } \\
\text { Electric Co }\end{array}$ & $\begin{array}{l}\text { Maseachuaretts } \\
\text { Montaup } \\
\text { Electric Co }\end{array}$ & $\begin{array}{l}\text { Masaschusetts } \\
\text { New England } \\
\text { Hydro- } \\
\text { Tran } \\
\text { Elec Co }\end{array}$ \\
\hline 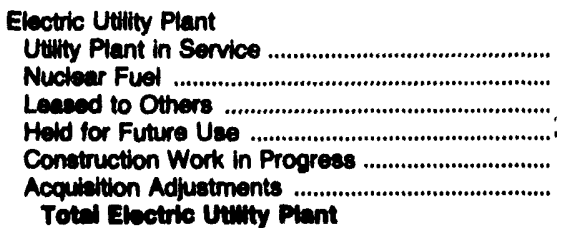 & $\begin{array}{r}56,935 \\
282 \\
0 \\
27 \\
-60 \\
168\end{array}$ & $\begin{array}{r}1,433 \\
0 \\
0 \\
0 \\
4 \\
0\end{array}$ & $\begin{array}{r}85,807 \\
0 \\
0 \\
0 \\
3,512 \\
0\end{array}$ & $\begin{array}{r}1,222,321 \\
0 \\
0 \\
785 \\
14,376 \\
0\end{array}$ & $\begin{array}{r}548,417 \\
21,261 \\
0 \\
604 \\
2,210 \\
0\end{array}$ & $\begin{array}{r}212,228 \\
0 \\
0 \\
0 \\
0 \\
0\end{array}$ \\
\hline 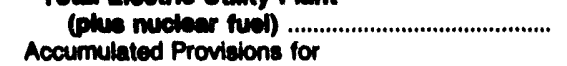 & 57,071 & 1,437 & 89,318 & $1,237,402$ & 681,232 & 212,228 \\
\hline Depreciation and Amortization ............................... & 19,233 & 791 & 36,003 & 331,842 & 137,477 & 17,866 \\
\hline $\begin{array}{l}\text { Not Electrle Utilty Plant } \\
\text { (plus nuckear fuel) ............................................ }\end{array}$ & 37,838 & 646 & 63,316 & 805,641 & 413,766 & 104,262 \\
\hline 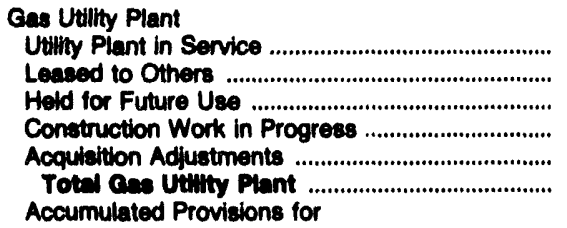 & $\begin{array}{r}22,320 \\
0 \\
0 \\
58 \\
0 \\
22,370\end{array}$ & $\begin{array}{l}0 \\
0 \\
0 \\
0 \\
0 \\
0\end{array}$ & $\begin{array}{l}0 \\
0 \\
0 \\
0 \\
0 \\
0\end{array}$ & $\begin{array}{l}0 \\
0 \\
0 \\
0 \\
0 \\
0\end{array}$ & $\begin{array}{l}0 \\
0 \\
0 \\
0 \\
0 \\
0\end{array}$ & $\begin{array}{l}0 \\
0 \\
0 \\
0 \\
0 \\
0\end{array}$ \\
\hline 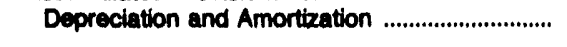 & 4,752 & 0 & 0 & 0 & 0 & 0 \\
\hline 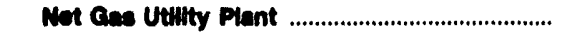 & 17,626 & o & 0 & $\mathbf{0}$ & 0 & 0 \\
\hline 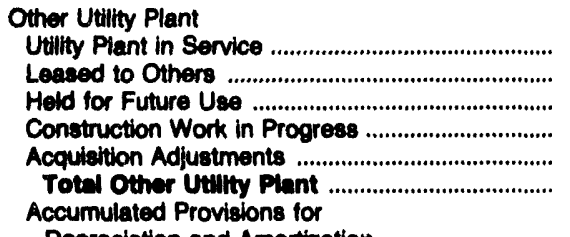 & $\begin{array}{r}4,612 \\
0 \\
0 \\
617 \\
0 \\
5,220\end{array}$ & $\begin{array}{l}0 \\
0 \\
0 \\
0 \\
0 \\
0\end{array}$ & $\begin{array}{l}0 \\
0 \\
0 \\
0 \\
0 \\
0\end{array}$ & $\begin{array}{l}0 \\
0 \\
0 \\
0 \\
0 \\
0\end{array}$ & $\begin{array}{l}0 \\
0 \\
0 \\
0 \\
0 \\
0\end{array}$ & $\begin{array}{l}0 \\
0 \\
0 \\
0 \\
0 \\
0\end{array}$ \\
\hline 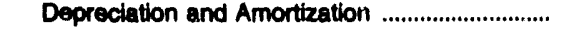 & 462 & 0 & 0 & 0 & 0 & 0 \\
\hline 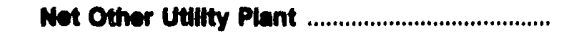 & 4,768 & $\mathbf{0}$ & 0 & $\mathbf{0}$ & 0 & 0 \\
\hline 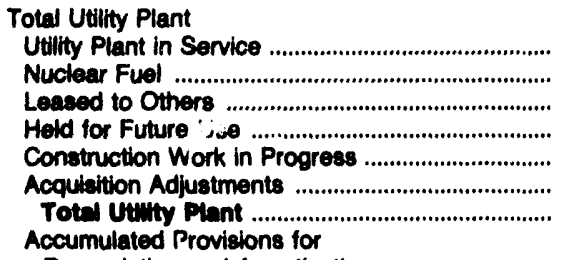 & $\begin{array}{r}83,868 \\
282 \\
0 \\
27 \\
616 \\
616 \\
168 \\
\mathbf{9 4 , 9 2 0}\end{array}$ & $\begin{array}{r}1,433 \\
0 \\
0 \\
0 \\
4 \\
0 \\
1,437\end{array}$ & $\begin{array}{r}85,807 \\
0 \\
0 \\
0 \\
0,512 \\
0 \\
89,318\end{array}$ & $\begin{array}{r}1,222,321 \\
0 \\
0 \\
785 \\
14,376 \\
0 \\
1,237,492\end{array}$ & $\begin{array}{r}548,417 \\
21,261 \\
0 \\
604 \\
2,210 \\
0 \\
572,403\end{array}$ & $\begin{array}{r}212,228 \\
0 \\
0 \\
0 \\
0 \\
0 \\
212,228\end{array}$ \\
\hline 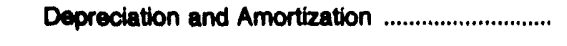 & 24,565 & 791 & 36,003 & 331,842 & 147,227 & 17,866 \\
\hline 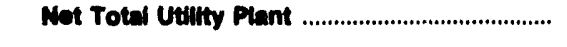 & 60,396 & 646 & 53,316 & 005,541 & 426,266 & 194,202 \\
\hline 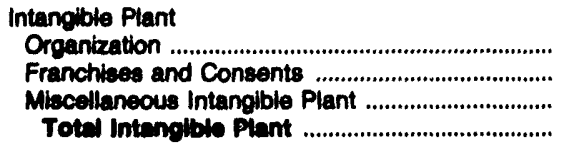 & $\begin{array}{l}0 \\
0 \\
0 \\
0\end{array}$ & $\begin{array}{l}0 \\
0 \\
0 \\
0\end{array}$ & $\begin{array}{l}0 \\
0 \\
0 \\
0\end{array}$ & $\begin{array}{l}0 \\
0 \\
0 \\
0\end{array}$ & $\begin{array}{r}0 \\
273 \\
0 \\
273\end{array}$ & $\begin{array}{r}0 \\
0 \\
702 \\
702\end{array}$ \\
\hline 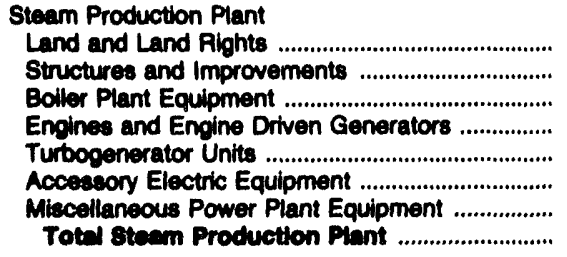 & $\begin{array}{r}185 \\
961 \\
4,004 \\
0 \\
1,681 \\
666 \\
99 \\
7,586\end{array}$ & $\begin{array}{l}0 \\
0 \\
0 \\
0 \\
0 \\
0 \\
0 \\
0\end{array}$ & $\begin{array}{r}170 \\
6,105 \\
12,307 \\
0 \\
7,460 \\
1,984 \\
1,102 \\
29,120\end{array}$ & $\begin{array}{l}0 \\
0 \\
0 \\
0 \\
0 \\
0 \\
0 \\
0\end{array}$ & $\begin{array}{r}658 \\
24,058 \\
56,704 \\
0 \\
32,992 \\
6,613 \\
1,353 \\
124,377\end{array}$ & $\begin{array}{l}0 \\
0 \\
0 \\
0 \\
0 \\
0 \\
0 \\
0\end{array}$ \\
\hline
\end{tabular}

See endnotes at end of an individual electric utility. 
Table 42. Utility Plant by Major U.S. Inveator-Owned Electric Utility Within State on December 31, 1982 (Continued) (Thousand Dollars)

\begin{tabular}{|c|c|c|c|c|c|c|}
\hline Item & $\begin{array}{c}\text { Maseachusetts } \\
\text { Fitchburg } \\
\text { Gas \& } \\
\text { Elec Lught Co }\end{array}$ & $\begin{array}{c}\text { Massachusetts } \\
\text { Holyoke } \\
\text { Power } \\
2 \\
\text { Electric Co } \\
\end{array}$ & $\begin{array}{c}\text { Maseachusetts } \\
\text { Holyoke } \\
\text { Water } \\
\text { Power } \\
\text { Co } \\
\end{array}$ & $\begin{array}{l}\text { Maseachusetts } \\
\text { Maseachusetts } \\
\text { Electric Co }\end{array}$ & $\begin{array}{l}\text { Massachusetts } \\
\text { Montaup } \\
\text { Electric Co }\end{array}$ & $\begin{array}{l}\text { Maseachusetts } \\
\text { New England } \\
\text { Hydro- } \\
\text { Tran } \\
\text { Elec Co }\end{array}$ \\
\hline 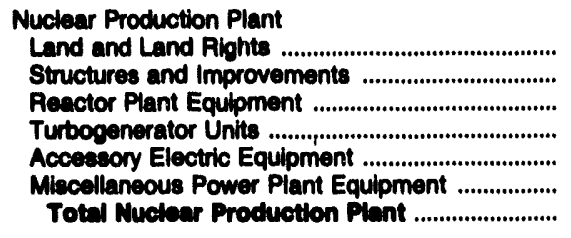 & $\begin{array}{r}3 \\
3,955 \\
4,718 \\
1,419 \\
1,025 \\
249 \\
11,360\end{array}$ & $\begin{array}{l}0 \\
0 \\
0 \\
0 \\
0 \\
0 \\
0\end{array}$ & $\begin{array}{l}0 \\
0 \\
0 \\
0 \\
0 \\
0 \\
0\end{array}$ & $\begin{array}{l}0 \\
0 \\
0 \\
0 \\
0 \\
0 \\
0\end{array}$ & $\begin{array}{r}144 \\
110,825 \\
172,820 \\
35,227 \\
37,554 \\
10,523 \\
\mathbf{3 6 7 , 1 9 3}\end{array}$ & $\begin{array}{l}0 \\
0 \\
0 \\
0 \\
0 \\
0 \\
0\end{array}$ \\
\hline 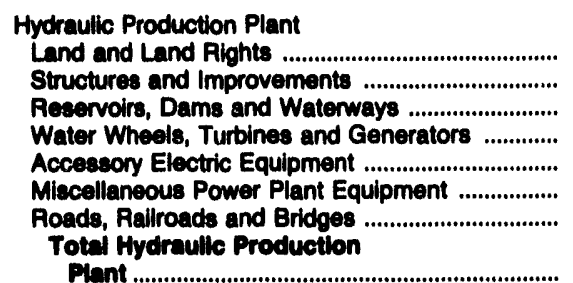 & $\begin{array}{l}0 \\
0 \\
0 \\
0 \\
0 \\
0 \\
0\end{array}$ & $\begin{array}{l}0 \\
0 \\
0 \\
0 \\
0 \\
0 \\
0 \\
0\end{array}$ & $\begin{array}{r}148 \\
9,508 \\
17,146 \\
14,316 \\
4,050 \\
772 \\
104 \\
46,043\end{array}$ & $\begin{array}{l}0 \\
0 \\
0 \\
0 \\
0 \\
0 \\
0\end{array}$ & $\begin{array}{l}0 \\
0 \\
0 \\
0 \\
0 \\
0 \\
0\end{array}$ & $\begin{array}{l}0 \\
0 \\
0 \\
0 \\
0 \\
0 \\
0\end{array}$ \\
\hline Plant & 0 & 0 & 46,043 & $\mathbf{0}$ & 0 & $\mathbf{0}$ \\
\hline 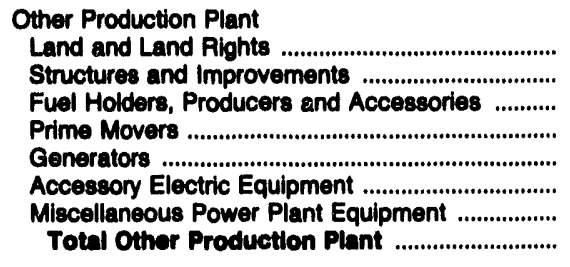 & $\begin{array}{r}0 \\
0 \\
351 \\
2,355 \\
0 \\
0 \\
0 \\
2,705\end{array}$ & $\begin{array}{l}0 \\
0 \\
0 \\
0 \\
0 \\
0 \\
0 \\
0\end{array}$ & $\begin{array}{l}0 \\
0 \\
0 \\
0 \\
0 \\
0 \\
0 \\
0\end{array}$ & $\begin{array}{l}0 \\
0 \\
0 \\
0 \\
0 \\
0 \\
0 \\
0\end{array}$ & $\begin{array}{r}0 \\
21 \\
224 \\
2,057 \\
1,074 \\
286 \\
9 \\
4,572\end{array}$ & $\begin{array}{l}0 \\
0 \\
0 \\
0 \\
0 \\
0 \\
0 \\
0\end{array}$ \\
\hline Total Production Plant ........................................... & 21,681 & $\mathbf{0}$ & 75,172 & o & 496,143 & $\mathbf{0}$ \\
\hline 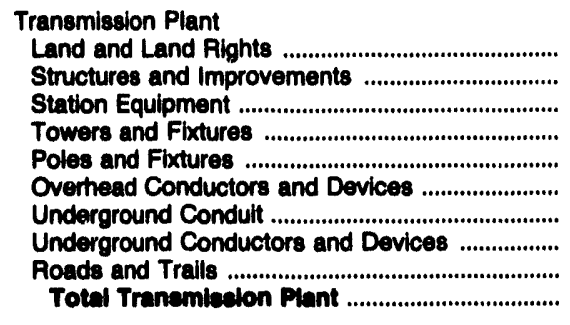 & $\begin{array}{r}691 \\
92 \\
4,634 \\
-288 \\
1,826 \\
1,072 \\
8 \\
249 \\
10 \\
0,205\end{array}$ & $\begin{array}{r}222 \\
0 \\
0 \\
147 \\
300 \\
413 \\
0 \\
0 \\
0 \\
1,002\end{array}$ & $\begin{array}{r}0 \\
246 \\
3,644 \\
0 \\
0 \\
0 \\
0 \\
0 \\
0 \\
3,091\end{array}$ & $\begin{array}{r}715 \\
0 \\
469 \\
0 \\
2,332 \\
1,896 \\
190 \\
530 \\
43 \\
6,175\end{array}$ & $\begin{array}{r}2,905 \\
1,981 \\
27,879 \\
6,127 \\
1,867 \\
4,216 \\
0 \\
0 \\
1,010 \\
46,086\end{array}$ & $\begin{array}{r}2,302 \\
37,660 \\
154,825 \\
0 \\
10,461 \\
6,277 \\
0 \\
0 \\
0 \\
211,626\end{array}$ \\
\hline 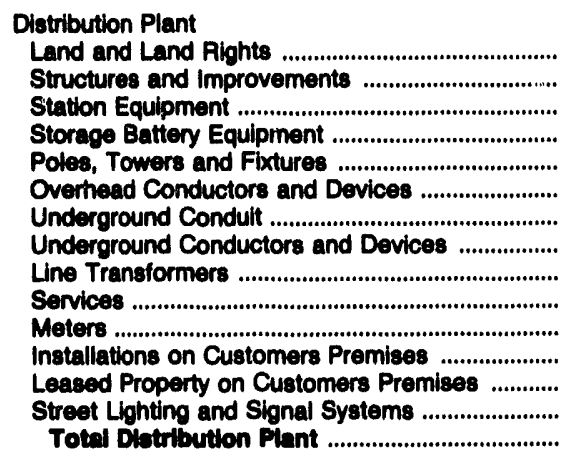 & $\begin{array}{r}65 \\
891 \\
3,302 \\
0 \\
3,744 \\
5,573 \\
780 \\
1,938 \\
4,408 \\
1,853 \\
2,189 \\
648 \\
143 \\
778 \\
28,323\end{array}$ & $\begin{array}{r}16 \\
0 \\
335 \\
0 \\
0 \\
0 \\
0 \\
0 \\
0 \\
0 \\
0 \\
0 \\
0 \\
0 \\
351\end{array}$ & $\begin{array}{r}11 \\
1 \\
873 \\
0 \\
869 \\
1,310 \\
194 \\
435 \\
852 \\
132 \\
389 \\
43 \\
0 \\
0 \\
5,100\end{array}$ & $\begin{array}{r}9,725 \\
7,837 \\
117,564 \\
0 \\
0 \\
186,490 \\
292,638 \\
60,501 \\
114,103 \\
176,391 \\
66,490 \\
61,871 \\
0 \\
17,530 \\
70,448 \\
1,181,608\end{array}$ & $\begin{array}{l}0 \\
0 \\
0 \\
0 \\
0 \\
0 \\
0 \\
0 \\
0 \\
0 \\
0 \\
0 \\
0 \\
0 \\
0\end{array}$ & $\begin{array}{l}0 \\
0 \\
0 \\
0 \\
0 \\
0 \\
0 \\
0 \\
0 \\
0 \\
0 \\
0 \\
0 \\
0 \\
0\end{array}$ \\
\hline
\end{tabular}

See endnotes at end of an individual electric utility. 
Table 42. Utility Plant by Major U.S. Inveator-Owned Electric Utility Within State on December 31, 1992 (Continued) (Thousand Dollars)

\begin{tabular}{|c|c|c|c|c|c|c|}
\hline Item & $\begin{array}{l}\text { Maseachusetts } \\
\text { Fitchburg } \\
\text { Gas \& } \\
\text { Elec Light Co }\end{array}$ & $\begin{array}{c}\text { Massachusetts } \\
\text { Holyoke } \\
\text { Power } \\
\& \\
\text { Electric Co }\end{array}$ & $\begin{array}{c}\text { Maseachusetts } \\
\text { Holyoke } \\
\text { Water } \\
\text { Power } \\
\text { Co }\end{array}$ & $\begin{array}{l}\text { Massachusetts } \\
\text { Massachusetts } \\
\text { Electric Co }\end{array}$ & $\begin{array}{l}\text { Massachusetts } \\
\text { Montaup } \\
\text { Electric Co }\end{array}$ & $\begin{array}{c}\text { Massachusetts } \\
\text { New England } \\
\text { Hydro- } \\
\text { Tran } \\
\text { Eloc Co }\end{array}$ \\
\hline 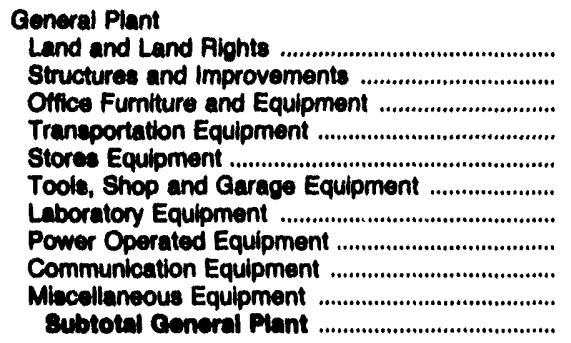 & $\begin{array}{r}0 \\
2,092 \\
40 \\
328 \\
0 \\
55 \\
52 \\
15 \\
0 \\
36 \\
2,610\end{array}$ & $\begin{array}{l}0 \\
0 \\
0 \\
0 \\
0 \\
0 \\
0 \\
0 \\
0 \\
0 \\
0\end{array}$ & $\begin{array}{r}146 \\
708 \\
184 \\
0 \\
113 \\
154 \\
31 \\
0 \\
241 \\
27 \\
1,603\end{array}$ & $\begin{array}{r}815 \\
20,050 \\
1,679 \\
0 \\
1,606 \\
6,060 \\
1,862 \\
0 \\
2,234 \\
372 \\
34,680\end{array}$ & $\begin{array}{r}0 \\
2,456 \\
1,851 \\
70 \\
100 \\
624 \\
219 \\
0 \\
482 \\
106 \\
6,017\end{array}$ & $\begin{array}{l}0 \\
0 \\
0 \\
0 \\
0 \\
0 \\
0 \\
0 \\
0 \\
0 \\
0\end{array}$ \\
\hline 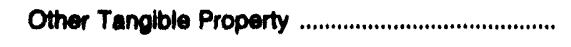 & $-1,861$ & $\mathbf{0}$ & 34 & 0 & 0 & 0 \\
\hline 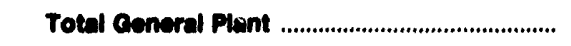 & 657 & $\mathbf{0}$ & 1,030 & 34,680 & 5,017 & $\mathbf{0}$ \\
\hline $\begin{array}{c}\text { Electric Plant Purchased and Sold (net) ................... } \\
\text { Experimental Electric Plant Unclaselfied ............... }\end{array}$ & $\begin{array}{l}0 \\
0\end{array}$ & $\begin{array}{l}0 \\
0\end{array}$ & $\begin{array}{l}0 \\
0\end{array}$ & $\begin{array}{l}0 \\
0\end{array}$ & $\begin{array}{l}0 \\
0\end{array}$ & $\begin{array}{l}0 \\
0\end{array}$ \\
\hline Total Electric Utillty Plant in service .............. & 88,935 & 1,433 & 85,807 & $1,222,321$ & 840,417 & 212,228 \\
\hline 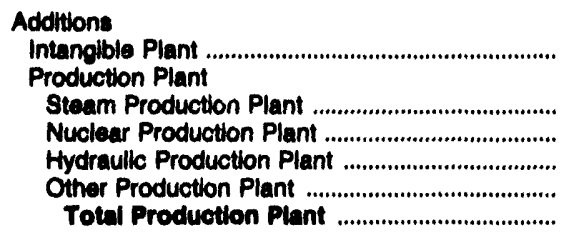 & $\begin{array}{r}-287 \\
13 \\
0 \\
538 \\
284\end{array}$ & $\begin{array}{l}0 \\
0 \\
0 \\
0 \\
0\end{array}$ & $\begin{array}{r}162 \\
0 \\
6,032 \\
0 \\
6,194\end{array}$ & $\begin{array}{l}0 \\
0 \\
0 \\
0 \\
0\end{array}$ & $\begin{array}{r}0 \\
2,409 \\
654 \\
0 \\
7 \\
3,070\end{array}$ & $\begin{array}{l}0 \\
0 \\
0 \\
0 \\
0 \\
0\end{array}$ \\
\hline 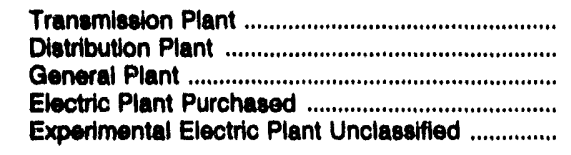 & $\begin{array}{r}-65 \\
2,024 \\
38 \\
0 \\
0\end{array}$ & $\begin{array}{r}0 \\
19 \\
0 \\
0 \\
0\end{array}$ & $\begin{array}{r}10 \\
373 \\
68 \\
0 \\
0\end{array}$ & $\begin{array}{r}1 \\
65,646 \\
2,680 \\
0 \\
0\end{array}$ & $\begin{array}{r}2,660 \\
0 \\
162 \\
0 \\
0\end{array}$ & $\begin{array}{r}2,294 \\
0 \\
0 \\
0 \\
0\end{array}$ \\
\hline Total Eleotric Plant Additions .............................. & 2,261 & 10 & 0,644 & 68,326 & 5,892 & 2,204 \\
\hline 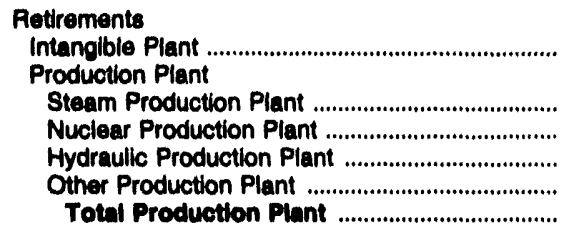 & $\begin{array}{r}100 \\
31 \\
0 \\
10 \\
140\end{array}$ & $\begin{array}{l}0 \\
0 \\
0 \\
0 \\
0\end{array}$ & $\begin{array}{r}66 \\
0 \\
5 \\
0 \\
70\end{array}$ & $\begin{array}{l}0 \\
0 \\
0 \\
0 \\
0\end{array}$ & $\begin{array}{r}371 \\
500 \\
0 \\
0 \\
800\end{array}$ & $\begin{array}{l}0 \\
0 \\
0 \\
0 \\
0 \\
0\end{array}$ \\
\hline 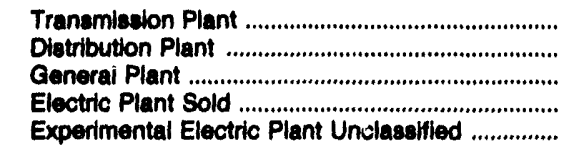 & $\begin{array}{r}317 \\
377 \\
238 \\
0 \\
0\end{array}$ & $\begin{array}{l}0 \\
4 \\
0 \\
0 \\
0\end{array}$ & $\begin{array}{l}1 \\
0 \\
0 \\
0 \\
0\end{array}$ & $\begin{array}{r}0 \\
13,414 \\
591 \\
0 \\
0\end{array}$ & $\begin{array}{r}70 \\
0 \\
8 \\
0 \\
0\end{array}$ & $\begin{array}{l}0 \\
0 \\
0 \\
0 \\
0\end{array}$ \\
\hline $\begin{array}{l}\text { Total Electrle Plant } \\
\text { Petiremonts }\end{array}$ & 1,072 & 4 & 72 & 14,005 & 960 & 0 \\
\hline
\end{tabular}

Note: Totals may not equal sum of components because of independent rounding. Summary data are provided in Table 28.

Source: Federal Energy Regulatory Commission, FERC Form 1. "Annual Report of Major Electric Utilities, Licensees and Others." 
Table 42. Utility Plant by Major U.S. Investor-Owned Electric Utility Within State on December 31, 1992 (Continued)

(Thousand Dollars)

\begin{tabular}{|c|c|c|c|c|c|c|}
\hline Item & $\begin{array}{l}\text { Massachusetts } \\
\text { Now England } \\
\text { Power Co }\end{array}$ & $\begin{array}{l}\text { Massachusetts } \\
\text { Westem } \\
\text { Massachusetts } \\
\text { Elec Co }\end{array}$ & $\begin{array}{l}\text { Michigan } \\
\text { Consumers } \\
\text { Power Co }\end{array}$ & $\begin{array}{l}\text { Michigan } \\
\text { Detrolt } \\
\text { Edison Co }\end{array}$ & $\begin{array}{c}\text { Michigan } \\
\text { Edison } \\
\text { Sault } \\
\text { Electric } \\
\text { Co }\end{array}$ & $\begin{array}{l}\text { Michigan } \\
\text { Upper } \\
\text { Peninsula } \\
\text { Power Co }\end{array}$ \\
\hline 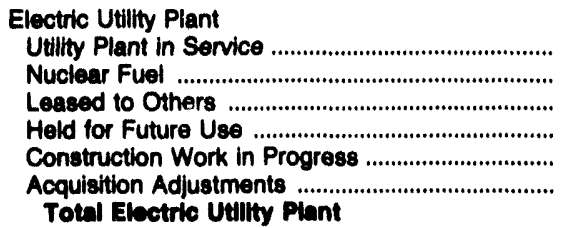 & $\begin{array}{r}2,678,078 \\
45,592 \\
0 \\
7,951 \\
74,640 \\
0\end{array}$ & $\begin{array}{r}1,157,793 \\
168,552 \\
0 \\
368 \\
18,522 \\
0\end{array}$ & $\begin{array}{r}4,703,046 \\
236,581 \\
0 \\
13,150 \\
182,823 \\
0\end{array}$ & $\begin{array}{r}12,389,652 \\
141,646 \\
0 \\
18,716 \\
130,802 \\
0\end{array}$ & $\begin{array}{r}60,980 \\
0 \\
0 \\
0 \\
0 \\
0\end{array}$ & $\begin{array}{r}143,813 \\
0 \\
0 \\
77 \\
4,539 \\
3,576\end{array}$ \\
\hline $\begin{array}{l}\text { (plue nuclear fuel) } \\
\text { Accumulated Provisions for }\end{array}$ & $2,760,668$ & $1,176,692$ & $4,890,110$ & $12,538,970$ & 60,960 & 152,004 \\
\hline 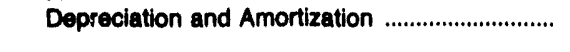 & $1,032,869$ & 364,702 & $1,875,275$ & $3,736,362$ & 21,628 & 57,598 \\
\hline $\begin{array}{l}\text { Not Electrlc Utillty Plant } \\
\text { (plus nuctear fuel) }\end{array}$ & $1,727,690$ & 811,080 & $2,023,843$ & $8,802,608$ & 39,352 & 94,406 \\
\hline 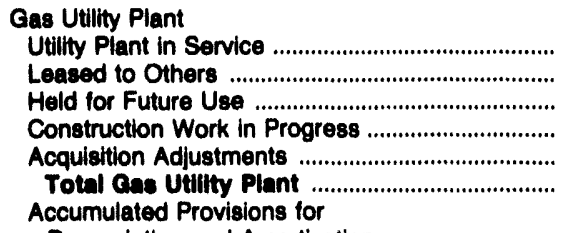 & $\begin{array}{l}0 \\
0 \\
0 \\
0 \\
0 \\
0\end{array}$ & $\begin{array}{l}0 \\
0 \\
0 \\
0 \\
0 \\
0\end{array}$ & $\begin{array}{r}1,517,562 \\
0 \\
142,220 \\
18,936 \\
0 \\
1,678,718\end{array}$ & $\begin{array}{l}0 \\
0 \\
0 \\
0 \\
0 \\
0\end{array}$ & $\begin{array}{l}0 \\
0 \\
0 \\
0 \\
0 \\
0\end{array}$ & $\begin{array}{l}0 \\
0 \\
0 \\
0 \\
0 \\
0\end{array}$ \\
\hline 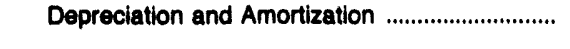 & 0 & 0 & 922,258 & 0 & 0 & 0 \\
\hline 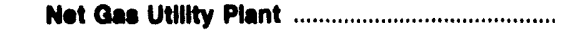 & $\mathbf{0}$ & 0 & 758,460 & 0 & 0 & $\mathbf{0}$ \\
\hline 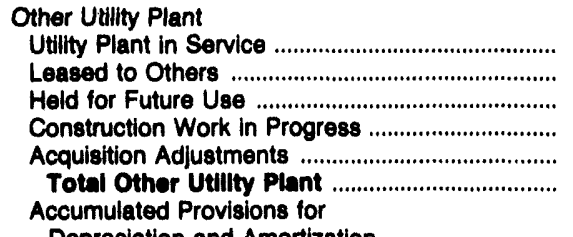 & $\begin{array}{l}0 \\
0 \\
0 \\
0 \\
0 \\
0\end{array}$ & $\begin{array}{l}0 \\
0 \\
0 \\
0 \\
0 \\
0\end{array}$ & $\begin{array}{r}160,229 \\
0 \\
182 \\
42,362 \\
0 \\
202,773\end{array}$ & $\begin{array}{r}68,226 \\
0 \\
0 \\
0 \\
0 \\
68,226\end{array}$ & $\begin{array}{l}0 \\
0 \\
0 \\
0 \\
0 \\
0\end{array}$ & $\begin{array}{l}0 \\
0 \\
0 \\
0 \\
0 \\
0\end{array}$ \\
\hline 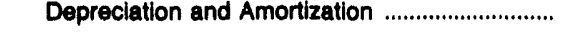 & 0 & 0 & 32,389 & 28,243 & 0 & 0 \\
\hline Not Other Utility Plant & 0 & $\mathbf{0}$ & 170,384 & 39,983 & $\mathbf{0}$ & $\mathbf{0}$ \\
\hline 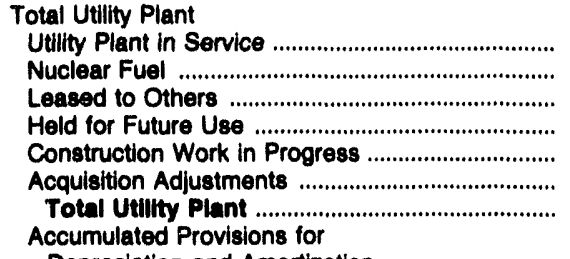 & $\begin{array}{r}2,678,078 \\
45,592 \\
0 \\
0 \\
7,951 \\
74,640 \\
0 \\
2,806,260\end{array}$ & $\begin{array}{r}1,157,793 \\
168,552 \\
0 \\
368 \\
18,522 \\
0 \\
1,345,234\end{array}$ & $\begin{array}{r}6,380,836 \\
236,591 \\
0 \\
0 \\
155,552 \\
244,222 \\
0 \\
0 \\
7,017,201\end{array}$ & $\begin{array}{r}12,457,878 \\
141,646 \\
0 \\
18,716 \\
130,602 \\
0 \\
12,748,042\end{array}$ & $\begin{array}{r}60,980 \\
0 \\
0 \\
0 \\
0 \\
0 \\
60,980\end{array}$ & $\begin{array}{r}143,813 \\
0 \\
0 \\
77 \\
4,539 \\
3,576 \\
152,004\end{array}$ \\
\hline 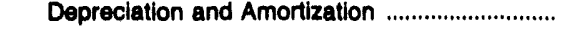 & $1,064,513$ & 525,083 & $3,158,788$ & $3,764,605$ & 21,628 & 57,598 \\
\hline 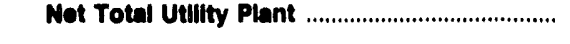 & $1,741,747$ & 820,151 & $3,858,411$ & $8,084,237$ & 39,362 & 94,408 \\
\hline 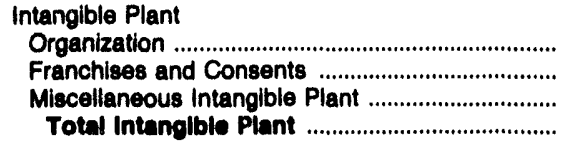 & $\begin{array}{r}21 \\
539 \\
843 \\
1,402\end{array}$ & $\begin{array}{l}0 \\
0 \\
0 \\
0\end{array}$ & $\begin{array}{r}96 \\
531 \\
1,714 \\
2,341\end{array}$ & $\begin{array}{r}0 \\
0 \\
17,287 \\
17,287\end{array}$ & $\begin{array}{r}1 \\
17 \\
0 \\
17\end{array}$ & $\begin{array}{r}2 \\
33 \\
0 \\
35\end{array}$ \\
\hline 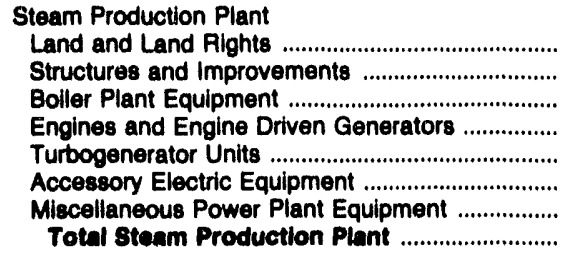 & $\begin{array}{r}2,943 \\
103,525 \\
622,802 \\
0 \\
160,238 \\
75,664 \\
5,278 \\
970,450\end{array}$ & $\begin{array}{r}342 \\
9,255 \\
22,999 \\
0 \\
5,301 \\
5,226 \\
1,550 \\
44,672\end{array}$ & $\begin{array}{r}3,417 \\
347,846 \\
686,366 \\
0 \\
215,005 \\
85,628 \\
14,628 \\
1,382,890\end{array}$ & $\begin{array}{r}13,217 \\
667,530 \\
2,845,559 \\
0 \\
601,939 \\
145,533 \\
18,317 \\
4,292,005\end{array}$ & $\begin{array}{l}0 \\
0 \\
0 \\
0 \\
0 \\
0 \\
0 \\
0\end{array}$ & $\begin{array}{r}12 \\
1,374 \\
3,574 \\
0 \\
1,421 \\
537 \\
192 \\
7,110\end{array}$ \\
\hline
\end{tabular}

See endnotes at end of an individual electric utility. 
Table 42. Utility Plant by Major U.S. Investor-Owned Electrlc UtIlity Within State on December 31, 1992 (Continued) (Thousand Dollars)

\begin{tabular}{|c|c|c|c|c|c|c|}
\hline Item & $\begin{array}{l}\text { Massachusetts } \\
\text { New England } \\
\text { Power Co }\end{array}$ & $\begin{array}{l}\text { Massachusetts } \\
\text { Western } \\
\text { Massachusetts } \\
\text { Eloc Co }\end{array}$ & $\begin{array}{l}\text { Michigan } \\
\text { Consumers } \\
\text { Power Co }\end{array}$ & $\begin{array}{c}\text { Michigan } \\
\text { Detroit } \\
\text { Edison Co }\end{array}$ & $\begin{array}{c}\text { Michigan } \\
\text { Edison } \\
\text { Sault } \\
\text { Electric } \\
\text { Co }\end{array}$ & $\begin{array}{c}\text { Michigan } \\
\text { Upper } \\
\text { Peninsula } \\
\text { Power Co }\end{array}$ \\
\hline
\end{tabular}

Nuclear Production Plant

Land and Land Fights

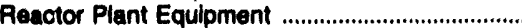

Turtogenerator Units

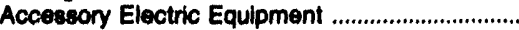

Miecellaneous Power Plant Equipment

Total Nuclear Production Ptent

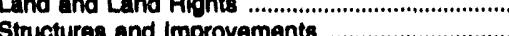

601

259,834

411,113

87,302

87,170

23,475

869,598

Hydraulic Production Plant

Land and Land Pighto

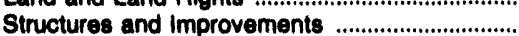

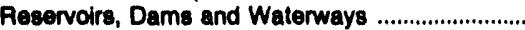

Water Wheels, Turbines and Generators

Accessory Electric Equipment

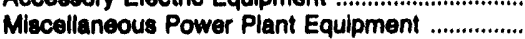

Roads, Railroeds and Bridges

Total Hydraulle Production

Pint

611
153,773
308,649
75,790
49,615
8,466
500,004

\section{2,783}

165,906

334,400

96,852

42,048

22,567

604,657
1,901

673,967

$2,586,698$

270,358

191,785

119,828

$3,844,536$
20,818

35,839

171,043

43,459

18,351

3,638

4,854

298, 102

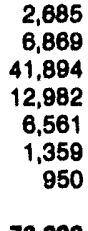

73,290
2,462

19,104

112,632

24,836

6,337

1,461

1,863

188,694

169,366

$\begin{array}{ll}0 & 0 \\ 0 & 0 \\ 0 & 0 \\ 0 & 0 \\ 0 & 0 \\ 0 & 0 \\ 0 & 0\end{array}$

68

904
1,173

2,701

4,967

4,867
186

nos

720

16,388

618

567

348
191

19,274

132

753
462

0
34,155

34,155
1,117

277

38,896

$2,233,709$
0
687
2,052

9,491

35,688

5,541

53,660

$8,368,985$
Total Production Plant

$2,143,092$

719,804

$\begin{array}{rrr}25,163 & 10,617 & 73,202 \\ 10,890 & 3,952 & 14,219 \\ 223,985 & 46,079 & 269,065 \\ 21,623 & 1,476 & 97,128 \\ 109,990 & 11,708 & 88,363 \\ 105,725 & 15,538 & 134,088 \\ 427 & 42 & 447 \\ 7,507 & 1,759 & 7,786 \\ 5,455 & 45 & 1,042 \\ 510,768 & 91,217 & 685,339\end{array}$

45,197

43,677

415,459

150,811

48,737

152,188

78,948

125,325

$1,080,452$

Underground Conductors and Devices

Totel Trenemlenion Pient

510,786

01,217

$\begin{array}{rr}0 & 63 \\ 0 & 460 \\ 6 & 392 \\ 0 & 2,220 \\ 435 & 1,016 \\ 65 & 408 \\ 3 & 29 \\ 500 & 4,587\end{array}$

10,507

30,971

2,382

432
11,790

125

15,355

8,164

1,894

0

2,947

0
12,278

286

59
.573

Distribution Plant

Land and Land Rights

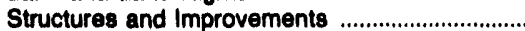

Station Equipment

Storage Battery Equipment

Poles, Towers and Fixtures

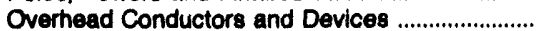

Underground Condult....

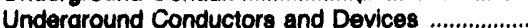

Une Transformers

Services

Meters

Installations on Customers Premises

Leased Property on Customers Premises ...........

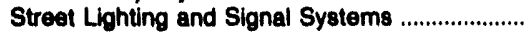

Total Dibtribution Plant .....................................

See endnotes at end of an individual electric utility.

\begin{tabular}{|c|c|c|c|c|c|}
\hline $\begin{array}{l}0 \\
0\end{array}$ & $\begin{array}{l}1,698 \\
2,313\end{array}$ & $\begin{array}{r}16,476 \\
8,254\end{array}$ & $\begin{array}{r}7,798 \\
47,902\end{array}$ & $\begin{array}{l}36 \\
52\end{array}$ & $\begin{array}{l}272 \\
416\end{array}$ \\
\hline 158 & 29,201 & 156,827 & 349,060 & 2,936 & 7,005 \\
\hline 0 & & 0 & 0 & 0 & 0 \\
\hline $\begin{array}{l}154 \\
217\end{array}$ & $\begin{array}{l}33,551 \\
50,393\end{array}$ & $\begin{array}{l}318,584 \\
282,691\end{array}$ & $\begin{array}{l}326,712 \\
624,570\end{array}$ & $\begin{array}{l}7,160 \\
4,510\end{array}$ & $\begin{array}{l}16,883 \\
10,319\end{array}$ \\
\hline 1 & 34,750 & 26,117 & 86,198 & 62 & 617 \\
\hline 16 & 54,218 & 173,712 & 316,477 & 4,325 & 4,816 \\
\hline 12 & 45,483 & 324,318 & 258,416 & 6,223 & 8,353 \\
\hline 0 & 40,125 & 225,001 & $152,85 \theta$ & 2,635 & 4,181 \\
\hline 4,289 & 14,095 & 86,618 & 111,919 & 1,905 & 4,265 \\
\hline 13 & 6,640 & 4,014 & 16,532 & 340 & 407 \\
\hline 0 & 0 & 0 & 0 & 0 & 0 \\
\hline 0 & 9,075 & 49,866 & 106,624 & 647 & 1,274 \\
\hline 4,860 & 321,541 & $1,682,479$ & $2,405,087$ & 30,830 & 58,000 \\
\hline
\end{tabular}


Table 42. Utility Plant by Major U.8. Investor-Owned Electric Utillity Within state on Decomber 31, 1992 (Continued)

(Thousand Dollars)

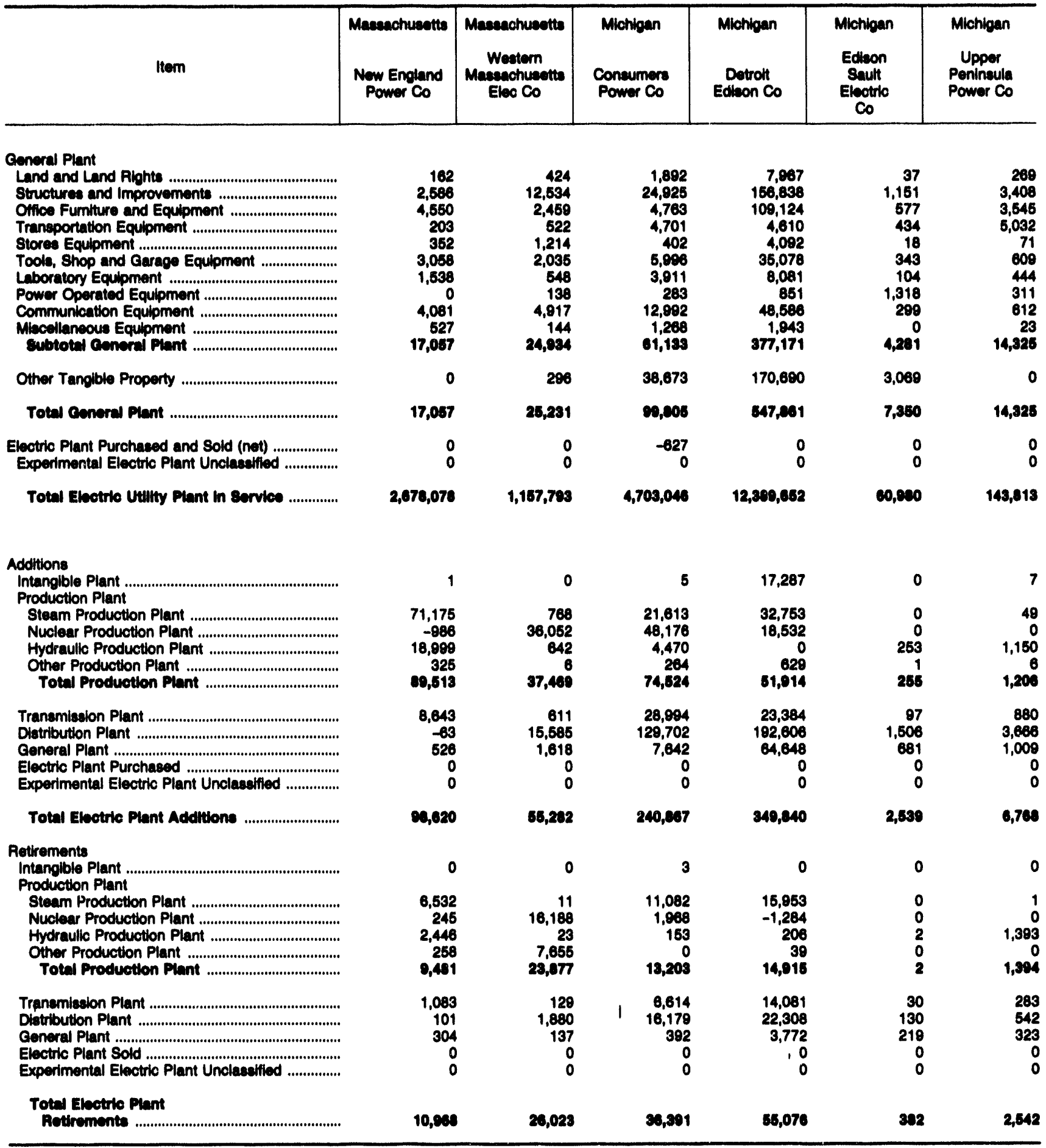

Note: Totals may not equal sum of components because of independent rounding. Summary data are provided in Table 28. Source: Federal Energy Regulatory Commieaion, FEAC Form 1, "Annual Report of Major Electric Utilties, Licensees and Others." 
Table 42. Utility Plant by Major U.8. Inveator-Owned Electric Utility Within State on December 31, 1992 (Continued) (Thousand Dollars)

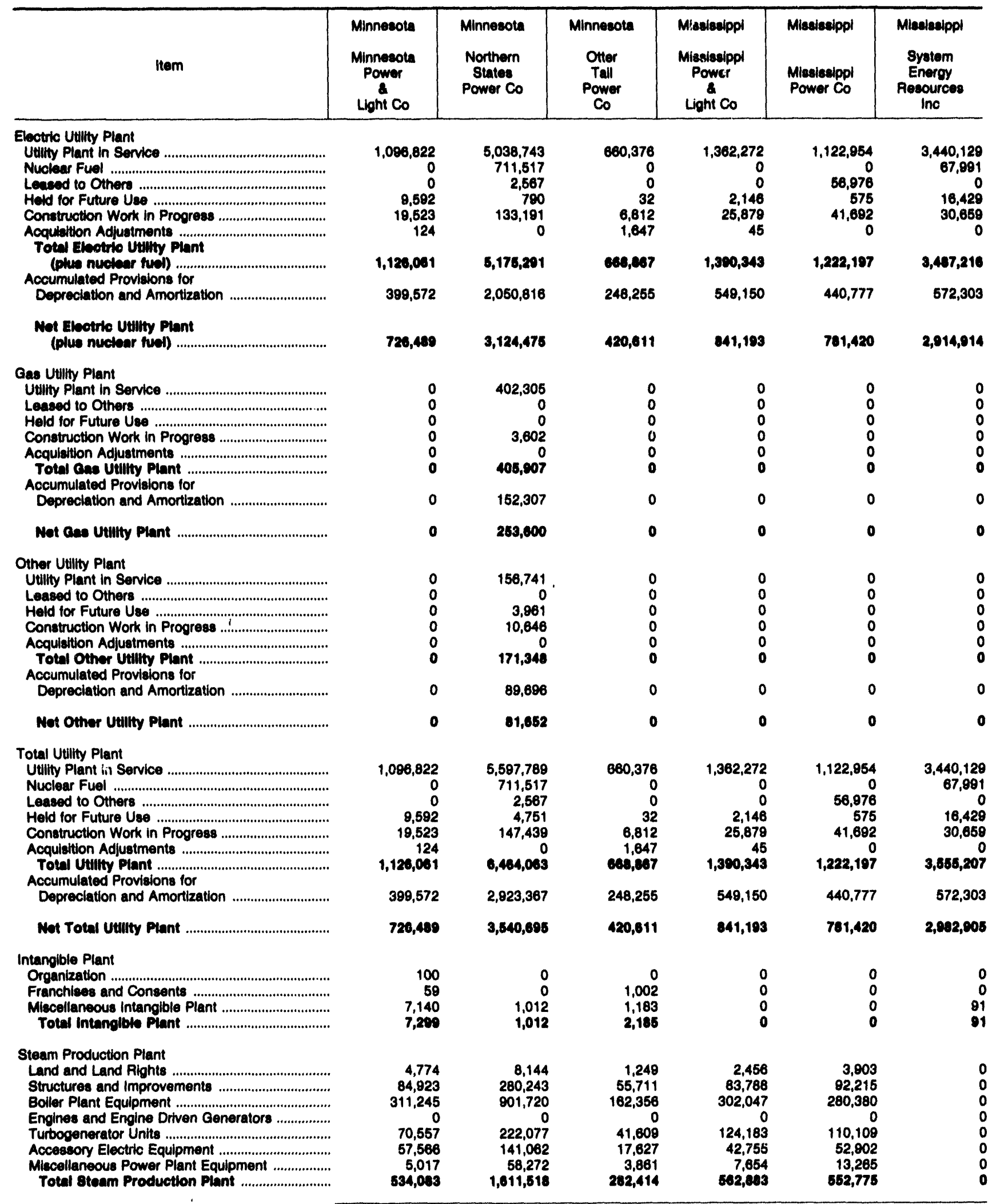

See endnotes at end of an indlividual electric utility. 
Table 42. Utility Plant by Major U.8. Inveotor-Owned Electric Utility Within State on Decomber 31, 1992 (Continued) (Thousand Dollars)

\begin{tabular}{|c|c|c|c|c|c|c|}
\hline Hem & $\begin{array}{l}\text { Minnesota } \\
\text { Minnesota } \\
\text { Power } \\
\text { Light Co }\end{array}$ & $\begin{array}{l}\text { Minnesota } \\
\text { Northem } \\
\text { States } \\
\text { Power Co }\end{array}$ & $\begin{array}{c}\text { Minnesota } \\
\text { Otter } \\
\text { Tall } \\
\text { Power } \\
\text { Co }\end{array}$ & 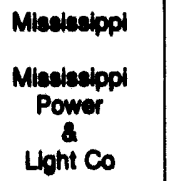 & $\begin{array}{l}\text { Minclesippl } \\
\text { Minchelpol } \\
\text { Power Co }\end{array}$ & $\begin{array}{l}\text { Mhatacippl } \\
\text { Syatom } \\
\text { Eneroy } \\
\text { Resouroes } \\
\text { Ino }\end{array}$ \\
\hline 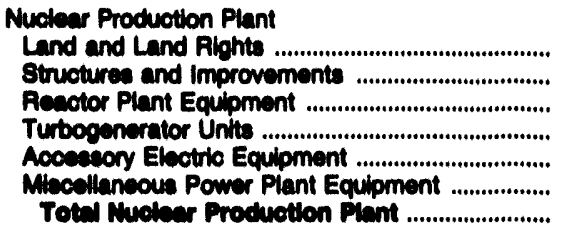 & $\begin{array}{l}0 \\
0 \\
0 \\
0 \\
0 \\
0 \\
0\end{array}$ & $\begin{array}{r}865 \\
274,566 \\
668,568 \\
138,410 \\
184,427 \\
129,792 \\
1,280,810\end{array}$ & $\begin{array}{l}0 \\
0 \\
0 \\
0 \\
0 \\
0 \\
0\end{array}$ & $\begin{array}{l}0 \\
0 \\
0 \\
0 \\
0 \\
0 \\
0\end{array}$ & $\begin{array}{l}0 \\
0 \\
0 \\
0 \\
0 \\
0 \\
0\end{array}$ & $\begin{array}{r}902 \\
1,313,300 \\
928,608 \\
428,668 \\
608,221 \\
265,877 \\
3,428,988\end{array}$ \\
\hline 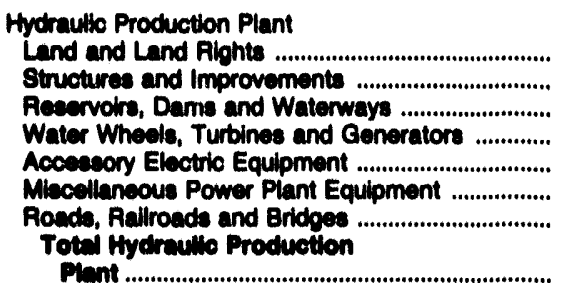 & $\begin{array}{r}4,469 \\
4,887 \\
17,186 \\
12,838 \\
7,520 \\
596 \\
51 \\
47,647\end{array}$ & $\begin{array}{r}1,699 \\
432 \\
2,656 \\
1,042 \\
254 \\
42 \\
0 \\
6,125\end{array}$ & $\begin{array}{r}206 \\
127 \\
1,163 \\
202 \\
59 \\
116 \\
0 \\
1,070\end{array}$ & $\begin{array}{l}0 \\
0 \\
0 \\
0 \\
0 \\
0 \\
0\end{array}$ & $\begin{array}{l}0 \\
0 \\
0 \\
0 \\
0 \\
0 \\
0\end{array}$ & $\begin{array}{l}0 \\
0 \\
0 \\
0 \\
0 \\
0 \\
0\end{array}$ \\
\hline 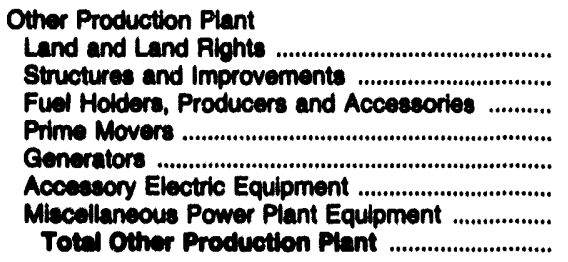 & $\begin{array}{l}0 \\
0 \\
0 \\
0 \\
0 \\
0 \\
0 \\
0\end{array}$ & $\begin{array}{r}588 \\
2,359 \\
3,384 \\
0 \\
60,638 \\
2,813 \\
426 \\
70,103\end{array}$ & $\begin{array}{r}26 \\
354 \\
673 \\
8,610 \\
0 \\
318 \\
78 \\
10,058\end{array}$ & $\begin{array}{l}0 \\
0 \\
0 \\
0 \\
0 \\
0 \\
0 \\
0\end{array}$ & $\begin{array}{r}0 \\
1,035 \\
978 \\
18,421 \\
3,401 \\
2,095 \\
173 \\
24,074\end{array}$ & $\begin{array}{l}0 \\
0 \\
0 \\
0 \\
0 \\
0 \\
0 \\
0\end{array}$ \\
\hline Toted Production Plant ........................................... & $\mathbf{5 8 1 , 7 3 0}$ & $2,077,445$ & 204,349 & 892,038 & 570,949 & $3,428,368$ \\
\hline 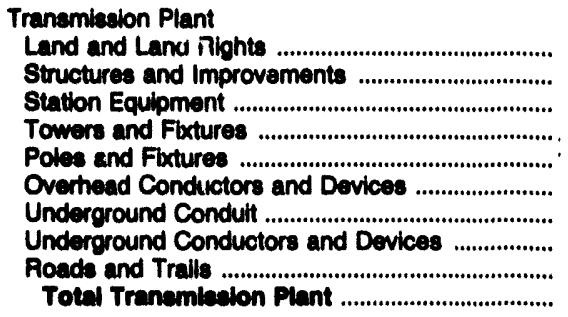 & $\begin{array}{r}6,082 \\
2,595 \\
62,742 \\
3,508 \\
48,120 \\
41,425 \\
0 \\
0 \\
68 \\
184,540\end{array}$ & $\begin{array}{r}36,118 \\
7,962 \\
191,271 \\
92,548 \\
91,105 \\
111,799 \\
4,784 \\
4,320 \\
0 \\
539,907\end{array}$ & $\begin{array}{r}287 \\
0 \\
37,425 \\
4,692 \\
44,170 \\
38,533 \\
0 \\
70 \\
0 \\
128,188\end{array}$ & $\begin{array}{r}20,468 \\
13,569 \\
155,857 \\
37,948 \\
36,494 \\
72,342 \\
0 \\
0 \\
0 \\
339,677\end{array}$ & $\begin{array}{r}12,621 \\
4,186 \\
72,789 \\
22,667 \\
26,990 \\
34,085 \\
0 \\
0 \\
40 \\
173,277\end{array}$ & $\begin{array}{r}0 \\
0 \\
16,683 \\
0 \\
0 \\
0 \\
0 \\
0 \\
0 \\
16,089\end{array}$ \\
\hline 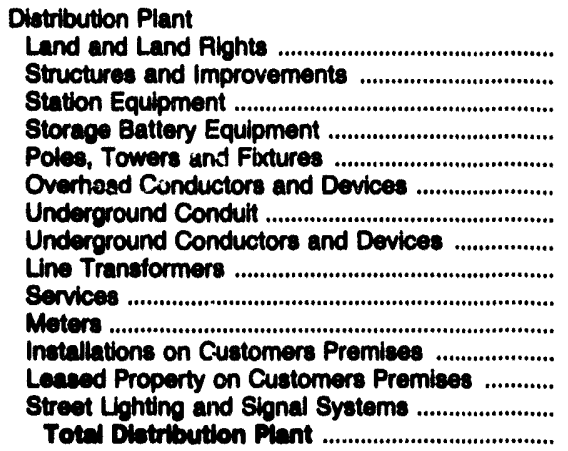 & $\begin{array}{r}1,050 \\
2,834 \\
39,569 \\
0 \\
40,479 \\
44,212 \\
6,714 \\
29,529 \\
37,204 \\
12,383 \\
13,491 \\
105 \\
816 \\
1,971 \\
280,457\end{array}$ & $\begin{array}{r}8,752 \\
18,083 \\
208,411 \\
0 \\
135,217 \\
155,443 \\
72,425 \\
324,131 \\
214,443 \\
116,937 \\
83,853 \\
6,817 \\
179 \\
20,688 \\
1,383,380\end{array}$ & $\begin{array}{r}718 \\
0 \\
31,750 \\
0 \\
30,559 \\
27,658 \\
22 \\
23,970 \\
28,722 \\
16,856 \\
16,339 \\
1,927 \\
0 \\
2,453 \\
180,975\end{array}$ & $\begin{array}{r}4,488 \\
5,586 \\
65,852 \\
0 \\
74,700 \\
65,921 \\
2,886 \\
14,375 \\
88,550 \\
29,063 \\
20,614 \\
0 \\
0 \\
20,491 \\
392,624\end{array}$ & $\begin{array}{r}1,545 \\
3,313 \\
61,807 \\
0 \\
40,547 \\
40,552 \\
373 \\
10,474 \\
62,229 \\
28,392 \\
18,543 \\
0 \\
0 \\
11,460 \\
279,334\end{array}$ & $\begin{array}{l}0 \\
0 \\
0 \\
0 \\
0 \\
0 \\
0 \\
0 \\
0 \\
0 \\
0 \\
0 \\
0 \\
0 \\
0\end{array}$ \\
\hline
\end{tabular}

800 endnotes at end of an individual electric utility. 
Table 42. Utility Plant by Major U.8. Invector-Owned Electrlo Utillty Within 8tate on Decomber 31, 1992 (Continued)

(Thousand Dollars)

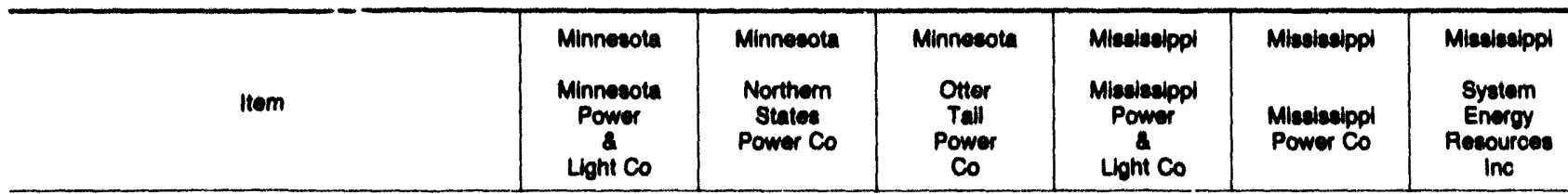

\section{General Piant}

Land and Land Righte

Ofice Fumiture and Equipment

Traneportation Equipment

Laboratory Equipment.

Power Operated Equipment

Communication Equipment.

Miscellaneous Equipment

cencral Ptant

Other Tanglble Property

Total Ceneral Plant

2,284

36,802

20,871

16,349

1,169

2,680

3,849

2,439

25,873

361

112,797

0

112,797

4,760

42,003

7,120

37,838

1,978

16,432

$\mathbf{5 , 8 0 8}$

5,328

35,475

329

188,210

680

188,994

Electric Plant Purchased and Sold (net)

Experimental Electric Piant Unclassified

Total Electric Utility Plant in 8

$8,034,743$

$\begin{array}{rr}1,055 & 2,571 \\ 20,041 & 22,697 \\ 10,862 & 7,328 \\ 14,171 & 4,881 \\ 584 & 347 \\ 2,811 & 3,309 \\ 1,835 & 294 \\ 400 & 689 \\ 7,848 & 11,041 \\ 7 & 872 \\ 50,716 & 84,728\end{array}$

4,468

31,848

17,173

14,057

1,126

1,746

3,285

1,286

17,128

1,409

9.,404

15,481

70,100

08,494

59,710

0

$1,392,272$

$1,122,954$

$3,440,129$

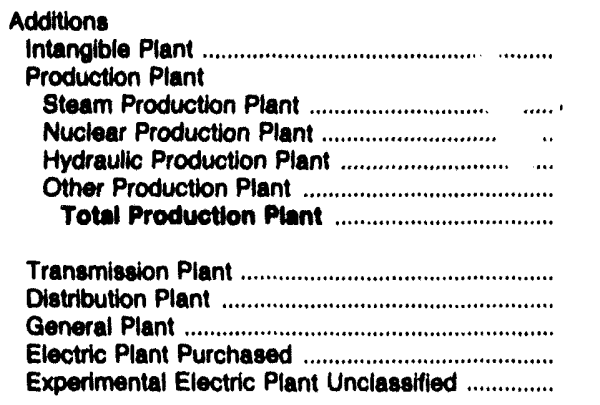

Total Electric Plant Additions

Retirements

Intangible Plant

Production Plant

Steam Production Plant

Nuclear Production Plant

Hydraulic Production Plant

Other Production Plant ....

Total Production Ptant ....................................

Transmiselon Plant

Distribution Plant

General Plant ...

Electric Plant Sold

iotal Electris Piant

Retirements

$\begin{array}{rr}705 & 0 \\ 6,883 & 24,446 \\ 0 & 154,019 \\ 1,868 & 62 \\ 0 & 2,242 \\ 8,846 & 180,770 \\ 0,137 & 19,120 \\ 15,277 & 102,863 \\ 10,880 & 9,316 \\ 0 & 0 \\ 0 & 0\end{array}$

386
4,468
0
70
7
4,544
3,532
8,539
5,974
0
0

0
3,442
0
0
0
3,442
11,132
28,188
6,649
0
0

49,411

$\begin{array}{rr}0 & 91 \\ 11,037 & 0 \\ 0 & 30,492 \\ 0 & 0 \\ 1,581 & 0 \\ 12,619 & 30,492 \\ 12,284 & -3 \\ 23,804 & 0 \\ 10,869 & 0 \\ 0 & 0 \\ 0 & 0\end{array}$

41,047

312,082

22,075

50,576

30,620

$\begin{array}{rr}0 & \\ 1,750 & 2,468 \\ 0 & 7,410 \\ 210 & 5 \\ 0 & 100 \\ 1,980 & 10,038 \\ 875 & 4,431 \\ 1,581 & 15,572 \\ 5,312 & 2,663 \\ 0 & 0 \\ 0 & 0\end{array}$

367
2,156
0
9
3
2,108
021
1,465
1,715
0
0

0
290
0
0
0
290
233
4,114
3,933
0
0

$$
\begin{array}{r}
0 \\
3,402 \\
0 \\
0 \\
38 \\
3,438 \\
1,261 \\
4,453 \\
1,377 \\
0 \\
0
\end{array}
$$

10,530

40,09

Note: Totals may not equal sum of components because of independent rounding. Summary data are provided in Table 28.

Source: Foderal Energy Regulatory Commission, FERC Form 1, "Annual Report of Major Electric Utilties, Licensees and Others." 
Table 42. Utility Plant by Major U.8. Investor-Owned Electrle Utillty Within State on December 31, 1992 (Continued)

(Thousand Dollars)

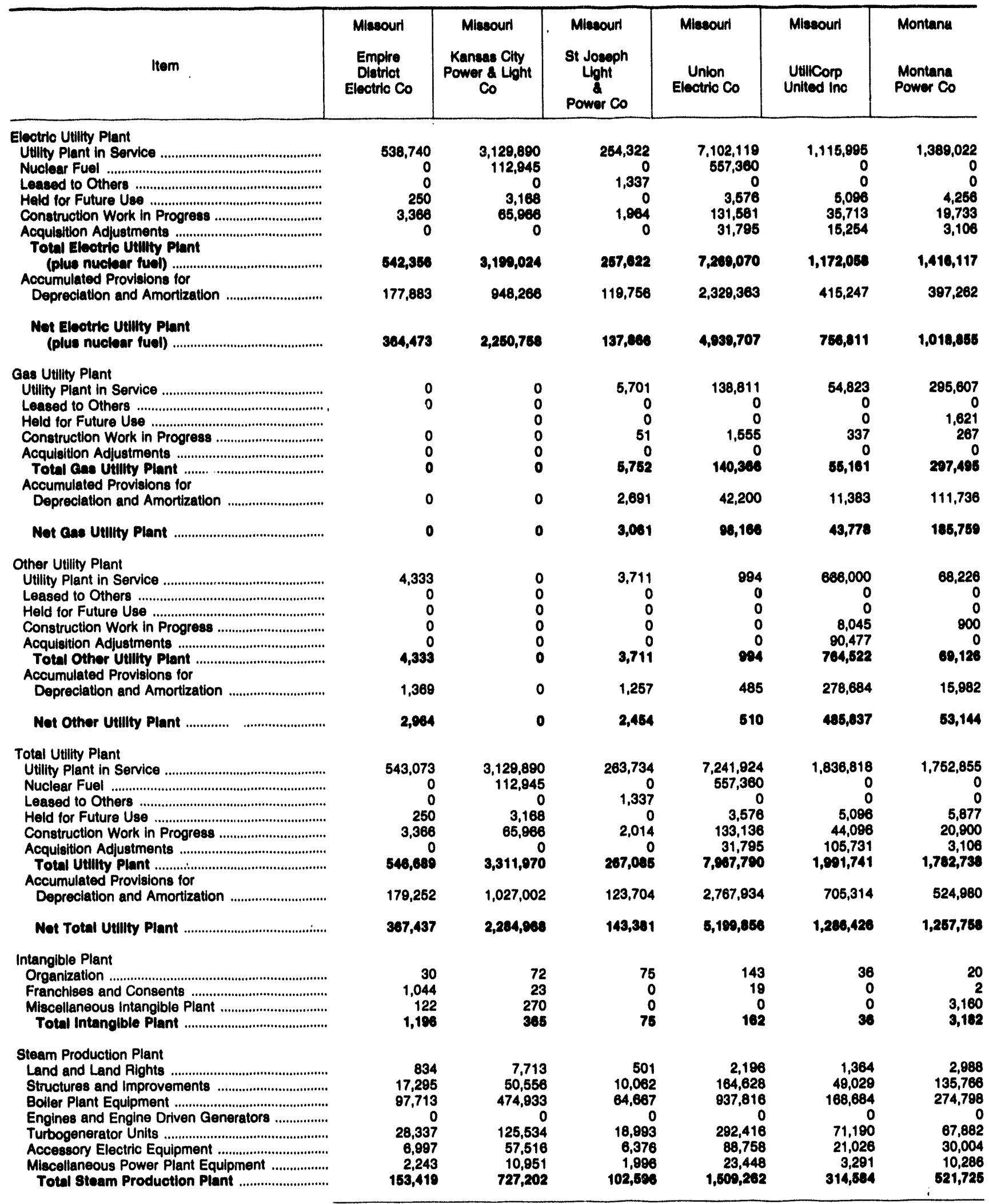

See endnotes at end of an individual electric utility. 
Table 42. Utility Plant by Major U.8. Inveator-Owned Eloetric Utillty Within state on December 31, 1982 (Continued) (Thousand Dollars)

\begin{tabular}{|c|c|c|c|c|c|c|}
\hline Itom & $\begin{array}{l}\text { Mlacourl } \\
\text { Emplre } \\
\text { Diatriot } \\
\text { Electric Co }\end{array}$ & $\begin{array}{c}\text { Miseourt } \\
\text { Kaneas City } \\
\text { Power \& Light } \\
\text { Co }\end{array}$ & $\begin{array}{l}\text { Milasourt } \\
\text { St Joseph } \\
\text { Light } \\
\text { Power Co }\end{array}$ & $\begin{array}{l}\text { Miesouri } \\
\text { Union } \\
\text { Eloctrio Co }\end{array}$ & $\begin{array}{l}\text { Misesourt } \\
\text { UtilCorp } \\
\text { United Inc }\end{array}$ & $\begin{array}{l}\text { Montana } \\
\text { Montana } \\
\text { Power Co }\end{array}$ \\
\hline 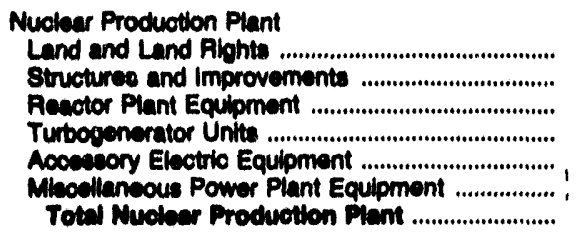 & $\begin{array}{l}0 \\
0 \\
0 \\
0 \\
0 \\
0 \\
0\end{array}$ & $\begin{array}{r}3,379 \\
409,653 \\
531,012 \\
170,092 \\
136,104 \\
64,782 \\
1,304,021\end{array}$ & $\begin{array}{l}0 \\
0 \\
0 \\
0 \\
0 \\
0 \\
0\end{array}$ & $\begin{array}{r}5,432 \\
899,651 \\
892,640 \\
151,927 \\
243,614 \\
125,649 \\
2,618,712\end{array}$ & $\begin{array}{l}0 \\
0 \\
0 \\
0 \\
0 \\
0 \\
0\end{array}$ & $\begin{array}{l}0 \\
0 \\
0 \\
0 \\
0 \\
0 \\
0\end{array}$ \\
\hline 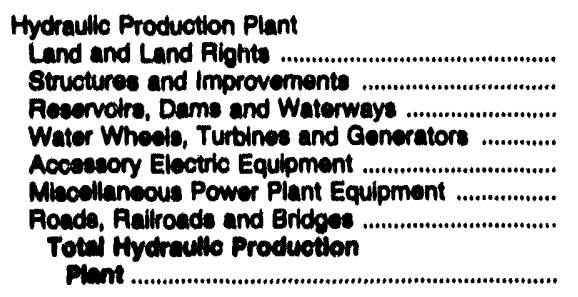 & $\begin{array}{r}223 \\
331 \\
1,377 \\
354 \\
110 \\
199 \\
0 \\
2,604\end{array}$ & $\begin{array}{l}0 \\
0 \\
0 \\
0 \\
0 \\
0 \\
0\end{array}$ & $\begin{array}{l}0 \\
0 \\
0 \\
0 \\
0 \\
0 \\
0\end{array}$ & $\begin{array}{r}18,068 \\
10,838 \\
59,441 \\
29,672 \\
6,570 \\
1,052 \\
152 \\
128,603\end{array}$ & $\begin{array}{l}0 \\
0 \\
0 \\
0 \\
0 \\
0 \\
0\end{array}$ & $\begin{array}{r}6,166 \\
12,281 \\
79,583 \\
19,320 \\
7,726 \\
2,307 \\
2,601 \\
129,074\end{array}$ \\
\hline 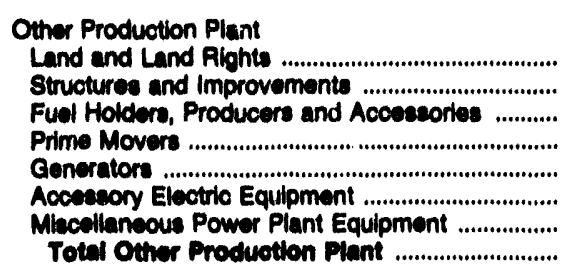 & $\begin{array}{r}163 \\
1,867 \\
1,068 \\
28,826 \\
5,087 \\
671 \\
1,187 \\
36,769\end{array}$ & $\begin{array}{r}137 \\
0 \\
1,182 \\
0 \\
36,568 \\
5,094 \\
0 \\
41,940\end{array}$ & $\begin{array}{r}0 \\
1,087 \\
587 \\
0 \\
12,682 \\
528 \\
30 \\
14,094\end{array}$ & $\begin{array}{r}66 \\
1,010 \\
1,269 \\
0 \\
36,164 \\
3,070 \\
177 \\
41,766\end{array}$ & $\begin{array}{r}336 \\
787 \\
593 \\
553 \\
19,062 \\
1,634 \\
30 \\
22,005\end{array}$ & $\begin{array}{r}0 \\
12 \\
112 \\
0 \\
744 \\
94 \\
2 \\
244\end{array}$ \\
\hline Total Production Plant '......................................... & 192,701 & $2,074,072$ & 117,400 & $4,200,332$ & 397,670 & 682,603 \\
\hline 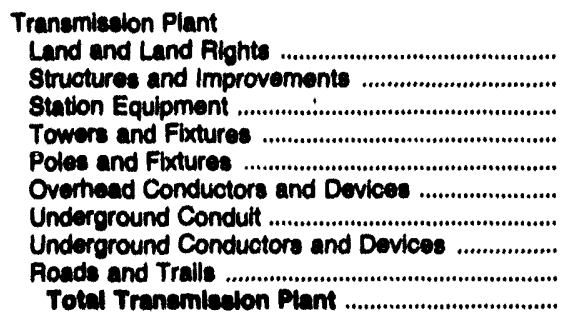 & $\begin{array}{r}5,109 \\
1,653 \\
41,720 \\
482 \\
14,497 \\
27,544 \\
0 \\
0 \\
0 \\
\infty 0,005\end{array}$ & $\begin{array}{r}19,034 \\
2,846 \\
53,192 \\
3,982 \\
50,524 \\
44,864 \\
2,509 \\
2,565 \\
0 \\
179,607\end{array}$ & $\begin{array}{r}1,781 \\
114 \\
13,577 \\
0 \\
8,259 \\
9,508 \\
10 \\
34 \\
0 \\
33,204\end{array}$ & $\begin{array}{r}19,599 \\
6,323 \\
155,683 \\
72,676 \\
43,618 \\
89,578 \\
0 \\
0 \\
136 \\
307,812\end{array}$ & $\begin{array}{r}11,025 \\
4,108 \\
92,097 \\
332 \\
56,212 \\
56,567 \\
0 \\
62 \\
0 \\
220,301\end{array}$ & $\begin{array}{r}12,383 \\
2,651 \\
107,379 \\
27,403 \\
76,364 \\
82,069 \\
0 \\
0 \\
1,654 \\
310,001\end{array}$ \\
\hline 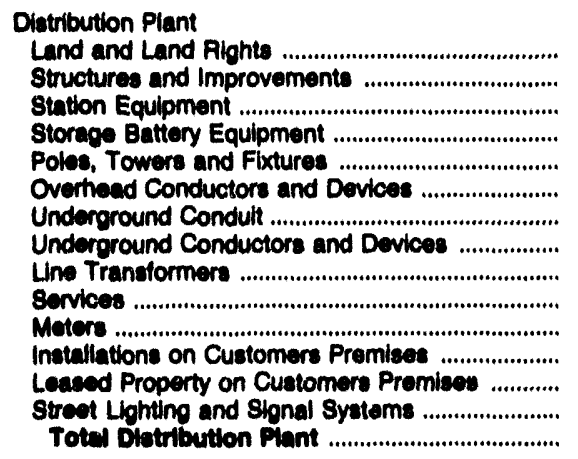 & $\begin{array}{r}1,147 \\
6,008 \\
31,091 \\
0 \\
45,239 \\
47,950 \\
4,533 \\
11,076 \\
34,196 \\
19,806 \\
0,201 \\
6,112 \\
0 \\
5,234 \\
221,193\end{array}$ & $\begin{array}{r}14,234 \\
6,034 \\
87,290 \\
0 \\
116,464 \\
100,896 \\
62,226 \\
140,323 \\
124,283 \\
40,456 \\
50,837 \\
4,249 \\
0 \\
62,680 \\
810,053\end{array}$ & $\begin{array}{r}292 \\
5 \\
11,042 \\
0 \\
13,022 \\
13,078 \\
2,291 \\
6,285 \\
14,382 \\
6,139 \\
5,228 \\
1,601 \\
0 \\
859 \\
76,123\end{array}$ & $\begin{array}{r}12,748 \\
10,336 \\
323,658 \\
0 \\
404,883 \\
441,574 \\
77,068 \\
239,600 \\
248,717 \\
146,633 \\
88,801 \\
698 \\
0 \\
64,065 \\
2,060,069\end{array}$ & $\begin{array}{r}1,313 \\
2,285 \\
68,850 \\
0 \\
0 \\
119,581 \\
83,802 \\
11,613 \\
38,119 \\
94,416 \\
44,095 \\
31,020 \\
5,634 \\
0 \\
18,021 \\
517,640\end{array}$ & $\begin{array}{r}2,856 \\
1,899 \\
57,823 \\
0 \\
04,684 \\
44,153 \\
6,886 \\
27,858 \\
80,836 \\
30,864 \\
18,442 \\
0 \\
0 \\
26,322 \\
364,533\end{array}$ \\
\hline
\end{tabular}

See endnotes at end of an individual eleotric utility. 
Table 42. Utility Plant by Major U.S. Investor-Owned Electric Utility Within State on Decomber 31, 1992 (Continued) (Thousand Dollars)

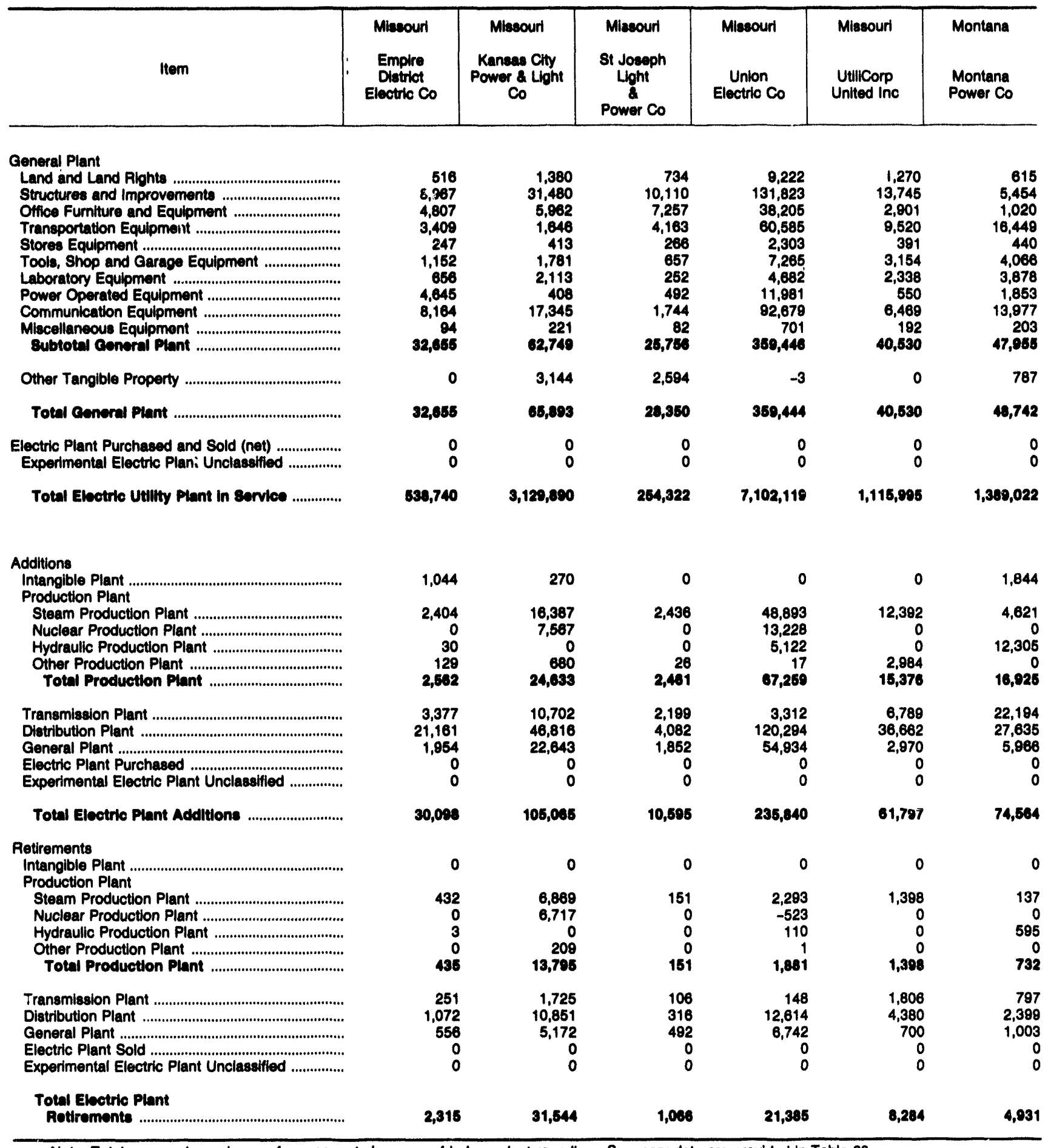

Note: Totals may not equal sum of components because of independent rounding. Summary data are provided in Table 28.

Source: Federal Energy Regulatory Commlesion, FERC Form 1, "Annual Report of Major Electric Utilties, Licensees and Others." 
Table 42. Utility Plant by Major U.S. Investor-Owned Electric Utility Within State on December 31, 1992 (Continued) (Thousand Dollars)

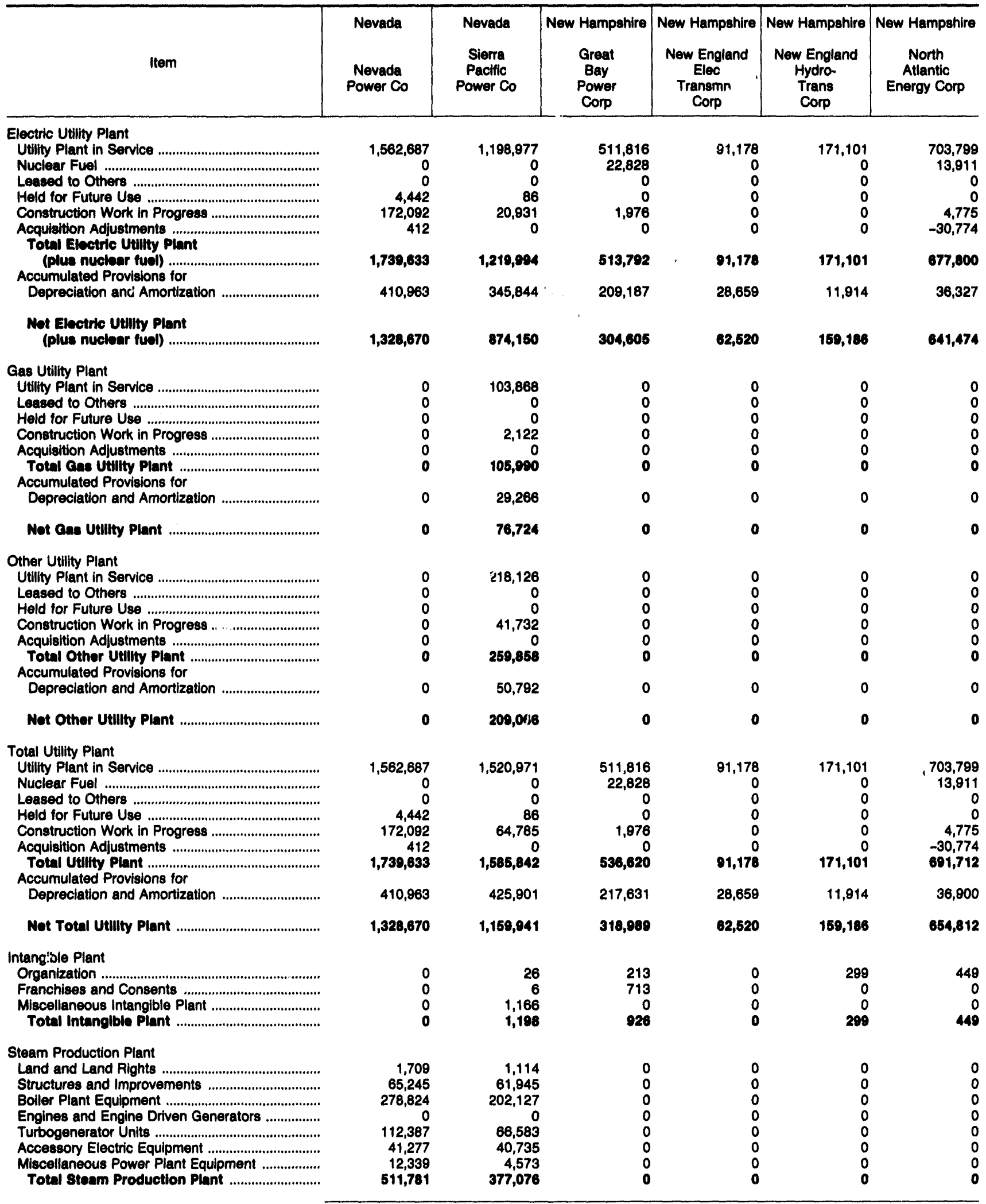

See endnotes at end of an individual electric utility. 
Table 42. Utility Plant by Major U.S. Inveator-Owned Electric Utility Whin state on December 31, 1992 (Continued) (Thousand Dollars)

\begin{tabular}{|c|c|c|c|c|c|c|}
\hline liem & $\begin{array}{l}\text { Nevada } \\
\text { Nevada } \\
\text { Power Co }\end{array}$ & $\begin{array}{c}\text { Nevada } \\
\text { Sierra } \\
\text { Pacific } \\
\text { Power Co }\end{array}$ & $\begin{array}{c}\text { New Hampshire } \\
\text { Great } \\
\text { Bay } \\
\text { Power } \\
\text { Corp }\end{array}$ & $\begin{array}{c}\text { New Hampahire } \\
\text { New England } \\
\text { Elec } \\
\text { Tranemn } \\
\text { Corp }\end{array}$ & $\begin{array}{c}\text { Now Hampehire } \\
\text { New England } \\
\text { Hydro- } \\
\text { Trans } \\
\text { Corp }\end{array}$ & $\begin{array}{c}\text { New Hampehire } \\
\text { North } \\
\text { Atlantic } \\
\text { Energy Corp }\end{array}$ \\
\hline 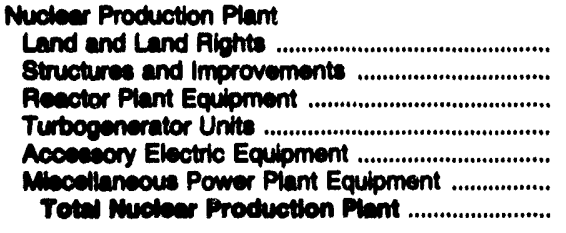 & $\begin{array}{l}0 \\
0 \\
0 \\
0 \\
0 \\
0 \\
0\end{array}$ & $\begin{array}{l}0 \\
0 \\
0 \\
0 \\
0 \\
0 \\
0\end{array}$ & $\begin{array}{r}250 \\
155,517 \\
230,841 \\
37,722 \\
55,740 \\
17,650 \\
497,724\end{array}$ & $\begin{array}{l}0 \\
0 \\
0 \\
0 \\
0 \\
0 \\
0\end{array}$ & $\begin{array}{l}0 \\
0 \\
0 \\
0 \\
0 \\
0 \\
0\end{array}$ & $\begin{array}{r}2,518 \\
215,787 \\
316,780 \\
51,460 \\
76,413 \\
24,783 \\
997,731\end{array}$ \\
\hline 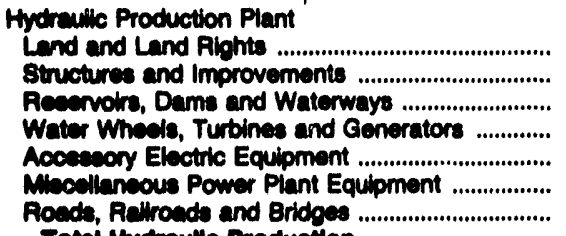 & $\begin{array}{l}0 \\
0 \\
0 \\
0 \\
0 \\
0 \\
0\end{array}$ & $\begin{array}{r}355 \\
405 \\
12,314 \\
562 \\
782 \\
3 \\
112\end{array}$ & $\begin{array}{l}0 \\
0 \\
0 \\
0 \\
0 \\
0 \\
0\end{array}$ & $\begin{array}{l}0 \\
0 \\
0 \\
0 \\
0 \\
0 \\
0\end{array}$ & $\begin{array}{l}0 \\
0 \\
0 \\
0 \\
0 \\
0 \\
0\end{array}$ & $\begin{array}{l}0 \\
0 \\
0 \\
0 \\
0 \\
0 \\
0\end{array}$ \\
\hline 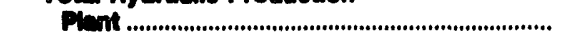 & $\mathbf{0}$ & 14,633 & 0 & $\mathbf{0}$ & $\mathbf{0}$ & 0 \\
\hline 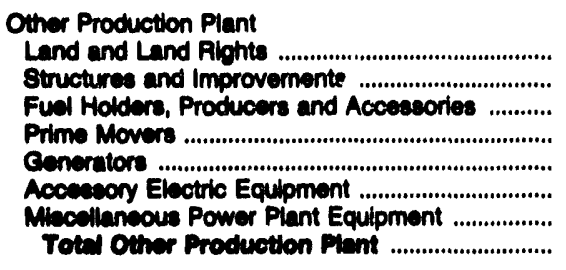 & $\begin{array}{r}0 \\
4,286 \\
5,327 \\
0 \\
63,771 \\
3,318 \\
0 \\
76,712\end{array}$ & $\begin{array}{r}208 \\
462 \\
237 \\
0 \\
7,982 \\
2,815 \\
0 \\
11,874\end{array}$ & $\begin{array}{l}0 \\
0 \\
0 \\
0 \\
0 \\
0 \\
0 \\
0\end{array}$ & $\begin{array}{l}0 \\
0 \\
0 \\
0 \\
0 \\
0 \\
0 \\
0\end{array}$ & $\begin{array}{l}0 \\
0 \\
0 \\
0 \\
0 \\
0 \\
0 \\
0\end{array}$ & $\begin{array}{l}0 \\
0 \\
0 \\
0 \\
0 \\
0 \\
0 \\
0\end{array}$ \\
\hline Totell Production Plant ............................................ & $\mathbf{8 9 8 , 4 0 2}$ & 408,218 & 407,728 & $\mathbf{0}$ & $\mathbf{0}$ & 697,731 \\
\hline 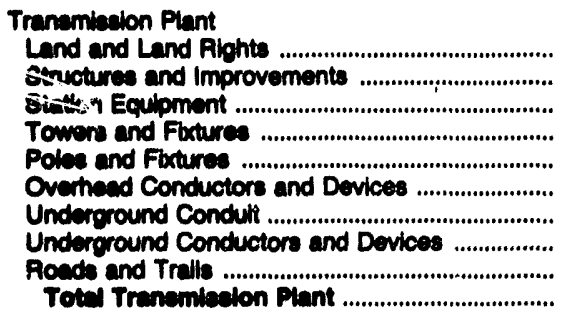 & $\begin{array}{r}5,614 \\
1,683 \\
132,249 \\
8,684 \\
70,333 \\
44,757 \\
0 \\
0 \\
487 \\
203,807\end{array}$ & $\begin{array}{r}9,862 \\
1,627 \\
112,241 \\
31,508 \\
53,606 \\
72,704 \\
0 \\
0 \\
420 \\
202,038\end{array}$ & $\begin{array}{r}0 \\
0 \\
7,184 \\
0 \\
0 \\
0 \\
0 \\
0 \\
0 \\
7,184\end{array}$ & $\begin{array}{r}440 \\
8,388 \\
71,058 \\
186 \\
5,358 \\
3,558 \\
0 \\
0 \\
512 \\
0,801\end{array}$ & $\begin{array}{r}0 \\
3,584 \\
29,022 \\
84,142 \\
11,020 \\
31,840 \\
0 \\
0 \\
0 \\
189,609\end{array}$ & $\begin{array}{r}0 \\
0 \\
9,876 \\
0 \\
0 \\
0 \\
0 \\
0 \\
0 \\
0,070\end{array}$ \\
\hline 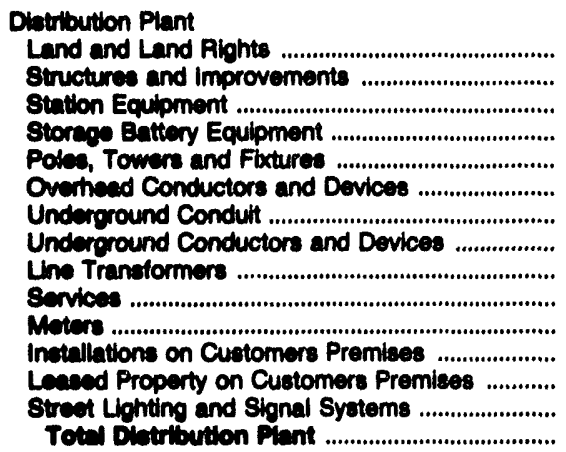 & $\begin{array}{r}12,287 \\
86 \\
91,447 \\
0 \\
24,503 \\
43,083 \\
25,230 \\
139,302 \\
125,087 \\
44,231 \\
28,707 \\
0 \\
1,338 \\
931 \\
638,232\end{array}$ & $\begin{array}{r}3,849 \\
609 \\
39,012 \\
0 \\
67,845 \\
65,386 \\
44,006 \\
81,880 \\
78,599 \\
42,193 \\
21,800 \\
6,253 \\
0 \\
10,176 \\
461,808\end{array}$ & $\begin{array}{l}0 \\
0 \\
0 \\
0 \\
0 \\
0 \\
0 \\
0 \\
0 \\
0 \\
0 \\
0 \\
0 \\
0 \\
0\end{array}$ & $\begin{array}{l}0 \\
0 \\
0 \\
0 \\
0 \\
0 \\
0 \\
0 \\
0 \\
0 \\
0 \\
0 \\
0 \\
0 \\
0\end{array}$ & $\begin{array}{l}0 \\
0 \\
0 \\
0 \\
0 \\
0 \\
0 \\
0 \\
0 \\
0 \\
0 \\
0 \\
0 \\
0 \\
0\end{array}$ & $\begin{array}{l}0 \\
0 \\
0 \\
0 \\
0 \\
0 \\
0 \\
0 \\
0 \\
0 \\
0 \\
0 \\
0 \\
0 \\
0\end{array}$ \\
\hline
\end{tabular}

ses endinotes at end of an individual electric utility. 
Table 42. Utility Plant by Major U.S. Investor-Owned Electric Utility Within State on December 31, 1992 (Continued)

(Thousand Dollars)

\begin{tabular}{|c|c|c|c|c|c|c|}
\hline Item & $\begin{array}{l}\text { Nevada } \\
\text { Nevada } \\
\text { Power Co }\end{array}$ & $\begin{array}{l}\text { Nevada } \\
\text { Sierra } \\
\text { Pactic } \\
\text { Power Co }\end{array}$ & $\begin{array}{c}\text { Now Hampshire } \\
\text { Great } \\
\text { Bay } \\
\text { Power } \\
\text { Corp }\end{array}$ & \begin{tabular}{|c|} 
Now Hampshire \\
Now England \\
Elec \\
Tranemn \\
Corp
\end{tabular} & $\begin{array}{c}\text { Now Hampshire } \\
\text { New England } \\
\text { Hydro- } \\
\text { Trans } \\
\text { Corp }\end{array}$ & $\begin{array}{l}\text { New Hampshire } \\
\text { North } \\
\text { Allantic } \\
\text { Energy Corp }\end{array}$ \\
\hline 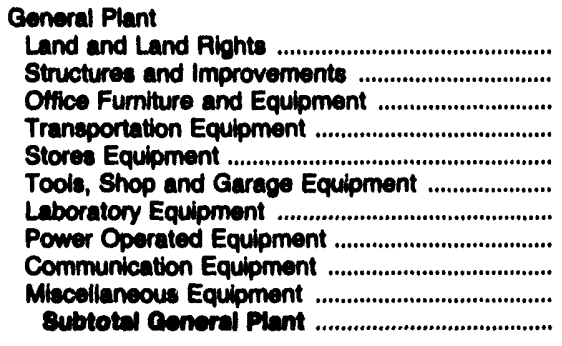 & $\begin{array}{r}4,688 \\
24,661 \\
11,689 \\
7,286 \\
550 \\
1,986 \\
2,028 \\
7,785 \\
15,794 \\
58 \\
77,402\end{array}$ & $\begin{array}{r}1,454 \\
5,384 \\
13,572 \\
17,830 \\
218 \\
3,718 \\
638 \\
168 \\
7,630 \\
7 \\
50,621\end{array}$ & $\begin{array}{r}0 \\
1,984 \\
3,945 \\
0 \\
0 \\
0 \\
0 \\
0 \\
0 \\
52 \\
5,001\end{array}$ & $\begin{array}{r}0 \\
0 \\
0 \\
0 \\
0 \\
50 \\
0 \\
0 \\
570 \\
57 \\
677\end{array}$ & $\begin{array}{r}0 \\
0 \\
0 \\
0 \\
0 \\
0 \\
0 \\
0 \\
1,195 \\
0 \\
1,198\end{array}$ & $\begin{array}{r}0 \\
0 \\
5,744 \\
0 \\
0 \\
0 \\
0 \\
0 \\
0 \\
0 \\
5,744\end{array}$ \\
\hline 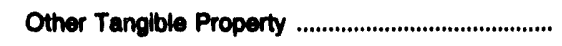 & 86,753 & 0 & 0 & 0 & 0 & 0 \\
\hline 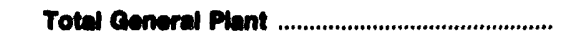 & 174,166 & 50,621 & 5,001 & 677 & 1,105 & 5,744 \\
\hline $\begin{array}{c}\text { Electric Plant Purchased and Sold (net) .................... } \\
\text { Experimental Electric Plant Unclasetied ................ }\end{array}$ & $\begin{array}{l}0 \\
0\end{array}$ & $\begin{array}{l}0 \\
0\end{array}$ & $\begin{array}{l}0 \\
0\end{array}$ & $\begin{array}{l}0 \\
0\end{array}$ & $\begin{array}{l}0 \\
0\end{array}$ & \\
\hline Total Electric Utillity Plant in Eorvice ............... & 1,682,607 & $1,198,977$ & 511,016 & 91,170 & 171,101 & 703,700 \\
\hline 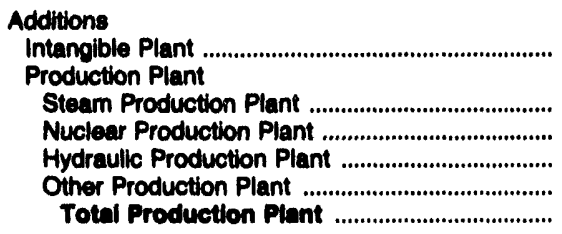 & $\begin{array}{r}0 \\
11,951 \\
0 \\
0 \\
271 \\
12,222\end{array}$ & $\begin{array}{r}263 \\
4,177 \\
0 \\
3,544 \\
289 \\
8,000\end{array}$ & $\begin{array}{r}0 \\
0 \\
0 \\
1,282 \\
0 \\
0 \\
1,282\end{array}$ & $\begin{array}{l}0 \\
0 \\
0 \\
0 \\
0 \\
0\end{array}$ & $\begin{array}{l}0 \\
0 \\
0 \\
0 \\
0 \\
0\end{array}$ & $\begin{array}{r}449 \\
0 \\
1,751 \\
0 \\
0 \\
1,751\end{array}$ \\
\hline 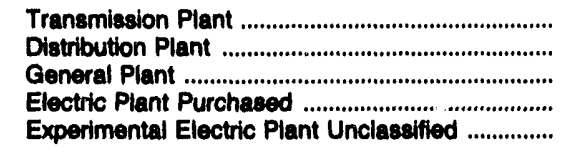 & $\begin{array}{r}28,719 \\
66,199 \\
8,913 \\
0 \\
0\end{array}$ & $\begin{array}{r}16,886 \\
33,717 \\
3,353 \\
0 \\
0\end{array}$ & $\begin{array}{r}-19 \\
0 \\
132 \\
0 \\
0\end{array}$ & $\begin{array}{l}0 \\
0 \\
0 \\
0 \\
0\end{array}$ & $\begin{array}{r}802 \\
0 \\
0 \\
0 \\
0\end{array}$ & $\begin{array}{r}0 \\
0 \\
431 \\
0 \\
0\end{array}$ \\
\hline 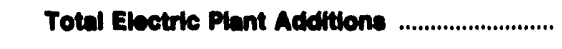 & 116,053 & 62,227 & 1,306 & 0 & $\infty 02$ & 2,031 \\
\hline 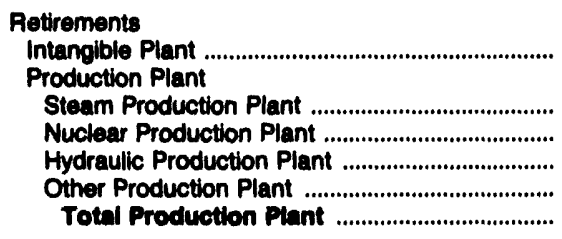 & $\begin{array}{r}0 \\
1,179 \\
0 \\
0 \\
116 \\
1,295\end{array}$ & $\begin{array}{r}1,581 \\
0 \\
26 \\
0 \\
1,557\end{array}$ & $\begin{array}{r}0 \\
130 \\
0 \\
0 \\
130\end{array}$ & $\begin{array}{l}0 \\
0 \\
0 \\
0 \\
0 \\
0\end{array}$ & $\begin{array}{l}0 \\
0 \\
0 \\
0 \\
0 \\
0\end{array}$ & $\begin{array}{r}0 \\
0 \\
168 \\
0 \\
0 \\
180\end{array}$ \\
\hline 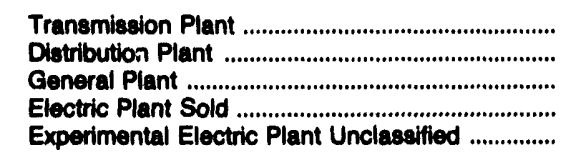 & $\begin{array}{r}184 \\
3,410 \\
2,428 \\
0 \\
0\end{array}$ & $\begin{array}{r}580 \\
5,870 \\
1,445 \\
0 \\
0\end{array}$ & $\begin{array}{l}0 \\
0 \\
0 \\
0 \\
0\end{array}$ & $\begin{array}{l}0 \\
0 \\
0 \\
0 \\
0\end{array}$ & $\begin{array}{l}0 \\
0 \\
0 \\
0 \\
0\end{array}$ & $\begin{array}{l}0 \\
0 \\
0 \\
0 \\
0\end{array}$ \\
\hline 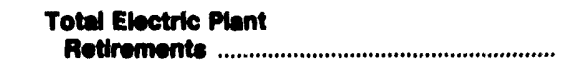 & 7,316 & 9,462 & 130 & $\mathbf{0}$ & 0 & 160 \\
\hline
\end{tabular}

Note: Totals may not equal sum of components because of independent rounding. Summary dath are provided in Table 28.

Source: Federal Energy Regulatory Commiesion, FERC. Form 1, "Annual Report of Major Electric Utillities, Licensees and Others." 
Table 42. Utility Plant by Major U.S. Investor-Owned Electrlc UtIIty Within State on December 31, 1992 (Continued)

(Thousand Dollars)

\begin{tabular}{|c|c|c|c|c|c|c|}
\hline Item & $\begin{array}{c}\text { New Hampahire } \\
\text { Public } \\
\text { Service } \\
\text { Co } \\
\text { of NH }\end{array}$ & $\begin{array}{c}\text { New Jereey } \\
\text { Atlantic } \\
\text { Clty } \\
\text { Electric } \\
\text { Co }\end{array}$ & $\begin{array}{c}\text { New Jersey } \\
\text { Jersey } \\
\text { Contral } \\
\text { Power\&Light } \\
\text { Co }\end{array}$ & $\begin{array}{c}\text { New Jersey } \\
\text { Public } \\
\text { Service } \\
\text { Electric\&Gas } \\
\text { Co }\end{array}$ & $\begin{array}{l}\text { Now Jersey } \\
\text { Pockland } \\
\text { Electric Co }\end{array}$ & $\begin{array}{l}\text { New Mexico } \\
\text { Public } \\
\text { Sorvice } \\
\text { Co } \\
\text { of NM }\end{array}$ \\
\hline \multirow{3}{*}{ 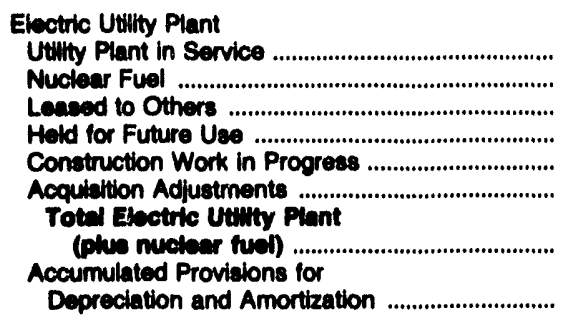 } & $\begin{array}{r}1,883,035 \\
9,766 \\
0 \\
4,688 \\
4,363 \\
0\end{array}$ & $\begin{array}{r}2,101,484 \\
43,830 \\
0 \\
5,045 \\
130,685 \\
0\end{array}$ & $\begin{array}{r}3,699,816 \\
134,217 \\
0 \\
15,517 \\
178,803 \\
0\end{array}$ & $\begin{array}{r}11,621,610 \\
772,243 \\
0 \\
22,252 \\
407,680 \\
0\end{array}$ & $\begin{array}{r}133,358 \\
0 \\
0 \\
1,007 \\
3,616 \\
0\end{array}$ & $\begin{array}{r}1,844,586 \\
63,306 \\
0 \\
1,136 \\
64,980 \\
40,600\end{array}$ \\
\hline & $1,002,005$ & $2,297,214$ & $3,004,235$ & $11,961,543$ & 137,001 & $2,051,314$ \\
\hline & 410,089 & 599,100 & $1,262,562$ & $3,438,650$ & 34,530 & 608,578 \\
\hline $\begin{array}{l}\text { Not Eloctule Utilty Plant } \\
\text { (plus nuctear fuel) .......................................... }\end{array}$ & $1,401, \infty 60$ & $1,638,114$ & $2,631,673$ & $8,512,003$ & 108,481 & $1,444,730$ \\
\hline 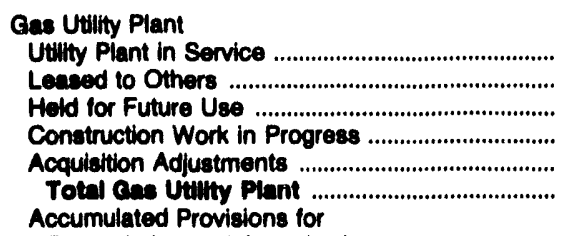 & $\begin{array}{l}0 \\
0 \\
0 \\
0 \\
0 \\
0\end{array}$ & $\begin{array}{l}0 \\
0 \\
0 \\
0 \\
0 \\
0\end{array}$ & $\begin{array}{l}0 \\
0 \\
0 \\
0 \\
0 \\
0\end{array}$ & $\begin{array}{r}2,044,944 \\
0 \\
0 \\
16,444 \\
0 \\
2,061,300\end{array}$ & $\begin{array}{l}0 \\
0 \\
0 \\
0 \\
0 \\
0\end{array}$ & $\begin{array}{r}418,541 \\
12,267 \\
0 \\
10,594 \\
-156 \\
441,246\end{array}$ \\
\hline 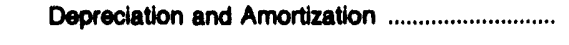 & 0 & 0 & 0 & 853,808 & 0 & 180,212 \\
\hline 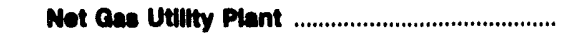 & $\mathbf{0}$ & $\mathbf{0}$ & 0 & $1,207,401$ & 0 & 281,034 \\
\hline 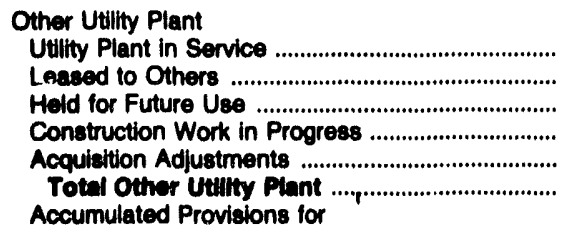 & $\begin{array}{l}0 \\
0 \\
0 \\
0 \\
0 \\
0\end{array}$ & $\begin{array}{l}0 \\
0 \\
0 \\
0 \\
0 \\
0\end{array}$ & $\begin{array}{l}0 \\
0 \\
0 \\
0 \\
0 \\
0\end{array}$ & $\begin{array}{r}479,972 \\
0 \\
0 \\
0 \\
0 \\
479,972\end{array}$ & $\begin{array}{l}0 \\
0 \\
0 \\
0 \\
0 \\
0\end{array}$ & $\begin{array}{r}92,329 \\
0 \\
122 \\
11,155 \\
0 \\
103,008\end{array}$ \\
\hline 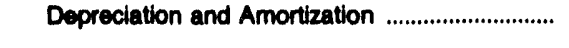 & 0 & 0 & 0 & 122,805 & 0 & 22,874 \\
\hline 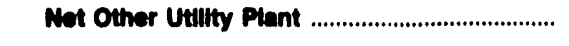 & 0 & 0 & $\mathbf{0}$ & 357,167 & $\mathbf{0}$ & 80,631 \\
\hline 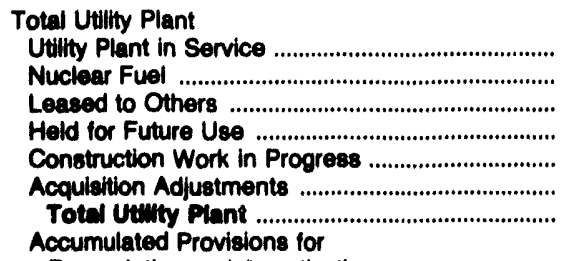 & $\begin{array}{r}1,883,035 \\
9,766 \\
0 \\
0,688 \\
4,363 \\
0 \\
1,901,062\end{array}$ & $\begin{array}{r}2,101,484 \\
43,830 \\
0 \\
5,045 \\
130,685 \\
0 \\
0 \\
2,281,045\end{array}$ & $\begin{array}{r}3,699,816 \\
134,217 \\
0 \\
0 \\
15,517 \\
178,903 \\
0 \\
4,028,162\end{array}$ & $\begin{array}{r}14,046,527 \\
772,243 \\
0 \\
22,252 \\
424,125 \\
0 \\
16,286,147\end{array}$ & $\begin{array}{r}133,358 \\
0 \\
0 \\
1,007 \\
3,616 \\
0 \\
137,001\end{array}$ & $\begin{array}{r}2,465,466 \\
63,306 \\
12,267 \\
1,258 \\
86,729 \\
40,445 \\
2,650,471\end{array}$ \\
\hline 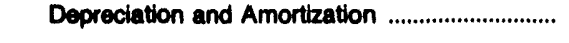 & 417,519 & 599,100 & $1,262,562$ & $4,884,820$ & 34,530 & 815,240 \\
\hline Not Total Uttity Plant ............................................. & $1,404,333$ & $1,081,045$ & $2,765,090$ & $10,280,327$ & 103,451 & $1,844,231$ \\
\hline 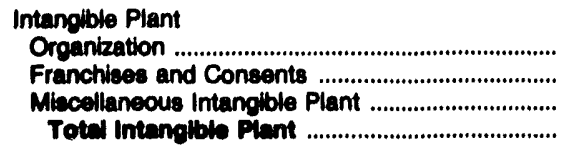 & $\begin{array}{r}45 \\
0 \\
0 \\
46\end{array}$ & $\begin{array}{l}0 \\
0 \\
0 \\
0\end{array}$ & $\begin{array}{r}51 \\
20 \\
18,942 \\
20,013\end{array}$ & $\begin{array}{r}0 \\
0 \\
4,598 \\
4,5 \oplus 8\end{array}$ & $\begin{array}{l}6 \\
0 \\
0 \\
6\end{array}$ & $\begin{array}{r}14 \\
1,142 \\
27,188 \\
28,344\end{array}$ \\
\hline 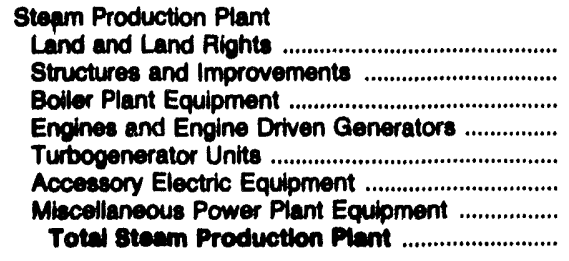 & $\begin{array}{r}720 \\
50,118 \\
182,168 \\
0 \\
80,835 \\
15,883 \\
13,827 \\
343,840\end{array}$ & $\begin{array}{r}1,241 \\
57,811 \\
228,762 \\
0 \\
75,159 \\
22,818 \\
8,856 \\
394,746\end{array}$ & $\begin{array}{r}971 \\
47,608 \\
85,200 \\
0 \\
46,683 \\
11,751 \\
6,621 \\
198,034\end{array}$ & $\begin{array}{r}14,300 \\
183,278 \\
804,996 \\
0 \\
276,480 \\
249,745 \\
34,134 \\
1,892,932\end{array}$ & $\begin{array}{l}0 \\
0 \\
0 \\
0 \\
0 \\
0 \\
0 \\
0\end{array}$ & $\begin{array}{r}1,264 \\
152,096 \\
517,674 \\
0 \\
150,268 \\
85,975 \\
24,177 \\
931,463\end{array}$ \\
\hline
\end{tabular}

See endnotes at end of an individual electric utility. 
Tabie 42. Utility Plant by Major U.S. Inveator-Owned Electric Utility Within State on December 31, 1992 (Continued)

(Thousand Dollars)

\begin{tabular}{|c|c|c|c|c|c|c|}
\hline Item & \begin{tabular}{|c|} 
Now Hampshire \\
Public \\
Service \\
Co \\
of NH
\end{tabular} & $\begin{array}{l}\text { Now Jersey } \\
\text { Atlantic } \\
\text { City } \\
\text { Electric } \\
\text { Co }\end{array}$ & $\begin{array}{l}\text { Now Jersey } \\
\text { Jersey } \\
\text { Contral } \\
\text { Power\&Light } \\
\text { Co }\end{array}$ & $\begin{array}{l}\text { Now Jersey } \\
\text { Public } \\
\text { Service } \\
\text { Electric\&Gas } \\
\text { Co }\end{array}$ & $\begin{array}{l}\text { New Jersey } \\
\text { Rockland } \\
\text { Electric Co }\end{array}$ & $\begin{array}{c}\text { New Mexico } \\
\text { Public } \\
\text { Service } \\
\text { Co } \\
\text { of NM }\end{array}$ \\
\hline 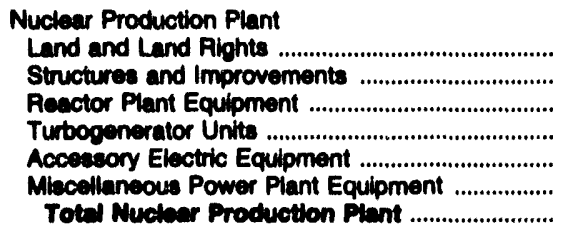 & $\begin{array}{r}8 \\
33,680 \\
56,433 \\
13,619 \\
10,881 \\
2,585 \\
117,296\end{array}$ & $\begin{array}{r}722 \\
151,281 \\
233,261 \\
65,452 \\
82,855 \\
16,803 \\
580,474\end{array}$ & $\begin{array}{r}9,075 \\
213,284 \\
477,819 \\
75,859 \\
130,340 \\
85,837 \\
992,215\end{array}$ & $\begin{array}{r}4,266 \\
1,672,207 \\
2,346,074 \\
574,435 \\
974,081 \\
179,863 \\
5,750,024\end{array}$ & $\begin{array}{l}0 \\
0 \\
0 \\
0 \\
0 \\
0 \\
0\end{array}$ & $\begin{array}{r}101 \\
71,110 \\
116,340 \\
40,178 \\
30,788 \\
15,826 \\
274,342\end{array}$ \\
\hline 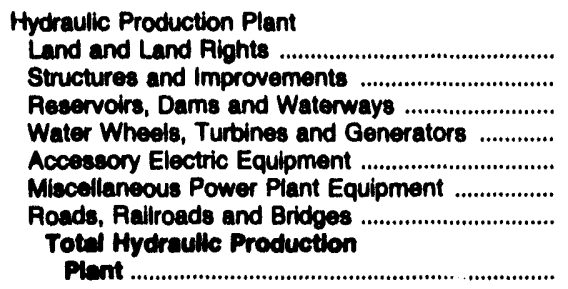 & $\begin{array}{r}1,865 \\
9,798 \\
14,603 \\
8,485 \\
2,591 \\
782 \\
171 \\
38,295\end{array}$ & $\begin{array}{l}0 \\
0 \\
0 \\
0 \\
0 \\
0 \\
0\end{array}$ & $\begin{array}{r}284 \\
3,285 \\
6,893 \\
6,988 \\
1,195 \\
1,081 \\
215 \\
19,030\end{array}$ & $\begin{array}{r}291 \\
3,224 \\
6,937 \\
7,119 \\
1,207 \\
902 \\
204 \\
19,003\end{array}$ & $\begin{array}{l}0 \\
0 \\
0 \\
0 \\
0 \\
0 \\
0 \\
0\end{array}$ & $\begin{array}{l}0 \\
0 \\
0 \\
0 \\
0 \\
0 \\
0 \\
0\end{array}$ \\
\hline 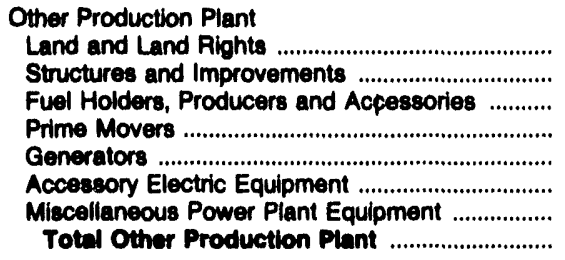 & $\begin{array}{r}13 \\
555 \\
460 \\
631 \\
7,272 \\
88 \\
95 \\
9,115\end{array}$ & $\begin{array}{r}1,316 \\
1,637 \\
8,192 \\
26,761 \\
58,833 \\
656 \\
354 \\
98,848\end{array}$ & $\begin{array}{r}1,255 \\
33,277 \\
40,662 \\
149,443 \\
15,840 \\
16, \ell 63 \\
2,476 \\
250,616\end{array}$ & $\begin{array}{r}115 \\
11,839 \\
23,541 \\
71,329 \\
192,894 \\
43,020 \\
4,378 \\
347,216\end{array}$ & $\begin{array}{l}0 \\
0 \\
0 \\
0 \\
0 \\
0 \\
0 \\
0\end{array}$ & $\begin{array}{r}0 \\
123 \\
173 \\
0 \\
2,323 \\
33 \\
18 \\
18 \\
2,668\end{array}$ \\
\hline Total Production Plant & 508,344 & $1,044,068$ & $1,470,705$ & $7,780,955$ & 0 & $1,208,465$ \\
\hline 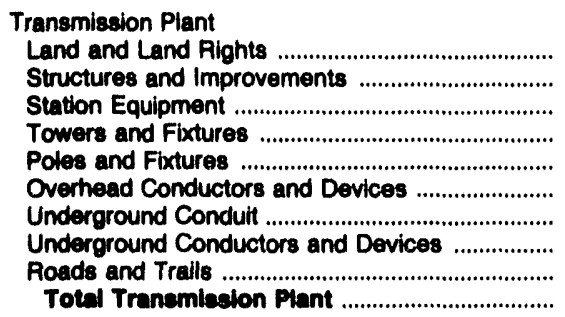 & $\begin{array}{r}16,160 \\
2,048 \\
67,263 \\
19,485 \\
35,662 \\
28,114 \\
375 \\
902 \\
884 \\
170,894\end{array}$ & $\begin{array}{r}20,761 \\
9,710 \\
130,167 \\
21,245 \\
47,665 \\
54,197 \\
6,659 \\
21,970 \\
0 \\
312,374\end{array}$ & $\begin{array}{r}41,416 \\
7,137 \\
277,204 \\
35,953 \\
92,800 \\
129,131 \\
1,432 \\
4,441 \\
2,083 \\
601,786\end{array}$ & $\begin{array}{r}68,712 \\
26,602 \\
506,626 \\
155,178 \\
63 \\
93,200 \\
101,121 \\
67,145 \\
4,416 \\
1,023,062\end{array}$ & $\begin{array}{r}1,923 \\
728 \\
15,111 \\
642 \\
1,980 \\
2,678 \\
4,467 \\
4,098 \\
83 \\
31,711\end{array}$ & $\begin{array}{r}15,793 \\
4,945 \\
85,774 \\
13,828 \\
52,513 \\
44,874 \\
1,759 \\
90 \\
498 \\
220,073\end{array}$ \\
\hline 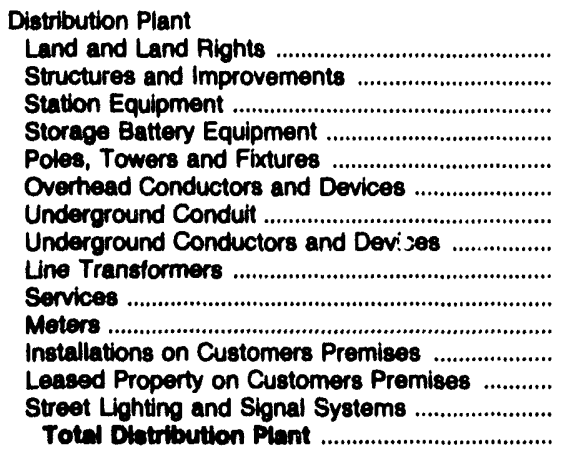 & $\begin{array}{r}640 \\
184 \\
14,493 \\
0 \\
0 \\
91,823 \\
72,925 \\
4,241 \\
23,419 \\
86,233 \\
31,158 \\
35,793 \\
3,600 \\
0 \\
2,979 \\
387,489\end{array}$ & $\begin{array}{r}13,751 \\
6,470 \\
45,874 \\
0 \\
0 \\
106,962 \\
108,987 \\
19,606 \\
25,767 \\
126,013 \\
54,766 \\
38,988 \\
9,668 \\
422 \\
26,637 \\
583,890\end{array}$ & $\begin{array}{r}23,816 \\
4,003 \\
187,290 \\
0 \\
219,066 \\
252,292 \\
51,097 \\
136,263 \\
248,394 \\
191,718 \\
67,252 \\
3,950 \\
0 \\
62,403 \\
1,447,543\end{array}$ & $\begin{array}{r}25,884 \\
73,372 \\
395,144 \\
0 \\
277,049 \\
497,442 \\
199,355 \\
331,845 \\
405,231 \\
161,174 \\
109,249 \\
0 \\
0 \\
98,342 \\
2,574,030\end{array}$ & $\begin{array}{r}569 \\
1,411 \\
15,806 \\
0 \\
14,457 \\
17,356 \\
3,636 \\
12,223 \\
16,053 \\
8,559 \\
4,716 \\
147 \\
0 \\
2,593 \\
08,627\end{array}$ & $\begin{array}{r}1,689 \\
3,220 \\
38,157 \\
0 \\
50,561 \\
48,284 \\
42,750 \\
87,465 \\
69,391 \\
34,763 \\
22,153 \\
7,745 \\
0 \\
12,540 \\
416,726\end{array}$ \\
\hline
\end{tabular}

See endnotes at end of an indlvidual electric utility. 
Table 42. Utility Plant by Major U.S. Investor-Owned Electric Utility Within State on Decomber 31, 1992 (Continued)

(Thousand Dollars)

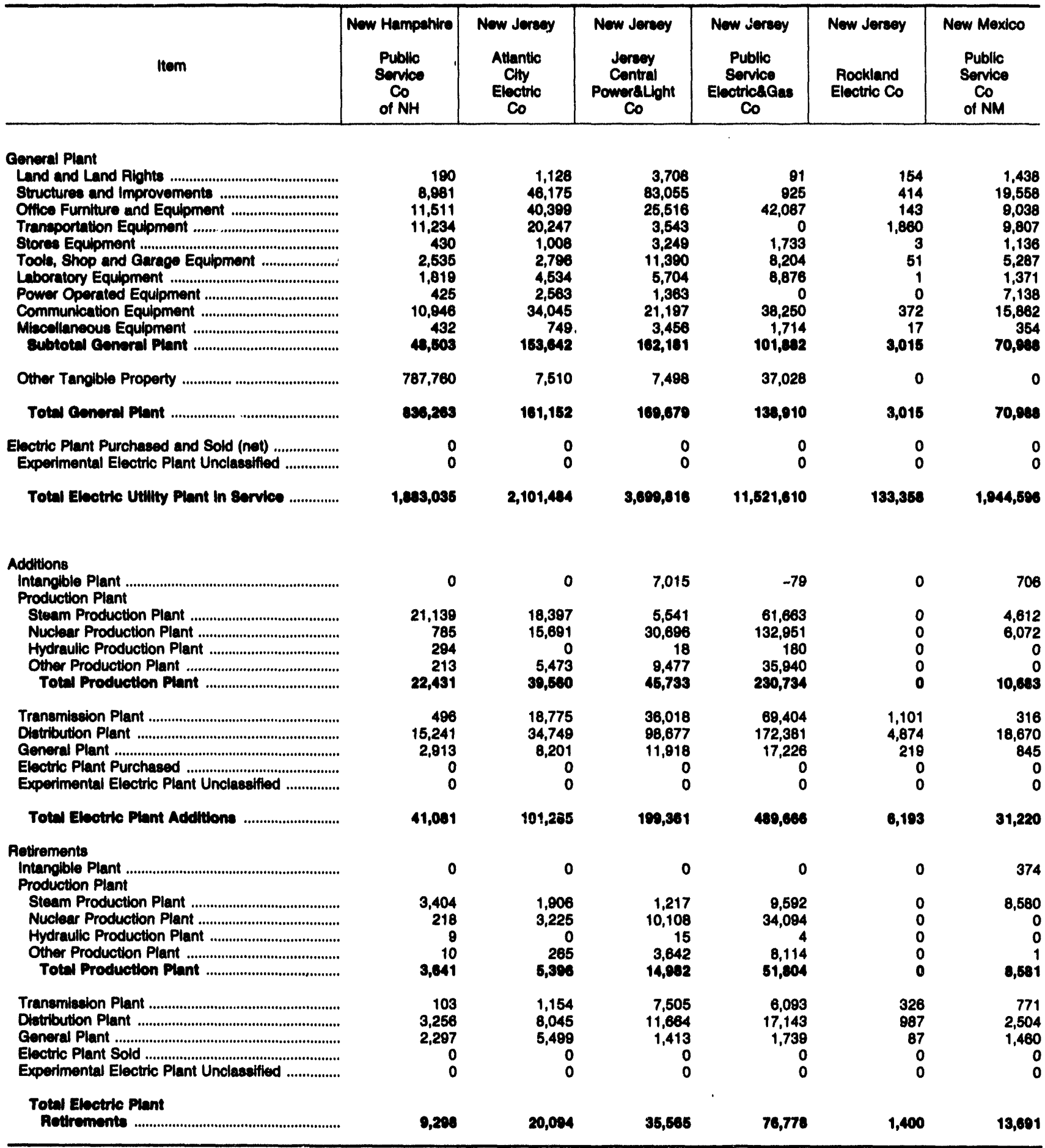

Note: Totals may not equal sum of cornponents because of independent rounding. Summary data are provided in Table 28.

Source: Federal Energy Regulatory Commisaion, FERC Form 1, "Annual Report of Major Electric Utilities, Licensees and Others." 
Table 42. Utillty Plant by Major U.S. Investor-Owned Electric Utility Within State on Decomber 31, 1982 (Continued)

(Thousand Dollars)

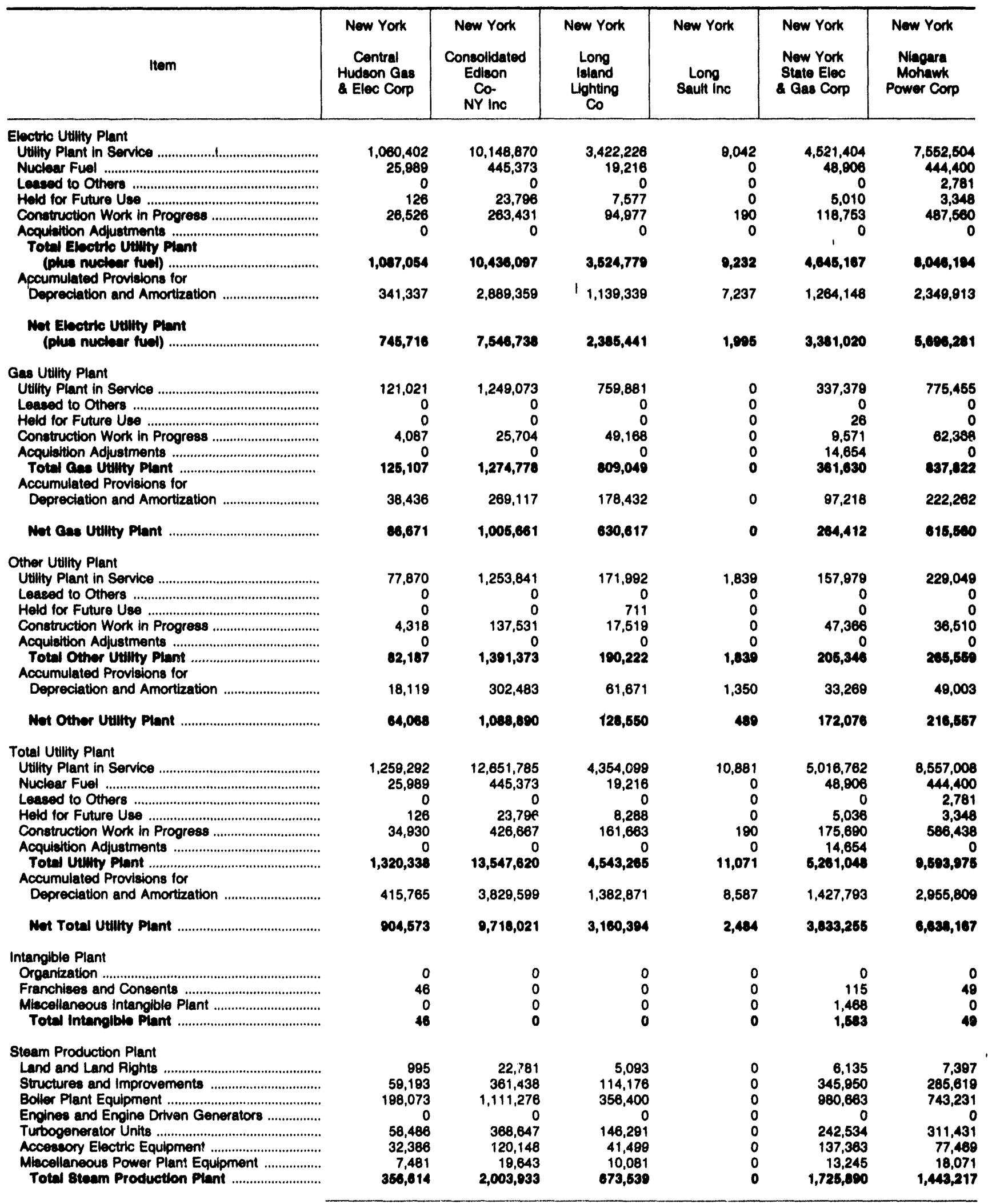

See endnotes at end of an individual electric utlitity. 
Table 42. UtIlity Plant by Major U.S. Investor-Owned Electric Utility Within State on December 31, 1982 (Continued) (Thousand Dollars)

\begin{tabular}{|c|c|c|c|c|c|c|}
\hline Item & $\begin{array}{c}\text { New York } \\
\text { Central } \\
\text { Hudson Gas } \\
\text { Elec Corp }\end{array}$ & $\begin{array}{l}\text { New York } \\
\text { Consolidated } \\
\text { Edlson } \\
\text { Co- } \\
\text { NY Inc }\end{array}$ & $\begin{array}{l}\text { New York } \\
\text { Long } \\
\text { Island } \\
\text { Lighting } \\
1 \text { Co }\end{array}$ & $\begin{array}{c}\text { Now York } \\
\text { Long } \\
\text { Sault inc }\end{array}$ & $\begin{array}{l}\text { New York } \\
\text { Now York } \\
\text { State Elec } \\
\text { \& Gas Corp }\end{array}$ & $\begin{array}{c}\text { New York } \\
\text { Niagara } \\
\text { Mohawk } \\
\text { Power Corp }\end{array}$ \\
\hline 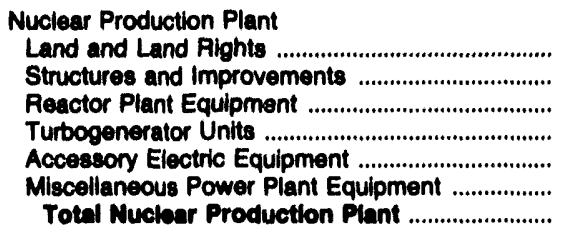 & $\begin{array}{r}13 \\
107,526 \\
98,344 \\
28,514 \\
48,841 \\
12,572 \\
205,811\end{array}$ & $\begin{array}{r}1,813 \\
204,796 \\
284,249 \\
141,318 \\
21,020 \\
22,462 \\
675,057\end{array}$ & $\begin{array}{r}7 \\
268,827 \\
304,602 \\
82,957 \\
139,871 \\
94,708 \\
899,171\end{array}$ & $\begin{array}{l}0 \\
0 \\
0 \\
0 \\
0 \\
0 \\
0\end{array}$ & $\begin{array}{r}3 \\
345,323 \\
244,572 \\
70,341 \\
66,704 \\
4,494 \\
740,437\end{array}$ & $\begin{array}{r}938 \\
678,341 \\
837,552 \\
198,891 \\
284,186 \\
122,265 \\
2,122,184\end{array}$ \\
\hline 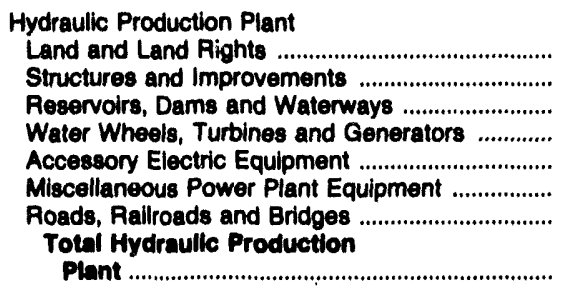 & $\begin{array}{r}1,187 \\
2,445 \\
8,048 \\
5,208 \\
1,669 \\
127 \\
0\end{array}$ & $\begin{array}{l}0 \\
0 \\
0 \\
0 \\
0 \\
0 \\
0\end{array}$ & $\begin{array}{l}0 \\
0 \\
0 \\
0 \\
0 \\
0 \\
0\end{array}$ & $\begin{array}{l}0 \\
0 \\
0 \\
0 \\
0 \\
0 \\
0\end{array}$ & $\begin{array}{r}6,278 \\
12,369 \\
48,604 \\
37,140 \\
7,384 \\
1,303 \\
26 \\
113,105\end{array}$ & $\begin{array}{r}25,765 \\
34,997 \\
224,031 \\
62,142 \\
24,772 \\
2,665 \\
1,933 \\
376,305\end{array}$ \\
\hline & & & & & 1 & \\
\hline 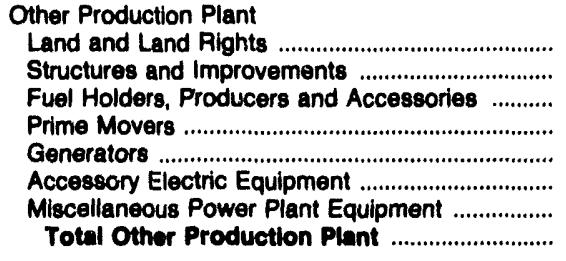 & $\begin{array}{r}11 \\
377 \\
415 \\
2,060 \\
645 \\
241 \\
4 \\
3,752\end{array}$ & $\begin{array}{r}4,040 \\
20,488 \\
18,077 \\
0 \\
181,480 \\
29,294 \\
0 \\
253,380\end{array}$ & $\begin{array}{r}528 \\
7,655 \\
11,030 \\
0 \\
206,664 \\
3,925 \\
1,886 \\
231,689\end{array}$ & $\begin{array}{l}0 \\
0 \\
0 \\
0 \\
0 \\
0 \\
0 \\
0\end{array}$ & $\begin{array}{r}22 \\
6 \\
28 \\
362 \\
175 \\
119 \\
0 \\
712\end{array}$ & $\begin{array}{r}0 \\
1,332 \\
920 \\
0 \\
12,219 \\
1,010 \\
15 \\
15,498\end{array}$ \\
\hline Total Production Plant ......................................... & 674,861 & $2,932,970$ & $1,794,400$ & $\mathbf{0}$ & $2,580,145$ & $3,957,202$ \\
\hline \multicolumn{7}{|l|}{ Transmission Plant } \\
\hline 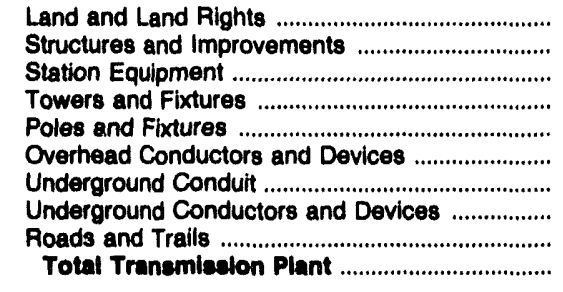 & $\begin{array}{r}8,097 \\
2,984 \\
55,973 \\
1,950 \\
11,635 \\
14,650 \\
15 \\
5,634 \\
0 \\
100,938\end{array}$ & $\begin{array}{r}35,438 \\
52,264 \\
828,777 \\
139,721 \\
0 \\
81,682 \\
299,685 \\
183,061 \\
0 \\
1,620,629\end{array}$ & $\begin{array}{r}16,843 \\
4,443 \\
156,489 \\
6,486 \\
45,585 \\
81,497 \\
56,496 \\
85,819 \\
0 \\
453,658\end{array}$ & $\begin{array}{r}12 \\
86 \\
7,068 \\
1,089 \\
158 \\
445 \\
0 \\
0 \\
14 \\
8,871\end{array}$ & $\begin{array}{r}43,409 \\
7,390 \\
249,830 \\
16,930 \\
133,488 \\
130,363 \\
1,921 \\
6,415 \\
0 \\
589,747\end{array}$ & $\begin{array}{r}88,403 \\
14,750 \\
480,649 \\
117,186 \\
204,331 \\
158,009 \\
24,070 \\
59,012 \\
52 \\
1,156,462\end{array}$ \\
\hline \multicolumn{7}{|l|}{ Distribution Plant } \\
\hline 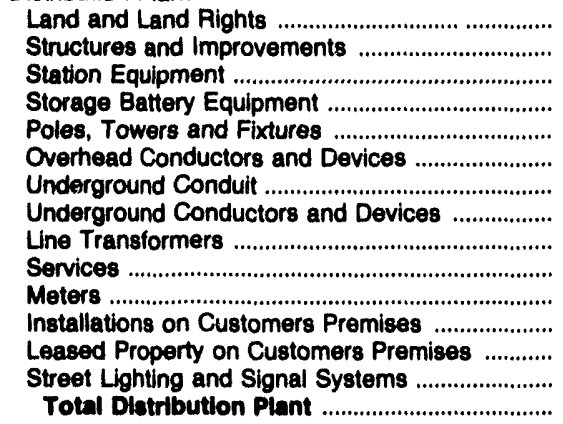 & $\begin{array}{r}1,556 \\
1,599 \\
39,077 \\
0 \\
48,916 \\
62,560 \\
8,633 \\
20,348 \\
56,819 \\
15,115 \\
20,866 \\
1,046 \\
13 \\
5,838 \\
282,385\end{array}$ & $\begin{array}{r}32,716 \\
104,275 \\
709,399 \\
0 \\
184,287 \\
287,637 \\
996,563 \\
1,627,422 \\
898,385 \\
444,324 \\
221,007 \\
3,772 \\
0 \\
85,484 \\
5,595,271\end{array}$ & $\begin{array}{r}5,886 \\
2,772 \\
140,906 \\
0 \\
144,383 \\
176,909 \\
58,130 \\
151,480 \\
273,823 \\
91,003 \\
76,219 \\
5,746 \\
0 \\
3,264 \\
1,130,520\end{array}$ & $\begin{array}{l}0 \\
0 \\
0 \\
0 \\
0 \\
0 \\
0 \\
0 \\
0 \\
0 \\
0 \\
0 \\
0 \\
0 \\
0\end{array}$ & $\begin{array}{r}36,304 \\
1,855 \\
106,214 \\
0 \\
267,693 \\
286,969 \\
13,994 \\
74,475 \\
261,082 \\
96,631 \\
82,031 \\
5,244 \\
0 \\
32,544 \\
1,265,035\end{array}$ & $\begin{array}{r}7,450 \\
10,855 \\
235,740 \\
0 \\
419,088 \\
426,795 \\
76,749 \\
171,166 \\
400,740 \\
213,336 \\
111,001 \\
4,765 \\
0 \\
109,963 \\
2,187,648\end{array}$ \\
\hline
\end{tabular}

See endnotes at end of an individual electric utility. 
Tablo 42. Utility Plant by Major U.8. Inveotor-Owned Electric Utility Within State on Decomber 31, 1902 (Continued) (Thousand Dollars)

\begin{tabular}{|c|c|c|c|c|c|c|}
\hline Item & $\begin{array}{l}\text { Now York } \\
\text { Central } \\
\text { Hudeon Cas } \\
\text { Eleo Corp }\end{array}$ & $\begin{array}{l}\text { Now York } \\
\text { Consolldated } \\
\text { Edison } \\
\text { Co- } \\
\text { NY ine }\end{array}$ & $\begin{array}{l}\text { Now York } \\
\text { Long } \\
\text { leland } \\
\text { Lionting } \\
\text { Co }\end{array}$ & $\begin{array}{l}\text { New York } \\
\text { Long } \\
\text { Sault ino }\end{array}$ & $\begin{array}{l}\text { New York } \\
\text { New York } \\
\text { State Elec } \\
\text { Gas Corp }\end{array}$ & $\begin{array}{l}\text { Now York } \\
\text { Niagara } \\
\text { Mohawk } \\
\text { Power Corp }\end{array}$ \\
\hline 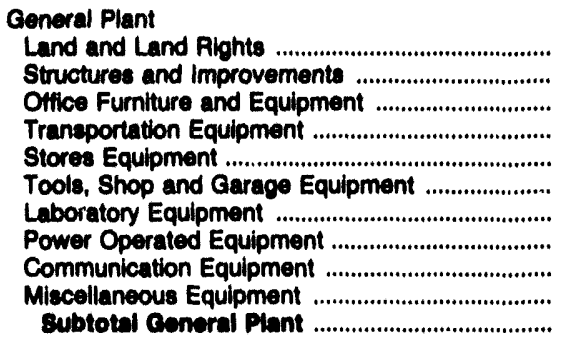 & $\begin{array}{r}12 \\
482 \\
748 \\
93 \\
43 \\
64 \\
2 \\
0 \\
727 \\
0 \\
2,172\end{array}$ & $\begin{array}{l}0 \\
0 \\
0 \\
0 \\
0 \\
0 \\
0 \\
0 \\
0 \\
0 \\
0\end{array}$ & $\begin{array}{r}33 \\
2,579 \\
637 \\
15,188 \\
19 \\
10,128 \\
4,228 \\
442 \\
1,847 \\
165 \\
36,281\end{array}$ & $\begin{array}{r}0 \\
0 \\
100 \\
30 \\
0 \\
0 \\
4 \\
0 \\
36 \\
0 \\
170\end{array}$ & $\begin{array}{r}2,094 \\
49,468 \\
5,197 \\
3,912 \\
394 \\
1,670 \\
3,273 \\
17,821 \\
1,131 \\
146 \\
4,098\end{array}$ & $\begin{array}{r}3,315 \\
86,710 \\
44,622 \\
857 \\
1,529 \\
15,606 \\
10,844 \\
432 \\
27,448 \\
49,780 \\
251,143\end{array}$ \\
\hline Other Tangible Property .......................................... & 0 & 0 & 0 & 0 & 0 & 0 \\
\hline 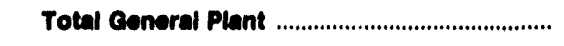 & 2,172 & $\mathbf{0}$ & 35,281 & 170 & 04,095 & 251,143 \\
\hline 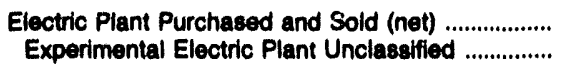 & $\begin{array}{l}0 \\
0\end{array}$ & $\begin{array}{l}0 \\
0\end{array}$ & $\begin{array}{r}8,386 \\
0\end{array}$ & $\begin{array}{l}0 \\
0\end{array}$ & $\begin{array}{l}0 \\
0\end{array}$ & $\begin{array}{l}0 \\
0\end{array}$ \\
\hline Total Electric Utilty Plant in Service .............. & $1,040,402$ & $10,149,070$ & $3,422,228$ & 9,042 & $4,621,404$ & $7,662,604$ \\
\hline 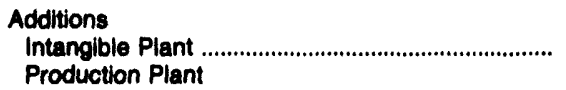 & 0 & 0 & 0 & 0 & 0 & 0 \\
\hline 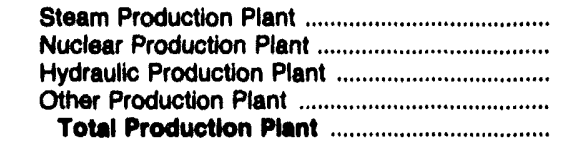 & $\begin{array}{r}11,730 \\
1,102 \\
675 \\
208 \\
13,713\end{array}$ & $\begin{array}{r}114,978 \\
6,955 \\
0 \\
7,572 \\
131,804\end{array}$ & $\begin{array}{r}41,071 \\
3,517 \\
0 \\
13,773 \\
\mathbf{6 9 , 3 8 1}\end{array}$ & $\begin{array}{l}0 \\
0 \\
0 \\
0 \\
0\end{array}$ & $\begin{array}{r}35,386 \\
8,032 \\
8,262 \\
0 \\
51,081\end{array}$ & $\begin{array}{r}40,050 \\
23,242 \\
45,370 \\
-148 \\
108,614\end{array}$ \\
\hline 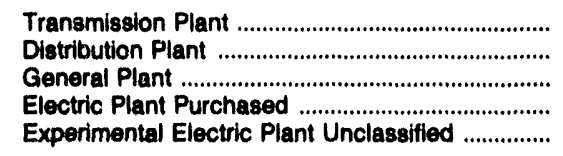 & $\begin{array}{r}9,712 \\
14,486 \\
228 \\
0 \\
0\end{array}$ & $\begin{array}{r}54,704 \\
329,731 \\
0 \\
0 \\
0\end{array}$ & $\begin{array}{r}-3,694 \\
91,822 \\
1,071 \\
0 \\
0\end{array}$ & $\begin{array}{r}118 \\
0 \\
0 \\
0 \\
0\end{array}$ & $\begin{array}{r}19,455 \\
81,468 \\
17,409 \\
0 \\
0\end{array}$ & $\begin{array}{r}49,964 \\
152,023 \\
21,390 \\
0 \\
0\end{array}$ \\
\hline Total Electric Plant Additions ............................ & 38,138 & 515,039 & 147,600 & 118 & 170,013 & 331,890 \\
\hline 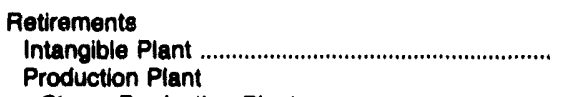 & 0 & 0 & 0 & 0 & 0 & 0 \\
\hline 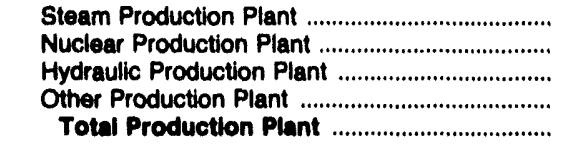 & $\begin{array}{r}2,241 \\
1,378 \\
48 \\
0 \\
3,987\end{array}$ & $\begin{array}{r}25,069 \\
1,340 \\
0 \\
1,302 \\
27,710\end{array}$ & $\begin{array}{r}20,894 \\
5,588 \\
0 \\
3,002 \\
20,484\end{array}$ & $\begin{array}{l}0 \\
0 \\
0 \\
0 \\
0\end{array}$ & $\begin{array}{r}14,570 \\
456 \\
252 \\
0 \\
15,277\end{array}$ & $\begin{array}{r}8,828 \\
7,051 \\
1,582 \\
5,779 \\
23,250\end{array}$ \\
\hline 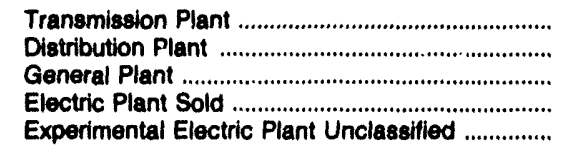 & $\begin{array}{r}124 \\
2,186 \\
18 \\
0 \\
0\end{array}$ & $\begin{array}{r}4,015 \\
48,809 \\
0 \\
0 \\
0\end{array}$ & $\begin{array}{r}2,824 \\
14,379 \\
2,395 \\
0 \\
0\end{array}$ & $\begin{array}{r}11 \\
0 \\
0 \\
0 \\
0\end{array}$ & $\begin{array}{r}1,255 \\
11,444 \\
75 \\
0 \\
0\end{array}$ & $\begin{array}{r}4,184 \\
12,468 \\
2,529 \\
0 \\
0\end{array}$ \\
\hline $\begin{array}{l}\text { Total Electric Plant } \\
\text { Rotirements }\end{array}$ & 6,004 & 00,534 & 49,081 & 11 & 28,051 & 42,431 \\
\hline
\end{tabular}

Note: Totals may not equal sum of co ponents because of independent rounding. Summary data are provided in Table 28.

Source: Federal Energy Regulatory Co nmission, FERC Form 1, "Annual Report of Major Electric Utillties, Licensees and Others." 
Table 42. Utility Plant by Major U.8. Investor-Owned Eloctrle Utility Within state on December 31, 1902 (Continued) (Thousand Dollars)

\begin{tabular}{|c|c|c|c|c|c|c|}
\hline Item & $\begin{array}{l}\text { Now York } \\
\text { Orange a } \\
\text { Pockiand } \\
\text { Utils } \\
\text { Ino }\end{array}$ & $\begin{array}{l}\text { Now York } \\
\text { Rocheoter } \\
\text { Cas } \\
\text { Electric Corp }\end{array}$ & $\begin{array}{l}\text { North Caroline } \\
\text { Carolina } \\
\text { Power } \\
\text { Light Co }\end{array}$ & $\begin{array}{c}\text { North Carolina } \\
\text { Duke } \\
\text { Power Co }\end{array}$ & $\begin{array}{c}\text { North Carolina } \\
\text { Nantanala } \\
\text { Power } \\
\text { Light Co }\end{array}$ & $\begin{array}{c}\text { North Carolina } \\
\text { Yadkin } \\
\text { Inc }\end{array}$ \\
\hline 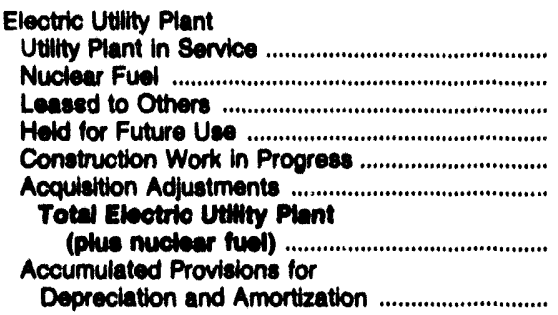 & $\begin{array}{r}766,763 \\
0 \\
0 \\
2,688 \\
16,848 \\
0 \\
724,118 \\
231,111\end{array}$ & $\begin{array}{r}2,171,654 \\
158,405 \\
0 \\
1,978 \\
70,516 \\
1,728 \\
2,246,770 \\
980,215\end{array}$ & $\begin{array}{r}8,674,783 \\
410,024 \\
0 \\
13,385 \\
251,238 \\
3,671 \\
\\
0,843,070 \\
2,632,677\end{array}$ & $\begin{array}{r}12,129,838 \\
2,417,893 \\
0 \\
65,869 \\
341,463 \\
8,180 \\
12,838,351 \\
4,187,605\end{array}$ & $\begin{array}{r}131,262 \\
0 \\
0 \\
160 \\
7,776 \\
0 \\
130,118 \\
68,102\end{array}$ & $\begin{array}{r}52,689 \\
0 \\
0 \\
0 \\
5,832 \\
0 \\
50,600 \\
38,297\end{array}$ \\
\hline $\begin{array}{l}\text { Net Evotric Utilty Piant } \\
\text { (plus nuctear fuel) }\end{array}$ & 889,077 & $1,208,055$ & $0,210,400$ & $0,397,048$ & 73,009 & 22,203 \\
\hline 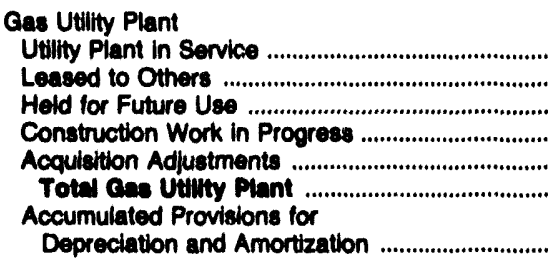 & $\begin{array}{r}176,811 \\
0 \\
88 \\
3,941 \\
0 \\
180,940 \\
63,421\end{array}$ & $\begin{array}{r}341,468 \\
0 \\
0 \\
5,259 \\
0 \\
348,724\end{array}$ & $\begin{array}{l}0 \\
0 \\
0 \\
0 \\
0 \\
0\end{array}$ & $\begin{array}{l}0 \\
0 \\
0 \\
0 \\
0 \\
0\end{array}$ & $\begin{array}{l}0 \\
0 \\
0 \\
0 \\
0 \\
0\end{array}$ & $\begin{array}{l}0 \\
0 \\
0 \\
0 \\
0 \\
0\end{array}$ \\
\hline Not ens Utulty Plant ......................................... & 117,520 & 285,190 & 0 & $\mathbf{0}$ & $\mathbf{0}$ & $\mathbf{0}$ \\
\hline 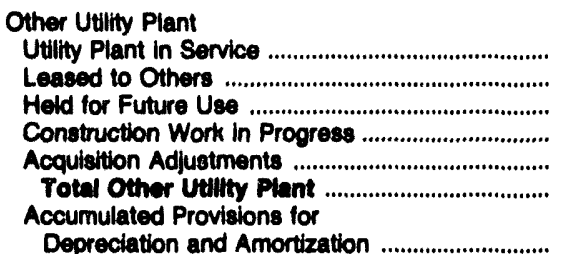 & $\begin{array}{r}50,172 \\
0 \\
0 \\
3,305 \\
0 \\
58,476\end{array}$ & $\begin{array}{r}123,034 \\
0 \\
0 \\
8,057 \\
0 \\
131,002\end{array}$ & $\begin{array}{l}0 \\
0 \\
0 \\
0 \\
0 \\
0\end{array}$ & $\begin{array}{r}35,652 \\
0 \\
0 \\
2 \\
0 \\
35,854\end{array}$ & $\begin{array}{l}0 \\
0 \\
0 \\
0 \\
0 \\
0\end{array}$ & $\begin{array}{l}0 \\
0 \\
0 \\
0 \\
0 \\
0\end{array}$ \\
\hline Not Other Utility Pant ............................................ & 35,768 & 77,330 & o & 27,028 & 0 & 0 \\
\hline 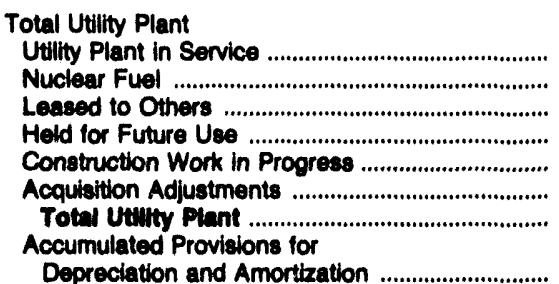 & $\begin{array}{r}992,835 \\
0 \\
0 \\
2,670 \\
23,094 \\
0 \\
1,018,008 \\
312,248\end{array}$ & $\begin{array}{r}2,636,054 \\
158,405 \\
0 \\
1,978 \\
83,832 \\
1,723 \\
2,81,002\end{array}$ & $\begin{array}{r}8,574,783 \\
410,924 \\
0 \\
13,385 \\
251,238 \\
3,671 \\
9,284,000\end{array}$ & $\begin{array}{r}12,165,490 \\
2,417,893 \\
0 \\
55,869 \\
341,465 \\
8,180 \\
14,098,097 \\
6,079,921\end{array}$ & $\begin{array}{r}131,252 \\
0 \\
0 \\
160 \\
7,776 \\
0 \\
139,188 \\
68,102\end{array}$ & $\begin{array}{r}52,689 \\
0 \\
0 \\
0 \\
5,832 \\
0 \\
09,800 \\
36,297\end{array}$ \\
\hline Not Total Utulty Piant .............................................. & $708,38 s$ & $1,803,807$ & $6,425,57$ & $8,909,978$ & 73,098 & 22,203 \\
\hline 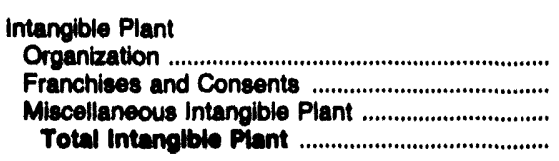 & $\begin{array}{r}0 \\
3,662 \\
846 \\
4,808\end{array}$ & $\begin{array}{l}0 \\
0 \\
0 \\
0\end{array}$ & $\begin{array}{r}177 \\
0 \\
0 \\
177\end{array}$ & $\begin{array}{l}0 \\
0 \\
0 \\
0\end{array}$ & $\begin{array}{r}0 \\
182 \\
0 \\
192\end{array}$ & $\begin{array}{l}0 \\
0 \\
0 \\
0\end{array}$ \\
\hline 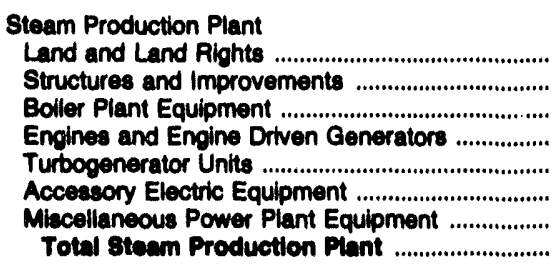 & $\begin{array}{r}4,517 \\
46,825 \\
212,935 \\
0 \\
49,913 \\
22,685 \\
3,124 \\
399,790\end{array}$ & $\begin{array}{r}559 \\
38,349 \\
103,941 \\
0 \\
45,714 \\
14,010 \\
3,797 \\
208,370\end{array}$ & $\begin{array}{r}25,340 \\
205,541 \\
763,776 \\
0 \\
303,272 \\
88,402 \\
21,411 \\
1,417,742\end{array}$ & $\begin{array}{r}18,317 \\
187,736 \\
818,287 \\
0 \\
330,950 \\
88,430 \\
25,568 \\
1,460,247\end{array}$ & $\begin{array}{l}0 \\
0 \\
0 \\
0 \\
0 \\
0 \\
0 \\
0\end{array}$ & $\begin{array}{l}0 \\
0 \\
0 \\
0 \\
0 \\
0 \\
0 \\
0\end{array}$ \\
\hline
\end{tabular}


Table 42. Utility Plant by Major U.8. Inveotor-Owned Eleotric Utillty Within state on Decomber 31, 1992 (Continued) (Thousand Dollars)

\begin{tabular}{|c|c|c|c|c|c|c|}
\hline Item & $\begin{array}{l}\text { New York } \\
\text { Orange a } \\
\text { Rookland } \\
\text { Utils } \\
\text { Inc }\end{array}$ & $\begin{array}{l}\text { Now York } \\
\text { Roohester } \\
\text { Cas } \\
\text { Elootric Corp }\end{array}$ & $\begin{array}{c}\text { North Carolina } \\
\text { Carolina } \\
\text { Power } \\
\text { Loht Co }\end{array}$ & $\begin{array}{c}\text { North Carolina } \\
\text { Duke } \\
\text { Power Co }\end{array}$ & $\begin{array}{c}\text { North Carolina } \\
\text { Nantahala } \\
\text { Power } \\
\text { Light Co }\end{array}$ & $\begin{array}{l}\text { North Carolina } \\
\text { Yadkin } \\
\text { Inc }\end{array}$ \\
\hline 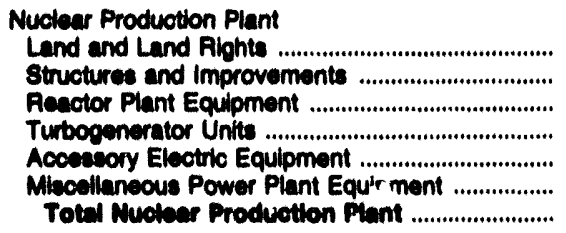 & $\begin{array}{l}0 \\
0 \\
0 \\
0 \\
0 \\
0 \\
0\end{array}$ & $\begin{array}{r}450 \\
407,384 \\
515,314 \\
128,181 \\
179,785 \\
72,784 \\
1,308,609\end{array}$ & $\begin{array}{r}55,249 \\
1,821,839 \\
1,238,475 \\
415,846 \\
445,768 \\
160,126 \\
4,136,400\end{array}$ & $\begin{array}{r}2,368 \\
976,839 \\
1,686,686 \\
526,952 \\
296,652 \\
158,084 \\
3,685,681\end{array}$ & $\begin{array}{l}0 \\
0 \\
0 \\
0 \\
0 \\
0 \\
0\end{array}$ & $\begin{array}{l}0 \\
0 \\
0 \\
0 \\
n \\
\vdots\end{array}$ \\
\hline 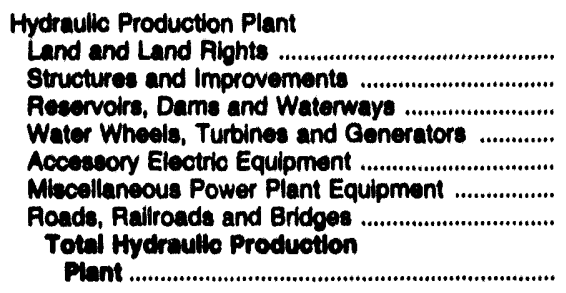 & $\begin{array}{r}1,205 \\
1,842 \\
18,367 \\
2,182 \\
982 \\
353 \\
61 \\
24,973\end{array}$ & $\begin{array}{r}1,733 \\
2,204 \\
11,603 \\
5,638 \\
788 \\
64 \\
228 \\
22,267\end{array}$ & $\begin{array}{r}2,208 \\
4,516 \\
21,413 \\
16,230 \\
4,165 \\
824 \\
21 \\
49,387\end{array}$ & $\begin{array}{r}47,626 \\
170,919 \\
674,625 \\
217,793 \\
138,661 \\
43,246 \\
18,837 \\
1,312,706\end{array}$ & $\begin{array}{r}847 \\
1,648 \\
22,003 \\
2,658 \\
1,176 \\
209 \\
386 \\
28,228\end{array}$ & $\begin{array}{r}6,772 \\
935 \\
17,263 \\
12,993 \\
3,556 \\
2,298 \\
147 \\
43,905\end{array}$ \\
\hline 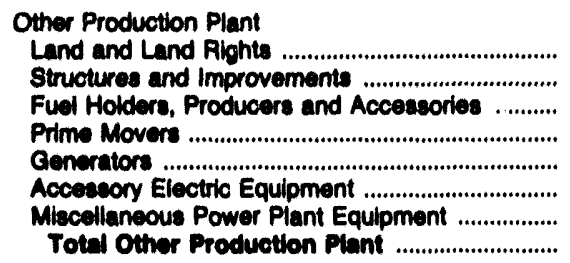 & $\begin{array}{r}3 \\
638 \\
363 \\
385 \\
2,278 \\
611 \\
9 \\
4,186\end{array}$ & $\begin{array}{r}0 \\
0 \\
101 \\
0 \\
3,531 \\
290 \\
0 \\
3,923\end{array}$ & $\begin{array}{r}258 \\
12,458 \\
11,642 \\
35,278 \\
11,768 \\
6,008 \\
702 \\
70,202\end{array}$ & $\begin{array}{r}3 \\
50 \\
231 \\
575 \\
67,885 \\
614 \\
249 \\
69,603\end{array}$ & $\begin{array}{l}0 \\
0 \\
0 \\
0 \\
0 \\
0 \\
0 \\
0\end{array}$ & $\begin{array}{l}0 \\
0 \\
0 \\
0 \\
0 \\
0 \\
0 \\
0\end{array}$ \\
\hline 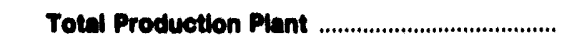 & 399,085 & $1,380,469$ & $5,679,712$ & $6,407,160$ & 28,928 & 43,985 \\
\hline 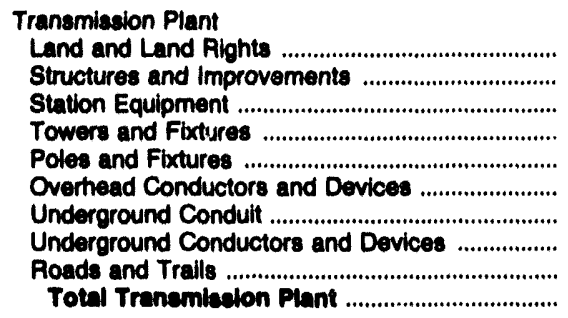 & $\begin{array}{r}8,130 \\
5,137 \\
46,253 \\
4,561 \\
16,848 \\
15,525 \\
1,243 \\
1,480 \\
805 \\
99,982\end{array}$ & $\begin{array}{r}8,806 \\
5,909 \\
79,852 \\
3,568 \\
16,591 \\
14,138 \\
12,731 \\
27,113 \\
0 \\
168,707\end{array}$ & $\begin{array}{r}98,690 \\
31,501 \\
328,792 \\
57,952 \\
133,963 \\
187,804 \\
0 \\
0 \\
15 \\
848,716\end{array}$ & $\begin{array}{r}123,155 \\
14,663 \\
609,522 \\
287,884 \\
60,887 \\
233,920 \\
105 \\
1,432 \\
0 \\
1,331,668\end{array}$ & $\begin{array}{r}1,440 \\
0 \\
12,111 \\
6,618 \\
2,840 \\
6,958 \\
0 \\
0 \\
2 \\
20,980\end{array}$ & $\begin{array}{r}8 \\
124 \\
5,526 \\
543 \\
10 \\
1,324 \\
0 \\
0 \\
3 \\
7,538\end{array}$ \\
\hline 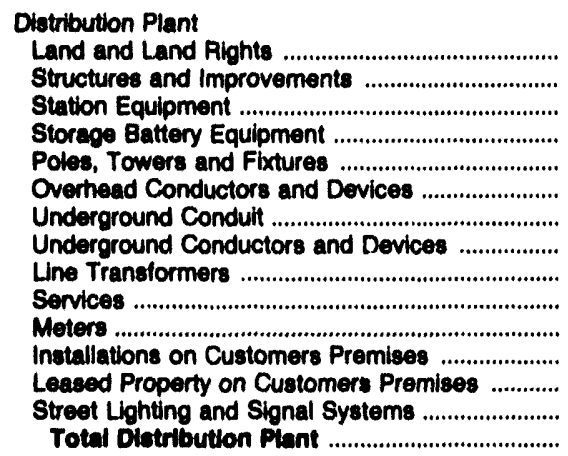 & $\begin{array}{r}1,031 \\
1,762 \\
31,118 \\
0 \\
51,257 \\
52,339 \\
6,847 \\
34,186 \\
49,116 \\
16,488 \\
14,195 \\
0 \\
0 \\
8,026 \\
286,376\end{array}$ & $\begin{array}{r}6,624 \\
5,324 \\
50,349 \\
0 \\
45,265 \\
50,800 \\
81,576 \\
58,609 \\
71,787 \\
23,065 \\
30,623 \\
0 \\
0 \\
22,809 \\
448,830\end{array}$ & $\begin{array}{r}36,635 \\
21,165 \\
186,832 \\
0 \\
215,278 \\
264,784 \\
29,182 \\
209,727 \\
386,851 \\
167,592 \\
114,375 \\
58,218 \\
0 \\
37,052 \\
1,738,670\end{array}$ & $\begin{array}{r}14,486 \\
46,170 \\
326,221 \\
0 \\
641,755 \\
515,808 \\
131,798 \\
441,849 \\
714,241 \\
306,217 \\
166,917 \\
137,996 \\
0 \\
75,777 \\
3,519,236\end{array}$ & $\begin{array}{r}1,082 \\
3 \\
494 \\
0 \\
25,539 \\
9,642 \\
0 \\
2,589 \\
13,436 \\
7,192 \\
3,746 \\
665 \\
0 \\
196 \\
64,594\end{array}$ & $\begin{array}{l}0 \\
0 \\
0 \\
0 \\
0 \\
0 \\
0 \\
0 \\
0 \\
0 \\
0 \\
0 \\
0 \\
0 \\
0\end{array}$ \\
\hline
\end{tabular}

See endnotes at end of an indlvidual electric utility. 
Table 42. Utility Plant by Major U.8. Investor-Owned Electric Utillty Within 8tate on Decomber 31, 1992 (Continued)

(Thousand Dollars)

\begin{tabular}{|c|c|c|c|c|c|c|}
\hline Item & $\begin{array}{l}\text { New York } \\
\text { Orange } \\
\text { Rockland } \\
\text { Utils } \\
\text { Ine }\end{array}$ & $\begin{array}{l}\text { Now York } \\
\text { Aochester } \\
\text { Gas } \\
\text { Electrio Corp }\end{array}$ & $\begin{array}{c}\text { North Carolina } \\
\text { Caroline } \\
\text { Power } \\
\text { Light Co }\end{array}$ & $\begin{array}{c}\text { North Carolina } \\
\text { Duke } \\
\text { Power Co }\end{array}$ & $\begin{array}{c}\text { North Carolina } \\
\text { Nantahala } \\
\text { Power } \\
\text { Lught Co }\end{array}$ & $\begin{array}{l}\text { North Carolina } \\
\text { Yadkin } \\
\text { Inc }\end{array}$ \\
\hline 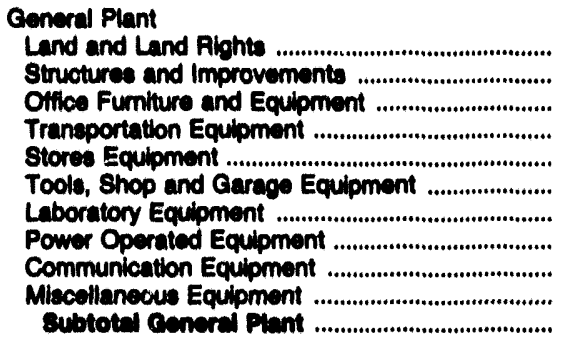 & $\begin{array}{r}12 \\
1,939 \\
6,735 \\
10,971 \\
99 \\
1,172 \\
1,979 \\
1,104 \\
1,696 \\
221 \\
26,920\end{array}$ & $\begin{array}{r}57 \\
1,799 \\
6,310 \\
0 \\
13 \\
3,207 \\
2,719 \\
0 \\
5,802 \\
3 \\
18,910\end{array}$ & $\begin{array}{r}6,236 \\
43,647 \\
37,689 \\
80,081 \\
2,611 \\
4,693 \\
33,289 \\
2,420 \\
78,627 \\
1,350 \\
290,643\end{array}$ & $\begin{array}{r}28,095 \\
334,050 \\
151,664 \\
84,007 \\
8,443 \\
33,875 \\
30,004 \\
29,317 \\
154,806 \\
6,649 \\
871,711\end{array}$ & $\begin{array}{r}388 \\
2,588 \\
826 \\
1,807 \\
125 \\
1,247 \\
155 \\
0 \\
481 \\
83 \\
7,569\end{array}$ & $\begin{array}{r}0 \\
12 \\
478 \\
340 \\
0 \\
127 \\
80 \\
12 \\
106 \\
0 \\
1,168\end{array}$ \\
\hline 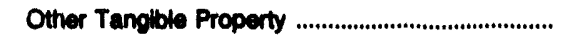 & 0 & 638 & 46,864 & 0 & 0 & 0 \\
\hline 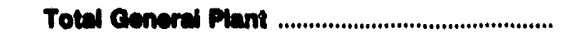 & 28,020 & 18,546 & 307,507 & 871,711 & 7,600 & 1,168 \\
\hline $\begin{array}{l}\text { Electric Plant Purchased and Sold (net) ..................... } \\
\text { Experimental Electric Plant Uncleselfied ............... }\end{array}$ & $\begin{array}{l}0 \\
0\end{array}$ & $\begin{array}{l}0 \\
0\end{array}$ & $\begin{array}{l}0 \\
0\end{array}$ & $\begin{array}{r}63 \\
0\end{array}$ & $\begin{array}{l}0 \\
0\end{array}$ & $\begin{array}{l}0 \\
0\end{array}$ \\
\hline Total Electric Utivity Plant in Servios ............... & 768,763 & $2,171,684$ & $8,874,703$ & $12,129,039$ & 131,232 & 52,609 \\
\hline 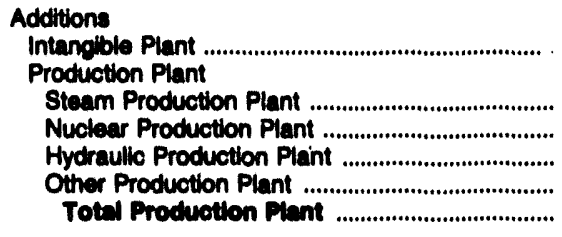 & $\begin{array}{r}3,642 \\
10,026 \\
0 \\
49 \\
241 \\
10,316\end{array}$ & $\begin{array}{r}0 \\
7,596 \\
28,800 \\
2,773 \\
10 \\
40,170\end{array}$ & $\begin{array}{r}28,654 \\
88,940 \\
3,574 \\
1,585 \\
122,702\end{array}$ & $\begin{array}{r}66,933 \\
31,117 \\
21,721 \\
1,583 \\
121,383\end{array}$ & $\begin{array}{r}0 \\
0 \\
448 \\
0 \\
140\end{array}$ & $\begin{array}{r}0 \\
0 \\
0 \\
1,078 \\
0 \\
1,070\end{array}$ \\
\hline 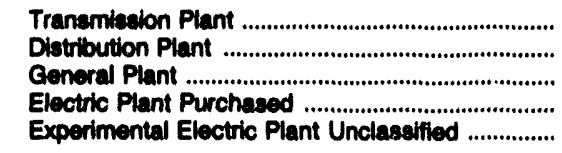 & $\begin{array}{r}3,431 \\
19,866 \\
2,405 \\
0 \\
0\end{array}$ & $\begin{array}{r}6,581 \\
19,988 \\
3,759 \\
0 \\
0\end{array}$ & $\begin{array}{r}34,760 \\
105,304 \\
18,142 \\
0 \\
0\end{array}$ & $\begin{array}{r}34,235 \\
236,777 \\
53,114 \\
0 \\
0\end{array}$ & $\begin{array}{r}9,285 \\
4,839 \\
758 \\
0 \\
0\end{array}$ & $\begin{array}{r}20 \\
0 \\
278 \\
0 \\
0\end{array}$ \\
\hline 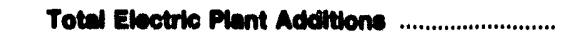 & 30,661 & 70,607 & 200,000 & 445,551 & 15,331 & 1,370 \\
\hline 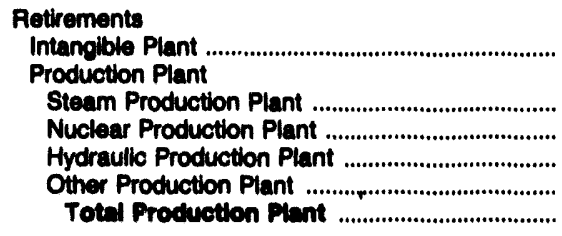 & $\begin{array}{r}2,316 \\
0 \\
16 \\
410 \\
2,741\end{array}$ & $\begin{array}{r}3,547 \\
5,043 \\
130 \\
19 \\
8,739\end{array}$ & $\begin{array}{r}3,472 \\
107 \\
550 \\
1,563 \\
\mathbf{5 , 6 9 1}\end{array}$ & $\begin{array}{r}0 \\
2,328 \\
168 \\
24 \\
0 \\
2,521\end{array}$ & $\begin{array}{l}0 \\
0 \\
0 \\
6 \\
0 \\
6\end{array}$ & $\begin{array}{r}0 \\
0 \\
0 \\
319 \\
0 \\
310\end{array}$ \\
\hline $\begin{array}{l}\text { Transmisaion Plant } \\
\text { Dlstribution Plant } \\
\text { General Plant } \\
\text { Electric Plant Sold } \\
\text { Experimental Electric Plant Unclasesified }\end{array}$ & $\begin{array}{r}324 \\
3,491 \\
1,206 \\
0 \\
0\end{array}$ & $\begin{array}{r}1,413 \\
5,354 \\
832 \\
0 \\
0\end{array}$ & $\begin{array}{r}5,914 \\
24,447 \\
5,289 \\
0 \\
0\end{array}$ & $\begin{array}{r}2,114 \\
53,227 \\
25,046 \\
0 \\
0\end{array}$ & $\begin{array}{r}253 \\
80 \\
386 \\
0 \\
0\end{array}$ & $\begin{array}{r}302 \\
0 \\
113 \\
0 \\
0\end{array}$ \\
\hline $\begin{array}{l}\text { Total Electrile Plant } \\
\text { Retiremente ........... }\end{array}$ & 7,761 & 16,430 & 41,341 & 82,007 & 726 & 734 \\
\hline
\end{tabular}

Note: Totals may not equal sum of components because of independent rounding. Summary data are provided in Table 28.

Source: Federal Energy Regulatory Commission, FERC Form 1, "Annual Report of Major Electric Utilities, Licensees and Others." 
Table 42. Utility Plant by Major U.S. Investor-Owned Electric Utility Within State on Decomber 31, 1992 (Continued)

(Thousand Dollars)

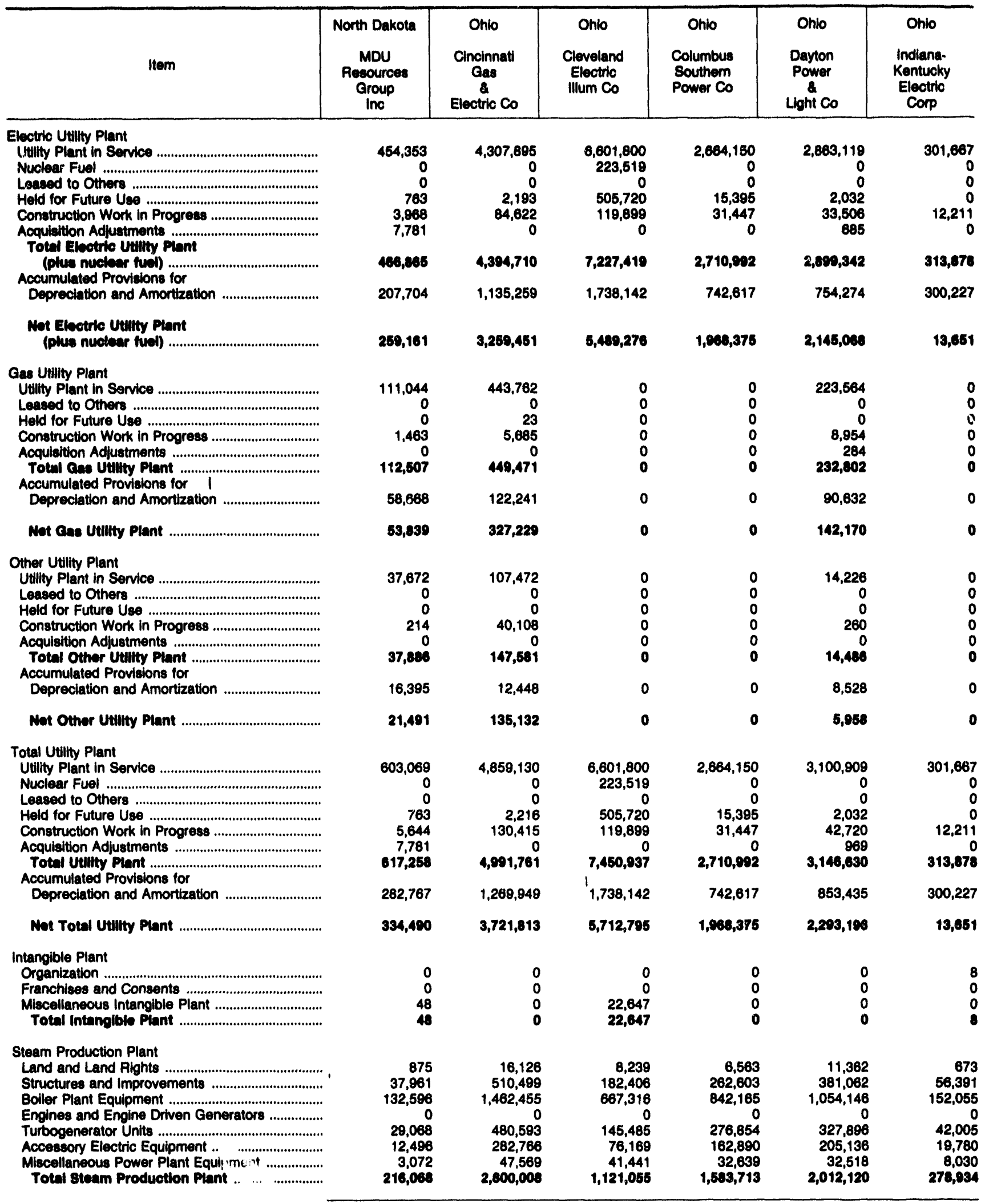

See endnotes at end of an indridual electric utility. 
Table 42. Utility Plant by Major U.8. Inveotor-Owned Electrle Utility Within state on Decomber 31, 1902 (Continued)

(Thousand Dollars)

\begin{tabular}{|c|c|c|c|c|c|c|}
\hline Item & $\begin{array}{c}\text { North Dakota } \\
\text { MDU } \\
\text { Peeources } \\
\text { Group } \\
\text {, Ino }\end{array}$ & $\begin{array}{c}\text { Ohio } \\
\text { Cincinnati } \\
\text { Gas } \\
\text { Electrio Co }\end{array}$ & $\begin{array}{l}\text { Ohio } \\
\text { Cloveland } \\
\text { Eleotrlc } \\
\text { Illum Co }\end{array}$ & $\begin{array}{l}\text { Ohio } \\
\text { Columbus } \\
\text { Southern } \\
\text { Power Co }\end{array}$ & $\begin{array}{l}\text { Ohio } \\
\text { Dayton } \\
\text { Pcwer } \\
\text { L Loht Co }\end{array}$ & $\begin{array}{l}\text { Ohio } \\
\text { Indiana- } \\
\text { Kentucky } \\
\text { Electric } \\
\text { Corp }\end{array}$ \\
\hline 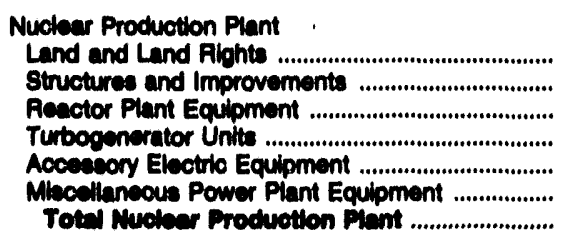 & $\begin{array}{l}0 \\
0 \\
0 \\
0 \\
0 \\
0 \\
0\end{array}$ & $\begin{array}{l}0 \\
0 \\
0 \\
0 \\
0 \\
0 \\
0\end{array}$ & $\begin{array}{r}847 \\
146,367 \\
3,115,605 \\
64,772 \\
66,780 \\
342,836 \\
3,797,100\end{array}$ & $\begin{array}{l}0 \\
0 \\
0 \\
0 \\
0 \\
0 \\
0\end{array}$ & $\begin{array}{l}0 \\
0 \\
0 \\
0 \\
0 \\
0 \\
0\end{array}$ & $\begin{array}{l}0 \\
0 \\
0 \\
0 \\
0 \\
0 \\
0\end{array}$ \\
\hline 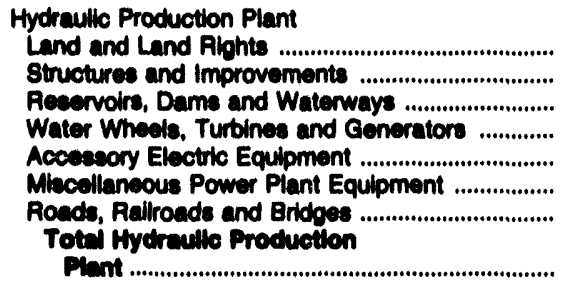 & $\begin{array}{l}0 \\
0 \\
0 \\
0 \\
0 \\
0 \\
0 \\
0\end{array}$ & $\begin{array}{l}0 \\
0 \\
0 \\
0 \\
0 \\
0 \\
0 \\
0\end{array}$ & $\begin{array}{r}0 \\
7,710 \\
34,817 \\
12,592 \\
2,850 \\
1,787 \\
0 \\
69,967\end{array}$ & $\begin{array}{l}0 \\
0 \\
0 \\
0 \\
0 \\
0 \\
0\end{array}$ & $\begin{array}{l}0 \\
0 \\
0 \\
0 \\
0 \\
0 \\
0\end{array}$ & $\begin{array}{l}0 \\
0 \\
0 \\
0 \\
0 \\
0 \\
0\end{array}$ \\
\hline 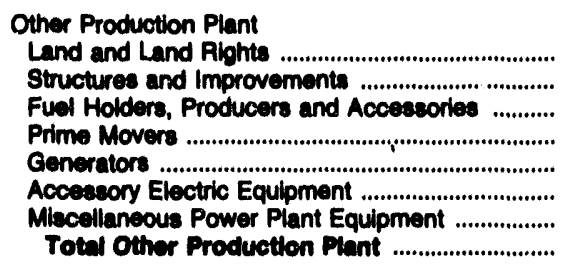 & $\begin{array}{r}48 \\
346 \\
194 \\
0 \\
8,784 \\
159 \\
26 \\
9,880\end{array}$ & $\begin{array}{r}5,800 \\
39,852 \\
18,602 \\
2,866 \\
178,861 \\
21,996 \\
2,881 \\
271,080\end{array}$ & $\begin{array}{r}0 \\
0 \\
874 \\
0 \\
7,202 \\
0 \\
0 \\
8,075\end{array}$ & $\begin{array}{l}0 \\
0 \\
0 \\
0 \\
0 \\
0 \\
0 \\
0\end{array}$ & $\begin{array}{r}353 \\
4,105 \\
1,946 \\
0 \\
15,538 \\
971 \\
29 \\
22,030\end{array}$ & $\begin{array}{l}0 \\
0 \\
0 \\
0 \\
0 \\
0 \\
0 \\
0\end{array}$ \\
\hline 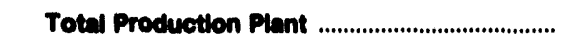 & 225,620 & $3,071,060$ & $4,226,008$ & $1,603,713$ & $2,035,050$ & 270,034 \\
\hline 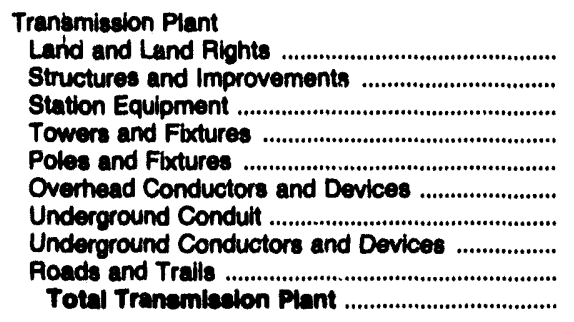 & $\begin{array}{r}3,241 \\
2 \\
51,792 \\
4,468 \\
23,677 \\
23,800 \\
0 \\
87 \\
0 \\
107,040\end{array}$ & $\begin{array}{r}25,624 \\
7,097 \\
187,002 \\
35,580 \\
27,848 \\
58,342 \\
1,238 \\
7,893 \\
0 \\
351,623\end{array}$ & $\begin{array}{r}60,068 \\
20,357 \\
185,857 \\
82,459 \\
60,334 \\
89,164 \\
28,215 \\
50,302 \\
7,056 \\
504,813\end{array}$ & $\begin{array}{r}25,873 \\
5,571 \\
127,674 \\
32,890 \\
31,269 \\
51,828 \\
8,688 \\
7,940 \\
0 \\
291,714\end{array}$ & $\begin{array}{r}24,522 \\
5,408 \\
98,686 \\
28,292 \\
32,428 \\
46,880 \\
434 \\
801 \\
9 \\
234,461\end{array}$ & $\begin{array}{r}177 \\
704 \\
16,272 \\
2,483 \\
0 \\
0 \\
2,320 \\
0 \\
0 \\
0 \\
21,967\end{array}$ \\
\hline 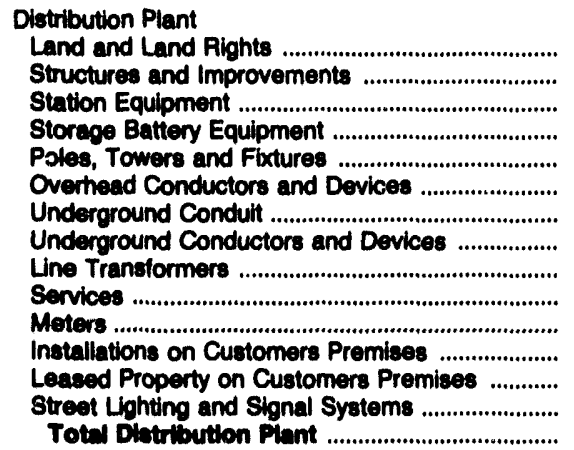 & $\begin{array}{r}740 \\
0 \\
17,851 \\
0 \\
14,500 \\
11,280 \\
73 \\
17,249 \\
22,291 \\
11,362 \\
8,049 \\
1,255 \\
0 \\
4,867 \\
100,518\end{array}$ & $\begin{array}{r}24,000 \\
3,859 \\
128,209 \\
0 \\
120,308 \\
137,798 \\
31,567 \\
86,4332 \\
184,341 \\
34,363 \\
48,814 \\
9 \\
955 \\
17,009 \\
827,753\end{array}$ & $\begin{array}{r}6,119 \\
18,126 \\
118,626 \\
1,921 \\
149,912 \\
124,344 \\
47,087 \\
93,426 \\
157,236 \\
100,036 \\
73,513 \\
0 \\
0 \\
0 \\
33,376 \\
923,023\end{array}$ & $\begin{array}{r}12,064 \\
7,536 \\
76,127 \\
0 \\
05,409 \\
90,349 \\
31,123 \\
126,122 \\
146,805 \\
61,066 \\
46,862 \\
17,368 \\
118 \\
8,833 \\
718,781\end{array}$ & $\begin{array}{r}10,658 \\
6,201 \\
68,512 \\
0 \\
88,509 \\
51,089 \\
4,626 \\
60,441 \\
117,865 \\
51,339 \\
27,650 \\
8,963 \\
64 \\
0 \\
496,016\end{array}$ & $\begin{array}{l}0 \\
0 \\
0 \\
0 \\
0 \\
0 \\
0 \\
0 \\
0 \\
0 \\
0 \\
0 \\
0 \\
0 \\
0\end{array}$ \\
\hline
\end{tabular}

See endnotes at end of an indwidual electric utility. 
Table 42. Utility Plant by Major U.S. Inveotor-Owned Eiectrlc Utillty Within State on December ,31, 1992 (Continued)

(Thousand Dollars)

\begin{tabular}{|c|c|c|c|c|c|c|}
\hline Item & $\begin{array}{c}\text { North Dakota } \\
\text { MDU } \\
\text { Resources } \\
\text { Group } \\
\text { Inc }\end{array}$ & $\begin{array}{c}\text { Ohio } \\
\text { Cincinnat } \\
\text { Ges } \\
\text { Electic Co }\end{array}$ & $\begin{array}{l}\text { Onio } \\
\text { Cleveland } \\
\text { Electric } \\
\text { Illum Co }\end{array}$ & $\begin{array}{l}\text { Onio } \\
\text { Columbus } \\
\text { Southern } \\
\text { Power Co }\end{array}$ & $\begin{array}{l}\text { Onio } \\
\text { Dayton } \\
\text { Power } \\
8 \\
\text { Light Co }\end{array}$ & $\begin{array}{l}\text { Ohio } \\
\text { Indlana- } \\
\text { Kentucky } \\
\text { Electric } \\
\text { Corp }\end{array}$ \\
\hline 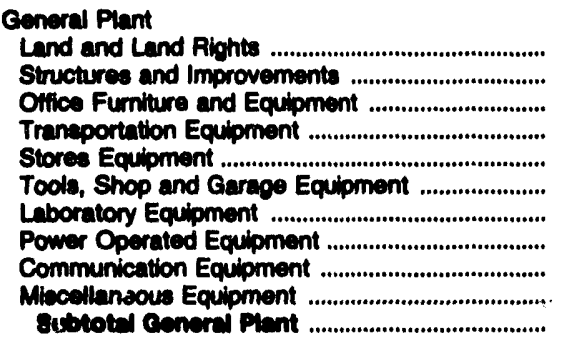 & $\begin{array}{r}65 \\
885 \\
808 \\
7 \\
118 \\
1,318 \\
1,135 \\
4,120 \\
3,587 \\
69 \\
12,114\end{array}$ & $\begin{array}{r}1,018 \\
13,236 \\
3,747 \\
26,950 \\
995 \\
4,020 \\
2,117 \\
3,337 \\
1,776 \\
123 \\
67,320\end{array}$ & $\begin{array}{r}2,128 \\
39,117 \\
21,699 \\
35,730 \\
2,271 \\
13,620 \\
5,442 \\
10,312 \\
14,865 \\
41 \\
146,224\end{array}$ & $\begin{array}{r}1,752 \\
34,755 \\
4,409 \\
1,060 \\
283 \\
5,335 \\
0 \\
183 \\
10,142 \\
334 \\
64,243\end{array}$ & $\begin{array}{r}\mathbf{6 , 2 5 4} \\
52,982 \\
14,465 \\
5,401 \\
1,019 \\
2,671 \\
1,165 \\
1,800 \\
10,527 \\
1,301 \\
97,604\end{array}$ & $\begin{array}{r}5 \\
15 \\
1 \\
0 \\
1 \\
0 \\
0 \\
1 \\
747 \\
0 \\
700\end{array}$ \\
\hline Other Tang'ble Property ............................................. & 0 & 133 & 0 & 9,396 & 0 & 0 \\
\hline Totel Eenered Pient ................................................ & 12,114 & 67,463 & 145,224 & 67,689 & 97,694 & 780 \\
\hline $\begin{array}{l}\text { Electric Plant Purchased and Sold (net) ................... } \\
\text { Experimental Electric Plant Unclaseified ............... }\end{array}$ & $\begin{array}{l}0 \\
0\end{array}$ & $\begin{array}{l}0 \\
0\end{array}$ & $\begin{array}{l}0 \\
0\end{array}$ & $\begin{array}{r}0 \\
1,284\end{array}$ & $\begin{array}{l}0 \\
0\end{array}$ & $\begin{array}{l}0 \\
0\end{array}$ \\
\hline 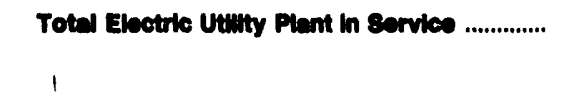 & 494,363 & $4,307,805$ & $6,601,600$ & $2,864,160$ & $2,808,119$ & 301,637 \\
\hline $\begin{array}{l}\text { Additions } \\
\text { Imtang"ble Plant ............................................................... } \\
\text { Production Plant }\end{array}$ & 0 & 0 & 185 & 0 & 0 & 0 \\
\hline 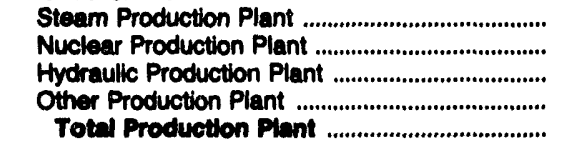 & $\begin{array}{r}1,234 \\
0 \\
0 \\
23 \\
1,253\end{array}$ & $\begin{array}{r}37,486 \\
0 \\
0 \\
213,628 \\
251,114\end{array}$ & $\begin{array}{r}38,056 \\
88,854 \\
5,024 \\
0 \\
131,896\end{array}$ & $\begin{array}{r}14,725 \\
0 \\
0 \\
0 \\
14,725\end{array}$ & $\begin{array}{r}22,749 \\
0 \\
0 \\
10 \\
22,750\end{array}$ & $\begin{array}{r}19,668 \\
0 \\
0 \\
0 \\
19,608\end{array}$ \\
\hline 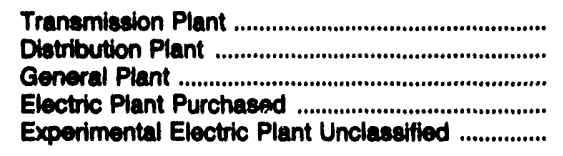 & $\begin{array}{r}3,053 \\
6,194 \\
616 \\
0 \\
0\end{array}$ & $\begin{array}{r}19,732 \\
53,404 \\
4,677 \\
0 \\
0\end{array}$ & $\begin{array}{r}17,586 \\
68,750 \\
20,599 \\
0 \\
0\end{array}$ & $\begin{array}{r}11,711 \\
39,908 \\
1,644 \\
0 \\
138\end{array}$ & $\begin{array}{r}1,594 \\
18,774 \\
1,188 \\
0 \\
0\end{array}$ & $\begin{array}{r}50 \\
0 \\
32 \\
0 \\
0\end{array}$ \\
\hline Total Ebetric Plent Additione ........................... & 11,121 & 320,794 & 237,036 & 68,125 & 44,315 & 19,750 \\
\hline 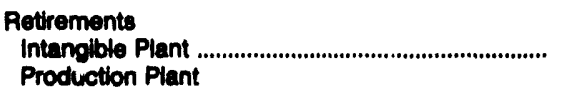 & 0 & 0 & 0 & 0 & 0 & 0 \\
\hline 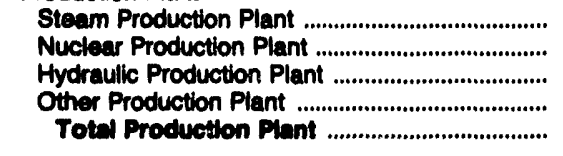 & $\begin{array}{r}189 \\
0 \\
0 \\
5 \\
184\end{array}$ & $\begin{array}{r}8,139 \\
0 \\
0 \\
143 \\
8,292\end{array}$ & $\begin{array}{r}35,012 \\
6,298 \\
594 \\
0 \\
41,003\end{array}$ & $\begin{array}{r}9,581 \\
0 \\
0 \\
0 \\
9,681\end{array}$ & $\begin{array}{r}6,464 \\
0 \\
0 \\
0 \\
6,484\end{array}$ & $\begin{array}{r}876 \\
0 \\
0 \\
0 \\
876\end{array}$ \\
\hline 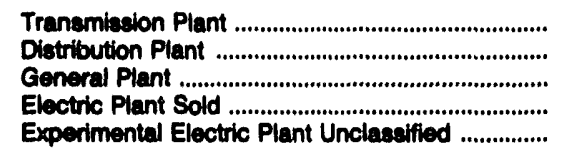 & $\begin{array}{r}748 \\
908 \\
205 \\
0 \\
0\end{array}$ & $\begin{array}{r}1,208 \\
10,615 \\
3,530 \\
0 \\
0\end{array}$ & $\begin{array}{r}1,028 \\
3,038 \\
767 \\
0 \\
0\end{array}$ & $\begin{array}{r}962 \\
6,851 \\
1,211 \\
0 \\
0\end{array}$ & $\begin{array}{r}530 \\
3,920 \\
617 \\
0 \\
0\end{array}$ & $\begin{array}{l}0 \\
0 \\
5 \\
0 \\
0\end{array}$ \\
\hline $\begin{array}{l}\text { Totel Electrte Plant } \\
\text { Retirements }\end{array}$ & 2,065 & 28,683 & 4,737 & 18,685 & 11,631 & 800 \\
\hline
\end{tabular}

Note: Totals may not equal sum of components because of independent rounding. Summary data are provided in Table 28. Source: Federal Energy Regulatory Commiseion, FERC Form 1. "Annual Report of Major Electric Utilities, Licensees and Others." 
Table 42. Utility Plant by Major U.S. Investor-Owned Electric Utility Within State on December 31, 1992 (Continued) (Thousand Dollars)

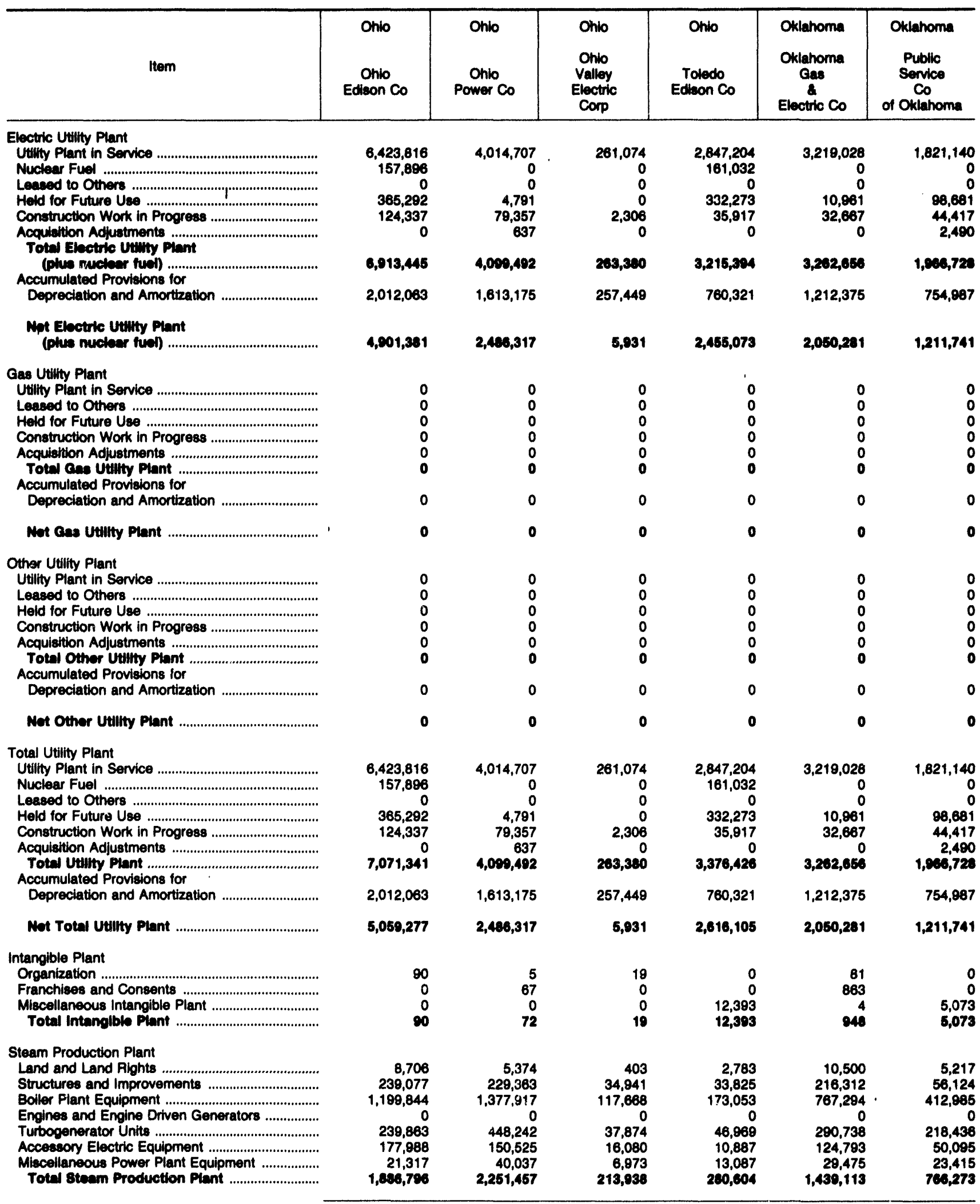

See endnotes at end of an individual electric utility. 
Table 42. Utility Plant by Major U.S. Investor-Owned Electric Utility Within State on December 31, 1992 (Continued) (Thousand Dollars)

\begin{tabular}{|c|c|c|c|c|c|c|}
\hline Item & $\begin{array}{c}\text { Ohio } \\
\text { Ohio } \\
\text { Edison Co }\end{array}$ & $\begin{array}{c}\text { Ohio } \\
\text { Ohio } \\
\text { Power Co }\end{array}$ & $\begin{array}{l}\text { Ohio } \\
\text { Ohio } \\
\text { Valiey } \\
\text { Electric } \\
\text { Corp }\end{array}$ & $\begin{array}{c}\text { Onio } \\
\text { Toledo } \\
\text { Edison Co }\end{array}$ & $\begin{array}{c}\text { Oklahoma } \\
\text { Oklahoma } \\
\text { Gas } \\
8 \\
\text { Electric Co }\end{array}$ & $\begin{array}{c}\text { Oklahoma } \\
\text { Public } \\
\text { Service } \\
\text { Co } \\
\text { of Oklahoma }\end{array}$ \\
\hline 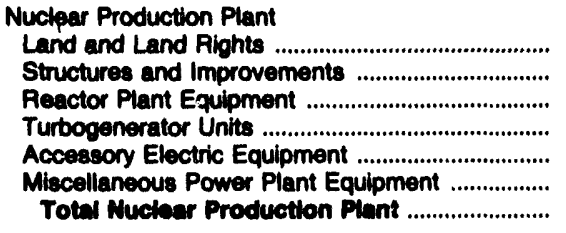 & $\begin{array}{r}4,367 \\
501,640 \\
1,293,219 \\
238,224 \\
382,692 \\
115,991 \\
2,586,133\end{array}$ & $\begin{array}{l}0 \\
0 \\
0 \\
0 \\
0 \\
0 \\
0\end{array}$ & $\begin{array}{l}0 \\
0 \\
0 \\
0 \\
0 \\
0 \\
0\end{array}$ & $\begin{array}{r}860 \\
140,656 \\
1,481,352 \\
64,416 \\
84,953 \\
179,308 \\
1,911,845\end{array}$ & $\begin{array}{l}0 \\
0 \\
0 \\
0 \\
0 \\
0 \\
0\end{array}$ & $\begin{array}{l}0 \\
0 \\
0 \\
0 \\
0 \\
0 \\
0\end{array}$ \\
\hline 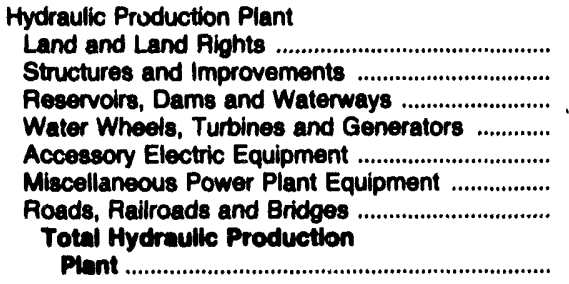 & $\begin{array}{l}0 \\
0 \\
0 \\
0 \\
0 \\
0 \\
0\end{array}$ & $\begin{array}{r}4 \\
49,958 \\
6,338 \\
40,044 \\
10,017 \\
3,409 \\
0\end{array}$ & $\begin{array}{l}0 \\
0 \\
0 \\
0 \\
0 \\
0 \\
0\end{array}$ & $\begin{array}{l}0 \\
0 \\
0 \\
0 \\
0 \\
0 \\
0\end{array}$ & $\begin{array}{l}0 \\
0 \\
0 \\
0 \\
0 \\
0 \\
0\end{array}$ & $\begin{array}{l}0 \\
0 \\
0 \\
0 \\
0 \\
0 \\
0\end{array}$ \\
\hline 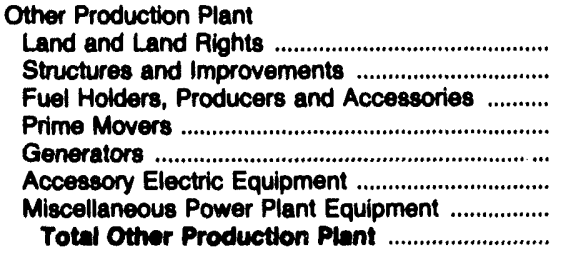 & $\begin{array}{r}3 \\
645 \\
1,211 \\
13,693 \\
2,970 \\
1,152 \\
86 \\
19,760\end{array}$ & $\begin{array}{l}0 \\
0 \\
0 \\
0 \\
0 \\
0 \\
0 \\
0\end{array}$ & $\begin{array}{l}0 \\
0 \\
0 \\
0 \\
0 \\
0 \\
0 \\
0\end{array}$ & $\begin{array}{r}15 \\
106 \\
89 \\
3,887 \\
2,332 \\
233 \\
14 \\
6,675\end{array}$ & $\begin{array}{r}0 \\
1,341 \\
12,132 \\
108 \\
30,490 \\
6,636 \\
585 \\
51,293\end{array}$ & $\begin{array}{r}72 \\
442 \\
645 \\
0 \\
21,097 \\
359 \\
116 \\
22,729\end{array}$ \\
\hline Total Production Plant ............................................ & $4,442,689$ & $2,361,228$ & 213,938 & $2,198,923$ & $1,480,406$ & 789,003 \\
\hline 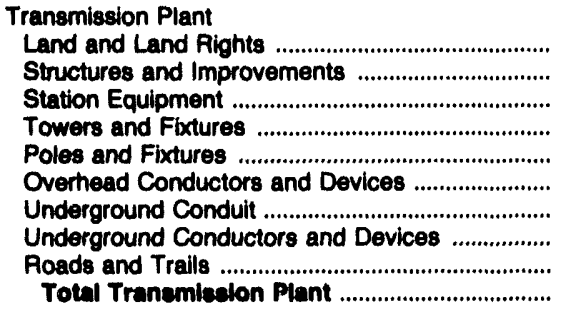 & $\begin{array}{r}73,660 \\
21,857 \\
253,036 \\
77,634 \\
90,483 \\
165,308 \\
1,233 \\
4,456 \\
2,620 \\
690,286\end{array}$ & $\begin{array}{r}56,894 \\
25,922 \\
320,746 \\
136,994 \\
65,092 \\
151,544 \\
309 \\
632 \\
0 \\
758,134\end{array}$ & $\begin{array}{r}1,980 \\
689 \\
16,187 \\
12,107 \\
0 \\
12,690 \\
0 \\
0 \\
0 \\
43,653\end{array}$ & $\begin{array}{r}13,836 \\
2,896 \\
65,949 \\
20,171 \\
16,179 \\
31,172 \\
0 \\
674 \\
642 \\
151,518\end{array}$ & $\begin{array}{r}22,674 \\
1,291 \\
219,387 \\
47,749 \\
89,464 \\
95,217 \\
0 \\
486 \\
0 \\
476,279\end{array}$ & $\begin{array}{r}20,471 \\
5,827 \\
140,268 \\
12,610 \\
53,859 \\
81,119 \\
0 \\
44 \\
0 \\
314,198\end{array}$ \\
\hline 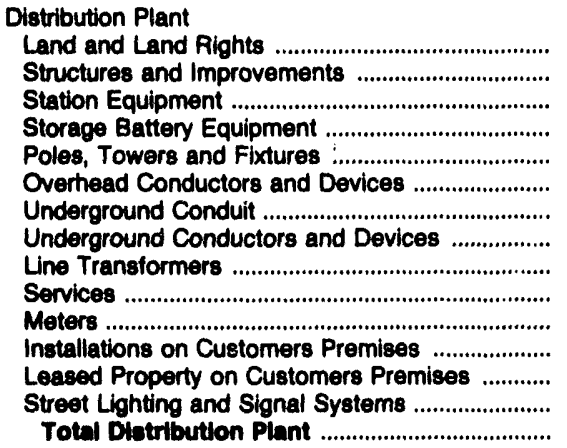 & $\begin{array}{r}9,529 \\
11,698 \\
143,353 \\
0 \\
220,446 \\
191,674 \\
30,799 \\
72,666 \\
199,777 \\
73,412 \\
101,524 \\
12,260 \\
0 \\
38,919 \\
1,108,057\end{array}$ & $\begin{array}{r}6,034 \\
5,496 \\
81,126 \\
0 \\
157,667 \\
117,481 \\
15,099 \\
24,226 \\
174,266 \\
64,837 \\
59,684 \\
9,870 \\
1 \\
15,771 \\
731,559\end{array}$ & $\begin{array}{l}0 \\
0 \\
0 \\
0 \\
0 \\
0 \\
0 \\
0 \\
0 \\
0 \\
0 \\
0 \\
0 \\
0 \\
0\end{array}$ & $\begin{array}{r}4,150 \\
1,281 \\
39,939 \\
199 \\
71,787 \\
65,475 \\
8,607 \\
33,313 \\
70,671 \\
48,897 \\
22,112 \\
13,934 \\
3,884 \\
23,579 \\
407,829\end{array}$ & $\begin{array}{r}4,150 \\
668 \\
127,255 \\
0 \\
193,265 \\
195,728 \\
47,070 \\
144,912 \\
161,882 \\
82,723 \\
54,242 \\
12,853 \\
31 \\
37,586 \\
1,062,386\end{array}$ & $\begin{array}{r}5,012 \\
24,998 \\
83,483 \\
0 \\
96,862 \\
77,344 \\
4,526 \\
48,975 \\
126,957 \\
61,206 \\
29,319 \\
14,627 \\
0 \\
17,575 \\
580,085\end{array}$ \\
\hline
\end{tabular}

See $\mathrm{s}$ dnotes at end of an individual electric utility. 
Table 42. Utility Plant by Major U.S. Investor-Owned Electrlc Utility Within State on December 31, 1992 (Continued) (Thousand Dollars)

\begin{tabular}{|c|c|c|c|c|c|c|}
\hline Item & $\begin{array}{l}\text { Ohio } \\
\text { Ohio } \\
\text { Edison Co }\end{array}$ & $\begin{array}{l}\text { Ohio } \\
\text { Onio } \\
\text { Power co }\end{array}$ & $\begin{array}{l}\text { Ohio } \\
\text { Onio } \\
\text { Valley } \\
\text { Electric } \\
\text { Corp }\end{array}$ & $\begin{array}{l}\text { Ohio } \\
\text { Toledo } \\
\text { Edison Co }\end{array}$ & $\begin{array}{c}\text { Oklahoma } \\
\text { Oklahoma } \\
\text { Gas } \\
\& \\
\text { Electric Co }\end{array}$ & $\begin{array}{c}\text { Oklahoma } \\
\text { Public } \\
\text { Service } \\
\text { Co } \\
\text { of Oklahoma }\end{array}$ \\
\hline 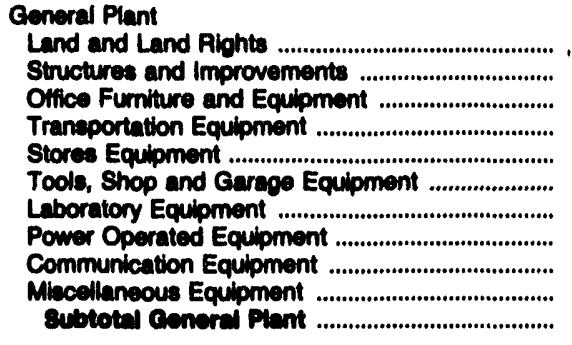 & $\begin{array}{r}3,531 \\
69,804 \\
36,891 \\
32,095 \\
1,360 \\
8,910 \\
6,672 \\
4,187 \\
20,403 \\
1,741 \\
184,603\end{array}$ & $\begin{array}{r}4,849 \\
45,808 \\
3,949 \\
36 \\
431 \\
4,172 \\
911 \\
19 \\
16,083 \\
671 \\
77,020\end{array}$ & $\begin{array}{r}25 \\
719 \\
608 \\
570 \\
1 \\
186 \\
397 \\
0 \\
958 \\
0 \\
3,404\end{array}$ & $\begin{array}{r}2,231 \\
31,361 \\
6,535 \\
20,142 \\
822 \\
5,776 \\
1,326 \\
1,815 \\
5,950 \\
584 \\
76,540\end{array}$ & $\begin{array}{r}4,123 \\
70,608 \\
24,383 \\
42,281 \\
1,805 \\
4,186 \\
5,157 \\
5,360 \\
18,400 \\
1,841 \\
178,256\end{array}$ & $\begin{array}{r}933 \\
9,648 \\
40,847 \\
24,017 \\
2,386 \\
5,945 \\
2,278 \\
906 \\
33,798 \\
694 \\
121,464\end{array}$ \\
\hline 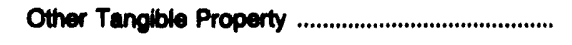 & 0 & 35,624 & 0 & 0 & 10,775 & 526 \\
\hline 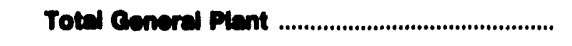 & 184,098 & 112,654 & 3,464 & 76,540 & 189,030 & 121,902 \\
\hline $\begin{array}{c}\text { Electric Plant Purchased and Sold (not) .................... } \\
\text { Experimental Electric Plant Unclaseified ................ }\end{array}$ & $\begin{array}{l}0 \\
0\end{array}$ & $\begin{array}{r}0 \\
51,060\end{array}$ & $\begin{array}{l}0 \\
0\end{array}$ & $\begin{array}{l}0 \\
0\end{array}$ & $\begin{array}{l}0 \\
0\end{array}$ & $\begin{array}{l}0 \\
0\end{array}$ \\
\hline Total Electric Uaitity Plant in Sorvice ............... & $6,423,816$ & $4,014,707$ & 281,074 & $2,847,204$ & $3,219,028$ & $1,821,140$ \\
\hline 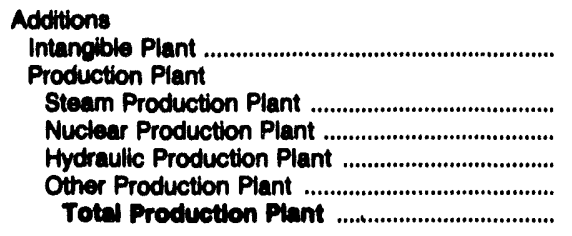 & $\begin{array}{r}0 \\
71,163 \\
40,402 \\
0 \\
378 \\
111,942\end{array}$ & $\begin{array}{r}0 \\
82,458 \\
0 \\
63 \\
0 \\
82,521\end{array}$ & $\begin{array}{r}0 \\
968 \\
0 \\
0 \\
0 \\
968\end{array}$ & $\begin{array}{r}81 \\
6,789 \\
6,7947 \\
26,847 \\
0 \\
0 \\
33,636\end{array}$ & $\begin{array}{r}274 \\
13,159 \\
0 \\
0 \\
323 \\
13,483\end{array}$ & $\begin{array}{r}0 \\
31,326 \\
0 \\
0 \\
225 \\
31,651\end{array}$ \\
\hline 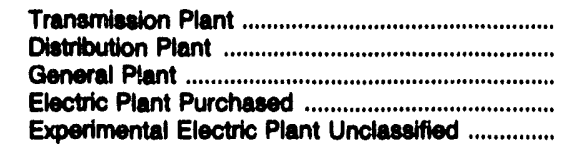 & $\begin{array}{r}17,057 \\
76,631 \\
12,194 \\
0 \\
0\end{array}$ & $\begin{array}{r}19,761 \\
56,441 \\
5,465 \\
0 \\
6,089\end{array}$ & $\begin{array}{r}24 \\
0 \\
504 \\
0 \\
0\end{array}$ & $\begin{array}{r}1,870 \\
32,756 \\
4,297 \\
0 \\
0\end{array}$ & $\begin{array}{r}25,313 \\
72,273 \\
12,217 \\
0 \\
0\end{array}$ & $\begin{array}{r}9,995 \\
33,712 \\
14,056 \\
0 \\
0\end{array}$ \\
\hline 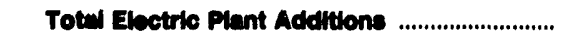 & 217,024 & 170,277 & 1,497 & 72,640 & 123,660 & 89,316 \\
\hline 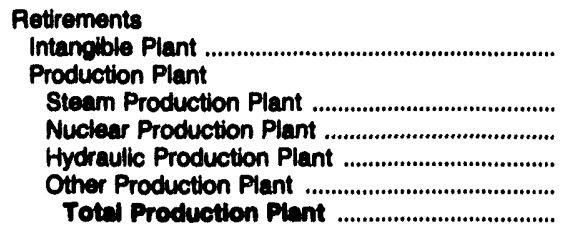 & $\begin{array}{r}0 \\
20,301 \\
5,502 \\
0 \\
28 \\
25,031\end{array}$ & $\begin{array}{r}0 \\
28,850 \\
0 \\
7 \\
0 \\
28,857\end{array}$ & $\begin{array}{r}0 \\
201 \\
0 \\
0 \\
0 \\
201\end{array}$ & $\begin{array}{r}0 \\
37,200 \\
5,830 \\
0 \\
0 \\
43,030\end{array}$ & $\begin{array}{r}0 \\
10,224 \\
0 \\
0 \\
0 \\
10,224\end{array}$ & $\begin{array}{r}0 \\
1,756 \\
0 \\
0 \\
5 \\
1,761\end{array}$ \\
\hline 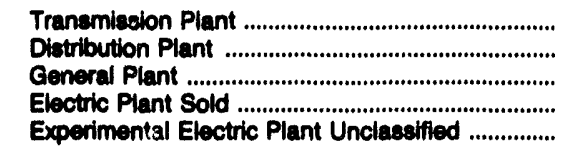 & $\begin{array}{r}3,481 \\
12,889 \\
6,880 \\
0 \\
0\end{array}$ & $\begin{array}{r}2,781 \\
14,401 \\
878 \\
0 \\
0\end{array}$ & $\begin{array}{r}14 \\
0 \\
1,371 \\
0 \\
0\end{array}$ & $\begin{array}{r}23 \\
911 \\
1,000 \\
0 \\
0\end{array}$ & $\begin{array}{r}4,023 \\
13,835 \\
2,873 \\
0 \\
0\end{array}$ & $\begin{array}{r}1,423 \\
6,647 \\
3,303 \\
0 \\
0\end{array}$ \\
\hline $\begin{array}{l}\text { Tolel Eleotilc Plant } \\
\text { Retirements ........... }\end{array}$ & 40,181 & 46,016 & 1,585 & 44,063 & 30,965 & 13,136 \\
\hline
\end{tabular}

Note: Totals may not equal eum of components because of independent rounding. Summary data are provided in Table 28.

Source: Federal Energy Regulatory Commiesion, FERC Form 1, "Annual Report of Major Electric Utilities, Licensees and Others." 
Table 42. Utility Plant by Major U.S. Investor-Owned Electric Utility Within State on December 31, 1992 (Continued) (Thousand Dollars)

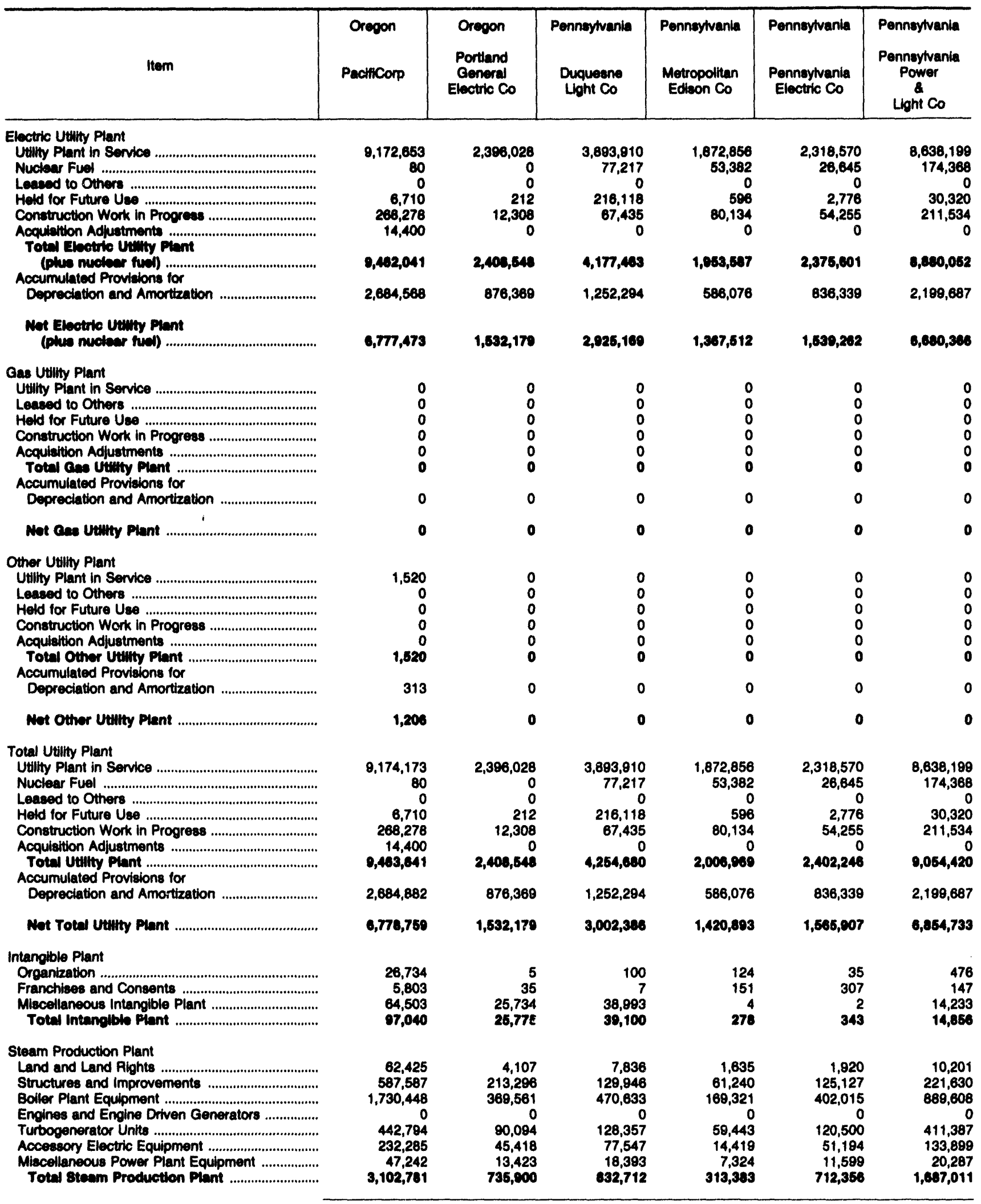

See endnotes at end of an individual electric utility. 
Table 42. Utility Plant by Major U.S. Investor-Owned Electric Utility Within State on December 31, 1902 (Continued)

(Thousand Dollars)

\begin{tabular}{|c|c|c|c|c|c|c|}
\hline ltom & $\begin{array}{l}\text { Oregon } \\
\text { Pactificorp }\end{array}$ & $\begin{array}{l}\text { Oregon } \\
\text { Portiand } \\
\text { General } \\
\text { Electric Co }\end{array}$ & $\begin{array}{l}\text { Pennoytvania } \\
\text { Duquesne } \\
\text { Light Co }\end{array}$ & $\begin{array}{l}\text { Pennsyivania } \\
\text { Metropolitan } \\
\text { Edison Co }\end{array}$ & $\begin{array}{c}\text { Pennsylvania } \\
\text { Pennoytvania } \\
\text { Electric Co }\end{array}$ & $\begin{array}{c}\text { Pennoytvania } \\
\text { Pennoytvania } \\
\text { Power } \\
\text { Light Co }\end{array}$ \\
\hline 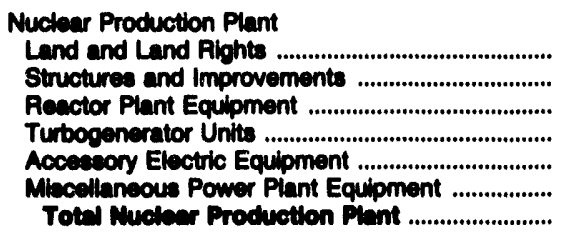 & $\begin{array}{l}0 \\
0 \\
0 \\
0 \\
0 \\
0 \\
0\end{array}$ & $\begin{array}{r}0 \\
61,686 \\
28,294 \\
1,721 \\
19,919 \\
15,692 \\
127,312 \\
\end{array}$ & $\begin{array}{r}750 \\
290,742 \\
671,017 \\
141,154 \\
188,667 \\
87,356 \\
1,370,686\end{array}$ & $\begin{array}{r}10,070 \\
85,243 \\
148,782 \\
38,309 \\
62,910 \\
41,561 \\
387,076\end{array}$ & $\begin{array}{r}5,029 \\
42,694 \\
74,776 \\
19,747 \\
31,400 \\
20,801 \\
194,447\end{array}$ & $\begin{array}{r}15,976 \\
905,045 \\
1,815,084 \\
547,663 \\
542,615 \\
114,040 \\
3,040,023\end{array}$ \\
\hline 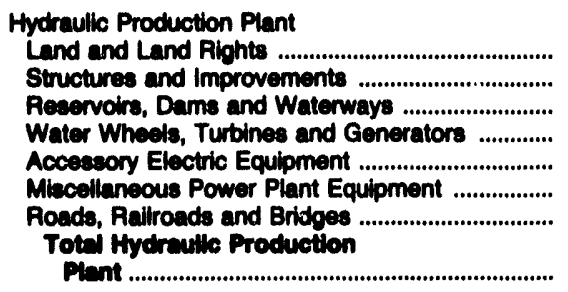 & $\begin{array}{r}16,347 \\
34,931 \\
220,825 \\
53,051 \\
19,179 \\
4,147 \\
6,461 \\
354,041\end{array}$ & $\begin{array}{r}4,687 \\
21,615 \\
118,033 \\
26,156 \\
5,097 \\
2,122 \\
5,028 \\
182,047\end{array}$ & $\begin{array}{l}0 \\
0 \\
0 \\
0 \\
0 \\
0 \\
0\end{array}$ & $\begin{array}{l}0 \\
0 \\
0 \\
0 \\
0 \\
0 \\
0\end{array}$ & $\begin{array}{r}2,756 \\
4,017 \\
16,745 \\
6,828 \\
3,220 \\
1,086 \\
136 \\
34,700\end{array}$ & $\begin{array}{r}4,787 \\
7,222 \\
24,810 \\
27,842 \\
3,259 \\
2,534 \\
260 \\
70,713\end{array}$ \\
\hline 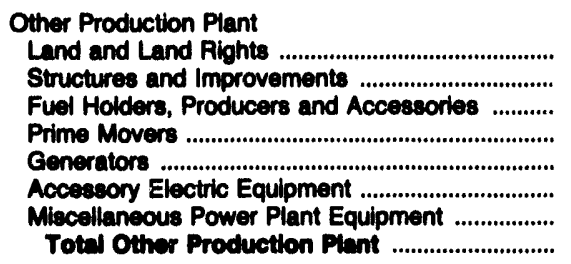 & $\begin{array}{r}1 \\
180 \\
121 \\
1,192 \\
1,646 \\
215 \\
71 \\
3,437\end{array}$ & $\begin{array}{r}340 \\
27,963 \\
76,449 \\
0 \\
23,288 \\
11,171 \\
3,451 \\
142,661\end{array}$ & $\begin{array}{r}394 \\
5,239 \\
2,140 \\
19 \\
7,107 \\
510 \\
714 \\
16,123\end{array}$ & $\begin{array}{r}0 \\
0 \\
3,183 \\
28,251 \\
7,901 \\
8,680 \\
348 \\
48,304\end{array}$ & $\begin{array}{r}44 \\
484 \\
586 \\
11,305 \\
2,996 \\
1,686 \\
196 \\
17,276\end{array}$ & $\begin{array}{r}68 \\
2,249 \\
1,852 \\
18,236 \\
6,672 \\
3,886 \\
180 \\
33,263\end{array}$ \\
\hline 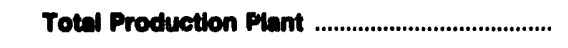 & $3,481,160$ & $1,188,821$ & $2,228,521$ & 749,623 & 958,807 & $\mathbf{5 , 7 3 1 , 6 1 0}$ \\
\hline 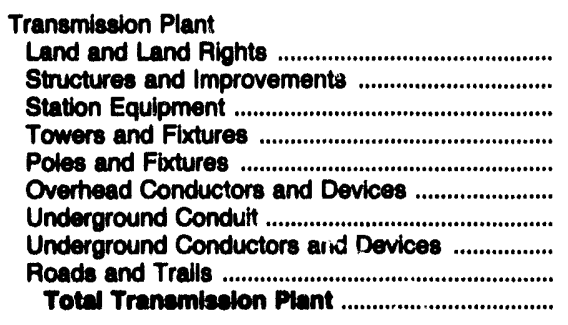 & $\begin{array}{r}76,830 \\
32,505 \\
562,597 \\
344,268 \\
255,141 \\
463,138 \\
172 \\
1,045 \\
2,489 \\
1,736,185\end{array}$ & $\begin{array}{r}11,530 \\
6,073 \\
104,821 \\
45,191 \\
18,263 \\
61,473 \\
0 \\
1,300 \\
353 \\
249,006 \\
\end{array}$ & $\begin{array}{r}9,888 \\
8,030 \\
106,182 \\
68,083 \\
4,146 \\
42,444 \\
34,740 \\
19,316 \\
14 \\
290,822\end{array}$ & $\begin{array}{r}27,231 \\
1,836 \\
105,116 \\
36,924 \\
23,521 \\
44,566 \\
0 \\
0 \\
713 \\
239,896\end{array}$ & $\begin{array}{r}11,701 \\
4,536 \\
79,280 \\
25,034 \\
39,342 \\
84,592 \\
4 \\
0 \\
7 \\
244,496\end{array}$ & $\begin{array}{r}22,963 \\
12,335 \\
185,057 \\
111,958 \\
2,080 \\
69,963 \\
0 \\
0 \\
5,472 \\
400,797\end{array}$ \\
\hline 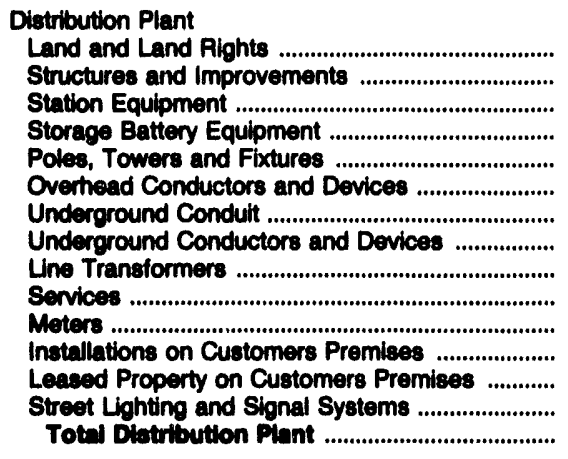 & $\begin{array}{r}21,781 \\
16,050 \\
300,096 \\
0 \\
402,762 \\
366,152 \\
89,540 \\
248,089 \\
514,385 \\
141,692 \\
132,953 \\
7,146 \\
50 \\
29,788 \\
2,260,403\end{array}$ & $\begin{array}{r}3,999 \\
8,711 \\
89,656 \\
0 \\
03,505 \\
97,617 \\
12,279 \\
124,140 \\
133,672 \\
147,442 \\
34,069 \\
0 \\
0 \\
24,563 \\
750,652\end{array}$ & $\begin{array}{r}7,631 \\
38,867 \\
232,342 \\
0 \\
0 \\
177,880 \\
148,972 \\
66,021 \\
97,001 \\
139,457 \\
50,000 \\
54,957 \\
123 \\
0 \\
19,749 \\
1,033,930\end{array}$ & $\begin{array}{r}22,861 \\
986 \\
75,603 \\
0 \\
0 \\
165,949 \\
128,286 \\
21,292 \\
54,637 \\
147,849 \\
71,489 \\
52,516 \\
1,485 \\
0 \\
5,476 \\
748,428\end{array}$ & $\begin{array}{r}14,728 \\
10,085 \\
117,026 \\
0 \\
177,827 \\
242,869 \\
16,853 \\
53,918 \\
151,222 \\
58,679 \\
58,263 \\
20,778 \\
199 \\
15,986 \\
938,434\end{array}$ & $\begin{array}{r}88,394 \\
27,788 \\
256,296 \\
0 \\
569,026 \\
394,642 \\
61,026 \\
129,074 \\
258,470 \\
249,668 \\
76,217 \\
3,770 \\
0 \\
40,544 \\
2,154,014\end{array}$ \\
\hline
\end{tabular}

See endnotes at end of an indtividual electric utility. 
Table 42. Utility Plant by Major U.S. Inveator-Owned Electric Utility Within State on December 31, 1982 (Continued) (Thousand Dollars)

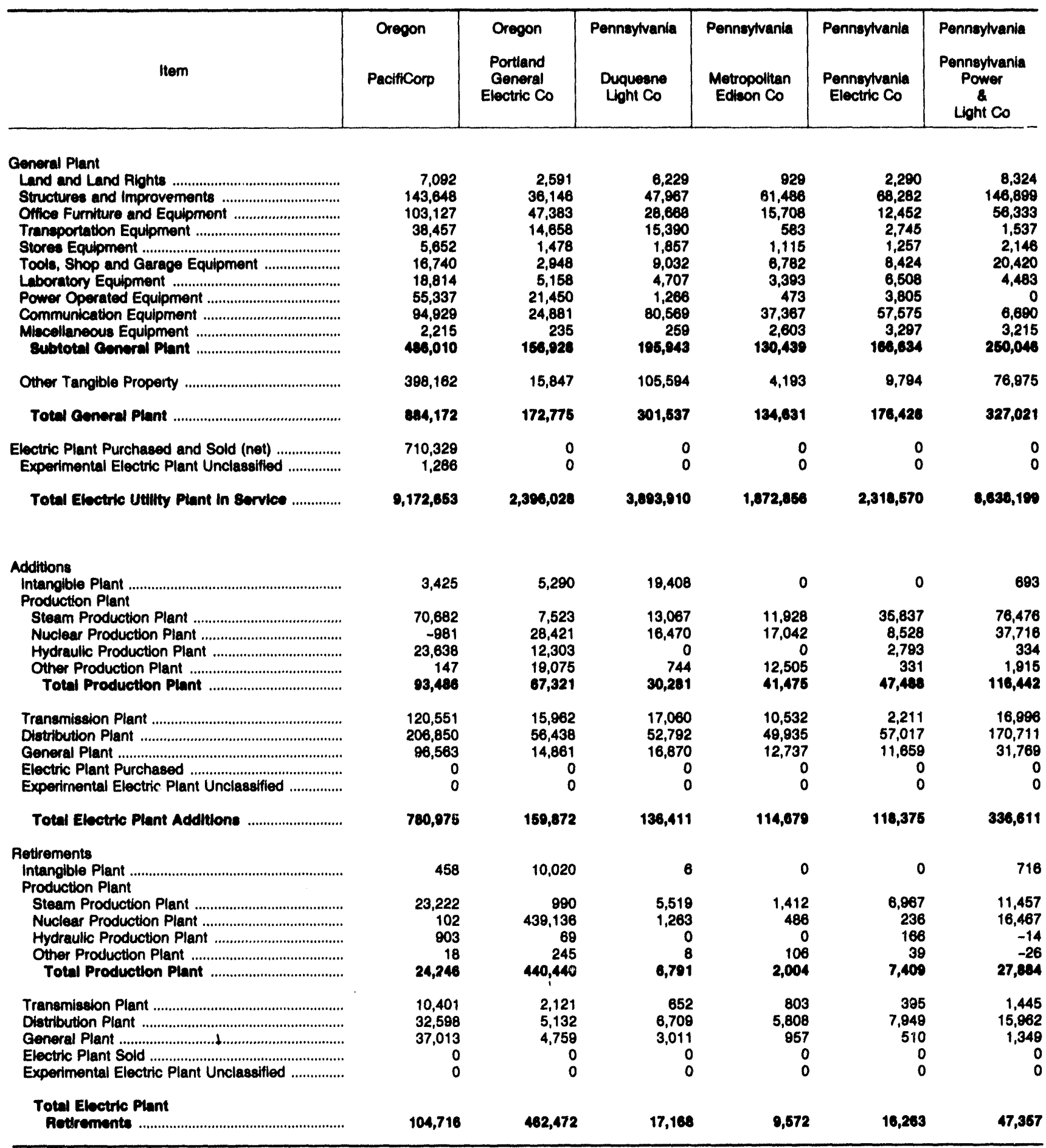

Note: Totals may not equal sum of components because of independent rounding. Summary data are provided in Table 28.

Source: Federal Energy Regulatory Commission, FERC Form 1, "Annual Report of Major Electric Utilfies, Licensees and Others." 
Table 42. Utillty Plant by Major U.8. Investor-Owned Electric Utility Within State on Decombor 31, 1892 (Continued)

(Thousand Dollars)

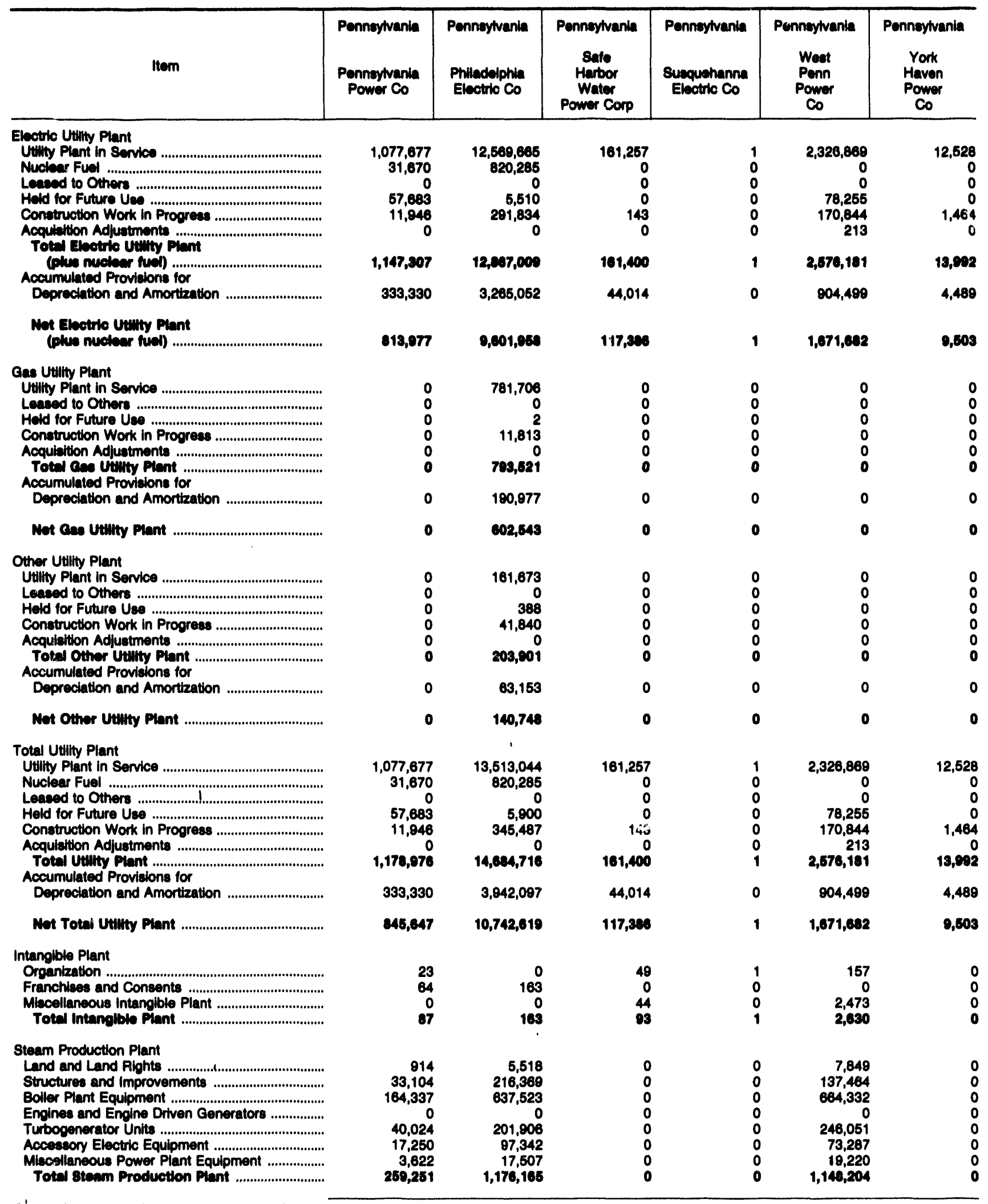

See endnotes at end of an indwidual electric utillty. 
Table 42. Utility Plant by Major U.S. Investor-Owned Electric Utility Within State on December 31, 1992 (Continued) (Thousand Dollars)

\begin{tabular}{|c|c|c|c|c|c|c|}
\hline Item & $\begin{array}{l}\text { Pennsylvania } \\
\text { Penneylvania } \\
\text { Power Co }\end{array}$ & $\begin{array}{l}\text { Pennoylvania } \\
\text { Philadolphia } \\
\text { Electric Co }\end{array}$ & $\begin{array}{c}\text { Penneytvania } \\
\text { Safe } \\
\text { Harbor } \\
\text { Water } \\
\text { Power Corp }\end{array}$ & $\begin{array}{l}\text { Pennoylvania } \\
\text { Susquehanna } \\
\text { Electric Co }\end{array}$ & $\begin{array}{c}\text { Pennoytvania } \\
\text { Weat } \\
\text { Penn } \\
\text { Power } \\
\text { Co }\end{array}$ & $\begin{array}{c}\text { Penneylvania } \\
\text { York } \\
\text { Haven } \\
\text { Power } \\
\text { Co }\end{array}$ \\
\hline 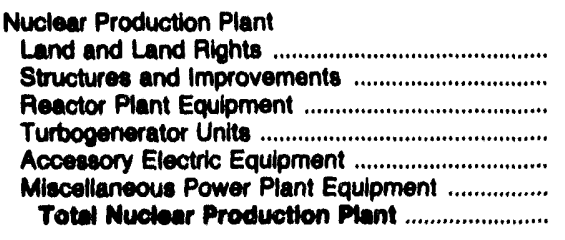 & $\begin{array}{r}382 \\
106,705 \\
267,708 \\
49,000 \\
68,474 \\
27,711 \\
600,080\end{array}$ & $\begin{array}{r}11,312 \\
1,804,394 \\
4,412,129 \\
853,390 \\
1,018,893 \\
394,614 \\
8,894,731\end{array}$ & $\begin{array}{l}0 \\
0 \\
0 \\
0 \\
0 \\
0 \\
0\end{array}$ & $\begin{array}{l}0 \\
0 \\
0 \\
0 \\
0 \\
0 \\
0\end{array}$ & $\begin{array}{l}0 \\
0 \\
0 \\
0 \\
0 \\
0 \\
0\end{array}$ & $\begin{array}{l}0 \\
0 \\
0 \\
0 \\
0 \\
0 \\
0\end{array}$ \\
\hline 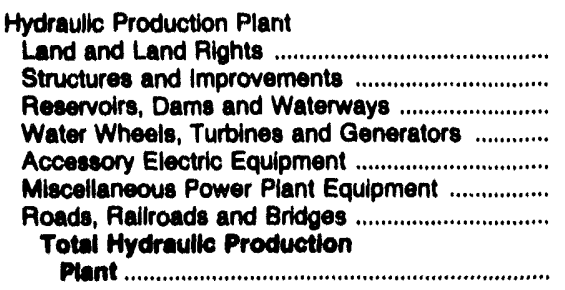 & $\begin{array}{l}0 \\
0 \\
0 \\
0 \\
0 \\
0 \\
0\end{array}$ & $\begin{array}{r}1,421 \\
15,103 \\
34,448 \\
27,018 \\
8,732 \\
2,147 \\
998\end{array}$ & $\begin{array}{r}3,280 \\
29,086 \\
14,909 \\
89,594 \\
12,980 \\
4,346 \\
156\end{array}$ & $\begin{array}{l}0 \\
0 \\
0 \\
0 \\
0 \\
0 \\
0\end{array}$ & $\begin{array}{r}443 \\
1,642 \\
10,356 \\
1,331 \\
8,080 \\
641 \\
3 \\
22,408\end{array}$ & $\begin{array}{r}915 \\
5,007 \\
2,044 \\
1,225 \\
1,119 \\
822 \\
0\end{array}$ \\
\hline 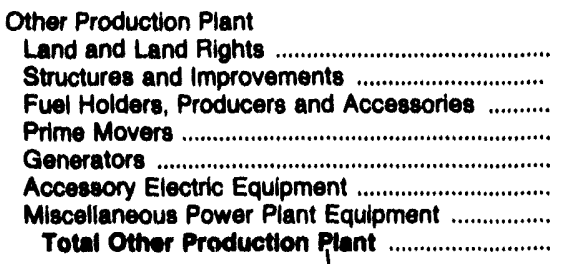 & $\begin{array}{r}0 \\
62 \\
236 \\
2,241 \\
685 \\
216 \\
14 \\
3,484\end{array}$ & $\begin{array}{r}841 \\
4,203 \\
22,361 \\
0 \\
92,354 \\
12,123 \\
2,260 \\
134,141\end{array}$ & $\begin{array}{l}0 \\
0 \\
0 \\
0 \\
0 \\
0 \\
0 \\
0\end{array}$ & $\begin{array}{l}0 \\
0 \\
0 \\
0 \\
0 \\
0 \\
0 \\
0\end{array}$ & $\begin{array}{l}0 \\
0 \\
0 \\
0 \\
0 \\
0 \\
0 \\
0\end{array}$ & $\begin{array}{l}0 \\
0 \\
0 \\
0\end{array}$ \\
\hline 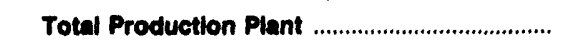 & 772,686 & $9,904,004$ & 164,381 & $\mathbf{0}$ & $1,170,090$ & 11,132 \\
\hline 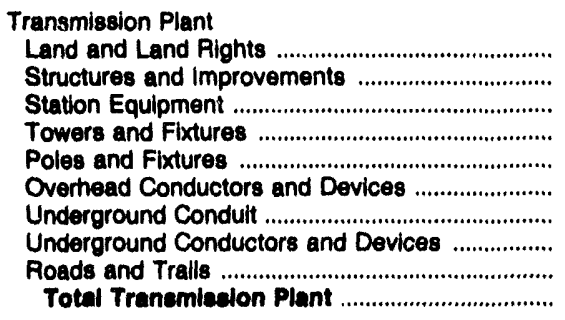 & $\begin{array}{r}9,101 \\
4,027 \\
45,059 \\
12,432 \\
16,481 \\
25,705 \\
74 \\
109 \\
88 \\
113,177\end{array}$ & $\begin{array}{r}54,148 \\
23,248 \\
274,08 ? \\
213,864 \\
453 \\
107,795 \\
2,756 \\
42,257 \\
1,736 \\
720,337\end{array}$ & $\begin{array}{r}0 \\
720 \\
5,282 \\
0 \\
0 \\
83 \\
0 \\
0 \\
0 \\
6,005\end{array}$ & $\begin{array}{l}0 \\
0 \\
0 \\
0 \\
0 \\
0 \\
0 \\
0 \\
0 \\
0\end{array}$ & $\begin{array}{r}24,180 \\
3,008 \\
95,680 \\
42,887 \\
37,108 \\
63,814 \\
0 \\
0 \\
65 \\
286,042\end{array}$ & $\begin{array}{r}0 \\
58 \\
1,338 \\
0 \\
0 \\
0 \\
0 \\
0 \\
0 \\
1,308\end{array}$ \\
\hline 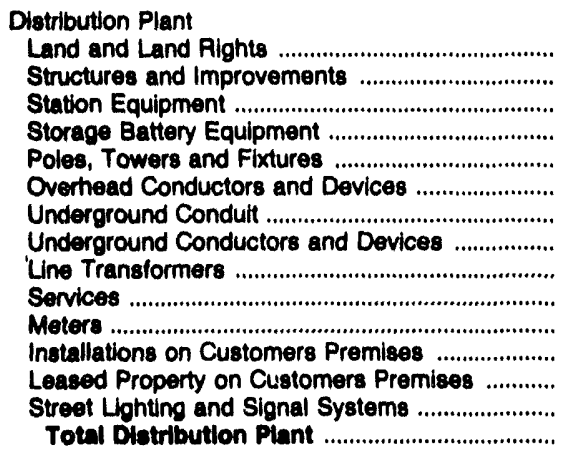 & $\begin{array}{r}5,129 \\
1,359 \\
18,714 \\
0 \\
40,413 \\
25,469 \\
1,421 \\
12,331 \\
34,177 \\
13,394 \\
19,242 \\
2,408 \\
0 \\
4,047 \\
178,105\end{array}$ & $\begin{array}{r}30,185 \\
41,646 \\
474,853 \\
0 \\
227,789 \\
332,408 \\
193,178 \\
398,949 \\
245,457 \\
192,094 \\
156,839 \\
571 \\
0 \\
15,952 \\
2,309,021\end{array}$ & $\begin{array}{l}0 \\
0 \\
0 \\
0 \\
0 \\
0 \\
0 \\
0 \\
0 \\
0 \\
0 \\
0 \\
0 \\
0 \\
0\end{array}$ & $\begin{array}{l}0 \\
0 \\
0 \\
0 \\
0 \\
0 \\
0 \\
0 \\
0 \\
0 \\
0 \\
0 \\
0 \\
0 \\
0\end{array}$ & $\begin{array}{r}10,198 \\
10,028 \\
166,243 \\
0 \\
135,710 \\
146,684 \\
8,124 \\
23,203 \\
163,020 \\
52,769 \\
44,392 \\
0 \\
223 \\
13,132 \\
773,725\end{array}$ & $\begin{array}{c}0 \\
0 \\
0 \\
0\end{array}$ \\
\hline
\end{tabular}

See endnotes at end of an individual electric utility. 
Table 42. UtIlity Plant by Major U.S. Inveator-Owned Electric Utility Within state on Decomber 31, 1992 (Continued) (Thousand Dollars)

\begin{tabular}{|c|c|c|c|c|c|c|}
\hline Item & $\begin{array}{c}\text { Pennaytvania } \\
\text { Pennoytvania } \\
\text { Power Co }\end{array}$ & $\begin{array}{l}\text { Penneylvania } \\
\text { Philadelphia } \\
\text { Electric Co }\end{array}$ & $\begin{array}{c}\text { Pennoytuania } \\
\text { Safe } \\
\text { Harbor } \\
\text { Water } \\
\text { Power Corp }\end{array}$ & $\begin{array}{l}\text { Pennoytuania } \\
\text { Suequehanna } \\
\text { Electric Co }\end{array}$ & $\begin{array}{c}\text { Pennoytvania } \\
\text { Weat } \\
\text { Ponn } \\
\text { Power } \\
\text { Co }\end{array}$ & $\begin{array}{c}\text { Penneytvania } \\
\text { York } \\
\text { Haven } \\
\text { Power } \\
\text { Co }\end{array}$ \\
\hline
\end{tabular}

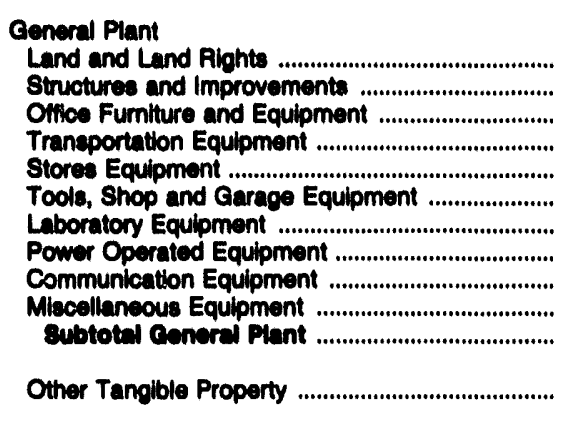

Total Ceneral Plant

Electric Plant Purchased and Sold (net)

Experimental Electric Plant Unclassified

Total Electric Utilty Plant in service

$\begin{array}{rr}68 & 2,028 \\ 4,338 & 29,416 \\ 1,308 & 10,598 \\ 4,189 & 0 \\ 288 & 191 \\ 1,651 & 8,120 \\ 254 & 16,310 \\ 177 & 0 \\ 1,374 & 6,211 \\ 89 & 2,043 \\ 13,928 & 73,910\end{array}$

$13,928 \quad 73,010$

$0 \quad-529,571$

$13,623 \quad-465,681$

$\begin{array}{ll}0 & 0 \\ 0 & 0\end{array}$

$1,077,077$

$12,699,698$

0
51
112
209
0
1
0
0
334
0
705
0
708
0
0

$$
\begin{array}{r}
1,823 \\
57,236 \\
17,692 \\
12,413 \\
641 \\
3,374 \\
1,857 \\
108 \\
16,727 \\
902 \\
112,873
\end{array}
$$

181,257

\section{Additions}

Intanglible Plant

Production Plant

Stanm Prod'jction Plant

Nuclear Production Plant

Hydraulic Production Plant

Other Production Plant

Total Production Plant

$\begin{array}{rr}0 & \\ 3,099 & 49,6 \\ 5,481 & 117,837 \\ 0 & 5,737 \\ 108 & 9,281 \\ 0,696 & 182,602 \\ 4,032 & 38,993 \\ 13,297 & 132,1 \\ 1,780 & 12,8 \\ 0 & \\ 0 & \end{array}$

Transmiseion Plant

Distribution Piant

General Plant

Electric Plant Purchased

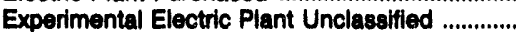

Total Electric Plant Additions

$27,005 \quad 396,424$

0
0
0
588
0
68
0
0
33
0
0

$-22$

0

41,207

0

1,624

1,463

42,831

0
1,488

3,064

51,317

5,873

620

1,493

Retirements

Intanglble Plant .

Production Plant

Steam Production Plant

Nuclear Production Plant

Hydraulic Production Plant

Other Production Plant

Total Production Plant

Transmission Plant

Distribution Plant

General Plant

Electric Plant Sold

Experimental Electric Plaint Unclassified

- to

Total Electric Plent

Rotirement

8,805

49,790

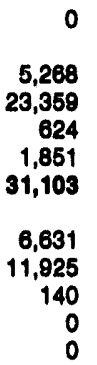

$$
\begin{array}{r}
0 \\
0 \\
0 \\
15 \\
0 \\
15 \\
0 \\
0 \\
12 \\
0 \\
0
\end{array}
$$

$\because$

Note: Totrils may not equal sum of components because of independent rounding. Summary da: are provided in Table 28.

Source: Federal Energy Regulatory Commission, FERC Form 1, "Annual Report of Major Electric Utilities, Licensees and Others." 
Table 42. Utility Plant by Major U.8. Investor-Owned Electric Utility Within state on Decomber 31, 1992 (Continued) (Thousand Dollars)

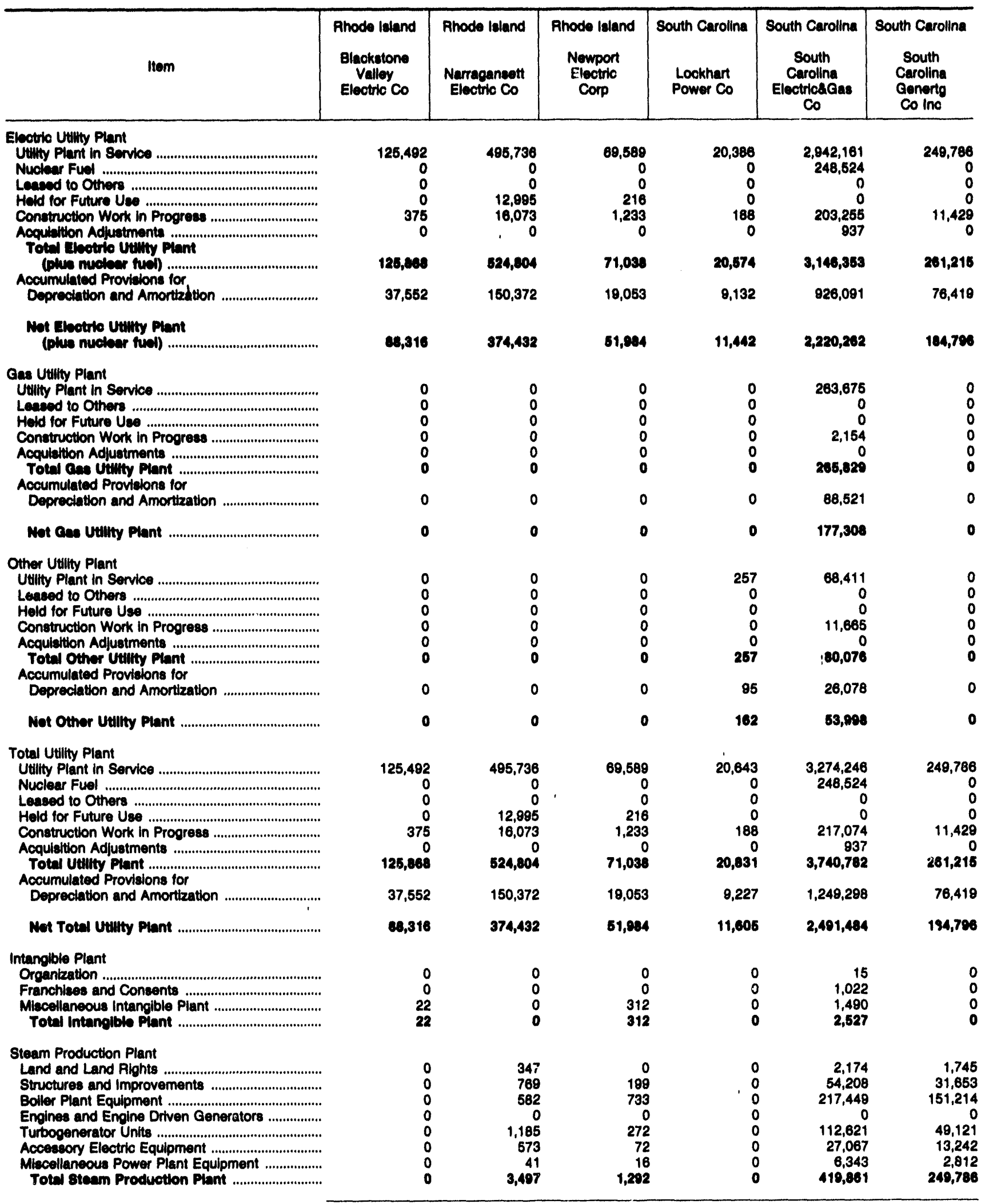

See endnotes at end of an individual electric utility. 
Table 42. Utility Plant by Major U.8. Investor-Owned Electrle Utility Within state on Decomber 31, 1902 (Continued) (Thousand Dollars)

\begin{tabular}{|c|c|c|c|c|c|c|}
\hline ltem & $\begin{array}{l}\text { Fhode Ieland } \\
\text { Bleckntone } \\
\text { Velley } \\
\text { Electrio Co }\end{array}$ & $\begin{array}{l}\text { Fhode laland } \\
\text { Nerreganeett } \\
\text { Elsotito Co }\end{array}$ & $\begin{array}{l}\text { Phode leiand } \\
\text { Nomport } \\
\text { Electrio } \\
\text { Corp }\end{array}$ & $\begin{array}{l}\text { South Caroine } \\
\text { Lookhart } \\
\text { Power Co }\end{array}$ & $\begin{array}{c}\text { South Curolin } \\
\text { South } \\
\text { Carollin } \\
\text { Eleotroscens } \\
\text { Co }\end{array}$ & $\begin{array}{l}\text { South Carolin } \\
\text { South } \\
\text { Carollna } \\
\text { Cenerto } \\
\text { Co Ino }\end{array}$ \\
\hline 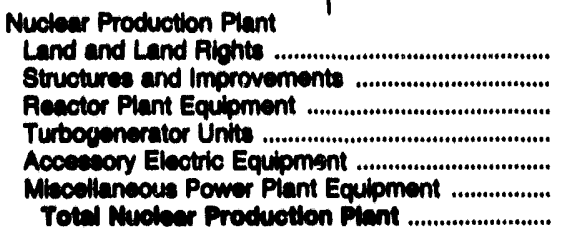 & $\begin{array}{l}0 \\
0 \\
0 \\
0 \\
0 \\
0 \\
0\end{array}$ & $\begin{array}{l}0 \\
0 \\
0 \\
0 \\
0 \\
0 \\
0\end{array}$ & $\begin{array}{l}0 \\
0 \\
0 \\
0 \\
0 \\
0 \\
0\end{array}$ & $\begin{array}{l}0 \\
0 \\
0 \\
0 \\
0 \\
0 \\
0\end{array}$ & $\begin{array}{r}598 \\
242,302 \\
409,000 \\
71,000 \\
98,700 \\
72,970 \\
000,000\end{array}$ & $\begin{array}{l}0 \\
0 \\
0 \\
0 \\
0 \\
0 \\
0\end{array}$ \\
\hline 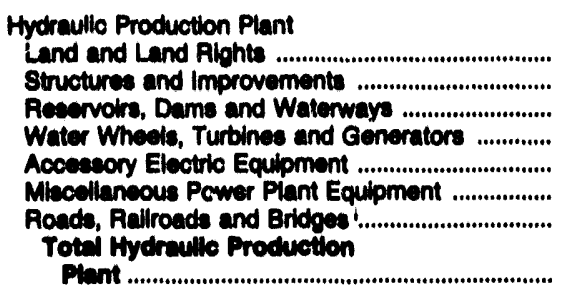 & $\begin{array}{r}286 \\
2,082 \\
1,828 \\
1,781 \\
619 \\
689 \\
0 \\
7,019\end{array}$ & $\begin{array}{l}0 \\
0 \\
0 \\
0 \\
0 \\
0 \\
0 \\
0\end{array}$ & $\begin{array}{l}0 \\
0 \\
0 \\
0 \\
0 \\
0 \\
0 \\
0\end{array}$ & $\begin{array}{r}219 \\
176 \\
2,080 \\
4,088 \\
828 \\
63 \\
6 \\
7,414\end{array}$ & $\begin{array}{r}28,678 \\
42,460 \\
108,710 \\
68,160 \\
8,721 \\
4,610 \\
1,681 \\
282,740\end{array}$ & $\begin{array}{l}0 \\
0 \\
0 \\
0 \\
0 \\
0 \\
0\end{array}$ \\
\hline 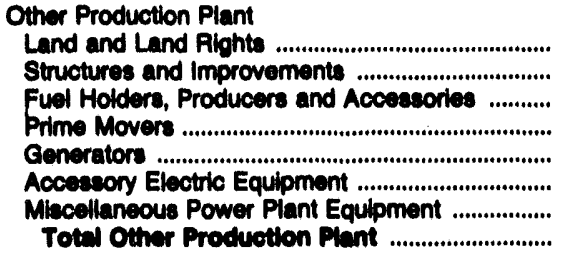 & $\begin{array}{l}0 \\
0 \\
0 \\
0 \\
0 \\
0 \\
0 \\
0\end{array}$ & $\begin{array}{r}0 \\
0 \\
10 \\
301 \\
147 \\
168 \\
0 \\
116\end{array}$ & $\begin{array}{r}21 \\
81 \\
164 \\
59 \\
2,428 \\
355 \\
0 \\
3,007\end{array}$ & $\begin{array}{l}0 \\
0 \\
0 \\
0 \\
0 \\
0 \\
0 \\
0\end{array}$ & $\begin{array}{r}108 \\
3,131 \\
3,313 \\
2,853 \\
47,284 \\
3,427 \\
121 \\
60,212\end{array}$ & $\begin{array}{l}0 \\
0 \\
0 \\
0 \\
0 \\
0 \\
0 \\
0\end{array}$ \\
\hline Total Production Plant .......................................... & 7,049 & 4,112 & 4,300 & 7,414 & $1,828,428$ & 249,70 \\
\hline 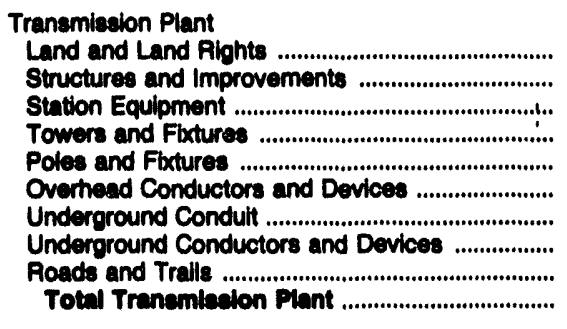 & $\begin{array}{r}2,319 \\
1,413 \\
16,993 \\
797 \\
2,973 \\
2,957 \\
0 \\
11 \\
181 \\
27,944\end{array}$ & $\begin{array}{r}6,002 \\
1,444 \\
15,702 \\
450 \\
14,609 \\
11,857 \\
582 \\
4,082 \\
432 \\
85,160\end{array}$ & $\begin{array}{r}1,023 \\
134 \\
4,308 \\
124 \\
2,034 \\
1,328 \\
0 \\
0 \\
0 \\
0,861\end{array}$ & $\begin{array}{r}27 \\
131 \\
1,298 \\
0 \\
364 \\
487 \\
0 \\
0 \\
0 \\
2,808\end{array}$ & $\begin{array}{r}24,682 \\
1,401 \\
122,686 \\
5,465 \\
79,808 \\
67,442 \\
1,783 \\
4,670 \\
9 \\
307,890\end{array}$ & $\begin{array}{l}0 \\
0 \\
0 \\
0 \\
0 \\
0 \\
0 \\
0 \\
0 \\
0\end{array}$ \\
\hline 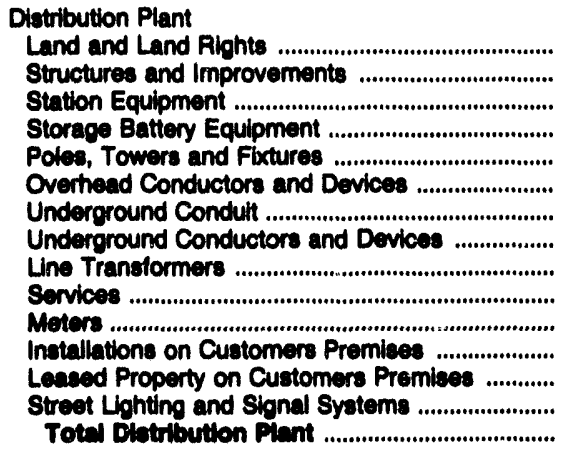 & $\begin{array}{r}808 \\
2,053 \\
14,040 \\
0 \\
11,779 \\
16,900 \\
4,698 \\
6,999 \\
13,741 \\
6,942 \\
6,132 \\
0 \\
0 \\
3,868 \\
8,960\end{array}$ & $\begin{array}{r}4,611 \\
1,897 \\
49,392 \\
0 \\
58,416 \\
102,632 \\
22,027 \\
37,634 \\
62,168 \\
24,682 \\
25,135 \\
3 \\
3,600 \\
27,389 \\
418,570\end{array}$ & $\begin{array}{r}416 \\
404 \\
11,877 \\
0 \\
5,889 \\
6,803 \\
2,809 \\
7,949 \\
5,658 \\
1,302 \\
3,212 \\
750 \\
0 \\
1,601 \\
48,670\end{array}$ & $\begin{array}{r}26 \\
215 \\
1,760 \\
0 \\
1,810 \\
1,808 \\
0 \\
95 \\
1,661 \\
918 \\
674 \\
0 \\
0 \\
597 \\
9,650\end{array}$ & $\begin{array}{r}19,518 \\
871 \\
108,773 \\
0 \\
120,797 \\
164,181 \\
30,709 \\
91,180 \\
169,296 \\
89,590 \\
54,064 \\
0 \\
0 \\
60,851 \\
909,990\end{array}$ & $\begin{array}{l}0 \\
0 \\
0 \\
0 \\
0 \\
0 \\
0 \\
0 \\
0 \\
0 \\
0 \\
0\end{array}$ \\
\hline
\end{tabular}

See endnotes at end of an individual electric utillty. 
Table 42. Utility Plant by Major U.8. Investor-Owned Electric Utility Within stpte on Decomber 31, 1992 (Continued) (Thousand Dollars)

\begin{tabular}{|c|c|c|c|c|c|c|}
\hline rem & $\begin{array}{l}\text { Rhode Ieland } \\
\text { Blacketone } \\
\text { Valley } \\
\text { Electrio co }\end{array}$ & $\begin{array}{l}\text { Rhode lelend } \\
\text { Nameganeott } \\
\text { Electric Co }\end{array}$ & $\begin{array}{l}\text { Rhode lalend } \\
\text { Newport } \\
\text { Electric } \\
\text { Corp }\end{array}$ & $\begin{array}{l}\text { South Croiln: } \\
\text { Lookhart } \\
\text { Pown Co }\end{array}$ & $\begin{array}{l}\text { South Curoling } \\
\text { South } \\
\text { Curolin } \\
\text { Electicaces } \\
\text { Co }\end{array}$ & $\begin{array}{l}\text { Eouth Curolina } \\
\text { South } \\
\text { Cerolln } \\
\text { Cenvitg } \\
\text { Co Ino }\end{array}$ \\
\hline 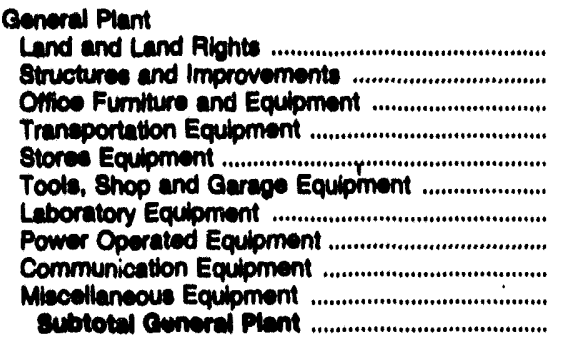 & $\begin{array}{r}21 \\
2,205 \\
667 \\
4 \\
13 \\
288 \\
168 \\
0 \\
378 \\
66 \\
3,045\end{array}$ & $\begin{array}{r}464 \\
11,686 \\
697 \\
0 \\
390 \\
1,937 \\
929 \\
0 \\
681 \\
216 \\
16,097\end{array}$ & $\begin{array}{r}171 \\
3,113 \\
679 \\
1,602 \\
63 \\
385 \\
212 \\
12 \\
497 \\
38 \\
6,888\end{array}$ & $\begin{array}{r}0 \\
288 \\
201 \\
428 \\
0 \\
107 \\
0 \\
0 \\
76 \\
0 \\
1,100\end{array}$ & $\begin{array}{r}2,038 \\
17,469 \\
10,581 \\
11,476 \\
376 \\
3,749 \\
3,727 \\
23,617 \\
21,612 \\
781 \\
98,417\end{array}$ & $\begin{array}{l}0 \\
0 \\
0 \\
0 \\
0 \\
0 \\
0 \\
0 \\
0 \\
0 \\
0\end{array}$ \\
\hline 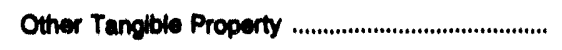 & 0 & 0 & 12 & 0 & 3,089 & 0 \\
\hline 'Total Cenerd Plant ................................................. & 3,293 & 18,907 & 8,696 & 1,100 & $\infty, 49$ & $\mathbf{0}$ \\
\hline $\begin{array}{l}\text { Eleotric Plant Purchased and Sold (net) ................... } \\
\text { Experimental Eloctrlo Plant Unclaseified .............. }\end{array}$ & $\begin{array}{l}0 \\
0\end{array}$ & $\begin{array}{l}0 \\
0\end{array}$ & $\begin{array}{l}0 \\
0\end{array}$ & $\begin{array}{l}0 \\
0\end{array}$ & $\begin{array}{l}0 \\
0\end{array}$ & $\begin{array}{l}0 \\
0\end{array}$ \\
\hline 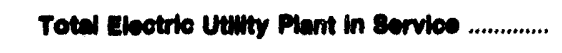 & 128,492 & 405,780 & 60,100 & 20,813 & $2,042,181$ & 240,708 \\
\hline 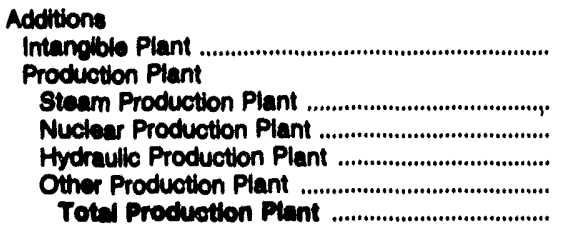 & $\begin{array}{l}0 \\
0 \\
0 \\
0 \\
0\end{array}$ & $\begin{array}{r}0 \\
844 \\
0 \\
0 \\
0 \\
044\end{array}$ & $\begin{array}{r}9 \\
0 \\
0 \\
38 \\
47\end{array}$ & $\begin{array}{r}0 \\
0 \\
94 \\
0 \\
94\end{array}$ & $\begin{array}{r}669 \\
39,282 \\
10,514 \\
729 \\
3,495 \\
84,020\end{array}$ & $\begin{array}{r}0 \\
1,560 \\
0 \\
0 \\
0 \\
1,600\end{array}$ \\
\hline 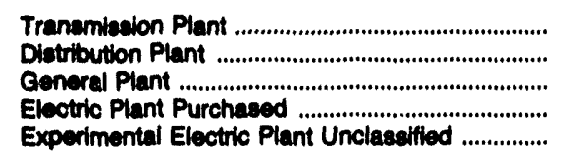 & $\begin{array}{r}114 \\
2,868 \\
941 \\
0 \\
0\end{array}$ & $\begin{array}{r}2,887 \\
28,117 \\
1,054 \\
0 \\
0\end{array}$ & $\begin{array}{r}76 \\
2,594 \\
479 \\
0 \\
0\end{array}$ & $\begin{array}{r}60 \\
584 \\
118 \\
0 \\
0\end{array}$ & $\begin{array}{r}23,379 \\
80,262 \\
12,212 \\
0 \\
0\end{array}$ & $\begin{array}{l}0 \\
0 \\
0 \\
0 \\
0\end{array}$ \\
\hline Total Ehotrite Plent Addittons .......................... & 3,021 & 30,082 & 3,198 & 828 & 170,842 & 1,860 \\
\hline 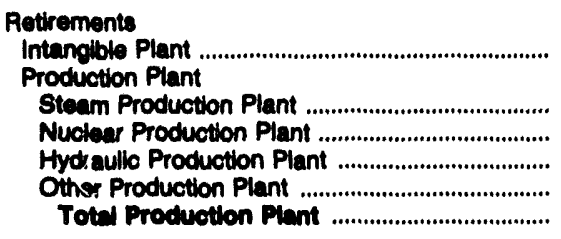 & $\begin{array}{l}0 \\
0 \\
0 \\
0 \\
0 \\
0\end{array}$ & $\begin{array}{r}0 \\
2,185 \\
0 \\
0 \\
0 \\
2,185\end{array}$ & $\begin{array}{l}0 \\
2 \\
0 \\
0 \\
2 \\
4\end{array}$ & $\begin{array}{l}0 \\
0 \\
0 \\
3 \\
0 \\
3\end{array}$ & $\begin{array}{r}0 \\
\\
6,311 \\
11,089 \\
11 \\
73 \\
17,494\end{array}$ & $\begin{array}{r}8,342 \\
0 \\
0 \\
0 \\
8,342\end{array}$ \\
\hline 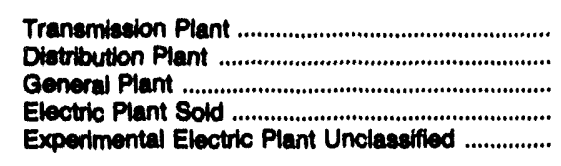 & $\begin{array}{r}5 \\
1,146 \\
33 \\
0 \\
0\end{array}$ & $\begin{array}{r}875 \\
7,438 \\
649 \\
0 \\
0\end{array}$ & $\begin{array}{r}4 \\
510 \\
518 \\
0 \\
0\end{array}$ & $\begin{array}{r}80 \\
158 \\
71 \\
0 \\
0\end{array}$ & $\begin{array}{r}346 \\
6,727 \\
2,219 \\
0 \\
0\end{array}$ & $\begin{array}{l}0 \\
0 \\
0 \\
0 \\
0\end{array}$ \\
\hline $\begin{array}{l}\text { Totel Eleotrle Piant } \\
\text { Retiremente ....................................................... }\end{array}$ & 1,184 & 11,147 & 1,089 & 323 & 28,776 & 8,342 \\
\hline
\end{tabular}

Note: Totals may not equal sum of components because of independent rounding. Summary data are provided in Table 28.

Source: Federal Energy Regulatory Commission, FERC Form 1, "Annual Report of Malor Electric Utillties, Licensees and Others." 
Table 42. Utility Plant by Major U.8. Inveotor-Owned Electric Utility Within state on Decomber 31, 1992 (Continued)

(Thousand Dollars)

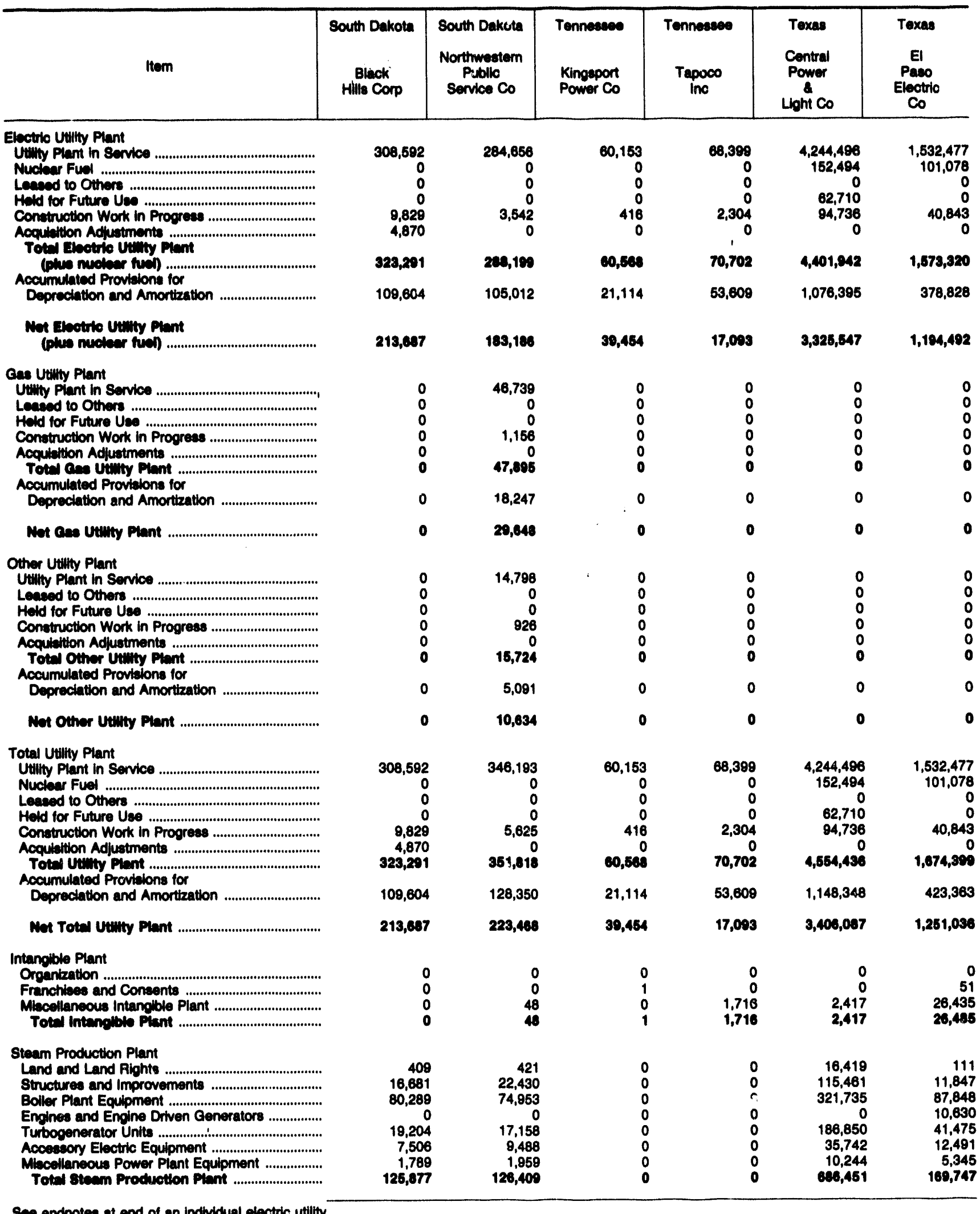


Table 42. Utility Plant by Major U.S. Investor-Owned Electric Utility Within State on December 31, 1992 (Continued)

(Thousand Dollars)

\begin{tabular}{|c|c|c|c|c|c|c|}
\hline Item & $\begin{array}{c}\text { South Dakota } \\
\text { Black } \\
\text { Hilis Corp }\end{array}$ & $\begin{array}{l}\text { South Dakota } \\
\text { Northweatern } \\
\text { Publlc } \\
\text { Service Co }\end{array}$ & $\begin{array}{l}\text { Tennessee } \\
\text { Kingeport } \\
\text { Power Co }\end{array}$ & $\begin{array}{l}\text { Tennessee } \\
\text { Tapoco } \\
\text { Inc }\end{array}$ & $\begin{array}{c}\text { Texas } \\
\text { Central } \\
\text { Power } \\
\mathbf{2} \\
\text { Light Co }\end{array}$ & $\begin{array}{c}\text { Texas } \\
\text { El } \\
\text { Paso } \\
\text { Electric } \\
\text { Co }\end{array}$ \\
\hline 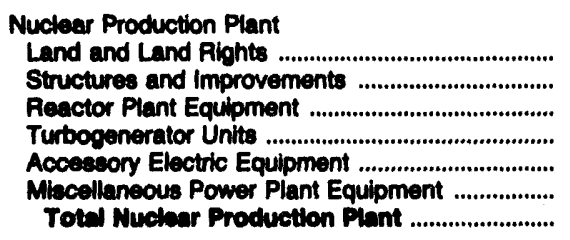 & $\begin{array}{l}0 \\
0 \\
0 \\
0 \\
0 \\
0 \\
0\end{array}$ & $\begin{array}{l}0 \\
0 \\
0 \\
0 \\
0 \\
0 \\
0\end{array}$ & $\begin{array}{l}0 \\
0 \\
0 \\
0 \\
0 \\
0 \\
0\end{array}$ & $\begin{array}{l}0 \\
0 \\
0 \\
0 \\
0 \\
0 \\
0\end{array}$ & $\begin{array}{r}4,653 \\
1,015,781 \\
694,512 \\
150,062 \\
415,449 \\
28,314 \\
2,309,772\end{array}$ & $\cdots$ \\
\hline 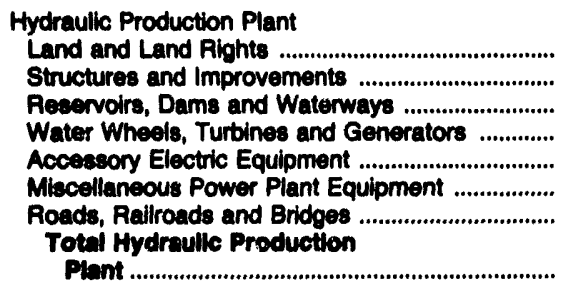 & $\begin{array}{l}0 \\
0 \\
0 \\
0 \\
0 \\
0 \\
0\end{array}$ & $\begin{array}{l}0 \\
0 \\
0 \\
0 \\
0 \\
0 \\
0\end{array}$ & $\begin{array}{l}0 \\
0 \\
0 \\
0 \\
0 \\
0 \\
0\end{array}$ & $\begin{array}{r}2,780 \\
3,741 \\
23,909 \\
8,274 \\
2,340 \\
1,528 \\
202\end{array}$ & $\begin{array}{r}2 \\
291 \\
238 \\
116 \\
233 \\
36 \\
0 \\
015\end{array}$ & $\begin{array}{l}0 \\
0 \\
0 \\
0 \\
0 \\
0 \\
0\end{array}$ \\
\hline 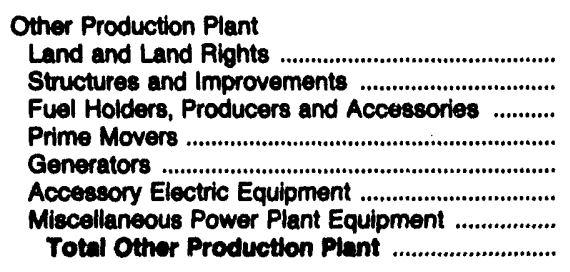 & $\begin{array}{r}0 \\
22 \\
2,608 \\
0 \\
14,839 \\
84 \\
15 \\
17,500\end{array}$ & $\begin{array}{r}60 \\
1,482 \\
758 \\
0 \\
0 \\
17,786 \\
834 \\
97 \\
21,016\end{array}$ & $\begin{array}{l}0 \\
0 \\
0 \\
0 \\
0 \\
0 \\
0 \\
0\end{array}$ & $\begin{array}{l}0 \\
0 \\
0 \\
0 \\
0 \\
0 \\
0 \\
0\end{array}$ & $\begin{array}{r}0 \\
392 \\
667 \\
415 \\
5,185 \\
113 \\
47 \\
6,819\end{array}$ & $\begin{array}{r}10 \\
815 \\
481 \\
0 \\
10,921 \\
451 \\
538 \\
13,014\end{array}$ \\
\hline 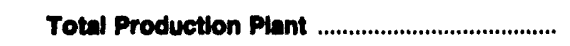 & 143,440 & 147,426 & & 42,803 & $3,002,957$ & 978,975 \\
\hline 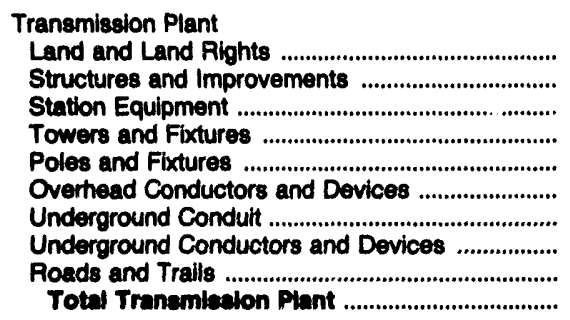 & $\begin{array}{r}1,192 \\
637 \\
22,247 \\
58 \\
21,437 \\
20,437 \\
0 \\
0 \\
47 \\
66,058\end{array}$ & $\begin{array}{r}875 \\
808 \\
24,952 \\
0 \\
17,537 \\
12,788 \\
0 \\
0 \\
0 \\
56,000\end{array}$ & $\begin{array}{r}521 \\
407 \\
6,159 \\
587 \\
880 \\
1,103 \\
0 \\
0 \\
0 \\
0 \\
9,656\end{array}$ & $\begin{array}{r}103 \\
337 \\
16,843 \\
1,087 \\
0 \\
692 \\
0 \\
0 \\
46 \\
10,108\end{array}$ & $\begin{array}{r}24,816 \\
3,000 \\
125,888 \\
28,901 \\
59,710 \\
85,355 \\
530 \\
801 \\
258 \\
329,368\end{array}$ & $\begin{array}{r}9,768 \\
4,443 \\
82,891 \\
24,250 \\
48,253 \\
63,097 \\
0 \\
0 \\
328 \\
234,028\end{array}$ \\
\hline 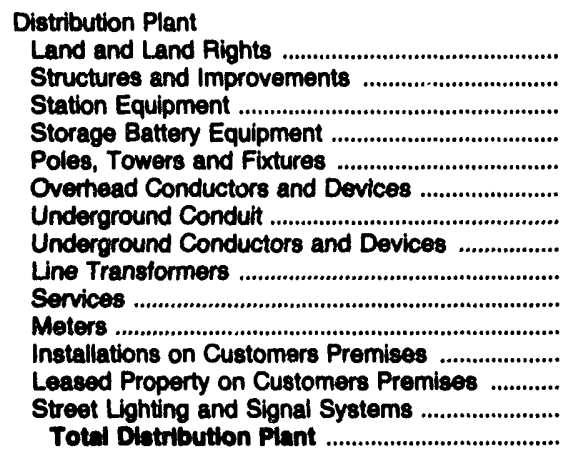 & $\begin{array}{r}213 \\
35 \\
10,892 \\
0 \\
16,590 \\
12,330 \\
45 \\
11,808 \\
12,534 \\
5,427 \\
3,786 \\
575 \\
0 \\
870 \\
75,205\end{array}$ & $\begin{array}{r}253 \\
0 \\
10,980 \\
0 \\
14,232 \\
9,676 \\
814 \\
6,880 \\
14,360 \\
5,953 \\
6,276 \\
707 \\
0 \\
2,138 \\
72,270\end{array}$ & $\begin{array}{r}765 \\
387 \\
3,855 \\
0 \\
8,893 \\
9,385 \\
1,354 \\
2,131 \\
11,296 \\
3,694 \\
3,732 \\
573 \\
0 \\
1,824 \\
47,868\end{array}$ & $\begin{array}{l}0 \\
0 \\
0 \\
0 \\
0 \\
0 \\
0 \\
0 \\
0 \\
0 \\
0 \\
0 \\
0 \\
0 \\
0\end{array}$ & $\begin{array}{r}2,299 \\
4,428 \\
35,874 \\
0 \\
181,829 \\
136,707 \\
9,113 \\
38,354 \\
158,764 \\
41,407 \\
40,292 \\
19,324 \\
0 \\
16,926 \\
715,316\end{array}$ & $\begin{array}{r}689 \\
2,135 \\
50,124 \\
0 \\
36,838 \\
26,202 \\
19,868 \\
16,063 \\
49,108 \\
19,985 \\
15,373 \\
2,419 \\
0 \\
5,070 \\
243,080\end{array}$ \\
\hline
\end{tabular}

See endnotes at end of an individual electric utility. 
Table 42. Utilty Plant by Major U.8. Inveotor-Owned Eloctric Utility Whinin State on Decomber 31, 1902 (Continued) (Thousand Dollars)

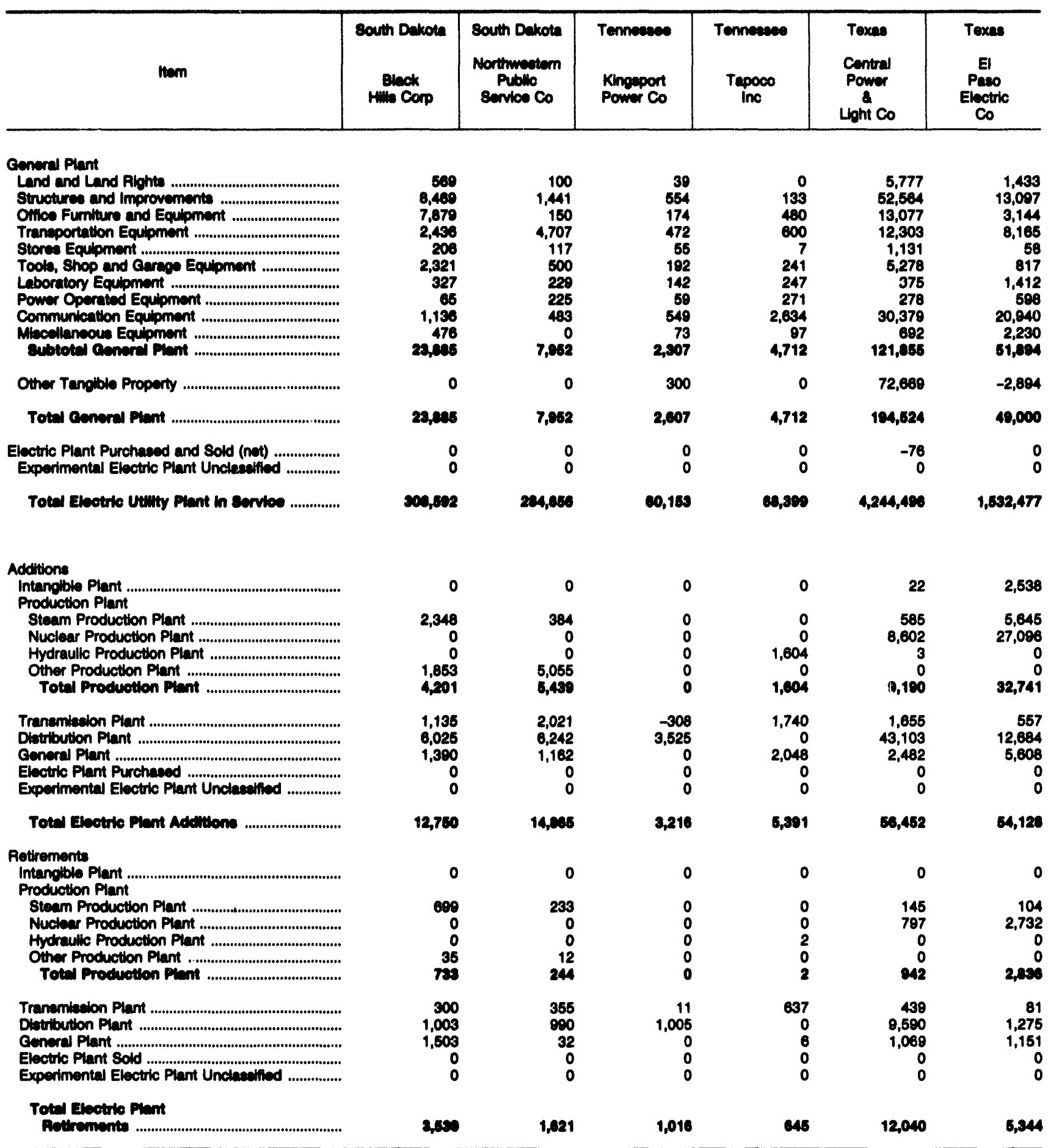

Note: Totals may not counl eum of components beceuse of independent rounding. Summary data are provided in Table 28. Source: Fedeial Energy Reculatory Commieion, FERC Form 1, "Annud Report of Major Electric Utilities, Licensees and Othere." 
Table 42. Utility Plant by Major U.S. Investor-Owned Electric Utility Within State on December 31, 1992 (Continued)

(Thousand Dollars)

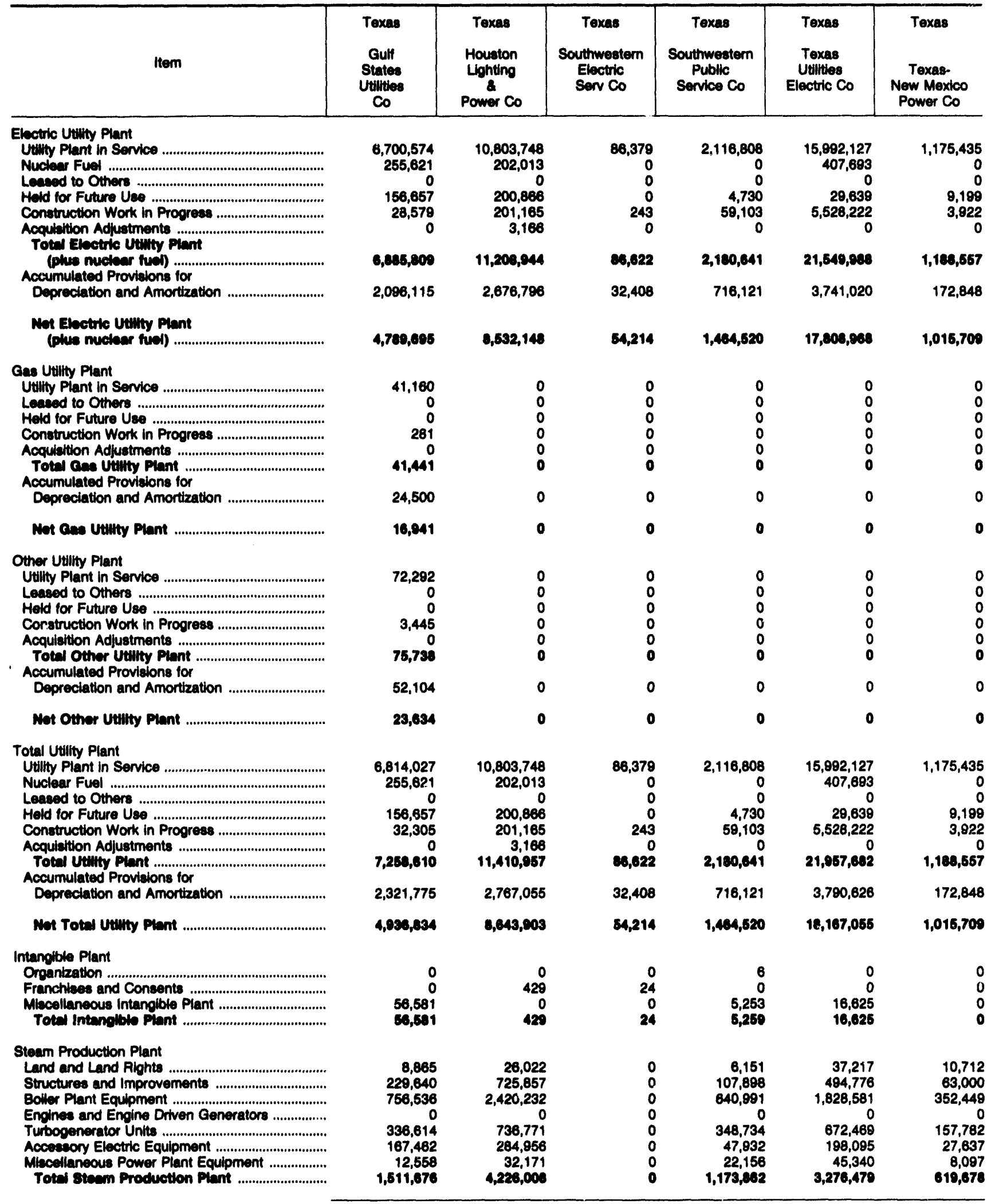

See endnotes at end of an individual electric utility. 
Table 42. Utility Plant by Major U.S. Investor-Owned Electric Utility Within State on December 31, 1992 (Continued) (Thousand Dollars)

\begin{tabular}{|c|c|c|c|c|c|c|}
\hline Item & $\begin{array}{l}\text { Texas } \\
\text { Guif } \\
\text { States } \\
\text { Utillies } \\
\text { Co }\end{array}$ & $\begin{array}{c}\text { Texas } \\
\text { Houston } \\
\text { Lighting } \\
2 \\
\text { Power Co }\end{array}$ & $\begin{array}{l}\text { Texas } \\
\text { Southwestern } \\
\text { Electric } \\
\text { Serv Co }\end{array}$ & $\begin{array}{c}\text { Texas } \\
\text { Southwestern } \\
\text { Public } \\
\text { Service Co }\end{array}$ & $\begin{array}{c}\text { Texas } \\
\text { Texas } \\
\text { Utillties } \\
\text { Electric Co }\end{array}$ & $\begin{array}{c}\text { Texas } \\
\text { Texas- } \\
\text { New Mexico } \\
\text { Power Co }\end{array}$ \\
\hline 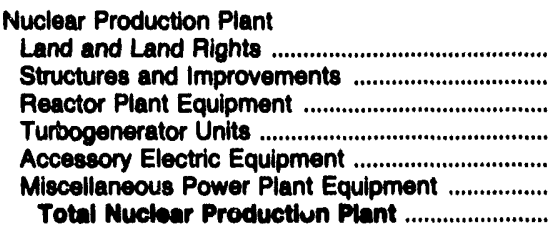 & $\begin{array}{r}8,506 \\
1,357,586 \\
685,042 \\
368,054 \\
626,535 \\
15,224 \\
3,070,047\end{array}$ & $\begin{array}{r}5,829 \\
1,077,443 \\
718,884 \\
157,274 \\
434,149 \\
28,045 \\
2,421,634\end{array}$ & $\begin{array}{l}0 \\
0 \\
0 \\
0 \\
0 \\
0 \\
0\end{array}$ & $\begin{array}{l}0 \\
0 \\
0 \\
0 \\
0 \\
0 \\
0\end{array}$ & $\begin{array}{r}25,425 \\
2,364,629 \\
2,794,906 \\
334,247 \\
1,528,941 \\
165,234 \\
7,213,392\end{array}$ & $\begin{array}{l}0 \\
0 \\
0 \\
0 \\
0 \\
0 \\
0\end{array}$ \\
\hline 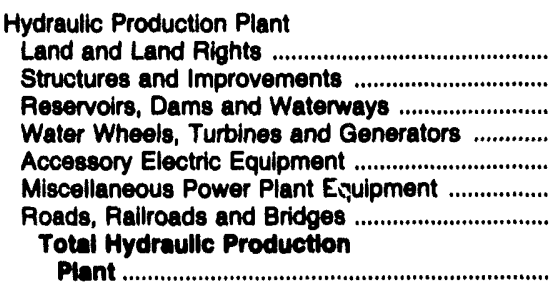 & $\begin{array}{r}0 \\
0 \\
0 \\
0 \\
219 \\
32 \\
0\end{array}$ & $\begin{array}{l}0 \\
0 \\
0 \\
0 \\
0 \\
0 \\
0\end{array}$ & $\begin{array}{l}0 \\
0 \\
0 \\
0 \\
0 \\
0 \\
0\end{array}$ & $\begin{array}{l}0 \\
0 \\
0 \\
0 \\
0 \\
0 \\
0\end{array}$ & $\begin{array}{l}0 \\
0 \\
0 \\
0 \\
0 \\
0 \\
0\end{array}$ & $\begin{array}{l}0 \\
0 \\
0 \\
0 \\
0 \\
0 \\
0\end{array}$ \\
\hline 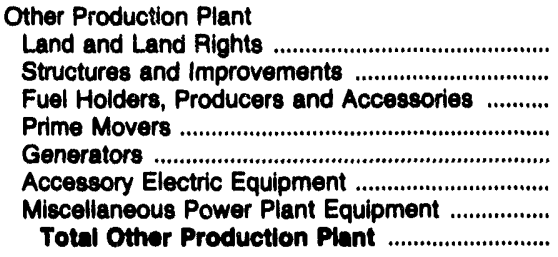 & $\begin{array}{l}0 \\
0 \\
0 \\
0 \\
0 \\
0 \\
0 \\
0\end{array}$ & $\begin{array}{r}0 \\
12,533 \\
5,391 \\
145,932 \\
28,056 \\
13,376 \\
333 \\
205,621\end{array}$ & $\begin{array}{l}0 \\
0 \\
0 \\
0 \\
0 \\
0 \\
0 \\
0\end{array}$ & $\begin{array}{r}12 \\
791 \\
493 \\
1,112 \\
18,696 \\
1,750 \\
89 \\
22,042\end{array}$ & $\begin{array}{r}0 \\
11 \\
0 \\
214 \\
0 \\
97 \\
32 \\
354\end{array}$ & $\begin{array}{l}0 \\
0 \\
0 \\
0 \\
0 \\
0 \\
0 \\
0\end{array}$ \\
\hline 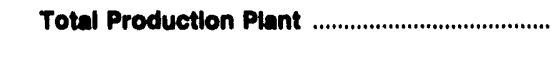 & $4,582,874$ & $6,853,263$ & $\begin{array}{l}0 \\
1\end{array}$ & $1,196,804$ & $10,490,215$ & 618,678 \\
\hline 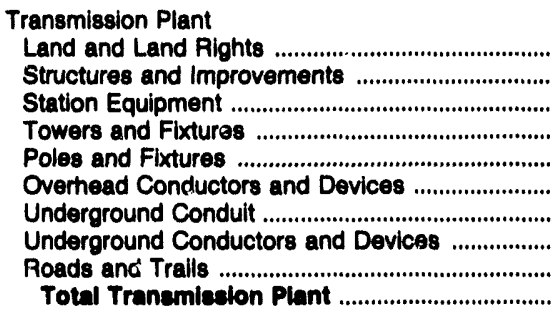 & $\begin{array}{r}76,614 \\
8,396 \\
399,187 \\
80,220 \\
124,656 \\
131,320 \\
8 \\
249 \\
364 \\
821,013\end{array}$ & $\begin{array}{r}78,835 \\
16,686 \\
270,454 \\
233,324 \\
22,321 \\
187,098 \\
2,430 \\
2,439 \\
4,898 \\
818,884\end{array}$ & $\begin{array}{r}161 \\
46 \\
2,599 \\
0 \\
2,682 \\
2,376 \\
0 \\
0 \\
3 \\
7,846\end{array}$ & $\begin{array}{r}17,874 \\
1,823 \\
153,445 \\
2,004 \\
109,447 \\
75,752 \\
255 \\
339 \\
0 \\
380,039\end{array}$ & $\begin{array}{r}160,451 \\
9,816 \\
605,238 \\
225,436 \\
184,965 \\
288,849 \\
8,879 \\
9,968 \\
0 \\
1,493,802\end{array}$ & $\begin{array}{r}6,034 \\
0 \\
58,283 \\
4,228 \\
25,408 \\
22,685 \\
0 \\
0 \\
0 \\
116,688\end{array}$ \\
\hline 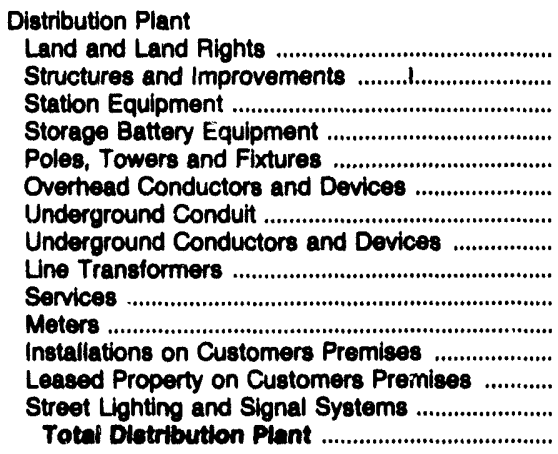 & $\begin{array}{r}15,655 \\
920 \\
101,382 \\
0 \\
0 \\
211,570 \\
183,895 \\
28,285 \\
89,220 \\
207,855 \\
86,321 \\
56,855 \\
648 \\
383 \\
51,620 \\
1,034,708\end{array}$ & $\begin{array}{r}11,773 \\
32,864 \\
409,982 \\
0 \\
278,712 \\
355,831 \\
142,993 \\
238,813 \\
524,661 \\
57,051 \\
210,199 \\
336 \\
0 \\
131,001 \\
2,394,228\end{array}$ & $\begin{array}{r}133 \\
220 \\
8,898 \\
0 \\
17,983 \\
14,920 \\
182 \\
1748 \\
15,595 \\
6,507 \\
5,244 \\
2 \\
0 \\
2,888 \\
73,320\end{array}$ & $\begin{array}{r}2,473 \\
211 \\
84,710 \\
0 \\
08,497 \\
77,163 \\
12,836 \\
16,427 \\
84,637 \\
30,948 \\
38,020 \\
8,333 \\
0 \\
12,836 \\
437,091\end{array}$ & $\begin{array}{r}41,131 \\
16,870 \\
498,688 \\
0 \\
641,680 \\
469,986 \\
176,448 \\
364,061 \\
744,287 \\
248,265 \\
261,134 \\
11,840 \\
0 \\
93,254 \\
3,567,646\end{array}$ & $\begin{array}{r}1,836 \\
20,039 \\
71,490 \\
0 \\
85,457 \\
95,647 \\
8,010 \\
15,991 \\
48,465 \\
32,582 \\
11,811 \\
6,728 \\
0 \\
5,708 \\
403,863\end{array}$ \\
\hline
\end{tabular}

See endnotes at end of an individual electric utility. 
Table 42. Utility Plant by Major U.S. Investor-Owned Electric Utility Within State on December 31, 1992 (Continued)

(Thousand Dollars)

\begin{tabular}{|c|c|c|c|c|c|c|}
\hline Item & $\begin{array}{c}\text { Texas } \\
\text { Gulf } \\
\text { States } \\
\text { Utilities } \\
\text { Co }\end{array}$ & $\begin{array}{l}\text { Texas } \\
\text { Houston } \\
\text { Lighting } \\
\& \\
\text { Power Co }\end{array}$ & $\begin{array}{l}\text { Texas } \\
\text { Southwestern } \\
\text { Electric } \\
\text { Serv Co }\end{array}$ & $\begin{array}{l}\text { Texas } \\
\text { Southwestern } \\
\text { Public } \\
\text { Service Co }\end{array}$ & $\begin{array}{l}\text { Texas } \\
\text { Texas } \\
\text { Utilities } \\
\text { Electric Co }\end{array}$ & $\begin{array}{l}\text { Texas } \\
\text { Texas- } \\
\text { Now Mexico } \\
\text { Power Co }\end{array}$ \\
\hline 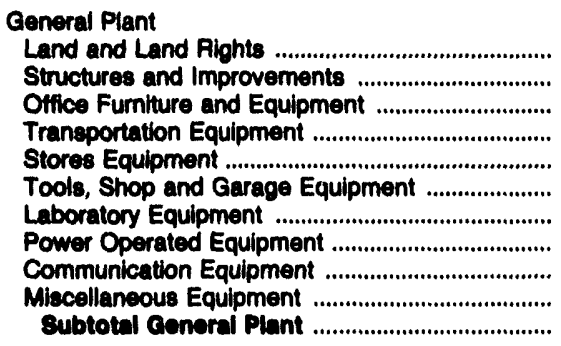 & $\begin{array}{r}7,493 \\
33,675 \\
11,265 \\
1,068 \\
1,418 \\
3,655 \\
7,462 \\
2,341 \\
48,728 \\
1,078 \\
118,184\end{array}$ & $\begin{array}{r}0 \\
257,310 \\
21,907 \\
115,884 \\
7,637 \\
19,623 \\
16,059 \\
16,120 \\
278,251 \\
4,454 \\
737,247\end{array}$ & $\begin{array}{r}165 \\
1,202 \\
801 \\
2,282 \\
27 \\
335 \\
167 \\
7 \\
166 \\
37 \\
5,168\end{array}$ & $\begin{array}{r}2,055 \\
43,600 \\
10,701 \\
22,186 \\
370 \\
2,813 \\
5,061 \\
3,466 \\
25,672 \\
791 \\
116,715\end{array}$ & $\begin{array}{r}18,862 \\
113,880 \\
29,251 \\
40,685 \\
4,724 \\
18,047 \\
30,243 \\
3,283 \\
74,367 \\
14,676 \\
348,018\end{array}$ & $\begin{array}{r}2,805 \\
0 \\
13,445 \\
14,343 \\
0 \\
2,040 \\
0 \\
2,623 \\
0 \\
0 \\
35,266\end{array}$ \\
\hline 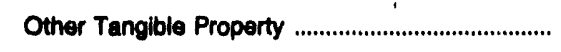 & 87,214 & 0 & 0 & 0 & 76,022 & 0 \\
\hline 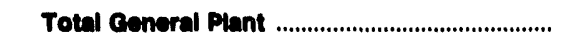 & 205,308 & 737,247 & 5,188 & 116,715 & 424,040 & 35,256 \\
\hline 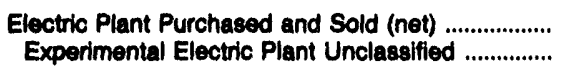 & $\begin{array}{l}0 \\
0\end{array}$ & $\begin{array}{l}0 \\
0\end{array}$ & $\begin{array}{l}0 \\
0\end{array}$ & $\begin{array}{l}0 \\
0\end{array}$ & $\begin{array}{l}0 \\
0\end{array}$ & $\begin{array}{l}0 \\
0\end{array}$ \\
\hline Total Electric Utllity Plant in Sorvice ............... & $6,700,574$ & $10,603,748$ & 86,379 & $2,116,808$ & $16,992,127$ & $1,175,435$ \\
\hline 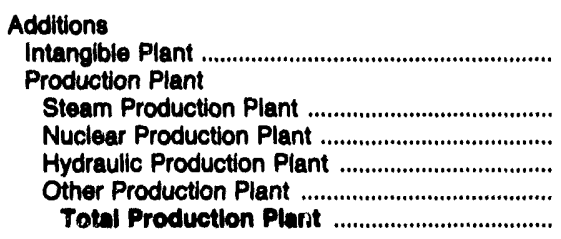 & $\begin{array}{r}0 \\
2,729 \\
30,503 \\
0 \\
0 \\
33,232\end{array}$ & $\begin{array}{r}0 \\
129,880 \\
9,726 \\
0 \\
154 \\
139,761\end{array}$ & $\begin{array}{l}0 \\
0 \\
0 \\
0 \\
0 \\
0\end{array}$ & $\begin{array}{r}299 \\
20,773 \\
0 \\
0 \\
3,487 \\
24,260\end{array}$ & $\begin{array}{r}16,625 \\
\\
63,467 \\
19,188 \\
0 \\
10 \\
82,865\end{array}$ & $\begin{array}{r}0 \\
-1,793 \\
0 \\
0 \\
0 \\
-1,793\end{array}$ \\
\hline $\begin{array}{l}\text { Transmission Plant } \\
\text { Distribution Plant } \\
\text { General Plant } \\
\text { Electric Plant Purchased } \\
\text { Experimental Electric Plant Unclassified }\end{array}$ & $\begin{array}{r}12,260 \\
47,281 \\
5,624 \\
0 \\
0\end{array}$ & $\begin{array}{r}21,576 \\
124,848 \\
65,146 \\
0 \\
0\end{array}$ & $\begin{array}{r}28 \\
3,681 \\
301 \\
0 \\
0\end{array}$ & $\begin{array}{r}29,355 \\
21,603 \\
8,815 \\
0 \\
0\end{array}$ & $\begin{array}{r}54,759 \\
216,853 \\
7,103 \\
0 \\
0\end{array}$ & $\begin{array}{r}2,465 \\
28,333 \\
3,746 \\
0 \\
0\end{array}$ \\
\hline 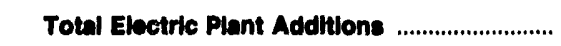 & 98,396 & 351,330 & 4,010 & 84,332 & 378,004 & 32,751 \\
\hline 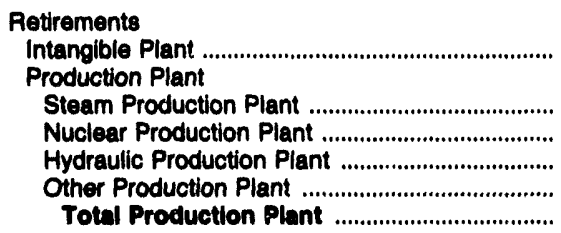 & $\begin{array}{r}0 \\
25,629 \\
35,501 \\
0 \\
0 \\
61,130\end{array}$ & $\begin{array}{r}0 \\
10,613 \\
574 \\
0 \\
46 \\
11,233\end{array}$ & $\begin{array}{l}0 \\
0 \\
0 \\
0 \\
0 \\
0\end{array}$ & $\begin{array}{r}0 \\
2,950 \\
0 \\
0 \\
846 \\
3,797\end{array}$ & $\begin{array}{r}0 \\
12,054 \\
0 \\
0 \\
0 \\
12,054\end{array}$ & $\begin{array}{r}0 \\
436 \\
0 \\
0 \\
0 \\
438\end{array}$ \\
\hline 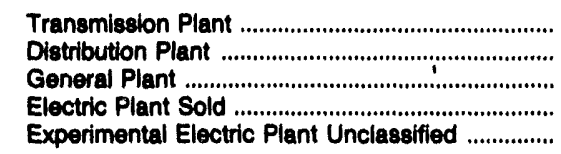 & $\begin{array}{r}1,546 \\
7,697 \\
635 \\
0 \\
0\end{array}$ & $\begin{array}{r}2,817 \\
34,848 \\
17,371 \\
0 \\
0\end{array}$ & $\begin{array}{r}5 \\
505 \\
98 \\
0 \\
0\end{array}$ & $\begin{array}{r}1,719 \\
3,558 \\
2,211 \\
0 \\
0\end{array}$ & $\begin{array}{r}5,037 \\
27,757 \\
8,977 \\
0 \\
0\end{array}$ & $\begin{array}{r}294 \\
6,084 \\
683 \\
0 \\
0\end{array}$ \\
\hline $\begin{array}{l}\text { Total Electric Piant } \\
\text { Retirements }\end{array}$ & 71,008 & 66,260 & 608 & 11,284 & 53,826 & 7,497 \\
\hline
\end{tabular}

Note: Totals may not equal sum of components because of independent rounding. Summary data are provided in Table 28.

Source: Federal Energy Regulatory Commission, FERC Form 1, "Annual Report of Major Electric Utilities, Licensees and Others." 
Table 42. Utility Plant by Major U.S. Inveetor-Owned Eloctric Utility Within state on December 31, 1992 (Continued)

(Thousand Dollars)

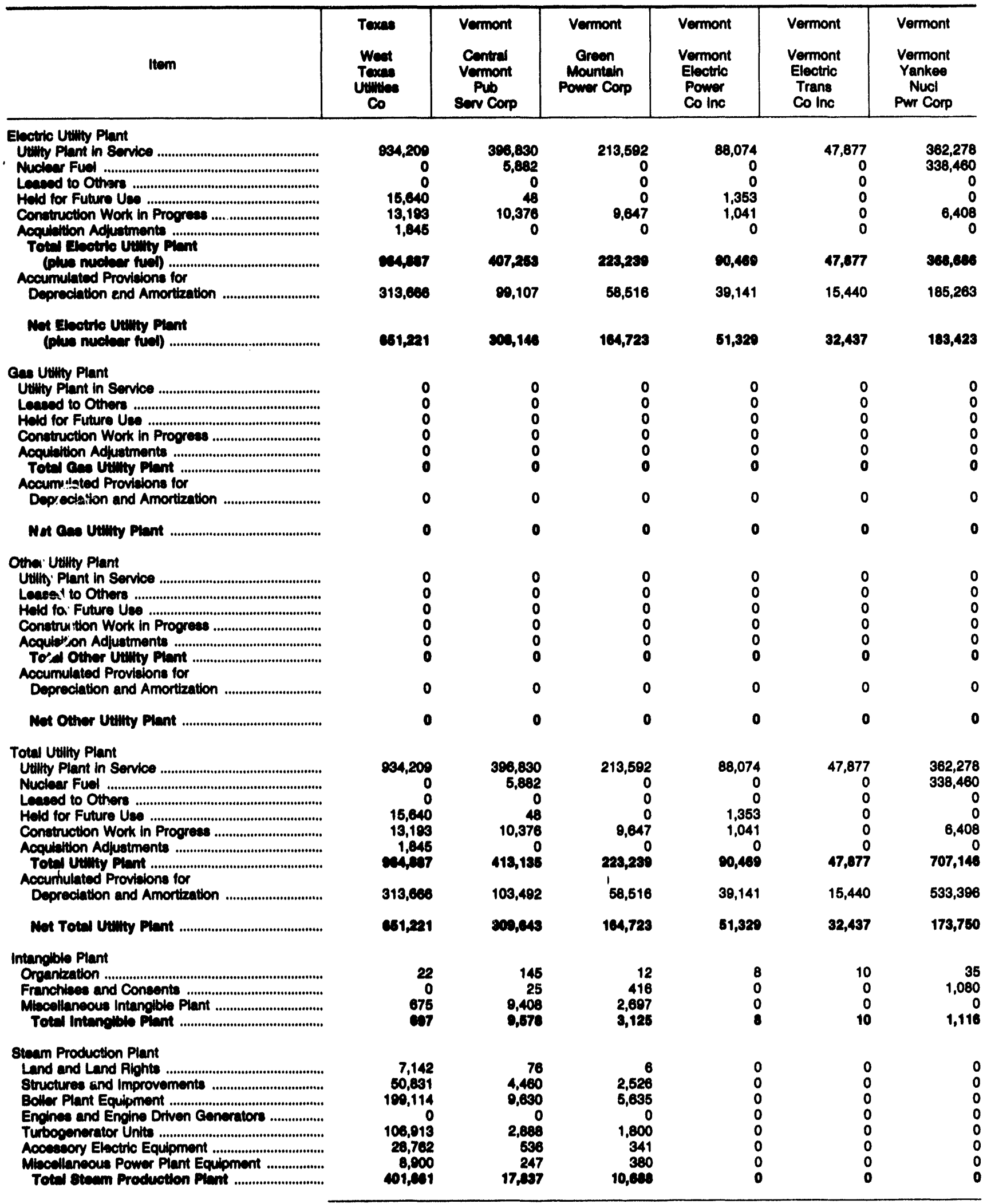

see endinotes at ond of an individual electric utitiby. 
Table 42. Utilty Plant by Major U.S. Inveotor-Owned Electric Utility Within state on December 31, 1992 (Continued)

(Thousand Dollars)

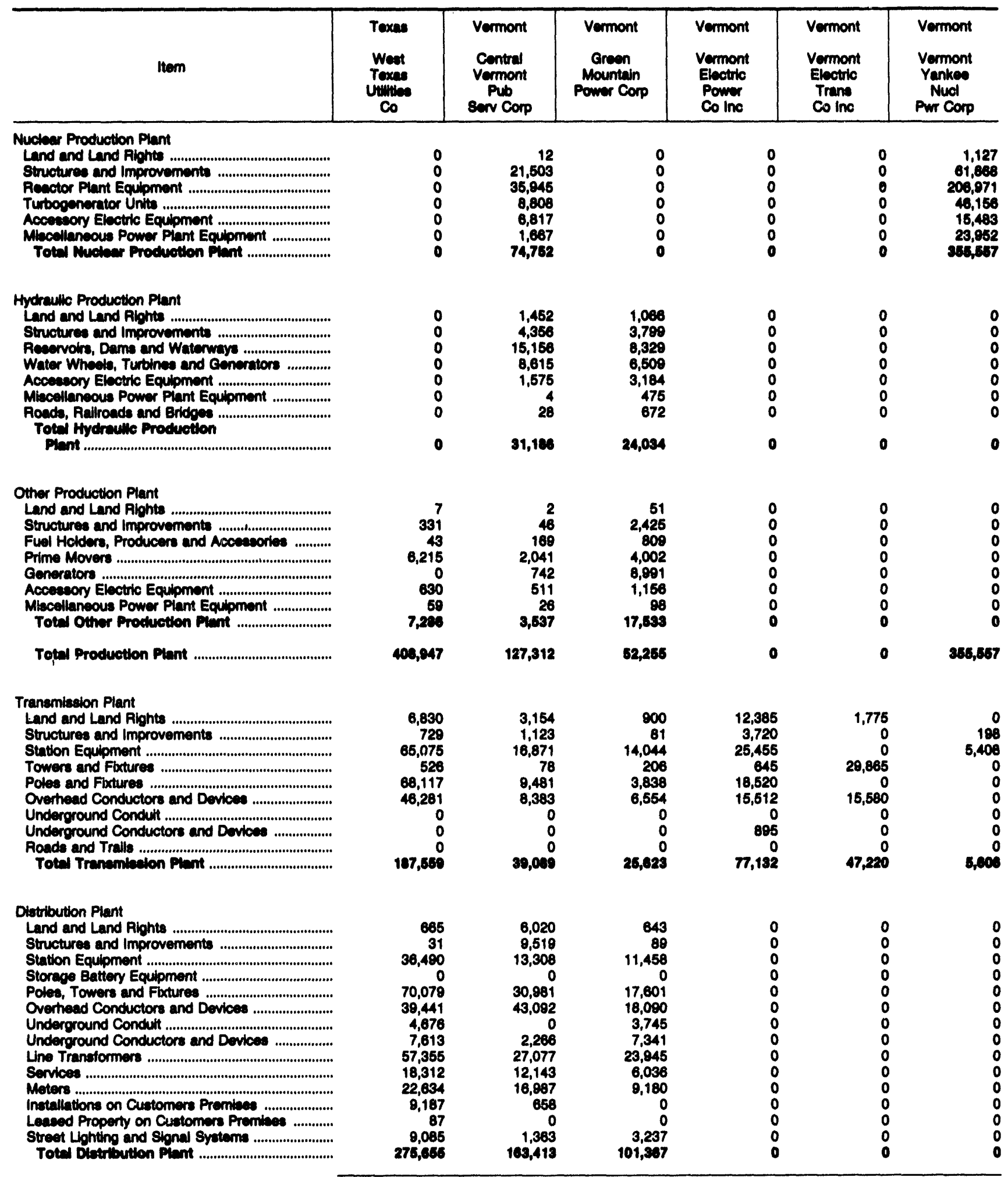

See endnotes at end of an individual electric utility. 
Table 42. Utility Plant by Major U.S. Investor-Owned Electric Utility Within State on December 31, 1992 (Continued) (Thousand Dollars)

\begin{tabular}{|c|c|c|c|c|c|c|}
\hline Item & $\begin{array}{c}\text { Texas } \\
\text { Woet } \\
\text { Texas } \\
\text { Utilties } \\
\text { Co }\end{array}$ & $\begin{array}{l}\text { Vermont } \\
\text { Central } \\
\text { Vermont } \\
\text { Pub } \\
\text { Serv Corp }\end{array}$ & $\begin{array}{l}\text { Vermont } \\
\text { Green } \\
\text { Mountain } \\
\text { Power Corp }\end{array}$ & $\begin{array}{l}\text { Vesmont } \\
\text { Vermont } \\
\text { Electric } \\
\text { Power } \\
\text { Co Inc }\end{array}$ & $\begin{array}{l}\text { Vermont } \\
\text { Vermont } \\
\text { Electric } \\
\text { Trans } \\
\text { Co Inc }\end{array}$ & $\begin{array}{l}\text { Vermont } \\
\text { Vermont } \\
\text { Yankee } \\
\text { Nucl } \\
\text { Pwr Corp }\end{array}$ \\
\hline 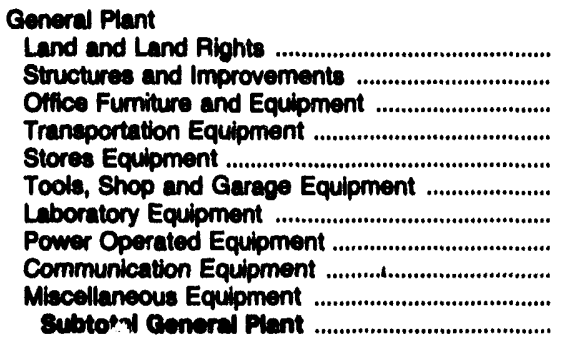 & $\begin{array}{r}2,485 \\
20,857 \\
8,923 \\
15,869 \\
391 \\
2,414 \\
985 \\
0 \\
0,192 \\
235 \\
61,350\end{array}$ & $\begin{array}{r}98 \\
17,544 \\
11,281 \\
286 \\
374 \\
798 \\
1,466 \\
0 \\
1,482 \\
85 \\
33,415\end{array}$ & $\begin{array}{r}446 \\
7,310 \\
3,911 \\
4,680 \\
187 \\
799 \\
416 \\
0 \\
1,197 \\
187 \\
10,144\end{array}$ & $\begin{array}{r}116 \\
2,527 \\
816 \\
197 \\
53 \\
105 \\
286 \\
0 \\
0,132 \\
65 \\
10,208\end{array}$ & $\begin{array}{r}41 \\
297 \\
7 \\
133 \\
0 \\
142 \\
0 \\
0 \\
23 \\
4 \\
647\end{array}$ & $\begin{array}{l}0 \\
0 \\
0 \\
0 \\
0 \\
0 \\
0 \\
0 \\
0 \\
0 \\
0\end{array}$ \\
\hline 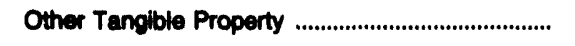 & 0 & 24,022 & 12,077 & 637 & 0 & 0 \\
\hline Total Genord Plent ................................................ & 61,360 & 57,437 & 31,221 & 10,036 & 647 & $\mathbf{0}$ \\
\hline $\begin{array}{l}\text { Elegtric Plant Purchased and Sold (net) ..................... } \\
\text { Experimental Electric Plant Unclaseified ................ }\end{array}$ & $\begin{array}{l}0 \\
0\end{array}$ & $\begin{array}{l}0 \\
0\end{array}$ & $\begin{array}{l}0 \\
0\end{array}$ & $\begin{array}{l}0 \\
0\end{array}$ & $\begin{array}{l}0 \\
0\end{array}$ & $\begin{array}{l}0 \\
0\end{array}$ \\
\hline Total Electric Utithy Plant in Service ................ & 934,200 & 396,830 & 213,592 & 80,074 & 47,877 & 302,270 \\
\hline 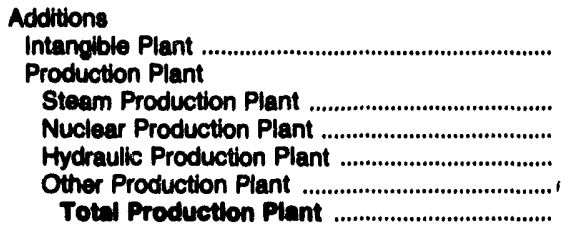 & $\begin{array}{r}3,029 \\
0 \\
0 \\
22 \\
3,051\end{array}$ & $\begin{array}{r}7,093 \\
\\
37 \\
142 \\
1,890 \\
0 \\
2,160\end{array}$ & $\begin{array}{r}520 \\
\\
9 \\
0 \\
220 \\
58 \\
286\end{array}$ & $\begin{array}{l}0 \\
0 \\
0 \\
0 \\
0\end{array}$ & $\begin{array}{l}0 \\
0 \\
0 \\
0 \\
0\end{array}$ & $\begin{array}{r}0 \\
0 \\
7,728 \\
0 \\
0 \\
7,728\end{array}$ \\
\hline 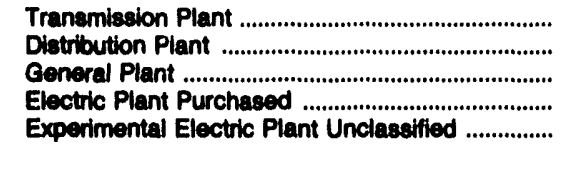 & $\begin{array}{r}5,323 \\
15,175 \\
5,655 \\
0 \\
0\end{array}$ & $\begin{array}{r}1,250 \\
11,346 \\
2,297 \\
0 \\
0\end{array}$ & $\begin{array}{r}352 \\
8,290 \\
2,195 \\
0 \\
0\end{array}$ & $\begin{array}{r}806 \\
0 \\
3,235 \\
0 \\
0 \\
\ldots-1\end{array}$ & $\begin{array}{r}0 \\
0 \\
31 \\
0 \\
0\end{array}$ & $\begin{array}{r}512 \\
0 \\
0 \\
0 \\
0\end{array}$ \\
\hline Total Eloctric Plant Additions .............................. & 29,204 & 23,602 & 11,643 & 4,041 & 31 & 8,240 \\
\hline 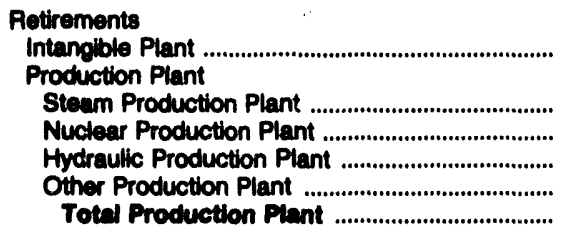 & $\begin{array}{r}4,761 \\
0 \\
0 \\
0 \\
4,761\end{array}$ & $\begin{array}{r}0 \\
0 \\
94 \\
0 \\
94\end{array}$ & $\begin{array}{r}0 \\
0 \\
5 \\
6 \\
12\end{array}$ & $\begin{array}{l}0 \\
0 \\
0 \\
0 \\
0\end{array}$ & $\begin{array}{l}0 \\
0 \\
0 \\
0 \\
0\end{array}$ & $\begin{array}{r}0 \\
0 \\
478 \\
0 \\
0 \\
478\end{array}$ \\
\hline 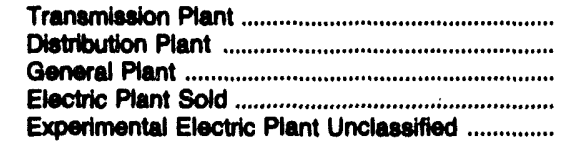 & $\begin{array}{r}343 \\
2,654 \\
1,409 \\
0 \\
0\end{array}$ & $\begin{array}{r}71 \\
898 \\
399 \\
0 \\
0\end{array}$ & $\begin{array}{r}40 \\
1,089 \\
1,062 \\
0 \\
0\end{array}$ & $\begin{array}{r}620 \\
0 \\
450 \\
0 \\
0\end{array}$ & $\begin{array}{r}0 \\
0 \\
23 \\
0 \\
0\end{array}$ & $\begin{array}{r}1,047 \\
0 \\
0 \\
0 \\
0\end{array}$ \\
\hline 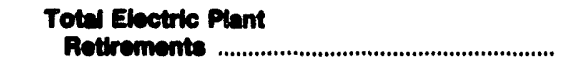 & 9,167 & 1,463 & 4,180 & 1,060 & 23 & 1,525 \\
\hline
\end{tabular}

Note: Totals may not equal aum of components because of independent rounding. Summary data are provided in Table 26.

Source: Federal Energy Regulatory Commission, FERC Form 1, "Annual Report of Major Electric Utillities, Licensees and Others." 
Table 42. Utility Plant by Major U.S. Investor-Owned Electric Utillty Within State on December 31, 1992 (Continued)

(Thousand Dollars)

\begin{tabular}{|c|c|c|c|c|c|c|}
\hline Item & $\begin{array}{l}\text { Virginia } \\
\text { Appalachian } \\
\text { Power Co }\end{array}$ & $\begin{array}{l}\text { Virginia } \\
\text { Virginia } \\
\text { Electric } \\
\text { \& Power } \\
\text { Co }\end{array}$ & $\begin{array}{l}\text { Washington } \\
\text { Puget Sound } \\
\text { Power \& Light } \\
\text { Co }\end{array}$ & $\begin{array}{l}\text { Washington } \\
\text { Washington } \\
\text { Waler } \\
\text { Power Co }\end{array}$ & $\begin{array}{l}\text { West Virginia } \\
\text { Kanawha } \\
\text { Valley } \\
\text { Power co }\end{array}$ & $\begin{array}{l}\text { Weat Virginia } \\
\text { Monongahela } \\
\text { Power Co }\end{array}$ \\
\hline 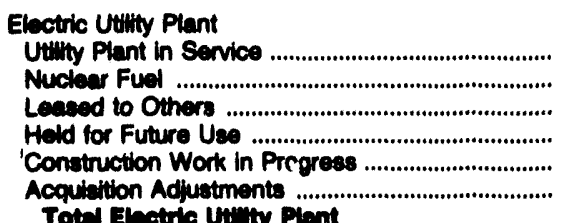 & $\begin{array}{r}3,852,154 \\
0 \\
0 \\
6,478 \\
45,272 \\
102\end{array}$ & $\begin{array}{r}12,053,852 \\
1,012,881 \\
0 \\
39,565 \\
840,941 \\
42,778\end{array}$ & $\begin{array}{r}2,899,972 \\
0 \\
0 \\
1,371 \\
90,042 \\
1,249\end{array}$ & $\begin{array}{r}1,338,231 \\
0 \\
C \\
0 \\
27,286 \\
0\end{array}$ & $\begin{array}{r}14,484 \\
0 \\
0 \\
0 \\
133 \\
0\end{array}$ & $\begin{array}{r}1,466,832 \\
0 \\
0 \\
379 \\
99,177 \\
0\end{array}$ \\
\hline $\begin{array}{l}\text { (phis muclear hull) ................................... } \\
\text { Accumulated Provisions for }\end{array}$ & $4,004,004$ & $12,977,136$ & $3,000,633$ & $1,395,527$ & 14,617 & $1,506,300$ \\
\hline Depreciation and Amortization ............................ & $1,452,621$ & $3,852,508$ & 909,686 & 352,612 & 4,423 & 628,501 \\
\hline 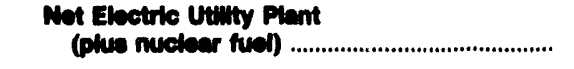 & $2,651,403$ & $9,124,628$ & $2,090,937$ & $1,012,915$ & 10,194 & 987,000 \\
\hline 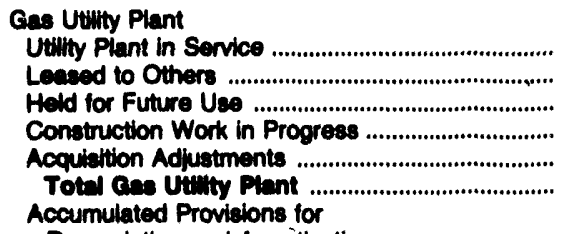 & $\begin{array}{l}0 \\
0 \\
0 \\
0 \\
0 \\
0\end{array}$ & $\begin{array}{l}0 \\
0 \\
0 \\
0 \\
0 \\
0\end{array}$ & $\begin{array}{l}0 \\
0 \\
0 \\
0 \\
0 \\
0\end{array}$ & $\begin{array}{r}223,357 \\
0 \\
0 \\
5,443 \\
27,173 \\
255,974\end{array}$ & $\begin{array}{l}0 \\
0 \\
0 \\
0 \\
0 \\
0\end{array}$ & $\begin{array}{l}0 \\
0 \\
0 \\
0 \\
0 \\
0\end{array}$ \\
\hline 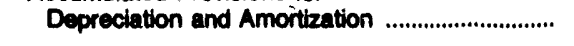 & 0 & 0 & 0 & 77,736 & 0 & 0 \\
\hline 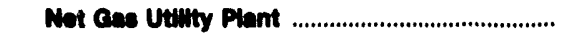 & o & 0 & 0 & 178,238 & 0 & $\mathbf{0}$ \\
\hline 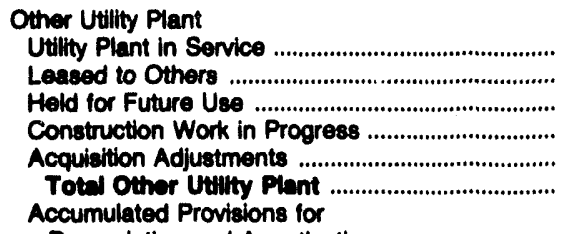 & $\begin{array}{l}0 \\
0 \\
0 \\
0 \\
0 \\
0\end{array}$ & $\begin{array}{l}0 \\
0 \\
0 \\
0 \\
0 \\
0\end{array}$ & $\begin{array}{l}0 \\
0 \\
0 \\
0 \\
0 \\
0\end{array}$ & $\begin{array}{l}0 \\
0 \\
0 \\
0 \\
0 \\
0\end{array}$ & $\begin{array}{l}0 \\
0 \\
0 \\
0 \\
0 \\
0\end{array}$ & $\begin{array}{l}0 \\
0 \\
0 \\
0 \\
0 \\
0\end{array}$ \\
\hline 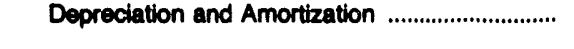 & 0 & 0 & 0 & 0 & 0 & 0 \\
\hline 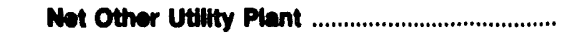 & $\mathbf{0}$ & 0 & $\mathbf{0}$ & $\mathbf{0}$ & 0 & $\mathbf{0}$ \\
\hline 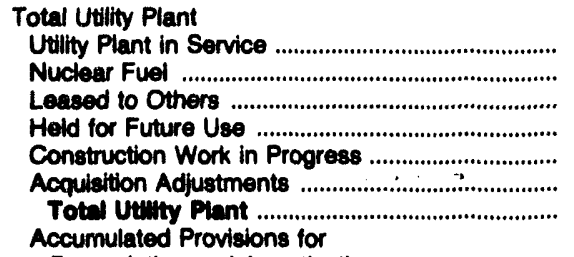 & $\begin{array}{r}3,952,154 \\
0 \\
0 \\
6,476 \\
45,272 \\
182 \\
4,004,044\end{array}$ & $\begin{array}{r}12,053,852 \\
1,012,881 \\
0 \\
39,565 \\
840,841 \\
42,778 \\
13,900,017\end{array}$ & $\begin{array}{r}2,899,972 \\
0 \\
0 \\
18,371 \\
90,042 \\
1,249 \\
3,000,633\end{array}$ & $\begin{array}{r}1,561,588 \\
0 \\
0 \\
0 \\
32,739 \\
27,173 \\
1,621,501\end{array}$ & $\begin{array}{r}14,484 \\
0 \\
0 \\
0 \\
133 \\
0 \\
14,617\end{array}$ & $\begin{array}{r}1,466,832 \\
0 \\
0 \\
379 \\
99,177 \\
0 \\
0 \\
1,566,300\end{array}$ \\
\hline 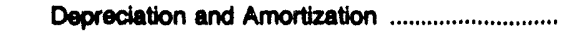 & $1,452,621$ & $4,703,734$ & 809,686 & 430,348 & 4,423 & 628,501 \\
\hline 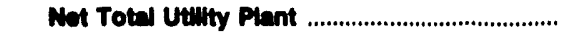 & $2,651,463$ & $9,286,283$ & $2,000,937$ & $1,191,153$ & 10,194 & 937,200 \\
\hline 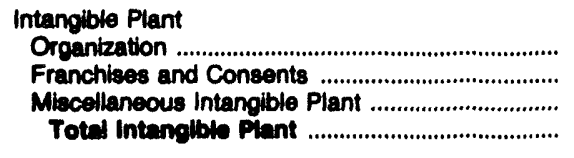 & $\begin{array}{r}129 \\
679 \\
702 \\
1,510\end{array}$ & $\begin{array}{r}80 \\
13 \\
85,653 \\
85,745\end{array}$ & $\begin{array}{r}114 \\
686 \\
29,759 \\
30,560\end{array}$ & $\begin{array}{r}0 \\
193 \\
5,092 \\
5,205\end{array}$ & $\begin{array}{l}1 \\
0 \\
0 \\
1\end{array}$ & $\begin{array}{r}4 \\
7 \\
12 \\
23\end{array}$ \\
\hline 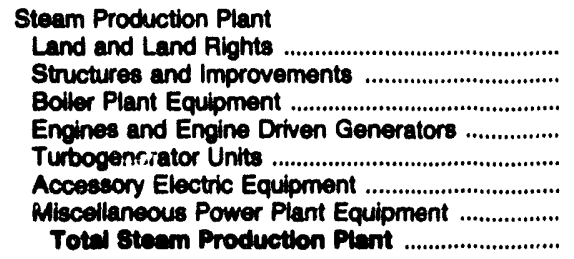 & $\begin{array}{r}5,997 \\
180,007 \\
946,590 \\
0 \\
288,734 \\
129,003 \\
38,390 \\
1,598,721\end{array}$ & $\begin{array}{r}8,296 \\
309,486 \\
1,252,388 \\
0 \\
509,112 \\
188,978 \\
52,841 \\
2,321,122\end{array}$ & $\begin{array}{r}3,773 \\
174,722 \\
336,487 \\
0 \\
83,468 \\
35,162 \\
11,388 \\
\mathbf{8 4 , 4 0 8}\end{array}$ & $\begin{array}{r}2,463 \\
127,781 \\
185,329 \\
0 \\
48,130 \\
26,734 \\
15,075 \\
405,510\end{array}$ & $\begin{array}{l}0 \\
0 \\
0 \\
0 \\
0 \\
0 \\
0 \\
0\end{array}$ & $\begin{array}{r}3,991 \\
77,293 \\
388,442 \\
0 \\
154,211 \\
40,438 \\
10,702 \\
875,070\end{array}$ \\
\hline
\end{tabular}

See endnotes at end of an indwidual electric utility. 
Table 42. Utility Plant by Major U.8. Investor-Owned Electric Utility Whin state on Decomber 31, 1902 (Continued)

(Thousand Dollars)

\begin{tabular}{|c|c|c|c|c|c|c|}
\hline Itom & $\begin{array}{l}\text { Virginia } \\
\text { Appelachian } \\
\text { Power Co }\end{array}$ & $\begin{array}{l}\text { Virginia } \\
\text { Virginia } \\
\text { Eleotric } \\
\text { a Power } \\
\text { Co }\end{array}$ & $\begin{array}{l}\text { Weanington } \\
\text { Puget Sound } \\
\text { Powner \& Light } \\
\text { Co }\end{array}$ & $\begin{array}{l}\text { Weahington } \\
\text { Weahington } \\
\text { Water } \\
\text { Power Co }\end{array}$ & $\begin{array}{l}\text { Weat Vrginla } \\
\text { Kanawha } \\
\text { Valloy } \\
\text { Powier Co }\end{array}$ & $\begin{array}{l}\text { Weat Virginia } \\
\text { Mononganela } \\
\text { Power Co }\end{array}$ \\
\hline
\end{tabular}

\section{Nuclear Production Plant}

Land and Land Pights

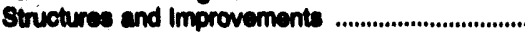

Turoogenerator Units

Accesecony Eloctric Equipment

Mhoceltaneous Power Piant Equipment

Total Nucien Produetion Pient.
Resotor Piant Equipment

Hydracico Production Plant

Land and Land Plohts

Structures and Improvemente..................................

Recenvoins, Dams and Waterwaye ..........................

Water Whella, Turbines and Generatore

Acceacory Electric Equipment

Mecallaneous Poure Plent Equipment

Roads, Rallroads and Bridges

Totel Afyerewle Production

Piant

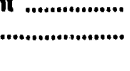

Production Plart

Land and Land Plights

Structures and Improvements

Fud Holders. Producers and Accessontes

Prime Movers

Generators

Miscellaneous Power Plant Equipment

Totel Other Production Pient

Totel Production Plam

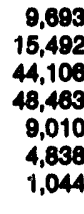

182,49
32,684

528,127

$1,425,160$

330,347

422,244

100,078

$2,89,841$

0
0
0
0
0
0
0

7,670

16,885

108,842

13,946

5,972

3,078

1,558

157,089

$1,104,900$

$6,561,184$

54,913

29,878

388,982

203,522

45,830

218,169

304

2,312

0

Rosds and Tralle

Totel Trenmiselon Plent

(..................

054,021
3,467

48,802

12,645

170,092

65,218

7,046

1,090

298,451

2,791

6,256

7,379

64

64,782

1,721

700

99,ens

22,483
2,260
132,844
40,188
66,488
124,397
1,214
3,195
1,498
394,608

$1,194,89$
10,013
5,000

78,825

18,890

50,880

51,763

567

1,315

1,802

218,235

$\begin{array}{ll}0 & 0 \\ 0 & 0 \\ 0 & 0 \\ 0 & 0 \\ 0 & 0 \\ 0 & 0 \\ 0 & 0\end{array}$

Diatribution Plant

Land and Land Rights

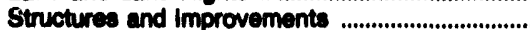

Stition Equipment .

Storese Battery Equipment

(n)

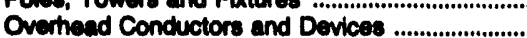

Underground Condutt.

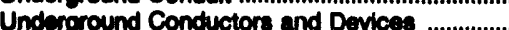

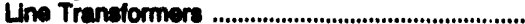

Eenvioes

netere

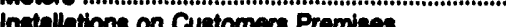

Leased Property on Customers Premises ............

Strect Lighting and Signal Syotems

Total Elutivition Pient

29,766

13,978

112,710

259.646

205,426

7,583

30,703

242,676

105,142

70,337

12,398

12,849

$1,188,213$

$$
\begin{array}{r}
33,361 \\
15,405 \\
418,374 \\
0 \\
356,953 \\
436,939 \\
112,007 \\
740,464 \\
684,517 \\
475,986 \\
177,474 \\
54,408 \\
0 \\
98,107 \\
3,681,946
\end{array}
$$

3,087

6,368

48,850

84,290

61,005

15,168

40,348

79,281

46,103

16,496

18,789

0

10,032
22,335

22,385
$1,350,297$

8eo endnotes at end of an I lividual electric utility. 
Table 42. Utility Plant by Major U.S. Inveotor-Owned Electric Utility Within State on December 31, 1902 (Continued) (Thousand Dollars)

\begin{tabular}{|c|c|c|c|c|c|c|}
\hline Item & $\begin{array}{l}\text { Virginia } \\
\text { Appalachian } \\
\text { Power Co }\end{array}$ & $\begin{array}{l}\text { Vroinia } \\
\text { Virginia } \\
\text { Elootric } \\
\text { A Power } \\
\text { Co }\end{array}$ & $\begin{array}{l}\text { Wachingion } \\
\text { Pupet Sound } \\
\text { Power \& Light } \\
\text { Co }\end{array}$ & $\begin{array}{l}\text { Washinoton } \\
\text { Waehington } \\
\text { Water } \\
\text { Power Co }\end{array}$ & $\begin{array}{l}\text { Weot Virginia } \\
\text { Kanawhio } \\
\text { Valley } \\
\text { Power Co }\end{array}$ & $\begin{array}{l}\text { Weat Vikginia } \\
\text { Monongahela } \\
\text { Power Co }\end{array}$ \\
\hline 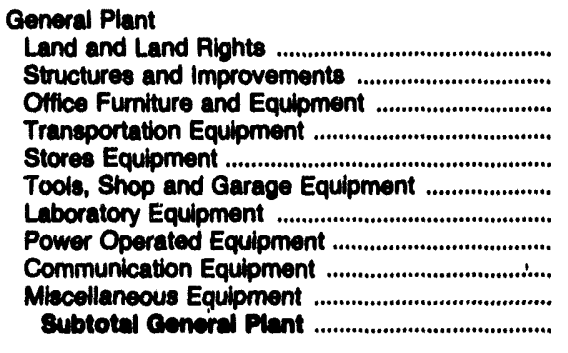 & $\begin{array}{r}8,670 \\
67,283 \\
3,539 \\
73 \\
839 \\
4,147 \\
3,558 \\
66 \\
13,233 \\
1,476 \\
102,003\end{array}$ & $\begin{array}{r}30,827 \\
231,652 \\
156,415 \\
92,213 \\
9,468 \\
14,341 \\
10,408 \\
9,005 \\
70,417 \\
6,610 \\
60,476\end{array}$ & $\begin{array}{r}3,627 \\
57,189 \\
51,026 \\
16,194 \\
2,162 \\
4,099 \\
7,690 \\
21,185 \\
72,751 \\
400 \\
207,408\end{array}$ & $\begin{array}{r}1,297 \\
10,121 \\
18,968 \\
11,310 \\
522 \\
2,236 \\
1,068 \\
11,045 \\
17,047 \\
189 \\
76,623\end{array}$ & $\begin{array}{l}0 \\
0 \\
0 \\
0 \\
0 \\
0 \\
0 \\
0 \\
0 \\
8 \\
0\end{array}$ & $\begin{array}{r}1,282 \\
14,865 \\
5,242 \\
3,765 \\
286 \\
1,718 \\
1,016 \\
552 \\
13,337 \\
281 \\
12,312\end{array}$ \\
\hline Other Tangible Property & 8,004 & 100 & $\mathbf{0}$ & $-5,940$ & 0 & 0 \\
\hline 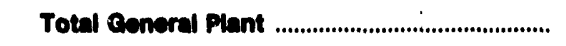 & 110,007 & 940,678 & 237,093 & 00,602 & - & 42,312 \\
\hline $\begin{array}{l}\text { Electric Plant Purchased and Sold (net) ..................... } \\
\text { Experimental Electric Plant Unclassified ............... }\end{array}$ & $\begin{array}{r}-187 \\
432\end{array}$ & $\begin{array}{l}0 \\
0\end{array}$ & $\begin{array}{l}0 \\
0\end{array}$ & $\begin{array}{r}1,177 \\
0\end{array}$ & $\begin{array}{l}0 \\
0\end{array}$ & $\begin{array}{l}\mathbf{0} \\
\mathbf{0}\end{array}$ \\
\hline Total Electric Utility Plant in service ............... & $3,062,154$ & $12,069,232$ & 2,000,072 & $1,394,231$ & 14,404 & $1,406,492$ \\
\hline 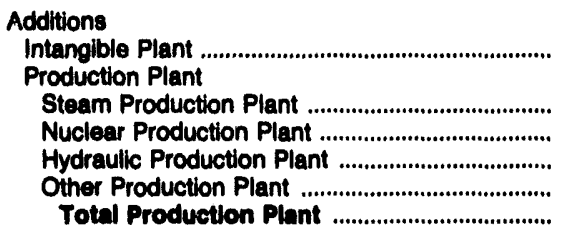 & $\begin{array}{r}7 \\
24,051 \\
0 \\
1,025 \\
0 \\
25,077\end{array}$ & $\begin{array}{r}23,551 \\
\\
105,866 \\
35,808 \\
5,378 \\
68,321 \\
215,402\end{array}$ & $\begin{array}{r}6,202 \\
5,052 \\
0 \\
1,384 \\
908 \\
7,424\end{array}$ & $\begin{array}{r}451 \\
\\
3,864 \\
0 \\
30,421 \\
0 \\
34,075\end{array}$ & $\begin{array}{r}0 \\
0 \\
0 \\
425 \\
0 \\
425\end{array}$ & $\begin{array}{r}12 \\
21,364 \\
0 \\
0 \\
0 \\
21,394\end{array}$ \\
\hline 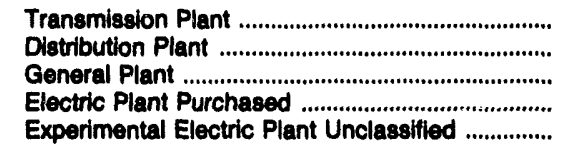 & $\begin{array}{r}67,569 \\
92,484 \\
14,215 \\
0 \\
-1\end{array}$ & $\begin{array}{r}56,178 \\
218,815 \\
38,761 \\
0 \\
0\end{array}$ & $\begin{array}{r}35,762 \\
97,464 \\
16,854 \\
0 \\
0\end{array}$ & $\begin{array}{r}3,892 \\
28,206 \\
6,648 \\
0 \\
0\end{array}$ & $\begin{array}{l}0 \\
0 \\
0 \\
0 \\
0\end{array}$ & $\begin{array}{r}6,349 \\
38,632 \\
2,427 \\
0 \\
0\end{array}$ \\
\hline 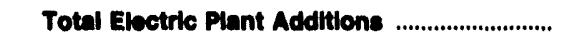 & 200,251 & 862,707 & 1035000 & 71,272 & 425 & 60,794 \\
\hline 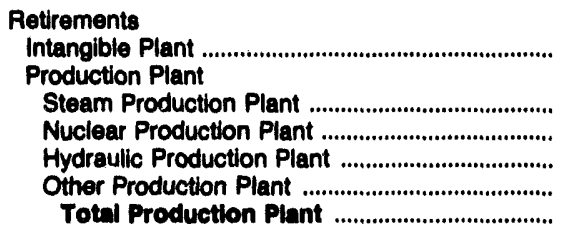 & $\begin{array}{r}0 \\
8,258 \\
0 \\
222 \\
0 \\
0,400\end{array}$ & $\begin{array}{r}9,796 \\
\\
25,406 \\
7,686 \\
676 \\
152 \\
33,700\end{array}$ & $\begin{array}{r}3 \\
146 \\
0 \\
244 \\
132 \\
822\end{array}$ & $\begin{array}{r}3,607 \\
70 \\
0 \\
90 \\
0 \\
0 \\
100\end{array}$ & $\begin{array}{r}0 \\
0 \\
0 \\
150 \\
0 \\
150\end{array}$ & $\begin{array}{r}0 \\
3,023 \\
0 \\
0 \\
0 \\
3,023\end{array}$ \\
\hline 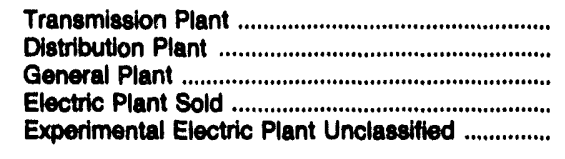 & $\begin{array}{r}4,668 \\
25,032 \\
112 \\
-187 \\
0\end{array}$ & $\begin{array}{r}1,181 \\
38,381 \\
30,686 \\
0 \\
0\end{array}$ & $\begin{array}{r}1,444 \\
7,087 \\
5,687 \\
0 \\
0\end{array}$ & $\begin{array}{r}167 \\
2,352 \\
1,715 \\
0 \\
0\end{array}$ & $\begin{array}{l}0 \\
0 \\
0 \\
0 \\
0\end{array}$ & $\begin{array}{r}196 \\
6,330 \\
1,214 \\
0 \\
0\end{array}$ \\
\hline 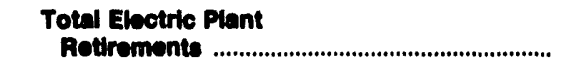 & $\mathbf{3 0 , 4 0 0}$ & 113,023 & 14,723 & 8,011 & 160 & 10,769 \\
\hline
\end{tabular}

Note: Totals may not equal sum of components because of independent rounding. summary data ere provided in Table 28.

Source: Federal Energy Regulatory Commiselon, FERC Form 1, "Annual Report of Malor Electric Utitities, Liceneees and Others." 
Table 42. Utillty Plant by Major U.S. Investor-Owned Electric Utility Within State on Decomber 31, 1992 (Continued) (Thousand Dollars)

\begin{tabular}{|c|c|c|c|c|c|c|}
\hline item & $\begin{array}{l}\text { West Virginia } \\
\text { Wheelling } \\
\text { Power Co }\end{array}$ & $\begin{array}{l}\text { Wisconsin } \\
\text { Consolidated } \\
\text { Water } \\
\text { Power Co }\end{array}$ & $\begin{array}{l}\text { Wheconsin } \\
\text { Madison } \\
\text { Gase } \\
2 \\
\text { Electric Co }\end{array}$ & $\begin{array}{l}\text { Wisconsin } \\
\text { Northern } \\
\text { States } \\
\text { Power Co }\end{array}$ & $\begin{array}{l}\text { Wisconsin } \\
\text { Northwestern } \\
\text { Wlaconsin } \\
\text { Elec Co }\end{array}$ & $\begin{array}{c}\text { Wisconsin } \\
\text { Pioneer } \\
\text { Power } \\
\& \\
\text { Light Co }\end{array}$ \\
\hline 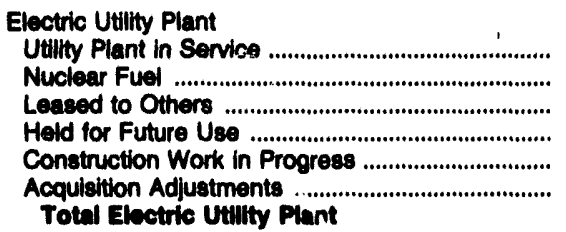 & $\begin{array}{r}77,900 \\
0 \\
0 \\
0 \\
1,060 \\
0\end{array}$ & $\begin{array}{r}31,880 \\
0 \\
0 \\
0 \\
408 \\
0\end{array}$ & $\begin{array}{r}438,159 \\
0 \\
0 \\
701 \\
5,215 \\
-1,659\end{array}$ & $\begin{array}{r}764,132 \\
0 \\
2,832 \\
38 \\
14,571 \\
0\end{array}$ & $\begin{array}{r}20,182 \\
0 \\
0 \\
0 \\
450 \\
0\end{array}$ & $\begin{array}{r}2,026 \\
0 \\
0 \\
0 \\
0 \\
0\end{array}$ \\
\hline $\begin{array}{l}\text { (plua nuclear fuel) } \\
\text { Accumulated Provisions for }\end{array}$ & 78,961 & 32,390 & 442,416 & 781,574 & 20,632 & 2,020 \\
\hline Depreciation and Amortization ............................... & 30,473 & 11,759 & 203,518 & 263,193 & 10,017 & 1,108 \\
\hline $\begin{array}{l}\text { Net Electric Utility Plant } \\
\text { (plus nuclear fuel) ............................................ }\end{array}$ & 48,488 & 20,620 & 238,098 & 518,381 & 10,615 & 917 \\
\hline 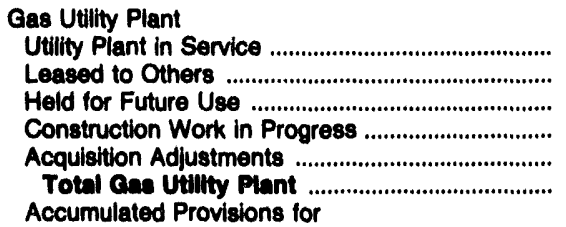 & $\begin{array}{l}0 \\
0 \\
0 \\
0 \\
0 \\
0\end{array}$ & $\begin{array}{l}0 \\
0 \\
0 \\
0 \\
0 \\
0\end{array}$ & $\begin{array}{r}141,933 \\
0 \\
0 \\
996 \\
0 \\
142,929\end{array}$ & $\begin{array}{r}70,638 \\
0 \\
0 \\
0 \\
4,611 \\
0 \\
75,250\end{array}$ & $\begin{array}{l}0 \\
0 \\
0 \\
0 \\
0 \\
0\end{array}$ & $\begin{array}{l}0 \\
0 \\
0 \\
0 \\
0 \\
0\end{array}$ \\
\hline 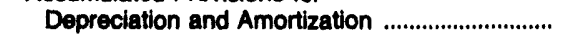 & 0 & 0 & 64,142 & 30,628 & 0 & 0 \\
\hline 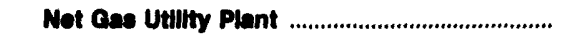 & o & $\mathbf{0}$ & 78,787 & 44,622 & 0 & o \\
\hline 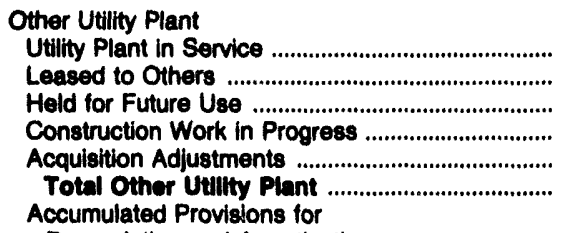 & $\begin{array}{l}0 \\
0 \\
0 \\
0 \\
0 \\
0\end{array}$ & $\begin{array}{l}0 \\
0 \\
0 \\
0 \\
0 \\
0\end{array}$ & $\begin{array}{r}33,602 \\
0 \\
183 \\
513 \\
0 \\
04,298\end{array}$ & $\begin{array}{r}23,192 \\
0 \\
0 \\
0 \\
5,373 \\
0 \\
28,585\end{array}$ & $\begin{array}{l}0 \\
0 \\
0 \\
0 \\
0 \\
0\end{array}$ & $\begin{array}{l}0 \\
0 \\
0 \\
0 \\
0 \\
0\end{array}$ \\
\hline 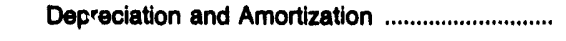 & 0 & 0 & 14,928 & 6,573 & 0 & 0 \\
\hline 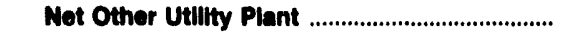 & 0 & $\mathbf{0}$ & 19,370 & 21,992 & $\mathbf{0}$ & $\mathbf{0}$ \\
\hline 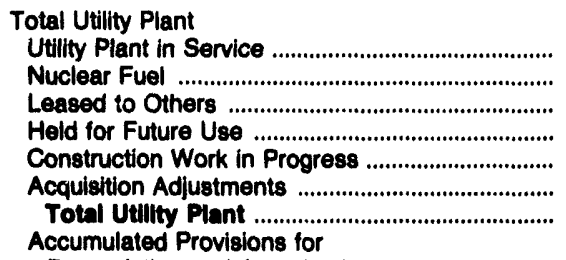 & $\begin{array}{r}77,900 \\
0 \\
0 \\
0 \\
1,060 \\
0 \\
78,961\end{array}$ & $\begin{array}{r}31,980 \\
0 \\
0 \\
0 \\
408 \\
0 \\
0 \\
32,388\end{array}$ & $\begin{array}{r}613,694 \\
0 \\
0 \\
884 \\
6,724 \\
-1,659 \\
619,643\end{array}$ & $\begin{array}{r}857,962 \\
0 \\
2,832 \\
38 \\
24,555 \\
0 \\
0 \\
885,388\end{array}$ & $\begin{array}{r}20,182 \\
0 \\
0 \\
0 \\
450 \\
0 \\
20,032\end{array}$ & $\begin{array}{r}2,026 \\
0 \\
0 \\
0 \\
0 \\
0 \\
2,026\end{array}$ \\
\hline 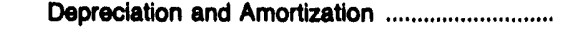 & 30,473 & 11,750 & 282,588 & 300,394 & 10,017 & 1,108 \\
\hline 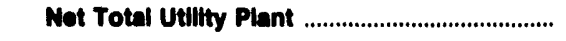 & 48,488 & 20,629 & 337,054 & 584,905 & 10,616 & 917 \\
\hline 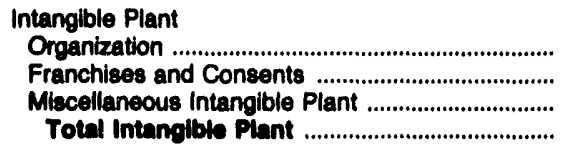 & $\begin{array}{l}0 \\
0 \\
0 \\
0\end{array}$ & $\begin{array}{l}0 \\
0 \\
0 \\
0\end{array}$ & $\begin{array}{l}0 \\
0 \\
0 \\
0\end{array}$ & $\begin{array}{l}0 \\
0 \\
0 \\
0\end{array}$ & $\begin{array}{l}0 \\
0 \\
0 \\
0\end{array}$ & $\begin{array}{l}0 \\
0 \\
0 \\
0\end{array}$ \\
\hline 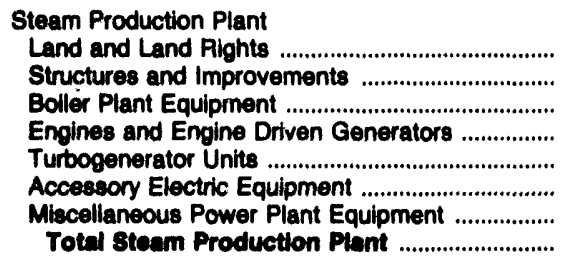 & $\begin{array}{l}0 \\
0 \\
0 \\
0 \\
0 \\
0 \\
0 \\
0\end{array}$ & $\begin{array}{l}1 \\
0 \\
0 \\
0 \\
0 \\
0 \\
0 \\
0\end{array}$ & $\begin{array}{r}419 \\
24,521 \\
68,348 \\
0 \\
19,498 \\
6,353 \\
1,800 \\
120,939\end{array}$ & $\begin{array}{r}31 \\
11,000 \\
44,409 \\
0 \\
5,702 \\
4,701 \\
579 \\
68,421\end{array}$ & $\begin{array}{l}0 \\
0 \\
0 \\
0 \\
0 \\
0 \\
0 \\
0\end{array}$ & $\begin{array}{l}0 \\
0 \\
0 \\
0 \\
0 \\
0 \\
0 \\
0\end{array}$ \\
\hline
\end{tabular}

See endnotes at end of an individual electric utility. 
Table 42. Utility Plant by Major U.S. Inveator-Owned Electric Utility Within State on Decomber 31, 1992 (Continued) (Thousand Dollars)

\begin{tabular}{|c|c|c|c|c|c|c|}
\hline Item & $\begin{array}{l}\text { Weat Virginia } \\
\text { Wheelling } \\
\text { Power Co }\end{array}$ & $\begin{array}{l}\text { Wieconaln } \\
\text { Conselidated } \\
\text { Water } \\
\text { Power Co }\end{array}$ & $\begin{array}{l}\text { Whaconein } \\
\text { Madieon } \\
\text { Gase } \\
\text { Electrio Co }\end{array}$ & $\begin{array}{l}\text { Wheconsin } \\
\text { Northem } \\
\text { States } \\
\text { Power Co }\end{array}$ & $\begin{array}{l}\text { Wheconaln } \\
\text { Northwestorn } \\
\text { Weconein } \\
\text { Elec Co }\end{array}$ & $\begin{array}{c}\text { Wisconsin } \\
\text { Ploneer } \\
\text { Power } \\
8 \\
\text { Light Co }\end{array}$ \\
\hline 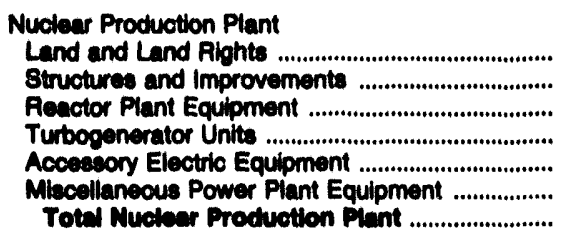 & $\begin{array}{l}0 \\
0 \\
0 \\
0 \\
0 \\
0 \\
0\end{array}$ & $\begin{array}{l}0 \\
0 \\
0 \\
0 \\
0 \\
0 \\
0\end{array}$ & $\begin{array}{r}188 \\
8,519 \\
28,036 \\
9,428 \\
6,048 \\
2,368 \\
24,012 \\
84,02\end{array}$ & $\begin{array}{l}0 \\
0 \\
0 \\
0 \\
0 \\
0 \\
0\end{array}$ & $\begin{array}{l}0 \\
0 \\
0 \\
0 \\
0 \\
0 \\
0\end{array}$ & $\begin{array}{l}0 \\
0 \\
0 \\
0 \\
0 \\
0 \\
0\end{array}$ \\
\hline 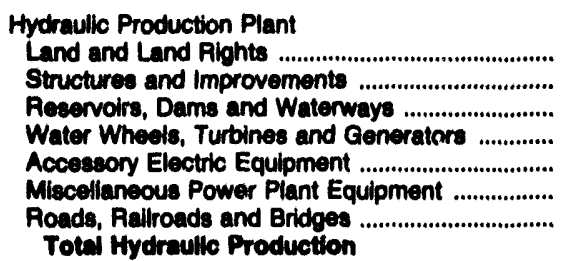 & $\begin{array}{l}0 \\
0 \\
0 \\
0 \\
0 \\
0 \\
0\end{array}$ & $\begin{array}{r}2,295 \\
1,361 \\
4,118 \\
4,058 \\
1,302 \\
102 \\
0\end{array}$ & $\begin{array}{l}0 \\
0 \\
0 \\
0 \\
0 \\
0 \\
0\end{array}$ & $\begin{array}{r}2,409 \\
15,466 \\
113,397 \\
29,488 \\
11,803 \\
3,124 \\
0\end{array}$ & $\begin{array}{r}83 \\
122 \\
1,302 \\
269 \\
105 \\
19 \\
0\end{array}$ & $\begin{array}{l}0 \\
0 \\
0 \\
0 \\
0 \\
0 \\
0\end{array}$ \\
\hline 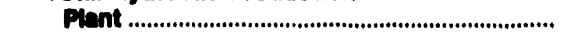 & $\mathbf{0}$ & 13,237 & $\mathbf{0}$ & 178,070 & 1,000 & 0 \\
\hline 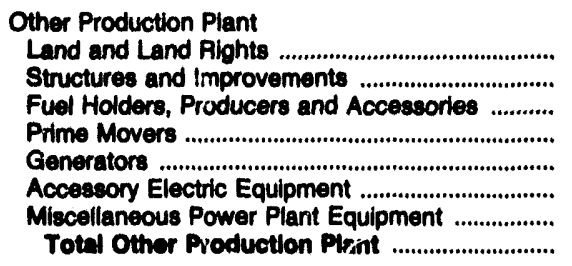 & $\begin{array}{l}0 \\
0 \\
0 \\
0 \\
0 \\
0 \\
0 \\
0\end{array}$ & $\begin{array}{l}0 \\
0 \\
0 \\
0 \\
0 \\
0 \\
0 \\
0\end{array}$ & $\begin{array}{r}5 \\
162 \\
694 \\
1,755 \\
764 \\
372 \\
114 \\
3,867\end{array}$ & $\begin{array}{r}196 \\
2,104 \\
2,307 \\
26,564 \\
12,862 \\
5,236 \\
545 \\
49,915\end{array}$ & $\begin{array}{r}34 \\
287 \\
51 \\
1,361 \\
405 \\
181 \\
18 \\
2,346\end{array}$ & $\begin{array}{l}0 \\
0 \\
0 \\
0 \\
0 \\
0 \\
0 \\
0\end{array}$ \\
\hline 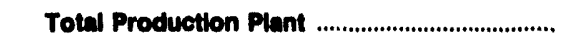 & 0 & 13,237 & 179,389 & 295,014 & 4,246 & $\mathbf{0}$ \\
\hline 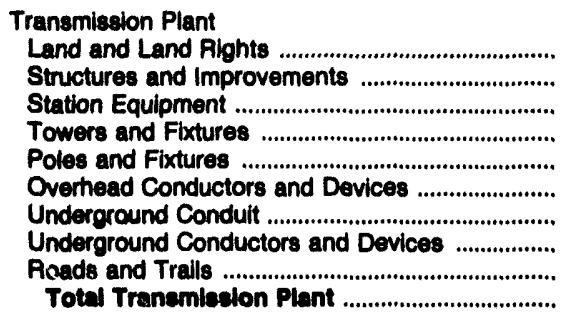 & $\begin{array}{r}948 \\
493 \\
7,725 \\
4,021 \\
1,174 \\
5,743 \\
11 \\
77 \\
0 \\
20,193\end{array}$ & $\begin{array}{r}52 \\
620 \\
13,512 \\
95 \\
1,214 \\
1,222 \\
0 \\
0 \\
3 \\
16,718\end{array}$ & $\begin{array}{r}4,449 \\
3,153 \\
40,085 \\
1,443 \\
23,892 \\
9,902 \\
10,462 \\
5,819 \\
0 \\
90,204\end{array}$ & $\begin{array}{r}6,507 \\
1,319 \\
79,452 \\
2,565 \\
40,330 \\
49,617 \\
8 \\
160 \\
103 \\
180,081\end{array}$ & $\begin{array}{r}58 \\
0 \\
1,110 \\
0 \\
978 \\
986 \\
1 \\
26 \\
0 \\
3,150\end{array}$ & $\begin{array}{l}0 \\
0 \\
0 \\
0 \\
0 \\
0 \\
0 \\
0 \\
0 \\
0\end{array}$ \\
\hline 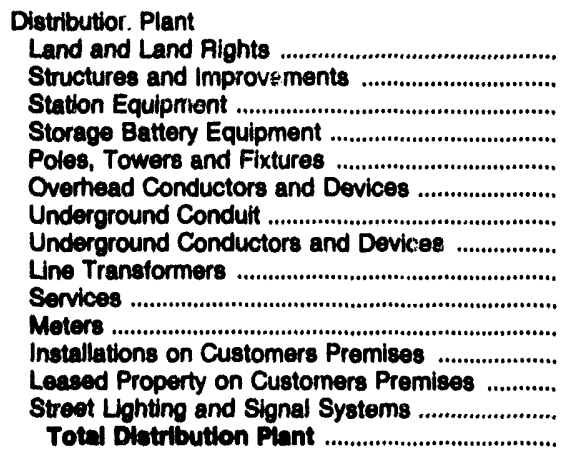 & $\begin{array}{r}671 \\
365 \\
6,682 \\
0 \\
0 \\
10,709 \\
8,152 \\
2,587 \\
3,396 \\
9,135 \\
4,632 \\
4,495 \\
747 \\
0 \\
1,147 \\
52,716\end{array}$ & $\begin{array}{r}0 \\
0 \\
237 \\
0 \\
165 \\
222 \\
0 \\
107 \\
233 \\
110 \\
48 \\
0 \\
0 \\
0 \\
1,122\end{array}$ & $\begin{array}{r}480 \\
190 \\
3,872 \\
0 \\
0 \\
10,771 \\
15,332 \\
23,537 \\
31,020 \\
23,927 \\
13,940 \\
8,169 \\
1,552 \\
0 \\
1,180 \\
133,001\end{array}$ & $\begin{array}{r}694 \\
695 \\
44,246 \\
0 \\
44,871 \\
46,074 \\
5,323 \\
23,304 \\
45,940 \\
28,350 \\
15,778 \\
4,437 \\
0 \\
4,323 \\
264,034\end{array}$ & $\begin{array}{r}44 \\
301 \\
497 \\
0 \\
0 \\
2,262 \\
2,428 \\
0 \\
1,783 \\
1,487 \\
1,286 \\
573 \\
0 \\
0 \\
209 \\
10,080\end{array}$ & $\begin{array}{r}3 \\
0 \\
50 \\
0 \\
95 \\
90 \\
10 \\
690 \\
426 \\
279 \\
72 \\
49 \\
0 \\
19 \\
1,783\end{array}$ \\
\hline
\end{tabular}

See endnotes at end of an intividual electric utility. 
Tablo 42. Utility Piant by Major U.8. Inveator-Owned Electrlo Utility Within 8tate on December 31, 1902 (Continued)

(Thousand Dollars)

\begin{tabular}{|c|c|c|c|c|c|c|}
\hline item & $\begin{array}{l}\text { Weat Virginia } \\
\text { Wheeling } \\
\text { Power Co }\end{array}$ & $\begin{array}{l}\text { Wheconein } \\
\text { Consoludated } \\
\text { Water } \\
\text { Power Co }\end{array}$ & $\begin{array}{l}\text { Weconein } \\
\text { Madieon } \\
\text { Gas } \\
\text { Electrio Co }\end{array}$ & $\begin{array}{l}\text { Wheconsin } \\
\text { Northem } \\
\text { States } \\
\text { Power Co }\end{array}$ & $\begin{array}{l}\text { Whecons: in } \\
\text { Northweetern } \\
\text { Wheconsin } \\
\text { Eles Co }\end{array}$ & $\begin{array}{c}\text { Wheconein } \\
\text { Plonear } \\
\text { Power } \\
\text { Light Co }\end{array}$ \\
\hline
\end{tabular}

General Piant
Lend and Land Ploht

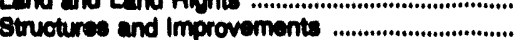

Oilice Fumiture and Equipment

Transportition Equipmant

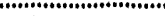

Tools, shop and Cerage Equipment

Laboratory Equipment

Miscellaneous Equipment

Subloted Conerd Pient

Other Tanquble Property

Totel Cenerd Pient

589

2,685

278

121

48

210
160
7

688

32

4,610

381

4,001

Electrio Plant Purchaned and Sold (nel)

Experimental Electric Plent Unclaselfied

Totel Elective Utity Piant in semice

(...............

77,000
Additions

Intancible Plent

Production Piant

Steam Production Plant

Nuclear Production Plant

Hydraulle Production Plant

Other Production Plant

Total Produr

Tranamission Plant

Distribution Plant

General Plant

Electric Plant Purchased

Experimental Electric Plant Unclaselfied ..

Totel Eketris Plant Additions

................

\section{Rethements}

Intang"ble Plant

Production Plant

Steam Production Plant

Nuclear Production Plant

Hydraullc Production Plant

Other Production Plant ...

Total Production Plant

Transmission Plant

Distribution Plant

Generd Plant

Electric Plant Sold.....

Total Ehotis Plent

Rotiremente

4,063

0
301
100
0
0
346
0
70
87
0
002

0
0
497
18
0
624
440
0
24,104
0
28,85

229

3,022

2,668

8,885

100
2,510

1,958

808

4,797

23

26,028

0

26,893

28,028

0

20,112

$\begin{array}{rr}38 & 0 \\ 430 & 39 \\ 57 & 12 \\ 344 & 73 \\ 0 & 0 \\ 68 & 3 \\ 42 & 5 \\ 749 & 88 \\ 77 & 12 \\ 104 & 12 \\ 1,004 & 249\end{array}$

0

243

0

31,000

49,160

724,132

2,023

$\begin{array}{rr}0 & \\ 0 & \\ 0 & \\ 0 & \\ 0 & 54 \\ 0 & \\ 1,183 & \\ 3,686 & 309 \\ 84 & 17 \\ 0 & \\ 0 & \end{array}$

1,001

0,221

37,001

0
657
0
4,382
1,747
8,698
12,408
17,297
721
0
0

0
0
0
96
22
117
128
898
285
0
0

1,427

0
0
0
0
0
0

$\begin{array}{rr}0 & \\ 0 & 678 \\ 0 & 13 \\ 26 & \\ 0 & \\ 20 & 898 \\ 2 & 207 \\ 3 & 837 \\ 0 & 24 \\ 0 & 0 \\ 0 & 0\end{array}$

0
78
0
-9
787
684
1,635
3,911
657
0
0

7,067

1,762

0
0
0
2
1
2
10
130
92
0
0

225

21

Note: Totals may not equal sum of components because of independent rounding. Summary data are provided in Table 28.

Source: Federal Energy Regulatory Commiecion, FERC Form 1, "Annual Report of Major Electris Utillies, Licensees and Others." 


$$
\begin{aligned}
& \text { 桭 }
\end{aligned}
$$

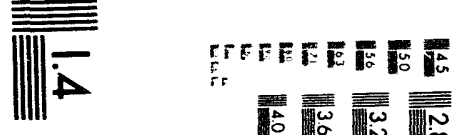

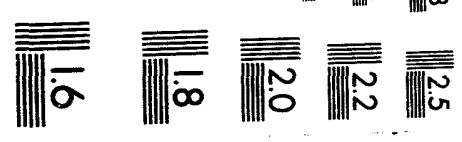



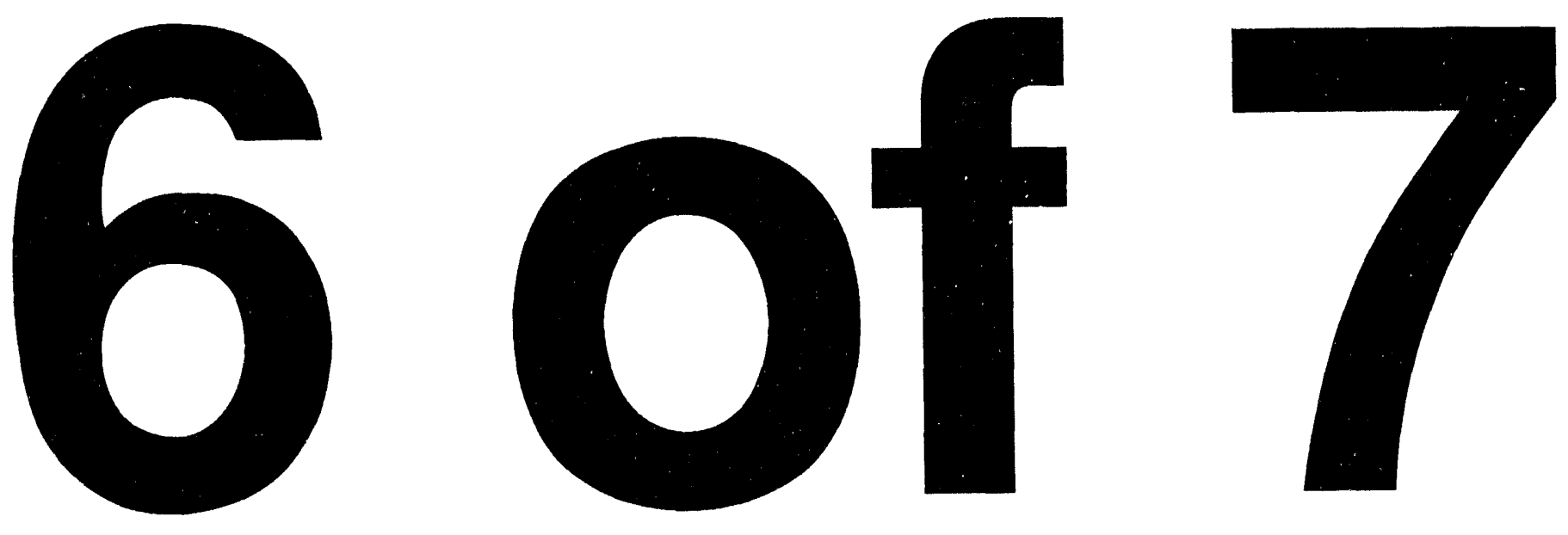
Table 42. Utility Plant by Major U.S. Investor-Owned Electric Utility Within State on Decomber 31, 1992 (Continued) (Thousand Dollars)

\begin{tabular}{|c|c|c|c|c|c|c|}
\hline Hem & $\begin{array}{l}\text { Whoconain } \\
\text { South } \\
\text { Beloit } \\
\text { Water } \\
\text { GasaElec Co }\end{array}$ & $\begin{array}{c}\text { Wiaconsin } \\
\text { Superior } \\
\text { Water } \\
\text { Lohidepower } \\
\text { Co }\end{array}$ & $\begin{array}{l}\text { Whaconain } \\
\text { Wheconsin } \\
\text { Electric } \\
\text { Power Co }\end{array}$ & $\begin{array}{l}\text { Wheconain } \\
\text { Wheconaln } \\
\text { Power } \\
\text { Light Co }\end{array}$ & $\begin{array}{l}\text { Wiaconsin } \\
\text { Wisconsin } \\
\text { Pubilc } \\
\text { Senvice Corp }\end{array}$ & $\begin{array}{l}\text { Wisconsin } \\
\text { Wisconsin } \\
\text { Rlver } \\
\text { Power Co }\end{array}$ \\
\hline 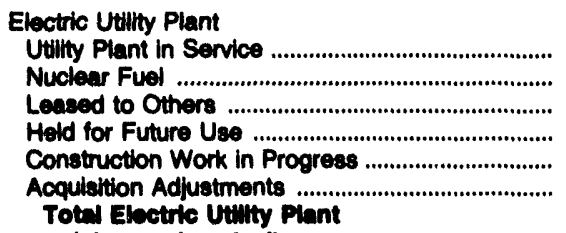 & $\begin{array}{r}8,502 \\
0 \\
0 \\
0 \\
0 \\
0\end{array}$ & $\begin{array}{r}27,269 \\
0 \\
0 \\
0 \\
0 \\
0\end{array}$ & $\begin{array}{r}3,815,680 \\
108,586 \\
0 \\
0 \\
5,800 \\
180,413 \\
0\end{array}$ & $\begin{array}{r}1,433,817 \\
140,652 \\
0 \\
0 \\
0 \\
54,316 \\
1,025\end{array}$ & $\begin{array}{r}1,240,873 \\
141,274 \\
0 \\
170 \\
25,870 \\
0\end{array}$ & $\begin{array}{r}24,658 \\
0 \\
0 \\
0 \\
102 \\
0\end{array}$ \\
\hline 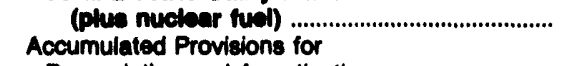 & 8,502 & 27,200 & $4,001,003$ & $1,490,160$ & $1,207,013$ & 24,780 \\
\hline Depreciation and Amortization .................................. & 3,127 & 12,041 & $1,653,090$ & 607,229 & 619,496 & 12,837 \\
\hline $\begin{array}{l}\text { Net Electric Utility Plant } \\
\text { (plue nuclear fuel) }\end{array}$ & $\mathbf{5 , 3 7 5}$ & 15,220 & $2,340,812$ & $\mathbf{2 0 1 , 9 8 0}$ & $\mathbf{9 4 7 , 5 1 8}$ & 11,823 \\
\hline 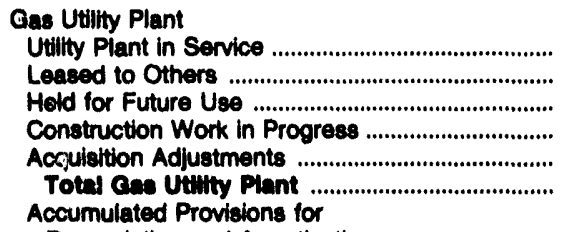 & $\begin{array}{r}6,192 \\
0 \\
0 \\
0 \\
0 \\
6,192\end{array}$ & $\begin{array}{r}7,842 \\
0 \\
1 \\
0 \\
0 \\
7,244\end{array}$ & $\begin{array}{l}0 \\
0 \\
0 \\
0 \\
0 \\
0\end{array}$ & $\begin{array}{r}173,541 \\
0 \\
0 \\
2,510 \\
0 \\
176,081\end{array}$ & $\begin{array}{r}153,345 \\
0 \\
0 \\
105 \\
0 \\
159,450\end{array}$ & $\begin{array}{l}0 \\
0 \\
0 \\
0 \\
0 \\
0\end{array}$ \\
\hline 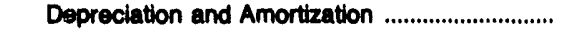 & 2,427 & 4,595 & 0 & 72,234 & 77,920 & 0 \\
\hline Mot Cas Utulty Piant ..... & 3,766 & 3,240 & $\mathbf{0}$ & 103,816 & 75,630 & 0 \\
\hline 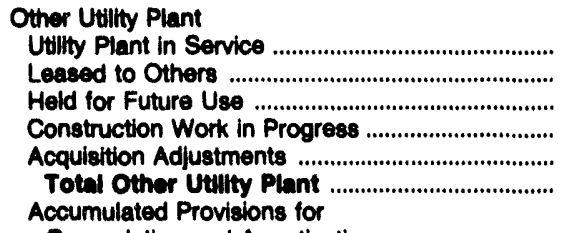 & $\begin{array}{r}2,405 \\
0 \\
0 \\
0 \\
0 \\
2,405\end{array}$ & $\begin{array}{r}18,532 \\
0 \\
5 \\
0 \\
364 \\
18,901\end{array}$ & $\begin{array}{r}33,177 \\
0 \\
0 \\
1,039 \\
0 \\
34,216\end{array}$ & $\begin{array}{r}111,109 \\
0 \\
0 \\
2,147 \\
0 \\
113,260\end{array}$ & $\begin{array}{r}106,338 \\
0 \\
0 \\
780 \\
0 \\
107,120\end{array}$ & $\begin{array}{l}0 \\
0 \\
0 \\
0 \\
0 \\
0\end{array}$ \\
\hline Depreciation and Amortization ............................... & 465 & 4,688 & 15,174 & 34,505 & 51,012 & 0 \\
\hline Net Other Utillty Plant ............................................. & 1,840 & 14,233 & 19,041 & 76,762 & 86,116 & 0 \\
\hline 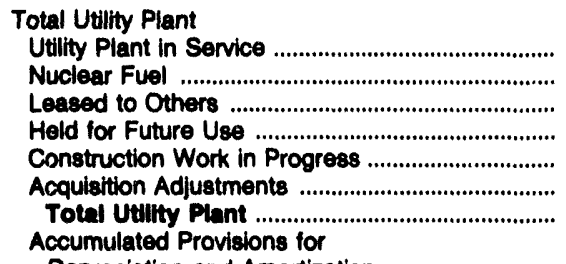 & $\begin{array}{r}17,100 \\
0 \\
0 \\
0 \\
0 \\
0 \\
17,100\end{array}$ & $\begin{array}{r}53,643 \\
0 \\
0 \\
7 \\
0 \\
364 \\
54,014\end{array}$ & $\begin{array}{r}3,848,867 \\
108,586 \\
0 \\
5,800 \\
181,461 \\
0 \\
0 \\
4,144,704\end{array}$ & $\begin{array}{r}1,718,467 \\
140,652 \\
0 \\
0 \\
58,974 \\
1,025 \\
1,010,117\end{array}$ & $\begin{array}{r}1,500,556 \\
141,274 \\
0 \\
170 \\
26,864 \\
0 \\
1,688,865\end{array}$ & $\begin{array}{r}24,658 \\
0 \\
0 \\
0 \\
102 \\
0 \\
24,760\end{array}$ \\
\hline Depreciation and Amortization .................................. & 6,010 & 21,304 & $1,723,050$ & 837,697 & 872,822 & 12,937 \\
\hline 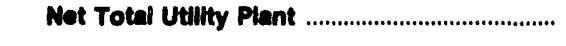 & 11,081 & 32,710 & $2,421,654$ & $1,001,420$ & 796,044 & 11,823 \\
\hline 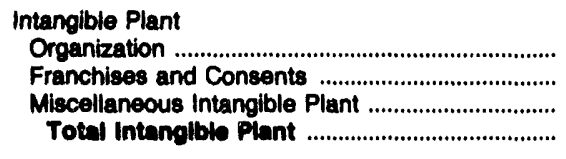 & $\begin{array}{l}0 \\
0 \\
0 \\
0\end{array}$ & $\begin{array}{l}1 \\
0 \\
0 \\
1\end{array}$ & $\begin{array}{l}0 \\
0 \\
0 \\
0\end{array}$ & $\begin{array}{r}51 \\
0 \\
0 \\
51\end{array}$ & $\begin{array}{l}0 \\
0 \\
0 \\
0\end{array}$ & $\begin{array}{r}12 \\
6 \\
0 \\
18\end{array}$ \\
\hline 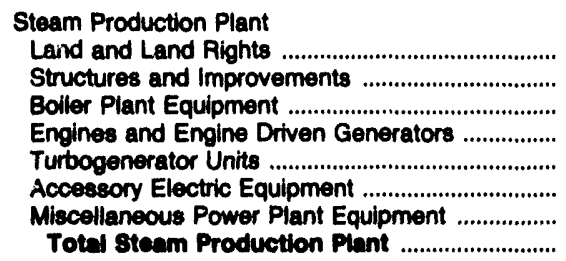 & $\begin{array}{l}0 \\
0 \\
0 \\
0 \\
0 \\
0 \\
0 \\
0\end{array}$ & $\begin{array}{r}67 \\
1,432 \\
2,044 \\
0 \\
1,113 \\
554 \\
43 \\
5,264\end{array}$ & $\begin{array}{r}8,590 \\
247,617 \\
881,512 \\
0 \\
221,601 \\
162,345 \\
27,739 \\
1,549,405\end{array}$ & $\begin{array}{r}6,516 \\
81,818 \\
343,856 \\
0 \\
85,719 \\
24,759 \\
9,501 \\
852,201\end{array}$ & $\begin{array}{r}3,822 \\
80,444 \\
320,107 \\
0 \\
74,647 \\
39,473 \\
11,437 \\
520,030\end{array}$ & $\begin{array}{l}0 \\
0 \\
0 \\
0 \\
0 \\
0 \\
0 \\
0\end{array}$ \\
\hline
\end{tabular}

See endnotes at end of an individual electric uatlity. 
Table 42. Utility Plant by Major U.S. Inveetor-Owned Electric Utility Within State on December 31, 1992 (Continued) (Thousand Dollars)

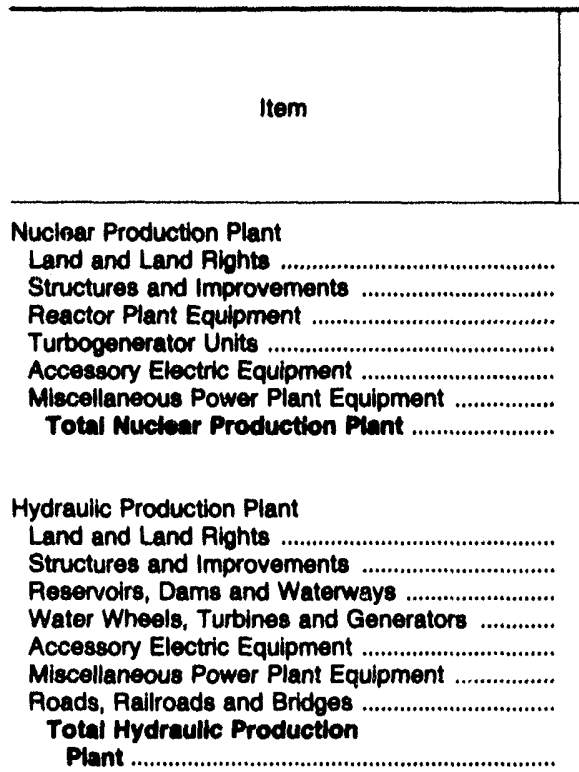

Other Production Plant

Land and Land Rights ...

Structures and improvements ................................

Fuel Holders, Producers and Accessories ..........

Prime Movers

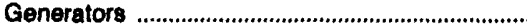

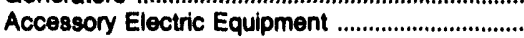

Miscellaneous Power Plant Equipment

Total Other Production Plant

Total Production Plant

.............................

\begin{tabular}{|} 
Wisconsin \\
South \\
Boloit \\
Water \\
GasdElec Co
\end{tabular}

\begin{tabular}{|c|c|}
\hline Wisconein & Wisconsin \\
$\begin{array}{c}\text { Superior } \\
\text { Water } \\
\text { Light\&Power } \\
\text { Co }\end{array}$ & $\begin{array}{c}\text { Wisconsin } \\
\text { Electric } \\
\text { Power Co }\end{array}$ \\
\hline
\end{tabular}

\begin{tabular}{|c|c|c|}
\hline Wisconsin & Wisconsin & Wisconsin \\
\hline $\begin{array}{c}\text { Wisconsin } \\
\text { Power } \\
8 \\
\text { Light Co }\end{array}$ & $\begin{array}{l}\text { Wisconsin } \\
\text { Public } \\
\text { Service Corp }\end{array}$ & $\begin{array}{l}\text { Wisconsin } \\
\text { Piver } \\
\text { Power Co }\end{array}$ \\
\hline
\end{tabular}

0
0
0
0
0
0
0

$\begin{array}{lr}0 & 631 \\ 0 & 46,926 \\ 0 & 128,403 \\ 0 & 58,953 \\ 0 & 31,387 \\ 0 & 23,798 \\ 0 & 290,099\end{array}$

434
19,744
67,233
20,536
13,998
5,706
127,651

436
19,579
66,807
20,626
14,024
5,597
127,009

0
0
0
0
0
0
0

Transmission Plant

Land and Land Rights

Structures and Improvements

Station Equipment

Towers and Fixtures

Poles and Fixtures

Conductors and Devices

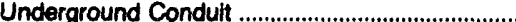

Underground Conductors and Devices

Roads and Trails

Total Transmiseion Pient

4,036

423
461

32,354

1,267
878
4,450
2,033
913
427
0

1,819

1,819
3,015

10,832

6,602

3,314

133

9,898

25,737

3,563
1,351
14,188
3,224
852
259
33
23,470

Distribution Plant

Land and Land Rights

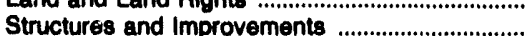

Station Equipment ...

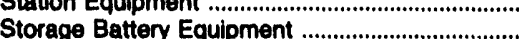

Poles, Towers and Fixtures

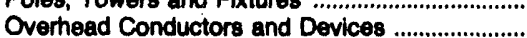

Underground Conduit

Underground Conductors and Devices

Line Transformers

Services

Meters

Installations on Customers Premises

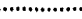

.

Street Lighting and Signal Systems ......................

Total Distribution Plant

...................................

$\begin{array}{rr}387 & 18,640 \\ 0 & 3,787 \\ 4,601 & 116,559 \\ 92 & 33,437 \\ 1,478 & 41,637 \\ 1,896 & 67,977 \\ 0 & 8,521 \\ 0 & 9,413 \\ 0 & 0 \\ 8,455 & 299,972\end{array}$

6,867

4,764

98,113

8,319

36,554

47,110

2,681

3

234

367
837

12,255

2,984

898
58

17,732

707,621

155
740
437
0
11,706
1,008
33
14,079

698,815

23,479

Ses endnotes at end of an individual electric utility. 
Table 42. Utility Plant by Major U.S. Investor-Owned Electric Utility Within State on December 31, 1992 (Continued)

(Thousand Dollars)

\begin{tabular}{|c|c|c|c|c|c|c|}
\hline litem & $\begin{array}{l}\text { Wisconsin } \\
\text { South } \\
\text { Beloit } \\
\text { Water } \\
\text { GaseElec Co }\end{array}$ & $\begin{array}{l}\text { Wieconsin } \\
\text { Superior } \\
\text { Water } \\
\text { Light\&Power } \\
\text { Co }\end{array}$ & $\begin{array}{l}\text { Wisconsiti } \\
\text { Wisconsin } \\
\text { Electric } \\
\text { Power Co }\end{array}$ & $\begin{array}{l}\text { Wisconsin } \\
\text { Wraconsin } \\
\text { Power } \\
8 \\
\text { Light Co }\end{array}$ & $\begin{array}{l}\text { Wisconsin } \\
\text { Wisconsin } \\
\text { Public } \\
\text { Service Corp }\end{array}$ & $\begin{array}{l}\text { Wiaconain } \\
\text { Wisconain } \\
\text { River } \\
\text { Power Co }\end{array}$ \\
\hline 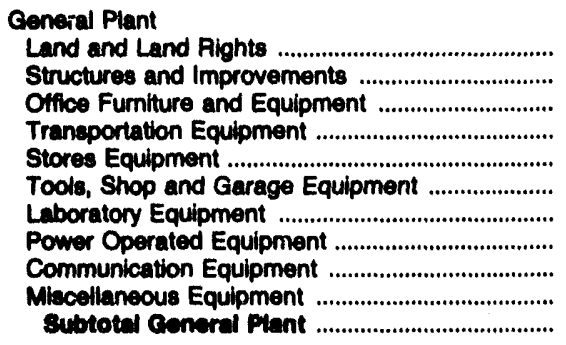 & $\begin{array}{r}0 \\
0 \\
0 \\
0 \\
0 \\
0 \\
0 \\
0 \\
11 \\
0 \\
11\end{array}$ & $\begin{array}{r}0 \\
0 \\
25 \\
0 \\
0 \\
119 \\
238 \\
0 \\
23 \\
0 \\
405\end{array}$ & $\begin{array}{r}6,164 \\
99,531 \\
39,212 \\
39,206 \\
2,794 \\
4,629 \\
5,490 \\
7,138 \\
50,185 \\
2,842 \\
257,101\end{array}$ & $\begin{array}{r}171 \\
2,684 \\
13,365 \\
18,145 \\
0 \\
2,100 \\
4,684 \\
2,211 \\
3,033 \\
123 \\
46,496\end{array}$ & $\begin{array}{r}502 \\
6,758 \\
1,283 \\
47 \\
0 \\
2,320 \\
2,922 \\
0 \\
9,515 \\
0 \\
23,347\end{array}$ & $\begin{array}{r}0 \\
209 \\
12 \\
144 \\
0 \\
85 \\
0 \\
159 \\
46 \\
0 \\
884\end{array}$ \\
\hline Other Tangible Property .............................................. & 0 & 0 & 0 & 0 & 0 & 0 \\
\hline Total Ceneral Plant ............................................... & 11 & 405 & 257,191 & $46,4 \oplus 8$ & 23,347 & 684 \\
\hline $\begin{array}{l}\text { Electric Plant Purchased and Sold (net) ................... } \\
\text { Experimental Electric Plant Unclassified .............. }\end{array}$ & $\begin{array}{l}0 \\
0\end{array}$ & $\begin{array}{l}0 \\
0\end{array}$ & $\begin{array}{r}-16 \\
0\end{array}$ & $\begin{array}{l}0 \\
0\end{array}$ & $\begin{array}{l}0 \\
0\end{array}$ & $\begin{array}{l}0 \\
0\end{array}$ \\
\hline Total Electric utilty Plant in sorvlce .............. & 8,502 & 27,289 & $3,815,680$ & $1,433,817$ & $1,240,873$ & 24,668 \\
\hline 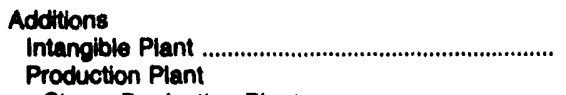 & 0 & 0 & 0 & 0 & 0 & 0 \\
\hline 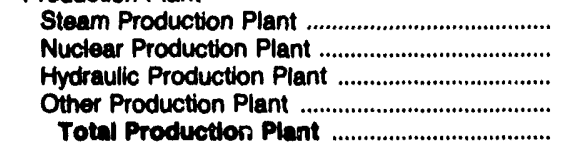 & $\begin{array}{l}0 \\
0 \\
3 \\
0 \\
3\end{array}$ & $\begin{array}{l}0 \\
0 \\
0 \\
0 \\
0\end{array}$ & $\begin{array}{r}82,712 \\
1,621 \\
1,528 \\
0 \\
86,882\end{array}$ & $\begin{array}{r}13,827 \\
4,020 \\
241 \\
224 \\
18,312\end{array}$ & $\begin{array}{r}27,787 \\
3,975 \\
862 \\
20 \\
32,843\end{array}$ & $\begin{array}{r}0 \\
0 \\
180 \\
0 \\
180\end{array}$ \\
\hline 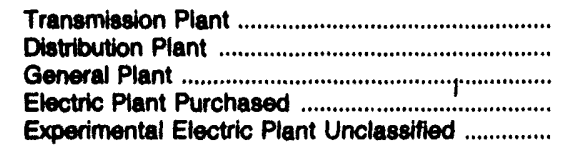 & $\begin{array}{r}0 \\
541 \\
0 \\
0 \\
0\end{array}$ & $\begin{array}{r}9 \\
805 \\
38 \\
0 \\
0\end{array}$ & $\begin{array}{r}49,346 \\
89,041 \\
25,219 \\
0 \\
0\end{array}$ & $\begin{array}{r}6,867 \\
32,022 \\
8,619 \\
0 \\
0\end{array}$ & $\begin{array}{r}-220 \\
26,721 \\
1,147 \\
0 \\
0\end{array}$ & $\begin{array}{r}0 \\
0 \\
87 \\
0 \\
0\end{array}$ \\
\hline Total Electrle Plant Additions ............................. & 544 & 852 & 249,460 & 85,920 & 80,201 & 298 \\
\hline 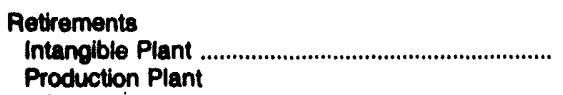 & 0 & 0 & 0 & 0 & 0 & 0 \\
\hline 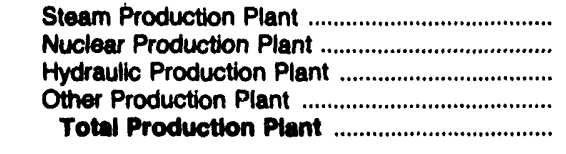 & $\begin{array}{l}0 \\
0 \\
0 \\
0 \\
0\end{array}$ & $\begin{array}{l}0 \\
0 \\
0 \\
0 \\
0\end{array}$ & $\begin{array}{r}11,611 \\
1,022 \\
109 \\
0 \\
12,742\end{array}$ & $\begin{array}{r}3,883 \\
689 \\
2 \\
0 \\
4,573\end{array}$ & $\begin{array}{r}946 \\
677 \\
42 \\
1 \\
1,668\end{array}$ & $\begin{array}{l}0 \\
0 \\
1 \\
0 \\
1\end{array}$ \\
\hline 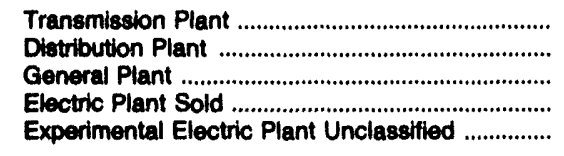 & $\begin{array}{r}0 \\
53 \\
0 \\
0 \\
0\end{array}$ & $\begin{array}{r}7 \\
141 \\
5 \\
0 \\
0\end{array}$ & $\begin{array}{r}379 \\
10,406 \\
3,715 \\
0 \\
0\end{array}$ & $\begin{array}{r}471 \\
6,199 \\
975 \\
0 \\
0\end{array}$ & $\begin{array}{r}588 \\
3,334 \\
245 \\
0 \\
0\end{array}$ & $\begin{array}{l}0 \\
0 \\
9 \\
0 \\
0\end{array}$ \\
\hline $\begin{array}{l}\text { Total Electidc Plant } \\
\text { Rotirements }\end{array}$ & 53 & 153 & 27,242 & 12,218 & 5,843 & 10 \\
\hline
\end{tabular}

Note: Totals may not equal sum of components because of independent rounding. Summary data are provided in Table 28.

Source: Federal Energy Regulatory Commission, FERC Form 1, "Annual Report of Major Electric Utilities, Licensees and Others." 
Table 43. Electric Energy Account by Major U.S. Investor-Owned Electric Utility Within State, 1992 (Megawatthours)

\begin{tabular}{|c|c|c|c|c|c|c|}
\hline Item & $\begin{array}{l}\text { Alabama } \\
\text { Alabama } \\
\text { Power Co }\end{array}$ & $\begin{array}{l}\text { Alabama } \\
\text { Southern } \\
\text { Electric } \\
\text { Generatg Co }\end{array}$ & $\begin{array}{c}\text { Arizona } \\
\text { Arizona } \\
\text { Public } \\
\text { Service Co }\end{array}$ & $\begin{array}{c}\text { Arizona } \\
\text { Century } \\
\text { Power Corp }\end{array}$ & $\begin{array}{l}\text { Arizona } \\
\text { Tucson } \\
\text { Electric } \\
\text { Power Co }\end{array}$ & $\begin{array}{c}\text { Arkansas } \\
\text { Arkansas } \\
\text { Power } \\
\& \\
\text { Light Co }\end{array}$ \\
\hline 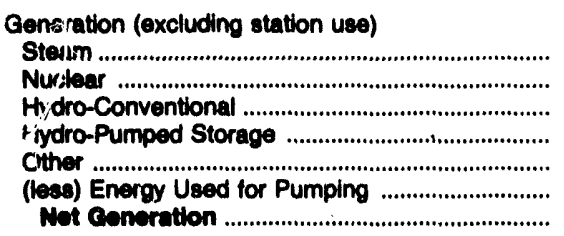 & $\begin{array}{r}37,480,014 \\
11,056,588 \\
4,869,928 \\
0 \\
0 \\
0 \\
53,508,530\end{array}$ & $\begin{array}{r}5,328,004 \\
0 \\
0 \\
0 \\
167 \\
0 \\
5,328,171\end{array}$ & $\begin{array}{r}12,380,055 \\
7,452,132 \\
33,767 \\
0 \\
579,212 \\
0 \\
20,445,168\end{array}$ & $\begin{array}{r}3,140,116 \\
0 \\
0 \\
0 \\
0 \\
0 \\
3,140,116\end{array}$ & $\begin{array}{r}6,673,490 \\
0 \\
0 \\
0 \\
2,739 \\
0 \\
6,676,229\end{array}$ & $\begin{array}{r}8,789,077 \\
11,325,661 \\
165,659 \\
0 \\
341 \\
0 \\
20,280,738\end{array}$ \\
\hline $\begin{array}{l}\text { Purchases } \\
\text { Utility } \\
\text { Nonutility } \\
\text { Total Purehases }\end{array}$ & $\begin{array}{r}4,550,208 \\
139,397 \\
4,689,605\end{array}$ & $\begin{array}{l}0 \\
0 \\
0\end{array}$ & $\begin{array}{r}1,311,606 \\
23 \\
1,311,629\end{array}$ & $\begin{array}{l}0 \\
0 \\
0\end{array}$ & $\begin{array}{r}2,465,714 \\
1,024 \\
2,466,738\end{array}$ & $\begin{array}{r}11,172,072 \\
59,668 \\
11,231,740\end{array}$ \\
\hline $\begin{array}{l}\text { Exchanges } \\
\text { In (gross) } \\
\text { Out (gross) }\end{array}$ & $\begin{array}{r}1,205 \\
1,717 \\
-512\end{array}$ & $\begin{array}{l}0 \\
0 \\
0\end{array}$ & $\begin{array}{r}25,288 \\
37,482 \\
-12,194\end{array}$ & $\begin{array}{l}0 \\
0 \\
0\end{array}$ & $\begin{array}{r}186,209 \\
139,964 \\
46,245\end{array}$ & $\begin{array}{r}243,947 \\
223,200 \\
20,747\end{array}$ \\
\hline 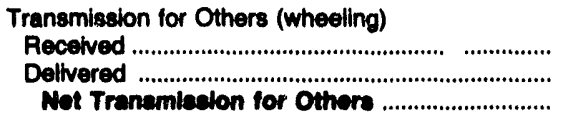 & $\begin{array}{r}2,211,435 \\
2,130,980 \\
80,465\end{array}$ & $\begin{array}{l}0 \\
0 \\
0\end{array}$ & $\begin{array}{r}1,954,640 \\
1,869,077 \\
85,563\end{array}$ & $\begin{array}{l}0 \\
0 \\
0\end{array}$ & $\begin{array}{r}2,377,430 \\
2,353,022 \\
24,408\end{array}$ & $\begin{array}{l}0 \\
0 \\
0\end{array}$ \\
\hline Tranemiedon by Other Losees ............................... & o & $\mathbf{0}$ & -485 & 0 & $-101,230$ & $\mathbf{0}$ \\
\hline $\begin{array}{l}\text { Total Net Energy Cenerated } \\
\text { and Pecelved }\end{array}$ & $58,276,078$ & $5,328,171$ & 21,829,703 & $3,140,116$ & $9,112,381$ & $31,533,225$ \\
\hline 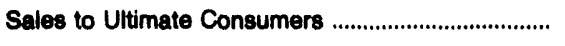 & $39,136,209$ & 0 & $16,034,731$ & 0 & $6,381,097$ & $14,699,692$ \\
\hline 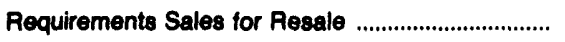 & $2,870,669$ & $5,328,171$ & $1,748,899$ & 0 & 0 & $3,503,377$ \\
\hline 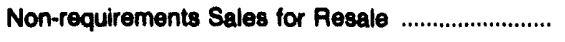 & $12,722,599$ & 0 & $2,779,273$ & $3,079,702$ & $2,121,245$ & $11,909,991$ \\
\hline 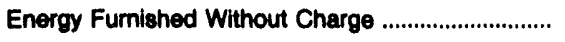 & 1,549 & 0 & 0 & 0 & 0 & 0 \\
\hline Energy Used by Company (exc station use) ........... & 746,283 & 0 & 74.031 & 25,607 & 15,012 & 50,370 \\
\hline 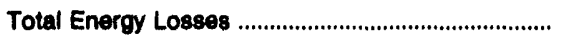 & $3,388,769$ & 0 & $1,192,769$ & 34,807 & 595,027 & $1,369,795$ \\
\hline Total 8ales and Diapoestion ............................... & $68,276,078$ & $5,328,171$ & $21,829,703$ & $3,140,116$ & $9,112,381$ & $31,633,225$ \\
\hline
\end{tabular}

Note: Totals may not equal sum of componente because of independent rounding. Double counting occurs in components of both sources and disposition of energy and thus neithen provides a true total. Purchases from utilities, net interchanges, and net wheeling (except for imports) are included in net generation. Sales for resale is included in sales to ultimate consumers. Summary data are provided in Table 30 .

Source: Federal Energy Regulatory Commission, FERC Form 1. "Annual Report of Major Electris Utilities, Licensees and Others." 
Table 43. Electric Energy Account by Major U.S. Investor-Owned Electric Utility Within State, 1992 (Continued)

(Megawatthours)

\begin{tabular}{|c|c|c|c|c|c|c|}
\hline Item & $\begin{array}{c}\text { California } \\
\text { Pacific } \\
\text { Gas } \\
\& \\
\text { Electric Co }\end{array}$ & $\begin{array}{c}\text { California } \\
\text { San Diego } \\
\text { Gas } \\
\& \\
\text { Electric Co }\end{array}$ & $\begin{array}{l}\text { Callfornia } \\
\text { Southern } \\
\text { California } \\
\text { Edison Co }\end{array}$ & $\begin{array}{c}\text { Colorado } \\
\text { Public } \\
\text { Service } \\
\text { Co } \\
\text { of Colorado }\end{array}$ & $\begin{array}{l}\text { Connecticut } \\
\text { Citizens } \\
\text { Utilities Co }\end{array}$ & $\begin{array}{l}\text { Connecticut } \\
\text { Connecticut } \\
\text { Light } \\
\& \\
\text { Power Co }\end{array}$ \\
\hline 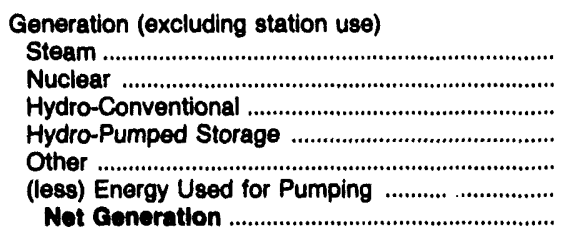 & $\begin{array}{r}33,610,981 \\
16,698,120 \\
7,193,549 \\
343,944 \\
19,370 \\
397,966 \\
57,467,998\end{array}$ & $\begin{array}{r}4,619,127 \\
3,710,091 \\
0 \\
0 \\
20,609 \\
0 \\
8,349,827\end{array}$ & $\begin{array}{r}29,554,149 \\
18,108,431 \\
2,727,673 \\
114,058 \\
1,478,070 \\
17,680 \\
51,964,701\end{array}$ & $\begin{array}{r}14,972,688 \\
0 \\
175,010 \\
79,609 \\
47,199 \\
126,266 \\
15,148,240\end{array}$ & $\begin{array}{r}41,910 \\
0 \\
18,902 \\
0 \\
234,210 \\
0 \\
295,022\end{array}$ & $\begin{array}{r}2,861,498 \\
8,976,598 \\
315,880 \\
991,680 \\
8,369 \\
1,355,461 \\
11,798,564\end{array}$ \\
\hline 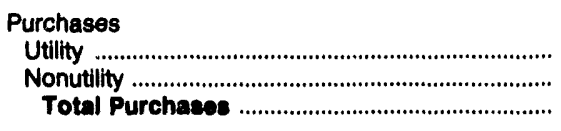 & $\begin{array}{r}6,144,103 \\
21,120,318 \\
27,264,421\end{array}$ & $\begin{array}{l}7,514,112 \\
1,021,940 \\
8,536,052\end{array}$ & $\begin{array}{r}5,114,714 \\
26,039,698 \\
31,154,412\end{array}$ & $\begin{array}{l}6,418,081 \\
1,068,243 \\
7,486,324\end{array}$ & $\begin{array}{r}1,118,715 \\
80,687 \\
1,190,402\end{array}$ & $\begin{array}{r}11,984,341 \\
3,583,763 \\
15,568,104\end{array}$ \\
\hline 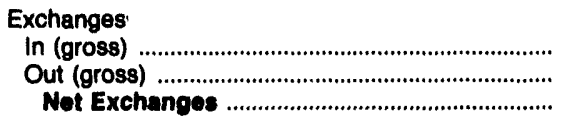 & $\begin{array}{r}1,960,188 \\
4,509,733 \\
-2,549,545\end{array}$ & $\begin{array}{l}173,517 \\
202,581 \\
-29,064\end{array}$ & $\begin{array}{l}442,526 \\
528,827 \\
-86,401\end{array}$ & $\begin{array}{r}6,322,624 \\
5,861,105 \\
461,510\end{array}$ & $\begin{array}{l}61,744 \\
28,420 \\
34,208\end{array}$ & $\begin{array}{l}0 \\
0 \\
0\end{array}$ \\
\hline 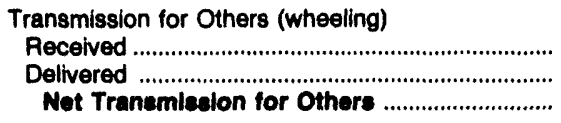 & $\begin{array}{r}16,548,118 \\
15,990,653 \\
557,465\end{array}$ & $\begin{array}{r}389,352 \\
389,352 \\
0\end{array}$ & $\begin{array}{r}20,013,158 \\
20,846,507 \\
-833,349\end{array}$ & $\begin{array}{r}882,508 \\
892,508 \\
0\end{array}$ & $\begin{array}{r}164,537 \\
160,659 \\
3,878\end{array}$ & $\begin{array}{r}2,676,514 \\
2,676,514 \\
0\end{array}$ \\
\hline 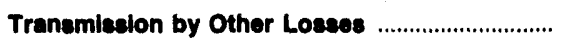 & 0 & $\mathbf{0}$ & 0 & $\mathbf{0}$ & 35,600 & 0 \\
\hline $\begin{array}{l}\text { Total Net Energy Generated } \\
\text { and Recelved }\end{array}$ & $82,740,339$ & $16,856,815$ & $82,199,363$ & $23,096,083$ & $1,667,235$ & $27,366,668$ \\
\hline 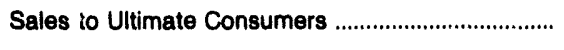 & $71,799,944$ & $15,093,221$ & $70,933,334$ & $19,003,387$ & $1,401,718$ & $20,365,822$ \\
\hline 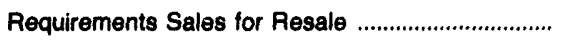 & $2,729,458$ & 0 & 901,805 & $1,880,366$ & 0 & 507,231 \\
\hline 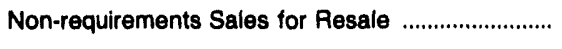 & 904,644 & 646,871 & $2,350,377$ & 274,409 & 1,214 & $4,936,312$ \\
\hline Energy Furnished Without Charge ,............................... & 0 & 0 & 0 & 0 & 332 & 0 \\
\hline Energy Used by Company (exc station use) ............. & 28,597 & 37,881 & 177,774 & 36,829 & 2,296 & 24,023 \\
\hline 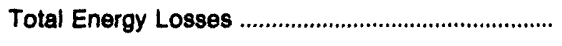 & $7,277,696$ & $1,078,842$ & $7,836,073$ & $1,901,092$ & 161,675 & $1,533,280$ \\
\hline Total Sales and Disposition & $82,740,330$ & $16,856,815$ & $82,199,363$ & $23,096,083$ & $1,567,235$ & $27,366,668$ \\
\hline
\end{tabular}

Note: Totals may not equal sum of components because of indepsndent rounding. Double counting occurs in components of both sources and dis. position of energy and thus neither provides a true total. Purchases from utilities, net interchanges, and net wheeling (except for imports) are included in net generation. Sales for resale is included in sales to ultimate consumers. Summary data are provided in Table 30 .

Source: Federal Energy Regulatory Commission, FERC Form 1, "Annual Report of Major Electric Utilities, Licensees and Others." 
Table 43. Electric Energy Account by Major U.S. Investor-Owned Electric Utility Within State, 1992 (Continued)

(Megawatthours)

\begin{tabular}{|c|c|c|c|c|c|c|}
\hline Item & $\begin{array}{l}\text { Connecticut } \\
\text { Connecticut } \\
\text { Yankee } \\
\text { Atom } \\
\text { Pwr Co }\end{array}$ & $\begin{array}{l}\text { Connecticut } \\
\text { United } \\
\text { Illuminating } \\
\text { Co }\end{array}$ & $\begin{array}{c}\text { Delaware } \\
\text { Delmarva } \\
\text { Power } \\
\& \\
\text { Light Co }\end{array}$ & $\begin{array}{l}\text { District of } \\
\text { Columbia } \\
\text { Potomac } \\
\text { Electric } \\
\text { Power Co }\end{array}$ & $\begin{array}{c}\text { Florida } \\
\text { Florida } \\
\text { Power } \\
\& \\
\text { Light Co }\end{array}$ & $\begin{array}{l}\text { Florida } \\
\text { Florida } \\
\text { Power Corp }\end{array}$ \\
\hline 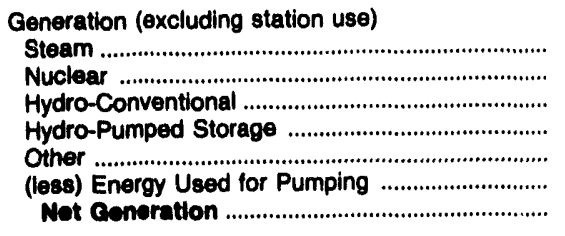 & $\begin{array}{r}0 \\
3,898,583 \\
0 \\
0 \\
0 \\
0 \\
3,898,583\end{array}$ & $\begin{array}{r}4,651,645 \\
1,621,182 \\
0 \\
0 \\
69 \\
0 \\
0 \\
6,272,896\end{array}$ & $\begin{array}{r}6,584,989 \\
1,696,072 \\
0 \\
0 \\
0 \\
267,172 \\
0 \\
0,548,233\end{array}$ & $\begin{array}{r}18,043,832 \\
0 \\
0 \\
0 \\
229,964 \\
0 \\
18,273,796\end{array}$ & $\begin{array}{r}31,364,726 \\
19,817,422 \\
0 \\
0 \\
0 \\
2,024,877 \\
0 \\
53,207,025\end{array}$ & $\begin{array}{r}20,345,242 \\
4,785,418 \\
0 \\
0 \\
0 \\
335,076 \\
0 \\
25,465,736\end{array}$ \\
\hline 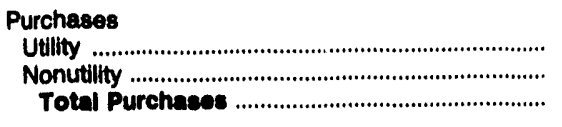 & $\begin{array}{l}0 \\
0 \\
0\end{array}$ & $\begin{array}{r}930,434 \\
453,623 \\
1,384,057\end{array}$ & $\begin{array}{r}2,809,157 \\
21,052 \\
2,830,209\end{array}$ & $\begin{array}{r}8,249,808 \\
28,370 \\
8,278,178\end{array}$ & $\begin{array}{r}19,173,361 \\
2,071,901 \\
21,245,262\end{array}$ & $\begin{array}{l}2,459,220 \\
1,204,410 \\
3,663,630\end{array}$ \\
\hline 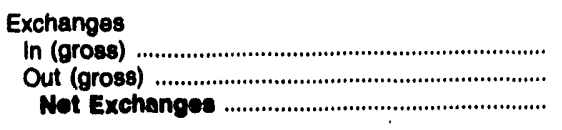 & $\begin{array}{l}0 \\
0 \\
0\end{array}$ & $\begin{array}{r}359,465 \\
15,374 \\
344,091\end{array}$ & $\begin{array}{r}1,749,312 \\
0 \\
1,749,312\end{array}$ & $\begin{array}{l}0 \\
0 \\
0\end{array}$ & $\begin{array}{r}4,009 \\
3,177 \\
832\end{array}$ & $\begin{array}{l}0 \\
0 \\
0\end{array}$ \\
\hline 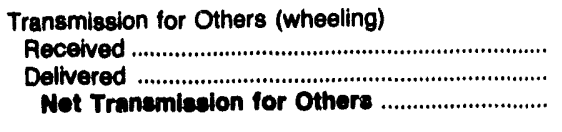 & $\begin{array}{l}0 \\
0 \\
0\end{array}$ & $\begin{array}{r}28,155 \\
28,155 \\
0\end{array}$ & $\begin{array}{r}1,545,646 \\
1,545,646 \\
0\end{array}$ & $\begin{array}{l}0 \\
0 \\
0\end{array}$ & $\begin{array}{r}6,486,731 \\
6,248,938 \\
\quad 237,793\end{array}$ & $\begin{array}{r}1,358,926 \\
1,296,291 \\
62,635\end{array}$ \\
\hline 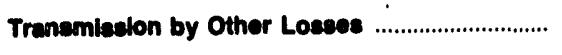 & 0 & 0 & o & 0 & -150 & $\mathbf{0}$ \\
\hline $\begin{array}{l}\text { Total Not Energy Generated } \\
\text { and Recelved }\end{array}$ & $3,898,583$ & $8,001,044$ & $13,127,754$ & $26,551,974$ & $74,690,762$ & $29,192,010$ \\
\hline 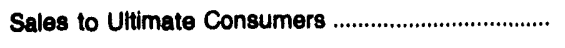 & 0 & $5,152,824$ & $9,533,418$ & $22,354,746$ & $66,380,636$ & $25,414,014$ \\
\hline 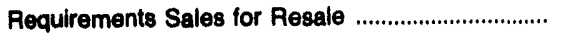 & 0 & 0 & $1,987,393$ & $2,129,698$ & 690,451 & $1,470,674$ \\
\hline 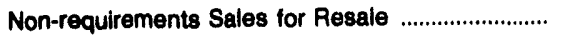 & $3,891,764$ & $2,525,380$ & 998,679 & 770,742 & $1,654,715$ & 490,826 \\
\hline Energy Furnished Without Charge ................................. & 0 & 0 & 0 & 0 & 0 & 0 \\
\hline Energy Used by Company (exc station use) ........... & 0 & 17,511 & 45,672 & 97,459 & 184,016 & 186,549 \\
\hline 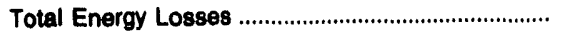 & 6,819 & 305,329 & 562,592 & $1,199,329$ & $5,780,794$ & $1,629,847$ \\
\hline 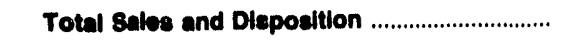 & $3,898,583$ & $8,001,044$ & $13,127,764$ & $26,551,974$ & $74,690,762$ & $29,192,010$ \\
\hline
\end{tabular}

Note: Totals may not equal sum of components because of independent rounding. Double counting occurs in components of both sources and disposition of energy and thus neither provides a true total. Purchases from utilities, net interchanges, and net wheeling (except for imports) are included in net generation. Sales for resale is included in sales to ultimate consumers. Summary data are provided in Table 30.

Source: Federal Energy Regulatory Commission, FERC Form 1, "Annual Report of Major Electric Utilities, Licensees and Others." 
Table 43. Electric Energy Account by Major U.S. Investor-Owned Electric Utility Within State, 1992 (Continued)

(Megawatthours)

\begin{tabular}{|c|c|c|c|c|c|c|}
\hline Item & $\begin{array}{l}\text { Florida } \\
\text { Gylf } \\
\text { Power Co }\end{array}$ & $\begin{array}{l}\text { Florida } \\
\text { Tampa } \\
\text { Electric Co }\end{array}$ & $\begin{array}{l}\text { Georgia } \\
\text { Georgia } \\
\text { Power Co }\end{array}$ & $\begin{array}{c}\text { Georgia } \\
\text { Savannah } \\
\text { Electric } \\
\text { \& Power } \\
\text { Co }\end{array}$ & $\begin{array}{l}\text { Hawall } \\
\text { Hawailan } \\
\text { Electric } \\
\text { Co Inc }\end{array}$ & $\begin{array}{l}\text { Hawall } \\
\text { Maui } \\
\text { Electric } \\
\text { Co } \\
\text { Lid }\end{array}$ \\
\hline 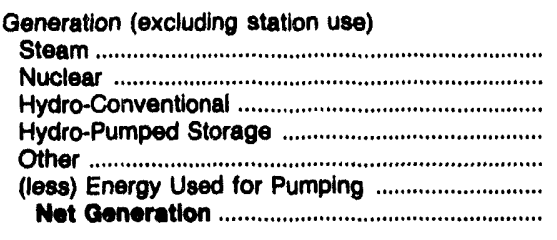 & $\begin{array}{r}9,829,644 \\
0 \\
0 \\
0 \\
884 \\
0 \\
0,830,528\end{array}$ & $\begin{array}{r}16,286,390 \\
0 \\
0 \\
0 \\
62,868 \\
0 \\
16,349,258\end{array}$ & $\begin{array}{r}48,048,755 \\
13,271,520 \\
2,021,182 \\
188,449 \\
30,864 \\
260,283 \\
63,300,507\end{array}$ & $\begin{array}{r}561,824 \\
0 \\
0 \\
0 \\
1,181 \\
0 \\
0 \\
683,005\end{array}$ & $\begin{array}{r}5,034,383 \\
0 \\
0 \\
0 \\
4,031 \\
0 \\
5,028,414\end{array}$ & $\begin{array}{r}260,538 \\
0 \\
0 \\
0 \\
579,771 \\
0 \\
240,300\end{array}$ \\
\hline 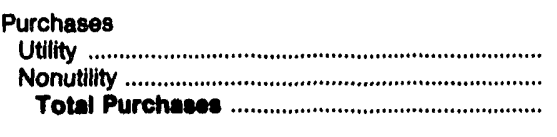 & $\begin{array}{r}1,370,256 \\
5,085 \\
1,376,341\end{array}$ & $\begin{array}{l}214,123 \\
413,025 \\
627,148\end{array}$ & $\begin{array}{r}13,688,437 \\
6,091 \\
13,694,528\end{array}$ & $\begin{array}{r}3,189,920 \\
654 \\
3,200,574\end{array}$ & $\begin{array}{r}0 \\
2,022,743 \\
2,022,743\end{array}$ & $\begin{array}{r}0 \\
120,684 \\
120,604\end{array}$ \\
\hline 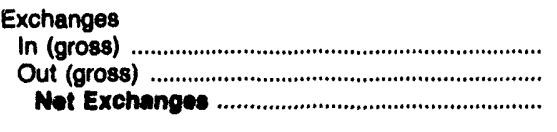 & $\begin{array}{l}0 \\
0 \\
0\end{array}$ & $\begin{array}{l}0 \\
0 \\
0\end{array}$ & $\begin{array}{l}0 \\
0 \\
0\end{array}$ & $\begin{array}{r}378,294 \\
378,359 \\
-65\end{array}$ & $\begin{array}{l}0 \\
0 \\
0\end{array}$ & $\begin{array}{r}3,645 \\
3,054 \\
501\end{array}$ \\
\hline 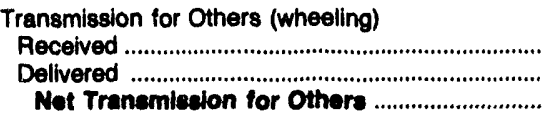 & $\begin{array}{l}0 \\
0 \\
0\end{array}$ & $\begin{array}{r}59,012 \\
58,052 \\
\mathbf{9 0 0}\end{array}$ & $\begin{array}{r}2,067,345 \\
863,945 \\
1,203,400\end{array}$ & $\begin{array}{l}0 \\
0 \\
0\end{array}$ & $\begin{array}{l}0 \\
0 \\
0\end{array}$ & $\begin{array}{l}0 \\
0 \\
0\end{array}$ \\
\hline 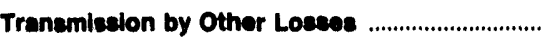 & $\mathbf{0}$ & -382 & o & o & 0 & o \\
\hline $\begin{array}{l}\text { Total Not Energy Gonorated } \\
\text { and Recolved }\end{array}$ & $11,205,860$ & $16,976,984$ & $78,198,435$ & $3,763,514$ & $7,061,157$ & 061,694 \\
\hline 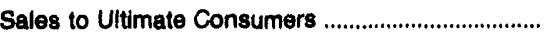 & $8,161,835$ & $13,551,758$ & $55,614,242$ & $3,142,224$ & $6,650,449$ & 890,681 \\
\hline 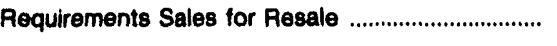 & 282,852 & 178,238 & $1,827,430$ & 0 & 0 & 0 \\
\hline 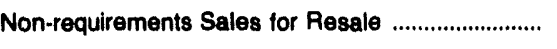 & $2,356,827$ & $2,531,800$ & $17,362,853$ & 404,698 & 0 & 0 \\
\hline 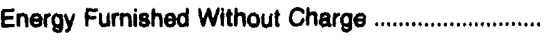 & 16,198 & 0 & 0 & 0 & 16,164 & 0 \\
\hline Energy Used by Company (exc station use) ........... & 18,267 & 33,210 & 133,407 & 57,196 & 0 & 1,587 \\
\hline 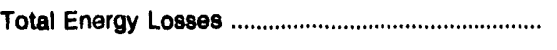 & 369,890 & 681,978 & $3,260,503$ & 159,396 & 394,544 & 68,316 \\
\hline 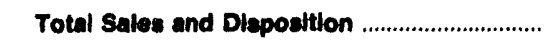 & $11,205,869$ & $16,976,984$ & $78,198,435$ & $3,763,514$ & $7,061,157$ & 961,584 \\
\hline
\end{tabular}

Note: Totals may not equal sum of components because of independent rounding. Double counting occurs in components of both sources and disposition of energy and thus neither provides a true total. Purchases from utilities, net interchanges, and net wheeling (except for imports) are included in net generation. Sales for resale is included in sales to ultimate consumers. Summary data are provided in Table 30 .

Source: Federal Energy Regulatory Commission, FERC Form 1, "Annual Report of Major Electric Utilities, Licensees and Others." 
Table 43. Electric Energy Account by Major U.S. Investor-Ownad Electric Utillty Within State, 1992 (Continued) (Megawatthours)

\begin{tabular}{|c|c|c|c|c|c|c|}
\hline Item & $\begin{array}{l}\text { Idaho } \\
\text { Idaho } \\
\text { Power Co }\end{array}$ & $\begin{array}{l}\text { Illinois } \\
\text { Central } \\
\text { Illinois } \\
\text { Light Co }\end{array}$ & $\begin{array}{l}\text { Illinois } \\
\text { Ceniral } \\
\text { Illinois } \\
\text { Pub } \\
\text { Serv Co }\end{array}$ & $\begin{array}{c}\text { Illinois } \\
\text { Commonwealth } \\
\text { Edison Co }\end{array}$ & $\begin{array}{l}\text { Illinois } \\
\text { Electric } \\
\text { Energy Inc }\end{array}$ & $\begin{array}{l}\text { Illinois } \\
\text { Illinois } \\
\text { Power Co }\end{array}$ \\
\hline 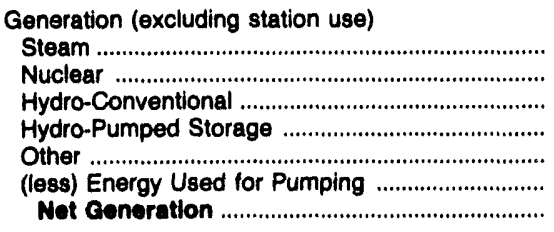 & $\begin{array}{r}7,295,159 \\
0 \\
4,990,264 \\
0 \\
475 \\
0 \\
12,285,898\end{array}$ & $\begin{array}{r}5,412,872 \\
0 \\
0 \\
0 \\
583 \\
0 \\
5,413,455\end{array}$ & $\begin{array}{r}9,349,513 \\
0 \\
0 \\
0 \\
73 \\
0 \\
9,349,586\end{array}$ & $\begin{array}{r}12,578,457 \\
66,682,624 \\
9,754 \\
0 \\
8,337 \\
0 \\
79,278,172\end{array}$ & $\begin{array}{r}7,471,662 \\
0 \\
0 \\
0 \\
0 \\
0 \\
0 \\
7,471,662\end{array}$ & $\begin{array}{r}13,454,576 \\
4,260,835 \\
0 \\
0 \\
369 \\
0 \\
17,715,780\end{array}$ \\
\hline 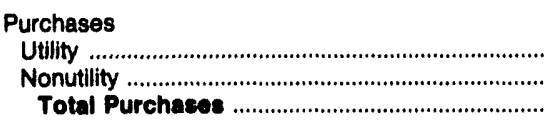 & $\begin{array}{r}1,675,977 \\
479,652 \\
2,155,629\end{array}$ & $\begin{array}{r}181,385 \\
9,860 \\
191,245\end{array}$ & $\begin{array}{r}1,512,925 \\
11 \\
1,512,936\end{array}$ & $\begin{array}{r}3,036,643 \\
128,385 \\
3,165,028\end{array}$ & $\begin{array}{r}7,475,630 \\
0 \\
7,475,630\end{array}$ & $\begin{array}{r}1,603,721 \\
21,339 \\
1,625,060\end{array}$ \\
\hline 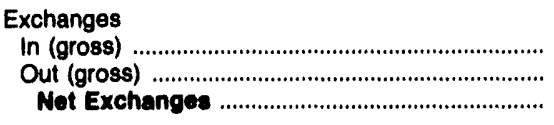 & $\begin{array}{l}514,008 \\
566,829 \\
-52,821\end{array}$ & $\begin{array}{r}364 \\
3,638 \\
-3,274\end{array}$ & $\begin{array}{r}2,411 \\
2,084 \\
327\end{array}$ & $\begin{array}{l}0 \\
0 \\
0\end{array}$ & $\begin{array}{l}0 \\
0 \\
0\end{array}$ & $\begin{array}{l}0 \\
0 \\
0\end{array}$ \\
\hline 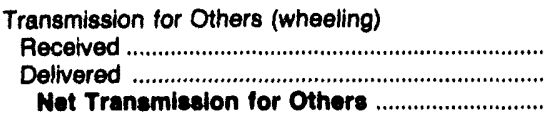 & $\begin{array}{r}3,394,178 \\
3,394,178 \\
0\end{array}$ & $\begin{array}{r}87,369 \\
87,369 \\
0\end{array}$ & $\begin{array}{r}1,406,285 \\
1,365,075 \\
41,210\end{array}$ & $\begin{array}{r}204,973 \\
196,558 \\
\mathbf{8 , 4 1 5}\end{array}$ & $\begin{array}{l}0 \\
0 \\
0\end{array}$ & $\begin{array}{r}402,468 \\
402,468 \\
0\end{array}$ \\
\hline 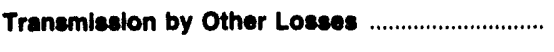 & o & 0 & 0 & 0 & o & 0 \\
\hline $\begin{array}{l}\text { Total Net Energy Gonerated } \\
\text { and Rocolved }\end{array}$ & $14,388,706$ & $5,91,426$ & $10,904,059$ & $82,452,615$ & $14,947,292$ & $19,340,840$ \\
\hline Sales to Ultimate Consumers & $11,606,254$ & $4,972,366$ & $7,327,890$ & $71,065,816$ & $13,583,703$ & $15,581,797$ \\
\hline 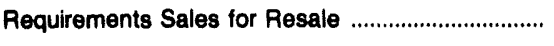 & 143,068 & 14,103 & 0 & $1,154,787$ & $1,297,056$ & 808 \\
\hline 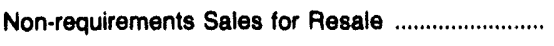 & $1,478,401$ & 428,245 & $3,018,395$ & $3,459,038$ & 0 & $2,966,006$ \\
\hline 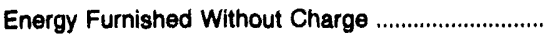 & 0 & 8,763 & 10,113 & 270,107 & 0 & 62,950 \\
\hline Energy Used by Company (exc station use) ........... & 0 & 17,541 & 2,972 & 0 & 0 & 54,186 \\
\hline 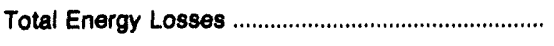 & $1,160,983$ & 160,408 & 544,689 & $6,502,867$ & 66,533 & 675,093 \\
\hline 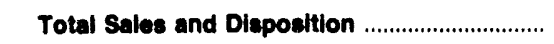 & $14,388,706$ & $5,601,426$ & $10,904,059$ & $82,452,615$ & $14,947,292$ & $19,340,840$ \\
\hline
\end{tabular}

Note: Totals may not equal sum of components because of independent rounding. Double counting occurs in components of both sources and disposition of energy and thus neither provides a true total. Purchases from utitities, net interchanges, and net wheeling (except for imports) are included in net generation. Sales for resale is included in sales to ultimate consumers. Summary data are provided in Table 30.

Source: Federal Energy Regulatory Commission, FERC Form 1. "Annual Report of Major Electric Utilities, Licensees and Others." 
Table 43. Electric Energy Account by Major U.S. Investor-Owned Electric Utillty Within State, 1992 (Continued)

(Megawatthours)

\begin{tabular}{|c|c|c|c|c|c|c|}
\hline Item & $\begin{array}{l}\text { Illinois } \\
\text { Mt } \\
\text { Carmel } \\
\text { Public } \\
\text { Utility Co }\end{array}$ & $\begin{array}{l}\text { Indlana } \\
\text { Alcoa } \\
\text { Generating } \\
\text { Corp }\end{array}$ & $\begin{array}{c}\text { Indlana } \\
\text { AEP } \\
\text { Generating } \\
\text { Co }\end{array}$ & $\begin{array}{c}\text { Indiana } \\
\text { Commonwealth } \\
\text { Edison } \\
\text { Co } \\
\text { IN Inc }\end{array}$ & $\begin{array}{l}\text { Indiana } \\
\text { Indiana } \\
\text { Mlchigan } \\
\text { Power Co }\end{array}$ & $\begin{array}{c}\text { Indiana } \\
\text { Indianapolis } \\
\text { Power } \\
\& \\
\text { Light Co }\end{array}$ \\
\hline 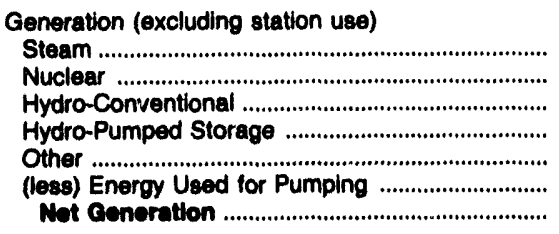 & $\begin{array}{l}0 \\
0 \\
0 \\
0 \\
0 \\
0 \\
0\end{array}$ & $\begin{array}{r}4,375,609 \\
0 \\
0 \\
0 \\
0 \\
0 \\
4,375,609\end{array}$ & $\begin{array}{r}8,595,671 \\
0 \\
0 \\
0 \\
0 \\
0 \\
8,595,671\end{array}$ & $\begin{array}{r}610,165 \\
0 \\
0 \\
0 \\
0 \\
0 \\
610,165\end{array}$ & $\begin{array}{r}11,597,435 \\
6,417,956 \\
100,990 \\
0 \\
99 \\
0 \\
18,118,480\end{array}$ & $\begin{array}{r}12,524,566 \\
0 \\
0 \\
0 \\
369 \\
0 \\
12,524,935\end{array}$ \\
\hline 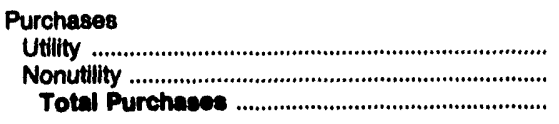 & $\begin{array}{r}164,036 \\
0 \\
164,036\end{array}$ & $\begin{array}{r}797,319 \\
0 \\
797,310\end{array}$ & $\begin{array}{r}96 \\
0 \\
96\end{array}$ & $\begin{array}{l}0 \\
0 \\
0\end{array}$ & $\begin{array}{r}9,341,916 \\
0 \\
9,341,916\end{array}$ & $\begin{array}{r}126,205 \\
0 \\
126,205\end{array}$ \\
\hline $\begin{array}{l}\text { Exchanges } \\
\text { In (gross) } \\
\text { Out (gross) } \\
\text { Not Exchanges }\end{array}$ & $\begin{array}{l}0 \\
0 \\
0\end{array}$ & $\begin{array}{r}150,652 \\
151,616 \\
-394\end{array}$ & $\begin{array}{l}0 \\
0 \\
0\end{array}$ & $\begin{array}{l}0 \\
0 \\
0\end{array}$ & $\begin{array}{l}0 \\
0 \\
0\end{array}$ & $\begin{array}{r}2,446 \\
2,868 \\
-522\end{array}$ \\
\hline 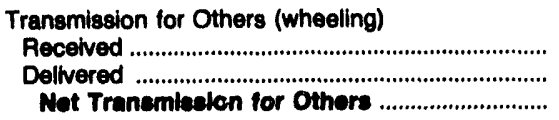 & $\begin{array}{l}0 \\
0 \\
0\end{array}$ & $\begin{array}{l}0 \\
0 \\
0\end{array}$ & $\begin{array}{l}0 \\
0 \\
0\end{array}$ & $\begin{array}{l}0 \\
0 \\
0\end{array}$ & $\begin{array}{r}1,258,601 \\
1,258,601 \\
0\end{array}$ & $\begin{array}{l}0 \\
0 \\
0\end{array}$ \\
\hline Tranemisalon by Other Loseses ................................ & $\mathbf{0}$ & $\mathbf{0}$ & $\mathbf{0}$ & $\mathbf{0}$ & $\mathbf{0}$ & $\mathbf{0}$ \\
\hline 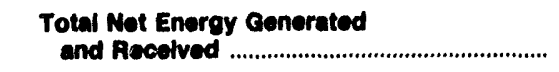 & 164,036 & $5,172,534$ & $8,595,767$ & 610,165 & $27,458,398$ & $12,650,618$ \\
\hline 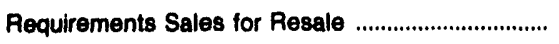 & 2,882 & 0 & 0 & 0 & $2,794,160$ & 23,232 \\
\hline 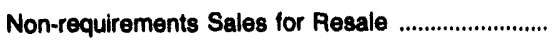 & 0 & 0 & $8,595,767$ & 610,165 & $8,937,280$ & 169,078 \\
\hline 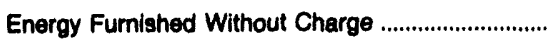 & 364 & 0 & 0 & 0 & 75 & 0 \\
\hline Energy Used by Company (exc station use) ........... & 386 & 0 & 0 & 0 & 25,801 & 30,569 \\
\hline 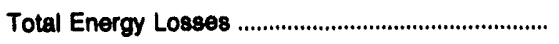 & 10,428 & 6,922 & 0 & 0 & $1,441,131$ & 675,298 \\
\hline Total Bales and Diaposition ............................. & 164,036 & $5,172,534$ & $8,595,767$ & 610,165 & $27,458,396$ & $12,650,618$ \\
\hline
\end{tabular}

Note: Totals may not equal sum of components because of independent rounding. Double counting occurs in components of both sources and disposition of energy and thus neither provides a true total. Purchases from utilities, net interchanges, and net wheellng (except for imports) are included in net generation. Sales for resale is included in sales to ultimate consumers. Summary data are provided in Table 30.

Source: Federal Energy Regulatory Commission, FERC Form 1, "Annual Report of Major Electric Utilities, Licensees and Others." 
Table 43. Electric Energy Account by Major U.S. Investor-Owned Electric Utility Within State, 1992 (Continued)

(Megawatthours)

\begin{tabular}{|c|c|c|c|c|c|c|}
\hline Item & $\begin{array}{l}\text { Indiana } \\
\text { Northern } \\
\text { Indiana } \\
\text { Pub Sern } \\
\text { Co }\end{array}$ & $\begin{array}{l}\text { Indiana } \\
\text { PSI } \\
\text { Energy Inc }\end{array}$ & $\begin{array}{l}\text { Indiana } \\
\text { Southern } \\
\text { Indiana Gas } \\
\text { \& Elec Co }\end{array}$ & $\begin{array}{l}\text { lowa } \\
\text { Interstate } \\
\text { Power Co }\end{array}$ & $\begin{array}{c}\text { lowa } \\
\text { lowa } \\
\text { Electric } \\
\text { Light \& Power } \\
\text { Co }\end{array}$ & $\begin{array}{l}\text { lowa } \\
\text { lowa } \\
\text { Southern } \\
\text { Utilities } \\
\text { Co }\end{array}$ \\
\hline 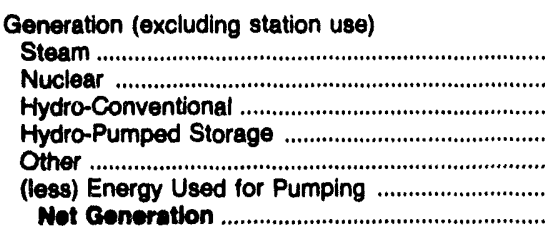 & $\begin{array}{r}14,188,336 \\
0 \\
68,844 \\
0 \\
4,820 \\
0 \\
14,262,000\end{array}$ & $\begin{array}{r}25,854,763 \\
0 \\
447,816 \\
0 \\
100 \\
0 \\
26,302,679\end{array}$ & $\begin{array}{r}5,218,636 \\
0 \\
0 \\
0 \\
0,011 \\
0 \\
0 \\
5,224,647\end{array}$ & $\begin{array}{r}3,194,988 \\
0 \\
0 \\
0 \\
-116 \\
0 \\
3,194,872\end{array}$ & $\begin{array}{r}1,451,241 \\
2,402,501 \\
7,579 \\
0 \\
0,886 \\
0 \\
0 \\
3,865,207\end{array}$ & $\begin{array}{r}2,862,827 \\
0 \\
0 \\
0 \\
-1,166 \\
0 \\
2,861,761\end{array}$ \\
\hline 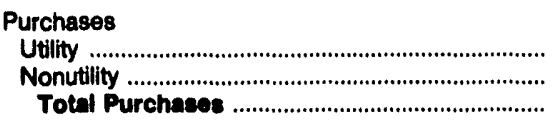 & $\begin{array}{r}694,097 \\
9,055 \\
703,152\end{array}$ & $\begin{array}{r}925,175 \\
0 \\
925,175\end{array}$ & $\begin{array}{r}193,793 \\
0 \\
193,793\end{array}$ & $\begin{array}{r}1,899,026 \\
0 \\
1,899,026\end{array}$ & $\begin{array}{r}2,220,368 \\
3,945 \\
2,224,313\end{array}$ & $\begin{array}{r}15,464 \\
0 \\
15,464\end{array}$ \\
\hline $\begin{array}{l}\text { Exchanges } \\
\text { In (gross) } \\
\text { Out (gross) }\end{array}$ & $\begin{array}{r}1,114 \\
946 \\
168\end{array}$ & $\begin{array}{r}84,687 \\
84,930 \\
-243\end{array}$ & $\begin{array}{l}0 \\
0 \\
0\end{array}$ & $\begin{array}{l}0 \\
0 \\
0\end{array}$ & $\begin{array}{r}22,767 \\
22,540 \\
227\end{array}$ & $\begin{array}{r}1,070,480 \\
1,238,435 \\
-167,955\end{array}$ \\
\hline 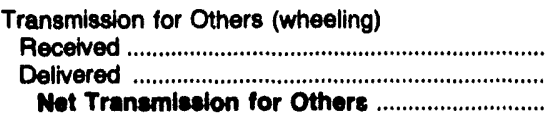 & $\begin{array}{r}952,000 \\
952,000 \\
0\end{array}$ & $\begin{array}{r}5,128,808 \\
5,042,215 \\
86,593\end{array}$ & $\begin{array}{r}36,879 \\
36,879 \\
0\end{array}$ & $\begin{array}{r}987,554 \\
957,310 \\
30,244\end{array}$ & $\begin{array}{r}326,729 \\
324,644 \\
2,085\end{array}$ & $\begin{array}{r}201,992 \\
195,246 \\
6,746\end{array}$ \\
\hline 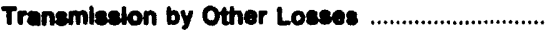 & $\mathbf{0}$ & $-5,877$ & $\mathbf{0}$ & 0 & -948 & $-2,403$ \\
\hline 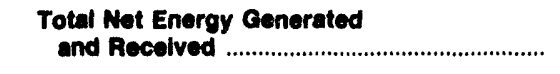 & $14,965,320$ & $27,308,327$ & $5,418,440$ & $5,124,142$ & $6,080,886$ & $2,713,613$ \\
\hline 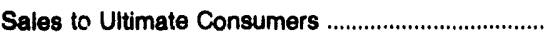 & $13,271,106$ & $19,460,853$ & $3,953,180$ & $4,534,839$ & $4,274,932$ & $2,361,162$ \\
\hline 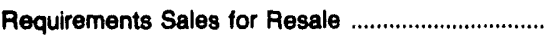 & 210,804 & $1,470,561$ & 272,194 & 189,523 & 362,967 & 170,585 \\
\hline 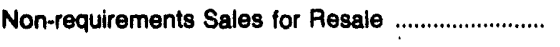 & 951,201 & $4,819,649$ & 993,102 & 79,894 & $1,034,778$ & 0 \\
\hline 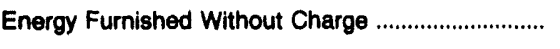 & 0 & 0 & $-1,985$ & 50 & 0 & 0 \\
\hline Energy Used by Company (exc station use) ............ & 0 & 61,388 & 2,922 & 7,924 & 15,630 & 6,678 \\
\hline 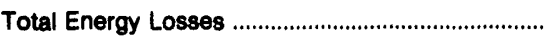 & 532,209 & $1,495,876$ & 199,025 & 311,912 & 402,579 & 175,188 \\
\hline 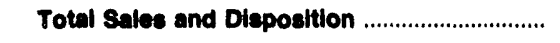 & $14,965,320$ & $27,308,327$ & $5,418,440$ & $5,124,142$ & $6,090,886$ & $2,713,613$ \\
\hline
\end{tabular}

Note: Totals may not equal sum of components because of independent rounding. Double counting occurs in components of both sources and disposition of energy and thus neither provides a true total. Purchases from utilities, net interchanges, and net wheeling (except for imports) are included in net generation. Sales for resale is included in sales to ultimate consumers. Summary data are provided in Table 30.

Source: Federal Energy Regulatory Commission, FERC Form 1, "Annual Report of Major Electric Utilities, Licensees and Others." 
Table 43. Electric Energy Account by Major U.S. Investor-Owned Electric Utility Within State, 1992 (Continued)

(Megawatthours)

\begin{tabular}{|c|c|c|c|c|c|c|}
\hline Item & $\begin{array}{c}\text { lowa } \\
\text { lowa- } \\
\text { llinols } \\
\text { Gas\&Eloctric } \\
\text { Co } \\
\end{array}$ & $\begin{array}{l}\text { lowa } \\
\text { Midwest } \\
\text { Power } \\
\text { Systems } \\
\text { Inc }\end{array}$ & $\begin{array}{c}\text { Kansas } \\
\text { Kansas } \\
\text { Gas } \\
\& \\
\text { Electric Co }\end{array}$ & $\begin{array}{l}\text { Kansas } \\
\text { Western } \\
\text { Resources } \\
\text { Inc }\end{array}$ & $\begin{array}{l}\text { Kentucky } \\
\text { Kentucky } \\
\text { Power Co }\end{array}$ & $\begin{array}{l}\text { Kentucky } \\
\text { Kentucky } \\
\text { Utilities Co }\end{array}$ \\
\hline 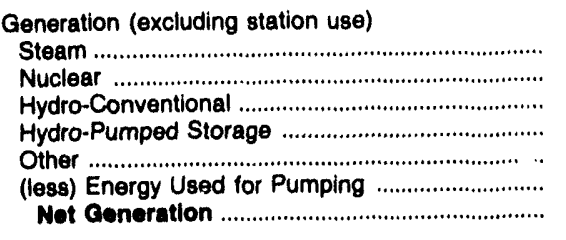 & $\begin{array}{r}3,825,219 \\
2,110,319 \\
18,296 \\
0 \\
-358 \\
0 \\
5,953,476\end{array}$ & $\begin{array}{r}9,731,462 \\
0 \\
0 \\
0 \\
21,314 \\
0 \\
9,752,776\end{array}$ & $\begin{array}{r}4,935,407 \\
3,990,599 \\
0 \\
0 \\
0 \\
0 \\
0 \\
8,926,006\end{array}$ & $\begin{array}{r}8,802,635 \\
0 \\
0 \\
0 \\
15,399 \\
0 \\
0,818,034\end{array}$ & $\begin{array}{r}6,889,525 \\
0 \\
0 \\
0 \\
0 \\
0 \\
6,889,525\end{array}$ & $\begin{array}{r}13,637,853 \\
0 \\
62,588 \\
0 \\
-128 \\
0 \\
13,700,313\end{array}$ \\
\hline 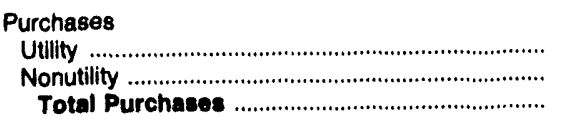 & $\begin{array}{r}268,557 \\
3,268 \\
271,825\end{array}$ & $\begin{array}{r}5,320,513 \\
1,569 \\
5,322,082\end{array}$ & $\begin{array}{r}545,203 \\
27 \\
545,230\end{array}$ & $\begin{array}{r}663,584 \\
10,066 \\
673,650\end{array}$ & $\begin{array}{r}3,418,087 \\
0 \\
3,418,087\end{array}$ & $\begin{array}{r}2,032,110 \\
0 \\
2,032,110\end{array}$ \\
\hline 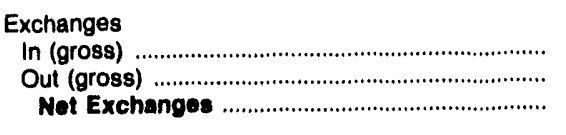 & $\begin{array}{l}0 \\
0 \\
0\end{array}$ & $\begin{array}{l}0 \\
0 \\
0\end{array}$ & $\begin{array}{r}21,621 \\
469,533 \\
-447,912\end{array}$ & $\begin{array}{r}472,409 \\
24,381 \\
448,028\end{array}$ & $\begin{array}{l}0 \\
0 \\
0\end{array}$ & $\begin{array}{r}399,423 \\
396,030 \\
3,393\end{array}$ \\
\hline 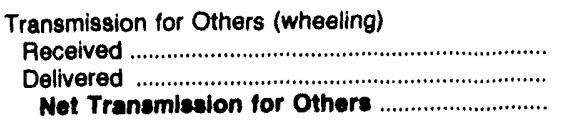 & $\begin{array}{l}0 \\
0 \\
0\end{array}$ & $\begin{array}{r}1,672,315 \\
1,586,733 \\
85,582\end{array}$ & $\begin{array}{r}225,466 \\
225,466 \\
0\end{array}$ & $\begin{array}{r}249,277 \\
237,163 \\
12,114\end{array}$ & $\begin{array}{r}189,138 \\
189,138 \\
0\end{array}$ & $\begin{array}{r}893,952 \\
893,952 \\
0\end{array}$ \\
\hline 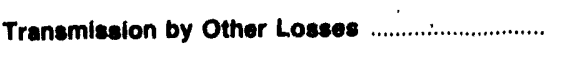 & 0 & 0 & 0 & 0 & $\mathbf{0}$ & $\mathbf{0}$ \\
\hline $\begin{array}{l}\text { Total Net Energy Gonerated } \\
\text { and Rocelved ...................................................... }\end{array}$ & $6,225,301$ & $15,160,440$ & $9,023,324$ & $9,951,626$ & $10,307,612$ & $15,735,816$ \\
\hline 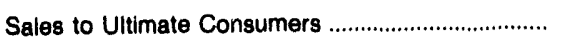 & $4,589,440$ & $8,858,682$ & $7,287,278$ & $7,270,291$ & $5,705,743$ & $12,551,782$ \\
\hline 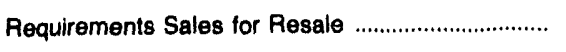 & 5,869 & 141,784 & 994,483 & $1,252,989$ & 26,536 & $1,421,193$ \\
\hline 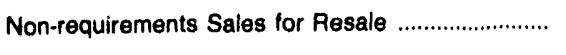 & $1,295,580$ & $4,943,252$ & 254,630 & 784,442 & $4,078,243$ & 885,979 \\
\hline 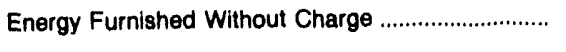 & 30,908 & 0 & 0 & 0 & 0 & 1,757 \\
\hline Energy Used by Company (exc station usb) ............ & 19,911 & 21,977 & 24,750 & 27,245 & 0 & 20,153 \\
\hline 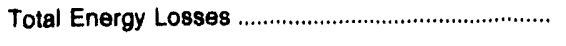 & 283,593 & $1,194,745$ & 462,183 & 616,859 & 497,090 & 854,952 \\
\hline 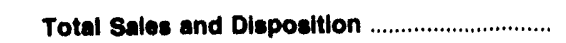 & $6,225,301$ & $15,160,440$ & $9,023,324$ & $9,951,826$ & $10,307,612$ & $15,735,816$ \\
\hline
\end{tabular}

Note: Totals may not equal sum of components because of independent rounding. Double counting occurs in components of both sources and disposition of benergy and thus neither provides a true total. Purchases from utilities, net interchanges, and net wheeling (except for imports) are included in net generation. Sales for resale is included in sales to ultimate consumers. Summary data are provided in Table 30.

Source: Federal Energy Regulatory Commission, FERC Form 1. "Annual Report of Major Electric Utilities, Licensees and Others." 
Table 43. Electric Energy Account by Major U.S. Inveator-Owned Electric Utility Within State, 1992 (Continued)

(Megawatthours)

\begin{tabular}{|c|c|c|c|c|c|c|}
\hline Item & $\begin{array}{l}\text { Kentucky } \\
\text { Louisville } \\
\text { Gas } \\
8 \\
\text { Electric Co }\end{array}$ & $\begin{array}{l}\text { Kentucky } \\
\text { Union Light } \\
\text { Heat \& Power } \\
\text { Co }\end{array}$ & $\begin{array}{l}\text { Louisiana } \\
\text { Central } \\
\text { Louisiana } \\
\text { Elec } \\
\text { Co inc } \\
\end{array}$ & $\begin{array}{c}\text { Louisiana } \\
\text { Louisiana } \\
\text { Power } \\
8 \\
\text { Light Co }\end{array}$ & $\begin{array}{l}\text { Louisiana } \\
\text { New Orleans } \\
\text { Public } \\
\text { Service inc }\end{array}$ & $\begin{array}{l}\text { Louldiana } \\
\text { Southwestern } \\
\text { Electric } \\
\text { Power Co }\end{array}$ \\
\hline 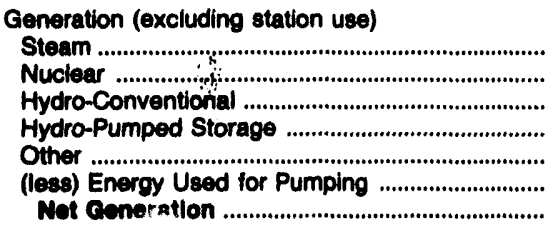 & $\begin{array}{r}11,753,865 \\
0 \\
413,264 \\
0 \\
1,722 \\
0 \\
12,168,051\end{array}$ & $\begin{array}{l}0 \\
0 \\
0 \\
0 \\
0 \\
0 \\
0\end{array}$ & $\begin{array}{r}6,029,498 \\
0 \\
0 \\
0 \\
113 \\
0 \\
6,020,612\end{array}$ & $\begin{array}{r}10,571,857 \\
7,616,865 \\
0 \\
0 \\
729 \\
0 \\
18,189,651\end{array}$ & $\begin{array}{r}2,219,406 \\
0 \\
0 \\
0 \\
0 \\
0 \\
2,219,408\end{array}$ & $\begin{array}{r}16,196,468 \\
0 \\
0 \\
0 \\
0 \\
0 \\
16,198,498\end{array}$ \\
\hline 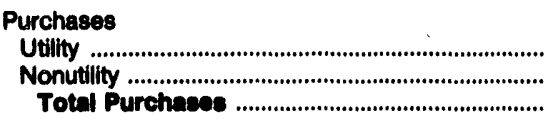 & $\begin{array}{r}8 \angle 3,728 \\
0 \\
828,720\end{array}$ & $\begin{array}{r}2,935,418 \\
0 \\
2,936,418\end{array}$ & $\begin{array}{r}523,643 \\
1 \\
523,644\end{array}$ & $\begin{array}{r}10,551,215 \\
741,531 \\
11,202,746\end{array}$ & $\begin{array}{r}3,640,429 \\
496 \\
3,640,026\end{array}$ & $\begin{array}{r}1,513,801 \\
9,024 \\
1,522,025\end{array}$ \\
\hline $\begin{array}{l}\text { Exchanges } \\
\text { In (gross) }\end{array}$ & $\begin{array}{r}20,856 \\
27,494 \\
-6,638\end{array}$ & $\begin{array}{l}0 \\
0 \\
0\end{array}$ & $\begin{array}{l}0 \\
0 \\
0\end{array}$ & $\begin{array}{l}0 \\
0 \\
0\end{array}$ & $\begin{array}{l}0 \\
0 \\
0\end{array}$ & $\begin{array}{l}0 \\
0 \\
0\end{array}$ \\
\hline 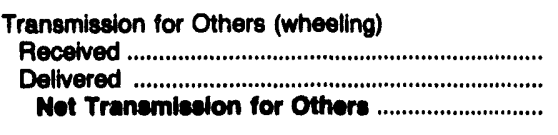 & $\begin{array}{r}165,370 \\
165,370 \\
0\end{array}$ & $\begin{array}{l}0 \\
0 \\
0\end{array}$ & $\begin{array}{r}3,139,038 \\
3,139,038 \\
0\end{array}$ & $\begin{array}{l}0 \\
0 \\
0\end{array}$ & $\begin{array}{l}0 \\
0 \\
0\end{array}$ & $\begin{array}{r}625,429 \\
625,429 \\
0\end{array}$ \\
\hline 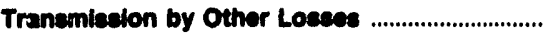 & $\mathbf{0}$ & 0 & $\mathbf{0}$ & $\mathbf{0}$ & 0 & $\mathbf{0}$ \\
\hline 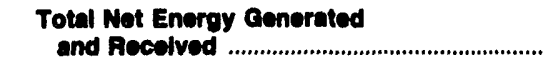 & $12,900,942$ & $2,935,418$ & $6,563,256$ & $29,492,297$ & $6,860,331$ & $17,719,293$ \\
\hline 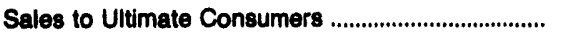 & $9,234,911$ & $2,807,171$ & $5,863,212$ & $26,701,341$ & $5,129,622$ & $12,876,170$ \\
\hline 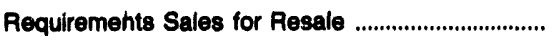 & 0 & 43,108 & 10,479 & 0 & 0 & $2,377,744$ \\
\hline Non-requirements Sales for Resale ............................. & $3,234,758$ & 0 & 224,125 & $1,305,067$ & 404,823 & $1,476,439$ \\
\hline Energy Furnished Without Charge ............................. & 637 & 0 & 5,044 & 0 & 0 & 481 \\
\hline Energy Used by Company (exc station use) ........... & 120,551 & 817 & 8,709 & 36,092 & 7,104 & 66,922 \\
\hline 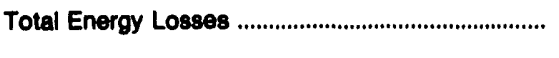 & 400,085 & 84,322 & 441,693 & $1,439,787$ & 318,782 & 821,537 \\
\hline Total Sales and Dlepoation ................................ & $12,900,942$ & $2,035,418$ & $6,658,263$ & $20,482,207$ & $5,860,381$ & $17,710,203$ \\
\hline
\end{tabular}

Note: Totals may not equal sum of components because of independent rounding. Double counting occurs in components of both sources and disposition of energy and thus neither provides a true total. Purchases from utilties, net interchanges, and net wheeling (except for imports) are included in net generation. Sales for resale is included in sales to ultimate consumers. Summary data are provided in Table 30.

Source: Federal Energy Regulatory Commission, FERC Form 1, "Annual Report of Major Electric Utilities, Licensees and Others." 
Table 43. Electric Energy Account by Major U.S. Investor-Owned Electric Utility Within State, 1992 (Continued)

(Megawatthours)

\begin{tabular}{|c|c|c|c|c|c|c|}
\hline Item & $\begin{array}{l}\text { Maine } \\
\text { Bangor } \\
\text { Hydro- } \\
\text { Electric } \\
\text { Co } \\
\end{array}$ & $\begin{array}{l}\text { Maine } \\
\text { Central } \\
\text { Maine } \\
\text { Power } \\
\text { Co } \\
\end{array}$ & $\begin{array}{l}\text { Maine } \\
\text { Maine } \\
\text { Electric } \\
\text { Power } \\
\text { Co Inc } \\
\end{array}$ & $\begin{array}{c}\text { Maine } \\
\text { Maine } \\
\text { Public } \\
\text { Service } \\
\text { Co }\end{array}$ & $\begin{array}{c}\text { Maine } \\
\text { Maine } \\
\text { Yankee } \\
\text { Atomic } \\
\text { Power Co }\end{array}$ & $\begin{array}{c}\text { Maryland } \\
\text { Baltimore } \\
\text { Gas } \\
\& \\
\text { Electric Co }\end{array}$ \\
\hline 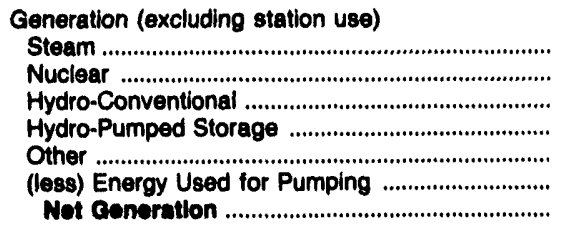 & $\begin{array}{r}78,125 \\
0 \\
189,762 \\
0 \\
1,519 \\
0 \\
0 \\
279,408\end{array}$ & $\begin{array}{r}915,115 \\
164,539 \\
1,503,013 \\
0 \\
-448 \\
0 \\
0 \\
2,582,215\end{array}$ & $\begin{array}{l}0 \\
0 \\
0 \\
0 \\
0 \\
0 \\
0\end{array}$ & $\begin{array}{r}33,509 \\
0 \\
0,369 \\
0 \\
-627 \\
0 \\
0 \\
39,251\end{array}$ & $\begin{array}{r}0 \\
5,357,999 \\
0 \\
0 \\
0 \\
0 \\
5,357,900\end{array}$ & $\begin{array}{r}14,933,127 \\
10,663,950 \\
0 \\
0 \\
28,621 \\
0 \\
25,825,608\end{array}$ \\
\hline 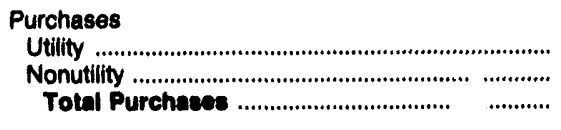 & $\begin{array}{r}1,123,537 \\
426,236 \\
1,549,773\end{array}$ & $\begin{array}{l}3,633,472 \\
3,846,353 \\
7,479,025\end{array}$ & $\begin{array}{r}341,711 \\
0 \\
341,711\end{array}$ & $\begin{array}{l}531,201 \\
131,896 \\
663,097\end{array}$ & $\begin{array}{l}0 \\
0 \\
0\end{array}$ & $\begin{array}{r}2,843,350 \\
332,337 \\
3,175,697\end{array}$ \\
\hline 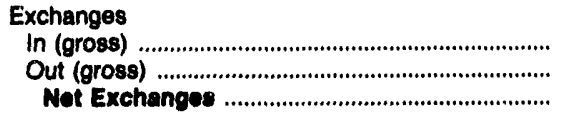 & $\begin{array}{l}0 \\
0 \\
0\end{array}$ & $\begin{array}{l}0 \\
0 \\
0\end{array}$ & $\begin{array}{l}0 \\
0 \\
0\end{array}$ & $\begin{array}{r}0 \\
2,232 \\
-2,232\end{array}$ & $\begin{array}{l}0 \\
0 \\
0\end{array}$ & $\begin{array}{r}1,147,276 \\
0 \\
1,147,276\end{array}$ \\
\hline 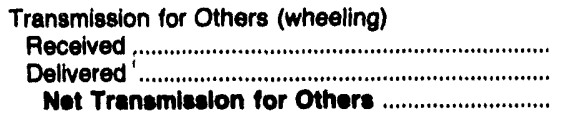 & $\begin{array}{r}71,747 \\
71,747 \\
0\end{array}$ & $\begin{array}{r}4,571,359 \\
4,571,359 \\
0\end{array}$ & $\begin{array}{r}2,426,896 \\
2,426,896 \\
0\end{array}$ & $\begin{array}{r}268,256 \\
269,256 \\
0\end{array}$ & $\begin{array}{l}0 \\
0 \\
0\end{array}$ & $\begin{array}{l}0 \\
0 \\
0\end{array}$ \\
\hline 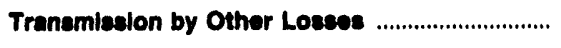 & 0 & 0 & 0 & 0 & 0 & 0 \\
\hline 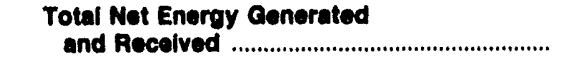 & $1,829,179$ & $10,062,044$ & 341,711 & 700,116 & $5,357,900$ & $29,948,681$ \\
\hline 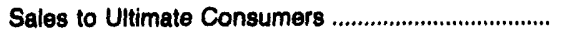 & $1,574,527$ & $9,062,878$ & 0 & 523,852 & 0 & $25,307,432$ \\
\hline 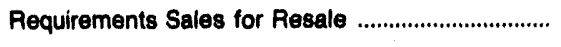 & 10,462 & 118,675 & 0 & 98,850 & 0 & $3,179,408$ \\
\hline 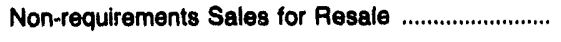 & 112,425 & 319,496 & 341.711 & 33,052 & $5,342,773$ & 0 \\
\hline 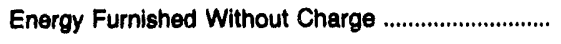 & 0 & 3,197 & 0 & 0 & 0 & 0 \\
\hline Energy Used by Company (exc station use) ............ & 5,150 & 21,312 & 0 & 1,012 & 0 & 111,768 \\
\hline 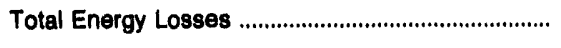 & 126,615 & 536,386 & 0 & 42,350 & 15,226 & $1,350,053$ \\
\hline Total Sales and Dieposition ................................ & $1,829,179$ & $10,062,044$ & 341,711 & 700,116 & $5,357,990$ & $29,048,861$ \\
\hline
\end{tabular}

Note: Totals may not equal sum of components because of independent rounding. Double counting occurs in components of both sources and disposition of energy and thus neither provides a true total. Purchases from utilities, net interchanges, and net wheeling (except for imports) are included in net generation. Sales for resale is included in sales to ultimate consumers. Summary data are provided in Table 30.

Source: Federal Energy Regulatory Commission, FERC Form 1, "Annual Report of Major Electric Utilities, Licensees and Others." 
Table 43. Electric Energy Account by Major U.S. Investor-Owned Electric Utility Within State, 1992 (Continued)

(Megawatthours)

\begin{tabular}{|c|c|c|c|c|c|c|}
\hline liem & $\begin{array}{l}\text { Maryland } \\
\text { Potomac } \\
\text { Edison Co }\end{array}$ & $\begin{array}{l}\text { Massachugetts } \\
\text { Boston } \\
\text { Edison Co }\end{array}$ & $\begin{array}{l}\text { Massachusetts } \\
\text { Cambridge } \\
\text { Electric } \\
\text { Light Co }\end{array}$ & $\begin{array}{l}\text { Massachusetts } \\
\text { Canal } \\
\text { Electric Co }\end{array}$ & $\begin{array}{l}\text { Massachusetts } \\
\text { Commonwealth } \\
\text { Electric Co }\end{array}$ & $\begin{array}{l}\text { Massachusetts } \\
\text { Eastern } \\
\text { Edison Co }\end{array}$ \\
\hline$T$ & & & & & & \\
\hline 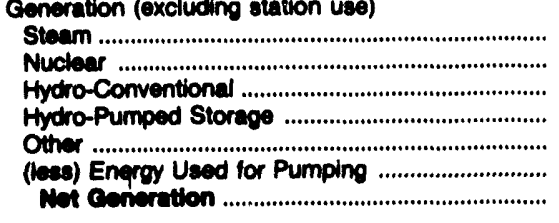 & $\begin{array}{r}10,713,987 \\
0 \\
32,681 \\
318,374 \\
0 \\
407,393 \\
10,067,629\end{array}$ & $\begin{array}{r}6,929,172 \\
4,741,868 \\
0 \\
0 \\
8,683 \\
0 \\
11,079,023\end{array}$ & $\begin{array}{r}102,047 \\
0 \\
0 \\
0 \\
019 \\
0 \\
102,068\end{array}$ & $\begin{array}{r}4,764,312 \\
273,859 \\
0 \\
0 \\
64 \\
0 \\
6,038,235\end{array}$ & $\begin{array}{r}25,544 \\
0 \\
0 \\
0 \\
190 \\
0 \\
25,734\end{array}$ & $\begin{array}{l}0 \\
0 \\
0 \\
0 \\
0 \\
0 \\
0\end{array}$ \\
\hline 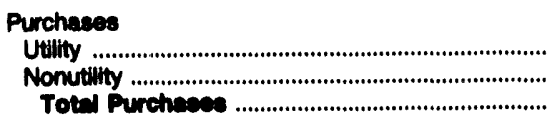 & $\begin{array}{r}6,928,644 \\
0 \\
6,928,644\end{array}$ & $\begin{array}{l}3,464,610 \\
2,916,737 \\
6,381,347\end{array}$ & $\begin{array}{r}1,480,388 \\
0 \\
1,400,396\end{array}$ & $\begin{array}{r}460,855 \\
0 \\
460,8555\end{array}$ & $\begin{array}{l}2,913,225 \\
1,509,454 \\
4,422,670\end{array}$ & $\begin{array}{r}2,561,133 \\
214 \\
2,561,347\end{array}$ \\
\hline 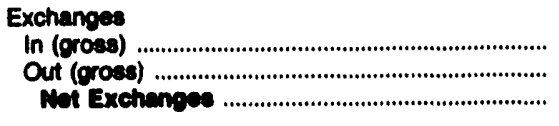 & $\begin{array}{r}203,888 \\
195,495 \\
8,393\end{array}$ & $\begin{array}{l}0 \\
0 \\
0\end{array}$ & $\begin{array}{l}0 \\
0 \\
0\end{array}$ & $\begin{array}{l}0 \\
0 \\
0\end{array}$ & $\begin{array}{l}0 \\
0 \\
0\end{array}$ & $\begin{array}{l}0 \\
0 \\
0\end{array}$ \\
\hline 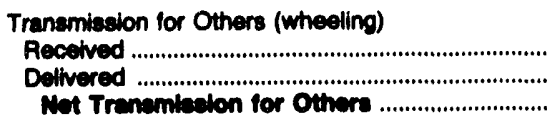 & $\begin{array}{r}238,214 \\
238,214 \\
0\end{array}$ & $\begin{array}{r}4,797,306 \\
4,797,306 \\
0\end{array}$ & $\begin{array}{l}0 \\
0 \\
0\end{array}$ & $\begin{array}{l}0 \\
0 \\
0\end{array}$ & $\begin{array}{l}0 \\
0 \\
0\end{array}$ & $\begin{array}{l}0 \\
0 \\
0\end{array}$ \\
\hline Trenembealon by Other Loeses ................................ & 0 & o & 0 & 0 & 0 & 0 \\
\hline $\begin{array}{l}\text { Total Mot Energy Conerated } \\
\text { and Recelved }\end{array}$ & $17,594,606$ & $18,001,170$ & $1,503,354$ & $5,490,080$ & $4,440,413$ & $2,581,347$ \\
\hline 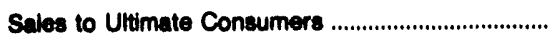 & $10,777,749$ & $12,597,607$ & $1,298,313$ & 0 & $3,206,036$ & $2,458,593$ \\
\hline 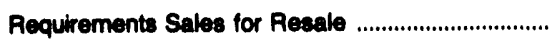 & 588,053 & 524,797 & 99,330 & 0 & 0 & 0 \\
\hline 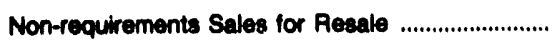 & $5,400,546$ & $3,890,509$ & 155,018 & $5,499,090$ & 991,954 & 0 \\
\hline 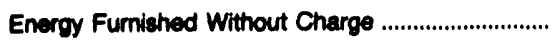 & 0 & 0 & 0 & 0 & 0 & 0 \\
\hline Energy Used by Company (exc station use) ........... & 16,274 & 92,188 & 1,232 & 0 & 8,779 & 3,515 \\
\hline Total Energy Losses & 812,044 & 956,069 & 39,461 & 0 & 241,644 & 99,239 \\
\hline Total sales and Diepoctition .................................. & $17,594,606$ & $18,061,170$ & $1,503,364$ & $5,490,000$ & $4,446,413$ & $2,581,347$ \\
\hline
\end{tabular}

Note: Totals may not equal sum of components because of independent rounding. Double counting occurs in components of both sources and disposition of energy and thus neither provides a true total. Purchases from utilties, net interchanges, and net wheeling (except for imports) are included in net generation. Sales for resale is included in sales to ultimate consumers. Summary data are provided in Table 30.

Source: Federal Energy Regulatory Commiseion, FERC Form 1, "Annual Report of Major Electric Utilities, Licensees and Others." 
Table 43. Electric Energy Account by Major U.S. Investor-Owned Electric Utility Within State, 1992 (Continued)

(Megawatthours)

\begin{tabular}{|c|c|c|c|c|c|c|}
\hline Item & $\begin{array}{c}\text { Massachusetts } \\
\text { Fitchburg } \\
\text { Gas \& } \\
\text { Elec Light Co }\end{array}$ & $\begin{array}{c}\text { Massachusetts } \\
\text { Holyoke } \\
\text { Power } \\
\& \\
\text { Electric Co } \\
\end{array}$ & $\begin{array}{c}\text { Massachusetts } \\
\text { Holyoke } \\
\text { Water } \\
\text { Power } \\
\text { Co }\end{array}$ & $\begin{array}{l}\text { Massachusetts } \\
\text { Massachusetts } \\
\text { Electric Co }\end{array}$ & $\begin{array}{c}\text { Massachusetts } \\
\text { Montaup } \\
\text { Electric Co }\end{array}$ & $\begin{array}{c}\text { Massachuseits } \\
\text { New England } \\
\text { Hydro- } \\
\text { Tran } \\
\text { Elec Co }\end{array}$ \\
\hline 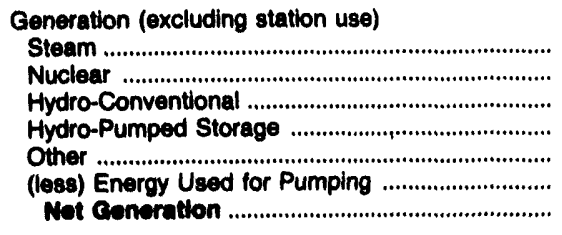 & $\begin{array}{r}90,989 \\
14,381 \\
0 \\
0 \\
1,623 \\
0 \\
106,903\end{array}$ & $\begin{array}{l}0 \\
0 \\
0 \\
0 \\
0 \\
0 \\
0\end{array}$ & $\begin{array}{r}1,034,897 \\
0 \\
223,436 \\
0 \\
0 \\
0 \\
0 \\
1,258,333\end{array}$ & $\begin{array}{l}0 \\
0 \\
0 \\
0 \\
0 \\
0 \\
0\end{array}$ & $\begin{array}{r}2,541,389 \\
492,856 \\
0 \\
0 \\
1,680 \\
0 \\
3,035,925\end{array}$ & $\begin{array}{l}0 \\
0 \\
0 \\
0 \\
0 \\
0 \\
0\end{array}$ \\
\hline 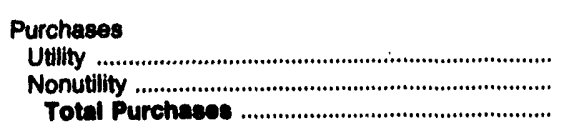 & $\begin{array}{r}261,600 \\
60,946 \\
322,646\end{array}$ & $\begin{array}{r}1,049,515 \\
0 \\
1,040,515\end{array}$ & $\begin{array}{r}710,892 \\
113 \\
711,005\end{array}$ & $\begin{array}{r}16,017,017 \\
1,987 \\
16,019,004\end{array}$ & $\begin{array}{l}1,964,749 \\
1,156,557 \\
\mathbf{3}, 121,306\end{array}$ & $\begin{array}{l}0 \\
0 \\
0\end{array}$ \\
\hline $\begin{array}{l}\text { Exchanges } \\
\text { In (gross) } \\
\text { Out (gross) } \\
\text { Not Exchanges }\end{array}$ & $\begin{array}{l}0 \\
0 \\
0\end{array}$ & $\begin{array}{l}\mathbf{0} \\
\mathbf{0} \\
\mathbf{0}\end{array}$ & $\begin{array}{l}0 \\
0 \\
0\end{array}$ & $\begin{array}{l}0 \\
0 \\
0\end{array}$ & $\begin{array}{l}0 \\
0 \\
0\end{array}$ & $\begin{array}{l}0 \\
0 \\
0\end{array}$ \\
\hline 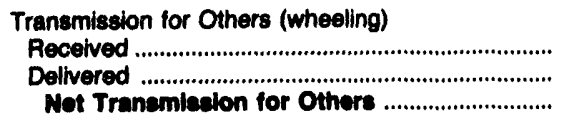 & $\begin{array}{l}0 \\
0 \\
\mathbf{0}\end{array}$ & $\begin{array}{l}0 \\
0 \\
0\end{array}$ & $\begin{array}{r}320 \\
320 \\
0\end{array}$ & $\begin{array}{l}0 \\
0 \\
0\end{array}$ & $\begin{array}{l}0 \\
0 \\
0\end{array}$ & $\begin{array}{l}0 \\
0 \\
0\end{array}$ \\
\hline 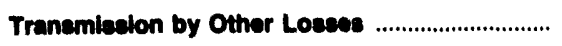 & $-9,096$ & $\mathbf{0}$ & $\mathbf{0}$ & $\mathbf{0}$ & $\mathbf{0}$ & $\mathbf{0}$ \\
\hline 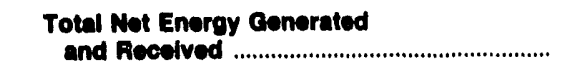 & 420,443 & $1,049,515$ & $1,969,338$ & $16,019,004$ & $6,157,231$ & $\mathbf{0}$ \\
\hline 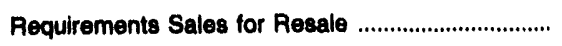 & 0 & 14,618 & 159,009 & 3,747 & $3,834,019$ & 0 \\
\hline Non-requirements Sales for Resale ............................ & 13,972 & $1,034,897$ & $1,695,008$ & 0 & $2,285,270$ & 0 \\
\hline Energy Furnished Without Charge .............................. & 0 & 0 & 0 & 0 & 0 & 0 \\
\hline Energy Used by Company (exc station use) ........... & 1,283 & 0 & 687 & 15,214 & 0 & 0 \\
\hline Total Energy Losse8 & 26,014 & 0 & 1,811 & 695,944 & 37,942 & 0 \\
\hline Total sales and Diepostion ............................... & 420,443 & $1,049,515$ & $1,969,338$ & $16,019,004$ & $6,157,231$ & 0 \\
\hline
\end{tabular}

Note: Totals may not equal sum of components because of independent rounding. Double counting occurs in components of both sources and disposition of energy and thus nelther provides a true total. Purchases from utilities, net interchanges, and net wheeling (except for imports) are included in net generation. Sales for resale is included in sales to ultimate consumers. Summary data are provided in Table 30.

Source: Federal Energy Regulatory Commission, FERC Form 1, "Annual Report of Major Electric Utilities, Licensees and Others." 
Table 43. Electric Energy Account by Major U.S. Investor-Owned Electric Utility Within State, 1992 (Continued)

(Megawatthours)

\begin{tabular}{|c|c|c|c|c|c|c|}
\hline Item & $\begin{array}{l}\text { Massachusetts } \\
\text { New England } \\
\text { Power Co }\end{array}$ & $\begin{array}{c}\text { Massachusetts } \\
\text { Western } \\
\text { Massachusetts } \\
\text { Elec Co }\end{array}$ & $\begin{array}{l}\text { Michigan } \\
\text { Consumers } \\
\text { Power Co }\end{array}$ & $\begin{array}{c}\text { Michigan } \\
\text { Detroit } \\
\text { Edison Co }\end{array}$ & $\begin{array}{l}\text { Michigan } \\
\text { Edison } \\
\text { Sault } \\
\text { Electric } \\
\text { Co }\end{array}$ & $\begin{array}{l}\text { Michigan } \\
\text { Upper } \\
\text { Peninsula } \\
\text { Power Co }\end{array}$ \\
\hline 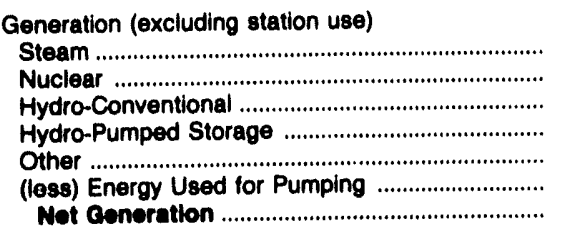 & $\begin{array}{r}12,074,622 \\
1,592,341 \\
1,212,155 \\
530,796 \\
13,153 \\
738,364 \\
14,684,703\end{array}$ & $\begin{array}{r}184,364 \\
2,018,901 \\
368,719 \\
229,159 \\
853 \\
315,500 \\
2,488,496\end{array}$ & $\begin{array}{r}17,229,807 \\
5,092,809 \\
490,206 \\
921,850 \\
12,257 \\
1,315,008 \\
22,431,921\end{array}$ & $\begin{array}{r}37,011,497 \\
7,337,965 \\
0 \\
886,283 \\
-2,667 \\
1,263,443 \\
43,969,635\end{array}$ & $\begin{array}{r}0 \\
0 \\
226,862 \\
0 \\
-41 \\
0 \\
226,821\end{array}$ & $\begin{array}{r}101,986 \\
0 \\
151,722 \\
0 \\
1,300 \\
0 \\
255,008\end{array}$ \\
\hline 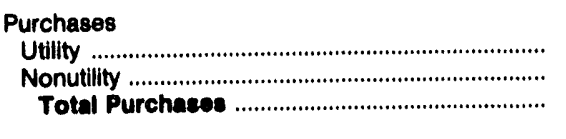 & $\begin{array}{l}4,460,458 \\
5,039,882 \\
9,500,340\end{array}$ & $\begin{array}{r}1,997,311 \\
47,710 \\
2,045,021\end{array}$ & $\begin{array}{r}3,701,430 \\
8,077,681 \\
11,779,111\end{array}$ & $\begin{array}{r}2,387,157 \\
317,732 \\
2,704,889\end{array}$ & $\begin{array}{r}493,418 \\
0 \\
493,418\end{array}$ & $\begin{array}{r}558,517 \\
0 \\
558,517\end{array}$ \\
\hline $\begin{array}{l}\text { Exchanges } \\
\text { In (gross) } \\
\text { Out (gross) } \\
\text { Not Exchanges }\end{array}$ & $\begin{array}{l}9,506 \\
7,014 \\
2,402\end{array}$ & $\begin{array}{l}0 \\
0 \\
0\end{array}$ & $\begin{array}{l}0 \\
0 \\
0\end{array}$ & $\begin{array}{r}281,751 \\
223,979 \\
57,772\end{array}$ & $\begin{array}{l}0 \\
0 \\
0\end{array}$ & $\begin{array}{r}47,849 \\
6,491 \\
41,358\end{array}$ \\
\hline 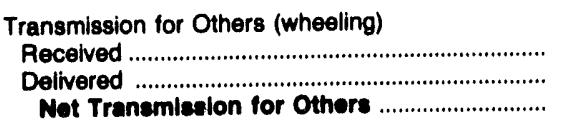 & $\begin{array}{r}10,323,857 \\
10,323,857 \\
0\end{array}$ & $\begin{array}{r}624,872 \\
624,872 \\
0\end{array}$ & $\begin{array}{r}1,706,199 \\
1,706,199 \\
0\end{array}$ & $\begin{array}{r}2,781 \\
2,781 \\
0\end{array}$ & $\begin{array}{l}0 \\
0 \\
0\end{array}$ & $\begin{array}{l}0 \\
0 \\
0\end{array}$ \\
\hline Tranemiselon by Other Losese ................................ & $\mathbf{0}$ & 0 & $\mathbf{0}$ & 0 & 0 & $\mathbf{0}$ \\
\hline $\begin{array}{l}\text { Total Net Energy Conerated } \\
\text { and Recelved }\end{array}$ & $24,187,535$ & $4,531,517$ & $34,211,032$ & $48,732,296$ & 720,239 & 854,883 \\
\hline 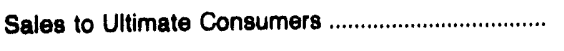 & 19,194 & $3,600,887$ & $29,427,788$ & $39,376,813$ & 557,375 & 879,683 \\
\hline 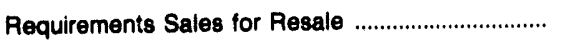 & $21,820,904$ & 11,823 & 862,874 & 847,089 & 127,288 & $i 27,426$ \\
\hline 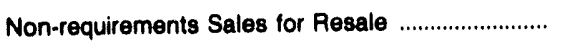 & $1,714,586$ & 541,847 & $1,310,433$ & $3,677,219$ & 66 & 0 \\
\hline Energy Furnished Without Charge .............................. & 0 & 9,686 & 0 & 0 & 0 & 0 \\
\hline Energy Used by Company (exc station use) ........... & 76,765 & 10,997 & 11,439 & 136,812 & 1,947 & 4,453 \\
\hline 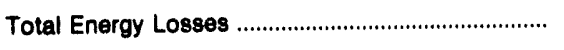 & 556,086 & 356,277 & $2,598,498$ & $2,694,363$ & 33,563 & 43,321 \\
\hline Total Sales and Dieposition ............................ & $24,187,535$ & $4,531,517$ & $34,211,032$ & $46,732,296$ & 720,230 & 854,883 \\
\hline
\end{tabular}

Note: Totals may not equal sum of components because of independent rounding. Double counting occurs in components of both sources and dispesition of energy and thus neither provides a true total. Purchases from utilities, net interchanges, and net wheeling (except for imports) are included in net generation. Sales for resale is included in sales to ultimate consumers. Summary data are provided in Table 30.

Source: Federal Energy Regulatory Commission, FERC Form 1, "Annual Report of Major Electric Utilities, Licensees and Others." 
Table 43. Electric Energy Account by Major U.S. Investor-Owned Electric Utility Within State, 1992 (Continued)

(Megawatthours)

\begin{tabular}{|c|c|c|c|c|c|c|}
\hline Item & $\begin{array}{c}\text { Minnesota } \\
\text { Minnesota } \\
\text { Power } \\
\& \\
\text { Light Co }\end{array}$ & $\begin{array}{l}\text { Minnesota } \\
\text { Northern } \\
\text { States } \\
\text { Power Co }\end{array}$ & $\begin{array}{c}\text { Minnesota } \\
\text { Otter } \\
\text { Tall } \\
\text { Power } \\
\text { Co }\end{array}$ & $\begin{array}{l}\text { Mississippl } \\
\text { Mississippl } \\
\text { Power } \\
\& \\
\text { Light Co }\end{array}$ & $\begin{array}{l}\text { Mississippi } \\
\text { Mississippi } \\
\text { Power Co }\end{array}$ & $\begin{array}{l}\text { Miseissippi } \\
\text { System } \\
\text { Energy } \\
\text { Resources } \\
\text { Inc }\end{array}$ \\
\hline 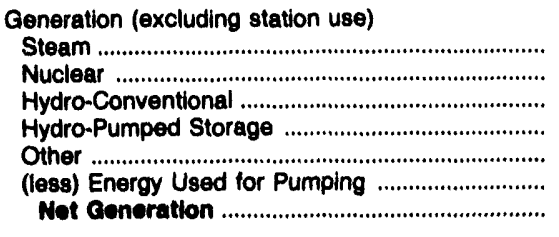 & $\begin{array}{r}4,819,076 \\
0 \\
644,382 \\
0 \\
0 \\
0 \\
0 \\
5,463,458\end{array}$ & $\begin{array}{r}19,119,639 \\
11,168,355 \\
71,387 \\
0 \\
-887 \\
0 \\
0 \\
30,358,404\end{array}$ & $\begin{array}{r}2,452,411 \\
0 \\
18,592 \\
0 \\
487 \\
0 \\
0 \\
2,471,480\end{array}$ & $\begin{array}{r}5,561,928 \\
0 \\
0 \\
0 \\
-45 \\
0 \\
0,561,803\end{array}$ & $\begin{array}{r}6,491,083 \\
0 \\
0 \\
0 \\
568,561 \\
0 \\
7,069,644\end{array}$ & $\begin{array}{r}0 \\
7,353,922 \\
0 \\
0 \\
0 \\
0 \\
7,353,022\end{array}$ \\
\hline 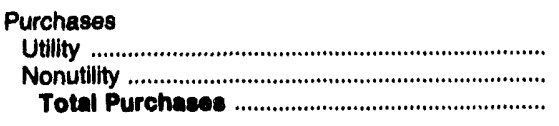 & $\begin{array}{r}4,379,381 \\
6,009 \\
4,385,390\end{array}$ & $\begin{array}{r}7,878,975 \\
489,261 \\
8,368,236\end{array}$ & $\begin{array}{r}1,332,728 \\
31,130 \\
1,363,856\end{array}$ & $\begin{array}{r}5,827,538 \\
8,737 \\
5,836,276\end{array}$ & $\begin{array}{r}3,574,339 \\
0 \\
3,574,330\end{array}$ & $\begin{array}{l}0 \\
0 \\
0\end{array}$ \\
\hline 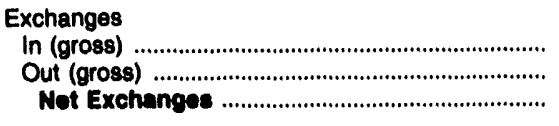 & $\begin{array}{l}0 \\
0 \\
0\end{array}$ & $\begin{array}{r}16,880,862 \\
21,837,946 \\
-4,957,084\end{array}$ & $\begin{array}{l}0 \\
0 \\
0\end{array}$ & $\begin{array}{l}0 \\
0 \\
0\end{array}$ & $\begin{array}{l}0 \\
0 \\
0\end{array}$ & $\begin{array}{l}0 \\
0 \\
0\end{array}$ \\
\hline 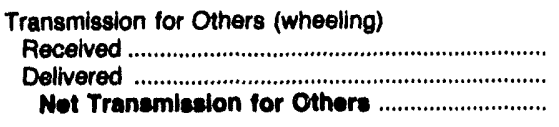 & $\begin{array}{r}1,378,532 \\
1,328,627 \\
49,005\end{array}$ & $\begin{array}{r}3,915,810 \\
3,803,810 \\
112,000\end{array}$ & $\begin{array}{l}865,931 \\
496,155 \\
369,776\end{array}$ & $\begin{array}{r}2,956,122 \\
2,956,122 \\
0\end{array}$ & $\begin{array}{r}662,288 \\
627,993 \\
34,295\end{array}$ & $\begin{array}{l}0 \\
0 \\
0\end{array}$ \\
\hline 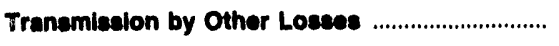 & o & 0 & $\mathbf{0}$ & $\mathbf{0}$ & $\mathbf{0}$ & 0 \\
\hline $\begin{array}{l}\text { Total Not Energy Conerated } \\
\text { and Recelved }\end{array}$ & $9,8<0,753$ & $33,879,646$ & $4,205,124$ & $11,398,158$ & $10,688,278$ & $7,358,922$ \\
\hline 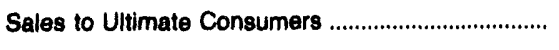 & $8,039,938$ & $26,111,894$ & $2,926,879$ & $9,397,402$ & $7,190,795$ & 0 \\
\hline 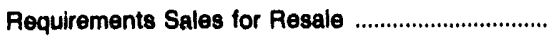 & 920,140 & 871,554 & 10,755 & 936,823 & $1,666,316$ & $7,353,922$ \\
\hline Non-requirements Sales for Resale .............................. & 389,317 & $5,334,521$ & 655,199 & 252,757 & $1,302,044$ & 0 \\
\hline 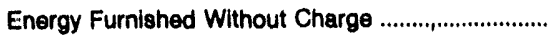 & 0 & 1,305 & 26 & 0 & 0 & 0 \\
\hline Energy Used by Company (exc station use) ............ & 18,633 & 56,257 & 12,181 & 16,040 & 19,214 & 0 \\
\hline Total Energy Losses & 530,725 & $1,504,115$ & 600,084 & 795,136 & 489,909 & 0 \\
\hline 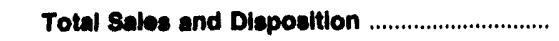 & $9,898,763$ & $33,870,646$ & $4,205,124$ & $11,300,168$ & $10,680,278$ & $7,353,922$ \\
\hline
\end{tabular}

Note: Totals may not equal sum of components because of independent rounding. Double counting occurs in components of both sources and disposition of energy and thus neither provides a true total. Purchases from utilities, net interchanges, and net wheeling (except for imports) are included in net generation. Sales for resale is included in sales to ultimate consumers. Summary data are provided in Table 30 .

Source: Federal Energy Regulatory Commission, FERC Form 1, "Annual Report of Major Electric Utilities, Licensees and Others." 
Table 43. Electric Energy Account by Major U.S. Investor-Owned Electric Utility Within State, 1992 (Continued)

(Megawatthours)

\begin{tabular}{|c|c|c|c|c|c|c|}
\hline Item & $\begin{array}{l}\text { Missourt } \\
\text { Empire } \\
\text { District } \\
\text { Electric Co }\end{array}$ & $\begin{array}{l}\text { Missouri } \\
\text { Kansas City } \\
\text { Power \& Light } \\
\text { Co }\end{array}$ & $\begin{array}{l}\text { Missouri } \\
\text { St Joseph } \\
\text { Light } \\
\& \\
\text { Power Co }\end{array}$ & $\begin{array}{l}\text { Missouri } \\
\text { Union } \\
\text { Electric Co }\end{array}$ & $\begin{array}{l}\text { Missouri } \\
\text { UtiliCorp } \\
\text { United Inc }\end{array}$ & $\begin{array}{l}\text { Montana } \\
\text { Montana } \\
\text { Power Co }\end{array}$ \\
\hline 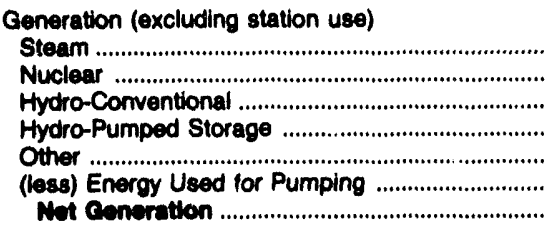 & $\begin{array}{r}2,307,854 \\
0 \\
77,644 \\
0 \\
0,048 \\
0 \\
0 \\
2,390,546\end{array}$ & $\begin{array}{r}9,428,631 \\
3,890,611 \\
0 \\
0 \\
-2,573 \\
0 \\
13,416,660\end{array}$ & $\begin{array}{r}983,015 \\
0 \\
0 \\
0 \\
-397 \\
0 \\
0 \\
982,618\end{array}$ & $\begin{array}{r}21,311,085 \\
8,083,875 \\
1,495,258 \\
13,750 \\
729 \\
45,492 \\
30,850,305\end{array}$ & $\begin{array}{r}4,465,831 \\
0 \\
0 \\
0 \\
12,008 \\
0 \\
4,477,939\end{array}$ & $\begin{array}{r}6,876,631 \\
0 \\
2,793,976 \\
0 \\
361 \\
0 \\
9,670,868\end{array}$ \\
\hline 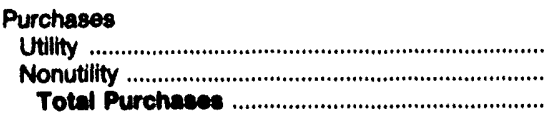 & $\begin{array}{r}1,119,044 \\
0 \\
1,119,044\end{array}$ & $\begin{array}{r}921,623 \\
6 \\
921,629\end{array}$ & $\begin{array}{r}490,617 \\
0 \\
490,617\end{array}$ & $\begin{array}{r}7,010,281 \\
14,626 \\
7,024,907\end{array}$ & $\begin{array}{r}2,772,728 \\
0 \\
2,772,728\end{array}$ & $\begin{array}{r}2,615,325 \\
365,505 \\
2,080,830\end{array}$ \\
\hline 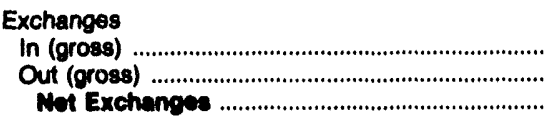 & $\begin{array}{l}6,783 \\
4,145 \\
2,638\end{array}$ & $\begin{array}{r}10,045 \\
7,567 \\
2,478\end{array}$ & $\begin{array}{l}0 \\
0 \\
0\end{array}$ & $\begin{array}{l}0 \\
0 \\
0\end{array}$ & $\begin{array}{r}1,465,654 \\
1,466,231 \\
-577\end{array}$ & $\begin{array}{r}10,082,520 \\
10,338,002 \\
-255,482\end{array}$ \\
\hline 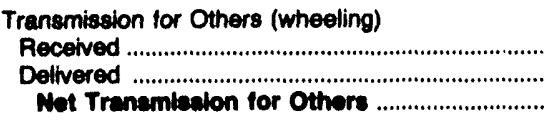 & $\begin{array}{r}286,969 \\
286,969 \\
0\end{array}$ & $\begin{array}{r}1,597,601 \\
1,597,601 \\
0\end{array}$ & $\begin{array}{r}335,143 \\
326,968 \\
8,175\end{array}$ & $\begin{array}{r}426,078 \\
390,695 \\
35,383\end{array}$ & $\begin{array}{r}446,024 \\
444,802 \\
1,222\end{array}$ & $\begin{array}{r}3,481,180 \\
3,483,071 \\
-1,891\end{array}$ \\
\hline Trenembelon by Other Losese .............................. & 0 & 0 & 0 & 0 & $\mathbf{0}$ & o \\
\hline 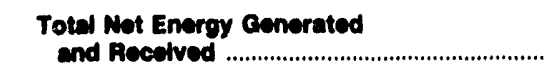 & $3,512,228$ & $14,340,776$ & $1,481,410$ & $37,919,595$ & $7,251,312$ & $12,394,425$ \\
\hline 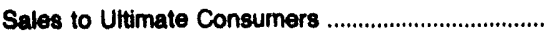 & $2,694,130$ & $10,658,908$ & $1,343,297$ & $29,418,239$ & $6,106,418$ & $6,973,801$ \\
\hline 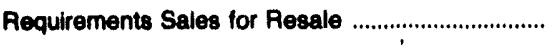 & 220,916 & 102,971 & 0 & $1,487,185$ & 270,244 & 484,112 \\
\hline 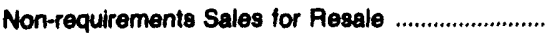 & 360,251 & $2,840,905$ & 27,355 & $4,840,783$ & 237,764 & $3,870,618$ \\
\hline 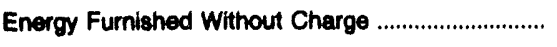 & 0 & 0 & 0 & 102 & 49 & 0 \\
\hline Energy Used by Company (exc station use) ............ & 7,539 & 27,768 & 6,700 & 0 & 18,017 & 0 \\
\hline 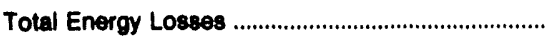 & 229,392 & 610,224 & 104,058 & $2,173,286$ & 618,820 & 965,894 \\
\hline Totel Saies and Diepoeltion ................................. & $3,512,228$ & $14,340,776$ & $1,481,410$ & $37,019,595$ & $7,251,312$ & $12,394,425$ \\
\hline
\end{tabular}

Note: Totals may not equal sum of components because of independent rounding. Double counting occurs in components of both sources and disposition of energy and thus neither provides a true total. Purchases from utilities, net interchanges, and net wheeling (except for imports) are included in net generation. Sales for resale is included in sales to ultimate consumers. Summary data are provided in Table 30.

Source: Federal Energy Regulatory Commission, FERC Form 1. "Annual Report of Major Electric Utilities, Licensees and Others." 
Table 43. Electric Energy Account by Major U.S. Investor-Owned Electric Utility Within State, 1992 (Continued)

(Megawatthours)

\begin{tabular}{|c|c|c|c|c|c|c|}
\hline Item & $\begin{array}{l}\text { Nevada } \\
\text { Nevada } \\
\text { Power Co }\end{array}$ & $\begin{array}{c}\text { Nevada } \\
\text { Sierra } \\
\text { Pacific } \\
\text { Power Co }\end{array}$ & $\begin{array}{c}\text { New Hampshire } \\
\text { Great } \\
\text { Bay } \\
\text { Power } \\
\text { Corp }\end{array}$ & $\begin{array}{c}\text { Now Hampshire } \\
\text { Now England } \\
\text { Eloc } \\
\text { Transmn } \\
\text { Corp }\end{array}$ & $\begin{array}{c}\text { New Hampshire } \\
\text { New England } \\
\text { Hydro- } \\
\text { Trans } \\
\text { Corp }\end{array}$ & $\begin{array}{c}\text { New Hampshire } \\
\text { North } \\
\text { Atlantio } \\
\text { Energy Corp }\end{array}$ \\
\hline 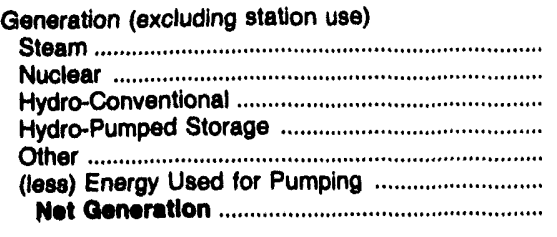 & $\begin{array}{r}5,368,374 \\
0 \\
0 \\
0 \\
93,759 \\
0 \\
5,462,133\end{array}$ & $\begin{array}{r}3,660,643 \\
0 \\
12,103 \\
0 \\
749 \\
0 \\
3,673,495\end{array}$ & $\begin{array}{r}0 \\
954,630 \\
0 \\
0 \\
0 \\
0 \\
954,630\end{array}$ & $\begin{array}{l}0 \\
0 \\
0 \\
0 \\
0 \\
0 \\
0\end{array}$ & $\begin{array}{l}0 \\
0 \\
0 \\
0 \\
0 \\
0 \\
0\end{array}$ & $\begin{array}{r}0 \\
1,271,515 \\
0 \\
0 \\
0 \\
0 \\
1,271,515\end{array}$ \\
\hline $\begin{array}{l}\text { Purchases } \\
\text { Utility } \\
\text { Nonutility } \\
\text { Total Purchases }\end{array}$ & $\begin{array}{l}4,554,940 \\
1,218,884 \\
5,773,824\end{array}$ & $\begin{array}{r}2,576,273 \\
516,279 \\
3,092,552\end{array}$ & $\begin{array}{l}0 \\
0 \\
0\end{array}$ & $\begin{array}{l}0 \\
0 \\
0\end{array}$ & $\begin{array}{l}0 \\
0 \\
0\end{array}$ & $\begin{array}{l}0 \\
0 \\
0\end{array}$ \\
\hline $\begin{array}{l}\text { Exchanges } \\
\text { In (gross) } \\
\text { Out (gross) } \\
\text { Not Exchanges }\end{array}$ & $\begin{array}{l}0 \\
0 \\
0\end{array}$ & $\begin{array}{l}0 \\
0 \\
0\end{array}$ & $\begin{array}{l}0 \\
0 \\
0\end{array}$ & $\begin{array}{l}0 \\
0 \\
0\end{array}$ & $\begin{array}{l}0 \\
0 \\
0\end{array}$ & $\begin{array}{l}0 \\
0 \\
0\end{array}$ \\
\hline 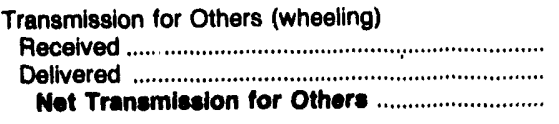 & $\begin{array}{r}1,017,667 \\
1,017,667 \\
0\end{array}$ & $\begin{array}{r}639,123 \\
618,993 \\
20,130\end{array}$ & $\begin{array}{l}0 \\
0 \\
0\end{array}$ & $\begin{array}{l}0 \\
0 \\
0\end{array}$ & $\begin{array}{l}0 \\
0 \\
0\end{array}$ & $\begin{array}{l}0 \\
0 \\
0\end{array}$ \\
\hline 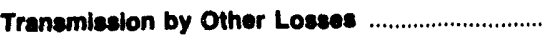 & 0 & $-25,958$ & 0 & 0 & 0 & $\mathbf{0}$ \\
\hline $\begin{array}{l}\text { Total Not Energy Cenerated } \\
\text { and Recelved }\end{array}$ & $11,235,957$ & $6,760,219$ & 954,630 & 0 & $\mathbf{0}$ & $1,271,615$ \\
\hline Requirements Sales for Resale ................................. & 35,405 & 159,421 & 0 & 0 & 0 & 0 \\
\hline Non-requirements Sales for Resale ......................... & 437,895 & 69,410 & 957,514 & 0 & 0 & $1,268,123$ \\
\hline 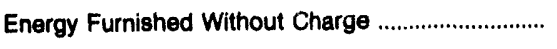 & 0 & 0 & 0 & 0 & 0 & 0 \\
\hline Energy Used by Company (exc station use) ........... & 37,177 & 18,398 & 0 & 0 & 0 & 0 \\
\hline 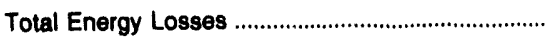 & 657,575 & 500,584 & $-2,884$ & 0 & 0 & 3,392 \\
\hline 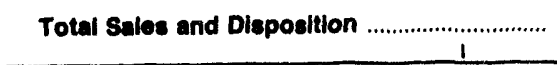 & $11,235,957$ & $6,760,219$ & 954,630 & 0 & 0 & $1,271,515$ \\
\hline
\end{tabular}

Note: Totals may not equal sum of components because of independent rounding. Double counting occurs in components of both sources and disposition of energy and thus neither provides a true total. Purchases from utilities, net interchanges, and net wheeling (except for imports) are included in net generation. Sales for resale is included in sales to ultimate consumers. Summary data are provided in Table 30 .

Source: Federal Energy Regulatory Commission, FERC Form 1, "Annual Report of Major Electric Utilities, Licensees and Others." 
Table 43. Electric Energy Account by Major U.S. Investor-Owned Electric Utility Within State, 1992 (Continued)

(Megawatthours)

\begin{tabular}{|c|c|c|c|c|c|c|}
\hline Item & $\begin{array}{c}\text { New Hampshire } \\
\text { Public } \\
\text { Service } \\
\text { Co } \\
\text { of NH }\end{array}$ & $\begin{array}{c}\text { New Jersey } \\
\text { Atlantic } \\
\text { City } \\
\text { Electric } \\
\text { Co }\end{array}$ & $\begin{array}{l}\text { New Jersey } \\
\text { Jersey } \\
\text { Central } \\
\text { Power\&Light } \\
\text { Co }\end{array}$ & $\begin{array}{c}\text { New Jersey } \\
\text { Public } \\
\text { Service } \\
\text { Electric\&Gas } \\
\text { Co }\end{array}$ & $\begin{array}{l}\text { New Jersey } \\
\text { Rockland } \\
\text { Electric Co }\end{array}$ & $\begin{array}{c}\text { New Mexico } \\
\text { Public } \\
\text { Service } \\
\text { Co } \\
\text { of NM }\end{array}$ \\
\hline Generation (excluding station use) & & & & & & \\
\hline 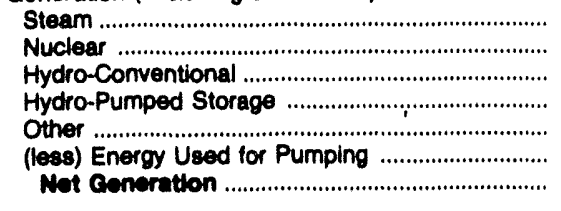 & $\begin{array}{r}4,642,226 \\
1,715,639 \\
345,200 \\
0 \\
101 \\
0 \\
6,703,168\end{array}$ & $\begin{array}{r}2,761,891 \\
2,047,747 \\
0 \\
0 \\
219,408 \\
0 \\
5,029,046\end{array}$ & $\begin{array}{r}2,174,084 \\
6,258,759 \\
0 \\
479,447 \\
344,863 \\
690,841 \\
\mathbf{8 , 6 6 6 , 3 1 2}\end{array}$ & $\begin{array}{r}12,079,984 \\
16,344,009 \\
0 \\
256,483 \\
272,216 \\
388,880 \\
28,685,812\end{array}$ & $\begin{array}{l}0 \\
0 \\
0 \\
0 \\
0 \\
0 \\
0\end{array}$ & $\begin{array}{r}5,952,323 \\
2,611,508 \\
0 \\
0 \\
5 \\
0 \\
8,563,836\end{array}$ \\
\hline 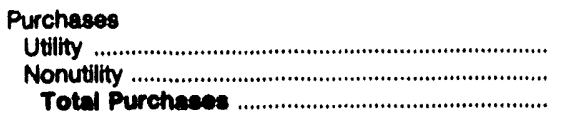 & $\begin{array}{l}4,526,406 \\
1,210,684 \\
5,737,090\end{array}$ & $\begin{array}{r}3,534,772 \\
764,527 \\
4,299,209\end{array}$ & $\begin{array}{r}7,118,487 \\
5,273,631 \\
12,392,118\end{array}$ & $\begin{array}{l}6,342,332 \\
2,554,518 \\
8,898,850\end{array}$ & $\begin{array}{r}1,281,443 \\
0 \\
1,281,443\end{array}$ & $\begin{array}{r}758,201 \\
0 \\
758,201\end{array}$ \\
\hline $\begin{array}{l}\text { Exchanges } \\
\text { In (gross) } \\
\text { Out (gross) } \\
\text { Not Exchanges }\end{array}$ & $\begin{array}{l}0 \\
0 \\
0\end{array}$ & $\begin{array}{l}0 \\
0 \\
0\end{array}$ & $\begin{array}{l}0 \\
0 \\
0\end{array}$ & $\begin{array}{r}4,129,375 \\
0 \\
4,129,375\end{array}$ & $\begin{array}{l}0 \\
0 \\
0\end{array}$ & $\begin{array}{l}281,343 \\
326,072 \\
-44,729\end{array}$ \\
\hline Transmission for Others (wheeling) & & $\operatorname{sen}$ & & & & \\
\hline 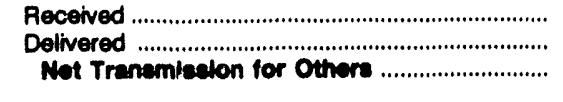 & $\begin{array}{r}2,216,974 \\
2,216,874 \\
0\end{array}$ & $\begin{array}{r}18,252 \\
18,252 \\
0\end{array}$ & $\begin{array}{r}197,245 \\
194,474 \\
2,771\end{array}$ & $\begin{array}{r}2,563,531 \\
2,563,531 \\
0\end{array}$ & $\begin{array}{l}0 \\
0 \\
0\end{array}$ & $\begin{array}{r}2,785,021 \\
2,684,090 \\
100,931\end{array}$ \\
\hline Tranemlasion by Other Loesee ............................... & 0 & 0 & 0 & 0 & 0 & $-1,600$ \\
\hline $\begin{array}{l}\text { Total Not Energy Generated } \\
\text { and Recelved }\end{array}$ & $12,440,266$ & $9,328,345$ & $20,081,201$ & $41,692,037$ & $1,281,443$ & $9,376,630$ \\
\hline 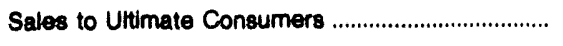 & $6,229,783$ & $7,668,300$ & $16,574,401$ & $36,786,395$ & $1,186,191$ & $5,358,246$ \\
\hline 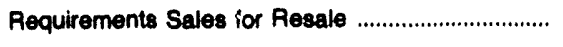 & 652,811 & 0 & 312,753 & 127,301 & 0 & 322,177 \\
\hline 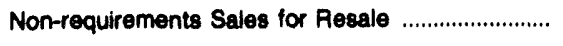 & $5,411,031$ & $1,053,081$ & $1,998,857$ & $2,124,722$ & 0 & $3,363,241$ \\
\hline 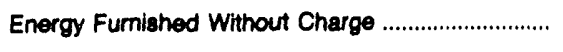 & 0 & 0 & 52,581 & 0 & 0 & 0 \\
\hline Energy Used by Company (exc station use) .......... & 28,699 & 25,111 & 69,463 & 394,455 & 1,497 & 24,851 \\
\hline 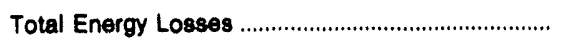 & 117,932 & 581,853 & $1,953,136$ & $2,159,164$ & 83,755 & 300,124 \\
\hline 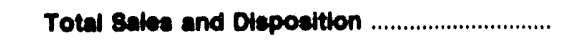 & $12,440,256$ & $9,328,345$ & $20,981,201$ & $41,502,037$ & $1,281,443$ & $9,378,630$ \\
\hline
\end{tabular}

Note: Totals may not equal sum of components because of independent rounding. Double counting occurs in components of both sources and dis. position of energy and thus neither provides a true total. Purchases from utilities, net interchanges, and net wheeling (except for imports) are included in net generation. Sales for resale is included in sales to ultimate consumers. Summary data are provided in Table 30.

Source: Federal Energy Regulatory Commission, FERC Form 1, "Annual Report of Major Electric Utilities, Licensees and Others." 
Table 43. Electric Energy Account by Major U.S. Investor-Owned Electric Utility Within State, 1992 (Continued)

(Megawatthours)

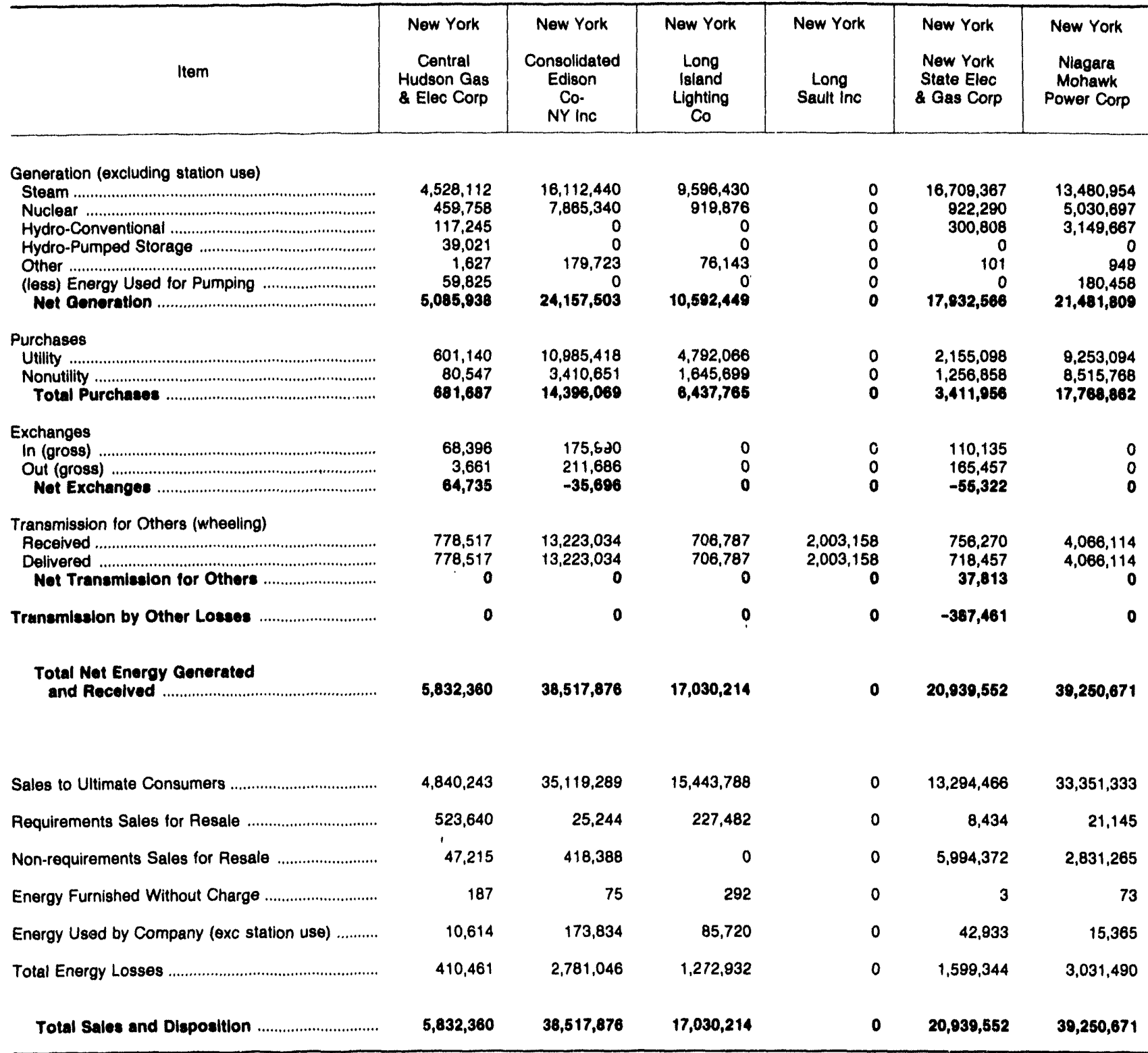

Note: Totals may not equal sum of components because of independent rounding. Double counting occurs in components of both sources and disposition of energy and thus neither provides a true total. Purchases from utilities, net interchanges, and net wheeling (except for imports) are included in net generation. Sales for resale is included in sales to ultimate consumers. Summary data are provided in Table 30.

Source: Federal Energy Regulatory Commission, FERC Form 1, "Annual Report of Major Electric Utilities, Licensees and Others." 
Table 43. Electrlc Energy Account by Major U.S. Investor-Owned Electric Utility Within State, 1992 (Continued)

(Megawatthours)

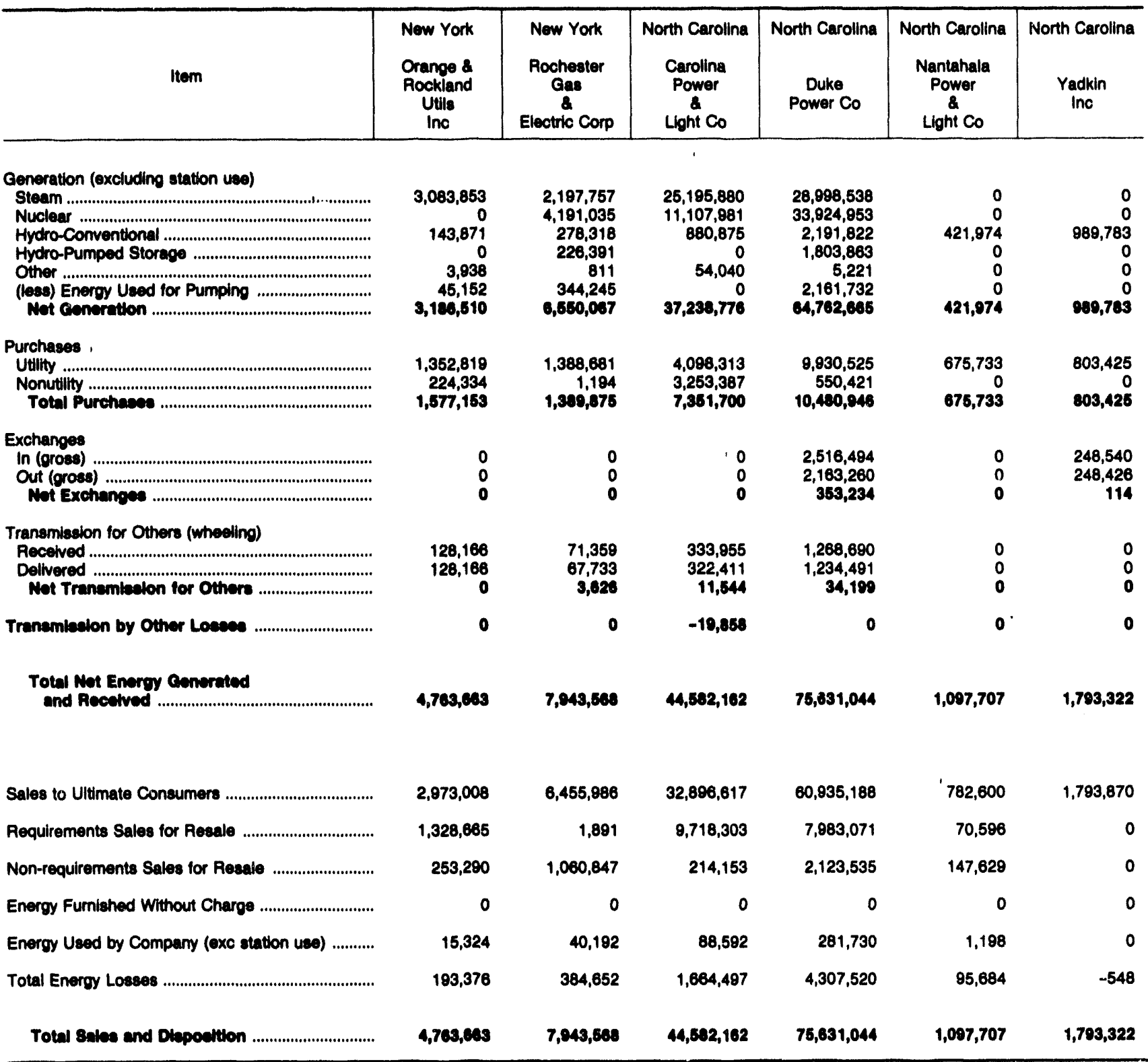

Note: Totals may not equal sum of components because of independent rounding. Double counting occurs in components of both sources and disposition of energy and thus neither provides a true total. Purchases from utilites, net interchanges, and net wheeling (except for imports) are included in net generation. Sales for resale is included in sales to uttimate consumers. Summary data are provided in Table 30.

Source: Federal Energy Regulatory Commiesion, FERC Form 1, "Annual Report of Major Electric Utilities, Licensees and Othars." 
Table 43. Electric Energy Account by Major U.S. Investor-Owned Electric Utility Within State, 1992 (Continued)

(Megawatthours)

\begin{tabular}{|c|c|c|c|c|c|c|}
\hline Item & $\begin{array}{l}\text { North Dakota } \\
\text { MDU } \\
\text { Resources } \\
\text { Group } \\
\text { inc }\end{array}$ & $\begin{array}{c}\text { Onio } \\
\text { Cincinnati } \\
\text { Gas } \\
\mathbf{a} \\
\text { Electric Co }\end{array}$ & $\begin{array}{c}\text { Onio } \\
\text { Cleveland } \\
\text { Electric } \\
\text { Illum Co' }\end{array}$ & $\begin{array}{l}\text { Onio } \\
\text { Columbus } \\
\text { Southern } \\
\text { Power Co }\end{array}$ & $\begin{array}{l}\text { Onio } \\
\text { Dayton } \\
\text { Power } \\
8 \\
\text { Light Co }\end{array}$ & $\begin{array}{l}\text { Onio } \\
\text { Indtana- } \\
\text { Kentucky } \\
\text { Eleciric } \\
\text { Corp }\end{array}$ \\
\hline 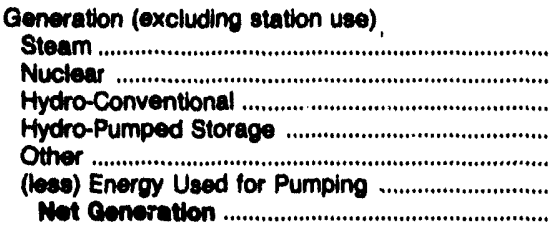 & $\begin{array}{r}1,766,546 \\
0 \\
0 \\
0 \\
7,776 \\
0 \\
1,774,322\end{array}$ & $\begin{array}{r}21,026,648 \\
0 \\
0 \\
0 \\
13,705 \\
0 \\
21,040,353\end{array}$ & $\begin{array}{r}12,715,361 \\
7,521,068 \\
0 \\
0 \\
506 \\
0 \\
20,286,935\end{array}$ & $\begin{array}{r}13,268,667 \\
0 \\
0 \\
0 \\
0 \\
0 \\
13,284,667\end{array}$ & $\begin{array}{r}13,638,575 \\
0 \\
0 \\
0 \\
3,414 \\
0 \\
13,941,990\end{array}$ & $\begin{array}{r}9,236,310 \\
0 \\
0 \\
0 \\
0 \\
0 \\
9,289,310\end{array}$ \\
\hline 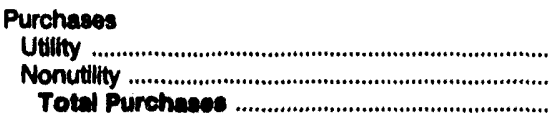 & $\begin{array}{r}605,576 \\
0 \\
605,576\end{array}$ & $\begin{array}{r}1,484,556 \\
0 \\
1,484,686\end{array}$ & $\begin{array}{r}1,675,371 \\
0 \\
1,675,371\end{array}$ & $\begin{array}{r}3,579,836 \\
0 \\
3,579,836\end{array}$ & $\begin{array}{r}1,480,800 \\
33,748 \\
1,614,640\end{array}$ & $\begin{array}{l}0 \\
0 \\
0\end{array}$ \\
\hline $\begin{array}{l}\text { Exchanges } \\
\text { In (gross) }\end{array}$ & $\begin{array}{r}19,779 \\
12,848 \\
7,131\end{array}$ & $\begin{array}{r}3,261 \\
61,203 \\
-57,242\end{array}$ & $\begin{array}{l}209,918 \\
236,684 \\
-26,788\end{array}$ & $\begin{array}{l}0 \\
0 \\
0\end{array}$ & $\begin{array}{r}22,617 \\
8,787 \\
13,830\end{array}$ & $\begin{array}{l}0 \\
0 \\
0\end{array}$ \\
\hline 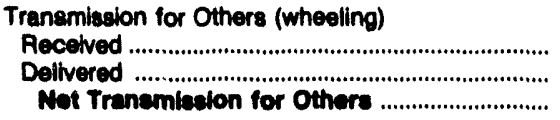 & $\begin{array}{r}910,850 \\
848,020 \\
82,830\end{array}$ & $\begin{array}{r}726,842 \\
712,625 \\
14,217\end{array}$ & $\begin{array}{r}4,004,332 \\
4,004,332 \\
0\end{array}$ & $\begin{array}{r}1,131,730 \\
1,131,730 \\
0\end{array}$ & $\begin{array}{r}1,466,385 \\
1,466,385 \\
0\end{array}$ & $\begin{array}{l}0 \\
0 \\
0\end{array}$ \\
\hline Tranemiasion by Othor Losese .............................. & $-34,380$ & $\mathbf{0}$ & $\mathbf{0}$ & $\mathbf{0}$ & $\mathbf{0}$ & $\mathbf{0}$ \\
\hline 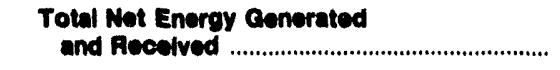 & $2,415,470$ & $22,491,184$ & $21,885,540$ & $16,868,603$ & $15,170,368$ & $9,238,310$ \\
\hline 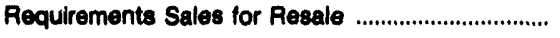 & 0 & $3,165,281$ & 161 & 357,634 & 37,777 & 0 \\
\hline Non-requirements Sales for Resale ............................. & 352,550 & $1,720,572$ & $1,988,485$ & $2,350,254$ & $1,611,041$ & $9,185,404$ \\
\hline Energy Furnished Without Charge ............................... & 48 & 0 & 0 & 0 & 0 & 0 \\
\hline Energy Used by Company (exc station use) ........... & 7,357 & 28,210 & 38,972 & 0 & 16,618 & 0 \\
\hline 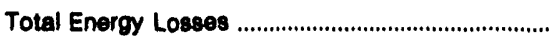 & 225,590 & $1,131,081$ & $1,145,108$ & 896,273 & $1,086,410$ & 50,806 \\
\hline Total Sales and Dieposition .............................. & $2,415,470$ & $22,481,184$ & $21,085,540$ & $18,888,603$ & $16,170,388$ & $9,238,310$ \\
\hline
\end{tabular}

Note: Totals may not equal sum of components because of independent rounding. Double counting occurs in components of both sources and disposition of energy and thus neither provides a true total. Purchases from utilities, net interchanges, and net wheellng (except for imports) are included in net generation. Sales for resale is included in sales to ultimate consumers. Summary data are provided in Table 30.

Source: Federal Energy Regulatory Commission, FERC Form 1, "Annual Report of Major Electric Utilities, Licensees and Others." 
Table 43. Electric Energy Account by Major U.S. Investor-Owned Electrlc UtIlity Within State, 1992 (Continued)

(Megawatthours)

\begin{tabular}{|c|c|c|c|c|c|c|}
\hline Item & $\begin{array}{l}\text { Ohio } \\
\text { Ónio } \\
\text { Edison Co }\end{array}$ & $\begin{array}{l}\text { Ohio } \\
\text { Ohio } \\
\text { Power Co }\end{array}$ & $\begin{array}{l}\text { Ohio } \\
\text { Ohio } \\
\text { Valley } \\
\text { Eloctric } \\
\text { Corp }\end{array}$ & $\begin{array}{l}\text { Ohio } \\
\text { Toledo } \\
\text { Edison Co }\end{array}$ & $\begin{array}{c}\text { Oklahoma } \\
\text { Oklahoma } \\
\text { Gas } \\
\& \\
\text { Electric Co }\end{array}$ & $\begin{array}{c}\text { Oklahoma } \\
\text { Public } \\
\text { Service } \\
\text { Co } \\
\text { of Oklahoma }\end{array}$ \\
\hline 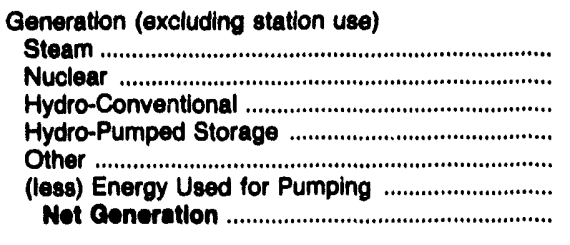 & $\begin{array}{r}21,397,014 \\
6,714,511 \\
0 \\
0 \\
969 \\
0 \\
0 \\
28,112,494\end{array}$ & $\begin{array}{r}43,605,219 \\
0 \\
240,867 \\
0 \\
0 \\
0 \\
43,846,086\end{array}$ & $\begin{array}{r}8,002,324 \\
0 \\
0 \\
0 \\
0 \\
0 \\
8,002,324\end{array}$ & $\begin{array}{r}4,655,923 \\
6,293,007 \\
0 \\
0 \\
1 \\
0 \\
10,948,031\end{array}$ & $\begin{array}{r}21,796,176 \\
0 \\
0 \\
0 \\
163,590 \\
0 \\
21,959,766\end{array}$ & $\begin{array}{r}12,376,883 \\
0 \\
0 \\
0 \\
0 \\
0 \\
12,376,883\end{array}$ \\
\hline $\begin{array}{l}\text { Purchases } \\
\text { Utlity } \\
\text { Nonutility } \\
\text { Total Purchases }\end{array}$ & $\begin{array}{r}1,851,400 \\
0 \\
0 \\
1,851,400\end{array}$ & $\begin{array}{r}3,372,327 \\
0 \\
3,372,327\end{array}$ & $\begin{array}{r}9,254,087 \\
0 \\
9,254087\end{array}$ & $\begin{array}{r}186,527 \\
9,327 \\
195,854\end{array}$ & $\begin{array}{r}33,645 \\
2,690,724 \\
2,724,369\end{array}$ & $\begin{array}{r}1,648,190 \\
328,131 \\
1,876,321\end{array}$ \\
\hline $\begin{array}{l}\text { Exchanges } \\
\text { In (gross) } \\
\text { Out (gross) } \\
\text { Not Exchanges }\end{array}$ & $\begin{array}{r}140,293 \\
76,550 \\
63,743\end{array}$ & $\begin{array}{l}67,566 \\
18,813 \\
46,753\end{array}$ & $\begin{array}{l}0 \\
0 \\
0\end{array}$ & $\begin{array}{r}452,255 \\
730,397 \\
-278,142\end{array}$ & $\begin{array}{l}0 \\
0 \\
0\end{array}$ & $\begin{array}{r}797,734 \\
.97,961 \\
-227\end{array}$ \\
\hline 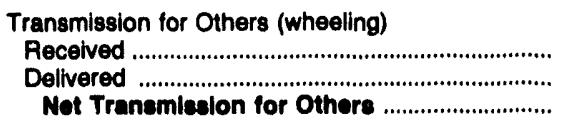 & $\begin{array}{r}2,429,175 \\
2,353,267 \\
75,008\end{array}$ & $\begin{array}{r}6,145,637 \\
6,145,637 \\
0\end{array}$ & $\begin{array}{r}103 \\
103 \\
0\end{array}$ & $\begin{array}{r}91,431 \\
91,431 \\
0\end{array}$ & $\begin{array}{r}1,055,703 \\
1,055,703 \\
0\end{array}$ & $\begin{array}{r}198,198 \\
192,711 \\
5,488\end{array}$ \\
\hline 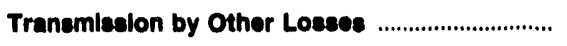 & $\mathbf{0}$ & 0 & $\mathbf{0}$ & $\mathbf{0}$ & $\mathbf{0}$ & $\mathbf{0}$ \\
\hline $\begin{array}{l}\text { Total Net Enorgy Gonorated } \\
\text { and Recelved }\end{array}$ & $30,103,545$ & $47,267,166$ & $17,256,411$ & $10,866,643$ & $24,684,135$ & $14,358,465$ \\
\hline 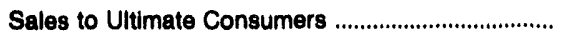 & $20,545,476$ & $28,848,620$ & $14,602,458$ & $7,601,055$ & $18,316,230$ & $12,736,132$ \\
\hline Requirements Sales for Resale .................................... & $2,907,336$ & $3,473,710$ & 0 & 263,324 & 920,613 & 49,353 \\
\hline 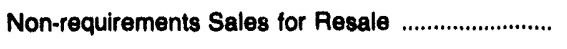 & $4,942,916$ & $12,802,162$ & $2,607,018$ & $2,488,608$ & $4,141,084$ & 615,470 \\
\hline 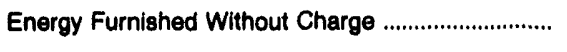 & 0 & $\theta$ & 0 & 0 & 56,164 & 0 \\
\hline Energy Used by Company (exc station use) ............ & 35,917 & 0 & 0 & 30,668 & 32,422 & 90,127 \\
\hline 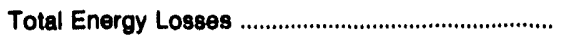 & $1,671,800$ & $2,042,668$ & 46,835 & 481,988 & $1,217,622$ & 867,383 \\
\hline 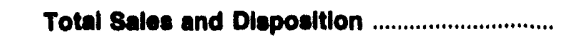 & $30,103,545$ & $47,267,166$ & $17,256,411$ & $10,866,643$ & $24,684,135$ & $14,358,465$ \\
\hline
\end{tabular}

Note: Totals may not equal sum of components because of independent rounding. Double counting occurs in components of both sources and disposition of energy and thus neither provides a true total. Purchases from utilities, net interchanges, and net wheeling (except for imports) are included in net generation. Sales for resale is included in sales to ultimate consumers. Summary data are provided in Table 30.

Source: Federal Energy Regulatory Commission, FEAC Form 1. "Annual Report of Major Electric Utilities, Licensees and Others." 
Table 43. Electric Energy Account by Major U.S. Investor-Owned Electric Utility Within State, 1992 (Continued)

(Megawatthours)

\begin{tabular}{|c|c|c|c|c|c|c|}
\hline Item & $\begin{array}{l}\text { Oregon } \\
\text { Paciticorp }\end{array}$ & $\begin{array}{l}\text { Oregon } \\
\text { Portland } \\
\text { General } \\
\text { Electric Co }\end{array}$ & $\begin{array}{l}\text { Pennaytvania } \\
\text { Duquesne } \\
\text { Llght Co }\end{array}$ & $\begin{array}{l}\text { Pennsylvania } \\
\text { Metropolitan } \\
\text { Edison Co }\end{array}$ & $\begin{array}{l}\text { Pennsylvania } \\
\text { Pennsylvania } \\
\text { Eloctric Co }\end{array}$ & $\begin{array}{l}\text { Pennsylvanla } \\
\text { Pennsylvania } \\
\text { Power } \\
\& \\
\text { Light Co }\end{array}$ \\
\hline 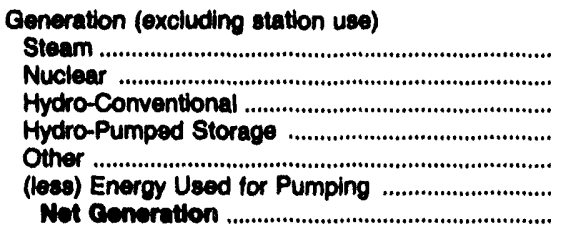 & $\begin{array}{r}48,934,365 \\
114,346 \\
2,630,055 \\
0 \\
79,036 \\
0 \\
51,757,802\end{array}$ & $\begin{array}{r}4,916,038 \\
3,066,353 \\
1,845,479 \\
0 \\
1,521,332 \\
0 \\
11,469,202\end{array}$ & $\begin{array}{r}11,056,432 \\
4,790,389 \\
0 \\
0 \\
-28,583 \\
0 \\
15,818,238\end{array}$ & $\begin{array}{r}4,809,350 \\
3,459,861 \\
0 \\
272,427 \\
137,321 \\
371,475 \\
8,307,464\end{array}$ & $\begin{array}{r}11,328,685 \\
1,729,929 \\
110,865 \\
123,839 \\
934,318 \\
168,850 \\
14,058,786\end{array}$ & $\begin{array}{r}26,210,068 \\
12,216,273 \\
760,388 \\
0 \\
9,686 \\
0 \\
39,186,425\end{array}$ \\
\hline 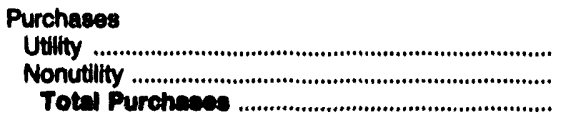 & $\begin{array}{r}7,234,003 \\
916,216 \\
8,150,219\end{array}$ & $\begin{array}{r}7,765,683 \\
321,047 \\
8,086,730\end{array}$ & $\begin{array}{l}410,075 \\
181,488 \\
501,603\end{array}$ & $\begin{array}{l}3,339,576 \\
1,333,382 \\
4,672,068\end{array}$ & $\begin{array}{l}1,717,707 \\
1,462,418 \\
3,160,126\end{array}$ & $\begin{array}{l}1,462,853 \\
3,884,189 \\
6,347,042\end{array}$ \\
\hline $\begin{array}{l}\text { Exchanges } \\
\text { In (gross) } \\
\text { Out (gross) }\end{array}$ & $\begin{array}{r}22,149,119 \\
22,058,780 \\
90,339\end{array}$ & $\begin{array}{r}1,202,564 \\
1,126,831 \\
75,733\end{array}$ & $\begin{array}{l}157,913 \\
194,125 \\
-38,212\end{array}$ & $\begin{array}{l}0 \\
0 \\
0\end{array}$ & $\begin{array}{l}0 \\
0 \\
0\end{array}$ & $\begin{array}{l}0 \\
0 \\
0\end{array}$ \\
\hline 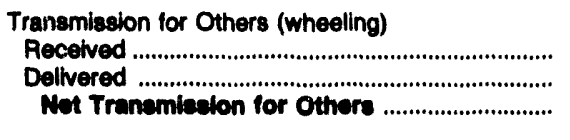 & $\begin{array}{r}1,438,392 \\
1,438,382 \\
0\end{array}$ & $\begin{array}{r}922,563 \\
922,563 \\
0\end{array}$ & $\begin{array}{r}964,209 \\
964,209 \\
0\end{array}$ & $\begin{array}{r}239,141 \\
234,375 \\
4,768\end{array}$ & $\begin{array}{r}3,735,854 \\
3,655,095 \\
80,859\end{array}$ & $\begin{array}{r}1,096,323 \\
1,096,323 \\
0\end{array}$ \\
\hline 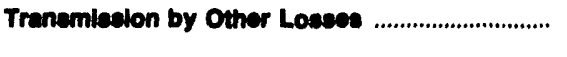 & $-359,800$ & 0 & $\mathbf{0}$ & 0 & 0 & 0 \\
\hline $\begin{array}{l}\text { Total Net Energy Conorated } \\
\text { and Recelved }\end{array}$ & $80,630,461$ & $19,631,665$ & $16,373,589$ & $12,995,208$ & $17,310,750$ & $44,633,467$ \\
\hline 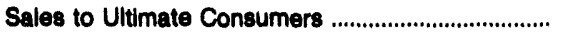 & $41,511,308$ & $15,643,858$ & $11,557,196$ & $9,834,412$ & $11,710,802$ & $28,477,129$ \\
\hline 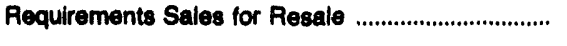 & $1,101,300$ & 16,667 & 11,780 & 188,611 & 541,052 & $1,277,475$ \\
\hline Non-requirements Sales for Resale ........................... & $12,318,612$ & $2,722,545$ & $4,059,889$ & $2,383,183$ & $2,778,738$ & $12,487,123$ \\
\hline 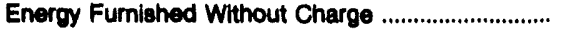 & 160 & 0 & 0 & 116,282 & 924,433 & 0 \\
\hline Energy Used by Company (exc station use) ............ & 80,608 & 34,241 & 53,041 & 40,148 & 50,381 & 116,875 \\
\hline 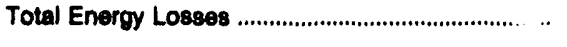 & $4,626,473$ & $1,214,354$ & 691,583 & 322,572 & $1,314,243$ & $2,174,766$ \\
\hline Total Sales and Dlepoaltion .............................. & $69,638,461$ & $19,631,665$ & $16,373,589$ & $12,085,208$ & $17,319,750$ & $44,633,467$ \\
\hline
\end{tabular}

Note: Totals may not equal sum of components because of independent rounding. Double counting occurs in components of both sources and disposition of energy and thus nelther provides a true total. Purchases from utilities, net interchanges, and net wheeling (except for imports) are included in net generation. Sales for resale is included in sales to ultimate nsumers. Summary data are provided in Table 30.

Source: Federal Energy Regulatory Commission, FERC Furm 1. "Annual Report of Major Electric Utilities, Licensees and Others." 
Table 43. Electric Energy Account by Major U.S. Investor-Owned Electrlc Utility Within State, 1992 (Continued)

(Megawatthours)

\begin{tabular}{|c|c|c|c|c|c|c|}
\hline Item & $\begin{array}{l}\text { Pennsylvania } \\
\text { Pennsylvania } \\
\text { Power Co }\end{array}$ & $\begin{array}{l}\text { Pennsylvania } \\
\text { Philadelphia } \\
\text { Electric Co }\end{array}$ & $\begin{array}{c}\text { Pennsylvania } \\
\text { Safe } \\
\text { Harbor } \\
\text { Water } \\
\text { Power Corp }\end{array}$ & $\begin{array}{l}\text { Pennsylvania } \\
\text { Susquehanna } \\
\text { Electric Co }\end{array}$ & $\begin{array}{c}\text { Pennsylvania } \\
\text { West } \\
\text { Penn } \\
\text { Power } \\
\text { Co }\end{array}$ & $\begin{array}{c}\text { Pennsylvania } \\
\text { York } \\
\text { Haven } \\
\text { Power } \\
\text { Co }\end{array}$ \\
\hline 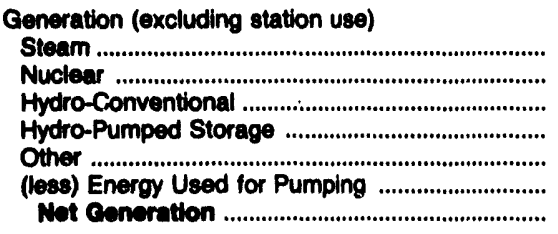 & $\begin{array}{r}3,180,253 \\
1,478,537 \\
0 \\
0 \\
194 \\
0 \\
4,658,984\end{array}$ & $\begin{array}{r}8,083,438 \\
24,427,747 \\
0 \\
1,596,561 \\
28,776 \\
2,217,068 \\
31,010,454\end{array}$ & $\begin{array}{r}0 \\
0 \\
1,094,390 \\
0 \\
0 \\
0 \\
1,094,390\end{array}$ & $\begin{array}{r}0 \\
0 \\
1,802,566 \\
0 \\
0 \\
0 \\
1,802,586\end{array}$ & $\begin{array}{r}19,066,445 \\
0 \\
124,409 \\
468,486 \\
0 \\
599,729 \\
19,059,611\end{array}$ & $\begin{array}{r}0 \\
0 \\
141,544 \\
0 \\
0 \\
0 \\
141,544\end{array}$ \\
\hline $\begin{array}{l}\text { Purchases } \\
\text { Utilty } \\
\text { Nonutility } \\
\text { Total Purehases }\end{array}$ & $\begin{array}{r}797,430 \\
771 \\
798,201\end{array}$ & $\begin{array}{r}5,941,742 \\
713,654 \\
6,855,396\end{array}$ & $\begin{array}{l}0 \\
0 \\
0\end{array}$ & $\begin{array}{l}0 \\
0 \\
0\end{array}$ & $\begin{array}{l}7,067,267 \\
1,060,734 \\
8,128,001\end{array}$ & $\begin{array}{l}0 \\
0 \\
0\end{array}$ \\
\hline $\begin{array}{l}\text { Exchanges } \\
\text { In (gross) } \\
\text { Out (gross) }\end{array}$ & $\begin{array}{l}0 \\
0 \\
0\end{array}$ & $\begin{array}{l}3,688,156 \\
1,231,293 \\
2,456,863\end{array}$ & $\begin{array}{l}0 \\
0 \\
0\end{array}$ & $\begin{array}{l}0 \\
0 \\
0\end{array}$ & $\begin{array}{l}70,782 \\
59,287 \\
11,405\end{array}$ & $\begin{array}{l}0 \\
0 \\
0\end{array}$ \\
\hline 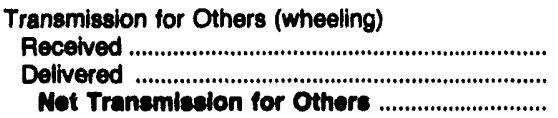 & $\begin{array}{r}150,635 \\
150,635 \\
0\end{array}$ & $\begin{array}{r}471,644 \\
471,644 \\
0\end{array}$ & $\begin{array}{l}0 \\
0 \\
0\end{array}$ & $\begin{array}{l}0 \\
0 \\
0\end{array}$ & $\begin{array}{r}350,614 \\
350,614 \\
0\end{array}$ & $\begin{array}{l}\mathbf{0} \\
\mathbf{0} \\
\mathbf{0}\end{array}$ \\
\hline 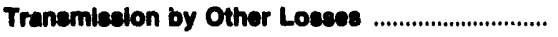 & $\mathbf{0}$ & $\mathbf{0}$ & $\mathbf{0}$ & $\mathbf{0}$ & $\mathbf{0}$ & $\mathbf{0}$ \\
\hline 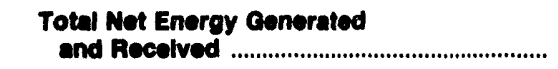 & $5,457,185$ & $41,031,713$ & $1,094,390$ & $1,802,566$ & $27,189,107$ & 141,544 \\
\hline 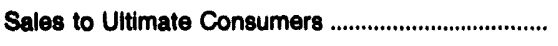 & $3,513,321$ & $31,264,490$ & 0 & 0 & $15,882,702$ & 0 \\
\hline Requirements Sales for Resale .................................. & 512,597 & 629,578 & $1,094,390$ & 0 & 506,215 & 141,544 \\
\hline Non-requirements Sales for Resale ............................. & $1,310,360$ & $7,930,129$ & 0 & $1,788,123$ & $9,469,364$ & 0 \\
\hline 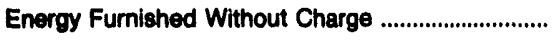 & 0 & 0 & 0 & 0 & 0 & 0 \\
\hline Energy Used by Company (exc station use) ........... & 7,067 & 31,427 & 0 & 0 & 26,605 & 3 \\
\hline 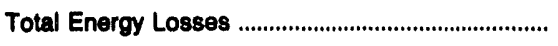 & 113,840 & $1,176,089$ & 0 & 14,443 & $1,314,221$ & 0 \\
\hline Total Sales and Dieposition & $5,467,185$ & $41,031,713$ & $1,004,390$ & $1,802,586$ & $27,199,107$ & 141,544 \\
\hline
\end{tabular}

Note: Totals may not equal sum of components because of independent rounding. Double counting occurs in components of both sources and disposition of energy and thus neither provides a true total. Purchases from utilities, net interchanges, and net wheeling (except for imports) are included in net generation. Sales for resale is included in sales to ultimate consumers. Summary data are provided in Table 30.

Source: Federal Energy Regulatory Commission, FERC Form 1, "Annual Report of Major Electric Utilities, Licensees and Others." 
Table 43. Electric Energy Account by Major U.S. Investor-Owned Electric Utility Within State, 1992 (Continued) (Megawatthours)

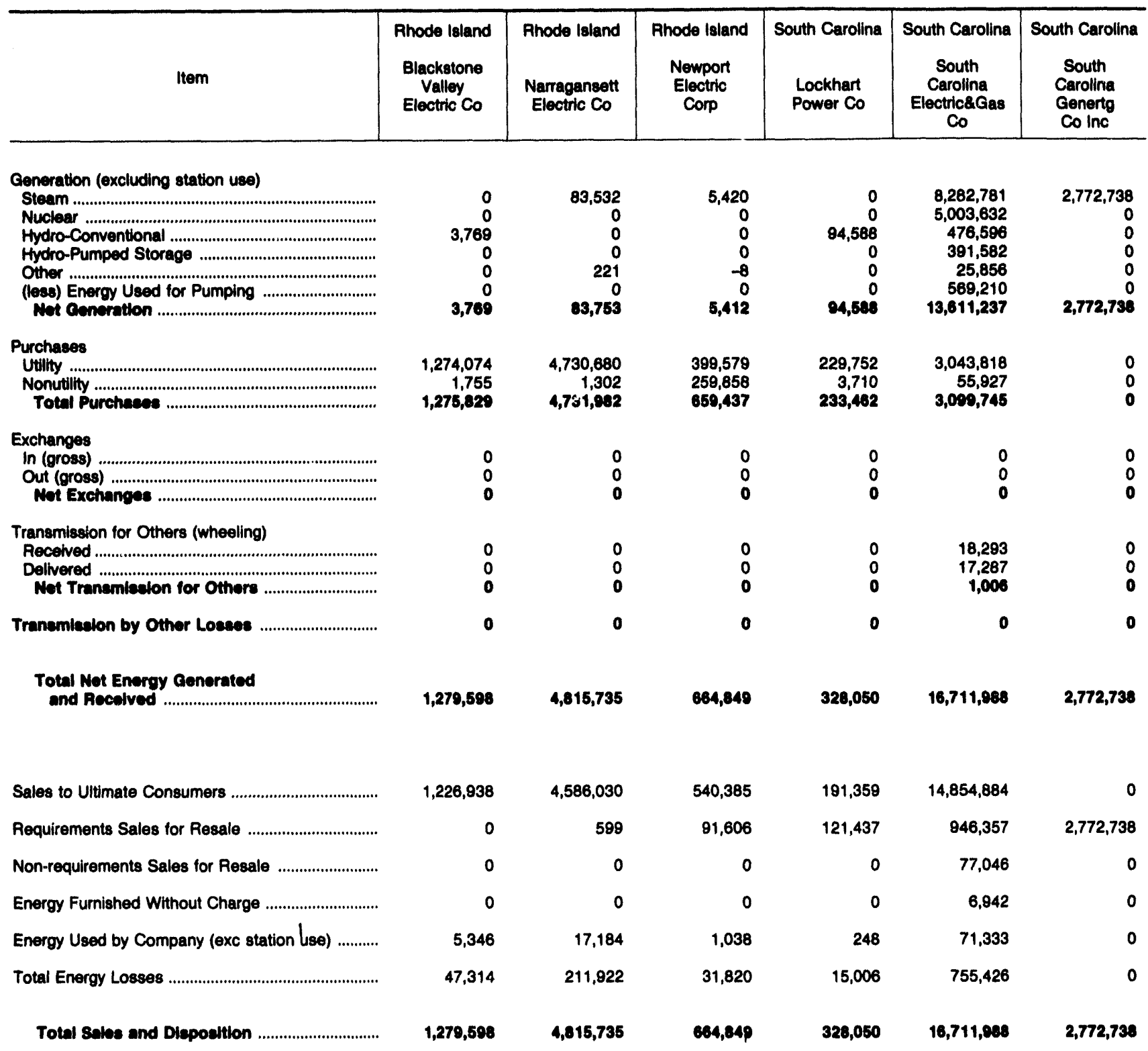

Note: Totals may not equal sum of components because of independent rounding. Double counting occurs in components of both sources and disposition of energy and thus neither provides a true total. Purchases from utilities, net interchanges, and net wheeling (except for imports) are included in net generation. Sales for resale is included in sales to ultimate consumers. Summary data are provided in Table 30.

Source: Federal Energy Regulatory Commission, FERC Form 1, "Annual Report of Major Electric Utilities, Licensees and Others." 
Table 43. Electric Energy Account by Major U.S. Investor-Owned Electric Utilly Within State, 1992 (Continued)

(Megawatthours)

\begin{tabular}{|c|c|c|c|c|c|c|}
\hline Hem & $\begin{array}{l}\text { South Dakota } \\
\text { Black } \\
\text { Hills Corp }\end{array}$ & $\begin{array}{l}\text { South Dakota } \\
\text { Northweatern } \\
\text { Public } \\
\text { Service Co }\end{array}$ & $\begin{array}{l}\text { Tennessee } \\
\text { Kingsport } \\
\text { Power Co }\end{array}$ & $\begin{array}{l}\text { Tennesese } \\
\text { Tapoco } \\
\text { Inc }\end{array}$ & $\begin{array}{c}\text { Texas } \\
\text { Central } \\
\text { Power } \\
8 \\
\text { Light Co }\end{array}$ & $\begin{array}{l}\text { Texas } \\
\text { E1 } \\
\text { Paso } \\
\text { Eloctric } \\
\text { Co }\end{array}$ \\
\hline 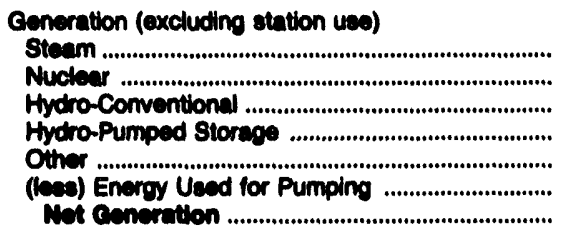 & $\begin{array}{r}1,218,062 \\
0 \\
0 \\
0 \\
0 \\
8,091 \\
0 \\
0 \\
1,226,153\end{array}$ & $\begin{array}{r}1,088,882 \\
0 \\
0 \\
0 \\
-109 \\
0 \\
1,008,703\end{array}$ & $\begin{array}{l}0 \\
0 \\
0 \\
0 \\
0 \\
0 \\
0\end{array}$ & $\begin{array}{r}0 \\
0 \\
1,537,053 \\
0 \\
0 \\
0 \\
1,637,053\end{array}$ & $\begin{array}{r}12,983,917 \\
4,436,740 \\
54,550 \\
0 \\
22,787 \\
0 \\
17,407,004\end{array}$ & $\begin{array}{r}3,252,909 \\
4,046,046 \\
0 \\
0 \\
, \quad 31,080 \\
0 \\
7,380,004\end{array}$ \\
\hline 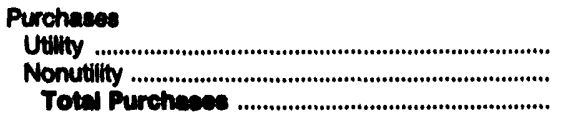 & $\begin{array}{r}386,541 \\
0 \\
306,541\end{array}$ & $\begin{array}{r}60,323 \\
0 \\
60,323\end{array}$ & $\begin{array}{r}1,871,580 \\
0 \\
1,871,600\end{array}$ & $\begin{array}{l}0 \\
0 \\
0\end{array}$ & $\begin{array}{r}723,600 \\
320,647 \\
1,044,247\end{array}$ & $\begin{array}{r}651,390 \\
0 \\
051,390\end{array}$ \\
\hline 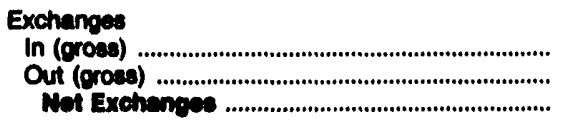 & $\begin{array}{l}16,762 \\
19,861 \\
-3,160\end{array}$ & $\begin{array}{l}0 \\
0 \\
0\end{array}$ & $\begin{array}{l}0 \\
0 \\
0\end{array}$ & $\begin{array}{l}0 \\
0 \\
0\end{array}$ & $\begin{array}{r}174,081 \\
170,917 \\
3,164\end{array}$ & $\begin{array}{r}17,568 \\
79,670 \\
-62,102\end{array}$ \\
\hline 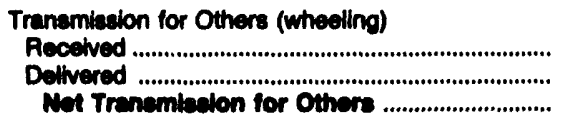 & $\begin{array}{r}1,198,818 \\
1,194,682 \\
4,136\end{array}$ & $\begin{array}{r}68,985 \\
62,975 \\
4,010\end{array}$ & $\begin{array}{l}0 \\
0 \\
0\end{array}$ & $\begin{array}{l}0 \\
0 \\
0\end{array}$ & $\begin{array}{r}612,346 \\
618,134 \\
-5,706\end{array}$ & $\begin{array}{r}132,068 \\
132,068 \\
0\end{array}$ \\
\hline 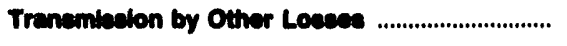 & 0 & $\mathbf{0}$ & o & 0 & 0 & $\mathbf{0}$ \\
\hline 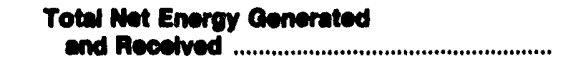 & $1,023,631$ & $1,163,116$ & $1,871,600$ & $1,537,053$ & $18,690,617$ & $7,019,292$ \\
\hline 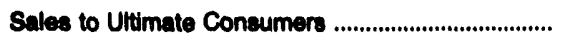 & $1,379,419$ & 894,077 & $1,804,267$ & $1,537,053$ & $15,803,038$ & $4,859,667$ \\
\hline 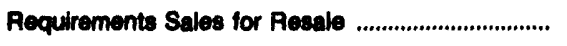 & 160,180 & 7,782 & 0 & 0 & 710,678 & $2,381,204$ \\
\hline 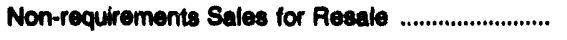 & 10,405 & 152,003 & 0 & 0 & 659,535 & 264,654 \\
\hline 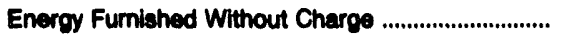 & 0 & 98 & 0 & 0 & 0 & 0 \\
\hline Energy Used by Company (exc station use) ............ & 710 & 4,164 & 0 & 0 & 39,363 & 10,397 \\
\hline 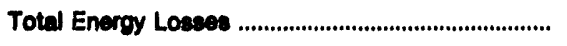 & 72,808 & 94,992 & 67,313 & 0 & $1,327,002$ & 423,370 \\
\hline Total sabes and Diapoaltion & $1,628,631$ & $1,163,118$ & $1,871,080$ & $1,537,053$ & $18,639,617$ & $7,019,292$ \\
\hline
\end{tabular}

Note: Totals may not equal sum of components because of independent rounding. Double counting occurs in components of both sources and dispoeltion of eneroy and thus neither provides a true total. Purchases from utilties, net interchanges, and net wheeling (except for imports) are included in net generation. Sales for reaale is included in sales to ultimate consumers. Summary date are provided in Table 30.

Source: Federal Energy Reculatory Commiesion, FERC Form 1, "Annual Report of Major Electric Utilities, Liceneees and Othere." 
Table 43. Electric Energy Account by Major U.S. Investor-Owned Electrlc Utility Within State, 1992 (Continued)

(Megawatthours)

\begin{tabular}{|c|c|c|c|c|c|c|}
\hline Item & $\begin{array}{c}\text { Texas } \\
\text { Gulf } \\
\text { States } \\
\text { Utilities } \\
\text { Co }\end{array}$ & $\begin{array}{c}\text { Texas } \\
\text { Houston } \\
\text { Lighting } \\
\& \\
\text { Power Co }\end{array}$ & $\begin{array}{l}\text { Texas } \\
\text { Southwestern } \\
\text { Electric } \\
\text { Serv Co }\end{array}$ & $\begin{array}{c}\text { Texas } \\
\text { Southwestern } \\
\text { Public } \\
\text { Service Co }\end{array}$ & $\begin{array}{c}\text { Texas } \\
\text { Texas } \\
\text { Utilities } \\
\text { Electric Co }\end{array}$ & $\begin{array}{c}\text { Texas } \\
\text { Texas- } \\
\text { New Mexico } \\
\text { Power Co }\end{array}$ \\
\hline 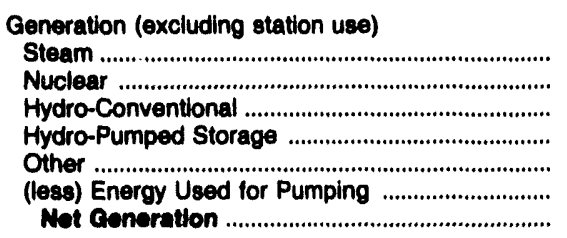 & $\begin{array}{r}22,643,957 \\
1,933,876 \\
0 \\
0 \\
0 \\
0 \\
24,577,833\end{array}$ & $\begin{array}{r}44,342,863 \\
5,364,029 \\
0 \\
0 \\
1,358,024 \\
0 \\
51,065,016\end{array}$ & $\begin{array}{l}0 \\
0 \\
0 \\
0 \\
0 \\
0 \\
0\end{array}$ & $\begin{array}{r}19,520,799 \\
0 \\
0 \\
0 \\
104,032 \\
0 \\
19,624,831\end{array}$ & $\begin{array}{r}67,406,868 \\
6,942,045 \\
0 \\
0 \\
303,426 \\
0 \\
74,652,330\end{array}$ & $\begin{array}{r}2,247,664 \\
0 \\
0 \\
0 \\
0 \\
0 \\
2,247,684\end{array}$ \\
\hline $\begin{array}{l}\text { Purchases } \\
\text { Utility } \\
\text { Nonutility } \\
\text { Total Purchases }\end{array}$ & $\begin{array}{l}3,595,173 \\
1,340,296 \\
4,035,460\end{array}$ & $\begin{array}{r}511,662 \\
11,026,210 \\
11,537,872\end{array}$ & $\begin{array}{r}1,043,579 \\
0 \\
1,043,579\end{array}$ & $\begin{array}{r}17,287 \\
257,580 \\
274,877\end{array}$ & $\begin{array}{r}353,058 \\
11,063,444 \\
11,416,502\end{array}$ & $\begin{array}{l}3,013,469 \\
1,253,560 \\
4,267,029\end{array}$ \\
\hline 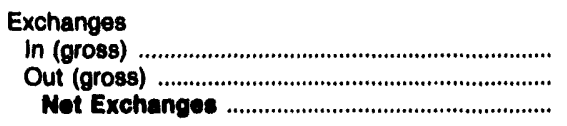 & $\begin{array}{l}0 \\
0 \\
0\end{array}$ & $\begin{array}{r}11,085,018 \\
11,084,814 \\
204\end{array}$ & $\begin{array}{l}0 \\
0 \\
0\end{array}$ & $\begin{array}{l}0 \\
0 \\
0\end{array}$ & $\begin{array}{r}16,317,287 \\
16,316,538 \\
749\end{array}$ & $\begin{array}{l}0 \\
0 \\
0\end{array}$ \\
\hline 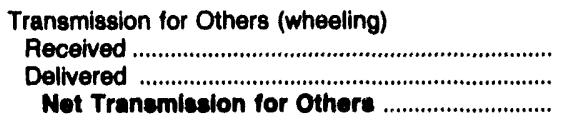 & $\begin{array}{r}9,831,656 \\
9,791,865 \\
39,791\end{array}$ & $\begin{array}{r}9,437,869 \\
9,437,869 \\
0\end{array}$ & $\begin{array}{l}0 \\
0 \\
0\end{array}$ & $\begin{array}{r}565 \\
565 \\
0\end{array}$ & $\begin{array}{r}10,004,271 \\
10,004,271 \\
0\end{array}$ & $\begin{array}{r}3,114,151 \\
3,114,151 \\
0\end{array}$ \\
\hline Tranemiselon by Other Losees ................................ & $\mathbf{0}$ & $\mathbf{0}$ & $\mathbf{0}$ & $\mathbf{0}$ & 0 & $\mathbf{0}$ \\
\hline $\begin{array}{l}\text { Total Not Energy Generated } \\
\text { and Recelved }\end{array}$ & $29,553,093$ & $62,603,092$ & $1,043,579$ & $18,899,708$ & $86,089,590$ & $6,514,693$ \\
\hline 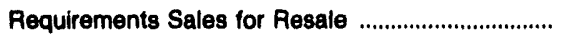 & 438,831 & 243,167 & 94,448 & $3,838,689$ & $3,987,144$ & 3,174 \\
\hline Non-requirements Sales for Resale .......................... & 101,455 & 322,802 & 0 & $1,953,161$ & 19,181 & 0 \\
\hline 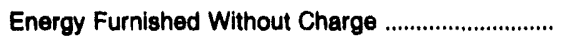 & 0 & 0 & 0 & 0 & 0 & 0 \\
\hline Energy Used by Company (exc station use) ........... & 165,300 & 0 & 1,426 & 35,046 & 0 & 12,649 \\
\hline Total Energy Losses & $1,410,689$ & $2,660,704$ & 70,175 & $1,298,362$ & $5,695,716$ & 435,733 \\
\hline Total Salos and Disposition ................................ & $29,553,003$ & $62,603,092$ & $1,043,579$ & $19,899,708$ & $86,089,590$ & $6,514,693$ \\
\hline
\end{tabular}

Note: Totals may not equal sum of components because of independent rounding. Double counting occurs in components of both sources and disposition of energy and thus neither provides a true total. Purchases from utilities, net interchanges, and net wheeling (except for imports) are included in net generation. Sales for resale is included in sales to ultimate consumers. Summary data are provided in Table 30.

Source: Federal Energy Regulatory Commission, FERC Form 1, "Annual Report of Major Electric Utilities, Licensees and Others." 
Table 43. Electric Energy Account by Major U.S. Investor-Owned Electric Utility Within State, 1992 (Continued)

(Megawatthours)

\begin{tabular}{|c|c|c|c|c|c|c|}
\hline litem & $\begin{array}{l}\text { Texas } \\
\text { West } \\
\text { Texas } \\
\text { Utilties } \\
\text { Co }\end{array}$ & $\begin{array}{l}\text { Vermont } \\
\text { Central } \\
\text { Vermont } \\
\text { Pub } \\
\text { Serv Corp }\end{array}$ & $\begin{array}{l}\text { Vermont } \\
\text { Green } \\
\text { Mountain } \\
\text { Power Corp }\end{array}$ & $\begin{array}{l}\text { Vermont } \\
\text { Vermont } \\
\text { Electric } \\
\text { Power } \\
\text { Co inc }\end{array}$ & $\begin{array}{l}\text { Vermont } \\
\text { Vermont } \\
\text { Electric } \\
\text { Trans } \\
\text { Co inc }\end{array}$ & $\begin{array}{l}\text { Vermont } \\
\text { Vermont } \\
\text { Yankee } \\
\text { Nucl } \\
\text { Pwr Corp }\end{array}$ \\
\hline 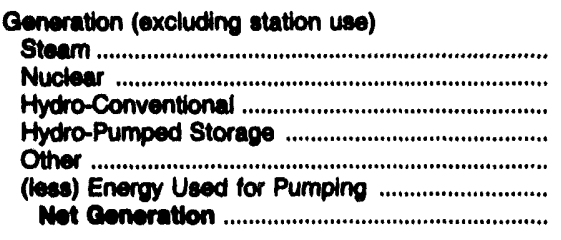 & $\begin{array}{r}6,297,206 \\
0 \\
0 \\
0 \\
-182 \\
0 \\
6,297,014\end{array}$ & $\begin{array}{r}45,873 \\
114,687 \\
163,856 \\
0 \\
62 \\
0 \\
324,470\end{array}$ & $\begin{array}{r}26,453 \\
0 \\
0 \\
108,336 \\
0 \\
0 \\
41,146 \\
0 \\
173,935\end{array}$ & $\begin{array}{l}0 \\
0 \\
0 \\
0 \\
0 \\
0 \\
0\end{array}$ & $\begin{array}{l}0 \\
0 \\
0 \\
0 \\
0 \\
0 \\
0\end{array}$ & $\begin{array}{r}0 \\
3,734,583 \\
0 \\
0 \\
0 \\
0 \\
3,734,593\end{array}$ \\
\hline 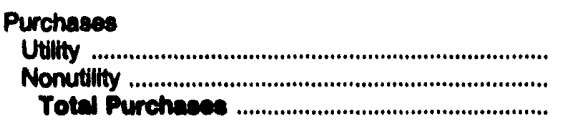 & $\begin{array}{r}188,821 \\
0 \\
188,821\end{array}$ & $\begin{array}{r}3,362,788 \\
77,861 \\
3,440,840\end{array}$ & $\begin{array}{r}1,944,874 \\
55,544 \\
2,000,418\end{array}$ & $\begin{array}{r}858,517 \\
0 \\
868,617\end{array}$ & $\begin{array}{l}0 \\
0 \\
0\end{array}$ & $\begin{array}{l}0 \\
0 \\
0\end{array}$ \\
\hline $\begin{array}{l}\text { Exchanges } \\
\text { In (gross) } \\
\text { Out (gross) }\end{array}$ & $\begin{array}{l}0 \\
0 \\
0\end{array}$ & $\begin{array}{l}0 \\
0 \\
0\end{array}$ & $\begin{array}{l}0 \\
0 \\
0\end{array}$ & $\begin{array}{l}0 \\
0 \\
0\end{array}$ & $\begin{array}{l}0 \\
0 \\
0\end{array}$ & $\begin{array}{l}0 \\
0 \\
0\end{array}$ \\
\hline 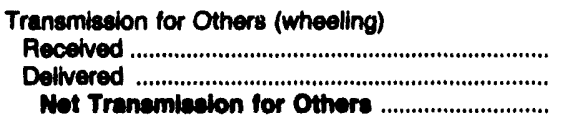 & $\begin{array}{r}553,269 \\
562,766 \\
-9,497\end{array}$ & $\begin{array}{r}346,566 \\
331,867 \\
14,690\end{array}$ & $\begin{array}{r}341,194 \\
326,521 \\
14,673\end{array}$ & $\begin{array}{r}4,344,835 \\
4,233,696 \\
111,039\end{array}$ & $\begin{array}{r}6,549,825 \\
6,549,825 \\
0\end{array}$ & $\begin{array}{l}0 \\
0 \\
0\end{array}$ \\
\hline Transembelon by Other Loeses ................................ & $\mathbf{0}$ & $-67,328$ & $\mathbf{0}$ & $\mathbf{0}$ & $\mathbf{0}$ & $\mathbf{0}$ \\
\hline 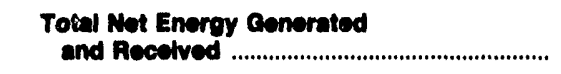 & $6,476,338$ & $3,722,498$ & $2,189,026$ & 969,656 & 0 & $3,734,693$ \\
\hline 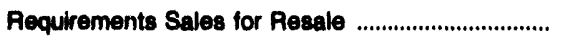 & $1,531,852$ & 210,755 & 102,807 & 0 & 0 & $3,734,593$ \\
\hline Non-requirements Sales for Resale ........................... & 419,133 & $1,386,868$ & 273,087 & 858,517 & 0 & 0 \\
\hline 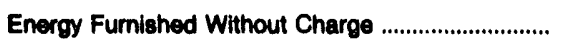 & 0 & 257 & 0 & 0 & 0 & 0 \\
\hline Energy Used by Company (exc station use) ........... & 15,290 & 5,755 & 4,866 & 0 & 0 & 0 \\
\hline 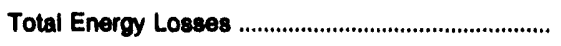 & 442,711 & 140,526 & 115,987 & 111,039 & 0 & 0 \\
\hline Total sales and Diepoeltion .............................. & $6,476,338$ & $3,722,408$ & $2,189,028$ & 989,566 & o & $3,734,688$ \\
\hline
\end{tabular}

Note: Totals may not equal sum of components because of independent rounding. Double counting occurs in components of both sources and disposition of energy and thus neither provides a true total. Purchases from utilities, net interchanges, and net wheeling (except for imports) are included in net generation. Sales for resale is included in sales to ultimate consumers. Summary data are provided in Table 30.

Source: Federal Energy Regulatory Commission, FERC Form 1, "Annual Report of Major Electric Utilities, Licensees and Others." 
Table 43. Electric Energy Account by Major U.S. Investor-Owned Electric Utility Within State, 1902 (Continued)

(Megawatthours)

\begin{tabular}{|c|c|c|c|c|c|c|}
\hline Item & $\begin{array}{l}\text { Virginia } \\
\text { Appalachlan } \\
\text { Power Co }\end{array}$ & $\begin{array}{l}\text { Virginia } \\
\text { Virginia } \\
\text { Electric } \\
\text { \& Power } \\
\text { Co }\end{array}$ & $\begin{array}{l}\text { Waahington } \\
\text { Puget Sound } \\
\text { Power \& Light } \\
\text { Co }\end{array}$ & $\begin{array}{l}\text { Washington } \\
\text { Washington } \\
\text { Waler } \\
\text { Power Co }\end{array}$ & $\begin{array}{l}\text { Weat Virginie } \\
\text { Kanawha } \\
\text { Valley } \\
\text { Power Co }\end{array}$ & $\begin{array}{l}\text { Weat Virginia } \\
\text { Monongahela } \\
\text { Power Co }\end{array}$ \\
\hline 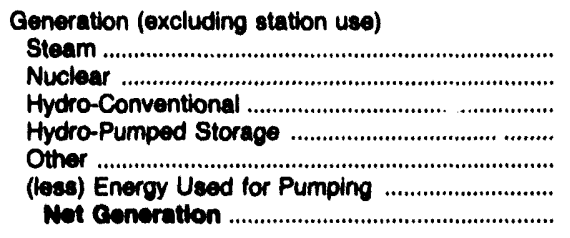 & $\begin{array}{r}23,047,592 \\
0 \\
483,602 \\
238,259 \\
0 \\
176,176 \\
23,503,277\end{array}$ & $\begin{array}{r}27,383,598 \\
21,978,988 \\
637,845 \\
1,855,220 \\
1,326,805 \\
2,317,631 \\
50,844,025\end{array}$ & $\begin{array}{r}5,755,288 \\
0 \\
1,213,444 \\
0 \\
451,326 \\
0 \\
0 \\
7,420,050\end{array}$ & $\begin{array}{r}3,301,871 \\
0 \\
2,869,462 \\
0 \\
8,630 \\
0 \\
0,270,603\end{array}$ & $\begin{array}{r}0 \\
0 \\
276,073 \\
0 \\
0 \\
0 \\
276,073\end{array}$ & $\begin{array}{r}10,593,059 \\
0 \\
0 \\
260,155 \\
0 \\
332,989 \\
10,520,225\end{array}$ \\
\hline $\begin{array}{l}\text { Purchases } \\
\text { Utlity } \\
\text { Nonutility } \\
\text { Total Purchases }\end{array}$ & $\begin{array}{r}11,441,246 \\
0 \\
11,441,246\end{array}$ & $\begin{array}{r}5,027,053 \\
7,018,477 \\
12,048,030\end{array}$ & $\begin{array}{r}12,422,703 \\
885,819 \\
13,406,6222\end{array}$ & $\begin{array}{r}3,706,765 \\
543,687 \\
4,260,362\end{array}$ & $\begin{array}{l}0 \\
0 \\
0\end{array}$ & $\begin{array}{r}3,995,044 \\
697,784 \\
4,692,828\end{array}$ \\
\hline $\begin{array}{l}\text { Exchanges } \\
\text { In (gross) } \\
\text { Out (gross) }\end{array}$ & $\begin{array}{l}0 \\
0 \\
0\end{array}$ & $\begin{array}{r}180,578 \\
188,660 \\
918\end{array}$ & $\begin{array}{r}1,215,974 \\
1,334,320 \\
-118,340\end{array}$ & $\begin{array}{r}1,301,672 \\
1,229,952 \\
71,720\end{array}$ & $\begin{array}{l}0 \\
0 \\
0\end{array}$ & $\begin{array}{l}40,365 \\
27,765 \\
12,500\end{array}$ \\
\hline 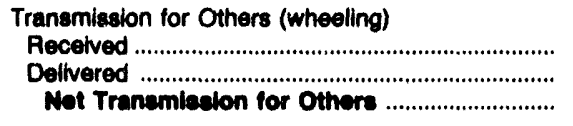 & $\begin{array}{r}749,085 \\
748,085 \\
0\end{array}$ & $\begin{array}{r}4,823,028 \\
4,810,895 \\
12,133\end{array}$ & $\begin{array}{r}1,763,501 \\
1,753,501 \\
0\end{array}$ & $\begin{array}{r}3,643,948 \\
3,543,248 \\
0\end{array}$ & $\begin{array}{l}0 \\
0 \\
0\end{array}$ & $\begin{array}{r}248,061 \\
248,081 \\
0\end{array}$ \\
\hline 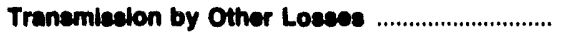 & $\mathbf{0}$ & o & 0 & 0 & 0 & Q \\
\hline $\begin{array}{l}\text { Total Not Energy Conerated } \\
\text { and Recelved }\end{array}$ & $35,034,523$ & $62,023,000$ & $20,710,234$ & $10,002,035$ & 276,073 & $16,225,643$ \\
\hline 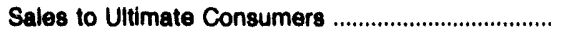 & $23,781,020$ & $54,664,734$ & $18,224,496$ & $6,820,831$ & 0 & $9,167,541$ \\
\hline 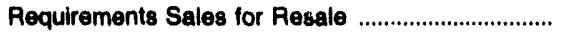 & $4,537,128$ & $3,144,692$ & 125,680 & 273,201 & 276,073 & 140,358 \\
\hline 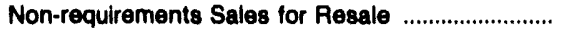 & $4,263,454$ & $1,507,713$ & $1,157,885$ & $2,889,246$ & 0 & $5,236,522$ \\
\hline 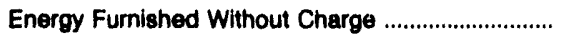 & 2,133 & 0 & 300 & 0 & 0 & 0 \\
\hline Energy Used by Company (exc station use) ............ & 0 & 410,208 & 30,876 & 0 & 0 & 21,949 \\
\hline 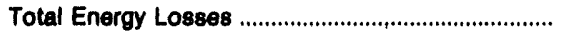 & $2,470,788$ & $3,196,159$ & $1,170,917$ & 518,757 & 0 & 659,272 \\
\hline 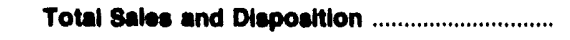 & $35,034,523$ & $62,023,606$ & $20,710,234$ & $10,402,035$ & 276,073 & $16,225,643$ \\
\hline
\end{tabular}

Note: Totals may not equal sum of components because of independent rounding. Double counting cocurs in components of both sources and disposition of energy and thus neither provides a true total. Purchases from utilities, net interchanges, and net wheeling (except for imports) are included in net generation. Sales for resale is included in sales to ultimate consumers. Summary data are provided in Table 30.

Source: Federal Energy Regulatory Commission, FERC Form 1, "Annual Report of Major Electric Utilities, Licensees and Others." 
Table 43. Electric Energy Account by Major U.S. Investor-Owned Electric Utility Within State, 1992 (Continued) (Megawatthours)

\begin{tabular}{|c|c|c|c|c|c|c|}
\hline Item & $\begin{array}{l}\text { Weat Virginia } \\
\text { Wheeling } \\
\text { Power Co }\end{array}$ & $\begin{array}{l}\text { Wisconsin } \\
\text { Consolidated } \\
\text { Water } \\
\text { Power Co }\end{array}$ & $\begin{array}{l}\text { Wisconsin } \\
\text { Madison } \\
\text { Gas } \\
\& \\
\text { Electric Co }\end{array}$ & $\begin{array}{l}\text { Wisconsin } \\
\text { Northern } \\
\text { States } \\
\text { Power Co }\end{array}$ & $\begin{array}{l}\text { Wisconsin } \\
\text { Northwestern } \\
\text { Wisconsin } \\
\text { Elec Co }\end{array}$ & $\begin{array}{c}\text { Wisconsin } \\
\text { Pioneer } \\
\text { Power } \\
\& \\
\text { Light Co }\end{array}$ \\
\hline 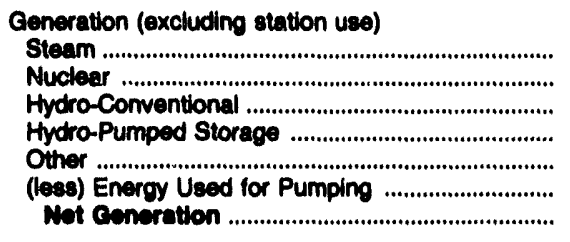 & $\begin{array}{l}0 \\
0 \\
0 \\
0 \\
0 \\
0 \\
0\end{array}$ & $\begin{array}{r}0 \\
0 \\
142,193 \\
0 \\
0 \\
0 \\
142,193\end{array}$ & $\begin{array}{r}1,433,893 \\
701,020 \\
0 \\
0 \\
0 \\
12,196 \\
0 \\
2,147,100\end{array}$ & $\begin{array}{r}182,613 \\
0 \\
052,252 \\
0 \\
94 \\
0 \\
0 \\
1,134,771\end{array}$ & $\begin{array}{r}0 \\
0 \\
10,704 \\
0 \\
80 \\
0 \\
10,784\end{array}$ & $\begin{array}{l}0 \\
0 \\
0 \\
0 \\
0 \\
0 \\
0\end{array}$ \\
\hline 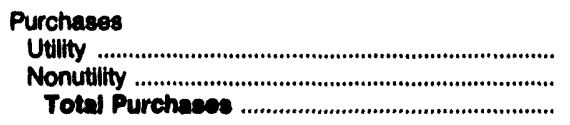 & $\begin{array}{r}1,861,253 \\
0 \\
1,861,253\end{array}$ & $\begin{array}{r}1,013,146 \\
0 \\
1,013,146\end{array}$ & $\begin{array}{r}300,310 \\
18,794 \\
319,104\end{array}$ & $\begin{array}{l}0 \\
0 \\
0\end{array}$ & $\begin{array}{r}123,023 \\
0 \\
123,023\end{array}$ & $\begin{array}{r}22,338 \\
0 \\
22,338\end{array}$ \\
\hline $\begin{array}{l}\text { Exchanges } \\
\text { In (gross) } \\
\text { Out (gross) } \\
\text { Net Exchanges }\end{array}$ & $\begin{array}{l}0 \\
0 \\
0\end{array}$ & $\begin{array}{l}0 \\
0 \\
0\end{array}$ & $\begin{array}{l}0 \\
0 \\
0\end{array}$ & $\begin{array}{r}11,480,745 \\
7,059,253 \\
4,431,492\end{array}$ & $\begin{array}{l}0 \\
0 \\
0\end{array}$ & $\begin{array}{l}0 \\
0 \\
0\end{array}$ \\
\hline 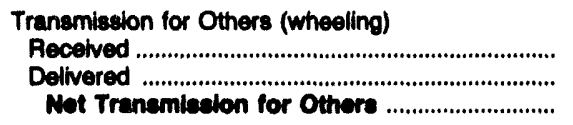 & $\begin{array}{l}0 \\
0 \\
0\end{array}$ & $\begin{array}{l}0 \\
0 \\
0\end{array}$ & $\begin{array}{l}0 \\
0 \\
0\end{array}$ & $\begin{array}{l}0 \\
0 \\
0\end{array}$ & $\begin{array}{r}13,647 \\
12,754 \\
893\end{array}$ & $\begin{array}{l}0 \\
0 \\
0\end{array}$ \\
\hline 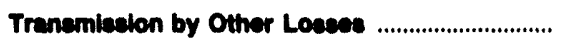 & $\mathbf{0}$ & 0 & -6 & $\mathbf{0}$ & o & $\mathbf{0}$ \\
\hline $\begin{array}{l}\text { Total Not Energy Conerated } \\
\text { and Recelved }\end{array}$ & $1,861,253$ & $1,155,389$ & $2,466,207$ & $5,568,263$ & 134,700 & 22,338 \\
\hline 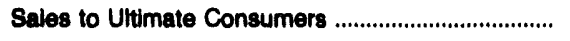 & $1,825,870$ & $1,140,252$ & $2,310,018$ & $4,529,793$ & 114,408 & 11,233 \\
\hline 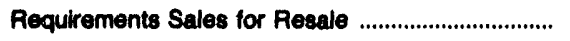 & 0 & 0 & 0 & 393,810 & 4,483 & 9,578 \\
\hline 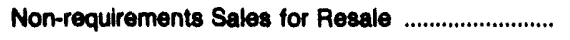 & 0 & 1,106 & 30,765 & 0 & 0 & 0 \\
\hline 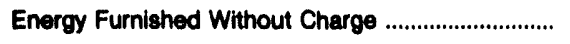 & 0 & 0 & 0 & 0 & 0 & 0 \\
\hline Energy Used by Company (exc station use) ............ & 0 & 427 & 704 & 3,790 & 605 & 13 \\
\hline 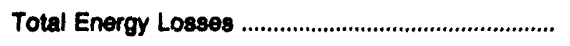 & 35,283 & 13,554 & 124,720 & 638,870 & 15,204 & 1,514 \\
\hline Total sales and Dlepoaltion & $1,861,253$ & $1,155,339$ & $2,466,207$ & $5,566,263$ & 134,700 & 22,330 \\
\hline
\end{tabular}

Note: Totals may not equal sum of components because of independent rounding. Double counting occurs in components of both sources and disposition of energy and thus neither provides a true total. Purchases from utilities, net interchanges, and net wheeling (except for imports) are ir Auded in net generation. Sales for resale is included in sales to ultimate consumers. Summary data are provided in Table 30.

Source: Federal Energy Regulatory Commiseion, FERC Form 1, "Annual Report of Major Electric Utilities, Licensees and Others." 
Table 43. Electric Energy Account by Major U.S. Investor-Owned Electric Utility Within State, 1992 (Continued)

(Megawatthours)

\begin{tabular}{|c|c|c|c|c|c|c|}
\hline Item & $\begin{array}{l}\text { Wisconsin } \\
\text { South } \\
\text { Beloit } \\
\text { Water } \\
\text { GassElec Co }\end{array}$ & $\begin{array}{l}\text { Wisconsin } \\
\text { Superior } \\
\text { Water } \\
\text { LightsPower } \\
\text { Co }\end{array}$ & $\begin{array}{l}\text { Wisconsin } \\
\text { Wisconsin } \\
\text { Electric } \\
\text { Power Co }\end{array}$ & $\begin{array}{l}\text { Wisconain } \\
\text { Wlaconain } \\
\text { Power } \\
\text { Light Co }\end{array}$ & $\begin{array}{l}\text { Wleconsin } \\
\text { Wlsconsin } \\
\text { Publlo } \\
\text { Service Corp }\end{array}$ & $\begin{array}{l}\text { Wisconsin } \\
\text { Wisconain } \\
\text { River } \\
\text { Power Co }\end{array}$ \\
\hline 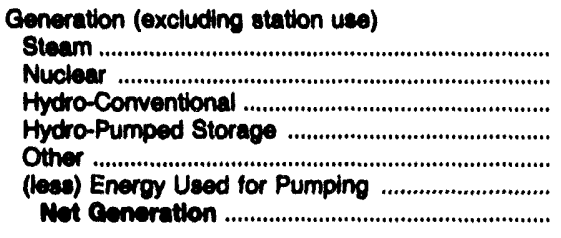 & $\begin{array}{r}0 \\
0 \\
5,900 \\
0 \\
0 \\
0 \\
5,900\end{array}$ & $\begin{array}{l}0 \\
0 \\
0 \\
0 \\
0 \\
0 \\
0\end{array}$ & $\begin{array}{r}15,973,617 \\
7,269,105 \\
404,003 \\
0 \\
1,067 \\
0 \\
23,047,792\end{array}$ & $\begin{array}{r}7,420,068 \\
1,614,781 \\
232,183 \\
0 \\
6,480 \\
0 \\
9,273,600\end{array}$ & $\begin{array}{r}0,796,975 \\
1,622,279 \\
325,663 \\
0 \\
3,623 \\
0 \\
0,748,640\end{array}$ & $\begin{array}{r}0 \\
0 \\
233,119 \\
0 \\
0 \\
0 \\
238,110\end{array}$ \\
\hline 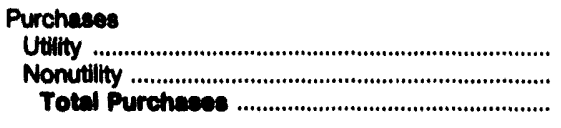 & $\begin{array}{r}167,210 \\
0 \\
167,210\end{array}$ & $\begin{array}{r}496,494 \\
0 \\
496,494\end{array}$ & $\begin{array}{r}2,463,347 \\
99,109 \\
2,802,486\end{array}$ & $\begin{array}{r}1,122,142 \\
9,057 \\
1,131,190\end{array}$ & $\begin{array}{r}1,599,925 \\
24,777 \\
1,824,702\end{array}$ & $\begin{array}{l}0 \\
0 \\
0\end{array}$ \\
\hline $\begin{array}{l}\text { Exchanges } \\
\text { In (gross) } \\
\text { Out (gross) }\end{array}$ & $\begin{array}{l}\mathbf{0} \\
\mathbf{0} \\
\mathbf{0}\end{array}$ & $\begin{array}{r}43,705 \\
0 \\
48,705\end{array}$ & $\begin{array}{l}\mathbf{0} \\
\mathbf{0} \\
\mathbf{0}\end{array}$ & $\begin{array}{r}31 \\
532 \\
-501\end{array}$ & $\begin{array}{r}767 \\
767 \\
0\end{array}$ & $\begin{array}{l}0 \\
0 \\
0\end{array}$ \\
\hline 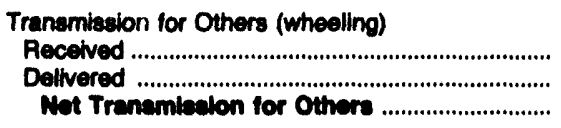 & $\begin{array}{l}0 \\
0 \\
0\end{array}$ & $\begin{array}{r}15,098 \\
15,098 \\
0\end{array}$ & $\begin{array}{r}499,228 \\
499,114 \\
112\end{array}$ & $\begin{array}{r}288,738 \\
298,738 \\
0\end{array}$ & $\begin{array}{l}0 \\
0 \\
0\end{array}$ & $\begin{array}{l}0 \\
0 \\
0\end{array}$ \\
\hline 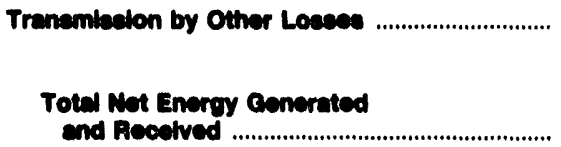 & 173,110 & 540,190 & $\begin{array}{r}-0,098 \\
26,201,272\end{array}$ & $-2,383$ & -100 & 283,110 \\
\hline Sales to Ultimate Consumers ..................................... & 165,608 & 526,876 & $22,303,551$ & $7,433,018$ & $7,702,176$ & 0 \\
\hline 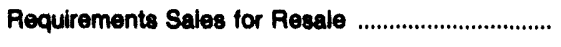 & 0 & 0 & $2,283,540$ & $2,161,932$ & $1,461,685$ & 0 \\
\hline Non-requirements Sales for Resalo .......................... & 6,532 & 0 & 150,490 & 213,697 & 583,308 & 229,280 \\
\hline Energy Furnished Without Charge .............................. & 0 & 0 & 0 & 0 & 0 & 0 \\
\hline Energy Used by Company (exc station use) ........... & 32 & 0 & 73,998 & 13,690 & 26,633 & 0 \\
\hline 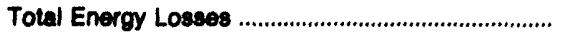 & 940 & 13,323 & $1,379,683$ & 579,495 & 599,334 & 3,829 \\
\hline 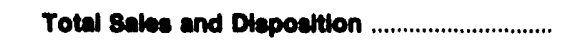 & 173,110 & 540,100 & $28,201,272$ & $10,401,832$ & $10,373,136$ & 233,110 \\
\hline
\end{tabular}

Note: Totals may not equal sum of components because of independent rounding. Double counting occurs in components of both sources and disposition of energy and thus neither provides a true total. Purchases from utilities, net interchanges, and net wheeling (except for imports) are included in net generation. Sales ior resale is included in sales to ultimate consumers. Summary data are provided in Table 30.

Source: Federal Energy Regulatory Commission, FERC Form 1. "Annual Report of Major Electric Utilities, Licensees and Others." 


\section{Selected Financial Indicators}

\section{Capitallzation Ratlos}

Capitalization ratios show how capital structure is proportioned. The capitalization ratio measures the volume of capital contributed by stockholders in relationship to that advanced by bond and note holders. The short-term notes have been included as a portion of capitalization due to their wide use in financing in recent years. Short-term notes payable include the face value of all notes, drafts, and acceptances, as well as other similar evidence of indebtedness payable on demand, or within a time not exceeding 1 year from date of issue to those other than associated companies. The ratios are based on year-end balances.

\section{Common Equity (Percent of Total Capitallzation)}

This, common equity percent of total capitalization is based on the average of the beginning- and the endof-the-year balances, and excludes short-term debt (notes payable) in the computation. This differs from the common equity shown in column 1 of the selected financial indicators table.

\section{Rate of Return on Common Equity}

The computed rates of return on common st sck (common equity) for the major investor-owned $\mathrm{flec}$ tric utilities are presented. For some of the calculations not shown, the omitted electric $u$ ility essentially functions as an operating departmert of another company (its return was not meaningful). For other companies the ratio is not shown because they are in a net-loss position.

The computed rate of return is the relationship of total earnings available for common stock to the average of the beginning- and year-end balances for proprietary capital, less preferred stock.

The presentation of the rates of return on common equity is not intended as an evaluation of the reasonableness for returns under the applicable regulatory standards.
UtIllty Operating Revanues / Total Assots and Other Doblts

This ratio measures the productivity of assets. As the ratio increases, it indicates that the assets have become more productive and are generating more revenues. This ratio is calculated by dividing utility operating revenues, as reported in Table 37 of this publication, by total assets and other debits, as reported in Table 38.

\section{Interest Coverage}

The number of times that fixed interest charges are earned (covered) is an indication of the margin of safety for interest on fixed debt. The times-interestearned ratios are calculated by using net earnings before taxes (Federal and other) on two different bases: with allowance for funds used during construction and 'without allowance for funds used during construction. In Table 44 these ratios of measurement have been omitted for electric utilities that either have no significant outstanding long-term debt or shortterm notes payable, or are subsidiary companies that receive interest-free financing from the parent, and therefore, have no significant interest charges. 
Table 44. Selected Financlal Indlcators by Major U.S. Investor-Owned Electrlc Utility Within State, 1992

\begin{tabular}{|c|c|c|c|c|c|}
\hline Utilities & $\begin{array}{l}\text { Common } \\
\text { Equity } \\
\text { (percent) }\end{array}$ & $\begin{array}{l}\text { Preferred } \\
\text { Stock } \\
\text { (percent) }\end{array}$ & $\begin{array}{l}\text { Long-Term } \\
\text { Debt } \\
\text { (percent) }\end{array}$ & $\begin{array}{l}\text { Short-Term } \\
\text { Debt } \\
\text { (Notes } \\
\text { Payable) } \\
\text { (percent) }\end{array}$ & $\begin{array}{l}\text { Common } \\
\text { Equity } \\
\text { Percent } \\
\text { of Total } \\
\text { Capital. } \\
\text { ization' }\end{array}$ \\
\hline 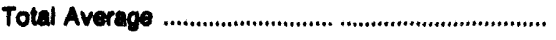 & 42.9 & 7.0 & 47.7 & 2.4 & 43.6 \\
\hline 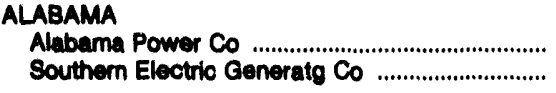 & $\begin{array}{l}46.2 \\
40.2\end{array}$ & $\begin{array}{r}\theta .3 \\
.0\end{array}$ & $\begin{array}{l}40.8 \\
59.8\end{array}$ & $\begin{array}{r}3.7 \\
.0\end{array}$ & $\begin{array}{l}46.9 \\
40.5\end{array}$ \\
\hline 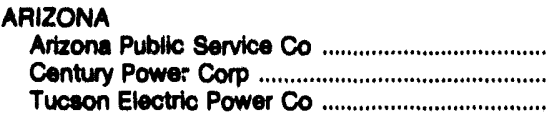 & $\begin{array}{l}36.3 \\
44.6 \\
-3.2\end{array}$ & $\begin{array}{r}9.4 \\
.0 \\
.0\end{array}$ & $\begin{array}{r}50.6 \\
55.4 \\
103.2\end{array}$ & $\begin{array}{r}4.7 \\
.0 \\
.0\end{array}$ & $\begin{array}{l}35.2 \\
29.2 \\
-9.5\end{array}$ \\
\hline 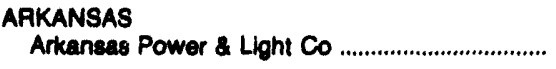 & 42.0 & 7.7 & 50.3 & .0 & 39.0 \\
\hline 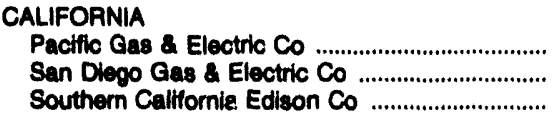 & $\begin{array}{l}44.3 \\
47.3 \\
42.2\end{array}$ & $\begin{array}{l}5.1 \\
4.3 \\
5.7\end{array}$ & $\begin{array}{l}45.7 \\
46.2 \\
46.8\end{array}$ & $\begin{array}{l}4.8 \\
2.2 \\
5.4\end{array}$ & $\begin{array}{l}46.0 \\
50.1 \\
43.5\end{array}$ \\
\hline $\begin{array}{l}\text { COLOAADO } \\
\text { Public Service Co of Colorado }\end{array}$ & 45.4 & 7.7 & 47.0 & .0 & 47.1 \\
\hline 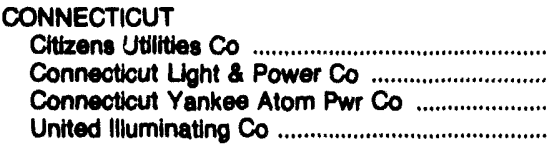 & $\begin{array}{l}63.6 \\
36.6 \\
31.1 \\
27.2\end{array}$ & $\begin{array}{r}.0 \\
10.5 \\
.0 \\
3.9\end{array}$ & $\begin{array}{l}36.4 \\
47.9 \\
61.8 \\
63.5\end{array}$ & $\begin{array}{l}.0 \\
5.0 \\
7.2 \\
5.4\end{array}$ & $\begin{array}{l}62.9 \\
38.7 \\
33.6 \\
28.6\end{array}$ \\
\hline 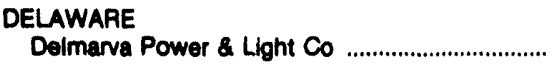 & 42.4 & 10.0 & 46.6 & 1.0 & 42.8 \\
\hline $\begin{array}{l}\text { DISTRICT OF COLUMBIA } \\
\text { Potomac Electric Power Co }\end{array}$ & 47.2 & 7.1 & 44.1 & 1.6 & 48.4 \\
\hline 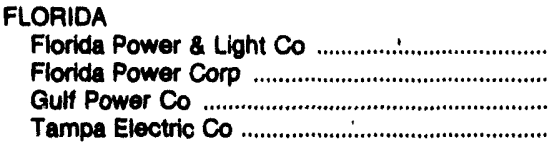 & $\begin{array}{l}47.9 \\
47.7 \\
43.8 \\
52.6\end{array}$ & $\begin{array}{l}7.1 \\
7.5 \\
8.4 \\
3.6\end{array}$ & $\begin{array}{l}45.0 \\
41.6 \\
43.0 \\
41.9\end{array}$ & $\begin{array}{l}.0 \\
3.2 \\
4.8 \\
1.8\end{array}$ & $\begin{array}{l}47.9 \\
49.6 \\
43.5 \\
55.8\end{array}$ \\
\hline 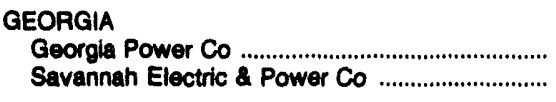 & $\begin{array}{l}41.7 \\
53.2\end{array}$ & $\begin{array}{l}8.2 \\
6.7\end{array}$ & $\begin{array}{l}44.3 \\
37.5\end{array}$ & $\begin{array}{l}5.7 \\
2.5\end{array}$ & $\begin{array}{l}43.0 \\
53.8\end{array}$ \\
\hline 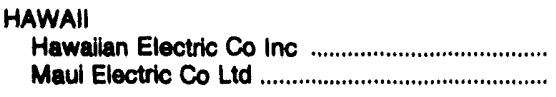 & $\begin{array}{l}54.5 \\
52.7\end{array}$ & $\begin{array}{l}6.8 \\
6.5\end{array}$ & $\begin{array}{l}25.4 \\
40.8\end{array}$ & $\begin{array}{r}13.3 \\
.0\end{array}$ & $\begin{array}{l}61.1 \\
51.0\end{array}$ \\
\hline $\begin{array}{l}\text { IDAHO } \\
\text { Idaho Power Co }\end{array}$ & 43.7 & 7.5 & 48.3 & .4 & 44.0 \\
\hline 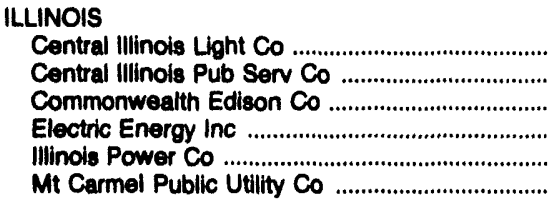 & $\begin{array}{l}43.9 \\
48.5 \\
38.3 \\
10.0 \\
37.5 \\
69.2\end{array}$ & $\begin{array}{r}10.2 \\
5.7 \\
5.3 \\
.0 \\
10.4 \\
.0\end{array}$ & $\begin{array}{l}42.1 \\
44.2 \\
56.4 \\
67.7 \\
50.4 \\
26.8\end{array}$ & $\begin{array}{r}3.9 \\
1.5 \\
.0 \\
22.3 \\
1.7 \\
4.0\end{array}$ & $\begin{array}{l}45.6 \\
49.0 \\
39.6 \\
12.8 \\
38.0 \\
79.6\end{array}$ \\
\hline 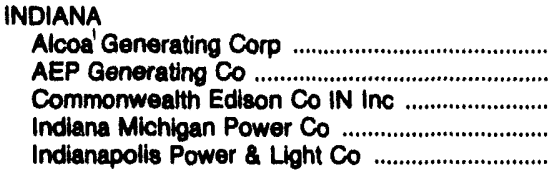 & $\begin{array}{r}100.0 \\
32.9 \\
54.6 \\
39.8 \\
51.9\end{array}$ & $\begin{array}{r}.0 \\
.0 \\
22.9 \\
8.2 \\
3.8\end{array}$ & $\begin{array}{l}.0 \\
67.1 \\
22.5 \\
50.2 \\
41.1\end{array}$ & $\begin{array}{r}.0 \\
.0 \\
.0 \\
1.8 \\
3.0\end{array}$ & $\begin{array}{r}100.0 \\
34.1 \\
53.6 \\
41.1 \\
53.3\end{array}$ \\
\hline
\end{tabular}

See endnotes at end of this table. 
Table 44. 8olected Finanelal Indloators by Major U.8. Investor-Owned Eloctric Utillty Within 8tato, 1992 (Continued)

\begin{tabular}{|c|c|c|c|c|c|}
\hline Utillibes & $\begin{array}{l}\text { Rate of } \\
\text { Rotum on } \\
\text { Averege } \\
\text { Common } \\
\text { Equity }\end{array}$ & $\begin{array}{l}\text { Tolal Utilly } \\
\text { Operating } \\
\text { Rovenue } \\
\text { Plus Other Income } \\
\text { os a Percent } \\
\text { of Total Aesets } \\
\text { \& Other Debits }\end{array}$ & $\begin{array}{l}\text { Intereat } \\
\text { Coverage } \\
\text { Botore } \\
\text { Taxes } \\
\text { With } \\
\text { AFUDC }\end{array}$ & $\begin{array}{l}\text { Intereat } \\
\text { Coverage } \\
\text { Bolore } \\
\text { Toxes } \\
\text { Whthout } \\
\text { AFUDC }\end{array}$ & $\begin{array}{l}\text { Current Aasets } \\
\text { to Current } \\
\text { Lisbillities }\end{array}$ \\
\hline 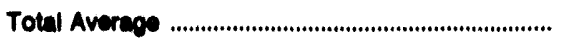 & 10.7 & 36.6 & 2.70 & 2.62 & 0.95 \\
\hline 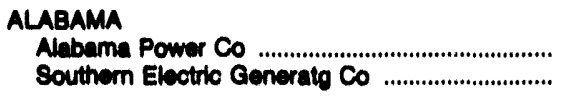 & $\begin{array}{l}14.0 \\
14.8\end{array}$ & $\begin{array}{l}38.4 \\
78.6\end{array}$ & $\begin{array}{l}3.33 \\
4.04\end{array}$ & $\begin{array}{l}3.31 \\
3.84\end{array}$ & $\begin{array}{l}1.08 \\
3.47\end{array}$ \\
\hline 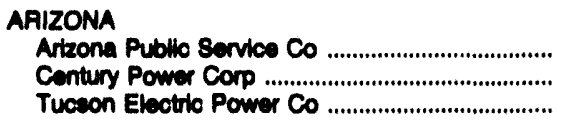 & $\begin{array}{r}14.7 \\
49.5 \\
103.5\end{array}$ & $\begin{array}{l}28.7 \\
70.8 \\
25.0\end{array}$ & $\begin{array}{c}2.88 \\
\text { NA } \\
.08\end{array}$ & $\begin{array}{r}2.84 \\
.09\end{array}$ & $\begin{array}{r}.88 \\
.07 \\
1.88\end{array}$ \\
\hline 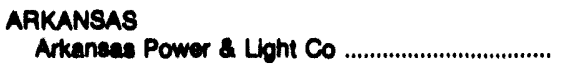 & 10.4 & 36.9 & 2.54 & 2.48 & .82 \\
\hline 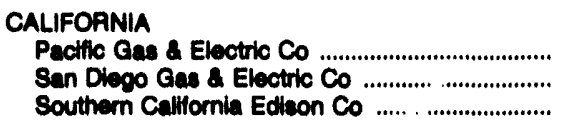 & $\begin{array}{l}13.6 \\
14.3 \\
13.5\end{array}$ & $\begin{array}{l}42.8 \\
40.2 \\
47.9\end{array}$ & $\begin{array}{l}3.53 \\
4.74 \\
3.44\end{array}$ & $\begin{array}{l}3.44 \\
4.63 \\
3.37\end{array}$ & $\begin{array}{r}1.07 \\
1.13 \\
.84\end{array}$ \\
\hline $\begin{array}{l}\text { COLOAADO } \\
\text { Public Service Co of Colorado }\end{array}$ & 11.7 & 50.5 & 3.16 & 3.08 & .67 \\
\hline 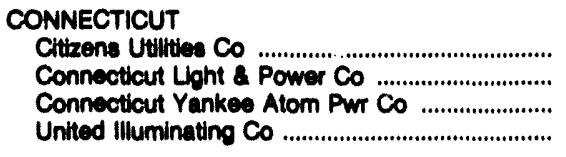 & $\begin{array}{l}14.8 \\
11.6 \\
18.1 \\
12.7\end{array}$ & $\begin{array}{l}19.1 \\
41.9 \\
46.8 \\
26.9\end{array}$ & $\begin{array}{l}4.68 \\
2.85 \\
2.86 \\
1.81\end{array}$ & $\begin{array}{l}4.54 \\
2.91 \\
2.94 \\
1.78\end{array}$ & $\begin{array}{r}1.78 \\
.02 \\
.88 \\
.71\end{array}$ \\
\hline $\begin{array}{l}\text { DELAWARE } \\
\text { Dolmarva Power \& Light Co }\end{array}$ & 12.4 & 37.5 & 3.20 & 3.05 & 1.18 \\
\hline 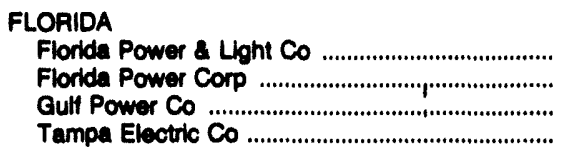 & $\begin{array}{l}13.1 \\
12.4 \\
13.6 \\
13.4\end{array}$ & $\begin{array}{l}44.0 \\
43.6 \\
44.4 \\
47.7\end{array}$ & $\begin{array}{l}3.38 \\
3.79 \\
3.32 \\
4.86\end{array}$ & $\begin{array}{l}3.20 \\
3.60 \\
3.32 \\
4.94\end{array}$ & $\begin{array}{r}.02 \\
.88 \\
1.38 \\
1.50\end{array}$ \\
\hline 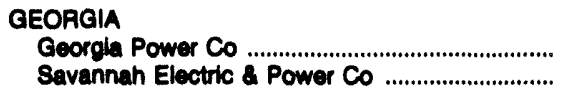 & $\begin{array}{l}13.6 \\
12.9\end{array}$ & $\begin{array}{l}33.8 \\
45.5\end{array}$ & $\begin{array}{l}2.77 \\
3.70\end{array}$ & $\begin{array}{l}2.73 \\
3.84\end{array}$ & $\begin{array}{l}.87 \\
.88\end{array}$ \\
\hline 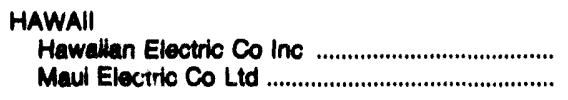 & $\begin{array}{l}10.5 \\
11.2\end{array}$ & $\begin{array}{l}47.5 \\
45.5\end{array}$ & $\begin{array}{l}4.51 \\
3.56\end{array}$ & $\begin{array}{l}4.29 \\
3.08\end{array}$ & $\begin{array}{l}.76 \\
.84\end{array}$ \\
\hline 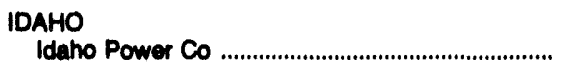 & 9.0 & 28.8 & 2.37 & 2.29 & 1.30 \\
\hline 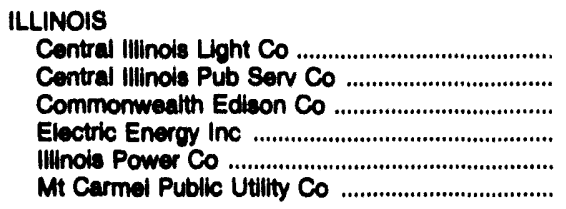 & $\begin{array}{r}11.2 \\
12.3 \\
7.8 \\
150.9 \\
4.8 \\
8.9\end{array}$ & $\begin{array}{r}44.6 \\
44.1 \\
28.5 \\
230.0 \\
26.2 \\
93.2\end{array}$ & $\begin{array}{l}3.45 \\
3.33 \\
1.84 \\
4.69 \\
1.89 \\
6.03\end{array}$ & $\begin{array}{l}3.44 \\
3.24 \\
1.89 \\
4.69 \\
1.85 \\
4.23\end{array}$ & $\begin{array}{l}1.20 \\
1.50 \\
1.38 \\
.08 \\
.72 \\
.85\end{array}$ \\
\hline 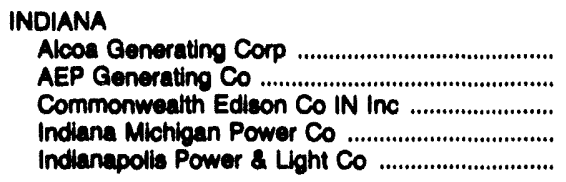 & $\begin{array}{r}4.5 \\
15.3 \\
8.4 \\
11.9 \\
13.3\end{array}$ & $\begin{array}{r}122.7 \\
35.6 \\
63.4 \\
31.7 \\
35.3\end{array}$ & $\begin{array}{l}N A \\
2.35 \\
4.63 \\
2.60 \\
4.38\end{array}$ & $\begin{array}{l}N A \\
2.34 \\
4.54 \\
2.55 \\
4.27\end{array}$ & $\begin{array}{r}2.88 \\
8.52 \\
3.82 \\
1.37 \\
.93\end{array}$ \\
\hline
\end{tabular}

See endnotes at end of this table. 
Table 44. Solected Financlal Indlcators by Major U.S. Investor-Owned Electrlc Utility Within State, 1992 (Continued)

\begin{tabular}{|c|c|c|c|c|c|}
\hline Utilities & $\begin{array}{l}\text { Net Income } \\
\text { Dhided by } \\
\text { Operating } \\
\text { Revenues } \\
\text { (Profit Margin) }\end{array}$ & $\begin{array}{l}\text { Electric } \\
\text { Fixed } \\
\text { Aseets } \\
\text { (Net Plant) } \\
\text { Tumover }\end{array}$ & $\begin{array}{l}\text { Internally } \\
\text { Generated } \\
\text { Funds to } \\
\text { Construction } \\
\text { Expenditures }\end{array}$ & $\begin{array}{l}\text { Return on } \\
\text { Average Common } \\
\text { Stock Equity }\end{array}$ & $\begin{array}{l}\text { Return } \\
\text { on } \\
\text { invesiment }\end{array}$ \\
\hline Total Average & 9.91 & 0.47 & 71.91 & 11.98 & 3.63 \\
\hline 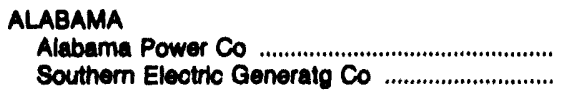 & $\begin{array}{r}13.10 \\
6.20\end{array}$ & $\begin{array}{r}.43 \\
1.08\end{array}$ & $\begin{array}{r}111.57 \\
23.40\end{array}$ & $\begin{array}{l}15.47 \\
14.76\end{array}$ & $\begin{array}{l}4.76 \\
4.87\end{array}$ \\
\hline 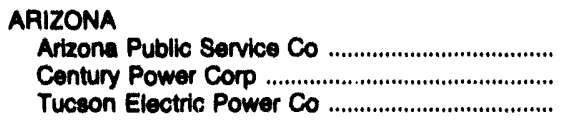 & $\begin{array}{r}14.78 \\
15.58 \\
-20.00\end{array}$ & $\begin{array}{l}.37 \\
.83 \\
.30\end{array}$ & $\begin{array}{r}108.53 \\
764.35 \\
95.45\end{array}$ & $\begin{array}{r}16.80 \\
49.54 \\
103.54\end{array}$ & $\begin{array}{r}4.24 \\
11.04 \\
-4.98\end{array}$ \\
\hline 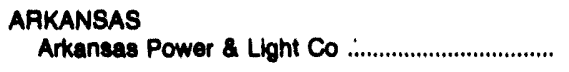 & 8.58 & .53 & 127.18 & 12.67 & 3.16 \\
\hline 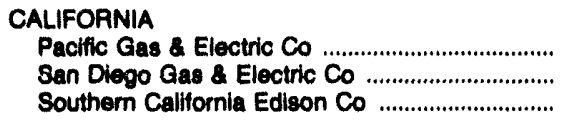 & $\begin{array}{r}11.31 \\
11.04 \\
8.72\end{array}$ & $\begin{array}{l}.57 \\
.58 \\
.65\end{array}$ & $\begin{array}{r}62.88 \\
63.22 \\
125.77\end{array}$ & $\begin{array}{l}14.66 \\
15.01 \\
14.37\end{array}$ & $\begin{array}{l}4.84 \\
5.10 \\
4.17\end{array}$ \\
\hline $\begin{array}{l}\text { COLORADO } \\
\text { Public Service Co of Colorado }\end{array}$ & 7.80 & .55 & 17.63 & 12.83 & 3.94 \\
\hline 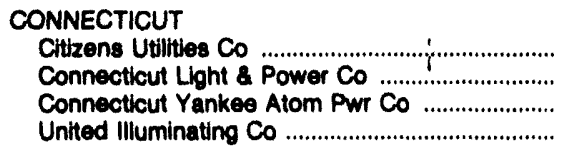 & $\begin{array}{r}34.25 \\
8.92 \\
8.71 \\
8.50\end{array}$ & $\begin{array}{r}.45 \\
.56 \\
1.79 \\
.51\end{array}$ & $\begin{array}{r}67.39 \\
87.75 \\
717.21 \\
113.88\end{array}$ & $\begin{array}{l}14.77 \\
13.76 \\
18.05 \\
13.77\end{array}$ & $\begin{array}{l}6.52 \\
3.73 \\
4.07 \\
2.29\end{array}$ \\
\hline 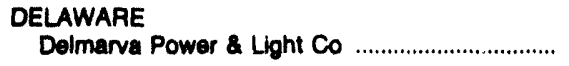 & 11.40 & .45 & 48.88 & 13.66 & 4.27 \\
\hline $\begin{array}{l}\text { DISTAIÇT OF COLUMBIA } \\
\text { Potomac Electric Power Co }\end{array}$ & 13.53 & .40 & 55.88 & 12.24 & 4.52 \\
\hline $\begin{array}{l}\text { FLORIDA } \\
\text { Florida Power \& Light Co } \\
\text { Florida Power Corp } \\
\text { Gulf Power Co } \\
\text { Tampa Electric Co }\end{array}$ & $\begin{array}{l}10.09 \\
10.53 \\
10.36 \\
11.01\end{array}$ & $\begin{array}{l}.54 \\
.52 \\
.56 \\
.56\end{array}$ & $\begin{array}{r}37.65 \\
38.26 \\
108.08 \\
72.23\end{array}$ & $\begin{array}{l}14.28 \\
13.58 \\
14.90 \\
13.80\end{array}$ & $\begin{array}{l}4.43 \\
4.59 \\
4.60 \\
5.25\end{array}$ \\
\hline 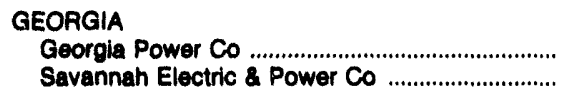 & $\begin{array}{l}13.46 \\
11.65\end{array}$ & $\begin{array}{l}.41 \\
.52\end{array}$ & $\begin{array}{r}118.85 \\
71.68\end{array}$ & $\begin{array}{l}15.11 \\
14.08\end{array}$ & $\begin{array}{l}4.55 \\
5.29\end{array}$ \\
\hline 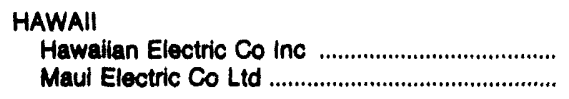 & $\begin{array}{l}9.47 \\
9.32\end{array}$ & $\begin{array}{l}.66 \\
.52\end{array}$ & $\begin{array}{l}41.94 \\
21.47\end{array}$ & $\begin{array}{l}11.41 \\
12.50\end{array}$ & $\begin{array}{l}4.50 \\
4.24\end{array}$ \\
\hline 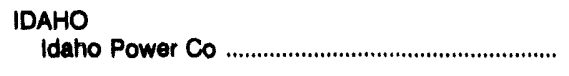 & 12.04 & .31 & 44.34 & 9.85 & 3.22 \\
\hline 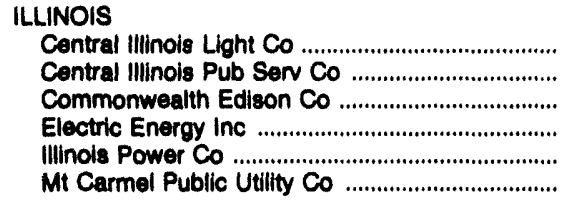 & $\begin{array}{l}8.21 \\
8.85 \\
8.52 \\
4.85 \\
8.25 \\
5.48\end{array}$ & $\begin{array}{r}.47 \\
.46 \\
.35 \\
4.57 \\
.30 \\
1.02\end{array}$ & $\begin{array}{l}67.73 \\
33.96 \\
53.64 \\
42.34 \\
75.76 \\
14.52\end{array}$ & $\begin{array}{r}12.80 \\
13.15 \\
8.88 \\
150.83 \\
8.29 \\
8.85\end{array}$ & $\begin{array}{r}3.66 \\
4.38 \\
2.43 \\
11.17 \\
2.15 \\
5.11\end{array}$ \\
\hline 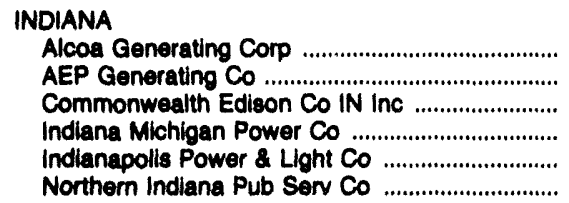 & $\begin{array}{r}2.79 \\
5.39 \\
7.08 \\
10.75 \\
14.69 \\
9.62\end{array}$ & $\begin{array}{r}1.83 \\
.51 \\
1.06 \\
.46 \\
.40 \\
.40\end{array}$ & $\begin{array}{r}54.99 \\
634.78 \\
76.60 \\
77.22 \\
68.74 \\
102.78\end{array}$ & \begin{tabular}{r|}
4.49 \\
15.29 \\
10.79 \\
13.47 \\
13.80 \\
14.70
\end{tabular} & $\begin{array}{l}3.43 \\
1.92 \\
4.49 \\
3.41 \\
5.18 \\
4.03\end{array}$ \\
\hline
\end{tabular}

See endnotes at end of this table. 
Table 44. Solected Financlal Indicators by Major U.S. Investor-Owned Electric Utility Within State, 1992 (Continued)

\begin{tabular}{|c|c|c|c|c|c|}
\hline Utilities & $\begin{array}{l}\text { Common } \\
\text { Equity } \\
\text { (percent) }\end{array}$ & $\begin{array}{l}\text { Preferred } \\
\text { Stock } \\
\text { (percent) }\end{array}$ & $\begin{array}{c}\text { Long-Term } \\
\text { Debt } \\
\text { 'percent) }\end{array}$ & $\begin{array}{c}\text { Short-Term } \\
\text { Debt } \\
\text { (Notes } \\
\text { Payable) } \\
\text { (percent) }\end{array}$ & $\begin{array}{l}\text { Common } \\
\text { Equity } \\
\text { Percent } \\
\text { of Total } \\
\text { Cepltal- } \\
\text { ization' }\end{array}$ \\
\hline 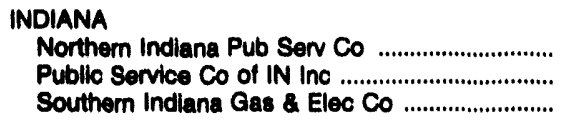 & $\begin{array}{l}40.5 \\
39.9 \\
49.9\end{array}$ & $\begin{array}{l}6.8 \\
5.3 \\
3.6\end{array}$ & $\begin{array}{l}43.8 \\
47.4 \\
45.6\end{array}$ & $\begin{array}{r}9.0 \\
7.4 \\
.8\end{array}$ & $\begin{array}{l}43.9 \\
42.6 \\
49.8\end{array}$ \\
\hline 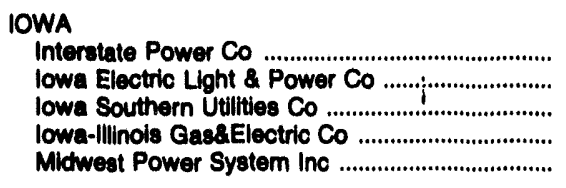 & $\begin{array}{l}46.0 \\
40.9 \\
50.2 \\
52.1 \\
39.6\end{array}$ & $\begin{array}{r}6.1 \\
2.4 \\
.0 \\
7.3 \\
3.3\end{array}$ & $\begin{array}{l}45.8 \\
45.2 \\
47.3 \\
35.1 \\
53.5\end{array}$ & $\begin{array}{r}2.1 \\
11.5 \\
2.5 \\
5.5 \\
3.6\end{array}$ & $\begin{array}{l}46.8 \\
47.1 \\
51.2 \\
53.8 \\
41.2\end{array}$ \\
\hline 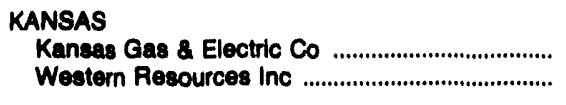 & $\begin{array}{l}52.0 \\
47.3\end{array}$ & $\begin{array}{r}.0 \\
7.2\end{array}$ & $\begin{array}{l}43.7 \\
40.4\end{array}$ & $\begin{array}{l}4.3 \\
5.0\end{array}$ & $\begin{array}{l}47.8 \\
48.6\end{array}$ \\
\hline 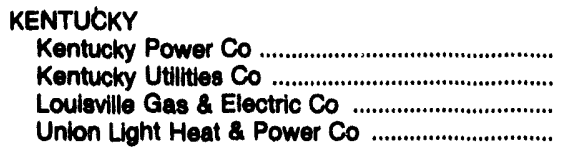 & $\begin{array}{l}42.4 \\
52.5 \\
42.5 \\
47.0\end{array}$ & $\begin{array}{r}.0 \\
3.9 \\
8.3 \\
.0\end{array}$ & $\begin{array}{l}54.0 \\
43.6 \\
48.5 \\
49.6\end{array}$ & $\begin{array}{r}3.6 \\
.0 \\
.6 \\
3.4\end{array}$ & $\begin{array}{l}43.6 \\
54.2 \\
42.8 \\
49.0\end{array}$ \\
\hline 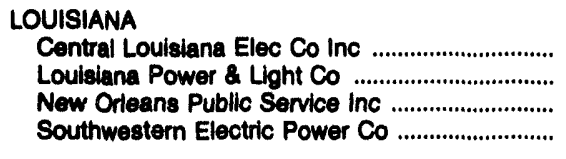 & $\begin{array}{l}47.1 \\
40.1 \\
42.3 \\
48.5\end{array}$ & $\begin{array}{r}1.4 \\
10.5 \\
6.6 \\
4.0\end{array}$ & $\begin{array}{l}42.8 \\
49.4 \\
51.2 \\
47.5\end{array}$ & $\begin{array}{r}8.8 \\
.0 \\
.0 \\
.0\end{array}$ & $\begin{array}{l}47.9 \\
40.6 \\
41.3 \\
49.4\end{array}$ \\
\hline 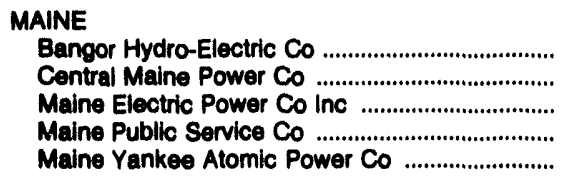 & $\begin{array}{l}36.8 \\
40.0 \\
16.8 \\
49.8 \\
21.6\end{array}$ & $\begin{array}{r}8.9 \\
11.7 \\
.0 \\
.0 \\
6.7\end{array}$ & $\begin{array}{l}47.6 \\
41.5 \\
83.1 \\
44.5 \\
70.3\end{array}$ & $\begin{array}{r}6.7 \\
6.8 \\
.0 \\
5.6 \\
1.4\end{array}$ & $\begin{array}{l}41.1 \\
44.2 \\
15.6 \\
50.6 \\
22.1\end{array}$ \\
\hline 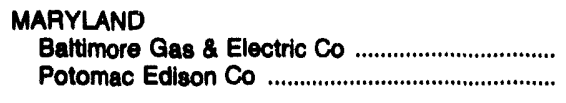 & $\begin{array}{l}48.7 \\
49.5\end{array}$ & $\begin{array}{r}10.9 \\
5.7\end{array}$ & $\begin{array}{l}40.2 \\
44.8\end{array}$ & $\begin{array}{l}.2 \\
.0\end{array}$ & $\begin{array}{l}47.4 \\
47.4\end{array}$ \\
\hline 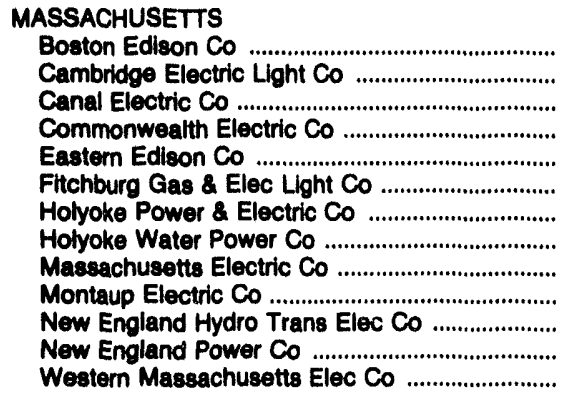 & $\begin{array}{l}34.8 \\
49.3 \\
48.2 \\
41.0 \\
40.7 \\
40.7 \\
37.0 \\
26.9 \\
48.6 \\
52.7 \\
38.7 \\
52.1 \\
34.5\end{array}$ & $\begin{array}{r}9.2 \\
.0 \\
.0 \\
.0 \\
7.8 \\
3.7 \\
.0 \\
.0 \\
7.3 \\
.4 \\
.0 \\
5.4 \\
13.2\end{array}$ & $\begin{array}{l}44.5 \\
48.9 \\
43.3 \\
37.4 \\
51.5 \\
50.1 \\
63.0 \\
73.1 \\
39.0 \\
46.9 \\
61.3 \\
42.0 \\
47.0\end{array}$ & $\begin{array}{r}11.5 \\
1.7 \\
8.4 \\
21.6 \\
.0 \\
5.4 \\
.0 \\
.0 \\
5.1 \\
.0 \\
.0 \\
.5 \\
5.4\end{array}$ & $\begin{array}{l}38.3 \\
50.2 \\
52.4 \\
51.4 \\
39.0 \\
43.9 \\
27.7 \\
29.4 \\
51.0 \\
51.1 \\
38.8 \\
50.7 \\
35.7\end{array}$ \\
\hline 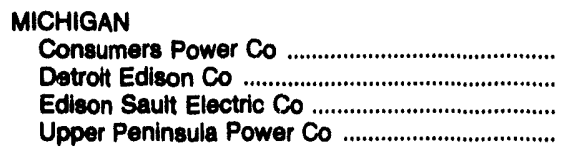 & $\begin{array}{l}33.0 \\
40.9 \\
42.8 \\
46.1\end{array}$ & $\begin{array}{r}4.4 \\
3.9 \\
.0 \\
1.0\end{array}$ & $\begin{array}{l}56.9 \\
54.9 \\
49.6 \\
53.0\end{array}$ & $\begin{array}{r}5.7 \\
.4 \\
7.7 \\
.0\end{array}$ & $\begin{array}{l}37.8 \\
41.1 \\
46.2 \\
45.7\end{array}$ \\
\hline $\begin{array}{l}\text { MINNESOTA } \\
\text { Minnesota Power \& Light Co } \\
\text { Northern States Power Co } \\
\text { Otter Tall Power Co }\end{array}$ & $\begin{array}{l}48.5 \\
50.4 \\
46.8\end{array}$ & $\begin{array}{r}5.0 \\
8.5 \\
11.0\end{array}$ & $\begin{array}{l}41.7 \\
36.5 \\
42.2\end{array}$ & $\begin{array}{r}4.8 \\
4.6 \\
.0\end{array}$ & $\begin{array}{l}50.5 \\
52.8 \\
47.5\end{array}$ \\
\hline
\end{tabular}

See endnotes at end of this table. 
Table 44. Selected Financlal Indicators by Major U.S. Investor-Owned Electric Utility Within State, 1992 (Continued)

\begin{tabular}{|c|c|c|c|c|c|}
\hline Utillties & $\begin{array}{l}\text { Rate of } \\
\text { Retum on } \\
\text { Average } \\
\text { Common } \\
\text { Equity }\end{array}$ & $\begin{array}{l}\text { Total Utility } \\
\text { Operating } \\
\text { Revenue } \\
\text { Plus Other Income } \\
\text { as a Percent } \\
\text { of Total Assets } \\
\text { a Other Debits }\end{array}$ & $\begin{array}{l}\text { Interest } \\
\text { Coverage } \\
\text { Bofore } \\
\text { Taxes } \\
\text { With } \\
\text { AFUDC }\end{array}$ & $\begin{array}{l}\text { Intereat } \\
\text { Coverage } \\
\text { Before } \\
\text { Taxes } \\
\text { Without } \\
\text { AFUDC }\end{array}$ & $\begin{array}{l}\text { Current Assets } \\
\text { to Current } \\
\text { Liabilities }\end{array}$ \\
\hline 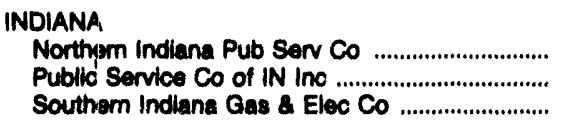 & $\begin{array}{l}13.7 \\
15.7 \\
13.5\end{array}$ & $\begin{array}{l}41.9 \\
44.4 \\
42.7\end{array}$ & $\begin{array}{l}3.44 \\
3.36 \\
4.15\end{array}$ & $\begin{array}{l}3.43 \\
3.21 \\
4.07\end{array}$ & $\begin{array}{r}0.60 \\
.39 \\
1.18\end{array}$ \\
\hline 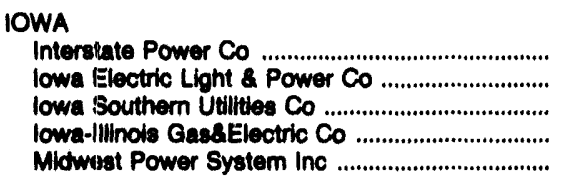 & $\begin{array}{r}8.1 \\
9.9 \\
13.1 \\
8.6 \\
7.1\end{array}$ & $\begin{array}{l}51.1 \\
38.4 \\
44.8 \\
37.1 \\
42.4\end{array}$ & $\begin{array}{l}2.68 \\
2.59 \\
3.41 \\
3.24 \\
2.20\end{array}$ & $\begin{array}{l}2.68 \\
2.53 \\
3.26 \\
3.20 \\
2.16\end{array}$ & $\begin{array}{r}1.09 \\
.46 \\
.62 \\
.88 \\
1.01\end{array}$ \\
\hline 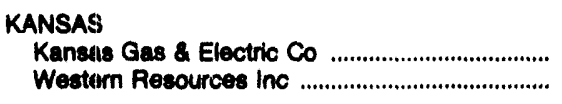 & $\begin{array}{r}8.9 \\
12.3\end{array}$ & $\begin{array}{l}13.8 \\
32.3\end{array}$ & $\begin{array}{l}2.30 \\
2.65\end{array}$ & $\begin{array}{l}2.27 \\
2.64\end{array}$ & $\begin{array}{l}.67 \\
.68\end{array}$ \\
\hline 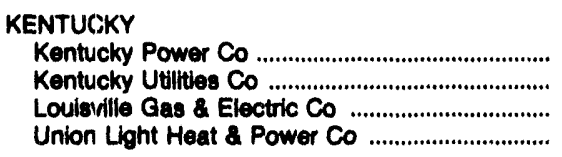 & $\begin{array}{r}13.5 \\
13.4 \\
11.0 \\
1.3\end{array}$ & $\begin{array}{l}50.3 \\
40.4 \\
35.5 \\
83.9\end{array}$ & $\begin{array}{r}2.61 \\
3.84 \\
2.88 \\
.98\end{array}$ & $\begin{array}{r}2.59 \\
3.83 \\
2.88 \\
.96\end{array}$ & $\begin{array}{l}.90 \\
3.41 \\
1.21 \\
1.25\end{array}$ \\
\hline 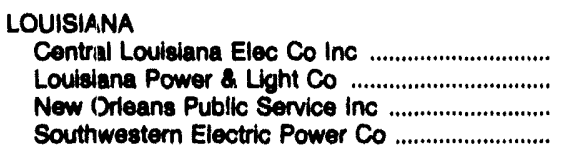 & $\begin{array}{l}12.8 \\
13.0 \\
14.2 \\
14.2\end{array}$ & $\begin{array}{l}36.1 \\
35.8 \\
70.3 \\
39.1\end{array}$ & $\begin{array}{l}3.07 \\
2.69 \\
2.77 \\
3.60\end{array}$ & $\begin{array}{l}3.02 \\
2.67 \\
2.76 \\
3.59\end{array}$ & $\begin{array}{r}.27 \\
1.03 \\
1.30 \\
1.08\end{array}$ \\
\hline 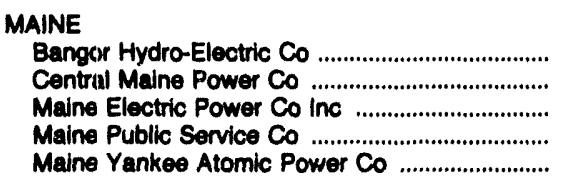 & $\begin{array}{l}10.7 \\
11.2 \\
12.0 \\
11.3 \\
12.4\end{array}$ & $\begin{array}{r}61.1 \\
48.2 \\
177.9 \\
50.9 \\
36.0\end{array}$ & $\begin{array}{l}2.23 \\
2.56 \\
2.72 \\
2.84 \\
2.06\end{array}$ & $\begin{array}{l}2.02 \\
2.50 \\
2.69 \\
2.82 \\
2.03\end{array}$ & $\begin{array}{r}1.02 \\
1.47 \\
5.40 \\
.89 \\
1.44\end{array}$ \\
\hline 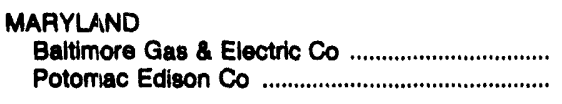 & $\begin{array}{r}9.5 \\
-11.7\end{array}$ & $\begin{array}{l}34.9 \\
49.5\end{array}$ & $\begin{array}{l}3.22 \\
3.36\end{array}$ & $\begin{array}{l}3.11 \\
3.22\end{array}$ & $\begin{array}{l}1.84 \\
1.67\end{array}$ \\
\hline 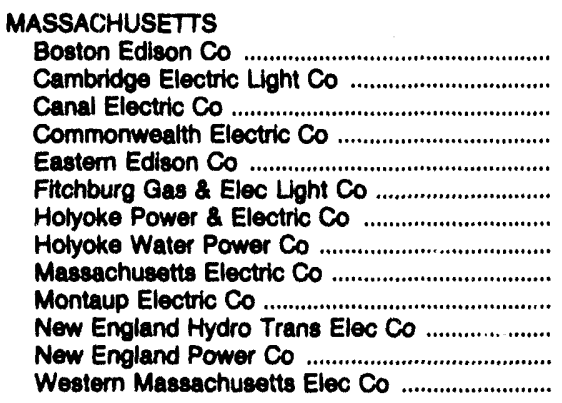 & $\begin{array}{r}11.1 \\
.2 \\
1.7 \\
7.0 \\
13.8 \\
13.4 \\
107.4 \\
8.0 \\
9.8 \\
13.5 \\
14.5 \\
15.8 \\
11.1\end{array}$ & $\begin{array}{r}42.3 \\
86.1 \\
61.5 \\
91.7 \\
42.9 \\
61.3 \\
442.9 \\
59.9 \\
122.5 \\
62.0 \\
21.4 \\
61.5 \\
37.0\end{array}$ & $\begin{array}{r}1.92 \\
.59 \\
3.56 \\
1.60 \\
2.25 \\
2.47 \\
2.43 \\
1.55 \\
2.56 \\
2.69 \\
2.18 \\
4.38 \\
2.82\end{array}$ & $\begin{array}{r}1.86 \\
.59 \\
3.21 \\
1.58 \\
2.24 \\
2.47 \\
2.43 \\
1.29 \\
2.55 \\
2.66 \\
2.18 \\
4.30 \\
2.77\end{array}$ & $\begin{array}{r}.66 \\
1.11 \\
.61 \\
.56 \\
1.99 \\
1.37 \\
1.01 \\
6.57 \\
.66 \\
1.45 \\
7.31 \\
1.53 \\
.63\end{array}$ \\
\hline 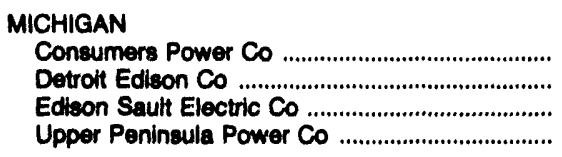 & $\begin{array}{r}N A \\
17.5 \\
13.5 \\
10.0\end{array}$ & $\begin{array}{l}40.6 \\
34.1 \\
64.6 \\
54.1\end{array}$ & $\begin{array}{l}\text { NA } \\
2.97 \\
2.62 \\
2.50\end{array}$ & $\begin{array}{l}N A \\
2.96 \\
2.62 \\
2.50\end{array}$ & $\begin{array}{r}1.01 \\
.74 \\
.68 \\
.92\end{array}$ \\
\hline $\begin{array}{l}\text { MINNESOTA } \\
\text { Minnesota Power \& Light Co } \\
\text { Northern States Power Co } \\
\text { Otter Tall Power Co }\end{array}$ & $\begin{array}{l}14.5 \\
11.9 \\
15.0\end{array}$ & $\begin{array}{l}28.4 \\
40.4 \\
34.5\end{array}$ & $\begin{array}{l}3.85 \\
3.64 \\
4.05\end{array}$ & $\begin{array}{l}3.83 \\
3.49 \\
4.04\end{array}$ & $\begin{array}{r}.80 \\
.88 \\
1.39\end{array}$ \\
\hline
\end{tabular}

See endnotes at end of this table. 
Table 44. Solected Financial Indicatore by Major U.S. Investor-Owned Electric Utility Within State, 1992 (Continued)

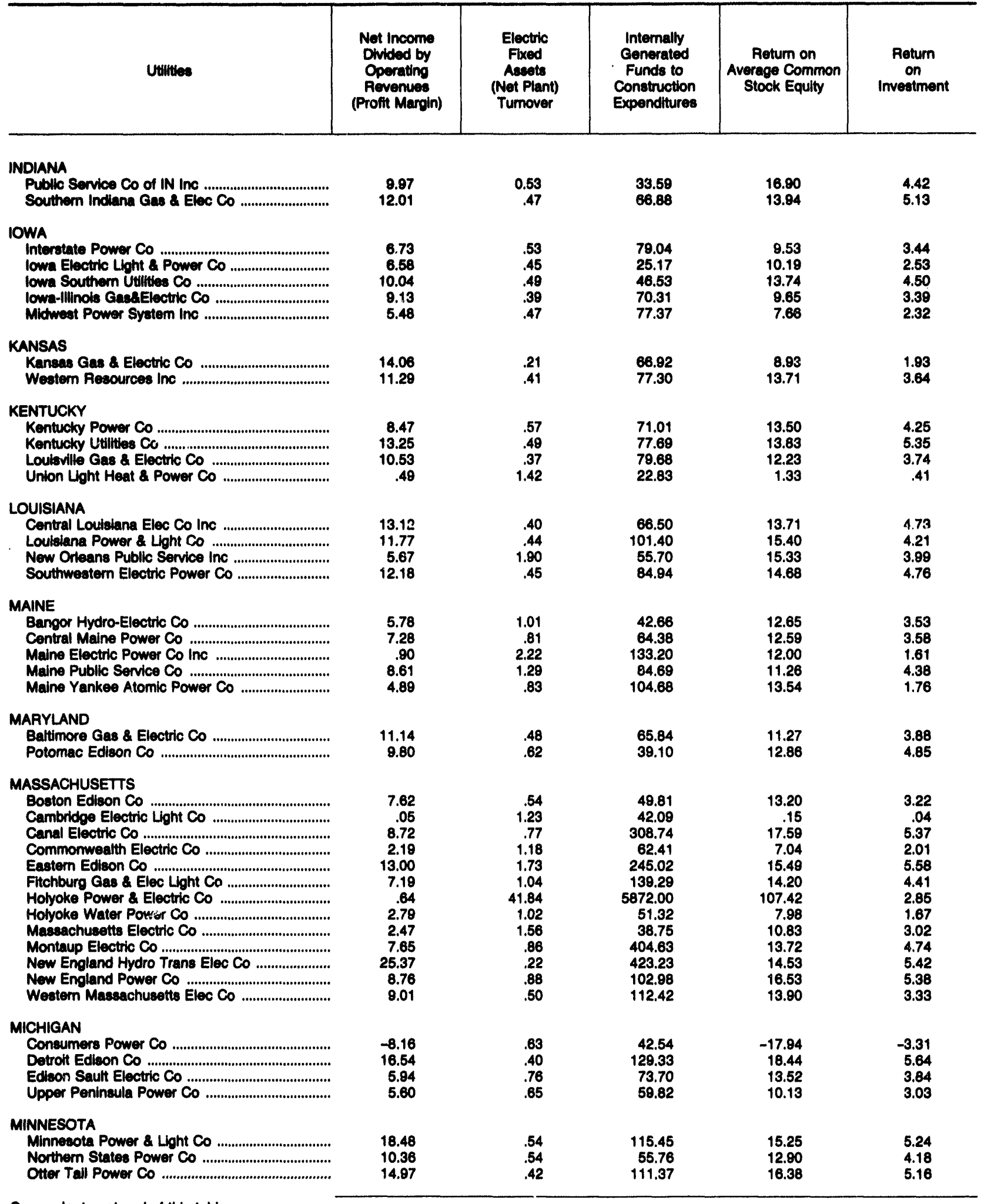

See endnotes at end of this table. 
Table 44. Selected Financlal Indicatore by Major U.S. Inveator-Owned Electric Utility Within State, 1992 (Continued)

\begin{tabular}{|c|c|c|c|c|c|}
\hline Utilities & $\begin{array}{l}\text { Common } \\
\text { Equily } \\
\text { (percent) }\end{array}$ & $\begin{array}{l}\text { Preferred } \\
\text { Stock } \\
\text { (percent) }\end{array}$ & $\begin{array}{l}\text { Long-Term } \\
\text { Debt } \\
\text { (percent) }\end{array}$ & $\begin{array}{l}\text { Short-Term } \\
\text { Debt } \\
\text { (Notes } \\
\text { Payable) } \\
\text { (Percent) }\end{array}$ & $\begin{array}{l}\text { Common } \\
\text { Equlty } \\
\text { Percent } \\
\text { of Total } \\
\text { Capltal- } \\
\text { ization' }\end{array}$ \\
\hline 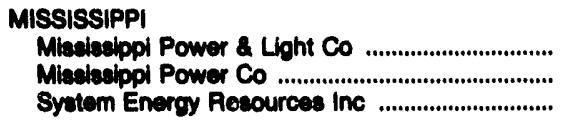 & $\begin{array}{l}38.2 \\
44.3 \\
38.3\end{array}$ & $\begin{array}{r}10.8 \\
11.7 \\
.0\end{array}$ & $\begin{array}{l}50.9 \\
39.1 \\
60.7\end{array}$ & $\begin{array}{r}0.0 \\
4.8 \\
.0\end{array}$ & $\begin{array}{l}37.5 \\
44.9 \\
39.3\end{array}$ \\
\hline 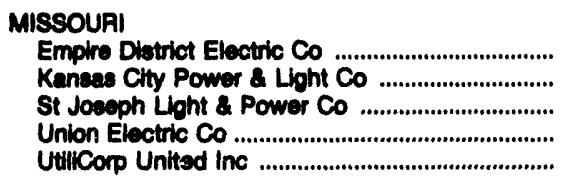 & $\begin{array}{l}48.5 \\
47.6 \\
58.7 \\
50.9 \\
44.0\end{array}$ & $\begin{array}{r}2.4 \\
5.1 \\
.0 \\
5.1 \\
5.7\end{array}$ & $\begin{array}{l}43.5 \\
45.4 \\
41.3 \\
43.5 \\
34.8\end{array}$ & $\begin{array}{r}4.5 \\
1.8 \\
.0 \\
.5 \\
15.4\end{array}$ & $\begin{array}{l}51.5 \\
48.0 \\
58.1 \\
50.8 \\
52.0\end{array}$ \\
\hline 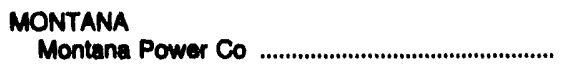 & 55.3 & 3.3 & 38.2 & 3.2 & 56.5 \\
\hline 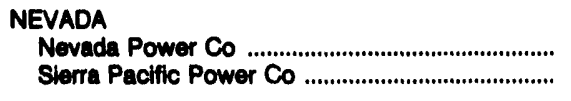 & $\begin{array}{l}45.1 \\
41.1\end{array}$ & $\begin{array}{r}3.6 \\
10.3\end{array}$ & $\begin{array}{l}51.3 \\
48.5\end{array}$ & $\begin{array}{l}.0 \\
.0\end{array}$ & $\begin{array}{l}45.7 \\
42.8\end{array}$ \\
\hline 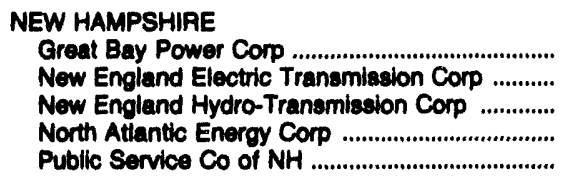 & $\begin{array}{r}-115.6 \\
10.6 \\
38.5 \\
23.7 \\
24.7\end{array}$ & $\begin{array}{r}56.0 \\
.0 \\
.0 \\
.0 \\
7.0\end{array}$ & $\begin{array}{r}159.7 \\
89.4 \\
61.5 \\
76.3 \\
68.3\end{array}$ & $\begin{array}{l}.0 \\
.0 \\
.0 \\
.0 \\
2.0\end{array}$ & $\begin{array}{r}-54.2 \\
10.8 \\
38.0 \\
23.7 \\
27.6\end{array}$ \\
\hline 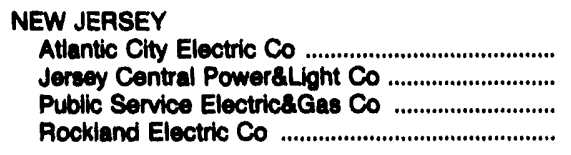 & $\begin{array}{l}46.1 \\
45.5 \\
45.5 \\
68.0\end{array}$ & $\begin{array}{r}14.3 \\
8.7 \\
5.7 \\
.0\end{array}$ & $\begin{array}{l}38.7 \\
45.6 \\
47.2 \\
31.0\end{array}$ & $\begin{array}{r}.9 \\
.2 \\
1.5 \\
.0\end{array}$ & $\begin{array}{l}46.8 \\
45.7 \\
45.3 \\
68.3\end{array}$ \\
\hline 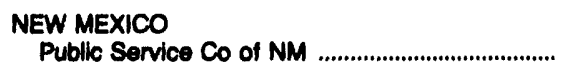 & 37.1 & 5.1 & 54.8 & 3.1 & 41.8 \\
\hline 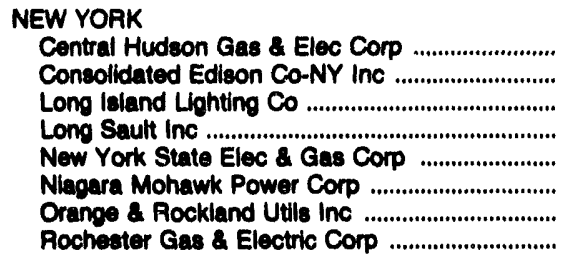 & $\begin{array}{r}41.5 \\
53.2 \\
28.5 \\
100.0 \\
42.4 \\
34.9 \\
46.3 \\
41.0\end{array}$ & $\begin{array}{r}8.9 \\
7.0 \\
8.7 \\
.0 \\
7.2 \\
7.6 \\
6.3 \\
7.8\end{array}$ & $\begin{array}{r}48.0 \\
39.8 \\
64.7 \\
.0 \\
48.7 \\
54.3 \\
41.6 \\
47.9\end{array}$ & $\begin{array}{r}1.6 \\
.0 \\
.0 \\
.0 \\
1.7 \\
3.2 \\
5.7 \\
3.2\end{array}$ & $\begin{array}{r}42.1 \\
52.6 \\
26.9 \\
100.0 \\
42.1 \\
35.4 \\
48.6 \\
41.1\end{array}$ \\
\hline 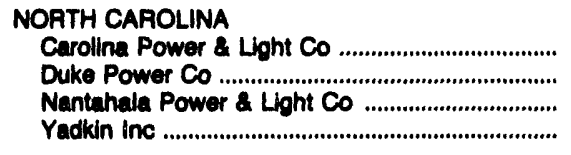 & $\begin{array}{r}47.3 \\
50.5 \\
58.1 \\
100.0\end{array}$ & $\begin{array}{r}2.5 \\
9.5 \\
.0 \\
.0\end{array}$ & $\begin{array}{r}49.4 \\
38.4 \\
43.8 \\
.0\end{array}$ & $\begin{array}{r}.8 \\
1.5 \\
.0 \\
.0\end{array}$ & $\begin{array}{r}46.4 \\
51.0 \\
63.1 \\
100.0\end{array}$ \\
\hline 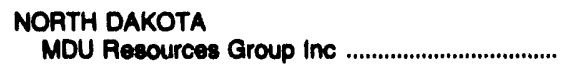 & 54.6 & 3.1 & 41.5 & .7 & 55.5 \\
\hline 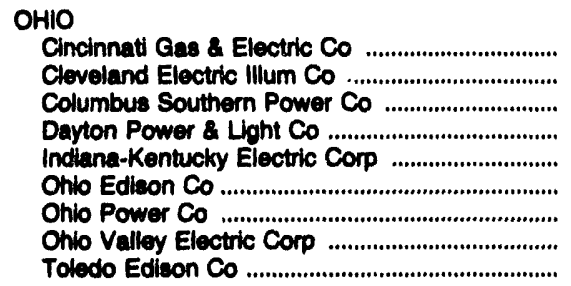 & $\begin{array}{r}44.2 \\
36.2 \\
38.8 \\
46.3 \\
100.0 \\
44.9 \\
45.4 \\
27.9 \\
37.8\end{array}$ & $\begin{array}{r}8.8 \\
9.6 \\
6.6 \\
5.7 \\
.0 \\
5.9 \\
8.6 \\
.0 \\
.0 \\
11.0\end{array}$ & $\begin{array}{r}45.9 \\
53.9 \\
51.7 \\
46.2 \\
.0 \\
48.5 \\
46.0 \\
27.7 \\
48.6\end{array}$ & $\begin{array}{r}1.1 \\
.2 \\
2.8 \\
2.8 \\
.0 \\
.6 \\
.0 \\
44.4 \\
1.6\end{array}$ & $\begin{array}{r}44.0 \\
36.6 \\
40.1 \\
47.2 \\
100.0 \\
45.0 \\
46.5 \\
35.6 \\
37.4\end{array}$ \\
\hline
\end{tabular}

See endnotes at end of this table. 
Table 44. Selected Financlal Indicators by Major U.S. Inveotor-Owned Electric Utility Within State, 1992 (Continued)

\begin{tabular}{|c|c|c|c|c|c|}
\hline Utilities & $\begin{array}{l}\text { Rate of } \\
\text { Rotum on } \\
\text { Averege } \\
\text { Common } \\
\text { Equity }\end{array}$ & $\begin{array}{c}\text { Total Utilty } \\
\text { Operating } \\
\text { Revenus } \\
\text { Puis Other Income } \\
\text { is a Percent } \\
\text { of Total Aresets } \\
\text { a Other Debit }\end{array}$ & $\begin{array}{l}\text { Intereat } \\
\text { Coverage } \\
\text { Betore } \\
\text { Taxes } \\
\text { With } \\
\text { AFUDC }\end{array}$ & $\begin{array}{l}\text { Interest } \\
\text { Coverage } \\
\text { Before } \\
\text { Taxes } \\
\text { Whthout } \\
\text { AFUDC }\end{array}$ & $\begin{array}{l}\text { Current Assets } \\
\text { to Current } \\
\text { Liabilities }\end{array}$ \\
\hline 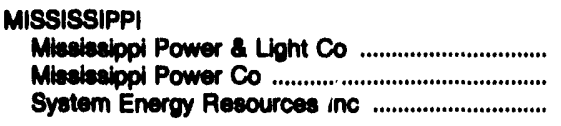 & $\begin{array}{l}13.2 \\
13.3 \\
11.2\end{array}$ & $\begin{array}{l}47.6 \\
47.0 \\
18.8\end{array}$ & $\begin{array}{l}2.14 \\
3.80 \\
1.87\end{array}$ & $\begin{array}{l}2.12 \\
3.75 \\
1.86\end{array}$ & $\begin{array}{r}1.65 \\
.81 \\
1.86\end{array}$ \\
\hline 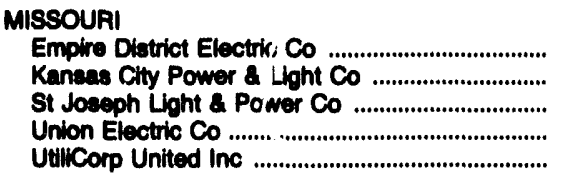 & $\begin{array}{r}10.3 \\
9.8 \\
12.0 \\
13.5 \\
7.0\end{array}$ & $\begin{array}{l}36.9 \\
30.3 \\
46.0 \\
36.1 \\
51.9\end{array}$ & $\begin{array}{l}2.83 \\
3.10 \\
3.72 \\
4.56 \\
2.53\end{array}$ & $\begin{array}{l}2.82 \\
3.05 \\
3.68 \\
4.50 \\
2.48\end{array}$ & $\begin{array}{r}1.05 \\
.64 \\
2.24 \\
1.17 \\
.51\end{array}$ \\
\hline $\begin{array}{l}\text { MONTANA } \\
\text { Montana Power Co }\end{array}$ & 12.2 & 27.8 & 3.92 & 3.86 & .84 \\
\hline 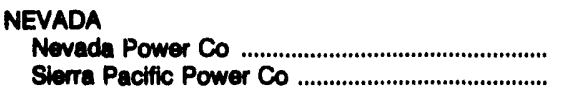 & $\begin{array}{l}10.5 \\
10.6\end{array}$ & $\begin{array}{l}38.0 \\
34.3\end{array}$ & $\begin{array}{l}2.50 \\
2.60\end{array}$ & $\begin{array}{l}2.24 \\
2.56\end{array}$ & $\begin{array}{l}1.23 \\
1.82\end{array}$ \\
\hline 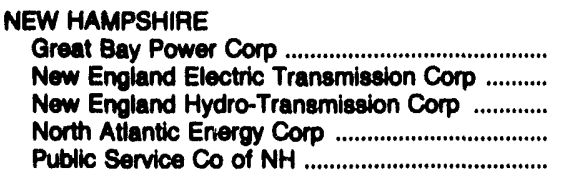 & $\begin{array}{r}44.5 \\
22.5 \\
15.6 \\
14.6 \\
5.1\end{array}$ & $\begin{array}{r}6.7 \\
19.6 \\
21.8 \\
9.5 \\
31.1\end{array}$ & $\begin{array}{r}\text { NA } \\
1.39 \\
2.20 \\
.91 \\
1.46\end{array}$ & $\begin{array}{r}\text { NA } \\
1.39 \\
2.20 \\
.80 \\
1.36\end{array}$ & $\begin{array}{r}.08 \\
1.12 \\
.58 \\
1.02 \\
.83\end{array}$ \\
\hline 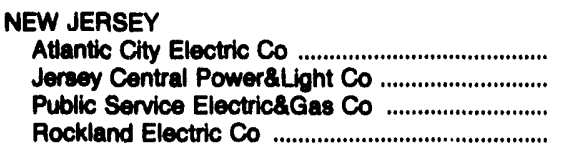 & $\begin{array}{r}12.2 \\
8.0 \\
11.3 \\
5.3\end{array}$ & $\begin{array}{l}38.4 \\
45.7 \\
40.5 \\
81.1\end{array}$ & $\begin{array}{l}3.69 \\
2.60 \\
2.83 \\
2.80\end{array}$ & $\begin{array}{l}3.62 \\
2.52 \\
2.77 \\
2.76\end{array}$ & $\begin{array}{r}1.27 \\
.90 \\
.80 \\
1.86\end{array}$ \\
\hline 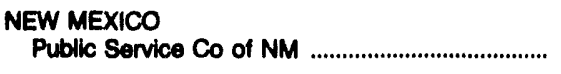 & NA & 32.4 & NA & NA & .73 \\
\hline 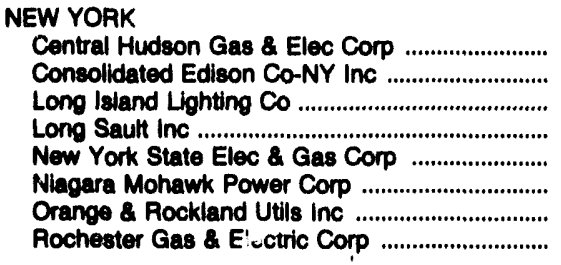 & $\begin{array}{r}11.4 \\
12.0 \\
11.1 \\
8.6 \\
10.9 \\
10.1 \\
11.8 \\
9.9\end{array}$ & $\begin{array}{l}43.5 \\
50.4 \\
24.5 \\
67.6 \\
32.4 \\
41.9 \\
52.6 \\
44.8\end{array}$ & $\begin{array}{l}3.00 \\
3.94 \\
1.73 \\
\text { NA } \\
2.54 \\
2.31 \\
2.94 \\
2.57\end{array}$ & $\begin{array}{l}2.86 \\
3.90 \\
1.70 \\
\text { NA } \\
2.50 \\
2.23 \\
2.94 \\
2.53\end{array}$ & $\begin{array}{r}1.60 \\
1.35 \\
1.54 \\
3.79 \\
1.60 \\
.82 \\
.95 \\
1.05\end{array}$ \\
\hline 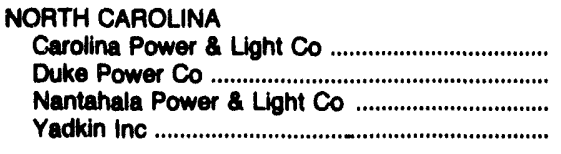 & $\begin{array}{r}13.4 \\
11.0 \\
8.6 \\
8.6\end{array}$ & $\begin{array}{r}33.8 \\
35.0 \\
62.9 \\
114.1\end{array}$ & $\begin{array}{c}3.22 \\
3.55 \\
4.34 \\
\text { NA }\end{array}$ & $\begin{array}{c}3.16 \\
3.48 \\
4.16 \\
\text { NA }\end{array}$ & $\begin{array}{r}1.06 \\
1.18 \\
1.78 \\
.02\end{array}$ \\
\hline $\begin{array}{l}\text { NORTH DAKOTA } \\
\text { MDU Resources Group Inc }\end{array}$ & 11.5 & 35.5 & 3.11 & 3.10 & 1.15 \\
\hline $\begin{array}{l}\text { OHIO } \\
\text { Cincinnati Gas \& Electric Co } \\
\text { Cleveland Electric Illum Co } \\
\text { Columbus Southern Power Co } \\
\text { Dayton Power \& Light Co } \\
\text { Indiana-Kentucky Electric Corp } \\
\text { Ohio Edison Co } \\
\text { Ohio Power Co } \\
\text { Ohio Valley Electric Corp } \\
\text { Toledo Edison Co }\end{array}$ & $\begin{array}{r}10.8 \\
8.7 \\
9.0 \\
13.1 \\
.0 \\
8.8 \\
11.7 \\
15.4 \\
5.1\end{array}$ & $\begin{array}{r}31.6 \\
20.5 \\
35.3 \\
35.7 \\
456.3 \\
27.8 \\
48.9 \\
308.8 \\
19.8\end{array}$ & $\begin{array}{l}2.50 \\
1.99 \\
1.82 \\
3.02 \\
1.22 \\
2.71 \\
3.04 \\
1.87 \\
1.89\end{array}$ & $\begin{array}{l}1.98 \\
1.99 \\
1.81 \\
3.02 \\
1.22 \\
2.67 \\
3.01 \\
1.87 \\
1.68\end{array}$ & $\begin{array}{r}1.29 \\
.97 \\
.59 \\
.84 \\
.78 \\
.66 \\
1.77 \\
1.52 \\
.93\end{array}$ \\
\hline
\end{tabular}

See endnotes at end of this table. 
Table 44. Selected Financlal Indlcators by Major U.S. Investor-Owned Electric Utility Within State, 1992 (Continued)

\begin{tabular}{|c|c|c|c|c|c|}
\hline Utilities & $\begin{array}{l}\text { Net Income } \\
\text { Divided by } \\
\text { Operating } \\
\text { Revenue } \\
\text { (Proft Margin) }\end{array}$ & $\begin{array}{l}\text { Electric } \\
\text { Fixed } \\
\text { Aseets } \\
\text { (Net Plant) } \\
\text { Tumover }\end{array}$ & $\begin{array}{l}\text { Internally } \\
\text { Generated } \\
\text { Funds to } \\
\text { Construction } \\
\text { Expenditures }\end{array}$ & $\begin{array}{l}\text { Return on } \\
\text { Average Common } \\
\text { Stock Equity }\end{array}$ & $\begin{array}{l}\text { Return } \\
\text { on } \\
\text { Investment }\end{array}$ \\
\hline 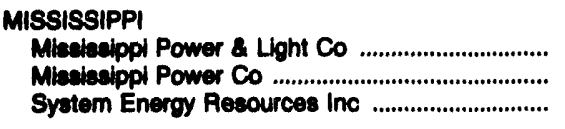 & $\begin{array}{r}7.95 \\
9.11 \\
17.88\end{array}$ & $\begin{array}{r}0.87 \\
.55 \\
.24\end{array}$ & $\begin{array}{r}119.68 \\
58.22 \\
407.81\end{array}$ & $\begin{array}{l}15.45 \\
14.66 \\
11.21\end{array}$ & $\begin{array}{l}3.78 \\
4.28 \\
3.38\end{array}$ \\
\hline 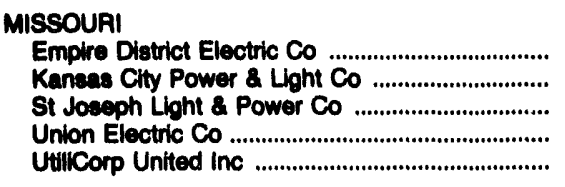 & $\begin{array}{r}11.24 \\
10.75 \\
10.85 \\
14.41 \\
5.61\end{array}$ & $\begin{array}{l}.41 \\
.35 \\
.51 \\
.40 \\
.56\end{array}$ & $\begin{array}{l}56.91 \\
91.68 \\
92.29 \\
95.94 \\
33.83\end{array}$ & $\begin{array}{r}10.55 \\
10.07 \\
12.00 \\
14.17 \\
8.00\end{array}$ & $\begin{array}{l}4.15 \\
3.26 \\
4.99 \\
5.20 \\
2.81\end{array}$ \\
\hline 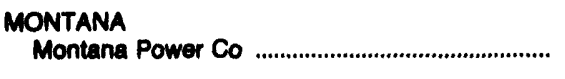 & 18.33 & .47 & 98.40 & 12.65 & 5.11 \\
\hline 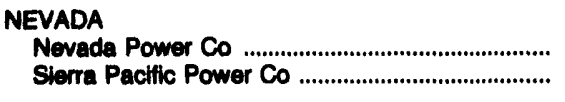 & $\begin{array}{r}9.44 \\
10.42\end{array}$ & .45 & $\begin{array}{l}29.72 \\
39.16\end{array}$ & $\begin{array}{l}11.43 \\
11.88\end{array}$ & $\begin{array}{l}3.68 \\
3.57\end{array}$ \\
\hline 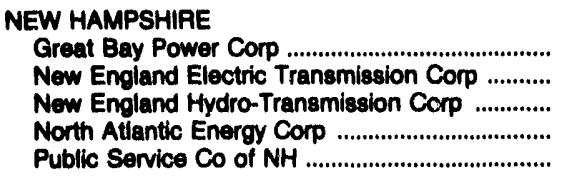 & $\begin{array}{r}-206.14 \\
9.71 \\
20.75 \\
16.19 \\
4.82\end{array}$ & $\begin{array}{l}.07 \\
.20 \\
.22 \\
.12 \\
.59\end{array}$ & $\begin{array}{r}135.25 \\
\text { NA } \\
873.92 \\
63.82 \\
95.15\end{array}$ & $\begin{array}{r}44.52 \\
22.54 \\
15.64 \\
14.62 \\
7.48\end{array}$ & $\begin{array}{r}-13.71 \\
1.90 \\
4.52 \\
1.54 \\
1.50\end{array}$ \\
\hline 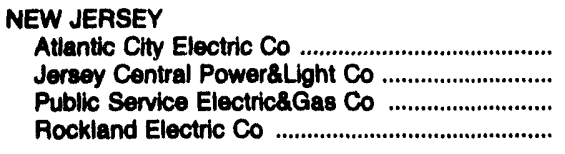 & $\begin{array}{r}13.15 \\
6.61 \\
9.53 \\
3.50\end{array}$ & $\begin{array}{r}.49 \\
.67 \\
.40 \\
1.22\end{array}$ & $\begin{array}{l}77.62 \\
58.68 \\
72.92 \\
53.40\end{array}$ & $\begin{array}{r}14.63 \\
9.76 \\
12.13 \\
5.34\end{array}$ & $\begin{array}{l}5.05 \\
3.02 \\
3.86 \\
2.84\end{array}$ \\
\hline 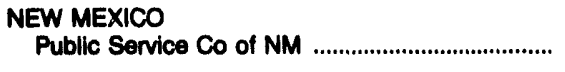 & -12.40 & .41 & 52.43 & -15.27 & -4.01 \\
\hline 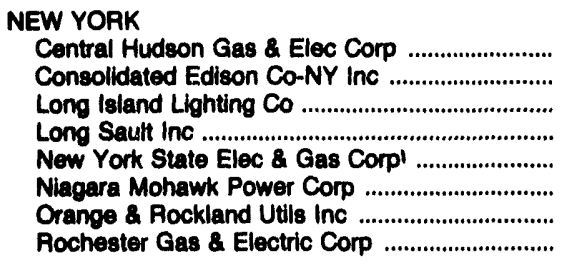 & $\begin{array}{r}9.10 \\
10.15 \\
11.46 \\
11.48 \\
10.87 \\
6.97 \\
8.42 \\
7.80\end{array}$ & $\begin{array}{l}.57 \\
.65 \\
.91 \\
.80 \\
.42 \\
.54 \\
.72 \\
.49\end{array}$ & $\begin{array}{l}80.49 \\
54.32 \\
55.77 \\
75.38 \\
63.14 \\
61.11 \\
70.55 \\
51.32\end{array}$ & $\begin{array}{r}12.91 \\
12.72 \\
13.99 \\
8.63 \\
12.29 \\
11.76 \\
12.73 \\
11.27\end{array}$ & $\begin{array}{l}3.95 \\
5.12 \\
2.80 \\
7.76 \\
3.52 \\
2.92 \\
4.43 \\
3.49\end{array}$ \\
\hline 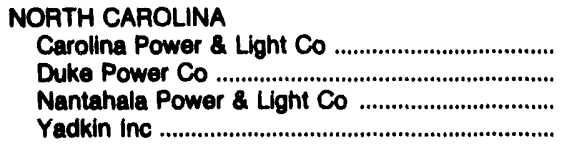 & $\begin{array}{r}13.72 \\
12.79 \\
5.85 \\
6.51\end{array}$ & $\begin{array}{r}.44 \\
.47 \\
.82 \\
1.14\end{array}$ & $\begin{array}{r}117.09 \\
101 \\
34.53 \\
28.69\end{array}$ & $\begin{array}{r}13.97 \\
12.36 \\
8.56 \\
8.60\end{array}$ & $\begin{array}{l}4.63 \\
4.47 \\
3.68 \\
7.43\end{array}$ \\
\hline 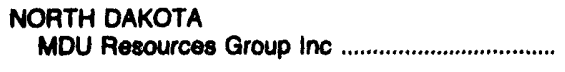 & 14.03 & .47 & 101.89 & 11.78 & 4.97 \\
\hline 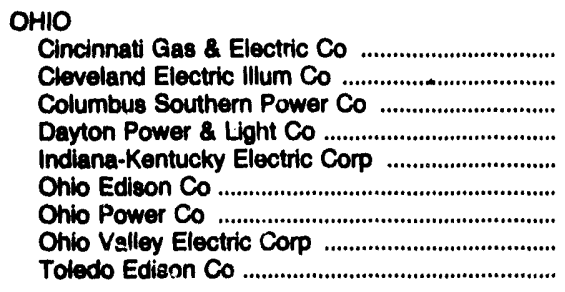 & $\begin{array}{r}13.89 \\
11.75 \\
9.03 \\
13.85 \\
\text { NA } \\
13.45 \\
9.43 \\
.54 \\
8.36\end{array}$ & $\begin{array}{r}.34 \\
.31 \\
.42 \\
.37 \\
10.30 \\
.42 \\
.68 \\
47.88 \\
.34\end{array}$ & $\begin{array}{r}73.08 \\
134.44 \\
80.25 \\
146.98 \\
10.13 \\
147.16 \\
85.61 \\
248.36 \\
114.90\end{array}$ & $\begin{array}{r}12.49 \\
10.89 \\
10.49 \\
14.05 \\
\text { NA } \\
10.73 \\
13.08 \\
15.43 \\
7.75\end{array}$ & $\begin{array}{l}4.39 \\
2.41 \\
3.19 \\
4.94 \\
\text { NA } \\
3.75 \\
4.60 \\
1.68 \\
1.65\end{array}$ \\
\hline
\end{tabular}

See endnotes at end of this table. 
Table 44. Solected Financlal Indlcators by Major U.S. Investor-Owned Electric Utllity Within State, 1992 (Continued)

\begin{tabular}{|c|c|c|c|c|c|}
\hline Utllities & $\begin{array}{l}\text { Common } \\
\text { Equity } \\
\text { (percent) }\end{array}$ & $\begin{array}{l}\text { Preferred } \\
\text { Stock } \\
\text { (percent) }\end{array}$ & $\begin{array}{l}\text { Long-Term } \\
\text { Debt } \\
\text { (percent) }\end{array}$ & $\begin{array}{l}\text { Short-Term } \\
\text { Debt } \\
\text { (Notes } \\
\text { Payable) } \\
\text { (percent) }\end{array}$ & $\begin{array}{l}\text { Common } \\
\text { Equity } \\
\text { Percent } \\
\text { of Total } \\
\text { Capital. } \\
\text { ization' }\end{array}$ \\
\hline 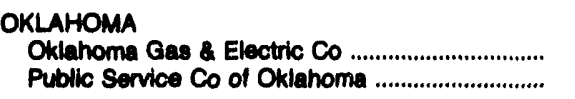 & $\begin{array}{l}51.7 \\
48.8\end{array}$ & $\begin{array}{l}2.9 \\
2.3\end{array}$ & $\begin{array}{l}43.8 \\
48.8\end{array}$ & $\begin{array}{r}1.5 \\
.0\end{array}$ & $\begin{array}{l}52.6 \\
50.1\end{array}$ \\
\hline 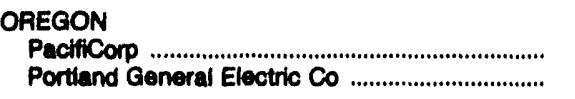 & $\begin{array}{l}42.5 \\
40.0\end{array}$ & $\begin{array}{l}8.1 \\
8.3\end{array}$ & $\begin{array}{l}43.2 \\
46.2\end{array}$ & $\begin{array}{l}5.2 \\
5.4\end{array}$ & $\begin{array}{l}48.4 \\
42.0\end{array}$ \\
\hline 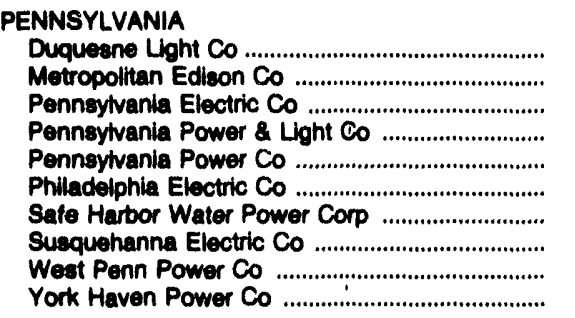 & $\begin{array}{r}43.6 \\
44.8 \\
47.1 \\
42.3 \\
34.9 \\
37.8 \\
53.3 \\
-102.0 \\
46.2 \\
100.0\end{array}$ & $\begin{array}{r}2.8 \\
11.5 \\
6.3 \\
9.8 \\
10.1 \\
8.6 \\
.0 \\
.0 \\
8.8 \\
.0\end{array}$ & $\begin{array}{r}53.6 \\
42.8 \\
43.1 \\
46.7 \\
53.0 \\
52.5 \\
46.7 \\
202.0 \\
45.0 \\
.0\end{array}$ & $\begin{array}{r}.0 \\
1.0 \\
3.5 \\
1.2 \\
2.0 \\
1.1 \\
.0 \\
.0 \\
.0 \\
.0\end{array}$ & $\begin{array}{r}42.6 \\
46.5 \\
49.7 \\
42.5 \\
35.4 \\
38.5 \\
51.9 \\
-24.8 \\
47.0 \\
100.0\end{array}$ \\
\hline 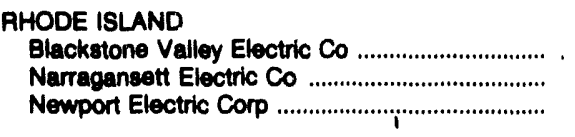 & $\begin{array}{l}43.3 \\
50.9 \\
42.0\end{array}$ & $\begin{array}{l}7.5 \\
7.7 \\
2.4\end{array}$ & $\begin{array}{l}49.3 \\
41.4 \\
55.6\end{array}$ & $\begin{array}{l}.0 \\
.0 \\
.0\end{array}$ & $\begin{array}{l}43.3 \\
49.5 \\
38.8\end{array}$ \\
\hline 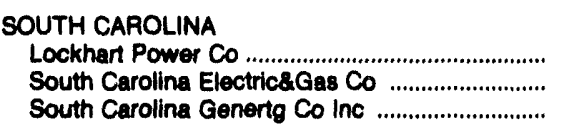 & $\begin{array}{r}100.0 \\
48.1 \\
18.1\end{array}$ & $\begin{array}{r}.0 \\
4.2 \\
.0\end{array}$ & $\begin{array}{r}.0 \\
47.6 \\
81.9\end{array}$ & $\begin{array}{l}.0 \\
.0 \\
.0\end{array}$ & $\begin{array}{r}100.0 \\
45.9 \\
18.3\end{array}$ \\
\hline 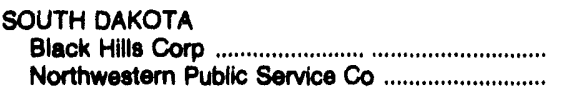 & $\begin{array}{l}60.8 \\
49.6\end{array}$ & $\begin{array}{r}.0 \\
1.3\end{array}$ & $\begin{array}{l}38.7 \\
48.9\end{array}$ & $\begin{array}{r}2.5 \\
.2\end{array}$ & $\begin{array}{l}61.4 \\
50.7\end{array}$ \\
\hline 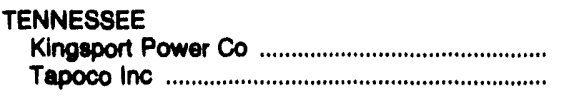 & $\begin{array}{r}40.3 \\
100.0\end{array}$ & $\begin{array}{l}.0 \\
.0\end{array}$ & $\begin{array}{r}47.7 \\
.0\end{array}$ & $\begin{array}{r}11.8 \\
.0\end{array}$ & $\begin{array}{r}46.9 \\
100.0\end{array}$ \\
\hline 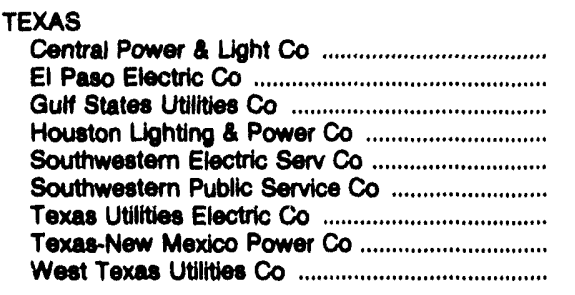 & $\begin{array}{l}44.0 \\
37.3 \\
40.2 \\
46.2 \\
68.7 \\
52.0 \\
40.7 \\
21.3 \\
50.4\end{array}$ & $\begin{array}{r}8.8 \\
10.5 \\
8.3 \\
7.5 \\
3.6 \\
5.5 \\
8.7 \\
1.1 \\
3.8\end{array}$ & $\begin{array}{r}47.2 \\
.0 \\
51.6 \\
44.1 \\
27.7 \\
42.5 \\
48.8 \\
77.7 \\
45.7\end{array}$ & $\begin{array}{r}.0 \\
52.2 \\
.0 \\
2.1 \\
.0 \\
.0 \\
1.6 \\
.0 \\
.0\end{array}$ & $\begin{array}{l}44.8 \\
38.8 \\
40.0 \\
46.1 \\
67.4 \\
52.2 \\
40.5 \\
20.1 \\
49.8\end{array}$ \\
\hline 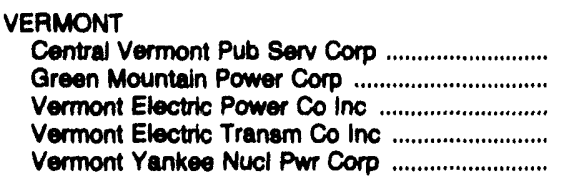 & $\begin{array}{l}50.6 \\
50.4 \\
11.4 \\
19.8 \\
39.7\end{array}$ & $\begin{array}{r}11.2 \\
5.2 \\
10.4 \\
.0 \\
.0\end{array}$ & $\begin{array}{l}37.6 \\
38.1 \\
\mathbf{6 8 . 3} \\
73.3 \\
\mathbf{6 0 . 3}\end{array}$ & $\begin{array}{r}.6 \\
6.3 \\
11.9 \\
6.8 \\
.0\end{array}$ & $\begin{array}{l}48.9 \\
54.6 \\
12.5 \\
21.3 \\
40.2\end{array}$ \\
\hline 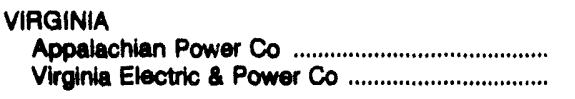 & $\begin{array}{l}39.5 \\
44.1\end{array}$ & $\begin{array}{l}8.7 \\
9.8\end{array}$ & $\begin{array}{l}48.8 \\
46.5\end{array}$ & $\begin{array}{r}3.1 \\
.6\end{array}$ & $\begin{array}{l}41.9 \\
44.4\end{array}$ \\
\hline 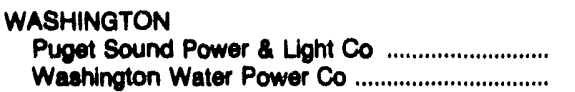 & $\begin{array}{l}40.1 \\
45.1\end{array}$ & $\begin{array}{r}10.0 \\
10.1\end{array}$ & $\begin{array}{l}46.5 \\
44.8\end{array}$ & $\begin{array}{r}3.5 \\
.0\end{array}$ & $\begin{array}{l}42.5 \\
43.6\end{array}$ \\
\hline
\end{tabular}

See endnotes at end of this table. 
Table 44. Solected Financlal Indicators by Major U.S. Investor-Owned Eloctric Utility Within State, 1992 (Continued)

\begin{tabular}{|c|c|c|c|c|c|}
\hline Utlities & $\begin{array}{l}\text { Aate of } \\
\text { Return on } \\
\text { Average } \\
\text { Common } \\
\text { Equity }\end{array}$ & $\begin{array}{l}\text { Total Utilly } \\
\text { Oparating } \\
\text { Revenue } \\
\text { Plus Other Income } \\
\text { as a Percent } \\
\text { of Total Assats } \\
\text { \& Other Debits }\end{array}$ & $\begin{array}{l}\text { Interest } \\
\text { Coverage } \\
\text { Betore } \\
\text { Taxes } \\
\text { With } \\
\text { AFUDC }\end{array}$ & $\begin{array}{l}\text { Intereat } \\
\text { Coverage } \\
\text { Before } \\
\text { Taxes } \\
\text { Without } \\
\text { AFUDC }\end{array}$ & $\begin{array}{l}\text { Current Assets } \\
\text { to Current } \\
\text { Liabilities }\end{array}$ \\
\hline 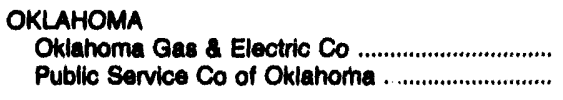 & $\begin{array}{r}10.8 \\
10.5\end{array}$ & $\begin{array}{l}48.0 \\
46.0\end{array}$ & $\begin{array}{l}3.30 \\
2.44\end{array}$ & $\begin{array}{l}3.28 \\
2.41\end{array}$ & $\begin{array}{r}0,89 \\
.86\end{array}$ \\
\hline $\begin{array}{l}\text { OAEGON } \\
\text { PactilCorp } \\
\text { Portland General Electric } \mathrm{Co}\end{array}$ & $\begin{array}{r}\text { NA } \\
12.8\end{array}$ & $\begin{array}{l}27.1 \\
28.1\end{array}$ & $\begin{array}{r}.14 \\
3.57\end{array}$ & $\begin{array}{r}.08 \\
3.53\end{array}$ & $\begin{array}{l}.64 \\
.80\end{array}$ \\
\hline 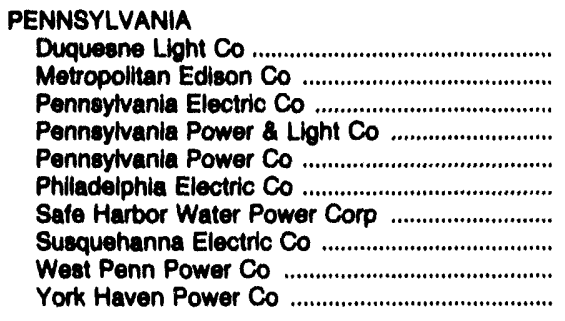 & $\begin{array}{r}12.1 \\
11.7 \\
14.3 \\
13.1 \\
9.3 \\
10.9 \\
12.5 \\
308.7 \\
11.7 \\
9.7\end{array}$ & $\begin{array}{r}30.9 \\
46.2 \\
47.4 \\
33.6 \\
31.3 \\
30.4 \\
21.8 \\
276.1 \\
50.6 \\
45.1\end{array}$ & $\begin{array}{l}3.08 \\
4.06 \\
4.35 \\
3.28 \\
2.48 \\
2.30 \\
3.10 \\
3.38 \\
3.60 \\
\text { NA }\end{array}$ & $\begin{array}{l}3.03 \\
4.00 \\
4.32 \\
3.22 \\
2.47 \\
2.26 \\
3.10 \\
3.38 \\
3.46 \\
\text { NA }\end{array}$ & $\begin{array}{r}.52 \\
.85 \\
1.00 \\
1.18 \\
.81 \\
.54 \\
3.73 \\
.94 \\
1.50 \\
1.81\end{array}$ \\
\hline $\begin{array}{l}\text { RHODE ISLAND } \\
\text { Blackstone Velley Electric Co } \\
\text { Narragansett Electric Co } \\
\text { Newpont Electric Corp }\end{array}$ & $\begin{array}{r}7.4 \\
11.8 \\
.8\end{array}$ & $\begin{array}{r}119.8 \\
85.9 \\
87.5\end{array}$ & $\begin{array}{r}2.06 \\
2.93 \\
.33\end{array}$ & $\begin{array}{r}2.04 \\
2.80 \\
.29\end{array}$ & $\begin{array}{r}.84 \\
1.02 \\
1.01\end{array}$ \\
\hline $\begin{array}{l}\text { SOUTH CAROLINA } \\
\text { Lockhart Power Co } \\
\text { South Carolina Electric\&Gas Co } \\
\text { South Carolina Genertg Co Inc }\end{array}$ & $\begin{array}{r}9.2 \\
10.6 \\
18.2\end{array}$ & $\begin{array}{r}114.3 \\
34.4 \\
34.7\end{array}$ & $\begin{array}{l}\text { NA } \\
3.01 \\
1.44\end{array}$ & $\begin{array}{l}\text { NA } \\
2.91 \\
1.40\end{array}$ & $\begin{array}{r}1.09 \\
.80 \\
2.24\end{array}$ \\
\hline 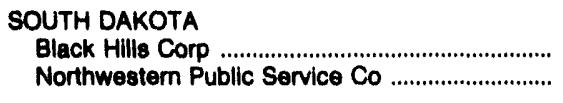 & $\begin{array}{l}16.2 \\
12.8\end{array}$ & $\begin{array}{l}32.4 \\
39.1\end{array}$ & $\begin{array}{l}4.30 \\
3.48\end{array}$ & $\begin{array}{l}4.26 \\
3.44\end{array}$ & $\begin{array}{r}.83 \\
1.17\end{array}$ \\
\hline $\begin{array}{l}\text { TENNESSEE } \\
\text { Kingsport Power Co } \\
\text { Tapoco Inc }\end{array}$ & $\begin{array}{l}10.0 \\
20.5\end{array}$ & $\begin{array}{r}146.8 \\
58.5\end{array}$ & $\begin{array}{c}2.32 \\
\text { NA }\end{array}$ & $\begin{array}{c}2.31 \\
\text { NA }\end{array}$ & $\begin{array}{r}.74 \\
1.38\end{array}$ \\
\hline 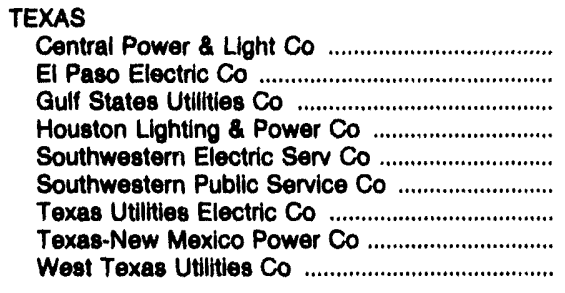 & $\begin{array}{c}14.2 \\
\text { NA } \\
\text { NA } \\
13.0 \\
10.9 \\
13.9 \\
11.8 \\
5.2 \\
12.7\end{array}$ & $\begin{array}{r}23.7 \\
19.2 \\
26.2 \\
36.0 \\
108.7 \\
44.9 \\
26.9 \\
38.4 \\
40.2\end{array}$ & $\begin{array}{r}3.03 \\
.88 \\
1.62 \\
\hat{\imath} .87 \\
4.81 \\
4.39 \\
2.28 \\
1.24 \\
3.21\end{array}$ & $\begin{array}{r}3.02 \\
.86 \\
1.61 \\
2.84 \\
4.80 \\
4.31 \\
1.83 \\
1.24 \\
3.20\end{array}$ & $\begin{array}{r}1.19 \\
.18 \\
2.03 \\
.48 \\
1.07 \\
1.08 \\
.39 \\
1.13 \\
1.01\end{array}$ \\
\hline 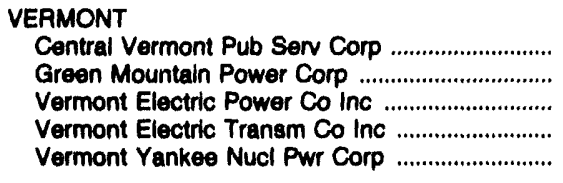 & $\begin{array}{r}12.1 \\
12.2 \\
8.3 \\
15.7 \\
14.6\end{array}$ & $\begin{array}{l}58.5 \\
56.1 \\
66.5 \\
20.9 \\
43.1\end{array}$ & $\begin{array}{l}3.59 \\
3.27 \\
1.48 \\
1.68 \\
2.44\end{array}$ & $\begin{array}{l}3.56 \\
3.21 \\
1.46 \\
1.68 \\
2.39\end{array}$ & $\begin{array}{r}.81 \\
1.01 \\
.70 \\
.28 \\
1.48\end{array}$ \\
\hline 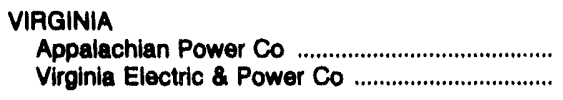 & $\begin{array}{l}11.8 \\
11.3\end{array}$ & $\begin{array}{l}45.3 \\
32.5\end{array}$ & $\begin{array}{l}2.48 \\
2.89\end{array}$ & $\begin{array}{l}2.47 \\
2.86\end{array}$ & $\begin{array}{l}1.18 \\
1.22\end{array}$ \\
\hline 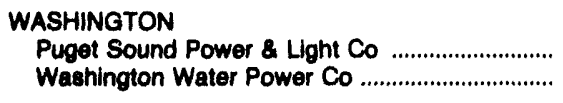 & $\begin{array}{l}12.5 \\
11.8\end{array}$ & $\begin{array}{l}33.8 \\
34.0\end{array}$ & $\begin{array}{l}3.09 \\
2.83\end{array}$ & $\begin{array}{l}3.05 \\
2.86\end{array}$ & $\begin{array}{r}1.57 \\
.71\end{array}$ \\
\hline
\end{tabular}

See endnotes at end of this table. 
Table 44. Solected Financial Indicators by Major U.8. Investor-Owned Electric Utility Within State, 1992 (Continued)

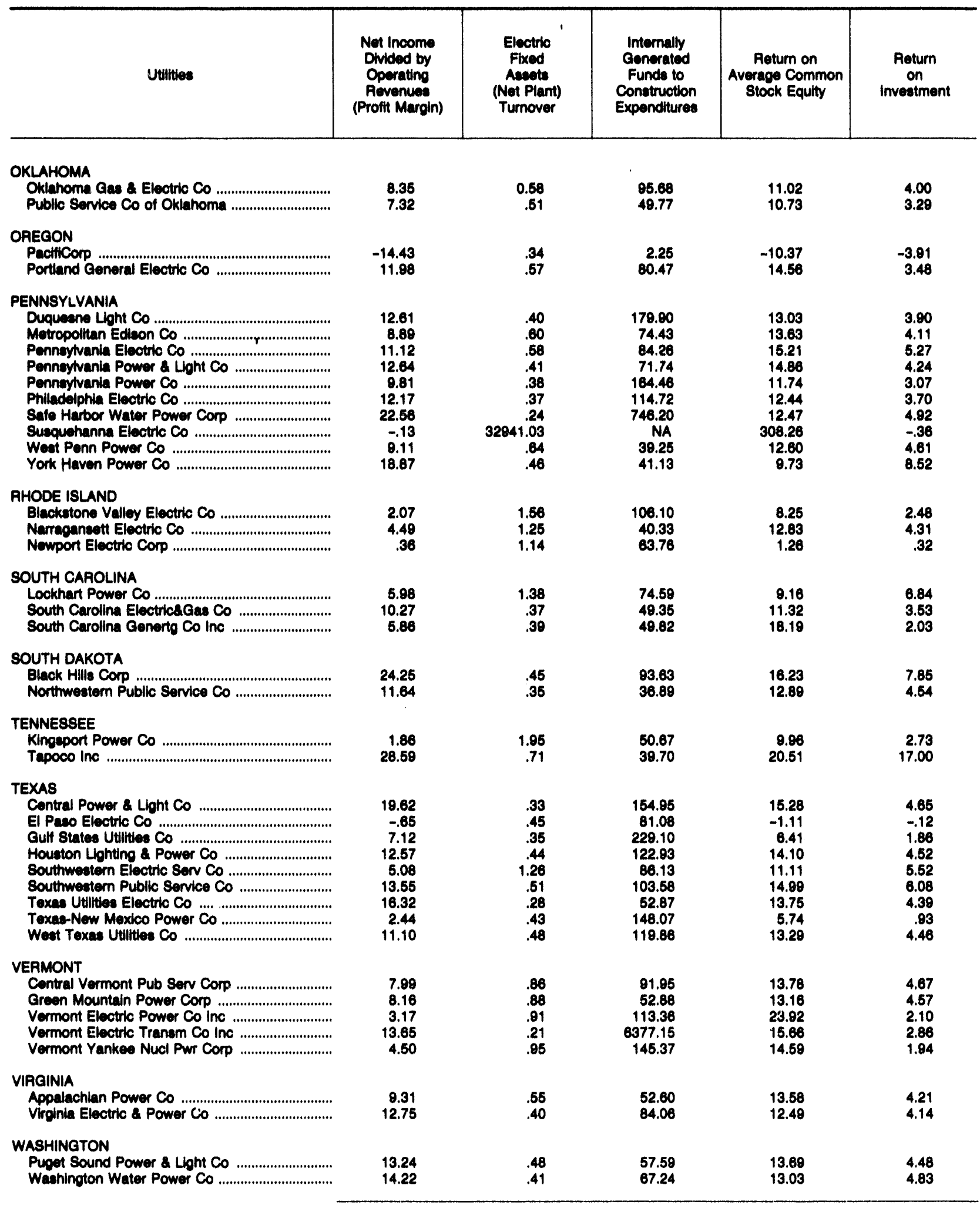

See endinotes at end of this table. 
Table 44. Solected Financlal Indicators by Major U.S. Investor-Owned Eloctric Utility Within State, 1992 (Continued)

\begin{tabular}{|c|c|c|c|c|c|}
\hline Utilties & $\begin{array}{l}\text { Common } \\
\text { Equity } \\
\text { (percent) }\end{array}$ & $\begin{array}{l}\text { Preferred } \\
\text { Stock } \\
\text { (percent) }\end{array}$ & $\begin{array}{c}\text { Long-Term } \\
\text { Debt }\end{array}$ & $\begin{array}{c}\text { Short-Term } \\
\text { Debt } \\
\text { (Notes } \\
\text { Payable) } \\
\text { (percent) }\end{array}$ & $\begin{array}{c}\text { Common } \\
\text { Equity } \\
\text { Percent } \\
\text { of Total } \\
\text { Capital. } \\
\text { ization' }\end{array}$ \\
\hline $\begin{array}{l}\text { WEST VIRGINIA } \\
\text { Kanawha Valley Power Co } \\
\text { Monognghela Power Co } \\
\text { Wheding Power Co }\end{array}$ & $\begin{array}{l}51.8 \\
48.2 \\
39.3\end{array}$ & $\begin{array}{r}0.0 \\
6.5 \\
.0\end{array}$ & $\begin{array}{r}0.0 \\
46.3 \\
48.8\end{array}$ & $\begin{array}{r}48.2 \\
.0 \\
11.0\end{array}$ & $\begin{array}{r}100.0 \\
48.7 \\
44.3\end{array}$ \\
\hline 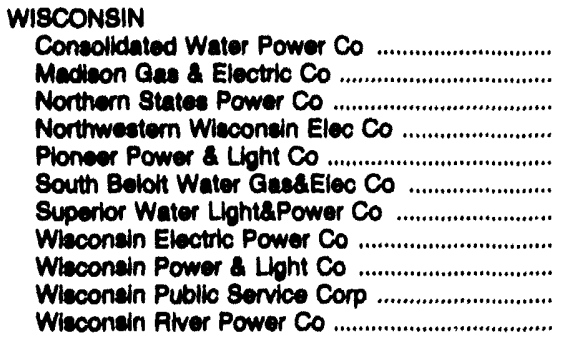 & $\begin{array}{r}100.0 \\
51.3 \\
58.5 \\
43.4 \\
82.8 \\
100.0 \\
53.6 \\
60.3 \\
60.6 \\
50.7 \\
100.0\end{array}$ & $\begin{array}{r}.0 \\
1.6 \\
.0 \\
.0 \\
.0 \\
.0 \\
.0 \\
3.8 \\
6.6 \\
6.3 \\
.0\end{array}$ & $\begin{array}{r}.0 \\
42.2 \\
40.5 \\
41.6 \\
16.1 \\
.0 \\
46.4 \\
43.0 \\
37.2 \\
40.6 \\
.0\end{array}$ & $\begin{array}{r}.0 \\
4.8 \\
.0 \\
15.1 \\
2.1 \\
.0 \\
.0 \\
2.9 \\
5.6 \\
2.5 \\
.0\end{array}$ & $\begin{array}{r}100.0 \\
54.6 \\
58.8 \\
47.5 \\
82.7 \\
100.0 \\
56.4 \\
51.9 \\
54.6 \\
50.6 \\
100.0\end{array}$ \\
\hline
\end{tabular}

See endnotes at end of this table.

Table 44. Selected FInanclal Indicatore by Major U.S. Investor-Owned Electric Utility Within State, 1992 (Continued)

\begin{tabular}{|c|c|c|c|c|c|}
\hline Utillites & $\begin{array}{l}\text { Rate of } \\
\text { Return on } \\
\text { Average } \\
\text { Common } \\
\text { Equity }\end{array}$ & $\begin{array}{c}\text { Total Utilly } \\
\text { Operating } \\
\text { Revenue } \\
\text { Plus Other Income } \\
\text { as a Percent } \\
\text { of Total Assets } \\
\text { \& Other Deblts }\end{array}$ & $\begin{array}{l}\text { Interest } \\
\text { Coverage } \\
\text { Betore } \\
\text { Texes } \\
\text { With } \\
\text { AFUDC }\end{array}$ & $\begin{array}{l}\text { Interest } \\
\text { Coverage } \\
\text { Before } \\
\text { Taxes } \\
\text { Without } \\
\text { AFUDC }\end{array}$ & $\begin{array}{l}\text { Current Assets } \\
\text { to Current } \\
\text { Llabilities }\end{array}$ \\
\hline $\begin{array}{l}\text { WEST VIRGINIA } \\
\text { Kanawha Valley Power Co } \\
\text { Monongahole Power Co } \\
\text { Wheelling Power Co }\end{array}$ & $\begin{array}{l}21.8 \\
11.8 \\
13.0\end{array}$ & $\begin{array}{l}38.9 \\
53.5 \\
86.9\end{array}$ & $\begin{array}{l}7.85 \\
3.26 \\
2.49\end{array}$ & $\begin{array}{l}7.85 \\
3.15 \\
2.48\end{array}$ & $\begin{array}{r}0.09 \\
1.41 \\
.82\end{array}$ \\
\hline 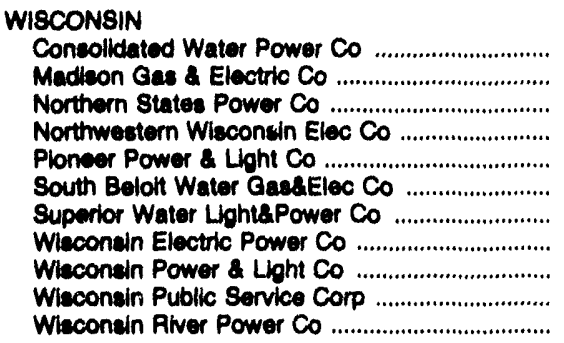 & $\begin{array}{r}9.7 \\
13.1 \\
13.5 \\
14.4 \\
10.8 \\
34.7 \\
12.4 \\
12.5 \\
12.3 \\
14.0 \\
7.6\end{array}$ & $\begin{array}{r}132.3 \\
47.3 \\
58.6 \\
62.8 \\
101.8 \\
94.8 \\
85.1 \\
38.8 \\
40.8 \\
54.2 \\
32.2\end{array}$ & $\begin{array}{c}\text { NA } \\
3.62 \\
4.30 \\
2.87 \\
6.60 \\
\text { NA } \\
3.86 \\
3.94 \\
3.70 \\
4.17 \\
\text { NA }\end{array}$ & $\begin{array}{c}\text { NA } \\
3.62 \\
4.22 \\
2.87 \\
6.60 \\
\text { NA } \\
3.86 \\
3.81 \\
3.58 \\
4.13 \\
\text { NA }\end{array}$ & $\begin{array}{r}.05 \\
1.72 \\
1.10 \\
.75 \\
2.32 \\
.26 \\
1.83 \\
1.86 \\
.54 \\
1.70 \\
.81\end{array}$ \\
\hline
\end{tabular}

See endnotes at end of this table. 
Table 44. Selected Financlal Indicatore by Major U.S. Investor-Owned Electrlc Utility Within State, 1992 (Continued)

\begin{tabular}{|c|c|c|c|c|c|}
\hline Utilties & $\begin{array}{c}\text { Nel Income } \\
\text { Divided by } \\
\text { Operating } \\
\text { Revenues } \\
\text { (Proftt Margin) }\end{array}$ & $\begin{array}{l}\text { Electric } \\
\text { Flxed } \\
\text { Assets } \\
\text { (Net Plant) } \\
\text { Turnover }\end{array}$ & $\begin{array}{l}\text { Internally } \\
\text { Generated } \\
\text { Funds to } \\
\text { Construction } \\
\text { Expendltures }\end{array}$ & $\begin{array}{l}\text { Return on } \\
\text { Average Common } \\
\text { Stock Equity }\end{array}$ & $\begin{array}{c}\text { Return } \\
\text { on } \\
\text { Investment }\end{array}$ \\
\hline 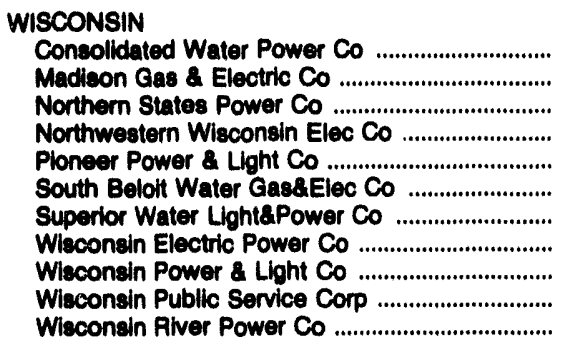 & $\begin{array}{r}4.33 \\
10.38 \\
9.39 \\
8.57 \\
7.47 \\
13.29 \\
4.96 \\
12.32 \\
9.96 \\
9.13 \\
21.20\end{array}$ & $\begin{array}{r}1.68 \\
.59 \\
.66 \\
.76 \\
1.31 \\
1.58 \\
1.63 \\
.55 \\
.53 \\
.73 \\
.48\end{array}$ & $\begin{array}{r}144.65 \\
98.23 \\
59.74 \\
41.65 \\
60.76 \\
83.15 \\
86.63 \\
54.31 \\
48.20 \\
53.10 \\
121.79\end{array}$ & $\begin{array}{r}9.68 \\
13.35 \\
13.50 \\
14.43 \\
10.77 \\
34.74 \\
12.38 \\
12.95 \\
13.17 \\
14.82 \\
7.64\end{array}$ & $\begin{array}{r}5.74 \\
4.91 \\
5.50 \\
5.38 \\
7.61 \\
12.61 \\
4.72 \\
4.82 \\
4.06 \\
4.95 \\
6.82\end{array}$ \\
\hline
\end{tabular}

1 Excludes short-term debt (notes payable) as a part of total capitalization.

NA $=$ Not avallable.

Note: Totals may not equal sum of components because of independent rounding.

Source: Federal Energy Regulatory Commission, FERC Form 1, "Annual Report of Major Electric Utilities, Licensees and Others." 
Tablo 45. Invootments in Environmental Protection by Major Investor-Owned Electric Utility Within state on Decomber 31, 1992

(Thousand Dollars)

\begin{tabular}{|c|c|c|c|c|c|}
\hline 8inte and Utility & $\begin{array}{l}\text { Alr } \\
\text { Pollution } \\
\text { Control }\end{array}$ & $\begin{array}{l}\text { Water } \\
\text { Pollution } \\
\text { Control }\end{array}$ & $\begin{array}{l}\text { Solid } \\
\text { Waste } \\
\text { Disposeal }\end{array}$ & $\begin{array}{l}\text { Nolee } \\
\text { Abatemiont } \\
\text { Equipment }\end{array}$ & Esthetlo \\
\hline Total & $24,110,824$ & $12,981,658$ & $5,151,129$ & 313,896 & $11,454,995$ \\
\hline 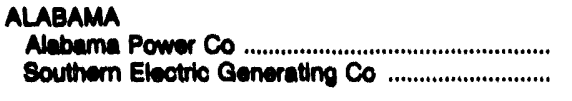 & $\begin{array}{r}578,361 \\
40,970\end{array}$ & $\begin{array}{r}126,312 \\
3,167\end{array}$ & $\begin{array}{r}106,023 \\
1,644\end{array}$ & 81 & $\begin{array}{r}123,169 \\
-\end{array}$ \\
\hline 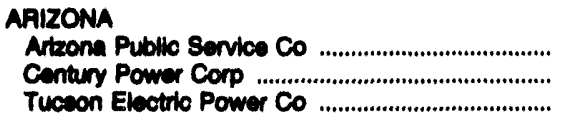 & $\begin{array}{r}248,708 \\
95,124 \\
228,475\end{array}$ & $\begin{array}{r}141,880 \\
27,329 \\
39,683\end{array}$ & $\begin{array}{r}425,977 \\
5,532 \\
41,499\end{array}$ & $\begin{array}{l}1,237 \\
2,392\end{array}$ & $\begin{array}{r}18,269 \\
85,189\end{array}$ \\
\hline 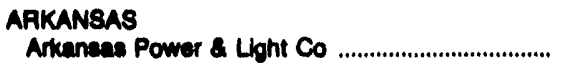 & 111,395 & 92,543 & 35,191 & 9,278 & 28,876 \\
\hline 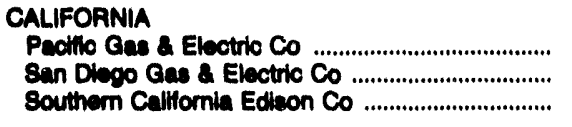 & $\begin{array}{r}314,000 \\
26,882 \\
713,652\end{array}$ & $\begin{array}{r}264,000 \\
28,655 \\
285,028\end{array}$ & $\begin{array}{r}58,000 \\
1,150 \\
48,989\end{array}$ & $\begin{array}{r}3,000 \\
1,641 \\
14,139\end{array}$ & $\begin{array}{r}1,025,000 \\
753,087 \\
2,309,311\end{array}$ \\
\hline 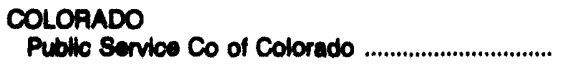 & 279,636 & 47,646 & 3,263 & - & 203,600 \\
\hline 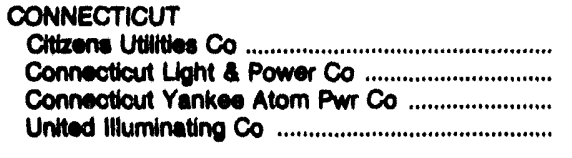 & $\begin{array}{r}3 \\
17,620 \\
42 \\
4,828\end{array}$ & $\begin{array}{r}76 \\
21,570 \\
1,209 \\
13,443\end{array}$ & $\begin{array}{r}23 \\
2,776 \\
17,214\end{array}$ & $\begin{array}{r}25 \\
80 \\
102 \\
1,593\end{array}$ & $\begin{array}{r}332 \\
2,503 \\
7 \\
6,198\end{array}$ \\
\hline 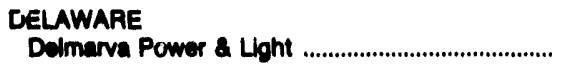 & 186,442 & 53,939 & 36,737 & 1,598 & 9,087 \\
\hline 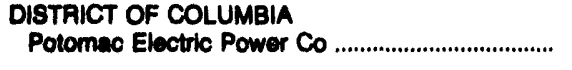 & 240,206 & 75,913 & 27,044 & 77,782 & 806,591 \\
\hline 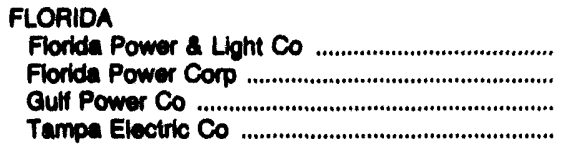 & $\begin{array}{l}387,214 \\
260,175 \\
128,223 \\
389,774\end{array}$ & $\begin{array}{r}554,390 \\
134,991 \\
56,318 \\
38,434\end{array}$ & $\begin{array}{r}51,423 \\
3,835 \\
41,842 \\
84,137\end{array}$ & $\begin{array}{r}45,112 \\
5,070 \\
541 \\
350\end{array}$ & $\begin{array}{r}11,778 \\
526 \\
680 \\
37\end{array}$ \\
\hline 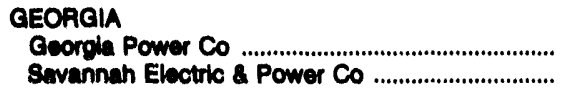 & $\begin{array}{r}700,387 \\
14\end{array}$ & $\begin{array}{r}724,031 \\
3\end{array}$ & $\begin{array}{r}152,528 \\
10\end{array}$ & 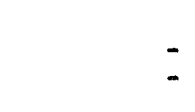 & 82,470 \\
\hline 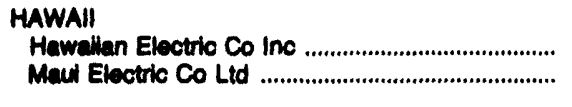 & 19,297 & 26,543 & $\overline{-}$ & 1,894 & 9,735 \\
\hline 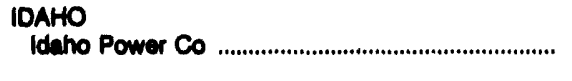 & 140,705 & 16,012 & 2,401 & 168 & 368 \\
\hline 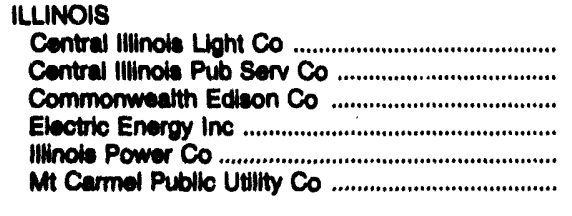 & $\begin{array}{r}71,261 \\
232,971 \\
460,283 \\
49,237 \\
220,138 \\
-\end{array}$ & $\begin{array}{r}21,485 \\
26,289 \\
1,045,033 \\
689 \\
413,687 \\
-\end{array}$ & $\begin{array}{r}20,220 \\
16,497 \\
11,687 \\
1,672 \\
83,568 \\
-\end{array}$ & $\begin{array}{r}32 \\
28 \\
6,567 \\
- \\
181 \\
-\end{array}$ & $\begin{array}{r}31,405 \\
777 \\
48,914 \\
- \\
4,838 \\
\end{array}$ \\
\hline 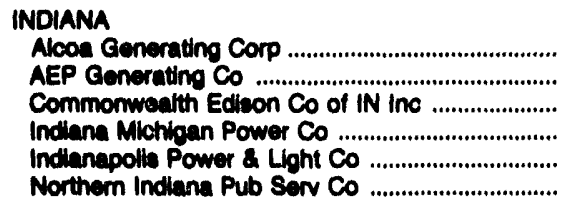 & $\begin{array}{r}14,973 \\
98,486 \\
6,170 \\
251,784 \\
268,783 \\
418,709\end{array}$ & $\begin{array}{r}6,568 \\
25,271 \\
47,583 \\
94,080 \\
90,796 \\
115,395\end{array}$ & $\begin{array}{r}12,031 \\
45 \\
23,907 \\
40,591 \\
11,744\end{array}$ & $\begin{array}{r}\overline{-} \\
1 \overline{-} \\
155 \\
1,336\end{array}$ & $\begin{array}{r}- \\
134 \\
10,037 \\
18,560 \\
3,248\end{array}$ \\
\hline
\end{tabular}

see endnotes at end of this table. 
Table 46. Investmente In Environmental Protection by Major Investor-Owned Electric Utility Within state on December 31, 1992 (Continued)

(Thousand Dollars)

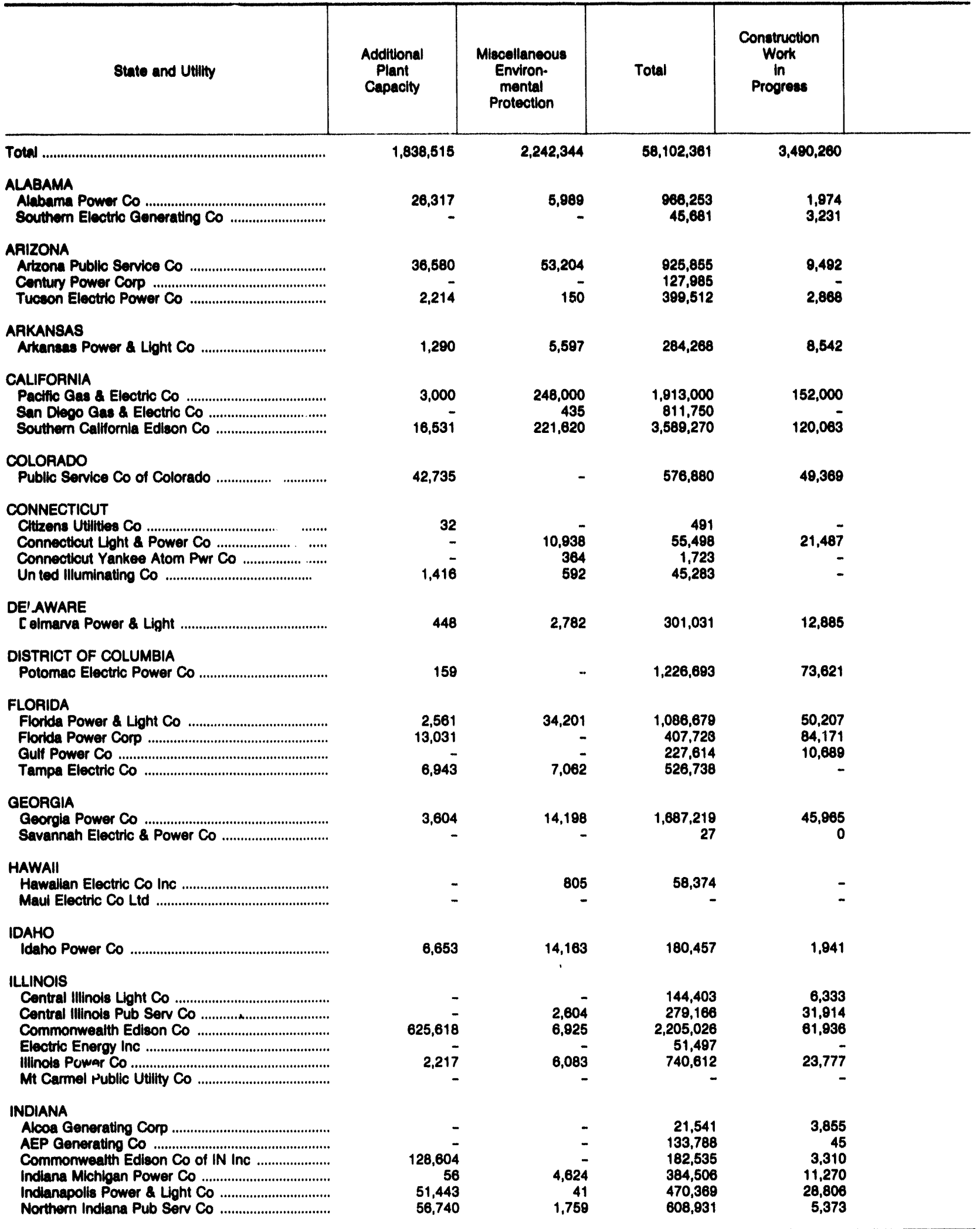

See endnotes at end of this table. 
Table 45. Investments In Environmental Protection by Major Investor-Owned Electric Utility Within state on December 31, 1992 (Continued) (Thousand Dollars)

\begin{tabular}{|c|c|c|c|c|c|}
\hline State and Utilty & $\begin{array}{l}\text { Air } \\
\text { Pollution } \\
\text { Control }\end{array}$ & $\begin{array}{l}\text { Water } \\
\text { Pollution } \\
\text { Control }\end{array}$ & $\begin{array}{l}\text { Solld } \\
\text { Waste } \\
\text { Disposal }\end{array}$ & $\begin{array}{l}\text { Nolee } \\
\text { Abatement } \\
\text { Equipment }\end{array}$ & Eothotio \\
\hline 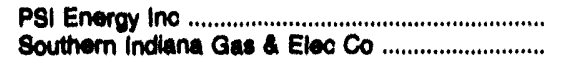 & $\begin{array}{r}178,103 \\
98,333\end{array}$ & $\begin{array}{l}26,542 \\
28,424\end{array}$ & $\begin{array}{l}37,007 \\
20,788\end{array}$ & 1,251 & $\begin{array}{r}4,338 \\
23\end{array}$ \\
\hline 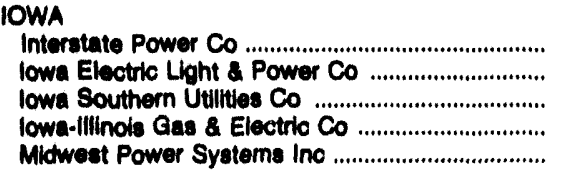 & $\begin{array}{r}50,622 \\
34,316 \\
19,652 \\
76,682 \\
116,685\end{array}$ & $\begin{array}{r}2,216 \\
25,024 \\
193 \\
25,438 \\
14,259\end{array}$ & $\begin{array}{r}4,489 \\
2,715 \\
4,046 \\
19,177 \\
20,916\end{array}$ & $\begin{array}{r}22 \\
89 \\
214 \\
178 \\
108\end{array}$ & $\begin{array}{r}528 \\
399 \\
104 \\
8,686 \\
45,623\end{array}$ \\
\hline 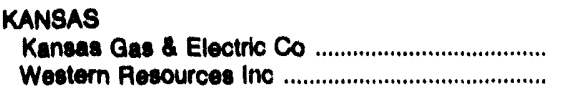 & $\begin{array}{l}121,176 \\
140,603\end{array}$ & $\begin{array}{r}163,469 \\
9,644\end{array}$ & $\begin{array}{r}151,440 \\
5,452\end{array}$ & $3 \overline{5}$ & $\begin{array}{l}18,633 \\
58,803\end{array}$ \\
\hline 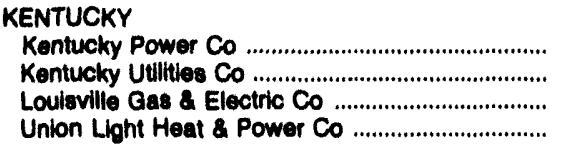 & $\begin{array}{r}12,368 \\
142,186 \\
376,698 \\
-\end{array}$ & $\begin{array}{r}2.177 \\
28,488 \\
76,890 \\
-\end{array}$ & $\begin{array}{r}5,568 \\
47,163 \\
65,129 \\
-\end{array}$ & $\begin{array}{r}109 \\
19 \\
79\end{array}$ & $\begin{array}{r}- \\
1,91 \overline{5} \\
6\end{array}$ \\
\hline 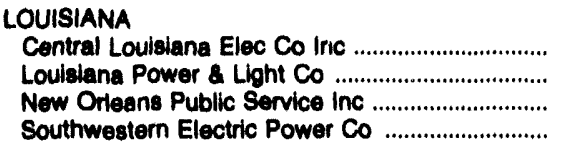 & $\begin{array}{r}35,033 \\
4,077 \\
1,232 \\
117,243\end{array}$ & $\begin{array}{r}6,887 \\
3,331 \\
1,941 \\
16,206\end{array}$ & $\begin{array}{r}9,540 \\
559 \\
411 \\
26,641\end{array}$ & $\overline{73}$ & $\begin{array}{r}34,825 \\
27,123 \\
698\end{array}$ \\
\hline 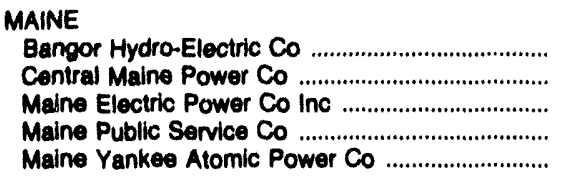 & $\begin{array}{r}1,495 \\
15,391 \\
- \\
529 \\
934\end{array}$ & $\begin{array}{r}770 \\
14,344 \\
200 \\
13,076\end{array}$ & $\begin{array}{r}30 \\
1,445 \\
- \\
11 \\
5,713\end{array}$ & $\begin{array}{r}389 \\
3,668 \\
13 \overline{-} \\
71\end{array}$ & $\begin{array}{r}19 \\
1,275 \\
34 \\
7\end{array}$ \\
\hline $\begin{array}{l}\text { MARYLAND } \\
\text { Baltimore Gas \& Electric Co } \ldots \ldots \ldots \ldots \ldots \ldots \ldots \ldots \ldots \ldots \\
\text { Potomac Edison Co }\end{array}$ & $\begin{array}{r}284,125 \\
84,944\end{array}$ & $\begin{array}{c}242,940 \\
40,253\end{array}$ & $\begin{array}{l}50,904 \\
30,195\end{array}$ & $\begin{array}{r}5,292 \\
33\end{array}$ & $\begin{array}{r}132,217 \\
70,393\end{array}$ \\
\hline 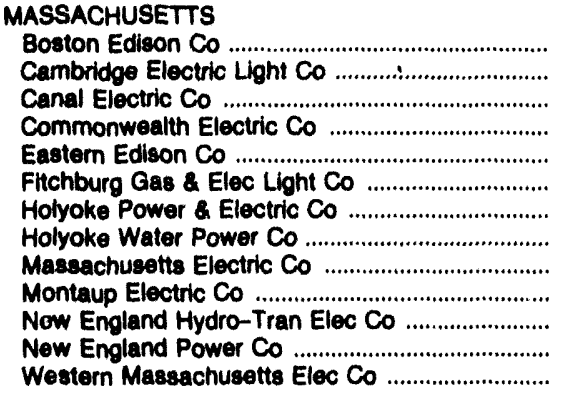 & $\begin{array}{r}47,530 \\
620 \\
16,893 \\
1,199 \\
- \\
9 \\
- \\
434 \\
209 \\
54,161 \\
136,387 \\
2,436\end{array}$ & $\begin{array}{r}66,637 \\
787 \\
25,402 \\
690 \\
- \\
- \\
- \\
181 \\
20 \\
22,046 \\
2,000 \\
53,043 \\
570\end{array}$ & $\begin{array}{r}9,832 \\
- \\
3,408 \\
23 \\
- \\
- \\
- \\
405 \\
1,789 \\
2,478 \\
52,632 \\
525\end{array}$ & $\begin{array}{r}4,542 \\
494 \\
221 \\
209 \\
- \\
198 \\
- \\
0 \\
34 \\
367 \\
70 \\
843 \\
15\end{array}$ & $\begin{array}{r}29,453 \\
33 \\
25 \\
380 \\
- \\
- \\
- \\
0 \\
12,790 \\
16 \\
4,304 \\
471\end{array}$ \\
\hline 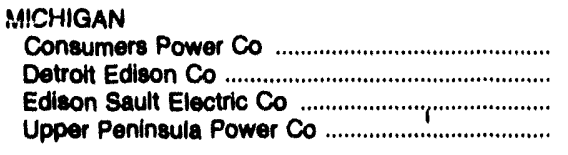 & $\begin{array}{r}191,783 \\
1,988 \\
- \\
1,631\end{array}$ & $\begin{array}{r}228,992 \\
609 \\
172\end{array}$ & $\begin{array}{r}39,734 \\
64 \\
- \\
16\end{array}$ & $\begin{array}{r}591 \\
11 \\
100\end{array}$ & $\begin{array}{r}26,944 \\
20 \\
- \\
-\end{array}$ \\
\hline 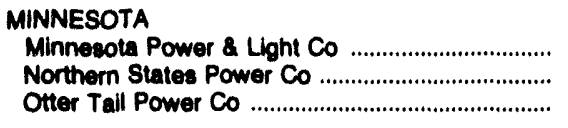 & $\begin{array}{r}128,874 \\
448,647 \\
52,815\end{array}$ & $\begin{array}{r}34,207 \\
126,075 \\
30,266\end{array}$ & $\begin{array}{r}34,602 \\
52,216 \\
4,407\end{array}$ & $\begin{array}{r}6,727 \\
7,096 \\
-\end{array}$ & $\begin{array}{r}3,051 \\
22,255 \\
15,955\end{array}$ \\
\hline 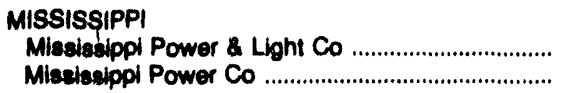 & $\begin{array}{l}26,789 \\
32,802\end{array}$ & $\begin{array}{l}23,260 \\
30,122\end{array}$ & $\begin{array}{r}4,161 \\
12,549\end{array}$ & 583 & $14,69 \overline{0}$ \\
\hline
\end{tabular}

See endnotes at end of this table. 
Table 45. Inveotments in Environmental Protection by Major Inveotor-Owned Elootric Utility Within State on Decomber 31, 1902 (Continued) (Thousand Dollars)

\begin{tabular}{|c|c|c|c|c|}
\hline State and Utilly & $\begin{array}{l}\text { Additional } \\
\text { Plant } \\
\text { Capactly }\end{array}$ & $\begin{array}{l}\text { Misoeilaneous } \\
\text { Emiron- } \\
\text { montal } \\
\text { Protection }\end{array}$ & Total & $\begin{array}{l}\text { Conatruction } \\
\text { Work } \\
\text { in } \\
\text { Proorees }\end{array}$ \\
\hline $\begin{array}{l}\text { PSI Energy Ino } \\
\text { Southern Indiana Gae \& Eleo Co }\end{array}$ & - & - & $\begin{array}{l}247,242 \\
147,578\end{array}$ & $\begin{array}{r}123,074 \\
10,266\end{array}$ \\
\hline 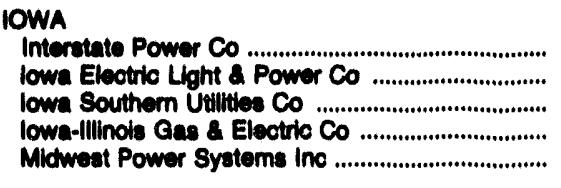 & $\begin{array}{r}559 \\
2,765 \\
1,171 \\
14,462 \\
13,683\end{array}$ & $\begin{array}{r}29 \\
24 \\
1,329 \\
-\end{array}$ & $\begin{array}{r}58,447 \\
66,326 \\
25,404 \\
145,912 \\
211,274\end{array}$ & $\begin{array}{r}525 \\
463 \\
1,332 \\
-\end{array}$ \\
\hline 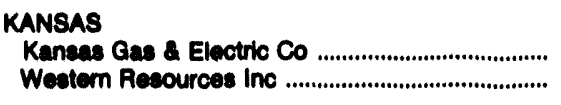 & $\begin{array}{r}5,289 \\
30,284\end{array}$ & 518 & $\begin{array}{l}460,008 \\
243,330\end{array}$ & $\begin{array}{r}7,314 \\
-\end{array}$ \\
\hline 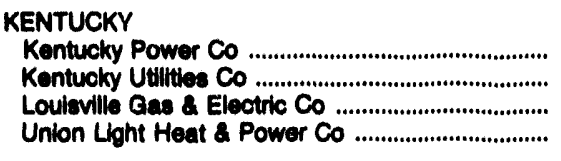 & $\begin{array}{r}1,845 \\
- \\
-\end{array}$ & $10 \overline{-}$ & $\begin{array}{r}22,057 \\
217,846 \\
520,859 \\
85\end{array}$ & $\begin{array}{r}216 \\
19,416 \\
13,888 \\
-\end{array}$ \\
\hline 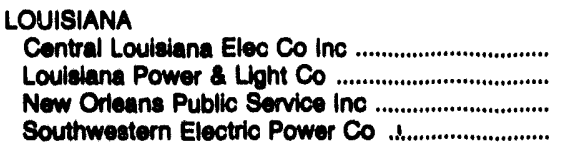 & $\begin{array}{l}- \\
-\end{array}$ & $\begin{array}{r}13 \\
- \\
3,899\end{array}$ & $\begin{array}{r}51,473 \\
42,892 \\
30,779 \\
165,039\end{array}$ & $\begin{array}{r}482 \\
- \\
-\end{array}$ \\
\hline 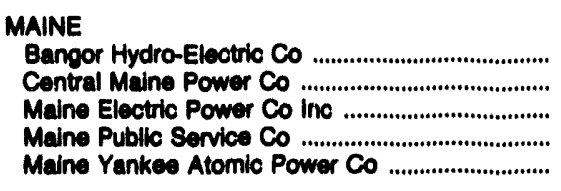 & $\begin{array}{r}126 \\
919 \\
45 \\
-\end{array}$ & $\begin{array}{r}13 \\
8,829 \\
\overline{5} \\
-\end{array}$ & $\begin{array}{r}2,843 \\
43,972 \\
- \\
931 \\
20,142\end{array}$ & $8,81 \overline{-}$ \\
\hline 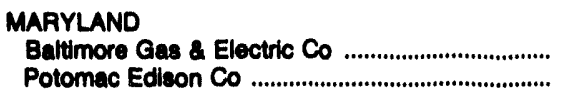 & 274 & $\begin{array}{l}2,867 \\
2,686\end{array}$ & $\begin{array}{l}718,719 \\
238,504\end{array}$ & $\begin{array}{l}23,203 \\
79,972\end{array}$ \\
\hline 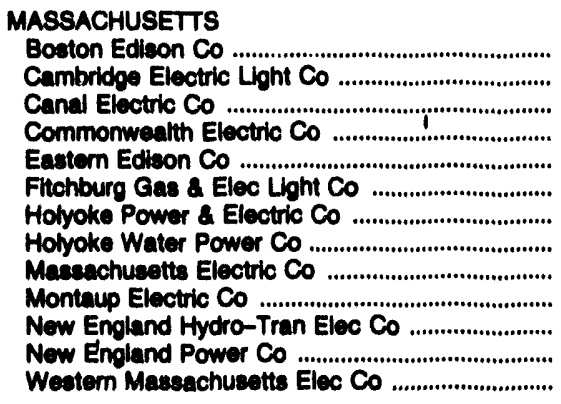 & $\begin{array}{r}\overline{-} \\
\overline{-} \\
\overline{-} \\
\overline{-} \\
26 \\
124 \\
-\end{array}$ & $\begin{array}{r}66,504 \\
- \\
1,278 \\
\overline{-} \\
\overline{3} \\
16,244 \\
1,206 \\
13 \\
13,854\end{array}$ & $\begin{array}{r}224,498 \\
1,934 \\
47,227 \\
2,501 \\
- \\
207 \\
3 \\
17,264 \\
14,841 \\
80,300 \\
2,070 \\
247,345 \\
17,871\end{array}$ & $\begin{array}{r}77,008 \\
31 \\
- \\
- \\
- \\
27,737 \\
49 \\
347 \\
3,589 \\
24,268\end{array}$ \\
\hline 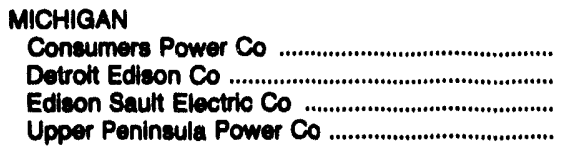 & $\begin{array}{r}13,460 \\
- \\
-\end{array}$ & $\begin{array}{r}21,785 \\
26\end{array}$ & $\begin{array}{r}523,269 \\
2,692 \\
1,245\end{array}$ & $\begin{array}{r}18,468 \\
28 \\
- \\
-\end{array}$ \\
\hline 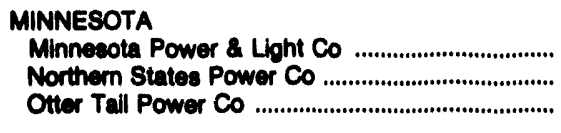 & $\begin{array}{r}8,389 \\
84,600 \\
2,477\end{array}$ & $\begin{array}{l}517 \\
317\end{array}$ & $\begin{array}{l}216,387 \\
740,888 \\
106,237\end{array}$ & $\begin{array}{r}10,769 \\
45\end{array}$ \\
\hline 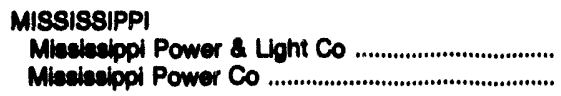 & 6,051 & $\begin{array}{r}735 \\
1,363\end{array}$ & $\begin{array}{l}54,844 \\
88,080\end{array}$ & $\begin{array}{r}59 \\
8,868\end{array}$ \\
\hline
\end{tabular}

See endnotee at end of this table. 
Table 45. Investmente in Environmental Protection by Major Investor-Owned Electrlc Utility Within State on December 31, 1982 (Continued) (Thousand Dollars)

\begin{tabular}{|c|c|c|c|c|c|}
\hline State and Utility & $\begin{array}{l}\text { Ar } \\
\text { Pollution } \\
\text { Control }\end{array}$ & $\begin{array}{l}\text { Water } \\
\text { Pollution } \\
\text { Control }\end{array}$ & $\begin{array}{c}\text { Solld } \\
\text { Weate } \\
\text { Dieposal }\end{array}$ & $\begin{array}{l}\text { Noise } \\
\text { Abatement } \\
\text { Equipment }\end{array}$ & Eathetic \\
\hline 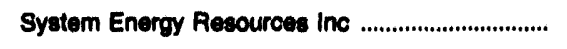 & 112,587 & 409,621 & 101,224 & - & - \\
\hline 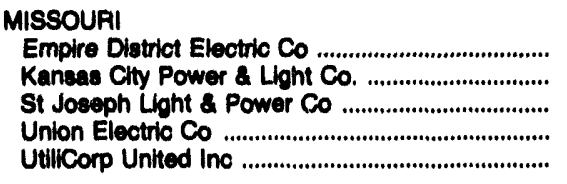 & $\begin{array}{r}147,84 \overline{-} \\
9,899 \\
320,184 \\
44,513\end{array}$ & $\begin{array}{r}183,984 \\
110 \\
312,682 \\
4,726\end{array}$ & $\begin{array}{r}160,668 \\
1,623 \\
38,209 \\
4,387\end{array}$ & $\begin{array}{r}721 \\
61 \\
4,227 \\
743\end{array}$ & $\begin{array}{r}124,019- \\
225,198 \\
10,338\end{array}$ \\
\hline 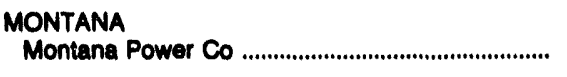 & 88,768 & 73,469 & 44,838 & 2,600 & 2,864 \\
\hline $\begin{array}{l}\text { NEVADA } \\
\text { Nevada Power Co } \\
\text { Slerra Pactic Power Co }\end{array}$ & $\begin{array}{l}69,264 \\
38,573\end{array}$ & $\begin{array}{r}56,104 \\
8,265\end{array}$ & $\begin{array}{r}13,915 \\
130\end{array}$ & $\begin{array}{l}695 \\
161\end{array}$ & 2,895 \\
\hline 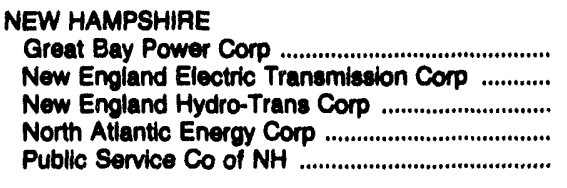 & $\begin{array}{r}6,070 \\
- \\
17,796 \\
45,678\end{array}$ & $\begin{array}{r}33,838 \\
49 \\
- \\
99,205 \\
14,103\end{array}$ & $\begin{array}{r}2,223 \\
- \\
6,517 \\
4,490\end{array}$ & $\overline{-}$ & 23,837 \\
\hline 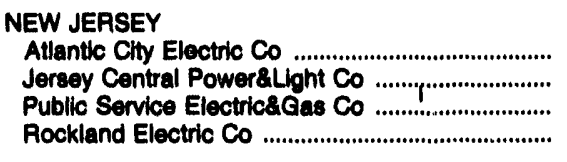 & $\begin{array}{r}136,743 \\
111,997 \\
794,518 \\
-\end{array}$ & $\begin{array}{r}56,805 \\
104,903 \\
206,102 \\
-\end{array}$ & $\begin{array}{r}1,590 \\
17,162 \\
29,568 \\
-\end{array}$ & $\begin{array}{r}2,139 \\
2,114 \\
12,080 \\
-\end{array}$ & $\begin{array}{r}37,382 \\
2,542 \\
107,415 \\
-\end{array}$ \\
\hline 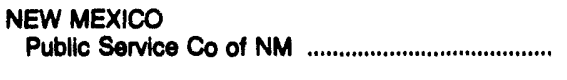 & 387,549 & 80,134 & 74 & - & - \\
\hline 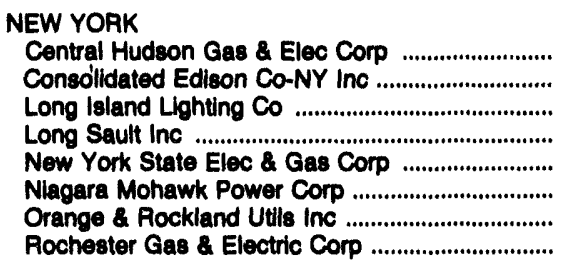 & $\begin{array}{r}46,038 \\
164,951 \\
57,307 \\
- \\
154,653 \\
183,991 \\
41,075 \\
41,039\end{array}$ & $\begin{array}{r}29,987 \\
69,258 \\
41,054 \\
- \\
42,146 \\
170,620 \\
5,160 \\
68,221\end{array}$ & $\begin{array}{r}29,713 \\
31,587 \\
2,272 \\
- \\
13,427 \\
73,042 \\
3,792 \\
11,284\end{array}$ & $\begin{array}{r}764 \\
4,190 \\
10,914 \\
4,08 \\
4,089 \\
2,198 \\
1,173 \\
87\end{array}$ & $\begin{array}{r}19,287 \\
3,201,097 \\
54,333 \\
- \\
99,183 \\
33,247 \\
30,233 \\
82,818\end{array}$ \\
\hline 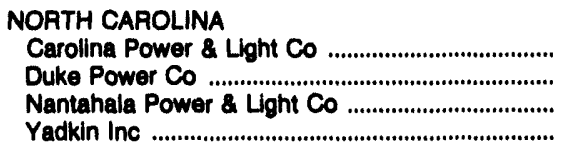 & $\begin{array}{r}777,206 \\
116,548 \\
- \\
-\end{array}$ & $\begin{array}{r}859,384 \\
126,256 \\
- \\
-\end{array}$ & $\begin{array}{r}379,701 \\
211,273 \\
- \\
-\end{array}$ & $\begin{array}{r}4,135 \\
5,166 \\
- \\
-\end{array}$ & $\begin{array}{r}104,567 \\
23,269 \\
- \\
-\end{array}$ \\
\hline 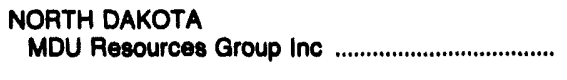 & 43,898 & 5,744 & 2,392 & 17 & 14,722 \\
\hline 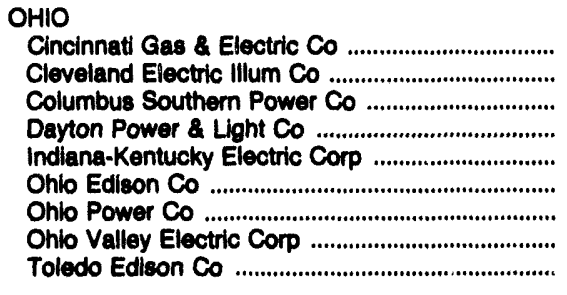 & $\begin{array}{r}413,239 \\
638,653 \\
256,760 \\
265,857 \\
99,253 \\
785,368 \\
391,355 \\
70,249 \\
324,861\end{array}$ & $\begin{array}{r}86,251 \\
375,043 \\
39,633 \\
71,077 \\
18,318 \\
216,183 \\
87,626 \\
648 \\
113,871\end{array}$ & $\begin{array}{r}86,686 \\
32,061 \\
40,381 \\
67,517 \\
13- \\
132,089 \\
65,671 \\
27,750\end{array}$ & $\begin{array}{r}7,059 \\
22 \\
148 \\
902 \\
- \\
985 \\
1,046 \\
- \\
273\end{array}$ & $\begin{array}{r}2,564 \\
14,074 \\
29,775 \\
9,462 \\
- \\
6,709 \\
595 \\
- \\
9,262\end{array}$ \\
\hline 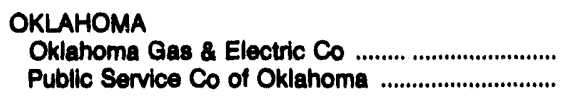 & $\begin{array}{l}109,171 \\
137,040\end{array}$ & $\begin{array}{l}43,673 \\
30,753\end{array}$ & $\begin{array}{r}41,968 \\
611\end{array}$ & $\begin{array}{r}155 \\
1,376\end{array}$ & $\begin{array}{r}133,495 \\
21,459\end{array}$ \\
\hline
\end{tabular}

See endinotes at end of this table. 
Table 45. Investments in Environmental Protection by

Major Inveator-Owned Eloctric Utility Whinin

State on Decomber 31, 1992 (Continued)

(Thousand Dollars)

\begin{tabular}{|c|c|c|c|c|}
\hline State and Utility & $\begin{array}{l}\text { Additional } \\
\text { Plant } \\
\text { Capactly }\end{array}$ & $\begin{array}{l}\text { Miscellanecui } \\
\text { Environ- } \\
\text { mental } \\
\text { Protection }\end{array}$ & Total & $\begin{array}{l}\text { Construction } \\
\text { Work } \\
\text { in } \\
\text { Progress }\end{array}$ \\
\hline 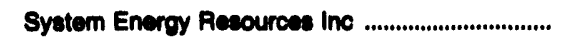 & - & - & 623,432 & 3,057 \\
\hline 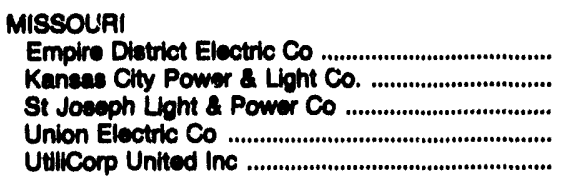 & $\begin{array}{r}8,709 \\
275 \\
- \\
-\end{array}$ & $\frac{-}{10,962}$ & $\begin{array}{r}625,944 \\
11,868 \\
911,449 \\
64,065\end{array}$ & $\begin{array}{r}13,930 \\
15 \\
35,182 \\
15,647\end{array}$ \\
\hline 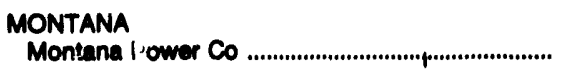 & 8,189 & 603 & 231,220 & 3,891 \\
\hline 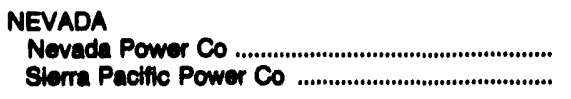 & 1,288 & 448 & $\begin{array}{r}144,610 \\
47,128\end{array}$ & $\begin{array}{r}18,727 \\
898\end{array}$ \\
\hline 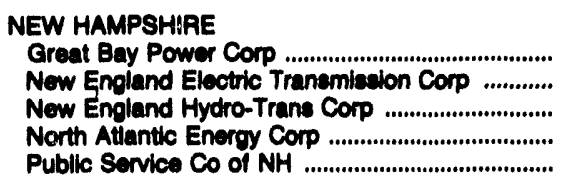 & $2, \overline{-}$ & $\begin{array}{r}1,826 \\
- \\
6,643 \\
6,773\end{array}$ & $\begin{array}{r}44,056 \\
49 \\
- \\
129,161 \\
98,497\end{array}$ & $\begin{array}{l}- \\
- \\
-\end{array}$ \\
\hline 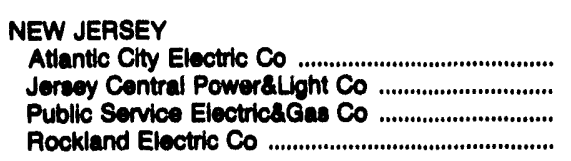 & $\begin{array}{r}81 \\
170 \\
302 \\
-\end{array}$ & $\begin{array}{r}831 \\
7,417 \\
13,034 \\
-\end{array}$ & $\begin{array}{r}235,772 \\
246,305 \\
1,163,021 \\
-\end{array}$ & $\begin{array}{r}11,830 \\
2,497 \\
210,418 \\
0\end{array}$ \\
\hline $\begin{array}{l}\text { NEW MEXICO } \\
\text { Public Service Co of NM ............................................ }\end{array}$ & - & - & 477,757 & 6 \\
\hline 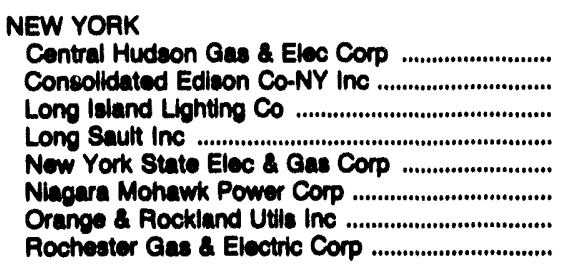 & $\begin{array}{l}- \\
\overline{-} \\
\overline{-} \\
-\end{array}$ & $\begin{array}{r}2,438 \\
867 \\
25,443 \\
6,308 \\
37,851 \\
1,281 \\
9,661\end{array}$ & $\begin{array}{r}128,227 \\
3,471,949 \\
191,323 \\
319,886 \\
500,849 \\
82,703 \\
213,010\end{array}$ & $\begin{array}{r}3,113 \\
65,440 \\
581,096 \\
398,821 \\
29 \\
2,014 \\
1,838\end{array}$ \\
\hline 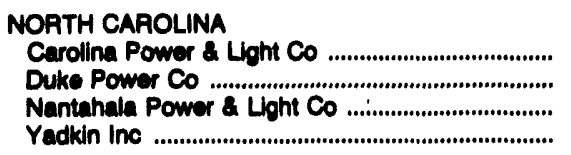 & $\begin{array}{r}62,638 \\
3,246 \\
- \\
-\end{array}$ & $\begin{array}{r}876 \\
2,782 \\
- \\
-\end{array}$ & $\begin{array}{r}2,188,385 \\
488,540 \\
-\end{array}$ & $\begin{array}{r}4,308 \\
13,849 \\
- \\
-\end{array}$ \\
\hline 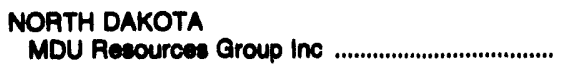 & 441 & 334 & 67,650 & 111 \\
\hline 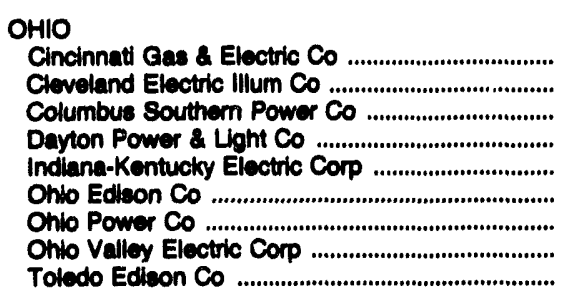 & $\begin{array}{r}64,628 \\
15,244 \\
39,599 \\
43,485 \\
8,34 \overline{-} \\
42,234 \\
4,960\end{array}$ & $\begin{array}{r}377 \\
886 \\
1,872 \\
412 \\
121,533 \\
- \\
1,193\end{array}$ & $\begin{array}{r}680,804 \\
1,078,884 \\
408,267 \\
468,512 \\
117,572 \\
1,271,192 \\
588,527 \\
70,898 \\
482,170\end{array}$ & $\begin{array}{r}11,014 \\
237 \\
5,225 \\
2,584 \\
12,- \\
12,935 \\
5,196 \\
15 \\
132\end{array}$ \\
\hline 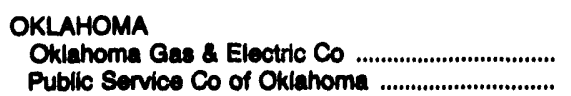 & 11,031 & $\begin{array}{r}6,024 \\
54,007\end{array}$ & $\begin{array}{l}345,517 \\
245,336\end{array}$ & 654 \\
\hline
\end{tabular}

See endinotes at end of this table. 
Table 45. Inveatmente in Environmental Protection by Major Investor-Owned Electric Utility Within State on December 31, 1992 (Continued) (Thousand Dollars)

\begin{tabular}{|c|c|c|c|c|c|}
\hline State and Utility & $\begin{array}{l}\text { Air } \\
\text { Pollution } \\
\text { Control }\end{array}$ & $\begin{array}{l}\text { Water } \\
\text { Pollution } \\
\text { Control }\end{array}$ & $\begin{array}{l}\text { Solld } \\
\text { Weate } \\
\text { Dieposal }\end{array}$ & $\begin{array}{l}\text { Nolise } \\
\text { Abatement } \\
\text { Equipment }\end{array}$ & Esthetic \\
\hline $\begin{array}{l}\text { OAEGON } \\
\text { Pacticorp } \\
\text { Portiand General Electric Co }\end{array}$ & $\begin{array}{l}728,155 \\
146,313\end{array}$ & $\begin{array}{l}88,335 \\
46,150\end{array}$ & $\begin{array}{r}166,882 \\
7,509\end{array}$ & $\begin{array}{r}212 \\
2,207\end{array}$ & $\begin{array}{r}49,991 \\
2,270\end{array}$ \\
\hline 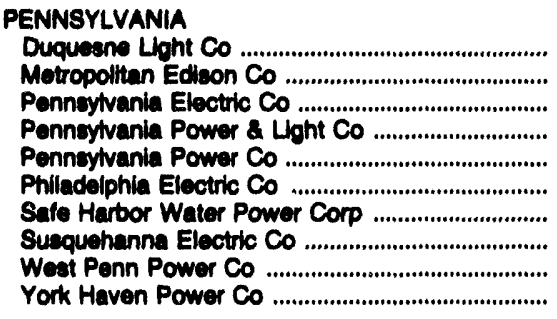 & $\begin{array}{r}388,374 \\
89,283 \\
285,768 \\
188,905 \\
134,627 \\
1,844,722 \\
- \\
=- \\
224,062 \\
-\end{array}$ & $\begin{array}{r}138,178 \\
73,678 \\
56,414 \\
127,480 \\
31,440 \\
449,331 \\
100 \\
70,480 \\
60\end{array}$ & $\begin{array}{r}49,604 \\
10,332 \\
1,063 \\
81,821 \\
16,797 \\
50,083 \\
- \\
71,530 \\
-\end{array}$ & $\begin{array}{r}750 \\
505 \\
358 \\
2,257 \\
330 \\
2,165 \\
- \\
577 \\
-\end{array}$ & $\begin{array}{r}24,956 \\
76 \\
417 \\
68,461 \\
125 \\
10,110 \\
- \\
13,548 \\
-\end{array}$ \\
\hline 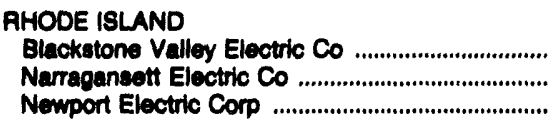 & $\begin{array}{r}25 \\
105\end{array}$ & $\begin{array}{l}7 \overline{7} \\
40\end{array}$ & $2,23 \overline{7}$ & 27 & $4,71 \bar{\theta}$ \\
\hline 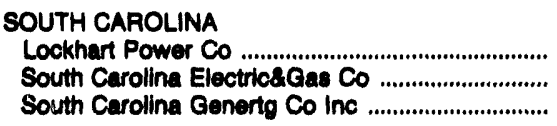 & $\begin{array}{l}76,61 \overline{0} \\
39,408\end{array}$ & $\begin{array}{r}82 \\
26,860 \\
10,139\end{array}$ & $4,140^{-}$ & $\overline{-}$ & $\overline{-}-$ \\
\hline $\begin{array}{l}\text { SOUTH DAKOTA } \\
\text { Black Hills Corp } \\
\text { Northwestern Public Service Co }\end{array}$ & $\begin{array}{l}32,628 \\
18,414\end{array}$ & $12,79 \overline{8}$ & $3,15 \overline{3}$ & 27 & $11 \overline{2}$ \\
\hline $\begin{array}{l}\text { TENNESSEE } \\
\text { Kingeport Power Co } \\
\text { Tapoco Inc }\end{array}$ & $\overline{-}$ & $\begin{array}{l}10 \\
-\end{array}$ & $\begin{array}{l}1 \\
-\end{array}$ & - & 2,032 \\
\hline 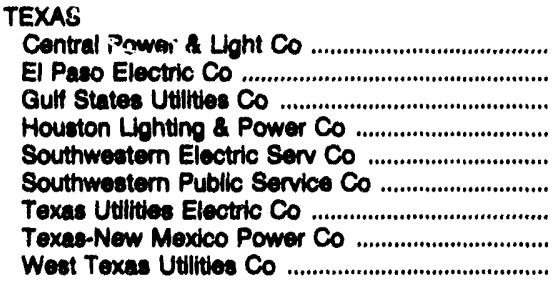 & $\begin{array}{r}86,152 \\
168,025 \\
82,707 \\
- \\
- \\
85,456 \\
338,916 \\
33,209 \\
33,257\end{array}$ & $\begin{array}{r}124,241 \\
46,035 \\
135,808 \\
- \\
- \\
33,403 \\
813,478 \\
39,788 \\
12,741\end{array}$ & $\begin{array}{r}5,804 \\
3,384 \\
17,593 \\
- \\
- \\
11,933 \\
540,797 \\
15,641 \\
4,862\end{array}$ & $\begin{array}{r}931 \\
\overline{-} \\
= \\
3,959 \\
7,382 \\
-\end{array}$ & $\begin{array}{r}3,180 \\
- \\
43,081 \\
- \\
164 \\
25,497 \\
272 \\
737\end{array}$ \\
\hline 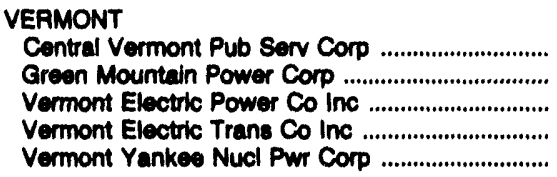 & $\begin{array}{r}- \\
\overline{-} \\
11,975\end{array}$ & $\begin{array}{r}18 \\
159 \\
- \\
-\end{array}$ & $\begin{array}{r}279 \\
- \\
-\end{array}$ & $\begin{array}{r}74 \\
42 \\
- \\
- \\
-\end{array}$ & $\begin{array}{r}448 \\
834 \\
3,050 \\
252\end{array}$ \\
\hline 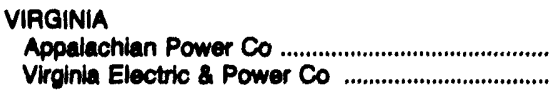 & $\begin{array}{l}275,759 \\
371,161\end{array}$ & $\begin{array}{r}65,580 \\
208,213\end{array}$ & $\begin{array}{r}34,289 \\
177,341\end{array}$ & $\begin{array}{r}348 \\
2,545\end{array}$ & $\begin{array}{l}61,833 \\
90,814\end{array}$ \\
\hline 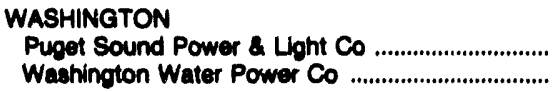 & $\begin{array}{r}165,480 \\
57,625\end{array}$ & $\begin{array}{r}22,511 \\
5,114\end{array}$ & $\begin{array}{r}15,646 \\
2,752\end{array}$ & $\begin{array}{r}2,970 \\
196\end{array}$ & $\begin{array}{r}207,387 \\
5,361\end{array}$ \\
\hline 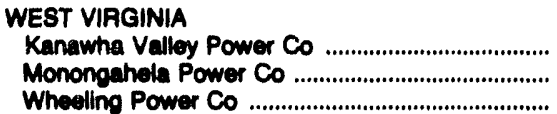 & 112,896 & $\begin{array}{r}414 \\
38,720 \\
287\end{array}$ & $29,81 \overline{7}$ & 263 & $3,59 \overline{4}$ \\
\hline
\end{tabular}

See endnotes at end of this table. 
Table 45. Investments in Environmental Protection by Major Investor-Owned Electrlc Utillty Within State on December 31, 1892 (Continued) (Thousand Dollars)

\begin{tabular}{|c|c|c|c|c|}
\hline State and Utility & $\begin{array}{l}\text { Additional } \\
\text { Plant } \\
\text { Capacity }\end{array}$ & $\begin{array}{l}\text { Miscellaneous } \\
\text { Environ- } \\
\text { mental } \\
\text { Protection }\end{array}$ & Total & $\begin{array}{l}\text { Construction } \\
\text { Work } \\
\text { in } \\
\text { Progress }\end{array}$ \\
\hline $\begin{array}{l}\text { OREGON } \\
\text { Pacficorp } \\
\text { Portland General Electric Co }\end{array}$ & $\begin{array}{r}64,850 \\
5,333\end{array}$ & $\begin{array}{r}7,136 \\
16,926\end{array}$ & $\begin{array}{r}1,095,562 \\
226,707\end{array}$ & $\begin{array}{r}4,093 \\
233\end{array}$ \\
\hline 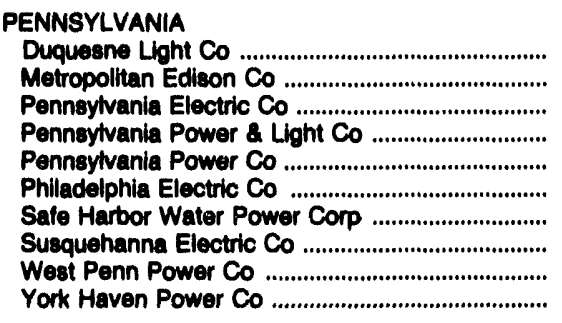 & $\begin{array}{r}45,299 \\
285 \\
3,869 \\
31,170 \\
1,278 \\
552 \\
- \\
- \\
- \\
-\end{array}$ & $\begin{array}{r}1,500 \\
994 \\
745 \\
36,492 \\
21,046 \\
432 \\
666 \\
- \\
2,970 \\
-\end{array}$ & $\begin{array}{r}658,660 \\
175,163 \\
298,631 \\
546,605 \\
204,644 \\
2,357,394 \\
767 \\
- \\
383,178 \\
80\end{array}$ & $\begin{array}{r}3,437 \\
25,509 \\
2,252 \\
28,835 \\
1,362 \\
27,975 \\
- \\
106,132 \\
397\end{array}$ \\
\hline 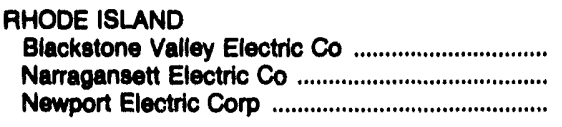 & $\overline{-}$ & $\overline{-}$ & $\begin{array}{r}- \\
7,053 \\
186\end{array}$ & $1,48 \overline{-}$ \\
\hline 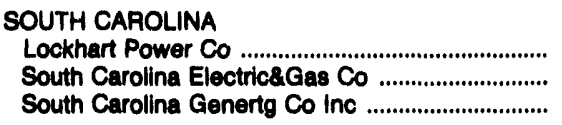 & $\overline{-}$ & $\begin{array}{l}- \\
-\end{array}$ & $\begin{array}{r}82 \\
109,611 \\
49,547\end{array}$ & $\begin{array}{r}31,900 \\
763\end{array}$ \\
\hline 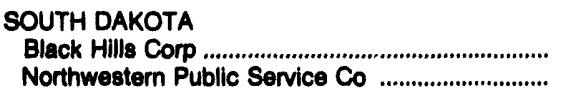 & $73 \overline{5}$ & 437 & $\begin{array}{l}32,628 \\
35,676\end{array}$ & 102 \\
\hline 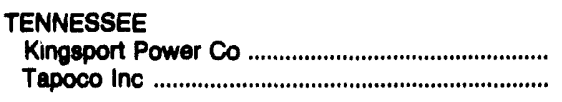 & - & - & $\begin{array}{r}2,043 \\
-\end{array}$ & 32 \\
\hline 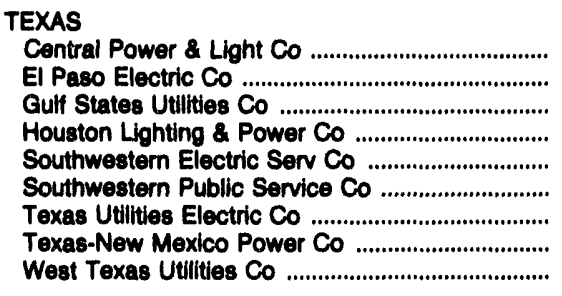 & $\begin{array}{r}\overline{2} \\
\overline{-} \\
\overline{-} \\
49,393 \\
\overline{-}\end{array}$ & $\begin{array}{r}985 \\
1,449 \\
- \\
958,069 \\
5 \\
- \\
581 \\
- \\
654\end{array}$ & $\begin{array}{r}221,403 \\
216,896 \\
279,188 \\
958,069 \\
5 \\
134,015 \\
1,776,045 \\
88,820 \\
52,264\end{array}$ & $\begin{array}{r}549 \\
368 \\
121 \\
- \\
60 \\
2,990 \\
386,060 \\
3 \\
417\end{array}$ \\
\hline 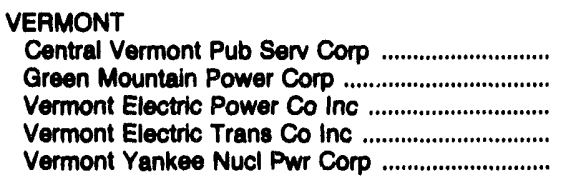 & $\begin{array}{l}9 \dot{-} \\
\overline{-} \\
-\end{array}$ & $\begin{array}{r}7 \\
41 \\
- \\
-\end{array}$ & $\begin{array}{r}825 \\
1,175 \\
3,059 \\
25,672\end{array}$ & 108 \\
\hline $\begin{array}{l}\text { VIRGINIA } \\
\text { Appalachian Power Co } \\
\text { Virginia Electric \& Power Co }\end{array}$ & $\begin{array}{r}89,681 \\
-\end{array}$ & $\begin{array}{r}148 \\
62,533\end{array}$ & $\begin{array}{l}527,637 \\
912,707\end{array}$ & $\begin{array}{l}16,221 \\
49,430\end{array}$ \\
\hline 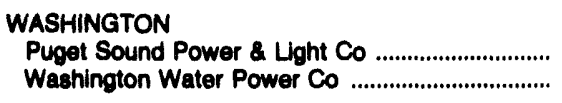 & $\begin{array}{r}8,479 \\
589\end{array}$ & $\begin{array}{r}16,380 \\
2,372\end{array}$ & $\begin{array}{r}438,862 \\
74,010\end{array}$ & $\begin{array}{r}4 \\
228\end{array}$ \\
\hline 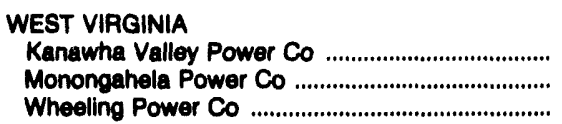 & $\overline{-}$ & 2,561 & $\begin{array}{r}414 \\
188,851 \\
287\end{array}$ & 61,821 \\
\hline
\end{tabular}

See endnotes at end of this table. 
Table 45. Investments in Environmental Protection by Major Investor-Owned Electric Utility Within State on Decomber 31, 1902 (Continued) (Thousand Dollars)

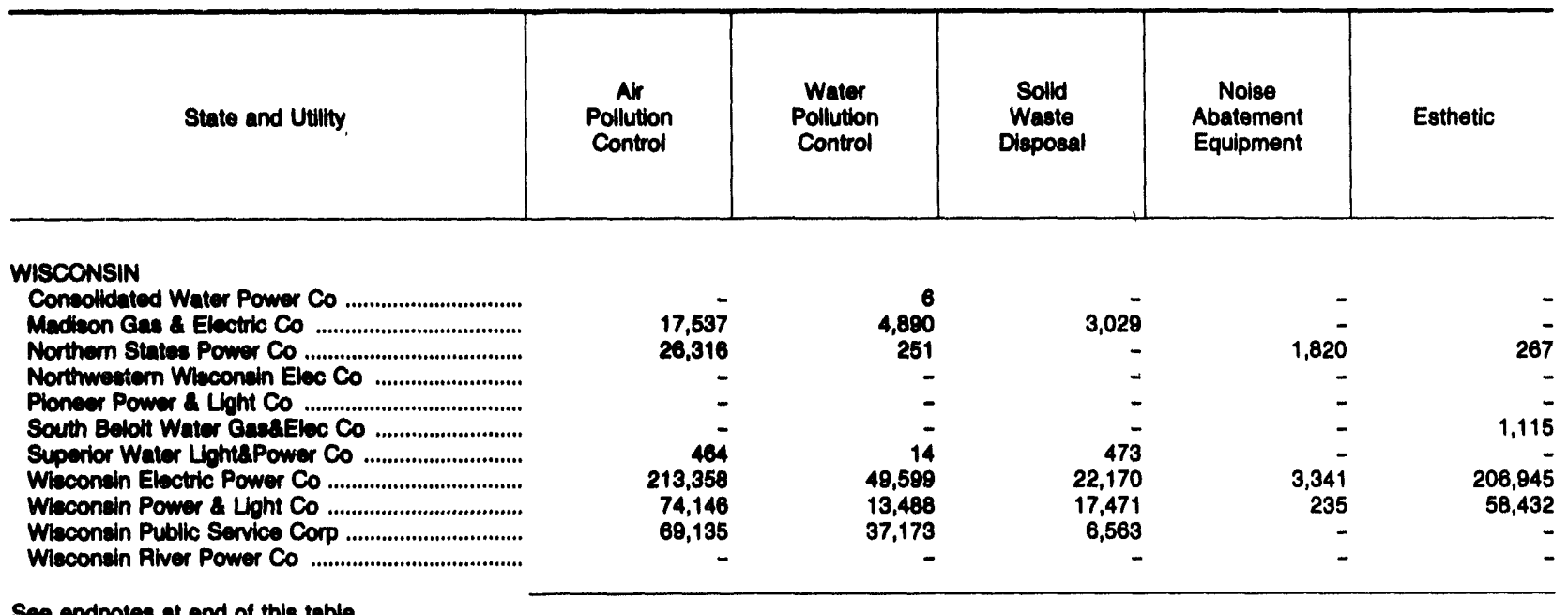

Table 45. Investments in Environmental Protection by Major Investor-Owned Electric Utility Within State on December 31, 1992 (Continued) (Thousand Dollars)

\begin{tabular}{|c|c|c|c|c|}
\hline State and Utilly & $\begin{array}{l}\text { Additional } \\
\text { Piant } \\
\text { Capecty }\end{array}$ & $\begin{array}{c}\text { Miscellaneous } \\
\text { Environ- } \\
\text { mental } \\
\text { Protection }\end{array}$ & Total & $\begin{array}{c}\text { Construction } \\
\text { Work } \\
\text { in } \\
\text { Progress }\end{array}$ \\
\hline 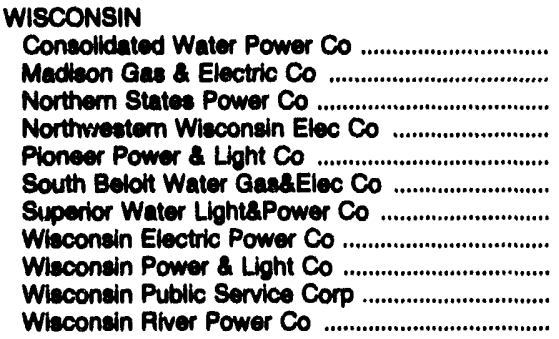 & $\begin{array}{r}1,126 \\
- \\
- \\
- \\
- \\
1,681 \\
2,365 \\
- \\
-\end{array}$ & $\begin{array}{r}- \\
182 \\
\overline{-} \\
\overline{-} \\
\overline{-} \\
381 \\
- \\
-191 \\
-\end{array}$ & $\begin{array}{r}6 \\
26,583 \\
28,836 \\
- \\
- \\
1,115 \\
951 \\
497,474 \\
168,137 \\
112,681 \\
-\end{array}$ & $\begin{array}{r}32 \\
- \\
- \\
- \\
- \\
22,628 \\
2,268 \\
753 \\
-\end{array}$ \\
\hline
\end{tabular}

- Data not avallable.

Note: Totals may not equal sum of components becaues of independent rounding.

Source: Federal Energy Regulatory Commisclon, FERC Form 1, "Annual Report of Major Electric Utilties, Licensees and Others." 
Figure 6. Investments In Air Pollution Control for Major U.S. Investor-Owned Electric Utilities, 1988-1992

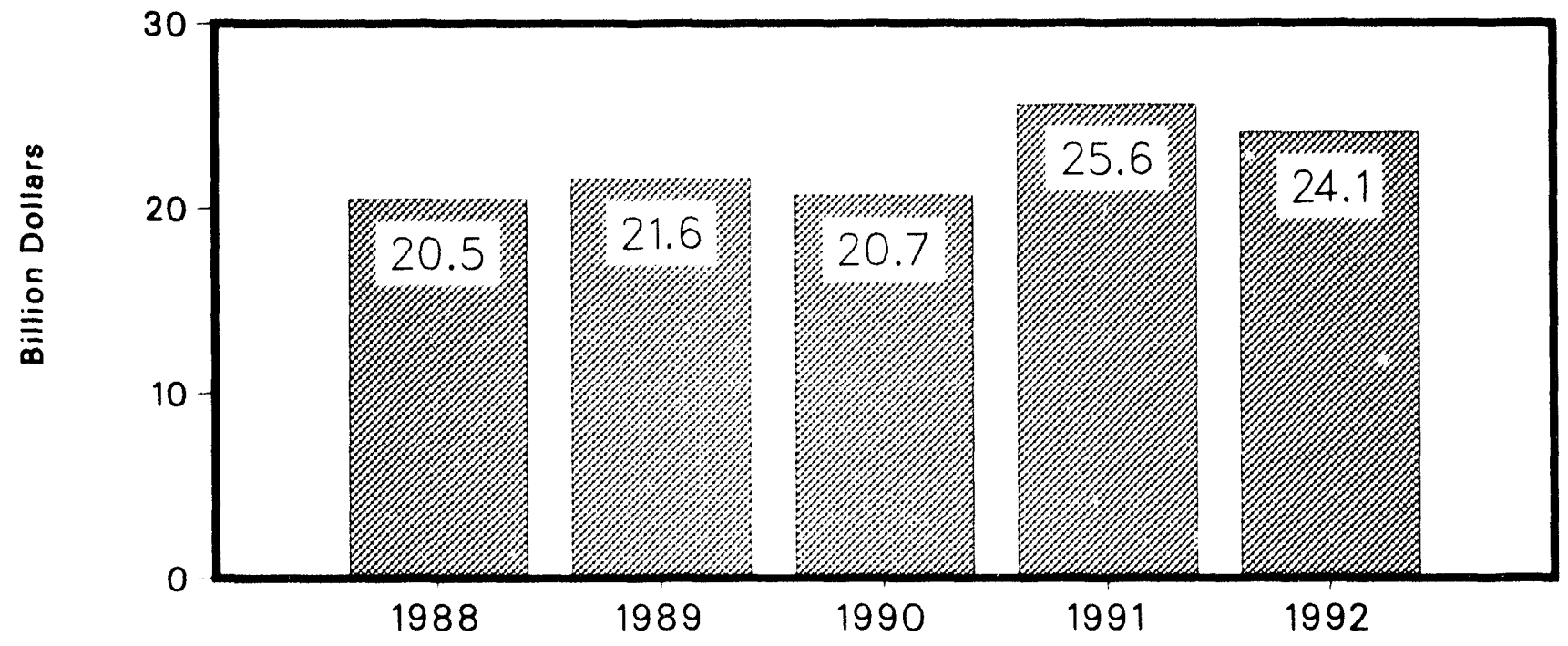

Note: Summery data are provided in Table 45

Source: Federal Energy Regulato y Commission. FERC Form 1. Annual Report of Major Electric Utilities. Licensees and Others.

Figure 7. Investments in Water Pollution Control for Major U.S. Investor - Owned Electric Utilities, 1988 1992

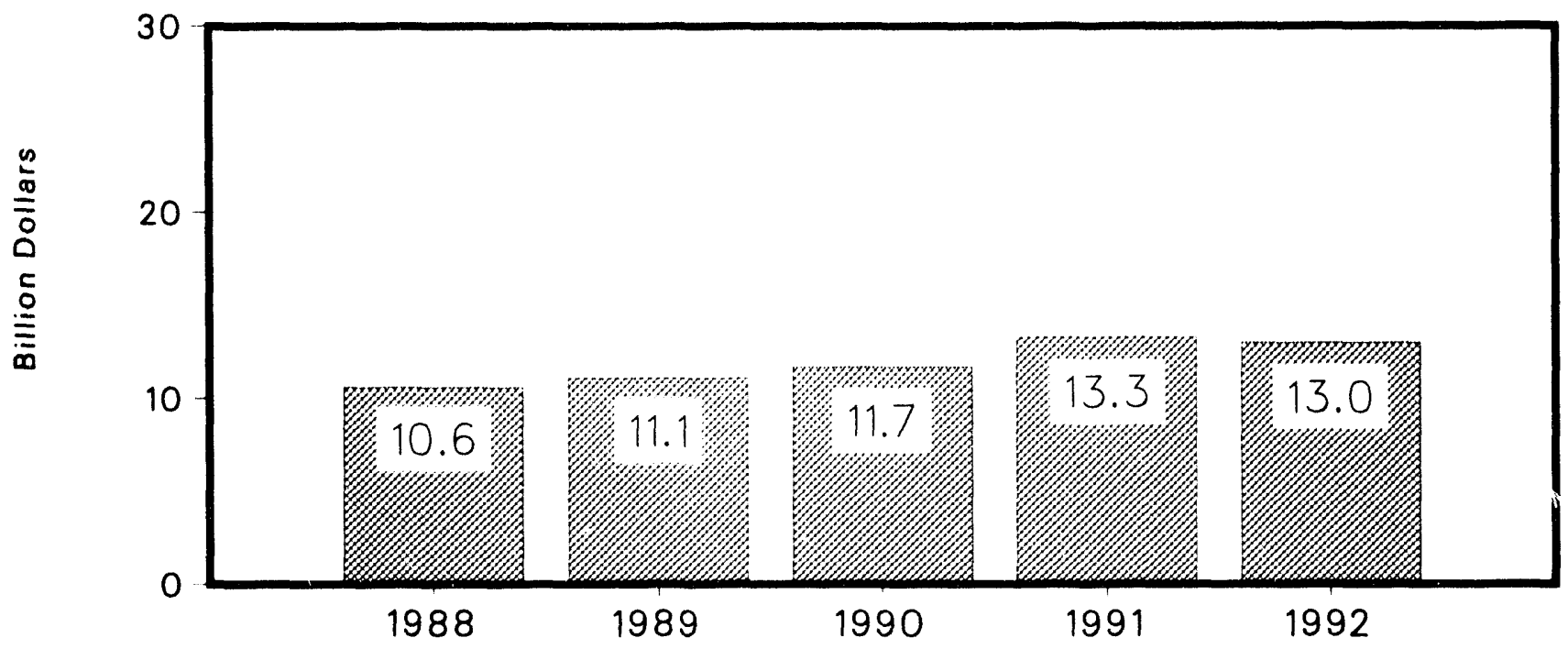

Note: Summary data are provided in Table 45

Source: Federal Energy Regulatory Commission. FERC Form 1. 'Annual Report of Major Electric Utilities, Licensees and Others.' 
Table 46. Expenditures for Environmental Protection by Major Investor-Owned Electric Utillty Within

State, 1992

(Thousand Dollars)

\begin{tabular}{|c|c|c|c|c|c|}
\hline State and Utility & $\begin{array}{c}\text { Depreciation } \\
\text { Expenses }\end{array}$ & $\begin{array}{l}\text { Labor, } \\
\text { Maintainance, } \\
\text { Materials, } \\
\text { and } \\
\text { Supplies }\end{array}$ & $\begin{array}{l}\text { Operation } \\
\text { of } \\
\text { Faclitiles }\end{array}$ & $\begin{array}{l}\text { Fly Ash } \\
\text { and } \\
\text { Sulphur } \\
\text { Removal }\end{array}$ & $\begin{array}{l}\text { Differences } \\
\text { in Cost of } \\
\text { Environmentally } \\
\text { Clean } \\
\text { Fuel }\end{array}$ \\
\hline Total & 915,740 & 816,587 & 84,711 & 204,778 & 379,059 \\
\hline 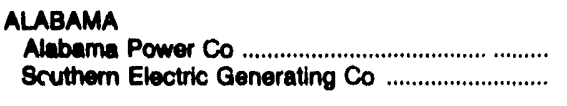 & $\overline{-}$ & $\begin{array}{r}13,633 \\
564\end{array}$ & $\overline{-}$ & $\begin{array}{l}7,336 \\
1,738\end{array}$ & - \\
\hline 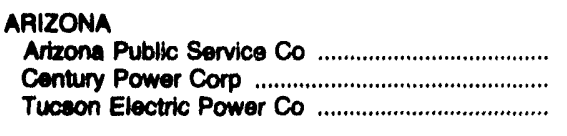 & $\begin{array}{r}30,372 \\
17,576\end{array}$ & $\begin{array}{r}14,774 \\
1,824 \\
4,544\end{array}$ & $\begin{array}{r}21 \\
2,633 \\
2,197\end{array}$ & $\begin{array}{r}3,758 \\
707 \\
1,164\end{array}$ & 170 \\
\hline 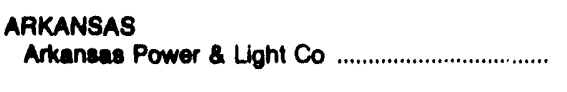 & - & - & - & - & - \\
\hline 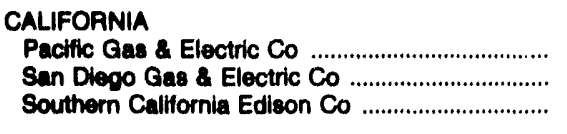 & $\begin{array}{r}93,000 \\
- \\
-\end{array}$ & $\begin{array}{r}88,000 \\
2,672 \\
-\end{array}$ & 63 & $\overline{-}$ & 2,000 \\
\hline $\begin{array}{l}\text { COLORADO } \\
\text { Public Service Co of Colorado }\end{array}$ & - & 3,650 & 1,824 & 3,626 & 180 \\
\hline 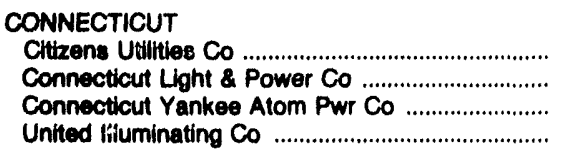 & $\begin{array}{l}- \\
- \\
-\end{array}$ & $\begin{array}{l}- \\
- \\
-\end{array}$ & $\begin{array}{l}- \\
\overline{-} \\
-\end{array}$ & $\begin{array}{l}- \\
- \\
-\end{array}$ & $\overline{-}$ \\
\hline 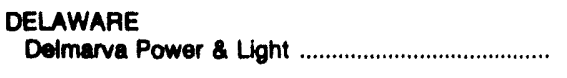 & - & - & - & - & \\
\hline $\begin{array}{l}\text { DISTRICT OF COLUMBIA } \\
\text { Potomac Electric Power Co }\end{array}$ & - & - & - & - & . \\
\hline 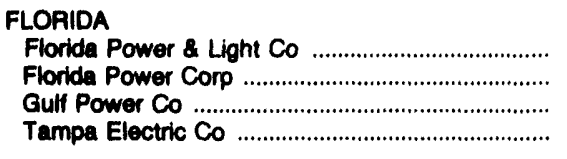 & $\begin{array}{r}15,607 \\
8,694 \\
-\end{array}$ & $\begin{array}{r}6,128 \\
2,586 \\
-\end{array}$ & $\begin{array}{r}3,611 \\
2,100 \\
-\end{array}$ & $\begin{array}{r}4 \overline{5} \\
1,859 \\
-\end{array}$ & $\begin{array}{r}23,374 \\
7,843\end{array}$ \\
\hline 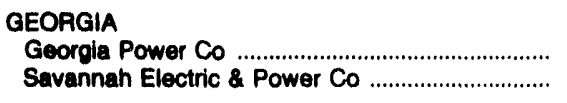 & $\begin{array}{r}41,066 \\
470\end{array}$ & $\begin{array}{r}35,152 \\
41\end{array}$ & - & 10 & - \\
\hline 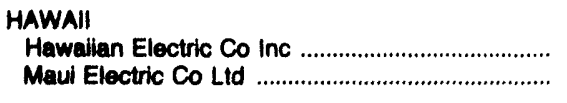 & $\overline{-}$ & $\overline{-}$ & $\overline{-}$ & - & 10,665 \\
\hline 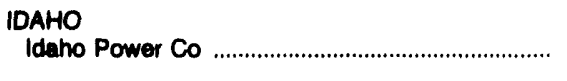 & - & 5,752 & 2,574 & 194 & \\
\hline 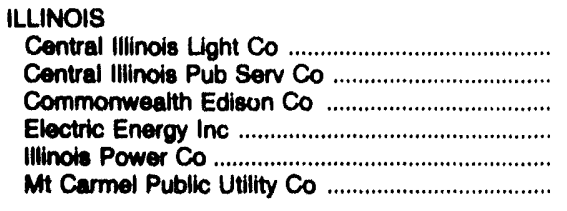 & $\begin{array}{r}8,526 \\
48,811 \\
1,374 \\
20,122 \\
-\end{array}$ & $\begin{array}{r}4,068 \\
10,682 \\
93,847 \\
638 \\
- \\
-\end{array}$ & $\begin{array}{l}- \\
\overline{-} \\
- \\
-\end{array}$ & $\begin{array}{r}1,490 \\
1,726 \\
- \\
- \\
-\end{array}$ & $\begin{array}{r}- \\
111,509 \\
-\end{array}$ \\
\hline 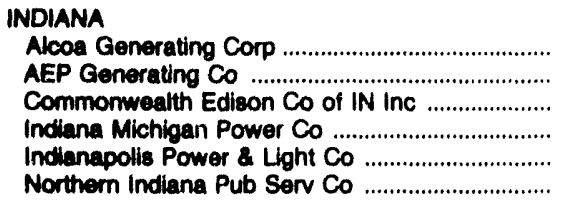 & $\begin{array}{r}1,066 \\
4,638 \\
2,336 \\
13,603 \\
15,765 \\
-\end{array}$ & $\begin{array}{r}1,519 \\
849 \\
482 \\
35,659 \\
2,175 \\
19,775\end{array}$ & $\begin{array}{r}1,48 \overline{-} \\
2,338 \\
953 \\
443\end{array}$ & $\begin{array}{r}- \\
- \\
31 \\
10,181 \\
1,687\end{array}$ & $\begin{array}{r}5 \overline{-} \\
5,682 \\
17,873\end{array}$ \\
\hline
\end{tabular}

See endnotes at end of this table. 
Table 46. Expenditures for Environmental Protection by Major Investor-Owned Electric Utility Within State, 1992 (Continued) (Thousand Dollars)

\begin{tabular}{|c|c|c|c|c|c|}
\hline State and Utility & $\begin{array}{l}\text { Replacement } \\
\text { Power } \\
\text { Coste }\end{array}$ & $\begin{array}{l}\text { Taxes } \\
\text { and } \\
\text { Fees }\end{array}$ & $\begin{array}{l}\text { Adminiatrative } \\
\text { and } \\
\text { General }\end{array}$ & $\begin{array}{l}\text { Other } \\
\text { Environmental } \\
\text { Protection } \\
\text { Expenees }\end{array}$ & Total \\
\hline Total & 41,188 & 148,217 & 160,575 & 206,332 & $2,857,197$ \\
\hline 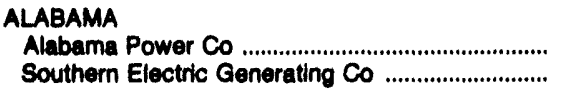 & - & $\overline{4}$ & $\overline{-}$ & $\begin{array}{r}41,142 \\
1,677\end{array}$ & $\begin{array}{r}62,111 \\
3,982\end{array}$ \\
\hline 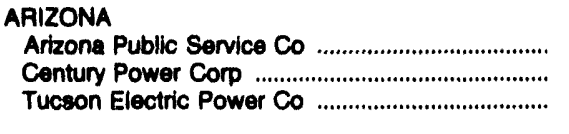 & $\overline{-}$ & $\begin{array}{r}7,639 \\
3,428\end{array}$ & $\begin{array}{r}1,347 \\
38 \overline{5}\end{array}$ & $\begin{array}{r}6,098 \\
- \\
-\end{array}$ & $\begin{array}{r}64,178 \\
5,264 \\
29,304\end{array}$ \\
\hline 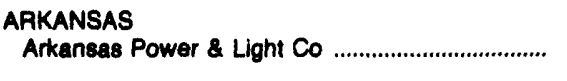 & - & - & - & - & - \\
\hline 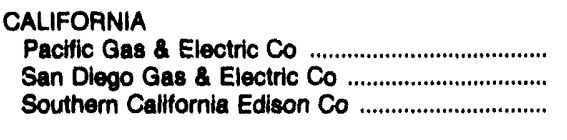 & $\overline{-}$ & $\begin{array}{r}16,000 \\
- \\
-\end{array}$ & $\begin{array}{r}75,000 \\
11 \\
-\end{array}$ & $\overline{-}$ & $\begin{array}{r}274,000 \\
2,746 \\
-\end{array}$ \\
\hline 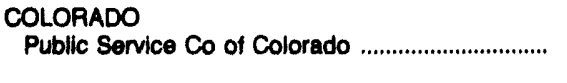 & 1,716 & - & - & - & 10,997 \\
\hline 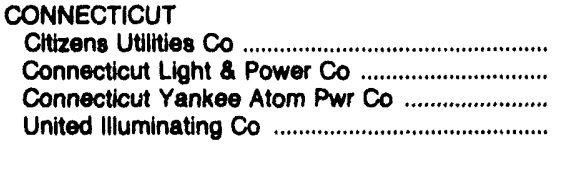 & $\begin{array}{l}- \\
- \\
-\end{array}$ & $\begin{array}{l}- \\
-\end{array}$ & $\begin{array}{l}- \\
-\end{array}$ & $\begin{array}{l}- \\
-\end{array}$ & $\begin{array}{l}- \\
- \\
-\end{array}$ \\
\hline 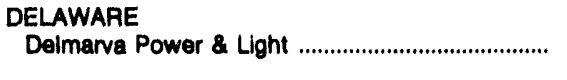 & - & - & - & - & - \\
\hline 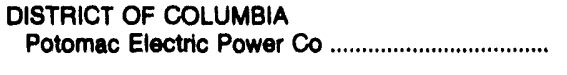 & - & - & - & - & - \\
\hline 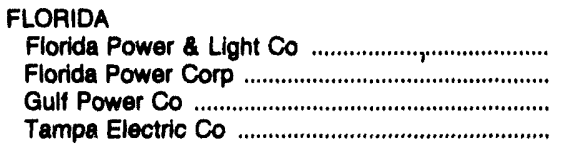 & 3,960 & $\begin{array}{r}46 \overline{2} \\
807 \\
-\end{array}$ & $2, \overline{-}$ & $\begin{array}{r}11 \overline{4} \\
690 \\
-\end{array}$ & $\begin{array}{r}48,33 \overline{2} \\
31,184 \\
-\end{array}$ \\
\hline 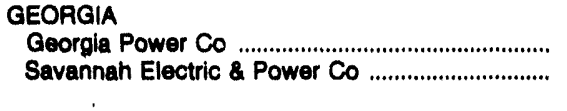 & $\overline{-}$ & 1,175 & 8,626 & - & $\begin{array}{r}86,019 \\
521\end{array}$ \\
\hline $\begin{array}{l}\text { HAWAII } \\
\text { Hawallan Electric Co Inc } \\
\text { Maul Electric Co Lid }\end{array}$ & $\overline{-}$ & $\overline{-}$ & $\overline{-}$ & - & 19,656 \\
\hline $\begin{array}{l}\text { IDAHO } \\
\text { Idaho Power Co }\end{array}$ & 582 & - & 510 & 0 & 0,602 \\
\hline 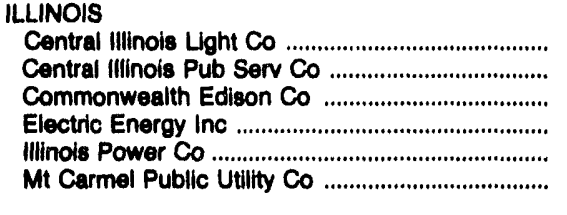 & $\overline{-}$ & $\begin{array}{r}40 \\
6,998 \\
- \\
-\end{array}$ & $\begin{array}{r}274 \\
3,277 \\
3,328 \\
2,335 \\
-\end{array}$ & $\begin{array}{r}138 \\
26,781 \\
- \\
-\end{array}$ & $\begin{array}{r}5,832 \\
24,387 \\
290,251 \\
2,364 \\
22,457 \\
-\end{array}$ \\
\hline 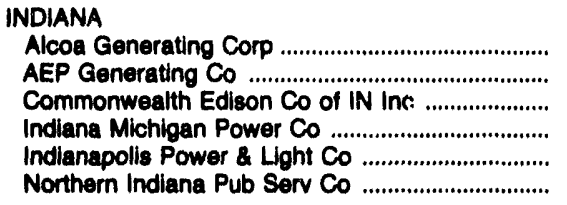 & $\begin{array}{r}1,87 \overline{-} \\
2,948 \overline{-} \\
-\end{array}$ & $\begin{array}{r}\overline{-} \\
\overline{5} \\
140 \\
-\end{array}$ & $\begin{array}{r}384 \\
7 \\
3,846 \\
-\overline{2}\end{array}$ & $\begin{array}{r}\overline{-} \\
1,847 \\
- \\
\overline{6}\end{array}$ & $\begin{array}{r}2,685 \\
9,218 \\
10,333 \\
76,302 \\
29,221 \\
22,653\end{array}$ \\
\hline
\end{tabular}

See endnotes at end of this table. 
Table 46. Expenditures for Environmental Protection by Major Investor-Owned Electric Utillity Within State, 1992 (Continued) (Thousand Dollars)

\begin{tabular}{|c|c|c|c|c|c|}
\hline State and Utilty & $\begin{array}{l}\text { Depreciation } \\
\text { Expenses }\end{array}$ & $\begin{array}{l}\text { Labor, } \\
\text { Maintainance, } \\
\text { Materlals, } \\
\text { and } \\
\text { Supplies }\end{array}$ & $\begin{array}{l}\text { Operation } \\
\text { of } \\
\text { Facilities }\end{array}$ & $\begin{array}{l}\text { Fly Aah } \\
\text { and } \\
\text { Sulphur } \\
\text { Removal }\end{array}$ & $\begin{array}{l}\text { Differences } \\
\text { in Cost of } \\
\text { Environmentally } \\
\text { Clean } \\
\text { Fuel }\end{array}$ \\
\hline $\begin{array}{l}\text { PSI Energy Inc } \\
\text { Southern Indiana Gas \& Elec Co }\end{array}$ & $\begin{array}{r}10,544 \\
-\end{array}$ & $\begin{array}{r}5,689 \\
-\end{array}$ & - & 4,886 & - \\
\hline 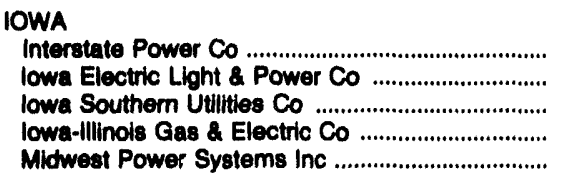 & $\begin{array}{r}2,139 \overline{-} \\
847 \\
4,301 \\
2,676\end{array}$ & $\begin{array}{r}126 \\
1,708 \\
168 \\
4,795 \\
2,140\end{array}$ & $\begin{array}{r}- \\
174 \\
875 \\
-\end{array}$ & $\begin{array}{r}583 \\
- \\
34 \\
55 \\
889\end{array}$ & $\begin{array}{l}- \\
- \\
-\end{array}$ \\
\hline 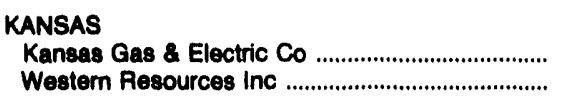 & - & 1,388 & $\begin{array}{r}15 \\
-\end{array}$ & 662 & 512 \\
\hline 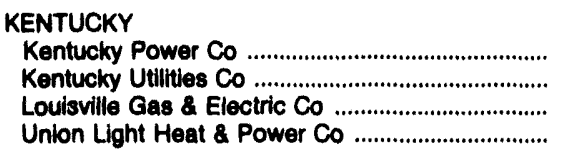 & $\begin{array}{r}813 \\
6,402 \\
23,440 \\
1\end{array}$ & $\begin{array}{r}287 \\
1,114 \\
16,358 \\
-161\end{array}$ & $\begin{array}{r}2,166 \\
422 \\
-\end{array}$ & 5,390 & $36,30 \overline{8}$ \\
\hline 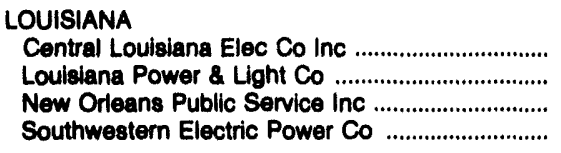 & $\begin{array}{r}1,737 \\
- \\
5,328\end{array}$ & $\begin{array}{r}628 \\
110 \\
5,110\end{array}$ & $\begin{array}{r}110 \\
54 \\
-\end{array}$ & 588 & $\begin{array}{l}- \\
- \\
-\end{array}$ \\
\hline 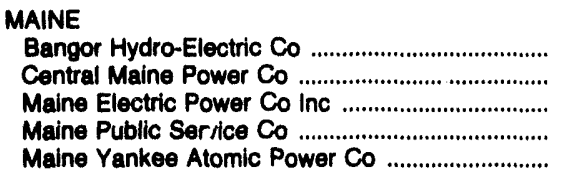 & $\begin{array}{l}- \\
- \\
-\end{array}$ & $\begin{array}{r}40 \\
2,889 \\
\overline{16} \\
-\end{array}$ & $\begin{array}{l}- \\
- \\
-\end{array}$ & $\begin{array}{r}2 \\
169 \\
- \\
1 \\
-\end{array}$ & $\begin{array}{r}74 \\
883 \\
50 \\
-\end{array}$ \\
\hline 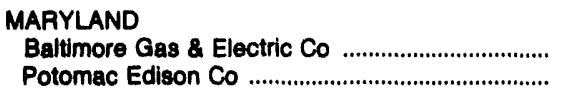 & $\overline{-}$ & $\overline{-}$ & - & - & - \\
\hline 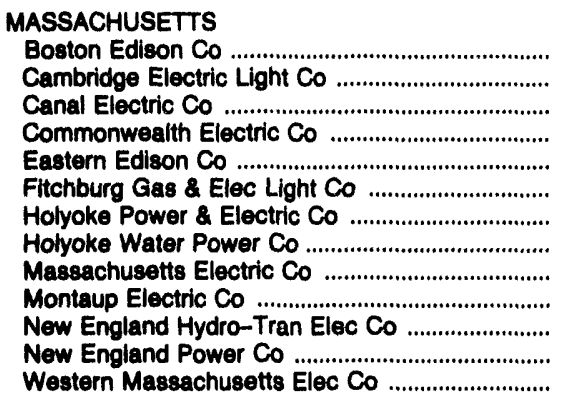 & $\begin{array}{l}- \\
- \\
- \\
- \\
- \\
- \\
- \\
- \\
- \\
-\end{array}$ & $\begin{array}{r}5,818 \\
52 \\
2,624 \\
- \\
- \\
- \\
- \\
- \\
1,189 \\
- \\
469 \\
-\end{array}$ & $\begin{array}{r}\overline{4} \\
21 \\
- \\
- \\
- \\
- \\
- \\
\overline{1} \\
\overline{-} \\
-\end{array}$ & $\begin{array}{r}29 \\
\overline{72} \\
- \\
- \\
- \\
- \\
- \\
- \\
24 \\
7,463 \\
-\end{array}$ & $\begin{array}{r}28,527 \\
- \\
- \\
- \\
- \\
- \\
- \\
- \\
- \\
29 \\
- \\
- \\
-\end{array}$ \\
\hline 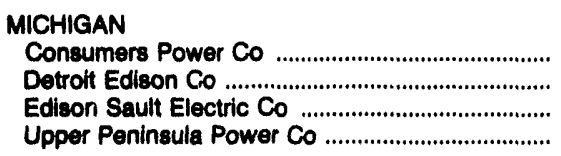 & $\begin{array}{r}82,41 \overline{5} \\
8 \overline{0}\end{array}$ & $\begin{array}{r}0,64 \overline{8} \\
18 \overline{8}\end{array}$ & $\begin{array}{r}13,957 \\
- \\
-\end{array}$ & $\begin{array}{r}1,500 \\
1,811 \\
180\end{array}$ & $\begin{array}{l}- \\
- \\
-\end{array}$ \\
\hline 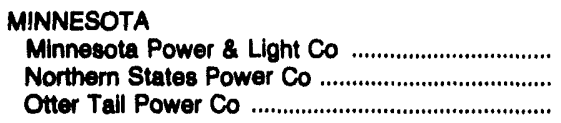 & $\begin{array}{r}5,388 \\
21,490 \\
2,909\end{array}$ & $\begin{array}{r}1,270 \\
10,639 \\
2,083\end{array}$ & $\begin{array}{l}- \\
625 \\
251\end{array}$ & $\begin{array}{r}531 \\
10,223 \\
-\end{array}$ & - \\
\hline 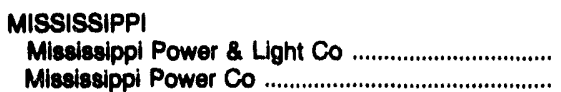 & $\begin{array}{r}1,025 \\
-\end{array}$ & $\begin{array}{r}626 \\
1,498\end{array}$ & $26 \overline{1}$ & $11 \overline{2}^{-}$ & - \\
\hline
\end{tabular}

See endnotes at end of this table. 
Table 46. Expenditures for Environmental Protection by Major Investor-Owned Eloctric Utility Within State, 1992 (Continued) (Thousand Dollars)

\begin{tabular}{|c|c|c|c|c|c|}
\hline State and Utility & $\begin{array}{l}\text { Replecement } \\
\text { Power } \\
\text { Cowts }\end{array}$ & $\begin{array}{l}\text { Taxes } \\
\text { and } \\
\text { Foes }\end{array}$ & $\begin{array}{l}\text { Adminiatrattve } \\
\text { and } \\
\text { General }\end{array}$ & $\begin{array}{l}\text { Other } \\
\text { Environmental } \\
\text { Protection } \\
\text { Expenses }\end{array}$ & Total \\
\hline $\begin{array}{l}\text { PSI Energy Inc } \\
\text { Southern Indlana Gas \& Elec Co }\end{array}$ & - & 202 & 1,254 & $\overline{-}$ & 22,656 \\
\hline 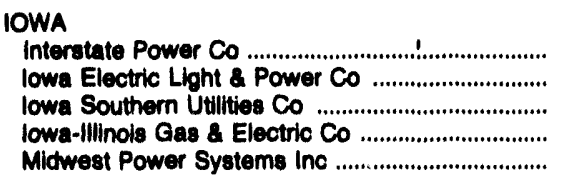 & $\begin{array}{r}- \\
- \\
-\end{array}$ & $\begin{array}{r}83 \\
-\overline{57} \\
395 \\
-\end{array}$ & $\begin{array}{r}- \\
\overline{-} \\
197\end{array}$ & $\begin{array}{r}1,47 \overline{5} \\
1,65 \overline{-} \\
-\end{array}$ & $\begin{array}{r}802 \\
5,321 \\
1,657 \\
12,275 \\
5,705\end{array}$ \\
\hline 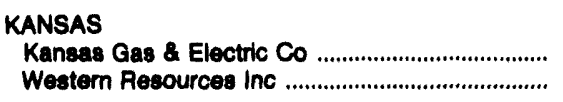 & - & $\overrightarrow{-}$ & $\overline{-}$ & 397 & $\begin{array}{r}2,973 \\
-\end{array}$ \\
\hline 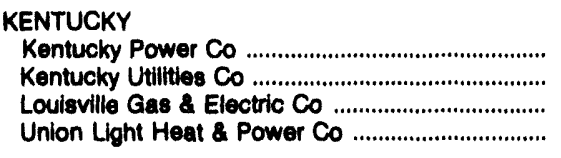 & $\begin{array}{l}- \\
-\end{array}$ & $\begin{array}{r}16 \\
202 \\
743 \\
0\end{array}$ & $\begin{array}{l}- \\
- \\
-\end{array}$ & $\begin{array}{l}- \\
- \\
-\end{array}$ & $\begin{array}{r}3,282 \\
44,026 \\
46,353 \\
-159\end{array}$ \\
\hline 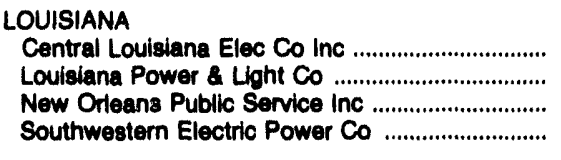 & $\begin{array}{r}1,031 \\
- \\
-\end{array}$ & $\begin{array}{r}14 \overline{1} \\
61 \\
-\end{array}$ & $\begin{array}{r}198 \\
56 \\
-\end{array}$ & $20 \overline{1}$ & $\begin{array}{r}3,357 \\
1,338 \\
281 \\
10,653\end{array}$ \\
\hline 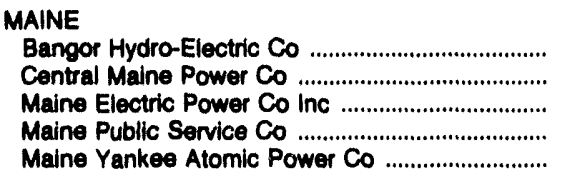 & $\begin{array}{l}- \\
- \\
-\end{array}$ & $\begin{array}{r}12 \\
84 \\
- \\
- \\
-\end{array}$ & $\begin{array}{l}- \\
- \\
-\end{array}$ & $\begin{array}{l}- \\
- \\
-\end{array}$ & $\begin{array}{r}128 \\
4,125 \\
69 \\
-\end{array}$ \\
\hline 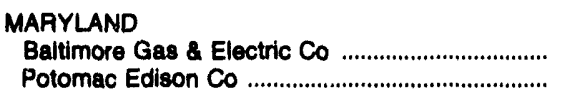 & - & - & - & - & - \\
\hline 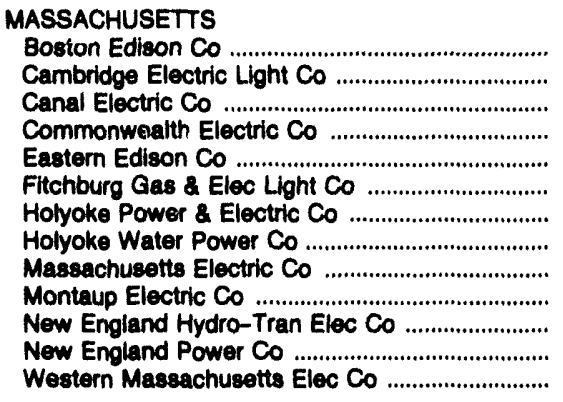 & $\begin{array}{r}- \\
200 \\
- \\
- \\
- \\
- \\
\overline{75} \\
- \\
-\end{array}$ & $\begin{array}{l}- \\
- \\
- \\
- \\
- \\
- \\
- \\
- \\
-\end{array}$ & $\begin{array}{r}- \\
- \\
- \\
- \\
- \\
- \\
- \\
77 \\
- \\
- \\
-\end{array}$ & $\begin{array}{l}- \\
- \\
- \\
- \\
- \\
- \\
- \\
- \\
- \\
- \\
-\end{array}$ & $\begin{array}{r}34,374 \\
56 \\
2,817 \\
- \\
- \\
- \\
- \\
- \\
77 \\
1,331 \\
8,839 \\
-\end{array}$ \\
\hline 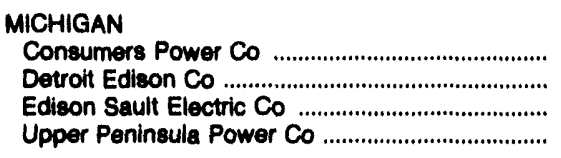 & $\begin{array}{l}- \\
-\end{array}$ & $\overline{-}$ & $\overline{-}$ & $\overline{-}$ & $\begin{array}{r}1,500 \\
107,831 \\
488\end{array}$ \\
\hline 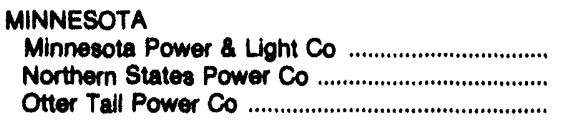 & $\begin{array}{l}4,068 \\
3,713 \\
1,152\end{array}$ & $\begin{array}{r}5,380 \\
709\end{array}$ & $\begin{array}{r}1,09 \overline{2} \\
188\end{array}$ & $13,01 \overline{8}$ & $\begin{array}{r}11,255 \\
66,180 \\
7,292\end{array}$ \\
\hline 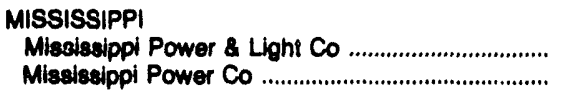 & - & - & $\begin{array}{r}47 \\
-\end{array}$ & $4,02 \overline{-}$ & $\begin{array}{l}1,698 \\
5,895\end{array}$ \\
\hline
\end{tabular}

See endnotes at end of this table. 
Table 46. Expendituree for Environmental Protection by Major Investor-Owned Eloctric Utility Within State, 1982 (Continued) (Thousand Dollars)

\begin{tabular}{|c|c|c|c|c|c|}
\hline State and Utilly & $\begin{array}{l}\text { Depreciation } \\
\text { Expenseses }\end{array}$ & $\begin{array}{l}\text { Labor, } \\
\text { Malntainanos, } \\
\text { Mationals, } \\
\text { and } \\
\text { supplies }\end{array}$ & $\begin{array}{l}\text { Operation } \\
\text { of } \\
\text { Fecillities }\end{array}$ & $\begin{array}{l}\text { Fly Auh } \\
\text { and } \\
\text { Sulphur } \\
\text { Removal }\end{array}$ & $\begin{array}{l}\text { Difiorences } \\
\text { In Cost of } \\
\text { Environmontally } \\
\text { Cloan } \\
\text { Fuel }\end{array}$ \\
\hline 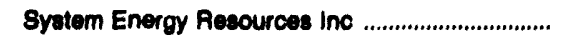 & - & - & - & - & - \\
\hline 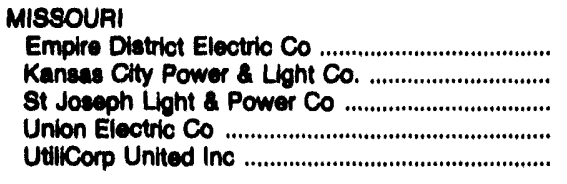 & $\begin{array}{l}- \\
- \\
-\end{array}$ & $\begin{array}{r}32 \\
4,745 \\
429 \\
- \\
-\end{array}$ & $\begin{array}{r}42 \\
57 \\
-\end{array}$ & $\begin{array}{r}-3 \\
713 \\
231 \\
- \\
-\end{array}$ & $\begin{array}{r}506 \\
- \\
-\end{array}$ \\
\hline $\begin{array}{l}\text { MONTANA } \\
\text { Montana Power Co }\end{array}$ & - & 1,016 & - & 4,896 & \\
\hline 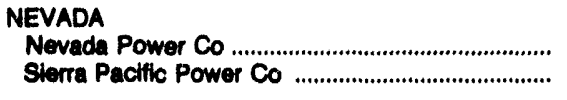 & $1,35 \overline{-}$ & $\begin{array}{l}4,682 \\
1,691\end{array}$ & - & - & - \\
\hline 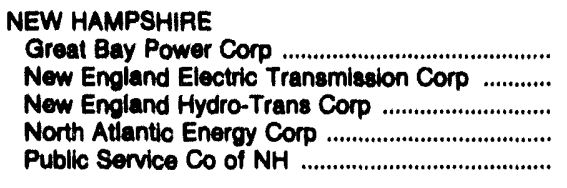 & $\begin{array}{r}- \\
\overline{-} \\
3,324\end{array}$ & $\begin{array}{r}84 \\
- \\
3,511\end{array}$ & $\begin{array}{l}- \\
- \\
-\end{array}$ & $\begin{array}{l}- \\
- \\
-\end{array}$ & $\begin{array}{l}\overline{-} \\
\overline{-} \\
\overline{-}\end{array}$ \\
\hline 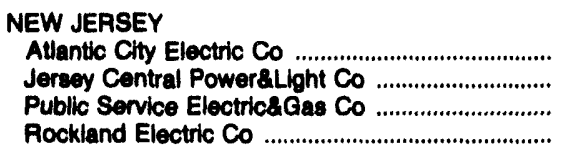 & $\begin{array}{r}5,031 \\
9,122 \\
- \\
-\end{array}$ & $\begin{array}{r}857 \\
-\end{array}$ & 300 & $\begin{array}{r}156 \\
- \\
-\end{array}$ & $\begin{array}{r}1,718 \\
- \\
-\end{array}$ \\
\hline $\begin{array}{l}\text { NEW MEXICO } \\
\text { Public Service Co of NM }\end{array}$ & - & - & - & - & \\
\hline 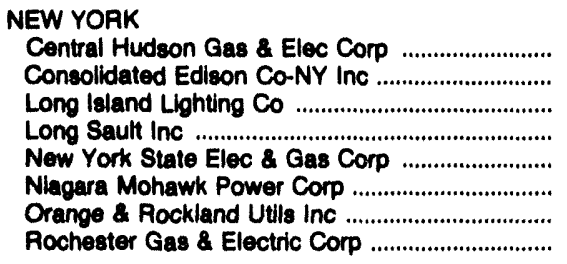 & $\begin{array}{r}- \\
\overline{-} \\
7,643 \\
16,598 \\
-\end{array}$ & $\begin{array}{r}= \\
= \\
20,202 \\
24,460 \\
4,148 \\
-\end{array}$ & $\begin{array}{r}- \\
\overline{-} \\
4,75 \overline{7} \\
\overline{2} \\
-\end{array}$ & $\begin{array}{r}- \\
- \\
3,413 \\
436 \\
79 \\
-\end{array}$ & $\begin{array}{r}\overline{-} \\
\overline{-} \\
16,478 \\
24 \\
3,831\end{array}$ \\
\hline 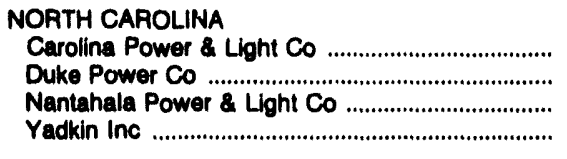 & $\begin{array}{r}66,808 \\
- \\
-\end{array}$ & $\begin{array}{r}2,836 \\
- \\
-\end{array}$ & $\begin{array}{l}- \\
-\end{array}$ & $\begin{array}{l}- \\
\overline{-} \\
-\end{array}$ & $\overline{-}$ \\
\hline 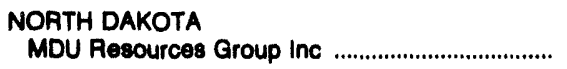 & 2,542 & 1,273 & - & - & \\
\hline 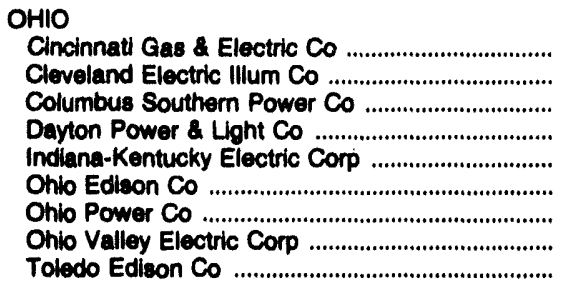 & $\begin{array}{r}17,198 \\
12,580 \\
14,488 \\
3,841 \\
33,728 \\
108 \\
-\end{array}$ & $\begin{array}{r}10,446 \\
2,280 \\
4,251 \\
3,357 \\
20,482 \\
4,115 \\
1,174 \\
-\end{array}$ & $\begin{array}{r}1,283 \\
32 \\
3,632 \\
496 \\
2,632 \\
-\end{array}$ & $\begin{array}{r}17,693 \\
19,082 \\
8,221 \\
2,644 \\
- \\
-\end{array}$ & $\begin{array}{r}- \\
20,500 \\
4,719 \\
3,897 \\
21,137 \\
-25\end{array}$ \\
\hline 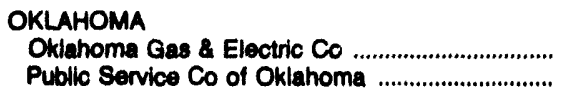 & $=$ & - & - & - & - \\
\hline
\end{tabular}

See endnotes at end of this table. 
Table 46. Expenditures for Environmental Protection by Major Inveotor-Owned Electrle Utility Within State, 1982 (Continued) (Thousand Dollars)

\begin{tabular}{|c|c|c|c|c|c|}
\hline State and Utilly & $\begin{array}{l}\text { Replecement } \\
\text { Power } \\
\text { Costs }\end{array}$ & $\begin{array}{l}\text { Taxes } \\
\text { and } \\
\text { Fees }\end{array}$ & $\begin{array}{l}\text { Adminiatrative } \\
\text { and } \\
\text { Coneral }\end{array}$ & $\begin{array}{l}\text { Other } \\
\text { Environmental } \\
\text { Protection } \\
\text { Expensed }\end{array}$ & Total \\
\hline 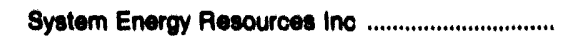 & - & - & - & - & - \\
\hline 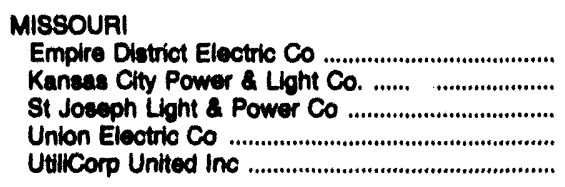 & $\overline{-}$ & $\begin{array}{l}- \\
\overline{-} \\
-\end{array}$ & $\begin{array}{l}- \\
\overline{-} \\
-\end{array}$ & $\begin{array}{r}11 \\
- \\
1,043 \\
-\end{array}$ & $\begin{array}{r}40 \\
6,095 \\
716 \\
1,043 \\
-\end{array}$ \\
\hline 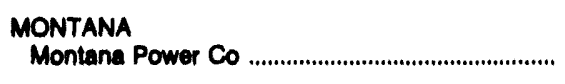 & - & 2,011 & - & - & 8,021 \\
\hline $\begin{array}{l}\text { NEVADA } \\
\text { Nevada Power Co } \\
\text { Sterra Pactic Power Co }\end{array}$ & $58 \overline{2}$ & $\overline{5}$ & $26 \overline{-}$ & $\overline{-}$ & $\begin{array}{l}4,992 \\
3,885\end{array}$ \\
\hline 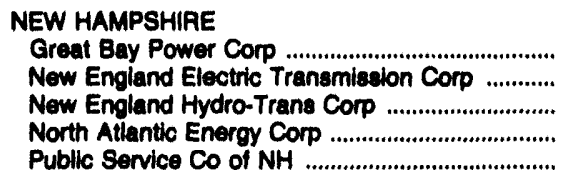 & $\begin{array}{l}\overline{-} \\
\overline{-}\end{array}$ & $\overline{-}$ & $\begin{array}{l}\overline{-} \\
\overline{-}\end{array}$ & $\begin{array}{l}\overline{-} \\
\overline{87}\end{array}$ & $\begin{array}{r}84 \\
\overline{-} \\
8,285\end{array}$ \\
\hline 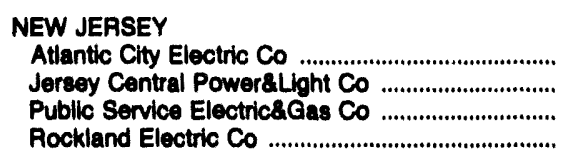 & $\begin{array}{l}47 \\
- \\
-\end{array}$ & $\begin{array}{r}25 \\
310 \\
- \\
-\end{array}$ & $\begin{array}{r}42 \\
1,241 \\
17\end{array}$ & $\begin{array}{r}664 \\
- \\
-\end{array}$ & $\begin{array}{r}8,940 \\
10,672 \\
326\end{array}$ \\
\hline 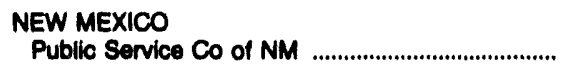 & - & - & - & - & - \\
\hline 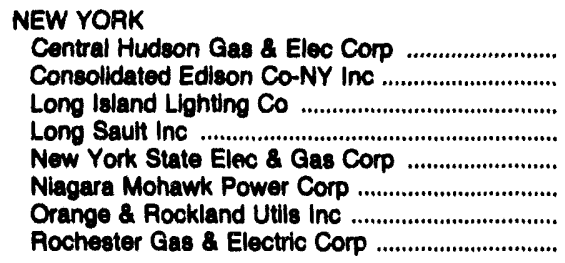 & $\begin{array}{r}\overline{-} \\
\overline{-} \\
1,074 \\
7,188 \\
- \\
-\end{array}$ & $\begin{array}{r}- \\
\overline{-} \\
14,028 \\
-\end{array}$ & $\begin{array}{r}\overline{-} \\
\overline{-} \\
2,114 \\
510 \\
55 \\
-\end{array}$ & $\begin{array}{r}- \\
- \\
- \\
-\end{array}$ & $\begin{array}{r}\overline{-} \\
\overline{-} \\
55,680 \\
63,676 \\
4,284 \\
3,831\end{array}$ \\
\hline 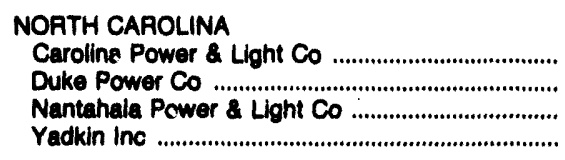 & $\begin{array}{l}- \\
-\end{array}$ & $\begin{array}{l}- \\
-\end{array}$ & $\overline{-}$ & $\overline{-}$ & $\begin{array}{r}69,843 \\
- \\
-\end{array}$ \\
\hline 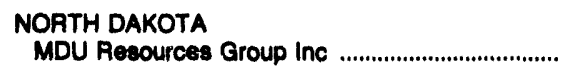 & - & - & - & - & 3,816 \\
\hline 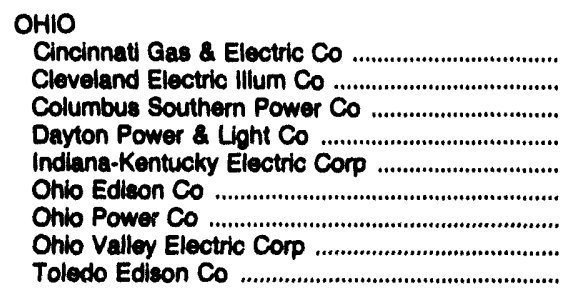 & $\begin{array}{r}- \\
20 \\
- \\
11\end{array}$ & $\begin{array}{r}895 \\
1,054 \\
\overline{12} \\
\overline{-} \\
22 \\
-\end{array}$ & $\begin{array}{r}196 \\
704 \\
1,361 \\
42 \\
- \\
568 \\
-\end{array}$ & $\begin{array}{r}14 \overline{-} \\
-1 \overline{-} \\
2 \overline{6} \\
278 \\
-\end{array}$ & $\begin{array}{r}47,711 \\
- \\
56,358 \\
33,040 \\
14,790 \\
78,387 \\
4,141 \\
4,759\end{array}$ \\
\hline 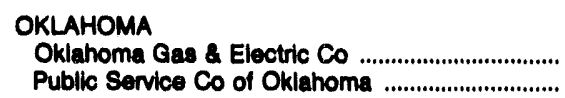 & $\overline{-}$ & - & I & - & - \\
\hline
\end{tabular}


Tablo 46. Expenditures for Environmental Protection by Major Inveotor-Owned Eloctrle Utillty Within Sthto, 1902 (Continued) (Thousand Dollars)

\begin{tabular}{|c|c|c|c|c|c|}
\hline State and Utillty & $\begin{array}{c}\text { Depreciation } \\
\text { Expensese }\end{array}$ & $\begin{array}{l}\text { Labor, } \\
\text { Maintainanoe, } \\
\text { Materiala, } \\
\text { and } \\
\text { supplies }\end{array}$ & $\begin{array}{l}\text { Operation } \\
\text { of } \\
\text { Facllitios }\end{array}$ & $\begin{array}{l}\text { Fly Ash } \\
\text { and } \\
\text { Sulphur } \\
\text { Aomoval }\end{array}$ & $\begin{array}{l}\text { Differences } \\
\text { in Cost of } \\
\text { Environmentally } \\
\text { Clean } \\
\text { Fuel }\end{array}$ \\
\hline 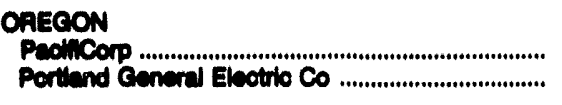 & - & $\begin{array}{r}7,046 \\
-\end{array}$ & $\begin{array}{r}10,443 \\
-\end{array}$ & $\begin{array}{r}8,470 \\
-\end{array}$ & - \\
\hline 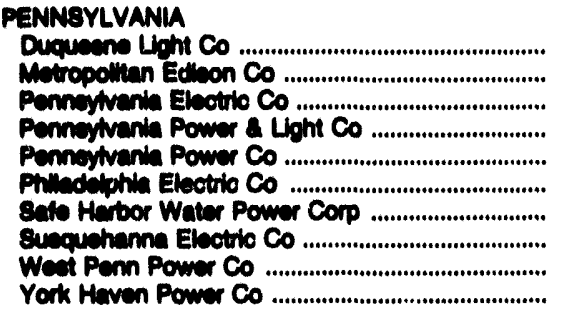 & $\begin{array}{r}16,264 \\
9,703 \\
5,617 \\
103,297 \\
- \\
= \\
-\end{array}$ & $\begin{array}{r}19,650 \\
25,678 \\
16,107 \\
2,536 \\
54,715 \\
- \\
= \\
-\end{array}$ & $\begin{array}{r}786 \\
0,878 \\
6 \overline{6} \\
6,243 \\
= \\
= \\
=\end{array}$ & $\begin{array}{r}6,643 \\
- \\
3,281 \\
2,430 \\
335 \\
4,163 \\
- \\
= \\
-\end{array}$ & $\begin{array}{r}- \\
32,642 \\
4,202 \\
6,481 \\
- \\
-\end{array}$ \\
\hline 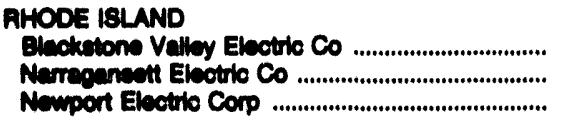 & $\overline{-}$ & $\begin{array}{r}11 \\
3\end{array}$ & $\overline{-}$ & $\overline{0}$ & $\overline{36}$ \\
\hline 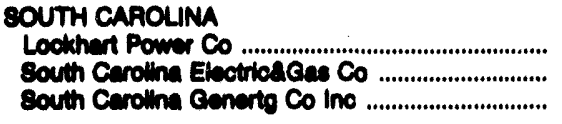 & $\begin{array}{r}1 \\
2,9,16 \\
1,19,1\end{array}$ & $\begin{array}{r}2,753 \\
165\end{array}$ & $\overline{-}$ & $\begin{array}{l}1,61 \overline{7} \\
1,109\end{array}$ & $\overline{-}$ \\
\hline 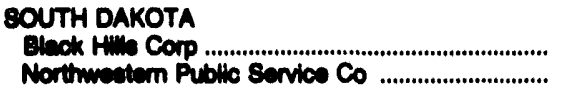 & $\begin{array}{l}1,043 \\
1,077\end{array}$ & $39 \overline{3}$ & $\begin{array}{l}156 \\
120\end{array}$ & $\begin{array}{r}85 \\
209\end{array}$ & $\overline{-}$ \\
\hline 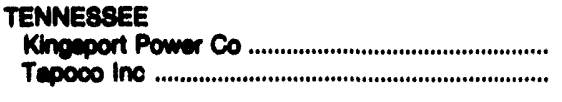 & $\overline{-}$ & $\overline{-}$ & - & - & - \\
\hline 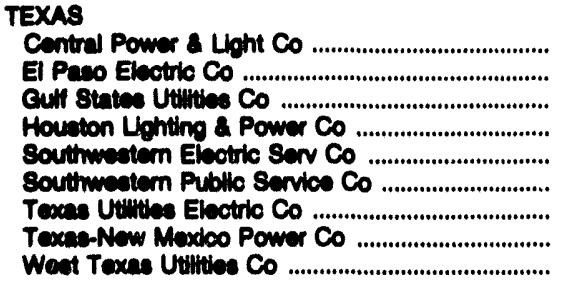 & $\begin{array}{r}- \\
- \\
- \\
- \\
- \\
39,377 \\
2,331 \\
-\end{array}$ & $\begin{array}{r}2,269 \\
1,727 \\
2,943 \\
- \\
- \\
- \\
97,987 \\
386 \\
-\end{array}$ & $\begin{array}{l}2 \\
2 \\
- \\
- \\
- \\
- \\
20 \\
-\end{array}$ & $\begin{array}{r}135 \\
417 \\
105 \\
- \\
- \\
- \\
27,253 \\
2,689 \\
-\end{array}$ & $\begin{array}{l}\overline{-} \\
\overline{-} \\
\overline{-} \\
-\end{array}$ \\
\hline 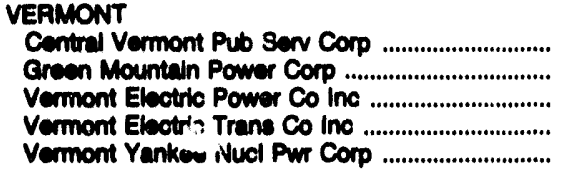 & $\begin{array}{r}19 \\
37 \\
- \\
450\end{array}$ & $\begin{array}{r}230 \\
130 \\
4,350\end{array}$ & $\begin{array}{l}\overline{-} \\
\overline{-} \\
-\end{array}$ & $\overline{-}$ & $\begin{array}{l}- \\
- \\
-\end{array}$ \\
\hline 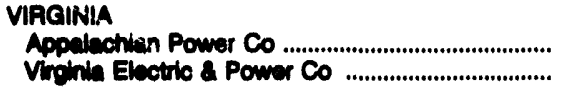 & $29,14 \overline{8}$ & $\begin{array}{l}8,271 \\
7,470\end{array}$ & $2,07 \overline{7}$ & $\begin{array}{r}755 \\
5,673\end{array}$ & 8,087 \\
\hline 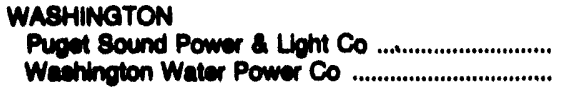 & $\overline{-}$ & $\begin{array}{r}3,064 \\
-\end{array}$ & - & $\begin{array}{r}4,527 \\
-\end{array}$ & - \\
\hline 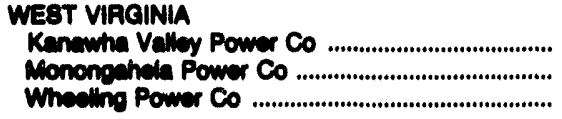 & $\overline{7}$ & $\overline{6}$ & $\overline{-}$ & $\overline{-}$ & $\overline{-}$ \\
\hline
\end{tabular}

eas endnotes at end of this tablo. 
Table 46. Expenditures for Environmental Protection by Major Investor-Owned Electric Utility Within 8tate, 1992 (Continued) (Thousand Dollars)

\begin{tabular}{|c|c|c|c|c|c|}
\hline State and Utilly & $\begin{array}{l}\text { Replacement } \\
\text { Power } \\
\text { Coste }\end{array}$ & $\begin{array}{l}\text { Taxes } \\
\text { and } \\
\text { Fees }\end{array}$ & $\begin{array}{l}\text { Adminiatrative } \\
\text { and } \\
\text { General }\end{array}$ & $\begin{array}{l}\text { Other } \\
\text { Environmental } \\
\text { Protection } \\
\text { Expenses }\end{array}$ & Total \\
\hline $\begin{array}{l}\text { OAEGON } \\
\text { Pecticorp ......... } \\
\text { Portland General Electric Co }\end{array}$ & - & - & $\begin{array}{r}10,539 \\
-\end{array}$ & $\begin{array}{r}39,486 \\
-\end{array}$ & $\begin{array}{r}75,992 \\
-\end{array}$ \\
\hline 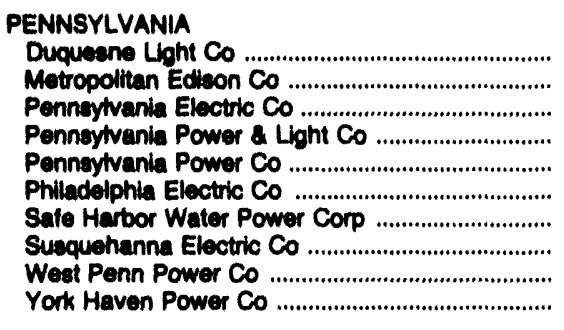 & $\begin{array}{r}- \\
1,62 \overline{-} \\
- \\
\overline{-}, 57 \overline{8} \\
- \\
- \\
-\end{array}$ & $\begin{array}{r}753 \\
252 \\
1,104 \\
127 \\
53,300 \\
- \\
= \\
-\end{array}$ & $\begin{array}{r}1,059 \\
1,213 \\
921 \\
- \\
224 \\
- \\
- \\
-\end{array}$ & $\begin{array}{r}25,797 \\
25,043 \\
1,792 \\
5,814 \\
- \\
- \\
-\end{array}$ & $\begin{array}{r}70,742 \\
262 \\
110,063 \\
21,250 \\
12,880 \\
236,884 \\
= \\
=\end{array}$ \\
\hline 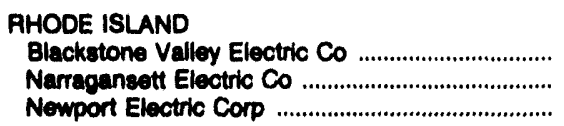 & $\overline{-}$ & $\overline{5}$ & $\begin{array}{r}1 \overline{4} \\
0\end{array}$ & $\begin{array}{l}- \\
-\end{array}$ & 25 \\
\hline 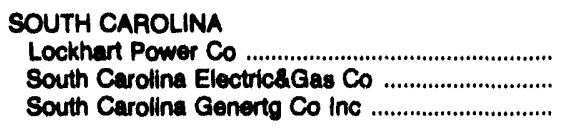 & $\begin{array}{r}1,353 \\
874\end{array}$ & $\begin{array}{l}1 \\
- \\
-\end{array}$ & $\overline{-}$ & - & $\begin{array}{r}3 \\
8,718 \\
3,347\end{array}$ \\
\hline $\begin{array}{l}\text { SOUTH DAKOTA } \\
\text { Black Hills Corp } \\
\text { Northwestern Public Service Co }\end{array}$ & $12 \overline{9}$ & $\begin{array}{l}173 \\
336\end{array}$ & - & - & $\begin{array}{l}1,457 \\
2,263\end{array}$ \\
\hline $\begin{array}{l}\text { TENNESSEE } \\
\text { Kingeport Power Co } \\
\text { Tapoco Inc }\end{array}$ & $\overline{-}$ & - & - & - & $=$ \\
\hline 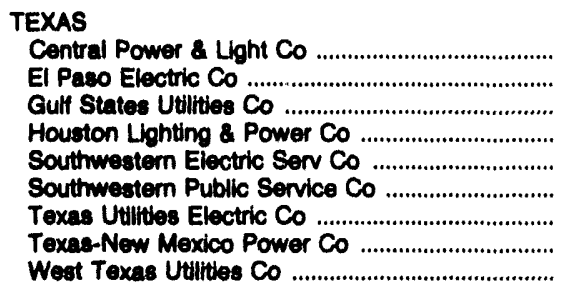 & $\begin{array}{r}1,01 \overline{6} \\
- \\
\overline{-} \\
\overline{-} \\
900 \\
-\end{array}$ & $\begin{array}{r}- \\
271 \\
- \\
- \\
17,713 \\
956 \\
-\end{array}$ & $\begin{array}{r}368 \\
- \\
- \\
- \\
- \\
- \\
- \\
-\end{array}$ & $\begin{array}{r}3,311 \\
= \\
= \\
= \\
=\end{array}$ & $\begin{array}{r}2,763 \\
6,474 \\
3,318 \\
- \\
- \\
202,716 \\
7,292\end{array}$ \\
\hline 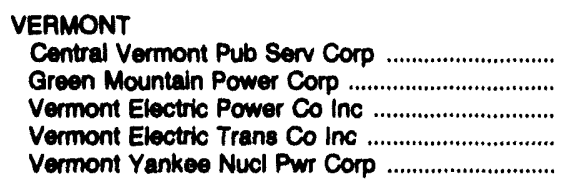 & $\begin{array}{l}\overline{-} \\
\overline{-} \\
-\end{array}$ & $\begin{array}{r}18 \\
24 \\
- \\
423\end{array}$ & $\begin{array}{r}131 \\
\overline{-} \\
187\end{array}$ & $\overline{-}$ & $\begin{array}{r}398 \\
191 \\
- \\
6,336\end{array}$ \\
\hline $\begin{array}{l}\text { VIRGINIA } \\
\text { Appalachian Power Co } \\
\text { Virginia Electric \& Power Co }\end{array}$ & 885 & $7,81 \overline{-}$ & $\begin{array}{l}9,222 \\
1,069\end{array}$ & $3,00 \overline{6}$ & $\begin{array}{l}18,248 \\
65,235\end{array}$ \\
\hline 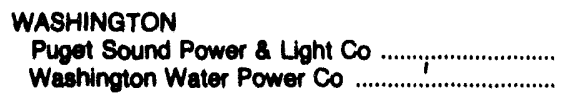 & $\overline{-}$ & - & - & - & 7,581 \\
\hline 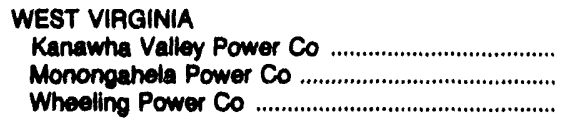 & - & $\overline{-}$ & $\overline{-}$ & $\overline{-}$ & $\overline{78}$ \\
\hline
\end{tabular}

See endinotes at end of this table. 
Table 46. Expenditures for Environmental Protection by Major Investor-Owned Electric UtIIIty Within State, 1992 (Continued) (Thousand Dollars)

\begin{tabular}{|c|c|c|c|c|c|}
\hline State and Utility & $\begin{array}{c}\text { Depreciation } \\
\text { Expenses }\end{array}$ & $\begin{array}{l}\text { Labor, } \\
\text { Maintainance, } \\
\text { Materlals, } \\
\text { and } \\
\text { Supplies }\end{array}$ & $\begin{array}{c}\text { Operation } \\
\text { of } \\
\text { Facillities }\end{array}$ & $\begin{array}{l}\text { Fly Anh } \\
\text { and } \\
\text { Sulphur } \\
\text { Removal }\end{array}$ & $\begin{array}{l}\text { Differences } \\
\text { In Coet of } \\
\text { Emwionmentilly } \\
\text { Ctean } \\
\text { Fual }\end{array}$ \\
\hline \multicolumn{6}{|l|}{ ONSIN } \\
\hline 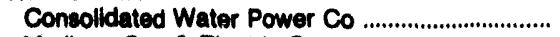 & 0 & - & - & - & - \\
\hline 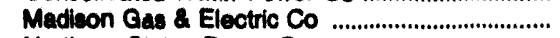 & - & - & - & - & - \\
\hline Northern States Power Co ...................................... & 1,087 & 273 & - & - & - \\
\hline 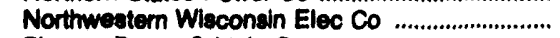 & - & - & - & - & - \\
\hline Ploneer Power \& Light Co ..................................... & - & - & - & - & - \\
\hline 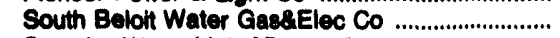 & 33 & - & - & - & - \\
\hline Superior Water LightaPower Co ............................. & - & - & - & - & - \\
\hline 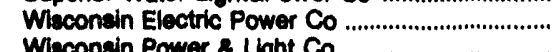 & 7,940 & 10,706 & 2,282 & 6,689 & - \\
\hline $\begin{array}{l}\text { Wiaconain Power \& Light Co } \\
\text { Wacongin Publle Service Corn }\end{array}$ & 5,083 & 3,449 & 81 & 139 & 86 \\
\hline 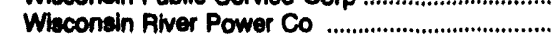 & - & - & - & - & - \\
\hline
\end{tabular}

See endnotes at end of this table.

Table 46. Expenditures for Environmental Protection by Major Investor-Owned Electric Utility Within State, 1992 (Continued) (Thousand Dollars)

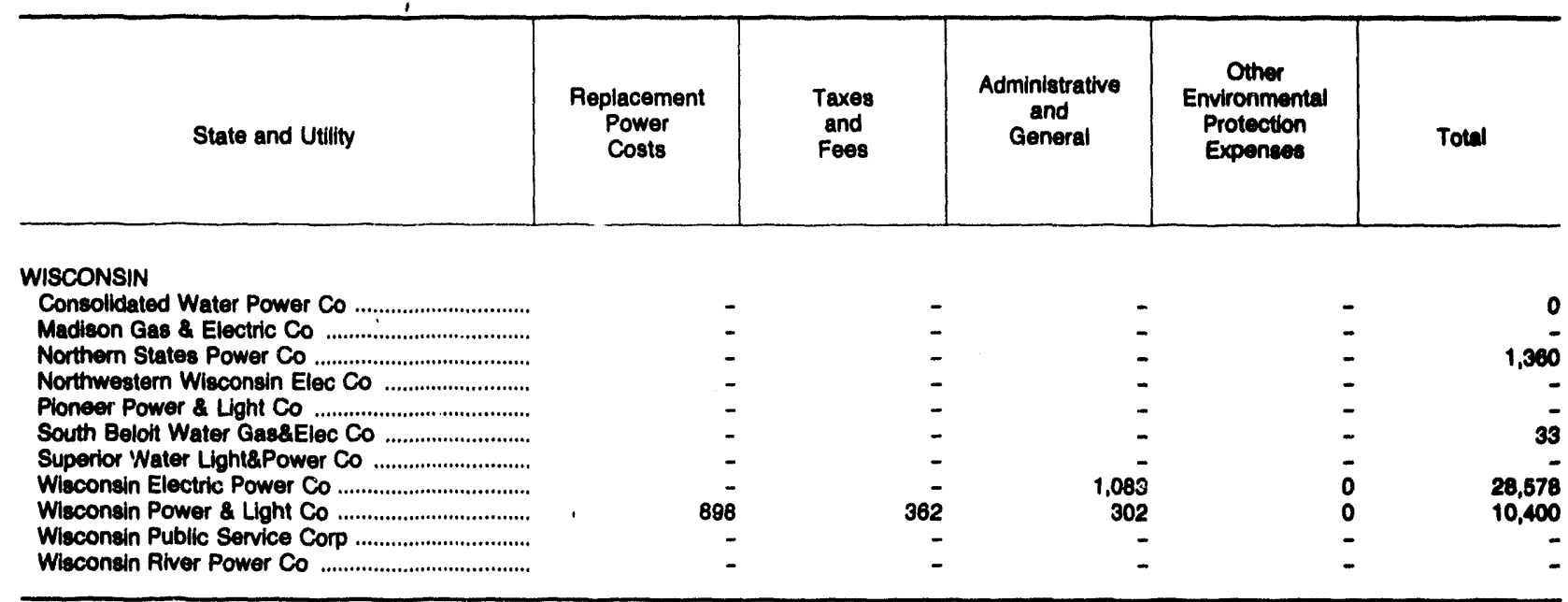

- Data not avaliable.

Note: Totals may not equal sum of components because of independent rounding.

Source: Federal Energy Regulatory Commission, FEPC Form 1, "Annual Report of Major Electric Utilities, Licenseses and Others." 


\section{Appendix A}

Classifications of Major U.S. Investor-Owned Electric Utilities 


\section{Classifications of Major U.S. Investor-Owned Electric Utilities}

Table A1. Major U.S. Inveotor-Owned Electric Utilties Added and Doloted, 1988-1992

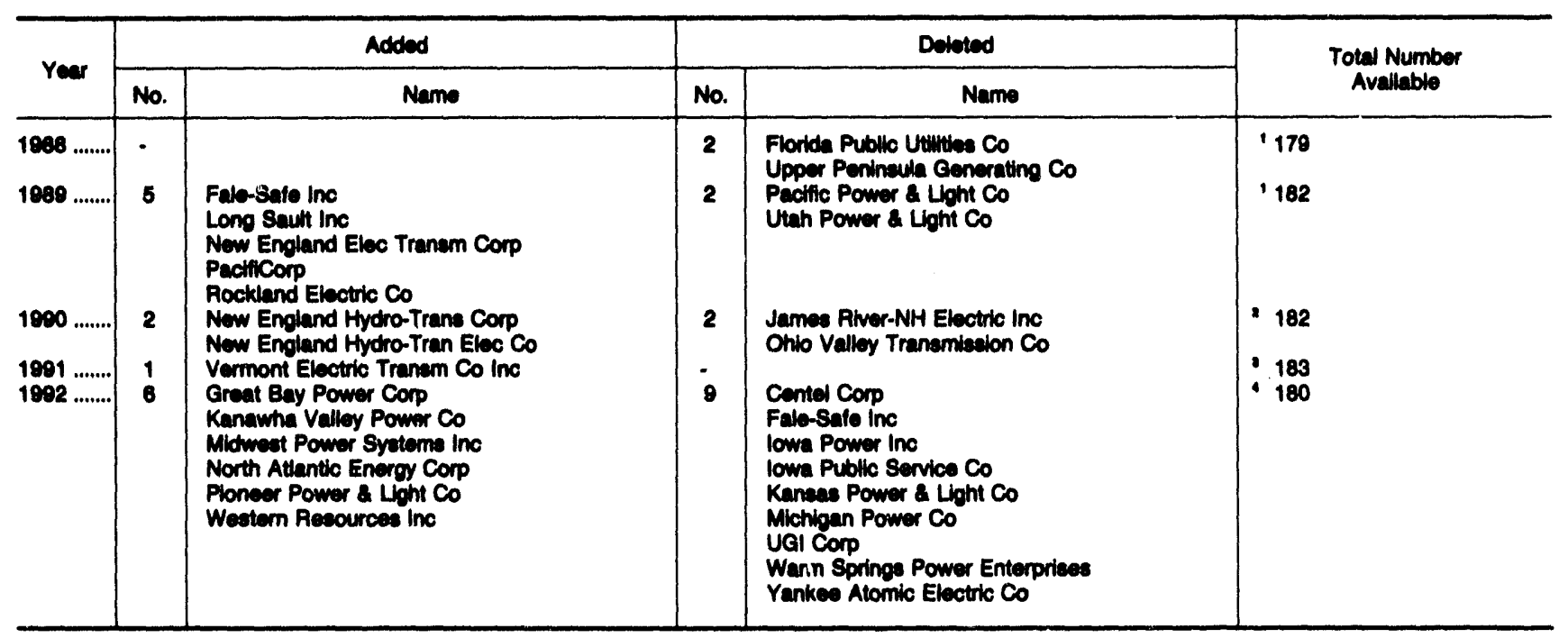

- Excluded is Northeast Nuclear Energy Co whose date were not included to prevent double-counting of data for the Millatone Nuclear Plant which Northeast Nuclear Energy Co operates for Connecticut Light \& Power Co and Weotern Maseachusette Eiec Co. Aleo excluded is Golden Spread Electric Cooperative whose data were not included elnce they are chaedfied as a cooperattve on the Form ElA-861; however, the Federal Energy Regulatory Commiedon (FERC) has determined that Golden Spread Electric Cooperative should filo a FERC Form 1 under Section 201 of the Federal Power Act.

2 Excluded is Golden Spread Electric Cooperative whoee data were not included aince they are claseified as a cooperative on the Form EIA-861; however, the FERC has determined that Golden Spread Electric Cooperative should file a FERC Form 1 under Section 201 of the Federal Power Act.

- Exciuded are Golden Spread Electric Cooperatve and independent power producere jurisdictional to the FERC in 1091. The independent power producers were Catalyst Old Piver Hydroelectric Limited Partnerehip, Entergy Power Inc, Nevada Sun-Peak Limited Partnerehip, Ocean State Power, and Terra Comfort Corporation.

- Excluded are Golden Spread Electric Cooperative, Old Dominion Electric Cooperative, and sbx independent power producers juriedictional to the FERC in 1992. The independent power producere are Catalyat Old Alver Hydroelectric Limited Partnerehip, Entergy Power Inc, Nevada Sun-Peak Limited Partnerchip, Ocoen State Power, Ocean State Power II, and Terra Comtort Corporation.

Source: Federal Energy Regulatory Commiabion, FERC Form 1, "Annual Report of Major Electric Utillities, Licensees and Others." 
Figure A1. Number of States Served by the Major U.S. Investor-Owned Electric Utilities, 1992

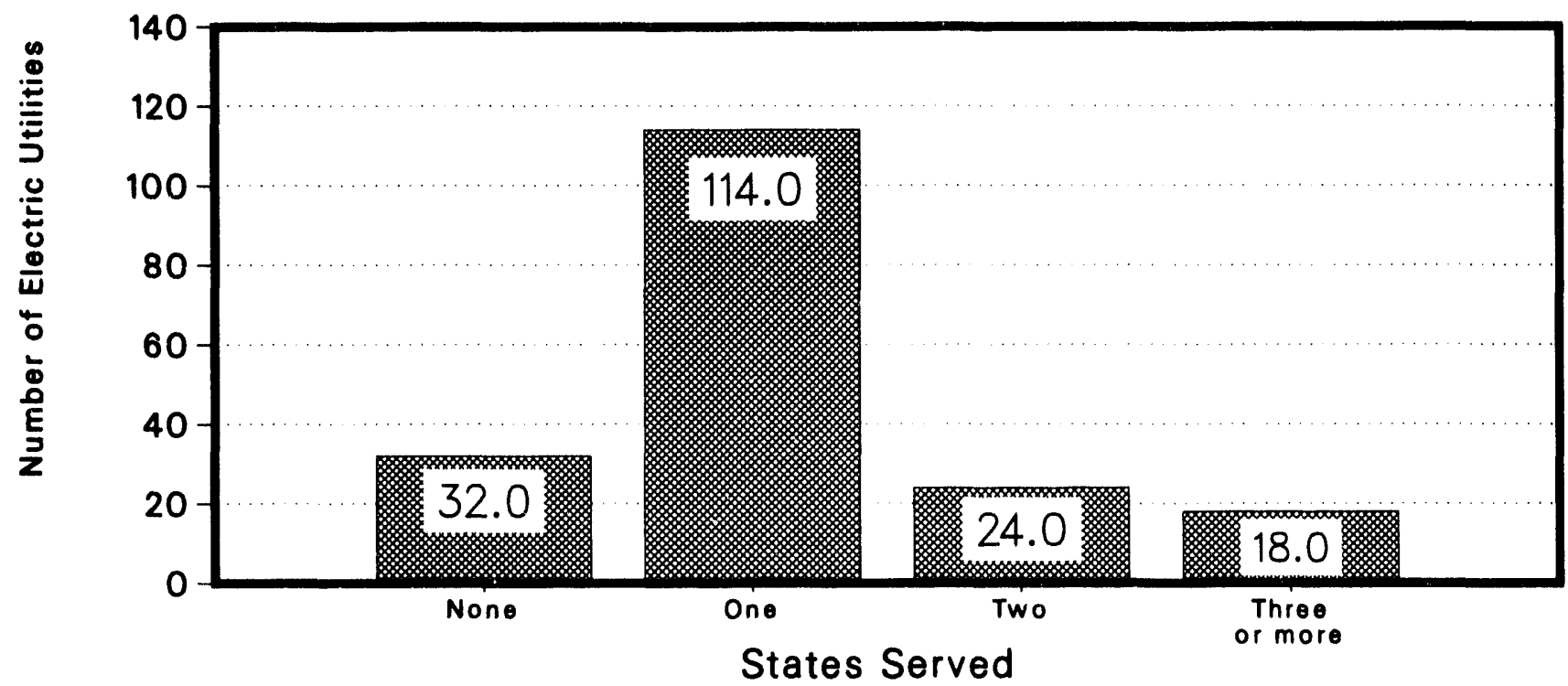

Source: Federal Energy Regulatory Commission. FERC Form 1. 'Annual Report of Major Electric Utilities, Licensees and Others.

Flgure A2. Corporaie Headquarters of Major U.S. Investor-Owned Electric Utillties, 1992

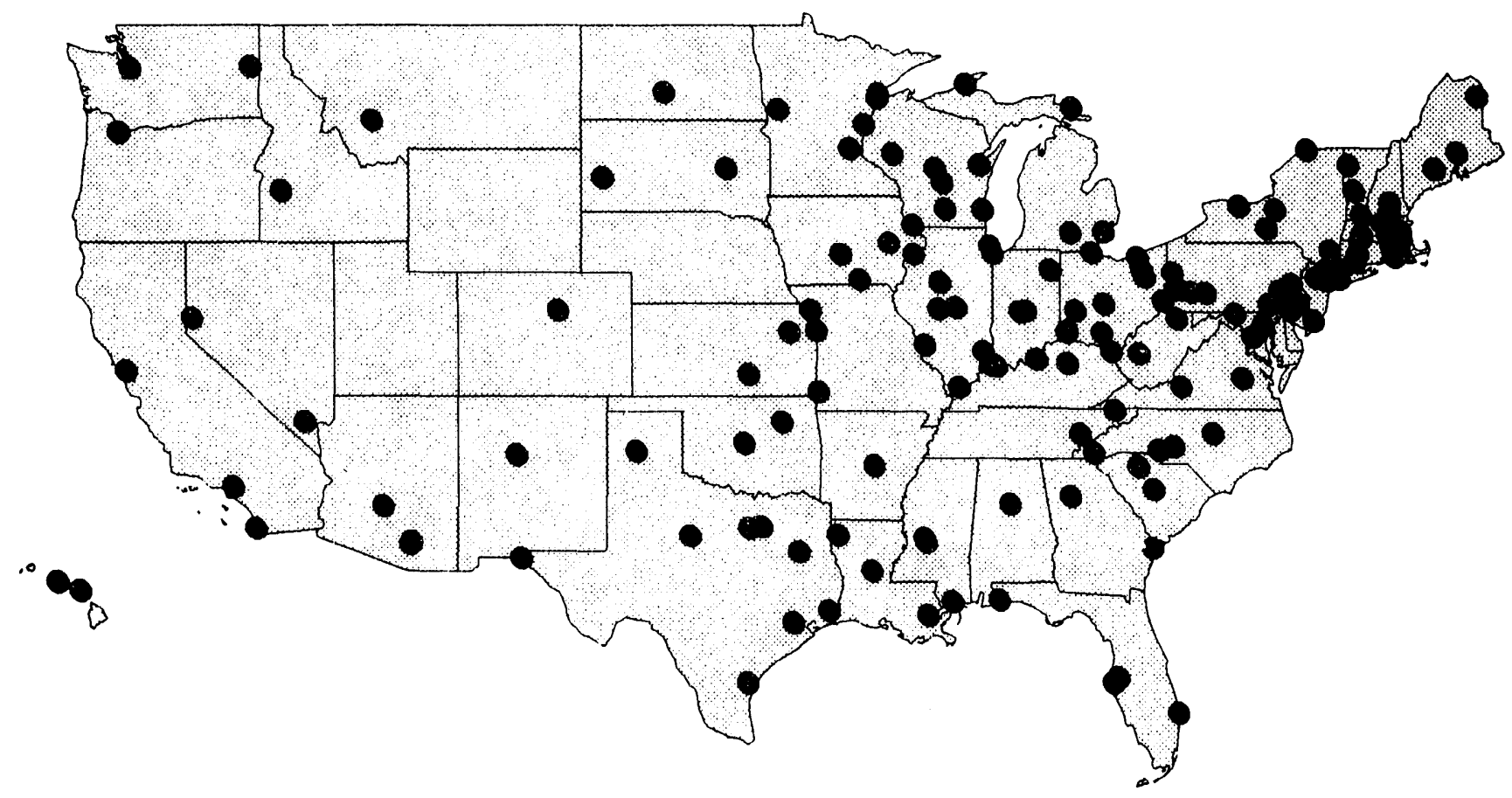

Note: Excluded from the publication is Golden Spread Electric Cooperative.

Source: Federal Energy Regulatory Commission. FERC Form 1. "Annual Report of Major Electric Utilities, Licensees and Others' and FERC Form IF. 'Annual Report for Nonmajor Utilitios and Licenses'. 
Table A2. Major and Nonmajor Claselfications of U.S. Electrle Utilitios by the FERC, 1988-1982

\begin{tabular}{|c|c|c|c|c|c|c|c|}
\hline Investor-Owned Electric Utillties & State & States Served & 1992 & 1891 & 1890 & 1989 & 1888 \\
\hline 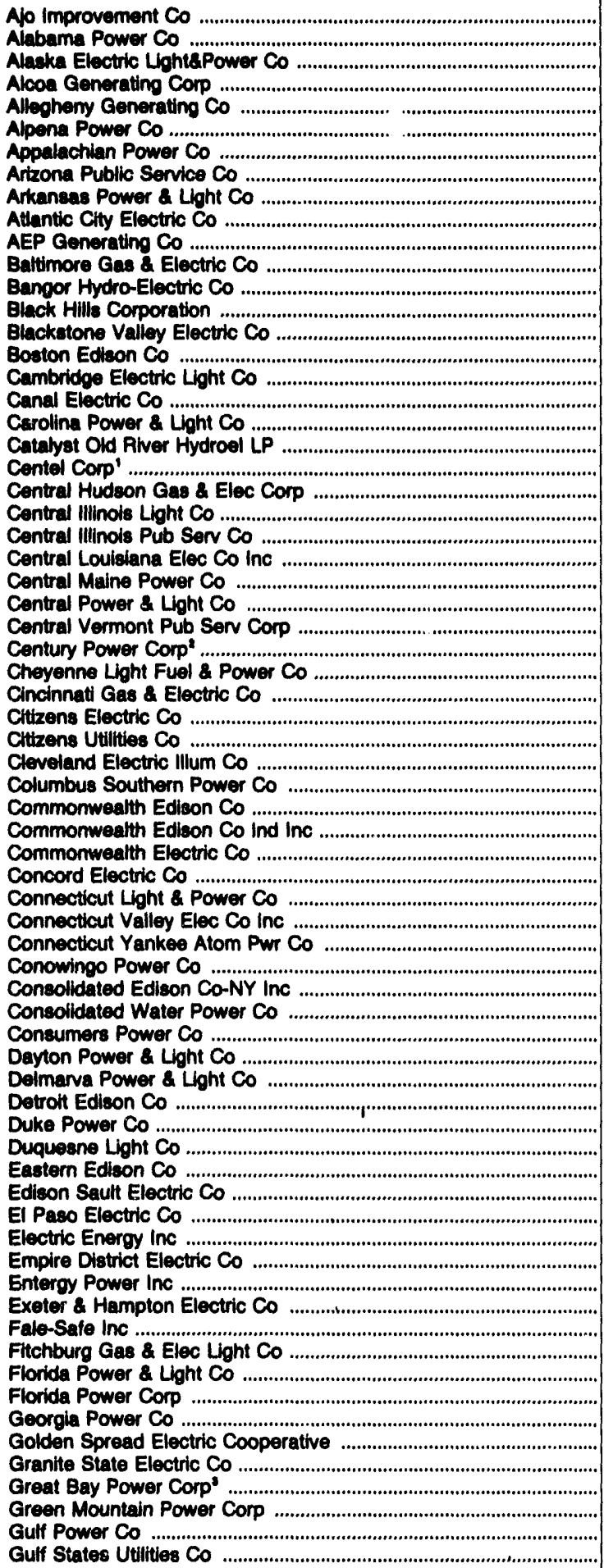 & 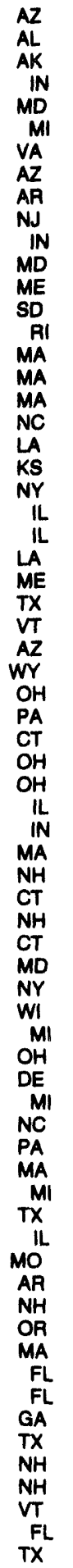 & 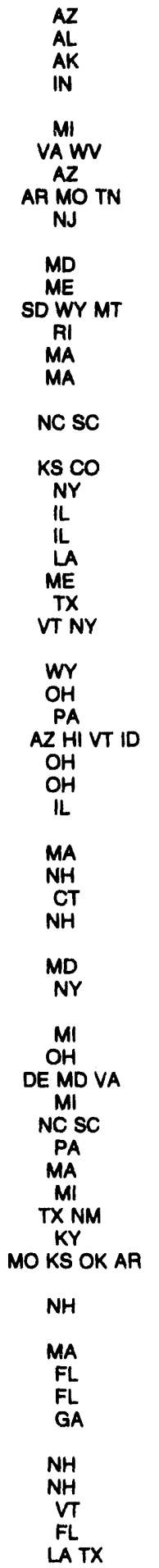 & 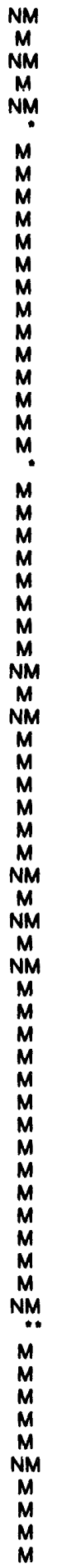 & 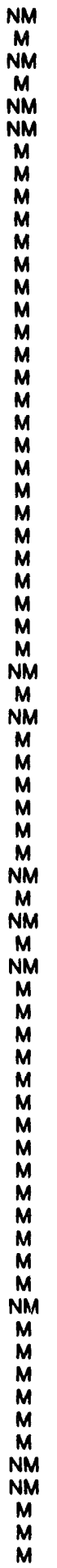 & 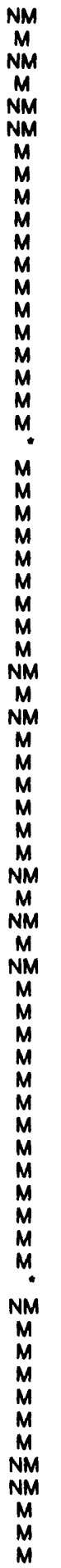 & 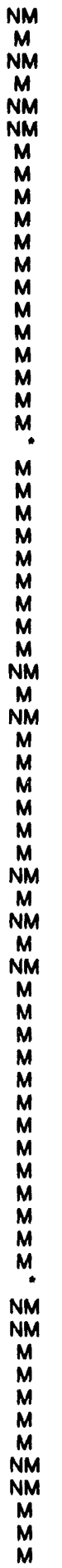 & 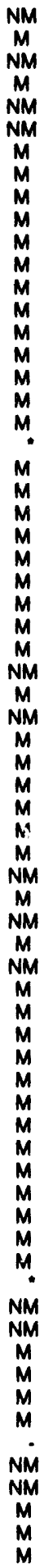 \\
\hline
\end{tabular}

See endnotes at end of this table. 
Table A2. Major and Nonmajor Classiflcations of U.S. Electric Utilities by the FERC, 1988-1992 (Continued)

\begin{tabular}{|c|c|c|c|c|c|c|c|}
\hline Investor-Owned Electric Utilities & State & States Served & 1982 & 1891 & 1980 & 1989 & 1988 \\
\hline 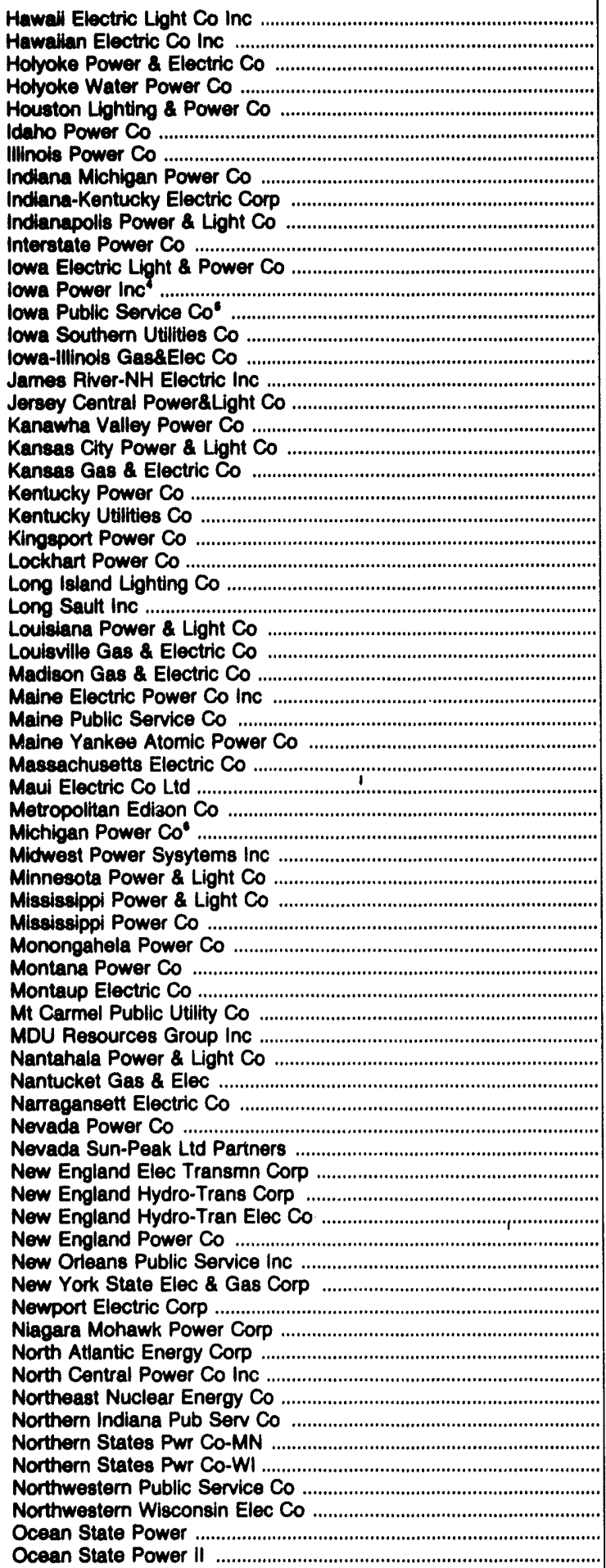 & 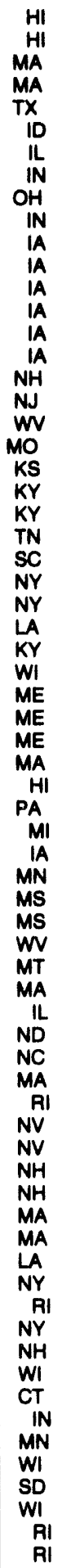 & 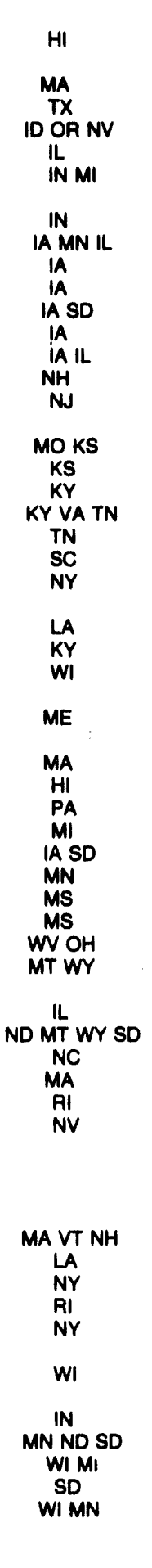 & 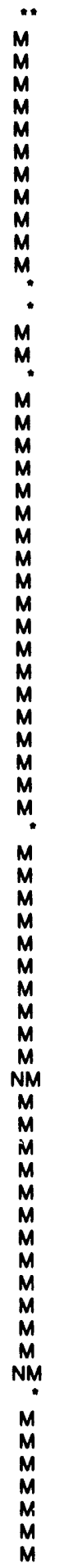 & 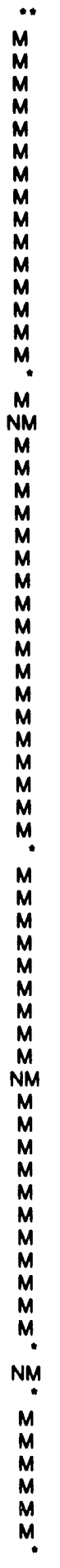 & 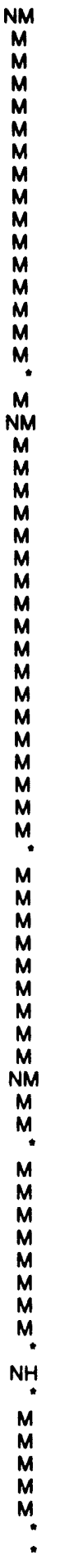 & 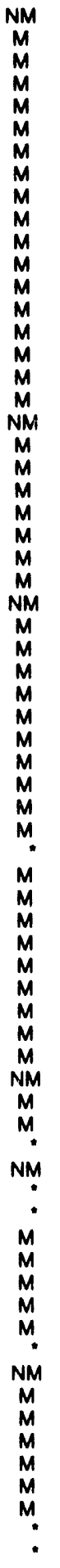 & 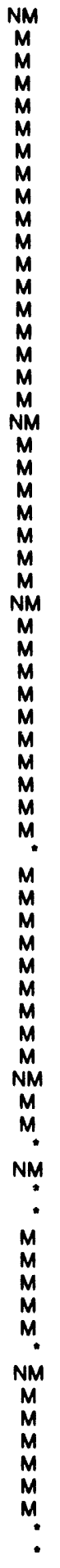 \\
\hline
\end{tabular}

See endnotes at end of this table. 
Table A2. Major and Nonmajor Claselfications of U.S. Electric Utilities by the FERC, 1988-1992 (Continued)

\begin{tabular}{|c|c|c|c|c|c|c|c|}
\hline Investor-Owned Electric Utilities & State & States Served & 1892 & 1991 & 1990 & 1989 & 1988 \\
\hline 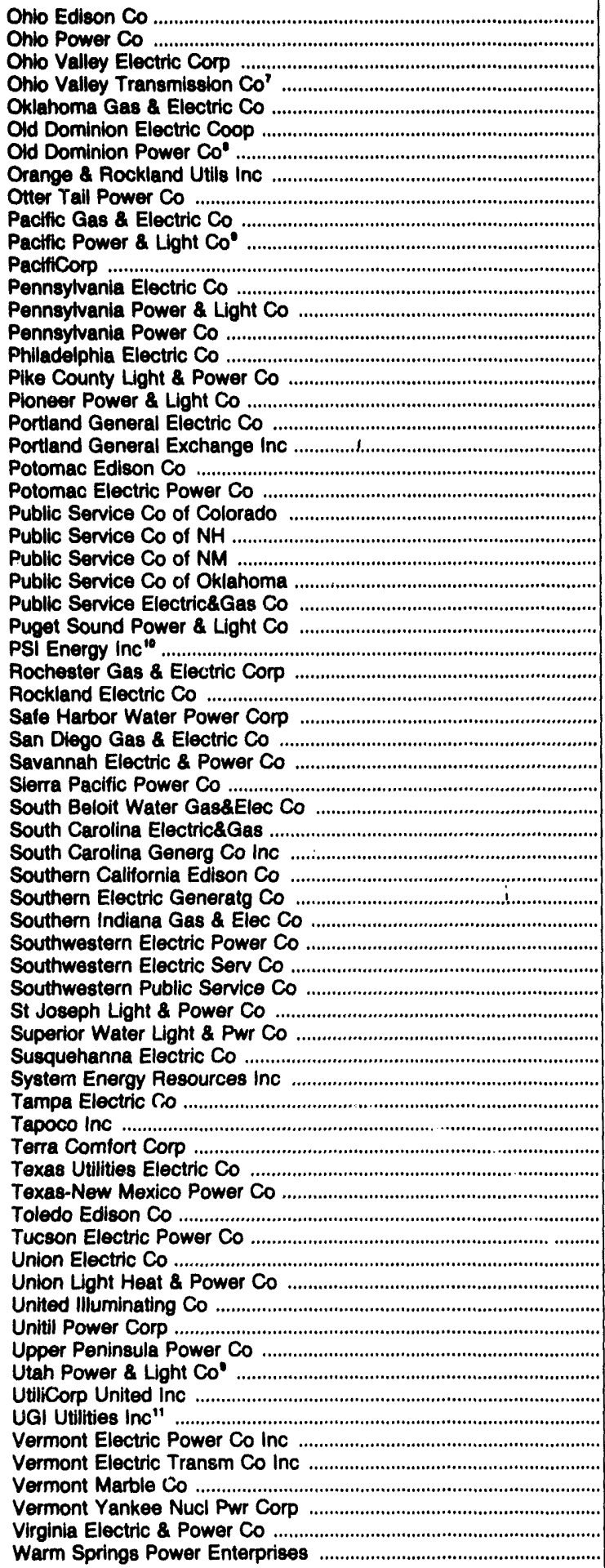 & 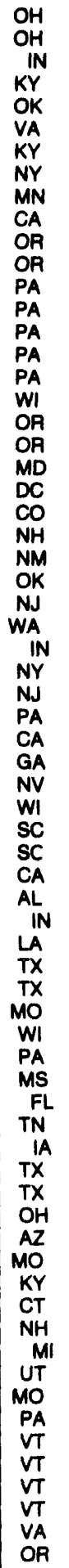 & 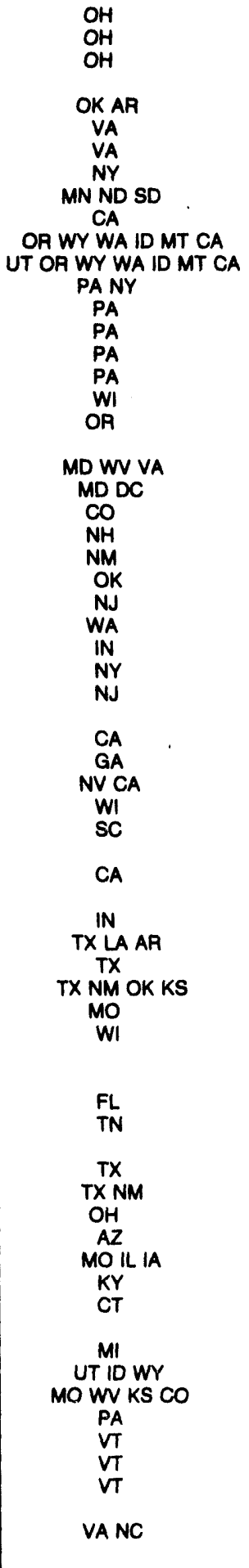 & 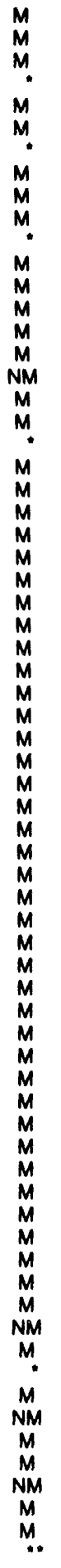 & 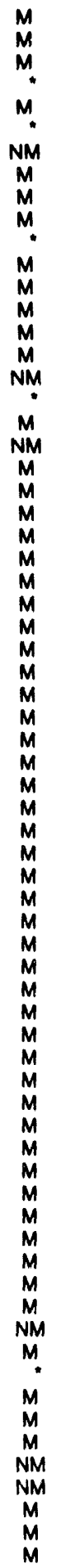 & 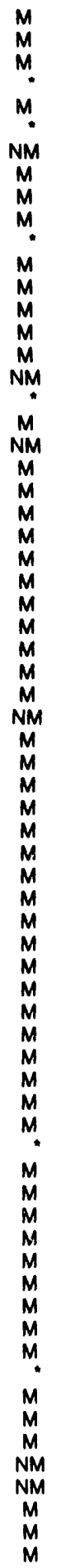 & 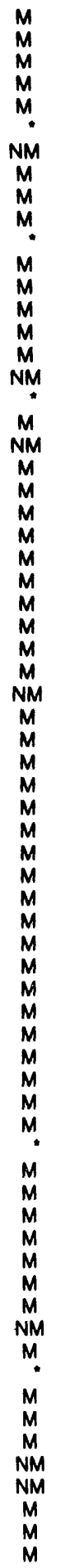 & 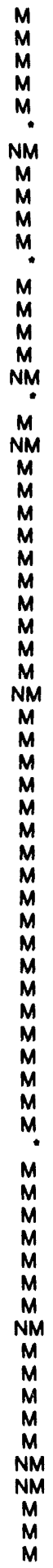 \\
\hline
\end{tabular}

See endnotes at end of this table. 
Tablo A2. Major and Nonmajor Claselfications of U.S. Electric Utilities by the FERC, 1988-1992 (Continued)

\begin{tabular}{|c|c|c|c|c|c|c|c|}
\hline Investor-Owned Electric Utilties & State & States Served & 1092 & 1891 & 1890 & 1889 & 1988 \\
\hline 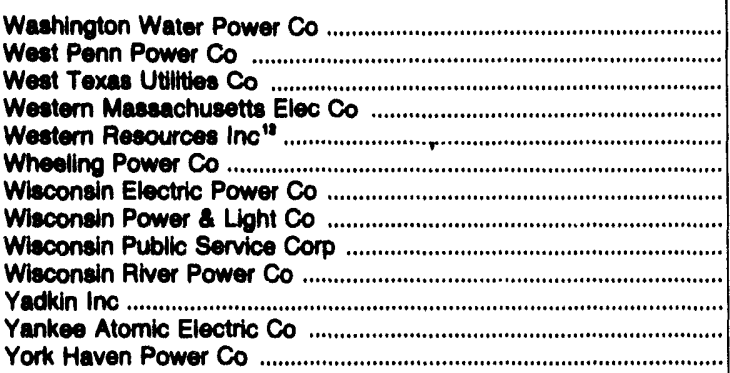 & $\begin{array}{l}\text { WA } \\
\text { PA } \\
\text { TX } \\
\text { MA } \\
\text { WS } \\
\text { WI } \\
\text { WI } \\
\text { WI } \\
\text { WI } \\
\text { NC } \\
\text { MA } \\
\text { PA }\end{array}$ & $\begin{array}{l}\text { WA ID MT } \\
\text { PA } \\
\text { TX } \\
\text { MA } \\
\text { KS } \\
\text { WV } \\
\text { WI MI } \\
\text { WI } \\
\text { WI MI } \\
\text { NC }\end{array}$ & $\begin{array}{l}M \\
M \\
M \\
M \\
M \\
M \\
M \\
M \\
M \\
M \\
M \\
M\end{array}$ & $\begin{array}{l}M \\
M \\
M \\
M \\
M \\
M \\
M \\
M \\
M \\
M \\
M \\
M\end{array}$ & $\begin{array}{l}M \\
M \\
M \\
M \\
M \\
M \\
M \\
M \\
M \\
M \\
M \\
M\end{array}$ & $\begin{array}{l}M \\
M \\
M \\
M \\
M \\
M \\
M \\
M \\
M \\
M \\
M \\
M\end{array}$ & $\begin{array}{c}M \\
M \\
M \\
M \\
M \\
M \\
M \\
M \\
M \\
M \\
M \\
M\end{array}$ \\
\hline
\end{tabular}

1 Eflective the reporting year 1992, the Centel Corp merged into Utilicorp United Inc.

Effective the reporting year 1989, the company name changed from Alamito Co.

- Effective the reporting year 1982, the company name changed from EUA Power Corp.

- Effective the reporting year 1890, the company name changed from lowa Power \& Light Co. Effective the reporting year 1992 , lowa Power Inc and lowa Public Sinvice Co merged into Midwest Power Systems Inc.

- Effective the reporting year 1992, lowa Power Inc and lowa Public Service Co merged into Midwest Power Systems Inc.

- Effective the reporting year 1992, the Michigan Power Co merged into Indiana Michigan Power Co.

- Effective the reporting year 1990, Ohio Valley Transmission Co merged into Loulsville Gas \& Electric Co.

- Effective the reporting year 1992, Old Dominion Power Co merged into Kentucky Utilities Co.

- Effective the reporting year 1989, Pacific Power \& Light Co and Utah Power \& Light Co merged into the PacifiCorp.

- Effective the reporting year 1990, the company name changed from Public Service Co of Ind inc.

1 Effective the reporting year 1982, the company name changed from UGI Corp.

12 Effective the reporting year 1992, the company name changed from Kansas Power \& Light Co. Note: Identifying the classifications for privately owned electric utilities as follows:

$M=$ Major

NM $=$ Nonmajor

$:=$ Unclassified

- Not in existence

" $=$ Exempted, determined by FERC

Source: Federal Energy Regulatory Commission, FERC Form 1, "Annual Report of Major Electric Utilities, Licensees and Others" and FERC Form 1F. "Annual Report of Nonmajor Public Utilities and Licensees." 
Holding Companies of Major U.S. Investor-Owned Electric Utilities

The current ownership structure of the investorowned segment of the electric utility industry is largely a function of the passage and implementation of the Public Utility Holding Company Act of 1935 (PUHCA). Prior to the passage of this act, the industry had evolved into a complicated intertwined network of subsidiary companies controlled by a few large holding companies. The persons controlling the parent holding companies used this structural mechanism to circumvent both State and Federal regulations. Because Congress felt that holding companies exerted undue control over supposedly regulated activities and extracted profits from the operating companies, it passed PUHCA. As a result of the passage and implementation of PUHCA, the current strucure of the investor-owned segment has the following characteristics:

- Registered holding companies' which are substantially restricted to owning subsidiary companies whose purpose tends towards the "economical and efficient development of an integrated publicutility system" and such companies are a part of a single integrated public-utility system

- Requiring the separation of electric and gas operations unless it can be shown that there are substantial economies of joint operation

- Preventing the ownership by a utility of any nonutility enterprise unless that enterprise was (a) reasonably incidental, or economically necessary or appropriate to the operations of an integrated utility system (or in the public interest)

- Provided for exempting holding companies from most of the provisions of PUHCA providing: 1) company business is conducted primarily within the borders of a single State, or 2) the holding company is a public utility operating within the State in which it is organized or within contiguous States.

Only nine entities at present are registered electric utility holding companies. However, a significant majority of the rest of the investor-owned electric utilities have applied for exempt holding company status under PUHCA. Table A3 provides a listing of the major investor-owned electric utilities and their associated holding company, if applicable.

The increase in applications for exempt holding company status is an outgrowth of the winding down in electric utility capital expenditures associated with a generating plant, the increase in internally generated cash flows in excess of dividend requirements, and the desire of many electric utility executives and board of directors to look to diversify in nonutility investments as a mechanism to stabilize and improve shareholder values.

It has been suggested that PUHCA seriously constrains competition in the wholesale electric power market by restricting entry into the business to those companies willing to be subject to the oversight and restrictive limitations on their activities imposed by PUHCA. It restricts investor-owned electric utilities from competing outside their service territories and imposes the stringent regulation as "electric utilities" on those nonutilities interested in entering the wholesale electric power business. The PUHCA reform legislation (Energy Policy Act of 1992) passed by the 102nd Congress focuses on introducing a new form of independent power producer called an "exempt wholesale generator" which would be exempt from the restrictions of PUHCA. The motivation behind supporters of this legislation is to increase baseload generating capacity without providers being considered "electric utilities" or limited to the singleintegrated system constraints.

1 According to the Public Utility Holding Company of 1935(Act), "holding company" means...

(A) any company which directly or indirectly owns, controls, or holds with power to vote, 10 percent or more of the outstanding securities of a public-utility company or a company which is a holding company by viture of this clause or clause (B), unless the Commission (i.e., the SEC), as within the Act provides by order or decree such company not to be holding company; and (B) any person which the Commission determines or indirectly to exercise such controlling influence over the management or policies of any public-utility or holding company as to make it necessary or appropriate in the public interest to be subject to the obligations, duties and liabilities iriposed in the Act upon holding companies.

Also, the Act defines a public-utility company to mean an electric utility company or a gas utility company. Further, it defines an electric utility company as any company which owns or operated facilities used for the generation, transmission, or distribution of electric energy for sale, other that sale to tenants or employees of the company operating such facilities for their own use and not for resale. The Commission may declare a company owning and operating any such facilities not to be an electric utility if the Commission finds that:

(A) such company is primarily engaged in one or more business other than the business of an electric utility company and by reason of the small amount of electric energy sold by such company, it is not in the public interest to be considered an electric utility company for purposes of the Act, or (B) such company is one operating within a single State and substantially all of its securities are owned directly or indirectly by another company to which such operating company sells or furnishes electric energy which it generates and such other company uses and does not resell such electric energy and, further is engaged primarily in manufacturing and is not controlled by any other company; and by reason of the small amount of electric energy sold or furnished by such operating company to other persons it is not in the public interest to be considered an electric utility company for purposes of the Act. 
Table A3. Major U.8. Investor-Owned Electric Utilities with Holding Company status Under the Publlc Utillity Holding Company Aot of 1935

\begin{tabular}{|c|c|c|c|}
\hline Operating Company & State & Holding Company & Status \\
\hline 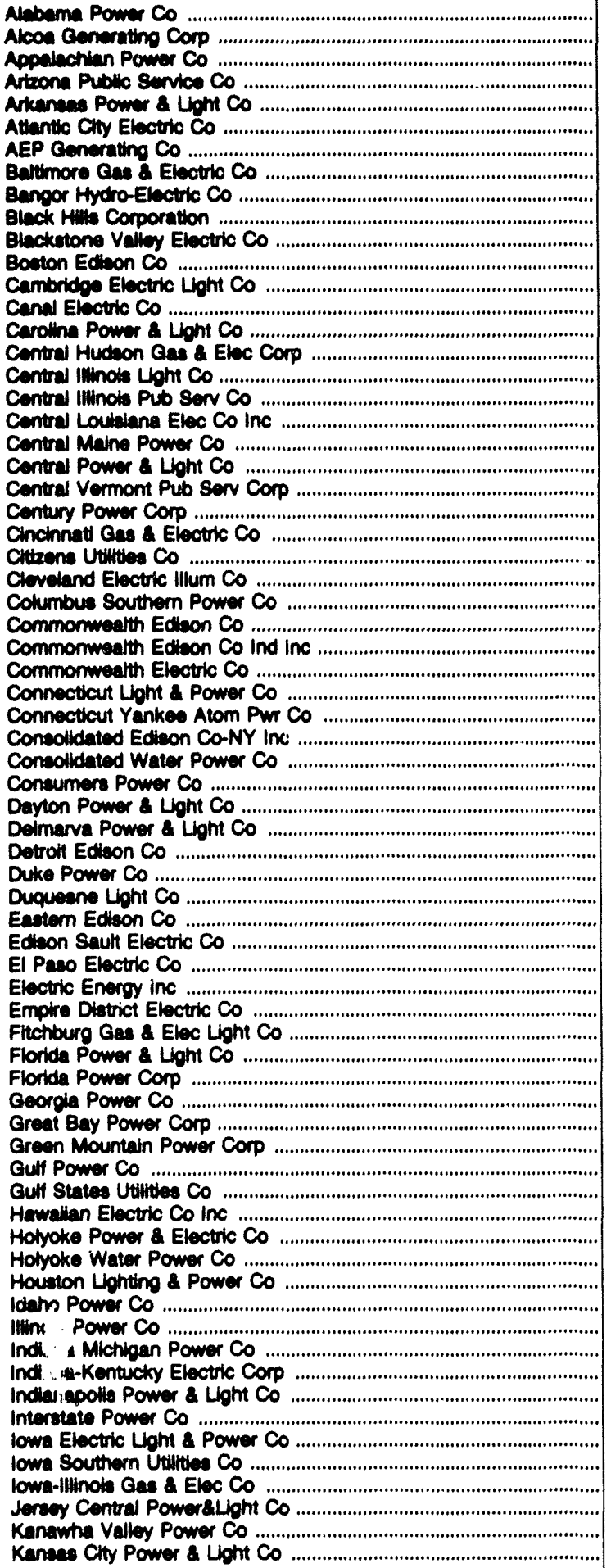 & 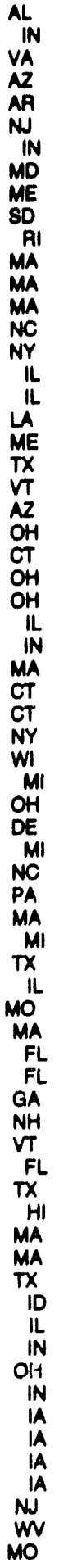 & 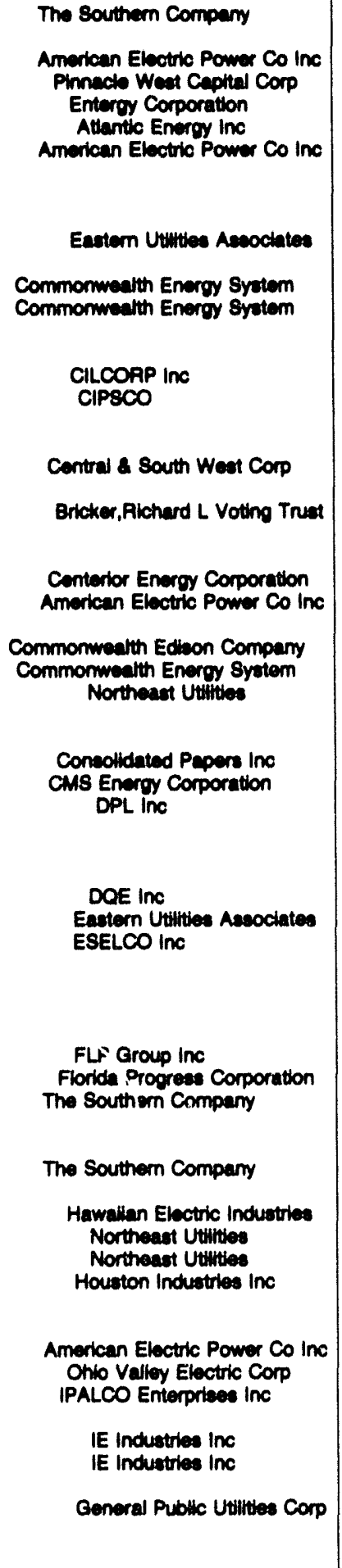 & 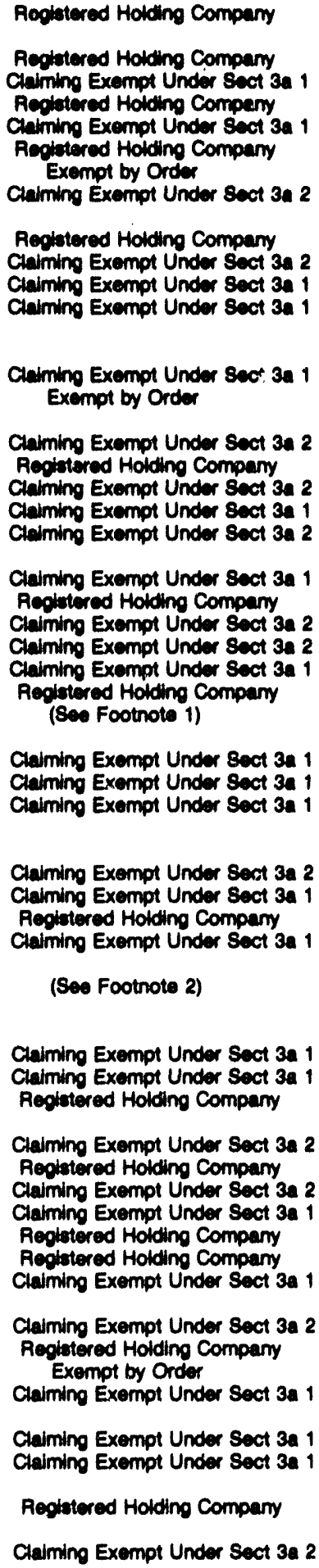 \\
\hline
\end{tabular}

See endnotes at end of this table. 
Table A3. Major U.S. Investor-Owned Eloctric Utilitles with Holding Company Status Under the Public Utility Holding Company Act of 1935 (Continued)

\begin{tabular}{|c|c|c|c|}
\hline Operating Company & State & Holding Company & Status \\
\hline 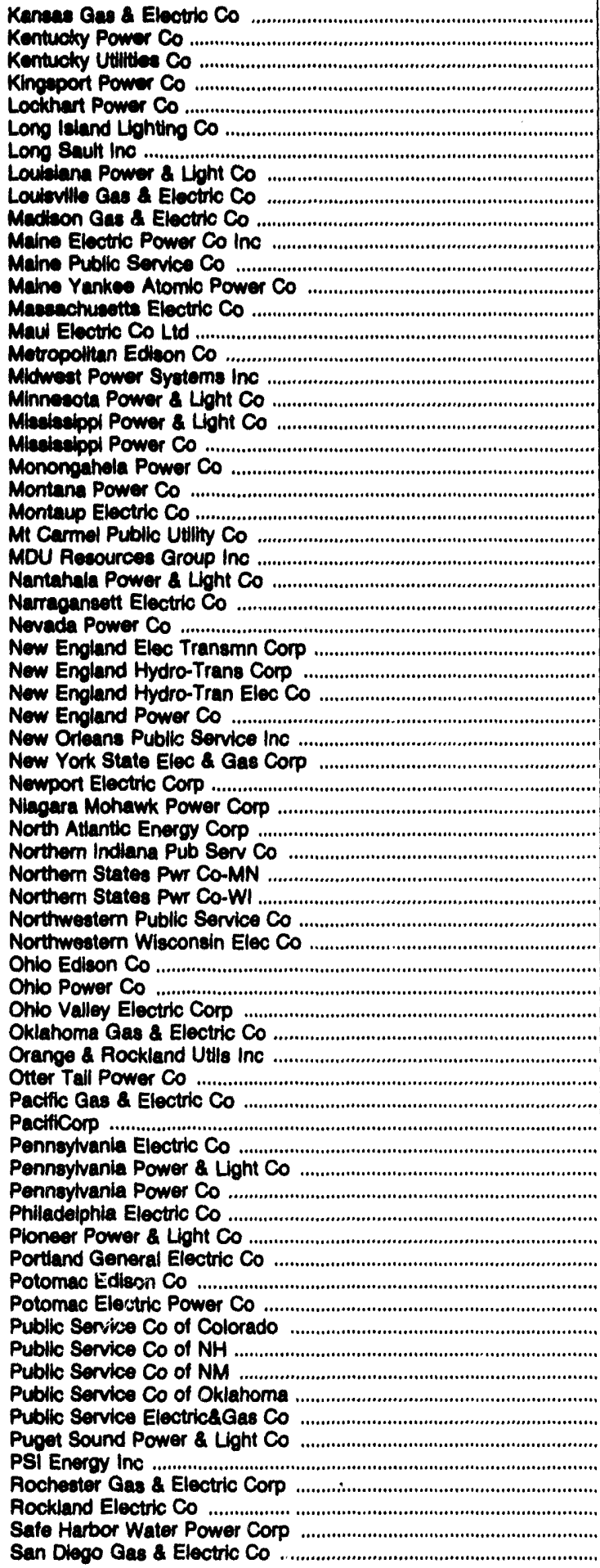 & 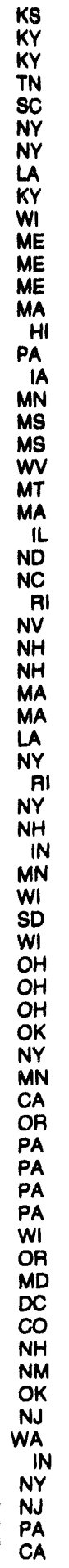 & $\begin{array}{l}\text { New England Electric System } \\
\text { Hawalian Electric Co Inc } \\
\text { General Public Utilities Corp } \\
\text { Midwest Resources Inc } \\
\text { Entergy Corporation } \\
\text { The Southern Company } \\
\text { Allegheny Power System Inc } \\
\text { Eastern Utilities Associates } \\
\text { Duke Power Co } \\
\text { New England Electric System } \\
\text { New England Electric System } \\
\text { New England Electric System } \\
\text { New England Electric System } \\
\text { New England Electric System } \\
\text { Entergy Corporation } \\
\text { Eastern Utilities Associates } \\
\text { Northeast Utilities } \\
\text { NIPSCO Industries Inc } \\
\text { Northern States Power - MN }\end{array}$ & 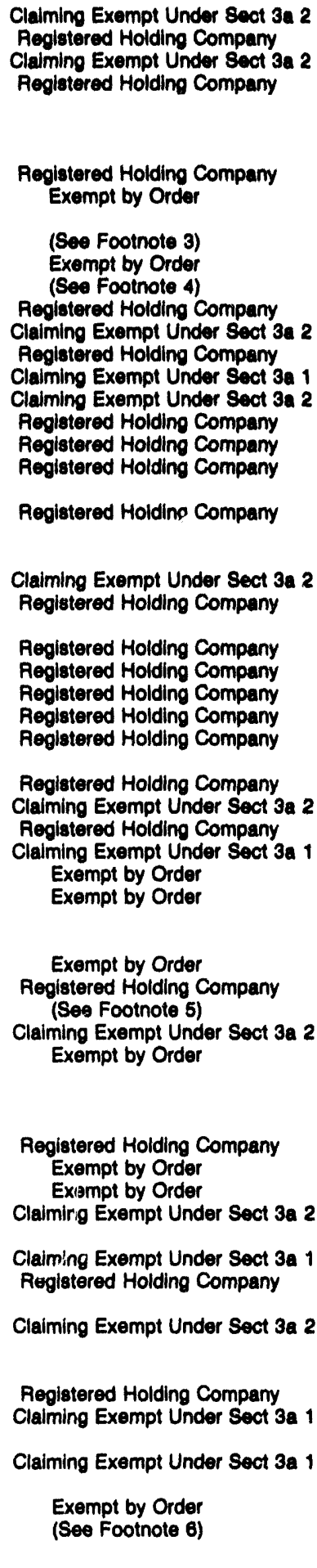 \\
\hline
\end{tabular}

See endnotes at end of this table. 
Table A3. Major U.S. Investor-Owned Electric Utilities with Holding Company Status Under the Public Utility Holding Company Act of 1935 (Continued)

\begin{tabular}{|c|c|c|c|}
\hline Operating Company & State & Holding Company & Status \\
\hline 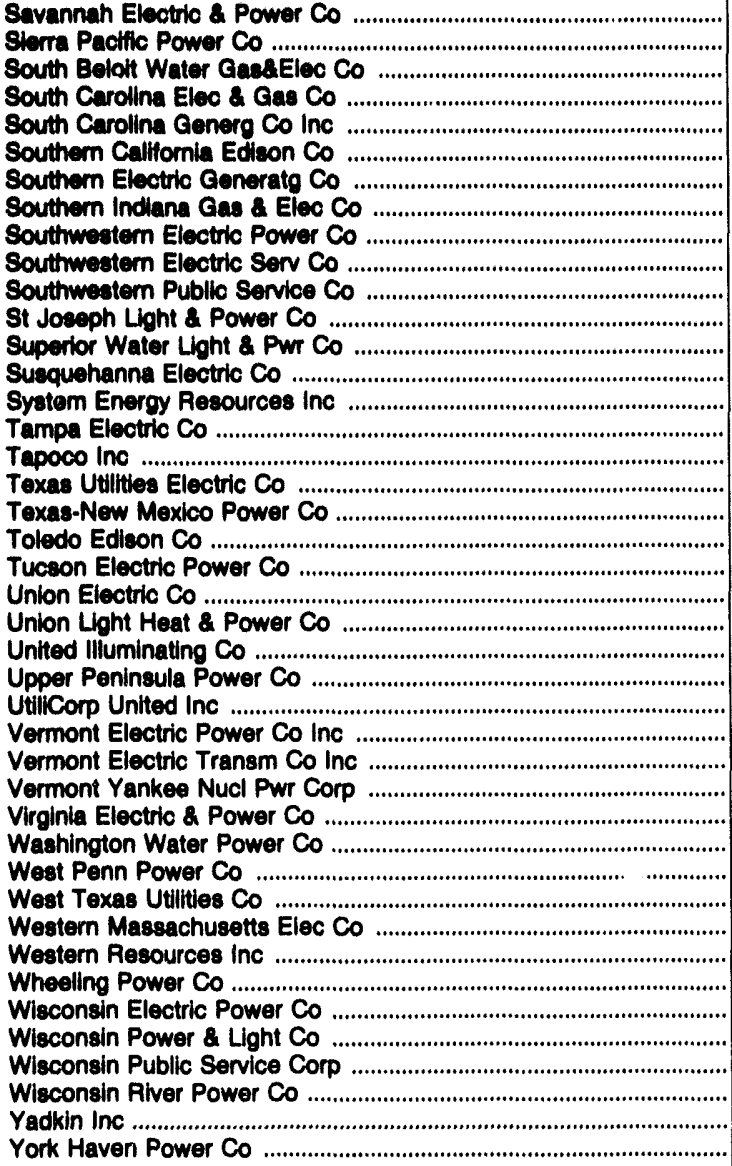 & $\begin{array}{l}\text { GA } \\
\text { NV } \\
W I \\
\text { SC } \\
\text { SC } \\
\text { CA } \\
\text { AL } \\
\text { IN } \\
\text { LA } \\
\text { TX } \\
\text { TX } \\
\text { MO } \\
W I \\
\text { PA } \\
\text { MS } \\
\text { FL } \\
\text { TN } \\
\text { TX } \\
\text { TX } \\
\text { OH } \\
\text { AZ } \\
\text { MO } \\
\text { KY } \\
\text { CT } \\
\text { MI } \\
\text { MO } \\
\text { VT } \\
\text { VT } \\
\text { VT } \\
\text { VA } \\
\text { WA } \\
\text { PA } \\
\text { TX } \\
\text { MA } \\
\text { KS } \\
W V \\
W I \\
W I \\
W I \\
W I \\
\text { NC } \\
\text { PA }\end{array}$ & $\begin{array}{l}\text { Minnesota Power \& Light Co } \\
\text { Philadelphia Electric Co } \\
\text { Entergy Corporation } \\
\text { TECO Energy Inc } \\
\text { Texas Utilities Company } \\
\text { TNP Enterprises Inc } \\
\text { Centerior Energy Corporation } \\
\text { - } \\
\text { Cincinnati Gas \& Electric Co } \\
\text { Upper Peninsula Energy Corp }\end{array}$ & $\begin{array}{l}\text { Regiatered Holding Company } \\
\text { Claiming Exempt Under Sect 3a } 1 \\
\text { Exempt by Order } \\
\text { Claiming Exempt Under Sect 3a } 1 \\
\text { Claiming Exempt Under Sect 3a } 1 \\
\text { Claiming Exempt Under Sect 3a } 1 \\
\text { (See Footnote 7) } \\
\text { Claiming Exempt Under Sect 3a } 2 \\
\text { Reglatered Holding Company } \\
\text { Claiming Exempt Under Sect 3a } 2 \\
\text { Claiming Exempt Under Sect 3a } 2 \\
\text { Registered Holding Company } \\
\text { Claiming Exempt Under Sect 3a } 1 \\
\text { Exempt by Order } \\
\text { Claiming Exempt Under Sect 3a } 1 \\
\text { Claiming Exempt Under Sect 3a } 1 \\
\text { Claiming Exempt Under Sect 3a } 2 \\
\text { Exempt by Order } \\
\text { Claiming Exempt Under Sect 3a } 2 \\
\text { Claiming Exempt Under Sect 3a } 2 \\
\text { Claiming Exempt Under Sect 3a } 1 \\
\text { (See Footnote 8) } \\
\text { (See Footnote 8) } \\
\text { (See Footnote 9) } \\
\text { Claiming Exempt Under Sect 3a } 1 \\
\text { Registered Holding Company } \\
\text { Regletered Holding Company } \\
\text { Registered Holding Company } \\
\text { Registered Holding Company } \\
\text { Exempt by Order } \\
\text { Exempt by Order } \\
\text { Claiming Exempt Under Sect 3a } 2 \\
\text { (See Footnote 10) } \\
\text { (See Footnote 11) }\end{array}$ \\
\hline
\end{tabular}

T Connecticut Light \& Power Co (Registered Holding Company) and New England Power Co (Registered Holding Company).

- CIPSCO (Exempt by Order), Illinois Power Co (Claiming Exemption Under Sect 3a 1), Kentucky Utilities Co (Claiming Exemption Under Sect 3a 2), and Union Electric Co (Exempt by Order).

2 Bangor Hydro-Electric Co (Claiming Exemption Under Sect 3a 2) and Central Maine Power Co (Claiming Exemption Under Sect 3a 2).

- Central Maine Power Co (Claiming Exemption Under Sect 3a 2), Connecticut Light \& Power Co (Registered Holding Company), and New England Power Co (Registered Holding Company).

- Owned by ten investor-owned electric utilities including American Electric Power Co Inc (Registered Holding Company), Allegheny Power System Inc (Registered Holding Company), Columbus Southern Power Co (owned by American Electric Power Co Inc, Registered Holding Company), and Ohio Edison Co (Exempt by Order).

- Baltimore Gas \& Electric Co (Exempt by Order) and Pennsylvania Power \& Light Co (Exempt by Order).

- Alabama Power Co (owned by The Southern Co, Registered Holding Company) and Georgia Power Co (owned by The Southern Co, Registered Holding Company).

- Central Vermont Pub Serv Corp (Claiming Exemption Under Sect 3a 2) and Green Mountain Power Corp (Claiming Exemption Under Sect 3a 2).

- Central Vermont Pub Serv Corp (Claiming Exemption Under Sect 3a 2), Green Mountain Power Corp (Claiming Exemption Under Sect 3a 2), and New England Power Co (Registered Holding Company).

Consolidated Papers Inc (Claiming Exemption Under Sect 3a 1), Wisconsin Power \& Light Co (Exempt by Order) and Wisconsin Public Service Corp (Claiming Exemption Under Sect 3a 2).

11 Metropolitan Edison Co (owned by General Public Utilities Corp, Registered Holding Company). Source: U.S. Securities and Exchange Commission. Financial and Corporate Report - Holding Companies Registered Under the Public Utility Holding Company Act of 1935 as of December 31,1990 , and Financial and Corporate Report - Holding Companies Exempt from the Public Utilty Holding Act of 1935 Under Sect 3a 1 and 3a 2 Pursuant to Rule 2 Filings or by Order as of September 1, 1991. 
Appendix B

Bond Ratings

for Major U.S.

Investor-Owned

Electric

Utilities 


\section{Appendlx B}

\section{Bond Ratings for Major U.S. Investor-Owned Electric Utilities}

Appendix B provides the Standard \& Poor's (S\&P) bond ratings for 1988 through 1992, for the investorowned electric utilities that file the FERC Form 1. The bond ratings reflect the evaluation of independent specialists on the ability of the electric utility to pay interest and principal on its bonds. The assessments consider the electric utility's operating efficiency, fuel/power supply, regulation, management, competition, long-term demand, construction, earnings, debt, cash flow, financial flexibility, and accounting quality.

As rated by $S \& P$, the bond ratings of the individual electric utilities range from AAA to $D$. The notation of '+' or '-' indicates a strong or weak assessment of the rating. The AAA is the highest rating assigned by S\&P to a debt obligation and indicates an extremely strong, capacity to pay principal and interest. Bonds rated AA qualify as high quality debt obligations and mean that the ability of the electric utility to pay interest is very strong. In general, AA bonds differ from AAA issues only in small degrees. Bonds rated $A$ are issued to electric utilities with a strong ability to pay principal and interest, but are judged somewhat more susceptible to the adverse effects of changes in economic conditions. The BBB rated bonds reflect an adequate ability to pay principal and interest. Although bonds in the $B$ category notmally exhibit adequate risk protection, adverse economic conditions or changing circumstances are more likely to weaken the ability of the electric utility to pay principal and interest when its bonds are rated as a B category rather than an A category. The BB and $\mathrm{B}$ rated bonds are regarded as predominantly speculative with respect to the ability of the issuer to meet the terms of the obligation. The various $\mathrm{C}$ categories are regarded by the investment community as very speculative and would not be fit for sale to institutional investors. They indicate inadequate risk protection with adverse economic changes or changing circumstances weakening the ability to pay principle and interest. The rating of $D$ indicates default on the payment on its bonds.

The bond rating is a valuable tool for gauging the financial prospects of an industry. Overall, corporate bond ratings indicate credit strength, the ability to attract debt-financed capital, solvency, and the ability to repay creditors. Specifically, the ratings provide a way of estimating financial prospects for a utility on long-term debt issues (15 to 30 years) and are made against the backdrop of economic, financial, social, and political trends affecting an industry. Future economic conditions are considered, for example, as part of the assessment process for each individual company, as well as specific factors, such as earnings, electricity demand, and construction. Further, the electric utilities are evaluated on their financial prospects considering past performance, present problems and how they plan to deal with their problems.

This publication contains 180 investor-owned electric utilities jurisdictional to the Federal Energy Regulatory Commission. However, the bond ratings for the 174 investor-owned electric utilities that filed the FERC Form 1 for the last two years were compared for 1991 and 1992. The results of the comparison were divided into five categories: no change in bond rating, no new bonds issued, bond rating decreased, bond rating improved, and no bond rating was issued. These data, with an S \& $P$ rating, showed that 84 electric utilities (47 percent) had no change in bond ratings, 16 electric utilities ( 9 percent) were not given ratings by $S \& P, 30$ electric utilities (17 percent) had issued no bonds, 9 electric utilities ( 5 percent) had a decrease in their bond rating from 1991 to 1992, and 24 electric utilities (13 percent) had an improvement in their bond rating from the previous year. The bond ratings were further compared for trends. From 1988 to 1992 , lower bond ratings occurred for 36 electric utilities while 35 electric utilities had higher bond ratings. In 1988, 33 electric' utilities had a bond rating of AA, compared with 29 electric utilites in 1992. The number of electric utilities with a bond rating of $A$ increased from 48 in 1988 to 53 in 1992. The number of electric utilites with a bond rating of BBB increased from 45 in 1988 to 48 in 1992. The increase in the number of BBB ratings resulted from upgrading for electric utilities that previously had bond ratings of BB or B. A major change in the bond ratings occurred for the El Paso Electric Company, which is in bankruptcy. 
Table B1. Summary of Bond Ratinge for Major U.S. Investor-Ownod Electric Utillties on December 31, 1988-1982

\begin{tabular}{|c|c|c|c|c|c|}
\hline Ratings. & 1992 & 1891 & 1900 & 1889 & 1888 \\
\hline 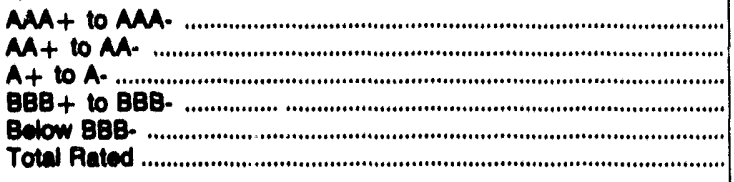 & $\begin{array}{r}1 \\
29 \\
53 \\
48 \\
3 \\
134\end{array}$ & $\begin{array}{r}1 \\
31 \\
51 \\
51 \\
3 \\
137\end{array}$ & $\begin{array}{r}1 \\
31 \\
49 \\
51 \\
5 \\
137\end{array}$ & $\begin{array}{r}1 \\
28 \\
54 \\
47 \\
7 \\
137\end{array}$ & $\begin{array}{r}1 \\
33 \\
48 \\
45 \\
8 \\
135\end{array}$ \\
\hline 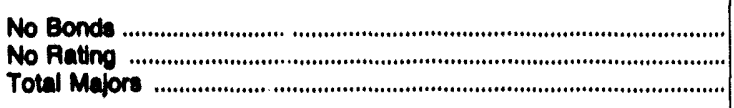 & $\begin{array}{r}30 \\
16 \\
180\end{array}$ & $\begin{array}{r}31 \\
15 \\
183\end{array}$ & $\begin{array}{r}30 \\
15 \\
182\end{array}$ & $\begin{array}{r}30 \\
15 \\
182\end{array}$ & $\begin{array}{r}23 \\
21 \\
179\end{array}$ \\
\hline $\begin{array}{l}\text { Number Improved } \\
\text { Number Declined }\end{array}$ & $\begin{array}{r}24 \\
9\end{array}$ & $\begin{array}{l}12 \\
14\end{array}$ & $\begin{array}{l}18 \\
13\end{array}$ & $\begin{array}{l}10 \\
23\end{array}$ & $\begin{array}{l}14 \\
18\end{array}$ \\
\hline
\end{tabular}

1 Fale-Safe Inc, UGI Corp, Warm Sprthos Power Enterprises, and Yankee Atomic Electric Co were exempt by the FERC. Centel Corp was acquired by UtilCorp United Inc; lowa Power Inc and lowa Publlc Service Co merged into Midwest Power Systems Ino; Kansas Power and Lloht Co was acquired by Western Resources Inc; and Michigan Power Co merged into Indiana Michigan Power Co. Great Bay Power Corp. Kanawha Valley Power Co, North Attantic Energy Corp, and Pioneer Power and Light Co were not major investor-owned electric utilities prior to 1982.

- Vermont Electric Tranamiseion Co Inc was not a major imvestor-owned electric utility prior to 1981.

- James Alver-NH Electric Inc was exempt by the FERC. Ohio Valley Transmission Co merged into Louleville Gas \& Electric Co. ,New England Hydro-Tranamiasion Corp and Naw England Hydro-Transmiseion Elec Co Inc were not major investor-owned electric utilties prior to 1980.

- Pacific Power L Light Co and Utah Power \& Lght Co merged into the PacifiCorp. Fale Safe Inc, Long Sault Inc, New England Electric Tranamiasion Corp, and 'Rockland Electric Co were not major investor-owned electric utilities pritor to 1989.

Attantic City Electric Co is included in this total as it was merged into Attantic Energy. Inc.

Note: Data provided for respondents to Federal Energy Regulatory Commission, FERC Form 1, "Annual Report of Major Electric Utilities, Licensees and Ot רers."

Source: Standard \& Poor's Utillty Compuatat II Services, Inc. 
Table B2. Bond Ratings by Major U.S. Investor-Owned Electric Utility on

December 31, 1988-1992

\begin{tabular}{|c|c|c|c|c|c|}
\hline Utilities & $\begin{array}{l}\text { SeP Bond } \\
\text { Rating } \\
1982\end{array}$ & $\begin{array}{l}\text { SeP Bond } \\
\text { Rating } \\
1991\end{array}$ & $\begin{array}{c}\text { S\&P Bond } \\
\text { Rating } \\
1990\end{array}$ & $\begin{array}{c}\text { S\&P Bond } \\
\text { Pating } \\
1889\end{array}$ & $\begin{array}{c}\text { SeP Bond } \\
\text { Rating } \\
1988\end{array}$ \\
\hline 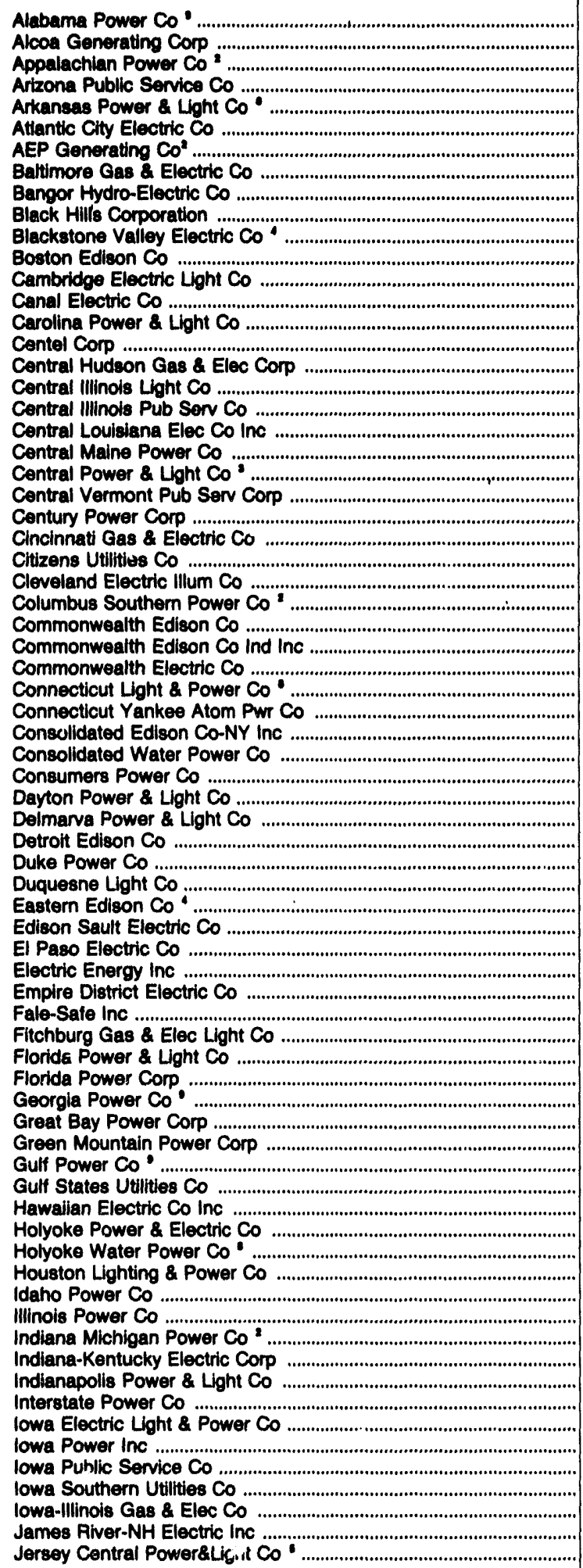 & 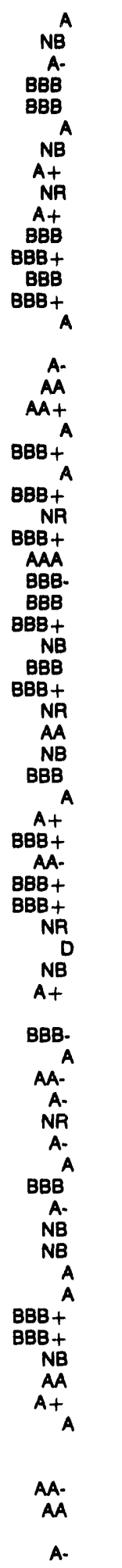 & 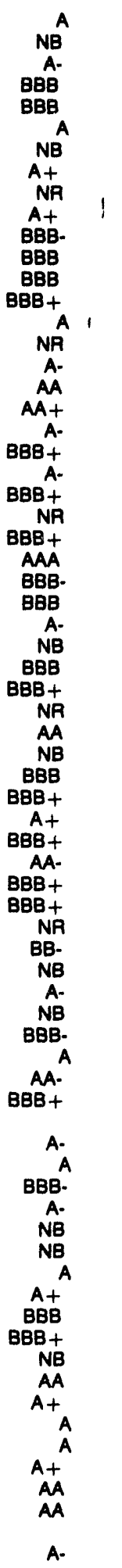 & $\begin{array}{c}A \\
\text { NB } \\
A- \\
\text { BBB- } \\
\text { BBB- } \\
A+ \\
\text { NB } \\
\text { AA- } \\
\text { NA } \\
\text { A } \\
\text { BBB- } \\
\text { BBB+ } \\
\text { BBB+ } \\
\text { BBB+ } \\
\text { A } \\
\text { NA } \\
\text { BBB+ } \\
\text { AA } \\
\text { AA+ } \\
\text { A- } \\
\text { BBB+ } \\
\text { A- } \\
\text { BBB+ } \\
\text { NR } \\
\text { BBB+ } \\
\text { AAA } \\
\text { BBB- } \\
\text { BBB } \\
\text { BBB++ } \\
\text { NB } \\
\text { BBB+ } \\
\text { BBB+ } \\
\text { NR } \\
\text { AA } \\
\text { NB }\end{array}$ & 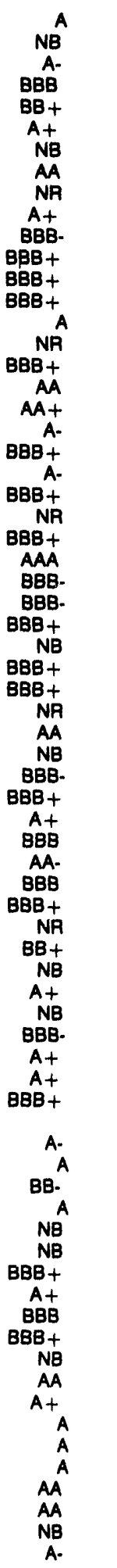 & 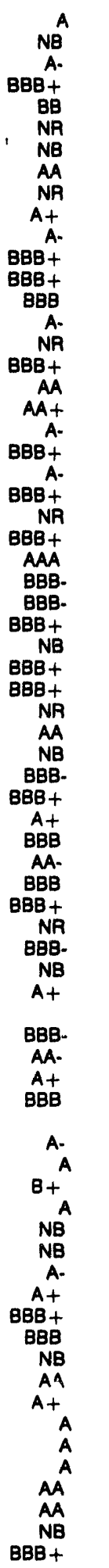 \\
\hline
\end{tabular}

See footnotes at end of table. 
Table B2. Bond Ratings by Major U.S. Investor-Owned Electric Utility on December 31, 1988-1982 (Continued)

\begin{tabular}{|c|c|c|c|c|c|}
\hline Uullites & $\begin{array}{c}\text { Sap Bond } \\
\text { Rating } \\
1992\end{array}$ & $\begin{array}{c}\text { Sap Bond } \\
\text { Rating : } \\
1991\end{array}$ & $\begin{array}{c}\text { SsP Bond } \\
\text { Rating } \\
1990\end{array}$ & $\begin{array}{c}\text { Sep Bond } \\
\text { Rating } \\
1889\end{array}$ & $\begin{array}{c}\text { S\&P Bond } \\
\text { Rating } \\
1888\end{array}$ \\
\hline 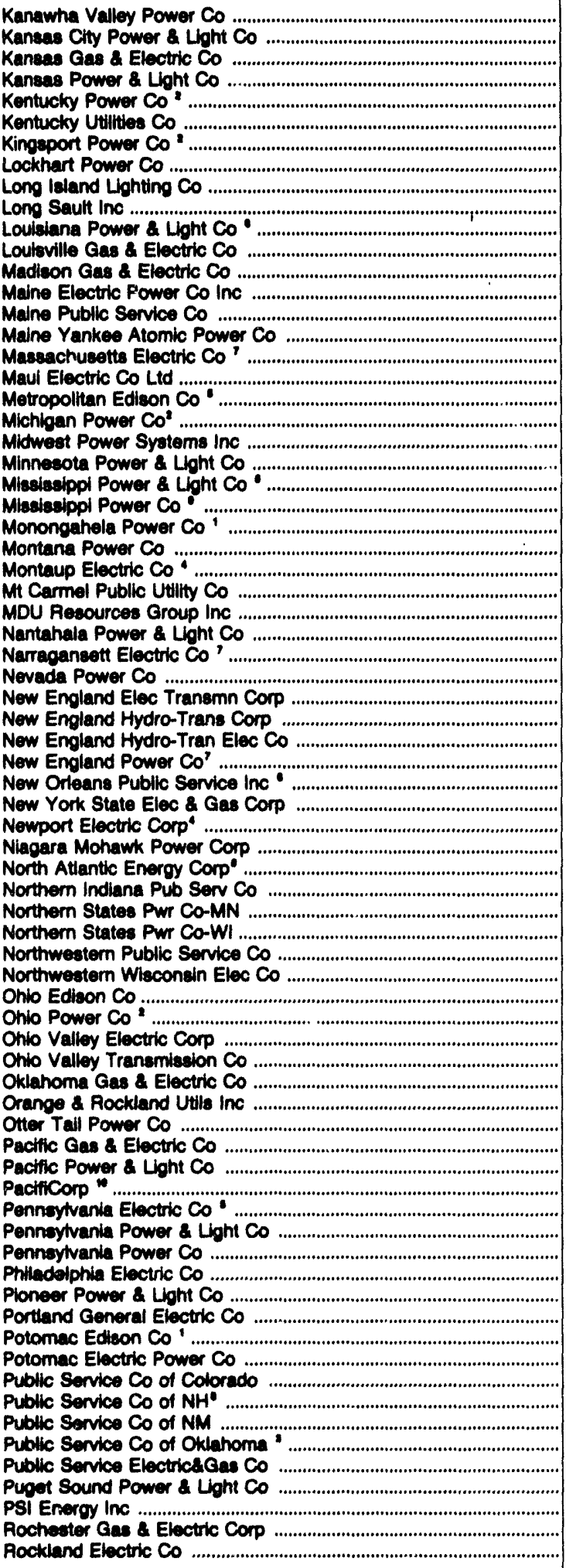 & 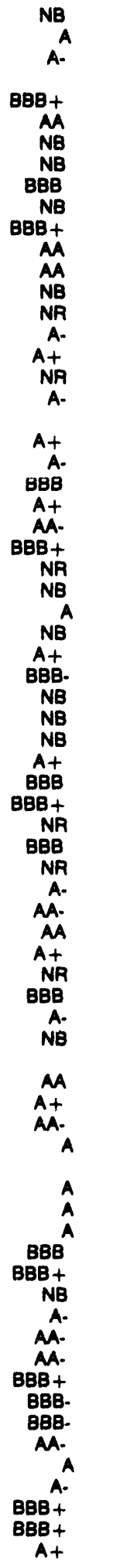 & 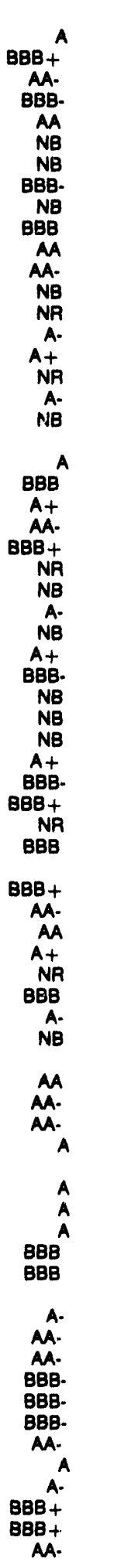 & 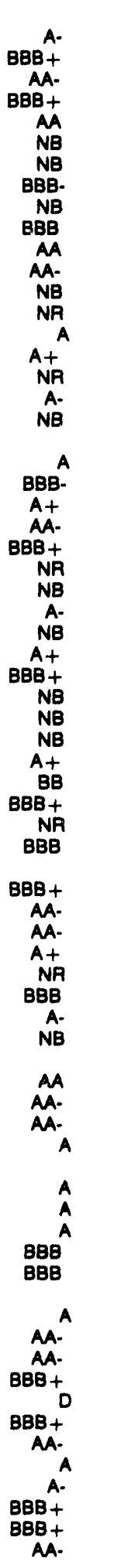 & 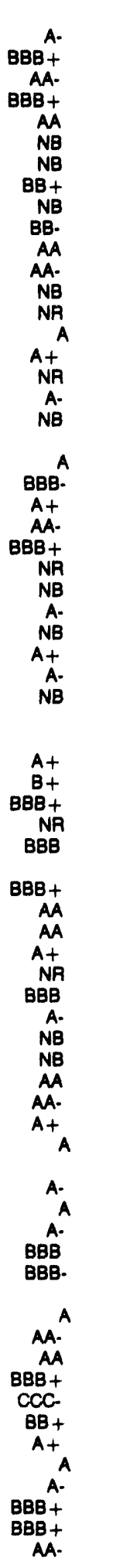 & 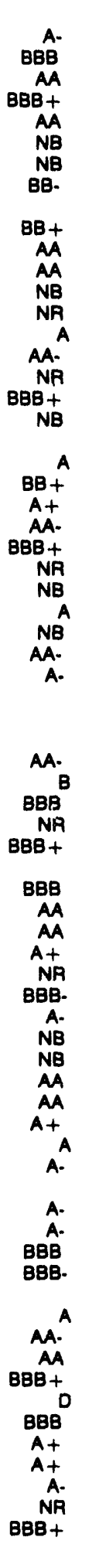 \\
\hline
\end{tabular}

See footnotes at end of table. 
Table B2. Bond Ratings by Major U.S. Investor-Owned Electric Utility on December 31, 1988-1992 (Continued)

\begin{tabular}{|c|c|c|c|c|c|}
\hline Utillies & $\begin{array}{c}\text { Sap Bond } \\
\text { Pating } \\
1992\end{array}$ & $\begin{array}{l}\text { Sap Bond } \\
\text { Rating } \\
1991\end{array}$ & $\begin{array}{c}\text { Sap Bond } \\
\text { Pating } \\
1900\end{array}$ & $\begin{array}{c}\text { sep Bond } \\
\text { Pating } \\
1989\end{array}$ & $\begin{array}{c}\text { S\&P Bond } \\
\text { Rating } \\
1888\end{array}$ \\
\hline 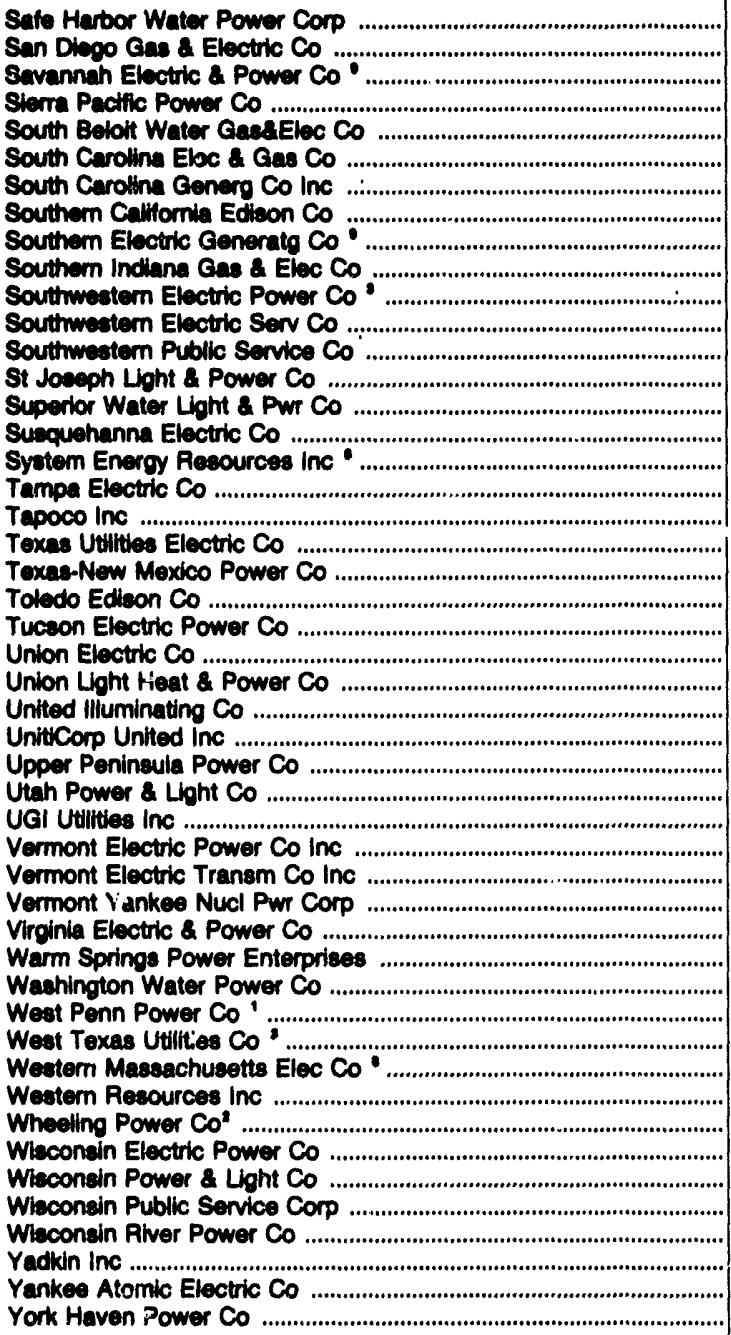 & 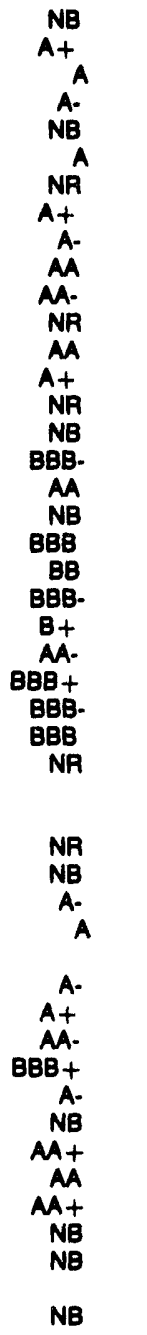 & 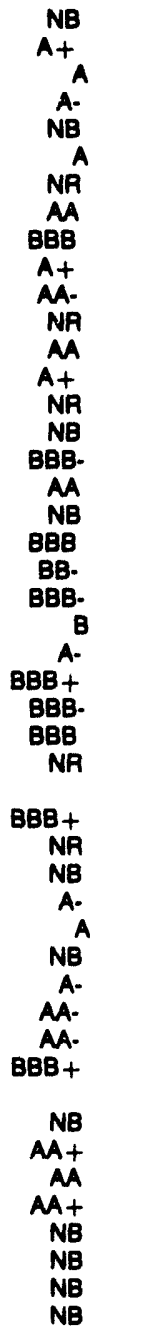 & 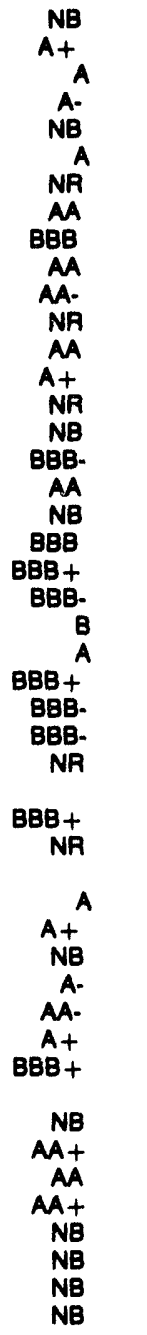 & 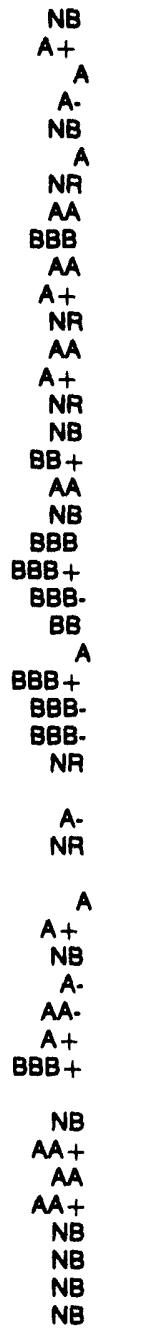 & 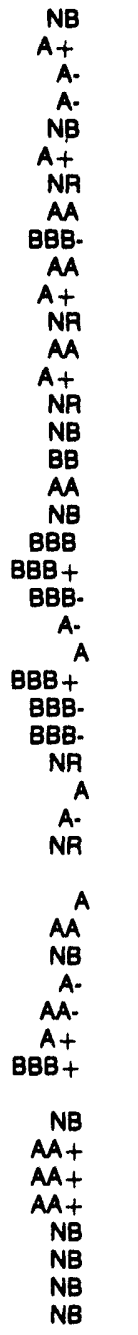 \\
\hline
\end{tabular}

- Electric utilfy is owned by the Allegheny Power Syetern Inc, a regletered holding company.

- Electric utillty is owned by the American Electric Power Company Inc, a regletered holding company.

- Electric utility is owned by the Central \& South Weet Corporation, a reglatered holding company.

- Electric utlity is owned by the Eastern Utillies Asecociates, a regiatered holding company.

- Electric utilty is owned by the General Public Utilities Corporation, a reglatered holding company.

- Electric utility is owned by the Entergy Corporation, a registered holding company.

- Electric utility is owned by the Now England Electric Syetem, a reglotered holding company.

- Electric utility is owned by the Northeent Utillities, a regietered holding company.

- Electric utility is owned by The Southern Company, a reglatered holding company.

- Pactic Power \& Light Co and Utah Power \& Loht Co merged into the Pacificorp. Note: NR - Standard \& Poor's has not rated the bonds lsewed by this electric uallity.

NB - This electric utilly has lesued no bonds for long-term debt.

Source: Standard \& Püi's Vitility Compustat II Services, Inc. 
Appendix C

Other U.S.

Entities

Jurisdictional

to the FERC 


\section{Other U.S. Entities Jurisdictional to the FERC}

Appendix C provides a group of entities that are being segregated from the investor-owned electric utility data because of their unique status. This group consists of six independent power producers and two generation and transmission cooperatives whose operating revenues come under the jurisdiction of the Federal Energy Regulatory Commission (FERC). Thus, each entity filed a FERC Form 1 in 1992.

Catalyst Old River Hydroelectric Limited Partnership runs a $192 \mathrm{MW}$ hydroelectric project (Sidney A. Murray Hydroelectric Station) built at Vidalia, Louisiana, on the Mississippi River. The project's power is sold to Louisiana Power and Light Company and the town of Vidalia, Louisiana. Entergy Power Incorporated purchased $265 \mathrm{MW}$ or 31.5 percent undivided ownership interest in the $842 \mathrm{MW}$ lignite coalfired plant (Independence 2) located near Newark, Arkansas, and the $544 \mathrm{MW}$ oil- and gas-fired plant (Robert Ritchie 2) located near Helena, Arkansas, from Arkansas Power and Light Company. Entergy Power Incorporated is marketing this capacity in the wholesale arena. Nevada Sun-Peak Limited Partnership owns a $210 \mathrm{MW}$ gas turbine plant (Nevada SunPeak) which has a power purchase agreement with Nevada Power Company. Ocean State Power and Ocean State Power II are two combined cycle gas turbine units built adjacent to each other at different times in Burrillville, Rhode Island. Both of the 254 MW units provide power to Boston Edison Company, New England Power Company, Montaup Electric Company, and Newport Electric Corporation. Terra Comfort Corporation is a wholly owned subsidiary of IES Industries, which also owns Iowa Southern Utilities Company. Terra Comfort Corporation owns two gas turbines, the $70 \mathrm{MW}$ Burlington plant and the $\mathbf{5 2}$ MW Centerville plant, that provide peaking power to lowa Electric Light and Power Company.

The other two entities in this appendix are generation and transmission cooperatives (G\&Ts). G\&Ts, which are usually tax exempt organizations owned by their member distribution cooperatives, produce and/or buy power for resale to their member distribution cooperations. Most G\&Ts are borrowers from the Rural Electrification Administration (REA), and as such, would be subject to REA rate jurisdiction and file the REA Form 12. Golden Spread Electric Cooperative is a "paper" G\&T in that it owns no generating assets. It purchases power for its 11 member distribution cooperatives from other generators (in this case from Southwestern Public Service Company). Golden Spread Electric Cooperative is not an REA borrower and, therefore, is not subject to REA regulations. Effective in 1987, the cooperative's operating revenues came under the jurisdiction of the FERC. Old Dominion Electric Cooperative, which has its own generating capacity $(227 \mathrm{MW}$ or 11.6 percent undivided ownership interest in both North Anna Nuclear units 1 and 2 located in Louisa County, Virginia) had been an REA borrower, but recently bought out its obligations to the REA. Starting in 1992, Old Dominion Electric Cooperative came under the jurisdiction of the FERC. It provides wholesale electric service to its 12 member distribution cooperatives.

The Energy Policy Act of 1992 (EPACT) contains a section on the Public Utility Holding Company Act (PUHCA) reform that created a new class of generating facilities called Exempt Wholesale Generators (EWGs). EWGs are described in the act as "any person determined by the Federal Energy Regulatory Commission to be engaged...in the business of owning (and) or operating...eligible facilities and selling electric energy at wholesale." EPACT exempts EWGs from PUHCA, allows for electric utility involvement with EWGs, expands transmission access, and clarifies regulatory jurisdiction to which EWGs will be subject. This PUHCA reform is the latest legislation encouraging deregulation of the electric generating industry -- a movement that began in 1978 with the passage of the Public Utility Regulatory Policies Act of 1978 (PURPA). If the established sales and transmission service thresholds are exceeded, a EWG status would not exempt the requirement to submit the FERC Form 1.

As of December 31, 1992, 11 applications were filed with the FERC. Four of the EWG applications (Commonwealth Atlantic Limited Partnership, Dorwell Limited Partnership, Hartwell Energy Limited Partnership, and Costanern Power Corporation) were approved in 1992. 
Table C1. Statement of Income and Rotained Earnings by Other U.S. Entity Within State, 1992 (Thousand Dollars)

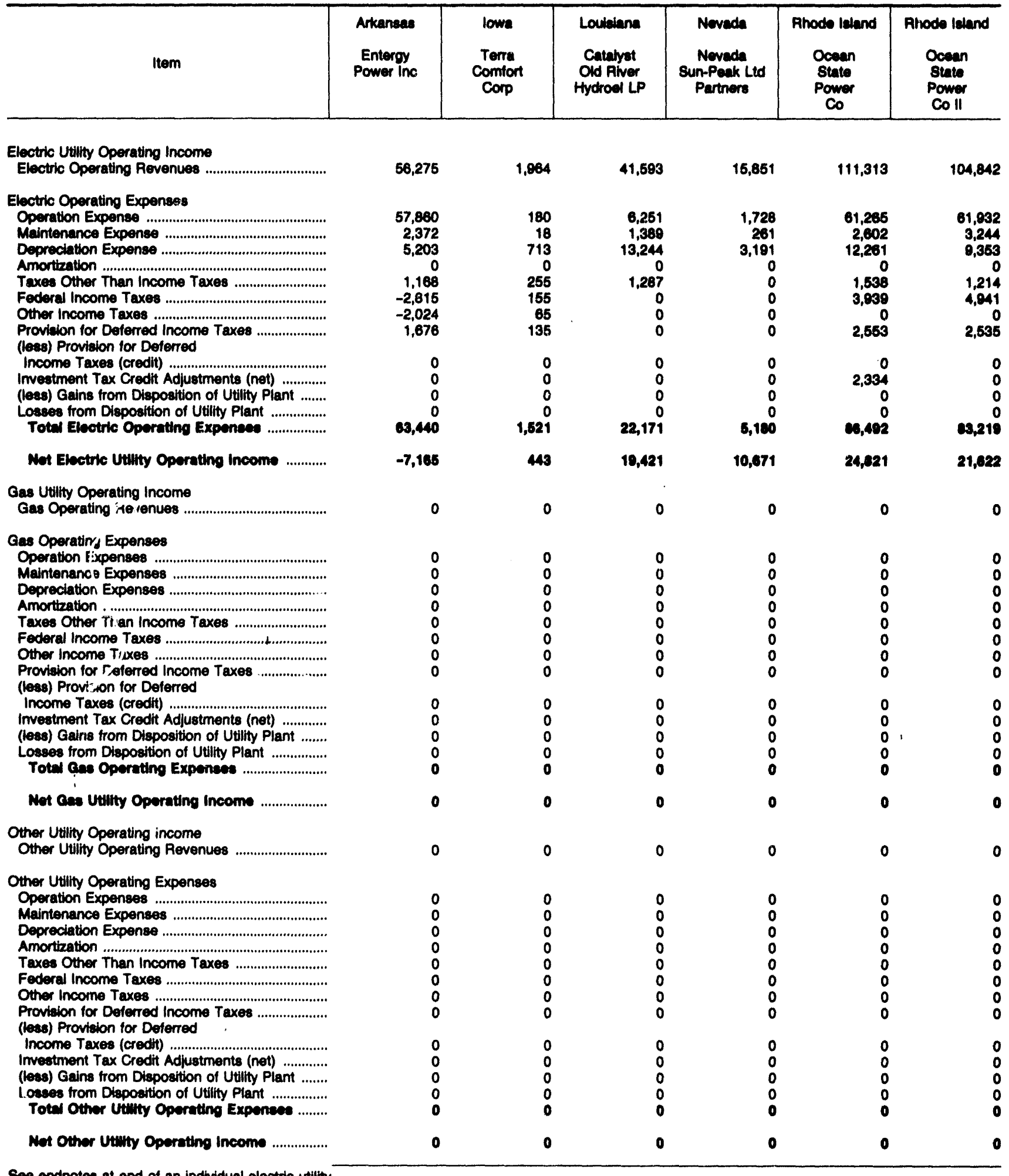

See endnotes at end of an individual electric utility. 
Table C1. Statement of Income and Retained Earninge by Other U.S. Entity Within State, 1992 (Continued)

(Thousand Dollars)

\begin{tabular}{|c|c|c|c|c|c|c|}
\hline Item & $\begin{array}{l}\text { Arkansas } \\
\text { Entergy } \\
\text { Power Inc }\end{array}$ & $\begin{array}{l}\text { lowa } \\
\text { Terra } \\
\text { Comfort } \\
\text { Corp }\end{array}$ & $\begin{array}{l}\text { Loulsiana } \\
\text { Catalyst } \\
\text { Old Fliver } \\
\text { Hydrool LP }\end{array}$ & $\begin{array}{l}\text { Nevada } \\
\text { Nevada } \\
\text { Sun-Peak Ltd } \\
\text { Partners }\end{array}$ & $\begin{array}{l}\text { Rhode laland } \\
\text { Ocean } \\
\text { State } \\
\text { Power } \\
\text { Co }\end{array}$ & $\begin{array}{l}\text { Phode leland } \\
\text { Ocean } \\
\text { State } \\
\text { Power } \\
\text { Co II }\end{array}$ \\
\hline $\begin{array}{l}\text { Total Utilty Operating Income } \\
\text { Total Utiflty Operating Revenues ................................. }\end{array}$ & 56,275 & 1,964 & 41,593 & 15,851 & 111,313 & 104,842 \\
\hline 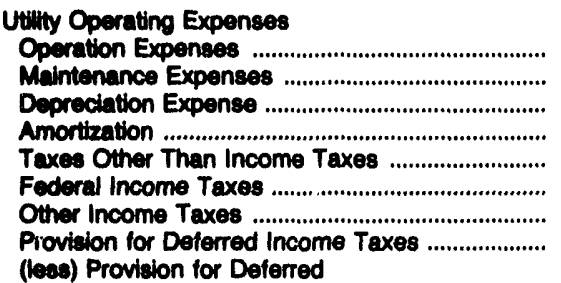 & $\begin{array}{r}57,860 \\
2,372 \\
5,203 \\
0 \\
1,168 \\
-2,815 \\
-2,024 \\
1,676\end{array}$ & $\begin{array}{r}180 \\
18 \\
713 \\
0 \\
255 \\
155 \\
65 \\
135\end{array}$ & $\begin{array}{r}6,251 \\
1,389 \\
13,244 \\
0 \\
1,287 \\
0 \\
0 \\
0\end{array}$ & $\begin{array}{r}1,728 \\
261 \\
3,191 \\
0 \\
0 \\
0 \\
0 \\
0\end{array}$ & $\begin{array}{r}61,265 \\
2,602 \\
12,261 \\
0 \\
1,538 \\
3,939 \\
0 \\
2,553\end{array}$ & $\begin{array}{r}61,932 \\
3,244 \\
9,363 \\
0 \\
0 \\
1,214 \\
4,941 \\
0 \\
2,535\end{array}$ \\
\hline 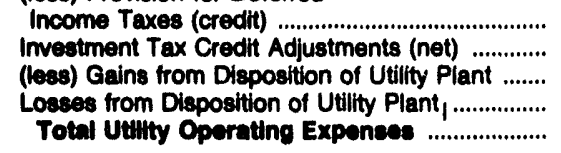 & $\begin{array}{r}0 \\
0 \\
0 \\
0 \\
63,440\end{array}$ & $\begin{array}{r}0 \\
0 \\
0 \\
0 \\
1,521\end{array}$ & $\begin{array}{r}0 \\
0 \\
0 \\
0 \\
22,171\end{array}$ & $\begin{array}{r}0 \\
0 \\
0 \\
0 \\
5,180\end{array}$ & $\begin{array}{r}0 \\
2,334 \\
0 \\
0 \\
86,402\end{array}$ & $\begin{array}{r}0 \\
0 \\
0 \\
0 \\
83,210\end{array}$ \\
\hline 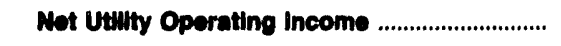 & $-7,165$ & 443 & 19,421 & 10,671 & 24,021 & 21,622 \\
\hline $\begin{array}{l}\text { Other Income and Deductions } \\
\text { Other income }\end{array}$ & & & & & & \\
\hline $\begin{array}{l}\text { Nonutility Operating Income .............................. } \\
\text { Equilty in Earnings of Subsidiary Companies ...... } \\
\text { Interest and Dividend Income ............................... } \\
\text { Allowance for Other Funds Used }\end{array}$ & $\begin{array}{r}0 \\
0 \\
467\end{array}$ & $\begin{array}{r}0 \\
0 \\
14\end{array}$ & $\begin{array}{r}1 \quad \begin{array}{r}0 \\
0 \\
0,052\end{array}\end{array}$ & $\begin{array}{r}0 \\
0 \\
92\end{array}$ & $\begin{array}{r}-1 \\
0 \\
280\end{array}$ & $\begin{array}{r}0 \\
0 \\
272\end{array}$ \\
\hline 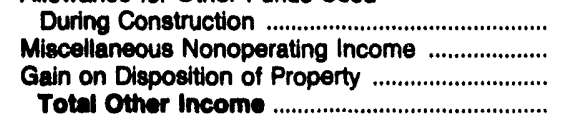 & $\begin{array}{r}0 \\
0 \\
0 \\
467\end{array}$ & $\begin{array}{r}0 \\
0 \\
0 \\
14\end{array}$ & $\begin{array}{r}0 \\
1 \\
0 \\
3,053\end{array}$ & $\begin{array}{r}0 \\
0 \\
0 \\
92\end{array}$ & $\begin{array}{r}0 \\
0 \\
0 \\
280\end{array}$ & $\begin{array}{r}0 \\
0 \\
0 \\
272\end{array}$ \\
\hline 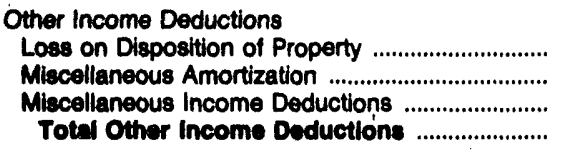 & $\begin{array}{r}0 \\
24 \\
72 \\
88\end{array}$ & $\begin{array}{l}0 \\
0 \\
0 \\
0\end{array}$ & $\begin{array}{r}9 \\
236 \\
3 \\
248\end{array}$ & $\begin{array}{l}0 \\
0 \\
1 \\
1\end{array}$ & $\begin{array}{l}0 \\
0 \\
0 \\
0\end{array}$ & $\begin{array}{l}0 \\
0 \\
0 \\
0\end{array}$ \\
\hline 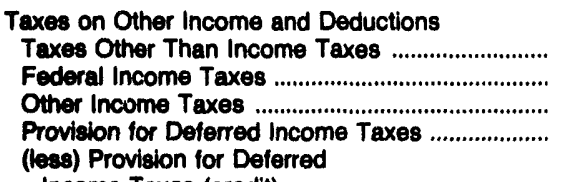 & $\begin{array}{l}0 \\
0 \\
0 \\
0\end{array}$ & $\begin{array}{l}0 \\
0 \\
0 \\
0\end{array}$ & $\begin{array}{l}0 \\
0 \\
0 \\
0\end{array}$ & $\begin{array}{l}0 \\
0 \\
0 \\
0\end{array}$ & $\begin{array}{l}0 \\
0 \\
0 \\
0\end{array}$ & $\begin{array}{l}0 \\
0 \\
0 \\
0\end{array}$ \\
\hline $\begin{array}{l}\text { Income Taxes (credit) ....................................... } \\
\text { Investment Tax Credit Adjustments (net) ........... } \\
\text { (lese) Investment Tax Credits ................................. } \\
\text { Totw Taxes on Other Income }\end{array}$ & $\begin{array}{l}0 \\
0 \\
0\end{array}$ & $\begin{array}{l}0 \\
0 \\
0\end{array}$ & $\begin{array}{l}0 \\
0 \\
0\end{array}$ & $\begin{array}{l}0 \\
0 \\
0\end{array}$ & $\begin{array}{l}0 \\
0 \\
0\end{array}$ & $\begin{array}{l}0 \\
0 \\
0\end{array}$ \\
\hline 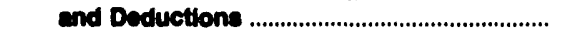 & 0 & 0 & $\mathbf{0}$ & 0 & 0 & $\mathbf{0}$ \\
\hline Not Other Income and Deductions .................. & 371 & 14 & 2,805 & 92 & 200 & 272 \\
\hline
\end{tabular}

See endnotes at end of an indlwidual electric utility. 
Table C1. Statement of Income and Rotained Earnings by Other U.S. Entity Within State, 1992 (Continued)

(Thousand Dollars)

\begin{tabular}{|c|c|c|c|c|c|c|}
\hline from & $\begin{array}{l}\text { Arkanass } \\
\text { Entergy } \\
\text { Power Inc }\end{array}$ & $\begin{array}{l}\text { lowa } \\
\text { Terra } \\
\text { Comfort } \\
\text { Corp }\end{array}$ & $\begin{array}{l}\text { Louldiana } \\
\text { Catalyot } \\
\text { Old Rlver } \\
\text { Hydroel LP }\end{array}$ & $\begin{array}{l}\text { Nevada } \\
\text { Nevada } \\
\text { Sun-Peak Lid } \\
\text { Partners }\end{array}$ & $\begin{array}{c}\text { Rhode Istand } \\
\text { Ocean } \\
\text { State } \\
\text { Power } \\
\text { Co }\end{array}$ & $\begin{array}{c}\text { Rhode Ialand } \\
\text { Ocean } \\
\text { State } \\
\text { Power } \\
\text { Co II }\end{array}$ \\
\hline
\end{tabular}

Intereet Charges

Interest on Long-term Dabt ......................................

Amortzzation of Debt Diecount and Expense......

Amortization of Loss on Reacquired Debt ............

(10e0) Amortization of Premium on Debt (credit).

(lesa) Amortization of Gain on

Resquired Debt (c. $\rightarrow d t$ )

imtereat on Dabt to Aseociat

Other Interest Expense ..............................................

(lese) Allpwance for Borrowed Funds

Used During Construction (credit)

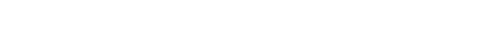

Income Belore Extreordinary Items

0
0
0
0
0
11,493
3
11,400

0
0
0
0
0
0
0
0
0

68,564

5,788

63

721

235

6,448

604

197

0

0

0
0

0

0

13

0

89,880

0
6,051

7,354

7,281

$-10,292$

467

$-44,404$

4,012

17,759

14,893

Extraordinary ftems

Extraordinary Income ...

Not Extraordinary ftems

0

(less) Federal and Other Income Taxes

Extraordinary Items After Taxes.

Net Income

d Rotained Eaminge

Unappropriated Rotained Eaminge

$-22,2$

$-697$

$-8,313$

1,500

$-1,678$

2,016

Balance Transferred from income

to Retalned Earnings

(less) Debits to Retained Earnings .......................

(less) Appropriations of Retained Earnings ..........

(less) Dividends Declared - Preferred Stock .......

(less) Dividends Declared - Common Stock ........

Unappropriated Undistributed Subsidlary

Earnings

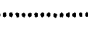

Retained Eamings - End of Year

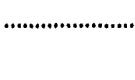

Appropriated Retained Earnings

Appropriated Retained Earnings -

Amortization Reserve, Federal

Total Rotinined Earninge .

$-18,282$

457
0

$-44,404$

0
0
0
0
0
0

$-40,546$

$-96$

$-52,717$

4,912
0
4,462
0
0
0

0

0

$-40,540$

457
0
0
0
0
605

0

19

$$
0
$$

0

$-804$

$-52,717$

17,756

3,838

35,100

14,033
4,041

29,500

0
0

0

0

$-7,011$

0

0

Note: Totals may not equal sum of components because of independent rounding

Source: Federal Energy Regulatory Commiscion, FERC Form 1, "Annual Report of Major Electric Utilities, Licensees and Others." 
Table C1. Statement of Income and Rotained Earnings by Other U.S. Entity Within State, 1992 (Continued) (Thousand Dollars)

\begin{tabular}{|c|c|c|}
\hline Item & $\begin{array}{l}\text { Texas } \\
\text { Golden } \\
\text { Spread } \\
\text { Eloctric } \\
\text { Coop }\end{array}$ & $\begin{array}{l}\text { Virginia } \\
\text { Old } \\
\text { Dominion } \\
\text { Electric } \\
\text { Coop }\end{array}$ \\
\hline
\end{tabular}

Electrio Utility Operating Income

Electrio Oparating Rever

$\begin{array}{rr}65,528 & 308,746 \\ 64,491 & 247,009 \\ 0 & 7,603 \\ 15 & 6,907 \\ 0 & 1,554 \\ 9 & 4,624 \\ 0 & 0 \\ 0 & 0 \\ 0 & 0 \\ 0 & 0 \\ 0 & 0 \\ 0 & 0 \\ 0 & 0 \\ 64,515 & 287,098 \\ 1,013 & 39,048\end{array}$

Electric Operating Expenses

Operation Expense...

Maintenance Expense

Depreciation Expense

Amortization

Taxes Other Than Income Taxes

Federal Income Taxes

Provision for Deferred Income Taxes ....................

(less) Provision for Deferred

Income Taxes (credit) ............................................

Investment Tax Credit Adjustments (net) ..............

(less) Gains from Disposition of Utillty Plant .......

Losses from Disposition of Utility Plant

Total Electric Operating Expenses .................

Net Electric Utilty Operating Income

1,013

39,048

Gas Utlity Operating Income

Gas Operating Revenues

0

0

Gas Operating Expenses

Operation Expenses

Depreciation Expenses

Amortization

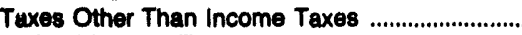

Federal Income Taxes

Other Income Taxes

Provision for Deferred income Taxes

(less) Provision for Deferred

Income Taxes (credit)

Investment Tax Credit Adjustments (net)

(less) Gains from Disposition of Utility Plant .......

Losses from Disposition of Utility Plant ...............

Total Cas Operating Expences

Not Cas Utility Operating Income

.....................

Other Utllity Operating Income

Other Utility Operating Revenues

Other Utility Operating Expenses

Operation Expenses

Maintenence Expenses .........................................

Depreciation Expense

Amortization

Taxes Other Than Income Taxes

Federal income Taxes

Proviaion for Deferred Income Taxes

(less) Provision for Deferred

Income Taxes (credit)

Investment Tax Credit Adjustments (net) .............

(less) Gains from Disposition of Utility Plant ......

Losses from Disposition of Utility Plant

Total Other Utility Operating Expeness ........

Net Other Utillty Operating Income

0

See endnotes at end of an individual electric utility. 
Table C1. Statement of Income and Rotained Earnings by Other U.S. Entity Within State, 1992 (Continued) (Thousand Dollars)

\begin{tabular}{l|c|c|c}
\hline Item & Texas & Virginia & \\
Golden & Old \\
Spread & Dominion \\
Electric & Electric \\
Coop & Coop & \\
\hline
\end{tabular}

Total Utility Operating Income

Utility Operating Expenses

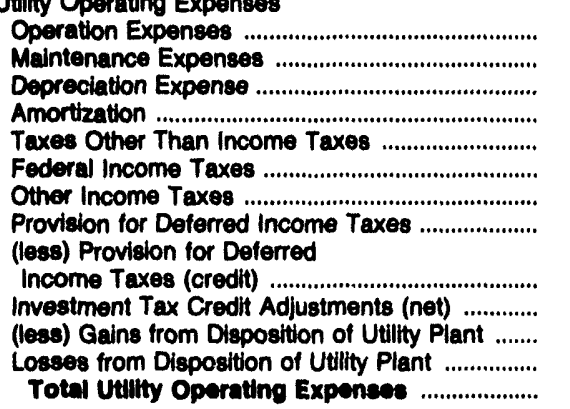

04,491

Net Utilty Operating Income

$\begin{array}{rr}64,491 & 247,009 \\ 0 & 7,603 \\ 15 & 6,807 \\ 0 & 1,554 \\ 0 & 4,624 \\ 0 & 0 \\ 0 & 0 \\ 0 & 0 \\ 0 & 0 \\ 0 & 0 \\ 0 & 0 \\ 0 & 0 \\ 64,515 & 297,698\end{array}$

1,013

39,048

Other Income and Deductions

Other Income

Nonutility Operating Income ..................................

Equity in Earnings of Subsidiary Companies ........

Interest and Dividend Income

Allowance for Other Funds Used

During Construction

Miscellaneous Nonoperating Income

Gain on Disposition of Property

Total Other Income

$\begin{array}{rr}0 & 0 \\ 0 & 861 \\ 45 & 1,876 \\ & \\ 0 & 0 \\ 0 & 10 \\ 0 & 0 \\ 45 & 2,747\end{array}$

Other Income Deductions

Loss on Disposition of Property

Miscellaneous Amortization

Miscellaneous income Deductions

Total Other Income Deductions

Taxes on Other Income and Deductions

Taxes Other Than Income Taxes

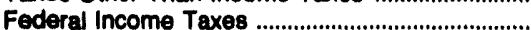

Other Income Taxes .................................................

Provision for Deferred Income Taxes .....................

(less) Provision for Deferred

Income Taxes (credit)

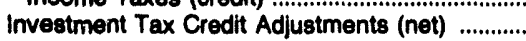

(less) Investment Tax Credits

Total Taxes on Other Income

and Deductions

\section{me.......}

Net Other income and peductions

n.....................

2,732

See endnotes at end of an individual electric utility. 
Table C1. Statement of Income and Rotained Earnings by Othor U.S. Entlty Within State, 1992 (Continued) (Thousand Dollars)

\begin{tabular}{|c|c|c|}
\hline Item & $\begin{array}{l}\text { Texas } \\
\text { Golden } \\
\text { Spread } \\
\text { Electric } \\
\text { Coop }\end{array}$ & $\begin{array}{l}\text { Virginia } \\
\text { Old } \\
\text { Dominion } \\
\text { Electrio } \\
\text { Coop }\end{array}$ \\
\hline
\end{tabular}

\section{Intereat Charges}

Interest on Long-term Debt .................................... Amortization of Debt Discount and Expense ......

Amortzation of Loss on Reacquired Dobt

(leas) Amortzation of Premium on Debt (credit).

(leas) Amortization of Gain on

Reaquired Debt (credit) .......................................... Interest on Debt to Associated Companies .........

Other interest Ext

(lese) Alowance for Borrowed Funds

Used During Construction (credit)

Not Imterest Charges .............................................

Income Bofore Extraordinary ltome

.................

Extraordinary ltems

Extraordinary Income ..............................................

(lese) Extraordinary Deductions

Not Extreordinary ltoms

(less) Federal and Other Income Taxes ..............

Extreordinary items After Taxes.

Not income

.....................

\section{Uneppropilated Rotained Earningo}

Rotained Eamings - Beginning of Year

Balance Transferred from Income

Credits to Retained Earnings

(less) Debits to Retained Eamings

(less) Appropriations of Retained Earnings ..........

(less) Dividends Declared - Preferred Stock .......

(less) Dividends Declared - Common Stock ........

Uneppropriated Undistributed Subsidlary

Earnings

Rotained Earnings - End of Year

Appropriated Retained Earnings ............................

Approprlated Retained Earnings .

Amortzation Reserve, Federal

Total Rotained Eaminge
523

50,118

36,684

274

603
0

0

0
282

17,521

$\mathbf{2 0 , 3 2 1}$

21,468

$\begin{array}{rr}1,058 & 21,458 \\ 0 & 0 \\ 0 & 0 \\ 0 & 0 \\ 0 & 0 \\ 0 & 0 \\ 0 & 0\end{array}$

$1,580 \quad 71,576$

0

0

0

0

1,580

71,576

Note: Totals may not equal sum of components because of independent rounding.

Source: Federal Energy Regulatory Commiselon, FERC Form 1, "Annual Report of Major Electric Utillies, Licensees and Others." 
Table C2. Balance Sheot by Other U.S. Entity Within State

on December 31, 1992

(Thousand Dollars)

\begin{tabular}{|c|c|c|c|c|c|c|}
\hline liem & $\begin{array}{l}\text { Arkansas } \\
\text { Entergy } \\
\text { Power Inc }\end{array}$ & $\begin{array}{l}\text { lowa } \\
\text { Terra } \\
\text { Comfort } \\
\text { Corp }\end{array}$ & $\begin{array}{c}\text { Louisiana } \\
\text { Catalyst } \\
\text { Old River } \\
\text { Hydroel LP }\end{array}$ & $\begin{array}{l}\text { Nevada } \\
\text { Nevada } \\
\text { Sun-Peak Lid } \\
\text { Partners }\end{array}$ & $\begin{array}{l}\text { Rhode Island } \\
\text { Ocean } \\
\text { State } \\
\text {, Power } \\
\text { Co }\end{array}$ & $\begin{array}{c}\text { Rhode Island } \\
\text { Ocean } \\
\text { State } \\
\text { Power } \\
\text { Co II }\end{array}$ \\
\hline 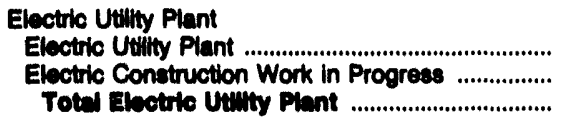 & $\begin{array}{r}217,130 \\
3,473 \\
220,002\end{array}$ & $\begin{array}{r}10,738 \\
0 \\
10,738\end{array}$ & $\begin{array}{r}543,091 \\
0 \\
543,001\end{array}$ & $\begin{array}{r}79,771 \\
0 \\
79,771\end{array}$ & $\begin{array}{r}230,683 \\
0 \\
280,683\end{array}$ & $\begin{array}{r}175,057 \\
0 \\
175,057\end{array}$ \\
\hline 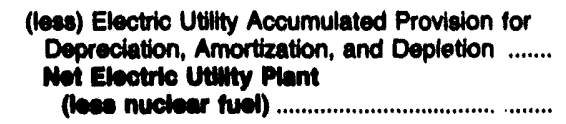 & $\begin{array}{r}76,250 \\
144,352\end{array}$ & $\begin{array}{l}1,903 \\
8,835\end{array}$ & $\begin{array}{r}26,511 \\
\mathbf{5 1 6 , 5 7 9}\end{array}$ & $\begin{array}{r}\mathbf{5 , 0 4 7} \\
\mathbf{7 4 , 7 2 4}\end{array}$ & $\begin{array}{r}22,756 \\
207,007\end{array}$ & $\begin{array}{r}10,935 \\
184,122\end{array}$ \\
\hline 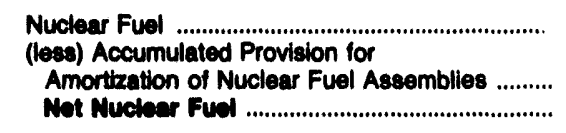 & $\begin{array}{l}0 \\
0\end{array}$ & $\begin{array}{l}0 \\
0\end{array}$ & $\begin{array}{l}0 \\
0\end{array}$ & $\begin{array}{l}0 \\
0\end{array}$ & $\begin{array}{l}0 \\
0\end{array}$ & $\begin{array}{l}0 \\
0\end{array}$ \\
\hline 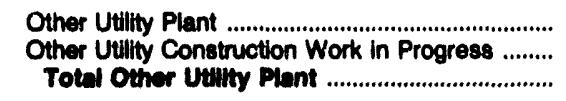 & $\begin{array}{l}0 \\
0 \\
0\end{array}$ & $\begin{array}{l}0 \\
0 \\
0\end{array}$ & $\begin{array}{l}0 \\
0 \\
0\end{array}$ & $\begin{array}{l}0 \\
0 \\
0\end{array}$ & $\begin{array}{l}0 \\
0 \\
0\end{array}$ & $\begin{array}{l}0 \\
0 \\
0\end{array}$ \\
\hline 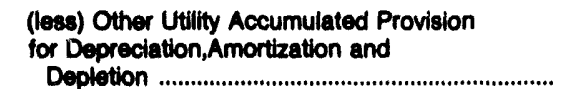 & 0 & 0 & 0 & 0 & 0 & 0 \\
\hline 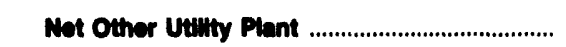 & 0 & 0 & 0 & 0 & 0 & 0 \\
\hline 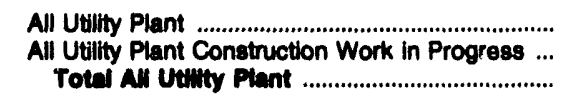 & $\begin{array}{r}217,130 \\
3,473 \\
220,602\end{array}$ & $\begin{array}{r}10,738 \\
0 \\
10,738\end{array}$ & $\begin{array}{r}543,091 \\
0 \\
543,091\end{array}$ & $\begin{array}{r}79,771 \\
0 \\
79,771\end{array}$ & $\begin{array}{r}230,663 \\
0 \\
230,863\end{array}$ & $\begin{array}{r}175,057 \\
0 \\
175,057\end{array}$ \\
\hline 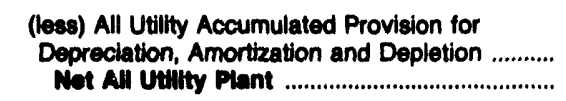 & $\begin{array}{r}76,250 \\
144,352\end{array}$ & $\begin{array}{l}1,903 \\
8,835\end{array}$ & $\begin{array}{r}26,511 \\
516,579\end{array}$ & $\begin{array}{r}5,047 \\
74,724\end{array}$ & $\begin{array}{r}22,756 \\
207,007\end{array}$ & $\begin{array}{r}10,935 \\
184,122\end{array}$ \\
\hline 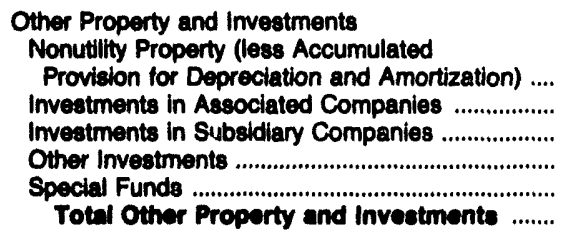 & $\begin{array}{l}0 \\
0 \\
0 \\
0 \\
0 \\
0\end{array}$ & $\begin{array}{l}0 \\
0 \\
0 \\
0 \\
0 \\
0\end{array}$ & $\begin{array}{r}0 \\
0 \\
0 \\
662 \\
37,396 \\
38,058\end{array}$ & $\begin{array}{l}5 \\
0 \\
0 \\
0 \\
0 \\
5\end{array}$ & $\begin{array}{r}0 \\
0 \\
1 \\
0 \\
1,237 \\
1,237\end{array}$ & $\begin{array}{r}0 \\
0 \\
1 \\
0 \\
745 \\
746\end{array}$ \\
\hline 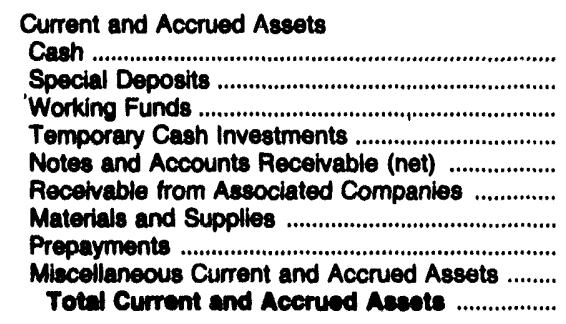 & $\begin{array}{r}136 \\
0 \\
0 \\
0 \\
2,286 \\
2,127 \\
7,101 \\
0 \\
262 \\
11,911\end{array}$ & $\begin{array}{r}17 \\
0 \\
0 \\
796 \\
0 \\
249 \\
132 \\
13 \\
0 \\
1,207\end{array}$ & $\begin{array}{r}394 \\
15,468 \\
0 \\
2,257 \\
5,846 \\
0 \\
0 \\
276 \\
0 \\
24,242\end{array}$ & $\begin{array}{r}56 \\
0 \\
0 \\
1,322 \\
2,672 \\
0 \\
0 \\
0 \\
0 \\
4,050\end{array}$ & $\begin{array}{r}728 \\
0 \\
0 \\
48 \\
4,338 \\
12,835 \\
3,809 \\
160 \\
458 \\
22,378\end{array}$ & $\begin{array}{r}1,689 \\
0 \\
0 \\
48 \\
48 \\
4,582 \\
15,087 \\
4,235 \\
2,971 \\
965 \\
20,560\end{array}$ \\
\hline $\begin{array}{l}\text { Deferred Debits } \\
\text { Unamortized Debt Expense ................................... } \\
\text { Extraordinary Property Loses ........................... } \\
\text { Unrecovered Plant and Regulatory Study Cost ... } \\
\text { Preliminary Survey and Imvestigation Charges .... } \\
\text { Clearing Accounts ................................................ } \\
\text { Deferred Losees from Dieposition of Utility Plant } \\
\text { Research, Development and Demonstration }\end{array}$ & $\begin{array}{l}0 \\
0 \\
0 \\
0 \\
0 \\
0\end{array}$ & $\begin{array}{l}0 \\
0 \\
0 \\
0 \\
0 \\
0\end{array}$ & $\begin{array}{r}29,868 \\
0 \\
0 \\
0 \\
0 \\
0\end{array}$ & $\begin{array}{r}324 \\
0 \\
0 \\
0 \\
0 \\
0\end{array}$ & $\begin{array}{r}1.403 \\
0 \\
0 \\
7 \\
0 \\
0\end{array}$ & $\begin{array}{r}2,853 \\
0 \\
0 \\
1 \\
0 \\
0\end{array}$ \\
\hline 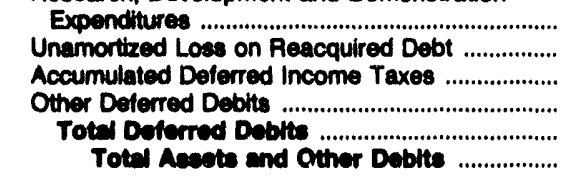 & $\begin{array}{r}0 \\
0 \\
0 \\
0 \\
0 \\
158,283\end{array}$ & $\begin{array}{r}0 \\
0 \\
31 \\
0 \\
31 \\
10,073\end{array}$ & $\begin{array}{r}0 \\
0 \\
0 \\
1,355 \\
31,223 \\
610,102\end{array}$ & $\begin{array}{r}0 \\
0 \\
0 \\
0 \\
324 \\
70,103\end{array}$ & $\begin{array}{r}0 \\
2,820 \\
0 \\
0 \\
4,280 \\
235,750\end{array}$ & $\begin{array}{r}0 \\
1,202 \\
0 \\
0 \\
4,158 \\
196,523\end{array}$ \\
\hline
\end{tabular}

See endnotes at end of an individual electric utility. 
Table C2. Balance Sheot by Other U.S. Entity Within State on December 31, 1892 (Continued) (Thousand Dollars)

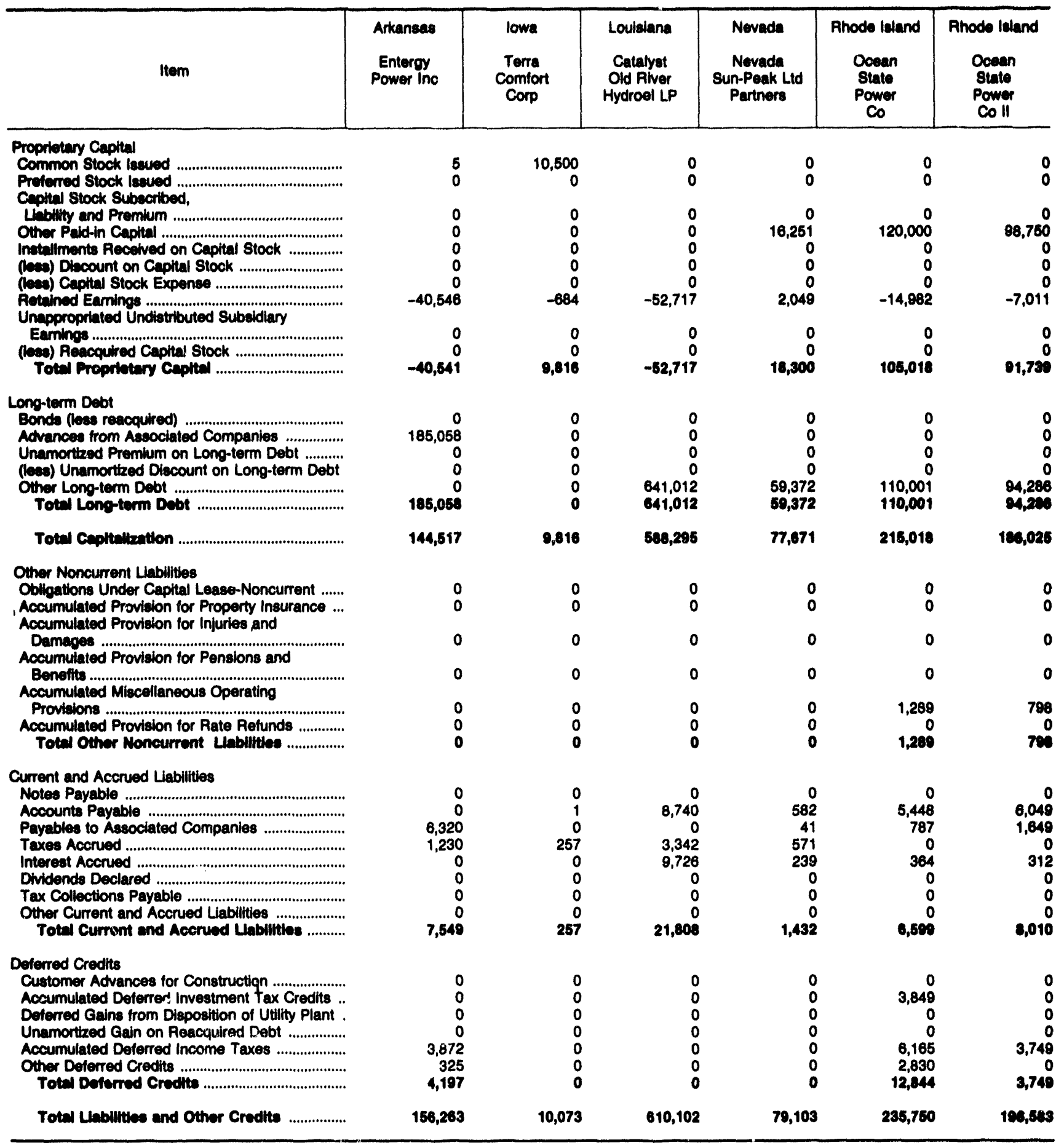

Note: Totals may not equal sum of components because of independent rounding.

Source: Federal Energy Regulatory Commission, FERC Form 1. "Annual Report of Major Electric Utilities, Licensees and Others." 
Table C2. Balance Sheot by Other U.8. Entity Within State on December 31, 1902 (Continued) (Thousand Dollars)

\begin{tabular}{|c|c|c|}
\hline them & $\begin{array}{l}\text { Toxas } \\
\text { Golden } \\
\text { Spread } \\
\text { Electrio } \\
\text { Coop }\end{array}$ & $\begin{array}{l}\text { Virginia } \\
\text { Old } \\
\text { Dominion } \\
\text { Electrio } \\
\text { Coop }\end{array}$ \\
\hline 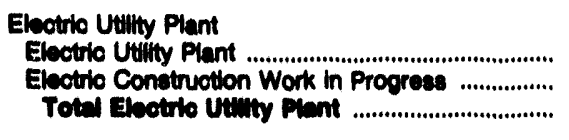 & $\begin{array}{r}114 \\
0 \\
114\end{array}$ & $\begin{array}{l}281,461 \\
322,602 \\
604,053\end{array}$ \\
\hline 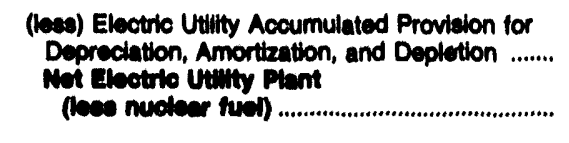 & $\begin{array}{l}72 \\
41\end{array}$ & $\begin{array}{r}89,518 \\
514,536\end{array}$ \\
\hline 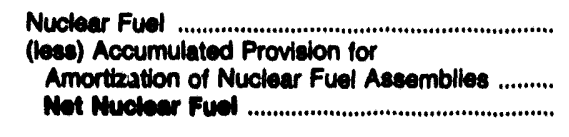 & $\begin{array}{l}0 \\
0 \\
0\end{array}$ & $\begin{array}{l}24,600 \\
14,217 \\
10,303\end{array}$ \\
\hline 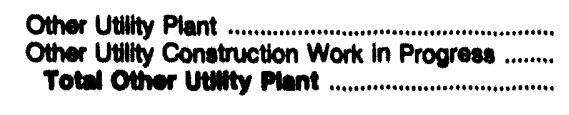 & $\begin{array}{l}\mathbf{0} \\
\mathbf{0} \\
\mathbf{0}\end{array}$ & $\begin{array}{l}0 \\
0 \\
0\end{array}$ \\
\hline 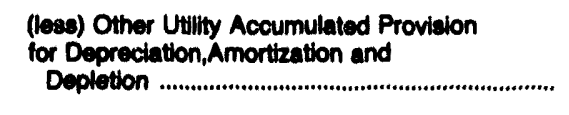 & 0 & 0 \\
\hline 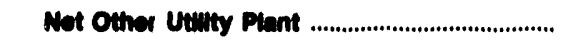 & 0 & 0 \\
\hline 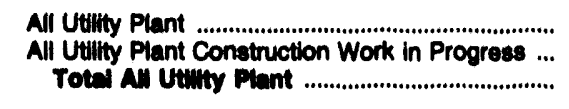 & $\begin{array}{r}114 \\
0 \\
114\end{array}$ & $\begin{array}{l}306,051 \\
322,602 \\
628,053\end{array}$ \\
\hline $\begin{array}{l}\text { (lesa) All Utility Accumulated Provision for } \\
\text { Depreciation, Amortization and Depletion ........... } \\
\text { Net All Utility Plant ............................................... }\end{array}$ & $\begin{array}{l}72 \\
11\end{array}$ & $\begin{array}{l}103,735 \\
824,018\end{array}$ \\
\hline 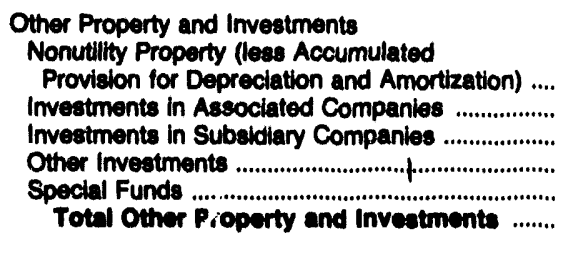 & $\begin{array}{r}0 \\
2 \\
0 \\
1,330 \\
5 \\
1,337\end{array}$ & $\begin{array}{r}0 \\
0 \\
1,373 \\
0 \\
161,576 \\
162,040\end{array}$ \\
\hline 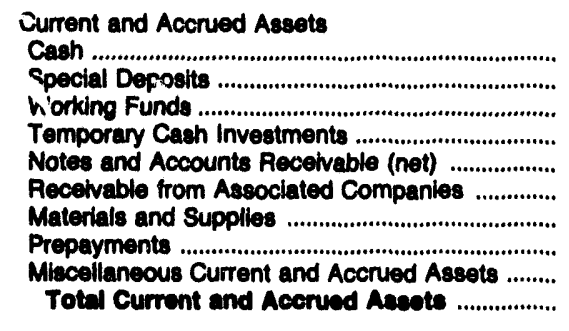 & $\begin{array}{r}1 \\
0 \\
0 \\
60 \\
5,150 \\
0 \\
0 \\
5 \\
25 \\
5,241\end{array}$ & $\begin{array}{r}663 \\
0 \\
1 \\
24,122 \\
46,806 \\
53 \\
5,326 \\
608 \\
655 \\
78,234\end{array}$ \\
\hline 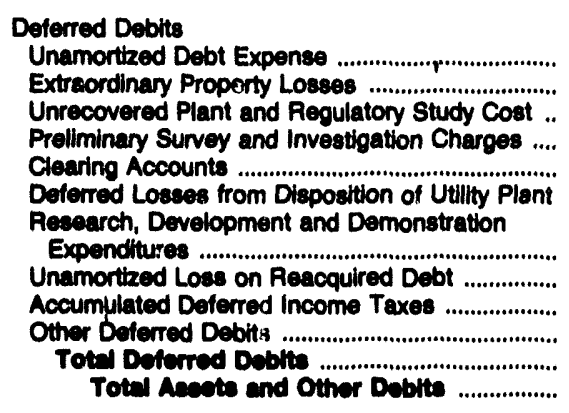 & $\begin{array}{r}0 \\
0 \\
0 \\
0 \\
0 \\
0 \\
0 \\
0 \\
0 \\
0 \\
0 \\
6,610\end{array}$ & $\begin{array}{r}3,518 \\
0 \\
2,296 \\
0 \\
0 \\
0 \\
0 \\
0 \\
15,722 \\
0 \\
14,985 \\
38,621 \\
\mathbf{2 0 2 , 6 2 2}\end{array}$ \\
\hline
\end{tabular}

See endnotes at end of an individual electric utility. 


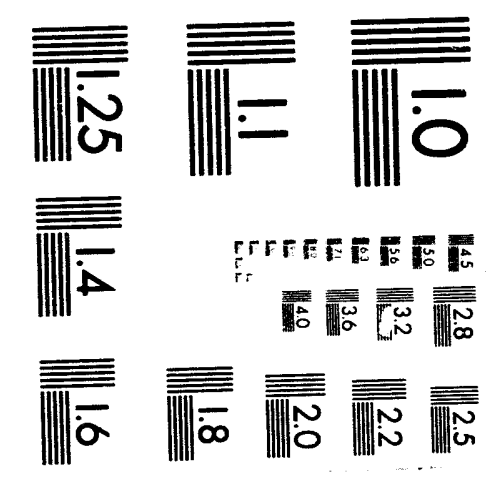



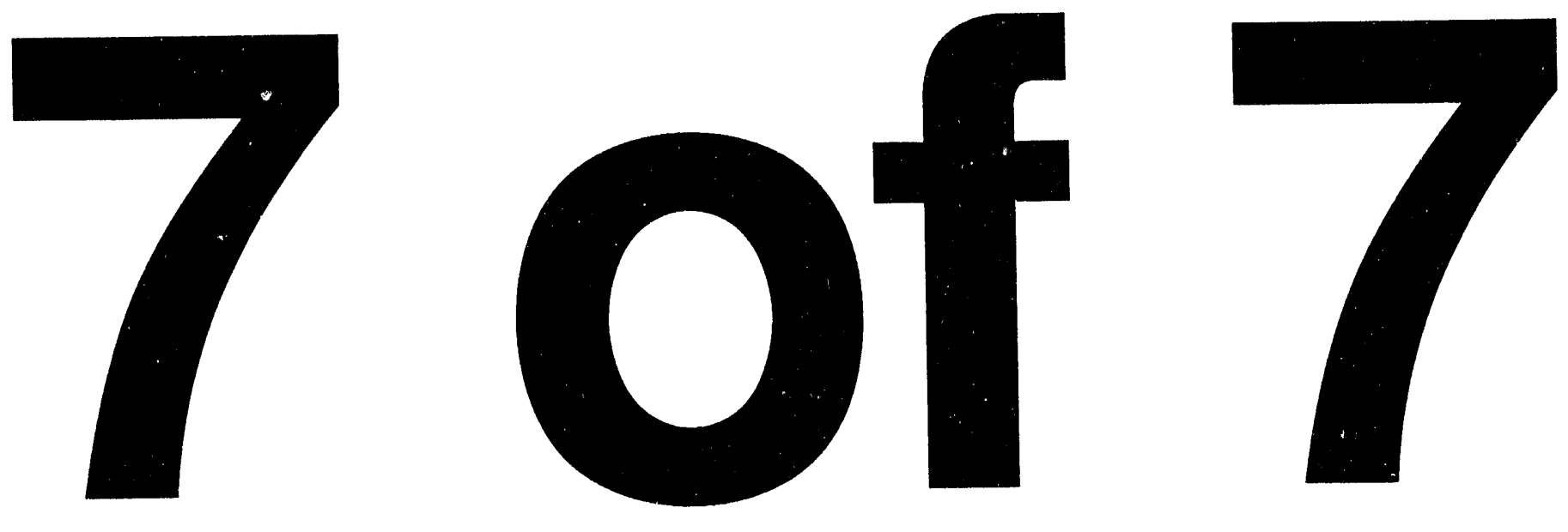
Table C2. Balance Sheet by Other U.S. Entity Within State on December 31, 1992 (Continued)

(Thousand Dollars)

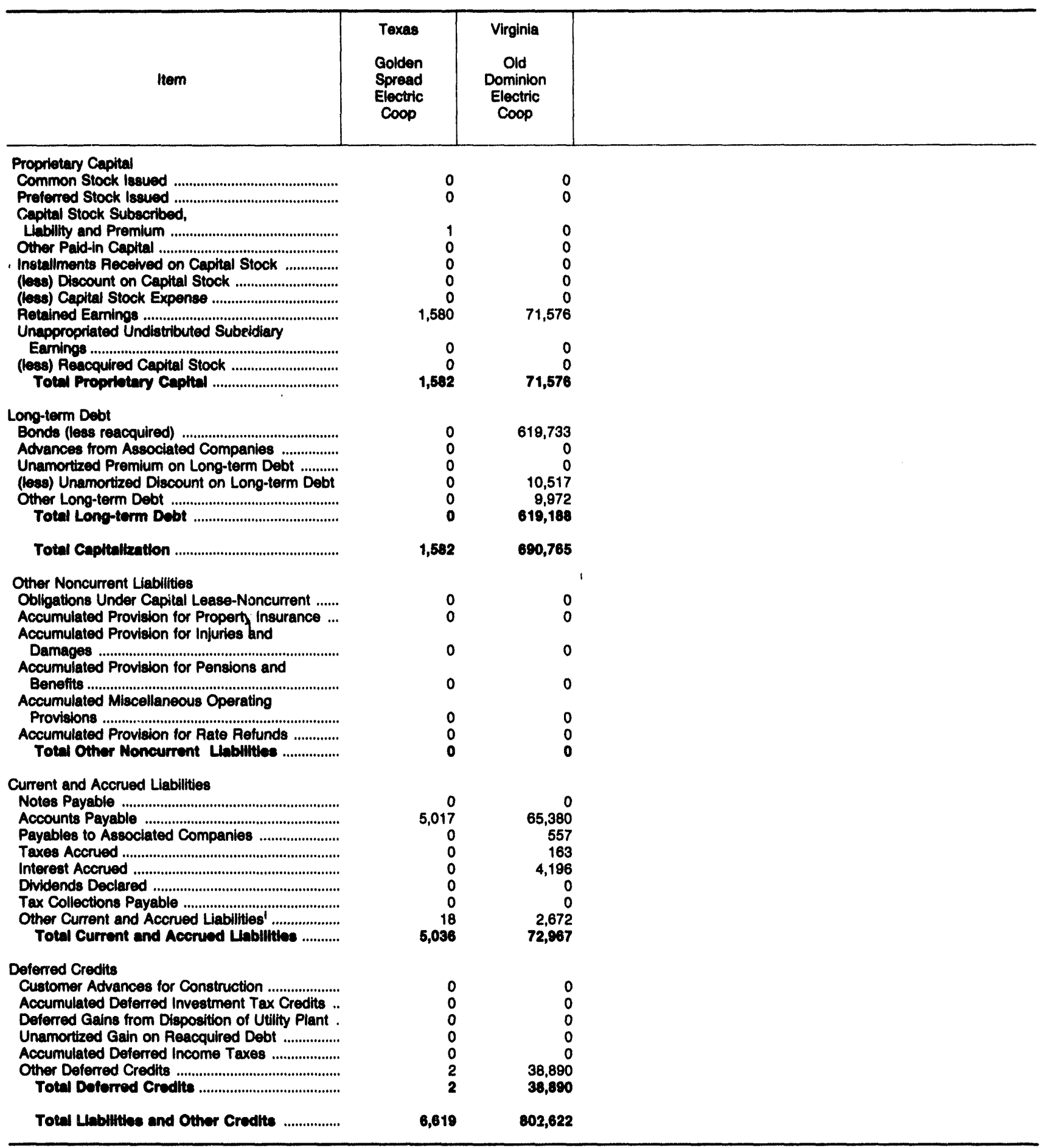

Note: Totals may not equal sum of components because of independent rounding.

Source: Federal Energy Regulatory Commission, FEAC Form 1, "Annual Report of Major Electric Utilities, Licensees and Others." 
Table C3. Statement of Cash Flows by Other U.S. Entity Within State, 1992 (Thousand Dollars)

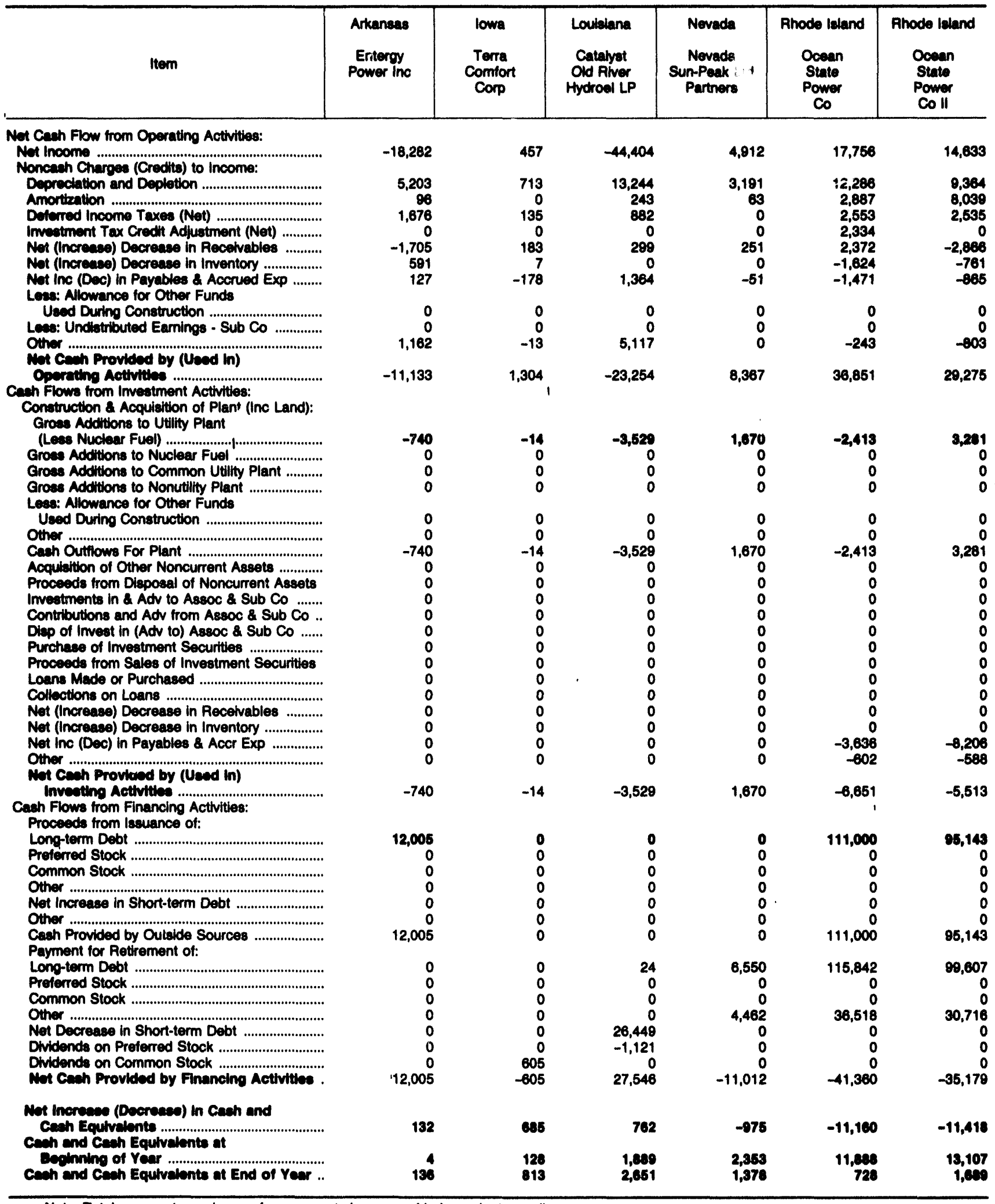

Note: Totals may not equal sum of components beceuse of independent rounding.

Source: Federal Energy Regulatory Commission, FERC Form 1, "Annual Report of Major Electric Utilities, Licensees and Others." 
Table C3. Statement of Caah Flows by Other U.S. Entity Within State, 1992 (Continued) (Thousand Dollars)

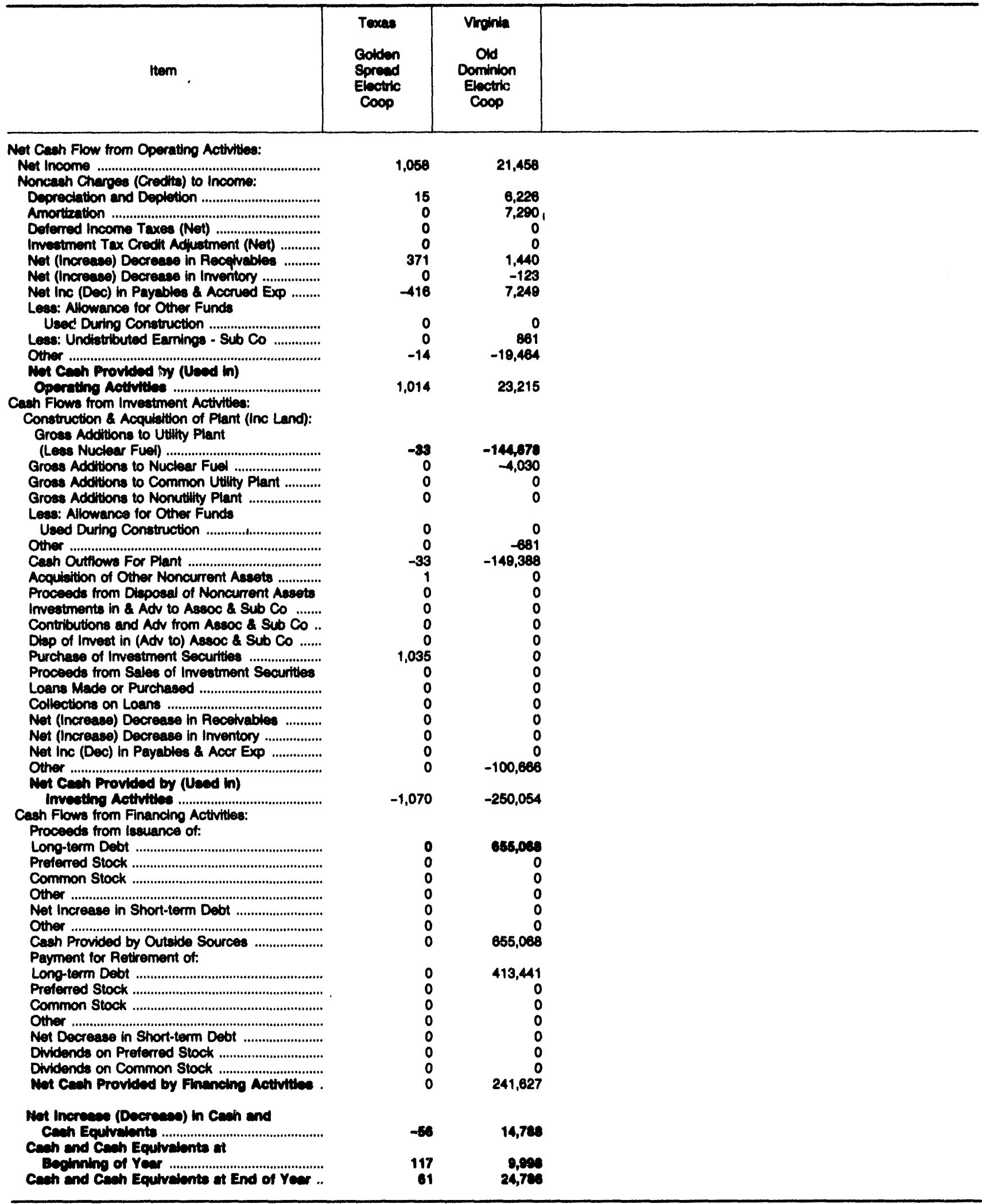

Note: Totals may not equal eum of components because of independent rounding.

Source: Federal Energy Regulatory Commisaion, FERC Form 1, "Annual Repart of Major Electric Utilliea, Licensees and Others." 
Table C4. Number of Conaumers, Sales, and Operating Revenue by Other U.S. Entlty Within Stato, 1982

\begin{tabular}{|c|c|c|c|c|c|c|}
\hline Item & $\begin{array}{c}\text { Arkansas } \\
\text { Entergy } \\
\text { Power Inc }\end{array}$ & $\begin{array}{l}\text { lowa } \\
\text { Terra } \\
\text { Comfort } \\
\text { Corp }\end{array}$ & $\begin{array}{l}\text { Louisiana } \\
\text { Catalyst } \\
\text { Old River } \\
\text { Hydroel LP }\end{array}$ & $\begin{array}{c}\text { Nevada } \\
\text { Nevada } \\
\text { Sun-Peak Ltd } \\
\text { Partners }\end{array}$ & $\begin{array}{l}\text { Rhode lsland } \\
\text { Ocean } \\
\text { State } \\
\text { Power } \\
\text { Co }\end{array}$ & $\begin{array}{c}\text { Rhode lsland } \\
\text { Ocean } \\
\text { State } \\
\text { Power } \\
\text { Co II }\end{array}$ \\
\hline 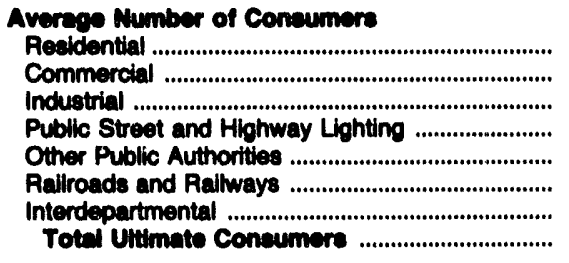 & $\begin{array}{l}0 \\
0 \\
0 \\
0 \\
0 \\
0 \\
0 \\
0\end{array}$ & $\begin{array}{l}0 \\
0 \\
0 \\
0 \\
0 \\
0 \\
0 \\
0\end{array}$ & $\begin{array}{l}0 \\
0 \\
0 \\
0 \\
0 \\
0 \\
0 \\
0\end{array}$ & $\begin{array}{l}0 \\
0 \\
0 \\
0 \\
0 \\
0 \\
0 \\
0\end{array}$ & $\begin{array}{l}0 \\
0 \\
0 \\
0 \\
0 \\
0 \\
0 \\
0\end{array}$ & $\begin{array}{l}0 \\
0 \\
0 \\
0 \\
0 \\
0 \\
0 \\
0\end{array}$ \\
\hline 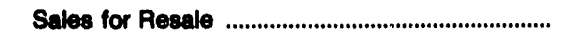 & 2 & 1 & 2 & 0 & 4 & 4 \\
\hline Total Number of Coneumere .............................. & 2 & 1 & 2 & $\mathbf{0}$ & 4 & 4 \\
\hline 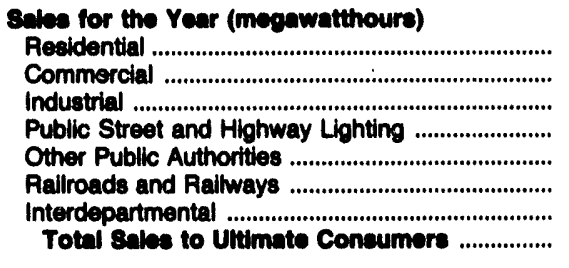 & $\begin{array}{l}0 \\
0 \\
0 \\
0 \\
0 \\
0 \\
0 \\
0\end{array}$ & $\begin{array}{l}0 \\
0 \\
0 \\
0 \\
0 \\
0 \\
0 \\
0\end{array}$ & $\begin{array}{l}0 \\
0 \\
0 \\
0 \\
0 \\
0 \\
0 \\
0\end{array}$ & $\begin{array}{l}0 \\
0 \\
0 \\
0 \\
0 \\
0 \\
0 \\
0\end{array}$ & $\begin{array}{l}0 \\
0 \\
0 \\
0 \\
0 \\
0 \\
0 \\
0\end{array}$ & $\begin{array}{l}0 \\
0 \\
0 \\
0 \\
0 \\
0 \\
0 \\
0\end{array}$ \\
\hline 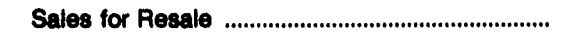 & $2,763,729$ & 230 & 639,887 & 0 & $2,188,160$ & $2,142,114$ \\
\hline 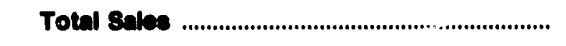 & $2,763,729$ & 230 & 639,887 & $\mathbf{0}$ & $2,188,160$ & $2,142,114$ \\
\hline 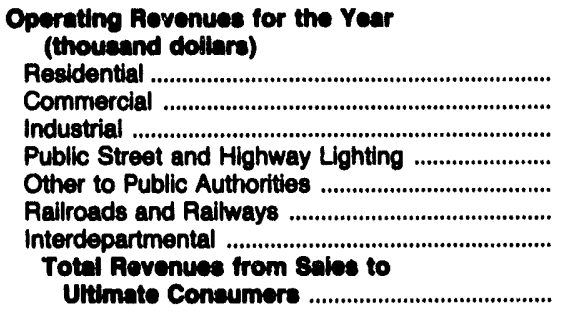 & $\begin{array}{l}0 \\
0 \\
0 \\
0 \\
0 \\
0 \\
0 \\
0\end{array}$ & $\begin{array}{l}0 \\
0 \\
0 \\
0 \\
0 \\
0 \\
0 \\
0\end{array}$ & $\begin{array}{l}0 \\
0 \\
0 \\
0 \\
0 \\
0 \\
0 \\
0\end{array}$ & $\begin{array}{l}0 \\
0 \\
0 \\
0 \\
0 \\
0 \\
0 \\
0\end{array}$ & $\begin{array}{l}0 \\
0 \\
0 \\
0 \\
0 \\
0 \\
0 \\
0\end{array}$ & $\begin{array}{l}0 \\
0 \\
0 \\
0 \\
0 \\
0 \\
0 \\
0\end{array}$ \\
\hline Sales for Resale & 56,145 & 1,964 & 41,593 & 0 & 107,318 & 104,842 \\
\hline 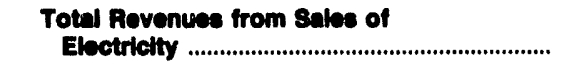 & 56,145 & 1,884 & 41,593 & $\mathbf{0}$ & 107,318 & 104,842 \\
\hline (less) Provision for Rate Refunds .......................... & 0 & 0 & 0 & 0 & 0 & 0 \\
\hline Net Rovenues from sales of Electrictly ....... & 56,145 & 1,864 & 41,593 & $\mathbf{0}$ & 107,318 & 104,842 \\
\hline Other Operating Revenues ......................................... & 130 & 0 & 0 & 15,851 & 3,996 & 0 \\
\hline 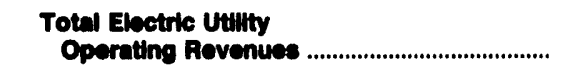 & 66,275 & 1,864 & 41,593 & 15,851 & 111,313 & 104,842 \\
\hline
\end{tabular}

Note: Totals may not equal sum of components because of independent rounding.

Source: Federal Energy Regulatory Commission, FERC Form 1, "Annual Report of Major Electric Utilities, Licensees and Others." 
Table C4. Number of Consumers, Sales, and Operating Revenue by Other U.S. Entity Within State, 1992 (Continued)

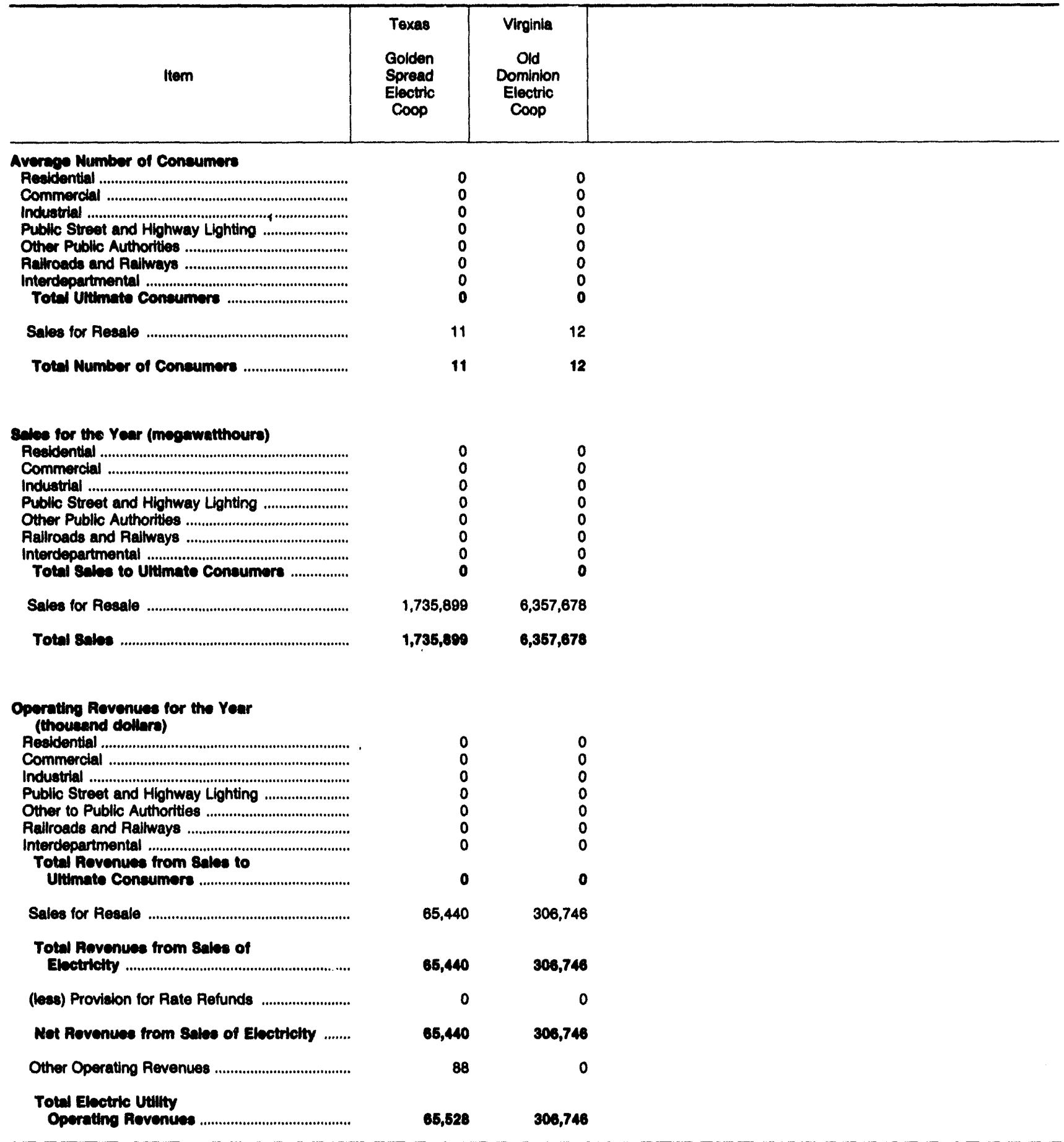

Note: Totals may not equal sum of components because of independent rounding.

Source: Federal Energy Regulatory Commission, FERC Form 1, "Annual Report of Major Electric Utilities, Licensees and Others." 
Table C5. Electric Operation and Maintenance Expenses by

Other U.S. Entity Within State, 1992

(Thousand Dollars)

\begin{tabular}{|c|c|c|c|c|c|c|}
\hline Item & $\begin{array}{l}\text { Arkansas } \\
\text { Entergy } \\
\text { Power Inc }\end{array}$ & $\begin{array}{l}\text { lowa } \\
\text { Terra } \\
\text { Comfort } \\
\text { Corp }\end{array}$ & $\begin{array}{l}\text { Loulsiana } \\
\text { Catalyst } \\
\text { Old River } \\
\text { Hydroel LP }\end{array}$ & $\begin{array}{c}\text { Nevada } \\
\text { Nevada } \\
\text { Sun-Peak Ltd } \\
\text { Partners }\end{array}$ & $\begin{array}{l}\text { Rhode Island } \\
\text { Ocean } \\
\text { State } \\
\text { Power } \\
\text { Co }\end{array}$ & $\begin{array}{c}\text { Rhode Island } \\
\text { Ocean } \\
\text { State } \\
\text { Power } \\
\text { Co II }\end{array}$ \\
\hline
\end{tabular}

Power Production Expenses

Steam Power

Operation Expenses

Supervision and Engineering ............................... 1,040

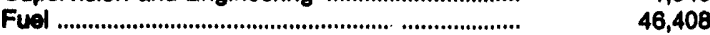

Steam Expenses ....................................................... 527

Steam from Other Sources ...................

(less) Steam Transferred (credit)

Electric Expenses ....................................................

Miscellaneous Steam Power Expenses ...............

Rents

Total Operation Expenses

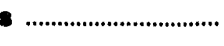

1
0
585
2,081
0
50,843

$\begin{array}{lrr}0 & 253 & 253 \\ 0 & 52,282 & 50,191 \\ 0 & 2,942 & 2,225 \\ 0 & 0 & 0 \\ 0 & 0 & 0 \\ 0 & 1,161 & 1,152 \\ 0 & 511 & 173 \\ 0 & 203 & 4,192 \\ 0 & 57,352 & 58,186\end{array}$

Maintenance Expenses

Supervision and Engineering ................................ 248

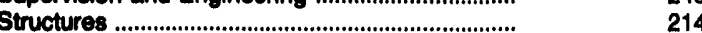

Boller Plant

Electric Plant

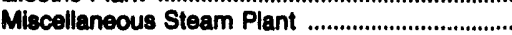

Total Maintenance Expenses

0
0
0
0
0
0
0
0
0

Total stewn Powor Production

Expenses

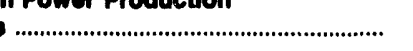

53,015

$\mathbf{0}$

50,781

61,285

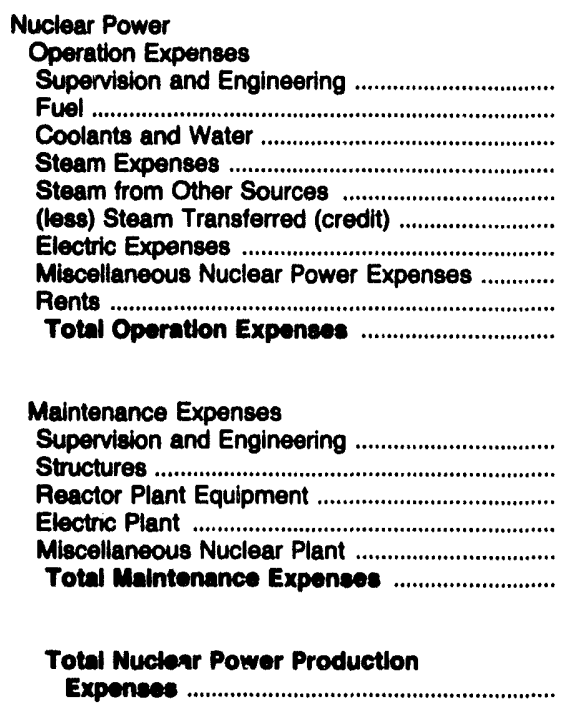

Nuclear Power

Operation Expenses

Supervision and Engineering

Coolants and Water

Steam Expenses

am from Other Sources

Electric Expenses

Miscellaneous Nuclear Power Expenses ...........

Rents

Maintenence Expenses

Supervision and Engineering

Reactor Plant Equipment

Electinc Plant

Miscellaneous Nuclear Plant

Expenses

o

$\begin{array}{rr}190 & 185 \\ 174 & 171 \\ 1,419 & 1,145 \\ 480 & 1,497 \\ 167 & 81 \\ 2,429 & 3,070\end{array}$

Hydraulic Power

Operation Expenses

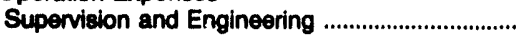

Water for Power

Hydraulic Expenses

Electric Expenses

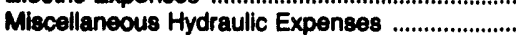

Rents

Total Operation Expenses

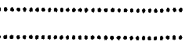

See endnotes at end of an individual electric utility 
Table C5. Electric Operation and Maintenance Expenses by Other U.S. Entity Within State, 1992 (Continued)

(Thousand Dollars)

\begin{tabular}{|c|c|c|c|c|c|c|}
\hline Item & $\begin{array}{l}\text { Arkansas } \\
\text { Entergy } \\
\text { Power Inc }\end{array}$ & $\begin{array}{c}\text { lowa } \\
\text { Terra } \\
\text { Comfort } \\
\text { Corp }\end{array}$ & $\begin{array}{l}\text { Louisiana } \\
\text { Catalyst } \\
\text { Old River } \\
\text { Hydroel L.P }\end{array}$ & $\begin{array}{c}\text { Nevada } \\
\text { Nevada } \\
\text { Sun-Peak Ltd } \\
\text { Partners }\end{array}$ & $\begin{array}{l}\text { Rhode lsland } \\
\text { Ocean } \\
\text { State } \\
\text { Power } \\
\text { Co }\end{array}$ & $\begin{array}{c}\text { Rhode Island } \\
\text { Ocean } \\
\text { State } \\
\text { Power } \\
\text { Co II }\end{array}$ \\
\hline
\end{tabular}

Maintenance Expenses

Supervision and Engineering

(n)

Reservoirs, Dams and Waterways

Electric Plant

Miscellaneous Hydraulic Plant

Total Malntenance Expenses.

Totel Hydraulk Power

Production Expenses

Other Power

Operation Expenses

Supervision and Engineering

Fuel ......................................

Generation Expenses ...........................................

Miscellaneous Other Power Expenses ................

Rents

Total Operation Exponses

0
0
0
0
0
0

o

$\mathbf{0}$

3,800

343
0

0

0

0

0

$\mathbf{0}$

0

Maintenance Expenses

Supervision and Engineering

Structures

Generating and Electric Plant

Miscellaneous Other Power P

Total Maintenance Expensea

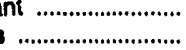

Totat Other Power Production

Exponees

$\mathbf{0}$

93

$\begin{array}{rll}-6 & 0 & 0 \\ 0 & 0 & 0 \\ 403 & 0 & 0 \\ 119 & 0 & 0 \\ 103 & 0 & 0 \\ 619 & 0 & 0\end{array}$

Other Power Supply Expenses

Purchased Power

System Control and Load Dis

ad Dispatching

Total Other Power Supply Expenees

1,587

1,587

54,602

98

3,908

880

59,781

61,295

Transmission

Operation Expenses

Supervision and Engineering

Load Dispatching

Station Expenses

Overhead Line Expenses

Underground Line Expenses

Transmission of Electricity by Others

Miecellaneous Transmission Expenses ..............

Rents

Total Operation Expenses

$\begin{array}{rrr}0 & 0 & 0 \\ 0 & 68 & 0 \\ 0 & 0 & 0 \\ 0 & 0 & 0 \\ 0 & 0 & 0 \\ 0 & 0 & 0 \\ 0 & 0 & 0 \\ 0 & 864 & 867 \\ 0 & 830 & 887\end{array}$

Meintenance Expenses

Supervision and Engineering

Structures

Station Equipment

Overtead Lines

Underground Lines

3,254

0

887

See endnotes at end of an individual electric utility 
Table C5. Electric Operatlon and Maintenance Expenses by

Other U.S. Entity Within State, 1992 (Continued)

(Thcusand Dollars)

\begin{tabular}{|c|c|c|c|c|c|c|}
\hline Item & $\begin{array}{c}\text { Arkansas } \\
\text { Entergy } \\
\text { Power Inc }\end{array}$ & $\begin{array}{l}\text { lowa } \\
\text { Terra } \\
\text { Comfort } \\
\text { Corp }\end{array}$ & $\begin{array}{l}\text { Louldiana } \\
\text { Catalyst } \\
\text { Old River } \\
\text { Hydroel LP }\end{array}$ & $\begin{array}{c}\text { Nevada } \\
\text { Nevada } \\
\text { Sun-Peak Ltd } \\
\text { Partners }\end{array}$ & $\begin{array}{c}\text { Phode Island } \\
\text { Ocean } \\
\text { State } \\
\text { Power } \\
\text { Co }\end{array}$ & $\begin{array}{l}\text { Phode leland } \\
\text { Ocean } \\
\text { State } \\
\text { Power } \\
\text { Co II }\end{array}$ \\
\hline
\end{tabular}

Maintenance Expenses

Miscellaneous Transmission Plant

Total Maintenance Expenses

0

0

46
48

0

0

0

Total Tranemiselon Expenese

3,254

0

48

083

112

Distribution

Operation Expenses

Supervision and Engineering

Load Dispatching

Station Expenses

Overhead Line Expenses

Underground Line Expeness

Street Lighting and Signal System Expenses .....

Moter Expenses

Customer Installations Expenses

Miscellaneous Distribution Expenses ...................

Rents

Total Operation Expenees

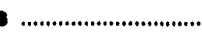

Maintenance Expenses

Supervision and Engineering

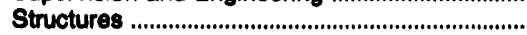

Station Equipment

Overhead Lines ......

Underground Lines

Line Transformers

Street Lighting and Signal Systems

Miscellaneous Distribution Plant

Total Malntenance Exponses

Total Diatribution Expenses

Customer Accounts Expenses

Supervision

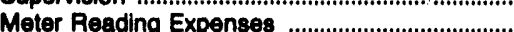

Customer Records and Collection Expenses ....

Uncollectible Accounts .

Miscellaneous Customer Accounts Expenses ....

Total Customer Accounts Expenese

0

0

0

0

0

o

97

Customer Service and Information Expenses
Supervilion

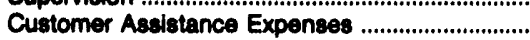
Informational and Instructional Expenses .............
Miscellaneous Customer Service
and Informational Expenses ................................
Total Customer service and
intormational Expenes

Sales Expenses

Supervision ...............................................................

Demonstrating and Selling Expenses ..................

Advertising Expenses

Miscellaneous Sales Expenses

Total Ealee Expentese ...

0
0
0
0
0
0
0
0
0
0

$\begin{array}{ll}0 & 0 \\ 0 & 0 \\ 0 & 0 \\ 0 & 0 \\ 0 & 0 \\ 0 & 0 \\ 0 & 0 \\ 0 & 0 \\ 0 & 0 \\ 0 & 0\end{array}$

See endnotes at end of an individual electric utility. 
Table C5. Electric Operation and Maintenance Expenses by Other U.S. Entity Within State, 1992 (Continued)

(Thousand Dollars)

\begin{tabular}{|c|c|c|c|c|c|c|}
\hline Item & $\begin{array}{c}\text { Arkansas } \\
\text { Entergy } \\
\text { Power Inc }\end{array}$ & $\begin{array}{l}\text { lowa } \\
\text { Terra } \\
\text { Comfort } \\
\text { Corp }\end{array}$ & $\begin{array}{l}\text { Loulaiana } \\
\text { Catahyat } \\
\text { Old Fiver } \\
\text { Hydroel LP }\end{array}$ & $\begin{array}{c}\text { Nevada } \\
\text { Nevada } \\
\text { Sun-Peak Ltd } \\
\text { Partners }\end{array}$ & $\begin{array}{c}\text { Phode Island } \\
\text { Ocean } \\
\text { State } \\
\text { Power } \\
\text { Co }\end{array}$ & $\begin{array}{c}\text { Rhode laland } \\
\text { Ocean } \\
\text { State } \\
\text { Power } \\
\text { Co II }\end{array}$ \\
\hline
\end{tabular}

Administrative and General Expenses

Operation Expenses

Administrattve and General Salaries

Oifice Supplies and Expenses

(less) Administrattve Expenses

Transferred (credit) ............

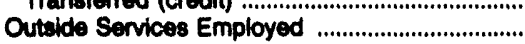

Property insurance ...

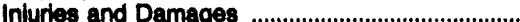

Employee Pensions and Benefits

Franchise Pequirements.

Regulatory Commiseion Expenses

(less) Duplicate Charges (credit)

General Advertising Expenses

Miscellaneous General Expenses

Rents

Totel Operation Expences

Maintenance of General Plant

Total Administrattve and

Ceneral Exponees

0
0
0
2,266
66
0
0
0
39
0
0
5
0
2,376

24
0
0
20
42
8
4
0
0
0
0
2
0
100

1,398
76

0

0
0

298

289

0
721

560

0

535

228

0
0

164
0
3,604

0
370
0

0
70
0
3

3
60

6

0

0
676

678
0

1,100

$306-419$

Total Eloctric Operation and

Maintenance Expenses

0
2,376

0

0

0
1,843
485
0
0
0
0
0
17
8
27
298

0
1,771
364
0
0
0
0
0
28
0
1
2,070

100

3,684

1,100

168

53

2,932

60,232

197

7,841

1,009

09,098

85,176

Olstribution of Salaries and

Wages Charged to Electric

Operation and Maintenance

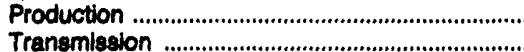

Distribution

Customer Accounts

Customer Service and

Informational Expenses

Sales Expenses

Adminstrattve and General

Allocated from Clearing Accounts

Total selartes and Wages

Number of Electric Department Employees

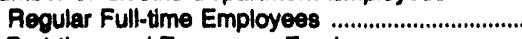

Part-time and Temporary Employees

....................

Total Electilc Department Employees .........

0
0
0
0
0
0
0
0
0

1,434
0
0
0
0
0
0
1,399
0
2,833

$$
\begin{aligned}
& 0 \\
& 0 \\
& 0 \\
& 0 \\
& 0 \\
& 0 \\
& 0 \\
& 0 \\
& 0
\end{aligned}
$$

0
0
0
0
0
0
0
0
0

Note: Operating expenses include fuel expenditures. Totals may not equal sum of components because of independent rounding.

Source: Federal Energy Regulatory Commission, FERC Form 1, "Afinual Report of Major Electric Utillies, Lcensees and Others." 
Table C5. Electrlc Operation and Malntenance Expenses by Othor U.S. Entity Within State, 1992 (Continued) (Thousand Dollars)

\begin{tabular}{c|c|c|c}
\hline Item & $\begin{array}{c}\text { Texas } \\
\text { Golden } \\
\text { Spread } \\
\text { Electric } \\
\text { Coop }\end{array}$ & $\begin{array}{c}\text { Virginia } \\
\text { Old } \\
\text { Dominion } \\
\text { Eloctric } \\
\text { Coop }\end{array}$ \\
\hline
\end{tabular}

Power Produotion Expencece

Stcam Power

Operation Expensea

Supervision and Encineering

Full.

Steam Expenses ........................................................

Steam from Other Sources .

(keo) Steam Tranoferred (credt)

Electric Expensen

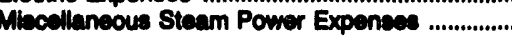

Rents

Toted Opertition Expersecs

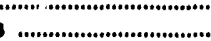

Mintenance Expenses

Supervision and Engineering

Structures

Boller Plant

Electirc Piant

Macellaneous Steam Plant

Toted Insintenence Expeniece

Totel stem Power Production

Exponsen

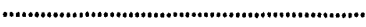

Nuclear Power

Operation Expenses

Supervidon and Engineering .................................

Fun

Coolante and Water

Steam Expenses

Steam from Other Sources

(leas) Steam Transferred (credit)

Mincellaneous Nuclear Power Expenses

Ronts

Totel Operretion Expenses

Maintenance Expenses

Supenvioion and Enoineering

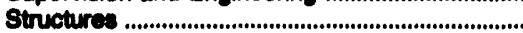

Reactor Plant Equipment

Electric Plant

Mhocelleneous Nuclear Plant

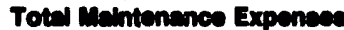

Totel Muciver Power Production

Expranteso

Hydraulic Power

Operation Expenes.

Supenvilon and Engineering

Water for Power .

Hychaulc Expenses

Electric Expenees

Mecellaneous Hydraulla Expenseg

Totel Opertion Expenses

- l............................

...................................

2,135

5,608

88

1,445

0

20

2,522

39

11,061

See endnotes at end of in individual electric utilty. 
Table C5. Electric Operation and Maintonance Expenses by Othor U.S. Entity Within State, 1992 (Continued) (Thousand Dollars)

\begin{tabular}{|c|c|c|}
\hline Item & $\begin{array}{l}\text { Toxas } \\
\text { Golden } \\
\text { Spread } \\
\text { Eloctric } \\
\text { Coop }\end{array}$ & $\begin{array}{l}\text { Virginia } \\
\text { Old } \\
\text { Dominion } \\
\text { Electric } \\
\text { Coop }\end{array}$ \\
\hline
\end{tabular}

Mintenance Expentes

Suporvition and Enginearing

Reaervoine, Dame and Waterways .......................

Electulc Plant

Miscellaneous Hydraullo Plant

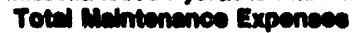

Totel Hydrumb Power

Production Exponsea

Other Power

Operation Expenses

Supervision and Engineering

Ceneration Expenees

Mhocellaneous Other Power Expenses ................

Rents

Totel Operation Expensese

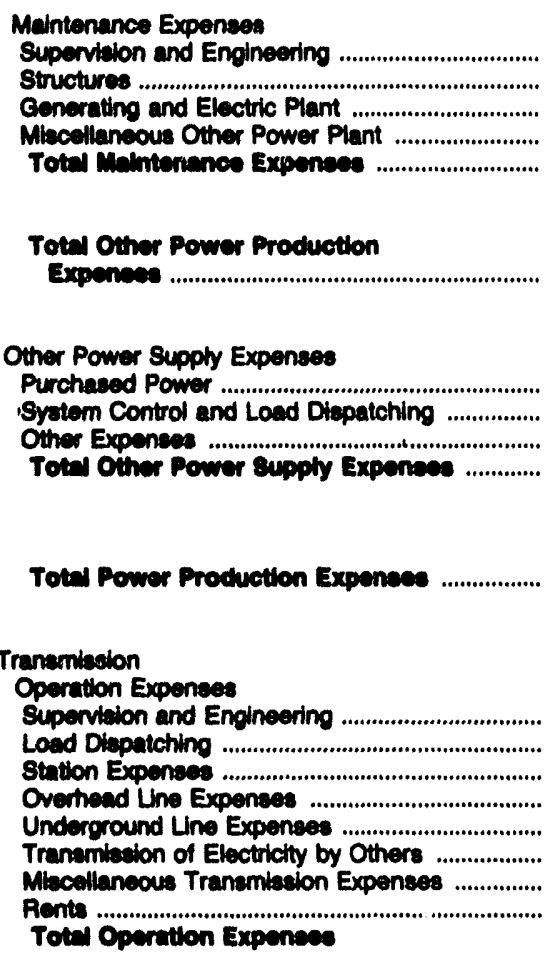

Mantenance Expenses

Supendion and Engineering

Cenerating and Electric Plant

Miecellaneous Other Power Plant

Totel Malmierience Expenses

Totel Other Power Production

Expensese

Other Power Supoly Expenser

yotem Control and Load Diepatching ................

Tot 1 Other Power enophy Expenses 
Table C5. Electric Operation and Malntenance Expenses by Other U.S. Entity Within State, 1992 (Continued)

(Thousand Dollars)

\begin{tabular}{l|c|c|c}
\hline & Texas & Virginia & \\
& Golden & Old \\
Stem & Spread & Dominion \\
& Electric & Eloctric \\
Coop & Coop & \\
\hline
\end{tabular}

Maintenance Expenses

Supervition and Engineering

Structures

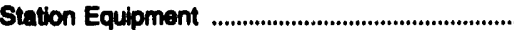

Underoround Lines

Miscellanecus Tranamiesion Plant

Total Mointenance Expensese

$\begin{array}{ll}0 & 0 \\ 0 & 0 \\ 0 & 0 \\ 0 & 0 \\ 0 & 0 \\ 0 & 0 \\ 0 & 0\end{array}$

Total Tranemiaslon Expensea

10,653

\section{Distribution}

Operation Expenseo

Supervision and Engineering

Load Dispatching

Station Expenses

Overhead Line Expenses

Underground Line Expenses

Street Lighting and Signal System Expenses ....

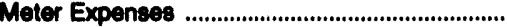

Customer Installations Expenses ....

Miscellaneous Distribution Expenses

Rents

Total Operation Exponese

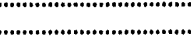

Maintenance Expenses

Supervision and Engineering

Station Equipment

Overhead Lines

Underoround Lines

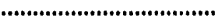

Une Transformers

Street Lighting and Signal Systems ......................

Meters

Miscellaneous Distribution Plant

Total Malntenance Expensese

Total Dietribution Expenses

Customer Accounts Expenses

Supervision

Meter Reading Expenses ....................................... Customer Records and Collection Expenses ... Uncollectible Accounts

Miscellaneous Customer Accounts Expenses ..

Totel Customer Accounts Expenses ..............

Customer Service and Information Expenses

Superviaton

Customer Aseistance Expenses

Informational and Instructional Expenses .............

Miscellaneous Customer Service

and Informational Expenses

Totwl Cutomer Sorvice and

Informational Expences

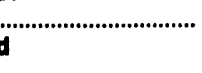

See endnotes at end of an individual electric utility. 
Table C5. Electrlc Operatlon and Malntenance Expences by Other U.S. Entity Within State, 1992 (Continued)

(Thousand Dollars)

\begin{tabular}{|c|c|c|}
\hline Item & $\begin{array}{c}\text { Texas } \\
\text { Colden } \\
\text { Spread } \\
\text { Electric } \\
\text { Coop }\end{array}$ & $\begin{array}{l}\text { Virginia } \\
\text { Old } \\
\text { Dominion } \\
\text { Electric } \\
\text { Coop }\end{array}$ \\
\hline
\end{tabular}

\section{Sales Expenses}

Supervition

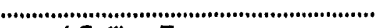

Advertiaing Expenees

Miscellaneous Sales Expenses

Totel sales Expensen

Administrattve and Generai Expenses

Operation Expenses

Administrathe and General Salartes

Office Supplies and Expenees

(lese) Adminiatrative Expenses

Transferred (credit) .

Outeide Services Employed

Property Inaurance

Injuries and Damages

Employeo Pensions and Benetit.

Franchime Requirements

Requlatory Commiseion Expenses

(lese) Duplicate Charges (credit)

Generul Advertieing Expenses

Miscellaneous General Expenses

Rents

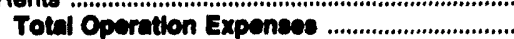

Malntenance of General Plant

Total Adimintetrative and

Conotal Expenses

$\begin{array}{ll}0 & 0 \\ 0 & 0 \\ 0 & 0 \\ 0 & 0 \\ 0 & 0\end{array}$

Total Eicotitc Oporation and

Malntenanes Exponese.

Distribution of Salarles and

Wages Charged to Electric

Operation and Maintenance

Production

Tranemineion

Diatribution

Customer Accounts

Customer Service and

Informational Expenses

Sales Expenses

Adminetrative and General

Allocated from Clearing Accounts

Total Ealartes and Woges

$\begin{array}{rr}148 & 3,811 \\ 165 & 1,354 \\ 0 & 70 \\ 728 & 2,842 \\ 15 & 417 \\ 0 & 125 \\ 12 & 1,990 \\ 0 & 0 \\ 94 & 693 \\ 0 & 13 \\ 0 & 0 \\ 24 & 182 \\ 22 & 454 \\ 1,208 & 11,780 \\ & \\ 0 & 117 \\ 1,208 & 11,003\end{array}$

Number of Electric Department Employees

Regular Full-time Employees .

Partime and Temporary Employees

Total Eketric Department Employees .........

Note: Operating expenees Include fuel expenditures. Totale may not equal sum of components because of independent rounding. Source: Federal Energy Regulatory Commission, FERC Form 1. "Annual Report of Major Electric Utilities, Llcensees and Othere." 
Table C6. Utility Plant by Other U.S. Entity Within State

on December 31, 1992

(Thousand Dollars)

\begin{tabular}{|c|c|c|c|c|c|c|}
\hline Item & $\begin{array}{l}\text { Arkansas } \\
\text { Entergy } \\
\text { Power Inc }\end{array}$ & $\begin{array}{l}\text { lowa } \\
\text { Terra } \\
\text { Comfort } \\
\text { Corp }\end{array}$ & $\begin{array}{l}\text { Louisiana } \\
\text { Catalyst } \\
\text { Old Plver } \\
\text { Hydroel LP }\end{array}$ & $\begin{array}{l}\text { Nevada } \\
\text { Nevada } \\
\text { Sun-Peak Ltd } \\
\text { Partners }\end{array}$ & $\begin{array}{c}\text { Rhode lsland } \\
\text { Ocean } \\
\text { State } \\
\text { Power } \\
\text { Co } \\
\end{array}$ & $\begin{array}{c}\text { Ahode lsiand } \\
\text { Ocean } \\
\text { State } \\
\text { Power } \\
\text { Co II } \\
\end{array}$ \\
\hline 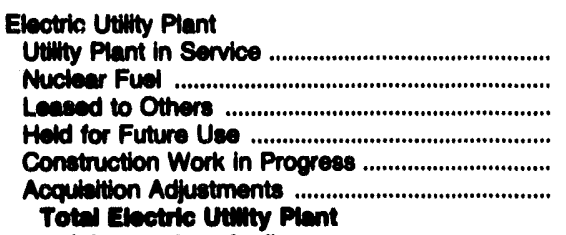 & $\begin{array}{r}216,342 \\
0 \\
0 \\
0 \\
3,473 \\
788\end{array}$ & $\begin{array}{r}10,738 \\
0 \\
0 \\
0 \\
0 \\
0\end{array}$ & $\begin{array}{r}543,091 \\
0 \\
0 \\
0 \\
0 \\
0\end{array}$ & $\begin{array}{r}79,771 \\
0 \\
0 \\
0 \\
0 \\
0\end{array}$ & $\begin{array}{r}230,663 \\
0 \\
0 \\
0 \\
0 \\
0\end{array}$ & $\begin{array}{r}175,057 \\
0 \\
0 \\
0 \\
0 \\
0\end{array}$ \\
\hline (phes muctear twel) .......................................... & 220,602 & 10,730 & 543,091 & 79,771 & 230,683 & 175,057 \\
\hline 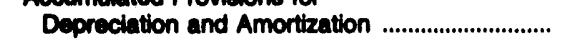 & 76,250 & 1,903 & 26,511 & 5,047 & 22,756 & 10,835 \\
\hline 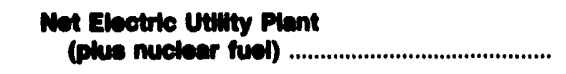 & 144,352 & 8,835 & 516,579 & 74,724 & 207,007 & 164,122 \\
\hline 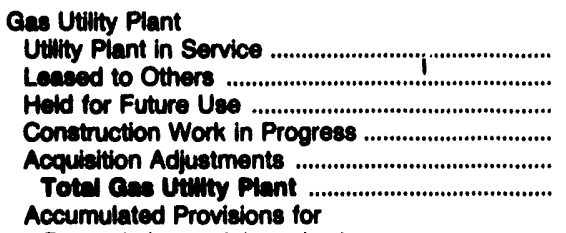 & $\begin{array}{l}0 \\
0 \\
0 \\
0 \\
0 \\
0\end{array}$ & $\begin{array}{l}0 \\
0 \\
0 \\
0 \\
0 \\
0\end{array}$ & $\begin{array}{l}0 \\
0 \\
0 \\
0 \\
0 \\
0\end{array}$ & $\begin{array}{l}0 \\
0 \\
0 \\
0 \\
0 \\
0\end{array}$ & $\begin{array}{l}0 \\
0 \\
0 \\
0 \\
0 \\
0\end{array}$ & $\begin{array}{l}0 \\
0 \\
0 \\
0 \\
0 \\
0\end{array}$ \\
\hline 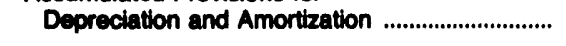 & 0 & 0 & 0 & 0 & 0 & 0 \\
\hline 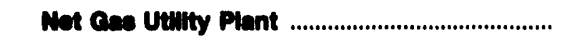 & $\mathbf{0}$ & 0 & $\mathbf{0}$ & 0 & $\mathbf{0}$ & $\mathbf{0}$ \\
\hline 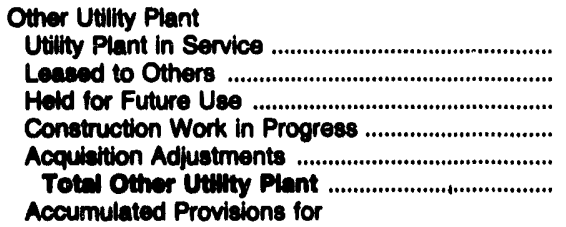 & $\begin{array}{l}0 \\
0 \\
0 \\
0 \\
0 \\
0\end{array}$ & $\begin{array}{l}0 \\
0 \\
0 \\
0 \\
0 \\
0\end{array}$ & $\begin{array}{l}0 \\
0 \\
0 \\
0 \\
0 \\
0\end{array}$ & $\begin{array}{l}0 \\
0 \\
0 \\
0 \\
0 \\
0\end{array}$ & $\begin{array}{l}0 \\
0 \\
0 \\
0 \\
0 \\
0\end{array}$ & $\begin{array}{l}0 \\
0 \\
0 \\
0 \\
0 \\
0\end{array}$ \\
\hline Depreciation and Amortization ................................ & 0 & 0 & 0 & 0 & 0 & 0 \\
\hline Net Other Utiky Plant ......................................... & $\mathbf{0}$ & $\mathbf{0}$ & $\mathbf{0}$ & $\mathbf{0}$ & $\mathbf{0}$ & $\mathbf{0}$ \\
\hline 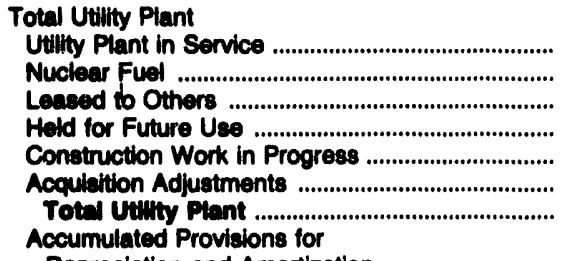 & $\begin{array}{r}216,342 \\
0 \\
0 \\
0 \\
3,473 \\
788 \\
220,602\end{array}$ & $\begin{array}{r}10,738 \\
0 \\
0 \\
0 \\
0 \\
0 \\
10,738\end{array}$ & $\begin{array}{r}543,091 \\
0 \\
0 \\
0 \\
0 \\
0 \\
543,001\end{array}$ & $\begin{array}{r}79,771 \\
0 \\
0 \\
0 \\
0 \\
0 \\
79,771\end{array}$ & $\begin{array}{r}230,663 \\
0 \\
0 \\
0 \\
0 \\
0 \\
230,683\end{array}$ & $\begin{array}{r}175,057 \\
0 \\
0 \\
0 \\
0 \\
0 \\
175,057\end{array}$ \\
\hline 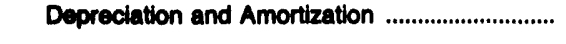 & 76,250 & 1,803 & 26,511 & 5,047 & 22,756 & 10,835 \\
\hline Net Total Uttinty Plant .............................................. & 144,352 & 8,835 & 516,579 & 74,724 & 207,007 & 164,122 \\
\hline 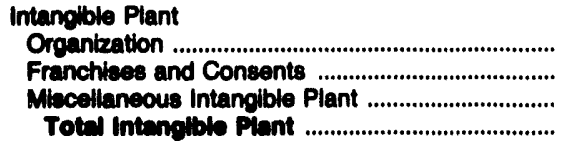 & $\begin{array}{r}360 \\
0 \\
0 \\
360\end{array}$ & $\begin{array}{l}0 \\
0 \\
0 \\
0\end{array}$ & $\begin{array}{l}0 \\
0 \\
0 \\
0\end{array}$ & $\begin{array}{l}0 \\
0 \\
0 \\
0\end{array}$ & $\begin{array}{l}0 \\
0 \\
0 \\
0\end{array}$ & $\begin{array}{l}\mathbf{0} \\
\mathbf{0} \\
\mathbf{0} \\
\mathbf{0}\end{array}$ \\
\hline 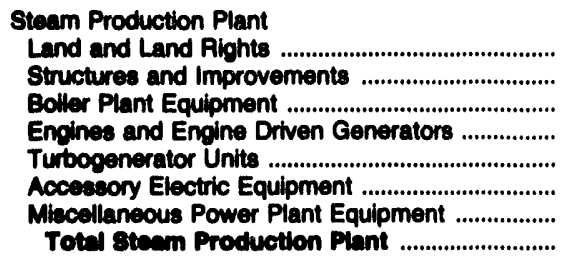 & $\begin{array}{r}892 \\
23,307 \\
122,199 \\
0 \\
44,286 \\
9,877 \\
2,075 \\
202,638\end{array}$ & $\begin{array}{l}0 \\
0 \\
0 \\
0 \\
0 \\
0 \\
0 \\
0\end{array}$ & $\begin{array}{l}0 \\
0 \\
0 \\
0 \\
0 \\
0 \\
0 \\
0\end{array}$ & $\begin{array}{l}0 \\
0 \\
0 \\
0 \\
0 \\
0 \\
0 \\
0\end{array}$ & $\begin{array}{r}4,103 \\
52,597 \\
61,303 \\
53,845 \\
30,111 \\
5,317 \\
0 \\
207,277\end{array}$ & $\begin{array}{r}0 \\
23,460 \\
56,607 \\
50,824 \\
29,615 \\
4,582 \\
169 \\
165,252\end{array}$ \\
\hline
\end{tabular}

See endnotes at end of an individual electric utility. 
Table C6. Utility Plant by Other U.S. Entity Within State on December 31, 1992 (Continued)

(Thousand Dollars)

\begin{tabular}{|c|c|c|c|c|c|c|}
\hline Item & $\begin{array}{c}\text { Arkansas } \\
\text { Entergy } \\
\text { Power Inc }\end{array}$ & $\begin{array}{l}\text { lowa } \\
\text { Terra } \\
\text { Comfort } \\
\text { Corp }\end{array}$ & $\begin{array}{l}\text { Loulsiana } \\
\text { Catalyst } \\
\text { Old Rlver } \\
\text { Hydroel LP }\end{array}$ & $\begin{array}{c}\text { Nevada } \\
\text { Nevada } \\
\text { Sun-Peak Ltd } \\
\text { Partners }\end{array}$ & $\begin{array}{c}\text { Rhode leland } \\
\text { Ocean } \\
\text { State } \\
\text { Power } \\
\text { Co }\end{array}$ & $\begin{array}{l}\text { Rhode liland } \\
\text { Ocean } \\
\text { State } \\
\text { Power } \\
\text { Co II }\end{array}$ \\
\hline 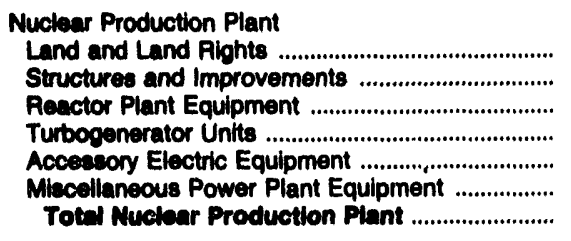 & $\begin{array}{l}0 \\
0 \\
0 \\
0 \\
0 \\
0 \\
0\end{array}$ & $\begin{array}{l}0 \\
0 \\
0 \\
0 \\
0 \\
0 \\
0\end{array}$ & $\begin{array}{l}0 \\
0 \\
0 \\
0 \\
0 \\
0 \\
0\end{array}$ & $\begin{array}{l}0 \\
0 \\
0 \\
0 \\
0 \\
0 \\
0\end{array}$ & $\begin{array}{l}0 \\
0 \\
0 \\
0 \\
0 \\
0 \\
0\end{array}$ & $\begin{array}{l}0 \\
0 \\
0 \\
0 \\
0 \\
0 \\
0\end{array}$ \\
\hline 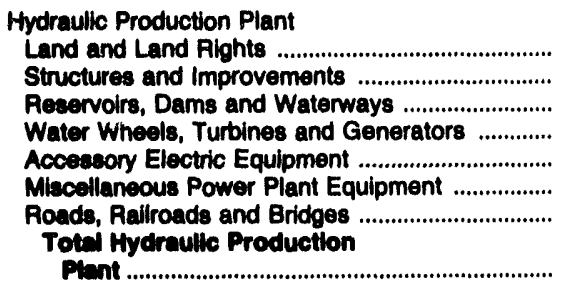 & $\begin{array}{l}0 \\
0 \\
0 \\
0 \\
0 \\
0 \\
0 \\
0\end{array}$ & $\begin{array}{l}0 \\
0 \\
0 \\
0 \\
0 \\
0 \\
0 \\
0\end{array}$ & $\begin{array}{r}32,414 \\
259,651 \\
95,774 \\
110,428 \\
21,309 \\
7,806 \\
0 \\
\\
527,382\end{array}$ & $\begin{array}{l}0 \\
0 \\
0 \\
0 \\
0 \\
0 \\
0 \\
0\end{array}$ & $\begin{array}{l}0 \\
0 \\
0 \\
0 \\
0 \\
0 \\
0 \\
0\end{array}$ & $\begin{array}{l}0 \\
0 \\
0 \\
0 \\
0 \\
0 \\
0\end{array}$ \\
\hline 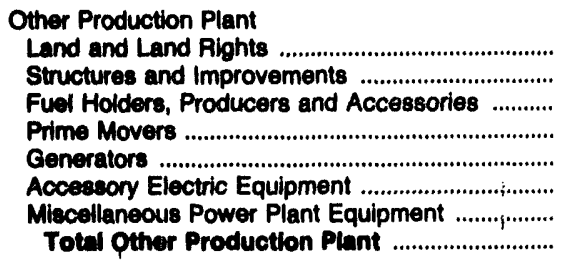 & $\begin{array}{l}0 \\
0 \\
0 \\
0 \\
0 \\
0 \\
0 \\
0\end{array}$ & $\begin{array}{r}33 \\
219 \\
280 \\
0 \\
9,070 \\
1,039 \\
96 \\
10,739\end{array}$ & $\begin{array}{l}0 \\
0 \\
0 \\
0 \\
0 \\
0 \\
0 \\
0\end{array}$ & $\begin{array}{r}90 \\
5,403 \\
303 \\
57,125 \\
9,190 \\
5,524 \\
1,678 \\
79,312\end{array}$ & $\begin{array}{l}0 \\
0 \\
0 \\
0 \\
0 \\
0 \\
0 \\
0\end{array}$ & $\begin{array}{l}0 \\
0 \\
0 \\
0 \\
0 \\
0 \\
0 \\
0\end{array}$ \\
\hline Total Production Plant ............................................ & 202,836 & 10,738 & 527,392 & 79,312 & 207,277 & 106,252 \\
\hline 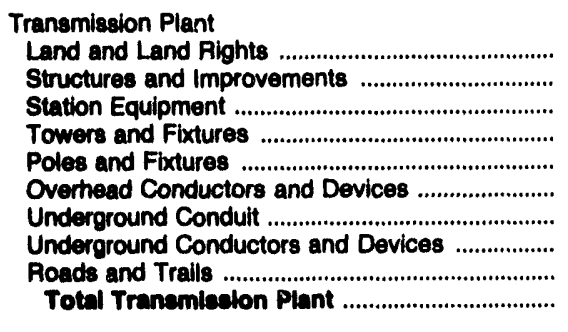 & $\begin{array}{r}0 \\
0 \\
2,026 \\
0 \\
0 \\
0 \\
0 \\
0 \\
0 \\
2,026\end{array}$ & $\begin{array}{l}0 \\
0 \\
0 \\
0 \\
0 \\
0 \\
0 \\
0 \\
0 \\
0\end{array}$ & $\begin{array}{r}1,905 \\
0 \\
0 \\
0 \\
5,374 \\
7,328 \\
0 \\
0 \\
0 \\
14,607\end{array}$ & $\begin{array}{r}0 \\
0 \\
458 \\
0 \\
0 \\
0 \\
0 \\
0 \\
0 \\
480\end{array}$ & $\begin{array}{r}0 \\
0 \\
17,409 \\
1,320 \\
0 \\
1,043 \\
0 \\
0 \\
0 \\
19,772\end{array}$ & $\begin{array}{r}0 \\
0 \\
8,619 \\
733 \\
453 \\
0 \\
0 \\
0 \\
0 \\
0,005\end{array}$ \\
\hline 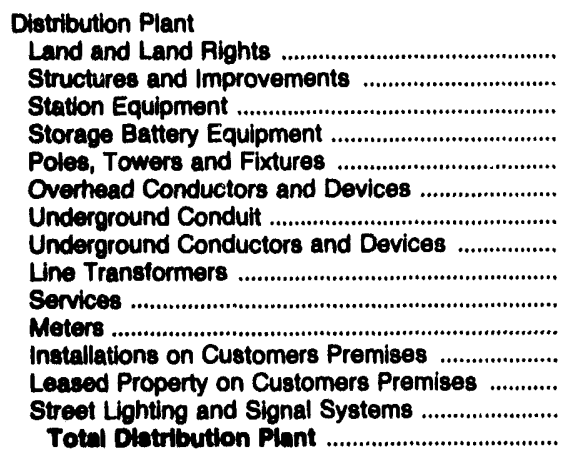 & $\begin{array}{l}0 \\
0 \\
0 \\
0 \\
0 \\
0 \\
0 \\
0 \\
0 \\
0 \\
0 \\
0 \\
0 \\
0 \\
0\end{array}$ & $\begin{array}{l}0 \\
0 \\
0 \\
0 \\
0 \\
0 \\
0 \\
0 \\
0 \\
0 \\
0 \\
0 \\
0 \\
0 \\
0\end{array}$ & $\begin{array}{l}0 \\
0 \\
0 \\
0 \\
0 \\
0 \\
0 \\
0 \\
0 \\
0 \\
0 \\
0 \\
0 \\
0 \\
0\end{array}$ & $\begin{array}{l}0 \\
0 \\
0 \\
0 \\
0 \\
0 \\
0 \\
0 \\
0 \\
0 \\
0 \\
0 \\
0 \\
0 \\
0\end{array}$ & $\begin{array}{l}0 \\
0 \\
0 \\
0 \\
0 \\
0 \\
0 \\
0 \\
0 \\
0 \\
0 \\
0 \\
0 \\
0 \\
0\end{array}$ & $\begin{array}{l}0 \\
0 \\
0 \\
0 \\
0 \\
0 \\
0 \\
0 \\
0 \\
0 \\
0 \\
0 \\
0 \\
0 \\
0\end{array}$ \\
\hline
\end{tabular}

See endnotes at end of an individual electric utility. 
Table C6. Utility Plant by Other U.S. Entlity Within State

on December 31, 1992 (Continued)

(Thousand Dollars)

\begin{tabular}{|c|c|c|c|c|c|c|}
\hline ltem & $\begin{array}{c}\text { Arkansas } \\
\text { Entergy } \\
\text { Power Inc }\end{array}$ & $\begin{array}{l}\text { lowa } \\
\text { Terra } \\
\text { Comfort } \\
\text { Corp }\end{array}$ & $\begin{array}{l}\text { Loulsiana } \\
\text { Catalyat } \\
\text { Old Alver } \\
\text { Hydroel LP }\end{array}$ & $\begin{array}{c}\text { Nevada } \\
\text { Nevada } \\
\text { Sun-Peak Ltd } \\
\text { Partners }\end{array}$ & $\begin{array}{c}\text { Rhode laland } \\
\text { Ocean } \\
\text { State } \\
\text { Power } \\
\text { Co }\end{array}$ & $\begin{array}{l}\text { Rhode laland } \\
\text { Ocean } \\
\text { State } \\
\text { Power } \\
\text { Co II }\end{array}$ \\
\hline
\end{tabular}

Ceneral Plant

Land and Land Plghts

Structures and Improvements

Otice Fumiture and Equipment

Transportation Equipment

Stores Equipment

Laboratory Equipment

Power Operated Equipment

Communication Equipment

Mircellaneous Equipment

Other Tangible Property

Totel Cenerd Plent

Electric Plant Purchased and Sold (net)

Experimental Electric Plant Unclaseffied

Total Eloctric Utilly Plant In service

0
0
0
0
0
0
0
0
0
0
0

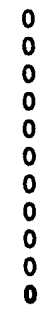

11,321

11,321

0

0

$\begin{array}{ll}0 & 0 \\ 0 & 0\end{array}$

218,342

10,738

0
183
237
168
2
5
131
0
0
375
1,101

0
2,182
554
404
67
257
0
0
149
0
3,613

0

(1)

1,101

3,813

0

543,001

175,057

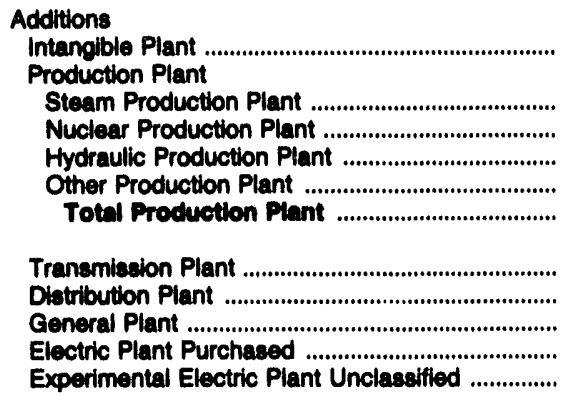

Total Electric Plant Additions

\section{Retirements}

Intangible Plant

Production Plant

Steam Production Plant

Nuclear Production Plant

Hydraulic Production Plant

Other Production Plant

Total Production Piant

Tranemisaion Plan

Diatribution Plant

General Plant ...

Electric Plant Sold

Experimental Electric Plant Unclasesified

Totel Electric Piant

Rotirements

$\begin{array}{lr}0 & 0 \\ 0 & \\ 0 & 0 \\ 0 & 0 \\ 0 & 0 \\ 0 & 14 \\ 0 & 14 \\ 0 & \\ 0 & 0 \\ 0 & \\ 0 & \\ 0 & \end{array}$

0
0
0
3,515
0
3,615

0
0
0
0
212
212

0

0

$-5,994$

$-13,086$

9
0

13

0

3,637

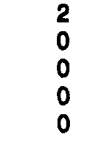

214

$-3,281$

$\begin{array}{rr}0 & 0 \\ 162 & 0 \\ 0 & 0 \\ 0 & 0 \\ 0 & 0 \\ 182 & 0\end{array}$

0
0
0
11
0
11

0
0
0
0
0
0

0

$\begin{array}{lll}0 & 0 & 0\end{array}$

0

9
0
0

172

0

11

$\mathbf{0}$

4

0

Note: Totals may not equal sum of components because of indeperdent rounding

Source: Federal Energy Regulatory Commission, FERC Form 1, "Annual Report of Major Electric Utilities, Licensees and Others." 
Table C6. UtIlity Plant by Other U.S. Entity Within State on December 31, 1992 (Continued) (Thousand Dollars)

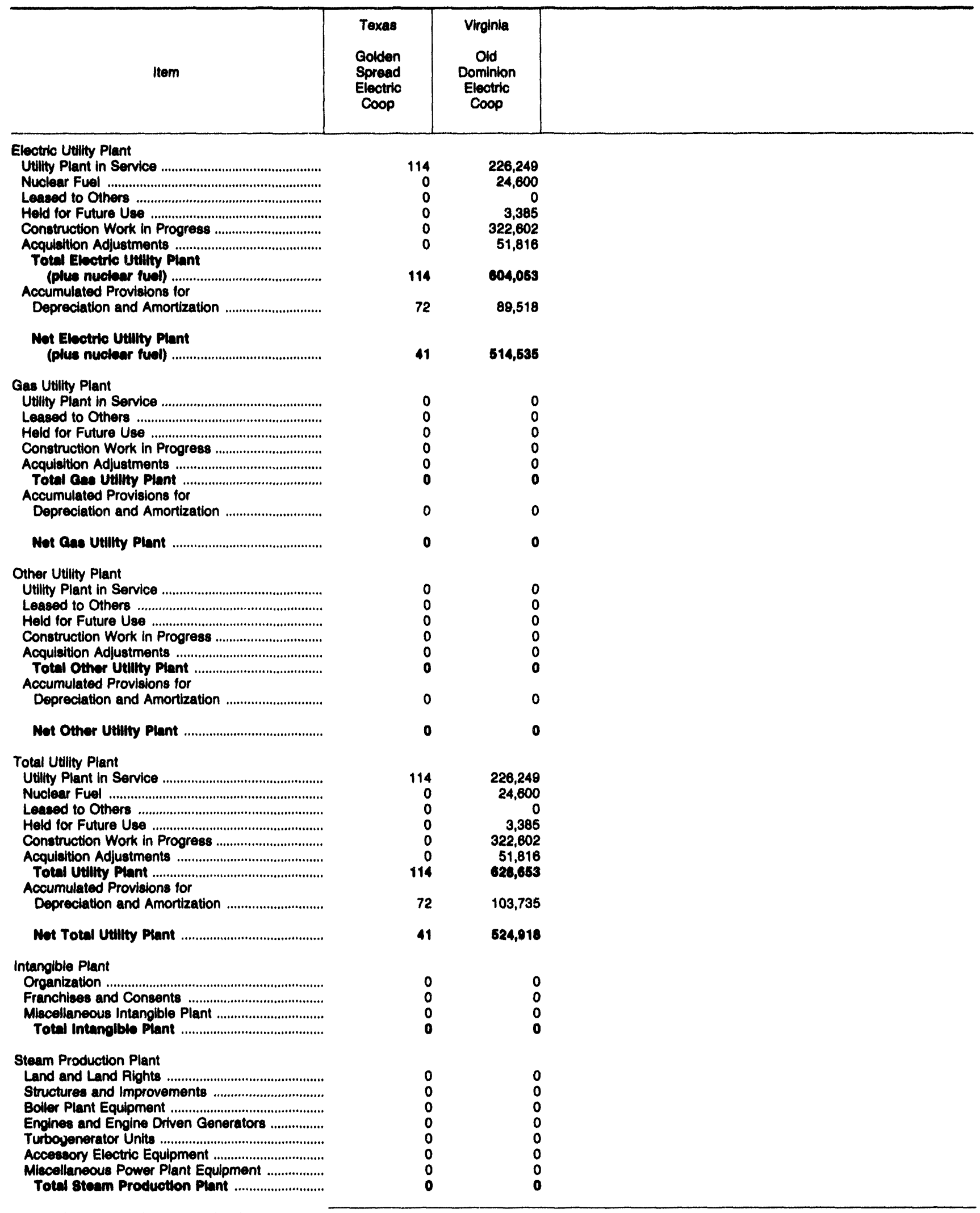

See endnotes at end of an individual electric utility. 
Table C6. Utility Plant by Other U.S. Entity Within State

on December 31, 1992 (Continued)

(Thousand Dollars)

\begin{tabular}{|c|c|c|c|}
\hline Hem & $\begin{array}{l}\text { Texas } \\
\text { Golden } \\
\text { Spread } \\
\text { Electric } \\
\text { Coop }\end{array}$ & $\begin{array}{l}\text { Virginia } \\
\text { Oid } \\
\text { Dominion } \\
\text { Electric } \\
\text { Coop }\end{array}$ & \\
\hline 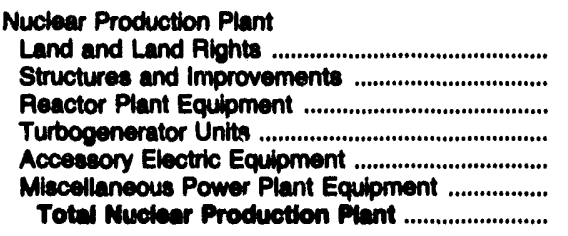 & & $\begin{array}{r}4,256 \\
49,258 \\
89,984 \\
22,415 \\
43,784 \\
6,045 \\
216,602\end{array}$ & \\
\hline 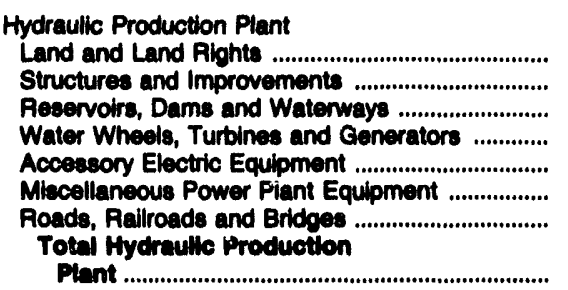 & & $\begin{array}{l}0 \\
0 \\
0 \\
0 \\
0 \\
0 \\
0 \\
0\end{array}$ & \\
\hline 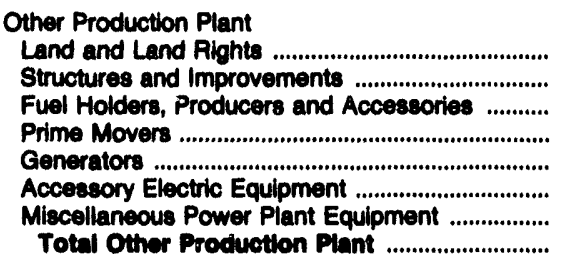 & & $\begin{array}{l}0 \\
0 \\
0 \\
0 \\
0 \\
0 \\
0 \\
0\end{array}$ & \\
\hline 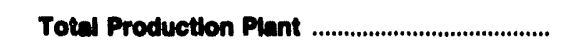 & & 216,692 & \\
\hline 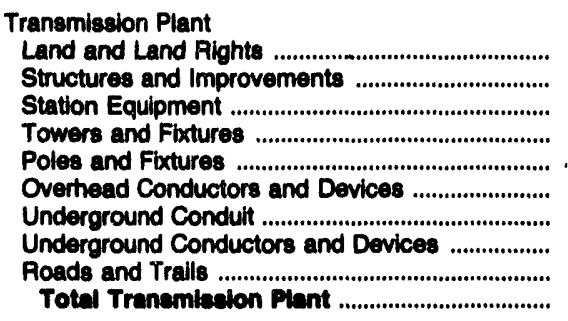 & & $\begin{array}{r}0 \\
17 \\
6,340 \\
0 \\
0 \\
0 \\
0 \\
0 \\
0 \\
6,368\end{array}$ & \\
\hline 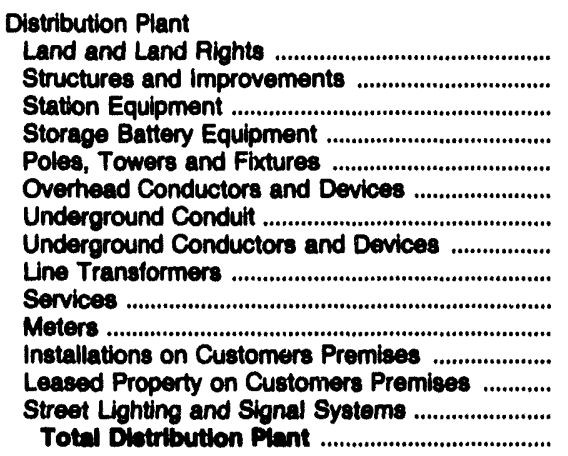 & & $\begin{array}{l}0 \\
0 \\
0 \\
0 \\
0 \\
0 \\
0 \\
0 \\
0 \\
0 \\
0 \\
0 \\
0 \\
0 \\
0\end{array}$ & \\
\hline
\end{tabular}

See endnotes at end of an individual electric utility. 
Table C6. Utility Plant by Other U.S. Entlty Within state on December 31, 1902 (Continued)

(Thousand Dollars)

\begin{tabular}{|c|c|c|c|}
\hline Item & $\begin{array}{l}\text { Texas } \\
\text { Golden } \\
\text { Spread } \\
\text { Electric } \\
\text { Coop }\end{array}$ & $\begin{array}{l}\text { Virginia } \\
\text { Old } \\
\text { Dominion } \\
\text { Electric } \\
\text { Coop }\end{array}$ & 1 \\
\hline
\end{tabular}

\section{General Plant}

Land and Land Rights .............................................

Office Fumiture and Equipment .............................

Transportation Equipment

Stores Equipment ...

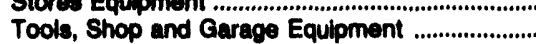

Laboratory Equioment

Power Operated Equipment

Communication Equipment

Miscellaneous Equlpment

8ubtotal Ceneral Piant

Other Tanglble Property ..........................................

Totel Ceneral Plant

Electric Plant Purchased and Sold (net)

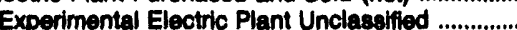

Total Electrle Uullty Piant in service

...............

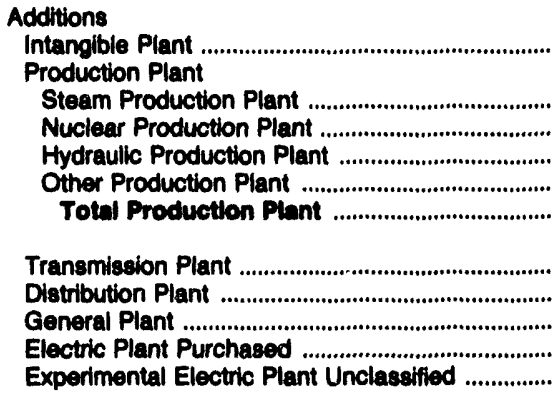

Total Electrite Plant Additione

Retirements

Intanglble Plant

Production Plant

Steam Production Plant

Nuclear Production Plant .

Hydraulic Production Plant

Other Production Plant

Total Production Plant

Transmiseion Plant

Distribution Plant

General Piant

Electric Plant Sold

Experimental Electric Plant Unclassified

Total Electric Plant

Restrements
00

$\begin{array}{rr}3 & 31 \\ 90 & 2,100\end{array}$

$21 \quad 139$

$0 \quad 12$

$\begin{array}{ll}0 & 0 \\ 0 & 1\end{array}$

$0 \quad 92$

$0 \quad 130$

$0 \quad 12$

$0 \quad 751$

$114 \quad 3,289$

$114 \quad 228,240$

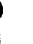

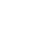

12

51

0

0

0

0

0

$\mathbf{0}$

582

0

254

0

$33 \quad 816$

0

$0 \quad 0$

$\begin{array}{ll}0 & 0 \\ 0 & 0 \\ 0 & 0\end{array}$

0

0

$\begin{array}{rr}0 & 0 \\ 0 & 0 \\ 0 & 52 \\ 0 & 0 \\ 0 & 0\end{array}$

62

Note: Totais may not equal sum of components because of independent rounding.

Source: Federal Energy Regulatory Commiseion, FERC Form 1, "Annual Report of Major Electric Utilities, Licensees and Others." 
Table C7. Electric Energy Account by Other U.S. Entity Within State, 1992

(Megawatthours)

\begin{tabular}{|c|c|c|c|c|c|c|}
\hline Item & $\begin{array}{l}\text { Arkansas } \\
\text { Entergy } \\
\text { Power Inc }\end{array}$ & $\begin{array}{l}\text { lowa } \\
\text { Terra } \\
\text { Comfort } \\
\text { Corp }\end{array}$ & $\begin{array}{l}\text { Louisiana } \\
\text { Catalyst } \\
\text { Old River } \\
\text { Hydroel LP }\end{array}$ & $\begin{array}{c}\text { Nevada } \\
\text { Nevada } \\
\text { Sun-Peak Ltd } \\
\text { Partners }\end{array}$ & $\begin{array}{l}\text { Rhode lsland } \\
\text { Ocean } \\
\text { Siete } \\
\text { Power } \\
\text { Co }\end{array}$ & $\begin{array}{c}\text { Rhode Island } \\
\text { Ocean } \\
\text { State } \\
\text { Power } \\
\text { Co II }\end{array}$ \\
\hline 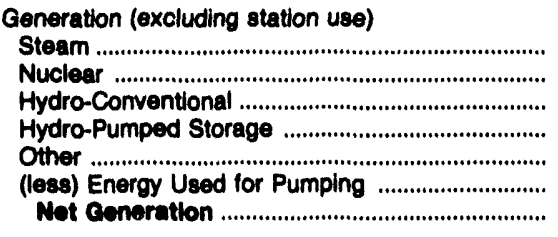 & $\begin{array}{r}2,685,627 \\
0 \\
0 \\
0 \\
0 \\
0 \\
2,685,627\end{array}$ & $\begin{array}{r}0 \\
0 \\
0 \\
0 \\
230 \\
0 \\
280\end{array}$ & $\begin{array}{r}0 \\
0 \\
663,123 \\
0 \\
0 \\
0 \\
683,123\end{array}$ & $\begin{array}{l}0 \\
0 \\
0 \\
0 \\
0 \\
0 \\
0\end{array}$ & $\begin{array}{r}2,188,160 \\
0 \\
0 \\
0 \\
0 \\
0 \\
2,184,160\end{array}$ & $\begin{array}{r}2,142,114 \\
0 \\
0 \\
0 \\
0 \\
0 \\
2,142,114\end{array}$ \\
\hline 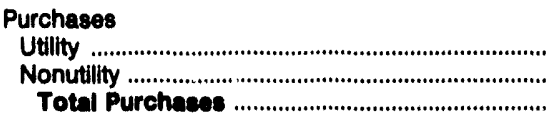 & $\begin{array}{r}88,018 \\
0 \\
89,018\end{array}$ & $\begin{array}{l}0 \\
0 \\
0\end{array}$ & $\begin{array}{l}0 \\
0 \\
0\end{array}$ & $\begin{array}{l}0 \\
0 \\
0\end{array}$ & $\begin{array}{l}0 \\
0 \\
0\end{array}$ & $\begin{array}{l}0 \\
0 \\
0\end{array}$ \\
\hline $\begin{array}{l}\text { Exchanges } \\
\text { In (gross) } \\
\text { Out (gross) } \\
\text { Net Exchanges }\end{array}$ & $\begin{array}{l}0 \\
0 \\
0\end{array}$ & $\begin{array}{l}0 \\
0 \\
0\end{array}$ & $\begin{array}{l}0 \\
0 \\
0\end{array}$ & $\begin{array}{l}0 \\
0 \\
0\end{array}$ & $\begin{array}{l}0 \\
0 \\
0\end{array}$ & $\begin{array}{l}0 \\
0 \\
0\end{array}$ \\
\hline 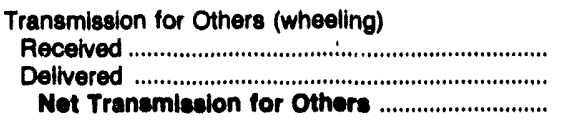 & $\begin{array}{l}0 \\
0 \\
0\end{array}$ & $\begin{array}{l}0 \\
0 \\
0\end{array}$ & $\begin{array}{l}0 \\
0 \\
0\end{array}$ & $\begin{array}{l}0 \\
0 \\
0\end{array}$ & $\begin{array}{l}0 \\
0 \\
0\end{array}$ & $\begin{array}{l}0 \\
0 \\
0\end{array}$ \\
\hline Tranemiacion by Other Losees ............................... & 0 & $\mathbf{0}$ & 0 & 0 & $\mathbf{0}$ & 0 \\
\hline $\begin{array}{l}\text { Total Not Enorgy Cenerated } \\
\text { and Recelved }\end{array}$ & $2,773,645$ & 230 & 683,123 & 0 & $2,188,160$ & $2,142,114$ \\
\hline 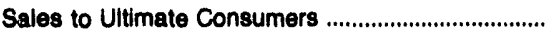 & 0 & 0 & 0 & 0 & 0 & 0 \\
\hline 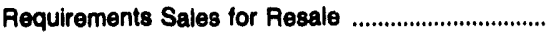 & 0 & 0 & 639,887 & 0 & $2,188,160$ & $2,142,114$ \\
\hline Non-requirements Sales for Resale .......................... & $2,763,729$ & 230 & 0 & 0 & 0 & 0 \\
\hline Energy Furnished Without Charge ............................ & 0 & 0 & 0 & 0 & 0 & 0 \\
\hline Energy Used by Company (exc station use) ........... & 8,166 & 0 & 8,491 & 0 & 0 & 0 \\
\hline 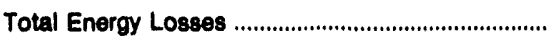 & 1.750 & 0 & 13,745 & 0 & 0 & 0 \\
\hline Total Sales and Diepostition ............................... & $2,773,645$ & 230 & 683,123 & $\mathbf{0}$ & $2,188,160$ & $2,142,114$ \\
\hline
\end{tabular}

Note: Totals may not equal sum of components because of independent rounding. Double counting occurs in components of both sources and dis. position of energy and thus neither provides a true total. Purchases from utlities, net interchanges, and net wheeling (except for imports) are included in net generation. Sales for resale is included in sales to ultimate consumers.

Source: Federal Energy Regulatory Commission, FERC Form 4, "Annual Report of Major Electric Utilities, Licensees and Others." 
Table C7. Electrlc Enorgy Account by Other U.S. Entity Within State, 1902 (Continued)

(Megawatthours)

\begin{tabular}{|c|c|c|}
\hline Item & $\begin{array}{l}\text { Toxas } \\
\text { Golden } \\
\text { Spread } \\
\text { Electrilo } \\
\text { Coop }\end{array}$ & $\begin{array}{l}\text { Virginia } \\
\text { Old } \\
\text { Dominion } \\
\text { Electric } \\
\text { Coop }\end{array}$ \\
\hline
\end{tabular}

Cencration (oxchuding station use)

Sicam .....

Nuclaer .

Hydro-Comentionel

Hydro-Pumped Storege

(iea) Eneroy Uesd for Pumping

Int enomition

Puraneses

Uinty

Nonitinty

Toted Purrohesese

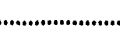

$\begin{array}{rrr}0 & 0 \\ & 0 & 1,355,352 \\ 0 & 0 \\ 0 & 0 \\ 0 & 0 \\ 0 & 0 \\ 0 & 1,355,352 \\ & 0 & \\ 1,735,889 & 5,147,567 \\ 0 & 1,241 \\ 1,795,800 & 5,146,800\end{array}$

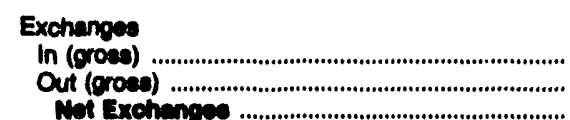

Trenemiecion for Others (wheeling)

Received.

Detwered

Net Trunsmiscion for Othere .............................

Tranemiecton by Other Leeses

Total net Eneroy Conernted

and Rechund

$1,735,090 \quad 0,504,160$

Sales to Uttimate Consumers

0

0

Requirements sales for Resale

$1,735,899$

$6,357,678$

Non-requirements Sales for Resale

$0 \quad 0$

Energy Furnithed Whthout Charge

0

0

Energy Ueed by Company (exc atation use) ..........

Total Energy Losese

0

0

o

Toted scise and Dispocition

$1,735,090$

$6,804,100$

Note: Totals may not equal sum of components because of independent rounding. Double counting occurs in components of both eources and die poeition of eneroy and thus netther provides a true total. Purchases from utilities, net interchanges, and not wheeling (except for imports) are included in not generation. Sales for reale is included in sales to ultimate consumers.

Source: Federal Energy Regulatory Commiscion, FERC Form 1, "Annual Report of Major Electric Uthltiea, Lceneees and Others." 


\section{Appendix D}

\section{Technical}

Notes 


\section{Technical Notes}

\section{Data Sources}

The Financial Statistics of Major U.S. Investor-Owned Electric Utilities publication is prepared by the Survey Management Division; Office of Coal, Nuclear, Electric and Alternate Fuels; Energy Information Administration (EIA); U.S. Department of Energy (DOE). Detailed financial data published in this publication are from the Federal Energy Regulatory Commission (FERC) Forrn 1, "Annual Report of Major Electric Utilities, Licensees and Others." The Form EIA-861, "Annual Electric Utility Report," data are used in Table 1 and 2 of this publication to show selected operational data for the total universe of electric utilities. A brief summary of both of these surveys is presented below.

\section{FERC Form 1}

The FERC Form 1 is a mandatory annual survey of "major" investor-owned electric utilities. These electric utilities had, in each of the last three consecutive years, sales or transmission service that exceeded one of the following:

- 1 million megawatthours of total annual sales

- 100 megawatthours of annual sales for resale

- 500 megawatthours of annual power exchanges delivered

- 500 megawatthours of annual wheeling for others (deliveries plus losses).

All major investor-owned electric utilities, licensees, or others subject to the Federal Power Act of 1935 must submit this survey to the FERC. Classification of these entities is provided in FERC's Uniform System of Accounts Prescribed for Private Utilities and Licensees and subject to the provisions of the Federal Power Act. About 180 electric utilities are classified as major.

The FERC Form 1 is used to collect data on income and earnings, taxes, depreciation and amortization, distribution of salaries and wages, electric operating revenues, electric maintenance expenses, generating plant statistics, planned construction data, year-end balance sheets, and general corporate information. Data are also required for electric plant cost and power production expenses from hydroelectric plants with a generator nameplate capacity of 10 megawatts or larger; steam-electric plants with a generator nameplate capacity of 25 megawatts or more; and gasturbine plants with a generator nameplate capacity of 10 megawatts or larger.

Instrument and Design History . The Federal Power Commission (FPC) Form 1, the predecessor of the FERC Form 1, was implemented in 1935 by the FPC. When the FPC was merged with the DOE in October 1977, collection and processing of the survey data became the responsibility of the EIA. In 1991, the collection responsibility reverted back to the FERC. This mandatory survey is conducted in accordance with the FERC's Uniform System of Accounts Prescribed for Private Utilities and Licensees.

Data Processing . Completed surveys containing data for the preceding calendar year are returned to the FERC on or before April 30. Copies are made available to the EIA for processing. Manual editing of data is completed before data entry. Additional edit checks of the data are performed through computer programs. The program edits include both deterministic checks, in which records are checked for the presence of data in required fields, and statistical checks, in which the data are checked against a range of values based on historical data values and for logical or mathematical consistency with data elements reported in the survey. Discrepancies found in the data, as a result of these checks, are resolved either by the processing office or by further information obtained from a telephone call to the respondent.

Uniformity of Treatment . The electric utilities' statements in this publication, were uniformly treated for easy comparison of items (information). These statements, were filed by all major U.S. investor-owned electric utilities that are subject to the accounting jurisdiction of the FERC. The Uniform System of Accounts for electric utilities under the jurisdiction of the FERC was prepared with the National Association of Regulatory Utility Commissioners. The National Association of Regulatory Utility Commissioners includes members of the railroad, public utilities, and public service commissions of the 50 States, the District of Columbia, the Commonwealth of Puerto Rico, and the territory of the Virgin Islands. The following Federal regulatory agencies were also included: the Interstate Commerce Commission, the Federal Energy Regulatory Commission, the Federal Communication Commission, the Securities and Exchange Commission, and the Civil Aeronautics 
Board. In all material respects, the Uniform System of Accounts conforms with the approved system of the National Association of Regulatory Utility Commissioners. The system was also adopted by certain State commissions. The major investor-owned electric utilities are required to follow the Uniform System of Accounts. Individual electric utility data are listed by the State in which its corporate records are kept.

Presentation . No attempt has been made to consolidate (in the technical accounting sense) the accounts of the electric utilities included in the summary statements of this publication. The combined totals repiresent the arithmetic sum of all accounts as reported by' the individual electric utilities. Consequently, duplications exist to a limited extent in the composite totals shown in several statements. For example, total assets and the totals for operating revenues and megawatthour sales include intercorporate sales. For this publication, investments in jointly owned subsidiaries are stated by the equity method of accounting.

As a result of mergers, consolidations, and property sales to public authorities, as well as the introduction of new electric utilities, the number of investor-owned electric utilities that qualify as a major varies from year-to-year. Year-to-year changes in the respondent population do not significantly affect year-to-year aggregate comparisons. Tables 3 and 5 through 30 contain historical data for 1988 through 1992, representing aggregate financial statistics for investor-owned electric utilities classified as major for that year. All calculations are made on the basis of the respondents' submissions which are in whole dollars and megawatthours.

\section{Publlc Service Company of New Hampshire Bankruptcy}

Public Service Company of New Hampshire filed a petition for reorganization under Chapter 11 of the Federal Bankruptcy Code on January 28, 1988. The electric utility acted as debtor-in-possession for a period of approximately 28 months and continued to operate its business substantially as before, subject to the supervision of the Bankruptcy Court. On May 16, 1991, Public Service Company of New Hampshire emerged from bankruptcy in accordance with a reorganization plan filed January 2, 1990, with the Bankruptcy Court. According to the terms of the reoganization plan, Public Service Company of New Hampshire would merge with Northeast Utilties Service Company (NUSCO) and NU Acquisition Corporation (NUCA) and would remain as the surviving corporation. Northeast Utilities (NU) would then acquire the surviving Public Service Company of New Hampshire. Regulatory approvals were granted and the closing of the merger occurred on June 5 , 1992.

The reorganization was accounted for using fresh-start accounting. All assets and liabilities were restated to their fair-market-value as of the reorganization date, and, a distribution of approximately $\$ 2.4$ billion in cash, securities, and assumed liabilities was made to former creditors and equity security holders. Unamortized debt expense associated with debt issues repaid under the reorganization plan was eliminated, and the expenses associated with the issuance of new debt and preferred stock, capitalized and amortized over the terms of these issues.

In order to properly reflect the emergence of the restructured Public Service Company of New Hampshire, the company filed its 1991 FERC Form 1 incorporating two Statements of Income and Retained Earnings, Cash Flows, and supporting schedules; one for the period January 1 through May 15, 1991, and the other for May 16 through December 31, 1991. A single Balance Sheet was submitted dated as of December 31, 1991. By filing in this manner, the fresh-start accounting associated with the emergence from the bankruptcy could be readily represented.

Pursuant to the reorganization plan resulting from the bankruptcy, the interest in the Seabrook plant was acquired on June 5, 1992, oy North Atlantic Energy Corporation, a subsidiary of Northeast Utilities. Both Public Service Company of New Hampshire and North Atlantic Energy Corporation submitted a FERC Form 1 for 1992 and are thus included in both the summary and detailed statistics.

\section{Form EIA-861}

The Form EIA-861 is a mandatory census of electric utilities in the United States, its territories, and Puerto Rico. The survey is used to collect information on power production and sales data from approximately 3.250 electric utilities. Data collected are used to maintain and update the electric utility frame data base for the EIA. This data base supports queries from the Executive Branch, Congress, other public agencies, and the general public. Summary data from the Form EIA-861 are also contained in the Electric Power Monthly, the Electric Power Annual, the Electric Sales and Revenue, the Annual Outlook for U.S. Electric Power, the Financial Statisics of Major U.S. InvestorOwned Electric Utilities, and the Financial Statistics of Major U.S. Publicly Owned Electric Utilities. These reports present aggregate totals for electric utilities on a national level, by State, and by ownership tyfe.

Instrument and Design History . The Form EIA-861 was implemented in January 1985 to collect data as of year-end 1984. The Federal Energy Administration Act of 1974 (Public Law 93-275) defines the legislative authority to collect these data.

Data Processing . The Form EIA-861 is mailed to the respondents in January to collect data of the preceding calendar year. The completed surveys are returned to the EIA by May 1. Data are manually edited before being entered into the interactive on-line system. Internal edit checks are performed to verify that current data total across and between schedules, and are comparable to data reported the previous year. Edit checks are also performed to compare data reported on the Form EIA-861 and similar data reported on the Form EIA-826, "Monthly Electric Utility Sales and Revenue Report with State Distrib. 
utions," the FERC Form 1, "Annual Report of Major Electric Utilities, Licensees and Others," and the Form EIA-412, "Annual Report of Public Electric Utilities." These are utility-level checks. Respondents are called to clarify reported data and to obtain missing data.

Detailed comparisons and descriptions of conceptual problems affecting the quality of the data are discussed in the report, An Assessment of the Quality of Selected EIA Data Series: Electric Power Data. One example of such a problent inherent in data on electricity sales is that the sectoral classification scheme can vary from utility to utility, as influenced by the local public utility commission.

\section{Data Quality}

The Office of Coal, Nuclear, Electric and Alternate Fuels (CNEAF) is responsible for routine data improvement and quality assurance. All operations at CNEAF are done in accordance with formal standards established by the EIA. Data improvement efforts include verification of data-keyed input by automatic computerized methods, editing by subject matter specialists, and follow-up on nonrespondents. The CNEAF reviews the structure of information requirements and proposed designs for new and revised data collection surveys and systems. Once started, the performance of working data collection systems is also validated. Computerized respondent data files are checked to identify those which fail to respond to the survey. The EIA tries to obtain required information by encouraging the cooperation of nonrespondents. By law, nonrespondents may be fined or penalized for not filing a survey.

The CNEAF screens survey: for completeness, and keys the data onto computer tapes for storage. The data are transferred to random access data bases for computer processing. The information coded on the computer tapes is manually spot-checked against the surveys to certify accuracy of the tapes. To ensure EIA quality standards, formulas using the past history of data values in the data base have been designed and implemented to automatically check data input for errors. Data values falling outside the ranges prescribed in the formulas are verified by telephoning respondents to resolve any discrepancies.

Conceptual problems affecting the quality of data are discussed in the report, An Assessment of the Quality of Selected EIA Data Series: Electric Power Data. This report is published by the Office of Statistical Standards in the EIA.

\section{Data Editing Systom}

Data from the surveys are edited using automated systems. The edit includes deterministic and statistical checks; the deterministic part of the edit checks for the presence of required fields and their validity. Statistical checks use estimation techniques to validate data according to their behavior in the past and in comparison to other current fields.

\section{Confidentlallty of the Data}

Data collected on the surveys for this publication are not confidential.

\section{Rounding Rules for Data}

Given a number with $r$ digits to the left of the decimal and $d+t$ digits in the fraction part, with $d$ being the place to which the number is to be rounded and $t$ being the remaining digits which will be truncated. This number is then rounded to $r+d$ digits by adding five to the $(r+d+1)$ th digit when the number is positive or by subtracting five when the number is negative. The $t$ digits are then truncated at the $(r+d+1)$ th digit.

\section{Data Correction and Revision Procedures}

The CNEAF has adopted the following policy with respect to the revision and correction of recurrent data in energy publications:

- Annual survey data collected by this office are published either as preliminary or final when first appearing in a data report. Data initially released as preliminary will be so noted in the report. These data will be revised, if necessary, and declared final in the next publication of the data.

- All monthly and quarterly survey data collected by this office are published as preliminary. These data are revised only after the completion of the 12-month cycle of the data. No revisions are made to the published data before this.

- The magnitudes of changes due to revisions experienced in the past will be included in the data reports, so that the reader can assess the accuracy of the data.

- After data are published as final, corrections will be made only in the event of a greater than one percent difference at the national level. Corrections for differences that are less than the before-mentioned threshold are left to the discretion of the Office Director.

In accordance with this policy, the CNEAF has revised the 1991 summary data to exclude the independent power producers. The restatement affected previous publication values by less than one percent at the national level. In addition, the 1991 data on Statement of Cash Flows had four values modified due to incorrect plant classifications. For Net Cash Flows from Operating Activities, "Amortization" was reduced \$1.4 billion and added to "Other." For Cash Flows from Investment Activities, "Collections on 
Loans" was reduced $\$ 1.0$ billion and added to "Other."

Table D1. Source of Data Used in Formulas and Calculations

\begin{tabular}{|c|c|c|}
\hline Abbreviation & Description & Table \\
\hline 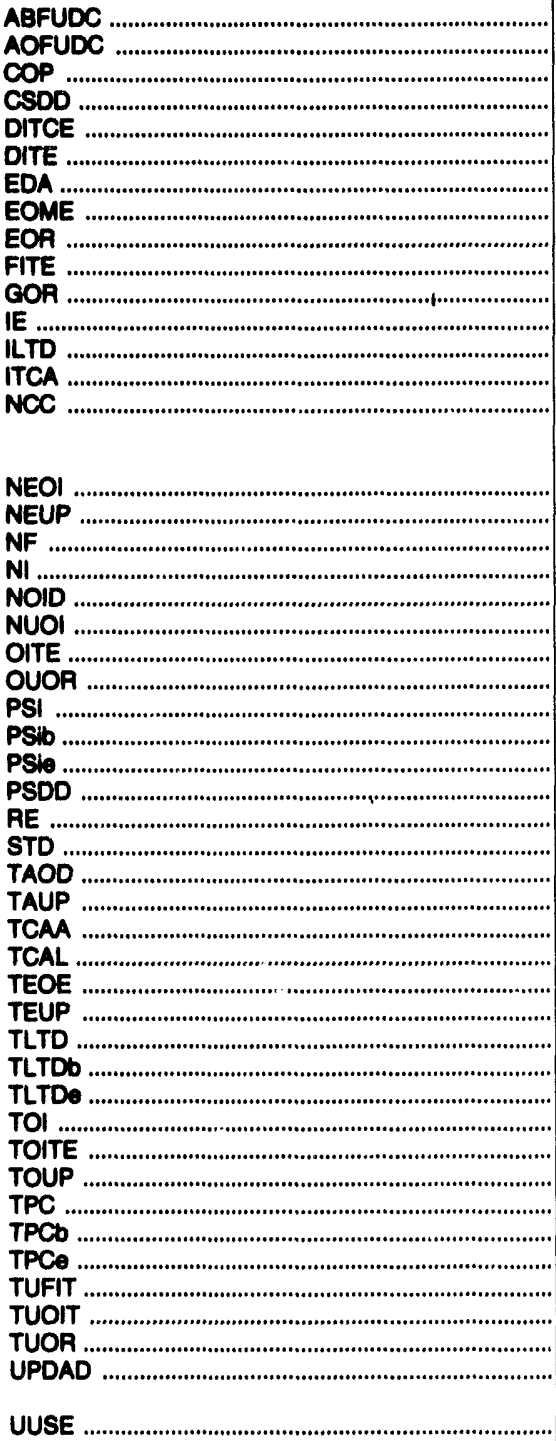 & 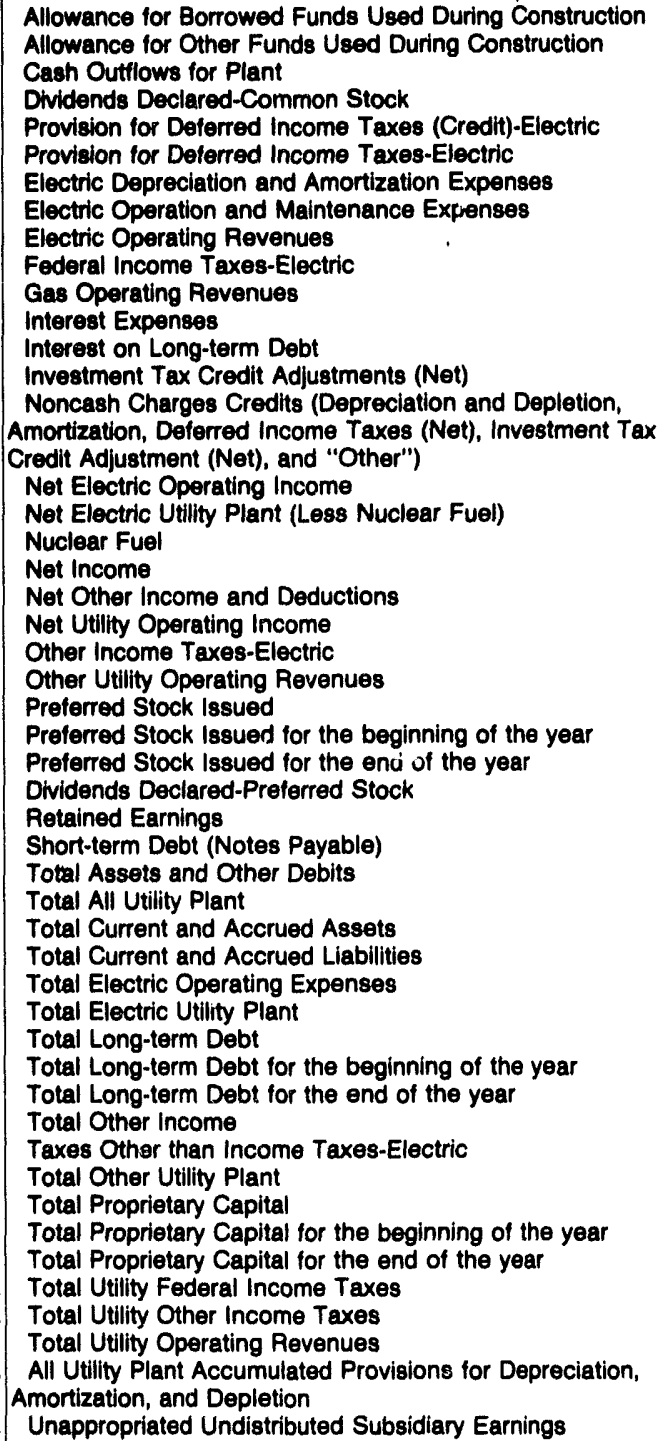 & $\begin{array}{l}\text { Statement of Income } \\
\text { Statement of Income } \\
\text { Cash Flows } \\
\text { Retained Earnings } \\
\text { Statement of Income } \\
\text { Statement of Income } \\
\text { Statement of Income } \\
\text { Statement of Income } \\
\text { Statement of Income } \\
\text { Statement of Income } \\
\text { Statement of Income } \\
\text { Statement of Income } \\
\text { Statement of Income } \\
\text { Statement of Income } \\
\text { Cash Flows } \\
\\
\text { Statement of Income } \\
\text { Balance Sheet } \\
\text { Balance Sheet } \\
\text { Statement of Income } \\
\text { Statement of Income } \\
\text { Statement of Income } \\
\text { Statement of Income } \\
\text { Statement of Income } \\
\text { Balance Sheet } \\
\text { Balance Sheet } \\
\text { Balance Sheet } \\
\text { Retained Earnings } \\
\text { Balance Sheet } \\
\text { Balance Sheet } \\
\text { Balance Sheet } \\
\text { Balance Sheet } \\
\text { Balance Sheet } \\
\text { Balance Sheet } \\
\text { Statement of Income } \\
\text { Balance Sheet } \\
\text { Balance Sheet } \\
\text { Balance Sheet } \\
\text { Balance Sheet } \\
\text { Statement of Income } \\
\text { Statement of Income } \\
\text { Balance Sheet } \\
\text { Balance Sheet } \\
\text { Balance Sheet } \\
\text { Balance Sheet } \\
\text { Statement of Income } \\
\text { Statement of Income } \\
\text { Statement of Income } \\
\text { Balance Sheet } \\
\text { Balance Sheet }\end{array}$ \\
\hline
\end{tabular}




\section{Formulas and Calculations}

\section{Ratlos Based on the Composite Statement of Income and Retalned Earnings for Investor-awned Eloctric Utilitios}

The following formulas are used to calculate the financial indicators of Investor-Owned Electric Utilities listed in Table 9, "Composit Financial Indicators by Major U.S. Investor-Owned Electric Utilities, 1988-1992."

Electric Operating Revenues as a Percent of Total Operating Revenues =

$$
\frac{\sum_{i}\left(E O R_{i}\right)}{\sum_{i}\left(T U O R_{i}\right)} \times 100
$$

where $E O R_{i}$ is the Electric Operating Revenues for the $i^{\text {th }}$ major utility; and, $T U O R_{i}$ is the Total Utility Operating Revenues for the $i^{\text {th }}$ major utility.

Electric Operation and Maintenance Expenses as a Percent of Electric Operating Revenues =

$$
\frac{\sum_{i}\left(E O M E_{i}\right)}{\sum_{i}\left(E O R_{i}\right)} \times 100
$$

where $E O M E_{l}$ is the Electric Operation and Maintenance Expenses for the $i^{\text {th }}$ major utility; and, $E O R_{i}$ is the Electric Operating Revenues for the $i^{\text {th }}$ major utility.

Electric Depreciation and Amortization as a Percent of Electric Operating Revenues =

$$
\frac{\sum_{i}\left(E D A_{i}\right)}{\sum_{i}\left(E O R_{i}\right)} \times 100
$$

where $E D A_{i}$ is the Electric Depreciation and Amortization Expenses for the $i^{\text {th }}$ major utility; and, $E O R_{i}$ is the Electric Operating Revenues for the $i^{\text {th }}$ inajor utility.

Federal Income Taxes-Electric as a Percent of Electric Operating Revenues =

$$
\frac{\sum_{i}\left(F I T E_{i}\right)}{\sum_{i}\left(E O R_{i}\right)} \times 100
$$

where $F I T E_{i}$ is the Federal Income Taxes-Electric for the $i^{\text {th }}$ major utility; and, EOR is the Electric Operating Revenues for the $i^{\text {th }}$ major utility.

Other Taxes-Electric as a Percent of Electric Operating Revenues $=$

$$
\frac{\sum_{i}\left(T_{O I T E_{i}}+\text { OITE }_{i}\right)}{\sum_{i}\left(E O R_{i}\right)} \times 100
$$

where TOITE $E_{i}$ is Taxes Other than Income TaxesElectric for the $i^{\text {th }}$ major utility; OITE $E_{i}$ is Other Income Taxes-Electric for the $i^{\text {th }}$ major utility; and, $E O R_{i}$ is the Electric Operating Revenues for the $i^{\text {th }}$ major utility.

Provision for Deferred Taxes on Income as a Percent of Electric Operating Revenues =

$$
\frac{\sum_{i}\left(D I T E_{i}\right)}{\sum_{i}\left(E O R_{i}\right)} \times 100
$$

where DITE is the Provision for Deferred Income Taxes-Electric for the $i^{i h}$ major utility; and, $E O R_{i}$ is the Electric Operating Revenues for the $i^{\text {th }}$ major utility.

Income Taxes Deferred in Prior Years (Credit) as a Percent of Electric Operating Revenues =

$$
\frac{\sum_{i}\left(D I T C E_{i}\right)}{\sum_{i}\left(E O R_{i}\right)} \times 100
$$

where $D I T C E_{i}$ is the Provision for Deferred Income Taxes (Credit)-Electric for the $i^{\text {th }}$ major utility; and, $E O R_{i}$ is the Electric Operating Revenues for the $i^{\text {th }}$ major utility.

Investment Tax Credit Adjustments (Net) as a Percent of Electric Operating Revenues =

$$
\frac{\sum_{i}\left(I T C A_{i}\right)}{\sum_{i}\left(E O R_{i}\right)} \times 100
$$

where $I T C A_{i}$ is the Investment Tax Credit Adjustments (Net) for the $i^{\text {th }}$ major utility; and, $E O R_{i}$ is the Electric Operating Revenues for the $i^{\text {th }}$ major utility. 
Total Electric Operating Expenses as a Percent of Electric Operating Revenues =

$$
\frac{\sum_{i}\left(T E O E_{i}\right)}{\sum_{i}\left(E O R_{i}\right)} \times 100
$$

where $T E O E_{1}$ is the Total Electric Operating Expenses for the $i^{\text {th }}$ major utility; and, $E O R_{i}$ is the Electric Operating Revenues for the $i^{\text {th }}$ major utility.

Net Electric Operating Income as a Percent of Electric Operating Revenues =

$$
\frac{\sum_{i}\left(N E O I_{i}\right)}{\sum_{i}\left(E O R_{i}\right)} \times 100
$$

where $N_{E O I_{i}}$ is the Net Electric Operating Income for the $i^{\text {th }}$ major utility; and, EOR is the Electric Operating Revenues for the $i^{\text {th }}$ major utility.

Preferred Stock Dividends Declared as a Percent of Operating Revenues =

$$
\frac{\sum_{i}\left(P S D D_{i}\right)}{\sum_{i}\left(T U O R_{i}\right)} \times 100
$$

where $P S D D_{1}$ is the Dividends Declared-Preferred Stock for the $i^{\text {th }}$ major utility; and, $T U O R_{i}$ is the Total Utility Operating Revenues for the $i^{\text {th }}$ major utility.

Preferred Stock Average Dividend Rate $=$

$$
-\frac{\sum_{i}\left(P S D D_{i}\right)}{\sum_{i} \frac{\left(\mathrm{PSI}_{B}\right)+\left(\mathrm{PSI}_{E}\right)}{2}} \times 100
$$

where $P S D D_{l}$ is the Dividends Declared-Preferrd Stock for the $i^{\text {th }}$ major utility; PSI $_{B}$ is the Preferred Stock Issued for the beginning of the year; and, $\mathrm{PSI}_{E}$ is the Preferred Stock Issued for the end of the year. The average is calculated by dividing the sum by two.

\section{Interest Coverage $=$}

$$
\frac{\sum_{i}\left(N I_{i}\right)}{\sum_{i}\left(P S D D_{i}\right)}
$$

where $N I_{i}$ is the Net Income for the $i^{\text {th }}$ major utility; and, $P S D D_{1}$ is the Dividends Declared-Preferred Stock for the $i^{\text {ih }}$ major utility.

Common Stock Dividends as a Percent of Operating Revenues =

$$
\frac{\sum_{i}\left(C S D D_{i}\right)}{\sum_{i}\left(T U O R_{i}\right)} \times 100
$$

where $C S D D_{\text {, }}$ is the Dividends Declared-Common Stock for the $i^{\text {th }}$ major utility; and, TUOR $R_{i}$ is the Total Utility Operating Revenues for the $i^{\text {th }}$ major utility.

Percent of Earnings Available for Common Stock =

$$
\frac{\sum_{i}\left(C S D D_{i}\right)}{\sum_{i}\left(N I_{i}-P S D D_{i}\right)} \times 100
$$

where $C S D D_{i}$ is the Dividends Declared-Common Stock for the $i^{\text {th }}$ major utility; $N I_{i}$ is the Net Income for the $i^{\text {th }}$ major utility; and, $P S D D_{i}$ is the Dividends Declared-Preferred Stock for the $i^{i t h}$ major utility.

Dividends Declared as Percent of Average Common Stock Equity =

$$
\frac{\sum_{i}\left(C S D D_{i}\right)}{\sum_{i} \frac{\left(T P C_{B}+T P C_{E}\right)-\left(\mathrm{PSI}_{B}+\mathrm{PSI}_{E}\right)}{2}} \times 100,
$$

where $C S D D_{i}$ is the Dividends Declared-Common Stock for the $i^{\text {th }}$ major utility; $T P C_{B}$ is the Total Proprietary Capital for the beginning of the year for the $i^{\text {th }}$ major utility; $T P C_{E}$ is the Total Proprietary Capital for the end of the year for the $i^{\text {th }}$ major utility; PSI $_{B}$ is the Preferred Stock Issued for the beginning of the year; and, $\mathrm{PSI}_{E}$ is the Preferred Stock Issued for the end of the year for the $i^{i t h}$ major utility. An average is calculated by dividing the sum by two.

Interest on Long-term Debt as a Percent of Total Operating Revenues $=$

$$
\frac{\sum_{i}\left(I L T D_{i}\right)}{\sum_{i}\left(T U O R_{i}\right)} \times 100
$$

where $I L T D_{i}$ is the Interest on Long-term Debt for the $i^{\text {th }}$ major utility; and, $T U O R_{i}$ is the Total Utility Operating Revenues for the $i^{\text {th }}$ major utility.

Average Interest Rate on Long-term Debt $=$

$$
\frac{\sum_{i}\left(I L T D_{i}\right)}{\sum_{i} \frac{\left(T L T D_{B}\right)+\left(T L T D_{E}\right)}{2}} \times 100
$$

where $I L T D_{i}$ is the Interest on Long-term Debt for the $i^{\text {th }}$ major utility; $T L T D_{B}$ is the Total Long-term 
Debt for the beginning of the year for the $i^{\text {th }}$ major utility; and, $T L T D_{B}$ is the Total Long-term Debt for the end of the year for the $i^{\text {ih }}$ major utility.

Net Income Divided by Operuting Revenues (Profit Margin) $=$

$\frac{\sum_{i}\left(N I_{i}\right)}{\sum_{i}\left(T U O R_{i}\right)}$

where $N I_{i}$ is the Net Income for the $i^{\text {th }}$ major utility; and, $T U O R_{i}$ is the Total Utility Operating Revenues for the $i^{\text {th }}$ major utility.

\section{Composite Financlal Indicators for Investor-Owned Electrlc UtIItles}

Electric Fixed Asset (Net Plant) Turnover =

$$
\frac{\sum_{i}\left(E O R_{i}\right)}{\sum_{i}\left(N E U P_{i}\right)}
$$

where $E O R_{l}$ is the Electric Operating Revenues for the $i^{\text {th }}$ major utility; and, NEUP, is the Net Electric Utility Plant (less nuclear fuel) for the $i^{\text {th }}$ major utility.

Total Asset Turnover $=$

$\frac{\sum_{i}\left(T U O R_{i}\right)}{\sum_{i}\left(T A O D_{i}\right)}$

where $T U O R_{i}$ is the Total Utility Operating Revenues for the $i^{\text {th }}$ major utility; and, $T A O D_{i}$ is the Total Assets and Other Debits for the $i^{\text {th }}$ major utility.

Total Electric Utility Plant plus Nuclear Fuel per Dollar of Revenue =

$$
\frac{\sum_{i}\left(T E U P_{i}+N F_{i}\right)}{\sum_{i}\left(E O R_{i}\right)}
$$

where TEUP is the Total Electric Utility Plant for the $i^{\text {th }}$ major utility; $N F_{i}$ is the Nuclear Fuel for the $i^{\text {th }}$ major utility; and, EOR is the Electric Operating Revenues for the $i^{\text {th }}$ major utility.

Other Utility Plant per Dollar of Revenue =

$$
\frac{\sum_{i}\left(\text { TOUP }_{i}\right)}{\sum_{i}\left(G^{\prime} R_{i}+O U O R_{i}\right)},
$$

where TOUP, is the Total Other Utility Plant for the $i^{\text {th }}$ major utility; $G O R_{\text {, is the Gas Operating Revenues }}$ for the $i^{\text {th }}$ major utility; and, $O U O R_{l}$ is the Other Utility Operating Revenues for the $i^{\text {th }}$ major utility.

Total Utility Plant per Dollar of Revenue =

$\frac{\sum_{i}\left(T A U P_{i}\right)}{\sum_{i}\left(T U O R_{i}\right)}$

where TAUP, is the Total All Utility Plant for the $i^{\text {th }}$ major utility; and, $T U O R_{l}$ is the Total Utility Operating Revenues for the $i^{\text {th }}$ major utility.

Total Electric Plant to Total Assets =

$$
\frac{\sum_{i}\left(T E U P_{i}\right)}{\sum_{i}\left(T A O D_{i}\right)} \times 100
$$

where TEUP, is the Total Electric Utility Plant for the $i^{\text {ih }}$ major utility; and, $T A O D_{1}$ is the Total Assets and Other Debits for the $i^{\text {ih }}$ major utility.

Net Electric Piant to Total Aswets =

$$
\frac{\sum_{i}\left(N E U P_{i}\right)}{\sum_{i}\left(T A O D_{i}\right)} \times 100
$$

where $N E U P_{i}$ is the Net Electric Utility Plant (less nuclear fuel) for the $i^{i t h}$ major utility; and, TAOD, is the Total Assets and Other Debits for the $i^{i h}$ major utility.

Total Utility Operating Revenue plus Other Income as a Percent of Total Assets and Other Debits =

$$
\frac{\sum_{i}\left(T U O R_{i}+T^{\prime} I_{i}\right)}{\sum_{i}\left(T A O D_{i}\right)} \times 100
$$

where $T U O R_{i}$ is the Total Utility Operating Revenues for the $i^{\text {ih }}$ majur utility; TOI is the Total Other Income for the $i^{\text {th }}$ major utility; and, $T A O D_{1}$ is the Total Assets and Other Debits for the $i^{\text {th }}$ major utility.

Electric Utility Depreciation and Amortization to Total Electric Utility Plant =

$$
\frac{\sum_{i}\left(E D A_{i}\right)}{\sum_{i}\left(T E U P_{i}\right)} \times 100
$$

where $E D A_{1}$ is the Electric Depreciation and Amortization Expenses for the $i^{\text {th }}$ major utility; and, TEUP, is the Total Electric Utility Plant for the $i^{\text {th }}$ major utility. 
Current Accets to Current Liabilities =

$$
\frac{\sum_{i}\left(T C A A_{i}\right)}{\sum_{i}\left(T C A L_{i}\right)}
$$

where TCAA, are the Total Current and Accrued Assets for the $i^{\text {ith }}$ major utility; and, $T C A L_{l}$ are the Total Current and Accrued Liabilities for the $i^{\text {in }}$ major utility.

\section{Long-term Debt to Capitalization =}

$$
\frac{\sum_{i}\left(T L T D_{i}\right)}{\sum_{i}\left(T P C_{i}+T L T D_{i}\right)} \times 100
$$

where $T L T D_{i}$ is the Total Long-term Debt for the $i^{\text {th }}$ major utility; and, $T P C_{i}$ is the Total Proprietary Capital for the $i^{\text {th }}$ major utility.

Preferred Stock to Capitalization $=$

$$
\frac{\sum_{i}\left(\mathrm{PSI}_{i}\right)}{\sum_{i}\left(T P C_{i}+T L T D_{i}\right)} \times 100
$$

where PSI is the Preferred Stock Issued for the $i^{\text {th }}$ major utility; $T P C_{i}$ is the Total Proprietary Capital for the $i^{\text {th }}$ major utiltiy; and, TLTD is the Total Longterm Debt for the $i^{\text {th }}$ major utility.

Common Stock and Paid-in Capital to Capitalization =

$$
\frac{\sum_{i}\left(T P C_{i}-\mathrm{PSI}_{i}-R E_{i}-U U S E_{i}\right)}{\sum_{i}\left(T P C_{i}+T L T D_{i}\right)} \times 100,
$$

where $T P C_{i}$ is the Total Proprietary Capital for the $i^{\text {th }}$ major utility; PSI is the Preferred Stock Issued for the $i^{\text {th }}$ major utility; $R E_{i}$ is the Retained Earnings for the $i^{\text {th }}$ major utility; $U U S E_{i}$ is the Unappropriated Undistributed Subsidiary Earnings for the $i^{\text {th }}$ major utility; and, $T L T D_{l}$ is the Total Long-term Debt for the $i^{\text {th }}$ major utility.

Retained Earnings to Capitalization =

$$
\frac{\sum_{i}\left(R E_{i}+U U S E_{i}\right)}{\sum_{i}\left(T P C_{i}+T L T D_{i}\right)} \times 100
$$

where $R E_{i}$ is the Retained Earnings for the $i^{\text {th }}$ major utility; $U U S E_{i}$ is the Unappropriated Undistributed Subsidiary Earnings for the th major utility; $T P C_{i}$ is the Total Proprietary Captial for the $i^{\text {th }}$ major utility; and, TLTD, is the Total Long-term Debt for the $i^{\text {ith }}$ major utility.

Common Equity as a Percent of Total Capitalization (Average) $=$

$$
\frac{\frac{\left(T P C_{B}+T P C_{E}\right)-\left(P S I_{B}+P S I_{E}\right)}{2}}{\frac{\left(T P C_{B}+T P C_{E}\right)+\left(T L T D_{B}+T L T D_{E}\right)}{2}} \times 100,(D 34)
$$

where $T P C_{B}$ is the Total Proprietary Capital for the beginning of the year for the $i^{\text {th }}$ major utility; $T P C_{E}$ is the Total Proprietary Capital for the end of the year for the $i^{\text {th }}$ major utility; PSI $_{B}$ is the Preferred Stock Issued for the beginning of the year for the $i^{\text {th }}$ major utility; PSI $_{E}$ is the Preferred Stock Issued for the end of the year for the $i^{\text {th }}$ major utility; TLTD is the Total Long-term Debt for the beginning of the year for the $i^{\text {th }}$ major utility; and, TLTD $D_{B}$ is the Total Long-term Debt for the end of the year for the $i^{\text {th }}$ major utility. An average year's balance is calculated by dividing the sum by two. Capitalization is the sum of an average year's balance of $(T P C+T L T D) / 2$.

Short-term Debt to Capitalization $=$

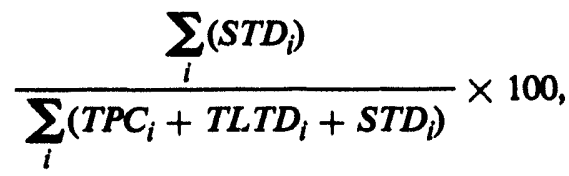

where $S T D_{i}$ is the Short-term Debt (Notes Payable) for the $i^{\text {th }}$ major utility; $T P C_{i}$ is the Total Proprietary Capital for the $i^{\text {th }}$ major utility; and, TLTD, is the Total Long-term Debt for the $i^{\text {th }}$ major utility.

Long-term Debt to Capitalization $=$

$$
\frac{\sum_{i}\left(T L T D_{i}\right)}{\sum_{i}\left(T P C_{i}+T L T D_{i}+S T D_{i}\right)} \times 100,
$$

where $T L T D_{1}$ is the Total Long-term Debt for the $i^{\text {th }}$ major utility; $T P C_{i}$ is the Total Proprietary Capital for the $i^{\text {th }}$ major utility; and, $S T D_{i}$ is the Short-term Debt (Notes Payable) for the $i^{\text {th }}$ major utility.

Preferred Stock to Capitalization $=$

$\frac{\sum_{i}\left(\mathrm{PSI}_{i}\right)}{\sum_{i}\left(T P C_{i}+T L T D+S T D_{i}\right)} \times 100$,

where $\mathrm{PSI}_{i}$ is the Preferred Stock Issued for the $i^{\text {th }}$ major utility; $T P C_{l}$ is the Total Proprietary Capital for the $i^{\text {th }}$ major utility; $T L T D_{l}$ is the Total Long-term Debt for the $i^{\text {th }}$ major utility; and, $S T D_{i}$ is the Shortterm Debt (Notes Payable) for the $i^{\text {th }}$ major utility. 
Common Equity to Capitalization $=$

$$
\frac{\sum_{i}\left(T P C_{i}-P S I_{i}\right)}{\sum_{i}\left(T P C_{i}+T L T D_{i}+S T D_{i}\right)} \times 100,
$$

where $T P C_{i}$ is the Total Proprietary Capital for the $i^{\text {th }}$ major utility; PSI, is the Preferred Stock Issued for the $i^{\text {th }}$ major utility; TLTD, is the Total Long-term Debt for the $i^{\text {th }}$ major utility; and, STD is the Shortterm Debt (Notes Payable) of the $i^{i \text { th }}$ major utility.

Internally Generated Funds to Cash Outflows for Plant $=$

$$
\frac{\sum_{i}\left(\begin{array}{c}
N I_{i}+N C C_{i}+A O F U D C_{i} \\
-P S D D_{i}-C S D D_{i}
\end{array}\right)}{\sum_{i}\left(C O P_{i}\right)} \times 100
$$

where $N I_{i}$ is Net Income of the $i^{\text {th }}$ major utility; $N C C_{i}$ is the Noncash Charges Credits (Depreciation and Depletion, Amortization, Deferred Income Taxes (Net), Investment Tax Credit Adjustment (Net), and "Other") for the $i^{\text {th }}$ major utility; $A O F U D C_{i}$ is the Allowance for Other Funds Used During Construction for the $i^{\text {th }}$ major utiltiy; $P S D D_{l}$ is the Dividends Declared-Preferred Stock for the $i^{\text {th }}$ major utility; $C S D D_{i}$ is the Dividends Declared-Common Stock for the $i^{\text {ih }}$ major utility; and, $C O P_{i}$ is the Cash Outflows for Plant for the $i^{\text {th }}$ major utility.

Internally Generated Funds to Electric Operating Revenues $=$

$$
\frac{\sum_{i}\left(\begin{array}{c}
N I_{i}+N C C_{i}-A O F U D C_{i} \\
-P S D D_{i}-C S D D_{i}
\end{array}\right)}{\sum_{i}\left(E O R_{i}\right)} \times 100,
$$

where $N I_{i}$ is Net Income of the $i^{\text {th }}$ major utility; $N C C_{i}$ is the Noncash Charges Credits (Depreciation and Depletion, Amortization, Deferred Income Taxes (Net), Investment Tax Credit Adjustment (Net), and "Other") for the $i^{\text {th }}$ major utility; $A O F U D C_{l}$ is the Allowance for Other Funds Used During Construction for the $i^{\text {th }}$ major utility; $P S D D_{i}$ is the Dividends Declared-Preferred Stock for the $i^{\text {th }}$ major utility; $C S D D_{i}$ is the Dividends Declared-Common Stock for the $i^{\text {th }}$ major utility; and, $E O R_{i}$ is the Electric Operating Revenues for the $i^{\text {th }}$ major utility.

$$
\begin{aligned}
& \text { Interest Coverage Before Taxes with AFUDC }= \\
& \frac{\sum_{i}\left(\begin{array}{c}
N U O I_{i}+T U F I T_{i}+T U O I T_{i} \\
+N O I D_{i}+A B F U D C_{i}
\end{array}\right)}{\sum_{i}\left(I E_{i}\right)}
\end{aligned}
$$

where $\mathrm{NUOI}_{i}$ is Net Utility Operating Income for the $i^{\text {th }}$ major utility; TUFIT is the Total Utility Federal
Income Taxes for the $i^{\text {th }}$ major utility; $T U O I T_{i}$ is the Total Utility Other Income Taxes for the $i^{t h}$ major utility; NOID, is the Net Other Income and Deductions for the $i^{\text {th }}$ major utility; $A B F U D C_{i}$ is the Allowance for Borrowed Funds Used During Construction for the $i^{\text {th }}$ major utility; and, $I E_{i}$ is the Interest Expenses for the $i^{\text {th }}$ major utility.

Interest Coverage Before Taxes without AFUDC =

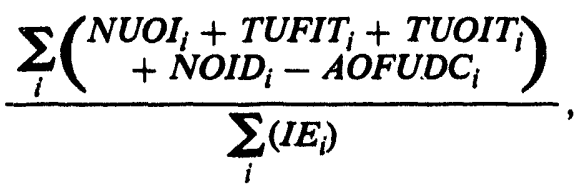

where $N U O I_{i}$ is Net Utility Operating Income for the $i^{\text {th }}$ major utility; TUFIT $T_{i}$ is the Total Utility Federal Income Taxes for the $i^{\text {th }}$ major utility; $T U O I T_{i}$ is the Total Utility Other Income Taxes for the $i^{\text {th }}$ major utility; NOID, is the Net Other Income and Deductions for the $i^{\text {th }}$ major utility; $A O F U D C_{i}$ is the Allowance for Other Funds Used During Construction for the $i^{\text {th }}$ major utility; and, $I E_{i}$ is the Interest Expenses for the $i^{\text {th }}$ major utility.

Total Debt to Total Assets =

$$
\frac{\sum_{i}\left(T L T D_{i} \cdot-S T D_{i}\right)}{\sum_{i}\left(T A O D_{i}\right)} \times 100
$$

where $T L T D_{i}$ is the Total Long-term Debt for the $i^{\text {th }}$ major utility; $S T D_{i}$ is the Short-term Debt (Notes Payable) for the $i^{t h}$ major utility; and, $T A O D_{l}$ is the Total Assets and Other Debits for the $i^{\text {th }}$ major utility.

Common Stock Equity to Total Assets =

$$
\frac{\sum_{i}\left(T P C_{i}-\mathrm{PSI}_{i}\right)}{\sum_{i}\left(T A O D_{i}\right)} \times 100,
$$

where $T P C_{i}$ is the Total Proprietary Capital for the $i^{\text {th }}$ major utility; $\mathbf{P S I}_{i}$ is the Preferred Stock Issued for the $i^{\text {th }}$ major utility; and, $T A O D_{i}$ is the Total Assets and Other Debits for the $i^{\text {it }}$ major utility.

Accumulated Provision for Depreciation as a Percent of Total Utility Plant $=$

$$
\frac{\sum_{i}\left(U P D A D_{i}\right)}{\sum_{i}\left(T A U P_{i}\right)} \times 100
$$

where $U P D A D_{i}$ is the All Utility Plant Accumulated Provisions for Depreciation, Amortization, and Depletion for the $i^{\text {th }}$ major utility; and, TAUP is the Total All Utility Plant for the $i^{\text {th }}$ major utility. 
Return on Average Common Stock Equity $=$

$$
\frac{\sum_{i}\left(N I_{i}\right)}{\sum_{i} \frac{\left(T P C_{B}+T P C_{E}\right)-\left(\mathrm{PSI}_{B}+\mathrm{PSI}_{E}\right)}{2}} \times 100,
$$

where $N I_{i}$ is the Net Income for the $i^{\text {th }}$ major utility; $T C_{B}$ is the Total Proprietary Capital for the beginning of the year for the $i^{\text {th }}$ major utility; $T P C_{E}$ is the Total Proprietary Capital for the end of the year for the $i^{\text {th }}$ major utility; $\mathrm{PSI}_{B}$ is the Preferred Stock Issued for the beginning of the year for the $i^{\text {th }}$ major utility; and, $\mathrm{PSI}_{E}$ is the Preferred Stock Issued for the end of the year for the $i^{\text {th }}$ major utility. An average for the year is calculated by dividing the sum by two.

Return on Average Common Equity =

$$
\frac{\sum_{i}\left(N I_{i}-P S D D_{i}\right)}{\sum_{i} \frac{\left(T P C_{B}+T P C_{E}\right)-\left(\mathrm{PSI}_{B}+\mathrm{PSI}_{E}\right)}{2}} \times 100,
$$

where $N I_{i}$ is the Net Income for the $i^{\text {th }}$ major utility; $P S D D_{i}$ is the Dividends Declared-Preferred Stock for the $i^{\text {th }}$ major utility; $T P C_{B}$ is the Total Proprietary Capital for the beginning of the year for the $i^{\text {th }}$ major utility; $T P C_{E}$ is the Total Proprietary Capital for the end of the year for the $i^{\text {th }}$ major utility; PSI $_{B}$ is the Preferred Stock Issued for the beginning of the year for the $i^{i \text { th }}$ major utility; and, $\mathrm{PSI}_{E}$ is the Preferred Stock Issued for the end of the year for the $i^{\text {th }}$ major utility. An average for the year is calculated by dividing the sum by two.

Return on Investment $=$

$$
\frac{\sum_{i}\left(N I_{i}\right)}{\sum_{i}\left(T A O D_{i}\right)} \times 100
$$

where $N I_{i}$ is the Net Income for the $i^{\text {th }}$ major utility; and, $T A O D_{i}$ is the Total Assets and Other Debits for the $i^{\text {ih }}$ major utiltiy.

\section{Selected Financlal Indicators for Investor-Owned Electric UtIIItles}

The following formulas are used to calculate the financial indicators of Investor-Owned Electric Utilities listed in Table 44, "Selected Financial Indicators by major U.S. Investor-Owned Electric Utility Within State, 1992."

Common Equity to Capitalization =

$\frac{T P C-\text { PSI }}{T P C+T L T D+S T D} \times 100$,

where TPC is the Total Proprietary Capital; PSI is the Preferred Stock Issued; TLTD is the Total Long-term
Debt; and, STD is the Short-term Debt (Notes Payable). Capitalization is the sum of $T P C+T L T D+S T D$.

Preferred Stock to Capitalization $=$

$\frac{\text { PSI }}{T P C+T L T D+S T D} \times 100$,

where PSI is the Preferred Stock Issued; TPC is the Total Proprietary Capital; TLTD is the Total Longterm Debt; and, STD is the Short-term Debt (Notes Payable). Capitalization is the sum of $T P C+T L T D+S T D$.

Long-term Debt to Capitalization $=$

$\frac{T L T D}{T P C+T L T D+S T D} \times 100$,

where TLTD is the Total Long-term Debt; TPC is the Total Proprietary Capital; and, STD is the Short-term Debt (Notes Payable). Capitalization is the sum of $T P C+T L T D+S T D$.

Short-term Debt to Capitalization $=$

$\frac{S T D}{T P C+T L T D+S T D} \times 100$,

where $S T D$ is the Short-term Debt (Notes Payable); $T P C$ is the Total Proprietary Capital; and, TLTD is the Total Long-term Debt. Capitalization is the sum of $T P C+L T D+S T D$.

Average Common Equity as a Percent of Total Capitalization $=$

$$
\frac{\frac{\left(T P C_{B}+T P C_{E}\right)-\left(P S I_{B}+P S I_{E}\right)}{2}}{\frac{\left(T P C_{B}+T P C_{E}\right)+\left(T L T D_{B}+T L T D_{E}\right)}{2}} \times 100,(D 53)
$$

where $T P C_{B}$ is the Total Proprietary Capital for the beginning of the year: $T P C_{E}$ is the Total Proprietary Capital for the end of the year; PSI $_{B}$ is the Preferred Stock Issued for the beginning of the year; $\mathbf{P S I}_{E}$ is the Preferred Stock Issued for the end of the year; $T L T D_{B}$ is the Total Long-term Debt for the beginning of the year; and, $T L T D_{E}$ is the Total Long-term Debt for the end of the year. An average year's balance is calculated by dividing the sum by two. Capitalization is the sum of an average year's balance of $(T P C+T L T D) / 2$.

Rate of Return on Average Common Equity =

$\frac{N I-P S D D}{\frac{\left(T P C_{B}+T P C_{E}\right)-\left(\mathrm{PSI}_{B}+\mathrm{PSI}_{E}\right)}{2}} \times 100$,

where $N I$ is the Net Income; PSDD is the Dividends Declared-Preferred Stock; $T P C_{B}$ is the Total Proprietary Capital for the beginning of the year; $T P C_{E}$ is the 
Total Proprietary Capital for the end of the year; PSI $_{B}$ is the Preferred Stock Issued for the beginning of the year; and, $\mathrm{PSI}_{E}$ is the Preferred Stock Issued for the end of the year. An average year's balance is calculated by dividing the sum by two.

Total Utility Operating Revenue Plus Other Income as a Percent of Total Assets and Other Debits =

$$
\frac{T U O R+T O I}{T A O D} \times 100
$$

where TUOR is the Total Utility Operating Revenues; TOI is the Total Other Income; and, TAOD is the Total Assets and Other Debits.

Interest Coverage Before Taxes with $A F U D C$

$$
\frac{\left(\begin{array}{c}
N U O I+T U F I T \\
+T U O I T+N O I D+A B F U D C
\end{array}\right)}{I E}
$$

where NUOI is the Net Utility Operating Income; TUFIT is the Total Utility Federal Income Taxes; TUOIT is the Total Utiltiy Other Income Taxes; NOID is the Net Other Income and Deductions; $A B F U D C$ is the Allowance for Borrowed Funds Used During Construction (AFUDC); and, IE is the Interest Expenses.

Interest Coverage Before Taxes without $A F U D C=$

$$
\frac{\left(\begin{array}{c}
N U O I+T U F I T \\
+T U O I T+N O I D-A O F U D C
\end{array}\right)}{I E}
$$

where NUOI is the Net Utility Operating Income; TUFIT is the Total Utility Federal Income Taxes; TUOIT is Total Utility Other Income Taxes; NOID is the Net Other Income and Deductions; AOFUDC is the Allowance for Other Funds Used During Construction; and, $I E$ is the Interest Expenses.

\section{Statement of Financial Accounting Standards}

\section{Accounting for the Effects of Certain Types of Regulation}

Companies in regulated industries, such as electric utilities, are required to maintain several sets of accounting records. At least one set is needed to meet the needs of state and federal regulators, while an additional set is required to comply with generally accepted accounting principles (GAAP).

Not suprisingly, conflicts may arise between treatments required by different governing agencies. For example, Financial Accounting Standards Board (FASB) issues SFAS No. 71 that applies to general purpose financial statements when all of the following conditions apply:

- Rates are established by an independent third party (e.g., FERC) or by a governing board established by statute;

- The rate structure is designed to recover the costs of providing services;

- It is likely that the regulated costs will be recovered.

The accounting treatment afforded capitalized expenditures and associated costs is of greatest concern. Frequently, regulators require the capitalization of certain costs that have been incurred, while GAAP would require that these costs be expensed. To allow for this accounting treatment, SFAS No. 71 explicitly recognizes that certain costs may be capitalized that otherwise would have been expensed, but only if the following preconditions exists:

- It is probable that future revenues will at least equal the capitalized costs, and

- The revenue are intended to recover incurred costs, rather than anticipated future costs.

There is a possibility that a regulated company met the requirements of SFAS No. 71 in prior periods but no longer can meet the specific requirements and therefore should discontinue the use of SFAS No. 71. The FASB has specifically anticipated this potential and issued SFAS No. 101 to provide for the accounting for the discontinuation of SFAS No. 71. Effectively, SFAS No. 101 calls for the explicit accounting for any capitalized costs that resulted from the historical regulatory treatment. Further, any impairment or write-off of assets should be netted and included as income in the accounting period that the SFAS No. 71 is discontinued.

\section{Accounting for Abandonments and Disallowances of Plant Costs}

According to the statement of the Financial Accounting Standards Board, SFAS No. 90 (issued in December 1987), when part of the cost of a completed plant is disallowed for ratemaking purposes and a reasonable estimate of the disallowance can be made, this estimated amount will be deducted from the cost of the plant as a loss. Several plants reported in this publication have been or are facing significant disallowances of costs. No attempt has been made to identify the plants or the amounts involved. 


\section{Accounting for Phase-In Plants}

When the cost of new generating plants increase quite substantially and to the extent that conventional ratemaking methods would result in significantly higher rates when the plant goes into service, some regulators have instituted phase-in plans to moderate the initial rate increase. In August 1987, the FASB issued SFAS No. 92 -- Regulated Enterprises. Phase-in plans were developed to morlerate the initial increase in rates that would otherwise result from traditional treatment of plants entering commercial service by deferring some of the initial rate increase to future years and providing the electric utility with a return on investment for those deferred amounts provided the phase-in plan meets certain criteria. Assuming a electric utility is operating under a phase-in plan that met the criteria, the electric utility could continue to capitalize allowable deferred costs associated with a generating plant subsequent to the plant entering service. Therefore, the capital cost will continue to increase as these deferred costs are added to the cost of the plant. No attempt has been made to identify or segregate the costs associated with phase-in plans for the generating plants included in this report.

\section{Statement of Cash Flows}

Statement of Cash Flows, SFAS No. 95 (Financial Accounting Standards Board), berame effective for annual financial statements for fiscal years ending after July 15, 1989. SFAS No. 95 :equires that a cash flow statement replace the chan zes in the financial position statement as a part of th: set of full financial statements.

SFAS No. 95 removes ambiguilies $c f$ terms such as funds; comparability problems arising from diversity in statement focus (cash, cash and short-term investments, quick assets or working capital) and the resulting differences in definitions of funds flows from operating activities (cash or working capital); differences in format (sources and uses or activity format); variations in classification of items in an activity format; and, reports of net changes of assets and liabilities rather than gross inflows and outflows.

SFAS No. 95 requires a statement of ca.n flows th th classifies cash receipts and payments according to whether they stem from operating, investing, or financial activities and provides definitions of each category. SFAS No. 95 requires the cash flow statement to explain the change in cash and cash equivalents, where cash equivalents are short-term, highly liquid investments (e.g. investments with original maturities of three months or less).

SFAS No. 95 requires the electric utilities to report gross cash receipts and payments rather than net changes. These receipts and payments are to be classi- fied into investing, financing or operating activities. SFAS No. 95 allows one of two methods for reporting - direct and indirect. The Federal Energy Regulatory Commission (FERC) issued Order No. 505, October 13,1989 , requiring electric utilities to use the indirect method which adjusts net income by reconciling it to net cash flow from operating activities. This reconciliation includes separately reporting all major classes of reconciling items.

\section{Accounting for Income Taxes}

FASB Statement No. 109, Accounting for Income Taxes, supersedes FASB Statement No 96. Statement No. 109 establishes standards for the financial accounting and reporting for tax effects of an enterprise's activities. The Statement requires an enterprise to recognize the amount of taxes payable for the current period and the estimated amounts which are payable or deductible in future years for events that have been recognized in the enterprise's financial statements or tax returns. These estimat $=d$ amounts which are to be recorded as deferred tax liabilities and/or deferred tax assets are attributable temporary differences: revenue, expenses, gains, or losse: that are included in taxable income of an earlier or iater year than the year in which they are recognized in financial income; other events that 'create differences between the tax basis of assets and liabilities and their amoutts of financial reporting; and, operating loss or tax credit carrybacks for refunds of taxes paid in prior years and carryforwards to reduce taxes payable in the future.

Deferred tax liabilities and assets are measured annually and calculated using the current applicable tax laws and rates. $A$ valuation allowance may need to be established when there is more than a 50 percent likelihood, that some portion of the deferred tax asset will not be realized. ${ }^{2}$

The Statement prohibits net-of-tax accounting and reporting and requires a deferred tax liability for tax benefits originating from temporary differences that are flowed through to consumers and for the equity component of the allowance for funds used during construction. An asset or liability must also be recognized for future revenue or reduction in revenue if it is probable that the resulting future increase or decrease in taxes payable will be recovered from or returned to consumers through future rate adjustments.

This Statement is effective for fiscal years beginning after December 15, 1992. Since FASB has had under consideration for a number of years to change for accounting of income taxes and a number of electric utilities have implemented the SFAS No. 96 accounting in prior years, the aggregated data reported in this publication contains a mixture of treatments. ${ }^{3}$

2 This concept of a valuation allowance based on the likelihood of recovery did not appear in SFAS No. 96.

3 Accounts of those investor-owned electric utilities that implemented SFAS No. 96 could be made by reviewing the footnotes to financial statements (in the annual report to stockholders). 


\section{Disclosures About Falr Value of Financlal Instruments}

Statements No. 107, effective for financial statements after December 15, 1992, sets forth disclosure requirements for financial instruments with off-balance sheet risk and/or credit risk.

Exempt from reporting requirements under this Statement are those obligations which fall under the requirements of other Statements issued by the FASB:

- post-retirements benefits

- substantively extinguished debt

- insurance contracts ।

- lease contracts

- warranty obligations and rights

- unconditional purchase obligations

- investments accounted for under the equity method

- equity investments on consolidated subsidiaries

- equity instruments issued by the entity

Financial instruments not recorded in the records of the entity may represent potential accounting losses, off-balance sheet credit, or market risk. Such financial instruments include futures contracts, interest rate swaps, forward purchase contracts, and guarantees for itself, a subsidiary, or other entity.

- Disclosures for Financial Instruments with OffBalance Sheet Risk - Extent, Nature, and Terms:

1. The contract, face, or notional amount of the financial instrument.

2. A description of the financial instrument's nature and terms with disclosure of market and credit risks, cash requirements, and disclosures required under APB Opinion No. 22, as a minimum.

- Financial Instruments with Credit Risks:

1. The company's policy for financial instrument, collateral, nature, and description of such collateral and company access to the collateral. ${ }^{5}$

2. The amount of accounting loss assuming that the counterparty to the contract defaults and any collateral related to the contract is of no value to the company.

- Disclosure for All Financial Instruments with Concentration of Credit Risks

1. All significant concentrations of credit risk including both individual and group concentrations.
2. For each significant concentration of credit risk, disclose the economic characteristics, region, or activity that identifies the concentration.

3. For each significant concentration of credit risk, disclose company policy for financial instrument collateral, nature, and description of such collateral and company access to the collateral.

4. For each significant concentration of credit risk, the best estimate of the amount of accounting loss assuming that counterparties to the contracts making up the concentration default and any collateral related to the contracts is of no value to the company.

While on a company specific basis the accounting treatment afforded to these times may be significant, on an industry wide aggregate basis they would not appear to have a significant impact on interperiod comparisons.

\section{Employors' Accounting for Postrot/rement Banefits Other Ponsions}

FA\$B Statement No. 106 requires a complex cost calculation for postretirement benefits similar to that which is required by Statement No. 87 for pension accounting. The Statement views postretirement benefits as a form of deferred compensation and may include such benefits as health care, legal service, day care, life insurance not included in pension benefits and tuition plans.

The requirements of this Statement replace the pay-asyou-go approach used by most entities in accounting for postretirements benefits.

Effective for financial statements beginning after December 15, 1992, the cost of postretirement benefits must be calculated using seven basic components:

- Service cost

- Interest cost

- Amortization of prior service cost

- Actual return on plan assets

- Deferred asset gain or loss

- Amortization of gain or loss

- Amortization of transitional asset or obligation.

Although the financial statement impact appears limited, the administrative burden could be significant based on the number of postretirement programs available with an entity and the number of eligible employees.

4 APB Opinion No. 22 requires the disclosure of all significant accounting policies used in the preparation of the financial statements.

3 An enterprise may wish to disclose additional information about collateral underlying financial instruments, especially if the additional disclosure mitigates the credit risk. 


\section{General Information}

\section{Use of the Glossary}

The terms in the glossary have been defined for general use. Restrictions on the definitions, as used in these data collection systems, are included in each definition when necessary to define the terms as they are used in this report.

\section{Obtaining Coples of Data}

Upon EIA approval of the Financial Statistics of Major U.S. Investor-Owned Electric Utilities, these data are available for public use.

Computer listings are obtained by submitting a written request to:

Energy Information Administration

Survey Management Division, EI-523

U.S. Department of Energy

1000 Independence Ave., S.W.

Washington, DC 20585

(202) 254-5440

FAX (202) 254-5765
Magnetic tapes may be purchased by using Visa, MasterCard, or American Express cards, as well as money orders or checks payable to the National Technical Information Service (NTIS). Purchasers may also use NTIS and Government Printing Office deposit accounts. To place an order, contact:

National Technical Information Service (NTIS)

Office of Data Base Services

U.S. Department of Commerce

5285 Port Royal Road

Springfield, Virginia 22161

(703) 487.4650

FAX (703) 321-8547

Personal computer diskette $\left(31 / 2^{\prime \prime}\right.$ or $\left.51 / 4^{\prime \prime}\right)$ may be purchased by using Visa or MasterCard, as well as money orders or cheoks payable to the Superintendent of Documents. Purchasers may also use Government Printing Office deposit accounts. To place an order, contact:

Superintendent of Documents

U.S. Government Printing Office

Attn: Electric Products Sales Coordinator

P.O. Box 37080

Washington, DC 20013-7082

(202) $512-1530$

FAX (202) 512-1262 


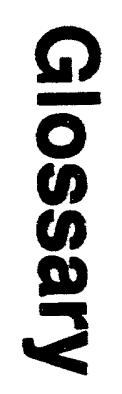


Accounting System. A method of recording accounting data for a utility or company or a method of supplying accounting information for controlling, evaluating, planning and decisionmaking.

Administrative and General Expenses. Expenses of an electric utility relating to the overall directions of its corporate offices and administrative affairs, as contrasted with expenses incurred for specialized functions. Examples include office salaries, office supplies, advertising, and other general expenses.

\begin{abstract}
Allowance for Funds Used During Construction (AFUDC). A noncash item representing the estimated composite interest costs of debt and a return on equity funds used to finance construction. The allowance is capitalized in the property accounts and included in income.
\end{abstract}

Amortization. The gradual write-off of an amount in an account by distributing such amount over a fixed period, over the life of the asset or liability to which it applies, or over the period during which it is anticipated the benefit will be realized.

Asset. An economic resource, tangible or intangible, which is expected to provide benefits to a business.

Average Stream Flow. The rate, usually expressed in cubic feet per second, at which water passes a given point in a stream over a set period of time.

Capacity. The amount of electric power delivered or required for which a generator, turbine, transformer, transmission circuit, station, or system is rated by the manufacturer.

Capacity (Purchased). The amount of energy and capacity available for purchase from outside the system.

Capital. The equity interest of the owners consisting of common stock, preferred stock, and retained earnings in the entity, that is the difference between assets and liabilities.

Capital (Financial). The line items on the right side of a balance sheet, that include debt, preferred stock, and common equity. A net increase in assets must be financed by an increase in one or more forms of capital.

Capital Intensive. A condition in which investment in plant and equipment is relatively large compared to labor and to operation and maintenance expenses.

Capitalization. The long-term sources of funds comprising an entity's total capitalization; that is, the longterm debt, preferred stock, and common equity. The short-term sources of capital are not included.
Capitalization Ratio. The percentage of debt, or preferred stock, or common stock, or other equity to the total capital structure of an entity.

Circuit. A conductor or a system of conductors through which electric current flows.

Circuit-Miles. The total length in miles of separate circuits regardless of the number of conductors used per circuit.

Classes of Service. Consumers grouped by similar characteristics in order to be identified for the purpose of setting a common rate for electric service. Usually classified into groups identified as residential, commercial, industrial and other.

Commercial. The commercial sector is generally defined as nonmanufacturing business establishments, including hotels, motels, restaurants, wholesale businesses, retail stores, and health, social, and educational institutions. The utility may classify commercial service as all consumers whose demand or annual use exceeds some specified limit. The limit may be set by the utility based on the rate schedule of the utility.

Commercial and Industrial. Classes of service supplied to a similar grouping of consumers. These customer groupings are usually subdivided into smaller segments by classifying such consumers as commercial or industrial using the Federal Government's Office Of Management and Budget's Standard Industrial Classification Guide and/or a scale of energy usage as yardsticks; other consumers are reclassified as commercial or industrial when their demands or annual use exceeds some specified limit. These limits are generally based on a utility's rate schedules, except for those consumers who are supplied under special contracts or agreements calling for particular services.

Common Equity, Book Value. The retained earnings and common stock earnings plus the balances in common equity reserves and all other common stock accounts. This also includes the capital surplus, the paid-in surplus, the premium on common stocks, except those balances specifically related to preferred or preference stocks; less any common stocks held in the treasury.

Common Stock Equity Ratio. The net income after interest taxes and the preferred dividends divided by the average common stock equity.

Condenser Cooling Water. A source of water external to a boiler's feed system is passed through the steam leaving the turbine in order to cool and condense the steam. This reduces the steam's exit pressure and recaptures its heat, which is then used to preheat fluid 
entering the boiler, thereby increasing the plant's thermodynamic efficiency.

Conditionally Effective Rates. An electric rate schedule that has been put into effect by the FERC subject to refund pending final disposition or refiling.

Construction Costs (of the electric power industry). All direct and indirect costs incurred in acquiring and constructing electric utility plant and equipment and proportionate shares of common utility plant. Included are the cost of land and improvements, nuclear fuel and spare parts, allowance for funds used during construction, general overheads capitalized, less the cost of acquiring plant and equipment previously operated in utility service.

Construction Expenditures (of the electric power industry). The gross expenditures for construction costs, including the cost of replacing worn-out plants, and electric construction costs and land held for future use.

Construction Work In Progress (CWIP). The balance shown on a utility's balance sheet for construction work not yet completed but in process. This balance line item may or may not be included in the rate base.

Conventional Hydroelectric Plant. A plant in which all of the power is produced from natural streamflow as regulated by available storage.

Cooperative Electric Utility. An electric utility legally established to be owned by and operated for the benefit of those using its service. The utility company will generate, transmit, and/or distribute supplies of electric energy to a specified area not being serviced by another utility. Such ventures are generally exempt from Federal income tax laws. Most electric cooperatives have been initially financed by the Rural Electrification Administration, U.S. Department of Agriculture.

Cost. The amount paid to acquire resources, such as plant and equipment, fuel, or labor services.

Cost of Capital. The rate of return an entity must offer to obtain additional funds. The cost of capital varies with the leverage ratio, the effective income tax rate, conditions in the bond and stock markets, growth rate of the firm, it; dividend strategy, stability of net income, the amouht of new capital required, and other factors dealing with business and financial risks. It is a composite of the cost for debt interest, preferred stock dividends, and common stockholders' earnings that provide the facilities used in supplying utility service.

Cost of Debt. The interest rate paid on new increments of debt capital multiplied by 1 minus the tax rate.

Cost of Preferred Stock. Equals the preferred dividend divided by the net price of preferred stock.
Cost of Retained Earnings. The residual of an entity's earnings over expenditures, including taxes and dividends, that are reinvested in its business. The cost of these funds is always lower than the cost of new equity capital, due to taxes and transactions costs. Therefore, the cost of retained earnings is the yield that retained earnings accrue upon reinvestment.

Cost of Service. A ratemaking concept used for the design and development of rate schedules to ensure that the filed rate schedules recover only the cost of providing the electric service at issue. These costs include operating and maintenance expenses, depreciation and amortization expenses, and income and other taxes found just and reasonable by the regulatory agency for ratemaking purposes plus, in the case of privately owned electric utilities, an allowance for a return on capital (usually computed by applying a rate of return to the rate base). This concept attempts to equate the cost incurred by the utility to the revenue received for the service provided to each of the consumer classes.

Current Assets. Cash and other assets that are expected to be turned into cash, sold, or exchanged within the normal operating cycle of the firm, usually one year. Current assets include cash, marketable securities, receivables, inventory and current prepayments.

Current Liabilities. A debt or other obligation that must be discharged within a short time, usually the earnings cycle or one year, normally by expending current assets.

Current Ratio. The ratio (current assets divided by current liabilities) that shows the ability of an entity to pay its current obligations from its current assets.

Debt. Money or services owed through a legal obligation to an outside party. Debt may be classified short-term which is 1 year or less or long-term which is more than 1 year.

Deferred Cost. An expenditure not recognized as a cost of operation of the period in which incurred, but carried forward to be written off in future periods.

Deferred Fuel Costs. An expenditure for fuel that is not recognized for bookkeeping practices as a cost in the operating period incurred, but carried forward to be written off in future periods.

Deferred Income Tax. Usually, a liability in the balance sheet representing the additional Federal income taxes that would have been due if a company had not been allowed to compute tax expenses differently for income tax reporting purposes than for ratemaking reporting purposes.

Depreciation. Charges made against income for distributing the cost of a tangible asset, so as to allocate it systematically across the period in which the asset is used. 
Design Head. The achieved river, pondage, or reservoir surface height (forebay elevation) that provides the water level to produce the full flow at the gate of the turbine in order to attain the manufacturer's installed nameplate rating for generation capacity.

Diesel-Electric Plant. A generating station that uses diesel engines to drive its electric generators.

Distribution System. The portion of an electric system that is dedicated to delivering electric energy to an end user.

Docket. A formal record of a Federal Energy Regulatory Commission proceeding. These records are available for inspection and copying by the public. Each individual case proceeding is identified by an assigned number.

Economy of Scale. The principle that larger production facilities have lower unit costs than smaller facilities.

Electric Expenses. The cost of labor, material, and expenses incurred in operating a facility's prime movers, generators, auxiliary apparatus, switching gear, and other electric equipment for each of the points where electricity enters the transmission or distribution grid.

Electric Operating Expenses. Summation of electric operation-related expenses, such as operation expenses, maintenance expenses, depreciation expenses, amortization, taxes other than income taxes, Federal income taxes, other income taxes, provision for deferred income taxes, provision for deferred income-credit, and investment tax credit adjustment.

Electric Plant (Financial). Assets comprising land, building, and equipment permanently employed.

Electric Power Industry. The privately, publicly, federally and cooperatively owned electric utilities of the United States taken as a whole. This includes all electric systems serving the public: regulated investorowned electric utility companies; Federal power projects; State, municipal, and other governmentowned systems, including electric public utility districts; electric cooperatives, including generation and transmission entities. Excluded from this definition are the special purpose electric facilities or systems that do not offer service to the public.

Electric Power System. An individual electric power entity -- a company, an electric cooperative, a public electric supply corporation as the Tennessee Valley Authority, a similar Federal department or agency as the Bonneville Power Administration, the Bureau of Reclamation or the Corps of Engineers, a municipally owned, electric department offering service to the public, or an electric public utility district (a "PUD "); also a jointly owned electric supply project such as the Keystone.

Electrir: Rate Schedule. A statement of the electric rate and the terms and conditions governing its appli- cation, including attendant contract terms and conditions that have been accepted by a regulatory body with appropriate oversite authority.

Electric Utility. A corporation, person, agency, authority, or other legal entity or instrumentality that owns and/or operates facilities within the United States, its territories, or Puerto Rico for the generation, transmission, distribution, or sale of electric energy primarily for use by the public and files forms listed in the Code of Federal Regulations, Title 18, Part 141. Facilities that qualify as cogenerators or small power producers under the Public Utility Regulatory Policies Act (PURPA) are not considered electric utilities.

Electrical System Energy Losses. The amount of energy lost during generation, transmission, and distribution of electricity, including plant and unaccounted for use.

End User. The final consumer of electricity.

Energy. The capacity for doing work as measured by the capability of doing work (potential energy) or the conversion of this capability to motion (kinetic energy). Energy has several forms, some of which are easily convertible and can be changed to another form useful for work. Most of the world's convertible energy comes from fossil fuels that are burned to produce heat that is then used as a transfer medium to mechanical or other means in order to accomplish tasks. Electrical energy is usually measured in kilowatthours, while heat energy is usually measured in British thermal units.

Energy Deliveries. Energy generated by one electric utility system and delivered to another system through one or more transmission lines.

Energy Information Administration (EIA). An independent agency within the U.S. Department of Energy that develops surveys, collects energy data, and does analytical and modeling analyses of energy issues. The Agency must satisfy the requests of Congress, other elements within the Department of Energy, Federal Energy Regulatory Commission, the Executive Branch, its own independent needs, and assist the general public, or other interest groups, without taking a policy position.

Energy Loss. The difference between energy input and output as a result of transfer of energy between two points.

Energy Receipts. Energy generated by one electric utility system and received by another system through one or more transmission lines.

Equity (Financial). Ownership interest of shareholders ip a corporation represented by stock.

Equity Capital. The sum of capital from retained earnings and the issuance of stocks. 
Expenditure. The incurrence of a liability to obtain an asset or service.

Federal Electric Utility. A utility that is either owned or financed by the Federal Government.

Federal Energy Regulatory Commission (FERC). A quasi-independent regulatory agency within the Department of Energy having jurisdiction over interstate electricity sales, wholesale electric rates, hydroelectric licensing, natural gas pricing, oil pipeline rates, and gas pipeline certification.

Federal Power Act. Enacted in 1920, and amended in 1935, the Act consists of three parts. The first part incorporated the Federal Water Power Act administered by the former Federal Power Commission, whose activities were confined almost entirely to licensing non-Federal hydroelectric projects. Parts II and III were added with the passage of the Public Utility Act. These parts extended the Act's jurisdiction to include regulating the interstate transmission of electrical energy and rates for its sale as wholesale in interstate commerce. The Federal Energy Regulatory Commission is now charged with the administration of this law.

Federal Power Commission. The predecessor agency of the Federal Energy Regulatory Commission. The Federal Power Commission (FPC) was created by an Act of Congress under the Federal Water Power Act on June 10,1920 . It was charged originally with regulating the electric power and natural gas industries. The FPC was abolished on September 20, 1977, when the Department of Energy was created. The functions of the FPC were divided between the Department of Energy and the Federal Energy Regulatory Commission.

FERC. The Federal Energy Regulatory Commission.

FERC Guidelines. A compilation of the Federal Energy Regulatory Commission's enabling statutes, procedural and program regulations, and orders, opinions and decisions.

Financial Accounting Standards Board (FASB). An independent board responsible, since 1973, for establishing generally accepted accounting principles. Its official pronouncement are called "Statements of Financial Accounting Standards" and "Interpretations of Financial Accounting Standards."

Fiscal Year. A financial year based on a predetermined starting date. The Federal Government's financial year runs from October 1 through September 30.

Fixed Asset Turnover. A ratio of revenue to fixed assets which is a measure of the productivity and efficiency of property, plant, and equipment in generating revenue.

Fixed Assets. Tangible property used in the operations of an entity, but not expected to be consumed or converted into cash in the ordinary course of events.

Fixed Charge Coverage. The ratio of earnings available to pay so-called fixed charges to such fixed charges. Fixed charges include interest on funded debt, including leases, plus the related amortization of debt discount, premium and expense. Earnings available for fixed charges may be computed before or after deducting income taxes. Occasionally credits for the "allowance for fund used during construction" are excluded from the earnings figures. The precise procedures followed in calculating fixed charge or interest coverages vary widely.

Fixed Cost (expense). An expenditure or expense that does not vary with volume of activity.

Fixed Operating Costs. Costs other than those associated with capital investment that do not vary with the operation, such as maintenance and payroll.

Fossil Fuel. Any naturally occurring organic fuel, such as petroleum, coal, and natural gas.

Fossil-Fuel Plant. A plant using coal, petroleum, or gas as its source of energy.

Fuel Expenses. These costs include the fuel used in the production of steam or driving another prime mover for the generation of electricity. Other associated expenses include unloading the shipped fuel and all handling of the fuel up to the point where it enters the first bunker, hopper, bucket, tank, or holder in the boiler-house structure.

Gas Turbine Plant. A plant in which the prime mover is a gas turbine. A gas turbine consists typically of an axial-flow 'air compressor, one or more combustion chambers, where liquid or gaseous fuel is burned and the hot gases are passed to the turbine and where the hot gases expand to drive the generator and are then used to run the compressor.

Generally Accepted Accounting Principles (GAAP). Defined by the FASB as the conventions, rules, and procedures necessary to define accepted accounting practice at a particular time; includes both broad guidelines and relatively detailed practices and procedures.

Generating Unit. Any combination of physically connected generator(s), reactor(s), boiler(s), combustion turbine(s), or other prime mover(s) operated together to produce electric power.

Generator Nameplate Capacity. The full-load continuous rating of a generator, prime mover, or other electric power production equipment under specific conditions as designated by the manufacturer. Installed generator nameplate rating is usually indicated on a nameplate physically attached to the generator.

Geothermal Plant. A plant in which the prime mover is a steam turbine. The turbine is driven either by 
steam produced from hot water or by natural steam that derives its energy from heat found in rocks or fluids at various depths beneath the surface of the earth. The energy is extracted by drilling and/or pumping.

Grid. The layout of an electrical distribution system.

Gross Generation. The total amount of electric energy produced by a generating facility, as measured at the generator terminals.

Head. The product of the water's weight and a usable difference in elevation gives a measurement of the potential energy possessed by water.

Historical Plant Cost of Equipment. The charges for equipment assigned to power production include: the net purchased price thereof; sales taxes; investigation and inspection expenses necessary for such purchases, any expenses of transportation when borne by the utility; labor employed charges; materials and supplies consumed; and expenses incurred by the utility in unloading and placing the equipment in readiness to operate.

Historical Plant Cost of Land and Land Rights. The cost of land purchased or the fees paid by the utility for rights, interests, and privileges to be held by the utility in land owned by others. The types of rights acquired include leaseholds, easements, water and water power rights, rights-of-way, and other like interests.

Historical Plant Cost of Structures and Improvements (Expenses). The cost of all buildings and facilities to house, support, or safeguard property or persons, including all fixtures permanently attached to and made a part of building. Also includes the cost incurred in connection with the first clearing and grading of land and rights-of-ways.

Holding Cornpany. A company that confines its activities to uwning stock in, and supervising management of, other companies. The Securities and Exchange Commission, as administrator of the Public Utility Holding Company Act of 1935, defines a holding company as "a company which directly or indirectly owns, controls or holds 10 percent or more of the outstanding voting securities of a holding company" (15 USC 79b, par. a (7)).

Hydroelectric Energy. The production of electricity from kinetic energy in flowing water.

Hydroelectric Plant. A plant in which the turbine generators are driven by falling water.

Hydroelectric Plant Capacity. This capacity figure is a function of fluid flow losses, hydraulic turbines, head, and water flow. The minimum net head limits the firm capacity of the plant.

Hydroelectric Power. The harnessing of flowing water to produce mechanical or electrical energy.
Independent Power Producer. A corporation, person, agency, authority, or other legal entity or instrumentality that owns electric generating capacity and is a wholesale electric producer without a designated franchised service area. The entity is not a qualifying facility as defined in the Public Utility Regulatory Policies Act of 1978.

Industrial. The industrial sector is generally defined as manufacturing, construction, nining, agriculture, fishing and forestry establishments Standard Industrial Classification (SIC) codes 01-39. The utility may classify industrial service using the SIC codes, or based on demand or annual usage exceeding some specified limit. The limit may be set by the utility based on the rate schedule of the utility.

Instantaneous Peak Demand. The maximum demand at the instant of greatest load.

Interchange Energy. Kilowatthours delivered to or received by one electric utility or pooling system from another. Settlement may be by payment, returned in kind at a later time or accumulated as energy balances until the end of the stated period.

Interconnection. Two or more electric systems having a common transmission line that permits a flow of energy between them. The physical connection of the electric power transmission facilities allows for the sale or exchange of energy.

Interdepartmental Service (Electric). Interdepartmental service includes amounts charged by the electric department at tariff or other specified rates for electricity supplied by it to other utility departments.

Interest Coverage Ratio. The number of times that fixed interest charges were earned indicates the margin of safety of interest on fixed debt. The timesinterest-earned ratio is calculated using net income before and after income taxes; and the credits of interest charged to construction being treated as other incomes. The interest charges include interest on longterm debt, interest on debt of associated companies, and other interest expense.

Interlocking Directorates. The holding of a significant position in management or a position on the corporate board of a utility, while simultaneously holding a comparable position with another utility, or with a firm doing business with the utility.

Internal Cash Flow. Composed of funds available for common stockholders after adjustments for common stock equivalents, depreciation and depletion, amortization, deferred income taxes (net), investment tax credit (net), and other internal sources (net); less common dividends and AFUDC (total).

Internal Combustion Plant. A plant in which the prime mover is an internal combustion engine. An internal combustion engine has one or more cylinders in which the process of combustion takes place, converting energy released from the rapid burning of a fuel-air mixture into mechanical energy. Diesel or gas- 
fired engines are the principal types used in electric plants. The plant is usually operated during periods of high demand for electricity.

Investor-Owned Electric Utility. A class of utility that is investor owned and organized as a tax paying business, usually financed by the sales of securities in the capital market.

Kilowatt (kW). One thousand watts.

Kilowatthour (kWh). One thousand watthours.

Leverage Ratio. A measure that indicates the financial ability to meet debt service requirements and increase the value of the investment to the stockholders. (i.e. the ratio of total debt to total assets).

Liability. An amount payable in dollars or by future services to be rendered.

Licensees. Entity that has been granted permission to engage in an activity otherwise unlawful (i.e. hydropower project).

Line Loss. Energy kilowatthours lost in transmission and distribution lines.

Load (Electric). The amount of electric power delivered or required at any specific point or points on a system. The requirement originates at the energyconsuming equipment of the consumers.

Long-term Debt. Debt securities or borrowings having a maturity of more than a year.

Maintenance Expenses. That portion of operating expenses consisting of labor, materials, and other direct and indirect expenses incurred for preserving the operating efficiency and/or physical condition of utility plants used for power production, transmission, and distribution of energy.

Maximum Demand. The greatest of all demands of the load that has occurred within a specified period of time.

Mcf. One thousand cubic feet.

Megawatt (MW). One million watts.

Megawatthour (MWh). One million watthours.

Mill. A monetary cost and billing unit used by utilities; it is equal to $1 / 1000$ of the U.S. dollar (equivalent to $1 / 10$ of 1 cent).

Multiple Purpose Reservoir. Stored water and its usage governed by advanced water resource conservation practices to achieve more than one water control objective. Some of the objectives include flood control, hydro- electric power development, irrigation, recreation usage, and wilderness protection.

Municipality. (As defined in section 3, paragraph (7) of the Federal Power Act, P.L. 66-280 as amended) A city, county, irrigation district, drainage district, or other political subdivision or agency of a State competent under the laws thereof to carry on the business of developing, transmitting, utilizing, or distributing power (41 Stat. 1064; 49 Stat. 838; 16 U.S.C. 796(7)).

Net Generation. Gross generation minus plant use from all electric utility owned plants. The energy required for pumping at a pumped-storage plant is regarded as plant use and must be deducted from the gross generation.

Net Income. The excess of all revenues and gains for a period over all expenses and losses of the period.

Nonutility Power Producer. A corporation, person, agency, authority, or other legal entity or instrumentality that owns electric generating capacity and is not an electric utility. Nonutility power producers include qualifying cogenerators, qualifying small power producers, and other nonutility generators (including independent power producers) without a designated franchised service area, and which do not file forms listed in the Code of Federal Regulations, Title 18, Part 141.

Nuclear Fuel. Fissionable materials that have been enriched to such a composition that, when placed in a nuclear reactor, will support a self-sustaining fission chain reaction, producing heat in a controlled manner for process use.

Nuclear Power Plant. A facility in which heat produced in a reactor by the fissioning of nuclear fuel is used to drive a steam turbine.

Nuclear Reactor. An apparatus in which the nuclear fission chain can be initiated, maintained, and controlled so that energy is released at a specific rate. The reactor includes fissionable material (fuel), such as uranium or plutonium; fertile material; moderating material (unless it is a fast reactor); a heavy-walled pressure vessel; shielding to protect personnel; provision for heat removal; and control elements and instrumentation.

Ohm. The unit of measurement of electrical resistance. The resistance of a circuit in which a potential difference of 1 volt produces a current of 1 ampere.

Operating Expenses. Expenses related to utility operations, which include operation and maintenance expenses, provisions for depreciation and amortization, taxes other than income taxes, income taxes, provision for deferred income taxes, income taxes deferred in prior years-- credit and investment tax credit adjustments--net.

Operating Income. Operating revenues less operating expenses.

Operation Expenses. The components of power production expenses that incur cost for operations that are directly related to producing electricity. The major item is almost always fuel that has to be burned to generate the electricity. 
Operation Supervision and Engineering (Expenses). These expenses include the cost of labor and expenses incurred in the general supervision and direction of the operation of power generation stations. The supervision and engineering costs consist of the pay and expenses of staff and consultants engaged in supervising and directing the operation of each utility function. Direct supervision and engineering of activities, such as fuel handling, boiler room operations, and generator operations, are charged to the appropriate accounts.

Original Cost. The initial amount of money spent to acquire an asset.

Other Generation. Electricity originating from these sources: biomass, fuel cells, geothermal heat, solar power, waste, wind, and wood.

Owners Equity. Interest of the owners in the assets of the business represented by capital contributions and retained earnings.

Parent Company. Company owning more than 50 percent of the voting shares of another company, called the subsidiary.

Plant. A facility at which are located prime movers, electric generators, and auxiliary equipment for converting mechanical, chemical, and/or nuclear energy into electric energy. A plant may contain more than one type of prime mover. Electric utility plants exclude facilities that satisfy the definition of a qualifying facility under the Public Utility Regulatory Policies Act of 1978.

Plant-Use Electricity. The electric energy used in the operation of a plant. This energy total is subtracted from the gross energy production of the plant; for reporting purposes the plant energy production is then reported as a net figure. The energy required for pumping at pumped-storage plants is, by definition, subtracted, and the energy production for these plants is then reported as a net figure.

Pole-Mile. A unit of measuring the simple length of a transmission line carrying electric conductors, without regard to the number of conductors carried.

Power. The rate at which energy is transferred. Electrical energy is usually measured in watts. Also used for a measurement of capacity.

Power (Electrical). An electric measurement unit of power called a voltampere is equal to the product of 1 volt and 1 ampere. This is equivalent to 1 Watt for a direct current system and a unit of apparent power is separated into real and reactive power. Real power is the work-producing part of apparent power that measures the rate of supply of energy and is denoted as Kilowatts (KW). Reactive power is the portion of apparent power that does no work and is referred to as kilovars; this type of power must be supplied to most types of magnetic equipment, such as motors, and is supplied by generator or by electrostatic equipment. Voltamperes are usually divided by 1,000 and called kilovoltamperes (kVA). Energy is denoted by the product of real power and the length of time utilized; this product is expressed as kilowatthours.

Power Production Plant. All the land and land rights, structures and improvements, boiler or reactor vessel equipment, engines and engine-driven generator, turbogenerator units, accessory electric equipment, and miscellaneous power plant equipment are grouped together for each individual facility.

Preferred Stock. Ownership interests in a corporation which have been granted a preference, usually in the distribution of dividends before payment of dividends to common stockholders and assets in dissolution. It is usually nonvoting.

Price. The amount of money or consideration-in-kind for which a service is bought, sold, or offered for sale.

Prime Mover. The motive force that drives an electric generator (e.g., steam engine, turbine, or water wheel).

Production (Electric). Act or process of producing electric energy from other forms of energy; also, the amount of electric energy expressed in watthours (Wh).

Production Expenses. Costs incurred in the production of electric power that conform to the accounting requirements of the Operation and Maintenance Expense Accounts of the FERC Uniform System of Accounts.

Profit. The income remaining after all business expenses are paid.

Public Authority Service to Public Authorities. Public authority service includes electricity supplied and services rendered to municipalities or divisions or agencies of State or Federal governments, under special contracts or agreements or service classifications applicable only to public authorities.

Public Street and Highway Lighting. Public street and highway lighting includes electricity supplied and services rendered for the purposes of lighting streets, highways, parks, and other public places; or for traffic or other signal system service, for municipalities, or other divisions or agencies of State or Federal governments.

Public Utility District. Municipal corporations organized to provide electric service to both incorporated cities and towns and unincorporated rural areas. Public utility districts, sometimes called "People's Utility Districts" or "Public Power Districts," operate in six States.

Pumped-Storage Hydroelectric Plant. A plant that usually generates electric energy during peak-load periods by using water previously pumped into an elevated storage reservoir during off-peak periods when excess generating capacity is available to do so. When additional generating capacity is needed, the water 
can be released from the reservoir through a conduit to turbine generators located in a power plant at a lower level.

Purchased Power. Power purchased or available for purchase from a source outside the system.

Railroad and Railway Services. Railroad and railway services include electricity supplied and services rendered to railroads and interurban and street railways, for general railroad use, including the propulsion of cars or locomotives, where such electricity is supplied under separate and distinct rate schedules.

Rate Base. The value of property upon which a utility is permitted to earn a specified rate of return as established by a regulatory authority. The rate base generally represents the value of property used by the utility in providing service and may be calculated by any one or a combination of the following accounting methods: fair value, prudent investment, reproduction cost, or original cost. Depending on which method is used, the rate base includes cash, working capital, materials and supplies, and deductions for accumulated provisions for depreciation, contributions in aid of construction, customer advances for construction, accumulated deferred income taxes, and accumulated deferred investment tax credits.

Ratemaking Authority. A utility commission's legal authority to fix, modify, approve, or disapprove rates, as determined by the powers given the commission by a State or Federal legislature.

Rate of Return. The ratio of net operating income earned by a utility is calculated as a percentage of its rate base.

Rate of Return on Rate Base. The ratio of net operating income to a specified rate base, expressed as a percentage.

Rate of Return on Common Equity. Net income less preferred stock dividends divided by common stock equity.

Refunding. Retirement of one security issue with proceeds received from selling another. Refunding provides for retiring maturing debt by taking advantage of favorable money market conditions.

Regulation. The governmental function of controlling or directing economic entities through the process of rulemaking and adjudication.

Residential. The residential sector is defined as private household establishments which consume energy primarily for space heating, water heating, air conditioning, lighting, refrigeration, cooking and clothes drying. The classification of an individual consumer's account, where the use is both residential and commercial, is based on principal use. For the residential class, do not duplicate consumer accounts due to multiple metering for special services (water, heating, etc.). Apartment houses are also included.
Retail. Sales covering electrical energy supplied for residential, commercial, and industrial end-use purposes. Other small classes, such as agriculture and street lighting, also are included in this category.

Retall Wheeling. An arrangement in which a utility transmits electricity from outside its service territory to a retail customer within its customer service territory.

Retained Earnings. The balance, either debit or credit, of appropriated or unappropriated earnings of an entity that are retained in the business.

Return on Common Equity. An entity's earnings available for common stockholders calculated as a percentage of its common equity capital.

Revenue. The total amount of money received by a firm from sales of its products and/or services, gains from the sales or exchange of assets, interest and dividends earned on investments, and other increases in the owner's equity except those arising from capital adjustments.

Revenue Requirement. The total revenue that the utility is authorized an opportunity to recover, wh.ch includes operating expenses and a reasonable return on rate base.

Rural Electrification Administration (REA). A lending agency of the U.S. Department of Agriculture, the REA makes self-liquidation loans to qualified borrowers to finance electric and telephone service to rural areas. The REA also finances the construction and operation of generating plants, electric transmission and distribution lines, or systems for the furnishing of initial and continued adequate electric services to persons in rural areas not receiving central station service.

Sales. The amount of kilowatthours sold in a given period of time; usually grouped by classes of service, such as residential, commercial, industrial, and other. Other sales include public street and highway lighting, other sales to public authorities and railways, and interdepartmental sales.

Sales for Resale. Energy supplied to other electric utilities, cooperatives, municipalities, and Federal and State electric agencies for resale to ultimate consumers.

Short-term Debt or Borrowings. Debt securities or borrowings having a maturity of less than 1 year.

Solar Energy. Energy produced from the sun's radiation.

Steam-Electric Plant (Conventional). A plant in which the prime mover is a steam turbine. The steam used to drive the turbine is produced in a boiler where fossil fuels are burned. 
Steam Expenses. The cost of labor, materials, fuel, and other expenses incurred in production of steam for electric gẹneration.

Steam from other Sources. Steam purchased, transferred from another department of the utility, or acquired from others under a joint-facility operating agreement.

Steam Transferred-Credit. The expenses of producing steam charged to others or to other utility departments under a joint operating arrangement.

Substation. Facility equipment that switches, changes, or regulates electric voltage.

Switching Station. Facility equipment used to tie together two or more, electric circuits through switches. The switches are selectively arranged to permit a circuit to be disconnected, or to change the electric connection between the circuits.

System (Electric). Physically connected generation, transmission, and distribution facilities operated as an integrated unit under one central management, or operating supervision.

Transformer. An electrical device for changing the voltage of alternating current.

Transmission. The movement or transfer of electric energy over an interconnected group of lines and associated equipment between points of supply and points at which it is transformed for delivery to consumers, or is delivered to other electric systems. Transmission is considered to end when the energy is transformed for distribution to the consumer.
Transmission System (Electric). An interconnected group of electric transmission lines and associated equipment for moving or transferring electric energy in bulk between points of supply and points at which it is transformed for delivery over the distribution system lines to consumers, or is delivered to other electric systems.

Turbine. A machine for generating rotary mechanical power from the energy of a stream of fluid (such as water, steam, or hot gas). Turbines convert the kinetic energy of fluids to mechanical energy through the principles of impulse and reaction, or a mixture of the two.

Ultimate Consumer. A consumer that purchases electricity for its own use and not for resale.

Uniform System of Accounts. Prescribed financial rules and regulations established by the Federal Energy Regulatory Commission for utilities subject to its jurisdiction under the authority granted by the Federal Power Act.

Utility Generation. Generation by electric systems engaged in selling electric energy to the public.

Watt. The electrical unit of power. The rate of energy transfer equivalent to 1 ampere flowing under a pressure of 1 volt at unity power factor.

Watthour (Wh). An electrical energy unit of measure equal to 1 watt of power supplied to, or taken from, an electric circuit steadily for 1 hour.

Wheeling Service. The movement of electricity from one system to another over transmission facilities of intervening systems. Wheeling service contracts can be established between two or more systems. 

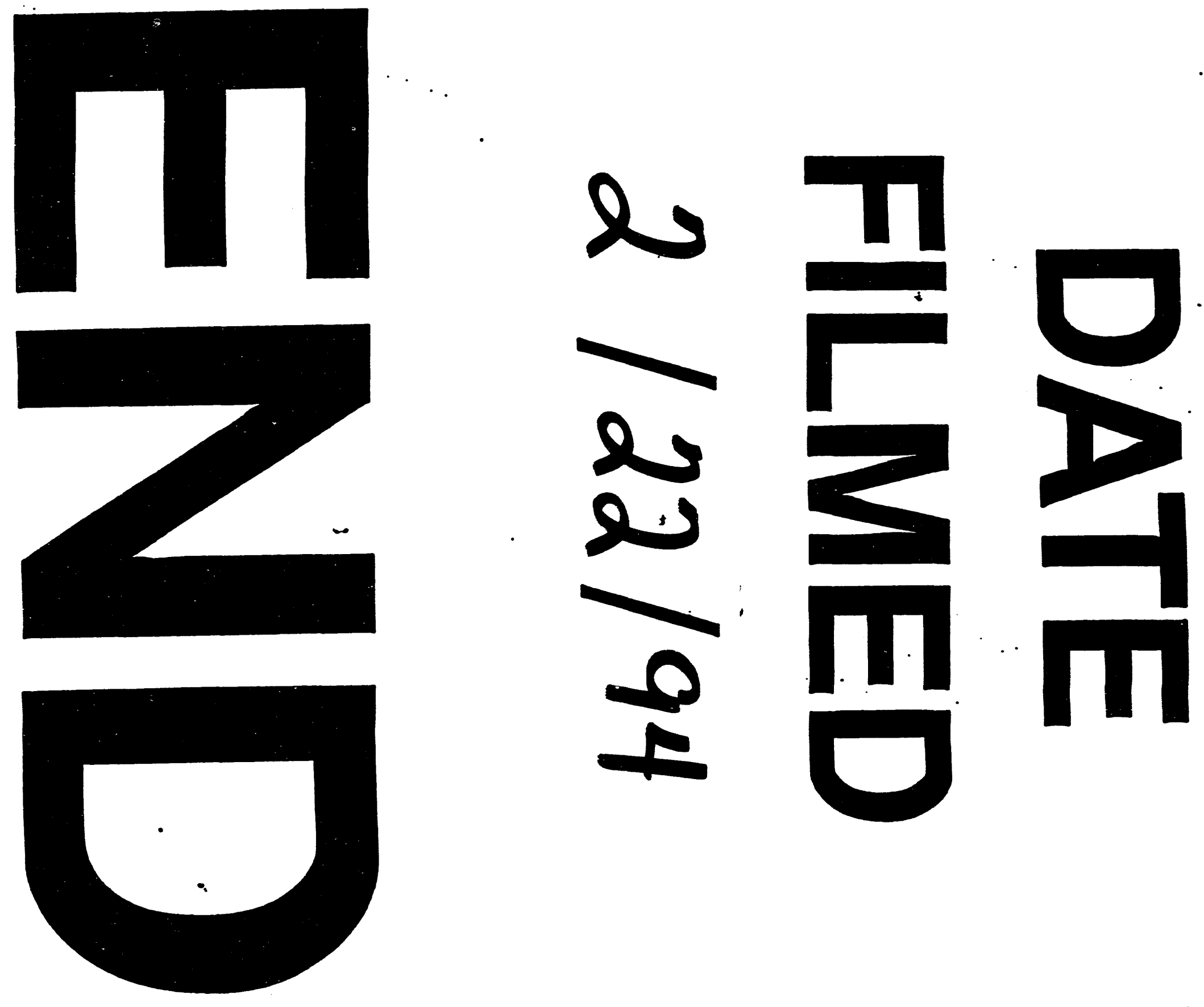
